Pacific Northwest

National Laboratory

Operated by Battelle for the

U.S. Department of Energy

\title{
Hanford Site Environmental Surveillance Data Report for Calendar Year 2003
}

\author{
L. E. Bisping
}

September 2004

Prepared for the U.S. Department of Energy under Contract DE-AC06-76RL01830 


\title{
DISCLAIMER
}

This report was prepared as an account of work sponsored by an agency of the United States Government. Neither the United States Government nor any agency thereof, nor Battelle Memorial Institute, nor any of their employees, makes any warranty, express or implied, or assumes any legal liability or responsibility for the accuracy, completeness, or usefulness of any information, apparatus, product, or process disclosed, or represents that its use would not infringe privately owned rights. Reference herein to any specific commercial product, process, or service by trade name, trademark, manufacturer, or otherwise does not necessarily constitute or imply its endorsement, recommendation, or favoring by the United States Government or any agency thereof, or Battelle Memorial Institute. The views and opinions of authors expressed herein do not necessarily state or reflect those of the United States Government or any agency thereof.

\author{
PACIFIC NORTHWEST NATIONAL LABORATORY \\ operated by \\ BATTELLE \\ for the
}

UNITED STATES DEPARTMENT OF ENERGY

under Contract DE-AC06-76RL01830

Printed in the United States of America

Available to DOE and DOE contractors from the

Office of Scientific and Technical Information,

P.O. Box 62, Oak Ridge, TN 37831-0062;

ph: (865) 576-8401

fax: (865) 576-5728

email: reports@adonis.osti.gov

\begin{abstract}
Available to the public from the National Technical Information Service, U.S. Department of Commerce, 5285 Port Royal Rd., Springfield, VA 22161 ph: (800) 553-6847 fax: (703) 605-6900

email: orders@ntis.fedworld.gov

online ordering: http://www.ntis.gov/ordering.htm
\end{abstract}

This document was printed on recycled paper.

$(8 / 00)$ 
HANFORD SITE ENVIRONMENTAL SURVEILLANCE DATA REPORT FOR CALENDAR YEAR 2003

L. E. Bisping

September 2004

Prepared for the U.S. Department of Energy under Contract DE-AC06-76RL01830

Pacific Northwest National Laboratory Richland, Washington 99352 


\section{PREFACE}

Environmental surveillance at the Hanford Site, located in southeastern Washington State, is conducted by Pacific Northwest National Laboratory (PNNL), which is operated by Battelle for the U.S. Department of Energy. The data collected provide a historical record of radionuclide and radiation levels attributable to natural causes, worldwide fallout, and Hanford operations. Data are also collected to monitor several chemicals and metals in Columbia River water and sediment. For more information regarding the 2003 sampling schedule for the Surface Environmental Surveillance Project (SESP) and Drinking Water Monitoring Project, refer to L. E. Bisping, Environmental Surveillance Master Sampling Schedule (PNNL-14184, Pacific Northwest National Laboratory, Richland, Washington).

PNNL publishes an annual environmental report for the Hanford Site each calendar year. The Hanford Site Environmental Report for Calendar Year 2003 describes the site mission and activities, general environmental features, radiological and chemical releases from operations, status of compliance with environmental regulations, status of programs to accomplish compliance, and environmental monitoring activities and results. Sections of the annual environmental report include tables and summaries of offsite and onsite environmental surveillance data collected by PNNL during 2003. This data report contains the actual raw data used to create those tables and summaries. In addition to providing raw data collected during routine sampling efforts in 2003 , this data report also includes data from special sampling studies performed by PNNL during 2003. Results for samples collected and submitted for analysis by PNNL in support of the 100-B/C Risk Assessment Pilot Project are also included in this data report.

For further information regarding environmental management activities and compliance issues, refer to T. M. Poston, R. W. Hanf, R. L. Dirkes, and L. F. Morasch, 2003, Hanford Site Environmental Report for Calendar Year 2003 (PNNL-14687, Pacific Northwest National Laboratory, Richland, Washington), Internet address: http://hanford-site.pnl.gov/envreport or contact T. M. Poston, Pacific Northwest National Laboratory, P.O. Box 999, Richland, Washington 99352 (ted.poston@pnl.gov). 


\section{INTRODUCTION}

The following sections provide tables of data on which PNNL's environmental surveillance summary information in the Hanford Site Environmental Report for Calendar Year 2003 was based. Information that may help the reader to understand these data tables is provided below.

\section{GENERAL}

Some degree of inherent uncertainty is associated with all analytical measurements. The total propagated analytical uncertainty for an individual result is a 2-sigma counting error. For samples that are prepared or manipulated in the laboratory prior to counting, the total propagated analytical uncertainty includes both the counting uncertainty and the uncertainty connected with sample preparation and chemical separations. For samples that are not manipulated in the laboratory before counting, the total propagated analytical uncertainty only accounts for the uncertainty associated with counting the sample. The uncertainty associated with samples that are analyzed but not counted includes only the analytical process uncertainty.

\section{EXTERNAL RADIATION DATA}

The thermoluminescent dosimeter (TLD) readings in this data volume are in milliroentgens per day (mR/day) and have been converted to mrem/year for presentation in the annual report. 
The following section provides definitions of column headings in the data tables in this document.

COLUMN

HEADING

OWNER ID

SAMP NUM

SAMP SITE NAME

DIST CLASS

MEDIA

SAMP FROM

SAMP ITEM

COLL MTHD

\section{DEFINITION}

Identifies the owner of the data (SESPMNT = PNNL SESP routine collection, SESPSPEC $=$ PNNL SESP special study, PNLGW $=$ PNNL Groundwater)

Sample Number is a unique identifier for a sample

Sample Site Name is the name of the sampling site as identified in the Hanford Environmental Information System (HEIS) database

Distant Classification is the location of the sampling site relative to the Hanford Site (Onsite, Offsite, Community, Distant, Perimeter, River_Shoreline). Field not utilized by OWNER ID PNLGW

Categorizes samples into logical groups or subject areas:

AT Air

BI Biota (foodstuffs, wildlife, vegetation)

ER External Radiation

GW Samples collected from wells, including engineered structures that provide access to the aquifer for groundwater samples at locations close to the river. ' $G W$ ' is also assigned to samples collected from tubes inserted $\sim 1$ meter or deeper into the always-submerged riverbed.

SO Soil/Sediment

SW Surface Water (also represents water collected from rivers, ponds and springs, and drinking water)

Sample From identifies the media-dependent entity that was sampled (e.g., COW, WINE, WHITEFISH, etc.). Field not utilized by OWNER ID PNLGW

Sample Item identifies the media-dependent item (e.g., MILK, RED WINE, MUSCLE, etc.) that was sampled from the entity identified in the SAMP FROM field

Collection Method is used to denote the type of method used for surface water (SW) collections

FILTER Filter material of cloth or paper

RESIN Resin sampler for collecting cations and anions from water 
COLUMN

HEADING

SAMP DATE

CON SHORT NAME

VALUE RPTD

ANAL UNITS RPTD

COUNTING

ERROR

TOTAL ANAL ERROR

LAB QUALIFIER

\section{DEFINITION}

Sample Date is the date the sample was collected

Constituent Short Name for the specific radiological or chemical compound or physical parameter

The concentration or result reported by the analytical laboratory or read from an instrument

The units in which the result was originally reported

The 2-sigma Counting Error for radioanalytical results only

The 2-sigma Total Analytical Error may be reported for any result

A flag identifying issues that could impact the quality of the reported result. Qualifiers that apply to the 2003 data include:

B For organics the analyte was found in the associated blank as well as in the sample, indicates possible/probable blank contamination. For inorganics or the analyte was detected at a value less than the contract required detection limit (RDL), but greater than or equal to the Instrument Detection Limit (IDL) or Method Detection Limit (MDL). ORGANICS - The analyte was detected in both the associated QC blank and in the sample.

C Possible contamination has occurred. For metals ' $C$ ' qualifier analyte was detected in the associated blank above lab detection limit.

BC Characteristics from both ' $\mathrm{B}$ ' and ' $\mathrm{C}$ ' qualifiers exist

D Identifies all compounds in an analysis at a secondary dilution factor

CD Characteristics from both ' $C$ ' and ' $D$ ' qualifiers exist

E Report value is estimated.

$\mathrm{J}$ Value is estimated; no ' $U$ ' qualifier has been assigned and the result is below the required detection level (RDL)

JB Characteristics from both ' $\mathrm{J}$ ' and 'B' qualifiers exist 
$\mathrm{N} \quad$ Matrix spike/matrix spike duplicate outside of the control limit.

JBN Characteristics from both 'JB' and 'N' qualifiers exist.

$\mathrm{U} \quad$ Indicates constituent was analyzed for but not detected or value reported < 0; value reported < counting error; value reported < total analytical error; value_rptd $<=$ contract Method Detection Limit (MDL), Instrument Detection Limit (IDL), Minimum Detectable Activity (MDA), or Practical Quantitation Limit (PQL). For metals, ' $U$ ' qualifier may be represented by the lab detection limit.

UN Characteristics from both ' $U$ ' and ' $N$ ' qualifiers exist

SAMP COMMENT Contains pertinent information about a sample, which may affect the quality and use of the data

RESULT COMMENT

Contains pertinent information about the result, which may effect the quality and use of the data

TAG ID

Identifier used to group the different portions collected from a single biota sample. For example, a single Tag ID would be used to group the muscle and bone samples collected from a single deer.

WELL NAME Name provided to identify ground-water wells including aquifer tubes.

FLOW RATE Columbia River daily average flow downstream of Priest Rapids Dam

FLOW RATE UNITS Columbia River flow in cubic feet per second (CFS)

REPLICATE ID Core sample number

REPLICATE VALUE Core value reported

RELATIVE \% DIFFERENCE

MIN DETECTABLE ACTIVITY
The relative percent difference between the measured concentration of the original value reported and the replicate value reported. The formula is:

100 * IVALUE RPTD - REPLICATE VALUE| / ((VALUE RPTD + REPLICATE VALUE) / 2)

Minimum detectable activity (MDA) is assumed to be a sampledependent estimate, typically dependent on the background of the measurement instrument and sample yield, reported in the same units as the result value for the reported analyte. 


\section{CONTENTS}

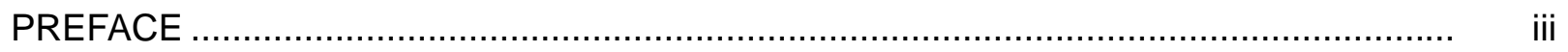

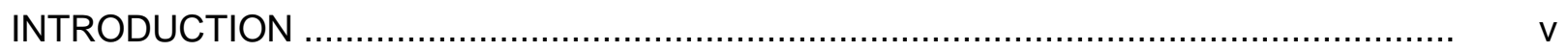

AIR

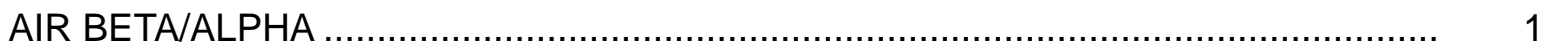

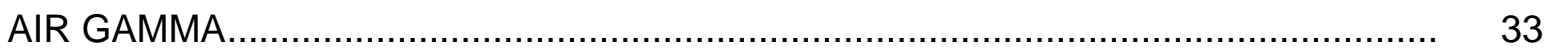

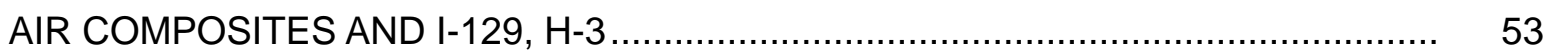

\section{WATER}

WATER - COLUMBIA RIVER COMPOSITES .................................................. 69

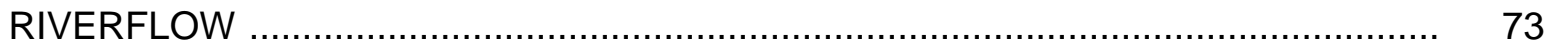

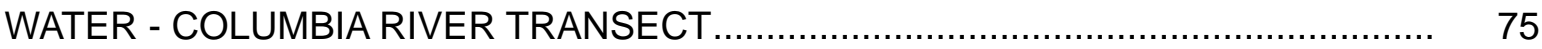

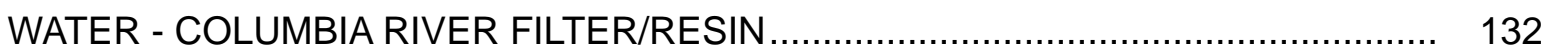

WATER - COLUMBIA RIVER SHORELINE SPRINGS .................................. 141

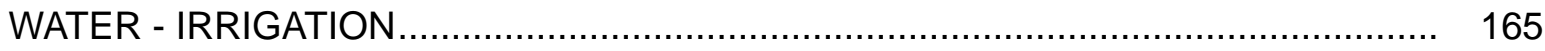

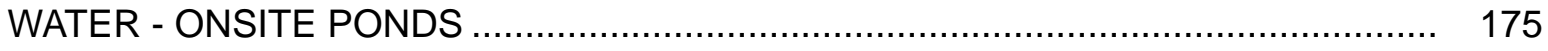

WATER - ASSORTED NON-ROUTINE SAMPLING EVENTS $\ldots \ldots \ldots \ldots \ldots \ldots \ldots \ldots \ldots \ldots \ldots \ldots \ldots \ldots \ldots$

TABLE W-1. Preliminary United States Geological Survey (USGS) Columbia River Water Quality Data for Vernita Bridge Near Priest Rapids Dam, Washington............. 204

TABLE W-2. Preliminary United States Geological Survey (USGS) Columbia River Water Quality Data for Richland, Washington Near the Richland Pumphouse ............ 205

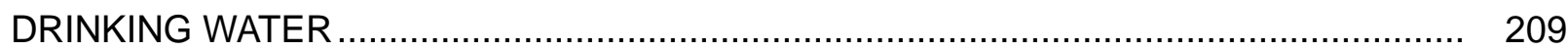

\section{BIOTA}

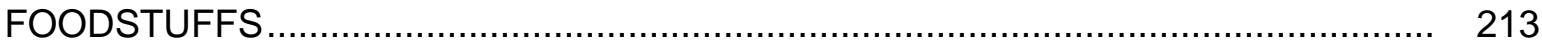


CONTENTS (contd)

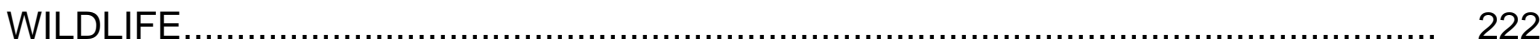

Table B-1. Metals in Biota, 2003 ……………………................................ 230

Table B-2. DDD, DDE, DDT in Biota, 2003 ...................................................... 233

SOIL

Table S-1. DDD, DDE, DDT in Soil, 2003 …................................................... 240

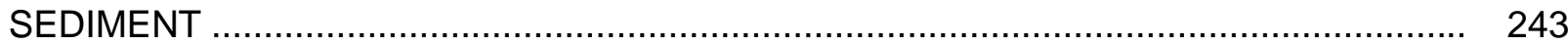

TABLE Sed-1. Acid Volatile Sulfide (AVS)/Simultaneously Extracted Metals (SEM) in Columbia River Sediment, 2003 ................................................................. 257

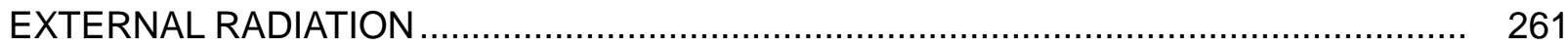

DOSE CALCULATIONS

TABLE D-1. Distribution of Population in 80-km Radius of the 100-K Area

by Grid Sector ............................................................................................ 271

TABLE D-2. Distribution of Population in 80-km Radius of the 200 Areas

by Grid Sector ....................................................................................... 272

TABLE D-3. Distribution of Population in 80-km Radius of the 300 Area

by Grid Sector ................................................................................... 273

TABLE D-4. Distribution of Population in 80-km Radius of the 400 Area

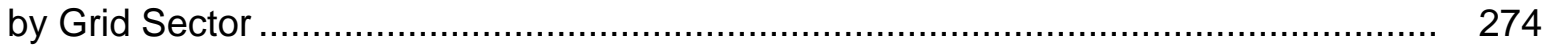

TABLE D-5. Annual Average Dispersion Factor Around the 100-K Area

During 2003 for a 10-Meter Release Height ....................................................... 275

TABLE D-6. Annual Average Dispersion Factor Around the 200 Areas

During 2003 for a 89-Meter Release Height .......................................................... 276

TABLE D-7. Annual Average Dispersion Factor Around the 300 Area

During 2003 for a 10-Meter Release Height ........................................................... 277

TABLE D-8. Annual Average Dispersion Factor Around the 400 Area

During 2003 for a 10-Meter Release Height 


\section{CONTENTS (contd)}

\section{QUALITY ASSURANCE}

TABLE Q-1. Severn Trent Laboratories (STL), Inc., Richland, WA, Performance

Data on Surface Environmental Surveillance Project Blind Spikes, 2003

TABLE Q-2. Severn Trent Laboratories (STL), Inc., Richland, WA, Performance Data on Environmental Resources Associates (ERA) Proficiency Testing Program Water Samples, 2003

TABLE Q-3. Severn Trent Laboratories (STL), Inc., Richland, WA, Performance Data on the DOE Environmental Measurements Laboratory (EML) Quality Assessment Program Studies, 2003.

TABLE Q-4. Biota Sample Field Duplicate Results, 2003 .................................... 285

TABLE Q-5. Water Sample Field Duplicate Results, 2003.................................. 287 
Air 
AIR BETA/ALPHA

\begin{tabular}{|c|c|c|c|c|c|c|c|c|c|c|c|c|c|}
\hline OWNER ID & \begin{tabular}{|l|} 
SAMP \\
NUM \\
81607
\end{tabular} & SAMP SITE NAME & \begin{tabular}{|l} 
DIST CLASS \\
ONSITE
\end{tabular} & MEDIA & SAMP DATE & $\begin{array}{l}\text { CON } \\
\text { SHORT } \\
\text { NAME } \\
\end{array}$ & VALUE RPTD & $\begin{array}{l}\text { ANAL } \\
\text { UNITS } \\
\text { RPTD } \\
\end{array}$ & $\begin{array}{c}\text { COUNTING } \\
\text { ERROR }\end{array}$ & \begin{tabular}{|c|} 
TOTAL \\
ANAL \\
ERROR \\
\end{tabular} & $\begin{array}{c}\text { LAB } \\
\text { QUALIFIER } \\
\end{array}$ & SAMP COMMENT & $\begin{array}{c}\text { RESULT } \\
\text { COMMENT } \\
\end{array}$ \\
\hline SESPMNT & B168D7 & 100 D AREA & ONSITE & AT & $21-\mathrm{Jan}-03 \mathrm{~B}$ & & $0.0355 \mathrm{p}$ & & 0.0018 & 0.0063 & & 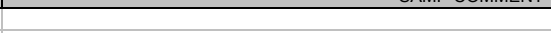 & \\
\hline SESPMNT & B168D8 & 100 D AREA & ONSITE & AT & 04-Feb-03 B & & $0.0114 \mathrm{p}$ & Ci/m3 & 0.0011 & 0.0023 & & & \\
\hline SESPMNT & B168D9 & 100 D AREA & ONSITE & AT & 18-Feb-03 B & & $0.026 \mathrm{p}$ & & 0.0016 & 0.0046 & & & \\
\hline $\begin{array}{l}\text { SESPMNT } \\
\text { SFONT }\end{array}$ & B168F0 & 100 D AREA & ONSITE & AT & 03-Mar-03 B & & $0.0163 \mathrm{p}$ & & 0.0014 & 0.0032 & & & \\
\hline SESPMNT & B168F1 & $100 \mathrm{D}$ AREA & ONSITE & AT & 18-Mar-03 B & & $0.00556 \mathrm{p}$ & Cilm3 & 0.00086 & 0.0014 & & & \\
\hline $\begin{array}{l}\text { SESPMNT } \\
\text { SESPMNT }\end{array}$ & B168F2 & $100 \mathrm{D}$ AREA & ONSITE & AT & 31-Mar-03 B & & $0.00607 p$ & & 0.001 & 0.0016 & & & \\
\hline $\begin{array}{l}\text { SESPMNT } \\
\text { SESPMNT }\end{array}$ & B16PTO & 100 D AREA & ONSITE & AT & 15-Apr-03 B & & $0.00723 p$ & Cilm3 & 0.00099 & 0.0017 & & & \\
\hline $\begin{array}{l}\text { SESPMNT } \\
\text { SESPMNT }\end{array}$ & $\begin{array}{l}\text { B16PT1 } \\
\text { B16P2 }\end{array}$ & $100 \mathrm{D}$ AREA & ONSITE & AT & 29-Apr-03 B & & $0.0083 p$ & Ci/m3 & 0.0011 & 0.0019 & & & \\
\hline SESPMNT & B16PT2 & 100 D AREA & ONSITE & AT & 12-May-03В & & $0.0103 \mathrm{p}$ & $\mathrm{C} / \mathrm{m} 3$ & 0.0012 & 0.0022 & & & \\
\hline $\begin{array}{l}\text { SESPMNT } \\
\text { SECDMNT }\end{array}$ & B16РT3 & 100 D AREA & ONSITE & AT & 29-May-03 В & & $0.0107 \mathrm{p}$ & Ci/m3 & 0.00099 & 0.0021 & & & \\
\hline $\begin{array}{l}\text { SESPMNT } \\
\text { SESPMNT }\end{array}$ & B16PT4 & 100 D AREA & ONSITE & AT & 11-Jun-03 B & & $0.0139 \mathrm{p}$ & $\mathrm{C} / \mathrm{m} 3$ & 0.0013 & 0.0028 & & & \\
\hline $\begin{array}{l}\text { SESPMNT } \\
\text { SESPMNT }\end{array}$ & $\begin{array}{l}\text { B16PT5 } \\
\text { B16PT6 }\end{array}$ & 100 D AREA & ONSITE & AT & 24-Jun-03B & & $0.00925 p$ & Ci/m3 & 0.0012 & 0.0021 & & & \\
\hline $\begin{array}{l}\text { SESPMNT } \\
\text { SESPMNT }\end{array}$ & $\begin{array}{l}\text { B16PT6 } \\
\text { B175N7 }\end{array}$ & $\begin{array}{l}100 \text { D AREA } \\
100 \text { D AREA }\end{array}$ & $\begin{array}{l}\text { ONSITE } \\
\text { ONSTIE }\end{array}$ & $\begin{array}{l}\text { AT } \\
\text { AT }\end{array}$ & 08-Jul-03B & BETA & $0.0112 \mathrm{p}$ & Ci/m3 & 0.0012 & 0.0024 & & & \\
\hline $\begin{array}{l}\text { SESPMNT } \\
\text { SESPN }\end{array}$ & $\begin{array}{l}\text { B175N7 } \\
\text { B175N8 }\end{array}$ & $\begin{array}{l}100 \text { D AREA } \\
100 \text { D AREA }\end{array}$ & $\begin{array}{l}\text { ONSTIE } \\
\text { ONSITE }\end{array}$ & $\begin{array}{l}\text { AT } \\
\text { AT }\end{array}$ & $\begin{array}{l}\text { 22-Jul-03B } \\
\text { 04-Aug-03 B }\end{array}$ & BETA & $\begin{aligned} 0.011 \mathrm{p} \\
0.0137 \mathrm{p}\end{aligned}$ & $\begin{array}{l}\mathrm{Ci} / \mathrm{m} 3 \\
\mathrm{C} / \mathrm{m} 3\end{array}$ & $\begin{array}{l}0.0011 \\
0.0013\end{array}$ & $\begin{array}{l}0.0023 \\
0.0028\end{array}$ & & & \\
\hline SESPMNT & B175N9 & 100 D AREA & ONSITE & AT & 18-Aug-03 B & BETA & $\begin{array}{l}0.013 / \mathrm{p} \\
0.0138 \mathrm{p}\end{array}$ & $\begin{array}{l}\mathrm{Cl} \text { Clm3 } \\
\mathrm{C} / \mathrm{m} 3\end{array}$ & $\begin{array}{l}0.0013 \\
0.0013\end{array}$ & $\begin{array}{l}0.0028 \\
0.0028\end{array}$ & & & \\
\hline SESPMNT & B175PO & 100 D AREA & ONSITE & AT & 02-Sep-03B & & $0.0178 \mathrm{p}$ & $\mathrm{Ci} / \mathrm{m} 3$ & 0.0012 & 0.0031 & & & \\
\hline SESPMNT & B175P1 & 100 D AREA & ONSITE & AT & 15-Sep-03 B & BETA & $0.0146 \mathrm{p}$ & $\mathrm{Ci} / \mathrm{m} 3$ & 0.0013 & 0.003 & & & \\
\hline SESPMNT & B175P2 & 100 D AREA & ONSITE & AT & 01-Oct-03 B & BETA & $0.012 \mathrm{p}$ & $\mathrm{C} i / \mathrm{m} 3$ & 0.0011 & 0.0024 & & & \\
\hline SESPMNT & B17P97 & 100 D AREA & ONSITE & AT & 13-Oct-03 B & BETA & $0.0248 \mathrm{p}$ & $\mathrm{C} / \mathrm{m} 3$ & 0.0017 & 0.0046 & & & \\
\hline SESPMNT & B17P98 & 100 D AREA & ONSITE & AT & 28-Oct-03 B & & $0.0248 \mathrm{p}$ & $\mathrm{C} / \mathrm{m} 3$ & 0.0015 & 0.0045 & & & \\
\hline SESPMNT & B17P99 & $100 \mathrm{D}$ AREA & ONSITE & AT & 11-Nov-03 B & & $0.0365 p$ & $\mathrm{C} / \mathrm{m} 3$ & 0.0017 & 0.0061 & & & \\
\hline $\begin{array}{l}\text { SESPMNT } \\
\end{array}$ & B17PBO & 100 D AREA & ONSITE & AT & 24-Nov-03 B & & $0.0177 \mathrm{p}$ & Ci/m3 & 0.0014 & 0.0034 & & & \\
\hline SESPMNT & B17PB1 & 100 D AREA & ONSITE & AT & 11-Dec-03 B & & $0.0113 p$ & Ci/m3 & 0.00097 & 0.0022 & & & \\
\hline $\begin{array}{l}\text { SESPMNT } \\
\text { SESPMNT }\end{array}$ & B17PB2 & 100 D AREA & ONSITE & AT & 22-Dec-03 B & & $0.0185 p$ & Ci/m3 & 0.0016 & 0.0036 & & & \\
\hline $\begin{array}{l}\text { SESPMNT } \\
\text { SESPMNT }\end{array}$ & $\begin{array}{l}\text { B17PB3 } \\
\text { B16987 }\end{array}$ & $\begin{array}{l}100 \text { D AREA } \\
100 \text { MFE }\end{array}$ & ONSITE & AT & 06-Jan-04B & BETA & $0.0189 p$ & Ci/m3 & 0.0013 & 0.0035 & & & \\
\hline $\begin{array}{l}\text { SESPMNT } \\
\text { SESPMNT }\end{array}$ & $\begin{array}{l}\text { B16987 } \\
\text { B16988 }\end{array}$ & $\begin{array}{l}100 \text { F MEET TOWER } \\
100 \text { F MET TOWWER }\end{array}$ & $\begin{array}{l}\text { ONSITE } \\
\text { ONSTIE }\end{array}$ & $\begin{array}{l}\text { AT } \\
\text { AT }\end{array}$ & $\begin{array}{l}\text { 21-Jan-03B } \\
\text { 04-- - } 03 \text { Beb }\end{array}$ & & $0.0303 \mathrm{p}$ & Cilm3 & $\begin{array}{r}0.0017 \\
0.0095\end{array}$ & 0.0053 & & & \\
\hline SESPMNT & 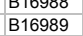 & $\begin{array}{l}100 \mathrm{FM} \text { MET TOWER } \\
100 \mathrm{~F} \text { TET }\end{array}$ & $\begin{array}{l}\text { ONSIIE } \\
\text { ONSITE }\end{array}$ & $\begin{array}{l}\text { AT } \\
\text { AT }\end{array}$ & $\begin{array}{l}\text { O4-Feb-03E } \\
18 \text {-Feb-03B }\end{array}$ & $\begin{array}{l}B \text { BIA } \\
\text { BETA }\end{array}$ & $\begin{array}{l}0.00666 \mathrm{p} \\
0.0221 \mathrm{p}\end{array}$ & $\begin{array}{l}\mathrm{Cl} \text { Clm3 } \\
\mathrm{C} / \mathrm{m} 3\end{array}$ & $\begin{array}{l}0.00095 \\
0.0015\end{array}$ & $\begin{array}{l}0.0016 \\
0.0041\end{array}$ & & & \\
\hline SESPMNT & B16990 & $100 \mathrm{~F}$ MET TOWER & ONSITE & AT & 03-Mar-03 B & BETA & $0.0172 \mathrm{p}$ & $\mathrm{Ci} / \mathrm{m} 3$ & 0.0014 & 0.0034 & & & \\
\hline SESPMNT & B16991 & $100 \mathrm{~F}$ MET TOWER & ONSITE & AT & 18-Mar-03 B & BETA & $0.00598 \mathrm{p}$ & $\mathrm{Ci} / \mathrm{m} 3$ & 0.00093 & 0.0015 & & & \\
\hline SESPMNT & B16992 & 100 F MET TOWER & ONSITE & AT & 31-Mar-03 B & BETA & $0.00675 p$ & $\mathrm{C} \mathrm{C} / \mathrm{m} 3$ & 0.0011 & 0.0017 & & & \\
\hline SESPMNT & B16RL6 & $100 \mathrm{~F}$ MET TOWER & ONSITE & AT & 15-Apr-03 B & BETA & $0.00568 \mathrm{p}$ & $\mathrm{C} / \mathrm{m} 3$ & 0.00086 & 0.0014 & & & \\
\hline SESPMNT & B16RL7 & 100 F MET TOWER & ONSITE & AT & 29-Apr-03 B & BETA & $0.00804 p$ & Cilm3 & 0.001 & 0.0018 & & & \\
\hline SESPMNT & B16RL8 & $100 \mathrm{~F}$ MET TOWER & ONSITE & AT & 12-May-03 В & BETA & $0.0096 \mathrm{p}$ & Ci/m3 & 0.0011 & 0.0021 & & & \\
\hline SESPMNT & B16RL9 & $100 \mathrm{~F}$ MET TOWER & ONSITE & AT & 29-May-03 В & BETA & $0.0106 \mathrm{p}$ & Ci/m3 & 0.00098 & 0.0022 & & & \\
\hline $\begin{array}{l}\text { SESPMNT } \\
\text { SECDMNT }\end{array}$ & B16RMO & 100 F MET TOWER & ONSITE & AT & 11-Jun-03B & BETA & $0.0163 \mathrm{p}$ & Ci/m3 & 0.0014 & 0.0031 & & & \\
\hline $\begin{array}{l}\text { SESPMNT } \\
\text { SESPMNT }\end{array}$ & B16RM1 & 100 F MET TOWER & ONSITE & AT & 24-Jun-03 B & BETA & $0.00831 \mathrm{p}$ & Ci/m3 & 0.0011 & 0.0019 & & & \\
\hline $\begin{array}{l}\text { SESPMNT } \\
\text { SESPMNT }\end{array}$ & B16RM2 & 100 F MET TOWER & ONSITE & AT & 08-Jul-03 B & BETA & $0.0114 p$ & Ci/m3 & 0.0012 & 0.0024 & & & \\
\hline $\begin{array}{l}\text { SESPMNT } \\
\text { SESPMNT }\end{array}$ & $\begin{array}{l}8176 \mathrm{~T} \\
176.8\end{array}$ & $\begin{array}{l}100 \text { F MET TOWER } \\
100 \text { FMET TOWER }\end{array}$ & ONSITE & AT & $\begin{array}{l}\text { 22-Jul-03B } \\
\text { 04-Aug-03 B }\end{array}$ & BETA & $0.0108 p$ & il/m3 & 0.0011 & 0.0023 & & & \\
\hline $\begin{array}{l}\text { SESPMNT } \\
\text { SESPMNT }\end{array}$ & 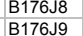 & $\begin{array}{l}100 \mathrm{~F} \text { MET TOWER } \\
100 \mathrm{~F} \text { MET TOWWER }\end{array}$ & $\begin{array}{l}\text { ONSITE } \\
\text { ONSTTE }\end{array}$ & $\begin{array}{l}\text { AT } \\
\text { AT }\end{array}$ & $\begin{array}{l}\text { 04-Aug-03B } \\
\text { 18-Aug-03B }\end{array}$ & BETA & $0.0147 \mathrm{p}$ & $\begin{array}{l}\text { Cilm3 } \\
\text { Ci/m3 }\end{array}$ & $\begin{array}{l}0.0013 \\
0.0013\end{array}$ & $\begin{array}{l}0.0029 \\
0.0026\end{array}$ & & & \\
\hline SESPMNT & B176K0 & $\begin{array}{l}100 \mathrm{FM} \text { MET TOWER } \\
100 \mathrm{~W}\end{array}$ & ONSITE & AT & $\begin{array}{l}\text { 18-Aug-03B } \\
02 \text {-Sep-03B }\end{array}$ & $\begin{array}{l}B \text { BIA } \\
\text { BETA }\end{array}$ & $\begin{array}{l}0.0123 \mathrm{p} \\
0.0185 \mathrm{p}\end{array}$ & $\begin{array}{l}\mathrm{Cl} \text { Clm3 } \\
\mathrm{C} / \mathrm{m} 3\end{array}$ & $\begin{array}{l}0.0013 \\
0.0013\end{array}$ & $\begin{array}{l}0.0026 \\
0.0033\end{array}$ & & & \\
\hline SESPMNT & B176K1 & $100 \mathrm{~F}$ MET TOWER & ONSITE & AT & 15-Sep-03B & BETA & $0.0161 \mathrm{p}$ & $\mathrm{Ci} / \mathrm{m} 3$ & 0.0014 & 0.0032 & & & \\
\hline SESPMNT & B176K2 & 100 F MET TOWER & ONSITE & AT & 01-Oct-03 B & BETA & $0.00917 p$ & $\mathrm{C} i / \mathrm{m} 3$ & 0.001 & 0.002 & & & \\
\hline SESPMNT & B17R53 & 100 F MET TOWER & ONSITE & AT & 13-Oct-03 B & BETA & $0.0293 p$ & $\mathrm{C} i / \mathrm{m}_{3}$ & 0.0018 & 0.0054 & & & \\
\hline SESPMNT & B17R54 & $100 \mathrm{~F}$ MET TOWER & ONSITE & AT & 28-Oct-03 B & BETA & & & & & & NO SAMPLE. SAVE FOR COMPOSITE. & \\
\hline SESPMNT & B17R55 & $100 \mathrm{~F}$ MET TOWER & ONSITE & AT & 11-Nov-03 B & BETA & $0.0274 \mathrm{p}$ & $\mathrm{C} / \mathrm{m} 3$ & 0.0015 & 0.0047 & & & \\
\hline SESPMNT & B17R56 & $100 \mathrm{~F}$ MET TOWER & ONSITE & AT & 24-Nov-03 B & BETA & $0.0171 \mathrm{p}$ & Ci/m3 & 0.0014 & 0.0033 & & & \\
\hline SESPMNT & B17R57 & 100 F MET TOWER & ONSITE & AT & 11-Dec-03B & BETA & $0.0114 \mathrm{p}$ & Ci/m3 & 0.00098 & 0.0023 & & & \\
\hline SESPMNT & B17R58 & 100 F MET TOWER & ONSITE & AT & 22-Dec-03B & BETA & $0.018 \mathrm{p}$ & $\mathrm{Ci} / \mathrm{m} 3$ & 0.0016 & 0.0036 & & & \\
\hline $\begin{array}{l}\text { SESPMNT } \\
\text { SESPMNT }\end{array}$ & $\begin{array}{l}817 R 59 \\
\text { B1685 }\end{array}$ & 100 F MET TOWER & ONSITE & AT & 06-Jan-04B & BETA & $0.0169 p$ & Ci/m3 & 0.0013 & 0.0032 & & & \\
\hline $\begin{array}{l}\text { SESPMNT } \\
\text { SESPMNT }\end{array}$ & $\begin{array}{l}\text { B16855 } \\
\text { B168C6 }\end{array}$ & $\begin{array}{l}100 \mathrm{~K} \text { AREA } \\
100 \mathrm{~K} \text { AREA }\end{array}$ & $\begin{array}{l}\text { ONSITE } \\
\text { ONSTIE }\end{array}$ & $\begin{array}{l}\text { AT } \\
\text { AT }\end{array}$ & $\begin{array}{l}\text { 21-Jan-03B } \\
04-\text { - } 03 \text { B }\end{array}$ & $\begin{array}{l}\text { BETA } \\
\text { BETA }\end{array}$ & $\begin{array}{l}0.0361 \mathrm{p} \\
0.00101 \mathrm{p}\end{array}$ & $\begin{array}{l}\text { Ci/m3 } \\
\text { Ci/m3 }\end{array}$ & 0.0019 & $\begin{array}{l}0.00622 \\
0.0022\end{array}$ & & & \\
\hline SESPMNT & B168C7 & 100 K AREA & ONSITE & AT & 18 -Feb-03 B & BETA & $0.0269 \mathrm{p}$ & $\mathrm{Ci} / \mathrm{m} 3$ & 0.0016 & 0.0048 & & & \\
\hline SESPMNT & B168C8 & $100 \mathrm{~K}$ AREA & ONSITE & AT & 03-Mar-03 B & BETA & $0.018 \mathrm{p}$ & $\mathrm{Ci} / \mathrm{m} 3$ & 0.0015 & 0.0034 & & & \\
\hline SESPMNT & B168C9 & $100 \mathrm{~K}$ AREA & ONSITE & AT & 18-Mar-03 B & BETA & $0.00574 \mathrm{p}$ & $\mathrm{Ci} / \mathrm{m} 3$ & 0.00092 & 0.0015 & & & \\
\hline SESPMNT & B168D0 & $100 \mathrm{~K}$ AREA & ONSITE & AT & 31-Mar-03 B & BETA & $0.00817 \mathrm{p}$ & $\mathrm{Ci} / \mathrm{m} 3$ & 0.0011 & 0.0019 & & & \\
\hline SESPMNT & B16PP6 & $100 \mathrm{~K}$ AREA & ONSITE & AT & 15-Apr-03 B & BETA & $0.00638 \mathrm{p}$ & $\mathrm{C} / \mathrm{m} 3$ & 0.00089 & 0.0016 & & & \\
\hline SESPMNT & B16PP7 & $100 \mathrm{~K}$ AREA & ONSITE & AT & 29-Apr-03 B & BETA & $0.00868 \mathrm{p}$ & $\mathrm{C} / \mathrm{m} 3$ & 0.001 & 0.002 & & & \\
\hline SESPMNT & B16PР8 & $100 \mathrm{~K}$ AREA & ONSITE & AT & 12-May-03 В & BETA & $0.00969 p$ & $\mathrm{C} / \mathrm{m} 3$ & 0.0011 & 0.0021 & & & \\
\hline SESPMNT & B16PP9 & $100 \mathrm{~K}$ AREA & ONSITE & AT & 29-May-03 В & BETA & $0.0104 p$ & Ci/m3 & 0.001 & 0.0021 & & & \\
\hline SESPMNT & B16PRO & $100 \mathrm{~K}$ AREA & ONSITE & AT & 11-Jun-03 B & BETA & $0.0151 \mathrm{p}$ & Ci/m3 & 0.0013 & 0.003 & & & \\
\hline $\begin{array}{l}\text { SESPMNT } \\
\text { SESPMNT }\end{array}$ & B16PR1 & $100 \mathrm{~K}$ AREA & ONSITE & AT & 24-Jun-03 B & BETA & $0.00802 \mathrm{p}$ & Ci/m3 & 0.0011 & 0.0019 & & & \\
\hline SESPMNT & B16PR2 & $100 \mathrm{~K}$ AREA & ONSITE & AT & 08-Jul-03 B & BETA & $0.00866 \mathrm{p}$ & Ci/m3 & 0.0011 & 0.0019 & & & \\
\hline $\begin{array}{l}\text { SESPMNT } \\
\text { SESPMNT }\end{array}$ & B175M5 & $100 \mathrm{~K}$ AREA & ONSITE & AT & 22-Jul-03 B & BETA & $0.0115 p$ & Ci/m3 & 0.0012 & 0.0024 & & & \\
\hline SESPMNT & B175M6 & $100 \mathrm{~K}$ AREA & ONSITE & AT & 04-Aug-03 B & BETA & $0.0137 p$ & Ci/m3 & 0.0013 & 0.0028 & & & \\
\hline $\begin{array}{l}\text { SESPMNT } \\
\text { SESPMNT }\end{array}$ & $\begin{array}{l}\text { B175M97 } \\
\text { B1758 }\end{array}$ & $\begin{array}{l}100 \mathrm{~K} \text { AREA } \\
100 \mathrm{~K} \text { AREA }\end{array}$ & $\begin{array}{l}\text { ONSITE } \\
\text { ONSITE }\end{array}$ & $\begin{array}{l}\text { AT } \\
\text { AT }\end{array}$ & $\begin{array}{l}\text { 18-Aug-03B } \\
02 \text {-Sep-03 B }\end{array}$ & $\begin{array}{l}\text { BETA } \\
\text { BETA }\end{array}$ & $0.0128 \mathrm{p}$ & $\begin{array}{l}\text { Cilm3 } \\
\text { Ciilm3 }\end{array}$ & 0.0012 & 0.0026 & & & \\
\hline SESPMNT & B175M8 & $100 \mathrm{KAREA}$ & ONSITE & $A T$ & 02-Sep-03B & BETA & $0.0162 p$ & cilm3 & 0.0011 & 0.0028 & & & \\
\hline
\end{tabular}


AIR BETA/ALPHA

\begin{tabular}{|c|c|c|c|c|c|c|c|c|c|c|c|c|}
\hline |OWNER ID & \begin{tabular}{|l|} 
SAMP \\
NUM
\end{tabular} & SAMP SITE NAME & DIST CLASS & MEDIA & \begin{tabular}{l|c} 
& CON \\
& SHORT \\
SAMP DATE & NAME
\end{tabular} & & $\begin{array}{l}\text { ANAL } \\
\text { UNITS } \\
\text { RPTD }\end{array}$ & $\left|\begin{array}{c}\text { COUNTING } \\
\text { ERROR }\end{array}\right|$ & \begin{tabular}{c|c} 
TOTAL \\
ANAL \\
ERROR
\end{tabular} & $\left|\begin{array}{c}\text { LAB } \\
\text { QUALIFIER }\end{array}\right|$ & SAMP COMMENT & $\begin{array}{l}\text { RESULT } \\
\text { COMMENT }\end{array}$ \\
\hline SESPMNT & B175M9 & 100 K AREA & ONSITE & AT & 15-Sep-03 BETA & $0.015 p$ & & 0.0013 & 0.003 & & & \\
\hline SESPMNT & B175NO & 100 K AREA & ONSITE & AT & 01-Oct-03 BETA & $0.0124 \mathrm{p}$ & Ci/m3 & 0.0011 & 0.0025 & & & \\
\hline SESPMNT & B17P83 & $100 \mathrm{~K}$ AREA & ONSITE & AT & 13-Oct-03 BETA & $0.0269 \mathrm{p}$ & & 0.0017 & 0.0049 & & & \\
\hline $\begin{array}{l}\text { SESPMNT } \\
\text { SFONT }\end{array}$ & B17P84 & $100 \mathrm{~K}$ AREA & ONSITE & AT & 28-Oct-03 BETA & & & 0.0016 & 0.005 & & & \\
\hline SESPMNT & B17P85 & $100 \mathrm{~K} \mathrm{AREA}$ & ONSITE & AT & 11-Nov-03 BETA & $0.0367 \mathrm{p}$ & Cilm3 & 0.0018 & 0.0062 & & & \\
\hline $\begin{array}{l}\text { SESPMNT } \\
\text { SESPMNT }\end{array}$ & B17P86 & $100 \mathrm{~K}$ AREA & ONSITE & AT & 24-Nov-03 BETA & $0.0175 \mathrm{p}$ & & 0.0014 & 0.0033 & & & \\
\hline $\begin{array}{l}\text { SESPMNT } \\
\text { SESPMNT }\end{array}$ & B17P87 & $100 \mathrm{~K}$ AREA & ONSITE & AT & 11-Dec-03 BETA & $0.0123 \mathrm{p}$ & Cilm3 & 0.001 & 0.0024 & & & \\
\hline SESPMNT & B17P88 & $100 \mathrm{~K}$ AREA & ONSITE & AT & 22-Dec-03 BETA & $0.0167 \mathrm{p}$ & Ci/m3 & 0.0015 & 0.0033 & & & \\
\hline SESPMNT & B17P89 & $100 \mathrm{~K}$ AREA & ONSITE & AT & 06-Jan-04 BETA & & $\mathrm{C} / \mathrm{m} 3$ & 0.0013 & 0.0033 & & & \\
\hline $\begin{array}{l}\text { SESPMNT } \\
\text { SECDMNT }\end{array}$ & B168D1 & $100 \mathrm{~N}-1325$ CRIB & ONSITE & & 21-Jan-03 BETA & $0.0241 \mathrm{p}$ & & 0.0016 & 0.0044 & & & \\
\hline SESPMNT & B168D2 & $100 \mathrm{~N}-1325$ CRIB & ONSITE & AT & 04-Feb-03 BETA & $0.00519 p$ & & 0.00087 & 0.0014 & & & \\
\hline $\begin{array}{l}\text { SESPMNT } \\
\text { SESPMNT }\end{array}$ & B168D3 & $\begin{array}{l}100 \mathrm{~N}-1325 \text { CRIB } \\
100 \mathrm{~N}-1325 \mathrm{CRIB}\end{array}$ & ONSITE & AT & 18-Feb-03 BETA & $0.0169 \mathrm{p}$ & Ci/m3 & 0.0015 & 0.0033 & & & \\
\hline $\begin{array}{l}\text { SESPMNT } \\
\text { SESPMNT }\end{array}$ & $\begin{array}{l}\text { B168D4 } \\
\text { B16805 }\end{array}$ & $\begin{array}{l}100 \mathrm{~N}-13255 \text { CRIB } \\
100 \mathrm{~N}-132 \mathrm{CRIB}\end{array}$ & $\begin{array}{l}\text { ONSITE } \\
\text { ONSTEF }\end{array}$ & AT & 03-Mar-03 BETA & $0.0176 p$ & Ci/m3 & 0.0014 & 0.0034 & & & \\
\hline $\begin{array}{l}\text { SESPMNT } \\
\text { SESPMNT }\end{array}$ & 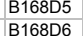 & $\begin{array}{l}100 \mathrm{~N}-1325 \text { CRIB } \\
100 \mathrm{~N}-1325 \text { CRIB }\end{array}$ & $\begin{array}{l}\text { ONSIIE } \\
\text { ONSITE }\end{array}$ & $\begin{array}{l}\text { AT } \\
\text { AT }\end{array}$ & $\begin{array}{l}\text { 18-Mar-03 BETA } \\
\text { 31-Mar-03 BETA }\end{array}$ & $\begin{array}{l}0.00658 \mathrm{p} \\
0.00662 \mathrm{p}\end{array}$ & $\begin{array}{l}\text { Cilm3 } \\
\text { Ci/m3 }\end{array}$ & $\begin{array}{l}0.00089 \\
0.00099\end{array}$ & $\begin{array}{l}0.0016 \\
0.0017\end{array}$ & & & \\
\hline SESPMNT & $\begin{array}{l}\text { D10000 } \\
\text { B16PR3 }\end{array}$ & $\begin{array}{l}100 \mathrm{~N}-1325 \mathrm{CRIB} \\
100 \mathrm{~N}-1325 \mathrm{CRIB}\end{array}$ & ONSITE & AT & $\begin{array}{l}\text { 31-Mar-03 BEIA } \\
\text { 15-Apr-03 BETA }\end{array}$ & $\begin{array}{l}0.00662 \mathrm{p} \\
0.00553 \mathrm{p}\end{array}$ & $\begin{array}{l}\mathrm{Cl} \text { Clm3 } \\
\mathrm{C} / \mathrm{m} 3\end{array}$ & $\begin{array}{l}0.00099 \\
0.00085\end{array}$ & $\begin{array}{l}0.0017 \\
0.0014\end{array}$ & & & \\
\hline SESPMNT & B16PR4 & $100 \mathrm{~N}-1325$ CRIB & ONSITE & AT & 29-Apr-03 BETA & $0.00883 p$ & $\mathrm{Ci} / \mathrm{m} 3$ & 0.0011 & 0.002 & & & \\
\hline SESPMNT & B16PR5 & $100 \mathrm{~N}-1325$ CRIB & ONSITE & AT & 12-May-03 BETA & $0.0108 p$ & $\mathrm{Ci} / \mathrm{m} 3$ & 0.0012 & 0.0023 & & & \\
\hline SESPMNT & B16PR6 & $100 \mathrm{~N}-1325$ CRIB & ONSITE & AT & 29-May-03 BETA & $0.0113 p$ & $\mathrm{C} i / \mathrm{m} 3$ & 0.001 & 0.0023 & & & \\
\hline SESPMNT & B16PR7 & $100 \mathrm{~N}-1325$ CRIB & ONSITE & AT & 11-Jun-03 BETA & $0.0135 \mathrm{p}$ & $\mathrm{C} / \mathrm{l} / \mathrm{m} 3$ & 0.0013 & 0.0028 & & & \\
\hline SESPMNT & B16PR8 & $100 \mathrm{~N}-1325$ CRIB & ONSITE & AT & 24-Jun-03 BETA & $0.00979 p$ & $\mathrm{C} / \mathrm{m} 3$ & 0.0011 & 0.0021 & & & \\
\hline SESPMNT & B16PR9 & $100 \mathrm{~N}-1325$ CRIB & ONSITE & AT & 08-Jul-03 BETA & $0.0121 \mathrm{p}$ & $\mathrm{C} / \mathrm{m} 3$ & 0.0013 & 0.0025 & & & \\
\hline SESPMNT & B175N1 & $100 \mathrm{~N}-1325$ CRIB & ONSITE & AT & 22-Jul-03 BETA & $0.014 \mathrm{p}$ & Ci/m3 & 0.0013 & 0.0028 & & & \\
\hline SESPMNT & B175N2 & $100 \mathrm{~N}-1325$ CRIB & ONSITE & AT & 04-Aug-03 BETA & $0.0152 \mathrm{p}$ & Ci/m3 & 0.0013 & 0.003 & & & \\
\hline SESPMNT & B175N33 & $100 \mathrm{~N}-1325$ CRIB & ONSITE & AT & 18-Aug-03 BETA & $0.0167 \mathrm{p}$ & Ci/m3 & 0.0016 & 0.0034 & & & \\
\hline $\begin{array}{l}\text { SESPMNT } \\
\text { SESPMNT }\end{array}$ & $\begin{array}{l}\text { B175N44 } \\
\text { B17555 }\end{array}$ & $\begin{array}{l}100 \mathrm{~N}-1325 \mathrm{CRIB} \\
100 \mathrm{~N}-132 \mathrm{CRIB}\end{array}$ & $\begin{array}{l}\text { ONSITE } \\
\text { ONSTIE }\end{array}$ & AT & 02-Sep-03 BETA & $\begin{array}{r}0.017 p \\
0.0149 n\end{array}$ & CCi/m3 & 0.0013 & 0.003 & & & \\
\hline $\begin{array}{l}\text { SESPMNT } \\
\text { SESPMNT }\end{array}$ & $\begin{array}{l}\text { B17555 } \\
\text { B175N6 }\end{array}$ & $\begin{array}{l}100 \mathrm{~N}-1325 \mathrm{CCRIB} \\
100 \mathrm{~N}-132 \mathrm{CRIB}\end{array}$ & $\begin{array}{l}\text { ONSITE } \\
\text { ONSTIE }\end{array}$ & AT & $\begin{array}{l}15-S-p-03 \text {-03ETA } \\
01-0 c-03 \text { BETA }\end{array}$ & $0.0149 p$ & Cil/m3 & 0.0013 & $\begin{array}{r}0.003 \\
0025\end{array}$ & & & \\
\hline $\begin{array}{l}\text { SESPMNT } \\
\text { SESPMNT }\end{array}$ & $\begin{array}{l}\text { B175N6 } \\
\text { B17N90 }\end{array}$ & $\begin{array}{l}100 \mathrm{~N}-1325 \mathrm{CR} / \mathrm{B} \\
100 \mathrm{~N}-1325 \mathrm{CR} B \mathrm{~B}\end{array}$ & $\begin{array}{l}\text { ONSTIE } \\
\text { ONSITE }\end{array}$ & $\begin{array}{l}\text { AT } \\
\text { AT }\end{array}$ & $\begin{array}{l}\text { 01-OCt-O3 BETA } \\
\text { 13-OCt-03 BETA }\end{array}$ & $0.0127 \mathrm{p}$ & Ci/m3 & $\begin{array}{l}0.0011 \\
0.0018\end{array}$ & 0.0025 & & & \\
\hline $\begin{array}{l}\text { SESPMNI } \\
\text { SESPMNT }\end{array}$ & $\begin{array}{l}\text { B17790 } \\
\text { B17P91 }\end{array}$ & $\begin{array}{l}100 \mathrm{~N}-1325 \text { CRIB } \\
100 \mathrm{~N}-1325 \text { CRIB }\end{array}$ & $\begin{array}{l}\text { ONSITE } \\
\text { ONE }\end{array}$ & AT & $\begin{array}{l}\text { 13-Oct-03 BETA } \\
\text { 28-Oct-03 BETA }\end{array}$ & $\begin{array}{l}0.0282 \mathrm{p} \\
0.0266 \mathrm{p}\end{array}$ & $\begin{array}{l}\mathrm{C} \text { Cim3 } \\
\mathrm{C} \text { Ci/m3 }\end{array}$ & $\begin{array}{l}0.0018 \\
0.0016\end{array}$ & $\begin{array}{l}0.0052 \\
0.0048\end{array}$ & & & \\
\hline SESPMNT & B17P92 & $100 \mathrm{~N}-1325$ CRIB & ONSITE & AT & 11-Nov-03 BETA & $0.0337 \mathrm{p}$ & $\mathrm{Ci} / \mathrm{m} 3$ & 0.0017 & 0.0056 & & & \\
\hline SESPMNT & B17P93 & $100 \mathrm{~N}-1325$ CRIB & ONSITE & AT & 24-Nov-03 BETA & $0.0299 p$ & $\mathrm{C} \mathrm{C} / \mathrm{m} 3$ & 0.0018 & 0.0054 & & & \\
\hline SESPMNT & B17P94 & $100 \mathrm{~N}-1325$ CRIB & ONSITE & AT & 11-Dec-03 BETA & $0.0116 \mathrm{p}$ & $\mathrm{C} / \mathrm{m} 3$ & 0.00099 & 0.0023 & & & \\
\hline SESPMNT & B17P95 & $100 \mathrm{~N}-1325$ CRIB & ONSITE & AT & 22-Dec-03 BETA & $0.0169 p$ & Cilm3 & 0.0015 & 0.0034 & & & \\
\hline SESPMNT & B17P96 & $100 \mathrm{~N}-1325$ CRIB & ONSITE & AT & 06-Jan-04 BETA & $0.0165 \mathrm{p}$ & Ci/m3 & 0.0013 & 0.0031 & & & \\
\hline SESPMNT & B168F4 & 200 ESE & ONSITE & AT & 14-Jan-03 BETA & $0.0199 \mathrm{p}$ & Ci/m3 & 0.0014 & 0.0037 & & & \\
\hline SESPMNT & B168F5 & 200 ESE & ONSITE & AT & 28-Jan-03 BETA & $0.0145 \mathrm{p}$ & Ci/m3 & 0.0013 & 0.0029 & & & \\
\hline $\begin{array}{l}\text { SESPMNT } \\
\text { SESPMNT }\end{array}$ & B168F6 & 200 ESE & ONSITE & AT & 11-Feb-03 BETA & $0.012 \mathrm{p}$ & Ci/m3 & 0.0012 & 0.0025 & & & \\
\hline $\begin{array}{l}\text { SESPMNT } \\
\text { SESPMNT }\end{array}$ & $\begin{array}{l}\text { B168F7 } \\
\text { B1688 }\end{array}$ & 200 ESE & $\begin{array}{l}\text { ONSITE } \\
\text { ONSTEF }\end{array}$ & AT & 25-Feb-03 BETA & $0.0176 p$ & Cilm3 & 0.0014 & 0.0033 & & & \\
\hline $\begin{array}{l}\text { SESPMNT } \\
\text { SESPMNT }\end{array}$ & $\begin{array}{l}\text { B16888 } \\
\text { B16859 }\end{array}$ & $\begin{array}{l}200 \mathrm{ESE} \\
200 \mathrm{ESE}\end{array}$ & $\begin{array}{l}\text { ONSIIE } \\
\text { ONSTIE }\end{array}$ & AT & $\begin{array}{l}10 \text {-Mar-03 BETA } \\
26 \text {-Mar-03 BETA }\end{array}$ & $\begin{array}{r}0.0203 p \\
0.0052\end{array}$ & Ci/m3 & $\begin{array}{r}0.0015 \\
0.00091\end{array}$ & 0.0038 & & & \\
\hline $\begin{array}{l}\text { SESPMNT } \\
\text { SESPMNT }\end{array}$ & 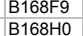 & $\begin{array}{l}200 \mathrm{ESE} \\
200 \mathrm{ESE}\end{array}$ & $\begin{array}{l}\text { ONSIIE } \\
\text { ONSITE }\end{array}$ & $\begin{array}{l}\text { AT } \\
\text { AT }\end{array}$ & $\begin{array}{l}\text { 26-Mar-D3 BETA } \\
\text { 08-Arp-03 BETA }\end{array}$ & $\begin{array}{l}0.00652 \mathrm{p} \\
0.00627 \mathrm{p}\end{array}$ & $\begin{array}{l}\text { Cilm3 } \\
\text { Ci/m3 }\end{array}$ & $\begin{array}{l}0.00001 \\
0.00098\end{array}$ & $\begin{array}{l}0.0016 \\
0.0016\end{array}$ & & & \\
\hline $\begin{array}{l}\text { SESPMNI } \\
\text { SESPMNT }\end{array}$ & $\begin{array}{l}\text { B16870 } \\
\text { B16PT8 }\end{array}$ & $\begin{array}{l}200 \mathrm{ESE} \\
200 \mathrm{ESE}\end{array}$ & $\begin{array}{l}\text { ONSITE } \\
\text { ONS }\end{array}$ & AT & $\begin{array}{l}\text { 38-Arp-03 BEIA } \\
\text { 21-Apr-03 BETA }\end{array}$ & $\begin{array}{l}0.00627 \mathrm{p} \\
0.00869 \mathrm{p}\end{array}$ & $\begin{array}{l}\mathrm{Cl} / \mathrm{m} 3 \\
\mathrm{C} / \mathrm{m} 3\end{array}$ & $\begin{array}{r}0.00098 \\
0.0011\end{array}$ & $\begin{array}{l}0.0016 \\
0.002\end{array}$ & & & \\
\hline SESPMNT & B16PT9 & 200 ESE & ONSITE & AT & 06-May-03 BETA & $0.00989 \mathrm{p}$ & $\mathrm{Ci} / \mathrm{m} 3$ & 0.001 & 0.0021 & & & \\
\hline SESPMNT & B16PVO & 200 ESE & ONSITE & AT & 20-May-03 BETA & $0.0118 \mathrm{p}$ & $\mathrm{C} i / \mathrm{m} 3$ & 0.0012 & 0.0024 & & & \\
\hline SESPMNT & B16PV1 & 200 ESE & ONSITE & AT & 02-Jun-03 BETA & $0.0117 p$ & $\mathrm{C} i / \mathrm{m} 3$ & 0.0012 & 0.0025 & & & \\
\hline SESPMNT & B16PV2 & 200 ESE & ONSITE & AT & 17-Jun-03 BETA & $0.0135 \mathrm{p}$ & $\mathrm{C} / \mathrm{m} 3$ & 0.0012 & 0.0027 & & & \\
\hline SESPMNT & B16PV3 & 200 ESE & ONSITE & AT & 30-Jun-03 BETA & $0.00966 p$ & $\mathrm{C} / \mathrm{m} 3$ & 0.0015 & 0.0024 & & & \\
\hline SESPMNT & B175P4 & 200 ESE & ONSITE & AT & 15-Jul-03 BETA & $0.00948 \mathrm{p}$ & Ci/m3 & 0.0011 & 0.0021 & & & \\
\hline SESPMNT & B175P5 & 200 ESE & ONSITE & AT & 29-Jul-03 BETA & $0.0154 p$ & Ci/m3 & 0.0013 & 0.003 & & & \\
\hline SESPMNT & B175P6 & 200 ESE & ONSITE & AT & 12-Aug-03 BETA & $0.0134 \mathrm{p}$ & Ci/m3 & 0.0012 & 0.0027 & & & \\
\hline $\begin{array}{l}\text { SESPMNT } \\
\text { SESPMNT }\end{array}$ & B175P7 & 200 ESE & ONSITE & AT & 25-Aug-03 BETA & $0.0163 p$ & Ci/m3 & 0.0013 & 0.0029 & & & \\
\hline $\begin{array}{l}\text { SESPMNT } \\
\text { SESPMNT }\end{array}$ & B175P8 & 200 ESE & ONSITE & AT & 10-Sep-03 BETA & $0.0148 p$ & Ci/m3 & 0.0012 & 0.0029 & & & \\
\hline $\begin{array}{l}\text { SESPMNT } \\
\text { SESPMNT }\end{array}$ & $\begin{array}{l}8175 P 9 \\
B 1750\end{array}$ & $\begin{array}{l}\text { 200 ESE } \\
200 \text { ESE }\end{array}$ & $\begin{array}{l}\text { ONSIIE } \\
\text { ONSTIE }\end{array}$ & AT & 22-Sep-03 BETA & $\begin{array}{l}0.0107 \mathrm{p} \\
0.0253 \mathrm{p}\end{array}$ & Cil/m3 & 0.0012 & 0.0023 & & & \\
\hline SESPMNT & $\begin{array}{l}\text { B175RO } \\
\text { B17RP5 }\end{array}$ & $\begin{array}{l}200 \mathrm{ESE} \\
200 \mathrm{ESE}\end{array}$ & $\begin{array}{l}\text { ONSTIE } \\
\text { ONSITE }\end{array}$ & $\begin{array}{l}\text { AT } \\
\text { AT }\end{array}$ & $\begin{array}{l}\text { 7-OCt-03 BETA } \\
\text { 21-Otc-03 BETA }\end{array}$ & $\begin{array}{r}0.0253 \mathrm{p} \\
0.0974 \mathrm{p}\end{array}$ & Cilm3 & 0.0015 & 0.0045 & & & \\
\hline $\begin{array}{l}\text { SESPMNT } \\
\text { SESPMNT }\end{array}$ & $\begin{array}{l}\text { B17PP5 } \\
\text { B17PB6 }\end{array}$ & $\begin{array}{l}200 \text { EEE } \\
200 \text { ESE }\end{array}$ & $\begin{array}{l}\text { ONSTIE } \\
\text { ONSITE }\end{array}$ & $\begin{array}{l}\text { AT } \\
\text { AT }\end{array}$ & $\begin{array}{l}\text { 21-OCt-03 BETA } \\
05 \text {-Nov-03 BETA }\end{array}$ & $0.00974 \mathrm{p}$ & Ci/m3 & 0.0011 & 0.0021 & & NO SAMPLE BAD REGULATOR UNKNOWN FLOW. & \\
\hline $\begin{array}{l}\text { SESPMNT } \\
\text { SESPMNT }\end{array}$ & $\begin{array}{l}\text { B1/TB6 } \\
\text { B17PB7 }\end{array}$ & $\begin{array}{l}200 \text { SE } \\
200 \text { ESE }\end{array}$ & $\begin{array}{l}\text { ONSIIE } \\
\text { ONSITE }\end{array}$ & $\begin{array}{l}\text { Al } \\
\text { AT }\end{array}$ & $\begin{array}{l}\text { O5-Nov-03 BEIA } \\
\text { 18-Nov-03 BETA }\end{array}$ & $0.0351 \mathrm{p}$ & Ci/m3 & & & & NO SAMPLE. BAD REGULAIOR, UNKNOWNFLOW. & \\
\hline $\begin{array}{l}\text { SESPMNT } \\
\text { SESPMNT }\end{array}$ & $\begin{array}{l}\text { B1/TB/ } \\
\text { B17PB8 }\end{array}$ & 200 ESE & ONSITE & AT & $\begin{array}{l}\text { 18-Nov-03BEIA } \\
\text { 01-Dec-03 BETA }\end{array}$ & $0.0134 \mathrm{p}$ & Clim3 & 0.0018 & 0.0027 & & & \\
\hline SESPMNT & B17PB9 & 200 ESE & ONSITE & AT & 17-Dec-03 BETA & $0.014 \mathrm{p}$ & $\mathrm{Ci} / \mathrm{m} 3$ & 0.0011 & 0.0027 & & & \\
\hline SESPMNT & B17PC0 & 200 ESE & ONSITE & AT & 30-Dec-03 BETA & $0.0171 \mathrm{p}$ & $\mathrm{Ci} / \mathrm{m} 3$ & 0.0014 & 0.0033 & & & \\
\hline SESPMNT & B168K4 & 200 TEL. EXCHANGE & ONSITE & AT & 14-Jan-03 BETA & $0.0208 \mathrm{p}$ & Ci/m3 & 0.0014 & 0.0038 & & & \\
\hline SESPMNT & B168k5 & 200 TEL. EXCHANGE & ONSITE & AT & 28-Jan-03 BETA & $0.016 \mathrm{p}$ & $\mathrm{C} / \mathrm{m} 3$ & 0.0013 & 0.0031 & & & \\
\hline SESPMNT & B168K6 & 200 TEL. EXCHANGE & ONSITE & AT & 11-Feb-03 BETA & $0.0113 p$ & Ci/m3 & 0.0012 & 0.0024 & & & \\
\hline SESPMNT & B168K7 & 200 TEL. EXCHANGE & ONSITE & AT & 25-Feb-03 BETA & $0.0157 \mathrm{p}$ & Ci/m3 & 0.0013 & 0.003 & & & \\
\hline SESPMNT & B168K8 & 200 TEL. EXCHANGE & ONSITE & AT & 10-Mar-03 BETA & $\begin{aligned} 0.0191 \mathrm{p} \\
0.0057\end{aligned}$ & Ci/m3 & 0.0015 & 0.0037 & & & \\
\hline SESPMNT & B168K9 & 200 TEL. EXCHANGE & $\begin{array}{l}\text { ONSIIE } \\
\text { ONSTIE }\end{array}$ & AT & $\begin{array}{l}\text { 26-Mar-03 BETA } \\
\text { 08-Ar-03 BETA }\end{array}$ & $0.00527 p$ & Ci/m3 & 0.0008 & 0.0013 & & & \\
\hline $\begin{array}{l}\text { SESPMNT } \\
\text { SESPMNT }\end{array}$ & $\begin{array}{l}\text { B168L0 } \\
\text { B16P4 }\end{array}$ & $\begin{array}{l}2000 \text { TEL. EXCHANGE } \\
200 \text { TEL. EXCHANGE }\end{array}$ & $\begin{array}{l}\text { ONSTIE } \\
\text { ONSITE }\end{array}$ & $\begin{array}{l}\text { AT } \\
\text { AT }\end{array}$ & $\begin{array}{l}\text { 88-A-Ar-03 BETA } \\
\text { 21-0 Dr-03 BETA }\end{array}$ & $\begin{array}{l}0.00592 \mathrm{p} \\
0.0835 \mathrm{p}\end{array}$ & $\begin{array}{l}\mathrm{C} \text { Cim3 } \\
\mathrm{CDi} / \mathrm{m} 3\end{array}$ & $\begin{array}{r}0.001 \\
0.0011\end{array}$ & $\begin{array}{l}0.0016 \\
0.002\end{array}$ & & & \\
\hline SESPMNT & B16PX4 & 200 TEL. EXCHANGE & ONSITE & Al & 21-Apr-03BETA & $0.00835 \mathrm{p}$ & Cilm3 & 0.0011 & 0.002 & & & \\
\hline
\end{tabular}


AIR BETA/ALPHA

\begin{tabular}{|c|c|c|c|c|c|c|c|c|c|c|c|c|}
\hline |OWNER ID & \begin{tabular}{|l|} 
SAMP \\
NUM
\end{tabular} & SAMP SITE NAME & DIST CLASS & MEDIA & \begin{tabular}{l|c} 
& CON \\
& SHORT \\
SAMP DATE & NAME
\end{tabular} & & $\begin{array}{l}\text { ANAL } \\
\text { UNITS } \\
\text { RPTD }\end{array}$ & $\begin{array}{c}\text { COUNTING } \\
\text { ERROR }\end{array}$ & \begin{tabular}{c|c} 
TOTAL \\
ANAL \\
ERROR
\end{tabular} & $\left|\begin{array}{c}\text { LAB } \\
\text { QUALIFIER }\end{array}\right|$ & SAMP COMMENT & $\begin{array}{l}\text { RESULT } \\
\text { COMMENT }\end{array}$ \\
\hline SESPMNT & & 200 TEL. EXCHANGE & ONSITE & AT & 06-May-03 BETA & $0.00999 \mathrm{p}$ & & 0.0011 & 0.0021 & & & \\
\hline SESPMNT & B16PX6 & 200 TEL. EXCHANGE & ONSITE & AT & 20-May-03 BETA & $0.00953 \mathrm{p}$ & Ci/m3 & 0.0011 & 0.0021 & & & \\
\hline SESPMNT & B16PX7 & 200 TEL. EXCHANGE & ONSITE & AT & 02-Jun-03 BETA & $0.0125 \mathrm{p}$ & $\mathrm{C} / \mathrm{m} 3$ & 0.0012 & 0.0026 & & & \\
\hline $\begin{array}{l}\text { SESPMNT } \\
\text { SFONT }\end{array}$ & B16PX8 & 200 TEL. EXCHANGE & ONSITE & AT & 17-Jun-03 BETA & & & 0.0011 & 0.0024 & & & \\
\hline SESPMNT & B16PX9 & 200 TEL. EXCHANGE & ONSITE & AT & 30-Jun-03 BETA & $0.0106 \mathrm{p}$ & Cilm3 & 0.0012 & 0.0023 & & & \\
\hline $\begin{array}{l}\text { SESPMNT } \\
\text { SESPMNT }\end{array}$ & B175V4 & 200 TEL. EXCHANGE & ONSITE & AT & 15-Jul-03 BETA & $0.00903 p$ & & 0.001 & 0.002 & & & \\
\hline $\begin{array}{l}\text { SESPMNT } \\
\text { SESPMNT }\end{array}$ & B175V5 & 200 TEL. EXCHANGE & ONSITE & AT & 29-Jul-03 BETA & $0.0142 \mathrm{p}$ & Cilm3 & 0.0013 & 0.0028 & & & \\
\hline $\begin{array}{l}\text { SESPMNT } \\
\text { SESPMNT }\end{array}$ & $\begin{array}{l}B 175 \mathrm{~V} 6 \\
\text { B17557 }\end{array}$ & 200 TEL. EXCHANGE & ONSITE & AT & 12-Aug-03 BETA & $0.014 \mathrm{p}$ & Ci/m3 & 0.0012 & 0.0028 & & & \\
\hline SESPMNT & B175V7 & 200 TEL. EXCHANGE & ONSITE & AT & 25-Aug-03 BETA & $0.0156 \mathrm{p}$ & $\mathrm{Ci} / \mathrm{m} 3$ & 0.0012 & 0.0028 & & & \\
\hline $\begin{array}{l}\text { SESPMNT } \\
\text { SECDMNT }\end{array}$ & B175V8 & 200 TEL. EXCHANGE & ONSITE & AT & 10-Sep-03 BETA & $0.0156 \mathrm{p}$ & Ci/m3 & 0.0012 & 0.0029 & & & \\
\hline $\begin{array}{l}\text { SESPMNT } \\
\text { SESPMNT }\end{array}$ & B175V9 & 200 TEL. EXCHANGE & ONSITE & AT & 22-Sep-03 BETA & $0.0105 \mathrm{p}$ & Ci/m3 & 0.0012 & 0.0023 & & & \\
\hline $\begin{array}{l}\text { SESPMNT } \\
\text { SESPMNT }\end{array}$ & $\begin{array}{l}\text { B175W0 } \\
\text { B17PP1 }\end{array}$ & 200 TEL. EXCHANGE & ONSITE & AT & 07-Oct-03 BETA & $0.025 p$ & Ci/m3 & 0.0015 & 0.0045 & & & \\
\hline $\begin{array}{l}\text { SESPMNT } \\
\text { SESPMNT }\end{array}$ & $\begin{array}{l}\text { B17PF1 } \\
\text { B17PF2 }\end{array}$ & 200 TEL. EXCHANGE & ONSITE & AT & $\begin{array}{l}\text { 21-Oct-03 BETA } \\
\text { O5-OFv-03 BETA }\end{array}$ & $0.00897 \mathrm{p}$ & Ci/m3 & 0.0011 & $\begin{array}{r}0.002 \\
\end{array}$ & & & \\
\hline $\begin{array}{l}\text { SESPMNT } \\
\text { SESPMNT }\end{array}$ & $\begin{array}{l}\text { B17PF2 } \\
\text { B17PF3 }\end{array}$ & $\begin{array}{l}2000 \text { TELL. EXCCANGE } \\
200 \text { TEL. EXCHANGE }\end{array}$ & $\begin{array}{l}\text { ONSIIE } \\
\text { ONSTIE }\end{array}$ & $\begin{array}{l}\text { AT } \\
\text { AT }\end{array}$ & $\begin{array}{l}\text { 05-Nov-03 BETA } \\
\text { 18-Nov-03 BETA }\end{array}$ & $\begin{array}{l}0.0163 \mathrm{p} \\
0.0329 \mathrm{p}\end{array}$ & $\begin{array}{l}\text { Cilm3 } \\
\text { Ci/m3 }\end{array}$ & 0.0012 & $\begin{array}{l}0.0031 \\
0.0058\end{array}$ & & & \\
\hline SESPMNT & B17PF4 & 200 TEL. EXCHANGE & ONSITE & AT & $\begin{array}{l}\text { 18-Nove-03 BEIA } \\
\text { 01-Dec-03 BETA }\end{array}$ & $0.00934 \mathrm{p}$ & $\mathrm{Ci} / \mathrm{m} 3$ & $\begin{array}{l}0.0019 \\
0.0011\end{array}$ & $\begin{array}{l}0.0058 \\
0.0021\end{array}$ & & & \\
\hline SESPMNT & B17PF5 & 200 TEL. EXCHANGE & ONSITE & AT & 17-Dec-03 BETA & $0.0128 p$ & $\mathrm{Ci} / \mathrm{m} 3$ & 0.0011 & 0.0025 & & & \\
\hline SESPMNT & B17PF6 & 200 TEL. EXCHANGE & ONSITE & AT & 30-Dec-03 BETA & $0.0168 \mathrm{p}$ & $\mathrm{Ci} / \mathrm{m} 3$ & 0.0014 & 0.0033 & & & \\
\hline SESPMNT & B168L9 & 200 W SE & ONSITE & AT & 14-Jan-03 BETA & $0.0174 \mathrm{p}$ & $\mathrm{C} i / \mathrm{m} 3$ & 0.0013 & 0.0033 & & & \\
\hline SESPMNT & B168MO & 200 W SE & ONSITE & AT & 28-Jan-03 BETA & $-0.000329 p$ & & 0.00065 & 0.00071 & u & & \\
\hline SESPMNT & B168M1 & 200 W SE & ONSITE & AT & 11-Feb-03 BETA & $0.0278 \mathrm{p}$ & & 0.0018 & 0.005 & & & \\
\hline SESPMNT & B168M2 & 200 W SE & ONSITE & AT & 25-Feb-03 BETA & $0.017 \mathrm{p}$ & $\mathrm{C} / \mathrm{m} 3$ & 0.0013 & 0.0032 & & & \\
\hline $\begin{array}{l}\text { SESPMNT } \\
\end{array}$ & В168M3 & 200 W SE & ONSITE & AT & 10-Mar-03 BETA & $0.0144 \mathrm{p}$ & Ci/m3 & 0.0013 & 0.0029 & & & \\
\hline SESPMNT & B168M4 & 200 W SE & ONSITE & AT & 26-Mar-03 BETA & $0.00555 p$ & Ci/m3 & 0.00084 & 0.0014 & & & \\
\hline $\begin{array}{l}\text { SESPMNT } \\
\text { SESPMNT }\end{array}$ & B168M5 & 200 W SE & ONSITE & AT & 08-Apr-03 BETA & $0.00595 p$ & Ci/m3 & 0.00096 & 0.0016 & & & \\
\hline $\begin{array}{l}\text { SESPMNT } \\
\text { SESPMNT }\end{array}$ & $\begin{array}{ll}\text { B16PY7 } \\
\text { B16P9 }\end{array}$ & 200 W SE & ONSITE & AT & $\begin{array}{l}\text { 21-Apr-03 BETA } \\
\text { O6-03-03 BETA }\end{array}$ & $0.00723 p$ & Ci/m3 & 0.001 & 0.0018 & & & \\
\hline $\begin{array}{l}\text { SESPMNT } \\
\text { SESPMNT }\end{array}$ & $\begin{array}{l}\text { B16PY8 } \\
\text { B16PY9 }\end{array}$ & $\begin{array}{l}200 \text { W SE } \\
200 \text { W SE }\end{array}$ & $\begin{array}{l}\text { ONSITE } \\
\text { ONSTIE }\end{array}$ & $\begin{array}{l}\text { AT } \\
\text { AT }\end{array}$ & $\begin{array}{l}\text { 06-May-03 BETA } \\
\text { 20-May-03 BETA }\end{array}$ & $0.00901 \mathrm{p}$ & Cil/m3 & $\begin{array}{r}0.001 \\
0.0011\end{array}$ & 0.002 & & & \\
\hline $\begin{array}{l}\text { SESPMNT } \\
\text { SESPMNT }\end{array}$ & 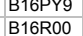 & $\begin{array}{l}200 \mathrm{~W} \text { SE } \\
200 \mathrm{~W} \text { SE }\end{array}$ & $\begin{array}{l}\text { ONSTIE } \\
\text { ONSITE }\end{array}$ & $\begin{array}{l}\text { AT } \\
\text { AT }\end{array}$ & $\begin{array}{l}\text { 20-May-03 BETA } \\
\text { 02-Jun-03 BETA }\end{array}$ & $\begin{array}{l}0.00936 \mathrm{p} \\
0.0143 \mathrm{p}\end{array}$ & $\begin{array}{l}\mathrm{C} \text { Cim3 } \\
\mathrm{CDi} / \mathrm{m} 3\end{array}$ & $\begin{array}{l}0.0011 \\
0.0013\end{array}$ & $\begin{array}{r}0.002 \\
0.0028\end{array}$ & & & \\
\hline $\begin{array}{l}\text { SESPMNT } \\
\text { SESPMNT }\end{array}$ & $\begin{array}{l}\text { B16R00 } \\
\text { B16R01 }\end{array}$ & $\begin{array}{l}200 \mathrm{WSE} \\
200 \mathrm{WSE}\end{array}$ & $\begin{array}{l}\text { ONSITE } \\
\text { ONSITE }\end{array}$ & $\begin{array}{l}\text { AT } \\
\text { AT }\end{array}$ & $\begin{array}{l}\text { 02-Jun-03 BETA } \\
\text { 17-Jun-03 BETA }\end{array}$ & $\begin{array}{l}0.0143 \mathrm{p} \\
0.0123 \mathrm{p}\end{array}$ & $\begin{array}{l}\mathrm{C} \text { Cim3 } \\
\mathrm{C} i \mathrm{~m} 3\end{array}$ & $\begin{array}{l}0.0013 \\
0.0011\end{array}$ & $\begin{array}{l}0.0028 \\
0.0025\end{array}$ & & & \\
\hline SESPMNT & B16R02 & 200 W SE & ONSITE & AT & 30-Jun-03 BETA & $0.0107 \mathrm{p}$ & $\mathrm{Ci} / \mathrm{m} 3$ & 0.0012 & 0.0023 & & & \\
\hline SESPMNT & B175W9 & 200 W SE & ONSITE & AT & 15-Jul-03 BETA & $0.00922 p$ & $\mathrm{C} \mathrm{C} / \mathrm{m} 3$ & 0.001 & 0.002 & & & \\
\hline SESPMNT & B175X0 & 200 W SE & ONSITE & AT & 29-Jul-03 BETA & $0.0115 \mathrm{p}$ & $\mathrm{C} / \mathrm{m} 3$ & 0.0012 & 0.0024 & & & \\
\hline SESPMNT & B175X1 & 200 W SE & ONSITE & AT & 12-Aug-03 BETA & $0.0157 \mathrm{p}$ & Cilm3 & 0.0013 & 0.003 & & & \\
\hline SESPMNT & $B 175 \times 2$ & 200 W SE & ONSITE & AT & 25-Aug-03 BETA & $0.0172 \mathrm{p}$ & Ci/m3 & 0.0013 & 0.003 & & & \\
\hline SESPMNT & B175X3 & 200 W SE & ONSITE & AT & 10-Sep-03 BETA & $0.0134 \mathrm{p}$ & Ci/m3 & 0.0011 & 0.0026 & & & \\
\hline SESPMNT & B175X4 & 200 W SE & ONSITE & AT & 22-Sep-03 BETA & $0.0114 \mathrm{p}$ & Ci/m3 & 0.0013 & 0.0025 & & & \\
\hline $\begin{array}{l}\text { SESPMNT } \\
\text { SESPMNT }\end{array}$ & B175X5 & 200 W SE & ONSITE & AT & 07-Oct-03 BETA & $0.0255 \mathrm{p}$ & Ci/m3 & 0.0016 & 0.0047 & & & \\
\hline $\begin{array}{l}\text { SESPMNT } \\
\text { SESPMNT }\end{array}$ & B17PH4 & 200 W SE & ONSITE & AT & 21-Oct-03 BETA & $0.00951 \mathrm{p}$ & Ci/m3 & 0.0011 & 0.0021 & & & \\
\hline $\begin{array}{l}\text { SESPMNT } \\
\text { SESPMNT }\end{array}$ & $\begin{array}{ll}\text { B17PH5 } \\
\text { B17PO6 }\end{array}$ & $\begin{array}{l}200 \text { W SE } \\
200 \text { W SE }\end{array}$ & $\begin{array}{l}\text { ONSITE } \\
\text { ONSIE }\end{array}$ & AT & 05-Nov-03 BETA & $\begin{array}{l}0.0171 \mathrm{p} \\
0.0348 \mathrm{p}\end{array}$ & Ci/m3 & 0.0012 & 0.0032 & & & \\
\hline $\begin{array}{l}\text { SESPMNT } \\
\text { SESPMNT }\end{array}$ & 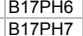 & $\begin{array}{l}200 \text { W SE } \\
200 \text { W SE }\end{array}$ & $\begin{array}{l}\text { ONSITE } \\
\text { ONSTTE }\end{array}$ & $\begin{array}{l}\text { AT } \\
\text { AT }\end{array}$ & $\begin{array}{l}\text { 8-N-Nov-03 BETA } \\
\text { 1-Dec-03 BETA }\end{array}$ & $\begin{array}{l}0.0348 \mathrm{p} \\
0.0101 \mathrm{p}\end{array}$ & $\begin{array}{l}\text { Cilm3 } \\
\text { Ci/m3 }\end{array}$ & $\begin{array}{l}0.0019 \\
0.0011\end{array}$ & $\begin{array}{l}0.0061 \\
0.0022\end{array}$ & & & \\
\hline $\begin{array}{l}\text { SESPMNT } \\
\text { SESPMNT }\end{array}$ & 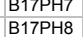 & $\begin{array}{l}200 \mathrm{~W} \text { SE } \\
200\end{array}$ & $\begin{array}{l}\text { ONSIIE } \\
\text { ONSITE }\end{array}$ & AT & $\begin{array}{l}\text { 01-Dec-03 BETA } \\
\text { 17-Dec-03 BETA }\end{array}$ & $\begin{array}{l}0.0101 \mathrm{p} \\
0.013 \mathrm{p}\end{array}$ & $\begin{array}{l}\text { Cilm3 } \\
\text { Ciilm3 }\end{array}$ & 0.0011 & 0.0022 & & & \\
\hline SESPMNT & B17PH9 & 200 W SE & ONSITE & AT & 30-Dec-03 BETA & $0.0161 \mathrm{p}$ & $\mathrm{Ci} / \mathrm{m} 3$ & 0.0014 & 0.0031 & & & \\
\hline SESPMNT & B167W1 & $300 \mathrm{NE}$ & ONSITE & AT & 22-Jan-03 BETA & $0.0186 \mathrm{p}$ & $\mathrm{C} i / \mathrm{m} 3$ & 0.0014 & 0.0035 & & & \\
\hline SESPMNT & B167W2 & $300 \mathrm{NE}$ & ONSITE & AT & 05-Feb-03 BETA & $0.00255 p$ & $\mathrm{C} i / \mathrm{m} 3$ & 0.00073 & 0.001 & & & \\
\hline SESPMNT & B167W3 & $300 \mathrm{NE}$ & ONSITE & AT & 19-Feb-03 BETA & & & & & & NO SAMPLE. NO FLOW, DO NOT SAVE FOR COMPOSITE. & \\
\hline SESPMNT & B167W4 & $300 \mathrm{NE}$ & ONSITE & AT & 05-Mar-03 BETA & $0.0169 \mathrm{p}$ & $\mathrm{C} / \mathrm{m} 3$ & 0.0013 & 0.0032 & & & \\
\hline SESPMNT & B167W5 & $300 \mathrm{NE}$ & ONSITE & AT & 20-Mar-03 BETA & $0.00683 p$ & $\mathrm{Ci} / \mathrm{m} 3$ & 0.00092 & 0.0016 & & & \\
\hline SESPMNT & B167W6 & $300 \mathrm{NE}$ & ONSITE & AT & 02-Apr-03 BETA & $0.00725 p$ & Ci/m3 & 0.001 & 0.0018 & & & \\
\hline SESPMNT & B16P74 & $300 \mathrm{NE}$ & ONSITE & AT & 15-Apr-03 BETA & $0.00846 p$ & $\mathrm{Ci} / \mathrm{m} 3$ & 0.0011 & 0.002 & & & \\
\hline SESPMNT & B16P75 & $300 \mathrm{NE}$ & ONSITE & AT & 30-Apr-03 BETA & $0.00894 p$ & Ci/m3 & 0.001 & 0.0019 & & & \\
\hline SESPMNT & B16P76 & $300 \mathrm{NE}$ & ONSITE & AT & 13-May-03 BETA & $0.0113 p$ & Ci/m3 & 0.0012 & 0.0024 & & & \\
\hline $\begin{array}{l}\text { SESPMNT } \\
\text { SESPMNT }\end{array}$ & $\begin{array}{l}\text { B16P77 } \\
\text { B1678 }\end{array}$ & $300 \mathrm{NE}$ & $\begin{array}{l}\text { ONSITE } \\
\text { ONSITE }\end{array}$ & AT & $\begin{array}{l}\text { 28-May-03 BETA } \\
\text { 12-JJn-03 BETA }\end{array}$ & $0.00993 p$ & Cilm3 & 0.001 & 0.0021 & & & \\
\hline $\begin{array}{l}\text { SESPMNT } \\
\text { SESPMNT }\end{array}$ & B16P78 & $\begin{array}{l}300 \mathrm{NE} \\
300 \mathrm{NE}\end{array}$ & $\begin{array}{l}\text { ONSITE } \\
\text { ONSITE }\end{array}$ & AT & $\begin{array}{l}\text { 12-Jun-03 BETA } \\
\text { 25-Jun-03 BETA }\end{array}$ & $0.0127 \mathrm{p}$ & & & & & NO SAMPLE. HOSE DISCONNECTED. DO NOT SAVE FOR COMPOSITE. & \\
\hline $\begin{array}{l}\text { SESPMNT } \\
\text { SESPMNT }\end{array}$ & 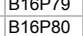 & $\begin{array}{l}300 \mathrm{NE} \\
300 \mathrm{NE}\end{array}$ & $\begin{array}{l}\text { ONSTIE } \\
\text { ONSITE }\end{array}$ & $\begin{array}{l}\text { AT } \\
\text { AT }\end{array}$ & $\begin{array}{l}\text { 25-Jun-03BEEA } \\
\text { 10-Jul-03 BETA }\end{array}$ & $\begin{array}{l}0.0127 \mathrm{p} \\
0.00934 \mathrm{p}\end{array}$ & Cilm3 & 0.0011 & 0.0023 & & & \\
\hline SESPMNT & B17555 & $300 \mathrm{NE}$ & ONSITE & AT & 23-Jul-03 BETA & $0.0129 \mathrm{p}$ & $\mathrm{Ci} / \mathrm{m} 3$ & 0.0013 & 0.0027 & & & \\
\hline SESPMNT & B17556 & $300 \mathrm{NE}$ & ONSITE & AT & 08-Aug-03 BETA & $0.0147 \mathrm{p}$ & $\mathrm{C} \mathrm{i} / \mathrm{m} 3$ & 0.0012 & 0.0028 & & & \\
\hline SESPMNT & B17557 & $300 \mathrm{NE}$ & ONSITE & AT & 20-Aug-03 BETA & $0.0166 \mathrm{p}$ & $\mathrm{Ci} / \mathrm{m} 3$ & 0.0014 & 0.0033 & & & \\
\hline SESPMNT & B17558 & $300 \mathrm{NE}$ & ONSITE & AT & 03-Sep-03 BETA & $0.0162 \mathrm{p}$ & $\mathrm{Ci} / \mathrm{m} 3$ & 0.0013 & 0.0031 & & & \\
\hline SESPMNT & B17559 & $300 \mathrm{NE}$ & ONSITE & AT & 17-Sep-03 BETA & $0.0144 \mathrm{p}$ & Ci/m3 & 0.0013 & 0.0029 & & & \\
\hline $\begin{array}{l}\text { SESPMNT } \\
\text { SECDMNT }\end{array}$ & B17560 & $300 \mathrm{NE}$ & ONSITE & AT & 30-Sep-03 BETA & $0.0152 \mathrm{p}$ & Ci/m3 & 0.0013 & 0.0031 & & & \\
\hline SESPMNT & B17NR5 & $300 \mathrm{NE}$ & ONSITE & AT & 15-Oct-03 BETA & $0.0252 \mathrm{p}$ & Ci/m3 & 0.0015 & 0.0045 & & & \\
\hline SESPMNT & B17NR6 & $300 \mathrm{NE}$ & ONSITE & AT & 29-Oct-03 BETA & $0.0156 \mathrm{p}$ & Ci/m3 & 0.0013 & 0.0031 & & & \\
\hline $\begin{array}{l}\text { SESPMNT } \\
\text { SESDMNT }\end{array}$ & B17NR7 & $300 \mathrm{NE}$ & ONSITE & AT & 12-Nov-03 BETA & $0.0366 \mathrm{p}$ & Ci/m3 & 0.0018 & 0.0061 & & & \\
\hline SESPMNT & B17NR8 & $300 \mathrm{NE}$ & ONSITE & AT & 25-Nov-03 BETA & $0.0191 \mathrm{p}$ & Ci/m3 & 0.0014 & 0.0036 & & & \\
\hline $\begin{array}{l}\text { SESPMNT } \\
\text { SESPMNT }\end{array}$ & B17NR9 & $\begin{array}{l}300 \mathrm{NE} \\
300 \mathrm{NE}\end{array}$ & $\begin{array}{l}\text { ONSITE } \\
\text { ONSTE }\end{array}$ & $\begin{array}{l}\text { AT } \\
\text { AT }\end{array}$ & $\begin{array}{l}\text { 12-Dec-03 BETA } \\
\text { 23-Dec-03 BETA }\end{array}$ & $\begin{array}{l}0.0148 \mathrm{p} \\
0.0223 \mathrm{p}\end{array}$ & $\begin{array}{l}\mathrm{C} \text { Cim3 } \\
\mathrm{CDi} / \mathrm{m} 3 \\
\end{array}$ & 0.0011 & 0.0028 & & CONSTRUC IION IN AREA. & \\
\hline SESPMNT & B17NTO & $300 \mathrm{NE}$ & ONSITE & Al & 23-Dec-03 BETA & $0.0223 p$ & Delim3 & 0.0016 & 0.0039 & & & \\
\hline
\end{tabular}


AIR BETA/ALPHA

\begin{tabular}{|c|c|c|c|c|c|c|c|c|c|c|c|c|}
\hline |OWNER ID & \begin{tabular}{|l|} 
SAMP \\
NUM
\end{tabular} & SAMP SITE NAME & DIST CLASS & MEDIA & \begin{tabular}{l|c} 
& CON \\
& SHORT \\
SAMP DATE & NAME
\end{tabular} & & $\begin{array}{l}\text { ANAL } \\
\text { UNITS } \\
\text { RPTD }\end{array}$ & $\left|\begin{array}{c}\text { COUNTING } \\
\text { ERROR }\end{array}\right|$ & \begin{tabular}{c|c} 
TOTAL \\
ANAL \\
ERROR
\end{tabular} & $\left|\begin{array}{c}\text { LAB } \\
\text { QUALIFIER }\end{array}\right|$ & SAMP COMMENT & $\begin{array}{l}\text { RESULT } \\
\text { COMMENT }\end{array}$ \\
\hline SESPMNT & & $300 \mathrm{NE}$ & ONSITE & AT & 08-Jan-04 BETA & $0.0218 p$ & & 0.0013 & 0.0039 & & & \\
\hline SESPMNT & B168N3 & 300 SOUTH GATE & ONSITE & AT & 22-Jan-03 BETA & $0.0406 \mathrm{p}$ & Ci/m3 & 0.0019 & 0.0071 & & & \\
\hline SESPMNT & B168N4 & 300 SOUTH GATE & ONSITE & AT & 05-Feb-03 BETA & $0.0105 \mathrm{p}$ & $\mathrm{C} / \mathrm{m} 3$ & 0.0011 & 0.0022 & & & \\
\hline $\begin{array}{l}\text { SESPMNT } \\
\text { SFONT }\end{array}$ & B168N5 & 300 SOUTH GATE & ONSITE & AT & 19-Feb-03 BETA & $0.0245 \mathrm{p}$ & & 0.0016 & 0.0044 & & & \\
\hline SESPMNT & B168NG & 300 SOUTH GATE & ONSITE & AT & 05-Mar-03 BETA & $0.0188 \mathrm{p}$ & Cilm3 & 0.0014 & 0.0036 & & & \\
\hline SESPMNT & B168N7 & 300 SOUTH GATE & ONSITE & AT & 20-Mar-03 BETA & $0.00577 p$ & & 0.00086 & 0.0015 & & & \\
\hline SESPMNT & B168N8 & 300 SOUTH GATE & ONSITE & AT & 02-Apr-03 BETA & $0.0068 \mathrm{p}$ & Cilm3 & 0.001 & 0.0017 & & & \\
\hline SESPMNT & B16R11 & 300 SOUTH GATE & ONSITE & AT & 15-Apr-03 BETA & $0.00681 \mathrm{p}$ & Cilm3 & 0.001 & 0.0017 & & & \\
\hline SESPMNT & B16R12 & 300 SOUTH GATE & ONSITE & AT & 30-Apr-03 BETA & $0.00775 p$ & $\mathrm{C} / \mathrm{m} 3$ & 0.001 & 0.0018 & & & \\
\hline $\begin{array}{l}\text { SESPMNT } \\
\text { SECDMNT }\end{array}$ & B16R13 & 300 SOUTH GATE & ONSITE & AT & 13-May-03 BETA & $0.012 \mathrm{p}$ & Ci/m3 & 0.0013 & 0.0025 & & & \\
\hline SESPMNT & B16R14 & 300 SOUTH GATE & ONSITE & AT & 28-May-03 BETA & $0.0103 p$ & Ci/m3 & 0.001 & 0.0022 & & & \\
\hline $\begin{array}{l}\text { SESPMNT } \\
\text { SESPMNT }\end{array}$ & B16R15 & 300 SOUTH GATE & ONSITE & AT & 12-Jun-03 BETA & $0.0134 p$ & Ci/m3 & 0.0012 & 0.0027 & & & \\
\hline $\begin{array}{l}\text { SESPMNT } \\
\text { SESPMNT }\end{array}$ & $\begin{array}{l}\text { B16R16 } \\
\text { B16R71 }\end{array}$ & 300 SOUTH GATE & $\begin{array}{l}\text { ONSITE } \\
\text { ONSTEF }\end{array}$ & AT & 25-Jun-03 BETA & $0.0115 p$ & Ci/m3 & 0.0011 & 0.0021 & & & \\
\hline $\begin{array}{l}\text { SESPMNT } \\
\text { SESPMNT }\end{array}$ & $\begin{array}{l}\text { B16R77 } \\
\text { B175Y3 }\end{array}$ & $\begin{array}{l}300 \text { SOUUH GATE } \\
300 \text { SOUTH GATE }\end{array}$ & $\begin{array}{l}\text { ONSIIE } \\
\text { ONSITE }\end{array}$ & $\begin{array}{l}\text { AT } \\
\text { AT }\end{array}$ & $\begin{array}{l}\text { 10-Jul-03 BETA } \\
\text { 23-Jul-03 BETA }\end{array}$ & $\begin{array}{l}0.0109 p \\
0.0114 p\end{array}$ & $\begin{array}{l}\text { Cilm3 } \\
\text { Ci/m3 }\end{array}$ & 0.0011 & $\begin{array}{l}0.0022 \\
0.0024\end{array}$ & & & \\
\hline SESPMNT & B175Y4 & 300 SOUTH GATE & ONSITE & AT & 08-Aug-03 BETA & $\begin{array}{l}0.0114 \mathrm{p} \\
0.0164 \mathrm{p}\end{array}$ & $\mathrm{Ci} / \mathrm{m} 3$ & 0.0012 & $\begin{array}{l}0.0024 \\
0.0031\end{array}$ & & & \\
\hline SESPMNT & B175Y5 & 300 SOUTH GATE & ONSITE & AT & 20-Aug-03 BETA & $0.0167 \mathrm{p}$ & $\mathrm{Ci} / \mathrm{m} 3$ & 0.0014 & 0.0033 & & & \\
\hline SESPMNT & B175Y6 & 300 SOUTH GATE & ONSITE & AT & 03-Sep-03 BETA & $0.0151 \mathrm{p}$ & $\mathrm{Ci} / \mathrm{m} 3$ & 0.0013 & 0.0029 & & & \\
\hline SESPMNT & B175Y7 & 300 SOUTH GATE & ONSITE & AT & 17-Sep-03 BETA & $0.0141 \mathrm{p}$ & $\mathrm{C} i / \mathrm{m} 3$ & 0.0012 & 0.0028 & & & \\
\hline SESPMNT & B175Y8 & 300 SOUTH GATE & ONSITE & AT & 30-Sep-03 BETA & $0.0139 \mathrm{p}$ & $\mathrm{C} / \mathrm{m} 3$ & 0.0013 & 0.0028 & & & \\
\hline SESPMNT & B17PJ8 & 300 SOUTH GATE & ONSITE & AT & 15-Oct-03 BETA & $0.0276 \mathrm{p}$ & $\mathrm{C} / \mathrm{m} 3$ & 0.0016 & 0.005 & & & \\
\hline SESPMNT & B17PJ9 & 300 SOUTH GATE & ONSITE & AT & 29-Oct-03 BETA & $0.0135 \mathrm{p}$ & $\mathrm{C} / \mathrm{m} 3$ & 0.0012 & 0.0027 & & & \\
\hline SESPMNT & B17PKO & 300 SOUTH GATE & ONSITE & AT & 12-Nov-03 BETA & $0.0364 p$ & & 0.0018 & 0.0062 & & & \\
\hline SESPMNT & B17PK1 & 300 SOUTH GATE & ONSITE & AT & 25-Nov-03 BETA & $0.0188 \mathrm{p}$ & Ci/m3 & 0.0014 & 0.0036 & & & \\
\hline SESPMNT & B17PK2 & 300 SOUTH GATE & ONSITE & AT & 12-Dec-03 BETA & $0.0148 \mathrm{p}$ & Ci/m3 & 0.0011 & 0.0028 & & & \\
\hline $\begin{array}{l}\text { SESPMNT } \\
\text { SESPMNT }\end{array}$ & $\begin{array}{l}\text { B17PK3 } \\
\text { B17PR4 }\end{array}$ & 300 SOUTH GATE & $\begin{array}{l}\text { ONSITE } \\
\text { ONSTIE }\end{array}$ & AT & 23-Dec-03 BETA & $0.0233 p$ & Ci/m3 & 0.0016 & 0.0041 & & & \\
\hline $\begin{array}{l}\text { SESPMNT } \\
\text { SESPMNT }\end{array}$ & $\begin{array}{l}\text { B17PR4 } \\
\text { B168N9 }\end{array}$ & 300 SOUUH GATE & $\begin{array}{l}\text { ONSIIE } \\
\text { ONSITE }\end{array}$ & $\begin{array}{l}\text { AT } \\
\text { AT }\end{array}$ & $\begin{array}{l}\text { 08-Jan-04 BETA } \\
\text { 22-Jan-03 BETA }\end{array}$ & $0.0197 \mathrm{p}$ & Cil/m3 & 0.0013 & 0.0036 & & & \\
\hline $\begin{array}{l}\text { SESPMNT } \\
\text { SESPMNT }\end{array}$ & 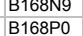 & $\begin{array}{l}300 \text { SOUTH WEST } \\
300 \text { SOUTH WEST }\end{array}$ & $\begin{array}{l}\text { ONSTIE } \\
\text { ONSITE }\end{array}$ & $\begin{array}{l}\text { AT } \\
\text { AT }\end{array}$ & $\begin{array}{l}\text { 22-Jan-03 BETA } \\
\text { 05-Feb-03 BETA }\end{array}$ & $\begin{array}{l}0.0258 \mathrm{p} \\
0.0271 \mathrm{p}\end{array}$ & $\begin{array}{l}\text { Cilm3 } \\
\text { Cil/m3 }\end{array}$ & $\begin{array}{r}0.0016 \\
0.00075\end{array}$ & $\begin{array}{l}0.0047 \\
0.001\end{array}$ & & & \\
\hline $\begin{array}{l}\text { SESPMNT } \\
\text { SESPMNT }\end{array}$ & $\begin{array}{l}\text { B168P0 } \\
\text { B168P1 }\end{array}$ & $\begin{array}{l}300 \text { SOOTH WEST } \\
300 \text { SOUTH WEST }\end{array}$ & $\begin{array}{l}\text { ONSSTE } \\
\text { ONSITE }\end{array}$ & $\begin{array}{l}\text { AT } \\
\text { AT }\end{array}$ & $\begin{array}{l}\text { 0-F-Fb-03 BETA } \\
\text { 19-Feb-03 BETA }\end{array}$ & $\begin{array}{l}0.00271 \mathrm{p} \\
0.0207 \mathrm{p}\end{array}$ & $\begin{array}{l}\mathrm{C} \text { Cim3 } \\
\mathrm{C} \text { Ci/m3 }\end{array}$ & $\begin{array}{r}0.00075 \\
0.0016\end{array}$ & $\begin{array}{r}0.001 \\
0.0039\end{array}$ & & & \\
\hline SESPMNT & B168P2 & 300 SOUTH WEST & ONSITE & AT & 05-Mar-03 BETA & $0.0167 \mathrm{p}$ & $\mathrm{Ci} / \mathrm{m} 3$ & 0.0014 & 0.0032 & & & \\
\hline SESPMNT & B168Р3 & 300 SOUTH WEST & ONSITE & AT & 20-Mar-03 BETA & $0.00584 p$ & $\mathrm{C} \mathrm{C} / \mathrm{m} 3$ & 0.00086 & 0.0014 & & & \\
\hline SESPMNT & B168P4 & 300 SOUTH WEST & ONSITE & AT & 02-Apr-03 BETA & $0.00715 p$ & $\mathrm{C} / \mathrm{m} 3$ & 0.001 & 0.0018 & & & \\
\hline SESPMNT & B16R18 & 300 SOUTH WEST & ONSITE & AT & 15-Apr-03 BETA & $0.0084 p$ & Cilm3 & 0.0011 & 0.0019 & & & \\
\hline SESPMNT & B16R19 & 300 SOUTH WEST & ONSITE & AT & 30-Apr-03 BETA & $0.00931 \mathrm{p}$ & Ci/m3 & 0.0011 & 0.002 & & & \\
\hline SESPMNT & B16R20 & 300 SOUTH WEST & ONSITE & AT & 13-May-03 BETA & $0.0155 \mathrm{p}$ & Ci/m3 & 0.0014 & 0.0031 & & & \\
\hline SESPMNT & B16R21 & 300 SOUTH WEST & ONSITE & AT & 28-May-03 BETA & $0.00969 p$ & Ci/m3 & 0.0011 & 0.0021 & & & \\
\hline $\begin{array}{l}\text { SESPMNT } \\
\text { SESPMNT }\end{array}$ & B16R22 & 300 SOUTH WEST & ONSITE & AT & 12-Jun-03 BETA & $0.0137 \mathrm{p}$ & Ci/m3 & 0.0012 & 0.0027 & & & \\
\hline $\begin{array}{l}\text { SESPMNT } \\
\text { SESPMNT }\end{array}$ & B16R23 & 300 SOUTH WEST & ONSITE & AT & 25-Jun-03 BETA & $0.01 \mathrm{p}$ & Ci/m3 & 0.0011 & 0.0019 & & & \\
\hline $\begin{array}{l}\text { SESPMNT } \\
\text { SESPMNT }\end{array}$ & $\begin{array}{l}\text { B16R24 } \\
\text { B175Y9 }\end{array}$ & 300 SOUTH WEST & $\begin{array}{l}\text { ONSITE } \\
\text { ONSIE }\end{array}$ & AT & $\begin{array}{l}\text { 10-Jul-03 BETA } \\
\text { 23-Ju-03 BETA }\end{array}$ & $0.00997 p$ & Ci/m3 & $\begin{array}{r}0.001 \\
0.0013\end{array}$ & 0.0021 & & & \\
\hline $\begin{array}{l}\text { SESPMNT } \\
\text { SESPMNT }\end{array}$ & 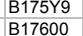 & $\begin{array}{l}300 \text { SOUTH WEST } \\
300 \text { SOUTH WEST }\end{array}$ & $\begin{array}{l}\text { ONSITE } \\
\text { ONSTTE }\end{array}$ & $\begin{array}{l}\text { AT } \\
\text { AT }\end{array}$ & $\begin{array}{c}\text { 23-Auu-03 BETA } \\
\text { 08-0ug BETA }\end{array}$ & $\begin{array}{l}0.0131 \mathrm{p} \\
0.0151 \mathrm{p}\end{array}$ & $\begin{array}{l}\text { Cilm3 } \\
\text { Ci/m3 }\end{array}$ & $\begin{array}{l}0.0013 \\
0.0012\end{array}$ & $\begin{array}{l}0.0027 \\
0.0029\end{array}$ & & & \\
\hline $\begin{array}{l}\text { SESPMNI } \\
\text { SESPMNT }\end{array}$ & $\begin{array}{l}\text { B1/600 } \\
\text { B17601 }\end{array}$ & $\begin{array}{l}300 \text { SOOTH WEST } \\
300 \text { SOUTH WEST }\end{array}$ & $\begin{array}{l}\text { ONSIIE } \\
\text { ONSITE }\end{array}$ & AT & $\begin{array}{l}\text { 08-Aug-03 BETA } \\
\text { 20-Aug-03 BETAA }\end{array}$ & $\begin{array}{l}0.0151 \mathrm{p} \\
0.0137 \mathrm{p}\end{array}$ & $\begin{array}{l}\text { Cilm3 } \\
\text { Ciilm3 }\end{array}$ & $\begin{array}{l}0.0012 \\
0.0013\end{array}$ & $\begin{array}{l}0.0029 \\
0.0028\end{array}$ & & & \\
\hline SESPMNT & B17602 & 300 SOUTH WEST & ONSITE & AT & 03-Sep-03 BETA & $0.0153 \mathrm{p}$ & $\mathrm{Ci} / \mathrm{m} 3$ & 0.0013 & 0.003 & & & \\
\hline SESPMNT & B17603 & 300 SOUTH WEST & ONSITE & AT & 17-Sep-03 BETA & $0.0146 \mathrm{p}$ & & 0.0012 & 0.0029 & & & \\
\hline SESPMNT & B17604 & 300 SOUTH WEST & ONSITE & AT & 30-Sep-03 BETA & $0.0136 \mathrm{p}$ & & 0.0013 & 0.0027 & & & \\
\hline SESPMNT & B17PK5 & 300 SOUTH WEST & ONSITE & AT & 15-Oct-03 BETA & $0.0246 \mathrm{p}$ & $\mathrm{C} / \mathrm{m} 3$ & 0.0015 & 0.0045 & & & \\
\hline SESPMNT & B17PK6 & 300 SOUTH WEST & ONSITE & AT & 29-Oct-03 BETA & $0.0147 \mathrm{p}$ & $\mathrm{C} / \mathrm{m} 3$ & 0.0013 & 0.0029 & & & \\
\hline SESPMNT & B17PK7 & 300 SOUTH WEST & ONSITE & AT & 12-Nov-03 BETA & $0.036 \mathrm{p}$ & Ci/m3 & 0.0017 & 0.006 & & & \\
\hline SESPMNT & B17PK8 & 300 SOUTH WEST & ONSITE & AT & 25-Nov-03 BETA & $0.02 \mathrm{p}$ & Ci/m3 & 0.0015 & 0.0038 & & & \\
\hline SESPMNT & B17PK9 & 300 SOUTH WEST & ONSITE & AT & 12-Dec-03 BETA & $0.0132 \mathrm{p}$ & Ci/m3 & 0.0011 & 0.0026 & & & \\
\hline $\begin{array}{l}\text { SESPMNT } \\
\text { SESPMNT }\end{array}$ & B17PL0 & 300 SOUTH WEST & ONSITE & AT & 23-Dec-03 BETA & $0.0208 \mathrm{p}$ & Ci/m3 & 0.0016 & 0.0037 & & & \\
\hline $\begin{array}{l}\text { SESPMNT } \\
\text { SESPMNT }\end{array}$ & B17PL1 & 300 SOUTH WEST & ONSITE & AT & 08-Jan-04 BETA & $0.0209 p$ & Ci/m3 & 0.0013 & 0.0038 & & & \\
\hline $\begin{array}{l}\text { SESPMNT } \\
\text { SESPMNT }\end{array}$ & B167V5 & $\begin{array}{l}\text { 300 TRENCH } \\
\text { 300 TRENCH }\end{array}$ & $\begin{array}{l}\text { ONSITE } \\
\text { ONSITE }\end{array}$ & $\begin{array}{l}\text { AT } \\
\text { AT }\end{array}$ & 22-Jan-03 BETA 0 & $\begin{array}{r}0.0222 p \\
0.00599 p\end{array}$ & Cil/m3 & $\begin{array}{r}0.0015 \\
0.00091\end{array}$ & $\begin{array}{l}0.0041 \\
0.0015\end{array}$ & & & \\
\hline $\begin{array}{l}\text { SESPMNT } \\
\text { SESPMNT }\end{array}$ & $\begin{array}{l}\text { B16776 } \\
\text { B1677/ }\end{array}$ & $\begin{array}{l}\text { 300 TRENCH } \\
\text { 300 TRENCH }\end{array}$ & $\begin{array}{l}\text { ONSIITE } \\
\text { ONSITE }\end{array}$ & $\begin{array}{l}\text { AT } \\
\text { AT }\end{array}$ & $\begin{array}{l}05-5-\mathrm{eb}-03 \text { BETA } \\
\text { 19-0eb BETA }\end{array}$ & $0.00599 \mathrm{p}$ & Cim3 & $\begin{aligned} 0.00091 \\
0.0916\end{aligned}$ & $\begin{array}{l}0.0015 \\
0.0037\end{array}$ & & & \\
\hline $\begin{array}{l}\text { SESPMNT } \\
\text { SESPMNT }\end{array}$ & $\begin{array}{l}\text { B16777 } \\
\text { B167/8 }\end{array}$ & $\begin{array}{l}300 \text { TRENCH } \\
\text { 300 TRENCH }\end{array}$ & $\begin{array}{l}\text { ONSITE } \\
\text { ONSITE }\end{array}$ & $\begin{array}{l}\text { AT } \\
\text { AT }\end{array}$ & $\begin{array}{l}\text { 19-F-eb-03 BETA } \\
05-\mathrm{Bar}-03 \mathrm{BETA}\end{array}$ & $\begin{array}{l}0.0191 \mathrm{p} \\
0.0162 \mathrm{p}\end{array}$ & $\begin{array}{l}\text { Cilm3 } \\
\text { Ci/m3 }\end{array}$ & 0.0016 & 0.0037 & & & \\
\hline $\begin{array}{l}\text { SESPMMNT } \\
\text { SESPMNT }\end{array}$ & B167V9 & 300 TRENCH & ONSITE & AT & $\begin{array}{l}\text { 50-Mar-03BEIA } \\
\text { 20-03 BETA }\end{array}$ & $\begin{array}{l}0.0062 \mathrm{p} \\
0.0064 \mathrm{p}\end{array}$ & CCim3 & 0.0011 & $\begin{array}{l}0.00317 \\
0.0017\end{array}$ & & & \\
\hline SESPMNT & B167W0 & 300 TRENCH & ONSITE & AT & 02-Apr-03 BETA & $0.00546 p$ & $\mathrm{C} / \mathrm{m} 3$ & 0.00096 & 0.0015 & & & \\
\hline SESPMNT & B16P67 & 300 TRENCH & ONSITE & AT & 15-Apr-03 BETA & $0.00698 p$ & $\mathrm{C} / \mathrm{m} 3$ & 0.00094 & 0.0017 & & & \\
\hline SESPMNT & B16P68 & 300 TRENCH & ONSITE & AT & 30-Apr-03 BETA & & & & & & NO SAMPLE. SAVE FOR COMPOSITE. & \\
\hline SESPMNT & B16P69 & 300 TRENCH & ONSITE & AT & 13-May-03 BETA & $0.00938 \mathrm{p}$ & Ci/m3 & 0.0012 & 0.0021 & & & \\
\hline SESPMNT & B16P70 & 300 TRENCH & ONSITE & AT & 28-May-03 BETA & $0.00891 p$ & $\mathrm{C} / \mathrm{m} 3$ & 0.0011 & 0.002 & & & \\
\hline SESPMNT & B16P71 & 300 TRENCH & ONSITE & AT & 12-Jun-03 BETA & $0.0135 \mathrm{p}$ & Ci/m3 & 0.0012 & 0.0027 & & & \\
\hline SESPMNT & B16P72 & 300 TRENCH & ONSITE & AT & 25-Jun-03 BETA & $0.0111 \mathrm{p}$ & Ci/m3 & 0.0011 & 0.0021 & & & \\
\hline SESPMNT & B16P73 & 300 TRENCH & ONSITE & AT & 10-Jul-03 BETA & $0.0092 \mathrm{p}$ & Ci/m3 & 0.001 & $\begin{array}{r}0.002 \\
0.027\end{array}$ & & & \\
\hline SESPMNT & B17549 & $\begin{array}{l}\text { 300 TRENCH } \\
\text { 300 TRENCH }\end{array}$ & ONSITE & AT & 23-Jul-03 BETA & $0.0129 \mathrm{p}$ & Ci/m3 & 0.0013 & 0.0027 & & & \\
\hline $\begin{array}{l}\text { SESPMNT } \\
\text { SESPMNT }\end{array}$ & $\begin{array}{l}\text { B17550 } \\
\text { B17551 }\end{array}$ & $\begin{array}{l}300 \text { TRENCH } \\
300 \text { TRENCH }\end{array}$ & $\begin{array}{l}\text { ONSTIE } \\
\text { ONSITE }\end{array}$ & $\begin{array}{l}\text { AT } \\
\text { AT }\end{array}$ & $\begin{array}{l}\text { 08-A-Ag-03 BETA } \\
\text { 20-Aug -03 BETA }\end{array}$ & $\begin{array}{l}0.0144 \mathrm{p} \\
0.0121 \mathrm{p}\end{array}$ & $\begin{array}{l}\mathrm{C} \text { Cim3 } \\
\mathrm{CDi} / \mathrm{m} 3 \\
\end{array}$ & 0.0012 & 0.0028 & & & \\
\hline SESPMNT & B17551 & & ONSITE & Al & 20-Aug-03 BETA & $0.0121 \mathrm{p}$ & & 0.0012 & 0.0025 & & & \\
\hline
\end{tabular}


AIR BETA/ALPHA

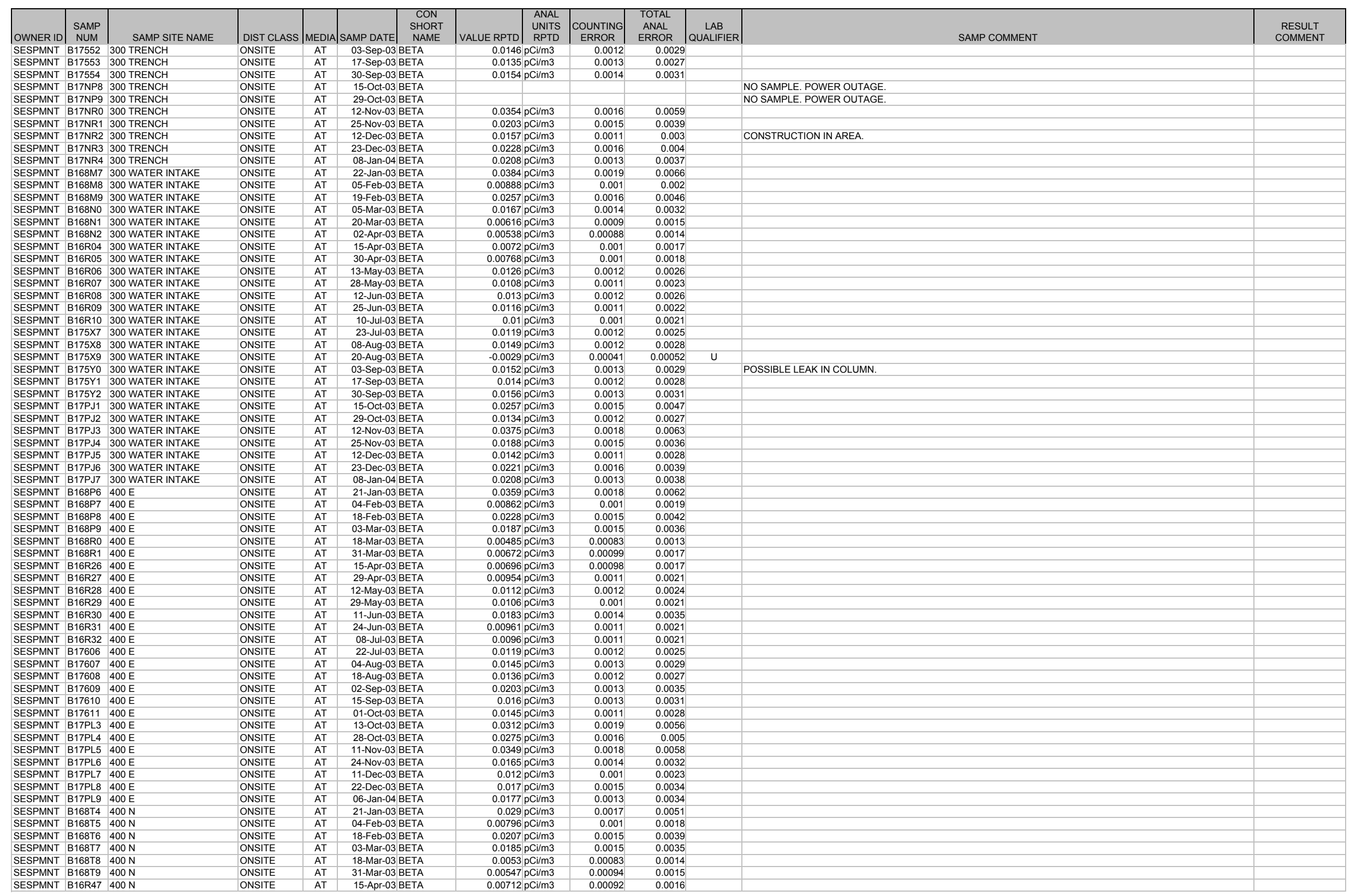


AIR BETA/ALPHA

\begin{tabular}{|c|c|c|c|c|c|c|c|c|c|c|c|c|}
\hline OWNER ID & \begin{tabular}{|l|} 
SAMP \\
NUM
\end{tabular} & SAMP SITE NAME & | DIST CLASS & MEDIA & \begin{tabular}{l|c} 
& CON \\
& SHORT \\
SAMP DATE & NAME
\end{tabular} & & \begin{tabular}{|l|} 
ANAL \\
UNITS \\
RPTD
\end{tabular} & $\left|\begin{array}{c}\text { COUNTING } \\
\text { ERROR }\end{array}\right|$ & \begin{tabular}{c|} 
TOTAL \\
ANAL \\
ERROR
\end{tabular} & $\begin{array}{c}\text { LAB } \\
\text { QUALIFIER }\end{array}$ & SAMP COMMENT & $\begin{array}{l}\text { RESULT } \\
\text { COMMENT }\end{array}$ \\
\hline SESPMNT & B16R48 & $400 \mathrm{~N}$ & ONSITE & AT & 29-Apr-03 BETA & 0.00845 & & 0.001 & 0.0019 & & & \\
\hline SESPMNT & B16R49 & $400 \mathrm{~N}$ & ONSITE & AT & 12-May-03 BETA & 0.0108 & pCilm3 & 0.0012 & 0.0023 & & & \\
\hline SESPMNT & B16R50 & $400 \mathrm{~N}$ & ONSITE & AT & 29-May-03 BETA & 0.0107 & $\mathrm{pCi} / \mathrm{m} 3$ & 0.00099 & 0.0022 & & & \\
\hline SESPMNT & B16R51 & $400 \mathrm{~N}$ & ONSITE & AT & 11-Jun-03 BETA & & $\mathrm{pCi} / \mathrm{m} 3$ & 0.0013 & 0.003 & & & \\
\hline SESPMNT & B16R52 & $400 \mathrm{~N}$ & ONSITE & AT & 24-Jun-03 BETA & 0.0107 & $\mathrm{pCi} / \mathrm{m} 3$ & 0.0012 & 0.0023 & & & \\
\hline SESPMNT & B16R53 & $400 \mathrm{~N}$ & ONSITE & AT & 08-Jul-03 BETA & 0.0107 & $\mathrm{pCi} / \mathrm{m} 3$ & 0.0011 & 0.0023 & & & \\
\hline SESPMNT & B17624 & $400 \mathrm{~N}$ & ONSITE & AT & 22-Jul-03 BETA & 0.0106 & $\mathrm{pCi} / \mathrm{m} 3$ & 0.0012 & 0.0023 & & & \\
\hline SESPMNT & B17625 & $400 \mathrm{~N}$ & ONSITE & AT & 04-Aug-03 BETA & 0.0165 & $\mathrm{pCi} / \mathrm{m} 3$ & 0.0014 & 0.0033 & & & \\
\hline SESPMNT & B17626 & $400 \mathrm{~N}$ & ONSITE & AT & 18-Aug-03 BETA & 0.0142 & $\mathrm{pCi} / \mathrm{m} 3$ & 0.0012 & 0.0028 & & & \\
\hline SESPMNT & B17627 & $400 \mathrm{~N}$ & ONSITE & AT & 02-Sep-03 BETA & 0.0191 & $\mathrm{pCi} / \mathrm{m} 3$ & 0.0013 & 0.0033 & & & \\
\hline SESPMNT & B17628 & $400 \mathrm{~N}$ & ONSITE & AT & 15-Sep-03 BETA & & & & & & NO SAMPLE. SAVE FOR COMPOSITE. & \\
\hline $\begin{array}{l}\text { SESPMNT } \\
\text { SESPMNT }\end{array}$ & B17629 & $400 \mathrm{~N}$ & ONSITE & AT & 01-Oct-03 BETA & 0.0139 & $\mathrm{pCi} / \mathrm{m}_{3}$ & 0.0011 & 0.0027 & & & \\
\hline $\begin{array}{l}\text { SESPMNT } \\
\text { SESPMNT }\end{array}$ & $\begin{array}{l}\text { B17PN4 } \\
\text { B17N55 }\end{array}$ & $400 \mathrm{~N}$ & $\begin{array}{l}\text { ONSITE } \\
\text { ONSTEF }\end{array}$ & AT & $\begin{array}{l}\text { 13-Oct-03 BETA } \\
\text { 28-Oc-03 BETA }\end{array}$ & 0.029 & $\mathrm{pCl} / \mathrm{m}_{3}$ & 0.0018 & 0.0053 & & & \\
\hline $\begin{array}{l}\text { SESPMNT } \\
\text { SESPMNT }\end{array}$ & $\begin{array}{l}\text { B17PN5 } \\
\text { B17N6 }\end{array}$ & $\begin{array}{l}400 \mathrm{~N} \\
400 \mathrm{~N}\end{array}$ & $\begin{array}{l}\text { ONSITE } \\
\text { ONSTIE }\end{array}$ & AT & $\begin{array}{l}\text { 28-Oct-03 BETA } \\
\text { 11-Nov-03 BETA }\end{array}$ & 0.0267 & $\begin{array}{l}\mathrm{pC} / \mathrm{m} 3 \\
\mathrm{pC} / \mathrm{m} 3\end{array}$ & 0.0015 & 0.0047 & & & \\
\hline $\begin{array}{l}\text { SESPMNT } \\
\text { SESPMNT }\end{array}$ & $\begin{array}{l}\text { B17PN6 } \\
\text { B17PN7 }\end{array}$ & $\begin{array}{l}400 \mathrm{~N} \\
400 \mathrm{~N}\end{array}$ & $\begin{array}{l}\text { ONSTIE } \\
\text { ONSITE }\end{array}$ & $\begin{array}{l}\text { AT } \\
\text { AT }\end{array}$ & $\begin{array}{l}\text { 11-Nov-03 BETA } \\
\text { 24-Nov-03 BETA }\end{array}$ & 0.0348 & $\begin{array}{l}\mathrm{pC} / \mathrm{m} 3 \\
\mathrm{pCC} / \mathrm{m} 3\end{array}$ & $\begin{array}{l}0.0016 \\
0.0015\end{array}$ & 0.0059 & & & \\
\hline SESPMNT & B17PN8 & $400 \mathrm{~N}$ & ONSITE & AT & 11-Dec-03 BETA & & & & 0.0036 & & NO SAMPLE. SAVE FOR COMPOSITE. & \\
\hline SESPMNT & B17PN9 & $400 \mathrm{~N}$ & ONSITE & AT & 22-Dec-03 BETA & 0.0172 & $\mathrm{pCi} / \mathrm{m} 3$ & 0.0015 & 0.0035 & & & \\
\hline SESPMNT & B17PPO & $400 \mathrm{~N}$ & ONSITE & AT & 06-Jan-04 BETA & 0.0171 & $\mathrm{pCi} / \mathrm{m} 3$ & 0.0013 & 0.0032 & & & \\
\hline SESPMNT & B168R8 & $400 \mathrm{~S}$ & ONSITE & AT & 21-Jan-03 BETA & 0.034 & $\mathrm{pCi} / \mathrm{m} 3$ & 0.0018 & 0.0059 & & & \\
\hline SESPMNT & B168R9 & $400 \mathrm{~S}$ & ONSITE & AT & 04-Feb-03 BETA & 0.00925 & $\mathrm{pCi} / \mathrm{m} 3$ & 0.0011 & 0.002 & & & \\
\hline SESPMNT & B168T0 & $400 \mathrm{~S}$ & ONSITE & AT & 18-Feb-03 BETA & 0.0234 & $\mathrm{pCi} / \mathrm{m} 3$ & 0.0016 & 0.0043 & & & \\
\hline SESPMNT & B168T1 & $400 \mathrm{~S}$ & ONSITE & AT & 03-Mar-03 BETA & 0.0188 & $\mathrm{pCi} / \mathrm{m} 3$ & 0.0015 & 0.0036 & & & \\
\hline SESPMNT & B168T2 & $400 \mathrm{~S}$ & ONSITE & AT & 18-Mar-03 BETA & 0.00569 & $\mathrm{pCi} / \mathrm{m} 3$ & 0.00085 & 0.0014 & & & \\
\hline SESPMNT & B168т3 & $400 \mathrm{~s}$ & ONSITE & AT & 31-Mar-03 BETA & 0.00979 & $\mathrm{pCi} / \mathrm{m} 3$ & 0.0011 & 0.0022 & & & \\
\hline $\begin{array}{l}\text { SESPMNT } \\
\text { SESPMNT }\end{array}$ & $\begin{array}{l}\text { B16R40 } \\
\text { B16441 }\end{array}$ & $\begin{array}{l}400 \mathrm{~S} \\
400 \mathrm{~S}\end{array}$ & $\begin{array}{l}\text { ONSITE } \\
\text { ONSTIE }\end{array}$ & $\begin{array}{l}\text { AT } \\
\text { AT }\end{array}$ & $\begin{array}{l}\text { 15-Apr-03 BETA } \\
\text { 29-Ar-03 BETA }\end{array}$ & 0.00614 & pCi/m3 & 0.00088 & 0.0015 & & & \\
\hline $\begin{array}{l}\text { SESPMNT } \\
\text { SESPMNT }\end{array}$ & $\begin{array}{l}\text { B16R41 } \\
\text { B16424 }\end{array}$ & $\begin{array}{l}400 \mathrm{~S} \\
400 \mathrm{~S}\end{array}$ & $\begin{array}{l}\text { ONSIIE } \\
\text { ONSTIE }\end{array}$ & $\begin{array}{l}\text { AT } \\
\text { AT }\end{array}$ & $\begin{array}{l}\text { 29-Apr-03 BETA } \\
\text { 12--03 BETA }\end{array}$ & $\begin{array}{l}0.00759 \\
0.0103\end{array}$ & pCi/m3 & $\begin{array}{r}0.00098 \\
0.0021\end{array}$ & 0.0018 & & & \\
\hline $\begin{array}{l}\text { SESPMNT } \\
\text { SESPMNT }\end{array}$ & $\begin{array}{l}\text { B16R42 } \\
\text { B16433 }\end{array}$ & $\begin{array}{l}400 \mathrm{~S} \\
400 \mathrm{~S}\end{array}$ & $\begin{array}{l}\text { ONSITE } \\
\text { ONSTTE }\end{array}$ & $\begin{array}{l}\text { AT } \\
\text { AT }\end{array}$ & $\begin{array}{l}\text { 21-May-03 BETA } \\
\text { 29-My BETA }\end{array}$ & $\begin{array}{l}0.0103 \\
0.0106\end{array}$ & $\begin{array}{l}\mathrm{pC} / \mathrm{m} 3 \\
\mathrm{pC} / \mathrm{m} 3\end{array}$ & $\begin{array}{r}0.0012 \\
0.00098\end{array}$ & 0.0022 & & & \\
\hline $\begin{array}{l}\text { SESPMNT } \\
\text { SESPMNT }\end{array}$ & 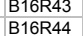 & $\begin{array}{ll}400 \mathrm{~S} \\
400 \mathrm{~s}\end{array}$ & ONSITE & AT & $\begin{array}{l}\text { 29-May-03 BETA } \\
\text { 11-Jun-03 BETAA }\end{array}$ & $\begin{array}{l}0.0106 \\
0.0144\end{array}$ & $\begin{array}{l}\mathrm{pC} / \mathrm{m} 3 \\
\mathrm{pCi} / \mathrm{m3}\end{array}$ & $\begin{array}{c}0.00008 \\
0.0013\end{array}$ & $\begin{array}{l}0.0022 \\
0.0029\end{array}$ & & & \\
\hline SESPMNT & B16R45 & $400 \mathrm{~S}$ & ONSITE & AT & 24-Jun-03 BETA & 0.00918 & $\mathrm{pCi} / \mathrm{m} 3$ & 0.0011 & $\begin{array}{r}0.0029 \\
0.002\end{array}$ & & & \\
\hline SESPMNT & B16R46 & $400 \mathrm{~S}$ & ONSITE & AT & 08-Jul-03 BETA & 0.0109 & $\mathrm{pCi} / \mathrm{m} 3$ & 0.0012 & 0.0023 & & & \\
\hline SESPMNT & B17618 & $400 \mathrm{~S}$ & ONSITE & AT & 22-Jul-03 BETA & 0.0124 & $\mathrm{pCi} / \mathrm{m} 3$ & 0.0012 & 0.0025 & & & \\
\hline SESPMNT & B17619 & $400 \mathrm{~S}$ & ONSITE & AT & 04-Aug-03 BETA & 0.0151 & $\mathrm{pCi} / \mathrm{m} 3$ & 0.0013 & 0.003 & & & \\
\hline SESPMNT & B17620 & $400 \mathrm{~S}$ & ONSITE & AT & 18-Aug-03 BETA & 0.0141 & $\mathrm{pCi} / \mathrm{m} 3$ & 0.0012 & 0.0028 & & & \\
\hline SESPMNT & B17621 & $400 \mathrm{~S}$ & ONSITE & AT & 02-Sep-03 BETA & 0.0192 & $\mathrm{pCi} / \mathrm{m} 3$ & 0.0012 & 0.0033 & & & \\
\hline SESPMNT & B17622 & $400 \mathrm{~S}$ & ONSITE & AT & 15-Sep-03 BETA & 0.0169 & $\mathrm{pCi} / \mathrm{m} 3$ & 0.0014 & 0.0033 & & & \\
\hline SESPMNT & B17623 & $400 \mathrm{~s}$ & ONSITE & AT & 01-Oct-03 BETA & 0.0132 & $\mathrm{pCi} / \mathrm{m} 3$ & 0.0012 & 0.0026 & & & \\
\hline $\begin{array}{l}\text { SESPMNT } \\
\text { SESPMNT }\end{array}$ & B17PM7 & $400 \mathrm{~s}$ & ONSITE & AT & 13-Oct-03 BETA & & & & & & NO SAMPLE. PUMP RUNNING BUT NO FLOW, DO NOT SAVE FOR COMPOSITE. & \\
\hline $\begin{array}{l}\text { SESPMNT } \\
\text { SESPMNT }\end{array}$ & 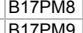 & $400 \mathrm{~S}$ & ONSITE & AT & $\begin{array}{l}\text { 28-Oct-03 BETA } \\
\text { 11-Nov-03 BETA }\end{array}$ & 0.0249 & $\mathrm{pCl} / \mathrm{m}^{3}$ & 0.0016 & 0.0045 & & & \\
\hline $\begin{array}{l}\text { SESPMNT } \\
\text { SESPMNT }\end{array}$ & $\begin{array}{l}\text { B17PM9 } \\
\text { B17PNO }\end{array}$ & $\begin{array}{l}400 \mathrm{~S} \\
400 \mathrm{~S}\end{array}$ & $\begin{array}{l}\text { ONSITE } \\
\text { ONSTTE }\end{array}$ & $\begin{array}{l}\text { AT } \\
\text { AT }\end{array}$ & $\begin{array}{l}\text { 11-N-Nv-03 BETA } \\
\text { 24-Nov-03 BETA }\end{array}$ & 0.03672 & pCim3 & 0.0018 & 0.0061 & & & \\
\hline $\begin{array}{l}\text { SESPMNT } \\
\text { SESPMNT }\end{array}$ & $\begin{array}{l}\text { B17PNo } \\
\text { B17PN1 }\end{array}$ & $400 \mathrm{~S}$ & $\begin{array}{l}\text { ONSIIT } \\
\text { ONSITE }\end{array}$ & AT & $\begin{array}{l}\text { 24-Nov-03BEIA } \\
\text { 11-Dec-03 BETA }\end{array}$ & 0.0111 & $\begin{array}{l}\mathrm{pCC} / \mathrm{m} 3 \\
\mathrm{pCi} / \mathrm{m} 3\end{array}$ & $\begin{array}{r}0.0014 \\
0.00099\end{array}$ & 0.0034 & & 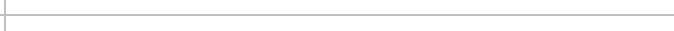 & \\
\hline SESPMNT & B17PN2 & $400 \mathrm{~s}$ & ONSITE & AT & & 0.0154 & $\mathrm{pCi} / \mathrm{m} 3$ & 0.0014 & 0.0032 & & & \\
\hline SESPMNT & B17PN3 & $400 \mathrm{~s}$ & ONSITE & AT & 06-Jan-04 BETA & 0.0173 & $\mathrm{pCi} / \mathrm{m} 3$ & 0.0013 & 0.0033 & & & \\
\hline SESPMNT & B168R2 & $400 \mathrm{~W}$ & ONSITE & AT & 21-Jan-03 BETA & 0.0339 & $\mathrm{pCi} / \mathrm{m} 3$ & 0.0018 & 0.0059 & & & \\
\hline SESPMNT & B168R3 & $400 \mathrm{~W}$ & ONSITE & AT & 04-Feb-03 BETA & 0.00855 & $\mathrm{pCi} / \mathrm{m} 3$ & 0.001 & 0.0019 & & & \\
\hline SESPMNT & B168R4 & $400 \mathrm{~W}$ & ONSITE & AT & 18-Feb-03 BETA & 0.0219 & $\mathrm{pCi} / \mathrm{m} 3$ & 0.0015 & 0.0041 & & & \\
\hline SESPMNT & B168R5 & $400 \mathrm{~W}$ & ONSITE & AT & 03-Mar-03 BETA & 0.0166 & $\mathrm{pCi} / \mathrm{m} 3$ & 0.0014 & 0.0033 & & & \\
\hline SESPMNT & B168R6 & $400 \mathrm{~W}$ & ONSITE & AT & 18-Mar-03 BETA & 0.00576 & $\mathrm{pCi} / \mathrm{m} 3$ & 0.00092 & 0.0015 & & & \\
\hline SESPMNT & B168R7 & $400 \mathrm{~W}$ & ONSITE & AT & 31-Mar-03 BETA & 0.00539 & $\mathrm{pCi} / \mathrm{m} 3$ & 0.00094 & 0.0015 & & & \\
\hline SESPMNT & B16R33 & $400 \mathrm{~W}$ & ONSITE & AT & 15-Apr-03 BETA & 0.00738 & $\mathrm{pCi} / \mathrm{m}^{2}$ & 0.00092 & 0.0017 & & & \\
\hline $\begin{array}{l}\text { SESPMNT } \\
\text { SESPMNT }\end{array}$ & 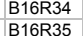 & $\begin{array}{l}400 \mathrm{~W} \\
400 \mathrm{~W}\end{array}$ & $\begin{array}{l}\text { ONSIE } \\
\text { ONSITE }\end{array}$ & $\begin{array}{l}\text { AT } \\
\text { AT }\end{array}$ & $\begin{array}{l}\text { 29-Apr-D3 BETA } \\
\text { 12-May-03 BETA }\end{array}$ & $\begin{array}{l}0.009065 \\
0.0097\end{array}$ & $\begin{array}{l}\text { pCim3 } \\
\text { pCi/m3 }\end{array}$ & $\begin{array}{l}0.0011 \\
0.0017\end{array}$ & $\begin{array}{l}0.0021 \\
0.0026\end{array}$ & & & \\
\hline SESPMNT & B16R36 & $400 \mathrm{~W}$ & ONSITE & AT & 29-May-03 BETA & 0.00977 & $\mathrm{pCi} / \mathrm{m} 3$ & 0.001 & 0.002 & & & \\
\hline SESPMNT & B16R37 & $400 \mathrm{~W}$ & ONSITE & AT & 11-Jun-03 BETA & 0.0137 & $\mathrm{pCi} / \mathrm{m} 3$ & 0.0013 & 0.0028 & & & \\
\hline SESPMNT & B16R38 & $400 \mathrm{~W}$ & ONSITE & AT & 24-Jun-03 BETA & 0.0096 & $\mathrm{pCl} / \mathrm{m} 3$ & 0.0011 & 0.0021 & & & \\
\hline SESPMNT & B16R39 & $400 \mathrm{~W}$ & ONSITE & AT & 08-Jul-03 BETA & 0.01 & $\mathrm{pCi} / \mathrm{m} 3$ & 0.0011 & 0.0022 & & & \\
\hline SESPMNT & B17612 & $400 \mathrm{~W}$ & ONSITE & AT & 22-Jul-03 BETA & 0.0131 & $\mathrm{pCi} / \mathrm{m} 3$ & 0.0012 & 0.0026 & & & \\
\hline SESPMNT & B17613 & $400 \mathrm{~W}$ & ONSITE & AT & 04-Aug-03 BETA & 0.0139 & $\mathrm{pCi} / \mathrm{m} 3$ & 0.0013 & 0.0028 & & & \\
\hline SESPMNT & B17614 & $400 \mathrm{~W}$ & ONSITE & AT & 18-Aug-03 BETA & 0.0136 & $\mathrm{pCi} / \mathrm{m} 3$ & 0.0012 & 0.0027 & & & \\
\hline SESPMNT & B17615 & $400 \mathrm{~W}$ & ONSITE & AT & 02-Sep-03 BETA & 0.0183 & $\mathrm{pCi} / \mathrm{m} 3$ & 0.0013 & 0.0032 & & & \\
\hline SESPMNT & B17616 & $400 \mathrm{~W}$ & ONSITE & AT & 15-Sep-03 BETA & 0.0159 & $\mathrm{pCi} / \mathrm{m} 3$ & 0.0013 & 0.0031 & & & \\
\hline SESPMNT & B17617 & $400 \mathrm{~W}$ & ONSITE & AT & 01-Oct-03 BETA & 0.0137 & $\mathrm{pCi} / \mathrm{m} 3$ & 0.0012 & 0.0027 & & & \\
\hline SESPMNT & B17PMO & $400 \mathrm{~W}$ & ONSITE & AT & 13-Oct-03 BETA & 0.0287 & $\mathrm{pCi} / \mathrm{m} 3$ & 0.0018 & 0.0052 & & & \\
\hline SESPMNT & $\begin{array}{l}\text { B17PM1 } \\
\text { B17PM? }\end{array}$ & $400 \mathrm{~W}$ & ONSITE & AT & 28-Oct-03 BETA & 0.0265 & $\mathrm{pCi} / \mathrm{m} 3$ & 0.0016 & 0.0048 & & & \\
\hline $\begin{array}{l}\text { SESPMNI } \\
\text { SESPMNT }\end{array}$ & $\begin{array}{l}\text { B17PM2 } \\
\text { B17PM3 }\end{array}$ & $\begin{array}{l}400 \mathrm{~W} \\
400 \mathrm{~W}\end{array}$ & $\begin{array}{l}\text { ONSTIE } \\
\text { ONSITE }\end{array}$ & $\begin{array}{l}\text { AT } \\
\text { AT }\end{array}$ & $\begin{array}{l}\text { 11-Novo-03 BETA } \\
\text { 24-Nov-03 BETA }\end{array}$ & 0.0181 & & 0.0014 & 0.0034 & & $\begin{array}{l}\text { NO SAAPLE. SAVE FOR COMPOSIIE. } \\
\text { HUTCH BLOWN OVER. }\end{array}$ & \\
\hline SESPMNT & B17PM4 & $400 \mathrm{~W}$ & ONSITE & AT & 11-Dec-03 BETA & 0.00933 & $\mathrm{pCi} / \mathrm{m} 3$ & 0.00099 & 0.002 & & & \\
\hline
\end{tabular}


AIR BETA/ALPHA

\begin{tabular}{|c|c|c|c|c|c|c|c|c|c|c|c|c|}
\hline |OWNER ID & \begin{tabular}{|l|} 
SAMP \\
NUM \\
\end{tabular} & SAMP SITE NAME & | DIST CLASS | & MEDIA & \begin{tabular}{c|c} 
& CON \\
& SHORT \\
SAMP DATE & NAME
\end{tabular} & |VALUE RPTD | & \begin{tabular}{|l|} 
ANAL \\
UNITS \\
RPTD \\
\end{tabular} & $\left|\begin{array}{c}\text { COUNTING } \\
\text { ERROR }\end{array}\right|$ & $\begin{array}{c}\text { TOTAL } \\
\text { ANAL } \\
\text { ERROR }\end{array}$ & $\left|\begin{array}{c}\text { LAB } \\
\text { QUALIFIER }\end{array}\right|$ & SAMP COMMENT & $\begin{array}{c}\text { RESULT } \\
\text { COMMENT }\end{array}$ \\
\hline $\begin{array}{l}\text { SESPMNT } \\
\text { SESPMNT }\end{array}$ & B17PM5 & $\begin{array}{l}400 \mathrm{~W} \\
400 \mathrm{~W}\end{array}$ & $\begin{array}{l}\text { ONSITE } \\
\text { ONSITE }\end{array}$ & $\begin{array}{l}\text { AT } \\
\text { AT }\end{array}$ & $\begin{array}{l}\text { 22-Dec-03 BETA } \\
\text { 06-Jan-04 BETA }\end{array}$ & 0.0164 & pCilm3 & & & & 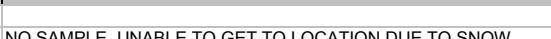 & \\
\hline $\begin{array}{l}\text { SESPMNT } \\
\text { SESPMNT }\end{array}$ & $\begin{array}{l}\text { B17PM6 } \\
\text { B168J7 }\end{array}$ & $\begin{array}{l}400 \mathrm{~W} \\
\text { ARMY LOOP CAMP }\end{array}$ & $\begin{array}{l}\text { ONSSITE } \\
\text { ONSE }\end{array}$ & AT & $\begin{array}{l}\text { O6--Jan-04BEIA } \\
\text { 14-Jan-03 BETA }\end{array}$ & 0.0213 & $\mathrm{pCi} / \mathrm{m} 3$ & 0.0015 & 0.004 & & NO SAMPLE. UNABLE TO GET TO LOCATION DUE TO SNOW. & \\
\hline $\begin{array}{l}\text { SESPMNI } \\
\text { SESPMNT }\end{array}$ & B168J8 & ARMY LOOP CAMP & ONSITE & AT & 28-Jan-03 BETA & 0.00407 & $\mathrm{pCi} / \mathrm{m} 3$ & 0.0009 & 0.0013 & & & \\
\hline SESPMNT & B168J9 & ARMY LOOP CAMP & ONSITE & AT & 11-Feb-03 BETA & 0.0155 & $\mathrm{pCi} / \mathrm{m} 3$ & 0.0012 & 0.0029 & & & \\
\hline SESPMNT & B168K0 & ARMY LOOP CAMP & ONSITE & AT & 25-Feb-03 BETA & 0.017 & $\mathrm{pCi} / \mathrm{m} 3$ & 0.0014 & 0.0033 & & & \\
\hline SESPMNT & B168K1 & ARMY LOOP CAMP & ONSITE & AT & 10-Mar-03 BETA & 0.0155 & $\mathrm{pCi} / \mathrm{m} 3$ & 0.0013 & 0.003 & & & \\
\hline SESPMNT & B168K2 & ARMY LOOP CAMP & ONSITE & AT & 26-Mar-03 BETA & 0.00552 & $\mathrm{pCi} / \mathrm{m} 3$ & 0.00082 & 0.0014 & & & \\
\hline SESPMNT & B168K3 & ARMY LOOP CAMP & ONSITE & AT & 08-Apr-03 BETA & 0.00522 & $\mathrm{pCi} / \mathrm{m} 3$ & 0.00087 & 0.0014 & & & \\
\hline $\begin{array}{l}\text { SESPMNT } \\
\text { SECDMNT }\end{array}$ & B16PW8 & ARMY LOOP CAMP & ONSITE & AT & 21-Apr-03 BETA & 0.00966 & $\mathrm{pCi} / \mathrm{m} 3$ & 0.0012 & 0.0022 & & & \\
\hline SESPMNT & B16PW9 & ARMY LOOP CAMP & ONSITE & AT & 06-May-03 BETA & 0.00921 & $\mathrm{pCi} / \mathrm{m} 3$ & 0.001 & 0.002 & & & \\
\hline $\begin{array}{l}\text { SESPMNT } \\
\text { SESPMNT }\end{array}$ & $\begin{array}{l}\text { B16PXO } \\
\text { B16P1 }\end{array}$ & $\begin{array}{l}\text { ARMY LOOP CAMP } \\
\text { ARMY LOOP CAMP }\end{array}$ & ONSITE & AT & 20-May-03 BETA & 0.0109 & $\mathrm{pCi} / \mathrm{m}^{2}$ & 0.0011 & 0.0023 & & & \\
\hline $\begin{array}{l}\text { SESPMNT } \\
\text { SESPMNT }\end{array}$ & $\begin{array}{l}\text { B16P11 } \\
\text { B16PX2 }\end{array}$ & $\begin{array}{l}\text { ARMY LOOP CAMP } \\
\text { ARMY LOP CAMP }\end{array}$ & $\begin{array}{l}\text { ONSITE } \\
\text { ONSTIE }\end{array}$ & $\begin{array}{l}\text { AT } \\
\text { AT }\end{array}$ & $\begin{array}{l}\text { 02-Junn-03 BETA } \\
\text { 17-Jun-03 BETA }\end{array}$ & 0.01179 & $\mathrm{pCl} / \mathrm{p}_{3}$ & 0.0012 & 0.0025 & & & \\
\hline SESPMNT & B16PX3 & ARMY LOOP CAMP & ONSITE & AT & $\begin{array}{l}\text { 17--Jun-03 BETA } \\
\text { 30-Jun-03 BETA }\end{array}$ & $\begin{array}{r}0.01399 \\
0.00969\end{array}$ & $\begin{array}{l}\mathrm{pC} / \mathrm{m} 3 \\
\mathrm{pCi} / \mathrm{m} 3\end{array}$ & $\begin{array}{l}0.0011 \\
0.0011\end{array}$ & $\begin{array}{l}0.0026 \\
0.0022\end{array}$ & & & \\
\hline SESPMNT & B175T7 & ARMY LOOP CAMP & ONSITE & AT & 15-Jul-03 BETA & 0.00923 & $\mathrm{pCi} / \mathrm{m} 3$ & 0.001 & $\begin{array}{r}0.0024 \\
0.002\end{array}$ & & & \\
\hline SESPMNT & B175T8 & ARMY LOOP CAMP & ONSITE & AT & 29-Jul-03 BETA & 0.0126 & $\mathrm{pCi} / \mathrm{m} 3$ & 0.0012 & 0.0026 & & & \\
\hline SESPMNT & B175T9 & ARMY LOOP CAMP & ONSITE & AT & 12-Aug-03 BETA & 0.0143 & $\mathrm{pCi} / \mathrm{m} 3$ & 0.0012 & 0.0028 & & & \\
\hline SESPMNT & B175VO & ARMY LOOP CAMP & ONSITE & AT & 25-Aug-03 BETA & 0.0179 & $\mathrm{pCi} / \mathrm{m} 3$ & 0.0013 & 0.0031 & & & \\
\hline SESPMNT & B175V1 & ARMY LOOP CAMP & ONSITE & AT & 10-Sep-03 BETA & 0.0149 & $\mathrm{pCi} / \mathrm{m} 3$ & 0.0012 & 0.0028 & & & \\
\hline SESPMNT & B175V2 & ARMY LOOP CAMP & ONSITE & AT & 22-Sep-03 BETA & 0.0104 & $\mathrm{pCi} / \mathrm{m} 3$ & 0.0013 & 0.0023 & & & \\
\hline SESPMNT & B175V3 & ARMY LOOP CAMP & ONSITE & AT & 07-Oct-03 BETA & 0.0273 & $\mathrm{pCi} / \mathrm{m} 3$ & 0.0016 & 0.0048 & & & \\
\hline $\begin{array}{l}\text { SESPMNT } \\
\end{array}$ & B17PD5 & ARMY LOOP CAMP & ONSITE & AT & 21-Oct-03 BETA & 0.00974 & $\mathrm{pCi} / \mathrm{m} 3$ & 0.0011 & 0.0021 & & & \\
\hline SESPMNT & B17PD6 & ARMY LOOP CAMP & ONSITE & AT & 05-Nov-03 BETA & 0.0176 & $\mathrm{pCi} / \mathrm{m} 3$ & 0.0013 & 0.0033 & & & \\
\hline $\begin{array}{l}\text { SESPMNT } \\
\text { SESPMNT }\end{array}$ & B17PD7 & ARMY LOOP CAMP & ONSITE & AT & 18-Nov-03 BETA & 0.0343 & $\mathrm{pCi} / \mathrm{m} 3$ & 0.0019 & 0.006 & & & \\
\hline $\begin{array}{l}\text { SESPMNT } \\
\text { SESPMNT }\end{array}$ & B17PD8 & $\begin{array}{l}\text { ARMY LOOP CAMP } \\
\text { ARMY LOP CAMP }\end{array}$ & ONSITE & AT & 01-Dec-03 BETA & 0.0106 & pCi/m3 & 0.0012 & 0.0023 & & & \\
\hline $\begin{array}{l}\text { SESPMNT } \\
\text { SESPMNT }\end{array}$ & $\begin{array}{l}\text { B17PD9 } \\
\text { B17PFO }\end{array}$ & $\begin{array}{l}\text { ARMY LOOO CAMP } \\
\text { ARMY LOOP CAMP }\end{array}$ & $\begin{array}{l}\text { ONSITE } \\
\text { ONSTIE }\end{array}$ & $\begin{array}{l}\text { AT } \\
\text { AT }\end{array}$ & $\begin{array}{l}\text { 17-Dec-03 BETA } \\
\text { 30-Dec-03 BETA }\end{array}$ & $\begin{array}{l}0.0121 \\
0.0171\end{array}$ & pCim3 & $\begin{array}{r}0.001 \\
0.0014\end{array}$ & 0.0024 & & & \\
\hline SESPMNT & B168H9 & B POND & ONSITE & AT & 14-Jan-03 BETA & 0.0256 & $\begin{array}{l}\mathrm{pCl} / \mathrm{m3} 3 \\
\mathrm{pCi} / \mathrm{m} 3\end{array}$ & $\begin{array}{l}0.0014 \\
0.0016\end{array}$ & $\begin{array}{l}0.0034 \\
0.0046\end{array}$ & & & \\
\hline SESPMNT & B168J0 & B POND & ONSITE & AT & 28-Jan-03 BETA & 0.0204 & $\mathrm{pCi} / \mathrm{m} 3$ & 0.0014 & 0.0038 & & & \\
\hline SESPMNT & B168J1 & B POND & ONSITE & AT & 11-Feb-03 BETA & 0.0167 & $\mathrm{pCi} / \mathrm{m} 3$ & 0.0013 & 0.0032 & & & \\
\hline SESPMNT & B168J2 & B POND & ONSITE & AT & 25-Feb-03 BETA & 0.0181 & $\mathrm{pCi} / \mathrm{m} 3$ & 0.0014 & 0.0034 & & & \\
\hline SESPMNT & B168J3 & B POND & ONSITE & AT & 10-Mar-03 BETA & 0.0153 & $\mathrm{pCi} / \mathrm{m} 3$ & 0.0014 & 0.0031 & & & \\
\hline SESPMNT & B168J4 & B POND & ONSITE & AT & 26-Mar-03 BETA & 0.00571 & $\mathrm{pCi} / \mathrm{m} 3$ & 0.00083 & 0.0014 & & & \\
\hline SESPMNT & B168J5 & B POND & ONSITE & AT & 08-Apr-03 BETA & 0.00573 & $\mathrm{pCi} / \mathrm{m} 3$ & 0.001 & 0.0016 & & & \\
\hline SESPMNT & B16PW1 & B POND & ONSITE & AT & 21-Apr-03 BETA & 0.0106 & $\mathrm{pCi} / \mathrm{m} 3$ & 0.0012 & 0.0023 & & & \\
\hline $\begin{array}{l}\text { SESPMNT } \\
\text { SECDMNT }\end{array}$ & B16PW2 & B POND & ONSITE & AT & 06-May-03 BETA & 0.00944 & $\mathrm{pCi} / \mathrm{m} 3$ & 0.0011 & 0.002 & & & \\
\hline $\begin{array}{l}\text { SESPMNT } \\
\text { SESPMNT }\end{array}$ & B16PW3 & B POND & ONSITE & AT & 20-May-03 BETA & & & & & & NO SAMPLE. SAVE FOR COMPOSITE. & \\
\hline $\begin{array}{l}\text { SESPMNT } \\
\text { SESPMNT }\end{array}$ & B16PW4 & B POND & ONSITE & AT & 02-Jun-03 BETA & 0.0118 & $\mathrm{pCi} / \mathrm{m} 3$ & 0.0012 & 0.0025 & & & \\
\hline $\begin{array}{l}\text { SESPMNT } \\
\text { SESPMNT }\end{array}$ & B16PW5 & $\begin{array}{l}\text { B POND } \\
\text { B POND }\end{array}$ & $\begin{array}{l}\text { ONSITE } \\
\text { ONSTIE }\end{array}$ & AT & $\begin{array}{l}\text { 17-Jun-03 BETA } \\
\text { 30--Jun-03 BETA }\end{array}$ & 0.012 & $\mathrm{pCl} / \mathrm{m}^{3}$ & 0.0012 & 0.0024 & & & \\
\hline $\begin{array}{l}\text { SESPMNT } \\
\text { SESPMNT }\end{array}$ & $\begin{array}{l}\text { B16PW6 } \\
\text { B17559 }\end{array}$ & $\begin{array}{l}\text { B POND } \\
\text { B POND }\end{array}$ & $\begin{array}{l}\text { ONSTIE } \\
\text { ONSITE }\end{array}$ & $\begin{array}{l}\text { Al } \\
\text { AT }\end{array}$ & $\begin{array}{l}\text { 30-J-Jun-03 BETA } \\
\text { 15-Jul-03 BETA }\end{array}$ & $\begin{array}{r}0.01 \\
0.00815\end{array}$ & $\begin{array}{l}\mathrm{pC} / \mathrm{m} 3 \\
\mathrm{pC} / \mathrm{m} 3\end{array}$ & $\begin{array}{r}0.0011 \\
0.00098\end{array}$ & 0.0022 & & & \\
\hline $\begin{array}{l}\text { SESPMNI } \\
\text { SESPMNT }\end{array}$ & $\begin{array}{l}\begin{array}{l}\text { B1775R9 } \\
\text { B175T0 }\end{array}\end{array}$ & $\begin{array}{l}\text { B POND } \\
\text { B POND }\end{array}$ & ONSITE & AT & $\begin{array}{l}\text { 15-Jul-03B BEAA } \\
\text { 29-Jul-03 BETA }\end{array}$ & $\begin{aligned} 0.00815 \\
0.0153\end{aligned}$ & $\begin{array}{l}\mathrm{pCl} / \mathrm{m} 3 \\
\mathrm{pCi} / \mathrm{m} 3\end{array}$ & $\begin{array}{r}0.00098 \\
0.0013\end{array}$ & $\begin{array}{l}0.0018 \\
0.003\end{array}$ & & & \\
\hline SESPMNT & B175T1 & B POND & ONSITE & AT & 12-Aug-03 BETA & 0.0158 & $\mathrm{pCi} / \mathrm{m} 3$ & 0.0013 & 0.0031 & & & \\
\hline SESPMNT & B175T2 & B POND & ONSITE & AT & 25-Aug-03 BETA & 0.0173 & $\mathrm{pCi} / \mathrm{m} 3$ & 0.0013 & 0.003 & & & \\
\hline SESPMNT & B175T3 & B POND & ONSITE & AT & 10-Sep-03 BETA & 0.0161 & $\mathrm{pCi} / \mathrm{m} 3$ & 0.0012 & 0.003 & & & \\
\hline SESPMNT & B175T4 & B POND & ONSITE & AT & 22-Sep-03 BETA & 0.0104 & $\mathrm{pCi} / \mathrm{m} 3$ & 0.0012 & 0.0023 & & & \\
\hline SESPMNT & B175T5 & B POND & ONSITE & AT & 07-Oct-03 BETA & 0.0278 & $\mathrm{pCi} / \mathrm{m} 3$ & 0.0016 & 0.0049 & & & \\
\hline SESPMNT & B17PC8 & B POND & ONSITE & AT & 21-Oct-03 BETA & 0.00943 & pCilm3 & 0.001 & 0.002 & & & \\
\hline SESPMNT & B17PC9 & B POND & ONSITE & AT & 05-Nov-03 BETA & & & & & & NO SAMPLE. BAD REGULATOR, UNKNOWN FLOW. & \\
\hline SESPMNT & B17PDO & B POND & ONSITE & AT & 18-Nov-03 BETA & 0.0321 & $\mathrm{pCi} / \mathrm{m} 3$ & 0.0018 & 0.0057 & & & \\
\hline 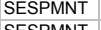 & B17PD1 & B POND & ONSITE & AT & 01-Dec-03 BETA & 0.0124 & $\mathrm{pCi} / \mathrm{m}^{3}$ & 0.0012 & 0.0026 & & & \\
\hline $\begin{array}{l}\text { SESPMNT } \\
\text { SESPMNT }\end{array}$ & $\begin{array}{l}\text { B17PD2 } \\
\text { B17DD3 }\end{array}$ & $\begin{array}{l}\text { B POND } \\
\text { B POND }\end{array}$ & $\begin{array}{l}\text { ONSITE } \\
\text { ONSTIE }\end{array}$ & $\begin{array}{l}\text { AT } \\
\text { AT }\end{array}$ & $\begin{array}{l}\text { 17-Dec-03 BETA } \\
\text { 30-Dec-03 BETA }\end{array}$ & 0.0133 & pCim3 & 0.0011 & 0.0026 & & & \\
\hline SESPMNT & B16963 & BASIN CITY SCHOOL & COMMUNITY & AT & 15-Jan-03 BETA & 0.0254 & $\begin{array}{ll}\mathrm{pCl} / \mathrm{ms} \\
\mathrm{pC} / \mathrm{m}\end{array}$ & 0.0015 & 0.0046 & & & \\
\hline SESPMNT & B16964 & BASIN CITY SCHOOL & COMMUNITY & AT & 29-Jan-03 BETA & 0.0179 & $\mathrm{pCC} / \mathrm{m} 3$ & 0.0014 & 0.0034 & & & \\
\hline SESPMNT & B16965 & BASIN CITY SCHOOL & COMMUNITY & AT & 12-Feb-03 BETA & 0.0176 & $\mathrm{pCi} / \mathrm{m} 3$ & 0.0014 & 0.0033 & & & \\
\hline SESPMNT & B16966 & BASIN CITY SCHOOL & COMMUNITY & AT & 26-Feb-03 BETA & 0.0228 & pCi/m3 & 0.0014 & 0.0039 & & & \\
\hline SESPMNT & B16967 & BASIN CITY SCHOOL & COMMUNITY & AT & 12-Mar-03 BETA & 0.0129 & $\mathrm{pCi} / \mathrm{m} 3$ & 0.0012 & 0.0026 & & & \\
\hline SESPMNT & B16968 & BASIN CITY SCHOOL & COMMUNITY & AT & 26-Mar-03 BETA & 0.00666 & $\mathrm{pCi} / \mathrm{m} 3$ & 0.00095 & 0.0016 & & & \\
\hline SESPMNT & B16969 & BASIN CITY SCHOOL & COMMUNITY & AT & 09-Apr-03 BETA & 0.00795 & $\mathrm{pCi} / \mathrm{m} 3$ & 0.001 & 0.0018 & & & \\
\hline SESPMNT & B16RJ5 & BASIN CITY SCHOOL & COMMUNITY & AT & 23-Apr-03 BETA & 0.00991 & $\mathrm{pCi} / \mathrm{m} 3$ & 0.0011 & 0.0021 & & & \\
\hline $\begin{array}{l}\text { SESPMNT } \\
\end{array}$ & B16RJ6 & BASIN CITY SCHOOL & COMMUNITY & AT & 07-May-03 BETA & 0.00902 & $\mathrm{pCi} / \mathrm{m} 3$ & 0.001 & 0.002 & & & \\
\hline $\begin{array}{l}\text { SESPMNT } \\
\text { SESPMNT }\end{array}$ & B16RJ7 & BASIN CITY SCHOOL & COMMUNITY & AT & 21-May-03 BETA & 0.0123 & $\mathrm{pCi} / \mathrm{m} 3$ & 0.0012 & 0.0025 & & & \\
\hline SESPMNT & B16RJ8 & BASIN CITY SCHOOL & COMMUNITY & AT & 04-Jun-03 BETA & 0.0126 & pCim3 & 0.0012 & 0.0025 & & & \\
\hline $\begin{array}{l}\text { SESPMNT } \\
\text { SESPMNT }\end{array}$ & B16RJg & BASIN CITY SCHOOL & COMMUNITY & AT & 18-Jun-03 BETA & 0.014 & pCi/m3 & 0.0012 & 0.0028 & & & \\
\hline $\begin{array}{l}\text { SESPMNI } \\
\text { SESPMNT }\end{array}$ & 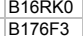 & $\begin{array}{l}\text { BASSN CIIY SCHOOL } \\
\text { BASIN CITY SCHOOL }\end{array}$ & $\begin{array}{l}\text { COMMUNITY } \\
\text { COMMUNITY }\end{array}$ & $\begin{array}{l}\text { AI } \\
\text { AT }\end{array}$ & $\begin{array}{l}\text { 02-Julu-03 BETA } \\
\text { 16-Jul-03 BETA }\end{array}$ & $\begin{array}{l}0.00879 \\
0.012\end{array}$ & $\begin{array}{l}\text { pCim3 } \\
\text { pCi/m3 }\end{array}$ & $\begin{array}{l}0.0011 \\
0.0012\end{array}$ & $\begin{array}{r}0.002 \\
0.0025\end{array}$ & & & \\
\hline SESPMNT & B176F4 & BASIN CITY SCHOOL & COMMUNITY & AT & 30-Jul-03 BETA & 0.0123 & $\mathrm{pCi} / \mathrm{m} 3$ & 0.0016 & 0.0029 & & & \\
\hline
\end{tabular}


AIR BETA/ALPHA

\begin{tabular}{|c|c|c|c|c|c|c|c|c|c|c|c|c|c|}
\hline |OWNER ID & \begin{tabular}{|l|} 
SAMP \\
NUM
\end{tabular} & SAMP SITE NAME & | DIST CLASS | & MEDIA & SAMP DATE| & $\begin{array}{l}\text { CON } \\
\text { SHORT } \\
\text { NAME }\end{array}$ & & $\begin{array}{l}\text { ANAL } \\
\text { UNITS } \\
\text { RPTD }\end{array}$ & $\left|\begin{array}{c}\text { COUNTING } \\
\text { ERROR }\end{array}\right|$ & \begin{tabular}{|c|c|} 
TOTAL \\
ANAL \\
ERROR
\end{tabular} & $\left|\begin{array}{c}\text { LAB } \\
\text { QUALIFIER }\end{array}\right|$ & SAMP COMMENT & $\begin{array}{l}\text { RESULT } \\
\text { COMMENT }\end{array}$ \\
\hline SESPMNT & & BASIN CITY SCHOOL & COMMUNITY & AT & 13-Aug-03 BE & & $0.0154 \mathrm{p}$ & & 0.0013 & 0.003 & & & \\
\hline SESPMNT & B176F6 & BASIN CITY SCHOOL & COMMUNITY & AT & 27-Aug-03 BE & & $0.0148 \mathrm{p}$ & & 0.0012 & 0.0029 & & & \\
\hline SESPMNT & B176F7 & BASIN CITY SCHOOL & COMMUNITY & AT & 10-Sep-03 BE & & $0.0184 \mathrm{p}$ & & 0.0014 & 0.0035 & & & \\
\hline $\begin{array}{l}\text { SESPMNT } \\
\text { SFONT }\end{array}$ & B176F8 & BASIN CITY SCHOOL & COMMUNITY & AT & 24-Sep-03 BE & & $0.0111 \mathrm{p}$ & & 0.0012 & 0.0024 & & & \\
\hline SESPMNT & B176F9 & BASIN CITY SCHOOL & COMMUNITY & AT & 08-Oct-03 BE & & $0.0303 p$ & Cilm3 & 0.0017 & 0.0053 & & & \\
\hline $\begin{array}{l}\text { SESPMNT } \\
\text { SESPMNT }\end{array}$ & B17R32 & BASIN CITY SCHOOL & COMMUNITY & AT & 22-Oct-03 BE & & $0.0106 \mathrm{p}$ & & 0.0011 & 0.0022 & & & \\
\hline $\begin{array}{l}\text { SESPMNT } \\
\text { SESPMNT }\end{array}$ & B17R33 & BASIN CITY SCHOOL & COMMUNITY & AT & 05-Nov-03 BE & & $0.0211 \mathrm{p}$ & Cilm3 & 0.0014 & 0.0039 & & & \\
\hline $\begin{array}{l}\text { SESPMNT } \\
\text { SESPMNT }\end{array}$ & $\begin{array}{l}\text { B17R34 } \\
\text { B17835 }\end{array}$ & BASIN CITY SCHOOL & COMMUNITY & AT & 19-Nov-03 BE & & $\begin{aligned} 0.037 \mathrm{p} \\
0.0163\end{aligned}$ & Ci/m3 & 0.0019 & 0.0066 & & & \\
\hline SESPMNT & B17R35 & BASIN CITY SCHOOL & COMMUNITY & AT & 03-Dec-03 BE & & $0.0163 \mathrm{p}$ & $\mathrm{C} / \mathrm{m} 3$ & 0.0015 & 0.0032 & & & \\
\hline $\begin{array}{l}\text { SESPMNT } \\
\text { SECDMNT }\end{array}$ & B17R36 & BASIN CITY SCHOOL & COMMUNITY & AT & 17-Dec-03BE & & $0.0166 \mathrm{p}$ & Ci/m3 & 0.0012 & 0.003 & & & \\
\hline SESPMNT & B17R37 & BASIN CITY SCHOOL & COMMUNITY & AT & 31-Dec-03BE & & $0.0209 \mathrm{p}$ & Ci/m3 & 0.0014 & 0.0039 & & & \\
\hline $\begin{array}{l}\text { SESPMNT } \\
\text { SESPMNT }\end{array}$ & B16821 & BATTELLE COMPLEX & $\begin{array}{l}\text { PERIMETER } \\
\text { PFRIMETER }\end{array}$ & AT & 22-Jan-03 BE & BETA & $0.0306 \mathrm{p}$ & Ci/m3 & 0.0017 & 0.0054 & & & \\
\hline $\begin{array}{l}\text { SESPMNT } \\
\text { SESPMNT }\end{array}$ & $\begin{array}{l}B 16822 \\
B 1623\end{array}$ & $\begin{array}{l}\text { BATTELLE COMPLEX } \\
\text { BATTFIE }\end{array}$ & $\begin{array}{l}\text { PERIMETER } \\
\text { PPRIMETTR }\end{array}$ & AT & $\begin{array}{l}05-F e b-03 \mathrm{BE} \\
\text { 19-Feh-03 } \mathrm{BE}\end{array}$ & EETA & $0.00894 p$ & Cilm3 & $\begin{array}{r}0.001 \\
0.0016\end{array}$ & 0.002 & & & \\
\hline $\begin{array}{l}\text { SESPMNT } \\
\text { SESPMNT }\end{array}$ & 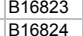 & $\begin{array}{l}\text { BATTELLE COMPLEX } \\
\text { BATTELE COMPLEX }\end{array}$ & $\begin{array}{l}\text { PERIMETER } \\
\text { PERIMETER }\end{array}$ & $\begin{array}{l}\text { AT } \\
\text { AT }\end{array}$ & $\begin{array}{l}\text { 19-Fe-b-033 BE } \\
\text { 05-Mar-03 BE }\end{array}$ & EETA & $\begin{array}{l}0.0243 \mathrm{p} \\
0.0174 \mathrm{p}\end{array}$ & $\begin{array}{l}\text { Cilm3 } \\
\text { Ci/m3 }\end{array}$ & 0.0016 & $\begin{array}{l}0.0044 \\
0.0033\end{array}$ & & & \\
\hline SESPMNT & B16825 & BATTELLE COMPLEX & PERIMETER & AT & 20-Mar-03 BE & EETA & $\begin{array}{l}0.0174 \mathrm{p} \\
0.00803 \mathrm{p}\end{array}$ & $\mathrm{Ci} / \mathrm{m} 3$ & 0.00096 & $\begin{array}{l}0.0033 \\
0.0018\end{array}$ & & & \\
\hline SESPMNT & B16826 & BATTELLE COMPLEX & PERIMETER & AT & 02-Apr-03 BE & SETA & $0.00759 p$ & $\mathrm{Ci} / \mathrm{m} 3$ & 0.0011 & 0.0019 & & & \\
\hline SESPMNT & B16PD5 & BATTELLE COMPLEX & PERIMETER & AT & 16-Apr-03 BE & SETA & $0.0074 p$ & $\mathrm{Ci} / \mathrm{m} 3$ & 0.001 & 0.0018 & & & \\
\hline SESPMNT & B16PD6 & BATTELLE COMPLEX & PERIMETER & AT & 30-Apr-03 BE & SETA & $0.01 \mathrm{p}$ & $\mathrm{C} i / \mathrm{m} 3$ & 0.0012 & 0.0022 & & & \\
\hline SESPMNT & B16PD7 & BATTELLE COMPLEX & PERIMETER & AT & 13-May-03 BE & SETA & $0.0104 p$ & $\mathrm{C} / \mathrm{m} 3$ & 0.0011 & 0.0022 & & & \\
\hline SESPMNT & B16PD8 & BATTELLE COMPLEX & PERIMETER & AT & 28-May-03 BE & & $0.00898 p$ & & 0.001 & 0.002 & & & \\
\hline SESPMNT & B16PD9 & BATTELLE COMPLEX & PERIMETER & AT & 12-Jun-03 BE & BETA & $0.0139 \mathrm{p}$ & $\mathrm{C} / \mathrm{m} 3$ & 0.0012 & 0.0027 & & & \\
\hline $\begin{array}{l}\text { SESPMNT } \\
\end{array}$ & B16PF0 & BATTELLE COMPLEX & PERIMETER & AT & 25-Jun-03 BE & BETA & $0.0119 \mathrm{p}$ & Ci/m3 & 0.0011 & 0.0022 & & & \\
\hline SESPMNT & B16PF1 & BATTELLE COMPLEX & PERIMETER & AT & 10-Jul-03 BE & BETA & $0.0101 \mathrm{p}$ & Ci/m3 & 0.0011 & 0.0021 & & & \\
\hline $\begin{array}{l}\text { SESPMNT } \\
\text { SESPMNT }\end{array}$ & B17585 & BATTELLE COMPLEX & PERIMETER & AT & 23-Jul-03 BE & SETA & $0.0119 p$ & Ci/m3 & 0.0013 & 0.0025 & & & \\
\hline $\begin{array}{l}\text { SESPMNT } \\
\text { SESPMNT }\end{array}$ & $\begin{array}{l}\text { B175B6 } \\
\text { B1757 }\end{array}$ & BATTELLE COMPLEX & $\begin{array}{l}\text { PERIMETER } \\
\text { PFRIMETER }\end{array}$ & AT & 08-Aug-03 BE & BETA & $0.0145 p$ & Ci/m3 & 0.0011 & 0.0028 & & & \\
\hline $\begin{array}{l}\text { SESPMNT } \\
\text { SESPMNT }\end{array}$ & $\begin{array}{l}\text { B17557 } \\
\text { B175888 }\end{array}$ & $\begin{array}{l}\text { BAATELLE COMPLEX } \\
\text { BATTELE COMPLEX }\end{array}$ & $\begin{array}{l}\text { PERIMETER } \\
\text { PERIMETER }\end{array}$ & $\begin{array}{l}\text { AT } \\
\text { AT }\end{array}$ & $\begin{array}{l}\text { 20-Aug-033BE } \\
\text { 03-Sep-03BBE }\end{array}$ & EETA & $\begin{array}{rl}0.013 p & p \\
0.0147 & \end{array}$ & Cil/m3 & 0.0013 & 0.0027 & & & \\
\hline $\begin{array}{l}\text { SESPMNT } \\
\text { SESPMNT }\end{array}$ & $\begin{array}{l}\begin{array}{l}B 175 B 8 \\
B 175 B 9\end{array} \\
\text { B. }\end{array}$ & $\begin{array}{l}\text { BATTELLE COMPLEX } \\
\text { BATTELLE COMPLEX }\end{array}$ & $\begin{array}{l}\text { PERIMEETER } \\
\text { PERIMETER }\end{array}$ & $\begin{array}{l}\text { AT } \\
\text { AT }\end{array}$ & $\begin{array}{l}\text { 03-Sep-03BE } \\
\text { 17-Sep-03 BE }\end{array}$ & $\begin{array}{l}\text { SETA } \\
\text { SETA }\end{array}$ & $\begin{array}{l}0.0147 \mathrm{p} \\
0.0141 \mathrm{p}\end{array}$ & $\begin{array}{l}\mathrm{C} \text { Cim3 } \\
\mathrm{CDi} / \mathrm{m} 3\end{array}$ & 0.0012 & $\begin{array}{l}0.0029 \\
0.0028\end{array}$ & & & \\
\hline SESPMNT & B175C0 & BATTELLE COMPLEX & PERIMETER & AT & 30-Sep-03 BE & EETA & $0.0144 \mathrm{p}$ & $\mathrm{Ci} / \mathrm{m} 3$ & 0.0013 & $\begin{array}{l}0.0028 \\
0.0029\end{array}$ & & & \\
\hline SESPMNT & B17NY8 & BATTELLE COMPLEX & PERIMETER & AT & 15-Oct-03 BE & SETA & $0.0263 \mathrm{p}$ & $\mathrm{Ci} / \mathrm{m} 3$ & 0.0015 & 0.0047 & & & \\
\hline SESPMNT & B17NY9 & BATTELLE COMPLEX & PERIMETER & AT & 29-0ct-03 BE & SETA & $0.0125 \mathrm{p}$ & $\mathrm{C} \mathrm{C} / \mathrm{m} 3$ & 0.0012 & 0.0026 & & & \\
\hline SESPMNT & B17P00 & BATTELLE COMPLEX & PERIMETER & AT & 12-Nov-03 BE & SETA & $0.0384 \mathrm{p}$ & $\mathrm{C} / \mathrm{m} 3$ & 0.0018 & 0.0064 & & & \\
\hline SESPMNT & B17P01 & BATTELLE COMPLEX & PERIMETER & AT & 25-Nov-03 BE & BETA & $0.0183 p$ & Cilm3 & 0.0014 & 0.0035 & & & \\
\hline SESPMNT & B17P02 & BATTELLE COMPLEX & PERIMETER & AT & 12-Dec-03 BE & SETA & $0.0147 \mathrm{p}$ & Ci/m3 & 0.0011 & 0.0028 & & & \\
\hline SESPMNT & B17P03 & BATTELLE COMPLEX & PERIMETER & AT & 23-Dec-03 BE & BETA & $0.0229 \mathrm{p}$ & Ci/m3 & 0.0016 & 0.004 & & & \\
\hline $\begin{array}{l}\text { SESPMNT } \\
\text { SECDMNT }\end{array}$ & B17P04 & BATTELLE COMPLEX & PERIMETER & AT & 08-Jan-04 BE & SETA & $0.0199 \mathrm{p}$ & Ci/m3 & 0.0013 & 0.0036 & & & \\
\hline $\begin{array}{l}\text { SESPMNT } \\
\text { SESPMNT }\end{array}$ & B16828 & BENTON CITY & COMMUNITY & AT & 23-Jan-03 BE & SETA & $0.0291 \mathrm{p}$ & Ci/m3 & 0.0017 & 0.0052 & & & \\
\hline $\begin{array}{l}\text { SESPMNT } \\
\text { SESPMNT }\end{array}$ & B16829 & BENTON CITY & COMMUNITY & AT & 06-Feb-03 BE & BETA & $0.00659 p$ & Cilm3 & 0.00094 & 0.0016 & & & \\
\hline $\begin{array}{l}\text { SESPMNT } \\
\text { SESPMNT }\end{array}$ & $\begin{array}{l}816830 \\
B 1631\end{array}$ & $\begin{array}{l}\text { BENTON CITY } \\
\text { BENTON CITY }\end{array}$ & $\begin{array}{l}\text { COMMUNITY } \\
\text { COMMUNTY }\end{array}$ & AT & 20-Feb-03 BE & EETA & $0.02 p$ & Ci/m3 & 0.0015 & 0.0038 & & & \\
\hline $\begin{array}{l}\text { SESPMNI } \\
\text { SESPMNT }\end{array}$ & 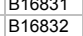 & $\begin{array}{l}\text { BENION CIIY } \\
\text { BENTON CITY }\end{array}$ & $\begin{array}{l}\text { COMMUNIIY } \\
\text { COMMUITY }\end{array}$ & AT & $\begin{array}{l}\text { O6-Mar-03BE } \\
\text { 21-Mar-03 BE }\end{array}$ & $\begin{array}{l}\text { SETA } \\
\text { SETA }\end{array}$ & $\begin{array}{l}0.00111 \mathrm{p} \\
0.0583 \mathrm{p}\end{array}$ & 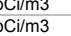 & $\begin{array}{r}0.00033 \\
0.0089\end{array}$ & $\begin{array}{l}0.0029 \\
0.0015\end{array}$ & & & \\
\hline SESPMNT & B16833 & BENTON CITY & COMMUNITY & AT & 03-Apr-03 BE & EETA & $0.00894 \mathrm{p}$ & & 0.0012 & 0.0021 & & & \\
\hline SESPMNT & B16PF3 & BENTON CITY & COMMUNITY & AT & 18-Apr-03 BE & SETA & $0.00843 p$ & $\mathrm{Ci} / \mathrm{m} 3$ & 0.001 & 0.0019 & & & \\
\hline SESPMNT & B16PF4 & BENTON CITY & COMMUNITY & AT & 01-May-03 BE & SETA & $0.00837 p$ & & 0.0011 & 0.002 & & & \\
\hline SESPMNT & B16PF5 & BENTON CITY & COMMUNITY & AT & 16-May-03 BE & SETA & $0.0102 p$ & & 0.001 & 0.0021 & & & \\
\hline SESPMNT & B16PF6 & BENTON CITY & COMMUNITY & AT & 30-May-03 BE & SETA & $0.0103 p$ & $\mathrm{C} / \mathrm{m} 3$ & 0.0012 & 0.0022 & & & \\
\hline SESPMNT & B16PF7 & BENTON CITY & COMMUNITY & AT & 13-Jun-03 BE & BETA & $0.0131 \mathrm{p}$ & $\mathrm{C} / \mathrm{m} 3$ & 0.0012 & 0.0026 & & & \\
\hline SESPMNT & B16PF8 & BENTON CITY & COMMUNITY & AT & 26-Jun-03 BE & SETA & $0.00197 p$ & Ci/m3 & 0.00085 & 0.001 & & & \\
\hline SESPMNT & B16PF9 & BENTON CITY & COMMUNITY & AT & 11-Jul-03 BE & BETA & $0.0102 \mathrm{p}$ & Ci/m3 & 0.0011 & 0.0022 & & & \\
\hline SESPMNT & B175C2 & BENTON CITY & COMMUNITY & AT & 24-Jul-03 BE & SETA & $0.0117 \mathrm{p}$ & Ci/m3 & 0.0013 & 0.0025 & & & \\
\hline $\begin{array}{l}\text { SESPMNT } \\
\text { SESPMNT }\end{array}$ & B175C3 & BENTON CITY & COMMUNITY & AT & 07-Aug-03 BE & SETA & $0.0145 p$ & Ci/m3 & 0.0013 & 0.0029 & & & \\
\hline $\begin{array}{l}\text { SESPMNT } \\
\text { SESPMNT }\end{array}$ & $\begin{array}{l}\text { B17554 } \\
\text { B175C5 }\end{array}$ & $\begin{array}{l}\text { BENTON CIIY } \\
\text { BENTON CITY }\end{array}$ & $\begin{array}{l}\text { COMMUNITY } \\
\text { COMMUITY }\end{array}$ & $\begin{array}{l}\text { AT } \\
\text { AT }\end{array}$ & $\begin{array}{l}\text { 22-Aug-03 BE } \\
\text { 05-Sep-03 BE }\end{array}$ & BETA & $0.0159 \mathrm{p}$ & CCi/m3 & 0.0011 & 0.0028 & & NO SAMPLE. MOTOR RUNNING, PUMP NOT, UNKNOWN END FLOW. DO NOT SAVE FOR COMPOSITE. & \\
\hline SESPMNT & B175C6 & BENTON CITY & COMMUNITY & AT & 18-Sep-03 BE & EETA & $0.0107 \mathrm{p}$ & $\mathrm{C} / \mathrm{m} 3$ & 0.0011 & 0.0023 & & 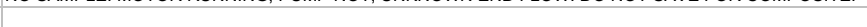 & \\
\hline SESPMNT & B175C7 & BENTON CITY & COMMUNITY & AT & 03-Oct-03 BE & SETA & $0.021 \mathrm{p}$ & $\mathrm{Ci} / \mathrm{m} 3$ & 0.0013 & 0.0036 & & & \\
\hline SESPMNT & B17P06 & BENTON CITY & COMMUNITY & AT & 17-Oct-03 BE & SETA & $0.0186 \mathrm{p}$ & $\mathrm{Ci} / \mathrm{m} 3$ & 0.0014 & 0.0035 & & & \\
\hline SESPMNT & B17P07 & BENTON CITY & COMMUNITY & AT & 30-Oct-03 BE & SETA & $0.0126 \mathrm{p}$ & $\mathrm{Ci} / \mathrm{m} 3$ & 0.0012 & 0.0026 & & & \\
\hline SESPMNT & B17P08 & BENTON CITY & COMMUNITY & AT & 14-Nov-03 BE & SETA & $0.0292 \mathrm{p}$ & $\mathrm{C} \mathrm{i} / \mathrm{m} 3$ & 0.0016 & 0.0051 & & & \\
\hline SESPMNT & B17P09 & BENTON CITY & COMMUNITY & AT & 26-Nov-03 BE & SETA & $0.0175 \mathrm{p}$ & $\mathrm{C} / \mathrm{m} 3$ & 0.0014 & 0.0034 & & & \\
\hline SESPMNT & B17P10 & BENTON CITY & COMMUNITY & AT & 16-Dec-03 BE & BETA & $0.0115 \mathrm{p}$ & Ci/m3 & 0.00091 & 0.0022 & & & \\
\hline SESPMNT & B17P11 & BENTON CITY & COMMUNITY & AT & 29-Dec-03 BE & BETA & $0.0192 \mathrm{p}$ & Ci/m3 & 0.0014 & 0.0036 & & & \\
\hline SESPMNT & B17P12 & BENTON CITY & COMMUNITY & AT & 09-Jan-04 BE & BETA & $0.032 \mathrm{p}$ & $\mathrm{C} / \mathrm{m} 3$ & 0.002 & 0.0059 & & & \\
\hline SESPMNT & B168Y2 & BYERS LANDING & PERIMETER & AT & 16-Jan-03 BE & BETA & $0.0288 \mathrm{p}$ & Ci/m3 & 0.0018 & 0.0052 & & & \\
\hline SESPMNT & B168Y3 & BYERS LANDING & PERIMETER & AT & 30-Jan-03BE $\mathrm{BE}$ & 远 & $0.0168 \mathrm{p}$ & DCi/m3 & 0.0014 & 0.0032 & & & \\
\hline SESPMNT & B168Y4 & $\begin{array}{l}\text { BYERS LANDING } \\
\text { RYFPS }\end{array}$ & PERIMETER & AT & 13-Feb-03 BE & BETA & $0.0175 p$ & Ci/m3 & 0.0014 & 0.0033 & & & \\
\hline SESPMNT & B168Y5 & $\begin{array}{l}\text { YYERS LANDING } \\
\text { BYERS LANDING }\end{array}$ & $\begin{array}{l}\text { PERIMETER } \\
\text { PEPIETER }\end{array}$ & AT & 28-Feb-03 BE & BETA & $0.0228 \mathrm{p}$ & Ci/m3 & 0.0014 & 0.0039 & & & \\
\hline $\begin{array}{l}\text { SESPMNT } \\
\text { SESPMNT }\end{array}$ & $\begin{array}{l}\text { B168Y6 } \\
\text { B1687 }\end{array}$ & $\begin{array}{l}\text { BYRS LANDING } \\
\text { BYERS LANDING }\end{array}$ & $\begin{array}{l}\text { PERIMETER } \\
\text { PERIMETER }\end{array}$ & $\begin{array}{l}\text { AT } \\
\text { AT }\end{array}$ & $\begin{array}{l}\text { 13-Mar-03 BE } \\
\text { 28-Mar-03 BE }\end{array}$ & $\begin{array}{l}\text { EETA } \\
\text { SETA }\end{array}$ & $\begin{array}{l}0.0112 \mathrm{p} \\
0.0058 \mathrm{p}\end{array}$ & $\begin{array}{l}\text { Cilm3 } \\
\text { Ciilm3 }\end{array}$ & 0.0012 & 0.0024 & & & \\
\hline SESPMNT & B168Y7 & BYERS LANDING & PERIMETER & & & & $0.0058 \mathrm{p}$ & Cilm3 & 0.0011 & 0.0016 & & & \\
\hline
\end{tabular}


AIR BETA/ALPHA

\begin{tabular}{|c|c|c|c|c|c|c|c|c|c|c|c|c|}
\hline |OWNER ID & \begin{tabular}{|l|} 
SAMP \\
NAMM
\end{tabular} & SAMP SITE NAME & | DIST CLASS | & MEDIA & \begin{tabular}{c|c} 
& CON \\
& SHORT \\
SAMP DATE & NAME
\end{tabular} & & $\begin{array}{l}\text { ANAL } \\
\text { UNITS } \\
\text { RPTD }\end{array}$ & $\left|\begin{array}{c}\text { COUNTING } \\
\text { ERROR }\end{array}\right|$ & $\begin{array}{c}\text { TOTAL } \\
\text { ANAL } \\
\text { ERROR }\end{array}$ & $\left|\begin{array}{c}\text { LAB } \\
\text { QUALIFIER } \mid\end{array}\right|$ & SAMP COMMENT & $\begin{array}{l}\text { RESULT } \\
\text { COMMENT }\end{array}$ \\
\hline SESPMNT & B168Y8 & BYERS LANDING & PERIMETER & AT & 10-Apr-03 BETA & $0.00659 p$ & & & & & 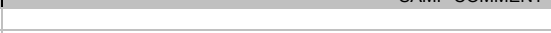 & \\
\hline SESPMNT & B16R84 & BYERS LANDING & PERIMETER & AT & 25-Apr-03 BETA & $0.0105 \mathrm{p}$ & pCilm3 & 0.001 & 0.0021 & & & \\
\hline SESPMNT & B16R85 & BYERS LANDING & PERIMETER & AT & 08-May-03 BETA & $0.00802 p$ & pCi/m3 & 0.0011 & 0.0019 & & & \\
\hline $\begin{array}{l}\text { SESPMNT } \\
\text { SFONT }\end{array}$ & B16R86 & BYERS LANDING & $\begin{array}{l}\text { PERIMETER } \\
\text { DEIMTER }\end{array}$ & AT & 22-May-03 BETA & $0.0097 \mathrm{p}$ & $\mathrm{pC} / \mathrm{m} 3$ & 0.0012 & 0.0023 & & & \\
\hline SESPMNT & B16R87 & BYERS LANDING & $\begin{array}{l}\text { PERIMETER } \\
\end{array}$ & AT & 06-Jun-03 BETA & $0.0135 p$ & $\mathrm{pCi} / \mathrm{m} 3$ & 0.0012 & 0.0026 & & & \\
\hline SESPMNT & B16R88 & BYERS LANDING & PERIMETER & AT & 19-Jun-03 BETA & $0.0141 p$ & pCi/m3 & 0.0014 & 0.0029 & & & \\
\hline SESPMNT & B16R89 & BYERS LANDING & PERIMETER & AT & 07-Jul-03 BETA & $0.00975 p$ & pCi/m3 & 0.001 & 0.002 & & & \\
\hline SESPMNT & B17662 & BYERS LANDING & PERIMETER & AT & 18-Jul-03 BETA & $0.011 \mathrm{p}$ & pCi/m3 & 0.0013 & 0.0025 & & & \\
\hline SESPMNT & B17663 & BYERS LANDING & PERIMETER & AT & 31-Jul-03 BETA & $0.014 \mathrm{p}$ & pCi/m3 & 0.0013 & 0.0028 & & & \\
\hline $\begin{array}{l}\text { SESPMNT } \\
\text { SECDMNT }\end{array}$ & B17664 & BYERS LANDING & PERIMETER & AT & 15-Aug-03 BETA & $0.0137 \mathrm{p}$ & & 0.0012 & 0.0027 & & & \\
\hline SESPMNT & B17665 & BYERS LANDING & PERIMETER & AT & 28-Aug-03 BETA & $0.014 p$ & & 0.0013 & 0.0029 & & & \\
\hline $\begin{array}{l}\text { SESPMNT } \\
\text { SESPMNT }\end{array}$ & $\begin{array}{l}\text { B17666 } \\
\text { B17667 }\end{array}$ & $\begin{array}{l}\text { BYERS LANDING } \\
\text { BYERS }\end{array}$ & $\begin{array}{l}\text { PERIMETER } \\
\text { PFRIMETER }\end{array}$ & AT & 12-Sep-03 BETA & $0.0153 \mathrm{p}$ & pCi/m3 & 0.0012 & 0.003 & & & \\
\hline $\begin{array}{l}\text { SESPMNT } \\
\text { SESPMNT }\end{array}$ & $\begin{array}{l}B 17667 \\
B 1768\end{array}$ & $\begin{array}{l}\text { BYERS LANDING } \\
\text { BYERSIANDNG }\end{array}$ & $\begin{array}{l}\text { PERIMETER } \\
\text { PFRIMETER }\end{array}$ & AT & 25-Sep-03 BETA & & & & & & NO SAMPLE. SAVE FOR COMPOSITE. & \\
\hline $\begin{array}{l}\text { SESPMNT } \\
\text { SESPMNT }\end{array}$ & 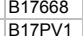 & $\begin{array}{l}\text { 林RS LANDDNG } \\
\text { BYERS LANDING }\end{array}$ & $\begin{array}{l}\text { PERIMETER } \\
\text { PERIMETER }\end{array}$ & $\begin{array}{l}\text { AT } \\
\text { AT }\end{array}$ & $\begin{array}{l}\text { 10-Oct--03 BETA } \\
\text { 23-Ot-03 BETA }\end{array}$ & $0.0266 \mathrm{p}$ & pCim3 & 0.0015 & 0.0048 & & & \\
\hline SESPMNT & $\begin{array}{ll}\text { B17PV2 } \\
\text { B17PV }\end{array}$ & $\begin{array}{l}\text { BYERS LANDDNG } \\
\text { BYERS LANDING }\end{array}$ & $\begin{array}{l}\text { PERIMEIER } \\
\text { PERIMETER }\end{array}$ & AT & $\begin{array}{l}\text { 23-OCt-03 BEIA } \\
\text { 07-Nov-03 BETA }\end{array}$ & $\begin{array}{l}0.0111 \\
0.0249 \mathrm{p}\end{array}$ & $\begin{array}{l}\mathrm{plClm3} \\
\mathrm{pCi} / \mathrm{m} 3\end{array}$ & $\begin{array}{l}0.0012 \\
0.0014\end{array}$ & $\begin{array}{l}0.0024 \\
0.0044\end{array}$ & & & \\
\hline SESPMNT & B17PV3 & BYERS LANDING & PERIMETER & AT & 21-Nov-03 BETA & $0.0249 \mathrm{p}$ & pCilm3 & 0.0015 & 0.0045 & & & \\
\hline SESPMNT & B17PV4 & BYERS LANDING & PERIMETER & AT & 05-Dec-03 BETA & $0.0149 \mathrm{p}$ & pCilm3 & 0.0012 & 0.0029 & & & \\
\hline SESPMNT & B17PV5 & BYERS LANDING & PERIMETER & AT & 19-Dec-03 BETA & $0.0159 \mathrm{p}$ & pCi/m3 & 0.0012 & 0.0028 & & & \\
\hline SESPMNT & B17PV6 & BYERS LANDING & PERIMETER & AT & 05-Jan-04 BETA & $0.0201 \mathrm{p}$ & pCi/m3 & 0.0013 & 0.0037 & & & \\
\hline SESPMNT & B168X4 & DOGWOOD MET TOWER & PERIMETER & AT & 16-Jan-03 BETA & $0.0214 \mathrm{p}$ & pCi/m3 & 0.0016 & 0.004 & & & \\
\hline SESPMNT & B168X5 & DOGWOOD MET TOWER & PERIMETER & AT & 30-Jan-03 BETA & $0.0138 \mathrm{p}$ & pCi/m3 & 0.0013 & 0.0027 & & & \\
\hline SESPMNT & B168X6 & DOGWOOD MET TOWER & PERIMETER & AT & 13-Feb-03 BETA & $0.015 \mathrm{p}$ & pCilm3 & 0.0014 & 0.003 & & & \\
\hline SESPMNT & B168X7 & DOGWOOD MET TOWER & PERIMETER & AT & 28-Feb-03 BETA & $0.0208 \mathrm{p}$ & pCi/m3 & 0.0013 & 0.0036 & & & \\
\hline SESPMNT & B168X8 & DOGWOOD MET TOWER & PERIMETER & AT & 13-Mar-03 BETA & $0.0102 \mathrm{p}$ & pCi/m3 & 0.0011 & 0.0022 & & & \\
\hline $\begin{array}{l}\text { SESPMNT } \\
\text { SESPMNT }\end{array}$ & $\begin{array}{l}\text { B16889 } \\
\text { B16890 }\end{array}$ & DOGWOOD MET TOWER & $\begin{array}{l}\text { PERIMETER } \\
\text { PFRIMETER }\end{array}$ & AT & $\begin{array}{l}\text { 28-Mar-03 BETA } \\
\text { 10-Añ-03 BETA }\end{array}$ & $0.00669 p$ & pCim3 & 0.00091 & 0.0016 & & & \\
\hline $\begin{array}{l}\text { SESPMNT } \\
\text { SESPMNT }\end{array}$ & $\begin{array}{l}\text { B16880 } \\
\text { B16777 }\end{array}$ & $\begin{array}{l}\text { DOGWOOD MET TOWER } \\
\text { DOGWOOD MET TOWER }\end{array}$ & $\begin{array}{l}\text { PERIMETER } \\
\text { PERIMETER }\end{array}$ & $\begin{array}{l}\text { AT } \\
\text { AT }\end{array}$ & $\begin{array}{l}\text { 10-Apr-03 BETA } \\
\text { 25-Ar--03 BETA }\end{array}$ & $0.00634 \mathrm{p}$ & pCim3 & $\begin{array}{l}0.001 \\
0.01\end{array}$ & 0.0017 & & & \\
\hline $\begin{array}{l}\text { SESPMNT } \\
\text { SESPMNT }\end{array}$ & $\begin{array}{l}\text { B16R77 } \\
\text { B16R78 }\end{array}$ & $\begin{array}{l}\text { DOGWOOD MET TOWER } \\
\text { DOGWOOD MET TOWER }\end{array}$ & $\begin{array}{l}\text { PERIMEETER } \\
\text { PERIMETER }\end{array}$ & $\begin{array}{l}\text { AT } \\
\text { AT }\end{array}$ & $\begin{array}{l}\text { 25-App--33 BETA } \\
\text { 08-May-03 BETA }\end{array}$ & $\begin{array}{l}0.00991 \mathrm{p} \\
0.0082 \mathrm{p}\end{array}$ & $\begin{array}{l}\frac{p \mathrm{pC} / m 3}{\mathrm{pCi} 3 \mathrm{~m} 3} \\
\mathrm{p}\end{array}$ & $\begin{array}{r}0.001 \\
0.0011\end{array}$ & $\begin{array}{r}0.0021 \\
0.002\end{array}$ & & & \\
\hline SESPMNT & B16R79 & DOGWOOD MET TOWER & PERIMETER & AT & 22-May-03 BETA & $0.0104 \mathrm{p}$ & $\mathrm{pC} / \mathrm{m} 3$ & 0.0013 & $\begin{array}{l}0.002 \\
0.0023\end{array}$ & & & \\
\hline SESPMNT & B16R80 & DOGWOOD MET TOWER & PERIMETER & AT & 06-Jun-03 BETA & $0.014 \mathrm{p}$ & pCilm3 & 0.0012 & 0.0028 & & & \\
\hline SESPMNT & B16R81 & DOGWOOD MET TOWER & PERIMETER & AT & 19-Jun-03 BETA & $0.0114 p$ & pCi/m3 & 0.0012 & 0.0024 & & & \\
\hline SESPMNT & B16R82 & DOGWOOD MET TOWER & PERIMETER & AT & 07-Jul-03 BETA & $0.00765 p$ & pCi/m3 & 0.00094 & 0.0017 & & & \\
\hline SESPMNT & B17654 & DOGWOOD MET TOWER & PERIMETER & AT & 18-Jul-03 BETA & $0.0102 p$ & pCi/m3 & 0.0014 & 0.0024 & & & \\
\hline SESPMNT & B17655 & DOGWOOD MET TOWER & PERIMETER & AT & 31-Jul-03 BETA & $0.0142 \mathrm{p}$ & pCi/m3 & 0.0013 & 0.0028 & & & \\
\hline SESPMNT & B17656 & DOGWOOD MET TOWER & PERIMETER & AT & 15-Aug-03 BETA & $0.0127 \mathrm{p}$ & pCi/m3 & 0.0011 & 0.0025 & & & \\
\hline SESPMNT & B17657 & DOGWOOD MET TOWER & PERIMETER & AT & 28-Aug-03 BETA & $0.0131 \mathrm{p}$ & pCilm3 & 0.0012 & 0.0027 & & & \\
\hline $\begin{array}{l}\text { SESPMNT } \\
\text { SESPMNT }\end{array}$ & B17658 & DOGWOOD MET TOWER & PERIMETER & AT & 12-Sep-03 BETA & $0.0156 \mathrm{p}$ & pCi/m3 & 0.0012 & 0.003 & & & \\
\hline $\begin{array}{l}\text { SESPMNT } \\
\text { SESPMNT }\end{array}$ & B17659 & DOGWOOD MET TOWER & $\begin{array}{l}\text { PERIMETER } \\
\text { PEPIMETER }\end{array}$ & AT & 25-Sep-03 BETA & $0.0114 p$ & pCilm3 & 0.0012 & 0.0024 & & & \\
\hline $\begin{array}{l}\text { SESPMNT } \\
\text { SESPMNT }\end{array}$ & $\begin{array}{l}\text { B17660 } \\
\text { B17PT4 }\end{array}$ & DOGWOOD MET TOWER & $\begin{array}{l}\text { PERIMETER } \\
\text { PERIMETER }\end{array}$ & AT & $\begin{array}{l}\text { 10-Oct-03 BETA } \\
\text { 23-Oct-03 BETA }\end{array}$ & $\begin{array}{r}0.0262 \mathrm{p} \\
0.00906 \mathrm{p}\end{array}$ & pCim3 & 0.0015 & 0.0047 & & & \\
\hline $\begin{array}{l}\text { SESPMNT } \\
\text { SESPMNT }\end{array}$ & 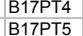 & $\begin{array}{l}\text { DOGWOOD MET TOWER } \\
\text { DOGWOOD MET TOWER }\end{array}$ & $\begin{array}{l}\text { PERIMETER } \\
\text { PERIMETER }\end{array}$ & $\begin{array}{l}\text { AT } \\
\text { AT }\end{array}$ & $\begin{array}{l}\text { 23-Oct-03 BETA } \\
\text { 07-Nov-03 BETA }\end{array}$ & $\begin{array}{l}0.00906 \mathrm{p} \\
0.0234 \mathrm{p}\end{array}$ & $\begin{array}{l}\mathrm{pCi/m3} \\
\mathrm{pCi} / \mathrm{m} 3\end{array}$ & 0.0011 & $\begin{array}{l}0.0021 \\
0.0043\end{array}$ & & & \\
\hline $\begin{array}{l}\text { SESPMNI } \\
\text { SESPMNT }\end{array}$ & $\begin{array}{l}\text { B1/17P5 } \\
\text { B17PT6 }\end{array}$ & $\begin{array}{l}\text { DOGWOOD MET TOWER } \\
\text { DOGWOOD MET TOWER }\end{array}$ & $\begin{array}{l}\text { PERIMEIER } \\
\text { PERIMETER }\end{array}$ & AT & $\begin{array}{l}\text { 7)-Nov-03 BEIA } \\
\text { 21-Nov-03 BETA }\end{array}$ & $\begin{array}{l}0.0234 \mathrm{p} \\
0.0251 \mathrm{p}\end{array}$ & $\begin{array}{l}\mathrm{plClm3} \\
\mathrm{pCi} / \mathrm{m} 3\end{array}$ & $\begin{array}{l}0.0015 \\
0.0016\end{array}$ & 0.0043 & & & \\
\hline SESPMNT & B17PT7 & DOGWOOD MET TOWER & PERIMETER & AT & 05-Dec-03 BETA & $0.0126 \mathrm{p}$ & pCi/m3 & 0.0012 & 0.0026 & & & \\
\hline SESPMNT & B17PT8 & DOGWOOD MET TOWER & PERIMETER & AT & 19-Dec-03 BETA & $0.0117 p$ & pCi/m3 & 0.001 & 0.0021 & & ICE ON FILTER. & \\
\hline SESPMNT & B17PT9 & DOGWOOD MET TOWER & PERIMETER & AT & 05-Jan-04 BETA & $0.0177 p$ & pCi/m3 & 0.0012 & 0.0032 & & & \\
\hline SESPMNT & B16979 & EDWIN MARKHAM SCHOOL & COMMUNITY & AT & 15-Jan-03 BETA & $0.0275 p$ & pCi/m3 & 0.0016 & 0.0049 & & & \\
\hline SESPMNT & B16980 & EDWIN MARKHAM SCHOOL & COMMUNITY & AT & 29-Jan-03 BETA & $0.0195 p$ & pCi/m3 & 0.0015 & 0.0036 & & & \\
\hline $\begin{array}{l}\text { SESPMNT } \\
\end{array}$ & B16981 & EDWIN MARKHAM SCHOOL & COMMUNITY & AT & 12-Feb-03 BETA & $0.0176 \mathrm{p}$ & pCi/m3 & 0.0014 & 0.0033 & & & \\
\hline SESPMNT & B16982 & EDWIN MARKHAM SCHOOL & COMMUNITY & AT & 26-Feb-03 BETA & $0.0221 \mathrm{p}$ & pCilm3 & 0.0014 & 0.0038 & & & \\
\hline SESPMNT & B16983 & EDWIN MARKHAM SCHOOL & COMMUNITY & AT & 12-Mar-03 BETA & $0.014 \mathrm{p}$ & pCi/m3 & 0.0012 & 0.0028 & & & \\
\hline $\begin{array}{l}\text { SESPMNT } \\
\text { SESPMNT }\end{array}$ & B16984 & EDWIN MARKHAM SCHOOL & COMMUNITY & AT & 26-Mar-03 BETA & $0.00958 \mathrm{p}$ & pCim3 & 0.0011 & 0.0021 & & & \\
\hline $\begin{array}{l}\text { SESPMNT } \\
\text { SESPMNT }\end{array}$ & B16985 & EDWIN MARKHAM SCHOOL & COMMUNITY & AT & 10-Apr-03 BETA & $0.00693 p$ & pCi/m3 & 0.0009 & 0.0016 & & & \\
\hline $\begin{array}{l}\text { SESPMNT } \\
\text { SESPMNT }\end{array}$ & $\begin{array}{l}\text { B16RK9 } \\
\text { B16R0 }\end{array}$ & EDWIN MARKHAM SCHOOL & $\begin{array}{l}\text { COMMUNIIY } \\
\text { COMMUNTY }\end{array}$ & $\begin{array}{l}\text { AT } \\
\text { AT }\end{array}$ & $\begin{array}{l}\text { 23-Apr-03 BETA } \\
07 \text { BMav-03 BETA }\end{array}$ & 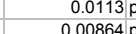 & $\begin{array}{l}\mathrm{pC} \text { Cim3 } \\
\mathrm{p} \text { Cimm3 }\end{array}$ & $\begin{aligned} 0.0013 \\
0.001\end{aligned}$ & 0.0024 & & & \\
\hline $\begin{array}{l}\text { SESPMNT } \\
\text { SESPMNT }\end{array}$ & 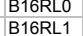 & $\begin{array}{l}\text { EDWIN MARKHAM SCHOOL } \\
\text { EDWIN MARKHAM SCHOOL }\end{array}$ & $\begin{array}{l}\text { COMMUNITY } \\
\text { COMMUITY }\end{array}$ & $\begin{array}{l}\text { AT } \\
\text { AT }\end{array}$ & $\begin{array}{l}\text { 71-May-03 BETA } \\
\text { 21-May-03 BETA }\end{array}$ & $\begin{array}{r}0.00684 \mathrm{p} \\
0.0105 \mathrm{p}\end{array}$ & $\begin{array}{l}\text { pilm3 } \\
\text { pCi/m3 }\end{array}$ & $\begin{array}{r}0.001 \\
0.0011\end{array}$ & $\begin{array}{l}0.0019 \\
0.0022\end{array}$ & & & \\
\hline SESPMNT & B16RL2 & EDWIN MARKHAM SCHOOL & COMMUNITY & AT & 04-Jun-03 BETA & $0.0124 \mathrm{p}$ & pCilm3 & 0.0012 & 0.0025 & & & \\
\hline SESPMNT & B16RL3 & EDWIN MARKHAM SCHOOL & COMMUNITY & AT & 18-Jun-03 BETA & $0.0127 \mathrm{p}$ & pCilm3 & 0.0013 & 0.0026 & & & \\
\hline SESPMNT & B16RL4 & EDWIN MARKHAM SCHOOL & COMMUNITY & AT & 02-Jul-03 BETA & $0.00895 \mathrm{p}$ & pCi/m3 & 0.0011 & 0.002 & & & \\
\hline SESPMNT & B176H9 & EDWIN MARKHAM SCHOOL & COMMUNITY & AT & 16-Jul-03 BETA & $0.0108 \mathrm{p}$ & pCi/m3 & 0.0011 & 0.0023 & & & \\
\hline SESPMNT & B176J0 & EDWIN MARKHAM SCHOOL & COMMUNITY & AT & 30-Jul-03 BETA & $0.0136 \mathrm{p}$ & pCi/m3 & 0.0012 & 0.0027 & & & \\
\hline SESPMNT & B176J1 & EDWIN MARKHAM SCHOOL & COMMUNITY & AT & 13-Aug-03 BETA & $0.0144 \mathrm{p}$ & pCi/m3 & 0.0012 & 0.0028 & & & \\
\hline SESPMNT & B176J2 & EDWIN MARKHAM SCHOOL & COMMUNITY & AT & 27-Aug-03 BETA & $0.0148 \mathrm{p}$ & pCi/m3 & 0.0013 & 0.0029 & & & \\
\hline SESPMNT & B176J33 & EDWIN MARKHAM SCHOOL & COMMUNITY & AT & 10-Sep-03 BETA & $0.0181 \mathrm{p}$ & pCilm3 & 0.0014 & 0.0035 & & & \\
\hline SESPMNT & B176J4 & EDWIN MARKHAM SCHOOL & COMMUNITY & AT & 24-Sep-03 BETA & $0.0109 p$ & pCi/m3 & 0.0011 & 0.0023 & & & \\
\hline $\begin{array}{l}\text { SESPMNT } \\
\text { SESDMNT }\end{array}$ & B176J5 & EDWIN MARKHAM SCHOOL & COMMUNITY & AT & 08-Oct-03 BETA & $0.0306 \mathrm{p}$ & pCim3 & 0.0017 & 0.0055 & & & \\
\hline SESPMNT & B17R46 & EDWIN MARKHAM SCHOOL & COMMUNITY & AT & $\begin{array}{l}\text { 22-Oct-03 BETA } \\
\text { 05-Noy-03 BETA }\end{array}$ & $0.0116 \mathrm{p}$ & pCi/m3 & 0.0012 & 0.0024 & & & \\
\hline $\begin{array}{l}\text { SESPMNT } \\
\text { SESPMNT }\end{array}$ & $\begin{array}{l}\text { B17R474 } \\
\text { B17448 }\end{array}$ & $\begin{array}{l}\text { EDWIN MARKHAM SCHOOLL } \\
\text { EDWIIKKHAM SCHOOOL }\end{array}$ & $\begin{array}{l}\text { COMMUNNTY } \\
\text { COMMUITY }\end{array}$ & $\begin{array}{l}\text { AT } \\
\text { AT }\end{array}$ & $\begin{array}{l}\text { 05-Nov-03 BETA } \\
\text { 19-Nov-03 BETA }\end{array}$ & $\begin{array}{l}0.0209 \mathrm{p} \\
0.0328 \mathrm{p}\end{array}$ & $\begin{array}{l}\mathrm{pCC/m3} \\
\mathrm{pCi} / \mathrm{m} 3\end{array}$ & 0 & 0.0038 & & & \\
\hline SESPMNT & B17R48 & EDWN MARKHAM SCHOOL & & & 19-Nov-03 BETA & $0.0328 \mathrm{p}$ & & 0.0018 & 0.0057 & & & \\
\hline
\end{tabular}


AIR BETA/ALPHA

\begin{tabular}{|c|c|c|c|c|c|c|c|c|c|c|c|c|c|}
\hline |OWNER ID & $\mid \begin{array}{l}\text { SAMP } \\
\text { NUM }\end{array}$ & SAMP SITE NAME & $\mid$ DIST CLASS $\mid$ & MEDIA & SAMP DATE & $\begin{array}{l}\text { CON } \\
\text { SHORT } \\
\text { NAME }\end{array}$ & VALUE RPTD & $\begin{array}{l}\text { ANAL } \\
\text { UNITS } \\
\text { RPTD }\end{array}$ & $\left|\begin{array}{c}\text { COUNTING } \\
\text { ERROR }\end{array}\right|$ & \begin{tabular}{c|c} 
TOTAL \\
ANAL \\
ERROR
\end{tabular} & $\begin{array}{c}\text { LAB } \\
\text { QUALIFIER }\end{array}$ & SAMP COMMENT & $\begin{array}{l}\text { RESULT } \\
\text { COMMENT }\end{array}$ \\
\hline SESPMNT & B17R49 & EDWIN MARKHAM SCHOOL & COMMUNITY & AT & 03-Dec-03E & BETA & $0.0147 \mathrm{p}$ & $\mathrm{C} i / m 3$ & 0.0013 & 0.0029 & & & \\
\hline SESPMNT & B17R50 & EDWIN MARKHAM SCHOOL & COMMUNITY & AT & 17-Dec-03 & BETA & $0.0152 \mathrm{p}$ & $\mathrm{Ci} / \mathrm{m} 3$ & 0.0012 & 0.0027 & & & \\
\hline SESPMNT & B17R51 & EDWIN MARKHAM SCHOOL & COMMUNITY & AT & 31-Dec-03 E & BETA & $0.0208 \mathrm{p}$ & $\mathrm{C} / \mathrm{m} 3$ & 0.0014 & 0.0038 & & & \\
\hline $\begin{array}{l}\text { SESPMNT } \\
\text { SESPMNT }\end{array}$ & B16993 & HANFORD TOWNSITE & ONSITE & AT & 21-Jan-03 E & BETA & $0.0339 \mathrm{p}$ & $\mathrm{C} / \mathrm{m} 3$ & 0.0018 & 0.006 & & & \\
\hline $\begin{array}{l}\text { SESPMNT } \\
\text { SESPMNT }\end{array}$ & B16994 & HANFORD TOWNSITE & ONSITE & AT & 04-Feb-03E & BETA & $0.00997 \mathrm{p}$ & Ci/m3 & 0.0011 & 0.0021 & & & \\
\hline $\begin{array}{l}\text { SESPMNT } \\
\text { SESPMNT }\end{array}$ & $\begin{array}{l}\text { B16995 } \\
\text { B1696 }\end{array}$ & $\begin{array}{l}\text { HANFFRD TOWNSITE } \\
\text { HAFFORD TOWNITE }\end{array}$ & ONSITE & AT & 18-Feb-03 E & BETA & $0.0238 \mathrm{p}$ & CCi/m3 & 0.0015 & 0.0044 & & & \\
\hline SESPMNT & B16997 & HANFORD TOWNSITE & ONSITE & AT & 18-Mar-03 E & & $0.00567 \mathrm{p}$ & Cim3 & $\begin{array}{l}0.00087 \\
0.0087\end{array}$ & $\begin{array}{l}0.0035 \\
0.0014\end{array}$ & & & \\
\hline SESPMNT & B16998 & HANFORD TOWNSITE & ONSITE & AT & 31-Mar-03 E & & $0.00613 \mathrm{p}$ & & 0.00097 & 0.0016 & & & \\
\hline SESPMNT & B16RM3 & HANFORD TOWNSITE & ONSITE & AT & 15-Apr-03E & & $0.00756 \mathrm{p}$ & & 0.001 & 0.0018 & & & \\
\hline SESPMNT & B16RM4 & HANFORD TOWNSITE & ONSITE & AT & 29-Apr-03 & & $0.0071 \mathrm{p}$ & & 0.0011 & 0.0018 & & & \\
\hline SESPMNT & B16RM5 & HANFORD TOWNSITE & ONSITE & AT & 12-May-03 & & & $\mathrm{Ci} / \mathrm{m} 3$ & 0.0011 & 0.0022 & & & \\
\hline SESPMNT & B16RM6 & HANFORD TOWNSITE & ONSITE & AT & 29-May-03 & & $0.0107 \mathrm{p}$ & & 0.00099 & 0.0021 & & & \\
\hline SESPMNT & B16RM7 & HANFORD TOWNSITE & ONSITE & AT & 11-Jun-03 & & $0.0154 \mathrm{p}$ & & 0.0014 & 0.003 & & & \\
\hline SESPMNT & B16RM8 & HANFORD TOWNSITE & ONSITE & AT & 24-Jun-03 E & & $0.0101 p$ & & 0.0012 & 0.0022 & & & \\
\hline SESPMNT & B16RM9 & HANFORD TOWNSITE & ONSITE & AT & 08-Jul-03 E & & $0.0123 p$ & & 0.0013 & 0.0025 & & & \\
\hline SESPMNT & B176K3 & HANFORD TOWNSITE & ONSITE & AT & 22-Jul-03 E & & & & 0.0012 & 0.0025 & & & \\
\hline $\begin{array}{l}\text { SESPMNT } \\
\text { SESPMNT }\end{array}$ & B176K4 & HANFORD TOWNSITE & ONSITE & AT & 04-Aug-03 E & & $0.0143 p$ & & 0.0013 & 0.0029 & & & \\
\hline $\begin{array}{l}\text { SESPMNT } \\
\text { SESPMNT }\end{array}$ & B176K5 & HANFORD TOWNSITE & ONSITE & AT & 18-Aug-03 E & & $0.0138 \mathrm{p}$ & & 0.0014 & 0.0028 & & & \\
\hline $\begin{array}{l}\text { SESPMNT } \\
\text { SESPMNT }\end{array}$ & $\begin{array}{l}\text { B176K6 } \\
\text { B1766K }\end{array}$ & $\begin{array}{l}\text { HANFORD TOWNSITE } \\
\text { HANORD TOONSTE }\end{array}$ & $\begin{array}{l}\text { ONSITE } \\
\text { ONSTEE }\end{array}$ & AT & $\begin{array}{l}02-S e p-03 E \\
15-S e p-03 E\end{array}$ & & $0.0178 p$ & Cilm3 & 0.0013 & 0.0032 & & & \\
\hline $\begin{array}{l}\text { SESPMMNT } \\
\text { SESPMT }\end{array}$ & B176K8 & $\begin{array}{l}\text { HANFORD INANSIIT } \\
\text { HANFORD TOWNITE }\end{array}$ & $\begin{array}{l}\text { ONSIIE } \\
\text { ONSITE }\end{array}$ & AT & $\begin{array}{l}\text { 15-Sep-03 E } \\
01-O c t-03 \text { E }\end{array}$ & $\begin{array}{l}B \text { BIA } \\
\text { BETA }\end{array}$ & $\begin{array}{l}0.0156 \mathrm{p} \\
0.0146 \mathrm{p}\end{array}$ & $\begin{array}{l}\mathrm{Cl} / \mathrm{m} 3 \\
\mathrm{Ci} / \mathrm{m} 3\end{array}$ & $\begin{array}{l}0.0013 \\
0.0012\end{array}$ & $\begin{array}{r}0.003 \\
0.0028\end{array}$ & & & \\
\hline SESPMNT & B17R60 & HANFORD TOWNSITE & ONSITE & AT & 13-Oct-03 E & BETA & $0.029 \mathrm{p}$ & $\mathrm{Ci} / \mathrm{m} 3$ & 0.0018 & 0.0053 & & & \\
\hline SESPMNT & B17R61 & HANFORD TOWNSITE & ONSITE & AT & 28-Oct-03 E & BETA & $0.0295 \mathrm{p}$ & $\mathrm{Ci} / \mathrm{m} 3$ & 0.0016 & 0.0053 & & & \\
\hline SESPMNT & B17R62 & HANFORD TOWNSITE & ONSITE & AT & 11-Nov-03 & BETA & $0.0356 \mathrm{p}$ & $\mathrm{Ci} / \mathrm{m} 3$ & 0.0018 & 0.0059 & & & \\
\hline SESPMNT & B17R63 & HANFORD TOWNSITE & ONSITE & AT & 24-Nov-03 & BETA & $0.0194 \mathrm{p}$ & $\mathrm{Ci} / \mathrm{m} 3$ & 0.0015 & 0.0037 & & & \\
\hline SESPMNT & B17R64 & HANFORD TOWNSITE & ONSITE & AT & 11-Dec-03 & BETA & $0.0119 \mathrm{p}$ & $\mathrm{Ci} / \mathrm{m} 3$ & 0.001 & 0.0023 & & & \\
\hline SESPMNT & B17R65 & HANFORD TOWNSITE & ONSITE & AT & 22-Dec-03 E & BETA & $0.0163 \mathrm{p}$ & $\mathrm{Ci} / \mathrm{m} 3$ & 0.0015 & 0.0032 & & & \\
\hline SESPMNT & B17R66 & HANFORD TOWNSITE & ONSITE & AT & 06-Jan-04 E & BETA & $0.0176 \mathrm{p}$ & $\mathrm{C} i / \mathrm{m} 3$ & 0.0013 & 0.0033 & & & \\
\hline SESPMNT & B16900 & HORN RAPIDS SUBSTA & PERIMETER & AT & 23-Jan-03 E & BETA & $0.019 p$ & $\mathrm{Ci} / \mathrm{m} 3$ & 0.0014 & 0.0035 & & & \\
\hline SESPMNT & B16901 & HORN RAPIDS SUBSTA & PERIMETER & AT & 06-Feb-03 E & BETA & $0.00442 \mathrm{p}$ & $\mathrm{C} / \mathrm{m} 3$ & 0.00084 & 0.0013 & & & \\
\hline $\begin{array}{l}\text { SESPMNT } \\
\text { SESPMNT }\end{array}$ & B16902 & HORN RAPIDS SUBSTA & PERIMETER & AT & 20-Feb-03E & BETA & $0.0151 \mathrm{p}$ & Ci/m3 & 0.0015 & 0.0031 & & & \\
\hline $\begin{array}{l}\text { SESPMNT } \\
\text { SESPMNT }\end{array}$ & $\begin{array}{l}\text { B16903 } \\
\text { B16094 }\end{array}$ & $\begin{array}{l}\text { HORN RAPIDS SUBSTA } \\
\text { HORN RAPISS SUBSTA }\end{array}$ & $\begin{array}{l}\text { PERIMETER } \\
\text { PERIMTER }\end{array}$ & $\begin{array}{l}\text { AT } \\
\text { AT }\end{array}$ & $\begin{array}{l}\text { 06-Mar-03 } \\
\text { 21-Mar-03 }\end{array}$ & BETA & $\begin{array}{l}0.0163 \mathrm{p} \\
0.0061 \mathrm{p}\end{array}$ & $\begin{array}{l}\text { Ci/m3 } \\
\text { Cimm3 }\end{array}$ & $\begin{array}{r}0.0014 \\
0.00086\end{array}$ & $\begin{array}{l}0.0031 \\
0.0015\end{array}$ & & & \\
\hline SESPMNT & \begin{tabular}{|l|} 
\\
B16905
\end{tabular} & HORN RAPIDS SUBSTA & PERIMETER & AT & 03-Apr-03 B & & $0.00686 \mathrm{p}$ & $\mathrm{Ci} / \mathrm{m} 3$ & 0.00093 & 0.0016 & & & \\
\hline SESPMNT & B16R91 & HORN RAPIDS SUBSTA & PERIMETER & AT & 18-Apr-03 B & & $0.00726 \mathrm{p}$ & $\mathrm{Ci} / \mathrm{m} 3$ & 0.001 & 0.0017 & & & \\
\hline SESPMNT & B16R92 & HORN RAPIDS SUBSTA & PERIMETER & AT & 01-May-03 в & BETA & $0.00833 \mathrm{p}$ & $\mathrm{Ci} / \mathrm{m} 3$ & 0.0011 & 0.002 & & & \\
\hline SESPMNT & B16R93 & HORN RAPIDS SUBSTA & PERIMETER & AT & 16-May-03 B & BETA & $0.0106 \mathrm{p}$ & $\mathrm{Ci} / \mathrm{m} 3$ & 0.001 & 0.0022 & & & \\
\hline SESPMNT & B16R94 & HORN RAPIDS SUBSTA & PERIMETER & AT & 30-May-03 в & BETA & $0.0101 \mathrm{p}$ & $\mathrm{Ci} / \mathrm{m} 3$ & 0.0011 & 0.0021 & & & \\
\hline SESPMNT & B16R95 & HORN RAPIDS SUBSTA & PERIMETER & AT & 13-Jun-03 B & BETA & $0.0131 \mathrm{p}$ & $\mathrm{Ci} / \mathrm{m} 3$ & 0.0012 & 0.0026 & & & \\
\hline SESPMNT & B16R96 & HORN RAPIDS SUBSTA & PERIMETER & AT & 26-Jun-03 B & BETA & $0.00938 \mathrm{p}$ & $\mathrm{Ci} / \mathrm{m} 3$ & 0.0011 & 0.0021 & & & \\
\hline SESPMNT & B16R97 & HORN RAPIDS SUBSTA & PERIMETER & AT & 11-Jul-03 B & BETA & $0.00978 \mathrm{p}$ & $\mathrm{Ci} / \mathrm{m} 3$ & 0.001 & 0.0021 & & & \\
\hline SESPMNT & B17670 & HORN RAPIDS SUBSTA & PERIMETER & AT & 24-Jul-03 B & BETA & $0.0121 \mathrm{p}$ & $\mathrm{Ci} / \mathrm{m} 3$ & 0.0012 & 0.0025 & & & \\
\hline SESPMNT & B17671 & HORN RAPIDS SUBSTA & PERIMETER & AT & 07-Aug-03 B & BETA & $0.0152 \mathrm{p}$ & $\mathrm{Ci} / \mathrm{m} 3$ & 0.0013 & 0.003 & & & \\
\hline SESPMNT & B17672 & HORN RAPIDS SUBSTA & PERIMETER & AT & 22-Aug-03B & BETA & $0.0161 \mathrm{p}$ & $\mathrm{Ci} / \mathrm{m} 3$ & 0.0012 & 0.0028 & & & \\
\hline $\begin{array}{l}\text { SESPMNT } \\
\text { SESPMNT }\end{array}$ & B17673 & HORN RAPIDS SUBSTA & PERIMETER & AT & 05-Sep-03B & BETA & $0.0124 p$ & Ci/m3 & 0.002 & 0.0033 & & & \\
\hline $\begin{array}{l}\text { SESPMNT } \\
\text { SESPMNT }\end{array}$ & B17674 & HORN RAPIDS SUBSTA & $\begin{array}{l}\text { PERIMETER } \\
\text { PEPIMETRP }\end{array}$ & AT & 18-Sep-03 В & BETA & $0.0106 \mathrm{p}$ & Ci/m3 & 0.0012 & 0.0023 & & & \\
\hline $\begin{array}{l}\text { SESPMNT } \\
\text { SESPMNT }\end{array}$ & $\begin{array}{l}\text { B17675 } \\
\text { B17P/8 }\end{array}$ & $\begin{array}{l}\text { HORN RAPIDS SUBSTA } \\
\text { HORN RAPISS SUBSTA }\end{array}$ & $\begin{array}{l}\text { PERIMETER } \\
\text { PERIMETTR }\end{array}$ & AT & 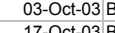 & BETA & $0.0221 \mathrm{p}$ & Ci/m3 & 0.0013 & 0.0038 & & & \\
\hline $\begin{array}{l}\text { SESPMNT } \\
\text { SESPMNT }\end{array}$ & $\begin{array}{l}\text { B177V8 } \\
\text { B17PV9 }\end{array}$ & $\begin{array}{l}\text { HORN RAPIDS SUBSTA } \\
\text { HORN RAPIDS SUBSTA }\end{array}$ & $\begin{array}{l}\text { PERIMETER } \\
\text { PERIMETER }\end{array}$ & $\begin{array}{l}\text { AT } \\
\text { AT }\end{array}$ & 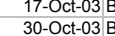 & $\begin{array}{l}\text { BETA } \\
\text { BETA }-10 \text { - } 10\end{array}$ & $\begin{array}{l}0.0224 \mathrm{p} \\
0.0128 \mathrm{p}\end{array}$ & $\begin{array}{l}\mathrm{C} \text { Cim3 } \\
\mathrm{C} \mathrm{C} / \mathrm{m} 3\end{array}$ & $\begin{array}{l}0.0015 \\
0.0012\end{array}$ & 0.0042 & & & \\
\hline SESPMNT & B17PW0 & HORN RAPIDS SUBSTA & PERIMETER & AT & 14-Nov-03 B & BETA & $0.0315 p$ & $\mathrm{Ci} / \mathrm{m} 3$ & 0.0017 & 0.0056 & & & \\
\hline SESPMNT & B17PW1 & HORN RAPIDS SUBSTA & PERIMETER & AT & 26-Nov-03 B & BETA & $0.0186 \mathrm{p}$ & $\mathrm{Ci} / \mathrm{m} 3$ & 0.0015 & 0.0036 & & & \\
\hline SESPMNT & B17PW2 & HORN RAPIDS SUBSTA & PERIMETER & AT & 16-Dec-03 B & BETA & $0.0111 \mathrm{p}$ & $\mathrm{Ci} / \mathrm{m} 3$ & 0.00088 & 0.0022 & & & \\
\hline SESPMNT & B17PW3 & HORN RAPIDS SUBSTA & PERIMETER & AT & 29-Dec-03B & BETA & $0.0199 \mathrm{p}$ & $\mathrm{Ci} / \mathrm{m} 3$ & 0.0015 & 0.0038 & & & \\
\hline SESPMNT & B17PW4 & HORN RAPIDS SUBSTA & PERIMETER & AT & 09-Jan-04 B & BETA & & & & & & NO SAMPLE. SAVE FOR COMPOSITE. & \\
\hline SESPMNT & B16948 & KENNEWICK-ELYY STREET & COMMUNITY & AT & 16-Jan-03 B & BETA & $0.0278 p$ & $\mathrm{Ci} / \mathrm{m} 3$ & 0.0017 & 0.005 & & & \\
\hline SESPMNT & B16949 & KENNEWICK-ELY STREET & COMMUNITY & AT & 30-Jan-03B & BETA & $0.018 \mathrm{p}$ & $\mathrm{C} / \mathrm{m} 3$ & 0.0014 & 0.0034 & & & \\
\hline SESPMNT & B16950 & KENNEWICK-ELY STREET & COMMUNITY & AT & 13-Feb-03B & BETA & $0.0143 p$ & Ci/m3 & 0.0012 & 0.0028 & & & \\
\hline $\begin{array}{l}\text { SESPMNT } \\
\text { SECPPINT }\end{array}$ & B16951 & KENNEWICK-ELY STREET & COMMUNITY & AT & 28-Feb-03B & BETA & $0.0211 \mathrm{p}$ & Ci/m3 & 0.0013 & 0.0037 & & & \\
\hline $\begin{array}{l}\text { SESPMNT } \\
\text { SESPMNT }\end{array}$ & $\begin{array}{l}\text { B16952 } \\
\text { B1653 }\end{array}$ & $\begin{array}{l}\text { KENNEWICK-ELY STREET } \\
\text { KENNEFWIK-EYY STREFE }\end{array}$ & COMMUNITY & AT & 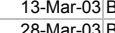 & BETA & $\begin{array}{l}0.008919 \mathrm{p} \\
0.00578 \mathrm{p}\end{array}$ & il/m3 & $\begin{array}{r}0.0011 \\
0.0085\end{array}$ & 0.0019 & & & \\
\hline SESPMNT & B16954 & KENNEWICK-ELY STREET & COMMUNITY & AT & 10-Apr-03 B & BETA & $0.00778 \mathrm{p}$ & $\mathrm{Ci} / \mathrm{m} 3$ & 0.0012 & 0.0019 & & & \\
\hline SESPMNT & B16RHO & KENNEWICK-ELY STREET & COMMUNITY & AT & 25-Apr-03 B & BETA & $0.00834 \mathrm{p}$ & $\mathrm{Ci} / \mathrm{m} 3$ & 0.001 & 0.0018 & & & \\
\hline SESPMNT E & B16RH1 & KENNEWICK-ELY STREET & COMMUNITY & AT & 08-May-03 В & 3ETA & $0.00818 \mathrm{p}$ & Cilm3 & 0.0011 & 0.0019 & & & \\
\hline SESPMNT & B16RH2 & KENNEWICK-ELY STREET & COMMUNITY & AT & 22-May-03 В & BETA & $0.00949 \mathrm{p}$ & $\mathrm{Ci} / \mathrm{m} 3$ & 0.0013 & 0.0022 & & & \\
\hline SESPMNT & B16RH3 & KENNEWICK-ELY STREET & COMMUNITY & AT & 06-Jun-03 B & BETA & $0.0144 \mathrm{p}$ & $\mathrm{Ci} / \mathrm{m} 3$ & 0.0012 & 0.0028 & & & \\
\hline SESPMNT & B16RH4 & KENNEWICK-ELY STREET & COMMUNITY & AT & 19-Jun-03B & BETA & $0.0132 \mathrm{p}$ & $\mathrm{C} i / \mathrm{m} 3$ & 0.0013 & 0.0027 & & & \\
\hline SESPMNT & B16RH5 & KENNEWICK-ELY STREET & COMMUNITY & AT & 07-Jul-03 B & BETA & $0.0092 p$ & $\mathrm{C} / \mathrm{m} 3$ & 0.00094 & 0.0019 & & & \\
\hline & & & & & & & & & & & & & \\
\hline
\end{tabular}


AIR BETA/ALPHA

\begin{tabular}{|c|c|c|c|c|c|c|c|c|c|c|c|c|}
\hline |OWNER ID & \begin{tabular}{|l|} 
SAMP \\
NUM
\end{tabular} & SAMP SITE NAME & | DIST CLASS | & MEDIA & \begin{tabular}{l|c} 
& CON \\
& SHORT \\
SAMP DATE & NAME
\end{tabular} & & $\begin{array}{l}\text { ANAL } \\
\text { UNITS } \\
\text { RPTD }\end{array}$ & $\begin{array}{c}\text { COUNTING } \\
\text { ERROR }\end{array}$ & \begin{tabular}{c|c} 
TOTAL \\
ANAL \\
ERROR
\end{tabular} & $\begin{array}{c}\text { LAB } \\
\text { QUALLIFIER }\end{array}$ & SAMP COMMENT & $\begin{array}{l}\text { RESULT } \\
\text { COMMENT }\end{array}$ \\
\hline SESPMNT & & KENNEWICK-ELY STREET & COMMUNITY & AT & 31-Jul-03 BETA & $0.0159 p$ & & 0.0014 & 0.0032 & & & \\
\hline SESPMNT & B176DO & KENNEWICK-ELY STREET & COMMUNITY & AT & 15-Aug-03 BETA & $0.0143 \mathrm{p}$ & $\mathrm{pCi} / \mathrm{m} 3$ & 0.0013 & 0.0029 & & & \\
\hline SESPMNT & B176D1 & KENNEWICK-ELY STREET & COMMUNITY & AT & 28-Aug-03 BETA & $0.0136 \mathrm{p}$ & $\mathrm{pC} / \mathrm{m} 3$ & 0.0013 & 0.0027 & & & \\
\hline SESPMNT & B17602 & KENNEWICK-ELY STREET & COMMUNITY & AT & 12-Sep-03 BETA & $0.0165 \mathrm{p}$ & $\mathrm{pC} / \mathrm{m} 3$ & 0.0012 & 0.0031 & & & \\
\hline $\begin{array}{l}\text { SESPMNT } \\
\end{array}$ & B176D3 & KENNEWICK-ELY STREET & COMMUNITY & AT & 25-Sep-03 BETA & $0.0132 \mathrm{p}$ & $\mathrm{pCi} / \mathrm{m} 3$ & 0.0012 & 0.0027 & & & \\
\hline SESPMNT & B17604 & KENNEWICK-ELY STREET & COMMUNITY & AT & 10-Oct-03 BETA & $0.0282 \mathrm{p}$ & $\mathrm{pci} / \mathrm{m} 3$ & 0.0016 & 0.005 & & & \\
\hline SESPMNT & B17R17 & KENNEWICK-ELY STREET & COMMUNITY & AT & 23-Oct-03 BETA & $0.0126 \mathrm{p}$ & pCi/m3 & 0.0012 & 0.0025 & & & \\
\hline $\begin{array}{l}\text { SESPMNT } \\
\text { SFSPMNT }\end{array}$ & B17R18 & KENNEWICK-ELY STREET & COMMUNITY & AT & 07-Nov-03 BETA & $0.0199 \mathrm{p}$ & pCim3 & 0.0013 & 0.0036 & & & \\
\hline SESPMNT & B17R19 & KENNEWICK-ELY STREET & COMMUNITY & AT & 21-Nov-03 BETA & $0.0233 \mathrm{p}$ & pCi/m3 & 0.0015 & 0.0042 & & & \\
\hline $\begin{array}{l}\text { SESPMNT } \\
\text { SECDMNT }\end{array}$ & B17R20 & KENNEWICK-ELY STREET & COMMUNITY & AT & 05-Dec-03 BETA & $0.013 p$ & pCi/m3 & 0.0012 & 0.0026 & & & \\
\hline SESPMNT & B17R21 & KENNEWICK-ELY STREET & COMMUNITY & & 19-Dec-03 BETA & $0.0166 \mathrm{p}$ & pCi/m3 & 0.0012 & 0.003 & & & \\
\hline $\begin{array}{l}\text { SESPMNT } \\
\text { SESPMNT }\end{array}$ & B17R22 & KENNEWICK-ELY STREET & COMMUNITY & AT & 05-Jan-04 BETA & $0.0203 p$ & pCi/m3 & 0.0013 & 0.0037 & & & \\
\hline $\begin{array}{l}\text { SESPMNT } \\
\text { SESPMNT }\end{array}$ & $\begin{array}{l}B 16971 \\
\text { B1692 }\end{array}$ & $\begin{array}{l}\text { LESLIE GROVES-RCHLND } \\
\end{array}$ & COMMUNITY & AT & 14-Jan-03 BETA & $0.0242 \mathrm{p}$ & pCi/m3 & 0.0015 & 0.0044 & & & \\
\hline $\begin{array}{l}\text { SESPMNT } \\
\text { SESPMNT }\end{array}$ & 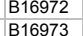 & $\begin{array}{l}\text { LESLLE GROVES-RCHLND } \\
\text { LESLIE GROVES-RCHLND }\end{array}$ & $\begin{array}{l}\text { COMMUUITY } \\
\text { COMMUNITY }\end{array}$ & $\begin{array}{l}\text { AT } \\
\text { AT }\end{array}$ & $\begin{array}{l}\text { 28-Jan-03 BETA } \\
\text { 11-Feb-03 BETA }\end{array}$ & $\begin{array}{l}0.0192 \mathrm{p} \\
0.0127 \mathrm{p}\end{array}$ & $\begin{array}{l}\mathrm{pCC/m3} \\
\mathrm{pCi} / \mathrm{m} 3\end{array}$ & 0.0014 & 0.0036 & & & \\
\hline $\begin{array}{l}\text { SESPMNI } \\
\text { SESPMNT }\end{array}$ & $\begin{array}{l}\begin{array}{l}\text { B16993 } \\
\text { B16974 }\end{array}\end{array}$ & $\begin{array}{l}\text { LESLE GROVES-RCHLND } \\
\text { LESLIE GROVES-RCHLND }\end{array}$ & $\begin{array}{l}\text { COMMUNIIT } \\
\text { COMMUNITY }\end{array}$ & $\begin{array}{l}\text { AI } \\
\text { AT }\end{array}$ & $\begin{array}{l}\text { 11-reb-03 BEIA } \\
\text { 25-Feb-03 BETA }\end{array}$ & $\begin{array}{l}0.012 / \mathrm{p} \\
0.0192 \mathrm{p}\end{array}$ & $\begin{array}{l}\mathrm{plClm3} \\
\mathrm{pCi} / \mathrm{m} 3\end{array}$ & $\begin{array}{l}0.0012 \\
0.0013\end{array}$ & $\begin{array}{l}0.0026 \\
0.0033\end{array}$ & & & \\
\hline SESPMNT & B16975 & LESLIE GROVES-RCHLND & COMMUNITY & AT & 11-Mar-03 BETA & $0.0126 \mathrm{p}$ & pCim3 & 0.0012 & 0.0025 & & & \\
\hline SESPMNT & B16976 & LESLIE GROVES-RCHLND & COMMUNITY & AT & 25-Mar-03 BETA & $0.00614 p$ & pCilm3 & 0.00099 & 0.0016 & & & \\
\hline SESPMNT & B16977 & LESLIE GROVES-RCHLND & COMMUNITY & AT & 08-Apr-03 BETA & $0.00693 p$ & pCi/m3 & 0.001 & 0.0017 & & & \\
\hline SESPMNT & B16RK2 & LESLIE GROVES-RCHLND & COMMUNITY & AT & 22-Apr-03 BETA & $0.01 \mathrm{p}$ & pCi/m3 & 0.0012 & 0.0022 & & & \\
\hline SESPMNT & B16RK3 & LESLIE GROVES-RCHLND & COMMUNITY & AT & 06-May-03 BETA & $0.00851 \mathrm{p}$ & pCi/m3 & 0.0011 & 0.002 & & & \\
\hline SESPMNT & B16RK4 & LESLIE GROVES-RCHLND & COMMUNITY & AT & 20-May-03 BETA & $0.0102 \mathrm{p}$ & pCi/m3 & 0.0011 & 0.0022 & & & \\
\hline SESPMNT & B16RK5 & LESLIE GROVES-RCHLND & COMMUNITY & AT & 03-Jun-03 BETA & $0.0121 \mathrm{p}$ & pCilm3 & 0.0012 & 0.0025 & & & \\
\hline SESPMNT & B16RK6 & LESLIE GROVES-RCHLND & COMMUNITY & AT & 17-Jun-03 BETA & $0.0133 p$ & pCi/m3 & 0.0012 & 0.0026 & & & \\
\hline $\begin{array}{l}\text { SESPMNT } \\
\text { SESPMNT }\end{array}$ & B16RK7 & LESLIE GROVES-RCHLND & COMMUNITY & AT & 01-Jul-03 BETA & $0.01 \mathrm{p}$ & pCi/m3 & 0.0011 & 0.0021 & & & \\
\hline $\begin{array}{l}\text { SESPMNT } \\
\text { SESPMNT }\end{array}$ & 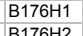 & 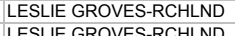 & COMMUNITY & AT & $\begin{array}{l}\text { 16-Jul-03 BETA } \\
\text { 29-1L-03 BETA }\end{array}$ & $0.0103 p$ & pCim3 & 0.0011 & 0.0022 & & & \\
\hline $\begin{array}{l}\text { SESPMNT } \\
\text { SESPMNT }\end{array}$ & $\begin{array}{l}\mathrm{B} 17 \mathrm{H} \mathrm{H} 2 \\
\mathrm{~B} 17 \mathrm{H} 3 \mathrm{H}\end{array}$ & $\begin{array}{l}\text { LESLLE GROVES-RCHLND } \\
\text { LESLEF GROVES-RCHLND }\end{array}$ & $\begin{array}{l}\text { COMMUUITY } \\
\text { COMMUNITY }\end{array}$ & $\begin{array}{l}\text { AT } \\
\text { AT }\end{array}$ & $\begin{array}{l}\text { 29-Aul-03 BETA } \\
\text { 12-Auq-03 BETA }\end{array}$ & $\begin{array}{l}0.0131 \mathrm{p} \\
0.0138 \mathrm{p}\end{array}$ & pCim3 & 0.0013 & 0.0027 & & & \\
\hline $\begin{array}{l}\text { SESPMNT } \\
\text { SESPMNT }\end{array}$ & 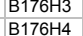 & $\begin{array}{l}\text { LESLLE GROVES-RCHLND } \\
\text { LESLIE GROVES-RCHLND }\end{array}$ & $\begin{array}{l}\text { COMMUUITY } \\
\text { COMMUNITY }\end{array}$ & $\begin{array}{l}\text { AT } \\
\text { AT }\end{array}$ & $\begin{array}{l}\text { 12-A-Ag-03 BETA } \\
\text { 26-Aug-03 BETA }\end{array}$ & $\begin{array}{l}0.0138 \mathrm{p} \\
0.014 \mathrm{p}\end{array}$ & pilm3 & 0.0013 & 0.0028 & & & \\
\hline $\begin{array}{l}\text { SESPMNT } \\
\text { SESPMNT }\end{array}$ & $\begin{array}{l}\text { B176H4 } \\
\text { B176H5 }\end{array}$ & $\begin{array}{l}\text { LELLIE GROVES-RCHLDD } \\
\text { LESLIE GROVES-RCHLND }\end{array}$ & $\begin{array}{l}\text { COMMMUITY } \\
\text { COMMUNITY }\end{array}$ & $\begin{array}{l}\text { AT } \\
\text { AT }\end{array}$ & $\begin{array}{l}\text { 26-Agug-03BEAA } \\
\text { 09-Sep-03 BETA }\end{array}$ & $\begin{array}{l}0.014 \mathrm{p} \\
0.0174 \mathrm{p}\end{array}$ & $\begin{array}{l}\mathrm{plim3} \\
\mathrm{pCi} / \mathrm{m} 3\end{array}$ & 0.0012 & $\begin{array}{l}0.0028 \\
0.0033\end{array}$ & & & \\
\hline SESPMNT & $\mathrm{B} 176 \mathrm{H6}$ & LESLIE GROVES-RCHLND & COMMUNITY & AT & 23-Sep-03 BETA & $0.011 \mathrm{p}$ & pCilm3 & 0.0011 & 0.0023 & & & \\
\hline SESPMNT & B176H7 & LESLIE GROVES-RCHLND & COMMUNITY & AT & 07-Oct-03 BETA & $0.0347 \mathrm{p}$ & pCi/m3 & 0.0018 & 0.0061 & & & \\
\hline SESPMNT & B17R39 & LESLIE GROVES-RCHLND & COMMUNITY & AT & 21-Oct-03 BETA & $0.0121 \mathrm{p}$ & pCi/m3 & 0.0012 & 0.0025 & & & \\
\hline SESPMNT & B17R40 & LESLIE GROVES-RCHLND & COMMUNITY & AT & 04-Nov-03 BETA & $0.0147 \mathrm{p}$ & pCi/m3 & 0.0012 & 0.0029 & & LAYER OF SOIL FALLING FROM AIR FILTER. & \\
\hline SESPMNT & B17R41 & LESLIE GROVES-RCHLND & COMMUNITY & AT & 18-Nov-03 BETA & $0.0344 \mathrm{p}$ & pCi/m3 & 0.0018 & 0.0061 & & & \\
\hline SESPMNT & B17R42 & LESLIE GROVES-RCHLND & COMMUNITY & AT & 02-Dec-03 BETA & $0.0132 \mathrm{p}$ & pCi/m3 & 0.0012 & 0.0027 & & & \\
\hline SESPMNT & B17R43 & LESLIE GROVES-RCHLND & COMMUNITY & AT & 16-Dec-03 BETA & $0.0137 \mathrm{p}$ & pCilm3 & 0.0012 & 0.0028 & & & \\
\hline $\begin{array}{l}\text { SESPMNT } \\
\text { SESPMNT }\end{array}$ & B17R44 & LESLIE GROVES-RCHLND & COMMUNITY & AT & 30-Dec-03 BETA & $0.0188 \mathrm{p}$ & pCi/m3 & 0.0014 & 0.0035 & & & \\
\hline $\begin{array}{l}\text { SESPMNT } \\
\text { SESPMNT }\end{array}$ & B16835 & MATTAWA & COMMUNITY & AT & 15-Jan-03 BETA & $0.0178 \mathrm{p}$ & pCilm3 & 0.0014 & 0.0034 & & & \\
\hline $\begin{array}{l}\text { SESPMNT } \\
\text { SESPMNT }\end{array}$ & $\begin{array}{l}\text { B16836 } \\
\text { B1637 }-2\end{array}$ & $\begin{array}{l}\text { MAATAWA } \\
\text { MATTAWA }\end{array}$ & $\begin{array}{l}\text { COMMUNITY } \\
\text { COMMUNTY }\end{array}$ & AT & $\begin{array}{l}\text { 29-Jan-03 BETA } \\
\text { 12-er-03 BETA }\end{array}$ & $0.00966 \mathrm{p}$ & pCim3 & 0.0011 & 0.0021 & & & \\
\hline $\begin{array}{l}\text { SESPMNT } \\
\text { SESPMNT }\end{array}$ & 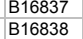 & $\begin{array}{l}\text { MATTAWA } \\
\text { MATTAWA }\end{array}$ & $\begin{array}{l}\text { COMMUUITY } \\
\text { COMMUNITY }\end{array}$ & $\begin{array}{l}\text { AT } \\
\text { AT }\end{array}$ & $\begin{array}{l}\text { 12-Feb-03 BETA } \\
\text { 26-Feb-03 BETA }\end{array}$ & $\begin{array}{l}0.0107 \mathrm{p} \\
0.0196 \mathrm{p}\end{array}$ & $\begin{array}{l}\text { pCim3 } \\
\text { pCim3 }\end{array}$ & $\begin{array}{l}0.0014 \\
0.0014\end{array}$ & $\begin{array}{l}0.0025 \\
0.0034\end{array}$ & & BURNING DITCH BY AIR SAMPLER. & \\
\hline SESPMNT & B16839 & MATTAWA & COMMUNITY & AT & 12-Mar-03 BETA & $0.0112 \mathrm{p}$ & $\mathrm{pC} / \mathrm{m} 3$ & 0.0011 & 0.0023 & & & \\
\hline SESPMNT & B16840 & MATTAWA & COMMUNITY & AT & 27-Mar-03 BETA & $0.00479 p$ & pCi/m3 & 0.00088 & 0.0013 & & & \\
\hline SESPMNT & B16841 & MATTAWA & COMMUNITY & AT & 09-Apr-03 BETA & $0.00514 p$ & pCi/m3 & 0.001 & 0.0015 & & & \\
\hline SESPMNT & B16PH1 & MATTAWA & COMMUNITY & AT & 23-Apr-03 BETA & $0.00927 p$ & pCi/m3 & 0.0011 & 0.002 & & & \\
\hline SESPMNT & B16PH2 & MATTAWA & COMMUNITY & AT & 07-May-03 BETA & $0.00714 p$ & pCi/m3 & 0.00092 & 0.0017 & & & \\
\hline SESPMNT & $\mathrm{B} 16 \mathrm{PH} 3$ & MATTAWA & COMMUNITY & AT & 21-May-03 BETA & $0.0104 p$ & pCi/m3 & 0.0012 & 0.0022 & & SUSPECT AIR CALIBRATOR ERROR ON 5/7/03, 1.5 CFM START FLOW MAY ACTUALLY BE 1.2 CFM. & \\
\hline SESPMNT & $\mathrm{B} 16 \mathrm{PH} 4$ & MATTAWA & COMMUNITY & AT & 05-Jun-03 BETA & $0.0125 \mathrm{p}$ & pCi/m3 & 0.0012 & 0.0025 & & & \\
\hline SESPMNT & B16PH5 & MATTAWA & COMMUNITY & AT & 18-Jun-03 BETA & $0.0122 \mathrm{p}$ & pCilm3 & 0.0012 & 0.0026 & & & \\
\hline SESPMNT & B16PH6 & MATTAWA & COMMUNITY & AT & 01-Jul-03 BETA & $0.00905 p$ & pCi/m3 & 0.0011 & 0.002 & & & \\
\hline SESPMNT & B175C9 & MATTAWA & COMMUNITY & AT & 17-Jul-03 BETA & $0.00639 \mathrm{p}$ & pCilm3 & 0.0014 & 0.002 & & & \\
\hline $\begin{array}{l}\text { SESPMNT } \\
\text { SESPMNT }\end{array}$ & $\begin{array}{l}B 17550 \\
\text { B17501 }\end{array}$ & $\begin{array}{l}\text { MAATTAWA } \\
\text { MATTAWA }\end{array}$ & $\begin{array}{l}\text { COMMUUIITY } \\
\text { COMMUNITY }\end{array}$ & $\begin{array}{l}\text { AT } \\
\text { AT }\end{array}$ & $\begin{array}{r}\text { 30-Auu-03 BETA } \\
\text { 13-Auq-03 BETA }\end{array}$ & $\begin{array}{l}0.01111 \mathrm{p} \\
0.0135 \mathrm{p}\end{array}$ & $\begin{array}{l}\text { pilm3 } \\
\text { piimm3 }\end{array}$ & $\begin{array}{l}0.0012 \\
0.0012\end{array}$ & $\begin{array}{l}0.0024 \\
0.0027\end{array}$ & & & \\
\hline SESPMNT & B175D2 & MATTAWA & COMMUNITY & AT & $\begin{array}{l}\text { 23-Augg-03BEIA } \\
\text { 27-Aug-03 BETA }\end{array}$ & $0.0115 \mathrm{p}$ & $\begin{array}{l}\mathrm{plim3} \\
\mathrm{pC} / \mathrm{m} 3\end{array}$ & 0.0012 & $\begin{array}{l}0.0027 \\
0.0024\end{array}$ & & & \\
\hline SESPMNT & B175D3 & MATTAWA & COMMUNITY & AT & 11-Sep-03 BETA & $0.0132 \mathrm{p}$ & pCi/m3 & 0.0011 & 0.0026 & & & \\
\hline SESPMNT & B175D4 & MATTAWA & COMMUNITY & AT & 24-Sep-03 BETA & $0.00973 p$ & pCi/m3 & 0.0011 & 0.0022 & & & \\
\hline SESPMNT & B175D5 & MATTAWA & COMMUNITY & AT & 09-Oct-03 BETA & $0.0245 \mathrm{p}$ & pCi/m3 & 0.0015 & 0.0044 & & & \\
\hline SESPMNT & B17P14 & MATTAWA & COMMUNITY & AT & 22-Oct-03 BETA & $0.0143 p$ & pCi/m3 & 0.0013 & 0.0028 & & & \\
\hline SESPMNT & B17P15 & MATTAWA & COMMUNITY & AT & 06-Nov-03 BETA & $0.0167 \mathrm{p}$ & pCi/m3 & 0.0013 & 0.0032 & & & \\
\hline SESPMNT & B17P16 & MATTAWA & COMMUNITY & AT & 19-Nov-03 BETA & $0.0263 p$ & pCi/m3 & 0.0017 & 0.0049 & & & \\
\hline SESPMNT & B17P17 & MATTAWA & COMMUNITY & AT & 03-Dec-03 BETA & $0.0108 \mathrm{p}$ & pCi/m3 & 0.0011 & 0.0023 & & & \\
\hline SESPMNT & B17P18 & MATTAWA & COMMUNITY & AT & 18-Dec-03 BETA & $0.0122 \mathrm{p}$ & pCi/m3 & 0.0011 & 0.0025 & & & \\
\hline SESPMNT & B17P19 & MATTAWA & COMMUNITY & AT & 31-Dec-03 BETA & $0.018 \mathrm{p}$ & pCi/m3 & 0.0014 & 0.0034 & & & \\
\hline SESPMNT & B16813 & NOF $200 \mathrm{E}$ & ONSITE & AT & 14-Jan-03 BETA & $0.0184 \mathrm{p}$ & pCi/m3 & 0.0014 & 0.0035 & & & \\
\hline SESPMNT & B16814 & N OF $200 \mathrm{E}$ & ONSITE & AT & 28-Jan-03 BETA & $0.0152 p$ & pCi/m3 & 0.0013 & 0.003 & & & \\
\hline SESPMNT & B16815 & N OF $200 \mathrm{E}$ & ONSITE & AT & 11-Feb-03 BETA & $0.0127 \mathrm{p}$ & pCi/m3 & 0.0012 & 0.0026 & & & \\
\hline $\begin{array}{l}\text { SESPMNT } \\
\text { SESPMNT }\end{array}$ & B16816 & $\begin{array}{l}\text { NOF 200E } \\
\text { NOF 200 E }\end{array}$ & $\begin{array}{l}\text { ONSIIE } \\
\text { ONSITE }\end{array}$ & $\begin{array}{l}\text { AT } \\
\text { AT }\end{array}$ & 25-Feb-03 BETA & & $\mathrm{pCi} / \mathrm{m}^{3}$ & 0.0015 & 0.0033 & & NO SAMPLE. NO ARR FLOW, DO NOI SAVE FOR COMPOSIIE. & \\
\hline SESPMNT & B16817 & NOF $200 \mathrm{E}$ & ONSITE & AT & & $0.017 \mathrm{p}$ & pCim3 & 0.0015 & 0.0033 & & & \\
\hline
\end{tabular}


AIR BETA/ALPHA

\begin{tabular}{|c|c|c|c|c|c|c|c|c|c|c|c|c|}
\hline |OWNER ID & \begin{tabular}{|l|} 
SAMP \\
NUM
\end{tabular} & SAMP SITE NAME & | DIST CLASS | & MEDIA & \begin{tabular}{c|c} 
& CON \\
& SHORT \\
SAMP DATE & NAME
\end{tabular} & | VALUE RPTD| & \begin{tabular}{|l|} 
ANAL \\
UNITS \\
RPTD \\
\end{tabular} & $\left|\begin{array}{c}\text { COUNTING } \\
\text { ERROR }\end{array}\right|$ & $\begin{array}{c}\text { TOTAL } \\
\text { ANAL } \\
\text { ERROR }\end{array}$ & $\left|\begin{array}{c}\text { LAB } \\
\text { QUALIFIER }\end{array}\right|$ & SAMP COMMENT & $\begin{array}{l}\text { RESULT } \\
\text { COMMENT }\end{array}$ \\
\hline SESPMNT & B16818 & N OF $200 \mathrm{E}$ & ONSITE & AT & 26-Mar-03 BETA & 0.00591 & & 0.00083 & & & 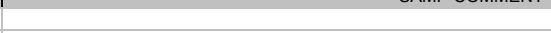 & \\
\hline SESPMNT & B16819 & N OF $200 \mathrm{E}$ & ONSITE & AT & 08-Apr-03 BETA & 0.00643 & pCilm3 & 0.00098 & 0.0016 & & & \\
\hline SESPMNT & B16PC8 & N OF $200 \mathrm{E}$ & ONSITE & AT & 21-Apr-03 BETA & 0.00977 & $\mathrm{pCi} / \mathrm{m} 3$ & 0.0012 & 0.0022 & & & \\
\hline $\begin{array}{l}\text { SESPMNT } \\
\text { SFONT }\end{array}$ & B16PC9 & N OF $200 \mathrm{E}$ & ONSITE & AT & 06-May-03 BETA & 0.00881 & $\mathrm{pCi} / \mathrm{m} 3$ & 0.00099 & 0.0019 & & & \\
\hline SESPMNT & B16PDO & NOF $200 \mathrm{E}$ & ONSITE & AT & 20-May-03 BETA & 0.015 & $\mathrm{pCi} / \mathrm{m} 3$ & 0.0013 & 0.0029 & & & \\
\hline SESPMNT & B16PD1 & N OF $200 \mathrm{E}$ & ONSITE & AT & 02-Jun-03 BETA & & $\mathrm{pCi} / \mathrm{m} 3$ & 0.0013 & 0.0027 & & & \\
\hline SESPMNT & B16PD2 & N OF $200 \mathrm{E}$ & ONSITE & AT & 17-Jun-03 BETA & 0.0104 & $\mathrm{pCi} / \mathrm{m} 3$ & 0.001 & 0.0021 & & & \\
\hline SESPMNT & B16PD3 & N OF $200 \mathrm{E}$ & ONSITE & AT & 30-Jun-03 BETA & 0.0102 & $\mathrm{pCi} / \mathrm{m} 3$ & 0.0012 & 0.0023 & & & \\
\hline SESPMNT & B17597 & NOF $200 \mathrm{E}$ & ONSITE & AT & 15-Jul-03 BETA & 0.00826 & $\mathrm{pCi} / \mathrm{m} 3$ & 0.001 & 0.0019 & & & \\
\hline $\begin{array}{l}\text { SESPMNT } \\
\text { SECDMNT }\end{array}$ & B17598 & NOF $200 \mathrm{E}$ & ONSITE & AT & 29-Jul-03 BETA & 0.0141 & & 0.0012 & 0.0028 & & & \\
\hline SESPMNT & B17599 & N OF $200 \mathrm{E}$ & ONSITE & AT & 12-Aug-03 BETA & 0.015 & $\mathrm{pCi} / \mathrm{m} 3$ & 0.0013 & 0.0029 & & & \\
\hline $\begin{array}{l}\text { SESPMNT } \\
\text { SESPMNT }\end{array}$ & $\begin{array}{l}\text { B175BO } \\
\text { B17561. }\end{array}$ & NOF $200 \mathrm{E}$ & ONSITE & AT & 25-Aug-03 BETA & 0.016 & pCi/m3 & 0.0012 & 0.0028 & & & \\
\hline $\begin{array}{l}\text { SESPMNT } \\
\text { SESPMNT }\end{array}$ & $\begin{array}{l}\text { B17581 } \\
\text { B17582 }\end{array}$ & $\begin{array}{l}\text { N OF } 200 \mathrm{E} \\
\text { NOF }\end{array}$ & ONSITE & AT & $\begin{array}{l}\text { 10-Sep-03 BETA } \\
22 \text {-Sen-03 BETA }\end{array}$ & $\begin{array}{r}0.016 \\
0.0107\end{array}$ & $\mathrm{pCl} / \mathrm{p}_{3}$ & 0.0012 & $\begin{array}{r}0.003 \\
0023\end{array}$ & & & \\
\hline $\begin{array}{l}\text { SESPMNT } \\
\text { SESPMNT }\end{array}$ & 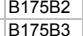 & $\begin{array}{l}\text { NOF } 200 \mathrm{E} \\
\text { NOF } 200 \mathrm{E}\end{array}$ & $\begin{array}{l}\text { ONSIIE } \\
\text { ONSTIE }\end{array}$ & $\begin{array}{l}\text { AT } \\
\text { AT }\end{array}$ & $\begin{array}{l}\text { 22-S-Pp--03 BETA } \\
\text { 07-Oct-03 BETA }\end{array}$ & $\begin{array}{l}0.0107 \\
0.026\end{array}$ & $\begin{array}{l}\mathrm{pC} / \mathrm{m} 3 \\
\mathrm{pC} / \mathrm{m} 3\end{array}$ & 0.0012 & $\begin{array}{l}0.0023 \\
0.0047\end{array}$ & & & \\
\hline SESPMNT & B17NY1 & N OF $200 E$ & ONSITE & AT & $\begin{array}{l}\text { 01-OCt-03 BEIA } \\
\text { 21-Oct-03 BETA }\end{array}$ & 0.026 & $\begin{array}{l}\mathrm{pCi} / \mathrm{m} 3 \\
\mathrm{p} 3\end{array}$ & 0.0011 & $\begin{array}{l}0.004 l \\
0.0023\end{array}$ & & & \\
\hline SESPMNT & B17NY2 & N OF $200 \mathrm{E}$ & ONSITE & AT & 05-Nov-03 BETA & 0.0171 & $\mathrm{pCi} / \mathrm{m} 3$ & 0.0013 & 0.0033 & & & \\
\hline SESPMNT & B17NY3 & N OF $200 \mathrm{E}$ & ONSITE & AT & 18-Nov-03 BETA & 0.0343 & $\mathrm{pCi} / \mathrm{m} 3$ & 0.0019 & 0.006 & & & \\
\hline SESPMNT & B17NY4 & N OF $200 \mathrm{E}$ & ONSITE & AT & 01-Dec-03 BETA & 0.0118 & $\mathrm{pCi} / \mathrm{m} 3$ & 0.0012 & 0.0025 & & & \\
\hline SESPMNT & B17NY5 & N OF $200 \mathrm{E}$ & ONSITE & AT & 17-Dec-03 BETA & 0.0127 & $\mathrm{pCi} / \mathrm{m} 3$ & 0.0011 & 0.0025 & & & \\
\hline SESPMNT & B17NY6 & N OF $200 \mathrm{E}$ & ONSITE & AT & 30-Dec-03 BETA & 0.0202 & $\mathrm{pCi} / \mathrm{m} 3$ & 0.0013 & 0.0037 & & & \\
\hline SESPMNT & B16843 & OTHELLO & COMMUNITY & AT & 15-Jan-03 BETA & 0.0196 & $\mathrm{pCi} / \mathrm{m} 3$ & 0.0015 & 0.0037 & & & \\
\hline SESPMNT & B16844 & OTHELLO & COMMUNITY & AT & 29-Jan-03 BETA & 0.0155 & $\mathrm{pCi} / \mathrm{m} 3$ & 0.0013 & 0.003 & & & \\
\hline SESPMNT & B16845 & OTHELLO & COMMUNITY & AT & 12-Feb-03 BETA & 0.0136 & $\mathrm{pCi} / \mathrm{m} 3$ & 0.0013 & 0.0027 & & & \\
\hline SESPMNT & B16846 & OTHELLO & COMMUNITY & AT & 26-Feb-03 BETA & 0.0214 & $\mathrm{pCi} / \mathrm{m} 3$ & 0.0014 & 0.0037 & & & \\
\hline $\begin{array}{l}\text { SESPMNT } \\
\text { SESPMNT }\end{array}$ & $\begin{array}{l}\text { B16847 } \\
\text { B16848 }\end{array}$ & OTHELLO & COMMUNITY & AT & 12-Mar-03 BETA & $\begin{array}{r}0.0132 \\
0.00639\end{array}$ & pCi/m3 & 0.0012 & 0.0026 & & & \\
\hline $\begin{array}{l}\text { SESPMNT } \\
\text { SESPMNT }\end{array}$ & $\begin{array}{l}\text { B16848 } \\
\text { B16849 }\end{array}$ & $\begin{array}{l}\text { OTHELLO } \\
\text { OTHELLO }\end{array}$ & $\begin{array}{l}\text { COMMUNITY } \\
\text { COMMUNITY }\end{array}$ & $\begin{array}{l}\text { AT } \\
\text { AT }\end{array}$ & $\begin{array}{l}\text { 27-Mar-03 BETA } \\
\text { 0-Aros BETA }\end{array}$ & 0.00639 & pCi/m3 & $\begin{array}{l}0.0009 \\
0.001\end{array}$ & 0.0015 & & & \\
\hline $\begin{array}{l}\text { SESPMNT } \\
\text { SESPMNT }\end{array}$ & $\begin{array}{l}\text { B16849 } \\
\text { B16PH8 }\end{array}$ & $\begin{array}{l}\text { OTHELLO } \\
\text { OTHELLO }\end{array}$ & $\begin{array}{l}\text { COMMUNITY } \\
\text { COMMUNITY }\end{array}$ & $\begin{array}{l}\text { AT } \\
\text { AT }\end{array}$ & $\begin{array}{l}\text { 09-App--03 BETA } \\
\text { 23-Apr-03 BETAA }\end{array}$ & $\begin{array}{l}0.00666 \\
0.00971\end{array}$ & $\begin{array}{l}\mathrm{pClim3} \\
\mathrm{pCi} / \mathrm{m} 3\end{array}$ & $\begin{array}{r}0.001 \\
0.0011\end{array}$ & $\begin{array}{l}0.0017 \\
0.0021\end{array}$ & & & \\
\hline SESPMNT & B16PH9 & OTHELLO & COMMUNITY & AT & 07-May-03 BETA & 0.0088 & $\mathrm{pCi} / \mathrm{m} 3$ & 0.001 & $\begin{array}{r}0.0021 \\
0.002\end{array}$ & & & \\
\hline SESPMNT & B16PJO & OTHELLO & COMMUNITY & AT & 21-May-03 BETA & 0.01 & $\mathrm{pCi} / \mathrm{m} 3$ & 0.0011 & 0.0021 & & & \\
\hline SESPMNT & B16PJ1 & OTHELLO & COMMUNITY & AT & 05-Jun-03 BETA & 0.0126 & $\mathrm{pCi} / \mathrm{m} 3$ & 0.0011 & 0.0025 & & & \\
\hline SESPMNT & B16PJ2 & OTHELLO & COMMUNITY & AT & 18-Jun-03 BETA & & & & & & NO SAMPLE. SAVE FOR COMPOSITE. & \\
\hline SESPMNT & B16PJ3 & OTHELLO & COMMUNITY & AT & 01-Jul-03 BETA & 0.0091 & $\mathrm{pCi} / \mathrm{m} 3$ & 0.0011 & 0.0021 & & & \\
\hline SESPMNT & B175D7 & OTHELLO & COMMUNITY & AT & 17-Jul-03 BETA & 0.0091 & $\mathrm{pCi} / \mathrm{m} 3$ & 0.00096 & 0.0019 & & & \\
\hline SESPMNT & B175D8 & OTHELLO & COMMUNITY & AT & 30-Jul-03 BETA & 0.0133 & $\mathrm{pCi} / \mathrm{m} 3$ & 0.0013 & 0.0027 & & & \\
\hline SESPMNT & B175D9 & OTHELLO & COMMUNITY & AT & 13-Aug-03 BETA & 0.0132 & $\mathrm{pCi} / \mathrm{m} 3$ & 0.0012 & 0.0026 & & & \\
\hline $\begin{array}{l}\text { SESPMNT } \\
\text { SESPMNT }\end{array}$ & B175F0 & OTHELLO & COMMUNITY & AT & 27-Aug-03 BETA & 0.014 & $\mathrm{pCi} / \mathrm{m} 3$ & 0.0012 & 0.0028 & & & \\
\hline $\begin{array}{l}\text { SESPMNT } \\
\text { SESPMNT }\end{array}$ & B175F1 & OTHELLO & COMMUNITY & AT & 11-Sep-03 BETA & 0.0171 & $\mathrm{pCi} / \mathrm{m} 3$ & 0.0013 & 0.0033 & & & \\
\hline $\begin{array}{l}\text { SESPMNT } \\
\text { SESPMNT }\end{array}$ & $\begin{array}{l}817552 \\
B 1752^{2}\end{array}$ & $\begin{array}{l}\text { OTHELLO } \\
\text { OTHELLO }\end{array}$ & COMMUNITY & AT & 24-Sep-03 BETA & 0.0101 & $\mathrm{pCl} / \mathrm{m}^{3}$ & 0.0011 & 0.0022 & & & \\
\hline $\begin{array}{l}\text { SESPMNT } \\
\text { SESPMNT }\end{array}$ & 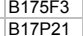 & $\begin{array}{l}\text { OTHELLO } \\
\text { OTHELLO }\end{array}$ & $\begin{array}{l}\text { COMMUNNTY } \\
\text { COMMUNITY }\end{array}$ & $\begin{array}{l}\text { AT } \\
\text { AT }\end{array}$ & $\begin{array}{l}\text { 09-Oct--03 BETA } \\
\text { 22-Ot-03 BETA }\end{array}$ & 0.0257 & $\begin{array}{l}\mathrm{pC} / \mathrm{m} 3 \\
\mathrm{pC} / \mathrm{m} 3\end{array}$ & 0.0015 & $\begin{array}{l}0.0046 \\
0.0041\end{array}$ & & & \\
\hline $\begin{array}{l}\text { SESPMNI } \\
\text { SESPMNT }\end{array}$ & $\begin{array}{l}\text { B1/1721 } \\
\text { B17P22 }\end{array}$ & $\begin{array}{l}\text { OTHELLO } \\
\text { OTHELLO }\end{array}$ & $\begin{array}{l}\text { COMMUNIIYY } \\
\text { COMMU⿴囗十 }\end{array}$ & AT & $\begin{array}{l}\text { 22-Oct-03 BETA } \\
\text { 06-Nov-03 BETA }\end{array}$ & 0.0223 & $\begin{array}{l}\mathrm{pCim} 3 \\
\mathrm{pCi} / \mathrm{m} 3\end{array}$ & 0.0016 & $\begin{array}{l}0.0041 \\
0.0035\end{array}$ & & & \\
\hline SESPMNT & B17P23 & OTHELLO & COMMUNITY & AT & 19-Nov-03 BETA & 0.0307 & $\mathrm{pCi} / \mathrm{m} 3$ & 0.0018 & 0.0054 & & & \\
\hline SESPMNT & B17P24 & OTHELLO & COMMUNITY & AT & 03-Dec-03 BETA & 0.0166 & $\mathrm{pCi} / \mathrm{m} 3$ & 0.0013 & 0.0032 & & & \\
\hline SESPMNT & B17P25 & OTHELLO & COMMUNITY & AT & 18-Dec-03 BETA & 0.0118 & $\mathrm{pCi} / \mathrm{m} 3$ & 0.0011 & 0.0024 & & & \\
\hline SESPMNT & B17P26 & OTHELLO & COMMUNITY & AT & 31-Dec-03 BETA & 0.0169 & $\mathrm{pCi} / \mathrm{m} 3$ & 0.0014 & 0.0033 & & & \\
\hline SESPMNT & B16941 & PASCO & COMMUNITY & AT & 16-Jan-03 BETA & 0.0261 & $\mathrm{pCi} / \mathrm{m} 3$ & 0.0017 & 0.0048 & & & \\
\hline SESPMNT & B16942 & PASCO & COMMUNITY & AT & 30-Jan-03 BETA & 0.0174 & $\mathrm{pCi} / \mathrm{m} 3$ & 0.0014 & 0.0033 & & & \\
\hline SESPMNT & B16943 & PASCO & COMMUNITY & AT & 13-Feb-03 BETA & 0.0175 & $\mathrm{pCi} / \mathrm{m} 3$ & 0.0014 & 0.0033 & & & \\
\hline SESPMNT & B16944 & PASCO & COMMUNITY & AT & 28-Feb-03 BETA & 0.023 & $\mathrm{pCi} / \mathrm{m} 3$ & 0.0014 & 0.0039 & & & \\
\hline $\begin{array}{l}\text { SESPMNT } \\
\text { SESPMNT }\end{array}$ & B16945 & $\begin{array}{l}\text { PASCO } \\
\text { PASCO }\end{array}$ & COMMUNITY & AT & 13-Mar-03 BETA & 0.00786 & $\mathrm{pCi} / \mathrm{m}^{2}$ & $\begin{array}{r}0.0011 \\
0.0007\end{array}$ & 0.0019 & & & \\
\hline $\begin{array}{l}\text { SESPMNT } \\
\text { SESPMNT }\end{array}$ & $\begin{array}{l}\text { 每6946 } \\
\text { B16947 }\end{array}$ & $\begin{array}{l}\text { PASCO } \\
\text { PASCO }\end{array}$ & $\begin{array}{l}\text { COMMUNITY } \\
\text { COMMUNITY }\end{array}$ & $\begin{array}{l}\text { AT } \\
\text { AT }\end{array}$ & $\begin{array}{l}\text { 28-Mar--03 BETA } \\
\text { 10-Ar-03 BETA }\end{array}$ & $\begin{array}{l}0.00563 \\
0.00711\end{array}$ & $\begin{array}{l}\text { pCim3 } \\
\text { pCi/m3 }\end{array}$ & $\begin{array}{l}0.00007 \\
0.001\end{array}$ & $\begin{array}{l}0.0014 \\
0.0017\end{array}$ & & & \\
\hline SESPMNT & B16RF4 & PASCO & COMMUNITY & AT & 25-Apr-03 BETA & 0.0108 & $\mathrm{pCi} / \mathrm{m} 3$ & 0.0011 & 0.0022 & & & \\
\hline SESPMNT & B16RF5 & PASCO & COMMUNITY & AT & 08-May-03 BETA & 0.00843 & $\mathrm{pCi} / \mathrm{m} 3$ & 0.0011 & 0.002 & & & \\
\hline SESPMNT & B16RF6 & PASCO & COMMUNITY & AT & 22-May-03 BETA & 0.0126 & $\mathrm{pCi} / \mathrm{m} 3$ & 0.0019 & 0.0032 & & & \\
\hline SESPMNT & B16RF7 & PASCO & COMMUNITY & AT & 06-Jun-03 BETA & 0.0144 & $\mathrm{pCi} / \mathrm{m} 3$ & 0.0012 & 0.0028 & & & \\
\hline SESPMNT & B16RF8 & PASCO & COMMUNITY & AT & 19-Jun-03 BETA & 0.0116 & $\mathrm{pCi} / \mathrm{m} 3$ & 0.0013 & 0.0025 & & & \\
\hline SESPMNT & B16RF9 & PASCO & COMMUNITY & AT & 07-Jul-03 BETA & 0.00881 & $\mathrm{pCi} / \mathrm{m} 3$ & 0.00088 & 0.0018 & & & \\
\hline SESPMNT & B176C1 & PASCO & COMMUNITY & AT & 18-Jul-03 BETA & 0.0126 & $\mathrm{pCi} / \mathrm{m} 3$ & 0.0014 & 0.0027 & & & \\
\hline SESPMNT & B176C2 & PASCO & COMMUNITY & AT & 31-Jul-03 BETA & 0.0139 & $\mathrm{pCi} / \mathrm{m} 3$ & 0.0013 & 0.0028 & & & \\
\hline SESPMNT & B176C3 & PASCO & COMMUNITY & AT & 15-Aug-03 BETA & 0.0137 & $\mathrm{pCi} / \mathrm{m} 3$ & 0.0012 & 0.0027 & & & \\
\hline $\begin{array}{l}\text { SESPMNT } \\
\text { SESPMNT }\end{array}$ & B176C4 & PASCO & COMMUNITY & AT & 28-Aug-03 BETA & 0.0153 & $\mathrm{pCi} / \mathrm{m} 3$ & 0.0013 & 0.003 & & & \\
\hline SESPMNT & B176C5 & PASCO & COMMUNITY & AT & 12-Sep-03 BETA & 0.016 & $\mathrm{pC} / \mathrm{m} 3$ & 0.0012 & 0.003 & & & \\
\hline SESPMNT & B176C6 & $\begin{array}{l}\text { PASCO } \\
\text { PASCO }\end{array}$ & COMMUNITY & AT & 25-Sep-03 BETA & 0.0134 & pCi/m3 & 0.0012 & 0.0027 & & & \\
\hline SESPMNT & B176C7 & $\begin{array}{l}\text { PASCO } \\
\text { PASCO }\end{array}$ & COMMUNITY & AT & $\begin{array}{l}10-0 \mathrm{ct}-03 \text { BETA } \\
\text { 23-0.ct-03 BETA }\end{array}$ & 0.0304 & $\mathrm{pCi} / \mathrm{m}^{2}$ & 0.0016 & 0.0053 & & & \\
\hline $\begin{array}{l}\text { SESPMNT } \\
\text { SESPMNT }\end{array}$ & $\begin{array}{l}\text { B17R11 } \\
\text { B17R212 }\end{array}$ & $\begin{array}{l}\text { PASCO } \\
\text { PASCO }\end{array}$ & $\begin{array}{l}\text { COMMUNNTY } \\
\text { COMMUNITY }\end{array}$ & $\begin{array}{l}\text { AT } \\
\text { AT }\end{array}$ & $\begin{array}{c}\text { 23-Oct-03 BETA } \\
\text { 37-Nov-03 BETA }\end{array}$ & $\begin{array}{l}0.0104 \\
0.0163\end{array}$ & $\begin{array}{l}\mathrm{pClim3} \\
\mathrm{pCi} / \mathrm{m} 3\end{array}$ & $\begin{array}{l}0.0011 \\
0.0012\end{array}$ & 0.0022 & & & \\
\hline SESPMNT & B17R12 & PASCO & COMINUNIIIY & & 07-Nov-03 BETA & 0.0163 & & 0.0012 & 0.0031 & & & \\
\hline
\end{tabular}


AIR BETA/ALPHA

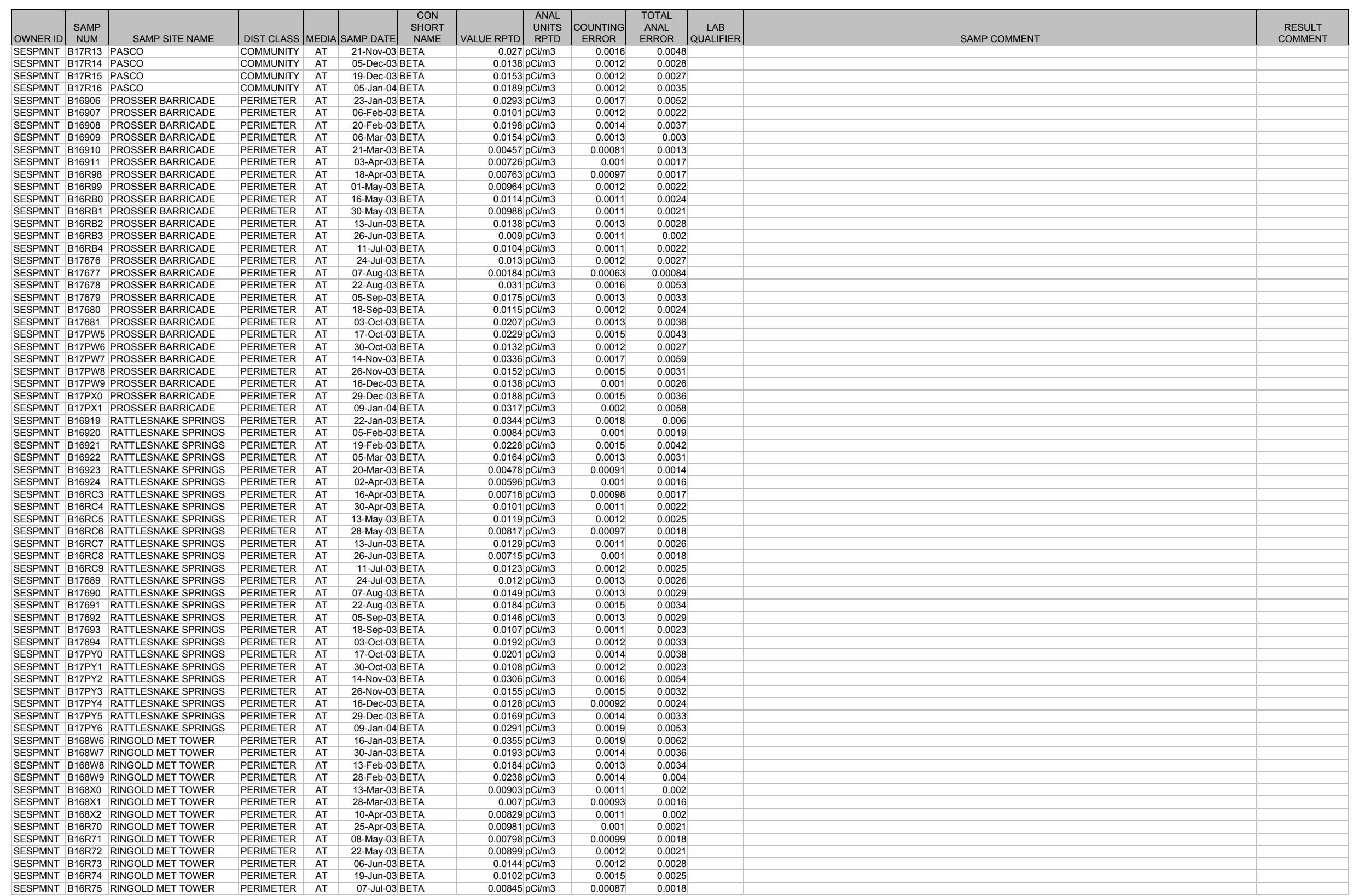


AIR BETA/ALPHA

\begin{tabular}{|c|c|c|c|c|c|c|c|c|c|c|c|c|c|}
\hline |OWNER ID & \begin{tabular}{|l|} 
SAMP \\
NUM
\end{tabular} & SAMP SITE NAME & DIST CLASS & MEDIA & & $\begin{array}{l}\text { CON } \\
\text { SHORT } \\
\text { NAME }\end{array}$ & & $\begin{array}{l}\text { ANAL } \\
\text { UNITS } \\
\text { RPTD }\end{array}$ & $\left|\begin{array}{c}\text { COUNTING } \\
\text { ERROR }\end{array}\right|$ & \begin{tabular}{|c|c|} 
TOTAL \\
ANAL \\
ERROR
\end{tabular} & $\left|\begin{array}{c}\text { LAB } \\
\text { QUALIFIER }\end{array}\right|$ & SAMP COMMENT & $\begin{array}{c}\text { RESULT } \\
\text { COMMENT }\end{array}$ \\
\hline SESPMNT & B17646 & RINGOLD MET TOWER & PERIMETER & AT & 18-Jul-03 BE & & $0.0116 p$ & & 0.0014 & 0.0026 & & & \\
\hline SESPMNT & B17647 & RINGOLD MET TOWER & PERIMETER & AT & 31-Jul-03 BE & & $0.0138 \mathrm{p}$ & Ci/m3 & 0.0013 & 0.0028 & & & \\
\hline SESPMNT & B17648 & RINGOLD MET TOWER & PERIMETER & AT & 15-Aug-03 BE & & $0.0141 \mathrm{p}$ & $\mathrm{Ci} / \mathrm{m} 3$ & 0.0012 & 0.0027 & & & \\
\hline SESPMNT & B17649 & RINGOLD MET TOWER & PERIMETER & AT & 28-Aug-03 BE & & & & 0.0013 & 0.0031 & & & \\
\hline SESPMNT & B17650 & RINGOLD MET TOWER & PERIMETER & AT & 12-Sep-03 BE & & $0.0153 \mathrm{p}$ & $\mathrm{C} / \mathrm{m} 3$ & 0.0012 & 0.0029 & & & \\
\hline SESPMNT & B17651 & RINGOLD MET TOWER & PERIMETER & AT & 25-Sep-03 BE & & $0.0116 \mathrm{p}$ & & 0.0012 & 0.0025 & & & \\
\hline SESPMNT & B17652 & RINGOLD MET TOWER & PERIMETER & AT & 10-Oct-03 BE & & $0.026 \mathrm{p}$ & Ci/m3 & 0.0015 & 0.0046 & & & \\
\hline SESPMNT & B17PR7 & RINGOLD MET TOWER & PERIMETER & AT & 23-Oct-03 BE & & $0.0114 p$ & Ci/m3 & 0.0012 & 0.0024 & & & \\
\hline SESPMNT & B17PR8 & RINGOLD MET TOWER & PERIMETER & AT & 07-Nov-03 BE & & $0.0249 \mathrm{p}$ & & 0.0014 & 0.0045 & & & \\
\hline $\begin{array}{l}\text { SESPMNT } \\
\text { SECDMNT }\end{array}$ & B17PR9 & RINGOLD MET TOWER & PERIMETER & AT & 21-Nov-03 BE & & $0.0249 \mathrm{p}$ & & 0.0015 & 0.0045 & & & \\
\hline SESPMNT & B17PTO & RINGOLD MET TOWER & PERIMETER & AT & 05-Dec-03 BE & & $0.0148 \mathrm{p}$ & Ci/m3 & 0.0012 & 0.0029 & & & \\
\hline $\begin{array}{l}\text { SESPMNT } \\
\text { SESPMNT }\end{array}$ & $\begin{array}{l}\text { B17PT1 } \\
\text { B17P2 }\end{array}$ & 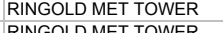 & $\begin{array}{l}\text { PERIMETER } \\
\text { PERIMETER }\end{array}$ & AT & 19-Dec-03BE & & $0.0152 p$ & Ci/m3 & 0.0012 & 0.0027 & & & \\
\hline $\begin{array}{l}\text { SESPMNT } \\
\text { SESPMNT }\end{array}$ & B17PT2 & $\begin{array}{l}\text { RINGOLD MET TOWER } \\
\text { SFND MERNTA }\end{array}$ & $\begin{array}{l}\text { PERIMETER } \\
\text { PERIMETER }\end{array}$ & AT & 05-Jan-04 BE & EETA & $0.0197 p$ & Ci/m3 & 0.0013 & 0.0036 & & & \\
\hline $\begin{array}{l}\text { SESPMNT } \\
\text { SESPMNT }\end{array}$ & $\begin{array}{l}\text { B16933 } \\
\text { B1634 }\end{array}$ & $\begin{array}{l}\text { S END VERNIIA BRIIGEE } \\
\text { S END VERNITA BRIDGE }\end{array}$ & $\begin{array}{l}\text { PERRMETER } \\
\text { PERIMETER }\end{array}$ & $\begin{array}{l}\text { AT } \\
\text { AT }\end{array}$ & $\begin{array}{l}\text { 15-Jan-03BE } \\
\text { 29-Jan-03 BE }\end{array}$ & EETA & $\begin{array}{l}0.0193 \mathrm{p} \\
0.0118 \mathrm{p}\end{array}$ & il/m3 & 0.0015 & 0.0036 & & & \\
\hline SESPMNT & 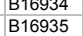 & $\begin{array}{l}\text { SEND VERNIIA BRIDGE } \\
\text { S END VERNITA BRIDGE }\end{array}$ & $\begin{array}{l}\text { PERMEIRR } \\
\text { PERIMETER }\end{array}$ & $\begin{array}{l}\text { AI } \\
\text { AT }\end{array}$ & $\begin{array}{l}\text { 29-Jan-03B BE } \\
\text { 12-Feb-03 BE }\end{array}$ & $\begin{array}{l}\text { SETA } \\
\text { STA }\end{array}$ & $\begin{array}{l}0.0118 \mathrm{p} \\
0.0121 \mathrm{p}\end{array}$ & $\begin{array}{l}\mathrm{Cl} \text { Clm3 } \\
\mathrm{C} / \mathrm{m} 3\end{array}$ & $\begin{array}{l}0.0012 \\
0.0013\end{array}$ & $\begin{array}{l}0.0024 \\
0.0026\end{array}$ & & & \\
\hline SESPMNT & B16936 & $S$ END VERNITA BRIDGE & PERIMETER & AT & 26-Feb-03 BE & SETA & $0.0218 \mathrm{p}$ & $\mathrm{Ci} / \mathrm{m} 3$ & 0.0014 & 0.0037 & & & \\
\hline SESPMNT & B16937 & $S$ END VERNITA BRIDGE & PERIMETER & AT & 12-Mar-03 BE & SETA & $0.0126 \mathrm{p}$ & $\mathrm{Ci} / \mathrm{m} 3$ & 0.0012 & 0.0025 & & & \\
\hline SESPMNT & B16938 & $S$ END VERNITA BRIDGE & PERIMETER & AT & 27-Mar-03 BE & SETA & $0.00554 \mathrm{p}$ & $\mathrm{C} i / \mathrm{m} 3$ & 0.00086 & 0.0014 & & & \\
\hline SESPMNT & B16939 & $S$ END VERNITA BRIDGE & PERIMETER & AT & 09-Apr-03 BE & SETA & $0.00695 p$ & $\mathrm{C} / \mathrm{m} 3$ & 0.001 & 0.0017 & & & \\
\hline SESPMNT & B16RD7 & $S$ END VERNITA BRIDGE & PERIMETER & AT & 23-Apr-03 BE & & $0.00976 p$ & $\mathrm{C} / \mathrm{m} 3$ & 0.0012 & 0.0021 & & & \\
\hline SESPMNT & B16RD8 & $S$ END VERNITA BRIDGE & PERIMETER & AT & 07-May-03 BE & & $0.00782 p$ & $\mathrm{C} / \mathrm{m} 3$ & 0.00095 & 0.0018 & & & \\
\hline SESPMNT & B16RD9 & S END VERNITA BRIDGE & PERIMETER & AT & 21-May-03 BE & & $0.00965 p$ & CCilm3 & 0.0012 & 0.0022 & & SUSPECT AIR CALIBRATOR ERROR ON 5/7/03, 1.5 CFM START FLOW MAY ACTUALLY BE 1.2 CFM. & \\
\hline SESPMNT & B16RF0 & $S$ END VERNITA BRIDGE & PERIMETER & AT & 05-Jun-03 BE & BETA & $0.0125 \mathrm{p}$ & Ci/m3 & 0.0011 & 0.0025 & & & \\
\hline $\begin{array}{l}\text { SESPMNT } \\
\text { SESPMNT }\end{array}$ & B16RF1 & S END VERNITA BRIDGE & PERIMETER & AT & 18-Jun-03 BE & SETA & $0.0129 \mathrm{p}$ & Ci/m3 & 0.0013 & 0.0027 & & & \\
\hline $\begin{array}{l}\text { SESPMNT } \\
\text { SESPMNT }\end{array}$ & $\begin{array}{ll}\text { B16RF2 } \\
\text { B17683 }\end{array}$ & S END VERNITA BRIDGE & $\begin{array}{l}\text { PERIMETER } \\
\text { PERMETER }\end{array}$ & AT & 01-Jul-03 BE & BETA & $0.00875 p$ & CCi/m3 & $\begin{array}{r}0.0011 \\
0.0007\end{array}$ & $\begin{array}{r}0.002 \\
0019\end{array}$ & & & \\
\hline $\begin{array}{l}\text { SESPMNT } \\
\text { SESPMNT }\end{array}$ & $\begin{array}{l}\text { B176B3 } \\
\text { B17604 }\end{array}$ & $\begin{array}{l}\text { S END VERNITA BRIDGE } \\
\text { S SND VERNIA BRDEGE }\end{array}$ & $\begin{array}{l}\text { PERIMETER } \\
\text { PEIMETER }\end{array}$ & AT & $\begin{array}{l}\text { 17-Jul-03 BE } \\
30-0 \text { - }\end{array}$ & EETA & $0.00918 p$ & Cilm3 & 0.00097 & 0.0019 & & & \\
\hline $\begin{array}{l}\text { SESPMNT } \\
\text { SESPMNT }\end{array}$ & $\begin{array}{l}\text { B17664 } \\
\text { B176855 }\end{array}$ & $\begin{array}{l}\text { SEND VERNITA BRIDGE } \\
\text { S END VERNTAA BRIDGE }\end{array}$ & $\begin{array}{l}\text { PERIMETER } \\
\text { PERIMETER }\end{array}$ & $\begin{array}{l}\text { AT } \\
\text { AT }\end{array}$ & & EETA & $\begin{array}{l}0.0135 \mathrm{p} \\
0.0137 \mathrm{p}\end{array}$ & Ci/m3 & $\begin{array}{l}0.0013 \\
0.0013\end{array}$ & 0.0028 & & & \\
\hline $\begin{array}{l}\text { SESPMNT } \\
\text { SESPMNT }\end{array}$ & 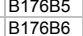 & $\begin{array}{l}\text { SEND VERNITA BRRDGE } \\
\text { S END VERNITA BRIDGE }\end{array}$ & $\begin{array}{l}\text { PERIMEIER } \\
\text { PERIMETER }\end{array}$ & $\begin{array}{l}\text { AI } \\
\text { AT }\end{array}$ & $\begin{array}{l}\text { 13-Aug-03B BE } \\
\text { 27-Au-03 BE }\end{array}$ & $\begin{array}{l}\text { SETA } \\
\text { SETA }\end{array}$ & $\begin{array}{l}0.0137 \mathrm{p} \\
0.0134 \mathrm{p}\end{array}$ & $\begin{array}{l}\mathrm{C} \text { Cim3 } \\
\mathrm{C} \mathrm{C} / \mathrm{m} 3\end{array}$ & $\begin{array}{l}0.0013 \\
0.0012\end{array}$ & $\begin{array}{l}0.0028 \\
0.0027\end{array}$ & & & \\
\hline $\begin{array}{l}\text { SESPMNI } \\
\text { SESPMNT }\end{array}$ & $\begin{array}{l}\mathrm{B} 1 / 1666 \\
\mathrm{~B} 176 \mathrm{~B} 7\end{array}$ & $\begin{array}{l}\text { S END VERNITA BRIDGE } \\
\text { S ENRER BER }\end{array}$ & $\begin{array}{l}\text { PERIMEITER } \\
\text { PERIMET }\end{array}$ & AT & $\begin{array}{l}\text { 21-Aug-03BE } \\
\text { 11-Sep-03BE }\end{array}$ & EETA & $\begin{array}{l}0.0134 \mathrm{p} \\
0.0148 \mathrm{p}\end{array}$ & 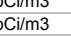 & 0.0012 & $\begin{array}{l}0.0027 \\
0.0029\end{array}$ & & & \\
\hline SESPMNT & B176B8 & $S$ END VERNITA BRIDGE & PERIMETER & AT & 24-Sep-03 BE & SETA & $0.0101 \mathrm{p}$ & $\mathrm{C} \mathrm{C} / \mathrm{m} 3$ & 0.0011 & 0.0022 & & & \\
\hline SESPMNT & B176B9 & $S$ END VERNITA BRIDGE & PERIMETER & AT & 09-Oct-03 BE & SETA & $0.0238 \mathrm{p}$ & $\mathrm{C} / \mathrm{m} 3$ & 0.0015 & 0.0044 & & & \\
\hline SESPMNT & B17R04 & $S$ END VERNITA BRIDGE & PERIMETER & AT & 22-Oct-03 BE & BETA & $0.0161 \mathrm{p}$ & Cilm3 & 0.0013 & 0.0031 & & & \\
\hline SESPMNT & B17R05 & $S$ END VERNITA BRIDGE & PERIMETER & AT & 06-Nov-03 BE & SETA & $0.0168 \mathrm{p}$ & Ci/m3 & 0.0012 & 0.0032 & & & \\
\hline SESPMNT & B17R06 & $S$ END VERNITA BRIDGE & PERIMETER & AT & 19-Nov-03 BE & BETA & $0.0271 \mathrm{p}$ & Ci/m3 & 0.0017 & 0.0049 & & & \\
\hline SESPMNT & B17R07 & S END VERNITA BRIDGE & PERIMETER & AT & 03-Dec-03 BE & BETA & $0.0141 \mathrm{p}$ & Ci/m3 & 0.0012 & 0.0028 & & & \\
\hline SESPMNT & B17R08 & S END VERNITA BRIDGE & PERIMETER & AT & 18-Dec-03BE & BETA & $0.0121 \mathrm{p}$ & Ci/m3 & 0.0011 & 0.0025 & & & \\
\hline $\begin{array}{l}\text { SESPMNT } \\
\text { SESPMNT }\end{array}$ & B17R09 & S END VERNITA BRIDGE & PERIMETER & AT & 31-Dec-03 BE & BETA & $0.0184 p$ & Ci/m3 & 0.0015 & 0.0036 & & & \\
\hline $\begin{array}{l}\text { SESPMNT } \\
\text { SESPMNT }\end{array}$ & 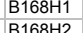 & $\begin{array}{l}\text { S OF } 200 \mathrm{E} \\
\text { SOF } 200 \mathrm{E}\end{array}$ & $\begin{array}{l}\text { ONSITE } \\
\text { ONSTIE }\end{array}$ & $\begin{array}{l}\text { AT } \\
\text { AT }\end{array}$ & $\begin{array}{l}\text { 14-Jan-3 BE } \\
\text { 28-Jan-03 BE }\end{array}$ & EETA & $\begin{array}{r}0.029 \mathrm{p} \\
0.0246 \mathrm{p}\end{array}$ & Ci/m3 & 0.0017 & 0.0051 & & & \\
\hline $\begin{array}{l}\text { SESPMNT } \\
\text { SESPMNT }\end{array}$ & $\begin{array}{ll}\mathrm{B} 168 \mathrm{~B} 2 \\
\mathrm{~B} 16 \mathrm{~B} / 3\end{array}$ & $\begin{array}{l}\text { SOF } 200 E \\
\text { S OF } 200 \mathrm{E}\end{array}$ & $\begin{array}{l}\text { ONSITE } \\
\text { ONSITE }\end{array}$ & $\begin{array}{l}\text { AT } \\
\text { AT }\end{array}$ & $\begin{array}{l}\text { 28-Jan-03BE } \\
\text { 11-Feb-03 BE }\end{array}$ & $\begin{array}{l}\text { SETA } \\
\text { SETA }\end{array}$ & $\begin{array}{c}0.0246 \mathrm{p} \\
0.017 \mathrm{p}\end{array}$ & $\begin{array}{l}\mathrm{C} \text { Cim3 } \\
\mathrm{CD} / \mathrm{m} 3\end{array}$ & 0.0016 & 0.0044 & & & \\
\hline $\begin{array}{l}\text { SESPMNT } \\
\text { SESPMNT }\end{array}$ & 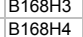 & $\begin{array}{l}\text { SOF } 200 \mathrm{E} \\
\text { SOF } 200 \mathrm{E}\end{array}$ & ONSITE & AT & $\begin{array}{l}11 \text {-Feb-03BE } \\
25-\text { Feb-03 BE }\end{array}$ & $\begin{array}{l}\text { EETA } \\
\text { ETA }\end{array}$ & $\begin{array}{l}0.01 / \mathrm{p} \\
0.0171 \mathrm{p}\end{array}$ & $\begin{array}{ll}\mathrm{Cl} / \mathrm{m} 3 \\
\mathrm{Ci} / \mathrm{m} 3\end{array}$ & $\begin{array}{l}0.0012 \\
0.0013\end{array}$ & 0.0032 & & & \\
\hline SESPMNT & B168H5 & $S O F 200 \mathrm{E}$ & ONSITE & AT & 10-Mar-03 BE & BETA & $0.0145 \mathrm{p}$ & $\mathrm{Ci} / \mathrm{m} 3$ & 0.0013 & 0.0029 & & & \\
\hline SESPMNT & $\mathrm{B} 168 \mathrm{H} 6$ & $S O F 200 \mathrm{E}$ & ONSITE & AT & 26-Mar-03 BE & SETA & $0.00603 p$ & & 0.00089 & 0.0015 & & & \\
\hline SESPMNT & $\mathrm{B} 168 \mathrm{H} 7$ & $S O F 200 \mathrm{E}$ & ONSITE & AT & 08-Apr-03 BE & SETA & $0.006 \mathrm{p}$ & & 0.0011 & 0.0016 & & & \\
\hline SESPMNT & B16PV4 & $S$ OF $200 \mathrm{E}$ & ONSITE & AT & 21-Apr-03 BE & SETA & $0.00975 p$ & & 0.0011 & 0.0022 & & & \\
\hline SESPMNT & B16PV5 & $S$ OF $200 \mathrm{E}$ & ONSITE & AT & 06-May-03 BE & BETA & $0.00922 p$ & $\mathrm{C} / \mathrm{m} 3$ & 0.0011 & 0.002 & & & \\
\hline SESPMNT & B16PV6 & $S O F 200 E$ & ONSITE & AT & 20-May-03 BE & SETA & $0.0111 \mathrm{p}$ & Ci/m3 & 0.0011 & 0.0023 & & & \\
\hline SESPMNT & B16PV7 & $S$ OF $200 \mathrm{E}$ & ONSITE & AT & 02-Jun-03 BE & BETA & $0.0124 p$ & Ci/m3 & 0.0012 & 0.0026 & & & \\
\hline SESPMNT & B16PV8 & $S O F 200 E$ & ONSITE & AT & 17-Jun-03 BE & SETA & $0.0117 \mathrm{p}$ & Ci/m3 & 0.0011 & 0.0024 & & & \\
\hline $\begin{array}{l}\text { SESPMNT } \\
\text { SESPMNT }\end{array}$ & B16PV9 & $S$ OF $200 \mathrm{E}$ & ONSITE & AT & 30-Jun-03 BE & SETA & $0.0105 \mathrm{p}$ & Ci/m3 & 0.0012 & 0.0023 & & & \\
\hline $\begin{array}{l}\text { SESPMNT } \\
\text { SESPMNT }\end{array}$ & B175R1 & $S$ OF $200 \mathrm{E}$ & ONSITE & AT & 15-Jul-03 BE & BETA & $0.00885 p$ & Cilm3 & 0.001 & 0.0019 & & & \\
\hline $\begin{array}{l}\text { SESPMNT } \\
\text { SESPMNT }\end{array}$ & B175R2 & $\begin{array}{l}\text { S OF 200E } \\
\text { SOF 200 E }\end{array}$ & ONSITE & AT & $\begin{array}{l}\text { 29-Jul-03 BE } \\
\text { 12-Aug-03 BE }\end{array}$ & EETA & $\begin{array}{l}0.0132 \mathrm{p} \\
0.0153 \mathrm{p}\end{array}$ & Ci/m3 & 0.0012 & $\begin{aligned} 0.0026 \\
0.003\end{aligned}$ & & & \\
\hline $\begin{array}{l}\text { SESPMNT } \\
\text { SESPMNT }\end{array}$ & B175R3 & $\begin{array}{l}\text { SOF } 200 E \\
\text { SOF } 200 E\end{array}$ & $\begin{array}{l}\text { ONSIE } \\
\text { ONSTIE }\end{array}$ & $\begin{array}{l}\text { AT } \\
\text { AT }\end{array}$ & $\begin{array}{l}\text { 12-Aug- } 03 \text { BE } \\
\text { 25-Aug-03 BE }\end{array}$ & $\begin{array}{l}\text { BETA } \\
\text { BETA }\end{array}$ & $\begin{array}{l}0.0153 \mathrm{p} \\
0.018 \mathrm{p}\end{array}$ & Cilm3 & 0.0013 & $\begin{array}{r}0.003 \\
0.0032\end{array}$ & & & \\
\hline $\begin{array}{l}\text { SESPMNT } \\
\text { SESPMNT }\end{array}$ & $\begin{array}{l}\text { B17554 } \\
\text { B17525 }\end{array}$ & $\begin{array}{l}\text { SOF } 200 E \\
\text { SOF } 200 \mathrm{E}\end{array}$ & $\begin{array}{l}\text { ONSITE } \\
\text { ONSITE }\end{array}$ & $\begin{array}{l}\text { AT } \\
\text { AT }\end{array}$ & $\begin{array}{l}\text { 25-Aug- } 03 \text { BEE } \\
\text { 10-Sep-03 BE }\end{array}$ & $\begin{array}{l}\text { EETA } \\
\text { BETA }\end{array}$ & $\begin{array}{l}0.018 \mathrm{p} \\
0.016 \mathrm{p}\end{array}$ & $\begin{array}{l}\text { Cilm3 } \\
\text { Ci/m3 }\end{array}$ & $\begin{array}{l}0.0013 \\
0.0012\end{array}$ & $\begin{array}{l}0.0032 \\
0.0031\end{array}$ & & & \\
\hline $\begin{array}{l}\text { SESPMNT } \\
\text { SESPMNT }\end{array}$ & 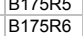 & $\begin{array}{l}\text { SOF } 200 \mathrm{E} \\
\text { S OF } 200 \mathrm{E}\end{array}$ & $\begin{array}{l}\text { ONSSIE } \\
\text { ONSITE }\end{array}$ & $\begin{array}{l}\text { AI } \\
\text { AT }\end{array}$ & $\begin{array}{l}\text { 10-Seep-00BE } \\
\text { 22-Sep-03 BE }\end{array}$ & $\begin{array}{l}\text { BEIA } \\
\text { BETA }\end{array}$ & $\begin{array}{l}0.016 \mathrm{p} \\
0.0097 \mathrm{p}\end{array}$ & $\begin{array}{l}\mathrm{C} \text { Clim3 } \\
\mathrm{C} \text { Cim3 }\end{array}$ & $\begin{array}{l}0.0012 \\
0.0012\end{array}$ & $\begin{array}{l}0.0031 \\
0.0023\end{array}$ & & & \\
\hline SESPMNT & B175R7 & $S O F 200 \mathrm{E}$ & ONSITE & AT & 07-Oct-03 BE & EETA & & & & & & NO SAMPLE. DO NOT SAVE FOR COMPOSITE. FILTER APPEARED TO HAVE BEEN PECKED AWAY BY A BIRD. & \\
\hline SESPMNT & B17PC1 & $S O F 200 \mathrm{E}$ & ONSITE & AT & 21-Oct-03 BE & SETA & & & & & & NO SAMPLE. DO NOT SAVE FOR COMPOSITE. FILTER APPEARED TO HAVE BEEN PECKED AWAY BY A BIRD. & \\
\hline SESPMNT & B17PC2 & SOF $200 \mathrm{E}$ & ONSITE & AT & 05-Nov-03 BE & SETA & $0.0176 \mathrm{p}$ & $\mathrm{Ci} / \mathrm{m} 3$ & 0.0013 & 0.0033 & & & \\
\hline SESPMNT & B17PC3 & $S O F 200 \mathrm{E}$ & ONSITE & AT & 18-Nov-03 BE & BETA & $0.0345 \mathrm{p}$ & Ci/m3 & 0.0019 & 0.0061 & & & \\
\hline SES & B17PC4 & $S O F 200 \mathrm{E}$ & ONSITE & AT & 01-Dec-03 BE & BETA & $0.011 \mathrm{p}$ & Ci/m3 & 0.0011 & 0.0024 & & & \\
\hline SESPMNT & B17PC5 & $S O F 200 E$ & ONSITE & AT & 17-Dec-03BE & BETA & $0.0136 \mathrm{p}$ & Ci/m3 & 0.0011 & 0.0027 & & & \\
\hline SESPMNT & B17PC6 & $S$ OF $200 \mathrm{E}$ & ONSITE & AT & 30-Dec-03BE & SETA & $0.0176 \mathrm{p}$ & Ci/m3 & 0.0014 & 0.0034 & & & \\
\hline $\begin{array}{l}\text { SESPMNT } \\
\text { SESPMNT }\end{array}$ & B168L1 & SW OF B/C CRIBS & ONSITE & AT & 14-Jan-03 BE & BETA & $0.0236 \mathrm{p}$ & Cilm3 & 0.0015 & 0.0043 & & & \\
\hline SESPMNT & B168L2 & SW OF B/C CRIBS & ONSITE & AT & 28-Jan-03 BE & EETA & $\begin{array}{l}0.0186 \mathrm{p} \\
0.0138 \mathrm{p}\end{array}$ & Ci/m3 & 0.0014 & 0.0035 & & & \\
\hline $\begin{array}{l}\text { SESPMNT } \\
\text { SESPMNT }\end{array}$ & $\begin{array}{l}\text { B168L3 } \\
\text { B16844 }\end{array}$ & $\begin{array}{l}\text { SW OF B BC CRRBS } \\
\text { SW OF B/C CRIBS }\end{array}$ & $\begin{array}{l}\text { ONSITE } \\
\text { ONSITE }\end{array}$ & $\begin{array}{l}\text { AT } \\
\text { AT }\end{array}$ & 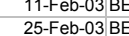 & $\begin{array}{l}\text { EETA } \\
\text { SETA }\end{array}$ & $\begin{array}{l}0.0138 \mathrm{p} \\
0.0158 \mathrm{p}\end{array}$ & $\begin{array}{l}\text { Cilm3 } \\
\text { Ciilm3 }\end{array}$ & $\begin{array}{l}0.0013 \\
0.0013\end{array}$ & 0.0027 & & & \\
\hline SESPMNT & B168:4 & SW OF B/C CRIBS & ONSITE & & 25-Feb-03 BE & & 0.0158 p & COIIm3 & 0.0013 & 0.0031 & & & \\
\hline
\end{tabular}


AIR BETA/ALPHA

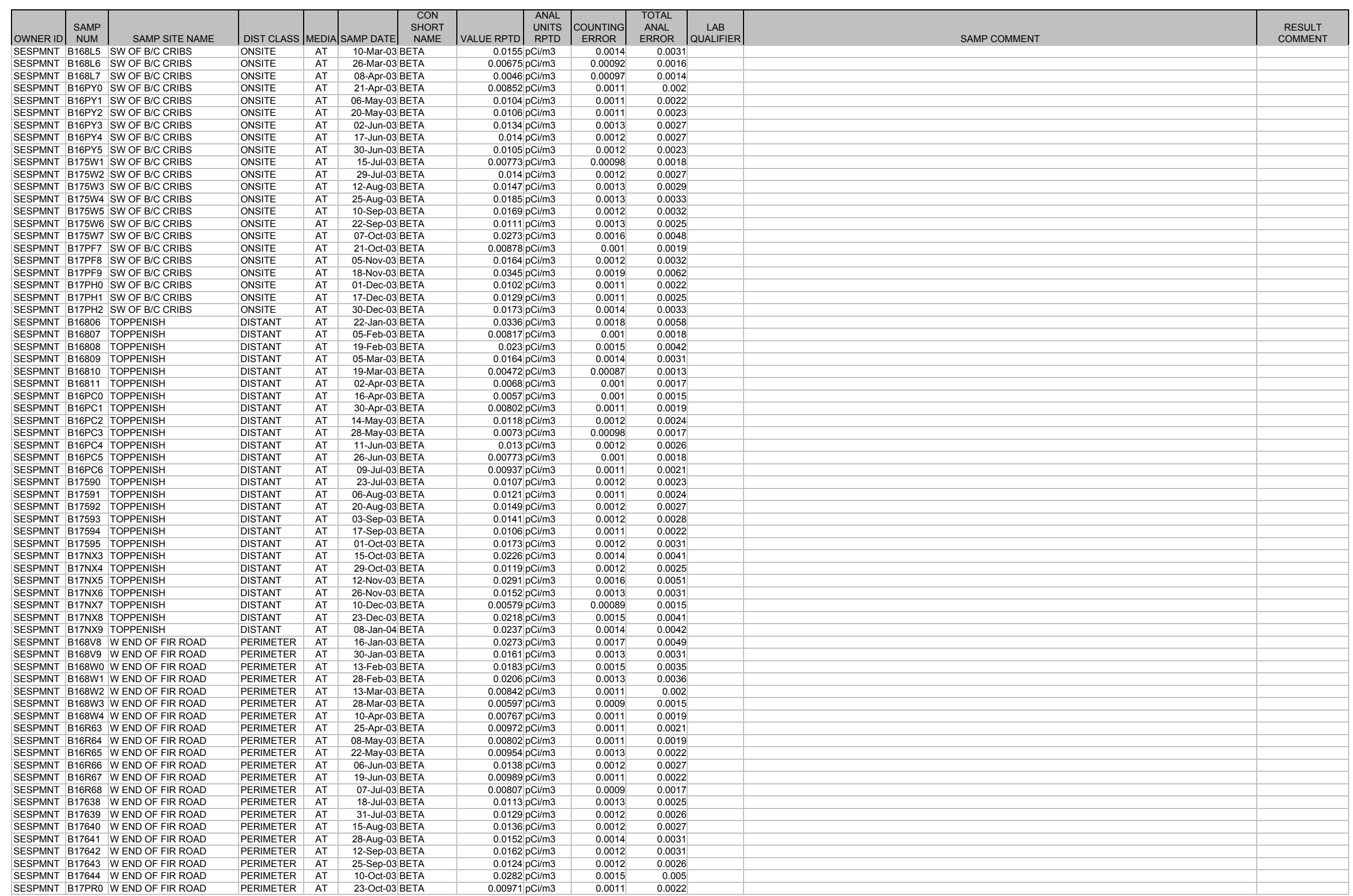


AIR BETA/ALPHA

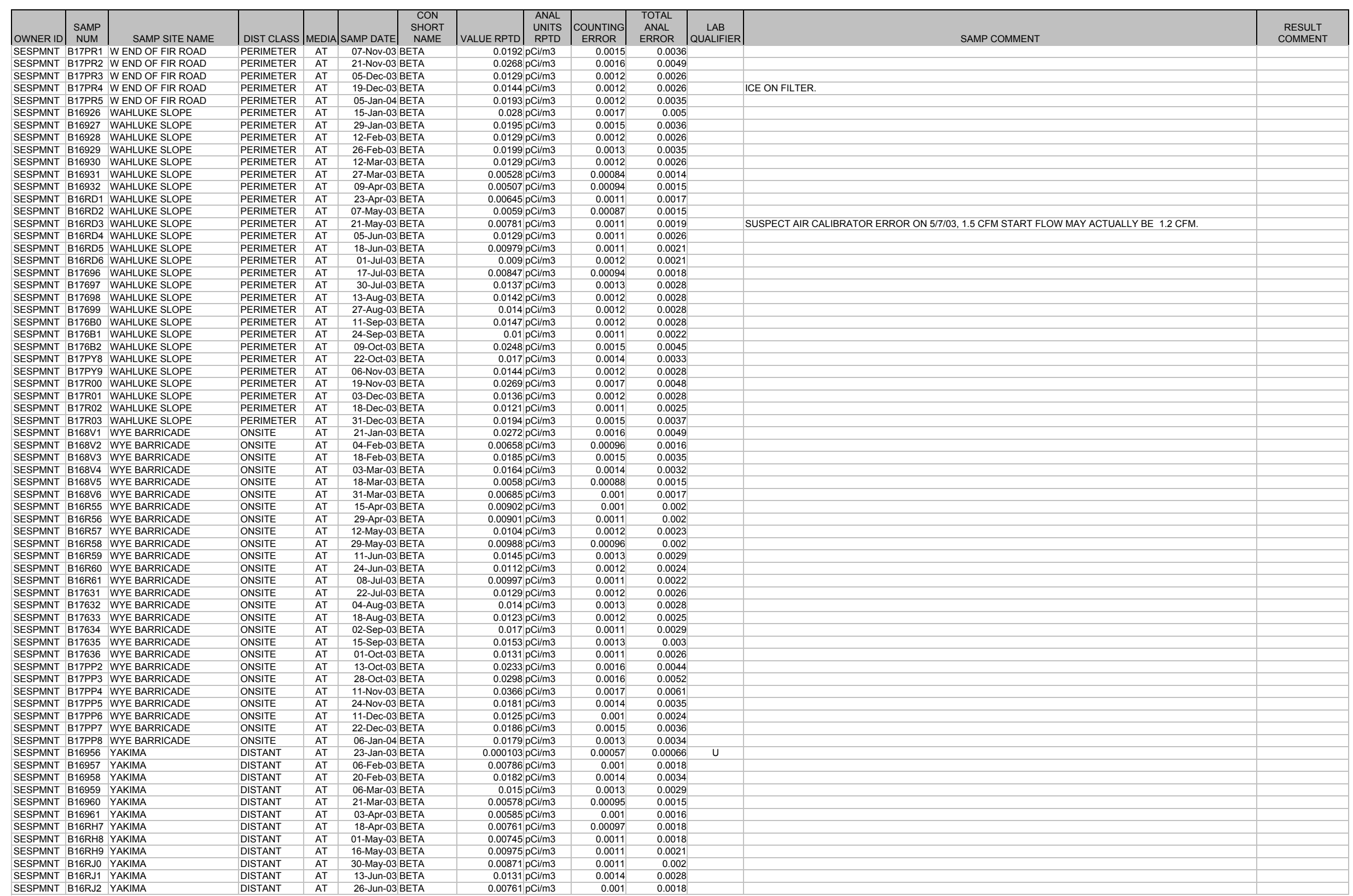


AIR BETA/ALPHA

\begin{tabular}{|c|c|c|c|c|c|c|c|c|c|c|c|c|}
\hline OWNER ID & \begin{tabular}{|l|} 
SAMP \\
NUMM
\end{tabular} & SAMP SITE NAME & DIST CLASS & MEDIA & \begin{tabular}{l|c} 
& CON \\
& SHORT \\
SAMP DATE & NAME
\end{tabular} & |VALUE RPTD | & $\begin{array}{l}\text { ANAL } \\
\text { UNITS } \\
\text { RPTD }\end{array}$ & $\left|\begin{array}{c}\text { COUNTING } \\
\text { ERROR }\end{array}\right|$ & \begin{tabular}{c|} 
TOTAL \\
ANAL \\
ERROR
\end{tabular} & $\mid \begin{array}{c}\text { LAB } \\
\text { QUALIFIER }\end{array}$ & SAMP COMMENT & $\begin{array}{l}\text { RESULT } \\
\text { COMMENT }\end{array}$ \\
\hline SESPMNT & B16RJ3 & YAKIMA & $\begin{array}{l}\text { DISTANT } \\
\text { DIST }\end{array}$ & AT & 11-Jul-03 BETA & $0.0113 \mathrm{p}$ & & 0.0011 & 0.0023 & & & \\
\hline SESPMNT & B176D6 & YAKIMA & DISTANT & AT & 24-Jul-03 BETA & $0.011 \mathrm{p}$ & Ci/m3 & 0.0012 & 0.0023 & & & \\
\hline SESPMNT & B176D7 & YAKIMA & DISTANT & AT & 07-Aug-03 BETA & $0.0129 \mathrm{p}$ & & 0.0012 & 0.0026 & & & \\
\hline SESPMNT & B176D8 & YAKIMA & DISTANT & AT & 22-Aug-03 BETA & $0.0144 \mathrm{p}$ & $\mathrm{Ci} / \mathrm{m} 3$ & 0.0011 & 0.0025 & & & \\
\hline SESPMNT & B176D9 & YAKIMA & DISTANT & AT & 05-Sep-03 BETA & $0.0141 \mathrm{p}$ & $\mathrm{C} / \mathrm{m} 3$ & 0.0012 & 0.0028 & & & \\
\hline SESPMNT & B176F0 & YAKIMA & DISTANT & AT & 18-Sep-03 BETA & $0.00736 p$ & $\mathrm{C} i / \mathrm{m} 3$ & 0.001 & 0.0017 & & & \\
\hline SESPMNT & B176F1 & YAKIMA & DISTANT & AT & 03-Oct-03 BETA & $0.0168 \mathrm{p}$ & Cilm3 & 0.0012 & 0.003 & & & \\
\hline $\begin{array}{l}\text { SESPMNT } \\
\text { SECPMNT }\end{array}$ & B17R24 & YAKIMA & DISTANT & AT & 17-Oct-03 BETA & $0.0172 \mathrm{p}$ & Ci/m3 & 0.0013 & 0.0033 & & & \\
\hline $\begin{array}{l}\text { SESPMNT } \\
\text { SECDMNT }\end{array}$ & B17R25 & YAKIMA & DISTANT & AT & 30-Oct-03 BETA & $0.0116 \mathrm{p}$ & $\mathrm{Ci} / \mathrm{m} 3$ & 0.0012 & 0.0024 & & & \\
\hline $\begin{array}{l}\text { SESPMNT } \\
\text { SESPMNT }\end{array}$ & $\begin{array}{l}\text { B17R26 } \\
\text { B17P27 }\end{array}$ & $\begin{array}{l}\text { YAKIMA } \\
\text { YAKIMA }\end{array}$ & & AT & 14-Nov-03 BETA & $0.0267 p$ & Ci/m3 & 0.0015 & 0.0047 & & & \\
\hline $\begin{array}{l}\text { SESPMNT } \\
\text { SESPMNT }\end{array}$ & $\begin{array}{l}\text { B17R27 } \\
\text { B1728 }\end{array}$ & $\begin{array}{l}\text { YAKIIIA } \\
\text { YAKIMA }\end{array}$ & $\begin{array}{l}\text { DISTANT } \\
\text { DISTANT }\end{array}$ & AT & $\begin{array}{l}\text { 26-Nov-03 BETA } \\
\text { 16-Dec-03 BETA }\end{array}$ & $0.0138 \mathrm{p}$ & SCi/m3 & 0.0013 & 0.0028 & & & \\
\hline $\begin{array}{l}\text { SESPMNT } \\
\text { SESPIIT }\end{array}$ & B17R29 & $\begin{array}{l}\text { YAKIMA } \\
\text { YAKIA }\end{array}$ & $\begin{array}{l}\text { DISIANI } \\
\text { DISTANT }\end{array}$ & AT & $\begin{array}{l}\text { 16-Dec-03 BETA } \\
\text { 29-Dec-03 BETA }\end{array}$ & $\begin{array}{rl}0.012 \mathrm{p} & 0.0153 \mathrm{p}\end{array}$ & Ci/m3 & $\begin{array}{l}0.00095 \\
0.0013\end{array}$ & 0.0023 & & & \\
\hline SESPMNT & B17R30 & YAKIMA & DISTANT & AT & 09-Jan-04 BETA & $0.0251 \mathrm{p}$ & $\mathrm{Ci} / \mathrm{m} 3$ & 0.0018 & $\begin{array}{l}0.0031 \\
0.0047\end{array}$ & & & \\
\hline SESPMNT & B16913 & YAKIMA BARRICADE & PERIMETER & AT & 22-Jan-03 BETA & $0.0304 \mathrm{p}$ & & 0.0017 & 0.0054 & & & \\
\hline SESPMNT & B16914 & YAKIMA BARRICADE & PERIMETER & AT & 05-Feb-03 BETA & $0.00716 \mathrm{p}$ & & 0.00097 & 0.0017 & & & \\
\hline SESPMNT & B16915 & YAKIMA BARRICADE & PERIMETER & AT & 19-Feb-03 BETA & $0.021 \mathrm{p}$ & & 0.0014 & 0.0039 & & & \\
\hline SESPMNT & B16916 & YAKIMA BARRICADE & PERIMETER & AT & 05-Mar-03 BETA & $0.0148 \mathrm{p}$ & $\mathrm{Ci} / \mathrm{m} 3$ & 0.0013 & 0.0029 & & & \\
\hline SESPMNT & B16917 & YAKIMA BARRICADE & PERIMETER & AT & 20-Mar-03 BETA & $0.00667 \mathrm{p}$ & & 0.00091 & 0.0016 & & & \\
\hline SESPMNT & B16918 & YAKIMA BARRICADE & PERIMETER & AT & 02-Apr-03 BETA & $0.00607 p$ & & 0.00096 & 0.0016 & & & \\
\hline SESPMNT & B16RB6 & YAKIMA BARRICADE & PERIMETER & AT & 16-Apr-03 BETA & $0.00634 p$ & & 0.00094 & 0.0016 & & & \\
\hline SESPMNT & B16RB7 & YAKIMA BARRICADE & PERIMETER & AT & 30-Apr-03 BETA & $0.00909 p$ & & 0.0011 & 0.002 & & & \\
\hline SESPMNT & B16RB8 & YAKIMA BARRICADE & PERIMETER & AT & 13-May-03 BETA & $0.0112 p$ & Ci/m3 & 0.0012 & 0.0024 & & & \\
\hline $\begin{array}{l}\text { SESPMNT } \\
\text { SESPMNT }\end{array}$ & $\begin{array}{ll}\text { B16RB9 } \\
\text { B16PCP }\end{array}$ & $\begin{array}{l}\text { YAKIMA BARRICADE } \\
\text { YAKIIA BARRIACDE }\end{array}$ & $\begin{array}{l}\text { PERIMETER } \\
\text { PEIMETER }\end{array}$ & AT & 28-May-03 BETA & $0.00941 p$ & Ci/m3 & 0.001 & $\begin{array}{r}0.002 \\
0.025\end{array}$ & & & \\
\hline $\begin{array}{l}\text { SESPMNT } \\
\text { SESPMNT }\end{array}$ & $\begin{array}{l}\text { B16RCO } \\
\text { B16RC1 }\end{array}$ & $\begin{array}{l}\text { YAKIIIA BARRIIADE } \\
\text { YAKIMA BARRICADE }\end{array}$ & $\begin{array}{l}\text { PERIMETRR } \\
\text { PERIMETER }\end{array}$ & $\begin{array}{l}\text { AT } \\
\text { AT }\end{array}$ & $\begin{array}{l}\text { 13-Jun-03 BETA } \\
\text { 26-Jun-03 BETA }\end{array}$ & $\begin{array}{r}0.0127 \mathrm{p} \\
0.00721 \mathrm{p}\end{array}$ & 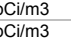 & $\begin{array}{l}0.0011 \\
0.0011\end{array}$ & $\begin{array}{l}0.0025 \\
0.0018\end{array}$ & & & \\
\hline SESPMNT & B16RC2 & YAKIMA BARRICADE & PERIMETER & AT & 11-Jul-03 BETA & $0.0102 \mathrm{p}$ & $\mathrm{Ci} / \mathrm{m} 3$ & 0.0011 & 0.0022 & & & \\
\hline SESPMNT & B17683 & YAKIMA BARRICADE & PERIMETER & AT & 24-Jul-03 BETA & $0.0129 \mathrm{p}$ & $\mathrm{Ci} / \mathrm{m} 3$ & 0.0013 & 0.0026 & & & \\
\hline SESPMNT & B17684 & YAKIMA BARRICADE & PERIMETER & AT & 07-Aug-03 BETA & $0.014 \mathrm{p}$ & $\mathrm{Ci} / \mathrm{m} 3$ & 0.0012 & 0.0028 & & & \\
\hline SESPMNT & B17685 & YAKIMA BARRICADE & PERIMETER & AT & 22-Aug-03 BETA & $0.0161 \mathrm{p}$ & $\mathrm{Ci} / \mathrm{m} 3$ & 0.0012 & 0.0028 & & & \\
\hline SESPMNT & B17686 & YAKIMA BARRICADE & PERIMETER & AT & 05-Sep-03 BETA & $0.0129 \mathrm{p}$ & $\mathrm{Ci} / \mathrm{m} 3$ & 0.0012 & 0.0026 & & & \\
\hline SESPMNT & B17687 & YAKIMA BARRICADE & PERIMETER & AT & 18-Sep-03 BETA & $0.00921 p$ & $\mathrm{C} \mathrm{C} / \mathrm{m} 3$ & 0.0011 & 0.0021 & & & \\
\hline SESPMNT & B17688 & YAKIMA BARRICADE & PERIMETER & AT & 03-Oct-03 BETA & $0.0181 \mathrm{p}$ & $\mathrm{C} / \mathrm{m} 3$ & 0.0012 & 0.0031 & & & \\
\hline SESPMNT & B17PX3 & YAKIMA BARRICADE & PERIMETER & AT & 17-Oct-03 BETA & $0.0182 \mathrm{p}$ & Cilm3 & 0.0014 & 0.0034 & & & \\
\hline SESPMNT & B17PX4 & YAKIMA BARRICADE & PERIMETER & AT & 30-Oct-03 BETA & $0.0116 \mathrm{p}$ & $\mathrm{C} / \mathrm{m} 3$ & 0.0012 & 0.0025 & & & \\
\hline SESPMNT & B17PX5 & YAKIMA BARRICADE & PERIMETER & AT & 14-Nov-03 BETA & $0.0305 \mathrm{p}$ & Ci/m3 & 0.0016 & 0.0053 & & & \\
\hline $\begin{array}{l}\text { SESPMNT } \\
\text { SESPMNT }\end{array}$ & $\begin{array}{ll}\text { B17PX6 } \\
\text { 81707Y }\end{array}$ & YAKIMA BARRICADE & $\begin{array}{l}\text { PERIMETER } \\
\text { PERIMETER }\end{array}$ & AT & 26-Nov-03 BETA & $0.0168 \mathrm{p}$ & Ci/m3 & 0.0014 & 0.0033 & & & \\
\hline $\begin{array}{l}\text { SESPMNT } \\
\text { SESPMNT }\end{array}$ & $\begin{array}{l}\text { B17PX7 } \\
\text { B17P8 }\end{array}$ & $\begin{array}{l}\text { YAKIMA BARRICADE } \\
\text { YAKIMA BARRICDEE }\end{array}$ & $\begin{array}{l}\text { PERIMETER } \\
\text { PERIMETER }\end{array}$ & AT & $\begin{array}{l}\text { 16-Dec-03 BETA } \\
\text { 29-0ec-03 BETA }\end{array}$ & $0.0126 \mathrm{p}$ & Ci/m3 & 0.00095 & 0.0024 & & & \\
\hline $\begin{array}{l}\text { SESPMNT } \\
\text { SESPMNT }\end{array}$ & $\begin{array}{l}\text { B17PX8 } \\
\text { B17PX9 }\end{array}$ & $\begin{array}{l}\text { YAKIIIA BARRIIADE } \\
\text { YAKIMA BARRICADE }\end{array}$ & $\begin{array}{l}\text { PERRMETRR } \\
\text { PERIMETER }\end{array}$ & $\begin{array}{l}\text { AT } \\
\text { AT }\end{array}$ & $\begin{array}{l}\text { 29-D-Dac-03 BEEA } \\
\text { 0--Jan-04 BETA }\end{array}$ & $\begin{array}{l}0.0173 \mathrm{p} \\
0.0286 \mathrm{p}\end{array}$ & $\begin{array}{l}\text { Sim3 } \\
\text { cilm3 }\end{array}$ & $\begin{array}{l}0.0014 \\
0.0019\end{array}$ & $\begin{array}{l}0.0033 \\
0.0052\end{array}$ & & & \\
\hline SESPMNT & B168D7 & 100 D AREA & ONSITE & AT & 21-Jan-03 ALPHA & $0.000847 \mathrm{p}$ & $\mathrm{Ci} / \mathrm{m} 3$ & 0.00043 & 0.00048 & & & \\
\hline SESPMNT & B168D8 & 100 D AREA & ONSITE & AT & 04-Feb-03 ALPHA & $0.00038 \mathrm{p}$ & $\mathrm{Ci} / \mathrm{m} 3$ & 0.00031 & 0.00033 & & & \\
\hline SESPMNT & B168D9 & 100 D AREA & ONSITE & AT & 18-Feb-03 ALPHA & $0.000623 \mathrm{p}$ & & 0.00038 & 0.00041 & & & \\
\hline SESPMNT & B168F0 & 100 D AREA & ONSITE & AT & 03-Mar-03 ALPHA & $0.000471 p$ & $\mathrm{Ci} / \mathrm{m} 3$ & 0.00035 & 0.00038 & & & \\
\hline SESPMNT & B168F1 & 100 D AREA & ONSITE & AT & 18-Mar-03 ALPHA & $0.000239 p$ & $\mathrm{C} i / \mathrm{m} 3$ & 0.00025 & 0.00026 & U & & \\
\hline SESPMNT & B168F2 & 100 D AREA & ONSITE & AT & 31-Mar-03 ALPHA & $0.000182 p$ & $\mathrm{C} i / \mathrm{m} 3$ & 0.00027 & 0.00028 & u & & \\
\hline SESPMNT & B16PT0 & 100 D AREA & ONSITE & AT & 15-Apr-03 ALPHA & $0.000994 p$ & $\mathrm{C} / \mathrm{m} 3$ & 0.00038 & 0.00045 & & & \\
\hline SESPMNT & B16PT1 & $100 \mathrm{D}$ AREA & ONSITE & AT & 29-Apr-03 ALPHA & $0.000243 p$ & $\mathrm{C} / \mathrm{m} 3$ & 0.00028 & 0.00029 & $u$ & & \\
\hline SESPMNT & B16PT2 & $100 \mathrm{D}$ AREA & ONSITE & AT & 12-May-03 ALPHA & $0.00039 \mathrm{p}$ & Ci/m3 & 0.00032 & 0.00034 & & & \\
\hline SESPMNT & B16РT3 & 100 D AREA & ONSITE & AT & 29-May-03 ALPHA & $0.000399 \mathrm{p}$ & Ci/m3 & 0.00027 & 0.0003 & & & \\
\hline $\begin{array}{l}\text { SESPMNT } \\
\text { SESPMNT }\end{array}$ & $\begin{array}{l}\text { B16PP4 } \\
\text { B16PT5 }\end{array}$ & $\begin{array}{l}\text { 100 D AREA } \\
\text { 100 D AREA }\end{array}$ & $\begin{array}{l}\text { ONSIIE } \\
\text { ONSTIE }\end{array}$ & $\begin{array}{l}\text { AT } \\
\text { AT }\end{array}$ & $\begin{array}{l}\text { 11-1un-033 ALPHA } \\
\text { 24-Jun-0 ALPHA }\end{array}$ & $\begin{array}{l}0.000709 p \\
0.00045 p\end{array}$ & $\begin{array}{l}\mathrm{s} \text { Ci/m3 } \\
\text { Di/m3 }\end{array}$ & $\begin{array}{l}0.00038 \\
0.00034\end{array}$ & $\begin{array}{l}0.00043 \\
0.00036\end{array}$ & & & \\
\hline SESPMNT & B16PT6 & 100 D AREA & ONSITE & AT & 08-Jul-03 ALPHA & $0.000327 \mathrm{p}$ & $\mathrm{Ci} / \mathrm{m} 3$ & 0.00032 & 0.00033 & u & & \\
\hline SESPMNT & B175N7 & 100 D AREA & ONSITE & AT & 22-Jul-03 ALPHA & $0.000474 p$ & Cilm3 & 0.00033 & 0.00035 & & & \\
\hline SESPMNT & B175N8 & 100 D AREA & ONSITE & AT & 04-Aug-03 ALPHA & $0.000356 \mathrm{p}$ & $\mathrm{Ci} / \mathrm{m} 3$ & 0.00033 & 0.00035 & & & \\
\hline SESPMNT & B175N9 & 100 D AREA & ONSITE & AT & 18-Aug-03 ALPHA & $0.000816 \mathrm{p}$ & $\mathrm{Ci} / \mathrm{m} 3$ & 0.00042 & 0.00047 & & & \\
\hline SESPMNT & B175PO & 100 D AREA & ONSITE & AT & 02-Sep-03 ALPHA & $0.0018 \mathrm{p}$ & $\mathrm{Ci} / \mathrm{m} 3$ & 0.00046 & 0.0006 & & & \\
\hline SESPMNT & B175P1 & 100 D AREA & ONSITE & AT & 15-Sep-03 ALPHA & $0.000724 p$ & $\mathrm{Ci} / \mathrm{m} 3$ & 0.00038 & 0.00042 & & & \\
\hline SESPMNT & B175P2 & 100 D AREA & ONSITE & AT & 01-Oct-03 ALPHA & $0.000666 \mathrm{p}$ & $\mathrm{C} / \mathrm{m} 3$ & 0.00032 & 0.00036 & & & \\
\hline SESPMNT & B17P97 & 100 D AREA & ONSITE & AT & 13-Oct-03 ALPHA & $0.000852 p$ & $\mathrm{C} / \mathrm{m} 3$ & 0.00044 & 0.00049 & & & \\
\hline SESPMNT & B17P98 & 100 D AREA & ONSITE & AT & 28-Oct-03 ALPHA & $0.00118 \mathrm{p}$ & $\mathrm{C} i / \mathrm{m} 3$ & 0.00041 & 0.0005 & & & \\
\hline SESPMNT & B17P99 & 100 D AREA & ONSITE & AT & 11-Nov-03 ALPHA & $0.000739 p$ & Ci/m3 & 0.00039 & 0.00042 & & & \\
\hline SESPMNT & B17PBO & $100 \mathrm{D}$ AREA & ONSITE & AT & 24-Nov-03 ALPHA & $0.000648 \mathrm{p}$ & Ci/m3 & 0.00037 & 0.00041 & & & \\
\hline SESPMNT & B17PB1 & 100 D AREA & ONSITE & AT & 11-Dec-03 ALPHA & $0.000301 \mathrm{p}$ & Ci/m3 & 0.00025 & 0.00026 & & & \\
\hline SESPMNT & B17PB2 & 100 D AREA & ONSITE & AT & 22-Dec-03 ALPHA & $0.000319 p$ & Ci/m3 & 0.00036 & 0.00038 & U & & \\
\hline SESPMNT & B17PB3 & $\begin{array}{l}100 \text { D AREA } \\
100 \text { TER }\end{array}$ & ONSITE & AT & 06-Jan-04 ALPHA & $0.00065 p$ & Ci/m3 & 0.00036 & 0.00039 & & & \\
\hline $\begin{array}{l}\text { SESPMNT } \\
\text { SESPMNT }\end{array}$ & $\begin{array}{l}\text { B16987 } \\
\text { B16988 }\end{array}$ & $\begin{array}{l}100 \mathrm{FM} \text { MET TOWER } \\
100 \mathrm{~W} \text {. }\end{array}$ & $\begin{array}{l}\text { ONSSITE } \\
\text { ONSE }\end{array}$ & $\begin{array}{l}\text { AT } \\
\text { AT }\end{array}$ & $\begin{array}{l}\text { 21-Jan-03ALAPHA } \\
\text { 04-Feb-03 ALPHA }\end{array}$ & $\begin{array}{r}0.00133 \mathrm{p} \\
0.000803 \mathrm{p}\end{array}$ & $\begin{array}{l}\text { Cim3 } \\
\text { ciilm3 }\end{array}$ & $\begin{array}{l}0.00049 \\
0.00023\end{array}$ & $\begin{array}{l}0.000059 \\
0.0024\end{array}$ & u & & \\
\hline $\begin{array}{l}\text { SESPMNT } \\
\text { SESPII }\end{array}$ & B16989 & $100 \mathrm{~F}$ MET TOWER & ONSITE & AT & 18-Feb-03 ALPHA & $0.000603 \mathrm{p}$ & $\mathrm{Ci} / \mathrm{m} 3$ & 0.00039 & 0.00042 & & & \\
\hline
\end{tabular}


AIR BETA/ALPHA

\begin{tabular}{|c|c|c|c|c|c|c|c|c|c|c|c|c|c|}
\hline |OWNER ID & \begin{tabular}{|l|} 
SAMP \\
NUM
\end{tabular} & SAMP SITE NAME & DIST CLASS & MEDIA & SAMP DATE & $\begin{array}{l}\text { CON } \\
\text { SHORT } \\
\text { NAME }\end{array}$ & | VALUE RPTD & $\begin{array}{l}\text { ANAL } \\
\text { UNITS } \\
\text { RPTD }\end{array}$ & $\left|\begin{array}{c}\text { COUNTING } \\
\text { ERROR }\end{array}\right|$ & \begin{tabular}{c|} 
TOTAL \\
ANAL \\
ERROR
\end{tabular} & $\left|\begin{array}{c}\text { LAB } \\
\text { QUALIFIER }\end{array}\right|$ & SAMP COMMENT & $\begin{array}{c}\text { RESULT } \\
\text { COMMENT }\end{array}$ \\
\hline SESPMNT & B16990 & $100 \mathrm{~F}$ MET TOWER & ONSITE & AT & 03-Mar-03 A & & $0.000581 \mathrm{p}$ & & 0.00037 & & & & \\
\hline SESPMNT & B16991 & 100 F MET TOWER & ONSITE & AT & 18-Mar-03 A & ALPHA & $0.000416 \mathrm{p}$ & pCilm3 & 0.00029 & 0.00032 & & & \\
\hline SESPMNT & B16992 & 100 F MET TOWER & ONSITE & AT & 31-Mar-03A & & $0.0000858 \mathrm{p}$ & pci/m3 & 0.00026 & 0.00027 & u & & \\
\hline SESPMNT & B16RL6 & 100 F MET TOWER & ONSITE & AT & 15-Apr-03 A & ALPHA & $0.000453 \mathrm{p}$ & $\mathrm{pC}$ Ci/m3 & 0.00029 & 0.00031 & & & \\
\hline SESPMNT & B16RL7 & 100 F MET TOWER & ONSITE & AT & 29-Apr-03 A & ALPHA & $0.000211 \mathrm{p}$ & $\mathrm{pCi} / \mathrm{m} 3$ & 0.00027 & 0.00028 & u & & \\
\hline SESPMNT & B16RL8 & 100 F MET TOWER & ONSITE & AT & 12-May-03 A & ALPHA & $0.000398 p$ & pCi/m3 & 0.00032 & 0.00034 & & & \\
\hline SESPMNT & B16RL9 & 100 F MET TOWER & ONSITE & AT & 29-May-03 A & ALPHA & $0.000357 \mathrm{p}$ & pCi/m3 & 0.00026 & 0.00028 & & & \\
\hline $\begin{array}{l}\text { SESPMNT } \\
\text { SESDMNT }\end{array}$ & B16RMO & 100 F MET TOWER & ONSITE & AT & 11-Jun-03A & ALPHA & $0.000795 \mathrm{p}$ & pCi/m3 & 0.0004 & 0.00045 & & & \\
\hline $\begin{array}{l}\text { SESPMNT } \\
\text { SECDMNT }\end{array}$ & B16RM1 & 100 F MET TOWER & ONSITE & AT & 24-Jun-03A & ALPHA & $0.000436 \mathrm{p}$ & pCi/m3 & 0.00032 & 0.00034 & & & \\
\hline $\begin{array}{l}\text { SESPMNT } \\
\text { SESPMNT }\end{array}$ & $\begin{array}{l}\text { B16RM2 } \\
\text { B17667 }\end{array}$ & $\begin{array}{l}100 \text { F MET TOWER } \\
1\end{array}$ & ONSITE & AT & $\begin{array}{l}\text { 08-Jul-03 A } \\
22-14 \mathrm{H}-03 \mathrm{~A}\end{array}$ & ALPHA & $0.000118 p$ & pCi/m3 & $\begin{array}{l}0.00027 \\
0.00034\end{array}$ & 0.00027 & u & & \\
\hline $\begin{array}{l}\text { SESPMNT } \\
\text { SESPMNT }\end{array}$ & $\begin{array}{l}8176 J 7 \\
B 17688\end{array}$ & $\begin{array}{l}100 \text { F MEET TOWER } \\
100 \text { F MET TOWER }\end{array}$ & $\begin{array}{l}\text { ONSIIE } \\
\text { ONSTIE }\end{array}$ & AT & $\begin{array}{l}\text { 22-Jul-03 A } \\
04-0403 \mathrm{~A}\end{array}$ & ALPHA & $0.000603 p$ & pCi/m3 & $\begin{array}{l}0.00034 \\
0.00036\end{array}$ & 0.00038 & & & \\
\hline SESPMNT & 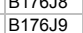 & $\begin{array}{l}100 \text { O F MEET TOWER } \\
100 \text { F MET TOWER }\end{array}$ & $\begin{array}{l}\text { ONSIIT } \\
\text { ONSITE }\end{array}$ & AT & $\begin{array}{l}\text { 04-Aug-03A } \\
\text { 18-Aug-03A }\end{array}$ & ALLHA & $\begin{array}{l}0.000422 \mathrm{p} \\
0.00027 \mathrm{p}\end{array}$ & $\begin{array}{l}\frac{p \mathrm{pC} / m 3}{\mathrm{pCi} 3 \mathrm{~m} 3} \\
\mathrm{p}\end{array}$ & $\begin{array}{l}0.00036 \\
0.00032\end{array}$ & 0.00039 & u & & \\
\hline SESPMNT & B176K0 & 100 F MET TOWER & ONSITE & AT & $02-S e p-03 A$ & ALPHA & $0.00228 \mathrm{p}$ & pCi/m3 & 0.00052 & 0.00072 & 0 & & \\
\hline SESPMNT & B176K1 & 100 F MET TOWER & ONSITE & AT & 15-Sep-03A & ALPHA & $0.000859 \mathrm{p}$ & pCilm3 & 0.00043 & 0.00048 & & & \\
\hline SESPMNT & B176K2 & 100 F MET TOWER & ONSITE & AT & 01-Oct-03 A & ALPHA & $0.00054 \mathrm{p}$ & & 0.00031 & 0.00034 & & & \\
\hline SESPMNT & B17R53 & 100 F MET TOWER & ONSITE & AT & 13-Oct-03 A & ALPHA & $0.00145 p$ & pCilm3 & 0.00053 & 0.00064 & & & \\
\hline SESPMNT & B17R54 & 100 F MET TOWER & ONSITE & AT & 28-Oct-03A & & & & & & & NO SAMPLE. SAVE FOR COMPOSITE. & \\
\hline SESPMNT & B17R55 & 100 F MET TOWER & ONSITE & AT & 11-Nov-03A & & $0.000626 \mathrm{p}$ & $\mathrm{pCi} / \mathrm{m} 3$ & 0.00034 & 0.00037 & & & \\
\hline SESPMNT & B17R56 & 100 F MET TOWER & ONSITE & AT & 24-Nov-03A & ALPHA & $0.000678 \mathrm{p}$ & & 0.00041 & 0.00044 & & & \\
\hline SESPMNT & B17R57 & 100 F MET TOWER & ONSITE & AT & 11-Dec-03A & & $0.0000889 \mathrm{p}$ & & 0.0002 & 0.00021 & U & & \\
\hline SESPMNT & B17R58 & 100 F MET TOWER & ONSITE & AT & 22-Dec-03A & & $0.000663 p$ & & 0.00041 & 0.00045 & & & \\
\hline $\begin{array}{l}\text { SESPMNT } \\
\text { SESPMNT }\end{array}$ & $\begin{array}{l}B 17 R 59 \\
81695\end{array}$ & 100 F MET TOWER & ONSITE & AT & 06-Jan-04 A & ALPHA & $0.000239 \mathrm{p}$ & pCim3 & 0.00028 & 0.00029 & u & & \\
\hline $\begin{array}{l}\text { SESPMNT } \\
\text { SESPMNT }\end{array}$ & $\begin{array}{l}\text { B168C5 } \\
\text { B16866 }\end{array}$ & 100 K AREA & $\begin{array}{l}\text { ONSITE } \\
\text { ONSIE }\end{array}$ & AT & $\begin{array}{l}\text { 21-Jan-03A } \\
04-03 \mathrm{~A}-03 \mathrm{~A}\end{array}$ & ALPHA & $\begin{aligned} 0.00114 p \\
0.00015 p\end{aligned}$ & pCim3 & 0.00048 & 0.00056 & & & \\
\hline $\begin{array}{l}\text { SESPMNT } \\
\text { SESPMNT }\end{array}$ & 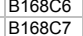 & $\begin{array}{l}100 \mathrm{KAREA} \\
100 \mathrm{~K} \text { AREA }\end{array}$ & $\begin{array}{l}\text { ONSTIE } \\
\text { ONSITE }\end{array}$ & $\begin{array}{l}\text { AT } \\
\text { AT }\end{array}$ & $\begin{array}{l}\text { 04-Feb-03A } \\
\text { 18-Feb-03A }\end{array}$ & ALPHA & $\begin{array}{l}0.000115 \mathrm{p} \\
0.000457 \mathrm{p}\end{array}$ & $\begin{array}{l}\mathrm{pCim3} \\
\mathrm{pCi} / \mathrm{m} 3\end{array}$ & $\begin{array}{l}0.000025 \\
0.00036\end{array}$ & 0.00026 & U & & \\
\hline SESPMNT & B168C8 & $100 \mathrm{~K}$ AREA & ONSITE & AT & 03-Mar-03 A & ALPHA & $0.0009 \mathrm{p}$ & $\mathrm{pC} / \mathrm{m} 3$ & 0.00043 & 0.00048 & & & \\
\hline SESPMNT & B168C9 & $100 \mathrm{~K}$ AREA & ONSITE & AT & 18-Mr-03 A & ALPHA & $0.000211 \mathrm{p}$ & $\mathrm{pC} / \mathrm{m} 3$ & 0.00025 & 0.00027 & U & & \\
\hline SESPMNT & B168D0 & $100 \mathrm{~K}$ AREA & ONSITE & AT & 31-Mar-03 A & ALPHA & $0.00111 \mathrm{p}$ & pCilm3 & 0.00043 & 0.00051 & & & \\
\hline SESPMNT & B16PP6 & $100 \mathrm{~K}$ AREA & ONSITE & AT & 15-Apr-03 A & ALPHA & $0.000417 \mathrm{p}$ & pCilm3 & 0.00028 & 0.00031 & & & \\
\hline SESPMNT & B16PP7 & $100 \mathrm{~K}$ AREA & ONSITE & AT & 29-Apr-03 A & ALPHA & $0.000663 p$ & pCilm3 & 0.00035 & 0.00039 & & & \\
\hline SESPMNT & B16PP8 & $100 \mathrm{~K}$ AREA & ONSITE & AT & 12-May-03 A & ALPHA & $0.000338 p$ & pCi/m3 & 0.00031 & 0.00033 & & & \\
\hline SESPMNT & B16PP9 & $100 \mathrm{~K}$ AREA & ONSITE & AT & 29-May-03 A & ALPHA & $0.00036 p$ & pCi/m3 & 0.00028 & 0.0003 & & & \\
\hline SESPMNT & B16PRO & $100 \mathrm{~K}$ AREA & ONSITE & AT & 11-Jun-03 A & ALPHA & $0.00132 p$ & pCi/m3 & 0.00047 & 0.00057 & & & \\
\hline SESPMNT & B16PR1 & $100 \mathrm{~K}$ AREA & ONSITE & AT & 24-Jun-03 A & ALPHA & $0.000566 \mathrm{p}$ & pCi/m3 & 0.00035 & 0.00038 & & & \\
\hline $\begin{array}{l}\text { SESPMNT } \\
\text { SESPMNT }\end{array}$ & $\begin{array}{l}\text { B16PR2 } \\
\text { B175015 }\end{array}$ & $100 \mathrm{~K}$ AREA & ONSITE & AT & 08-Jul-03 A & ALPHA & $0.000226 \mathrm{p}$ & pCi/m3 & 0.00028 & 0.00029 & u & & \\
\hline $\begin{array}{l}\text { SESPMNT } \\
\text { SESPMNT }\end{array}$ & B175M5 & $100 \mathrm{~K}$ AREA & ONSITE & AT & 22-Jul-03 A & ALPHA & $0.00068 \mathrm{p}$ & pCi/m3 & 0.00037 & 0.00041 & & & \\
\hline $\begin{array}{l}\text { SESPMNT } \\
\text { SESPMNT }\end{array}$ & $\begin{array}{l}\text { B17556 } \\
\text { B17597 }\end{array}$ & $\begin{array}{l}100 \mathrm{~K} \text { AREA } \\
100 \mathrm{~K} \text { AREA }\end{array}$ & $\begin{array}{l}\text { ONSITE } \\
\text { ONSTEE }\end{array}$ & $\begin{array}{ll}\text { AT } \\
\text { AT }\end{array}$ & 04-Aug-03 A & ALPHA & $\begin{array}{l}0.000531 \mathrm{p} \\
0.00044 \mathrm{p}\end{array}$ & $\begin{array}{l}\text { pCim3 } \\
\text { picm3 }\end{array}$ & 0.00035 & 0.00038 & & & \\
\hline $\begin{array}{l}\text { SESPMNT } \\
\text { SESPMNT }\end{array}$ & $\begin{array}{l}\text { B175577 } \\
\text { B175M8 }\end{array}$ & $\begin{array}{l}100 \mathrm{~K} \mathrm{AREA} \\
100 \mathrm{~K} \text { AREA }\end{array}$ & $\begin{array}{l}\text { ONSTIE } \\
\text { ONSITE }\end{array}$ & $\begin{array}{l}\text { AT } \\
\text { AT }\end{array}$ & $\begin{array}{l}\text { 18-Aug-03A } \\
02 \text {-Sep-03A }\end{array}$ & $\begin{array}{l}\text { ALPHA } \\
\text { ALPHA }\end{array}$ & $\begin{array}{c}0.000441 \mathrm{p} \\
0.00105 \mathrm{p}\end{array}$ & $\begin{array}{l}\text { pilm3 } \\
\text { pCi/m3 }\end{array}$ & $\begin{array}{l}0.000031 \\
0.00037\end{array}$ & $\begin{array}{l}0.000034 \\
0.00044\end{array}$ & & & \\
\hline SESPMNT & B175M9 & 100 K AREA & ONSITE & AT & $15-$ Sep-03A & ALPHA & $0.000663 \mathrm{p}$ & pCi/m3 & 0.00039 & 0.00042 & & & \\
\hline SESPMNT & B175NO & $100 \mathrm{~K}$ AREA & ONSITE & AT & 01-Oct-03 A & ALPHA & $0.000359 \mathrm{p}$ & pCilm3 & 0.00029 & 0.0003 & & & \\
\hline SESPMNT & B17P83 & $100 \mathrm{~K}$ AREA & ONSITE & AT & 13-Oct-03 A & ALPHA & $0.000831 \mathrm{p}$ & pCilm3 & 0.00045 & 0.0005 & & & \\
\hline SESPMNT & B17P84 & $100 \mathrm{~K}$ AREA & ONSITE & AT & 28-Oct-03 A & ALPHA & $0.0001 \mathrm{p}$ & pCi/m3 & 0.00024 & 0.00025 & U & & \\
\hline SESPMNT & B17P85 & $100 \mathrm{~K}$ AREA & ONSITE & AT & 11-Nov-03 A & ALPHA & $0.000849 p$ & pCi/m3 & 0.0004 & 0.00044 & & & \\
\hline SESPMNT & B17P86 & $100 \mathrm{~K}$ AREA & ONSITE & AT & 24-Nov-03 A & ALPHA & $0.000616 p$ & pCi/m3 & 0.00037 & 0.00041 & & & \\
\hline SESPMNT & B17P87 & $100 \mathrm{~K}$ AREA & ONSITE & AT & 11-Dec-03 A & ALPHA & $0.000271 \mathrm{p}$ & pCi/m3 & 0.00024 & 0.00025 & & & \\
\hline SESPMNT & B17P88 & $100 \mathrm{~K}$ AREA & ONSITE & AT & 22-Dec-03A & ALPHA & $0.000174 p$ & pCi/m3 & 0.00034 & 0.00034 & u & & \\
\hline SESPMNT & B17P89 & $100 \mathrm{~K}$ AREA & ONSITE & AT & 06-Jan-04 A & ALPHA & $0.000586 \mathrm{p}$ & pCi/m3 & 0.00034 & 0.00037 & & & \\
\hline $\begin{array}{l}\text { SESPMNT } \\
\text { SESPMNT }\end{array}$ & $\begin{array}{l}\text { B168D1 } \\
\text { B16802 }\end{array}$ & $100 \mathrm{~N}-1325$ CRIB & ONSITE & AT & 21-Jan-03A & ALPHA & $0.00167 \mathrm{p}$ & pCim3 & 0.00052 & 0.00065 & & & \\
\hline $\begin{array}{l}\text { SESPMNT } \\
\text { SESPMNT }\end{array}$ & $\begin{array}{l}\text { B16822 } \\
\text { B168D3 }\end{array}$ & $\begin{array}{l}100 \mathrm{~N}-1325 \mathrm{CRIB} \\
100 \mathrm{~N}-1325 \mathrm{CRBB}\end{array}$ & $\begin{array}{l}\text { ONSIIE } \\
\text { ONSTIE }\end{array}$ & $\begin{array}{l}\text { AT } \\
\text { AT }\end{array}$ & $\begin{array}{l}\text { O4-Feb-03 } \\
\text { 18-Feb-03A }\end{array}$ & $\begin{array}{l}\text { ALLHA } \\
\text { ALPHA }\end{array}$ & $\begin{array}{r}0.00000181 \mathrm{p} \\
0.000451 \mathrm{p}\end{array}$ & $\begin{array}{l}\text { pilm3 } \\
\text { pilm3 }\end{array}$ & $\begin{array}{l}0.00021 \\
0.00038\end{array}$ & $\begin{array}{l}0.00022 \\
0.0004\end{array}$ & U & & \\
\hline SESPMNT & B168D4 & $100 \mathrm{~N}-1325 \mathrm{CRIB}$ & ONSITE & AT & $03-M a r-03 \mathrm{~A}$ & ALPHA & $0.000463 \mathrm{p}$ & pCi/m3 & 0.00035 & 0.00037 & & & \\
\hline SESPMNT & B168D5 & $100 \mathrm{~N}-1325$ CRIB & ONSITE & AT & 18-Mar-03 A & ALPHA & $0.000201 \mathrm{p}$ & $\mathrm{pC} i / \mathrm{p}^{3}$ & 0.00024 & 0.00025 & U & & \\
\hline SESPMNT & B168D6 & $100 \mathrm{~N}-1325$ CRIB & ONSITE & AT & 31-Mr-03 A & ALPHA & $0.000308 \mathrm{p}$ & pCi/m3 & 0.00029 & 0.00031 & & & \\
\hline SESPMNT & B16PR3 & $100 \mathrm{~N}-1325$ CRIB & ONSITE & AT & 15-Apr-03 A & ALPHA & $0.000777 \mathrm{p}$ & pCi/m3 & 0.00035 & 0.0004 & & & \\
\hline SESPMNT & B16PR4 & $100 \mathrm{~N}-1325$ CRIB & ONSITE & AT & 29-Apr-03 A & ALPHA & $0.000627 \mathrm{p}$ & pCi/m3 & 0.00036 & 0.0004 & & & \\
\hline SESPMNT & B16PR5 & $100 \mathrm{~N}-1325$ CRIB & ONSITE & AT & 12-May-03 A & ALPHA & $0.000622 \mathrm{p}$ & pCilm3 & 0.00036 & 0.0004 & & & \\
\hline SESPMNT & B16PR6 & $100 \mathrm{~N}-1325$ CRIB & ONSITE & AT & 29-May-03 A & ALPHA & $0.000534 \mathrm{p}$ & pCi/m3 & 0.00029 & 0.00033 & & & \\
\hline SESPMNT & B16PR7 & $100 \mathrm{~N}-1325$ CRIB & ONSITE & AT & 11-Jun-03 A & ALPHA & $0.00103 p$ & pCi/m3 & 0.00043 & 0.0005 & & & \\
\hline SESPMNT & B16PR8 & $100 \mathrm{~N}-1325$ CRIB & ONSITE & AT & 24-Jun-03 A & ALPHA & $0.000385 \mathrm{p}$ & pCi/m3 & 0.00032 & 0.00034 & & & \\
\hline SESPMNT & B16PR9 & $100 \mathrm{~N}-1325$ CRIB & ONSITE & AT & 08-Jul-03 A & ALPHA & $0.000473 p$ & pCi/m3 & 0.00036 & 0.00038 & & & \\
\hline $\begin{array}{l}\text { SESPMNT } \\
\text { SESPMNT }\end{array}$ & $\begin{array}{l}8175 \mathrm{~N} 1 \\
\mathrm{~B} 175 \mathrm{~N} 2\end{array}$ & $100 \mathrm{~N}-1325$ CRIB & $\begin{array}{l}\text { ONSITE } \\
\text { ONSITE }\end{array}$ & AT & 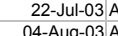 & ALPHA & $0.000649 p$ & pCi/m3 & 0.00036 & $\begin{array}{r}0.0004 \\
000042\end{array}$ & & & \\
\hline SESPMNT & B175N3 & $100 \mathrm{~N}-1325$ CRIB & ONSITE & AT & $\begin{array}{l}\text { O4-Augg-03A } \\
\text { 18-Aug-03A }\end{array}$ & $\begin{array}{l}\text { ALPHA } \\
\text { ALPHA }\end{array}$ & $\begin{array}{l}0.0006547 \mathrm{p} \\
0.000647 \mathrm{p}\end{array}$ & $\begin{array}{l}\text { pCim3 } \\
\text { pCi/m3 }\end{array}$ & $\begin{array}{l}0.000039 \\
0.00043\end{array}$ & $\begin{array}{l}0.000042 \\
0.00047\end{array}$ & & & \\
\hline SESPMNT & B175N4 & $100 \mathrm{~N}-1325$ CRIB & ONSITE & AT & 02 -Sep-03A & ALPHA & $0.00126 \mathrm{p}$ & pCim3 & 0.00042 & 0.0005 & & & \\
\hline SESPMNT & B175N5 & $100 \mathrm{~N}-1325$ CRIB & ONSITE & AT & 15-Sер-03A & ALPHA & $0.000693 \mathrm{p}$ & pCi/m3 & 0.00037 & 0.00041 & & & \\
\hline SESPMNT & B175N6 & $100 \mathrm{~N}-1325$ CRIB & ONSITE & AT & 01-Oct-03 A & ALPHA & $0.000539 \mathrm{p}$ & pCilm3 & 0.00031 & 0.00034 & & & \\
\hline SESPMNT & B17P90 & $100 \mathrm{~N}-1325$ CRIB & ONSITE & AT & 13-Oct-03 A & ALPHA & $0.00106 \mathrm{p}$ & pCilm3 & 0.00048 & 0.00055 & & & \\
\hline
\end{tabular}


AIR BETA/ALPHA

\begin{tabular}{|c|c|c|c|c|c|c|c|c|c|c|c|c|c|}
\hline |OWNER ID & \begin{tabular}{|l|} 
SAMP \\
NUM
\end{tabular} & SAMP SITE NAME & DIST CLASS & MEDIA & SAMP DATE| & $\begin{array}{l}\text { CON } \\
\text { SHORT } \\
\text { NAME }\end{array}$ & | VALUE RPTD & $\begin{array}{l}\text { ANAL } \\
\text { UNITS } \\
\text { RPTD }\end{array}$ & $\left|\begin{array}{c}\text { COUNTING } \\
\text { ERROR }\end{array}\right|$ & \begin{tabular}{c|c} 
TOTAL \\
ANAL \\
ERROR
\end{tabular} & $\left|\begin{array}{c}\text { LAB } \\
\text { QUALIFIER }\end{array}\right|$ & SAMP COMMENT & $\begin{array}{c}\text { RESULT } \\
\text { COMMENT }\end{array}$ \\
\hline SESPMNT & B17P91 & $100 \mathrm{~N}-1325$ CRIB & ONSITE & AT & & & $0.00104 \mathrm{p}$ & & 0.0004 & 0.00047 & & & \\
\hline SESPMNT & B17P92 & $100 \mathrm{~N}-1325$ CRIB & ONSITE & AT & 11-Nov-03 A & ALPHA & $0.000514 \mathrm{p}$ & pCilm3 & 0.00035 & 0.00037 & & & \\
\hline SESPMNT & B17P93 & $100 \mathrm{~N}-1325$ CRIB & ONSITE & AT & 24-Nov-03 A & ALPHA & $0.00105 p$ & pCi/m3 & 0.00046 & 0.00052 & & & \\
\hline SESPMNT & B17P94 & $100 \mathrm{~N}-1325$ CRIB & ONSITE & AT & 11-Dec-03 A & ALPHA & $0.000425 \mathrm{p}$ & pCilm3 & 0.00027 & 0.00029 & & & \\
\hline SESPMNT & B17P95 & $100 \mathrm{~N}-1325$ CRIB & ONSITE & AT & 22-Dec-03A & ALPHA & $0.000269 p$ & pCi/m3 & 0.00034 & 0.00035 & U & & \\
\hline SESPMNT & B17P96 & $100 \mathrm{~N}-1325$ CRIB & ONSITE & AT & 06-Jan-04 A & ALPHA & $0.000328 p$ & pCi/m3 & 0.0003 & 0.00032 & & & \\
\hline SESPMNT & B168F4 & 200 ESE & ONSITE & AT & 14-Jan-03 A & ALPHA & $0.000312 p$ & pCi/m3 & 0.00032 & 0.00033 & u & & \\
\hline $\begin{array}{l}\text { SESPMNT } \\
\text { SESDMNT }\end{array}$ & B168F5 & 200 ESE & ONSITE & AT & 28-Jan-03A & & $0.000676 p$ & pCi/m3 & 0.00037 & 0.00041 & & & \\
\hline $\begin{array}{l}\text { SESPMNT } \\
\text { SECDMNT }\end{array}$ & B168F6 & 200 ESE & ONSITE & AT & 11-Feb-03A & ALPHA & $0.000178 \mathrm{p}$ & pCi/m3 & 0.00029 & 0.0003 & U & & \\
\hline $\begin{array}{l}\text { SESPMNT } \\
\text { SESPMNT }\end{array}$ & $\begin{array}{l}\text { B168F7 } \\
\text { B1688 }\end{array}$ & $\begin{array}{l}200 \text { ESE } \\
200 \text { SEE }\end{array}$ & ONSITE & AT & $\begin{array}{l}\text { 25-Feb-03A } \\
10-M a r-03 A\end{array}$ & ALPHA & $0.00113 p$ & pCi/m3 & $\begin{array}{l}0.00043 \\
0.00045\end{array}$ & $\begin{array}{l}0.00052 \\
0.00058\end{array}$ & & & \\
\hline $\begin{array}{l}\text { SESPMNT } \\
\text { SESPMNT }\end{array}$ & $\begin{array}{l}\text { B168F8 } \\
\text { B16899 }\end{array}$ & $\begin{array}{l}200 \text { ESE } \\
20 \text { ESE }\end{array}$ & $\begin{array}{l}\text { ONSITE } \\
\text { ONSITE }\end{array}$ & AT & $\begin{array}{l}10-M a r-03 A \\
26-M a r-03 A\end{array}$ & ALPHA & $\begin{array}{r}0.00151 p \\
0.00037 p\end{array}$ & pCi/m3 & $\begin{array}{l}0.00045 \\
0.00028\end{array}$ & 0.00058 & & & \\
\hline SESPMNT & 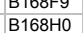 & $\begin{array}{l}200 \mathrm{ESE} \\
200 \mathrm{ESE}\end{array}$ & ONSITE & AT & $\begin{array}{l}\text { 26-Mar-03A } \\
08 \text {-Apr-03A }\end{array}$ & ALLHA & $\begin{array}{l}0.000379 \mathrm{p} \\
0.000557 \mathrm{p}\end{array}$ & $\begin{array}{l}\mathrm{pCC/m3} \\
\mathrm{pC} \operatorname{cim} 3\end{array}$ & $\begin{array}{l}0.00028 \\
0.00034\end{array}$ & $\begin{array}{r}0.0003 \\
0.00037\end{array}$ & & & \\
\hline SESPMNT & B16PT8 & 200 ESE & ONSITE & AT & 21-Apr-03 A & & $0.000531 \mathrm{p}$ & pCi/m3 & 0.00035 & 0.00038 & & & \\
\hline SESPMNT & B16PT9 & $200 \mathrm{ESE}$ & ONSITE & AT & $06-$ May-03 A & ALPHA & $0.000556 \mathrm{p}$ & pCilm3 & 0.00032 & 0.00035 & & & \\
\hline SESPMNT & B16PVO & 200 ESE & ONSITE & AT & 20-May-03 A & ALPHA & $0.00145 p$ & pCilm3 & 0.00046 & 0.00058 & & & \\
\hline SESPMNT & B16PV1 & $200 \mathrm{ESE}$ & ONSITE & AT & 02-Jun-03A & ALPHA & $0.000786 \mathrm{p}$ & & 0.00039 & 0.00044 & & & \\
\hline SESPMNT & B16PV2 & 200 ESE & ONSITE & AT & 17-Jun-03 A & ALPHA & $0.00138 p$ & pCilm3 & 0.00045 & 0.00056 & & & \\
\hline SESPMNT & B16PV3 & 200 ESE & ONSITE & AT & 30-Jun-03A & ALPHA & $0.00024 p$ & pCi/m3 & 0.00039 & 0.0004 & U & & \\
\hline SESPMNT & B175P4 & 200 ESE & ONSITE & AT & 15-Jul-03 A & ALPHA & $0.000577 p$ & pCi/m3 & 0.00034 & 0.00037 & & & \\
\hline SESPMNT & B175P5 & 200 ESE & ONSITE & AT & 29-Jul-03 A & ALPHA & $0.00209 p$ & pCi/m3 & 0.00054 & 0.00073 & & & \\
\hline SESPMNT & B175P6 & 200 ESE & ONSITE & AT & 12-Aug-03 & ALPHA & $0.000376 p$ & pCi/m3 & 0.00032 & 0.00034 & & & \\
\hline SESPMNT & B175P7 & 200 ESE & ONSITE & AT & 25-Aug-03 A & ALPHA & $0.000831 \mathrm{p}$ & pCilm3 & 0.00037 & 0.00042 & & & \\
\hline $\begin{array}{l}\text { SESPMNT } \\
\text { SESPMNT }\end{array}$ & $\begin{array}{l}\text { B175P8 } \\
817509\end{array}$ & $\begin{array}{l}200 \text { ESE } \\
200 \text { ESE }\end{array}$ & ONSITE & AT & 10-Sep-03A & ALPHA & $0.000623 p$ & pCi/m3 & 0.00032 & 0.00036 & & & \\
\hline $\begin{array}{l}\text { SESPMNT } \\
\text { SESPMNT }\end{array}$ & 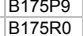 & $\begin{array}{l}200 \mathrm{ESE} \\
200 \mathrm{ESE}\end{array}$ & $\begin{array}{l}\text { ONSTIE } \\
\text { ONSITE }\end{array}$ & $\begin{array}{l}\text { AT } \\
\text { AT }\end{array}$ & $\begin{array}{r}22-\text {-epp-03 } \\
07-0 \mathrm{ct}-03\end{array}$ & $\begin{array}{l}\text { ALPHA } \\
\text { ALPHA }\end{array}$ & $\begin{array}{r}0.0006 \mathrm{p} \\
0.00133 \mathrm{p}\end{array}$ & $\begin{array}{l}\text { pilm3 } \\
\text { pilim3 }\end{array}$ & $\begin{array}{l}0.000037 \\
0.00046\end{array}$ & $\begin{array}{r}0.0004 \\
0.00056\end{array}$ & & & \\
\hline SESPMNT & B17PB5 & 200 ESE & ONSITE & AT & 21-Oct-03 A & ALPHA & $0.000467 \mathrm{p}$ & pCi/m3 & 0.00032 & 0.00034 & & & \\
\hline SESPMNT & B17PB6 & 200 ESE & ONSITE & AT & 05-Nov-03 A & ALPHA & & & & & & NO SAMPLE. BAD REGULATOR, UNKNOWN FLOW. & \\
\hline SESPMNT & B17PB7 & 200 ESE & ONSITE & AT & 18-Nov-03 A & ALPHA & $0.0015 \mathrm{p}$ & $\mathrm{pCi} / \mathrm{m} 3$ & 0.00051 & 0.00062 & & & \\
\hline SESPMNT & B17PB8 & 200 ESE & ONSITE & AT & 01-Dec-03 A & ALPHA & $0.000914 \mathrm{p}$ & $\mathrm{pCi} / \mathrm{m} 3$ & 0.0004 & 0.00046 & & & \\
\hline SESPMNT & B17PB9 & 200 ESE & ONSITE & AT & 17-Dec-03A & ALPHA & $0.000637 \mathrm{p}$ & pCilm3 & 0.00032 & 0.00036 & & & \\
\hline SESPMNT & B17PC0 & 200 ESE & ONSITE & AT & 30-Dec-03A & ALPHA & $0.000228 \mathrm{p}$ & pCi/m3 & 0.00032 & 0.00033 & $\mathrm{u}$ & & \\
\hline SESPMNT & B168K4 & 200 TEL. EXCHANGE & ONSITE & AT & 14-Jan-03A & ALPHA & $0.00066 \mathrm{p}$ & pCi/m3 & 0.00038 & 0.00042 & & & \\
\hline SESPMNT & B168K5 & 200 TEL. EXCHANGE & ONSITE & AT & 28-Jan-03A & ALPHA & $0.000464 \mathrm{p}$ & pCi/m3 & 0.00034 & 0.00036 & & & \\
\hline SESPMNT & B168K6 & 200 TEL. EXCHANGE & ONSITE & AT & 11-Feb-03A & ALPHA & $0.000164 \mathrm{p}$ & pCi/m3 & 0.00028 & 0.00029 & $\mathrm{u}$ & & \\
\hline $\begin{array}{l}\text { SESPMNT } \\
\text { SESPMNT }\end{array}$ & B168K7 & 200 TEL. EXCHANGE & ONSITE & AT & 25-Feb-03A & ALPHA & $0.000921 \mathrm{p}$ & $\mathrm{pCi} / \mathrm{m} 3$ & 0.00041 & 0.00047 & & & \\
\hline $\begin{array}{l}\text { SESPMNT } \\
\text { SESPMNT }\end{array}$ & B168K8 & 200 TEL. EXCHANGE & ONSITE & AT & 10-Mar-03A & ALPHA & $0.00136 \mathrm{p}$ & pCi/m3 & $\begin{array}{l}0.00046 \\
0.00028\end{array}$ & 0.00057 & & & \\
\hline $\begin{array}{l}\text { SESPMNT } \\
\text { SESPMNT }\end{array}$ & $\begin{array}{l}\text { B168K9 } \\
\text { B1680 }\end{array}$ & $\begin{array}{l}200 \text { TEL. EXCHANGE } \\
200 \text { TEL. EXCANGE }\end{array}$ & $\begin{array}{l}\text { ONSITE } \\
\text { ONSTE }\end{array}$ & $\begin{array}{ll}\text { AT } \\
\text { AT }\end{array}$ & $\begin{array}{l}\text { 26-Mar-03A } \\
\text { 08-Ar-03A }\end{array}$ & ALPHA & $\begin{array}{l}0.000478 p \\
0.00037 p p\end{array}$ & $\begin{array}{l}\text { pCim3 } \\
\text { pCim3 }\end{array}$ & $\begin{array}{l}0.00028 \\
0.00032\end{array}$ & $\begin{array}{l}0.00031 \\
0.00034\end{array}$ & 11 & & \\
\hline SESPMNT & $\begin{array}{l}\text { B1000 } \\
\text { B16PX4 }\end{array}$ & 200 TEL. EXCHANGE & ONSITE & AT & 21-Apr-03 A & ALPHA & $\begin{array}{r}0.0003 / 9 \mathrm{p} \\
0.0014 \mathrm{p}\end{array}$ & pCim3 & $\begin{array}{l}0.000022 \\
0.0049\end{array}$ & $\begin{array}{r}0.00034 \\
0.0006\end{array}$ & 0 & & \\
\hline SESPMNT & B16PX5 & 200 TEL. EXCHANGE & ONSITE & AT & $06-$ May-03 A & ALPHA & $0.000765 \mathrm{p}$ & $\mathrm{pC} / \mathrm{m} 3$ & 0.00036 & 0.00041 & & & \\
\hline SESPMNT & B16PX6 & 200 TEL. EXCHANGE & ONSITE & AT & 20-May-03 A & ALPHA & $0.000845 \mathrm{p}$ & pCilm3 & 0.00038 & 0.00044 & & & \\
\hline SESPMNT & B16PX7 & 200 TEL. EXCHANGE & ONSITE & AT & 02-Jun-03 A & ALPHA & $0.00099 \mathrm{p}$ & pCilm3 & 0.00042 & 0.00049 & & & \\
\hline SESPMNT & B16PX8 & 200 TEL. EXCHANGE & ONSITE & AT & 17-Jun-03 A & ALPHA & $0.000557 \mathrm{p}$ & pCi/m3 & 0.00032 & 0.00036 & & & \\
\hline SESPMNT & B16PX9 & 200 TEL. EXCHANGE & ONSITE & AT & 30-Jun-03 A & ALPHA & $0.000665 p$ & pCi/m3 & 0.00038 & 0.00042 & & & \\
\hline SESPMNT & B175V4 & 200 TEL. EXCHANGE & ONSITE & AT & 15-Jul-03 A & ALPHA & $0.000321 \mathrm{p}$ & pCi/m3 & 0.00028 & 0.0003 & & & \\
\hline SESPMNT & B175V5 & 200 TEL. EXCHANGE & ONSITE & AT & 29-Jul-03 A & ALPHA & $0.00255 \mathrm{p}$ & pCi/m3 & 0.00058 & 0.00084 & & & \\
\hline SESPMNT & B175V6 & 200 TEL. EXCHANGE & ONSITE & AT & 12-Aug-03 A & ALPHA & $0.000428 \mathrm{p}$ & pCi/m3 & 0.00031 & 0.00034 & & & \\
\hline $\begin{array}{l}\text { SESPMNT } \\
\text { SESPMNT }\end{array}$ & $\begin{array}{l}\text { B175V7 } \\
\text { B17558 }\end{array}$ & $\begin{array}{l}200 \text { TEL. EXCHANGE } \\
200 \text { TEF EXCANGE }\end{array}$ & ONSITE & AT & 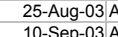 & ALPHA & $0.000826 \mathrm{p}$ & pCi/m3 & 0.00037 & 0.00041 & & & \\
\hline $\begin{array}{l}\text { SESPMNT } \\
\text { SESPMNT }\end{array}$ & B175V9 & 200 TEL. EXCHANGE & ONSITE & $\begin{array}{l}\text { AI } \\
\text { AT }\end{array}$ & 22-Sep-03A & $\begin{array}{l}\text { ALPHA } \\
\text { ALPHA }\end{array}$ & $\begin{array}{r}0.000 / 2 \mathrm{p} \\
0.00112 \mathrm{p}\end{array}$ & $\begin{array}{l}\mathrm{pllm} \\
\mathrm{pCi} 3 \mathrm{~m}\end{array}$ & $\begin{array}{l}0.000045 \\
0.0005\end{array}$ & 0.000059 & & & \\
\hline SESPMNT & B175W0 & 200 TEL. EXCHANGE & ONSITE & AT & 07-Oct-03 A & ALPHA & $0.00101 \mathrm{p}$ & $\mathrm{pC} / / m 3$ & 0.00041 & 0.00048 & & & \\
\hline SESPMNT & B17PF1 & 200 TEL. EXCHANGE & ONSITE & AT & 21-Oct-03 A & ALPHA & $0.000417 \mathrm{p}$ & pCi/m3 & 0.00031 & 0.00033 & & & \\
\hline SESPMNT & B17PF2 & 200 TEL. EXCHANGE & ONSITE & AT & 05-Nov-03 A & ALPHA & $0.000768 \mathrm{p}$ & $\mathrm{pC} i / \mathrm{p}^{2}$ & 0.00035 & 0.0004 & & & \\
\hline SESPMNT & B17PF3 & 200 TEL. EXCHANGE & ONSITE & AT & 18-Nov-03 A & ALPHA & $0.00098 \mathrm{p}$ & pCi/m3 & 0.00048 & 0.00054 & & & \\
\hline SESPMNT & B17PF4 & 200 TEL. EXCHANGE & ONSITE & AT & 01-Dec-03 A & ALPHA & $0.000641 \mathrm{p}$ & pCi/m3 & 0.00037 & 0.0004 & & & \\
\hline SESPMNT & B17PF5 & 200 TEL. EXCHANGE & ONSITE & AT & 17-Dec-03 A & ALPHA & $0.000514 \mathrm{p}$ & pCi/m3 & 0.0003 & 0.00033 & & & \\
\hline SESPMNT & B17PF6 & 200 TEL. EXCHANGE & ONSITE & AT & 30-Dec-03 A & ALPHA & $0.00051 \mathrm{p}$ & pCilm3 & 0.00037 & 0.0004 & & & \\
\hline SESPMNT & B168L9 & 200 W SE & ONSITE & AT & 14-Jan-03 A & ALPHA & $0.000397 \mathrm{p}$ & pCi/m3 & 0.00032 & 0.00034 & & & \\
\hline SESPMNT & B168M0 & 200 W SE & ONSITE & AT & 28-Jan-03 A & ALPHA & $-0.0000314 p$ & pCi/m3 & 0.00019 & 0.00019 & $U$ & & \\
\hline SESPMNT & B168M1 & 200 W SE & ONSITE & AT & 11-Feb-03A & ALPHA & $0.00102 p$ & pCi/m3 & 0.00048 & 0.00055 & & & \\
\hline SESPMNT & B168M2 & 200 W SE & ONSITE & AT & 25-Feb-03A & ALPHA & $0.000186 \mathrm{p}$ & pCi/m3 & 0.00029 & 0.00029 & U & & \\
\hline SESPMNT & B168M3 & 200 W SE & ONSITE & AT & 10-Mar-03A & ALPHA & $0.001 \mathrm{p}$ & pCi/m3 & 0.00038 & 0.00046 & & & \\
\hline $\begin{array}{l}\text { SESPMNT } \\
\text { SESPMNT }\end{array}$ & B168M4 & 200 W SE & ONSITE & AT & 26-Mar-03A & ALPHA & $\begin{array}{r}0.00029 p \\
0000379 n\end{array}$ & pCilm3 & 0.00025 & 0.00027 & & & \\
\hline $\begin{array}{l}\text { SESPMNT } \\
\text { SESPMNT }\end{array}$ & $\begin{array}{l}\text { B168M5 } \\
\text { B16P7 }\end{array}$ & $\begin{array}{l}200 \mathrm{WSE} \\
200 \mathrm{WSE}\end{array}$ & $\begin{array}{l}\text { ONSIIE } \\
\text { ONSITE }\end{array}$ & $\begin{array}{l}\text { AT } \\
\text { AT }\end{array}$ & $\begin{array}{l}\text { 08-Apr-03A } \\
\text { 21-Ar-03A }\end{array}$ & ALLHA & $\begin{array}{l}0.000379 \mathrm{p} \\
0.000531 \mathrm{p}\end{array}$ & 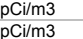 & $\begin{array}{l}0.00001 \\
0.00035\end{array}$ & $\begin{array}{l}0.00033 \\
0.0038\end{array}$ & & & \\
\hline $\begin{array}{l}\text { SESPMNI } \\
\text { SESPMNT }\end{array}$ & B16PY8 & 200 W SE & ONSITE & AT & $06-M a y-03 \mathrm{~A}$ & ALPHA & $0.000801 \mathrm{p}$ & pCim3 & 0.00035 & 0.00041 & & & \\
\hline SESPMNT & B16PY9 & 200 W SE & ONSITE & AT & 20-May-03 A & ALPHA & $0.000347 \mathrm{p}$ & pCilm3 & 0.00029 & 0.00031 & & & \\
\hline SESPMNT & B16R00 & 200 W SE & ONSITE & AT & 02-Jun-03 A & ALPHA & $0.000576 \mathrm{p}$ & pCi/m3 & 0.00036 & 0.0004 & & & \\
\hline
\end{tabular}


AIR BETA/ALPHA

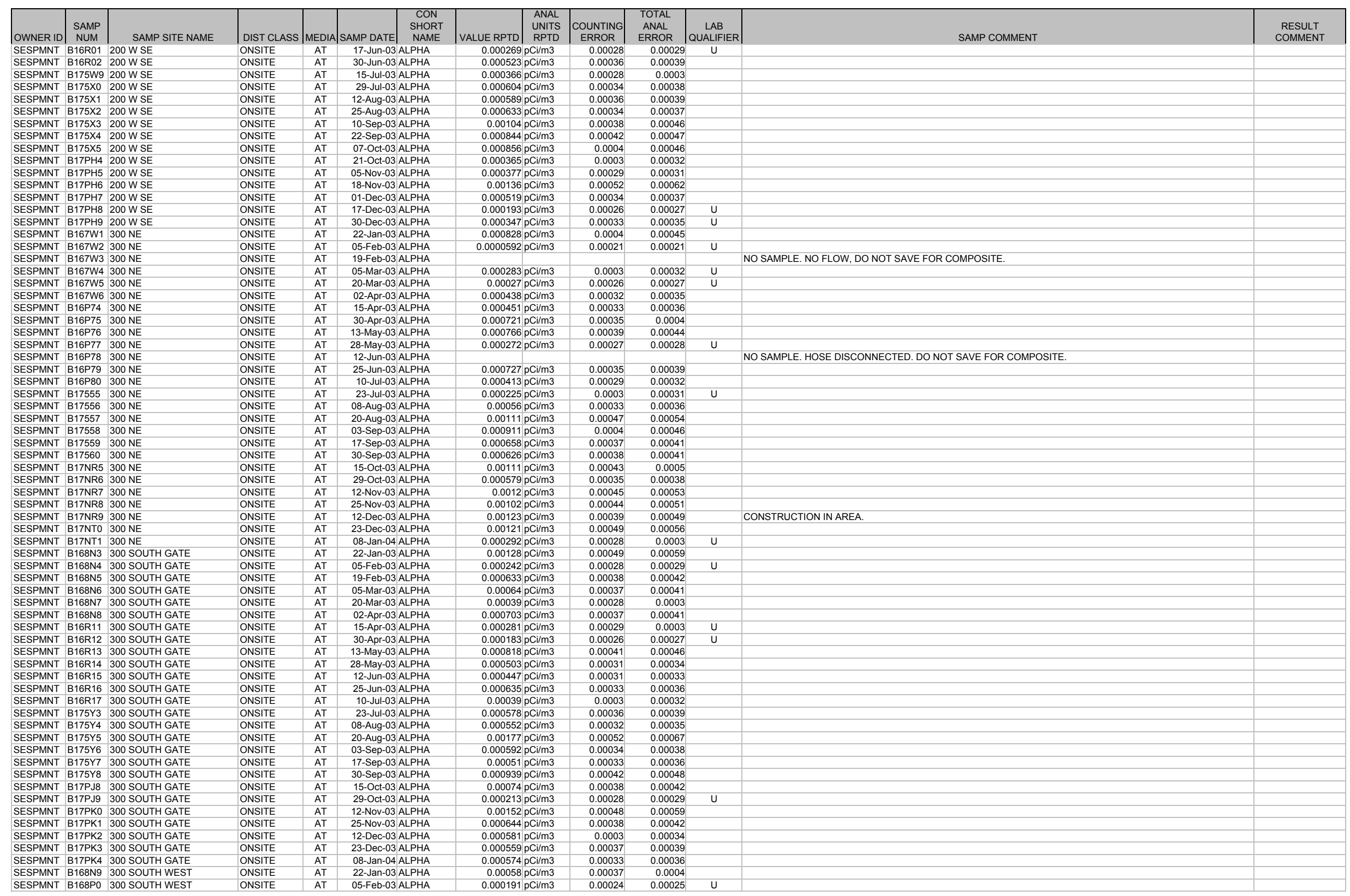


AIR BETA/ALPHA

\begin{tabular}{|c|c|c|c|c|c|c|c|c|c|c|c|c|c|}
\hline OWNER ID & \begin{tabular}{|l|} 
SAMP \\
NUMM
\end{tabular} & SAMP SITE NAME & DIST CLASS & MEDIA & SAMP DATE| & $\begin{array}{l}\text { CON } \\
\text { SHORT } \\
\text { NAME }\end{array}$ & | VALUE RPTD | & $\begin{array}{l}\text { ANAL } \\
\text { UNITS } \\
\text { RPTD }\end{array}$ & $\left|\begin{array}{c}\text { COUNTING } \\
\text { ERROR }\end{array}\right|$ & \begin{tabular}{|c|c|} 
TOTAL \\
ANAL \\
ERROR
\end{tabular} & $\begin{array}{c}\text { LAB } \\
\text { QUALIFIER }\end{array}$ & SAMP COMMENT & $\begin{array}{c}\text { RESULT } \\
\text { COMMENT }\end{array}$ \\
\hline SESPMNT & B168P1 & 300 SOUTH WEST & ONSITE & AT & 19-Feb-03 A & & $0.000569 \mathrm{p}$ & & 0.0004 & 0.00043 & & & \\
\hline SESPMNT & B168P2 & 300 SOUTH WEST & ONSITE & AT & 05-Mar-03 A & ALPHA & $0.000702 \mathrm{p}$ & Ci/m3 & 0.00038 & 0.00042 & & & \\
\hline SESPMNT & B168P3 & 300 SOUTH WEST & ONSITE & AT & 20-Mar-03A & ALPHA & $0.000239 \mathrm{p}$ & & 0.00025 & 0.00026 & u & & \\
\hline SESPMNT & B168P4 & 300 SOUTH WEST & ONSITE & AT & 02-Apr-03 A & ALPHA & $0.001 \mathrm{p}$ & $\mathrm{Ci} / \mathrm{m} 3$ & 0.00042 & 0.00049 & & & \\
\hline SESPMNT & B16R18 & 300 SOUTH WEST & ONSITE & AT & 15-Apr-03 A & ALPHA & $0.000611 \mathrm{p}$ & $\mathrm{C} / \mathrm{m} 3$ & 0.00035 & 0.00039 & & & \\
\hline SESPMNT & B16R19 & 300 SOUTH WEST & ONSITE & AT & 30-Apr-03 A & ALPHA & $0.000454 p$ & $\mathrm{C} i / \mathrm{m} 3$ & 0.00031 & 0.00034 & & & \\
\hline SESPMNT & B16R20 & 300 SOUTH WEST & ONSITE & AT & 13-May-03 A & ALPHA & $0.00262 p$ & Cilm3 & 0.00062 & 0.00088 & & & \\
\hline $\begin{array}{l}\text { SESPMNT } \\
\text { SECPMNT }\end{array}$ & B16R21 & 300 SOUTH WEST & ONSITE & AT & 28-May-03 A & ALPHA & $0.000154 p$ & Ci/m3 & 0.00025 & 0.00026 & u & & \\
\hline $\begin{array}{l}\text { SESPMNT } \\
\text { SECDMNT }\end{array}$ & B16R22 & 300 SOUTH WEST & ONSITE & AT & 12-Jun-03A & ALPHA & $0.000753 \mathrm{p}$ & $\mathrm{Ci} / \mathrm{m} 3$ & 0.00036 & 0.00041 & & & \\
\hline $\begin{array}{l}\text { SESPMNT } \\
\text { SESPMNT }\end{array}$ & B16R23 & $\begin{array}{l}300 \text { SOUTH WEST } \\
300 \text { SOTH WEST }\end{array}$ & & AT & 25-Jun-03A & ALPHA & $0.000282 p$ & Ci/m3 & 0.00027 & 0.00028 & U & & \\
\hline $\begin{array}{l}\text { SESPMNT } \\
\text { SESPMNT }\end{array}$ & $\begin{array}{l}\text { B16R24 } \\
\text { B17599 }\end{array}$ & $\begin{array}{l}300 \text { SOUTH WEST } \\
300 \text { SOUTH WEST }\end{array}$ & $\begin{array}{l}\text { ONSITE } \\
\text { ONSIE }\end{array}$ & AT & $\begin{array}{l}\text { 10-Jul-03 A } \\
23-\mathrm{Ju}-03 \mathrm{~A}\end{array}$ & ALPHA & $0.000558 p$ & SCi/m3 & $\begin{array}{l}0.00032 \\
0.00039\end{array}$ & 0.00036 & & & \\
\hline $\begin{array}{l}\text { SESPMNT } \\
\text { SESPIN }\end{array}$ & 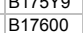 & $\begin{array}{l}300 \text { SOUTH WEST } \\
300 \text { SOUTH WEST }\end{array}$ & $\begin{array}{l}\text { ONSIIIE } \\
\text { ONSTE }\end{array}$ & AT & $\begin{array}{r}\text { 23-Jul-03A } \\
08 \text {-Aug-03A }\end{array}$ & ALLHA & $\begin{array}{l}0.000724 \mathrm{p} \\
0.000568 \mathrm{p}\end{array}$ & Ci/m3 & $\begin{array}{l}0.00039 \\
0.00032\end{array}$ & $\begin{array}{l}0.00043 \\
0.00035\end{array}$ & & & \\
\hline SESPMNT & B17601 & 300 SOUTH WEST & ONSITE & AT & 20-Aug-03 A & ALPHA & $0.00033 \mathrm{p}$ & $\mathrm{Ci} / \mathrm{m} 3$ & 0.00034 & 0.00036 & $u$ & & \\
\hline SESPMNT & B17602 & 300 SOUTH WEST & ONSITE & AT & 03-Sep-03A & ALPHA & $0.000629 \mathrm{p}$ & & 0.00035 & 0.00039 & & & \\
\hline SESPMNT & B17603 & 300 SOUTH WEST & ONSITE & AT & 17-Sep-03 A & ALPHA & $0.000527 \mathrm{p}$ & $\mathrm{Ci} / \mathrm{m} 3$ & 0.00035 & 0.00037 & & & \\
\hline SESPMNT & B17604 & 300 SOUTH WEST & ONSITE & AT & 30-Sep-03A & ALPHA & $0.000974 \mathrm{p}$ & $\mathrm{Ci} / \mathrm{m} 3$ & 0.00043 & 0.00049 & & & \\
\hline SESPMNT & B17PK5 & 300 SOUTH WEST & ONSITE & AT & 15-Oct-03 A & ALPHA & $0.000899 p$ & $\mathrm{Ci} / \mathrm{m} 3$ & 0.00039 & 0.00045 & & & \\
\hline SESPMNT & B17PK6 & 300 SOUTH WEST & ONSITE & AT & 29-Oct-03 A & ALPHA & $0.000448 p$ & & 0.00033 & 0.00036 & & & \\
\hline SESPMNT & B17PK7 & 300 SOUTH WEST & ONSITE & AT & 12-Nov-03 A & ALPHA & $0.00133 p$ & & 0.00046 & 0.00055 & & & \\
\hline SESPMNT & B17PK8 & 300 SOUTH WEST & ONSITE & AT & 25-Nov-03 A & & $0.000552 p$ & & 0.00037 & 0.0004 & & & \\
\hline SESPMNT & B17PK9 & 300 SOUTH WEST & ONSITE & AT & 12-Dec-03A & ALPHA & $0.000583 \mathrm{p}$ & & 0.0003 & 0.00034 & & & \\
\hline SESPMNT & B17PLO & 300 SOUTH WEST & ONSITE & AT & 23-Dec-03A & ALPHA & $0.000625 p$ & Ci/m3 & 0.0004 & 0.00042 & & & \\
\hline $\begin{array}{l}\text { SESPMNT } \\
\text { SESPMNT }\end{array}$ & B17PL1 & 300 SOUTH WEST & ONSITE & AT & 08-Jan-04 A & ALPHA & $\begin{array}{r}0.00044 \mathrm{p} \\
0.00562\end{array}$ & Ci/m3 & $\begin{array}{r}0.0003 \\
0.002\end{array}$ & 0.00033 & & & \\
\hline $\begin{array}{l}\text { SESPMNT } \\
\text { SESPMNT }\end{array}$ & $\begin{array}{l}\text { B16775 } \\
\text { B16776 }\end{array}$ & $\begin{array}{l}300 \text { TRENCH } \\
\text { 300 TRENCH }\end{array}$ & $\begin{array}{l}\text { ONSITE } \\
\text { ONSTEE }\end{array}$ & $\begin{array}{l}\text { AT } \\
\text { AT }\end{array}$ & $\begin{array}{l}\text { 22-Jan-03 A } \\
05-5 \text {-eb-03 A }\end{array}$ & ALPHA & $\begin{array}{l}0.000563 \mathrm{p} \\
0.00015 \mathrm{p}\end{array}$ & Cil/m3 & $\begin{array}{l}0.00037 \\
0.00025\end{array}$ & $\begin{array}{r}0.0002 \\
0.00025\end{array}$ & u & & \\
\hline SESPMNT & $\begin{array}{l}\text { B16No } \\
\text { B167V7 }\end{array}$ & 300 TRENCH & $\begin{array}{l}\text { ONSSITE } \\
\text { ONTE }\end{array}$ & $\begin{array}{l}\text { AT } \\
\text { AT }\end{array}$ & $19-$ Feb-03A & ALPHA & $\begin{array}{r}0.000152 \mathrm{p} \\
0.0004 \mathrm{p}\end{array}$ & DClim3 & $\begin{array}{l}0.00025 \\
0.00038\end{array}$ & $\begin{array}{r}0.00005 \\
0.0004\end{array}$ & u & & \\
\hline SESPMNT & B167V8 & 300 TRENCH & ONSITE & AT & 05-Mar-03 A & ALPHA & $0.000761 \mathrm{p}$ & $\mathrm{Ci} / \mathrm{m} 3$ & 0.00038 & 0.00043 & & & \\
\hline SESPMNT & B167V9 & 300 TRENCH & ONSITE & AT & 20-Mar-03 A & ALPHA & $0.000516 \mathrm{p}$ & $\mathrm{Ci} / \mathrm{m} 3$ & 0.00034 & 0.00037 & & & \\
\hline SESPMNT & B167W0 & 300 TRENCH & ONSITE & AT & 02-Apr-03 A & ALPHA & $0.000365 \mathrm{p}$ & $\mathrm{Ci} / \mathrm{m} 3$ & 0.0003 & 0.00032 & & & \\
\hline SESPMNT & B16P67 & 300 TRENCH & ONSITE & AT & 15-Apr-03 A & ALPHA & $0.000699 \mathrm{p}$ & $\mathrm{Ci} / \mathrm{m} 3$ & 0.00034 & 0.00039 & & & \\
\hline SESPMNT & B16P68 & 300 TRENCH & ONSITE & AT & 30-Apr-03 A & ALPHA & & & & & & NO SAMPLE. SAVE FOR COMPOSITE. & \\
\hline SESPMNT & B16P69 & 300 TRENCH & ONSITE & AT & 13-May-03 A & ALPHA & $0.000596 \mathrm{p}$ & DCi/m3 & 0.00037 & 0.00041 & & & \\
\hline SESPMNT & B16P70 & 300 TRENCH & ONSITE & AT & 28-May-03 A & ALPHA & $0.000441 \mathrm{p}$ & Cilm3 & 0.00031 & 0.00034 & & & \\
\hline SESPMNT & B16P71 & 300 TRENCH & ONSITE & AT & 12-Jun-03A & ALPHA & $0.000587 \mathrm{p}$ & Ci/m3 & 0.00034 & 0.00037 & & & \\
\hline SESPMNT & B16P72 & 300 TRENCH & ONSITE & AT & 25-Jun-03A & ALPHA & $0.000271 \mathrm{p}$ & Ci/m3 & 0.00027 & 0.00028 & $\mathrm{U}$ & & \\
\hline $\begin{array}{l}\text { SESPMNT } \\
\text { SESPMNT }\end{array}$ & B16P73 & 300 TRENCH & ONSITE & AT & 10-Jul-03A & ALPHA & $0.000243 p$ & $\mathrm{C}_{\mathrm{C} / \mathrm{m} 3}$ & 0.00027 & 0.00028 & U & & \\
\hline $\begin{array}{l}\text { SESPMNT } \\
\text { SESPMNT }\end{array}$ & B17549 & $\begin{array}{l}300 \text { TRENCH } \\
\text { 300 TRENCH }\end{array}$ & ONSITE & AT & 23-Jul-03A & ALPHA & $0.000336 \mathrm{p}$ & Ci/m3 & 0.00033 & 0.00035 & u & & \\
\hline $\begin{array}{l}\text { SESPMNT } \\
\text { SESPMNT }\end{array}$ & $\begin{array}{l}\begin{array}{l}\text { B17550 } \\
\text { B17551 }\end{array}\end{array}$ & $\begin{array}{l}\text { 300 TRENCH } \\
\text { 300 TRENCH }\end{array}$ & $\begin{array}{l}\text { ONSIIE } \\
\text { ONSITE }\end{array}$ & $\begin{array}{l}\text { AT } \\
\text { AT }\end{array}$ & $\begin{array}{l}\text { 20-Aug -03A } 03 \text { A } \\
\text { 20-Aug }\end{array}$ & ALPHA & $\begin{array}{l}0.000365 \mathrm{p} \\
0.000272 \mathrm{p}\end{array}$ & $\begin{array}{l}\text { SCim3 } \\
\text { cilm3 }\end{array}$ & $\begin{array}{l}0.000029 \\
0.00032\end{array}$ & $\begin{array}{l}0.000031 \\
0.00033\end{array}$ & $u$ & & \\
\hline SESPMNT & B17552 & 300 TRENCH & ONSITE & AT & $03-$ Sep-03A & ALPHA & $0.000579 \mathrm{p}$ & $\mathrm{Ci} / \mathrm{m} 3$ & 0.00034 & 0.00037 & & & \\
\hline SESPMNT & B17553 & 300 TRENCH & ONSITE & AT & 17-Sep-03A & ALPHA & $0.000652 \mathrm{p}$ & & 0.00038 & 0.00041 & & & \\
\hline SESPMNT & B17554 & 300 TRENCH & ONSITE & AT & 30-Sep-03A & ALPHA & $0.000261 \mathrm{p}$ & $\mathrm{Ci} / \mathrm{m} 3$ & 0.00032 & 0.00034 & U & & \\
\hline SESPMNT & B17NP8 & 300 TRENCH & ONSITE & AT & 15-Oct-03 A & ALPHA & & & & & & NO SAMPLE. POWER OUTAGE. & \\
\hline SESPMNT & B17NP9 & 300 TRENCH & ONSITE & AT & 29-Oct-03 A & ALPHA & & & & & & NO SAMPLE. POWER OUTAGE. & \\
\hline SESPMNT & B17NRO & 300 TRENCH & ONSITE & AT & 12-Nov-03A & ALPHA & $0.00176 p$ & $\mathrm{C} i / \mathrm{m} 3$ & 0.00049 & 0.00062 & & & \\
\hline SESPMNT & B17NR1 & 300 TRENCH & ONSITE & AT & 25-Nov-03A & ALPHA & $0.00065 p$ & $\mathrm{C} / \mathrm{m} 3$ & 0.0004 & 0.00043 & & & \\
\hline SESPMNT & B17NR2 & 300 TRENCH & ONSITE & AT & 12-Dec-03A & ALPHA & $0.00086 p$ & $\mathrm{C} / \mathrm{m} 3$ & 0.00035 & 0.0004 & & CONSTRUCTION IN AREA. & \\
\hline SESPMNT & B17NR3 & 300 TRENCH & ONSITE & AT & 23-Dec-03A & ALPHA & $0.00046 \mathrm{p}$ & Ci/m3 & 0.00037 & 0.00038 & & & \\
\hline SESPMNT & B17NR4 & 300 TRENCH & ONSITE & AT & 08-Jan-04 A & ALPHA & $0.000486 \mathrm{p}$ & Ci/m3 & 0.00031 & 0.00033 & & & \\
\hline $\begin{array}{l}\text { SESPMNT } \\
\text { SESPMNT }\end{array}$ & $\begin{array}{l}\text { B16887 } \\
\text { B168M8 }\end{array}$ & $\begin{array}{l}\text { 300 WATER IITAKE } \\
\text { 300 WATER INTAKE }\end{array}$ & $\begin{array}{l}\text { ONSIIE } \\
\text { ONSTIE }\end{array}$ & $\begin{array}{l}\text { AT } \\
\text { AT }\end{array}$ & $\begin{array}{l}\text { 22-Jan-03A } \\
\text { 05- } 5 \text { - } 03 \mathrm{~A} A\end{array}$ & ALLHA & $\begin{array}{r}0.0012 \mathrm{p} \\
0.00028 \mathrm{p}\end{array}$ & 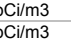 & $\begin{array}{l}0.00048 \\
0.00028\end{array}$ & $\begin{array}{l}0.00057 \\
0.0003\end{array}$ & $u$ & & \\
\hline SESPMNT & B168M9 & 300 WATER INTAKE & ONSITE & AT & $19-\mathrm{Feb}-03 \mathrm{~A}$ & ALPHA & $0.00064 \mathrm{p}$ & $\mathrm{Ci} / \mathrm{m} 3$ & 0.00038 & 0.00041 & & & \\
\hline SESPMNT & B168NO & 300 WATER INTAKE & ONSITE & AT & 05-Mar-03 A & ALPHA & $0.000422 p$ & Cilm3 & 0.00033 & 0.00035 & & & \\
\hline SESPMNT & B168N1 & 300 WATER INTAKE & ONSITE & AT & 20-Mar-03 A & ALPHA & $0.000645 \mathrm{p}$ & $\mathrm{Ci} / \mathrm{m} 3$ & 0.00033 & 0.00037 & & & \\
\hline SESPMNT & B168N2 & 300 WATER INTAKE & ONSITE & AT & 02-Apr-03 A & ALPHA & $0.000704 p$ & $\mathrm{Ci} / \mathrm{m} 3$ & 0.00034 & 0.00039 & & & \\
\hline SESPMNT & B16R04 & 300 WATER INTAKE & ONSITE & AT & 15-Apr-03 A & ALPHA & $0.000738 \mathrm{p}$ & $\mathrm{Ci} / \mathrm{m} 3$ & 0.00035 & 0.0004 & & & \\
\hline SESPMNT & B16R05 & 300 WATER INTAKE & ONSITE & AT & 30-Apr-03 A & ALPHA & $0.000447 \mathrm{p}$ & $\mathrm{Ci} / \mathrm{m} 3$ & 0.00031 & 0.00033 & & & \\
\hline SESPMNT & B16R06 & 300 WATER INTAKE & ONSITE & AT & 13-May-03 A & ALPHA & $0.000717 p$ & $\mathrm{Ci} / \mathrm{m} 3$ & 0.00038 & 0.00042 & & & \\
\hline SESPMNT & B16R07 & 300 WATER INTAKE & ONSITE & AT & 28-May-03 A & ALPHA & $0.000311 \mathrm{p}$ & $\mathrm{C} i / \mathrm{m} 3$ & 0.00029 & 0.00031 & U & & \\
\hline SESPMNT & B16R08 & 300 WATER INTAKE & ONSITE & AT & 12-Jun-03A & ALPHA & $0.000217 \mathrm{p}$ & $\mathrm{C} i / \mathrm{m} 3$ & 0.00027 & 0.00028 & U & & \\
\hline SESPMNT & B16R09 & 300 WATER INTAKE & ONSITE & AT & 25-Jun-03A & ALPHA & $0.000558 \mathrm{p}$ & Ci/m3 & 0.00032 & 0.00035 & & & \\
\hline SESPMNT & B16R10 & 300 WATER INTAKE & ONSITE & AT & 10-Jul-03 A & ALPHA & $0.000667 \mathrm{p}$ & Ci/m3 & 0.00034 & 0.00038 & & & \\
\hline SESPMNT & B175X7 & 300 WATER INTAKE & ONSITE & AT & 23-Jul-03A & ALPHA & $0.000317 \mathrm{p}$ & Ci/m3 & 0.00032 & 0.00034 & u & & \\
\hline $\begin{array}{l}\text { SESPMNT } \\
\text { SESPMNT }\end{array}$ & $\begin{array}{l}817558 \\
B 1759\end{array}$ & $\begin{array}{l}300 \text { WATER INTAKE } \\
300 \text { WATER ITAKEE }\end{array}$ & $\begin{array}{l}\text { ONSITE } \\
\text { ONSTE }\end{array}$ & $\begin{array}{ll}\text { AT } \\
\text { AT }\end{array}$ & $\begin{array}{l}08 \text {-Aug-03A } \\
\text { 20-Aug-03A }\end{array}$ & ALPHA & $\begin{array}{l}0.000714 \mathrm{p} \\
-0.00016 \mathrm{p}\end{array}$ & Cilm3 & $\begin{array}{l}0.00035 \\
0.00021\end{array}$ & 0.00039 & u & & \\
\hline $\begin{array}{l}\text { SESPMNI } \\
\text { SESPMNT }\end{array}$ & B175Y0 & 300 WATER INTAKE & ONSITE & AT & $03-\operatorname{Sep}-03$ A & ALPHA & $0.000509 \mathrm{p}$ & $\mathrm{Ci} / \mathrm{m} 3$ & 0.00033 & 0.00036 & & POSSIBLE LEAK IN COLUMN. & \\
\hline SESPMNT & B175Y1 & 300 WATER INTAKE & ONSITE & AT & 17-Sep-03A & ALPHA & $0.00062 p$ & $\mathrm{Ci} / \mathrm{m} 3$ & 0.00035 & 0.00038 & & & \\
\hline SESPMNT & B175Y2 & 300 WATER INTAKE & ONSITE & AT & 30-Sep-03A & ALPHA & $0.00062 p$ & $\mathrm{Ci} / \mathrm{m} 3$ & 0.00038 & 0.00041 & & & \\
\hline
\end{tabular}


AIR BETA/ALPHA

\begin{tabular}{|c|c|c|c|c|c|c|c|c|c|c|c|c|c|}
\hline |OWNER ID & \begin{tabular}{|l|} 
SAMP \\
NUM
\end{tabular} & SAMP SITE NAME & DIST CLASS & MEDIA & SAMP DATE| & $\begin{array}{l}\text { CON } \\
\text { SHORT } \\
\text { NAME }\end{array}$ & & $\begin{array}{l}\text { ANAL } \\
\text { UNITS } \\
\text { RPTD }\end{array}$ & $\left|\begin{array}{c}\text { COUNTING } \\
\text { ERROR }\end{array}\right|$ & \begin{tabular}{|c|} 
TOTAL \\
ANAL \\
ERROR
\end{tabular} & $\left|\begin{array}{c}\text { LAB } \\
\text { QUALIFIER }\end{array}\right|$ & SAMP COMMENT & $\begin{array}{l}\text { RESULT } \\
\text { COMMENT }\end{array}$ \\
\hline SESPMNT & & 300 WATER INTAKE & ONSITE & AT & 15-Oct-03 A & & $0.000988 \mathrm{p}$ & & 0.00041 & & & 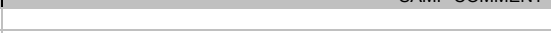 & \\
\hline SESPMNT & B17PJ2 & 300 WATER INTAKE & ONSITE & AT & 29-0ct-03 A & & $0.000348 \mathrm{p}$ & $\mathrm{pCi} / \mathrm{m} 3$ & 0.0003 & 0.00032 & & & \\
\hline SESPMNT & B17PJ3 & 300 WATER INTAKE & ONSITE & AT & 12-Nov-03 A & & $0.00126 \mathrm{p}$ & pCi/m3 & 0.00045 & 0.00053 & & & \\
\hline $\begin{array}{l}\text { SESPMNT } \\
\text { SFONT }\end{array}$ & B17PJ4 & 300 WATER INTAKE & ONSITE & AT & 25-Nov-03A & & $0.00055 p$ & $\mathrm{pC} / \mathrm{m} 3$ & 0.00039 & 0.00041 & & & \\
\hline SESPMNT & B17PJ5 & 300 WATER INTAKE & ONSITE & AT & 12-Dec-03A & & $0.000637 \mathrm{p}$ & pCi/m3 & 0.00032 & 0.00036 & & & \\
\hline SESPMNT & B17PJ6 & 300 WATER INTAKE & ONSITE & AT & 23-Dec-03A & & $0.000511 \mathrm{p}$ & pCi/m3 & 0.00035 & 0.00037 & & & \\
\hline SESPMNT & B17PJ7 & 300 WATER INTAKE & ONSITE & AT & 08-Jan-04 A & ALPHA & $0.000442 p$ & pCilm3 & 0.00031 & 0.00033 & & & \\
\hline $\begin{array}{l}\text { SESPMNT } \\
\text { SESDMNT }\end{array}$ & $\begin{array}{l}\text { B168P6 } \\
\text { B1687 }\end{array}$ & $400 \mathrm{E}$ & $\begin{array}{l}\text { ONSITE } \\
\text { ONSITEF }\end{array}$ & AT & 21-Jan-03A & ALPHA & $0.000975 p$ & pCi/m3 & 0.00046 & 0.00052 & & & \\
\hline $\begin{array}{l}\text { SESPMNT } \\
\text { SECDMNT }\end{array}$ & B168P7 & $400 \mathrm{E}$ & $\begin{array}{l}\text { ONSITE } \\
\text { ONSITEF }\end{array}$ & AT & 04-Feb-03A & & $0.000302 \mathrm{p}$ & pCi/m3 & 0.00028 & 0.0003 & & & \\
\hline $\begin{array}{l}\text { SESPMNT } \\
\text { SESPMNT }\end{array}$ & $\begin{array}{l}\text { B168P8 } \\
\text { B1689 }\end{array}$ & $400 \mathrm{E}$ & $\begin{array}{l}\text { ONSITE } \\
\text { ONSITE }\end{array}$ & AT & $\begin{array}{l}\text { 18-Feb-03A } \\
03-\mathrm{Mar}-03 \mathrm{~A}\end{array}$ & ALPHA & $\begin{array}{l}0.000791 p \\
0.000475\end{array}$ & pCi/m3 & $\begin{array}{r}0.0004 \\
0.0036\end{array}$ & 0.00045 & & & \\
\hline $\begin{array}{l}\text { SESPMNT } \\
\text { SESPMNT }\end{array}$ & 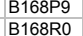 & $\begin{array}{l}400 \mathrm{E} \\
400 \mathrm{E}\end{array}$ & $\begin{array}{l}\text { ONSIIE } \\
\text { ONSITE }\end{array}$ & $\begin{array}{l}\text { AT } \\
\text { AT }\end{array}$ & $\begin{array}{l}\text { 03-Mar-03A } \\
\text { 18-Mar-03A }\end{array}$ & $\begin{array}{l}\text { ALPPA } \\
\text { ALPHA }\end{array}$ & $\begin{array}{l}0.000475 \mathrm{p} \\
0.000119 \mathrm{p}\end{array}$ & $\begin{array}{l}\text { pCim3 } \\
\text { piim3 }\end{array}$ & $\begin{array}{l}0.00036 \\
0.00022\end{array}$ & $\begin{array}{l}0.000392 \\
0.00022\end{array}$ & & & \\
\hline $\begin{array}{l}\text { SESPMNI } \\
\text { SESPMNT }\end{array}$ & $\begin{array}{l}\text { B16880 } \\
\text { B168R1 }\end{array}$ & $\begin{array}{l}400 \mathrm{E} \\
400 \mathrm{E}\end{array}$ & $\begin{array}{l}\text { ONSITE } \\
\text { ONSE }\end{array}$ & AT & 31-Mar-03 A & $\begin{array}{l}\text { ALPHA } \\
\text { ALPHA }\end{array}$ & $\begin{array}{l}0.000119 \mathrm{p} \\
0.000306 \mathrm{p}\end{array}$ & $\begin{array}{l}\mathrm{plClm3} \\
\mathrm{pCi} 3 \mathrm{~m} 3\end{array}$ & $\begin{array}{l}0.00022 \\
0.00029\end{array}$ & $\begin{array}{l}0.000222 \\
0.0003\end{array}$ & 0 & & \\
\hline SESPMNT & B16R26 & $400 \mathrm{E}$ & ONSITE & AT & 15-Apr-03 A & ALPHA & $0.000429 \mathrm{p}$ & pCim3 & 0.0003 & 0.00032 & & & \\
\hline SESPMNT & B16R27 & $400 \mathrm{E}$ & ONSITE & AT & 29-Apr-03 A & ALPHA & $0.000714 \mathrm{p}$ & pCilm3 & 0.00036 & 0.00041 & & & \\
\hline SESPMNT & B16R28 & $400 \mathrm{E}$ & ONSITE & AT & 12-May-03 A & ALPHA & $0.000821 \mathrm{p}$ & pCilm3 & 0.0004 & 0.00045 & & & \\
\hline SESPMNT & B16R29 & $400 \mathrm{E}$ & ONSITE & AT & 29-May-03 A & ALPHA & $0.00025 p$ & pCilm3 & 0.00025 & 0.00026 & U & & \\
\hline SESPMNT & B16R30 & $400 \mathrm{E}$ & ONSITE & AT & 11-Jun-03 A & ALPHA & $0.00179 p$ & pCilm3 & 0.00053 & 0.00069 & & & \\
\hline SESPMNT & B16R31 & $400 \mathrm{E}$ & ONSITE & AT & 24-Jun-03 A & ALPHA & $0.00121 p$ & pCi/m3 & 0.00045 & 0.00054 & & & \\
\hline SESPMNT & B16R32 & $400 \mathrm{E}$ & ONSITE & AT & 08-Jul-03 A & ALPHA & $0.000451 p$ & pCi/m3 & 0.00033 & 0.00035 & & & \\
\hline SESPMNT & B17606 & $400 \mathrm{E}$ & ONSITE & AT & 22-Jul-03 A & ALPHA & $0.000852 p$ & pCi/m3 & 0.0004 & 0.00045 & & & \\
\hline SESPMNT & B17607 & $400 \mathrm{E}$ & ONSITE & AT & 04-Aug-03 A & ALPHA & $0.000834 p$ & pCi/m3 & 0.00041 & 0.00046 & & & \\
\hline SESPMNT & B17608 & $400 \mathrm{E}$ & ONSITE & AT & 18-Aug-03 A & ALPHA & $0.000391 p$ & pCilm3 & 0.00032 & 0.00034 & & & \\
\hline SESPMNT & B17609 & $400 \mathrm{E}$ & ONSITE & AT & 02-Sep-03 A & ALPHA & $0.00207 p$ & pCi/m3 & 0.0005 & 0.00068 & & & \\
\hline SESPMNT & B17610 & $400 \mathrm{E}$ & ONSITE & AT & 15-Sep-03 A & ALPHA & $0.00073 p$ & pCi/m3 & 0.00039 & 0.00043 & & & \\
\hline $\begin{array}{l}\frac{S E S P M N T}{S E S P M N T} \\
\text { STM }\end{array}$ & B17611 & $400 \mathrm{E}$ & $\begin{array}{l}\text { ONSITE } \\
\text { ONSTIE }\end{array}$ & AT & 01-Oct-03A & ALPHA & $0.000566 \mathrm{p}$ & pCilm3 & $\begin{array}{l}0.00031 \\
\end{array}$ & 0.00034 & & & \\
\hline $\begin{array}{l}\text { SESPMNT } \\
\text { SESPMNT }\end{array}$ & $\begin{array}{l}\text { B17PL3 } \\
\text { B17PD4 }\end{array}$ & $400 \mathrm{E}$ & $\begin{array}{l}\text { ONSIIE } \\
\text { ONSTIE }\end{array}$ & $\begin{array}{l}\text { AT } \\
\text { AT }\end{array}$ & $\begin{array}{r}13-\mathrm{Occt}-03 \mathrm{~A} \\
28-0 \mathrm{Cl}-03\end{array}$ & ALPHA & $\begin{array}{r}0.00109 p \\
0.00068 p\end{array}$ & pCi/m3 & 0.00049 & 0.00056 & & & \\
\hline $\begin{array}{l}\text { SESPMNT } \\
\text { SESPMNT }\end{array}$ & $\begin{array}{l}\text { B17PL44 } \\
\text { B17DL5 }\end{array}$ & $\begin{array}{l}400 \mathrm{E} \\
400 \mathrm{E}\end{array}$ & $\begin{array}{l}\text { ONSITE } \\
\text { ONSITE }\end{array}$ & $\begin{array}{l}\text { AT } \\
\text { AT }\end{array}$ & $\begin{array}{l}28-\mathrm{OCt}-03 \\
11-\text {-Nov- }\end{array}$ & $\begin{array}{l}\text { ALPHA } \\
\text { ALPHA }\end{array}$ & $0.000668 \mathrm{p} p$ & $\begin{array}{c}\text { pilm3 } \\
\text { picim3 }\end{array}$ & $\begin{array}{l}0.00035 \\
0.00045\end{array}$ & $\begin{array}{l}0.000399 \\
0.00051\end{array}$ & & & \\
\hline $\begin{array}{l}\text { SESPMNT } \\
\text { SESPMNT }\end{array}$ & $\begin{array}{l}\text { B177L5 } \\
\text { B17PL6 }\end{array}$ & $\begin{array}{l}400 \mathrm{E} \\
400 \mathrm{E}\end{array}$ & $\begin{array}{l}\text { ONSITE } \\
\text { ONSITE }\end{array}$ & $\begin{array}{l}\text { AT } \\
\text { AT }\end{array}$ & $\begin{array}{l}11-\text {-Nov-03 } \\
24-\text { Nov }\end{array}$ & $\begin{array}{l}\text { ALPHA } \\
\text { ALPHA }\end{array}$ & $\begin{array}{c}0.00102 p \\
0.000879 p\end{array}$ & $\begin{array}{l}\text { pilm3 } \\
\text { pCi/m3 }\end{array}$ & $\begin{array}{l}0.000045 \\
0.00041\end{array}$ & $\begin{array}{l}0.00001 \\
0.00047\end{array}$ & & & \\
\hline SESPMNT & B17PL7 & $400 \mathrm{E}$ & ONSITE & AT & 11-Dec-03 A & ALPHA & $0.000427 \mathrm{p}$ & pCi/m3 & 0.00028 & 0.0003 & & & \\
\hline SESPMNT & B17PL8 & $400 \mathrm{E}$ & ONSITE & AT & 22-Dec-03 A & ALPHA & $0.000481 p$ & pCi/m3 & 0.0004 & 0.00042 & & & \\
\hline SESPMNT & B17PL9 & $400 \mathrm{E}$ & ONSITE & AT & 06-Jan-04 A & ALPHA & $0.000659 p$ & pCi/m3 & 0.00034 & 0.00038 & & & \\
\hline SESPMNT & B168T4 & $400 \mathrm{~N}$ & ONSITE & AT & 21-Jan-03A & ALPHA & $0.000996 \mathrm{p}$ & pCilm3 & 0.00045 & 0.00051 & & & \\
\hline SESPMNT & B168T5 & $400 \mathrm{~N}$ & ONSITE & AT & 04-Feb-03A & ALPHA & $0.0000867 \mathrm{p}$ & pCi/m3 & 0.00024 & 0.00024 & U & & \\
\hline SESPMNT & B168T6 & $400 \mathrm{~N}$ & ONSITE & AT & 18-Feb-03A & ALPHA & $0.00054 p$ & pCi/m3 & 0.00037 & 0.0004 & & & \\
\hline SESPMNT & B168T7 & $400 \mathrm{~N}$ & ONSITE & AT & 03-Mar-03 A & ALPHA & $0.000627 \mathrm{p}$ & pCi/m3 & 0.00039 & 0.00042 & & & \\
\hline SESPMNT & B168T8 & $400 \mathrm{~N}$ & ONSITE & AT & 18-Mar-03 A & ALPHA & $0.0000855 \mathrm{p}$ & pCilm3 & 0.00021 & 0.00021 & U & & \\
\hline SESPMNT & B168T9 & $400 \mathrm{~N}$ & ONSITE & AT & 31-Mar-03 A & ALPHA & $0.0002 \mathrm{p}$ & pCilm3 & 0.00026 & 0.00027 & u & & \\
\hline $\begin{array}{l}\text { SESPMNT } \\
\text { SESPMNT }\end{array}$ & $\begin{array}{l}\text { B16R474 } \\
\text { B16R8 }\end{array}$ & $400 \mathrm{~N}$ & $\begin{array}{l}\text { ONSITE } \\
\text { ONSIET }\end{array}$ & $\begin{array}{l}\text { AT } \\
\text { AT }\end{array}$ & $\begin{array}{l}15-\mathrm{Apr}-03 \mathrm{~A} \\
29-\mathrm{A} r-0\end{array}$ & ALPHA & $0.000651 \mathrm{p}$ & pCim3 & $\begin{array}{l}0.00033 \\
0.00031\end{array}$ & $\begin{array}{l}0.00037 \\
0.00033\end{array}$ & & & \\
\hline $\begin{array}{l}\frac{S E S P M N T}{} \\
\text { SESPMNT }\end{array}$ & $\begin{array}{l}\text { B16R48 } \\
\text { B16R49 }\end{array}$ & $\begin{array}{l}400 \mathrm{~N} \\
400 \mathrm{~N}\end{array}$ & $\begin{array}{l}\text { ONSITE } \\
\text { ONSITE }\end{array}$ & $\begin{array}{l}\text { AT } \\
\text { AT }\end{array}$ & $\begin{array}{r}29-\mathrm{APr}-\mathrm{D} 3 \mathrm{~A} \\
12 \mathrm{May}-\mathrm{a}\end{array}$ & $\begin{array}{l}\text { ALLHA } \\
\text { ALPHA }\end{array}$ & $0.000418 \mathrm{p}$ & picim3 & $\begin{array}{l}0.00031 \\
0.00035\end{array}$ & $\begin{array}{l}0.00033 \\
0.00038\end{array}$ & & & \\
\hline $\begin{array}{l}\text { SESPMNT } \\
\text { SESPMNT }\end{array}$ & 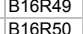 & $\begin{array}{l}400 \mathrm{~N} \\
400 \mathrm{~N}\end{array}$ & $\begin{array}{l}\text { ONSIIE } \\
\text { ONSITE }\end{array}$ & $\begin{array}{l}\mathrm{Al} \\
\mathrm{AT}\end{array}$ & $\begin{array}{l}12-\text {-ayy-03A } \\
29 \text {-May-03A }\end{array}$ & $\begin{array}{l}\text { ALPHA } \\
\text { ALPHA }\end{array}$ & $\begin{array}{l}0.000529 \mathrm{p} \\
0.000496 \mathrm{p}\end{array}$ & $\begin{array}{l}\text { pilm3 } \\
\text { pCi/m3 }\end{array}$ & $\begin{array}{l}0.00035 \\
0.00029\end{array}$ & $\begin{array}{l}0.000038 \\
0.00032\end{array}$ & & & \\
\hline SESPMNT & B16R51 & $400 \mathrm{~N}$ & ONSITE & AT & 11-Jun-03A & ALPHA & $0.000449 p p$ & pCim3 & $\begin{array}{l}0.00029 \\
0.00038\end{array}$ & $\begin{array}{l}0.000032 \\
0.00042\end{array}$ & & & \\
\hline SESPMNT & B16R52 & $400 \mathrm{~N}$ & ONSITE & AT & 24-Jun-03 A & ALPHA & $0.000792 p$ & pCi/m3 & 0.00039 & 0.00044 & & & \\
\hline SESPMNT & B16R53 & $400 \mathrm{~N}$ & ONSITE & AT & 08-Jul-03 A & ALPHA & $0.000581 p$ & pCi/m3 & 0.00035 & 0.00038 & & & \\
\hline SESPMNT & B17624 & $400 \mathrm{~N}$ & ONSITE & AT & 22-Jul-03 A & ALPHA & $0.000838 \mathrm{p}$ & pCi/m3 & 0.0004 & 0.00045 & & & \\
\hline SESPMNT & B17625 & $400 \mathrm{~N}$ & ONSITE & AT & 04-Aug-03 A & ALPHA & $0.000374 p$ & pCi/m3 & 0.00034 & 0.00036 & u & & \\
\hline SESPMNT & B17626 & $400 \mathrm{~N}$ & ONSITE & AT & 18-Aug-03A & ALPHA & $0.000287 \mathrm{p}$ & pCi/m3 & 0.00029 & 0.0003 & U & & \\
\hline SESPMNT & B17627 & $400 \mathrm{~N}$ & ONSITE & AT & 02-Sep-03A & ALPHA & $0.00136 \mathrm{p}$ & pCilm3 & 0.00042 & 0.00052 & & & \\
\hline SESPMNT & B17628 & $400 \mathrm{~N}$ & ONSITE & AT & 15-Sep-03A & ALPHA & & & & & & NO SAMPLE. SAVE FOR COMPOSITE. & \\
\hline $\begin{array}{l}\text { SESPMNT } \\
\text { SESPMNT }\end{array}$ & B17629 & $400 \mathrm{~N}$ & ONSITE & AT & 01-Oct-03 A & ALPHA & $0.000101 \mathrm{p}$ & pCim3 & 0.00025 & 0.00025 & u & & \\
\hline SESPMNT & B17PN4 & $400 \mathrm{~N}$ & ONSITE & AT & 13-Oct-03 A & ALPHA & $0.00092 p$ & pCim3 & 0.00047 & 0.00052 & & & \\
\hline $\begin{array}{l}\text { SESPMNT } \\
\text { SESPMNT }\end{array}$ & B17PN5 & $\begin{array}{ll}400 \mathrm{~N} \\
400 \mathrm{~N}\end{array}$ & ONSITE & AT & 28-Oct-03A & ALPHA & $\begin{array}{rl}0.00145 p & p\end{array}$ & pCim3 & 0.00044 & 0.00056 & & & \\
\hline $\begin{array}{l}\text { SESPMNT } \\
\text { SESPMNT }\end{array}$ & 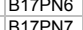 & $\begin{array}{l}400 \mathrm{~N} \\
400 \mathrm{~N}\end{array}$ & $\begin{array}{l}\text { ONSITE } \\
\text { ONSITE }\end{array}$ & AT & $\begin{array}{l}\text { 11-Nov-03A } \\
\text { 24-Noy } 03 \text { A }\end{array}$ & ALPHA & $\begin{array}{l}0.000818 \mathrm{p} \\
0.000575 \mathrm{p}\end{array}$ & pCim3 & 0.00037 & 0.00041 & & & \\
\hline $\begin{array}{l}\text { SESPMNT } \\
\text { SESPMNT }\end{array}$ & $\begin{array}{l}\text { B17PN7 } \\
\text { B17ND8 }\end{array}$ & $\begin{array}{l}400 \mathrm{~N} \\
400 \mathrm{~N}\end{array}$ & $\begin{array}{l}\text { ONSITE } \\
\text { ONSITE }\end{array}$ & AT & $\begin{array}{l}\text { 24--Nov-03A } \\
\text { 11-Dec-03A }\end{array}$ & ALPHA & $0.000575 \mathrm{p}$ & pCim3 & 0.00037 & 0.0004 & & NO SAMPLE SAVE FOR COMPOSITE. & \\
\hline $\begin{array}{l}\text { SESPMNT } \\
\text { SESPMNT }\end{array}$ & $\begin{array}{l}\text { B1/7N8 } \\
\text { B17PN9 }\end{array}$ & $\frac{400 \mathrm{~N}}{400 \mathrm{~N}}$ & $\begin{array}{l}\text { ONSIIE } \\
\text { ONSITE }\end{array}$ & $\begin{array}{l}\text { Al } \\
\text { AT }\end{array}$ & $\begin{array}{l}\text { 11--Dec-03A } \\
22 \text {-Dec- } 03 A\end{array}$ & ALPHA & & & & & $u$ & NO SAMPLE. SAVE FOR COMPOSIIE. & \\
\hline $\begin{array}{l}\text { SESPMNT } \\
\text { SESPMNT }\end{array}$ & $\begin{array}{l}\text { B1/TNA } \\
\text { B17PPO }\end{array}$ & $400 \mathrm{~N}$ & $\begin{array}{l}\text { ONSIIE } \\
\text { ONSITE }\end{array}$ & $\begin{array}{l}\text { Al } \\
\text { AT }\end{array}$ & $\begin{array}{l}22-\text {-ecc-03 } \\
06-\mathrm{Jan}-04 \mathrm{~A}\end{array}$ & $\begin{array}{l}\text { ALPHA } \\
\text { ALPHA }\end{array}$ & $\begin{array}{l}0.000315 p \\
0.000321 p\end{array}$ & $\begin{array}{l}\mathrm{plClm3} \\
\mathrm{pCi} / \mathrm{m} 3\end{array}$ & $\begin{array}{r}0.000034 \\
0.0003\end{array}$ & $\begin{array}{l}0.000036 \\
0.00032\end{array}$ & 0 & & \\
\hline $\begin{array}{l}\text { SESPMNINI } \\
\text { SESPMNT }\end{array}$ & B168R8 & $\begin{array}{l}400 \mathrm{~N} \\
400 \mathrm{~S}\end{array}$ & ONSITE & AT & $\begin{array}{l}06-\mathrm{Jan}-04 \\
21-\mathrm{Jan}-03 \mathrm{~A}\end{array}$ & $\begin{array}{l}\text { ALPHA } \\
\text { ALPHA }\end{array}$ & $0.00144 \mathrm{p}$ & 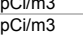 & $\begin{array}{c}0.0005 \\
0.0051\end{array}$ & 0.000062 & & & \\
\hline SESPMNT & B168R9 & $400 \mathrm{~S}$ & ONSITE & AT & 04-Feb-03 A & ALPHA & $0.000294 \mathrm{p}$ & pCilm3 & 0.00028 & 0.0003 & $U$ & & \\
\hline SESPMNT & B168TO & $400 \mathrm{~S}$ & ONSITE & AT & 18 -Feb-03A & ALPHA & $0.000204 \mathrm{p}$ & pCi/m3 & 0.00031 & 0.00032 & U & & \\
\hline SESPMNT & B16871 & $400 \mathrm{~S}$ & ONSITE & AT & 03-Mar-03 A & ALPHA & $0.00116 p$ & pCi/m3 & 0.00046 & 0.00055 & & & \\
\hline SESPMNT & B168T2 & $400 \mathrm{~S}$ & ONSITE & AT & 18-Mar-03 A & ALPHA & $0.000526 \mathrm{p}$ & pCi/m3 & 0.0003 & 0.00033 & & & \\
\hline SESPMNT & B168T3 & $400 \mathrm{~S}$ & ONSITE & AT & 31-Mar-03 A & ALPHA & $0.0018 \mathrm{p}$ & pCi/m3 & 0.00052 & 0.00068 & & & \\
\hline SESPMNT & B16R40 & $400 \mathrm{~S}$ & ONSITE & AT & 15-Apr-03 A & ALPHA & $0.000604 p$ & pCilm3 & 0.00031 & 0.00035 & & & \\
\hline SESPMNT & B16R41 & $400 \mathrm{~S}$ & ONSITE & AT & 29-Apr-03 A & ALPHA & $0.000374 p$ & pCi/m3 & 0.0003 & 0.00032 & & & \\
\hline SESPMNT & B16R42 & $\begin{array}{l}400 \mathrm{~S} \\
400 \mathrm{~S}\end{array}$ & $\begin{array}{l}\text { ONSITE } \\
\text { ONSTIE }\end{array}$ & $\begin{array}{l}\text { AT } \\
\text { AT }\end{array}$ & 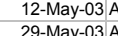 & ALPHA & $\begin{array}{l}0.000239 p \\
0.00045 p\end{array}$ & $\begin{array}{l}\text { pCi/m3 } \\
\text { pic/m3 }\end{array}$ & $\begin{array}{l}0.000299 \\
0.00028\end{array}$ & 0.0003 & U & & \\
\hline SESPMNT & B16R43 & $400 \mathrm{~S}$ & ONSITE & AT & 29-May-03/A & ALPHA & $0.00045 p$ & pCilm3 & 0.00028 & 0.0003 & & & \\
\hline
\end{tabular}


AIR BETA/ALPHA

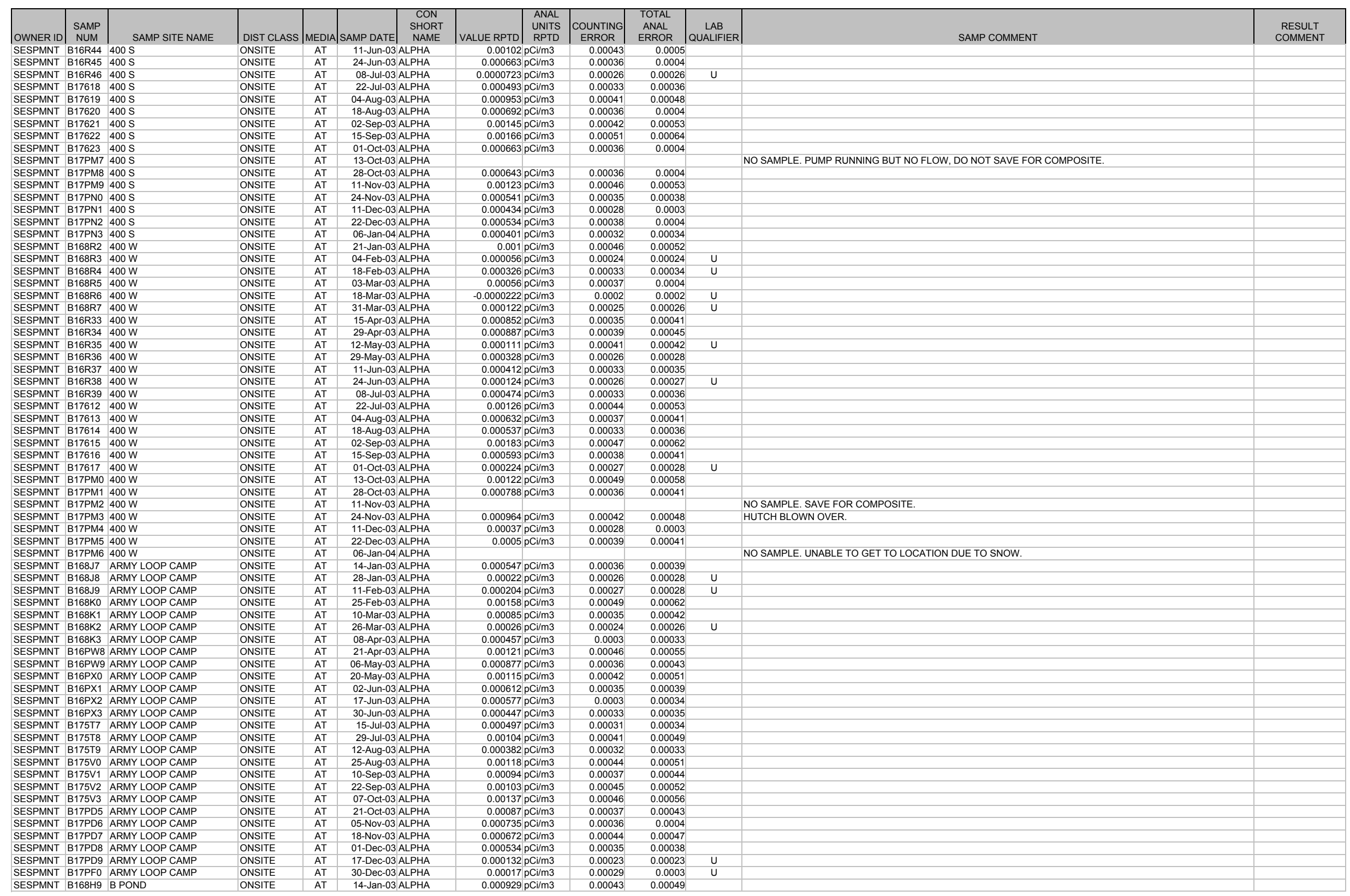


AIR BETA/ALPHA

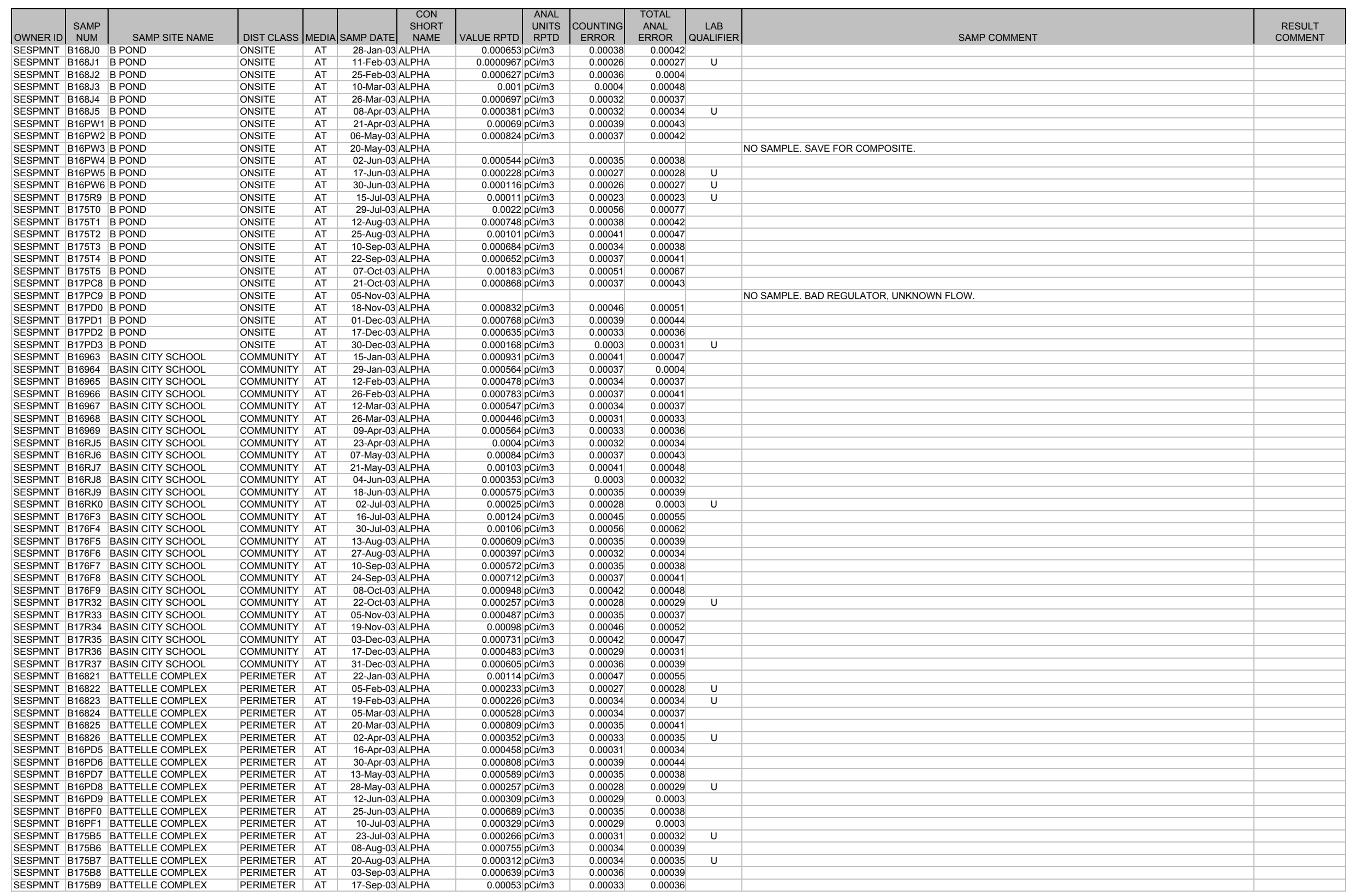


AIR BETA/ALPHA

\begin{tabular}{|c|c|c|c|c|c|c|c|c|c|c|c|c|c|}
\hline OWNER ID & \begin{tabular}{|l|} 
SAMP \\
NUMM
\end{tabular} & SAMP SITE NAME & | DIST CLASS | & MEDIA & SAMP DATE & $\begin{array}{l}\text { CON } \\
\text { SHORT } \\
\text { NAME }\end{array}$ & | VALUE RPTD & $\begin{array}{l}\text { ANAL } \\
\text { UNITS } \\
\text { RPTD }\end{array}$ & $\left|\begin{array}{c}\text { COUNTING } \\
\text { ERROR }\end{array}\right|$ & \begin{tabular}{c|} 
TOTAL \\
ANAL \\
ERROR
\end{tabular} & $\mid \begin{array}{c}\text { LAB } \\
\text { QUALIFIER }\end{array}$ & SAMP COMMENT & $\begin{array}{c}\text { RESULT } \\
\text { COMMENT }\end{array}$ \\
\hline SESPMNT & B175CO & BATTELLE COMPLEX & PERIMETER & AT & & & $0.000639 \mathrm{p}$ & & 0.00038 & 0.00042 & & & \\
\hline SESPMNT & B17NY8 & BATTELLE COMPLEX & PERIMETER & AT & 15-Oct-03 A & ALPHA & $0.000914 \mathrm{p}$ & pCilm3 & 0.0004 & 0.00046 & & & \\
\hline SESPMNT & B17NY9 & BATTELLE COMPLEX & PERIMETER & AT & 29-Oct-03 A & ALPHA & $0.000306 \mathrm{p}$ & pCi/m3 & 0.0003 & 0.00032 & u & & \\
\hline SESPMNT & B17P00 & BATTELLE COMPLEX & PERIMETER & AT & 12-Nov-03A & ALPHA & $0.00183 p$ & $\mathrm{pC}$ Ci/m3 & 0.00052 & 0.00066 & & & \\
\hline SESPMNT & B17P01 & BATTELLE COMPLEX & $\begin{array}{l}\text { PERIMETER } \\
\end{array}$ & AT & 25-Nov-03 A & ALPHA & $0.000625 p$ & pCi/m3 & 0.00039 & 0.00042 & & & \\
\hline SESPMNT & B17P02 & BATTELLE COMPLEX & PERIMETER & AT & 12-Dec-03A & ALPHA & $0.000649 p$ & pCi/m3 & 0.00031 & 0.00035 & & & \\
\hline SESPMNT & B17P03 & BATTELLE COMPLEX & PERIMETER & AT & 23-Dec-03A & ALPHA & $0.000402 p$ & pCi/m3 & 0.00034 & 0.00035 & & & \\
\hline $\begin{array}{l}\text { SESPMNT } \\
\text { SESPMNT }\end{array}$ & B17P04 & BATTELLE COMPLEX & PERIMETER & AT & 08-Jan-04 A & ALPHA & $0.000653 p$ & pCi/m3 & 0.00033 & 0.00037 & & & \\
\hline $\begin{array}{l}\text { SESPMNT } \\
\text { SECDMNT }\end{array}$ & B175C7 & BENTON CITY & COMMUNITY & AT & 03-Oct-03 A & ALPHA & $0.000546 \mathrm{p}$ & pCi/m3 & 0.00031 & 0.00034 & & & \\
\hline $\begin{array}{l}\text { SESPMNT } \\
\text { SESPMNT }\end{array}$ & $\begin{array}{ll}\text { B168Y2 } \\
\text { B16983 }\end{array}$ & $\begin{array}{l}\text { BYERS LANDING } \\
\text { BYERS LANDNG }\end{array}$ & $\begin{array}{l}\text { PERIMETER } \\
\text { PERIMETRE }\end{array}$ & AT & 16-Jan-03A & ALPHA & $0.000974 p$ & pCi/m3 & 0.00046 & 0.00052 & & & \\
\hline $\begin{array}{l}\text { SESPMNT } \\
\text { SESPMNT }\end{array}$ & $\begin{array}{l}\text { B168Y3 } \\
\text { B168Y4 }\end{array}$ & $\begin{array}{l}\text { BYERS LANDING } \\
\text { BYERS LADING }\end{array}$ & $\begin{array}{l}\text { PERIMETER } \\
\text { PERIMETER }\end{array}$ & AT & $\begin{array}{l}\text { 30-Jan-03 A } \\
\text { 13-erob-03A }\end{array}$ & ALPHA & $0.000182 p$ & pCi/m3 & $\begin{array}{r}0.0003 \\
0.00038\end{array}$ & $\begin{array}{r}0.0003 \\
0.00042\end{array}$ & u & & \\
\hline SESPMNT & B168Y5 & BYERS LANDING & PERIMETER & AT & $28-\mathrm{Feb}-03 \mathrm{~A}$ & ALPHA & $0.000883 \mathrm{p}$ & pCim3 & $\begin{array}{l}0.000038 \\
0.00037\end{array}$ & 0.000042 & & & \\
\hline SESPMNT & B168Y6 & BYERS LANDING & PERIMETER & AT & 13-Mar-03 A & ALPHA & $0.00128 \mathrm{p}$ & $\mathrm{pCi} / \mathrm{m} 3$ & 0.00047 & 0.00057 & & & \\
\hline SESPMNT & B168Y7 & BYERS LANDING & PERIMETER & AT & 28-Mar-03 A & ALPHA & $0.000581 \mathrm{p}$ & pCilm3 & 0.00037 & 0.0004 & & & \\
\hline SESPMNT & B168Y8 & BYERS LANDING & PERIMETER & AT & 10-Apr-03 A & ALPHA & $0.000419 \mathrm{p}$ & pCilm3 & 0.00033 & 0.00035 & & & \\
\hline SESPMNT & B16R84 & BYERS LANDING & PERIMETER & AT & 25-Apr-03 A & ALPHA & $0.000646 \mathrm{p}$ & pCilm3 & 0.00033 & 0.00037 & & & \\
\hline SESPMNT & B16R85 & BYERS LANDING & PERIMETER & AT & 08-May-03 A & ALPHA & $0.000269 p$ & pCilm3 & 0.00029 & 0.00031 & U & & \\
\hline SESPMNT & B16R86 & BYERS LANDING & PERIMETER & AT & 22-May-03 A & ALPHA & $0.000608 \mathrm{p}$ & pCi/m3 & 0.00039 & 0.00043 & & & \\
\hline SESPMNT & B16R87 & BYERS LANDING & PERIMETER & AT & 06-Jun-03A & ALPHA & $0.000607 p$ & & 0.00034 & 0.00037 & & & \\
\hline SESPMNT & B16R88 & BYERS LANDING & PERIMETER & AT & 19-Jun-03 A & & $0.00038 \mathrm{p}$ & pCi/m3 & 0.00036 & 0.00037 & U & & \\
\hline SESPMNT & B16R89 & BYERS LANDING & PERIMETER & AT & 07-Jul-03 A & & $0.00043 p$ & pCi/m3 & 0.0003 & 0.00032 & & & \\
\hline SESPMNT & B17662 & BYERS LANDING & PERIMETER & AT & 18-Jul-03 A & ALPHA & $0.000621 \mathrm{p}$ & pCilm3 & 0.00041 & 0.00044 & & & \\
\hline $\begin{array}{l}\text { SESPMNT } \\
\text { SESPMNT }\end{array}$ & $\begin{array}{l}\text { B17663 } \\
\text { B1764 }\end{array}$ & $\begin{array}{l}\text { BYERS LANDING } \\
\text { BYEPS }\end{array}$ & $\begin{array}{l}\text { PERIMETER } \\
\text { PERIMETRER }\end{array}$ & AT & 31-Jul-03 A & ALPHA & $\begin{array}{r}0.00098 \mathrm{p} \\
0.00202\end{array}$ & pCi/m3 & 0.00042 & 0.00049 & & & \\
\hline $\begin{array}{l}\text { SESPMNT } \\
\text { SESPMNT }\end{array}$ & $\begin{array}{ll}\text { B17664 } \\
\text { B17665 }\end{array}$ & $\begin{array}{l}\text { BYERS LANDING } \\
\text { BYERS LANING }\end{array}$ & $\begin{array}{l}\text { PERIMETER } \\
\text { PERIMETRR }\end{array}$ & AT & 15-Aug-03 A & ALPHA & $0.000302 p$ & pCi/m3 & 0.00029 & 0.0003 & & & \\
\hline $\begin{array}{l}\text { SESPMNT } \\
\text { SESPMNT }\end{array}$ & $\begin{array}{l}\text { B17665 } \\
\text { B17666 }\end{array}$ & $\begin{array}{l}\text { BVRS LANDDNG } \\
\text { BYERS LANDING }\end{array}$ & $\begin{array}{l}\text { PERIMETER } \\
\text { PERIMTERR }\end{array}$ & $\begin{array}{l}\text { AT } \\
\text { AT }\end{array}$ & $\begin{array}{l}\text { 28-ugg-03A } \\
\text { 12-Sep-03A }\end{array}$ & ALPHA & $\begin{array}{l}0.000414 \mathrm{p} \\
0.000775 \mathrm{p}\end{array}$ & $\begin{array}{l}\text { pCim3 } \\
\text { piimm3 }\end{array}$ & $\begin{array}{l}0.00034 \\
0.00036\end{array}$ & 0.00036 & & & \\
\hline SESPMNT & B17667 & BYERS LANDING & PERIMETER & AT & 25-Sep-03A & ALPHA & & & 0.00000 & & & NO SAMPLE. SAVE FOR COMPOSITE. & \\
\hline SESPMNT & B17668 & BYERS LANDING & PERIMETER & AT & 10-Oct-03 A & ALPHA & $0.000652 \mathrm{p}$ & $\mathrm{pCi} / \mathrm{m} 3$ & 0.00036 & 0.0004 & & & \\
\hline SESPMNT & B17PV1 & BYERS LANDING & PERIMETER & AT & 23-Oct-03 A & ALPHA & $0.000342 \mathrm{p}$ & $\mathrm{pCi} / \mathrm{m} 3$ & 0.00031 & 0.00032 & & & \\
\hline SESPMNT & B17PV2 & BYERS LANDING & PERIMETER & AT & 07-Nov-03 A & ALPHA & $0.00143 \mathrm{p}$ & pCilm3 & 0.00045 & 0.00056 & & & \\
\hline SESPMNT & B17PV3 & BYERS LANDING & PERIMETER & AT & 21-Nov-03 A & ALPHA & $0.000983 p$ & pCi/m3 & 0.0004 & 0.00047 & & & \\
\hline SESPMNT & B17PV4 & BYERS LANDING & PERIMETER & AT & 05-Dec-03A & ALPHA & $0.000808 \mathrm{p}$ & pCi/m3 & 0.00038 & 0.00043 & & & \\
\hline SESPMNT & B17PV5 & BYERS LANDING & PERIMETER & AT & 19-Dec-03A & ALPHA & $0.000343 p$ & pCi/m3 & 0.00028 & 0.00029 & & & \\
\hline SESPMNT & B17PV6 & BYERS LANDING & PERIMETER & AT & 05-Jan-04A & ALPHA & $0.00122 \mathrm{p}$ & pCi/m3 & 0.00039 & 0.00049 & & & \\
\hline $\begin{array}{l}\text { SESPMNT } \\
\text { SESPMNT }\end{array}$ & B168X4 & DOGWOOD MET TOWER & PERIMETER & AT & 16-Jan-03A & ALPHA & $0.000507 \mathrm{p}$ & pCi/m3 & 0.00038 & 0.00041 & & & \\
\hline $\begin{array}{l}\text { SESPMNT } \\
\text { SESPMNT }\end{array}$ & B168X5 & DOGWOOD MET TOWER & $\begin{array}{l}\text { PERIMETER } \\
\text { PEPIMETRP }\end{array}$ & AT & 30-Jan-03A & ALPHA & $0.000163 p$ & pCi/m3 & 0.00028 & 0.00029 & $\mathrm{U}$ & & \\
\hline $\begin{array}{l}\text { SESPMNT } \\
\text { SESPMNT }\end{array}$ & $\begin{array}{l}\text { B16886 } \\
\text { B16887 }\end{array}$ & $\begin{array}{l}\text { DOGWOOD MET TOWER } \\
\text { DOGWOOD MET TOWER }\end{array}$ & $\begin{array}{l}\text { PERIMETER } \\
\text { PERIMTER }\end{array}$ & $\begin{array}{ll}A T \\
A T\end{array}$ & $\begin{array}{l}\text { 13-Feb-03A } \\
28 \text { - } 2 \text { eb-03A }\end{array}$ & ALPHA & $\begin{array}{l}0.000434 \mathrm{p} \\
0.00053 \mathrm{p}\end{array}$ & $\begin{array}{l}\text { pCim3 } \\
\text { pCim3 }\end{array}$ & $\begin{array}{l}0.00035 \\
0.00031\end{array}$ & 0.00037 & & & \\
\hline $\begin{array}{l}\text { SESPMNT } \\
\text { SEST }\end{array}$ & $\begin{array}{l}\text { D1001 } \\
\text { B168X8 }\end{array}$ & DOGWOOD MET TOWER & PERIMETER & AT & 13-Mar-03 A & ALPHA & $\begin{array}{l}0.000533 \mathrm{p} \\
0.000613 \mathrm{p}\end{array}$ & $\begin{array}{l}\mathrm{pllm} / \mathrm{m} 3 \\
\mathrm{pCim3}\end{array}$ & $\begin{array}{l}0.000031 \\
0.0036\end{array}$ & $\begin{array}{l}0.000034 \\
0.00039\end{array}$ & & & \\
\hline SESPMNT & B168X9 & DOGWOOD MET TOWER & PERIMETER & AT & 28-Mar-03 A & ALPHA & $0.000807 \mathrm{p}$ & $\mathrm{pC} / \mathrm{m} 3$ & 0.00035 & 0.0004 & & & \\
\hline SESPMNT & B168Y0 & DOGWOOD MET TOWER & PERIMETER & AT & 10-Apr-03 A & ALPHA & $0.000892 \mathrm{p}$ & pCilm3 & 0.0004 & 0.00046 & & & \\
\hline SESPMNT & B16R77 & DOGWOOD MET TOWER & PERIMETER & AT & 25-Apr-03 A & ALPHA & $0.00084 \mathrm{p}$ & pCilm3 & 0.00036 & 0.00042 & & & \\
\hline SESPMNT & B16R78 & DOGWOOD MET TOWER & PERIMETER & AT & 08-May-03 A & ALPHA & $0.000914 p$ & pCi/m3 & 0.0004 & 0.00047 & & & \\
\hline SESPMNT & B16R79 & DOGWOOD MET TOWER & PERIMETER & AT & 22-May-03 A & ALPHA & $0.000371 \mathrm{p}$ & pCilm3 & 0.00035 & 0.00037 & U & & \\
\hline SESPMNT & B16R80 & DOGWOOD MET TOWER & PERIMETER & AT & 06-Jun-03 A & ALPHA & $0.000893 p$ & pCi/m3 & 0.00038 & 0.00044 & & & \\
\hline SESPMNT & B16R81 & DOGWOOD MET TOWER & PERIMETER & AT & 19-Jun-03A & ALPHA & $0.000686 \mathrm{p}$ & pCi/m3 & 0.00038 & 0.00042 & & & \\
\hline SESPMNT & B16R82 & DOGWOOD MET TOWER & PERIMETER & AT & 07-Jul-03 A & ALPHA & $0.000686 \mathrm{p}$ & pCi/m3 & 0.00033 & 0.00037 & & & \\
\hline SESPMNT & B17654 & DOGWOOD MET TOWER & PERIMETER & AT & 18-Jul-03 A & ALPHA & $0.000667 p$ & pCi/m3 & 0.00042 & 0.00046 & & & \\
\hline SESPMNT & B17655 & DOGWOOD MET TOWER & $\begin{array}{l}\text { PERIMETER } \\
\text { PEPIMETRP }\end{array}$ & AT & 31-Jul-03A & ALPHA & $0.00102 \mathrm{p}$ & pCi/m3 & 0.00044 & 0.0005 & & & \\
\hline $\begin{array}{l}\text { SESPMNT } \\
\text { SESPMNT }\end{array}$ & 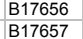 & $\begin{array}{l}\text { DOGWOOD MET TOWER } \\
\text { DOGWOOD MET TOWER }\end{array}$ & $\begin{array}{l}\text { PERIMEEER } \\
\text { PERIETER }\end{array}$ & $\begin{array}{l}\text { AT } \\
\text { AT }\end{array}$ & $\begin{array}{l}\text { 15-ugg-03A } \\
\text { 28-Aug-03 }\end{array}$ & ALLHA & $\begin{array}{l}0.000756 \mathrm{p} \\
0.00117 \mathrm{p}\end{array}$ & $\begin{array}{l}\mathrm{pCC/m3} \\
\mathrm{p} \mathrm{C} / \mathrm{m} 3\end{array}$ & $\begin{array}{l}0.00036 \\
0.00044\end{array}$ & $\begin{array}{l}0.00041 \\
0.00053\end{array}$ & & & \\
\hline SESPMNT & B17658 & DOGWOOD MET TOWER & PERIMETER & AT & $12-S e p-03 A$ & ALPHA & $0.000947 \mathrm{p}$ & pCim3 & 0.00038 & 0.00045 & & & \\
\hline SESPMNT & B17659 & DOGWOOD MET TOWER & PERIMETER & AT & 25-Sep-03A & ALPHA & $0.00065 \mathrm{p}$ & pCilm3 & 0.00037 & 0.00041 & & & \\
\hline SESPMNT & B17660 & DOGWOOD MET TOWER & PERIMETER & AT & 10-Oct-03 A & ALPHA & $0.000682 \mathrm{p}$ & pCi/m3 & 0.00036 & 0.0004 & & & \\
\hline SESPMNT & B17PT4 & DOGWOOD MET TOWER & PERIMETER & AT & 23-Oct-03 A & ALPHA & $0.000272 \mathrm{p}$ & pCi/m3 & 0.0003 & 0.00031 & u & & \\
\hline SESPMNT & B17PT5 & DOGWOOD MET TOWER & PERIMETER & AT & 07-Nov-03 A & ALPHA & $0.00118 \mathrm{p}$ & $\mathrm{pC} / \mathrm{m} 3$ & 0.00042 & 0.00051 & & & \\
\hline SESPMNT & B17PT6 & DOGWOOD MET TOWER & PERIMETER & AT & 21-Nov-03 A & ALPHA & $0.000443 \mathrm{p}$ & pCilm3 & 0.00034 & 0.00036 & & & \\
\hline SESPMNT & B17PT7 & DOGWOOD MET TOWER & PERIMETER & AT & 05-Dec-03A & ALPHA & $0.000515 p$ & pCi/m3 & 0.00034 & 0.00036 & & & \\
\hline SESPMNT & B17PT8 & DOGWOOD MET TOWER & PERIMETER & AT & 19-Dec-03A & ALPHA & $0.000451 \mathrm{p}$ & pCi/m3 & 0.00028 & 0.0003 & & ICE ON FILTER. & \\
\hline SESPMNT & B17PT9 & DOGWOOD MET TOWER & PERIMETER & AT & 05-Jan-04A & ALPHA & $0.000242 p$ & pCi/m3 & 0.00027 & 0.00028 & U & & \\
\hline SESPMNT & B16979 & EDWIN MARKHAM SCHOOL & COMMUNITY & AT & 15-Jan-03A & ALPHA & $0.000783 p$ & pCi/m3 & 0.0004 & 0.00045 & & & \\
\hline $\begin{array}{l}\text { SESPMNT } \\
\text { SFSPMNT }\end{array}$ & $\begin{array}{l}B 16980 \\
\text { B1691 }\end{array}$ & EDWIN MARKHAM SCHOOL & COMMUNITY & AT & $\begin{array}{l}\text { 29-Jan- } 03 A \\
\text { 12-3eh-03A }\end{array}$ & ALPHA & $0.000374 p$ & pCi/m3 & 0.00034 & $\begin{array}{l}0.00036 \\
0.00032\end{array}$ & 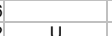 & & \\
\hline SESPMNT & B16982 & EDWIN MARKHAM SCHOOL & COMMUNITY & AT & $\begin{array}{l}12 \text {-Feb-03A } \\
26 \text {-Feb-03A }\end{array}$ & ALPHA & $\begin{array}{l}0.000273 \mathrm{p} \\
0.000899 \mathrm{p}\end{array}$ & $\begin{array}{l}\text { pCim3 } \\
\text { pCi/m3 }\end{array}$ & $\begin{array}{r}0.0003 \\
0.00038\end{array}$ & 0.00032 & 0 & & \\
\hline SESPMNT & B16983 & EDWIN MARKHAM SCHOOL & COMMUNITY & AT & 12-Mar-03 A & ALPHA & $0.00117 \mathrm{p}$ & pCi/m3 & 0.00043 & 0.00052 & & & \\
\hline SESPMNT & B16984 & EDWIN MARKHAM SCHOOL & COMMUNITY & AT & 26-Mar-03 A & ALPHA & $0.00193 p$ & pCi/m3 & 0.00052 & 0.0007 & & & \\
\hline SESPMNT & B16985 & EDWIN MARKHAM SCHOOL & COMMUNITY & AT & 10-Apr-03 A & ALPHA & $0.000891 \mathrm{p}$ & pCilm3 & 0.00036 & 0.00042 & & & \\
\hline SESPMNT & B16RK9 & EDWIN MARKHAM SCHOOL & COMMUNITY & AT & 23-Apr-03 A & ALPHA & $0.00082 p$ & pCi/m3 & 0.00041 & 0.00046 & & & \\
\hline
\end{tabular}


AIR BETA/ALPHA

\begin{tabular}{|c|c|c|c|c|c|c|c|c|c|c|c|c|}
\hline |OWNER ID & \begin{tabular}{|l|} 
SAMP \\
NUM
\end{tabular} & SAMP SITE NAME & | DIST CLASS | & MEDIA & \begin{tabular}{l|c} 
& CON \\
& SHORT \\
SAMP DATE & NAME
\end{tabular} & & $\begin{array}{l}\text { ANAL } \\
\text { UNITS } \\
\text { RPTD }\end{array}$ & $\left|\begin{array}{c}\text { COUNTING } \\
\text { ERROR }\end{array}\right|$ & \begin{tabular}{c|c} 
TOTAL \\
ANAL \\
ERROR
\end{tabular} & $\left|\begin{array}{c}\text { LAB } \\
\text { QUALIFIER }\end{array}\right|$ & SAMP COMMENT & $\begin{array}{l}\text { RESULT } \\
\text { COMMENT }\end{array}$ \\
\hline SESPMNT & B16RLO & EDWIN MARKHAM SCHOOL & COMMUNITY & AT & 07-May-03 ALPHA & $0.00073 \mathrm{p}$ & & 0.00036 & & & 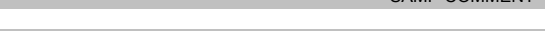 & \\
\hline SESPMNT & B16RL1 & EDWIN MARKHAM SCHOOL & COMMUNITY & AT & 21-May-03 ALPHA & $0.000712 \mathrm{p}$ & $\mathrm{pCi} / \mathrm{m} 3$ & 0.00036 & 0.00041 & & & \\
\hline SESPMNT & B16RL2 & EDWIN MARKHAM SCHOOL & COMMUNITY & AT & 04-Jun-03 ALPHA & $0.000477 \mathrm{p}$ & pCim3 & 0.00034 & 0.00036 & & & \\
\hline SESPMNT & B16RL3 & EDWIN MARKHAM SCHOOL & COMMUNITY & AT & 18-Jun-03 ALPHA & $0.000299 \mathrm{p}$ & & 0.00031 & 0.00032 & u & & \\
\hline SESPMNT & B16RL4 & EDWIN MARKHAM SCHOOL & COMMUNITY & AT & 02-Jul-03 ALPHA & $0.000244 \mathrm{p}$ & $\mathrm{pC} / \mathrm{m} 3$ & 0.00028 & 0.00029 & u & & \\
\hline SESPMNT & B176H9 & EDWIN MARKHAM SCHOOL & COMMUNITY & AT & 16-Jul-03 ALPHA & $0.000515 p$ & pCi/m3 & 0.00033 & 0.00036 & & & \\
\hline SESPMNT & B176J0 & EDWIN MARKHAM SCHOOL & COMMUNITY & AT & 30-Jul-03 ALPHA & $0.000853 p$ & pCi/m3 & 0.00038 & 0.00043 & & & \\
\hline SESPMNT & B176J1 & EDWIN MARKHAM SCHOOL & COMMUNITY & AT & 13-Aug-03 ALPHA & $0.000435 p$ & pCi/m3 & 0.00032 & 0.00035 & & & \\
\hline SESPMNT & B176J2 & EDWIN MARKHAM SCHOOL & COMMUNITY & AT & 27-Aug-03 ALPHA & $0.000546 \mathrm{p}$ & pCi/m3 & 0.00035 & 0.00038 & & & \\
\hline $\begin{array}{l}\text { SESPMNT } \\
\text { SECDMNT }\end{array}$ & B176J3 & EDWIN MARKHAM SCHOOL & COMMUNITY & AT & 10-Sep-03 ALPHA & $0.000393 p$ & pCi/m3 & 0.00032 & 0.00033 & & & \\
\hline SESPMNT & B176J4 & EDWIN MARKHAM SCHOOL & COMMUNITY & AT & 24-Sep-03 ALPHA & $0.000473 p$ & pCi/m3 & 0.00032 & 0.00034 & & & \\
\hline $\begin{array}{l}\text { SESPMNT } \\
\text { SESPMNT }\end{array}$ & B176J5 & EDWIN MARKHAM SCHOOL & COMMUNITY & AT & 08-Oct-03 ALPHA & $0.000648 \mathrm{p}$ & pCi/m3 & 0.00038 & 0.00042 & & & \\
\hline $\begin{array}{l}\text { SESPMNT } \\
\text { SESPMNT }\end{array}$ & $\begin{array}{l}\text { B17R46 } \\
\text { B17R74 }\end{array}$ & $\begin{array}{l}\text { EDWIN MARKHAM SCHOOL } \\
\text { EDAM SCHOOAM }\end{array}$ & COMMUNITY & AT & 22-Oct-03 ALPHA & $0.00054 p$ & pCi/m3 & 0.00034 & 0.00037 & & & \\
\hline $\begin{array}{l}\text { SESPMNT } \\
\text { SESPMNT }\end{array}$ & $\begin{array}{l}\text { B17R47 } \\
\text { B1748 }\end{array}$ & EDWII MARKHAM SCHOOL & $\begin{array}{l}\text { COMMUNITY } \\
\text { COMMUNTY }\end{array}$ & AT & $\begin{array}{l}\text { 05--Nov-03 ALPHA } \\
\text { 19-Nov-03 ALPHA }\end{array}$ & $\begin{array}{r}0.00102 p \\
0.000792 p\end{array}$ & pCim3 & 0.00041 & 0.00048 & & & \\
\hline $\begin{array}{l}\text { SESPMNT } \\
\text { SESPMNT }\end{array}$ & $\begin{array}{l}\begin{array}{l}\text { B17R248 } \\
\text { B17R49 }\end{array}\end{array}$ & $\begin{array}{l}\text { EDWIN MARKHAM SCHOOL } \\
\text { EDWIN MARKHAM SCHOOL }\end{array}$ & $\begin{array}{l}\text { COMMUNITY } \\
\text { COMMUNITY }\end{array}$ & $\begin{array}{l}\text { AT } \\
\text { AT }\end{array}$ & $\begin{array}{l}\text { 19--Nov-03 AAPHA } \\
\text { 03-Dec-03 ALPHA }\end{array}$ & $\begin{aligned} 0.000792 \mathrm{p} \\
0.00037 \mathrm{p}\end{aligned}$ & $\begin{array}{l}\text { pilm3 } \\
\text { pCi/m3 }\end{array}$ & $\begin{array}{l}0.000022 \\
0.00031\end{array}$ & $\begin{array}{l}0.00006 \\
0.00032\end{array}$ & & & \\
\hline SESPMNT & $\begin{array}{l}\text { D17425 } \\
\text { B17R50 }\end{array}$ & EDWIN MARKHAM SCHOOL & COMMUNITY & AT & 17-Dec-03 ALPHA & $0.000524 \mathrm{p}$ & $\begin{array}{l}\mathrm{plClm3} \\
\mathrm{pCi/m3}\end{array}$ & 0.00031 & $\begin{array}{l}0.000032 \\
0.00033\end{array}$ & & & \\
\hline SESPMNT & B17R51 & EDWIN MARKHAM SCHOOL & COMMUNITY & AT & 31-Dec-03 ALPHA & $0.00082 p$ & pCilm3 & 0.0004 & 0.00045 & & & \\
\hline SESPMNT & B16993 & HANFORD TOWNSITE & ONSITE & AT & 21-Jan-03 ALPHA & $0.00115 p$ & pCi/m3 & 0.00047 & 0.00055 & & & \\
\hline SESPMNT & B16994 & HANFORD TOWNSITE & ONSITE & AT & 04-Feb-03 ALPHA & $0.000287 \mathrm{p}$ & pCi/m3 & 0.00029 & 0.0003 & u & & \\
\hline SESPMNT & B16995 & HANFORD TOWNSITE & ONSITE & AT & 18-Feb-03 ALPHA & $0.000749 p$ & pCi/m3 & 0.0004 & 0.00044 & & & \\
\hline SESPMNT & B16996 & HANFORD TOWNSITE & ONSITE & AT & 03-Mar-03 ALPHA & $0.000569 p$ & & 0.00038 & 0.00041 & & & \\
\hline $\begin{array}{l}\text { SESPMNT } \\
\text { SECDMNT }\end{array}$ & B16997 & HANFORD TOWNSITE & ONSITE & AT & 18-Mar-03 ALPHA & $0.000134 p$ & pCilm3 & 0.00022 & 0.00023 & U & & \\
\hline SESPMNT & B16998 & HANFORD TOWNSITE & ONSITE & AT & 31-Mar-03 ALPHA & $0.000343 p$ & pCi/m3 & 0.00029 & 0.00031 & & & \\
\hline $\begin{array}{l}\text { SESPMNT } \\
\text { SESPMNT }\end{array}$ & B16RM3 & HANFORD TOWNSITE & ONSITE & AT & 15-Apr-03 ALPHA & $0.000814 p$ & pCi/m3 & 0.00036 & 0.00041 & & & \\
\hline $\begin{array}{l}\text { SESPMNT } \\
\text { SESPMNT }\end{array}$ & $\begin{array}{l}\text { B16RM4 } \\
\text { B16PM5 }\end{array}$ & HANFORD TOWNSITE & $\begin{array}{l}\text { ONSITE } \\
\text { ONSTEF }\end{array}$ & AT & 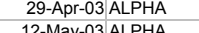 & $-0.000162 p$ & pCim3 & 0.00019 & 0.00019 & U & & \\
\hline $\begin{array}{l}\text { SESPMNT } \\
\text { SESPMNT }\end{array}$ & B16RM5 & $\begin{array}{l}\text { HAAFORD TOWNSITE } \\
\text { HANFORD TOWNTEE }\end{array}$ & $\begin{array}{l}\text { ONSITE } \\
\text { ONSTEE }\end{array}$ & AT & 12-May-03 ALPHA & $0.000304 p$ & pCim3 & $\begin{array}{r}0.0003 \\
0.0027\end{array}$ & $\begin{array}{l}0.00032 \\
0.0003\end{array}$ & u & & \\
\hline $\begin{array}{l}\text { SESPMNT } \\
\text { SESPMNT }\end{array}$ & $\begin{array}{l}\text { B16RM6 } \\
\text { B16RM7 }\end{array}$ & $\begin{array}{l}\text { HANAFORD TOWNSITE } \\
\text { HANFORD TOWSITE }\end{array}$ & $\begin{array}{l}\text { ONSTIE } \\
\text { ONSITE }\end{array}$ & $\begin{array}{l}\text { AT } \\
\text { AT }\end{array}$ & $\begin{array}{l}\text { 29-May-03 ALPHA } \\
\text { 11-1-Jun-03 LPPAA }\end{array}$ & $\begin{array}{l}0.000398 \mathrm{p} \\
0.00174 \mathrm{p}\end{array}$ & $\begin{array}{l}\text { pilm3 } \\
\text { piim3 }\end{array}$ & $\begin{array}{l}0.00027 \\
0.0052\end{array}$ & $\begin{array}{r}0.0003 \\
0.00067\end{array}$ & & & \\
\hline $\begin{array}{l}\text { SESPMNT } \\
\text { SESPMNT }\end{array}$ & $\begin{array}{l}\text { B16RM7 } \\
\text { B16RM8 }\end{array}$ & $\begin{array}{l}\text { HANFORD TOWNSITE } \\
\text { HANFORD TOWNSITE }\end{array}$ & $\begin{array}{l}\text { ONSITE } \\
\text { ONSITE }\end{array}$ & $\begin{array}{l}\text { AT } \\
\text { AT }\end{array}$ & $\begin{array}{l}\text { 11-1unn-033LAPHA } \\
\text { 24-Jun-03 ALPHA }\end{array}$ & $\begin{array}{r}0.00174 \mathrm{p} \\
0.000798 \mathrm{p}\end{array}$ & $\begin{array}{l}\mathrm{plim3} \\
\mathrm{pCi} / \mathrm{m} 3\end{array}$ & $\begin{array}{l}0.00052 \\
0.0004\end{array}$ & $\begin{array}{l}0.000067 \\
0.00045\end{array}$ & & & \\
\hline SESPMNT & B16RM9 & HANFORD TOWNSITE & ONSITE & AT & 08-Jul-03 ALPHA & $0.000155 p$ & pCilm3 & 0.00029 & 0.0003 & u & & \\
\hline SESPMNT & B176K3 & HANFORD TOWNSITE & ONSITE & AT & 22-Jul-03 ALPHA & $0.00056 \mathrm{p}$ & pCi/m3 & 0.00033 & 0.00037 & & & \\
\hline SESPMNT & B176K4 & HANFORD TOWNSITE & ONSITE & AT & 04-Aug-03 ALPHA & $0.000686 \mathrm{p}$ & pCi/m3 & 0.00038 & 0.00042 & & & \\
\hline SESPMNT & B176K5 & HANFORD TOWNSITE & ONSITE & AT & 18-Aug-03 ALPHA & $0.000561 \mathrm{p}$ & pCi/m3 & 0.00038 & 0.00041 & & & \\
\hline SESPMNT & B176K6 & HANFORD TOWNSITE & ONSITE & AT & 02-Sep-03 ALPHA & $0.00154 \mathrm{p}$ & pCi/m3 & 0.00045 & 0.00056 & & & \\
\hline SESPMNT & B176K7 & HANFORD TOWNSITE & ONSITE & AT & 15-Sep-03 ALPHA & $0.000648 \mathrm{p}$ & pCi/m3 & 0.00037 & 0.00041 & & & \\
\hline $\begin{array}{l}\text { SESPMNT } \\
\text { SECDMNT }\end{array}$ & B176K8 & HANFORD TOWNSITE & ONSITE & AT & 01-Oct-03 ALPHA & $0.000683 p$ & pCi/m3 & 0.00033 & 0.00037 & & & \\
\hline $\begin{array}{l}\text { SESPMNT } \\
\text { SESPMNT }\end{array}$ & B17R60 & HANFORD TOWNSITE & ONSITE & AT & 13-Oct-03 ALPHA & $0.00125 p$ & pCi/m3 & 0.00051 & 0.00059 & & & \\
\hline $\begin{array}{l}\text { SESPMNT } \\
\text { SESPMNT }\end{array}$ & B17R61 & HANFORD TOWNSITE & ONSITE & AT & 28-Oct-03 ALPHA & $0.000901 \mathrm{p}$ & pCilm3 & 0.00038 & 0.00044 & & & \\
\hline $\begin{array}{l}\text { SESPMNT } \\
\text { SESPMNT }\end{array}$ & $\begin{array}{l}\text { B17R62 } \\
\text { B17R23 }\end{array}$ & $\begin{array}{l}\text { HANFORD TOWNSITE } \\
\end{array}$ & $\begin{array}{l}\text { ONSIIE } \\
\text { ONSTIE }\end{array}$ & AT & 11-Nov-03 ALPHA & $0.00104 p$ & pCim3 & 0.00044 & 0.0005 & & & \\
\hline $\begin{array}{l}\text { SESPMNT } \\
\text { SESPMNT }\end{array}$ & $\begin{array}{l}\text { B17R63 } \\
\text { B17664 }\end{array}$ & $\begin{array}{l}\text { HANFFRD TOWNSITE } \\
\text { HANFORD TOWNITE }\end{array}$ & $\begin{array}{l}\text { ONSITE } \\
\text { ONSITE }\end{array}$ & $\begin{array}{l}\text { AT } \\
\text { AT }\end{array}$ & $\begin{array}{l}\text { 24-Nov-03 AAPHA } \\
\text { 11-Dec-03 ALPHA }\end{array}$ & $\begin{array}{r}0.00099 \mathrm{p} \\
0.000185 \mathrm{p}\end{array}$ & $\begin{array}{l}\mathrm{pCC/m3} \\
\mathrm{pCi} / \mathrm{m} 3\end{array}$ & 0.00043 & $\begin{array}{r}0.0005 \\
0.00024\end{array}$ & & & \\
\hline $\begin{array}{l}\text { SESPMNT } \\
\text { SESPMNT }\end{array}$ & 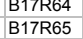 & $\begin{array}{l}\text { HANFORD TOWWSIE } \\
\text { HANFORD TOWNSITE }\end{array}$ & $\begin{array}{l}\text { ONSITE } \\
\text { ONSITE }\end{array}$ & $\begin{array}{l}\text { AT } \\
\text { AT }\end{array}$ & $\begin{array}{l}\text { 11-Dec-033ALPHA } \\
\text { 22-Dec-03 ALPHA }\end{array}$ & $\begin{array}{l}0.000155 \mathrm{p} \\
0.000495 \mathrm{p}\end{array}$ & $\begin{array}{l}\text { pilm3 } \\
\text { pCim3 }\end{array}$ & $\begin{array}{l}0.00024 \\
0.00038\end{array}$ & $\begin{aligned} 0.00024 \\
0.0004\end{aligned}$ & u & & \\
\hline SESPMNT & B17R66 & HANFORD TOWNSITE & ONSITE & AT & 06-Jan-04 ALPHA & $0.000388 \mathrm{p}$ & pCi/m3 & 0.00029 & 0.00031 & & & \\
\hline SESPMNT & B16900 & HORN RAPIDS SUBSTA & PERIMETER & AT & 23-Jan-03 ALPHA & $0.000499 p$ & pCi/m3 & 0.00035 & 0.00037 & & & \\
\hline SESPMNT & B16901 & HORN RAPIDS SUBSTA & PERIMETER & AT & 06-Feb-03 ALPHA & $-0.0000494 p$ & pCi/m3 & 0.00019 & 0.00019 & u & & \\
\hline SESPMNT & B16902 & HORN RAPIDS SUBSTA & PERIMETER & AT & 20-Feb-03 ALPHA & $0.000276 p$ & pCi/m3 & 0.00037 & 0.00038 & U & & \\
\hline SESPMNT & B16903 & HORN RAPIDS SUBSTA & PERIMETER & AT & 06-Mar-03 ALPHA & $0.00016 p$ & pCi/m3 & 0.00029 & 0.0003 & u & & \\
\hline SESPMNT & B16904 & HORN RAPIDS SUBSTA & PERIMETER & AT & 21-Mar-03 ALPHA & $0.000676 \mathrm{p}$ & pCi/m3 & 0.00032 & 0.00036 & & & \\
\hline SESPMNT & B16905 & HORN RAPIDS SUBSTA & PERIMETER & AT & 03-Apr-03 ALPHA & $0.000673 p$ & pCi/m3 & 0.00034 & 0.00038 & & & \\
\hline SESPMNT & B16R91 & HORN RAPIDS SUBSTA & PERIMETER & AT & 18-Apr-03 ALPHA & $0.000789 p$ & pCi/m3 & 0.00038 & 0.00043 & & & \\
\hline $\begin{array}{l}\text { SESPMNT } \\
\text { SESPMNT }\end{array}$ & B16R92 & HORN RAPIDS SUBSTA & $\begin{array}{l}\text { PERIMETER } \\
\end{array}$ & AT & 01-May-03 ALPHA & $0.000483 p$ & pCi/m3 & 0.00035 & 0.00037 & & & \\
\hline $\begin{array}{l}\text { SESPMNT } \\
\text { SESPMNT }\end{array}$ & $\begin{array}{l}\text { B16R93 } \\
\text { B1694 }\end{array}$ & $\begin{array}{l}\text { HORN RAAIDS SUBSTA } \\
\text { HORN RAPIDS SUBSTA }\end{array}$ & $\begin{array}{l}\text { PERIETER } \\
\text { PERIMETER }\end{array}$ & $\begin{array}{l}\text { AT } \\
\text { AT }\end{array}$ & $\begin{array}{l}\text { 16-May-03 ALPHA } \\
\text { 30-May } 03 \text { L PHA }\end{array}$ & $\begin{array}{l}0.000493 \mathrm{p} \\
0.00049 \mathrm{p}\end{array}$ & $\begin{array}{l}\text { pilm3 } \\
\text { piimm3 }\end{array}$ & $\begin{array}{r}0.0003 \\
0.00031\end{array}$ & $\begin{array}{l}0.00033 \\
0.00033\end{array}$ & & & \\
\hline SESPMNT & B16R95 & HORN RAPIDS SUBSTA & PERIMETER & AT & 13-Jun-03 ALPHA & $0.000577 \mathrm{p}$ & $\begin{array}{l}\mathrm{plim3} \\
\mathrm{pCi} 3 \mathrm{~m}\end{array}$ & 0.00034 & 0.00038 & & & \\
\hline SESPMNT & B16R96 & HORN RAPIDS SUBSTA & PERIMETER & AT & 26-Jun-03 ALPHA & $0.000337 \mathrm{p}$ & pCi/m3 & 0.00031 & 0.00033 & & & \\
\hline SESPMNT & B16R97 & HORN RAPIDS SUBSTA & PERIMETER & AT & 11-Jul-03 ALPHA & $0.000512 \mathrm{p}$ & pCi/m3 & 0.00031 & 0.00034 & & & \\
\hline SESPMNT & B17670 & HORN RAPIDS SUBSTA & PERIMETER & AT & 24-Jul-03 ALPHA & $0.000408 \mathrm{p}$ & pCilm3 & 0.00033 & 0.00035 & & & \\
\hline SESPMNT & B17671 & HORN RAPIDS SUBSTA & PERIMETER & AT & 07-Aug-03 ALPHA & $0.000621 \mathrm{p}$ & pCi/m3 & 0.00036 & 0.0004 & & & \\
\hline SESPMNT & B17672 & HORN RAPIDS SUBSTA & PERIMETER & AT & 22-Aug-03 ALPHA & $0.00042 p$ & pCi/m3 & 0.00028 & 0.0003 & & & \\
\hline SESPMNT & B17673 & HORN RAPIDS SUBSTA & PERIMETER & AT & 05-Sep-03 ALPHA & $0.00057 \mathrm{p}$ & pCi/m3 & 0.00058 & 0.0006 & $u$ & & \\
\hline SESPMNT & B17674 & HORN RAPIDS SUBSTA & PERIMETER & AT & 18-Sep-03 ALPHA & $0.000144 p$ & pCi/m3 & 0.00026 & 0.00027 & U & & \\
\hline SESPMNT & B17675 & HORN RAPIDS SUBSTA & PERIMETER & AT & 03-Oct-03 ALPHA & $0.000576 \mathrm{p}$ & pCi/m3 & 0.00032 & 0.00034 & & & \\
\hline SESPMNT & B17PV8 & HORN RAPIDS SUBSTA & PERIMETER & AT & 17-Oct-03 ALPHA & $0.000726 p$ & pCi/m3 & 0.00038 & 0.00042 & & & \\
\hline SESPMNT & B17PVI9 & HORN RAPIDS SUBSTA & PERIMETER & AT & 30-0ct-03 ALPHA & $0.000465 p$ & pcilm3 & 0.00034 & 0.00036 & & & \\
\hline $\begin{array}{l}\text { SESPMNT } \\
\text { SESDMNT }\end{array}$ & B17PWO & HORN RAPIDS SUBSTA & $\begin{array}{l}\text { PERIMETER } \\
\text { PERIMETER }\end{array}$ & AT & 14-Nov-03 ALPHA & $0.000891 \mathrm{p}$ & pCim3 & $\begin{array}{r}0.0004 \\
0.0056\end{array}$ & 0.00046 & & & \\
\hline SESPMNT & B17PW1 & HORN RAPIDS SUBSTA & $\begin{array}{l}\text { PERIMETER } \\
\text { PERIMETER }\end{array}$ & AT & 26-Nov-03 ALPHA & $\begin{array}{r}0.00189 \mathrm{p} \\
0\end{array}$ & pCi/m3 & 0.00056 & 0.00071 & & & \\
\hline $\begin{array}{l}\text { SESPMNT } \\
\text { SESPMNT }\end{array}$ & B17PW2 & $\begin{array}{l}\text { HORN RAAIDS SUBSTA } \\
\text { HORN RAPIDS SUBSTA }\end{array}$ & $\begin{array}{l}\text { PERIMETER } \\
\text { PERIMETER }\end{array}$ & $\begin{array}{l}\text { AT } \\
\text { AT }\end{array}$ & $\begin{array}{l}\text { 16-Dec-033LALPHA } \\
\text { 29-De-003 ALPHA }\end{array}$ & $\begin{array}{l}0.000219 \mathrm{p} \\
0.0011 \mathrm{p}\end{array}$ & $\begin{array}{l}\mathrm{pCC/m3} \\
\mathrm{pCi} / \mathrm{m} 3\end{array}$ & $\begin{array}{l}0.00021 \\
0.00045\end{array}$ & 0.00022 & & & \\
\hline SESPMNT & B17PW3 & HORN RAPIDS SUBSTA & PERIMETER & & 29-Dec-03ALPHA & $0.00111 p$ & pcilm3 & 0.00045 & 0.00053 & & & \\
\hline
\end{tabular}


AIR BETA/ALPHA

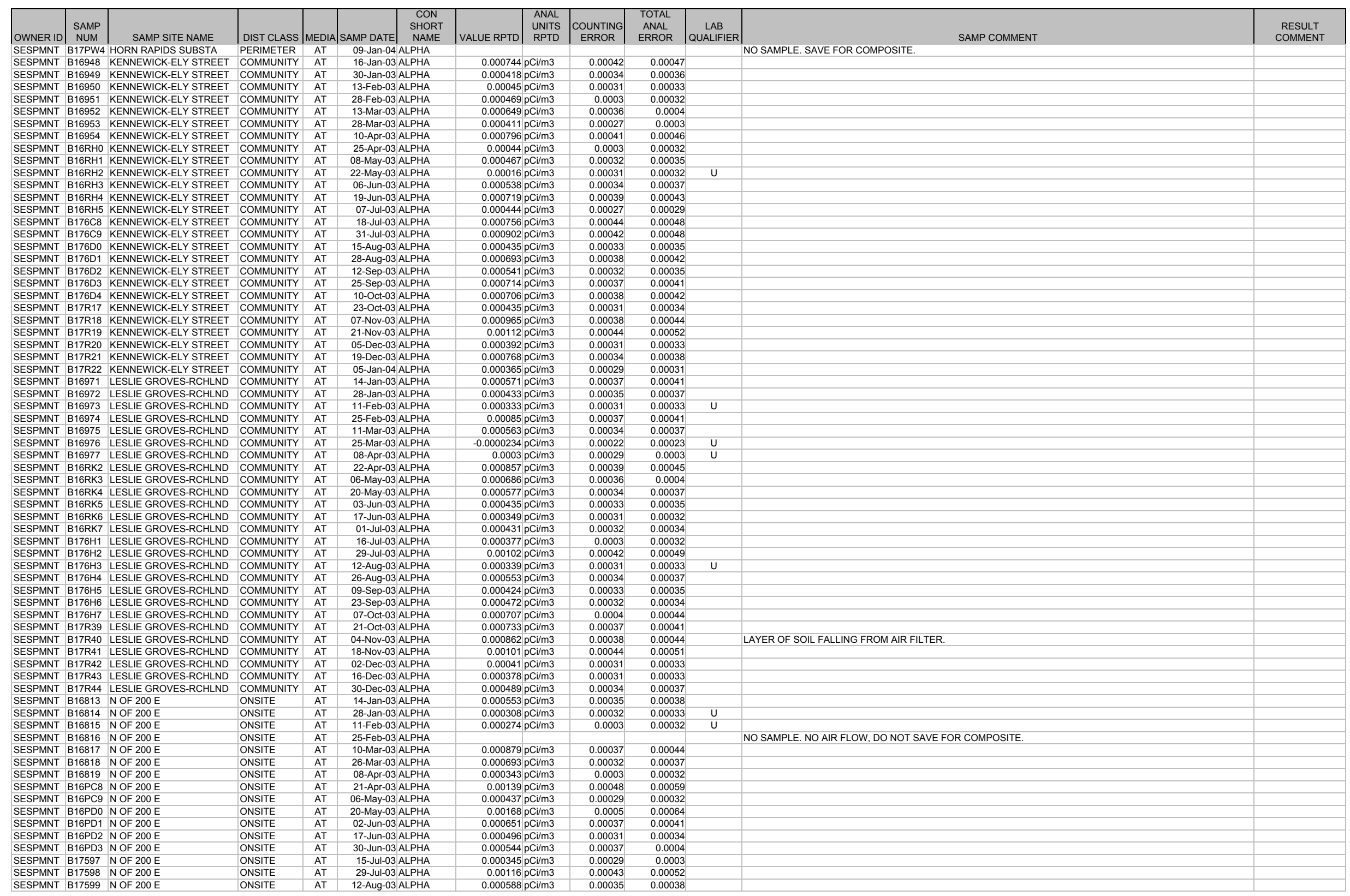


AIR BETA/ALPHA

\begin{tabular}{|c|c|c|c|c|c|c|c|c|c|c|c|c|c|}
\hline | OWNER ID & \begin{tabular}{|l|} 
SAMP \\
NUM
\end{tabular} & SAMP SITE NAME & DIST CLASS & $\mid$ MEDIA $\mid$ & SAMP DATE & $\begin{array}{l}\text { CON } \\
\text { SHORT } \\
\text { NAME }\end{array}$ & |VALUE RPTD| & $\begin{array}{l}\text { ANAL } \\
\text { UNITS } \\
\text { RPTD }\end{array}$ & $\left|\begin{array}{c}\text { COUNTING } \\
\text { ERROR }\end{array}\right|$ & \begin{tabular}{c|c} 
TOTAL \\
ANAL \\
ERROR
\end{tabular} & $\left|\begin{array}{c}\text { LAB } \\
\text { QUALIFIER }\end{array}\right|$ & SAMP COMMENT & $\begin{array}{l}\text { RESULT } \\
\text { COMMENT }\end{array}$ \\
\hline SESPMNT & B175BO & N OF $200 \mathrm{E}$ & ONSITE & AT & 25-Aug-03 A & NLPHA & $0.00088 \mathrm{p}$ & pCilm3 & 0.00038 & 0.00043 & & & \\
\hline SESPMNT & B175B1 & N OF $200 \mathrm{E}$ & ONSITE & AT & 10-Sep-03A & LLPHA & $0.00063 \mathrm{p}$ & pCilm3 & 0.00033 & 0.00037 & & & \\
\hline SESPMNT & B175B2 & N OF $200 \mathrm{E}$ & ONSITE & AT & 22-Sep-03A & LPHA & $0.000379 p$ & pCi/m3 & 0.00033 & 0.00035 & & & \\
\hline $\begin{array}{l}\text { SESPMNT } \\
\text { SFONT }\end{array}$ & B175B3 & N OF $200 \mathrm{E}$ & ONSITE & AT & 07-Oct-03A & ALPHA & $0.00187 \mathrm{p}$ & $\mathrm{pC}$ Ci/m3 & 0.0005 & 0.00067 & & & \\
\hline SESPMNT & B17NY1 & NOF $200 \mathrm{E}$ & ONSITE & AT & 21-Oct-03 A & ALPHA & $0.000441 \mathrm{p}$ & $\mathrm{pCi} / \mathrm{m} 3$ & 0.00031 & 0.00033 & & & \\
\hline $\begin{array}{l}\text { SESPMNT } \\
\text { SESPMNT }\end{array}$ & B17NY2 & NOF $200 \mathrm{E}$ & ONSITE & AT & 05-Nov-03A & ALPHA & $0.000717 p$ & pCi/m3 & 0.00035 & 0.0004 & & & \\
\hline $\begin{array}{l}\text { SESPMNT } \\
\text { SESPMNT }\end{array}$ & B17NY3 & NOF $200 \mathrm{E}$ & ONSITE & AT & 18-Nov-03A & ALPHA & $0.000866 \mathrm{p}$ & pCim3 & 0.00045 & 0.0005 & & & \\
\hline $\begin{array}{l}\text { SESPMNT } \\
\text { SESPMNT }\end{array}$ & $\begin{array}{l}\text { B17NY4 } \\
\text { B17N5 }\end{array}$ & $\begin{array}{l}\text { N OF } 200 \mathrm{E} \\
\text { N OF } 200 \mathrm{E}\end{array}$ & $\begin{array}{l}\text { ONSITE } \\
\text { ONSTE }\end{array}$ & $\begin{array}{l}\text { AT } \\
\text { AT }\end{array}$ & $\begin{array}{l}\text { 01-Dec-03 A } \\
\text { 17-0ec-03A }\end{array}$ & ALPHA & $\begin{array}{l}0.000703 \mathrm{p} \\
0.000475 \mathrm{p}\end{array}$ & $\begin{array}{l}\mathrm{pC} \text { Ci/m3 } \\
\text { pCim3 }\end{array}$ & 0.00037 & 0.00042 & & & \\
\hline SESPMNT & $\begin{array}{l}\text { DITNTE } \\
\text { B17NYG }\end{array}$ & NOF $200 E$ & ONSITE & AT & 30-Dec-03 A & LLPHA & $\begin{array}{l}0.0004 / 5 \mathrm{p} \\
0.000774 \mathrm{p}\end{array}$ & $\begin{array}{l}\mathrm{plClm3} \\
\mathrm{pC} i \mathrm{~m} 3 \mathrm{3}\end{array}$ & $\begin{array}{l}0.0003 \\
0.00037\end{array}$ & $\begin{array}{l}0.000033 \\
0.00041\end{array}$ & & & \\
\hline SESPMNT & B175F2 & OTHELLO & COMMUNITY & AT & 24-Sep-03A & LLPHA & $0.000756 \mathrm{p}$ & pCim3 & 0.00037 & 0.00042 & & & \\
\hline SESPMNT & B17P22 & OTHELLO & COMMUNITY & AT & 06-Nov-03 A & LLPHA & $0.00055 \mathrm{p}$ & $\mathrm{pCi/m3}$ & 0.00032 & 0.00035 & & & \\
\hline SESPMNT & B17P23 & OTHELLO & COMMUNITY & AT & 19-Nov-03A & LLPHA & $0.000929 \mathrm{p}$ & $\mathrm{pCi} / \mathrm{m} 3$ & 0.00046 & 0.00052 & & & \\
\hline SESPMNT & B17P24 & OTHELLO & COMMUNITY & AT & 03-Dec-03A & & $0.00126 \mathrm{p}$ & $\mathrm{pCi/m3}$ & 0.00044 & 0.00054 & & & \\
\hline SESPMNT & B176C3 & PASCO & COMMUNITY & AT & 15-Aug-03 A & ALPHA & $0.000334 \mathrm{p}$ & $\mathrm{pC} / \mathrm{m} 3$ & 0.00029 & 0.00031 & u & & \\
\hline SESPMNT & B176C5 & PASCO & COMMUNITY & AT & 12-Sep-03A & ALPHA & $0.000649 p$ & & 0.00034 & 0.00038 & & & \\
\hline SESPMNT & B17R12 & PASCO & COMMUNITY & AT & 07-Nov-03 A & ALPHA & $0.000784 \mathrm{p}$ & & 0.00036 & 0.00041 & & & \\
\hline SESPMNT & B17R15 & PASCO & COMMUNITY & AT & 19-Dec-03A & ALPHA & $0.000659 \mathrm{p}$ & & 0.00033 & 0.00036 & & & \\
\hline SESPMNT & B16906 & PROSSER BARRICADE & PERIMETER & AT & 23-Jan-03A & & $0.000925 p$ & & 0.00043 & 0.00049 & & & \\
\hline SESPMNT & B16907 & PROSSER BARRICADE & PERIMETER & AT & 06-Feb-03A & ALPHA & $0.00146 \mathrm{p}$ & & 0.00047 & 0.00059 & & & \\
\hline SESPMNT & B16908 & PROSSER BARRICADE & PERIMETER & AT & 20-Feb-03A & & $0.000997 p$ & & 0.00042 & 0.00049 & & & \\
\hline $\begin{array}{l}\text { SESPMNT } \\
\text { SESPMNT }\end{array}$ & B16909 & PROSSER BARRICADE & PERIMETER & AT & 06-Mar-03A & & $0.00042 p$ & pCi/m3 & 0.00033 & 0.00036 & & & \\
\hline $\begin{array}{l}\text { SESPMNT } \\
\text { SESPMNT }\end{array}$ & B16910 & PROSSER BARRICADE & PERIMETER & AT & 21-Mar-03A & ALPHA & $0.000385 p$ & pCim3 & 0.00027 & 0.00029 & & & \\
\hline $\begin{array}{l}\text { SESPMNT } \\
\text { SESPMNT }\end{array}$ & $\begin{array}{l}\text { B16911 } \\
\text { B16R8 }\end{array}$ & $\begin{array}{l}\text { PROSSER BARRICADE } \\
\text { PROSSER BARRICADE }\end{array}$ & $\begin{array}{l}\text { PERIMETER } \\
\text { PERMETER }\end{array}$ & AT & $\begin{array}{l}\text { 03-Apr-03A } \\
\text { 18-Ar-03A }\end{array}$ & ALPHA & $0.00034 \mathrm{p}$ & pCi/m3 & 0.0003 & 0.00032 & & & \\
\hline $\begin{array}{l}\text { SESPMNT } \\
\text { SESPMNT }\end{array}$ & $\begin{array}{l}\text { B16R898 } \\
\text { B16R99 }\end{array}$ & $\begin{array}{l}\text { PROSSER BARRIIIDE } \\
\text { PROSSER BARICADE }\end{array}$ & $\begin{array}{l}\text { PERIMETER } \\
\text { PERIMETER }\end{array}$ & $\begin{array}{l}\text { AT } \\
\text { AT }\end{array}$ & $\begin{array}{l}\text { 18-Arp-03A } \\
01 \text {-May-03A }\end{array}$ & $\begin{array}{l}\text { LLPHA } \\
\text { ALPHA }\end{array}$ & $\begin{array}{l}0.000445 \mathrm{p} \\
0.000825 \mathrm{p}\end{array}$ & $\begin{array}{l}\mathrm{pCim3} \\
\mathrm{pCi} / \mathrm{m} 3\end{array}$ & $\begin{array}{l}0.0003 \\
0.0004\end{array}$ & $\begin{array}{l}0.00033 \\
0.00046\end{array}$ & & & \\
\hline SESPMNT & B16RBO & PROSSER BARRICADE & PERIMETER & AT & 16-May-03 A & ALPHA & $0.000747 \mathrm{p}$ & $\mathrm{pC} / \mathrm{m} 3$ & 0.00036 & 0.00041 & & & \\
\hline SESPMNT & B16RB1 & PROSSER BARRICADE & PERIMETER & AT & 30-May-03 A & ALPHA & $0.00047 \mathrm{p}$ & $\mathrm{pC} / \mathrm{m} 3$ & 0.00031 & 0.00034 & & & \\
\hline SESPMNT & B16RB2 & PROSSER BARRICADE & PERIMETER & AT & 13-Jun-03 A & ALPHA & $0.000785 p$ & pCilm3 & 0.00039 & 0.00044 & & & \\
\hline SESPMNT & B16RB3 & PROSSER BARRICADE & PERIMETER & AT & 26-Jun-03 A & ALPHA & $0.000446 \mathrm{p}$ & $\mathrm{pCi} / \mathrm{m} 3$ & 0.00032 & 0.00035 & & & \\
\hline SESPMNT & B16RB4 & PROSSER BARRICADE & PERIMETER & AT & 11-Jul-03 A & ALPHA & $0.000528 \mathrm{p}$ & pCilm3 & 0.00032 & 0.00035 & & & \\
\hline SESPMNT & B17676 & PROSSER BARRICADE & PERIMETER & AT & 24-Jul-03 A & ALPHA & $0.000241 p$ & pCi/m3 & 0.0003 & 0.00031 & u & & \\
\hline SESPMNT & B17677 & PROSSER BARRICADE & PERIMETER & AT & 07-Aug-03A & ALPHA & $0.000286 \mathrm{p}$ & pCi/m3 & 0.00023 & 0.00025 & & & \\
\hline SESPMNT & B17678 & PROSSER BARRICADE & PERIMETER & AT & 22-Aug-03A & ALPHA & $0.000925 p$ & pCi/m3 & 0.00039 & 0.00044 & & & \\
\hline SESPMNT & B17679 & PROSSER BARRICADE & PERIMETER & AT & 05-Sep-03A & ALPHA & $0.00085 p$ & pCi/m3 & 0.00039 & 0.00044 & & & \\
\hline $\begin{array}{l}\text { SESPMNT } \\
\text { SESPMNT }\end{array}$ & B17680 & PROSSER BARRICADE & PERIMETER & AT & 18-Sep-03A & ALPHA & $0.00101 \mathrm{p}$ & $\mathrm{pCi} / \mathrm{m} 3$ & 0.00041 & 0.00048 & & & \\
\hline $\begin{array}{l}\text { SESPMNT } \\
\text { SESPMNT }\end{array}$ & B17681 & PROSSER BARRICADE & $\begin{array}{l}\text { PERIMETER } \\
\text { PERIMETER }\end{array}$ & AT & 03-Oct-03 A & ALPHA & $0.000684 p$ & pCi/m3 & 0.00035 & 0.00038 & & & \\
\hline $\begin{array}{l}\text { SESPMNT } \\
\text { SESPMNT }\end{array}$ & $\begin{array}{l}\text { B17PW5 } \\
\text { B17PP16 }\end{array}$ & $\begin{array}{l}\text { PROSSER BARRIICADE } \\
\text { PROSSER BARRICADE }\end{array}$ & $\begin{array}{l}\text { PERIMETER } \\
\text { PERMETER }\end{array}$ & AT & $\begin{array}{l}\text { 17-Oct-03 A } \\
30 \text {-otc-03 A }\end{array}$ & ALPHA & $0.000751 p$ & $\begin{array}{l}\text { pCim3 } \\
\text { pCim3 }\end{array}$ & 0.0004 & 0.00044 & & & \\
\hline $\begin{array}{l}\text { SESPMNI I } \\
\text { SESPMNT }\end{array}$ & $\begin{array}{l}\text { B1/17W6 } \\
\text { B17PW7 }\end{array}$ & $\begin{array}{l}\text { PROSSER BARRIIIADE } \\
\text { PROSSER BARICADE }\end{array}$ & $\begin{array}{l}\text { PERIMETER } \\
\text { PERIMETER }\end{array}$ & $\begin{array}{l}\text { AT } \\
\text { AT }\end{array}$ & $\begin{array}{l}\text { 30-OCt-03A } \\
\text { 14-Nov-03 A }\end{array}$ & $\begin{array}{l}\text { LLPHA } \\
\text { ALPHA }\end{array}$ & $\begin{array}{l}0.000477 \mathrm{p} \\
0.000852 \mathrm{p}\end{array}$ & $\begin{array}{l}\text { pilm3 } \\
\text { pCi/m3 }\end{array}$ & $\begin{array}{l}0.000034 \\
0.0039\end{array}$ & $\begin{array}{l}0.000037 \\
0.00045\end{array}$ & & & \\
\hline SESPMNT & B17PW8 & PROSSER BARRICADE & PERIMETER & AT & 26-Nov-03 A & ALPHA & $0.00112 \mathrm{p}$ & $\mathrm{pC} / \mathrm{m} 3$ & 0.00047 & 0.00055 & & & \\
\hline SESPMNT & B17PW9 & PROSSER BARRICADE & PERIMETER & AT & 16-Dec-03 A & ALPHA & $0.000761 \mathrm{p}$ & pCilm3 & 0.0003 & 0.00035 & & & \\
\hline SESPMNT & B17PX0 & PROSSER BARRICADE & PERIMETER & AT & 29-Dec-03A & ALPHA & $0.000629 \mathrm{p}$ & pCilm3 & 0.0004 & 0.00043 & & & \\
\hline SESPMNT & B17PX1 & PROSSER BARRICADE & PERIMETER & AT & 09-Jan-04 A & ALPHA & $0.000996 \mathrm{p}$ & pCi/m3 & 0.0005 & 0.00056 & & & \\
\hline SESPMNT & B16919 & RATTLESNAKE SPRINGS & PERIMETER & AT & 22-Jan-03A & ALPHA & $0.000753 p$ & pCi/m3 & 0.00043 & 0.00047 & & & \\
\hline SESPMNT & B16920 & RATTLESNAKE SPRINGS & PERIMETER & AT & 05-Feb-03A & ALPHA & $0.00023 p$ & pCi/m3 & 0.00027 & 0.00028 & $u$ & & \\
\hline SESPMNT & B16921 & RATTLESNAKE SPRINGS & PERIMETER & AT & 19-Feb-03A & ALPHA & $0.000873 p$ & pCi/m3 & 0.00041 & 0.00047 & & & \\
\hline SESPMNT & B16922 & RATTLESNAKE SPRINGS & PERIMETER & AT & 05-Mar-03 A & ALPHA & $0.000511 p$ & pCi/m3 & 0.00034 & 0.00037 & & & \\
\hline SESPMNT & B16923 & RATTLESNAKE SPRINGS & PERIMETER & AT & 20-Mar-03A & ALPHA & $0.000426 p$ & pCi/m3 & 0.00029 & 0.00032 & & & \\
\hline $\begin{array}{l}\text { SESPMNT } \\
\text { SESPMNT }\end{array}$ & B16924 & 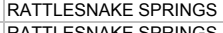 & $\begin{array}{l}\text { PERIMETER } \\
\text { PEPIMETER }\end{array}$ & AT & O2-Apr-03A & ALPHA & $0.000598 p$ & pCi/m3 & 0.00036 & 0.00039 & & & \\
\hline $\begin{array}{l}\text { SESPMNT } \\
\text { SESPMNT }\end{array}$ & B16RC3 & RATTLESNAKE SPRINGS & $\begin{array}{l}\text { PERIMETER } \\
\text { PEPIMETER }\end{array}$ & AT & 16-Apr-03 A & ALPHA & $0.00114 p$ & pCi/m3 & 0.00041 & 0.0005 & & & \\
\hline $\begin{array}{l}\text { SESPMNT } \\
\text { SESPMNT }\end{array}$ & $\begin{array}{ll}\text { B16RC4 } \\
\text { B16RC5 }\end{array}$ & $\begin{array}{l}\text { RATTLLSNAKE SPRINGS } \\
\text { RATTESNAKE PPRINGS }\end{array}$ & $\begin{array}{l}\text { PERRMETER } \\
\text { PEIMETER }\end{array}$ & $\begin{array}{l}\text { AT } \\
\text { AT }\end{array}$ & $\begin{array}{r}30-\mathrm{Apr}-03 \mathrm{~A} \\
13 \mathrm{May}-03 \mathrm{~A}\end{array}$ & ALPHA & $0.000914 p$ & pCi/m3 & 0.0004 & 0.00046 & & & \\
\hline $\begin{array}{l}\text { SESPMNT } \\
\text { SESPMNT }\end{array}$ & $\begin{array}{l}\text { B16RC5 } \\
\text { B16RC6 }\end{array}$ & $\begin{array}{l}\text { RATIESTAK SRRINGS } \\
\text { RATLESNAKE SPRINGS }\end{array}$ & $\begin{array}{l}\text { PERIMETER } \\
\text { PERIMETER }\end{array}$ & $\begin{array}{l}\text { AT } \\
\text { AT }\end{array}$ & $\begin{array}{l}\text { 13-May-03A } \\
\text { 28-May-03 A }\end{array}$ & $\begin{array}{l}\text { ALPHA } \\
\text { ALPHA }\end{array}$ & $\begin{array}{r}0.00159 \mathrm{p} \\
0.000477 \mathrm{p}\end{array}$ & $\begin{array}{l}\mathrm{pCC} / \mathrm{m} 3 \\
\mathrm{pCi} 3 \mathrm{~m}\end{array}$ & $\begin{array}{l}0.0005 \\
0.0003\end{array}$ & $\begin{array}{l}0.000063 \\
0.00033\end{array}$ & & & \\
\hline SESPMNT & B16RC7 & RATTLESNAKE SPRINGS & PERIMETER & AT & 13-Jun-03 A & ALPHA & $0.00107 \mathrm{p}$ & pCilm3 & 0.00039 & 0.00048 & & & \\
\hline SESPMNT & B16RC8 & RATTLESNAKE SPRINGS & PERIMETER & AT & 26-Jun-03 A & ALPHA & $0.000226 p$ & pCi/m3 & 0.00027 & 0.00028 & u & & \\
\hline SESPMNT & B16RC9 & RATTLESNAKE SPRINGS & PERIMETER & AT & 11-Jul-03 A & ALPHA & $0.00145 \mathrm{p}$ & pCilm3 & 0.00045 & 0.00057 & & & \\
\hline SESPMNT & B17689 & RATTLESNAKE SPRINGS & PERIMETER & AT & 24-Jul-03 A & ALPHA & $0.00086 p$ & pCilm3 & 0.00042 & 0.00048 & & & \\
\hline SESPMNT & B17690 & RATTLESNAKE SPRINGS & PERIMETER & AT & 07-Aug-03 A & ALPHA & $0.000563 \mathrm{p}$ & pCi/m3 & 0.00035 & 0.00038 & & & \\
\hline SESPMNT & B17691 & RATTLESNAKE SPRINGS & PERIMETER & AT & 22-Aug-03A & ALPHA & $0.00107 \mathrm{p}$ & pCi/m3 & 0.00048 & 0.00053 & & & \\
\hline SESPMNT & B17692 & RATTLESNAKE SPRINGS & PERIMETER & AT & 05-Sep-03A & ALPHA & $0.00103 p$ & pCi/m3 & 0.00042 & 0.00049 & & & \\
\hline SESPMNT & B17693 & RATTLESNAKE SPRINGS & PERIMETER & AT & 18-Sep-03A & ALPHA & $0.000192 p$ & pCi/m3 & 0.00027 & 0.00028 & U & & \\
\hline $\begin{array}{l}\text { SESPMNT } \\
\text { SESPMNT }\end{array}$ & $\begin{array}{l}\text { B17694 } \\
\text { B17PYO }\end{array}$ & $\begin{array}{l}\text { RATTLESNAKE SPRINGS } \\
\text { RATTISSNAKE SRI }\end{array}$ & $\begin{array}{l}\text { PERIMETER } \\
\text { PERMETFR }\end{array}$ & AT & 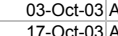 & ALPHA & $0.000589 p$ & pCi/m3 & 0.00031 & 0.00034 & & & \\
\hline $\begin{array}{l}\text { SESPMNT } \\
\text { SESPMNT }\end{array}$ & $\begin{array}{l}\text { B17PYO } \\
\text { B17PY1 }\end{array}$ & $\begin{array}{l}\text { RATLESAKE SRRINGS } \\
\text { RATLESNAE SPRINGS }\end{array}$ & $\begin{array}{l}\text { PERIMETER } \\
\text { PERIMETER }\end{array}$ & $\begin{array}{l}\text { AI } \\
\text { AT }\end{array}$ & $\begin{array}{l}\text { 17-OCt-03 A } \\
30-0 \text { ctt-03 A }\end{array}$ & ALLHA & $\begin{array}{r}0.00138 \mathrm{p} \\
0.000169 \mathrm{p}\end{array}$ & $\begin{array}{l}\mathrm{pCim3} \\
\mathrm{pCi} / \mathrm{m} 3\end{array}$ & $\begin{array}{l}0.00006 \\
0.0028\end{array}$ & $\begin{array}{l}0.00006 \\
0.00029\end{array}$ & U & & \\
\hline SESPMNT & B17PY2 & RATTLESNAKE SPRINGS & PERIMETER & AT & 14-Nov-03 A & ALPHA & $0.000669 p$ & pCim3 & 0.00039 & 0.00043 & & & \\
\hline SESPMNT & B17PY3 & RATTLESNAKE SPRINGS & PERIMETER & AT & 26-Nov-03 A & ALPHA & $0.000987 \mathrm{p}$ & pCi/m3 & 0.00045 & 0.00052 & & & \\
\hline SESPMNT & B17PY4 & RATTLESNAKE SPRINGS & PERIMETER & AT & 16-Dec-03 A & ALPHA & $0.000293 \mathrm{p}$ & pCi/m3 & 0.00022 & 0.00023 & & & \\
\hline SESPMNT & B17PY5 & RATTLESNAKE SPRINGS & PERIMETER & AT & 29-Dec-03 A & ALPHA & $0.00083 p$ & pCilm3 & 0.00041 & 0.00046 & & & \\
\hline
\end{tabular}


AIR BETA/ALPHA

\begin{tabular}{|c|c|c|c|c|c|c|c|c|c|c|c|c|c|}
\hline |OWNER ID & \begin{tabular}{|l|} 
SAMP \\
NUM
\end{tabular} & SAMP SITE NAME & DIST CLASS & MEDIA & SAMP DATE & $\begin{array}{l}\text { CON } \\
\text { SHORT } \\
\text { NAME }\end{array}$ & | VALUE RPTD & $\begin{array}{l}\text { ANAL } \\
\text { UNITS } \\
\text { RPTD }\end{array}$ & $\left|\begin{array}{c}\text { COUNTING } \\
\text { ERROR }\end{array}\right|$ & \begin{tabular}{|c|c|} 
TOTAL \\
ANAL \\
ERROR
\end{tabular} & $\left|\begin{array}{c}\text { LAB } \\
\text { QUALIFIER }\end{array}\right|$ & SAMP COMMENT & $\begin{array}{c}\text { RESULT } \\
\text { COMMENT }\end{array}$ \\
\hline SESPMNT & B17PY6 & RATTLESNAKE SPRINGS & PERIMETER & AT & & & $0.000997 \mathrm{p}$ & & 0.0005 & 0.00056 & & & \\
\hline SESPMNT & B168W6 & RINGOLD MET TOWER & PERIMETER & AT & 16-Jan-03 A & ALPHA & $0.000998 \mathrm{p}$ & $\mathrm{pCi} / \mathrm{m} 3$ & 0.00047 & 0.00054 & & & \\
\hline SESPMNT & B168W7 & RINGOLD MET TOWER & PERIMETER & AT & 30-Jan-03 A & & $0.00054 \mathrm{p}$ & $\mathrm{pC} / \mathrm{m} 3$ & 0.00036 & 0.00039 & & & \\
\hline SESPMNT & B168W8 & RINGOLD MET TOWER & PERIMETER & AT & 13-Feb-03 A & ALPHA & $0.000429 \mathrm{p}$ & $\mathrm{pCi} / \mathrm{m} 3$ & 0.00031 & 0.00034 & & & \\
\hline SESPMNT & B168W9 & RINGOLD MET TOWER & PERIMETER & AT & 28-Feb-03A & ALPHA & $0.000786 \mathrm{p}$ & $\mathrm{pCi} / \mathrm{m} 3$ & 0.00035 & 0.00039 & & & \\
\hline SESPMNT & B168X0 & RINGOLD MET TOWER & PERIMETER & AT & 13-Mar-03 A & ALPHA & $0.000539 p$ & $\mathrm{pC} / \mathrm{m} 3$ & 0.00034 & 0.00037 & & & \\
\hline SESPMNT & B168X1 & RINGOLD MET TOWER & PERIMETER & AT & 28-Mar-03A & ALPHA & $0.000464 p$ & $\mathrm{pCi} / \mathrm{m} 3$ & 0.00029 & 0.00032 & & & \\
\hline $\begin{array}{l}\text { SESPMNT } \\
\text { SESDMNT }\end{array}$ & B168X2 & RINGOLD MET TOWER & PERIMETER & AT & 10-Apr-03A & & $0.00061 \mathrm{p}$ & $\mathrm{pCi} / \mathrm{m} 3$ & 0.00037 & 0.0004 & & & \\
\hline $\begin{array}{l}\text { SESPMNT } \\
\text { SECDMNT }\end{array}$ & B16R70 & RINGOLD MET TOWER & PERIMETER & AT & 25-Apr-03A & & $0.000788 \mathrm{p}$ & $\mathrm{pCi} / \mathrm{m} 3$ & 0.00035 & 0.0004 & & & \\
\hline $\begin{array}{l}\text { SESPMNT } \\
\text { SESPMNT }\end{array}$ & $\begin{array}{l}\text { B16R71 } \\
\text { B16R2 }\end{array}$ & RINGOLD MET TOWER & $\begin{array}{l}\text { PERIMETER } \\
\text { PEIMETER }\end{array}$ & AT & 08-May-03A & ALPHA & $0.000446 \mathrm{p}$ & pCi/m3 & 0.0003 & 0.00033 & & & \\
\hline $\begin{array}{l}\text { SESPMNT } \\
\text { SESPMNT }\end{array}$ & $\begin{array}{l}\text { B16R72 } \\
\text { B16R3 }\end{array}$ & $\begin{array}{l}\text { RINGOLD MET TOWER } \\
\text { RINGOTET TOWER }\end{array}$ & $\begin{array}{l}\text { PERIMETER } \\
\text { PERMETER }\end{array}$ & AT & 22-May-03A & ALPHA & $0.000391 \mathrm{p}$ & pCi/m3 & $\begin{array}{l}0.00035 \\
0.00035\end{array}$ & 0.00037 & & & \\
\hline SESPMNT & B16R74 & $\begin{array}{l}\text { RINGOLD MET TOWER } \\
\text { RINGOD MET TOWER }\end{array}$ & $\begin{array}{l}\text { PERIMEIER } \\
\text { PERIMETER }\end{array}$ & AT & $\begin{array}{l}\text { O6--Jun-03A } \\
\text { 19-Jun- } 03 A\end{array}$ & $\begin{array}{l}\text { ALPHA } \\
\text { ALPHA }\end{array}$ & $\begin{array}{l}0.0007009 \mathrm{p} \\
0.000592 \mathrm{p}\end{array}$ & $\begin{array}{l}\mathrm{pCC/m3} \\
\mathrm{pCi} / \mathrm{m} 3\end{array}$ & $\begin{array}{l}0.00035 \\
0.00047\end{array}$ & $\begin{array}{l}0.0004 \\
0.0005\end{array}$ & & & \\
\hline SESPMNT & B16R75 & RINGOLD MET TOWER & PERIMETER & AT & 07-Jul-03 A & ALPHA & $0.000705 \mathrm{p}$ & $\mathrm{pCi} / \mathrm{m} 3$ & 0.0003 & 0.00035 & & & \\
\hline SESPMNT & B17646 & RINGOLD MET TOWER & PERIMETER & AT & 18-Jul-03 A & ALPHA & $0.000793 \mathrm{p}$ & $\mathrm{pCi} / \mathrm{m} 3$ & 0.00045 & 0.00049 & & & \\
\hline SESPMNT & B17647 & RINGOLD MET TOWER & PERIMETER & AT & 31-Jul-03 A & ALPHA & $0.000493 \mathrm{p}$ & & 0.00035 & 0.00038 & & & \\
\hline SESPMNT & B17648 & RINGOLD MET TOWER & PERIMETER & AT & 15-Aug-03 A & ALPHA & $0.000288 \mathrm{p}$ & & 0.00029 & 0.0003 & u & & \\
\hline SESPMNT & B17649 & RINGOLD MET TOWER & PERIMETER & AT & 28-Aug-03 A & ALPHA & $0.00104 \mathrm{p}$ & $\mathrm{pCi} / \mathrm{m} 3$ & 0.00043 & 0.0005 & & & \\
\hline SESPMNT & B17650 & RINGOLD MET TOWER & PERIMETER & AT & 12-Sep-03A & ALPHA & $0.000754 \mathrm{p}$ & & 0.00036 & 0.0004 & & & \\
\hline SESPMNT & B17651 & RINGOLD MET TOWER & PERIMETER & AT & 25-Sep-03A & ALPHA & $0.000963 p$ & $\mathrm{pC} / \mathrm{m} 3$ & 0.0004 & 0.00047 & & & \\
\hline SESPMNT & B17652 & RINGOLD MET TOWER & PERIMETER & AT & 10-Oct-03 A & & $0.000895 \mathrm{p}$ & $\mathrm{pCi} / \mathrm{m} 3$ & 0.00039 & 0.00045 & & & \\
\hline SESPMNT & B17PR7 & RINGOLD MET TOWER & PERIMETER & AT & 23-Oct-03 A & ALPHA & $0.000522 \mathrm{p}$ & & 0.00034 & 0.00037 & & & \\
\hline $\begin{array}{l}\text { SESPMNT } \\
\end{array}$ & B17PR8 & RINGOLD MET TOWER & PERIMETER & AT & 07-Nov-03 A & ALPHA & $0.000705 p$ & pCilm3 & 0.00035 & 0.0004 & & & \\
\hline $\begin{array}{l}\text { SESPMNT } \\
\text { SESPMNT }\end{array}$ & $\begin{array}{l}\text { B17PR9 } \\
\text { B17PTO }\end{array}$ & RINGOLD MET TOWER & $\begin{array}{l}\text { PERIMETER } \\
\text { PEIMETER }\end{array}$ & AT & 21-Nov-03 A & ALPHA & $\begin{array}{r}0.00046 \mathrm{p} \\
0.00581\end{array}$ & pCi/m3 & 0.00035 & 0.00037 & & & \\
\hline $\begin{array}{l}\text { SESPMNT } \\
\text { SESPMNT }\end{array}$ & $\begin{array}{l}\text { B17PPO } \\
\text { B17PT1 }\end{array}$ & $\begin{array}{l}\text { INGGOLD MET TOWER } \\
\text { RINGLD MET TOWER }\end{array}$ & $\begin{array}{l}\text { PERIMETRR } \\
\text { PERIMETER }\end{array}$ & $\begin{array}{l}\text { AT } \\
\text { AT }\end{array}$ & $\begin{array}{l}\text { 25-DDC- }-03 \mathrm{~A} \\
\text { 19-Dec-03A }\end{array}$ & ALPHA & $\begin{array}{l}0.000581 \mathrm{p} \\
0.00033 \mathrm{p}\end{array}$ & $\begin{array}{l}\mathrm{pCC/m3} \\
\mathrm{pC} / \mathrm{m} 3\end{array}$ & $\begin{array}{l}0.000034 \\
0.0027\end{array}$ & $\begin{array}{l}0.000037 \\
0.00028\end{array}$ & & & \\
\hline SESPMNT & B17PT2 & RINGOLD MET TOWER & PERIMETER & AT & 05-Jan-04 A & ALPHA & $0.00055 \mathrm{p}$ & $\mathrm{pCi/m3}$ & 0.00032 & 0.00035 & & & \\
\hline SESPMNT & B16933 & $S$ END VERNITA BRIDGE & PERIMETER & AT & 15-Jan-03 A & ALPHA & $0.000756 \mathrm{p}$ & $\mathrm{pCi/m3}$ & 0.00041 & 0.00045 & & & \\
\hline SESPMNT & B16934 & S END VERNITA BRIDGE & PERIMETER & AT & 29-Jan-03 A & ALPHA & $0.0003 \mathrm{p}$ & $\mathrm{pCi} / \mathrm{m} 3$ & 0.0003 & 0.00031 & u & & \\
\hline SESPMNT & B16935 & $S$ END VERNITA BRIDGE & PERIMETER & AT & 12-Feb-03 A & ALPHA & $0.000249 \mathrm{p}$ & $\mathrm{pCi} / \mathrm{m} 3$ & 0.00032 & 0.00033 & U & & \\
\hline SESPMNT & B16936 & $S$ END VERNITA BRIDGE & PERIMETER & AT & 26-Feb-03 A & ALPHA & $0.000942 \mathrm{p}$ & $\mathrm{pC} / \mathrm{m} 3$ & 0.00039 & 0.00044 & & & \\
\hline SESPMNT & B16937 & $S$ END VERNITA BRIDGE & PERIMETER & AT & 12-Mar-03 A & ALPHA & $0.00073 p$ & $\mathrm{pC} / \mathrm{m} 3$ & 0.00037 & 0.00041 & & & \\
\hline SESPMNT & B16938 & $S$ END VERNITA BRIDGE & PERIMETER & AT & 27-Mar-03A & ALPHA & $0.000567 \mathrm{p}$ & $\mathrm{pC} / \mathrm{m} 3$ & 0.00031 & 0.00035 & & & \\
\hline SESPMNT & B16939 & $S$ END VERNITA BRIDGE & PERIMETER & AT & 09-Apr-03A & ALPHA & $0.000516 p$ & $\mathrm{pCi} / \mathrm{m} 3$ & 0.00034 & 0.00037 & & & \\
\hline SESPMNT & B16RD7 & $S$ END VERNITA BRIDGE & PERIMETER & AT & 23-Apr-03A & ALPHA & $0.000576 \mathrm{p}$ & pCi/m3 & 0.00035 & 0.00039 & & & \\
\hline SESPMNT & B16RD8 & $S$ END VERNITA BRIDGE & PERIMETER & AT & 07-May-03A & ALPHA & $0.00128 \mathrm{p}$ & $\mathrm{pCi} / \mathrm{m} 3$ & 0.00041 & 0.00052 & & & \\
\hline $\begin{array}{l}\text { SESPMNT } \\
\text { SESPMNT }\end{array}$ & B16RD9 & S END VERNITA BRIDGE & $\begin{array}{l}\text { PERIMETER } \\
\text { PERIMETER }\end{array}$ & AT & 21-May-03A & ALPHA & $0.00015 \mathrm{p}$ & pCi/m3 & 0.00028 & 0.00029 & U & SUSPECT AIR CALIBRATOR ERROR ON 5/7/03, 1.5 CFM START FLOW MAY ACTUALLY BE 1.2 CFM. & \\
\hline $\begin{array}{l}\text { SESPMNT } \\
\text { SESPMNT }\end{array}$ & $\begin{array}{lll}\text { B16RFO } \\
\text { B16P1 }\end{array}$ & $\begin{array}{l}\text { S END VERNITA BRIDGE } \\
\text { S END VERNTABRDGE }\end{array}$ & $\begin{array}{l}\text { PERIMETER } \\
\text { PERIMETER }\end{array}$ & AT & 18-Jun- $03 \mathrm{~A} A$ & ALPHA & $0.000531 \mathrm{p}$ & pCi/m3 & 0.00032 & 0.00035 & & & \\
\hline $\begin{array}{l}\text { SESPMNT } \\
\text { SESPMNT }\end{array}$ & $\begin{array}{l}\text { B16R1 } \\
\text { B16RF2 }\end{array}$ & $\begin{array}{l}\text { SEND VERNITA BRDIDE } \\
\text { S END VERNITA BRIDGE }\end{array}$ & $\begin{array}{l}\text { PERIMETER } \\
\text { PERIMETER }\end{array}$ & $\begin{array}{l}\text { AT } \\
\text { AT }\end{array}$ & 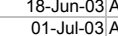 & ALPHA & $\begin{array}{l}0.000899 \mathrm{p} \\
0.00061 \mathrm{p}\end{array}$ & $\begin{array}{l}\mathrm{pCim3} \\
\mathrm{pCi} / \mathrm{m} 3\end{array}$ & $\begin{array}{l}0.00002 \\
0.00035\end{array}$ & 0.00039 & & & \\
\hline SESPMNT & B176B3 & S END VERNITA BRIDGE & PERIMETER & AT & 17-Jul-03 A & ALPHA & $0.000254 \mathrm{p}$ & $\mathrm{pCi} / \mathrm{m} 3$ & 0.00025 & 0.00027 & $\mathrm{U}$ & & \\
\hline SESPMNT & B176B4 & S END VERNITA BRIDGE & PERIMETER & AT & 30-Jul-03 A & ALPHA & $0.00148 \mathrm{p}$ & $\mathrm{pCi} / \mathrm{m} 3$ & 0.00048 & 0.00059 & & & \\
\hline SESPMNT & B176B5 & S END VERNITA BRIDGE & PERIMETER & AT & 13-Aug-03 A & ALPHA & $0.000753 \mathrm{p}$ & $\mathrm{pC} / \mathrm{m} 3$ & 0.00038 & 0.00042 & & & \\
\hline SESPMNT & B176B6 & $S$ END VERNITA BRIDGE & PERIMETER & AT & 27-Aug-03 A & ALPHA & $0.000798 \mathrm{p}$ & $\mathrm{pCi} / \mathrm{m} 3$ & 0.00038 & 0.00043 & & & \\
\hline SESPMNT & B176B7 & $S$ END VERNITA BRIDGE & PERIMETER & AT & 11-Sep-03A & ALPHA & $0.000579 p$ & $\mathrm{pCi} / \mathrm{m} 3$ & 0.00033 & 0.00036 & & & \\
\hline SESPMNT & B176B8 & $S$ END VERNITA BRIDGE & PERIMETER & AT & 24-Sep-03A & ALPHA & $-0.0000289 \mathrm{p}$ & $\mathrm{pCi} / \mathrm{m} 3$ & 0.00022 & 0.00022 & U & & \\
\hline SESPMNT & B176B9 & $S$ END VERNITA BRIDGE & PERIMETER & AT & 09-Oct-03A & ALPHA & $0.00104 p$ & $\mathrm{pCi} / \mathrm{m} 3$ & 0.00041 & 0.00048 & & & \\
\hline SESPMNT & B17R04 & $S$ END VERNITA BRIDGE & PERIMETER & AT & $22-0 c t-03$ A & ALPHA & $0.00292 p$ & $\mathrm{pCi} / \mathrm{m} 3$ & 0.00063 & 0.00092 & & & \\
\hline SESPMNT & B17R05 & $S$ END VERNITA BRIDGE & PERIMETER & AT & 06-Nov-03A & ALPHA & $0.000749 p$ & $\mathrm{pCi} / \mathrm{m} 3$ & 0.00034 & 0.00039 & & & \\
\hline SESPMNT & B17R06 & S END VERNITA BRIDGE & $\begin{array}{l}\text { PERIMETER } \\
\text { PEPIMETER }\end{array}$ & AT & 19-Nov-03 A & ALPHA & $0.000921 \mathrm{p}$ & pCi/m3 & 0.00047 & 0.00053 & & & \\
\hline $\begin{array}{l}\text { SESPMNT } \\
\text { SESPMNT }\end{array}$ & $\begin{array}{l}\text { B17R07 } \\
\text { B17008 }\end{array}$ & $\begin{array}{l}\text { S ENN VERNIIA BRIIIEE } \\
\text { S END VERNTAA BRIDGE }\end{array}$ & $\begin{array}{l}\text { PERRMETER } \\
\text { PERMETER }\end{array}$ & $\begin{array}{l}\text { AT } \\
\text { AT }\end{array}$ & $\begin{array}{l}\text { 3-D-Dec-03A } \\
\text { 18-0ec-03A }\end{array}$ & ALLHA & $\begin{array}{l}0.000513 \mathrm{p} \\
0.000807 \mathrm{p}\end{array}$ & $\begin{array}{l}\mathrm{pC} \text { c/m33 } \\
\mathrm{pC} / \mathrm{m} 3\end{array}$ & $\begin{array}{l}0.00032 \\
0.00035\end{array}$ & $\begin{aligned} 0.00035 \\
0.0004\end{aligned}$ & & & \\
\hline SESPMNT & B17R09 & S END VERNITA BRIDGE & PERIMETER & AT & 31-Dec-03A & ALPHA & $0.000377 \mathrm{p}$ & pCi/m3 & 0.00034 & 0.00036 & & & \\
\hline SESPMNT & B168H1 & $S$ OF $200 \mathrm{E}$ & ONSITE & AT & 14-Jan-03 A & ALPHA & $0.000938 \mathrm{p}$ & pCilm3 & 0.00043 & 0.00049 & & & \\
\hline SESPMNT & B1688 & SOF $200 \mathrm{E}$ & ONSITE & AT & $28-\operatorname{Jan}-03 \mathrm{~A}$ & ALPHA & $0.000264 \mathrm{p}$ & pCim3 & 0.00033 & 0.00034 & u & & \\
\hline SESPMNT & B1688 3 & SOF $200 E$ & ONSITE & AT & 11-Feb-03 A & ALPHA & $0.00042 \mathrm{p}$ & pCi/m3 & 0.0003 & 0.00032 & & & \\
\hline SESPMNT & B168H4 & SOF $200 \mathrm{E}$ & ONSITE & AT & 25-Feb-03A & ALPHA & $0.000643 \mathrm{p}$ & $\mathrm{pC} / \mathrm{m} 3$ & 0.00037 & 0.00041 & & & \\
\hline SESPMNT & B168H5 & S OF $200 \mathrm{E}$ & ONSITE & AT & 10-Mar-03A & ALPHA & $0.000969 \mathrm{p}$ & $\mathrm{pC} / \mathrm{m} 3$ & 0.00038 & 0.00046 & & & \\
\hline SESPMNT & B168H6 & SOF $200 \mathrm{E}$ & ONSITE & AT & 26-Mar-03A & ALPHA & $0.00041 \mathrm{p}$ & $\mathrm{pC}$ Ci/m3 & 0.00029 & 0.00031 & & & \\
\hline SESPMNT & B168H7 & SOF $200 \mathrm{E}$ & ONSITE & AT & 08-Apr-03A & ALPHA & $0.000145 p$ & $\mathrm{pC}$ Ci/m3 & 0.00028 & 0.00028 & u & & \\
\hline SESPMNT & B16PV4 & $S$ OF $200 \mathrm{E}$ & ONSITE & AT & 21-Apr-03A & ALPHA & $0.00119 p$ & pCilm3 & 0.00045 & 0.00054 & & & \\
\hline $\begin{array}{l}\text { SESPMNT } \\
\text { SESPMNT }\end{array}$ & $\begin{array}{l}\text { B16PV5 } \\
\text { B16PV }\end{array}$ & S OF $200 \mathrm{E}$ & $\begin{array}{l}\text { ONSITE } \\
\text { ONSITE }\end{array}$ & AT & $06-$-мау-03 А & ALPHA & $0.000439 \mathrm{p}$ & pCi/m3 & $\begin{array}{r}0.0003 \\
0.00037\end{array}$ & 0.00033 & & & \\
\hline $\begin{array}{l}\text { SESPMNT } \\
\text { SESPMNT }\end{array}$ & $\begin{array}{l}\text { B16PV6 } \\
\text { B16P77 }\end{array}$ & $\begin{array}{l}S O F=200 E \\
S O F 200 E\end{array}$ & $\begin{array}{l}\text { ONSITE } \\
\text { ONSITEE }\end{array}$ & $\begin{array}{l}\text { AT } \\
\text { AT }\end{array}$ & 20--Jay- $03 A$ & $\begin{array}{l}\text { ALLHA } \\
\text { ALPHA }\end{array}$ & $0.000767 p$ & $\begin{array}{l}\mathrm{pCC/m33} \\
\mathrm{p} \mathrm{c} / \mathrm{m} 3\end{array}$ & $\begin{array}{l}0.00037 \\
0.00034\end{array}$ & 0.00042 & & & \\
\hline SESPMNT & B16PV8 & $S O F 200 \mathrm{E}$ & ONSITE & AT & 17-Jun-03A & $\begin{array}{l}\text { ALLHA } \\
\text { ALPHA }\end{array}$ & $0.0004 / 89$ & pCi/m3 & 0.00034 & 0.00038 & & & \\
\hline SESPMNT & B16PV9 & $S O F 200 E$ & ONSITE & AT & 30-Jun-03 A & ALPHA & $0.000248 \mathrm{p}$ & pCilm3 & 0.00031 & 0.00032 & $U$ & & \\
\hline SESPMNT & B175R1 & $S O F 200 E$ & ONSITE & AT & 15-Jul-03 A & ALPHA & $0.000025 \mathrm{p}$ & $\mathrm{pC} i / \mathrm{m}_{3}$ & 0.00021 & 0.00022 & $u$ & & \\
\hline SESPMNT & B175R2 & $S O F 200 \mathrm{E}$ & ONSITE & AT & 29-Jul-03 A & ALPHA & $0.00101 p$ & pCi/m3 & 0.00039 & 0.00047 & & & \\
\hline SESPMNT & B175R3 & $S O F 200 E$ & ONSITE & AT & 12-Aug-03 A & ALPHA & $0.000576 \mathrm{p}$ & $\mathrm{pC} / \mathrm{m} 3$ & 0.00034 & 0.00037 & & & \\
\hline
\end{tabular}


AIR BETA/ALPHA

\begin{tabular}{|c|c|c|c|c|c|c|c|c|c|c|c|c|c|}
\hline | OWNER ID & \begin{tabular}{|l|} 
SAMP \\
NUM
\end{tabular} & SAMP SITE NAME & DIST CLASS & $\mid$ MEDIA $\mid$ & SAMP DATE & $\begin{array}{l}\text { CON } \\
\text { SHORT } \\
\text { NAME }\end{array}$ & |VALUE RPTD & \begin{tabular}{|l|} 
ANAL \\
UNITS \\
RPTD
\end{tabular} & $\left|\begin{array}{c}\text { COUNTING } \\
\text { ERROR }\end{array}\right|$ & $\begin{array}{c}\text { TOTAL } \\
\text { ANAL } \\
\text { ERROR }\end{array}$ & $\left|\begin{array}{c}\text { LAB } \\
\text { QUALIFIER }\end{array}\right|$ & SAMP COMMENT & $\begin{array}{l}\text { RESULT } \\
\text { COMMENT }\end{array}$ \\
\hline SESPMNT & B175R4 & $S O F=0 E$ & ONSITE & AT & 25-Aug-03 A & ALPHA & 0.00119 & & 0.00043 & 0.0005 & & & \\
\hline SESPMNT & B175R5 & S OF $200 \mathrm{E}$ & ONSITE & AT & 10-Sep-03A & ALPHA & 0.000728 & $\mathrm{pCi} / \mathrm{m} 3$ & 0.00034 & 0.00039 & & & \\
\hline SESPMNT & B175R6 & $S$ OF $200 \mathrm{E}$ & ONSITE & AT & 22-Sep-03A & & 0.00068 & $\mathrm{pCi} / \mathrm{m} 3$ & 0.00039 & 0.00043 & & & \\
\hline SESPMNT & B175R7 & S OF $200 \mathrm{E}$ & ONSITE & AT & 07-Oct-03A & & & & & & & NO SAMPLE. DO NOT SAVE FOR COMPOSITE. FILTER APPEARED TO HAVE BEEN PECKED AWAY BY A BIRD. & \\
\hline SESPMNT & B17PC1 & S OF $200 \mathrm{E}$ & ONSITE & AT & 21-0ct-03A & ALPHA & & & & & & NO SAMPLE. DO NOT SAVE FOR COMPOSITE. FILTER APPEARED TO HAVE BEEN PECKED AWAY BY A BIRD. & \\
\hline SESPMNT & B17PC2 & $S O F 200 \mathrm{E}$ & ONSITE & AT & 05-Nov-03A & ALPHA & 0.00146 & $\mathrm{pCi} / \mathrm{m} 3$ & 0.00045 & 0.00057 & & & \\
\hline SESPMNT & B17PC3 & SOF $200 \mathrm{E}$ & ONSITE & AT & 18-Nov-03A & ALPHA & 0.00149 & $\mathrm{pCi} / \mathrm{m} 3$ & 0.00052 & 0.00063 & & & \\
\hline SESPMNT & B17PC4 & $S O F 200 \mathrm{E}$ & ONSITE & AT & 01-Dec-03A & ALPHA & 0.000337 & $\mathrm{pCi} / \mathrm{m} 3$ & 0.0003 & 0.00032 & & & \\
\hline $\begin{array}{l}\text { SESPMNT } \\
\text { SECDMNT }\end{array}$ & B17PC5 & SOF $200 \mathrm{E}$ & ONSITE & AT & 17-Dec-03A & & 0.000645 & $\mathrm{pCi} / \mathrm{m} 3$ & 0.00032 & 0.00036 & & & \\
\hline $\begin{array}{l}\text { SESPMNT } \\
\text { SESPMNT }\end{array}$ & $\begin{array}{l}\text { B17PC6 } \\
\text { B16811 }\end{array}$ & $\begin{array}{l}\text { SOF } 200 \mathrm{E} \\
\text { SWIC }\end{array}$ & $\begin{array}{l}\text { ONSITE } \\
\text { ONSTEE }\end{array}$ & AT & 30-Dec-03A & ALPHA & $\begin{array}{l}0.000427 \\
0.000762\end{array}$ & pCilm3 & 0.00034 & 0.00036 & & & \\
\hline $\begin{array}{l}\text { SESPMNT } \\
\text { SESPMNT }\end{array}$ & $\begin{array}{ll}\text { B168L1 } \\
\text { B1682 }\end{array}$ & $\begin{array}{l}\text { SW OF B BC CRIBS } \\
\text { SW OF B/C CRRBS }\end{array}$ & $\begin{array}{l}\text { ONSSIE } \\
\text { ONSITE }\end{array}$ & AT & $\begin{array}{l}14-\mathrm{Jan}-03 \mathrm{~A} \\
28-\mathrm{Jan}-03 \mathrm{~A}\end{array}$ & ALPHA & $\begin{array}{l}0.000762 \\
0.000374\end{array}$ & pCi/m3 & $\begin{array}{r}0.0004 \\
0.00033\end{array}$ & 0.00044 & & & \\
\hline SESPMNT & B168L3 & $\begin{array}{l}\text { SWF BIC CRRS } \\
\text { SW BIC CRIBS }\end{array}$ & ONSITE & AT & $\begin{array}{l}\text { 28-Jan-03A } \\
\text { 11-Feb-03A }\end{array}$ & $\begin{array}{l}\text { ALPHA } \\
\text { ALPHA }\end{array}$ & 0.000374 & $\begin{array}{l}\mathrm{pClim3} \\
\mathrm{pCi} / \mathrm{m} 3\end{array}$ & $\begin{array}{l}0.00033 \\
0.0003\end{array}$ & 0.00035 & $u$ & & \\
\hline SESPMNT & B168L4 & SW OF B/C CRIBS & ONSITE & AT & 25-Feb-03 A & ALPHA & 0.000628 & $\mathrm{pCi} / \mathrm{m} 3$ & 0.00036 & 0.0004 & 0 & & \\
\hline SESPMNT & B168L5 & SW OF B/C CRIBS & ONSITE & AT & $10-\mathrm{Mar}-03 \mathrm{~A}$ & ALPHA & 0.00106 & $\mathrm{pCi} / \mathrm{m} 3$ & 0.00039 & 0.00048 & & & \\
\hline SESPMNT & B168L6 & SW OF B/C CRIBS & ONSITE & AT & 26-Mar-03 A & ALPHA & 0.00045 & $\mathrm{pCi} / \mathrm{m} 3$ & 0.00029 & 0.00032 & & & \\
\hline SESPMNT & B168L7 & SW OF B/C CRIBS & ONSITE & AT & 08-Apr-03 A & ALPHA & 0.0000949 & $\mathrm{pCi} / \mathrm{m} 3$ & 0.00025 & 0.00026 & U & & \\
\hline SESPMNT & B16PYO & SW OF B/C CRIBS & ONSITE & AT & 21-Apr-03 A & ALPHA & 0.000511 & $\mathrm{pCi} / \mathrm{m} 3$ & 0.00034 & 0.00037 & & & \\
\hline SESPMNT & B16PY1 & SW OF B/C CRIBS & ONSITE & AT & 06-May-03A & ALPHA & 0.000346 & $\mathrm{pCi} / \mathrm{m} 3$ & 0.00029 & 0.00031 & & & \\
\hline SESPMNT & B16PY2 & SW OF B/C CRIBS & ONSITE & AT & 20-May-03 A & ALPHA & 0.000901 & $\mathrm{pCi} / \mathrm{m} 3$ & 0.00039 & 0.00045 & & & \\
\hline SESPMNT & B16РY3 & SW OF B/C CRIBS & ONSITE & AT & 02-Jun-03 A & ALPHA & 0.000887 & $\mathrm{pCi} / \mathrm{m} 3$ & 0.00041 & 0.00047 & & & \\
\hline $\begin{array}{l}\text { SESPMNT } \\
\text { SESPMNT }\end{array}$ & B16PY4 & SW OF B/C CRIBS & ONSITE & AT & 17-Jun-03 A & & 0.000589 & $\mathrm{pCi} / \mathrm{m} 3$ & 0.00034 & 0.00037 & & & \\
\hline $\begin{array}{l}\text { SESPMNT } \\
\text { SESPMNT }\end{array}$ & B16PY5 & SW OF B/C CRIBS & ONSITE & AT & 30-Jun-03 A & ALPHA & 0.000248 & $\mathrm{pCi} / \mathrm{m} 3$ & 0.00031 & 0.00032 & $U$ & & \\
\hline $\begin{array}{l}\text { SESPMNT } \\
\text { SESPMNT }\end{array}$ & B175W1 & $\begin{array}{l}\text { SW OF B/C CRIBS } \\
S W W\end{array}$ & $\begin{array}{l}\text { ONSITE } \\
\text { ONSITE }\end{array}$ & AT & 15-Jul-03 A & ALPHA & 0.000201 & $\mathrm{pCi} / \mathrm{m}^{2}$ & 0.00025 & 0.00026 & U & & \\
\hline $\begin{array}{l}\text { SESPMNT } \\
\text { SESPMNT }\end{array}$ & $\begin{array}{l}\text { B17552 } 2 \\
\text { B175W3 }\end{array}$ & $\begin{array}{l}\text { SW OB B BC CRRBS } \\
\text { SW OF B/C CRRBS }\end{array}$ & $\begin{array}{l}\text { ONSIIE } \\
\text { ONSITE }\end{array}$ & $\begin{array}{l}\text { AT } \\
\text { AT }\end{array}$ & $\begin{array}{r}\text { 29-Jul-03A } \\
\text { 12-Aug-03A }\end{array}$ & $\begin{array}{l}\text { ALPHA } \\
\text { ALPHA }\end{array}$ & $\begin{array}{r}0.00113 \\
0.000194\end{array}$ & $\begin{array}{l}\text { pCim3 } \\
\text { pCi/m3 }\end{array}$ & $\begin{array}{l}0.00001 \\
0.0029\end{array}$ & $\begin{array}{l}0.0005 \\
0.0003\end{array}$ & $u$ & & \\
\hline SESPMNT & B175W/4 & SW OF B/C CRIBS & ONSITE & AT & 25-Aug-03 A & ALPHA & 0.000951 & $\mathrm{pCi} / \mathrm{m} 3$ & 0.0004 & 0.00045 & & & \\
\hline SESPMNT & B175W5 & SW OF B/C CRIBS & ONSITE & AT & 10-Sep-03A & ALPHA & 0.000388 & $\mathrm{pCi} / \mathrm{m} 3$ & 0.00029 & 0.00031 & & & \\
\hline SESPMNT & B175W6 & SW OF B/C CRIBS & ONSITE & AT & 22-Sep-03A & ALPHA & 0.000833 & $\mathrm{pCi} / \mathrm{m} 3$ & 0.00042 & 0.00047 & & & \\
\hline SESPMNT & B175W7 & SW OF B/C CRIBS & ONSITE & AT & 07-Oct-03 A & ALPHA & 0.0016 & $\mathrm{pCi} / \mathrm{m} 3$ & 0.00049 & 0.00062 & & & \\
\hline SESPMNT & B17PF7 & SW OF B/C CRIBS & ONSITE & AT & 21-Oct-03 A & ALPHA & 0.000374 & $\mathrm{pCi} / \mathrm{m} 3$ & 0.0003 & 0.00032 & & & \\
\hline SESPMNT & B17PF8 & SW OF B/C CRIBS & ONSITE & AT & 05-Nov-03 A & ALPHA & 0.000398 & $\mathrm{pCi} / \mathrm{m} 3$ & 0.0003 & 0.00032 & & & \\
\hline SESPMNT & B17PF9 & SW OF B/C CRIBS & ONSITE & AT & 18-Nov-03 A & ALPHA & 0.00132 & $\mathrm{pCi} / \mathrm{m} 3$ & 0.00051 & 0.0006 & & & \\
\hline SESPMNT & B17PHO & SW OF B/C CRIBS & ONSITE & AT & 01-Dec-03A & ALPHA & 0.000478 & $\mathrm{pCi} / \mathrm{m} 3$ & 0.00033 & 0.00036 & & & \\
\hline SESPMNT & B17PH1 & SW OF B/C CRIBS & ONSITE & AT & 17-Dec-03A & ALPHA & 0.00033 & $\mathrm{pCi} / \mathrm{m} 3$ & 0.00028 & 0.00029 & & & \\
\hline $\begin{array}{l}\text { SESPMNT } \\
\text { SESPMNT }\end{array}$ & B17PH2 & SW OF B/C CRIBS & ONSITE & AT & 30-Dec-03A & ALPHA & 0.000751 & pCilm3 & 0.00039 & 0.00044 & & & \\
\hline $\begin{array}{l}\text { SESPMNT } \\
\text { SESPMNT }\end{array}$ & B16806 & TOPPENISH & $\begin{array}{l}\text { DISTANT } \\
\end{array}$ & AT & 22-Jan-03A & ALPHA & 0.000884 & pCilm3 & 0.00044 & 0.00049 & & & \\
\hline $\begin{array}{l}\text { SESPMNT } \\
\text { SESPMNT }\end{array}$ & $\begin{array}{l}\text { B16807 } \\
\text { B16088 }\end{array}$ & $\begin{array}{l}\text { TOPPENIIH } \\
\text { TOPPENISH }\end{array}$ & \begin{tabular}{|l} 
DISTANT \\
DISTANT
\end{tabular} & $\begin{array}{ll}\text { AT } \\
\text { AT }\end{array}$ & $\begin{array}{l}05 \text {-Feb-03A } \\
19-\text { - }\end{array}$ & ALPHA & $\begin{array}{l}0.000698 \\
0.00789\end{array}$ & $\begin{array}{l}\mathrm{pC} / \mathrm{m} 3 \\
\mathrm{p} \mathrm{C} / \mathrm{m} 3\end{array}$ & 0.00035 & 0.0004 & & & \\
\hline SESPMNT & $\begin{array}{l}\text { D10000 } \\
\text { B16809 }\end{array}$ & TOPPENISH & $\begin{array}{l}\text { DISTANT } \\
\text { DIST }\end{array}$ & AT & $\begin{array}{l}\text { T9-F-eb-03 A } \\
05-\mathrm{Mr}-03 \mathrm{~A}\end{array}$ & $\begin{array}{l}\text { ALPHA } \\
\text { ALPHA }\end{array}$ & $\begin{array}{l}0.000059 \\
0.00517\end{array}$ & $\begin{array}{l}\mathrm{pCl} / \mathrm{m3} 3 \\
\mathrm{pCi} / \mathrm{m} 3\end{array}$ & $\begin{array}{r}0.0004 \\
0.0035\end{array}$ & $\begin{array}{l}0.000045 \\
0.00038\end{array}$ & & & \\
\hline SESPMNT & B16810 & TOPPENISH & DISTANT & AT & 19-Mar-03 A & ALPHA & 0.000906 & $\mathrm{pCi} / \mathrm{m} 3$ & 0.00038 & 0.00044 & & & \\
\hline SESPMNT & B16811 & TOPPENISH & DISTANT & AT & 02-Apr-03 A & ALPHA & 0.000913 & $\mathrm{pCi} / \mathrm{m} 3$ & 0.00039 & 0.00045 & & & \\
\hline SESPMNT & $\mathrm{B} 16 \mathrm{PCO}$ & TOPPENISH & DISTANT & AT & 16-Apr-03 A & ALPHA & 0.000346 & $\mathrm{pCi} / \mathrm{m} 3$ & 0.0003 & 0.00032 & U & & \\
\hline SESPMNT & B16PC1 & TOPPENISH & DISTANT & AT & 30-Apr-03 A & ALPHA & 0.000847 & $\mathrm{pCi} / \mathrm{m} 3$ & 0.00039 & 0.00044 & & & \\
\hline SESPMNT & B16PC2 & TOPPENISH & DISTANT & AT & 14-May-03 A & ALPHA & 0.000957 & $\mathrm{pCi} / \mathrm{m} 3$ & 0.0004 & 0.00047 & & & \\
\hline SESPMNT & $\mathrm{B} 16 \mathrm{PC} 3$ & TOPPENISH & DISTANT & AT & 28-May-03 A & ALPHA & 0.000435 & $\mathrm{pCi} / \mathrm{m} 3$ & 0.00031 & 0.00033 & & & \\
\hline SESPMNT & B16PC4 & TOPPENISH & DISTANT & AT & 11-Jun-03 A & ALPHA & 0.000664 & $\mathrm{pCi} / \mathrm{m} 3$ & 0.00036 & 0.0004 & & & \\
\hline SESPMNT & B16PC5 & TOPPENISH & DISTANT & AT & 26-Jun-03 A & ALPHA & 0.00044 & $\mathrm{pCi} / \mathrm{m} 3$ & 0.0003 & 0.00033 & & & \\
\hline SESPMNT & B16PC6 & TOPPENISH & DISTANT & AT & 09-Jul-03 A & ALPHA & 0.000359 & $\mathrm{pCi} / \mathrm{m} 3$ & 0.00032 & 0.00033 & & & \\
\hline $\begin{array}{l}\text { SESPMNT } \\
\text { SESPMNT }\end{array}$ & B17590 & TOPPENISH & $\begin{array}{l}\text { DISTANT } \\
\text { DISTANT }\end{array}$ & AT & 23-Jul-03 A & ALPHA & 0.00046 & pCi/m3 & 0.00034 & 0.00036 & & & \\
\hline $\begin{array}{l}\text { SESPMNT } \\
\text { SESPMNT }\end{array}$ & $\begin{array}{l}\text { B17551 } \\
\text { B17592 }\end{array}$ & $\begin{array}{l}\text { TOPENIIS } \\
\text { TOPPENISH }\end{array}$ & \begin{tabular}{|l} 
DISTANT \\
DISTANT
\end{tabular} & $\begin{array}{l}\text { AT } \\
\text { AT }\end{array}$ & $\begin{array}{l}\text { 06-ugg-03A } \\
\text { 20-Aug-03A }\end{array}$ & ALLHA & $\begin{array}{l}0.000283 \\
0.000461\end{array}$ & $\begin{array}{l}\text { pCim3 } \\
\text { pCilm3 }\end{array}$ & $\begin{array}{r}0.00027 \\
0.0003\end{array}$ & $\begin{array}{l}0.00029 \\
0.00032\end{array}$ & U & & \\
\hline SESPMNT & B17593 & TOPPENISH & DISTANT & AT & $03-S e p-03 A$ & ALPHA & 0.000361 & $\mathrm{pCi} / \mathrm{m} 3$ & 0.00031 & 0.00033 & & & \\
\hline SESPMNT & B17594 & TOPPENISH & DISTANT & AT & 17-Sep-03A & ALPHA & 0.000367 & $\mathrm{pCi} / \mathrm{m} 3$ & 0.00028 & 0.0003 & & & \\
\hline SESPMNT & B17595 & TOPPENISH & DISTANT & AT & $01-$ Oct-03 A & ALPHA & 0.000557 & pCi/m3 & 0.00031 & 0.00034 & & & \\
\hline SESPMNT & B17NX3 & TOPPENISH & DISTANT & AT & 15-Oct-03 A & ALPHA & 0.000655 & $\mathrm{pCi} / \mathrm{m} 3$ & 0.00035 & 0.00039 & & & \\
\hline SESPMNT & B17NX4 & TOPPENISH & DISTANT & AT & 29-Oct-03 A & ALPHA & 0.00026 & $\mathrm{pCi} / \mathrm{m} 3$ & 0.0003 & 0.00031 & u & & \\
\hline SESPMNT & B17N $\times 5$ & TOPPENISH & DISTANT & AT & 12-Nov-03A & ALPHA & 0.000416 & $\mathrm{pCi} / \mathrm{m} 3$ & 0.00034 & 0.00036 & & & \\
\hline SESPMNT & B17NX6 & TOPPENISH & DISTANT & AT & 26-Nov-03A & ALPHA & 0.000412 & $\mathrm{pCi} / \mathrm{m} 3$ & 0.00033 & 0.00035 & & & \\
\hline SESPMNT & B17NX7 & TOPPENISH & DISTANT & AT & 10-Dec-03A & ALPHA & 0.00073 & $\mathrm{pCi} / \mathrm{m} 3$ & 0.00035 & 0.00039 & & & \\
\hline $\begin{array}{l}\text { SESPMNT } \\
\end{array}$ & B17NX8 & TOPPENISH & DISTANT & AT & 23-Dec-03A & ALPHA & 0.000504 & $\mathrm{pCi} / \mathrm{m} 3$ & 0.00037 & 0.00039 & & & \\
\hline $\begin{array}{l}\text { SESPMNT } \\
\text { SESPMNT }\end{array}$ & $\begin{array}{ll}B 17 N \times 9 \\
B 1688\end{array}$ & TOPPENISH & $\begin{array}{l}\text { DISTANT } \\
\text { PERMETER }\end{array}$ & AT & 08-Jan-04 A & ALPHA & 0.000991 & pCi/m3 & 0.00039 & 0.00046 & & & \\
\hline $\begin{array}{l}\text { SESPMNT } \\
\text { SESPMNT }\end{array}$ & 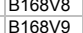 & $\begin{array}{l}\text { W END OF FFR ROAD } \\
\text { W END OF FIR ROAD }\end{array}$ & $\begin{array}{l}\text { PERIMETER } \\
\text { PERIMETER }\end{array}$ & $\begin{array}{l}\text { AT } \\
\text { AT }\end{array}$ & $\begin{array}{l}\text { 16-Jan-03A } \\
\text { 30-03A }\end{array}$ & ALPHA & $\begin{array}{r}0.000754 \\
0.0000253\end{array}$ & pCim3 & $\begin{array}{l}0.00043 \\
0.0026\end{array}$ & 0.00047 & $U$ & & \\
\hline SESPMNT & B168w0 & W END OF FIR ROAD & PERIMETER & AT & 13-Feb-03 A & ALPHA & 0.00052 & $\mathrm{pCi} / \mathrm{m} 3$ & 0.00037 & 0.0004 & & & \\
\hline SESPMNT & B168W1 & W END OF FIR ROAD & PERIMETER & AT & 28-Feb-03 A & ALPHA & 0.000658 & $\mathrm{pCi} / \mathrm{m} 3$ & 0.00034 & 0.00037 & & & \\
\hline SESPMNT & B168W2 & WEND OF FIR ROAD & PERIMETER & AT & 13-Mar-03 A & ALPHA & 0.000497 & $\mathrm{pCi} / \mathrm{m} 3$ & 0.00033 & 0.00036 & & & \\
\hline SESPMNT & B168W3 & W END OF FIR ROAD & PERIMETER & AT & 28-Mar-03 A & ALPHA & 0.000604 & $\mathrm{pCi} / \mathrm{m} 3$ & 0.00032 & 0.00036 & & & \\
\hline SESPMNT & B168W4 & W END OF FIR ROAD & PERIMETER & AT & 10-Apr-03 A & ALPHA & 0.00074 & $\mathrm{pCi} / \mathrm{m} 3$ & 0.00038 & 0.00043 & & & \\
\hline
\end{tabular}


AIR BETA/ALPHA

\begin{tabular}{|c|c|c|c|c|c|c|c|c|c|c|c|c|c|}
\hline |OWNER ID & \begin{tabular}{|l|} 
SAMP \\
NUM
\end{tabular} & SAMP SITE NAME & DIST CLASS & MEDIA & SAMP DATE & $\begin{array}{l}\text { CON } \\
\text { SHORT } \\
\text { NAME }\end{array}$ & | VALUE RPTD| & $\begin{array}{l}\text { ANAL } \\
\text { UNITS } \\
\text { RPTD }\end{array}$ & $\left|\begin{array}{c}\text { COUNTING } \\
\text { ERROR }\end{array}\right|$ & \begin{tabular}{c|c} 
TOTAL \\
ANAL \\
ERROR
\end{tabular} & $\left|\begin{array}{c}\text { LAB } \\
\text { QUALIFIER }\end{array}\right|$ & SAMP COMMENT & $\begin{array}{c}\text { RESULT } \\
\text { COMMENT }\end{array}$ \\
\hline SESPMNT & B16R63 & W END OF FIR ROAD & PERIMETER & AT & & ALPHA & 0.000466 & & 0.00031 & 0.00034 & & & \\
\hline SESPMNT & B16R64 & W END OF FIR ROAD & PERIMETER & AT & 08-May-03 A & LLPHA & 0.000499 & pCilm3 & 0.00033 & 0.00036 & & & \\
\hline SESPMNT & B16R65 & W END OF FIR ROAD & PERIMETER & AT & 22-May-03 A & & 0.000497 & pCi/m3 & 0.00037 & 0.0004 & & & \\
\hline SESPMNT & B16R66 & W END OF FIR ROAD & PERIMETER & AT & 06-Jun-03 A & & 0.000572 & pCilm3 & 0.00034 & 0.00037 & & & \\
\hline SESPMNT & B16R67 & W END OF FIR ROAD & PERIMETER & AT & 19-Jun-03 A & ALPHA & 0.000573 & pCi/m3 & 0.00035 & 0.00039 & & & \\
\hline SESPMNT & B16R68 & W END OF FIR ROAD & PERIMETER & AT & 07-Jul-03 A & ALPHA & 0.000177 & pCi/m3 & 0.00022 & 0.00023 & U & & \\
\hline SESPMNT & B17638 & W END OF FIR ROAD & PERIMETER & AT & 18-Jul-03 A & ALPHA & 0.000505 & pCi/m3 & 0.00039 & 0.00041 & & & \\
\hline $\begin{array}{l}\text { SESPMNT } \\
\text { SESDMNT }\end{array}$ & B17639 & W END OF FIR ROAD & PERIMETER & AT & 31-Jul-03 A & ALPHA & 0.000788 & pCi/m3 & 0.00039 & 0.00044 & & & \\
\hline $\begin{array}{l}\text { SESPMNT } \\
\text { SECDMNT }\end{array}$ & B17640 & W END OF FIR ROAD & PERIMETER & AT & 15-Aug-03A & & 0.000652 & pCi/m3 & 0.00034 & 0.00038 & & & \\
\hline $\begin{array}{l}\text { SESPMNT } \\
\text { SESPMNT }\end{array}$ & $\begin{array}{l}\text { B17641 } \\
\text { B17462 }\end{array}$ & $\begin{array}{l}\text { W END OF FIR ROAD } \\
\text { WEND OF FR ROAD }\end{array}$ & $\begin{array}{l}\text { PERIMETER } \\
\text { PERMETER }\end{array}$ & AT & $\begin{array}{l}\text { 28-Aug-03A } \\
12-\operatorname{sen}-03 \mathrm{~A}\end{array}$ & ALPHA & $\begin{array}{r}0.00134 \\
0.00505\end{array}$ & pCi/m3 & 0.00048 & 0.00058 & & & \\
\hline $\begin{array}{l}\text { SESPMNT } \\
\text { SESPMNT }\end{array}$ & $\begin{array}{l}817642 \\
B 17643\end{array}$ & $\begin{array}{l}\text { W END OF FIR ROAD } \\
\text { W END OF FIR ROAD }\end{array}$ & $\begin{array}{l}\text { PERIMETER } \\
\text { PERMETER }\end{array}$ & AT & $\begin{array}{l}\text { 12-Sep-03A } \\
25-\mathrm{Sep}-03 \mathrm{~A}\end{array}$ & LLPHA & 0.000505 & pCi/m3 & $\begin{array}{l}0.00032 \\
0.00038\end{array}$ & 0.00034 & & & \\
\hline SESPMNT & B17644 & $\begin{array}{l}\text { WEND OF FR ROAD } \\
\text { W END OF FIR ROAD }\end{array}$ & $\begin{array}{l}\text { PERIMEIER } \\
\text { PERIMETER }\end{array}$ & AT & $\begin{array}{l}\text { 25-Sep-03A } \\
10-0 \mathrm{Cct}-03 \mathrm{~A}\end{array}$ & $\begin{array}{l}\text { LLPHA } \\
\text { LLPHA }\end{array}$ & $\begin{array}{l}0.000698 \\
0.000884\end{array}$ & $\begin{array}{l}\frac{p \mathrm{pC} / m 3}{\mathrm{pCi} 3 \mathrm{~m} 3} \\
\mathrm{p}\end{array}$ & $\begin{array}{l}0.00038 \\
0.00038\end{array}$ & $\begin{array}{l}0.00042 \\
0.00044\end{array}$ & & & \\
\hline SESPMNT & B17PRO & W END OF FIR ROAD & PERIMETER & AT & 23-Oct-03 A & LLPHA & 0.0000963 & pCi/m3 & 0.00025 & 0.00026 & u & & \\
\hline SESPMNT & B17PR1 & W END OF FIR ROAD & PERIMETER & AT & 07-Nov-03 A & ALPHA & 0.000893 & pCilm3 & 0.00043 & 0.00048 & & & \\
\hline SESPMNT & B17PR2 & W END OF FIR ROAD & PERIMETER & AT & 21-Nov-03 A & ALPHA & 0.00084 & pCilm3 & 0.00041 & 0.00046 & & & \\
\hline SESPMNT & B17PR3 & W END OF FIR ROAD & PERIMETER & AT & 05-Dec-03 A & ALPHA & 0.000401 & & 0.00032 & 0.00034 & & & \\
\hline SESPMNT & B17PR4 & W END OF FIR ROAD & PERIMETER & AT & 19-Dec-03A & ALPHA & 0.000504 & pCilm3 & 0.0003 & 0.00032 & & ICE ON FILTER. & \\
\hline SESPMNT & B17PR5 & W END OF FIR ROAD & PERIMETER & AT & 05-Jan-04A & ALPHA & 0.000576 & & 0.00032 & 0.00035 & & & \\
\hline SESPMNT & B16926 & WAHLUKE SLOPE & PERIMETER & AT & 15-Jan-03A & ALPHA & 0.000582 & pCi/m3 & 0.00041 & 0.00044 & & & \\
\hline SESPMNT & B16927 & WAHLUKE SLOPE & PERIMETER & AT & 29-Jan-03 A & & 0.00143 & pCi/m3 & 0.00048 & 0.00059 & & & \\
\hline SESPMNT & B16928 & WAHLUKE SLOPE & PERIMETER & AT & 12-Feb-03A & ALPHA & 0.000191 & pCi/m3 & 0.00028 & 0.00029 & u & & \\
\hline $\begin{array}{l}\text { SESPMNT } \\
\text { SESPMNT }\end{array}$ & B16929 & WAHLUKE SLOPE & PERIMETER & AT & 26-Feb-03A & ALPHA & 0.000561 & pCilm3 & 0.00032 & 0.00034 & & & \\
\hline $\begin{array}{l}\text { SESPMNT } \\
\text { SESPMNT }\end{array}$ & B16930 & $\begin{array}{l}\text { WAHLUKE SLOPE } \\
\text { WAHUUKE SOPE }\end{array}$ & $\begin{array}{l}\text { PERIMETER } \\
\text { PEIMETER }\end{array}$ & AT & 12-Mar-03A & ALPHA & 0.00136 & pCim3 & 0.00045 & 0.00056 & & & \\
\hline $\begin{array}{l}\text { SESPMNT } \\
\text { SESPMNT }\end{array}$ & 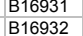 & $\begin{array}{l}\text { WAALUKE SLOPE } \\
\text { WAHLUKE SLOPE }\end{array}$ & $\begin{array}{l}\text { PERIMETER } \\
\text { PERIMETER }\end{array}$ & $\begin{array}{l}\text { AT } \\
\text { AT }\end{array}$ & $\begin{array}{l}\text { 27-Mar-03A } \\
09-\mathrm{Apr}-03 \mathrm{~A}\end{array}$ & $\begin{array}{l}\text { LLPHA } \\
\text { ALPHA }\end{array}$ & $\begin{array}{l}0.0000434 \\
0.000249\end{array}$ & $\begin{array}{l}\mathrm{pCim3} \\
\mathrm{pCi} / \mathrm{m} 3\end{array}$ & $\begin{array}{l}0.00029 \\
0.0028\end{array}$ & $\begin{array}{l}0.000031 \\
0.0029\end{array}$ & U & & \\
\hline SESPMNT & B16RD1 & WAHLUKE SLOPE & PERIMETER & AT & 23-Apr-03 A & ALPHA & 0.000759 & $\mathrm{pC} / \mathrm{m} 3$ & 0.00038 & 0.00043 & & & \\
\hline SESPMNT & B16RD2 & WAHLUKE SLOPE & PERIMETER & AT & $07-M a y-03 A$ & ALPHA & 0.000132 & $\mathrm{pC} / \mathrm{m} 3$ & 0.00022 & 0.00023 & $\mathrm{U}$ & & \\
\hline SESPMNT & B16RD3 & WAHLUKE SLOPE & PERIMETER & AT & 21-May-03 A & ALPHA & 0.000217 & pCilm3 & 0.00029 & 0.0003 & u & SUSPECT AIR CALIBRATOR ERROR ON 5/7/03, 1.5 CFM START FLOW MAY ACTUALLY BE 1.2 CFM. & \\
\hline SESPMNT & B16RD4 & WAHLUKE SLOPE & PERIMETER & AT & 05-Jun-03 A & ALPHA & 0.000593 & $\mathrm{pC} / \mathrm{m} 3$ & 0.00033 & 0.00037 & & & \\
\hline SESPMNT & B16RD5 & WAHLUKE SLOPE & PERIMETER & AT & 18-Jun-03 A & ALPHA & 0.000379 & pCilm3 & 0.00032 & 0.00034 & & & \\
\hline SESPMNT & B16RD6 & WAHLUKE SLOPE & PERIMETER & AT & 01-Jul-03A & ALPHA & 0.000304 & pCi/m3 & 0.00031 & 0.00033 & u & & \\
\hline SESPMNT & B17696 & WAHLUKE SLOPE & PERIMETER & AT & 17-Jul-03A & ALPHA & 0.000341 & pCi/m3 & 0.00027 & 0.00028 & & & \\
\hline SESPMNT & B17697 & WAHLUKE SLOPE & PERIMETER & AT & 30-Jul-03 A & ALPHA & 0.000846 & pCi/m3 & 0.00041 & 0.00046 & & & \\
\hline SESPMNT & B17698 & WAHLUKE SLOPE & PERIMETER & AT & 13-Aug-03 A & ALPHA & 0.000533 & pCi/m3 & 0.00033 & 0.00036 & & & \\
\hline SESPMNT & B17699 & WAHLUKE SLOPE & PERIMETER & AT & 27-Aug-03 A & ALPHA & 0.000569 & pCi/m3 & 0.00035 & 0.00038 & & & \\
\hline $\begin{array}{l}\text { SESPMNT } \\
\text { SESPMNT }\end{array}$ & B176BO & WAHLUKE SLOPE & $\begin{array}{l}\text { PERIMETER } \\
\text { PERIMETER }\end{array}$ & AT & 11-Sep-03A & ALPHA & 0.00077 & pCi/m3 & 0.00036 & 0.00041 & & & \\
\hline $\begin{array}{l}\text { SESPMNT } \\
\text { SESPMNT }\end{array}$ & $\begin{array}{l}\text { B17661 } \\
\text { B17682 }\end{array}$ & $\begin{array}{l}\text { WAALUKE SLOPE } \\
\text { WAALUKE SOPPE }\end{array}$ & $\begin{array}{l}\text { PERIMETER } \\
\text { PERMETER }\end{array}$ & $\begin{array}{l}\text { AT } \\
\text { AT }\end{array}$ & $\begin{array}{l}\text { 24-Sep--03 A } \\
0 \text { 0-0.-03 A }\end{array}$ & ALPHA & $\begin{array}{l}0.000437 \\
0.000974\end{array}$ & $\begin{array}{l}\text { pCim3 } \\
\text { picm3 }\end{array}$ & 0.00032 & 0.00034 & & & \\
\hline SESPMNT & $\begin{array}{l}\text { l1/16B2 } \\
\text { B17PY8 }\end{array}$ & $\begin{array}{l}\text { WAHLUKEE SLOPE } \\
\text { WAHLUK SLOPE }\end{array}$ & $\begin{array}{l}\text { PERIMETER } \\
\text { PERIMETER }\end{array}$ & AT & $\begin{array}{l}\text { O9-Clt-03 A } \\
22-0 \mathrm{ct}-03 \mathrm{~A}\end{array}$ & $\begin{array}{l}\text { ALPHA } \\
\text { ALPHA }\end{array}$ & $\begin{array}{r}0.0009 / 4 \\
0.00285\end{array}$ & $\begin{array}{l}\mathrm{pllm} / \mathrm{m} 3 \\
\mathrm{pCim3}\end{array}$ & $\begin{array}{r}0.0004 \\
0.00063\end{array}$ & $\begin{array}{l}0.00046 \\
0.00091\end{array}$ & & & \\
\hline SESPMNT & B17PY9 & WAHLUKE SLOPE & PERIMETER & AT & 06-Nov-03 A & ALPHA & 0.000475 & pCi/m3 & 0.00031 & 0.00034 & & & \\
\hline SESPMNT & B17R00 & WAHLUKE SLOPE & PERIMETER & AT & 19-Nov-03 A & ALPHA & 0.000671 & pCilm3 & 0.0004 & 0.00044 & & & \\
\hline SESPMNT & B17R01 & WAHLUKE SLOPE & PERIMETER & AT & 03-Dec-03 A & ALPHA & 0.00054 & $\mathrm{pC}$ Ci/m3 & 0.00033 & 0.00036 & & & \\
\hline SESPMNT & B17R02 & WAHLUKE SLOPE & PERIMETER & AT & 18-Dec-03A & ALPHA & 0.000431 & pCi/m3 & 0.00031 & 0.00033 & & & \\
\hline SESPMNT & B17R03 & WAHLUKE SLOPE & PERIMETER & AT & 31-Dec-03 A & ALPHA & 0.000619 & pCi/m3 & 0.00039 & 0.00042 & & & \\
\hline SESPMNT & B168V1 & WYE BARRICADE & ONSITE & AT & 21-Jan-03 A & ALPHA & 0.00157 & pCi/m3 & 0.0005 & 0.00063 & & & \\
\hline SESPMNT & B168V2 & WYE BARRICADE & ONSITE & AT & 04-Feb-03A & ALPHA & 0.000104 & pCi/m3 & 0.00023 & 0.00024 & U & & \\
\hline SESPMNT & B168V3 & WYE BARRICADE & ONSITE & AT & 18-Feb-03 A & ALPHA & 0.000592 & pCi/m3 & 0.00039 & 0.00042 & & & \\
\hline SESPMNT & B168V4 & WYE BARRICADE & ONSITE & AT & 03-Mar-03A & ALPHA & 0.000591 & pCi/m3 & 0.00038 & 0.00041 & & & \\
\hline $\begin{array}{l}\text { SESPMNT } \\
\text { SESPMNT }\end{array}$ & B168V5 & 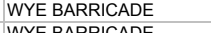 & ONSITE & AT & 18-Mar-03A & ALPHA & 0.000107 & pCi/m3 & 0.00022 & 0.00022 & U & & \\
\hline $\begin{array}{l}\text { SESPMNT } \\
\text { SESPMNT }\end{array}$ & $\begin{array}{l}\text { B16886 } \\
\text { B16R55 }\end{array}$ & $\begin{array}{l}\text { WY BARRIICADE } \\
\text { WYE BARRICADE }\end{array}$ & $\begin{array}{l}\text { ONSIIE } \\
\text { ONSTIE }\end{array}$ & $\begin{array}{l}\text { AT } \\
\text { AT }\end{array}$ & $\begin{array}{l}\text { 31-Mar-03 A } \\
\text { 15-APr-03A }\end{array}$ & $\begin{array}{l}\text { ALLHA } \\
\text { ALPHA }\end{array}$ & $\begin{array}{l}0.000172 \\
0.00159\end{array}$ & $\begin{array}{l}\text { pilm3 } \\
\text { pilm3 }\end{array}$ & $\begin{array}{l}0.00027 \\
0.00045\end{array}$ & $\begin{array}{l}0.00028 \\
0.00059\end{array}$ & U & & \\
\hline SESPMNT & B16R56 & WYE BARRICADE & ONSITE & AT & 29-Apr-03 A & ALPHA & 0.00018 & pCi/m3 & 0.00027 & 0.00028 & U & & \\
\hline SESPMNT & B16R57 & WYE BARRICADE & ONSITE & AT & 12-May-03 A & ALPHA & 0.000447 & $\mathrm{pC} i / \mathrm{p}^{2}$ & 0.00033 & 0.00036 & & & \\
\hline SESPMNT & B16R58 & WYE BARRICADE & ONSITE & AT & 29-May-03 A & ALPHA & 0.000409 & pCi/m3 & 0.00027 & 0.0003 & & & \\
\hline SESPMNT & B16R59 & WYE BARRICADE & ONSITE & AT & 11-Jun-03 A & ALPHA & 0.000717 & pCi/m3 & 0.00039 & 0.00044 & & & \\
\hline SESPMNT & B16R60 & WYE BARRICADE & ONSITE & AT & 24-Jun-03 A & ALPHA & 0.00138 & pCi/m3 & 0.00048 & 0.00059 & & & \\
\hline SESPMNT & B16R61 & WYE BARRICADE & ONSITE & AT & 08-Jul-03 A & ALPHA & 0.000784 & pCilm3 & 0.00038 & 0.00043 & & & \\
\hline SESPMNT & B17631 & WYE BARRICADE & ONSITE & AT & 22-Jul-03 A & ALPHA & 0.00107 & pCi/m3 & 0.00043 & 0.0005 & & & \\
\hline SESPMNT & B17632 & WYE BARRICADE & ONSITE & AT & 04-Aug-03 A & ALPHA & 0.000849 & pCi/m3 & 0.0004 & 0.00045 & & & \\
\hline SESPMNT & B17633 & WYE BARRICADE & ONSITE & AT & 18-Aug-03 A & ALPHA & 0.000582 & pCi/m3 & 0.00034 & 0.00037 & & & \\
\hline SESPMNT & B17634 & WYE BARRICADE & ONSITE & AT & 02-Sep-03A & ALPHA & 0.0015 & pCi/m3 & 0.00042 & 0.00054 & & & \\
\hline SESPMNT & B17635 & WYE BARRICADE & ONSITE & AT & 15-Sep-03A & ALPHA & 0.000764 & pCi/m3 & 0.00038 & 0.00043 & & & \\
\hline $\begin{array}{l}\text { SESPMNT } \\
\text { SESPMNT }\end{array}$ & B17636 & WYE BARRICADE & ONSITE & AT & 01-Oct-03 A & ALPHA & 0.000313 & pCilm3 & 0.00027 & 0.00029 & & & \\
\hline $\begin{array}{l}\text { SESPMNT } \\
\text { SESPMNT }\end{array}$ & $\begin{array}{l}\text { B17PP2 } \\
\text { B17P3 }\end{array}$ & $\begin{array}{l}\text { WYV BARRIIADE } \\
\text { WYE BARRICADE }\end{array}$ & $\begin{array}{l}\text { ONSITE } \\
\text { ONSTIE }\end{array}$ & $\begin{array}{l}\text { AT } \\
\text { AT }\end{array}$ & 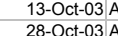 & ALPHA & $\begin{array}{r}0.000782 \\
0.0062\end{array}$ & $\begin{array}{l}\mathrm{pC} \text { Ci/m3 } \\
\mathrm{p} \text { Cimm3 }\end{array}$ & $\begin{array}{l}0.00044 \\
0.00033\end{array}$ & $\begin{array}{l}0.00048 \\
0.00037\end{array}$ & & & \\
\hline $\begin{array}{l}\text { SESPMNI I } \\
\text { SESPMNT }\end{array}$ & $\begin{array}{l}\text { D117PP4 } \\
\text { B17P4 }\end{array}$ & WYE BARRICADE & ONSITE & AT & 11-Nov-03 A & ALPHA & 0.000872 & pCi/m3 & 0.00042 & 0.00046 & & & \\
\hline SESPMNT & B17PP5 & WYE BARRICADE & ONSITE & AT & 24-Nov-03 A & ALPHA & 0.000731 & pCilm3 & 0.0004 & 0.00044 & & & \\
\hline SESPMNT & B17PP6 & WYE BARRICADE & ONSITE & AT & 11-Dec-03 A & ALPHA & 0.000418 & pCi/m3 & 0.00028 & 0.0003 & & & \\
\hline
\end{tabular}


AIR BETA/ALPHA

\begin{tabular}{|c|c|c|c|c|c|c|c|c|c|c|c|c|c|}
\hline |OWNER ID & \begin{tabular}{|l|} 
SAMP \\
NUMM
\end{tabular} & SAMP SITE NAME & | DIST CLASS & MEDIA & SAMP DATE & $\begin{array}{l}\text { CON } \\
\text { SHORT } \\
\text { NAME }\end{array}$ & |VALUE RPTD & $\begin{array}{l}\text { ANAL } \\
\text { UNITS } \\
\text { RPTD }\end{array}$ & $\left|\begin{array}{c}\text { COUNTING } \\
\text { ERROR }\end{array}\right|$ & \begin{tabular}{c|c} 
TOTAL \\
ANAL \\
ERROR
\end{tabular} & $\mid \begin{array}{c}\text { LAB } \\
\text { QUALIFIER }\end{array}$ & SAMP COMMENT & $\begin{array}{c}\text { RESULT } \\
\text { COMMENT }\end{array}$ \\
\hline SESPMNT & & WYE BARRICADE & ONSITE & AT & & & $0.000444 \mathrm{p}$ & & & 0.00039 & & & \\
\hline SESPMNT & B17PP8 & WYE BARRICADE & ONSITE & AT & 06-Jan-04 A & & $0.000631 \mathrm{p}$ & & 0.00034 & 0.00038 & & & \\
\hline SESPMNT & B16956 & YAKIMA & DISTANT & AT & 23-Jan-03A & & $-0.0000215 p$ & & 0.00016 & 0.00017 & u & & \\
\hline SESPMNT & B16957 & YAKIMA & DISTANT & AT & 06-Feb-03 A & & & & 0.00037 & & & & \\
\hline SESPMNT & B16958 & YAKIMA & DISTANT & AT & 20-Feb-03 A & & $0.000338 \mathrm{p}$ & $\mathrm{pCi} / \mathrm{m} 3$ & 0.00033 & 0.00035 & U & & \\
\hline SESPMNT & B16959 & YAKIMA & DISTANT & AT & 06-Mar-03 A & & $0.000787 p$ & & 0.00039 & 0.00044 & & & \\
\hline SESPMNT & B16960 & YAKIMA & DISTANT & AT & 21-Mar-03 A & & & & 0.00037 & 0.00042 & & & \\
\hline SESPMNT & B16961 & YAKIMA & DISTANT & AT & & & & & 0.00039 & 0.00043 & & & \\
\hline SESPMNT & B16RH7 & YAKIMA & DISTANT & AT & 18-Apr-03A & & & & & & & & \\
\hline $\begin{array}{l}\text { SESPMNT } \\
\text { SESPMNT }\end{array}$ & B16RH8 & YAKIMA & DISTANT & AT & 01-May-03A & ALPHA & $0.000617 p$ & $\mathrm{pCi} / \mathrm{m} 3$ & 0.00037 & 0.0004 & & & \\
\hline $\begin{array}{l}\text { SESPMNT } \\
\text { SESPMNT }\end{array}$ & B16RH9 & $\begin{array}{l}\text { YAKIMA } \\
\text { YAKIAA }\end{array}$ & DISTANT & AT & 16-May-03 A & ALPHA & $0.000216 p$ & $\mathrm{pCi} / \mathrm{m}_{3}$ & 0.00027 & 0.00028 & U & & \\
\hline $\begin{array}{l}\text { SESPMNT } \\
\text { SESPMNT }\end{array}$ & $\begin{array}{l}\text { B16RJo } \\
\text { B16R1 }\end{array}$ & $\begin{array}{l}\text { YAKIIA } \\
\text { YAKIMA }\end{array}$ & $\begin{array}{l}\text { DISTANT } \\
\text { DISTANT }\end{array}$ & AT & 30-May-03A & ALPHA & $0.000408 p$ & pCi/m3 & $\begin{array}{l}0.00032 \\
0.00038\end{array}$ & $\begin{array}{l}0.00035 \\
0.004\end{array}$ & u & & \\
\hline SESPMNT & B16RJ2 & YAKIMA & DISTANT & AT & 26-Jun-03 A & ALPHA & $0.000273 \mathrm{p}$ & $\mathrm{pCi} / \mathrm{m} 3$ & $\begin{array}{l}0.0030 \\
0.00029\end{array}$ & 0.00031 & u & & \\
\hline SESPMNT & B16RJ3 & YAKIMA & DISTANT & AT & 11-Jul-03 A & ALPHA & $0.00157 p$ & $\mathrm{pCl} / \mathrm{m} 3$ & 0.00046 & 0.0006 & & & \\
\hline SESPMNT & B176D6 & YAKIMA & DISTANT & AT & 24-Jul-03 A & ALPHA & $0.000222 \mathrm{p}$ & $\mathrm{pCi} / \mathrm{m} 3$ & 0.00029 & 0.0003 & u & & \\
\hline SESPMNT & B176D7 & YAKIMA & DISTANT & AT & 07-Aug-03 A & ALPHA & $0.000619 \mathrm{p}$ & $\mathrm{pCi} / \mathrm{m} 3$ & 0.00035 & 0.00039 & & & \\
\hline SESPMNT & B176D8 & YAKIMA & DISTANT & AT & 22-Aug-03 A & ALPHA & $0.000594 \mathrm{p}$ & $\mathrm{pCi} / \mathrm{m} 3$ & 0.00031 & 0.00033 & & & \\
\hline SESPMNT & B176D9 & YAKIMA & DISTANT & AT & 05-Sep-03A & ALPHA & $0.000375 p$ & $\mathrm{pCi} / \mathrm{m} 3$ & 0.00032 & 0.00033 & & & \\
\hline SESPMNT & B176F0 & YAKIMA & DISTANT & AT & 18-Sep-03A & ALPHA & $0.000128 p$ & $\mathrm{pCi} / \mathrm{m} 3$ & 0.00025 & 0.00025 & U & & \\
\hline SESPMNT & B176F1 & YAKIMA & DISTANT & AT & 03-Oct-03A & ALPHA & $0.000562 p$ & $\mathrm{pCi} / \mathrm{m} 3$ & 0.0003 & 0.00033 & & & \\
\hline $\begin{array}{l}\text { SESPMNT } \\
\text { SESPMNT }\end{array}$ & B17R24 & YAKIMA & DISTANT & AT & 17-Oct-03 A & ALPHA & $0.000704 p$ & $\mathrm{pCi} / \mathrm{m} 3$ & 0.00036 & 0.00041 & & & \\
\hline $\begin{array}{l}\text { SESPMNT } \\
\text { SESDMNT }\end{array}$ & B17R25 & YAKIMA & DISTANT & AT & 30-Oct-03 A & ALPHA & $0.000265 p$ & $\mathrm{pCi} / \mathrm{m} 3$ & 0.0003 & 0.00031 & U & & \\
\hline $\begin{array}{l}\text { SESPMNT } \\
\text { SESPMNT }\end{array}$ & $\begin{array}{l}\text { B17R26 } \\
\text { B17R27 }\end{array}$ & $\begin{array}{l}\text { YAKIMA } \\
\text { YAKIAA }\end{array}$ & $\begin{array}{l}\text { DISTANT } \\
\text { DISTANT }\end{array}$ & AT & 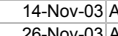 & ALPHA & $0.000843 p$ & $\mathrm{pCi} / \mathrm{m} 3$ & 0.00037 & 0.00043 & & & \\
\hline $\begin{array}{l}\text { SESPMNT } \\
\text { SESPMNT }\end{array}$ & $\begin{array}{l}\text { B17R27 } \\
\text { B1728 }\end{array}$ & $\begin{array}{l}\text { YAKIMA } \\
\text { YAKIAA }\end{array}$ & $\begin{array}{l}\text { DISTANT } \\
\text { DISTANT }\end{array}$ & AT & $\begin{array}{l}\text { 26-Nov-03A } \\
\text { 16-0ec-03A }\end{array}$ & ALPHA & $0.000812 \mathrm{p}$ & pCi/m3 & 0.00039 & 0.00044 & & & \\
\hline $\begin{array}{l}\text { SESPMNT } \\
\text { SESPMNT }\end{array}$ & $\begin{array}{l}\text { B17R28 } \\
\text { B1729 }\end{array}$ & $\begin{array}{l}\text { YAKIIIA } \\
\text { YAKIMA }\end{array}$ & \begin{tabular}{|l} 
DISTANT \\
DISTANT
\end{tabular} & $\begin{array}{l}\text { AT } \\
\text { AT }\end{array}$ & $\begin{array}{l}\text { 16-Dec-03A } \\
\text { 29-Dec-03A }\end{array}$ & ALPHA & $\begin{array}{r}0.00035 \mathrm{p} \\
0.000737 \mathrm{p}\end{array}$ & $\begin{array}{l}\mathrm{pC} / \mathrm{m} 3 \\
\mathrm{pC} / \mathrm{m} 3\end{array}$ & 0.00024 & 0.00026 & & & \\
\hline SESPMNT & $\begin{array}{l}\text { DIIRT2 } \\
\text { B17R30 }\end{array}$ & YAKIMA & DISTANT & AT & $09-\mathrm{Jan}-04 \mathrm{~A}$ & ALPHA & $\begin{array}{l}0.000 / 3 / p \\
0.000965 \mathrm{p}\end{array}$ & $\begin{array}{l}\mathrm{pCCl/m3} \\
\mathrm{pCi} / \mathrm{m} 3\end{array}$ & $\begin{array}{l}.00038 \\
0.00048 \\
\end{array}$ & $\begin{array}{l}0.000043 \\
0.0054\end{array}$ & & & \\
\hline SESPMNT & B16913 & YAKIMA BARRICADE & PERIMETER & AT & 22-Jan-03 A & ALPHA & $0.000917 \mathrm{p}$ & $\mathrm{pCi} / \mathrm{m} 3$ & 0.00043 & 0.00049 & & & \\
\hline SESPMNT & B16914 & YAKIMA BARRICADE & PERIMETER & AT & $05-\mathrm{Feb}-03 \mathrm{~A}$ & ALPHA & $0.000275 p$ & $\mathrm{pCi} / \mathrm{m} 3$ & 0.00028 & 0.00029 & U & & \\
\hline SESPMNT & B16915 & YAKIMA BARRICADE & PERIMETER & AT & 19-Feb-03 A & ALPHA & $0.000613 p$ & $\mathrm{pCi} / \mathrm{m} 3$ & 0.00037 & 0.00041 & & & \\
\hline SESPMNT & B16916 & YAKIMA BARRICADE & PERIMETER & AT & 05-Mar-03 A & ALPHA & $0.000632 p$ & $\mathrm{pCi} / \mathrm{m} 3$ & 0.00037 & 0.0004 & & & \\
\hline SESPMNT & B16917 & YAKIMA BARRICADE & PERIMETER & AT & 20-Mar-03 A & ALPHA & $0.000509 p$ & $\mathrm{pCi} / \mathrm{m} 3$ & 0.0003 & 0.00033 & & & \\
\hline SESPMNT & B16918 & YAKIMA BARRICADE & PERIMETER & AT & 02-Apr-03 A & ALPHA & $0.000372 p$ & $\mathrm{pCi} / \mathrm{m} 3$ & 0.0003 & 0.00032 & & & \\
\hline SESPMNT & B16RB6 & YAKIMA BARRICADE & PERIMETER & AT & 16-Apr-03A & ALPHA & $0.00064 p$ & $\mathrm{pCi} / \mathrm{m} 3$ & 0.00035 & 0.00039 & & & \\
\hline SESPMNT & B16RB7 & YAKIMA BARRICADE & PERIMETER & AT & 30-Apr-03A & ALPHA & $0.000568 p$ & $\mathrm{pCi} / \mathrm{m} 3$ & 0.00034 & 0.00038 & & & \\
\hline SESPMNT & B16RB8 & YAKIMA BARRICADE & PERIMETER & AT & 13-May-03 A & ALPHA & $0.000763 p$ & $\mathrm{pCi} / \mathrm{m} 3$ & 0.00039 & 0.00044 & & & \\
\hline $\begin{array}{l}\text { SESPMNT } \\
\text { SESPMNT }\end{array}$ & B16RB9 & YAKIMA BARRICADE & $\begin{array}{l}\text { PERIMETER } \\
\text { PERIMETER }\end{array}$ & AT & 28-May-03A & ALPHA & $0.00064 \mathrm{p}$ & pCi/m3 & 0.00033 & 0.00037 & & & \\
\hline $\begin{array}{l}\text { SESPMNT } \\
\text { SESPMNT }\end{array}$ & $\begin{array}{l}\text { B16RCO } \\
\text { B16RC1 }\end{array}$ & $\begin{array}{l}\text { YYKIMA BARRIIADE } \\
\text { YAKIMA BARRIIADE }\end{array}$ & $\begin{array}{l}\text { PERIMETTR } \\
\text { PERIMETER }\end{array}$ & $\begin{array}{l}\text { AT } \\
\text { AT }\end{array}$ & $\begin{array}{l}\text { 13-Jun- } 03 \mathrm{~A} A \\
\text { 26-03un }-03 \mathrm{~A}\end{array}$ & ALPHA & $\begin{array}{l}0.000539 \mathrm{p} \\
0.00002 \mathrm{p}\end{array}$ & $\begin{array}{l}\text { pCilm3 } \\
\text { pCi/m3 }\end{array}$ & $\begin{array}{r}0.00031 \\
0.0003\end{array}$ & $\begin{array}{l}0.00034 \\
0.0032\end{array}$ & u & & \\
\hline SESPMNT & B16RC2 & YAKIMA BARRICADE & PERIMETER & AT & 11-Jul-03 A & ALPHA & $0.000743 p$ & $\mathrm{pCi} / \mathrm{m} 3$ & 0.00036 & 0.00041 & & & \\
\hline SESPMNT & B17683 & YAKIMA BARRICADE & PERIMETER & AT & 24-Jul-03 A & ALPHA & $0.000431 \mathrm{p}$ & $\mathrm{pC} / \mathrm{m} 3$ & 0.00034 & 0.00036 & & & \\
\hline SESPMNT & B17684 & YAKIMA BARRICADE & PERIMETER & AT & 07-Aug-03 A & ALPHA & $0.0013 \mathrm{p}$ & $\mathrm{pCi} / \mathrm{m} 3$ & 0.00045 & 0.00055 & & & \\
\hline SESPMNT & B17685 & YAKIMA BARRICADE & PERIMETER & AT & 22-Aug-03 A & ALPHA & $0.000688 p$ & $\mathrm{pCi} / \mathrm{m} 3$ & 0.00033 & 0.00036 & & & \\
\hline SESPMNT & B17686 & YAKIMA BARRICADE & PERIMETER & AT & 05-Sep-03A & ALPHA & $0.000562 \mathrm{p}$ & $\mathrm{pCi} / \mathrm{m} 3$ & 0.00033 & 0.00036 & & & \\
\hline SESPMNT & B17687 & YAKIMA BARRICADE & PERIMETER & AT & 18-Sep-03A & ALPHA & $0.000236 \mathrm{p}$ & $\mathrm{pCi} / \mathrm{m} 3$ & 0.00027 & 0.00028 & U & & \\
\hline SESPMNT & B17688 & YAKIMA BARRICADE & PERIMETER & AT & 03-Oct-03 A & ALPHA & $0.000429 p$ & $\mathrm{pCi} / \mathrm{m} 3$ & 0.00029 & 0.0003 & & & \\
\hline SESPMNT & B17PX3 & YAKIMA BARRICADE & PERIMETER & AT & 17-Oct-03 A & ALPHA & $0.00076 \mathrm{p}$ & $\mathrm{pCi} / \mathrm{m} 3$ & 0.00038 & 0.00043 & & & \\
\hline SESPMNT & B17PX4 & YAKIMA BARRICADE & PERIMETER & AT & 30-Oct-03A & ALPHA & $0.000506 \mathrm{p}$ & $\mathrm{pCi} / \mathrm{m} 3$ & 0.00034 & 0.00037 & & & \\
\hline SESPMNT & B17PX5 & YAKIMA BARRICADE & PERIMETER & AT & 14-Nov-03 A & ALPHA & $0.000759 p$ & $\mathrm{pCi} / \mathrm{m} 3$ & 0.0004 & 0.00045 & & & \\
\hline SESPMNT & B17PX6 & YAKIMA BARRICADE & PERIMETER & AT & 26-Nov-03 A & ALPHA & $0.000522 p$ & $\mathrm{pCi} / \mathrm{m} 3$ & 0.00038 & 0.00041 & & & \\
\hline SESPMNT & B17PX7 & YAKIMA BARRICADE & $\begin{array}{l}\text { PERIMETER } \\
\text { PERIMETER }\end{array}$ & AT & 16-Dec-03A & ALPHA & $0.000352 p$ & $\mathrm{pCi} / \mathrm{m} 3$ & 0.00024 & 0.00026 & & & \\
\hline $\begin{array}{l}\text { SESPMNT } \\
\text { SESPMNT }\end{array}$ & $\begin{array}{l}\text { B17PX8 } \\
\text { B17PX9 }\end{array}$ & $\begin{array}{l}\text { YYKIMA ARRRIIADE } \\
\text { YAKIMA BARRICADE }\end{array}$ & $\begin{array}{l}\text { PERIMETER } \\
\text { PERIMETER }\end{array}$ & $\begin{array}{l}\text { AT } \\
\text { AT }\end{array}$ & $\begin{array}{l}\text { 29-D-Dac-03A } \\
\text { 09-Jan-04 A }\end{array}$ & $\begin{array}{l}\text { LLPHA } \\
\text { ALPHA }\end{array}$ & $\begin{array}{l}0.0006588 \mathrm{p} \\
0.000867 \mathrm{p}\end{array}$ & $\begin{array}{l}\mathrm{pCC} / \mathrm{m} 3 \\
\mathrm{pCi} / \mathrm{m} 3\end{array}$ & $\begin{array}{l}0.00038 \\
0.00048\end{array}$ & $\begin{array}{l}0.000042 \\
0.00053\end{array}$ & & & \\
\hline
\end{tabular}


AIR GAMMA

\begin{tabular}{|c|c|c|c|c|c|c|c|c|c|c|c|c|c|}
\hline OWNER ID & SAMP NUM & SAMP SITE NAME & DIST CLASS & MEDIA & SAMP DATE & $\begin{array}{l}\text { CON SHORT } \\
\text { NAME }\end{array}$ & VALUE RPTD & $\begin{array}{l}\text { ANAL } \\
\text { UNITS } \\
\text { RPTD }\end{array}$ & $\begin{array}{c}\text { COUNTING } \\
\text { ERROR }\end{array}$ & $\begin{array}{c}\text { TOTAL ANAL } \\
\text { ERROR }\end{array}$ & $\begin{array}{c}\text { LAB } \\
\text { QUALIFIER } \\
\end{array}$ & SAMP COMMENT & RESULT COMMENT \\
\hline SESPMNT & B168C4 & 100 AREAS & ONSITE & AT & 31-Mar-03 & $3 \mathrm{e}-7$ & 0.0825 & $\mathrm{pCi} / \mathrm{m} 3$ & 0.019 & 0.019 & & & \\
\hline SESPMNT & B16PP5 & 100 AREAS & ONSITE & AT & 08-Jul-03 & & 0.114 & $\mathrm{pCi} / \mathrm{m} 3$ & 0.02 & 0.02 & & & \\
\hline SESPMNT & B175M4 & 100 AREAS & ONSITE & AT & 01-Oct-03 & $3 e-7$ & 0.163 & $\mathrm{pCi} / \mathrm{m} 3$ & 0.031 & 0.031 & & & \\
\hline SESPMNT & B17P82 & 100 AREAS & ONSITE & AT & 06-Jan-04 & $3 e-7$ & 0.0553 & $\mathrm{pCi} / \mathrm{m} 3$ & 0.013 & 0.013 & & & \\
\hline SESPMNT & B168F3 & $200 \mathrm{E}$ AREA & ONSITE & AT & 08-Apr-03 & 3e-7 & 0.0825 & $\mathrm{pCi} / \mathrm{m} 3$ & 0.02 & 0.02 & & & \\
\hline SESPMNT & B16PT7 & 200 E AREA & ONSITE & AT & 30-Jun-03 & & 0.12 & $\mathrm{pCi} / \mathrm{m} 3$ & 0.023 & 0.023 & & & \\
\hline SESPMNT & B175P3 & 200 E AREA & ONSITE & AT & 07-Oct-03 & $3 e-7$ & 0.125 & $\mathrm{pCi} / \mathrm{m} 3$ & 0.027 & 0.027 & & & \\
\hline SESPMNT & B17PB4 & 200 E AREA & ONSITE & AT & 30-Dec-03 & $3 e-7$ & 0.056 & $\mathrm{pCi} / \mathrm{m} 3$ & 0.017 & 0.017 & & & \\
\hline SESPMNT & B168L8 & 200 W AREA & ONSITE & AT & 08-Apr-03 & 3e-7 & 0.1 & $\mathrm{pCi} / \mathrm{m} 3$ & 0.025 & 0.025 & & & \\
\hline SESPMNT & B16PY6 & 200 W AREA & ONSITE & AT & 30-Jun-03 & $3 e-7$ & 0.13 & $\mathrm{pCi} / \mathrm{m} 3$ & 0.031 & 0.031 & & & \\
\hline SESPMNT & B175W8 & 200 W AREA & ONSITE & AT & $07-0 c t-03$ & $3 e-7$ & 0.157 & $\mathrm{pCi} / \mathrm{m} 3$ & 0.037 & 0.037 & & & \\
\hline SESPMNT & $\mathrm{B} 17 \mathrm{PH} 3$ & 200 W AREA & ONSITE & AT & 30-Dec-03 & $3 \mathrm{e}-7$ & 0.0647 & $\mathrm{pCi} / \mathrm{m} 3$ & 0.022 & 0.022 & & & \\
\hline SESPMNT & B168J6 & 200 W SOUTH EAST & ONSITE & AT & 08-Apr-03 & 3e-7 & 0.071 & $\mathrm{pCi} / \mathrm{m} 3$ & 0.013 & 0.013 & & & \\
\hline SESPMNT & B16PW7 & 200 W SOUTH EAST & ONSITE & AT & 30-Jun-03 & $3 e-7$ & 0.115 & $\mathrm{pCi} / \mathrm{m} 3$ & 0.021 & 0.021 & & & \\
\hline SESPMNT & B175T6 & 200 W SOUTH EAST & ONSITE & AT & $07-0 c t-03$ & $3 e-7$ & 0.147 & $\mathrm{pCi} / \mathrm{m} 3$ & 0.024 & 0.024 & & & \\
\hline SESPMNT & B17PD4 & 200 W SOUTH EAST & ONSITE & AT & 30-Dec-03 & $3 \mathrm{e}-7$ & 0.0623 & $\mathrm{pCi} / \mathrm{m} 3$ & 0.017 & 0.017 & & & \\
\hline SESPMNT & B168M6 & 300 AREA & ONSITE & AT & 02-Apr-03 & $3 \mathrm{e}-7$ & 0.088 & $\mathrm{pCi} / \mathrm{m} 3$ & 0.018 & 0.018 & & & \\
\hline SESPMNT & B16R03 & 300 AREA & ONSITE & AT & 10-Jul-03 & $3 \mathrm{e}-7$ & 0.117 & $\mathrm{pCi} / \mathrm{m} 3$ & 0.02 & 0.02 & & & \\
\hline SESPMNT & B175X6 & 300 AREA & ONSITE & AT & 30-Sep-03 & $3 e-7$ & 0.166 & $\mathrm{pCi} / \mathrm{m} 3$ & 0.029 & 0.029 & & & \\
\hline SESPMNT & B17PJo & 300 AREA & ONSITE & AT & 08-Jan-04 & Be-7 & 0.0706 & $\mathrm{pCi} / \mathrm{m} 3$ & 0.015 & 0.015 & & & \\
\hline SESPMNT & B167V4 & $300 \mathrm{NE}$ & ONSITE & AT & 02-Apr-03 & $3 e-7$ & 0.0625 & $\mathrm{pCi} / \mathrm{m} 3$ & 0.024 & 0.024 & & & \\
\hline SESPMNT & B16P66 & $300 \mathrm{NE}$ & ONSITE & AT & 10-Jul-03 & $3 \mathrm{e}-7$ & 0.123 & $\mathrm{pCi} / \mathrm{m} 3$ & 0.036 & 0.036 & & & \\
\hline SESPMNT & B17548 & $300 \mathrm{NE}$ & ONSITE & AT & $30-S e p-03$ & Be-7 & 0.177 & $\mathrm{pCi} / \mathrm{m} 3$ & 0.049 & 0.049 & & & \\
\hline SESPMNT & B17NP7 & $300 \mathrm{NE}$ & ONSITE & AT & 08-Jan-04 & $3 e-7$ & 0.0649 & $\mathrm{pCi} / \mathrm{m} 3$ & 0.022 & 0.022 & & & \\
\hline SESPMNT & B167V3 & 300 TRENCH & ONSITE & AT & 02-Apr-03 & $3 e-7$ & 0.0894 & $\mathrm{pCi} / \mathrm{m} 3$ & 0.029 & 0.029 & & & \\
\hline SESPMNT & B16P65 & 300 TRENCH & ONSITE & AT & 10-Jul-03 & $3 \mathrm{e}-7$ & 0.133 & $\mathrm{pCi} / \mathrm{m} 3$ & 0.031 & 0.031 & & & \\
\hline SESPMNT & B17547 & 300 TRENCH & ONSITE & AT & $30-S e p-03$ & $3 e-7$ & 0.153 & $\mathrm{pCi} / \mathrm{m} 3$ & 0.045 & 0.045 & & & \\
\hline SESPMNT & B17NP6 6 & 300 TRENCH & ONSITE & AT & 08-Jan-04 & $3 e-7$ & 0.101 & $\mathrm{pCi} / \mathrm{m} 3$ & 0.035 & 0.035 & & & \\
\hline SESPMNT & B168P5 & 400 AREA & ONSITE & AT & 31-Mar-03 & $3 e-7$ & 0.082 & $\mathrm{pCi} / \mathrm{m} 3$ & 0.017 & 0.017 & & & \\
\hline SESPMNT & B16R25 & 400 AREA & ONSITE & AT & 08-Jul-03 & $3 e-7$ & 0.109 & $\mathrm{pCi} / \mathrm{m} 3$ & 0.018 & 0.018 & & & \\
\hline SESPMNT & B17605 & 400 AREA & ONSITE & AT & 01-Oct-03 & $3 e-7$ & 0.163 & $\mathrm{pCi} / \mathrm{m} 3$ & 0.029 & 0.029 & & & \\
\hline SESPMNT & B17PL2 & 400 AREA & ONSITE & AT & 05-Jan-04 & $3 e-7$ & 0.0676 & $\mathrm{pCi} / \mathrm{m} 3$ & 0.013 & 0.013 & & & \\
\hline SESPMNT & B168H8 & B POND & ONSITE & AT & 08-Apr-03 & $3 e-7$ & 0.0625 & $\mathrm{pCi} / \mathrm{m} 3$ & 0.02 & 0.02 & & & \\
\hline SESPMNT & B16PWO & B POND & ONSITE & AT & 30-Jun-03 & $3 e-7$ & 0.145 & $\mathrm{pCi} / \mathrm{m} 3$ & 0.034 & 0.034 & & & \\
\hline SESPMNT & B175R8 & B POND & ONSITE & AT & $07-0 c t-03$ & $3 e-7$ & 0.15 & $\mathrm{pCi} / \mathrm{m} 3$ & 0.037 & 0.037 & & & \\
\hline SESPMNT & B17PC7 & B POND & ONSITE & AT & 30-Dec-03 & $3 e-7$ & 0.0572 & $\mathrm{pCi} / \mathrm{m} 3$ & 0.026 & 0.026 & $\mathrm{U}$ & & \\
\hline SESPMNT & B16962 & BASIN CITY SCHOOL & COMMUNITY & AT & 09-Apr-03 & $3 e-7$ & 0.0748 & $\mathrm{pCi} / \mathrm{m} 3$ & 0.029 & 0.029 & & & \\
\hline SESPMNT & B16RJ4 & BASIN CITY SCHOOL & COMMUNITY & AT & 02-Jul-03 & $3 e-7$ & 0.137 & $\mathrm{pCi} / \mathrm{m} 3$ & 0.046 & 0.046 & & & \\
\hline SESPMNT & B176F2 & BASIN CITY SCHOOL & COMMUNITY & AT & 08-Oct-03 & $3 e-7$ & 0.188 & $\mathrm{pCi} / \mathrm{m} 3$ & 0.042 & 0.042 & & & \\
\hline SESPMNT & B17R31 & BASIN CITY SCHOOL & COMMUNITY & AT & 31-Dec-03 & $3 e-7$ & 0.0952 & $\mathrm{pCi} / \mathrm{m} 3$ & 0.03 & 0.03 & & & \\
\hline SESPMNT & B16820 & BATTELLE COMPLEX & PERIMETER & AT & 02-Apr-03 & $3 e-7$ & 0.0733 & $\mathrm{pCi} / \mathrm{m} 3$ & 0.025 & 0.025 & & & \\
\hline SESPMNT & B16PD4 & BATTELLE COMPLEX & PERIMETER & AT & 09-Jul-03 & $3 e-7$ & 0.106 & $\mathrm{pCi} / \mathrm{m} 3$ & 0.028 & 0.028 & & & \\
\hline SESPMNT & B175B4 & BATTELLE COMPLEX & PERIMETER & AT & 30-Sep-03 & $3 e-7$ & 0.175 & $\mathrm{pCi} / \mathrm{m} 3$ & 0.038 & 0.038 & & & \\
\hline $\begin{array}{l}\text { SESPMNT } \\
\text { SESP }\end{array}$ & B17NY7 & BATTELLE COMPLEX & PERIMETER & AT & $08-J a n-04$ & $3 e-7$ & 0.071 & $\mathrm{pCi} / \mathrm{m} 3$ & 0.028 & 0.028 & & & \\
\hline SESPMNT & B16827 & BENTON CITY & COMMUNITY & AT & 03-Apr-03 & Be-7 & 0.0619 & $\mathrm{pCi} / \mathrm{m} 3$ & 0.025 & 0.025 & & & \\
\hline SESPMNT & B16PF2 & BENTON CITY & COMMUNITY & AT & 11-Jul-03 & $3 e-7$ & 0.105 & $\mathrm{pCi} / \mathrm{m} 3$ & 0.023 & 0.023 & & & \\
\hline SESPMNT & B175C1 & BENTON CITY & COMMUNITY & AT & 03-Oct-03 & $3 e-7$ & 0.202 & $\mathrm{pCi} / \mathrm{m} 3$ & 0.046 & 0.046 & & & \\
\hline $\begin{array}{l}\text { SESPMNT } \\
\text { SESP }\end{array}$ & B17P05 & BENTON CITY & COMMUNITY & AT & $09-\mathrm{Jan}-04$ & $3 e-7$ & 0.0769 & $\mathrm{pCi} / \mathrm{m} 3$ & 0.023 & 0.023 & & & \\
\hline SESPMNT & B168Y1 & BYERS LANDING & PERIMETER & AT & 10-Apr-03 & Be-7 & 0.0788 & $\mathrm{pCi} / \mathrm{m} 3$ & 0.024 & 0.024 & & & \\
\hline SESPMNT & B16R83 & BYERS LANDING & PERIMETER & AT & 07-Jul-03 & $3 e-7$ & 0.15 & $\mathrm{pCi} / \mathrm{m} 3$ & 0.03 & 0.03 & & & \\
\hline SESPMNT & B17661 & BYERS LANDING & PERIMETER & AT & 10-Oct-03 & $3 e-7$ & 0.206 & $\mathrm{pCi} / \mathrm{m} 3$ & 0.043 & 0.043 & & & \\
\hline $\begin{array}{l}\text { SESPMNT } \\
\text { SESP }\end{array}$ & B17PVO & $\begin{array}{l}\text { BYERS LANDING } \\
\text { BYES }\end{array}$ & PERIMETER & AT & 05-Jan-04 & $3 e-7$ & 0.0653 & $\mathrm{pCi} / \mathrm{m} 3$ & 0.027 & 0.027 & & & \\
\hline SESPMNT & B168X3 & DOGWOOD MET TOWER & PERIMETER & AT & 10-Apr-03 & Be-7 & 0.0887 & $\mathrm{pCi} / \mathrm{m} 3$ & 0.022 & 0.022 & & & \\
\hline SESPMNT & B16R76 & DOGWOOD MET TOWER & PERIMETER & AT & 07-Jul-03 & $3 e-7$ & 0.136 & $\mathrm{pCi} / \mathrm{m} 3$ & 0.034 & 0.034 & & & \\
\hline SESPMNT & B17653 & DOGWOOD MET TOWER & PERIMETER & AT & 10-Oct-03 & $3 e-7$ & 0.151 & $\mathrm{pCi} / \mathrm{m} 3$ & 0.033 & 0.033 & & & \\
\hline SESPMNT & B17PT3 & DOGWOOD MET TOWER & PERIMETER & AT & 05-Jan-04 & $3 e-7$ & 0.0571 & $\mathrm{pCi} / \mathrm{m} 3$ & 0.021 & 0.021 & & & \\
\hline SESPMNT & B16978 & EDWIN MARKHAM SCHOOL & COMMUNITY & AT & 10-Apr-03 & Be-7 & 0.112 & $\mathrm{pCi} / \mathrm{m} 3$ & 0.028 & 0.028 & & & \\
\hline SESPMNT & B16RK8 & EDWIN MARKHAM SCHOOL & COMMUNITY & AT & 02-Jul-03 & $3 e-7$ & 0.128 & $\mathrm{pCi} / \mathrm{m} 3$ & 0.026 & 0.026 & & & \\
\hline
\end{tabular}


AIR GAMMA

\begin{tabular}{|c|c|c|c|c|c|c|c|c|c|c|c|c|c|}
\hline OWNER ID & SAMP NUM | & SAMP SITE NAME & | DIST CLASS $\mid$ & MEDIA & SAMP DATE & $\begin{array}{l}\text { CON SHORT } \\
\text { NAME }\end{array}$ & |VALUE RPTD | & $\begin{array}{l}\text { ANAL } \\
\text { UNITS } \\
\text { RPTD }\end{array}$ & $\begin{array}{c}\text { COUNTING } \\
\text { ERROR }\end{array}$ & $\begin{array}{c}\text { TOTAL ANAL } \\
\text { ERROR }\end{array} \mid$ & $\begin{array}{c}\text { LAB } \\
\text { QUALIFIER }\end{array}$ & SAMP COMMENT & RESULT COMMENT \\
\hline SESPMNT & B176H8 & EDWIN MARKHAM SCHOOL & COMMUNITY & AT & 08-Oct-03 & Be-7 & 0.185 & $\mathrm{pCi} / \mathrm{m} 3$ & 0.039 & 0.039 & & & \\
\hline SESPMNT & B17R45 & EDWIN MARKHAM SCHOOL & COMMUNITY & AT & 31-Dec-03 & $\mathrm{Be}-7$ & 0.0675 & $\mathrm{pCi} / \mathrm{m} 3$ & 0.03 & 0.03 & & & \\
\hline SESPMNT & B16986 & HANFORD TOWNSITE & ONSITE & AT & 31-Mar-03 & $\mathrm{Be}-7$ & 0.0944 & $\mathrm{pCi} / \mathrm{m} 3$ & 0.02 & 0.02 & & & \\
\hline SESPMNT & B16RL5 & HANFORD TOWNSITE & ONSITE & AT & 08-Jul-03 & $\mathrm{Be}-7$ & 0.143 & $\mathrm{pCi} / \mathrm{m} 3$ & 0.026 & 0.026 & & & \\
\hline SESPMNT & B176J6 & HANFORD TOWNSITE & ONSITE & AT & 01-Oct-03 & $\mathrm{Be}-7$ & 0.178 & $\mathrm{pCi} / \mathrm{m} 3$ & 0.034 & 0.034 & & & \\
\hline SESPMNT & B17R52 & HANFORD TOWNSITE & ONSITE & AT & 06-Jan-04 & $\mathrm{Be}-7$ & 0.0761 & $\mathrm{pCi} / \mathrm{m} 3$ & 0.018 & 0.018 & & & \\
\hline SESPMNT & B16970 & LESLIE GROVES-RCHLND & COMMUNITY & AT & 08-Apr-03 & $\mathrm{Be}-7$ & 0.0702 & $\mathrm{pCi} / \mathrm{m} 3$ & 0.029 & 0.029 & & & \\
\hline SESPMNT & B16RK1 & LESLIE GROVES-RCHLND & COMMUNITY & AT & 01-Jul-03 & $\mathrm{Be}-7$ & 0.135 & $\mathrm{pCi} / \mathrm{m} 3$ & 0.034 & 0.034 & & & \\
\hline SESPMNT & $\mathrm{B} 176 \mathrm{HO}$ & LESLIE GROVES-RCHLND & COMMUNITY & AT & $07-0 c t-03$ & $\mathrm{Be}-7$ & 0.191 & $\mathrm{pCi} / \mathrm{m} 3$ & 0.042 & 0.042 & & & \\
\hline SESPMNT & B17R38 & LESLIE GROVES-RCHLND & COMMUNITY & AT & 30-Dec-03 & $\mathrm{Be}-7$ & 0.0728 & $\mathrm{pCi} / \mathrm{m} 3$ & 0.024 & 0.024 & & & \\
\hline SESPMNT & B16834 & MATTAWA & COMMUNITY & AT & 09-Apr-03 & $\mathrm{Be}-7$ & 0.0668 & $\mathrm{pCi} / \mathrm{m} 3$ & 0.031 & 0.031 & & & \\
\hline SESPMNT & B16PHO & MATTAWA & COMMUNITY & AT & 01-Jul-03 & $\mathrm{Be}-7$ & 0.137 & $\mathrm{pCi} / \mathrm{m} 3$ & 0.043 & 0.043 & & & \\
\hline SESPMNT & B175C8 & MATTAWA & COMMUNITY & AT & $09-0 c t-03$ & $\mathrm{Be}-7$ & 0.165 & $\mathrm{pCi} / \mathrm{m} 3$ & 0.038 & 0.038 & & & \\
\hline SESPMNT & B17P13 & MATTAWA & COMMUNITY & AT & 31-Dec-03 & $\mathrm{Be}-7$ & 0.0709 & $\mathrm{pCi} / \mathrm{m} 3$ & 0.027 & 0.027 & & & \\
\hline SESPMNT & B16812 & N OF $200 \mathrm{E}$ & ONSITE & AT & 08-Apr-03 & $\mathrm{Be}-7$ & 0.0747 & $\mathrm{pCi} / \mathrm{m} 3$ & 0.022 & 0.022 & & & \\
\hline SESPMNT & B16PC7 & N OF $200 \mathrm{E}$ & ONSITE & AT & 30-Jun-03 & $\mathrm{Be}-7$ & 0.157 & $\mathrm{pCi} / \mathrm{m} 3$ & 0.04 & 0.04 & & & \\
\hline SESPMNT & B17596 & N OF $200 \mathrm{E}$ & ONSITE & AT & $07-0 c t-03$ & $\mathrm{Be}-7$ & 0.173 & $\mathrm{pCi} / \mathrm{m} 3$ & 0.043 & 0.043 & & & \\
\hline SESPMNT & B17NY0 & N OF $200 \mathrm{E}$ & ONSITE & AT & 30-Dec-03 & $\mathrm{Be}-7$ & 0.0631 & $\mathrm{pCi} / \mathrm{m} 3$ & 0.028 & 0.028 & & & \\
\hline SESPMNT & B16842 & OTHELLO & COMMUNITY & AT & 09-Apr-03 & $\mathrm{Be}-7$ & 0.0942 & $\mathrm{pCi} / \mathrm{m} 3$ & 0.025 & 0.025 & & & \\
\hline SESPMNT & B16PH7 & OTHELLO & COMMUNITY & AT & 01-Jul-03 & $\mathrm{Be}-7$ & 0.176 & $\mathrm{pCi} / \mathrm{m} 3$ & 0.037 & 0.037 & & & \\
\hline SESPMNT & B175D6 & OTHELLO & COMMUNITY & AT & $09-0 c t-03$ & $\mathrm{Be}-7$ & 0.14 & $\mathrm{pCi} / \mathrm{m} 3$ & 0.038 & 0.038 & & & \\
\hline SESPMNT & B17P20 & OTHELLO & COMMUNITY & AT & 31-Dec-03 & $\mathrm{Be}-7$ & 0.0832 & $\mathrm{pCi} / \mathrm{m} 3$ & 0.027 & 0.027 & & & \\
\hline SESPMNT & B168Y9 & PROSSER BARRICADE & PERIMETER & AT & 03-Apr-03 & $\mathrm{Be}-7$ & 0.0912 & $\mathrm{pCi} / \mathrm{m} 3$ & 0.024 & 0.024 & & & \\
\hline SESPMNT & B16R90 & PROSSER BARRICADE & PERIMETER & AT & 11-Jul-03 & $\mathrm{Be}-7$ & 0.169 & $\mathrm{pCi} / \mathrm{m} 3$ & 0.028 & 0.028 & & & \\
\hline SESPMNT & B17669 & PROSSER BARRICADE & PERIMETER & AT & 03-Oct-03 & $\mathrm{Be}-7$ & 0.17 & $\mathrm{pCi} / \mathrm{m} 3$ & 0.038 & 0.038 & & & \\
\hline SESPMNT & B17PV7 & PROSSER BARRICADE & PERIMETER & AT & 09-Jan-04 & $\mathrm{Be}-7$ & 0.0512 & $\mathrm{pCi} / \mathrm{m} 3$ & 0.015 & 0.015 & & & \\
\hline SESPMNT & B168W5 & RINGOLD MET TOWER & PERIMETER & AT & 10-Apr-03 & $\mathrm{Be}-7$ & 0.0781 & $\mathrm{pCi} / \mathrm{m} 3$ & 0.02 & 0.02 & & & \\
\hline SESPMNT & B16R69 & RINGOLD MET TOWER & PERIMETER & AT & 07-Jul-03 & $\mathrm{Be}-7$ & 0.133 & $\mathrm{pCi} / \mathrm{m} 3$ & 0.047 & 0.047 & & & \\
\hline SESPMNT & B17645 & RINGOLD MET TOWER & PERIMETER & AT & 10-Oct-03 & $\mathrm{Be}-7$ & 0.19 & $\mathrm{pCi} / \mathrm{m} 3$ & 0.039 & 0.039 & & & \\
\hline SESPMNT & B17PR6 & RINGOLD MET TOWER & PERIMETER & AT & 05-Jan-04 & $\mathrm{Be}-7$ & 0.0599 & $\mathrm{pCi} / \mathrm{m} 3$ & 0.025 & 0.025 & & & \\
\hline SESPMNT & B16805 & TOPPENISH & DISTANT & AT & 02-Apr-03 & $\mathrm{Be}-7$ & 0.0789 & $\mathrm{pCi} / \mathrm{m} 3$ & 0.025 & 0.025 & & & \\
\hline SESPMNT & B16PB9 & TOPPENISH & DISTANT & AT & 09-Jul-03 & $\mathrm{Be}-7$ & 0.111 & $\mathrm{pCi} / \mathrm{m} 3$ & 0.031 & 0.031 & & & \\
\hline SESPMNT & B17589 & TOPPENISH & DISTANT & AT & 01-Oct-03 & $\mathrm{Be}-7$ & 0.141 & $\mathrm{pCi} / \mathrm{m} 3$ & 0.037 & 0.037 & & & \\
\hline SESPMNT & B17NX2 & TOPPENISH & DISTANT & AT & 08-Jan-04 & $\mathrm{Be}-7$ & 0.0388 & $\mathrm{pCi} / \mathrm{m} 3$ & 0.02 & 0.02 & & & \\
\hline SESPMNT & B16940 & TRI CITIES & COMMUNITY & AT & 10-Apr-03 & $\mathrm{Be}-7$ & 0.0708 & $\mathrm{pCi} / \mathrm{m} 3$ & 0.018 & 0.018 & & & \\
\hline SESPMNT & B16RF3 & TRI CITIES & COMMUNITY & AT & 07-Jul-03 & $\mathrm{Be}-7$ & 0.16 & $\mathrm{pCi} / \mathrm{m} 3$ & 0.028 & 0.028 & & & \\
\hline SESPMNT & $\mathrm{B} 176 \mathrm{CO}$ & TRI CITIES & COMMUNITY & AT & 10-Oct-03 & $\mathrm{Be}-7$ & 0.163 & $\mathrm{pCi} / \mathrm{m} 3$ & 0.034 & 0.034 & & & \\
\hline SESPMNT & B17R10 & TRI CITIES & COMMUNITY & AT & 05-Jan-04 & $\mathrm{Be}-7$ & 0.0767 & $\mathrm{pCi} / \mathrm{m} 3$ & 0.02 & 0.02 & & & \\
\hline SESPMNT & B168V7 & W END OF FIR ROAD & PERIMETER & AT & 10-Apr-03 & $\mathrm{Be}-7$ & 0.0853 & $\mathrm{pCi} / \mathrm{m} 3$ & 0.022 & 0.022 & & & \\
\hline SESPMNT & B16R62 & W END OF FIR ROAD & PERIMETER & AT & 07-Jul-03 & $\mathrm{Be}-7$ & 0.146 & $\mathrm{pCi} / \mathrm{m} 3$ & 0.043 & 0.043 & & & \\
\hline SESPMNT & B17637 & W END OF FIR ROAD & PERIMETER & AT & 10-Oct-03 & $\mathrm{Be}-7$ & 0.163 & $\mathrm{pCi} / \mathrm{m} 3$ & 0.048 & 0.048 & & & \\
\hline SESPMNT & B17PP9 & W END OF FIR ROAD & PERIMETER & AT & 05-Jan-04 & $\mathrm{Be}-7$ & 0.0489 & $\mathrm{pCi} / \mathrm{m} 3$ & 0.023 & 0.023 & & & \\
\hline SESPMNT & B16925 & WAHLUKE SLOPE & PERIMETER & AT & 09-Apr-03 & $\mathrm{Be}-7$ & 0.0873 & $\mathrm{pCi} / \mathrm{m} 3$ & 0.016 & 0.016 & & & \\
\hline SESPMNT & B16RD0 & WAHLUKE SLOPE & PERIMETER & AT & 01-Jul-03 & $\mathrm{Be}-7$ & 0.139 & $\mathrm{pCi} / \mathrm{m} 3$ & 0.027 & 0.027 & & & \\
\hline SESPMNT & B17695 & WAHLUKE SLOPE & PERIMETER & AT & 08-Oct-03 & $\mathrm{Be}-7$ & 0.14 & $\mathrm{pCi} / \mathrm{m} 3$ & 0.031 & 0.031 & & & \\
\hline SESPMNT & B17PY7 & WAHLUKE SLOPE & PERIMETER & AT & 31-Dec-03 & $\mathrm{Be}-7$ & 0.0455 & $\mathrm{pCi} / \mathrm{m} 3$ & 0.016 & 0.016 & & & \\
\hline SESPMNT & B168Vo & WYE BARRICADE & ONSITE & AT & 31-Mar-03 & $\mathrm{Be}-7$ & 0.0972 & $\mathrm{pCi} / \mathrm{m} 3$ & 0.029 & 0.029 & & & \\
\hline SESPMNT & B16R54 & WYE BARRICADE & ONSITE & AT & 08-Jul-03 & $\mathrm{Be}-7$ & 0.154 & $\mathrm{pCi} / \mathrm{m} 3$ & 0.032 & 0.032 & & & \\
\hline SESPMNT & B17630 & WYE BARRICADE & ONSITE & AT & 01-Oct-03 & $\mathrm{Be}-7$ & 0.152 & $\mathrm{pCi} / \mathrm{m} 3$ & 0.043 & 0.043 & & & \\
\hline SESPMNT & B17PP1 & WYE BARRICADE & ONSITE & AT & 06-Jan-04 & $\mathrm{Be}-7$ & 0.0542 & $\mathrm{pCi} / \mathrm{m} 3$ & 0.028 & 0.028 & & & \\
\hline SESPMNT & B16955 & YAKIMA & DISTANT & AT & 03-Apr-03 & $\mathrm{Be}-7$ & 0.0896 & $\mathrm{pCi} / \mathrm{m} 3$ & 0.028 & 0.028 & & & \\
\hline SESPMNT & B16RH6 & YAKIMA & DISTANT & AT & 11-Jul-03 & $\mathrm{Be}-7$ & 0.136 & $\mathrm{pCi} / \mathrm{m} 3$ & 0.03 & 0.03 & & & \\
\hline SESPMNT & B176D5 & YAKIMA & DISTANT & AT & 03-Oct-03 & $\mathrm{Be}-7$ & 0.188 & $\mathrm{pCi} / \mathrm{m} 3$ & 0.044 & 0.044 & & & \\
\hline SESPMNT & B17R23 & YAKIMA & DISTANT & AT & 09-Jan-04 & $\mathrm{Be}-7$ & 0.0486 & $\mathrm{pCi} / \mathrm{m} 3$ & 0.026 & 0.026 & & & \\
\hline SESPMNT & B16912 & YAKIMA BARRICADE & PERIMETER & AT & 02-Apr-03 & $\mathrm{Be}-7$ & 0.088 & $\mathrm{pCi} / \mathrm{m} 3$ & 0.02 & 0.02 & & & \\
\hline SESPMNT & B16RB5 & YAKIMA BARRICADE & PERIMETER & AT & 11-Jul-03 & $\mathrm{Be}-7$ & 0.153 & $\mathrm{pCi} / \mathrm{m} 3$ & 0.029 & 0.029 & & & \\
\hline SESPMNT & B17682 & YAKIMA BARRICADE & PERIMETER & AT & 03-Oct-03 & $\mathrm{Be}-7$ & 0.165 & $\mathrm{pCi} / \mathrm{m} 3$ & 0.037 & 0.037 & & & \\
\hline SESPMNT & B17PX2 & YAKIMA BARRICADE & PERIMETER & AT & 09-Jan-04 & $\mathrm{Be}-7$ & 0.0738 & $\mathrm{pCi} / \mathrm{m} 3$ & 0.015 & 0.015 & & & \\
\hline
\end{tabular}


AIR GAMMA

\begin{tabular}{|c|c|c|c|c|c|c|c|c|c|c|c|c|c|}
\hline OWNER ID & SAMP NUM & SAMP SITE NAME & | DIST CLASS & MEDIA & SAMP DATE & $\begin{array}{l}\text { CON SHORT } \\
\text { NAME }\end{array}$ & |VALUE RPTD & $\begin{array}{l}\text { ANAL } \\
\text { UNITS } \\
\text { RPTD }\end{array}$ & $\left|\begin{array}{c}\text { COUNTING } \\
\text { ERROR }\end{array}\right|$ & $\begin{array}{c}\text { TOTAL ANAL } \\
\text { ERROR }\end{array}$ & $\mid \begin{array}{c}\text { LAB } \\
\text { QUALIFIER }\end{array}$ & SAMP COMMENT & RESULT COMMENT \\
\hline SESPMNT & B168C4 & 100 AREAS & ONSITE & AT & 31-Mar-03 & Co-60 & 0.0000797 & $\mathrm{pCi} / \mathrm{m} 3$ & 0.0003 & 0.0003 & u & & \\
\hline SESPMNT & B16PP5 & 100 AREAS & ONSITE & AT & 08-Jul-03 & Co-60 & 0.0000632 & $\mathrm{pCi} / \mathrm{m} 3$ & 0.00026 & 0.00026 & $U$ & & \\
\hline SESPMNT & B175M4 & 100 AREAS & ONSITE & AT & 01-Oct-03 & Co-60 & 0.000456 & $\mathrm{pCi} / \mathrm{m} 3$ & 0.00052 & 0.00052 & $U$ & & \\
\hline SESPMNT & B17P82 & 100 AREAS & ONSITE & AT & 06-Jan-04 & Co-60 & 0.00036 & $\mathrm{pC} / / \mathrm{m} 3$ & 0.00032 & 0.00032 & U & & \\
\hline SESPMNT & B168F3 & 200 E AREA & ONSITE & AT & 08-Apr-03 & Co-60 & -0.000228 & $\mathrm{pC} / / \mathrm{m} 3$ & 0.00035 & 0.00035 & $u$ & & \\
\hline SESPMNT & B16PT7 & 200 E AREA & ONSITE & AT & 30-Jun-03 & Co-60 & 0.000475 & $\mathrm{pC} / \mathrm{m} 3$ & 0.00049 & 0.00049 & u & & \\
\hline SESPMNT & B175P3 & 200 E AREA & ONSITE & AT & 07-Oct-03 & Co-60 & 0.00000669 & $\mathrm{pC} / / \mathrm{m} 3$ & 0.00032 & 0.00032 & $u$ & & \\
\hline SESPMNT & B17PB4 & 200 E AREA & ONSITE & AT & 30-Dec-03 & Co-60 & -0.000232 & $\mathrm{pCi} / \mathrm{m} 3$ & 0.00063 & 0.00063 & u & & \\
\hline SESPMNT & B168L8 & 200 W AREA & ONSITE & AT & 08-Apr-03 & Co-60 & -0.000309 & $\mathrm{pC} / \mathrm{m} 3$ & 0.00069 & 0.00069 & u & & \\
\hline SESPMNT & B16PY6 & 200 W AREA & ONSITE & AT & 30-Jun-03 & Co-60 & -0.000255 & $\mathrm{pC} / \mathrm{m} 3$ & 0.00055 & 0.00055 & u & & \\
\hline SESPMNT & B175W8 & 200 W AREA & ONSITE & AT & $07-\mathrm{Oct}-03$ & Co-60 & 0.000135 & $\mathrm{pC} / \mathrm{m} 3$ & 0.00064 & 0.00064 & u & & \\
\hline SESPMNT & $\mathrm{B} 17 \mathrm{PH} 3$ & 200 W AREA & ONSITE & AT & 30-Dec-03 & Co-60 & -0.000503 & $\mathrm{pCi} / \mathrm{m} 3$ & 0.00083 & 0.00083 & u & & \\
\hline SESPMNT & B168J6 & 200 W SOUTH EAST & ONSITE & AT & 08-Apr-03 & Co-60 & 0.000149 & $\mathrm{pC} / \mathrm{m} 3$ & 0.00018 & 0.00018 & u & & \\
\hline SESPMNT & B16PW7 & 200 W SOUTH EAST & ONSITE & AT & 30-Jun-03 & Co-60 & 0.0000754 & $\mathrm{pCi} / \mathrm{m} 3$ & 0.00022 & 0.00022 & u & & \\
\hline SESPMNT & B175T6 & 200 W SOUTH EAST & ONSITE & AT & $07-$ Oct-03 & Co-60 & -0.0000421 & $\mathrm{pC} / \mathrm{m} 3$ & 0.00021 & 0.00021 & u & & \\
\hline SESPMNT & B17PD4 & 200 W SOUTH EAST & ONSITE & AT & 30-Dec-03 & Co-60 & 0.000116 & $\mathrm{pCi} / \mathrm{m} 3$ & 0.00038 & 0.00038 & u & & \\
\hline SESPMNT & B168M6 & 300 AREA & ONSITE & AT & 02-Apr-03 & Co-60 & 0.000143 & $\mathrm{pC} / \mathrm{m} 3$ & 0.00021 & 0.00021 & $u$ & & \\
\hline SESPMNT & B16R03 & 300 AREA & ONSITE & AT & 10-Jul-03 & Co-60 & $\begin{array}{l}-0.000207 \\
-0.007\end{array}$ & $\mathrm{pCi} / \mathrm{m} 3$ & 0.00028 & 0.00028 & u & & \\
\hline SESPMNT & B175X6 & 300 AREA & ONSITE & AT & 30-Sep-03 & Co-60 & 0.000285 & $\mathrm{pC} / \mathrm{m} 3$ & 0.00042 & 0.00042 & u & & \\
\hline SESPMNT & B17PJo & 300 AREA & ONSITE & AT & 08-Jan-04 & Co-60 & -0.000227 & $\mathrm{pCi} / \mathrm{m} 3$ & 0.00028 & 0.00028 & u & & \\
\hline SESPMNT & B167V4 & $300 \mathrm{NE}$ & ONSITE & AT & 02-Apr-03 & Co-60 & 0.00015 & $\mathrm{pC} / \mathrm{m} 3$ & 0.00063 & 0.00063 & $u$ & & \\
\hline SESPMNT & B16P66 & $300 \mathrm{NE}$ & ONSITE & AT & 10-Jul-03 & Co-60 & 0.000466 & $\mathrm{pCi} / \mathrm{m} 3$ & 0.00064 & 0.00064 & u & & \\
\hline SESPMNT & B17548 & $300 \mathrm{NE}$ & ONSITE & AT & 30-Sep-03 & Co-60 & 0.000729 & $\mathrm{pC} / \mathrm{m} 3$ & 0.00095 & 0.00095 & $u$ & & \\
\hline SESPMNT & B17NP7 & $300 \mathrm{NE}$ & ONSITE & AT & 08-Jan-04 & Co-60 & 0.0006 & $\mathrm{pCi} / \mathrm{m} 3$ & 0.00075 & 0.00075 & U & & \\
\hline SESPMNT & B167V3 & 300 TRENCH & ONSITE & AT & 02-Apr-03 & Co-60 & -0.000116 & $\mathrm{pC} / \mathrm{m} 3$ & 0.0007 & 0.0007 & u & & \\
\hline SESPMNT & B16P65 & 300 TRENCH & ONSITE & AT & 10-Jul-03 & Co-60 & -0.000278 & $\mathrm{pCi} / \mathrm{m} 3$ & 0.00069 & 0.00069 & u & & \\
\hline SESPMNT & B17547 & 300 TRENCH & ONSITE & AT & 30-Sep-03 & Co-60 & 0.000162 & $\mathrm{pCl} / \mathrm{m} 3$ & 0.00086 & 0.00086 & $u$ & & \\
\hline SESPMNT & B17NP6 & 300 TRENCH & ONSITE & AT & 08-Jan-04 & Co-60 & -0.000579 & $\mathrm{pCi} / \mathrm{m} 3$ & 0.00084 & 0.00084 & U & & \\
\hline SESPMNT & B168P5 & 400 AREA & ONSITE & AT & 31-Mar-03 & Co-60 & 0.00000141 & $\mathrm{pCi} / \mathrm{m} 3$ & 0.0002 & 0.0002 & $u$ & & \\
\hline SESPMNT & B16R25 & 400 AREA & ONSITE & AT & 08-Jul-03 & Co-60 & 0.0000677 & $\mathrm{pC} / \mathrm{m} 3$ & 0.00017 & 0.00017 & U & & \\
\hline SESPMNT & B17605 & 400 AREA & ONSITE & AT & $01-O c t-03$ & Co-60 & -0.0000545 & $\mathrm{pCi} / \mathrm{m} 3$ & 0.00025 & 0.00025 & u & & \\
\hline SESPMNT & B17PL2 & 400 AREA & ONSITE & AT & 05-Jan-04 & Co-60 & 0.000112 & $\mathrm{pCi} / \mathrm{m} 3$ & 0.00018 & 0.00018 & U & & \\
\hline SESPMNT & B168H8 & B POND & ONSITE & AT & 08-Apr-03 & Co-60 & 0.000325 & $\mathrm{pCl} / \mathrm{m} 3$ & 0.00056 & 0.00056 & $U$ & & \\
\hline SESPMNT & B16PW0 & B POND & ONSITE & AT & 30-Jun-03 & Co-60 & 0.0006 & $\mathrm{pCi} / \mathrm{m} 3$ & 0.00088 & 0.00088 & $u$ & & \\
\hline SESPMNT & B175R8 & B POND & ONSITE & AT & $07-0 c t-03$ & Co-60 & -0.00000475 & $\mathrm{pCi} / \mathrm{m} 3$ & 0.00058 & 0.00058 & $u$ & & \\
\hline SESPMNT & B17PC7 & B POND & ONSITE & AT & 30-Dec-03 & Co-60 & 0.000132 & $\mathrm{pCi} / \mathrm{m} 3$ & 0.0011 & 0.0011 & 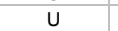 & & \\
\hline SESPMNT & B16962 & BASIN CITY SCHOOL & COMMUNITY & AT & 09-Apr-03 & Co-60 & 0.00023 & $\mathrm{pCl} / \mathrm{m} 3$ & 0.00054 & 0.00054 & $U$ & & \\
\hline SESPMNT & B16RJ4 & BASIN CITY SCHOOL & COMMUNITY & AT & 02-Jul-03 & Co-60 & -0.000536 & $\mathrm{pCi} / \mathrm{m} 3$ & 0.00063 & 0.00063 & u & & \\
\hline SESPMNT & B176F2 & BASIN CITY SCHOOL & COMMUNITY & AT & $08-O c t-03$ & Co-60 & 0.000272 & $\mathrm{pCi} / \mathrm{m} 3$ & 0.00096 & 0.00096 & $u$ & & \\
\hline SESPMNT & B17R31 & BASIN CITY SCHOOL & COMMUNITY & AT & 31-Dec-03 & Co-60 & -0.000166 & $\mathrm{pCi} / \mathrm{m} 3$ & 0.00069 & 0.00069 & $u$ & & \\
\hline SESPMNT & B16820 & BATTELLE COMPLEX & PERIMETER & AT & 02-Apr-03 & Co-60 & -0.000413 & $\mathrm{pCl} / \mathrm{m} 3$ & 0.00061 & 0.00061 & $u$ & & \\
\hline SESPMNT & B16PD4 & BATTELLE COMPLEX & PERIMETER & AT & 09-Jul-03 & Co-60 & -0.0000719 & $\mathrm{pCi} / \mathrm{m} 3$ & 0.00047 & 0.00047 & u & & \\
\hline SESPMNT & B175B4 & BATTELLE COMPLEX & PERIMETER & AT & 30-Sep-03 & Co-60 & -0.000125 & $\mathrm{pCi} / \mathrm{m} 3$ & 0.00073 & 0.00073 & $U$ & & \\
\hline SESPMNT & B17NY7 & BATTELLE COMPLEX & PERIMETER & AT & 08-Jan-04 & Co-60 & -0.000269 & $\mathrm{pCi} / \mathrm{m} 3$ & 0.0007 & 0.0007 & 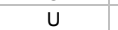 & & \\
\hline SESPMNT & B16827 & BENTON CITY & COMMUNITY & AT & 03-Apr-03 & Co-60 & 0.000531 & $\mathrm{pCi} / \mathrm{m} 3$ & 0.00074 & 0.00074 & $u$ & & \\
\hline SESPMNT & B16PF2 & BENTON CITY & COMMUNITY & AT & 11-Jul-03 & Co-60 & 0.000264 & $\mathrm{pCi} / \mathrm{m} 3$ & 0.00038 & 0.00038 & u & & \\
\hline $\begin{array}{l}\text { SESPMNT } \\
\text { SESPIV }\end{array}$ & B175C1 & BENTON CITY & COMMUNITY & AT & $03-$ Oct-03 & Co-60 & 0.000176 & $\mathrm{pCl} / \mathrm{m} 3$ & 0.00088 & 0.00088 & u & & \\
\hline SESPMNT & B17P05 & BENTON CITY & COMMUNITY & AT & 09-Jan-04 & Co-60 & 0.000461 & $\mathrm{pC} / \mathrm{m} 3$ & 0.00078 & 0.00078 & u & & \\
\hline SESPMNT & B168Y1 & BYERS LANDING & PERIMETER & AT & 10-Apr-03 & Co-60 & 0.000717 & $\mathrm{pCi} / \mathrm{m} 3$ & 0.00057 & 0.00057 & $u$ & & \\
\hline SESPMNT & B16R83 & BYERS LANDING & PERIMETER & AT & 07-Jul-03 & Co-60 & 0.000362 & $\mathrm{pCi} / \mathrm{m} 3$ & 0.00061 & 0.00061 & u & & \\
\hline $\begin{array}{l}\text { SESPMNT } \\
\text { SESPIV }\end{array}$ & B17661 & BYERS LANDING & PERIMETER & AT & $10-$ Oct-03 & Co-60 & 0.000424 & $\mathrm{pCl} / \mathrm{m} 3$ & 0.00062 & 0.00062 & u & & \\
\hline SESPMNT & B17PV0 & BYERS LANDING & PERIMETER & AT & 05-Jan-04 & Co-60 & -0.0000262 & $\mathrm{pCl} / \mathrm{m} 3$ & 0.00094 & 0.00094 & $u$ & & \\
\hline SESPMNT & B168X3 & DOGWOOD MET TOWER & PERIMETER & AT & 10-Apr-03 & Co-60 & -0.0000656 & $\mathrm{pCl} / \mathrm{m} 3$ & 0.00053 & 0.00053 & $\mathrm{u}$ & & \\
\hline SESPMNT & B16R76 & DOGWOOD MET TOWER & PERIMETER & AT & 07-Jul-03 & Co-60 & 0.000309 & $\mathrm{pCi} / \mathrm{m} 3$ & 0.00058 & 0.00058 & u & & \\
\hline SESPMNT & B17653 & DOGWOOD MET TOWER & PERIMETER & AT & $10-$ Oct-03 & Co-60 & 0.000488 & $\mathrm{pCl} / \mathrm{m} 3$ & $\begin{array}{r}0.0007 \\
0.000\end{array}$ & 0.0007 & u & & \\
\hline SESPMNT & B17РT3 & DOGWOOD MET TOWER & PERIMETER & AT & 05-Jan-04 & Co-60 & -0.0000116 & $\mathrm{pCi} / \mathrm{m} 3$ & 0.00064 & 0.00064 & u & & \\
\hline SESPMNT & B16978 & EDWIN MARKHAM SCHOOL & COMMUNITY & AT & 10-Apr-03 & Co-60 & -0.000224 & $\mathrm{pCl} / \mathrm{m} 3$ & 0.00052 & 0.00052 & U & & \\
\hline SESPMNT & B16RK8 & EDWIN MARKHAM SCHOOL & COMMUNITY & AT & 02-Jul-03 & Co-60 & -0.000222 & $\mathrm{pC} / \mathrm{m} 3$ & 0.00065 & 0.00065 & $\mathrm{U}$ & & \\
\hline
\end{tabular}


AIR GAMMA

\begin{tabular}{|c|c|c|c|c|c|c|c|c|c|c|c|c|c|}
\hline OWNER ID & | SAMP NUM | & SAMP SITE NAME & DIST CLASS & MEDIA & SAMP DATE & $\begin{array}{l}\text { CON SHORT } \\
\text { NAME }\end{array}$ & |VALUE RPTD | & $\mid \begin{array}{c}\text { ANAL } \\
\text { UNITS } \\
\text { RPTD }\end{array}$ & $\begin{array}{c}\text { COUNTING } \\
\text { ERROR }\end{array}$ & $\begin{array}{c}\text { TOTAL ANAL } \\
\text { ERROR }\end{array} \mid$ & $\begin{array}{c}\text { LAB } \\
\text { QUALIFIER }\end{array}$ & SAMP COMMENT & RESULT COMMENT \\
\hline SESPMNT & B176H8 & EDWIN MARKHAM SCHOOL & COMMUNITY & AT & 08-Oct-03 & Co-60 & 0.000206 & $\mathrm{pCi} / \mathrm{m} 3$ & 0.00061 & 0.00061 & u & & \\
\hline SESPMNT & B17R45 & EDWIN MARKHAM SCHOOL & COMMUNITY & AT & 31-Dec-03 & Co-60 & -0.000306 & $\mathrm{pCi} / \mathrm{m} 3$ & 0.00086 & 0.00086 & $u$ & & \\
\hline SESPMNT & B16986 & HANFORD TOWNSITE & ONSITE & AT & 31-Mar-03 & Co-60 & 0.000242 & $\mathrm{pC} / / \mathrm{m} 3$ & 0.00042 & 0.00042 & $u$ & & \\
\hline SESPMNT & B16RL5 & HANFORD TOWNSITE & ONSITE & AT & 08-Jul-03 & Co-60 & -0.000088 & $\mathrm{pCi} / \mathrm{m} 3$ & 0.00033 & 0.00033 & $u$ & & \\
\hline SESPMNT & B176J6 & HANFORD TOWNSITE & ONSITE & AT & $01-O c t-03$ & Co-60 & -0.0000868 & $\mathrm{pC} / \mathrm{m} 3$ & 0.00062 & 0.00062 & u & & \\
\hline SESPMNT & B17R52 & HANFORD TOWNSITE & ONSITE & AT & 06-Jan-04 & Co-60 & 0.0000597 & $\mathrm{pCi} / \mathrm{m} 3$ & 0.00033 & 0.00033 & $u$ & & \\
\hline SESPMNT & B16970 & LESLIE GROVES-RCHLND & COMMUNITY & AT & 08-Apr-03 & Co-60 & -0.000171 & $\mathrm{pC} / \mathrm{m} 3$ & 0.00058 & 0.00058 & $u$ & & \\
\hline SESPMNT & B16RK1 & LESLIE GROVES-RCHLND & COMMUNITY & AT & 01-Jul-03 & Co-60 & 0.000807 & $\mathrm{pCi} / \mathrm{m} 3$ & 0.00066 & 0.00066 & $u$ & & \\
\hline SESPMNT & $\mathrm{B} 176 \mathrm{HO}$ & LESLIE GROVES-RCHLND & COMMUNITY & AT & $07-0 c t-03$ & Co-60 & 0.000861 & $\mathrm{pC} / \mathrm{m} 3$ & 0.00081 & 0.00081 & u & & \\
\hline SESPMNT & B17R38 & LESLIE GROVES-RCHLND & COMMUNITY & AT & 30-Dec-03 & Co-60 & 0.000652 & $\mathrm{pCi} / \mathrm{m} 3$ & 0.00081 & 0.00081 & $\mathrm{U}$ & & \\
\hline SESPMNT & B16834 & MATTAWA & COMMUNITY & AT & 09-Apr-03 & Co-60 & 0.0000445 & $\mathrm{pCi} / \mathrm{m} 3$ & 0.00061 & 0.00061 & $u$ & & \\
\hline SESPMNT & B16PHO & MATTAWA & COMMUNITY & AT & 01-Jul-03 & Co-60 & 0.000113 & $\mathrm{pCi} / \mathrm{m} 3$ & 0.00055 & 0.00055 & $u$ & & \\
\hline SESPMNT & B175C8 & MATTAWA & COMMUNITY & AT & $09-0 c t-03$ & Co-60 & -0.000129 & $\mathrm{pC} / \mathrm{m} 3$ & 0.00078 & 0.00078 & u & & \\
\hline SESPMNT & B17P13 & MATTAWA & COMMUNITY & AT & 31-Dec-03 & Co-60 & 0.000519 & $\mathrm{pCi} / \mathrm{m} 3$ & 0.00095 & 0.00095 & U & & \\
\hline SESPMNT & B16812 & N OF $200 \mathrm{E}$ & ONSITE & AT & 08-Apr-03 & Co-60 & 0.000556 & $\mathrm{pCi} / \mathrm{m} 3$ & 0.0005 & 0.0005 & $u$ & & \\
\hline SESPMNT & B16PC7 & N OF $200 \mathrm{E}$ & ONSITE & AT & 30-Jun-03 & Co-60 & 0.0000525 & $\mathrm{pCi} / \mathrm{m} 3$ & 0.00068 & 0.00068 & $u$ & & \\
\hline SESPMNT & B17596 & N OF $200 \mathrm{E}$ & ONSITE & AT & $07-0 c t-03$ & Co-60 & -0.000112 & $\mathrm{pCi} / \mathrm{m} 3$ & 0.00072 & 0.00072 & $u$ & & \\
\hline SESPMNT & B17NY0 & N OF $200 \mathrm{E}$ & ONSITE & AT & 30-Dec-03 & Co-60 & -0.000147 & $\mathrm{pCi} / \mathrm{m} 3$ & 0.00085 & 0.00085 & $u$ & & \\
\hline SESPMNT & B16842 & OTHELLO & COMMUNITY & AT & 09-Apr-03 & Co-60 & -0.000503 & $\mathrm{pCi} / \mathrm{m} 3$ & 0.00053 & 0.00053 & $u$ & & \\
\hline SESPMNT & B16PH7 & OTHELLO & COMMUNITY & AT & 01-Jul-03 & Co-60 & -0.000213 & $\mathrm{pCi} / \mathrm{m} 3$ & 0.00059 & 0.00059 & $u$ & & \\
\hline SESPMNT & B175D6 & OTHELLO & COMMUNITY & AT & $09-0 c t-03$ & Co-60 & -0.000656 & $\mathrm{pCi} / \mathrm{m} 3$ & 0.00069 & 0.00069 & $u$ & & \\
\hline SESPMNT & B17P20 & OTHELLO & COMMUNITY & AT & 31-Dec-03 & Co-60 & -0.0000127 & $\mathrm{pCi} / \mathrm{m} 3$ & 0.001 & 0.001 & $u$ & & \\
\hline SESPMNT & B168Y9 & PROSSER BARRICADE & PERIMETER & AT & 03-Apr-03 & Co-60 & -0.000337 & $\mathrm{pCi} / \mathrm{m} 3$ & 0.00046 & 0.00046 & $U$ & & \\
\hline SESPMNT & B16R90 & PROSSER BARRICADE & PERIMETER & AT & 11-Jul-03 & Co-60 & -0.000205 & $\mathrm{pCi} / \mathrm{m} 3$ & 0.00037 & 0.00037 & U & & \\
\hline SESPMNT & B17669 & PROSSER BARRICADE & PERIMETER & AT & 03-Oct-03 & Co-60 & 0.000155 & $\mathrm{pCi} / \mathrm{m} 3$ & 0.00053 & 0.00053 & u & & \\
\hline SESPMNT & B17PV7 & PROSSER BARRICADE & PERIMETER & AT & 09-Jan-04 & Co-60 & -0.0000825 & $\mathrm{pCi} / \mathrm{m} 3$ & 0.00044 & 0.00044 & $u$ & & \\
\hline SESPMNT & B168W5 & RINGOLD MET TOWER & PERIMETER & AT & 10-Apr-03 & Co-60 & -0.0000172 & $\mathrm{pCi} / \mathrm{m} 3$ & 0.00042 & 0.00042 & $U$ & & \\
\hline SESPMNT & B16R69 & RINGOLD MET TOWER & PERIMETER & AT & 07-Jul-03 & Co-60 & 0.000101 & $\mathrm{pCi} / \mathrm{m} 3$ & $\begin{array}{l}0.00065 \\
\end{array}$ & 0.00065 & u & & \\
\hline SESPMNT & B17645 & RINGOLD MET TOWER & PERIMETER & AT & $10-$ Oct-03 & Co-60 & -0.000737 & $\mathrm{pCl} / \mathrm{m} 3$ & 0.00071 & 0.00071 & $u$ & & \\
\hline SESPMNT & B17PR6 & RINGOLD MET TOWER & PERIMETER & AT & 05-Jan-04 & Co-60 & 0.000637 & $\mathrm{pC} / \mathrm{m} 3$ & 0.00067 & 0.00067 & $u$ & & \\
\hline SESPMNT & B16805 & TOPPENISH & DISTANT & AT & 02-Apr-03 & Co-60 & 0.00000543 & $\mathrm{pCi} / \mathrm{m} 3$ & 0.00063 & 0.00063 & $U$ & & \\
\hline SESPMNT & B16PB9 & TOPPENISH & DISTANT & AT & 09-Jul-03 & Co-60 & -0.000103 & $\mathrm{pCi} / \mathrm{m} 3$ & 0.00059 & 0.00059 & u & & \\
\hline SESPMNT & B17589 & TOPPENISH & DISTANT & AT & $01-O c t-03$ & Co-60 & -0.000143 & $\mathrm{pCl} / \mathrm{m} 3$ & 0.00062 & 0.00062 & $u$ & & \\
\hline SESPMNT & B17NX2 & TOPPENISH & DISTANT & AT & 08-Jan-04 & Co-60 & -0.0000422 & $\mathrm{pCi} / \mathrm{m} 3$ & 0.0011 & 0.0011 & $U$ & & \\
\hline SESPMNT & B16940 & TRI CITIES & COMMUNITY & AT & 10-Apr-03 & Co-60 & 0.0000668 & $\mathrm{pCi} / \mathrm{m} 3$ & 0.00032 & 0.00032 & $u$ & & \\
\hline SESPMNT & B16RF3 & TRI CITIES & COMMUNITY & AT & 07-Jul-03 & Co-60 & 0.000198 & $\mathrm{pCi} / \mathrm{m} 3$ & 0.00038 & 0.00038 & u & & \\
\hline SESPMNT & $\mathrm{B} 176 \mathrm{CO}$ & TRI CITIES & COMMUNITY & AT & 10-Oct-03 & Co-60 & -0.000353 & $\mathrm{pCl} / \mathrm{m} 3$ & 0.00058 & 0.00058 & $u$ & & \\
\hline SESPMNT & B17R10 & TRI CITIES & COMMUNITY & AT & 05-Jan-04 & Co-60 & -0.000341 & $\mathrm{pCi} / \mathrm{m} 3$ & 0.00053 & 0.00053 & $u$ & & \\
\hline SESPMNT & B168V7 & W END OF FIR ROAD & PERIMETER & AT & 10-Apr-03 & Co-60 & -0.000187 & $\mathrm{pCl} / \mathrm{m} 3$ & 0.00048 & 0.00048 & $u$ & & \\
\hline SESPMNT & B16R62 & W END OF FIR ROAD & PERIMETER & AT & 07-Jul-03 & Co-60 & 0.000382 & $\mathrm{pCi} / \mathrm{m} 3$ & 0.00072 & 0.00072 & U & & \\
\hline SESPMNT & B17637 & W END OF FIR ROAD & PERIMETER & AT & 10-Oct-03 & Co-60 & -0.0000856 & $\mathrm{pCl} / \mathrm{m} 3$ & 0.00084 & 0.00084 & $u$ & & \\
\hline SESPMNT & B17PP9 & W END OF FIR ROAD & PERIMETER & AT & 05-Jan-04 & Co-60 & 0.000288 & $\mathrm{pCi} / \mathrm{m} 3$ & 0.00081 & 0.00081 & u & & \\
\hline SESPMNT & B16925 & WAHLUKE SLOPE & PERIMETER & AT & 09-Apr-03 & Co-60 & 0.000233 & $\mathrm{pCl} / \mathrm{m} 3$ & 0.00038 & 0.00038 & u & & \\
\hline SESPMNT & B16RD0 & WAHLUKE SLOPE & PERIMETER & AT & 01-Jul-03 & Co-60 & -0.000168 & $\mathrm{pCl} / \mathrm{m} 3$ & 0.00043 & 0.00043 & U & & \\
\hline SESPMNT & B17695 & WAHLUKE SLOPE & PERIMETER & AT & 08-Oct-03 & Co-60 & 0.0000707 & $\mathrm{pCl} / \mathrm{m} 3$ & 0.00055 & 0.00055 & $u$ & & \\
\hline SESPMNT & B17PY7 & WAHLUKE SLOPE & PERIMETER & AT & 31-Dec-03 & Co-60 & 0.000144 & $\mathrm{pCl} / \mathrm{m} 3$ & 0.0003 & 0.0003 & $u$ & & \\
\hline SESPMNT & B168Vo & WYE BARRICADE & ONSITE & AT & 31-Mar-03 & Co-60 & 0.00000675 & $\mathrm{pCi} / \mathrm{m} 3$ & 0.00071 & 0.00071 & U & & \\
\hline SESPMNT & B16R54 & WYE BARRICADE & ONSITE & AT & 08-Jul-03 & Co-60 & -0.00013 & $\mathrm{pCi} / \mathrm{m} 3$ & 0.00066 & 0.00066 & u & & \\
\hline SESPMNT & B17630 & WYE BARRICADE & ONSITE & AT & $01-0 c t-03$ & Co-60 & 0.0000885 & $\mathrm{pCl} / \mathrm{m} 3$ & 0.00096 & 0.00096 & $u$ & & \\
\hline SESPMNT & B17PP1 & WYE BARRICADE & ONSITE & AT & 06-Jan-04 & Co-60 & 0.000237 & $\mathrm{pCi} / \mathrm{m} 3$ & 0.00069 & 0.00069 & u & & \\
\hline SESPMNT & B16955 & YAKIMA & DISTANT & AT & 03-Apr-03 & Co-60 & 0.000225 & $\mathrm{pCi} / \mathrm{m} 3$ & 0.00064 & 0.00064 & U & & \\
\hline SESPMNT & B16RH6 & YAKIMA & DISTANT & AT & 11-Jul-03 & Co-60 & -0.00000138 & $\mathrm{pCl} / \mathrm{m} 3$ & 0.00053 & 0.00053 & $u$ & & \\
\hline SESPMNT & B176D5 & YAKIMA & DISTANT & AT & 03-Oct-03 & Co-60 & 0.000728 & $\mathrm{pCl} / \mathrm{m} 3$ & 0.001 & 0.001 & $u$ & & \\
\hline SESPMNT & B17R23 & YAKIMA & DISTANT & AT & 09-Jan-04 & Co-60 & -0.000204 & $\mathrm{pCi} / \mathrm{m} 3$ & 0.00069 & 0.00069 & u & & \\
\hline SESPMNT & B16912 & YAKIMA BARRICADE & PERIMETER & AT & 02-Apr-03 & Co-60 & 0.000227 & $\mathrm{pCi} / \mathrm{m} 3$ & 0.00032 & 0.00032 & $u$ & & \\
\hline SESPMNT & B16RB5 & YAKIMA BARRICADE & PERIMETER & AT & 11-Jul-03 & Co-60 & 0.000199 & $\mathrm{pCl} / \mathrm{m} 3$ & 0.0003 & 0.0003 & u & & \\
\hline SESPMNT & B17682 & YAKIMA BARRICADE & PERIMETER & AT & 03-Oct-03 & Co-60 & 0.0000782 & $\mathrm{pCi} / \mathrm{m} 3$ & 0.00033 & 0.00033 & 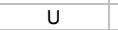 & & \\
\hline SESPMNT & B17PX2 & YAKIMA BARRICADE & PERIMETER & AT & 09-Jan-04 & Co-60 & -0.0000393 & $\mathrm{pCi} / \mathrm{m} 3$ & 0.0004 & 0.0004 & $u$ & & \\
\hline
\end{tabular}


AIR GAMMA

\begin{tabular}{|c|c|c|c|c|c|c|c|c|c|c|c|c|c|}
\hline OWNER ID & SAMP NUM & SAMP SITE NAME & | DIST CLASS & MEDIA & SAMP DATE & $\begin{array}{l}\text { CON SHORT } \\
\text { NAME }\end{array}$ & |VALUE RPTD & $\begin{array}{l}\text { ANAL } \\
\text { UNITS } \\
\text { RPTD }\end{array}$ & $\left|\begin{array}{c}\text { COUNTING } \\
\text { ERROR }\end{array}\right|$ & $\begin{array}{c}\text { TOTAL ANAL } \\
\text { ERROR }\end{array}$ & $\mid \begin{array}{c}\text { LAB } \\
\text { QUALIFIER }\end{array}$ & SAMP COMMENT & RESULT COMMENT \\
\hline SESPMNT & B168C4 & 100 AREAS & ONSITE & AT & 31-Mar-03 & Cs-134 & 0.0000572 & $\mathrm{pCi} / \mathrm{m} 3$ & 0.00028 & 0.00028 & u & & \\
\hline SESPMNT & B16PP5 & 100 AREAS & ONSITE & AT & 08-Jul-03 & Cs-134 & 0.0000992 & $\mathrm{pC} / \mathrm{m} 3$ & 0.0002 & 0.0002 & u & & \\
\hline SESPMNT & B175M4 & 100 AREAS & ONSITE & AT & 01-Oct-03 & Cs-134 & -0.000173 & $\mathrm{pCi} / \mathrm{m} 3$ & 0.00036 & 0.00036 & $U$ & & \\
\hline SESPMNT & B17P82 & 100 AREAS & ONSITE & AT & 06-Jan-04 & Cs-134 & 0.0000738 & $\mathrm{pC} / / \mathrm{m} 3$ & 0.00028 & 0.00028 & U & & \\
\hline SESPMNT & B168F3 & 200 E AREA & ONSITE & AT & 08-Apr-03 & Cs-134 & -0.000318 & $\mathrm{pC} / / \mathrm{m} 3$ & 0.00029 & 0.00029 & $u$ & & \\
\hline SESPMNT & B16PT7 & 200 E AREA & ONSITE & AT & 30-Jun-03 & Cs-134 & 0.000115 & $\mathrm{pCi} / \mathrm{m} 3$ & 0.00034 & 0.00034 & $u$ & & \\
\hline SESPMNT & B175P3 & 200 E AREA & ONSITE & AT & $07-$ Oct-03 & Cs-134 & -0.0000594 & $\mathrm{pC} / / \mathrm{m} 3$ & 0.00045 & 0.00045 & $u$ & & \\
\hline SESPMNT & B17PB4 & 200 E AREA & ONSITE & AT & 30-Dec-03 & Cs-134 & 0.000144 & $\mathrm{pCi} / \mathrm{m} 3$ & 0.00047 & 0.00047 & u & & \\
\hline SESPMNT & B168L8 & 200 W AREA & ONSITE & AT & 08-Apr-03 & Cs-134 & -0.000304 & $\mathrm{pC} / \mathrm{m} 3$ & 0.00068 & 0.00068 & u & & \\
\hline SESPMNT & B16PY6 & 200 W AREA & ONSITE & AT & 30-Jun-03 & Cs-134 & 0.000249 & $\mathrm{pC} / \mathrm{m} 3$ & 0.00038 & 0.00038 & u & & \\
\hline SESPMNT & B175W8 & 200 W AREA & ONSITE & AT & 07-Oct-03 & Cs-134 & 0.0000225 & $\mathrm{pC} / \mathrm{m} 3$ & 0.00067 & 0.00067 & u & & \\
\hline SESPMNT & $\mathrm{B} 17 \mathrm{PH} 3$ & 200 W AREA & ONSITE & AT & 30-Dec-03 & Cs-134 & 0.0000382 & $\mathrm{pCi} / \mathrm{m} 3$ & 0.00077 & 0.00077 & u & & \\
\hline SESPMNT & B168J6 & 200 W SOUTH EAST & ONSITE & AT & 08-Apr-03 & Cs-134 & -0.00000679 & $\mathrm{pC} / \mathrm{m} 3$ & 0.00017 & 0.00017 & u & & \\
\hline SESPMNT & B16PW7 & 200 W SOUTH EAST & ONSITE & AT & 30-Jun-03 & Cs-134 & 0.0000399 & $\mathrm{pCi} / \mathrm{m} 3$ & 0.00021 & 0.00021 & u & & \\
\hline SESPMNT & B175T6 & 200 W SOUTH EAST & ONSITE & AT & 07-Oct-03 & Cs-134 & 0.000071 & $\mathrm{pC} / \mathrm{m} 3$ & 0.00029 & 0.00029 & u & & \\
\hline SESPMNT & B17PD4 & 200 W SOUTH EAST & ONSITE & AT & 30-Dec-03 & Cs-134 & 0.00033 & $\mathrm{pCi} / \mathrm{m} 3$ & 0.00045 & 0.00045 & u & & \\
\hline SESPMNT & B168M6 & 300 AREA & ONSITE & AT & 02-Apr-03 & Cs-134 & 0.000212 & $\mathrm{pC} / \mathrm{m} 3$ & 0.00022 & 0.00022 & $u$ & & \\
\hline SESPMNT & B16R03 & 300 AREA & ONSITE & AT & 10-Jul-03 & Cs-134 & 0.0000362 & $\mathrm{pCi} / \mathrm{m} 3$ & $\begin{array}{l}0.00022 \\
\end{array}$ & 0.00022 & u & & \\
\hline SESPMNT & B175X6 & 300 AREA & ONSITE & AT & $30-$ Sep-03 & Cs-134 & 0.000476 & $\mathrm{pC} / \mathrm{m} 3$ & 0.0004 & 0.0004 & u & & \\
\hline SESPMNT & B17PJ0 & 300 AREA & ONSITE & AT & 08-Jan-04 & Cs-134 & 0.00015 & $\mathrm{pCi} / \mathrm{m} 3$ & 0.00017 & 0.00017 & u & & \\
\hline SESPMNT & B167V4 & $300 \mathrm{NE}$ & ONSITE & AT & 02-Apr-03 & Cs-134 & -0.0000476 & $\mathrm{pC} / \mathrm{m} 3$ & 0.00054 & 0.00054 & $u$ & & \\
\hline SESPMNT & B16P66 & $300 \mathrm{NE}$ & ONSITE & AT & 10-Jul-03 & Cs-134 & 0.000145 & $\mathrm{pCi} / \mathrm{m} 3$ & $\begin{array}{l}0.00057 \\
\end{array}$ & 0.00057 & u & & \\
\hline SESPMNT & B17548 & $300 \mathrm{NE}$ & ONSITE & AT & 30-Sep-03 & Cs-134 & 0.000252 & $\mathrm{pC} / \mathrm{m} 3$ & 0.00062 & 0.00062 & $u$ & & \\
\hline SESPMNT & B17NP7 & $300 \mathrm{NE}$ & ONSITE & AT & 08-Jan-04 & Cs-134 & 0.000078 & $\mathrm{pCi} / \mathrm{m} 3$ & 0.00053 & 0.00053 & U & & \\
\hline SESPMNT & B167V3 & 300 TRENCH & ONSITE & AT & 02-Apr-03 & Cs-134 & 0.00083 & $\mathrm{pC} / \mathrm{m} 3$ & 0.00075 & 0.00075 & u & & \\
\hline SESPMNT & B16P65 & 300 TRENCH & ONSITE & AT & 10-Jul-03 & Cs-134 & $\begin{array}{r}-0.000192 \\
-0.00\end{array}$ & $\mathrm{pCi} / \mathrm{m} 3$ & 0.00065 & 0.00065 & u & & \\
\hline SESPMNT & B17547 & 300 TRENCH & ONSITE & AT & 30-Sep-03 & Cs-134 & -0.00045 & $\mathrm{pCl} / \mathrm{m} 3$ & 0.00062 & 0.00062 & $u$ & & \\
\hline SESPMNT & B17NP6 & 300 TRENCH & ONSITE & AT & 08-Jan-04 & Cs-134 & 0.000534 & $\mathrm{pCi} / \mathrm{m} 3$ & 0.0011 & 0.0011 & U & & \\
\hline SESPMNT & B168P5 & 400 AREA & ONSITE & AT & 31-Mar-03 & Cs-134 & -0.000106 & $\mathrm{pCi} / \mathrm{m} 3$ & 0.00021 & 0.00021 & $u$ & & \\
\hline SESPMNT & B16R25 & 400 AREA & ONSITE & AT & 08-Jul-03 & Cs-134 & -0.0000331 & $\mathrm{pCi} / \mathrm{m} 3$ & 0.00016 & 0.00016 & u & & \\
\hline SESPMNT & B17605 & 400 AREA & ONSITE & AT & 01-Oct-03 & Cs-134 & -0.0000122 & $\mathrm{pCi} / \mathrm{m} 3$ & 0.00022 & 0.00022 & u & & \\
\hline SESPMNT & B17PL2 & 400 AREA & ONSITE & AT & 05-Jan-04 & Cs-134 & -0.000128 & $\mathrm{pCi} / \mathrm{m} 3$ & 0.00022 & 0.00022 & U & & \\
\hline SESPMNT & B168H8 & B POND & ONSITE & AT & 08-Apr-03 & Cs-134 & -0.000319 & $\mathrm{pCl} / \mathrm{m} 3$ & 0.00042 & 0.00042 & $U$ & & \\
\hline SESPMNT & B16PW0 & B POND & ONSITE & AT & 30-Jun-03 & Cs-134 & 0.000785 & $\mathrm{pCi} / \mathrm{m} 3$ & 0.0007 & 0.0007 & $u$ & & \\
\hline SESPMNT & B175R8 & B POND & ONSITE & AT & $07-O c t-03$ & Cs-134 & 0.0000762 & $\mathrm{pCi} / \mathrm{m} 3$ & 0.00079 & 0.00079 & U & & \\
\hline SESPMNT & B17PC7 & B POND & ONSITE & AT & 30-Dec-03 & Cs-134 & -0.000109 & $\mathrm{pCi} / \mathrm{m} 3$ & 0.0011 & 0.0011 & 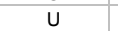 & & \\
\hline SESPMNT & B16962 & BASIN CITY SCHOOL & COMMUNITY & AT & 09-Apr-03 & Cs-134 & -0.000445 & $\mathrm{pCl} / \mathrm{m} 3$ & 0.0005 & 0.0005 & $u$ & & \\
\hline SESPMNT & B16RJ4 & BASIN CITY SCHOOL & COMMUNITY & AT & 02-Jul-03 & Cs-134 & 0.000346 & $\mathrm{pCi} / \mathrm{m} 3$ & 0.00075 & 0.00075 & u & & \\
\hline SESPMNT & B176F2 & BASIN CITY SCHOOL & COMMUNITY & AT & 08-Oct-03 & Cs-134 & -0.000225 & $\mathrm{pCl} / \mathrm{m} 3$ & 0.00071 & 0.00071 & $u$ & & \\
\hline SESPMNT & B17R31 & BASIN CITY SCHOOL & COMMUNITY & AT & 31-Dec-03 & Cs-134 & -0.0000981 & $\mathrm{pCi} / \mathrm{m} 3$ & 0.00086 & 0.00086 & $u$ & & \\
\hline SESPMNT & B16820 & BATTELLE COMPLEX & PERIMETER & AT & 02-Apr-03 & Cs-134 & -0.000416 & $\mathrm{pCl} / \mathrm{m} 3$ & 0.00063 & 0.00063 & $u$ & & \\
\hline SESPMNT & B16PD4 & BATTELLE COMPLEX & PERIMETER & AT & 09-Jul-03 & Cs-134 & -0.000193 & $\mathrm{pCi} / \mathrm{m} 3$ & 0.00049 & 0.00049 & u & & \\
\hline SESPMNT & B175B4 & BATTELLE COMPLEX & PERIMETER & AT & $30-$ Sep-03 & Cs-134 & 0.0000243 & $\mathrm{pCi} / \mathrm{m} 3$ & 0.0008 & 0.0008 & $U$ & & \\
\hline SESPMNT & B17NY7 & BATTELLE COMPLEX & PERIMETER & AT & 08-Jan-04 & Cs-134 & 0.000598 & $\mathrm{pCi} / \mathrm{m} 3$ & 0.00059 & 0.00059 & 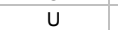 & & \\
\hline SESPMNT & B16827 & BENTON CITY & COMMUNITY & AT & 03-Apr-03 & Cs-134 & -0.000366 & $\mathrm{pCi} / \mathrm{m} 3$ & 0.00074 & 0.00074 & $u$ & & \\
\hline SESPMNT & B16PF2 & BENTON CITY & COMMUNITY & AT & 11-Jul-03 & Cs-134 & 0.000417 & $\mathrm{pCi} / \mathrm{m} 3$ & 0.00043 & 0.00043 & u & & \\
\hline SESPMNT & B175C1 & BENTON CITY & COMMUNITY & AT & $03-\mathrm{Oct}-03$ & Cs-134 & 0.000764 & $\mathrm{pCl} / \mathrm{m} 3$ & 0.00093 & 0.00093 & u & & \\
\hline SESPMNT & B17P05 & BENTON CITY & COMMUNITY & AT & 09-Jan-04 & Cs-134 & 0.0000645 & $\mathrm{pCl} / \mathrm{m} 3$ & 0.00066 & 0.00066 & u & & \\
\hline SESPMNT & B168Y1 & BYERS LANDING & PERIMETER & AT & 10-Apr-03 & Cs-134 & 0.000146 & $\mathrm{pCi} / \mathrm{m} 3$ & 0.00059 & 0.00059 & $u$ & & \\
\hline SESPMNT & B16R83 & BYERS LANDING & PERIMETER & AT & 07-Jul-03 & Cs-134 & 0.000537 & $\mathrm{pCi} / \mathrm{m} 3$ & 0.00059 & 0.00059 & u & & \\
\hline $\begin{array}{l}\text { SESPMNT } \\
\text { SESPIV }\end{array}$ & B17661 & BYERS LANDING & PERIMETER & AT & 10-Oct-03 & Cs-134 & 0.00012 & $\mathrm{pCi} / \mathrm{m} 3$ & 0.00083 & 0.00083 & u & & \\
\hline SESPMNT & B17PV0 & BYERS LANDING & PERIMETER & AT & 05-Jan-04 & Cs-134 & 0.000748 & $\mathrm{pCl} / \mathrm{m} 3$ & 0.00075 & 0.00075 & $u$ & & \\
\hline SESPMNT & B168X3 & DOGWOOD MET TOWER & PERIMETER & AT & 10-Apr-03 & Cs-134 & $\begin{array}{c}-0.000123 \\
-0.00140\end{array}$ & $\mathrm{pCi} / \mathrm{m} 3$ & 0.00039 & 0.00039 & $\mathrm{u}$ & & \\
\hline SESPMNT & B16R76 & DOGWOOD MET TOWER & PERIMETER & AT & 07-Jul-03 & Cs-134 & 0.000237 & $\mathrm{pCi} / \mathrm{m} 3$ & 0.00072 & 0.00072 & u & & \\
\hline SESPMNT & B17653 & DOGWOOD MET TOWER & PERIMETER & AT & $10-$ Oct-03 & Cs-134 & $\begin{array}{l}-0.000451 \\
-0.00041\end{array}$ & $\mathrm{pCl} / \mathrm{m} 3$ & 0.00054 & 0.00054 & u & & \\
\hline SESPMNT & B17РT3 & DOGWOOD MET TOWER & PERIMETER & AT & 05-Jan-04 & Cs-134 & -0.000192 & $\mathrm{pCi} / \mathrm{m} 3$ & 0.00075 & 0.00075 & u & & \\
\hline SESPMNT & B16978 & EDWIN MARKHAM SCHOOL & COMMUNITY & AT & 10-Apr-03 & Cs-134 & -0.000729 & $\mathrm{pCl} / \mathrm{m} 3$ & 0.00063 & 0.00063 & U & & \\
\hline SESPMNT & B16RK8 & EDWIN MARKHAM SCHOOL & COMMUNITY & AT & 02-Jul-03 & Cs-134 & -0.0000407 & $\mathrm{pCi} / \mathrm{m} 3$ & 0.00053 & 0.00053 & u & & \\
\hline
\end{tabular}


AIR GAMMA

\begin{tabular}{|c|c|c|c|c|c|c|c|c|c|c|c|c|c|}
\hline $\mid$ OWNER ID $\mid$ & SAMP NUM & SAMP SITE NAME & DIST CLASS & MEDIA & SAMP DATE & $\begin{array}{l}\text { CON SHORT } \\
\text { NAME }\end{array}$ & |VALUE RPTD & $\begin{array}{l}\text { ANAL } \\
\text { UNITS } \\
\text { RPTD }\end{array}$ & $\left|\begin{array}{c}\text { COUNTING } \\
\text { ERROR }\end{array}\right|$ & $\begin{array}{c}\text { TOTAL ANAL } \\
\text { ERROR }\end{array}$ & $\left|\begin{array}{c}\text { LAB } \\
\text { QUALIFIER }\end{array}\right|$ & SAMP COMMENT & RESULT COMMENT \\
\hline SESPMNT & $\mathrm{B} 176 \mathrm{H} 8$ & EDWIN MARKHAM SCHOOL & COMMUNITY & AT & 08-Oct-03 & Cs-134 & 0.0000185 & $\mathrm{pCi} / \mathrm{m} 3$ & 0.00067 & 0.00067 & u & & \\
\hline SESPMNT & B17R45 & EDWIN MARKHAM SCHOOL & COMMUNITY & AT & 31-Dec-03 & Cs-134 & -0.000166 & $\mathrm{pCi} / \mathrm{m} 3$ & 0.00093 & 0.00093 & u & & \\
\hline SESPMNT & B16986 & HANFORD TOWNSITE & ONSITE & AT & 31-Mar-03 & Cs-134 & 0.000314 & $\mathrm{pCi} / \mathrm{m} 3$ & 0.00036 & 0.00036 & $U$ & & \\
\hline SESPMNT & B16RL5 & HANFORD TOWNSITE & ONSITE & AT & 08-Jul-03 & Cs-134 & 0.0000249 & $\mathrm{pC} / / \mathrm{m} 3$ & 0.00022 & 0.00022 & $\mathrm{U}$ & & \\
\hline SESPMNT & B176J6 & HANFORD TOWNSITE & ONSITE & AT & 01-Oct-03 & Cs-134 & 0.000363 & $\mathrm{pC} / / \mathrm{m} 3$ & 0.00049 & 0.00049 & $\mathrm{U}$ & & \\
\hline SESPMNT & B17R52 & HANFORD TOWNSITE & ONSITE & AT & $06-J a n-04$ & Cs-134 & 0.0000486 & $\mathrm{pC} / \mathrm{m} 3$ & 0.00037 & 0.00037 & u & & \\
\hline SESPMNT & B16970 & LESLIE GROVES-RCHLND & COMMUNITY & AT & 08-Apr-03 & Cs-134 & 0.0000483 & $\mathrm{pC} / / \mathrm{m} 3$ & 0.00053 & 0.00053 & U & & \\
\hline SESPMNT & B16RK1 & LESLIE GROVES-RCHLND & COMMUNITY & AT & 01-Jul-03 & Cs-134 & -0.000385 & $\mathrm{pCi} / \mathrm{m} 3$ & 0.00068 & 0.00068 & u & & \\
\hline SESPMNT & B176HO & LESLIE GROVES-RCHLND & COMMUNITY & AT & 07-Oct-03 & Cs-134 & -0.0000434 & $\mathrm{pC} / \mathrm{m} 3$ & 0.00077 & 0.00077 & u & & \\
\hline SESPMNT & B17R38 & LESLIE GROVES-RCHLND & COMMUNITY & AT & 30-Dec-03 & Cs-134 & 0.000489 & $\mathrm{pCi} / \mathrm{m} 3$ & 0.00094 & 0.00094 & $\mathrm{u}$ & & \\
\hline SESPMNT & B16834 & MATTAWA & COMMUNITY & AT & 09-Apr-03 & Cs-134 & 0.00000338 & $\mathrm{pC} / \mathrm{m} 3$ & 0.00059 & 0.00059 & u & & \\
\hline SESPMNT & B16PHO & MATTAWA & COMMUNITY & AT & 01-Jul-03 & Cs-134 & -0.0000707 & $\mathrm{pCi} / \mathrm{m} 3$ & 0.00056 & 0.00056 & u & & \\
\hline SESPMNT & B175C8 & MATTAWA & COMMUNITY & AT & 09-Oct-03 & Cs-134 & 0.000303 & $\mathrm{pC} / \mathrm{m} 3$ & 0.00089 & 0.00089 & u & & \\
\hline SESPMNT & B17P13 & MATTAWA & COMMUNITY & AT & 31-Dec-03 & Cs-134 & -0.00104 & $\mathrm{pCi} / \mathrm{m} 3$ & 0.00095 & 0.00095 & u & & \\
\hline SESPMNT & B16812 & N OF $200 \mathrm{E}$ & ONSITE & AT & 08-Apr-03 & Cs-134 & 0.00055 & $\mathrm{pC} / \mathrm{m} 3$ & 0.0005 & 0.0005 & u & & \\
\hline SESPMNT & B16PC7 & N OF $200 E$ & ONSITE & AT & 30-Jun-03 & Cs-134 & -0.0000356 & $\mathrm{pCi} / \mathrm{m} 3$ & 0.00065 & 0.00065 & u & & \\
\hline SESPMNT & B17596 & N OF $200 \mathrm{E}$ & ONSITE & AT & $07-$ Oct-03 & Cs-134 & 0.00000958 & $\mathrm{pC} / \mathrm{m} 3$ & 0.00075 & 0.00075 & $u$ & & \\
\hline SESPMNT & B17NYO & N OF $200 \mathrm{E}$ & ONSITE & AT & 30-Dec-03 & Cs-134 & 0.000474 & $\mathrm{pCi} / \mathrm{m} 3$ & 0.001 & 0.001 & u & & \\
\hline SESPMNT & B16842 & OTHELLO & COMMUNITY & AT & 09-Apr-03 & Cs-134 & 0.000297 & $\mathrm{pC} / \mathrm{m} 3$ & 0.00058 & 0.00058 & u & & \\
\hline SESPMNT & B16PH7 & OTHELLO & COMMUNITY & AT & 01-Jul-03 & Cs-134 & 0.0000725 & $\mathrm{pCi} / \mathrm{m} 3$ & 0.00061 & 0.00061 & u & & \\
\hline SESPMNT & B175D6 & OTHELLO & COMMUNITY & AT & 09-Oct-03 & Cs-134 & -0.000418 & $\mathrm{pC} / \mathrm{m} 3$ & 0.00074 & 0.00074 & $u$ & & \\
\hline SESPMNT & B17P20 & OTHELLO & COMMUNITY & AT & 31-Dec-03 & Cs-134 & -0.0000286 & $\mathrm{pCi} / \mathrm{m} 3$ & 0.001 & 0.001 & u & & \\
\hline SESPMNT & B168Y9 & PROSSER BARRICADE & PERIMETER & AT & 03-Apr-03 & Cs-134 & 0.0000588 & $\mathrm{pC} / \mathrm{m} 3$ & 0.00039 & 0.00039 & $u$ & & \\
\hline SESPMNT & B16R90 & PROSSER BARRICADE & PERIMETER & AT & 11-Jul-03 & Cs-134 & 0.000201 & $\mathrm{pCi} / \mathrm{m} 3$ & 0.00031 & 0.00031 & U & & \\
\hline SESPMNT & B17669 & PROSSER BARRICADE & PERIMETER & AT & 03-Oct-03 & Cs-134 & 0.000455 & $\mathrm{pC} / \mathrm{m} 3$ & 0.00053 & 0.00053 & u & & \\
\hline SESPMNT & B17PV7 & PROSSER BARRICADE & PERIMETER & AT & $09-J a n-04$ & Cs-134 & 0.000113 & $\mathrm{pCi} / \mathrm{m} 3$ & 0.00031 & 0.00031 & u & & \\
\hline SESPMNT & B168W5 & RINGOLD MET TOWER & PERIMETER & AT & 10-Apr-03 & Cs-134 & -0.0000138 & $\mathrm{pCl} / \mathrm{m} 3$ & 0.00037 & 0.00037 & $u$ & & \\
\hline SESPMNT & B16R69 & RINGOLD MET TOWER & PERIMETER & AT & 07-Jul-03 & Cs-134 & 0.00026 & $\mathrm{pCi} / \mathrm{m} 3$ & 0.00058 & 0.00058 & U & & \\
\hline SESPMNT & B17645 & RINGOLD MET TOWER & PERIMETER & AT & $10-$ Oct-03 & Cs-134 & 0.000101 & $\mathrm{pCl} / \mathrm{m} 3$ & 0.00079 & 0.00079 & U & & \\
\hline SESPMNT & B17PR6 & RINGOLD MET TOWER & PERIMETER & AT & 05-Jan-04 & Cs-134 & 0.000124 & $\mathrm{pC} / / \mathrm{m} 3$ & 0.0008 & 0.0008 & U & & \\
\hline SESPMNT & B16805 & TOPPENISH & DISTANT & AT & 02-Apr-03 & Cs-134 & -0.000206 & $\mathrm{pCi} / \mathrm{m} 3$ & 0.00065 & 0.00065 & U & & \\
\hline SESPMNT & B16PB9 & TOPPENISH & DISTANT & AT & 09-Jul-03 & Cs-134 & 0.0000373 & $\mathrm{pCi} / \mathrm{m} 3$ & 0.00057 & 0.00057 & U & & \\
\hline SESPMNT & B17589 & TOPPENISH & DISTANT & AT & 01-Oct-03 & Cs-134 & -0.000184 & $\mathrm{pC} / \mathrm{m} 3$ & 0.00057 & 0.00057 & $U$ & & \\
\hline SESPMNT & B17NX2 & TOPPENISH & DISTANT & AT & 08-Jan-04 & Cs-134 & -0.000043 & $\mathrm{pCi} / \mathrm{m} 3$ & 0.00081 & 0.00081 & $u$ & & \\
\hline SESPMNT & B16940 & TRI CITIES & COMMUNITY & AT & 10-Apr-03 & Cs-134 & -0.0000682 & $\mathrm{pCi} / \mathrm{m} 3$ & 0.00028 & 0.00028 & U & & \\
\hline SESPMNT & B16RF3 & TRI CITIES & COMMUNITY & AT & 07-Jul-03 & Cs-134 & 0.0000359 & $\mathrm{pCi} / \mathrm{m} 3$ & 0.0004 & 0.0004 & 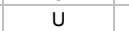 & & \\
\hline SESPMNT & B176C0 & TRI CITIES & COMMUNITY & AT & $10-$ Oct-03 & Cs-134 & 0.0000585 & $\mathrm{pCl} / \mathrm{m} 3$ & 0.00037 & 0.00037 & $U$ & & \\
\hline SESPMNT & B17R10 & TRI CITIES & COMMUNITY & AT & 05-Jan-04 & Cs-134 & 0.000178 & $\mathrm{pCi} / \mathrm{m} 3$ & 0.00043 & 0.00043 & U & & \\
\hline SESPMNT & B168V7 & W END OF FIR ROAD & PERIMETER & AT & 10-Apr-03 & Cs-134 & -0.000304 & $\mathrm{pCi} / \mathrm{m} 3$ & 0.00052 & 0.00052 & $u$ & & \\
\hline SESPMNT & B16R62 & W END OF FIR ROAD & PERIMETER & AT & 07-Jul-03 & Cs-134 & 0.0000443 & $\mathrm{pCi} / \mathrm{m} 3$ & 0.0008 & 0.0008 & $u$ & & \\
\hline SESPMNT & B17637 & W END OF FIR ROAD & PERIMETER & AT & $10-$ Oct-03 & Cs-134 & 0.000987 & $\mathrm{pCl} / \mathrm{m} 3$ & 0.00086 & 0.00086 & $U$ & & \\
\hline SESPMNT & B17PP9 & W END OF FIR ROAD & PERIMETER & AT & $05-J a n-04$ & Cs-134 & 0.000935 & $\mathrm{pCi} / \mathrm{m} 3$ & 0.00093 & 0.00093 & u & & \\
\hline SESPMNT & B16925 & WAHLUKE SLOPE & PERIMETER & AT & 09-Apr-03 & Cs-134 & -0.0000803 & $\mathrm{pCi} / \mathrm{m} 3$ & 0.00033 & 0.00033 & u & & \\
\hline SESPMNT & B16RD0 & WAHLUKE SLOPE & PERIMETER & AT & 01-Jul-03 & Cs-134 & 0.0000946 & $\mathrm{pCi} / \mathrm{m} 3$ & 0.00033 & 0.00033 & 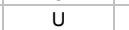 & & \\
\hline SESPMNT & B17695 & WAHLUKE SLOPE & PERIMETER & AT & 08-Oct-03 & Cs-134 & -0.0000631 & $\mathrm{pCi} / \mathrm{m} 3$ & 0.00038 & 0.00038 & $u$ & & \\
\hline SESPMNT & B17PY7 & WAHLUKE SLOPE & PERIMETER & AT & 31-Dec-03 & Cs-134 & 0.0000675 & $\mathrm{pCi} / \mathrm{m} 3$ & 0.00036 & 0.00036 & u & & \\
\hline SESPMNT & B168V0 & WYE BARRICADE & ONSITE & AT & 31-Mar-03 & Cs-134 & 0.000338 & $\mathrm{pCi} / \mathrm{m} 3$ & 0.00068 & 0.00068 & u & & \\
\hline SESPMNT & B16R54 & WYE BARRICADE & ONSITE & AT & 08-Jul-03 & Cs-134 & 0.0000485 & $\mathrm{pCi} / \mathrm{m} 3$ & 0.00064 & 0.00064 & u & & \\
\hline SESPMNT & B17630 & WYE BARRICADE & ONSITE & AT & 01-Oct-03 & Cs-134 & -0.0000894 & $\mathrm{pCi} / \mathrm{m} 3$ & 0.0008 & 0.0008 & $u$ & & \\
\hline SESPMNT & B17PP1 & WYE BARRICADE & ONSITE & AT & 06-Jan-04 & Cs-134 & 0.000387 & $\mathrm{pCi} / \mathrm{m} 3$ & 0.00071 & 0.00071 & u & & \\
\hline SESPMNT & B16955 & YAKIMA & DISTANT & AT & 03-Apr-03 & Cs-134 & -0.0000575 & $\mathrm{pCi} / \mathrm{m} 3$ & 0.00065 & 0.00065 & u & & \\
\hline SESPMNT & B16RH6 & YAKIMA & DISTANT & AT & 11-Jul-03 & Cs-134 & 0.000173 & $\mathrm{pCl} / \mathrm{m} 3$ & 0.00064 & 0.00064 & U & & \\
\hline SESPMNT & B176D5 & YAKIMA & DISTANT & AT & 03-Oct-03 & Cs-134 & 0.000428 & $\mathrm{pCi} / \mathrm{m} 3$ & 0.00077 & 0.00077 & $u$ & & \\
\hline SESPMNT & B17R23 & YAKIMA & DISTANT & AT & $09-J a n-04$ & Cs-134 & -0.000603 & $\mathrm{pCi} / \mathrm{m} 3$ & 0.00082 & 0.00082 & u & & \\
\hline SESPMNT & B16912 & YAKIMA BARRICADE & PERIMETER & AT & $02-\mathrm{Apr}-03$ & Cs-134 & $\begin{array}{l}-0.0000161 \\
-0.001\end{array}$ & $\mathrm{pCi} / \mathrm{m} 3$ & 0.00032 & 0.00032 & u & & \\
\hline SESPMNT & B16RB5 & YAKIMA BARRICADE & PERIMETER & AT & 11-Jul-03 & Cs-134 & -0.0000953 & $\mathrm{pCi} / \mathrm{m} 3$ & 0.00031 & 0.00031 & u & & \\
\hline SESPMNT & B17682 & YAKIMA BARRICADE & PERIMETER & AT & 03-Oct-03 & Cs-134 & -0.0000509 & $\mathrm{pCl} / \mathrm{m} 3$ & 0.00043 & 0.00043 & U & & \\
\hline SESPMNT & B17PX2 & YAKIMA BARRICADE & PERIMETER & AT & 09-Jan-04 & Cs-134 & 0.000161 & $\mathrm{pCi} / \mathrm{m} 3$ & 0.00029 & 0.00029 & u & & \\
\hline
\end{tabular}


AIR GAMMA

\begin{tabular}{|c|c|c|c|c|c|c|c|c|c|c|c|c|c|}
\hline OWNER ID & SAMP NUM & SAMP SITE NAME & | DIST CLASS & MEDIA & SAMP DATE & $\begin{array}{l}\text { CON SHORT } \\
\text { NAME }\end{array}$ & |VALUE RPTD & $\begin{array}{l}\text { ANAL } \\
\text { UNITS } \\
\text { RPTD }\end{array}$ & $\left|\begin{array}{c}\text { COUNTING } \\
\text { ERROR }\end{array}\right|$ & $\begin{array}{c}\text { TOTAL ANAL } \\
\text { ERROR }\end{array}$ & $\left|\begin{array}{c}\text { LAB } \\
\text { QUALIFIER }\end{array}\right|$ & SAMP COMMENT & RESULT COMMENT \\
\hline SESPMNT & B168C4 & 100 AREAS & ONSITE & AT & 31-Mar-03 & Cs-137 & -0.0000805 & $\mathrm{pCi} / \mathrm{m} 3$ & 0.00027 & 0.00027 & u & & \\
\hline SESPMNT & B16PP5 & 100 AREAS & ONSITE & AT & 08-Jul-03 & Cs-137 & 0.0000419 & $\mathrm{pCi} / \mathrm{m} 3$ & 0.00017 & 0.00017 & $U$ & & \\
\hline SESPMNT & B175M4 & 100 AREAS & ONSITE & AT & 01-Oct-03 & Cs-137 & 0.0000196 & $\mathrm{pCi} / \mathrm{m} 3$ & 0.00033 & 0.00033 & $U$ & & \\
\hline SESPMNT & B17P82 & 100 AREAS & ONSITE & AT & 06-Jan-04 & Cs-137 & 0.000117 & $\mathrm{pC} / / \mathrm{m} 3$ & 0.00033 & 0.00033 & U & & \\
\hline SESPMNT & B168F3 & 200 E AREA & ONSITE & AT & 08-Apr-03 & Cs-137 & 0.000121 & $\mathrm{pC} / / \mathrm{m} 3$ & 0.00026 & 0.00026 & $u$ & & \\
\hline SESPMNT & B16PT7 & 200 E AREA & ONSITE & AT & 30-Jun-03 & Cs-137 & 0.0000837 & $\mathrm{pC} / \mathrm{m} 3$ & 0.0003 & 0.0003 & u & & \\
\hline SESPMNT & B175P3 & 200 E AREA & ONSITE & AT & $07-$ Oct-03 & Cs-137 & -0.0000936 & $\mathrm{pC} / / \mathrm{m} 3$ & 0.00037 & 0.00037 & $u$ & & \\
\hline SESPMNT & B17PB4 & 200 E AREA & ONSITE & AT & 30-Dec-03 & Cs-137 & 0.000308 & $\mathrm{pCi} / \mathrm{m} 3$ & 0.00043 & 0.00043 & u & & \\
\hline SESPMNT & B168L8 & 200 W AREA & ONSITE & AT & 08-Apr-03 & Cs-137 & 0.000216 & $\mathrm{pC} / \mathrm{m} 3$ & 0.00047 & 0.00047 & u & & \\
\hline SESPMNT & B16PY6 & 200 W AREA & ONSITE & AT & 30-Jun-03 & Cs-137 & 0.000158 & $\mathrm{pC} / \mathrm{m} 3$ & 0.00045 & 0.00045 & u & & \\
\hline SESPMNT & B175W8 & 200 W AREA & ONSITE & AT & 07-Oct-03 & Cs-137 & 0.00000846 & $\mathrm{pC} / \mathrm{m} 3$ & 0.00061 & 0.00061 & u & & \\
\hline SESPMNT & $\mathrm{B} 17 \mathrm{PH} 3$ & 200 W AREA & ONSITE & AT & 30-Dec-03 & Cs-137 & 0.00000316 & $\mathrm{pCi} / \mathrm{m} 3$ & 0.00057 & 0.00057 & u & & \\
\hline SESPMNT & B168J6 & 200 W SOUTH EAST & ONSITE & AT & 08-Apr-03 & Cs-137 & -0.000062 & $\mathrm{pC} / \mathrm{m} 3$ & 0.00014 & 0.00014 & u & & \\
\hline SESPMNT & B16PW7 & 200 W SOUTH EAST & ONSITE & AT & 30-Jun-03 & Cs-137 & $\begin{array}{l}-0.0000163 \\
-0.003\end{array}$ & $\mathrm{pCi} / \mathrm{m} 3$ & 0.00019 & 0.00019 & u & & \\
\hline SESPMNT & B175T6 & 200 W SOUTH EAST & ONSITE & AT & 07-Oct-03 & Cs-137 & 0.0000503 & $\mathrm{pC} / \mathrm{m} 3$ & 0.00025 & 0.00025 & u & & \\
\hline SESPMNT & B17PD4 & 200 W SOUTH EAST & ONSITE & AT & 30-Dec-03 & Cs-137 & -0.000164 & $\mathrm{pCi} / \mathrm{m} 3$ & 0.0003 & 0.0003 & u & & \\
\hline SESPMNT & B168M6 & 300 AREA & ONSITE & AT & 02-Apr-03 & Cs-137 & 0.000015 & $\mathrm{pC} / \mathrm{m} 3$ & 0.00019 & 0.00019 & $u$ & & \\
\hline SESPMNT & B16R03 & 300 AREA & ONSITE & AT & 10-Jul-03 & Cs-137 & 0.00014 & $\mathrm{pCi} / \mathrm{m} 3$ & 0.00018 & 0.00018 & u & & \\
\hline SESPMNT & B175X6 & 300 AREA & ONSITE & AT & $30-$ Sep-03 & Cs-137 & 0.000116 & $\mathrm{pC} / \mathrm{m} 3$ & 0.00028 & 0.00028 & u & & \\
\hline SESPMNT & B17PJo & 300 AREA & ONSITE & AT & 08-Jan-04 & Cs-137 & -0.0000429 & $\mathrm{pCi} / \mathrm{m} 3$ & 0.00021 & 0.00021 & u & & \\
\hline SESPMNT & B167V4 & $300 \mathrm{NE}$ & ONSITE & AT & 02-Apr-03 & Cs-137 & 0.0000971 & $\mathrm{pC} / \mathrm{m} 3$ & 0.00052 & 0.00052 & $u$ & & \\
\hline SESPMNT & B16P66 & $300 \mathrm{NE}$ & ONSITE & AT & 10-Jul-03 & Cs-137 & 0.000207 & $\mathrm{pCi} / \mathrm{m} 3$ & \begin{tabular}{|l|}
0.00045 \\
\end{tabular} & 0.00045 & u & & \\
\hline SESPMNT & B17548 & $300 \mathrm{NE}$ & ONSITE & AT & 30-Sep-03 & Cs-137 & -0.000149 & $\mathrm{pC} / \mathrm{m} 3$ & 0.00072 & 0.00072 & $u$ & & \\
\hline SESPMNT & B17NP7 & $300 \mathrm{NE}$ & ONSITE & AT & 08-Jan-04 & Cs-137 & -0.000194 & $\mathrm{pCi} / \mathrm{m} 3$ & 0.00053 & 0.00053 & U & & \\
\hline SESPMNT & B167V3 & 300 TRENCH & ONSITE & AT & 02-Apr-03 & Cs-137 & 0.000228 & $\mathrm{pC} / \mathrm{m} 3$ & 0.00056 & 0.00056 & u & & \\
\hline SESPMNT & B16P65 & 300 TRENCH & ONSITE & AT & 10-Jul-03 & Cs-137 & $\begin{array}{l}-0.000159 \\
-0.00015\end{array}$ & $\mathrm{pCi} / \mathrm{m} 3$ & $\begin{array}{r}0.0005 \\
0.000\end{array}$ & 0.0005 & u & & \\
\hline SESPMNT & B17547 & 300 TRENCH & ONSITE & AT & 30-Sep-03 & Cs-137 & -0.000244 & $\mathrm{pCl} / \mathrm{m} 3$ & 0.00059 & 0.00059 & $u$ & & \\
\hline SESPMNT & B17NP6 & 300 TRENCH & ONSITE & AT & 08-Jan-04 & Cs-137 & 0.000319 & $\mathrm{pCi} / \mathrm{m} 3$ & 0.00084 & 0.00084 & U & & \\
\hline SESPMNT & B168P5 & 400 AREA & ONSITE & AT & 31-Mar-03 & Cs-137 & -0.0000932 & $\mathrm{pCi} / \mathrm{m} 3$ & 0.00017 & 0.00017 & $u$ & & \\
\hline SESPMNT & B16R25 & 400 AREA & ONSITE & AT & 08-Jul-03 & Cs-137 & -0.000016 & $\mathrm{pC} / \mathrm{m} 3$ & 0.00013 & 0.00013 & u & & \\
\hline SESPMNT & B17605 & 400 AREA & ONSITE & AT & 01-Oct-03 & Cs-137 & -0.000154 & $\mathrm{pCi} / \mathrm{m} 3$ & 0.0002 & 0.0002 & u & & \\
\hline SESPMNT & B17PL2 & 400 AREA & ONSITE & AT & 05-Jan-04 & Cs-137 & -0.000191 & $\mathrm{pCi} / \mathrm{m} 3$ & 0.00023 & 0.00023 & U & & \\
\hline SESPMNT & B168H8 & B POND & ONSITE & AT & 08-Apr-03 & Cs-137 & -0.000508 & $\mathrm{pCl} / \mathrm{m} 3$ & 0.00043 & 0.00043 & $U$ & & \\
\hline SESPMNT & B16PW0 & B POND & ONSITE & AT & 30-Jun-03 & Cs-137 & 0.000152 & $\mathrm{pCi} / \mathrm{m} 3$ & 0.00061 & 0.00061 & $u$ & & \\
\hline SESPMNT & B175R8 & B POND & ONSITE & AT & $07-O c t-03$ & Cs-137 & -0.000321 & $\mathrm{pCi} / \mathrm{m} 3$ & 0.00062 & 0.00062 & U & & \\
\hline SESPMNT & B17PC7 & B POND & ONSITE & AT & 30-Dec-03 & Cs-137 & 0.000425 & $\mathrm{pCi} / \mathrm{m} 3$ & 0.001 & 0.001 & 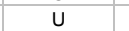 & & \\
\hline SESPMNT & B16962 & BASIN CITY SCHOOL & COMMUNITY & AT & 09-Apr-03 & Cs-137 & -0.000106 & $\mathrm{pCl} / \mathrm{m} 3$ & 0.0005 & 0.0005 & $u$ & & \\
\hline SESPMNT & B16RJ4 & BASIN CITY SCHOOL & COMMUNITY & AT & 02-Jul-03 & Cs-137 & -0.000452 & $\mathrm{pCi} / \mathrm{m} 3$ & 0.00059 & 0.00059 & U & & \\
\hline SESPMNT & B176F2 & BASIN CITY SCHOOL & COMMUNITY & AT & 08-Oct-03 & Cs-137 & 0.000678 & $\mathrm{pCi} / \mathrm{m} 3$ & 0.0007 & 0.0007 & $u$ & & \\
\hline SESPMNT & B17R31 & BASIN CITY SCHOOL & COMMUNITY & AT & 31-Dec-03 & Cs-137 & -0.000714 & $\mathrm{pC} / \mathrm{m} 3$ & 0.00082 & 0.00082 & $u$ & & \\
\hline SESPMNT & B16820 & BATTELLE COMPLEX & PERIMETER & AT & 02-Apr-03 & Cs-137 & -0.00036 & $\mathrm{pCl} / \mathrm{m} 3$ & 0.00052 & 0.00052 & $u$ & & \\
\hline SESPMNT & B16PD4 & BATTELLE COMPLEX & PERIMETER & AT & 09-Jul-03 & Cs-137 & -0.000179 & $\mathrm{pCi} / \mathrm{m} 3$ & $\begin{array}{l}0.00042 \\
\end{array}$ & 0.00042 & u & & \\
\hline SESPMNT & B175B4 & BATTELLE COMPLEX & PERIMETER & AT & $30-$ Sep-03 & Cs-137 & 0.00000808 & $\mathrm{pCi} / \mathrm{m} 3$ & 0.0005 & 0.0005 & $U$ & & \\
\hline SESPMNT & B17NY7 & BATTELLE COMPLEX & PERIMETER & AT & 08-Jan-04 & Cs-137 & -0.000264 & $\mathrm{pCi} / \mathrm{m} 3$ & 0.00046 & 0.00046 & 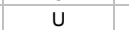 & & \\
\hline SESPMNT & B16827 & BENTON CITY & COMMUNITY & AT & 03-Apr-03 & Cs-137 & 0.000199 & $\mathrm{pCi} / \mathrm{m} 3$ & 0.0005 & 0.0005 & $u$ & & \\
\hline SESPMNT & B16PF2 & BENTON CITY & COMMUNITY & AT & 11-Jul-03 & Cs-137 & -0.00018 & $\mathrm{pCi} / \mathrm{m} 3$ & 0.00031 & 0.00031 & u & & \\
\hline $\begin{array}{l}\text { SESPMNT } \\
\text { SESPIV }\end{array}$ & B175C1 & BENTON CITY & COMMUNITY & AT & $03-\mathrm{Oct}-03$ & Cs-137 & 0.000688 & $\mathrm{pCl} / \mathrm{m} 3$ & 0.0009 & 0.0009 & u & & \\
\hline SESPMNT & B17P05 & BENTON CITY & COMMUNITY & AT & 09-Jan-04 & Cs-137 & -0.000257 & $\mathrm{pCi} / \mathrm{m} 3$ & 0.0007 & 0.0007 & u & & \\
\hline SESPMNT & B168Y1 & BYERS LANDING & PERIMETER & AT & 10-Apr-03 & Cs-137 & 0.000219 & $\mathrm{pCi} / \mathrm{m} 3$ & 0.00054 & 0.00054 & $u$ & & \\
\hline SESPMNT & B16R83 & BYERS LANDING & PERIMETER & AT & 07-Jul-03 & Cs-137 & 0.000302 & $\mathrm{pCi} / \mathrm{m} 3$ & 0.00045 & 0.00045 & u & & \\
\hline $\begin{array}{l}\text { SESPMNT } \\
\text { SESPIV }\end{array}$ & B17661 & BYERS LANDING & PERIMETER & AT & 10-Oct-03 & Cs-137 & -0.000308 & $\mathrm{pCi} / \mathrm{m} 3$ & 0.00074 & 0.00074 & u & & \\
\hline SESPMNT & B17PV0 & BYERS LANDING & PERIMETER & AT & 05-Jan-04 & Cs-137 & 0.000313 & $\mathrm{pCl} / \mathrm{m} 3$ & 0.00063 & 0.00063 & $u$ & & \\
\hline SESPMNT & B168X3 & DOGWOOD MET TOWER & PERIMETER & AT & 10-Apr-03 & Cs-137 & 0.000273 & $\mathrm{pCi} / \mathrm{m} 3$ & 0.00037 & 0.00037 & $\mathrm{u}$ & & \\
\hline SESPMNT & B16R76 & DOGWOOD MET TOWER & PERIMETER & AT & 07-Jul-03 & Cs-137 & 0.000127 & $\mathrm{pCi} / \mathrm{m} 3$ & 0.00058 & 0.00058 & u & & \\
\hline SESPMNT & B17653 & DOGWOOD MET TOWER & PERIMETER & AT & $10-$ Oct-03 & Cs-137 & $\begin{array}{r}-0.000409 \\
-0.009\end{array}$ & $\mathrm{pCl} / \mathrm{m} 3$ & $\begin{array}{r}0.0005 \\
0.000\end{array}$ & 0.0005 & u & & \\
\hline SESPMNT & B17РT3 & DOGWOOD MET TOWER & PERIMETER & AT & 05-Jan-04 & Cs-137 & -0.000424 & $\mathrm{pCi} / \mathrm{m} 3$ & 0.00068 & 0.00068 & u & & \\
\hline SESPMNT & B16978 & EDWIN MARKHAM SCHOOL & COMMUNITY & AT & 10-Apr-03 & Cs-137 & -0.0000768 & $\mathrm{pCl} / \mathrm{m} 3$ & 0.00052 & 0.00052 & U & & \\
\hline SESPMNT & B16RK8 & EDWIN MARKHAM SCHOOL & COMMUNITY & AT & 02-Jul-03 & Cs-137 & 0.000215 & $\mathrm{pCi} / \mathrm{m} 3$ & 0.00041 & 0.00041 & u & & \\
\hline
\end{tabular}


AIR GAMMA

\begin{tabular}{|c|c|c|c|c|c|c|c|c|c|c|c|c|c|}
\hline $\mid$ OWNER ID $\mid$ & SAMP NUM & SAMP SITE NAME & DIST CLASS & MEDIA & SAMP DATE & $\begin{array}{l}\text { CON SHORT } \\
\text { NAME }\end{array}$ & |VALUE RPTD & $\begin{array}{l}\text { ANAL } \\
\text { UNITS } \\
\text { RPTD }\end{array}$ & $\left|\begin{array}{c}\text { COUNTING } \\
\text { ERROR }\end{array}\right|$ & $\begin{array}{c}\text { TOTAL ANAL } \\
\text { ERROR }\end{array}$ & $\mid \begin{array}{c}\text { LAB } \\
\text { QUALIFIER }\end{array}$ & SAMP COMMENT & RESULT COMMENT \\
\hline SESPMNT & $\mathrm{B} 176 \mathrm{H} 8$ & EDWIN MARKHAM SCHOOL & COMMUNITY & AT & 08-Oct-03 & Cs-137 & -0.000274 & $\mathrm{pCi} / \mathrm{m} 3$ & 0.00053 & 0.00053 & u & & \\
\hline SESPMNT & B17R45 & EDWIN MARKHAM SCHOOL & COMMUNITY & AT & 31-Dec-03 & Cs-137 & 0.000436 & $\mathrm{pCi} / \mathrm{m} 3$ & 0.00076 & 0.00076 & $U$ & & \\
\hline SESPMNT & B16986 & HANFORD TOWNSITE & ONSITE & AT & 31-Mar-03 & Cs-137 & 0.000156 & $\mathrm{pCi} / \mathrm{m} 3$ & 0.00029 & 0.00029 & $U$ & & \\
\hline SESPMNT & B16RL5 & HANFORD TOWNSITE & ONSITE & AT & 08-Jul-03 & Cs-137 & 0.0000361 & $\mathrm{pC} / / \mathrm{m} 3$ & 0.00024 & 0.00024 & $\mathrm{U}$ & & \\
\hline SESPMNT & B176J6 & HANFORD TOWNSITE & ONSITE & AT & 01-Oct-03 & Cs-137 & -0.0000693 & $\mathrm{pC} / / \mathrm{m} 3$ & 0.00048 & 0.00048 & $\mathrm{U}$ & & \\
\hline SESPMNT & B17R52 & HANFORD TOWNSITE & ONSITE & AT & 06-Jan-04 & Cs-137 & -0.000144 & $\mathrm{pCi} / \mathrm{m} 3$ & 0.0003 & 0.0003 & $u$ & & \\
\hline SESPMNT & B16970 & LESLIE GROVES-RCHLND & COMMUNITY & AT & 08-Apr-03 & Cs-137 & -0.0000709 & $\mathrm{pC} / / \mathrm{m} 3$ & 0.00049 & 0.00049 & U & & \\
\hline SESPMNT & B16RK1 & LESLIE GROVES-RCHLND & COMMUNITY & AT & 01-Jul-03 & Cs-137 & 0.000534 & $\mathrm{pCi} / \mathrm{m} 3$ & 0.00057 & 0.00057 & u & & \\
\hline SESPMNT & B176HO & LESLIE GROVES-RCHLND & COMMUNITY & AT & 07-Oct-03 & Cs-137 & -0.0000288 & $\mathrm{pC} / \mathrm{m} 3$ & 0.00072 & 0.00072 & u & & \\
\hline SESPMNT & B17R38 & LESLIE GROVES-RCHLND & COMMUNITY & AT & 30-Dec-03 & Cs-137 & -0.000126 & $\mathrm{pC} / \mathrm{m} 3$ & 0.00074 & 0.00074 & U & & \\
\hline SESPMNT & B16834 & MATTAWA & COMMUNITY & AT & 09-Apr-03 & Cs-137 & 0.0000985 & $\mathrm{pC} / \mathrm{m} 3$ & 0.00053 & 0.00053 & u & & \\
\hline SESPMNT & B16PHO & MATTAWA & COMMUNITY & AT & 01-Jul-03 & Cs-137 & -0.0000437 & $\mathrm{pCi} / \mathrm{m} 3$ & 0.00053 & 0.00053 & u & & \\
\hline SESPMNT & B175C8 & MATTAWA & COMMUNITY & AT & 09-Oct-03 & Cs-137 & -0.000138 & $\mathrm{pC} / \mathrm{m} 3$ & 0.00062 & 0.00062 & u & & \\
\hline SESPMNT & B17P13 & MATTAWA & COMMUNITY & AT & 31-Dec-03 & Cs-137 & $\begin{array}{l}-0.000413 \\
-0.0004\end{array}$ & $\mathrm{pCi} / \mathrm{m} 3$ & $\begin{array}{l}0.00092 \\
\end{array}$ & 0.00092 & u & & \\
\hline SESPMNT & B16812 & N OF $200 \mathrm{E}$ & ONSITE & AT & 08-Apr-03 & Cs-137 & 0.000356 & $\mathrm{pC} / \mathrm{m} 3$ & 0.00045 & 0.00045 & u & & \\
\hline SESPMNT & B16PC7 & N OF $200 E$ & ONSITE & AT & 30-Jun-03 & Cs-137 & 0.000318 & $\mathrm{pCi} / \mathrm{m} 3$ & 0.00055 & 0.00055 & u & & \\
\hline SESPMNT & B17596 & N OF $200 \mathrm{E}$ & ONSITE & AT & $07-$ Oct-03 & Cs-137 & 0.000271 & $\mathrm{pC} / \mathrm{m} 3$ & 0.00078 & 0.00078 & $u$ & & \\
\hline SESPMNT & B17NYO & N OF $200 \mathrm{E}$ & ONSITE & AT & 30-Dec-03 & Cs-137 & 0.000142 & $\mathrm{pCi} / \mathrm{m} 3$ & 0.00075 & 0.00075 & u & & \\
\hline SESPMNT & B16842 & OTHELLO & COMMUNITY & AT & 09-Apr-03 & Cs-137 & -0.000411 & $\mathrm{pC} / \mathrm{m} 3$ & 0.00049 & 0.00049 & u & & \\
\hline SESPMNT & B16PH7 & OTHELLO & COMMUNITY & AT & 01-Jul-03 & Cs-137 & 0.0000814 & $\mathrm{pCi} / \mathrm{m} 3$ & 0.0006 & 0.0006 & u & & \\
\hline SESPMNT & B175D6 & OTHELLO & COMMUNITY & AT & $09-\mathrm{Oct}-03$ & Cs-137 & -0.00000388 & $\mathrm{pC} / / \mathrm{m} 3$ & 0.00049 & 0.00049 & $\mathrm{U}$ & & \\
\hline SESPMNT & B17P20 & OTHELLO & COMMUNITY & AT & 31-Dec-03 & Cs-137 & -0.000164 & $\mathrm{pCi} / \mathrm{m} 3$ & 0.00084 & 0.00084 & u & & \\
\hline SESPMNT & B168Y9 & PROSSER BARRICADE & PERIMETER & AT & 03-Apr-03 & Cs-137 & 0.000124 & $\mathrm{pC} / \mathrm{m} 3$ & 0.00029 & 0.00029 & $u$ & & \\
\hline SESPMNT & B16R90 & PROSSER BARRICADE & PERIMETER & AT & 11-Jul-03 & Cs-137 & 0.000151 & $\mathrm{pCi} / \mathrm{m} 3$ & 0.00026 & 0.00026 & U & & \\
\hline SESPMNT & B17669 & PROSSER BARRICADE & PERIMETER & AT & 03-Oct-03 & Cs-137 & 0.000315 & $\mathrm{pC} / \mathrm{m} 3$ & 0.00044 & 0.00044 & u & & \\
\hline SESPMNT & B17PV7 & PROSSER BARRICADE & PERIMETER & AT & $09-J a n-04$ & Cs-137 & 0.0000644 & $\mathrm{pCi} / \mathrm{m} 3$ & 0.00033 & 0.00033 & u & & \\
\hline SESPMNT & B168W5 & RINGOLD MET TOWER & PERIMETER & AT & 10-Apr-03 & Cs-137 & 0.0000315 & $\mathrm{pCl} / \mathrm{m} 3$ & 0.00041 & 0.00041 & $u$ & & \\
\hline SESPMNT & B16R69 & RINGOLD MET TOWER & PERIMETER & AT & 07-Jul-03 & Cs-137 & 0.000272 & $\mathrm{pCi} / \mathrm{m} 3$ & 0.00051 & 0.00051 & U & & \\
\hline SESPMNT & B17645 & RINGOLD MET TOWER & PERIMETER & AT & 10-Oct-03 & Cs-137 & 0.000545 & $\mathrm{pCi} / \mathrm{m} 3$ & 0.00074 & 0.00074 & $u$ & & \\
\hline SESPMNT & B17PR6 & RINGOLD MET TOWER & PERIMETER & AT & 05-Jan-04 & Cs-137 & -0.000268 & $\mathrm{pCi} / \mathrm{m} 3$ & 0.0008 & 0.0008 & U & & \\
\hline SESPMNT & B16805 & TOPPENISH & DISTANT & AT & 02-Apr-03 & Cs-137 & -0.0003 & $\mathrm{pCi} / \mathrm{m} 3$ & 0.0005 & 0.0005 & U & & \\
\hline SESPMNT & B16PB9 & TOPPENISH & DISTANT & AT & 09-Jul-03 & Cs-137 & 0.0000985 & $\mathrm{pCi} / \mathrm{m} 3$ & 0.00048 & 0.00048 & U & & \\
\hline SESPMNT & B17589 & TOPPENISH & DISTANT & AT & 01-Oct-03 & Cs-137 & -0.000151 & $\mathrm{pC} / \mathrm{m} 3$ & 0.00067 & 0.00067 & $U$ & & \\
\hline SESPMNT & B17NX2 & TOPPENISH & DISTANT & AT & 08-Jan-04 & Cs-137 & -0.0000166 & $\mathrm{pCi} / \mathrm{m} 3$ & 0.00081 & 0.00081 & $u$ & & \\
\hline SESPMNT & B16940 & TRI CITIES & COMMUNITY & AT & 10-Apr-03 & Cs-137 & 0.000329 & $\mathrm{pCi} / \mathrm{m} 3$ & 0.00025 & 0.00025 & U & & \\
\hline SESPMNT & B16RF3 & TRI CITIES & COMMUNITY & AT & 07-Jul-03 & Cs-137 & -0.0000537 & $\mathrm{pCi} / \mathrm{m} 3$ & 0.0003 & 0.0003 & 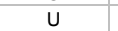 & & \\
\hline SESPMNT & B176C0 & TRI CITIES & COMMUNITY & AT & $10-$ Oct-03 & Cs-137 & -0.0000921 & $\mathrm{pCi} / \mathrm{m} 3$ & 0.00039 & 0.00039 & $U$ & & \\
\hline SESPMNT & B17R10 & TRI CITIES & COMMUNITY & AT & 05-Jan-04 & Cs-137 & 0.0000188 & $\mathrm{pCi} / \mathrm{m} 3$ & 0.00049 & 0.00049 & U & & \\
\hline SESPMNT & B168V7 & W END OF FIR ROAD & PERIMETER & AT & 10-Apr-03 & Cs-137 & -0.00015 & $\mathrm{pCi} / \mathrm{m} 3$ & 0.00039 & 0.00039 & $u$ & & \\
\hline SESPMNT & B16R62 & W END OF FIR ROAD & PERIMETER & AT & 07-Jul-03 & Cs-137 & 0.0000536 & $\mathrm{pCi} / \mathrm{m} 3$ & 0.00054 & 0.00054 & $u$ & & \\
\hline SESPMNT & B17637 & W END OF FIR ROAD & PERIMETER & AT & $10-$ Oct-03 & Cs-137 & -0.000421 & $\mathrm{pCi} / \mathrm{m} 3$ & 0.00071 & 0.00071 & $u$ & & \\
\hline SESPMNT & B17PP9 & W END OF FIR ROAD & PERIMETER & AT & $05-J a n-04$ & Cs-137 & 0.000853 & $\mathrm{pCi} / \mathrm{m} 3$ & 0.00077 & 0.00077 & u & & \\
\hline SESPMNT & B16925 & WAHLUKE SLOPE & PERIMETER & AT & 09-Apr-03 & Cs-137 & 0.000214 & $\mathrm{pCi} / \mathrm{m} 3$ & 0.00024 & 0.00024 & $U$ & & \\
\hline SESPMNT & B16RD0 & WAHLUKE SLOPE & PERIMETER & AT & 01-Jul-03 & Cs-137 & -0.000163 & $\mathrm{pCi} / \mathrm{m} 3$ & 0.00023 & 0.00023 & 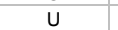 & & \\
\hline SESPMNT & B17695 & WAHLUKE SLOPE & PERIMETER & AT & 08-Oct-03 & Cs-137 & -0.0000582 & $\mathrm{pCi} / \mathrm{m} 3$ & 0.00035 & 0.00035 & $u$ & & \\
\hline SESPMNT & B17PY7 & WAHLUKE SLOPE & PERIMETER & AT & 31-Dec-03 & Cs-137 & -0.000306 & $\mathrm{pCi} / \mathrm{m} 3$ & 0.00034 & 0.00034 & u & & \\
\hline SESPMNT & B168V0 & WYE BARRICADE & ONSITE & AT & 31-Mar-03 & Cs-137 & 0.000122 & $\mathrm{pCl} / \mathrm{m} 3$ & $\begin{array}{l}0.00005 \\
0.005\end{array}$ & $\begin{array}{l}0.00005 \\
0.005\end{array}$ & u & & \\
\hline SESPMNT & B16R54 & WYE BARRICADE & ONSITE & AT & 08-Jul-03 & Cs-137 & 0.000119 & $\mathrm{pC} / \mathrm{m} 3$ & 0.0005 & 0.0005 & u & & \\
\hline SESPMNT & B17630 & WYE BARRICADE & ONSITE & AT & 01-Oct-03 & Cs-137 & 0.00092 & $\mathrm{pCi} / \mathrm{m} 3$ & 0.00069 & 0.00069 & $u$ & & \\
\hline SESPMNT & B17PP1 & WYE BARRICADE & ONSITE & AT & 06-Jan-04 & Cs-137 & -0.000204 & $\mathrm{pCi} / \mathrm{m} 3$ & 0.00063 & 0.00063 & u & & \\
\hline SESPMNT & B16955 & YAKIMA & DISTANT & AT & $03-A p r-03$ & Cs-137 & $\begin{array}{l}-0.0000161 \\
-0.001\end{array}$ & $\mathrm{pCl} / \mathrm{m} 3$ & $\begin{array}{l}0.00057 \\
0.0005\end{array}$ & 0.00057 & u & & \\
\hline SESPMNT & B16RH6 & YAKIMA & DISTANT & AT & 11-Jul-03 & Cs-137 & -0.000304 & $\mathrm{pCi} / \mathrm{m} 3$ & 0.00051 & 0.00051 & $u$ & & \\
\hline SESPMNT & B176D5 & YAKIMA & DISTANT & AT & 03-Oct-03 & Cs-137 & -0.00032 & $\mathrm{pCi} / \mathrm{m} 3$ & 0.00074 & 0.00074 & $u$ & & \\
\hline SESPMNT & B17R23 & YAKIMA & DISTANT & AT & $09-J a n-04$ & Cs-137 & 0.0000822 & $\mathrm{pCi} / \mathrm{m} 3$ & 0.00046 & 0.00046 & u & & \\
\hline SESPMNT & B16912 & YAKIMA BARRICADE & PERIMETER & AT & $02-\mathrm{Apr}-03$ & Cs-137 & 0.000175 & $\mathrm{pCl} / \mathrm{m} 3$ & 0.00033 & 0.00033 & u & & \\
\hline SESPMNT & B16RB5 & YAKIMA BARRICADE & PERIMETER & AT & 11-Jul-03 & Cs-137 & -0.000209 & $\mathrm{pCi} / \mathrm{m} 3$ & 0.00024 & 0.00024 & u & & \\
\hline SESPMNT & B17682 & YAKIMA BARRICADE & PERIMETER & AT & 03-Oct-03 & Cs-137 & -0.000241 & $\mathrm{pC} / \mathrm{m} 3$ & 0.00043 & 0.00043 & U & & \\
\hline SESPMNT & B17PX2 & YAKIMA BARRICADE & PERIMETER & AT & 09-Jan-04 & Cs-137 & -0.000216 & $\mathrm{pCi} / \mathrm{m} 3$ & 0.00025 & 0.00025 & u & & \\
\hline
\end{tabular}


AIR GAMMA

\begin{tabular}{|c|c|c|c|c|c|c|c|c|c|c|c|c|c|}
\hline OWNER ID & SAMP NUM & SAMP SITE NAME & | DIST CLASS & MEDIA & SAMP DATE & $\begin{array}{l}\text { CON SHORT } \\
\text { NAME }\end{array}$ & |VALUE RPTD & $\begin{array}{l}\text { ANAL } \\
\text { UNITS } \\
\text { RPTD }\end{array}$ & $\left|\begin{array}{c}\text { COUNTING } \\
\text { ERROR }\end{array}\right|$ & $\begin{array}{c}\text { TOTAL ANAL } \\
\text { ERROR }\end{array}$ & $\mid \begin{array}{c}\text { LAB } \\
\text { QUALIFIER }\end{array}$ & SAMP COMMENT & RESULT COMMENT \\
\hline SESPMNT & B168C4 & 100 AREAS & ONSITE & AT & 31-Mar-03 & Eu-152 & 0.000292 & $\mathrm{pCi} / \mathrm{m} 3$ & 0.00084 & 0.00084 & u & & \\
\hline SESPMNT & B16PP5 & 100 AREAS & ONSITE & AT & 08-Jul-03 & Eu-152 & 0.000402 & $\mathrm{pCi} / \mathrm{m} 3$ & 0.00049 & 0.00049 & $U$ & & \\
\hline SESPMNT & B175M4 & 100 AREAS & ONSITE & AT & 01-Oct-03 & Eu-152 & 0.000151 & $\mathrm{pCi} / \mathrm{m} 3$ & 0.0008 & 0.0008 & $U$ & & \\
\hline SESPMNT & B17P82 & 100 AREAS & ONSITE & AT & 06-Jan-04 & Eu-152 & -0.000472 & $\mathrm{pC} / / \mathrm{m} 3$ & 0.00066 & 0.00066 & U & & \\
\hline SESPMNT & B168F3 & 200 E AREA & ONSITE & AT & 08-Apr-03 & Eu-152 & 0.0000826 & $\mathrm{pC} / / \mathrm{m} 3$ & 0.00068 & 0.00068 & $u$ & & \\
\hline SESPMNT & B16PT7 & 200 E AREA & ONSITE & AT & 30-Jun-03 & Eu-152 & -0.000317 & $\mathrm{pC} / \mathrm{m} 3$ & 0.00092 & 0.00092 & u & & \\
\hline SESPMNT & B175P3 & 200 E AREA & ONSITE & AT & $07-$ Oct-03 & Eu-152 & -0.000255 & $\mathrm{pC} / / \mathrm{m} 3$ & 0.00079 & 0.00079 & $u$ & & \\
\hline SESPMNT & B17PB4 & 200 E AREA & ONSITE & AT & 30-Dec-03 & Eu-152 & -0.00154 & $\mathrm{pCi} / \mathrm{m} 3$ & 0.0013 & 0.0013 & u & & \\
\hline SESPMNT & B168L8 & 200 W AREA & ONSITE & AT & 08-Apr-03 & Eu-152 & -0.000421 & $\mathrm{pC} / \mathrm{m} 3$ & 0.0013 & 0.0013 & u & & \\
\hline SESPMNT & B16PY6 & 200 W AREA & ONSITE & AT & 30-Jun-03 & Eu-152 & -0.000136 & $\mathrm{pC} / \mathrm{m} 3$ & 0.0011 & 0.0011 & u & & \\
\hline SESPMNT & B175W8 & 200 W AREA & ONSITE & AT & 07-Oct-03 & Eu-152 & 0.000492 & $\mathrm{pC} / \mathrm{m} 3$ & 0.0016 & 0.0016 & u & & \\
\hline SESPMNT & $\mathrm{B} 17 \mathrm{PH} 3$ & 200 W AREA & ONSITE & AT & 30-Dec-03 & Eu-152 & 0.000553 & $\mathrm{pCi} / \mathrm{m} 3$ & 0.0015 & 0.0015 & u & & \\
\hline SESPMNT & B168J6 & 200 W SOUTH EAST & ONSITE & AT & 08-Apr-03 & Eu-152 & 0.000128 & $\mathrm{pC} / \mathrm{m} 3$ & 0.00037 & 0.00037 & u & & \\
\hline SESPMNT & B16PW7 & 200 W SOUTH EAST & ONSITE & AT & 30-Jun-03 & Eu-152 & 0.000122 & $\mathrm{pCi} / \mathrm{m} 3$ & 0.00058 & 0.00058 & u & & \\
\hline SESPMNT & B175T6 & 200 W SOUTH EAST & ONSITE & AT & 07-Oct-03 & Eu-152 & 0.000137 & $\mathrm{pC} / \mathrm{m} 3$ & 0.00057 & 0.00057 & u & & \\
\hline SESPMNT & B17PD4 & 200 W SOUTH EAST & ONSITE & AT & 30-Dec-03 & Eu-152 & 0.000162 & $\mathrm{pCi} / \mathrm{m} 3$ & 0.00084 & 0.00084 & u & & \\
\hline SESPMNT & B168M6 & 300 AREA & ONSITE & AT & 02-Apr-03 & Eu-152 & -0.000576 & $\mathrm{pC} / \mathrm{m} 3$ & 0.00061 & 0.00061 & $u$ & & \\
\hline SESPMNT & B16R03 & 300 AREA & ONSITE & AT & 10-Jul-03 & Eu-152 & 0.000174 & $\mathrm{pCi} / \mathrm{m} 3$ & 0.00048 & 0.00048 & u & & \\
\hline SESPMNT & B175X6 & 300 AREA & ONSITE & AT & $30-$ Sep-03 & Eu-152 & -0.000106 & $\mathrm{pC} / \mathrm{m} 3$ & 0.00079 & 0.00079 & u & & \\
\hline SESPMNT & B17PJo & 300 AREA & ONSITE & AT & 08-Jan-04 & Eu-152 & 0.00013 & $\mathrm{pCi} / \mathrm{m} 3$ & 0.00043 & 0.00043 & u & & \\
\hline SESPMNT & B167V4 & $300 \mathrm{NE}$ & ONSITE & AT & 02-Apr-03 & Eu-152 & 0.00096 & $\mathrm{pC} / \mathrm{m} 3$ & 0.0013 & 0.0013 & $u$ & & \\
\hline SESPMNT & B16P66 & $300 \mathrm{NE}$ & ONSITE & AT & 10-Jul-03 & Eu-152 & -0.000577 & $\mathrm{pCi} / \mathrm{m} 3$ & 0.0013 & 0.0013 & u & & \\
\hline SESPMNT & B17548 & $300 \mathrm{NE}$ & ONSITE & AT & 30-Sep-03 & Eu-152 & 0.000575 & $\mathrm{pC} / \mathrm{m} 3$ & 0.0016 & 0.0016 & $u$ & & \\
\hline SESPMNT & B17NP7 & $300 \mathrm{NE}$ & ONSITE & AT & 08-Jan-04 & Eu-152 & -0.000325 & $\mathrm{pCi} / \mathrm{m} 3$ & 0.0014 & 0.0014 & U & & \\
\hline SESPMNT & B167V3 & 300 TRENCH & ONSITE & AT & 02-Apr-03 & Eu-152 & -0.000392 & $\mathrm{pC} / \mathrm{m} 3$ & 0.0012 & 0.0012 & u & & \\
\hline SESPMNT & B16P65 & 300 TRENCH & ONSITE & AT & 10-Jul-03 & Eu-152 & -0.000331 & $\mathrm{pCi} / \mathrm{m} 3$ & 0.0013 & 0.0013 & u & & \\
\hline SESPMNT & B17547 & 300 TRENCH & ONSITE & AT & 30-Sep-03 & Eu-152 & 0.00116 & $\mathrm{pCl} / \mathrm{m} 3$ & 0.0018 & 0.0018 & $u$ & & \\
\hline SESPMNT & B17NP6 & 300 TRENCH & ONSITE & AT & 08-Jan-04 & Eu-152 & 0.00185 & $\mathrm{pCi} / \mathrm{m} 3$ & 0.0022 & 0.0022 & U & & \\
\hline SESPMNT & B168P5 & 400 AREA & ONSITE & AT & 31-Mar-03 & Eu-152 & -0.000375 & $\mathrm{pCi} / \mathrm{m} 3$ & 0.00062 & 0.00062 & $u$ & & \\
\hline SESPMNT & B16R25 & 400 AREA & ONSITE & AT & 08-Jul-03 & Eu-152 & -0.000152 & $\mathrm{pCi} / \mathrm{m} 3$ & 0.00035 & 0.00035 & U & & \\
\hline SESPMNT & B17605 & 400 AREA & ONSITE & AT & 01-Oct-03 & Eu-152 & 0.000592 & $\mathrm{pCi} / \mathrm{m} 3$ & 0.00069 & 0.00069 & u & & \\
\hline SESPMNT & B17PL2 & 400 AREA & ONSITE & AT & 05-Jan-04 & Eu-152 & 0.000216 & $\mathrm{pCi} / \mathrm{m} 3$ & 0.00046 & 0.00046 & U & & \\
\hline SESPMNT & B168H8 & B POND & ONSITE & AT & 08-Apr-03 & Eu-152 & 0.00012 & $\mathrm{pCl} / \mathrm{m} 3$ & 0.0011 & 0.0011 & $U$ & & \\
\hline SESPMNT & B16PW0 & B POND & ONSITE & AT & 30-Jun-03 & Eu-152 & -0.000429 & $\mathrm{pCi} / \mathrm{m} 3$ & 0.0016 & 0.0016 & $u$ & & \\
\hline SESPMNT & B175R8 & B POND & ONSITE & AT & $07-O c t-03$ & Eu-152 & 0.000814 & $\mathrm{pCi} / \mathrm{m} 3$ & 0.0014 & 0.0014 & U & & \\
\hline SESPMNT & B17PC7 & B POND & ONSITE & AT & 30-Dec-03 & Eu-152 & 0.000127 & $\mathrm{pCi} / \mathrm{m} 3$ & 0.0024 & 0.0024 & 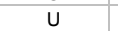 & & \\
\hline SESPMNT & B16962 & BASIN CITY SCHOOL & COMMUNITY & AT & 09-Apr-03 & Eu-152 & -0.000331 & $\mathrm{pCi} / \mathrm{m} 3$ & 0.001 & 0.001 & $U$ & & \\
\hline SESPMNT & B16RJ4 & BASIN CITY SCHOOL & COMMUNITY & AT & 02-Jul-03 & Eu-152 & 0.000805 & $\mathrm{pCi} / \mathrm{m} 3$ & 0.0016 & 0.0016 & u & & \\
\hline SESPMNT & B176F2 & BASIN CITY SCHOOL & COMMUNITY & AT & 08-Oct-03 & Eu-152 & -0.000099 & $\mathrm{pCi} / \mathrm{m} 3$ & 0.0015 & 0.0015 & $u$ & & \\
\hline SESPMNT & B17R31 & BASIN CITY SCHOOL & COMMUNITY & AT & 31-Dec-03 & Eu-152 & -0.000552 & $\mathrm{pC} / \mathrm{m} 3$ & 0.0017 & 0.0017 & $u$ & & \\
\hline SESPMNT & B16820 & BATTELLE COMPLEX & PERIMETER & AT & 02-Apr-03 & Eu-152 & -0.000652 & $\mathrm{pCi} / \mathrm{m} 3$ & 0.0012 & 0.0012 & $u$ & & \\
\hline SESPMNT & B16PD4 & BATTELLE COMPLEX & PERIMETER & AT & 09-Jul-03 & Eu-152 & -0.000309 & $\mathrm{pCi} / \mathrm{m} 3$ & $\begin{array}{r}0.001 \\
\end{array}$ & 0.001 & u & & \\
\hline SESPMNT & B175B4 & BATTELLE COMPLEX & PERIMETER & AT & $30-$ Sep-03 & $\mathrm{Eu}-152$ & 0.00042 & $\mathrm{pCi} / \mathrm{m} 3$ & 0.0016 & 0.0016 & $U$ & & \\
\hline SESPMNT & B17NY7 & BATTELLE COMPLEX & PERIMETER & AT & 08-Jan-04 & Eu-152 & 0.000355 & $\mathrm{pCi} / \mathrm{m} 3$ & 0.0015 & 0.0015 & 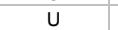 & & \\
\hline SESPMNT & B16827 & BENTON CITY & COMMUNITY & AT & 03-Apr-03 & Eu-152 & 0.00148 & $\mathrm{pCl} / \mathrm{m} 3$ & 0.0014 & 0.0014 & $u$ & & \\
\hline SESPMNT & B16PF2 & BENTON CITY & COMMUNITY & AT & 11-Jul-03 & Eu-152 & -0.000398 & $\mathrm{pCi} / \mathrm{m} 3$ & 0.001 & 0.001 & u & & \\
\hline $\begin{array}{l}\text { SESPMNT } \\
\text { SESPIV }\end{array}$ & B175C1 & BENTON CITY & COMMUNITY & AT & $03-\mathrm{Oct}-03$ & Eu-152 & $\begin{array}{l}-0.0000746 \\
-0.000\end{array}$ & $\mathrm{pCl} / \mathrm{m} 3$ & 0.0022 & 0.0022 & u & & \\
\hline SESPMNT & B17P05 & BENTON CITY & COMMUNITY & AT & 09-Jan-04 & Eu-152 & 0.000203 & $\mathrm{pCi} / \mathrm{m} 3$ & 0.0015 & 0.0015 & u & & \\
\hline SESPMNT & B168Y1 & BYERS LANDING & PERIMETER & AT & 10-Apr-03 & Eu-152 & 0.0000862 & $\mathrm{pCi} / \mathrm{m} 3$ & 0.0011 & 0.0011 & $u$ & & \\
\hline SESPMNT & B16R83 & BYERS LANDING & PERIMETER & AT & 07-Jul-03 & Eu-152 & 0.00000641 & $\mathrm{pCi} / \mathrm{m} 3$ & 0.0013 & 0.0013 & u & & \\
\hline $\begin{array}{l}\text { SESPMNT } \\
\text { SESPIV }\end{array}$ & B17661 & BYERS LANDING & PERIMETER & AT & 10-Oct-03 & Eu-152 & 0.000117 & $\mathrm{pCi} / \mathrm{m} 3$ & 0.0019 & 0.0019 & u & & \\
\hline SESPMNT & B17PV0 & BYERS LANDING & PERIMETER & AT & 05-Jan-04 & Eu-152 & 0.00098 & $\mathrm{pCl} / \mathrm{m} 3$ & 0.0018 & 0.0018 & $u$ & & \\
\hline SESPMNT & B168X3 & DOGWOOD MET TOWER & PERIMETER & AT & 10-Apr-03 & Eu-152 & -0.000395 & $\mathrm{pCl} / \mathrm{m} 3$ & 0.001 & 0.001 & $\mathrm{u}$ & & \\
\hline SESPMNT & B16R76 & DOGWOOD MET TOWER & PERIMETER & AT & 07-Jul-03 & Eu-152 & -0.000427 & $\mathrm{pCi} / \mathrm{m} 3$ & 0.0016 & 0.0016 & u & & \\
\hline SESPMNT & B17653 & DOGWOOD MET TOWER & PERIMETER & AT & $10-$ Oct-03 & Eu-152 & -0.00142 & $\mathrm{pCi} / \mathrm{m} 3$ & 0.0014 & 0.0014 & u & & \\
\hline SESPMNT & B17РT3 & DOGWOOD MET TOWER & PERIMETER & AT & 05-Jan-04 & Eu-152 & -0.000137 & $\mathrm{pCi} / \mathrm{m} 3$ & 0.0017 & 0.0017 & u & & \\
\hline SESPMNT & B16978 & EDWIN MARKHAM SCHOOL & COMMUNITY & AT & 10-Apr-03 & Eu-152 & 0.00128 & $\mathrm{pCl} / \mathrm{m} 3$ & 0.0014 & 0.0014 & U & & \\
\hline SESPMNT & B16RK8 & EDWIN MARKHAM SCHOOL & COMMUNITY & AT & 02-Jul-03 & Eu-152 & -0.000533 & $\mathrm{pCi} / \mathrm{m} 3$ & 0.0011 & 0.0011 & u & & \\
\hline
\end{tabular}


AIR GAMMA

\begin{tabular}{|c|c|c|c|c|c|c|c|c|c|c|c|c|c|}
\hline $\mid$ OWNER ID $\mid$ & SAMP NUM & SAMP SITE NAME & DIST CLASS & MEDIA & SAMP DATE & $\begin{array}{l}\text { CON SHORT } \\
\text { NAME }\end{array}$ & |VALUE RPTD & $\begin{array}{l}\text { ANAL } \\
\text { UNITS } \\
\text { RPTD }\end{array}$ & $\left|\begin{array}{c}\text { COUNTING } \\
\text { ERROR }\end{array}\right|$ & $\begin{array}{c}\text { TOTAL ANAL } \\
\text { ERROR }\end{array}$ & $\mid \begin{array}{c}\text { LAB } \\
\text { QUALIFIER }\end{array}$ & SAMP COMMENT & RESULT COMMENT \\
\hline SESPMNT & B176H8 & EDWIN MARKHAM SCHOOL & COMMUNITY & AT & 08-Oct-03 & Eu-152 & 0.000489 & $\mathrm{pC} / \mathrm{m} 3$ & 0.0018 & 0.0018 & u & & \\
\hline SESPMNT & B17R45 & EDWIN MARKHAM SCHOOL & COMMUNITY & AT & 31-Dec-03 & $\mathrm{Eu}-152$ & 0.0000246 & $\mathrm{pCi} / \mathrm{m} 3$ & 0.0018 & 0.0018 & $U$ & & \\
\hline SESPMNT & B16986 & HANFORD TOWNSITE & ONSITE & AT & 31-Mar-03 & Eu-152 & -0.000156 & $\mathrm{pCi} / \mathrm{m} 3$ & 0.00085 & 0.00085 & $U$ & & \\
\hline SESPMNT & B16RL5 & HANFORD TOWNSITE & ONSITE & AT & 08-Jul-03 & Eu-152 & 0.000501 & $\mathrm{pC} / / \mathrm{m} 3$ & 0.00073 & 0.00073 & $\mathrm{U}$ & & \\
\hline SESPMNT & B176J6 & HANFORD TOWNSITE & ONSITE & AT & $01-$ Oct-03 & Eu-152 & -0.000214 & $\mathrm{pC} / / \mathrm{m} 3$ & 0.0012 & 0.0012 & $\mathrm{U}$ & & \\
\hline SESPMNT & B17R52 & HANFORD TOWNSITE & ONSITE & AT & $06-J a n-04$ & Eu-152 & -0.000884 & $\mathrm{pC} / \mathrm{m} 3$ & 0.00089 & 0.00089 & u & & \\
\hline SESPMNT & B16970 & LESLIE GROVES-RCHLND & COMMUNITY & AT & 08-Apr-03 & Eu-152 & 0.0000519 & $\mathrm{pC} / / \mathrm{m} 3$ & 0.0011 & 0.0011 & $u$ & & \\
\hline SESPMNT & B16RK1 & LESLIE GROVES-RCHLND & COMMUNITY & AT & 01-Jul-03 & Eu-152 & 0.000436 & $\mathrm{pCi} / \mathrm{m} 3$ & 0.0014 & 0.0014 & u & & \\
\hline SESPMNT & B176HO & LESLIE GROVES-RCHLND & COMMUNITY & AT & 07-Oct-03 & Eu-152 & -0.000105 & $\mathrm{pC} / \mathrm{m} 3$ & 0.0017 & 0.0017 & u & & \\
\hline SESPMNT & B17R38 & LESLIE GROVES-RCHLND & COMMUNITY & AT & 30-Dec-03 & Eu-152 & -0.0000909 & $\mathrm{pC} / \mathrm{m} 3$ & 0.0016 & 0.0016 & u & & \\
\hline SESPMNT & B16834 & MATTAWA & COMMUNITY & AT & 09-Apr-03 & Eu-152 & 0.000718 & $\mathrm{pC} / \mathrm{m} 3$ & 0.0012 & 0.0012 & u & & \\
\hline SESPMNT & B16PHO & MATTAWA & COMMUNITY & AT & 01-Jul-03 & Eu-152 & -0.0000281 & $\mathrm{pCi} / \mathrm{m} 3$ & 0.0013 & 0.0013 & u & & \\
\hline SESPMNT & B175C8 & MATTAWA & COMMUNITY & AT & 09-Oct-03 & Eu-152 & -0.00066 & $\mathrm{pC} / \mathrm{m} 3$ & 0.0018 & 0.0018 & u & & \\
\hline SESPMNT & B17P13 & MATTAWA & COMMUNITY & AT & 31-Dec-03 & Eu-152 & 0.000348 & $\mathrm{pCi} / \mathrm{m} 3$ & 0.0018 & 0.0018 & u & & \\
\hline SESPMNT & B16812 & N OF $200 E$ & ONSITE & AT & 08-Apr-03 & Eu-152 & -0.000668 & $\mathrm{pC} / \mathrm{m} 3$ & 0.001 & 0.001 & U & & \\
\hline SESPMNT & B16PC7 & N OF $200 E$ & ONSITE & AT & 30-Jun-03 & Eu-152 & 0.00161 & $\mathrm{pCi} / \mathrm{m} 3$ & 0.0015 & 0.0015 & U & & \\
\hline SESPMNT & B17596 & N OF $200 \mathrm{E}$ & ONSITE & AT & $07-$ Oct-03 & Eu-152 & 0.0000346 & $\mathrm{pC} / \mathrm{m} 3$ & 0.0015 & 0.0015 & $u$ & & \\
\hline SESPMNT & B17NYO & N OF $200 \mathrm{E}$ & ONSITE & AT & 30-Dec-03 & Eu-152 & $\begin{array}{l}0.000149 \\
0.000\end{array}$ & $\mathrm{pCi} / \mathrm{m} 3$ & 0.0016 & 0.0016 & u & & \\
\hline SESPMNT & B16842 & OTHELLO & COMMUNITY & AT & 09-Apr-03 & Eu-152 & 0.000127 & $\mathrm{pC} / \mathrm{m} 3$ & 0.0014 & 0.0014 & u & & \\
\hline SESPMNT & B16PH7 & OTHELLO & COMMUNITY & AT & 01-Jul-03 & Eu-152 & -0.00135 & $\mathrm{pCi} / \mathrm{m} 3$ & 0.0015 & 0.0015 & u & & \\
\hline SESPMNT & B175D6 & OTHELLO & COMMUNITY & AT & 09-Oct-03 & Eu-152 & 0.00065 & $\mathrm{pC} / \mathrm{m} 3$ & 0.0014 & 0.0014 & $u$ & & \\
\hline SESPMNT & B17P20 & OTHELLO & COMMUNITY & AT & 31-Dec-03 & Eu-152 & -0.000789 & $\mathrm{pCi} / \mathrm{m} 3$ & 0.0018 & 0.0018 & u & & \\
\hline SESPMNT & B168Y9 & PROSSER BARRICADE & PERIMETER & AT & 03-Apr-03 & Eu-152 & -0.000748 & $\mathrm{pC} / \mathrm{m} 3$ & 0.00078 & 0.00078 & $u$ & & \\
\hline SESPMNT & B16R90 & PROSSER BARRICADE & PERIMETER & AT & 11-Jul-03 & Eu-152 & 0.000208 & $\mathrm{pCi} / \mathrm{m} 3$ & 0.00078 & 0.00078 & U & & \\
\hline SESPMNT & B17669 & PROSSER BARRICADE & PERIMETER & AT & 03-Oct-03 & Eu-152 & -0.000475 & $\mathrm{pC} / \mathrm{m} 3$ & 0.0013 & 0.0013 & u & & \\
\hline SESPMNT & B17PV7 & PROSSER BARRICADE & PERIMETER & AT & $09-J a n-04$ & Eu-152 & 0.000217 & $\mathrm{pCi} / \mathrm{m} 3$ & 0.00081 & 0.00081 & u & & \\
\hline SESPMNT & B168W5 & RINGOLD MET TOWER & PERIMETER & AT & 10-Apr-03 & Eu-152 & 0.000297 & $\mathrm{pCi} / \mathrm{m} 3$ & 0.00098 & 0.00098 & U & & \\
\hline SESPMNT & B16R69 & RINGOLD MET TOWER & PERIMETER & AT & 07-Jul-03 & Eu-152 & 0.00046 & $\mathrm{pCi} / \mathrm{m} 3$ & 0.0015 & 0.0015 & U & & \\
\hline SESPMNT & B17645 & RINGOLD MET TOWER & PERIMETER & AT & 10-Oct-03 & Eu-152 & -0.00128 & $\mathrm{pCi} / \mathrm{m} 3$ & 0.0015 & 0.0015 & $u$ & & \\
\hline SESPMNT & B17PR6 & RINGOLD MET TOWER & PERIMETER & AT & 05-Jan-04 & Eu-152 & -0.000333 & $\mathrm{pCi} / \mathrm{m} 3$ & 0.0018 & 0.0018 & U & & \\
\hline SESPMNT & B16805 & TOPPENISH & DISTANT & AT & 02-Apr-03 & Eu-152 & 0.000566 & $\mathrm{pCi} / \mathrm{m} 3$ & 0.0011 & 0.0011 & U & & \\
\hline SESPMNT & B16PB9 & TOPPENISH & DISTANT & AT & 09-Jul-03 & Eu-152 & -0.000573 & $\mathrm{pCi} / \mathrm{m} 3$ & 0.0012 & 0.0012 & U & & \\
\hline SESPMNT & B17589 & TOPPENISH & DISTANT & AT & 01-Oct-03 & Eu-152 & 0.000909 & $\mathrm{pCl} / \mathrm{m} 3$ & 0.0014 & 0.0014 & $U$ & & \\
\hline SESPMNT & B17NX2 & TOPPENISH & DISTANT & AT & 08-Jan-04 & Eu-152 & -0.000683 & $\mathrm{pCi} / \mathrm{m} 3$ & 0.0015 & 0.0015 & $u$ & & \\
\hline SESPMNT & B16940 & TRI CITIES & COMMUNITY & AT & 10-Apr-03 & Eu-152 & 0.00036 & $\mathrm{pCi} / \mathrm{m} 3$ & 0.00064 & 0.00064 & $u$ & & \\
\hline SESPMNT & B16RF3 & TRI CITIES & COMMUNITY & AT & 07-Jul-03 & Eu-152 & -0.0000954 & $\mathrm{pCi} / \mathrm{m} 3$ & 0.00087 & 0.00087 & 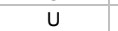 & & \\
\hline SESPMNT & B176C0 & TRI CITIES & COMMUNITY & AT & $10-$ Oct-03 & Eu-152 & -0.000312 & $\mathrm{pCi} / \mathrm{m} 3$ & 0.00096 & 0.00096 & $U$ & & \\
\hline SESPMNT & B17R10 & TRI CITIES & COMMUNITY & AT & 05-Jan-04 & Eu-152 & -0.00102 & $\mathrm{pCi} / \mathrm{m} 3$ & 0.0011 & 0.0011 & U & & \\
\hline SESPMNT & B168V7 & W END OF FIR ROAD & PERIMETER & AT & 10-Apr-03 & Eu-152 & 0.000155 & $\mathrm{pCl} / \mathrm{m} 3$ & 0.00093 & 0.00093 & $u$ & & \\
\hline SESPMNT & B16R62 & W END OF FIR ROAD & PERIMETER & AT & 07-Jul-03 & Eu-152 & -0.000492 & $\mathrm{pC} / \mathrm{m} 3$ & 0.0013 & 0.0013 & $u$ & & \\
\hline SESPMNT & B17637 & W END OF FIR ROAD & PERIMETER & AT & $10-$ Oct-03 & Eu-152 & -0.000155 & $\mathrm{pCl} / \mathrm{m} 3$ & 0.0014 & 0.0014 & $U$ & & \\
\hline SESPMNT & B17PP9 & W END OF FIR ROAD & PERIMETER & AT & $05-J a n-04$ & Eu-152 & -0.00045 & $\mathrm{pCi} / \mathrm{m} 3$ & 0.0019 & 0.0019 & u & & \\
\hline SESPMNT & B16925 & WAHLUKE SLOPE & PERIMETER & AT & 09-Apr-03 & Eu-152 & 0.000574 & $\mathrm{pCi} / \mathrm{m} 3$ & 0.00064 & 0.00064 & $U$ & & \\
\hline SESPMNT & B16RD0 & WAHLUKE SLOPE & PERIMETER & AT & 01-Jul-03 & Eu-152 & 0.000691 & $\mathrm{pCi} / \mathrm{m} 3$ & 0.00085 & 0.00085 & 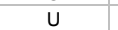 & & \\
\hline SESPMNT & B17695 & WAHLUKE SLOPE & PERIMETER & AT & 08-Oct-03 & Eu-152 & 0.000378 & $\mathrm{pCl} / \mathrm{m} 3$ & 0.00098 & 0.00098 & $u$ & & \\
\hline SESPMNT & B17PY7 & WAHLUKE SLOPE & PERIMETER & AT & 31-Dec-03 & Eu-152 & 0.000395 & $\mathrm{pCi} / \mathrm{m} 3$ & 0.00082 & 0.00082 & u & & \\
\hline SESPMNT & B168V0 & WYE BARRICADE & ONSITE & AT & 31-Mar-03 & Eu-152 & 0.000822 & $\mathrm{pCl} / \mathrm{m} 3$ & $\begin{array}{r}0.00012 \\
0.0012\end{array}$ & $\begin{array}{r}0.00012 \\
0.004\end{array}$ & u & & \\
\hline SESPMNT & B16R54 & WYE BARRICADE & ONSITE & AT & 08-Jul-03 & Eu-152 & 0.00034 & $\mathrm{pCi} / \mathrm{m} 3$ & 0.0012 & 0.0012 & $u$ & & \\
\hline SESPMNT & B17630 & WYE BARRICADE & ONSITE & AT & 01-Oct-03 & Eu-152 & -0.000435 & $\mathrm{pCi} / \mathrm{m} 3$ & 0.0018 & 0.0018 & $u$ & & \\
\hline SESPMNT & B17PP1 & WYE BARRICADE & ONSITE & AT & 06-Jan-04 & Eu-152 & 0.000587 & $\mathrm{pCi} / \mathrm{m} 3$ & 0.0017 & 0.0017 & u & & \\
\hline SESPMNT & B16955 & YAKIMA & DISTANT & AT & 03-Apr-03 & Eu-152 & -0.000102 & $\mathrm{pCi} / \mathrm{m} 3$ & 0.0013 & 0.0013 & u & & \\
\hline SESPMNT & B16RH6 & YAKIMA & DISTANT & AT & 11-Jul-03 & Eu-152 & 0.000506 & $\mathrm{pCl} / \mathrm{m} 3$ & 0.0012 & 0.0012 & $u$ & & \\
\hline SESPMNT & B176D5 & YAKIMA & DISTANT & AT & 03-Oct-03 & Eu-152 & -0.00124 & $\mathrm{pCi} / \mathrm{m} 3$ & 0.0019 & 0.0019 & $u$ & & \\
\hline SESPMNT & B17R23 & YAKIMA & DISTANT & AT & $09-J a n-04$ & Eu-152 & -0.00015 & $\mathrm{pCi} / \mathrm{m} 3$ & 0.0016 & 0.0016 & u & & \\
\hline SESPMNT & B16912 & YAKIMA BARRICADE & PERIMETER & AT & 02-Apr-03 & Eu-152 & 0.000571 & $\mathrm{pCi} / \mathrm{m} 3$ & 0.00064 & 0.00064 & u & & \\
\hline SESPMNT & B16RB5 & YAKIMA BARRICADE & PERIMETER & AT & 11-Jul-03 & Eu-152 & -0.00017 & $\mathrm{pCi} / \mathrm{m} 3$ & 0.00067 & 0.00067 & u & & \\
\hline SESPMNT & B17682 & YAKIMA BARRICADE & PERIMETER & AT & 03-Oct-03 & Eu-152 & -0.00109 & $\mathrm{pCl} / \mathrm{m} 3$ & 0.0012 & 0.0012 & U & & \\
\hline SESPMNT & B17PX2 & YAKIMA BARRICADE & PERIMETER & AT & 09-Jan-04 & Eu-152 & -0.000196 & $\mathrm{pCi} / \mathrm{m} 3$ & 0.00069 & 0.00069 & u & & \\
\hline
\end{tabular}


AIR GAMMA

\begin{tabular}{|c|c|c|c|c|c|c|c|c|c|c|c|c|c|}
\hline OWNER ID & | SAMP NUM & SAMP SITE NAME & | DIST CLASS | & MEDIA & SAMP DATE & $\begin{array}{l}\text { CON SHORT } \\
\text { NAME }\end{array}$ & |VALUE RPTD | & $\mid \begin{array}{l}\text { ANAL } \\
\text { UNITS } \\
\text { RPTD }\end{array}$ & $\left|\begin{array}{c}\text { COUNTING } \\
\text { ERROR }\end{array}\right|$ & $\begin{array}{c}\text { TOTAL ANAL } \\
\text { ERROR }\end{array} \mid$ & $\left|\begin{array}{c}\text { LAB } \\
\text { QUALIFIER }\end{array}\right|$ & SAMP COMMENT & RESULT COMMENT \\
\hline SESPMNT & B168C4 & 100 AREAS & ONSITE & AT & 31-Mar-03 & Eu-154 & -0.000561 & $\mathrm{pCi} / \mathrm{m} 3$ & 0.00074 & 0.00074 & U & & \\
\hline SESPMNT & B16PP5 & 100 AREAS & ONSITE & AT & 08-Jul-03 & Eu-154 & 0.000128 & $\mathrm{pCi} / \mathrm{m} 3$ & 0.00058 & 0.00058 & $U$ & & \\
\hline SESPMNT & B175M4 & 100 AREAS & ONSITE & AT & 01-Oct-03 & Eu-154 & 0.000564 & $\mathrm{pCi} / \mathrm{m} 3$ & 0.0015 & 0.0015 & $u$ & & \\
\hline SESPMNT & B17P82 & 100 AREAS & ONSITE & AT & 06-Jan-04 & Eu-154 & 0.000554 & $\mathrm{pCi} / \mathrm{m} 3$ & 0.00059 & 0.00059 & u & & \\
\hline SESPMNT & B168F3 & $200 \mathrm{E}$ AREA & ONSITE & AT & 08-Apr-03 & Eu-154 & -0.000672 & $\mathrm{pCi} / \mathrm{m} 3$ & 0.00088 & 0.00088 & $u$ & & \\
\hline SESPMNT & B16PT7 & $200 \mathrm{E}$ AREA & ONSITE & AT & 30-Jun-03 & Eu-154 & -0.000126 & $\mathrm{pC} / \mathrm{m} 3$ & 0.0012 & 0.0012 & u & & \\
\hline SESPMNT & B175P3 & 200 E AREA & ONSITE & AT & 07-Oct-03 & Eu-154 & 0.000189 & $\mathrm{pCi} / \mathrm{m} 3$ & 0.0013 & 0.0013 & u & & \\
\hline SESPMNT & B17PB4 & 200 E AREA & ONSITE & AT & 30-Dec-03 & Eu-154 & -0.000147 & $\mathrm{pCl} / \mathrm{m} 3$ & 0.0015 & 0.0015 & u & & \\
\hline SESPMNT & B168L8 & 200 W AREA & ONSITE & AT & 08-Apr-03 & Eu-154 & -0.000483 & $\mathrm{pCi} / \mathrm{m} 3$ & 0.0018 & 0.0018 & $u$ & & \\
\hline SESPMNT & B16PY6 & 200 W AREA & ONSITE & AT & 30-Jun-03 & Eu-154 & -0.00106 & $\mathrm{pC} / \mathrm{m} 3$ & 0.0015 & 0.0015 & u & & \\
\hline SESPMNT & B175W8 & 200 W AREA & ONSITE & AT & 07-Oct-03 & Eu-154 & 0.00127 & $\mathrm{pCi} / \mathrm{m} 3$ & 0.0019 & 0.0019 & $u$ & & \\
\hline SESPMNT & $\mathrm{B} 17 \mathrm{PH} 3$ & 200 W AREA & ONSITE & AT & 30-Dec-03 & Eu-154 & 0.000704 & $\mathrm{pCl} / \mathrm{m} 3$ & 0.0015 & 0.0015 & u & & \\
\hline SESPMNT & B168J6 & 200 W SOUTH EAST & ONSITE & AT & 08-Apr-03 & Eu-154 & 0.000212 & $\mathrm{pCi} / \mathrm{m} 3$ & 0.0005 & 0.0005 & $u$ & & \\
\hline SESPMNT & B16PW7 & 200 W SOUTH EAST & ONSITE & AT & 30-Jun-03 & Eu-154 & 0.000432 & $\mathrm{pCi} / \mathrm{m} 3$ & 0.00075 & 0.00075 & U & & \\
\hline SESPMNT & B175T6 & 200 W SOUTH EAST & ONSITE & AT & 07-Oct-03 & Eu-154 & 0.000214 & $\mathrm{pCi} / \mathrm{m} 3$ & 0.00052 & 0.00052 & $u$ & & \\
\hline SESPMNT & B17PD4 & 200 W SOUTH EAST & ONSITE & AT & 30-Dec-03 & Eu-154 & -0.000468 & $\mathrm{pCl} / \mathrm{m} 3$ & 0.0015 & 0.0015 & u & & \\
\hline SESPMNT & B168M6 & 300 AREA & ONSITE & AT & 02-Apr-03 & Eu-154 & -0.000428 & $\mathrm{pCi} / \mathrm{m} 3$ & 0.00059 & 0.00059 & $u$ & & \\
\hline SESPMNT & B16R03 & 300 AREA & ONSITE & AT & 10-Jul-03 & Eu-154 & 0.000212 & $\mathrm{pC} / / \mathrm{m} 3$ & 0.00059 & 0.00059 & 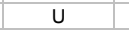 & & \\
\hline SESPMNT & B175X6 & 300 AREA & ONSITE & AT & 30-Sep-03 & Eu-154 & -0.000142 & $\mathrm{pCi} / \mathrm{m} 3$ & 0.0013 & 0.0013 & $u$ & & \\
\hline SESPMNT & B17PJo & 300 AREA & ONSITE & AT & 08-Jan-04 & Eu-154 & -0.000304 & $\mathrm{pCi} / \mathrm{m} 3$ & 0.00057 & 0.00057 & $u$ & & \\
\hline SESPMNT & B167V4 & $300 \mathrm{NE}$ & ONSITE & AT & 02-Apr-03 & Eu-154 & 0.000873 & $\mathrm{pCi} / \mathrm{m} 3$ & 0.0014 & 0.0014 & $u$ & & \\
\hline SESPMNT & B16P66 & $300 \mathrm{NE}$ & ONSITE & AT & 10-Jul-03 & Eu-154 & -0.00111 & $\mathrm{pCi} / \mathrm{m} 3$ & 0.0021 & 0.0021 & $u$ & & \\
\hline SESPMNT & B17548 & $300 \mathrm{NE}$ & ONSITE & AT & 30-Sep-03 & Eu-154 & 0.00114 & $\mathrm{pCi} / \mathrm{m} 3$ & 0.0013 & 0.0013 & $U$ & & \\
\hline SESPMNT & B17NP7 & $300 \mathrm{NE}$ & ONSITE & AT & 08-Jan-04 & Eu-154 & 0.0000881 & $\mathrm{pC} / \mathrm{m} 3$ & 0.0017 & 0.0017 & u & & \\
\hline SESPMNT & B167V3 & 300 TRENCH & ONSITE & AT & 02-Apr-03 & Eu-154 & -0.00108 & $\mathrm{pCi} / \mathrm{m} 3$ & 0.002 & 0.002 & $u$ & & \\
\hline SESPMNT & B16P65 & 300 TRENCH & ONSITE & AT & 10-Jul-03 & Eu-154 & 0.00136 & $\mathrm{pCi} / \mathrm{m} 3$ & 0.0018 & 0.0018 & U & & \\
\hline SESPMNT & B17547 & 300 TRENCH & ONSITE & AT & 30-Sep-03 & Eu-154 & 0.00162 & $\mathrm{pCi} / \mathrm{m} 3$ & 0.0029 & 0.0029 & $U$ & & \\
\hline SESPMNT & B17NP6 & 300 TRENCH & ONSITE & AT & 08-Jan-04 & Eu-154 & -0.0018 & $\mathrm{pCi} / \mathrm{m} 3$ & 0.0031 & 0.0031 & $u$ & & \\
\hline SESPMNT & B168P5 & 400 AREA & ONSITE & AT & 31-Mar-03 & Eu-154 & 0.0000954 & $\mathrm{pCi} / \mathrm{m} 3$ & 0.00054 & 0.00054 & $u$ & & \\
\hline SESPMNT & B16R25 & 400 AREA & ONSITE & AT & 08-Jul-03 & Eu-154 & 0.00038 & $\mathrm{pCi} / \mathrm{m} 3$ & 0.00052 & 0.00052 & U & & \\
\hline SESPMNT & B17605 & 400 AREA & ONSITE & AT & 01-Oct-03 & Eu-154 & 0.000244 & $\mathrm{pCi} / \mathrm{m} 3$ & 0.00062 & 0.00062 & u & & \\
\hline SESPMNT & B17PL2 & 400 AREA & ONSITE & AT & 05-Jan-04 & Eu-154 & 0.0000895 & $\mathrm{pCl} / \mathrm{m} 3$ & 0.00067 & 0.00067 & $u$ & & \\
\hline SESPMNT & $\mathrm{B} 168 \mathrm{H} 8$ & B POND & ONSITE & AT & 08-Apr-03 & Eu-154 & 0.000371 & $\mathrm{pCi} / \mathrm{m} 3$ & 0.0013 & 0.0013 & $u$ & & \\
\hline SESPMNT & B16PW0 & B POND & ONSITE & AT & 30-Jun-03 & Eu-154 & 0.00121 & $\mathrm{pCi} / \mathrm{m} 3$ & 0.002 & 0.002 & $U$ & & \\
\hline SESPMNT & B175R8 & B POND & ONSITE & AT & $07-0 c t-03$ & Eu-154 & -0.00000212 & $\mathrm{pCi} / \mathrm{m} 3$ & 0.0013 & 0.0013 & u & & \\
\hline SESPMNT & B17PC7 & B POND & ONSITE & AT & 30-Dec-03 & Eu-154 & 0.000793 & $\mathrm{pCl} / \mathrm{m} 3$ & 0.0035 & 0.0035 & $u$ & & \\
\hline SESPMNT & B16962 & BASIN CITY SCHOOL & COMMUNITY & AT & 09-Apr-03 & Eu-154 & 0.000514 & $\mathrm{pCi} / \mathrm{m} 3$ & 0.0015 & 0.0015 & $u$ & & \\
\hline SESPMNT & B16RJ4 & BASIN CITY SCHOOL & COMMUNITY & AT & 02-Jul-03 & Eu-154 & 0.000127 & $\mathrm{pCl} / \mathrm{m} 3$ & 0.0018 & 0.0018 & $u$ & & \\
\hline SESPMNT & B176F2 & BASIN CITY SCHOOL & COMMUNITY & AT & 08-Oct-03 & Eu-154 & 0.0000202 & $\mathrm{pCi} / \mathrm{m} 3$ & 0.0023 & 0.0023 & $u$ & & \\
\hline SESPMNT & B17R31 & BASIN CITY SCHOOL & COMMUNITY & AT & 31-Dec-03 & Eu-154 & -0.000599 & $\mathrm{pCi} / \mathrm{m} 3$ & 0.0018 & 0.0018 & $u$ & & \\
\hline SESPMNT & B16820 & BATTELLE COMPLEX & PERIMETER & AT & 02-Apr-03 & Eu-154 & 0.000376 & $\mathrm{pCl} / \mathrm{m} 3$ & 0.0016 & 0.0016 & $u$ & & \\
\hline SESPMNT & B16PD4 & BATTELLE COMPLEX & PERIMETER & AT & 09-Jul-03 & Eu-154 & 0.000338 & $\mathrm{pCi} / \mathrm{m} 3$ & 0.0014 & 0.0014 & $u$ & & \\
\hline SESPMNT & B175B4 & BATTELLE COMPLEX & PERIMETER & AT & $30-\mathrm{Sep}-03$ & Eu-154 & -0.000332 & $\mathrm{pCi} / \mathrm{m} 3$ & 0.0016 & 0.0016 & u & & \\
\hline SESPMNT & B17NY7 & BATTELLE COMPLEX & PERIMETER & AT & 08-Jan-04 & Eu-154 & -0.000341 & $\mathrm{pCi} / \mathrm{m} 3$ & 0.0011 & 0.0011 & $u$ & & \\
\hline SESPMNT & B16827 & BENTON CITY & COMMUNITY & AT & 03-Apr-03 & Eu-154 & -0.000521 & $\mathrm{pCi} / \mathrm{m} 3$ & 0.0014 & 0.0014 & u & & \\
\hline SESPMNT & B16PF2 & BENTON CITY & COMMUNITY & AT & 11-Jul-03 & Eu-154 & -0.00035 & $\mathrm{pCl} / \mathrm{m} 3$ & 0.00091 & 0.00091 & u & & \\
\hline SESPMNT & B175C1 & BENTON CITY & COMMUNITY & AT & 03-Oct-03 & Eu-154 & 0.00178 & $\mathrm{pCi} / \mathrm{m} 3$ & 0.0035 & 0.0035 & $U$ & & \\
\hline SESPMNT & B17P05 & BENTON CITY & COMMUNITY & AT & 09-Jan-04 & Eu-154 & 0.00176 & $\mathrm{pCl} / \mathrm{m} 3$ & 0.0023 & 0.0023 & $u$ & & \\
\hline SESPMNT & B168Y1 & BYERS LANDING & PERIMETER & AT & 10-Apr-03 & Eu-154 & 0.00126 & $\mathrm{pCi} / \mathrm{m} 3$ & 0.0014 & 0.0014 & $u$ & & \\
\hline SESPMNT & B16R83 & BYERS LANDING & PERIMETER & AT & 07-Jul-03 & Eu-154 & 0.00129 & $\mathrm{pCi} / \mathrm{m} 3$ & 0.0016 & 0.0016 & U & & \\
\hline SESPMNT & B17661 & BYERS LANDING & PERIMETER & AT & 10-Oct-03 & Eu-154 & -0.000795 & $\mathrm{pCi} / \mathrm{m} 3$ & 0.0015 & 0.0015 & $U$ & & \\
\hline SESPMNT & B17PVO & BYERS LANDING & PERIMETER & AT & 05-Jan-04 & Eu-154 & 0.00166 & $\mathrm{pCl} / \mathrm{m} 3$ & 0.0018 & 0.0018 & $u$ & & \\
\hline SESPMNT & B168X3 & DOGWOOD MET TOWER & PERIMETER & AT & 10-Apr-03 & Eu-154 & 0.000165 & $\mathrm{pCi} / \mathrm{m} 3$ & 0.0012 & 0.0012 & u & & \\
\hline SESPMNT & B16R76 & DOGWOOD MET TOWER & PERIMETER & AT & 07-Jul-03 & Eu-154 & -0.00101 & $\mathrm{pCi} / \mathrm{m} 3$ & 0.0016 & 0.0016 & U & & \\
\hline SESPMNT & B17653 & DOGWOOD MET TOWER & PERIMETER & AT & 10-Oct-03 & Eu-154 & -0.000964 & $\mathrm{pCi} / \mathrm{m} 3$ & 0.002 & 0.002 & $\mathrm{U}$ & & \\
\hline SESPMNT & B17PT3 & DOGWOOD MET TOWER & PERIMETER & AT & 05-Jan-04 & Eu-154 & -0.00209 & $\mathrm{pCi} / \mathrm{m} 3$ & 0.0028 & 0.0028 & $u$ & & \\
\hline SESPMNT & B16978 & EDWIN MARKHAM SCHOOL & COMMUNITY & AT & 10-Apr-03 & Eu-154 & 0.000238 & $\mathrm{pCi} / \mathrm{m} 3$ & 0.0014 & 0.0014 & u & & \\
\hline SESPMNT & B16RK8 & EDWIN MARKHAM SCHOOL & COMMUNITY & AT & 02-Jul-03 & Eu-154 & 0.000782 & $\mathrm{pCl} / \mathrm{m} 3$ & 0.0014 & 0.0014 & u & & \\
\hline
\end{tabular}


AIR GAMMA

\begin{tabular}{|c|c|c|c|c|c|c|c|c|c|c|c|c|c|}
\hline $\mid$ OWNER ID $\mid$ & SAMP NUM & SAMP SITE NAME & | DIST CLASS | & MEDIA & SAMP DATE & $\begin{array}{l}\text { CON SHORT } \\
\text { NAME }\end{array}$ & |VALUE RPTD & $\begin{array}{l}\text { ANAL } \\
\text { UNITS } \\
\text { RPTD }\end{array}$ & $\left|\begin{array}{c}\text { COUNTING } \\
\text { ERROR }\end{array}\right|$ & $\begin{array}{c}\text { TOTAL ANAL } \\
\text { ERROR }\end{array}$ & $\mid \begin{array}{c}\text { LAB } \\
\text { QUALIFIER }\end{array}$ & SAMP COMMENT & RESULT COMMENT \\
\hline SESPMNT & $\mathrm{B} 176 \mathrm{H} 8$ & EDWIN MARKHAM SCHOOL & COMMUNITY & AT & 08-Oct-03 & Eu-154 & 0.000355 & $\mathrm{pCi} / \mathrm{m} 3$ & 0.002 & 0.002 & u & & \\
\hline SESPMNT & B17R45 & EDWIN MARKHAM SCHOOL & COMMUNITY & AT & 31-Dec-03 & Eu-154 & -0.00127 & $\mathrm{pCi} / \mathrm{m} 3$ & 0.0026 & 0.0026 & $U$ & & \\
\hline SESPMNT & B16986 & HANFORD TOWNSITE & ONSITE & AT & 31-Mar-03 & Eu-154 & 0.000636 & $\mathrm{pCi} / \mathrm{m} 3$ & 0.0011 & 0.0011 & $U$ & & \\
\hline SESPMNT & B16RL5 & HANFORD TOWNSITE & ONSITE & AT & 08-Jul-03 & Eu-154 & 0.000182 & $\mathrm{pC} / / \mathrm{m} 3$ & 0.00096 & 0.00096 & $\mathrm{U}$ & & \\
\hline SESPMNT & B176J6 & HANFORD TOWNSITE & ONSITE & AT & $01-$ Oct-03 & Eu-154 & 0.000249 & $\mathrm{pC} / / \mathrm{m} 3$ & 0.0015 & 0.0015 & $\mathrm{U}$ & & \\
\hline SESPMNT & B17R52 & HANFORD TOWNSITE & ONSITE & AT & $06-J a n-04$ & Eu-154 & 0.000809 & $\mathrm{pC} / \mathrm{m} 3$ & 0.0011 & 0.0011 & u & & \\
\hline SESPMNT & B16970 & LESLIE GROVES-RCHLND & COMMUNITY & AT & 08-Apr-03 & Eu-154 & 0.000906 & $\mathrm{pC} / / \mathrm{m} 3$ & 0.0015 & 0.0015 & $u$ & & \\
\hline SESPMNT & B16RK1 & LESLIE GROVES-RCHLND & COMMUNITY & AT & 01-Jul-03 & Eu-154 & -0.000491 & $\mathrm{pCi} / \mathrm{m} 3$ & 0.002 & 0.002 & u & & \\
\hline SESPMNT & B176HO & LESLIE GROVES-RCHLND & COMMUNITY & AT & 07-Oct-03 & Eu-154 & 0.00028 & $\mathrm{pC} / \mathrm{m} 3$ & 0.0017 & 0.0017 & u & & \\
\hline SESPMNT & B17R38 & LESLIE GROVES-RCHLND & COMMUNITY & AT & 30-Dec-03 & Eu-154 & -0.00123 & $\mathrm{pC} / \mathrm{m} 3$ & 0.0029 & 0.0029 & u & & \\
\hline SESPMNT & B16834 & MATTAWA & COMMUNITY & AT & 09-Apr-03 & Eu-154 & 0.000381 & $\mathrm{pC} / \mathrm{m} 3$ & 0.0015 & 0.0015 & u & & \\
\hline SESPMNT & B16PHO & MATTAWA & COMMUNITY & AT & 01-Jul-03 & Eu-154 & 0.000487 & $\mathrm{pCi} / \mathrm{m} 3$ & 0.0021 & 0.0021 & u & & \\
\hline SESPMNT & B175C8 & MATTAWA & COMMUNITY & AT & 09-Oct-03 & Eu-154 & -0.00367 & $\mathrm{pC} / \mathrm{m} 3$ & 0.0033 & 0.0033 & u & & \\
\hline SESPMNT & B17P13 & MATTAWA & COMMUNITY & AT & 31-Dec-03 & Eu-154 & 0.000132 & $\mathrm{pCi} / \mathrm{m} 3$ & 0.0036 & 0.0036 & u & & \\
\hline SESPMNT & B16812 & N OF $200 \mathrm{E}$ & ONSITE & AT & 08-Apr-03 & Eu-154 & 0.00168 & $\mathrm{pC} / \mathrm{m} 3$ & 0.0013 & 0.0013 & u & & \\
\hline SESPMNT & B16PC7 & N OF $200 \mathrm{E}$ & ONSITE & AT & 30-Jun-03 & Eu-154 & 0.0012 & $\mathrm{pCi} / \mathrm{m} 3$ & 0.0014 & 0.0014 & u & & \\
\hline SESPMNT & B17596 & N OF $200 \mathrm{E}$ & ONSITE & AT & $07-$ Oct-03 & Eu-154 & -0.000885 & $\mathrm{pC} / \mathrm{m} 3$ & 0.0023 & 0.0023 & $u$ & & \\
\hline SESPMNT & B17NYO & N OF $200 \mathrm{E}$ & ONSITE & AT & 30-Dec-03 & Eu-154 & 0.00226 & $\mathrm{pCi} / \mathrm{m} 3$ & 0.0024 & 0.0024 & u & & \\
\hline SESPMNT & B16842 & OTHELLO & COMMUNITY & AT & 09-Apr-03 & Eu-154 & 0.000218 & $\mathrm{pC} / \mathrm{m} 3$ & 0.0016 & 0.0016 & u & & \\
\hline SESPMNT & B16PH7 & OTHELLO & COMMUNITY & AT & 01-Jul-03 & Eu-154 & -0.00134 & $\mathrm{pCi} / \mathrm{m} 3$ & 0.0017 & 0.0017 & U & & \\
\hline SESPMNT & B175D6 & OTHELLO & COMMUNITY & AT & 09-Oct-03 & Eu-154 & -0.000357 & $\mathrm{pC} / \mathrm{m} 3$ & 0.0015 & 0.0015 & $u$ & & \\
\hline SESPMNT & B17P20 & OTHELLO & COMMUNITY & AT & 31-Dec-03 & Eu-154 & 0.000387 & $\mathrm{pCi} / \mathrm{m} 3$ & $\begin{array}{l}0.002 \\
\end{array}$ & 0.002 & u & & \\
\hline SESPMNT & B168Y9 & PROSSER BARRICADE & $\begin{array}{l}\text { PERIMETER } \\
\end{array}$ & AT & 03-Apr-03 & Eu-154 & -0.000342 & $\mathrm{pC} / \mathrm{m} 3$ & 0.001 & 0.001 & $u$ & & \\
\hline SESPMNT & B16R90 & PROSSER BARRICADE & PERIMETER & AT & 11-Jul-03 & Eu-154 & 0.00021 & $\mathrm{pCi} / \mathrm{m} 3$ & 0.00099 & 0.00099 & U & & \\
\hline SESPMNT & B17669 & PROSSER BARRICADE & PERIMETER & AT & 03-Oct-03 & Eu-154 & 0.000257 & $\mathrm{pC} / \mathrm{m} 3$ & 0.00088 & 0.00088 & u & & \\
\hline SESPMNT & B17PV7 & PROSSER BARRICADE & PERIMETER & AT & $09-J a n-04$ & Eu-154 & 0.000134 & $\mathrm{pCi} / \mathrm{m} 3$ & 0.0011 & 0.0011 & u & & \\
\hline SESPMNT & B168W5 & RINGOLD MET TOWER & PERIMETER & AT & 10-Apr-03 & Eu-154 & -0.0000352 & $\mathrm{pCi} / \mathrm{m} 3$ & 0.0011 & 0.0011 & U & & \\
\hline SESPMNT & B16R69 & RINGOLD MET TOWER & PERIMETER & AT & 07-Jul-03 & Eu-154 & 0.0000128 & $\mathrm{pCi} / \mathrm{m} 3$ & 0.002 & 0.002 & U & & \\
\hline SESPMNT & B17645 & RINGOLD MET TOWER & PERIMETER & AT & 10-Oct-03 & Eu-154 & 0.000722 & $\mathrm{pCi} / \mathrm{m} 3$ & 0.0023 & 0.0023 & $u$ & & \\
\hline SESPMNT & B17PR6 & RINGOLD MET TOWER & PERIMETER & AT & 05-Jan-04 & Eu-154 & 0.00198 & $\mathrm{pCi} / \mathrm{m} 3$ & 0.0025 & 0.0025 & U & & \\
\hline SESPMNT & B16805 & TOPPENISH & DISTANT & AT & 02-Apr-03 & Eu-154 & -0.000322 & $\mathrm{pCi} / \mathrm{m} 3$ & 0.0017 & 0.0017 & U & & \\
\hline SESPMNT & B16PB9 & TOPPENISH & DISTANT & AT & 09-Jul-03 & Eu-154 & -0.00104 & $\mathrm{pCi} / \mathrm{m} 3$ & 0.0016 & 0.0016 & U & & \\
\hline SESPMNT & B17589 & TOPPENISH & DISTANT & AT & 01-Oct-03 & Eu-154 & -0.00000491 & $\mathrm{pC} / \mathrm{m} 3$ & 0.0021 & 0.0021 & $U$ & & \\
\hline SESPMNT & B17NX2 & TOPPENISH & DISTANT & AT & 08-Jan-04 & Eu-154 & 0.00114 & $\mathrm{pCi} / \mathrm{m} 3$ & 0.0022 & 0.0022 & $u$ & & \\
\hline SESPMNT & B16940 & TRI CITIES & COMMUNITY & AT & 10-Apr-03 & Eu-154 & 0.0000997 & $\mathrm{pCi} / \mathrm{m} 3$ & 0.00088 & 0.00088 & U & & \\
\hline SESPMNT & B16RF3 & TRI CITIES & COMMUNITY & AT & 07-Jul-03 & Eu-154 & 0.000447 & $\mathrm{pCi} / \mathrm{m} 3$ & 0.0013 & 0.0013 & 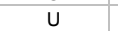 & & \\
\hline SESPMNT & B176C0 & TRI CITIES & COMMUNITY & AT & $10-$ Oct-03 & Eu-154 & -0.000274 & $\mathrm{pC} / \mathrm{m} 3$ & 0.0013 & 0.0013 & $U$ & & \\
\hline SESPMNT & B17R10 & TRI CITIES & COMMUNITY & AT & 05-Jan-04 & Eu-154 & 0.000223 & $\mathrm{pCi} / \mathrm{m} 3$ & 0.0015 & 0.0015 & U & & \\
\hline SESPMNT & B168V7 & W END OF FIR ROAD & PERIMETER & AT & 10-Apr-03 & Eu-154 & 0.000562 & $\mathrm{pCi} / \mathrm{m} 3$ & 0.0015 & 0.0015 & $u$ & & \\
\hline SESPMNT & B16R62 & W END OF FIR ROAD & PERIMETER & AT & 07-Jul-03 & Eu-154 & -0.00103 & $\mathrm{pCi} / \mathrm{m} 3$ & 0.0018 & 0.0018 & $u$ & & \\
\hline SESPMNT & B17637 & W END OF FIR ROAD & PERIMETER & AT & $10-$ Oct-03 & Eu-154 & -0.000973 & $\mathrm{pCl} / \mathrm{m} 3$ & 0.002 & 0.002 & $U$ & & \\
\hline SESPMNT & B17PP9 & W END OF FIR ROAD & PERIMETER & AT & $05-J a n-04$ & Eu-154 & 0.000788 & $\mathrm{pCi} / \mathrm{m} 3$ & 0.0026 & 0.0026 & u & & \\
\hline SESPMNT & B16925 & WAHLUKE SLOPE & PERIMETER & AT & 09-Apr-03 & Eu-154 & 0.0000807 & $\mathrm{pCi} / \mathrm{m} 3$ & 0.00087 & 0.00087 & $U$ & & \\
\hline SESPMNT & B16RD0 & WAHLUKE SLOPE & PERIMETER & AT & 01-Jul-03 & Eu-154 & 0.000288 & $\mathrm{pCi} / \mathrm{m} 3$ & 0.0011 & 0.0011 & 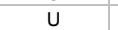 & & \\
\hline SESPMNT & B17695 & WAHLUKE SLOPE & PERIMETER & AT & 08-Oct-03 & Eu-154 & -0.000531 & $\mathrm{pCi} / \mathrm{m} 3$ & 0.0015 & 0.0015 & $u$ & & \\
\hline SESPMNT & B17PY7 & WAHLUKE SLOPE & PERIMETER & AT & 31-Dec-03 & Eu-154 & -0.00000553 & $\mathrm{pCi} / \mathrm{m} 3$ & 0.00056 & 0.00056 & u & & \\
\hline SESPMNT & B168V0 & WYE BARRICADE & ONSITE & AT & 31-Mar-03 & Eu-154 & -0.000381 & $\mathrm{pCl} / \mathrm{m} 3$ & $\begin{array}{r}0.0019 \\
0.0019\end{array}$ & 0.0019 & u & & \\
\hline SESPMNT & B16R54 & WYE BARRICADE & ONSITE & AT & 08-Jul-03 & Eu-154 & -0.000835 & $\mathrm{pCi} / \mathrm{m} 3$ & 0.0017 & 0.0017 & u & & \\
\hline SESPMNT & B17630 & WYE BARRICADE & ONSITE & AT & 01-Oct-03 & Eu-154 & -0.000764 & $\mathrm{pCi} / \mathrm{m} 3$ & 0.0019 & 0.0019 & $u$ & & \\
\hline SESPMNT & B17PP1 & WYE BARRICADE & ONSITE & AT & 06-Jan-04 & Eu-154 & -0.000765 & $\mathrm{pCi} / \mathrm{m} 3$ & 0.002 & 0.002 & u & & \\
\hline SESPMNT & B16955 & YAKIMA & DISTANT & AT & $03-A p r-03$ & Eu-154 & 0.00154 & $\mathrm{pCl} / \mathrm{m} 3$ & 0.0019 & 0.0019 & u & & \\
\hline SESPMNT & B16RH6 & YAKIMA & DISTANT & AT & 11-Jul-03 & Eu-154 & -0.000496 & $\mathrm{pCl} / \mathrm{m} 3$ & 0.002 & 0.002 & $u$ & & \\
\hline SESPMNT & B176D5 & YAKIMA & DISTANT & AT & 03-Oct-03 & Eu-154 & 0.000703 & $\mathrm{pCi} / \mathrm{m} 3$ & 0.0022 & 0.0022 & $u$ & & \\
\hline SESPMNT & B17R23 & YAKIMA & DISTANT & AT & $09-J a n-04$ & Eu-154 & -0.000634 & $\mathrm{pCi} / \mathrm{m} 3$ & 0.0015 & 0.0015 & u & & \\
\hline SESPMNT & B16912 & YAKIMA BARRICADE & PERIMETER & AT & 02-Apr-03 & Eu-154 & 0.0000505 & $\mathrm{pCi} / \mathrm{m} 3$ & 0.001 & 0.001 & u & & \\
\hline SESPMNT & B16RB5 & YAKIMA BARRICADE & PERIMETER & AT & 11-Jul-03 & Eu-154 & 0.000271 & $\mathrm{pCi} / \mathrm{m} 3$ & 0.00078 & 0.00078 & u & & \\
\hline SESPMNT & B17682 & YAKIMA BARRICADE & PERIMETER & AT & 03-Oct-03 & Eu-154 & -0.00104 & $\mathrm{pC} / \mathrm{m} 3$ & 0.0013 & 0.0013 & U & & \\
\hline SESPMNT & B17PX2 & YAKIMA BARRICADE & PERIMETER & AT & 09-Jan-04 & Eu-154 & 0.00133 & $\mathrm{pCi} / \mathrm{m} 3$ & 0.001 & 0.001 & u & & \\
\hline
\end{tabular}


AIR GAMMA

\begin{tabular}{|c|c|c|c|c|c|c|c|c|c|c|c|c|c|}
\hline OWNER ID & SAMP NUM & SAMP SITE NAME & | DIST CLASS | & MEDIA & SAMP DATE & $\begin{array}{l}\text { CON SHORT } \\
\text { NAME }\end{array}$ & |VALUE RPTD & $\mid \begin{array}{l}\text { ANAL } \\
\text { UNITS } \\
\text { RPTD }\end{array}$ & $\begin{array}{c}\text { COUNTING } \\
\text { ERROR }\end{array}$ & $\begin{array}{c}\text { TOTAL ANAL } \\
\text { ERROR }\end{array}$ & $\begin{array}{c}\text { LAB } \\
\text { QUALIFIER }\end{array}$ & SAMP COMMENT & RESULT COMMENT \\
\hline SESPMNT & B168C4 & 100 AREAS & ONSITE & AT & 31-Mar-03 & Eu-155 & -0.000166 & $\mathrm{pC} / \mathrm{m} 3$ & 0.00073 & 0.00073 & u & & \\
\hline SESPMNT & B16PP5 & 100 AREAS & ONSITE & AT & 08-Jul-03 & Eu-155 & -0.00015 & $\mathrm{pC} / / \mathrm{m} 3$ & 0.00038 & 0.00038 & $U$ & & \\
\hline SESPMNT & B175M4 & 100 AREAS & ONSITE & AT & 01-Oct-03 & Eu-155 & 0.000655 & $\mathrm{pC} / \mathrm{m} 3$ & 0.00062 & 0.00062 & U & & \\
\hline SESPMNT & B17P82 & 100 AREAS & ONSITE & AT & 06-Jan-04 & Eu-155 & 0.00018 & $\mathrm{pCl} / \mathrm{m} 3$ & 0.00044 & 0.00044 & u & & \\
\hline SESPMNT & B168F3 & 200 E AREA & ONSITE & AT & 08-Apr-03 & Eu-155 & 0.0000293 & $\mathrm{pCi} / \mathrm{m} 3$ & 0.00045 & 0.00045 & u & & \\
\hline SESPMNT & B16PT7 & 200 E AREA & ONSITE & AT & 30-Jun-03 & Eu-155 & 0.000344 & $\mathrm{pC} / \mathrm{m} 3$ & 0.00069 & 0.00069 & $u$ & & \\
\hline SESPMNT & B175P3 & $200 \mathrm{E}$ AREA & ONSITE & AT & $07-\mathrm{Oct}-03$ & Eu-155 & -0.000224 & $\mathrm{pCi} / \mathrm{m} 3$ & 0.00087 & 0.00087 & U & & \\
\hline SESPMNT & B17PB4 & $200 \mathrm{E}$ AREA & ONSITE & AT & 30-Dec-03 & Eu-155 & 0.000373 & $\mathrm{pC} / / \mathrm{m} 3$ & 0.0011 & 0.0011 & u & & \\
\hline SESPMNT & B168L8 & 200 W AREA & ONSITE & AT & 08-Apr-03 & Eu-155 & 0.000374 & $\mathrm{pCi} / \mathrm{m} 3$ & 0.00093 & 0.00093 & u & & \\
\hline SESPMNT & B16PY6 & 200 W AREA & ONSITE & AT & 30-Jun-03 & Eu-155 & -0.0000364 & $\mathrm{pC} / \mathrm{m} 3$ & 0.00069 & 0.00069 & $u$ & & \\
\hline SESPMNT & B175W8 & 200 W AREA & ONSITE & AT & $07-O c t-03$ & Eu-155 & 0.000527 & $\mathrm{pC} / / \mathrm{m} 3$ & 0.0016 & 0.0016 & $\mathrm{U}$ & & \\
\hline SESPMNT & B17PH3 & 200 W AREA & ONSITE & AT & 30-Dec-03 & Eu-155 & -0.00000684 & $\mathrm{pCi} / \mathrm{m} 3$ & 0.00094 & 0.00094 & U & & \\
\hline SESPMNT & B168J6 & 200 W SOUTH EAST & ONSITE & AT & 08-Apr-03 & Eu-155 & -0.000236 & $\mathrm{pCi} / \mathrm{m} 3$ & 0.00026 & 0.00026 & u & & \\
\hline SESPMNT & B16PW7 & 200 W SOUTH EAST & ONSITE & AT & 30-Jun-03 & Eu-155 & 0.00027 & $\mathrm{pCl} / \mathrm{m} 3$ & 0.00042 & 0.00042 & u & & \\
\hline SESPMNT & B175T6 & 200 W SOUTH EAST & ONSITE & AT & $07-$ Oct-03 & Eu-155 & -0.0000158 & $\mathrm{pCi} / \mathrm{m} 3$ & 0.00046 & 0.00046 & $U$ & & \\
\hline SESPMNT & B17PD4 & 200 W SOUTH EAST & ONSITE & AT & 30-Dec-03 & Eu-155 & 0.000417 & $\mathrm{pCi} / \mathrm{m} 3$ & 0.00059 & 0.00059 & U & & \\
\hline SESPMNT & B168M6 & 300 AREA & ONSITE & AT & 02-Apr-03 & Eu-155 & -0.0000131 & $\mathrm{pCi} / \mathrm{m} 3$ & 0.00038 & 0.00038 & $U$ & & \\
\hline SESPMNT & B16R03 & 300 AREA & ONSITE & AT & 10-Jul-03 & Eu-155 & -0.0000339 & $\mathrm{pC} / \mathrm{m} 3$ & 0.00037 & 0.00037 & u & & \\
\hline SESPMNT & B175X6 & 300 AREA & ONSITE & AT & 30-Sep-03 & Eu-155 & -0.000355 & $\mathrm{pCi} / \mathrm{m} 3$ & 0.00062 & 0.00062 & U & & \\
\hline SESPMNT & B17PJ0 & 300 AREA & ONSITE & AT & 08-Jan-04 & Eu-155 & -0.000257 & $\mathrm{pCi} / \mathrm{m} 3$ & 0.00042 & 0.00042 & $u$ & & \\
\hline SESPMNT & B167V4 & $300 \mathrm{NE}$ & ONSITE & AT & 02-Apr-03 & Eu-155 & -0.000911 & $\mathrm{pC} / \mathrm{m} 3$ & 0.00083 & 0.00083 & u & & \\
\hline SESPMNT & B16P66 & $300 \mathrm{NE}$ & ONSITE & AT & 10-Jul-03 & Eu-155 & 0.000902 & $\mathrm{pCl} / \mathrm{m} 3$ & 0.0012 & 0.0012 & u & & \\
\hline SESPMNT & B17548 & $300 \mathrm{NE}$ & ONSITE & AT & 30-Sep-03 & Eu-155 & -0.000637 & $\mathrm{pC} / / \mathrm{m} 3$ & 0.00088 & 0.00088 & U & & \\
\hline $\begin{array}{l}\text { SESPMNT } \\
\text { SESP }\end{array}$ & B17NP7 & $300 \mathrm{NE}$ & ONSITE & AT & 08-Jan-04 & Eu-155 & 0.000893 & $\mathrm{pC} / \mathrm{m} 3$ & $\begin{array}{l}0.00098 \\
0.0008\end{array}$ & 0.00098 & u & & \\
\hline SESPMNT & B167V3 & 300 TRENCH & ONSITE & AT & 02-Apr-03 & Eu-155 & 0.000598 & $\mathrm{pC} / \mathrm{m} 3$ & 0.001 & 0.001 & u & & \\
\hline SESPMNT & B16P65 & 300 TRENCH & ONSITE & AT & 10-Jul-03 & Eu-155 & 0.00028 & $\mathrm{pCl} / \mathrm{m} 3$ & 0.00087 & 0.00087 & u & & \\
\hline SESPMNT & B17547 & 300 TRENCH & ONSITE & AT & 30-Sep-03 & Eu-155 & -0.00035 & $\mathrm{pCi} / \mathrm{m} 3$ & 0.0011 & 0.0011 & $u$ & & \\
\hline $\begin{array}{l}\text { SESPMNT } \\
\text { SESP }\end{array}$ & B17NP6 & 300 TRENCH & ONSITE & AT & $08-J a n-04$ & Eu-155 & $\begin{array}{l}-0.000387 \\
-0.0037\end{array}$ & $\mathrm{pCl} / \mathrm{m} 3$ & 0.0016 & 0.0016 & u & & \\
\hline SESPMNT & B168P5 & 400 AREA & ONSITE & AT & 31-Mar-03 & Eu-155 & 0.000445 & $\mathrm{pCi} / \mathrm{m} 3$ & 0.0006 & 0.0006 & u & & \\
\hline SESPMNT & B16R25 & 400 AREA & ONSITE & AT & 08-Jul-03 & Eu-155 & 0.000359 & $\mathrm{pC} / \mathrm{m} 3$ & 0.0003 & 0.0003 & U & & \\
\hline SESPMNT & B17605 & 400 AREA & ONSITE & AT & 01-Oct-03 & Eu-155 & 0.000102 & $\mathrm{pCi} / \mathrm{m} 3$ & 0.00047 & 0.00047 & u & & \\
\hline SESPMNT & B17PL2 & 400 AREA & ONSITE & AT & 05-Jan-04 & Eu-155 & -0.000433 & $\mathrm{pCl} / \mathrm{m} 3$ & 0.00034 & 0.00034 & u & & \\
\hline SESPMNT & $\mathrm{B} 168 \mathrm{H} 8$ & B POND & ONSITE & AT & 08-Apr-03 & Eu-155 & 0.000709 & $\mathrm{pCi} / \mathrm{m} 3$ & 0.00071 & 0.00071 & u & & \\
\hline SESPMNT & B16PW0 & B POND & ONSITE & AT & 30-Jun-03 & Eu-155 & -0.0000293 & $\mathrm{pCl} / \mathrm{m} 3$ & 0.0014 & 0.0014 & u & & \\
\hline SESPMNT & B175R8 & B POND & ONSITE & AT & $07-0 c t-03$ & Eu-155 & -0.000326 & $\mathrm{pCl} / \mathrm{m} 3$ & 0.0009 & 0.0009 & $\mathrm{U}$ & & \\
\hline SESPMNT & B17PC7 & B POND & ONSITE & AT & 30-Dec-03 & Eu-155 & -0.000932 & $\mathrm{pCl} / \mathrm{m} 3$ & 0.0019 & 0.0019 & U & & \\
\hline SESPMNT & B16962 & BASIN CITY SCHOOL & COMMUNITY & AT & 09-Apr-03 & Eu-155 & -0.000253 & $\mathrm{pCi} / \mathrm{m} 3$ & 0.00096 & 0.00096 & u & & \\
\hline SESPMNT & B16RJ4 & BASIN CITY SCHOOL & COMMUNITY & AT & 02-Jul-03 & Eu-155 & 0.000442 & $\mathrm{pCi} / \mathrm{m} 3$ & 0.001 & 0.001 & u & & \\
\hline SESPMNT & B176F2 & BASIN CITY SCHOOL & COMMUNITY & AT & $08-\mathrm{Oct}-03$ & Eu-155 & -0.000679 & $\mathrm{pCi} / \mathrm{m} 3$ & 0.0012 & 0.0012 & u & & \\
\hline SESPMNT & B17R31 & BASIN CITY SCHOOL & COMMUNITY & AT & 31-Dec-03 & Eu-155 & 0.00000442 & $\mathrm{pCi} / \mathrm{m} 3$ & 0.0014 & 0.0014 & u & & \\
\hline SESPMNT & B16820 & BATTELLE COMPLEX & PERIMETER & AT & 02-Apr-03 & Eu-155 & 0.000124 & $\mathrm{pCi} / \mathrm{m} 3$ & 0.00081 & 0.00081 & u & & \\
\hline SESPMNT & B16PD4 & BATTELLE COMPLEX & PERIMETER & AT & 09-Jul-03 & Eu-155 & -0.000205 & $\mathrm{pCl} / \mathrm{m} 3$ & 0.00079 & 0.00079 & $\mathrm{u}$ & & \\
\hline SESPMNT & B175B4 & BATTELLE COMPLEX & PERIMETER & AT & $30-$ Sep-03 & Eu-155 & 0.000413 & $\mathrm{pCl} / \mathrm{m} 3$ & 0.0011 & 0.0011 & U & & \\
\hline SESPMNT & B17NY7 & BATTELLE COMPLEX & PERIMETER & AT & 08-Jan-04 & Eu-155 & -0.00173 & $\mathrm{pCl} / \mathrm{m} 3$ & 0.0013 & 0.0013 & U & & \\
\hline SESPMNT & B16827 & BENTON CITY & COMMUNITY & AT & 03-Apr-03 & Eu-155 & -0.000666 & $\mathrm{pCi} / \mathrm{m} 3$ & 0.0013 & 0.0013 & u & & \\
\hline SESPMNT & B16PF2 & BENTON CITY & COMMUNITY & AT & 11-Jul-03 & Eu-155 & -0.0000906 & $\mathrm{pCl} / \mathrm{m} 3$ & 0.00057 & 0.00057 & U & & \\
\hline SESPMNT & B175C1 & BENTON CITY & COMMUNITY & AT & 03-Oct-03 & Eu-155 & -0.000322 & $\mathrm{pCi} / \mathrm{m} 3$ & 0.0021 & 0.0021 & U & & \\
\hline SESPMNT & B17P05 & BENTON CITY & COMMUNITY & AT & 09-Jan-04 & Eu-155 & 0.0000568 & $\mathrm{pCl} / \mathrm{m} 3$ & 0.0011 & 0.0011 & u & & \\
\hline SESPMNT & B168Y1 & BYERS LANDING & PERIMETER & AT & 10-Apr-03 & Eu-155 & -0.000669 & $\mathrm{pCi} / \mathrm{m} 3$ & 0.0011 & 0.0011 & $u$ & & \\
\hline SESPMNT & B16R83 & BYERS LANDING & PERIMETER & AT & 07-Jul-03 & Eu-155 & -0.000139 & $\mathrm{pC} / \mathrm{m} 3$ & 0.00082 & 0.00082 & U & & \\
\hline SESPMNT & B17661 & BYERS LANDING & PERIMETER & AT & 10-Oct-03 & Eu-155 & 0.000698 & $\mathrm{pCl} / \mathrm{m} 3$ & 0.0017 & 0.0017 & U & & \\
\hline SESPMNT & B17PV0 & BYERS LANDING & PERIMETER & AT & 05-Jan-04 & Eu-155 & 0.000144 & $\mathrm{pCi} / \mathrm{m} 3$ & 0.0012 & 0.0012 & u & & \\
\hline SESPMNT & B168X3 & DOGWOOD MET TOWER & PERIMETER & AT & 10-Apr-03 & Eu-155 & -0.000367 & $\mathrm{pCi} / \mathrm{m} 3$ & 0.00068 & 0.00068 & u & & \\
\hline SESPMNT & B16R76 & DOGWOOD MET TOWER & PERIMETER & AT & $07-J u l-03$ & Eu-155 & 0.000368 & $\mathrm{pCl} / \mathrm{m} 3$ & 0.00092 & 0.00092 & u & & \\
\hline SESPMNT & B17653 & DOGWOOD MET TOWER & PERIMETER & AT & 10-Oct-03 & Eu-155 & 0.0000344 & $\mathrm{pCi} / \mathrm{m} 3$ & 0.00098 & 0.00098 & u & & \\
\hline SESPMNT & B17PT3 & DOGWOOD MET TOWER & PERIMETER & AT & 05-Jan-04 & Eu-155 & 0.000277 & $\mathrm{pCi} / \mathrm{m} 3$ & 0.0012 & 0.0012 & u & & \\
\hline SESPMNT & B16978 & EDWIN MARKHAM SCHOOL & COMMUNITY & AT & 10-Apr-03 & Eu-155 & -0.000159 & $\mathrm{pCi} / \mathrm{m} 3$ & 0.00091 & 0.00091 & u & & \\
\hline SESPMNT & B16RK8 & EDWIN MARKHAM SCHOOL & COMMUNITY & AT & 02-Jul-03 & Eu-155 & -0.0000339 & $\mathrm{pC} / \mathrm{m} 3$ & 0.00079 & 0.00079 & u & & \\
\hline
\end{tabular}


AIR GAMMA

\begin{tabular}{|c|c|c|c|c|c|c|c|c|c|c|c|c|c|}
\hline $\mid$ OWNER ID $\mid$ & SAMP NUM & SAMP SITE NAME & | DIST CLASS | & MEDIA & SAMP DATE & $\begin{array}{l}\text { CON SHORT } \\
\text { NAME }\end{array}$ & |VALUE RPTD & $\begin{array}{l}\text { ANAL } \\
\text { UNITS } \\
\text { RPTD }\end{array}$ & $\left|\begin{array}{c}\text { COUNTING } \\
\text { ERROR }\end{array}\right|$ & $\begin{array}{c}\text { TOTAL ANAL } \\
\text { ERROR }\end{array}$ & $\mid \begin{array}{c}\text { LAB } \\
\text { QUALIFIER }\end{array}$ & SAMP COMMENT & RESULT COMMENT \\
\hline SESPMNT & B176H8 & EDWIN MARKHAM SCHOOL & COMMUNITY & AT & 08-Oct-03 & Eu-155 & -0.000676 & $\mathrm{pCi} / \mathrm{m} 3$ & 0.0011 & 0.0011 & u & & \\
\hline SESPMNT & B17R45 & EDWIN MARKHAM SCHOOL & COMMUNITY & AT & 31-Dec-03 & Eu-155 & 0.00116 & $\mathrm{pCi} / \mathrm{m} 3$ & 0.0016 & 0.0016 & $U$ & & \\
\hline SESPMNT & B16986 & HANFORD TOWNSITE & ONSITE & AT & 31-Mar-03 & Eu-155 & 0.0000103 & $\mathrm{pCi} / \mathrm{m} 3$ & 0.00056 & 0.00056 & $U$ & & \\
\hline SESPMNT & B16RL5 & HANFORD TOWNSITE & ONSITE & AT & 08-Jul-03 & Eu-155 & -0.000367 & $\mathrm{pC} / / \mathrm{m} 3$ & 0.00056 & 0.00056 & $\mathrm{U}$ & & \\
\hline SESPMNT & B176J6 & HANFORD TOWNSITE & ONSITE & AT & $01-$ Oct-03 & Eu-155 & -0.0000238 & $\mathrm{pC} / / \mathrm{m} 3$ & 0.00097 & 0.00097 & $\mathrm{U}$ & & \\
\hline SESPMNT & B17R52 & HANFORD TOWNSITE & ONSITE & AT & $06-J a n-04$ & Eu-155 & -0.000199 & $\mathrm{pC} / \mathrm{m} 3$ & 0.00063 & 0.00063 & u & & \\
\hline SESPMNT & B16970 & LESLIE GROVES-RCHLND & COMMUNITY & AT & 08-Apr-03 & Eu-155 & 0.000353 & $\mathrm{pC} / / \mathrm{m} 3$ & 0.00095 & 0.00095 & $u$ & & \\
\hline SESPMNT & B16RK1 & LESLIE GROVES-RCHLND & COMMUNITY & AT & 01-Jul-03 & Eu-155 & 0.000192 & $\mathrm{pCi} / \mathrm{m} 3$ & 0.0013 & 0.0013 & u & & \\
\hline SESPMNT & B176HO & LESLIE GROVES-RCHLND & COMMUNITY & AT & 07-Oct-03 & Eu-155 & 0.000998 & $\mathrm{pC} / \mathrm{m} 3$ & 0.0015 & 0.0015 & u & & \\
\hline SESPMNT & B17R38 & LESLIE GROVES-RCHLND & COMMUNITY & AT & 30-Dec-03 & Eu-155 & -0.00022 & $\mathrm{pC} / \mathrm{m} 3$ & 0.0013 & 0.0013 & u & & \\
\hline SESPMNT & B16834 & MATTAWA & COMMUNITY & AT & 09-Apr-03 & Eu-155 & 0.000892 & $\mathrm{pC} / \mathrm{m} 3$ & 0.0011 & 0.0011 & u & & \\
\hline SESPMNT & B16PHO & MATTAWA & COMMUNITY & AT & 01-Jul-03 & Eu-155 & 0.0000604 & $\mathrm{pCi} / \mathrm{m} 3$ & 0.00096 & 0.00096 & u & & \\
\hline SESPMNT & B175C8 & MATTAWA & COMMUNITY & AT & 09-Oct-03 & Eu-155 & -0.000621 & $\mathrm{pC} / \mathrm{m} 3$ & 0.0013 & 0.0013 & u & & \\
\hline SESPMNT & B17P13 & MATTAWA & COMMUNITY & AT & 31-Dec-03 & Eu-155 & $\begin{array}{l}-0.0000553 \\
-0.0005\end{array}$ & $\mathrm{pCi} / \mathrm{m} 3$ & 0.0017 & 0.0017 & u & & \\
\hline SESPMNT & B16812 & N OF $200 E$ & ONSITE & AT & 08-Apr-03 & Eu-155 & -0.000337 & $\mathrm{pC} / \mathrm{m} 3$ & 0.00077 & 0.00077 & U & & \\
\hline SESPMNT & B16PC7 & N OF $200 \mathrm{E}$ & ONSITE & AT & 30-Jun-03 & Eu-155 & 0.0000729 & $\mathrm{pCi} / \mathrm{m} 3$ & 0.0011 & 0.0011 & u & & \\
\hline SESPMNT & B17596 & N OF $200 \mathrm{E}$ & ONSITE & AT & $07-$ Oct-03 & Eu-155 & 0.00109 & $\mathrm{pC} / \mathrm{m} 3$ & 0.0014 & 0.0014 & $u$ & & \\
\hline SESPMNT & B17NYO & N OF $200 \mathrm{E}$ & ONSITE & AT & 30-Dec-03 & Eu-155 & 0.000107 & $\mathrm{pCi} / \mathrm{m} 3$ & 0.0013 & 0.0013 & u & & \\
\hline SESPMNT & B16842 & OTHELLO & COMMUNITY & AT & 09-Apr-03 & Eu-155 & -0.00123 & $\mathrm{pC} / \mathrm{m} 3$ & 0.0014 & 0.0014 & u & & \\
\hline SESPMNT & B16PH7 & OTHELLO & COMMUNITY & AT & 01-Jul-03 & Eu-155 & -0.000626 & $\mathrm{pCi} / \mathrm{m} 3$ & 0.0011 & 0.0011 & U & & \\
\hline SESPMNT & B175D6 & OTHELLO & COMMUNITY & AT & 09-Oct-03 & Eu-155 & -0.000547 & $\mathrm{pC} / \mathrm{m} 3$ & 0.00093 & 0.00093 & $u$ & & \\
\hline SESPMNT & B17P20 & OTHELLO & COMMUNITY & AT & 31-Dec-03 & Eu-155 & -0.000428 & $\mathrm{pCi} / \mathrm{m} 3$ & 0.0016 & 0.0016 & u & & \\
\hline SESPMNT & B168Y9 & PROSSER BARRICADE & $\begin{array}{l}\text { PERIMETER } \\
\end{array}$ & AT & 03-Apr-03 & Eu-155 & -0.000197 & $\mathrm{pC} / \mathrm{m} 3$ & 0.00057 & 0.00057 & $u$ & & \\
\hline SESPMNT & B16R90 & PROSSER BARRICADE & PERIMETER & AT & 11-Jul-03 & Eu-155 & -0.0000728 & $\mathrm{pCi} / \mathrm{m} 3$ & 0.00055 & 0.00055 & U & & \\
\hline SESPMNT & B17669 & PROSSER BARRICADE & PERIMETER & AT & 03-Oct-03 & Eu-155 & -0.000751 & $\mathrm{pC} / \mathrm{m} 3$ & 0.0009 & 0.0009 & u & & \\
\hline SESPMNT & B17PV7 & PROSSER BARRICADE & PERIMETER & AT & $09-J a n-04$ & Eu-155 & -0.0000244 & $\mathrm{pCi} / \mathrm{m} 3$ & 0.00053 & 0.00053 & u & & \\
\hline SESPMNT & B168W5 & RINGOLD MET TOWER & PERIMETER & AT & 10-Apr-03 & Eu-155 & 0.000292 & $\mathrm{pCl} / \mathrm{m} 3$ & 0.00071 & 0.00071 & $u$ & & \\
\hline SESPMNT & B16R69 & RINGOLD MET TOWER & PERIMETER & AT & 07-Jul-03 & Eu-155 & 0.0000358 & $\mathrm{pCi} / \mathrm{m} 3$ & 0.0012 & 0.0012 & U & & \\
\hline SESPMNT & B17645 & RINGOLD MET TOWER & PERIMETER & AT & 10-Oct-03 & Eu-155 & -0.000253 & $\mathrm{pCi} / \mathrm{m} 3$ & 0.0014 & 0.0014 & $u$ & & \\
\hline SESPMNT & B17PR6 & RINGOLD MET TOWER & PERIMETER & AT & 05-Jan-04 & Eu-155 & 0.00145 & $\mathrm{pCi} / \mathrm{m} 3$ & 0.0014 & 0.0014 & U & & \\
\hline SESPMNT & B16805 & TOPPENISH & DISTANT & AT & 02-Apr-03 & Eu-155 & 0.000122 & $\mathrm{pCi} / \mathrm{m} 3$ & 0.00089 & 0.00089 & U & & \\
\hline SESPMNT & B16PB9 & TOPPENISH & DISTANT & AT & 09-Jul-03 & Eu-155 & -0.000162 & $\mathrm{pCi} / \mathrm{m} 3$ & 0.001 & 0.001 & U & & \\
\hline SESPMNT & B17589 & TOPPENISH & DISTANT & AT & 01-Oct-03 & Eu-155 & 0.0012 & $\mathrm{pCl} / \mathrm{m} 3$ & 0.0012 & 0.0012 & $U$ & & \\
\hline SESPMNT & B17NX2 & TOPPENISH & DISTANT & AT & 08-Jan-04 & Eu-155 & -0.000183 & $\mathrm{pCi} / \mathrm{m} 3$ & 0.0014 & 0.0014 & $u$ & & \\
\hline SESPMNT & B16940 & TRI CITIES & COMMUNITY & AT & 10-Apr-03 & Eu-155 & 0.000373 & $\mathrm{pCi} / \mathrm{m} 3$ & 0.00053 & 0.00053 & U & & \\
\hline SESPMNT & B16RF3 & TRI CITIES & COMMUNITY & AT & 07-Jul-03 & Eu-155 & -0.0000468 & $\mathrm{pCi} / \mathrm{m} 3$ & 0.00063 & 0.00063 & 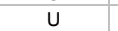 & & \\
\hline SESPMNT & B176C0 & TRI CITIES & COMMUNITY & AT & $10-$ Oct-03 & Eu-155 & 0.000253 & $\mathrm{pCl} / \mathrm{m} 3$ & 0.00073 & 0.00073 & $U$ & & \\
\hline SESPMNT & B17R10 & TRI CITIES & COMMUNITY & AT & 05-Jan-04 & Eu-155 & -0.000447 & $\mathrm{pCi} / \mathrm{m} 3$ & 0.00085 & 0.00085 & U & & \\
\hline SESPMNT & B168V7 & W END OF FIR ROAD & PERIMETER & AT & 10-Apr-03 & Eu-155 & 0.0000851 & $\mathrm{pCi} / \mathrm{m} 3$ & 0.00079 & 0.00079 & $\mathrm{U}$ & & \\
\hline SESPMNT & B16R62 & W END OF FIR ROAD & PERIMETER & AT & 07-Jul-03 & Eu-155 & 0.000274 & $\mathrm{pCi} / \mathrm{m} 3$ & 0.0013 & 0.0013 & $u$ & & \\
\hline SESPMNT & B17637 & W END OF FIR ROAD & PERIMETER & AT & $10-$ Oct-03 & Eu-155 & -0.000657 & $\mathrm{pCl} / \mathrm{m} 3$ & 0.0015 & 0.0015 & $U$ & & \\
\hline SESPMNT & B17PP9 & W END OF FIR ROAD & PERIMETER & AT & $05-J a n-04$ & Eu-155 & 0.000283 & $\mathrm{pCi} / \mathrm{m} 3$ & 0.0017 & 0.0017 & u & & \\
\hline SESPMNT & B16925 & WAHLUKE SLOPE & PERIMETER & AT & 09-Apr-03 & Eu-155 & 0.00028 & $\mathrm{pCl} / \mathrm{m} 3$ & 0.00052 & 0.00052 & $U$ & & \\
\hline SESPMNT & B16RD0 & WAHLUKE SLOPE & PERIMETER & AT & 01-Jul-03 & Eu-155 & 0.000464 & $\mathrm{pCi} / \mathrm{m} 3$ & 0.00057 & 0.00057 & 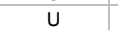 & & \\
\hline SESPMNT & B17695 & WAHLUKE SLOPE & PERIMETER & AT & 08-Oct-03 & Eu-155 & 0.000364 & $\mathrm{pCi} / \mathrm{m} 3$ & 0.00076 & 0.00076 & $u$ & & \\
\hline SESPMNT & B17PY7 & WAHLUKE SLOPE & PERIMETER & AT & 31-Dec-03 & Eu-155 & 0.0000179 & $\mathrm{pCi} / \mathrm{m} 3$ & 0.00059 & 0.00059 & u & & \\
\hline SESPMNT & B168v0 & WYE BARRICADE & ONSITE & AT & 31-Mar-03 & Eu-155 & 0.000134 & $\mathrm{pCl} / \mathrm{m} 3$ & 0.00091 & 0.00091 & u & & \\
\hline SESPMNT & B16R54 & WYE BARRICADE & ONSITE & AT & 08-Jul-03 & Eu-155 & -0.000165 & $\mathrm{pCl} / \mathrm{m} 3$ & 0.0008 & 0.0008 & u & & \\
\hline SESPMNT & B17630 & WYE BARRICADE & ONSITE & AT & 01-Oct-03 & Eu-155 & 0.000639 & $\mathrm{pCi} / \mathrm{m} 3$ & 0.0012 & 0.0012 & $u$ & & \\
\hline SESPMNT & B17PP1 & WYE BARRICADE & ONSITE & AT & 06-Jan-04 & Eu-155 & -0.000119 & $\mathrm{pCi} / \mathrm{m} 3$ & 0.0012 & 0.0012 & u & & \\
\hline SESPMNT & B16955 & YAKIMA & DISTANT & AT & 03-Apr-03 & Eu-155 & 0.000184 & $\mathrm{pCi} / \mathrm{m} 3$ & 0.00093 & 0.00093 & u & & \\
\hline SESPMNT & B16RH6 & YAKIMA & DISTANT & AT & 11-Jul-03 & Eu-155 & -0.000168 & $\mathrm{pCl} / \mathrm{m} 3$ & 0.0011 & 0.0011 & $u$ & & \\
\hline SESPMNT & B176D5 & YAKIMA & DISTANT & AT & 03-Oct-03 & Eu-155 & 0.000803 & $\mathrm{pCi} / \mathrm{m} 3$ & 0.0017 & 0.0017 & $u$ & & \\
\hline SESPMNT & B17R23 & YAKIMA & DISTANT & AT & $09-J a n-04$ & Eu-155 & 0.000955 & $\mathrm{pCi} / \mathrm{m} 3$ & 0.001 & 0.001 & u & & \\
\hline SESPMNT & B16912 & YAKIMA BARRICADE & PERIMETER & AT & $02-\mathrm{Apr}-03$ & Eu-155 & -0.0000267 & $\mathrm{pCi} / \mathrm{m} 3$ & 0.0006 & 0.0006 & u & & \\
\hline SESPMNT & B16RB5 & YAKIMA BARRICADE & PERIMETER & AT & 11-Jul-03 & Eu-155 & -0.000309 & $\mathrm{pCi} / \mathrm{m} 3$ & 0.00054 & 0.00054 & u & & \\
\hline SESPMNT & B17682 & YAKIMA BARRICADE & PERIMETER & AT & 03-Oct-03 & Eu-155 & 0.0000158 & $\mathrm{pCl} / \mathrm{m} 3$ & 0.00093 & 0.00093 & U & & \\
\hline SESPMNT & B17PX2 & YAKIMA BARRICADE & PERIMETER & AT & 09-Jan-04 & Eu-155 & 0.000211 & $\mathrm{pCi} / \mathrm{m} 3$ & 0.00059 & 0.00059 & u & & \\
\hline
\end{tabular}


AIR GAMMA

\begin{tabular}{|c|c|c|c|c|c|c|c|c|c|c|c|c|c|}
\hline OWNER ID & | SAMP NUM & SAMP SITE NAME & | DIST CLASS | & MEDIA & SAMP DATE & $\begin{array}{l}\text { CON SHORT } \\
\text { NAME }\end{array}$ & |VALUE RPTD | & $\mid$\begin{tabular}{|l} 
ANAL \\
UNITS \\
RPTD
\end{tabular} & $\left|\begin{array}{c}\text { COUNTING } \\
\text { ERROR }\end{array}\right|$ & $\begin{array}{c}\text { TOTAL ANAL } \\
\text { ERROR }\end{array} \mid$ & $\left|\begin{array}{c}\text { LAB } \\
\text { QUALIFIER }\end{array}\right|$ & SAMP COMMENT & RESULT COMMENT \\
\hline SESPMNT & B168C4 & 100 AREAS & ONSITE & AT & 31-Mar-03 & $\mathrm{k}-40$ & 0.00451 & $\mathrm{pCi} / \mathrm{m} 3$ & 0.0063 & 0.0063 & U & & \\
\hline SESPMNT & B16PP5 & 100 AREAS & ONSITE & AT & 08-Jul-03 r & $<-40$ & 0.000755 & pCi/m3 & 0.0052 & 0.0052 & $u$ & & \\
\hline SESPMNT & B175M4 & 100 AREAS & ONSITE & AT & 01-Oct-03 r & $\mathrm{k}-40$ & 0.00348 & $\mathrm{pCi} / \mathrm{m} 3$ & 0.0095 & 0.0095 & $u$ & & \\
\hline SESPMNT & B17P82 & 100 AREAS & ONSITE & AT & 06-Jan-04 r & $\mathrm{k}-40$ & 0.00384 & $\mathrm{pCi} / \mathrm{m} 3$ & 0.0063 & 0.0063 & u & & \\
\hline SESPMNT & B168F3 & 200 E AREA & ONSITE & AT & 08-Apr-03 r & & 0.00415 & pCi/m3 & 0.0076 & 0.0076 & $u$ & & \\
\hline SESPMNT & B16PT7 & 200 E AREA & ONSITE & AT & 30-Jun-03 & $\mathrm{k}-40$ & 0.000075 & $\mathrm{pCl} / \mathrm{m} 3$ & 0.0099 & 0.0099 & u & & \\
\hline SESPMNT & B175P3 & 200 E AREA & ONSITE & AT & $07-0 c t-03$ & $\mathrm{k}-40$ & 0.000579 & $\mathrm{pCi} / \mathrm{m} 3$ & 0.011 & 0.011 & u & & \\
\hline SESPMNT & B17PB4 & 200 E AREA & ONSITE & AT & 30-Dec-03 r & $\mathrm{k}-40$ & 0.00254 & $\mathrm{pCi} / \mathrm{m} 3$ & 0.014 & 0.014 & u & & \\
\hline SESPMNT & B168L8 & 200 W AREA & ONSITE & AT & 08-Apr-03 r & -40 & 0.00918 & $\mathrm{pCi} / \mathrm{m} 3$ & 0.012 & 0.012 & $u$ & & \\
\hline SESPMNT & B16PY6 & 200 W AREA & ONSITE & AT & 30-Jun-03 & K-40 & -0.00218 & $\mathrm{pCi} / \mathrm{m} 3$ & 0.0065 & 0.0065 & u & & \\
\hline SESPMNT & B175W8 & 200 W AREA & ONSITE & AT & 07-Oct-03 r & $\mathrm{k}-40$ & 0.00648 & $\mathrm{pCi} / \mathrm{m} 3$ & 0.022 & 0.022 & $u$ & & \\
\hline SESPMNT & $\mathrm{B} 17 \mathrm{PH} 3$ & 200 W AREA & ONSITE & AT & 30-Dec-03 r & $\mathrm{k}-40$ & -0.00883 & $\mathrm{pCi} / \mathrm{m} 3$ & 0.011 & 0.011 & u & & \\
\hline SESPMNT & B168J6 & 200 W SOUTH EAST & ONSITE & AT & 08-Apr-03 r & -40 & 0.0132 & $\mathrm{pCi} / \mathrm{m} 3$ & 0.0047 & 0.0047 & & & \\
\hline SESPMNT & B16PW7 & 200 W SOUTH EAST & ONSITE & AT & 30-Jun-03 r & $\mathrm{k}-40$ & 0.00549 & $\mathrm{pCi} / \mathrm{m} 3$ & 0.0049 & 0.0049 & U & & \\
\hline SESPMNT & B175T6 & 200 W SOUTH EAST & ONSITE & AT & $07-0 c t-03 r$ & $<-40$ & 0.00517 & $\mathrm{pCi} / \mathrm{m} 3$ & 0.007 & 0.007 & $u$ & & \\
\hline SESPMNT & B17PD4 & 200 W SOUTH EAST & ONSITE & AT & 30-Dec-03 r & $\mathrm{k}-40$ & 0.00432 & $\mathrm{pCi} / \mathrm{m} 3$ & 0.0087 & 0.0087 & u & & \\
\hline SESPMNT & B168M6 & 300 AREA & ONSITE & AT & 02-Apr-03 r & $\mathrm{k}-40$ & 0.00494 & $\mathrm{pCi} / \mathrm{m} 3$ & 0.0062 & 0.0062 & $u$ & & \\
\hline SESPMNT & B16R03 & 300 AREA & ONSITE & AT & 10-Jul-03 r & $<-40$ & 0.00243 & $\mathrm{pCi} / \mathrm{m} 3$ & 0.0055 & 0.0055 & U & & \\
\hline SESPMNT & B175X6 & 300 AREA & ONSITE & AT & 30-Sep-03 r & $\mathrm{k}-40$ & 0.00508 & $\mathrm{pCi} / \mathrm{m} 3$ & 0.0093 & 0.0093 & $u$ & & \\
\hline SESPMNT & B17PJo & 300 AREA & ONSITE & AT & 08-Jan-04 r & $<-40$ & 0.00257 & $\mathrm{pCi} / \mathrm{m} 3$ & 0.0039 & 0.0039 & $u$ & & \\
\hline SESPMNT & B167V4 & $300 \mathrm{NE}$ & ONSITE & AT & 02-Apr-03 r & $<-40$ & 0.00535 & $\mathrm{pCi} / \mathrm{m} 3$ & 0.0089 & 0.0089 & $u$ & & \\
\hline SESPMNT & B16P66 & $300 \mathrm{NE}$ & ONSITE & AT & 10-Jul-03 r & $<-40$ & 0.00094 & $\mathrm{pCi} / \mathrm{m} 3$ & 0.016 & 0.016 & $u$ & & \\
\hline SESPMNT & B17548 & $300 \mathrm{NE}$ & ONSITE & AT & 30-Sep-03 r & $<-40$ & 0.00449 & $\mathrm{pCi} / \mathrm{m} 3$ & 0.012 & 0.012 & $U$ & & \\
\hline SESPMNT & B17NP7 & $300 \mathrm{NE}$ & ONSITE & AT & 08-Jan-04 r & $<-40$ & 0.0161 & $\mathrm{pCi} / \mathrm{m} 3$ & 0.014 & 0.014 & u & & \\
\hline SESPMNT & B167V3 & 300 TRENCH & ONSITE & AT & 02-Apr-03 r & -40 & -0.016 & $\mathrm{pCi} / \mathrm{m} 3$ & 0.015 & 0.015 & $u$ & & \\
\hline SESPMNT & B16P65 & 300 TRENCH & ONSITE & AT & 10-Jul-03 r & $<-40$ & -0.00329 & $\mathrm{pCi} / \mathrm{m} 3$ & 0.014 & 0.014 & U & & \\
\hline SESPMNT & B17547 & 300 TRENCH & ONSITE & AT & $30-S e p-03$ & $<-40$ & 0.0106 & $\mathrm{pCi} / \mathrm{m} 3$ & 0.013 & 0.013 & $U$ & & \\
\hline SESPMNT & B17NP6 & 300 TRENCH & ONSITE & AT & 08-Jan-04 I & $\mathrm{k}-40$ & -0.0106 & $\mathrm{pCi} / \mathrm{m} 3$ & 0.022 & 0.022 & $u$ & & \\
\hline SESPMNT & B168P5 & 400 AREA & ONSITE & AT & 31-Mar-03 r & -40 & 0.00217 & $\mathrm{pCi} / \mathrm{m} 3$ & 0.0055 & 0.0055 & $u$ & & \\
\hline SESPMNT & B16R25 & 400 AREA & ONSITE & AT & 08-Jul-03 r & $<-40$ & 0.00309 & $\mathrm{pCi} / \mathrm{m} 3$ & 0.0045 & 0.0045 & U & & \\
\hline SESPMNT & B17605 & 400 AREA & ONSITE & AT & $01-O c t-03 \mathrm{r}$ & $\mathrm{k}-40$ & 0.00107 & $\mathrm{pC} / \mathrm{m} 3$ & 0.0046 & 0.0046 & u & & \\
\hline SESPMNT & B17PL2 & 400 AREA & ONSITE & AT & 05-Jan-04 r & $k-40$ & 0.0019 & $\mathrm{pCi} / \mathrm{m} 3$ & 0.0032 & 0.0032 & $u$ & & \\
\hline SESPMNT & $\mathrm{B} 168 \mathrm{H} 8$ & B POND & ONSITE & AT & 08-Apr-03 r & $<-40$ & 0.00759 & $\mathrm{pCi} / \mathrm{m} 3$ & 0.0089 & 0.0089 & $u$ & & \\
\hline SESPMNT & B16PW0 & B POND & ONSITE & AT & 30-Jun-03 r & $<-40$ & -0.00506 & $\mathrm{pCi} / \mathrm{m} 3$ & 0.018 & 0.018 & $U$ & & \\
\hline SESPMNT & B175R8 & B POND & ONSITE & AT & $07-0 c t-03$ & $\mathrm{k}-40$ & 0.000407 & $\mathrm{pC} / \mathrm{m} 3$ & 0.0081 & 0.0081 & u & & \\
\hline SESPMNT & B17PC7 & B POND & ONSITE & AT & 30-Dec-03 r & $k-40$ & 0.0111 & $\mathrm{pCi} / \mathrm{m} 3$ & 0.022 & 0.022 & $u$ & & \\
\hline SESPMNT & B16962 & BASIN CITY SCHOOL & COMMUNITY & AT & 09-Apr-03 r & $<-40$ & 0.00508 & $\mathrm{pCi} / \mathrm{m} 3$ & 0.013 & 0.013 & U & & \\
\hline SESPMNT & B16RJ4 & BASIN CITY SCHOOL & COMMUNITY & AT & 02-Jul-03 r & $<-40$ & 0.0115 & $\mathrm{pCi} / \mathrm{m} 3$ & 0.017 & 0.017 & $U$ & & \\
\hline SESPMNT & B176F2 & BASIN CITY SCHOOL & COMMUNITY & AT & $08-\mathrm{Oct}-03 \mathrm{r}$ & $\mathrm{k}-40$ & 0.0126 & $\mathrm{pC} / \mathrm{m} 3$ & 0.014 & 0.014 & u & & \\
\hline SESPMNT & B17R31 & BASIN CITY SCHOOL & COMMUNITY & AT & 31-Dec-03 r & $\mathrm{k}-40$ & 0.0028 & $\mathrm{pCi} / \mathrm{m} 3$ & 0.016 & 0.016 & $u$ & & \\
\hline SESPMNT & B16820 & BATTELLE COMPLEX & PERIMETER & AT & 02-Apr-03 & $\mathrm{k}-40$ & 0.00329 & $\mathrm{pCi} / \mathrm{m} 3$ & 0.012 & 0.012 & u & & \\
\hline SESPMNT & B16PD4 & BATTELLE COMPLEX & PERIMETER & AT & 09-Jul-03 r & $\mathrm{k}-40$ & 0.00512 & $\mathrm{pCi} / \mathrm{m} 3$ & 0.0089 & 0.0089 & $u$ & & \\
\hline SESPMNT & B175B4 & BATTELLE COMPLEX & PERIMETER & AT & $30-S e p-03 r$ & $\mathrm{k}-40$ & -0.00224 & $\mathrm{pCl} / \mathrm{m} 3$ & 0.011 & 0.011 & u & & \\
\hline SESPMNT & B17NY7 & BATTELLE COMPLEX & PERIMETER & AT & 08-Jan-04 r & $<-40$ & 0.00803 & $\mathrm{pCi} / \mathrm{m} 3$ & 0.012 & 0.012 & $u$ & & \\
\hline SESPMNT & B16827 & BENTON CITY & COMMUNITY & AT & 03-Apr-03 r & $<-40$ & 0.00391 & $\mathrm{pCi} / \mathrm{m} 3$ & 0.017 & 0.017 & u & & \\
\hline SESPMNT & B16PF2 & BENTON CITY & COMMUNITY & AT & 11-Jul-03 r & $\mathrm{k}-40$ & 0.00363 & $\mathrm{pCi} / \mathrm{m} 3$ & 0.0067 & 0.0067 & u & & \\
\hline SESPMNT & B175C1 & BENTON CITY & COMMUNITY & AT & 03-Oct-03 r & $\mathrm{k}-40$ & 0.0116 & $\mathrm{pCl} / \mathrm{m} 3$ & 0.028 & 0.028 & u & & \\
\hline SESPMNT & B17P05 & BENTON CITY & COMMUNITY & AT & 09-Jan-04 r & $\mathrm{k}-40$ & -0.000548 & $\mathrm{pCi} / \mathrm{m} 3$ & 0.017 & 0.017 & $u$ & & \\
\hline SESPMNT & B168Y1 & BYERS LANDING & PERIMETER & AT & 10-Apr-03 r & $<-40$ & 0.0116 & $\mathrm{pCi} / \mathrm{m} 3$ & 0.015 & 0.015 & $u$ & & \\
\hline SESPMNT & B16R83 & BYERS LANDING & PERIMETER & AT & 07-Jul-03 r & $<-40$ & -0.00363 & $\mathrm{pCi} / \mathrm{m} 3$ & 0.0063 & 0.0063 & 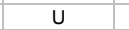 & & \\
\hline SESPMNT & B17661 & BYERS LANDING & PERIMETER & AT & 10-Oct-03 r & $<-40$ & 0.0137 & $\mathrm{pCi} / \mathrm{m} 3$ & 0.022 & 0.022 & $U$ & & \\
\hline SESPMNT & B17PVO & BYERS LANDING & PERIMETER & AT & 05-Jan-04 r & -40 & -0.0126 & $\mathrm{pCi} / \mathrm{m} 3$ & 0.019 & 0.019 & $u$ & & \\
\hline SESPMNT & B168X3 & DOGWOOD MET TOWER & PERIMETER & AT & 10-Apr-03 r & K-40 & 0.00378 & $\mathrm{pCi} / \mathrm{m} 3$ & 0.0065 & 0.0065 & $\mathrm{U}$ & & \\
\hline SESPMNT & B16R76 & DOGWOOD MET TOWER & PERIMETER & AT & 07-Jul-03 r & $<-40$ & 0.00222 & $\mathrm{pCi} / \mathrm{m} 3$ & 0.015 & 0.015 & U & & \\
\hline SESPMNT & B17653 & DOGWOOD MET TOWER & PERIMETER & AT & 10-Oct-03 r & $<-40$ & -0.000881 & $\mathrm{pCi} / \mathrm{m} 3$ & 0.0095 & 0.0095 & u & & \\
\hline SESPMNT & B17PT3 & DOGWOOD MET TOWER & PERIMETER & AT & 05-Jan-04 r & $\mathrm{k}-40$ & -0.00361 & $\mathrm{pCi} / \mathrm{m} 3$ & 0.019 & 0.019 & $u$ & & \\
\hline SESPMNT & B16978 & EDWIN MARKHAM SCHOOL & COMMUNITY & AT & 10-Apr-03 r & $\mathrm{k}-40$ & -0.000447 & $\mathrm{pCi} / \mathrm{m} 3$ & 0.014 & 0.014 & u & & \\
\hline SESPMNT & B16RK8 & EDWIN MARKHAM SCHOOL & COMMUNITY & AT & 02-Jul-03 r & $\mathrm{k}-40$ & 0.00827 & $\mathrm{pCi} / \mathrm{m} 3$ & 0.0078 & 0.0078 & u & & \\
\hline
\end{tabular}


AIR GAMMA

\begin{tabular}{|c|c|c|c|c|c|c|c|c|c|c|c|c|c|}
\hline $\mid$ OWNER ID $\mid$ & SAMP NUM & SAMP SITE NAME & $\mid$ DIST CLASS & MEDIA & SAMP DATE & $\begin{array}{l}\text { CON SHORT } \\
\text { NAME }\end{array}$ & |VALUE RPTD & \begin{tabular}{|l|l} 
ANAL \\
UNITS \\
RPTD
\end{tabular} & $\left|\begin{array}{c}\text { COUNTING } \\
\text { ERROR }\end{array}\right|$ & $\begin{array}{c}\text { TOTAL ANAL } \\
\text { ERROR }\end{array}$ & $\mid \begin{array}{c}\text { LAB } \\
\text { QUALIFIER }\end{array}$ & SAMP COMMENT & RESULT COMMENT \\
\hline SESPMNT & B176H8 & EDWIN MARKHAM SCHOOL & COMMUNITY & AT & 08-Oct-03 K & $\mathrm{K}-40$ & 0.0204 & $\mathrm{pCl} / \mathrm{m} 3$ & 0.016 & 0.016 & u & & \\
\hline SESPMNT & B17R45 & EDWIN MARKHAM SCHOOL & COMMUNITY & AT & 31-Dec-03 K & $\mathrm{K}-40$ & -0.0105 & $\mathrm{pCi} / \mathrm{m} 3$ & 0.019 & 0.019 & $u$ & & \\
\hline SESPMNT & B16986 & HANFORD TOWNSITE & ONSITE & AT & 31-Mar-03 K & & 0.0161 & $\mathrm{pCi} / \mathrm{m} 3$ & 0.011 & 0.011 & & & \\
\hline SESPMNT & B16RL5 & HANFORD TOWNSITE & ONSITE & AT & 08-Jul-03 K & $\mathrm{k}-40$ & 0.00785 & $\mathrm{pC} / / \mathrm{m} 3$ & 0.0067 & 0.0067 & & & \\
\hline SESPMNT & B176J6 & HANFORD TOWNSITE & ONSITE & AT & $01-$ Oct-03 K & $\mathrm{k}-40$ & 0.0016 & $\mathrm{pCi} / \mathrm{m} 3$ & 0.014 & 0.014 & $\mathrm{U}$ & & \\
\hline SESPMNT & B17R52 & HANFORD TOWNSITE & ONSITE & AT & 06-Jan-04 K & $\mathrm{K}-40$ & -0.000994 & $\mathrm{pCi} / \mathrm{m} 3$ & 0.0046 & 0.0046 & $u$ & & \\
\hline SESPMNT & B16970 & LESLIE GROVES-RCHLND & COMMUNITY & AT & 08-Apr-03 K & & -0.00246 & $\mathrm{pC} / / \mathrm{m} 3$ & 0.013 & 0.013 & $u$ & & \\
\hline SESPMNT & B16RK1 & LESLIE GROVES-RCHLND & COMMUNITY & AT & 01-Jul-03 K & $\mathrm{K}-40$ & 0.00629 & $\mathrm{pCi} / \mathrm{m} 3$ & 0.018 & 0.018 & u & & \\
\hline SESPMNT & B176HO & LESLIE GROVES-RCHLND & COMMUNITY & AT & $07-0 c t-03 \mathrm{~K}$ & $\mathrm{~K}-40$ & 0.00833 & $\mathrm{pCi} / \mathrm{m} 3$ & 0.019 & 0.019 & u & & \\
\hline SESPMNT & B17R38 & LESLIE GROVES-RCHLND & COMMUNITY & AT & 30-Dec-03 K & $\mathrm{K}-40$ & -0.00208 & $\mathrm{pCi} / \mathrm{m} 3$ & 0.02 & 0.02 & U & & \\
\hline SESPMNT & B16834 & MATTAWA & COMMUNITY & AT & 09-Apr-03 K & $\mathrm{K}-40$ & 0.00572 & $\mathrm{pCi} / \mathrm{m} 3$ & 0.014 & 0.014 & u & & \\
\hline SESPMNT & B16PHO & MATTAWA & COMMUNITY & AT & 01-Jul-03 K & $\mathrm{k}-40$ & 0.00334 & $\mathrm{pCi} / \mathrm{m} 3$ & 0.015 & 0.015 & u & & \\
\hline SESPMNT & B175C8 & MATTAWA & COMMUNITY & AT & $09-0 c t-03 \mathrm{~K}$ & $\mathrm{~K}-40$ & -0.00777 & $\mathrm{pCi} / \mathrm{m} 3$ & 0.018 & 0.018 & u & & \\
\hline SESPMNT & B17P13 & MATTAWA & COMMUNITY & AT & 31-Dec-03 K & $\mathrm{k}-40$ & 0.0066 & $\mathrm{pCi} / \mathrm{m} 3$ & 0.016 & 0.016 & u & & \\
\hline SESPMNT & B16812 & N OF $200 E$ & ONSITE & AT & 08-Apr-03 K & $\mathrm{K}-40$ & 0.00244 & $\mathrm{pCi} / \mathrm{m} 3$ & 0.0066 & 0.0066 & U & & \\
\hline SESPMNT & B16PC7 & N OF $200 \mathrm{E}$ & ONSITE & AT & 30-Jun-03 K & $\mathrm{k}-40$ & 0.0163 & $\mathrm{pCi} / \mathrm{m} 3$ & 0.017 & 0.017 & u & & \\
\hline SESPMNT & B17596 & N OF $200 \mathrm{E}$ & ONSITE & AT & $07-$ Oct- $03 \mathrm{~K}$ & $\mathrm{k}-40$ & 0.0184 & $\mathrm{pCi} / \mathrm{m} 3$ & 0.025 & 0.025 & $u$ & & \\
\hline SESPMNT & B17NYO & N OF $200 \mathrm{E}$ & ONSITE & AT & 30-Dec-03 K & $k-40$ & 0.00713 & $\mathrm{pCi} / \mathrm{m} 3$ & 0.024 & 0.024 & u & & \\
\hline SESPMNT & B16842 & OTHELLO & COMMUNITY & AT & 09-Apr-03 K & $\mathrm{k}-40$ & -0.00352 & $\mathrm{pCi} / \mathrm{m} 3$ & 0.012 & 0.012 & u & & \\
\hline SESPMNT & B16PH7 & OTHELLO & COMMUNITY & AT & 01-Jul-03 K & $\mathrm{k}-40$ & 0.00159 & $\mathrm{pCi} / \mathrm{m} 3$ & 0.017 & 0.017 & u & & \\
\hline SESPMNT & B175D6 & OTHELLO & COMMUNITY & AT & $09-0 c t-03 \mathrm{~K}$ & $\mathrm{k}-40$ & -0.00339 & $\mathrm{pCi} / \mathrm{m} 3$ & 0.011 & 0.011 & $u$ & & \\
\hline SESPMNT & B17P20 & OTHELLO & COMMUNITY & AT & 31-Dec-03 K & $\mathrm{k}-40$ & 0.0148 & $\mathrm{pCi} / \mathrm{m} 3$ & 0.022 & 0.022 & u & & \\
\hline SESPMNT & B168Y9 & PROSSER BARRICADE & $\begin{array}{l}\text { PERIMETER } \\
\end{array}$ & AT & 03-Apr-03 K & $\mathrm{k}-40$ & 0.00598 & $\mathrm{pCi} / \mathrm{m} 3$ & 0.0092 & 0.0092 & $u$ & & \\
\hline SESPMNT & B16R90 & PROSSER BARRICADE & PERIMETER & AT & 11-Jul-03 K & $\mathrm{k}-40$ & -0.00357 & $\mathrm{pCi} / \mathrm{m} 3$ & 0.0077 & 0.0077 & u & & \\
\hline SESPMNT & B17669 & PROSSER BARRICADE & PERIMETER & AT & 03-Oct-03 K & $\mathrm{k}-40$ & 0.0135 & $\mathrm{pCi} / \mathrm{m} 3$ & 0.012 & 0.012 & u & & \\
\hline SESPMNT & B17PV7 & PROSSER BARRICADE & PERIMETER & AT & $09-J a n-04 \mathrm{~K}$ & $\mathrm{k}-40$ & -0.0000454 & $\mathrm{pCi} / \mathrm{m} 3$ & 0.006 & 0.006 & u & & \\
\hline SESPMNT & B168W5 & RINGOLD MET TOWER & PERIMETER & AT & 10-Apr-03 K & $\mathrm{k}-40$ & 0.00586 & $\mathrm{pCi} / \mathrm{m} 3$ & 0.0067 & 0.0067 & U & & \\
\hline SESPMNT & B16R69 & RINGOLD MET TOWER & PERIMETER & AT & 07-Jul-03 K & $\mathrm{k}-40$ & 0.00531 & $\mathrm{pCi} / \mathrm{m} 3$ & 0.017 & 0.017 & U & & \\
\hline SESPMNT & B17645 & RINGOLD MET TOWER & PERIMETER & AT & $10-$ oct- $03 \mathrm{~K}$ & $\mathrm{k}-40$ & 0.00146 & $\mathrm{pCi} / \mathrm{m} 3$ & 0.019 & 0.019 & $u$ & & \\
\hline SESPMNT & B17PR6 & RINGOLD MET TOWER & PERIMETER & AT & 05-Jan- $04 \mathrm{~K}$ & $\mathrm{k}-40$ & 0.00194 & $\mathrm{pCi} / \mathrm{m} 3$ & 0.017 & 0.017 & U & & \\
\hline SESPMNT & B16805 & TOPPENISH & DISTANT & AT & 02-Apr-03 K & $\mathrm{k}-40$ & 0.00286 & $\mathrm{pCi} / \mathrm{m} 3$ & 0.015 & 0.015 & U & & \\
\hline SESPMNT & B16PB9 & TOPPENISH & DISTANT & AT & 09-Jul-03 K & $\mathrm{k}-40$ & -0.00469 & $\mathrm{pCi} / \mathrm{m} 3$ & 0.014 & 0.014 & U & & \\
\hline SESPMNT & B17589 & TOPPENISH & DISTANT & AT & $01-\mathrm{Oct}-03 \mathrm{~K}$ & $\mathrm{k}-40$ & 0.0061 & $\mathrm{pCi} / \mathrm{m} 3$ & 0.012 & 0.012 & $u$ & & \\
\hline SESPMNT & B17NX2 & TOPPENISH & DISTANT & AT & 08-Jan-04 K & $\mathrm{k}-40$ & 0.00544 & $\mathrm{pCi} / \mathrm{m} 3$ & 0.014 & 0.014 & $u$ & & \\
\hline SESPMNT & B16940 & TRI CITIES & COMMUNITY & AT & 10-Apr-03 K & & 0.0068 & $\mathrm{pCi} / \mathrm{m} 3$ & 0.0058 & 0.0058 & & & \\
\hline SESPMNT & B16RF3 & TRI CITIES & COMMUNITY & AT & 07-Jul-03 K & $\mathrm{k}-40$ & 0.0009 & $\mathrm{pCi} / \mathrm{m} 3$ & 0.0091 & 0.0091 & $u$ & & \\
\hline SESPMNT & B176C0 & TRI CITIES & COMMUNITY & AT & 10-Oct-03 K & $\mathrm{k}-40$ & 0.00271 & $\mathrm{pCi} / \mathrm{m} 3$ & 0.009 & 0.009 & $u$ & & \\
\hline SESPMNT & B17R10 & TRI CITIES & COMMUNITY & AT & 05-Jan- $04 \mathrm{~K}$ & $\mathrm{k}-40$ & 0.00697 & $\mathrm{pCi} / \mathrm{m} 3$ & 0.0093 & 0.0093 & U & & \\
\hline SESPMNT & B168V7 & W END OF FIR ROAD & PERIMETER & AT & 10-Apr-03 K & & 0.0019 & $\mathrm{pCi} / \mathrm{m} 3$ & 0.0088 & 0.0088 & U & & \\
\hline SESPMNT & B16R62 & W END OF FIR ROAD & PERIMETER & AT & 07-Jul-03 K & $\mathrm{k}-40$ & -0.00963 & $\mathrm{pCi} / \mathrm{m} 3$ & 0.015 & 0.015 & $u$ & & \\
\hline SESPMNT & B17637 & W END OF FIR ROAD & PERIMETER & AT & 10-Oct-03 K & $\mathrm{k}-40$ & 0.00129 & $\mathrm{pCi} / \mathrm{m} 3$ & 0.02 & 0.02 & $u$ & & \\
\hline SESPMNT & B17PP9 & W END OF FIR ROAD & PERIMETER & AT & 05-Jan-04 K & $\mathrm{k}-40$ & 0.0667 & $\mathrm{pCi} / \mathrm{m} 3$ & 0.025 & 0.025 & & & \\
\hline SESPMNT & B16925 & WAHLUKE SLOPE & PERIMETER & AT & 09 -Apr-03 K & & 0.0147 & $\mathrm{pCi} / \mathrm{m} 3$ & 0.0084 & 0.0084 & & & \\
\hline SESPMNT & B16RD0 & WAHLUKE SLOPE & PERIMETER & AT & 01-Jul-03 K & $\mathrm{k}-40$ & 0.00861 & $\mathrm{pCi} / \mathrm{m} 3$ & 0.0078 & 0.0078 & $u$ & & \\
\hline SESPMNT & B17695 & WAHLUKE SLOPE & PERIMETER & AT & 08-Oct-03 K & $\mathrm{k}-40$ & -0.000771 & $\mathrm{pCi} / \mathrm{m} 3$ & 0.01 & 0.01 & $u$ & & \\
\hline SESPMNT & B17PY7 & WAHLUKE SLOPE & PERIMETER & AT & 31-Dec-03 K & $\mathrm{k}-40$ & -0.00308 & $\mathrm{pCi} / \mathrm{m} 3$ & 0.007 & 0.007 & u & & \\
\hline SESPMNT & B168v0 & WYE BARRICADE & ONSITE & AT & 31-Mar-03 K & $\frac{N-40}{k-40}$ & $\begin{array}{l}-0.003065 \\
-0.00865\end{array}$ & $\mathrm{pCi} / \mathrm{m} 3$ & 0.015 & 0.015 & $\mathrm{u}$ & & \\
\hline SESPMNT & B16R54 & WYE BARRICADE & ONSITE & AT & 08-Jul-03 K & $\mathrm{k}-40$ & 0.00335 & $\mathrm{pCi} / \mathrm{m} 3$ & 0.015 & 0.015 & u & & \\
\hline SESPMNT & B17630 & WYE BARRICADE & ONSITE & AT & $01-$ Oct-03 K & $\mathrm{k}-40$ & 0.0134 & $\mathrm{pCi} / \mathrm{m} 3$ & 0.016 & 0.016 & $u$ & & \\
\hline SESPMNT & B17PP1 & WYE BARRICADE & ONSITE & AT & $06-\mathrm{Jan}-04 \mathrm{~K}$ & $\mathrm{k}-40$ & -0.0106 & $\mathrm{pCi} / \mathrm{m} 3$ & 0.017 & 0.017 & u & & \\
\hline SESPMNT & B16955 & YAKIMA & DISTANT & AT & 03-Apr-03 K & $\mathrm{k}-40$ & -0.00838 & $\mathrm{pCi} / \mathrm{m} 3$ & 0.015 & 0.015 & u & & \\
\hline SESPMNT & B16RH6 & YAKIMA & DISTANT & AT & 11-Jul-03 K & $\mathrm{K}-40$ & 0.00984 & $\mathrm{pCi} / \mathrm{m} 3$ & 0.014 & 0.014 & $u$ & & \\
\hline SESPMNT & B176D5 & YAKIMA & DISTANT & AT & 03-Oct-03 K & $\mathrm{k}-40$ & $\begin{array}{l}-0.0128 \\
-0.04\end{array}$ & $\mathrm{pCi} / \mathrm{m} 3$ & 0.021 & 0.021 & u & & \\
\hline SESPMNT & B17R23 & YAKIMA & DISTANT & AT & 09-Jan-04 K & $\mathrm{k}-40$ & -0.00539 & $\mathrm{pCi} / \mathrm{m} 3$ & 0.016 & 0.016 & u & & \\
\hline SESPMNT & B16912 & YAKIMA BARRICADE & PERIMETER & AT & 02-Apr-03 K & $\mathrm{k}-40$ & 0.00336 & $\mathrm{pC} / / \mathrm{m} 3$ & 0.0067 & 0.0067 & u & & \\
\hline SESPMNT & B16RB5 & YAKIMA BARRICADE & PERIMETER & AT & 11-Jul-03 K & $\mathrm{K}-40$ & 0.00328 & $\mathrm{pC} / \mathrm{m} 3$ & 0.0072 & 0.0072 & u & & \\
\hline SESPMNT & B17682 & YAKIMA BARRICADE & PERIMETER & AT & 03-Oct-03 K & $\mathrm{K}-40$ & 0.00976 & $\mathrm{pCi} / \mathrm{m} 3$ & 0.011 & 0.011 & U & & \\
\hline SESPMNT & B17PX2 & YAKIMA BARRICADE & PERIMETER & AT & 09-Jan-04 K & $\mathrm{K}-40$ & 0.000635 & $\mathrm{pCi} / \mathrm{m} 3$ & 0.0088 & 0.0088 & u & & \\
\hline
\end{tabular}


AIR GAMMA

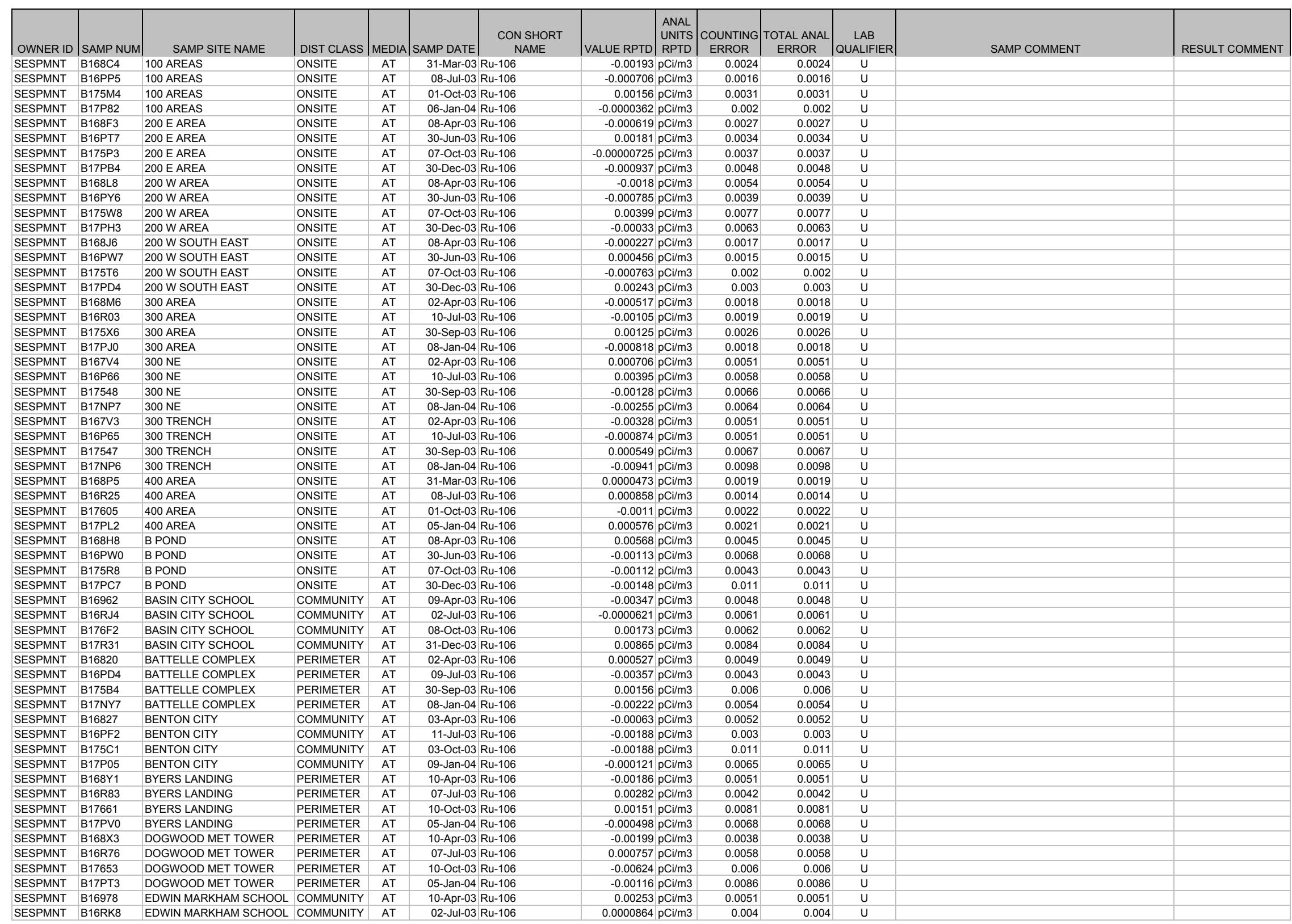


AIR GAMMA

\begin{tabular}{|c|c|c|c|c|c|c|c|c|c|c|c|c|c|}
\hline $\mid$ OWNER ID $\mid$ & SAMP NUM & SAMP SITE NAME & | DIST CLASS | & MEDIA & SAMP DATE & $\begin{array}{l}\text { CON SHORT } \\
\text { NAME }\end{array}$ & |VALUE RPTD & \begin{tabular}{|l|l} 
ANAL \\
UNITS \\
RPTD
\end{tabular} & $\left|\begin{array}{c}\text { COUNTING } \\
\text { ERROR }\end{array}\right|$ & $\begin{array}{c}\text { TOTAL ANAL } \\
\text { ERROR }\end{array}$ & $\mid \begin{array}{c}\text { LAB } \\
\text { QUALIFIER }\end{array}$ & SAMP COMMENT & RESULT COMMENT \\
\hline SESPMNT & $\mathrm{B} 176 \mathrm{H} 8$ & EDWIN MARKHAM SCHOOL & COMMUNITY & AT & 08-Oct-03 & Ru-106 & 0.00385 & $\mathrm{pCi} / \mathrm{m} 3$ & 0.0066 & 0.0066 & u & & \\
\hline SESPMNT & B17R45 & EDWIN MARKHAM SCHOOL & COMMUNITY & AT & 31-Dec-03 & Ru-106 & 0.00275 & $\mathrm{pCi} / \mathrm{m} 3$ & 0.0074 & 0.0074 & $U$ & & \\
\hline SESPMNT & B16986 & HANFORD TOWNSITE & ONSITE & AT & 31-Mar-03 & Ru-106 & -0.000116 & $\mathrm{pCi} / \mathrm{m} 3$ & 0.0032 & 0.0032 & $U$ & & \\
\hline SESPMNT & B16RL5 & HANFORD TOWNSITE & ONSITE & AT & 08-Jul-03 & Ru-106 & -0.00102 & $\mathrm{pC} / / \mathrm{m} 3$ & 0.0028 & 0.0028 & $\mathrm{U}$ & & \\
\hline SESPMNT & B176J6 & HANFORD TOWNSITE & ONSITE & AT & 01-Oct-03 & Ru-106 & 0.00116 & $\mathrm{pC} / \mathrm{m} 3$ & 0.0045 & 0.0045 & $\mathrm{U}$ & & \\
\hline SESPMNT & B17R52 & HANFORD TOWNSITE & ONSITE & AT & 06-Jan-04 & Ru-106 & 0.000425 & $\mathrm{pCi} / \mathrm{m} 3$ & 0.0033 & 0.0033 & $u$ & & \\
\hline SESPMNT & B16970 & LESLIE GROVES-RCHLND & COMMUNITY & AT & 08-Apr-03 & Ru-106 & 0.00154 & $\mathrm{pC} / / \mathrm{m} 3$ & 0.0048 & 0.0048 & U & & \\
\hline SESPMNT & B16RK1 & LESLIE GROVES-RCHLND & COMMUNITY & AT & 01-Jul-03 & Ru-106 & 0.00542 & $\mathrm{pCi} / \mathrm{m} 3$ & 0.0057 & 0.0057 & u & & \\
\hline SESPMNT & B176HO & LESLIE GROVES-RCHLND & COMMUNITY & AT & 07-Oct-03 & Ru-106 & 0.00608 & $\mathrm{pCi} / \mathrm{m} 3$ & 0.0068 & 0.0068 & u & & \\
\hline SESPMNT & B17R38 & LESLIE GROVES-RCHLND & COMMUNITY & AT & 30-Dec-03 & Ru-106 & 0.00458 & $\mathrm{pCi} / \mathrm{m} 3$ & 0.0082 & 0.0082 & $\mathrm{u}$ & & \\
\hline SESPMNT & B16834 & MATTAWA & COMMUNITY & AT & 09-Apr-03 & Ru-106 & 0.000108 & $\mathrm{pCi} / \mathrm{m} 3$ & 0.0048 & 0.0048 & u & & \\
\hline SESPMNT & B16PHO & MATTAWA & COMMUNITY & AT & 01-Jul-03 & Ru-106 & -0.00117 & $\mathrm{pCi} / \mathrm{m} 3$ & 0.0054 & 0.0054 & u & & \\
\hline SESPMNT & B175C8 & MATTAWA & COMMUNITY & AT & 09-Oct-03 & Ru-106 & 0.00176 & $\mathrm{pCi} / \mathrm{m} 3$ & 0.0076 & 0.0076 & u & & \\
\hline SESPMNT & B17P13 & MATTAWA & COMMUNITY & AT & 31-Dec-03 & Ru-106 & -0.00958 & $\mathrm{pCi} / \mathrm{m} 3$ & 0.007 & 0.007 & u & & \\
\hline SESPMNT & B16812 & N OF $200 \mathrm{E}$ & ONSITE & AT & 08-Apr-03 & Ru-106 & -0.00399 & $\mathrm{pCi} / \mathrm{m} 3$ & 0.0043 & 0.0043 & u & & \\
\hline SESPMNT & B16PC7 & N OF $200 E$ & ONSITE & AT & 30-Jun-03 & Ru-106 & -0.00201 & $\mathrm{pCi} / \mathrm{m} 3$ & 0.0052 & 0.0052 & u & & \\
\hline SESPMNT & B17596 & N OF $200 \mathrm{E}$ & ONSITE & AT & $07-$ Oct-03 & Ru-106 & 0.00209 & $\mathrm{pCi} / \mathrm{m} 3$ & 0.0065 & 0.0065 & $u$ & & \\
\hline SESPMNT & B17NYO & N OF $200 \mathrm{E}$ & ONSITE & AT & 30-Dec-03 & Ru-106 & -0.00515 & $\mathrm{pCi} / \mathrm{m} 3$ & 0.0072 & 0.0072 & u & & \\
\hline SESPMNT & B16842 & OTHELLO & COMMUNITY & AT & 09-Apr-03 & Ru-106 & 0.00073 & $\mathrm{pCi} / \mathrm{m} 3$ & 0.0055 & 0.0055 & u & & \\
\hline SESPMNT & B16PH7 & OTHELLO & COMMUNITY & AT & 01-Jul-03 & Ru-106 & 0.00193 & $\mathrm{pCi} / \mathrm{m} 3$ & 0.0059 & 0.0059 & u & & \\
\hline SESPMNT & B175D6 & OTHELLO & COMMUNITY & AT & 09-Oct-03 & Ru-106 & -0.00403 & $\mathrm{pCi} / \mathrm{m} 3$ & 0.0047 & 0.0047 & $u$ & & \\
\hline SESPMNT & B17P20 & OTHELLO & COMMUNITY & AT & 31-Dec-03 & Ru-106 & -0.00314 & $\mathrm{pCi} / \mathrm{m} 3$ & 0.0071 & 0.0071 & u & & \\
\hline SESPMNT & B168Y9 & PROSSER BARRICADE & $\begin{array}{l}\text { PERIMETER } \\
\end{array}$ & AT & 03-Apr-03 & Ru-106 & -0.00215 & $\mathrm{pCi} / \mathrm{m} 3$ & 0.0027 & 0.0027 & $u$ & & \\
\hline SESPMNT & B16R90 & PROSSER BARRICADE & PERIMETER & AT & 11-Jul-03 & Ru-106 & -0.00127 & $\mathrm{pCi} / \mathrm{m} 3$ & 0.0027 & 0.0027 & U & & \\
\hline SESPMNT & B17669 & PROSSER BARRICADE & PERIMETER & AT & 03-Oct-03 & Ru-106 & 0.000632 & $\mathrm{pCi} / \mathrm{m} 3$ & 0.0049 & 0.0049 & u & & \\
\hline SESPMNT & B17PV7 & PROSSER BARRICADE & PERIMETER & AT & $09-J a n-04$ & Ru-106 & $\begin{array}{l}-0.000927 \\
-0.00027\end{array}$ & $\mathrm{pCi} / \mathrm{m} 3$ & 0.0028 & 0.0028 & u & & \\
\hline SESPMNT & B168W5 & RINGOLD MET TOWER & PERIMETER & AT & 10-Apr-03 & Ru-106 & -0.000193 & $\mathrm{pCl} / \mathrm{m} 3$ & 0.0038 & 0.0038 & $u$ & & \\
\hline SESPMNT & B16R69 & RINGOLD MET TOWER & PERIMETER & AT & 07-Jul-03 & Ru-106 & 0.00452 & $\mathrm{pCi} / \mathrm{m} 3$ & 0.0057 & 0.0057 & U & & \\
\hline SESPMNT & B17645 & RINGOLD MET TOWER & PERIMETER & AT & $10-$ Oct-03 & Ru-106 & 0.000852 & $\mathrm{pCi} / \mathrm{m} 3$ & 0.005 & 0.005 & U & & \\
\hline SESPMNT & B17PR6 & RINGOLD MET TOWER & PERIMETER & AT & 05-Jan-04 & Ru-106 & -0.00081 & $\mathrm{pCi} / \mathrm{m} 3$ & 0.0072 & 0.0072 & U & & \\
\hline SESPMNT & B16805 & TOPPENISH & DISTANT & AT & 02-Apr-03 & Ru-106 & 0.00107 & $\mathrm{pCi} / \mathrm{m} 3$ & 0.0046 & 0.0046 & U & & \\
\hline SESPMNT & B16PB9 & TOPPENISH & DISTANT & AT & 09-Jul-03 & Ru-106 & 0.00109 & $\mathrm{pCi} / \mathrm{m} 3$ & 0.005 & 0.005 & U & & \\
\hline SESPMNT & B17589 & TOPPENISH & DISTANT & AT & 01-Oct-03 & Ru-106 & 0.000251 & $\mathrm{pCi} / \mathrm{m} 3$ & 0.0065 & 0.0065 & $U$ & & \\
\hline SESPMNT & B17NX2 & TOPPENISH & DISTANT & AT & 08-Jan-04 & Ru-106 & 0.0014 & $\mathrm{pCi} / \mathrm{m} 3$ & 0.0079 & 0.0079 & $u$ & & \\
\hline SESPMNT & B16940 & TRI CITIES & COMMUNITY & AT & 10-Apr-03 & Ru-106 & 0.00043 & $\mathrm{pCi} / \mathrm{m} 3$ & 0.0024 & 0.0024 & U & & \\
\hline SESPMNT & B16RF3 & TRI CITIES & COMMUNITY & AT & 07-Jul-03 & Ru-106 & -0.000347 & $\mathrm{pCi} / \mathrm{m} 3$ & 0.0028 & 0.0028 & 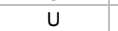 & & \\
\hline SESPMNT & B176C0 & TRI CITIES & COMMUNITY & AT & $10-$ Oct-03 & Ru-106 & 0.00115 & $\mathrm{pCi} / \mathrm{m} 3$ & 0.0036 & 0.0036 & $U$ & & \\
\hline SESPMNT & B17R10 & TRI CITIES & COMMUNITY & AT & 05-Jan-04 & Ru-106 & -0.00159 & $\mathrm{pCi} / \mathrm{m} 3$ & 0.0045 & 0.0045 & U & & \\
\hline SESPMNT & B168V7 & W END OF FIR ROAD & PERIMETER & AT & 10-Apr-03 & Ru-106 & 0.000952 & $\mathrm{pCi} / \mathrm{m} 3$ & 0.0044 & 0.0044 & $u$ & & \\
\hline SESPMNT & B16R62 & W END OF FIR ROAD & PERIMETER & AT & 07-Jul-03 & Ru-106 & 0.00339 & $\mathrm{pCi} / \mathrm{m} 3$ & 0.0056 & 0.0056 & $u$ & & \\
\hline SESPMNT & B17637 & W END OF FIR ROAD & PERIMETER & AT & $10-$ Oct-03 & Ru-106 & 0.00118 & $\mathrm{pCi} / \mathrm{m} 3$ & 0.0066 & 0.0066 & $u$ & & \\
\hline SESPMNT & B17PP9 & W END OF FIR ROAD & PERIMETER & AT & $05-J a n-04$ & Ru-106 & -0.000295 & $\mathrm{pCi} / \mathrm{m} 3$ & 0.0086 & 0.0086 & u & & \\
\hline SESPMNT & B16925 & WAHLUKE SLOPE & PERIMETER & AT & 09-Apr-03 & Ru-106 & 0.000196 & $\mathrm{pCi} / \mathrm{m} 3$ & 0.0026 & 0.0026 & $U$ & & \\
\hline SESPMNT & B16RD0 & WAHLUKE SLOPE & PERIMETER & AT & 01-Jul-03 & Ru-106 & -0.00227 & $\mathrm{pCi} / \mathrm{m} 3$ & 0.0029 & 0.0029 & 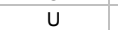 & & \\
\hline SESPMNT & B17695 & WAHLUKE SLOPE & PERIMETER & AT & 08-Oct-03 & Ru-106 & -0.00124 & $\mathrm{pCi} / \mathrm{m} 3$ & 0.0036 & 0.0036 & $u$ & & \\
\hline SESPMNT & B17PY7 & WAHLUKE SLOPE & PERIMETER & AT & 31-Dec-03 & Ru-106 & 0.00049 & $\mathrm{pCi} / \mathrm{m} 3$ & 0.0036 & 0.0036 & u & & \\
\hline SESPMNT & B168V0 & WYE BARRICADE & ONSITE & AT & 31-Mar-03 & Ru-106 & $\begin{array}{c}0.000264 \\
-0.0026\end{array}$ & $\mathrm{pCi} / \mathrm{m} 3$ & 0.0055 & 0.0055 & u & & \\
\hline SESPMNT & B16R54 & WYE BARRICADE & ONSITE & AT & 08-Jul-03 & Ru-106 & 0.00654 & $\mathrm{pCi} / \mathrm{m} 3$ & 0.0053 & 0.0053 & u & & \\
\hline SESPMNT & B17630 & WYE BARRICADE & ONSITE & AT & 01-Oct-03 & Ru-106 & -0.00822 & $\mathrm{pCi} / \mathrm{m} 3$ & 0.0072 & 0.0072 & $u$ & & \\
\hline SESPMNT & B17PP1 & WYE BARRICADE & ONSITE & AT & 06-Jan-04 & Ru-106 & 0.0049 & $\mathrm{pCi} / \mathrm{m} 3$ & 0.0056 & 0.0056 & u & & \\
\hline SESPMNT & B16955 & YAKIMA & DISTANT & AT & 03-Apr-03 & Ru-106 & 0.000458 & $\mathrm{pCi} / \mathrm{m} 3$ & 0.0054 & 0.0054 & u & & \\
\hline SESPMNT & B16RH6 & YAKIMA & DISTANT & AT & 11-Jul-03 & Ru-106 & 0.00148 & $\mathrm{pCi} / \mathrm{m} 3$ & 0.0056 & 0.0056 & U & & \\
\hline SESPMNT & B176D5 & YAKIMA & DISTANT & AT & $03-\mathrm{Oct}-03$ & Ru-106 & -0.000618 & $\mathrm{pCi} / \mathrm{m} 3$ & 0.0079 & 0.0079 & u & & \\
\hline SESPMNT & B17R23 & YAKIMA & DISTANT & AT & $09-J a n-04$ & Ru-106 & 0.000196 & $\mathrm{pCi} / \mathrm{m} 3$ & 0.006 & 0.006 & u & & \\
\hline SESPMNT & B16912 & YAKIMA BARRICADE & PERIMETER & AT & 02-Apr-03 & Ru-106 & -0.000148 & $\mathrm{pC} / / \mathrm{m} 3$ & 0.0029 & 0.0029 & u & & \\
\hline SESPMNT & B16RB5 & YAKIMA BARRICADE & PERIMETER & AT & 11-Jul-03 & Ru-106 & -0.00141 & $\mathrm{pC} / \mathrm{m} 3$ & 0.0024 & 0.0024 & u & & \\
\hline SESPMNT & B17682 & YAKIMA BARRICADE & PERIMETER & AT & 03-Oct-03 & Ru-106 & -0.00126 & $\mathrm{pCi} / \mathrm{m} 3$ & 0.0039 & 0.0039 & U & & \\
\hline SESPMNT & B17PX2 & YAKIMA BARRICADE & PERIMETER & AT & 09-Jan-04 & Ru-106 & -0.00066 & $\mathrm{pCi} / \mathrm{m} 3$ & 0.003 & 0.003 & u & & \\
\hline
\end{tabular}


AIR GAMMA

\begin{tabular}{|c|c|c|c|c|c|c|c|c|c|c|c|c|c|}
\hline OWNER ID & | SAMP NUM & SAMP SITE NAME & | DIST CLASS | & MEDIA & SAMP DATE & $\begin{array}{l}\text { CON SHORT } \\
\text { NAME }\end{array}$ & |VALUE RPTD | & $\mid \begin{array}{l}\text { ANAL } \\
\text { UNITS } \\
\text { RPTD }\end{array}$ & $\left|\begin{array}{c}\text { COUNTING } \\
\text { ERROR }\end{array}\right|$ & $\begin{array}{c}\text { TOTAL ANAL } \\
\text { ERROR }\end{array} \mid$ & $\left|\begin{array}{c}\text { LAB } \\
\text { QUALIFIER }\end{array}\right|$ & SAMP COMMENT & RESULT COMMENT \\
\hline SESPMNT & B168C4 & 100 AREAS & ONSITE & AT & 31-Mar-03 & sb-125 & -0.00049 & $\mathrm{pCi} / \mathrm{m} 3$ & 0.00067 & 0.00067 & u & & \\
\hline SESPMNT & B16PP5 & 100 AREAS & ONSITE & AT & 08-Jul-03 s & bb-125 & -0.000189 & $\mathrm{pCi} / \mathrm{m} 3$ & 0.00046 & 0.00046 & $U$ & & \\
\hline SESPMNT & B175M4 & 100 AREAS & ONSITE & AT & $01-$ Oct-03 & bb-125 & -0.0000542 & $\mathrm{pCi} / \mathrm{m} 3$ & 0.00077 & 0.00077 & u & & \\
\hline SESPMNT & B17P82 & 100 AREAS & ONSITE & AT & $06-J a n-04$ & Sb-125 & 0.000233 & $\mathrm{pCi} / \mathrm{m} 3$ & 0.00066 & 0.00066 & u & & \\
\hline SESPMNT & B168F3 & $200 \mathrm{E}$ AREA & ONSITE & AT & 08-Apr-03 & bb-125 & 0.000393 & $\mathrm{pCi} / \mathrm{m} 3$ & 0.00066 & 0.00066 & $u$ & & \\
\hline SESPMNT & B16PT7 & $200 \mathrm{E}$ AREA & ONSITE & AT & 30-Jun-03 & b- -125 & -0.0000808 & $\mathrm{pC} / \mathrm{m} 3$ & 0.00087 & 0.00087 & u & & \\
\hline SESPMNT & B175P3 & 200 E AREA & ONSITE & AT & $07-0 c t-03$ & bb-125 & 0.000322 & $\mathrm{pCi} / \mathrm{m} 3$ & 0.0011 & 0.0011 & u & & \\
\hline SESPMNT & B17PB4 & 200 E AREA & ONSITE & AT & 30-Dec-03s & Sb-125 & -0.0000674 & $\mathrm{pCl} / \mathrm{m} 3$ & 0.0011 & 0.0011 & u & & \\
\hline SESPMNT & B168L8 & 200 W AREA & ONSITE & AT & 08-Apr-03 & bb-125 & -0.000833 & $\mathrm{pCi} / \mathrm{m} 3$ & 0.0012 & 0.0012 & $u$ & & \\
\hline SESPMNT & B16PY6 & 200 W AREA & ONSITE & AT & 30-Jun-03 & b-125 & 0.000412 & $\mathrm{pC} / \mathrm{m} 3$ & 0.0011 & 0.0011 & u & & \\
\hline SESPMNT & B175W8 & 200 W AREA & ONSITE & AT & 07-Oct-03 s & bb-125 & -0.000245 & $\mathrm{pCi} / \mathrm{m} 3$ & 0.0013 & 0.0013 & $u$ & & \\
\hline SESPMNT & $\mathrm{B} 17 \mathrm{PH} 3$ & 200 W AREA & ONSITE & AT & 30-Dec-03s & Sb-125 & -0.000544 & $\mathrm{pCl} / \mathrm{m} 3$ & 0.0015 & 0.0015 & u & & \\
\hline SESPMNT & B168J6 & 200 W SOUTH EAST & ONSITE & AT & 08-Apr-03 & bb-125 & -0.000129 & $\mathrm{pCi} / \mathrm{m} 3$ & 0.00037 & 0.00037 & $u$ & & \\
\hline SESPMNT & B16PW7 & 200 W SOUTH EAST & ONSITE & AT & 30-Jun-03 s & Sb-125 & 0.000058 & $\mathrm{pCi} / \mathrm{m} 3$ & 0.00043 & 0.00043 & U & & \\
\hline SESPMNT & B175T6 & 200 W SOUTH EAST & ONSITE & AT & 07-Oct-03 s & Sb-125 & -0.000483 & $\mathrm{pCi} / \mathrm{m} 3$ & 0.00054 & 0.00054 & $u$ & & \\
\hline SESPMNT & B17PD4 & 200 W SOUTH EAST & ONSITE & AT & 30-Dec-03s & Sb-125 & 0.000226 & $\mathrm{pCl} / \mathrm{m} 3$ & 0.00072 & 0.00072 & u & & \\
\hline SESPMNT & B168M6 & 300 AREA & ONSITE & AT & 02-Apr-03 & bb-125 & -0.000141 & $\mathrm{pCi} / \mathrm{m} 3$ & 0.00051 & 0.00051 & $u$ & & \\
\hline SESPMNT & B16R03 & 300 AREA & ONSITE & AT & 10-Jul-03 s & Sb-125 & -0.0000681 & $\mathrm{pC} / / \mathrm{m} 3$ & 0.0005 & 0.0005 & 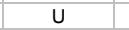 & & \\
\hline SESPMNT & B175X6 & 300 AREA & ONSITE & AT & 30-Sep-03 s & Sb-125 & 0.000168 & $\mathrm{pCi} / \mathrm{m} 3$ & 0.00074 & 0.00074 & $u$ & & \\
\hline SESPMNT & B17PJo & 300 AREA & ONSITE & AT & 08-Jan-04 S & Sb-125 & -0.0000768 & $\mathrm{pCl} / \mathrm{m} 3$ & 0.00061 & 0.00061 & $u$ & & \\
\hline SESPMNT & B167V4 & $300 \mathrm{NE}$ & ONSITE & AT & 02-Apr-03 & Sb-125 & 0.00107 & $\mathrm{pCi} / \mathrm{m} 3$ & 0.0017 & 0.0017 & $u$ & & \\
\hline SESPMNT & B16P66 & $300 \mathrm{NE}$ & ONSITE & AT & 10-Jul-03 s & Sb-125 & 0.00177 & $\mathrm{pCi} / \mathrm{m} 3$ & 0.0015 & 0.0015 & $u$ & & \\
\hline SESPMNT & B17548 & $300 \mathrm{NE}$ & ONSITE & AT & $30-$ Sep-03 s & Sb-125 & -0.00138 & $\mathrm{pCi} / \mathrm{m} 3$ & 0.0014 & 0.0014 & $U$ & & \\
\hline SESPMNT & B17NP7 & $300 \mathrm{NE}$ & ONSITE & AT & 08-Jan-04 S & Sb-125 & -0.000547 & $\mathrm{pC} / \mathrm{m} 3$ & 0.0012 & 0.0012 & u & & \\
\hline SESPMNT & B167V3 & 300 TRENCH & ONSITE & AT & 02-Apr-03 & bb-125 & -0.00058 & $\mathrm{pCi} / \mathrm{m} 3$ & 0.0015 & 0.0015 & $u$ & & \\
\hline SESPMNT & B16P65 & 300 TRENCH & ONSITE & AT & 10-Jul-03 s & Sb-125 & -0.000258 & $\mathrm{pCi} / \mathrm{m} 3$ & 0.0013 & 0.0013 & U & & \\
\hline SESPMNT & B17547 & 300 TRENCH & ONSITE & AT & $30-S e p-03$ & Sb-125 & -0.00024 & $\mathrm{pC} / \mathrm{m} 3$ & 0.0017 & 0.0017 & u & & \\
\hline SESPMNT & B17NP6 & 300 TRENCH & ONSITE & AT & 08-Jan-04 & bb-125 & 0.000365 & $\mathrm{pCi} / \mathrm{m} 3$ & 0.002 & 0.002 & $u$ & & \\
\hline SESPMNT & B168P5 & 400 AREA & ONSITE & AT & 31-Mar-03 s & b- -125 & 0.0000772 & $\mathrm{pCi} / \mathrm{m} 3$ & 0.00051 & 0.00051 & $u$ & & \\
\hline SESPMNT & B16R25 & 400 AREA & ONSITE & AT & 08-Jul-03 s & Sb-125 & -0.0000324 & $\mathrm{pCi} / \mathrm{m} 3$ & 0.00036 & 0.00036 & U & & \\
\hline SESPMNT & B17605 & 400 AREA & ONSITE & AT & $01-O c t-03 s$ & bb-125 & 0.000109 & $\mathrm{pCi} / \mathrm{m} 3$ & 0.00054 & 0.00054 & u & & \\
\hline SESPMNT & B17PL2 & 400 AREA & ONSITE & AT & 05-Jan-04 & Sb-125 & 0.000111 & $\mathrm{pCl} / \mathrm{m} 3$ & 0.00056 & 0.00056 & $u$ & & \\
\hline SESPMNT & $\mathrm{B} 168 \mathrm{H} 8$ & B POND & ONSITE & AT & 08-Apr-03 & Sb-125 & 0.00055 & $\mathrm{pCi} / \mathrm{m} 3$ & 0.00092 & 0.00092 & U & & \\
\hline SESPMNT & B16PW0 & B POND & ONSITE & AT & 30-Jun-03 s & Sb-125 & 0.00103 & $\mathrm{pCi} / \mathrm{m} 3$ & 0.0015 & 0.0015 & $U$ & & \\
\hline SESPMNT & B175R8 & B POND & ONSITE & AT & $07-0 c t-03$ & bb-125 & -0.000802 & $\mathrm{pCi} / \mathrm{m} 3$ & 0.0013 & 0.0013 & u & & \\
\hline SESPMNT & B17PC7 & B POND & ONSITE & AT & 30-Dec-03 & Sb-125 & 0.000806 & $\mathrm{pCl} / \mathrm{m} 3$ & 0.0022 & 0.0022 & $u$ & & \\
\hline SESPMNT & B16962 & BASIN CITY SCHOOL & COMMUNITY & AT & 09-Apr-03 & Sb-125 & -0.000232 & $\mathrm{pCi} / \mathrm{m} 3$ & 0.001 & 0.001 & u & & \\
\hline SESPMNT & B16RJ4 & BASIN CITY SCHOOL & COMMUNITY & AT & 02-Jul-03 & bb-125 & 0.0002 & $\mathrm{pCl} / \mathrm{m} 3$ & 0.0015 & 0.0015 & $u$ & & \\
\hline SESPMNT & B176F2 & BASIN CITY SCHOOL & COMMUNITY & AT & $08-\mathrm{Oct}-03 \leqslant$ & Sb-125 & -0.00105 & $\mathrm{pCi} / \mathrm{m} 3$ & 0.0016 & 0.0016 & $u$ & & \\
\hline SESPMNT & B17R31 & BASIN CITY SCHOOL & COMMUNITY & AT & 31-Dec-03 s & bb-125 & 0.00017 & $\mathrm{pC} / \mathrm{m} 3$ & 0.0017 & 0.0017 & $u$ & & \\
\hline SESPMNT & B16820 & BATTELLE COMPLEX & PERIMETER & AT & $02-A p r-03$ & Sb-125 & 0.000572 & $\mathrm{pCi} / \mathrm{m} 3$ & 0.0013 & 0.0013 & u & & \\
\hline SESPMNT & B16PD4 & BATTELLE COMPLEX & PERIMETER & AT & 09-Jul-03 & bb-125 & 0.000974 & $\mathrm{pCi} / \mathrm{m} 3$ & 0.00095 & 0.00095 & $u$ & & \\
\hline SESPMNT & B175B4 & BATTELLE COMPLEX & PERIMETER & AT & $30-\mathrm{Sep}-03$ & $\mathrm{bb}-125$ & -0.00145 & $\mathrm{pCi} / \mathrm{m} 3$ & 0.0018 & 0.0018 & u & & \\
\hline SESPMNT & B17NY7 & BATTELLE COMPLEX & PERIMETER & AT & 08-Jan-04 & bb-125 & 0.000776 & $\mathrm{pCl} / \mathrm{m} 3$ & 0.0011 & 0.0011 & $u$ & & \\
\hline SESPMNT & B16827 & BENTON CITY & COMMUNITY & AT & 03-Apr-03 & Sb-125 & -0.000843 & $\mathrm{pCi} / \mathrm{m} 3$ & 0.0013 & 0.0013 & u & & \\
\hline SESPMNT & B16PF2 & BENTON CITY & COMMUNITY & AT & 11-Jul-03 s & bb-125 & -0.000303 & $\mathrm{pCl} / \mathrm{m} 3$ & 0.0008 & 0.0008 & u & & \\
\hline SESPMNT & B175C1 & BENTON CITY & COMMUNITY & AT & $03-0 c t-03 \leqslant$ & Sb-125 & -0.000793 & $\mathrm{pCi} / \mathrm{m} 3$ & 0.002 & 0.002 & U & & \\
\hline SESPMNT & B17P05 & BENTON CITY & COMMUNITY & AT & 09-Jan-04 & Sb-125 & 0.000715 & $\mathrm{pCl} / \mathrm{m} 3$ & 0.0017 & 0.0017 & $u$ & & \\
\hline SESPMNT & B168Y1 & BYERS LANDING & PERIMETER & AT & 10-Apr-03 & Sb-125 & 0.000272 & $\mathrm{pCl} / \mathrm{m} 3$ & 0.0012 & 0.0012 & $u$ & & \\
\hline SESPMNT & B16R83 & BYERS LANDING & PERIMETER & AT & 07-Jul-03 & Sb-125 & 0.000734 & $\mathrm{pCi} / \mathrm{m} 3$ & 0.0013 & 0.0013 & U & & \\
\hline SESPMNT & B17661 & BYERS LANDING & PERIMETER & AT & $10-0 c t-03 \leqslant$ & Sb-125 & -0.000297 & $\mathrm{pCi} / \mathrm{m} 3$ & 0.0018 & 0.0018 & $U$ & & \\
\hline SESPMNT & B17PVO & BYERS LANDING & PERIMETER & AT & 05-Jan-04 & bb-125 & -0.000568 & $\mathrm{pCl} / \mathrm{m} 3$ & 0.0016 & 0.0016 & $u$ & & \\
\hline SESPMNT & B168X3 & DOGWOOD MET TOWER & PERIMETER & AT & 10-Apr-03 & Sb-125 & 0.000188 & $\mathrm{pCi} / \mathrm{m} 3$ & 0.00084 & 0.00084 & $\mathrm{U}$ & & \\
\hline SESPMNT & B16R76 & DOGWOOD MET TOWER & PERIMETER & AT & 07-Jul-03 s & Sb-125 & -0.00125 & $\mathrm{pCi} / \mathrm{m} 3$ & 0.0015 & 0.0015 & U & & \\
\hline SESPMNT & B17653 & DOGWOOD MET TOWER & PERIMETER & AT & $10-0 c t-03 \leqslant$ & Sb-125 & -0.000865 & $\mathrm{pCi} / \mathrm{m} 3$ & 0.0011 & 0.0011 & $\mathrm{U}$ & & \\
\hline SESPMNT & B17PT3 & DOGWOOD MET TOWER & PERIMETER & AT & 05-Jan-04 & Sb-125 & -0.00195 & $\mathrm{pCl} / \mathrm{m} 3$ & 0.0023 & 0.0023 & $u$ & & \\
\hline SESPMNT & B16978 & EDWIN MARKHAM SCHOOL & COMMUNITY & AT & 10-Apr-03 & Sb-125 & 0.000561 & $\mathrm{pCi} / \mathrm{m} 3$ & 0.0014 & 0.0014 & $u$ & & \\
\hline SESPMNT & B16RK8 & EDWIN MARKHAM SCHOOL & COMMUNITY & AT & 02-Jul-03 & Sb-125 & -0.00118 & $\mathrm{pCl} / \mathrm{m} 3$ & 0.0011 & 0.0011 & u & & \\
\hline
\end{tabular}


AIR GAMMA

\begin{tabular}{|c|c|c|c|c|c|c|c|c|c|c|c|c|c|}
\hline $\mid$ OWNER ID $\mid$ & SAMP NUM & SAMP SITE NAME & | DIST CLASS | & MEDIA & SAMP DATE & $\begin{array}{l}\text { CON SHORT } \\
\text { NAME }\end{array}$ & |VALUE RPTD & $\begin{array}{l}\text { ANAL } \\
\text { UNITS } \\
\text { RPTD }\end{array}$ & $\left|\begin{array}{c}\text { COUNTING } \\
\text { ERROR }\end{array}\right|$ & $\begin{array}{c}\text { TOTAL ANAL } \\
\text { ERROR }\end{array}$ & $\mid \begin{array}{c}\text { LAB } \\
\text { QUALIFIER }\end{array}$ & SAMP COMMENT & RESULT COMMENT \\
\hline SESPMNT & B176H8 & EDWIN MARKHAM SCHOOL & COMMUNITY & AT & 08-Oct-03 & Sb-125 & 0.000795 & $\mathrm{pC} / \mathrm{m} 3$ & 0.0014 & 0.0014 & u & & \\
\hline SESPMNT & B17R45 & EDWIN MARKHAM SCHOOL & COMMUNITY & AT & 31-Dec-03 & Sb-125 & 0.000363 & $\mathrm{pCi} / \mathrm{m} 3$ & 0.0018 & 0.0018 & $U$ & & \\
\hline SESPMNT & B16986 & HANFORD TOWNSITE & ONSITE & AT & 31-Mar-03 & Sb-125 & 0.000197 & $\mathrm{pCi} / \mathrm{m} 3$ & 0.00082 & 0.00082 & $U$ & & \\
\hline SESPMNT & B16RL5 & HANFORD TOWNSITE & ONSITE & AT & 08-Jul-03 & Sb-125 & 0.000175 & $\mathrm{pC} / / \mathrm{m} 3$ & 0.00056 & 0.00056 & $\mathrm{U}$ & & \\
\hline SESPMNT & B176J6 & HANFORD TOWNSITE & ONSITE & AT & 01-Oct-03 & Sb-125 & 0.0000471 & $\mathrm{pC} / / \mathrm{m} 3$ & 0.0013 & 0.0013 & $\mathrm{U}$ & & \\
\hline SESPMNT & B17R52 & HANFORD TOWNSITE & ONSITE & AT & $06-J a n-04$ & Sb-125 & 0.000523 & $\mathrm{pC} / \mathrm{m} 3$ & 0.00086 & 0.00086 & u & & \\
\hline SESPMNT & B16970 & LESLIE GROVES-RCHLND & COMMUNITY & AT & 08-Apr-03 & Sb-125 & 0.00102 & $\mathrm{pC} / / \mathrm{m} 3$ & 0.0012 & 0.0012 & $u$ & & \\
\hline SESPMNT & B16RK1 & LESLIE GROVES-RCHLND & COMMUNITY & AT & 01-Jul-03 & Sb-125 & 0.000155 & $\mathrm{pCi} / \mathrm{m} 3$ & 0.0013 & 0.0013 & u & & \\
\hline SESPMNT & B176HO & LESLIE GROVES-RCHLND & COMMUNITY & AT & 07-Oct-03 & Sb-125 & 0.00107 & $\mathrm{pC} / \mathrm{m} 3$ & 0.0015 & 0.0015 & u & & \\
\hline SESPMNT & B17R38 & LESLIE GROVES-RCHLND & COMMUNITY & AT & 30-Dec-03 & Sb-125 & 0.000109 & $\mathrm{pC} / \mathrm{m} 3$ & 0.0021 & 0.0021 & u & & \\
\hline SESPMNT & B16834 & MATTAWA & COMMUNITY & AT & 09-Apr-03 & Sb-125 & 0.00103 & $\mathrm{pC} / \mathrm{m} 3$ & 0.0013 & 0.0013 & u & & \\
\hline SESPMNT & B16PHO & MATTAWA & COMMUNITY & AT & 01-Jul-03 & Sb-125 & -0.000147 & $\mathrm{pCi} / \mathrm{m} 3$ & 0.0016 & 0.0016 & u & & \\
\hline SESPMNT & B175C8 & MATTAWA & COMMUNITY & AT & 09-Oct-03 & Sb-125 & 0.000866 & $\mathrm{pC} / \mathrm{m} 3$ & 0.0018 & 0.0018 & u & & \\
\hline SESPMNT & B17P13 & MATTAWA & COMMUNITY & AT & 31-Dec-03 & Sb-125 & $\begin{array}{l}-0.000497 \\
-0.0004\end{array}$ & $\mathrm{pCi} / \mathrm{m} 3$ & 0.0019 & 0.0019 & u & & \\
\hline SESPMNT & B16812 & N OF $200 \mathrm{E}$ & ONSITE & AT & 08-Apr-03 & Sb-125 & 0.000302 & $\mathrm{pC} / \mathrm{m} 3$ & 0.0011 & 0.0011 & u & & \\
\hline SESPMNT & B16PC7 & N OF $200 \mathrm{E}$ & ONSITE & AT & 30-Jun-03 & Sb-125 & $\begin{array}{l}-0.000872 \\
-0.003\end{array}$ & $\mathrm{pCi} / \mathrm{m} 3$ & 0.0013 & 0.0013 & u & & \\
\hline SESPMNT & B17596 & N OF $200 \mathrm{E}$ & ONSITE & AT & $07-$ Oct-03 & Sb-125 & -0.000508 & $\mathrm{pC} / \mathrm{m} 3$ & 0.0014 & 0.0014 & $u$ & & \\
\hline SESPMNT & B17NYO & N OF $200 \mathrm{E}$ & ONSITE & AT & 30-Dec-03 & Sb-125 & $\begin{array}{l}-0.000783 \\
-0.0007\end{array}$ & $\mathrm{pCi} / \mathrm{m} 3$ & $\begin{array}{r}0.002 \\
0.002\end{array}$ & 0.002 & u & & \\
\hline SESPMNT & B16842 & OTHELLO & COMMUNITY & AT & 09-Apr-03 & Sb-125 & -0.00137 & $\mathrm{pC} / \mathrm{m} 3$ & \begin{tabular}{|c|c|}
0.0015 \\
\end{tabular} & 0.0015 & u & & \\
\hline SESPMNT & B16PH7 & OTHELLO & COMMUNITY & AT & 01-Jul-03 & Sb-125 & -0.000147 & $\mathrm{pCi} / \mathrm{m} 3$ & 0.0015 & 0.0015 & u & & \\
\hline SESPMNT & B175D6 & OTHELLO & COMMUNITY & AT & 09-Oct-03 & Sb-125 & -0.00156 & $\mathrm{pC} / \mathrm{m} 3$ & 0.0014 & 0.0014 & $u$ & & \\
\hline SESPMNT & B17P20 & OTHELLO & COMMUNITY & AT & 31-Dec-03 & Sb-125 & -0.00116 & $\mathrm{pCi} / \mathrm{m} 3$ & 0.0021 & 0.0021 & u & & \\
\hline SESPMNT & B168Y9 & PROSSER BARRICADE & $\begin{array}{l}\text { PERIMETER } \\
\end{array}$ & AT & 03-Apr-03 & Sb-125 & -0.0000131 & $\mathrm{pC} / \mathrm{m} 3$ & 0.00072 & 0.00072 & $u$ & & \\
\hline SESPMNT & B16R90 & PROSSER BARRICADE & PERIMETER & AT & 11-Jul-03 & Sb-125 & -0.000325 & $\mathrm{pCi} / \mathrm{m} 3$ & 0.00067 & 0.00067 & U & & \\
\hline SESPMNT & B17669 & PROSSER BARRICADE & PERIMETER & AT & 03-Oct-03 & Sb-125 & 0.000992 & $\mathrm{pC} / \mathrm{m} 3$ & 0.0011 & 0.0011 & u & & \\
\hline SESPMNT & B17PV7 & PROSSER BARRICADE & PERIMETER & AT & $09-J a n-04$ & Sb-125 & $\begin{array}{l}-0.000319 \\
-0.003\end{array}$ & $\mathrm{pCi} / \mathrm{m} 3$ & 0.00068 & 0.00068 & u & & \\
\hline SESPMNT & B168W5 & RINGOLD MET TOWER & PERIMETER & AT & 10-Apr-03 & Sb-125 & 0.00109 & $\mathrm{pCi} / \mathrm{m} 3$ & 0.00093 & 0.00093 & U & & \\
\hline SESPMNT & B16R69 & RINGOLD MET TOWER & PERIMETER & AT & 07-Jul-03 & Sb-125 & 0.0000565 & $\mathrm{pCi} / \mathrm{m} 3$ & 0.0015 & 0.0015 & U & & \\
\hline SESPMNT & B17645 & RINGOLD MET TOWER & PERIMETER & AT & 10-Oct-03 & Sb-125 & 0.00125 & $\mathrm{pCi} / \mathrm{m} 3$ & 0.0019 & 0.0019 & $u$ & & \\
\hline SESPMNT & B17PR6 & RINGOLD MET TOWER & PERIMETER & AT & 05-Jan-04 & Sb-125 & 0.000984 & $\mathrm{pC} / / \mathrm{m} 3$ & 0.002 & 0.002 & U & & \\
\hline SESPMNT & B16805 & TOPPENISH & DISTANT & AT & 02-Apr-03 & Sb-125 & 0.00105 & $\mathrm{pCi} / \mathrm{m} 3$ & 0.0013 & 0.0013 & U & & \\
\hline SESPMNT & B16PB9 & TOPPENISH & DISTANT & AT & 09-Jul-03 & Sb-125 & 0.0000059 & $\mathrm{pCi} / \mathrm{m} 3$ & 0.0012 & 0.0012 & U & & \\
\hline SESPMNT & B17589 & TOPPENISH & DISTANT & AT & 01-Oct-03 & Sb-125 & 0.000117 & $\mathrm{pC} / \mathrm{m} 3$ & 0.0016 & 0.0016 & $U$ & & \\
\hline SESPMNT & B17NX2 & TOPPENISH & DISTANT & AT & 08-Jan-04 & Sb-125 & -0.000323 & $\mathrm{pCi} / \mathrm{m} 3$ & 0.0016 & 0.0016 & $u$ & & \\
\hline SESPMNT & B16940 & TRI CITIES & COMMUNITY & AT & 10-Apr-03 & Sb-125 & 0.000187 & $\mathrm{pCi} / \mathrm{m} 3$ & 0.00066 & 0.00066 & U & & \\
\hline SESPMNT & B16RF3 & TRI CITIES & COMMUNITY & AT & 07-Jul-03 & Sb-125 & -0.000135 & $\mathrm{pCi} / \mathrm{m} 3$ & 0.00083 & 0.00083 & 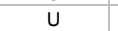 & & \\
\hline SESPMNT & B176C0 & TRI CITIES & COMMUNITY & AT & $10-$ Oct-03 & Sb-125 & -0.000000367 & $\mathrm{pCi} / \mathrm{m} 3$ & 0.001 & 0.001 & $U$ & & \\
\hline SESPMNT & B17R10 & TRI CITIES & COMMUNITY & AT & 05-Jan-04 & Sb-125 & -0.000464 & $\mathrm{pCi} / \mathrm{m} 3$ & 0.0011 & 0.0011 & U & & \\
\hline SESPMNT & B168V7 & W END OF FIR ROAD & PERIMETER & AT & 10-Apr-03 & Sb-125 & 0.000303 & $\mathrm{pCi} / \mathrm{m} 3$ & 0.001 & 0.001 & $\mathrm{U}$ & & \\
\hline SESPMNT & B16R62 & W END OF FIR ROAD & PERIMETER & AT & 07-Jul-03 & Sb-125 & -0.000232 & $\mathrm{pC} / \mathrm{m} 3$ & 0.0015 & 0.0015 & $u$ & & \\
\hline SESPMNT & B17637 & W END OF FIR ROAD & PERIMETER & AT & $10-$ Oct-03 & Sb-125 & 0.000148 & $\mathrm{pCl} / \mathrm{m} 3$ & 0.0016 & 0.0016 & $u$ & & \\
\hline SESPMNT & B17PP9 & W END OF FIR ROAD & PERIMETER & AT & $05-J a n-04$ & Sb-125 & 0.00000602 & $\mathrm{pCi} / \mathrm{m} 3$ & 0.0021 & 0.0021 & u & & \\
\hline SESPMNT & B16925 & WAHLUKE SLOPE & PERIMETER & AT & 09-Apr-03 & Sb-125 & 0.000164 & $\mathrm{pCi} / \mathrm{m} 3$ & 0.00072 & 0.00072 & $U$ & & \\
\hline SESPMNT & B16RD0 & WAHLUKE SLOPE & PERIMETER & AT & 01-Jul-03 & Sb-125 & 0.000279 & $\mathrm{pCi} / \mathrm{m} 3$ & 0.00076 & 0.00076 & 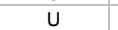 & & \\
\hline SESPMNT & B17695 & WAHLUKE SLOPE & PERIMETER & AT & 08-Oct-03 & Sb-125 & -0.000787 & $\mathrm{pC} / \mathrm{m} 3$ & 0.00099 & 0.00099 & $u$ & & \\
\hline SESPMNT & B17PY7 & WAHLUKE SLOPE & PERIMETER & AT & 31-Dec-03 & Sb-125 & 0.000108 & $\mathrm{pCi} / \mathrm{m} 3$ & 0.0008 & 0.0008 & u & & \\
\hline SESPMNT & B168V0 & WYE BARRICADE & ONSITE & AT & 31-Mar-03 & Sb-125 & -0.000104 & $\mathrm{pCl} / \mathrm{m} 3$ & 0.0013 & 0.0013 & u & & \\
\hline SESPMNT & B16R54 & WYE BARRICADE & ONSITE & AT & 08-Jul-03 & Sb-125 & 0.000476 & $\mathrm{pCl} / \mathrm{m} 3$ & 0.0014 & 0.0014 & u & & \\
\hline SESPMNT & B17630 & WYE BARRICADE & ONSITE & AT & 01-Oct-03 & Sb-125 & -0.0012 & $\mathrm{pCi} / \mathrm{m} 3$ & 0.0015 & 0.0015 & $u$ & & \\
\hline SESPMNT & B17PP1 & WYE BARRICADE & ONSITE & AT & 06-Jan-04 & Sb-125 & -0.00159 & $\mathrm{pCi} / \mathrm{m} 3$ & 0.0017 & 0.0017 & u & & \\
\hline SESPMNT & B16955 & YAKIMA & DISTANT & AT & $03-A p r-03$ & Sb-125 & & $\mathrm{pCl} / \mathrm{m} 3$ & 0 & 0 & u & & \\
\hline SESPMNT & B16RH6 & YAKIMA & DISTANT & AT & 11-Jul-03 & Sb-125 & -0.000122 & $\mathrm{pCl} / \mathrm{m} 3$ & 0.0012 & 0.0012 & $u$ & & \\
\hline SESPMNT & B176D5 & YAKIMA & DISTANT & AT & 03-Oct-03 & Sb-125 & 0.000116 & $\mathrm{pCi} / \mathrm{m} 3$ & 0.0021 & 0.0021 & $u$ & & \\
\hline SESPMNT & B17R23 & YAKIMA & DISTANT & AT & $09-J a n-04$ & Sb-125 & -0.00124 & $\mathrm{pCi} / \mathrm{m} 3$ & 0.0015 & 0.0015 & u & & \\
\hline SESPMNT & B16912 & YAKIMA BARRICADE & PERIMETER & AT & 02-Apr-03 & Sb-125 & $-1.34 \mathrm{E}-08$ & $\mathrm{pCi} / \mathrm{m} 3$ & 0.00085 & 0.00085 & u & & \\
\hline SESPMNT & B16RB5 & YAKIMA BARRICADE & PERIMETER & AT & 11-Jul-03 & Sb-125 & -0.00013 & $\mathrm{pCi} / \mathrm{m} 3$ & 0.00062 & 0.00062 & u & & \\
\hline SESPMNT & B17682 & YAKIMA BARRICADE & PERIMETER & AT & 03-Oct-03 & Sb-125 & -0.000525 & $\mathrm{pC} / \mathrm{m} 3$ & 0.0011 & 0.0011 & U & & \\
\hline SESPMNT & B17PX2 & YAKIMA BARRICADE & PERIMETER & AT & 09-Jan-04 & Sb-125 & 0.000196 & $\mathrm{pCi} / \mathrm{m} 3$ & 0.00079 & 0.00079 & u & & \\
\hline
\end{tabular}


AIR COMPOSITES AND I-129, H-3

\begin{tabular}{|c|c|c|c|c|c|c|c|c|c|c|c|c|c|}
\hline OWNER ID & SAMP NUM & SAMP SITE NAME & DIST CLASS & MEDIA & SAMP DATE & $\begin{array}{c}\text { CON SHORT } \\
\text { NAME }\end{array}$ & VALUE RPTD & \begin{tabular}{|l|} 
ANAL \\
UNITS \\
RPTD \\
\end{tabular} & $\begin{array}{c}\text { COUNTING } \\
\text { ERROR }\end{array}$ & $\begin{array}{c}\text { TOTAL ANAL } \\
\text { ERROR }\end{array}$ & $\begin{array}{c}\text { LAB } \\
\text { QUALIFIER }\end{array}$ & SAMP COMMENT & RESULT COMMENT \\
\hline SESPMNT & B16897 & $200 \mathrm{ESE}$ & ONSITE & AT & $26-\mathrm{Mar}-03 \mid$ & $1-129$ & 0.000025888 & $\mathrm{pCi} / \mathrm{m} 3$ & & $2.64058 \mathrm{E}-06$ & & & \\
\hline SESPMNT & B16PM8 & 200 ESE & ONSITE & AT & 30-Jun-03 I & & 0.000024022 & $\mathrm{pCi} / \mathrm{m} 3$ & & 2.64242E-06 & & & \\
\hline SESPMNT & B175K8 & 200 ESE & ONSITE & AT & 22-Sep-03। & $1-129$ & 0.00001623 & $\mathrm{pCi} / \mathrm{m} 3$ & & $1.39578 \mathrm{E}-06$ & & & \\
\hline SESPMNT & B17P63 & 200 ESE & ONSITE & AT & 12-Jan-04 I & $1-129$ & 0.000018923 & $\mathrm{pCi} / \mathrm{m} 3$ & & 1.70307E-06 & & & \\
\hline SESPMNT & B168B5 & BYERS LANDING & PERIMETER & AT & 10-Apr-03 I & $1-129$ & 0.000000569 & $\mathrm{pCi} / \mathrm{m} 3$ & & $4.552 \mathrm{E}-08$ & & & \\
\hline SESPMNT & B16PN7 & BYERS LANDING & PERIMETER & AT & 07-Jul-03 I & $1-129$ & 0.000000662 & $\mathrm{pCi} / \mathrm{m} 3$ & & $5.0312 \mathrm{E}-08$ & & & \\
\hline SESPMNT & B175L6 & BYERS LANDING & PERIMETER & AT & 25-Sep-03। & $1-129$ & 0.000000666 & $\mathrm{pCi} / \mathrm{m} 3$ & & $7.992 \mathrm{E}-08$ & & & \\
\hline SESPMNT & B17P73 & BYERS LANDING & PERIMETER & AT & 15-Jan-04 I & $\mid-129$ & 0.000000782 & $\mathrm{pCi} / \mathrm{m} 3$ & & $6.256 \mathrm{E}-08$ & & & \\
\hline SESPMNT & B168B1 & RINGOLD MET TOWER & PERIMETER & AT & 10-Apr-03 I & $1-129$ & 0.000000309 & $\mathrm{pCi} / \mathrm{m} 3$ & & $2.8428 \mathrm{E}-08$ & & & \\
\hline SESPMNT & B16PN3 & RINGOLD MET TOWER & PERIMETER & AT & 07-Jul-03 I & $1-129$ & 0.000000293 & $\mathrm{pCi} / \mathrm{m} 3$ & & $2.4026 \mathrm{E}-08$ & & & \\
\hline SESPMNT & B175L2 & RINGOLD MET TOWER & PERIMETER & AT & $25-$ Sep-03। & $1-129$ & 0.000000358 & $\mathrm{pCi} / \mathrm{m} 3$ & & $3.8664 \mathrm{E}-08$ & & & \\
\hline SESPMNT & B17P68 & RINGOLD MET TOWER & PERIMETER & AT & 15-Jan-04 I & $1-129$ & 0.00000029 & $\mathrm{pCi} / \mathrm{m} 3$ & & $2.494 \mathrm{E}-08$ & & & \\
\hline SESPMNT & B168B9 & YAKIMA & DISTANT & AT & 18-Apr-03 | & $1-129$ & 0.000000024 & $\mathrm{pCi} / \mathrm{m} 3$ & & $2.736 \mathrm{E}-09$ & & & \\
\hline SESPMNT & B16PP1 & YAKIMA & DISTANT & AT & 11-Jul-03 I & $1-129$ & 0.000000022 & $\mathrm{pCi} / \mathrm{m} 3$ & & 2.816E-09 & & & \\
\hline SESPMNT & B175M0 & YAKIMA & DISTANT & AT & 03-Oct-03 | & I-129 & 0.000000023 & $\mathrm{pCi} / \mathrm{m} 3$ & & $3.22 \mathrm{E}-09$ & & & \\
\hline SESPMNT & B17P78 & YAKIMA & DISTANT & AT & 29-Dec-03| & $1-129$ & 0.000000029 & $\mathrm{pCi} / \mathrm{m} 3$ & & $3.712 \mathrm{E}-09$ & & & \\
\hline SESPMNT & B168C4 & 100 AREAS & ONSITE & AT & 31-Mar-03 F & Pu-238 & 0.000000576 & $\mathrm{pCi} / \mathrm{m} 3$ & 0.000001 & 0.0000011 & u & & \\
\hline SESPMNT & B16PP5 & 100 AREAS & ONSITE & AT & 08-Jul-03 F & Pu-238 & 0.000000431 & $\mathrm{pCi} / \mathrm{m} 3$ & 0.00000053 & 0.00000055 & u & & \\
\hline SESPMNT & B175M4 & 100 AREAS & ONSITE & AT & 01-Oct-03 F & Pu-238 & 0.000000621 & $\mathrm{pCi} / \mathrm{m} 3$ & 0.0000011 & \begin{tabular}{|l|l|} 
& 0.0000011 \\
\end{tabular} & u & & \\
\hline SESPMNT & B17P82 & 100 AREAS & ONSITE & AT & 06-Jan-04 P & Pu-238 & 0.00000249 & $\mathrm{pCi} / \mathrm{m} 3$ & 0.0000016 & 0.0000016 & & & \\
\hline SESPMNT & B168F3 & 200 E AREA & ONSITE & AT & 08-Apr-03 F & Pu-238 & -0.000000249 & $\mathrm{pCi} / \mathrm{m} 3$ & 0.00000085 & 0.00000085 & u & & \\
\hline SESPMNT & B16PT7 & 200 E AREA & ONSITE & AT & 30-Jun-03 F & Pu-238 & -0.000000305 & $\mathrm{pCi} / \mathrm{m} 3$ & 0.0000011 & 0.0000012 & u & & \\
\hline SESPMNT & B175P3 & 200 E AREA & ONSITE & AT & $07-0 c t-03$ & Pu-238 & $-2.12 \mathrm{E}-08$ & $\mathrm{pCi} / \mathrm{m} 3$ & 0.0000005 & 0.0000006 & u & & \\
\hline SESPMNT & B17PB4 & 200 E AREA & ONSITE & AT & 30-Dec-03 & Pu-238 & 0.000000389 & $\mathrm{pCi} / \mathrm{m} 3$ & 0.000001 & 0.0000011 & u & & \\
\hline SESPMNT & B168L8 & 200 W AREA & ONSITE & AT & 08-Apr-03 & Pu-238 & -0.000000511 & $\mathrm{pCi} / \mathrm{m} 3$ & 0.0000015 & $\quad 0.0000015$ & u & & \\
\hline SESPMNT & B16PY6 & 200 W AREA & ONSITE & AT & 30-Jun-03 F & Pu-238 & -0.000000592 & $\mathrm{pCi} / \mathrm{m} 3$ & 0.0000025 & 0.0000025 & u & & \\
\hline SESPMNT & B175W8 & 200 W AREA & ONSITE & AT & 07-Oct-03 F & Pu-238 & 0.000000501 & $\mathrm{pCi} / \mathrm{m} 3$ & 0.0000014 & 0.0000016 & U & & \\
\hline SESPMNT & B17PH3 & 200 W AREA & ONSITE & AT & 30-Dec-03 & Pu-238 & 0.000000901 & $\mathrm{pCi} / \mathrm{m} 3$ & 0.0000021 & 0.0000022 & U & & \\
\hline SESPMNT & B168J6 & 200 W SOUTH EAST & ONSITE & AT & 08-Apr-03 & Pu-238 & -0.000000166 & $\mathrm{pCi} / \mathrm{m} 3$ & 0.00000056 & $\begin{array}{l}0.00000056 \\
\end{array}$ & u & & \\
\hline SESPMNT & B16PW7 & 200 W SOUTH EAST & ONSITE & AT & 30-Jun-03 F & $\mathrm{Pu}-238$ & -0.000000669 & $\mathrm{pCi} / \mathrm{m} 3$ & 0.00000095 & 0.00000098 & u & & \\
\hline SESPMNT & B175T6 & 200 W SOUTH EAST & ONSITE & AT & $07-0 c t-03$ & Pu-238 & 0.00000104 & $\mathrm{pCi} / \mathrm{m} 3$ & 0.00000091 & 0.00000095 & & & \\
\hline SESPMNT & B17PD4 & 200 W SOUTH EAST & ONSITE & AT & 30-Dec-03 F & Pu-238 & -0.000000195 & $\mathrm{pCi} / \mathrm{m} 3$ & 0.00000066 & 0.0000007 & u & & \\
\hline SESPMNT & B168M6 & 300 AREA & ONSITE & AT & 02-Apr-03 F & Pu-238 & -0.000000195 & $\mathrm{pCi} / \mathrm{m} 3$ & 0.00000065 & 0.00000069 & $u$ & & \\
\hline SESPMNT & B16R03 & 300 AREA & ONSITE & AT & 10-Jul-03 F & $\mathrm{Pu}-238$ & -0.000000164 & $\mathrm{pCi} / \mathrm{m} 3$ & 0.00000058 & $\begin{array}{l}3 \\
3\end{array}$ & $u$ & & \\
\hline SESPMNT & B175X6 & 300 AREA & ONSITE & AT & 30-Sep-03 & Pu-238 & -0.000000198 & $\mathrm{pCi} / \mathrm{m} 3$ & 0.00000093 & 0.00000097 & u & & \\
\hline SESPMNT & B17PJ0 & 300 AREA & ONSITE & AT & 08-Jan-04 F & Pu-238 & -0.00000037 & $\mathrm{pCi} / \mathrm{m} 3$ & 0.00000041 & 0.00000046 & $u$ & & \\
\hline SESPMNT & B167V2 & $300 \mathrm{NE}$ & ONSITE & AT & 02-Apr-03 F & Pu-238 & -0.000000329 & $\mathrm{pCi} / \mathrm{m} 3$ & 0.000001 & \begin{tabular}{|l|} 
\\
0.0000011 \\
\end{tabular} & $u$ & & \\
\hline SESPMNT & B16P64 & $300 \mathrm{NE}$ & ONSITE & AT & 09-Jul-03 F & Pu-238 & -0.000000804 & $\mathrm{pCi} / \mathrm{m} 3$ & 0.000001 & 0.0000011 & $u$ & & \\
\hline SESPMNT & B17546 & $300 \mathrm{NE}$ & ONSITE & AT & 30-Sep-03 & Pu-238 & 0.000000534 & $\mathrm{pCi} / \mathrm{m} 3$ & 0.00000097 & 0.000001 & u & & \\
\hline SESPMNT & B17NP5 & $300 \mathrm{NE}$ & ONSITE & AT & 08-Jan-04 F & Pu-238 & 0.000000158 & $\mathrm{pCi} / \mathrm{m} 3$ & 0.00000088 & 0.00000095 & $u$ & & \\
\hline SESPMNT & B168P5 & 400 AREA & ONSITE & AT & 31-Mar-03 F & Pu-238 & -0.000000199 & $\mathrm{pCi} / \mathrm{m} 3$ & 0.00000022 & 0.00000025 & $u$ & & \\
\hline SESPMNT & B16R25 & 400 AREA & ONSITE & AT & 08-Jul-03 F & Pu-238 & -0.000000171 & $\mathrm{pCi} / \mathrm{m} 3$ & 0.00000019 & 0.00000022 & u & & \\
\hline SESPMNT & B17605 & 400 AREA & ONSITE & AT & 01-Oct-03 F & Pu-238 & 0.000000761 & $\mathrm{pCi} / \mathrm{m} 3$ & 0.00000069 & 0.00000071 & & & \\
\hline SESPMNT & B17PL2 & 400 AREA & ONSITE & AT & 05-Jan-04 & Pu-238 & 0.000000359 & $\mathrm{pCi} / \mathrm{m} 3$ & 0.00000051 & 0.00000051 & $u$ & & \\
\hline SESPMNT & B168H8 & B POND & ONSITE & AT & 08-Apr-03 F & Pu-238 & -0.000000498 & $\mathrm{pCi} / \mathrm{m} 3$ & 0.0000014 & 0.0000015 & u & & \\
\hline SESPMNT & B16PW0 & B POND & ONSITE & AT & 30-Jun-03 F & Pu-238 & -0.000000654 & $\mathrm{pCi} / \mathrm{m} 3$ & 0.0000023 & 0.0000023 & u & & \\
\hline SESPMNT & B175R8 & B POND & ONSITE & AT & $07-0 c t-03 \mathrm{~F}$ & Pu-238 & -0.000000497 & $\mathrm{pCi} / \mathrm{m} 3$ & 0.0000013 & 30.0000013 & $u$ & & \\
\hline SESPMNT & B17PC7 & B POND & ONSITE & AT & 30-Dec-03 F & Pu-238 & 0.00000136 & $\mathrm{pCi} / \mathrm{m} 3$ & 0.0000029 & 0.0000031 & $u$ & & \\
\hline SESPMNT & B16962 & BASIN CITY SCHOOL & COMMUNITY & AT & 09-Apr-03 F & Pu-238 & 0.000000181 & $\mathrm{pCi} / \mathrm{m} 3$ & 0.0000014 & 0.0000015 & $u$ & & \\
\hline SESPMNT & B16RJ4 & BASIN CITY SCHOOL & COMMUNITY & AT & 02-Jul-03 F & $\mathrm{Pu}-238$ & -0.000000585 & $\mathrm{pCi} / \mathrm{m} 3$ & 0.0000026 & 0.0000027 & $u$ & & \\
\hline SESPMNT & B176F2 & BASIN CITY SCHOOL & COMMUNITY & AT & 08-Oct-03 F & Pu-238 & 0.00000374 & $\mathrm{pCi} / \mathrm{m} 3$ & 0.0000035 & 0.0000036 & & & \\
\hline SESPMNT & B17R31 & BASIN CITY SCHOOL & COMMUNITY & AT & 31-Dec-03 F & Pu-238 & 0.0000019 & $\mathrm{pCi} / \mathrm{m} 3$ & 0.0000037 & 0.0000038 & U & & \\
\hline SESPMNT & B168Y1 & BYERS LANDING & PERIMETER & AT & 10-Apr-03 F & Pu-238 & -0.00000103 & $\mathrm{pCi} / \mathrm{m} 3$ & 0.0000017 & 0.0000019 & $u$ & & \\
\hline SESPMNT & B16R83 & BYERS LANDING & PERIMETER & AT & 07-Jul-03 F & Pu-238 & -0.00000145 & $\mathrm{pCi} / \mathrm{m} 3$ & 0.0000017 & 0.0000019 & u & & \\
\hline SESPMNT & B17661 & BYERS LANDING & PERIMETER & AT & 10-Oct-03 F & Pu-238 & 0.00000115 & $\mathrm{pCi} / \mathrm{m} 3$ & 0.0000034 & 0.0000035 & u & & \\
\hline SESPMNT & B17PV0 & BYERS LANDING & PERIMETER & AT & 05-Jan-04 F & Pu-238 & -0.00000143 & $\mathrm{pCi} / \mathrm{m} 3$ & 0.0000018 & 0.0000019 & $u$ & & \\
\hline SESPMNT & B168X3 & DOGWOOD MET T & PERIMETER & AT & 10-Apr-03 F & Pu-238 & $-1.87 \mathrm{E}-\mathrm{C}$ & $\mathrm{pCi} / \mathrm{m} 3$ & 0.00000099 & 0.0000012 & u & & \\
\hline SESPMNT & B16R76 & DOGWOOD MET TOWER & PERIMETER & AT & 07-Jul-03 F & Pu-238 & 0.000000358 & $\mathrm{pC} / / \mathrm{m} 3$ & 0.0000033 & 0.0000034 & u & & \\
\hline
\end{tabular}


AIR COMPOSITES AND I-129, H-3

\begin{tabular}{|c|c|c|c|c|c|c|c|c|c|c|c|c|c|}
\hline OWNER ID & SAMP NUM & SAMP SITE NAME & | DIST CLASS & MEDIA & $\mid$ SAMP DATE & $\left|\begin{array}{c}\text { CON SHORT } \\
\text { NAME }\end{array}\right|$ & VALUE RPTD & \begin{tabular}{|l} 
ANAL \\
UNITS \\
RPTD
\end{tabular} & $\begin{array}{c}\text { COUNTING } \\
\text { ERROR }\end{array}$ & $\left|\begin{array}{c}\text { TOTAL ANAL } \\
\text { ERROR }\end{array}\right|$ & $\begin{array}{c}\text { LAB } \\
\text { QUALIFIER }\end{array}$ & SAMP COMMENT & RESULT COMMENT \\
\hline SESPMNT & B17653 & DOGWOOD MET TOWER & PERIMETER & AT & 10-Oct-03 & Pu-238 & -0.00000121 & $\mathrm{pCi} / \mathrm{m} 3$ & 0.0000024 & 0.0000025 & u & & \\
\hline SESPMNT & B17PT3 & DOGWOOD MET TOWER & PERIMETER & AT & 05-Jan-04 F & Pu-238 & -0.000000565 & $\mathrm{pCi} / \mathrm{m} 3$ & 0.0000016 & 0.0000016 & u & & \\
\hline SESPMNT & B16978 & EDWIN MARKHAM SCHOOL & COMMUNITY & AT & 10-Apr-03 & Pu-238 & -0.000000487 & $\mathrm{pC} / \mathrm{m} 3$ & 0.0000013 & 0.0000013 & $u$ & & \\
\hline SESPMNT & B16RK8 & EDWIN MARKHAM SCHOOL & COMMUNITY & AT & 02-Jul-03 F & $\mathrm{Pu}-238$ & 0.000000817 & $\mathrm{pCi} / \mathrm{m} 3$ & 0.000002 & 0.0000021 & $u$ & & \\
\hline SESPMNT & B176H8 & EDWIN MARKHAM SCHOOL & COMMUNITY & AT & $08-0 c t-03$ F & Pu-238 & -0.000000497 & $\mathrm{pCi} / \mathrm{m} 3$ & 0.0000014 & 0.0000014 & u & & \\
\hline SESPMNT & B17R45 & EDWIN MARKHAM SCHOOL & COMMUNITY & AT & 31-Dec-03 F & Pu-238 & 0.000000257 & $\mathrm{pCi} / \mathrm{m} 3$ & 0.0000017 & 0.0000018 & u & & \\
\hline SESPMNT & B16986 & HANFORD TOWNSITE & ONSITE & AT & 31-Mar-03 F & Pu-238 & -0.000000179 & $\mathrm{pCi} / \mathrm{m} 3$ & 0.00000055 & 0.0000006 & $\mathrm{u}$ & & \\
\hline SESPMNT & B16RL5 & HANFORD TOWNSITE & ONSITE & AT & 08-Jul-03 F & Pu-238 & $6.65 \mathrm{E}-08$ & $\mathrm{pCi} / \mathrm{m} 3$ & 0.00000043 & 0.00000047 & $\mathrm{U}$ & & \\
\hline SESPMNT & B176J6 & HANFORD TOWNSITE & ONSITE & AT & 01-Oct-03 F & Pu-238 & -0.000000179 & $\mathrm{pC} / \mathrm{m} 3$ & 0.00000065 & 0.00000068 & u & & \\
\hline SESPMNT & B17R52 & HANFORD TOWNSITE & ONSITE & AT & $06-J a n-04 \mathrm{~F}$ & Pu-238 & 0.000000844 & $\mathrm{pCi} / \mathrm{m} 3$ & 0.00000097 & 0.00000098 & u & & \\
\hline SESPMNT & B16970 & LESLIE GROVES-RCHLND & COMMUNITY & AT & 08-Apr-03 F & Pu-238 & 0.000000154 & $\mathrm{pC} / \mathrm{m} 3$ & 0.0000023 & 0.0000023 & $\mathrm{U}$ & & \\
\hline SESPMNT & B16RK1 & LESLIE GROVES-RCHLND & COMMUNITY & AT & 01-Jul-03 F & Pu-238 & 0.000000224 & $\mathrm{pCi} / \mathrm{m} 3$ & 0.0000016 & 0.0000018 & $\mathrm{U}$ & & \\
\hline SESPMNT & B176HO & LESLIE GROVES-RCHLND & COMMUNITY & AT & 07-Oct-03 & Pu-238 & $-2.79 \mathrm{E}-09$ & $\mathrm{pCi} / \mathrm{m} 3$ & 0.00000099 & 0.0000012 & $\mathrm{u}$ & & \\
\hline SESPMNT & B17R38 & LESLIE GROVES-RCHLND & COMMUNITY & AT & 30-Dec-03 F & Pu-238 & 0.000000277 & $\mathrm{pCi} / \mathrm{m} 3$ & 0.0000017 & 0.0000019 & u & & \\
\hline SESPMNT & B168Y9 & PROSSER BARRICADE & PERIMETER & AT & 03-Apr-03 F & Pu-238 & -0.000000615 & $\mathrm{pCi} / \mathrm{m} 3$ & 0.00000064 & 0.00000074 & $\mathrm{U}$ & & \\
\hline SESPMNT & B16R90 & PROSSER BARRICADE & PERIMETER & AT & 11-Jul-03 F & Pu-238 & -0.00000025 & $\mathrm{pCi} / \mathrm{m} 3$ & 0.00000076 & 0.00000076 & $\mathrm{U}$ & & \\
\hline SESPMNT & B17669 & PROSSER BARRICADE & PERIMETER & AT & 03-Oct-03 & Pu-238 & -0.000000302 & $\mathrm{pCi} / \mathrm{m} 3$ & 0.00000072 & 0.00000072 & u & & \\
\hline SESPMNT & B17PV7 & PROSSER BARRICADE & PERIMETER & AT & 09-Jan-04 F & Pu-238 & 0.000000672 & $\mathrm{pCi} / \mathrm{m} 3$ & 0.0000011 & 0.0000011 & $\mathrm{u}$ & & \\
\hline SESPMNT & B168W5 & RINGOLD MET TOWER & PERIMETER & AT & 10-Apr-03 F & Pu-238 & -0.000000297 & $\mathrm{pC} / \mathrm{m} 3$ & 0.0000011 & 0.0000012 & $\mathrm{U}$ & & \\
\hline SESPMNT & B16R69 & RINGOLD MET TOWER & PERIMETER & AT & 07-Jul-03 F & Pu-238 & 0.000000551 & $\mathrm{pCi} / \mathrm{m} 3$ & 0.0000018 & $\begin{array}{l}0.0000019 \\
\end{array}$ & u & & \\
\hline SESPMNT & B17645 & RINGOLD MET TOWER & PERIMETER & AT & 10-Oct-03 & Pu-238 & -0.000000691 & $\mathrm{pC} / \mathrm{m} 3$ & 0.0000013 & $\begin{array}{ll}3 & 0.0000014\end{array}$ & u & & \\
\hline SESPMNT & B17PR6 & RINGOLD MET TOWER & PERIMETER & AT & 05-Jan-04 & Pu-238 & -0.000000414 & $\mathrm{pC} / \mathrm{m} 3$ & 0.00000083 & 0.00000083 & u & & \\
\hline SESPMNT & B16805 & TOPPENISH & DISTANT & AT & 02-Apr-03 F & Pu-238 & -0.00000196 & $\mathrm{pCi} / \mathrm{m} 3$ & 0.0000028 & 0.0000029 & u & & \\
\hline SESPMNT & B16PB9 & TOPPENISH & DISTANT & AT & 09-Jul-03 & Pu-238 & $-5.07 \mathrm{E}-08$ & $\mathrm{pC} / / \mathrm{m} 3$ & 0.00000019 & 0.00000019 & u & & \\
\hline SESPMNT & B17589 & TOPPENISH & DISTANT & AT & 01-Oct-03 F & Pu-238 & $6.29 \mathrm{E}-08$ & $\mathrm{pCC} / \mathrm{m} 3$ & 0.0000013 & $\begin{array}{ll}3 & 0.0000015\end{array}$ & u & & \\
\hline SESPMNT & B17NX2 & TOPPENISH & DISTANT & AT & 08-Jan-04 F & Pu-238 & -0.000000491 & $\mathrm{pCi} / \mathrm{m} 3$ & 0.0000021 & 0.0000021 & u & & \\
\hline SESPMNT & B16940 & TRI CITIES & COMMUNITY & AT & 10-Apr-03 & Pu-238 & -0.00000015 & $\mathrm{pC} / \mathrm{m} 3$ & 0.00000063 & 0.00000063 & $\mathrm{U}$ & & \\
\hline SESPMNT & B16RF3 & TRI CITIES & COMMUNITY & AT & 07-Jul-03 F & Pu-238 & 0.000000145 & $\mathrm{pCi} / \mathrm{m} 3$ & 0.00000064 & 0.00000068 & u & & \\
\hline SESPMNT & B176C0 & TRI CITIES & COMMUNITY & AT & 10-Oct-03 & Pu-238 & 0.00000141 & $\mathrm{pCi} / \mathrm{m} 3$ & 0.0000012 & 0.0000013 & u & & \\
\hline SESPMNT & B17R10 & TRI CITIES & COMMUNITY & AT & 05-Jan-04 & Pu-238 & & $\mathrm{pC} / / \mathrm{m} 3$ & 0.00000056 & 0.00000056 & u & & \\
\hline SESPMNT & B168V7 & W END OF FIR ROAD & PERIMETER & AT & 10-Apr-03 & Pu-238 & -0.00000156 & $\mathrm{pC} / \mathrm{m} 3$ & 0.0000015 & 0.0000016 & $\mathrm{u}$ & & \\
\hline SESPMNT & B16R62 & W END OF FIR ROAD & PERIMETER & AT & 07-Jul-03 F & Pu-238 & 0.00000148 & $\mathrm{pCi} / \mathrm{m} 3$ & 0.0000029 & 0.000003 & u & & \\
\hline SESPMNT & B17637 & W END OF FIR ROAD & PERIMETER & AT & 10-Oct-03 & Pu-238 & 0.000000158 & $\mathrm{pCi} / \mathrm{m} 3$ & 0.0000013 & $\begin{array}{l}3.0000015 \\
\end{array}$ & u & & \\
\hline SESPMNT & B17PP9 & W END OF FIR ROAD & PERIMETER & AT & 05-Jan-04 & Pu-238 & 0.000000259 & $\mathrm{pC} / / \mathrm{m} 3$ & 0.0000017 & 0.0000018 & u & & \\
\hline SESPMNT & B16925 & WAHLUKE SLOPE & PERIMETER & AT & 09-Apr-03 & Pu-238 & 0.000000048 & $\mathrm{pC} / \mathrm{m} 3$ & 0.0000004 & 0.00000044 & $\mathrm{U}$ & & \\
\hline SESPMNT & B16RD0 & WAHLUKE SLOPE & PERIMETER & AT & 01-Jul-03 F & Pu-238 & -0.000000581 & $\mathrm{pC} / \mathrm{m} 3$ & 0.0000008 & 0.00000084 & u & & \\
\hline SESPMNT & B17695 & WAHLUKE SLOPE & PERIMETER & AT & 08-Oct-03 F & Pu-238 & -0.000000344 & $\mathrm{pCi} / \mathrm{m} 3$ & 0.00000068 & 0.00000071 & u & & \\
\hline SESPMNT & B17PY7 & WAHLUKE SLOPE & PERIMETER & AT & 31-Dec-03 F & Pu-238 & $-4.4 \mathrm{E}-11$ & $\mathrm{pC} / \mathrm{m} 3$ & 0.00000083 & 0.00000083 & u & & \\
\hline SESPMNT & B168V0 & WYE BARRICADE & ONSITE & AT & 31-Mar-03 F & Pu-238 & $-6.42 \mathrm{E}-09$ & $\mathrm{pC} / \mathrm{m} 3$ & 0.0000012 & 0.0000014 & $\mathrm{U}$ & & \\
\hline SESPMNT & B16R54 & WYE BARRICADE & ONSITE & AT & 08-Jul-03 F & Pu-238 & -0.000000493 & $\mathrm{pC} / \mathrm{m} 3$ & 0.0000021 & 0.0000021 & u & & \\
\hline SESPMNT & B17630 & WYE BARRICADE & ONSITE & AT & 01-Oct-03 F & Pu-238 & -0.000000572 & $\mathrm{pC} / \mathrm{m} 3$ & 0.0000026 & 0.0000027 & u & & \\
\hline SESPMNT & B17PP1 & WYE BARRICADE & ONSITE & AT & 06-Jan-04 & Pu-238 & -0.000000495 & $\mathrm{pC} / \mathrm{m} 3$ & 0.000003 & 0.000003 & u & & \\
\hline SESPMNT & B16955 & YAKIMA & DISTANT & AT & 03-Apr-03 F & Pu-238 & -0.00000134 & $\mathrm{pCi} / \mathrm{m} 3$ & 0.0000015 & 0.0000017 & $\mathrm{U}$ & & \\
\hline SESPMNT & B16RH6 & YAKIMA & DISTANT & AT & 11-Jul-03 F & Pu-238 & -0.00000136 & $\mathrm{pC} / \mathrm{m} 3$ & 0.0000017 & 0.0000018 & u & & \\
\hline $\begin{array}{l}\text { SESPMNT } \\
\text { SESPMT }\end{array}$ & B176D5 & $\begin{array}{l}\text { TANIMIA } \\
\text { YAKMA }\end{array}$ & $\begin{array}{l}\text { DISTANT } \\
\end{array}$ & AT & $03-0 \mathrm{Ct}-03 \mathrm{r}$ & Pu-238 & -0.00000173 & $\mathrm{pCi} / \mathrm{m} 3$ & 0.0000028 & $\begin{array}{l}0.0000029 \\
\end{array}$ & u & & \\
\hline SESPMNT & B17R23 & YAKIMA & DISTANT & AT & 09-Jan-04 & Pu-238 & -0.00000049 & $\mathrm{pCi} / \mathrm{m} 3$ & 0.0000016 & 0.0000016 & u & & \\
\hline SESPMNT & B16912 & YAKIMA BARRICADE & PERIMETER & AT & 02-Apr-03 F & Pu-238 & -0.000000431 & $\mathrm{pCi} / \mathrm{m} 3$ & 0.00000051 & 0.00000056 & $\mathrm{U}$ & & \\
\hline SESPMNT & B16RB5 & YAKIMA BARRICADE & PERIMETER & AT & 11-Jul-03 F & Pu-238 & 0.000000232 & $\mathrm{pC} / \mathrm{m} 3$ & 0.00000076 & 0.00000078 & u & & \\
\hline SESPMNT & B17682 & YAKIMA BARRICADE & PERIMETER & AT & $03-0 \mathrm{ct}-03 \mathrm{r}$ & Pu-238 & $2.49 \mathrm{E}-08$ & $\mathrm{pCi} / \mathrm{m} 3$ & 0.00000041 & 0.00000047 & u & & \\
\hline SESPMNT & B17PX2 & YAKIMA BARRICADE & PERIMETER & AT & 09-Jan-04 & Pu-238 & & $\mathrm{pC} / / \mathrm{m} 3$ & 0.00000063 & 0.00000063 & u & & \\
\hline SESPMNT & B168C4 & 100 AREAS & ONSITE & AT & 31-Mar-03 F & Pu-239/240 & 0.0000025 & $\mathrm{pCi} / \mathrm{m} 3$ & 0.0000017 & 0.0000017 & & & \\
\hline SESPMNT & B16PP5 & 100 AREAS & ONSITE & AT & 08-Jul-03 F & $\mathrm{Pu}-239 / 240$ & 0.00000659 & $\mathrm{pCi} / \mathrm{m} 3$ & 0.0000019 & 0.0000021 & & & \\
\hline SESPMNT & B175M4 & 100 AREAS & ONSITE & AT & $01-0 c t-03$ F & $\mathrm{Pu}-239 / 240$ & 0.00000379 & $\mathrm{pCi} / \mathrm{m} 3$ & 0.0000015 & 0.0000016 & & & \\
\hline SESPMNT & B17P82 & 100 AREAS & ONSITE & AT & 06-Jan-04 & Pu-239/240 & 0.0000141 & $\mathrm{pCi} / \mathrm{m} 3$ & 0.0000037 & 0.0000043 & & & \\
\hline SESPMNT & B168F3 & 200 E AREA & ONSITE & AT & 08-Apr-03 F & Pu-239/240 & 0.000000234 & $\mathrm{pC} / \mathrm{m} 3$ & 0.00000065 & 0.00000067 & $u$ & & \\
\hline SESPMNT & B16PT7 & 200 E AREA & ONSITE & AT & 30-Jun-03 F & $\mathrm{Pu}-239 / 240$ & 0.000000695 & $\mathrm{pCi} / \mathrm{m} 3$ & 0.0000011 & 0.0000012 & u & & \\
\hline SESPMNT & B175P3 & 200 E AREA & ONSITE & AT & 07-Oct-03 F & $\mathrm{Pu}-239 / 240$ & 0.000000152 & $\mathrm{pCi} / \mathrm{m} 3$ & 0.00000086 & 0.00000088 & u & & \\
\hline SESPMNT & B17PB4 & 200 E AREA & ONSITE & AT & 30-Dec-03 F & Pu-239/240 & 0.00000135 & $\mathrm{pC} / \mathrm{m} 3$ & 0.0000015 & 0.0000015 & u & & \\
\hline
\end{tabular}


AIR COMPOSITES AND I-129, H-3

\begin{tabular}{|c|c|c|c|c|c|c|c|c|c|c|c|c|c|}
\hline OWNER ID & SAMP NUM & SAMP SITE NAME & DIST CLASS & MEDIA & |SAMP DATE & $\begin{array}{c}\text { CON SHORT } \\
\text { NAME }\end{array}$ & VALUE RPTD & $\mid$\begin{tabular}{|l|} 
ANAL \\
UNITS \\
RPTD
\end{tabular} & $\begin{array}{c}\text { COUNTING } \\
\text { ERROR }\end{array}$ & $\begin{array}{c}\text { TOTAL ANAL } \\
\text { ERROR }\end{array}$ & $\mid \begin{array}{c}\text { LAB } \\
\text { QUALIFIER }\end{array}$ & SAMP COMMENT & | RESULT COMMENT \\
\hline SESPMNT & B168L8 & 200 W AREA & ONSITE & AT & 08-Apr-03 & Pu-239/240 & 0.000002 & $\mathrm{pCi} / \mathrm{m} 3$ & 0.0000022 & 0.0000022 & u & & \\
\hline SESPMNT & B16PY6 & 200 W AREA & ONSITE & AT & 30-Jun-03 & Pu-239/240 & 0.00000271 & $\mathrm{pCi} / \mathrm{m} 3$ & 0.0000034 & 0.0000034 & u & & \\
\hline SESPMNT & B175W8 & 200 W AREA & ONSITE & AT & 07-Oct-03 & $\mathrm{Pu}-239 / 240$ & 0.00000532 & $\mathrm{pCi} / \mathrm{m} 3$ & 0.0000033 & $\begin{array}{l}3 \\
\end{array}$ & & & \\
\hline SESPMNT & $\mathrm{B} 17 \mathrm{PH} 3$ & 200 W AREA & ONSITE & AT & 30-Dec-03 & $\mathrm{Pu}-239 / 240$ & 0.00000201 & $\mathrm{pCi} / \mathrm{m} 3$ & 0.0000033 & $\begin{array}{l}3 \\
3\end{array}$ & $u$ & & \\
\hline SESPMNT & B168J6 & $200 \mathrm{~W}$ SOUTH EAST & ONSITE & AT & 08-Apr-03 & Pu-239/240 & $-5.91 \mathrm{E}-08$ & $\mathrm{pCi} / \mathrm{m} 3$ & 0.00000054 & 0.00000054 & $u$ & & \\
\hline SESPMNT & B16PW7 & $200 \mathrm{~W}$ SOUTH EAST & ONSITE & AT & 30-Jun-03 & Pu-239/240 & 0.000000877 & $\mathrm{pCi} / \mathrm{m} 3$ & 0.0000013 & \begin{tabular}{l|l}
3 & 0.0000014 \\
\end{tabular} & u & & \\
\hline SESPMNT & B175T6 & $200 \mathrm{~W}$ SOUTH EAST & ONSITE & AT & 07-Oct-03 & Pu-239/240 & 0.000000113 & $\mathrm{pCi} / \mathrm{m} 3$ & 0.00000034 & 0.00000037 & $u$ & & \\
\hline SESPMNT & B17PD4 & $200 \mathrm{~W}$ SOUTH EAST & ONSITE & AT & 30-Dec-03 & Pu-239/240 & 0.000000863 & $\mathrm{pCi} / \mathrm{m} 3$ & 0.00000093 & $\begin{array}{l}3.00000095 \\
\end{array}$ & u & & \\
\hline SESPMNT & B168M6 & 300 AREA & ONSITE & AT & 02-Apr-03 & Pu-239/240 & -0.000000298 & $\mathrm{pCi} / \mathrm{m} 3$ & 0.00000046 & 0.00000048 & u & & \\
\hline SESPMNT & B16R03 & 300 AREA & ONSITE & AT & 10-Jul-03 & $\mathrm{Pu}-239 / 240$ & 0.000000383 & $\mathrm{pCi} / \mathrm{m} 3$ & 0.00000062 & 0.00000064 & u & & \\
\hline SESPMNT & B175X6 & 300 AREA & ONSITE & AT & 30-Sep-03 & Pu-239/240 & $-7.07 \mathrm{E}-08$ & $\mathrm{pCi} / \mathrm{m} 3$ & 0.00000093 & \begin{tabular}{l|l}
3 & 0.00000094 \\
\end{tabular} & $u$ & & \\
\hline SESPMNT & B17PJo & 300 AREA & ONSITE & AT & 08-Jan-04 & Pu-239/240 & -0.000000265 & $\mathrm{pCi} / \mathrm{m} 3$ & 0.00000092 & 0.00000093 & u & & \\
\hline SESPMNT & B167V2 & $300 \mathrm{NE}$ & ONSITE & AT & 02-Apr-03 & $\mathrm{Pu}-239 / 240$ & 0.000000623 & $\mathrm{pCi} / \mathrm{m} 3$ & 0.000001 & 0.0000011 & $u$ & & \\
\hline SESPMNT & B16P64 & $300 \mathrm{NE}$ & ONSITE & AT & 09-Jul-03 & Pu-239/240 & -0.000000621 & $\mathrm{pCi} / \mathrm{m} 3$ & 0.000001 & 0.0000011 & u & & \\
\hline SESPMNT & B17546 & $300 \mathrm{NE}$ & ONSITE & AT & 30-Sep-03 & Pu-239/240 & 0.00000017 & $\mathrm{pCi} / \mathrm{m} 3$ & 0.00000056 & 0.0000006 & u & & \\
\hline SESPMNT & B17NP5 & $300 \mathrm{NE}$ & ONSITE & AT & 08-Jan-04 & Pu-239/240 & 0.00000165 & $\mathrm{pCi} / \mathrm{m} 3$ & 0.0000018 & 0.0000018 & u & & \\
\hline SESPMNT & B168P5 & 400 AREA & ONSITE & AT & 31-Mar-03 & Pu-239/240 & $-3.16 \mathrm{E}-08$ & $\mathrm{pCi} / \mathrm{m} 3$ & 0.00000031 & 0.00000032 & $u$ & & \\
\hline SESPMNT & B16R25 & 400 AREA & ONSITE & AT & 08-Jul-03 & Pu-239/240 & $6.92 \mathrm{E}-08$ & $\mathrm{pCl} / \mathrm{m} 3$ & 0.00000033 & 0.00000034 & u & & \\
\hline SESPMNT & B17605 & 400 AREA & ONSITE & AT & 01-Oct-03 & Pu-239/240 & 0.0000011 & $\mathrm{pCi} / \mathrm{m} 3$ & 0.00000089 & 0.00000091 & & & \\
\hline SESPMNT & B17PL2 & 400 AREA & ONSITE & AT & 05-Jan-04 & Pu-239/240 & 0.000000179 & $\mathrm{pCi} / \mathrm{m} 3$ & 0.00000062 & 0.00000062 & $u$ & & \\
\hline SESPMNT & B168H8 & B POND & ONSITE & AT & 08-Apr-03 & Pu-239/240 & -0.000000177 & $\mathrm{pCi} / \mathrm{m} 3$ & 0.0000014 & 0.0000014 & $u$ & & \\
\hline SESPMNT & B16PW0 & B POND & ONSITE & AT & 30-Jun-03 & Pu-239/240 & 0.000000629 & $\mathrm{pCi} / \mathrm{m} 3$ & 0.0000017 & 0.0000018 & u & & \\
\hline SESPMNT & B175R8 & B POND & ONSITE & AT & 07-Oct-03 & Pu-239/240 & 0.000000275 & $\mathrm{pCi} / \mathrm{m} 3$ & 0.0000009 & 0.00000098 & u & & \\
\hline SESPMNT & B17PC7 & B POND & ONSITE & AT & 30-Dec-03 & Pu-239/240 & -0.000000254 & $\mathrm{pCi} / \mathrm{m} 3$ & 0.0000029 & 0.000003 & u & & \\
\hline SESPMNT & B16962 & BASIN CITY SCHOOL & COMMUNITY & AT & 09-Apr-03 & $\mathrm{Pu}-239 / 240$ & 0.000000498 & $\mathrm{pCi} / \mathrm{m} 3$ & 0.0000013 & 0.0000014 & u & & \\
\hline SESPMNT & B16RJ4 & BASIN CITY SCHOOL & COMMUNITY & AT & 02-Jul-03 & Pu-239/240 & -0.000000208 & $\mathrm{pCi} / \mathrm{m} 3$ & 0.0000023 & 0.0000023 & u & & \\
\hline SESPMNT & B176F2 & BASIN CITY SCHOOL & COMMUNITY & AT & 08-Oct-03 & Pu-239/240 & 0.00000194 & $\mathrm{pCi} / \mathrm{m} 3$ & 0.0000025 & $\begin{array}{l}5.0000025 \\
\end{array}$ & $\mathrm{u}$ & & \\
\hline SESPMNT & B17R31 & BASIN CITY SCHOOL & COMMUNITY & AT & 31-Dec-03 & Pu-239/240 & 0.000000617 & $\mathrm{pCi} / \mathrm{m} 3$ & 0.0000017 & 0.0000017 & $u$ & & \\
\hline SESPMNT & B168Y1 & BYERS LANDING & PERIMETER & AT & 10-Apr-03 & $\mathrm{Pu}-239 / 240$ & -0.000000187 & $\mathrm{pCi} / \mathrm{m} 3$ & 0.0000013 & 0.0000013 & u & & \\
\hline SESPMNT & B16R83 & BYERS LANDING & PERIMETER & AT & 07-Jul-03 & Pu-239/240 & 0.000000638 & $\mathrm{pCi} / \mathrm{m} 3$ & 0.000003 & 0.000003 & $u$ & & \\
\hline SESPMNT & B17661 & BYERS LANDING & PERIMETER & AT & 10-Oct-03 & $\mathrm{Pu}-239 / 240$ & -0.000000204 & $\mathrm{pCi} / \mathrm{m} 3$ & 0.0000021 & 0.0000021 & u & & \\
\hline SESPMNT & B17PV0 & BYERS LANDING & PERIMETER & AT & 05-Jan-04 & Pu-239/240 & -0.00000283 & $\mathrm{pCi} / \mathrm{m} 3$ & 0.000003 & \begin{tabular}{l|l}
3 & 0.0000031 \\
\end{tabular} & $u$ & & \\
\hline SESPMNT & B168X3 & DOGWOOD MET TOWER & PERIMETER & AT & 10-Apr-03 & $\mathrm{Pu}-239 / 240$ & -0.000000183 & $\mathrm{pCi} / \mathrm{m} 3$ & 0.0000014 & 0.0000014 & $u$ & & \\
\hline SESPMNT & B16R76 & DOGWOOD MET TOWER & PERIMETER & AT & 07-Jul-03 & Pu-239/240 & 0.00000169 & $\mathrm{pCi} / \mathrm{m} 3$ & 0.0000027 & 0.0000027 & u & & \\
\hline SESPMNT & B17653 & DOGWOOD MET TOWER & PERIMETER & AT & 10-Oct-03 & Pu-239/240 & -0.000000184 & $\mathrm{pCi} / \mathrm{m} 3$ & 0.0000017 & 0.0000017 & $\mathrm{u}$ & & \\
\hline SESPMNT & B17PT3 & DOGWOOD MET TOWER & PERIMETER & AT & 05-Jan-04 & Pu-239/240 & -0.000000796 & $\mathrm{pCi} / \mathrm{m} 3$ & 0.0000012 & 0.0000013 & $u$ & & \\
\hline SESPMNT & B16978 & EDWIN MARKHAM SCHOOL & COMMUNITY & AT & 10-Apr-03 & Pu-239/240 & -0.000000173 & $\mathrm{pCi} / \mathrm{m} 3$ & 0.0000013 & 0.0000013 & u & & \\
\hline SESPMNT & B16RK8 & EDWIN MARKHAM SCHOOL & COMMUNITY & AT & 02-Jul-03 & Pu-239/240 & 0.0000012 & $\mathrm{pCi} / \mathrm{m} 3$ & 0.0000034 & 0.0000035 & u & & \\
\hline SESPMNT & B176H8 & EDWIN MARKHAM SCHOOL & COMMUNITY & AT & $08-0 c t-03$ & $\mathrm{Pu}-239 / 240$ & 0.000000269 & $\mathrm{pCi} / \mathrm{m} 3$ & 0.00000089 & 0.00000097 & u & & \\
\hline SESPMNT & B17R45 & EDWIN MARKHAM SCHOOL & COMMUNITY & AT & 31-Dec-03 & Pu-239/240 & -0.000000207 & $\mathrm{pCi} / \mathrm{m} 3$ & 0.0000021 & 0.0000021 & $u$ & & \\
\hline SESPMNT & B16986 & HANFORD TOWNSITE & ONSITE & AT & 31-Mar-03 & Pu-239/240 & 0.000000131 & $\mathrm{pCi} / \mathrm{m} 3$ & 0.00000068 & 0.00000069 & u & & \\
\hline SESPMNT & B16RL5 & HANFORD TOWNSITE & ONSITE & AT & 08-Jul-03 & Pu-239/240 & 0.000000162 & $\mathrm{pCi} / \mathrm{m} 3$ & 0.00000096 & 0.00000097 & $\mathrm{u}$ & & \\
\hline SESPMNT & B176J6 & HANFORD TOWNSITE & ONSITE & AT & 01-Oct-03 & Pu-239/240 & $-6.37 \mathrm{E}-08$ & $\mathrm{pCi} / \mathrm{m} 3$ & 0.00000065 & $\begin{array}{l}5.00000066 \\
\end{array}$ & $u$ & & \\
\hline SESPMNT & B17R52 & HANFORD TOWNSITE & ONSITE & AT & 06-Jan-04 & Pu-239/240 & 0.000000281 & $\mathrm{pCi} / \mathrm{m} 3$ & 0.00000056 & 0.00000056 & $u$ & & \\
\hline SESPMNT & B16970 & LESLIE GROVES-RCHLND & COMMUNITY & AT & 08-Apr-03 & $\mathrm{Pu}-239 / 240$ & -0.000000178 & $\mathrm{pCi} / \mathrm{m} 3$ & 0.0000016 & 0.0000016 & u & & \\
\hline SESPMNT & B16RK1 & LESLIE GROVES-RCHLND & COMMUNITY & AT & 01-Jul-03 & Pu-239/240 & 0.00000141 & $\mathrm{pCi} / \mathrm{m} 3$ & 0.0000046 & 0.0000046 & u & & \\
\hline SESPMNT & B176HO & LESLIE GROVES-RCHLND & COMMUNITY & AT & $07-0 c t-03$ & Pu-239/240 & 0.000000316 & $\mathrm{pCi} / \mathrm{m} 3$ & 0.00000099 & 0.0000011 & $u$ & & \\
\hline SESPMNT & B17R38 & LESLIE GROVES-RCHLND & COMMUNITY & AT & 30-Dec-03 & Pu-239/240 & 0.000000651 & $\mathrm{pCi} / \mathrm{m} 3$ & 0.0000017 & 0.0000018 & $u$ & & \\
\hline SESPMNT & B168Y9 & PROSSER BARRICADE & PERIMETER & AT & 03-Apr-03 & Pu-239/240 & 0.000000535 & $\mathrm{pCi} / \mathrm{m} 3$ & 0.0000013 & \begin{tabular}{l|l}
3 & 0.0000013 \\
\end{tabular} & u & & \\
\hline SESPMNT & B16R90 & PROSSER BARRICADE & PERIMETER & AT & 11-Jul-03 & Pu-239/240 & 0.00000161 & $\mathrm{pCi} / \mathrm{m} 3$ & 0.0000014 & 0.0000014 & & & \\
\hline SESPMNT & B17669 & PROSSER BARRICADE & PERIMETER & AT & 03-Oct-03 & Pu-239/240 & 0.000000636 & $\mathrm{pCi} / \mathrm{m} 3$ & 0.00000086 & 0.00000089 & $u$ & & \\
\hline SESPMNT & B17PV7 & PROSSER BARRICADE & PERIMETER & AT & 09-Jan-04 & $\mathrm{Pu}-239 / 240$ & 0.000000837 & $\mathrm{pCi} / \mathrm{m} 3$ & 0.0000014 & 0.0000014 & u & & \\
\hline SESPMNT & B168W5 & RINGOLD MET TOWER & PERIMETER & AT & 10-Apr-03 & Pu-239/240 & -0.000000106 & $\mathrm{pCi} / \mathrm{m} 3$ & 0.00000071 & 0.00000071 & $u$ & & \\
\hline SESPMNT & B16R69 & RINGOLD MET TOWER & PERIMETER & AT & 07-Jul-03 & Pu-239/240 & 0.000000325 & $\mathrm{pCi} / \mathrm{m} 3$ & 0.0000009 & 0.00000094 & u & & \\
\hline SESPMNT & B17645 & RINGOLD MET TOWER & PERIMETER & AT & 10-Oct-03 & Pu-239/240 & 0.00000142 & $\mathrm{pCi} / \mathrm{m} 3$ & 0.0000015 & \begin{tabular}{|l|l}
5 & 0.0000016 \\
\end{tabular} & $u$ & & \\
\hline SESPMNT & B17PR6 & RINGOLD MET TOWER & PERIMETER & AT & 05-Jan-04 & $\mathrm{Pu}-239 / 240$ & 0.000000826 & $\mathrm{pCi} / \mathrm{m} 3$ & 0.0000012 & 0.0000012 & u & & \\
\hline SESPMNT & B16805 & TOPPENISH & DISTANT & AT & 02-Apr-03 & Pu-239/240 & -0.000000207 & $\mathrm{pCi} / \mathrm{m} 3$ & 0.0000039 & 0.0000039 & U & & \\
\hline SESPMNT & B16PB9 & TOPPENISH & DISTANT & AT & 09-Jul-03 & Pu-239/240 & 0.000000129 & $\mathrm{pC} / / \mathrm{m} 3$ & 0.00000029 & 0.0000003 & $\mathrm{u}$ & & \\
\hline
\end{tabular}


AIR COMPOSITES AND I-129, H-3

\begin{tabular}{|c|c|c|c|c|c|c|c|c|c|c|c|c|c|}
\hline |OWNER ID & SAMP NUM & SAMP SITE NAME & DIST CLASS & MEDIA & |SAMP DATE & $\left|\begin{array}{c}\text { CON SHORT } \\
\text { NAME }\end{array}\right|$ & VALUE RPTD & \begin{tabular}{|l|} 
ANAL \\
UNITS \\
RPTD
\end{tabular} & $\begin{array}{l}\text { COUNTING } \\
\text { ERROR }\end{array}$ & $\begin{array}{c}\text { TOTAL ANAL } \\
\text { ERROR }\end{array}$ & $\begin{array}{c}\text { LAB } \\
\text { QUALIFIER }\end{array}$ & SAMP COMMENT & RESULT COMMENT \\
\hline SESPMNT & B17589 & TOPPENISH & DISTANT & AT & 01-Oct-03 & Pu-239/240 & 0.000000432 & $2 \mathrm{pCi} / \mathrm{m} 3$ & 0.0000022 & 0.0000023 & u & & \\
\hline SESPMNT & B17NX2 & TOPPENISH & DISTANT & AT & 08-Jan-04 & Pu-239/240 & -0.000000175 & $5 \mathrm{pC} / \mathrm{m} 3$ & 0.0000023 & $\begin{array}{ll}0.0000023 \\
\end{array}$ & u & & \\
\hline SESPMNT & B16940 & TRI CITIES & COMMUNITY & AT & 10-Apr-03 & Pu-239/240 & 0.000000191 & $1 \mathrm{pCi} / \mathrm{m} 3$ & 0.00000085 & 0.00000086 & $u$ & & \\
\hline SESPMNT & B16RF3 & TRI CITIES & COMMUNITY & AT & 07-Jul-03 & $\mathrm{Pu}-239 / 240$ & 0.000000579 & $9 \mathrm{pC} / \mathrm{m} 3$ & 0.00000091 & 0.00000092 & $u$ & & \\
\hline SESPMNT & B176C0 & TRI CITIES & COMMUNITY & AT & 10-Oct-03 & Pu-239/240 & 0.000000532 & $2 \mathrm{pCi} / \mathrm{m} 3$ & 0.00000068 & 0.00000069 & u & & \\
\hline SESPMNT & B17R10 & TRI CITIES & COMMUNITY & AT & 05-Jan-04 & Pu-239/240 & 0.000000229 & $\mathrm{pC} / \mathrm{m} 3$ & 0.00000079 & 0.00000079 & u & & \\
\hline SESPMNT & B168V7 & W END OF FIR ROAD & PERIMETER & AT & 10-Apr-03 & Pu-239/240 & -0.000000183 & $3 \mathrm{pCi} / \mathrm{m} 3$ & 0.0000013 & $3 \quad 0.0000013$ & u & & \\
\hline SESPMNT & B16R62 & W END OF FIR ROAD & PERIMETER & AT & 07-Jul-03 & Pu-239/240 & 0.000000818 & $3 \mathrm{pC} / \mathrm{m} 3$ & 0.000002 & 0.0000021 & U & & \\
\hline SESPMNT & B17637 & W END OF FIR ROAD & PERIMETER & AT & $10-$ Oct-03 & Pu-239/240 & -0.000000182 & $2 \mathrm{pC} / \mathrm{m} 3$ & 0.0000017 & 0.0000017 & u & & \\
\hline SESPMNT & B17PP9 & W END OF FIR ROAD & PERIMETER & AT & 05-Jan-04 & Pu-239/240 & 0.000000633 & $3 \mathrm{pC} / \mathrm{m} 3$ & 0.0000017 & 0.0000017 & u & & \\
\hline SESPMNT & B16925 & WAHLUKE SLOPE & PERIMETER & AT & 09-Apr-03 & Pu-239/240 & 0.000000146 & $\mathrm{pCC} / \mathrm{m} 3$ & 0.00000069 & 0.0000007 & u & & \\
\hline SESPMNT & B16RD0 & WAHLUKE SLOPE & PERIMETER & AT & 01-Jul-03 & 3 Pu-239/240 & 0.000000336 & $\mathrm{pC} / \mathrm{m} 3$ & 0.0000008 & 0.00000081 & u & & \\
\hline SESPMNT & B17695 & WAHLUKE SLOPE & PERIMETER & AT & $08-O c t-03$ & 3 Pu-239/240 & $-5.23 \mathrm{E}-0 \varepsilon$ & $3 \mathrm{pCi} / \mathrm{m} 3$ & 0.00000056 & 0.00000057 & u & & \\
\hline SESPMNT & B17PY7 & WAHLUKE SLOPE & PERIMETER & AT & 31-Dec-03 & 3 Pu-239/240 & 0.000000878 & $3 \mathrm{pC} / \mathrm{m} 3$ & 0.000001 & \begin{tabular}{|l|}
0.000001 \\
\end{tabular} & u & & \\
\hline SESPMNT & B168V0 & WYE BARRICADE & ONSITE & AT & 31-Mar-03 & Pu-239/240 & -0.00000081 & $1 \mathrm{pC} / \mathrm{m} 3$ & 0.0000012 & 0.0000013 & $u$ & & \\
\hline SESPMNT & B16R54 & WYE BARRICADE & ONSITE & AT & 08-Jul-03 & Pu-239/240 & -0.000000899 & p $\mathrm{pC} / \mathrm{m} 3$ & 0.0000025 & 0.0000025 & u & & \\
\hline SESPMNT & B17630 & WYE BARRICADE & ONSITE & AT & $01-$ Oct-03 & Pu-239/240 & 0.00000108 & $3 \mathrm{pCi} / \mathrm{m} 3$ & 0.0000018 & 0.0000019 & u & & \\
\hline SESPMNT & B17PP1 & WYE BARRICADE & ONSITE & AT & 06-Jan-04 & Pu-239/240 & -0.000000176 & $5 \mathrm{pC} / \mathrm{m} 3$ & 0.0000029 & 0.0000029 & u & & \\
\hline SESPMNT & B16955 & YAKIMA & DISTANT & AT & 03-Apr-03 & Pu-239/240 & 0.00000125 & $5 \mathrm{pCi} / \mathrm{m} 3$ & 0.0000021 & \begin{tabular}{|l|} 
\\
0.0000021 \\
\end{tabular} & u & & \\
\hline SESPMNT & B16RH6 & YAKIMA & DISTANT & AT & 11-Jul-03 & Pu-239/240 & 0.0000015 & $5 \mathrm{pCi} / \mathrm{m} 3$ & 0.0000024 & \begin{tabular}{|l|l|} 
& 0.0000024 \\
\end{tabular} & u & & \\
\hline SESPMNT & B176D5 & YAKIMA & DISTANT & AT & 03-Oct-03 & $\mathrm{Pu}-239 / 240$ & 0.000000366 & $\mathrm{p} \mathrm{pCi/m3}$ & 0.0000011 & 0.0000012 & u & & \\
\hline SESPMNT & B17R23 & YAKIMA & DISTANT & AT & 09-Jan-04 & Pu-239/240 & 0.000000428 & $3 \mathrm{pCi} / \mathrm{m} 3$ & 0.0000012 & 0.0000013 & u & & \\
\hline SESPMNT & B16912 & YAKIMA BARRICADE & PERIMETER & AT & 02-Apr-03 & Pu-239/240 & 0.000000699 & $9 \mathrm{pC} / \mathrm{m} 3$ & 0.00000088 & 0.0000009 & u & & \\
\hline SESPMNT & B16RB5 & YAKIMA BARRICADE & PERIMETER & AT & 11-Jul-03 & Pu-239/240 & 0.000000515 & $5 \mathrm{pCi} / \mathrm{m} 3$ & 0.00000066 & 0.00000067 & u & & \\
\hline SESPMNT & B17682 & YAKIMA BARRICADE & PERIMETER & AT & 03-Oct-03 & $\mathrm{Pu}-239 / 240$ & 0.00000014 & $4 \mathrm{pC} / \mathrm{m} 3$ & 0.00000041 & 0.00000043 & u & & \\
\hline SESPMNT & B17PX2 & YAKIMA BARRICADE & PERIMETER & AT & 09-Jan-04 & Pu-239/240 & & $\mathrm{pCC} / \mathrm{m} 3$ & 0.00000062 & 0.00000062 & u & & \\
\hline SESPMNT & B168C4 & 100 AREAS & ONSITE & AT & 31-Mar-03 & $3 \mathrm{Sr}-90$ & 0.0000323 & $3 \mathrm{pC} / \mathrm{m} 3$ & 0.00002 & $\quad 0.000022$ & & & \\
\hline SESPMNT & B16PP5 & 100 AREAS & ONSITE & AT & 08-Jul-03 & $3 r-90$ & 0.0000112 & $2 \mathrm{pC} / \mathrm{m} 3$ & 0.000017 & 0.000025 & u & & \\
\hline SESPMNT & B175M4 & 100 AREAS & ONSITE & AT & 01-Oct-03 & $3 r-90$ & 0.0000298 & $3 \mathrm{pC} / \mathrm{m} 3$ & 0.000011 & 0.000013 & & & \\
\hline SESPMNT & B17P82 & 100 AREAS & ONSITE & AT & 06-Jan-04 & Sr-90 & 0.000102 & $2 \mathrm{pC} / \mathrm{m} 3$ & 0.000014 & 0.000021 & & & \\
\hline SESPMNT & B168F3 & 200 E AREA & ONSITE & AT & 08-Apr-03 & Sr-90 & 0.0000573 & $3 \mathrm{pC} / \mathrm{m} 3$ & 0.000033 & 0.000037 & & & \\
\hline SESPMNT & B16PT7 & 200 E AREA & ONSITE & AT & 30-Jun-03 & Sr-90 & -0.00000479 & $9 \mathrm{pCi} / \mathrm{m} 3$ & 0.00005 & 0.000064 & u & & \\
\hline SESPMNT & B175P3 & 200 E AREA & ONSITE & AT & 07-Oct-03 & $3 \mathrm{Sr}-90$ & 0.0000527 & $7 \mathrm{pC} / \mathrm{m} 3$ & 0.000032 & 0.000034 & u & & \\
\hline SESPMNT & B17PB4 & 200 E AREA & ONSITE & AT & 30-Dec-03 & $\mathrm{Sr}-90$ & 0.0000582 & $2 \mathrm{pC} / \mathrm{m} 3$ & 0.000029 & 0.000033 & & & \\
\hline SESPMNT & B168L8 & 200 W AREA & ONSITE & AT & 08-Apr-03 & Sr-90 & 0.000126 & $6 \mathrm{pC} / \mathrm{m} 3$ & 0.000084 & 0.000092 & $u$ & & \\
\hline SESPMNT & B16PY6 & 200 W AREA & ONSITE & AT & 30-Jun-03 & Sr-90 & -0.000045 & $5 \mathrm{pC} / \mathrm{m} 3$ & 0.00009 & 0.00011 & u & & \\
\hline SESPMNT & B175W8 & 200 W AREA & ONSITE & AT & 07-Oct-03 & $3 r-90$ & 0.0000214 & $4 \mathrm{pC} / \mathrm{m} 3$ & 0.00004 & 0.000043 & u & & \\
\hline SESPMNT & B17PH3 & 200 W AREA & ONSITE & AT & 30-Dec-03 & $\mathrm{Sr}-90$ & 0.0000832 & $2 \mathrm{pC} / \mathrm{m} 3$ & 0.000049 & 0.000055 & & & \\
\hline SESPMNT & B168J6 & 200 W SOUTH EAST & ONSITE & AT & 08-Apr-03 & $3 \mathrm{Sr}-90$ & 0.0000408 & $3 \mathrm{pC} / \mathrm{m} 3$ & 0.000025 & 0.000028 & $u$ & & \\
\hline SESPMNT & B16PW7 & 200 W SOUTH EAST & ONSITE & AT & 30-Jun-03 & Sr-90 & 0.00000417 & $\mathrm{pCC} / \mathrm{m} 3$ & 0.000032 & 0.000041 & u & & \\
\hline SESPMNT & B175T6 & 200 W SOUTH EAST & ONSITE & AT & 07-Oct-03 & $3 \mathrm{Sr}-90$ & 0.00000997 & $7 \mathrm{pC} / \mathrm{m} 3$ & 0.000013 & 0.000014 & u & & \\
\hline SESPMNT & B17PD4 & 200 W SOUTH EAST & ONSITE & AT & 30-Dec-03 & $\mathrm{Sr}-90$ & 0.0000284 & $4 \mathrm{pC} / \mathrm{m} 3$ & 0.000015 & 0.000017 & & & \\
\hline SESPMNT & B168M6 & 300 AREA & ONSITE & AT & 02-Apr-03 & $3 \mathrm{Sr}-90$ & 0.0000528 & $3 \mathrm{pC} / \mathrm{m} 3$ & 0.000025 & 0.000029 & & & \\
\hline SESPMNT & B16R03 & 300 AREA & ONSITE & AT & 10-Jul-03 & $3 \mathrm{Sr}-90$ & 0.000000623 & $3 \mathrm{pC} / \mathrm{m} 3$ & 0.000025 & 0.000033 & u & & \\
\hline SESPMNT & B175X6 & 300 AREA & ONSITE & AT & 30-Sep-03 & $3 \mathrm{Sr}-90$ & 0.0000191 & $1 \mathrm{pC} / \mathrm{m} 3$ & 0.000017 & 0.000018 & u & & \\
\hline SESPMNT & B17PJO & 300 AREA & ONSITE & AT & 08-Jan-04 & $4 \mathrm{Sr}-90$ & 0.0000343 & $3 \mathrm{pCi} / \mathrm{m} 3$ & 0.000014 & 0.000016 & & & \\
\hline SESPMNT & B167V2 & $300 \mathrm{NE}$ & ONSITE & AT & 02-Apr-03 & $3 \mathrm{Sr}-90$ & 0.0000252 & $2 \mathrm{pC} / \mathrm{m} 3$ & 0.000052 & 0.000057 & $u$ & & \\
\hline SESPMNT & B16P64 & $300 \mathrm{NE}$ & ONSITE & AT & 09-Jul-03 & $3 \mathrm{Sr}-90$ & -0.00000909 & $9 \mathrm{pC} / \mathrm{m} 3$ & 0.000041 & 0.000052 & u & & \\
\hline SESPMNT & B17546 & $300 \mathrm{NE}$ & ONSITE & AT & 30-Sep-03 & $3 \mathrm{Sr}-90$ & 0.0000262 & $2 \mathrm{pC} / \mathrm{m} 3$ & 0.000027 & 0.000029 & u & & \\
\hline SESPMNT & B17NP5 & $300 \mathrm{NE}$ & ONSITE & AT & 08-Jan-04 & $4 \mathrm{Sr}-90$ & 0.000059 & $9 \mathrm{pC} / \mathrm{m} 3$ & 0.00003 & 0.000034 & & & \\
\hline SESPMNT & B168P5 & 400 AREA & ONSITE & AT & 31-Mar-03 & $3 \mathrm{Sr}-90$ & 0.0000101 & $1 \mathrm{pC} / \mathrm{m} 3$ & 0.000013 & 0.000014 & $u$ & & \\
\hline SESPMNT & B16R25 & 400 AREA & ONSITE & AT & 08-Jul-03 & $3 \mathrm{Sr}-90$ & -0.0000043 & $3 \mathrm{pC} / \mathrm{m} 3$ & 0.000012 & 0.000017 & u & & \\
\hline SESPMNT & B17605 & 400 AREA & ONSITE & AT & 01-Oct-03 & $3 \mathrm{Sr}-90$ & 0.000021 & $1 \mathrm{pC} / \mathrm{m} 3$ & 0.0000084 & 0.0000096 & & & \\
\hline SESPMNT & B17PL2 & 400 AREA & ONSITE & AT & 05-Jan-04 & $4 \mathrm{Sr}-90$ & 0.0000169 & $9 \mathrm{pC} / \mathrm{m} 3$ & 0.0000076 & 0.0000087 & & & \\
\hline SESPMNT & B168H8 & B POND & ONSITE & AT & 08-Apr-03 & $3 \mathrm{Sr}-90$ & 0.000179 & $9 \mathrm{pC} / \mathrm{m} 3$ & 0.000072 & 0.000086 & & & \\
\hline SESPMNT & B16PW0 & B POND & ONSITE & AT & 30-Jun-03 & $3 \mathrm{Sr}-90$ & 0.0000178 & $3 \mathrm{pC} / \mathrm{m} 3$ & 0.000097 & 0.00013 & U & & \\
\hline SESPMNT & B175R8 & B POND & ONSITE & AT & 07-Oct-03 & $3 \mathrm{Sr}-90$ & 0.0000293 & $3 \mathrm{pC} / \mathrm{m} 3$ & 0.00005 & 0.000053 & U & & \\
\hline SESPMNT & B17PC7 & B POND & ONSITE & AT & 30-Dec-03 & 3 Sr-90 & 0.000162 & $2 \mathrm{pC} / \mathrm{m} 3$ & 0.000063 & 0.000072 & & & \\
\hline
\end{tabular}


AIR COMPOSITES AND I-129, H-3

\begin{tabular}{|c|c|c|c|c|c|c|c|c|c|c|c|c|c|}
\hline OWNER ID & SAMP NUM & SAMP SITE NAME & | DIST CLASS & MEDIA & SAMP DATE & $\begin{array}{c}\text { CON SHORT } \\
\text { NAME }\end{array}$ & VALUE RPTD & \begin{tabular}{|l|} 
ANAL \\
UNITS \\
RPTD
\end{tabular} & $\begin{array}{l}\text { COUNTING } \\
\text { ERROR }\end{array}$ & $\begin{array}{c}\text { TOTAL ANAL } \\
\text { ERROR }\end{array}$ & $\begin{array}{c}\text { LAB } \\
\text { QUALIFIER }\end{array}$ & SAMP COMMENT & | RESULT COMMENT \\
\hline SESPMNT & B16962 & BASIN CITY SCHOOL & COMMUNITY & AT & 09-Apr-03 & Sr-90 & 0.0000974 & $\mathrm{pCi} / \mathrm{m} 3$ & 0.000073 & 0.000079 & u & & \\
\hline SESPMNT & B16RJ4 & BASIN CITY SCHOOL & COMMUNITY & AT & 02-Jul-03 & Sr-90 & 0.00000312 & $\mathrm{pCi} / \mathrm{m} 3$ & 0.000093 & 0.00012 & u & & \\
\hline SESPMNT & B176F2 & BASIN CITY SCHOOL & COMMUNITY & AT & 08-Oct-03 & Sr-90 & 0.0000552 & $\mathrm{pCi} / \mathrm{m} 3$ & 0.000042 & 0.000047 & $u$ & & \\
\hline SESPMNT & B17R31 & BASIN CITY SCHOOL & COMMUNITY & AT & 31-Dec-03 & Sr-90 & 0.000107 & $\mathrm{pCi} / \mathrm{m} 3$ & 0.00005 & 0.000058 & & & \\
\hline SESPMNT & B168Y1 & BYERS LANDING & PERIMETER & AT & 10-Apr-03 & Sr-90 & 0.0000668 & $\mathrm{pCi} / \mathrm{m} 3$ & 0.000058 & 0.000064 & u & & \\
\hline SESPMNT & B16R83 & BYERS LANDING & PERIMETER & AT & 07-Jul-03 & Sr-90 & -0.0000579 & $\mathrm{pCi} / \mathrm{m} 3$ & 0.000096 & 0.00012 & u & & \\
\hline SESPMNT & B17661 & BYERS LANDING & PERIMETER & AT & $10-0 c t-03$ & Sr-90 & 0.0000445 & $\mathrm{pCi} / \mathrm{m} 3$ & 0.000051 & 0.000054 & u & & \\
\hline SESPMNT & B17PV0 & BYERS LANDING & PERIMETER & AT & 05-Jan-04 & Sr-90 & 0.000108 & $\mathrm{pCi} / \mathrm{m} 3$ & 0.000056 & 0.000064 & & & \\
\hline SESPMNT & B168X3 & DOGWOOD MET TOWER & PERIMETER & AT & 10-Apr-03 & Sr-90 & 0.0000803 & $\mathrm{pCi} / \mathrm{m} 3$ & 0.00006 & 0.000066 & u & & \\
\hline SESPMNT & B16R76 & DOGWOOD MET TOWER & PERIMETER & AT & 07-Jul-03 & Sr-90 & -0.0000108 & $\mathrm{pCi} / \mathrm{m} 3$ & 0.000093 & 0.00012 & u & & \\
\hline SESPMNT & B17653 & DOGWOOD MET TOWER & PERIMETER & AT & $10-0 c t-03$ & Sr-90 & 0.0000534 & $\mathrm{pCi} / \mathrm{m} 3$ & 0.000045 & 0.000049 & u & & \\
\hline \begin{tabular}{|l} 
SESPMNT \\
\end{tabular} & B17PT3 & DOGWOOD MET TOWER & PERIMETER & AT & 05-Jan-04 & Sr-90 & 0.0000955 & $\mathrm{pCi} / \mathrm{m} 3$ & 0.000057 & 0.000062 & u & & \\
\hline SESPMNT & B16978 & EDWIN MARKHAM SCHOOL & COMMUNITY & AT & 10-Apr-03 & Sr-90 & 0.0000696 & $\mathrm{pCi} / \mathrm{m} 3$ & 0.000071 & 0.000074 & u & & \\
\hline SESPMNT & B16RK8 & EDWIN MARKHAM SCHOOL & COMMUNITY & AT & 02-Jul-03 & Sr-90 & 0.0000146 & $\mathrm{pCi} / \mathrm{m} 3$ & 0.0001 & 0.00013 & u & & \\
\hline \begin{tabular}{|l|} 
SESPMNT \\
\end{tabular} & B176H8 & EDWIN MARKHAM SCHOOL & COMMUNITY & AT & 08-Oct-03 & Sr-90 & 0.0000097 & $\mathrm{pCi} / \mathrm{m} 3$ & 0.000045 & 0.000052 & $\mathrm{U}$ & & \\
\hline $\begin{array}{l}\text { SESPMNT } \\
\end{array}$ & B17R45 & EDWIN MARKHAM SCHOOL & COMMUNITY & AT & 31-Dec-03 & Sr-90 & 0.000156 & $\mathrm{pCi} / \mathrm{m} 3$ & 0.000053 & 0.000062 & & & \\
\hline SESPMNT & B16986 & HANFORD TOWNSITE & ONSITE & AT & 31-Mar-03 & Sr-90 & 0.0000154 & $\mathrm{pCi} / \mathrm{m} 3$ & 0.000023 & 0.000025 & $u$ & & \\
\hline SESPMNT & B16RL5 & HANFORD TOWNSITE & ONSITE & AT & $08-\mathrm{Jul}-03$ & Sr-90 & 0.000000614 & $\mathrm{pCi} / \mathrm{m} 3$ & 0.000025 & 0.000035 & u & & \\
\hline SESPMNT & B176J6 & HANFORD TOWNSITE & ONSITE & AT & $01-$ Oct-03 & Sr-90 & 0.0000228 & $\mathrm{pCi} / \mathrm{m} 3$ & 0.000015 & 0.000016 & u & & \\
\hline SESPMNT & B17R52 & HANFORD TOWNSITE & ONSITE & AT & 06-Jan-04 & Sr-90 & 0.0000301 & $\mathrm{pCi} / \mathrm{m} 3$ & 0.000015 & 0.000017 & & & \\
\hline SESPMNT & B16970 & LESLIE GROVES-RCHLND & COMMUNITY & AT & 08-Apr-03 & Sr-90 & 0.0000764 & $\mathrm{pCi} / \mathrm{m} 3$ & 0.000072 & 0.000076 & $u$ & & \\
\hline SESPMNT & B16RK1 & LESLIE GROVES-RCHLND & COMMUNITY & AT & 01-Jul-03 & Sr-90 & 0.0000327 & $\mathrm{pCi} / \mathrm{m} 3$ & 0.000097 & 0.00013 & u & & \\
\hline SESPMNT & B176HO & LESLIE GROVES-RCHLND & COMMUNITY & AT & $07-$ Oct- 03 & Sr-90 & 0.0000377 & $\mathrm{pCi} / \mathrm{m} 3$ & 0.000053 & 0.000055 & $u$ & & \\
\hline SESPMNT & B17R38 & LESLIE GROVES-RCHLND & COMMUNITY & AT & 30-Dec-03 & Sr-90 & 0.000128 & $\mathrm{pCi} / \mathrm{m} 3$ & 0.000048 & 0.000056 & & & \\
\hline SESPMNT & B168Y9 & PROSSER BARRICADE & PERIMETER & AT & 03-Apr-03 & Sr-90 & 0.0000622 & $\mathrm{pCi} / \mathrm{m} 3$ & 0.000037 & 0.000042 & & & \\
\hline SESPMNT & B16R90 & PROSSER BARRICADE & PERIMETER & AT & 11-Jul-03 & Sr-90 & -0.000000644 & $\mathrm{pCi} / \mathrm{m} 3$ & 0.000043 & 0.000053 & u & & \\
\hline SESPMNT & B17669 & PROSSER BARRICADE & PERIMETER & AT & $03-0 c t-03$ & Sr-90 & 0.0000241 & $\mathrm{pCi} / \mathrm{m} 3$ & 0.000029 & 0.000031 & $u$ & & \\
\hline SESPMNT & B17PV7 & PROSSER BARRICADE & PERIMETER & AT & 09-Jan-04 & Sr-90 & 0.0000536 & $\mathrm{pCi} / \mathrm{m} 3$ & 0.000022 & 0.000025 & & & \\
\hline SESPMNT & B168W5 & RINGOLD MET TOWER & PERIMETER & AT & 10-Apr-03 & Sr-90 & 0.0000285 & $\mathrm{pC} / \mathrm{m} 3$ & 0.000047 & 0.000051 & $u$ & & \\
\hline SESPMNT & B16R69 & RINGOLD MET TOWER & PERIMETER & AT & 07-Jul-03 & Sr-90 & -0.0000794 & $\mathrm{pCi} / \mathrm{m} 3$ & 0.000057 & 0.000075 & u & & \\
\hline SESPMNT & B17645 & RINGOLD MET TOWER & PERIMETER & AT & $10-$ Oct-03 & Sr-90 & 0.0000274 & $\mathrm{pC} / \mathrm{m} 3$ & 0.000024 & 0.000026 & u & & \\
\hline SESPMNT & B17PR6 & RINGOLD MET TOWER & PERIMETER & AT & 05-Jan-04 & Sr-90 & 0.0000663 & $\mathrm{pCi} / \mathrm{m} 3$ & 0.000029 & 0.000033 & & & \\
\hline SESPMNT & B16805 & TOPPENISH & DISTANT & AT & 02-Apr-03 & Sr-90 & 0.000101 & $\mathrm{pCi} / \mathrm{m} 3$ & 0.000064 & 0.000074 & $u$ & & \\
\hline SESPMNT & B16PB9 & TOPPENISH & DISTANT & AT & 09-Jul-03 & Sr-90 & -0.000000387 & $\mathrm{pCi} / \mathrm{m} 3$ & 0.0000078 & 0.00001 & u & & \\
\hline SESPMNT & B17589 & TOPPENISH & DISTANT & AT & $01-$ Oct-03 & Sr-90 & 0.000021 & $\mathrm{pC} / \mathrm{m} 3$ & 0.000042 & 0.000044 & u & & \\
\hline SESPMNT & B17NX2 & TOPPENISH & DISTANT & AT & 08-Jan-04 & Sr-90 & 0.0000613 & $\mathrm{pCi} / \mathrm{m} 3$ & 0.000037 & 0.000044 & u & & \\
\hline SESPMNT & B16940 & TRI CITIES & COMMUNITY & AT & 10-Apr-03 & Sr-90 & 0.0000115 & $\mathrm{pCi} / \mathrm{m} 3$ & 0.000023 & 0.000024 & u & & \\
\hline SESPMNT & B16RF3 & TRI CITIES & COMMUNITY & AT & 07-Jul-03 & Sr-90 & -0.0000394 & $\mathrm{pCi} / \mathrm{m} 3$ & 0.000029 & 0.000038 & u & & \\
\hline $\begin{array}{l}\text { SESPMNT } \\
\end{array}$ & B176C0 & TRI CITIES & COMMUNITY & AT & $10-$ Oct-03 & Sr-90 & 0.0000166 & $\mathrm{pCi} / \mathrm{m} 3$ & 0.000013 & 0.000014 & u & & \\
\hline SESPMNT & B17R10 & TRI CITIES & COMMUNITY & AT & 05-Jan-04 & Sr-90 & 0.0000292 & $\mathrm{pCi} / \mathrm{m} 3$ & 0.000014 & 0.000016 & & & \\
\hline SESPMNT & B168V7 & W END OF FIR ROAD & PERIMETER & AT & 10-Apr-03 & Sr-90 & 0.0000861 & $\mathrm{pC} / \mathrm{m} 3$ & 0.000073 & 0.000077 & $u$ & & \\
\hline SESPMNT & B16R62 & W END OF FIR ROAD & PERIMETER & AT & 07-Jul-03 & Sr-90 & 0.000082 & $\mathrm{pCi} / \mathrm{m} 3$ & 0.000096 & 0.00013 & u & & \\
\hline $\begin{array}{l}\text { SESPMNT } \\
\end{array}$ & B17637 & W END OF FIR ROAD & PERIMETER & AT & $10-$ Oct-03 & Sr-90 & 0.0000313 & $\mathrm{pC} / \mathrm{m} 3$ & 0.00004 & 0.000043 & u & & \\
\hline SESPMNT & B17PP9 & W END OF FIR ROAD & PERIMETER & AT & 05-Jan-04 & Sr-90 & 0.0000969 & $\mathrm{pCi} / \mathrm{m} 3$ & 0.000057 & 0.000063 & u & & \\
\hline SESPMNT & B16925 & WAHLUKE SLOPE & PERIMETER & AT & 09-Apr-03 & Sr-90 & 0.000013 & $\mathrm{pCC} / \mathrm{m} 3$ & 0.000021 & 0.000024 & u & & \\
\hline SESPMNT & B16RD0 & WAHLUKE SLOPE & PERIMETER & AT & 01-Jul-03 & Sr-90 & -0.0000354 & $\mathrm{pC} / \mathrm{m} 3$ & 0.000026 & 0.000037 & $u$ & & \\
\hline \begin{tabular}{|l} 
SESPMNT \\
\end{tabular} & B17695 & WAHLUKE SLOPE & PERIMETER & AT & $08-$ Oct-03 & Sr-90 & 0.00000777 & $\mathrm{pC} / \mathrm{m} 3$ & 0.000011 & 0.000012 & u & & \\
\hline SESPMNT & B17PY7 & WAHLUKE SLOPE & PERIMETER & AT & 31-Dec-03 & Sr-90 & 0.0000374 & $\mathrm{pCi} / \mathrm{m} 3$ & 0.000016 & 0.000019 & & & \\
\hline SESPMNT & B168V0 & WYE BARRICADE & ONSITE & AT & 31-Mar-03 & Sr-90 & 0.0000689 & $\mathrm{pCi} / \mathrm{m} 3$ & 0.000069 & 0.000077 & $u$ & & \\
\hline SESPMNT & B16R54 & WYE BARRICADE & ONSITE & AT & 08-Jul-03 & Sr-90 & 0.000016 & $\mathrm{pC} / \mathrm{m} 3$ & 0.000079 & 0.0001 & u & & \\
\hline \begin{tabular}{|l|} 
SESPMNT \\
\end{tabular} & B17630 & WYE BARRICADE & ONSITE & AT & $01-$ Oct-03 & Sr-90 & 0.0000697 & $\mathrm{pC} / \mathrm{m} 3$ & 0.000047 & 0.000052 & u & & \\
\hline SESPMNT & B17PP1 & WYE BARRICADE & ONSITE & AT & 06-Jan-04 & Sr-90 & 0.0000899 & $\mathrm{pCi} / \mathrm{m} 3$ & 0.000042 & 0.000048 & & & \\
\hline SESPMNT & B16955 & YAKIMA & DISTANT & AT & 03-Apr-03 & Sr-90 & 0.0000851 & $\mathrm{pCi} / \mathrm{m} 3$ & 0.000076 & 0.000082 & $\mathrm{U}$ & & \\
\hline SESPMNT & B16RH6 & YAKIMA & DISTANT & AT & 11-Jul-03 & Sr-90 & -0.0000441 & $\mathrm{pC} / \mathrm{m} 3$ & 0.000077 & 0.000099 & u & & \\
\hline SESPMNT & B176D5 & YAKIMA & DISTANT & AT & 03-Oct-03 & Sr-90 & -0.0000196 & $\mathrm{pC} / \mathrm{m} 3$ & 0.000044 & 0.000049 & u & & \\
\hline SESPMNT & B17R23 & YAKIMA & DISTANT & AT & 09-Jan-04 & Sr-90 & 0.000 & $\mathrm{pCi} / \mathrm{m} 3$ & 0.00004 & 0.000047 & & & \\
\hline SESPMNT & B16912 & YAKIMA BARRICADE & PERIMETER & AT & 02-Apr-03 & Sr-90 & 0.0000254 & $\mathrm{pC} / \mathrm{m} 3$ & 0.000027 & 0.000029 & $\mathrm{U}$ & & \\
\hline SESPMNT & B16RB5 & YAKIMA BARRICADE & PERIMETER & AT & 11-Jul-03 & Sr-90 & -0.0000141 & $\mathrm{pCi} / \mathrm{m} 3$ & 0.000025 & 0.000034 & u & & \\
\hline
\end{tabular}


AIR COMPOSITES AND I-129, H-3

\begin{tabular}{|c|c|c|c|c|c|c|c|c|c|c|c|c|c|}
\hline OWNER ID & SAMP NUM & SAMP SITE NAME & DIST CLASS & $\mid$ MEDIA & SAMP DATE & $\left|\begin{array}{c}\text { CON SHORT } \\
\text { NAME }\end{array}\right|$ & VALUE RPTD & $\mid \begin{array}{l}\text { ANAL } \\
\text { UNITS } \\
\text { RPTD }\end{array}$ & $\begin{array}{l}\text { COUNTING } \\
\text { ERROR }\end{array}$ & $\left|\begin{array}{c}\text { TOTAL ANAL } \\
\text { ERROR }\end{array}\right|$ & $\begin{array}{c}\text { LAB } \\
\text { QUALIFIER }\end{array}$ & SAMP COMMENT & RESULT COMMENT \\
\hline SESPMNT & B17682 & YAKIMA BARRICADE & PERIMETER & AT & 03-Oct-03 & Sr-90 & & & & & & & LOST AT LAB. \\
\hline SESPMNT & B17PX2 & YAKIMA BARRICADE & PERIMETER & AT & 09-Jan-04 S & Sr-90 & 0.0000356 & $\mathrm{pCi} / \mathrm{m} 3$ & 0.000013 & 0.000016 & & & \\
\hline SESPMNT & B16BV5 & $100 \mathrm{~K}$ AREA & ONSITE & AT & 21-Jan-03 & TRITIUM & 4.29 & $\mathrm{pCi} / \mathrm{m} 3$ & 0.66 & 0.9 & & & \\
\hline SESPMNT & B16FP9 & $100 \mathrm{~K}$ AREA & ONSITE & AT & $18-F e b-03$ & TRITIUM & 1.09 & $\mathrm{pCi} / \mathrm{m} 3$ & 0.5 & 0.6 & & & \\
\hline SESPMNT & B16KK2 & $100 \mathrm{~K}$ AREA & ONSITE & AT & 18-Mar-03 & TRITIUM & 8.17 & $\mathrm{pCi} / \mathrm{m} 3$ & 0.95 & 1.5 & & & \\
\hline SESPMNT & B16T63 & $100 \mathrm{~K}$ AREA & ONSITE & AT & 15-Apr-03] & TRITIUM & 3.63 & $\mathrm{pCi} / \mathrm{m} 3$ & 0.74 & 0.93 & & & \\
\hline SESPMNT & B170N4 & $100 \mathrm{~K}$ AREA & ONSITE & AT & 12-May-03 & TRITIUM & 3.29 & $\mathrm{pCi} / \mathrm{m} 3$ & 0.65 & 0.83 & & & \\
\hline SESPMNT & B171X1 & $100 \mathrm{~K}$ AREA & ONSITE & AT & 11-Jun-03 & TRITIUM & 3.78 & $\mathrm{pCi} / \mathrm{m} 3$ & 0.71 & 0.93 & & & \\
\hline SESPMNT & B176R1 & $100 \mathrm{~K}$ AREA & ONSITE & AT & 08-Jul-03 & TRITIUM & 2.31 & $\mathrm{pCi} / \mathrm{m} 3$ & 0.47 & 0.56 & & & \\
\hline SESPMNT & B179V2 & $100 \mathrm{~K}$ AREA & ONSITE & AT & 04-Aug-03 & TRITIUM & 4.88 & $\mathrm{pCi} / \mathrm{m} 3$ & 0.8 & 1.1 & & & \\
\hline SESPMNT & B17DN5 & $100 \mathrm{~K}$ AREA & ONSITE & AT & 02-Sep-03 & TRITIUM & 5.43 & $\mathrm{pCi} / \mathrm{m} 3$ & 0.89 & 1.2 & & & \\
\hline SESPMNT & B17LP5 & $100 \mathrm{~K}$ AREA & ONSITE & AT & 01-Oct-03 & TRITIUM & 2.92 & $\mathrm{pC} / \mathrm{m} 3$ & 0.52 & 0.6 & & & \\
\hline SESPMNT & B17TN3 & $100 \mathrm{~K}$ AREA & ONSITE & AT & $28-O c t-03$ & TRITIUM & 8.57 & $\mathrm{pCi} / \mathrm{m} 3$ & 0.98 & 1.6 & & & \\
\hline SESPMNT & B181KO & $100 \mathrm{~K}$ AREA & ONSITE & AT & 24-Nov-03 & TRITIUM & 3.73 & $\mathrm{pCi} / \mathrm{m} 3$ & 0.53 & 0.76 & & & \\
\hline SESPMNT & B186K7 & $100 \mathrm{~K}$ AREA & ONSITE & AT & 22-Dec-03 & TRITIUM & 3.81 & $\mathrm{pCi} / \mathrm{m} 3$ & 0.62 & 0.86 & & & \\
\hline SESPMNT & B16BV6 & $100 \mathrm{~N}-1325$ CRIB & ONSITE & AT & 21-Jan-03 & TRITIUM & 5.32 & $\mathrm{pCi} / \mathrm{m} 3$ & 0.75 & 1.1 & & & \\
\hline SESPMNT & B16FR0 & $100 \mathrm{~N}-1325 \mathrm{CRIB}$ & ONSITE & AT & 18-Feb-03 & TRITIUM & 7.39 & $\mathrm{pCi} / \mathrm{m} 3$ & 0.93 & 1.4 & & & \\
\hline SESPMNT & B16KK3 & $100 \mathrm{~N}-1325$ CRIB & ONSITE & AT & 18-Mar-03 & TRITIUM & 7.63 & $\mathrm{pCi} / \mathrm{m} 3$ & 0.91 & 1.4 & & & \\
\hline SESPMNT & B16T64 & $100 \mathrm{~N}-1325 \mathrm{CRIB}$ & ONSITE & AT & 15-Apr-03 & TRITIUM & 8.94 & $\mathrm{pCi} / \mathrm{m} 3$ & 1 & 1.6 & & & \\
\hline SESPMNT & B170N5 & $100 \mathrm{~N}-1325$ CRIB & ONSITE & AT & 12-May-03 & TRITIUM & 4.18 & $\mathrm{pCi} / \mathrm{m} 3$ & 0.75 & 0.99 & & & \\
\hline SESPMNT & B171X2 & $100 \mathrm{~N}-1325$ CRIB & ONSITE & AT & 11-Jun-03 & TRITIUM & 4.42 & $\mathrm{pCi} / \mathrm{m} 3$ & 0.75 & 1 & & & \\
\hline SESPMNT & B176R2 & $100 \mathrm{~N}-1325$ CRIB & ONSITE & AT & 08-Jul-03 & TRITIUM & 5.61 & $\mathrm{pCi} / \mathrm{m} 3$ & 0.57 & 0.76 & & & \\
\hline SESPMNT & B179V3 & $100 \mathrm{~N}-1325 \mathrm{CRIB}$ & ONSITE & AT & 04-Aug-03 & TRITIUM & 3.52 & $\mathrm{pCi} / \mathrm{m} 3$ & 0.77 & 0.97 & & & \\
\hline SESPMNT & B17DN6 & $100 \mathrm{~N}-1325$ CRIB & ONSITE & AT & 02-Sep-03 & TRITIUM & 11.4 & $\mathrm{pCi} / \mathrm{m} 3$ & 1.2 & 2 & & & \\
\hline SESPMNT & B17LP6 & $100 \mathrm{~N}-1325$ CRIB & ONSITE & AT & 01-Oct-03 & TRITIUM & 3.46 & $\mathrm{pCi} / \mathrm{m} 3$ & 0.58 & 0.68 & & & \\
\hline SESPMNT & B17TN4 & $100 \mathrm{~N}-1325 \mathrm{CRIB}$ & ONSITE & AT & 28-Oct-03 & TRITIUM & 15.1 & $\mathrm{pCi} / \mathrm{m} 3$ & 1.3 & 2.5 & & & \\
\hline SESPMNT & B181K1 & $100 \mathrm{~N}-1325 \mathrm{CRIB}$ & ONSITE & AT & 24-Nov-03 & TRITIUM & 3.05 & $\mathrm{pCi} / \mathrm{m} 3$ & 0.46 & 0.65 & & & \\
\hline SESPMNT & B186K8 & $100 \mathrm{~N}-1325$ CRIB & ONSITE & AT & 22-Dec-03 & TRITIUM & 3.48 & $\mathrm{pCi} / \mathrm{m} 3$ & 0.57 & 0.79 & & & \\
\hline SESPMNT & B16BK3 & 200 ESE & ONSITE & AT & 14-Jan-03 & TRITIUM & & $\mathrm{pCi} / \mathrm{m} 3$ & 0.57 & 0.68 & & & \\
\hline SESPMNT & B16DJ3 & $200 \mathrm{ESE}$ & ONSITE & AT & 11-Feb-03 & TRITIUM & 4.95 & $\mathrm{pCi} / \mathrm{m} 3$ & 0.79 & 1.1 & & & \\
\hline SESPMNT & B16K67 & 200 ESE & ONSITE & AT & 10-Mar-03 & TRITIUM & 4.71 & $\mathrm{pCi} / \mathrm{m} 3$ & 0.68 & 0.96 & & & \\
\hline SESPMNT & B16RR2 & 200 ESE & ONSITE & AT & 08-Apr-03 & TRITIUM & 1.78 & $\mathrm{pCi} / \mathrm{m} 3$ & 0.5 & 0.59 & & & \\
\hline SESPMNT & B16WJ2 & 200 ESE & ONSITE & AT & $06-$ May-03 & TRITIUM & 7.45 & $\mathrm{pCi} / \mathrm{m} 3$ & 0.88 & 1.4 & & & \\
\hline SESPMNT & B171J6 & $200 \mathrm{ESE}$ & ONSITE & AT & 02-Jun-03 & TRITIUM & 7.32 & $\mathrm{pCi} / \mathrm{m} 3$ & 0.59 & 0.8 & & & \\
\hline SESPMNT & B174J5 & 200 ESE & ONSITE & AT & 30-Jun-03 & TRITIUM & 5.73 & $\mathrm{pCi} / \mathrm{m} 3$ & 0.91 & 1.3 & & & \\
\hline SESPMNT & B17962 & 200 ESE & ONSITE & AT & 29-Jul-03 & TRITIUM & 4.58 & $\mathrm{pCi} / \mathrm{m} 3$ & 0.73 & 0.98 & & & \\
\hline SESPMNT & B17C79 & 200 ESE & ONSITE & AT & 25-Aug-03 & TRITIUM & 3.13 & $\mathrm{pCi} / \mathrm{m} 3$ & 0.82 & 1 & & & \\
\hline SESPMNT & B17JR9 & $200 \mathrm{ESE}$ & ONSITE & AT & 22-Sep-03 & TRITIUM & 3.84 & $\mathrm{pCi} / \mathrm{m} 3$ & 0.8 & 1.1 & & & \\
\hline SESPMNT & B17T57 & 200 ESE & ONSITE & AT & $21-\mathrm{Oct}-03$ & TRITIUM & 2.56 & $\mathrm{pCi} / \mathrm{m} 3$ & 0.68 & 0.9 & & & \\
\hline SESPMNT & B18116 & $200 \mathrm{ESE}$ & ONSITE & AT & 18-Nov-03 & TRITIUM & 15.7 & $\mathrm{pCi} / \mathrm{m} 3$ & 1.1 & 2.4 & & & \\
\hline SESPMNT & B184V3 & 200 ESE & ONSITE & AT & 17-Dec-037 & TRITIUM & 4.32 & $\mathrm{pCi} / \mathrm{m} 3$ & 0.65 & 0.96 & & & \\
\hline SESPMNT & B18BKO & 200 ESE & ONSITE & AT & 12-Jan-04 & TRITIUM & 8.1 & $\mathrm{pCi} / \mathrm{m} 3$ & 0.76 & 1.4 & & & \\
\hline SESPMNT & B16BK4 & 200 TEL. EXCHANGE & ONSITE & AT & 14-Jan-03 & TRITIUM & 2.98 & $\mathrm{pCi} / \mathrm{m} 3$ & 0.7 & 0.85 & & & \\
\hline SESPMNT & B16DJ4 & 200 TEL. EXCHANGE & ONSITE & AT & 11-Feb-03 & TRITIUM & 1.4 & $\mathrm{pCi} / \mathrm{m} 3$ & 0.49 & 0.58 & & & \\
\hline SESPMNT & B16K68 & 200 TEL. EXCHANGE & ONSITE & AT & 10-Mar-03 & TRITIUM & 4.26 & $\mathrm{pCi} / \mathrm{m} 3$ & 0.71 & 0.95 & & & \\
\hline SESPMNT & B16RR3 & 200 TEL. EXCHANGE & ONSITE & AT & 08-Apr-03 & TRITIUM & 11.8 & $\mathrm{pCi} / \mathrm{m} 3$ & 1 & 1.9 & & & \\
\hline SESPMNT & B16WJ3 & 200 TEL. EXCHANGE & ONSITE & AT & 06-May-03 & TRITIUM & 4.87 & $\mathrm{pCi} / \mathrm{m} 3$ & 0.8 & 1.1 & & & \\
\hline SESPMNT & B171J7 & 200 TEL. EXCHANGE & ONSITE & AT & 02-Jun-037 & TRITIUM & 3.92 & $\mathrm{pCi} / \mathrm{m} 3$ & 0.6 & 0.71 & & & \\
\hline SESPMNT & B174J6 & 200 TEL. EXCHANGE & ONSITE & AT & 30-Jun-03 & TRITIUM & 2.8 & $\mathrm{pC} / \mathrm{m} 3$ & 0.64 & 0.85 & & & \\
\hline SESPMNT & B17963 & 200 TEL. EXCHANGE & ONSITE & AT & 29-Jul-03 & TRITIUM & & $\mathrm{pCi} / \mathrm{m} 3$ & 0.94 & 1.4 & & & \\
\hline SESPMNT & B17C80 & 200 TEL. EXCHANGE & ONSITE & AT & 25-Aug-03 & TRITIUM & 4.28 & $\mathrm{pCi} / \mathrm{m} 3$ & 0.87 & 1.1 & & & \\
\hline SESPMNT & B17JT0 & 200 TEL. EXCHANGE & ONSITE & AT & $22-\mathrm{Sep}-037$ & TRITIUM & 6.75 & $\mathrm{pCi} / \mathrm{m} 3$ & 0.9 & 1.4 & & & \\
\hline SESPMNT & B17T58 & 200 TEL. EXCHANGE & ONSITE & AT & 21-Oct-03 & TRITIUM & 1.59 & $\mathrm{pC} / \mathrm{m} 3$ & 0.6 & 0.81 & & & \\
\hline SESPMNT & B18117 & 200 TEL. EXCHANGE & ONSITE & AT & 18-Nov-03 & TRITIUM & 13.7 & $\mathrm{pC} / \mathrm{m} 3$ & 1.1 & 2.2 & & & \\
\hline SESPMNT & B184V4 & 200 TEL. EXCHANGE & ONSITE & AT & 17-Dec-03 & TRITIUM & 5.05 & $\mathrm{pC} / \mathrm{m} 3$ & 0.69 & 1 & & & \\
\hline SESPMNT & B18BK1 & 200 TEL. EXCHANGE & ONSITE & AT & 12-Jan-04 & TRITIUM & 4.04 & $\mathrm{pCi} / \mathrm{m} 3$ & 0.53 & 0.83 & & & \\
\hline SESPMNT & B16BV9 & $300 \mathrm{NE}$ & ONSITE & AT & 22-Jan-037 & TRITIUM & 7.96 & $\mathrm{pC} / \mathrm{m} 3$ & 0.91 & 1.4 & & & \\
\hline
\end{tabular}


AIR COMPOSITES AND I-129, H-3

\begin{tabular}{|c|c|c|c|c|c|c|c|c|c|c|c|c|c|}
\hline OWNER ID & SAMP NUM & SAMP SITE NAME & DIST CLASS & MEDIA & |SAMP DATE & $\begin{array}{c}\text { CON SHORT } \\
\text { NAME }\end{array}$ & VALUE RPTD & \begin{tabular}{|l|} 
ANAL \\
UNITS \\
RPTD
\end{tabular} & $\begin{array}{l}\text { COUNTING } \\
\text { ERROR }\end{array}$ & $\left|\begin{array}{c}\text { TOTAL ANAL } \\
\text { ERROR }\end{array}\right|$ & $\mid \begin{array}{c}\text { LAB } \\
\text { QUALIFIER }\end{array}$ & SAMP COMMENT & RESULT COMMENT \\
\hline SESPMNT & B16FR3 & $300 \mathrm{NE}$ & ONSITE & AT & 19-Feb-03 & TRITIUM & & & & & & NO SAMPLE. LOW FLOW. & \\
\hline SESPMNT & B16KK6 & $300 \mathrm{NE}$ & ONSITE & AT & 20-Mar-03 & B TRITIUM & & $3 \mathrm{pCi} / \mathrm{m} 3$ & 1.1 & 1.5 & & & \\
\hline SESPMNT & B16T67 & $300 \mathrm{NE}$ & ONSITE & AT & 15-Apr-03 & 3 TRITIUM & & $6 \mathrm{pCi} / \mathrm{m} 3$ & 0.8 & 1.2 & & & \\
\hline SESPMNT & B170N8 & $300 \mathrm{NE}$ & ONSITE & AT & 13-May-03 & 3 TRITIUM & & $5 \mathrm{pCi} / \mathrm{m} 3$ & 0.9 & 1.3 & & & \\
\hline SESPMNT & B171X5 & $300 \mathrm{NE}$ & ONSITE & AT & 12-Jun-03 & 3 TRITIUM & 8.23 & $3 \mathrm{pCi} / \mathrm{m} 3$ & 1 & 1.6 & & & \\
\hline SESPMNT & B176R5 & $300 \mathrm{NE}$ & ONSITE & AT & 10-Jul-03 & 3 TRITIUM & & $2 \mathrm{pCi} / \mathrm{m} 3$ & 0.76 & 1.2 & & & \\
\hline SESPMNT & B179V6 & $300 \mathrm{NE}$ & ONSITE & AT & 08-Aug-03 & 3 TRITIUM & 8.4. & $9 \mathrm{pCi} / \mathrm{m} 3$ & 1.1 & 1.7 & & & \\
\hline SESPMNT & B17DN9 & $300 \mathrm{NE}$ & ONSITE & AT & $03-S e p-03$ & TRITIUM & 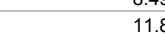 & $8 \mathrm{pCi} / \mathrm{m} 3$ & 1.3 & 2.1 & & & \\
\hline SESPMNT & B17LP9 & $300 \mathrm{NE}$ & ONSITE & AT & 30-Sep-03 & 3 TRITIUM & 8.95 & $5 \mathrm{pCi} / \mathrm{m} 3$ & 0.82 & 1.1 & & & \\
\hline SESPMNT & B17TN7 & $300 \mathrm{NE}$ & ONSITE & AT & 29-Oct-03 & 3 TRITIUM & 13.8 & $8 \mathrm{pCi} / \mathrm{m} 3$ & 1.3 & 2.3 & & & \\
\hline SESPMNT & B181K4 & $300 \mathrm{NE}$ & ONSITE & AT & $25-$ Nov- 03 & 3 TRITIUM & 3.75 & $5 \mathrm{pCi} / \mathrm{m} 3$ & 0.5 & 0.74 & & & \\
\hline SESPMNT & B186L1 & $300 \mathrm{NE}$ & ONSITE & AT & $23-$ Dec-03 & TRITIUM & 11. & $1 \mathrm{pCi} / \mathrm{m} 3$ & 0.99 & 1.8 & & & \\
\hline SESPMNT & B16BV3 & 300 SOUTH GATE & ONSITE & AT & 22-Jan-03 & 3 TRITIUM & 19.6 & $6 \mathrm{pCi} / \mathrm{m} 3$ & 1.9 & 3.3 & & & \\
\hline SESPMNT & B16BV7 & 300 SOUTH GATE & ONSITE & AT & 22-Jan-03 & TRITIUM & 6.33 & $3 \mathrm{pCi} / \mathrm{m} 3$ & 0.78 & 1.2 & & & \\
\hline SESPMNT & B16FP7 & 300 SOUTH GATE & ONSITE & AT & $19-$ Feb-03 & 3 TRITIUM & 3.23 & $3 \mathrm{pCi} / \mathrm{m} 3$ & 0.72 & 0.9 & & & \\
\hline SESPMNT & B16FR1 & 300 SOUTH GATE & ONSITE & AT & $19-$ Feb-03 & 3 TRITIUM & 10.4 & $4 \mathrm{pCi} / \mathrm{m} 3$ & 1.1 & 1.8 & & & \\
\hline SESPMNT & B16KJ9 & 300 SOUTH GATE & ONSITE & AT & 20-Mar-03 & 3 TRITIUM & 7.5 & $1 \mathrm{pCi} / \mathrm{m} 3$ & 0.93 & 1.4 & & & \\
\hline SESPMNT & B16KK4 & 300 SOUTH GATE & ONSITE & AT & 20-Mar-03 & 3 TRITIUM & 4.04 & $4 \mathrm{pCi} / \mathrm{m} 3$ & 0.74 & 0.98 & & & \\
\hline SESPMNT & B16T61 & 300 SOUTH GATE & ONSITE & AT & 15-Apr-03 & 3 TRITIUM & 3.90 & $9 \mathrm{pCi} / \mathrm{m} 3$ & 0.79 & 1 & & & \\
\hline SESPMNT & B16T65 & 300 SOUTH GATE & ONSITE & AT & 15-Apr-03 & 3 TRITIUM & 5.3 & $3 \mathrm{pCi} / \mathrm{m} 3$ & 0.76 & 1.1 & & & \\
\hline SESPMNT & B170N1 & 300 SOUTH GATE & ONSITE & AT & 13-May-03 & 3 TRITIUM & 11.3 & $3 \mathrm{pCi} / \mathrm{m} 3$ & 1.1 & 1.9 & & & \\
\hline SESPMNT & B170N6 & 300 SOUTH GATE & ONSITE & AT & 13-May-03 & 3 TRITIUM & 6.74 & $4 \mathrm{pCi} / \mathrm{m} 3$ & 0.86 & 1.3 & & & \\
\hline SESPMNT & B171T9 & 300 SOUTH GATE & ONSITE & AT & 12-Jun-03 & 3 TRITIUM & & $0 \mathrm{pCi} / \mathrm{m} 3$ & 1.1 & 1.8 & & & \\
\hline SESPMNT & B171X3 & 300 SOUTH GATE & ONSITE & AT & 12-Jun-03 & TRITIUM & 5.47 & $7 \mathrm{pCi} / \mathrm{m} 3$ & 0.89 & 1.2 & & & \\
\hline SESPMNT & B176M9 & 300 SOUTH GATE & ONSITE & AT & 10-Jul-03 & 3 TRITIUM & 11.7 & $7 \mathrm{pCi} / \mathrm{m} 3$ & 0.76 & 1.2 & & & \\
\hline SESPMNT & B176R3 & 300 SOUTH GATE & ONSITE & AT & 10-Jul-03 & 3 TRITIUM & 11.7 & $7 \mathrm{pCi} / \mathrm{m} 3$ & 0.78 & 1.2 & & & \\
\hline SESPMNT & B179V0 & 300 SOUTH GATE & ONSITE & AT & 08-Aug-03 & 3 TRITIUM & 10.4 & $4 \mathrm{pCi} / \mathrm{m} 3$ & 1.2 & 2 & & & \\
\hline SESPMNT & B179V4 & 300 SOUTH GATE & ONSITE & AT & 08-Aug-03 & 3 TRITIUM & & $4 \mathrm{pCi} / \mathrm{m} 3$ & 1.8 & 2.8 & & & \\
\hline SESPMNT & B17DL7 & 300 SOUTH GATE & ONSITE & AT & 03-Sep-03 & 3 TRITIUM & 10. & $1 \mathrm{pCi} / \mathrm{m} 3$ & 1.2 & 1.9 & & & \\
\hline SESPMNT & B17DN7 & 300 SOUTH GATE & ONSITE & AT & 03-Sep-03 & 3 TRITIUM & 8.8 & $8 \mathrm{pCi} / \mathrm{m} 3$ & 1.1 & 1.7 & & & \\
\hline SESPMNT & B17LP3 & 300 SOUTH GATE & ONSITE & AT & 30-Sep-03 & 3 TRITIUM & 5.31 & $1 \mathrm{pCi} / \mathrm{m} 3$ & 0.7 & 0.84 & & & \\
\hline SESPMNT & B17LP7 & 300 SOUTH GATE & ONSITE & AT & 30-Sep-03 & 3 TRITIUM & 5.25 & $5 \mathrm{pCi} / \mathrm{m} 3$ & 0.68 & 0.82 & & & \\
\hline SESPMNT & B17TNO & 300 SOUTH GATE & ONSITE & AT & 29-Oct-03 & 3 TRITIUM & $4.8 \mathrm{~s}$ & $9 \mathrm{pCi} / \mathrm{m} 3$ & 0.46 & 0.82 & & & \\
\hline SESPMNT & B17TN5 & 300 SOUTH GATE & ONSITE & AT & $29-$ Oct-03 & 3 TRITIUM & 15.6 & $6 \mathrm{pCi} / \mathrm{m} 3$ & 1.4 & 2.6 & & & \\
\hline SESPMNT & B181J8 & 300 SOUTH GATE & ONSITE & AT & 25 -Nov-03 & 3 TRITIUM & 10.6 & $6 \mathrm{pCi} / \mathrm{m} 3$ & 0.84 & 1.7 & & & \\
\hline SESPMNT & B181K2 & 300 SOUTH GATE & ONSITE & AT & $25-$ Nov-03 & 3 TRITIUM & 3.26 & $6 \mathrm{pCi} / \mathrm{m} 3$ & 0.49 & 0.69 & & & \\
\hline SESPMNT & B186K5 & 300 SOUTH GATE & ONSITE & AT & 23-Dec-03 & 3 TRITIUM & 8.34 & $4 \mathrm{pCi} / \mathrm{m} 3$ & 0.85 & 1.4 & & & \\
\hline SESPMNT & B186K9 & 300 SOUTH GATE & ONSITE & AT & 23-Dec-03 & 3 TRITIUM & 5.67 & $7 \mathrm{pCi} / \mathrm{m} 3$ & 0.69 & 1.1 & & & \\
\hline SESPMNT & B16BW4 & 300 SOUTH WEST & ONSITE & AT & 22-Jan-03 & 3 TRITIUM & & $1 \mathrm{pCi} / \mathrm{m} 3$ & 1.5 & 2.2 & & & \\
\hline SESPMNT & B16FT0 & 300 SOUTH WEST & ONSITE & AT & 19-Feb-03 & 3 TRITIUM & 2.70 & $9 \mathrm{pCi} / \mathrm{m} 3$ & 0.67 & 0.83 & & & \\
\hline SESPMNT & B16KN9 & 300 SOUTH WEST & ONSITE & AT & 20-Mar-03 & 3 TRITIUM & $4.4 \mathrm{C}$ & $9 \mathrm{pCi} / \mathrm{m} 3$ & 0.71 & 0.98 & & & \\
\hline SESPMNT & B16T72 & 300 SOUTH WEST & ONSITE & AT & 15-Apr-03 & TRITIUM & 7.07 & $7 \mathrm{pCi} / \mathrm{m} 3$ & 0.9 & 1.3 & & & \\
\hline SESPMNT & B170P5 & 300 SOUTH WEST & ONSITE & AT & 13-May-03 & 3 TRITIUM & 9.66 & $6 \mathrm{pCi} / \mathrm{m} 3$ & 1 & 1.7 & & & \\
\hline SESPMNT & B171Y0 & 300 SOUTH WEST & ONSITE & AT & 12-Jun-03 & 3 TRITIUM & 5.58 & $8 \mathrm{pCi} / \mathrm{m} 3$ & 0.89 & 1.2 & & & \\
\hline SESPMNT & B176T0 & 300 SOUTH WEST & ONSITE & AT & 10-Jul-03 & 3 TRITIUM & 8.43 & $3 \mathrm{pCi} / \mathrm{m} 3$ & 0.69 & 0.97 & & & \\
\hline SESPMNT & B179W3 & 300 SOUTH WEST & ONSITE & AT & 08-Aug-03 & TRITIUM & & & & & & & LOST AT LAB. \\
\hline SESPMNT & B17DP4 & 300 SOUTH WEST & ONSITE & AT & 03-Sep-03 & 3 TRITIUM & & $9 \mathrm{pCi} / \mathrm{m} 3$ & 1.3 & 2.1 & & & \\
\hline SESPMNT & B17LR4 & 300 SOUTH WEST & ONSITE & AT & 30-Sep-03 & 3 TRITIUM & 10.6 & $6 \mathrm{pCi} / \mathrm{m} 3$ & 0.83 & 1.1 & & & \\
\hline SESPMNT & B17TP4 & 300 SOUTH WEST & ONSITE & AT & $29-$ Oct-03 & 3 TRITIUM & 22.7 & $7 \mathrm{pCi} / \mathrm{m} 3$ & 1.6 & 3.5 & & & \\
\hline SESPMNT & B181K9 & 300 SOUTH WEST & ONSITE & AT & $25-\mathrm{Nov}-03$ & 3 TRITIUM & & $6 \mathrm{pCi} / \mathrm{m} 3$ & 0.68 & 1.1 & & & \\
\hline SESPMNT & B186P4 & 300 SOUTH WEST & ONSITE & AT & 23-Dec-03 & 3 TRITIUM & 5.07 & $7 \mathrm{pCC} / \mathrm{m} 3$ & 0.72 & 1 & & & \\
\hline SESPMNT & B16BV8 & 300 TRENCH & ONSITE & AT & 22-Jan-03 & 3 TRITIUM & 3.83 & $3 \mathrm{pCi} / \mathrm{m} 3$ & 0.71 & 0.91 & & & \\
\hline SESPMNT & B16FR2 & 300 TRENCH & ONSITE & AT & 19-Feb-03 & TRITIUM & 9.72 & $2 \mathrm{pCi} / \mathrm{m} 3$ & 1.1 & 1.8 & & & \\
\hline SESPMNT & B16KK5 & 300 TRENCH & ONSITE & AT & 20-Mar-03 & B TRITIUM & 5.22 & $2 \mathrm{pC} / \mathrm{m} 3$ & 0.77 & 1.1 & & & \\
\hline SESPMNT & B16T66 & 300 TRENCH & ONSITE & AT & 15-Apr-03 & 3 TRITIUM & 4.7 & $1 \mathrm{pCi} / \mathrm{m} 3$ & 0.78 & 1 & & & \\
\hline SESPMNT & B170N7 & 300 TRENCH & ONSITE & AT & 13-May-03 & 3 TRITIUM & 7.31 & $1 \mathrm{pCi} / \mathrm{m} 3$ & 0.94 & 1.4 & & & \\
\hline SESPMNT & B171X4 & 300 TRENCH & ONSITE & AT & 12-Jun-03 & 3 TRITIUM & 8.0 & $1 \mathrm{pCi} / \mathrm{m} 3$ & 1 & 1.5 & & & \\
\hline
\end{tabular}


AIR COMPOSITES AND I-129, H-3

\begin{tabular}{|c|c|c|c|c|c|c|c|c|c|c|c|c|c|}
\hline OWNER ID & SAMP NUM & SAMP SITE NAME & DIST CLASS & MEDIA & SAMP DATE & $\left|\begin{array}{c}\text { CON SHORT } \\
\text { NAME }\end{array}\right|$ & VALUE RPTD & \begin{tabular}{|l|} 
ANAL \\
UNITS \\
RPTD
\end{tabular} & $\begin{array}{l}\text { COUNTING } \\
\text { ERROR }\end{array}$ & $\begin{array}{c}\text { TOTAL ANAL } \\
\text { ERROR }\end{array}$ & $\begin{array}{c}\text { LAB } \\
\text { QUALIFIER }\end{array}$ & SAMP COMMENT & RESULT COMMENT \\
\hline SESPMNT & B176R4 & 300 TRENCH & ONSITE & AT & 10-Jul-03 & TRITIUM & 5.47 & $7 \mathrm{pCi} / \mathrm{m} 3$ & 0.6 & 0.78 & & & \\
\hline SESPMNT & B179V5 & 300 TRENCH & ONSITE & AT & 08-Aug-03 & TRITIUM & & $8 \mathrm{pCi} / \mathrm{m} 3$ & 1.1 & 1.7 & & & \\
\hline SESPMNT & B17DN8 & 300 TRENCH & ONSITE & AT & 03-Sep-03 & TRITIUM & & $\mathrm{pCCi} / \mathrm{m} 3$ & 1.2 & 1.9 & & & \\
\hline SESPMNT & B17LP8 & 300 TRENCH & ONSITE & AT & 30-Sep-03 & TRITIUM & 6.76 & $5 \mathrm{pCi} / \mathrm{m} 3$ & 0.74 & 0.92 & & & \\
\hline SESPMNT & B17TN6 & 300 TRENCH & ONSITE & AT & 29-Oct-03 & TRITIUM & & & & & & NO SAMPLE. POWER OUTAGE. & \\
\hline SESPMNT & B181K3 & 300 TRENCH & ONSITE & AT & 25-Nov-03 & TRITIUM & & $4 \mathrm{pCi} / \mathrm{m} 3$ & 0.48 & 0.63 & & & \\
\hline SESPMNT & B186L0 & 300 TRENCH & ONSITE & AT & 23-Dec-03 & TRITIUM & & $7 \mathrm{pCi} / \mathrm{m} 3$ & 0.61 & 0.85 & & & \\
\hline SESPMNT & B16BW3 & 300 WATER INTAKE & ONSITE & AT & 22-Jan-03 & TRITIUM & & $2 \mathrm{pCi} / \mathrm{m} 3$ & 1.6 & 2.3 & & & \\
\hline SESPMNT & B16FR9 & 300 WATER INTAKE & ONSITE & AT & 19-Feb-03 & TRITIUM & 6.91 & $1 \mathrm{pCi} / \mathrm{m} 3$ & 1 & 1.4 & & & \\
\hline SESPMNT & B16KN8 & 300 WATER INTAKE & ONSITE & AT & 20-Mar-03 & TRITIUM & & $2 \mathrm{pCi} / \mathrm{m} 3$ & 0.65 & 0.82 & & & \\
\hline SESPMNT & B16T71 & 300 WATER INTAKE & ONSITE & AT & 15-Apr-03 & 3 TRITIUM & & $4 \mathrm{pCi} / \mathrm{m} 3$ & 0.94 & 1.6 & & & \\
\hline SESPMNT & B170P4 & 300 WATER INTAKE & ONSITE & AT & 13-May-03 & 3 TRITIUM & $10 . \varepsilon$ & $8 \mathrm{pCC} / \mathrm{m} 3$ & 1.1 & 1.8 & & & \\
\hline SESPMNT & B171X9 & 300 WATER INTAKE & ONSITE & AT & 12-Jun-03 & 3 TRITIUM & 9.0 & $1 \mathrm{pCi} / \mathrm{m} 3$ & 1.1 & 1.7 & & & \\
\hline SESPMNT & B176R9 & 300 WATER INTAKE & ONSITE & AT & 10-Jul-03 & 3 TRITIUM & 8.36 & $6 \mathrm{pC} / \mathrm{m} 3$ & 0.68 & 0.95 & & & \\
\hline SESPMNT & B179W2 & 300 WATER INTAKE & ONSITE & AT & 08-Aug-03 & TRITIUM & & & & & & & LOST AT LAB. \\
\hline SESPMNT & B17DP3 & 300 WATER INTAKE & ONSITE & AT & 03-Sep-03 & 3 TRITIUM & 16.6 & $6 \mathrm{pCi} / \mathrm{m} 3$ & 2.1 & 3.2 & & & \\
\hline SESPMNT & B17LR3 & 300 WATER INTAKE & ONSITE & AT & $30-$ Sep-03 & 3 TRITIUM & 5.5 & $3 \mathrm{pCi} / \mathrm{m} 3$ & 0.7 & 0.85 & & & \\
\hline SESPMNT & B17TP3 & 300 WATER INTAKE & ONSITE & AT & $29-$ Oct- 03 & 3 TRITIUM & 10.3 & $3 \mathrm{pC} / \mathrm{m} 3$ & 1.2 & 1.9 & & & \\
\hline SESPMNT & B181K8 & 300 WATER INTAKE & ONSITE & AT & $25-$ Nov- 03 & 3 TRITIUM & & $5 \mathrm{pCi} / \mathrm{m} 3$ & 0.61 & 0.94 & & & \\
\hline SESPMNT & B186P3 & 300 WATER INTAKE & ONSITE & AT & 23-Dec-03 & 3 TRITIUM & 6.02 & $2 \mathrm{pCi} / \mathrm{m} 3$ & 0.74 & 1.1 & & & \\
\hline SESPMNT & B16BW0 & $400 \mathrm{E}$ & ONSITE & AT & 21-Jan-03 & 3 TRITIUM & 9.35 & $5 \mathrm{pCi} / \mathrm{m} 3$ & 1 & 1.7 & & & \\
\hline SESPMNT & B16FR4 & $400 \mathrm{E}$ & ONSITE & AT & $18-\mathrm{Feb}-03$ & 3 TRITIUM & 1.87 & $7 \mathrm{pCi} / \mathrm{m} 3$ & 0.58 & 0.71 & & & \\
\hline SESPMNT & B16KK7 & $400 \mathrm{E}$ & ONSITE & AT & 18-Mar-03 & 3 TRITIUM & $4.4 c$ & $9 \mathrm{pCi} / \mathrm{m} 3$ & 0.8 & 1.1 & & & \\
\hline SESPMNT & B16T68 & $400 \mathrm{E}$ & ONSITE & AT & 15-Apr-03 & 3 TRITIUM & 6.38 & $8 \mathrm{pCi} / \mathrm{m} 3$ & 0.78 & 1.2 & & & \\
\hline SESPMNT & B170N9 & $400 \mathrm{E}$ & ONSITE & AT & 12-May-03 & 3 TRITIUM & 2.95 & $5 \mathrm{pCi} / \mathrm{m} 3$ & 0.65 & 0.81 & & & \\
\hline SESPMNT & B171X6 & $400 \mathrm{E}$ & ONSITE & AT & 11-Jun-03 & 3 TRITIUM & 8.27 & $7 \mathrm{pCi} / \mathrm{m} 3$ & 1 & 1.6 & & & \\
\hline SESPMNT & B176R6 & $400 \mathrm{E}$ & ONSITE & AT & 08-Jul-03 & 3 TRITIUM & 3.72 & $2 \mathrm{pCi} / \mathrm{m} 3$ & 0.58 & 0.71 & & & \\
\hline SESPMNT & B179V7 & $400 \mathrm{E}$ & ONSITE & AT & 04-Aug-03 & 3 TRITIUM & 7.94 & $4 \mathrm{pCi} / \mathrm{m} 3$ & 1 & 1.5 & & & \\
\hline SESPMNT & B17DP0 & $400 \mathrm{E}$ & ONSITE & AT & $02-S e p-03$ & 3 TRITIUM & 10.4 & $4 \mathrm{pC} / \mathrm{m} 3$ & 1.2 & 1.9 & & & \\
\hline SESPMNT & B17LR0 & $400 \mathrm{E}$ & ONSITE & AT & 01-Oct-03 & 3 TRITIUM & 8.66 & $6 \mathrm{pC} / \mathrm{m} 3$ & 0.73 & 0.97 & & & \\
\hline SESPMNT & B17TN8 & $400 \mathrm{E}$ & ONSITE & AT & 28-Oct-03 & 3 TRITIUM & 1.55 & $5 \mathrm{pCi} / \mathrm{m} 3$ & 0.2 & 0.31 & & & \\
\hline SESPMNT & B181K5 & $400 \mathrm{E}$ & ONSITE & AT & 24-Nov-03 & 3 TRITIUM & 2.99 & $9 \mathrm{pCi} / \mathrm{m} 3$ & 0.47 & 0.66 & & & \\
\hline SESPMNT & B186L2 & $400 \mathrm{E}$ & ONSITE & AT & 22-Dec-03 & 3 TRITIUM & 6.07 & $7 \mathrm{pC} / \mathrm{m} 3$ & 0.71 & 1.1 & & & \\
\hline SESPMNT & B16BK9 & BASIN CITY SCHOOL & COMMUNITY & AT & 15-Jan- 03 & 3 TRITIUM & 1.68 & $8 \mathrm{pCi} / \mathrm{m} 3$ & 0.47 & 0.55 & & & \\
\hline SESPMNT & B16DJ9 & BASIN CITY SCHOOL & COMMUNITY & AT & 12-Feb-03 & 3 TRITIUM & $3.2 \mathrm{~s}$ & $9 \mathrm{pCi} / \mathrm{m} 3$ & 0.67 & 0.86 & & & \\
\hline SESPMNT & B16K73 & BASIN CITY SCHOOL & COMMUNITY & AT & 12-Mar-03 & 3 TRITIUM & 1.55 & $5 \mathrm{pCi} / \mathrm{m} 3$ & 0.47 & 0.56 & & & \\
\hline SESPMNT & B16RR8 & BASIN CITY SCHOOL & COMMUNITY & AT & 09-Apr-03 & 3 TRITIUM & 24.7 & $7 \mathrm{pC} / \mathrm{m} 3$ & 1.6 & 3.7 & & & \\
\hline SESPMNT & B16WJ8 & BASIN CITY SCHOOL & COMMUNITY & AT & 07-May-03 & 3 TRITIUM & 1.9 & $1 \mathrm{pCi} / \mathrm{m} 3$ & 0.64 & 0.78 & & & \\
\hline SESPMNT & B171K2 & BASIN CITY SCHOOL & COMMUNITY & AT & 04-Jun-03 & 3 TRITIUM & 1.36 & $6 \mathrm{pCi} / \mathrm{m} 3$ & 0.41 & 0.47 & & & \\
\hline SESPMNT & B174K1 & BASIN CITY SCHOOL & COMMUNITY & AT & 02-Jul-03 & 3 TRITIUM & & $4 \mathrm{pCi} / \mathrm{m} 3$ & 0.61 & 0.82 & & & \\
\hline SESPMNT & B17968 & BASIN CITY SCHOOL & COMMUNITY & AT & 30-Jul-03 & 3 TRITIUM & 1.84 & $4 \mathrm{pC} / \mathrm{m} 3$ & 0.73 & 0.84 & & & \\
\hline SESPMNT & B17C85 & BASIN CITY SCHOOL & COMMUNITY & AT & 27-Aug-03 & 3 TRITIUM & 6.88 & $8 \mathrm{pCi} / \mathrm{m} 3$ & 1.1 & 1.5 & & & \\
\hline SESPMNT & B17JT5 & BASIN CITY SCHOOL & COMMUNITY & AT & 24-Sep-03 & 3 TRITIUM & 6.78 & $8 \mathrm{pCi} / \mathrm{m} 3$ & 1.1 & 1.5 & & & \\
\hline SESPMNT & B17T63 & BASIN CITY SCHOOL & COMMUNITY & AT & 22-Oct-03 & 3 TRITIUM & 0.698 & $8 \mathrm{pCi} / \mathrm{m} 3$ & 0.24 & 0.32 & & & \\
\hline SESPMNT & B18122 & BASIN CITY SCHOOL & COMMUNITY & AT & 19-Nov-03 & 3 TRITIUM & 5.04 & $4 \mathrm{pC} / \mathrm{m} 3$ & 0.65 & 0.98 & & & \\
\hline SESPMNT & B184V9 & BASIN CITY SCHOOL & COMMUNITY & AT & 17-Dec-03 & 3 TRITIUM & 3.96 & $6 \mathrm{pCi} / \mathrm{m} 3$ & 0.64 & 0.88 & & & \\
\hline SESPMNT & B18BK6 & BASIN CITY SCHOOL & COMMUNITY & AT & 14-Jan-04 & 4 TRITIUM & 3.08 & $8 \mathrm{pCi} / \mathrm{m} 3$ & 0.49 & 0.72 & & & \\
\hline SESPMNT & B16BW5 & BATTELLE COMPLEX & PERIMETER & AT & 22-Jan-03 & 3 TRITIUM & 29.3 & $3 \mathrm{pCC} / \mathrm{m} 3$ & 2.1 & 4.5 & & & \\
\hline SESPMNT & B16FT1 & BATTELLE COMPLEX & PERIMETER & AT & $19-$ Feb-03 & 3 TRITIUM & 18.2 & $2 \mathrm{pC} / \mathrm{m} 3$ & 1.4 & 2.9 & & & \\
\hline SESPMNT & B16KP0 & BATTELLE COMPLEX & PERIMETER & AT & 20-Mar-03 & 3 TRITIUM & 7.56 & $6 \mathrm{pCi} / \mathrm{m} 3$ & 0.92 & 1.4 & & & \\
\hline SESPMNT & B16T73 & BATTELLE COMPLEX & PERIMETER & AT & 16-Apr-03 & 3 TRITIUM & 19.6 & $6 \mathrm{pCi} / \mathrm{m} 3$ & 1.3 & 3 & & & \\
\hline SESPMNT & B170P6 & BATTELLE COMPLEX & PERIMETER & AT & 13-May-03 & 3 TRITIUM & 17.2 & $2 \mathrm{pCi} / \mathrm{m} 3$ & 1.4 & 2.7 & & & \\
\hline SESPMNT & B17213 & BATTELLE COMPLEX & PERIMETER & AT & 12-Jun-03 & 3 TRITIUM & 15.6 & $6 \mathrm{pC} / \mathrm{m} 3$ & 1.4 & 2.6 & & & \\
\hline SESPMNT & B176T2 & BATTELLE COMPLEX & PERIMETER & AT & 10-Jul-03 & 3 TRITIUM & 30.6 & $6 \mathrm{pCi} / \mathrm{m} 3$ & 1.1 & 2.3 & & & \\
\hline SESPMNT & B179W4 & BATTELLE COMPLEX & PERIMETER & AT & 08-Aug-03 & 3 TRITIUM & 73.5 & $5 \mathrm{pC} / \mathrm{m} 3$ & 3.3 & 10 & & & \\
\hline SESPMNT & B17DP5 & BATTELLE COMPLEX & PERIMETER & AT & 03-Sep-03 & 3 TRITIUM & 22.5 & $5 \mathrm{pCi} / \mathrm{m} 3$ & 1.7 & 3.5 & & & \\
\hline SESPMNT & B17LR5 & BATTELLE COMPLEX & PERIMETER & AT & 30-Sep-03 & 3 TRITIUM & & $8 \mathrm{pC} / \mathrm{m} 3$ & 1.1 & 2.1 & & & \\
\hline
\end{tabular}


AIR COMPOSITES AND I-129, H-3

\begin{tabular}{|c|c|c|c|c|c|c|c|c|c|c|c|c|c|}
\hline OWNER ID & SAMP NUM & SAMP SITE NAME & | DIST CLASS & MEDIA & SAMP DATE & $\begin{array}{c}\text { CON SHORT } \\
\text { NAME }\end{array}$ & VALUE RPTD & $\mid \begin{array}{l}\text { ANAL } \\
\text { UNITS } \\
\text { RPTD }\end{array}$ & $\begin{array}{c}\text { COUNTING } \\
\text { ERROR }\end{array}$ & $\begin{array}{c}\text { TOTAL ANAL } \\
\text { ERROR }\end{array}$ & $\begin{array}{c}\text { LAB } \\
\text { QUALIFIER }\end{array}$ & SAMP COMMENT & | RESULT COMMENT \\
\hline SESPMNT & B17TP5 & BATTELLE COMPLEX & PERIMETER & AT & 29-Oct-03 & TRITIUM & 12.3 & $\mathrm{pCi} / \mathrm{m} 3$ & 0.59 & 1.8 & & & \\
\hline SESPMNT & B181L0 & BATTELLE COMPLEX & PERIMETER & AT & 25-Nov-03 & 3 TRITIUM & & $\mathrm{pC} / \mathrm{m} 3$ & 0.77 & 1.5 & & & \\
\hline SESPMNT & B186P5 & BATTELLE COMPLEX & PERIMETER & AT & 23-Dec-03 & 3 TRITIUM & 18.9 & $\mathrm{pCl} / \mathrm{m} 3$ & 1.2 & 2.9 & & & \\
\hline SESPMNT & B16BK7 & BYERS LANDING & PERIMETER & AT & 16-Jan-03 & TRITIUM & 4.11 & $\mathrm{pC} / \mathrm{m} 3$ & 0.73 & 0.95 & & & \\
\hline SESPMNT & B16DJ7 & BYERS LANDING & PERIMETER & AT & 13-Feb-03 & 3 TRITIUM & 3.39 & $\mathrm{pC} / \mathrm{m} 3$ & 0.67 & 0.86 & & & \\
\hline SESPMNT & B16K71 & BYERS LANDING & PERIMETER & AT & 13-Mar-03 & 3 TRITIUM & & $\mathrm{pCl} / \mathrm{m} 3$ & 0.66 & 0.94 & & & \\
\hline SESPMNT & B16RR6 & BYERS LANDING & PERIMETER & AT & 10-Apr-03 & 3 TRITIUM & & $\mathrm{pCl} / \mathrm{m} 3$ & 1.1 & 2.1 & & & \\
\hline SESPMNT & B16WJ6 & BYERS LANDING & PERIMETER & AT & 08-May-03 & 3 TRITIUM & 9.26 & $\mathrm{pCl} / \mathrm{m} 3$ & 1 & 1.7 & & & \\
\hline SESPMNT & B171K0 & BYERS LANDING & PERIMETER & AT & 06-Jun-03 & 3 TRITIUM & 4.47 & $\mathrm{pC} / \mathrm{m} 3$ & 0.59 & 0.72 & & & \\
\hline SESPMNT & B174J9 & BYERS LANDING & PERIMETER & AT & 07-Jul-03 & 3 TRITIUM & 7.56 & $\mathrm{pCl} / \mathrm{m} 3$ & 0.7 & 0.95 & & & \\
\hline SESPMNT & B17966 & BYERS LANDING & PERIMETER & AT & 31-Jul-03 & 3 TRITIUM & 6.65 & $\mathrm{pCl} / \mathrm{m} 3$ & 1 & 1.4 & & & \\
\hline SESPMNT & B17C83 & BYERS LANDING & PERIMETER & AT & 28-Aug-03 & 3 TRITIUM & 9.29 & $\mathrm{pCl} / \mathrm{m} 3$ & 1.3 & 1.9 & & & \\
\hline SESPMNT & B17JT3 & BYERS LANDING & PERIMETER & AT & 25-Sep-03 & 3 TRITIUM & & $\mathrm{pCi} / \mathrm{m} 3$ & 1.1 & 1.6 & & & \\
\hline SESPMNT & B17T61 & BYERS LANDING & PERIMETER & AT & 23-Oct-03 & 3 TRITIUM & 13.4 & $\mathrm{pCl} / \mathrm{m} 3$ & 1.3 & 2.3 & & & \\
\hline SESPMNT & B18120 & BYERS LANDING & PERIMETER & AT & $21-$ Nov-03 & 3 TRITIUM & 15.2 & $\mathrm{pCi} / \mathrm{m} 3$ & 1 & 2.3 & & & \\
\hline SESPMNT & B184V7 & BYERS LANDING & PERIMETER & AT & 19-Dec-03 & 3 TRITIUM & 4.85 & $\mathrm{pCl} / \mathrm{m} 3$ & 0.66 & 0.97 & & & \\
\hline SESPMNT & B18BK4 & BYERS LANDING & PERIMETER & AT & 15-Jan-04 & TRITIUM & 4.78 & $\mathrm{pCl} / \mathrm{m} 3$ & 0.53 & 0.88 & & & \\
\hline SESPMNT & B16BK6 & DOGWOOD MET TOWER & PERIMETER & AT & 16-Jan-03 & 3 TRITIUM & 5.33 & $\mathrm{pCl} / \mathrm{m} 3$ & 0.77 & 1.1 & & & \\
\hline SESPMNT & B16DJ6 & DOGWOOD MET TOWER & PERIMETER & AT & $13-$ Feb-03 & 3 TRITIUM & 2.49 & $\mathrm{pCi} / \mathrm{m} 3$ & 0.68 & 0.83 & & & \\
\hline SESPMNT & B16K70 & DOGWOOD MET TOWER & PERIMETER & AT & 13-Mar-03 & B TRITIUM & 9.99 & $\mathrm{pCl} / \mathrm{m} 3$ & 1.3 & 1.9 & & & \\
\hline SESPMNT & B16RR5 & DOGWOOD MET TOWER & PERIMETER & AT & 10-Apr-03 & 3 TRITIUM & 5.65 & $\mathrm{pCi} / \mathrm{m} 3$ & 0.73 & 1.1 & & & \\
\hline SESPMNT & B16WJ5 & DOGWOOD MET TOWER & PERIMETER & AT & 08-May-03 & 3 TRITIUM & 8.11 & $\mathrm{pCi} / \mathrm{m} 3$ & 0.93 & 1.5 & & & \\
\hline SESPMNT & B171J9 & DOGWOOD MET TOWER & PERIMETER & AT & 06-Jun- 03 & 3 TRITIUM & 3.86 & $\mathrm{pCi} / \mathrm{m} 3$ & 0.61 & 0.73 & & & \\
\hline SESPMNT & B174J8 & DOGWOOD MET TOWER & PERIMETER & AT & 07-Jul-03 & 3 TRITIUM & 3.12 & $\mathrm{pCi} / \mathrm{m} 3$ & 0.84 & 0.98 & & & \\
\hline SESPMNT & B17965 & DOGWOOD MET TOWER & PERIMETER & AT & 31-Jul-03 & 3 TRITIUM & 5.03 & $\mathrm{pCi} / \mathrm{m} 3$ & 0.98 & 1.2 & & & \\
\hline SESPMNT & B17C82 & DOGWOOD MET TOWER & PERIMETER & AT & 28-Aug-03 & 3 TRITIUM & 6.61 & $\mathrm{pCi} / \mathrm{m} 3$ & 1.2 & 1.6 & & & \\
\hline SESPMNT & B17JT2 & DOGWOOD MET TOWER & PERIMETER & AT & $25-$ Sep-03 & 3 TRITIUM & 3.36 & $\mathrm{pCi} / \mathrm{m} 3$ & 0.75 & 1 & & & \\
\hline SESPMNT & B17T60 & DOGWOOD MET TOWER & PERIMETER & AT & 23-Oct-03 & 3 TRITIUM & 9.68 & $\mathrm{pCi} / \mathrm{m} 3$ & 1.2 & 1.9 & & & \\
\hline SESPMNT & B18119 & DOGWOOD MET TOWER & PERIMETER & AT & $21-$ Nov- 03 & 3 TRITIUM & 6.74 & $\mathrm{pCi} / \mathrm{m} 3$ & 0.7 & 1.2 & & & \\
\hline SESPMNT & B184V6 & DOGWOOD MET TOWER & PERIMETER & AT & 19-Dec-03 & 3 TRITIUM & 3.89 & $\mathrm{pCi} / \mathrm{m} 3$ & 0.63 & 0.87 & & & \\
\hline SESPMNT & B18BK3 & DOGWOOD MET TOWER & PERIMETER & AT & 15-Jan-04 & TRITIUM & & $\mathrm{pCl} / \mathrm{m} 3$ & 0.6 & 1 & & & \\
\hline SESPMNT & B16BL1 & EDWIN MARKHAM SCHOOL & COMMUNITY & AT & 15-Jan-03 & TRITIUM & 3.07 & $\mathrm{pCi} / \mathrm{m} 3$ & 0.64 & 0.8 & & & \\
\hline SESPMNT & B16DK1 & EDWIN MARKHAM SCHOOL & COMMUNITY & AT & $13-F e b-03$ & 3 TRITIUM & 2.63 & $\mathrm{pCi} / \mathrm{m} 3$ & 0.6 & 0.75 & & & \\
\hline SESPMNT & B16K75 & EDWIN MARKHAM SCHOOL & COMMUNITY & AT & 12-Mar-03 & 3 TRITIUM & 1.16 & $\mathrm{pCi} / \mathrm{m} 3$ & 0.46 & 0.54 & & & \\
\hline SESPMNT & B16RT0 & EDWIN MARKHAM SCHOOL & COMMUNITY & AT & 10-Apr-03 & 3 TRITIUM & 4.62 & $\mathrm{pCl} / \mathrm{m} 3$ & 0.72 & 0.98 & & & \\
\hline SESPMNT & B16WK0 & EDWIN MARKHAM SCHOOL & COMMUNITY & AT & 07-May-03 & 3 TRITIUM & 6.53 & $\mathrm{pCi} / \mathrm{m} 3$ & 0.84 & 1.3 & & & \\
\hline SESPMNT & B171K4 & EDWIN MARKHAM SCHOOL & COMMUNITY & AT & 04-Jun- 03 & 3 TRITIUM & 5.33 & $\mathrm{pCi} / \mathrm{m} 3$ & 0.57 & 0.72 & & & \\
\hline SESPMNT & B174K3 & EDWIN MARKHAM SCHOOL & COMMUNITY & AT & 02-Jul-03 & 3 TRITIUM & 9.51 & $\mathrm{pCi} / \mathrm{m} 3$ & 0.74 & 1.1 & & & \\
\hline SESPMNT & B17970 & EDWIN MARKHAM SCHOOL & COMMUNITY & AT & $30-\mathrm{Jul}-03$ & 3 TRITIUM & 5.3 & $\mathrm{pCC} / \mathrm{m} 3$ & 0.85 & 1.1 & & & \\
\hline SESPMNT & B17C87 & EDWIN MARKHAM SCHOOL & COMMUNITY & AT & 27-Aug-03 & 3 TRITIUM & 9.03 & $\mathrm{pCi} / \mathrm{m} 3$ & 1.2 & 1.7 & & & \\
\hline SESPMNT & B17JT7 & EDWIN MARKHAM SCHOOL & COMMUNITY & AT & 24-Sep-03 & 3 TRITIUM & 5.63 & $\mathrm{pCi} / \mathrm{m} 3$ & 0.9 & 1.3 & & & \\
\hline SESPMNT & B17T65 & EDWIN MARKHAM SCHOOL & COMMUNITY & AT & 22-Oct-03 & 3 TRITIUM & 6.05 & $\mathrm{pCi} / \mathrm{m} 3$ & 0.93 & 1.3 & & & \\
\hline SESPMNT & B18124 & EDWIN MARKHAM SCHOOL & COMMUNITY & AT & 19-Nov-03 & 3 TRITIUM & 10.5 & $\mathrm{pCi} / \mathrm{m} 3$ & 0.86 & 1.7 & & & \\
\hline SESPMNT & B184W1 & EDWIN MARKHAM SCHOOL & COMMUNITY & AT & 17-Dec-03 & 3 TRITIUM & 7.85 & $\mathrm{pCi} / \mathrm{m} 3$ & 0.85 & 1.4 & & & \\
\hline SESPMNT & B18BK8 & EDWIN MARKHAM SCHOOL & COMMUNITY & AT & 13-Jan-04 & TRITIUM & 2.79 & $\mathrm{pCi} / \mathrm{m} 3$ & 0.44 & 0.66 & & & \\
\hline SESPMNT & B16BL0 & LESLIE GROVES-RCHLND & COMMUNITY & AT & 14-Jan-03 & 3 TRITIUM & & $\mathrm{pCi} / \mathrm{m} 3$ & 2.4 & 6.8 & & & \\
\hline SESPMNT & B16DK0 & LESLIE GROVES-RCHLND & COMMUNITY & AT & $11-\mathrm{Feb}-03$ & 3 TRITIUM & 31.5 & $5 \mathrm{pCi} / \mathrm{m} 3$ & 2 & 4.7 & & & \\
\hline SESPMNT & B16K74 & LESLIE GROVES-RCHLND & COMMUNITY & AT & 11-Mar-03 & 3 TRITIUM & 12.8 & $\mathrm{pCi} / \mathrm{m} 3$ & 1.2 & 2.1 & & & \\
\hline SESPMNT & B16RR9 & LESLIE GROVES-RCHLND & COMMUNITY & AT & 08-Apr-03 & 3 TRITIUM & 6.11 & $\mathrm{pCi} / \mathrm{m} 3$ & 0.8 & 1.2 & & & \\
\hline SESPMNT & B16WJ9 & LESLIE GROVES-RCHLND & COMMUNITY & AT & 06-May-03 & 3 TRITIUM & 8.86 & $\mathrm{pCi} / \mathrm{m} 3$ & 1 & 1.6 & & & \\
\hline SESPMNT & B171K3 & LESLIE GROVES-RCHLND & COMMUNITY & AT & 03-Jun-03 & 3 TRITIUM & 10.5 & $\mathrm{pCi} / \mathrm{m} 3$ & 0.8 & 1.1 & & & \\
\hline SESPMNT & B174K2 & LESLIE GROVES-RCHLND & COMMUNITY & AT & 01-Jul-03 & 3 TRITIUM & 9.53 & $\mathrm{pCi} / \mathrm{m} 3$ & 1.2 & 1.8 & & & \\
\hline SESPMNT & B17969 & LESLIE GROVES-RCHLND & COMMUNITY & AT & 30-Jul-03 & 3 TRITIUM & 16.7 & $\mathrm{pCi} / \mathrm{m} 3$ & 1.6 & 2.8 & & & \\
\hline SESPMNT & B17C86 & LESLIE GROVES-RCHLND & COMMUNITY & AT & 26-Aug-03 & 3 TRITIUM & 10.6 & $\mathrm{pCi} / \mathrm{m} 3$ & 1.4 & 2 & & & \\
\hline SESPMNT & B17JT6 & LESLIE GROVES-RCHLND & COMMUNITY & AT & 23-Sep-03 & 3 TRITIUM & 19.1 & $\mathrm{pCi} / \mathrm{m} 3$ & 1.7 & 3.2 & & & \\
\hline SESPMNT & B17T64 & LESLIE GROVES-RCHLND & COMMUNITY & AT & 21-Oct-03 & 3 TRITIUM & 15.7 & $\mathrm{pCi} / \mathrm{m} 3$ & 1.4 & 2.6 & & & \\
\hline SESPMNT & B18123 & LESLIE GROVES-RCHLND & COMMUNITY & AT & 18-Nov-03 & 3 TRITIUM & 7.95 & $\mathrm{pCi} / \mathrm{m} 3$ & 0.79 & 1.4 & & & \\
\hline SESPMNT & B184W0 & LESLIE GROVES-RCHLND & COMMUNITY & AT & 16-Dec-03 & 3 TRITIUM & 13.5 & $5 \mathrm{pCi} / \mathrm{m} 3$ & 1.1 & 2.2 & & & \\
\hline
\end{tabular}


AIR COMPOSITES AND I-129, H-3

\begin{tabular}{|c|c|c|c|c|c|c|c|c|c|c|c|c|c|}
\hline OWNER ID & SAMP NUM & SAMP SITE NAME & DIST CLASS & MEDIA & SAMP DATE & $\begin{array}{c}\text { CON SHORT } \\
\text { NAME }\end{array}$ & VALUE RPTD & \begin{tabular}{|l|} 
ANAL \\
UNITS \\
RPTD
\end{tabular} & $\begin{array}{l}\text { COUNTING } \\
\text { ERROR }\end{array}$ & $\begin{array}{c}\text { TOTAL ANAL } \\
\text { ERROR }\end{array}$ & $\begin{array}{c}\text { LAB } \\
\text { QUALIFIER }\end{array}$ & SAMP COMMENT & | RESULT COMMENT \\
\hline SESPMNT & B18BK7 & LESLIE GROVES-RCHLND & COMMUNITY & AT & 13-Jan-04 & TRITIUM & 22.8 & $8 \mathrm{pCi} / \mathrm{m} 3$ & 1.2 & 3.3 & & & \\
\hline SESPMNT & B16BW1 & PROSSER BARRICADE & PERIMETER & AT & 23-Jan-03 & 3 TRITIUM & 3.84 & $4 \mathrm{pC} / \mathrm{m} 3$ & 1.3 & 1.5 & & & \\
\hline SESPMNT & B16FR5 & PROSSER BARRICADE & PERIMETER & AT & 20-Feb-03 & 3 TRITIUM & 6.75 & $5 \mathrm{pC} / \mathrm{m} 3$ & 0.96 & 1.4 & & & \\
\hline SESPMNT & B16KK8 & PROSSER BARRICADE & PERIMETER & AT & 21-Mar-03 & 3 TRITIUM & & $6 \mathrm{pC} / \mathrm{m} 3$ & 0.73 & 1 & & & \\
\hline SESPMNT & B16T69 & PROSSER BARRICADE & PERIMETER & AT & 18-Apr-03 & 3 TRITIUM & 3.36 & $6 \mathrm{pC} / \mathrm{m} 3$ & 0.66 & 0.85 & & & \\
\hline SESPMNT & B170P0 & PROSSER BARRICADE & PERIMETER & AT & 16-May-03 & 3 TRITIUM & 2.56 & $6 \mathrm{pC} / \mathrm{m} 3$ & 0.58 & 0.72 & & & \\
\hline SESPMNT & B171X7 & PROSSER BARRICADE & PERIMETER & AT & 13-Jun-03 & 3 TRITIUM & & $8 \mathrm{pCi} / \mathrm{m} 3$ & 0.74 & 0.99 & & & \\
\hline SESPMNT & B176R7 & PROSSER BARRICADE & PERIMETER & AT & 11-Jul-03 & 3 TRITIUM & & $1 \mathrm{pC} / \mathrm{m} 3$ & 0.59 & 0.82 & & & \\
\hline SESPMNT & B179V8 & PROSSER BARRICADE & PERIMETER & AT & $07-$ Aug-03 & 3 TRITIUM & & $6 \mathrm{pC} / \mathrm{m} 3$ & 0.87 & 1.2 & & & \\
\hline SESPMNT & B17DP1 & PROSSER BARRICADE & PERIMETER & AT & 05-Sep-03 & 3 TRITIUM & 4.72 & $2 \mathrm{pC} / \mathrm{m} 3$ & 1.1 & 1.6 & & & \\
\hline SESPMNT & B17LR1 & PROSSER BARRICADE & PERIMETER & AT & 03-Oct-03 & 3 TRITIUM & & $1 \mathrm{pCi} / \mathrm{m} 3$ & 1 & 1.7 & & & \\
\hline \begin{tabular}{|l} 
SESPMNT \\
\end{tabular} & B17TN9 & PROSSER BARRICADE & PERIMETER & AT & 30-Oct-03 & 3 TRITIUM & & $3 \mathrm{pC} / \mathrm{m} 3$ & 0.62 & 0.81 & & & \\
\hline SESPMNT & B181K6 & PROSSER BARRICADE & PERIMETER & AT & 26-Nov-03 & 3 TRITIUM & & $5 \mathrm{pC} / \mathrm{m} 3$ & 0.55 & 0.89 & & & \\
\hline SESPMNT & B186L3 & PROSSER BARRICADE & PERIMETER & AT & 29-Dec-03 & 3 TRITIUM & $3.1 \varepsilon$ & $8 \mathrm{pC} / \mathrm{m} 3$ & 0.57 & 0.86 & & & \\
\hline \begin{tabular}{|l|} 
SESPMNT \\
\end{tabular} & B16BK5 & RINGOLD MET TOWER & PERIMETER & AT & 16-Jan-03 & 3 TRITIUM & & $9 \mathrm{pC} / \mathrm{m} 3$ & 0.76 & 1 & & & \\
\hline \begin{tabular}{|l|} 
SESPMNT \\
\end{tabular} & B16DJ5 & RINGOLD MET TOWER & PERIMETER & AT & $13-$ Feb-03 & 3 TRITIUM & 1.23 & $3 \mathrm{pC} / \mathrm{m} 3$ & 0.52 & 0.61 & & & \\
\hline SESPMNT & B16K69 & RINGOLD MET TOWER & PERIMETER & AT & 13-Mar-03 & 3 TRITIUM & 6.0 & $1 \mathrm{pC} / \mathrm{m} 3$ & 0.8 & 1.2 & & & \\
\hline SESPMNT & B16RR4 & RINGOLD MET TOWER & PERIMETER & AT & 10-Apr-03 & 3 TRITIUM & 6.82 & $2 \mathrm{pC} / \mathrm{m} 3$ & 0.9 & 1.3 & & & \\
\hline \begin{tabular}{|l|} 
SESPMNT \\
\end{tabular} & B16WJ4 & RINGOLD MET TOWER & PERIMETER & AT & 08-May-03 & 3 TRITIUM & & $7 \mathrm{pC} / \mathrm{m} 3$ & 1.1 & 1.7 & & & \\
\hline SESPMNT & B171J8 & RINGOLD MET TOWER & PERIMETER & AT & 06-Jun- 03 & 3 TRITIUM & $2.2 \varepsilon$ & $8 \mathrm{pC} / \mathrm{m} 3$ & 0.54 & 0.62 & & & \\
\hline SESPMNT & B174J7 & RINGOLD MET TOWER & PERIMETER & AT & $07-J u l-03$ & 3 TRITIUM & 2.84 & $4 \mathrm{pCi} / \mathrm{m} 3$ & 0.63 & 0.75 & & & \\
\hline SESPMNT & B17964 & RINGOLD MET TOWER & PERIMETER & AT & 31-Jul-03 & 3 TRITIUM & 5.64 & $4 \mathrm{pC} / \mathrm{m} 3$ & 1 & 1.3 & & & \\
\hline SESPMNT & B17C81 & RINGOLD MET TOWER & PERIMETER & AT & 28-Aug-03 & 3 TRITIUM & & $6 \mathrm{pC} / \mathrm{m} 3$ & 1.2 & 1.6 & & & \\
\hline SESPMNT & B17JT1 & RINGOLD MET TOWER & PERIMETER & AT & 25-Sep-03 & 3 TRITIUM & 3.45 & $5 \mathrm{pC} / \mathrm{m} 3$ & 0.85 & 1.1 & & & \\
\hline SESPMNT & B17T59 & RINGOLD MET TOWER & PERIMETER & AT & 23-Oct-03 & 3 TRITIUM & 11.8 & $8 \mathrm{pC} / \mathrm{m} 3$ & 1.2 & 2.1 & & & \\
\hline SESPMNT & B18118 & RINGOLD MET TOWER & PERIMETER & AT & 21-Nov-03 & 3 TRITIUM & 4.34 & $4 \mathrm{pC} / \mathrm{m} 3$ & 0.6 & 0.88 & & & \\
\hline $\begin{array}{l}\text { SESPMNT } \\
\end{array}$ & B184V5 & RINGOLD MET TOWER & PERIMETER & AT & 19-Dec-03 & 3 TRITIUM & 1.77 & $7 \mathrm{pC} / \mathrm{m} 3$ & 0.43 & 0.56 & & & \\
\hline SESPMNT & B18BK2 & RINGOLD MET TOWER & PERIMETER & AT & 15-Jan-04 & TRITIUM & 8.26 & $6 \mathrm{pC} / \mathrm{m} 3$ & 0.73 & 1.4 & & & \\
\hline SESPMNT & B16BV4 & TOPPENISH & DISTANT & AT & 22-Jan- 03 & $\begin{array}{l}3 \text { TRITIUM } \\
\end{array}$ & 2.26 & $6 \mathrm{pC} / \mathrm{m} 3$ & 0.86 & $\begin{array}{r}1.4 \\
0.98\end{array}$ & & & \\
\hline SESPMNT & B16FP8 & TOPPENISH & DISTANT & AT & $19-$ Feb-03 & 3 TRITIUM & 0.523 & $3 \mathrm{pC} / \mathrm{m} 3$ & 0.93 & 1.1 & u & & \\
\hline SESPMNT & B16KKO & TOPPENISH & DISTANT & AT & 19-Mar-03 & 3 TRITIUM & & $8 \mathrm{pC} / \mathrm{m} 3$ & 1.3 & 1.7 & & & \\
\hline SESPMNT & B16T62 & TOPPENISH & DISTANT & AT & 16-Apr-03 & 3 TRITIUM & 2.95 & $5 \mathrm{pC} / \mathrm{m} 3$ & 0.96 & 1.2 & & & \\
\hline SESPMNT & B170N2 & TOPPENISH & DISTANT & AT & 14-May-03 & 3 TRITIUM & 3.35 & $5 \mathrm{pC} / \mathrm{m} 3$ & 1.1 & 1.3 & & & \\
\hline SESPMNT & B171W0 & TOPPENISH & DISTANT & AT & 11-Jun-03 & 3 TRITIUM & 0.922 & $2 \mathrm{pCC} / \mathrm{m} 3$ & 0.63 & 0.75 & $u$ & & \\
\hline SESPMNT & B176N0 & TOPPENISH & DISTANT & AT & 09-Jul-03 & 3 TRITIUM & & $3 \mathrm{pC} / \mathrm{m} 3$ & 0.73 & 0.85 & & & \\
\hline SESPMNT & B179V1 & TOPPENISH & DISTANT & AT & 06-Aug-03 & 3 TRITIUM & & $9 \mathrm{pC} / \mathrm{m} 3$ & 1.2 & 1.5 & & & \\
\hline SESPMNT & B17DL8 & TOPPENISH & DISTANT & AT & $03-$ Sep-03 & 3 TRITIUM & -2.12 & $2 \mathrm{pC} / \mathrm{m} 3$ & 1.2 & 2 & $u$ & & \\
\hline SESPMNT & B17LP4 & TOPPENISH & DISTANT & AT & $01-$ Oct-03 & 3 TRITIUM & 9.05 & $5 \mathrm{pC} / \mathrm{m} 3$ & 1.4 & 2 & & & \\
\hline $\begin{array}{l}\text { SESPMNT } \\
\end{array}$ & B17TN1 & TOPPENISH & DISTANT & AT & 29-Oct-03 & 3 TRITIUM & & $3 \mathrm{pC} / \mathrm{m} 3$ & 0.16 & 0.2 & & & \\
\hline SESPMNT & B181J9 & TOPPENISH & DISTANT & AT & 26-Nov-03 & 3 TRITIUM & & $5 \mathrm{pC} / \mathrm{m} 3$ & 0.77 & 1.1 & & & \\
\hline SESPMNT & B186J2 & TOPPENISH & DISTANT & AT & 23-Dec-03 & 3 TRITIUM & & $1 \mathrm{pC} / \mathrm{m} 3$ & 1.4 & 2.2 & & & \\
\hline SESPMNT & B16BK8 & WAHLUKE SLOPE & PERIMETER & AT & 15-Jan-03 & 3 TRITIUM & 6.93 & $3 \mathrm{pC} / \mathrm{m} 3$ & 0.93 & 1.4 & & & \\
\hline $\begin{array}{l}\text { SESPMNT } \\
\end{array}$ & B16DJ8 & WAHLUKE SLOPE & PERIMETER & AT & 12-Feb-03 & 3 TRITIUM & & $5 \mathrm{pC} / \mathrm{m} 3$ & 0.69 & 0.95 & & & \\
\hline SESPMNT & B16K72 & WAHLUKE SLOPE & PERIMETER & AT & 12-Mar-03 & 3 TRITIUM & 8.5 & $1 \mathrm{pC} / \mathrm{m} 3$ & 0.93 & 1.5 & & & \\
\hline SESPMNT & B16RR7 & WAHLUKE SLOPE & PERIMETER & AT & 09-Apr-03 & 3 TRITIUM & 5.74 & $4 \mathrm{pC} / \mathrm{m} 3$ & 0.76 & 1.1 & & & \\
\hline SESPMNT & B16WJ7 & WAHLUKE SLOPE & PERIMETER & AT & 07-May-03 & 3 TRITIUM & $3.2 \varepsilon$ & $8 \mathrm{pC} / \mathrm{m} 3$ & 0.73 & 0.93 & & & \\
\hline \begin{tabular}{|l} 
SESPMNT \\
\end{tabular} & B171K1 & WAHLUKE SLOPE & PERIMETER & AT & 05-Jun-03 & TRITIUM & $2.5 \subseteq$ & $9 \mathrm{pC} / \mathrm{m} 3$ & 0.49 & 0.57 & & & \\
\hline SESPMNT & B174K0 & WAHLUKE SLOPE & PERIMETER & AT & 01-Jul-03 & 3 TRITIUM & 9.50 & $9 \mathrm{pC} / \mathrm{m} 3$ & 1.1 & 1.8 & & & \\
\hline SESPMNT & B17967 & WAHLUKE SLOPE & PERIMETER & AT & 30-Jul-03 & 3 TRITIUM & 4.57 & $7 \mathrm{pC} / \mathrm{m} 3$ & 0.86 & 1.1 & & & \\
\hline SESPMNT & B17C84 & WAHLUKE SLOPE & PERIMETER & AT & 27-Aug-03 & 3 TRITIUM & 3.36 & $6 \mathrm{pC} / \mathrm{m} 3$ & 0.77 & 0.98 & & & \\
\hline \begin{tabular}{|l|} 
SESPMNT \\
\end{tabular} & B17JT4 & WAHLUKE SLOPE & PERIMETER & AT & 24-Sep-03 & TRITIUM & 6.08 & $8 \mathrm{pC} / \mathrm{m} 3$ & 1 & 1.4 & & & \\
\hline SESPMNT & B17T62 & WAHLUKE SLOPE & PERIMETER & AT & $22-$ Oct-03 & 3 TRITIUM & & $7 \mathrm{pC} / \mathrm{m} 3$ & 0.83 & 1.1 & & & \\
\hline SESPMNT & B18121 & WAHLUKE SLOPE & PERIMETER & AT & 21-Nov-03 & 3 TRITIUM & 3.73 & $3 \mathrm{pC} / \mathrm{m} 3$ & 0.55 & 0.78 & & & \\
\hline SESPMNT & B184V8 & WAHLUKE SLOPE & PERIMETER & AT & 18-Dec-03 & 3 TRITIUM & 2.06 & $6 \mathrm{pC} / \mathrm{m} 3$ & 0.5 & 0.67 & & & \\
\hline SESPMNT & B18BK5 & WAHLUKE SLOPE & PERIMETER & AT & 14-Jan-04 & TRITIUM & 7.45 & $5 \mathrm{pC} / \mathrm{m} 3$ & 0.8 & 1.4 & & & \\
\hline SESPMNT & B16BW2 & YAKIMA & DISTANT & AT & 23-Jan-03 & 3 TRITIUM & 0.737 & $7 \mathrm{pC} / \mathrm{m} 3$ & 0.19 & 0.22 & & & \\
\hline SESPMNT & B16FR6 & YAKIMA & DISTANT & AT & 20-Feb-03 & 3 TRITIUM & & $1 \mathrm{pC} / \mathrm{m} 3$ & 0.57 & 0.68 & & & \\
\hline SESPMNT & B16KK9 & YAKIMA & DISTANT & AT & 21-Mar-03 & 3 TRITIUM & 3.06 & $6 \mathrm{pCi} / \mathrm{m} 3$ & 0.62 & 0.79 & & & \\
\hline
\end{tabular}


AIR COMPOSITES AND I-129, H-3

\begin{tabular}{|c|c|c|c|c|c|c|c|c|c|c|c|c|c|}
\hline OWNER ID & SAMP NUM & SAMP SITE NAME & | DIST CLASS & MEDIA & |SAMP DATE & $\begin{array}{c}\text { CON SHORT } \\
\text { NAME }\end{array}$ & VALUE RPTD & \begin{tabular}{|l|} 
ANAL \\
UNITS \\
RPTD
\end{tabular} & $\begin{array}{l}\text { COUNTING } \\
\text { ERROR }\end{array}$ & $\left|\begin{array}{c}\text { TOTAL ANAL } \\
\text { ERROR }\end{array}\right|$ & $\mid \begin{array}{c}\text { LAB } \\
\text { QUALIFIER }\end{array}$ & SAMP COMMENT & RESULT COMMENT \\
\hline SESPMNT & B16T70 & YAKIMA & DISTANT & AT & 18-Apr-03 & TRITIUM & & & & & & NO SAMPLE. KINK IN HOSE. & \\
\hline SESPMNT & B170P1 & YAKIMA & DISTANT & AT & 16-May-03 & 3 TRITIUM & 6.42 & $\mathrm{pCi} / \mathrm{m} 3$ & 0.76 & 1.2 & & & \\
\hline SESPMNT & B171X8 & YAKIMA & DISTANT & AT & 13-Jun-03 & 3 TRITIUM & & $\mathrm{pCl} / \mathrm{m} 3$ & 0.8 & 1.1 & & & \\
\hline SESPMNT & B176R8 & YAKIMA & DISTANT & AT & 11-Jul-03 & 3 TRITIUM & & $\mathrm{pCi} / \mathrm{m} 3$ & 0.61 & 0.78 & & & \\
\hline SESPMNT & B179V9 & YAKIMA & DISTANT & AT & 07-Aug-03 & TRITIUM & 4.26 & $\mathrm{pCi} / \mathrm{m} 3$ & 0.88 & 1.1 & & & \\
\hline SESPMNT & B17DP2 & YAKIMA & DISTANT & AT & 05-Sep-03 & 3 TRITIUM & -0.328 & $\mathrm{pCl} / \mathrm{m} 3$ & 0.81 & 1.3 & $u$ & & \\
\hline SESPMNT & B17LR2 & YAKIMA & DISTANT & AT & $03-$ Oct-03 & 3 TRITIUM & 9.41 & $\mathrm{pCi} / \mathrm{m} 3$ & 1.1 & 1.7 & & & \\
\hline SESPMNT & B17TP0 & YAKIMA & DISTANT & AT & $30-0 c t-03$ & 3 TRITIUM & $\begin{array}{c}3.41 \\
6.6\end{array}$ & $\mathrm{pCl} / \mathrm{m} 3$ & 0.58 & 0.79 & & & \\
\hline SESPMNT & B181K7 & YAKIMA & DISTANT & AT & $26-$ Nov-03 & 3 TRITIUM & 5.64 & $\mathrm{pCi} / \mathrm{m} 3$ & 0.56 & 0.96 & & & \\
\hline SESPMNT & B186L4 & YAKIMA & DISTANT & AT & 29-Dec-03 & 3 TRITIUM & 5.07 & $\mathrm{pCi} / \mathrm{m} 3$ & 0.68 & 1.1 & & & \\
\hline SESPMNT & B168F3 & 200 E AREA & ONSITE & AT & 08-Apr-03 & $\mathrm{U}-234$ & 0.0000165 & $\mathrm{pCi} / \mathrm{m} 3$ & 0.000008 & 0.0000085 & & & \\
\hline SESPMNT & B16PT7 & 200 E AREA & ONSITE & AT & 30-Jun-03 & $\mathrm{U}-234$ & 0.0000166 & $\mathrm{pCi} / \mathrm{m} 3$ & 0.0000059 & 0.0000066 & & & \\
\hline SESPMNT & B175P3 & 200 E AREA & ONSITE & AT & $07-$ Oct-03 & U-234 & 0.0000189 & $\mathrm{pCi} / \mathrm{m} 3$ & 0.0000058 & 0.0000066 & & & \\
\hline SESPMNT & B17PB4 & 200 E AREA & ONSITE & AT & 30-Dec-03 & $\mathrm{U}-234$ & 0.0000101 & $\mathrm{pCl} / \mathrm{m} 3$ & 0.0000049 & 0.0000052 & & & \\
\hline SESPMNT & B168L8 & 200 W AREA & ONSITE & AT & 08-Apr-03 & U-234 & & & & & & & LOST AT LAB. \\
\hline SESPMNT & B16PY6 & 200 W AREA & ONSITE & AT & 30-Jun-03 & U-234 & 0.000015 & $\mathrm{pCi} / \mathrm{m} 3$ & 0.0000077 & 0.0000083 & & & \\
\hline SESPMNT & B175W8 & 200 W AREA & ONSITE & AT & 07-Oct-03 & U-234 & 0.000022 & $\mathrm{pC} / \mathrm{m} 3$ & 0.0000084 & 0.0000093 & & & \\
\hline SESPMNT & B17PH3 & 200 W AREA & ONSITE & AT & 30-Dec-03 & U-234 & 0.0000448 & $\mathrm{pCl} / \mathrm{m} 3$ & 0.000014 & \begin{tabular}{|l|l|}
0.000016 \\
\end{tabular} & & & \\
\hline SESPMNT & B168J6 & 200 W SOUTH EAST & ONSITE & AT & 08-Apr-03 & U-234 & 0.0000149 & $\mathrm{pCi} / \mathrm{m} 3$ & 0.0000047 & 0.0000053 & & & \\
\hline SESPMNT & B16PW7 & 200 W SOUTH EAST & ONSITE & AT & 30-Jun-03 & $\mathrm{U}-234$ & 0.0000192 & $\mathrm{pC} / \mathrm{m} 3$ & 0.000005 & 0.000006 & & & \\
\hline SESPMNT & B175T6 & 200 W SOUTH EAST & ONSITE & AT & 07-Oct-03 & U-234 & 0.0000193 & $\mathrm{pCi} / \mathrm{m} 3$ & 0.0000045 & 0.0000055 & & & \\
\hline SESPMNT & B17PD4 & $200 \mathrm{~W}$ SOUTH EAST & ONSITE & AT & 30-Dec-03 & $\mathrm{U}-234$ & 0.0000217 & $\mathrm{pCi} / \mathrm{m} 3$ & 0.0000054 & 0.0000064 & & & \\
\hline SESPMNT & B168M6 & 300 AREA & ONSITE & AT & 02-Apr-03 & U-234 & 0.0000504 & $\mathrm{PC} / \mathrm{m} 3$ & 0.0000091 & 0.000012 & & & \\
\hline SESPMNT & B16R03 & 300 AREA & ONSITE & AT & 10-Jul-03 & U-234 & 0.0000275 & $\mathrm{pCl} / \mathrm{m} 3$ & 0.0000079 & 0.0000092 & & & \\
\hline SESPMNT & B175X6 & 300 AREA & ONSITE & AT & 30-Sep-03 & U-234 & 0.0000421 & $\mathrm{pCi} / \mathrm{m} 3$ & 0.0000076 & 0.00001 & & & \\
\hline SESPMNT & B17PJ0 & 300 AREA & ONSITE & AT & 08-Jan-04 & $\mathrm{U}-234$ & 0.0000451 & $\mathrm{pCi} / \mathrm{m} 3$ & 0.0000084 & 0.000011 & & & \\
\hline SESPMNT & B167V4 & $300 \mathrm{NE}$ & ONSITE & AT & 02-Apr-03 & U-234 & 0.0000411 & $\mathrm{pCi} / \mathrm{m} 3$ & 0.000015 & 0.000017 & & & \\
\hline SESPMNT & B16P66 & $300 \mathrm{NE}$ & ONSITE & AT & 10-Jul-03 & U-234 & 0.0000205 & $\mathrm{pCi} / \mathrm{m} 3$ & 0.000014 & 0.000015 & & & \\
\hline SESPMNT & B17548 & $300 \mathrm{NE}$ & ONSITE & AT & 30-Sep-03 & $\mathrm{U}-234$ & 0.0000595 & $\mathrm{pCi} / \mathrm{m} 3$ & 0.000015 & 0.000018 & & & \\
\hline SESPMNT & B17NP7 & $300 \mathrm{NE}$ & ONSITE & AT & 08-Jan-04 & $\mathrm{U}-234$ & 0.000116 & $\mathrm{pCi} / \mathrm{m} 3$ & 0.000025 & 0.000031 & & & \\
\hline SESPMNT & B167V3 & 300 TRENCH & ONSITE & AT & 02-Apr-03 & U-234 & 0.0000147 & CCi/m3 & 0.000013 & 0.000013 & u & & \\
\hline SESPMNT & B16P65 & 300 TRENCH & ONSITE & AT & 10-Jul-03 & U-234 & 0.0000214 & $\mathrm{pC} / \mathrm{m} 3$ & 0.000011 & 0.000012 & & & \\
\hline SESPMNT & B17547 & 300 TRENCH & ONSITE & AT & 30-Sep-03 & $\mathrm{U}-234$ & 0.0000624 & $\mathrm{pC} / / \mathrm{m} 3$ & 0.000018 & 0.00002 & & & \\
\hline SESPMNT & B17NP6 & 300 TRENCH & ONSITE & AT & 08-Jan-04 & $\mathrm{U}-234$ & 0.0001 & $\mathrm{pCl} / \mathrm{m} 3$ & 0.000025 & 0.00003 & & & \\
\hline SESPMNT & B168H8 & B POND & ONSITE & AT & 08-Apr-03 & U-234 & 0.0000225 & $\mathrm{pCl} / \mathrm{m} 3$ & 0.0000093 & 0.00001 & & & \\
\hline SESPMNT & B16PW0 & B POND & ONSITE & AT & 30-Jun-03 & U-234 & 0.0000227 & $\mathrm{pC} / \mathrm{m} 3$ & 0.000016 & 0.000016 & & & \\
\hline SESPMNT & B175R8 & B POND & ONSITE & AT & 07-Oct-03 & $3 \mathrm{U}-234$ & 0.0000245 & $\mathrm{pCl} / \mathrm{m} 3$ & 0.000014 & 0.000014 & & & \\
\hline SESPMNT & B17PC7 & B POND & ONSITE & AT & 30-Dec-03 & U-234 & 0.0000257 & $\mathrm{pC} / \mathrm{m} 3$ & 0.000011 & 0.000012 & & & \\
\hline SESPMNT & B16962 & BASIN CITY SCHOOL & COMMUNITY & AT & 09-Apr-03 & U-234 & 0.0000148 & $\mathrm{pCl} / \mathrm{m} 3$ & 0.000011 & 0.000012 & & & \\
\hline SESPMNT & B16RJ4 & BASIN CITY SCHOOL & COMMUNITY & AT & 02-Jul-03 & U-234 & 0.0000321 & $\mathrm{pCi} / \mathrm{m} 3$ & 0.000017 & 0.000018 & & & \\
\hline SESPMNT & B176F2 & BASIN CITY SCHOOL & COMMUNITY & AT & 08-Oct-03 & $\mathrm{U}-234$ & 0.0000491 & $\mathrm{pCi} / \mathrm{m} 3$ & 0.000014 & 0.000016 & & & \\
\hline SESPMNT & B17R31 & BASIN CITY SCHOOL & COMMUNITY & AT & 31-Dec-03 & U-234 & 0.0000317 & $7 \mathrm{pCi} / \mathrm{m} 3$ & 0.000012 & 0.000013 & & & \\
\hline SESPMNT & B168Y1 & BYERS LANDING & PERIMETER & AT & 10-Apr-03 & U-234 & 0.0000264 & $4 \mathrm{pCi} / \mathrm{m} 3$ & 0.000014 & 0.000015 & & & \\
\hline SESPMNT & B16R83 & BYERS LANDING & PERIMETER & AT & 07-Jul-03 & U-234 & 0.000042 & $2 \mathrm{pCi} / \mathrm{m} 3$ & 0.000014 & 0.000015 & & & \\
\hline SESPMNT & B17661 & BYERS LANDING & PERIMETER & AT & 10-Oct-03 & $\mathrm{U}-234$ & 0.0000694 & $4 \mathrm{pC} / \mathrm{m} 3$ & 0.000016 & 0.000019 & & & \\
\hline SESPMNT & B17PV0 & BYERS LANDING & PERIMETER & AT & 05-Jan-04 & $\mathrm{U}-234$ & 0.0000441 & $\mathrm{pCi} / \mathrm{m} 3$ & 0.000016 & 0.000018 & & & \\
\hline SESPMNT & B168X3 & DOGWOOD MET TOWER & PERIMETER & AT & 10-Apr-03 & U-234 & 0.0000265 & $5 \mathrm{pC} / \mathrm{m} 3$ & 0.000014 & 0.000015 & & & \\
\hline SESPMNT & B16R76 & DOGWOOD MET TOWER & PERIMETER & AT & 07-Jul-03 & U-234 & 0.0000343 & $3 \mathrm{pC} / \mathrm{m} 3$ & 0.000013 & 0.000014 & & & \\
\hline SESPMNT & B17653 & DOGWOOD MET TOWER & PERIMETER & AT & 10-Oct-03 & $\mathrm{U}-234$ & 0.0000755 & $5 \mathrm{pC} / \mathrm{m} 3$ & 0.000016 & 0.00002 & & & \\
\hline SESPMNT & B17PT3 & DOGWOOD MET TOWER & PERIMETER & AT & 05-Jan-04 & $\mathrm{U}-234$ & 0.0000275 & $5 \mathrm{pCi} / \mathrm{m} 3$ & 0.000014 & 0.000014 & & & \\
\hline SESPMNT & B16978 & EDWIN MARKHAM SCHOOL & COMMUNITY & AT & 10-Apr-03 & U-234 & 0.0000317 & $7 \mathrm{pCi} / \mathrm{m} 3$ & 0.000012 & 0.000013 & & & \\
\hline SESPMNT & B16RK8 & EDWIN MARKHAM SCHOOL & COMMUNITY & AT & 02-Jul-03 & U-234 & 0.000036 & $6 \mathrm{pC} / \mathrm{m} 3$ & 0.000011 & 0.000013 & & & \\
\hline SESPMNT & B176H8 & EDWIN MARKHAM SCHOOL & COMMUNITY & AT & 08-Oct-03 & $\mathrm{U}-234$ & 0.0000502 & $2 \mathrm{pC} / \mathrm{m} 3$ & 0.000015 & 0.000017 & & & \\
\hline SESPMNT & B17R45 & EDWIN MARKHAM SCHOOL & COMMUNITY & AT & 31-Dec-03 & U-234 & 0.0000273 & $3 \mathrm{pC} / \mathrm{m} 3$ & 0.000011 & 0.000012 & & & \\
\hline SESPMNT & B16970 & LESLIE GROVES-RCHLND & COMMUNITY & AT & 08-Apr-03 & $\mathrm{U}-234$ & 0.0000218 & $3 \mathrm{pCi} / \mathrm{m} 3$ & 0.0000081 & 0.000009 & & & \\
\hline SESPMNT & B16RK1 & LESLIE GROVES-RCHLND & COMMUNITY & AT & 01-Jul-03 & $3 \mathrm{U}-234$ & 0.0000253 & $3 \mathrm{pC} / \mathrm{m} 3$ & 0.000011 & 0.000012 & & & \\
\hline SESPMNT & B176HO & LESLIE GROVES-RCHLND & COMMUNITY & AT & $\begin{array}{l}07-O c t-03 \\
0\end{array}$ & $3 \mathrm{U}-234$ & 0.0000528 & $3 \mathrm{pCi} / \mathrm{m} 3$ & 0.000013 & 0.000015 & & & \\
\hline
\end{tabular}


AIR COMPOSITES AND I-129, H-3

\begin{tabular}{|c|c|c|c|c|c|c|c|c|c|c|c|c|c|}
\hline OWNER ID & SAMP NUM & SAMP SITE NAME & | DIST CLASS & MEDIA & SAMP DATE & $\begin{array}{c}\text { CON SHORT } \\
\text { NAME }\end{array}$ & VALUE RPTD & \begin{tabular}{|l|} 
ANAL \\
UNITS \\
RPTD
\end{tabular} & $\begin{array}{c}\text { COUNTING } \\
\text { ERROR }\end{array}$ & $\left|\begin{array}{c}\text { TOTAL ANAL } \\
\text { ERROR }\end{array}\right|$ & $\begin{array}{c}\text { LAB } \\
\text { QUALIFIER }\end{array}$ & SAMP COMMENT & | RESULT COMMENT \\
\hline SESPMNT & B17R38 & LESLIE GROVES-RCHLND & COMMUNITY & AT & 30-Dec-03 & $\mathrm{U}-234$ & 0.0000415 & $5 \mathrm{pCi} / \mathrm{m} 3$ & 0.000014 & $\quad 0.000016$ & & & \\
\hline SESPMNT & B168Y9 & PROSSER BARRICADE & PERIMETER & AT & 03-Apr-03 & $\mathrm{U}-234$ & 0.0000185 & $5 \mathrm{pCi} / \mathrm{m} 3$ & 0.0000066 & 0.0000073 & & & \\
\hline SESPMNT & B16R90 & PROSSER BARRICADE & PERIMETER & AT & 11-Jul-03 & $\mathrm{U}-234$ & 0.0000209 & $9 \mathrm{pCi} / \mathrm{m} 3$ & 0.0000061 & 0.000007 & & & \\
\hline SESPMNT & B17669 & PROSSER BARRICADE & PERIMETER & AT & $03-O c t-03$ & $\mathrm{U}-234$ & 0.0000284 & $4 \mathrm{pCi} / \mathrm{m} 3$ & 0.000011 & 0.000012 & & & \\
\hline SESPMNT & B17PV7 & PROSSER BARRICADE & PERIMETER & AT & 09-Jan-04 & U-234 & 0.0000218 & $3 \mathrm{pCi} / \mathrm{m} 3$ & 0.0000084 & 0.0000092 & & & \\
\hline SESPMNT & B16805 & TOPPENISH & DISTANT & AT & 02-Apr-03 & $\mathrm{U}-234$ & 0.0000189 & $9 \mathrm{pCi} / \mathrm{m} 3$ & 0.0000097 & 0.00001 & & & \\
\hline SESPMNT & B16PB9 & TOPPENISH & DISTANT & AT & 09-Jul-03 & $\mathrm{U}-234$ & 0.00000805 & $5 \mathrm{pCi} / \mathrm{m} 3$ & 0.0000094 & 0.0000096 & $u$ & & \\
\hline SESPMNT & B17589 & TOPPENISH & DISTANT & AT & 01-Oct-03 & $\mathrm{U}-234$ & 0.000034 & $4 \mathrm{pCi} / \mathrm{m} 3$ & 0.000013 & 0.000014 & & & \\
\hline SESPMNT & B17NX2 & TOPPENISH & DISTANT & AT & 08-Jan-04 & U-234 & 0.0000262 & $2 \mathrm{pCi} / \mathrm{m} 3$ & 0.0000094 & 0.00001 & & & \\
\hline SESPMNT & B168V7 & W END OF FIR ROAD & PERIMETER & AT & 10-Apr-03 & $\mathrm{U}-234$ & 0.0000185 & $5 \mathrm{pCi} / \mathrm{m} 3$ & 0.000011 & 0.000012 & & & \\
\hline SESPMNT & B16R62 & W END OF FIR ROAD & PERIMETER & AT & 07-Jul-03 & $\mathrm{U}-234$ & 0.0000174 & $4 \mathrm{pCi} / \mathrm{m} 3$ & 0.0000089 & 0.0000095 & & & \\
\hline SESPMNT & B17637 & W END OF FIR ROAD & PERIMETER & AT & $10-O c t-03$ & $\mathrm{U}-234$ & 0.0000348 & $3 \mathrm{pCi} / \mathrm{m} 3$ & 0.000013 & 0.000014 & & & \\
\hline SESPMNT & B17PP9 & W END OF FIR ROAD & PERIMETER & AT & 05-Jan-04 & U-234 & 0.000024 & $4 \mathrm{pCi} / \mathrm{m} 3$ & 0.000012 & 0.000013 & & & \\
\hline SESPMNT & B168V0 & WYE BARRICADE & ONSITE & AT & 31-Mar-03 & $3 \mathrm{U}-234$ & 0.0000104 & $4 \mathrm{pCi} / \mathrm{m} 3$ & 0.0000084 & 0.0000087 & & & \\
\hline SESPMNT & B16R54 & WYE BARRICADE & ONSITE & AT & 08-Jul-03 & $\mathrm{U}-234$ & 0.0000178 & $3 \mathrm{pCi} / \mathrm{m} 3$ & 0.000012 & 0.000013 & & & \\
\hline SESPMNT & B17630 & WYE BARRICADE & ONSITE & AT & 01-Oct-03 & $\mathrm{U}-234$ & 0.0000141 & $1 \mathrm{pCi} / \mathrm{m} 3$ & 0.0000088 & 0.0000093 & & & \\
\hline SESPMNT & B17PP1 & WYE BARRICADE & ONSITE & AT & 06-Jan-04 & U-234 & 0.0000213 & $3 \mathrm{pCi} / \mathrm{m} 3$ & 0.0000088 & $\begin{array}{l}3.0000095 \\
\end{array}$ & & & \\
\hline SESPMNT & B16955 & YAKIMA & DISTANT & AT & 03-Apr-03 & $\mathrm{U}-234$ & 0.0000126 & pCi/m3 & 0.0000083 & 0.0000087 & & & \\
\hline SESPMNT & B16RH6 & YAKIMA & DISTANT & AT & 11-Jul-03 & $\mathrm{U}-234$ & 0.0000228 & $3 \mathrm{pCi} / \mathrm{m} 3$ & 0.000015 & $\quad 0.000015$ & & & \\
\hline SESPMNT & B176D5 & YAKIMA & DISTANT & AT & 03-Oct-03 & $\mathrm{U}-234$ & 0.000024 & $4 \mathrm{pCi} / \mathrm{m} 3$ & 0.00001 & 0.000011 & & & \\
\hline SESPMNT & B17R23 & YAKIMA & DISTANT & AT & 09-Jan-04 & $\mathrm{U}-234$ & 0.0000161 & $1 \mathrm{pCi} / \mathrm{m} 3$ & 0.0000078 & \begin{tabular}{l|l}
3 & 0.0000082 \\
\end{tabular} & & & \\
\hline SESPMNT & B168F3 & 200 E AREA & ONSITE & AT & 08-Apr-03 & $\mathrm{U}-235$ & -0.000000967 & $7 \mathrm{pCi} / \mathrm{m} 3$ & 0.0000025 & 0.0000025 & u & & \\
\hline SESPMNT & B16PT7 & 200 E AREA & ONSITE & AT & 30-Jun-03 & U-235 & 0.000000314 & $4 \mathrm{pCi} / \mathrm{m} 3$ & 0.0000014 & $\begin{array}{l}0.0000015 \\
\end{array}$ & u & & \\
\hline SESPMNT & B175P3 & 200 E AREA & ONSITE & AT & 07-Oct-03 & U-235 & -0.000000172 & $2 \mathrm{pCi} / \mathrm{m} 3$ & 0.0000019 & 0.000002 & u & & \\
\hline SESPMNT & B17PB4 & 200 E AREA & ONSITE & AT & 30-Dec-03 & $\mathrm{U}-235$ & -0.000000239 & $9 \mathrm{pC} / \mathrm{m} 3$ & 0.00000048 & $\begin{array}{l}3 \\
3\end{array}$ & u & & \\
\hline SESPMNT & B168L8 & 200 W AREA & ONSITE & AT & 08-Apr-03 & $\mathrm{U}-235$ & & & & & & & LOST AT LAB. \\
\hline SESPMNT & B16PY6 & 200 W AREA & ONSITE & AT & 30-Jun-03 & $\mathrm{U}-235$ & -0.000000446 & $\mathrm{pCC} / \mathrm{m} 3$ & 0.0000017 & 0.0000021 & u & & \\
\hline SESPMNT & B175W8 & 200 W AREA & ONSITE & AT & 07-Oct-03 & $\mathrm{U}-235$ & -0.000000441 & $1 \mathrm{pCi} / \mathrm{m} 3$ & 0.0000023 & $\begin{array}{l}3.0000025 \\
\end{array}$ & u & & \\
\hline SESPMNT & B17PH3 & 200 W AREA & ONSITE & AT & 30-Dec-03 & U-235 & -0.000000206 & $5 \mathrm{pC} / \mathrm{m} 3$ & 0.0000043 & $\begin{array}{ll}3 & 0.0000043\end{array}$ & u & & \\
\hline SESPMNT & B168J6 & 200 W SOUTH EAST & ONSITE & AT & 08-Apr-03 & $\mathrm{U}-235$ & 0.00000016 & $\mathrm{pCi} / \mathrm{m} 3$ & 0.000002 & 0.000002 & $u$ & & \\
\hline SESPMNT & B16PW7 & 200 W SOUTH EAST & ONSITE & AT & 30-Jun-03 & U-235 & 0.000000201 & $1 \mathrm{pC} / \mathrm{m} 3$ & 0.0000009 & 0.00000097 & u & & \\
\hline SESPMNT & B175T6 & 200 W SOUTH EAST & ONSITE & AT & 07-Oct-03 & $\mathrm{U}-235$ & 0.000000133 & $3 \mathrm{pCi} / \mathrm{m} 3$ & 0.00000071 & 0.00000077 & u & & \\
\hline SESPMNT & B17PD4 & 200 W SOUTH EAST & ONSITE & AT & 30-Dec-03 & $\mathrm{U}-235$ & 0.000000868 & $3 \mathrm{pC} / \mathrm{m} 3$ & 0.0000013 & 30.0000013 & $u$ & & \\
\hline SESPMNT & B168M6 & 300 AREA & ONSITE & AT & 02-Apr-03 & $\mathrm{U}-235$ & 0.000000446 & $\mathrm{pCi} / \mathrm{m} 3$ & 0.0000015 & 5.0000015 & $u$ & & \\
\hline SESPMNT & B16R03 & 300 AREA & ONSITE & AT & 10-Jul-03 & U-235 & 0.00000131 & $\mathrm{pCC} / \mathrm{m} 3$ & 0.0000022 & 0.0000022 & u & & \\
\hline SESPMNT & B175X6 & 300 AREA & ONSITE & AT & 30-Sep-03 & $\mathrm{U}-235$ & 0.000000226 & $\mathrm{pCi} / \mathrm{m} 3$ & 0.0000013 & $\begin{array}{l}3.0000014 \\
\end{array}$ & $u$ & & \\
\hline SESPMNT & B17PJo & 300 AREA & ONSITE & AT & 08-Jan-04 & $\mathrm{U}-235$ & 0.0000015 & $5 \mathrm{pC} / \mathrm{m} 3$ & 0.0000021 & 0.0000021 & $u$ & & \\
\hline SESPMNT & B167V4 & $300 \mathrm{NE}$ & ONSITE & AT & 02-Apr-03 & $\mathrm{U}-235$ & 0.0000011 & $1 \mathrm{pCi} / \mathrm{m} 3$ & 0.0000053 & 0.0000055 & u & & \\
\hline SESPMNT & B16P66 & $300 \mathrm{NE}$ & ONSITE & AT & 10-Jul-03 & U-235 & 0.00000398 & $3 \mathrm{pCi} / \mathrm{m} 3$ & 0.0000078 & 0.000008 & u & & \\
\hline SESPMNT & B17548 & $300 \mathrm{NE}$ & ONSITE & AT & 30-Sep-03 & $\mathrm{U}-235$ & 0.00000131 & $1 \mathrm{pCi} / \mathrm{m} 3$ & 0.0000031 & 0.0000033 & $u$ & & \\
\hline SESPMNT & B17NP7 & $300 \mathrm{NE}$ & ONSITE & AT & 08-Jan-04 & $\mathrm{U}-235$ & 0.0000037 & $7 \mathrm{pCi} / \mathrm{m} 3$ & 0.0000069 & 0.000007 & $u$ & & \\
\hline SESPMNT & B167V3 & 300 TRENCH & ONSITE & AT & 02-Apr-03 & $\mathrm{U}-235$ & 0.00000468 & $3 \mathrm{pCi} / \mathrm{m} 3$ & 0.0000049 & 0.0000051 & u & & \\
\hline SESPMNT & B16P65 & 300 TRENCH & ONSITE & AT & 10-Jul-03 & $\mathrm{U}-235$ & -0.000000432 & $2 \mathrm{pCi} / \mathrm{m} 3$ & 0.0000047 & 0.0000048 & $u$ & & \\
\hline SESPMNT & B17547 & 300 TRENCH & ONSITE & AT & 30-Sep-03 & $\mathrm{U}-235$ & 0.000000771 & $1 \mathrm{pCi} / \mathrm{m} 3$ & 0.000003 & $\begin{array}{l}3.0000032 \\
\end{array}$ & $u$ & & \\
\hline SESPMNT & B17NP6 & 300 TRENCH & ONSITE & AT & 08-Jan-04 & U-235 & 0.00000645 & $5 \mathrm{pC} / \mathrm{m} 3$ & 0.0000084 & 0.0000085 & u & & \\
\hline SESPMNT & $\mathrm{B} 168 \mathrm{H} 8$ & B POND & ONSITE & AT & 08-Apr-03 & $\mathrm{U}-235$ & 0.00000126 & $\mathrm{pCC} / \mathrm{m} 3$ & 0.0000035 & 0.0000037 & u & & \\
\hline SESPMNT & B16PW0 & B POND & ONSITE & AT & 30-Jun-03 & U-235 & -0.00000265 & $5 \mathrm{pCi} / \mathrm{m} 3$ & 0.0000064 & 0.0000065 & $u$ & & \\
\hline SESPMNT & B175R8 & B POND & ONSITE & AT & $07-0 c t-03$ & $\mathrm{U}-235$ & -0.0000011 & $1 \mathrm{pCi} / \mathrm{m} 3$ & 0.0000029 & 0.000003 & $u$ & & \\
\hline SESPMNT & B17PC7 & B POND & ONSITE & AT & 30-Dec-03 & U-235 & -0.000000214 & $4 \mathrm{pCi} / \mathrm{m} 3$ & 0.0000026 & 0.0000026 & u & & \\
\hline SESPMNT & B16962 & BASIN CITY SCHOOL & COMMUNITY & AT & 09-Apr-03 & U U-235 & -0.00000483 & $3 \mathrm{pCi} / \mathrm{m} 3$ & 0.0000053 & $\begin{array}{l}3 \quad 0.0000054 \\
\end{array}$ & $u$ & & \\
\hline SESPMNT & B16RJ4 & BASIN CITY SCHOOL & COMMUNITY & AT & 02-Jul-03 & $\mathrm{U}-235$ & -0.00000462 & $2 \mathrm{pCi} / \mathrm{m} 3$ & 0.0000074 & 0.0000075 & $u$ & & \\
\hline SESPMNT & B176F2 & BASIN CITY SCHOOL & COMMUNITY & AT & $08-0 c t-03$ & $\mathrm{U}-235$ & 0.00000151 & $1 \mathrm{pCi} / \mathrm{m} 3$ & 0.000004 & 0.0000042 & u & & \\
\hline SESPMNT & B17R31 & BASIN CITY SCHOOL & COMMUNITY & AT & 31-Dec-03 & $\mathrm{U}-235$ & $2.83 \mathrm{E}-10$ & $\mathrm{pCi} / \mathrm{m} 3$ & 0.0000032 & 0.0000032 & $u$ & & \\
\hline SESPMNT & B168Y1 & BYERS LANDING & PERIMETER & AT & 10-Apr-03 & $\mathrm{U}-235$ & -0.00000116 & $5 \mathrm{pCi} / \mathrm{m} 3$ & 0.0000047 & 0.0000048 & u & & \\
\hline SESPMNT & B16R83 & BYERS LANDING & PERIMETER & AT & 07-Jul-03 & $\mathrm{U}-235$ & 0.000000702 & $2 \mathrm{pCi} / \mathrm{m} 3$ & 0.0000029 & 0.0000031 & $u$ & & \\
\hline SESPMNT & B17661 & BYERS LANDING & PERIMETER & AT & 10-Oct-03 & $\mathrm{U}-235$ & -0.000000424 & $4 \mathrm{pCi} / \mathrm{m} 3$ & 0.0000017 & 0.000002 & u & & \\
\hline SESPMNT & B17PV0 & BYERS LANDING & PERIMETER & AT & 05-Jan-04 & $\mathrm{U}-235$ & 0.00000389 & $9 \mathrm{pCi} / \mathrm{m} 3$ & 0.0000058 & 0.0000058 & U & & \\
\hline SESPMNT & B168X3 & DOGWOOD MET TOWER & PERIMETER & AT & 10-Apr-03 & U-235 & 0.000000448 & $3 \mathrm{pC} / \mathrm{m} 3$ & 0.0000032 & 0.0000033 & u & & \\
\hline
\end{tabular}


AIR COMPOSITES AND I-129, H-3

\begin{tabular}{|c|c|c|c|c|c|c|c|c|c|c|c|c|c|}
\hline | OWNER ID & SAMP NUM & SAMP SITE NAME & | DIST CLASS & MEDIA & SAMP DATE & $\left|\begin{array}{c}\text { CON SHORT } \\
\text { NAME }\end{array}\right|$ & VALUE RPTD & \begin{tabular}{|l|} 
ANAL \\
UNITS \\
RPTD
\end{tabular} & $\begin{array}{l}\text { COUNTING } \\
\text { ERROR }\end{array}$ & $\left|\begin{array}{c}\text { TOTAL ANAL } \\
\text { ERROR }\end{array}\right|$ & $\begin{array}{c}\text { LAB } \\
\text { QUALIFIER }\end{array}$ & SAMP COMMENT & RESULT COMMENT \\
\hline SESPMNT & B16R76 & DOGWOOD MET TOWER & PERIMETER & AT & 07-Jul-03 & $\mathrm{U}-235$ & -0.000000298 & $3 \mathrm{pCi} / \mathrm{m} 3$ & 0.000002 & 0.0000023 & u & & \\
\hline SESPMNT & B17653 & DOGWOOD MET TOWER & PERIMETER & AT & $10-0 c t-034$ & $\mathrm{U}-235$ & 0.00000302 & $2 \mathrm{pC} / \mathrm{m} 3$ & 0.0000037 & 0.0000039 & u & & \\
\hline SESPMNT & B17PT3 & DOGWOOD MET TOWER & PERIMETER & AT & 05-Jan-04 L & $\mathrm{U}-235$ & 0.00000131 & $1 \mathrm{pCi} / \mathrm{m} 3$ & 0.0000058 & $\begin{array}{l}3.0000059 \\
\end{array}$ & $u$ & & \\
\hline SESPMNT & B16978 & EDWIN MARKHAM SCHOOL & COMMUNITY & AT & 10-Apr-03 L & $\mathrm{U}-235$ & -0.00000108 & $3 \mathrm{pC} / \mathrm{m} 3$ & 0.0000028 & 0.0000028 & $\mathrm{U}$ & & \\
\hline SESPMNT & B16RK8 & EDWIN MARKHAM SCHOOL & COMMUNITY & AT & 02-Jul-03 & $\mathrm{U}-235$ & 0.00000113 & $3 \mathrm{pCi} / \mathrm{m} 3$ & 0.0000028 & $\begin{array}{l}0.000003 \\
\end{array}$ & u & & \\
\hline SESPMNT & B176H8 & EDWIN MARKHAM SCHOOL & COMMUNITY & AT & $08-0 c t-03$ & $\mathrm{U}-235$ & 0.000000236 & $\mathrm{p} \mathrm{C} / \mathrm{m} 3$ & 0.0000046 & 0.0000047 & u & & \\
\hline SESPMNT & B17R45 & EDWIN MARKHAM SCHOOL & COMMUNITY & AT & 31-Dec-03 L & $\mathrm{U}-235$ & 0.0000021 & $1 \mathrm{pCi} / \mathrm{m} 3$ & 0.000003 & 0.000003 & u & & \\
\hline SESPMNT & B16970 & LESLIE GROVES-RCHLND & COMMUNITY & AT & 08-Apr-03 L & $\mathrm{U}-235$ & -0.0000011 & $1 \mathrm{pC} / \mathrm{m} 3$ & 0.000002 & 0.0000022 & $\mathrm{U}$ & & \\
\hline SESPMNT & B16RK1 & LESLIE GROVES-RCHLND & COMMUNITY & AT & $01-J u l-03$ L & $\mathrm{U}-235$ & -0.000000277 & $7 \mathrm{pC} / \mathrm{m} 3$ & 0.000002 & 0.0000023 & u & & \\
\hline SESPMNT & B176HO & LESLIE GROVES-RCHLND & COMMUNITY & AT & $07-0 c t-034$ & $\mathrm{U}-235$ & -0.0000011 & $1 \mathrm{pCi} / \mathrm{m} 3$ & 0.0000034 & 0.0000035 & u & & \\
\hline SESPMNT & B17R38 & LESLIE GROVES-RCHLND & COMMUNITY & AT & 30-Dec-03 L & $\mathrm{U}-235$ & 0.00000115 & $5 \mathrm{pCi} / \mathrm{m} 3$ & 0.000004 & 0.000004 & u & & \\
\hline SESPMNT & B168Y9 & PROSSER BARRICADE & PERIMETER & AT & 03-Apr-03 & $\mathrm{U}-235$ & 0.00000067 & $7 \mathrm{pCi} / \mathrm{m} 3$ & 0.0000018 & $\begin{array}{ll} & 0.0000019\end{array}$ & u & & \\
\hline SESPMNT & B16R90 & PROSSER BARRICADE & PERIMETER & AT & 11-Jul-03 & $U-235$ & 0.00000257 & $7 \mathrm{pCi} / \mathrm{m} 3$ & 0.0000025 & 0.0000026 & u & & \\
\hline SESPMNT & B17669 & PROSSER BARRICADE & PERIMETER & AT & 03-Oct-03 L & $\mathrm{U}-235$ & 0.000000985 & $5 \mathrm{pCi} / \mathrm{m} 3$ & 0.0000034 & 0.0000035 & u & & \\
\hline SESPMNT & B17PV7 & PROSSER BARRICADE & PERIMETER & AT & $09-J a n-04 L$ & $U-235$ & 0.00000101 & $1 \mathrm{pC} / \mathrm{m} 3$ & 0.0000028 & 0.0000028 & u & & \\
\hline SESPMNT & B16805 & TOPPENISH & DISTANT & AT & 02-Apr-03 L & $\mathrm{U}-235$ & -0.00000129 & $9 \mathrm{pC} / \mathrm{m} 3$ & 0.0000034 & 0.0000036 & u & & \\
\hline SESPMNT & B16PB9 & TOPPENISH & DISTANT & AT & 09-Jul-03 & $U-235$ & -0.00000342 & $2 \mathrm{pC} / \mathrm{m} 3$ & 0.0000034 & 0.0000036 & u & & \\
\hline SESPMNT & B17589 & TOPPENISH & DISTANT & AT & $01-O c t-034$ & $\mathrm{U}-235$ & 0.00000173 & $3 \mathrm{pCi} / \mathrm{m} 3$ & 0.0000045 & 0.0000047 & u & & \\
\hline SESPMNT & B17NX2 & TOPPENISH & DISTANT & AT & 08-Jan-04 L & $\mathrm{U}-235$ & 0.000000845 & $5 \mathrm{pC} / \mathrm{m} 3$ & 0.0000017 & 0.0000017 & u & & \\
\hline SESPMNT & B168V7 & W END OF FIR ROAD & PERIMETER & AT & 10-Apr-03 L & $\mathrm{U}-235$ & 0.00000133 & $3 \mathrm{pC} / \mathrm{m} 3$ & 0.0000037 & 0.0000038 & $u$ & & \\
\hline SESPMNT & B16R62 & W END OF FIR ROAD & PERIMETER & AT & 07-Jul-03 L & U-235 & 0.00000129 & $9 \mathrm{pC} / \mathrm{m} 3$ & 0.000003 & 0.0000032 & u & & \\
\hline SESPMNT & B17637 & W END OF FIR ROAD & PERIMETER & AT & 10-Oct-03 L & $\mathrm{U}-235$ & -0.000000365 & $5 \mathrm{pC} / \mathrm{m} 3$ & 0.0000041 & \begin{tabular}{|l|}
0.0000042 \\
\end{tabular} & u & & \\
\hline SESPMNT & B17PP9 & W END OF FIR ROAD & PERIMETER & AT & 05-Jan-04 L & $\mathrm{U}-235$ & 0.00000089 & $9 \mathrm{pC} / \mathrm{m} 3$ & 0.0000053 & $\begin{array}{l}3 \\
\end{array}$ & $u$ & & \\
\hline SESPMNT & B168V0 & WYE BARRICADE & ONSITE & AT & 31-Mar-03 L & $\mathrm{U}-235$ & -0.00000249 & $9 \mathrm{pC} / \mathrm{m} 3$ & 0.000004 & $\begin{array}{l}0.0000042 \\
\end{array}$ & u & & \\
\hline SESPMNT & B16R54 & WYE BARRICADE & ONSITE & AT & 08-Jul-03 L & U-235 & -0.00000274 & $4 \mathrm{pC} / \mathrm{m} 3$ & 0.0000047 & 0.0000048 & u & & \\
\hline SESPMNT & B17630 & WYE BARRICADE & ONSITE & AT & $01-\mathrm{Oct}-03 \mathrm{~L}$ & $\mathrm{U}-235$ & -0.00000127 & $7 \mathrm{pC} / \mathrm{m} 3$ & 0.0000026 & 0.0000026 & u & & \\
\hline SESPMNT & B17PP1 & WYE BARRICADE & ONSITE & AT & 06-Jan-04 L & $\mathrm{U}-235$ & 0.00000255 & $5 \mathrm{pC} / \mathrm{m} 3$ & 0.0000045 & 0.0000045 & $u$ & & \\
\hline SESPMNT & B16955 & YAKIMA & DISTANT & AT & 03-Apr-03 L & $\mathrm{U}-235$ & -0.000000498 & $3 \mathrm{pC} / \mathrm{m} 3$ & 0.0000033 & $\begin{array}{l}3 \\
0.0000035\end{array}$ & u & & \\
\hline SESPMNT & B16RH6 & YAKIMA & DISTANT & AT & 11-Jul-03 L & U-235 & 0.00000267 & $7 \mathrm{pC} / \mathrm{m} 3$ & 0.0000076 & 0.0000077 & u & & \\
\hline SESPMNT & B176D5 & YAKIMA & DISTANT & AT & 03-Oct-03 L & $\mathrm{U}-235$ & 0.00000269 & $9 \mathrm{pC} / \mathrm{m} 3$ & 0.0000042 & 0.0000044 & u & & \\
\hline SESPMNT & B17R23 & YAKIMA & DISTANT & AT & 09-Jan-04 L & $\mathrm{U}-235$ & 0.000000946 & $\mathrm{p} \mathrm{pC} / \mathrm{m} 3$ & 0.0000019 & 0.0000019 & u & & \\
\hline SESPMNT & B168F3 & 200 E AREA & ONSITE & AT & 08-Apr-03 L & $\mathrm{U}-238$ & 0.0000179 & $9 \mathrm{pC} / \mathrm{m} 3$ & 0.0000073 & $\begin{array}{l}3 \\
3\end{array}$ & & & \\
\hline SESPMNT & B16PT7 & 200 E AREA & ONSITE & AT & 30-Jun-03 L & $\mathrm{U}-238$ & 0.0000141 & $1 \mathrm{pC} / \mathrm{m} 3$ & 0.0000056 & 0.0000062 & & & \\
\hline SESPMNT & B175P3 & 200 E AREA & ONSITE & AT & $07-0 c t-034$ & $\mathrm{U}-238$ & 0.0000178 & $3 \mathrm{pC} / \mathrm{m} 3$ & 0.0000059 & 0.0000067 & & & \\
\hline SESPMNT & B17PB4 & 200 E AREA & ONSITE & AT & 30-Dec-03 L & $\mathrm{U}-238$ & 0.0000242 & $2 \mathrm{pCi} / \mathrm{m} 3$ & 0.0000077 & 0.0000086 & & & \\
\hline SESPMNT & B168L8 & 200 W AREA & ONSITE & AT & 08-Apr-03 L & $\mathrm{U}-238$ & & & & & & & LOST AT LAB. \\
\hline SESPMNT & B16PY6 & 200 W AREA & ONSITE & AT & 30-Jun-03 L & $\mathrm{U}-238$ & 0.0000273 & $3 \mathrm{pCi} / \mathrm{m} 3$ & 0.00001 & 0.000011 & & & \\
\hline SESPMNT & B175W8 & 200 W AREA & ONSITE & AT & $07-0 c t-034$ & $\mathrm{U}-238$ & 0.0000268 & $3 \mathrm{pC} / \mathrm{m} 3$ & 0.000009 & 0.00001 & & & \\
\hline SESPMNT & B17PH3 & 200 W AREA & ONSITE & AT & 30-Dec-03 L & $\mathrm{U}-238$ & 0.000164 & $4 \mathrm{pC} / \mathrm{m} 3$ & 0.000026 & 0.000037 & & & \\
\hline SESPMNT & B168J6 & 200 W SOUTH EAST & ONSITE & AT & 08-Apr-03 L & $\mathrm{U}-238$ & 0.0000163 & $3 \mathrm{pC} / \mathrm{m} 3$ & 0.0000045 & 0.0000053 & & & \\
\hline SESPMNT & B16PW7 & 200 W SOUTH EAST & ONSITE & AT & 30-Jun-03 L & $\mathrm{U}-238$ & 0.0000152 & $2 \mathrm{pC} / \mathrm{m} 3$ & 0.0000045 & 0.0000052 & & & \\
\hline SESPMNT & B175T6 & 200 W SOUTH EAST & ONSITE & AT & 07-Oct-03 & $\mathrm{U}-238$ & 0.0000219 & $9 \mathrm{pC} / \mathrm{m} 3$ & 0.0000049 & 0.0000061 & & & \\
\hline SESPMNT & B17PD4 & 200 W SOUTH EAST & ONSITE & AT & 30-Dec-03 L & $\mathrm{U}-238$ & 0.0000217 & $7 \mathrm{pC} / \mathrm{m} 3$ & 0.0000053 & 0.0000063 & & & \\
\hline SESPMNT & B168M6 & 300 AREA & ONSITE & AT & 02-Apr-03 L & $\mathrm{U}-238$ & 0.0000226 & $5 \mathrm{pC} / \mathrm{m} 3$ & 0.0000062 & 0.0000073 & & & \\
\hline SESPMNT & B16R03 & 300 AREA & ONSITE & AT & 10-Jul-03 & $\mathrm{U}-238$ & 0.0000174 & $4 \mathrm{pC} / \mathrm{m} 3$ & 0.0000063 & 0.000007 & & & \\
\hline SESPMNT & B175X6 & 300 AREA & ONSITE & AT & 30-Sep-03 L & $\mathrm{U}-238$ & 0.0000399 & $9 \mathrm{pC} / \mathrm{m} 3$ & 0.0000074 & 0.0000099 & & & \\
\hline SESPMNT & B17PJ0 & 300 AREA & ONSITE & AT & 08-Jan-04 L & $\mathrm{U}-238$ & 0.0000361 & $1 \mathrm{pC} / \mathrm{m} 3$ & 0.0000075 & 0.0000096 & & & \\
\hline SESPMNT & B167V4 & $300 \mathrm{NE}$ & ONSITE & AT & 02-Apr-03 & $\mathrm{U}-238$ & 0.0000151 & $1 \mathrm{pC} / \mathrm{m} 3$ & 0.000011 & 0.000012 & & & \\
\hline SESPMNT & B16P66 & $300 \mathrm{NE}$ & ONSITE & AT & 10-Jul-03 L & $\mathrm{U}-238$ & 0.0000269 & $9 \mathrm{pC} / \mathrm{m} 3$ & 0.000018 & 0.000018 & & & \\
\hline SESPMNT & B17548 & $300 \mathrm{NE}$ & ONSITE & AT & 30-Sep-03 L & $\mathrm{U}-238$ & 0.0000385 & $5 \mathrm{pC} / \mathrm{m} 3$ & 0.000012 & 0.000014 & & & \\
\hline SESPMNT & B17NP7 & $300 \mathrm{NE}$ & ONSITE & AT & 08-Jan-04 L & $\mathrm{U}-238$ & 0.000103 & $3 \mathrm{pC} / \mathrm{m} 3$ & 0.000023 & 0.000028 & & & \\
\hline SESPMNT & B167V3 & 300 TRENCH & ONSITE & AT & 02-Apr-03 & $\mathrm{U}-238$ & 0.0000191 & $1 \mathrm{pC} / \mathrm{m} 3$ & 0.000014 & 0.000015 & U & & \\
\hline SESPMNT & B16P65 & 300 TRENCH & ONSITE & AT & 10-Jul-03 L & $\mathrm{U}-238$ & 0.0000428 & $3 \mathrm{pC} / \mathrm{m} 3$ & 0.000013 & 0.000015 & & & \\
\hline SESPMNT & B17547 & 300 TRENCH & ONSITE & AT & 30-Sep-03 L & $\mathrm{U}-238$ & 0.0000415 & $5 \mathrm{pC} / \mathrm{m} 3$ & 0.000014 & 0.000016 & & & \\
\hline SESPMNT & B17NP6 & 300 TRENCH & ONSITE & AT & 08-Jan-04 L & $\mathrm{U}-238$ & 0.0000891 & $1 \mathrm{pC} / \mathrm{m} 3$ & 0.000023 & 0.000028 & & & \\
\hline SESPMNT & B168H8 & B POND & ONSITE & AT & 08-Apr-03 L & $\mathrm{U}-238$ & 0.0000196 & $5 \mathrm{pC} / \mathrm{m} 3$ & 0.00001 & 0.000011 & & & \\
\hline SESPMNT & B16PW0 & B POND & ONSITE & AT & 30-Jun-03 L & $\mathrm{U}-238$ & 0.0000268 & $3 \mathrm{pC} / \mathrm{m} 3$ & 0.000014 & 0.000015 & & & \\
\hline SESPMNT & B175R8 & B POND & ONSITE & AT & 07-Oct-03 L & $\mathrm{U}-238$ & 0.0000209 & $9 \mathrm{pC} / \mathrm{m} 3$ & 0.000013 & 0.000013 & & & \\
\hline
\end{tabular}


AIR COMPOSITES AND I-129, H-3

\begin{tabular}{|c|c|c|c|c|c|c|c|c|c|c|c|c|c|}
\hline OWNER ID & SAMP NUM & SAMP SITE NAME & DIST CLASS & MEDIA & SAMP DATE & $\left|\begin{array}{c}\text { CON SHORT } \\
\text { NAME }\end{array}\right|$ & VALUE RPTD & \begin{tabular}{|l|} 
ANAL \\
UNITS \\
RPTD
\end{tabular} & $\begin{array}{c}\text { COUNTING } \\
\text { ERROR }\end{array}$ & $\left|\begin{array}{c}\text { TOTAL ANAL } \\
\text { ERROR }\end{array}\right|$ & $\begin{array}{c}\text { LAB } \\
\text { QUALIFIER }\end{array}$ & SAMP COMMENT & | RESULT COMMENT | \\
\hline SESPMNT & B17PC7 & B POND & ONSITE & AT & 30-Dec-03 & U-238 & 0.0000195 & $\mathrm{pCi} / \mathrm{m} 3$ & 0.0000094 & 0.0000099 & & & \\
\hline SESPMNT & B16962 & BASIN CITY SCHOOL & COMMUNITY & AT & 09-Apr-03 & $\mathrm{U}-238$ & 0.0000162 & $\mathrm{pCi} / \mathrm{m} 3$ & 0.000012 & 0.000012 & & & \\
\hline SESPMNT & B16RJ4 & BASIN CITY SCHOOL & COMMUNITY & AT & 02-Jul-03 & $\mathrm{U}-238$ & 0.0000359 & $\mathrm{pCi} / \mathrm{m} 3$ & 0.000017 & 0.000018 & & & \\
\hline SESPMNT & B176F2 & BASIN CITY SCHOOL & COMMUNITY & AT & $08-0 c t-03$ & $\mathrm{U}-238$ & 0.0000395 & $\mathrm{pCi} / \mathrm{m} 3$ & 0.000012 & 0.000014 & & & \\
\hline SESPMNT & B17R31 & BASIN CITY SCHOOL & COMMUNITY & AT & 31-Dec-03 & $\mathrm{U}-238$ & 0.0000317 & $\mathrm{pCi} / \mathrm{m} 3$ & 0.000012 & 0.000013 & & & \\
\hline SESPMNT & B168Y1 & BYERS LANDING & PERIMETER & AT & 10-Apr-03 & $\mathrm{U}-238$ & 0.0000258 & $\mathrm{pCi} / \mathrm{m} 3$ & 0.000016 & 0.000017 & & & \\
\hline SESPMNT & B16R83 & BYERS LANDING & PERIMETER & AT & 07-Jul-03 & $\mathrm{U}-238$ & 0.0000443 & $\mathrm{pCi} / \mathrm{m} 3$ & 0.000014 & 0.000016 & & & \\
\hline SESPMNT & B17661 & BYERS LANDING & PERIMETER & AT & $10-$ Oct-03 & $\mathrm{U}-238$ & 0.0000612 & $\mathrm{pCi} / \mathrm{m} 3$ & 0.000015 & 0.000018 & & & \\
\hline SESPMNT & B17PV0 & BYERS LANDING & PERIMETER & AT & 05-Jan-04 & $\mathrm{U}-238$ & 0.0000428 & $\mathrm{pCi} / \mathrm{m} 3$ & 0.000015 & 0.000016 & & & \\
\hline SESPMNT & B168X3 & DOGWOOD MET TOWER & PERIMETER & AT & 10-Apr-03 & $\mathrm{U}-238$ & 0.0000133 & $\mathrm{pCi} / \mathrm{m} 3$ & 0.00001 & 0.00001 & & & \\
\hline SESPMNT & B16R76 & DOGWOOD MET TOWER & PERIMETER & AT & 07-Jul-03 & $\mathrm{U}-238$ & 0.0000438 & $\mathrm{pCi} / \mathrm{m} 3$ & 0.000014 & 0.000016 & & & \\
\hline SESPMNT & B17653 & DOGWOOD MET TOWER & PERIMETER & AT & $10-$ Oct-03 & $\mathrm{U}-238$ & 0.0000599 & $\mathrm{pCi} / \mathrm{m} 3$ & 0.000015 & 0.000018 & & & \\
\hline SESPMNT & B17PT3 & DOGWOOD MET TOWER & PERIMETER & AT & 05-Jan-04 & $\mathrm{U}-238$ & 0.0000288 & $\mathrm{pCi} / \mathrm{m} 3$ & 0.000013 & 0.000014 & & & \\
\hline SESPMNT & B16978 & EDWIN MARKHAM SCHOOL & COMMUNITY & AT & 10-Apr-03 & $\mathrm{U}-238$ & 0.000016 & $\mathrm{pCi} / \mathrm{m} 3$ & 0.0000089 & 0.0000095 & & & \\
\hline SESPMNT & B16RK8 & EDWIN MARKHAM SCHOOL & COMMUNITY & AT & 02-Jul-03 & $\mathrm{U}-238$ & 0.0000345 & $\mathrm{pCi} / \mathrm{m} 3$ & 0.000011 & 0.000013 & & & \\
\hline SESPMNT & B176H8 & EDWIN MARKHAM SCHOOL & COMMUNITY & AT & 08-Oct-03 & $\mathrm{U}-238$ & 0.0000383 & $\mathrm{pCi} / \mathrm{m} 3$ & 0.000012 & 0.000013 & & & \\
\hline SESPMNT & B17R45 & EDWIN MARKHAM SCHOOL & COMMUNITY & AT & 31-Dec-03 & $\mathrm{U}-238$ & 0.0000294 & $\mathrm{pCi} / \mathrm{m} 3$ & 0.000011 & 0.000012 & & & \\
\hline SESPMNT & B16970 & LESLIE GROVES-RCHLND & COMMUNITY & AT & 08-Apr-03 & $\mathrm{U}-238$ & 0.0000184 & $\mathrm{pCi} / \mathrm{m} 3$ & 0.0000081 & 0.0000089 & & & \\
\hline SESPMNT & B16RK1 & LESLIE GROVES-RCHLND & COMMUNITY & AT & 01-Jul-03 & $\mathrm{U}-238$ & 0.0000175 & $\mathrm{pCi} / \mathrm{m} 3$ & 0.0000092 & 0.0000098 & & & \\
\hline SESPMNT & B176Ho & LESLIE GROVES-RCHLND & COMMUNITY & AT & 07-Oct-03 & $\mathrm{U}-238$ & 0.0000187 & $\mathrm{pCi} / \mathrm{m} 3$ & 0.0000092 & 0.0000099 & & & \\
\hline SESPMNT & B17R38 & LESLIE GROVES-RCHLND & COMMUNITY & AT & 30-Dec-03 & $\mathrm{U}-238$ & 0.0000381 & $\mathrm{pCi} / \mathrm{m} 3$ & 0.000013 & 0.000015 & & & \\
\hline SESPMNT & B168Y9 & PROSSER BARRICADE & PERIMETER & AT & 03-Apr-03 & $\mathrm{U}-238$ & 0.0000205 & $\mathrm{pCi} / \mathrm{m} 3$ & 0.0000068 & $\quad 0.0000077$ & & & \\
\hline SESPMNT & B16R90 & PROSSER BARRICADE & PERIMETER & AT & 11-Jul-03 & $\mathrm{U}-238$ & 0.0000195 & $\mathrm{pCi} / \mathrm{m} 3$ & 0.000006 & 0.0000069 & & & \\
\hline SESPMNT & B17669 & PROSSER BARRICADE & PERIMETER & AT & 03-Oct-03 & $\mathrm{U}-238$ & 0.000024 & $\mathrm{pCi} / \mathrm{m} 3$ & 0.00001 & 0.000011 & & & \\
\hline SESPMNT & B17PV7 & PROSSER BARRICADE & PERIMETER & AT & 09-Jan-04 & $\mathrm{U}-238$ & 0.0000228 & $\mathrm{pCi} / \mathrm{m} 3$ & 0.0000082 & 0.000009 & & & \\
\hline SESPMNT & B16805 & TOPPENISH & DISTANT & AT & 02-Apr-03 & $\mathrm{U}-238$ & 0.0000266 & $\mathrm{pCi} / \mathrm{m} 3$ & 0.000011 & 0.000012 & & & \\
\hline SESPMNT & B16PB9 & TOPPENISH & DISTANT & AT & 09-Jul-03 & $\mathrm{U}-238$ & 0.0000167 & $\mathrm{pCi} / \mathrm{m} 3$ & 0.0000088 & 0.0000095 & & & \\
\hline SESPMNT & B17589 & TOPPENISH & DISTANT & AT & 01-Oct-03 & $\mathrm{U}-238$ & 0.0000151 & $\mathrm{pCi} / \mathrm{m} 3$ & 0.0000099 & 0.00001 & & & \\
\hline SESPMNT & B17NX2 & TOPPENISH & DISTANT & AT & 08-Jan-04 & $\mathrm{U}-238$ & 0.0000279 & $\mathrm{pCi} / \mathrm{m} 3$ & 0.00001 & 0.000011 & & & \\
\hline SESPMNT & B168V7 & W END OF FIR ROAD & PERIMETER & AT & 10-Apr-03 & $\mathrm{U}-238$ & 0.000018 & $\mathrm{pCi} / \mathrm{m} 3$ & 0.0000097 & 0.00001 & & & \\
\hline SESPMNT & B16R62 & W END OF FIR ROAD & PERIMETER & AT & 07-Jul-03 & $\mathrm{U}-238$ & 0.0000313 & $\mathrm{pCi} / \mathrm{m} 3$ & 0.000011 & 0.000012 & & & \\
\hline SESPMNT & B17637 & W END OF FIR ROAD & PERIMETER & AT & $10-$ Oct-03 & $\mathrm{U}-238$ & 0.0000465 & $\mathrm{pCi} / \mathrm{m} 3$ & 0.000013 & 0.000015 & & & \\
\hline SESPMNT & B17PP9 & W END OF FIR ROAD & PERIMETER & AT & 05-Jan-04 & $\mathrm{U}-238$ & 0.0000151 & $\mathrm{pCi} / \mathrm{m} 3$ & 0.0000096 & 0.0000099 & & & \\
\hline SESPMNT & B168V0 & WYE BARRICADE & ONSITE & AT & 31-Mar-03 & $\mathrm{U}-238$ & 0.0000155 & $\mathrm{pCi} / \mathrm{m} 3$ & 0.0000093 & $3 \quad 0.0000099$ & & & \\
\hline SESPMNT & B16R54 & WYE BARRICADE & ONSITE & AT & 08-Jul-03 & $\mathrm{U}-238$ & 0.0000132 & $\mathrm{pCi} / \mathrm{m} 3$ & 0.000011 & 0.000011 & u & & \\
\hline SESPMNT & B17630 & WYE BARRICADE & ONSITE & AT & 01-Oct-03 & $\mathrm{U}-238$ & 0.0000154 & $\mathrm{pCi} / \mathrm{m} 3$ & 0.0000084 & 0.000009 & & & \\
\hline SESPMNT & B17PP1 & WYE BARRICADE & ONSITE & AT & 06-Jan-04 & $\mathrm{U}-238$ & 0.0000179 & $\mathrm{pCi} / \mathrm{m} 3$ & 0.0000085 & 0.000009 & & & \\
\hline SESPMNT & B16955 & YAKIMA & DISTANT & AT & 03-Apr-03 & $\mathrm{U}-238$ & 0.0000219 & $\mathrm{pC} / \mathrm{m} 3$ & 0.00001 & 0.000011 & & & \\
\hline SESPMNT & B16RH6 & YAKIMA & DISTANT & AT & 11-Jul-03 & $\mathrm{U}-238$ & 0.0000146 & $\mathrm{pCi} / \mathrm{m} 3$ & 0.000013 & 0.000013 & & & \\
\hline SESPMNT & B176D5 & YAKIMA & DISTANT & AT & 03-Oct-03 & $\mathrm{U}-238$ & 0.0000117 & $\mathrm{pCi} / \mathrm{m} 3$ & 0.0000076 & 0.0000081 & & & \\
\hline SESPMNT & B17R23 & YAKIMA & DISTANT & AT & 09-Jan-04 & $\mathrm{U}-238$ & 0.000018 & $\mathrm{pCi} / \mathrm{m} 3$ & 0.0000083 & 0.0000088 & & & \\
\hline
\end{tabular}




\section{Water}


WATER - COLUMBIA RIVER COMPOSITES

\begin{tabular}{|c|c|c|c|c|c|c|c|c|c|c|c|c|c|c|c|c|}
\hline OWNER ID & SAMP NUM & SAMP SITE NAME & DIST CLASS & MEDIA & $\begin{array}{c}\text { FILTERED } \\
\text { FLAG } \\
\end{array}$ & SAMP FROM & COLL MTHD & SAMP DATE & $\begin{array}{c}\text { CON SHORT } \\
\text { NAME }\end{array}$ & VALUE RPTD & \begin{tabular}{|l|} 
ANAL \\
UNITS \\
RPTD \\
\end{tabular} & $\begin{array}{c}\text { COUNTING } \\
\text { ERROR }\end{array}$ & $\begin{array}{c}\text { TOTAL ANAL } \\
\text { ERROR } \\
\end{array}$ & $\begin{array}{c}\text { LAB } \\
\text { QUALIFIER } \\
\end{array}$ & SAMP COMMENT & RESULT COMMENT \\
\hline SESPMNT & B16858 & PRIEST RAPIDS-RIVER & OFFSITE & sW & $\mathrm{N}$ & RIVER & UNFILTERED & 05 -Feb-03 A & ALPHA & $0.67 \mathrm{p}$ & $\mathrm{pCi} / \mathrm{L}$ & 0.62 & 0.64 & $U$ & & \\
\hline SESPMNT & B16BY2 & PRIEST RAPIDS-RIVER & OFFSITE & sW & $\mathrm{N}$ & RIVER & UNFILTERED & 05-Mar-03 A & ALPHA & $0.935 \mathrm{p}$ & $\mathrm{pCi} / \mathrm{L}$ & 0.82 & 0.85 & $u$ & & \\
\hline SESPMNT & B16JL8 & PRIEST RAPIDS-RIVER & OFFSITE & sw & $\mathrm{N}$ & RIVER & UNFILTERED & 02-Apr-03 A & ALPHA & $0.66 \mathrm{p}$ & $\mathrm{pCi} / \mathrm{L}$ & 0.74 & 0.75 & u & & \\
\hline SESPMNT & B16PJ4 & PRIEST RAPIDS-RIVER & OFFSITE & sW & $\mathrm{N}$ & RIVER & UNFILTERED & 30-Apr-03 A & ALPHA & $0.487 \mathrm{~F}$ & $\mathrm{pCi} / \mathrm{L}$ & 0.73 & 0.75 & $\mathrm{U}$ & & \\
\hline SESPMNT & B16WD8 & PRIEST RAPIDS-RIVER & OFFSITE & sW & $\mathrm{N}$ & RIVER & UNFILTERED & 28-May-03A & ALPHA & $0.597 \mathrm{p}$ & $\mathrm{pCi} / \mathrm{L}$ & 0.77 & 0.79 & $u$ & & \\
\hline SESPMNT & B171D2 & PRIEST RAPIDS-RIVER & OFFSITE & sw & $\mathrm{N}$ & RIVER & UNFILTERED & 10-Jul-03 A & ALPHA & $0.439 \mathrm{p}$ & $\mathrm{pCi} / \mathrm{L}$ & 0.7 & 0.71 & u & & \\
\hline SESPMNT & B175F4 & PRIEST RAPIDS-RIVER & OFFSITE & sw & $\mathrm{N}$ & RIVER & UNFILTERED & 08-Aug-03 A & ALPHA & $-0.0574 \mathrm{~F}$ & $\mathrm{pCi} / \mathrm{L}$ & 0.4 & 0.41 & $u$ & & \\
\hline SESPMNT & B179R2 & PRIEST RAPIDS-RIVER & OFFSITE & sW & $\mathrm{N}$ & RIVER & UNFILTERED & 03-Sep-03 A & ALPHA & $0.443 \mathrm{p}$ & & 0.44 & 0.45 & $\mathrm{U}$ & & \\
\hline SESPMNT & B17DJ7 & PRIEST RAPIDS-RIVER & OFFSITE & sw & $\mathrm{N}$ & RIVER & UNFILTERED & 30-Sep-03 A & ALPHA & $0.792 \mathrm{~F}$ & $\mathrm{pCi/L}$ & 0.82 & 0.86 & u & & \\
\hline SESPMNT & B17P27 & PRIEST RAPIDS-RIVER & OFFSITE & sw & $\mathrm{N}$ & RIVER & UNFILTERED & 29-Oct-03 A & ALPHA & $0.279 \mathrm{p}$ & $\mathrm{pCi} / \mathrm{L}$ & 0.6 & 0.61 & u & & \\
\hline SESPMNT & B17VB4 & PRIEST RAPIDS-RIVER & OFFSITE & sw & $\mathrm{N}$ & RIVER & UNFILTERED & 25-Nov-03 A & ALPHA & $0.0972 \mathrm{~F}$ & $\mathrm{pCi} / \mathrm{L}$ & 0.58 & 0.58 & $u$ & & \\
\hline SESPMNT & B183H6 & PRIEST RAPIDS-RIVER & OFFSITE & sW & $\mathrm{N}$ & RIVER & UNFILTERED & 08-Jan-04 A & ALPHA & $0.364 \mathrm{~F}$ & $\mathrm{pCi} / \mathrm{L}$ & 0.66 & 0.68 & u & & \\
\hline SESPMNT & B16868 & RICH.PMPHS HRM 46.4 & OFFSITE & sw & $\mathrm{N}$ & RIVER & UNFILTERED & $05-\mathrm{Feb}-03 \mathrm{~A}$ & ALPHA & $0.159 \mathrm{p}$ & $\mathrm{pCi/L}$ & 0.38 & 0.38 & u & & \\
\hline SESPMNT & B16BY7 & RICH.PMPHS HRM 46.4 & OFFSITE & sw & $\mathrm{N}$ & RIVER & UNFILTERED & 05-Mar-03 A & ALPHA & $1.2 \mathrm{p}$ & $\mathrm{pCi} / \mathrm{L}$ & 0.85 & 0.89 & & & \\
\hline SESPMNT & B16JM4 & RICH.PMPHS HRM 46.4 & OFFSITE & sW & $\mathrm{N}$ & RIVER & UNFILTERED & 02-Apr-03 A & ALPHA & $0.858 \mathrm{p}$ & $\mathrm{pCi} / \mathrm{L}$ & 0.88 & 0.9 & $\mathrm{U}$ & & \\
\hline SESPMNT & B16PJ9 & RICH.PMPHS HRM 46.4 & OFFSITE & sW & $\mathrm{N}$ & RIVER & UNFILTERED & 30-Apr-03 A & ALPHA & $0.669 \mathrm{p}$ & $\mathrm{pCi} / \mathrm{L}$ & 0.77 & 0.79 & $u$ & & \\
\hline SESPMNT & B16WF4 & RICH.PMPHS HRM 46.4 & OFFSITE & sw & $\mathrm{N}$ & RIVER & UNFILTERED & 28-May-03 A & ALPHA & $-0.129 \mathrm{p}$ & $\mathrm{pCi/L}$ & 0.39 & 0.4 & u & & \\
\hline SESPMNT & B171F6 & RICH.PMPHS HRM 46.4 & OFFSITE & sw & $\mathrm{N}$ & RIVER & UNFILTERED & 10-Jul-03 A & ALPHA & $0.161 \mathrm{p}$ & $\mathrm{pCi} / \mathrm{L}$ & 0.56 & 0.57 & u & & \\
\hline SESPMNT & B175F9 & RICH.PMPHS HRM 46.4 & OFFSITE & sW & $\mathrm{N}$ & RIVER & UNFILTERED & 08-Aug-03 A & ALPHA & $1.55 \mathrm{p}$ & $\mathrm{pCi} / \mathrm{L}$ & 1 & 1.1 & & & \\
\hline SESPMNT & B179R7 & RICH.PMPHS HRM 46.4 & OFFSITE & sW & $\mathrm{N}$ & RIVER & UNFILTERED & 03-Sep-03 A & ALPHA & $0.777 \mathrm{~F}$ & $\mathrm{pCi} / \mathrm{L}$ & 0.55 & 0.58 & $u$ & & \\
\hline SESPMNT & B17DK3 & RICH.PMPHS HRM 46.4 & OFFSITE & sw & $\mathrm{N}$ & RIVER & UNFILTERED & 30-Sep-03 A & ALPHA & $0.861 \mathrm{p}$ & $\mathrm{pCi/L}$ & 0.87 & 0.9 & u & & \\
\hline SESPMNT & B17P33 & RICH.PMPHS HRM 46.4 & OFFSITE & sw & $\mathrm{N}$ & RIVER & UNFILTERED & 29-Oct-03 A & ALPHA & $0.359 \mathrm{p}$ & $\mathrm{pCi} / \mathrm{L}$ & 0.67 & 0.68 & $u$ & & \\
\hline SESPMNT & B17VC0 & RICH.PMPHS HRM 46.4 & OFFSITE & sW & $\mathrm{N}$ & RIVER & UNFILTERED & 25 -Nov-03 A & ALPHA & $0.697 \mathrm{~F}$ & $\mathrm{pCi} / \mathrm{L}$ & 0.81 & 0.84 & $u$ & & \\
\hline SESPMNT & B183J3 & RICH.PMPHS HRM 46.4 & OFFSITE & sW & $\mathrm{N}$ & RIVER & UNFILTERED & 08-Jan-04 A & ALPHA & $0.533 \mathrm{p}$ & $\mathrm{pCi} / \mathrm{L}$ & 0.71 & 0.73 & $u$ & & \\
\hline SESPMNT & B16858 & PRIEST RAPIDS-RIVER & OFFSITE & sw & $\mathrm{N}$ & RIVER & UNFILTERED & 05-Feb-03 B & BETA & $0.491 \mathrm{p}$ & $\mathrm{pCi} / \mathrm{L}$ & 1.3 & 1.3 & $U$ & & \\
\hline SESPMNT & B16BY2 & PRIEST RAPIDS-RIVER & OFFSITE & sw & $\mathrm{N}$ & RIVER & UNFILTERED & 05-Mar-03 & BETA & $0.068 \mathrm{~F}$ & $\mathrm{pCi} / \mathrm{L}$ & 1.3 & 1.4 & $u$ & & \\
\hline SESPMNT & B16JL8 & PRIEST RAPIDS-RIVER & OFFSITE & sw & $\mathrm{N}$ & RIVER & UNFILTERED & 02-Apr-03 B & BETA & $0.665 \mathrm{p}$ & $\mathrm{pCi} / \mathrm{L}$ & 1.2 & 1.3 & u & & \\
\hline SESPMNT & B16PJ4 & PRIEST RAPIDS-RIVER & OFFSITE & sW & $\mathrm{N}$ & RIVER & UNFILTERED & 30-Apr-03 & BETA & $1.3 \mathrm{p}$ & $\mathrm{pCi} / \mathrm{L}$ & 1.4 & 1.5 & $u$ & & \\
\hline SESPMNT & B16WD8 & PRIEST RAPIDS-RIVER & OFFSITE & sw & $\mathrm{N}$ & RIVER & UNFILTERED & 28-May-03 & BETA & & $\mathrm{pCi/L}$ & 1.2 & 1.3 & u & & \\
\hline SESPMNT & B171D2 & PRIEST RAPIDS-RIVER & OFFSITE & sw & $\mathrm{N}$ & RIVER & UNFILTERED & 10-Jul-03 & BETA & $0.53 \mathrm{r}$ & $\mathrm{pCi} / \mathrm{L}$ & 1.3 & 1.4 & u & & \\
\hline SESPMNT & B175F4 & PRIEST RAPIDS-RIVER & OFFSITE & sw & $\mathrm{N}$ & RIVER & UNFILTERED & 08-Aug-03 E & BETA & $-0.565 p$ & $\mathrm{pCi} / \mathrm{L}$ & 1.3 & 1.4 & $u$ & & \\
\hline SESPMNT & B179R2 & PRIEST RAPIDS-RIVER & OFFSITE & sW & $\mathrm{N}$ & RIVER & UNFILTERED & 03-Sep-03 & BETA & $1.96 \mathrm{~F}$ & $\mathrm{pCi} / \mathrm{L}$ & 1.3 & 1.3 & $u$ & & \\
\hline SESPMNT & B17DJ7 & PRIEST RAPIDS-RIVER & OFFSITE & sw & $\mathrm{N}$ & RIVER & UNFILTERED & 30-Sep-03 & BETA & $0.525 \mathrm{p}$ & $\mathrm{pCi} / \mathrm{L}$ & 1.3 & 1.4 & U & & \\
\hline SESPMNT & B17P27 & PRIEST RAPIDS-RIVER & OFFSITE & sw & $\mathrm{N}$ & RIVER & UNFILTERED & 29-Oct-03 & BETA & $-0.351 \mathrm{p}$ & $\mathrm{pCi} / \mathrm{L}$ & 1.2 & 1.3 & $u$ & & \\
\hline SESPMNT & B17VB4 & PRIEST RAPIDS-RIVER & OFFSITE & sw & $\mathrm{N}$ & RIVER & UNFILTERED & 25-Nov-03 & BETA & $2.46 \mathrm{p}$ & $\mathrm{pCill}$ & 2 & 2.1 & u & & \\
\hline SESPMNT & B183H6 & PRIEST RAPIDS-RIVER & OFFSITE & sw & $\mathrm{N}$ & RIVER & UNFILTERED & 08-Jan-04 & BETA & $0.711 \mathrm{p}$ & $\mathrm{pCi} / \mathrm{L}$ & 1.3 & 1.4 & $u$ & & \\
\hline SESPMNT & B16868 & RICH.PMPHS HRM 46.4 & OFFSITE & sW & $\mathrm{N}$ & RIVER & UNFILTERED & $05-\mathrm{Feb}-03 \mathrm{E}$ & BETA & $1.2 \mathrm{~F}$ & $\mathrm{pCi} / \mathrm{L}$ & 1.3 & 1.3 & 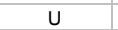 & & \\
\hline SESPMNT & B16BY7 & RICH.PMPHS HRM 46.4 & OFFSITE & sw & $\mathrm{N}$ & RIVER & UNFILTERED & 05-Mar-03 & BETA & $0.541 \mathrm{~F}$ & $\mathrm{pCi} / \mathrm{L}$ & 1.3 & 1.4 & $u$ & & \\
\hline SESPMNT & B16JM4 & RICH.PMPHS HRM 46.4 & OFFSITE & sw & $\mathrm{N}$ & RIVER & UNFILTERED & 02-Apr-03 & BETA & $2.5 p$ & $\mathrm{pCi} / \mathrm{L}$ & 1.5 & 1.6 & $u$ & & \\
\hline SESPMNT & B16PJ9 & RICH.PMPHS HRM 46.4 & OFFSITE & sw & $\mathrm{N}$ & RIVER & UNFILTERED & 30-Apr-03 & BETA & $0.313 \mathrm{p}$ & $\mathrm{pCi} / \mathrm{L}$ & 1.3 & 1.4 & $u$ & & \\
\hline SESPMNT & B16WF4 & RICH.PMPHS HRM 46.4 & OFFSITE & sW & $\mathrm{N}$ & RIVER & UNFILTERED & 28-May-03 & BETA & $0.876 \mathrm{p}$ & $\mathrm{pCi} / \mathrm{L}$ & 1.3 & 1.4 & U & & \\
\hline SESPMNT & B171F6 & RICH.PMPHS HRM 46.4 & OFFSITE & sw & $\mathrm{N}$ & RIVER & UNFILTERED & 10-Jul-03 & BETA & $1.27 \mathrm{p}$ & $\mathrm{pCi} / \mathrm{L}$ & 1.4 & 1.5 & $u$ & & \\
\hline SESPMNT & B175F9 & RICH.PMPHS HRM 46.4 & OFFSITE & sw & $\mathrm{N}$ & RIVER & UNFILTERED & 08-Aug-03 & BETA & $0.143 \mathrm{p}$ & $\mathrm{pCi} / \mathrm{L}$ & 1.3 & 1.4 & $u$ & & \\
\hline SESPMNT & B179R7 & RICH.PMPHS HRM 46.4 & OFFSITE & sW & $\mathrm{N}$ & RIVER & UNFILTERED & 03-Sep-03 & BETA & $1.31 \mathrm{p}$ & $\mathrm{pCi} / \mathrm{L}$ & 1.3 & 1.3 & $u$ & & \\
\hline SESPMNT & B17DK3 & RICH.PMPHS HRM 46.4 & OFFSITE & sw & $\mathrm{N}$ & RIVER & UNFILTERED & 30-Sep-03 & BETA & $-0.224 \mathrm{~F}$ & $\mathrm{pCi} / \mathrm{L}$ & 1.3 & 1.4 & u & & \\
\hline SESPMNT & B17P33 & RICH.PMPHS HRM 46.4 & OFFSITE & sw & $\mathrm{N}$ & RIVER & UNFILTERED & 29-Oct-03 & BETA & $0.515 \mathrm{p}$ & $\mathrm{pCi} / \mathrm{L}$ & 1.3 & 1.4 & u & & \\
\hline SESPMNT & B17VC0 & RICH.PMPHS HRM 46.4 & OFFSITE & sw & $\mathrm{N}$ & RIVER & UNFILTERED & 25-Nov-03 & BETA & $2.77 \mathrm{~F}$ & $\mathrm{pCi} / \mathrm{L}$ & 2 & 2.1 & u & & \\
\hline SESPMNT & B183J3 & RICH.PMPHS HRM 46.4 & OFFSITE & sW & $\mathrm{N}$ & RIVER & UNFILTERED & 08-Jan-04 E & BETA & $0.356 \mathrm{p}$ & $\mathrm{pCi} / \mathrm{L}$ & 1.3 & 1.4 & U & & \\
\hline SESPSPEC & B16WL1 & PRIEST RAPIDS-RIVER & OFFSITE & sW & $\mathrm{N}$ & RIVER & UNFILTERED & 30-Apr-03 C & C-14 & $-0.895 p$ & $\mathrm{pCi} / \mathrm{L}$ & 3.2 & 3.5 & u & & \\
\hline SESPSPEC & B16WL3 & PRIEST RAPIDS-RIVER & OFFSITE & sw & $\mathrm{N}$ & RIVER & UNFILTERED & 07-May-03 & C-14 & $3.34 \mathrm{p}$ & $\mathrm{pCi} / \mathrm{L}$ & 3.3 & 3.7 & u & & \\
\hline SESPSPEC & B170P7 & PRIEST RAPIDS-RIVER & OFFSITE & sW & $\mathrm{N}$ & RIVER & UNFILTERED & 13-May-03 & C-14 & $3.45 p$ & $\mathrm{pCi} / \mathrm{L}$ & 3.3 & 3.7 & u & & \\
\hline SESPSPEC & B170X7 & PRIEST RAPIDS-RIVER & OFFSITE & sW & $\mathrm{N}$ & RIVER & UNFILTERED & 21-May-03 C & C-14 & $8.02 \mathrm{~F}$ & $\mathrm{pCi} / \mathrm{L}$ & 6.8 & 7.5 & U & & \\
\hline SESPSPEC & B17140 & PRIEST RAPIDS-RIVER & OFFSITE & sW & $\mathrm{N}$ & RIVER & UNFILTERED & 28-May-03 C & C-14 & $8.77 \mathrm{p}$ & $\mathrm{pCi} / \mathrm{L}$ & 3.6 & 3.9 & & & \\
\hline SESPSPEC & B171K6 & PRIEST RAPIDS-RIVER & OFFSITE & sw & $\mathrm{N}$ & RIVER & UNFILTERED & $05-J u n-03$ & C-14 & $1.52 \mathrm{~F}$ & $\mathrm{pCi} / \mathrm{L}$ & 6.8 & 7.5 & u & & \\
\hline SESPSPEC & B17214 & PRIEST RAPIDS-RIVER & OFFSITE & sw & $\mathrm{N}$ & RIVER & UNFILTERED & 12-Jun-03 & C-14 & $2.7 \mathrm{~F}$ & $\mathrm{pCi/L}$ & 6.6 & 7.2 & u & & \\
\hline SESPSPEC & B172F1 & PRIEST RAPIDS-RIVER & OFFSITE & sw & $\mathrm{N}$ & RIVER & UNFILTERED & 18-Jun-03 C & C-14 & $-0.506 p$ & $\mathrm{pCi} / \mathrm{L}$ & 3.2 & 3.5 & U & & \\
\hline SESPSPEC & B172K0 & PRIEST RAPIDS-RIVER & OFFSITE & sW & $\mathrm{N}$ & RIVER & UNFILTERED & 25-Jun-03 C & C-14 & $-2.75 p$ & $\mathrm{pCi} / \mathrm{L}$ & 3.2 & 3.5 & U & & \\
\hline SESPSPEC & B16WL2 & RICH.PMPHS HRM 46.4 & OFFSITE & sw & $\mathrm{N}$ & RIVER & UNFILTERED & 30-Apr-0 & C-14 & -0.3 & pCill & 3.2 & 3.5 & u & & \\
\hline
\end{tabular}


WATER - COLUMBIA RIVER COMPOSITES

\begin{tabular}{|c|c|c|c|c|c|c|c|c|c|c|c|c|c|c|c|c|}
\hline OWNER ID & SAMP NUM | & SAMP SITE NAME & DIST CLASS & MEDIA & $\begin{array}{c}\text { FILTERED } \\
\text { FLAG }\end{array}$ & SAMP FROM & COLL MTHD & SAMP DATE & $\begin{array}{c}\text { CON SHORT } \\
\text { NAME }\end{array}$ & VALUE RPTD & \begin{tabular}{|l|} 
ANAL \\
UNITS \\
RPTD
\end{tabular} & $\left|\begin{array}{c}\text { COUNTING } \\
\text { ERROR }\end{array}\right|$ & $\left|\begin{array}{c}\text { TOTAL ANAL } \\
\text { ERROR }\end{array}\right|$ & $\begin{array}{c}\text { LAB } \\
\text { QUALIFIER }\end{array}$ & SAMP COMMENT & RESULT COMMENT \\
\hline SESPSPEC & B16WL4 & RICH.PMPHS HRM 46.4 & OFFSITE & SW & $\mathrm{N}$ & RIVER & UNFILTERED & 07-May-03 C & C-14 & & $\mathrm{pCi} / \mathrm{L}$ & 3.3 & 3.6 & u & & \\
\hline SESPSPEC & B170P8 & RICH.PMPHS HRM 46.4 & OFFSITE & sw & $\mathrm{N}$ & RIVER & UNFILTERED & 13-May-03 C & C-14 & $3.41 \mathrm{p}$ & $\mathrm{pCi} / \mathrm{L}$ & 3.3 & 3.7 & u & & \\
\hline SESPSPEC & B170X8 & RICH.PMPHS HRM 46.4 & OFFSITE & sW & $\mathrm{N}$ & RIVER & UNFILTERED & 21-May-03 C & C-14 & & $\mathrm{pCi} / \mathrm{L}$ & 3.6 & 4 & & & \\
\hline SESPSPEC & B17141 & RICH.PMPHS HRM 46.4 & OFFSITE & sW & $\mathrm{N}$ & RIVER & UNFILTERED & 28-May-03 C & C-14 & $9.22 \mathrm{p}$ & $\mathrm{pCi} / \mathrm{L}$ & 3.6 & 4 & & & \\
\hline SESPSPEC & B171K7 & RICH.PMPHS HRM 46.4 & OFFSITE & sw & $\mathrm{N}$ & RIVER & UNFILTERED & 05-Jun-03 C & $\mathrm{C}-14$ & $-1.93 p$ & & 3.3 & 3.6 & U & & \\
\hline SESPSPEC & B17215 & RICH.PMPHS HRM 46.4 & OFFSITE & sw & $\mathrm{N}$ & RIVER & UNFILTERED & 12-Jun-03 C & C-14 & $-1.75 p$ & $\mathrm{pCi} / \mathrm{L}$ & 3.2 & 3.5 & U & & \\
\hline SESPSPEC & B172F2 & RICH.PMPHS HRM 46.4 & OFFSITE & sw & $\mathrm{N}$ & RIVER & UNFILTERED & 18-Jun-03 C & C-14 & $1.16 \mathrm{p}$ & $\mathrm{pCi} / \mathrm{L}$ & 3.3 & 3.6 & U & & \\
\hline SESPSPEC & B172K1 & RICH.PMPHS HRM 46.4 & OFFSITE & sw & $\mathrm{N}$ & RIVER & UNFILTERED & 25-Jun-03 C & C-14 & $-2.57 \mathrm{p}$ & $\mathrm{pCi} / \mathrm{L}$ & 3.2 & 3.6 & U & & \\
\hline SESPMNT & B167W7 & PRIEST RAPIDS-RIVER & OFFSITE & sw & & RIVER & UNFILTERED & 09-Apr-03 I- & I-129 & $0.0000037 p$ & $\mathrm{pCi} / \mathrm{L}$ & & 0.000000407 & & & \\
\hline SESPMNT & B16P81 & PRIEST RAPIDS-RIVER & OFFSITE & sW & & RIVER & UNFILTERED & 10-Jul-03 | & I-129 & $0.0000048 \mathrm{p}$ & $\mathrm{pCi} / \mathrm{L}$ & & 0.000000768 & & & \\
\hline SESPMNT & B17561 & PRIEST RAPIDS-RIVER & OFFSITE & sw & & RIVER & UNFILTERED & 30-Sep-03 I- & I-129 & $0.0000059 \mathrm{p}$ & $\mathrm{pCi} / \mathrm{L}$ & & $1.6048 \mathrm{E}-06$ & & & \\
\hline SESPMNT & B17NT2 & PRIEST RAPIDS-RIVER & OFFSITE & sW & & RIVER & UNFILTERED & $08-J a n-041$. & I-129 & $0.0000039 \mathrm{p}$ & $\mathrm{pCi/L}$ & & $7.098 \mathrm{E}-07$ & & & \\
\hline SESPMNT & B167Y1 & RICH.PMPHS HRM 46.4 & OFFSITE & sw & & $\begin{array}{l}\text { RIVER } \\
\text { RIVER }\end{array}$ & UNFILTERED & 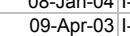 & $\begin{array}{l}1-129 \\
\mid-129\end{array}$ & $0.0000912 \mathrm{p}$ & $\begin{array}{l}\mathrm{pCi} / \mathrm{L} \\
\mathrm{pC}\end{array}$ & & 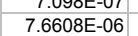 & & & \\
\hline SESPMNT & B16P95 & RICH.PMPHS HRM 46.4 & OFFSITE & sw & & RIVER & UNFILTERED & 10-Jul-03 I- & I-129 & $0.0000386 \mathrm{p}$ & $\mathrm{pCi/L}$ & & 3.1652E-06 & & & \\
\hline SESPMNT & B17575 & RICH.PMPHS HRM 46.4 & OFFSITE & sw & & RIVER & UNFILTERED & 30-Sep-03 I- & I-129 & $0.0001171 \mathrm{p}$ & $\mathrm{pCi/L}$ & & $9.6022 \mathrm{E}-06$ & & & \\
\hline SESPMNT & B17NV7 & RICH.PMPHS HRM 46.4 & OFFSITE & sw & & RIVER & UNFILTERED & 08-Jan-04 I. & I-129 & $0.0000787 \mathrm{p}$ & $\mathrm{pCi/L}$ & & 0.000007083 & & & \\
\hline SESPMNT & B16858 & PRIEST RAPIDS-RIVER & OFFSITE & sW & $\mathrm{N}$ & RIVER & UNFILTERED & $05-\mathrm{Feb}-03 \mathrm{~s}$ & SR-90 & $0.0998 \mathrm{p}$ & $\mathrm{pCi} / \mathrm{L}$ & 0.047 & 0.053 & & & \\
\hline SESPMNT & B16BY2 & PRIEST RAPIDS-RIVER & OFFSITE & sw & $\mathrm{N}$ & RIVER & UNFILTERED & $05-\mathrm{Mar}-03 \mathrm{~S}$ & SR-90 & $0.0667 \mathrm{p}$ & $\mathrm{pCi} / \mathrm{L}$ & 0.023 & 0.029 & & & \\
\hline SESPMNT & B16JL8 & PRIEST RAPIDS-RIVER & OFFSITE & sw & $\mathrm{N}$ & RIVER & UNFILTERED & 02-Apr-03 S & SR-90 & $0.0733 \mathrm{p}$ & $\mathrm{pCi} / \mathrm{L}$ & 0.032 & 0.037 & & & \\
\hline SESPMNT & B16PJ4 & PRIEST RAPIDS-RIVER & OFFSITE & sw & $\mathrm{N}$ & RIVER & UNFILTERED & 30-Apr-03s & SR-90 & $0.0878 \mathrm{p}$ & $\mathrm{pCi} / \mathrm{L}$ & 0.039 & 0.044 & & & \\
\hline SESPMNT & B16WD8 & PRIEST RAPIDS-RIVER & OFFSITE & sw & $\mathrm{N}$ & RIVER & UNFILTERED & 28-May-03s & SR-90 & $0.0919 \mathrm{p}$ & $\mathrm{pCi} / \mathrm{L}$ & 0.029 & 0.036 & & & \\
\hline SESPMNT & B171D2 & PRIEST RAPIDS-RIVER & OFFSITE & sw & $\mathrm{N}$ & RIVER & UNFILTERED & 10-Jul-03 S & SR-90 & $0.0909 \mathrm{p}$ & $\mathrm{pCi} / \mathrm{L}$ & 0.028 & 0.036 & & & \\
\hline SESPMNT & B175F4 & PRIEST RAPIDS-RIVER & OFFSITE & sw & $\mathrm{N}$ & RIVER & UNFILTERED & 08-Aug-03 s & SR-90 & $0.147 \mathrm{p}$ & $\mathrm{pCi} / \mathrm{L}$ & 0.034 & 0.047 & & & \\
\hline SESPMNT & B179R2 & PRIEST RAPIDS-RIVER & OFFSITE & sw & $\mathrm{N}$ & RIVER & UNFILTERED & 03-Sep-03s & SR-90 & $0.0625 \mathrm{p}$ & $\mathrm{pCi} / \mathrm{L}$ & 0.024 & 0.028 & & & \\
\hline SESPMNT & B17DJ7 & PRIEST RAPIDS-RIVER & OFFSITE & sW & $\mathrm{N}$ & RIVER & UNFILTERED & 30 -Sep-03s & SR-90 & $0.0601 \mathrm{p}$ & $\mathrm{pCi} / \mathrm{L}$ & 0.021 & 0.024 & & & \\
\hline SESPMNT & B17P27 & PRIEST RAPIDS-RIVER & OFFSITE & sw & $\mathrm{N}$ & RIVER & UNFILTERED & $29-\mathrm{Oct}-03 \mathrm{~s}$ & SR-90 & $0.0862 \mathrm{p}$ & $\mathrm{pCi} / \mathrm{L}$ & 0.018 & 0.022 & & & \\
\hline SESPMNT & B17VB4 & PRIEST RAPIDS-RIVER & OFFSITE & sw & $\mathrm{N}$ & RIVER & UNFILTERED & 25-Nov-03s & SR-90 & $0.0692 \mathrm{p}$ & $\mathrm{pCi} / \mathrm{L}$ & 0.02 & 0.024 & & & \\
\hline SESPMNT & B183H6 & PRIEST RAPIDS-RIVER & OFFSITE & sw & $\mathrm{N}$ & RIVER & UNFILTERED & $08-J a n-04 \mathrm{~s}$ & SR-90 & $0.125 \mathrm{p}$ & $\mathrm{pCi/L}$ & 0.025 & 0.032 & & & \\
\hline SESPMNT & B16868 & RICH.PMPHS HRM 46.4 & OFFSITE & sW & $\mathrm{N}$ & RIVER & UNFILTERED & $05-$ Feb-03S & SR-90 & $0.098 \mathrm{p}$ & $\mathrm{pCi/L}$ & 0.034 & 0.041 & & & \\
\hline SESPMNT & B16BY7 & RICH.PMPHS HRM 46.4 & OFFSITE & sw & $\mathrm{N}$ & RIVER & UNFILTERED & $05-\mathrm{Mar}-03 \mathrm{~S}$ & SR-90 & $0.0983 \mathrm{p}$ & $\mathrm{pCi} / \mathrm{L}$ & 0.029 & 0.037 & & & \\
\hline SESPMNT & B16JM4 & RICH.PMPHS HRM 46.4 & OFFSITE & sw & $\mathrm{N}$ & RIVER & UNFILTERED & $02-\mathrm{Apr}-03 \mathrm{~s}$ & SR-90 & $0.106 \mathrm{p}$ & $\mathrm{pCi/L}$ & 0.029 & 0.038 & & & \\
\hline SESPMNT & B16PJ9 & RICH.PMPHS HRM 46.4 & OFFSITE & sw & $\mathrm{N}$ & RIVER & UNFILTERED & 30-Apr-03s & SR-90 & $0.107 \mathrm{p}$ & $\mathrm{pCi/L}$ & 0.039 & 0.046 & & & \\
\hline SESPMNT & B16WF4 & RICH.PMPHS HRM 46.4 & OFFSITE & sw & $\mathrm{N}$ & RIVER & UNFILTERED & 28-May-03s & SR-90 & $0.0878 \mathrm{p}$ & $\mathrm{pCi} / \mathrm{L}$ & 0.029 & 0.036 & & & \\
\hline SESPMNT & B171F6 & RICH.PMPHS HRM 46.4 & OFFSITE & sw & $\mathrm{N}$ & RIVER & UNFILTERED & 10-Jul-03 S & SR-90 & $0.0903 \mathrm{p}$ & $\mathrm{pCi} / \mathrm{L}$ & 0.033 & 0.04 & & & \\
\hline SESPMNT & B175F9 & RICH.PMPHS HRM 46.4 & OFFSITE & sw & $\mathrm{N}$ & RIVER & UNFILTERED & 08 -Aug-03s & SR-90 & $0.122 \mathrm{p}$ & $\mathrm{pCi/L}$ & 0.032 & 0.042 & & & \\
\hline SESPMNT & B179R7 & RICH.PMPHS HRM 46.4 & OFFSITE & sw & $\mathrm{N}$ & RIVER & UNFILTERED & $03-S e p-03 s$ & SR-90 & $0.0472 \mathrm{p}$ & $\mathrm{pCi/L}$ & 0.025 & 0.028 & & & \\
\hline SESPMNT & B17DK3 & RICH.PMPHS HRM 46.4 & OFFSITE & sw & $\mathrm{N}$ & RIVER & UNFILTERED & 30 -Sep-03s & SR-90 & $0.0778 \mathrm{p}$ & $\mathrm{pCi/L}$ & 0.023 & 0.027 & & & \\
\hline SESPMNT & B17P33 & RICH.PMPHS HRM 46.4 & OFFSITE & sw & $\mathrm{N}$ & RIVER & UNFILTERED & $29-\mathrm{Oct}-03 \mathrm{~s}$ & SR-90 & $0.121 \mathrm{p}$ & $\mathrm{pCi} / \mathrm{L}$ & 0.021 & 0.027 & & & \\
\hline SESPMNT & B17VC0 & RICH.PMPHS HRM 46.4 & OFFSITE & sw & $\mathrm{N}$ & RIVER & UNFILTERED & 25 -Nov-03s & SR-90 & $0.0792 \mathrm{p}$ & $\mathrm{pCi/L}$ & 0.021 & 0.025 & & & \\
\hline SESPMNT & B183J3 & RICH.PMPHS HRM 46.4 & OFFSITE & sw & $\mathrm{N}$ & RIVER & UNFILTERED & $08-J a n-04 \mathrm{~s}$ & SR-90 & $0.141 \mathrm{p}$ & $\mathrm{pCi/L}$ & 0.027 & 0.035 & & & \\
\hline SESPMNT & B16858 & $\begin{array}{l}\text { PRIEST RAPIDS-RIVER } \\
\end{array}$ & OFFSITE & sw & $\mathrm{N}$ & RIVER & UNFILTERED & 05-Feb-03 T & TC-99 & $-0.312 p$ & $\mathrm{pCi/L}$ & 0.25 & 0.56 & $u$ & & \\
\hline SESPMNT & B16BY2 & PRIEST RAPIDS-RIVER & OFFSITE & sw & $\mathrm{N}$ & RIVER & UNFILTERED & 05-Mar-03 T & TC-99 & $0.199 \mathrm{p}$ & $\mathrm{pCi/L}$ & 0.26 & 0.56 & U & & \\
\hline SESPMNT & B16JL8 & PRIEST RAPIDS-RIVER & OFFSITE & sw & $\mathrm{N}$ & RIVER & UNFILTERED & 02-Apr-03 T & TC-99 & $0.455 \mathrm{p}$ & $\mathrm{pCi/L}$ & 0.25 & 0.53 & U & & \\
\hline SESPMNT & B16PJ4 & PRIEST RAPIDS-RIVER & OFFSITE & sw & $\mathrm{N}$ & RIVER & UNFILTERED & 30-Apr-03 T & TC-99 & $0.171 \mathrm{p}$ & $\mathrm{pCi/L}$ & 0.24 & 0.52 & u & & \\
\hline SESPMNT & B16WD8 & PRIEST RAPIDS-RIVER & OFFSITE & sw & $\mathrm{N}$ & RIVER & UNFILTERED & 28-May-03 T & TC-99 & $0.156 \mathrm{p}$ & $\mathrm{pCi/L}$ & 0.24 & 0.5 & u & & \\
\hline SESPMNT & B171D2 & PRIEST RAPIDS-RIVER & OFFSITE & sw & $\mathrm{N}$ & RIVER & UNFILTERED & 10-Jul-03 T & TC-99 & $0.523 \mathrm{pr}$ & $\mathrm{pCi/L}$ & 0.25 & 0.53 & U & & \\
\hline SESPMNT & B175F4 & PRIEST RAPIDS-RIVER & OFFSITE & sw & $\mathrm{N}$ & RIVER & UNFILTERED & 08-Aug-03 T & TC-99 & $-0.0622 \mathrm{p}$ & $\mathrm{pCi/L}$ & 0.24 & 0.52 & U & & \\
\hline SESPMNT & B179R2 & PRIEST RAPIDS-RIVER & OFFSITE & sw & $\mathrm{N}$ & RIVER & UNFILTERED & 03-Sep-03 T & TC-99 & $-0.0269 \mathrm{pc}$ & $\mathrm{pCi} / \mathrm{L}$ & 0.25 & 0.53 & u & & \\
\hline SESPMNT & B17DJ7 & PRIEST RAPIDS-RIVER & OFFSITE & sw & $\mathrm{N}$ & RIVER & UNFILTERED & 30-Sep-03 T & TC-99 & $-0.054 \mathrm{pc}$ & $\mathrm{pCi/L}$ & 0.19 & 0.32 & u & & \\
\hline SESPMNT & B17P27 & PRIEST RAPIDS-RIVER & OFFSITE & sw & $\mathrm{N}$ & RIVER & UNFILTERED & 29-Oct-03 T & TC-99 & $0.00191 \mathrm{ps}$ & $\mathrm{pCi/L}$ & 0.2 & 0.35 & U & & \\
\hline SESPMNT & B17VB4 & PRIEST RAPIDS-RIVER & OFFSITE & sw & $\mathrm{N}$ & RIVER & UNFILTERED & 25-Nov-03 T & TC-99 & $0.113 \mathrm{p}$ & $\mathrm{pCi/L}$ & 0.21 & 0.36 & $\mathrm{u}$ & & \\
\hline SESPMNT & B183H6 & PRIEST RAPIDS-RIVER & OFFSITE & sw & $\mathrm{N}$ & RIVER & UNFILTERED & 08-Jan-04 T & TC-99 & $-0.0321 \mathrm{pc}$ & $\mathrm{pCi/L}$ & 0.2 & 0.35 & u & & \\
\hline SESPMNT & B16868 & RICH.PMPHS HRM 46.4 & OFFSITE & sw & $\mathrm{N}$ & RIVER & UNFILTERED & $05-\mathrm{Feb}-03 \mathrm{~T}$ & TC-99 & $-0.412 p$ & $\mathrm{pCi/L}$ & 0.25 & 0.56 & u & & \\
\hline SESPMNT & B16BY7 & RICH.PMPHS HRM 46.4 & OFFSITE & sw & $\mathrm{N}$ & RIVER & UNFILTERED & 05-Mar-03 T & TC-99 & $0.125 \mathrm{p}$ & $\mathrm{pCi} / \mathrm{L}$ & 0.26 & 0.56 & U & & \\
\hline SESPMNT & B16JM4 & RICH.PMPHS HRM 46.4 & OFFSITE & sw & $\mathrm{N}$ & RIVER & UNFILTERED & 02-Apr-03 T & TC-99 & $0.493 \mathrm{pc}$ & $\mathrm{pCi} / \mathrm{L}$ & 0.25 & 0.53 & u & & \\
\hline SESPMNT & B16PJ9 & RICH.PMPHS HRM 46.4 & OFFSITE & sw & $\mathrm{N}$ & RIVER & UNFILTERED & 30-Apr-03 T & TC-99 & $1.15 \mathrm{ps}$ & $\mathrm{pCi/L}$ & 0.26 & 0.57 & & & \\
\hline SESPMNT & B16WF4 & RICH.PMPHS HRM 46.4 & OFFSITE & sw & $\mathrm{N}$ & RIVER & UNFILTERED & 28-May-03 T & TC-99 & $0.141 \mathrm{p}$ & $\mathrm{pCi/L}$ & 0.23 & 0.5 & u & & \\
\hline SESPMNT & B171F6 & RICH.PMPHS HRM 46.4 & OFFSITE & sw & $\mathrm{N}$ & RIVER & UNFILTERED & 10-Jul-03 T & TC-99 & $0.737 \mathrm{p}$ & $\mathrm{pCi} / \mathrm{L}$ & 0.25 & 0.54 & & & \\
\hline SESPMNT & B175F9 & RICH.PMPHS HRM 46.4 & OFFSITE & sw & $\mathrm{N}$ & RIVER & UNFILTERED & 08-Aug-03 T & & & & 0.25 & 0.53 & & & \\
\hline
\end{tabular}


WATER - COLUMBIA RIVER COMPOSITES

\begin{tabular}{|c|c|c|c|c|c|c|c|c|c|c|c|c|c|c|c|c|}
\hline OWNER ID & SAMP NUM & SAMP SITE NAME & DIST CLASS & MEDIA & $\begin{array}{l}\text { FILTERED } \\
\text { FLAG }\end{array}$ & SAMP FROM & COLL MTHD & SAMP DATE $\mid$ & $\left|\begin{array}{c}\text { CON SHORT } \\
\text { NAME }\end{array}\right|$ & | VALUE RPTD | & \begin{tabular}{|l|} 
ANAL \\
UNITS \\
RPTD
\end{tabular} & $\left|\begin{array}{c}\text { COUNTING } \\
\text { ERROR }\end{array}\right|$ & $\begin{array}{c}\text { TOTAL ANAL } \\
\text { ERROR }\end{array}$ & $\begin{array}{c}\text { LAB } \\
\text { QUALIFIER }\end{array}$ & SAMP COMMENT & |RESULT COMMENT \\
\hline SESPMNT & B179R7 & RICH.PMPHS HRM 46.4 & OFFSITE & sw & $\mathrm{N}$ & RIVER & UNFILTERED & 03-Sep-03 & TC-99 & $0.396 \mathrm{p}$ & $\mathrm{pCi} / \mathrm{L}$ & 0.25 & 0.55 & $\mathrm{U}$ & & \\
\hline SESPMNT & B17DK3 & RICH.PMPHS HRM 46.4 & OFFSITE & sW & $\mathrm{N}$ & RIVER & UNFILTERED & $30-$-Sep-03 & TC-99 & $-0.00333 \mathrm{~F}$ & $\mathrm{pCi} / \mathrm{L}$ & 0.19 & 0.33 & u & & \\
\hline SESPMNT & B17P33 & RICH.PMPHS HRM 46.4 & OFFSITE & sw & $\mathrm{N}$ & RIVER & UNFILTERED & 29-Oct-03] & TC-99 & $0.0731 \mathrm{p}$ & $\mathrm{pCi} / \mathrm{L}$ & 0.21 & 0.35 & $\mathrm{U}$ & & \\
\hline SESPMNT & B17VC0 & RICH.PMPHS HRM 46.4 & OFFSITE & sW & $\mathrm{N}$ & RIVER & UNFILTERED & 25-Nov-03 & TC-99 & $0.0867 \mathrm{~F}$ & $\mathrm{pCi} / \mathrm{L}$ & 0.21 & 0.36 & $\mathrm{U}$ & & \\
\hline SESPMNT & B183J3 & RICH.PMPHS HRM 46.4 & OFFSITE & sW & $\mathrm{N}$ & RIVER & UNFILTERED & $08-\operatorname{Jan}-04$ & TC-99 & $0.225 \mathrm{p}$ & $\mathrm{pCi} / \mathrm{L}$ & 0.21 & 0.36 & $u$ & & \\
\hline SESPMNT & B16858 & PRIEST RAPIDS-RIVER & OFFSITE & sW & $\mathrm{N}$ & RIVER & UNFILTERED & 05-Feb-03 L & LO TRITIUM & $46.9 \mathrm{p}$ & $\mathrm{pCi} / \mathrm{L}$ & 3.8 & 9 & & & \\
\hline SESPMNT & B16BY2 & PRIEST RAPIDS-RIVER & OFFSITE & sw & $\mathrm{N}$ & RIVER & UNFILTERED & 05-Mar-03 L & LO TRITIUM & $30.7 \mathrm{~F}$ & $\mathrm{pCi} / \mathrm{L}$ & 3 & 6.2 & & & \\
\hline SESPMNT & B16JL8 & PRIEST RAPIDS-RIVER & OFFSITE & sW & $\mathrm{N}$ & RIVER & UNFILTERED & 02-Apr-03 L & LO TRITIUM & & & 2.8 & 4.5 & & & \\
\hline SESPMNT & B16PJ4 & PRIEST RAPIDS-RIVER & OFFSITE & sw & $\mathrm{N}$ & RIVER & UNFILTERED & 30-Apr-03 L & LO TRITIUM & $24.4 p$ & $\mathrm{pCi/L}$ & 2.7 & 4.3 & & & \\
\hline SESPMNT & B16WD8 & PRIEST RAPIDS-RIVER & OFFSITE & sw & $\mathrm{N}$ & RIVER & UNFILTERED & 28-May-03 L & LO TRITIUM & $27.8 \mathrm{p}$ & $\mathrm{pCi} / \mathrm{L}$ & 2.9 & 4.4 & & & \\
\hline SESPMNT & B171D2 & PRIEST RAPIDS-RIVER & OFFSITE & sw & $\mathrm{N}$ & RIVER & UNFILTERED & 10-Jul-03 L & LO TRITIUM & & $\mathrm{pCi} / \mathrm{L}$ & 2.9 & 5.3 & & & \\
\hline SESPMNT & B175F4 & PRIEST RAPIDS-RIVER & OFFSITE & sW & $\mathrm{N}$ & RIVER & UNFILTERED & 08-Aug-03 L & LO TRITIUM & $27.6 \mathrm{p}$ & $\mathrm{pCi} / \mathrm{L}$ & 2.8 & 4.8 & & & \\
\hline SESPMNT & B179R2 & $\begin{array}{l}\text { PRIEST RAPIDS-RIVER } \\
\end{array}$ & OFFSITE & sw & $\mathrm{N}$ & RIVER & UNFILTERED & 03-Sep-03 L & LO TRITIUM & $27.3 \mathrm{p}$ & $\mathrm{pCi/L}$ & 4.1 & 6.5 & & & \\
\hline SESPMNT & B17DJ7 & PRIEST RAPIDS-RIVER & OFFSITE & sw & $\mathrm{N}$ & RIVER & UNFILTERED & 30-Sep-03 L & LO TRITIUM & $80.2 p$ & $\mathrm{pCi} / \mathrm{L}$ & 3.8 & 9 & & & \\
\hline SESPMNT & B17P27 & PRIEST RAPIDS-RIVER & OFFSITE & sW & $\mathrm{N}$ & RIVER & UNFILTERED & 29-Oct-03 L & LO TRITIUM & $56.2 p$ & $\mathrm{pCi} / \mathrm{L}$ & 3.2 & 6.8 & & & \\
\hline SESPMNT & B17VB4 & PRIEST RAPIDS-RIVER & OFFSITE & sW & $\mathrm{N}$ & RIVER & UNFILTERED & 25-Nov-03 L & LO TRITIUM & $27.2 \mathrm{~F}$ & $\mathrm{pCi/L}$ & 2.8 & 4.3 & & & \\
\hline SESPMNT & B183H6 & $\begin{array}{l}\text { PRIEST RAPIDS-RIVER } \\
\end{array}$ & OFFSITE & sw & $\mathrm{N}$ & RIVER & UNFILTERED & 08-Jan-04 L & LO TRITIUM & $16.7 p$ & $\mathrm{pCi/L}$ & 4.3 & 5.7 & & & \\
\hline SESPMNT & B16868 & RICH.PMPHS HRM 46.4 & OFFSITE & sw & $\mathrm{N}$ & RIVER & UNFILTERED & 05-Feb-03 L & LO TRITIUM & $94.6 \mathrm{p}$ & $\mathrm{pCi} / \mathrm{L}$ & 5.2 & 17 & & & \\
\hline SESPMNT & B16BY7 & RICH.PMPHS HRM 46.4 & OFFSITE & sw & $\mathrm{N}$ & RIVER & UNFILTERED & 05-Mar-03 L & LO TRITIUM & $60.1 \mathrm{p}$ & $\mathrm{pCi} / \mathrm{L}$ & 4.6 & 11 & & & \\
\hline SESPMNT & B16JM4 & RICH.PMPHS HRM 46.4 & OFFSITE & sw & $\mathrm{N}$ & RIVER & UNFILTERED & 02-Apr-03 L & LO TRITIUM & $56.3 \mathrm{r}$ & $\mathrm{pCi} / \mathrm{L}$ & 3.2 & 6.7 & & & \\
\hline SESPMNT & B16PJ9 & RICH.PMPHS HRM 46.4 & OFFSITE & sw & $\mathrm{N}$ & RIVER & UNFILTERED & 30-Apr-03 L & LO TRITIUM & $39.3 \mathrm{p}$ & $\mathrm{pCi} / \mathrm{L}$ & 3 & 5.4 & & & \\
\hline SESPMNT & B16WF4 & RICH.PMPHS HRM 46.4 & OFFSITE & sw & $\mathrm{N}$ & RIVER & UNFILTERED & 28-May-03 L & LO TRITIUM & $36.1 \mathrm{r}$ & $\mathrm{pCi} / \mathrm{L}$ & 3.1 & 5 & & & \\
\hline SESPMNT & B171F6 & RICH.PMPHS HRM 46.4 & OFFSITE & sW & $\mathrm{N}$ & RIVER & UNFILTERED & 10-Jul-03 L & LO TRITIUM & $50.3 p$ & $\mathrm{pCi} / \mathrm{L}$ & 3.1 & 6.4 & & & \\
\hline SESPMNT & B175F9 & RICH.PMPHS HRM 46.4 & OFFSITE & sw & $\mathrm{N}$ & RIVER & UNFILTERED & 08-Aug-03 L & LO TRITIUM & $73.3 \mathrm{r}$ & $\mathrm{pCi} / \mathrm{L}$ & 3.5 & 8.2 & & & \\
\hline SESPMNT & B179R7 & RICH.PMPHS HRM 46.4 & OFFSITE & sw & $\mathrm{N}$ & RIVER & UNFILTERED & 03-Sep-03 L & LO TRITIUM & $62.4 \mathrm{p}$ & $\mathrm{pCi/L}$ & 5.6 & 12 & & & \\
\hline SESPMNT & B17DK3 & RICH.PMPHS HRM 46.4 & OFFSITE & sW & $\mathrm{N}$ & RIVER & UNFILTERED & $30-S e p-03 L$ & LO TRITIUM & $139 \mathrm{p}$ & $\mathrm{pCilL}$ & 4.3 & 14 & & & \\
\hline SESPMNT & B17P33 & RICH.PMPHS HRM 46.4 & OFFSITE & sW & $\mathrm{N}$ & RIVER & UNFILTERED & 29-Oct-03 L & LO TRITIUM & $118 \mathrm{p}$ & $\mathrm{pCi} / \mathrm{L}$ & 4.3 & 12 & & & \\
\hline SESPMNT & B17VCO & RICH.PMPHS HRM 46.4 & OFFSITE & sw & $\mathrm{N}$ & RIVER & UNFILTERED & 25-Nov-03 L & LO TRITIUM & $41.5 \mathrm{p}$ & $\mathrm{pCi} / \mathrm{L}$ & 3.1 & 5.3 & & & \\
\hline SESPMNT & B183J3 & RICH.PMPHS HRM 46.4 & OFFSITE & sw & $\mathrm{N}$ & RIVER & UNFILTERED & 08-Jan-04 L & LO TRITIUM & $77.5 \mathrm{p}$ & $\mathrm{pCi/L}$ & 10 & 17 & & & \\
\hline SESPMNT & B16858 & PRIEST RAPIDS-RIVER & OFFSITE & sW & $\mathrm{N}$ & RIVER & UNFILTERED & $05-$ Feb-03 & $\mathrm{U}-234$ & $0.18 \mathrm{p}$ & $\mathrm{pCi} / \mathrm{L}$ & 0.032 & 0.044 & & & \\
\hline SESPMNT & B16BY2 & $\begin{array}{l}\text { PRIEST RAPIDS-RIVER } \\
\end{array}$ & OFFSITE & sw & $\mathrm{N}$ & RIVER & UNFILTERED & $05-\mathrm{Mar}-03$ & U-234 & $0.229 \mathrm{p}$ & pCill & 0.035 & 0.051 & & & \\
\hline SESPMNT & B16JL8 & PRIEST RAPIDS-RIVER & OFFSITE & sw & $\mathrm{N}$ & RIVER & UNFILTERED & 02-Apr-03 & $\mathrm{U}-234$ & $0.257 \mathrm{p}$ & $\mathrm{pCi} / \mathrm{L}$ & 0.04 & 0.058 & & & \\
\hline SESPMNT & B16PJ4 & PRIEST RAPIDS-RIVER & OFFSITE & sw & $\mathrm{N}$ & RIVER & UNFILTERED & 30-Apr-03 & $\mathrm{U}-234$ & $0.23 \mathrm{p}$ & $\mathrm{pCi} / \mathrm{L}$ & 0.036 & 0.051 & & & \\
\hline SESPMNT & B16WD8 & PRIEST RAPIDS-RIVER & OFFSITE & sw & $\mathrm{N}$ & RIVER & UNFILTERED & 28-May-03 & $\mathrm{U}-234$ & $0.247 \mathrm{p}$ & $\mathrm{pCi} / \mathrm{L}$ & 0.041 & 0.057 & & & \\
\hline SESPMNT & B171D2 & $\begin{array}{l}\text { PRIEST RAPIDS-RIVER } \\
\end{array}$ & OFFSITE & sw & $\mathrm{N}$ & RIVER & UNFILTERED & 10-Jul-03 & U-234 & $0.213 \mathrm{p}$ & $\mathrm{pCliL}$ & 0.037 & 0.05 & & & \\
\hline SESPMNT & B175F4 & PRIEST RAPIDS-RIVER & OFFSITE & sw & $\mathrm{N}$ & RIVER & UNFILTERED & 08-Aug-03 L & U-234 & $0.245 \mathrm{p}$ & $\mathrm{pCi} / \mathrm{L}$ & 0.042 & 0.057 & & & \\
\hline SESPMNT & B179R2 & PRIEST RAPIDS-RIVER & OFFSITE & sw & $\mathrm{N}$ & RIVER & UNFILTERED & 03-Sep-03 L & U-234 & $0.205 \mathrm{p}$ & $\mathrm{pCi} / \mathrm{L}$ & 0.041 & 0.052 & & & \\
\hline SESPMNT & B17DJ7 & PRIEST RAPIDS-RIVER & OFFSITE & sW & $\mathrm{N}$ & RIVER & UNFILTERED & $30-S e p-034$ & $\mathrm{U}-234$ & $0.168 \mathrm{p}$ & $\mathrm{pCi} / \mathrm{L}$ & 0.034 & 0.043 & & & \\
\hline SESPMNT & B17P27 & PRIEST RAPIDS-RIVER & OFFSITE & sw & $\mathrm{N}$ & RIVER & UNFILTERED & 29-Oct-03 L & U-234 & $0.208 \mathrm{p}$ & $\mathrm{pCi/L}$ & 0.041 & 0.053 & & & \\
\hline SESPMNT & B17VB4 & PRIEST RAPIDS-RIVER & OFFSITE & sw & $\mathrm{N}$ & RIVER & UNFILTERED & 25-Nov-03 4 & U-234 & $0.214 \mathrm{p}$ & $\mathrm{pCi} / \mathrm{L}$ & 0.037 & 0.05 & & & \\
\hline SESPMNT & B183H6 & PRIEST RAPIDS-RIVER & OFFSITE & sw & $\mathrm{N}$ & RIVER & UNFILTERED & 08-Jan-04 L & U-234 & $0.224 \mathrm{p}$ & $\mathrm{pCi} / \mathrm{L}$ & 0.038 & 0.052 & & & \\
\hline SESPMNT & B16868 & RICH.PMPHS HRM 46.4 & OFFSITE & sw & $\mathrm{N}$ & RIVER & UNFILTERED & 05 -Feb-03 L & $\mathrm{U}-234$ & $0.278 \mathrm{p}$ & $\mathrm{pCi} / \mathrm{L}$ & 0.038 & 0.059 & & & \\
\hline SESPMNT & B16BY7 & RICH.PMPHS HRM 46.4 & OFFSITE & sw & $\mathrm{N}$ & RIVER & UNFILTERED & 05-Mar-03 L & U-234 & $0.312 \mathrm{p}$ & $\mathrm{pCi/L}$ & 0.041 & 0.065 & & & \\
\hline SESPMNT & B16JM4 & RICH.PMPHS HRM 46.4 & OFFSITE & sw & $\mathrm{N}$ & RIVER & UNFILTERED & 02-Apr-03 L & U-234 & $0.296 \mathrm{p}$ & $\mathrm{pCi} / \mathrm{L}$ & 0.043 & 0.065 & & & \\
\hline SESPMNT & B16PJ9 & RICH.PMPHS HRM 46.4 & OFFSITE & sw & $\mathrm{N}$ & RIVER & UNFILTERED & 30-Apr-03 L & U-234 & $0.304 \mathrm{p}$ & $\mathrm{pCi} / \mathrm{L}$ & 0.042 & 0.064 & & & \\
\hline SESPMNT & B16WF4 & RICH.PMPHS HRM 46.4 & OFFSITE & sw & $\mathrm{N}$ & RIVER & UNFILTERED & 28-May-03 & U-234 & $0.248 \mathrm{p}$ & $\mathrm{pCi} / \mathrm{L}$ & 0.046 & 0.061 & & & \\
\hline SESPMNT & B171F6 & RICH.PMPHS HRM 46.4 & OFFSITE & sW & $\mathrm{N}$ & RIVER & UNFILTERED & 10-Jul-03 & U-234 & $0.227 p$ & $\mathrm{pCi/L}$ & 0.036 & 0.051 & & & \\
\hline SESPMNT & B175F9 & RICH.PMPHS HRM 46.4 & OFFSITE & sw & $\mathrm{N}$ & RIVER & UNFILTERED & 08-Aug-03 L & U-234 & $0.287 \mathrm{p}$ & $\mathrm{pCi} / \mathrm{L}$ & 0.046 & 0.066 & & & \\
\hline SESPMNT & B179R7 & RICH.PMPHS HRM 46.4 & OFFSITE & sw & $\mathrm{N}$ & RIVER & UNFILTERED & 03-Sep-03 L & U-234 & $0.319 p$ & $\mathrm{pCi} / \mathrm{L}$ & 0.054 & 0.073 & & & \\
\hline SESPMNT & B17DK3 & RICH.PMPHS HRM 46.4 & OFFSITE & sw & $\mathrm{N}$ & RIVER & UNFILTERED & $30-S e p-034$ & U-234 & $0.271 \mathrm{p}$ & $\mathrm{pCi/L}$ & 0.042 & 0.06 & & & \\
\hline SESPMNT & B17P33 & RICH.PMPHS HRM 46.4 & OFFSITE & sw & $\mathrm{N}$ & RIVER & UNFILTERED & 29-Oct-03 & $\mathrm{U}-234$ & $0.311 \mathrm{p}$ & $\mathrm{pCi/L}$ & 0.055 & 0.075 & & & \\
\hline SESPMNT & B17VC0 & RICH.PMPHS HRM 46.4 & OFFSITE & sw & $\mathrm{N}$ & RIVER & UNFILTERED & 25-Nov-03 L & U-234 & $0.229 \mathrm{p}$ & $\mathrm{pCi} / \mathrm{L}$ & 0.038 & 0.053 & & & \\
\hline SESPMNT & B183J3 & RICH.PMPHS HRM 46.4 & OFFSITE & sw & $\mathrm{N}$ & RIVER & UNFILTERED & 08-Jan-04 L & U-234 & $0.287 \mathrm{p}$ & $\mathrm{pCi/L}$ & 0.052 & 0.07 & & & \\
\hline SESPMNT & B16858 & PRIEST RAPIDS-RIVER & OFFSITE & sw & $\mathrm{N}$ & RIVER & UNFILTERED & $05-$ Feb-03 L & U-235 & $0.00489 p$ & $\mathrm{pCi} / \mathrm{L}$ & 0.0066 & 0.0069 & u & & \\
\hline SESPMNT & B16BY2 & PRIEST RAPIDS-RIVER & OFFSITE & sw & $\mathrm{N}$ & RIVER & UNFILTERED & 05-Mar-03 L & U-235 & $0.00429 p$ & $\mathrm{pCi} / \mathrm{L}$ & 0.0061 & 0.0064 & u & & \\
\hline SESPMNT & B16JL8 & PRIEST RAPIDS-RIVER & OFFSITE & sW & $\mathrm{N}$ & RIVER & UNFILTERED & 02-Apr-03 L & $\mathrm{U}-235$ & $0.0145 \mathrm{p}$ & $\mathrm{pCi} / \mathrm{L}$ & 0.014 & 0.014 & U & & \\
\hline SESPMNT & B16PJ4 & PRIEST RAPIDS-RIVER & OFFSITE & sw & $\mathrm{N}$ & RIVER & UNFILTERED & 30-Apr-03 L & U-235 & $-0.0039 p$ & $\mathrm{pCi} / \mathrm{L}$ & 0.0094 & 0.0094 & $\mathrm{U}$ & & \\
\hline SESPMNT & B16WD8 & PRIEST RAPIDS-RIVER & OFFSITE & sw & $\mathrm{N}$ & RIVER & UNFILTERED & 28-May-03 & U-235 & $0.00311 \mathrm{p}$ & $\mathrm{pCi} / \mathrm{L}$ & 0.0065 & 0.0068 & u & & \\
\hline
\end{tabular}


WATER - COLUMBIA RIVER COMPOSITES

\begin{tabular}{|c|c|c|c|c|c|c|c|c|c|c|c|c|c|c|c|c|}
\hline OWNER ID & SAMP NUM & SAMP SITE NAME & DIST CLASS & MEDIA & $\begin{array}{l}\text { FILTERED } \\
\text { FLAG }\end{array}$ & SAMP FROM & COLL MTHD & SAMP DATE & $\left|\begin{array}{c}\text { CON SHORT } \\
\text { NAME }\end{array}\right|$ & | VALUE RPTD $\mid$ & $\left|\begin{array}{|}\text { ANAL } \\
\text { UNITS } \\
\text { RPTD }\end{array}\right|$ & $\begin{array}{c}\text { COUNTING } \\
\text { ERROR }\end{array}$ & $\begin{array}{c}\text { TOTAL ANAL } \\
\text { ERROR }\end{array}$ & $\begin{array}{c}\text { LAB } \\
\text { QUALIFIER }\end{array}$ & SAMP COMMENT & |RESULT COMMENT| \\
\hline SESPMNT & B171D2 & PRIEST RAPIDS-RIVER & OFFSITE & sw & $\mathrm{N}$ & RIVER & UNFILTERED & 10-Jul-03 L & U-235 & 0.000725 & $\mathrm{pCi} / \mathrm{L}$ & 0.0055 & 0.0058 & U & & \\
\hline SESPMNT & B175F4 & PRIEST RAPIDS-RIVER & OFFSITE & sw & $\mathrm{N}$ & RIVER & UNFILTERED & 08-Aug-03 L & $\mathrm{U}-235$ & 0.00297 & $\mathrm{pCi} / \mathrm{L}$ & 0.0071 & 0.0074 & u & & \\
\hline SESPMNT & B179R2 & PRIEST RAPIDS-RIVER & OFFSITE & sw & $\mathrm{N}$ & RIVER & UNFILTERED & 03-Sep-03 L & U-235 & 0.00798 & $\mathrm{pCi} / \mathrm{L}$ & 0.008 & 0.0081 & $u$ & & \\
\hline SESPMNT & B17DJ7 & PRIEST RAPIDS-RIVER & OFFSITE & sw & $\mathrm{N}$ & RIVER & UNFILTERED & 30-Sep-03 L & U-235 & -0.00191 & $\mathrm{pCi} / \mathrm{L}$ & 0.0076 & 0.0078 & U & & \\
\hline SESPMNT & B17P27 & $\begin{array}{l}\text { PRIEST RAPIDS-RIVER } \\
\end{array}$ & OFFSITE & sw & $\mathrm{N}$ & RIVER & UNFILTERED & $29-0 c t-034$ & $\mathrm{U}-235$ & 0.00222 & $\mathrm{pCi} / \mathrm{L}$ & 0.0064 & 0.0067 & u & & \\
\hline SESPMNT & B17VB4 & PRIEST RAPIDS-RIVER & OFFSITE & sw & $\mathrm{N}$ & RIVER & UNFILTERED & 25-Nov-03 & $\mathrm{U}-235$ & 0.0056 & $\mathrm{pCi} / \mathrm{L}$ & 0.0073 & 0.0076 & u & & \\
\hline SESPMNT & B183H6 & PRIEST RAPIDS-RIVER & OFFSITE & sW & $\mathrm{N}$ & RIVER & UNFILTERED & 08-Jan-04 L & U-235 & 0.00249 & $\mathrm{pCi} / \mathrm{L}$ & 0.0064 & 0.0067 & U & & \\
\hline SESPMNT & B16868 & RICH.PMPHS HRM 46.4 & OFFSITE & sw & $\mathrm{N}$ & RIVER & UNFILTERED & $05-\mathrm{Feb}-03 \mathrm{~L}$ & $\mathrm{U}-235$ & 0.00576 & $\mathrm{pCi} / \mathrm{L}$ & 0.0067 & 0.0071 & u & & \\
\hline SESPMNT & B16BY7 & RICH.PMPHS HRM 46.4 & OFFSITE & sw & $\mathrm{N}$ & RIVER & UNFILTERED & 05-Mar-03 & $\mathrm{U}-235$ & 0.00208 & $\mathrm{pCi} / \mathrm{L}$ & 0.0053 & 0.0056 & u & & \\
\hline SESPMNT & B16JM4 & RICH.PMPHS HRM 46.4 & OFFSITE & sw & $\mathrm{N}$ & RIVER & UNFILTERED & 02-Apr-03 & U-235 & 0.0149 & $\mathrm{pCi} / \mathrm{L}$ & 0.011 & 0.012 & & & \\
\hline SESPMNT & B16PJ9 & RICH.PMPHS HRM 46.4 & OFFSITE & sw & $\mathrm{N}$ & RIVER & UNFILTERED & 30-Apr-03 L & U-235 & 0.00844 & pCi/L & 0.0097 & 0.0098 & $u$ & & \\
\hline SESPMNT & B16WF4 & RICH.PMPHS HRM 46.4 & OFFSITE & sW & $\mathrm{N}$ & RIVER & UNFILTERED & 28-May-03 L & U-235 & 0.000688 & $\mathrm{pCi} / \mathrm{L}$ & 0.008 & 0.0083 & U & & \\
\hline SESPMNT & B171F6 & RICH.PMPHS HRM 46.4 & OFFSITE & sw & $\mathrm{N}$ & RIVER & UNFILTERED & 10-Jul-03 L & $\mathrm{U}-235$ & 0.00319 & $\mathrm{pCi} / \mathrm{L}$ & 0.0064 & 0.0067 & u & & \\
\hline SESPMNT & B175F9 & RICH.PMPHS HRM 46.4 & OFFSITE & sw & $\mathrm{N}$ & RIVER & UNFILTERED & 08-Aug-03 L & U-235 & 0.0101 & $\mathrm{pCi} / \mathrm{L}$ & 0.01 & 0.01 & u & & \\
\hline SESPMNT & B179R7 & RICH.PMPHS HRM 46.4 & OFFSITE & sW & $\mathrm{N}$ & RIVER & UNFILTERED & 03-Sep-03 L & $\mathrm{U}-235$ & 0.00905 & $\mathrm{pCi} / \mathrm{L}$ & 0.0091 & 0.0092 & U & & \\
\hline SESPMNT & B17DK3 & RICH.PMPHS HRM 46.4 & OFFSITE & sW & $\mathrm{N}$ & RIVER & UNFILTERED & 30-Sep-03 L & $\mathrm{U}-235$ & 0.0105 & $\mathrm{pCi} / \mathrm{L}$ & 0.012 & 0.012 & U & & \\
\hline SESPMNT & B17P33 & RICH.PMPHS HRM 46.4 & OFFSITE & sw & $\mathrm{N}$ & RIVER & UNFILTERED & $29-0 c t-034$ & $\mathrm{U}-235$ & 0.00628 & $\mathrm{pCi} / \mathrm{L}$ & 0.0096 & 0.0098 & u & & \\
\hline SESPMNT & B17VCO & RICH.PMPHS HRM 46.4 & OFFSITE & sW & $\mathrm{N}$ & RIVER & UNFILTERED & 25-Nov-03 & $\mathrm{U}-235$ & 0.00125 & $\mathrm{pCi} / \mathrm{L}$ & 0.0053 & 0.0056 & $u$ & & \\
\hline SESPMNT & B183J3 & RICH.PMPHS HRM 46.4 & OFFSITE & sw & $\mathrm{N}$ & RIVER & UNFILTERED & 08-Jan-04 & U-235 & 0.00594 & pCill & 0.0092 & 0.0094 & u & & \\
\hline SESPMNT & B16858 & PRIEST RAPIDS-RIVER & OFFSITE & sw & $\mathrm{N}$ & RIVER & UNFILTERED & $05-\mathrm{Feb}-03 \mathrm{~L}$ & U-238 & 0.163 & $\mathrm{pCi} / \mathrm{L}$ & 0.03 & 0.04 & & & \\
\hline SESPMNT & B16BY2 & $\begin{array}{l}\text { PRIEST RAPIDS-RIVER } \\
\end{array}$ & OFFSITE & sw & $\mathrm{N}$ & RIVER & UNFILTERED & 05-Mar-03 & $\mathrm{U}-238$ & 0.173 & $\mathrm{pCi} / \mathrm{L}$ & 0.03 & 0.041 & & & \\
\hline SESPMNT & B16JL8 & PRIEST RAPIDS-RIVER & OFFSITE & sW & $\mathrm{N}$ & RIVER & UNFILTERED & 02-Apr-03 L & $\mathrm{U}-238$ & 0.232 & $\mathrm{pCi} / \mathrm{L}$ & 0.037 & 0.053 & & & \\
\hline SESPMNT & B16PJ4 & PRIEST RAPIDS-RIVER & OFFSITE & sw & $\mathrm{N}$ & RIVER & UNFILTERED & 30-Apr-03 & $\mathrm{U}-238$ & 0.201 & pCill & 0.033 & 0.046 & & & \\
\hline SESPMNT & B16WD8 & PRIEST RAPIDS-RIVER & OFFSITE & sw & $\mathrm{N}$ & RIVER & UNFILTERED & 28-May-03 & U-238 & 0.161 & pCi/L & 0.033 & 0.042 & & & \\
\hline SESPMNT & B171D2 & $\begin{array}{l}\text { PRIEST RAPIDS-RIVER } \\
\end{array}$ & OFFSITE & sw & $\mathrm{N}$ & RIVER & UNFILTERED & 10-Jul-03 L & $\mathrm{U}-238$ & 0.176 & $\mathrm{pCi} / \mathrm{L}$ & 0.034 & 0.044 & & & \\
\hline SESPMNT & B175F4 & PRIEST RAPIDS-RIVER & OFFSITE & sW & $\mathrm{N}$ & RIVER & UNFILTERED & 08-Aug-03 L & $\mathrm{U}-238$ & 0.171 & pCill & 0.035 & 0.044 & & & \\
\hline SESPMNT & B179R2 & PRIEST RAPIDS-RIVER & OFFSITE & sw & $\mathrm{N}$ & RIVER & UNFILTERED & 03-Sep-03 L & $\mathrm{U}-238$ & 0.177 & $\mathrm{pCi} / \mathrm{L}$ & 0.038 & 0.047 & & & \\
\hline SESPMNT & B17DJ7 & PRIEST RAPIDS-RIVER & OFFSITE & sw & $\mathrm{N}$ & RIVER & UNFILTERED & 30-Sep-03 L & $\mathrm{U}-238$ & 0.137 & $\mathrm{pCi} / \mathrm{L}$ & 0.031 & 0.038 & & & \\
\hline SESPMNT & B17P27 & PRIEST RAPIDS-RIVER & OFFSITE & sw & $\mathrm{N}$ & RIVER & UNFILTERED & 29-Oct-03 & $\mathrm{U}-238$ & 0.159 & $\mathrm{pCi} / \mathrm{L}$ & 0.035 & 0.043 & & & \\
\hline SESPMNT & B17VB4 & PRIEST RAPIDS-RIVER & OFFSITE & sw & $\mathrm{N}$ & RIVER & UNFILTERED & 25-Nov-03 & $\mathrm{U}-238$ & 0.148 & $\mathrm{pCi} / \mathrm{L}$ & 0.031 & 0.039 & & & \\
\hline SESPMNT & B183H6 & $\begin{array}{l}\text { PRIEST RAPIDS-RIVER } \\
\end{array}$ & OFFSITE & sw & $\mathrm{N}$ & RIVER & UNFILTERED & 08-Jan-04 & U-238 & 0.177 & pCill & 0.034 & 0.044 & & & \\
\hline SESPMNT & B16868 & RICH.PMPHS HRM 46.4 & OFFSITE & sw & $\mathrm{N}$ & RIVER & UNFILTERED & 05-Feb-03 & $\mathrm{U}-238$ & 0.199 & $\mathrm{pCi} / \mathrm{L}$ & 0.032 & 0.046 & & & \\
\hline SESPMNT & B16BY7 & RICH.PMPHS HRM 46.4 & OFFSITE & sw & $\mathrm{N}$ & RIVER & UNFILTERED & 05-Mar-03 L & $\mathrm{U}-238$ & 0.255 & $\mathrm{pCi} / \mathrm{L}$ & 0.037 & 0.055 & & & \\
\hline SESPMNT & B16JM4 & RICH.PMPHS HRM 46.4 & OFFSITE & sW & $\mathrm{N}$ & RIVER & UNFILTERED & 02-Apr-03 L & $\mathrm{U}-238$ & 0.301 & $\mathrm{pCi} / \mathrm{L}$ & 0.044 & 0.066 & & & \\
\hline SESPMNT & B16PJ9 & RICH.PMPHS HRM 46.4 & OFFSITE & sw & $\mathrm{N}$ & RIVER & UNFILTERED & 30-Apr-03 & $\mathrm{U}-238$ & 0.238 & $\mathrm{pCi} / \mathrm{L}$ & 0.037 & 0.053 & & & \\
\hline SESPMNT & B16WF4 & RICH.PMPHS HRM 46.4 & OFFSITE & sW & $\mathrm{N}$ & RIVER & UNFILTERED & 28-May-03 L & $\mathrm{U}-238$ & 0.18 & $\mathrm{pCi} / \mathrm{L}$ & 0.04 & 0.05 & & & \\
\hline SESPMNT & B171F6 & RICH.PMPHS HRM 46.4 & OFFSITE & sw & $\mathrm{N}$ & RIVER & UNFILTERED & 10-Jul-03 L & $\mathrm{U}-238$ & 0.192 & $\mathrm{pCi} / \mathrm{L}$ & 0.033 & 0.045 & & & \\
\hline SESPMNT & B175F9 & RICH.PMPHS HRM 46.4 & OFFSITE & sw & $\mathrm{N}$ & RIVER & UNFILTERED & 08-Aug-03 L & $\mathrm{U}-238$ & 0.214 & $\mathrm{pCi} / \mathrm{L}$ & 0.039 & 0.053 & & & \\
\hline SESPMNT & B179R7 & RICH.PMPHS HRM 46.4 & OFFSITE & sw & $\mathrm{N}$ & RIVER & UNFILTERED & 03-Sep-03 L & U-238 & 0.232 & $\mathrm{pCi} / \mathrm{L}$ & 0.046 & 0.059 & & & \\
\hline SESPMNT & B17DK3 & RICH.PMPHS HRM 46.4 & OFFSITE & sw & $\mathrm{N}$ & RIVER & UNFILTERED & $30-S e p-034$ & $\mathrm{U}-238$ & 0.203 & $\mathrm{pCi} / \mathrm{L}$ & 0.037 & 0.049 & & & \\
\hline SESPMNT & B17P33 & RICH.PMPHS HRM 46.4 & OFFSITE & sw & $\mathrm{N}$ & RIVER & UNFILTERED & $29-0 c t-034$ & $\mathrm{U}-238$ & 0.217 & $\mathrm{pCi} / \mathrm{L}$ & 0.046 & 0.058 & & & \\
\hline SESPMNT & B17VCO & RICH.PMPHS HRM 46.4 & OFFSITE & sW & $\mathrm{N}$ & RIVER & UNFILTERED & 25-Nov-034 & U-238 & & $\mathrm{pCi} / \mathrm{L}$ & 0.035 & 0.046 & & & \\
\hline SESPMNT & B183J3 & RICH.PMPHS HRM 46.4 & OFFSITE & sW & $\mathrm{N}$ & RIVER & UNFILTERED & 08-Jan-04 L & $\mathrm{U}-238$ & 0.227 & $\mathrm{pCi} / \mathrm{L}$ & 0.046 & 0.059 & & & \\
\hline
\end{tabular}




\begin{tabular}{|c|c|c|c|c|}
\hline OWNER ID & SAMP SITE NAME & SAMP DATE & FLOW RATE & \begin{tabular}{|l}
$\begin{array}{l}\text { FLOW RATE } \\
\text { UNITS }\end{array}$ \\
\end{tabular} \\
\hline & & 01-Jan-03 & & \\
\hline & BELOW PRIEST RAPIDS & & & \\
\hline SESPMNT & BELOW PRIEST RAPIDS & 03-Jan-03 & 71576.77 & \\
\hline & BELOW PRIEST RAPIDS & & & \\
\hline & BELOW PRIEST RAPIDS & & 72039.83 & \\
\hline & BELOW PRIEST RAPIDS & 06-Jan-03 & 78740.55 & \\
\hline & BELOW PRIEST RAPIDS & 07-Jan-03 & 92216.45 & \\
\hline & BELOW PRIEST RAPIDS & 08-Jan-03 & 95480.85 & \\
\hline SESPMNT & BELOW PRIEST RAPIDS & 09-Jan-03 & 89806.41 & \\
\hline SESPMNT & BELOW PRIEST RAPIDS & 10-Jan-03 & 83033.07 & \\
\hline SESPMNT & BELOW PRIEST RAPIDS & 11-Jan-03 & 72516.23 & \\
\hline SESPMNT & BELOW PRIEST RAPIDS & 12-Jan-03 & 71321.52 & \\
\hline SESPMNT & BELOW PRIEST RAPIDS & 13-Jan-03 & 71499.05 & \\
\hline SE & BELOW PRIEST RAPIDS & 14-Jan-03 & 72496.95 & \\
\hline SESPMNT & BELOW PRIEST RAPIDS & 15-Jan-03 & 96029.62 & CFS \\
\hline SESPMNT & BELOW PRIEST RAPIDS & 16-Jan-03 & 106524.1 & \\
\hline MNT & BELOW PRIEST RAPIDS & 17-Jan-03 & 99279.6 & CFS \\
\hline SESPMNT & BELOW PRIEST RAPIDS & 18-Jan-03 & 90427.29 & CFS \\
\hline SESPMNT & BELOW PRIEST RAPIDS & 19-Jan-03 & 71408.23 & CFS \\
\hline SESPMNT & BELOW PRIEST RAPIDS & 20-Jan-03 & 82672.52 & CFS \\
\hline SESPMNT & BELOW PRIEST RAPIDS & 21-Jan-03 & 108365.4 & CFS \\
\hline SESPMNT & BELOW PRIEST RAPIDS & 22-Jan-03 & 101386 & CFS \\
\hline SESPMNT & BELOW PRIEST RAPIDS & 23-Jan-03 & 81094.09 & CFS \\
\hline MNT & BELOW PRIEST RAPIDS & 24-Jan-03 & 76360.71 & CFS \\
\hline SESPMNT & BELOW PRIEST RAPIDS & 25-Jan-03 & 71249.94 & CFS \\
\hline SESPMNT & BELOW PRIEST RAPIDS & 26-Jan-03 & 71450.27 & CF \\
\hline SESPMNT & BELOW PRIEST RAPIDS & 27-Jan-03 & 71587.15 & CFS \\
\hline SESPMNT & BELOW PRIEST RAPIDS & 28-Jan-03 & 73710.56 & CF \\
\hline SESPMNT & BELOW PRIEST RAPIDS & 29-Jan-03 & 72594.7 & CF \\
\hline SESPMNT & BELOW PRIEST RAPIDS & 30-Jan-03 _ & 71219.66 & CF \\
\hline SESPMNT & BELOW PRIEST RAPIDS & 31-Jan-03 & 71563.51 & CF \\
\hline SESPMNT & BELOW PRIEST RAPIDS & 01-Feb-03 & 71353.36 & CF \\
\hline SESPMNT & BELOW PRIEST RAPIDS & 02-Feb-03 & 70981.31 & CF \\
\hline SES & BELOW PRIEST RAPIDS & 03-Feb-03 & 71043.41 & CF \\
\hline SESF & BELOW PRIEST RAPIDS & 04-Feb-03 & 70650.66 & CF \\
\hline SES & BELOW PRIEST RAPIDS & 05-Feb-03 & 70788.62 & CFS \\
\hline & BELOW PRIEST RAPIDS & 06-Feb-03 & 82103.34 & CFS \\
\hline SESF & BELOW PRIEST RAPIDS & 07-Feb-03 & 100193.5 & \\
\hline SES & BELOW PRIEST RAPIDS & 08-Feb-03 & 72728.48 & \\
\hline & BELOW PRIEST RAPIDS & 09-Feb-03 & 71072.07 & CFS \\
\hline SES & BELOW PRIEST RAPIDS & 10-Feb-03 & 71597.39 & \\
\hline SE & BELOW PRIEST RAPIDS & 11-Feb-03 & 77422.36 & CFS \\
\hline & BELOW PRIEST RAPIDS & 12-Feb-03 & 71974.05 & \\
\hline T & BELOW PRIEST RAPIDS & 13-Feb-03 & 71867.27 & CF \\
\hline T & BELOW PRIEST RAPIDS & 14-Feb-03 & 70841.92 & CFS \\
\hline & BELOW PRIEST RAPIDS & 15-Feb-03 & 70972.27 & \\
\hline$T$ & BELOW PRIEST RAPIDS & 16-Feb-03 & 70870.19 & CF \\
\hline$T$ & BELOW PRIEST RAPIDS & 17-Feb-03 & 71557.29 & CFS \\
\hline$T$ & BELOW PRIEST RAPIDS & 18-Feb-03 & 71292.95 & CFS \\
\hline$-t$ & BELOW PRIEST RA & 19-Feb-03 & 71524.36 & CFS \\
\hline & BELOW PRIEST RAPIDS & 20-Feb-03 & 72744 & \\
\hline & BELOW PF & 21-Feb-03 & 71878.44 & CFS \\
\hline & BELOW $\mathrm{P}$ & 22-Feb-03 & 71216.67 & CF \\
\hline & BELOW P & 23-Feb-03 & 72686.31 & CFS \\
\hline & BELOW F & 24-Feb-03 & 71541.42 & CFS \\
\hline & $B E$ & $25-\mathrm{Fe}$ & & \\
\hline & $\mathrm{BE}$ & $26-\mathrm{F}$ & 742 & $\mathrm{CF}$ \\
\hline & BE & 3 & 835 & S \\
\hline & & 3 & 760 & \\
\hline & & 3 & 38 & 3 \\
\hline & & 02-Mar-03 & 729 & 1 \\
\hline & & 03 & & 3 \\
\hline & & 04-Mar & 994 & 7 \\
\hline & & 05-Mar-03 & 88 & \\
\hline & & Mar-03 & 02 & 2 \\
\hline & BE & 3 & 1.72 & $=s$ \\
\hline & & & & \\
\hline
\end{tabular}

\begin{tabular}{|c|c|c|c|c|}
\hline $\begin{array}{l}\text { OWNER } \\
\text { ID }\end{array}$ & & & $\begin{array}{l}\text { FLOW } \\
\text { RATE }\end{array}$ & $\begin{array}{l}\text { RATE } \\
\text { UNITS }\end{array}$ \\
\hline & LOW PRIEST RAPII & $09-M a r-03$ & 71059.94 & CFS \\
\hline & & $10-N$ & 70671.59 & CFS \\
\hline & & & 70 & $=S$ \\
\hline & & 12 & 71 & \\
\hline & & 13. & 1.1 & S \\
\hline & & & 70 & ES \\
\hline & & 15 & 707 & S \\
\hline & & $16-\mathrm{N}$ & 719 & S \\
\hline & & $17-\mathrm{N}$ & 826 & S \\
\hline & & $18-\mathrm{M}$ & & S \\
\hline & & $19-\mathrm{M}$ & 7997 & SS \\
\hline & & $20-M$ & 70987.52 & S \\
\hline & |PRIEST F & 21-M & 72407.89 & S \\
\hline & & 22-Mar-03 & 74086.73 & \\
\hline & & 23-Mar-03 & 71750.32 & \\
\hline & IPRI & 24-Mar-03 & 71244.66 & \\
\hline & & -Mar-03 & 87249.27 & \\
\hline & & -Mar-03 & 126979.1 & \\
\hline & V PRIEST & 27-Mar-03 & 131893.9 & \\
\hline & & & 125533.1 & \\
\hline & & 29-Mar-03 & & \\
\hline & VPR & 30-Mar-03 & & \\
\hline & & & & \\
\hline & & 01-Apr-03 & & \\
\hline & $\mathrm{VPF}$ & 02-Apr-03 & & \\
\hline & & & 98109.68 & \\
\hline & & $r-03$ & 104993.3 & \\
\hline & & 05-Apr-03 & & \\
\hline & & 03 & & \\
\hline & & Apr-03 & 98100.03 & \\
\hline & & 08-Apr-03 & 117543.6 & \\
\hline & & 03 & 1.89 & \\
\hline & & -03 & 10 & \\
\hline & & -Apr-03 & & \\
\hline & & -03 & 90865.88 & \\
\hline & & Apr-03 & 84 & \\
\hline & & 14-Apr-03 & 96341.69 & \\
\hline & $s$ & -03 & 104695.2 & \\
\hline & & -Apr-03 & 129522.6 & \\
\hline & s & 17-Apr-03 & 145978 & \\
\hline & s & 03 & 11 & \\
\hline & & $19-\mathrm{A}_{\mathrm{A}}$ & 11. & \\
\hline & s & 20-Apr-03 & 98 & S \\
\hline & s & $21-\frac{1}{2}$ & 11 & \\
\hline & & $22-A_{1}$ & 156934.1 & \\
\hline SES & s & 23-Apr-03 & 143773 & S \\
\hline & $s$ & $24-\mathrm{A}$ & 135803 & S \\
\hline & & $25-A_{1}$ & 155486.9 & SS \\
\hline SES & s & 26-Apr-03 & 125346.4 & ES \\
\hline & s & $27-A_{1}$ & 108619.9 & SS \\
\hline & S & $28-A_{1}$ & 123176.3 & S \\
\hline SE & s & 29-Apr-03 & 144933.8 & FS \\
\hline & 5 & 30-Apr-03 & 144638.9 & S \\
\hline & & 01-May-03 & 126607.4 & S \\
\hline SES & 5 & 02-May-03 & 119281.5 & S \\
\hline & & 03 & 126610.2 & ES \\
\hline & & 04-May-03 & 134014.4 & S \\
\hline & & 5-May-03 & 145150 & \\
\hline & & 03 & 155526.8 & ES \\
\hline & & 07-May-03 & 141517.6 & \\
\hline & & 08-May-03 & 157368 & \\
\hline & & 9-May-03 & 134834.9 & \\
\hline & & -May-03 & 1.3 & \\
\hline & & 11-May-03 & 4.5 & \\
\hline & & 3 & & \\
\hline & & & & \\
\hline
\end{tabular}

\begin{tabular}{|c|c|c|c|c|}
\hline $\begin{array}{l}\text { OWNER } \\
\text { ID }\end{array}$ & & & $\begin{array}{l}\text { FLOW } \\
\text { RATE }\end{array}$ & $\begin{array}{l}\text { RATE } \\
\text { UNITS }\end{array}$ \\
\hline & ELOW PRIEST RAPIDS & 15-May-03 & & \\
\hline SPMNT & LOW PRIEST RAPIDS & 16-May-03 & 152668 & CFS \\
\hline & & & & \\
\hline & ST F & 18-Ma & 127362.3 & CFS \\
\hline & EST F $F$ & 19-May-03 & 5.3. & CFS \\
\hline & WF & & 1436355 & \\
\hline & BELOW PRIEST R & 21-Mav-03 & 1993674 & CFS \\
\hline & BELOW PRIEST R & 22-May-03 & 181159.9 & CFS \\
\hline & WF & & 174530.9 & CFS \\
\hline & BELOW PRIEST RAPIDS & 24-Mav-03 & 1215143 & CFS \\
\hline & BELOWP & 25-May-03 & 88175.07 & CFS \\
\hline & DWF & & 5.4 & CFS \\
\hline PMNT & BELOW PRIEST RAPIDS & 27-Mav-03 & 128643.9 & CFS \\
\hline & BELOWP & $28-1$ & 135573.9 & CFS \\
\hline & DWF & & & CFS \\
\hline DM & BELOW PF & 30-Mav-03 & 158931.1 & CFS \\
\hline & BELOWP & $31-1$ & & CFS \\
\hline & Low & & & CFS \\
\hline$P M N$ & BELOWP & 02- & & CFS \\
\hline & OWF & & & CFS \\
\hline & BELOW & & & CFS \\
\hline & BELOW P & 05-Jun- 03 & & CFS \\
\hline & LoW F & & & CFS \\
\hline & BELOW & & $\frac{170886.5}{170}$ & CFS \\
\hline & BELOW F & & 6.2 & CFS \\
\hline & & & & CFS \\
\hline & & & & CFS \\
\hline & BELOV & & 171 & CFS \\
\hline & & & 5.3 & CFS \\
\hline & & & 0.9 & CFS \\
\hline & & & 12.2 & CFS \\
\hline & & & 68.3 & \\
\hline & & & 1.4 & \\
\hline & & & 0.6 & \\
\hline & & & & \\
\hline & BE & & 4.6 & \\
\hline & BELOW & & 12 & \\
\hline & BELOW & & & \\
\hline & BELOW F & -03 & 158 & \\
\hline & BELOW & .03 & & \\
\hline & BELOW & & & \\
\hline & BELO & & & \\
\hline & BELOV & 03 & & \\
\hline & BELOW & & & \\
\hline & BELO & & & \\
\hline & BELOV & 03 & & \\
\hline & BELOV & & & \\
\hline & $\mathrm{BEI}$ & & & \\
\hline & BELOW & 03 & 6.2 & \\
\hline & & & & \\
\hline & BELOV & 03 & 301 & \\
\hline & BELOW & 03 & 417.82 & \\
\hline & & & 014.02 & \\
\hline & BELOW & Jul-03 & 1772.4 & \\
\hline & BELOW & Jul-03 & & \\
\hline & ST RAPIDS & 3 & 125938 & \\
\hline & BELOW & -Jul-03 & 125443 & \\
\hline & EST RAPIDS & 03 & 4595.6 & \\
\hline & ST RAPIDS & 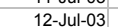 & 3.1 & \\
\hline & ST RAPIDS & 03 & 99655.81 & CFS \\
\hline & BELOW PRIEST RAPIDS & 03 & 119562 & \\
\hline & & & 9 & \\
\hline & STR & & 1247 & \\
\hline & BELOW & & 109148.8 & \\
\hline & & & 110112 & \\
\hline & EST & 19 & $1040 \leqq$ & \\
\hline ESPMNT & BELOW PRIEST RAPIDS & 20-Jul-03 & 85834.52 & CFS \\
\hline
\end{tabular}




\begin{tabular}{|c|c|c|c|c|}
\hline & AMP SITE NAME & MP DATE & & $\begin{array}{l}\text { FLOW RATE } \\
\text { UNITS }\end{array}$ \\
\hline & & 21-Jul-03 & 101812.4 & CFS \\
\hline & & & & $=S$ \\
\hline & & & & \\
\hline & & 3 & .2 & \\
\hline SESPM & ow & 13 & .5 & \\
\hline & & 3 & & \\
\hline & LO & 13 & 86 & \\
\hline SESPMN & ELOW & 3 & 2.4 & \\
\hline & & 13 & 7.9 & \\
\hline & BELOW & 13 & 8.7 & \\
\hline & BELOW & & & \\
\hline & (0) & $-A L$ & & \\
\hline & BELOW & $02-A_{L}$ & 92 & \\
\hline & BELOW & 03-A & & \\
\hline & 0 & & & \\
\hline & BELOW & $05-\mathrm{Al}_{\mathrm{L}}$ & & \\
\hline & BELOW & 06-A & & \\
\hline & & & & \\
\hline & BELOW & $08-\mathrm{Al}_{\mathrm{L}}$ & & \\
\hline & ELOW & 09-A & & \\
\hline & & & & \\
\hline & BELOW & 11-A & & \\
\hline & ELOV & & & \\
\hline & & & & \\
\hline & BELOW & & & \\
\hline & BELOV & & & \\
\hline & & & & \\
\hline & BELOW & & & \\
\hline & SELO & & & \\
\hline & BELOV & & & \\
\hline & BELOW & & & \\
\hline & SELO & & & \\
\hline & BELOV & & & \\
\hline SES & BELOV & & & \\
\hline & SELC & & & \\
\hline & BELOI & & 9252.4 & \\
\hline SES & BELOI & & 127166.5 & \\
\hline & & & & \\
\hline SES & BELO & & 7.77 & \\
\hline SES & BELO & & 9.22 & \\
\hline SES & BEI & & & \\
\hline SES & BELO & & 3.15 & \\
\hline SES & BE & & 6.64 & \\
\hline SES & $\mathrm{BE}$ & & 0.09 & \\
\hline SES & BELO & & 5.79 & \\
\hline SES & BEI & & 184.09 & \\
\hline SES & BELO & & 311.58 & \\
\hline SES & BEL & & 10.44 & \\
\hline SES & BELO & & 367.85 & s \\
\hline SES & BELO & & 468.68 & \\
\hline SES & BELO) & 09 & 118.51 & \\
\hline SES & BELOV & $10-5$ & 102.91 & \\
\hline SES & BELO & & 464.43 & \\
\hline SES & ov & $12-$ & 63693.68 & \\
\hline SES & BELOV & & 60499.9 & \\
\hline SES & BELOW & 3 & 621.62 & \\
\hline SES & ov & 3 & 57685.14 & \\
\hline & BELOW & 3 & 155.96 & \\
\hline$S E S$ & BELOW & 3 & 865.62 & \\
\hline SES & ELOW & 18-S & 59374.54 & \\
\hline & 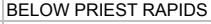 & & & \\
\hline & 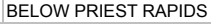 & $0-\mathrm{Se}_{\mathrm{e}}$ & 551 & \\
\hline & & & & \\
\hline & & & & \\
\hline
\end{tabular}

\begin{tabular}{|c|c|c|c|c|}
\hline $\begin{array}{l}\text { OWNER } \\
\text { ID }\end{array}$ & & & $\begin{array}{l}\text { FLOW } \\
\text { RATE }\end{array}$ & $\begin{array}{l}\text { RATE } \\
\text { UNITS }\end{array}$ \\
\hline & ELOW PRIEST RAPIC & 23-Sep-03 & & \\
\hline SMM & BELOW PBEST RA & $24-\operatorname{Sen}-03$ & $\begin{array}{l}7524.094 \\
75249\end{array}$ & CFS \\
\hline & $\begin{array}{l}\text { BELOW PIEST RA } \\
\text {, }\end{array}$ & $25-\mathrm{Sp}-03$ & & CFS \\
\hline & BELOW PRIEST RAPIDS & 26-Sep-03 & 93517.41 & CFS \\
\hline & BELOW PRIEST RAPIDS & $\begin{array}{l}27-\mathrm{Sep}-03 \\
2\end{array}$ & 7549345 & CFS \\
\hline & BELOW PRIEST RAPIDS & $28-\operatorname{Sep}-03$ & 5916662 & CFS \\
\hline & BELOW PRIEST RAPIDS & 29-Sep-03 & 85379.2 & CFS \\
\hline & BELOW PRIEST RAPIDS & 30-Sep-03 & 84477.73 & CFS \\
\hline & BELOW PRIEST RAPIDS & $\begin{array}{l}0 \\
01-0 c t-03 \\
01-03\end{array}$ & 88680.77 & CFS \\
\hline & BELOW PRIEST RAPIDS & $02-0 \mathrm{ct}-03$ & 78645.28 & CFS \\
\hline SESPMNT & BELOW PRIEST RAPIDS & 03-Oct-03 & 6838286 & CFS \\
\hline & BELOW PRIEST RAPIDS & $04-0 c t-03$ & 58193.16 & CFS \\
\hline & BELOW PRIEST RAPIDS & $\begin{array}{r}05-\mathrm{Oct}-03 \\
05\end{array}$ & 52384.47 & CFS \\
\hline & BELOW PRIEST RAPIDS & $06-$ Oct-03 & 76311.34 & CFS \\
\hline & BELOW PRIEST RAPIDS & $\begin{array}{l}0.0 \mathrm{cc}-00 \\
07-\mathrm{Oct}-03\end{array}$ & 74907.9 & CFS \\
\hline $\begin{array}{l}\text { SESPMNT } \\
\text { SESP }\end{array}$ & BELOW PRIEST RAPIDS & $08-0 c t-03$ & 81587.92 & CFS \\
\hline 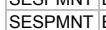 & BELOW PRIEST RAPIDS & $09-0$ - & 8423484 & CFS \\
\hline Jeorim the & BELOW PRIEST RAPIDS & $\begin{array}{l}10-O c t-03 \\
10-03\end{array}$ & $\begin{array}{l}04524.04 \\
82159.7\end{array}$ & CFS \\
\hline 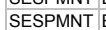 & BELOW PRIEST RAPIDS & $11-0 c t-03$ & 71612.34 & CFS \\
\hline 年 & BELOW PRIEST RAPIDS & $12-0$ ct-03 & 5941985 & CFS \\
\hline Jestim the & BELOW PRIEST RAPIDS & $13-\mathrm{Oct}-03$ & 82443.39 & CFS \\
\hline 年 & BELOW PRIEST RAPIDS & $14-0 c t-03$ & 73710.61 & CFS \\
\hline SESPM & BELOW PRIEST RAPIDS & 15-Oct-03 & 93020.59 & CFS \\
\hline Jeorim & BELOW PRIEST RAPIDS & $16-$ Oct-03 & 84489.98 & CFS \\
\hline SESPM & BELOW PRIEST RAPIDS & $17-0 \mathrm{Oct}-03$ & 80872.04 & CFS \\
\hline SESPM & BELOW PRIEST RAPIDS & 18-Oct-03 & 64136.19 & CFS \\
\hline SESPM & BELOW PRIEST RAPIDS & $19-0 c t-03$ & 64419.85 & CFS \\
\hline SESPM & BELOW PRIEST RAPIDS & $20-0 \mathrm{Oct}-03$ & 63135.77 & CFS \\
\hline SESPM & BELOW PRIEST RAPIDS & $21-O c t-03$ & 66036.24 & CFS \\
\hline SESPM & BELOW PRIEST RAPIDS & $22-0 c t-03$ & 86409.23 & CFS \\
\hline SESPMNT & BELOW PRIEST RAPIDS & $23-\mathrm{Oct}-03$ & 111230.5 & CFS \\
\hline SESPM & BELOW PRIEST RAPIDS & $24-0 c t-03$ & 108700.3 & CFS \\
\hline SESPM & BELOW PRIEST RAPIDS & $25-0 c t-03$ & 111630.7 & CFS \\
\hline SESPMNT & BELOW PRIEST RAPIDS & $26-$ Oct-03 & 85266.7 & CFS \\
\hline SESPM & BELOW PRIEST RAPIDS & $27-0 c t-03$ & 90841.91 & CFS \\
\hline SESF & BELOW PRIEST RAPIDS & 28 -Oct-03 & 110978.3 & CFS \\
\hline SES & BELOW PRIEST RAPIDS & $29-0 c t-03$ & 106580.7 & CFS \\
\hline SES & BELOW PRIEST RAPIDS & 30-Oct-03 & 95145.38 & CFS \\
\hline- & BELOW PRIEST RAPIDS & $31-0 c t-03$ & 98037.91 & CFS \\
\hline-1 & BELOW PRIEST RAPIDS & 01-Nov-03 & 111588.6 & CFS \\
\hline & BELOW PRIEST RAPIDS & $02-\mathrm{No}$ & 113445.4 & CFS \\
\hline- & BELOW PRIEST RAPIDS & 03 -Nov-03 & & CFS \\
\hline & BELOW PRIEST RAPIDS & 04-Nov-03 & 92532.12 & CFS \\
\hline & BELOW PRIEST RAPIDS & 05 -Nov-03 & 110898.3 & CFS \\
\hline & BELOW PRIEST RA & 06 -Nov-03 & 121671.7 & CFS \\
\hline & BELOW PRIEST RAPIDS & $07-$ Nov-03 & 114678.9 & CFS \\
\hline & BELOW PRIEST RAPIDS & 08-Nov-03 & 110652.2 & CFS \\
\hline & BELOW PF & $09-$ Nov-03 & 74111.73 & CFS \\
\hline & BELOW PRIEST RAPIDS & 10-Nov-03 & 91114.34 & CFS \\
\hline & BELOW PRIEST RAPIDS & 11-Nov-03 & 90392.05 & CFS \\
\hline & BELOW PF & 12-Nov-03 & 104685.4 & CFS \\
\hline & BELOW PRIEST RAPIDS & 13-Nov-03 & 106500.8 & CFS \\
\hline & BELOW PRIEST RAPIDS & 14-Nov-03 & 97800.69 & CFS \\
\hline & BELOW PF & 15-Nov-03 & 90494.68 & CFS \\
\hline & BELOW PRIEST RAPIDS & 16-Nov-03 & 82979.91 & CFS \\
\hline & ST RAPIDS & 17-Nov-03 & 95351.59 & CFS \\
\hline & BELOW PRIEST RAPIDS & 18-Nov-03 & 9177 & CFS \\
\hline & BELOW PRIEST RAPIDS & 19-Nov-03 & 9746 & CFS \\
\hline & ST RAPIDS & 20-Nov-03 & 114265.8 & \\
\hline & BELOW PRIEST RAPIDS & 21-Nov-03 & 123875.6 & CFS \\
\hline & ST RAPIDS & 22-Nov-03 & 121728.5 & CFS \\
\hline & & 23-Nov-03 & 82686.42 & \\
\hline & BELOW P & 24-Nov-03 & 90635.48 & CFS \\
\hline & BELOW PRIEST RAPIDS & $\begin{array}{l}\text { 24-N-Nov-003 } \\
25 \text { ov }\end{array}$ & 102130.3 & CFS \\
\hline
\end{tabular}

\section{\begin{tabular}{c|c|c|c|c|}
\hline $\begin{array}{c}\text { OWNER } \\
\text { ID }\end{array}$ & SAMP SITE NAME & SAMP DATE & $\begin{array}{l}\text { FLOW } \\
\text { RATE }\end{array}$ & $\begin{array}{c}\text { RATE } \\
\text { UNITS }\end{array}$ \\
\hline
\end{tabular}}

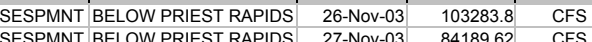
\begin{tabular}{|l|l|l|l|}
\hline SESPMNT BELOW PRIEST RAPIDS & $28-$ Novo-03 & 72093.38 & CFS \\
\hline SESPMNT BELOW PRIEST RAPIDS & $29-$ Nov-03 & 69606.14 & CFS \\
\hline
\end{tabular}

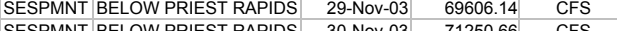
\begin{tabular}{|l|lll|}
\hline SESPMNT BELOW PRIEST RAPIDS & $30-$ Nov-03 & 71250.66 & CFS \\
\hline SESPMNT BELOW PRIEST RAPIDS & $01-$ Dec-03 & 84145.94 & CFS \\
\hline SESPMNT BELOW PRIEST RAPIDS & $02-$ Dec-03 & 90012.98 & CFS
\end{tabular} SESPMNT BELOW PRIEST RAPIDS 03 -Dec-03 1224973 CFS \begin{tabular}{|l|l|l|l|}
\hline SESPMNT BELOW PRIEST RAPIDS & 04-Dec-03 & 120621.2 & CFS \\
\hline
\end{tabular}

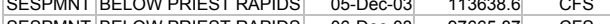
\begin{tabular}{lllll} 
SESPMNT BELOW PRIEST RAPIDS & $06-$ Dec-03 & 97665.87 & CFS \\
\hline SESPMNT BELOW PRIEST RAPIDS & $07-D c-03$ & 947032 & CFS
\end{tabular} \begin{tabular}{lllll}
\hline SESPMNT BELOW PRIEST RAPIDS & $08-$ Dec-03 & 87862.85 & CFS \\
\hline
\end{tabular} SESPMNT BELOW PRIEST RAPIDS 09 -Dec-03 113868 CFS

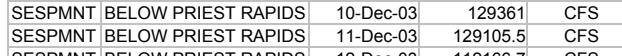
\begin{tabular}{|l|l|l|l|}
\hline SESPMNT BELOW PRIEST RAPIDS & 12-Dec-03 & 112166.7 & CFS \\
\hline SESPMNT BELOW PRIEST RAPIDS & 13 -Dec-03 & 108373.2 & CFS \\
\hline
\end{tabular} \begin{tabular}{|l|lll}
\hline SESPMNT BELOW PRIEST RAPIDS & $14-D e c-03$ & 119708.2 & CFS
\end{tabular} \begin{tabular}{|l|l|l|l|}
\hline SESPMNT BELOW PRIEST RAPIDS & $15-\mathrm{Dec}-03$ & 133130.4 & CFS \\
\hline
\end{tabular} \begin{tabular}{|l|l|l|l|}
\hline SESPMNT BELOW PRIEST RAPIDS & $16-D e c-03$ & 126917.5 & CFS \\
\hline SESPMNT BELOW PRIEST RAPIDS & $17-D e c-03$ & 127424.7 & CFS \\
\hline
\end{tabular} \begin{tabular}{|l|l|l|l|}
\hline SESPMNT BELOW PRIEST RAPIDS & $17-$ Dec-03 & 127424.7 & CFS \\
\hline
\end{tabular} \begin{tabular}{|l|r|r|r|}
\hline SESPMNT BELOW PRIEST RAPIDS & 18 -Dec-03 & 120614.5 & CFS \\
\hline SESPMNT BELOW PRIEST RAPIDS & $19-$ Dec-03 & 116760.3 & CFS \\
\hline
\end{tabular} \begin{tabular}{lllll}
\hline SESPMNT BELOW PRIEST RAPIDS & $20-\mathrm{Dec}-03$ & 114585 & CFS
\end{tabular} \begin{tabular}{|l|l|l|l|}
\hline SESPMNT BELOW PRIEST RAPIDS & 21 -Dec-03 & 85072.95 & CFS \\
\hline
\end{tabular} \begin{tabular}{|l|l|l|l|}
\hline SESPMNT BELOW PRIEST RAPIDS & $22-$ Dec-03 & 112804.4 & CFS \\
\hline SESPMNT BELOW PRIEST RAPIDS & $23-$ Dec-03 & 130371.6 & CFS \\
\hline
\end{tabular} \begin{tabular}{lllll}
\hline SESPMNT BELOW PRIEST RAPIDS & $23-\mathrm{Dec}-03$ & 130371.6 & CFS \\
\hline
\end{tabular} \begin{tabular}{|l|l|l|l|}
\hline SESPMNT BELOW PRIEST RAPIDS & 24-Dec-03 & 111034.4 & CFS \\
\hline SESPMNT BELOW PRIEST RAPIDS & 25 -Dec-03 & 86685.15 & CFS \\
\hline
\end{tabular} \begin{tabular}{|l|l|l|l|}
\hline SESPMNT BELOW PRIEST RAPIDS & $26-$ Dec-03 & 81576.66 & CFS \\
\hline
\end{tabular} \begin{tabular}{|l|l|l|l|}
\hline SESPMNT BELOW PRIEST RAPIDS & $27-D e c-03$ & 108730.2 & CFS \\
\hline SESPNT
\end{tabular} \begin{tabular}{|l|l|l|l|}
\hline SESPMNT BELOW PRIEST RAPIDS & $28-$ Dec-03 & 110384.2 & CFS \\
\hline SESPMNT BELOW PRIEST RAPIDS & $29-D e c-03$ & 126300.7 & CFS \\
\hline
\end{tabular} \begin{tabular}{|l|l|l|l|l|}
\hline SESPMNT BELOW PRIEST RAPIDS & $29-D e c-03$ & 126300.7 & CFS \\
\hline SESPMNT BELOW PRIEST RAPIDS & 30 -Dec-03 & 131730.3 & CFS \\
\hline
\end{tabular}

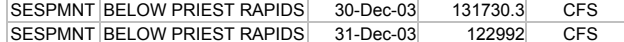

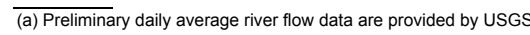


WATER - COLUMBIA RIVER TRANSECT

\begin{tabular}{|c|c|c|c|c|c|c|c|c|c|c|c|c|c|c|c|c|}
\hline OWNER ID & SAMP NUM & SAMP SITE NAME & DIST CLASS & MEDIA & $\begin{array}{c}\text { FILTERED } \\
\text { FLAG } \\
\end{array}$ & \begin{tabular}{|l} 
SAMP \\
SAROM \\
FR
\end{tabular} & COLL MTHD & SAMP DATE & CON SHORT NAME & $\begin{array}{l}\text { VALUE } \\
\text { RPTD } \\
\end{array}$ & \begin{tabular}{|l|} 
ANAL \\
UNITS \\
RPTD \\
\end{tabular} & \begin{tabular}{|c|} 
COUNTING \\
ERROR \\
\end{tabular} & \begin{tabular}{ll|} 
TOTAL \\
S ANAL \\
ERROR \\
ERR
\end{tabular} & $\begin{array}{c}\text { LAB } \\
\text { QUALIFIER } \\
\end{array}$ & SAMP COMMENT & $\begin{array}{c}\text { RESULT } \\
\text { COMMENT } \\
\end{array}$ \\
\hline SESPMNT & \begin{tabular}{|l|} 
B16L97 \\
\end{tabular} & VERNITA-1 HRM 0.3 & OFFSITE & SW & $\mathrm{N}$ & RIVER T & TRANSECT & $24-\mathrm{Mar}-03 \mathrm{~S}$ & & \multirow{2}{*}{\multicolumn{2}{|c|}{$0.0869 \mathrm{pCi} / \mathrm{L}$}} & 0.038 & $8 \quad 0.044$ & & & \\
\hline SESPMNT & B16L98 & VERNITA-2 HRM 0.3 & OFFSITE & SW & $\mathrm{N}$ & RIVER T & TRANSECT & 24-Mar-03 s & & & & 0.036 & $\begin{array}{ll}6 & 0.041\end{array}$ & & & \\
\hline SESPMNT & B16L99 & VERNITA-3 HRM 0.3 & OFFSITE & sw & $\mathrm{N}$ & RIVER T & TRANSECT & $24-M a r-03 \varsigma$ & & \multicolumn{2}{|c|}{$0.0819 \mathrm{pCi} / \mathrm{L}$} & 0.038 & $8 \quad 0.043$ & & & \\
\hline SESPMNT & B16LBO & VERNITA-4 HRM 0.3 & OFFSITE & sw & $\mathrm{N}$ & RIVER T & TRANSECT & 24-Mar-03s & & \multicolumn{2}{|c|}{$\begin{array}{l}0.0893 \mathrm{pC} / \mathrm{L} \\
0.0619 \mathrm{pCi} / \mathrm{L}\end{array}$} & 0.035 & $5 \quad 0.038$ & & & \\
\hline SESPMNT & B16LD0 & RICH.PMPHS HRM 43.5 & OFFSITE & sw & $\mathrm{N}$ & RIVER T & TRANSECT & 25-Mar-03 s & & \multicolumn{2}{|c|}{$0.0604 \mathrm{pCi} / \mathrm{L}$} & 0.029 & $\begin{array}{ll}9 & 0.033 \\
9\end{array}$ & & & \\
\hline SESPMNT & B16LC9 & RICH.PMPHS HRM 43.9 & OFFSITE & sw & $\mathrm{N}$ & RIVER T & TRANSECT & $25-\mathrm{Mar}-03 \mathrm{~s}$ & & \multicolumn{2}{|c|}{$0.0508 \mathrm{pCilL}$} & 0.03 & $\begin{array}{ll}3 & 0.032\end{array}$ & & & \\
\hline SESPMNT & B16LC8 & RICH.PMPHS HRM 45.0 & OFFSITE & sw & $\mathrm{N}$ & RIVER T & TRANSECT & $25-\mathrm{Mar}-03 \varsigma$ & & \multirow{2}{*}{\multicolumn{2}{|c|}{$0.0708 \mathrm{pCi} / \mathrm{L}$}} & 0.026 & 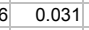 & & & \\
\hline SESPMNT & B16LC7 & RICH.PMPHS HRM 45.8 & OFFSITE & SW & $\mathrm{N}$ & RIVER T & TRANSECT & $25-M a r-03 s$ & & & & 0.028 & $8 \quad 0.033$ & & & \\
\hline SESPMNT & B16LB1 & RICH.PMPHS-1 HRM46.4 & OFFSITE & SW & $\mathrm{N}$ & RIVER T & TRANSECT & $25-\mathrm{Mar}-03 \mathrm{~s}$ & & & 0.032 & $\begin{array}{ll}2 & 0.037\end{array}$ & & & \\
\hline SESPSPEC & B16L96 & RICH.PMPHS-1 HRM46.4 & OFFSITE & SW & $\mathrm{N}$ & RIVER T & TRANSECT & 25 -Mar-03 s & & & 0.029 & $9 \quad 0.035$ & & & \\
\hline SESPMNT & B16LB6 & RICH.PMPHS-10 HRM46.4 & OFFSITE & SW & $\mathrm{N}$ & RIVER T & TRANSECT & $25-M a r-03 s$ & & \multicolumn{2}{|c|}{$\begin{array}{l}0.0857 \mathrm{pCi} / \mathrm{L} \\
0.0792 \mathrm{pCi} / \mathrm{L}\end{array}$} & 0.03 & $\begin{array}{ll}3 & 0.035\end{array}$ & & & \\
\hline SESPMNT & B16LB2 & RICH.PMPHS-2 HRM46.4 & OFFSITE & sw & $\mathrm{N}$ & RIVER T & TRANSECT & $25-\mathrm{Mar}-03 \varsigma$ & & 0.0806 & $p C i / L$ & 0.03 & $\begin{array}{ll}3 & 0.036\end{array}$ & & & \\
\hline SESPMNT & B16LB3 & RICH.PMPHS-3 HRM46.4 & OFFSITE & sW & $\mathrm{N}$ & RIVER T & TRANSECT & $25-\mathrm{Mar}-03 \mathrm{~s}$ & & 0.0793 & $\mathrm{pCi} / \mathrm{L}$ & 0.031 & 10.037 & & & \\
\hline SESPMNT & B16LB4 & RICH.PMPHS-5 HRM46.4 & OFFSITE & sw & $\mathrm{N}$ & RIVER T & TRANSECT & $25-M a r-03 s$ & & 0.0502 & $\mathrm{pCCi/L}$ & 0.024 & $4 \quad 0.029$ & & & \\
\hline SESPMNT & B16LB5 & RICH.PMPHS-7 HRM46.4 & OFFSITE & sw & $\mathrm{N}$ & RIVER T & TRANSECT & $25-\mathrm{Mar}-03 \varsigma$ & & 0.0741 & $\mathrm{pCi} / \mathrm{L}$ & 0.028 & $\begin{array}{ll}3 & 0.033 \\
\end{array}$ & & & \\
\hline SESPMNT & B171W1 & VERNITA-1 HRM 0.3 & OFFSITE & sw & $\mathrm{N}$ & RIVER T & TRANSECT & $09-J u n-03 \varsigma$ & & 0.0933 & $\mathrm{pCi} / \mathrm{L}$ & 0.038 & $\begin{array}{ll}3 & 0.045 \\
\end{array}$ & & & \\
\hline SESPMNT & B171W3 & VERNITA-3 HRM 0.3 & OFFSITE & sw & $\mathrm{N}$ & RIVER T & TRANSECT & $09-J u n-03 \varsigma$ & & 0.0817 & $\mathrm{pCi} / \mathrm{L}$ & 0.031 & $\begin{array}{ll}1 & 0.037 \\
\end{array}$ & & & \\
\hline SESPMNT & B171W4 & VERNITA-4 HRM 0.3 & OFFSITE & SW & $\mathrm{N}$ & RIVER T & TRANSECT & 09-Jun-03 s & & 0.0729 & $\mathrm{pCi} / \mathrm{L}$ & 0.033 & $\begin{array}{ll}3 & 0.037\end{array}$ & & & \\
\hline SESPMNT & B171W2 & VERNITA-2 HRM 0.3 & OFFSITE & sw & $\mathrm{N}$ & RIVER T & TRANSECT & 09-Jun-03 s & & 0.0741 & $\mathrm{pCi} / \mathrm{L}$ & 0.041 & $\begin{array}{l}1 \\
0.046\end{array}$ & & & \\
\hline SESPMNT & B17204 & RICH.PMPHS HRM 43.5 & OFFSITE & SW & $\mathrm{N}$ & RIVER T & TRANSECT & 10-Jun-03 s & & 0.0692 & $\mathrm{pCi} / \mathrm{L}$ & 0.032 & 20.036 & & & \\
\hline SESPMNT & B17203 & RICH.PMPHS HRM 43.9 & OFFSITE & SW & $\mathrm{N}$ & RIVER T & TRANSECT & 10-Jun-03 s & & 0.0701 & & 0.035 & $\begin{array}{ll}5 & 0.039\end{array}$ & & & \\
\hline SESPMNT & B17202 & RICH.PMPHS HRM 45.0 & OFFSITE & sw & $\mathrm{N}$ & RIVER T & TRANSECT & 10-Jun-03s & & 0.0837 & & 0.034 & $4 \quad 0.039$ & & & \\
\hline SESPMNT & B17201 & RICH.PMPHS HRM 45.8 & OFFSITE & sw & $\mathrm{N}$ & RIVER T & TRANSECT & 10-Jun-03s & & 0.0727 & & 0.037 & $7 \quad 0.04$ & & & \\
\hline SESPMNT & B171W5 & RICH.PMPHS-1 HRM46.4 & OFFSITE & sw & $\mathrm{N}$ & RIVER T & TRANSECT & 10-Jun-03s & & 0.0955 & & 0.036 & 60.043 & & & \\
\hline SESPMNT & B171X0 & $\begin{array}{l}\text { RICH.PMPHS-10 HRM46.4 } \\
\end{array}$ & OFFSITE & sw & $\mathrm{N}$ & RIVER T & TRANSECT & 10-Jun-03s & & 0.089 & $\mathrm{pCi} / \mathrm{L}$ & 0.04 & $\begin{array}{ll}4 & 0.045\end{array}$ & & & \\
\hline SESPMNT & B171W6 & RICH.PMPHS-2 HRM46.4 & OFFSITE & sw & $\mathrm{N}$ & RIVER T & TRANSECT & 10-Jun-03 s & & 0.0778 & $\mathrm{pCi} / \mathrm{L}$ & 0.034 & $\begin{array}{l}4 \quad 0.039 \\
\end{array}$ & & & \\
\hline SESPMNT & B171W7 & RICH.PMPHS-3 HRM46.4 & OFFSITE & sw & $\mathrm{N}$ & RIVER T & TRANSECT & 10-Jun-03 s & & 0.0783 & $\mathrm{pCi} / \mathrm{L}$ & 0.049 & $\begin{array}{l}9 \\
9\end{array}$ & U & & \\
\hline SESPMNT & B171W8 & RICH.PMPHS-5 HRM46.4 & OFFSITE & SW & $\mathrm{N}$ & RIVER T & TRANSECT & 10-Jun-03 s & & 0.0589 & $\mathrm{pCi} / \mathrm{L}$ & 0.048 & $\begin{array}{l}3 \\
3\end{array}$ & U & & \\
\hline SESPMNT & B171W9 & RICH.PMPHS-7 HRM46.4 & OFFSITE & sw & $\mathrm{N}$ & RIVER T & TRANSECT & 10-Jun-03 s & & 0.0716 & & 0.042 & $2 \quad 0.047$ & $\mathrm{U}$ & & \\
\hline SESPMNT & B17CF2 & $100 \mathrm{~N}-1$ HRM 9.5 & ONSITE & SW & $\mathrm{N}$ & RIVER T & TRANSECT & 04-Sep-03 s & & & & & & & & Failed Sample \\
\hline SESPSPEC & B17CD7 & $100 \mathrm{~N}-1$ HRM 9.5 & ONSITE & sw & $\mathrm{N}$ & RIVER T & TRANSECT & $04-$ Sep- 03 s & & & & & & & & Failed Sample \\
\hline SESPMNT & B17CK8 & $100 \mathrm{~N}-10 \mathrm{HRM} 9.5$ & ONSITE & sW & $\mathrm{N}$ & RIVER T & TRANSECT & 04-Sep-03 s & & 0.0713 & $\mathrm{pCi} / \mathrm{L}$ & 0.026 & $\begin{array}{ll}6 & 0.031\end{array}$ & & & \\
\hline SESPMNT & B17CF4 & $100 \mathrm{~N}-2$ HRM 9.5 & ONSITE & sw & $\mathrm{N}$ & RIVER T & TRANSECT & 04-Sep-03s & & 0.0863 & $\mathrm{pCilL}$ & 0.029 & $\begin{array}{l}9 \\
9\end{array}$ & & & \\
\hline SESPMNT & B17CLO & $100 \mathrm{~N}-3$ HRM 9.5 & ONSITE & sw & $\mathrm{N}$ & RIVER T & TRANSECT & $04-$ Sep-03 s & & 0.0704 & $\mathrm{pCi} / \mathrm{L}$ & 0.026 & $\begin{array}{ll}6 & 0.031 \\
\end{array}$ & & & \\
\hline SESPMNT & B17CF6 & $100 \mathrm{~N}-5$ HRM 9.5 & ONSITE & sw & $\mathrm{N}$ & RIVER T & TRANSECT & 04-Sep-03 s & & 0.0587 & pCi/L & 0.027 & $7 \quad 0.031$ & & & \\
\hline SESPMNT & B17CL2 & $100 \mathrm{~N}-7$ HRM 9.5 & ONSITE & sw & $\mathrm{N}$ & RIVER T & TRANSECT & 04-Sep-03 s & & 0.0576 & $\mathrm{pCi} / \mathrm{L}$ & 0.025 & $\begin{array}{ll}5 & 0.029 \\
\end{array}$ & & & \\
\hline SESPMNT & В17СТ9 & 100 N SHORE HRM 8.4 & ONSITE & sw & $\mathrm{N}$ & RIVER T & TRANSECT & 04-Sep-03 s & & 0.0911 & $\mathrm{pCi} / \mathrm{L}$ & 0.026 & $6 \quad 0.03$ & & & \\
\hline SESPMNT & B17CV3 & 100 N SHORE HRM 8.9 & ONSITE & SW & $\mathrm{N}$ & RIVER T & TRANSECT & 04-Sep-03s & & 0.0935 & $\mathrm{pCi} / \mathrm{L}$ & 0.024 & $\begin{array}{ll}4 & 0.029\end{array}$ & & & \\
\hline SESPMNT & B17CV7 & 100 N SHORE HRM 9.2 & ONSITE & sw & $\mathrm{N}$ & RIVER T & TRANSECT & 04-Sep-03 s & & 0.429 & $\mathrm{pCi} / \mathrm{L}$ & 0.04 & $\begin{array}{ll}4 & 0.075 \\
\end{array}$ & & & \\
\hline SESPMNT & B17CW1 & 100 N SHORE HRM 9.8 & ONSITE & sw & $\mathrm{N}$ & RIVER T & TRANSECT & 04-Sep-03s & & 0.0717 & $\mathrm{pCi} / \mathrm{L}$ & 0.023 & 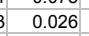 & & & \\
\hline SESPMNT & B17CD8 & VERNITA-1 HRM 0.3 & OFFSITE & sw & $\mathrm{N}$ & RIVER T & TRANSECT & 04-Sep-03 s & & 0.0811 & $\mathrm{pCi} / \mathrm{L}$ & 0.03 & $\begin{array}{ll}3 & 0.036\end{array}$ & & & \\
\hline SESPMNT & B17CD9 & VERNITA-2 HRM 0.3 & OFFSITE & SW & $\mathrm{N}$ & RIVER T & TRANSECT & 04-Sep-03s & & 0.0843 & $\mathrm{pCi} / \mathrm{L}$ & 0.027 & $7 \quad 0.034$ & & & \\
\hline SESPMNT & B17CF0 & VERNITA-3 HRM 0.3 & OFFSITE & sw & $\mathrm{N}$ & RIVER T & TRANSECT & 04-Sep-03s & & 0.0644 & $\mathrm{pCi} / \mathrm{L}$ & 0.031 & 10.036 & & & \\
\hline SESPMNT & B17CF1 & VERNITA-4 HRM 0.3 & OFFSITE & sw & $\mathrm{N}$ & RIVER T & TRANSECT & $04-$ Sep-03 s & & 0.0625 & $\mathrm{pCi} / \mathrm{L}$ & 0.03 & 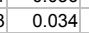 & & & \\
\hline SESPMNT & B17CF8 & $100 \mathrm{~F}-1 \mathrm{HRM} 19.0$ & ONSITE & SW & $\mathrm{N}$ & RIVER T & TRANSECT & 08-Sep-03s & & 0.0838 & $\mathrm{pCi} / \mathrm{L}$ & 0.021 & 10.026 & & & \\
\hline SESPMNT & $\mathrm{B} 17 \mathrm{CH} 4$ & $100 \mathrm{~F}-10 \mathrm{HRM} 19.0$ & ONSITE & sW & $\mathrm{N}$ & RIVER T & TRANSECT & 08-Sep-03 s & & 0.0753 & $\mathrm{pCi} / \mathrm{L}$ & 0.021 & $\begin{array}{ll}1 & 0.025 \\
\end{array}$ & & & \\
\hline SESPMNT & $\mathrm{B} 17 \mathrm{CH} 1$ & 100 F -2 HRM 19.0 & ONSITE & SW & $\mathrm{N}$ & RIVER T & TRANSECT & $08-$ Sep-03 s & & 0.0787 & $\mathrm{pCi} / \mathrm{L}$ & 0.021 & $\begin{array}{ll}1 & 0.025 \\
\end{array}$ & & & \\
\hline SESPMNT & B17CF9 & 100 F -3 HRM 19.0 & ONSITE & sw & $\mathrm{N}$ & RIVER T & TRANSECT & 08-Sep-03s & & 0.0835 & $\mathrm{pCi} / \mathrm{L}$ & 0.022 & 0.027 & & & \\
\hline SESPMNT & $\mathrm{B} 17 \mathrm{CH} 2$ & 100 F -5 HRM 19.0 & ONSITE & sw & $\mathrm{N}$ & RIVER T & TRANSECT & $08-$ Sep-03s & & 0.0947 & $\mathrm{pCi} / \mathrm{L}$ & 0.024 & 0.029 & & & \\
\hline SESPMNT & $\mathrm{B} 17 \mathrm{CH} 3$ & 100 F -7 HRM 19.0 & ONSITE & SW & $\mathrm{N}$ & RIVER T & TRANSECT & $08-S e p-03 s$ & & 0.0763 & $\mathrm{pCi} / \mathrm{L}$ & 0.022 & 0.025 & & & \\
\hline SESPMNT & B17CY4 & $100 \mathrm{~F}$ SHORE HRM 18 & ONSITE & sw & $\mathrm{N}$ & RIVER T & TRANSECT & $08-$ Sep-03 s & & 0.0646 & $\mathrm{pCi} / \mathrm{L}$ & 0.021 & 0.024 & & & \\
\hline SESPMNT & B17CY7 & 100 F SHORE HRM 22 & ONSITE & SW & $\mathrm{N}$ & RIVER T & TRANSECT & 08-Sep-03s & & 0.0622 & $\mathrm{pCi} / \mathrm{L}$ & 0.021 & 0.024 & & & \\
\hline SESPMNT & B17D00 & 100 F SHORE HRM 23 & ONSITE & sw & $\mathrm{N}$ & RIVER T & TRANSECT & $08-$ Sep-03 s & & 0.0945 & $5 \mathrm{pCi}$ & 0.023 & 0.028 & & & \\
\hline SESPMNT & $\mathrm{B} 17 \mathrm{CH} 5$ & HANFRD TS-1 HRM 28.7 & ONSITE & sw & $\mathrm{N}$ & RIVER T & TRANSECT & $08-$ Sep-03s & & 0.0556 & $\mathrm{pCi} / \mathrm{L}$ & 0.018 & 0.02 & & & \\
\hline SESPMNT & $\mathrm{B} 17 \mathrm{CH} 8$ & HANFRD TS-10 HRM 28.7 & ONSITE & sw & $\mathrm{N}$ & RIVER T & TRANSECT & $08-\mathrm{Sep}-03 \mathrm{~s}$ & & 0.0904 & $\mathrm{pCi} / \mathrm{L}$ & 0.023 & 0.028 & & & \\
\hline SESPMNT & $\mathrm{B} 17 \mathrm{CH} 6$ & HANFRD TS-2 HRM 28.7 & ONSITE & sw & $\mathrm{N}$ & RIVER T & TRANSECT & 08-Sep-03 s & & 0.0678 & $\mathrm{pCi} / \mathrm{L}$ & 0.018 & 0.022 & & & \\
\hline SESPMNT & $\mathrm{B} 17 \mathrm{CH} 9$ & HANFRD TS-3 HRM 28.7 & ONSITE & SW & $\mathrm{N}$ & RIVER T & TRANSECT & $08-$ Sep-03s & & 0.0713 & $\mathrm{pCi} / \mathrm{L}$ & 0.022 & 0.025 & & & \\
\hline SESPMNT & $\mathrm{B} 17 \mathrm{CHO}$ & HANFRD TS-5 HRM 28.7 & ONSITE & sW & $\mathrm{N}$ & RIVER T & TRANSECT & 08-Sep-03 s & & 0.0825 & $\mathrm{pCi} / \mathrm{L}$ & 0.023 & 0.027 & & & \\
\hline SESPMNT & $\mathrm{B} 17 \mathrm{CH} 7$ & HANFRD TS-7 HRM 28.7 & ONSITE & sw & $\mathrm{N}$ & RIVER T & TRANSECT & 08 -Sep-03 s & & 0.0889 & $\mathrm{pCi} / \mathrm{L}$ & 0.023 & 0.027 & & & \\
\hline SESPMNT & B17CL4 & HANFRD TWNSITE HRM26 & 6 ONSITE & sw & $\mathrm{N}$ & RIVER T & TRANSECT & 08-Sep-03s & & & & 0.019 & 0.023 & & & \\
\hline SESPMNT & B17CL5 & HANFRD TWNSITE HRM27 & 7 ONSITE & sW & $\mathrm{N}$ & RIVER T & TRANSECT & 08-Sep-03 s & & 0.0601 & $\mathrm{pCi} / \mathrm{L}$ & 0.018 & 0.022 & & & \\
\hline SESPMNT & B17CY1 & HANFRD TWNSITE HRM28 & 3 ONSITE & sw & $\mathrm{N}$ & RIVER T & TRANSECT & $08-S e p-03 s$ & & 0.0515 & $\mathrm{pCi} / \mathrm{L}$ & 0.017 & 0.019 & & & \\
\hline
\end{tabular}


WATER - COLUMBIA RIVER TRANSECT

\begin{tabular}{|c|c|c|c|c|c|c|c|c|c|c|c|c|c|c|c|c|c|}
\hline | OWNER ID & SAMP NUM & SAMP SITE NAME & DIST CLASS & MEDIA $\left.\right|^{F}$ & \begin{tabular}{|c|} 
FILTERED \\
FLAG
\end{tabular} & $\begin{array}{l}\text { SAMP } \\
\text { FROM }\end{array}$ & COLL MTHD & SAMP DATE & & CON SHORT NAME & \begin{tabular}{c|c} 
VALUE & $f$ \\
RPTD & F
\end{tabular} & \begin{tabular}{|l|} 
ANAL \\
UNITS \\
RPTD
\end{tabular} & $\mid \begin{array}{c}\text { COUNTING } \\
\text { ERROR }\end{array}$ & \begin{tabular}{|l|} 
TOTAL \\
ANAL \\
ERROR Q
\end{tabular} & $\begin{array}{c}\text { LAB } \\
\text { QUALIFIER }\end{array}$ & SAMP COMMENT & $\begin{array}{l}\text { RESULT } \\
\text { COMMENT }\end{array}$ \\
\hline SESPMNT & B17CL6 6 & HANFRD TWNSITE HRM30 & ONSITE & SW & $\mathrm{N}$ & RIVER & TRANSECT & 08-Sep-03S & Sr-90 & & & & 0.018 & 0.022 & & & \\
\hline SESPMNT & B17CJO & 300 AREA -1 HRM 43.1 & ONSITE & sw & $\mathrm{N}$ & RIVER & TRANSECT & $09-$ Sep-03 s & Sr-90 & & $0.0497 p$ & $\mathrm{pCi} / \mathrm{L}$ & 0.018 & 0.02 & & & \\
\hline SESPMNT & B17CJ2 & 300 AREA -2 HRM 43.1 & ONSITE & sw & $\mathrm{N}$ & RIVER & TRANSECT & $09-S e p-03 \varsigma$ & Sr-90 & & $0.0622 \mathrm{p}$ & $\mathrm{pCi} / \mathrm{L}$ & 0.021 & 0.023 & & & \\
\hline SESPMNT & B17CJ4 & 300 AREA -3 HRM 43.1 & ONSITE & sw & $\mathrm{N}$ & RIVER & TRANSECT & $09-S e p-03 s$ & $8-90$ & & $0.0778 \mathrm{p}$ & $\mathrm{pCilL}$ & 0.022 & 0.026 & & & \\
\hline SESPMNT & B17CJ6 & 300 AREA -5 HRM 43.1 & ONSITE & sw & $\mathrm{N}$ & RIVER & TRANSECT & 09-Sep-03 s & Sr-90 & & $0.0768 \mathrm{p}$ & pCi/L & 0.03 & 0.033 & & & \\
\hline SESPMNT & B17CJ8 & 300 AREA - 7 HRM 43.1 & ONSITE & sw & $\mathrm{N}$ & RIVER & TRANSECT & 09-Sep-03 s & Sr-90 & & $0.0663 p$ & $\mathrm{pCi} / \mathrm{L}$ & 0.024 & 0.026 & & & \\
\hline SESPMNT & B17CW5 & 300 AREA SHR HRM41.5 & ONSITE & sw & $\mathrm{N}$ & RIVER & TRANSECT & $09-\mathrm{Sep}-03 \varsigma$ & & & & $\mathrm{pCi} / \mathrm{L}$ & 0.019 & 0.022 & & & \\
\hline SESPMNT & B17CX7 & 300 AREA SHR HRM42.9 & ONSITE & sw & $\mathrm{N}$ & RIVER & TRANSECT & $09-S e p-03 s$ & & & & $\mathrm{pCi} / \mathrm{L}$ & 0.02 & 0.023 & & & \\
\hline SESPMNT & B17CKO & 300 AREA-10 HRM 43.1 & ONSITE & sw & $\mathrm{N}$ & RIVER & TRANSECT & $09-S e p-03 s$ & Sr-90 & & $0.0645 p$ & $\mathrm{pCi} / \mathrm{L}$ & 0.021 & 0.024 & & & \\
\hline SESPMNT & В17СT0 & RICH.PMPHS HRM 43.5 & OFFSITE & sw & $\mathrm{N}$ & RIVER & TRANSECT & $09-S e p-03 s$ & Sr-90 & & $0.0838 \mathrm{p}$ & $\mathrm{pCi} / \mathrm{L}$ & 0.025 & 0.029 & & & \\
\hline SESPMNT & B17CR8 & RICH.PMPHS HRM 45.0 & OFFSITE & sw & $\mathrm{N}$ & RIVER & TRANSECT & $09-S e p-03 s$ & Sr-90 & & $0.0855 \mathrm{p}$ & $\mathrm{pCi} / \mathrm{L}$ & 0.02 & 0.025 & & & \\
\hline SESPMNT & B17CR7 & RICH.PMPHS HRM 45.8 & OFFSITE & sw & $\mathrm{N}$ & RIVER & TRANSECT & $09-S e p-03 s$ & Sr-90 & & $0.081 \mathrm{p}$ & $\mathrm{pCi} / \mathrm{L}$ & 0.021 & 0.025 & & & \\
\hline SESPMNT & B17CK2 & RICH.PMPHS-1 HRM46.4 & OFFSITE & sw & $\mathrm{N}$ & RIVER & TRANSECT & $09-S e p-03 s$ & Sr-90 & & $0.0707 \mathrm{p}$ & $\mathrm{pCi} / \mathrm{L}$ & 0.018 & 0.021 & & & \\
\hline SESPMNT & B17CK7 & RICH.PMPHS-10 HRM46.4 & OFFSITE & sw & $\mathrm{N}$ & RIVER & $\begin{array}{l}\text { TRANSECT } \\
\text { TRES }\end{array}$ & $09-$ Sep-03s & Sr-90 & & $0.0521 \mathrm{p}$ & $\mathrm{pCi} / \mathrm{L}$ & 0.019 & 0.021 & & & \\
\hline SESPMNT & B17CK3 & RICH.PMPHS-2 HRM46.4 & OFFSITE & sw & $\mathrm{N}$ & RIVER & TRANSECT & $09-\mathrm{Sep}-03 \mathrm{~s}$ & Sr-90 & & $0.0565 \mathrm{p}$ & & 0.03 & 0.031 & & & \\
\hline SESPMNT & B17CK4 & RICH.PMPHS-3 HRM46.4 & OFFSITE & sw & $\mathrm{N}$ & RIVER & TRANSECT & $09-S e p-03 \varsigma$ & Sr-90 & & $0.0709 p$ & & 0.019 & 0.022 & & & \\
\hline SESPMNT & B17CK5 & RICH.PMPHS-5 HRM 46.4 & OFFSITE & sw & $\mathrm{N}$ & RIVER & TRANSECT & $09-S e p-03 s$ & Sr-90 & & $0.0859 p$ & $\mathrm{pCi} / \mathrm{L}$ & 0.019 & 0.024 & & & \\
\hline SESPMNT & B17CK6 & RICH.PMPHS-7 HRM46.4 & OFFSITE & sw & $\mathrm{N}$ & RIVER & TRANSECT & $09-S e p-03 s$ & Sr-90 & & $0.0678 \mathrm{p}$ & $\mathrm{pCi} / \mathrm{L}$ & 0.019 & 0.022 & & & \\
\hline SESPMNT & B17CR9 & RICH.PMPHS HRM 43.9 & OFFSITE & sw & $\mathrm{N}$ & RIVER & TRANSECT & $09-$ Sep-03s & Sr-90 & & & & & & & NO SAMPLE. THICK MILFOIL. & \\
\hline SESPMNT & B17CW9 & 300 AREA SHR HRM42.1 & ONSITE & sW & $\mathrm{N}$ & RIVER & TRANSECT & $09-\mathrm{Sep}-03 \mathrm{~s}$ & Sr-90 & & $0.077 \mathrm{p}$ & $\mathrm{pCi} / \mathrm{L}$ & 0.02 & 0.024 & & DIRECTLY DOWNRIVER FROM 300 AREA SPRING 42-2. & \\
\hline SESPMNT & B17CX3 & 300 AREA SHR HRM42.5 & ONSITE & sw & $\mathrm{N}$ & RIVER & TRANSECT & $09-\mathrm{Sep}-03 \mathrm{~s}$ & Sr-90 & & $0.089 \mathrm{p}$ & & 0.022 & 0.027 & & DIRECTLY DOWNRIVER FROM 300 AREA SPRING 42-2. & \\
\hline SESPMNT & B183W0 & RICH.PMPHS HRM 43.5 & OFFSITE & sw & $\mathrm{N}$ & RIVER & TRANSECT & 08-Dec-03s & Sr-90 & & $0.0843 \mathrm{p}$ & & 0.018 & 0.022 & & & \\
\hline SESPMNT & B183V9 & RICH.PMPHS HRM 43.9 & OFFSITE & sw & $\mathrm{N}$ & RIVER & TRANSECT & 08-Dec-03s & Sr-90 & & $0.0975 \mathrm{p}$ & & 0.02 & 0.025 & & & \\
\hline SESPMNT & B183V8 & RICH.PMPHS HRM 45.0 & OFFSITE & sw & $\mathrm{N}$ & RIVER & TRANSECT & $08-\mathrm{Dec}-03 \mathrm{~s}$ & Sr-90 & & $0.0863 \mathrm{p}$ & $\mathrm{pCi} / \mathrm{L}$ & 0.019 & 0.023 & & & \\
\hline SESPMNT & B183V7 & RICH.PMPHS HRM 45.8 & OFFSITE & sw & $\mathrm{N}$ & RIVER & TRANSECT & 08-Dec-03 s & Sr-90 & & $0.0918 \mathrm{p}$ & $\mathrm{pCi} / \mathrm{L}$ & 0.021 & 0.026 & & & \\
\hline SESPMNT & B183T1 & RICH.PMPHS-1 HRM46.4 & OFFSITE & sw & $\mathrm{N}$ & RIVER & TRANSECT & 08-Dec-03 s & Sr-90 & & $0.0869 p$ & $\mathrm{pCi} / \mathrm{L}$ & 0.022 & 0.026 & & & \\
\hline SESPSPEC & B183R6 & RICH.PMPHS-1 HRM46.4 & OFFSITE & sw & $\mathrm{N}$ & RIVER & TRANSECT & 08-Dec-03 s & Sr-90 & & $0.0997 \mathrm{p}$ & $\mathrm{pCi} / \mathrm{L}$ & 0.023 & 0.027 & & & \\
\hline SESPMNT & B183T6 & RICH.PMPHS-10 HRM46.4 & OFFSITE & sw & $\mathrm{N}$ & RIVER & TRANSECT & 08-Dec-03s & Sr-90 & & $0.0919 \mathrm{p}$ & $\mathrm{pCi} / \mathrm{L}$ & 0.025 & 0.028 & & & \\
\hline SESPMNT & B183T2 & RICH.PMPHS-2 HRM 46.4 & OFFSITE & sw & $\mathrm{N}$ & RIVER & TRANSECT & 08-Dec-03 s & Sr-90 & & $0.0815 p$ & $\mathrm{pCi} / \mathrm{L}$ & 0.023 & 0.026 & & & \\
\hline SESPMNT & B183T3 & RICH.PMPHS-3 HRM46.4 & OFFSITE & sw & $\mathrm{N}$ & RIVER & TRANSECT & 08-Dec-03 s & & & $0.0825 \mathrm{p}$ & $\mathrm{pCi} / \mathrm{L}$ & 0.022 & 0.025 & & & \\
\hline SESPMNT & B183T4 & RICH.PMPHS-5 HRM46.4 & OFFSITE & sw & $\mathrm{N}$ & RIVER & TRANSECT & 08-Dec-03s & Sr-90 & & $0.0791 \mathrm{p}$ & $\mathrm{pCi} / \mathrm{L}$ & 0.019 & 0.023 & & & \\
\hline SESPMNT & B183T5 & RICH.PMPHS-7 HRM46.4 & OFFSITE & sW & $\mathrm{N}$ & RIVER & TRANSECT & 08-Dec-03s & Sr-90 & & $0.0894 \mathrm{p}$ & $\mathrm{pCi} / \mathrm{L}$ & 0.02 & 0.024 & & & \\
\hline SESPMNT & B183R7 & VERNITA-1 HRM 0.3 & OFFSITE & sw & $\mathrm{N}$ & RIVER & TRANSECT & $09-\mathrm{Dec}-03$ s & Sr-90 & & $0.119 \mathrm{p}$ & $\mathrm{pCi} / \mathrm{L}$ & 0.022 & 0.028 & & & \\
\hline SESPMNT & B183R8 & VERNITA-2 HRM 0.3 & OFFSITE & sw & $\mathrm{N}$ & RIVER & TRANSECT & $09-\mathrm{Dec}-03 \mathrm{~s}$ & Sr-90 & & $0.0915 \mathrm{p}$ & $\mathrm{pCi} / \mathrm{L}$ & 0.021 & 0.025 & & & \\
\hline SESPMNT & B183R9 & VERNITA-3 HRM 0.3 & OFFSITE & sw & $\mathrm{N}$ & RIVER & TRANSECT & 09-Dec-03 s & Sr-90 & & $0.086 \mathrm{p}$ & $\mathrm{pCi} / \mathrm{L}$ & 0.023 & 0.025 & & & \\
\hline SESPMNT & B183T0 & VERNITA-4 HRM 0.3 & OFFSITE & sw & $\mathrm{N}$ & RIVER & TRANSECT & 09-Dec-03 s & Sr-90 & & $0.0827 p$ & $\mathrm{pCi} / \mathrm{L}$ & 0.019 & 0.023 & & & \\
\hline SESPMNT & B17CH6 & HANFRD TS-2 HRM 28.7 & ONSITE & sw & $\mathrm{N}$ & RIVER & TRANSECT & 08-Sep-037 & TRITIUM & & $74.3 p$ & $\mathrm{pCi} / \mathrm{L}$ & 61 & 73 & U & & \\
\hline SESPMNT & $\mathrm{B} 17 \mathrm{CY} 1$ & HANFRD TWNSITE HRM28 & ONSITE & sw & $\mathrm{N}$ & RIVER & TRANSECT & 08-Sep-037 & TRITIUM & & $19300 \mathrm{p}$ & $\mathrm{pCi} / \mathrm{L}$ & 490 & 1400 & & & \\
\hline SESPMNT & B17CL6 & HANFRD TWNSITE HRM30 & ONSITE & sw & $\mathrm{N}$ & RIVER & TRANSECT & $08-$ Sep-037 & TRITIUM & & $1880 \mathrm{p}$ & $\mathrm{pCi/L}$ & 160 & 220 & & & \\
\hline SESPMNT & B17CX3 & 300 AREA SHR HRM42.5 & ONSITE & sw & $\mathrm{N}$ & RIVER & TRANSECT & 09-Sep-037 & TRITIUM & & $1780 \mathrm{p}$ & $\mathrm{pCi} / \mathrm{L}$ & 160 & 210 & & DIRECTLY DOWNRIVER FROM 300 AREA SPRING 42-2. & \\
\hline SESPMNT & B16L97 & VERNITA-1 HRM 0.3 & OFFSITE & sw & $\mathrm{N}$ & RIVER & TRANSECT & 24-Mar-03 L & _O TRITIUM & & $26.5 \mathrm{p}$ & $\mathrm{pCi} / \mathrm{L}$ & 2.8 & 5.5 & & & \\
\hline SESPMNT & B16L98 & VERNITA-2 HRM 0.3 & OFFSITE & sw & $\mathrm{N}$ & RIVER & TRANSECT & 24-Mar-03L & O TRITIUM & & $27.5 \mathrm{p}$ & $\mathrm{pCi} / \mathrm{L}$ & 3 & 5.8 & & & \\
\hline SESPMNT & B16L99 & VERNITA-3 HRM 0.3 & OFFSITE & sw & $\mathrm{N}$ & RIVER & TRANSECT & 24-Mar-03L & O TRITIUM & & & $\mathrm{pCilL}$ & 2.6 & 4.7 & & & \\
\hline SESPMNT & B16LBO & VERNITA-4 HRM 0.3 & OFFSITE & sw & $\mathrm{N}$ & RIVER & TRANSECT & 24-Mar-03 L & O TRITIUM & & & $\mathrm{pCi} / \mathrm{L}$ & 12 & 25 & & & \\
\hline SESPMNT & B16LD0 & RICH.PMPHS HRM 43.5 & OFFSITE & sw & $\mathrm{N}$ & RIVER & TRANSECT & 25-Mar-03 L & _O TRITIUM & & $77.6 \mathrm{p}$ & $\mathrm{pCi} / \mathrm{L}$ & 4.2 & 13 & & & \\
\hline SESPMNT & B16LC9 & RICH.PMPHS HRM 43.9 & OFFSITE & sw & $\mathrm{N}$ & RIVER & TRANSECT & 25-Mar-03 L & -O TRITIUM & & & $\mathrm{pCi} / \mathrm{L}$ & 4.2 & 13 & & & \\
\hline SESPMNT & B16LB1 & RICH.PMPHS-1 HRM46.4 & OFFSITE & sW & $\mathrm{N}$ & RIVER & TRANSECT & 25-Mar-03 L & _O TRITIUM & & $64.3 \mathrm{p}$ & $\mathrm{pCi} / \mathrm{L}$ & 4 & 11 & & & \\
\hline SESPSPEC & B16L96 & RICH.PMPHS-1 HRM46.4 & OFFSITE & sw & $\mathrm{N}$ & RIVER & TRANSECT & 25-Mar-03 L & O TRITIUM & & $75.6 \mathrm{p}$ & $\mathrm{pCi} / \mathrm{L}$ & 4.4 & 13 & & & \\
\hline SESPMNT & B16LB6 & RICH.PMPHS-10 HRM46.4 & OFFSITE & sW & $\mathrm{N}$ & RIVER & TRANSECT & 25-Mar-03 L & -O TRITIUM & & & $\mathrm{pCi} / \mathrm{L}$ & 3.4 & 8 & & & \\
\hline SESPMNT & B16LB2 & RICH.PMPHS-2 HRM46.4 & OFFSITE & sw & $\mathrm{N}$ & RIVER & TRANSECT & 25-Mar-03 L & _O TRITIUM & & $72.3 p$ & $\mathrm{pCi} / \mathrm{L}$ & 4.1 & 12 & & & \\
\hline SESPMNT & B16LB3 & RICH.PMPHS-3 HRM46.4 & OFFSITE & sw & $\mathrm{N}$ & RIVER & TRANSECT & 25-Mar-03 L & O TRITIUM & & & $\mathrm{pCi} / \mathrm{L}$ & 3.9 & 9.5 & & & \\
\hline SESPMNT & B16LB4 & RICH.PMPHS-5 HRM46.4 & OFFSITE & sw & $\mathrm{N}$ & RIVER & TRANSECT & 25-Mar-03L & O TRITIUM & & & $\mathrm{pCi} / \mathrm{L}$ & 3.2 & 7.3 & & & \\
\hline SESPMNT & B16LB5 & RICH.PMPHS-7 HRM46.4 & OFFSITE & sw & $\mathrm{N}$ & RIVER & TRANSECT & 25-Mar-03 L & O TRITIUM & & $33.4 \mathrm{p}$ & $\mathrm{pCi/L}$ & 3 & 6.5 & & & \\
\hline SESPMNT & B16LC8 & RICH.PMPHS HRM 45.0 & OFFSITE & sw & $\mathrm{N}$ & RIVER & TRANSECT & $25-M a r-03 L$ & O TRITIUM & & $68.5 \mathrm{p}$ & $\mathrm{pCi/L}$ & 3.8 & 7.5 & & & \\
\hline SESPMNT & B16LC7 & RICH.PMPHS HRM 45.8 & OFFSITE & sw & $\mathrm{N}$ & RIVER & TRANSECT & 25-Mar-03 L & -O TRITIUM & & $66.8 \mathrm{p}$ & $\mathrm{pCi} / \mathrm{L}$ & 3.8 & 7.4 & & & \\
\hline SESPMNT & B171W1 & VERNITA-1 HRM 0.3 & OFFSITE & sW & $\mathrm{N}$ & RIVER & TRANSECT & 09-Jun-03 L & -O TRITIUM & & $22.2 p$ & $\mathrm{pCi} / \mathrm{L}$ & 2.6 & 4.2 & & & \\
\hline SESPMNT & B171W2 & VERNITA-2 HRM 0.3 & OFFSITE & sW & $\mathrm{N}$ & RIVER & TRANSECT & 09-Jun-03 L & O TRITIUM & & $18.7 \mathrm{p}$ & $\mathrm{pCi} / \mathrm{L}$ & 2.6 & 3.9 & & & \\
\hline SESPMNT & B171W3 & VERNITA-3 HRM 0.3 & OFFSITE & SW & $\mathrm{N}$ & RIVER & TRANSECT & 09-Jun-03 L & _O TRITIUM & & & $\mathrm{pCi} / \mathrm{L}$ & 2.7 & 4.3 & & & \\
\hline SESPMNT & B171W4 & VERNITA-4 HRM 0.3 & OFFSITE & sw & $\mathrm{N}$ & RIVER & TRANSECT & 09-Jun-03 L & _O TRITIUM & & & $\mathrm{pCi} / \mathrm{L}$ & 3 & 4.9 & & & \\
\hline SESPMNT & B17204 & RICH.PMPHS HRM 43.5 & OFFSITE & sw & $\mathrm{N}$ & RIVER & TRANSECT & 10-Jun-03 L & _O TRITIUM & & & & 2.8 & 4.2 & & & \\
\hline SESPMNT & B17203 & RICH.PMPHS HRM 43.9 & OFFSITE & SW & $\mathrm{N}$ & RIVER & TRANSECT & 10-Jun-03 L & _O TRITIUM & & $26.3 p$ & $\mathrm{pCi} / \mathrm{L}$ & 2.9 & 4.3 & & & \\
\hline SESPMNT & B17202 & RICH.PMPHS HRM 45.0 & OFFSITE & sw & $\mathrm{N}$ & RIVER & TRANSECT & 10-Jun-03 L & _O TRITIUM & & $26.8 \mathrm{p}$ & $\mathrm{pCi} / \mathrm{L}$ & 2.9 & 4.4 & & & \\
\hline
\end{tabular}




\begin{tabular}{|c|c|c|c|c|c|c|c|c|c|c|c|c|c|c|c|}
\hline OWNER ID & | SAMP NUM| & SAMP SITE NAME & DIST CLASS & MEDIA $\left.\right|^{\mid h}$ & \begin{tabular}{|c|} 
FILTERED \\
FLAG
\end{tabular} & $\begin{array}{l}\text { SAMP } \\
\text { FROM }\end{array}$ & COLL MTHD & SAMP DATE & CON SHORT NAME & \begin{tabular}{l|l} 
VALUE & $A$ \\
RPTD & R
\end{tabular} & \begin{tabular}{|l|l|} 
ANAL \\
UNITS \\
RPTD \\
\end{tabular} & $\begin{array}{c}\text { COUNTING } \\
\text { ERROR }\end{array}$ & \begin{tabular}{|c|c|} 
TOTAL & \\
ANAL & LAB \\
ERROR & QUALIFIER \\
\end{tabular} & SAMP COMMENT & $\begin{array}{l}\text { RESULT } \\
\text { COMMENT }\end{array}$ \\
\hline SESPMNT & B17201 & RICH.PMPHS HRM 45.8 & OFFSITE & SW & $\mathrm{N}$ & RIVER T & TRANSECT & 10-Jun-03 LO TRITIUM & & & $\mathrm{pCi} / \mathrm{L}$ & 2.9 & 4.4 & & \\
\hline SESPMNT & B171W5 & RICH.PMPHS-1 HRM46.4 & OFFSITE & sw & $\mathrm{N}$ & RIVER 7 & TRANSECT & 10-Jun-03 LO TRITIUM & & $19.6 \mathrm{p}$ & $\mathrm{pCi} / \mathrm{L}$ & 2.7 & 3.9 & & \\
\hline SESPMNT & B171X0 & RICH.PMPHS-10 HRM46.4 & OFFSITE & sw & $\mathrm{N}$ & RIVER 7 & TRANSECT & 10-Jun-03 LO TRITIUM & & $18.2 \mathrm{p}$ & $\mathrm{pCi} / \mathrm{L}$ & 2.7 & 3.8 & & \\
\hline SESPMNT & B171W6 & RICH.PMPHS-2 HRM46.4 & OFFSITE & sw & $\mathrm{N}$ & RIVER T & TRANSECT & 10-Jun-03 LO TRITIUM & & $21.4 p$ & $\mathrm{pCilL}$ & 2.8 & 4 & & \\
\hline SESPMNT & B171W7 & RICH.PMPHS-3 HRM46.4 & OFFSITE & sw & $\mathrm{N}$ & RIVER & TRANSECT & 10-Jun-03 LO TRITIUM & & $18.9 p$ & pCi/L & 2.7 & 3.9 & & \\
\hline SESPMNT & B171W8 & RICH.PMPHS-5 HRM46.4 & OFFSITE & sw & $\mathrm{N}$ & RIVER & TRANSECT & 10-Jun-03 LO TRITIUM & & & $\mathrm{pCi} / \mathrm{L}$ & 2.8 & 4.1 & & \\
\hline SESPMNT & B171W9 & RICH.PMPHS-7 HRM46.4 & OFFSITE & sw & $\mathrm{N}$ & RIVER 7 & TRANSECT & 10-Jun-03 LO TRITIUM & & & & 2.9 & 4.2 & & \\
\hline SESPMNT & B17CF2 & $100 \mathrm{~N}-1$ HRM 9.5 & ONSITE & sw & $\mathrm{N}$ & RIVER T & TRANSECT & 04-Sep-03 LO TRITIUM & & & & 5.5 & 24 & & \\
\hline SESPSPEC & B17CD7 & $100 \mathrm{~N}-1$ HRM 9.5 & ONSITE & sw & $\mathrm{N}$ & RIVER 7 & TRANSECT & 04-Sep-03 LO TRITIUM & & & $\mathrm{pCi} / \mathrm{L}$ & 5.7 & 26 & & \\
\hline SESPMNT & B17CK8 & $100 \mathrm{~N}-10$ HRM 9.5 & ONSITE & sw & $\mathrm{N}$ & RIVER T & TRANSECT & 04-Sep-03 LO TRITIUM & & & $\mathrm{pCi} / \mathrm{L}$ & 2.9 & 5.8 & & \\
\hline SESPMNT & B17CF4 & $100 \mathrm{~N}-2$ HRM 9.5 & ONSITE & sw & $\mathrm{N}$ & RIVER T & TRANSECT & 04-Sep-03 LO TRITIUM & & & $\mathrm{pCi} / \mathrm{L}$ & 3.1 & 6.2 & & \\
\hline SESPMNT & B17CL0 & $100 \mathrm{~N}-3$ HRM 9.5 & ONSITE & sw & $\mathrm{N}$ & RIVER 7 & TRANSECT & 04-Sep-03 LO TRITIUM & & $27.6 \mathrm{p}$ & $\mathrm{pCi} / \mathrm{L}$ & 2.9 & 6 & & \\
\hline SESPMNT & B17CF6 & $100 \mathrm{~N}-5$ HRM 9.5 & ONSITE & sw & $\mathrm{N}$ & RIVER T & TRANSECT & 04-Sep-03 LO TRITIUM & & $24.6 \mathrm{p}$ & $\mathrm{pCi} / \mathrm{L}$ & 2.9 & 5.6 & & \\
\hline SESPMNT & B17CL2 & $100 \mathrm{~N}-7$ HRM 9.5 & ONSITE & sw & $\mathrm{N}$ & RIVER T & $\begin{array}{l}\text { TRANSECT } \\
\text { TRES }\end{array}$ & 04-Sep-03 LO TRITIUM & & $24.3 p$ & $\mathrm{pCi} / \mathrm{L}$ & 2.8 & 5.5 & & \\
\hline SESPMNT & В17СT9 & $100 \mathrm{~N}$ SHORE HRM 8.4 & ONSITE & sw & $\mathrm{N}$ & RIVER 7 & TRANSECT & 04-Sep-03 LO TRITIUM & & & & 3.4 & 7.7 & & \\
\hline SESPMNT & B17CV3 & $100 \mathrm{~N}$ SHORE HRM 8.9 & ONSITE & sw & $\mathrm{N}$ & RIVER 7 & TRANSECT & 04-Sep-03 LO TRITIUM & & & & 3.4 & 8.5 & & \\
\hline SESPMNT & B17CV7 & $100 \mathrm{~N}$ SHORE HRM 9.2 & ONSITE & sw & $\mathrm{N}$ & RIVER 7 & TRANSECT & 04-Sep-03 LO TRITIUM & & $29.3 \mathrm{p}$ & $\mathrm{pCi} / \mathrm{L}$ & 2.9 & 6.2 & & \\
\hline SESPMNT & B17CW1 & $100 \mathrm{~N}$ SHORE HRM 9.8 & ONSITE & sw & $\mathrm{N}$ & RIVER T & TRANSECT & 04-Sep-03 LO TRITIUM & & $32.2 \mathrm{p}$ & $\mathrm{pCi} / \mathrm{L}$ & 3 & 6.7 & & \\
\hline SESPMNT & B17CD8 & VERNITA-1 HRM 0.3 & OFFSITE & sw & $\mathrm{N}$ & RIVER T & TRANSECT & 04-Sep-03 LO TRITIUM & & $26.3 p$ & $\mathrm{pCi} / \mathrm{L}$ & 2.9 & 5.8 & & \\
\hline SESPMNT & B17CD9 & VERNITA-2 HRM 0.3 & OFFSITE & sw & $\mathrm{N}$ & RIVER T & TRANSECT & 04-Sep-03 LO TRITIUM & & $24.4 \mathrm{p}$ & $\mathrm{pCi/L}$ & 2.8 & 5.5 & & \\
\hline SESPMNT & B17CF0 & VERNITA-3 HRM 0.3 & OFFSITE & sw & $\mathrm{N}$ & RIVER T & TRANSECT & 04-Sep-03 LO TRITIUM & & $28.3 p$ & & 2.9 & 6.1 & & \\
\hline SESPMNT & B17CF1 & VERNITA-4 HRM 0.3 & OFFSITE & sw & $\mathrm{N}$ & RIVER T & TRANSECT & 04-Sep-03 LO TRITIUM & & & & 2.8 & 5.5 & & \\
\hline SESPMNT & B17CF8 & $100 \mathrm{~F}-1$ HRM 19.0 & ONSITE & sw & $\mathrm{N}$ & RIVER & TRANSECT & 08-Sep-03 LO TRITIUM & & & & 5.2 & 8.1 & & \\
\hline SESPMNT & $\mathrm{B} 17 \mathrm{CH} 4$ & $100 \mathrm{~F}-10$ HRM 19.0 & ONSITE & sw & $\mathrm{N}$ & RIVER T & TRANSECT & 08-Sep-03 LO TRITIUM & & $24.1 \mathrm{p}$ & $\mathrm{pCi/L}$ & 4.8 & 6.8 & & \\
\hline SESPMNT & $\mathrm{B} 17 \mathrm{CH} 1$ & $100 \mathrm{~F}-2$ HRM 19.0 & ONSITE & sw & $\mathrm{N}$ & RIVER T & TRANSECT & 08-Sep-03 LO TRITIUM & & $32.8 \mathrm{p}$ & $\mathrm{pCi} / \mathrm{L}$ & 5.2 & 8 & & \\
\hline SESPMNT & B17CF9 & $100 \mathrm{~F}-3$ HRM 19.0 & ONSITE & sw & $\mathrm{N}$ & RIVER 7 & TRANSECT & 08-Sep-03 LO TRITIUM & & $27.6 \mathrm{p}$ & $\mathrm{pCi} / \mathrm{L}$ & 4.7 & 7.1 & & \\
\hline SESPMNT & $\mathrm{B} 17 \mathrm{CH} 2$ & 100 F -5 HRM 19.0 & ONSITE & sw & $\mathrm{N}$ & RIVER T & TRANSECT & 08-Sep-03 LO TRITIUM & & $30.5 \mathrm{p}$ & $\mathrm{pCi} / \mathrm{L}$ & 5.1 & 7.7 & & \\
\hline SESPMNT & $\mathrm{B} 17 \mathrm{CH} 3$ & 100 F -7 HRM 19.0 & ONSITE & sw & $\mathrm{N}$ & RIVER 7 & TRANSECT & 08-Sep-03 LO TRITIUM & & $34.9 \mathrm{p}$ & $\mathrm{pCi} / \mathrm{L}$ & 6.2 & 9.2 & & \\
\hline SESPMNT & B17CY4 & 100 F SHORE HRM 18 & ONSITE & sw & $\mathrm{N}$ & RIVER T & TRANSECT & 08-Sep-03 LO TRITIUM & & $33.2 \mathrm{p}$ & $\mathrm{pCi/L}$ & 5.3 & 8.2 & & \\
\hline SESPMNT & B17CY7 & 100 F SHORE HRM 22 & ONSITE & sw & $\mathrm{N}$ & RIVER T & TRANSECT & 08-Sep-03 LO TRITIUM & & $31.3 \mathrm{p}$ & & 5.2 & 7.9 & & \\
\hline SESPMNT & B17D00 & $100 \mathrm{~F}$ SHORE HRM 23 & ONSITE & sw & $\mathrm{N}$ & RIVER T & TRANSECT & 08-Sep-03 LO TRITIUM & & & & 4.9 & 7 & & \\
\hline SESPMNT & $\mathrm{B} 17 \mathrm{CH} 5$ & HANFRD TS-1 HRM 28.7 & ONSITE & sw & $\mathrm{N}$ & RIVER T & TRANSECT & 08-Sep-03 LO TRITIUM & & $3390 \mathrm{p}$ & $\mathrm{pCi} / \mathrm{L}$ & 42 & 560 & & \\
\hline SESPMNT & $\mathrm{B} 17 \mathrm{CH} 8$ & HANFRD TS-10 HRM 28.7 & ONSITE & sw & $\mathrm{N}$ & RIVER T & TRANSECT & 08-Sep-03 LO TRITIUM & & $29.4 \mathrm{p}$ & $\mathrm{pCi/L}$ & 4.9 & 7.4 & & \\
\hline SESPMNT & B17CH9 & HANFRD TS-3 HRM 28.7 & ONSITE & sw & $\mathrm{N}$ & RIVER T & TRANSECT & 08-Sep-03 LO TRITIUM & & $25.5 \mathrm{p}$ & $\mathrm{pCi} / \mathrm{L}$ & 5 & 7.1 & & \\
\hline SESPMNT & $\mathrm{B} 17 \mathrm{CHO}$ & HANFRD TS-5 HRM 28.7 & ONSITE & sw & $\mathrm{N}$ & RIVER T & TRANSECT & 08-Sep-03 LO TRITIUM & & & $\mathrm{pCi} / \mathrm{L}$ & 5.6 & 8.5 & & \\
\hline SESPMNT & $\mathrm{B} 17 \mathrm{CH} 7$ & HANFRD TS-7 HRM 28.7 & ONSITE & sw & $\mathrm{N}$ & RIVER 7 & TRANSECT & 08-Sep-03 LO TRITIUM & & $26.8 \mathrm{p}$ & $\mathrm{pCi} / \mathrm{L}$ & 5 & 7.2 & & \\
\hline SESPMNT & B17CL4 & HANFRD TWNSITE HRM26 & ONSITE & sw & $\mathrm{N}$ & RIVER 7 & TRANSECT & 08-Sep-03 LO TRITIUM & & $27.3 \mathrm{p}$ & $\mathrm{pCi} / \mathrm{L}$ & 5 & 7.3 & & \\
\hline SESPMNT & B17CL5 & HANFRD TWNSITE HRM27 & ONSITE & sw & $\mathrm{N}$ & RIVER T & TRANSECT & 08-Sep-03 LO TRITIUM & & $28.1 \mathrm{p}$ & & 5 & 7.4 & & \\
\hline SESPMNT & B17CJO & 300 AREA - 1 HRM 43.1 & ONSITE & sw & $\mathrm{N}$ & RIVER T & TRANSECT & 09-Sep-03 LO TRITIUM & & $119 p$ & $\mathrm{pCi/L}$ & 4 & 12 & & \\
\hline SESPMNT & B17CJ2 & 300 AREA -2 HRM 43.1 & ONSITE & sw & $\mathrm{N}$ & RIVER T & TRANSECT & 09-Sep-03 LO TRITIUM & & $124 \mathrm{p}$ & $\mathrm{pCi} / \mathrm{L}$ & 7.4 & 22 & & \\
\hline SESPMNT & B17CJ4 & 300 AREA -3 HRM 43.1 & ONSITE & sw & $\mathrm{N}$ & RIVER T & TRANSECT & 09-Sep-03 LO TRITIUM & & & $\mathrm{pCi} / \mathrm{L}$ & 4.9 & 9.9 & & \\
\hline SESPMNT & B17CJ6 & 300 AREA -5 HRM 43.1 & ONSITE & sw & $\mathrm{N}$ & RIVER T & TRANSECT & 09-Sep-03 LO TRITIUM & & $41.2 \mathrm{p}$ & $\mathrm{pCi} / \mathrm{L}$ & 4.6 & 8.6 & & \\
\hline SESPMNT & B17CJ8 & 300 AREA -7 HRM 43.1 & ONSITE & sw & $\mathrm{N}$ & RIVER & TRANSECT & 09-Sep-03 LO TRITIUM & & $35.7 \mathrm{p}$ & $\mathrm{pCi/L}$ & 4.4 & 7.8 & & \\
\hline SESPMNT & B17CW5 & 300 AREA SHR HRM41.5 & ONSITE & sw & $\mathrm{N}$ & RIVER T & TRANSECT & 09-Sep-03 LO TRITIUM & & & $\mathrm{pCi} / \mathrm{L}$ & 5.6 & 25 & & \\
\hline SESPMNT & B17CX7 & 300 AREA SHR HRM42.9 & ONSITE & sw & $\mathrm{N}$ & RIVER 7 & TRANSECT & 09-Sep-03 LO TRITIUM & & & $\mathrm{pCi} / \mathrm{L}$ & 4.7 & 17 & & \\
\hline SESPMNT & B17CK0 & 300 AREA-10 HRM 43.1 & ONSITE & sw & $\mathrm{N}$ & RIVER 7 & TRANSECT & 09-Sep-03 LO TRITIUM & & $32.9 p$ & $\mathrm{pCi} / \mathrm{L}$ & 4.3 & 7.4 & & \\
\hline SESPMNT & В17СT0 & RICH.PMPHS HRM 43.5 & OFFSITE & sw & $\mathrm{N}$ & RIVER 7 & TRANSECT & 09-Sep-03 LO TRITIUM & & $135 \mathrm{p}$ & $\mathrm{pCi} / \mathrm{L}$ & 7.6 & 24 & & \\
\hline SESPMNT & B17CR8 & RICH.PMPHS HRM 45.0 & OFFSITE & sw & $\mathrm{N}$ & RIVER T & TRANSECT & 09-Sep-03 LO TRITIUM & & $139 \mathrm{p}$ & $\mathrm{pCi} / \mathrm{L}$ & 7.9 & 25 & & \\
\hline SESPMNT & B17CR7 & RICH.PMPHS HRM 45.8 & OFFSITE & sw & $\mathrm{N}$ & RIVER T & TRANSECT & 09-Sep-03 LO TRITIUM & & $139 \mathrm{p}$ & $\mathrm{pCi} / \mathrm{L}$ & 7.7 & 25 & & \\
\hline SESPMNT & B17CK2 & RICH.PMPHS-1 HRM46.4 & OFFSITE & sw & $\mathrm{N}$ & RIVER 7 & TRANSECT & 09-Sep-03 LO TRITIUM & & $136 \mathrm{p}$ & $\mathrm{pCi} / \mathrm{L}$ & 7.9 & 24 & & \\
\hline SESPMNT & B17CK7 & RICH.PMPHS-10 HRM46.4 & OFFSITE & sw & $\mathrm{N}$ & RIVER T & TRANSECT & 09-Sep-03 LO TRITIUM & & $34.3 \mathrm{p}$ & $\mathrm{pCi} / \mathrm{L}$ & 4.3 & 7.5 & & \\
\hline SESPMNT & B17CK3 & RICH.PMPHS-2 HRM46.4 & OFFSITE & sw & $\mathrm{N}$ & RIVER T & TRANSECT & 09-Sep-03 LO TRITIUM & & & $\mathrm{pCi} / \mathrm{L}$ & 7.8 & 22 & & \\
\hline SESPMNT & B17CK4 & RICH.PMPHS-3 HRM46.4 & OFFSITE & sw & $\mathrm{N}$ & RIVER T & TRANSECT & 09-Sep-03 LO TRITIUM & & $45.1 \mathrm{p}$ & $\mathrm{pCi} / \mathrm{L}$ & 4.8 & 9.3 & & \\
\hline SESPMNT & B17CK5 & RICH.PMPHS-5 HRM46.4 & OFFSITE & sw & $\mathrm{N}$ & RIVER T & TRANSECT & 09-Sep-03 LO TRITIUM & & $41.7 \mathrm{p}$ & $\mathrm{pCi} / \mathrm{L}$ & 4.6 & 8.7 & & \\
\hline SESPMNT & B17CK6 & RICH.PMPHS-7 HRM46.4 & OFFSITE & sw & $\mathrm{N}$ & RIVER 7 & TRANSECT & 09-Sep-03 LO TRITIUM & & & $\mathrm{pCi} / \mathrm{L}$ & 4.3 & 7.4 & & \\
\hline SESPMNT & B17CR9 & RICH.PMPHS HRM 43.9 & OFFSITE & sW & $\mathrm{N}$ & RIVER 7 & TRANSECT & 09-Sep-03 LO TRITIUM & & & & & & NO SAMPLE. THICK MILFOIL. & \\
\hline SESPMNT & B17CW9 & 300 AREA SHR HRM42.1 & ONSITE & sW & $\mathrm{N}$ & RIVER T & TRANSECT & 09-Sep-03 LO TRITIUM & & $947 \mathrm{p}$ & $\mathrm{pCi} / \mathrm{L}$ & 9.8 & 83 & DIRECTLY DOWNRIVER FROM 300 AREA SPRING 42-2. & \\
\hline SESPMNT & B183Wo & RICH.PMPHS HRM 43.5 & OFFSITE & sw & $\mathrm{N}$ & RIVER 7 & TRANSECT & 08-Dec-03 LO TRITIUM & & $58.5 \mathrm{p}$ & $\mathrm{pCi} / \mathrm{L}$ & 3.7 & 11 & & \\
\hline SESPMNT & B183V9 & RICH.PMPHS HRM 43.9 & OFFSITE & sW & $\mathrm{N}$ & RIVER T & TRANSECT & 08-Dec-03 LO TRITIUM & & $63.3 \mathrm{p}$ & $\mathrm{pCi} / \mathrm{L}$ & 4.6 & 12 & & \\
\hline SESPMNT & B183V8 & RICH.PMPHS HRM 45.0 & OFFSITE & sw & $\mathrm{N}$ & RIVER 7 & TRANSECT & 08-Dec-03 LO TRITIUM & & & & 3.8 & 11 & & \\
\hline SESPMNT & B183V7 & RICH.PMPHS HRM 45.8 & OFFSITE & sw & $\mathrm{N}$ & RIVER 7 & TRANSECT & 08-Dec-03 LO TRITIUM & & $47.5 p$ & $\mathrm{pCi} / \mathrm{L}$ & 3.5 & 8.9 & & \\
\hline SESPMNT & B183T1 & RICH.PMPHS-1 HRM46.4 & OFFSITE & sw & $\mathrm{N}$ & RIVER T & TRANSECT & 08-Dec-03 LO TRITIUM & & $60.9 \mathrm{p}$ & $\mathrm{pCi} / \mathrm{L}$ & 3.8 & 11 & & \\
\hline
\end{tabular}


WATER - COLUMBIA RIVER TRANSEC

\begin{tabular}{|c|c|c|c|c|c|c|c|c|c|c|c|c|c|c|c|}
\hline | OWNER ID & |SAMP NUM| & SAMP SITE NAME & DIST CLASS & $\mid$ MEDIA & \begin{tabular}{|c|} 
FILTERED \\
FLAG
\end{tabular} & $\begin{array}{l}\text { SAMP } \\
\text { FROM }\end{array}$ & COLL MTHD & SAMP DATE & CON SHORT NAME & \begin{tabular}{l|l} 
VALUE & $A$ \\
RPTD & $R$ \\
\end{tabular} & \begin{tabular}{|l|l|} 
ANAL \\
UNITS \\
RPTD \\
\end{tabular} & $\begin{array}{c}\text { COUNTING } \\
\text { ERROR }\end{array}$ & \begin{tabular}{|c|c|} 
TOTAL & \\
ANAL & LAB \\
ERROR & QUALIFIER \\
\end{tabular} & SAMP COMMENT & $\begin{array}{l}\text { RESULT } \\
\text { COMMENT }\end{array}$ \\
\hline SESPSPEC & B183R6 & RICH.PMPHS-1 HRM46.4 & OFFSITE & SW & $\mathrm{N}$ & RIVER & TRANSECT & 08-Dec-03 LO TRITIUM & & & & 3.7 & 9.6 & 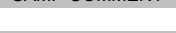 & \\
\hline SESPMNT & B183T6 & RICH.PMPHS-10 HRM46.4 & OFFSITE & sw & $\mathrm{N}$ & RIVER & TRANSECT & 08-Dec-03 LO TRITIUM & & $33.6 \mathrm{p}$ & $\mathrm{pCi} / \mathrm{L}$ & 3 & 6.7 & & \\
\hline SESPMNT & B183T2 & RICH.PMPHS-2 HRM46.4 & OFFSITE & sw & $\mathrm{N}$ & RIVER & TRANSECT & 08-Dec-03 LO TRITIUM & & $42.6 \mathrm{p}$ & $\mathrm{pCi} / \mathrm{L}$ & 3.4 & 8.1 & & \\
\hline SESPMNT & B183T3 & RICH.PMPHS-3 HRM46.4 & OFFSITE & sw & $\mathrm{N}$ & RIVER & TRANSECT & 08-Dec-03 LO TRITIUM & & $34.6 \mathrm{p}$ & $\mathrm{pCilL}$ & 3.1 & 6.8 & & \\
\hline SESPMNT & B183T4 & RICH.PMPHS-5 HRM46.4 & OFFSITE & sw & $\mathrm{N}$ & RIVER & TRANSECT & 08-Dec-03 LO TRITIUM & & $33.9 p$ & pCi/L & 3.1 & 6.7 & & \\
\hline SESPMNT & B183T5 & RICH.PMPHS-7 HRM46.4 & OFFSITE & sw & $\mathrm{N}$ & RIVER & TRANSECT & 08-Dec-03 LO TRITIUM & & & & 3.5 & 7.2 & & \\
\hline SESPMNT & B183R7 & VERNITA-1 HRM 0.3 & OFFSITE & sw & $\mathrm{N}$ & RIVER & TRANSECT & 09-Dec-03 LO TRITIUM & & & & 3.1 & 6.7 & & \\
\hline SESPMNT & B183R8 & VERNITA-2 HRM 0.3 & OFFSITE & sw & $\mathrm{N}$ & RIVER & TRANSECT & 09-Dec-03 LO TRITIUM & & & & 2.9 & 5.7 & & \\
\hline SESPMNT & B183R9 & VERNITA-3 HRM 0.3 & OFFSITE & sw & $\mathrm{N}$ & RIVER & TRANSECT & 09-Dec-03 LO TRITIUM & & $31.2 \mathrm{p}$ & $\mathrm{pCi} / \mathrm{L}$ & 2.9 & 6.3 & & \\
\hline SESPMNT & B183T0 & VERNITA-4 HRM 0.3 & OFFSITE & sw & $\mathrm{N}$ & RIVER & TRANSECT & 09-Dec-03 LO TRITIUM & & $34.4 \mathrm{p}$ & $\mathrm{pCi} / \mathrm{L}$ & 3.4 & 7.1 & & \\
\hline SESPMNT & B16L97 & VERNITA-1 HRM 0.3 & OFFSITE & sw & $\mathrm{N}$ & RIVER & TRANSECT & 24-Mar-03 U-234 & & $0.269 \mathrm{p}$ & $\mathrm{pCi} / \mathrm{L}$ & 0.037 & 0.057 & & \\
\hline SESPMNT & B16L98 & VERNITA-2 HRM 0.3 & OFFSITE & sw & $\mathrm{N}$ & RIVER & TRANSECT & 24-Mar-03 U-234 & & $0.301 \mathrm{p}$ & $\mathrm{pCi} / \mathrm{L}$ & 0.042 & 0.064 & & \\
\hline SESPMNT & B16L99 & VERNITA-3 HRM 0.3 & OFFSITE & sw & $\mathrm{N}$ & RIVER & TRANSECT & 24-Mar-03 U-234 & & $0.251 \mathrm{p}$ & $\mathrm{pCi} / \mathrm{L}$ & 0.038 & 0.056 & & \\
\hline SESPMNT & B16LBO & VERNITA-4 HRM 0.3 & OFFSITE & sw & $\mathrm{N}$ & RIVER & TRANSECT & 24-Mar-03 U-234 & & $0.263 \mathrm{p}$ & $\mathrm{pCi} / \mathrm{L}$ & 0.064 & 0.078 & & \\
\hline SESPMNT & B16LD0 & RICH.PMPHS HRM 43.5 & OFFSITE & sw & $\mathrm{N}$ & RIVER & TRANSECT & 25-Mar-03 U-234 & & $0.274 \mathrm{p}$ & & 0.045 & 0.064 & & \\
\hline SESPMNT & B16LC9 & RICH.PMPHS HRM 43.9 & OFFSITE & sw & $\mathrm{N}$ & RIVER & TRANSECT & 25-Mar-03 U-234 & & $0.264 \mathrm{p}$ & & 0.038 & 0.058 & & \\
\hline SESPMNT & B16LC8 & RICH.PMPHS HRM 45.0 & OFFSITE & sw & $\mathrm{N}$ & RIVER & TRANSECT & 25-Mar-03 U-234 & & $0.271 \mathrm{p}$ & $\mathrm{pCi} / \mathrm{L}$ & 0.039 & 0.059 & & \\
\hline SESPMNT & B16LC7 & RICH.PMPHS HRM 45.8 & OFFSITE & sw & $\mathrm{N}$ & RIVER & TRANSECT & 25-Mar-03 U-234 & & $0.275 \mathrm{p}$ & $\mathrm{pCi} / \mathrm{L}$ & 0.039 & 0.059 & & \\
\hline SESPMNT & B16LB1 & RICH.PMPHS-1 HRM46.4 & OFFSITE & sw & $\mathrm{N}$ & RIVER & TRANSECT & 25-Mar-03 U-234 & & $0.278 \mathrm{p}$ & $\mathrm{pCi} / \mathrm{L}$ & 0.039 & 0.06 & & \\
\hline SESPSPEC & B16L96 & RICH.PMPHS-1 HRM46.4 & OFFSITE & sW & $\mathrm{N}$ & RIVER & TRANSECT & 25-Mar-03 U-234 & & $0.292 \mathrm{p}$ & $\mathrm{pCi} / \mathrm{L}$ & 0.04 & 0.062 & & \\
\hline SESPMNT & B16LB6 & RICH.PMPHS-10 HRM46.4 & OFFSITE & sw & $\mathrm{N}$ & RIVER & TRANSECT & 25-Mar-03 U-234 & & $0.622 \mathrm{p}$ & & 0.059 & 0.12 & & \\
\hline SESPMNT & B16LB2 & RICH.PMPHS-2 HRM46.4 & OFFSITE & sw & $\mathrm{N}$ & RIVER & TRANSECT & 25-Mar-03 U-234 & & $0.256 \mathrm{p}$ & & 0.039 & 0.057 & & \\
\hline SESPMNT & B16LB3 & RICH.PMPHS-3 HRM 46.4 & OFFSITE & sw & $\mathrm{N}$ & RIVER & TRANSECT & 25-Mar-03 U-234 & & $0.274 \mathrm{p}$ & & 0.039 & 0.059 & & \\
\hline SESPMNT & B16LB4 & RICH.PMPHS-5 HRM46.4 & OFFSITE & sw & $\mathrm{N}$ & RIVER & TRANSECT & 25-Mar-03 U-234 & & $0.293 \mathrm{p}$ & $\mathrm{pCi/L}$ & 0.04 & 0.062 & & \\
\hline SESPMNT & B16LB5 & RICH.PMPHS-7 HRM46.4 & OFFSITE & sw & $\mathrm{N}$ & RIVER & TRANSECT & 25-Mar-03 U-234 & & $0.365 \mathrm{p}$ & $\mathrm{pCi} / \mathrm{L}$ & 0.049 & 0.077 & & \\
\hline SESPMNT & B171W1 & VERNITA-1 HRM 0.3 & OFFSITE & sw & $\mathrm{N}$ & RIVER & TRANSECT & 09-Jun-03 U-234 & & $0.205 \mathrm{p}$ & $\mathrm{pCi} / \mathrm{L}$ & 0.049 & 0.059 & & \\
\hline SESPMNT & B171W2 & VERNITA-2 HRM 0.3 & OFFSITE & sw & $\mathrm{N}$ & RIVER & TRANSECT & 09-Jun-03 U-234 & & $0.226 \mathrm{p}$ & $\mathrm{pCi} / \mathrm{L}$ & 0.04 & 0.053 & & \\
\hline SESPMNT & B171W3 & VERNITA-3 HRM 0.3 & OFFSITE & sw & $\mathrm{N}$ & RIVER & TRANSECT & 09-Jun-03 U-234 & & $0.217 \mathrm{p}$ & $\mathrm{pCi} / \mathrm{L}$ & 0.046 & 0.058 & & \\
\hline SESPMNT & B171W4 & VERNITA-4 HRM 0.3 & OFFSITE & sw & $\mathrm{N}$ & RIVER & TRANSECT & 09-Jun-03 U-234 & & $0.248 \mathrm{p}$ & $\mathrm{pCi/L}$ & 0.049 & 0.063 & & \\
\hline SESPMNT & B17204 & RICH.PMPHS HRM 43.5 & OFFSITE & sw & $\mathrm{N}$ & RIVER & TRANSECT & 10-Jun-03 U-234 & & $0.21 \mathrm{p}$ & & 0.038 & 0.051 & & \\
\hline SESPMNT & B17203 & RICH.PMPHS HRM 43.9 & OFFSITE & sw & $\mathrm{N}$ & RIVER & TRANSECT & 10-Jun-03 U-234 & & & $\mathrm{pCi} / \mathrm{L}$ & 0.06 & 0.069 & & \\
\hline SESPMNT & B17202 & RICH.PMPHS HRM 45.0 & OFFSITE & sw & $\mathrm{N}$ & RIVER & TRANSECT & 10-Jun-03 U-234 & & $0.212 \mathrm{p}$ & $\mathrm{pCi} / \mathrm{L}$ & 0.035 & 0.049 & & \\
\hline SESPMNT & B17201 & RICH.PMPHS HRM 45.8 & OFFSITE & sw & $\mathrm{N}$ & RIVER & TRANSECT & 10-Jun-03 U-234 & & $0.223 \mathrm{p}$ & $\mathrm{pCi/L}$ & 0.04 & 0.054 & & \\
\hline SESPMNT & B171W5 & RICH.PMPHS-1 HRM46.4 & OFFSITE & sw & $\mathrm{N}$ & RIVER & TRANSECT & 10-Jun-03 U-234 & & $0.208 \mathrm{p}$ & $\mathrm{pCi} / \mathrm{L}$ & 0.047 & 0.058 & & \\
\hline SESPMNT & B171X0 & RICH.PMPHS-10 HRM46.4 & OFFSITE & sw & $\mathrm{N}$ & RIVER & TRANSECT & 10-Jun-03 U-234 & & $0.285 \mathrm{p}$ & $\mathrm{pCi} / \mathrm{L}$ & 0.043 & 0.062 & & \\
\hline SESPMNT & B171W6 & RICH.PMPHS-2 HRM46.4 & OFFSITE & sw & $\mathrm{N}$ & RIVER & TRANSECT & 10-Jun-03 U-234 & & $0.212 \mathrm{p}$ & $\mathrm{pCi} / \mathrm{L}$ & 0.037 & 0.05 & & \\
\hline SESPMNT & B171W7 & RICH.PMPHS-3 HRM46.4 & OFFSITE & sw & $\mathrm{N}$ & RIVER & TRANSECT & 10-Jun-03 U-234 & & $0.202 \mathrm{p}$ & $\mathrm{pCi} / \mathrm{L}$ & 0.042 & 0.053 & & \\
\hline SESPMNT & B171W8 & RICH.PMPHS-5 HRM46.4 & OFFSITE & sw & $\mathrm{N}$ & RIVER & TRANSECT & 10-Jun-03 U-234 & & $0.192 \mathrm{p}$ & & 0.036 & 0.047 & & \\
\hline SESPMNT & B171W9 & RICH.PMPHS-7 HRM46.4 & OFFSITE & sw & $\mathrm{N}$ & RIVER & TRANSECT & 10-Jun-03 U-234 & & $0.219 \mathrm{p}$ & $\mathrm{pCi/L}$ & 0.043 & 0.055 & & \\
\hline SESPMNT & B17CF2 & $100 \mathrm{~N}-1$ HRM 9.5 & ONSITE & sw & $\mathrm{N}$ & RIVER & TRANSECT & 04-Sep-03 U-234 & & $0.234 \mathrm{p}$ & $\mathrm{pCi} / \mathrm{L}$ & 0.044 & 0.057 & & \\
\hline SESPSPEC & B17CD7 & $100 \mathrm{~N}-1$ HRM 9.5 & ONSITE & sw & $\mathrm{N}$ & RIVER & TRANSECT & 04-Sep-03 U-234 & & $0.266 \mathrm{p}$ & $\mathrm{pCi} / \mathrm{L}$ & 0.044 & 0.061 & & \\
\hline SESPMNT & B17CK8 & $100 \mathrm{~N}-10$ HRM 9.5 & ONSITE & sw & $\mathrm{N}$ & RIVER & TRANSECT & 04-Sep-03 U-234 & & $0.288 \mathrm{p}$ & $\mathrm{pCi} / \mathrm{L}$ & 0.046 & 0.065 & & \\
\hline SESPMNT & B17CF4 & $100 \mathrm{~N}-2$ HRM 9.5 & ONSITE & sw & $\mathrm{N}$ & RIVER - & TRANSECT & 04-Sep-03 U-234 & & $0.19 \mathrm{p}$ & $\mathrm{pCi} / \mathrm{L}$ & 0.035 & 0.046 & & \\
\hline SESPMNT & B17CLO & $100 \mathrm{~N}-3$ HRM 9.5 & ONSITE & sw & $\mathrm{N}$ & RIVER & TRANSECT & $04-$ Sep-03 U-234 & & $0.196 \mathrm{p}$ & $\mathrm{pCi} / \mathrm{L}$ & 0.035 & 0.047 & & \\
\hline SESPMNT & B17CF6 & $100 \mathrm{~N}-5$ HRM 9.5 & ONSITE & sw & $\mathrm{N}$ & RIVER & TRANSECT & 04-Sep-03 U-234 & & $0.213 \mathrm{p}$ & & 0.04 & 0.053 & & \\
\hline SESPMNT & B17CL2 & $100 \mathrm{~N}-7$ HRM 9.5 & ONSITE & sw & $\mathrm{N}$ & RIVER & TRANSECT & 04-Sep-03 U-234 & & $0.225 \mathrm{p}$ & $\mathrm{pCi} / \mathrm{L}$ & 0.038 & 0.052 & & \\
\hline SESPMNT & B17CT9 & $100 \mathrm{~N}$ SHORE HRM 8.4 & ONSITE & sw & $\mathrm{N}$ & RIVER & TRANSECT & 04-Sep-03 U-234 & & $0.196 \mathrm{p}$ & $\mathrm{pCi} / \mathrm{L}$ & 0.041 & 0.052 & & \\
\hline SESPMNT & B17CV3 & 100 N SHORE HRM 8.9 & ONSITE & sw & $\mathrm{N}$ & RIVER & TRANSECT & 04-Sep-03 U-234 & & $0.245 p$ & $\mathrm{pCi} / \mathrm{L}$ & 0.045 & 0.06 & & \\
\hline SESPMNT & B17CV7 & 100 N SHORE HRM 9.2 & ONSITE & sw & $\mathrm{N}$ & RIVER & TRANSECT & 04-Sep-03 U-234 & & $0.265 \mathrm{p}$ & $\mathrm{pCi} / \mathrm{L}$ & 0.054 & 0.069 & & \\
\hline SESPMNT & B17CW1 & 100 N SHORE HRM 9.8 & ONSITE & sw & $\mathrm{N}$ & RIVER & TRANSECT & 04-Sep-03 U-234 & & $0.182 \mathrm{p}$ & $\mathrm{pCi} / \mathrm{L}$ & 0.047 & 0.056 & & \\
\hline SESPMNT & B17CD8 & VERNITA-1 HRM 0.3 & OFFSITE & sw & $\mathrm{N}$ & RIVER & TRANSECT & 04-Sep-03 U-234 & & $0.218 \mathrm{p}$ & $\mathrm{pCi} / \mathrm{L}$ & 0.039 & 0.052 & & \\
\hline SESPMNT & B17CD9 & VERNITA-2 HRM 0.3 & OFFSITE & sw & $\mathrm{N}$ & RIVER & TRANSECT & 04-Sep-03 U-234 & & $0.203 \mathrm{p}$ & $\mathrm{pCi} / \mathrm{L}$ & 0.036 & 0.049 & & \\
\hline SESPMNT & B17CF0 & VERNITA-3 HRM 0.3 & OFFSITE & sw & $\mathrm{N}$ & RIVER & TRANSECT & 04-Sep-03 U-234 & & $0.185 \mathrm{p}$ & $\mathrm{pCi} / \mathrm{L}$ & 0.042 & 0.052 & & \\
\hline SESPMNT & B17CF1 & VERNITA-4 HRM 0.3 & OFFSITE & sw & $\mathrm{N}$ & RIVER & TRANSECT & 04-Sep-03 U-234 & & $0.205 \mathrm{p}$ & $\mathrm{pCi} / \mathrm{L}$ & 0.042 & 0.054 & & \\
\hline SESPMNT & B17CF8 & 100 F - 1 HRM 19.0 & ONSITE & sw & $\mathrm{N}$ & RIVER & TRANSECT & 08-Sep-03 U-234 & & $0.239 \mathrm{p}$ & $\mathrm{pCi} / \mathrm{L}$ & 0.038 & 0.054 & & \\
\hline SESPMNT & $\mathrm{B} 17 \mathrm{CH} 4$ & $100 \mathrm{~F}-10 \mathrm{HRM} 19.0$ & ONSITE & sW & $\mathrm{N}$ & RIVER & TRANSECT & 08-Sep-03 U-234 & & $0.301 \mathrm{p}$ & $\mathrm{pCi} / \mathrm{L}$ & 0.042 & 0.063 & & \\
\hline SESPMNT & $\mathrm{B} 17 \mathrm{CH} 1$ & $100 \mathrm{~F}-2$ HRM 19.0 & ONSITE & sW & $\mathrm{N}$ & RIVER & TRANSECT & 08-Sep-03 U-234 & & $0.224 \mathrm{p}$ & $\mathrm{pCi} / \mathrm{L}$ & 0.039 & 0.053 & & \\
\hline SESPMNT & B17CF9 & $100 \mathrm{~F}-3$ HRM 19.0 & ONSITE & SW & $\mathrm{N}$ & RIVER & TRANSECT & $08-\mathrm{Sep}-03 \mathrm{U}-234$ & & $0.231 \mathrm{p}$ & $\mathrm{pCi/L}$ & 0.037 & 0.052 & & \\
\hline SESPMNT & $\mathrm{B} 17 \mathrm{CH} 2$ & 100 F - 5 HRM 19.0 & ONSITE & sW & $\mathrm{N}$ & RIVER & TRANSECT & 08-Sep-03 U-234 & & $0.238 \mathrm{p}$ & $\mathrm{pCi} / \mathrm{L}$ & 0.037 & 0.053 & & \\
\hline SESPMNT & $\mathrm{B} 17 \mathrm{CH} 3$ & 100 F -7 HRM 19.0 & ONSITE & sw & $\mathrm{N}$ & RIVER & TRANSECT & 08-Sep-03 U-234 & & $0.209 \mathrm{p}$ & $\mathrm{pCi} / \mathrm{L}$ & 0.034 & 0.047 & & \\
\hline SESPMNT & B17CY4 & $100 \mathrm{~F}$ SHORE HRM 18 & ONSITE & SW & $\mathrm{N}$ & RIVER & TRANSECT & 08-Sep-03 U-234 & & $0.231 \mathrm{p}$ & $\mathrm{pCi} / \mathrm{L}$ & 0.036 & 0.051 & & \\
\hline SESPMNT & B17CY7 & $100 \mathrm{~F}$ SHORE HRM 22 & ONSITE & sw & $\mathrm{N}$ & RIVER & TRANSECT & 08-Sep-03 U-234 & & $0.21 \mathrm{p}$ & $\mathrm{pCi} / \mathrm{L}$ & 0.035 & 0.049 & & \\
\hline
\end{tabular}


WATER - COLUMBIA RIVER TRANSEC

\begin{tabular}{|c|c|c|c|c|c|c|c|c|c|c|c|c|c|c|c|c|}
\hline | OWNER ID & SAMP NUM & SAMP SITE NAME & DIST CLASS & MEDIA $\left.\right|^{\mid h}$ & \begin{tabular}{|c|} 
FILTERED \\
FLAG
\end{tabular} & $\begin{array}{l}\text { SAMP } \\
\text { FROM }\end{array}$ & COLL MTHD & SAMP DATE & CON SHORT NAME & 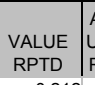 & \begin{tabular}{|l|} 
ANAL \\
UNITS \\
RPTD \\
\end{tabular} & $\begin{array}{c}\text { COUNTING } \\
\text { ERROR }\end{array}$ & \begin{tabular}{|c|} 
TOTAL \\
ANAL \\
ERROR
\end{tabular} & $\begin{array}{c}\text { LAB } \\
\text { QUALIFIER }\end{array}$ & SAMP COMMENT & $\begin{array}{l}\text { RESULT } \\
\text { COMMENT }\end{array}$ \\
\hline SESPMNT & B17D00 & 100 F SHORE HRM 23 & ONSITE & SW & $\mathrm{N}$ & RIVER & TRANSECT & 08-Sep-03 U-234 & & & & 0.035 & 0.049 & & - & \\
\hline SESPMNT & B17CH5 & HANFRD TS-1 HRM 28.7 & ONSITE & sw & $\mathrm{N}$ & RIVER & TRANSECT & 08-Sep-03 U-234 & & $0.302 p$ & $\mathrm{pCi} / \mathrm{L}$ & 0.042 & 0.063 & & & \\
\hline SESPMNT & $\mathrm{B} 17 \mathrm{CH} 8$ & HANFRD TS-10 HRM 28.7 & ONSITE & sw & $\mathrm{N}$ & RIVER & TRANSECT & 08-Sep-03 U-234 & & $0.236 \mathrm{p}$ & $\mathrm{pCi} / \mathrm{L}$ & 0.036 & 0.052 & & & \\
\hline SESPMNT & $\mathrm{B} 17 \mathrm{CH} 6$ & HANFRD TS-2 HRM 28.7 & ONSITE & sw & $\mathrm{N}$ & RIVER & TRANSECT & $08-\mathrm{Sep}-03 \mathrm{U}-234$ & & $0.175 \mathrm{p}$ & $\mathrm{pCilL}$ & 0.034 & 0.044 & & & \\
\hline SESPMNT & B17CH9 & HANFRD TS-3 HRM 28.7 & ONSITE & sw & $\mathrm{N}$ & RIVER & TRANSECT & 08-Sep-03 U-234 & & $0.223 \mathrm{p}$ & pCi/L & 0.039 & 0.052 & & & \\
\hline SESPMNT & $\mathrm{B} 17 \mathrm{CHO}$ & HANFRD TS-5 HRM 28.7 & ONSITE & sw & $\mathrm{N}$ & RIVER & TRANSECT & 08-Sep-03 U-234 & & & $\mathrm{pCi} / \mathrm{L}$ & 0.04 & 0.054 & & & \\
\hline SESPMNT & $\mathrm{B} 17 \mathrm{CH} 7$ & HANFRD TS-7 HRM 28.7 & ONSITE & sw & $\mathrm{N}$ & RIVER & TRANSECT & 08-Sep-03 U-234 & & & $\mathrm{pCi} / \mathrm{L}$ & 0.034 & 0.049 & & & \\
\hline SESPMNT & B17CL4 & HANFRD TWNSITE HRM26 & ONSITE & sw & $\mathrm{N}$ & RIVER & TRANSECT & 08-Sep-03 U-234 & & $0.201 \mathrm{p}$ & & 0.04 & 0.051 & & & \\
\hline SESPMNT & B17CL5 & HANFRD TWNSITE HRM27 & ONSITE & sw & $\mathrm{N}$ & RIVER & TRANSECT & 08-Sep-03 U-234 & & $0.184 \mathrm{p}$ & $\mathrm{pCi} / \mathrm{L}$ & 0.037 & 0.047 & & & \\
\hline SESPMNT & B17CY1 & HANFRD TWNSITE HRM28 & ONSITE & sw & $\mathrm{N}$ & RIVER & TRANSECT & 08-Sep-03 U-234 & & $0.702 \mathrm{p}$ & $\mathrm{pCi} / \mathrm{L}$ & 0.064 & 0.13 & & & \\
\hline SESPMNT & B17CL6 & HANFRD TWNSITE HRM 30 & ONSITE & sw & $\mathrm{N}$ & RIVER & TRANSECT & 08-Sep-03 U-234 & & $0.231 \mathrm{p}$ & $\mathrm{pCi} / \mathrm{L}$ & 0.037 & 0.052 & & & \\
\hline SESPMNT & B17CJO & 300 AREA - 1 HRM 43.1 & ONSITE & sw & $\mathrm{N}$ & RIVER & TRANSECT & 09-Sep-03 U-234 & & $0.487 p$ & $\mathrm{pCi} / \mathrm{L}$ & 0.055 & 0.094 & & & \\
\hline SESPMNT & B17CJ2 & 300 AREA -2 HRM 43.1 & ONSITE & sw & $\mathrm{N}$ & RIVER & TRANSECT & 09-Sep-03 U-234 & & $0.264 p$ & $\mathrm{pCi} / \mathrm{L}$ & 0.042 & 0.06 & & & \\
\hline SESPMNT & B17CJ4 & 300 AREA -3 HRM 43.1 & ONSITE & sw & $\mathrm{N}$ & RIVER & $\begin{array}{l}\text { TRANSECT } \\
\text { TRES }\end{array}$ & $09-$ Sep-03 U-234 & & $0.254 \mathrm{p}$ & $\mathrm{pCi} / \mathrm{L}$ & 0.041 & 0.057 & & & \\
\hline SESPMNT & B17CJ6 & 300 AREA -5 HRM 43.1 & ONSITE & sw & $\mathrm{N}$ & RIVER & TRANSECT & 09-Sep-03 U-234 & & $0.228 \mathrm{p}$ & & 0.04 & 0.054 & & & \\
\hline SESPMNT & B17CJ8 & 300 AREA -7 HRM 43.1 & ONSITE & sw & $\mathrm{N}$ & RIVER & TRANSECT & 09-Sep-03 U-234 & & $0.252 p$ & & 0.038 & 0.055 & & & \\
\hline SESPMNT & B17CW5 & 300 AREA SHR HRM 41.5 & ONSITE & sw & $\mathrm{N}$ & RIVER & TRANSECT & 09-Sep-03 U-234 & & $0.27 p$ & $\mathrm{pCi} / \mathrm{L}$ & 0.039 & 0.057 & & & \\
\hline SESPMNT & B17CX7 & 300 AREA SHR HRM42.9 & ONSITE & sw & $\mathrm{N}$ & RIVER & TRANSECT & 09-Sep-03 U-234 & & $0.601 \mathrm{p}$ & $\mathrm{pCi} / \mathrm{L}$ & 0.056 & 0.11 & & & \\
\hline SESPMNT & B17CKO & 300 AREA-10 HRM 43.1 & ONSITE & sw & $\mathrm{N}$ & RIVER & TRANSECT & 09-Sep-03 U-234 & & $0.467 p$ & $\mathrm{pCi} / \mathrm{L}$ & 0.059 & 0.094 & & & \\
\hline SESPMNT & В17СT0 & RICH.PMPHS HRM 43.5 & OFFSITE & sW & $\mathrm{N}$ & RIVER & TRANSECT & 09-Sep-03 U-234 & & $0.452 \mathrm{p}$ & $\mathrm{pCi} / \mathrm{L}$ & 0.08 & 0.11 & & & \\
\hline SESPMNT & B17CR8 & RICH.PMPHS HRM 45.0 & OFFSITE & sw & $\mathrm{N}$ & RIVER & TRANSECT & 09-Sep-03 U-234 & & $0.274 p$ & $\mathrm{pCi} / \mathrm{L}$ & 0.041 & 0.06 & & & \\
\hline SESPMNT & B17CR7 & RICH.PMPHS HRM 45.8 & OFFSITE & sw & $\mathrm{N}$ & RIVER & TRANSECT & 09-Sep-03 U-234 & & $0.295 \mathrm{p}$ & & 0.04 & 0.061 & & & \\
\hline SESPMNT & B17CK2 & RICH.PMPHS-1 HRM46.4 & OFFSITE & sw & $\mathrm{N}$ & RIVER & TRANSECT & $09-S e p-03$ U-234 & & $0.289 \mathrm{p}$ & & 0.042 & 0.062 & & & \\
\hline SESPMNT & B17CK7 & RICH.PMPHS-10 HRM46. 4 & OFFSITE & sw & $\mathrm{N}$ & RIVER & TRANSECT & $09-5 e p-03$ U-234 & & $0.529 \mathrm{p}$ & $\mathrm{pCi/L}$ & 0.057 & 0.1 & & & \\
\hline SESPMNT & B17CK3 & RICH.PMPHS-2 HRM46.4 & OFFSITE & sw & $\mathrm{N}$ & RIVER & TRANSECT & 09-Sep-03 U-234 & & $0.28 \mathrm{p}$ & $\mathrm{pCi} / \mathrm{L}$ & 0.043 & 0.062 & & & \\
\hline SESPMNT & B17CK4 & RICH.PMPHS-3 HRM46.4 & OFFSITE & sw & $\mathrm{N}$ & RIVER & TRANSECT & 09-Sep-03 U-234 & & $0.222 \mathrm{p}$ & $\mathrm{pCi} / \mathrm{L}$ & 0.038 & 0.052 & & & \\
\hline SESPMNT & B17CK5 & RICH.PMPHS-5 HRM46.4 & OFFSITE & sw & $\mathrm{N}$ & RIVER & TRANSECT & 09-Sep-03 U-234 & & $0.249 \mathrm{p}$ & $\mathrm{pCi} / \mathrm{L}$ & 0.038 & 0.054 & & & \\
\hline SESPMNT & B17CK6 & RICH.PMPHS-7 HRM46.4 & OFFSITE & sw & $\mathrm{N}$ & RIVER & TRANSECT & 09-Sep-03 U-234 & & $0.269 \mathrm{p}$ & $\mathrm{pCi} / \mathrm{L}$ & 0.04 & 0.059 & & & \\
\hline SESPMNT & B17CR9 & RICH.PMPHS HRM 43.9 & OFFSITE & sw & $\mathrm{N}$ & RIVER & TRANSECT & 09-Sep-03 U-234 & & & & & & & NO SAMPLE. THICK MILFOIL. & \\
\hline SESPMNT & B17CW9 & 300 AREA SHR HRM42.1 & ONSITE & sw & $\mathrm{N}$ & RIVER & TRANSECT & 09-Sep-03 U-234 & & $0.373 p$ & $\mathrm{pCi} / \mathrm{L}$ & 0.045 & 0.074 & & DIRECTLY DOWNRIVER FROM 300 AREA SPRING 42-2. & \\
\hline SESPMNT & $\mathrm{B} 17 \mathrm{CX} 3$ & 300 AREA SHR HRM42.5 & ONSITE & sw & $\mathrm{N}$ & RIVER & TRANSECT & 09-Sep-03 U-234 & & $6.72 \mathrm{p}$ & $\mathrm{pCi} / \mathrm{L}$ & 0.18 & 1.1 & & DIRECTLY DOWNRIVER FROM 300 AREA SPRING 42-2. & \\
\hline SESPMNT & B183W0 & RICH.PMPHS HRM 43.5 & OFFSITE & SW & $\mathrm{N}$ & RIVER & TRANSECT & 08-Dec-03 U-234 & & $0.259 \mathrm{p}$ & $\mathrm{pCi} / \mathrm{L}$ & 0.047 & 0.063 & & & \\
\hline SESPMNT & B183V9 & RICH.PMPHS HRM 43.9 & OFFSITE & sw & $\mathrm{N}$ & RIVER & TRANSECT & $08-$-Dec-03 U-234 & & $0.318 \mathrm{p}$ & $\mathrm{pCi/L}$ & 0.055 & 0.075 & & & \\
\hline SESPMNT & B183V8 & RICH.PMPHS HRM 45.0 & OFFSITE & sw & $\mathrm{N}$ & RIVER & TRANSECT & $08-D e c-03$ U-234 & & $0.236 \mathrm{p}$ & $\mathrm{pCi} / \mathrm{L}$ & 0.045 & 0.059 & & & \\
\hline SESPMNT & B183V7 & RICH.PMPHS HRM 45.8 & OFFSITE & sw & $\mathrm{N}$ & RIVER & TRANSECT & 08-Dec-03 U-234 & & $0.202 \mathrm{p}$ & $\mathrm{pCi} / \mathrm{L}$ & 0.04 & 0.052 & & & \\
\hline SESPMNT & B183T1 & RICH.PMPHS-1 HRM46.4 & OFFSITE & sw & $\mathrm{N}$ & RIVER & TRANSECT & 08-Dec-03 U-234 & & $0.221 \mathrm{p}$ & $\mathrm{pCi} / \mathrm{L}$ & 0.045 & 0.058 & & & \\
\hline SESPSPEC & B183R6 & RICH.PMPHS-1 HRM46.4 & OFFSITE & sw & $\mathrm{N}$ & RIVER & TRANSECT & 08-Dec-03 U-234 & & $0.246 p$ & $\mathrm{pCi} / \mathrm{L}$ & 0.054 & 0.067 & & & \\
\hline SESPMNT & B183T6 & RICH.PMPHS-10 HRM46.4 & OFFSITE & sw & $\mathrm{N}$ & RIVER & TRANSECT & 08-Dec-03 U-234 & & & $\mathrm{pCi} / \mathrm{L}$ & 0.065 & 0.1 & & & \\
\hline SESPMNT & B183T2 & RICH.PMPHS-2 HRM46.4 & OFFSITE & sw & $\mathrm{N}$ & RIVER & TRANSECT & $08-D e c-03$ U-234 & & $0.248 \mathrm{p}$ & $\mathrm{pCi/L}$ & 0.047 & 0.061 & & & \\
\hline SESPMNT & B183T3 & RICH.PMPHS-3 HRM46.4 & OFFSITE & sw & $\mathrm{N}$ & RIVER & TRANSECT & 08-Dec-03 U-234 & & $0.19 \mathrm{p}$ & $\mathrm{pCi} / \mathrm{L}$ & 0.046 & 0.056 & & & \\
\hline SESPMNT & B183T4 & RICH.PMPHS-5 HRM46.4 & OFFSITE & sw & $\mathrm{N}$ & RIVER & TRANSECT & 08-Dec-03 U-234 & & $0.22 \mathrm{p}$ & $\mathrm{pCi} / \mathrm{L}$ & 0.062 & 0.072 & & & \\
\hline SESPMNT & B183T5 & RICH.PMPHS-7 HRM46.4 & OFFSITE & sw & $\mathrm{N}$ & RIVER & TRANSECT & 08-Dec-03 U-234 & & $0.257 \mathrm{p}$ & $\mathrm{pCi} / \mathrm{L}$ & 0.047 & 0.063 & & & \\
\hline SESPMNT & B183R7 & VERNITA-1 HRM 0.3 & OFFSITE & sw & $\mathrm{N}$ & RIVER & TRANSECT & 09-Dec-03 U-234 & & $0.187 \mathrm{p}$ & $\mathrm{pCi/L}$ & 0.039 & 0.049 & & & \\
\hline SESPMNT & B183R8 & VERNITA-2 HRM 0.3 & OFFSITE & sw & $\mathrm{N}$ & RIVER & TRANSECT & $09-$ Dec-03 U-234 & & $0.192 \mathrm{p}$ & $\mathrm{pCi} / \mathrm{L}$ & 0.041 & 0.051 & & & \\
\hline SESPMNT & B183R9 & VERNITA-3 HRM 0.3 & OFFSITE & sw & $\mathrm{N}$ & RIVER & TRANSECT & 09-Dec-03 U-234 & & $0.276 \mathrm{p}$ & & 0.05 & 0.067 & & & \\
\hline SESPMNT & B183T0 & VERNITA-4 HRM 0.3 & OFFSITE & sw & $\mathrm{N}$ & RIVER & TRANSECT & 09-Dec-03 U-234 & & $0.196 \mathrm{p}$ & $\mathrm{pCi} / \mathrm{L}$ & 0.047 & 0.057 & & & \\
\hline SESPMNT & B16L97 & VERNITA-1 HRM 0.3 & OFFSITE & sW & $\mathrm{N}$ & RIVER & TRANSECT & 24-Mar-03 U-235 & & $0.00289 \mathrm{p}$ & $\mathrm{pCi} / \mathrm{L}$ & 0.0055 & 0.0058 & U & & \\
\hline SESPMNT & B16L98 & VERNITA-2 HRM 0.3 & OFFSITE & sw & $\mathrm{N}$ & RIVER & TRANSECT & 24-Mar-03 U-235 & & $0.00219 p$ & $\mathrm{pCi} / \mathrm{L}$ & 0.0055 & 0.0058 & $\mathrm{u}$ & & \\
\hline SESPMNT & B16L99 & VERNITA-3 HRM 0.3 & OFFSITE & sw & $\mathrm{N}$ & RIVER & TRANSECT & 24-Mar-03 U-235 & & $0.000884 \mathrm{p}$ & $\mathrm{pCi} / \mathrm{L}$ & 0.0061 & 0.0064 & $u$ & & \\
\hline SESPMNT & B16LB0 & VERNITA-4 HRM 0.3 & OFFSITE & sw & $\mathrm{N}$ & RIVER & TRANSECT & 24-Mar-03 U-235 & & $0.0108 p$ & $\mathrm{pCi} / \mathrm{L}$ & 0.02 & 0.02 & U & & \\
\hline SESPMNT & B16LDO & RICH.PMPHS HRM 43.5 & OFFSITE & sw & $\mathrm{N}$ & RIVER & TRANSECT & 25-Mar-03 U-235 & & $0.0135 p$ & $\mathrm{pCi} / \mathrm{L}$ & 0.012 & 0.013 & u & & \\
\hline SESPMNT & B16LC9 & RICH.PMPHS HRM 43.9 & OFFSITE & sw & $\mathrm{N}$ & RIVER & TRANSECT & 25-Mar-03 U-235 & & $0.00231 \mathrm{p}$ & $\mathrm{pCi} / \mathrm{L}$ & 0.0062 & 0.0065 & u & & \\
\hline SESPMNT & B16LC8 & RICH.PMPHS HRM 45.0 & OFFSITE & sw & $\mathrm{N}$ & RIVER & TRANSECT & 25-Mar-03 U-235 & & $-0.00114 p$ & $\mathrm{pCi} / \mathrm{L}$ & 0.004 & 0.0044 & u & & \\
\hline SESPMNT & B16LC7 & RICH.PMPHS HRM 45.8 & OFFSITE & sw & $\mathrm{N}$ & RIVER & TRANSECT & 25-Mar-03 U-235 & & $0.00848 \mathrm{p}$ & $\mathrm{pCi} / \mathrm{L}$ & 0.0079 & 0.0083 & & & \\
\hline SESPMNT & B16LB1 & RICH.PMPHS-1 HRM46.4 & OFFSITE & sw & $\mathrm{N}$ & RIVER & TRANSECT & 25-Mar-03 U-235 & & $0.0058 p$ & $\mathrm{pCi} / \mathrm{L}$ & 0.0068 & 0.0072 & $\mathrm{u}$ & & \\
\hline SESPSPEC & B16L96 & RICH.PMPHS-1 HRM46.4 & OFFSITE & sW & $\mathrm{N}$ & RIVER & TRANSECT & 25-Mar-03 U-235 & & $0.00452 p$ & $\mathrm{pCi} / \mathrm{L}$ & 0.0064 & 0.0067 & U & & \\
\hline SESPMNT & B16LB6 & RICH.PMPHS-10 HRM46.4 & OFFSITE & sW & $\mathrm{N}$ & RIVER & TRANSECT & 25-Mar-03 U-235 & & $0.0129 p$ & $\mathrm{pCi} / \mathrm{L}$ & 0.0097 & 0.01 & & & \\
\hline SESPMNT & B16LB2 & RICH.PMPHS-2 HRM46.4 & OFFSITE & SW & $\mathrm{N}$ & RIVER & TRANSECT & 25-Mar-03 U-235 & & $0.0037 \mathrm{p}$ & $\mathrm{pCi/L}$ & 0.0074 & 0.0077 & $\mathrm{u}$ & & \\
\hline SESPMNT & B16LB3 & RICH.PMPHS-3 HRM46.4 & OFFSITE & sW & $\mathrm{N}$ & RIVER & TRANSECT & 25-Mar-03 U-235 & & $0.00407 p$ & $\mathrm{pCi} / \mathrm{L}$ & 0.0078 & 0.0081 & U & & \\
\hline SESPMNT & B16LB4 & RICH.PMPHS-5 HRM46.4 & OFFSITE & sw & $\mathrm{N}$ & RIVER & TRANSECT & 25-Mar-03 U-235 & & $0.00756 \mathrm{p}$ & & 0.0077 & 0.008 & u & & \\
\hline SESPMNT & B16LB5 & RICH.PMPHS-7 HRM46.4 & OFFSITE & SW & $\mathrm{N}$ & RIVER & TRANSECT & 25-Mar-03 U-235 & & $0.00611 \mathrm{p}$ & $\mathrm{pCi} / \mathrm{L}$ & 0.0077 & 0.008 & u & & \\
\hline SESPMNT & B171W1 & VERNITA-1 HRM 0.3 & OFFSITE & sw & $\mathrm{N}$ & RIVER & TRANSECT & 09-Jun-03 U-235 & & $0.0186 \mathrm{p}$ & $\mathrm{pCi} / \mathrm{L}$ & 0.015 & 0.015 & & & \\
\hline
\end{tabular}


WATER - COLUMBIA RIVER TRANSECT

\begin{tabular}{|c|c|c|c|c|c|c|c|c|c|c|c|c|c|c|c|c|}
\hline | OWNER ID & SAMP NUM & SAMP SITE NAME & DIST CLASS & MEDIA $\left.\right|^{\mid h}$ & \begin{tabular}{|c|} 
FILTERED \\
FLAG
\end{tabular} & $\begin{array}{l}\text { SAMP } \\
\text { FROM }\end{array}$ & COLL MTHD & SAMP DATE & CON SHORT NAME & $\begin{array}{c}\text { VALUE } \\
\text { RPTD }\end{array}$ & \begin{tabular}{|l|} 
ANAL \\
UNITS \\
RPTD \\
\end{tabular} & $\begin{array}{c}\text { COUNTING } \\
\text { ERROR }\end{array}$ & \begin{tabular}{|c|} 
TOTAL \\
ANAL \\
ERROR
\end{tabular} & $\begin{array}{c}\text { LAB } \\
\text { QUALIFIER }\end{array}$ & SAMP COMMENT & $\begin{array}{l}\text { RESULT } \\
\text { COMMENT }\end{array}$ \\
\hline SESPMNT & B171W2 & VERNITA-2 HRM 0.3 & OFFSITE & SW & $\mathrm{N}$ & RIVER & TRANSECT & 09-Jun-03 U-235 & & & & 0.01 & 0.01 & u & - & \\
\hline SESPMNT & B171W3 & VERNITA-3 HRM 0.3 & OFFSITE & sw & $\mathrm{N}$ & RIVER & TRANSECT & 09-Jun-03 U-235 & & $0.00291 \mathrm{p}$ & $\mathrm{pCi} / \mathrm{L}$ & 0.014 & 0.014 & $\mathrm{U}$ & & \\
\hline SESPMNT & B171W4 & VERNITA-4 HRM 0.3 & OFFSITE & sw & $\mathrm{N}$ & RIVER & TRANSECT & 09-Jun-03 U-235 & & $0.00524 \mathrm{p}$ & $\mathrm{pCO} / \mathrm{L}$ & 0.012 & 0.012 & u & & \\
\hline SESPMNT & B17204 & RICH.PMPHS HRM 43.5 & OFFSITE & sw & $\mathrm{N}$ & RIVER & TRANSECT & 10-Jun-03 U-235 & & $0.00672 \mathrm{p}$ & $\mathrm{pCilL}$ & 0.0082 & 0.0085 & u & & \\
\hline SESPMNT & B17203 & RICH.PMPHS HRM 43.9 & OFFSITE & sw & $\mathrm{N}$ & RIVER & TRANSECT & 10-Jun-03 U-235 & & $0.0125 p$ & pCi/L & 0.017 & 0.017 & u & & \\
\hline SESPMNT & B17202 & RICH.PMPHS HRM 45.0 & OFFSITE & sw & $\mathrm{N}$ & RIVER & TRANSECT & 10-Jun-03 U-235 & & $0.00223 \mathrm{p}$ & $\mathrm{pCi} / \mathrm{L}$ & 0.0078 & 0.0081 & $u$ & & \\
\hline SESPMNT & B17201 & RICH.PMPHS HRM 45.8 & OFFSITE & sw & $\mathrm{N}$ & RIVER & TRANSECT & 10-Jun-03 U-235 & & $0.0138 p$ & $\mathrm{pCi} / \mathrm{L}$ & 0.011 & 0.011 & & & \\
\hline SESPMNT & B171W5 & RICH.PMPHS-1 HRM46.4 & OFFSITE & sw & $\mathrm{N}$ & RIVER & TRANSECT & 10-Jun-03 U-235 & & $0.00554 \mathrm{p}$ & & 0.011 & 0.011 & U & & \\
\hline SESPMNT & B171X0 & RICH.PMPHS-10 HRM46.4 & OFFSITE & sw & $\mathrm{N}$ & RIVER & TRANSECT & 10-Jun-03 U-235 & & $0.00899 \mathrm{p}$ & $\mathrm{pCi} / \mathrm{L}$ & 0.0087 & 0.0091 & u & & \\
\hline SESPMNT & B171W6 & RICH.PMPHS-2 HRM46.4 & OFFSITE & sw & $\mathrm{N}$ & RIVER & TRANSECT & 10-Jun-03 U-235 & & $0.00276 \mathrm{p}$ & $\mathrm{pCi} / \mathrm{L}$ & 0.0086 & 0.0088 & U & & \\
\hline SESPMNT & B171W7 & RICH.PMPHS-3 HRM46.4 & OFFSITE & sw & $\mathrm{N}$ & RIVER & TRANSECT & 10-Jun-03 U-235 & & $0.0147 \mathrm{p}$ & $\mathrm{pCi} / \mathrm{L}$ & 0.015 & 0.015 & U & & \\
\hline SESPMNT & B171W8 & RICH.PMPHS-5 HRM46.4 & OFFSITE & sw & $\mathrm{N}$ & RIVER & TRANSECT & 10-Jun-03 U-235 & & $0.00391 p$ & $\mathrm{pCi} / \mathrm{L}$ & 0.01 & 0.011 & $\mathrm{U}$ & & \\
\hline SESPMNT & B171W9 & RICH.PMPHS-7 HRM46.4 & OFFSITE & sw & $\mathrm{N}$ & RIVER & TRANSECT & 10-Jun-03 U-235 & & $0.00266 \mathrm{p}$ & $\mathrm{pCi} / \mathrm{L}$ & 0.0089 & 0.0092 & U & & \\
\hline SESPMNT & B17CF2 & $100 \mathrm{~N}-1$ HRM 9.5 & ONSITE & sw & $\mathrm{N}$ & RIVER & TRANSECT & 04-Sep-03 U-235 & & $0.00266 \mathrm{p}$ & $\mathrm{pCi/L}$ & 0.0078 & 0.008 & u & & \\
\hline SESPSPEC & B17CD7 & $100 \mathrm{~N}-1$ HRM 9.5 & ONSITE & sw & $\mathrm{N}$ & RIVER & TRANSECT & 04-Sep-03 U-235 & & $0.00471 p$ & & 0.0079 & 0.0081 & u & & \\
\hline SESPMNT & B17CK8 & $100 \mathrm{~N}-10$ HRM 9.5 & ONSITE & sw & $\mathrm{N}$ & RIVER & TRANSECT & 04-Sep-03 U-235 & & $0.00554 \mathrm{p}$ & & 0.0079 & 0.0082 & u & & \\
\hline SESPMNT & B17CF4 & $100 \mathrm{~N}-2$ HRM 9.5 & ONSITE & sw & $\mathrm{N}$ & RIVER & TRANSECT & 04-Sep-03 U-235 & & $0.00716 p$ & $\mathrm{pCi} / \mathrm{L}$ & 0.0079 & 0.0082 & $u$ & & \\
\hline SESPMNT & B17CL0 & $100 \mathrm{~N}-3$ HRM 9.5 & ONSITE & sw & $\mathrm{N}$ & RIVER & TRANSECT & 04-Sep-03 U-235 & & $0.000715 p$ & $\mathrm{pCi} / \mathrm{L}$ & 0.0089 & 0.0091 & u & & \\
\hline SESPMNT & B17CF6 & $100 \mathrm{~N}-5$ HRM 9.5 & ONSITE & sw & $\mathrm{N}$ & RIVER & TRANSECT & 04-Sep-03 U-235 & & $-0.0015 p$ & $\mathrm{pCi} / \mathrm{L}$ & 0.0036 & 0.004 & $u$ & & \\
\hline SESPMNT & B17CL2 & $100 \mathrm{~N}-7$ HRM 9.5 & ONSITE & sW & $\mathrm{N}$ & RIVER & TRANSECT & 04-Sep-03 U-235 & & $0.00263 p$ & $\mathrm{pCi} / \mathrm{L}$ & 0.0059 & 0.0063 & U & & \\
\hline SESPMNT & B17CT9 & 100 N SHORE HRM 8.4 & ONSITE & sw & $\mathrm{N}$ & RIVER - & TRANSECT & 04-Sep-03 U-235 & & $0.0111 \mathrm{p}$ & $\mathrm{pCi} / \mathrm{L}$ & 0.011 & 0.011 & U & & \\
\hline SESPMNT & $\mathrm{B} 17 \mathrm{CV} 3$ & 100 N SHORE HRM 8.9 & ONSITE & sw & $\mathrm{N}$ & RIVER & TRANSECT & 04-Sep-03 U-235 & & $0.0086 p$ & & 0.0097 & 0.01 & u & & \\
\hline SESPMNT & B17CV7 & 100 N SHORE HRM 9.2 & ONSITE & sw & $\mathrm{N}$ & RIVER & TRANSECT & 04-Sep-03 U-235 & & $-0.00026 \mathrm{p}$ & & 0.0078 & 0.008 & u & & \\
\hline SESPMNT & B17CW1 & 100 N SHORE HRM 9.8 & ONSITE & sw & $\mathrm{N}$ & RIVER & TRANSECT & 04-Sep-03 U-235 & & $0.0223 \mathrm{p}$ & $\mathrm{pCi/L}$ & 0.019 & 0.019 & 列 & & \\
\hline SESPMNT & B17CD8 & VERNITA-1 HRM 0.3 & OFFSITE & sw & $\mathrm{N}$ & RIVER & TRANSECT & 04-Sep-03 U-235 & & $0.00371 p$ & $\mathrm{pCi} / \mathrm{L}$ & 0.013 & 0.013 & $u$ & & \\
\hline SESPMNT & B17CD9 & VERNITA-2 HRM 0.3 & OFFSITE & sw & $\mathrm{N}$ & RIVER & TRANSECT & 04-Sep-03 U-235 & & $0.000802 p$ & $\mathrm{pCi} / \mathrm{L}$ & 0.0091 & 0.0093 & U & & \\
\hline SESPMNT & B17CF0 & VERNITA-3 HRM 0.3 & OFFSITE & sw & $\mathrm{N}$ & RIVER & TRANSECT & 04-Sep-03 U-235 & & $0.00813 p$ & $\mathrm{pCi} / \mathrm{L}$ & 0.01 & 0.011 & U & & \\
\hline SESPMNT & B17CF1 & VERNITA-4 HRM 0.3 & OFFSITE & sw & $\mathrm{N}$ & RIVER & TRANSECT & 04-Sep-03 U-235 & & $0.0111 \mathrm{p}$ & $\mathrm{pCi} / \mathrm{L}$ & 0.011 & 0.011 & U & & \\
\hline SESPMNT & B17CF8 & $100 \mathrm{~F}-1 \mathrm{HRM} 19.0$ & ONSITE & sw & $\mathrm{N}$ & RIVER & TRANSECT & 08-Sep-03 U-235 & & $0.00946 \mathrm{p}$ & $\mathrm{pCi} / \mathrm{L}$ & 0.0094 & 0.0098 & $u$ & & \\
\hline SESPMNT & $\mathrm{B} 17 \mathrm{CH} 4$ & $100 \mathrm{~F}-10 \mathrm{HRM} 19.0$ & ONSITE & sw & $\mathrm{N}$ & RIVER & TRANSECT & 08-Sep-03 U-235 & & $0.0079 p$ & $\mathrm{pCi} / \mathrm{L}$ & 0.0079 & 0.0083 & U & & \\
\hline SESPMNT & $\mathrm{B} 17 \mathrm{CH} 1$ & $100 \mathrm{~F}-2$ HRM 19.0 & ONSITE & sw & $\mathrm{N}$ & RIVER & TRANSECT & 08-Sep-03 U-235 & & $-0.00466 p$ & $\mathrm{pCi} / \mathrm{L}$ & 0.0079 & 0.0081 & u & & \\
\hline SESPMNT & B17CF9 & $100 \mathrm{~F}-3 \mathrm{HRM} 19.0$ & ONSITE & sw & $\mathrm{N}$ & RIVER & TRANSECT & 08-Sep-03 U-235 & & $0.00736 \mathrm{p}$ & $\mathrm{pCi} / \mathrm{L}$ & 0.01 & 0.01 & u & & \\
\hline SESPMNT & $\mathrm{B} 17 \mathrm{CH} 2$ & $100 \mathrm{~F}-5$ HRM 19.0 & ONSITE & sw & $\mathrm{N}$ & RIVER & TRANSECT & $08-\mathrm{Sep}-03 \mathrm{U}-235$ & & $0.00474 \mathrm{p}$ & $\mathrm{pCi/L}$ & 0.0066 & 0.0069 & u & & \\
\hline SESPMNT & $\mathrm{B} 17 \mathrm{CH} 3$ & 100 F -7 HRM 19.0 & ONSITE & sw & $\mathrm{N}$ & RIVER & TRANSECT & $08-\mathrm{Sep}-03 \mathrm{U}-235$ & & $0.00945 \mathrm{p}$ & $\mathrm{pCi} / \mathrm{L}$ & 0.0081 & 0.0085 & & & \\
\hline SESPMNT & B17CY4 & 100 F SHORE HRM 18 & ONSITE & sw & $\mathrm{N}$ & RIVER & TRANSECT & 08-Sep-03 U-235 & & $-0.00082 p$ & $\mathrm{pCi} / \mathrm{L}$ & 0.008 & 0.0082 & U & & \\
\hline SESPMNT & B17CY7 & 100 F SHORE HRM 22 & ONSITE & sw & $\mathrm{N}$ & RIVER & TRANSECT & 08-Sep-03 U-235 & & $0.00374 p$ & $\mathrm{pCi} / \mathrm{L}$ & 0.0063 & 0.0066 & $u$ & & \\
\hline SESPMNT & B17D00 & $100 \mathrm{~F}$ SHORE HRM 23 & ONSITE & sw & $\mathrm{N}$ & RIVER & TRANSECT & 08-Sep-03 U-235 & & $0.000666 p$ & $\mathrm{pCi} / \mathrm{L}$ & 0.0046 & 0.005 & u & & \\
\hline SESPMNT & B17CH5 & HANFRD TS-1 HRM 28.7 & ONSITE & sw & $\mathrm{N}$ & RIVER & TRANSECT & 08-Sep-03 U-235 & & $-0.00194 \mathrm{p}$ & $\mathrm{pCi} / \mathrm{L}$ & 0.0028 & 0.0033 & u & & \\
\hline SESPMNT & $\mathrm{B} 17 \mathrm{CH} 8$ & HANFRD TS-10 HRM 28.7 & ONSITE & sw & $\mathrm{N}$ & RIVER & TRANSECT & $08-\mathrm{Sep}-03 \mathrm{U}-235$ & & $0.00457 \mathrm{p}$ & $\mathrm{pCi/L}$ & 0.0069 & 0.0072 & u & & \\
\hline SESPMNT & $\mathrm{B} 17 \mathrm{CH} 6$ & HANFRD TS-2 HRM 28.7 & ONSITE & sw & $\mathrm{N}$ & RIVER & TRANSECT & 08-Sep-03 U-235 & & $0.00753 p$ & $\mathrm{pCi} / \mathrm{L}$ & 0.01 & 0.01 & U & & \\
\hline SESPMNT & $\mathrm{B} 17 \mathrm{CH} 9$ & HANFRD TS-3 HRM 28.7 & ONSITE & sw & $\mathrm{N}$ & RIVER & TRANSECT & 08-Sep-03 U-235 & & $0.0014 \mathrm{p}$ & $\mathrm{pCi} / \mathrm{L}$ & 0.0055 & 0.0058 & $u$ & & \\
\hline SESPMNT & $\mathrm{B} 17 \mathrm{CHO}$ & HANFRD TS-5 HRM 28.7 & ONSITE & sw & $\mathrm{N}$ & RIVER & TRANSECT & 08-Sep-03 U-235 & & $0.00393 \mathrm{p}$ & $\mathrm{pCi} / \mathrm{L}$ & 0.0085 & 0.0088 & u & & \\
\hline SESPMNT & $\mathrm{B} 17 \mathrm{CH} 7$ & HANFRD TS-7 HRM 28.7 & ONSITE & sw & $\mathrm{N}$ & RIVER & TRANSECT & $08-S e p-03$ U-235 & & $0.0042 p$ & $\mathrm{pCi/L}$ & 0.0062 & 0.0065 & u & & \\
\hline SESPMNT & B17CL4 & HANFRD TWNSITE HRM26 & ONSITE & sw & $\mathrm{N}$ & RIVER & TRANSECT & $08-S e p-03$ U-235 & & $0.0134 \mathrm{p}$ & $\mathrm{pCi} / \mathrm{L}$ & 0.012 & 0.012 & & & \\
\hline SESPMNT & B17CL5 & HANFRD TWNSITE HRM27 & ONSITE & sw & $\mathrm{N}$ & RIVER & TRANSECT & 08-Sep-03 U-235 & & $0.0103 p$ & $\mathrm{pCi} / \mathrm{L}$ & 0.011 & 0.011 & U & & \\
\hline SESPMNT & B17CY1 & HANFRD TWNSITE HRM28 & ONSITE & sw & $\mathrm{N}$ & RIVER & TRANSECT & 08-Sep-03 U-235 & & $0.0109 p$ & $\mathrm{pCi} / \mathrm{L}$ & 0.0099 & 0.01 & & & \\
\hline SESPMNT & B17CL6 & HANFRD TWNSITE HRM30 & ONSITE & sw & $\mathrm{N}$ & RIVER & TRANSECT & 08-Sep-03 U-235 & & $0.0102 p$ & $\mathrm{pCi} / \mathrm{L}$ & 0.011 & 0.012 & U & & \\
\hline SESPMNT & B17CJO & 300 AREA - 1 HRM 43.1 & ONSITE & sw & $\mathrm{N}$ & RIVER & TRANSECT & 09-Sep-03 U-235 & & $0.00244 \mathrm{p}$ & $\mathrm{pCi} / \mathrm{L}$ & 0.01 & 0.01 & $\mathrm{u}$ & & \\
\hline SESPMNT & B17CJ2 & 300 AREA -2 HRM 43.1 & ONSITE & sw & $\mathrm{N}$ & RIVER & TRANSECT & 09-Sep-03 U-235 & & $0.00785 p$ & $\mathrm{pCi} / \mathrm{L}$ & 0.0085 & 0.0088 & $u$ & & \\
\hline SESPMNT & B17CJ4 & 300 AREA -3 HRM 43.1 & ONSITE & sw & $\mathrm{N}$ & RIVER & TRANSECT & 09-Sep-03 U-235 & & $0.00294 \mathrm{p}$ & $\mathrm{pCi} / \mathrm{L}$ & 0.0063 & 0.0066 & u & & \\
\hline SESPMNT & B17CJ6 & 300 AREA -5 HRM 43.1 & ONSITE & sw & $\mathrm{N}$ & RIVER & TRANSECT & 09-Sep-03 U-235 & & $-0.00172 p$ & $\mathrm{pCi} / \mathrm{L}$ & 0.0063 & 0.0066 & u & & \\
\hline SESPMNT & B17CJ8 & 300 AREA -7 HRM 43.1 & ONSITE & sw & $\mathrm{N}$ & RIVER & TRANSECT & 09-Sep-03 U-235 & & $0.000897 \mathrm{p}$ & $\mathrm{pCi} / \mathrm{L}$ & 0.0049 & 0.0052 & u & & \\
\hline SESPMNT & B17CW5 & 300 AREA SHR HRM41.5 & ONSITE & sw & $\mathrm{N}$ & RIVER & TRANSECT & 09-Sep-03 U-235 & & $0.00331 \mathrm{p}$ & $\mathrm{pCi} / \mathrm{L}$ & 0.0059 & 0.0063 & u & & \\
\hline SESPMNT & B17CX7 & 300 AREA SHR HRM42.9 & ONSITE & sw & $\mathrm{N}$ & RIVER & TRANSECT & $09-S e p-03$ U-235 & & $0.0161 \mathrm{p}$ & $\mathrm{pCi} / \mathrm{L}$ & 0.01 & 0.011 & & & \\
\hline SESPMNT & B17CKO & 300 AREA-10 HRM 43.1 & ONSITE & sw & $\mathrm{N}$ & RIVER & TRANSECT & 09-Sep-03 U-235 & & $0.0112 p$ & $\mathrm{pCi} / \mathrm{L}$ & 0.011 & 0.011 & u & & \\
\hline SESPMNT & В17CT0 & RICH.PMPHS HRM 43.5 & OFFSITE & sW & $\mathrm{N}$ & RIVER & TRANSECT & 09-Sep-03 U-235 & & $0.017 \mathrm{p}$ & $\mathrm{pCi} / \mathrm{L}$ & 0.017 & 0.017 & & & \\
\hline SESPMNT & B17CR8 & RICH.PMPHS HRM 45.0 & OFFSITE & sW & $\mathrm{N}$ & RIVER & TRANSECT & 09-Sep-03 U-235 & & $0.00496 \mathrm{p}$ & $\mathrm{pCi} / \mathrm{L}$ & 0.01 & 0.011 & u & & \\
\hline SESPMNT & B17CR7 & RICH.PMPHS HRM 45.8 & OFFSITE & SW & $\mathrm{N}$ & RIVER & TRANSECT & $09-S e p-03$ U-235 & & $0.00711 \mathrm{p}$ & $\mathrm{pCi/L}$ & 0.0074 & 0.0077 & u & & \\
\hline SESPMNT & B17CK2 & RICH.PMPHS-1 HRM46.4 & OFFSITE & sW & $\mathrm{N}$ & RIVER & TRANSECT & 09-Sep-03 U-235 & & $0.00623 \mathrm{p}$ & $\mathrm{pCi} / \mathrm{L}$ & 0.0099 & 0.01 & U & & \\
\hline SESPMNT & B17CK7 & RICH.PMPHS-10 HRM46.4 & OFFSITE & sw & $\mathrm{N}$ & RIVER & TRANSECT & 09-Sep-03 U-235 & & $0.00567 \mathrm{p}$ & $\mathrm{pCi} / \mathrm{L}$ & 0.0074 & 0.0077 & u & & \\
\hline SESPMNT & B17CK3 & RICH.PMPHS-2 HRM46.4 & OFFSITE & SW & $\mathrm{N}$ & RIVER & TRANSECT & 09-Sep-03 U-235 & & $-0.00014 p$ & $\mathrm{pCi} / \mathrm{L}$ & 0.0064 & 0.0067 & U & & \\
\hline SESPMNT & B17CK4 & RICH.PMPHS-3 HRM46. 4 & OFFSITE & sw & $\mathrm{N}$ & RIVER & TRANSECT & 09-Sep-03 U-235 & & $0.00447 p$ & $\mathrm{pCi} / \mathrm{L}$ & 0.01 & 0.011 & $\mathrm{u}$ & & \\
\hline
\end{tabular}


WATER - COLUMBIA RIVER TRANSEC

\begin{tabular}{|c|c|c|c|c|c|c|c|c|c|c|c|c|c|c|c|c|}
\hline OWNER ID & |SAMP NUM | & SAMP SITE NAME & | DIST CLASS & MEDIA & \begin{tabular}{|c|} 
FILTERED \\
FLAG
\end{tabular} & $\begin{array}{l}\text { SAMP } \\
\text { FROM }\end{array}$ & COLL MTHD & SAMP DATE & CON SHORT NAME & \begin{tabular}{l|} 
VALUE \\
RPTD
\end{tabular} & $\left|\begin{array}{|c|}\text { ANAL } \\
\text { UNITS } \\
\text { RPDD }\end{array}\right|$ & $\begin{array}{c}\text { COUNTING } \\
\text { ERROR }\end{array}$ & \begin{tabular}{|c|} 
TOTAL \\
ANAL \\
ERROR
\end{tabular} & $\begin{array}{c}\text { LAB } \\
\text { QUALIFIER }\end{array}$ & SAMP COMMENT & $\begin{array}{c}\text { RESULT } \\
\text { COMMENT }\end{array}$ \\
\hline SESPMNT & B17CK5 & RICH.PMPHS-5 HRM46.4 & OFFSITE & SW & $\mathrm{N}$ & RIVER & TRANSECT & 09-Sep-03 U-235 & & & & 0.0072 & 0.0074 & $\mathrm{U}$ & & \\
\hline SESPMNT & B17CK6 & RICH.PMPHS-7 HRM46.4 & OFFSITE & sw & $\mathrm{N}$ & RIVER & TRANSECT & 09-Sep-03 U-235 & & $0.00844 p$ & $\mathrm{pCi} / \mathrm{L}$ & 0.0083 & 0.0087 & $\mathrm{U}$ & & \\
\hline SESPMNT & B17CR9 & RICH.PMPHS HRM 43.9 & OFFSITE & sw & $\mathrm{N}$ & RIVER & TRANSECT & 09-Sep-03 U-235 & & & & & & & NO SAMPLE. THICK MILFOIL. & \\
\hline SESPMNT & B17CW9 & 300 AREA SHR HRM42.1 & ONSITE & sw & $\mathrm{N}$ & RIVER & TRANSECT & 09-Sep-03 U-235 & & $0.00339 \mathrm{p}$ & $\mathrm{pCi} / \mathrm{L}$ & 0.006 & 0.0063 & $\mathrm{U}$ & DIRECTLY DOWNRIVER FROM 300 AREA SPRING 42-2. & \\
\hline SESPMNT & B17CX3 & 300 AREA SHR HRM42.5 & ONSITE & sw & $\mathrm{N}$ & RIVER & TRANSECT & 09-Sep-03 U-235 & & $0.169 \mathrm{p}$ & pCi/L & 0.029 & 0.039 & & DIRECTLY DOWNRIVER FROM 300 AREA SPRING 42-2. & \\
\hline SESPMNT & B183W0 & RICH.PMPHS HRM 43.5 & OFFSITE & SW & $\mathrm{N}$ & RIVER & TRANSECT & 08-Dec-03 U-235 & & $0.000313 p$ & $\mathrm{pCi} / \mathrm{L}$ & 0.012 & 0.012 & $u$ & & \\
\hline SESPMNT & B183V9 & RICH.PMPHS HRM 43.9 & OFFSITE & sw & $\mathrm{N}$ & RIVER & TRANSECT & 08-Dec-03 U-235 & & $0.00123 p$ & $\mathrm{pCi} / \mathrm{L}$ & 0.0092 & 0.0094 & $\mathrm{U}$ & & \\
\hline SESPMNT & B183V8 & RICH.PMPHS HRM 45.0 & OFFSITE & sW & $\mathrm{N}$ & RIVER & TRANSECT & 08-Dec-03 U-235 & & $0.00687 \mathrm{p}$ & $\mathrm{pCi} / \mathrm{L}$ & 0.011 & 0.011 & U & & \\
\hline SESPMNT & B183V7 & RICH.PMPHS HRM 45.8 & OFFSITE & sW & $\mathrm{N}$ & RIVER & TRANSECT & 08-Dec-03 U-235 & & $0.00426 \mathrm{p}$ & $\mathrm{pCi} / \mathrm{L}$ & 0.0076 & 0.0079 & u & & \\
\hline SESPMNT & B183T1 & RICH.PMPHS-1 HRM46.4 & OFFSITE & sW & $\mathrm{N}$ & RIVER & TRANSECT & 08-Dec-03 U-235 & & $0.0153 \mathrm{p}$ & $\mathrm{pCi} / \mathrm{L}$ & 0.015 & 0.015 & $\mathrm{U}$ & & \\
\hline SESPSPEC & B183R6 & RICH.PMPHS-1 HRM46.4 & OFFSITE & sw & $\mathrm{N}$ & RIVER & TRANSECT & 08-Dec-03 U-235 & & $-0.00059 p$ & $\mathrm{pCi} / \mathrm{L}$ & 0.015 & 0.015 & U & & \\
\hline SESPMNT & B183T6 & RICH.PMPHS-10 HRM46.4 & OFFSITE & sw & $\mathrm{N}$ & RIVER & TRANSECT & 08-Dec-03 U-235 & & $0.00913 p$ & $\mathrm{pCi} / \mathrm{L}$ & 0.01 & 0.01 & $\mathrm{U}$ & & \\
\hline SESPMNT & B183T2 & RICH.PMPHS-2 HRM46.4 & OFFSITE & sW & $\mathrm{N}$ & RIVER & TRANSECT & 08-Dec-03 U-235 & & $0.0106 p$ & $\mathrm{pCi} / \mathrm{L}$ & 0.014 & 0.014 & U & & \\
\hline SESPMNT & B183T3 & RICH.PMPHS-3 HRM46.4 & OFFSITE & sw & $\mathrm{N}$ & RIVER & TRANSECT & 08-Dec-03 U-235 & & $-0.0102 p$ & $\mathrm{pCi/L}$ & 0.014 & 0.014 & u & & \\
\hline SESPMNT & B183T4 & RICH.PMPHS-5 HRM46.4 & OFFSITE & sw & $\mathrm{N}$ & RIVER & TRANSECT & 08-Dec-03 U-235 & & $0.000755 p$ & & 0.0082 & 0.0084 & U & & \\
\hline SESPMNT & B183T5 & RICH.PMPHS-7 HRM46.4 & OFFSITE & sw & $\mathrm{N}$ & RIVER & TRANSECT & 08-Dec-03 U-235 & & $-0.00334 p$ & & 0.0054 & 0.0054 & u & & \\
\hline SESPMNT & B183R7 & VERNITA-1 HRM 0.3 & OFFSITE & sw & $\mathrm{N}$ & RIVER & TRANSECT & 09-Dec-03 U-235 & & $0.00422 p$ & $\mathrm{pCi} / \mathrm{L}$ & 0.0076 & 0.0078 & $u$ & & \\
\hline SESPMNT & B183R8 & VERNITA-2 HRM 0.3 & OFFSITE & sW & $\mathrm{N}$ & RIVER & TRANSECT & 09-Dec-03 U-235 & & $-0.00253 p$ & $\mathrm{pCi} / \mathrm{L}$ & 0.0066 & 0.0068 & U & & \\
\hline SESPMNT & B183R9 & VERNITA-3 HRM 0.3 & OFFSITE & sw & $\mathrm{N}$ & RIVER & TRANSECT & 09-Dec-03 U-235 & & $-0.00377 p$ & $\mathrm{pCi} / \mathrm{L}$ & 0.0052 & 0.0055 & u & & \\
\hline SESPMNT & B183T0 & VERNITA-4 HRM 0.3 & OFFSITE & sW & $\mathrm{N}$ & RIVER & TRANSECT & 09-Dec-03 U-235 & & $-0.00126 p$ & $\mathrm{pCi} / \mathrm{L}$ & 0.0082 & 0.0084 & U & & \\
\hline SESPMNT & B16L97 & VERNITA-1 HRM 0.3 & OFFSITE & sw & $\mathrm{N}$ & RIVER & TRANSECT & 24-Mar-03 U-238 & & $0.217 \mathrm{p}$ & $\mathrm{pCi} / \mathrm{L}$ & 0.033 & 0.048 & & & \\
\hline SESPMNT & B16L98 & VERNITA-2 HRM 0.3 & OFFSITE & sW & $\mathrm{N}$ & RIVER & TRANSECT & 24-Mar-03 U-238 & & $0.219 \mathrm{p}$ & & 0.035 & 0.05 & & & \\
\hline SESPMNT & B16L99 & VERNITA-3 HRM 0.3 & OFFSITE & sW & $\mathrm{N}$ & RIVER & TRANSECT & 24-Mar-03 U-238 & & $0.231 \mathrm{p}$ & $\mathrm{pCi} / \mathrm{L}$ & 0.036 & 0.052 & & & \\
\hline SESPMNT & B16LBO & VERNITA-4 HRM 0.3 & OFFSITE & sw & $\mathrm{N}$ & RIVER & TRANSECT & 24-Mar-03 U-238 & & $0.245 \mathrm{p}$ & $\mathrm{pCi/L}$ & 0.064 & 0.076 & & & \\
\hline SESPMNT & B16LD0 & RICH.PMPHS HRM 43.5 & OFFSITE & SW & $\mathrm{N}$ & RIVER & TRANSECT & 25-Mar-03 U-238 & & $0.215 p$ & $\mathrm{pCi} / \mathrm{L}$ & 0.04 & 0.053 & & & \\
\hline SESPMNT & B16LC9 & RICH.PMPHS HRM 43.9 & OFFSITE & sw & $\mathrm{N}$ & RIVER & TRANSECT & 25-Mar-03 U-238 & & $0.23 p$ & $\mathrm{pCi} / \mathrm{L}$ & 0.036 & 0.052 & & & \\
\hline SESPMNT & B16LC8 & RICH.PMPHS HRM 45.0 & OFFSITE & sw & $\mathrm{N}$ & RIVER & TRANSECT & 25-Mar-03 U-238 & & $0.198 \mathrm{p}$ & $\mathrm{pCi} / \mathrm{L}$ & 0.033 & 0.046 & & & \\
\hline SESPMNT & B16LC7 & RICH.PMPHS HRM 45.8 & OFFSITE & sW & $\mathrm{N}$ & RIVER & TRANSECT & 25-Mar-03 U-238 & & $0.241 \mathrm{p}$ & $\mathrm{pCi} / \mathrm{L}$ & 0.036 & 0.053 & & & \\
\hline SESPMNT & B16LB1 & RICH.PMPHS-1 HRM46.4 & OFFSITE & sw & $\mathrm{N}$ & RIVER & TRANSECT & 25-Mar-03 U-238 & & $0.212 p$ & $\mathrm{pCi} / \mathrm{L}$ & 0.034 & 0.048 & & & \\
\hline SESPSPEC & B16L96 & RICH.PMPHS-1 HRM46.4 & OFFSITE & sW & $\mathrm{N}$ & RIVER & TRANSECT & 25-Mar-03 U-238 & & $0.215 p$ & $\mathrm{pCi} / \mathrm{L}$ & 0.034 & 0.049 & & & \\
\hline SESPMNT & B16LB6 & RICH.PMPHS-10 HRM46.4 & OFFSITE & sw & $\mathrm{N}$ & RIVER & TRANSECT & 25-Mar-03 U-238 & & $0.54 \mathrm{p}$ & $\mathrm{pCi} / \mathrm{L}$ & 0.055 & 0.1 & & & \\
\hline SESPMNT & B16LB2 & RICH.PMPHS-2 HRM46.4 & OFFSITE & sw & $\mathrm{N}$ & RIVER & TRANSECT & 25-Mar-03 U-238 & & $0.208 \mathrm{p}$ & $\mathrm{pCi} / \mathrm{L}$ & 0.035 & 0.048 & & & \\
\hline SESPMNT & B16LB3 & RICH.PMPHS-3 HRM46.4 & OFFSITE & sw & $\mathrm{N}$ & RIVER & TRANSECT & 25-Mar-03 U-238 & & $0.226 \mathrm{p}$ & $\mathrm{pCi/L}$ & 0.035 & 0.05 & & & \\
\hline SESPMNT & B16LB4 & RICH.PMPHS-5 HRM46.4 & OFFSITE & sw & $\mathrm{N}$ & RIVER & TRANSECT & $25-M a r-03$ U-238 & & $0.251 \mathrm{p}$ & $\mathrm{pCi} / \mathrm{L}$ & 0.037 & 0.055 & & & \\
\hline SESPMNT & B16LB5 & RICH.PMPHS-7 HRM46.4 & OFFSITE & SW & $\mathrm{N}$ & RIVER & TRANSECT & 25-Mar-03 U-238 & & $0.278 \mathrm{p}$ & $\mathrm{pCi} / \mathrm{L}$ & 0.042 & 0.062 & & & \\
\hline SESPMNT & B171W1 & VERNITA-1 HRM 0.3 & OFFSITE & sw & $\mathrm{N}$ & RIVER & TRANSECT & 09-Jun-03 U-238 & & $0.153 p$ & $\mathrm{pCi} / \mathrm{L}$ & 0.042 & 0.049 & & & \\
\hline SESPMNT & B171W2 & VERNITA-2 HRM 0.3 & OFFSITE & sw & $\mathrm{N}$ & RIVER & TRANSECT & 09-Jun-03 U-238 & & $0.188 \mathrm{p}$ & $\mathrm{pCi} / \mathrm{L}$ & 0.037 & 0.047 & & & \\
\hline SESPMNT & B171W3 & VERNITA-3 HRM 0.3 & OFFSITE & sw & $\mathrm{N}$ & RIVER & TRANSECT & 09-Jun-03 U-238 & & $0.148 \mathrm{p}$ & $\mathrm{pCi} / \mathrm{L}$ & 0.039 & 0.046 & & & \\
\hline SESPMNT & B171W4 & VERNITA-4 HRM 0.3 & OFFSITE & sw & $\mathrm{N}$ & RIVER & TRANSECT & 09-Jun-03 U-238 & & $0.183 \mathrm{p}$ & $\mathrm{pCi} / \mathrm{L}$ & 0.042 & 0.051 & & & \\
\hline SESPMNT & B17204 & RICH.PMPHS HRM 43.5 & OFFSITE & sW & $\mathrm{N}$ & RIVER & TRANSECT & 10-Jun-03 U-238 & & $0.186 \mathrm{p}$ & $\mathrm{pCi} / \mathrm{L}$ & 0.036 & 0.047 & & & \\
\hline SESPMNT & B17203 & RICH.PMPHS HRM 43.9 & OFFSITE & sw & $\mathrm{N}$ & RIVER & TRANSECT & 10-Jun-03 U-238 & & $0.188 \mathrm{p}$ & $\mathrm{pCi} / \mathrm{L}$ & 0.055 & 0.063 & & & \\
\hline SESPMNT & B17202 & RICH.PMPHS HRM 45.0 & OFFSITE & sw & $\mathrm{N}$ & RIVER & TRANSECT & 10-Jun-03 U-238 & & $0.147 \mathrm{p}$ & $\mathrm{pCi} / \mathrm{L}$ & 0.029 & 0.037 & & & \\
\hline SESPMNT & B17201 & RICH.PMPHS HRM 45.8 & OFFSITE & sw & $\mathrm{N}$ & RIVER & TRANSECT & 10-Jun-03 U-238 & & $0.154 \mathrm{p}$ & $\mathrm{pCi/L}$ & 0.033 & 0.041 & & & \\
\hline SESPMNT & B171W5 & RICH.PMPHS-1 HRM46.4 & OFFSITE & sw & $\mathrm{N}$ & RIVER & TRANSECT & 10-Jun-03 U-238 & & $0.143 \mathrm{p}$ & $\mathrm{pCi} / \mathrm{L}$ & 0.041 & 0.047 & & & \\
\hline SESPMNT & B171X0 & RICH.PMPHS-10 HRM46.4 & OFFSITE & sw & $\mathrm{N}$ & RIVER & TRANSECT & 10-Jun-03 U-238 & & $0.25 \mathrm{p}$ & $\mathrm{pCi} / \mathrm{L}$ & 0.04 & 0.056 & & & \\
\hline SESPMNT & B171W6 & RICH.PMPHS-2 HRM46.4 & OFFSITE & sw & $\mathrm{N}$ & RIVER & TRANSECT & 10-Jun-03 U-238 & & $0.156 \mathrm{p}$ & $\mathrm{pCi} / \mathrm{L}$ & 0.033 & 0.041 & & & \\
\hline SESPMNT & B171W7 & RICH.PMPHS-3 HRM46.4 & OFFSITE & sW & $\mathrm{N}$ & RIVER & TRANSECT & 10-Jun-03 U-238 & & $0.207 \mathrm{p}$ & $\mathrm{pCi} / \mathrm{L}$ & 0.04 & 0.052 & & & \\
\hline SESPMNT & B171W8 & RICH.PMPHS-5 HRM46.4 & OFFSITE & sw & $\mathrm{N}$ & RIVER & TRANSECT & 10-Jun-03 U-238 & & $0.198 \mathrm{p}$ & $\mathrm{pCi} / \mathrm{L}$ & 0.035 & 0.047 & & & \\
\hline SESPMNT & B171W9 & RICH.PMPHS-7 HRM46.4 & OFFSITE & SW & $\mathrm{N}$ & RIVER & TRANSECT & 10-Jun-03 U-238 & & $0.143 \mathrm{p}$ & $\mathrm{pCi} / \mathrm{L}$ & 0.034 & 0.041 & & & \\
\hline SESPMNT & B17CF2 & $100 \mathrm{~N}-1$ HRM 9.5 & ONSITE & sW & $\mathrm{N}$ & RIVER & TRANSECT & 04-Sep-03 U-238 & & $0.184 \mathrm{p}$ & $\mathrm{pCi} / \mathrm{L}$ & 0.038 & 0.048 & & & \\
\hline SESPSPEC & B17CD7 & $100 \mathrm{~N}-1$ HRM 9.5 & ONSITE & sw & $\mathrm{N}$ & RIVER & TRANSECT & 04-Sep-03 U-238 & & $0.153 p$ & $\mathrm{pCi} / \mathrm{L}$ & 0.034 & 0.042 & & & \\
\hline SESPMNT & B17CK8 & $100 \mathrm{~N}-10$ HRM 9.5 & ONSITE & sW & $\mathrm{N}$ & RIVER & TRANSECT & 04-Sep-03 U-238 & & $0.228 \mathrm{p}$ & $\mathrm{pCi} / \mathrm{L}$ & 0.041 & 0.055 & & & \\
\hline SESPMNT & B17CF4 & $100 \mathrm{~N}-2$ HRM 9.5 & ONSITE & sw & $\mathrm{N}$ & RIVER & TRANSECT & 04-Sep-03 U-238 & & $0.165 \mathrm{p}$ & $\mathrm{pCi/L}$ & 0.032 & 0.041 & & & \\
\hline SESPMNT & B17CLO & $100 \mathrm{~N}-3$ HRM 9.5 & ONSITE & sw & $\mathrm{N}$ & RIVER & TRANSECT & $04-\mathrm{Sep}-03 \mathrm{U}-238$ & & $0.16 \mathrm{p}$ & $\mathrm{pCi/L}$ & 0.031 & 0.04 & & & \\
\hline SESPMNT & B17CF6 & $100 \mathrm{~N}-5$ HRM 9.5 & ONSITE & sw & $\mathrm{N}$ & RIVER & TRANSECT & 04-Sep-03 U-238 & & $0.167 p$ & $\mathrm{pCi} / \mathrm{L}$ & 0.035 & 0.044 & & & \\
\hline SESPMNT & B17CL2 & $100 \mathrm{~N}-7$ HRM 9.5 & ONSITE & sW & $\mathrm{N}$ & RIVER & TRANSECT & 04-Sep-03 U-238 & & $0.136 \mathrm{p}$ & $\mathrm{pCi} / \mathrm{L}$ & 0.029 & 0.036 & & & \\
\hline SESPMNT & В17СТ9 & 100 N SHORE HRM 8.4 & ONSITE & SW & $\mathrm{N}$ & RIVER & TRANSECT & 04-Sep-03 U-238 & & $0.177 \mathrm{p}$ & $\mathrm{pCi} / \mathrm{L}$ & 0.039 & 0.048 & & & \\
\hline SESPMNT & B17CV3 & $100 \mathrm{~N}$ SHORE HRM 8.9 & ONSITE & SW & $\mathrm{N}$ & RIVER & TRANSECT & 04-Sep-03 U-238 & & $0.165 p$ & $\mathrm{pCi} / \mathrm{L}$ & 0.037 & 0.045 & & & \\
\hline SESPMNT & B17CV7 & $100 \mathrm{~N}$ SHORE HRM 9.2 & ONSITE & sW & $\mathrm{N}$ & RIVER & TRANSECT & 04-Sep-03 U-238 & & $0.209 \mathrm{p}$ & $\mathrm{pCi} / \mathrm{L}$ & 0.047 & 0.058 & & & \\
\hline SESPMNT & B17CW1 & 100 N SHORE HRM 9.8 & ONSITE & sw & $\mathrm{N}$ & RIVER & TRANSECT & 04-Sep-03 U-238 & & & $\mathrm{pCi} / \mathrm{L}$ & 0.047 & 0.055 & & & \\
\hline SESPMNT & B17CD8 & VERNITA-1 HRM 0.3 & OFFSITE & sw & $\mathrm{N}$ & RIVER & TRANSECT & 04-Sep-03 U-238 & & $0.182 \mathrm{p}$ & $\mathrm{pCi} / \mathrm{L}$ & 0.036 & 0.046 & & & \\
\hline SESPMNT & B17CD9 & VERNITA-2 HRM 0.3 & OFFSITE & sw & $\mathrm{N}$ & RIVER & TRANSECT & 04-Sep-03 U-238 & & $0.173 p$ & $\mathrm{pCi} / \mathrm{L}$ & 0.032 & 0.042 & & & \\
\hline
\end{tabular}


WATER - COLUMBIA RIVER TRANSECT

\begin{tabular}{|c|c|c|c|c|c|c|c|c|c|c|c|c|c|c|c|c|}
\hline | OWNER ID & SAMP NUM & SAMP SITE NAME & DIST CLASS & MEDIA $\left.\right|^{\mid h}$ & \begin{tabular}{|c|} 
FILTERED \\
FLAG
\end{tabular} & $\begin{array}{l}\text { SAMP } \\
\text { FROM }\end{array}$ & COLL MTHD & SAMP DATE & CON SHORT NAME & \begin{tabular}{c|c} 
VALUE & $A$ \\
RPTD & $R$
\end{tabular} & \begin{tabular}{|l|l|} 
ANAL \\
UNITS \\
RPTD \\
\end{tabular} & $\begin{array}{c}\text { COUNTING } \\
\text { ERROR }\end{array}$ & \begin{tabular}{|c|} 
TOTAL \\
ANAL \\
ERROR \\
ERRe
\end{tabular} & $\begin{array}{c}\text { LAB } \\
\text { QUALIFIER }\end{array}$ & SAMP COMMENT & $\begin{array}{l}\text { RESULT } \\
\text { COMMENT }\end{array}$ \\
\hline SESPMNT & B17CF0 & VERNITA-3 HRM 0.3 & OFFSITE & SW & $\mathrm{N}$ & RIVER & TRANSECT & 04-Sep-03 U-238 & & & & 0.04 & 0.048 & & & \\
\hline SESPMNT & B17CF1 & VERNITA-4 HRM 0.3 & OFFSITE & sw & $\mathrm{N}$ & RIVER & TRANSECT & 04-Sep-03 U-238 & & $0.182 \mathrm{p}$ & $\mathrm{pCi} / \mathrm{L}$ & 0.039 & 0.049 & & & \\
\hline SESPMNT & B17CF8 & 100 F -1 HRM 19.0 & ONSITE & sw & $\mathrm{N}$ & RIVER & TRANSECT & 08-Sep-03 U-238 & & $0.182 \mathrm{p}$ & $\mathrm{pCi} / \mathrm{L}$ & 0.033 & 0.044 & & & \\
\hline SESPMNT & $\mathrm{B} 17 \mathrm{CH} 4$ & $100 \mathrm{~F}-10$ HRM 19.0 & ONSITE & sW & $\mathrm{N}$ & RIVER & TRANSECT & 08-Sep-03 U-238 & & $0.226 \mathrm{p}$ & $\mathrm{pCi} / \mathrm{L}$ & 0.036 & 0.051 & & & \\
\hline SESPMNT & $\mathrm{B} 17 \mathrm{CH} 1$ & $100 \mathrm{~F}-2 \mathrm{HRM} 19.0$ & ONSITE & sw & $\mathrm{N}$ & RIVER & TRANSECT & 08-Sep-03 U-238 & & $0.206 \mathrm{p}$ & $\mathrm{pCi} / \mathrm{L}$ & 0.036 & 0.048 & & & \\
\hline SESPMNT & B17CF9 & $100 \mathrm{~F}-3 \mathrm{HRM} 19.0$ & ONSITE & sw & $\mathrm{N}$ & RIVER & TRANSECT & 08-Sep-03 U-238 & & $0.195 \mathrm{p}$ & $\mathrm{pCi} / \mathrm{L}$ & 0.034 & 0.045 & & & \\
\hline SESPMNT & $\mathrm{B} 17 \mathrm{CH} 2$ & 100 F - 5 HRM 19.0 & ONSITE & sw & $\mathrm{N}$ & RIVER & TRANSECT & 08-Sep-03 U-238 & & & & 0.03 & 0.04 & & & \\
\hline SESPMNT & $\mathrm{B} 17 \mathrm{CH} 3$ & 100 F - 7 HRM 19.0 & ONSITE & sw & $\mathrm{N}$ & RIVER & TRANSECT & 08-Sep-03 U-238 & & & & 0.032 & 0.044 & & & \\
\hline SESPMNT & B17CY4 & $100 \mathrm{~F}$ SHORE HRM 18 & ONSITE & sw & $\mathrm{N}$ & RIVER & TRANSECT & 08-Sep-03 U-238 & & $0.139 \mathrm{p}$ & $\mathrm{pCi} / \mathrm{L}$ & 0.029 & 0.036 & & & \\
\hline SESPMNT & B17CY7 & 100 F SHORE HRM 22 & ONSITE & sw & $\mathrm{N}$ & RIVER & TRANSECT & 08-Sep-03 U-238 & & $0.146 \mathrm{p}$ & $\mathrm{pCi} / \mathrm{L}$ & 0.03 & 0.038 & & & \\
\hline SESPMNT & B17D00 & $100 \mathrm{~F}$ SHORE HRM 23 & ONSITE & sw & $\mathrm{N}$ & RIVER & TRANSECT & $08-$ Sep-03 U-238 & & $0.15 \mathrm{p}$ & $\mathrm{pCi} / \mathrm{L}$ & 0.029 & 0.037 & & & \\
\hline SESPMNT & $\mathrm{B} 17 \mathrm{CH} 5$ & HANFRD TS-1 HRM 28.7 & ONSITE & sw & $\mathrm{N}$ & RIVER & TRANSECT & 08-Sep-03 U-238 & & $0.259 \mathrm{p}$ & $\mathrm{pCi} / \mathrm{L}$ & 0.038 & 0.056 & & & \\
\hline SESPMNT & $\mathrm{B} 17 \mathrm{CH} 8$ & HANFRD TS-10 HRM 28.7 & ONSITE & sw & $\mathrm{N}$ & RIVER & TRANSECT & 08-Sep-03 U-238 & & $0.18 \mathrm{p}$ & $\mathrm{pCi} / \mathrm{L}$ & 0.031 & 0.042 & & & \\
\hline SESPMNT & $\mathrm{B} 17 \mathrm{CH} 6$ & HANFRD TS-2 HRM 28.7 & ONSITE & sw & $\mathrm{N}$ & RIVER & TRANSECT & 08-Sep-03 U-238 & & $0.168 \mathrm{p}$ & $\mathrm{pCi/L}$ & 0.032 & 0.041 & & & \\
\hline SESPMNT & $\mathrm{B} 17 \mathrm{CH} 9$ & HANFRD TS-3 HRM 28.7 & ONSITE & sw & $\mathrm{N}$ & RIVER & TRANSECT & 08-Sep-03 U-238 & & $0.157 \mathrm{p}$ & & 0.032 & 0.041 & & & \\
\hline SESPMNT & $\mathrm{B} 17 \mathrm{CHO}$ & HANFRD TS-5 HRM 28.7 & ONSITE & sw & $\mathrm{N}$ & RIVER & TRANSECT & 08-Sep-03 U-238 & & $0.169 \mathrm{p}$ & & 0.034 & 0.044 & & & \\
\hline SESPMNT & $\mathrm{B} 17 \mathrm{CH} 7$ & HANFRD TS-7 HRM 28.7 & ONSITE & sw & $\mathrm{N}$ & RIVER & TRANSECT & 08-Sep-03 U-238 & & $0.163 \mathrm{p}$ & $\mathrm{pCi} / \mathrm{L}$ & 0.029 & 0.039 & & & \\
\hline SESPMNT & B17CL4 & HANFRD TWNSITE HRM26 & ONSITE & sw & $\mathrm{N}$ & RIVER & TRANSECT & 08-Sep-03 U-238 & & $0.166 \mathrm{p}$ & $\mathrm{pCi} / \mathrm{L}$ & 0.036 & 0.044 & & & \\
\hline SESPMNT & B17CL5 & HANFRD TWNSITE HRM27 & ONSITE & sw & $\mathrm{N}$ & RIVER & TRANSECT & 08-Sep-03 U-238 & & $0.148 \mathrm{p}$ & $\mathrm{pCi} / \mathrm{L}$ & 0.033 & 0.04 & & & \\
\hline SESPMNT & B17CY1 & HANFRD TWNSITE HRM28 & ONSITE & sW & $\mathrm{N}$ & RIVER & TRANSECT & 08-Sep-03 U-238 & & $0.452 \mathrm{p}$ & $\mathrm{pCi} / \mathrm{L}$ & 0.052 & 0.087 & & & \\
\hline SESPMNT & B17CL6 & HANFRD TWNSITE HRM30 & ONSITE & sw & $\mathrm{N}$ & RIVER & TRANSECT & 08-Sep-03 U-238 & & & $\mathrm{pCi} / \mathrm{L}$ & 0.033 & 0.045 & & & \\
\hline SESPMNT & B17CJO & 300 AREA - 1 HRM 43.1 & ONSITE & sw & $\mathrm{N}$ & RIVER & TRANSECT & 09-Sep-03 U-238 & & $0.403 \mathrm{p}$ & & 0.049 & 0.08 & & & \\
\hline SESPMNT & B17CJ2 & 300 AREA - 2 HRM 43.1 & ONSITE & sw & $\mathrm{N}$ & RIVER & TRANSECT & 09-Sep-03 U-238 & & $0.206 \mathrm{p}$ & & 0.037 & 0.049 & & & \\
\hline SESPMNT & B17CJ4 & 300 AREA -3 HRM 43.1 & ONSITE & sw & $\mathrm{N}$ & RIVER & TRANSECT & $09-S e p-03$ U-238 & & $0.22 \mathrm{p}$ & $\mathrm{pCi} / \mathrm{L}$ & 0.038 & 0.051 & & & \\
\hline SESPMNT & B17CJ6 & 300 AREA -5 HRM 43.1 & ONSITE & sw & $\mathrm{N}$ & RIVER & TRANSECT & 09-Sep-03 U-238 & & $0.189 \mathrm{p}$ & $\mathrm{pCi} / \mathrm{L}$ & 0.036 & 0.047 & & & \\
\hline SESPMNT & B17CJ8 & 300 AREA -7 HRM 43.1 & ONSITE & sw & $\mathrm{N}$ & RIVER & TRANSECT & 09-Sep-03 U-238 & & $0.204 \mathrm{p}$ & $\mathrm{pCi} / \mathrm{L}$ & 0.034 & 0.047 & & & \\
\hline SESPMNT & B17CW5 & 300 AREA SHR HRM41.5 & ONSITE & sw & $\mathrm{N}$ & RIVER & TRANSECT & 09-Sep-03 U-238 & & $0.21 \mathrm{p}$ & $\mathrm{pCi} / \mathrm{L}$ & 0.034 & 0.047 & & & \\
\hline SESPMNT & B17CX7 & 300 AREA SHR HRM42.9 & ONSITE & sw & $\mathrm{N}$ & RIVER & TRANSECT & 09-Sep-03 U-238 & & $0.508 \mathrm{p}$ & $\mathrm{pCi} / \mathrm{L}$ & 0.052 & 0.094 & & & \\
\hline SESPMNT & B17CK0 & 300 AREA-10 HRM 43.1 & ONSITE & sw & $\mathrm{N}$ & RIVER & TRANSECT & 09-Sep-03 U-238 & & $0.355 \mathrm{p}$ & $\mathrm{pCi} / \mathrm{L}$ & 0.051 & 0.075 & & & \\
\hline SESPMNT & В17СT0 & RICH.PMPHS HRM 43.5 & OFFSITE & sw & $\mathrm{N}$ & RIVER & TRANSECT & 09-Sep-03 U-238 & & $0.334 \mathrm{p}$ & $\mathrm{pCi} / \mathrm{L}$ & 0.068 & 0.087 & & & \\
\hline SESPMNT & B17CR8 & RICH.PMPHS HRM 45.0 & OFFSITE & sw & $\mathrm{N}$ & RIVER & TRANSECT & 09-Sep-03 U-238 & & $0.231 \mathrm{p}$ & $\mathrm{pCi} / \mathrm{L}$ & 0.037 & 0.052 & & & \\
\hline SESPMNT & B17CR7 & RICH.PMPHS HRM 45.8 & OFFSITE & sW & $\mathrm{N}$ & RIVER & TRANSECT & 09-Sep-03 U-238 & & $0.24 \mathrm{p}$ & $\mathrm{pCi} / \mathrm{L}$ & 0.036 & 0.052 & & & \\
\hline SESPMNT & B17CK2 & RICH.PMPHS-1 HRM46.4 & OFFSITE & sw & $\mathrm{N}$ & RIVER & TRANSECT & $09-\mathrm{Sep}-03 \mathrm{U}-238$ & & $0.252 \mathrm{p}$ & $\mathrm{pCi} / \mathrm{L}$ & 0.038 & 0.055 & & & \\
\hline SESPMNT & B17CK7 & RICH.PMPHS-10 HRM46.4 & OFFSITE & sw & $\mathrm{N}$ & RIVER & TRANSECT & $09-\mathrm{Sep}-03 \mathrm{U}-238$ & & $0.46 \mathrm{p}$ & $\mathrm{pCi} / \mathrm{L}$ & 0.053 & 0.089 & & & \\
\hline SESPMNT & B17CK3 & RICH.PMPHS-2 HRM46.4 & OFFSITE & sw & $\mathrm{N}$ & RIVER & TRANSECT & 09-Sep-03 U-238 & & & $\mathrm{pCi} / \mathrm{L}$ & 0.042 & 0.059 & & & \\
\hline SESPMNT & B17CK4 & RICH.PMPHS-3 HRM46.4 & OFFSITE & sw & $\mathrm{N}$ & RIVER & TRANSECT & 09-Sep-03 U-238 & & $0.233 \mathrm{p}$ & $\mathrm{pCi} / \mathrm{L}$ & 0.037 & 0.052 & & & \\
\hline SESPMNT & B17CK5 & RICH.PMPHS-5 HRM46.4 & OFFSITE & sw & $\mathrm{N}$ & RIVER & TRANSECT & 09-Sep-03 U-238 & & $0.192 \mathrm{p}$ & $\mathrm{pCi} / \mathrm{L}$ & 0.032 & 0.044 & & & \\
\hline SESPMNT & B17CK6 & RICH.PMPHS-7 HRM46.4 & OFFSITE & sw & $\mathrm{N}$ & RIVER & TRANSECT & 09-Sep-03 U-238 & & $0.165 \mathrm{p}$ & $\mathrm{pCi} / \mathrm{L}$ & 0.032 & 0.041 & & & \\
\hline SESPMNT & B17CR9 & RICH.PMPHS HRM 43.9 & OFFSITE & sw & $\mathrm{N}$ & RIVER & TRANSECT & 09-Sep-03 U-238 & & & & & & & NO SAMPLE. THICK MILFOIL. & \\
\hline SESPMNT & B17CW9 & 300 AREA SHR HRM42.1 & ONSITE & sw & $\mathrm{N}$ & RIVER & TRANSECT & 09-Sep-03 U-238 & & $0.354 \mathrm{p}$ & $\mathrm{pCi} / \mathrm{L}$ & 0.044 & 0.071 & & DIRECTLY DOWNRIVER FROM 300 AREA SPRING 42-2. & \\
\hline SESPMNT & $B 17 C \times 3$ & 300 AREA SHR HRM42.5 & ONSITE & sw & $\mathrm{N}$ & RIVER & TRANSECT & 09-Sep-03 U-238 & & $6.19 \mathrm{p}$ & $\mathrm{pCi} / \mathrm{L}$ & 0.17 & 0.97 & & DIRECTLY DOWNRIVER FROM 300 AREA SPRING 42-2. & \\
\hline SESPMNT & B183W0 & RICH.PMPHS HRM 43.5 & OFFSITE & sw & $\mathrm{N}$ & RIVER & TRANSECT & 08-Dec-03 U-238 & & $0.241 \mathrm{p}$ & $\mathrm{pCi} / \mathrm{L}$ & 0.045 & 0.059 & & & \\
\hline SESPMNT & B183V9 & RICH.PMPHS HRM 43.9 & OFFSITE & sw & $\mathrm{N}$ & RIVER & TRANSECT & 08-Dec-03 U-238 & & $0.196 \mathrm{p}$ & $\mathrm{pCilL}$ & 0.043 & 0.054 & & & \\
\hline SESPMNT & B183V8 & RICH.PMPHS HRM 45.0 & OFFSITE & sw & $\mathrm{N}$ & RIVER & TRANSECT & 08 -Dec-03 U-238 & & $0.187 \mathrm{p}$ & $\mathrm{pCi} / \mathrm{L}$ & 0.04 & 0.05 & & & \\
\hline SESPMNT & B183V7 & RICH.PMPHS HRM 45.8 & OFFSITE & sw & $\mathrm{N}$ & RIVER & TRANSECT & 08-Dec-03 U-238 & & $0.183 \mathrm{p}$ & & 0.038 & 0.048 & & & \\
\hline SESPMNT & B183T1 & RICH.PMPHS-1 HRM46.4 & OFFSITE & sw & $\mathrm{N}$ & RIVER & TRANSECT & 08-Dec-03 U-238 & & $0.202 \mathrm{p}$ & $\mathrm{pCi} / \mathrm{L}$ & 0.043 & 0.054 & & & \\
\hline SESPSPEC & B183R6 & RICH.PMPHS-1 HRM46.4 & OFFSITE & sw & $\mathrm{N}$ & RIVER & TRANSECT & 08-Dec-03 U-238 & & $0.231 \mathrm{p}$ & $\mathrm{pCi} / \mathrm{L}$ & 0.052 & 0.064 & & & \\
\hline SESPMNT & B183T6 & RICH.PMPHS-10 HRM46. 4 & OFFSITE & sw & $\mathrm{N}$ & RIVER & TRANSECT & 08-Dec-03 U-238 & & $0.394 \mathrm{p}$ & $\mathrm{pCi} / \mathrm{L}$ & 0.058 & 0.085 & & & \\
\hline SESPMNT & B183T2 & 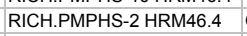 & OFFSITE & sw & $\mathrm{N}$ & RIVER & TRANSECT & 08-Dec-03 U-238 & & $0.192 \mathrm{p}$ & $\mathrm{pCi/L}$ & 0.042 & 0.052 & & & \\
\hline SESPMNT & B183T3 & RICH.PMPHS-3 HRM46.4 & OFFSITE & sw & $\mathrm{N}$ & RIVER & TRANSECT & 08-Dec-03 U-238 & & $0.162 \mathrm{p}$ & $\mathrm{pCi} / \mathrm{L}$ & 0.043 & 0.05 & & & \\
\hline SESPMNT & B183T4 & RICH.PMPHS-5 HRM46.4 & OFFSITE & sw & $\mathrm{N}$ & RIVER & TRANSECT & 08-Dec-03 U-238 & & $0.208 \mathrm{p}$ & $\mathrm{pCi} / \mathrm{L}$ & 0.062 & 0.071 & & & \\
\hline SESPMNT & B183T5 & RICH.PMPHS-7 HRM46.4 & OFFSITE & sw & $\mathrm{N}$ & RIVER & TRANSECT & 08-Dec-03 U-238 & & $0.216 \mathrm{p}$ & $\mathrm{pCi} / \mathrm{L}$ & 0.043 & 0.055 & & & \\
\hline SESPMNT & B183R7 & VERNITA-1 HRM 0.3 & OFFSITE & sw & $\mathrm{N}$ & RIVER & TRANSECT & 09-Dec-03 U-238 & & $0.172 \mathrm{p}$ & $\mathrm{pCi/L}$ & 0.037 & 0.046 & & & \\
\hline SESPMNT & B183R8 & VERNITA-2 HRM 0.3 & OFFSITE & sw & $\mathrm{N}$ & RIVER & TRANSECT & 09-Dec-03 U-238 & & $0.152 \mathrm{p}$ & $\mathrm{pCi} / \mathrm{L}$ & 0.037 & 0.044 & & & \\
\hline SESPMNT & B183R9 & VERNITA-3 HRM 0.3 & OFFSITE & sw & $\mathrm{N}$ & RIVER & TRANSECT & 09-Dec-03 U-238 & & $0.189 \mathrm{p}$ & $\mathrm{pCi} / \mathrm{L}$ & 0.041 & 0.051 & & & \\
\hline SESPMNT & B183T0 & VERNITA-4 HRM 0.3 & OFFSITE & sW & $\mathrm{N}$ & RIVER & TRANSECT & 09-Dec-03 U-238 & & $0.164 \mathrm{p}$ & $\mathrm{pCi} / \mathrm{L}$ & 0.042 & 0.05 & & & \\
\hline SESPMNT & B16L95 & VERNITA-1 HRM 0.3 & OFFSITE & sW & $\mathrm{N}$ & RIVER & TRANSECT & 24-Mar-03 Hg & & $0.000423 \mathrm{ug}$ & ug/L & & & & & \\
\hline SESPMNT & B16L86 & VERNITA-2 HRM 0.3 & OFFSITE & SW & $\mathrm{N}$ & RIVER & TRANSECT & 24-Mar-03 Hg & & $0.000489 \mathrm{u}$ & & & & & & \\
\hline SESPMNT & B16L87 & VERNITA-3 HRM 0.3 & OFFSITE & sw & $\mathrm{N}$ & RIVER & TRANSECT & 24-Mar-03 Hg & & $0.0007 \mathrm{u}$ & ug/L & & & & & \\
\hline SESPMNT & B16L88 & VERNITA-4 HRM 0.3 & OFFSITE & sw & $\mathrm{N}$ & RIVER & TRANSECT & 24-Mar-03 Hg & & $0.000932 \mathrm{ug}$ & ug/L & & & & & \\
\hline SESPMNT & B16LD8 & RICH.PMPHS HRM 43.5 & OFFSITE & SW & $\mathrm{N}$ & RIVER & TRANSECT & 25-Mar-03 Hg & & $0.000619 \mathrm{u}$ & & & & & & \\
\hline SESPMNT & B16LD7 & RICH.PMPHS HRM 43.9 & OFFSITE & sw & $\mathrm{N}$ & RIVER & TRANSECT & 25-Mar-03 Hg & & $0.000598 \mathrm{u}$ & $\mathrm{ug} / \mathrm{L}$ & & & & & \\
\hline
\end{tabular}


WATER - COLUMBIA RIVER TRANSECT

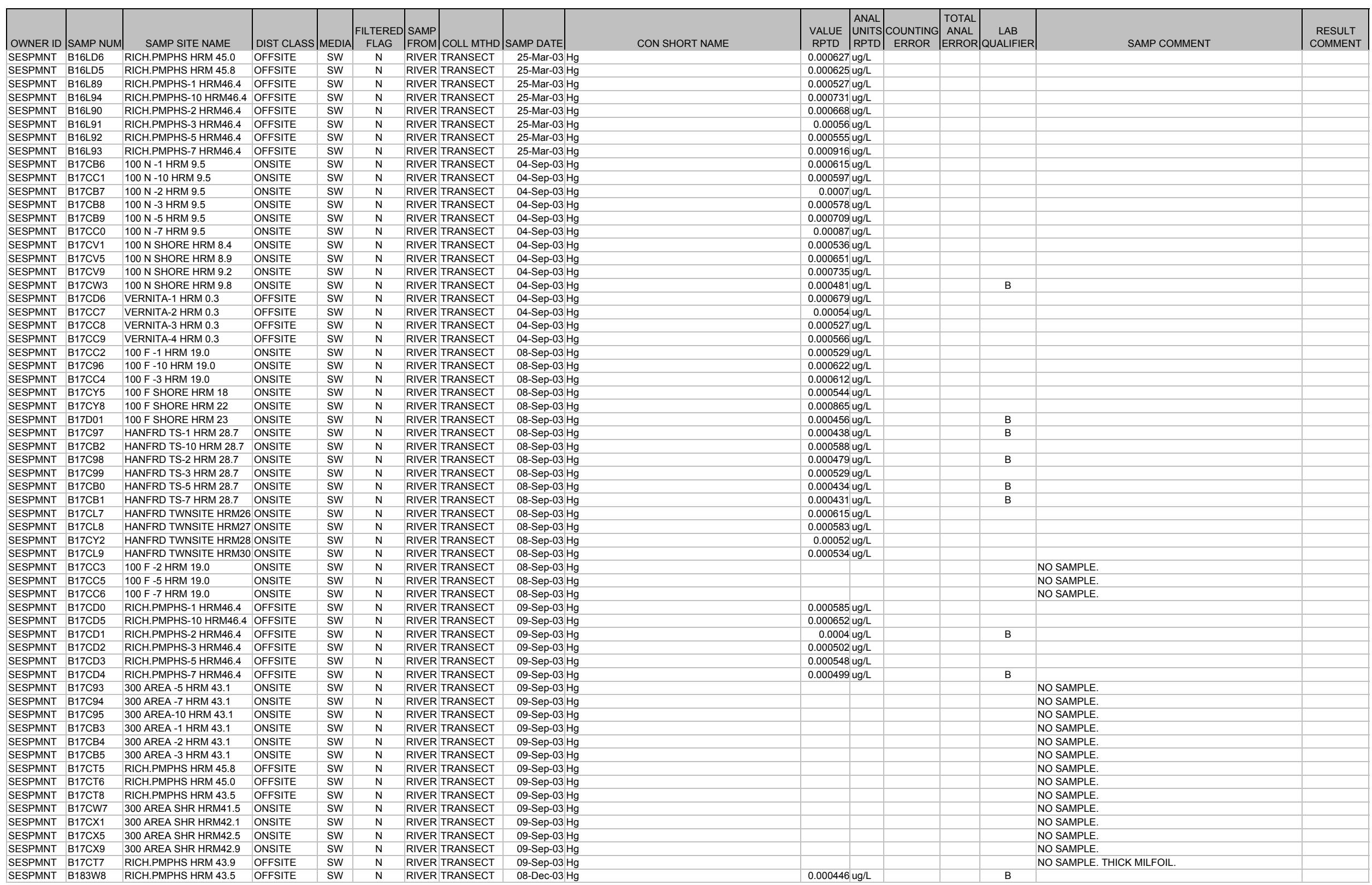


WATER - COLUMBIA RIVER TRANSECT

\begin{tabular}{|c|c|c|c|c|c|c|c|c|c|c|c|c|c|c|c|c|}
\hline | OWNER ID & SAMP NUM & SAMP SITE NAME & DIST CLASS & $\mid$ MEDIA & \begin{tabular}{|c|} 
FILTERED \\
FLAG
\end{tabular} & $\begin{array}{l}\text { SAMP } \\
\text { FROM }\end{array}$ & COLL MTHD & SAMP DATE & CON SHORT NAME & \begin{tabular}{c|c} 
VALUE & 4 \\
RPTD
\end{tabular} & \begin{tabular}{|l|l|} 
ANAL \\
UNITS \\
RPTD \\
\end{tabular} & \begin{tabular}{|l|} 
COUNTING \\
ERROR
\end{tabular} & \begin{tabular}{|c|} 
TOTAL \\
ANAL \\
ERROR
\end{tabular} & $\begin{array}{c}\text { LAB } \\
\text { QUALIFIER }\end{array}$ & SAMP COMMENT & $\begin{array}{l}\text { RESULT } \\
\text { COMMENT }\end{array}$ \\
\hline SESPMNT & B183W7 & RICH.PMPHS HRM 43.9 & OFFSITE & SW & $\mathrm{N}$ & RIVER & TRANSECT & 08-Dec-03 Hg & & & & & & & & \\
\hline SESPMNT & B183W6 & RICH.PMPHS HRM 45.0 & OFFSITE & sw & $\mathrm{N}$ & RIVER & TRANSECT & 08-Dec-03 Hg & & $0.000406 u$ & ug/L & & & B & & \\
\hline SESPMNT & B183W5 & RICH.PMPHS HRM 45.8 & OFFSITE & sw & $\mathrm{N}$ & RIVER & TRANSECT & $08-\mathrm{Dec}-03 \mathrm{Hg}$ & & $0.000642 u$ & $\mathrm{ug} / \mathrm{L}$ & & & & & \\
\hline SESPMNT & B183P9 & RICH.PMPHS-1 HRM46.4 & OFFSITE & sw & $\mathrm{N}$ & RIVER & TRANSECT & $08-\mathrm{Dec}-03 \mathrm{Hg}$ & & $0.000371 \mathrm{u}$ & $\mathrm{ug} / \mathrm{L}$ & & & B & & \\
\hline SESPMNT & B183R4 & RICH.PMPHS-10 HRM46. 4 & OFFSITE & sw & $\mathrm{N}$ & RIVER & TRANSECT & $08-\mathrm{Dec}-03 \mathrm{Hg}$ & & $0.00117 u$ & $\mathrm{ug} / \mathrm{L}$ & & & & & \\
\hline SESPMNT & B183R0 & RICH.PMPHS-2 HRM46.4 & OFFSITE & sw & $\mathrm{N}$ & RIVER & TRANSECT & 08-Dec-03 Hg & & $0.000347 u$ & & & & B & & \\
\hline SESPMNT & B183R1 & RICH.PMPHS-3 HRM46.4 & OFFSITE & sw & $\mathrm{N}$ & RIVER & TRANSECT & 08-Dec-03 Hg & & $0.000439 u$ & & & & B & & \\
\hline SESPMNT & B183R2 & RICH.PMPHS-5 HRM46.4 & OFFSITE & sw & $\mathrm{N}$ & RIVER & TRANSECT & 08-Dec-03 Hg & & $0.000627 u$ & & & & & & \\
\hline SESPMNT & B183R3 & RICH.PMPHS-7 HRM46.4 & OFFSITE & sw & $\mathrm{N}$ & RIVER & TRANSECT & 08-Dec-03 Hg & & $0.000397 \mathrm{u}$ & $\mathrm{ug} / \mathrm{L}$ & & & B & & \\
\hline SESPMNT & B183R5 & VERNITA-1 HRM 0.3 & OFFSITE & sw & $\mathrm{N}$ & RIVER & TRANSECT & 09-Dec-03 Hg & & $0.000497 \mathrm{u}$ & $\mathrm{ug} / \mathrm{L}$ & & & B & & \\
\hline SESPMNT & B183P6 & VERNITA-2 HRM 0.3 & OFFSITE & sw & $\mathrm{N}$ & RIVER & TRANSECT & $09-\mathrm{Dec}-03 \mathrm{Hg}$ & & $0.000541 \mathrm{u}$ & $\mathrm{ug} / \mathrm{L}$ & & & & & \\
\hline SESPMNT & B183P7 & VERNITA-3 HRM 0.3 & OFFSITE & sw & $\mathrm{N}$ & RIVER & TRANSECT & 09-Dec- $03 \mathrm{Hg}$ & & $0.000527 u$ & ug/L & & & & & \\
\hline SESPMNT & B183P8 & VERNITA-4 HRM 0.3 & OFFSITE & sw & $\mathrm{N}$ & RIVER & TRANSECT & 09-Dec-03 Hg & & $0.000581 \mathrm{u}$ & $\mathrm{ug} / \mathrm{L}$ & & & & & \\
\hline SESPMNT & B16L95 & VERNITA-1 HRM 0.3 & OFFSITE & sw & $\mathrm{N}$ & RIVER & TRANSECT & $24-\mathrm{Mar}-03 \mathrm{Ag}$ & & $0.0126 \mathrm{u}$ & ug/L & & & $\mathrm{BC}$ & & \\
\hline SESPMNT & B16LB7 & VERNITA-1 HRM 0.3 & OFFSITE & sw & $\mathrm{Y}$ & RIVER & TRANSECT & 24-Mar-03 Ag & & $0.00486 \mathrm{u}$ & & & & $B C$ & & \\
\hline SESPMNT & B16L86 & VERNITA-2 HRM 0.3 & OFFSITE & sw & $\mathrm{N}$ & RIVER & TRANSECT & 24-Mar-03 Ag & & $0.00945 u$ & & & & BC & & \\
\hline SESPMNT & B16LB8 & VERNITA-2 HRM 0.3 & OFFSITE & sw & Y & RIVER & TRANSECT & 24-Mar-03 Ag & & $0.004 u$ & $\mathrm{ug} / \mathrm{L}$ & & & u & & \\
\hline SESPMNT & B16L87 & VERNITA-3 HRM 0.3 & OFFSITE & sw & $\mathrm{N}$ & RIVER & TRANSECT & 24-Mar-03 Ag & & $0.00641 \mathrm{u}$ & $\mathrm{ug} / \mathrm{L}$ & & & $\mathrm{BC}$ & & \\
\hline SESPMNT & B16LB9 & VERNITA-3 HRM 0.3 & OFFSITE & sw & Y & RIVER & TRANSECT & 24-Mar-03 Ag & & $0.004 u$ & $\mathrm{ug} / \mathrm{L}$ & & & $u$ & & \\
\hline SESPMNT & B16L88 & VERNITA-4 HRM 0.3 & OFFSITE & sw & $\mathrm{N}$ & RIVER & TRANSECT & 24-Mar-03 Ag & & $0.00793 \mathrm{u}$ & & & & $\mathrm{BC}$ & & \\
\hline SESPMNT & B16LC0 & VERNITA-4 HRM 0.3 & OFFSITE & sw & $\mathrm{Y}$ & RIVER - & TRANSECT & 24-Mar-03 Ag & & $0.004 u$ & & & & $u$ & & \\
\hline SESPMNT & B16LD4 & RICH.PMPHS HRM 43.5 & OFFSITE & sw & Y & RIVER & TRANSECT & 25-Mar-03 Ag & & $0.004 u$ & & & & $u$ & & \\
\hline SESPMNT & B16LD8 & RICH.PMPHS HRM 43.5 & OFFSITE & sw & $\mathrm{N}$ & RIVER & TRANSECT & 25-Mar-03 Ag & & $0.00411 \mathrm{u}$ & & & & $\mathrm{BC}$ & & \\
\hline SESPMNT & B16LD3 & RICH.PMPHS HRM 43.9 & OFFSITE & sw & $\mathrm{Y}$ & RIVER & TRANSECT & 25 -Mar-03 Ag & & $0.004 u$ & ug/L & & & u & & \\
\hline SESPMNT & B16LD7 & RICH.PMPHS HRM 43.9 & OFFSITE & sw & $\mathrm{N}$ & RIVER & TRANSECT & $25-\mathrm{Mar}-03 \mathrm{Ag}$ & & $0.00528 u$ & ug/L & & & $B C$ & & \\
\hline SESPMNT & B16LD2 & RICH.PMPHS HRM 45.0 & OFFSITE & sw & $\mathrm{Y}$ & RIVER & TRANSECT & 25-Mar-03 Ag & & $0.004 \mathrm{u}$ & $\mathrm{ug} / \mathrm{L}$ & & & $u$ & & \\
\hline SESPMNT & B16LD6 & RICH.PMPHS HRM 45.0 & OFFSITE & sw & $\mathrm{N}$ & RIVER & TRANSECT & 25-Mar-03 Ag & & $0.00418 u$ & $\mathrm{ug} / \mathrm{L}$ & & & $\mathrm{BC}$ & & \\
\hline SESPMNT & B16LD1 & RICH.PMPHS HRM 45.8 & OFFSITE & sw & $\mathrm{Y}$ & RIVER & TRANSECT & 25-Mar-03 Ag & & $0.004 u$ & $\mathrm{ug} / \mathrm{L}$ & & & $u$ & & \\
\hline SESPMNT & B16LD5 & RICH.PMPHS HRM 45.8 & OFFSITE & sw & $\mathrm{N}$ & RIVER & TRANSECT & $25-\mathrm{Mar}-03 \mathrm{Ag}$ & & $0.004 u$ & & & & u & & \\
\hline SESPMNT & B16L89 & RICH.PMPHS-1 HRM46.4 & OFFSITE & sw & $\mathrm{N}$ & RIVER & TRANSECT & 25-Mar-03 Ag & & $0.00633 \mathrm{u}$ & & & & $\mathrm{BC}$ & & \\
\hline SESPMNT & B16LC1 & RICH.PMPHS-1 HRM46.4 & OFFSITE & sw & $\mathrm{Y}$ & RIVER & TRANSECT & 25-Mar-03 Ag & & $0.004 \mathrm{u}$ & & & & $u$ & & \\
\hline SESPMNT & B16L94 & RICH.PMPHS-10 HRM46.4 & OFFSITE & sw & $\mathrm{N}$ & RIVER & TRANSECT & 25-Mar-03 Ag & & $0.004 \mathrm{u}$ & $\mathrm{ug} / \mathrm{L}$ & & & U & & \\
\hline SESPMNT & B16LC6 & RICH.PMPHS-10 HRM46. 4 & OFFSITE & sw & $\mathrm{Y}$ & RIVER & TRANSECT & 25-Mar-03 Ag & & $0.004 \mathrm{u}$ & $\mathrm{ug} / \mathrm{L}$ & & & u & & \\
\hline SESPMNT & B16L90 & RICH.PMPHS-2 HRM46.4 & OFFSITE & sw & $\mathrm{N}$ & RIVER & TRANSECT & $25-\mathrm{Mar}-03 \mathrm{Ag}$ & & 0.00479 u & ug/L & & & $\mathrm{BC}$ & & \\
\hline SESPMNT & B16LC2 & RICH.PMPHS-2 HRM46.4 & OFFSITE & sw & $\mathrm{Y}$ & RIVER & TRANSECT & $25-\mathrm{Mar}-03 \mathrm{Ag}$ & & $0.004 \mathrm{us}$ & $\mathrm{ug} / \mathrm{L}$ & & & U & & \\
\hline SESPMNT & B16L91 & RICH.PMPHS-3 HRM46.4 & OFFSITE & sw & $\mathrm{N}$ & RIVER & TRANSECT & 25-Mar-03 Ag & & $0.00548 \mathrm{u}$ & & & & $\mathrm{BC}$ & & \\
\hline SESPMNT & B16LC3 & RICH.PMPHS-3 HRM46.4 & OFFSITE & sw & $\mathrm{Y}$ & RIVER & TRANSECT & 25-Mar-03 Ag & & $0.004 \mathrm{u}$ & $\mathrm{ug} / \mathrm{L}$ & & & u & & \\
\hline SESPMNT & B16L92 & RICH.PMPHS-5 HRM46.4 & OFFSITE & sw & $\mathrm{N}$ & RIVER & TRANSECT & 25-Mar-03 Ag & & $0.00509 \mathrm{u}$ & & & & $\mathrm{BC}$ & & \\
\hline SESPMNT & B16LC4 & RICH.PMPHS-5 HRM46.4 & OFFSITE & sw & $\mathrm{Y}$ & RIVER & TRANSECT & $25-\mathrm{Mar}-03 \mathrm{Ag}$ & & $0.004 \mathrm{u}$ & $\mathrm{ug} / \mathrm{L}$ & & & u & & \\
\hline SESPMNT & B16L93 & RICH.PMPHS-7 HRM46.4 & OFFSITE & sw & $\mathrm{N}$ & RIVER & TRANSECT & 25-Mar-03 Ag & & $0.00572 \mathrm{u}$ & $\mathrm{ug} / \mathrm{L}$ & & & $\mathrm{BC}$ & & \\
\hline SESPMNT & B16LC5 & RICH.PMPHS-7 HRM46.4 & OFFSITE & sw & Y & RIVER & TRANSECT & 25-Mar-03 Ag & & $0.004 \mathrm{u}$ & $\mathrm{ug} / \mathrm{L}$ & & & $u$ & & \\
\hline SESPMNT & B171V9 & VERNITA-1 HRM 0.3 & OFFSITE & sw & $\mathrm{N}$ & RIVER & TRANSECT & 09-Jun-03 Ag & & $0.004 \mathrm{u}$ & $\mathrm{ug} / \mathrm{L}$ & & & u & & \\
\hline SESPMNT & B171Y1 & VERNITA-1 HRM 0.3 & OFFSITE & sw & $\mathrm{Y}$ & RIVER & TRANSECT & 09-Jun-03 Ag & & $0.004 \mathrm{u}$ & ug/L & & & u & & \\
\hline SESPMNT & B171V0 & VERNITA-2 HRM 0.3 & OFFSITE & sw & $\mathrm{N}$ & RIVER & TRANSECT & 09-Jun-03 Ag & & $0.004 \mathrm{u}$ & ug/L & & & U & & \\
\hline SESPMNT & B171Y2 & VERNITA-2 HRM 0.3 & OFFSITE & sw & $\mathrm{Y}$ & RIVER & TRANSECT & 09-Jun-03 Ag & & $0.004 \mathrm{us}$ & & & & U & & \\
\hline SESPMNT & B171V1 & VERNITA-3 HRM 0.3 & OFFSITE & sw & $\mathrm{N}$ & RIVER & TRANSECT & 09-Jun- $03 \mathrm{Ag}$ & & $0.004 \mathrm{us}$ & ug/L & & & u & & \\
\hline SESPMNT & B171Y3 & VERNITA-3 HRM 0.3 & OFFSITE & sW & $\mathrm{Y}$ & RIVER & TRANSECT & 09-Jun-03 Ag & & $0.004 \mathrm{us}$ & $\mathrm{ug} / \mathrm{L}$ & & & U & & \\
\hline SESPMNT & B171V2 & VERNITA-4 HRM 0.3 & OFFSITE & sw & $\mathrm{N}$ & RIVER & TRANSECT & 09-Jun-03 Ag & & $0.004 \mathrm{u}$ & $\mathrm{ug} / \mathrm{L}$ & & & u & & \\
\hline SESPMNT & B171Y4 & VERNITA-4 HRM 0.3 & OFFSITE & sw & $\mathrm{Y}$ & RIVER & TRANSECT & $09-\mathrm{Jun}-03 \mathrm{Ag}$ & & $0.004 \mathrm{u}$ & $\mathrm{ug} / \mathrm{L}$ & & & u & & \\
\hline SESPMNT & B17208 & RICH.PMPHS HRM 43.5 & OFFSITE & sw & $\mathrm{Y}$ & RIVER & TRANSECT & 10-Jun-03 Ag & & $0.004 \mathrm{us}$ & $\mathrm{ug} / \mathrm{L}$ & & & u & & \\
\hline SESPMNT & B17212 & RICH.PMPHS HRM 43.5 & OFFSITE & sw & $\mathrm{N}$ & RIVER & TRANSECT & 10-Jun-03 Ag & & $0.004 \mathrm{u}$ & $\mathrm{ug} / \mathrm{L}$ & & & u & & \\
\hline SESPMNT & B17207 & RICH.PMPHS HRM 43.9 & OFFSITE & sw & $\mathrm{Y}$ & RIVER & TRANSECT & 10-Jun- $03 \mathrm{Ag}$ & & $0.004 \mathrm{u}$ & $\mathrm{ug} / \mathrm{L}$ & & & u & & \\
\hline SESPMNT & B17211 & RICH.PMPHS HRM 43.9 & OFFSITE & sw & $\mathrm{N}$ & RIVER & TRANSECT & 10-Jun- $03 \mathrm{Ag}$ & & $0.004 \mathrm{u}$ & ug/L & & & u & & \\
\hline SESPMNT & B17206 & RICH.PMPHS HRM 45.0 & OFFSITE & sw & $\mathrm{Y}$ & RIVER & TRANSECT & 10-Jun-03 Ag & & $0.004 \mathrm{u}$ & ug/L & & & u & & \\
\hline SESPMNT & B17210 & RICH.PMPHS HRM 45.0 & OFFSITE & sw & $\mathrm{N}$ & RIVER & TRANSECT & 10-Jun-03 Ag & & $0.004 \mathrm{us}$ & ug/L & & & u & & \\
\hline SESPMNT & B17205 & RICH.PMPHS HRM 45.8 & OFFSITE & sW & $\mathrm{Y}$ & RIVER & TRANSECT & 10-Jun-03 Ag & & $0.004 \mathrm{ug}$ & $\mathrm{ug} / \mathrm{L}$ & & & u & & \\
\hline SESPMNT & B17209 & RICH.PMPHS HRM 45.8 & OFFSITE & sW & $\mathrm{N}$ & RIVER & TRANSECT & 10-Jun-03 Ag & & $0.004 \mathrm{us}$ & $\mathrm{ug} / \mathrm{L}$ & & & $u$ & & \\
\hline SESPMNT & B171V3 & RICH.PMPHS-1 HRM46.4 & OFFSITE & SW & $\mathrm{N}$ & RIVER & TRANSECT & 10-Jun-03 Ag & & $0.004 \mathrm{u}$ & $\mathrm{ug} / \mathrm{L}$ & & & u & & \\
\hline SESPMNT & B171Y5 & RICH.PMPHS-1 HRM46.4 & OFFSITE & sW & $\mathrm{Y}$ & RIVER & TRANSECT & 10-Jun-03 Ag & & $0.004 \mathrm{us}$ & $\mathrm{ug} / \mathrm{L}$ & & & U & & \\
\hline SESPMNT & B171V8 & RICH.PMPHS-10 HRM46.4 & OFFSITE & sw & $\mathrm{N}$ & RIVER & TRANSECT & 10-Jun-03 Ag & & & ug/L & & & u & & \\
\hline SESPMNT & B17200 & RICH.PMPHS-10 HRM46.4 & OFFSITE & SW & $\mathrm{Y}$ & RIVER & TRANSECT & 10-Jun-03 Ag & & $0.004 \mathrm{u}$ & $\mathrm{ug} / \mathrm{L}$ & & & U & & \\
\hline SESPMNT & B171V4 & RICH.PMPHS-2 HRM46.4 & OFFSITE & sw & $\mathrm{N}$ & RIVER & TRANSECT & 10-Jun-03 Ag & & $0.004 \mathrm{us}$ & $\mathrm{ug} / \mathrm{L}$ & & & $\mathrm{u}$ & & \\
\hline
\end{tabular}


WATER - COLUMBIA RIVER TRANSECT

\begin{tabular}{|c|c|c|c|c|c|c|c|c|c|c|c|c|c|c|c|c|}
\hline | OWNER ID & SAMP NUM & SAMP SITE NAME & DIST CLASS & $\mid$ MEDIA & \begin{tabular}{|c|} 
FILTERED \\
FLAG
\end{tabular} & $\begin{array}{l}\text { SAMP } \\
\text { FROM }\end{array}$ & COLL MTHD & SAMP DATE & CON SHORT NAME & \begin{tabular}{c|c} 
VALUE \\
RPTD
\end{tabular} & \begin{tabular}{|l|l|} 
ANAL \\
UNITS \\
RPTD \\
\end{tabular} & \begin{tabular}{|l|} 
COUNTING \\
ERROR
\end{tabular} & \begin{tabular}{|c|} 
TOTAL \\
ANAL \\
ERROR
\end{tabular} & $\begin{array}{c}\text { LAB } \\
\text { QUALIFIER }\end{array}$ & SAMP COMMENT & $\begin{array}{l}\text { RESULT } \\
\text { COMMENT }\end{array}$ \\
\hline SESPMNT & B171Y6 & RICH.PMPHS-2 HRM46.4 & OFFSITE & SW & Y & RIVER T & TRANSECT & 10-Jun-03 Ag & & & & & & U & - & \\
\hline SESPMNT & B171V5 & RICH.PMPHS-3 HRM 46.4 & OFFSITE & sw & $\mathrm{N}$ & RIVER T & TRANSECT & 10-Jun-03 Ag & & $0.004 u$ & $\mathrm{ug} / \mathrm{L}$ & & & $\mathrm{U}$ & & \\
\hline SESPMNT & B171Y7 & RICH.PMPHS-3 HRM46.4 & OFFSITE & sw & $\mathrm{Y}$ & RIVER T & TRANSECT & 10-Jun-03 Ag & & $0.004 u$ & $\mathrm{ug} / \mathrm{L}$ & & & u & & \\
\hline SESPMNT & B171V6 & RICH.PMPHS-5 HRM46.4 & OFFSITE & sw & $\mathrm{N}$ & RIVER T & TRANSECT & 10-Jun-03 Ag & & $0.004 u$ & $\mathrm{ug} / \mathrm{L}$ & & & u & & \\
\hline SESPMNT & B171Y8 & RICH.PMPHS-5 HRM46. 4 & OFFSITE & sw & Y & RIVER & TRANSECT & 10-Jun-03 Ag & & $0.004 u$ & $\mathrm{ug} / \mathrm{L}$ & & & $u$ & & \\
\hline SESPMNT & B171V7 & RICH.PMPHS-7 HRM46.4 & OFFSITE & sw & $\mathrm{N}$ & RIVER & TRANSECT & 10-Jun-03 Ag & & & & & & $u$ & & \\
\hline SESPMNT & B171Y9 & RICH.PMPHS-7 HRM46.4 & OFFSITE & sw & $\mathrm{Y}$ & RIVER 7 & TRANSECT & 10-Jun-03 Ag & & & & & & $\mathrm{U}$ & & \\
\hline SESPMNT & B17CB6 & $100 \mathrm{~N}-1$ HRM 9.5 & ONSITE & sw & $\mathrm{N}$ & RIVER T & TRANSECT & 04-Sep-03 Ag & & & & & & U & & \\
\hline SESPMNT & B17CM7 & $100 \mathrm{~N}-1$ HRM 9.5 & ONSITE & sw & $\mathrm{Y}$ & RIVER 7 & TRANSECT & $04-\mathrm{Sep}-03 \mathrm{Ag}$ & & $0.0085 u$ & $\mathrm{ug} / \mathrm{L}$ & & & u & & \\
\hline SESPMNT & B17CC1 & $100 \mathrm{~N}-10$ HRM 9.5 & ONSITE & sw & $\mathrm{N}$ & RIVER T & TRANSECT & 04-Sep-03 Ag & & $0.0085 u$ & $\mathrm{ug} / \mathrm{L}$ & & & U & & \\
\hline SESPMNT & B17CN2 & $100 \mathrm{~N}-10$ HRM 9.5 & ONSITE & sw & $\mathrm{Y}$ & RIVER T & TRANSECT & $04-\mathrm{Sep}-03 \mathrm{Ag}$ & & $0.0085 \mathrm{u}$ & $\mathrm{ug} / \mathrm{L}$ & & & U & & \\
\hline SESPMNT & B17CB7 & $100 \mathrm{~N}-2$ HRM 9.5 & ONSITE & sw & $\mathrm{N}$ & RIVER 7 & TRANSECT & 04-Sep-03 Ag & & $0.0085 \mathrm{u}$ & $\mathrm{ug} / \mathrm{L}$ & & & u & & \\
\hline SESPMNT & B17CM8 & $100 \mathrm{~N}-2$ HRM 9.5 & ONSITE & sw & $\mathrm{Y}$ & RIVER T & TRANSECT & 04-Sep-03 Ag & & $0.0085 u$ & $\mathrm{ug} / \mathrm{L}$ & & & U & & \\
\hline SESPMNT & B17CB8 & $100 \mathrm{~N}-3$ HRM 9.5 & ONSITE & sw & $\mathrm{N}$ & RIVER T & TRANSECT & 04-Sep-03 Ag & & $0.0085 \mathrm{u}$ & $\mathrm{ug} / \mathrm{L}$ & & & u & & \\
\hline SESPMNT & B17CM9 & $100 \mathrm{~N}-3$ HRM 9.5 & ONSITE & sw & $\mathrm{Y}$ & RIVER 7 & TRANSECT & 04-Sep-03 Ag & & $0.0085 u$ & & & & U & & \\
\hline SESPMNT & B17CB9 & $100 \mathrm{~N}-5$ HRM 9.5 & ONSITE & sw & $\mathrm{N}$ & RIVER 7 & TRANSECT & 04-Sep-03 Ag & & $0.0085 \mathrm{u}$ & & & & U & & \\
\hline SESPMNT & B17CNO & $100 \mathrm{~N}-5$ HRM 9.5 & ONSITE & sw & Y & RIVER 7 & TRANSECT & 04-Sep-03 Ag & & $0.0085 \mathrm{u}$ & $\mathrm{ug} / \mathrm{L}$ & & & $u$ & & \\
\hline SESPMNT & B17CCO & $100 \mathrm{~N}-7$ HRM 9.5 & ONSITE & sw & $\mathrm{N}$ & RIVER T & TRANSECT & 04-Sep-03 Ag & & $0.0085 u$ & $\mathrm{ug} / \mathrm{L}$ & & & U & & \\
\hline SESPMNT & $\mathrm{B} 17 \mathrm{CN} 1$ & $100 \mathrm{~N}-7$ HRM 9.5 & ONSITE & sw & Y & RIVER T & TRANSECT & $04-\mathrm{Sep}-03 \mathrm{Ag}$ & & $0.0085 \mathrm{u}$ & $\mathrm{ug} / \mathrm{L}$ & & & u & & \\
\hline SESPMNT & B17CV1 & 100 N SHORE HRM 8.4 & ONSITE & sw & $\mathrm{N}$ & RIVER T & TRANSECT & 04-Sep-03 Ag & & $0.0085 \mathrm{u}$ & & & & u & & \\
\hline SESPMNT & B17CV2 & 100 N SHORE HRM 8.4 & ONSITE & sw & $\mathrm{Y}$ & RIVER T & TRANSECT & $04-\mathrm{Sep}-03 \mathrm{Ag}$ & & $0.0085 u$ & & & & U & & \\
\hline SESPMNT & B17CV5 & 100 N SHORE HRM 8.9 & ONSITE & sw & $\mathrm{N}$ & RIVER & TRANSECT & 04-Sep-03 Ag & & $0.0085 \mathrm{u}$ & & & & u & & \\
\hline SESPMNT & B17CV6 & 100 N SHORE HRM 8.9 & ONSITE & sw & $\mathrm{Y}$ & RIVER & TRANSECT & 04-Sep-03 Ag & & $0.0085 \mathrm{u}$ & & & & u & & \\
\hline SESPMNT & B17CV9 & 100 N SHORE HRM 9.2 & ONSITE & sw & $\mathrm{N}$ & RIVER T & TRANSECT & 04-Sep-03 Ag & & $0.0085 \mathrm{u}$ & $\mathrm{ug} / \mathrm{L}$ & & & u & & \\
\hline SESPMNT & B17CWO & 100 N SHORE HRM 9.2 & ONSITE & sw & $\mathrm{Y}$ & RIVER T & TRANSECT & 04-Sep-03 Ag & & $0.0085 u$ & $\mathrm{ug} / \mathrm{L}$ & & & $U$ & & \\
\hline SESPMNT & B17CW3 & 100 N SHORE HRM 9.8 & ONSITE & sw & $\mathrm{N}$ & RIVER 7 & TRANSECT & 04-Sep-03 Ag & & $0.0085 \mathrm{u}$ & $\mathrm{ug} / \mathrm{L}$ & & & $u$ & & \\
\hline SESPMNT & B17CW4 & 100 N SHORE HRM 9.8 & ONSITE & sw & $\mathrm{Y}$ & RIVER T & TRANSECT & 04-Sep-03 Ag & & $0.0085 \mathrm{u}$ & $\mathrm{ug} / \mathrm{L}$ & & & U & & \\
\hline SESPMNT & B17CD6 & VERNITA-1 HRM 0.3 & OFFSITE & sw & $\mathrm{N}$ & RIVER 7 & TRANSECT & $04-\mathrm{Sep}-03 \mathrm{Ag}$ & & $0.0085 u$ & $\mathrm{ug} / \mathrm{L}$ & & & U & & \\
\hline SESPMNT & B17CM3 & VERNITA-1 HRM 0.3 & OFFSITE & sw & Y & RIVER T & TRANSECT & 04-Sep-03 Ag & & $0.0085 \mathrm{u}$ & & & & u & & \\
\hline SESPMNT & B17CC7 & VERNITA-2 HRM 0.3 & OFFSITE & sw & $\mathrm{N}$ & RIVER T & TRANSECT & 04-Sep-03 Ag & & $0.0085 \mathrm{u}$ & & & & U & & \\
\hline SESPMNT & B17CM4 & VERNITA-2 HRM 0.3 & OFFSITE & sw & Y & RIVER T & TRANSECT & $04-\mathrm{Sep}-03 \mathrm{Ag}$ & & $0.0085 \mathrm{u}$ & & & & u & & \\
\hline SESPMNT & B17CC8 & VERNITA-3 HRM 0.3 & OFFSITE & sw & $\mathrm{N}$ & RIVER T & TRANSECT & 04-Sep-03 Ag & & $0.0085 \mathrm{u}$ & $\mathrm{ug} / \mathrm{L}$ & & & U & & \\
\hline SESPMNT & B17CM5 & VERNITA-3 HRM 0.3 & OFFSITE & sw & $\mathrm{Y}$ & RIVER T & TRANSECT & 04-Sep-03 Ag & & $0.0085 \mathrm{u}$ & $\mathrm{ug} / \mathrm{L}$ & & & u & & \\
\hline SESPMNT & B17CC9 & VERNITA-4 HRM 0.3 & OFFSITE & sw & $\mathrm{N}$ & RIVER T & TRANSECT & 04-Sep-03 Ag & & $0.0085 \mathrm{u}$ & ug/L & & & u & & \\
\hline SESPMNT & B17CM6 & VERNITA-4 HRM 0.3 & OFFSITE & sw & $\mathrm{Y}$ & RIVER T & TRANSECT & 04-Sep-03 Ag & & $0.0085 u$ & ug/L & & & U & & \\
\hline SESPMNT & B17CC2 & $100 \mathrm{~F}-1$ HRM 19.0 & ONSITE & sw & $\mathrm{N}$ & RIVER 7 & TRANSECT & $08-\mathrm{Sep}-03 \mathrm{Ag}$ & & $0.0085 u$ & ug/L & & & $u$ & & \\
\hline SESPMNT & B17CR1 & $100 \mathrm{~F}-1$ HRM 19.0 & ONSITE & sw & $\mathrm{Y}$ & RIVER 7 & TRANSECT & $08-\mathrm{Sep}-03 \mathrm{Ag}$ & & $0.0085 u$ & & & & U & & \\
\hline SESPMNT & B17C96 & $100 \mathrm{~F}-10$ HRM 19.0 & ONSITE & sw & $\mathrm{N}$ & RIVER T & TRANSECT & $08-\mathrm{Sep}-03 \mathrm{Ag}$ & & $0.0085 u$ & $\mathrm{ug} / \mathrm{L}$ & & & U & & \\
\hline SESPMNT & B17CR6 & $100 \mathrm{~F}-10 \mathrm{HRM} 19.0$ & ONSITE & sw & $\mathrm{Y}$ & RIVER T & TRANSECT & 08-Sep-03 Ag & & $0.0085 \mathrm{u}$ & $\mathrm{ug} / \mathrm{L}$ & & & u & & \\
\hline SESPMNT & B17CR2 & $100 \mathrm{~F}-2$ HRM 19.0 & ONSITE & sW & $\mathrm{Y}$ & RIVER T & TRANSECT & $08-\mathrm{Sep}-03 \mathrm{Ag}$ & & $0.0085 u$ & $\mathrm{ug} / \mathrm{L}$ & & & U & & \\
\hline SESPMNT & B17CC4 & $100 \mathrm{~F}-3 \mathrm{HRM} 19.0$ & ONSITE & sw & $\mathrm{N}$ & RIVER T & TRANSECT & $08-\mathrm{Sep}-03 \mathrm{Ag}$ & & $0.0085 \mathrm{u}$ & $\mathrm{ug} / \mathrm{L}$ & & & $u$ & & \\
\hline SESPMNT & B17CR3 & $100 \mathrm{~F}-3$ HRM 19.0 & ONSITE & sw & Y & RIVER 7 & TRANSECT & $08-\mathrm{Sep}-03 \mathrm{Ag}$ & & $0.0085 \mathrm{u}$ & ug/L $/ \mathrm{L}$ & & & u & & \\
\hline SESPMNT & B17CR4 & 100 F - 5 HRM 19.0 & ONSITE & sw & Y & RIVER & TRANSECT & 08-Sep-03 Ag & & $0.0085 \mathrm{u}$ & ug/L & & & u & & \\
\hline SESPMNT & B17CR5 & 100 F -7 HRM 19.0 & ONSITE & sw & $\mathrm{Y}$ & RIVER T & TRANSECT & 08-Sep-03 Ag & & $0.0085 \mathrm{u}$ & ug/L & & & U & & \\
\hline SESPMNT & B17CY5 & 100 F SHORE HRM 18 & ONSITE & sw & $\mathrm{N}$ & RIVER T & TRANSECT & $08-\mathrm{Sep}-03 \mathrm{Ag}$ & & $0.0085 u$ & & & & U & & \\
\hline SESPMNT & B17CY6 & 100 F SHORE HRM 18 & ONSITE & sw & Y & RIVER 7 & TRANSECT & $08-\mathrm{Sep}-03 \mathrm{Ag}$ & & $0.0085 \mathrm{u}$ & $\mathrm{ug} / \mathrm{L}$ & & & $u$ & & \\
\hline SESPMNT & B17CY8 & 100 F SHORE HRM 22 & ONSITE & sW & $\mathrm{N}$ & RIVER 7 & TRANSECT & $08-\mathrm{Sep}-03 \mathrm{Ag}$ & & $0.0085 u$ & $\mathrm{ug} / \mathrm{L}$ & & & U & & \\
\hline SESPMNT & B17CY9 & 100 F SHORE HRM 22 & ONSITE & sw & Y & RIVER T & TRANSECT & $08-\mathrm{Sep}-03 \mathrm{Ag}$ & & $0.0085 \mathrm{u}$ & $\mathrm{ug} / \mathrm{L}$ & & & u & & \\
\hline SESPMNT & B17D01 & $100 \mathrm{~F}$ SHORE HRM 23 & ONSITE & sw & $\mathrm{N}$ & RIVER T & TRANSECT & 08-Sep-03 Ag & & $0.0085 \mathrm{u}$ & $\mathrm{ug} / \mathrm{L}$ & & & u & & \\
\hline SESPMNT & B17D02 & 100 F SHORE HRM 23 & ONSITE & sw & $\mathrm{Y}$ & RIVER 7 & TRANSECT & 08-Sep-03 Ag & & $0.0085 u$ & $\mathrm{ug} / \mathrm{L}$ & & & U & & \\
\hline SESPMNT & B17C97 & HANFRD TS-1 HRM 28.7 & ONSITE & sw & $\mathrm{N}$ & RIVER T & TRANSECT & $08-\mathrm{Sep}-03 \mathrm{Ag}$ & & $0.0085 \mathrm{u}$ & $\mathrm{ug} / \mathrm{L}$ & & & u & & \\
\hline SESPMNT & B17CP5 & HANFRD TS-1 HRM 28.7 & ONSITE & sw & $\mathrm{Y}$ & RIVER T & TRANSECT & 08-Sep-03 Ag & & $0.0085 \mathrm{u}$ & $\mathrm{ug} / \mathrm{L}$ & & & u & & \\
\hline SESPMNT & B17CB2 & HANFRD TS-10 HRM 28.7 & ONSITE & sw & $\mathrm{N}$ & RIVER T & TRANSECT & 08-Sep-03 Ag & & $0.0085 \mathrm{u}$ & ug/L & & & u & & \\
\hline SESPMNT & B17CRO & HANFRD TS-10 HRM 28.7 & ONSITE & sw & $\mathrm{Y}$ & RIVER T & TRANSECT & 08-Sep-03 Ag & & $0.0085 \mathrm{u}$ & ug/L & & & u & & \\
\hline SESPMNT & B17C98 & HANFRD TS-2 HRM 28.7 & ONSITE & sw & $\mathrm{N}$ & RIVER 7 & TRANSECT & 08-Sep-03 Ag & & $0.0085 \mathrm{u}$ & ug/L & & & u & & \\
\hline SESPMNT & B17CP6 & HANFRD TS-2 HRM 28.7 & ONSITE & sW & $\mathrm{Y}$ & RIVER T & TRANSECT & $08-\mathrm{Sep}-03 \mathrm{Ag}$ & & $0.0085 u$ & $\mathrm{ug} / \mathrm{L}$ & & & U & & \\
\hline SESPMNT & B17C99 & HANFRD TS-3 HRM 28.7 & ONSITE & sW & $\mathrm{N}$ & RIVER T & TRANSECT & $08-\mathrm{Sep}-03 \mathrm{Ag}$ & & $0.0085 u$ & $\mathrm{ug} / \mathrm{L}$ & & & U & & \\
\hline SESPMNT & B17CP7 & HANFRD TS-3 HRM 28.7 & ONSITE & SW & $\mathrm{Y}$ & RIVER T & TRANSECT & 08-Sep-03 Ag & & $0.0085 \mathrm{u}$ & $\mathrm{ug} / \mathrm{L}$ & & & u & & \\
\hline SESPMNT & B17CB0 & HANFRD TS-5 HRM 28.7 & ONSITE & sW & $\mathrm{N}$ & RIVER T & TRANSECT & 08-Sep-03 Ag & & $0.0085 u$ & $\mathrm{ug} / \mathrm{L}$ & & & U & & \\
\hline SESPMNT & B17CP8 & HANFRD TS-5 HRM 28.7 & ONSITE & sw & $\mathrm{Y}$ & RIVER T & TRANSECT & $08-\mathrm{Sep}-03 \mathrm{Ag}$ & & $0.0085 u$ & ug/L & & & u & & \\
\hline SESPMNT & B17CB1 & HANFRD TS-7 HRM 28.7 & ONSITE & sw & $\mathrm{N}$ & RIVER 7 & TRANSECT & 08-Sep-03 Ag & & $0.0085 \mathrm{u}$ & & & & u & & \\
\hline SESPMNT & B17CP9 & HANFRD TS-7 HRM 28.7 & ONSITE & sw & Y & RIVER T & TRANSECT & 08-Sep-03 Ag & & $0.0085 \mathrm{u}$ & $\mathrm{ug} / \mathrm{L}$ & & & u & & \\
\hline
\end{tabular}


WATER - COLUMBIA RIVER TRANSECT

\begin{tabular}{|c|c|c|c|c|c|c|c|c|c|c|c|c|c|c|c|c|}
\hline | OWNER ID & SAMP NUM & SAMP SITE NAME & DIST CLASS & $\mid$ MEDIA & \begin{tabular}{|c|} 
FILTERED \\
FLAG
\end{tabular} & $\begin{array}{l}\text { SAMP } \\
\text { FROM }\end{array}$ & COLL MTHD & SAMP DATE & CON SHORT NAME & \begin{tabular}{c|c} 
VALUE \\
RPTD
\end{tabular} & \begin{tabular}{|l|l|} 
ANAL \\
UNITS \\
RPTD \\
\end{tabular} & $\begin{array}{c}\text { COUNTING } \\
\text { ERROR }\end{array}$ & \begin{tabular}{|c|} 
TOTAL \\
ANAL \\
ERROR
\end{tabular} & $\begin{array}{c}\text { LAB } \\
\text { QUALIFIER }\end{array}$ & SAMP COMMENT & $\begin{array}{l}\text { RESULT } \\
\text { COMMENT }\end{array}$ \\
\hline SESPMNT & B17CL7 & HANFRD TWNSITE HRM26 & ONSITE & sW & $\mathrm{N}$ & RIVER & TRANSECT & 08-Sep-03 Ag & & & & & & U & - & \\
\hline SESPMNT & B17CMO & HANFRD TWNSITE HRM26 & ONSITE & sw & $\mathrm{Y}$ & RIVER & TRANSECT & $08-\mathrm{Sep}-03 \mathrm{Ag}$ & & $0.0085 \mathrm{u}$ & $\mathrm{ug} / \mathrm{L}$ & & & $\mathrm{U}$ & & \\
\hline SESPMNT & B17CL8 & HANFRD TWNSITE HRM27 & ONSITE & sw & $\mathrm{N}$ & RIVER & TRANSECT & 08-Sep-03 Ag & & $0.0085 \mathrm{u}$ & $\mathrm{ug} / \mathrm{L}$ & & & u & & \\
\hline SESPMNT & B17CM1 & HANFRD TWNSITE HRM27 & ONSITE & sw & $\mathrm{Y}$ & RIVER & TRANSECT & 08-Sep-03 Ag & & $0.0085 \mathrm{u}$ & $\mathrm{ug} / \mathrm{L}$ & & & u & & \\
\hline SESPMNT & $\mathrm{B} 17 \mathrm{CY} 2$ & HANFRD TWNSITE HRM28 & ONSITE & sw & $\mathrm{N}$ & RIVER & TRANSECT & 08-Sep-03 Ag & & $0.0085 \mathrm{u}$ & $\mathrm{ug} / \mathrm{L}$ & & & $u$ & & \\
\hline SESPMNT & B17CY3 & HANFRD TWNSITE HRM28 & ONSITE & sw & $\mathrm{Y}$ & RIVER & TRANSECT & $08-\mathrm{Sep}-03 \mathrm{Ag}$ & & $0.0085 \mathrm{u}$ & & & & $u$ & & \\
\hline SESPMNT & B17CL9 & HANFRD TWNSITE HRM30 & ONSITE & sw & $\mathrm{N}$ & RIVER & TRANSECT & $08-\mathrm{Sep}-03 \mathrm{Ag}$ & & $0.0085 \mathrm{u}$ & & & & $\mathrm{U}$ & & \\
\hline SESPMNT & B17CM2 & HANFRD TWNSITE HRM30 & ONSITE & sw & $\mathrm{Y}$ & RIVER & TRANSECT & $08-\mathrm{Sep}-03 \mathrm{Ag}$ & & & & & & U & & \\
\hline SESPMNT & B17CN9 & 300 AREA - 1 HRM 43.1 & ONSITE & sw & $\mathrm{Y}$ & RIVER & TRANSECT & $09-\mathrm{Sep}-03 \mathrm{Ag}$ & & $0.0085 u$ & $\mathrm{ug} / \mathrm{L}$ & & & u & & \\
\hline SESPMNT & B17CP0 & 300 AREA -2 HRM 43.1 & ONSITE & sw & $\mathrm{Y}$ & RIVER & TRANSECT & $09-\mathrm{Sep}-03 \mathrm{Ag}$ & & $0.0085 u$ & $\mathrm{ug} / \mathrm{L}$ & & & U & & \\
\hline SESPMNT & B17CP1 & 300 AREA -3 HRM 43.1 & ONSITE & sw & $\mathrm{Y}$ & RIVER & TRANSECT & $09-\mathrm{Sep}-03 \mathrm{Ag}$ & & $0.0085 \mathrm{u}$ & $\mathrm{ug} / \mathrm{L}$ & & & u & & \\
\hline SESPMNT & B17CP2 & 300 AREA -5 HRM 43.1 & ONSITE & sw & $\mathrm{Y}$ & RIVER & TRANSECT & $09-\mathrm{Sep}-03 \mathrm{Ag}$ & & $0.0085 \mathrm{u}$ & $\mathrm{ug} / \mathrm{L}$ & & & u & & \\
\hline SESPMNT & B17CP3 & 300 AREA -7 HRM 43.1 & ONSITE & sw & $\mathrm{Y}$ & RIVER & TRANSECT & $09-\mathrm{Sep}-03 \mathrm{Ag}$ & & $0.0085 u$ & $\mathrm{ug} / \mathrm{L}$ & & & U & & \\
\hline SESPMNT & B17CW8 & 300 AREA SHR HRM41.5 & ONSITE & sw & $\mathrm{Y}$ & RIVER & TRANSECT & 09-Sep-03 Ag & & $0.0085 \mathrm{u}$ & $\mathrm{ug} / \mathrm{L}$ & & & u & & \\
\hline SESPMNT & B17CX2 & 300 AREA SHR HRM42.1 & ONSITE & sw & Y & RIVER & TRANSECT & $09-S e p-03 \mathrm{Ag}$ & & $0.0085 u$ & & & & U & & \\
\hline SESPMNT & B17CX6 & 300 AREA SHR HRM 42.5 & ONSITE & sw & $\mathrm{Y}$ & RIVER & TRANSECT & 09-Sep-03 Ag & & $0.0085 \mathrm{u}$ & & & & u & & \\
\hline SESPMNT & B17CY0 & 300 AREA SHR HRM 42.9 & ONSITE & sw & Y & RIVER & TRANSECT & $09-\mathrm{Sep}-03 \mathrm{Ag}$ & & $0.0085 \mathrm{u}$ & $\mathrm{ug} / \mathrm{L}$ & & & $u$ & & \\
\hline SESPMNT & B17CP4 & 300 AREA-10 HRM 43.1 & ONSITE & sw & $\mathrm{Y}$ & RIVER & TRANSECT & $09-\mathrm{Sep}-03 \mathrm{Ag}$ & & $0.0085 \mathrm{u}$ & $\mathrm{ug} / \mathrm{L}$ & & & U & & \\
\hline SESPMNT & B17CT4 & RICH.PMPHS HRM 43.5 & OFFSITE & sw & Y & RIVER & TRANSECT & $09-\mathrm{Sep}-03 \mathrm{Ag}$ & & $0.0085 \mathrm{u}$ & $\mathrm{ug} / \mathrm{L}$ & & & u & & \\
\hline SESPMNT & B17CT2 & RICH.PMPHS HRM 45.0 & OFFSITE & sw & $\mathrm{Y}$ & RIVER & TRANSECT & 09-Sep-03 Ag & & $0.0085 \mathrm{u}$ & $\mathrm{ug} / \mathrm{L}$ & & & u & & \\
\hline SESPMNT & B17CT1 & RICH.PMPHS HRM 45.8 & OFFSITE & sw & $\mathrm{Y}$ & RIVER & TRANSECT & $09-\mathrm{Sep}-03 \mathrm{Ag}$ & & $0.0085 u$ & $\mathrm{ug} / \mathrm{L}$ & & & U & & \\
\hline SESPMNT & B17CD0 & RICH.PMPHS-1 HRM46.4 & OFFSITE & sw & $\mathrm{N}$ & RIVER & TRANSECT & 09-Sep-03 Ag & & $0.0085 \mathrm{u}$ & & & & u & & \\
\hline SESPMNT & B17CN3 & RICH.PMPHS-1 HRM46.4 & OFFSITE & sw & $\mathrm{Y}$ & RIVER & TRANSECT & $09-$ Sep-03 Ag & & $0.0085 \mathrm{u}$ & & & & u & & \\
\hline SESPMNT & B17CD5 & RICH.PMPHS-10 HRM46.4 & OFFSITE & sw & $\mathrm{N}$ & RIVER & TRANSECT & 09-Sep-03 Ag & & $0.0085 \mathrm{u}$ & $\mathrm{ug} / \mathrm{L}$ & & & u & & \\
\hline SESPMNT & B17CN8 & RICH.PMPHS-10 HRM46.4 & OFFSITE & sw & $\mathrm{Y}$ & RIVER & TRANSECT & $09-\mathrm{Sep}-03 \mathrm{Ag}$ & & $0.0085 u$ & $\mathrm{ug} / \mathrm{L}$ & & & U & & \\
\hline SESPMNT & B17CD1 & RICH.PMPHS-2 HRM46.4 & OFFSITE & sw & $\mathrm{N}$ & RIVER & TRANSECT & $09-\mathrm{Sep}-03 \mathrm{Ag}$ & & $0.0085 u$ & $\mathrm{ug} / \mathrm{L}$ & & & u & & \\
\hline SESPMNT & B17CN4 & RICH.PMPHS-2 HRM46.4 & OFFSITE & sw & $\mathrm{Y}$ & RIVER & TRANSECT & $09-S e p-03 \mathrm{Ag}$ & & $0.0085 \mathrm{u}$ & $\mathrm{ug} / \mathrm{L}$ & & & U & & \\
\hline SESPMNT & B17CD2 & RICH.PMPHS-3 HRM46.4 & OFFSITE & sw & $\mathrm{N}$ & RIVER & TRANSECT & $09-\mathrm{Sep}-03 \mathrm{Ag}$ & & $0.0085 u$ & $\mathrm{ug} / \mathrm{L}$ & & & U & & \\
\hline SESPMNT & B17CN5 & RICH.PMPHS-3 HRM46.4 & OFFSITE & sw & Y & RIVER & TRANSECT & $09-\mathrm{Sep}-03 \mathrm{Ag}$ & & $0.0085 \mathrm{u}$ & $\mathrm{ug} / \mathrm{L}$ & & & $u$ & & \\
\hline SESPMNT & B17CD3 & RICH.PMPHS-5 HRM46.4 & OFFSITE & sw & $\mathrm{N}$ & RIVER & TRANSECT & $09-\mathrm{Sep}-03 \mathrm{Ag}$ & & $0.0085 \mathrm{u}$ & & & & U & & \\
\hline SESPMNT & B17CN6 & RICH.PMPHS-5 HRM46.4 & OFFSITE & sw & $\mathrm{Y}$ & RIVER & TRANSECT & $09-\mathrm{Sep}-03 \mathrm{Ag}$ & & $0.0085 \mathrm{u}$ & & & & u & & \\
\hline SESPMNT & B17CD4 & RICH.PMPHS-7 HRM46.4 & OFFSITE & sw & $\mathrm{N}$ & RIVER & TRANSECT & $09-\mathrm{Sep}-03 \mathrm{Ag}$ & & $0.0085 \mathrm{u}$ & $\mathrm{ug} / \mathrm{L}$ & & & U & & \\
\hline SESPMNT & B17CN7 & RICH.PMPHS-7 HRM46.4 & OFFSITE & sw & $\mathrm{Y}$ & RIVER & TRANSECT & 09-Sep-03 Ag & & $0.0085 \mathrm{u}$ & $\mathrm{ug} / \mathrm{L}$ & & & u & & \\
\hline SESPMNT & B183W4 & RICH.PMPHS HRM 43.5 & OFFSITE & sw & Y & RIVER & TRANSECT & 08-Dec-03 Ag & & $0.0085 \mathrm{u}$ & ug/L & & & u & & \\
\hline SESPMNT & B183W8 & RICH.PMPHS HRM 43.5 & OFFSITE & sw & $\mathrm{N}$ & RIVER & TRANSECT & $08-\mathrm{Dec}-03 \mathrm{Ag}$ & & $0.009 \mathrm{u}$ & ug/L & & & $\mathrm{U}$ & & \\
\hline SESPMNT & B183W3 & RICH.PMPHS HRM 43.9 & OFFSITE & sw & $\mathrm{Y}$ & RIVER & TRANSECT & $08-\mathrm{Dec}-03 \mathrm{Ag}$ & & $0.0085 \mathrm{u}$ & ug/L & & & $\mathrm{U}$ & & \\
\hline SESPMNT & B183W7 & RICH.PMPHS HRM 43.9 & OFFSITE & sw & $\mathrm{N}$ & RIVER & TRANSECT & 08-Dec-03 Ag & & $0.0085 u$ & & & & u & & \\
\hline SESPMNT & B183W2 & RICH.PMPHS HRM 45.0 & OFFSITE & sw & $\mathrm{Y}$ & RIVER & TRANSECT & $08-D e c-03 \mathrm{Ag}$ & & $0.0085 u$ & $\mathrm{ug} / \mathrm{L}$ & & & u & & \\
\hline SESPMNT & B183W6 & RICH.PMPHS HRM 45.0 & OFFSITE & sw & $\mathrm{N}$ & RIVER & TRANSECT & 08-Dec-03 Ag & & $0.0085 \mathrm{u}$ & $\mathrm{ug} / \mathrm{L}$ & & & u & & \\
\hline SESPMNT & B183W1 & RICH.PMPHS HRM 45.8 & OFFSITE & sw & $\mathrm{Y}$ & RIVER & TRANSECT & $08-\mathrm{Dec}-03 \mathrm{Ag}$ & & $0.0085 u$ & $\mathrm{ug} / \mathrm{L}$ & & & U & & \\
\hline SESPMNT & B183W5 & RICH.PMPHS HRM 45.8 & OFFSITE & sw & $\mathrm{N}$ & RIVER & TRANSECT & $08-\mathrm{Dec}-03 \mathrm{Ag}$ & & $0.0085 \mathrm{u}$ & $\mathrm{ug} / \mathrm{L}$ & & & $u$ & & \\
\hline SESPMNT & B183P9 & RICH.PMPHS-1 HRM46.4 & OFFSITE & sw & $\mathrm{N}$ & RIVER & TRANSECT & 08-Dec-03 Ag & & $0.0085 u$ & $\mathrm{ug} / \mathrm{L}$ & & & u & & \\
\hline SESPMNT & B183V1 & RICH.PMPHS-1 HRM46.4 & OFFSITE & sw & $\mathrm{Y}$ & RIVER & TRANSECT & 08-Dec-03 Ag & & $0.0085 \mathrm{u}$ & ug/L & & & u & & \\
\hline SESPMNT & B183R4 & RICH.PMPHS-10 HRM46.4 & OFFSITE & sw & $\mathrm{N}$ & RIVER & TRANSECT & 08-Dec-03 Ag & & $0.0085 \mathrm{u}$ & ug/L & & & u & & \\
\hline SESPMNT & B183V6 & RICH.PMPHS-10 HRM46.4 & OFFSITE & sw & $\mathrm{Y}$ & RIVER & TRANSECT & $08-D e c-03 \mathrm{Ag}$ & & $0.0085 u$ & & & & U & & \\
\hline SESPMNT & B183R0 & RICH.PMPHS-2 HRM46.4 & OFFSITE & sw & $\mathrm{N}$ & RIVER & TRANSECT & $08-\mathrm{Dec}-03 \mathrm{Ag}$ & & $0.0085 \mathrm{u}$ & $\mathrm{ug} / \mathrm{L}$ & & & u & & \\
\hline SESPMNT & B183V2 & RICH.PMPHS-2 HRM46.4 & OFFSITE & sW & $\mathrm{Y}$ & RIVER & TRANSECT & $08-\mathrm{Dec}-03 \mathrm{Ag}$ & & $0.0085 u$ & $\mathrm{ug} / \mathrm{L}$ & & & U & & \\
\hline SESPMNT & B183R1 & RICH.PMPHS-3 HRM46.4 & OFFSITE & sw & $\mathrm{N}$ & RIVER & TRANSECT & 08 -Dec-03 Ag & & $0.0085 \mathrm{u}$ & $\mathrm{ug} / \mathrm{L}$ & & & u & & \\
\hline SESPMNT & B183V3 & RICH.PMPHS-3 HRM46.4 & OFFSITE & sw & $\mathrm{Y}$ & RIVER & TRANSECT & 08-Dec-03 Ag & & $0.0085 \mathrm{u}$ & $\mathrm{ug} / \mathrm{L}$ & & & $u$ & & \\
\hline SESPMNT & B183R2 & RICH.PMPHS-5 HRM46.4 & OFFSITE & sw & $\mathrm{N}$ & RIVER & TRANSECT & 08 -Dec-03 Ag & & $0.0085 u$ & $\mathrm{ug} / \mathrm{L}$ & & & u & & \\
\hline SESPMNT & B183V4 & RICH.PMPHS-5 HRM46.4 & OFFSITE & sw & $\mathrm{Y}$ & RIVER & TRANSECT & 08 -Dec-03 Ag & & $0.0085 \mathrm{u}$ & $\mathrm{ug} / \mathrm{L}$ & & & u & & \\
\hline SESPMNT & B183R3 & RICH.PMPHS-7 HRM46.4 & OFFSITE & sw & $\mathrm{N}$ & RIVER & TRANSECT & 08-Dec-03 Ag & & $0.0085 \mathrm{u}$ & $\mathrm{ug} / \mathrm{L}$ & & & u & & \\
\hline SESPMNT & B183v5 & RICH.PMPHS-7 HRM46.4 & OFFSITE & sw & $\mathrm{Y}$ & RIVER & TRANSECT & 08-Dec-03 Ag & & $0.0085 \mathrm{u}$ & ug/L & & & u & & \\
\hline SESPMNT & B183R5 & VERNITA-1 HRM 0.3 & OFFSITE & sw & $\mathrm{N}$ & RIVER & TRANSECT & 09-Dec-03 Ag & & $0.0085 \mathrm{u}$ & ug/L & & & u & & \\
\hline SESPMNT & B183T7 & VERNITA-1 HRM 0.3 & OFFSITE & sw & $\mathrm{Y}$ & RIVER & TRANSECT & 09-Dec-03 Ag & & $0.0085 \mathrm{u}$ & ug/L & & & U & & \\
\hline SESPMNT & B183P6 & VERNITA-2 HRM 0.3 & OFFSITE & sW & $\mathrm{N}$ & RIVER & TRANSECT & 09-Dec-03 Ag & & $0.0085 u$ & $\mathrm{ug} / \mathrm{L}$ & & & U & & \\
\hline SESPMNT & B183T8 & VERNITA-2 HRM 0.3 & OFFSITE & sW & $\mathrm{Y}$ & RIVER & TRANSECT & 09-Dec-03 Ag & & $0.0085 u$ & $\mathrm{ug} / \mathrm{L}$ & & & U & & \\
\hline SESPMNT & B183P7 & VERNITA-3 HRM 0.3 & OFFSITE & SW & $\mathrm{N}$ & RIVER & TRANSECT & 09-Dec-03 Ag & & $0.0085 \mathrm{u}$ & $\mathrm{ug} / \mathrm{L}$ & & & u & & \\
\hline SESPMNT & B183T9 & VERNITA-3 HRM 0.3 & OFFSITE & sW & $\mathrm{Y}$ & RIVER & TRANSECT & 09-Dec-03 Ag & & $0.0085 u$ & $\mathrm{ug} / \mathrm{L}$ & & & U & & \\
\hline SESPMNT & B183Р8 & VERNITA-4 HRM 0.3 & OFFSITE & sw & $\mathrm{N}$ & RIVER & TRANSECT & $09-D e c-03 \mathrm{Ag}$ & & $0.0085 u$ & ug/L & & & u & & \\
\hline SESPMNT & B183Vo & VERNITA-4 HRM 0.3 & OFFSITE & sw & $\mathrm{Y}$ & RIVER & TRANSECT & 09-Dec-03 Ag & & $0.0085 \mathrm{u}$ & $\mathrm{ug} / \mathrm{L}$ & & & U & & \\
\hline SESPMNT & B16L95 & VERNITA-1 HRM 0.3 & OFFSITE & sw & $\mathrm{N}$ & RIVER & TRANSECT & 24-Mar-03 As & & $0.551 u$ & $\mathrm{ug} / \mathrm{L}$ & & & c & & \\
\hline
\end{tabular}


WATER - COLUMBIA RIVER TRANSECT

\begin{tabular}{|c|c|c|c|c|c|c|c|c|c|c|c|c|c|c|c|c|}
\hline | OWNER ID & | SAMP NUM| & SAMP SITE NAME & |DIST CLASS | & MEDIA $\left.\right|^{\mid h}$ & \begin{tabular}{|c|} 
FILTERED \\
FLAG
\end{tabular} & $\begin{array}{l}\text { SAMP } \\
\text { FROM }\end{array}$ & COLL MTHD & SAMP DATE & CON SHORT NAME & $\begin{array}{l}\text { VALUE } \\
\text { RPTD }\end{array}$ & \begin{tabular}{|l|} 
ANAL \\
UNITS \\
RPTD \\
\end{tabular} & $\begin{array}{c}\text { COUNTING } \\
\text { ERROR }\end{array}$ & \begin{tabular}{|c|c|} 
TOTAL \\
ANAL \\
ANROR
\end{tabular} & $\begin{array}{c}\text { LAB } \\
\text { QUALIFIER }\end{array}$ & SAMP COMMENT & $\begin{array}{l}\text { RESULT } \\
\text { COMMENT }\end{array}$ \\
\hline SESPMNT & B16LB7 & VERNITA-1 HRM 0.3 & OFFSITE & SW & Y & & TRANSECT & 24-Mar-03 As & & & & & & $\mathrm{C}$ & - & \\
\hline SESPMNT & B16L86 & VERNITA-2 HRM 0.3 & OFFSITE & sw & $\mathrm{N}$ & RIVER & TRANSECT & 24-Mar-03 As & & 0.584 & $\mathrm{ug} / \mathrm{L}$ & & & c & & \\
\hline SESPMNT & B16LB8 & VERNITA-2 HRM 0.3 & OFFSITE & sW & $\mathrm{Y}$ & RIVER & TRANSECT & 24-Mar-03 As & & 0.589 & $\mathrm{ug} / \mathrm{L}$ & & & C & & \\
\hline SESPMNT & B16L87 & VERNITA-3 HRM 0.3 & OFFSITE & SW & $\mathrm{N}$ & RIVER & TRANSECT & 24-Mar-03 As & & 0.598 & $3 \mathrm{ug} / \mathrm{L}$ & & & c & & \\
\hline SESPMNT & B16LB9 & VERNITA-3 HRM 0.3 & OFFSITE & sW & Y & RIVER & TRANSECT & 24-Mar-03 As & & 0.606 & $\mathrm{ug} / \mathrm{L}$ & & & c & & \\
\hline SESPMNT & B16L88 & VERNITA-4 HRM 0.3 & OFFSITE & sW & $\mathrm{N}$ & RIVER & TRANSECT & 24-Mar-03 As & & & igg/L & & & C & & \\
\hline SESPMNT & B16LC0 & VERNITA-4 HRM 0.3 & OFFSITE & sw & $\mathrm{Y}$ & RIVER & TRANSECT & 24-Mar-03 As & & & & & & C & & \\
\hline SESPMNT & B16LD4 & RICH.PMPHS HRM 43.5 & OFFSITE & sW & $\mathrm{Y}$ & RIVER & TRANSECT & 25-Mar-03 As & & & & & & C & & \\
\hline SESPMNT & B16LD8 & RICH.PMPHS HRM 43.5 & OFFSITE & SW & $\mathrm{N}$ & RIVER & TRANSECT & 25-Mar-03 As & & 0.58 & $3 \mathrm{ug} / \mathrm{L}$ & & & C & & \\
\hline SESPMNT & B16LD3 & RICH.PMPHS HRM 43.9 & OFFSITE & sw & $\mathrm{Y}$ & RIVER & TRANSECT & 25-Mar-03 As & & 0.585 & $\mathrm{sug} / \mathrm{L}$ & & & C & & \\
\hline SESPMNT & B16LD7 & RICH.PMPHS HRM 43.9 & OFFSITE & SW & $\mathrm{N}$ & RIVER & TRANSECT & 25-Mar-03 As & & 0.599 & $\mathrm{ug} / \mathrm{L}$ & & & C & & \\
\hline SESPMNT & B16LD2 & RICH.PMPHS HRM 45.0 & OFFSITE & sw & $\mathrm{Y}$ & RIVER & TRANSECT & 25-Mar-03 As & & 0.563 & $3 \mathrm{ug} / \mathrm{L}$ & & & C & & \\
\hline SESPMNT & B16LD6 & RICH.PMPHS HRM 45.0 & OFFSITE & sW & $\mathrm{N}$ & RIVER & TRANSECT & 25-Mar-03 As & & 0.587 & & & & C & & \\
\hline SESPMNT & B16LD1 & RICH.PMPHS HRM 45.8 & OFFSITE & sw & $\mathrm{Y}$ & RIVER & TRANSECT & 25-Mar-03 As & & 0.597 & & & & c & & \\
\hline SESPMNT & B16LD5 & RICH.PMPHS HRM 45.8 & OFFSITE & sW & $\mathrm{N}$ & RIVER & TRANSECT & 25-Mar-03 As & & 0.614 & & & & C & & \\
\hline SESPMNT & B16L89 & RICH.PMPHS-1 HRM46.4 & OFFSITE & sw & $\mathrm{N}$ & RIVER & TRANSECT & 25-Mar-03 As & & 0.615 & & & & C & & \\
\hline SESPMNT & B16LC1 & RICH.PMPHS-1 HRM46.4 & OFFSITE & sw & $\mathrm{Y}$ & RIVER & TRANSECT & 25-Mar-03 As & & 0.592 & e.ug/L & & & c & & \\
\hline SESPMNT & B16L94 & RICH.PMPHS-10 HRM46.4 & OFFSITE & sW & $\mathrm{N}$ & RIVER & TRANSECT & 25-Mar-03 As & & 1.04 & igg/L & & & C & & \\
\hline SESPMNT & B16LC6 & RICH.PMPHS-10 HRM46.4 & OFFSITE & sw & Y & RIVER & TRANSECT & 25-Mar-03 As & & 1.07 & $\mathrm{ug} / \mathrm{L}$ & & & c & & \\
\hline SESPMNT & B16L90 & RICH.PMPHS-2 HRM46.4 & OFFSITE & SW & $\mathrm{N}$ & RIVER & TRANSECT & $25-M a r-03$ As & & 0.583 & $3 \mathrm{ug} / \mathrm{L}$ & & & $\mathrm{c}$ & & \\
\hline SESPMNT & B16LC2 & RICH.PMPHS-2 HRM46.4 & OFFSITE & sW & $\mathrm{Y}$ & RIVER & TRANSECT & 25-Mar-03 As & & 0.602 & & & & $\mathrm{C}$ & & \\
\hline SESPMNT & B16L91 & RICH.PMPHS-3 HRM46.4 & OFFSITE & sW & $\mathrm{N}$ & RIVER & TRANSECT & 25-Mar-03 As & & 0.599 & & & & c & & \\
\hline SESPMNT & B16LC3 & RICH.PMPHS-3 HRM 46.4 & OFFSITE & sW & $\mathrm{Y}$ & RIVER & TRANSECT & 25-Mar-03 As & & 0.583 & & & & c & & \\
\hline SESPMNT & B16L92 & RICH.PMPHS-5 HRM46.4 & OFFSITE & sw & $\mathrm{N}$ & RIVER & TRANSECT & $25-\mathrm{Mar}-03 \mathrm{As}$ & & 0.563 & $3 \mathrm{ug} / \mathrm{L}$ & & & $\mathrm{c}$ & & \\
\hline SESPMNT & B16LC4 & RICH.PMPHS-5 HRM46.4 & OFFSITE & sW & $\mathrm{Y}$ & RIVER & TRANSECT & 25-Mar-03 As & & 0.593 & $3 \mathrm{ug} / \mathrm{L}$ & & & C & & \\
\hline SESPMNT & B16L93 & RICH.PMPHS-7 HRM46.4 & OFFSITE & sw & $\mathrm{N}$ & RIVER & TRANSECT & 25-Mar-03 As & & 0.605 & sug/L & & & C & & \\
\hline SESPMNT & B16LC5 & RICH.PMPHS-7 HRM46.4 & OFFSITE & sW & $\mathrm{Y}$ & RIVER & TRANSECT & 25-Mar-03 As & & 0.587 & ug/L & & & C & & \\
\hline SESPMNT & B171V9 & VERNITA-1 HRM 0.3 & OFFSITE & sW & $\mathrm{N}$ & RIVER & TRANSECT & 09-Jun-03 As & & 0.769 & $\mathrm{ug} / \mathrm{L}$ & & & C & & \\
\hline SESPMNT & B171Y1 & VERNITA-1 HRM 0.3 & OFFSITE & sw & $\mathrm{Y}$ & RIVER & TRANSECT & 09-Jun-03 As & & 0.644 & $\mathrm{ug} / \mathrm{L}$ & & & C & & \\
\hline SESPMNT & B171V0 & VERNITA-2 HRM 0.3 & OFFSITE & sw & $\mathrm{N}$ & RIVER & TRANSECT & 09-Jun-03 As & & 0.755 & & & & C & & \\
\hline SESPMNT & B171Y2 & VERNITA-2 HRM 0.3 & OFFSITE & sw & Y & RIVER & TRANSECT & 09-Jun-03 As & & 0.598 & & & & c & & \\
\hline SESPMNT & B171V1 & VERNITA-3 HRM 0.3 & OFFSITE & sW & $\mathrm{N}$ & RIVER & TRANSECT & 09-Jun-03 As & & 0.82 & ug/L $/ \mathrm{L} / \mathrm{h} / \mathrm{h}$ & & & C & & \\
\hline SESPMNT & B171Y3 & VERNITA-3 HRM 0.3 & OFFSITE & SW & Y & RIVER & TRANSECT & 09-Jun-03 As & & 0.664 & ug/L & & & $\mathrm{c}$ & & \\
\hline SESPMNT & B171V2 & VERNITA-4 HRM 0.3 & OFFSITE & sw & $\mathrm{N}$ & RIVER & TRANSECT & 09-Jun-03 As & & 0.866 & ug/L & & & $\mathrm{c}$ & & \\
\hline SESPMNT & B171Y4 & VERNITA-4 HRM 0.3 & OFFSITE & sW & $\mathrm{Y}$ & RIVER & TRANSECT & 09-Jun-03 As & & 0.646 & $\mathrm{igg} / \mathrm{L}$ & & & C & & \\
\hline SESPMNT & B17208 & RICH.PMPHS HRM 43.5 & OFFSITE & sw & Y & RIVER & TRANSECT & 10-Jun-03 As & & 0.623 & & & & C & & \\
\hline SESPMNT & B17212 & RICH.PMPHS HRM 43.5 & OFFSITE & sw & $\mathrm{N}$ & RIVER & TRANSECT & 10-Jun-03 As & & 0.842 & & & & C & & \\
\hline SESPMNT & B17207 & RICH.PMPHS HRM 43.9 & OFFSITE & sW & $\mathrm{Y}$ & RIVER & TRANSECT & 10-Jun-03 As & & 0.636 & & & & c & & \\
\hline SESPMNT & B17211 & RICH.PMPHS HRM 43.9 & OFFSITE & sw & $\mathrm{N}$ & RIVER & TRANSECT & 10-Jun-03 As & & 0.846 & ug/L/ & & & $\mathrm{c}$ & & \\
\hline SESPMNT & B17206 & RICH.PMPHS HRM 45.0 & OFFSITE & sW & $\mathrm{Y}$ & RIVER & TRANSECT & 10-Jun-03 As & & 0.662 & ing/L & & & C & & \\
\hline SESPMNT & B17210 & RICH.PMPHS HRM 45.0 & OFFSITE & sw & $\mathrm{N}$ & RIVER & TRANSECT & 10-Jun-03 As & & 0.812 & ug/L & & & $\mathrm{c}$ & & \\
\hline SESPMNT & B17205 & RICH.PMPHS HRM 45.8 & OFFSITE & sW & $\mathrm{Y}$ & RIVER & TRANSECT & 10-Jun-03 As & & 0.59 & $\mathrm{ug} / \mathrm{L}$ & & & c & & \\
\hline SESPMNT & B17209 & RICH.PMPHS HRM 45.8 & OFFSITE & sw & $\mathrm{N}$ & RIVER & TRANSECT & 10-Jun-03 As & & 0.845 & ug/L & & & c & & \\
\hline SESPMNT & B171V3 & RICH.PMPHS-1 HRM46.4 & OFFSITE & sw & $\mathrm{N}$ & RIVER & TRANSECT & 10-Jun-03 As & & 0.847 & ug/L $/ \mathrm{L}$ & & & $\mathrm{c}$ & & \\
\hline SESPMNT & B171Y5 & RICH.PMPHS-1 HRM46.4 & OFFSITE & sW & $\mathrm{Y}$ & RIVER & TRANSECT & 10-Jun-03 As & & 0.666 & & & & C & & \\
\hline SESPMNT & B171V8 & RICH.PMPHS-10 HRM46.4 & OFFSITE & sw & $\mathrm{N}$ & RIVER & TRANSECT & 10-Jun-03 As & & & & & & C & & \\
\hline SESPMNT & B17200 & RICH.PMPHS-10 HRM46.4 & OFFSITE & sW & $\mathrm{Y}$ & RIVER & TRANSECT & 10-Jun-03 As & & 0.697 & ug/L & & & C & & \\
\hline SESPMNT & B171V4 & RICH.PMPHS-2 HRM 46.4 & OFFSITE & sw & $\mathrm{N}$ & RIVER & TRANSECT & 10-Jun-03 As & & 0.87 & ug/L $/ \mathrm{L}$ & & & c & & \\
\hline SESPMNT & B171Y6 & RICH.PMPHS-2 HRM46.4 & OFFSITE & SW & $\mathrm{Y}$ & RIVER & TRANSECT & 10-Jun-03 As & & 0.596 & ing/L & & & $\mathrm{c}$ & & \\
\hline SESPMNT & B171V5 & RICH.PMPHS-3 HRM46.4 & OFFSITE & sW & $\mathrm{N}$ & RIVER & TRANSECT & 10-Jun-03 As & & 0.863 & $3 \mathrm{ug} / \mathrm{L}$ & & & C & & \\
\hline SESPMNT & B171Y7 & RICH.PMPHS-3 HRM46.4 & OFFSITE & sw & $\mathrm{Y}$ & RIVER & TRANSECT & 10-Jun-03 As & & 0.613 & $3 \mathrm{ug} / \mathrm{L}$ & & & $\mathrm{c}$ & & \\
\hline SESPMNT & B171V6 & RICH.PMPHS-5 HRM46.4 & OFFSITE & sW & $\mathrm{N}$ & RIVER & TRANSECT & 10-Jun-03 As & & 0.797 & ug/L & & & c & & \\
\hline SESPMNT & B171Y8 & RICH.PMPHS-5 HRM46.4 & OFFSITE & sw & Y & RIVER & TRANSECT & 10-Jun-03 As & & 0.652 & ug/L & & & $\mathrm{c}$ & & \\
\hline SESPMNT & B171V7 & RICH.PMPHS-7 HRM46.4 & OFFSITE & SW & $\mathrm{N}$ & RIVER & TRANSECT & 10-Jun-03 As & & 0.835 & 3 ug/L & & & $\mathrm{c}$ & & \\
\hline SESPMNT & B171Y9 & RICH.PMPHS-7 HRM46.4 & OFFSITE & sw & $\mathrm{Y}$ & RIVER & TRANSECT & 10-Jun-03 As & & 0.649 & $\mathrm{ug} / \mathrm{L}$ & & & c & & \\
\hline SESPMNT & B17CB6 & $100 \mathrm{~N}-1$ HRM 9.5 & ONSITE & sW & $\mathrm{N}$ & RIVER & TRANSECT & 04-Sep-03 As & & 0.63 & $3 \mathrm{ug} / \mathrm{L}$ & & & & & \\
\hline SESPMNT & B17CM7 & $100 \mathrm{~N}-1$ HRM 9.5 & ONSITE & sW & $\mathrm{Y}$ & RIVER & TRANSECT & 04-Sep-03 As & & 0.577 & ug/L & & & & & \\
\hline SESPMNT & B17CC1 & $100 \mathrm{~N}-10 \mathrm{HRM} 9.5$ & ONSITE & SW & $\mathrm{N}$ & RIVER & TRANSECT & 04-Sep-03 As & & 0.582 & ug/L $/ 2$ & & & & & \\
\hline SESPMNT & B17CN2 & $100 \mathrm{~N}-10$ HRM 9.5 & ONSITE & sW & $\mathrm{Y}$ & RIVER & TRANSECT & 04-Sep-03 As & & 0.571 & ug/L & & & & & \\
\hline SESPMNT & B17CB7 & $100 \mathrm{~N}-2$ HRM 9.5 & ONSITE & sW & $\mathrm{N}$ & RIVER & TRANSECT & 04-Sep-03 As & & 0.528 & $3 \mathrm{ug} / \mathrm{L}$ & & & & & \\
\hline SESPMNT & B17CM8 & $100 \mathrm{~N}-2$ HRM 9.5 & ONSITE & SW & Y & RIVER & TRANSECT & 04-Sep-03 As & & 0.559 & ug/L $/ \mathrm{L}$ & & & & & \\
\hline SESPMNT & B17CB8 & $100 \mathrm{~N}-3$ HRM 9.5 & ONSITE & sw & $\mathrm{N}$ & RIVER & TRANSECT & 04-Sep-03 As & & 0.562 & ug/L & & & & & \\
\hline
\end{tabular}


WATER - COLUMBIA RIVER TRANSECT

\begin{tabular}{|c|c|c|c|c|c|c|c|c|c|c|c|c|c|c|c|c|}
\hline | OWNER ID & | SAMP NUM| & SAMP SITE NAME & | DIST CLASS| & MEDIA $\left.\right|^{\mid h}$ & \begin{tabular}{|c|} 
FILTERED \\
FLAG
\end{tabular} & $\begin{array}{l}\text { SAMP } \\
\text { FROM }\end{array}$ & COLL MTHD & SAMP DATE & CON SHORT NAME & $\begin{array}{l}\text { VALUE } \\
\text { RPTD }\end{array}$ & \begin{tabular}{|l|} 
ANAL \\
UNITS \\
RPTD
\end{tabular} & $\begin{array}{c}\text { COUNTING } \\
\text { ERROR }\end{array}$ & \begin{tabular}{|c|c|} 
TOTAL \\
ANAL \\
ANROR
\end{tabular} & $\begin{array}{c}\text { LAB } \\
\text { QUALIFIER }\end{array}$ & SAMP COMMENT & $\begin{array}{l}\text { RESULT } \\
\text { COMMENT }\end{array}$ \\
\hline SESPMNT & B17CM9 & $100 \mathrm{~N}-3$ HRM 9.5 & ONSITE & SW & & & TRANSECT & 04-Sep-03 As & & & & & & & - & \\
\hline SESPMNT & B17CB9 & $100 \mathrm{~N}-5$ HRM 9.5 & ONSITE & sw & $\mathrm{N}$ & RIVER & TRANSECT & 04-Sep-03 As & & 0.538 & $3 \mathrm{ug} / \mathrm{L}$ & & & & & \\
\hline SESPMNT & B17CN0 & $100 \mathrm{~N}-5$ HRM 9.5 & ONSITE & sW & $\mathrm{Y}$ & RIVER & TRANSECT & 04-Sep-03 As & & 0.498 & $3 \mathrm{ug} / \mathrm{L}$ & & & & & \\
\hline SESPMNT & B17CCO & $100 \mathrm{~N}-7$ HRM 9.5 & ONSITE & SW & $\mathrm{N}$ & RIVER & TRANSECT & 04-Sep-03 As & & 0.574 & $4 \mathrm{ug} / \mathrm{L}$ & & & & & \\
\hline SESPMNT & B17CN1 & $100 \mathrm{~N}-7$ HRM 9.5 & ONSITE & sW & Y & RIVER & TRANSECT & 04-Sep-03 As & & 0.536 & $6 \mathrm{ug} / \mathrm{L}$ & & & & & \\
\hline SESPMNT & B17CV1 & 100 N SHORE HRM 8.4 & ONSITE & sW & $\mathrm{N}$ & RIVER & TRANSECT & 04-Sep-03 As & & & & & & & & \\
\hline SESPMNT & B17CV2 & $100 \mathrm{~N}$ SHORE HRM 8.4 & ONSITE & sw & $\mathrm{Y}$ & RIVER & TRANSECT & 04-Sep-03 As & & & & & & & & \\
\hline SESPMNT & B17CV5 & $100 \mathrm{~N}$ SHORE HRM 8.9 & ONSITE & sW & $\mathrm{N}$ & RIVER & TRANSECT & 04-Sep-03 As & & & & & & & & \\
\hline SESPMNT & B17CV6 & 100 N SHORE HRM 8.9 & ONSITE & SW & $\mathrm{Y}$ & RIVER & TRANSECT & 04-Sep-03 As & & 0.56 & $6 \mathrm{ug} / \mathrm{L}$ & & & & & \\
\hline SESPMNT & B17CV9 & $100 \mathrm{~N}$ SHORE HRM 9.2 & ONSITE & sw & $\mathrm{N}$ & RIVER & TRANSECT & 04-Sep-03 As & & 0.554 & $4 \mathrm{ug} / \mathrm{L}$ & & & & & \\
\hline SESPMNT & B17CW0 & 100 N SHORE HRM 9.2 & ONSITE & sw & $\mathrm{Y}$ & RIVER & TRANSECT & 04-Sep-03 As & & 0.546 & $6 \mathrm{ug} / \mathrm{L}$ & & & & & \\
\hline SESPMNT & B17CW3 & $100 \mathrm{~N}$ SHORE HRM 9.8 & ONSITE & sw & $\mathrm{N}$ & RIVER & TRANSECT & 04-Sep-03 As & & 0.566 & $6 \mathrm{ug} / \mathrm{L}$ & & & & & \\
\hline SESPMNT & B17CW4 & 100 N SHORE HRM 9.8 & ONSITE & sw & $\mathrm{Y}$ & RIVER & TRANSECT & 04-Sep-03 As & & 0.552 & $2 \mathrm{ug} / \mathrm{L}$ & & & & & \\
\hline SESPMNT & B17CD6 & VERNITA-1 HRM 0.3 & OFFSITE & SW & $\mathrm{N}$ & RIVER & TRANSECT & 04-Sep-03 As & & 0.564 & $4 \mathrm{ug} / \mathrm{L}$ & & & & & \\
\hline SESPMNT & B17CM3 & VERNITA-1 HRM 0.3 & OFFSITE & sW & $\mathrm{Y}$ & RIVER & TRANSECT & 04-Sep-03 As & & 0.572 & & & & & & \\
\hline SESPMNT & B17CC7 & VERNITA-2 HRM 0.3 & OFFSITE & sw & $\mathrm{N}$ & RIVER & TRANSECT & 04-Sep-03 As & & 0.571 & $1 \mathrm{ug} / \mathrm{L}$ & & & & & \\
\hline SESPMNT & B17CM4 & VERNITA-2 HRM 0.3 & OFFSITE & sw & Y & RIVER & TRANSECT & 04-Sep-03 As & & 0.572 & $2 \mathrm{ug} / \mathrm{L}$ & & & & & \\
\hline SESPMNT & B17CC8 & VERNITA-3 HRM 0.3 & OFFSITE & sW & $\mathrm{N}$ & RIVER & TRANSECT & 04-Sep-03 As & & 0.592 & $2 \mathrm{ug} / \mathrm{L}$ & & & & & \\
\hline SESPMNT & B17CM5 & VERNITA-3 HRM 0.3 & OFFSITE & sW & Y & RIVER & TRANSECT & 04-Sep-03 As & & 0.532 & $2 \mathrm{ug} / \mathrm{L}$ & & & & & \\
\hline SESPMNT & B17CC9 & VERNITA-4 HRM 0.3 & OFFSITE & SW & $\mathrm{N}$ & RIVER & TRANSECT & 04-Sep-03 As & & 0.587 & $7 \mathrm{ug} / \mathrm{L}$ & & & & & \\
\hline SESPMNT & B17CM6 & VERNITA-4 HRM 0.3 & OFFSITE & SW & Y & RIVER & TRANSECT & 04-Sep-03 As & & 0.543 & & & & & & \\
\hline SESPMNT & B17CC2 & $100 \mathrm{~F}-1$ HRM 19.0 & ONSITE & sW & $\mathrm{N}$ & RIVER & TRANSECT & 08-Sep-03 As & & 0.542 & & & & & & \\
\hline SESPMNT & B17CR1 & $100 \mathrm{~F}-1 \mathrm{HRM} 19.0$ & ONSITE & sW & $\mathrm{Y}$ & RIVER & TRANSECT & 08-Sep-03 As & & 0.525 & 5 ug/L & & & & & \\
\hline SESPMNT & B17C96 & $100 \mathrm{~F}-10 \mathrm{HRM} 19.0$ & ONSITE & sw & $\mathrm{N}$ & RIVER & TRANSECT & 08-Sep-03 As & & 0.629 & $9 \mathrm{ug} / \mathrm{L}$ & & & & & \\
\hline SESPMNT & B17CR6 & $100 \mathrm{~F}-10$ HRM 19.0 & ONSITE & sw & $\mathrm{Y}$ & RIVER & TRANSECT & 08-Sep-03 As & & 0.542 & $2 \mathrm{ug} / \mathrm{L}$ & & & & & \\
\hline SESPMNT & B17CR2 & $100 \mathrm{~F}-2 \mathrm{HRM} 19.0$ & ONSITE & sW & $\mathrm{Y}$ & RIVER & TRANSECT & 08-Sep-03 As & & 0.496 & $6 \mathrm{ug} / \mathrm{L}$ & & & & & \\
\hline SESPMNT & B17CC4 & $100 \mathrm{~F}-3 \mathrm{HRM} 19.0$ & ONSITE & sW & $\mathrm{N}$ & RIVER & TRANSECT & 08-Sep-03 As & & 0.572 & $2 \mathrm{ug} / \mathrm{L}$ & & & & & \\
\hline SESPMNT & B17CR3 & 100 F -3 HRM 19.0 & ONSITE & SW & Y & RIVER & TRANSECT & $08-\mathrm{Sep}-03$ As & & 0.58 & $3 \mathrm{ug} / \mathrm{L}$ & & & & & \\
\hline SESPMNT & B17CR4 & 100 F - 5 HRM 19.0 & ONSITE & sw & Y & RIVER & TRANSECT & 08-Sep-03 As & & 0.625 & $5 \mathrm{ug} / \mathrm{L}$ & & & & & \\
\hline SESPMNT & B17CR5 & 100 F -7 HRM 19.0 & ONSITE & sW & $\mathrm{Y}$ & RIVER & TRANSECT & 08-Sep-03 As & & 0.567 & & & & & & \\
\hline SESPMNT & B17CY5 & 100 F SHORE HRM 18 & ONSITE & sw & $\mathrm{N}$ & RIVER & TRANSECT & $08-\mathrm{Sep}-03 \mathrm{As}$ & & 0.625 & & & & & & \\
\hline SESPMNT & B17CY6 & $100 \mathrm{~F}$ SHORE HRM 18 & ONSITE & sw & $\mathrm{Y}$ & RIVER & TRANSECT & 08-Sep-03 As & & 0.565 & $5 \mathrm{ug} / \mathrm{L}$ & & & & & \\
\hline SESPMNT & B17CY8 & $100 \mathrm{~F}$ SHORE HRM 22 & ONSITE & SW & $\mathrm{N}$ & RIVER & TRANSECT & 08-Sep-03 As & & 0.573 & $3 \mathrm{ug} / \mathrm{L}$ & & & & & \\
\hline SESPMNT & B17CY9 & $100 \mathrm{~F}$ SHORE HRM 22 & ONSITE & sw & Y & RIVER & TRANSECT & 08-Sep-03 As & & 0.589 & 9 ug $/ \mathrm{L}$ & & & & & \\
\hline SESPMNT & B17D01 & $100 \mathrm{~F}$ SHORE HRM 23 & ONSITE & sW & $\mathrm{N}$ & RIVER & TRANSECT & 08-Sep-03 As & & 0.586 & $6 \mathrm{ug} / \mathrm{L}$ & & & & & \\
\hline SESPMNT & B17D02 & $100 \mathrm{~F}$ SHORE HRM 23 & ONSITE & sw & $\mathrm{Y}$ & RIVER & TRANSECT & 08-Sep-03 As & & 0.55 & $5 \mathrm{ug} / \mathrm{L}$ & & & & & \\
\hline SESPMNT & B17C97 & HANFRD TS-1 HRM 28.7 & ONSITE & sw & $\mathrm{N}$ & RIVER & TRANSECT & 08-Sep-03 As & & 0.797 & $7 \mathrm{ug} / \mathrm{L}$ & & & & & \\
\hline SESPMNT & B17CP5 & HANFRD TS-1 HRM 28.7 & ONSITE & sW & $\mathrm{Y}$ & RIVER & TRANSECT & $08-\mathrm{Sep}-03$ As & & 0.646 & & & & & & \\
\hline SESPMNT & B17CB2 & HANFRD TS-10 HRM 28.7 & ONSITE & sw & $\mathrm{N}$ & RIVER & TRANSECT & 08-Sep-03 As & & 0.625 & $5 \mathrm{ug} / \mathrm{L}$ & & & & & \\
\hline SESPMNT & B17CR0 & HANFRD TS-10 HRM 28.7 & ONSITE & sW & $\mathrm{Y}$ & RIVER & TRANSECT & 08-Sep-03 As & & 0.598 & 3 ug $/ \mathrm{L}$ & & & & & \\
\hline SESPMNT & B17C98 & HANFRD TS-2 HRM 28.7 & ONSITE & sw & $\mathrm{N}$ & RIVER & TRANSECT & $08-\mathrm{Sep}-03$ As & & 0.538 & $3 \mathrm{ug} / \mathrm{L}$ & & & & & \\
\hline SESPMNT & B17CP6 & HANFRD TS-2 HRM 28.7 & ONSITE & sW & $\mathrm{Y}$ & RIVER & TRANSECT & 08-Sep-03 As & & 0.609 & $9 \mathrm{ug} / \mathrm{L}$ & & & & & \\
\hline SESPMNT & B17C99 & HANFRD TS-3 HRM 28.7 & ONSITE & sw & $\mathrm{N}$ & RIVER & TRANSECT & 08-Sep-03 As & & 0.556 & $6 \mathrm{ug} / \mathrm{L}$ & & & & & \\
\hline SESPMNT & B17CP7 & HANFRD TS-3 HRM 28.7 & ONSITE & sW & $\mathrm{Y}$ & RIVER & TRANSECT & 08-Sep-03 As & & 0.585 & $5 \mathrm{ug} / \mathrm{L}$ & & & & & \\
\hline SESPMNT & B17CB0 & HANFRD TS-5 HRM 28.7 & ONSITE & sW & $\mathrm{N}$ & RIVER & TRANSECT & $08-\mathrm{Sep}-03$ As & & 0.559 & 9 ug $/ \mathrm{L}$ & & & & & \\
\hline SESPMNT & B17CP8 & HANFRD TS-5 HRM 28.7 & ONSITE & sw & $\mathrm{Y}$ & RIVER & TRANSECT & 08-Sep-03 As & & 0.569 & & & & & & \\
\hline SESPMNT & B17CB1 & HANFRD TS-7 HRM 28.7 & ONSITE & sW & $\mathrm{N}$ & RIVER & TRANSECT & 08-Sep-03 As & & 0.598 & $3 \mathrm{ug} / \mathrm{L}$ & & & & & \\
\hline SESPMNT & B17CP9 & HANFRD TS-7 HRM 28.7 & ONSITE & sw & Y & RIVER & TRANSECT & $08-\mathrm{Sep}-03$ As & & 0.522 & $2 \mathrm{ug} / \mathrm{L}$ & & & & & \\
\hline SESPMNT & B17CL7 & HANFRD TWNSITE HRM26 & ONSITE & SW & $\mathrm{N}$ & RIVER & TRANSECT & 08-Sep-03 As & & 0.559 & $9 \mathrm{ug} / \mathrm{L}$ & & & & & \\
\hline SESPMNT & B17CM0 & HANFRD TWNSITE HRM26 & ONSITE & sW & $\mathrm{Y}$ & RIVER & TRANSECT & 08-Sep-03 As & & 0.505 & $5 \mathrm{ug} / \mathrm{L}$ & & & & & \\
\hline SESPMNT & B17CL8 & HANFRD TWNSITE HRM27 & ONSITE & sw & $\mathrm{N}$ & RIVER & TRANSECT & $08-\mathrm{Sep}-03$ As & & 0.63 & $3 \mathrm{ug} / \mathrm{L}$ & & & & & \\
\hline SESPMNT & B17CM1 & HANFRD TWNSITE HRM27 & ONSITE & sW & $\mathrm{Y}$ & RIVER & TRANSECT & 08-Sep-03 As & & 0.514 & $4 \mathrm{ug} / \mathrm{L}$ & & & & & \\
\hline SESPMNT & B17CY2 & HANFRD TWNSITE HRM28 & ONSITE & sw & $\mathrm{N}$ & RIVER & TRANSECT & 08-Sep-03 As & & 1.44 & 4 ug/L & & & & & \\
\hline SESPMNT & B17CY3 & HANFRD TWNSITE HRM28 & ONSITE & sW & $\mathrm{Y}$ & RIVER & TRANSECT & 08-Sep-03 As & & 1.38 & $3 \mathrm{ug} / \mathrm{L}$ & & & & & \\
\hline SESPMNT & B17CL9 & HANFRD TWNSITE HRM30 & ONSITE & sw & $\mathrm{N}$ & RIVER & TRANSECT & 08-Sep-03 As & & 0.637 & $7 \mathrm{ug} / \mathrm{L}$ & & & & & \\
\hline SESPMNT & B17CM2 & HANFRD TWNSITE HRM30 & ONSITE & sW & $\mathrm{Y}$ & RIVER & TRANSECT & 08-Sep-03 As & & 0.625 & $5 \mathrm{ug} / \mathrm{L}$ & & & & & \\
\hline SESPMNT & B17CN9 & 300 AREA -1 HRM 43.1 & ONSITE & sW & $\mathrm{Y}$ & RIVER & TRANSECT & 09-Sep-03 As & & 0.704 & $4 \mathrm{ug} / \mathrm{L}$ & & & & & \\
\hline SESPMNT & B17CP0 & 300 AREA - 2 HRM 43.1 & ONSITE & SW & $\mathrm{Y}$ & RIVER & TRANSECT & 09-Sep-03 As & & & $5 \mathrm{ug} / \mathrm{L}$ & & & & & \\
\hline SESPMNT & B17CP1 & 300 AREA -3 HRM 43.1 & ONSITE & sW & $\mathrm{Y}$ & RIVER & TRANSECT & 09-Sep-03 As & & & $7 \mathrm{ug} / \mathrm{L}$ & & & & & \\
\hline SESPMNT & B17CP2 & 300 AREA -5 HRM 43.1 & ONSITE & sw & $\mathrm{Y}$ & RIVER & TRANSECT & $09-\mathrm{Sep}-03$ As & & & $2 u g / L$ & & & & & \\
\hline SESPMNT & B17CP3 & 300 AREA -7 HRM 43.1 & ONSITE & sw & $\mathrm{Y}$ & RIVER & TRANSECT & 09-Sep-03 As & & 0.657 & $7 \mathrm{ug} / \mathrm{L}$ & & & & & \\
\hline SESPMNT & B17CW8 & 300 AREA SHR HRM 41.5 & ONSITE & sw & $\mathrm{Y}$ & RIVER & TRANSECT & 09-Sep-03 As & & 0.564 & $4 \mathrm{ug} / \mathrm{L}$ & & & & & \\
\hline
\end{tabular}


WATER - COLUMBIA RIVER TRANSECT

\begin{tabular}{|c|c|c|c|c|c|c|c|c|c|c|c|c|c|c|c|c|}
\hline | OWNER ID & SAMP NUM & SAMP SITE NAME & DIST CLASS & MEDIA $\left.\right|^{F}$ & \begin{tabular}{|c|} 
FILTERED \\
FLAG
\end{tabular} & $\begin{array}{l}\text { SAMP } \\
\text { FROM }\end{array}$ & COLL MTHD & SAMP DATE & CON SHORT NAME & $\begin{array}{l}\text { VALUE } \\
\text { RPTD }\end{array}$ & \begin{tabular}{|l|} 
ANAL \\
UNITS \\
RPTD \\
\end{tabular} & \begin{tabular}{|l|} 
COUNTING \\
ERROR
\end{tabular} & \begin{tabular}{|c|} 
TOTAL \\
ANAL \\
ERROR
\end{tabular} & $\begin{array}{c}\text { LAB } \\
\text { QUALIFIER }\end{array}$ & SAMP COMMENT & $\begin{array}{l}\text { RESULT } \\
\text { COMMENT }\end{array}$ \\
\hline SESPMNT & $\mathrm{B} 17 \mathrm{CX} 2$ & 300 AREA SHR HRM42.1 & ONSITE & SW & Y & RIVER T & TRANSECT & 09-Sep-03 As & & & & & & & - & \\
\hline SESPMNT & B17CX6 & 300 AREA SHR HRM42.5 & ONSITE & sW & $\mathrm{Y}$ & RIVER T & TRANSECT & 09-Sep-03 As & & 0.734 & ug/L $/ \mathrm{L}$ & & & & & \\
\hline SESPMNT & B17CY0 & 300 AREA SHR HRM42.9 & ONSITE & sw & Y & RIVER T & TRANSECT & 09-Sep-03 As & & 0.619 & $\mathrm{ug} / \mathrm{L}$ & & & & & \\
\hline SESPMNT & B17CP4 & 300 AREA-10 HRM 43.1 & ONSITE & sW & $\mathrm{Y}$ & RIVER T & TRANSECT & 09-Sep-03 As & & 0.936 & ug/L & & & & & \\
\hline SESPMNT & B17CT4 & RICH.PMPHS HRM 43.5 & OFFSITE & sw & Y & RIVER & TRANSECT & 09-Sep-03 As & & 0.649 & $\mathrm{ug} / \mathrm{L}$ & & & & & \\
\hline SESPMNT & B17CT2 & RICH.PMPHS HRM 45.0 & OFFSITE & SW & $\mathrm{Y}$ & RIVER 7 & TRANSECT & 09-Sep-03 As & & & & & & & & \\
\hline SESPMNT & B17CT1 & RICH.PMPHS HRM 45.8 & OFFSITE & sw & $\mathrm{Y}$ & RIVER 7 & TRANSECT & 09-Sep-03 As & & & & & & & & \\
\hline SESPMNT & B17CD0 & RICH.PMPHS-1 HRM46.4 & OFFSITE & sW & $\mathrm{N}$ & RIVER T & TRANSECT & 09-Sep-03 As & & & & & & & & \\
\hline SESPMNT & B17CN3 & RICH.PMPHS-1 HRM46.4 & OFFSITE & SW & $\mathrm{Y}$ & RIVER 7 & TRANSECT & 09-Sep-03 As & & 0.678 & & & & & & \\
\hline SESPMNT & B17CD5 & RICH.PMPHS-10 HRM46.4 & OFFSITE & sw & $\mathrm{N}$ & RIVER T & TRANSECT & 09-Sep-03 As & & 1.09 & & & & & & \\
\hline SESPMNT & B17CN8 & RICH.PMPHS-10 HRM46.4 & OFFSITE & SW & $\mathrm{Y}$ & RIVER T & TRANSECT & $09-S e p-03$ As & & 0.962 & ing/L & & & & & \\
\hline SESPMNT & B17CD1 & RICH.PMPHS-2 HRM46.4 & OFFSITE & sw & $\mathrm{N}$ & RIVER 7 & TRANSECT & 09-Sep-03 As & & 0.624 & & & & & & \\
\hline SESPMNT & B17CN4 & RICH.PMPHS-2 HRM46.4 & OFFSITE & sW & $\mathrm{Y}$ & RIVER T & TRANSECT & 09-Sep-03 As & & 0.649 & & & & & & \\
\hline SESPMNT & B17CD2 & RICH.PMPHS-3 HRM46.4 & OFFSITE & SW & $\mathrm{N}$ & RIVER T & $\begin{array}{l}\text { TRANSECT } \\
\text { TRES }\end{array}$ & 09-Sep-03 As & & 0.632 & ug/L & & & & & \\
\hline SESPMNT & B17CN5 & RICH.PMPHS-3 HRM46.4 & OFFSITE & SW & Y & RIVER T & TRANSECT & 09-Sep-03 As & & 0.547 & & & & & & \\
\hline SESPMNT & B17CD3 & RICH.PMPHS-5 HRM46.4 & OFFSITE & sw & $\mathrm{N}$ & RIVER 7 & TRANSECT & 09-Sep-03 As & & & & & & & & \\
\hline SESPMNT & B17CN6 & RICH.PMPHS-5 HRM 46.4 & OFFSITE & sw & Y & RIVER 7 & TRANSECT & 09-Sep-03 As & & 0.589 & & & & & & \\
\hline SESPMNT & B17CD4 & RICH.PMPHS-7 HRM46.4 & OFFSITE & sW & $\mathrm{N}$ & RIVER T & TRANSECT & 09-Sep-03 As & & 0.57 & ug/L & & & & & \\
\hline SESPMNT & B17CN7 & RICH.PMPHS-7 HRM46.4 & OFFSITE & sW & Y & RIVER T & TRANSECT & 09-Sep-03 As & & 0.538 & & & & & & \\
\hline SESPMNT & B183W4 & RICH.PMPHS HRM 43.5 & OFFSITE & SW & $\mathrm{Y}$ & RIVER T & TRANSECT & 08-Dec-03 As & & 0.83 & & & & c & & \\
\hline SESPMNT & B183W8 & RICH.PMPHS HRM 43.5 & OFFSITE & SW & $\mathrm{N}$ & RIVER T & TRANSECT & 08-Dec-03 As & & 0.474 & & & & & & \\
\hline SESPMNT & B183W3 & RICH.PMPHS HRM 43.9 & OFFSITE & sW & Y & RIVER T & TRANSECT & 08-Dec-03 As & & 0.737 & & & & c & & \\
\hline SESPMNT & B183W7 & RICH.PMPHS HRM 43.9 & OFFSITE & sw & $\mathrm{N}$ & RIVER T & TRANSECT & 08-Dec-03 As & & 0.596 & & & & & & \\
\hline SESPMNT & B183W2 & RICH.PMPHS HRM 45.0 & OFFSITE & sw & $\mathrm{Y}$ & RIVER T & TRANSECT & 08-Dec-03 As & & 0.372 & ug/L & & & C & & \\
\hline SESPMNT & B183W6 & RICH.PMPHS HRM 45.0 & OFFSITE & sw & $\mathrm{N}$ & RIVER T & TRANSECT & 08-Dec-03 As & & 0.572 & ug/L & & & & & \\
\hline SESPMNT & B183W1 & RICH.PMPHS HRM 45.8 & OFFSITE & sw & $\mathrm{Y}$ & RIVER 7 & TRANSECT & 08-Dec-03 As & & 0.617 & ug/L & & & C & & \\
\hline SESPMNT & B183W5 & RICH.PMPHS HRM 45.8 & OFFSITE & sW & $\mathrm{N}$ & RIVER T & TRANSECT & 08-Dec-03 As & & 0.599 & $\mathrm{ug} / \mathrm{L}$ & & & & & \\
\hline SESPMNT & B183P9 & RICH.PMPHS-1 HRM46.4 & OFFSITE & SW & $\mathrm{N}$ & RIVER 7 & TRANSECT & 08-Dec-03 As & & 0.323 & $3 \mathrm{ug} / \mathrm{L}$ & & & & & \\
\hline SESPMNT & B183V1 & RICH.PMPHS-1 HRM46.4 & OFFSITE & sw & $\mathrm{Y}$ & RIVER T & TRANSECT & 08-Dec-03 As & & 0.541 & & & & c & & \\
\hline SESPMNT & B183R4 & RICH.PMPHS-10 HRM46.4 & OFFSITE & sW & $\mathrm{N}$ & RIVER T & TRANSECT & 08-Dec-03 As & & 0.894 & & & & & & \\
\hline SESPMNT & B183V6 & RICH.PMPHS-10 HRM46.4 & OFFSITE & sW & $\mathrm{Y}$ & RIVER T & TRANSECT & 08-Dec-03 As & & 0.62 & & & & c & & \\
\hline SESPMNT & B183R0 & RICH.PMPHS-2 HRM46.4 & OFFSITE & SW & $\mathrm{N}$ & RIVER T & TRANSECT & 08-Dec-03 As & & 0.485 & & & & & & \\
\hline SESPMNT & B183V2 & RICH.PMPHS-2 HRM46.4 & OFFSITE & sW & $\mathrm{Y}$ & RIVER T & TRANSECT & 08-Dec-03 As & & 0.395 & ug/L & & & c & & \\
\hline SESPMNT & B183R1 & RICH.PMPHS-3 HRM46.4 & OFFSITE & sw & $\mathrm{N}$ & RIVER T & TRANSECT & 08-Dec-03 As & & 0.645 & $5 \mathrm{ug} / \mathrm{L}$ & & & & & \\
\hline SESPMNT & B183V3 & RICH.PMPHS-3 HRM46.4 & OFFSITE & SW & $\mathrm{Y}$ & RIVER T & TRANSECT & 08-Dec-03 As & & 0.367 & & & & C & & \\
\hline SESPMNT & B183R2 & RICH.PMPHS-5 HRM 46.4 & OFFSITE & sw & $\mathrm{N}$ & RIVER 7 & TRANSECT & 08-Dec-03 As & & 0.612 & & & & & & \\
\hline SESPMNT & B183V4 & RICH.PMPHS-5 HRM46.4 & OFFSITE & sW & $\mathrm{Y}$ & RIVER 7 & TRANSECT & 08-Dec-03 As & & 0.584 & & & & C & & \\
\hline SESPMNT & B183R3 & RICH.PMPHS-7 HRM46.4 & OFFSITE & sW & $\mathrm{N}$ & RIVER T & TRANSECT & 08-Dec-03 As & & 0.661 & & & & & & \\
\hline SESPMNT & B183V5 & RICH.PMPHS-7 HRM46.4 & OFFSITE & SW & $\mathrm{Y}$ & RIVER T & TRANSECT & 08-Dec-03 As & & 0.539 & ug/L $/ \mathrm{L}$ & & & c & & \\
\hline SESPMNT & B183R5 & VERNITA-1 HRM 0.3 & OFFSITE & SW & $\mathrm{N}$ & RIVER T & TRANSECT & 09-Dec-03 As & & 0.576 & $\mathrm{ing} / \mathrm{L}$ & & & & & \\
\hline SESPMNT & B183T7 & VERNITA-1 HRM 0.3 & OFFSITE & sW & Y & RIVER T & TRANSECT & 09-Dec-03 As & & 0.654 & $\mathrm{ug} / \mathrm{L}$ & & & c & & \\
\hline SESPMNT & B183P6 & VERNITA-2 HRM 0.3 & OFFSITE & SW & $\mathrm{N}$ & RIVER T & TRANSECT & 09-Dec-03 As & & 0.501 & ug/L & & & & & \\
\hline SESPMNT & B183T8 & VERNITA-2 HRM 0.3 & OFFSITE & sw & $\mathrm{Y}$ & RIVER & TRANSECT & 09-Dec-03 As & & 0.547 & ug/L & & & c & & \\
\hline SESPMNT & B183P7 & VERNITA-3 HRM 0.3 & OFFSITE & sw & $\mathrm{N}$ & RIVER T & TRANSECT & 09-Dec-03 As & & 0.362 & & & & & & \\
\hline SESPMNT & B183T9 & VERNITA-3 HRM 0.3 & OFFSITE & SW & $\mathrm{Y}$ & RIVER 7 & TRANSECT & 09-Dec-03 As & & 0.512 & & & & C & & \\
\hline SESPMNT & B183P8 & VERNITA-4 HRM 0.3 & OFFSITE & sw & $\mathrm{N}$ & RIVER 7 & TRANSECT & 09-Dec-03 As & & 0.482 & & & & & & \\
\hline SESPMNT & B183Vo & VERNITA-4 HRM 0.3 & OFFSITE & sW & $\mathrm{Y}$ & RIVER 7 & TRANSECT & 09-Dec-03 As & & 0.671 & $\mathrm{ug} / \mathrm{L}$ & & & C & & \\
\hline SESPMNT & B16L95 & VERNITA-1 HRM 0.3 & OFFSITE & sW & $\mathrm{N}$ & RIVER T & TRANSECT & 24-Mar-03 Be & & 0.028 & & & & $\mathrm{u}$ & & \\
\hline SESPMNT & B16LB7 & VERNITA-1 HRM 0.3 & OFFSITE & SW & $\mathrm{Y}$ & RIVER T & TRANSECT & 24-Mar-03 Be & & 0.028 & $3 \mathrm{ug} / \mathrm{L}$ & & & u & & \\
\hline SESPMNT & B16L86 & VERNITA-2 HRM 0.3 & OFFSITE & SW & $\mathrm{N}$ & RIVER 7 & TRANSECT & 24-Mar-03 Be & & 0.028 & $3 \mathrm{ug} / \mathrm{L}$ & & & U & & \\
\hline SESPMNT & B16LB8 & VERNITA-2 HRM 0.3 & OFFSITE & sw & $\mathrm{Y}$ & RIVER 7 & TRANSECT & 24-Mar-03 Be & & 0.028 & $3 \mathrm{ug} / \mathrm{L}$ & & & u & & \\
\hline SESPMNT & B16L87 & VERNITA-3 HRM 0.3 & OFFSITE & sw & $\mathrm{N}$ & RIVER & TRANSECT & 24-Mar-03 Be & & 0.028 & & & & u & & \\
\hline SESPMNT & B16LB9 & VERNITA-3 HRM 0.3 & OFFSITE & sW & Y & RIVER T & TRANSECT & 24-Mar-03 Be & & 0.028 & & & & U & & \\
\hline SESPMNT & B16L88 & VERNITA-4 HRM 0.3 & OFFSITE & SW & $\mathrm{N}$ & RIVER T & TRANSECT & 24-Mar-03 Be & & 0.028 & $3 \mathrm{ug} / \mathrm{L}$ & & & u & & \\
\hline SESPMNT & B16LC0 & VERNITA-4 HRM 0.3 & OFFSITE & sW & $\mathrm{Y}$ & RIVER 7 & TRANSECT & 24-Mar-03 Be & & 0.028 & $3 \mathrm{ug} / \mathrm{L}$ & & & U & & \\
\hline SESPMNT & B16LD4 & RICH.PMPHS HRM 43.5 & OFFSITE & sw & $\mathrm{Y}$ & RIVER 7 & TRANSECT & 25-Mar-03 Be & & 0.028 & $3 \mathrm{ug} / \mathrm{L}$ & & & U & & \\
\hline SESPMNT & B16LD8 & RICH.PMPHS HRM 43.5 & OFFSITE & SW & $\mathrm{N}$ & RIVER T & TRANSECT & 25-Mar-03 Be & & 0.028 & $3 \mathrm{ug} / \mathrm{L}$ & & & U & & \\
\hline SESPMNT & B16LD3 & RICH.PMPHS HRM 43.9 & OFFSITE & SW & $\mathrm{Y}$ & RIVER T & TRANSECT & 25-Mar-03 Be & & 0.028 & $3 \mathrm{ug} / \mathrm{L}$ & & & u & & \\
\hline SESPMNT & B16LD7 & RICH.PMPHS HRM 43.9 & OFFSITE & SW & $\mathrm{N}$ & RIVER T & TRANSECT & 25-Mar-03 Be & & 0.028 & $3 \mathrm{ug} / \mathrm{L}$ & & & U & & \\
\hline SESPMNT & B16LD2 & RICH.PMPHS HRM 45.0 & OFFSITE & SW & Y & RIVER 7 & TRANSECT & 25-Mar-03 Be & & & $3 \mathrm{ug} / \mathrm{L}$ & & & u & & \\
\hline SESPMNT & B16LD6 & RICH.PMPHS HRM 45.0 & OFFSITE & SW & $\mathrm{N}$ & RIVER 7 & TRANSECT & 25-Mar-03 Be & & 0.028 & & & & U & & \\
\hline SESPMNT & B16LD1 & RICH.PMPHS HRM 45.8 & OFFSITE & sW & Y & RIVER T & TRANSECT & 25-Mar-03 Be & & 0.028 & $3 \mathrm{ug} / \mathrm{L}$ & & & u & & \\
\hline
\end{tabular}


WATER - COLUMBIA RIVER TRANSECT

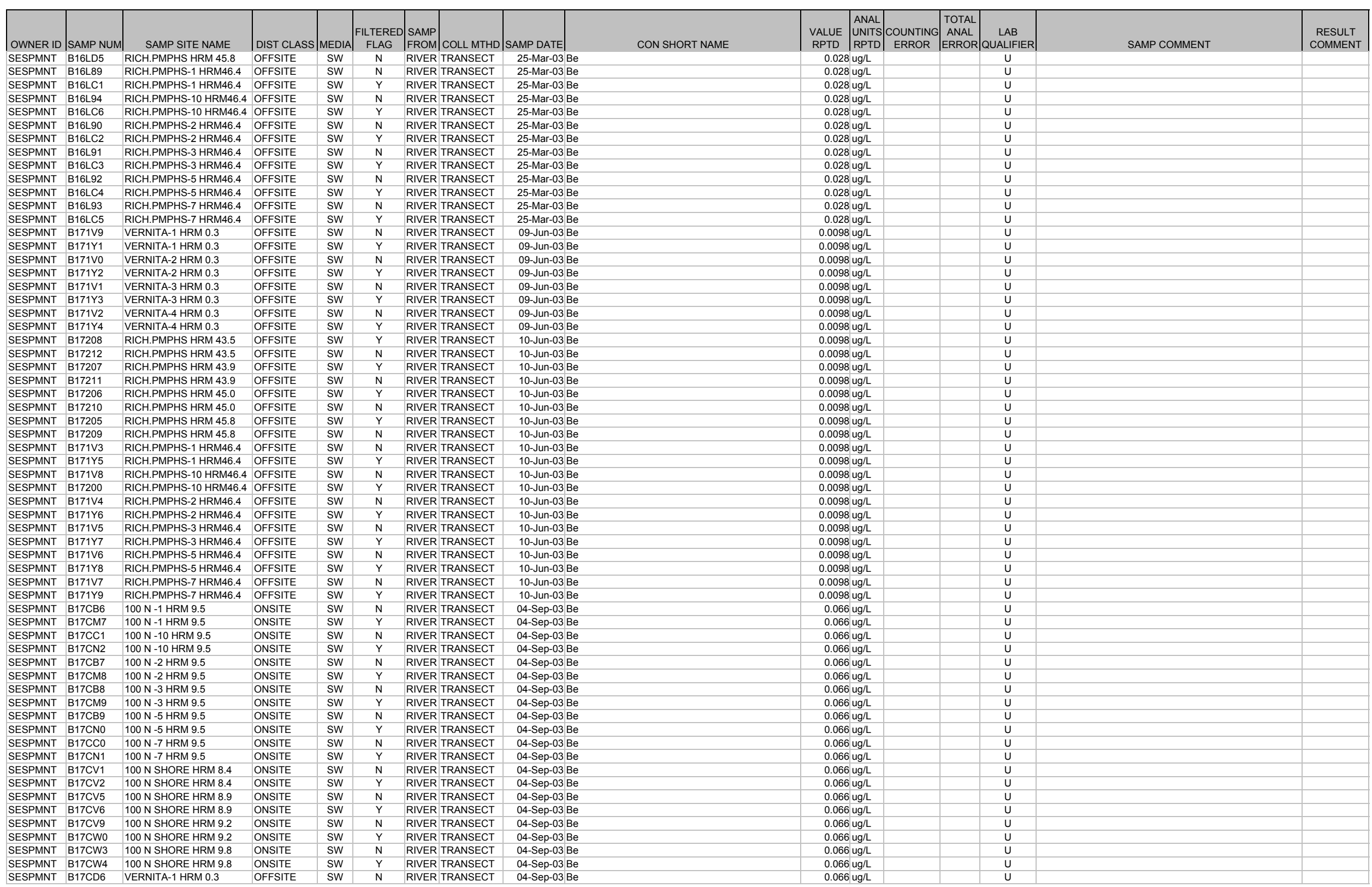


WATER - COLUMBIA RIVER TRANSECT

\begin{tabular}{|c|c|c|c|c|c|c|c|c|c|c|c|c|c|c|c|c|}
\hline | OWNER ID & SAMP NUM & SAMP SITE NAME & DIST CLASS & MEDIA $\left.\right|^{\mid h}$ & \begin{tabular}{|c|} 
FILTERED \\
FLAG
\end{tabular} & $\begin{array}{l}\text { SAMP } \\
\text { FROM }\end{array}$ & COLL MTHD & SAMP DATE & CON SHORT NAME & \begin{tabular}{c|c} 
VALUE \\
RPTD
\end{tabular} & \begin{tabular}{|l|l|} 
ANAL \\
UNITS \\
RPTD \\
\end{tabular} & \begin{tabular}{|l|} 
COUNTING \\
ERROR
\end{tabular} & \begin{tabular}{|c|} 
TOTAL \\
ANAL \\
ERROR
\end{tabular} & $\begin{array}{c}\text { LAB } \\
\text { QUALIFIER }\end{array}$ & SAMP COMMENT & $\begin{array}{l}\text { RESULT } \\
\text { COMMENT }\end{array}$ \\
\hline SESPMNT & B17CM3 & VERNITA-1 HRM 0.3 & OFFSITE & SW & & RIVER & TRANSECT & 04-Sep-03 Be & & & & & & U & - & \\
\hline SESPMNT & B17CC7 & VERNITA-2 HRM 0.3 & OFFSITE & sw & $\mathrm{N}$ & RIVER & TRANSECT & 04-Sep-03 Be & & $0.066 \mathrm{u}$ & $\mathrm{ug} / \mathrm{L}$ & & & U & & \\
\hline SESPMNT & B17CM4 & VERNITA-2 HRM 0.3 & OFFSITE & sw & $\mathrm{Y}$ & RIVER & TRANSECT & 04-Sep-03 Be & & $0.066 \mathrm{u}$ & $\mathrm{ug} / \mathrm{L}$ & & & u & & \\
\hline SESPMNT & B17CC8 & VERNITA-3 HRM 0.3 & OFFSITE & sw & $\mathrm{N}$ & RIVER & TRANSECT & 04-Sep-03 Be & & $0.066 \mathrm{u}$ & $\mathrm{ug} / \mathrm{L}$ & & & u & & \\
\hline SESPMNT & B17CM5 & VERNITA-3 HRM 0.3 & OFFSITE & sw & Y & RIVER & TRANSECT & 04-Sep-03 Be & & $0.066 \mathrm{u}$ & $\mathrm{ug} / \mathrm{L}$ & & & $u$ & & \\
\hline SESPMNT & B17CC9 & VERNITA-4 HRM 0.3 & OFFSITE & sw & $\mathrm{N}$ & RIVER & TRANSECT & 04-Sep-03 Be & & & & & & $u$ & & \\
\hline SESPMNT & B17CM6 & VERNITA-4 HRM 0.3 & OFFSITE & sw & $\mathrm{Y}$ & RIVER & TRANSECT & 04-Sep-03 Be & & & & & & U & & \\
\hline SESPMNT & B17CC2 & $100 \mathrm{~F}-1 \mathrm{HRM} 19.0$ & ONSITE & sw & $\mathrm{N}$ & RIVER & TRANSECT & 08-Sep-03 Be & & & & & & U & & \\
\hline SESPMNT & B17CR1 & $100 \mathrm{~F}-1 \mathrm{HRM} 19.0$ & ONSITE & sw & $\mathrm{Y}$ & RIVER & TRANSECT & 08-Sep-03 Be & & $0.066 u$ & $\mathrm{ug} / \mathrm{L}$ & & & U & & \\
\hline SESPMNT & B17C96 & $100 \mathrm{~F}-10 \mathrm{HRM} 19.0$ & ONSITE & sw & $\mathrm{N}$ & RIVER & TRANSECT & 08-Sep-03 Be & & $0.066 u$ & $\mathrm{ug} / \mathrm{L}$ & & & U & & \\
\hline SESPMNT & B17CR6 & $100 \mathrm{~F}-10$ HRM 19.0 & ONSITE & sw & $\mathrm{Y}$ & RIVER & TRANSECT & 08-Sep-03 Be & & $0.066 \mathrm{u}$ & $\mathrm{ug} / \mathrm{L}$ & & & U & & \\
\hline SESPMNT & B17CR2 & 100 F -2 HRM 19.0 & ONSITE & sw & $\mathrm{Y}$ & RIVER & TRANSECT & 08-Sep-03 Be & & $0.066 u$ & $\mathrm{ug} / \mathrm{L}$ & & & u & & \\
\hline SESPMNT & B17CC4 & 100 F -3 HRM 19.0 & ONSITE & sw & $\mathrm{N}$ & RIVER & TRANSECT & 08-Sep-03 Be & & $0.066 u$ & $\mathrm{ug} / \mathrm{L}$ & & & U & & \\
\hline SESPMNT & B17CR3 & $100 \mathrm{~F}-3$ HRM 19.0 & ONSITE & sw & $\mathrm{Y}$ & RIVER & TRANSECT & 08 -Sep-03 Be & & $0.066 \mathrm{u}$ & $\mathrm{ug} / \mathrm{L}$ & & & u & & \\
\hline SESPMNT & B17CR4 & 100 F -5 HRM 19.0 & ONSITE & sw & $\mathrm{Y}$ & RIVER & TRANSECT & 08-Sep-03 Be & & & & & & U & & \\
\hline SESPMNT & B17CR5 & 100 F -7 HRM 19.0 & ONSITE & sw & $\mathrm{Y}$ & RIVER & TRANSECT & 08-Sep-03 Be & & & & & & u & & \\
\hline SESPMNT & B17CY5 & 100 F SHORE HRM 18 & ONSITE & sw & $\mathrm{N}$ & RIVER & TRANSECT & 08-Sep-03 Be & & $0.066 \mathrm{u}$ & $\mathrm{ug} / \mathrm{L}$ & & & $u$ & & \\
\hline SESPMNT & B17CY6 & $100 \mathrm{~F}$ SHORE HRM 18 & ONSITE & sw & $\mathrm{Y}$ & RIVER & TRANSECT & 08-Sep-03 Be & & $0.066 u$ & $\mathrm{ug} / \mathrm{L}$ & & & U & & \\
\hline SESPMNT & B17CY8 & 100 F SHORE HRM 22 & ONSITE & sw & $\mathrm{N}$ & RIVER & TRANSECT & 08-Sep-03 Be & & $0.066 \mathrm{u}$ & $\mathrm{ug} / \mathrm{L}$ & & & u & & \\
\hline SESPMNT & B17CY9 & $100 \mathrm{~F}$ SHORE HRM 22 & ONSITE & sw & $\mathrm{Y}$ & RIVER & TRANSECT & 08 -Sep-03 Be & & $0.066 \mathrm{u}$ & & & & u & & \\
\hline SESPMNT & B17D01 & $100 \mathrm{~F}$ SHORE HRM 23 & ONSITE & sw & $\mathrm{N}$ & RIVER & TRANSECT & 08-Sep-03 Be & & $0.066 u$ & & & & U & & \\
\hline SESPMNT & B17D02 & $100 \mathrm{~F}$ SHORE HRM 23 & ONSITE & sw & $\mathrm{Y}$ & RIVER & TRANSECT & 08-Sep-03 Be & & $0.066 \mathrm{u}$ & & & & u & & \\
\hline SESPMNT & B17C97 & HANFRD TS-1 HRM 28.7 & ONSITE & sw & $\mathrm{N}$ & RIVER & TRANSECT & 08-Sep-03 Be & & $0.066 \mathrm{u}$ & & & & u & & \\
\hline SESPMNT & B17CP5 & HANFRD TS-1 HRM 28.7 & ONSITE & sw & $\mathrm{Y}$ & RIVER & TRANSECT & 08-Sep-03 Be & & $0.066 \mathrm{u}$ & $\mathrm{ug} / \mathrm{L}$ & & & u & & \\
\hline SESPMNT & B17CB2 & HANFRD TS-10 HRM 28.7 & ONSITE & sw & $\mathrm{N}$ & RIVER & TRANSECT & 08-Sep-03 Be & & $0.066 u$ & $\mathrm{ug} / \mathrm{L}$ & & & U & & \\
\hline SESPMNT & B17CR0 & HANFRD TS-10 HRM 28.7 & ONSITE & sw & $\mathrm{Y}$ & RIVER & TRANSECT & 08-Sep-03 Be & & $0.066 u$ & $\mathrm{ug} / \mathrm{L}$ & & & U & & \\
\hline SESPMNT & B17C98 & HANFRD TS-2 HRM 28.7 & ONSITE & sw & $\mathrm{N}$ & RIVER & TRANSECT & 08-Sep-03 Be & & $0.066 u$ & $\mathrm{ug} / \mathrm{L}$ & & & U & & \\
\hline SESPMNT & B17CP6 & HANFRD TS-2 HRM 28.7 & ONSITE & sw & $\mathrm{Y}$ & RIVER & TRANSECT & 08-Sep-03 Be & & $0.066 u$ & $\mathrm{ug} / \mathrm{L}$ & & & u & & \\
\hline SESPMNT & B17C99 & HANFRD TS-3 HRM 28.7 & ONSITE & sw & $\mathrm{N}$ & RIVER & TRANSECT & 08 -Sep-03 Be & & $0.066 \mathrm{u}$ & & & & u & & \\
\hline SESPMNT & B17CP7 & HANFRD TS-3 HRM 28.7 & ONSITE & sw & $\mathrm{Y}$ & RIVER & TRANSECT & 08-Sep-03 Be & & $0.066 u$ & & & & U & & \\
\hline SESPMNT & B17CB0 & HANFRD TS-5 HRM 28.7 & ONSITE & sw & $\mathrm{N}$ & RIVER & TRANSECT & 08-Sep-03 Be & & $0.066 \mathrm{u}$ & & & & u & & \\
\hline SESPMNT & B17CP8 & HANFRD TS-5 HRM 28.7 & ONSITE & sw & $\mathrm{Y}$ & RIVER & TRANSECT & 08-Sep-03 Be & & $0.066 \mathrm{u}$ & $\mathrm{ug} / \mathrm{L}$ & & & U & & \\
\hline SESPMNT & B17CB1 & HANFRD TS-7 HRM 28.7 & ONSITE & sw & $\mathrm{N}$ & RIVER & TRANSECT & 08-Sep-03 Be & & $0.066 \mathrm{u}$ & $\mathrm{ug} / \mathrm{L}$ & & & u & & \\
\hline SESPMNT & B17CP9 & HANFRD TS-7 HRM 28.7 & ONSITE & sw & $\mathrm{Y}$ & RIVER & TRANSECT & 08-Sep-03 Be & & $0.066 \mathrm{u}$ & ug/L & & & u & & \\
\hline SESPMNT & B17CL7 & HANFRD TWNSITE HRM26 & ONSITE & sw & $\mathrm{N}$ & RIVER & TRANSECT & 08-Sep-03 Be & & $0.066 u$ & & & & U & & \\
\hline SESPMNT & B17CM0 & HANFRD TWNSITE HRM26 & ONSITE & sw & $\mathrm{Y}$ & RIVER & TRANSECT & 08-Sep-03 Be & & $0.066 u$ & & & & U & & \\
\hline SESPMNT & B17CL8 & HANFRD TWNSITE HRM27 & ONSITE & sw & $\mathrm{N}$ & RIVER & TRANSECT & 08-Sep-03 Be & & $0.066 u$ & & & & u & & \\
\hline SESPMNT & B17CM1 & HANFRD TWNSITE HRM27 & ONSITE & sw & $\mathrm{Y}$ & RIVER & TRANSECT & 08-Sep-03 Be & & $0.066 u$ & & & & u & & \\
\hline SESPMNT & B17CY2 & HANFRD TWNSITE HRM28 & ONSITE & sw & $\mathrm{N}$ & RIVER & TRANSECT & 08 -Sep-03 Be & & $0.066 \mathrm{u}$ & $\mathrm{ug} / \mathrm{L}$ & & & u & & \\
\hline SESPMNT & B17CY3 & HANFRD TWNSITE HRM28 & ONSITE & sw & $\mathrm{Y}$ & RIVER & TRANSECT & 08-Sep-03 Be & & $0.066 \mathrm{u}$ & $\mathrm{ug} / \mathrm{L}$ & & & U & & \\
\hline SESPMNT & B17CL9 & HANFRD TWNSITE HRM30 & ONSITE & sw & $\mathrm{N}$ & RIVER & TRANSECT & 08-Sep-03 Be & & $0.066 \mathrm{u}$ & $\mathrm{ug} / \mathrm{L}$ & & & $u$ & & \\
\hline SESPMNT & B17CM2 & HANFRD TWNSITE HRM30 & ONSITE & sw & $\mathrm{Y}$ & RIVER & TRANSECT & 08-Sep-03 Be & & $0.066 u$ & $\mathrm{ug} / \mathrm{L}$ & & & u & & \\
\hline SESPMNT & B17CN9 & 300 AREA - 1 HRM 43.1 & ONSITE & sw & $\mathrm{Y}$ & RIVER & TRANSECT & 09-Sep-03 Be & & $0.066 \mathrm{u}$ & ug/L & & & u & & \\
\hline SESPMNT & B17CPO & 300 AREA -2 HRM 43.1 & ONSITE & sw & $\mathrm{Y}$ & RIVER & TRANSECT & $09-\mathrm{Sep}-03 \mathrm{Be}$ & & $0.066 \mathrm{u}$ & & & & U & & \\
\hline SESPMNT & B17CP1 & 300 AREA -3 HRM 43.1 & ONSITE & sw & $\mathrm{Y}$ & RIVER & TRANSECT & 09-Sep-03 Be & & $0.066 u$ & & & & U & & \\
\hline SESPMNT & B17CP2 & 300 AREA -5 HRM 43.1 & ONSITE & sw & $\mathrm{Y}$ & RIVER & TRANSECT & 09-Sep-03 Be & & $0.066 u$ & & & & u & & \\
\hline SESPMNT & B17CP3 & 300 AREA -7 HRM 43.1 & ONSITE & sw & $\mathrm{Y}$ & RIVER & TRANSECT & 09-Sep-03 Be & & $0.066 u$ & $\mathrm{ug} / \mathrm{L}$ & & & U & & \\
\hline SESPMNT & B17CW8 & 300 AREA SHR HRM41.5 & ONSITE & sw & Y & RIVER & TRANSECT & 09-Sep-03 Be & & $0.066 \mathrm{u}$ & & & & u & & \\
\hline SESPMNT & B17CX2 & 300 AREA SHR HRM42.1 & ONSITE & sw & $\mathrm{Y}$ & RIVER & TRANSECT & 09-Sep-03 Be & & $0.066 \mathrm{u}$ & $\mathrm{ug} / \mathrm{L}$ & & & u & & \\
\hline SESPMNT & B17CX6 & 300 AREA SHR HRM42.5 & ONSITE & sw & $\mathrm{Y}$ & RIVER & TRANSECT & 09-Sep-03 Be & & $0.066 u$ & $\mathrm{ug} / \mathrm{L}$ & & & u & & \\
\hline SESPMNT & B17CY0 & 300 AREA SHR HRM42.9 & ONSITE & sw & $\mathrm{Y}$ & RIVER & TRANSECT & 09-Sep-03 Be & & $0.066 \mathrm{u}$ & $\mathrm{ug} / \mathrm{L}$ & & & u & & \\
\hline SESPMNT & B17CP4 & 300 AREA-10 HRM 43.1 & ONSITE & sw & $\mathrm{Y}$ & RIVER & TRANSECT & 09-Sep-03 Be & & $0.066 \mathrm{u}$ & & & & u & & \\
\hline SESPMNT & B17CT4 & RICH.PMPHS HRM 43.5 & OFFSITE & sw & Y & RIVER & TRANSECT & 09-Sep-03 Be & & $0.066 \mathrm{u}$ & & & & u & & \\
\hline SESPMNT & B17CT2 & RICH.PMPHS HRM 45.0 & OFFSITE & sw & $\mathrm{Y}$ & RIVER & TRANSECT & 09-Sep-03 Be & & $0.066 \mathrm{u}$ & ug/L & & & u & & \\
\hline SESPMNT & B17CT1 & RICH.PMPHS HRM 45.8 & OFFSITE & sw & $\mathrm{Y}$ & RIVER & TRANSECT & 09-Sep-03 Be & & $0.066 u$ & ug/L & & & u & & \\
\hline SESPMNT & B17CD0 & RICH.PMPHS-1 HRM46.4 & OFFSITE & sW & $\mathrm{N}$ & RIVER & TRANSECT & 09-Sep-03 Be & & $0.066 u$ & $\mathrm{ug} / \mathrm{L}$ & & & U & & \\
\hline SESPMNT & B17CN3 & RICH.PMPHS-1 HRM46.4 & OFFSITE & sW & $\mathrm{Y}$ & RIVER & TRANSECT & 09-Sep-03 Be & & $0.066 \mathrm{u}$ & $\mathrm{ug} / \mathrm{L}$ & & & U & & \\
\hline SESPMNT & B17CD5 & RICH.PMPHS-10 HRM46.4 & OFFSITE & SW & $\mathrm{N}$ & RIVER & TRANSECT & 09-Sep-03 Be & & $0.066 \mathrm{u}$ & $\mathrm{ug} / \mathrm{L}$ & & & u & & \\
\hline SESPMNT & B17CN8 & RICH.PMPHS-10 HRM46.4 & OFFSITE & sW & $\mathrm{Y}$ & RIVER & TRANSECT & 09-Sep-03 Be & & $0.066 u$ & $\mathrm{ug} / \mathrm{L}$ & & & U & & \\
\hline SESPMNT & B17CD1 & RICH.PMPHS-2 HRM46.4 & OFFSITE & sw & $\mathrm{N}$ & RIVER & TRANSECT & 09-Sep-03 Be & & & ug/L & & & u & & \\
\hline SESPMNT & B17CN4 & RICH.PMPHS-2 HRM46.4 & OFFSITE & sw & $\mathrm{Y}$ & RIVER & TRANSECT & 09-Sep-03 Be & & $0.066 \mathrm{u}$ & & & & u & & \\
\hline SESPMNT & $\mathrm{B} 17 \mathrm{CD} 2$ & RICH.PMPHS-3 HRM46.4 & OFFSITE & sw & $\mathrm{N}$ & RIVER & TRANSECT & 09-Sep-03 Be & & $0.066 \mathrm{u}$ & $\mathrm{ug} / \mathrm{L}$ & & & u & & \\
\hline
\end{tabular}


WATER - COLUMBIA RIVER TRANSECT

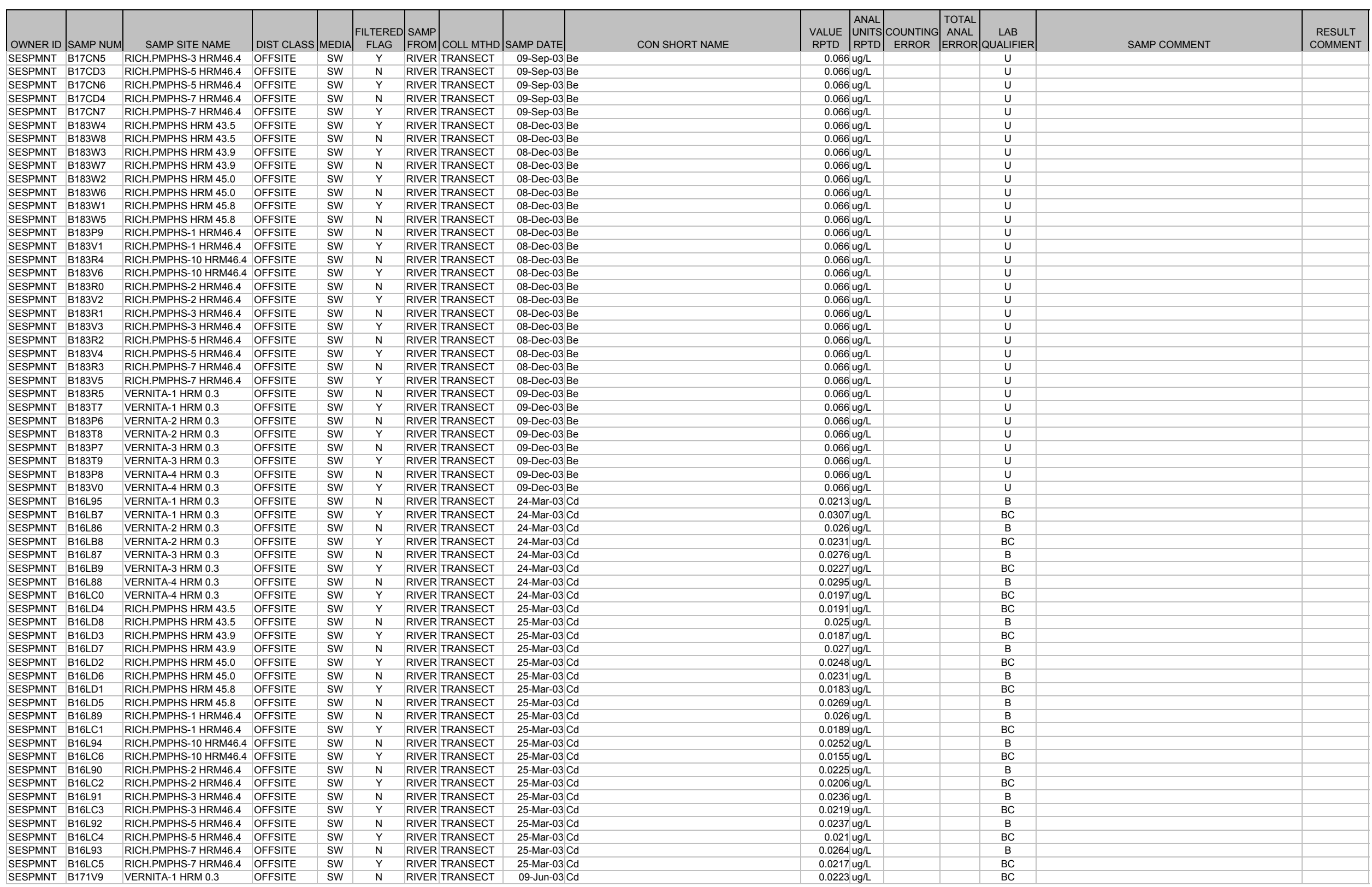


WATER - COLUMBIA RIVER TRANSECT

\begin{tabular}{|c|c|c|c|c|c|c|c|c|c|c|c|c|c|c|c|c|}
\hline | OWNER ID & | SAMP NUM| & SAMP SITE NAME & |DIST CLASS | & $\mid$ MEDIA & \begin{tabular}{|c|} 
FILTERED \\
FLAG
\end{tabular} & $\begin{array}{l}\text { SAMP } \\
\text { FROM }\end{array}$ & COLL MTHD & SAMP DATE & CON SHORT NAME & $\begin{array}{l}\text { VALUE } \\
\text { RPTD }\end{array}$ & \begin{tabular}{|l|} 
ANAL \\
UNITS \\
RPTD \\
\end{tabular} & \begin{tabular}{|l|} 
COUNTING \\
ERROR
\end{tabular} & 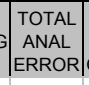 & $\begin{array}{c}\text { LAB } \\
\text { QUALIFIER }\end{array}$ & SAMP COMMENT & $\begin{array}{l}\text { RESULT } \\
\text { COMMENT }\end{array}$ \\
\hline SESPMNT & B171Y1 & VERNITA-1 HRM 0.3 & OFFSITE & SW & & RIVER T & TRANSECT & 09-Jun-03 Cd & & 0.0154 & & & & B & - & \\
\hline SESPMNT & B171Vo & VERNITA-2 HRM 0.3 & OFFSITE & sw & $\mathrm{N}$ & RIVER T & TRANSECT & 09-Jun-03 Cd & & 0.0288 & $3 \mathrm{ug} / \mathrm{L}$ & & & $\mathrm{BC}$ & & \\
\hline SESPMNT & B171Y2 & VERNITA-2 HRM 0.3 & OFFSITE & sw & $\mathrm{Y}$ & RIVER T & TRANSECT & 09-Jun- $03 \mathrm{Cd}$ & & 0.0154 & ug/L $/ 2$ & & & $\mathrm{~B}$ & & \\
\hline SESPMNT & B171V1 & VERNITA-3 HRM 0.3 & OFFSITE & sw & $\mathrm{N}$ & RIVER T & TRANSECT & 09-Jun- $03 \mathrm{Cd}$ & & 0.023 & $3 \mathrm{ug} / \mathrm{L}$ & & & $B C$ & & \\
\hline SESPMNT & B171Y3 & VERNITA-3 HRM 0.3 & OFFSITE & sw & Y & RIVER & TRANSECT & 09-Jun-03 Cd & & 0.0194 & ig/L & & & B & & \\
\hline SESPMNT & B171V2 & VERNITA-4 HRM 0.3 & OFFSITE & sw & $\mathrm{N}$ & RIVER & TRANSECT & 09-Jun- 03 Cd & & 0.0296 & & & & $B C$ & & \\
\hline SESPMNT & B171Y4 & VERNITA-4 HRM 0.3 & OFFSITE & sw & $\mathrm{Y}$ & RIVER 7 & TRANSECT & 09-Jun- 03 Cd & & & & & & B & & \\
\hline SESPMNT & B17208 & RICH.PMPHS HRM 43.5 & OFFSITE & sw & $\mathrm{Y}$ & RIVER T & TRANSECT & 10-Jun-03 Cd & & & & & & B & & \\
\hline SESPMNT & B17212 & RICH.PMPHS HRM 43.5 & OFFSITE & sw & $\mathrm{N}$ & RIVER 7 & TRANSECT & 10-Jun-03 Cd & & 0.0258 & $3 \mathrm{ug} / \mathrm{L}$ & & & $\mathrm{BC}$ & & \\
\hline SESPMNT & B17207 & RICH.PMPHS HRM 43.9 & OFFSITE & sw & $\mathrm{Y}$ & RIVER T & TRANSECT & 10-Jun- $03 \mathrm{Cd}$ & & 0.0143 & $3 \mathrm{ug} / \mathrm{L}$ & & & B & & \\
\hline SESPMNT & B17211 & RICH.PMPHS HRM 43.9 & OFFSITE & sw & $\mathrm{N}$ & RIVER T & TRANSECT & 10-Jun- $03 \mathrm{Cd}$ & & 0.0261 & ug/L $/ \mathrm{L}$ & & & $\mathrm{BC}$ & & \\
\hline SESPMNT & B17206 & RICH.PMPHS HRM 45.0 & OFFSITE & sw & $\mathrm{Y}$ & RIVER 7 & TRANSECT & 10-Jun-03 Cd & & 0.0162 & $\mathrm{ug} / \mathrm{L}$ & & & B & & \\
\hline SESPMNT & B17210 & RICH.PMPHS HRM 45.0 & OFFSITE & sw & $\mathrm{N}$ & RIVER T & TRANSECT & 10-Jun-03 Cd & & 0.03 & $3 \mathrm{ug} / \mathrm{L}$ & & & $\mathrm{BC}$ & & \\
\hline SESPMNT & B17205 & RICH.PMPHS HRM 45.8 & OFFSITE & sw & $\mathrm{Y}$ & RIVER T & TRANSECT & 10-Jun-03 Cd & & 0.0144 & ug/L & & & $\mathrm{B}$ & & \\
\hline SESPMNT & B17209 & RICH.PMPHS HRM 45.8 & OFFSITE & sw & $\mathrm{N}$ & RIVER 7 & TRANSECT & 10-Jun- $03 \mathrm{Cd}$ & & 0.0292 & & & & $B C$ & & \\
\hline SESPMNT & B171V3 & RICH.PMPHS-1 HRM46.4 & OFFSITE & sw & $\mathrm{N}$ & RIVER 7 & TRANSECT & 10-Jun-03 Cd & & 0.0276 & & & & BC & & \\
\hline SESPMNT & B171Y5 & RICH.PMPHS-1 HRM46.4 & OFFSITE & sw & Y & RIVER 7 & TRANSECT & 10-Jun- $03 \mathrm{Cd}$ & & 0.0173 & $3 \mathrm{ug} / \mathrm{L}$ & & & B & & \\
\hline SESPMNT & B171V8 & RICH.PMPHS-10 HRM46.4 & OFFSITE & sw & $\mathrm{N}$ & RIVER T & TRANSECT & 10-Jun-03 Cd & & 0.0248 & $3 \mathrm{ug} / \mathrm{L}$ & & & $\mathrm{BC}$ & & \\
\hline SESPMNT & B17200 & RICH.PMPHS-10 HRM46.4 & OFFSITE & sw & Y & RIVER T & TRANSECT & 10-Jun- $03 \mathrm{Cd}$ & & 0.012 & ug/L & & & B & & \\
\hline SESPMNT & B171V4 & RICH.PMPHS-2 HRM46.4 & OFFSITE & sw & $\mathrm{N}$ & RIVER T & TRANSECT & 10-Jun-03 Cd & & 0.0333 & 3 ug/L $/ 2$ & & & $\mathrm{BC}$ & & \\
\hline SESPMNT & B171Y6 & RICH.PMPHS-2 HRM46.4 & OFFSITE & sw & $\mathrm{Y}$ & RIVER T & TRANSECT & 10-Jun- $03 \mathrm{Cd}$ & & 0.0171 & ug/L & & & B & & \\
\hline SESPMNT & B171V5 & RICH.PMPHS-3 HRM46.4 & OFFSITE & sw & $\mathrm{N}$ & RIVER & TRANSECT & 10-Jun- $03 \mathrm{Cd}$ & & 0.0248 & & & & $\mathrm{BC}$ & & \\
\hline SESPMNT & B171Y7 & RICH.PMPHS-3 HRM46.4 & OFFSITE & sw & $\mathrm{Y}$ & RIVER T & TRANSECT & $10-\mathrm{Jun}-03 \mathrm{Cd}$ & & 0.0174 & & & & B & & \\
\hline SESPMNT & B171V6 & RICH.PMPHS-5 HRM 46.4 & OFFSITE & sw & $\mathrm{N}$ & RIVER T & TRANSECT & 10-Jun- $03 \mathrm{Cd}$ & & 0.0233 & $3 \mathrm{ug} / \mathrm{L}$ & & & $\mathrm{BC}$ & & \\
\hline SESPMNT & B171Y8 & RICH.PMPHS-5 HRM46.4 & OFFSITE & sw & $\mathrm{Y}$ & RIVER 7 & TRANSECT & 10-Jun- $03 \mathrm{Cd}$ & & 0.0151 & ug/L & & & B & & \\
\hline SESPMNT & B171V7 & RICH.PMPHS-7 HRM46.4 & OFFSITE & sw & $\mathrm{N}$ & RIVER 7 & TRANSECT & 10-Jun-03 Cd & & 0.028 & $3 \mathrm{ug} / \mathrm{L}$ & & & $\mathrm{BC}$ & & \\
\hline SESPMNT & B171Y9 & RICH.PMPHS-7 HRM46.4 & OFFSITE & sw & $\mathrm{Y}$ & RIVER T & TRANSECT & 10-Jun-03 Cd & & 0.0149 & $\mathrm{ug} / \mathrm{L}$ & & & B & & \\
\hline SESPMNT & B17CB6 & $100 \mathrm{~N}-1$ HRM 9.5 & ONSITE & sw & $\mathrm{N}$ & RIVER 7 & TRANSECT & $04-\mathrm{Sep}-03 \mathrm{Cd}$ & & 0.023 & $3 \mathrm{ug} / \mathrm{L}$ & & & u & & \\
\hline SESPMNT & B17CM7 & $100 \mathrm{~N}-1$ HRM 9.5 & ONSITE & sw & Y & RIVER T & TRANSECT & $04-S e p-03 \mathrm{Cd}$ & & 0.023 & $3 \mathrm{ug} / \mathrm{L}$ & & & $\mathrm{U}$ & & \\
\hline SESPMNT & B17CC1 & $100 \mathrm{~N}-10$ HRM 9.5 & ONSITE & sw & $\mathrm{N}$ & RIVER T & TRANSECT & 04-Sep-03 Cd & & 0.0308 & & & & B & & \\
\hline SESPMNT & B17CN2 & $100 \mathrm{~N}-10 \mathrm{HRM} 9.5$ & ONSITE & sw & $\mathrm{Y}$ & RIVER T & TRANSECT & 04-Sep-03 Cd & & 0.0275 & & & & B & & \\
\hline SESPMNT & B17CB7 & $100 \mathrm{~N}-2$ HRM 9.5 & ONSITE & sw & $\mathrm{N}$ & RIVER T & TRANSECT & $04-S e p-03 \mathrm{Cd}$ & & 0.023 & $3 \mathrm{ug} / \mathrm{L}$ & & & u & & \\
\hline SESPMNT & B17CM8 & $100 \mathrm{~N}-2 \mathrm{HRM} 9.5$ & ONSITE & sw & $\mathrm{Y}$ & RIVER T & TRANSECT & 04-Sep-03Cd & & 0.023 & $3 \mathrm{ug} / \mathrm{L}$ & & & u & & \\
\hline SESPMNT & B17CB8 & $100 \mathrm{~N}-3$ HRM 9.5 & ONSITE & sw & $\mathrm{N}$ & RIVER T & TRANSECT & 04-Sep-03 Cd & & 0.023 & $3 \mathrm{ug} / \mathrm{L}$ & & & u & & \\
\hline SESPMNT & B17CM9 & $100 \mathrm{~N}-3$ HRM 9.5 & ONSITE & sw & $\mathrm{Y}$ & RIVER T & TRANSECT & 04-Sep-03 Cd & & 0.023 & $\mathrm{ug} / \mathrm{L}$ & & & $\mathrm{U}$ & & \\
\hline SESPMNT & B17CB9 & $100 \mathrm{~N}-5$ HRM 9.5 & ONSITE & sw & $\mathrm{N}$ & RIVER 7 & TRANSECT & 04-Sep-03 Cd & & 0.023 & $\mathrm{ug} / \mathrm{L}$ & & & U & & \\
\hline SESPMNT & B17CN0 & $100 \mathrm{~N}-5$ HRM 9.5 & ONSITE & sw & $\mathrm{Y}$ & RIVER 7 & TRANSECT & 04-Sep-03 Cd & & 0.023 & $3 \mathrm{ug} / \mathrm{L}$ & & & U & & \\
\hline SESPMNT & B17CC0 & $100 \mathrm{~N}-7$ HRM 9.5 & ONSITE & sw & $\mathrm{N}$ & RIVER T & TRANSECT & $04-S e p-03 \mathrm{Cd}$ & & 0.023 & & & & u & & \\
\hline SESPMNT & $\mathrm{B} 17 \mathrm{CN} 1$ & $100 \mathrm{~N}-7$ HRM 9.5 & ONSITE & sw & $\mathrm{Y}$ & RIVER T & TRANSECT & 04-Sep-03 Cd & & 0.023 & $3 \mathrm{ug} / \mathrm{L}$ & & & u & & \\
\hline SESPMNT & B17CV1 & 100 N SHORE HRM 8.4 & ONSITE & sW & $\mathrm{N}$ & RIVER T & TRANSECT & $04-S e p-03 \mathrm{Cd}$ & & 0.023 & $3 \mathrm{ug} / \mathrm{L}$ & & & U & & \\
\hline SESPMNT & B17CV2 & 100 N SHORE HRM 8.4 & ONSITE & sw & Y & RIVER T & TRANSECT & $04-S e p-03 \mathrm{Cd}$ & & 0.023 & $3 \mathrm{ug} / \mathrm{L}$ & & & $u$ & & \\
\hline SESPMNT & B17CV5 & 100 N SHORE HRM 8.9 & ONSITE & sw & $\mathrm{N}$ & RIVER 7 & TRANSECT & $04-S e p-03 \mathrm{Cd}$ & & 0.023 & 3 ug/L & & & U & & \\
\hline SESPMNT & B17CV6 & 100 N SHORE HRM 8.9 & ONSITE & sw & $\mathrm{Y}$ & RIVER & TRANSECT & 04-Sep-03 Cd & & 0.023 & $3 \mathrm{ug} / \mathrm{L}$ & & & u & & \\
\hline SESPMNT & B17CV9 & 100 N SHORE HRM 9.2 & ONSITE & sw & $\mathrm{N}$ & RIVER T & TRANSECT & 04-Sep-03 Cd & & 0.027 & ug/L & & & B & & \\
\hline SESPMNT & B17CW0 & 100 N SHORE HRM 9.2 & ONSITE & sw & $\mathrm{Y}$ & RIVER T & TRANSECT & $04-S e p-03 \mathrm{Cd}$ & & 0.023 & & & & U & & \\
\hline SESPMNT & B17CW3 & $100 \mathrm{~N}$ SHORE HRM 9.8 & ONSITE & sw & $\mathrm{N}$ & RIVER 7 & TRANSECT & 04-Sep-03 Cd & & 0.023 & $3 \mathrm{ug} / \mathrm{L}$ & & & $u$ & & \\
\hline SESPMNT & B17CW4 & $100 \mathrm{~N}$ SHORE HRM 9.8 & ONSITE & sw & $\mathrm{Y}$ & RIVER 7 & TRANSECT & 04-Sep-03 Cd & & 0.023 & $3 \mathrm{ug} / \mathrm{L}$ & & & U & & \\
\hline SESPMNT & B17CD6 & VERNITA-1 HRM 0.3 & OFFSITE & sw & $\mathrm{N}$ & RIVER T & TRANSECT & $04-S e p-03 \mathrm{Cd}$ & & 0.023 & $3 \mathrm{ug} / \mathrm{L}$ & & & u & & \\
\hline SESPMNT & B17CM3 & VERNITA-1 HRM 0.3 & OFFSITE & sw & $\mathrm{Y}$ & RIVER T & TRANSECT & 04-Sep-03 Cd & & 0.023 & 3 ug/L & & & u & & \\
\hline SESPMNT & B17CC7 & VERNITA-2 HRM 0.3 & OFFSITE & sw & $\mathrm{N}$ & RIVER 7 & TRANSECT & $04-S e p-03 \mathrm{Cd}$ & & 0.023 & $3 \mathrm{ug} / \mathrm{L}$ & & & U & & \\
\hline SESPMNT & B17CM4 & VERNITA-2 HRM 0.3 & OFFSITE & sw & $\mathrm{Y}$ & RIVER 7 & TRANSECT & $04-S e p-03 \mathrm{Cd}$ & & 0.023 & 3 ug/L & & & $u$ & & \\
\hline SESPMNT & B17CC8 & VERNITA-3 HRM 0.3 & OFFSITE & sw & $\mathrm{N}$ & RIVER T & TRANSECT & 04-Sep-03 Cd & & 0.023 & & & & u & & \\
\hline SESPMNT & B17CM5 & VERNITA-3 HRM 0.3 & OFFSITE & sw & Y & RIVER T & TRANSECT & $04-$ Sep-03 Cd & & 0.023 & $\mathrm{ug} / \mathrm{L}$ & & & $u$ & & \\
\hline SESPMNT & B17CC9 & VERNITA-4 HRM 0.3 & OFFSITE & sw & $\mathrm{N}$ & RIVER T & TRANSECT & 04-Sep-03 Cd & & 0.023 & $3 \mathrm{ug} / \mathrm{L}$ & & & U & & \\
\hline SESPMNT & B17CM6 & VERNITA-4 HRM 0.3 & OFFSITE & sw & $\mathrm{Y}$ & RIVER 7 & TRANSECT & 04-Sep-03 Cd & & 0.023 & ug $/ \mathrm{L}$ & & & U & & \\
\hline SESPMNT & B17CC2 & $100 \mathrm{~F}-1$ HRM 19.0 & ONSITE & sW & $\mathrm{N}$ & RIVER 7 & TRANSECT & 08-Sep-03 Cd & & 0.0278 & $3 \mathrm{ug} / \mathrm{L}$ & & & B & & \\
\hline SESPMNT & B17CR1 & $100 \mathrm{~F}-1$ HRM 19.0 & ONSITE & sW & $\mathrm{Y}$ & RIVER T & TRANSECT & 08-Sep-03 Cd & & 0.023 & $3 \mathrm{ug} / \mathrm{L}$ & & & $u$ & & \\
\hline SESPMNT & B17C96 & $100 \mathrm{~F}-10$ HRM 19.0 & ONSITE & SW & $\mathrm{N}$ & RIVER T & TRANSECT & 08-Sep-03 Cd & & 0.023 & $3 \mathrm{ug} / \mathrm{L}$ & & & u & & \\
\hline SESPMNT & B17CR6 & $100 \mathrm{~F}-10 \mathrm{HRM} 19.0$ & ONSITE & sw & $\mathrm{Y}$ & RIVER T & TRANSECT & 08-Sep-03 Cd & & 0.023 & $3 \mathrm{ug} / \mathrm{L}$ & & & U & & \\
\hline SESPMNT & B17CR2 & $100 \mathrm{~F}-2 \mathrm{HRM} 19.0$ & ONSITE & sw & $\mathrm{Y}$ & RIVER 7 & TRANSECT & $08-S e p-03 \mathrm{Cd}$ & & & $3 \mathrm{ug} / \mathrm{L}$ & & & u & & \\
\hline SESPMNT & B17CC4 & $100 \mathrm{~F}-3$ HRM 19.0 & ONSITE & sw & $\mathrm{N}$ & RIVER 7 & TRANSECT & 08-Sep-03 Cd & & 0.023 & & & & U & & \\
\hline SESPMNT & B17CR3 & 100 F -3 HRM 19.0 & ONSITE & sw & Y & RIVER T & TRANSECT & 08-Sep-03 Cd & & 0.023 & $3 \mathrm{ug} / \mathrm{L}$ & & & u & & \\
\hline
\end{tabular}


WATER - COLUMBIA RIVER TRANSECT

\begin{tabular}{|c|c|c|c|c|c|c|c|c|c|c|c|c|c|c|c|c|}
\hline | OWNER ID & | SAMP NUM| & SAMP SITE NAME & DIST CLASS & $\mid$ MEDIA & \begin{tabular}{|c|} 
FILTERED \\
FLAG
\end{tabular} & $\begin{array}{l}\text { SAMP } \\
\text { FROM }\end{array}$ & COLL MTHD & SAMP DATE & CON SHORT NAME & \begin{tabular}{c|c} 
VALUE & L \\
RPTD & F
\end{tabular} & \begin{tabular}{|l|l|} 
ANAL \\
UNITS \\
RPTD \\
\end{tabular} & \begin{tabular}{|l|} 
COUNTING \\
ERROR
\end{tabular} & 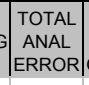 & $\begin{array}{c}\text { LAB } \\
\text { QUALIFIER }\end{array}$ & SAMP COMMENT & $\begin{array}{l}\text { RESULT } \\
\text { COMMENT }\end{array}$ \\
\hline SESPMNT & B17CR4 & 100 F -5 HRM 19.0 & ONSITE & SW & Y & RIVER & TRANSECT & 08-Sep-03 Cd & & & & & & u & - & \\
\hline SESPMNT & B17CR5 & 100 F -7 HRM 19.0 & ONSITE & sw & $\mathrm{Y}$ & RIVER & TRANSECT & 08-Sep-03 Cd & & 0.0234 & $\mathrm{ug} / \mathrm{L}$ & & & $\mathrm{U}$ & & \\
\hline SESPMNT & B17CY5 & $100 \mathrm{~F}$ SHORE HRM 18 & ONSITE & sw & $\mathrm{N}$ & RIVER & TRANSECT & 08 -Sep-03 Cd & & 0.0234 & $\mathrm{ug} / \mathrm{L}$ & & & u & & \\
\hline SESPMNT & B17CY6 & $100 \mathrm{~F}$ SHORE HRM 18 & ONSITE & sw & $\mathrm{Y}$ & RIVER & TRANSECT & $08-S e p-03 \mathrm{Cd}$ & & 0.0234 & $\mathrm{ug} / \mathrm{L}$ & & & u & & \\
\hline SESPMNT & B17CY8 & $100 \mathrm{~F}$ SHORE HRM 22 & ONSITE & sw & $\mathrm{N}$ & RIVER & TRANSECT & 08-Sep-03 Cd & & 0.0234 & $\mathrm{ug} / \mathrm{L}$ & & & $u$ & & \\
\hline SESPMNT & B17CY9 & $100 \mathrm{~F}$ SHORE HRM 22 & ONSITE & sw & $\mathrm{Y}$ & RIVER & TRANSECT & 08-Sep-03 Cd & & & $\mathrm{ug} / \mathrm{L}$ & & & $u$ & & \\
\hline SESPMNT & B17D01 & $100 \mathrm{~F}$ SHORE HRM 23 & ONSITE & sw & $\mathrm{N}$ & RIVER & TRANSECT & 08-Sep-03 Cd & & 0.02474 & & & & B & & \\
\hline SESPMNT & B17D02 & $100 \mathrm{~F}$ SHORE HRM 23 & ONSITE & sw & $\mathrm{Y}$ & RIVER & TRANSECT & 08-Sep-03 Cd & & $0.0259 u$ & & & & B & & \\
\hline SESPMNT & B17C97 & HANFRD TS-1 HRM 28.7 & ONSITE & sw & $\mathrm{N}$ & RIVER & TRANSECT & $08-S e p-03 \mathrm{Cd}$ & & 0.0234 & $\mathrm{ug} / \mathrm{L}$ & & & $\mathrm{U}$ & & \\
\hline SESPMNT & B17CP5 & HANFRD TS-1 HRM 28.7 & ONSITE & sw & $\mathrm{Y}$ & RIVER & TRANSECT & 08-Sep-03 Cd & & $0.023 \mathrm{c}$ & $\mathrm{ug} / \mathrm{L}$ & & & U & & \\
\hline SESPMNT & B17CB2 & HANFRD TS-10 HRM 28.7 & ONSITE & sw & $\mathrm{N}$ & RIVER & TRANSECT & $08-S e p-03 \mathrm{Cd}$ & & 0.0234 & $\mathrm{ug} / \mathrm{L}$ & & & U & & \\
\hline SESPMNT & B17CR0 & HANFRD TS-10 HRM 28.7 & ONSITE & sw & $\mathrm{Y}$ & RIVER & TRANSECT & 08-Sep-03 Cd & & 0.0234 & $\mathrm{ug} / \mathrm{L}$ & & & $\mathrm{U}$ & & \\
\hline SESPMNT & B17C98 & HANFRD TS-2 HRM 28.7 & ONSITE & sw & $\mathrm{N}$ & RIVER & TRANSECT & 08-Sep-03 Cd & & 0.0295 & $\mathrm{ug} / \mathrm{L}$ & & & B & & \\
\hline SESPMNT & B17CP6 & HANFRD TS-2 HRM 28.7 & ONSITE & sw & $\mathrm{Y}$ & RIVER & TRANSECT & 08 -Sep-03 Cd & & 0.023 & $\mathrm{ug} / \mathrm{L}$ & & & u & & \\
\hline SESPMNT & B17C99 & HANFRD TS-3 HRM 28.7 & ONSITE & sw & $\mathrm{N}$ & RIVER & TRANSECT & 08-Sep-03 Cd & & 0.0234 & & & & U & & \\
\hline SESPMNT & B17CP7 & HANFRD TS-3 HRM 28.7 & ONSITE & sw & $\mathrm{Y}$ & RIVER & TRANSECT & 08-Sep-03 Cd & & 0.0234 & & & & $\mathrm{U}$ & & \\
\hline SESPMNT & B17CB0 & HANFRD TS-5 HRM 28.7 & ONSITE & sw & $\mathrm{N}$ & RIVER & TRANSECT & 08-Sep-03 Cd & & 0.0234 & $\mathrm{ug} / \mathrm{L}$ & & & $\mathrm{u}$ & & \\
\hline SESPMNT & B17CP8 & HANFRD TS-5 HRM 28.7 & ONSITE & sw & $\mathrm{Y}$ & RIVER & TRANSECT & 08-Sep-03 Cd & & $0.023 \mathrm{c}$ & $\mathrm{ug} / \mathrm{L}$ & & & U & & \\
\hline SESPMNT & B17CB1 & HANFRD TS-7 HRM 28.7 & ONSITE & sw & $\mathrm{N}$ & RIVER & TRANSECT & $08-S e p-03 \mathrm{Cd}$ & & 0.0234 & $\mathrm{ug} / \mathrm{L}$ & & & u & & \\
\hline SESPMNT & B17CP9 & HANFRD TS-7 HRM 28.7 & ONSITE & sw & $\mathrm{Y}$ & RIVER & TRANSECT & 08 -Sep-03 Cd & & 0.0234 & & & & u & & \\
\hline SESPMNT & B17CL7 & HANFRD TWNSITE HRM26 & ONSITE & sw & $\mathrm{N}$ & RIVER & TRANSECT & $08-S e p-03 \mathrm{Cd}$ & & 0.02344 & & & & B & & \\
\hline SESPMNT & B17CM0 & HANFRD TWNSITE HRM26 & ONSITE & sw & Y & RIVER & TRANSECT & 08-Sep-03 Cd & & 0.0234 & & & & u & & \\
\hline SESPMNT & B17CL8 & HANFRD TWNSITE HRM27 & ONSITE & sw & $\mathrm{N}$ & RIVER & TRANSECT & $08-S e p-03 \mathrm{Cd}$ & & 0.02344 & & & & B & & \\
\hline SESPMNT & B17CM1 & HANFRD TWNSITE HRM27 & ONSITE & sw & $\mathrm{Y}$ & RIVER & TRANSECT & 08 -Sep-03 Cd & & 0.023 & $\mathrm{ug} / \mathrm{L}$ & & & u & & \\
\hline SESPMNT & B17CY2 & HANFRD TWNSITE HRM28 & ONSITE & sw & $\mathrm{N}$ & RIVER & TRANSECT & $08-S e p-03 \mathrm{Cd}$ & & 0.0234 & $\mathrm{ug} / \mathrm{L}$ & & & U & & \\
\hline SESPMNT & B17CY3 & HANFRD TWNSITE HRM28 & ONSITE & sw & $\mathrm{Y}$ & RIVER & TRANSECT & 08-Sep-03 Cd & & 0.0234 & $\mathrm{ug} / \mathrm{L}$ & & & $\mathrm{U}$ & & \\
\hline SESPMNT & B17CL9 & HANFRD TWNSITE HRM30 & ONSITE & sw & $\mathrm{N}$ & RIVER & TRANSECT & 08-Sep-03 Cd & & 0.04464 & $\mathrm{ug} / \mathrm{L}$ & & & B & & \\
\hline SESPMNT & B17CM2 & HANFRD TWNSITE HRM30 & ONSITE & sw & $\mathrm{Y}$ & RIVER & TRANSECT & $08-S e p-03 \mathrm{Cd}$ & & 0.0234 & $\mathrm{ug} / \mathrm{L}$ & & & U & & \\
\hline SESPMNT & B17CN9 & 300 AREA -1 HRM 43.1 & ONSITE & sw & Y & RIVER & TRANSECT & $09-S e p-03$ Cd & & 0.0234 & $\mathrm{ug} / \mathrm{L}$ & & & u & & \\
\hline SESPMNT & B17CP0 & 300 AREA -2 HRM 43.1 & ONSITE & sw & $\mathrm{Y}$ & RIVER & TRANSECT & 09-Sep-03 Cd & & 0.0234 & $\mathrm{ug} / \mathrm{L}$ & & & U & & \\
\hline SESPMNT & B17CP1 & 300 AREA -3 HRM 43.1 & ONSITE & sw & Y & RIVER & TRANSECT & $09-S e p-03 \mathrm{Cd}$ & & 0.0234 & & & & u & & \\
\hline SESPMNT & B17CP2 & 300 AREA -5 HRM 43.1 & ONSITE & sW & $\mathrm{Y}$ & RIVER & TRANSECT & $09-S e p-03 \mathrm{Cd}$ & & 0.0234 & $\mathrm{ug} / \mathrm{L}$ & & & U & & \\
\hline SESPMNT & B17CP3 & 300 AREA -7 HRM 43.1 & ONSITE & sw & $\mathrm{Y}$ & RIVER & TRANSECT & $09-S e p-03 \mathrm{Cd}$ & & 0.0234 & $\mathrm{ug} / \mathrm{L}$ & & & u & & \\
\hline SESPMNT & B17CW8 & 300 AREA SHR HRM41.5 & ONSITE & sw & Y & RIVER & TRANSECT & $09-S e p-03$ Cd & & 0.0234 & ug/L & & & u & & \\
\hline SESPMNT & $B 17 C X 2$ & 300 AREA SHR HRM42.1 & ONSITE & sw & $\mathrm{Y}$ & RIVER & TRANSECT & 09-Sep-03 Cd & & 0.0234 & ug/L & & & $\mathrm{U}$ & & \\
\hline SESPMNT & B17CX6 & 300 AREA SHR HRM42.5 & ONSITE & sw & $\mathrm{Y}$ & RIVER & TRANSECT & $09-S e p-03$ Cd & & $0.023 \mathrm{c}$ & ug/L & & & U & & \\
\hline SESPMNT & B17CY0 & 300 AREA SHR HRM 42.9 & ONSITE & sw & $\mathrm{Y}$ & RIVER & TRANSECT & $09-S e p-03 \mathrm{Cd}$ & & 0.0234 & $\mathrm{ug} / \mathrm{L}$ & & & u & & \\
\hline SESPMNT & B17CP4 & 300 AREA-10 HRM 43.1 & ONSITE & sw & $\mathrm{Y}$ & RIVER & TRANSECT & $09-S e p-03 \mathrm{Cd}$ & & 0.0234 & $\mathrm{ug} / \mathrm{L}$ & & & u & & \\
\hline SESPMNT & B17CT4 & RICH.PMPHS HRM 43.5 & OFFSITE & sw & $\mathrm{Y}$ & RIVER & TRANSECT & $09-S e p-03$ Cd & & 0.0234 & $\mathrm{ug} / \mathrm{L}$ & & & u & & \\
\hline SESPMNT & B17CT2 & RICH.PMPHS HRM 45.0 & OFFSITE & sw & $\mathrm{Y}$ & RIVER & TRANSECT & $09-S e p-03 \mathrm{Cd}$ & & 0.0234 & $\mathrm{ug} / \mathrm{L}$ & & & U & & \\
\hline SESPMNT & B17CT1 & RICH.PMPHS HRM 45.8 & OFFSITE & sw & Y & RIVER & TRANSECT & $09-S e p-03 \mathrm{Cd}$ & & 0.0234 & $\mathrm{ug} / \mathrm{L}$ & & & $u$ & & \\
\hline SESPMNT & B17CD0 & RICH.PMPHS-1 HRM46.4 & OFFSITE & sw & $\mathrm{N}$ & RIVER & TRANSECT & $09-S e p-03 \mathrm{Cd}$ & & 0.0234 & $\mathrm{ug} / \mathrm{L}$ & & & u & & \\
\hline SESPMNT & B17CN3 & RICH.PMPHS-1 HRM46.4 & OFFSITE & sw & $\mathrm{Y}$ & RIVER & TRANSECT & $09-S e p-03 \mathrm{Cd}$ & & 0.0234 & ug/L & & & u & & \\
\hline SESPMNT & B17CD5 & $\begin{array}{l}\text { RICH.PMPHS-10 HRM46. } 4 \\
\end{array}$ & OFFSITE & sw & $\mathrm{N}$ & RIVER & TRANSECT & $09-S e p-03 \mathrm{Cd}$ & & 0.0234 & ug/L & & & U & & \\
\hline SESPMNT & B17CN8 & RICH.PMPHS-10 HRM46.4 & OFFSITE & sw & $\mathrm{Y}$ & RIVER & TRANSECT & $09-S e p-03 \mathrm{Cd}$ & & 0.0234 & $\mathrm{ug} / \mathrm{L}$ & & & U & & \\
\hline SESPMNT & B17CD1 & RICH.PMPHS-2 HRM46.4 & OFFSITE & sw & $\mathrm{N}$ & RIVER & TRANSECT & 09-Sep-03 Cd & & 0.0234 & $\mathrm{ug} / \mathrm{L}$ & & & u & & \\
\hline SESPMNT & B17CN4 & RICH.PMPHS-2 HRM46.4 & OFFSITE & sW & $\mathrm{Y}$ & RIVER & TRANSECT & 09-Sep-03 Cd & & 0.0234 & $\mathrm{ug} / \mathrm{L}$ & & & U & & \\
\hline SESPMNT & B17CD2 & RICH.PMPHS-3 HRM46.4 & OFFSITE & sw & $\mathrm{N}$ & RIVER & TRANSECT & $09-S e p-03 \mathrm{Cd}$ & & 0.0234 & $\mathrm{ug} / \mathrm{L}$ & & & u & & \\
\hline SESPMNT & B17CN5 & RICH.PMPHS-3 HRM46.4 & OFFSITE & sw & $\mathrm{Y}$ & RIVER & TRANSECT & $09-S e p-03 \mathrm{Cd}$ & & 0.0234 & $\mathrm{ug} / \mathrm{L}$ & & & $u$ & & \\
\hline SESPMNT & B17CD3 & RICH.PMPHS-5 HRM46.4 & OFFSITE & sw & $\mathrm{N}$ & RIVER & TRANSECT & $09-S e p-03 \mathrm{Cd}$ & & 0.0234 & $\mathrm{ug} / \mathrm{L}$ & & & u & & \\
\hline SESPMNT & B17CN6 & RICH.PMPHS-5 HRM46.4 & OFFSITE & sw & $\mathrm{Y}$ & RIVER & TRANSECT & $09-S e p-03 \mathrm{Cd}$ & & 0.0234 & $\mathrm{ug} / \mathrm{L}$ & & & u & & \\
\hline SESPMNT & B17CD4 & RICH.PMPHS-7 HRM46.4 & OFFSITE & sw & $\mathrm{N}$ & RIVER & TRANSECT & $09-S e p-03 \mathrm{Cd}$ & & 0.02534 & & & & B & & \\
\hline SESPMNT & B17CN7 & RICH.PMPHS-7 HRM46.4 & OFFSITE & sw & Y & RIVER & TRANSECT & $09-S e p-03$ Cd & & 0.0234 & ug/L & & & u & & \\
\hline SESPMNT & B183W4 & RICH.PMPHS HRM 43.5 & OFFSITE & sw & $\mathrm{Y}$ & RIVER & TRANSECT & 08 -Dec-03 Cd & & 0.0234 & ug/L & & & U & & \\
\hline SESPMNT & B183W8 & RICH.PMPHS HRM 43.5 & OFFSITE & sw & $\mathrm{N}$ & RIVER - & TRANSECT & 08-Dec-03 Cd & & $0.023 \mathrm{c}$ & ug/L & & & u & & \\
\hline SESPMNT & B183W3 & RICH.PMPHS HRM 43.9 & OFFSITE & sW & $\mathrm{Y}$ & RIVER & TRANSECT & 08-Dec-03 Cd & & 0.0234 & $\mathrm{ug} / \mathrm{L}$ & & & U & & \\
\hline SESPMNT & B183W7 & RICH.PMPHS HRM 43.9 & OFFSITE & sW & $\mathrm{N}$ & RIVER & TRANSECT & 08-Dec-03 Cd & & 0.0234 & $\mathrm{ug} / \mathrm{L}$ & & & U & & \\
\hline SESPMNT & B183W2 & RICH.PMPHS HRM 45.0 & OFFSITE & SW & $\mathrm{Y}$ & RIVER & TRANSECT & 08 -Dec-03 Cd & & 0.0234 & $\mathrm{ug} / \mathrm{L}$ & & & u & & \\
\hline SESPMNT & B183W6 & RICH.PMPHS HRM 45.0 & OFFSITE & sW & $\mathrm{N}$ & RIVER & TRANSECT & 08-Dec-03 Cd & & $0.023 \mathrm{c}$ & $\mathrm{ug} / \mathrm{L}$ & & & U & & \\
\hline SESPMNT & B183W1 & RICH.PMPHS HRM 45.8 & OFFSITE & sw & $\mathrm{Y}$ & RIVER & TRANSECT & $08-D e c-03$ Cd & & & ug/L & & & u & & \\
\hline SESPMNT & B183W5 & RICH.PMPHS HRM 45.8 & OFFSITE & sw & $\mathrm{N}$ & RIVER & TRANSECT & $08-D e c-03 \mathrm{Cd}$ & & 0.0234 & $\mathrm{ug} / \mathrm{L}$ & & & u & & \\
\hline SESPMNT & B183P9 & RICH.PMPHS-1 HRM46.4 & OFFSITE & sw & $\mathrm{N}$ & RIVER & TRANSECT & $08-D e c-03$ Cd & & 0.0234 & $\mathrm{ug} / \mathrm{L}$ & & & u & & \\
\hline
\end{tabular}


WATER - COLUMBIA RIVER TRANSECT

\begin{tabular}{|c|c|c|c|c|c|c|c|c|c|c|c|c|c|c|c|c|}
\hline | OWNER ID & SAMP NUN & SAMP SITE NAME & |DIST CLASS & $\mid$ MEDIA & \begin{tabular}{|c|} 
FILTERED \\
FLAG
\end{tabular} & $\begin{array}{l}\text { SAMP } \\
\text { FROM }\end{array}$ & COLL MTHD & SAMP DATE & CON SHORT NAME & $\begin{array}{l}\text { VALUE } \\
\text { RPTD }\end{array}$ & \begin{tabular}{|l|} 
ANAL \\
UNITS \\
RPTD
\end{tabular} & $\begin{array}{c}\text { COUNTING } \\
\text { ERROR }\end{array}$ & \begin{tabular}{|c|c|} 
TOTAL \\
ANAL \\
ANROR
\end{tabular} & $\begin{array}{c}\text { LAB } \\
\text { QUALIFIER }\end{array}$ & SAMP COMMENT & $\begin{array}{l}\text { RESULT } \\
\text { COMMENT }\end{array}$ \\
\hline SESPMNT & B183V1 & RICH.PMPHS-1 HRM46.4 & OFFSITE & SW & Y & RIVER & TRANSECT & 08-Dec-03 Cd & & & & & & U & 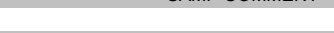 & \\
\hline SESPMNT & B183R4 & RICH.PMPHS-10 HRM46.4 & OFFSITE & sw & $\mathrm{N}$ & RIVER & TRANSECT & 08-Dec-03 Cd & & 0.023 & $3 \mathrm{ug} / \mathrm{L}$ & & & u & & \\
\hline SESPMNT & B183V6 & RICH.PMPHS-10 HRM 46.4 & OFFSITE & sw & $\mathrm{Y}$ & RIVER & TRANSECT & $08-\mathrm{Dec}-03 \mathrm{Cd}$ & & 0.023 & $3 \mathrm{ug} / \mathrm{L}$ & & & u & & \\
\hline SESPMNT & B183RO & RICH.PMPHS-2 HRM46.4 & OFFSITE & sw & $\mathrm{N}$ & RIVER & TRANSECT & $08-\mathrm{Dec}-03 \mathrm{Cd}$ & & 0.023 & $3 \mathrm{ug} / \mathrm{L}$ & & & u & & \\
\hline SESPMNT & B183V2 & RICH.PMPHS-2 HRM46.4 & OFFSITE & sw & Y & RIVER & TRANSECT & 08-Dec-03 Cd & & 0.023 & $3 \mathrm{ug} / \mathrm{L}$ & & & $u$ & & \\
\hline SESPMNT & B183R1 & RICH.PMPHS-3 HRM46.4 & OFFSITE & sw & $\mathrm{N}$ & RIVER & TRANSECT & 08-Dec-03 Cd & & & & & & $u$ & & \\
\hline SESPMNT & B183V3 & RICH.PMPHS-3 HRM46.4 & OFFSITE & sw & $\mathrm{Y}$ & RIVER & TRANSECT & 08-Dec-03 Cd & & & & & & $\mathrm{U}$ & & \\
\hline SESPMNT & B183R2 & RICH.PMPHS-5 HRM46.4 & OFFSITE & SW & $\mathrm{N}$ & RIVER & TRANSECT & 08-Dec-03 Cd & & & & & & U & & \\
\hline SESPMNT & B183V4 & RICH.PMPHS-5 HRM46.4 & OFFSITE & SW & $\mathrm{Y}$ & RIVER & TRANSECT & 08-Dec-03 Cd & & 0.023 & & & & U & & \\
\hline SESPMNT & B183R3 & RICH.PMPHS-7 HRM46.4 & OFFSITE & sw & $\mathrm{N}$ & RIVER & TRANSECT & 08-Dec-03 Cd & & 0.023 & $3 \mathrm{ug} / \mathrm{L}$ & & & U & & \\
\hline SESPMNT & B183V5 & RICH.PMPHS-7 HRM46.4 & OFFSITE & SW & $\mathrm{Y}$ & RIVER & TRANSECT & $08-$ Dec- 03 Cd & & 0.023 & $3 \mathrm{ug} / \mathrm{L}$ & & & U & & \\
\hline SESPMNT & B183R5 & VERNITA-1 HRM 0.3 & OFFSITE & sw & $\mathrm{N}$ & RIVER & TRANSECT & 09-Dec-03 Cd & & 0.023 & $3 \mathrm{ug} / \mathrm{L}$ & & & U & & \\
\hline SESPMNT & B183T7 & VERNITA-1 HRM 0.3 & OFFSITE & SW & $\mathrm{Y}$ & RIVER & TRANSECT & 09-Dec-03 Cd & & 0.023 & & & & U & & \\
\hline SESPMNT & B183P6 & VERNITA-2 HRM 0.3 & OFFSITE & sw & $\mathrm{N}$ & RIVER & TRANSECT & 09-Dec-03 Cd & & 0.023 & $3 \mathrm{ug} / \mathrm{L}$ & & & u & & \\
\hline SESPMNT & B183T8 & VERNITA-2 HRM 0.3 & OFFSITE & sW & Y & RIVER & TRANSECT & 09-Dec-03 Cd & & 0.023 & & & & U & & \\
\hline SESPMNT & B183P7 & VERNITA-3 HRM 0.3 & OFFSITE & sw & $\mathrm{N}$ & RIVER & TRANSECT & 09-Dec-03 Cd & & 0.023 & & & & $u$ & & \\
\hline SESPMNT & B183T9 & VERNITA-3 HRM 0.3 & OFFSITE & sw & Y & RIVER & TRANSECT & 09-Dec-03 Cd & & 0.023 & $3 \mathrm{ug} / \mathrm{L}$ & & & $u$ & & \\
\hline SESPMNT & B183P8 & VERNITA-4 HRM 0.3 & OFFSITE & SW & $\mathrm{N}$ & RIVER & TRANSECT & 09-Dec-03 Cd & & 0.023 & $3 \mathrm{ug} / \mathrm{L}$ & & & $u$ & & \\
\hline SESPMNT & B183V0 & VERNITA-4 HRM 0.3 & OFFSITE & sw & Y & RIVER & TRANSECT & 09-Dec-03 Cd & & 0.023 & $3 \mathrm{ug} / \mathrm{L}$ & & & $u$ & & \\
\hline SESPMNT & B16L95 & VERNITA-1 HRM 0.3 & OFFSITE & sw & $\mathrm{N}$ & RIVER & TRANSECT & $24-\mathrm{Mar}-03 \mathrm{Cr}$ & & 0.0663 & & & & B & & \\
\hline SESPMNT & B16LB7 & VERNITA-1 HRM 0.3 & OFFSITE & SW & Y & RIVER - & TRANSECT & 24-Mar-03 Cr & & 0.271 & & & & C & & \\
\hline SESPMNT & B16L86 & VERNITA-2 HRM 0.3 & OFFSITE & sw & $\mathrm{N}$ & RIVER & TRANSECT & 24-Mar-03 Cr & & & & & & & & \\
\hline SESPMNT & B16LB8 & VERNITA-2 HRM 0.3 & OFFSITE & SW & $\mathrm{Y}$ & RIVER & TRANSECT & 24-Mar-03 Cr & & 0.195 & & & & C & & \\
\hline SESPMNT & B16L87 & VERNITA-3 HRM 0.3 & OFFSITE & sw & $\mathrm{N}$ & RIVER & TRANSECT & 24-Mar-03 Cr & & 0.154 & $4 \mathrm{ug} / \mathrm{L}$ & & & 列 & & \\
\hline SESPMNT & B16LB9 & VERNITA-3 HRM 0.3 & OFFSITE & sw & $\mathrm{Y}$ & RIVER & TRANSECT & 24-Mar-03 Cr & & 0.209 & $9 \mathrm{ug} / \mathrm{L}$ & & & C & & \\
\hline SESPMNT & B16L88 & VERNITA-4 HRM 0.3 & OFFSITE & sw & $\mathrm{N}$ & RIVER & TRANSECT & 24-Mar-03 Cr & & 0.121 & $1 \mathrm{ug} / \mathrm{L}$ & & & & & \\
\hline SESPMNT & B16LC0 & VERNITA-4 HRM 0.3 & OFFSITE & sw & $\mathrm{Y}$ & RIVER & TRANSECT & 24-Mar-03 Cr & & 0.198 & $3 \mathrm{ug} / \mathrm{L}$ & & & C & & \\
\hline SESPMNT & B16LD4 & RICH.PMPHS HRM 43.5 & OFFSITE & SW & $\mathrm{Y}$ & RIVER & TRANSECT & $25-\mathrm{Mar}-03 \mathrm{Cr}$ & & 0.186 & $6 \mathrm{ug} / \mathrm{L}$ & & & c & & \\
\hline SESPMNT & B16LD8 & RICH.PMPHS HRM 43.5 & OFFSITE & sw & $\mathrm{N}$ & RIVER & TRANSECT & $25-\mathrm{Mar}-03 \mathrm{Cr}$ & & 0.16 & & & & & & \\
\hline SESPMNT & B16LD3 & RICH.PMPHS HRM 43.9 & OFFSITE & SW & $\mathrm{Y}$ & RIVER & TRANSECT & $25-\mathrm{Mar}-03 \mathrm{Cr}$ & & 0.253 & & & & C & & \\
\hline SESPMNT & B16LD7 & RICH.PMPHS HRM 43.9 & OFFSITE & sw & $\mathrm{N}$ & RIVER & TRANSECT & $25-\mathrm{Mar}-03 \mathrm{Cr}$ & & 0.0854 & 4 ug $/ \mathrm{L}$ & & & B & & \\
\hline SESPMNT & B16LD2 & RICH.PMPHS HRM 45.0 & OFFSITE & SW & $\mathrm{Y}$ & RIVER & TRANSECT & $25-\mathrm{Mar}-03 \mathrm{Cr}$ & & 0.177 & $7 \mathrm{ug} / \mathrm{L}$ & & & C & & \\
\hline SESPMNT & B16LD6 & RICH.PMPHS HRM 45.0 & OFFSITE & SW & $\mathrm{N}$ & RIVER - & TRANSECT & $25-\mathrm{Mar}-03 \mathrm{Cr}$ & & 0.137 & $7 \mathrm{ug} / \mathrm{L}$ & & & & & \\
\hline SESPMNT & B16LD1 & RICH.PMPHS HRM 45.8 & OFFSITE & sw & Y & RIVER & TRANSECT & 25-Mar-03 Cr & & 0.142 & $2 \mathrm{ug} / \mathrm{L}$ & & & c & & \\
\hline SESPMNT & B16LD5 & RICH.PMPHS HRM 45.8 & OFFSITE & sw & $\mathrm{N}$ & RIVER & TRANSECT & 25-Mar-03 Cr & & 0.0992 & & & & B & & \\
\hline SESPMNT & B16L89 & RICH.PMPHS-1 HRM46.4 & OFFSITE & sw & $\mathrm{N}$ & RIVER & TRANSECT & 25-Mar-03 Cr & & 0.0884 & $4 \mathrm{ug} / \mathrm{L}$ & & & B & & \\
\hline SESPMNT & B16LC1 & RICH.PMPHS-1 HRM46.4 & OFFSITE & sw & $\mathrm{Y}$ & RIVER & TRANSECT & 25-Mar-03 Cr & & 0.0584 & & & & $\mathrm{BC}$ & & \\
\hline SESPMNT & B16L94 & RICH.PMPHS-10 HRM46.4 & OFFSITE & sW & $\mathrm{N}$ & RIVER & TRANSECT & $25-\mathrm{Mar}-03 \mathrm{Cr}$ & & 0.176 & & & & & & \\
\hline SESPMNT & B16LC6 & RICH.PMPHS-10 HRM46.4 & OFFSITE & sw & $\mathrm{Y}$ & RIVER & TRANSECT & $25-\mathrm{Mar}-03 \mathrm{Cr}$ & & 0.405 & $5 \mathrm{ug} / \mathrm{L}$ & & & c & & \\
\hline SESPMNT & B16L90 & RICH.PMPHS-2 HRM46.4 & OFFSITE & SW & $\mathrm{N}$ & RIVER & TRANSECT & $25-\mathrm{Mar}-03 \mathrm{Cr}$ & & 0.15 & $5 \mathrm{ug} / \mathrm{L}$ & & & & & \\
\hline SESPMNT & B16LC2 & RICH.PMPHS-2 HRM46.4 & OFFSITE & sw & Y & RIVER & TRANSECT & $25-\mathrm{Mar}-03 \mathrm{Cr}$ & & 0.206 & $6 \mathrm{ug} / \mathrm{L}$ & & & c & & \\
\hline SESPMNT & B16L91 & RICH.PMPHS-3 HRM46.4 & OFFSITE & SW & $\mathrm{N}$ & RIVER & TRANSECT & 25-Mar-03 Cr & & 0.125 & $5 \mathrm{ug} / \mathrm{L}$ & & & & & \\
\hline SESPMNT & B16LC3 & RICH.PMPHS-3 HRM46.4 & OFFSITE & sw & $\mathrm{Y}$ & RIVER & TRANSECT & $25-\mathrm{Mar}-03 \mathrm{Cr}$ & & 0.203 & $3 \mathrm{ug} / \mathrm{L}$ & & & c & & \\
\hline SESPMNT & B16L92 & RICH.PMPHS-5 HRM46.4 & OFFSITE & sw & $\mathrm{N}$ & RIVER & TRANSECT & $25-\mathrm{Mar}-03 \mathrm{Cr}$ & & 0.126 & & & & & & \\
\hline SESPMNT & B16LC4 & RICH.PMPHS-5 HRM46.4 & OFFSITE & sw & $\mathrm{Y}$ & RIVER & TRANSECT & $25-\mathrm{Mar}-03 \mathrm{Cr}$ & & 0.185 & & & & C & & \\
\hline SESPMNT & B16L93 & RICH.PMPHS-7 HRM46.4 & OFFSITE & sw & $\mathrm{N}$ & RIVER & TRANSECT & $25-\mathrm{Mar}-03 \mathrm{Cr}$ & & 0.11 & & & & & & \\
\hline SESPMNT & B16LC5 & RICH.PMPHS-7 HRM46.4 & OFFSITE & SW & $\mathrm{Y}$ & RIVER & TRANSECT & $25-\mathrm{Mar}-03 \mathrm{Cr}$ & & 0.185 & $5 \mathrm{ug} / \mathrm{L}$ & & & C & & \\
\hline SESPMNT & B171V9 & VERNITA-1 HRM 0.3 & OFFSITE & sw & $\mathrm{N}$ & RIVER & TRANSECT & 09-Jun- $03 \mathrm{Cr}$ & & 0.153 & $3 \mathrm{ug} / \mathrm{L}$ & & & $\mathrm{c}$ & & \\
\hline SESPMNT & B171Y1 & VERNITA-1 HRM 0.3 & OFFSITE & sw & Y & RIVER & TRANSECT & 09-Jun-03 Cr & & 0.141 & 1 ug/L & & & & & \\
\hline SESPMNT & B171V0 & VERNITA-2 HRM 0.3 & OFFSITE & SW & $\mathrm{N}$ & RIVER & TRANSECT & 09-Jun-03 Cr & & 0.158 & $3 \mathrm{ug} / \mathrm{L}$ & & & C & & \\
\hline SESPMNT & B171Y2 & VERNITA-2 HRM 0.3 & OFFSITE & sw & $\mathrm{Y}$ & RIVER & TRANSECT & 09-Jun-03 Cr & & & $1 \mathrm{ug} / \mathrm{L}$ & & & & & \\
\hline SESPMNT & B171V1 & VERNITA-3 HRM 0.3 & OFFSITE & sw & $\mathrm{N}$ & RIVER & TRANSECT & 09-Jun-03 Cr & & 0.171 & & & & c & & \\
\hline SESPMNT & B171Y3 & $\begin{array}{l}\text { VERNITA-3 HRM } 0.3 \\
\end{array}$ & OFFSITE & sw & Y & RIVER & TRANSECT & 09-Jun-03 Cr & & 0.178 & & & & ( & & \\
\hline SESPMNT & B171V2 & VERNITA-4 HRM 0.3 & OFFSITE & sw & $\mathrm{N}$ & RIVER & TRANSECT & 09-Jun- $03 \mathrm{Cr}$ & & 0.168 & 8 ug $/ \mathrm{L}$ & & & C & & \\
\hline SESPMNT & B171Y4 & VERNITA-4 HRM 0.3 & OFFSITE & sw & $\mathrm{Y}$ & RIVER & TRANSECT & 09-Jun-03 Cr & & 0.137 & $7 \mathrm{ug} / \mathrm{L}$ & & & & & \\
\hline SESPMNT & B17208 & RICH.PMPHS HRM 43.5 & OFFSITE & sW & $\mathrm{Y}$ & RIVER & TRANSECT & 10-Jun-03 Cr & & 0.0722 & $2 \mathrm{ug} / \mathrm{L}$ & & & B & & \\
\hline SESPMNT & B17212 & RICH.PMPHS HRM 43.5 & OFFSITE & SW & $\mathrm{N}$ & RIVER & TRANSECT & 10-Jun-03 Cr & & 0.118 & $3 \mathrm{ug} / \mathrm{L}$ & & & C & & \\
\hline SESPMNT & B17207 & RICH.PMPHS HRM 43.9 & OFFSITE & SW & Y & RIVER & TRANSECT & 10-Jun-03 Cr & & 0.0757 & $7 \mathrm{ug} / \mathrm{L}$ & & & B & & \\
\hline SESPMNT & B17211 & RICH.PMPHS HRM 43.9 & OFFSITE & SW & $\mathrm{N}$ & RIVER & TRANSECT & 10-Jun-03 Cr & & 0.125 & $5 \mathrm{ug} / \mathrm{L}$ & & & C & & \\
\hline SESPMNT & B17206 & RICH.PMPHS HRM 45.0 & OFFSITE & sw & Y & RIVER & TRANSECT & 10-Jun-03 Cr & & 0.0619 & & & & B & & \\
\hline SESPMNT & B17210 & RICH.PMPHS HRM 45.0 & OFFSITE & sW & $\mathrm{N}$ & RIVER & TRANSECT & 10-Jun-03 Cr & & 0.136 & $6 \mathrm{ug} / \mathrm{L}$ & & & C & & \\
\hline SESPMNT & B17205 & RICH.PMPHS HRM 45.8 & OFFSITE & sw & $\mathrm{Y}$ & RIVER & TRANSECT & 10-Jun-03 Cr & & 0.02 & $2 \mathrm{ug} / \mathrm{L}$ & & & u & & \\
\hline
\end{tabular}


WATER - COLUMBIA RIVER TRANSECT

\begin{tabular}{|c|c|c|c|c|c|c|c|c|c|c|c|c|c|c|c|c|}
\hline | OWNER ID & | SAMP NUM| & SAMP SITE NAME & |DIST CLASS & $\mid$ MEDIA & \begin{tabular}{|c|} 
FILTERED \\
FLAG
\end{tabular} & $\begin{array}{l}\text { SAMP } \\
\text { FROM }\end{array}$ & COLL MTHD & SAMP DATE & CON SHORT NAME & $\begin{array}{l}\text { VALUE } \\
\text { RPTD }\end{array}$ & \begin{tabular}{|l|} 
ANAL \\
UNITS \\
RPTD
\end{tabular} & $\begin{array}{c}\text { COUNTING } \\
\text { ERROR }\end{array}$ & \begin{tabular}{|l|} 
TOTAL \\
ANAL \\
ERROR
\end{tabular} & $\begin{array}{c}\text { LAB } \\
\text { QUALIFIER }\end{array}$ & SAMP COMMENT & $\begin{array}{l}\text { RESULT } \\
\text { COMMENT }\end{array}$ \\
\hline SESPMNT & B17209 & RICH.PMPHS HRM 45.8 & OFFSITE & SW & $\mathrm{N}$ & RIVER & TRANSECT & 10-Jun-03 Cr & & & & & & $\mathrm{C}$ & 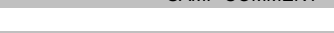 & \\
\hline SESPMNT & B171V3 & RICH.PMPHS-1 HRM46.4 & OFFSITE & sw & $\mathrm{N}$ & RIVER & TRANSECT & 10-Jun-03 Cr & & 0.222 & $2 \mathrm{ug} / \mathrm{L}$ & & & C & & \\
\hline SESPMNT & B171Y5 & RICH.PMPHS-1 HRM46.4 & OFFSITE & sw & $\mathrm{Y}$ & RIVER & TRANSECT & 10-Jun-03 Cr & & 0.161 & $1 \mathrm{ug} / \mathrm{L}$ & & & & & \\
\hline SESPMNT & B171V8 & RICH.PMPHS-10 HRM46. 4 & OFFSITE & sw & $\mathrm{N}$ & RIVER & TRANSECT & 10-Jun-03 Cr & & 0.161 & $1 \mathrm{ug} / \mathrm{L}$ & & & c & & \\
\hline SESPMNT & B17200 & RICH.PMPHS-10 HRM46.4 & OFFSITE & sw & Y & RIVER & TRANSECT & 10-Jun-03 $\mathrm{Cr}$ & & 0.0756 & $6 \mathrm{ug} / \mathrm{L}$ & & & B & & \\
\hline SESPMNT & B171V4 & RICH.PMPHS-2 HRM46.4 & OFFSITE & sw & $\mathrm{N}$ & RIVER & TRANSECT & 10-Jun-03 Cr & & & & & & C & & \\
\hline SESPMNT & B171Y6 & RICH.PMPHS-2 HRM46.4 & OFFSITE & sw & $\mathrm{Y}$ & RIVER & TRANSECT & 10-Jun-03 Cr & & & & & & & & \\
\hline SESPMNT & B171V5 & RICH.PMPHS-3 HRM46.4 & OFFSITE & SW & $\mathrm{N}$ & RIVER & TRANSECT & 10-Jun-03 Cr & & & & & & C & & \\
\hline SESPMNT & B171Y7 & RICH.PMPHS-3 HRM46.4 & OFFSITE & SW & $\mathrm{Y}$ & RIVER & TRANSECT & 10-Jun-03 Cr & & 0.091 & $1 \mathrm{ug} / \mathrm{L}$ & & & B & & \\
\hline SESPMNT & B171V6 & RICH.PMPHS-5 HRM46.4 & OFFSITE & sw & $\mathrm{N}$ & RIVER & TRANSECT & 10-Jun-03 Cr & & 0.158 & $8 \mathrm{ug} / \mathrm{L}$ & & & C & & \\
\hline SESPMNT & B171Y8 & RICH.PMPHS-5 HRM46.4 & OFFSITE & SW & $\mathrm{Y}$ & RIVER & TRANSECT & 10-Jun-03 Cr & & 0.103 & $3 \mathrm{ug} / \mathrm{L}$ & & & & & \\
\hline SESPMNT & B171V7 & RICH.PMPHS-7 HRM46.4 & OFFSITE & sw & $\mathrm{N}$ & RIVER & TRANSECT & 10-Jun-03 Cr & & 0.149 & $9 \mathrm{ug} / \mathrm{L}$ & & & C & & \\
\hline SESPMNT & B171Y9 & RICH.PMPHS-7 HRM46.4 & OFFSITE & SW & $\mathrm{Y}$ & RIVER & TRANSECT & 10-Jun-03 Cr & & 0.0639 & $9 \mathrm{ug} / \mathrm{L}$ & & & B & & \\
\hline SESPMNT & B17CB6 & $100 \mathrm{~N}-1$ HRM 9.5 & ONSITE & sw & $\mathrm{N}$ & RIVER & TRANSECT & 04-Sep-03 Cr & & 0.0746 & $6 \mathrm{ug} / \mathrm{L}$ & & & S & & \\
\hline SESPMNT & B17CM7 & $100 \mathrm{~N}-1$ HRM 9.5 & ONSITE & sw & Y & RIVER & TRANSECT & 04-Sep-03 Cr & & 0.273 & $3 \mathrm{ug} / \mathrm{L}$ & & & & & \\
\hline SESPMNT & B17CC1 & $100 \mathrm{~N}-10$ HRM 9.5 & ONSITE & sw & $\mathrm{N}$ & RIVER & TRANSECT & 04-Sep-03 Cr & & 0.047 & 7 ug/L & & & u & & \\
\hline SESPMNT & B17CN2 & $100 \mathrm{~N}-10$ HRM 9.5 & ONSITE & sw & $\mathrm{Y}$ & RIVER & TRANSECT & 04-Sep-03 Cr & & 0.047 & $7 \mathrm{ug} / \mathrm{L}$ & & & $u$ & & \\
\hline SESPMNT & B17CB7 & $100 \mathrm{~N}-2$ HRM 9.5 & ONSITE & SW & $\mathrm{N}$ & RIVER & TRANSECT & 04-Sep-03 Cr & & 0.047 & $7 \mathrm{ug} / \mathrm{L}$ & & & $u$ & & \\
\hline SESPMNT & B17CM8 & $100 \mathrm{~N}-2$ HRM 9.5 & ONSITE & sw & Y & RIVER & TRANSECT & 04-Sep-03 Cr & & 0.047 & $7 \mathrm{ug} / \mathrm{L}$ & & & $u$ & & \\
\hline SESPMNT & B17CB8 & $100 \mathrm{~N}-3$ HRM 9.5 & ONSITE & SW & $\mathrm{N}$ & RIVER & TRANSECT & 04-Sep- $03 \mathrm{Cr}$ & & 0.047 & $7 \mathrm{ug} / \mathrm{L}$ & & & U & & \\
\hline SESPMNT & B17CM9 & $100 \mathrm{~N}-3$ HRM 9.5 & ONSITE & SW & $\mathrm{Y}$ & RIVER & TRANSECT & $04-\mathrm{Sep}-03 \mathrm{Cr}$ & & 0.047 & $7 \mathrm{ug} / \mathrm{L}$ & & & U & & \\
\hline SESPMNT & B17CB9 & $100 \mathrm{~N}-5$ HRM 9.5 & ONSITE & sw & $\mathrm{N}$ & RIVER & TRANSECT & 04-Sep-03 Cr & & 0.047 & $7 \mathrm{ug} / \mathrm{L}$ & & & u & & \\
\hline SESPMNT & B17CNO & $100 \mathrm{~N}-5$ HRM 9.5 & ONSITE & sw & $\mathrm{Y}$ & RIVER & TRANSECT & 04-Sep-03 Cr & & 0.047 & $7 \mathrm{ug} / \mathrm{L}$ & & & u & & \\
\hline SESPMNT & B17CC0 & $100 \mathrm{~N}-7$ HRM 9.5 & ONSITE & sw & $\mathrm{N}$ & RIVER & TRANSECT & 04-Sep-03 Cr & & 0.047 & $7 \mathrm{ug} / \mathrm{L}$ & & & u & & \\
\hline SESPMNT & B17CN1 & $100 \mathrm{~N}-7$ HRM 9.5 & ONSITE & sw & $\mathrm{Y}$ & RIVER & TRANSECT & 04-Sep-03 Cr & & 0.047 & $7 \mathrm{ug} / \mathrm{L}$ & & & $\mathrm{U}$ & & \\
\hline SESPMNT & B17CV1 & 100 N SHORE HRM 8.4 & ONSITE & sw & $\mathrm{N}$ & RIVER & TRANSECT & 04-Sep-03 Cr & & 0.047 & $7 \mathrm{ug} / \mathrm{L}$ & & & U & & \\
\hline SESPMNT & B17CV2 & 100 N SHORE HRM 8.4 & ONSITE & sW & $\mathrm{Y}$ & RIVER & TRANSECT & 04-Sep-03 Cr & & 0.047 & $7 \mathrm{ug} / \mathrm{L}$ & & & U & & \\
\hline SESPMNT & B17CV5 & 100 N SHORE HRM 8.9 & ONSITE & SW & $\mathrm{N}$ & RIVER & TRANSECT & $04-\mathrm{Sep}-03 \mathrm{Cr}$ & & 0.047 & $7 \mathrm{ug} / \mathrm{L}$ & & & U & & \\
\hline SESPMNT & B17CV6 & 100 N SHORE HRM 8.9 & ONSITE & sw & Y & RIVER & TRANSECT & 04-Sep-03 Cr & & 0.047 & $7 \mathrm{ug} / \mathrm{L}$ & & & u & & \\
\hline SESPMNT & B17CV9 & 100 N SHORE HRM 9.2 & ONSITE & sW & $\mathrm{N}$ & RIVER & TRANSECT & 04-Sep-03 Cr & & 0.047 & $7 \mathrm{ug} / \mathrm{L}$ & & & U & & \\
\hline SESPMNT & B17CW0 & 100 N SHORE HRM 9.2 & ONSITE & sw & Y & RIVER & TRANSECT & 04-Sep-03 Cr & & 0.047 & $7 \mathrm{ug} / \mathrm{L}$ & & & $u$ & & \\
\hline SESPMNT & B17CW3 & 100 N SHORE HRM 9.8 & ONSITE & sw & $\mathrm{N}$ & RIVER & TRANSECT & 04-Sep-03 Cr & & 0.047 & $7 \mathrm{ug} / \mathrm{L}$ & & & U & & \\
\hline SESPMNT & B17CW4 & 100 N SHORE HRM 9.8 & ONSITE & sw & Y & RIVER & TRANSECT & 04-Sep-03 Cr & & 0.047 & $7 \mathrm{ug} / \mathrm{L}$ & & & u & & \\
\hline SESPMNT & B17CD6 & VERNITA-1 HRM 0.3 & OFFSITE & sw & $\mathrm{N}$ & RIVER & TRANSECT & 04-Sep-03 Cr & & 0.047 & $7 \mathrm{ug} / \mathrm{L}$ & & & u & & \\
\hline SESPMNT & B17CM3 & VERNITA-1 HRM 0.3 & OFFSITE & SW & $\mathrm{Y}$ & RIVER & TRANSECT & 04-Sep-03 Cr & & 0.047 & $7 \mathrm{ug} / \mathrm{L}$ & & & $\mathrm{U}$ & & \\
\hline SESPMNT & B17CC7 & VERNITA-2 HRM 0.3 & OFFSITE & sw & $\mathrm{N}$ & RIVER & TRANSECT & 04-Sep-03 Cr & & 0.047 & $7 \mathrm{ug} / \mathrm{L}$ & & & U & & \\
\hline SESPMNT & B17CM4 & VERNITA-2 HRM 0.3 & OFFSITE & sw & $\mathrm{Y}$ & RIVER & TRANSECT & 04-Sep-03 Cr & & 0.047 & $7 \mathrm{ug} / \mathrm{L}$ & & & U & & \\
\hline SESPMNT & B17CC8 & VERNITA-3 HRM 0.3 & OFFSITE & SW & $\mathrm{N}$ & RIVER & TRANSECT & $04-\mathrm{Sep}-03 \mathrm{Cr}$ & & 0.047 & $7 \mathrm{ug} / \mathrm{L}$ & & & u & & \\
\hline SESPMNT & B17CM5 & VERNITA-3 HRM 0.3 & OFFSITE & sw & Y & RIVER & TRANSECT & 04-Sep-03 Cr & & 0.047 & $7 \mathrm{ug} / \mathrm{L}$ & & & u & & \\
\hline SESPMNT & B17CC9 & VERNITA-4 HRM 0.3 & OFFSITE & SW & $\mathrm{N}$ & RIVER & TRANSECT & 04-Sep-03 Cr & & 0.047 & $7 \mathrm{ug} / \mathrm{L}$ & & & U & & \\
\hline SESPMNT & B17CM6 & VERNITA-4 HRM 0.3 & OFFSITE & sw & Y & RIVER & TRANSECT & 04-Sep-03 Cr & & 0.047 & $7 \mathrm{ug} / \mathrm{L}$ & & & U & & \\
\hline SESPMNT & B17CC2 & $100 \mathrm{~F}-1 \mathrm{HRM} 19.0$ & ONSITE & sw & $\mathrm{N}$ & RIVER & TRANSECT & 08-Sep-03 Cr & & 0.047 & $7 \mathrm{ug} / \mathrm{L}$ & & & u & & \\
\hline SESPMNT & B17CR1 & $100 \mathrm{~F}-1$ HRM 19.0 & ONSITE & sW & Y & RIVER - & TRANSECT & 08-Sep-03 Cr & & 0.047 & $7 \mathrm{ug} / \mathrm{L}$ & & & u & & \\
\hline SESPMNT & B17C96 & $100 \mathrm{~F}-10 \mathrm{HRM} 19.0$ & ONSITE & sw & $\mathrm{N}$ & RIVER & TRANSECT & 08 -Sep-03 Cr & & 0.047 & $7 \mathrm{ug} / \mathrm{L}$ & & & U & & \\
\hline SESPMNT & B17CR6 & $100 \mathrm{~F}-10 \mathrm{HRM} 19.0$ & ONSITE & SW & $\mathrm{Y}$ & RIVER & TRANSECT & $08-\mathrm{Sep}-03 \mathrm{Cr}$ & & 0.047 & $7 \mathrm{ug} / \mathrm{L}$ & & & U & & \\
\hline SESPMNT & B17CR2 & $100 \mathrm{~F}-2$ HRM 19.0 & ONSITE & sw & Y & RIVER & TRANSECT & $08-\mathrm{Sep}-03 \mathrm{Cr}$ & & 0.047 & $7 \mathrm{ug} / \mathrm{L}$ & & & U & & \\
\hline SESPMNT & B17CC4 & $100 \mathrm{~F}-3$ HRM 19.0 & ONSITE & SW & $\mathrm{N}$ & RIVER & TRANSECT & $08-\mathrm{Sep}-03 \mathrm{Cr}$ & & 0.047 & $7 \mathrm{ug} / \mathrm{L}$ & & & U & & \\
\hline SESPMNT & B17CR3 & $100 \mathrm{~F}-3$ HRM 19.0 & ONSITE & sW & Y & RIVER & TRANSECT & $08-\mathrm{Sep}-03 \mathrm{Cr}$ & & 0.047 & $7 \mathrm{ug} / \mathrm{L}$ & & & u & & \\
\hline SESPMNT & B17CR4 & $100 \mathrm{~F}-5$ HRM 19.0 & ONSITE & sw & $\mathrm{Y}$ & RIVER & TRANSECT & 08-Sep-03 Cr & & 0.047 & $7 \mathrm{ug} / \mathrm{L}$ & & & $u$ & & \\
\hline SESPMNT & B17CR5 & $100 \mathrm{~F}-7$ HRM 19.0 & ONSITE & SW & $\mathrm{Y}$ & RIVER & TRANSECT & 08-Sep-03 Cr & & 0.047 & $7 \mathrm{ug} / \mathrm{L}$ & & & U & & \\
\hline SESPMNT & B17CY5 & $100 \mathrm{~F} \mathrm{SHORE} \mathrm{HRM} 18$ & ONSITE & sw & $\mathrm{N}$ & RIVER & TRANSECT & $08-\mathrm{Sep}-03 \mathrm{Cr}$ & & 0.047 & $7 \mathrm{ug} / \mathrm{L}$ & & & u & & \\
\hline SESPMNT & B17CY6 & $100 \mathrm{~F}$ SHORE HRM 18 & ONSITE & SW & $\mathrm{Y}$ & RIVER & TRANSECT & 08-Sep-03 Cr & & 0.047 & $7 \mathrm{ug} / \mathrm{L}$ & & & u & & \\
\hline SESPMNT & B17CY8 & 100 F SHORE HRM 22 & ONSITE & sw & $\mathrm{N}$ & RIVER & TRANSECT & 08-Sep-03 Cr & & 0.047 & $7 \mathrm{ug} / \mathrm{L}$ & & & u & & \\
\hline SESPMNT & B17CY9 & 100 F SHORE HRM 22 & ONSITE & sw & $\mathrm{Y}$ & RIVER & TRANSECT & 08 -Sep-03 Cr & & 0.047 & $7 \mathrm{ug} / \mathrm{L}$ & & & u & & \\
\hline SESPMNT & B17D01 & $100 \mathrm{~F}$ SHORE HRM 23 & ONSITE & sw & $\mathrm{N}$ & RIVER & TRANSECT & 08-Sep-03 Cr & & 0.047 & $7 \mathrm{ug} / \mathrm{L}$ & & & U & & \\
\hline SESPMNT & B17D02 & $100 \mathrm{~F}$ SHORE HRM 23 & ONSITE & sw & $\mathrm{Y}$ & RIVER & TRANSECT & 08-Sep-03 Cr & & 0.047 & $7 \mathrm{ug} / \mathrm{L}$ & & & u & & \\
\hline SESPMNT & B17C97 & HANFRD TS-1 HRM 28.7 & ONSITE & SW & $\mathrm{N}$ & RIVER & TRANSECT & $08-\mathrm{Sep}-03 \mathrm{Cr}$ & & 0.0567 & $7 \mathrm{ug} / \mathrm{L}$ & & & B & & \\
\hline SESPMNT & B17CP5 & HANFRD TS-1 HRM 28.7 & ONSITE & sw & Y & RIVER & TRANSECT & 08-Sep-03 Cr & & 0.118 & $8 \mathrm{ug} / \mathrm{L}$ & & & & & \\
\hline SESPMNT & B17CB2 & HANFRD TS-10 HRM 28.7 & ONSITE & SW & $\mathrm{N}$ & RIVER & TRANSECT & 08-Sep-03 Cr & & 0.047 & $7 \mathrm{ug} / \mathrm{L}$ & & & U & & \\
\hline SESPMNT & B17CR0 & HANFRD TS-10 HRM 28.7 & ONSITE & sw & Y & RIVER & TRANSECT & $08-\mathrm{Sep}-03 \mathrm{Cr}$ & & 0.047 & $7 \mathrm{ug} / \mathrm{L}$ & & & $\mathrm{u}$ & & \\
\hline SESPMNT & B17C98 & HANFRD TS-2 HRM 28.7 & ONSITE & sW & $\mathrm{N}$ & RIVER & TRANSECT & 08 -Sep-03 Cr & & 0.047 & $7 \mathrm{ug} / \mathrm{L}$ & & & U & & \\
\hline SESPMNT & B17CP6 & HANFRD TS-2 HRM 28.7 & ONSITE & sw & $\mathrm{Y}$ & RIVER & TRANSECT & 08-Sep-03 Cr & & 0.047 & $7 \mathrm{ug} / \mathrm{L}$ & & & u & & \\
\hline
\end{tabular}


WATER - COLUMBIA RIVER TRANSECT

\begin{tabular}{|c|c|c|c|c|c|c|c|c|c|c|c|c|c|c|c|c|}
\hline | OWNER ID & | SAMP NUM| & SAMP SITE NAME & DIST CLASS & $\mid$ MEDIA & $\begin{array}{c}\text { FILTERED } \\
\text { FLAG }\end{array}$ & $\begin{array}{l}\text { SAMP } \\
\text { FROM }\end{array}$ & COLL MTHD & SAMP DATE & CON SHORT NAME & $\begin{array}{l}\text { VALUE } \\
\text { RPTD }\end{array}$ & \begin{tabular}{|l|} 
ANAL \\
UNITS \\
RPTD \\
\end{tabular} & $\begin{array}{c}\text { COUNTING } \\
\text { ERROR }\end{array}$ & \begin{tabular}{|c|c|} 
TOTAL \\
ANAL \\
ANROR
\end{tabular} & $\begin{array}{c}\text { LAB } \\
\text { QUALIFIER }\end{array}$ & SAMP COMMENT & $\begin{array}{l}\text { RESULT } \\
\text { COMMENT }\end{array}$ \\
\hline SESPMNT & B17C99 & HANFRD TS-3 HRM 28.7 & ONSITE & SW & $\mathrm{N}$ & & TRANSECT & 08-Sep-03 Cr & & & & & & u & 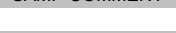 & \\
\hline SESPMNT & B17CP7 & HANFRD TS-3 HRM 28.7 & ONSITE & sw & $\mathrm{Y}$ & RIVER & TRANSECT & $08-\mathrm{Sep}-03 \mathrm{Cr}$ & & 0.047 & $\mathrm{ug} / \mathrm{L}$ & & & $u$ & & \\
\hline SESPMNT & B17CBO & HANFRD TS-5 HRM 28.7 & ONSITE & sw & $\mathrm{N}$ & RIVER & TRANSECT & 08-Sep-03 Cr & & 0.047 & $\mathrm{ug} / \mathrm{L}$ & & & u & & \\
\hline SESPMNT & B17CP8 & HANFRD TS-5 HRM 28.7 & ONSITE & sw & $\mathrm{Y}$ & RIVER & TRANSECT & $08-\mathrm{Sep}-03 \mathrm{Cr}$ & & 0.047 & ug/L & & & u & & \\
\hline SESPMNT & B17CB1 & HANFRD TS-7 HRM 28.7 & ONSITE & sw & $\mathrm{N}$ & RIVER & TRANSECT & 08-Sep-03 Cr & & 0.047 & $\mathrm{ug} / \mathrm{L}$ & & & $u$ & & \\
\hline SESPMNT & B17CP9 & HANFRD TS-7 HRM 28.7 & ONSITE & sw & $\mathrm{Y}$ & RIVER & TRANSECT & 08-Sep-03 Cr & & 0.047 & & & & $u$ & & \\
\hline SESPMNT & B17CL7 & HANFRD TWNSITE HRM 26 & ONSITE & sw & $\mathrm{N}$ & RIVER & TRANSECT & $08-\mathrm{Sep}-03 \mathrm{Cr}$ & & 0.047 & & & & $\mathrm{U}$ & & \\
\hline SESPMNT & B17CM0 & HANFRD TWNSITE HRM26 & 6 ONSITE & SW & $\mathrm{Y}$ & RIVER & TRANSECT & $08-\mathrm{Sep}-03 \mathrm{Cr}$ & & & & & & U & & \\
\hline SESPMNT & B17CL8 & HANFRD TWNSITE HRM27 & 7 ONSITE & SW & $\mathrm{N}$ & RIVER & TRANSECT & $08-\mathrm{Sep}-03 \mathrm{Cr}$ & & 0.047 & ug/L & & & U & & \\
\hline SESPMNT & B17CM1 & HANFRD TWNSITE HRM27 & 7 ONSITE & sw & $\mathrm{Y}$ & RIVER & TRANSECT & 08 -Sep-03 Cr & & 0.047 & ing/L & & & U & & \\
\hline SESPMNT & B17CY2 & HANFRD TWNSITE HRM28 & 3 ONSITE & SW & $\mathrm{N}$ & RIVER & TRANSECT & $08-\mathrm{Sep}-03 \mathrm{Cr}$ & & 0.671 & ug/L $/ \mathrm{L}$ & & & & & \\
\hline SESPMNT & $\mathrm{B} 17 \mathrm{CY} 3$ & HANFRD TWNSITE HRM 28 & 3 ONSITE & sw & $\mathrm{Y}$ & RIVER & TRANSECT & $08-\mathrm{Sep}-03 \mathrm{Cr}$ & & 0.775 & & & & & & \\
\hline SESPMNT & B17CL9 & HANFRD TWNSITE HRM30 & ONSITE & SW & $\mathrm{N}$ & RIVER & TRANSECT & $08-\mathrm{Sep}-03 \mathrm{Cr}$ & & 0.047 & ug/L & & & U & & \\
\hline SESPMNT & B17CM2 & HANFRD TWNSITE HRM 30 & ONSITE & sw & $\mathrm{Y}$ & RIVER & TRANSECT & 08-Sep-03 Cr & & 0.047 & ug/L & & & $\mathrm{U}$ & & \\
\hline SESPMNT & B17CN9 & 300 AREA -1 HRM 43.1 & ONSITE & sw & $\mathrm{Y}$ & RIVER & TRANSECT & $09-\mathrm{Sep}-03 \mathrm{Cr}$ & & 0.047 & & & & U & & \\
\hline SESPMNT & B17CP0 & 300 AREA -2 HRM 43.1 & ONSITE & sw & $\mathrm{Y}$ & RIVER & TRANSECT & 09-Sep-03 Cr & & 0.047 & & & & $\mathrm{U}$ & & \\
\hline SESPMNT & B17CP1 & 300 AREA -3 HRM 43.1 & ONSITE & sw & Y & RIVER & TRANSECT & 09-Sep-03 Cr & & 0.047 & $\mathrm{ug} / \mathrm{L}$ & & & $\mathrm{u}$ & & \\
\hline SESPMNT & B17CP2 & 300 AREA -5 HRM 43.1 & ONSITE & SW & $\mathrm{Y}$ & RIVER & TRANSECT & $09-\mathrm{Sep}-03 \mathrm{Cr}$ & & 0.047 & ug/L & & & $u$ & & \\
\hline SESPMNT & B17CP3 & 300 AREA -7 HRM 43.1 & ONSITE & sw & Y & RIVER & TRANSECT & $09-\mathrm{Sep}-03 \mathrm{Cr}$ & & 0.047 & ug/L $/ \mathrm{L}$ & & & $u$ & & \\
\hline SESPMNT & B17CW8 & 300 AREA SHR HRM41.5 & ONSITE & sw & $\mathrm{Y}$ & RIVER & TRANSECT & $09-\mathrm{Sep}-03 \mathrm{Cr}$ & & 0.047 & ug/L $/ 2$ & & & u & & \\
\hline SESPMNT & B17CX2 & 300 AREA SHR HRM42.1 & ONSITE & SW & $\mathrm{Y}$ & RIVER & TRANSECT & $09-\mathrm{Sep}-03 \mathrm{Cr}$ & & 0.0812 & & & & B & & \\
\hline SESPMNT & B17CX6 & 300 AREA SHR HRM 42.5 & ONSITE & sw & Y & RIVER & TRANSECT & $09-S e p-03 \mathrm{Cr}$ & & 0.247 & & & & & & \\
\hline SESPMNT & B17CY0 & 300 AREA SHR HRM42.9 & ONSITE & SW & $\mathrm{Y}$ & RIVER & TRANSECT & $09-\mathrm{Sep}-03 \mathrm{Cr}$ & & 0.047 & & & & u & & \\
\hline SESPMNT & B17CP4 & 300 AREA-10 HRM 43.1 & ONSITE & sw & $\mathrm{Y}$ & RIVER & TRANSECT & $09-\mathrm{Sep}-03 \mathrm{Cr}$ & & 0.047 & ug/L & & & u & & \\
\hline SESPMNT & B17CT4 & RICH.PMPHS HRM 43.5 & OFFSITE & sw & $\mathrm{Y}$ & RIVER & TRANSECT & 09-Sep-03 Cr & & 0.047 & ing/L & & & $\mathrm{U}$ & & \\
\hline SESPMNT & B17CT2 & RICH.PMPHS HRM 45.0 & OFFSITE & sw & $\mathrm{Y}$ & RIVER & TRANSECT & $09-\mathrm{Sep}-03 \mathrm{Cr}$ & & 0.047 & ug/L & & & U & & \\
\hline SESPMNT & B17CT1 & RICH.PMPHS HRM 45.8 & OFFSITE & sw & $\mathrm{Y}$ & RIVER & TRANSECT & $09-\mathrm{Sep}-03 \mathrm{Cr}$ & & 0.047 & ug/L & & & U & & \\
\hline SESPMNT & B17CD0 & RICH.PMPHS-1 HRM46.4 & OFFSITE & SW & $\mathrm{N}$ & RIVER & TRANSECT & $09-\mathrm{Sep}-03 \mathrm{Cr}$ & & 0.047 & ug/L & & & U & & \\
\hline SESPMNT & B17CN3 & RICH.PMPHS-1 HRM46.4 & OFFSITE & sw & Y & RIVER & TRANSECT & $09-\mathrm{Sep}-03 \mathrm{Cr}$ & & 0.047 & $\mathrm{ug} / \mathrm{L}$ & & & $\mathrm{U}$ & & \\
\hline SESPMNT & B17CD5 & RICH.PMPHS-10 HRM46.4 & OFFSITE & SW & $\mathrm{N}$ & RIVER & TRANSECT & $09-\mathrm{Sep}-03 \mathrm{Cr}$ & & 0.047 & & & & U & & \\
\hline SESPMNT & B17CN8 & RICH.PMPHS-10 HRM46.4 & OFFSITE & sw & $\mathrm{Y}$ & RIVER & TRANSECT & $09-\mathrm{Sep}-03 \mathrm{Cr}$ & & 0.047 & & & & u & & \\
\hline SESPMNT & B17CD1 & RICH.PMPHS-2 HRM46.4 & OFFSITE & sW & $\mathrm{N}$ & RIVER & TRANSECT & 09-Sep-03 Cr & & 0.047 & ug/L $/ \mathrm{L}$ & & & U & & \\
\hline SESPMNT & B17CN4 & RICH.PMPHS-2 HRM46.4 & OFFSITE & sw & Y & RIVER & TRANSECT & $09-\mathrm{Sep}-03 \mathrm{Cr}$ & & 0.047 & ug/L & & & u & & \\
\hline SESPMNT & B17CD2 & $\begin{array}{l}\text { RICH.PMPHS-3 HRM46.4 } \\
\text { R Hen }\end{array}$ & OFFSITE & sw & $\mathrm{N}$ & RIVER & TRANSECT & $09-\mathrm{Sep}-03 \mathrm{Cr}$ & & 0.047 & ug/L & & & u & & \\
\hline SESPMNT & B17CN5 & RICH.PMPHS-3 HRM46.4 & OFFSITE & sw & $\mathrm{Y}$ & RIVER & TRANSECT & $09-\mathrm{Sep}-03 \mathrm{Cr}$ & & 0.047 & igg/L & & & $\mathrm{U}$ & & \\
\hline SESPMNT & B17CD3 & RICH.PMPHS-5 HRM46.4 & OFFSITE & sw & $\mathrm{N}$ & RIVER & TRANSECT & $09-\mathrm{Sep}-03 \mathrm{Cr}$ & & 0.047 & ug/L & & & $\mathrm{U}$ & & \\
\hline SESPMNT & B17CN6 & RICH.PMPHS-5 HRM46.4 & OFFSITE & sw & $\mathrm{Y}$ & RIVER & TRANSECT & 09-Sep-03 Cr & & 0.047 & ug/L & & & U & & \\
\hline SESPMNT & B17CD4 & RICH.PMPHS-7 HRM46.4 & OFFSITE & sW & $\mathrm{N}$ & RIVER & TRANSECT & $09-\mathrm{Sep}-03 \mathrm{Cr}$ & & 0.047 & & & & $\mathrm{u}$ & & \\
\hline SESPMNT & B17CN7 & $\begin{array}{l}\text { RICH.PMPHS-7 HRM46. } \\
\end{array}$ & OFFSITE & sw & $\mathrm{Y}$ & RIVER & TRANSECT & $09-\mathrm{Sep}-03 \mathrm{Cr}$ & & 0.047 & ug/L & & & u & & \\
\hline SESPMNT & B183W4 & RICH.PMPHS HRM 43.5 & OFFSITE & SW & $\mathrm{Y}$ & RIVER & TRANSECT & 08-Dec-03 Cr & & 0.047 & ug/L & & & $u$ & & \\
\hline SESPMNT & B183W8 & RICH.PMPHS HRM 43.5 & OFFSITE & sw & $\mathrm{N}$ & RIVER & TRANSECT & 08-Dec-03 Cr & & 0.111 & ug/L & & & & & \\
\hline SESPMNT & B183W3 & RICH.PMPHS HRM 43.9 & OFFSITE & sw & $\mathrm{Y}$ & RIVER & TRANSECT & 08-Dec-03 Cr & & 0.047 & ug/L & & & u & & \\
\hline SESPMNT & B183W7 & RICH.PMPHS HRM 43.9 & OFFSITE & sw & $\mathrm{N}$ & RIVER & TRANSECT & 08-Dec-03 Cr & & 0.0982 & ug/L & & & B & & \\
\hline SESPMNT & B183W2 & RICH.PMPHS HRM 45.0 & OFFSITE & sw & $\mathrm{Y}$ & RIVER & TRANSECT & 08-Dec-03 Cr & & 0.047 & ug/L & & & U & & \\
\hline SESPMNT & B183W6 & RICH.PMPHS HRM 45.0 & OFFSITE & SW & $\mathrm{N}$ & RIVER & TRANSECT & 08-Dec-03 Cr & & 0.0684 & & & & B & & \\
\hline SESPMNT & B183W1 & RICH.PMPHS HRM 45.8 & OFFSITE & sw & $\mathrm{Y}$ & RIVER & TRANSECT & 08-Dec-03 Cr & & 0.047 & ug/L & & & $\mathrm{U}$ & & \\
\hline SESPMNT & B183W5 & RICH.PMPHS HRM 45.8 & OFFSITE & SW & $\mathrm{N}$ & RIVER & TRANSECT & 08-Dec-03 Cr & & 0.0472 & ing/L & & & B & & \\
\hline SESPMNT & B183P9 & RICH.PMPHS-1 HRM46.4 & OFFSITE & sw & $\mathrm{N}$ & RIVER & TRANSECT & 08-Dec-03 Cr & & 0.047 & ug/L & & & u & & \\
\hline SESPMNT & B183V1 & RICH.PMPHS-1 HRM46.4 & OFFSITE & sw & $\mathrm{Y}$ & RIVER & TRANSECT & 08-Dec-03 Cr & & 0.0819 & ug/L $/ \mathrm{L}$ & & & B & & \\
\hline SESPMNT & B183R4 & RICH.PMPHS-10 HRM46.4 & OFFSITE & SW & $\mathrm{N}$ & RIVER & TRANSECT & 08-Dec-03 Cr & & 0.233 & $3 \mathrm{ug} / \mathrm{L}$ & & & & & \\
\hline SESPMNT & B183V6 & RICH.PMPHS-10 HRM46.4 & OFFSITE & sw & $\mathrm{Y}$ & RIVER & TRANSECT & 08 -Dec-03 Cr & & 0.047 & ug/L $/ \mathrm{L}$ & & & $u$ & & \\
\hline SESPMNT & B183R0 & RICH.PMPHS-2 HRM46.4 & OFFSITE & sw & $\mathrm{N}$ & RIVER & TRANSECT & 08-Dec-03 Cr & & 0.0541 & ug/L $/ \mathrm{L}$ & & & B & & \\
\hline SESPMNT & B183V2 & RICH.PMPHS-2 HRM46.4 & OFFSITE & sw & $\mathrm{Y}$ & RIVER & TRANSECT & 08-Dec-03 Cr & & 0.047 & $\mathrm{ug} / \mathrm{L}$ & & & $u$ & & \\
\hline SESPMNT & B183R1 & RICH.PMPHS-3 HRM46.4 & OFFSITE & sw & $\mathrm{N}$ & RIVER & TRANSECT & 08-Dec-03 Cr & & 0.0609 & $\mathrm{ug} / \mathrm{L}$ & & & B & & \\
\hline SESPMNT & B183V3 & RICH.PMPHS-3 HRM46.4 & OFFSITE & sw & $\mathrm{Y}$ & RIVER & TRANSECT & 08-Dec-03 Cr & & 0.047 & ug/L & & & $u$ & & \\
\hline SESPMNT & B183R2 & RICH.PMPHS-5 HRM46.4 & OFFSITE & sw & $\mathrm{N}$ & RIVER & TRANSECT & 08-Dec-03 Cr & & 0.126 & $\mathrm{igg} / \mathrm{L}$ & & & & & \\
\hline SESPMNT & B183V4 & RICH.PMPHS-5 HRM46.4 & OFFSITE & SW & $\mathrm{Y}$ & RIVER & TRANSECT & 08-Dec-03 Cr & & 0.047 & ug/L & & & $u$ & & \\
\hline SESPMNT & B183R3 & RICH.PMPHS-7 HRM46.4 & OFFSITE & sw & $\mathrm{N}$ & RIVER & TRANSECT & 08-Dec-03 Cr & & 0.0517 & ug/L $/ 2$ & & & B & & \\
\hline SESPMNT & B183V5 & RICH.PMPHS-7 HRM46.4 & OFFSITE & SW & $\mathrm{Y}$ & RIVER & TRANSECT & 08-Dec-03 Cr & & 0.047 & ug/L & & & U & & \\
\hline SESPMNT & B183R5 & VERNITA-1 HRM 0.3 & OFFSITE & SW & $\mathrm{N}$ & RIVER & TRANSECT & 09-Dec-03 Cr & & 0.0497 & ug/L & & & B & & \\
\hline SESPMNT & B183T7 & VERNITA-1 HRM 0.3 & OFFSITE & sw & $\mathrm{Y}$ & RIVER & TRANSECT & 09-Dec-03 Cr & & 0.047 & ug/L $/ \mathrm{L}$ & & & u & & \\
\hline SESPMNT & B183P6 & VERNITA-2 HRM 0.3 & OFFSITE & sw & $\mathrm{N}$ & RIVER & TRANSECT & 09-Dec-03 Cr & & 0.171 & ug/L $/ 2$ & & & & & \\
\hline
\end{tabular}


WATER - COLUMBIA RIVER TRANSECT

\begin{tabular}{|c|c|c|c|c|c|c|c|c|c|c|c|c|c|c|c|c|}
\hline | OWNER ID & |SAMP NUM| & SAMP SITE NAME & DIST CLASS & $\mid$ MEDIA & \begin{tabular}{|c|} 
FILTERED \\
FLAG
\end{tabular} & $\begin{array}{l}\text { SAMP } \\
\text { FROM }\end{array}$ & COLL MTHD & SAMP DATE & CON SHORT NAME & $\begin{array}{l}\text { VALUE } \\
\text { RPTD }\end{array}$ & \begin{tabular}{|l|} 
ANAL \\
UNITS \\
RPTD \\
\end{tabular} & \begin{tabular}{|l|} 
COUNTING \\
ERROR
\end{tabular} & \begin{tabular}{|c|} 
TOTAL \\
ANAL \\
ERROR
\end{tabular} & $\begin{array}{c}\text { LAB } \\
\text { QUALIFIER }\end{array}$ & SAMP COMMENT & $\begin{array}{l}\text { RESULT } \\
\text { COMMENT }\end{array}$ \\
\hline SESPMNT & В183T8 & VERNITA-2 HRM 0.3 & OFFSITE & SW & & RIVER & TRANSECT & 09-Dec-03 Cr & & & & & & U & - & \\
\hline SESPMNT & B183P7 & VERNITA-3 HRM 0.3 & OFFSITE & sw & $\mathrm{N}$ & RIVER & TRANSECT & 09-Dec-03 Cr & & 0.047 & ug/L $/ \mathrm{L}$ & & & U & & \\
\hline SESPMNT & B183T9 & VERNITA-3 HRM 0.3 & OFFSITE & sw & $\mathrm{Y}$ & RIVER & TRANSECT & 09-Dec-03 Cr & & 0.047 & $\mathrm{ug} / \mathrm{L}$ & & & u & & \\
\hline SESPMNT & B183P8 & VERNITA-4 HRM 0.3 & OFFSITE & sw & $\mathrm{N}$ & RIVER & TRANSECT & 09-Dec-03 Cr & & 0.047 & ug/L & & & u & & \\
\hline SESPMNT & B183V0 & VERNITA-4 HRM 0.3 & OFFSITE & sw & Y & RIVER & TRANSECT & 09-Dec-03 Cr & & 0.047 & $\mathrm{ug} / \mathrm{L}$ & & & $u$ & & \\
\hline SESPMNT & B16L95 & VERNITA-1 HRM 0.3 & OFFSITE & sw & $\mathrm{N}$ & RIVER & TRANSECT & 24-Mar-03 Cu & & 0.468 & & & & & & \\
\hline SESPMNT & B16LB7 & VERNITA-1 HRM 0.3 & OFFSITE & sw & $\mathrm{Y}$ & RIVER & TRANSECT & 24-Mar-03 Cu & & 0.643 & & & & C & & \\
\hline SESPMNT & B16L86 & VERNITA-2 HRM 0.3 & OFFSITE & sw & $\mathrm{N}$ & RIVER & TRANSECT & 24-Mar-03 Cu & & 0.527 & & & & & & \\
\hline SESPMNT & B16LB8 & VERNITA-2 HRM 0.3 & OFFSITE & sw & $\mathrm{Y}$ & RIVER & TRANSECT & 24-Mar-03 Cu & & 0.457 & ug/L & & & C & & \\
\hline SESPMNT & B16L87 & VERNITA-3 HRM 0.3 & OFFSITE & sw & $\mathrm{N}$ & RIVER & TRANSECT & 24-Mar-03 Cu & & 0.53 & $3 \mathrm{ug} / \mathrm{L}$ & & & & & \\
\hline SESPMNT & B16LB9 & VERNITA-3 HRM 0.3 & OFFSITE & sw & $\mathrm{Y}$ & RIVER & TRANSECT & 24-Mar-03 Cu & & 0.446 & $\mathrm{iug} / \mathrm{L}$ & & & C & & \\
\hline SESPMNT & B16L88 & VERNITA-4 HRM 0.3 & OFFSITE & sw & $\mathrm{N}$ & RIVER & TRANSECT & 24-Mar-03 Cu & & 0.542 & ng/L & & & & & \\
\hline SESPMNT & B16LC0 & VERNITA-4 HRM 0.3 & OFFSITE & sw & $\mathrm{Y}$ & RIVER & TRANSECT & 24-Mar-03 Cu & & 0.455 & $\mathrm{sug} / \mathrm{L}$ & & & C & & \\
\hline SESPMNT & B16LD4 & RICH.PMPHS HRM 43.5 & OFFSITE & sw & $\mathrm{Y}$ & RIVER & TRANSECT & 25-Mar-03 Cu & & 0.448 & $3 \mathrm{ug} / \mathrm{L}$ & & & $\mathrm{c}$ & & \\
\hline SESPMNT & B16LD8 & RICH.PMPHS HRM 43.5 & OFFSITE & sw & $\mathrm{N}$ & RIVER & TRANSECT & 25-Mar-03 Cu & & 0.539 & & & & & & \\
\hline SESPMNT & B16LD3 & RICH.PMPHS HRM 43.9 & OFFSITE & sw & $\mathrm{Y}$ & RIVER & TRANSECT & 25-Mar-03 Cu & & & igg/L & & & C & & \\
\hline SESPMNT & B16LD7 & RICH.PMPHS HRM 43.9 & OFFSITE & sw & $\mathrm{N}$ & RIVER & TRANSECT & 25-Mar-03 Cu & & 0.52 & igg/L & & & & & \\
\hline SESPMNT & B16LD2 & RICH.PMPHS HRM 45.0 & OFFSITE & sw & $\mathrm{Y}$ & RIVER & TRANSECT & 25-Mar-03 Cu & & 0.537 & ug/L & & & C & & \\
\hline SESPMNT & B16LD6 & RICH.PMPHS HRM 45.0 & OFFSITE & sw & $\mathrm{N}$ & RIVER & TRANSECT & 25-Mar-03 Cu & & 0.517 & ug/L $/ \mathrm{L}$ & & & & & \\
\hline SESPMNT & B16LD1 & RICH.PMPHS HRM 45.8 & OFFSITE & sw & $\mathrm{Y}$ & RIVER & TRANSECT & 25 -Mar-03 Cu & & 0.444 & & & & c & & \\
\hline SESPMNT & B16LD5 & RICH.PMPHS HRM 45.8 & OFFSITE & sw & $\mathrm{N}$ & RIVER & TRANSECT & 25-Mar-03 Cu & & 0.544 & & & & & & \\
\hline SESPMNT & B16L89 & RICH.PMPHS-1 HRM46.4 & OFFSITE & sw & $\mathrm{N}$ & RIVER & TRANSECT & 25-Mar-03 Cu & & 0.527 & & & & & & \\
\hline SESPMNT & B16LC1 & RICH.PMPHS-1 HRM46.4 & OFFSITE & sw & $\mathrm{Y}$ & RIVER & TRANSECT & 25-Mar-03 Cu & & 0.457 & & & & c & & \\
\hline SESPMNT & B16L94 & RICH.PMPHS-10 HRM46. 4 & OFFSITE & sw & $\mathrm{N}$ & RIVER & TRANSECT & $25-\mathrm{Mar}-03 \mathrm{Cu}$ & & 0.677 & ug/L & & & 列 & & \\
\hline SESPMNT & B16LC6 & RICH.PMPHS-10 HRM46.4 & OFFSITE & sw & $\mathrm{Y}$ & RIVER & TRANSECT & 25-Mar-03 Cu & & 0.452 & ing/L & & & C & & \\
\hline SESPMNT & B16L90 & RICH.PMPHS-2 HRM46.4 & OFFSITE & sw & $\mathrm{N}$ & RIVER & TRANSECT & 25-Mar-03 Cu & & 0.521 & ug/L & & & & & \\
\hline SESPMNT & B16LC2 & RICH.PMPHS-2 HRM46.4 & OFFSITE & sw & $\mathrm{Y}$ & RIVER & TRANSECT & 25-Mar-03 Cu & & 0.487 & ug/L & & & C & & \\
\hline SESPMNT & B16L91 & RICH.PMPHS-3 HRM46.4 & OFFSITE & sw & $\mathrm{N}$ & RIVER & TRANSECT & 25-Mar-03 Cu & & 0.52 & ing/L & & & & & \\
\hline SESPMNT & B16LC3 & RICH.PMPHS-3 HRM46.4 & OFFSITE & sw & $\mathrm{Y}$ & RIVER & TRANSECT & 25-Mar-03 Cu & & 0.462 & ug/L & & & c & & \\
\hline SESPMNT & B16L92 & RICH.PMPHS-5 HRM46.4 & OFFSITE & sw & $\mathrm{N}$ & RIVER & TRANSECT & 25-Mar-03 Cu & & 0.527 & & & & & & \\
\hline SESPMNT & B16LC4 & RICH.PMPHS-5 HRM46.4 & OFFSITE & sw & $\mathrm{Y}$ & RIVER & TRANSECT & 25-Mar-03 Cu & & 1.06 & $\mathrm{ug} / \mathrm{L}$ & & & c & & \\
\hline SESPMNT & B16L93 & RICH.PMPHS-7 HRM46.4 & OFFSITE & sw & $\mathrm{N}$ & RIVER & TRANSECT & 25-Mar-03 Cu & & 0.522 & ug/L & & & & & \\
\hline SESPMNT & B16LC5 & RICH.PMPHS-7 HRM46.4 & OFFSITE & sw & $\mathrm{Y}$ & RIVER & TRANSECT & 25-Mar-03 Cu & & 0.45 & $\mathrm{ug} / \mathrm{L}$ & & & c & & \\
\hline SESPMNT & B171V9 & VERNITA-1 HRM 0.3 & OFFSITE & sw & $\mathrm{N}$ & RIVER & TRANSECT & 09-Jun- $03 \mathrm{Cu}$ & & 0.799 & ug/L & & & 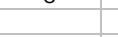 & & \\
\hline SESPMNT & B171Y1 & VERNITA-1 HRM 0.3 & OFFSITE & sw & $\mathrm{Y}$ & RIVER & TRANSECT & 09-Jun-03 Cu & & 0.68 & $\mathrm{ug} / \mathrm{L}$ & & & C & & \\
\hline SESPMNT & B171V0 & VERNITA-2 HRM 0.3 & OFFSITE & sw & $\mathrm{N}$ & RIVER & TRANSECT & 09-Jun-03 Cu & & 0.846 & & & & & & \\
\hline SESPMNT & B171Y2 & VERNITA-2 HRM 0.3 & OFFSITE & sw & $\mathrm{Y}$ & RIVER & TRANSECT & 09-Jun-03 Cu & & 0.633 & $3 \mathrm{ug} / \mathrm{L}$ & & & C & & \\
\hline SESPMNT & B171V1 & VERNITA-3 HRM 0.3 & OFFSITE & sw & $\mathrm{N}$ & RIVER & TRANSECT & 09-Jun-03 Cu & & 0.787 & & & & & & \\
\hline SESPMNT & B171Y3 & VERNITA-3 HRM 0.3 & OFFSITE & sw & $\mathrm{Y}$ & RIVER & TRANSECT & 09-Jun-03 Cu & & 0.673 & $3 \mathrm{ug} / \mathrm{L}$ & & & c & & \\
\hline SESPMNT & B171V2 & VERNITA-4 HRM 0.3 & OFFSITE & sW & $\mathrm{N}$ & RIVER & TRANSECT & 09-Jun-03 Cu & & 0.857 & ug/L & & & & & \\
\hline SESPMNT & B171Y4 & VERNITA-4 HRM 0.3 & OFFSITE & sw & Y & RIVER & TRANSECT & 09-Jun- $03 \mathrm{Cu}$ & & 0.657 & ug/L & & & C & & \\
\hline SESPMNT & B17208 & RICH.PMPHS HRM 43.5 & OFFSITE & sw & $\mathrm{Y}$ & RIVER & TRANSECT & 10-Jun-03 Cu & & 0.635 & jug/L & & & $\mathrm{c}$ & & \\
\hline SESPMNT & B17212 & RICH.PMPHS HRM 43.5 & OFFSITE & sw & $\mathrm{N}$ & RIVER - & TRANSECT & 10-Jun-03 Cu & & 0.893 & $\mathrm{ug} / \mathrm{L}$ & & & & & \\
\hline SESPMNT & B17207 & RICH.PMPHS HRM 43.9 & OFFSITE & sw & $\mathrm{Y}$ & RIVER & TRANSECT & 10-Jun-03 Cu & & 0.675 & ug/L & & & C & & \\
\hline SESPMNT & B17211 & RICH.PMPHS HRM 43.9 & OFFSITE & sw & $\mathrm{N}$ & RIVER & TRANSECT & 10-Jun-03 Cu & & 0.876 & & & & & & \\
\hline SESPMNT & B17206 & RICH.PMPHS HRM 45.0 & OFFSITE & sw & Y & RIVER & TRANSECT & 10-Jun-03 Cu & & 0.658 & $\mathrm{ug} / \mathrm{L}$ & & & C & & \\
\hline SESPMNT & B17210 & RICH.PMPHS HRM 45.0 & OFFSITE & sw & $\mathrm{N}$ & RIVER & TRANSECT & 10-Jun-03 Cu & & 0.879 & $\mathrm{ug} / \mathrm{L}$ & & & & & \\
\hline SESPMNT & B17205 & RICH.PMPHS HRM 45.8 & OFFSITE & sw & Y & RIVER & TRANSECT & 10-Jun-03 Cu & & 0.627 & ug/L & & & c & & \\
\hline SESPMNT & B17209 & RICH.PMPHS HRM 45.8 & OFFSITE & sw & $\mathrm{N}$ & RIVER & TRANSECT & 10-Jun-03 Cu & & 0.912 & ug/L/L & & & & & \\
\hline SESPMNT & B171V3 & RICH.PMPHS-1 HRM46.4 & OFFSITE & sw & $\mathrm{N}$ & RIVER & TRANSECT & 10-Jun-03 Cu & & 0.872 & ing/L & & & & & \\
\hline SESPMNT & B171Y5 & RICH.PMPHS-1 HRM46.4 & OFFSITE & sw & $\mathrm{Y}$ & RIVER & TRANSECT & 10-Jun- $03 \mathrm{Cu}$ & & 0.652 & ug/L & & & C & & \\
\hline SESPMNT & B171V8 & RICH.PMPHS-10 HRM46. 4 & OFFSITE & sw & $\mathrm{N}$ & RIVER & TRANSECT & 10-Jun- $03 \mathrm{Cu}$ & & & $\mathrm{ug} / \mathrm{L}$ & & & & & \\
\hline SESPMNT & B17200 & RICH.PMPHS-10 HRM46.4 & OFFSITE & sw & $\mathrm{Y}$ & RIVER & TRANSECT & 10-Jun- $03 \mathrm{Cu}$ & & 0.891 & & & & c & & \\
\hline SESPMNT & B171V4 & RICH.PMPHS-2 HRM46.4 & OFFSITE & sw & $\mathrm{N}$ & RIVER & TRANSECT & 10-Jun-03 Cu & & 0.88 & $3 \mathrm{ug} / \mathrm{L}$ & & & 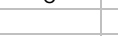 & & \\
\hline SESPMNT & B171Y6 & RICH.PMPHS-2 HRM46.4 & OFFSITE & sw & $\mathrm{Y}$ & RIVER & TRANSECT & 10-Jun- $03 \mathrm{Cu}$ & & 0.66 & ug/L & & & C & & \\
\hline SESPMNT & B171V5 & RICH.PMPHS-3 HRM46.4 & OFFSITE & sW & $\mathrm{N}$ & RIVER & TRANSECT & 10-Jun- $03 \mathrm{Cu}$ & & 0.911 & ug/L & & & & & \\
\hline SESPMNT & B171Y7 & RICH.PMPHS-3 HRM46.4 & OFFSITE & sW & $\mathrm{Y}$ & RIVER & TRANSECT & 10-Jun-03 Cu & & 0.667 & ug/L & & & C & & \\
\hline SESPMNT & B171V6 & RICH.PMPHS-5 HRM46.4 & OFFSITE & SW & $\mathrm{N}$ & RIVER & TRANSECT & 10-Jun-03 Cu & & 0.885 & 3 ug/L & & & & & \\
\hline SESPMNT & B171Y8 & RICH.PMPHS-5 HRM46.4 & OFFSITE & sW & $\mathrm{Y}$ & RIVER & TRANSECT & 10-Jun-03 Cu & & 0.637 & ug/L & & & C & & \\
\hline SESPMNT & B171V7 & RICH.PMPHS-7 HRM46.4 & OFFSITE & sw & $\mathrm{N}$ & RIVER & TRANSECT & 10-Jun-03 Cu & & & & & & & & \\
\hline SESPMNT & B171Y9 & RICH.PMPHS-7 HRM46.4 & OFFSITE & sw & $\mathrm{Y}$ & RIVER & TRANSECT & 10-Jun- $03 \mathrm{Cu}$ & & 0.623 & 3 ug/L & & & C & & \\
\hline SESPMNT & B17CB6 & $100 \mathrm{~N}-1$ HRM 9.5 & ONSITE & sw & $\mathrm{N}$ & RIVER - & TRANSECT & 04-Sep-03 Cu & & 0.683 & $3 \mathrm{ug} / \mathrm{L}$ & & & & & \\
\hline
\end{tabular}


WATER - COLUMBIA RIVER TRANSECT

\begin{tabular}{|c|c|c|c|c|c|c|c|c|c|c|c|c|c|c|c|c|}
\hline | OWNER ID & SAMP NUM & SAMP SITE NAME & |DIST CLASS | & $\mid$ MEDIA & \begin{tabular}{|c|} 
FILTERED \\
FLAG
\end{tabular} & $\begin{array}{l}\text { SAMP } \\
\text { FROM }\end{array}$ & COLL MTHD & SAMP DATE & CON SHORT NAME & $\begin{array}{l}\text { VALUE } \\
\text { RPTD }\end{array}$ & \begin{tabular}{|l|} 
ANAL \\
UNITS \\
RPTD \\
\end{tabular} & \begin{tabular}{|l|} 
COUNTING \\
ERROR
\end{tabular} & \begin{tabular}{|c|} 
TOTAL \\
ANAL \\
ERROR
\end{tabular} & $\begin{array}{c}\text { LAB } \\
\text { QUALIFIER }\end{array}$ & SAMP COMMENT & $\begin{array}{l}\text { RESULT } \\
\text { COMMENT }\end{array}$ \\
\hline SESPMNT & B17CM7 & $100 \mathrm{~N}-1$ HRM 9.5 & ONSITE & SW & & RIVER T & TRANSECT & 04-Sep-03 Cu & & & & & & & & \\
\hline SESPMNT & B17CC1 & $100 \mathrm{~N}-10$ HRM 9.5 & ONSITE & sw & $\mathrm{N}$ & RIVER T & TRANSECT & 04-Sep-03 Cu & & 0.609 & $9 \mathrm{ug} / \mathrm{L}$ & & & & & \\
\hline SESPMNT & $\mathrm{B} 17 \mathrm{CN} 2$ & $100 \mathrm{~N}-10 \mathrm{HRM} 9.5$ & ONSITE & sw & $\mathrm{Y}$ & RIVER T & TRANSECT & 04-Sep-03 Cu & & 0.523 & $3 \mathrm{ug} / \mathrm{L}$ & & & & & \\
\hline SESPMNT & B17CB7 & $100 \mathrm{~N}-2$ HRM 9.5 & ONSITE & sw & $\mathrm{N}$ & RIVER T & TRANSECT & 04-Sep-03 Cu & & 0.62 & $2 \mathrm{ug} / \mathrm{L}$ & & & & & \\
\hline SESPMNT & B17CM8 & $100 \mathrm{~N}-2$ HRM 9.5 & ONSITE & sw & Y & RIVER & TRANSECT & 04-Sep-03 Cu & & 0.524 & $4 \mathrm{ug} / \mathrm{L}$ & & & & & \\
\hline SESPMNT & B17CB8 & $100 \mathrm{~N}-3$ HRM 9.5 & ONSITE & sw & $\mathrm{N}$ & RIVER & TRANSECT & 04-Sep-03 Cu & & & & & & & & \\
\hline SESPMNT & B17CM9 & $100 \mathrm{~N}-3$ HRM 9.5 & ONSITE & sw & $\mathrm{Y}$ & RIVER 7 & TRANSECT & 04-Sep-03 Cu & & 0.522 & & & & & & \\
\hline SESPMNT & B17CB9 & $100 \mathrm{~N}-5$ HRM 9.5 & ONSITE & sw & $\mathrm{N}$ & RIVER T & TRANSECT & 04-Sep-03 Cu & & & & & & & & \\
\hline SESPMNT & B17CNO & $100 \mathrm{~N}-5$ HRM 9.5 & ONSITE & sw & $\mathrm{Y}$ & RIVER 7 & TRANSECT & 04-Sep-03 Cu & & 0.515 & $5 \mathrm{ug} / \mathrm{L}$ & & & & & \\
\hline SESPMNT & B17CCO & $100 \mathrm{~N}-7$ HRM 9.5 & ONSITE & sw & $\mathrm{N}$ & RIVER T & TRANSECT & 04-Sep-03 Cu & & 0.616 & & & & & & \\
\hline SESPMNT & $\mathrm{B} 17 \mathrm{CN} 1$ & $100 \mathrm{~N}-7$ HRM 9.5 & ONSITE & sw & $\mathrm{Y}$ & RIVER T & TRANSECT & 04-Sep-03 Cu & & 0.508 & $3 \mathrm{ug} / \mathrm{L}$ & & & & & \\
\hline SESPMNT & B17CV1 & $100 \mathrm{~N}$ SHORE HRM 8.4 & ONSITE & sw & $\mathrm{N}$ & RIVER 7 & TRANSECT & 04-Sep-03 Cu & & 0.607 & $7 \mathrm{ug} / \mathrm{L}$ & & & & & \\
\hline SESPMNT & B17CV2 & $100 \mathrm{~N}$ SHORE HRM 8.4 & ONSITE & sw & $\mathrm{Y}$ & RIVER T & TRANSECT & 04-Sep-03 Cu & & 0.554 & $4 \mathrm{ug} / \mathrm{L}$ & & & & & \\
\hline SESPMNT & B17CV5 & 100 N SHORE HRM 8.9 & ONSITE & sw & $\mathrm{N}$ & RIVER T & $\begin{array}{l}\text { TRANSECT } \\
\text { TRES }\end{array}$ & 04-Sep-03 Cu & & 0.594 & $4 \mathrm{ug} / \mathrm{L}$ & & & & & \\
\hline SESPMNT & B17CV6 & 100 N SHORE HRM 8.9 & ONSITE & sw & Y & RIVER T & TRANSECT & 04-Sep-03 Cu & & 0.484 & & & & & & \\
\hline SESPMNT & B17CV9 & $100 \mathrm{~N}$ SHORE HRM 9.2 & ONSITE & sw & $\mathrm{N}$ & RIVER 7 & TRANSECT & 04-Sep-03 Cu & & 0.645 & & & & & & \\
\hline SESPMNT & B17CW0 & $100 \mathrm{~N}$ SHORE HRM 9.2 & ONSITE & sw & Y & RIVER 7 & TRANSECT & 04-Sep-03 Cu & & 0.53 & $3 \mathrm{ug} / \mathrm{L}$ & & & & & \\
\hline SESPMNT & B17CW3 & $100 \mathrm{~N}$ SHORE HRM 9.8 & ONSITE & sw & $\mathrm{N}$ & RIVER T & TRANSECT & 04-Sep-03 Cu & & 0.602 & $2 \mathrm{ug} / \mathrm{L}$ & & & & & \\
\hline SESPMNT & B17CW4 & 100 N SHORE HRM 9.8 & ONSITE & sw & Y & RIVER T & TRANSECT & 04-Sep-03 Cu & & 0.555 & $5 \mathrm{ug} / \mathrm{L}$ & & & & & \\
\hline SESPMNT & B17CD6 & VERNITA-1 HRM 0.3 & OFFSITE & sw & $\mathrm{N}$ & RIVER T & TRANSECT & 04-Sep-03 Cu & & 0.638 & $3 \mathrm{ug} / \mathrm{L}$ & & & & & \\
\hline SESPMNT & B17CM3 & VERNITA-1 HRM 0.3 & OFFSITE & sw & $\mathrm{Y}$ & RIVER T & TRANSECT & 04-Sep-03 Cu & & 0.523 & & & & & & \\
\hline SESPMNT & $\mathrm{B} 17 \mathrm{CC} 7$ & VERNITA-2 HRM 0.3 & OFFSITE & sw & $\mathrm{N}$ & RIVER & TRANSECT & 04-Sep-03 Cu & & 0.612 & & & & & & \\
\hline SESPMNT & B17CM4 & VERNITA-2 HRM 0.3 & OFFSITE & sw & $\mathrm{Y}$ & RIVER & TRANSECT & 04-Sep-03 Cu & & 0.512 & & & & & & \\
\hline SESPMNT & B17CC8 & VERNITA-3 HRM 0.3 & OFFSITE & sw & $\mathrm{N}$ & RIVER T & TRANSECT & 04-Sep-03 Cu & & 0.606 & $6 \mathrm{ug} / \mathrm{L}$ & & & & & \\
\hline SESPMNT & B17CM5 & VERNITA-3 HRM 0.3 & OFFSITE & sw & $\mathrm{Y}$ & RIVER 7 & TRANSECT & 04-Sep-03 Cu & & 0.565 & $5 \mathrm{ug} / \mathrm{L}$ & & & & & \\
\hline SESPMNT & B17CC9 & VERNITA-4 HRM 0.3 & OFFSITE & sw & $\mathrm{N}$ & RIVER 7 & TRANSECT & 04-Sep-03 Cu & & 0.564 & $4 \mathrm{ug} / \mathrm{L}$ & & & & & \\
\hline SESPMNT & B17CM6 & VERNITA-4 HRM 0.3 & OFFSITE & sw & $\mathrm{Y}$ & RIVER T & TRANSECT & 04-Sep-03 Cu & & 0.562 & $2 \mathrm{ug} / \mathrm{L}$ & & & & & \\
\hline SESPMNT & B17CC2 & $100 \mathrm{~F}-1$ HRM 19.0 & ONSITE & sw & $\mathrm{N}$ & RIVER 7 & TRANSECT & 08-Sep-03 Cu & & 0.615 & $5 \mathrm{ug} / \mathrm{L}$ & & & & & \\
\hline SESPMNT & B17CR1 & $100 \mathrm{~F}-1 \mathrm{HRM} 19.0$ & ONSITE & sw & Y & RIVER T & TRANSECT & 08-Sep-03 Cu & & 0.488 & $3 \mathrm{ug} / \mathrm{L}$ & & & & & \\
\hline SESPMNT & B17C96 & $100 \mathrm{~F}-10 \mathrm{HRM} 19.0$ & ONSITE & sw & $\mathrm{N}$ & RIVER T & TRANSECT & 08-Sep-03 Cu & & 0.536 & $6 \mathrm{ug} / \mathrm{L}$ & & & C & & \\
\hline SESPMNT & B17CR6 & $100 \mathrm{~F}-10 \mathrm{HRM} 19.0$ & ONSITE & sw & Y & RIVER T & TRANSECT & 08-Sep-03 Cu & & 0.525 & & & & & & \\
\hline SESPMNT & B17CR2 & $100 \mathrm{~F}-2$ HRM 19.0 & ONSITE & sw & Y & RIVER T & TRANSECT & 08-Sep-03 Cu & & 0.506 & $6 \mathrm{ug} / \mathrm{L}$ & & & & & \\
\hline SESPMNT & B17CC4 & $100 \mathrm{~F}-3$ HRM 19.0 & ONSITE & sw & $\mathrm{N}$ & RIVER T & TRANSECT & $08-S e p-03 \mathrm{Cu}$ & & 0.622 & $2 \mathrm{ug} / \mathrm{L}$ & & & & & \\
\hline SESPMNT & B17CR3 & $100 \mathrm{~F}-3 \mathrm{HRM} 19.0$ & ONSITE & sw & Y & RIVER T & TRANSECT & 08-Sep-03 Cu & & 0.556 & $6 \mathrm{ug} / \mathrm{L}$ & & & & & \\
\hline SESPMNT & B17CR4 & $100 \mathrm{~F}-5$ HRM 19.0 & ONSITE & sw & $\mathrm{Y}$ & RIVER T & TRANSECT & 08-Sep-03 Cu & & 0.534 & $4 \mathrm{ug} / \mathrm{L}$ & & & & & \\
\hline SESPMNT & B17CR5 & 100 F -7 HRM 19.0 & ONSITE & sw & Y & RIVER T & TRANSECT & 08-Sep-03 Cu & & 0.491 & & & & & & \\
\hline SESPMNT & B17CY5 & $100 \mathrm{~F}$ SHORE HRM 18 & ONSITE & sw & $\mathrm{N}$ & RIVER 7 & TRANSECT & 08-Sep-03 Cu & & 0.549 & $9 \mathrm{ug} / \mathrm{L}$ & & & C & & \\
\hline SESPMNT & B17CY6 & 100 F SHORE HRM 18 & ONSITE & sw & $\mathrm{Y}$ & RIVER T & TRANSECT & 08-Sep-03 Cu & & 0.48 & $3 \mathrm{ug} / \mathrm{L}$ & & & & & \\
\hline SESPMNT & B17CY8 & $100 \mathrm{~F}$ SHORE HRM 22 & ONSITE & sw & $\mathrm{N}$ & RIVER T & TRANSECT & 08 -Sep-03 Cu & & 0.682 & $2 \mathrm{ug} / \mathrm{L}$ & & & c & & \\
\hline SESPMNT & B17CY9 & 100 F SHORE HRM 22 & ONSITE & sW & $\mathrm{Y}$ & RIVER T & TRANSECT & 08-Sep-03 Cu & & 0.526 & $6 \mathrm{ug} / \mathrm{L}$ & & & & & \\
\hline SESPMNT & B17D01 & $100 \mathrm{~F}$ SHORE HRM 23 & ONSITE & sw & $\mathrm{N}$ & RIVER T & TRANSECT & 08-Sep-03 Cu & & 0.556 & $6 \mathrm{ug} / \mathrm{L}$ & & & C & & \\
\hline SESPMNT & B17D02 & $100 \mathrm{~F}$ SHORE HRM 23 & ONSITE & sw & Y & RIVER 7 & TRANSECT & 08-Sep-03 Cu & & 0.45 & $5 \mathrm{ug} / \mathrm{L}$ & & & & & \\
\hline SESPMNT & B17C97 & HANFRD TS-1 HRM 28.7 & ONSITE & sw & $\mathrm{N}$ & RIVER & TRANSECT & 08-Sep-03 Cu & & 0.565 & 5 ug/L & & & & & \\
\hline SESPMNT & B17CP5 & HANFRD TS-1 HRM 28.7 & ONSITE & sw & $\mathrm{Y}$ & RIVER T & TRANSECT & 08 -Sep-03 Cu & & 0.499 & 9 ug/L & & & & & \\
\hline SESPMNT & B17CB2 & HANFRD TS-10 HRM 28.7 & ONSITE & sw & $\mathrm{N}$ & RIVER 7 & TRANSECT & $08-\mathrm{Sep}-03 \mathrm{Cu}$ & & 0.668 & $3 \mathrm{ug} / \mathrm{L}$ & & & C & & \\
\hline SESPMNT & B17CR0 & HANFRD TS-10 HRM 28.7 & ONSITE & sw & $\mathrm{Y}$ & RIVER 7 & TRANSECT & 08-Sep-03 Cu & & 0.628 & & & & & & \\
\hline SESPMNT & B17C98 & HANFRD TS-2 HRM 28.7 & ONSITE & sW & $\mathrm{N}$ & RIVER 7 & TRANSECT & 08-Sep-03 Cu & & 0.606 & $6 \mathrm{ug} / \mathrm{L}$ & & & & & \\
\hline SESPMNT & B17CP6 & HANFRD TS-2 HRM 28.7 & ONSITE & sw & $\mathrm{Y}$ & RIVER T & TRANSECT & $08-\mathrm{Sep}-03 \mathrm{Cu}$ & & 0.501 & $1 \mathrm{ug} / \mathrm{L}$ & & & & & \\
\hline SESPMNT & B17C99 & HANFRD TS-3 HRM 28.7 & ONSITE & SW & $\mathrm{N}$ & RIVER T & TRANSECT & 08 -Sep-03 Cu & & 0.577 & $7 \mathrm{ug} / \mathrm{L}$ & & & c & & \\
\hline SESPMNT & B17CP7 & HANFRD TS-3 HRM 28.7 & ONSITE & sw & $\mathrm{Y}$ & RIVER 7 & TRANSECT & $08-\mathrm{Sep}-03 \mathrm{Cu}$ & & 0.541 & 1 ug/L & & & & & \\
\hline SESPMNT & B17CB0 & HANFRD TS-5 HRM 28.7 & ONSITE & sw & $\mathrm{N}$ & RIVER T & TRANSECT & $08-\mathrm{Sep}-03 \mathrm{Cu}$ & & 0.588 & $3 \mathrm{ug} / \mathrm{L}$ & & & C & & \\
\hline SESPMNT & B17CP8 & HANFRD TS-5 HRM 28.7 & ONSITE & sw & $\mathrm{Y}$ & RIVER T & TRANSECT & 08-Sep-03 Cu & & 0.517 & $7 \mathrm{ug} / \mathrm{L}$ & & & & & \\
\hline SESPMNT & B17CB1 & HANFRD TS-7 HRM 28.7 & ONSITE & sw & $\mathrm{N}$ & RIVER T & TRANSECT & 08-Sep-03 Cu & & 0.577 & $7 \mathrm{ug} / \mathrm{L}$ & & & c & & \\
\hline SESPMNT & B17CP9 & HANFRD TS-7 HRM 28.7 & ONSITE & sw & $\mathrm{Y}$ & RIVER T & TRANSECT & 08 -Sep-03 Cu & & 0.466 & 6 ug/L & & & 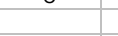 & & \\
\hline SESPMNT & B17CL7 & HANFRD TWNSITE HRM26 & ONSITE & sw & $\mathrm{N}$ & RIVER T & TRANSECT & $08-\mathrm{Sep}-03 \mathrm{Cu}$ & & 0.597 & $7 \mathrm{ug} / \mathrm{L}$ & & & C & & \\
\hline SESPMNT & B17CM0 & HANFRD TWNSITE HRM26 & ONSITE & sW & $\mathrm{Y}$ & RIVER T & TRANSECT & 08-Sep-03 Cu & & 0.446 & $6 \mathrm{ug} / \mathrm{L}$ & & & & & \\
\hline SESPMNT & B17CL8 & HANFRD TWNSITE HRM27 & ONSITE & sW & $\mathrm{N}$ & RIVER T & TRANSECT & 08-Sep-03 Cu & & 0.576 & $6 \mathrm{ug} / \mathrm{L}$ & & & C & & \\
\hline SESPMNT & B17CM1 & HANFRD TWNSITE HRM27 & ONSITE & SW & $\mathrm{Y}$ & RIVER T & TRANSECT & 08 -Sep-03 Cu & & 0.478 & $3 \mathrm{ug} / \mathrm{L}$ & & & & & \\
\hline SESPMNT & B17CY2 & HANFRD TWNSITE HRM28 & ONSITE & sw & $\mathrm{N}$ & RIVER T & TRANSECT & 08-Sep-03 Cu & & 0.456 & $6 \mathrm{ug} / \mathrm{L}$ & & & C & & \\
\hline SESPMNT & B17CY3 & HANFRD TWNSITE HRM28 & ONSITE & sw & $\mathrm{Y}$ & RIVER T & TRANSECT & $08-\mathrm{Sep}-03 \mathrm{Cu}$ & & & $6 \mathrm{ug} / \mathrm{L}$ & & & & & \\
\hline SESPMNT & B17CL9 & HANFRD TWNSITE HRM30 & ONSITE & sw & $\mathrm{N}$ & RIVER 7 & TRANSECT & 08-Sep-03 Cu & & 0.579 & $9 \mathrm{ug} / \mathrm{L}$ & & & c & & \\
\hline SESPMNT & B17CM2 & HANFRD TWNSITE HRM30 & ONSITE & sw & Y & RIVER T & TRANSECT & $08-\mathrm{Sep}-03 \mathrm{Cu}$ & & 0.475 & $5 \mathrm{ug} / \mathrm{L}$ & & & & & \\
\hline
\end{tabular}


WATER - COLUMBIA RIVER TRANSECT

\begin{tabular}{|c|c|c|c|c|c|c|c|c|c|c|c|c|c|c|c|}
\hline OWNER ID & | SAMP NUM| & SAMP SITE NAME & DIST CLASS & MEDIA $\left.\right|^{\mid h}$ & \begin{tabular}{|c|} 
FILTERED \\
FLAG
\end{tabular} & $\begin{array}{l}\text { SAMP } \\
\text { FROM }\end{array}$ & COLL MTHD & CON SHORT NAME & \begin{tabular}{c|c} 
VALLE & $A$ \\
RPTD & $R$
\end{tabular} & $\left|\begin{array}{|c|}\text { ANAL } \\
\text { UNITS } \\
\text { RPTD }\end{array}\right|$ & \begin{tabular}{|l|} 
COUNTING \\
ERROR
\end{tabular} & $\begin{array}{c}\text { TOTAL } \\
\text { s ANAL } \\
\text { ERROR }\end{array}$ & $\begin{array}{c}\text { LAB } \\
\text { QUALIFIER }\end{array}$ & SAMP COMMENT & $\begin{array}{l}\text { RESULT } \\
\text { COMMENT }\end{array}$ \\
\hline SESPMNT & B17CN9 & 300 AREA -1 HRM 43.1 & ONSITE & sW & $\mathrm{Y}$ & RIVER & TRANSECT & 09-Sep-03 Cu & & & & & & & \\
\hline SESPMNT & B17CP0 & 300 AREA -2 HRM 43.1 & ONSITE & sw & $\mathrm{Y}$ & RIVER & TRANSECT & 09-Sep-03 Cu & $0.494 \mathrm{u}$ & $\mathrm{ug} / \mathrm{L}$ & & & & & \\
\hline SESPMNT & B17CP1 & 300 AREA - 3 HRM 43.1 & ONSITE & sw & Y & RIVER & TRANSECT & $09-\mathrm{Sep}-03 \mathrm{Cu}$ & $0.515 \mathrm{u}$ & $\mathrm{ug} / \mathrm{L}$ & & & & & \\
\hline SESPMNT & B17CP2 & 300 AREA -5 HRM 43.1 & ONSITE & sw & $\mathrm{Y}$ & RIVER & TRANSECT & 09-Sep-03 Cu & $0.497 \mathrm{us}$ & $\mathrm{ug} / \mathrm{L}$ & & & & & \\
\hline SESPMNT & B17CP3 & 300 AREA -7 HRM 43.1 & ONSITE & sw & Y & RIVER & TRANSECT & 09-Sep-03 Cu & $0.499 \mathrm{u}$ & $\mathrm{ug} / \mathrm{L}$ & & & & & \\
\hline SESPMNT & B17CW8 & 300 AREA SHR HRM 41.5 & ONSITE & sw & $\mathrm{Y}$ & RIVER & TRANSECT & 09-Sep-03 Cu & $0.527 \mathrm{u}$ & & & & & & \\
\hline SESPMNT & $B 17 C X 2$ & 300 AREA SHR HRM42.1 & ONSITE & sw & $\mathrm{Y}$ & RIVER & TRANSECT & 09-Sep-03 Cu & & & & & & & \\
\hline SESPMNT & B17CX6 & 300 AREA SHR HRM42.5 & ONSITE & sw & $\mathrm{Y}$ & RIVER & TRANSECT & 09-Sep-03 Cu & & & & & & & \\
\hline SESPMNT & B17CY0 & 300 AREA SHR HRM42.9 & ONSITE & sw & $\mathrm{Y}$ & RIVER & TRANSECT & 09-Sep-03 Cu & $0.506 \mathrm{us}$ & $\mathrm{ug} / \mathrm{L}$ & & & & & \\
\hline SESPMNT & B17CP4 & 300 AREA-10 HRM 43.1 & ONSITE & sw & $\mathrm{Y}$ & RIVER & TRANSECT & 09-Sep-03 Cu & $0.592 \mathrm{us}$ & $\mathrm{ug} / \mathrm{L}$ & & & & & \\
\hline SESPMNT & B17CT4 & RICH.PMPHS HRM 43.5 & OFFSITE & sw & $\mathrm{Y}$ & RIVER & TRANSECT & 09-Sep-03 Cu & $0.512 \mathrm{u}$ & $\mathrm{ug} / \mathrm{L}$ & & & & & \\
\hline SESPMNT & B17CT2 & RICH.PMPHS HRM 45.0 & OFFSITE & sw & $\mathrm{Y}$ & RIVER & TRANSECT & 09-Sep-03 Cu & $0.479 \mathrm{us}$ & $\mathrm{ug} / \mathrm{L}$ & & & & & \\
\hline SESPMNT & B17CT1 & RICH.PMPHS HRM 45.8 & OFFSITE & sw & $\mathrm{Y}$ & RIVER & TRANSECT & $09-\mathrm{Sep}-03 \mathrm{Cu}$ & $0.508 \mathrm{u}$ & $\mathrm{ug} / \mathrm{L}$ & & & & & \\
\hline SESPMNT & B17CD0 & RICH.PMPHS-1 HRM46.4 & OFFSITE & sw & $\mathrm{N}$ & RIVER & $\begin{array}{l}\text { TRANSECT } \\
\text { TRES }\end{array}$ & 09-Sep-03 Cu & $0.688 \mathrm{u}$ & ug/L & & & c & & \\
\hline SESPMNT & B17CN3 & RICH.PMPHS-1 HRM46.4 & OFFSITE & sw & Y & RIVER & TRANSECT & 09-Sep-03 Cu & $0.518 \mathrm{u}$ & & & & & & \\
\hline SESPMNT & B17CD5 & RICH.PMPHS-10 HRM46.4 & OFFSITE & sw & $\mathrm{N}$ & RIVER & TRANSECT & 09-Sep-03 Cu & $0.751 \mathrm{u}$ & & & & C & & \\
\hline SESPMNT & B17CN8 & RICH.PMPHS-10 HRM46.4 & OFFSITE & sw & Y & RIVER & TRANSECT & 09-Sep-03 Cu & $0.661 \mathrm{u}$ & $\mathrm{ug} / \mathrm{L}$ & & & & & \\
\hline SESPMNT & B17CD1 & RICH.PMPHS-2 HRM46.4 & OFFSITE & sw & $\mathrm{N}$ & RIVER & TRANSECT & 09-Sep-03 Cu & $0.629 u$ & $\mathrm{ug} / \mathrm{L}$ & & & C & & \\
\hline SESPMNT & B17CN4 & RICH.PMPHS-2 HRM46.4 & OFFSITE & sw & Y & RIVER & TRANSECT & 09-Sep-03 Cu & $0.491 \mathrm{u}$ & $\mathrm{ug} / \mathrm{L}$ & & & & & \\
\hline SESPMNT & B17CD2 & RICH.PMPHS-3 HRM46.4 & OFFSITE & sW & $\mathrm{N}$ & RIVER & TRANSECT & 09-Sep-03 Cu & $0.572 u$ & $\mathrm{ug} / \mathrm{L}$ & & & c & & \\
\hline SESPMNT & B17CN5 & RICH.PMPHS-3 HRM46.4 & OFFSITE & sw & $\mathrm{Y}$ & RIVER & TRANSECT & 09-Sep-03 Cu & $0.518 u$ & & & & & & \\
\hline SESPMNT & B17CD3 & RICH.PMPHS-5 HRM46.4 & OFFSITE & sw & $\mathrm{N}$ & RIVER & TRANSECT & 09-Sep-03 Cu & $0.563 \mathrm{u}$ & & & & c & & \\
\hline SESPMNT & B17CN6 & RICH.PMPHS-5 HRM46.4 & OFFSITE & sw & $\mathrm{Y}$ & RIVER & TRANSECT & 09-Sep-03 Cu & $0.509 \mathrm{u}$ & $\mathrm{ug} / \mathrm{L}$ & & & & & \\
\hline SESPMNT & B17CD4 & RICH.PMPHS-7 HRM46.4 & OFFSITE & sw & $\mathrm{N}$ & RIVER & TRANSECT & 09-Sep-03 Cu & $0.563 \mathrm{u}$ & $\mathrm{ug} / \mathrm{L}$ & & & c & & \\
\hline SESPMNT & B17CN7 & RICH.PMPHS-7 HRM46.4 & OFFSITE & sw & $\mathrm{Y}$ & RIVER & TRANSECT & 09-Sep-03 Cu & $0.739 u$ & ug/L & & & & & \\
\hline SESPMNT & B183W4 & RICH.PMPHS HRM 43.5 & OFFSITE & sw & $\mathrm{Y}$ & RIVER & TRANSECT & 08-Dec-03 Cu & $0.519 u$ & $\mathrm{ug} / \mathrm{L}$ & & & & & \\
\hline SESPMNT & B183W8 & RICH.PMPHS HRM 43.5 & OFFSITE & sw & $\mathrm{N}$ & RIVER & TRANSECT & 08-Dec-03 Cu & $0.583 \mathrm{u}$ & $\mathrm{ug} / \mathrm{L}$ & & & & & \\
\hline SESPMNT & B183W3 & RICH.PMPHS HRM 43.9 & OFFSITE & sw & $\mathrm{Y}$ & RIVER & TRANSECT & 08-Dec-03 Cu & $0.387 u$ & $\mathrm{ug} / \mathrm{L}$ & & & & & \\
\hline SESPMNT & B183W7 & RICH.PMPHS HRM 43.9 & OFFSITE & sw & $\mathrm{N}$ & RIVER & TRANSECT & 08-Dec-03 Cu & $0.515 u$ & $\mathrm{ug} / \mathrm{L}$ & & & & & \\
\hline SESPMNT & B183W2 & RICH.PMPHS HRM 45.0 & OFFSITE & sw & $\mathrm{Y}$ & RIVER & TRANSECT & 08-Dec-03 Cu & $0.381 \mathrm{u}$ & & & & & & \\
\hline SESPMNT & B183W6 & RICH.PMPHS HRM 45.0 & OFFSITE & sw & $\mathrm{N}$ & RIVER & TRANSECT & 08-Dec-03 Cu & $0.438 \mathrm{u}$ & & & & & & \\
\hline SESPMNT & B183W1 & RICH.PMPHS HRM 45.8 & OFFSITE & sW & $\mathrm{Y}$ & RIVER & TRANSECT & 08-Dec-03 Cu & $0.392 u$ & $\mathrm{ug} / \mathrm{L}$ & & & & & \\
\hline SESPMNT & B183W5 & RICH.PMPHS HRM 45.8 & OFFSITE & sw & $\mathrm{N}$ & RIVER & TRANSECT & 08-Dec-03 Cu & $0.451 \mathrm{u}$ & $\mathrm{ug} / \mathrm{L}$ & & & & & \\
\hline SESPMNT & B183P9 & RICH.PMPHS-1 HRM46.4 & OFFSITE & sw & $\mathrm{N}$ & RIVER & TRANSECT & 08 -Dec-03 Cu & $0.433 \mathrm{u}$ & ug/L & & & & & \\
\hline SESPMNT & B183V1 & RICH.PMPHS-1 HRM46.4 & OFFSITE & sw & $\mathrm{Y}$ & RIVER & TRANSECT & 08-Dec-03 Cu & $0.507 \mathrm{u}$ & ug/L & & & & & \\
\hline SESPMNT & B183R4 & RICH.PMPHS-10 HRM46.4 & OFFSITE & sw & $\mathrm{N}$ & RIVER & TRANSECT & 08-Dec-03 Cu & $0.806 u$ & ug/L & & & & & \\
\hline SESPMNT & B183V6 & RICH.PMPHS-10 HRM46.4 & OFFSITE & sw & $\mathrm{Y}$ & RIVER & TRANSECT & 08-Dec-03 Cu & $0.414 u$ & $\mathrm{ug} / \mathrm{L}$ & & & & & \\
\hline SESPMNT & B183R0 & RICH.PMPHS-2 HRM46.4 & OFFSITE & sw & $\mathrm{N}$ & RIVER & TRANSECT & 08-Dec-03 Cu & $0.431 \mathrm{u}$ & $\mathrm{ug} / \mathrm{L}$ & & & & & \\
\hline SESPMNT & B183V2 & RICH.PMPHS-2 HRM46.4 & OFFSITE & sw & $\mathrm{Y}$ & RIVER & TRANSECT & 08-Dec-03 Cu & 0.3934 & $\mathrm{ug} / \mathrm{L}$ & & & & & \\
\hline SESPMNT & B183R1 & RICH.PMPHS-3 HRM46.4 & OFFSITE & sw & $\mathrm{N}$ & RIVER & TRANSECT & 08-Dec-03 Cu & $0.453 u$ & $\mathrm{ug} / \mathrm{L}$ & & & & & \\
\hline SESPMNT & B183V3 & RICH.PMPHS-3 HRM46.4 & OFFSITE & sw & Y & RIVER & TRANSECT & 08-Dec-03 Cu & $0.384 \mathrm{u}$ & $\mathrm{ug} / \mathrm{L}$ & & & & & \\
\hline SESPMNT & B183R2 & RICH.PMPHS-5 HRM46.4 & OFFSITE & sw & $\mathrm{N}$ & RIVER & TRANSECT & 08-Dec-03 Cu & $0.532 u$ & $\mathrm{ug} / \mathrm{L}$ & & & & & \\
\hline SESPMNT & B183V4 & RICH.PMPHS-5 HRM46.4 & OFFSITE & sw & $\mathrm{Y}$ & RIVER & TRANSECT & 08-Dec-03 Cu & $0.395 \mathrm{u}$ & ug/L & & & & & \\
\hline SESPMNT & B183R3 & RICH.PMPHS-7 HRM46.4 & OFFSITE & sw & $\mathrm{N}$ & RIVER & TRANSECT & 08-Dec-03 Cu & $0.453 u$ & ug/L & & & & & \\
\hline SESPMNT & B183V5 & RICH.PMPHS-7 HRM46.4 & OFFSITE & sw & $\mathrm{Y}$ & RIVER & TRANSECT & 08-Dec-03 Cu & $0.388 u$ & & & & & & \\
\hline SESPMNT & B183R5 & VERNITA-1 HRM 0.3 & OFFSITE & sw & $\mathrm{N}$ & RIVER & TRANSECT & 09-Dec-03 Cu & $0.449 u$ & & & & & & \\
\hline SESPMNT & B183T7 & VERNITA-1 HRM 0.3 & OFFSITE & sW & $\mathrm{Y}$ & RIVER & TRANSECT & 09-Dec-03 Cu & $0.338 \mathrm{u}$ & & & & & & \\
\hline SESPMNT & B183P6 & VERNITA-2 HRM 0.3 & OFFSITE & sw & $\mathrm{N}$ & RIVER & TRANSECT & 09-Dec-03 Cu & 0.45 & & & & & & \\
\hline SESPMNT & B183T8 & VERNITA-2 HRM 0.3 & OFFSITE & SW & $\mathrm{Y}$ & RIVER & TRANSECT & $09-\mathrm{Dec}-03 \mathrm{Cu}$ & $0.354 \mathrm{u}$ & & & & & & \\
\hline SESPMNT & B183P7 & VERNITA-3 HRM 0.3 & OFFSITE & sw & $\mathrm{N}$ & RIVER & TRANSECT & 09-Dec-03 Cu & 0.4434 & $\mathrm{ug} / \mathrm{L}$ & & & & & \\
\hline SESPMNT & B183T9 & VERNITA-3 HRM 0.3 & OFFSITE & sw & $\mathrm{Y}$ & RIVER & TRANSECT & 09-Dec-03 Cu & 0.3894 & & & & & & \\
\hline SESPMNT & B183P8 & VERNITA-4 HRM 0.3 & OFFSITE & sw & $\mathrm{N}$ & RIVER & TRANSECT & 09-Dec-03 Cu & 0.4874 & & & & & & \\
\hline SESPMNT & B183V0 & VERNITA-4 HRM 0.3 & OFFSITE & sw & $\mathrm{Y}$ & RIVER & TRANSECT & 09-Dec-03 Cu & $0.366 \mathrm{u}$ & ug/L & & & & & \\
\hline SESPMNT & B17CC3 & $100 \mathrm{~F}-2$ HRM 19.0 & ONSITE & sw & $\mathrm{N}$ & RIVER & TRANSECT & 08-Sep-03 METALS ICPMS & 0.000 & & & & & NO SAMPLE. & \\
\hline SESPMNT & B17CC5 & 100 F -5 HRM 19.0 & ONSITE & sw & $\mathrm{N}$ & RIVER - & TRANSECT & 08-Sep-03 METALS ICPMS & & & & & & NO SAMPLE. & \\
\hline SESPMNT & B17CC6 & 100 F -7 HRM 19.0 & ONSITE & sw & $\mathrm{N}$ & RIVER & TRANSECT & 08-Sep-03 METALS ICPMS & & & & & & NO SAMPLE. & \\
\hline SESPMNT & B17C93 & 300 AREA -5 HRM 43.1 & ONSITE & sW & $\mathrm{N}$ & RIVER & TRANSECT & 09-Sep-03 METALS ICPMS & & & & & & NO SAMPLE. & \\
\hline SESPMNT & B17C94 & 300 AREA -7 HRM 43.1 & ONSITE & SW & $\mathrm{N}$ & RIVER & TRANSECT & 09-Sep-03 METALS ICPMS & & & & & & NO SAMPLE. & \\
\hline SESPMNT & B17C95 & 300 AREA-10 HRM 43.1 & ONSITE & sw & $\mathrm{N}$ & RIVER & TRANSECT & 09-Sep-03 METALS ICPMS & & & & & & NO SAMPLE. & \\
\hline SESPMNT & B17CB3 & 300 AREA - 1 HRM 43.1 & ONSITE & sw & $\mathrm{N}$ & RIVER & TRANSECT & 09-Sep-03 METALS ICPMS & & & & & & NO SAMPLE. & \\
\hline SESPMNT & B17CB4 & 300 AREA -2 HRM 43.1 & ONSITE & sw & $\mathrm{N}$ & RIVER & TRANSECT & 09-Sep-03 METALS ICPMS & & & & & & NO SAMPLE. & \\
\hline SESPMNT & B17CB5 & 300 AREA -3 HRM 43.1 & ONSITE & sw & $\mathrm{N}$ & RIVER & TRANSECT & 09-Sep-03 METALS ICPMS & & & & & & NO SAMPLE & \\
\hline
\end{tabular}


WATER - COLUMBIA RIVER TRANSEC

\begin{tabular}{|c|c|c|c|c|c|c|c|c|c|c|c|c|c|c|c|}
\hline OWNER ID & SAMP NUM & SAMP SITE NAME & | DIST CLASS & MEDIA & \begin{tabular}{|c|} 
FILTERED \\
FLAG
\end{tabular} & $\begin{array}{l}\text { SAMP } \\
\text { FROM }\end{array}$ & COLL MTHD & SAMP DATE CON SHORT NAME & $\begin{array}{l}\text { VALUE } \\
\text { RPTD }\end{array}$ & $\left|\begin{array}{|c|}\text { ANAL } \\
\text { UNITS } \\
\text { RPTD }\end{array}\right|$ & \begin{tabular}{|c} 
COUNTING \\
ERROR
\end{tabular} & \begin{tabular}{|c|} 
TOTAL \\
ANAL \\
ERROR
\end{tabular} & $\begin{array}{c}\text { LAB } \\
\text { QUALIFIER }\end{array}$ & SAMP COMMENT & $\begin{array}{l}\text { RESULT } \\
\text { COMMENT }\end{array}$ \\
\hline SESPMNT & B17CT5 & RICH.PMPHS HRM 45.8 & OFFSITE & SW & $\mathrm{N}$ & RIVER & TRANSECT & 09-Sep-03 METALS ICPMS & & & & & & NO SAMPLE. & \\
\hline SESPMNT & B17CT6 & RICH.PMPHS HRM 45.0 & OFFSITE & sw & $\mathrm{N}$ & RIVER & TRANSECT & 09-Sep-03 METALS ICPMS & & & & & & NO SAMPLE. & \\
\hline SESPMNT & B17CT8 & RICH.PMPHS HRM 43.5 & OFFSITE & sw & $\mathrm{N}$ & RIVER & TRANSECT & 09-Sep-03 METALS ICPMS & & & & & & NO SAMPLE. & \\
\hline SESPMNT & B17CW7 & 300 AREA SHR HRM41.5 & ONSITE & sw & $\mathrm{N}$ & RIVER & TRANSECT & 09-Sep-03 METALS ICPMS & & & & & & NO SAMPLE. & \\
\hline SESPMNT & B17CX1 & 300 AREA SHR HRM42.1 & ONSITE & sw & $\mathrm{N}$ & RIVER & TRANSECT & 09-Sep-03 METALS ICPMS & & & & & & NO SAMPLE. & \\
\hline SESPMNT & B17CX5 & 300 AREA SHR HRM42.5 & ONSITE & sw & $\mathrm{N}$ & RIVER & TRANSECT & 09-Sep-03 METALS ICPMS & & & & & & NO SAMPLE. & \\
\hline SESPMNT & B17CX9 & 300 AREA SHR HRM42.9 & ONSITE & sw & $\mathrm{N}$ & RIVER & TRANSECT & 09-Sep-03 METALS ICPMS & & & & & & NO SAMPLE. & \\
\hline SESPMNT & B17CT3 & RICH.PMPHS HRM 43.9 & OFFSITE & sw & $\mathrm{Y}$ & RIVER & TRANSECT & 09-Sep-03 METALS ICPMS & & & & & & NO SAMPLE. THICK MILFOIL. & \\
\hline SESPMNT & B17CT7 & RICH.PMPHS HRM 43.9 & OFFSITE & sw & $\mathrm{N}$ & RIVER & TRANSECT & 09-Sep-03 METALS ICPMS & & & & & & NO SAMPLE. THICK MILFOIL. & \\
\hline SESPMNT & B16L95 & VERNITA-1 HRM 0.3 & OFFSITE & sw & $\mathrm{N}$ & RIVER & TRANSECT & 24-Mar-03 Ni & 0.602 & $\mathrm{ug} / \mathrm{L}$ & & & & & \\
\hline SESPMNT & B16LB7 & VERNITA-1 HRM 0.3 & OFFSITE & sw & $\mathrm{Y}$ & RIVER & TRANSECT & 24-Mar-03 Ni & 0.651 & $\mathrm{ug} / \mathrm{L}$ & & & C & & \\
\hline SESPMNT & B16L86 & VERNITA-2 HRM 0.3 & OFFSITE & sw & $\mathrm{N}$ & RIVER & TRANSECT & 24-Mar-03 Ni & 0.699 & $\mathrm{ug} / \mathrm{L}$ & & & & & \\
\hline SESPMNT & B16LB8 & VERNITA-2 HRM 0.3 & OFFSITE & sw & $\mathrm{Y}$ & RIVER & TRANSECT & 24-Mar-03 Ni & 0.597 & & & & C & & \\
\hline SESPMNT & B16L87 & VERNITA-3 HRM 0.3 & OFFSITE & sw & $\mathrm{N}$ & RIVER & TRANSECT & 24-Mar-03 Ni & 0.666 & & & & & & \\
\hline SESPMNT & B16LB9 & VERNITA-3 HRM 0.3 & OFFSITE & sw & Y & RIVER & TRANSECT & 24-Mar-03 Ni & & & & & C & & \\
\hline SESPMNT & B16L88 & VERNITA-4 HRM 0.3 & OFFSITE & sw & $\mathrm{N}$ & RIVER & TRANSECT & 24-Mar-03 Ni & 0.676 & & & & & & \\
\hline SESPMNT & B16LC0 & VERNITA-4 HRM 0.3 & OFFSITE & sw & Y & RIVER & TRANSECT & 24-Mar-03 Ni & 0.612 & $\mathrm{ug} / \mathrm{L}$ & & & c & & \\
\hline SESPMNT & B16LD4 & RICH.PMPHS HRM 43.5 & OFFSITE & sw & $\mathrm{Y}$ & RIVER & TRANSECT & 25-Mar-03 Ni & 0.577 & $\mathrm{ug} / \mathrm{L}$ & & & C & & \\
\hline SESPMNT & B16LD8 & RICH.PMPHS HRM 43.5 & OFFSITE & sw & $\mathrm{N}$ & RIVER & TRANSECT & $25-\mathrm{Mar}-03 \mathrm{Ni}$ & 0.65 & $\mathrm{ug} / \mathrm{L}$ & & & & & \\
\hline SESPMNT & B16LD3 & RICH.PMPHS HRM 43.9 & OFFSITE & sw & $\mathrm{Y}$ & RIVER & TRANSECT & 25-Mar-03 Ni & 0.624 & & & & C & & \\
\hline SESPMNT & B16LD7 & RICH.PMPHS HRM 43.9 & OFFSITE & sw & $\mathrm{N}$ & RIVER & TRANSECT & 25-Mar-03 Ni & 0.638 & & & & & & \\
\hline SESPMNT & B16LD2 & RICH.PMPHS HRM 45.0 & OFFSITE & sw & $\mathrm{Y}$ & RIVER & TRANSECT & $25-\mathrm{Mar}-03 \mathrm{Ni}$ & & $\mathrm{ug} / \mathrm{L}$ & & & c & & \\
\hline SESPMNT & B16LD6 & RICH.PMPHS HRM 45.0 & OFFSITE & sw & $\mathrm{N}$ & RIVER & TRANSECT & 25-Mar-03 Ni & 0.662 & & & & & & \\
\hline SESPMNT & B16LD1 & RICH.PMPHS HRM 45.8 & OFFSITE & sw & $\mathrm{Y}$ & RIVER & TRANSECT & $25-\mathrm{Mar}-03 \mathrm{Ni}$ & 0.573 & $\mathrm{ug} / \mathrm{L}$ & & & c & & \\
\hline SESPMNT & B16LD5 & RICH.PMPHS HRM 45.8 & OFFSITE & sw & $\mathrm{N}$ & RIVER & TRANSECT & $25-\mathrm{Mar}-03 \mathrm{Ni}$ & 0.658 & $\mathrm{ug} / \mathrm{L}$ & & & & & \\
\hline SESPMNT & B16L89 & RICH.PMPHS-1 HRM46.4 & OFFSITE & sw & $\mathrm{N}$ & RIVER & TRANSECT & $25-\mathrm{Mar}-03 \mathrm{Ni}$ & 0.671 & $\mathrm{ug} / \mathrm{L}$ & & & & & \\
\hline SESPMNT & B16LC1 & RICH.PMPHS-1 HRM46.4 & OFFSITE & sw & $\mathrm{Y}$ & RIVER & TRANSECT & 25-Mar-03 Ni & 0.573 & $\mathrm{ug} / \mathrm{L}$ & & & C & & \\
\hline SESPMNT & B16L94 & RICH.PMPHS-10 HRM46.4 & OFFSITE & sw & $\mathrm{N}$ & RIVER & TRANSECT & 25-Mar-03 Ni & 0.69 & $\mathrm{ug} / \mathrm{L}$ & & & & & \\
\hline SESPMNT & B16LC6 & RICH.PMPHS-10 HRM46. 4 & OFFSITE & sw & $\mathrm{Y}$ & RIVER & TRANSECT & $25-\mathrm{Mar}-03 \mathrm{Ni}$ & 0.629 & & & & c & & \\
\hline SESPMNT & B16L90 & RICH.PMPHS-2 HRM46.4 & OFFSITE & sw & $\mathrm{N}$ & RIVER & TRANSECT & 25-Mar-03 Ni & 0.657 & & & & & & \\
\hline SESPMNT & B16LC2 & RICH.PMPHS-2 HRM46.4 & OFFSITE & sw & $\mathrm{Y}$ & RIVER & TRANSECT & $25-\mathrm{Mar}-03 \mathrm{Ni}$ & 0.594 & $\mathrm{ug} / \mathrm{L}$ & & & c & & \\
\hline SESPMNT & B16L91 & RICH.PMPHS-3 HRM46.4 & OFFSITE & sw & $\mathrm{N}$ & RIVER & TRANSECT & 25-Mar-03 Ni & 0.655 & $\mathrm{ug} / \mathrm{L}$ & & & & & \\
\hline SESPMNT & B16LC3 & RICH.PMPHS-3 HRM46.4 & OFFSITE & sW & $\mathrm{Y}$ & RIVER - & TRANSECT & 25-Mar-03 Ni & 0.589 & ug/L & & & C & & \\
\hline SESPMNT & B16L92 & RICH.PMPHS-5 HRM46.4 & OFFSITE & sw & $\mathrm{N}$ & RIVER & TRANSECT & $25-\mathrm{Mar}-03 \mathrm{Ni}$ & 0.66 & ug/L & & & 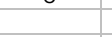 & & \\
\hline SESPMNT & B16LC4 & RICH.PMPHS-5 HRM46.4 & OFFSITE & sw & $\mathrm{Y}$ & RIVER & TRANSECT & $25-\mathrm{Mar}-03 \mathrm{Ni}$ & 0.603 & ug/L & & & C & & \\
\hline SESPMNT & B16L93 & RICH.PMPHS-7 HRM46.4 & OFFSITE & sw & $\mathrm{N}$ & RIVER & TRANSECT & $25-\mathrm{Mar}-03 \mathrm{Ni}$ & 0.637 & & & & & & \\
\hline SESPMNT & B16LC5 & RICH.PMPHS-7 HRM46.4 & OFFSITE & sw & $\mathrm{Y}$ & RIVER & TRANSECT & 25-Mar-03 Ni & 0.599 & ug/L & & & C & & \\
\hline SESPMNT & B171V9 & VERNITA-1 HRM 0.3 & OFFSITE & sw & $\mathrm{N}$ & RIVER & TRANSECT & 09-Jun- $03 \mathrm{Ni}$ & 0.73 & $\mathrm{ug} / \mathrm{L}$ & & & c & & \\
\hline SESPMNT & B171Y1 & VERNITA-1 HRM 0.3 & OFFSITE & sw & $\mathrm{Y}$ & RIVER & TRANSECT & $09-J u n-03 \mathrm{Ni}$ & 0.644 & $\mathrm{ug} / \mathrm{L}$ & & & & & \\
\hline SESPMNT & B171V0 & VERNITA-2 HRM 0.3 & OFFSITE & sw & $\mathrm{N}$ & RIVER & TRANSECT & 09-Jun-03 Ni & 0.742 & $\mathrm{ug} / \mathrm{L}$ & & & C & & \\
\hline SESPMNT & B171Y2 & VERNITA-2 HRM 0.3 & OFFSITE & sw & Y & RIVER & TRANSECT & $09-J u n-03 \mathrm{Ni}$ & 0.609 & $\mathrm{ug} / \mathrm{L}$ & & & & & \\
\hline SESPMNT & B171V1 & VERNITA-3 HRM 0.3 & OFFSITE & sw & $\mathrm{N}$ & RIVER & TRANSECT & $09-\mathrm{Jun}-03 \mathrm{Ni}$ & 0.755 & $\mathrm{ug} / \mathrm{L}$ & & & c & & \\
\hline SESPMNT & B171Y3 & VERNITA-3 HRM 0.3 & OFFSITE & sw & $\mathrm{Y}$ & RIVER & TRANSECT & $09-J u n-03 \mathrm{Ni}$ & 0.681 & ug/L & & & & & \\
\hline SESPMNT & B171V2 & VERNITA-4 HRM 0.3 & OFFSITE & sw & $\mathrm{N}$ & RIVER & TRANSECT & $09-\mathrm{Jun}-03 \mathrm{Ni}$ & 0.788 & ug/L & & & C & & \\
\hline SESPMNT & B171Y4 & VERNITA-4 HRM 0.3 & OFFSITE & sw & $\mathrm{Y}$ & RIVER & TRANSECT & 09-Jun-03 Ni & 0.628 & & & & & & \\
\hline SESPMNT & B17208 & RICH.PMPHS HRM 43.5 & OFFSITE & sw & $\mathrm{Y}$ & RIVER & TRANSECT & 10-Jun-03 Ni & 0.655 & & & & & & \\
\hline SESPMNT & B17212 & RICH.PMPHS HRM 43.5 & OFFSITE & sw & $\mathrm{N}$ & RIVER & TRANSECT & 10-Jun-03 Ni & 0.766 & $\mathrm{ug} / \mathrm{L}$ & & & C & & \\
\hline SESPMNT & B17207 & RICH.PMPHS HRM 43.9 & OFFSITE & sw & $\mathrm{Y}$ & RIVER & TRANSECT & 10-Jun-03 Ni & 0.649 & $\mathrm{ug} / \mathrm{L}$ & & & & & \\
\hline SESPMNT & B17211 & RICH.PMPHS HRM 43.9 & OFFSITE & sW & $\mathrm{N}$ & RIVER & TRANSECT & 10-Jun-03 Ni & 0.776 & $\mathrm{ug} / \mathrm{L}$ & & & C & & \\
\hline SESPMNT & B17206 & RICH.PMPHS HRM 45.0 & OFFSITE & sw & $\mathrm{Y}$ & RIVER & TRANSECT & 10-Jun-03 Ni & 0.661 & $\mathrm{ug} / \mathrm{L}$ & & & & & \\
\hline SESPMNT & B17210 & RICH.PMPHS HRM 45.0 & OFFSITE & sw & $\mathrm{N}$ & RIVER & TRANSECT & 10-Jun-03 Ni & 0.823 & $\mathrm{ug} / \mathrm{L}$ & & & C & & \\
\hline SESPMNT & B17205 & RICH.PMPHS HRM 45.8 & OFFSITE & sw & $\mathrm{Y}$ & RIVER & TRANSECT & 10-Jun-03 Ni & 0.644 & ug/L & & & & & \\
\hline SESPMNT & B17209 & RICH.PMPHS HRM 45.8 & OFFSITE & sw & $\mathrm{N}$ & RIVER & TRANSECT & 10-Jun-03 Ni & 0.817 & & & & c & & \\
\hline SESPMNT & B171V3 & RICH.PMPHS-1 HRM46.4 & OFFSITE & sw & $\mathrm{N}$ & RIVER & TRANSECT & 10-Jun-03 Ni & 0.833 & ug/L & & & $\mathrm{c}$ & & \\
\hline SESPMNT & B171Y5 & RICH.PMPHS-1 HRM46.4 & OFFSITE & sw & $\mathrm{Y}$ & RIVER & TRANSECT & 10-Jun-03 Ni & 0.675 & ug/L & & & & & \\
\hline SESPMNT & B171V8 & RICH.PMPHS-10 HRM46.4 & OFFSITE & sW & $\mathrm{N}$ & RIVER & TRANSECT & 10-Jun-03 Ni & 0.869 & $\mathrm{ug} / \mathrm{L}$ & & & C & & \\
\hline SESPMNT & B17200 & RICH.PMPHS-10 HRM46.4 & OFFSITE & sW & $\mathrm{Y}$ & RIVER & TRANSECT & 10-Jun-03 Ni & 0.641 & $\mathrm{ug} / \mathrm{L}$ & & & & & \\
\hline SESPMNT & B171V4 & RICH.PMPHS-2 HRM46.4 & OFFSITE & sw & $\mathrm{N}$ & RIVER & TRANSECT & 10-Jun-03 Ni & 0.813 & $\mathrm{ug} / \mathrm{L}$ & & & C & & \\
\hline SESPMNT & B171Y6 & RICH.PMPHS-2 HRM46.4 & OFFSITE & sW & $\mathrm{Y}$ & RIVER & TRANSECT & 10-Jun-03 Ni & 0.676 & $\mathrm{ug} / \mathrm{L}$ & & & & & \\
\hline SESPMNT & B171V5 & RICH.PMPHS-3 HRM46.4 & OFFSITE & sw & $\mathrm{N}$ & RIVER & TRANSECT & 10-Jun-03 Ni & & & & & c & & \\
\hline SESPMNT & B171Y7 & RICH.PMPHS-3 HRM46.4 & OFFSITE & SW & $\mathrm{Y}$ & RIVER & TRANSECT & 10-Jun-03 Ni & 0.666 & $\mathrm{ug} / \mathrm{L}$ & & & & & \\
\hline SESPMNT & B171V6 & RICH.PMPHS-5 HRM46.4 & OFFSITE & sw & $\mathrm{N}$ & RIVER & TRANSECT & 10-Jun-03 Ni & 0.814 & $\mathrm{ug} / \mathrm{L}$ & & & C & & \\
\hline
\end{tabular}


WATER - COLUMBIA RIVER TRANSECT

\begin{tabular}{|c|c|c|c|c|c|c|c|c|c|c|c|c|c|c|c|c|}
\hline | OWNER ID & SAMP NUM & SAMP SITE NAME & | DIST CLASS | & $\mid$ MEDIA & \begin{tabular}{|c|} 
FILTERED \\
FLAG
\end{tabular} & $\begin{array}{l}\text { SAMP } \\
\text { FROM }\end{array}$ & COLL MTHD & SAMP DATE & CON SHORT NAME & $\begin{array}{l}\text { VALUE } \\
\text { RPTD }\end{array}$ & \begin{tabular}{|l|} 
ANAL \\
UNITS \\
RPTD \\
\end{tabular} & \begin{tabular}{|l|} 
COUNTING \\
ERROR
\end{tabular} & \begin{tabular}{|c|} 
TOTAL \\
ANAL \\
ERROR
\end{tabular} & $\begin{array}{c}\text { LAB } \\
\text { QUALIFIER }\end{array}$ & SAMP COMMENT & $\begin{array}{l}\text { RESULT } \\
\text { COMMENT }\end{array}$ \\
\hline SESPMNT & B171Y8 & RICH.PMPHS-5 HRM46.4 & OFFSITE & SW & & RIVER T & TRANSECT & 10-Jun-03 Ni & & & & & & & - & \\
\hline SESPMNT & B171V7 & RICH.PMPHS-7 HRM46.4 & OFFSITE & sw & $\mathrm{N}$ & RIVER 7 & TRANSECT & 10-Jun-03 Ni & & 0.824 & $4 \mathrm{ug} / \mathrm{L}$ & & & C & & \\
\hline SESPMNT & B171Y9 & RICH.PMPHS-7 HRM46.4 & OFFSITE & sw & $\mathrm{Y}$ & RIVER T & TRANSECT & 10-Jun-03 Ni & & 0.656 & $6 \mathrm{ug} / \mathrm{L}$ & & & & & \\
\hline SESPMNT & B17CB6 & $100 \mathrm{~N}-1 \mathrm{HRM} 9.5$ & ONSITE & sw & $\mathrm{N}$ & RIVER T & TRANSECT & $04-\mathrm{Sep}-03 \mathrm{Ni}$ & & 0.551 & $1 \mathrm{ug} / \mathrm{L}$ & & & & & \\
\hline SESPMNT & B17CM7 & $100 \mathrm{~N}-1$ HRM 9.5 & ONSITE & sw & Y & RIVER & TRANSECT & $04-\mathrm{Sep}-03 \mathrm{Ni}$ & & 0.56 & $6 \mathrm{ug} / \mathrm{L}$ & & & & & \\
\hline SESPMNT & B17CC1 & $100 \mathrm{~N}-10 \mathrm{HRM} 9.5$ & ONSITE & sw & $\mathrm{N}$ & RIVER 7 & TRANSECT & $04-\mathrm{Sep}-03 \mathrm{Ni}$ & & 0.534 & & & & & & \\
\hline SESPMNT & B17CN2 & $100 \mathrm{~N}-10 \mathrm{HRM} 9.5$ & ONSITE & sw & $\mathrm{Y}$ & RIVER 7 & TRANSECT & $04-\mathrm{Sep}-03 \mathrm{Ni}$ & & & & & & & & \\
\hline SESPMNT & B17CB7 & $100 \mathrm{~N}-2$ HRM 9.5 & ONSITE & sw & $\mathrm{N}$ & RIVER T & TRANSECT & $04-\mathrm{Sep}-03 \mathrm{Ni}$ & & 0.523 & & & & & & \\
\hline SESPMNT & B17CM8 & $100 \mathrm{~N}-2$ HRM 9.5 & ONSITE & sw & $\mathrm{Y}$ & RIVER 7 & TRANSECT & $04-\mathrm{Sep}-03 \mathrm{Ni}$ & & 0.613 & $3 \mathrm{ug} / \mathrm{L}$ & & & & & \\
\hline SESPMNT & B17CB8 & $100 \mathrm{~N}-3$ HRM 9.5 & ONSITE & sw & $\mathrm{N}$ & RIVER T & TRANSECT & $04-\mathrm{Sep}-03 \mathrm{Ni}$ & & 0.506 & $6 \mathrm{ug} / \mathrm{L}$ & & & & & \\
\hline SESPMNT & B17CM9 & $100 \mathrm{~N}-3$ HRM 9.5 & ONSITE & sw & $\mathrm{Y}$ & RIVER T & TRANSECT & $04-\mathrm{Sep}-03 \mathrm{Ni}$ & & 0.484 & $4 \mathrm{ug} / \mathrm{L}$ & & & & & \\
\hline SESPMNT & B17CB9 & $100 \mathrm{~N}-5$ HRM 9.5 & ONSITE & sw & $\mathrm{N}$ & RIVER 7 & TRANSECT & 04-Sep-03 Ni & & 0.552 & & & & & & \\
\hline SESPMNT & B17CNO & $100 \mathrm{~N}-5$ HRM 9.5 & ONSITE & sw & $\mathrm{Y}$ & RIVER T & TRANSECT & $04-\mathrm{Sep}-03 \mathrm{Ni}$ & & 0.51 & $1 \mathrm{ug} / \mathrm{L}$ & & & & & \\
\hline SESPMNT & B17CCO & $100 \mathrm{~N}-7$ HRM 9.5 & ONSITE & sw & $\mathrm{N}$ & RIVER T & TRANSECT & $04-\mathrm{Sep}-03 \mathrm{Ni}$ & & 0.568 & & & & & & \\
\hline SESPMNT & B17CN1 & $100 \mathrm{~N}-7$ HRM 9.5 & ONSITE & sw & $\mathrm{Y}$ & RIVER 7 & TRANSECT & 04-Sep-03 Ni & & 0.552 & & & & & & \\
\hline SESPMNT & B17CV1 & $100 \mathrm{~N}$ SHORE HRM 8.4 & ONSITE & sw & $\mathrm{N}$ & RIVER 7 & TRANSECT & 04-Sep-03 Ni & & 0.511 & & & & & & \\
\hline SESPMNT & B17CV2 & $100 \mathrm{~N}$ SHORE HRM 8.4 & ONSITE & sw & Y & RIVER 7 & TRANSECT & 04-Sep-03 Ni & & 0.519 & $9 \mathrm{ug} / \mathrm{L}$ & & & & & \\
\hline SESPMNT & B17CV5 & $100 \mathrm{~N}$ SHORE HRM 8.9 & ONSITE & sw & $\mathrm{N}$ & RIVER T & TRANSECT & 04-Sep-03 Ni & & 0.556 & $6 \mathrm{ug} / \mathrm{L}$ & & & & & \\
\hline SESPMNT & B17CV6 & 100 N SHORE HRM 8.9 & ONSITE & sw & Y & RIVER T & TRANSECT & $04-\mathrm{Sep}-03 \mathrm{Ni}$ & & 0.605 & $5 \mathrm{ug} / \mathrm{L}$ & & & & & \\
\hline SESPMNT & B17CV9 & 100 N SHORE HRM 9.2 & ONSITE & sw & $\mathrm{N}$ & RIVER T & TRANSECT & $04-\mathrm{Sep}-03 \mathrm{Ni}$ & & 0.54 & & & & & & \\
\hline SESPMNT & B17CW0 & 100 N SHORE HRM 9.2 & ONSITE & sw & $\mathrm{Y}$ & RIVER T & TRANSECT & $04-\mathrm{Sep}-03 \mathrm{Ni}$ & & 0.526 & & & & & & \\
\hline SESPMNT & $\mathrm{B} 17 \mathrm{CW} 3$ & 100 N SHORE HRM 9.8 & ONSITE & sw & $\mathrm{N}$ & RIVER & TRANSECT & 04-Sep-03 Ni & & 0.532 & & & & & & \\
\hline SESPMNT & B17CW4 & 100 N SHORE HRM 9.8 & ONSITE & sw & $\mathrm{Y}$ & RIVER & TRANSECT & 04-Sep-03 Ni & & 0.544 & & & & & & \\
\hline SESPMNT & B17CD6 & VERNITA-1 HRM 0.3 & OFFSITE & sw & $\mathrm{N}$ & RIVER T & TRANSECT & $04-\mathrm{Sep}-03 \mathrm{Ni}$ & & 0.631 & $1 \mathrm{ug} / \mathrm{L}$ & & & & & \\
\hline SESPMNT & B17CM3 & VERNITA-1 HRM 0.3 & OFFSITE & sw & $\mathrm{Y}$ & RIVER 7 & TRANSECT & 04-Sep-03 Ni & & 0.639 & $9 \mathrm{ug} / \mathrm{L}$ & & & & & \\
\hline SESPMNT & B17CC7 & VERNITA-2 HRM 0.3 & OFFSITE & sw & $\mathrm{N}$ & RIVER 7 & TRANSECT & 04-Sep-03 Ni & & 0.522 & $2 \mathrm{ug} / \mathrm{L}$ & & & & & \\
\hline SESPMNT & B17CM4 & VERNITA-2 HRM 0.3 & OFFSITE & sw & $\mathrm{Y}$ & RIVER T & TRANSECT & 04-Sep-03 Ni & & 0.608 & $8 \mathrm{ug} / \mathrm{L}$ & & & & & \\
\hline SESPMNT & B17CC8 & VERNITA-3 HRM 0.3 & OFFSITE & sw & $\mathrm{N}$ & RIVER 7 & TRANSECT & $04-\mathrm{Sep}-03 \mathrm{Ni}$ & & 0.53 & $3 \mathrm{ug} / \mathrm{L}$ & & & & & \\
\hline SESPMNT & B17CM5 & VERNITA-3 HRM 0.3 & OFFSITE & sw & Y & RIVER T & TRANSECT & $04-\mathrm{Sep}-03 \mathrm{Ni}$ & & 0.628 & & & & & & \\
\hline SESPMNT & B17CC9 & VERNITA-4 HRM 0.3 & OFFSITE & sw & $\mathrm{N}$ & RIVER T & TRANSECT & 04-Sep-03 Ni & & 0.531 & & & & & & \\
\hline SESPMNT & B17CM6 & VERNITA-4 HRM 0.3 & OFFSITE & sw & Y & RIVER T & TRANSECT & $04-\mathrm{Sep}-03 \mathrm{Ni}$ & & 0.49 & & & & & & \\
\hline SESPMNT & B17CC2 & $100 \mathrm{~F}-1$ HRM 19.0 & ONSITE & sw & $\mathrm{N}$ & RIVER T & TRANSECT & $08-\mathrm{Sep}-03 \mathrm{Ni}$ & & 0.54 & $4 \mathrm{ug} / \mathrm{L}$ & & & & & \\
\hline SESPMNT & B17CR1 & $100 \mathrm{~F}-1$ HRM 19.0 & ONSITE & sw & $\mathrm{Y}$ & RIVER T & TRANSECT & $08-\mathrm{Sep}-03 \mathrm{Ni}$ & & 0.437 & $7 \mathrm{ug} / \mathrm{L}$ & & & & & \\
\hline SESPMNT & B17C96 & $100 \mathrm{~F}-10 \mathrm{HRM} 19.0$ & ONSITE & sw & $\mathrm{N}$ & RIVER T & TRANSECT & $08-\mathrm{Sep}-03 \mathrm{Ni}$ & & 0.627 & $7 \mathrm{ug} / \mathrm{L}$ & & & & & \\
\hline SESPMNT & B17CR6 & $100 \mathrm{~F}-10 \mathrm{HRM} 19.0$ & ONSITE & sw & $\mathrm{Y}$ & RIVER T & TRANSECT & $08-\mathrm{Sep}-03 \mathrm{Ni}$ & & 0.489 & & & & & & \\
\hline SESPMNT & B17CR2 & $100 \mathrm{~F}-2$ HRM 19.0 & ONSITE & sw & Y & RIVER T & TRANSECT & $08-\mathrm{Sep}-03 \mathrm{Ni}$ & & 0.453 & & & & & & \\
\hline SESPMNT & B17CC4 & $100 \mathrm{~F}-3$ HRM 19.0 & ONSITE & sw & $\mathrm{N}$ & RIVER 7 & TRANSECT & $08-\mathrm{Sep}-03 \mathrm{Ni}$ & & 0.574 & & & & & & \\
\hline SESPMNT & B17CR3 & 100 F -3 HRM 19.0 & ONSITE & sw & $\mathrm{Y}$ & RIVER T & TRANSECT & $08-\mathrm{Sep}-03 \mathrm{Ni}$ & & 0.474 & & & & & & \\
\hline SESPMNT & B17CR4 & 100 F - 5 HRM 19.0 & ONSITE & sw & $\mathrm{Y}$ & RIVER T & TRANSECT & $08-\mathrm{Sep}-03 \mathrm{Ni}$ & & 0.462 & $2 \mathrm{ug} / \mathrm{L}$ & & & & & \\
\hline SESPMNT & B17CR5 & 100 F -7 HRM 19.0 & ONSITE & sW & $\mathrm{Y}$ & RIVER T & TRANSECT & $08-\mathrm{Sep}-03 \mathrm{Ni}$ & & 0.486 & $6 \mathrm{ug} / \mathrm{L}$ & & & & & \\
\hline SESPMNT & B17CY5 & 100 F SHORE HRM 18 & ONSITE & sw & $\mathrm{N}$ & RIVER T & TRANSECT & $08-\mathrm{Sep}-03 \mathrm{Ni}$ & & 0.585 & $5 \mathrm{ug} / \mathrm{L}$ & & & & & \\
\hline SESPMNT & B17CY6 & $100 \mathrm{~F}$ SHORE HRM 18 & ONSITE & sw & Y & RIVER 7 & TRANSECT & $08-\mathrm{Sep}-03 \mathrm{Ni}$ & & 0.615 & $5 \mathrm{ug} / \mathrm{L}$ & & & & & \\
\hline SESPMNT & B17CY8 & $100 \mathrm{~F}$ SHORE HRM 22 & ONSITE & sw & $\mathrm{N}$ & RIVER & TRANSECT & $08-\mathrm{Sep}-03 \mathrm{Ni}$ & & 0.771 & $1 \mathrm{ug} / \mathrm{L}$ & & & & & \\
\hline SESPMNT & B17CY9 & $100 \mathrm{~F}$ SHORE HRM 22 & ONSITE & sw & $\mathrm{Y}$ & RIVER T & TRANSECT & $08-\mathrm{Sep}-03 \mathrm{Ni}$ & & 0.643 & & & & & & \\
\hline SESPMNT & B17D01 & 100 F SHORE HRM 23 & ONSITE & sw & $\mathrm{N}$ & RIVER 7 & TRANSECT & $08-\mathrm{Sep}-03 \mathrm{Ni}$ & & 0.678 & & & & & & \\
\hline SESPMNT & B17D02 & $100 \mathrm{~F}$ SHORE HRM 23 & ONSITE & sw & $\mathrm{Y}$ & RIVER 7 & TRANSECT & $08-\mathrm{Sep}-03 \mathrm{Ni}$ & & 0.565 & & & & & & \\
\hline SESPMNT & B17C97 & HANFRD TS-1 HRM 28.7 & ONSITE & sw & $\mathrm{N}$ & RIVER 7 & TRANSECT & $08-\mathrm{Sep}-03 \mathrm{Ni}$ & & 0.575 & $5 \mathrm{ug} / \mathrm{L}$ & & & & & \\
\hline SESPMNT & B17CP5 & HANFRD TS-1 HRM 28.7 & ONSITE & sw & $\mathrm{Y}$ & RIVER T & TRANSECT & $08-\mathrm{Sep}-03 \mathrm{Ni}$ & & 0.57 & $7 \mathrm{ug} / \mathrm{L}$ & & & & & \\
\hline SESPMNT & B17CB2 & HANFRD TS-10 HRM 28.7 & ONSITE & sw & $\mathrm{N}$ & RIVER T & TRANSECT & $08-\mathrm{Sep}-03 \mathrm{Ni}$ & & 0.692 & $2 \mathrm{ug} / \mathrm{L}$ & & & & & \\
\hline SESPMNT & B17CR0 & HANFRD TS-10 HRM 28.7 & ONSITE & sw & $\mathrm{Y}$ & RIVER 7 & TRANSECT & $08-\mathrm{Sep}-03 \mathrm{Ni}$ & & 0.655 & $5 \mathrm{ug} / \mathrm{L}$ & & & & & \\
\hline SESPMNT & B17C98 & HANFRD TS-2 HRM 28.7 & ONSITE & sw & $\mathrm{N}$ & RIVER T & TRANSECT & $08-\mathrm{Sep}-03 \mathrm{Ni}$ & & 0.585 & $5 \mathrm{ug} / \mathrm{L}$ & & & & & \\
\hline SESPMNT & B17CP6 & HANFRD TS-2 HRM 28.7 & ONSITE & sw & $\mathrm{Y}$ & RIVER T & TRANSECT & $08-S e p-03 \mathrm{Ni}$ & & 0.502 & & & & & & \\
\hline SESPMNT & B17C99 & HANFRD TS-3 HRM 28.7 & ONSITE & sw & $\mathrm{N}$ & RIVER T & TRANSECT & $08-\mathrm{Sep}-03 \mathrm{Ni}$ & & 0.601 & & & & & & \\
\hline SESPMNT & B17CP7 & HANFRD TS-3 HRM 28.7 & ONSITE & sw & $\mathrm{Y}$ & RIVER T & TRANSECT & $08-\mathrm{Sep}-03 \mathrm{Ni}$ & & 0.634 & $4 \mathrm{ug} / \mathrm{L}$ & & & & & \\
\hline SESPMNT & B17CB0 & HANFRD TS-5 HRM 28.7 & ONSITE & sw & $\mathrm{N}$ & RIVER 7 & TRANSECT & 08-Sep-03 Ni & & 0.641 & 1 ug $/ \mathrm{L}$ & & & & & \\
\hline SESPMNT & B17CP8 & HANFRD TS-5 HRM 28.7 & ONSITE & sW & $\mathrm{Y}$ & RIVER T & TRANSECT & $08-\mathrm{Sep}-03 \mathrm{Ni}$ & & 0.598 & $8 \mathrm{ug} / \mathrm{L}$ & & & & & \\
\hline SESPMNT & B17CB1 & HANFRD TS-7 HRM 28.7 & ONSITE & sW & $\mathrm{N}$ & RIVER T & TRANSECT & $08-\mathrm{Sep}-03 \mathrm{Ni}$ & & 0.612 & $2 \mathrm{ug} / \mathrm{L}$ & & & & & \\
\hline SESPMNT & B17CP9 & HANFRD TS-7 HRM 28.7 & ONSITE & SW & $\mathrm{Y}$ & RIVER T & TRANSECT & 08 -Sep-03 Ni & & 0.602 & $2 \mathrm{ug} / \mathrm{L}$ & & & & & \\
\hline SESPMNT & B17CL7 & HANFRD TWNSITE HRM26 & ONSITE & sw & $\mathrm{N}$ & RIVER T & TRANSECT & $08-\mathrm{Sep}-03 \mathrm{Ni}$ & & 0.563 & $3 \mathrm{ug} / \mathrm{L}$ & & & & & \\
\hline SESPMNT & B17CM0 & HANFRD TWNSITE HRM26 & ONSITE & sw & $\mathrm{Y}$ & RIVER T & TRANSECT & $08-\mathrm{Sep}-03 \mathrm{Ni}$ & & & $7 \mathrm{ug} / \mathrm{L}$ & & & & & \\
\hline SESPMNT & B17CL8 & HANFRD TWNSITE HRM27 & ONSITE & sw & $\mathrm{N}$ & RIVER 7 & TRANSECT & $08-\mathrm{Sep}-03 \mathrm{Ni}$ & & 0.589 & & & & & & \\
\hline SESPMNT & B17CM1 & HANFRD TWNSITE HRM27 & ONSITE & sw & Y & RIVER T & TRANSECT & $08-\mathrm{Sep}-03 \mathrm{Ni}$ & & 0.531 & $1 \mathrm{ug} / \mathrm{L}$ & & & & & \\
\hline
\end{tabular}


WATER - COLUMBIA RIVER TRANSECT

\begin{tabular}{|c|c|c|c|c|c|c|c|c|c|c|c|c|c|c|c|c|}
\hline | OWNER ID & SAMP NUM & SAMP SITE NAME & DIST CLASS & MEDIA $\left.\right|^{\mid F}$ & $\begin{array}{c}\text { FILTERED } \\
\text { FLAG }\end{array}$ & $\begin{array}{l}\text { SAMP } \\
\text { FROM }\end{array}$ & COLL MTHD & SAMP DATE & CON SHORT NAME & $\begin{array}{l}\text { VALUE } \\
\text { RPTD }\end{array}$ & \begin{tabular}{|l|} 
ANAL \\
UNITS \\
RPTD \\
\end{tabular} & \begin{tabular}{|l|} 
COUNTING \\
ERROR
\end{tabular} & \begin{tabular}{|c|} 
TOTAL \\
ANAL \\
ERROR
\end{tabular} & $\begin{array}{c}\text { LAB } \\
\text { QUALIFIER }\end{array}$ & SAMP COMMENT & $\begin{array}{l}\text { RESULT } \\
\text { COMMENT }\end{array}$ \\
\hline SESPMNT & $\mathrm{B} 17 \mathrm{CY} 2$ & HANFRD TWNSITE HRM28 & 3 ONSITE & SW & $\mathrm{N}$ & RIVER & TRANSECT & $08-\mathrm{Sep}-03 \mathrm{Ni}$ & & & & & & & & \\
\hline SESPMNT & B17CY3 & HANFRD TWNSITE HRM28 & 3 ONSITE & sW & $\mathrm{Y}$ & RIVER & TRANSECT & $08-\mathrm{Sep}-03 \mathrm{Ni}$ & & 0.765 & $3 \mathrm{ug} / \mathrm{L}$ & & & & & \\
\hline SESPMNT & B17CL9 & HANFRD TWNSITE HRM30 & D ONSITE & sw & $\mathrm{N}$ & RIVER & TRANSECT & $08-\mathrm{Sep}-03 \mathrm{Ni}$ & & 0.654 & ug/L $/ 2$ & & & & & \\
\hline SESPMNT & B17CM2 & HANFRD TWNSITE HRM30 & ONSITE & sW & $\mathrm{Y}$ & RIVER & TRANSECT & $08-\mathrm{Sep}-03 \mathrm{Ni}$ & & 0.591 & ug/L $/ 2$ & & & & & \\
\hline SESPMNT & B17CN9 & 300 AREA -1 HRM 43.1 & ONSITE & sw & Y & RIVER & TRANSECT & $09-\mathrm{Sep}-03 \mathrm{Ni}$ & & 0.724 & ig/L & & & & & \\
\hline SESPMNT & B17CP0 & 300 AREA -2 HRM 43.1 & ONSITE & SW & $\mathrm{Y}$ & RIVER & TRANSECT & $09-\mathrm{Sep}-03 \mathrm{Ni}$ & & & & & & & & \\
\hline SESPMNT & B17CP1 & 300 AREA -3 HRM 43.1 & ONSITE & sw & $\mathrm{Y}$ & RIVER & TRANSECT & $09-\mathrm{Sep}-03 \mathrm{Ni}$ & & & & & & & & \\
\hline SESPMNT & B17CP2 & 300 AREA -5 HRM 43.1 & ONSITE & sW & $\mathrm{Y}$ & RIVER & TRANSECT & $09-\mathrm{Sep}-03 \mathrm{Ni}$ & & & & & & & & \\
\hline SESPMNT & B17CP3 & 300 AREA -7 HRM 43.1 & ONSITE & SW & $\mathrm{Y}$ & RIVER & TRANSECT & $09-\mathrm{Sep}-03 \mathrm{Ni}$ & & 0.666 & & & & & & \\
\hline SESPMNT & B17CW8 & 300 AREA SHR HRM41.5 & ONSITE & sw & $\mathrm{Y}$ & RIVER & TRANSECT & $09-\mathrm{Sep}-03 \mathrm{Ni}$ & & 0.66 & $\mathrm{ing} / \mathrm{L}$ & & & & & \\
\hline SESPMNT & B17CX2 & 300 AREA SHR HRM42.1 & ONSITE & SW & $\mathrm{Y}$ & RIVER & TRANSECT & $09-\mathrm{Sep}-03 \mathrm{Ni}$ & & 0.647 & $\mathrm{ug} / \mathrm{L}$ & & & & & \\
\hline SESPMNT & B17CX6 & 300 AREA SHR HRM42.5 & ONSITE & sw & $\mathrm{Y}$ & RIVER & TRANSECT & $09-\mathrm{Sep}-03 \mathrm{Ni}$ & & 0.84 & & & & & & \\
\hline SESPMNT & B17CYO & 300 AREA SHR HRM42.9 & ONSITE & sW & $\mathrm{Y}$ & RIVER & TRANSECT & $09-\mathrm{Sep}-03 \mathrm{Ni}$ & & 0.698 & & & & & & \\
\hline SESPMNT & B17CP4 & 300 AREA-10 HRM 43.1 & ONSITE & SW & $\mathrm{Y}$ & RIVER & $\begin{array}{l}\text { TRANSECT } \\
\text { TRES }\end{array}$ & $09-\mathrm{Sep}-03 \mathrm{Ni}$ & & 0.775 & & & & & & \\
\hline SESPMNT & B17CT4 & RICH.PMPHS HRM 43.5 & OFFSITE & SW & Y & RIVER & TRANSECT & $09-\mathrm{Sep}-03 \mathrm{Ni}$ & & & & & & & & \\
\hline SESPMNT & B17CT2 & RICH.PMPHS HRM 45.0 & OFFSITE & sw & $\mathrm{Y}$ & RIVER & TRANSECT & $09-\mathrm{Sep}-03 \mathrm{Ni}$ & & 0.616 & & & & & & \\
\hline SESPMNT & B17CT1 & RICH.PMPHS HRM 45.8 & OFFSITE & sw & Y & RIVER & TRANSECT & $09-\mathrm{Sep}-03 \mathrm{Ni}$ & & 0.61 & $\mathrm{ug} / \mathrm{L}$ & & & & & \\
\hline SESPMNT & B17CD0 & RICH.PMPHS-1 HRM46.4 & OFFSITE & sW & $\mathrm{N}$ & RIVER & TRANSECT & $09-\mathrm{Sep}-03 \mathrm{Ni}$ & & 0.68 & $3 \mathrm{ug} / \mathrm{L}$ & & & & & \\
\hline SESPMNT & B17CN3 & RICH.PMPHS-1 HRM46.4 & OFFSITE & sW & Y & RIVER & TRANSECT & $09-\mathrm{Sep}-03 \mathrm{Ni}$ & & 0.603 & & & & & & \\
\hline SESPMNT & B17CD5 & RICH.PMPHS-10 HRM46.4 & OFFSITE & SW & $\mathrm{N}$ & RIVER & TRANSECT & $09-\mathrm{Sep}-03 \mathrm{Ni}$ & & 0.729 & & & & & & \\
\hline SESPMNT & B17CN8 & RICH.PMPHS-10 HRM46.4 & OFFSITE & SW & $\mathrm{Y}$ & RIVER & TRANSECT & $09-\mathrm{Sep}-03 \mathrm{Ni}$ & & 0.675 & & & & & & \\
\hline SESPMNT & B17CD1 & RICH.PMPHS-2 HRM46.4 & OFFSITE & sw & $\mathrm{N}$ & RIVER & TRANSECT & $09-\mathrm{Sep}-03 \mathrm{Ni}$ & & 0.692 & & & & & & \\
\hline SESPMNT & B17CN4 & RICH.PMPHS-2 HRM46.4 & OFFSITE & sw & $\mathrm{Y}$ & RIVER & TRANSECT & $09-\mathrm{Sep}-03 \mathrm{Ni}$ & & 0.681 & & & & & & \\
\hline SESPMNT & B17CD2 & RICH.PMPHS-3 HRM 46.4 & OFFSITE & sw & $\mathrm{N}$ & RIVER & TRANSECT & $09-\mathrm{Sep}-03 \mathrm{Ni}$ & & 0.605 & & & & & & \\
\hline SESPMNT & B17CN5 & RICH.PMPHS-3 HRM46.4 & OFFSITE & sw & $\mathrm{Y}$ & RIVER & TRANSECT & $09-\mathrm{Sep}-03 \mathrm{Ni}$ & & 0.685 & $5 \mathrm{ug} / \mathrm{L}$ & & & & & \\
\hline SESPMNT & B17CD3 & RICH.PMPHS-5 HRM46.4 & OFFSITE & sw & $\mathrm{N}$ & RIVER & TRANSECT & $09-\mathrm{Sep}-03 \mathrm{Ni}$ & & 0.648 & $3 \mathrm{ug} / \mathrm{L}$ & & & & & \\
\hline SESPMNT & B17CN6 & RICH.PMPHS-5 HRM46.4 & OFFSITE & sW & $\mathrm{Y}$ & RIVER & TRANSECT & $09-\mathrm{Sep}-03 \mathrm{Ni}$ & & 0.607 & ug/L & & & & & \\
\hline SESPMNT & B17CD4 & RICH.PMPHS-7 HRM46.4 & OFFSITE & SW & $\mathrm{N}$ & RIVER & TRANSECT & $09-\mathrm{Sep}-03 \mathrm{Ni}$ & & 0.626 & $\mathrm{ing} / \mathrm{L}$ & & & & & \\
\hline SESPMNT & B17CN7 & RICH.PMPHS-7 HRM46.4 & OFFSITE & sw & $\mathrm{Y}$ & RIVER & TRANSECT & $09-\mathrm{Sep}-03 \mathrm{Ni}$ & & 0.641 & & & & & & \\
\hline SESPMNT & B183W4 & RICH.PMPHS HRM 43.5 & OFFSITE & sW & $\mathrm{Y}$ & RIVER & TRANSECT & 08-Dec-03 Ni & & 0.549 & & & & & & \\
\hline SESPMNT & B183W8 & RICH.PMPHS HRM 43.5 & OFFSITE & sW & $\mathrm{N}$ & RIVER & TRANSECT & $08-\mathrm{Dec}-03 \mathrm{Ni}$ & & 0.685 & & & & & & \\
\hline SESPMNT & B183W3 & RICH.PMPHS HRM 43.9 & OFFSITE & SW & $\mathrm{Y}$ & RIVER & TRANSECT & $08-\mathrm{Dec}-03 \mathrm{Ni}$ & & 0.573 & & & & & & \\
\hline SESPMNT & B183W7 & RICH.PMPHS HRM 43.9 & OFFSITE & sW & $\mathrm{N}$ & RIVER & TRANSECT & $08-\mathrm{Dec}-03 \mathrm{Ni}$ & & 0.682 & ug/L & & & & & \\
\hline SESPMNT & B183W2 & RICH.PMPHS HRM 45.0 & OFFSITE & sw & Y & RIVER & TRANSECT & $08-\mathrm{Dec}-03 \mathrm{Ni}$ & & 0.561 & & & & & & \\
\hline SESPMNT & B183W6 & RICH.PMPHS HRM 45.0 & OFFSITE & SW & $\mathrm{N}$ & RIVER & TRANSECT & 08-Dec-03 Ni & & 0.611 & & & & & & \\
\hline SESPMNT & B183W1 & RICH.PMPHS HRM 45.8 & OFFSITE & sw & $\mathrm{Y}$ & RIVER & TRANSECT & $08-\mathrm{Dec}-03 \mathrm{Ni}$ & & 0.493 & & & & & & \\
\hline SESPMNT & B183W5 & RICH.PMPHS HRM 45.8 & OFFSITE & sW & $\mathrm{N}$ & RIVER & TRANSECT & $08-\mathrm{Dec}-03 \mathrm{Ni}$ & & 0.594 & & & & & & \\
\hline SESPMNT & B183P9 & RICH.PMPHS-1 HRM46.4 & OFFSITE & sW & $\mathrm{N}$ & RIVER & TRANSECT & $08-\mathrm{Dec}-03 \mathrm{Ni}$ & & 0.639 & & & & & & \\
\hline SESPMNT & B183V1 & RICH.PMPHS-1 HRM46.4 & OFFSITE & SW & $\mathrm{Y}$ & RIVER & TRANSECT & $08-\mathrm{Dec}-03 \mathrm{Ni}$ & & 0.536 & ug/L/ & & & & & \\
\hline SESPMNT & B183R4 & RICH.PMPHS-10 HRM46.4 & OFFSITE & SW & $\mathrm{N}$ & RIVER & TRANSECT & $08-\mathrm{Dec}-03 \mathrm{Ni}$ & & 0.885 & $3 \mathrm{ug} / \mathrm{L}$ & & & & & \\
\hline SESPMNT & B183V6 & RICH.PMPHS-10 HRM46.4 & OFFSITE & sW & Y & RIVER & TRANSECT & $08-\mathrm{Dec}-03 \mathrm{Ni}$ & & 0.603 & $3 \mathrm{ug} / \mathrm{L}$ & & & & & \\
\hline SESPMNT & B183R0 & RICH.PMPHS-2 HRM46.4 & OFFSITE & SW & $\mathrm{N}$ & RIVER & TRANSECT & $08-\mathrm{Dec}-03 \mathrm{Ni}$ & & 0.635 & ugh/L & & & & & \\
\hline SESPMNT & B183V2 & RICH.PMPHS-2 HRM46.4 & OFFSITE & sw & $\mathrm{Y}$ & RIVER & TRANSECT & $08-\mathrm{Dec}-03 \mathrm{Ni}$ & & 0.554 & ug/L & & & & & \\
\hline SESPMNT & B183R1 & RICH.PMPHS-3 HRM46.4 & OFFSITE & SW & $\mathrm{N}$ & RIVER & TRANSECT & $08-\mathrm{Dec}-03 \mathrm{Ni}$ & & 0.618 & & & & & & \\
\hline SESPMNT & B183V3 & RICH.PMPHS-3 HRM46.4 & OFFSITE & SW & $\mathrm{Y}$ & RIVER & TRANSECT & $08-\mathrm{Dec}-03 \mathrm{Ni}$ & & 0.526 & & & & & & \\
\hline SESPMNT & B183R2 & RICH.PMPHS-5 HRM46.4 & OFFSITE & sw & $\mathrm{N}$ & RIVER & TRANSECT & $08-\mathrm{Dec}-03 \mathrm{Ni}$ & & 0.762 & & & & & & \\
\hline SESPMNT & B183V4 & RICH.PMPHS-5 HRM46.4 & OFFSITE & sW & $\mathrm{Y}$ & RIVER & TRANSECT & $08-\mathrm{Dec}-03 \mathrm{Ni}$ & & 0.518 & $3 \mathrm{ug} / \mathrm{L}$ & & & & & \\
\hline SESPMNT & B183R3 & RICH.PMPHS-7 HRM46.4 & OFFSITE & sW & $\mathrm{N}$ & RIVER & TRANSECT & $08-\mathrm{Dec}-03 \mathrm{Ni}$ & & 0.619 & $\mathrm{ug} / \mathrm{L}$ & & & & & \\
\hline SESPMNT & B183V5 & RICH.PMPHS-7 HRM46.4 & OFFSITE & SW & $\mathrm{Y}$ & RIVER & TRANSECT & $08-\mathrm{Dec}-03 \mathrm{Ni}$ & & 0.523 & $3 \mathrm{ug} / \mathrm{L}$ & & & & & \\
\hline SESPMNT & B183R5 & VERNITA-1 HRM 0.3 & OFFSITE & SW & $\mathrm{N}$ & RIVER & TRANSECT & $09-\mathrm{Dec}-03 \mathrm{Ni}$ & & 0.63 & $3 \mathrm{ug} / \mathrm{L}$ & & & & & \\
\hline SESPMNT & B183T7 & VERNITA-1 HRM 0.3 & OFFSITE & sw & $\mathrm{Y}$ & RIVER & TRANSECT & $09-\mathrm{Dec}-03 \mathrm{Ni}$ & & 0.402 & & & & & & \\
\hline SESPMNT & B183P6 & VERNITA-2 HRM 0.3 & OFFSITE & sw & $\mathrm{N}$ & RIVER & TRANSECT & $09-\mathrm{Dec}-03 \mathrm{Ni}$ & & & & & & & & \\
\hline SESPMNT & B183T8 & VERNITA-2 HRM 0.3 & OFFSITE & sW & Y & RIVER & TRANSECT & $09-\mathrm{Dec}-03 \mathrm{Ni}$ & & & & & & & & \\
\hline SESPMNT & B183P7 & VERNITA-3 HRM 0.3 & OFFSITE & SW & $\mathrm{N}$ & RIVER & TRANSECT & $09-\mathrm{Dec}-03 \mathrm{Ni}$ & & 0.63 & ug/L & & & & & \\
\hline SESPMNT & B183T9 & VERNITA-3 HRM 0.3 & OFFSITE & sW & $\mathrm{Y}$ & RIVER & TRANSECT & 09-Dec-03 Ni & & 0.55 & $\mathrm{sug} / \mathrm{L}$ & & & & & \\
\hline SESPMNT & B183P8 & VERNITA-4 HRM 0.3 & OFFSITE & sw & $\mathrm{N}$ & RIVER & TRANSECT & 09-Dec-03 Ni & & 0.68 & $3 \mathrm{ug} / \mathrm{L}$ & & & & & \\
\hline SESPMNT & B183Vo & VERNITA-4 HRM 0.3 & OFFSITE & SW & $\mathrm{Y}$ & RIVER & TRANSECT & 09-Dec-03 Ni & & 0.558 & $3 \mathrm{ug} / \mathrm{L}$ & & & & & \\
\hline SESPMNT & B16L95 & VERNITA-1 HRM 0.3 & OFFSITE & SW & $\mathrm{N}$ & RIVER & TRANSECT & 24-Mar-03 Pb & & 0.00835 & ugg/L & & & B & & \\
\hline SESPMNT & B16LB7 & VERNITA-1 HRM 0.3 & OFFSITE & SW & $\mathrm{Y}$ & RIVER & TRANSECT & 24-Mar-03 Pb & & 0.0658 & $3 \mathrm{ug} / \mathrm{L}$ & & & C & & \\
\hline SESPMNT & B16L86 & VERNITA-2 HRM 0.3 & OFFSITE & SW & $\mathrm{N}$ & RIVER & TRANSECT & 24-Mar-03 Pb & & 0.0669 & $\mathrm{ug} / \mathrm{L}$ & & & & & \\
\hline SESPMNT & B16LB8 & VERNITA-2 HRM 0.3 & OFFSITE & SW & $\mathrm{Y}$ & RIVER & TRANSECT & 24-Mar-03 Pb & & 0.00996 & ug/L & & & $\mathrm{BC}$ & & \\
\hline SESPMNT & B16L87 & VERNITA-3 HRM 0.3 & OFFSITE & sW & $\mathrm{N}$ & RIVER & TRANSECT & 24-Mar-03 Pb & & 0.067 & ug/L & & & & & \\
\hline
\end{tabular}


WATER - COLUMBIA RIVER TRANSECT

\begin{tabular}{|c|c|c|c|c|c|c|c|c|c|c|c|c|c|c|c|c|}
\hline | OWNER ID & SAMP NUM & SAMP SITE NAME & |DIST CLASS & MEDIA $\left.\right|^{\mid h}$ & \begin{tabular}{|c|} 
FILTERED \\
FLAG
\end{tabular} & $\mid \begin{array}{l}\text { SAMP } \\
\text { FROM }\end{array}$ & COLL MTHD & SAMP DATE & CON SHORT NAME & $\begin{array}{l}\text { VALUE } \\
\text { RPTD }\end{array}$ & \begin{tabular}{|l|} 
ANAL \\
UNITS \\
RPTD \\
\end{tabular} & $\begin{array}{c}\text { COUNTING } \\
\text { ERROR }\end{array}$ & \begin{tabular}{|l|} 
TOTAL \\
ANAL \\
ERROR
\end{tabular} & $\begin{array}{c}\text { LAB } \\
\text { QUALIFIER }\end{array}$ & SAMP COMMENT & $\begin{array}{l}\text { RESULT } \\
\text { COMMENT }\end{array}$ \\
\hline SESPMNT & B16LB9 & VERNITA-3 HRM 0.3 & OFFSITE & SW & Y & & TRANSECT & 24-Mar-03 Pb & & & & & & $B C$ & 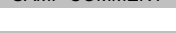 & \\
\hline SESPMNT & B16L88 & VERNITA-4 HRM 0.3 & OFFSITE & sw & $\mathrm{N}$ & RIVER & TRANSECT & 24-Mar-03 Pb & & 0.0737 & $7 \mathrm{ug} / \mathrm{L}$ & & & & & \\
\hline SESPMNT & B16LC0 & VERNITA-4 HRM 0.3 & OFFSITE & sw & $\mathrm{Y}$ & RIVER & TRANSECT & 24-Mar-03 Pb & & 0.00904 & $4 \mathrm{ug} / \mathrm{L}$ & & & $\mathrm{BC}$ & & \\
\hline SESPMNT & B16LD4 & RICH.PMPHS HRM 43.5 & OFFSITE & SW & $\mathrm{Y}$ & RIVER & TRANSECT & 25-Mar-03 Pb & & 0.00781 & $1 \mathrm{ug} / \mathrm{L}$ & & & $\mathrm{BC}$ & & \\
\hline SESPMNT & B16LD8 & RICH.PMPHS HRM 43.5 & OFFSITE & sW & $\mathrm{N}$ & RIVER & TRANSECT & 25-Mar-03 Pb & & 0.0686 & $6 \mathrm{ug} / \mathrm{L}$ & & & & & \\
\hline SESPMNT & B16LD3 & RICH.PMPHS HRM 43.9 & OFFSITE & sW & $\mathrm{Y}$ & RIVER & TRANSECT & 25-Mar-03 Pb & & 0.0156 & & & & $B C$ & & \\
\hline SESPMNT & B16LD7 & RICH.PMPHS HRM 43.9 & OFFSITE & sw & $\mathrm{N}$ & RIVER & TRANSECT & 25-Mar-03 Pb & & & & & & & & \\
\hline SESPMNT & B16LD2 & RICH.PMPHS HRM 45.0 & OFFSITE & sW & $\mathrm{Y}$ & RIVER & TRANSECT & 25-Mar-03 Pb & & & & & & $\mathrm{BC}$ & & \\
\hline SESPMNT & B16LD6 & RICH.PMPHS HRM 45.0 & OFFSITE & sW & $\mathrm{N}$ & RIVER & TRANSECT & 25-Mar-03 Pb & & 0.0586 & $6 \mathrm{ug} / \mathrm{L}$ & & & & & \\
\hline SESPMNT & B16LD1 & RICH.PMPHS HRM 45.8 & OFFSITE & sw & $\mathrm{Y}$ & RIVER & TRANSECT & 25-Mar-03 Pb & & 0.00621 & $1 \mathrm{ug} / \mathrm{L}$ & & & $\mathrm{BC}$ & & \\
\hline SESPMNT & B16LD5 & RICH.PMPHS HRM 45.8 & OFFSITE & SW & $\mathrm{N}$ & RIVER & TRANSECT & 25-Mar-03 Pb & & 0.073 & $3 \mathrm{ug} / \mathrm{L}$ & & & & & \\
\hline SESPMNT & B16L89 & RICH.PMPHS-1 HRM46.4 & OFFSITE & sw & $\mathrm{N}$ & RIVER & TRANSECT & 25-Mar-03 Pb & & 0.0732 & $2 \mathrm{ug} / \mathrm{L}$ & & & & & \\
\hline SESPMNT & B16LC1 & RICH.PMPHS-1 HRM46.4 & OFFSITE & sW & $\mathrm{Y}$ & RIVER & TRANSECT & 25-Mar-03 Pb & & 0.00966 & $6 \mathrm{ug} / \mathrm{L}$ & & & $\mathrm{BC}$ & & \\
\hline SESPMNT & B16L94 & RICH.PMPHS-10 HRM46. 4 & OFFSITE & sW & $\mathrm{N}$ & RIVER & TRANSECT & $25-\mathrm{Mar}-03 \mathrm{~Pb}$ & & 0.0685 & $5 \mathrm{ug} / \mathrm{L}$ & & & to & & \\
\hline SESPMNT & B16LC6 & RICH.PMPHS-10 HRM46.4 & OFFSITE & SW & Y & RIVER & TRANSECT & 25-Mar-03 Pb & & 0.00662 & & & & $\mathrm{BC}$ & & \\
\hline SESPMNT & B16L90 & RICH.PMPHS-2 HRM46.4 & OFFSITE & sw & $\mathrm{N}$ & RIVER & TRANSECT & 25-Mar-03 Pb & & 0.0529 & & & & & & \\
\hline SESPMNT & B16LC2 & RICH.PMPHS-2 HRM 46.4 & OFFSITE & sw & Y & RIVER & TRANSECT & 25-Mar-03 Pb & & 0.0105 & $5 \mathrm{ug} / \mathrm{L}$ & & & $\mathrm{BC}$ & & \\
\hline SESPMNT & B16L91 & RICH.PMPHS-3 HRM46.4 & OFFSITE & sW & $\mathrm{N}$ & RIVER & TRANSECT & 25-Mar-03 Pb & & 0.0565 & $5 \mathrm{ug} / \mathrm{L}$ & & & & & \\
\hline SESPMNT & B16LC3 & RICH.PMPHS-3 HRM46.4 & OFFSITE & sw & Y & RIVER & TRANSECT & $25-\mathrm{Mar}-03 \mathrm{~Pb}$ & & 0.0126 & $6 \mathrm{ug} / \mathrm{L}$ & & & $\mathrm{BC}$ & & \\
\hline SESPMNT & B16L92 & RICH.PMPHS-5 HRM46.4 & OFFSITE & SW & $\mathrm{N}$ & RIVER & TRANSECT & $25-\mathrm{Mar}-03 \mathrm{~Pb}$ & & 0.0725 & $5 \mathrm{ug} / \mathrm{L}$ & & & 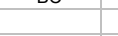 & & \\
\hline SESPMNT & B16LC4 & RICH.PMPHS-5 HRM46.4 & OFFSITE & sW & $\mathrm{Y}$ & RIVER & TRANSECT & 25-Mar-03 Pb & & 0.0127 & & & & $\mathrm{BC}$ & & \\
\hline SESPMNT & B16L93 & RICH.PMPHS-7 HRM46.4 & OFFSITE & sw & $\mathrm{N}$ & RIVER & TRANSECT & 25-Mar-03 Pb & & 0.0584 & & & & & & \\
\hline SESPMNT & B16LC5 & RICH.PMPHS-7 HRM46.4 & OFFSITE & sW & $\mathrm{Y}$ & RIVER & TRANSECT & 25-Mar-03 Pb & & 0.00717 & $7 \mathrm{ug} / \mathrm{L}$ & & & $\mathrm{BC}$ & & \\
\hline SESPMNT & B171V9 & VERNITA-1 HRM 0.3 & OFFSITE & sw & $\mathrm{N}$ & RIVER & TRANSECT & 09-Jun-03 Pb & & 0.112 & $2 u g / L$ & & & $\mathrm{c}$ & & \\
\hline SESPMNT & B171Y1 & VERNITA-1 HRM 0.3 & OFFSITE & sW & $\mathrm{Y}$ & RIVER & TRANSECT & 09-Jun- $03 \mathrm{~Pb}$ & & 0.0115 & $5 \mathrm{ug} / \mathrm{L}$ & & & B & & \\
\hline SESPMNT & B171V0 & VERNITA-2 HRM 0.3 & OFFSITE & sw & $\mathrm{N}$ & RIVER & TRANSECT & 09-Jun- $03 \mathrm{~Pb}$ & & 0.107 & $7 \mathrm{ug} / \mathrm{L}$ & & & C & & \\
\hline SESPMNT & B171Y2 & VERNITA-2 HRM 0.3 & OFFSITE & sW & $\mathrm{Y}$ & RIVER & TRANSECT & 09-Jun- $03 \mathrm{~Pb}$ & & 0.0129 & $9 \mathrm{ug} / \mathrm{L}$ & & & B & & \\
\hline SESPMNT & B171V1 & VERNITA-3 HRM 0.3 & OFFSITE & sW & $\mathrm{N}$ & RIVER & TRANSECT & 09-Jun- $03 \mathrm{~Pb}$ & & 0.117 & 7 ug/L & & & C & & \\
\hline SESPMNT & B171Y3 & VERNITA-3 HRM 0.3 & OFFSITE & sw & Y & RIVER & TRANSECT & 09-Jun- $03 \mathrm{~Pb}$ & & 0.011 & $1 \mathrm{ug} / \mathrm{L}$ & & & B & & \\
\hline SESPMNT & B171V2 & VERNITA-4 HRM 0.3 & OFFSITE & sw & $\mathrm{N}$ & RIVER & TRANSECT & 09-Jun- $03 \mathrm{~Pb}$ & & 0.137 & & & & C & & \\
\hline SESPMNT & B171Y4 & VERNITA-4 HRM 0.3 & OFFSITE & sw & $\mathrm{Y}$ & RIVER & TRANSECT & 09-Jun- $03 \mathrm{~Pb}$ & & 0.0113 & $3 \mathrm{ug} / \mathrm{L}$ & & & B & & \\
\hline SESPMNT & B17208 & RICH.PMPHS HRM 43.5 & OFFSITE & sW & Y & RIVER & TRANSECT & 10-Jun-03 Pb & & 0.0116 & $6 \mathrm{ug} / \mathrm{L}$ & & & B & & \\
\hline SESPMNT & B17212 & RICH.PMPHS HRM 43.5 & OFFSITE & SW & $\mathrm{N}$ & RIVER & TRANSECT & 10-Jun-03 Pb & & & $5 \mathrm{ug} / \mathrm{L}$ & & & C & & \\
\hline SESPMNT & B17207 & RICH.PMPHS HRM 43.9 & OFFSITE & sw & Y & RIVER & TRANSECT & 10-Jun-03 Pb & & 0.0147 & $7 \mathrm{ug} / \mathrm{L}$ & & & B & & \\
\hline SESPMNT & B17211 & RICH.PMPHS HRM 43.9 & OFFSITE & sW & $\mathrm{N}$ & RIVER & TRANSECT & 10-Jun-03 Pb & & 0.144 & $4 \mathrm{ug} / \mathrm{L}$ & & & C & & \\
\hline SESPMNT & B17206 & RICH.PMPHS HRM 45.0 & OFFSITE & sw & $\mathrm{Y}$ & RIVER & TRANSECT & 10-Jun-03 Pb & & 0.0114 & $4 \mathrm{ug} / \mathrm{L}$ & & & B & & \\
\hline SESPMNT & B17210 & RICH.PMPHS HRM 45.0 & OFFSITE & sw & $\mathrm{N}$ & RIVER & TRANSECT & 10-Jun-03 Pb & & 0.171 & $1 \mathrm{ug} / \mathrm{L}$ & & & C & & \\
\hline SESPMNT & B17205 & RICH.PMPHS HRM 45.8 & OFFSITE & sW & $\mathrm{Y}$ & RIVER & TRANSECT & 10-Jun-03 Pb & & 0.0113 & $3 \mathrm{ug} / \mathrm{L}$ & & & B & & \\
\hline SESPMNT & B17209 & RICH.PMPHS HRM 45.8 & OFFSITE & sw & $\mathrm{N}$ & RIVER & TRANSECT & 10-Jun-03 Pb & & 0.198 & $3 \mathrm{ug} / \mathrm{L}$ & & & $\mathrm{c}$ & & \\
\hline SESPMNT & B171V3 & RICH.PMPHS-1 HRM46.4 & OFFSITE & sW & $\mathrm{N}$ & RIVER & TRANSECT & 10-Jun- $03 \mathrm{~Pb}$ & & 0.267 & $7 \mathrm{ug} / \mathrm{L}$ & & & C & & \\
\hline SESPMNT & B171Y5 & RICH.PMPHS-1 HRM46.4 & OFFSITE & sw & Y & RIVER & TRANSECT & 10-Jun-03 Pb & & 0.0134 & $4 \mathrm{ug} / \mathrm{L}$ & & & B & & \\
\hline SESPMNT & B171V8 & RICH.PMPHS-10 HRM46.4 & OFFSITE & SW & $\mathrm{N}$ & RIVER & TRANSECT & 10-Jun-03 Pb & & 0.181 & $1 \mathrm{ug} / \mathrm{L}$ & & & c & & \\
\hline SESPMNT & B17200 & RICH.PMPHS-10 HRM46. 4 & OFFSITE & sw & Y & RIVER & TRANSECT & 10-Jun-03 Pb & & 0.0102 & $2 u g / L$ & & & B & & \\
\hline SESPMNT & B171V4 & RICH.PMPHS-2 HRM46.4 & OFFSITE & sw & $\mathrm{N}$ & RIVER & TRANSECT & 10-Jun-03 Pb & & 0.208 & $3 \mathrm{ug} / \mathrm{L}$ & & & $\mathrm{c}$ & & \\
\hline SESPMNT & B171Y6 & RICH.PMPHS-2 HRM46.4 & OFFSITE & sW & $\mathrm{Y}$ & RIVER & TRANSECT & 10-Jun- $03 \mathrm{~Pb}$ & & 0.0113 & & & & B & & \\
\hline SESPMNT & B171V5 & RICH.PMPHS-3 HRM46.4 & OFFSITE & sw & $\mathrm{N}$ & RIVER & TRANSECT & 10-Jun- $03 \mathrm{~Pb}$ & & 0.169 & $9 \mathrm{ug} / \mathrm{L}$ & & & C & & \\
\hline SESPMNT & B171Y7 & RICH.PMPHS-3 HRM46.4 & OFFSITE & sW & $\mathrm{Y}$ & RIVER & TRANSECT & 10-Jun-03 Pb & & 0.0113 & $3 \mathrm{ug} / \mathrm{L}$ & & & B & & \\
\hline SESPMNT & B171V6 & RICH.PMPHS-5 HRM46.4 & OFFSITE & sw & $\mathrm{N}$ & RIVER & TRANSECT & 10-Jun-03 Pb & & 0.161 & $1 \mathrm{ug} / \mathrm{L}$ & & & c & & \\
\hline SESPMNT & B171Y8 & RICH.PMPHS-5 HRM46.4 & OFFSITE & sW & $\mathrm{Y}$ & RIVER & TRANSECT & 10-Jun-03 Pb & & 0.0134 & $4 \mathrm{ug} / \mathrm{L}$ & & & B & & \\
\hline SESPMNT & B171V7 & RICH.PMPHS-7 HRM46.4 & OFFSITE & sW & $\mathrm{N}$ & RIVER & TRANSECT & 10-Jun-03 Pb & & 0.166 & 6 ug $/ \mathrm{L}$ & & & C & & \\
\hline SESPMNT & B171Y9 & RICH.PMPHS-7 HRM46.4 & OFFSITE & sw & $\mathrm{Y}$ & RIVER & TRANSECT & 10-Jun-03 Pb & & 0.0107 & $7 \mathrm{ug} / \mathrm{L}$ & & & B & & \\
\hline SESPMNT & B17CB6 & $100 \mathrm{~N}-1$ HRM 9.5 & ONSITE & sw & $\mathrm{N}$ & RIVER & TRANSECT & 04-Sep-03 Pb & & 0.0336 & $6 \mathrm{ug} / \mathrm{L}$ & & & & & \\
\hline SESPMNT & B17CM7 & $100 \mathrm{~N}-1$ HRM 9.5 & ONSITE & sw & Y & RIVER & TRANSECT & 04-Sep-03 Pb & & 0.0134 & $4 \mathrm{ug} / \mathrm{L}$ & & & B & & \\
\hline SESPMNT & B17CC1 & $100 \mathrm{~N}-10 \mathrm{HRM} 9.5$ & ONSITE & SW & $\mathrm{N}$ & RIVER & TRANSECT & 04-Sep-03 Pb & & 0.0638 & $3 \mathrm{ug} / \mathrm{L}$ & & & 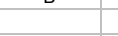 & & \\
\hline SESPMNT & B17CN2 & $100 \mathrm{~N}-10$ HRM 9.5 & ONSITE & sw & $\mathrm{Y}$ & RIVER & TRANSECT & 04-Sep-03 Pb & & 0.011 & $1 \mathrm{ug} / \mathrm{L}$ & & & u & & \\
\hline SESPMNT & B17CB7 & $100 \mathrm{~N}-2$ HRM 9.5 & ONSITE & sW & $\mathrm{N}$ & RIVER & TRANSECT & 04-Sep-03 Pb & & 0.0715 & $5 \mathrm{ug} / \mathrm{L}$ & & & & & \\
\hline SESPMNT & B17CM8 & $100 \mathrm{~N}-2$ HRM 9.5 & ONSITE & SW & Y & RIVER & TRANSECT & 04-Sep-03 Pb & & 0.0125 & $5 \mathrm{ug} / \mathrm{L}$ & & & B & & \\
\hline SESPMNT & B17CB8 & $100 \mathrm{~N}-3 \mathrm{HRM} 9.5$ & ONSITE & SW & $\mathrm{N}$ & RIVER & TRANSECT & 04-Sep-03 Pb & & 0.0711 & $1 \mathrm{ug} / \mathrm{L}$ & & & & & \\
\hline SESPMNT & B17CM9 & $100 \mathrm{~N}-3$ HRM 9.5 & ONSITE & SW & $\mathrm{Y}$ & RIVER & TRANSECT & 04-Sep-03 Pb & & 0.011 & $1 \mathrm{ug} / \mathrm{L}$ & & & $U$ & & \\
\hline SESPMNT & B17CB9 & $100 \mathrm{~N}-5$ HRM 9.5 & ONSITE & sw & $\mathrm{N}$ & RIVER & TRANSECT & 04-Sep-03 Pb & & & 3 ug $/ \mathrm{L}$ & & & & & \\
\hline SESPMNT & B17CNO & $100 \mathrm{~N}-5$ HRM 9.5 & ONSITE & SW & $\mathrm{Y}$ & RIVER & TRANSECT & 04-Sep-03 Pb & & 0.011 & $1 \mathrm{ug} / \mathrm{L}$ & & & U & & \\
\hline SESPMNT & B17CCO & $100 \mathrm{~N}-7$ HRM 9.5 & ONSITE & sw & $\mathrm{N}$ & RIVER & TRANSECT & 04-Sep-03 Pb & & 0.069 & $9 \mathrm{ug} / \mathrm{L}$ & & & & & \\
\hline
\end{tabular}


WATER - COLUMBIA RIVER TRANSECT

\begin{tabular}{|c|c|c|c|c|c|c|c|c|c|c|c|c|c|c|c|c|}
\hline | OWNER ID & | SAMP NUM| & SAMP SITE NAME & |DIST CLASS | & MEDIA $\left.\right|^{\mid h}$ & \begin{tabular}{|c|} 
FILTERED \\
FLAG
\end{tabular} & $\begin{array}{l}\text { SAMP } \\
\text { FROM }\end{array}$ & COLL MTHD & SAMP DATE & CON SHORT NAME & $\begin{array}{l}\text { VALUE } \\
\text { RPTD }\end{array}$ & \begin{tabular}{|l|} 
ANAL \\
UNITS \\
RPTD \\
\end{tabular} & $\begin{array}{c}\text { COUNTING } \\
\text { ERROR }\end{array}$ & \begin{tabular}{|l|} 
TOTAL \\
ANAL \\
ERROR
\end{tabular} & $\begin{array}{c}\text { LAB } \\
\text { QUALIFIER }\end{array}$ & SAMP COMMENT & $\begin{array}{l}\text { RESULT } \\
\text { COMMENT }\end{array}$ \\
\hline SESPMNT & B17CN1 & $100 \mathrm{~N}-7$ HRM 9.5 & ONSITE & SW & Y & RIVER T & TRANSECT & 04-Sep-03 Pb & & & & & & U & 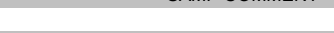 & \\
\hline SESPMNT & B17CV1 & 100 N SHORE HRM 8.4 & ONSITE & sw & $\mathrm{N}$ & RIVER T & TRANSECT & 04-Sep-03 Pb & & 0.0591 & $1 \mathrm{ug} / \mathrm{L}$ & & & & & \\
\hline SESPMNT & B17CV2 & 100 N SHORE HRM 8.4 & ONSITE & sw & $\mathrm{Y}$ & RIVER 7 & TRANSECT & 04-Sep-03 Pb & & 0.011 & $1 \mathrm{ug} / \mathrm{L}$ & & & u & & \\
\hline SESPMNT & B17CV5 & 100 N SHORE HRM 8.9 & ONSITE & SW & $\mathrm{N}$ & RIVER T & TRANSECT & 04-Sep-03 Pb & & 0.0265 & $5 \mathrm{ug} / \mathrm{L}$ & & & & & \\
\hline SESPMNT & B17CV6 & 100 N SHORE HRM 8.9 & ONSITE & sW & Y & RIVER & TRANSECT & 04-Sep-03 Pb & & 0.011 & $1 \mathrm{ug} / \mathrm{L}$ & & & $u$ & & \\
\hline SESPMNT & B17CV9 & $100 \mathrm{~N}$ SHORE HRM 9.2 & ONSITE & sW & $\mathrm{N}$ & RIVER 7 & TRANSECT & 04-Sep-03 Pb & & & & & & & & \\
\hline SESPMNT & B17CW0 & $100 \mathrm{~N}$ SHORE HRM 9.2 & ONSITE & sw & $\mathrm{Y}$ & RIVER 7 & TRANSECT & 04-Sep-03 Pb & & & & & & $\mathrm{U}$ & & \\
\hline SESPMNT & B17CW3 & 100 N SHORE HRM 9.8 & ONSITE & sW & $\mathrm{N}$ & RIVER T & TRANSECT & 04-Sep-03 Pb & & & & & & & & \\
\hline SESPMNT & B17CW4 & 100 N SHORE HRM 9.8 & ONSITE & SW & $\mathrm{Y}$ & RIVER 7 & TRANSECT & 04-Sep-03 Pb & & 0.011 & 1 ug/L & & & U & & \\
\hline SESPMNT & B17CD6 & VERNITA-1 HRM 0.3 & OFFSITE & sw & $\mathrm{N}$ & RIVER T & TRANSECT & 04-Sep-03 Pb & & 0.0533 & $3 \mathrm{ug} / \mathrm{L}$ & & & & & \\
\hline SESPMNT & B17CM3 & VERNITA-1 HRM 0.3 & OFFSITE & SW & $\mathrm{Y}$ & RIVER T & TRANSECT & 04-Sep-03 Pb & & 0.011 & $1 \mathrm{ug} / \mathrm{L}$ & & & $u$ & & \\
\hline SESPMNT & B17CC7 & VERNITA-2 HRM 0.3 & OFFSITE & sw & $\mathrm{N}$ & RIVER 7 & TRANSECT & 04-Sep-03 Pb & & 0.061 & 1 ug $/ \mathrm{L}$ & & & & & \\
\hline SESPMNT & B17CM4 & VERNITA-2 HRM 0.3 & OFFSITE & sW & $\mathrm{Y}$ & RIVER T & TRANSECT & 04-Sep-03 Pb & & 0.011 & $1 \mathrm{ug} / \mathrm{L}$ & & & U & & \\
\hline SESPMNT & B17CC8 & VERNITA-3 HRM 0.3 & OFFSITE & SW & $\mathrm{N}$ & RIVER T & TRANSECT & 04-Sep-03 Pb & & 0.0629 & $9 \mathrm{ug} / \mathrm{L}$ & & & 政 & & \\
\hline SESPMNT & B17CM5 & VERNITA-3 HRM 0.3 & OFFSITE & sW & $\mathrm{Y}$ & RIVER 7 & TRANSECT & 04-Sep-03 Pb & & 0.011 & & & & $u$ & & \\
\hline SESPMNT & B17CC9 & VERNITA-4 HRM 0.3 & OFFSITE & sw & $\mathrm{N}$ & RIVER 7 & TRANSECT & 04-Sep-03 Pb & & & $5 \mathrm{ug} / \mathrm{L}$ & & & & & \\
\hline SESPMNT & B17CM6 & VERNITA-4 HRM 0.3 & OFFSITE & sw & Y & RIVER 7 & TRANSECT & 04-Sep-03 Pb & & 0.011 & $1 \mathrm{ug} / \mathrm{L}$ & & & $u$ & & \\
\hline SESPMNT & B17CC2 & $100 \mathrm{~F}-1 \mathrm{HRM} 19.0$ & ONSITE & sW & $\mathrm{N}$ & RIVER T & TRANSECT & 08-Sep-03 Pb & & 0.0515 & $5 \mathrm{ug} / \mathrm{L}$ & & & & & \\
\hline SESPMNT & B17CR1 & $100 \mathrm{~F}-1 \mathrm{HRM} 19.0$ & ONSITE & sW & Y & RIVER T & TRANSECT & 08-Sep-03 Pb & & 0.011 & $1 \mathrm{ug} / \mathrm{L}$ & & & $u$ & & \\
\hline SESPMNT & B17C96 & $100 \mathrm{~F}-10$ HRM 19.0 & ONSITE & SW & $\mathrm{N}$ & RIVER T & TRANSECT & 08-Sep-03 Pb & & 0.0347 & & & & 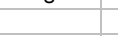 & & \\
\hline SESPMNT & B17CR6 & $100 \mathrm{~F}-10$ HRM 19.0 & ONSITE & SW & Y & RIVER T & TRANSECT & 08-Sep-03 Pb & & 0.011 & & & & U & & \\
\hline SESPMNT & B17CR2 & $100 \mathrm{~F}-2$ HRM 19.0 & ONSITE & sW & Y & RIVER & TRANSECT & 08-Sep-03 Pb & & 0.011 & & & & u & & \\
\hline SESPMNT & B17CC4 & $100 \mathrm{~F}-3 \mathrm{HRM} 19.0$ & ONSITE & sW & $\mathrm{N}$ & RIVER & TRANSECT & 08-Sep-03 Pb & & 0.0541 & & & & 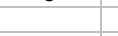 & & \\
\hline SESPMNT & B17CR3 & 100 F - 3 HRM 19.0 & ONSITE & sw & Y & RIVER T & TRANSECT & 08-Sep-03 Pb & & 0.011 & 1 ug/L & & & $u$ & & \\
\hline SESPMNT & B17CR4 & $100 \mathrm{~F}-5$ HRM 19.0 & ONSITE & sW & $\mathrm{Y}$ & RIVER T & TRANSECT & 08-Sep-03 Pb & & 0.011 & $1 \mathrm{ug} / \mathrm{L}$ & & & $\mathrm{U}$ & & \\
\hline SESPMNT & B17CR5 & $100 \mathrm{~F}-7$ HRM 19.0 & ONSITE & sW & $\mathrm{Y}$ & RIVER 7 & TRANSECT & 08-Sep-03 Pb & & 0.011 & $1 \mathrm{ug} / \mathrm{L}$ & & & U & & \\
\hline SESPMNT & B17CY5 & $100 \mathrm{~F}$ SHORE HRM 18 & ONSITE & sW & $\mathrm{N}$ & RIVER T & TRANSECT & 08-Sep-03 Pb & & 0.121 & $1 \mathrm{ug} / \mathrm{L}$ & & & & & \\
\hline SESPMNT & B17CY6 & 100 F SHORE HRM 18 & ONSITE & SW & Y & RIVER 7 & TRANSECT & 08-Sep-03 Pb & & 0.011 & 1 ug/L & & & $u$ & & \\
\hline SESPMNT & B17CY8 & $100 \mathrm{~F}$ SHORE HRM 22 & ONSITE & sw & $\mathrm{N}$ & RIVER T & TRANSECT & 08 -Sep-03 Pb & & 0.129 & & & & & & \\
\hline SESPMNT & B17CY9 & 100 F SHORE HRM 22 & ONSITE & sw & $\mathrm{Y}$ & RIVER T & TRANSECT & 08-Sep-03 Pb & & 0.0125 & & & & & & \\
\hline SESPMNT & B17D01 & $100 \mathrm{~F}$ SHORE HRM 23 & ONSITE & sw & $\mathrm{N}$ & RIVER T & TRANSECT & 08-Sep-03 Pb & & 0.0401 & & & & & & \\
\hline SESPMNT & B17D02 & $100 \mathrm{~F}$ SHORE HRM 23 & ONSITE & sw & $\mathrm{Y}$ & RIVER T & TRANSECT & 08-Sep-03 Pb & & 0.011 & 1 ug $/ \mathrm{L}$ & & & u & & \\
\hline SESPMNT & B17C97 & HANFRD TS-1 HRM 28.7 & ONSITE & SW & $\mathrm{N}$ & RIVER T & TRANSECT & 08-Sep-03 Pb & & 0.0386 & $6 \mathrm{ug} / \mathrm{L}$ & & & & & \\
\hline SESPMNT & B17CP5 & HANFRD TS-1 HRM 28.7 & ONSITE & sw & Y & RIVER T & TRANSECT & 08-Sep-03 Pb & & 0.011 & $1 \mathrm{ug} / \mathrm{L}$ & & & $u$ & & \\
\hline SESPMNT & B17CB2 & HANFRD TS-10 HRM 28.7 & ONSITE & sW & $\mathrm{N}$ & RIVER T & TRANSECT & 08-Sep-03 Pb & & 0.096 & & & & & & \\
\hline SESPMNT & B17CR0 & HANFRD TS-10 HRM 28.7 & ONSITE & sw & $\mathrm{Y}$ & RIVER 7 & TRANSECT & 08-Sep-03 Pb & & 0.011 & & & & u & & \\
\hline SESPMNT & B17C98 & HANFRD TS-2 HRM 28.7 & ONSITE & sw & $\mathrm{N}$ & RIVER 7 & TRANSECT & 08-Sep-03 Pb & & 0.0448 & & & & & & \\
\hline SESPMNT & B17CP6 & HANFRD TS-2 HRM 28.7 & ONSITE & sW & $\mathrm{Y}$ & RIVER T & TRANSECT & 08-Sep-03 Pb & & 0.011 & & & & $u$ & & \\
\hline SESPMNT & B17C99 & HANFRD TS-3 HRM 28.7 & ONSITE & sw & $\mathrm{N}$ & RIVER T & TRANSECT & 08-Sep-03 Pb & & 0.0402 & $2 \mathrm{ug} / \mathrm{L}$ & & & 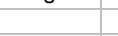 & & \\
\hline SESPMNT & B17CP7 & HANFRD TS-3 HRM 28.7 & ONSITE & sW & $\mathrm{Y}$ & RIVER T & TRANSECT & 08-Sep-03 Pb & & 0.011 & $1 \mathrm{ug} / \mathrm{L}$ & & & u & & \\
\hline SESPMNT & B17CB0 & HANFRD TS-5 HRM 28.7 & ONSITE & sw & $\mathrm{N}$ & RIVER T & TRANSECT & 08-Sep-03 Pb & & 0.0378 & $3 \mathrm{ug} / \mathrm{L}$ & & & & & \\
\hline SESPMNT & B17CP8 & HANFRD TS-5 HRM 28.7 & ONSITE & sW & Y & RIVER 7 & TRANSECT & 08-Sep-03 Pb & & 0.011 & $1 \mathrm{ug} / \mathrm{L}$ & & & $\mathrm{U}$ & & \\
\hline SESPMNT & B17CB1 & HANFRD TS-7 HRM 28.7 & ONSITE & sW & $\mathrm{N}$ & RIVER 7 & TRANSECT & 08-Sep-03 Pb & & 0.0302 & $2 \mathrm{ug} / \mathrm{L}$ & & & & & \\
\hline SESPMNT & B17CP9 & HANFRD TS-7 HRM 28.7 & ONSITE & sW & $\mathrm{Y}$ & RIVER & TRANSECT & 08-Sep-03 Pb & & 0.011 & 1 ug $/ \mathrm{L}$ & & & U & & \\
\hline SESPMNT & B17CL7 & HANFRD TWNSITE HRM26 & ONSITE & sW & $\mathrm{N}$ & RIVER 7 & TRANSECT & 08-Sep-03 Pb & & 0.0498 & & & & & & \\
\hline SESPMNT & B17CM0 & HANFRD TWNSITE HRM26 & ONSITE & sw & $\mathrm{Y}$ & RIVER 7 & TRANSECT & 08-Sep-03 Pb & & 0.011 & $1 \mathrm{ug} / \mathrm{L}$ & & & $\mathrm{U}$ & & \\
\hline SESPMNT & B17CL8 & HANFRD TWNSITE HRM27 & ONSITE & sW & $\mathrm{N}$ & RIVER 7 & TRANSECT & 08-Sep-03 Pb & & 0.0361 & $1 \mathrm{ug} / \mathrm{L}$ & & & & & \\
\hline SESPMNT & B17CM1 & HANFRD TWNSITE HRM27 & ONSITE & sw & Y & RIVER T & TRANSECT & 08-Sep-03 Pb & & 0.011 & $1 \mathrm{ug} / \mathrm{L}$ & & & $u$ & & \\
\hline SESPMNT & B17CY2 & HANFRD TWNSITE HRM28 & ONSITE & sW & $\mathrm{N}$ & RIVER T & TRANSECT & 08-Sep-03 Pb & & 0.0262 & $2 \mathrm{ug} / \mathrm{L}$ & & & & & \\
\hline SESPMNT & $\mathrm{B} 17 \mathrm{CY} 3$ & HANFRD TWNSITE HRM28 & ONSITE & sW & $\mathrm{Y}$ & RIVER 7 & TRANSECT & 08-Sep-03 Pb & & 0.011 & 1 ug/L & & & $\mathrm{U}$ & & \\
\hline SESPMNT & B17CL9 & HANFRD TWNSITE HRM30 & ONSITE & sw & $\mathrm{N}$ & RIVER T & TRANSECT & 08-Sep-03 Pb & & 0.0633 & $3 \mathrm{ug} / \mathrm{L}$ & & & & & \\
\hline SESPMNT & B17CM2 & HANFRD TWNSITE HRM30 & ONSITE & sW & $\mathrm{Y}$ & RIVER T & TRANSECT & 08-Sep-03 Pb & & 0.011 & $1 \mathrm{ug} / \mathrm{L}$ & & & u & & \\
\hline SESPMNT & B17CN9 & 300 AREA - 1 HRM 43.1 & ONSITE & sw & Y & RIVER T & TRANSECT & 09-Sep-03 Pb & & 0.011 & & & & u & & \\
\hline SESPMNT & B17CP0 & 300 AREA - 2 HRM 43.1 & ONSITE & SW & $\mathrm{Y}$ & RIVER T & TRANSECT & 09-Sep-03 Pb & & 0.011 & $1 \mathrm{ug} / \mathrm{L}$ & & & u & & \\
\hline SESPMNT & B17CP1 & 300 AREA -3 HRM 43.1 & ONSITE & sw & $\mathrm{Y}$ & RIVER 7 & TRANSECT & 09-Sep-03 Pb & & 0.011 & $1 \mathrm{ug} / \mathrm{L}$ & & & U & & \\
\hline SESPMNT & B17CP2 & 300 AREA -5 HRM 43.1 & ONSITE & sW & $\mathrm{Y}$ & RIVER T & TRANSECT & 09-Sep-03 Pb & & 0.011 & $1 \mathrm{ug} / \mathrm{L}$ & & & u & & \\
\hline SESPMNT & B17CP3 & 300 AREA - 7 HRM 43.1 & ONSITE & sW & $\mathrm{Y}$ & RIVER T & TRANSECT & 09-Sep-03 Pb & & 0.011 & $1 \mathrm{ug} / \mathrm{L}$ & & & $u$ & & \\
\hline SESPMNT & B17CW8 & 300 AREA SHR HRM41.5 & ONSITE & SW & $\mathrm{Y}$ & RIVER T & TRANSECT & 09-Sep-03 Pb & & 0.0902 & $2 u g / L$ & & & & & \\
\hline SESPMNT & B17CX2 & 300 AREA SHR HRM 42.1 & ONSITE & sW & $\mathrm{Y}$ & RIVER T & TRANSECT & 09-Sep-03 Pb & & 0.0748 & $3 \mathrm{ug} / \mathrm{L}$ & & & & & \\
\hline SESPMNT & B17CX6 & 300 AREA SHR HRM42.5 & ONSITE & sw & $\mathrm{Y}$ & RIVER T & TRANSECT & 09-Sep-03 Pb & & 0.0759 & 9 ug $/ \mathrm{L}$ & & & & & \\
\hline SESPMNT & B17CYO & 300 AREA SHR HRM42.9 & ONSITE & SW & $\mathrm{Y}$ & RIVER 7 & TRANSECT & 09-Sep-03 Pb & & 0.0507 & & & & & & \\
\hline SESPMNT & B17CP4 & 300 AREA-10 HRM 43.1 & ONSITE & sw & Y & RIVER T & TRANSECT & 09-Sep-03 Pb & & 0.011 & $1 \mathrm{ug} / \mathrm{L}$ & & & U & & \\
\hline
\end{tabular}


WATER - COLUMBIA RIVER TRANSECT

\begin{tabular}{|c|c|c|c|c|c|c|c|c|c|c|c|c|c|c|c|c|}
\hline | OWNER ID & | SAMP NUM| & SAMP SITE NAME & |DIST CLASS & MEDIA $\left.\right|^{\mid h}$ & \begin{tabular}{|c|} 
FILTERED \\
FLAG
\end{tabular} & $\mid \begin{array}{l}\text { SAMP } \\
\text { FROM }\end{array}$ & COLL MTHD & SAMP DATE & CON SHORT NAME & $\begin{array}{l}\text { VALUE } \\
\text { RPTD }\end{array}$ & \begin{tabular}{|l|} 
ANAL \\
UNITS \\
RPTD
\end{tabular} & $\begin{array}{c}\text { COUNTING } \\
\text { ERROR }\end{array}$ & \begin{tabular}{|c|c|} 
TOTAL \\
ANAL \\
ANROR
\end{tabular} & $\begin{array}{c}\text { LAB } \\
\text { QUALIFIER }\end{array}$ & SAMP COMMENT & $\begin{array}{l}\text { RESULT } \\
\text { COMMENT }\end{array}$ \\
\hline SESPMNT & B17CT4 & RICH.PMPHS HRM 43.5 & OFFSITE & SW & Y & & TRANSECT & 09-Sep-03 Pb & & & & & & & - & \\
\hline SESPMNT & B17CT2 & RICH.PMPHS HRM 45.0 & OFFSITE & sW & $\mathrm{Y}$ & RIVER & TRANSECT & 09-Sep-03 Pb & & 0.0469 & $9 \mathrm{ug} / \mathrm{L}$ & & & & & \\
\hline SESPMNT & B17CT1 & RICH.PMPHS HRM 45.8 & OFFSITE & sw & $\mathrm{Y}$ & RIVER & TRANSECT & 09-Sep-03 Pb & & 0.0288 & $3 \mathrm{ug} / \mathrm{L}$ & & & & & \\
\hline SESPMNT & B17CD0 & RICH.PMPHS-1 HRM46.4 & OFFSITE & SW & $\mathrm{N}$ & RIVER & TRANSECT & 09-Sep-03 Pb & & 0.105 & 5 ug $/ \mathrm{L}$ & & & & & \\
\hline SESPMNT & B17CN3 & RICH.PMPHS-1 HRM46.4 & OFFSITE & sw & Y & RIVER & TRANSECT & 09-Sep-03 Pb & & 0.0424 & $4 \mathrm{ug} / \mathrm{L}$ & & & & & \\
\hline SESPMNT & B17CD5 & RICH.PMPHS-10 HRM46. 4 & OFFSITE & sW & $\mathrm{N}$ & RIVER & TRANSECT & 09-Sep-03 Pb & & & & & & & & \\
\hline SESPMNT & B17CN8 & RICH.PMPHS-10 HRM46.4 & OFFSITE & sw & $\mathrm{Y}$ & RIVER & TRANSECT & 09-Sep-03 Pb & & 0.0602 & & & & & & \\
\hline SESPMNT & B17CD1 & RICH.PMPHS-2 HRM46.4 & OFFSITE & sW & $\mathrm{N}$ & RIVER & TRANSECT & 09-Sep-03 Pb & & & & & & & & \\
\hline SESPMNT & B17CN4 & RICH.PMPHS-2 HRM46.4 & OFFSITE & sW & $\mathrm{Y}$ & RIVER & TRANSECT & 09-Sep-03 Pb & & 0.0459 & & & & & & \\
\hline SESPMNT & B17CD2 & RICH.PMPHS-3 HRM46.4 & OFFSITE & sw & $\mathrm{N}$ & RIVER & TRANSECT & 09-Sep-03 Pb & & 0.116 & $6 \mathrm{ug} / \mathrm{L}$ & & & & & \\
\hline SESPMNT & B17CN5 & RICH.PMPHS-3 HRM46.4 & OFFSITE & sw & $\mathrm{Y}$ & RIVER & TRANSECT & $09-\mathrm{Sep}-03 \mathrm{~Pb}$ & & 0.0188 & $3 \mathrm{ug} / \mathrm{L}$ & & & B & & \\
\hline SESPMNT & B17CD3 & RICH.PMPHS-5 HRM46.4 & OFFSITE & sw & $\mathrm{N}$ & RIVER & TRANSECT & 09-Sep-03 Pb & & 0.0933 & $3 \mathrm{ug} / \mathrm{L}$ & & & & & \\
\hline SESPMNT & B17CN6 & RICH.PMPHS-5 HRM46.4 & OFFSITE & sW & $\mathrm{Y}$ & RIVER & TRANSECT & 09-Sep-03 Pb & & 0.0544 & $4 \mathrm{ug} / \mathrm{L}$ & & & & & \\
\hline SESPMNT & B17CD4 & & OFFSITE & sW & $\mathrm{N}$ & RIVER & TRANSECT & 09-Sep-03 Pb & & 0.107 & & & & & & \\
\hline SESPMNT & B17CN7 & RICH.PMPHS-7 HRM46.4 & OFFSITE & SW & $\mathrm{Y}$ & RIVER & TRANSECT & 09-Sep-03 Pb & & & & & & & & \\
\hline SESPMNT & B183W4 & RICH.PMPHS HRM 43.5 & OFFSITE & sw & $\mathrm{Y}$ & RIVER & TRANSECT & 08-Dec-03 Pb & & 0.0308 & & & & & & \\
\hline SESPMNT & B183W8 & RICH.PMPHS HRM 43.5 & OFFSITE & sw & $\mathrm{N}$ & RIVER & TRANSECT & 08-Dec-03 Pb & & 0.255 & $5 \mathrm{ug} / \mathrm{L}$ & & & & & \\
\hline SESPMNT & B183W3 & RICH.PMPHS HRM 43.9 & OFFSITE & sW & $\mathrm{Y}$ & RIVER & TRANSECT & 08-Dec-03 Pb & & 0.0184 & $4 \mathrm{ug} / \mathrm{L}$ & & & B & & \\
\hline SESPMNT & B183W7 & RICH.PMPHS HRM 43.9 & OFFSITE & sw & $\mathrm{N}$ & RIVER & TRANSECT & 08-Dec-03 Pb & & 0.161 & $1 \mathrm{ug} / \mathrm{L}$ & & & & & \\
\hline SESPMNT & B183W2 & RICH.PMPHS HRM 45.0 & OFFSITE & sw & $\mathrm{Y}$ & RIVER & TRANSECT & 08-Dec-03 Pb & & 0.0251 & & & & & & \\
\hline SESPMNT & B183W6 & RICH.PMPHS HRM 45.0 & OFFSITE & sW & $\mathrm{N}$ & RIVER & TRANSECT & 08-Dec-03 Pb & & 0.0382 & & & & & & \\
\hline SESPMNT & B183W1 & RICH.PMPHS HRM 45.8 & OFFSITE & sw & Y & RIVER & TRANSECT & 08-Dec-03 Pb & & 0.0458 & & & & & & \\
\hline SESPMNT & B183W5 & RICH.PMPHS HRM 45.8 & OFFSITE & sW & $\mathrm{N}$ & RIVER & TRANSECT & 08-Dec-03 Pb & & 0.0571 & & & & & & \\
\hline SESPMNT & B183P9 & RICH.PMPHS-1 HRM46.4 & OFFSITE & sw & $\mathrm{N}$ & RIVER & TRANSECT & 08-Dec-03 Pb & & 0.0278 & $3 \mathrm{ug} / \mathrm{L}$ & & & & & \\
\hline SESPMNT & B183V1 & RICH.PMPHS-1 HRM46.4 & OFFSITE & sW & $\mathrm{Y}$ & RIVER & TRANSECT & 08-Dec-03 Pb & & 0.011 & $1 \mathrm{ug} / \mathrm{L}$ & & & $\mathrm{U}$ & & \\
\hline SESPMNT & B183R4 & RICH.PMPHS-10 HRM46.4 & OFFSITE & sw & $\mathrm{N}$ & RIVER & TRANSECT & 08-Dec-03 Pb & & 0.425 & $5 \mathrm{ug} / \mathrm{L}$ & & & & & \\
\hline SESPMNT & B183V6 & RICH.PMPHS-10 HRM46.4 & OFFSITE & sW & $\mathrm{Y}$ & RIVER & TRANSECT & 08-Dec-03 Pb & & 0.0167 & $7 \mathrm{ug} / \mathrm{L}$ & & & B & & \\
\hline SESPMNT & B183R0 & RICH.PMPHS-2 HRM46.4 & OFFSITE & sW & $\mathrm{N}$ & RIVER & TRANSECT & 08-Dec-03 Pb & & 0.0413 & 3 ug $/ \mathrm{L}$ & & & & & \\
\hline SESPMNT & B183V2 & RICH.PMPHS-2 HRM46.4 & OFFSITE & sw & Y & RIVER & TRANSECT & 08-Dec-03 Pb & & 0.011 & & & & $\mathrm{u}$ & & \\
\hline SESPMNT & B183R1 & RICH.PMPHS-3 HRM46.4 & OFFSITE & sw & $\mathrm{N}$ & RIVER & TRANSECT & 08-Dec-03 Pb & & 0.082 & & & & & & \\
\hline SESPMNT & B183V3 & RICH.PMPHS-3 HRM46.4 & OFFSITE & sw & $\mathrm{Y}$ & RIVER & TRANSECT & 08-Dec-03 Pb & & 0.011 & $1 \mathrm{ug} / \mathrm{L}$ & & & $\mathrm{u}$ & & \\
\hline SESPMNT & B183R2 & RICH.PMPHS-5 HRM46.4 & OFFSITE & sW & $\mathrm{N}$ & RIVER & TRANSECT & 08-Dec-03 Pb & & 0.153 & $3 \mathrm{ug} / \mathrm{L}$ & & & & & \\
\hline SESPMNT & B183V4 & RICH.PMPHS-5 HRM46.4 & OFFSITE & SW & $\mathrm{Y}$ & RIVER & TRANSECT & 08-Dec-03 Pb & & 0.0153 & $3 \mathrm{ug} / \mathrm{L}$ & & & B & & \\
\hline SESPMNT & B183R3 & RICH.PMPHS-7 HRM46.4 & OFFSITE & sw & $\mathrm{N}$ & RIVER & TRANSECT & 08-Dec-03 Pb & & 0.0641 & $1 \mathrm{ug} / \mathrm{L}$ & & & & & \\
\hline SESPMNT & B183V5 & RICH.PMPHS-7 HRM46.4 & OFFSITE & sW & $\mathrm{Y}$ & RIVER & TRANSECT & 08-Dec-03 Pb & & 0.011 & & & & $\mathrm{U}$ & & \\
\hline SESPMNT & B183R5 & VERNITA-1 HRM 0.3 & OFFSITE & sw & $\mathrm{N}$ & RIVER & TRANSECT & 09-Dec-03 Pb & & 0.0642 & & & & & & \\
\hline SESPMNT & B183T7 & VERNITA-1 HRM 0.3 & OFFSITE & sw & $\mathrm{Y}$ & RIVER & TRANSECT & 09-Dec-03 Pb & & 0.0186 & & & & B & & \\
\hline SESPMNT & B183P6 & VERNITA-2 HRM 0.3 & OFFSITE & sW & $\mathrm{N}$ & RIVER & TRANSECT & 09-Dec-03 Pb & & 0.0551 & & & & & & \\
\hline SESPMNT & B183T8 & $\begin{array}{l}\text { VERNITA-2 HRM } 0.3 \\
\end{array}$ & OFFSITE & SW & $\mathrm{Y}$ & RIVER & TRANSECT & 09-Dec-03 Pb & & 0.011 & $1 \mathrm{ug} / \mathrm{L}$ & & & u & & \\
\hline SESPMNT & B183P7 & VERNITA-3 HRM 0.3 & OFFSITE & sW & $\mathrm{N}$ & RIVER & TRANSECT & 09-Dec-03 Pb & & 0.0782 & $2 \mathrm{ug} / \mathrm{L}$ & & & & & \\
\hline SESPMNT & B183T9 & VERNITA-3 HRM 0.3 & OFFSITE & sw & Y & RIVER & TRANSECT & 09-Dec-03 Pb & & 0.014 & $4 \mathrm{ug} / \mathrm{L}$ & & & B & & \\
\hline SESPMNT & B183P8 & VERNITA-4 HRM 0.3 & OFFSITE & sW & $\mathrm{N}$ & RIVER & TRANSECT & 09-Dec-03 Pb & & 0.067 & 7 ug/L & & & & & \\
\hline SESPMNT & B183Vo & VERNITA-4 HRM 0.3 & OFFSITE & sw & Y & RIVER & TRANSECT & 09-Dec-03 Pb & & 0.011 & $1 \mathrm{ug} / \mathrm{L}$ & & & $u$ & & \\
\hline SESPMNT & B16L95 & VERNITA-1 HRM 0.3 & OFFSITE & SW & $\mathrm{N}$ & RIVER & TRANSECT & $24-\mathrm{Mar}-03 \mathrm{Sb}$ & & 0.165 & & & & 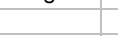 & & \\
\hline SESPMNT & B16LB7 & VERNITA-1 HRM 0.3 & OFFSITE & sW & $\mathrm{Y}$ & RIVER & TRANSECT & 24-Mar-03 Sb & & 0.166 & & & & C & & \\
\hline SESPMNT & B16L86 & VERNITA-2 HRM 0.3 & OFFSITE & sw & $\mathrm{N}$ & RIVER & TRANSECT & 24-Mar-03 Sb & & 0.169 & & & & & & \\
\hline SESPMNT & B16LB8 & VERNITA-2 HRM 0.3 & OFFSITE & sW & $\mathrm{Y}$ & RIVER & TRANSECT & 24-Mar-03 Sb & & 0.169 & $9 \mathrm{ug} / \mathrm{L}$ & & & C & & \\
\hline SESPMNT & B16L87 & VERNITA-3 HRM 0.3 & OFFSITE & sw & $\mathrm{N}$ & RIVER & TRANSECT & 24-Mar-03 Sb & & 0.164 & & & & & & \\
\hline SESPMNT & B16LB9 & VERNITA-3 HRM 0.3 & OFFSITE & SW & $\mathrm{Y}$ & RIVER & TRANSECT & $24-\mathrm{Mar}-03 \mathrm{Sb}$ & & 0.169 & $9 \mathrm{ug} / \mathrm{L}$ & & & c & & \\
\hline SESPMNT & B16L88 & VERNITA-4 HRM 0.3 & OFFSITE & SW & $\mathrm{N}$ & RIVER & TRANSECT & 24-Mar-03 Sb & & 0.165 & $5 \mathrm{ug} / \mathrm{L}$ & & & & & \\
\hline SESPMNT & B16LC0 & VERNITA-4 HRM 0.3 & OFFSITE & sw & $\mathrm{Y}$ & RIVER & TRANSECT & 24-Mar-03 Sb & & 0.164 & $4 \mathrm{ug} / \mathrm{L}$ & & & C & & \\
\hline SESPMNT & B16LD4 & RICH.PMPHS HRM 43.5 & OFFSITE & sW & $\mathrm{Y}$ & RIVER & TRANSECT & 25-Mar-03 Sb & & 0.171 & & & & c & & \\
\hline SESPMNT & B16LD8 & RICH.PMPHS HRM 43.5 & OFFSITE & sw & $\mathrm{N}$ & RIVER & TRANSECT & 25-Mar-03 Sb & & 0.158 & & & & & & \\
\hline SESPMNT & B16LD3 & RICH.PMPHS HRM 43.9 & OFFSITE & sw & $\mathrm{Y}$ & RIVER & TRANSECT & 25-Mar-03 Sb & & 0.163 & 3 ug $/ \mathrm{L}$ & & & C & & \\
\hline SESPMNT & B16LD7 & RICH.PMPHS HRM 43.9 & OFFSITE & sw & $\mathrm{N}$ & RIVER & TRANSECT & 25-Mar-03 Sb & & 0.169 & $9 \mathrm{ug} / \mathrm{L}$ & & & & & \\
\hline SESPMNT & B16LD2 & RICH.PMPHS HRM 45.0 & OFFSITE & sW & $\mathrm{Y}$ & RIVER & TRANSECT & 25-Mar-03 Sb & & 0.166 & $6 \mathrm{ug} / \mathrm{L}$ & & & C & & \\
\hline SESPMNT & B16LD6 & RICH.PMPHS HRM 45.0 & OFFSITE & sW & $\mathrm{N}$ & RIVER & TRANSECT & 25-Mar-03 Sb & & 0.161 & $1 \mathrm{ug} / \mathrm{L}$ & & & & & \\
\hline SESPMNT & B16LD1 & RICH.PMPHS HRM 45.8 & OFFSITE & SW & Y & RIVER & TRANSECT & $25-\mathrm{Mar}-03 \mathrm{Sb}$ & & 0.163 & $3 \mathrm{ug} / \mathrm{L}$ & & & c & & \\
\hline SESPMNT & B16LD5 & RICH.PMPHS HRM 45.8 & OFFSITE & sW & $\mathrm{N}$ & RIVER & TRANSECT & 25-Mar-03 Sb & & 0.151 & $1 \mathrm{ug} / \mathrm{L}$ & & & & & \\
\hline SESPMNT & B16L89 & RICH.PMPHS-1 HRM46.4 & OFFSITE & sw & $\mathrm{N}$ & RIVER & TRANSECT & 25-Mar-03 Sb & & & 9 ug $/ \mathrm{L}$ & & & & & \\
\hline SESPMNT & B16LC1 & RICH.PMPHS-1 HRM46.4 & OFFSITE & SW & $\mathrm{Y}$ & RIVER & TRANSECT & $25-\mathrm{Mar}-03 \mathrm{Sb}$ & & & $6 \mathrm{ug} / \mathrm{L}$ & & & c & & \\
\hline SESPMNT & B16L94 & RICH.PMPHS-10 HRM46.4 & OFFSITE & sw & $\mathrm{N}$ & RIVER & TRANSECT & 25-Mar-03 Sb & & 0.159 & $9 \mathrm{ug} / \mathrm{L}$ & & & & & \\
\hline
\end{tabular}


WATER - COLUMBIA RIVER TRANSECT

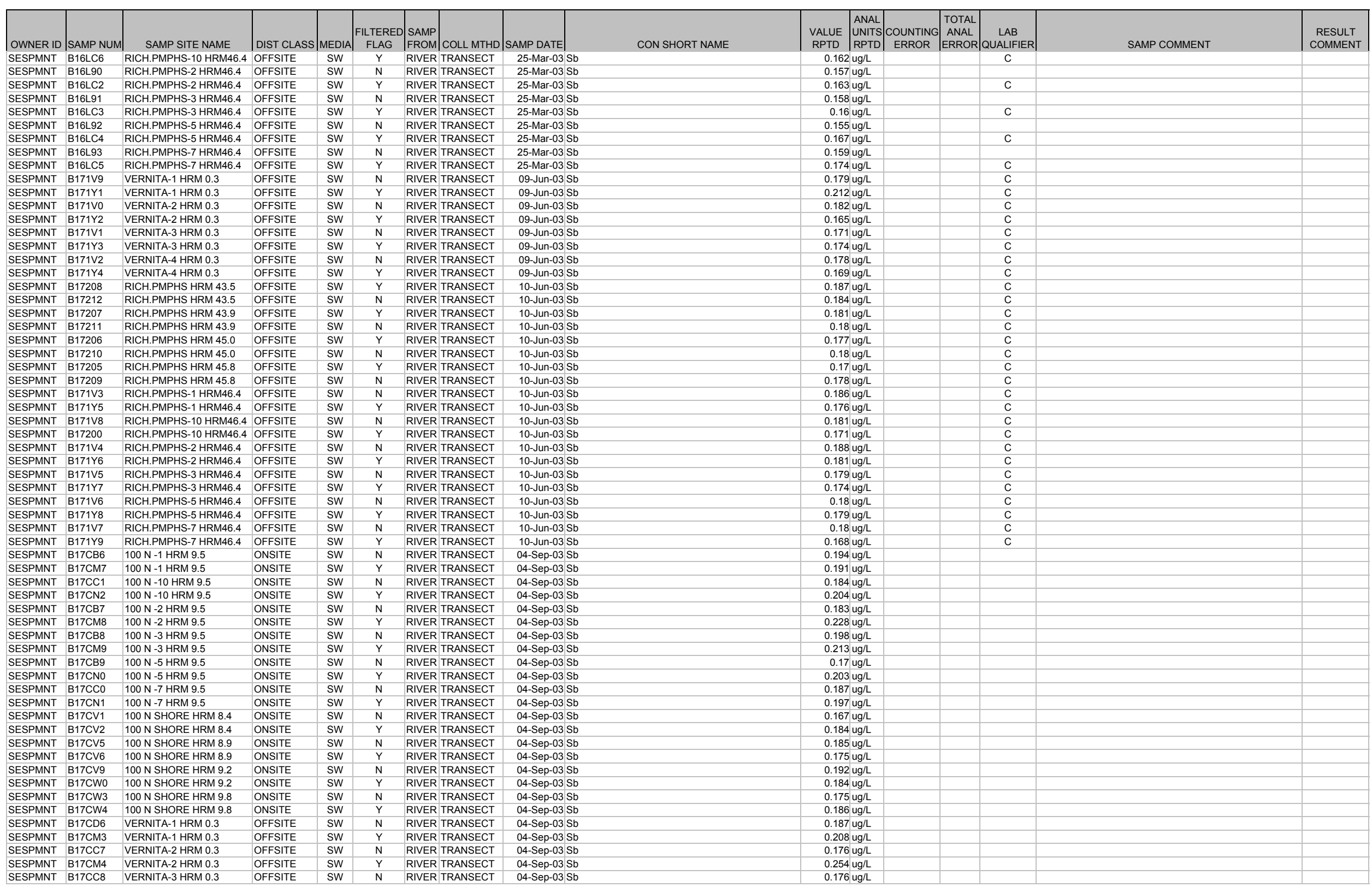


WATER - COLUMBIA RIVER TRANSECT

\begin{tabular}{|c|c|c|c|c|c|c|c|c|c|c|c|c|c|c|c|c|}
\hline | OWNER ID & SAMP NUM & SAMP SITE NAME & DIST CLASS & $\mid$ MEDIA & \begin{tabular}{|c|} 
FILTERED \\
FLAG
\end{tabular} & $\begin{array}{l}\text { SAMP } \\
\text { FROM }\end{array}$ & COLL MTHD & SAMP DATE & CON SHORT NAME & $\begin{array}{l}\text { VALUE } \\
\text { RPTD }\end{array}$ & \begin{tabular}{|l|} 
ANAL \\
UNITS \\
RPTD \\
\end{tabular} & $\begin{array}{c}\text { COUNTING } \\
\text { ERROR }\end{array}$ & \begin{tabular}{|c|} 
TOTAL \\
ANAL \\
ERROR
\end{tabular} & $\begin{array}{c}\text { LAB } \\
\text { QUALIFIER }\end{array}$ & SAMP COMMENT & $\begin{array}{l}\text { RESULT } \\
\text { COMMENT }\end{array}$ \\
\hline SESPMNT & B17CM5 & VERNITA-3 HRM 0.3 & OFFSITE & SW & & & TRANSECT & 04-Sep-03 Sb & & & & & & & 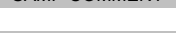 & \\
\hline SESPMNT & B17CC9 & VERNITA-4 HRM 0.3 & OFFSITE & sw & $\mathrm{N}$ & RIVER & TRANSECT & 04-Sep-03 Sb & & 0.179 & ug/L $/ \mathrm{L}$ & & & & & \\
\hline SESPMNT & B17CM6 & VERNITA-4 HRM 0.3 & OFFSITE & sw & $\mathrm{Y}$ & RIVER & TRANSECT & 04-Sep-03 Sb & & 0.208 & $\mathrm{ug} / \mathrm{L}$ & & & & & \\
\hline SESPMNT & B17CC2 & $100 \mathrm{~F}-1$ HRM 19.0 & ONSITE & sw & $\mathrm{N}$ & RIVER & TRANSECT & 08-Sep-03 Sb & & 0.199 & ug/L & & & & & \\
\hline SESPMNT & B17CR1 & $100 \mathrm{~F}-1$ HRM 19.0 & ONSITE & sw & Y & RIVER & TRANSECT & 08-Sep-03 Sb & & 0.161 & & & & & & \\
\hline SESPMNT & B17C96 & $100 \mathrm{~F}-10 \mathrm{HRM} 19.0$ & ONSITE & sw & $\mathrm{N}$ & RIVER & TRANSECT & 08-Sep-03 Sb & & & & & & & & \\
\hline SESPMNT & B17CR6 & $100 \mathrm{~F}-10 \mathrm{HRM} 19.0$ & ONSITE & sw & $\mathrm{Y}$ & RIVER & TRANSECT & 08-Sep-03 Sb & & & & & & & & \\
\hline SESPMNT & B17CR2 & 100 F -2 HRM 19.0 & ONSITE & sw & $\mathrm{Y}$ & RIVER & TRANSECT & $08-\mathrm{Sep}-03 \mathrm{Sb}$ & & & & & & & & \\
\hline SESPMNT & B17CC4 & 100 F -3 HRM 19.0 & ONSITE & sw & $\mathrm{N}$ & RIVER & TRANSECT & $08-\mathrm{Sep}-03 \mathrm{Sb}$ & & 0.197 & ug/L & & & & & \\
\hline SESPMNT & B17CR3 & 100 F - 3 HRM 19.0 & ONSITE & sw & $\mathrm{Y}$ & RIVER & TRANSECT & 08-Sep-03 Sb & & 0.203 & $3 \mathrm{ug} / \mathrm{L}$ & & & & & \\
\hline SESPMNT & B17CR4 & 100 F - 5 HRM 19.0 & ONSITE & sw & $\mathrm{Y}$ & RIVER & TRANSECT & $08-\mathrm{Sep}-03 \mathrm{Sb}$ & & 0.188 & $3 \mathrm{ug} / \mathrm{L}$ & & & & & \\
\hline SESPMNT & B17CR5 & 100 F -7 HRM 19.0 & ONSITE & sw & $\mathrm{Y}$ & RIVER & TRANSECT & $08-\mathrm{Sep}-03 \mathrm{Sb}$ & & 0.188 & $3 \mathrm{ug} / \mathrm{L}$ & & & & & \\
\hline SESPMNT & B17CY5 & 100 F SHORE HRM 18 & ONSITE & sw & $\mathrm{N}$ & RIVER & TRANSECT & $08-\mathrm{Sep}-03 \mathrm{Sb}$ & & 0.183 & & & & & & \\
\hline SESPMNT & B17CY6 & $100 \mathrm{~F}$ SHORE HRM 18 & ONSITE & sw & $\mathrm{Y}$ & RIVER & $\begin{array}{l}\text { TRANSECT } \\
\text { TRES }\end{array}$ & $08-\mathrm{Sep}-03 \mathrm{Sb}$ & & 0.191 & ug/L & & & & & \\
\hline SESPMNT & B17CY8 & $100 \mathrm{~F}$ SHORE HRM 22 & ONSITE & sw & $\mathrm{N}$ & RIVER & TRANSECT & 08-Sep-03 Sb & & 0.176 & & & & & & \\
\hline SESPMNT & B17CY9 & $100 \mathrm{~F}$ SHORE HRM 22 & ONSITE & sw & $\mathrm{Y}$ & RIVER & TRANSECT & 08-Sep-03 Sb & & 0.179 & & & & & & \\
\hline SESPMNT & B17D01 & $100 \mathrm{~F}$ SHORE HRM 23 & ONSITE & sw & $\mathrm{N}$ & RIVER & TRANSECT & 08-Sep-03 Sb & & 0.204 & igg/L & & & & & \\
\hline SESPMNT & B17D02 & $100 \mathrm{~F}$ SHORE HRM 23 & ONSITE & sw & $\mathrm{Y}$ & RIVER & TRANSECT & $08-\mathrm{Sep}-03 \mathrm{Sb}$ & & 0.186 & $\mathrm{ug} / \mathrm{L}$ & & & & & \\
\hline SESPMNT & B17C97 & HANFRD TS-1 HRM 28.7 & ONSITE & sw & $\mathrm{N}$ & RIVER & TRANSECT & $08-\mathrm{Sep}-03 \mathrm{Sb}$ & & 0.192 & ug/L & & & & & \\
\hline SESPMNT & B17CP5 & HANFRD TS-1 HRM 28.7 & ONSITE & sw & $\mathrm{Y}$ & RIVER & TRANSECT & $08-S e p-03$ Sb & & 0.184 & ug/L $/ 2$ & & & & & \\
\hline SESPMNT & B17CB2 & HANFRD TS-10 HRM 28.7 & ONSITE & sw & $\mathrm{N}$ & RIVER & TRANSECT & $08-\mathrm{Sep}-03 \mathrm{Sb}$ & & & & & & & & \\
\hline SESPMNT & B17CR0 & HANFRD TS-10 HRM 28.7 & ONSITE & sw & Y & RIVER & TRANSECT & $08-\mathrm{Sep}-03 \mathrm{Sb}$ & & 0.202 & & & & & & \\
\hline SESPMNT & B17C98 & HANFRD TS-2 HRM 28.7 & ONSITE & sw & $\mathrm{N}$ & RIVER & TRANSECT & $08-S e p-03 \mathrm{Sb}$ & & 0.175 & & & & & & \\
\hline SESPMNT & B17CP6 & HANFRD TS-2 HRM 28.7 & ONSITE & sw & $\mathrm{Y}$ & RIVER & TRANSECT & $08-\mathrm{Sep}-03 \mathrm{Sb}$ & & 0.198 & $3 \mathrm{ug} / \mathrm{L}$ & & & & & \\
\hline SESPMNT & B17C99 & HANFRD TS-3 HRM 28.7 & ONSITE & sw & $\mathrm{N}$ & RIVER & TRANSECT & $08-\mathrm{Sep}-03 \mathrm{Sb}$ & & 0.183 & $\mathrm{ug} / \mathrm{L}$ & & & & & \\
\hline SESPMNT & B17CP7 & HANFRD TS-3 HRM 28.7 & ONSITE & sw & $\mathrm{Y}$ & RIVER & TRANSECT & $08-\mathrm{Sep}-03 \mathrm{Sb}$ & & 0.209 & $\mathrm{ug} / \mathrm{L}$ & & & & & \\
\hline SESPMNT & B17CB0 & HANFRD TS-5 HRM 28.7 & ONSITE & sw & $\mathrm{N}$ & RIVER & TRANSECT & 08-Sep-03 Sb & & 0.187 & ug/L & & & & & \\
\hline SESPMNT & B17CP8 & HANFRD TS-5 HRM 28.7 & ONSITE & sw & $\mathrm{Y}$ & RIVER & TRANSECT & $08-\mathrm{Sep}-03 \mathrm{Sb}$ & & 0.193 & $3 \mathrm{ug} / \mathrm{L}$ & & & & & \\
\hline SESPMNT & B17CB1 & HANFRD TS-7 HRM 28.7 & ONSITE & sw & $\mathrm{N}$ & RIVER & TRANSECT & 08-Sep-03 Sb & & 0.188 & $3 \mathrm{ug} / \mathrm{L}$ & & & & & \\
\hline SESPMNT & B17CP9 & HANFRD TS-7 HRM 28.7 & ONSITE & sw & $\mathrm{Y}$ & RIVER & TRANSECT & 08-Sep-03 Sb & & 0.187 & & & & & & \\
\hline SESPMNT & B17CL7 & HANFRD TWNSITE HRM26 & ONSITE & sw & $\mathrm{N}$ & RIVER & TRANSECT & $08-\mathrm{Sep}-03 \mathrm{Sb}$ & & 0.182 & & & & & & \\
\hline SESPMNT & B17CM0 & HANFRD TWNSITE HRM26 & ONSITE & sW & $\mathrm{Y}$ & RIVER & TRANSECT & $08-\mathrm{Sep}-03 \mathrm{Sb}$ & & 0.16 & ug/L $/ 2$ & & & & & \\
\hline SESPMNT & B17CL8 & HANFRD TWNSITE HRM27 & ONSITE & sw & $\mathrm{N}$ & RIVER & TRANSECT & $08-\mathrm{Sep}-03 \mathrm{Sb}$ & & 0.171 & $\mathrm{ug} / \mathrm{L}$ & & & & & \\
\hline SESPMNT & B17CM1 & HANFRD TWNSITE HRM27 & ONSITE & sw & $\mathrm{Y}$ & RIVER & TRANSECT & $08-S e p-03$ Sb & & 0.179 & $\mathrm{ug} / \mathrm{L}$ & & & & & \\
\hline SESPMNT & B17CY2 & HANFRD TWNSITE HRM28 & ONSITE & sw & $\mathrm{N}$ & RIVER & TRANSECT & $08-\mathrm{Sep}-03 \mathrm{Sb}$ & & 0.155 & & & & & & \\
\hline SESPMNT & $\mathrm{B} 17 \mathrm{CY} 3$ & HANFRD TWNSITE HRM28 & ONSITE & sw & $\mathrm{Y}$ & RIVER & TRANSECT & $08-\mathrm{Sep}-03 \mathrm{Sb}$ & & 0.16 & & & & & & \\
\hline SESPMNT & B17CL9 & HANFRD TWNSITE HRM30 & ONSITE & sw & $\mathrm{N}$ & RIVER & TRANSECT & 08-Sep-03 Sb & & 0.184 & ug/L & & & & & \\
\hline SESPMNT & B17CM2 & HANFRD TWNSITE HRM30 & ONSITE & sw & $\mathrm{Y}$ & RIVER & TRANSECT & $08-\mathrm{Sep}-03 \mathrm{Sb}$ & & 0.159 & $\mathrm{ug} / \mathrm{L}$ & & & & & \\
\hline SESPMNT & B17CN9 & 300 AREA -1 HRM 43.1 & ONSITE & sw & $\mathrm{Y}$ & RIVER & TRANSECT & 09-Sep-03 Sb & & 0.173 & $3 \mathrm{ug} / \mathrm{L}$ & & & & & \\
\hline SESPMNT & B17CP0 & 300 AREA -2 HRM 43.1 & ONSITE & sw & $\mathrm{Y}$ & RIVER & TRANSECT & $09-\mathrm{Sep}-03 \mathrm{Sb}$ & & 0.198 & $3 \mathrm{ug} / \mathrm{L}$ & & & & & \\
\hline SESPMNT & B17CP1 & 300 AREA -3 HRM 43.1 & ONSITE & sw & Y & RIVER & TRANSECT & $09-\mathrm{Sep}-03 \mathrm{Sb}$ & & 0.194 & $\mathrm{ug} / \mathrm{L}$ & & & & & \\
\hline SESPMNT & B17CP2 & 300 AREA -5 HRM 43.1 & ONSITE & sw & $\mathrm{Y}$ & RIVER & TRANSECT & $09-\mathrm{Sep}-03 \mathrm{Sb}$ & & 0.171 & ug/L & & & & & \\
\hline SESPMNT & B17CP3 & 300 AREA -7 HRM 43.1 & ONSITE & sw & $\mathrm{Y}$ & RIVER & TRANSECT & $09-S e p-03 \mathrm{Sb}$ & & 0.188 & $3 \mathrm{ug} / \mathrm{L}$ & & & & & \\
\hline SESPMNT & B17CW8 & 300 AREA SHR HRM 41.5 & ONSITE & sw & $\mathrm{Y}$ & RIVER & TRANSECT & 09-Sep-03 Sb & & 0.167 & $\mathrm{ug} / \mathrm{L}$ & & & & & \\
\hline SESPMNT & B17CX2 & 300 AREA SHR HRM42.1 & ONSITE & sw & $\mathrm{Y}$ & RIVER & TRANSECT & $09-\mathrm{Sep}-03 \mathrm{Sb}$ & & 0.175 & & & & & & \\
\hline SESPMNT & B17CX6 & 300 AREA SHR HRM42.5 & ONSITE & sw & $\mathrm{Y}$ & RIVER & TRANSECT & 09-Sep-03 Sb & & 0.191 & & & & & & \\
\hline SESPMNT & B17CY0 & 300 AREA SHR HRM42.9 & ONSITE & sw & $\mathrm{Y}$ & RIVER & TRANSECT & $09-\mathrm{Sep}-03 \mathrm{Sb}$ & & 0.196 & & & & & & \\
\hline SESPMNT & B17CP4 & 300 AREA-10 HRM 43.1 & ONSITE & sw & Y & RIVER & TRANSECT & $09-\mathrm{Sep}-03 \mathrm{Sb}$ & & 0.191 & ug/L $/ \mathrm{L} / \mathrm{h} / \mathrm{h}$ & & & & & \\
\hline SESPMNT & B17CT4 & RICH.PMPHS HRM 43.5 & OFFSITE & sw & $\mathrm{Y}$ & RIVER & TRANSECT & $09-\mathrm{Sep}-03 \mathrm{Sb}$ & & 0.176 & $3 \mathrm{ug} / \mathrm{L}$ & & & & & \\
\hline SESPMNT & B17CT2 & RICH.PMPHS HRM 45.0 & OFFSITE & sw & $\mathrm{Y}$ & RIVER & TRANSECT & $09-\mathrm{Sep}-03 \mathrm{Sb}$ & & 0.242 & ing/L & & & & & \\
\hline SESPMNT & B17CT1 & RICH.PMPHS HRM 45.8 & OFFSITE & sw & $\mathrm{Y}$ & RIVER & TRANSECT & $09-\mathrm{Sep}-03 \mathrm{Sb}$ & & & ug/L & & & & & \\
\hline SESPMNT & B17CD0 & RICH.PMPHS-1 HRM46.4 & OFFSITE & sw & $\mathrm{N}$ & RIVER & TRANSECT & $09-\mathrm{Sep}-03 \mathrm{Sb}$ & & 0.195 & $\mathrm{ug} / \mathrm{L}$ & & & & & \\
\hline SESPMNT & B17CN3 & RICH.PMPHS-1 HRM46.4 & OFFSITE & sw & $\mathrm{Y}$ & RIVER & TRANSECT & $09-\mathrm{Sep}-03 \mathrm{Sb}$ & & 0.194 & ug/L & & & & & \\
\hline SESPMNT & B17CD5 & $\begin{array}{l}\text { RICH.PMPHS-10 HRM46.4 } \\
\end{array}$ & OFFSITE & sw & $\mathrm{N}$ & RIVER & TRANSECT & $09-\mathrm{Sep}-03 \mathrm{Sb}$ & & 0.189 & $\mathrm{ug} / \mathrm{L}$ & & & & & \\
\hline SESPMNT & B17CN8 & RICH.PMPHS-10 HRM46.4 & OFFSITE & sw & $\mathrm{Y}$ & RIVER & TRANSECT & 09-Sep-03 Sb & & 0.199 & ug $/ \mathrm{L}$ & & & & & \\
\hline SESPMNT & B17CD1 & RICH.PMPHS-2 HRM46.4 & OFFSITE & sW & $\mathrm{N}$ & RIVER & TRANSECT & 09-Sep-03 Sb & & 0.184 & $\mathrm{igg} / \mathrm{L}$ & & & & & \\
\hline SESPMNT & B17CN4 & RICH.PMPHS-2 HRM46.4 & OFFSITE & sW & $\mathrm{Y}$ & RIVER & TRANSECT & $09-\mathrm{Sep}-03 \mathrm{Sb}$ & & & $\mathrm{ug} / \mathrm{L}$ & & & & & \\
\hline SESPMNT & B17CD2 & RICH.PMPHS-3 HRM46.4 & OFFSITE & SW & $\mathrm{N}$ & RIVER & TRANSECT & $09-\mathrm{Sep}-03 \mathrm{Sb}$ & & & & & & & & \\
\hline SESPMNT & B17CN5 & RICH.PMPHS-3 HRM46.4 & OFFSITE & sw & $\mathrm{Y}$ & RIVER & TRANSECT & $09-\mathrm{Sep}-03 \mathrm{Sb}$ & & & $\mathrm{ug} / \mathrm{L}$ & & & & & \\
\hline SESPMNT & B17CD3 & RICH.PMPHS-5 HRM46.4 & OFFSITE & sw & $\mathrm{N}$ & RIVER & TRANSECT & $09-\mathrm{Sep}-03 \mathrm{Sb}$ & & 0.188 & & & & & & \\
\hline SESPMNT & B17CN6 & RICH.PMPHS-5 HRM46.4 & OFFSITE & sw & $\mathrm{Y}$ & RIVER & TRANSECT & 09-Sep-03 Sb & & 0.194 & ug/L $/ 2$ & & & & & \\
\hline SESPMNT & B17CD4 & RICH.PMPHS-7 HRM46.4 & OFFSITE & sw & $\mathrm{N}$ & RIVER & TRANSECT & $09-\mathrm{Sep}-03 \mathrm{Sb}$ & & 0.178 & $3 \mathrm{ug} / \mathrm{L}$ & & & & & \\
\hline
\end{tabular}


WATER - COLUMBIA RIVER TRANSECT

\begin{tabular}{|c|c|c|c|c|c|c|c|c|c|c|c|c|c|c|c|c|}
\hline | OWNER ID & SAMP NUM & SAMP SITE NAME & DIST CLASS & $\mid$ MEDIA & \begin{tabular}{|c|} 
FILTERED \\
FLAG
\end{tabular} & $\begin{array}{l}\text { SAMP } \\
\text { FROM }\end{array}$ & COLL MTHD & SAMP DATE & CON SHORT NAME & $\begin{array}{l}\text { VALUE } \\
\text { RPTD }\end{array}$ & \begin{tabular}{|l|} 
ANAL \\
UNITS \\
RPTD \\
\end{tabular} & \begin{tabular}{|l|} 
COUNTING \\
ERROR
\end{tabular} & \begin{tabular}{|c|} 
TOTAL \\
ANAL \\
ERROR
\end{tabular} & $\begin{array}{c}\text { LAB } \\
\text { QUALIFIER }\end{array}$ & SAMP COMMENT & $\begin{array}{l}\text { RESULT } \\
\text { COMMENT }\end{array}$ \\
\hline SESPMNT & B17CN7 & RICH.PMPHS-7 HRM46.4 & OFFSITE & SW & Y & RIVER & TRANSECT & 09-Sep-03 Sb & & & & & & & - & \\
\hline SESPMNT & B183W4 & RICH.PMPHS HRM 43.5 & OFFSITE & sw & $\mathrm{Y}$ & RIVER & TRANSECT & 08-Dec-03 Sb & & 0.164 & ug/L $/ \mathrm{L}$ & & & & & \\
\hline SESPMNT & B183W8 & RICH.PMPHS HRM 43.5 & OFFSITE & sw & $\mathrm{N}$ & RIVER & TRANSECT & $08-\mathrm{Dec}-03 \mathrm{Sb}$ & & 0.142 & ug/L $/ \mathrm{L}$ & & & & & \\
\hline SESPMNT & B183W3 & RICH.PMPHS HRM 43.9 & OFFSITE & sw & $\mathrm{Y}$ & RIVER & TRANSECT & 08-Dec-03 Sb & & 0.159 & ug/L & & & & & \\
\hline SESPMNT & B183W7 & RICH.PMPHS HRM 43.9 & OFFSITE & sw & $\mathrm{N}$ & RIVER & TRANSECT & 08-Dec-03 Sb & & 0.149 & $\mathrm{ug} / \mathrm{L}$ & & & & & \\
\hline SESPMNT & B183W2 & RICH.PMPHS HRM 45.0 & OFFSITE & sw & $\mathrm{Y}$ & RIVER & TRANSECT & 08-Dec-03 Sb & & & & & & & & \\
\hline SESPMNT & B183W6 & RICH.PMPHS HRM 45.0 & OFFSITE & sw & $\mathrm{N}$ & RIVER & TRANSECT & 08-Dec-03 Sb & & & & & & & & \\
\hline SESPMNT & B183W1 & RICH.PMPHS HRM 45.8 & OFFSITE & sw & $\mathrm{Y}$ & RIVER & TRANSECT & 08-Dec-03 Sb & & & & & & & & \\
\hline SESPMNT & B183W5 & RICH.PMPHS HRM 45.8 & OFFSITE & sw & $\mathrm{N}$ & RIVER & TRANSECT & 08-Dec-03 Sb & & 0.155 & & & & & & \\
\hline SESPMNT & B183P9 & RICH.PMPHS-1 HRM46.4 & OFFSITE & sw & $\mathrm{N}$ & RIVER & TRANSECT & 08-Dec-03 Sb & & 0.133 & & & & & & \\
\hline SESPMNT & B183V1 & RICH.PMPHS-1 HRM46.4 & OFFSITE & sw & $\mathrm{Y}$ & RIVER & TRANSECT & $08-\mathrm{Dec}-03 \mathrm{Sb}$ & & 0.206 & $\mathrm{iug} / \mathrm{L}$ & & & & & \\
\hline SESPMNT & B183R4 & RICH.PMPHS-10 HRM46.4 & OFFSITE & sw & $\mathrm{N}$ & RIVER & TRANSECT & 08-Dec-03 Sb & & 0.142 & & & & & & \\
\hline SESPMNT & B183V6 & RICH.PMPHS-10 HRM46.4 & OFFSITE & sw & $\mathrm{Y}$ & RIVER & TRANSECT & 08-Dec-03 Sb & & 0.152 & & & & & & \\
\hline SESPMNT & B183R0 & RICH.PMPHS-2 HRM46.4 & OFFSITE & sw & $\mathrm{N}$ & RIVER & TRANSECT & 08 -Dec-03 Sb & & 0.139 & ug/ / & & & & & \\
\hline SESPMNT & B183V2 & RICH.PMPHS-2 HRM46.4 & OFFSITE & sw & Y & RIVER & TRANSECT & 08-Dec-03 Sb & & 0.156 & & & & & & \\
\hline SESPMNT & B183R1 & RICH.PMPHS-3 HRM46.4 & OFFSITE & sw & $\mathrm{N}$ & RIVER & TRANSECT & 08-Dec-03 Sb & & & & & & & & \\
\hline SESPMNT & B183V3 & RICH.PMPHS-3 HRM46.4 & OFFSITE & sw & Y & RIVER & TRANSECT & 08-Dec-03 Sb & & 0.154 & igg/L & & & & & \\
\hline SESPMNT & B183R2 & RICH.PMPHS-5 HRM46.4 & OFFSITE & sw & $\mathrm{N}$ & RIVER & TRANSECT & 08-Dec-03 Sb & & 0.141 & ug/L $/ \mathrm{L}$ & & & & & \\
\hline SESPMNT & B183V4 & RICH.PMPHS-5 HRM46.4 & OFFSITE & sw & Y & RIVER & TRANSECT & 08-Dec-03 Sb & & 0.197 & $\mathrm{ug} / \mathrm{L}$ & & & & & \\
\hline SESPMNT & B183R3 & RICH.PMPHS-7 HRM46.4 & OFFSITE & sw & $\mathrm{N}$ & RIVER & TRANSECT & 08 -Dec-03 Sb & & 0.14 & & & & & & \\
\hline SESPMNT & B183V5 & RICH.PMPHS-7 HRM46.4 & OFFSITE & sw & $\mathrm{Y}$ & RIVER & TRANSECT & $08-D e c-03 \mathrm{Sb}$ & & & & & & & & \\
\hline SESPMNT & B183R5 & VERNITA-1 HRM 0.3 & OFFSITE & sw & $\mathrm{N}$ & RIVER & TRANSECT & 09-Dec-03 Sb & & 0.144 & & & & & & \\
\hline SESPMNT & B183T7 & VERNITA-1 HRM 0.3 & OFFSITE & sw & $\mathrm{Y}$ & RIVER & TRANSECT & 09-Dec-03 Sb & & 0.199 & & & & & & \\
\hline SESPMNT & B183P6 & VERNITA-2 HRM 0.3 & OFFSITE & sw & $\mathrm{N}$ & RIVER & TRANSECT & 09-Dec-03 Sb & & 0.153 & $3 \mathrm{ug} / \mathrm{L}$ & & & & & \\
\hline SESPMNT & B183T8 & VERNITA-2 HRM 0.3 & OFFSITE & sw & $\mathrm{Y}$ & RIVER & TRANSECT & 09-Dec-03 Sb & & 0.205 & $5 \mathrm{ug} / \mathrm{L}$ & & & & & \\
\hline SESPMNT & B183P7 & VERNITA-3 HRM 0.3 & OFFSITE & sw & $\mathrm{N}$ & RIVER & TRANSECT & 09-Dec-03 Sb & & 0.153 & $3 \mathrm{ug} / \mathrm{L}$ & & & & & \\
\hline SESPMNT & B183T9 & VERNITA-3 HRM 0.3 & OFFSITE & sw & $\mathrm{Y}$ & RIVER & TRANSECT & 09-Dec-03 Sb & & 0.18 & $3 \mathrm{ug} / \mathrm{L}$ & & & & & \\
\hline SESPMNT & B183P8 & VERNITA-4 HRM 0.3 & OFFSITE & sw & $\mathrm{N}$ & RIVER & TRANSECT & 09-Dec-03 Sb & & 0.141 & ug/L & & & & & \\
\hline SESPMNT & B183V0 & VERNITA-4 HRM 0.3 & OFFSITE & sw & Y & RIVER & TRANSECT & 09-Dec-03 Sb & & 0.195 & & & & & & \\
\hline SESPMNT & B16L95 & VERNITA-1 HRM 0.3 & OFFSITE & sw & $\mathrm{N}$ & RIVER & TRANSECT & 24-Mar-03 Se & & & & & & U & & \\
\hline SESPMNT & B16LB7 & VERNITA-1 HRM 0.3 & OFFSITE & sw & Y & RIVER & TRANSECT & 24-Mar-03 Se & & & $3 \mathrm{ug} / \mathrm{L}$ & & & $u$ & & \\
\hline SESPMNT & B16L86 & VERNITA-2 HRM 0.3 & OFFSITE & sw & $\mathrm{N}$ & RIVER & TRANSECT & 24-Mar-03 Se & & 0.08 & $3 \mathrm{ug} / \mathrm{L}$ & & & u & & \\
\hline SESPMNT & B16LB8 & VERNITA-2 HRM 0.3 & OFFSITE & sw & $\mathrm{Y}$ & RIVER & TRANSECT & 24-Mar-03 Se & & 0.08 & $3 \mathrm{ug} / \mathrm{L}$ & & & u & & \\
\hline SESPMNT & B16L87 & VERNITA-3 HRM 0.3 & OFFSITE & sw & $\mathrm{N}$ & RIVER & TRANSECT & 24-Mar-03 Se & & & $3 \mathrm{ug} / \mathrm{L}$ & & & u & & \\
\hline SESPMNT & B16LB9 & VERNITA-3 HRM 0.3 & OFFSITE & sw & $\mathrm{Y}$ & RIVER & TRANSECT & 24-Mar-03 Se & & & $\mathrm{ug} / \mathrm{L}$ & & & $\mathrm{U}$ & & \\
\hline SESPMNT & B16L88 & VERNITA-4 HRM 0.3 & OFFSITE & sw & $\mathrm{N}$ & RIVER & TRANSECT & 24-Mar-03 Se & & & $\mathrm{ug} / \mathrm{L}$ & & & U & & \\
\hline SESPMNT & B16LC0 & VERNITA-4 HRM 0.3 & OFFSITE & sw & $\mathrm{Y}$ & RIVER & TRANSECT & 24-Mar-03 Se & & 0.08 & $3 \mathrm{ug} / \mathrm{L}$ & & & U & & \\
\hline SESPMNT & B16LD4 & RICH.PMPHS HRM 43.5 & OFFSITE & sw & $\mathrm{Y}$ & RIVER & TRANSECT & 25-Mar-03 Se & & 0.068 & & & & u & & \\
\hline SESPMNT & B16LD8 & RICH.PMPHS HRM 43.5 & OFFSITE & sw & $\mathrm{N}$ & RIVER & TRANSECT & 25 -Mar-03 Se & & 0.102 & ug/L $/ \mathrm{L}$ & & & B & & \\
\hline SESPMNT & B16LD3 & RICH.PMPHS HRM 43.9 & OFFSITE & sw & $\mathrm{Y}$ & RIVER & TRANSECT & 25-Mar-03 Se & & 0.08 & $3 \mathrm{ug} / \mathrm{L}$ & & & U & & \\
\hline SESPMNT & B16LD7 & RICH.PMPHS HRM 43.9 & OFFSITE & sw & $\mathrm{N}$ & RIVER & TRANSECT & 25-Mar-03 Se & & 0.08 & $3 \mathrm{ug} / \mathrm{L}$ & & & $u$ & & \\
\hline SESPMNT & B16LD2 & RICH.PMPHS HRM 45.0 & OFFSITE & sw & $\mathrm{Y}$ & RIVER & TRANSECT & 25-Mar-03 Se & & 0.08 & $3 \mathrm{ug} / \mathrm{L}$ & & & u & & \\
\hline SESPMNT & B16LD6 & RICH.PMPHS HRM 45.0 & OFFSITE & sw & $\mathrm{N}$ & RIVER & TRANSECT & 25-Mar-03 Se & & 0.0953 & $3 \mathrm{ug} / \mathrm{L}$ & & & B & & \\
\hline SESPMNT & B16LD1 & RICH.PMPHS HRM 45.8 & OFFSITE & sw & $\mathrm{Y}$ & RIVER & TRANSECT & $25-\mathrm{Mar}-03 \mathrm{Se}$ & & & $\mathrm{ug} / \mathrm{L}$ & & & u & & \\
\hline SESPMNT & B16LD5 & RICH.PMPHS HRM 45.8 & OFFSITE & sw & $\mathrm{N}$ & RIVER & TRANSECT & 25-Mar-03 Se & & & & & & U & & \\
\hline SESPMNT & B16L89 & RICH.PMPHS-1 HRM46.4 & OFFSITE & sw & $\mathrm{N}$ & RIVER & TRANSECT & 25-Mar-03 Se & & & $3 \mathrm{ug} / \mathrm{L}$ & & & u & & \\
\hline SESPMNT & B16LC1 & RICH.PMPHS-1 HRM46.4 & OFFSITE & sW & $\mathrm{Y}$ & RIVER & TRANSECT & 25-Mar-03 Se & & 0.08 & $3 \mathrm{ug} / \mathrm{L}$ & & & U & & \\
\hline SESPMNT & B16L94 & RICH.PMPHS-10 HRM46.4 & OFFSITE & sw & $\mathrm{N}$ & RIVER & TRANSECT & 25-Mar-03 Se & & 0.161 & & & & B & & \\
\hline SESPMNT & B16LC6 & RICH.PMPHS-10 HRM46.4 & OFFSITE & sw & $\mathrm{Y}$ & RIVER & TRANSECT & 25 -Mar-03 Se & & 0.181 & 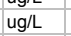 & & & B & & \\
\hline SESPMNT & B16L90 & RICH.PMPHS-2 HRM46.4 & OFFSITE & sw & $\mathrm{N}$ & RIVER & TRANSECT & 25-Mar-03 Se & & & $3 \mathrm{ug} / \mathrm{L}$ & & & u & & \\
\hline SESPMNT & B16LC2 & RICH.PMPHS-2 HRM46.4 & OFFSITE & sw & $\mathrm{Y}$ & RIVER & TRANSECT & 25-Mar-03 Se & & & $3 \mathrm{ug} / \mathrm{L}$ & & & u & & \\
\hline SESPMNT & B16L91 & RICH.PMPHS-3 HRM46.4 & OFFSITE & sw & $\mathrm{N}$ & RIVER & TRANSECT & 25-Mar-03 Se & & & & & & u & & \\
\hline SESPMNT & B16LC3 & RICH.PMPHS-3 HRM46.4 & OFFSITE & sw & Y & RIVER & TRANSECT & 25-Mar-03 Se & & & & & & u & & \\
\hline SESPMNT & B16L92 & RICH.PMPHS-5 HRM46.4 & OFFSITE & sw & $\mathrm{N}$ & RIVER & TRANSECT & 25 -Mar-03 Se & & 0.08 & $3 \mathrm{ug} / \mathrm{L}$ & & & u & & \\
\hline SESPMNT & B16LC4 & RICH.PMPHS-5 HRM46.4 & OFFSITE & sw & $\mathrm{Y}$ & RIVER & TRANSECT & 25-Mar-03 Se & & 0.08 & $3 \mathrm{ug} / \mathrm{L}$ & & & u & & \\
\hline SESPMNT & B16L93 & RICH.PMPHS-7 HRM46.4 & OFFSITE & sW & $\mathrm{N}$ & RIVER & TRANSECT & 25-Mar-03 Se & & 0.08 & $3 \mathrm{ug} / \mathrm{L}$ & & & U & & \\
\hline SESPMNT & B16LC5 & RICH.PMPHS-7 HRM46.4 & OFFSITE & sW & $\mathrm{Y}$ & RIVER & TRANSECT & 25-Mar-03 Se & & 0.08 & $3 \mathrm{ug} / \mathrm{L}$ & & & U & & \\
\hline SESPMNT & B171V9 & VERNITA-1 HRM 0.3 & OFFSITE & SW & $\mathrm{N}$ & RIVER & TRANSECT & 09-Jun-03 Se & & 0.177 & ug/L $/ 2$ & & & B & & \\
\hline SESPMNT & B171Y1 & VERNITA-1 HRM 0.3 & OFFSITE & sW & $\mathrm{Y}$ & RIVER & TRANSECT & 09-Jun-03 Se & & 0.124 & ing/L & & & B & & \\
\hline SESPMNT & B171Vo & VERNITA-2 HRM 0.3 & OFFSITE & sw & $\mathrm{N}$ & RIVER & TRANSECT & 09-Jun-03 Se & & & $3 \mathrm{ug} / \mathrm{L}$ & & & B & & \\
\hline SESPMNT & B171Y2 & VERNITA-2 HRM 0.3 & OFFSITE & sw & $\mathrm{Y}$ & RIVER & TRANSECT & 09-Jun-03 Se & & 0.151 & ug/L $/ \mathrm{L}$ & & & B & & \\
\hline SESPMNT & B171V1 & VERNITA-3 HRM 0.3 & OFFSITE & sw & $\mathrm{N}$ & RIVER & TRANSECT & 09-Jun-03 Se & & 0.08 & $3 \mathrm{ug} / \mathrm{L}$ & & & $\mathrm{u}$ & & \\
\hline
\end{tabular}


WATER - COLUMBIA RIVER TRANSECT

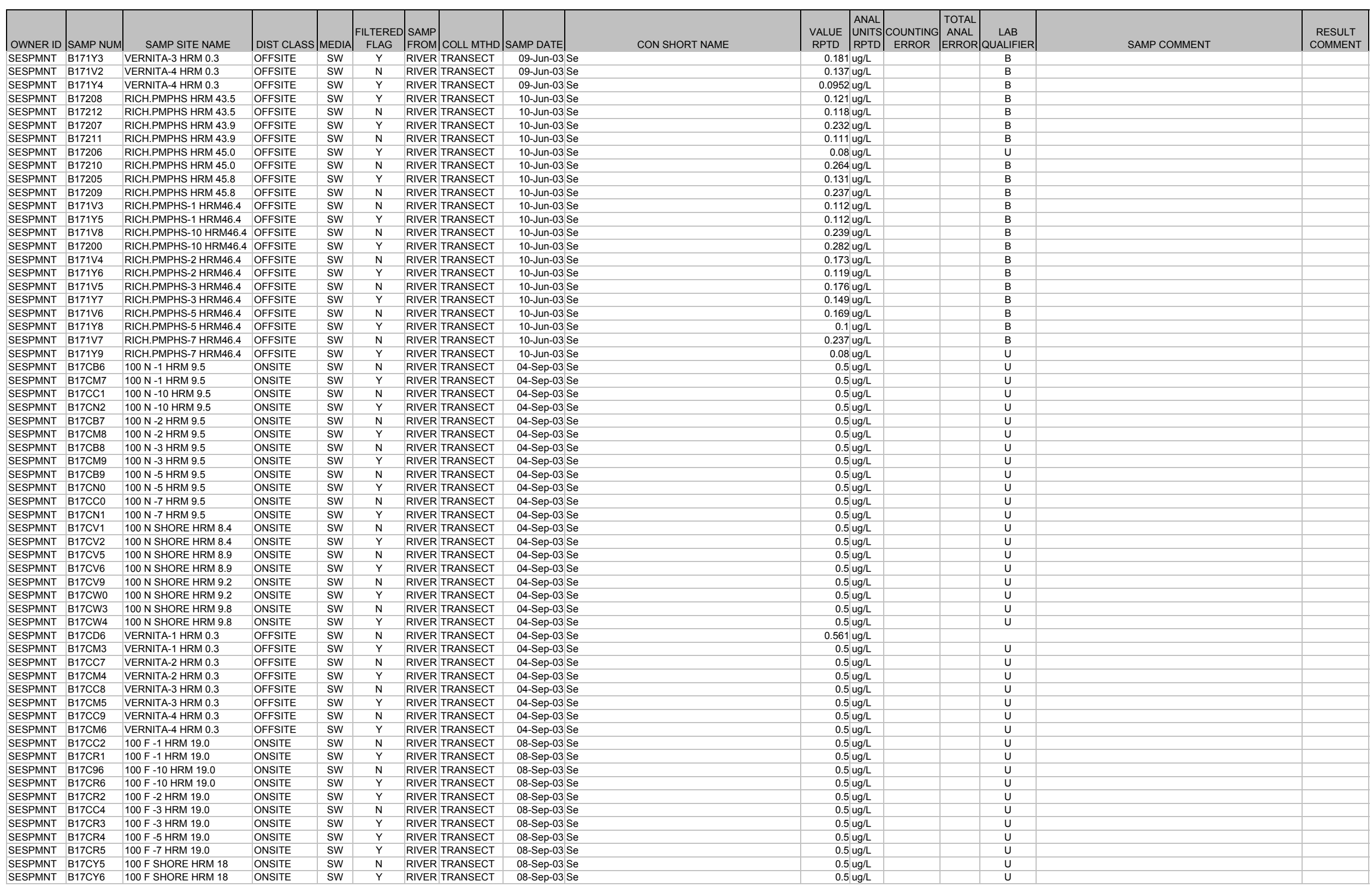


WATER - COLUMBIA RIVER TRANSECT

\begin{tabular}{|c|c|c|c|c|c|c|c|c|c|c|c|c|c|c|c|c|}
\hline | OWNER ID & | SAMP NUM| & SAMP SITE NAME & DIST CLASS & $\mid$ MEDIA & \begin{tabular}{|c|} 
FILTERED \\
FLAG
\end{tabular} & $\begin{array}{l}\text { SAMP } \\
\text { FROM }\end{array}$ & COLL MTHD & SAMP DATE & CON SHORT NAME & \begin{tabular}{c|c} 
VALUE & $A$ \\
RPTD & $R$
\end{tabular} & \begin{tabular}{|l|l|} 
ANAL \\
UNITS \\
RPTD \\
\end{tabular} & \begin{tabular}{|l|} 
COUNTING \\
ERROR
\end{tabular} & 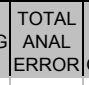 & $\begin{array}{c}\text { LAB } \\
\text { QUALIFIER }\end{array}$ & SAMP COMMENT & $\begin{array}{l}\text { RESULT } \\
\text { COMMENT }\end{array}$ \\
\hline SESPMNT & B17CY8 & 100 F SHORE HRM 22 & ONSITE & SW & $\mathrm{N}$ & RIVER & TRANSECT & 08-Sep-03 Se & & & ug/L & & & U & - & \\
\hline SESPMNT & B17CY9 & 100 F SHORE HRM 22 & ONSITE & sw & $\mathrm{Y}$ & RIVER & TRANSECT & 08-Sep-03 Se & & & $\mathrm{ug} / \mathrm{L}$ & & & $\mathrm{U}$ & & \\
\hline SESPMNT & B17D01 & $100 \mathrm{~F} \mathrm{SHORE} \mathrm{HRM} 23$ & ONSITE & sw & $\mathrm{N}$ & RIVER & TRANSECT & 08-Sep-03 Se & & & $\mathrm{ug} / \mathrm{L}$ & & & u & & \\
\hline SESPMNT & B17D02 & $100 \mathrm{~F}$ SHORE HRM 23 & ONSITE & sw & $\mathrm{Y}$ & RIVER & TRANSECT & 08 -Sep-03 Se & & & $\mathrm{ug} / \mathrm{L}$ & & & u & & \\
\hline SESPMNT & B17C97 & HANFRD TS-1 HRM 28.7 & ONSITE & sw & $\mathrm{N}$ & RIVER & TRANSECT & 08-Sep-03 Se & & $0.525 \mathrm{u}$ & & & & & & \\
\hline SESPMNT & B17CP5 & HANFRD TS-1 HRM 28.7 & ONSITE & sw & $\mathrm{Y}$ & RIVER & TRANSECT & 08-Sep-03 Se & & & & & & $u$ & & \\
\hline SESPMNT & B17CB2 & HANFRD TS-10 HRM 28.7 & ONSITE & sw & $\mathrm{N}$ & RIVER & TRANSECT & 08-Sep-03 Se & & & & & & $\mathrm{U}$ & & \\
\hline SESPMNT & B17CR0 & HANFRD TS-10 HRM 28.7 & ONSITE & sw & $\mathrm{Y}$ & RIVER & TRANSECT & 08-Sep-03 Se & & & & & & U & & \\
\hline SESPMNT & B17C98 & HANFRD TS-2 HRM 28.7 & ONSITE & sw & $\mathrm{N}$ & RIVER & TRANSECT & $08-\mathrm{Sep}-03 \mathrm{Se}$ & & & $\mathrm{ug} / \mathrm{L}$ & & & u & & \\
\hline SESPMNT & B17CP6 & HANFRD TS-2 HRM 28.7 & ONSITE & sw & $\mathrm{Y}$ & RIVER & TRANSECT & 08-Sep-03 Se & & & $\mathrm{ug} / \mathrm{L}$ & & & U & & \\
\hline SESPMNT & B17C99 & HANFRD TS-3 HRM 28.7 & ONSITE & sw & $\mathrm{N}$ & RIVER & TRANSECT & $08-\mathrm{Sep}-03 \mathrm{Se}$ & & & $\mathrm{ug} / \mathrm{L}$ & & & u & & \\
\hline SESPMNT & B17CP7 & HANFRD TS-3 HRM 28.7 & ONSITE & sw & $\mathrm{Y}$ & RIVER & TRANSECT & 08-Sep-03 Se & & & $\mathrm{ug} / \mathrm{L}$ & & & u & & \\
\hline SESPMNT & B17CB0 & HANFRD TS-5 HRM 28.7 & ONSITE & sw & $\mathrm{N}$ & RIVER & TRANSECT & 08-Sep-03 Se & & & $\mathrm{ug} / \mathrm{L}$ & & & U & & \\
\hline SESPMNT & B17CP8 & HANFRD TS-5 HRM 28.7 & ONSITE & sw & $\mathrm{Y}$ & RIVER & TRANSECT & 08 -Sep-03 Se & & & $\mathrm{ug} / \mathrm{L}$ & & & u & & \\
\hline SESPMNT & B17CB1 & HANFRD TS-7 HRM 28.7 & ONSITE & sw & $\mathrm{N}$ & RIVER & TRANSECT & 08-Sep-03 Se & & & & & & U & & \\
\hline SESPMNT & B17CP9 & HANFRD TS-7 HRM 28.7 & ONSITE & sw & $\mathrm{Y}$ & RIVER & TRANSECT & 08-Sep-03 Se & & & $\mathrm{ug} / \mathrm{L}$ & & & u & & \\
\hline SESPMNT & B17CL7 & HANFRD TWNSITE HRM26 & ONSITE & sw & $\mathrm{N}$ & RIVER & TRANSECT & $08-\mathrm{Sep}-03 \mathrm{Se}$ & & & $\mathrm{ug} / \mathrm{L}$ & & & $u$ & & \\
\hline SESPMNT & B17CM0 & HANFRD TWNSITE HRM26 & ONSITE & sw & $\mathrm{Y}$ & RIVER & TRANSECT & 08-Sep-03 Se & & & $\mathrm{ug} / \mathrm{L}$ & & & U & & \\
\hline SESPMNT & B17CL8 & HANFRD TWNSITE HRM27 & ONSITE & sw & $\mathrm{N}$ & RIVER & TRANSECT & $08-\mathrm{Sep}-03 \mathrm{Se}$ & & & $\mathrm{ug} / \mathrm{L}$ & & & u & & \\
\hline SESPMNT & B17CM1 & HANFRD TWNSITE HRM27 & ONSITE & sw & $\mathrm{Y}$ & RIVER & TRANSECT & 08 -Sep-03 Se & & & $\mathrm{ug} / \mathrm{L}$ & & & u & & \\
\hline SESPMNT & B17CY2 & HANFRD TWNSITE HRM28 & ONSITE & sw & $\mathrm{N}$ & RIVER & TRANSECT & $08-\mathrm{Sep}-03 \mathrm{Se}$ & & & $\mathrm{ug} / \mathrm{L}$ & & & U & & \\
\hline SESPMNT & $\mathrm{B} 17 \mathrm{CY} 3$ & HANFRD TWNSITE HRM28 & ONSITE & sw & Y & RIVER & TRANSECT & 08-Sep-03 Se & & $0.501 \mathrm{u}$ & & & & & & \\
\hline SESPMNT & B17CL9 & HANFRD TWNSITE HRM30 & ONSITE & sw & $\mathrm{N}$ & RIVER & TRANSECT & $08-\mathrm{Sep}-03 \mathrm{Se}$ & & & & & & U & & \\
\hline SESPMNT & B17CM2 & HANFRD TWNSITE HRM30 & ONSITE & sw & $\mathrm{Y}$ & RIVER & TRANSECT & 08 -Sep-03 Se & & & ug/L & & & u & & \\
\hline SESPMNT & B17CN9 & 300 AREA -1 HRM 43.1 & ONSITE & sw & $\mathrm{Y}$ & RIVER & TRANSECT & 09-Sep-03 Se & & & $\mathrm{ug} / \mathrm{L}$ & & & U & & \\
\hline SESPMNT & B17CP0 & 300 AREA -2 HRM 43.1 & ONSITE & sw & $\mathrm{Y}$ & RIVER & TRANSECT & 09-Sep-03 Se & & & $\mathrm{ug} / \mathrm{L}$ & & & u & & \\
\hline SESPMNT & B17CP1 & 300 AREA -3 HRM 43.1 & ONSITE & sw & $\mathrm{Y}$ & RIVER & TRANSECT & 09-Sep-03 Se & & & $\mathrm{ug} / \mathrm{L}$ & & & U & & \\
\hline SESPMNT & B17CP2 & 300 AREA -5 HRM 43.1 & ONSITE & sw & $\mathrm{Y}$ & RIVER & TRANSECT & $09-\mathrm{Sep}-03 \mathrm{Se}$ & & & $\mathrm{ug} / \mathrm{L}$ & & & u & & \\
\hline SESPMNT & B17CP3 & 300 AREA -7 HRM 43.1 & ONSITE & sw & Y & RIVER & TRANSECT & $09-S e p-03 \mathrm{Se}$ & & & $\mathrm{ug} / \mathrm{L}$ & & & u & & \\
\hline SESPMNT & B17CW8 & 300 AREA SHR HRM41.5 & ONSITE & sw & $\mathrm{Y}$ & RIVER & TRANSECT & 09-Sep-03 Se & & & & & & U & & \\
\hline SESPMNT & $B 17 C \times 2$ & 300 AREA SHR HRM42.1 & ONSITE & sw & Y & RIVER & TRANSECT & $09-\mathrm{Sep}-03 \mathrm{Se}$ & & & $\mathrm{ug} / \mathrm{L}$ & & & u & & \\
\hline SESPMNT & B17CX6 & 300 AREA SHR HRM42.5 & ONSITE & sw & $\mathrm{Y}$ & RIVER & TRANSECT & 09-Sep-03 Se & & & $\mathrm{ug} / \mathrm{L}$ & & & U & & \\
\hline SESPMNT & B17CYo & 300 AREA SHR HRM42.9 & ONSITE & sw & $\mathrm{Y}$ & RIVER & TRANSECT & $09-S e p-03 \mathrm{Se}$ & & & $\mathrm{ug} / \mathrm{L}$ & & & u & & \\
\hline SESPMNT & B17CP4 & 300 AREA-10 HRM 43.1 & ONSITE & sw & Y & RIVER & TRANSECT & $09-\mathrm{Sep}-03 \mathrm{Se}$ & & & ug/L & & & u & & \\
\hline SESPMNT & B17CT4 & RICH.PMPHS HRM 43.5 & OFFSITE & sw & $\mathrm{Y}$ & RIVER & TRANSECT & 09-Sep-03 Se & & & $\mathrm{ug} / \mathrm{L}$ & & & $\mathrm{U}$ & & \\
\hline SESPMNT & B17CT2 & RICH.PMPHS HRM 45.0 & OFFSITE & sw & $\mathrm{Y}$ & RIVER & TRANSECT & $09-\mathrm{Sep}-03 \mathrm{Se}$ & & & ug/L & & & $\mathrm{U}$ & & \\
\hline SESPMNT & B17CT1 & RICH.PMPHS HRM 45.8 & OFFSITE & sw & $\mathrm{Y}$ & RIVER & TRANSECT & $09-\mathrm{Sep}-03 \mathrm{Se}$ & & & $\mathrm{ug} / \mathrm{L}$ & & & u & & \\
\hline SESPMNT & B17CD0 & RICH.PMPHS-1 HRM46.4 & OFFSITE & sw & $\mathrm{N}$ & RIVER & TRANSECT & $09-\mathrm{Sep}-03 \mathrm{Se}$ & & & $\mathrm{ug} / \mathrm{L}$ & & & u & & \\
\hline SESPMNT & B17CN3 & $\begin{array}{l}\text { RICH.PMPHS-1 HRM46.4 } \\
\end{array}$ & OFFSITE & sw & $\mathrm{Y}$ & RIVER & TRANSECT & $09-S e p-03 \mathrm{Se}$ & & & $\mathrm{ug} / \mathrm{L}$ & & & u & & \\
\hline SESPMNT & B17CD5 & RICH.PMPHS-10 HRM46.4 & OFFSITE & sw & $\mathrm{N}$ & RIVER & TRANSECT & $09-\mathrm{Sep}-03 \mathrm{Se}$ & & & $\mathrm{ug} / \mathrm{L}$ & & & U & & \\
\hline SESPMNT & B17CN8 & RICH.PMPHS-10 HRM46.4 & OFFSITE & sw & Y & RIVER & TRANSECT & $09-\mathrm{Sep}-03 \mathrm{Se}$ & & & $\mathrm{ug} / \mathrm{L}$ & & & $u$ & & \\
\hline SESPMNT & B17CD1 & RICH.PMPHS-2 HRM46.4 & OFFSITE & sw & $\mathrm{N}$ & RIVER & TRANSECT & $09-\mathrm{Sep}-03 \mathrm{Se}$ & & & $\mathrm{ug} / \mathrm{L}$ & & & U & & \\
\hline SESPMNT & B17CN4 & RICH.PMPHS-2 HRM46.4 & OFFSITE & sw & $\mathrm{Y}$ & RIVER & TRANSECT & $09-S e p-03$ Se & & & ug/L & & & u & & \\
\hline SESPMNT & B17CD2 & RICH.PMPHS-3 HRM46.4 & OFFSITE & sw & $\mathrm{N}$ & RIVER & TRANSECT & $09-\mathrm{Sep}-03 \mathrm{Se}$ & & & ug/L & & & U & & \\
\hline SESPMNT & B17CN5 & RICH.PMPHS-3 HRM46.4 & OFFSITE & sw & $\mathrm{Y}$ & RIVER & TRANSECT & $09-\mathrm{Sep}-03 \mathrm{Se}$ & & & $\mathrm{ug} / \mathrm{L}$ & & & U & & \\
\hline SESPMNT & B17CD3 & RICH.PMPHS-5 HRM46.4 & OFFSITE & sw & $\mathrm{N}$ & RIVER & TRANSECT & 09-Sep-03 Se & & & $\mathrm{ug} / \mathrm{L}$ & & & u & & \\
\hline SESPMNT & B17CN6 & RICH.PMPHS-5 HRM46.4 & OFFSITE & sW & $\mathrm{Y}$ & RIVER & TRANSECT & 09-Sep-03 Se & & & $\mathrm{ug} / \mathrm{L}$ & & & U & & \\
\hline SESPMNT & B17CD4 & RICH.PMPHS-7 HRM46.4 & OFFSITE & sw & $\mathrm{N}$ & RIVER & TRANSECT & $09-\mathrm{Sep}-03 \mathrm{Se}$ & & & $\mathrm{ug} / \mathrm{L}$ & & & u & & \\
\hline SESPMNT & B17CN7 & RICH.PMPHS-7 HRM46.4 & OFFSITE & sw & $\mathrm{Y}$ & RIVER & TRANSECT & $09-\mathrm{Sep}-03 \mathrm{Se}$ & & & $\mathrm{ug} / \mathrm{L}$ & & & $u$ & & \\
\hline SESPMNT & B183W4 & RICH.PMPHS HRM 43.5 & OFFSITE & sW & $\mathrm{Y}$ & RIVER & TRANSECT & 08-Dec-03 Se & & $0.496 u$ & $\mathrm{ug} / \mathrm{L}$ & & & u & & \\
\hline SESPMNT & B183W8 & RICH.PMPHS HRM 43.5 & OFFSITE & sw & $\mathrm{N}$ & RIVER & TRANSECT & $08-\mathrm{Dec}-03 \mathrm{Se}$ & & $0.496 \mathrm{u}$ & & & & u & & \\
\hline SESPMNT & B183W3 & RICH.PMPHS HRM 43.9 & OFFSITE & sw & $\mathrm{Y}$ & RIVER & TRANSECT & 08-Dec-03 Se & & $0.496 \mathrm{u}$ & & & & u & & \\
\hline SESPMNT & B183W7 & RICH.PMPHS HRM 43.9 & OFFSITE & sw & $\mathrm{N}$ & RIVER & TRANSECT & $08-D e c-03 \mathrm{Se}$ & & $0.496 \mathrm{u}$ & & & & u & & \\
\hline SESPMNT & B183W2 & RICH.PMPHS HRM 45.0 & OFFSITE & sw & $\mathrm{Y}$ & RIVER & TRANSECT & 08-Dec-03 Se & & $0.496 \mathrm{u}$ & ug/L & & & u & & \\
\hline SESPMNT & B183W6 & RICH.PMPHS HRM 45.0 & OFFSITE & sw & $\mathrm{N}$ & RIVER & TRANSECT & 08-Dec-03 Se & & $0.496 \mathrm{u}$ & ug/L & & & $u$ & & \\
\hline SESPMNT & B183W1 & RICH.PMPHS HRM 45.8 & OFFSITE & sW & $\mathrm{Y}$ & RIVER & TRANSECT & 08-Dec-03 Se & & $0.496 \mathrm{u}$ & $\mathrm{ug} / \mathrm{L}$ & & & U & & \\
\hline SESPMNT & B183W5 & RICH.PMPHS HRM 45.8 & OFFSITE & sW & $\mathrm{N}$ & RIVER & TRANSECT & 08-Dec-03 Se & & $0.496 \mathrm{u}$ & $\mathrm{ug} / \mathrm{L}$ & & & U & & \\
\hline SESPMNT & B183P9 & RICH.PMPHS-1 HRM46.4 & OFFSITE & SW & $\mathrm{N}$ & RIVER & TRANSECT & 08 -Dec-03 Se & & $0.496 \mathrm{u}$ & & & & u & & \\
\hline SESPMNT & B183V1 & RICH.PMPHS-1 HRM46.4 & OFFSITE & sW & $\mathrm{Y}$ & RIVER & TRANSECT & 08-Dec-03 Se & & $0.496 \mathrm{u}$ & & & & U & & \\
\hline SESPMNT & B183R4 & RICH.PMPHS-10 HRM46.4 & OFFSITE & sw & $\mathrm{N}$ & RIVER & TRANSECT & 08-Dec-03 Se & & & & & & u & & \\
\hline SESPMNT & B183V6 & RICH.PMPHS-10 HRM46.4 & OFFSITE & sw & $\mathrm{Y}$ & RIVER & TRANSECT & 08-Dec-03 Se & & $0.496 \mathrm{u}$ & & & & u & & \\
\hline SESPMNT & B183R0 & RICH.PMPHS-2 HRM46.4 & OFFSITE & sw & $\mathrm{N}$ & RIVER & TRANSECT & $08-D e c-03 \mathrm{Se}$ & & $0.496 \mathrm{u}$ & $\mathrm{ug} / \mathrm{L}$ & & & u & & \\
\hline
\end{tabular}


WATER - COLUMBIA RIVER TRANSECT

\begin{tabular}{|c|c|c|c|c|c|c|c|c|c|c|c|c|c|c|c|c|}
\hline | OWNER ID & SAMP NUM & SAMP SITE NAME & |DIST CLASS & MEDIA $\left.\right|^{\mid h}$ & \begin{tabular}{|c|} 
FILTERED \\
FLAG
\end{tabular} & $\mid \begin{array}{l}\text { SAMP } \\
\text { FROM }\end{array}$ & COLL MTHD & SAMP DATE & CON SHORT NAME & $\begin{array}{l}\text { VALUE } \\
\text { RPTD }\end{array}$ & \begin{tabular}{|l|} 
ANAL \\
UNITS \\
RPTD
\end{tabular} & $\begin{array}{c}\text { COUNTING } \\
\text { ERROR }\end{array}$ & \begin{tabular}{|c|} 
TOTAL \\
ANAL \\
ERROR
\end{tabular} & $\begin{array}{c}\text { LAB } \\
\text { QUALIFIER }\end{array}$ & SAMP COMMENT & $\begin{array}{l}\text { RESULT } \\
\text { COMMENT }\end{array}$ \\
\hline SESPMNT & B183V2 & RICH.PMPHS-2 HRM46.4 & OFFSITE & SW & Y & & TRANSECT & 08-Dec-03 Se & & & & & & U & 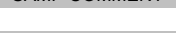 & \\
\hline SESPMNT & B183R1 & RICH.PMPHS-3 HRM 46.4 & OFFSITE & sW & $\mathrm{N}$ & RIVER & TRANSECT & 08-Dec-03 Se & & 0.496 & $3 \mathrm{ug} / \mathrm{L}$ & & & $u$ & & \\
\hline SESPMNT & B183V3 & RICH.PMPHS-3 HRM46.4 & OFFSITE & sw & $\mathrm{Y}$ & RIVER & TRANSECT & 08-Dec-03 Se & & 0.496 & $\mathrm{ug} / \mathrm{L}$ & & & U & & \\
\hline SESPMNT & B183R2 & RICH.PMPHS-5 HRM46.4 & OFFSITE & sw & $\mathrm{N}$ & RIVER & TRANSECT & 08-Dec-03 Se & & 0.496 & $\mathrm{iug} / \mathrm{L}$ & & & $u$ & & \\
\hline SESPMNT & B183V4 & RICH.PMPHS-5 HRM46.4 & OFFSITE & sw & Y & RIVER & TRANSECT & 08-Dec-03 Se & & 0.496 & $\mathrm{igg} / \mathrm{L}$ & & & $u$ & & \\
\hline SESPMNT & B183R3 & RICH.PMPHS-7 HRM46.4 & OFFSITE & sW & $\mathrm{N}$ & RIVER & TRANSECT & 08-Dec-03 Se & & & & & & $u$ & & \\
\hline SESPMNT & B183V5 & RICH.PMPHS-7 HRM46.4 & OFFSITE & sw & $\mathrm{Y}$ & RIVER & TRANSECT & 08-Dec-03 Se & & & & & & $\mathrm{U}$ & & \\
\hline SESPMNT & B183R5 & VERNITA-1 HRM 0.3 & OFFSITE & sW & $\mathrm{N}$ & RIVER & TRANSECT & 09-Dec-03 Se & & & & & & U & & \\
\hline SESPMNT & B183T7 & VERNITA-1 HRM 0.3 & OFFSITE & sW & $\mathrm{Y}$ & RIVER & TRANSECT & 09-Dec-03 Se & & 0.496 & ing/L & & & U & & \\
\hline SESPMNT & B183P6 & VERNITA-2 HRM 0.3 & OFFSITE & sw & $\mathrm{N}$ & RIVER & TRANSECT & 09-Dec-03 Se & & 0.496 & $\mathrm{iug} / \mathrm{L}$ & & & U & & \\
\hline SESPMNT & B183T8 & VERNITA-2 HRM 0.3 & OFFSITE & SW & $\mathrm{Y}$ & RIVER & TRANSECT & 09-Dec-03 Se & & 0.496 & $\mathrm{iug} / \mathrm{L}$ & & & U & & \\
\hline SESPMNT & B183P7 & VERNITA-3 HRM 0.3 & OFFSITE & sw & $\mathrm{N}$ & RIVER & TRANSECT & 09-Dec-03 Se & & 0.496 & ing/L & & & U & & \\
\hline SESPMNT & B183T9 & VERNITA-3 HRM 0.3 & OFFSITE & sw & $\mathrm{Y}$ & RIVER & TRANSECT & 09-Dec-03 Se & & 0.565 & & & & & & \\
\hline SESPMNT & B183P8 & VERNITA-4 HRM 0.3 & OFFSITE & sw & $\mathrm{N}$ & RIVER & TRANSECT & 09-Dec-03 Se & & 0.496 & $\mathrm{ug} / \mathrm{L}$ & & & u & & \\
\hline SESPMNT & B183V0 & VERNITA-4 HRM 0.3 & OFFSITE & sW & $\mathrm{Y}$ & RIVER & TRANSECT & 09-Dec-03 Se & & 0.496 & & & & U & & \\
\hline SESPMNT & B16L95 & VERNITA-1 HRM 0.3 & OFFSITE & sw & $\mathrm{N}$ & RIVER & TRANSECT & 24-Mar-03 TI & & 0.003 & & & & $u$ & & \\
\hline SESPMNT & B16LB7 & VERNITA-1 HRM 0.3 & OFFSITE & sw & Y & RIVER & TRANSECT & 24-Mar-03 TI & & 0.0219 & $\mathrm{ug} / \mathrm{L}$ & & & C & & \\
\hline SESPMNT & B16L86 & VERNITA-2 HRM 0.3 & OFFSITE & sW & $\mathrm{N}$ & RIVER & TRANSECT & 24-Mar-03 TI & & 0.003 & $3 \mathrm{ug} / \mathrm{L}$ & & & $u$ & & \\
\hline SESPMNT & B16LB8 & VERNITA-2 HRM 0.3 & OFFSITE & sW & Y & RIVER & TRANSECT & 24-Mar-03 TI & & 0.0201 & ug/L $/ \mathrm{L}$ & & & c & & \\
\hline SESPMNT & B16L87 & VERNITA-3 HRM 0.3 & OFFSITE & SW & $\mathrm{N}$ & RIVER & TRANSECT & 24-Mar-03 TI & & 0.003 & $3 \mathrm{ug} / \mathrm{L}$ & & & u & & \\
\hline SESPMNT & B16LB9 & VERNITA-3 HRM 0.3 & OFFSITE & SW & Y & RIVER & TRANSECT & 24-Mar-03 TI & & 0.0193 & & & & $\mathrm{BC}$ & & \\
\hline SESPMNT & B16L88 & VERNITA-4 HRM 0.3 & OFFSITE & sW & $\mathrm{N}$ & RIVER & TRANSECT & 24-Mar-03 TI & & 0.003 & & & & u & & \\
\hline SESPMNT & B16LCO & VERNITA-4 HRM 0.3 & OFFSITE & sW & $\mathrm{Y}$ & RIVER & TRANSECT & 24-Mar-03 TI & & 0.0141 & & & & $\mathrm{BC}$ & & \\
\hline SESPMNT & B16LD4 & RICH.PMPHS HRM 43.5 & OFFSITE & sw & $\mathrm{Y}$ & RIVER & TRANSECT & $25-\mathrm{Mar}-03 \mathrm{TI}$ & & 0.0174 & ug/L & & & $\mathrm{BC}$ & & \\
\hline SESPMNT & B16LD8 & RICH.PMPHS HRM 43.5 & OFFSITE & sW & $\mathrm{N}$ & RIVER & TRANSECT & 25-Mar-03 TI & & 0.003 & $3 \mathrm{ug} / \mathrm{L}$ & & & U & & \\
\hline SESPMNT & B16LD3 & RICH.PMPHS HRM 43.9 & OFFSITE & sw & $\mathrm{Y}$ & RIVER & TRANSECT & 25-Mar-03 TI & & 0.0177 & ing/L & & & $B C$ & & \\
\hline SESPMNT & B16LD7 & RICH.PMPHS HRM 43.9 & OFFSITE & sW & $\mathrm{N}$ & RIVER & TRANSECT & 25-Mar-03 TI & & 0.003 & $3 \mathrm{ug} / \mathrm{L}$ & & & u & & \\
\hline SESPMNT & B16LD2 & RICH.PMPHS HRM 45.0 & OFFSITE & sW & $\mathrm{Y}$ & RIVER & TRANSECT & 25-Mar-03 TI & & 0.0166 & $\mathrm{ing} / \mathrm{L}$ & & & $\mathrm{BC}$ & & \\
\hline SESPMNT & B16LD6 & RICH.PMPHS HRM 45.0 & OFFSITE & sw & $\mathrm{N}$ & RIVER & TRANSECT & 25-Mar-03 TI & & 0.003 & $3 \mathrm{ug} / \mathrm{L}$ & & & u & & \\
\hline SESPMNT & B16LD1 & RICH.PMPHS HRM 45.8 & OFFSITE & sw & $\mathrm{Y}$ & RIVER & TRANSECT & 25-Mar-03 TI & & 0.0123 & & & & $\mathrm{BC}$ & & \\
\hline SESPMNT & B16LD5 & RICH.PMPHS HRM 45.8 & OFFSITE & sw & $\mathrm{N}$ & RIVER & TRANSECT & 25-Mar-03 TI & & 0.003 & & & & $u$ & & \\
\hline SESPMNT & B16L89 & RICH.PMPHS-1 HRM46.4 & OFFSITE & SW & $\mathrm{N}$ & RIVER & TRANSECT & 25-Mar-03 TI & & 0.003 & $3 \mathrm{ug} / \mathrm{L}$ & & & u & & \\
\hline SESPMNT & B16LC1 & RICH.PMPHS-1 HRM46.4 & OFFSITE & SW & Y & RIVER & TRANSECT & 25-Mar-03 TI & & 0.0191 & ug/L $/ 2$ & & & $\mathrm{BC}$ & & \\
\hline SESPMNT & B16L94 & RICH.PMPHS-10 HRM46.4 & OFFSITE & sw & $\mathrm{N}$ & RIVER & TRANSECT & $25-\mathrm{Mar}-03 \mathrm{TI}$ & & 0.003 & $3 \mathrm{ug} / \mathrm{L}$ & & & u & & \\
\hline SESPMNT & B16LC6 & RICH.PMPHS-10 HRM46.4 & OFFSITE & sW & $\mathrm{Y}$ & RIVER & TRANSECT & 25-Mar-03 TI & & 0.0125 & $5 \mathrm{ug} / \mathrm{L}$ & & & $B C$ & & \\
\hline SESPMNT & B16L90 & RICH.PMPHS-2 HRM 46.4 & OFFSITE & sw & $\mathrm{N}$ & RIVER & TRANSECT & 25-Mar-03 TI & & 0.003 & & & & u & & \\
\hline SESPMNT & B16LC2 & RICH.PMPHS-2 HRM46.4 & OFFSITE & sw & $\mathrm{Y}$ & RIVER & TRANSECT & 25-Mar-03 TI & & 0.0164 & & & & $\mathrm{BC}$ & & \\
\hline SESPMNT & B16L91 & RICH.PMPHS-3 HRM46.4 & OFFSITE & sW & $\mathrm{N}$ & RIVER & TRANSECT & 25-Mar-03 TI & & 0.003 & & & & u & & \\
\hline SESPMNT & B16LC3 & RICH.PMPHS-3 HRM46.4 & OFFSITE & sw & $\mathrm{Y}$ & RIVER & TRANSECT & $25-\mathrm{Mar}-03 \mathrm{TI}$ & & 0.0185 & ugg/L & & & $\mathrm{BC}$ & & \\
\hline SESPMNT & B16L92 & RICH.PMPHS-5 HRM46.4 & OFFSITE & sW & $\mathrm{N}$ & RIVER & TRANSECT & 25-Mar-03 TI & & 0.003 & $3 \mathrm{ug} / \mathrm{L}$ & & & u & & \\
\hline SESPMNT & B16LC4 & RICH.PMPHS-5 HRM46.4 & OFFSITE & sw & Y & RIVER & TRANSECT & 25-Mar-03 TI & & 0.0179 & $\mathrm{ug} / \mathrm{L}$ & & & $\mathrm{BC}$ & & \\
\hline SESPMNT & B16L93 & RICH.PMPHS-7 HRM46.4 & OFFSITE & sW & $\mathrm{N}$ & RIVER & TRANSECT & 25-Mar-03 TI & & 0.003 & 3 ug/L & & & $\mathrm{u}$ & & \\
\hline SESPMNT & B16LC5 & RICH.PMPHS-7 HRM46.4 & OFFSITE & sw & Y & RIVER & TRANSECT & 25-Mar-03 TI & & 0.011 & ug/L $/ 2$ & & & $\mathrm{BC}$ & & \\
\hline SESPMNT & B171V9 & VERNITA-1 HRM 0.3 & OFFSITE & sW & $\mathrm{N}$ & RIVER & TRANSECT & 09-Jun-03 TI & & 0.00977 & ug/L & & & B & & \\
\hline SESPMNT & B171Y1 & VERNITA-1 HRM 0.3 & OFFSITE & sW & $\mathrm{Y}$ & RIVER & TRANSECT & 09-Jun-03 TI & & 0.0128 & & & & & & \\
\hline SESPMNT & B171Vo & VERNITA-2 HRM 0.3 & OFFSITE & sw & $\mathrm{N}$ & RIVER & TRANSECT & 09-Jun-03 TI & & 0.0113 & & & & B & & \\
\hline SESPMNT & B171Y2 & VERNITA-2 HRM 0.3 & OFFSITE & sW & $\mathrm{Y}$ & RIVER & TRANSECT & 09-Jun-03 TI & & 0.0124 & ing/L & & & B & & \\
\hline SESPMNT & B171V1 & VERNITA-3 HRM 0.3 & OFFSITE & sw & $\mathrm{N}$ & RIVER & TRANSECT & 09-Jun-03 TI & & 0.00885 & $5 \mathrm{ug} / \mathrm{L}$ & & & B & & \\
\hline SESPMNT & B171Y3 & VERNITA-3 HRM 0.3 & OFFSITE & SW & Y & RIVER & TRANSECT & 09-Jun-03 TI & & 0.012 & ug/L $/ \mathrm{L}$ & & & B & & \\
\hline SESPMNT & B171V2 & VERNITA-4 HRM 0.3 & OFFSITE & SW & $\mathrm{N}$ & RIVER & TRANSECT & 09-Jun-03 TI & & 0.0104 & ing/L & & & B & & \\
\hline SESPMNT & B171Y4 & VERNITA-4 HRM 0.3 & OFFSITE & sw & $\mathrm{Y}$ & RIVER & TRANSECT & 09-Jun-03 TI & & 0.0126 & $3 \mathrm{ug} / \mathrm{L}$ & & & B & & \\
\hline SESPMNT & B17208 & RICH.PMPHS HRM 43.5 & OFFSITE & SW & $\mathrm{Y}$ & RIVER & TRANSECT & 10-Jun-03 TI & & 0.0125 & ug/L & & & B & & \\
\hline SESPMNT & B17212 & RICH.PMPHS HRM 43.5 & OFFSITE & sw & $\mathrm{N}$ & RIVER & TRANSECT & 10-Jun-03 TI & & 0.0111 & ug/ $/ \mathrm{L}$ & & & B & & \\
\hline SESPMNT & B17207 & RICH.PMPHS HRM 43.9 & OFFSITE & SW & $\mathrm{Y}$ & RIVER & TRANSECT & 10-Jun-03 TI & & 0.012 & ug/L $/ \mathrm{L}$ & & & B & & \\
\hline SESPMNT & B17211 & RICH.PMPHS HRM 43.9 & OFFSITE & sw & $\mathrm{N}$ & RIVER & TRANSECT & 10-Jun-03 TI & & 0.0137 & ing/L & & & B & & \\
\hline SESPMNT & B17206 & RICH.PMPHS HRM 45.0 & OFFSITE & sW & $\mathrm{Y}$ & RIVER & TRANSECT & 10-Jun-03 TI & & 0.0102 & $2 \mathrm{ug} / \mathrm{L}$ & & & B & & \\
\hline SESPMNT & B17210 & RICH.PMPHS HRM 45.0 & OFFSITE & sW & $\mathrm{N}$ & RIVER & TRANSECT & 10-Jun-03 TI & & 0.0132 & ing/L & & & B & & \\
\hline SESPMNT & B17205 & RICH.PMPHS HRM 45.8 & OFFSITE & sW & Y & RIVER & TRANSECT & 10-Jun-03 TI & & 0.011 & ug/L $/ \mathrm{L}$ & & & B & & \\
\hline SESPMNT & B17209 & RICH.PMPHS HRM 45.8 & OFFSITE & sW & $\mathrm{N}$ & RIVER & TRANSECT & 10-Jun-03 TI & & 0.0107 & ug/L & & & B & & \\
\hline SESPMNT & B171V3 & RICH.PMPHS-1 HRM46.4 & OFFSITE & sw & $\mathrm{N}$ & RIVER & TRANSECT & 10-Jun-03 TI & & 0.0118 & $3 \mathrm{ug} / \mathrm{L}$ & & & B & & \\
\hline SESPMNT & B171Y5 & RICH.PMPHS-1 HRM46.4 & OFFSITE & SW & $\mathrm{Y}$ & RIVER & TRANSECT & 10-Jun-03 TI & & 0.014 & ug/L $/ 2$ & & & B & & \\
\hline SESPMNT & B171V8 & RICH.PMPHS-10 HRM46.4 & OFFSITE & sw & $\mathrm{N}$ & RIVER & TRANSECT & 10-Jun-03 TI & & 0.0125 & $3 \mathrm{ug} / \mathrm{L}$ & & & B & & \\
\hline
\end{tabular}


WATER - COLUMBIA RIVER TRANSECT

\begin{tabular}{|c|c|c|c|c|c|c|c|c|c|c|c|c|c|c|c|c|}
\hline | OWNER ID & | SAMP NUM| & SAMP SITE NAME & |DIST CLASS & $\mid$ MEDIA & \begin{tabular}{|c|} 
FILTERED \\
FLAG
\end{tabular} & $\begin{array}{l}\text { SAMP } \\
\text { FROM }\end{array}$ & COLL MTHD & SAMP DATE & CON SHORT NAME & $\begin{array}{c}\text { VALUE } \\
\text { RPTD }\end{array}$ & \begin{tabular}{|l|} 
ANAL \\
UNITS \\
RPTD \\
\end{tabular} & $\begin{array}{c}\text { COUNTING } \\
\text { ERROR }\end{array}$ & \begin{tabular}{|c|c|} 
TOTAL \\
ANAL \\
ANROR
\end{tabular} & $\begin{array}{c}\text { LAB } \\
\text { QUALIFIER }\end{array}$ & SAMP COMMENT & $\begin{array}{l}\text { RESULT } \\
\text { COMMENT }\end{array}$ \\
\hline SESPMNT & B17200 & RICH.PMPHS-10 HRM 46.4 & OFFSITE & SW & Y & RIVER T & TRANSECT & 10-Jun-03 TI & & & & & & B & 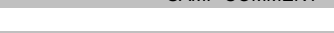 & \\
\hline SESPMNT & B171V4 & RICH.PMPHS-2 HRM46.4 & OFFSITE & sw & $\mathrm{N}$ & RIVER T & TRANSECT & 10-Jun-03 TI & & 0.0131 & ug/L $/ \mathrm{L}$ & & & B & & \\
\hline SESPMNT & B171Y6 & RICH.PMPHS-2 HRM46.4 & OFFSITE & sw & $\mathrm{Y}$ & RIVER T & TRANSECT & 10-Jun-03 TI & & 0.0125 & $\mathrm{ug} / \mathrm{L}$ & & & B & & \\
\hline SESPMNT & B171V5 & RICH.PMPHS-3 HRM46.4 & OFFSITE & sw & $\mathrm{N}$ & RIVER T & TRANSECT & 10-Jun-03 TI & & 0.0113 & $3 \mathrm{ug} / \mathrm{L}$ & & & B & & \\
\hline SESPMNT & B171Y7 & RICH.PMPHS-3 HRM46.4 & OFFSITE & sw & Y & RIVER & TRANSECT & 10-Jun-03 TI & & 0.0131 & $\mathrm{ug} / \mathrm{L}$ & & & B & & \\
\hline SESPMNT & B171V6 & RICH.PMPHS-5 HRM46.4 & OFFSITE & sw & $\mathrm{N}$ & RIVER 7 & TRANSECT & 10-Jun-03 TI & & 0.0114 & & & & B & & \\
\hline SESPMNT & B171Y8 & RICH.PMPHS-5 HRM46.4 & OFFSITE & sw & $\mathrm{Y}$ & RIVER 7 & TRANSECT & 10-Jun-03 TI & & & $3 \mathrm{ug} / \mathrm{L}$ & & & B & & \\
\hline SESPMNT & B171V7 & RICH.PMPHS-7 HRM46.4 & OFFSITE & SW & $\mathrm{N}$ & RIVER T & TRANSECT & 10-Jun-03 TI & & 0.00984 & & & & B & & \\
\hline SESPMNT & B171Y9 & RICH.PMPHS-7 HRM46.4 & OFFSITE & SW & $\mathrm{Y}$ & RIVER 7 & TRANSECT & 10-Jun-03 TI & & 0.0113 & $3 \mathrm{ug} / \mathrm{L}$ & & & B & & \\
\hline SESPMNT & B17CB6 & $100 \mathrm{~N}-1$ HRM 9.5 & ONSITE & sw & $\mathrm{N}$ & RIVER T & TRANSECT & 04-Sep-03 TI & & 0.0209 & $\mathrm{ug} / \mathrm{L}$ & & & & & \\
\hline SESPMNT & B17CM7 & $100 \mathrm{~N}-1$ HRM 9.5 & ONSITE & SW & $\mathrm{Y}$ & RIVER T & TRANSECT & 04-Sep-03 TI & & 0.0149 & $\mathrm{ug} / \mathrm{L}$ & & & B & & \\
\hline SESPMNT & B17CC1 & $100 \mathrm{~N}-10 \mathrm{HRM} 9.5$ & ONSITE & sw & $\mathrm{N}$ & RIVER 7 & TRANSECT & 04-Sep-03 TI & & 0.0195 & $\mathrm{ug} / \mathrm{L}$ & & & B & & \\
\hline SESPMNT & B17CN2 & $100 \mathrm{~N}-10$ HRM 9.5 & ONSITE & SW & $\mathrm{Y}$ & RIVER T & TRANSECT & 04-Sep-03 TI & & 0.0099 & & & & B & & \\
\hline SESPMNT & B17CB7 & $100 \mathrm{~N}-2$ HRM 9.5 & ONSITE & sw & $\mathrm{N}$ & RIVER T & TRANSECT & 04-Sep-03 TI & & 0.016 & $\mathrm{ug} / \mathrm{L}$ & & & B & & \\
\hline SESPMNT & B17CM8 & $100 \mathrm{~N}-2$ HRM 9.5 & ONSITE & sw & $\mathrm{Y}$ & RIVER 7 & TRANSECT & 04-Sep-03 TI & & 0.0105 & & & & B & & \\
\hline SESPMNT & B17CB8 & $100 \mathrm{~N}-3$ HRM 9.5 & ONSITE & sw & $\mathrm{N}$ & RIVER 7 & TRANSECT & 04-Sep-03 TI & & 0.0122 & & & & B & & \\
\hline SESPMNT & B17CM9 & $100 \mathrm{~N}-3$ HRM 9.5 & ONSITE & sw & Y & RIVER 7 & TRANSECT & 04-Sep-03 TI & & 0.0167 & $\mathrm{ug} / \mathrm{L}$ & & & B & & \\
\hline SESPMNT & B17CB9 & $100 \mathrm{~N}-5$ HRM 9.5 & ONSITE & SW & $\mathrm{N}$ & RIVER T & TRANSECT & 04-Sep-03 TI & & 0.017 & ug/L & & & B & & \\
\hline SESPMNT & B17CN0 & $100 \mathrm{~N}-5$ HRM 9.5 & ONSITE & sw & Y & RIVER T & TRANSECT & 04-Sep-03 TI & & 0.0132 & ug/L & & & B & & \\
\hline SESPMNT & B17CC0 & $100 \mathrm{~N}-7$ HRM 9.5 & ONSITE & sw & $\mathrm{N}$ & RIVER T & TRANSECT & 04-Sep-03 TI & & 0.0174 & & & & B & & \\
\hline SESPMNT & B17CN1 & $100 \mathrm{~N}-7$ HRM 9.5 & ONSITE & SW & Y & RIVER T & TRANSECT & 04-Sep-03 TI & & 0.0157 & & & & B & & \\
\hline SESPMNT & $\mathrm{B} 17 \mathrm{CV} 1$ & 100 N SHORE HRM 8.4 & ONSITE & sw & $\mathrm{N}$ & RIVER & TRANSECT & 04-Sep-03 TI & & 0.0106 & & & & B & & \\
\hline SESPMNT & $\mathrm{B} 17 \mathrm{CV} 2$ & 100 N SHORE HRM 8.4 & ONSITE & sw & $\mathrm{Y}$ & RIVER & TRANSECT & 04-Sep-03 TI & & 0.0191 & & & & B & & \\
\hline SESPMNT & B17CV5 & 100 N SHORE HRM 8.9 & ONSITE & sw & $\mathrm{N}$ & RIVER T & TRANSECT & 04-Sep-03 TI & & 0.0161 & $\mathrm{ug} / \mathrm{L}$ & & & B & & \\
\hline SESPMNT & B17CV6 & 100 N SHORE HRM 8.9 & ONSITE & sw & Y & RIVER & TRANSECT & 04-Sep-03 TI & & 0.0142 & igg/L & & & B & & \\
\hline SESPMNT & B17CV9 & 100 N SHORE HRM 9.2 & ONSITE & sw & $\mathrm{N}$ & RIVER 7 & TRANSECT & 04-Sep-03 TI & & 0.0206 & $\mathrm{iug} / \mathrm{L}$ & & & & & \\
\hline SESPMNT & B17CW0 & 100 N SHORE HRM 9.2 & ONSITE & sW & $\mathrm{Y}$ & RIVER T & TRANSECT & 04-Sep-03 TI & & 0.02 & $2 \mathrm{ug} / \mathrm{L}$ & & & & & \\
\hline SESPMNT & B17CW3 & 100 N SHORE HRM 9.8 & ONSITE & SW & $\mathrm{N}$ & RIVER 7 & TRANSECT & 04-Sep-03 TI & & 0.0142 & ing/L & & & B & & \\
\hline SESPMNT & B17CW4 & 100 N SHORE HRM 9.8 & ONSITE & sw & Y & RIVER T & TRANSECT & 04-Sep-03 TI & & 0.0137 & & & & B & & \\
\hline SESPMNT & B17CD6 & VERNITA-1 HRM 0.3 & OFFSITE & SW & $\mathrm{N}$ & RIVER T & TRANSECT & 04-Sep-03 TI & & 0.017 & & & & B & & \\
\hline SESPMNT & B17CM3 & VERNITA-1 HRM 0.3 & OFFSITE & sw & Y & RIVER T & TRANSECT & 04-Sep-03 TI & & 0.009 & & & & $u$ & & \\
\hline SESPMNT & B17CC7 & VERNITA-2 HRM 0.3 & OFFSITE & SW & $\mathrm{N}$ & RIVER T & TRANSECT & 04-Sep-03 TI & & 0.0136 & ug/L & & & B & & \\
\hline SESPMNT & B17CM4 & VERNITA-2 HRM 0.3 & OFFSITE & sw & Y & RIVER T & TRANSECT & 04-Sep-03 TI & & 0.0156 & ug/L & & & B & & \\
\hline SESPMNT & B17CC8 & VERNITA-3 HRM 0.3 & OFFSITE & sw & $\mathrm{N}$ & RIVER T & TRANSECT & 04-Sep-03 TI & & 0.0116 & ug/L & & & B & & \\
\hline SESPMNT & B17CM5 & VERNITA-3 HRM 0.3 & OFFSITE & SW & $\mathrm{Y}$ & RIVER T & TRANSECT & 04-Sep-03 TI & & 0.0154 & & & & B & & \\
\hline SESPMNT & B17CC9 & VERNITA-4 HRM 0.3 & OFFSITE & sw & $\mathrm{N}$ & RIVER 7 & TRANSECT & 04-Sep-03 TI & & 0.0151 & igg/L & & & B & & \\
\hline SESPMNT & B17CM6 & VERNITA-4 HRM 0.3 & OFFSITE & sw & $\mathrm{Y}$ & RIVER 7 & TRANSECT & 04-Sep-03 TI & & 0.0136 & $\mathrm{ug} / \mathrm{L}$ & & & B & & \\
\hline SESPMNT & B17CC2 & $100 \mathrm{~F}-1$ HRM 19.0 & ONSITE & SW & $\mathrm{N}$ & RIVER T & TRANSECT & 08-Sep-03 TI & & 0.0188 & & & & B & & \\
\hline SESPMNT & B17CR1 & $100 \mathrm{~F}-1$ HRM 19.0 & ONSITE & sw & Y & RIVER T & TRANSECT & 08-Sep-03 TI & & 0.0102 & ug/L $/ \mathrm{L}$ & & & B & & \\
\hline SESPMNT & B17C96 & $100 \mathrm{~F}-10$ HRM 19.0 & ONSITE & SW & $\mathrm{N}$ & RIVER T & TRANSECT & 08-Sep-03 TI & & 0.0104 & ing/L & & & B & & \\
\hline SESPMNT & B17CR6 & $100 \mathrm{~F}-10 \mathrm{HRM} 19.0$ & ONSITE & sw & Y & RIVER T & TRANSECT & 08-Sep-03 TI & & 0.017 & ug/L & & & B & & \\
\hline SESPMNT & B17CR2 & $100 \mathrm{~F}-2$ HRM 19.0 & ONSITE & sw & $\mathrm{Y}$ & RIVER & TRANSECT & 08-Sep-03 TI & & 0.0145 & ug/L & & & B & & \\
\hline SESPMNT & B17CC4 & 100 F - 3 HRM 19.0 & ONSITE & sw & $\mathrm{N}$ & RIVER & TRANSECT & 08-Sep-03 TI & & 0.0159 & ug/L & & & B & & \\
\hline SESPMNT & B17CR3 & $100 \mathrm{~F}-3$ HRM 19.0 & ONSITE & sw & $\mathrm{Y}$ & RIVER & TRANSECT & 08-Sep-03 TI & & 0.0119 & ug/L $/ 2$ & & & B & & \\
\hline SESPMNT & B17CR4 & $100 \mathrm{~F}-5$ HRM 19.0 & ONSITE & SW & $\mathrm{Y}$ & RIVER T & TRANSECT & 08-Sep-03 TI & & 0.0105 & & & & B & & \\
\hline SESPMNT & B17CR5 & $100 \mathrm{~F}-7$ HRM 19.0 & ONSITE & sw & Y & RIVER 7 & TRANSECT & 08-Sep-03 TI & & 0.015 & sug/L & & & B & & \\
\hline SESPMNT & B17CY5 & $100 \mathrm{~F}$ SHORE HRM 18 & ONSITE & SW & $\mathrm{N}$ & RIVER 7 & TRANSECT & 08-Sep-03 TI & & 0.009 & $\mathrm{ug} / \mathrm{L}$ & & & U & & \\
\hline SESPMNT & B17CY6 & $100 \mathrm{~F} \mathrm{SHORE} \mathrm{HRM} 18$ & ONSITE & sW & Y & RIVER T & TRANSECT & 08-Sep-03 TI & & 0.009 & $\mathrm{ug} / \mathrm{L}$ & & & u & & \\
\hline SESPMNT & B17CY8 & $100 \mathrm{~F}$ SHORE HRM 22 & ONSITE & sw & $\mathrm{N}$ & RIVER T & TRANSECT & 08-Sep-03 TI & & 0.009 & ug/L $/ \mathrm{L}$ & & & u & & \\
\hline SESPMNT & B17CY9 & $100 \mathrm{~F}$ SHORE HRM 22 & ONSITE & SW & $\mathrm{Y}$ & RIVER 7 & TRANSECT & 08-Sep-03 TI & & 0.009 & ing/L & & & U & & \\
\hline SESPMNT & B17D01 & $100 \mathrm{~F}$ SHORE HRM 23 & ONSITE & sw & $\mathrm{N}$ & RIVER 7 & TRANSECT & 08-Sep-03 TI & & 0.009 & ug/L $/ \mathrm{L}$ & & & u & & \\
\hline SESPMNT & B17D02 & $100 \mathrm{~F}$ SHORE HRM 23 & ONSITE & sw & $\mathrm{Y}$ & RIVER & TRANSECT & 08-Sep-03 TI & & 0.009 & & & & u & & \\
\hline SESPMNT & B17C97 & HANFRD TS-1 HRM 28.7 & ONSITE & sw & $\mathrm{N}$ & RIVER T & TRANSECT & 08-Sep-03 TI & & 0.0178 & 3 ug/L & & & B & & \\
\hline SESPMNT & B17CP5 & HANFRD TS-1 HRM 28.7 & ONSITE & sw & $\mathrm{Y}$ & RIVER T & TRANSECT & 08-Sep-03 TI & & 0.0188 & $3 \mathrm{ug} / \mathrm{L}$ & & & B & & \\
\hline SESPMNT & B17CB2 & HANFRD TS-10 HRM 28.7 & ONSITE & sw & $\mathrm{N}$ & RIVER 7 & TRANSECT & 08-Sep-03 TI & & 0.009 & $\mathrm{ug} / \mathrm{L}$ & & & U & & \\
\hline SESPMNT & B17CR0 & HANFRD TS-10 HRM 28.7 & ONSITE & sw & $\mathrm{Y}$ & RIVER T & TRANSECT & 08-Sep-03 TI & & 0.009 & $\mathrm{ug} / \mathrm{L}$ & & & U & & \\
\hline SESPMNT & B17C98 & HANFRD TS-2 HRM 28.7 & ONSITE & SW & $\mathrm{N}$ & RIVER T & TRANSECT & 08-Sep-03 TI & & 0.0188 & $3 \mathrm{ug} / \mathrm{L}$ & & & B & & \\
\hline SESPMNT & B17CP6 & HANFRD TS-2 HRM 28.7 & ONSITE & sw & Y & RIVER T & TRANSECT & 08-Sep-03 TI & & 0.011 & 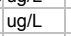 & & & B & & \\
\hline SESPMNT & B17C99 & HANFRD TS-3 HRM 28.7 & ONSITE & SW & $\mathrm{N}$ & RIVER T & TRANSECT & 08-Sep-03 TI & & 0.009 & $\mathrm{ug} / \mathrm{L}$ & & & $u$ & & \\
\hline SESPMNT & B17CP7 & HANFRD TS-3 HRM 28.7 & ONSITE & sw & Y & RIVER T & TRANSECT & 08-Sep-03 TI & & & $\mathrm{ug} / \mathrm{L}$ & & & u & & \\
\hline SESPMNT & B17CB0 & HANFRD TS-5 HRM 28.7 & ONSITE & sw & $\mathrm{N}$ & RIVER T & TRANSECT & 08-Sep-03 TI & & 0.009 & & & & U & & \\
\hline SESPMNT & B17CP8 & HANFRD TS-5 HRM 28.7 & ONSITE & sw & $\mathrm{Y}$ & RIVER T & TRANSECT & 08-Sep-03 TI & & 0.009 & ug/L & & & u & & \\
\hline
\end{tabular}


WATER - COLUMBIA RIVER TRANSECT

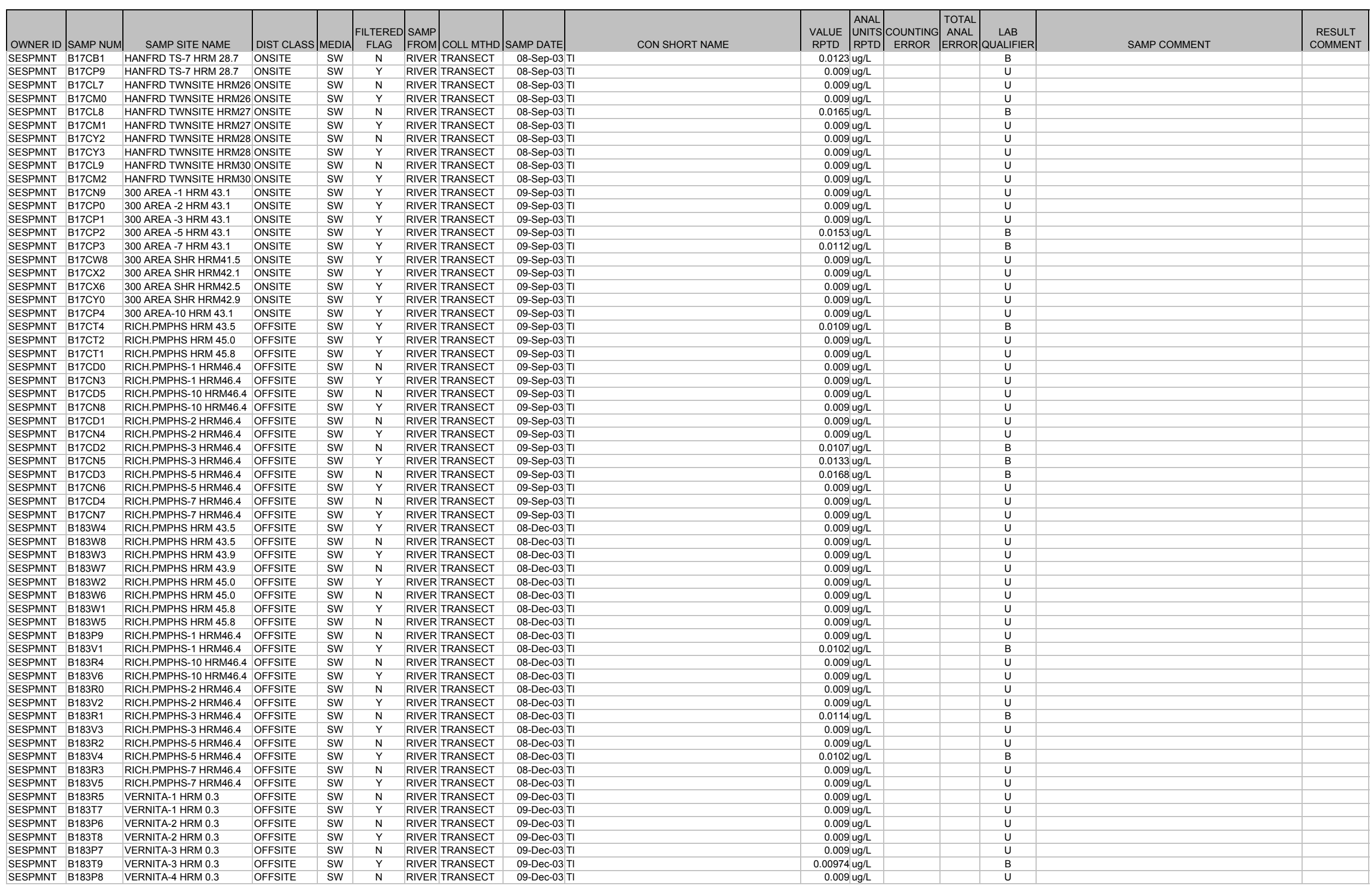


WATER - COLUMBIA RIVER TRANSECT

\begin{tabular}{|c|c|c|c|c|c|c|c|c|c|c|c|c|c|c|c|c|}
\hline | OWNER ID & SAMP NUM & SAMP SITE NAME & |DIST CLASS & MEDIA $\left.\right|^{\mid h}$ & \begin{tabular}{|c|} 
FILTERED \\
FLAG
\end{tabular} & $\begin{array}{l}\text { SAMP } \\
\text { FROM }\end{array}$ & COLL MTHD & SAMP DATE & CON SHORT NAME & $\begin{array}{l}\text { VALUE } \\
\text { RPTD }\end{array}$ & \begin{tabular}{|l|} 
ANAL \\
UNITS \\
RPTD
\end{tabular} & $\begin{array}{c}\text { COUNTING } \\
\text { ERROR }\end{array}$ & \begin{tabular}{|l|} 
TOTAL \\
ANAL \\
ERROR
\end{tabular} & $\begin{array}{c}\text { LAB } \\
\text { QUALIFIER }\end{array}$ & SAMP COMMENT & $\begin{array}{l}\text { RESULT } \\
\text { COMMENT }\end{array}$ \\
\hline SESPMNT & B183Vo & VERNITA-4 HRM 0.3 & OFFSITE & SW & Y & & TRANSECT & 09-Dec-03 TI & & & & & & & 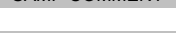 & \\
\hline SESPMNT & B16L95 & VERNITA-1 HRM 0.3 & OFFSITE & sw & $\mathrm{N}$ & RIVER T & TRANSECT & 24-Mar-03 Zn & & & $3 \mathrm{ug} / \mathrm{L}$ & & & & & \\
\hline SESPMNT & B16LB7 & VERNITA-1 HRM 0.3 & OFFSITE & sw & $\mathrm{Y}$ & RIVER T & TRANSECT & 24-Mar-03 Zn & & & ug/L $/ \mathrm{L}$ & & & c & & \\
\hline SESPMNT & B16L86 & VERNITA-2 HRM 0.3 & OFFSITE & SW & $\mathrm{N}$ & RIVER T & TRANSECT & 24-Mar-03 Zn & & & ug/L & & & & & \\
\hline SESPMNT & B16LB8 & VERNITA-2 HRM 0.3 & OFFSITE & sW & Y & RIVER & TRANSECT & 24-Mar-03 Zn & & & $\mathrm{ug} / \mathrm{L}$ & & & c & & \\
\hline SESPMNT & B16L87 & VERNITA-3 HRM 0.3 & OFFSITE & sW & $\mathrm{N}$ & RIVER 7 & TRANSECT & 24-Mar-03 Zn & & & & & & & & \\
\hline SESPMNT & B16LB9 & VERNITA-3 HRM 0.3 & OFFSITE & sw & $\mathrm{Y}$ & RIVER 7 & TRANSECT & 24-Mar-03 Zn & & & & & & C & & \\
\hline SESPMNT & B16L88 & VERNITA-4 HRM 0.3 & OFFSITE & sW & $\mathrm{N}$ & RIVER T & TRANSECT & 24-Mar-03 Zn & & & & & & & & \\
\hline SESPMNT & B16LC0 & VERNITA-4 HRM 0.3 & OFFSITE & SW & $\mathrm{Y}$ & RIVER 7 & TRANSECT & 24-Mar-03 Zn & & 1.37 & ug/L & & & C & & \\
\hline SESPMNT & B16LD4 & RICH.PMPHS HRM 43.5 & OFFSITE & sw & $\mathrm{Y}$ & RIVER T & TRANSECT & 25-Mar-03 Zn & & 1.13 & $3 \mathrm{ug} / \mathrm{L}$ & & & C & & \\
\hline SESPMNT & B16LD8 & RICH.PMPHS HRM 43.5 & OFFSITE & SW & $\mathrm{N}$ & RIVER T & TRANSECT & 25-Mar-03 Zn & & 1.91 & $\mathrm{ug} / \mathrm{L}$ & & & & & \\
\hline SESPMNT & B16LD3 & RICH.PMPHS HRM 43.9 & OFFSITE & sw & $\mathrm{Y}$ & RIVER 7 & TRANSECT & 25-Mar-03 Zn & & 1.65 & $\mathrm{sg} / \mathrm{L}$ & & & C & & \\
\hline SESPMNT & B16LD7 & RICH.PMPHS HRM 43.9 & OFFSITE & sW & $\mathrm{N}$ & RIVER T & TRANSECT & 25-Mar-03 Zn & & & $\mathrm{ug} / \mathrm{L}$ & & & & & \\
\hline SESPMNT & B16LD2 & RICH.PMPHS HRM 45.0 & OFFSITE & SW & $\mathrm{Y}$ & RIVER T & TRANSECT & 25-Mar-03 Zn & & 1.22 & ug/L $/ 2$ & & & c & & \\
\hline SESPMNT & B16LD6 & RICH.PMPHS HRM 45.0 & OFFSITE & sW & $\mathrm{N}$ & RIVER 7 & TRANSECT & 25-Mar-03 Zn & & & & & & & & \\
\hline SESPMNT & B16LD1 & RICH.PMPHS HRM 45.8 & OFFSITE & sw & $\mathrm{Y}$ & RIVER 7 & TRANSECT & 25-Mar-03 Zn & & & ug/L & & & C & & \\
\hline SESPMNT & B16LD5 & RICH.PMPHS HRM 45.8 & OFFSITE & sw & $\mathrm{N}$ & RIVER 7 & TRANSECT & 25-Mar-03 Zn & & 1.92 & igg/L & & & & & \\
\hline SESPMNT & B16L89 & RICH.PMPHS-1 HRM46.4 & OFFSITE & sW & $\mathrm{N}$ & RIVER T & TRANSECT & 25-Mar-03 Zn & & 2.07 & ug/L & & & & & \\
\hline SESPMNT & B16LC1 & RICH.PMPHS-1 HRM46.4 & OFFSITE & sw & Y & RIVER T & TRANSECT & 25-Mar-03 Zn & & & $3 \mathrm{ug} / \mathrm{L}$ & & & c & & \\
\hline SESPMNT & B16L94 & RICH.PMPHS-10 HRM46.4 & OFFSITE & SW & $\mathrm{N}$ & RIVER T & $\begin{array}{l}\text { TRANSECT } \\
\text { TRAT }\end{array}$ & $25-\mathrm{Mar}-03 \mathrm{Zn}$ & & & $3 \mathrm{ug} / \mathrm{L}$ & & & 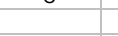 & & \\
\hline SESPMNT & B16LC6 & RICH.PMPHS-10 HRM46.4 & OFFSITE & sW & $\mathrm{Y}$ & RIVER T & TRANSECT & 25-Mar-03 Zn & & 1.64 & ing/L & & & C & & \\
\hline SESPMNT & B16L90 & RICH.PMPHS-2 HRM46.4 & OFFSITE & sW & $\mathrm{N}$ & RIVER & TRANSECT & 25-Mar-03 Zn & & 1.96 & $\mathrm{ug} / \mathrm{L}$ & & & & & \\
\hline SESPMNT & B16LC2 & RICH.PMPHS-2 HRM 46.4 & OFFSITE & sW & $\mathrm{Y}$ & RIVER 7 & TRANSECT & 25-Mar-03 Zn & & & $\mathrm{ug} / \mathrm{L}$ & & & C & & \\
\hline SESPMNT & B16L91 & RICH.PMPHS-3 HRM46.4 & OFFSITE & sw & $\mathrm{N}$ & RIVER T & TRANSECT & 25-Mar-03 Zn & & 2.03 & $3 \mathrm{ug} / \mathrm{L}$ & & & 列 & & \\
\hline SESPMNT & B16LC3 & RICH.PMPHS-3 HRM46.4 & OFFSITE & sW & $\mathrm{Y}$ & RIVER T & TRANSECT & 25-Mar-03 Zn & & 1.37 & ug/L & & & C & & \\
\hline SESPMNT & B16L92 & RICH.PMPHS-5 HRM46.4 & OFFSITE & sw & $\mathrm{N}$ & RIVER 7 & TRANSECT & 25-Mar-03 Zn & & & $3 \mathrm{ug} / \mathrm{L}$ & & & & & \\
\hline SESPMNT & B16LC4 & RICH.PMPHS-5 HRM46.4 & OFFSITE & sW & $\mathrm{Y}$ & RIVER T & TRANSECT & 25-Mar-03 Zn & & 1.36 & $\mathrm{igg} / \mathrm{L}$ & & & C & & \\
\hline SESPMNT & B16L93 & RICH.PMPHS-7 HRM46.4 & OFFSITE & sW & $\mathrm{N}$ & RIVER 7 & TRANSECT & 25-Mar-03 Zn & & 2.04 & ing/L & & & & & \\
\hline SESPMNT & B16LC5 & RICH.PMPHS-7 HRM46.4 & OFFSITE & sw & Y & RIVER T & TRANSECT & 25-Mar-03 Zn & & 1.31 & ug/L & & & c & & \\
\hline SESPMNT & B171V9 & VERNITA-1 HRM 0.3 & OFFSITE & sw & $\mathrm{N}$ & RIVER T & TRANSECT & 09-Jun-03 Zn & & & $3 \mathrm{ug} / \mathrm{L}$ & & & & & \\
\hline SESPMNT & B171Y1 & VERNITA-1 HRM 0.3 & OFFSITE & sw & $\mathrm{Y}$ & RIVER T & TRANSECT & 09-Jun-03 Zn & & 1.61 & $\mathrm{ug} / \mathrm{L}$ & & & & & \\
\hline SESPMNT & B171V0 & VERNITA-2 HRM 0.3 & OFFSITE & sW & $\mathrm{N}$ & RIVER T & TRANSECT & 09-Jun- $03 \mathrm{Zn}$ & & & ug/L & & & & & \\
\hline SESPMNT & B171Y2 & VERNITA-2 HRM 0.3 & OFFSITE & SW & $\mathrm{Y}$ & RIVER 7 & TRANSECT & 09-Jun-03 Zn & & 1.58 & $3 \mathrm{ug} / \mathrm{L}$ & & & & & \\
\hline SESPMNT & B171V1 & VERNITA-3 HRM 0.3 & OFFSITE & sw & $\mathrm{N}$ & RIVER T & TRANSECT & 09-Jun-03 Zn & & 2.95 & ug/L $/ 2$ & & & & & \\
\hline SESPMNT & B171Y3 & VERNITA-3 HRM 0.3 & OFFSITE & sW & $\mathrm{Y}$ & RIVER T & TRANSECT & 09-Jun- $03 \mathrm{Zn}$ & & 1.69 & igg/L & & & & & \\
\hline SESPMNT & B171V2 & VERNITA-4 HRM 0.3 & OFFSITE & sw & $\mathrm{N}$ & RIVER T & TRANSECT & 09-Jun-03 Zn & & 3.14 & igg/L & & & & & \\
\hline SESPMNT & B171Y4 & VERNITA-4 HRM 0.3 & OFFSITE & sw & $\mathrm{Y}$ & RIVER 7 & TRANSECT & 09-Jun-03 Zn & & 1.44 & ing/L & & & & & \\
\hline SESPMNT & B17208 & RICH.PMPHS HRM 43.5 & OFFSITE & sW & $\mathrm{Y}$ & RIVER T & TRANSECT & 10-Jun-03 Zn & & & & & & & & \\
\hline SESPMNT & B17212 & RICH.PMPHS HRM 43.5 & OFFSITE & sw & $\mathrm{N}$ & RIVER T & TRANSECT & 10-Jun-03 Zn & & & 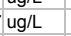 & & & & & \\
\hline SESPMNT & B17207 & RICH.PMPHS HRM 43.9 & OFFSITE & sW & $\mathrm{Y}$ & RIVER T & TRANSECT & 10-Jun-03 Zn & & 1.75 & $\mathrm{sug} / \mathrm{L}$ & & & & & \\
\hline SESPMNT & B17211 & RICH.PMPHS HRM 43.9 & OFFSITE & sw & $\mathrm{N}$ & RIVER T & TRANSECT & 10-Jun-03 Zn & & 3.73 & $3 \mathrm{ug} / \mathrm{L}$ & & & & & \\
\hline SESPMNT & B17206 & RICH.PMPHS HRM 45.0 & OFFSITE & sW & Y & RIVER 7 & TRANSECT & 10-Jun-03 Zn & & 1.73 & 3 ug/L & & & & & \\
\hline SESPMNT & B17210 & RICH.PMPHS HRM 45.0 & OFFSITE & sw & $\mathrm{N}$ & RIVER & TRANSECT & 10-Jun-03 Zn & & 3.79 & ug/L & & & & & \\
\hline SESPMNT & B17205 & RICH.PMPHS HRM 45.8 & OFFSITE & sw & $\mathrm{Y}$ & RIVER T & $\begin{array}{l}\text { TRANSECT } \\
\text { TRAT }\end{array}$ & 10-Jun-03 Zn & & 1.65 & 3 ug/L & & & & & \\
\hline SESPMNT & B17209 & RICH.PMPHS HRM 45.8 & OFFSITE & sW & $\mathrm{N}$ & RIVER 7 & TRANSECT & 10-Jun-03 Zn & & & $\mathrm{ug} / \mathrm{L}$ & & & & & \\
\hline SESPMNT & B171V3 & RICH.PMPHS-1 HRM46.4 & OFFSITE & sw & $\mathrm{N}$ & RIVER 7 & TRANSECT & 10-Jun-03 Zn & & & & & & & & \\
\hline SESPMNT & B171Y5 & RICH.PMPHS-1 HRM46.4 & OFFSITE & sW & $\mathrm{Y}$ & RIVER 7 & TRANSECT & 10-Jun-03 Zn & & & $3 \mathrm{ug} / \mathrm{L}$ & & & & & \\
\hline SESPMNT & B171V8 & RICH.PMPHS-10 HRM46.4 & OFFSITE & sw & $\mathrm{N}$ & RIVER T & TRANSECT & 10-Jun-03 Zn & & 3.35 & $3 \mathrm{ug} / \mathrm{L}$ & & & & & \\
\hline SESPMNT & B17200 & RICH.PMPHS-10 HRM46.4 & OFFSITE & sW & $\mathrm{Y}$ & RIVER T & TRANSECT & 10-Jun-03 Zn & & 1.48 & $3 \mathrm{ug} / \mathrm{L}$ & & & & & \\
\hline SESPMNT & B171V4 & RICH.PMPHS-2 HRM46.4 & OFFSITE & sW & $\mathrm{N}$ & RIVER 7 & TRANSECT & 10-Jun-03 Zn & & 3.75 & $3 \mathrm{ug} / \mathrm{L}$ & & & & & \\
\hline SESPMNT & B171Y6 & RICH.PMPHS-2 HRM46.4 & OFFSITE & sw & $\mathrm{Y}$ & RIVER T & TRANSECT & 10-Jun-03 Zn & & & $3 \mathrm{ug} / \mathrm{L}$ & & & & & \\
\hline SESPMNT & B171V5 & RICH.PMPHS-3 HRM46.4 & OFFSITE & sW & $\mathrm{N}$ & RIVER T & TRANSECT & 10-Jun-03 Zn & & 4.25 & $\mathrm{ug} / \mathrm{L}$ & & & & & \\
\hline SESPMNT & B171Y7 & RICH.PMPHS-3 HRM46.4 & OFFSITE & sw & Y & RIVER T & TRANSECT & 10-Jun-03 Zn & & 1.86 & ug/L & & & & & \\
\hline SESPMNT & B171V6 & RICH.PMPHS-5 HRM46.4 & OFFSITE & sW & $\mathrm{N}$ & RIVER 7 & TRANSECT & 10-Jun-03 Zn & & 3.42 & ing/L & & & & & \\
\hline SESPMNT & B171Y8 & RICH.PMPHS-5 HRM46.4 & OFFSITE & sw & $\mathrm{Y}$ & RIVER 7 & TRANSECT & 10-Jun-03 Zn & & & igg/L & & & & & \\
\hline SESPMNT & B171V7 & RICH.PMPHS-7 HRM46.4 & OFFSITE & sW & $\mathrm{N}$ & RIVER T & TRANSECT & 10-Jun-03 Zn & & & ug/L & & & & & \\
\hline SESPMNT & B171Y9 & RICH.PMPHS-7 HRM46.4 & OFFSITE & sW & $\mathrm{Y}$ & RIVER T & TRANSECT & 10-Jun-03 Zn & & & $\mathrm{ug} / \mathrm{L}$ & & & & & \\
\hline SESPMNT & B17CB6 & $100 \mathrm{~N}-1 \mathrm{HRM} 9.5$ & ONSITE & SW & $\mathrm{N}$ & RIVER T & TRANSECT & 04-Sep-03 Zn & & 1.15 & ug/L $/ 2$ & & & & & \\
\hline SESPMNT & B17CM7 & $100 \mathrm{~N}-1$ HRM 9.5 & ONSITE & sW & $\mathrm{Y}$ & RIVER T & TRANSECT & 04-Sep-03 Zn & & 0.993 & $3 \mathrm{ug} / \mathrm{L}$ & & & & & \\
\hline SESPMNT & B17CC1 & $100 \mathrm{~N}-10$ HRM 9.5 & ONSITE & sw & $\mathrm{N}$ & RIVER T & TRANSECT & 04-Sep-03 Zn & & 1.06 & $\mathrm{iug} / \mathrm{L}$ & & & & & \\
\hline SESPMNT & B17CN2 & $100 \mathrm{~N}-10$ HRM 9.5 & ONSITE & SW & $\mathrm{Y}$ & RIVER 7 & TRANSECT & 04-Sep-03 Zn & & 0.696 & ug/L $/ 2$ & & & & & \\
\hline SESPMNT & B17CB7 & $100 \mathrm{~N}-2$ HRM 9.5 & ONSITE & sw & $\mathrm{N}$ & RIVER T & TRANSECT & $04-S e p-03 Z \mathrm{Zn}$ & & 1.13 & $3 \mathrm{ug} / \mathrm{L}$ & & & & & \\
\hline
\end{tabular}


WATER - COLUMBIA RIVER TRANSECT

\begin{tabular}{|c|c|c|c|c|c|c|c|c|c|c|c|c|c|c|c|c|}
\hline | OWNER ID & SAMP NUM & SAMP SITE NAME & |DIST CLASS | & MEDIA $\left.\right|^{\mid h}$ & \begin{tabular}{|c|} 
FILTERED \\
FLAG
\end{tabular} & $\begin{array}{l}\text { SAMP } \\
\text { FROM }\end{array}$ & COLL MTHD & SAMP DATE & CON SHORT NAME & $\begin{array}{l}\text { VALUE } \\
\text { RPTD }\end{array}$ & \begin{tabular}{|l|} 
ANAL \\
UNITS \\
RPTD \\
\end{tabular} & $\begin{array}{c}\text { COUNTING } \\
\text { ERROR }\end{array}$ & \begin{tabular}{|c|c|} 
TOTAL \\
ANAL \\
ANROR
\end{tabular} & $\begin{array}{c}\text { LAB } \\
\text { QUALIFIER }\end{array}$ & SAMP COMMENT & $\begin{array}{l}\text { RESULT } \\
\text { COMMENT }\end{array}$ \\
\hline SESPMNT & B17CM8 & $100 \mathrm{~N}-2$ HRM 9.5 & ONSITE & SW & & & TRANSECT & 04-Sep-03 Zn & & & & & & & - & \\
\hline SESPMNT & B17CB8 & $100 \mathrm{~N}-3$ HRM 9.5 & ONSITE & sw & $\mathrm{N}$ & RIVER & TRANSECT & 04-Sep-03 Zn & & & $\mathrm{ug} / \mathrm{L}$ & & & & & \\
\hline SESPMNT & B17CM9 & $100 \mathrm{~N}-3$ HRM 9.5 & ONSITE & sw & $\mathrm{Y}$ & RIVER & TRANSECT & 04-Sep-03 Zn & & 0.748 & $\mathrm{ug} / \mathrm{L}$ & & & & & \\
\hline SESPMNT & B17CB9 & $100 \mathrm{~N}-5$ HRM 9.5 & ONSITE & SW & $\mathrm{N}$ & RIVER & TRANSECT & 04-Sep-03 Zn & & 1.14 & ug/L & & & & & \\
\hline SESPMNT & B17CNO & $100 \mathrm{~N}-5$ HRM 9.5 & ONSITE & sW & Y & RIVER & TRANSECT & 04-Sep-03 Zn & & 0.807 & $\mathrm{ug} / \mathrm{L}$ & & & & & \\
\hline SESPMNT & B17CCO & $100 \mathrm{~N}-7$ HRM 9.5 & ONSITE & sW & $\mathrm{N}$ & RIVER & TRANSECT & 04-Sep-03 Zn & & & & & & & & \\
\hline SESPMNT & B17CN1 & $100 \mathrm{~N}-7$ HRM 9.5 & ONSITE & sw & $\mathrm{Y}$ & RIVER & TRANSECT & 04-Sep-03 Zn & & & & & & & & \\
\hline SESPMNT & B17CV1 & 100 N SHORE HRM 8.4 & ONSITE & sW & $\mathrm{N}$ & RIVER & TRANSECT & 04-Sep-03 Zn & & & & & & & & \\
\hline SESPMNT & B17CV2 & 100 N SHORE HRM 8.4 & ONSITE & SW & $\mathrm{Y}$ & RIVER & TRANSECT & 04-Sep-03 Zn & & 0.673 & $3 \mathrm{ug} / \mathrm{L}$ & & & & & \\
\hline SESPMNT & B17CV5 & $100 \mathrm{~N}$ SHORE HRM 8.9 & ONSITE & sw & $\mathrm{N}$ & RIVER & TRANSECT & 04-Sep-03 Zn & & 1.04 & ing/L & & & & & \\
\hline SESPMNT & B17CV6 & 100 N SHORE HRM 8.9 & ONSITE & sw & $\mathrm{Y}$ & RIVER & TRANSECT & $04-S e p-03 Z \mathrm{Zn}$ & & 0.634 & ing/L & & & & & \\
\hline SESPMNT & B17CV9 & $100 \mathrm{~N}$ SHORE HRM 9.2 & ONSITE & sw & $\mathrm{N}$ & RIVER & TRANSECT & 04-Sep-03 Zn & & 1.31 & $\mathrm{ug} / \mathrm{L}$ & & & & & \\
\hline SESPMNT & B17CW0 & $100 \mathrm{~N}$ SHORE HRM 9.2 & ONSITE & sW & $\mathrm{Y}$ & RIVER & TRANSECT & 04-Sep-03 Zn & & 0.661 & & & & & & \\
\hline SESPMNT & B17CW3 & 100 N SHORE HRM 9.8 & ONSITE & SW & $\mathrm{N}$ & RIVER & TRANSECT & 04-Sep-03 Zn & & 1.08 & $3 \mathrm{ug} / \mathrm{L}$ & & & & & \\
\hline SESPMNT & B17CW4 & 100 N SHORE HRM 9.8 & ONSITE & sW & $\mathrm{Y}$ & RIVER & TRANSECT & 04-Sep-03 Zn & & 0.638 & & & & & & \\
\hline SESPMNT & B17CD6 & VERNITA-1 HRM 0.3 & OFFSITE & sw & $\mathrm{N}$ & RIVER & TRANSECT & 04-Sep-03 Zn & & & igg/L & & & & & \\
\hline SESPMNT & B17CM3 & VERNITA-1 HRM 0.3 & OFFSITE & sw & Y & RIVER & TRANSECT & 04-Sep-03 Zn & & 0.731 & ug/L $/ \mathrm{L}$ & & & & & \\
\hline SESPMNT & B17CC7 & VERNITA-2 HRM 0.3 & OFFSITE & sW & $\mathrm{N}$ & RIVER & TRANSECT & 04-Sep-03 Zn & & 1.29 & $\mathrm{ug} / \mathrm{L}$ & & & & & \\
\hline SESPMNT & B17CM4 & VERNITA-2 HRM 0.3 & OFFSITE & sW & Y & RIVER & TRANSECT & 04-Sep-03 Zn & & 0.95 & $3 \mathrm{ug} / \mathrm{L}$ & & & & & \\
\hline SESPMNT & B17CC8 & VERNITA-3 HRM 0.3 & OFFSITE & SW & $\mathrm{N}$ & RIVER & TRANSECT & 04-Sep-03 Zn & & 1.25 & ugg/L & & & & & \\
\hline SESPMNT & B17CM5 & VERNITA-3 HRM 0.3 & OFFSITE & SW & $\mathrm{Y}$ & RIVER & TRANSECT & 04-Sep-03 Zn & & 0.875 & & & & & & \\
\hline SESPMNT & B17CC9 & VERNITA-4 HRM 0.3 & OFFSITE & sw & $\mathrm{N}$ & RIVER & TRANSECT & 04-Sep-03 Zn & & 1.64 & & & & & & \\
\hline SESPMNT & B17CM6 & VERNITA-4 HRM 0.3 & OFFSITE & sW & $\mathrm{Y}$ & RIVER & TRANSECT & 04-Sep-03 Zn & & 0.995 & $\mathrm{ug} / \mathrm{L}$ & & & & & \\
\hline SESPMNT & B17CC2 & $100 \mathrm{~F}-1$ HRM 19.0 & ONSITE & sw & $\mathrm{N}$ & RIVER & TRANSECT & 08-Sep-03 Zn & & 1.56 & $\mathrm{ug} / \mathrm{L}$ & & & & & \\
\hline SESPMNT & B17CR1 & $100 \mathrm{~F}-1$ HRM 19.0 & ONSITE & sw & $\mathrm{Y}$ & RIVER & TRANSECT & 08-Sep-03 Zn & & 1.17 & ug/L & & & & & \\
\hline SESPMNT & B17C96 & $100 \mathrm{~F}-10 \mathrm{HRM} 19.0$ & ONSITE & sW & $\mathrm{N}$ & RIVER & TRANSECT & $08-S e p-03 \mathrm{Zn}$ & & 1.54 & ing/L & & & & & \\
\hline SESPMNT & B17CR6 & $100 \mathrm{~F}-10 \mathrm{HRM} 19.0$ & ONSITE & sW & $\mathrm{Y}$ & RIVER & TRANSECT & 08-Sep-03 Zn & & 0.639 & $\mathrm{ug} / \mathrm{L}$ & & & & & \\
\hline SESPMNT & B17CR2 & $100 \mathrm{~F}-2$ HRM 19.0 & ONSITE & SW & Y & RIVER & TRANSECT & $08-\mathrm{Sep}-03 \mathrm{Zn}$ & & 0.752 & ing/L & & & & & \\
\hline SESPMNT & B17CC4 & 100 F -3 HRM 19.0 & ONSITE & sw & $\mathrm{N}$ & RIVER & TRANSECT & $08-\mathrm{Sep}-03 \mathrm{Zn}$ & & 1.25 & $\mathrm{jug} / \mathrm{L}$ & & & & & \\
\hline SESPMNT & B17CR3 & 100 F -3 HRM 19.0 & ONSITE & sW & $\mathrm{Y}$ & RIVER & TRANSECT & 08-Sep-03 Zn & & 0.833 & & & & & & \\
\hline SESPMNT & B17CR4 & 100 F - 5 HRM 19.0 & ONSITE & sw & Y & RIVER & TRANSECT & $08-S e p-03 Z n$ & & 0.756 & & & & & & \\
\hline SESPMNT & B17CR5 & 100 F - 7 HRM 19.0 & ONSITE & SW & Y & RIVER & TRANSECT & 08-Sep-03 Zn & & 0.681 & ug/L $/ 2$ & & & & & \\
\hline SESPMNT & B17CY5 & 100 F SHORE HRM 18 & ONSITE & SW & $\mathrm{N}$ & RIVER & TRANSECT & $08-\mathrm{Sep}-03 \mathrm{Zn}$ & & 1.64 & ing/L & & & & & \\
\hline SESPMNT & B17CY6 & $100 \mathrm{~F}$ SHORE HRM 18 & ONSITE & sw & Y & RIVER & TRANSECT & $08-S e p-03 Z n$ & & 1.24 & igg/L & & & & & \\
\hline SESPMNT & B17CY8 & $100 \mathrm{~F}$ SHORE HRM 22 & ONSITE & sW & $\mathrm{N}$ & RIVER & TRANSECT & $08-S e p-03 Z n$ & & 2.48 & $3 \mathrm{ug} / \mathrm{L}$ & & & & & \\
\hline SESPMNT & B17CY9 & 100 F SHORE HRM 22 & ONSITE & sw & $\mathrm{Y}$ & RIVER & TRANSECT & $08-S e p-03 Z n$ & & 1.56 & $\mathrm{ing} / \mathrm{L}$ & & & & & \\
\hline SESPMNT & B17D01 & $100 \mathrm{~F}$ SHORE HRM 23 & ONSITE & sw & $\mathrm{N}$ & RIVER & TRANSECT & $08-S e p-03 Z n$ & & 2.43 & $3 \mathrm{ug} / \mathrm{L}$ & & & & & \\
\hline SESPMNT & B17D02 & $100 \mathrm{~F}$ SHORE HRM 23 & ONSITE & sW & $\mathrm{Y}$ & RIVER & TRANSECT & $08-\operatorname{Sep}-03 \mathrm{Zn}$ & & 1.72 & & & & & & \\
\hline SESPMNT & B17C97 & HANFRD TS-1 HRM 28.7 & ONSITE & sw & $\mathrm{N}$ & RIVER & TRANSECT & $08-S e p-03 \mathrm{Zn}$ & & 1.23 & $3 \mathrm{ug} / \mathrm{L}$ & & & & & \\
\hline SESPMNT & B17CP5 & HANFRD TS-1 HRM 28.7 & ONSITE & sW & $\mathrm{Y}$ & RIVER & TRANSECT & $08-\mathrm{Sep}-03 \mathrm{Zn}$ & & 0.885 & $3 \mathrm{ug} / \mathrm{L}$ & & & & & \\
\hline SESPMNT & B17CB2 & HANFRD TS-10 HRM 28.7 & ONSITE & sw & $\mathrm{N}$ & RIVER & TRANSECT & $08-\mathrm{Sep}-03 \mathrm{Zn}$ & & 2.77 & $\mathrm{ug} / \mathrm{L}$ & & & & & \\
\hline SESPMNT & B17CR0 & HANFRD TS-10 HRM 28.7 & ONSITE & sW & $\mathrm{Y}$ & RIVER & TRANSECT & $08-S e p-03 Z n$ & & & $\mathrm{ug} / \mathrm{L}$ & & & & & \\
\hline SESPMNT & B17C98 & HANFRD TS-2 HRM 28.7 & ONSITE & sw & $\mathrm{N}$ & RIVER & TRANSECT & 08-Sep-03 Zn & & 1.32 & ug/L & & & & & \\
\hline SESPMNT & B17CP6 & HANFRD TS-2 HRM 28.7 & ONSITE & sW & $\mathrm{Y}$ & RIVER & TRANSECT & 08-Sep-03 Zn & & 0.796 & $\mathrm{ug} / \mathrm{L}$ & & & & & \\
\hline SESPMNT & B17C99 & HANFRD TS-3 HRM 28.7 & ONSITE & sW & $\mathrm{N}$ & RIVER & TRANSECT & $08-S e p-03 Z n$ & & & ing/L & & & & & \\
\hline SESPMNT & B17CP7 & HANFRD TS-3 HRM 28.7 & ONSITE & sw & $\mathrm{Y}$ & RIVER & TRANSECT & $08-S e p-03 Z n$ & & & $\mathrm{sg} / \mathrm{L}$ & & & & & \\
\hline SESPMNT & B17CB0 & HANFRD TS-5 HRM 28.7 & ONSITE & sW & $\mathrm{N}$ & RIVER & TRANSECT & $08-S e p-03 Z n$ & & & ing/L & & & & & \\
\hline SESPMNT & B17CP8 & HANFRD TS-5 HRM 28.7 & ONSITE & sw & Y & RIVER & TRANSECT & $08-S e p-03 Z n$ & & & $3 \mathrm{ug} / \mathrm{L}$ & & & & & \\
\hline SESPMNT & B17CB1 & HANFRD TS-7 HRM 28.7 & ONSITE & SW & $\mathrm{N}$ & RIVER & TRANSECT & 08-Sep-03 Zn & & & ug/L/L & & & & & \\
\hline SESPMNT & B17CP9 & HANFRD TS-7 HRM 28.7 & ONSITE & sW & $\mathrm{Y}$ & RIVER & TRANSECT & 08-Sep-03 Zn & & 1.18 & $3 \mathrm{ug} / \mathrm{L}$ & & & & & \\
\hline SESPMNT & B17CL7 & HANFRD TWNSITE HRM26 & 6 ONSITE & sw & $\mathrm{N}$ & RIVER & TRANSECT & $08-S e p-03 Z n$ & & 2.16 & ug/L & & & & & \\
\hline SESPMNT & B17CM0 & HANFRD TWNSITE HRM 26 & 6 ONSITE & sW & $\mathrm{Y}$ & RIVER & TRANSECT & $08-S e p-03 Z n$ & & 1.22 & ug/L & & & & & \\
\hline SESPMNT & B17CL8 & HANFRD TWNSITE HRM27 & 7 ONSITE & sw & $\mathrm{N}$ & RIVER & TRANSECT & $08-\mathrm{Sep}-03 \mathrm{Zn}$ & & 2.47 & 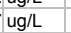 & & & & & \\
\hline SESPMNT & B17CM1 & HANFRD TWNSITE HRM27 & 7 ONSITE & SW & $\mathrm{Y}$ & RIVER & TRANSECT & $08-S e p-03$ Zn & & 1.64 & ug/L $/ 2$ & & & & & \\
\hline SESPMNT & B17CY2 & HANFRD TWNSITE HRM28 & 3 ONSITE & sw & $\mathrm{N}$ & RIVER & TRANSECT & 08-Sep-03 Zn & & 2.26 & $\mathrm{ing} / \mathrm{L}$ & & & & & \\
\hline SESPMNT & B17CY3 & HANFRD TWNSITE HRM28 & 3 ONSITE & sW & $\mathrm{Y}$ & RIVER & TRANSECT & 08-Sep-03 Zn & & 2.24 & igg/L & & & & & \\
\hline SESPMNT & B17CL9 & HANFRD TWNSITE HRM30 & ONSITE & sW & $\mathrm{N}$ & RIVER & TRANSECT & 08-Sep-03 Zn & & 2.24 & ing/L & & & & & \\
\hline SESPMNT & B17CM2 & HANFRD TWNSITE HRM30 & ONSITE & SW & Y & RIVER & TRANSECT & 08-Sep-03 Zn & & 1.62 & ug/L $/ 2$ & & & & & \\
\hline SESPMNT & B17CN9 & 300 AREA - 1 HRM 43.1 & ONSITE & sW & $\mathrm{Y}$ & RIVER & TRANSECT & $09-S e p-03 Z n$ & & 1.58 & $3 \mathrm{ug} / \mathrm{L}$ & & & & & \\
\hline SESPMNT & B17CP0 & 300 AREA - 2 HRM 43.1 & ONSITE & sw & $\mathrm{Y}$ & RIVER & TRANSECT & $09-S e p-03 Z \mathrm{Zn}$ & & & $3 \mathrm{ug} / \mathrm{L}$ & & & & & \\
\hline SESPMNT & B17CP1 & 300 AREA -3 HRM 43.1 & ONSITE & SW & $\mathrm{Y}$ & RIVER & TRANSECT & 09-Sep-03 Zn & & & $3 \mathrm{ug} / \mathrm{L}$ & & & & & \\
\hline SESPMNT & B17CP2 & 300 AREA - 5 HRM 43.1 & ONSITE & sw & Y & RIVER & TRANSECT & $09-S e p-03 \mathrm{Zn}$ & & & 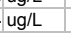 & & & & & \\
\hline
\end{tabular}


WATER - COLUMBIA RIVER TRANSECT

\begin{tabular}{|c|c|c|c|c|c|c|c|c|c|c|c|c|c|c|c|c|}
\hline | OWNER ID & | SAMP NUM| & SAMP SITE NAME & DIST CLASS & $\mid$ MEDIA & \begin{tabular}{|c|} 
FILTERED \\
FLAG
\end{tabular} & $\begin{array}{l}\text { SAMP } \\
\text { FROM }\end{array}$ & COLL MTHD & SAMP DATE & CON SHORT NAME & $\begin{array}{c}\text { VALUE } \\
\text { RPTD }\end{array}$ & \begin{tabular}{|l|} 
ANAL \\
UNITS \\
RPTD \\
\end{tabular} & \begin{tabular}{|c|} 
COUNTING \\
ERROR
\end{tabular} & 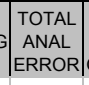 & $\begin{array}{c}\text { LAB } \\
\text { QUALIFIER }\end{array}$ & SAMP COMMENT & $\begin{array}{l}\text { RESULT } \\
\text { COMMENT }\end{array}$ \\
\hline SESPMNT & B17CP3 & 300 AREA -7 HRM 43.1 & ONSITE & SW & Y & RIVER & TRANSECT & 09-Sep-03 Zn & & & & & & & 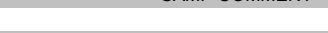 & \\
\hline SESPMNT & B17CW8 & 300 AREA SHR HRM41.5 & ONSITE & sw & $\mathrm{Y}$ & RIVER & TRANSECT & 09-Sep-03 Zn & & & $\mathrm{ug} / \mathrm{L}$ & & & & & \\
\hline SESPMNT & $B 17 C \times 2$ & 300 AREA SHR HRM42.1 & ONSITE & sw & Y & RIVER & TRANSECT & $09-S e p-03 Z n$ & & & $\mathrm{ug} / \mathrm{L}$ & & & & & \\
\hline SESPMNT & B17CX6 & 300 AREA SHR HRM 42.5 & ONSITE & sw & $\mathrm{Y}$ & RIVER & TRANSECT & $09-S \mathrm{pp}-03 \mathrm{Zn}$ & & 1.97 & ug/L & & & & & \\
\hline SESPMNT & B17CY0 & 300 AREA SHR HRM42.9 & ONSITE & sw & Y & RIVER & TRANSECT & 09-Sep-03 Zn & & & $3 \mathrm{gg} / \mathrm{L}$ & & & & & \\
\hline SESPMNT & B17CP4 & 300 AREA-10 HRM 43.1 & ONSITE & sw & $\mathrm{Y}$ & RIVER & TRANSECT & 09-Sep-03 Zn & & & & & & & & \\
\hline SESPMNT & B17CT4 & RICH.PMPHS HRM 43.5 & OFFSITE & sw & $\mathrm{Y}$ & RIVER & TRANSECT & 09-Sep-03 Zn & & & & & & & & \\
\hline SESPMNT & B17CT2 & RICH.PMPHS HRM 45.0 & OFFSITE & sw & $\mathrm{Y}$ & RIVER & TRANSECT & 09-Sep-03 Zn & & & & & & & & \\
\hline SESPMNT & B17CT1 & RICH.PMPHS HRM 45.8 & OFFSITE & sw & $\mathrm{Y}$ & RIVER & TRANSECT & 09-Sep-03 Zn & & 1.37 & ug/L & & & & & \\
\hline SESPMNT & B17CD0 & RICH.PMPHS-1 HRM46.4 & OFFSITE & sw & $\mathrm{N}$ & RIVER & TRANSECT & 09-Sep-03 Zn & & 1.63 & $3 \mathrm{ug} / \mathrm{L}$ & & & & & \\
\hline SESPMNT & B17CN3 & RICH.PMPHS-1 HRM46.4 & OFFSITE & sw & $\mathrm{Y}$ & RIVER & TRANSECT & 09-Sep-03 Zn & & 1.03 & $3 \mathrm{ug} / \mathrm{L}$ & & & & & \\
\hline SESPMNT & B17CD5 & RICH.PMPHS-10 HRM46.4 & OFFSITE & sw & $\mathrm{N}$ & RIVER & TRANSECT & 09-Sep-03 Zn & & 2.22 & & & & & & \\
\hline SESPMNT & B17CN8 & RICH.PMPHS-10 HRM46.4 & OFFSITE & sw & $\mathrm{Y}$ & RIVER & TRANSECT & 09-Sep-03 Zn & & 1.83 & & & & & & \\
\hline SESPMNT & B17CD1 & RICH.PMPHS-2 HRM46.4 & OFFSITE & sw & $\mathrm{N}$ & RIVER & TRANSECT & $09-S e p-03 \mathrm{Zn}$ & & & $3 \mathrm{ug} / \mathrm{L}$ & & & & & \\
\hline SESPMNT & B17CN4 & RICH.PMPHS-2 HRM46.4 & OFFSITE & sw & $\mathrm{Y}$ & RIVER & TRANSECT & 09-Sep-03 Zn & & & & & & & & \\
\hline SESPMNT & B17CD2 & RICH.PMPHS-3 HRM46.4 & OFFSITE & sw & $\mathrm{N}$ & RIVER & TRANSECT & 09-Sep-03 Zn & & & & & & & & \\
\hline SESPMNT & B17CN5 & RICH.PMPHS-3 HRM46.4 & OFFSITE & sw & Y & RIVER & TRANSECT & 09-Sep-03 Zn & & 1.56 & $\mathrm{ug} / \mathrm{L}$ & & & & & \\
\hline SESPMNT & B17CD3 & RICH.PMPHS-5 HRM46.4 & OFFSITE & sw & $\mathrm{N}$ & RIVER & TRANSECT & 09-Sep-03 Zn & & 2.32 & ing/L & & & & & \\
\hline SESPMNT & B17CN6 & RICH.PMPHS-5 HRM46.4 & OFFSITE & sw & Y & RIVER & TRANSECT & 09-Sep-03 Zn & & 1.34 & $\mathrm{ug} / \mathrm{L}$ & & & & & \\
\hline SESPMNT & B17CD4 & RICH.PMPHS-7 HRM46.4 & OFFSITE & sw & $\mathrm{N}$ & RIVER & TRANSECT & $09-\mathrm{Sep}-03 \mathrm{Zn}$ & & 1.64 & & & & & & \\
\hline SESPMNT & B17CN7 & RICH.PMPHS-7 HRM46.4 & OFFSITE & sw & $\mathrm{Y}$ & RIVER & TRANSECT & 09-Sep-03 Zn & & & & & & & & \\
\hline SESPMNT & B183W4 & RICH.PMPHS HRM 43.5 & OFFSITE & sw & Y & RIVER & TRANSECT & 08-Dec-03 Zn & & 0.941 & & & & & & \\
\hline SESPMNT & B183W8 & RICH.PMPHS HRM 43.5 & OFFSITE & sw & $\mathrm{N}$ & RIVER & TRANSECT & 08 -Dec-03 Zn & & 1.47 & & & & & & \\
\hline SESPMNT & B183W3 & RICH.PMPHS HRM 43.9 & OFFSITE & sw & $\mathrm{Y}$ & RIVER & TRANSECT & 08 -Dec-03 Zn & & 0.619 & ug/ $/ \mathrm{L}$ & & & & & \\
\hline SESPMNT & B183W7 & RICH.PMPHS HRM 43.9 & OFFSITE & sw & $\mathrm{N}$ & RIVER & TRANSECT & 08-Dec-03 Zn & & & $3 \mathrm{ug} / \mathrm{L}$ & & & & & \\
\hline SESPMNT & B183W2 & RICH.PMPHS HRM 45.0 & OFFSITE & sw & $\mathrm{Y}$ & RIVER & TRANSECT & 08-Dec-03 Zn & & 0.584 & & & & & & \\
\hline SESPMNT & B183W6 & RICH.PMPHS HRM 45.0 & OFFSITE & sw & $\mathrm{N}$ & RIVER & TRANSECT & 08-Dec-03 Zn & & 0.805 & $5 \mathrm{ug} / \mathrm{L}$ & & & & & \\
\hline SESPMNT & B183W1 & RICH.PMPHS HRM 45.8 & OFFSITE & sw & $\mathrm{Y}$ & RIVER & TRANSECT & 08-Dec-03 Zn & & 0.59 & $\mathrm{ug} / \mathrm{L}$ & & & & & \\
\hline SESPMNT & B183W5 & RICH.PMPHS HRM 45.8 & OFFSITE & sw & $\mathrm{N}$ & RIVER & TRANSECT & 08-Dec-03 Zn & & 0.816 & & & & & & \\
\hline SESPMNT & B183P9 & RICH.PMPHS-1 HRM46.4 & OFFSITE & sw & $\mathrm{N}$ & RIVER & TRANSECT & 08-Dec-03 Zn & & 0.601 & & & & & & \\
\hline SESPMNT & B183V1 & RICH.PMPHS-1 HRM46.4 & OFFSITE & sw & $\mathrm{Y}$ & RIVER & TRANSECT & 08-Dec-03 Zn & & 0.484 & & & & & & \\
\hline SESPMNT & B183R4 & RICH.PMPHS-10 HRM46.4 & OFFSITE & sw & $\mathrm{N}$ & RIVER & TRANSECT & 08-Dec-03 Zn & & 2.81 & ug/L $/ \mathrm{L}$ & & & & & \\
\hline SESPMNT & B183v6 & RICH.PMPHS-10 HRM46. 4 & OFFSITE & sw & $\mathrm{Y}$ & RIVER & TRANSECT & 08 -Dec-03 Zn & & 0.546 & ug/L & & & & & \\
\hline SESPMNT & B183R0 & RICH.PMPHS-2 HRM46.4 & OFFSITE & sw & $\mathrm{N}$ & RIVER & TRANSECT & 08-Dec-03 Zn & & 0.824 & & & & & & \\
\hline SESPMNT & B183V2 & RICH.PMPHS-2 HRM46.4 & OFFSITE & sw & $\mathrm{Y}$ & RIVER & TRANSECT & 08-Dec-03 Zn & & 0.707 & & & & & & \\
\hline SESPMNT & B183R1 & RICH.PMPHS-3 HRM 46.4 & OFFSITE & sw & $\mathrm{N}$ & RIVER & TRANSECT & 08-Dec-03 Zn & & 0.97 & & & & & & \\
\hline SESPMNT & B183V3 & RICH.PMPHS-3 HRM46.4 & OFFSITE & sw & $\mathrm{Y}$ & RIVER & TRANSECT & 08-Dec-03 Zn & & 0.562 & & & & & & \\
\hline SESPMNT & B183R2 & RICH.PMPHS-5 HRM46.4 & OFFSITE & sw & $\mathrm{N}$ & RIVER & TRANSECT & 08-Dec-03 Zn & & & $\mathrm{ug} / \mathrm{L}$ & & & & & \\
\hline SESPMNT & B183V4 & RICH.PMPHS-5 HRM46.4 & OFFSITE & sw & $\mathrm{Y}$ & RIVER & TRANSECT & 08 -Dec-03 Zn & & 0.613 & $3 \mathrm{ug} / \mathrm{L}$ & & & & & \\
\hline SESPMNT & B183R3 & RICH.PMPHS-7 HRM46.4 & OFFSITE & sw & $\mathrm{N}$ & RIVER & TRANSECT & 08-Dec-03 Zn & & 0.956 & $\mathrm{ing} / \mathrm{L}$ & & & & & \\
\hline SESPMNT & B183V5 & RICH.PMPHS-7 HRM46.4 & OFFSITE & sw & Y & RIVER & TRANSECT & 08-Dec-03 Zn & & 0.55 & $\mathrm{ug} / \mathrm{L}$ & & & & & \\
\hline SESPMNT & B183R5 & VERNITA-1 HRM 0.3 & OFFSITE & sw & $\mathrm{N}$ & RIVER & TRANSECT & 09-Dec-03 Zn & & 0.971 & ug/L & & & & & \\
\hline SESPMNT & B183T7 & VERNITA-1 HRM 0.3 & OFFSITE & sw & $\mathrm{Y}$ & RIVER & TRANSECT & 09-Dec-03 Zn & & 0.536 & $\mathrm{ug} / \mathrm{L}$ & & & & & \\
\hline SESPMNT & B183P6 & VERNITA-2 HRM 0.3 & OFFSITE & sw & $\mathrm{N}$ & RIVER & TRANSECT & 09-Dec-03 Zn & & & & & & & & \\
\hline SESPMNT & B183T8 & VERNITA-2 HRM 0.3 & OFFSITE & sw & $\mathrm{Y}$ & RIVER & TRANSECT & 09-Dec-03 Zn & & 0.617 & & & & & & \\
\hline SESPMNT & B183P7 & VERNITA-3 HRM 0.3 & OFFSITE & sw & $\mathrm{N}$ & RIVER & TRANSECT & 09-Dec-03 Zn & & 1.04 & & & & & & \\
\hline SESPMNT & B183T9 & VERNITA-3 HRM 0.3 & OFFSITE & sW & $\mathrm{Y}$ & RIVER & TRANSECT & 09-Dec-03 Zn & & 0.835 & $\mathrm{sug} / \mathrm{L}$ & & & & & \\
\hline SESPMNT & B183P8 & VERNITA-4 HRM 0.3 & OFFSITE & sw & $\mathrm{N}$ & RIVER & TRANSECT & 09-Dec-03 Zn & & 1.72 & ug/L & & & & & \\
\hline SESPMNT & B183V0 & VERNITA-4 HRM 0.3 & OFFSITE & sw & $\mathrm{Y}$ & RIVER & TRANSECT & 09-Dec-03 Zn & & 1.31 & ug/L & & & & & \\
\hline SESPMNT & B16KC6 & RICH.PMPHS-10 HRM46.4 & OFFSITE & sw & $\mathrm{N}$ & RIVER & TRANSECT & 25-Mar-03 CHLORIDE & & & $\mathrm{mg} / \mathrm{L}$ & & & C & & \\
\hline SESPMNT & B16KC7 & RICH.PMPHS-1 HRM46.4 & OFFSITE & sw & $\mathrm{N}$ & RIVER & TRANSECT & 25-Mar-03 CHLORIDE & & & $\mathrm{mg} / \mathrm{L}$ & & & $\mathrm{c}$ & & \\
\hline SESPMNT & B16KC8 & RICH.PMPHS-2 HRM46.4 & OFFSITE & sw & $\mathrm{N}$ & RIVER & TRANSECT & 25-Mar-03 CHLORIDE & & & $\mathrm{mg} / \mathrm{L}$ & & & C & & \\
\hline SESPMNT & B16KC9 & RICH.PMPHS-3 HRM46.4 & OFFSITE & sw & $\mathrm{N}$ & RIVER & TRANSECT & 25-Mar-03 CHLORIDE & & & $\mathrm{mg} / \mathrm{L}$ & & & c & & \\
\hline SESPMNT & B16KD0 & RICH.PMPHS-5 HRM46.4 & OFFSITE & sw & $\mathrm{N}$ & RIVER & TRANSECT & 25-Mar-03 CHLORIDE & & & $\mathrm{mg} / \mathrm{L}$ & & & $\mathrm{c}$ & & \\
\hline SESPMNT & B16KD1 & RICH.PMPHS-7 HRM46.4 & OFFSITE & sw & $\mathrm{N}$ & RIVER - & TRANSECT & 25-Mar-03 CHLORIDE & & & $\mathrm{mg} / \mathrm{L}$ & & & C & & \\
\hline SESPMNT & B16KD2 & RICH.PMPHS HRM 43.5 & OFFSITE & sW & $\mathrm{N}$ & RIVER & TRANSECT & 25-Mar-03 CHLORIDE & & & $\mathrm{mg} / \mathrm{L}$ & & & C & & \\
\hline SESPMNT & B16KD3 & RICH.PMPHS HRM 43.9 & OFFSITE & sW & $\mathrm{N}$ & RIVER & TRANSECT & 25-Mar-03 CHLORIDE & & & $\mathrm{mg} / \mathrm{L}$ & & & C & & \\
\hline SESPMNT & B16KD4 & RICH.PMPHS HRM 45.0 & OFFSITE & SW & $\mathrm{N}$ & RIVER & TRANSECT & 25-Mar-03 CHLORIDE & & & $3 \mathrm{mg} / \mathrm{L}$ & & & $\mathrm{c}$ & & \\
\hline SESPMNT & B16KD5 & RICH.PMPHS HRM 45.8 & OFFSITE & sW & $\mathrm{N}$ & RIVER & TRANSECT & 25-Mar-03 CHLORIDE & & & $\mathrm{mg} / \mathrm{L}$ & & & C & & \\
\hline SESPMNT & B16KD6 & VERNITA-1 HRM 0.3 & OFFSITE & sw & $\mathrm{N}$ & RIVER & TRANSECT & 24-Mar-03 CHLORIDE & & & & & & c & & \\
\hline SESPMNT & B16KD7 & VERNITA-2 HRM 0.3 & OFFSITE & sw & $\mathrm{N}$ & RIVER & TRANSECT & 24-Mar-03 CHLORIDE & & & $\mathrm{mg} / \mathrm{L}$ & & & $\mathrm{C}$ & & \\
\hline SESPMNT & B16KD8 & VERNITA-3 HRM 0.3 & OFFSITE & sw & $\mathrm{N}$ & RIVER & TRANSECT & 24-Mar-03 CHLORIDE & & & $\mathrm{mg} / \mathrm{L}$ & & & C & & \\
\hline
\end{tabular}


WATER - COLUMBIA RIVER TRANSEC

\begin{tabular}{|c|c|c|c|c|c|c|c|c|c|c|c|c|c|c|c|c|}
\hline | OWNER ID & SAMP NUM & SAMP SITE NAME & DIST CLASS & $\mid$ MEDIA & \begin{tabular}{|c|} 
FILTERED \\
FLAG
\end{tabular} & $\begin{array}{l}\text { SAMP } \\
\text { FROM }\end{array}$ & COLL MTHD & SAMP DATE & CON SHORT NAME & $\begin{array}{l}\text { VALUE } \\
\text { RPTD }\end{array}$ & \begin{tabular}{|c|} 
ANAL \\
UNITS \\
RPTD
\end{tabular} & $\begin{array}{c}\text { COUNTING } \\
\text { ERROR }\end{array}$ & $=\begin{array}{l}\text { TOTAL } \\
\text { ANAL } \\
\text { ERROR }\end{array}$ & $\begin{array}{c}\text { LAB } \\
\text { QUALIFIER }\end{array}$ & SAMP COMMENT & $\begin{array}{l}\text { RESULT } \\
\text { COMMENT }\end{array}$ \\
\hline SESPMNT & B16KD9 & VERNITA-4 HRM 0.3 & OFFSITE & SW & $\mathrm{N}$ & RIVER & TRANSECT & 24-Mar-03 CHLORIDE & & & & & & $\mathrm{C}$ & & \\
\hline SESPMNT & B17276 & RICH.PMPHS-10 HRM46.4 & OFFSITE & sw & $\mathrm{N}$ & RIVER & TRANSECT & 10-Jun-03 CHLORIDE & & & $3 \mathrm{mg} / \mathrm{L}$ & & & & & \\
\hline SESPMNT & B17277 & RICH.PMPHS-1 HRM46.4 & OFFSITE & sw & $\mathrm{N}$ & RIVER & TRANSECT & 10-Jun-03 CHLORIDE & & 0.97 & $7 \mathrm{mg} / \mathrm{L}$ & & & & & \\
\hline SESPMNT & B17278 & RICH.PMPHS-2 HRM46.4 & OFFSITE & sw & $\mathrm{N}$ & RIVER & TRANSECT & 10-Jun-03 CHLORIDE & & 0.97 & $7 \mathrm{mg} / \mathrm{L}$ & & & & & \\
\hline SESPMNT & B17279 & RICH.PMPHS-3 HRM46.4 & OFFSITE & sw & $\mathrm{N}$ & RIVER & TRANSECT & 10-Jun-03 CHLORIDE & & & $6 \mathrm{mg} / \mathrm{L}$ & & & & & \\
\hline SESPMNT & B17280 & RICH.PMPHS-5 HRM46.4 & OFFSITE & sw & $\mathrm{N}$ & RIVER & TRANSECT & 10-Jun-03 CHLORIDE & & & $1 \mathrm{mg} / \mathrm{L}$ & & & & & \\
\hline SESPMNT & B17281 & RICH.PMPHS-7 HRM46.4 & OFFSITE & sw & $\mathrm{N}$ & RIVER & TRANSECT & 10-Jun-03 CHLORIDE & & & & & & & & \\
\hline SESPMNT & B17282 & RICH.PMPHS HRM 43.5 & OFFSITE & sw & $\mathrm{N}$ & RIVER & TRANSECT & 10-Jun-03 CHLORIDE & & & & & & & & \\
\hline SESPMNT & B17283 & RICH.PMPHS HRM 43.9 & OFFSITE & sw & $\mathrm{N}$ & RIVER & TRANSECT & 10-Jun-03 CHLORIDE & & & $7 \mathrm{mg} / \mathrm{L}$ & & & & & \\
\hline SESPMNT & B17284 & RICH.PMPHS HRM 45.0 & OFFSITE & sw & $\mathrm{N}$ & RIVER & TRANSECT & 10-Jun-03 CHLORIDE & & 0.99 & $9 \mathrm{mg} / \mathrm{L}$ & & & & & \\
\hline SESPMNT & B17285 & RICH.PMPHS HRM 45.8 & OFFSITE & sw & $\mathrm{N}$ & RIVER & TRANSECT & 10-Jun-03 CHLORIDE & & & $1 \mathrm{mg} / \mathrm{L}$ & & & & & \\
\hline SESPMNT & B17286 & VERNITA-1 HRM 0.3 & OFFSITE & sw & $\mathrm{N}$ & RIVER & TRANSECT & 09-Jun-03 CHLORIDE & & 0.93 & $3 \mathrm{mg} / \mathrm{L}$ & & & & & \\
\hline SESPMNT & B17287 & VERNITA-2 HRM 0.3 & OFFSITE & sw & $\mathrm{N}$ & RIVER & TRANSECT & 09-Jun-03 CHLORIDE & & 0.93 & $3 \mathrm{mg} / \mathrm{L}$ & & & & & \\
\hline SESPMNT & B17288 & VERNITA-3 HRM 0.3 & OFFSITE & sw & $\mathrm{N}$ & RIVER & TRANSECT & 09-Jun-03 CHLORIDE & & & $9 \mathrm{mg} / \mathrm{L}$ & & & & & \\
\hline SESPMNT & B17289 & VERNITA-4 HRM 0.3 & OFFSITE & sw & $\mathrm{N}$ & RIVER & TRANSECT & 09-Jun-03 CHLORIDE & & & $1 \mathrm{mg} / \mathrm{L}$ & & & & & \\
\hline SESPMNT & B17HF0 & $100 \mathrm{~F}-10 \mathrm{HRM} 19.0$ & ONSITE & sw & $\mathrm{N}$ & RIVER & TRANSECT & 08-Sep-03 CHLORIDE & & & $3 \mathrm{mg} / \mathrm{L}$ & & & & & \\
\hline SESPMNT & B17HF1 & $100 \mathrm{~F}-1$ HRM 19.0 & ONSITE & sw & $\mathrm{N}$ & RIVER & TRANSECT & 08-Sep-03 CHLORIDE & & & $1 \mathrm{mg} / \mathrm{L}$ & & & & & \\
\hline SESPMNT & B17HF2 & $100 \mathrm{~F}-2 \mathrm{HRM} 19.0$ & ONSITE & sw & $\mathrm{N}$ & RIVER & TRANSECT & 08-Sep-03 CHLORIDE & & & $1 \mathrm{mg} / \mathrm{L}$ & & & & & \\
\hline SESPMNT & B17HF3 & 100 F -3 HRM 19.0 & ONSITE & sw & $\mathrm{N}$ & RIVER & TRANSECT & 08-Sep-03 CHLORIDE & & & $1 \mathrm{mg} / \mathrm{L}$ & & & & & \\
\hline SESPMNT & B17HF4 & 100 F - 5 HRM 19.0 & ONSITE & sw & $\mathrm{N}$ & RIVER & TRANSECT & 08-Sep-03 CHLORIDE & & & $1 \mathrm{mg} / \mathrm{L}$ & & & & & \\
\hline SESPMNT & B17HF5 & 100 F - 7 HRM 19.0 & ONSITE & sw & $\mathrm{N}$ & RIVER - & TRANSECT & 08-Sep-03 CHLORIDE & & & $1 \mathrm{mg} / \mathrm{L}$ & & & & & \\
\hline SESPMNT & B17HF6 & $100 \mathrm{~F}$ SHORE HRM 18 & ONSITE & sw & $\mathrm{N}$ & RIVER & TRANSECT & 08-Sep-03 CHLORIDE & & & $1 \mathrm{mg} / \mathrm{L}$ & & & & & \\
\hline SESPMNT & B17HF7 & $100 \mathrm{~F}$ SHORE HRM 22 & ONSITE & sw & $\mathrm{N}$ & RIVER & TRANSECT & 08-Sep-03 CHLORIDE & & & $1 \mathrm{mg} / \mathrm{L}$ & & & & & \\
\hline SESPMNT & B17HF8 & $100 \mathrm{~F}$ SHORE HRM 23 & ONSITE & sw & $\mathrm{N}$ & RIVER & TRANSECT & 08-Sep-03 CHLORIDE & & & $1 \mathrm{mg} / \mathrm{L}$ & & & & & \\
\hline SESPMNT & B17HF9 & $100 \mathrm{~N}-1$ HRM 9.5 & ONSITE & sw & $\mathrm{N}$ & RIVER & TRANSECT & 04-Sep-03 CHLORIDE & & & $9 \mathrm{mg} / \mathrm{L}$ & & & C & & \\
\hline SESPMNT & $\mathrm{B} 17 \mathrm{HHO}$ & $100 \mathrm{~N}-10 \mathrm{HRM} 9.5$ & ONSITE & sw & $\mathrm{N}$ & RIVER & TRANSECT & 04-Sep-03 CHLORIDE & & & $1 \mathrm{mg} / \mathrm{L}$ & & & & & \\
\hline SESPMNT & B17HH1 & $100 \mathrm{~N}-2$ HRM 9.5 & ONSITE & sw & $\mathrm{N}$ & RIVER & TRANSECT & 04-Sep-03 CHLORIDE & & & $1 \mathrm{mg} / \mathrm{L}$ & & & C & & \\
\hline SESPMNT & B17HH2 & $100 \mathrm{~N}-3$ HRM 9.5 & ONSITE & sw & $\mathrm{N}$ & RIVER & TRANSECT & 04-Sep-03 CHLORIDE & & 0.89 & $9 \mathrm{mg} / \mathrm{L}$ & & & C & & \\
\hline SESPMNT & $\mathrm{B} 17 \mathrm{HH} 3$ & $100 \mathrm{~N}-5$ HRM 9.5 & ONSITE & sw & $\mathrm{N}$ & RIVER & TRANSECT & 04-Sep-03 CHLORIDE & & 0.92 & & & & & & \\
\hline SESPMNT & B17HH4 & $100 \mathrm{~N}-7$ HRM 9.5 & ONSITE & sw & $\mathrm{N}$ & RIVER & TRANSECT & 04-Sep-03 CHLORIDE & & & $9 \mathrm{mg} / \mathrm{L}$ & & & & & \\
\hline SESPMNT & B17HH5 & 100 N SHORE HRM 8.4 & ONSITE & sw & $\mathrm{N}$ & RIVER & TRANSECT & 04-Sep-03 CHLORIDE & & & $6 \mathrm{mg} / \mathrm{L}$ & & & c & & \\
\hline SESPMNT & B17HH6 & $100 \mathrm{~N}$ SHORE HRM 8.9 & ONSITE & sW & $\mathrm{N}$ & RIVER & TRANSECT & 04-Sep-03 CHLORIDE & & & $2 \mathrm{mg} / \mathrm{L}$ & & & C & & \\
\hline SESPMNT & B17HH7 & 100 N SHORE HRM 9.2 & ONSITE & sw & $\mathrm{N}$ & RIVER & TRANSECT & 04-Sep-03 CHLORIDE & & & $3 \mathrm{mg} / \mathrm{L}$ & & & c & & \\
\hline SESPMNT & B17HH8 & 100 N SHORE HRM 9.8 & ONSITE & sw & $\mathrm{N}$ & RIVER & TRANSECT & 04-Sep-03 CHLORIDE & & & $4 \mathrm{mg} / \mathrm{L}$ & & & C & & \\
\hline SESPMNT & B17HH9 & 300 AREA - 1 HRM 43.1 & ONSITE & sw & $\mathrm{N}$ & RIVER & TRANSECT & 09-Sep-03 CHLORIDE & & & $9 \mathrm{mg} / \mathrm{L}$ & & & C & & \\
\hline SESPMNT & B17HJO & 300 AREA-10 HRM 43.1 & ONSITE & sw & $\mathrm{N}$ & RIVER & TRANSECT & 09-Sep-03 CHLORIDE & & & $9 \mathrm{mg} / \mathrm{L}$ & & & C & & \\
\hline SESPMNT & B17HJ1 & 300 AREA -2 HRM 43.1 & ONSITE & sw & $\mathrm{N}$ & RIVER & TRANSECT & 09-Sep-03 CHLORIDE & & & $1 \mathrm{mg} / \mathrm{L}$ & & & C & & \\
\hline SESPMNT & B17HJ2 & 300 AREA -3 HRM 43.1 & ONSITE & sw & $\mathrm{N}$ & RIVER & TRANSECT & 09-Sep-03 CHLORIDE & & & $1 \mathrm{mg} / \mathrm{L}$ & & & C & & \\
\hline SESPMNT & B17HJ3 & 300 AREA -5 HRM 43.1 & ONSITE & sw & $\mathrm{N}$ & RIVER & TRANSECT & 09-Sep-03 CHLORIDE & & & $1 \mathrm{mg} / \mathrm{L}$ & & & $\mathrm{c}$ & & \\
\hline SESPMNT & B17HJ4 & 300 AREA -7 HRM 43.1 & ONSITE & sW & $\mathrm{N}$ & RIVER & TRANSECT & 09-Sep-03 CHLORIDE & & & $2 \mathrm{mg} / \mathrm{L}$ & & & C & & \\
\hline SESPMNT & B17HJ5 & 300 AREA SHR HRM41.5 & ONSITE & sw & $\mathrm{N}$ & RIVER & TRANSECT & 09-Sep-03 CHLORIDE & & & $1 \mathrm{mg} / \mathrm{L}$ & & & $\mathrm{c}$ & & \\
\hline SESPMNT & B17HJ6 & 300 AREA SHR HRM42.1 & ONSITE & sw & $\mathrm{N}$ & RIVER & TRANSECT & 09-Sep-03 CHLORIDE & & & $3 \mathrm{mg} / \mathrm{L}$ & & & C & & \\
\hline SESPMNT & B17HJ7 & 300 AREA SHR HRM 42.5 & ONSITE & sw & $\mathrm{N}$ & RIVER & TRANSECT & 09-Sep-03 CHLORIDE & & & $7 \mathrm{mg} / \mathrm{L}$ & & & c & & \\
\hline SESPMNT & B17HJ8 & & ONSITE & sw & $\mathrm{N}$ & RIVER & TRANSECT & 09-Sep-03 CHLORIDE & & & $5 \mathrm{mg} / \mathrm{L}$ & & & c & & \\
\hline SESPMNT & B17HJ9 & HANFRD TS-1 HRM 28.7 & ONSITE & sw & $\mathrm{N}$ & RIVER & TRANSECT & 08-Sep-03 CHLORIDE & & & $6 \mathrm{mg} / \mathrm{L}$ & & & & & \\
\hline SESPMNT & B17HKO & HANFRD TS-2 HRM 28.7 & ONSITE & sw & $\mathrm{N}$ & RIVER & TRANSECT & 08-Sep-03 CHLORIDE & & 0.98 & $8 \mathrm{mg} / \mathrm{L}$ & & & C & & \\
\hline SESPMNT & B17HK1 & HANFRD TS-3 HRM 28.7 & ONSITE & sw & $\mathrm{N}$ & RIVER & TRANSECT & 08-Sep-03 CHLORIDE & & 0.97 & $7 \mathrm{mg} / \mathrm{L}$ & & & C & & \\
\hline SESPMNT & B17HK2 & HANFRD TS-5 HRM 28.7 & ONSITE & sw & $\mathrm{N}$ & RIVER & TRANSECT & 08-Sep-03 CHLORIDE & & 0.97 & $7 \mathrm{mg} / \mathrm{L}$ & & & c & & \\
\hline SESPMNT & B17HK3 & HANFRD TS-7 HRM 28.7 & ONSITE & sw & $\mathrm{N}$ & RIVER & TRANSECT & 08-Sep-03 CHLORIDE & & & $2 \mathrm{mg} / \mathrm{L}$ & & & c & & \\
\hline SESPMNT & B17HK4 & HANFRD TS-10 HRM 28.7 & ONSITE & sw & $\mathrm{N}$ & RIVER & TRANSECT & 08-Sep-03 CHLORIDE & & & $1 \mathrm{mg} / \mathrm{L}$ & & & C & & \\
\hline SESPMNT & B17HK5 & HANFRD TWNSITE HRM26 & ONSITE & sw & $\mathrm{N}$ & RIVER & TRANSECT & 08-Sep-03 CHLORIDE & & 0.96 & $6 \mathrm{mg} / \mathrm{L}$ & & & $\mathrm{c}$ & & \\
\hline SESPMNT & B17HK6 & HANFRD TWNSITE HRM27 & ONSITE & sw & $\mathrm{N}$ & RIVER & TRANSECT & 08-Sep-03 CHLORIDE & & & $1 \mathrm{mg} / \mathrm{L}$ & & & c & & \\
\hline SESPMNT & B17HK7 & HANFRD TWNSITE HRM28 & ONSITE & sw & $\mathrm{N}$ & RIVER & TRANSECT & 08-Sep-03 CHLORIDE & & & $1 \mathrm{mg} / \mathrm{L}$ & & & $\mathrm{c}$ & & \\
\hline SESPMNT & B17HK8 & HANFRD TWNSITE HRM30 & ONSITE & sw & $\mathrm{N}$ & RIVER & TRANSECT & 08-Sep-03 CHLORIDE & & & $3 \mathrm{mg} / \mathrm{L}$ & & & C & & \\
\hline SESPMNT & B17HL6 & RICH.PMPHS HRM 43.9 & OFFSITE & sw & $\mathrm{N}$ & RIVER - & TRANSECT & 09-Sep-03 ANIONS & & & & & & & NO SAMPLE. THICK MILFOIL. & \\
\hline SESPMNT & B17HK9 & RICH.PMPHS-1 HRM46.4 & OFFSITE & sW & $\mathrm{N}$ & RIVER & TRANSECT & 09-Sep-03 CHLORIDE & & & $2 \mathrm{mg} / \mathrm{L}$ & & & C & & \\
\hline SESPMNT & B17HLO & RICH.PMPHS-2 HRM46.4 & OFFSITE & sW & $\mathrm{N}$ & RIVER & TRANSECT & 09-Sep-03 CHLORIDE & & & $1 \mathrm{mg} / \mathrm{L}$ & & & C & & \\
\hline SESPMNT & B17HL1 & RICH.PMPHS-3 HRM46.4 & OFFSITE & SW & $\mathrm{N}$ & RIVER & TRANSECT & 09-Sep-03 CHLORIDE & & & $1 \mathrm{mg} / \mathrm{L}$ & & & $\mathrm{c}$ & & \\
\hline SESPMNT & B17HL2 & RICH.PMPHS-5 HRM46.4 & OFFSITE & sW & $\mathrm{N}$ & RIVER & TRANSECT & 09-Sep-03 CHLORIDE & & & $1 \mathrm{mg} / \mathrm{L}$ & & & C & & \\
\hline SESPMNT & B17HL3 & RICH.PMPHS-7 HRM46.4 & OFFSITE & sw & $\mathrm{N}$ & RIVER & TRANSECT & 09-Sep-03 CHLORIDE & & & $1 \mathrm{mg} / \mathrm{L}$ & & & c & & \\
\hline SESPMNT & B17HL4 & RICH.PMPHS-10 HRM46.4 & OFFSITE & SW & $\mathrm{N}$ & RIVER & TRANSECT & 09-Sep-03 CHLORIDE & & & $5 \mathrm{mg} / \mathrm{L}$ & & & c & & \\
\hline SESPMNT & B17HL5 & RICH.PMPHS HRM 43.5 & OFFSITE & sw & $\mathrm{N}$ & RIVER & TRANSECT & 09-Sep-03 CHLORIDE & & & $8 \mathrm{mg} / \mathrm{L}$ & & & c & & \\
\hline
\end{tabular}


WATER - COLUMBIA RIVER TRANSECT

\begin{tabular}{|c|c|c|c|c|c|c|c|c|c|c|c|c|c|c|c|c|}
\hline | OWNER ID & |SAMP NUM| & SAMP SITE NAME & DIST CLASS & $\mid$ MEDIA & \begin{tabular}{|c|} 
FILTERED \\
FLAG
\end{tabular} & $\begin{array}{l}\text { SAMP } \\
\text { FROM }\end{array}$ & COLL MTHD & SAMP DATE & CON SHORT NAME & $\begin{array}{c}\text { VALUE } \\
\text { RPTD }\end{array}$ & \begin{tabular}{|l|l|} 
ANAL \\
UNITS \\
RPTD \\
\end{tabular} & $\begin{array}{c}\text { COUNTING } \\
\text { ERROR }\end{array}$ & \begin{tabular}{|c|} 
TOTAL \\
ANAL \\
ERROR
\end{tabular} & $\begin{array}{c}\text { LAB } \\
\text { QUALIFIER }\end{array}$ & SAMP COMMENT & $\begin{array}{l}\text { RESULT } \\
\text { COMMENT }\end{array}$ \\
\hline SESPMNT & B17HL7 & RICH.PMPHS HRM 45.0 & OFFSITE & SW & $\mathrm{N}$ & RIVER & TRANSECT & 09-Sep-03 CHLORIDE & & & & & & $\mathrm{C}$ & & \\
\hline SESPMNT & B17HL8 & RICH.PMPHS HRM 45.8 & OFFSITE & sw & $\mathrm{N}$ & RIVER & TRANSECT & 09-Sep-03 CHLORIDE & & & $\mathrm{mg} / \mathrm{L}$ & & & C & & \\
\hline SESPMNT & B17HL9 & VERNITA-1 HRM 0.3 & OFFSITE & sw & $\mathrm{N}$ & RIVER & TRANSECT & 04-Sep-03 CHLORIDE & & $0.91 \mathrm{n}$ & $\mathrm{mg} / \mathrm{L}$ & & & c & & \\
\hline SESPMNT & B17HMO & VERNITA-2 HRM 0.3 & OFFSITE & sw & $\mathrm{N}$ & RIVER & TRANSECT & 04-Sep-03 CHLORIDE & & $0.87 n$ & $\mathrm{mg} / \mathrm{L}$ & & & c & & \\
\hline SESPMNT & B17HM1 & VERNITA-3 HRM 0.3 & OFFSITE & sw & $\mathrm{N}$ & RIVER & TRANSECT & 04-Sep-03 CHLORIDE & & & $\mathrm{mg} / \mathrm{L}$ & & & c & & \\
\hline SESPMNT & B17HM2 & VERNITA-4 HRM 0.3 & OFFSITE & sw & $\mathrm{N}$ & RIVER & TRANSECT & 04-Sep-03 CHLORIDE & & & & & & c & & \\
\hline SESPMNT & B184P5 & VERNITA-1 HRM 0.3 & OFFSITE & sw & $\mathrm{N}$ & RIVER & TRANSECT & 09-Dec-03 CHLORIDE & & & & & & C & & \\
\hline SESPMNT & B184P6 & VERNITA-2 HRM 0.3 & OFFSITE & sw & $\mathrm{N}$ & RIVER & TRANSECT & 09-Dec-03 CHLORIDE & & & & & & C & & \\
\hline SESPMNT & B184P7 & VERNITA-3 HRM 0.3 & OFFSITE & sw & $\mathrm{N}$ & RIVER & TRANSECT & 09-Dec-03 CHLORIDE & & & $\mathrm{mg} / \mathrm{L}$ & & & C & & \\
\hline SESPMNT & B184P8 & VERNITA-4 HRM 0.3 & OFFSITE & sw & $\mathrm{N}$ & RIVER & TRANSECT & 09-Dec-03 CHLORIDE & & $0.94 n$ & $\mathrm{mg} / \mathrm{L}$ & & & C & & \\
\hline SESPMNT & B184P9 & RICH.PMPHS-1 HRM 46.4 & OFFSITE & sw & $\mathrm{N}$ & RIVER & TRANSECT & 08-Dec-03 CHLORIDE & & & $\mathrm{mg} / \mathrm{L}$ & & & C & & \\
\hline SESPMNT & B184R0 & RICH.PMPHS-2 HRM46.4 & OFFSITE & sw & $\mathrm{N}$ & RIVER & TRANSECT & 08-Dec-03 CHLORIDE & & $0.93 n$ & $\mathrm{mg} / \mathrm{L}$ & & & C & & \\
\hline SESPMNT & B184R1 & RICH.PMPHS-3 HRM46.4 & OFFSITE & sw & $\mathrm{N}$ & RIVER & TRANSECT & 08-Dec-03 CHLORIDE & & $0.96 \mathrm{n}$ & $\mathrm{mg} / \mathrm{L}$ & & & C & & \\
\hline SESPMNT & B184R2 & RICH.PMPHS-5 HRM46.4 & OFFSITE & sw & $\mathrm{N}$ & RIVER & $\begin{array}{l}\text { TRANSECT } \\
\text { TRES }\end{array}$ & 08-Dec-03 CHLORIDE & & & & & & c & & \\
\hline SESPMNT & B184R3 & RICH.PMPHS-7 HRM46.4 & OFFSITE & sw & $\mathrm{N}$ & RIVER & TRANSECT & 08-Dec-03 CHLORIDE & & & & & & C & & \\
\hline SESPMNT & B184R4 & RICH.PMPHS-10 HRM46.4 & OFFSITE & sw & $\mathrm{N}$ & RIVER & TRANSECT & 08-Dec-03 CHLORIDE & & & $\mathrm{mg} / \mathrm{L}$ & & & C & & \\
\hline SESPMNT & B184R5 & RICH.PMPHS HRM 43.5 & OFFSITE & sw & $\mathrm{N}$ & RIVER & TRANSECT & 08-Dec-03 CHLORIDE & & & $\mathrm{mg} / \mathrm{L}$ & & & c & & \\
\hline SESPMNT & B184R6 & RICH.PMPHS HRM 43.9 & OFFSITE & sw & $\mathrm{N}$ & RIVER & TRANSECT & 08-Dec-03 CHLORIDE & & & $\mathrm{mg} / \mathrm{L}$ & & & C & & \\
\hline SESPMNT & B184R7 & RICH.PMPHS HRM 45.0 & OFFSITE & sw & $\mathrm{N}$ & RIVER & TRANSECT & 08-Dec-03 CHLORIDE & & & $\mathrm{mg} / \mathrm{L}$ & & & c & & \\
\hline SESPMNT & B184R8 & RICH.PMPHS HRM 45.8 & OFFSITE & sw & $\mathrm{N}$ & RIVER & TRANSECT & 08-Dec-03 CHLORIDE & & & $\mathrm{mg} / \mathrm{L}$ & & & $\mathrm{c}$ & & \\
\hline SESPMNT & B16KC6 & RICH.PMPHS-10 HRM46.4 & OFFSITE & sw & $\mathrm{N}$ & RIVER & TRANSECT & 25-Mar-03 FLUORIDE & & $0.11 \mathrm{n}$ & & & & C & & \\
\hline SESPMNT & B16KC7 & RICH.PMPHS-1 HRM46.4 & OFFSITE & sw & $\mathrm{N}$ & RIVER & TRANSECT & 25-Mar-03 FLUORIDE & & $0.074 n$ & & & & $\mathrm{BC}$ & & \\
\hline SESPMNT & B16KC8 & RICH.PMPHS-2 HRM46.4 & OFFSITE & sw & $\mathrm{N}$ & RIVER & TRANSECT & 25-Mar-03 FLUORIDE & & $0.072 n$ & & & & $\mathrm{BC}$ & & \\
\hline SESPMNT & B16KC9 & RICH.PMPHS-3 HRM 46.4 & OFFSITE & sw & $\mathrm{N}$ & RIVER & TRANSECT & 25-Mar-03 FLUORIDE & & $0.079 n$ & $\mathrm{mg} / \mathrm{L}$ & & & $\mathrm{BC}$ & & \\
\hline SESPMNT & B16KD0 & RICH.PMPHS-5 HRM46.4 & OFFSITE & sw & $\mathrm{N}$ & RIVER & TRANSECT & 25-Mar-03 FLUORIDE & & $0.072 n$ & $\mathrm{mg} / \mathrm{L}$ & & & $B C$ & & \\
\hline SESPMNT & B16KD1 & RICH.PMPHS-7 HRM46.4 & OFFSITE & sw & $\mathrm{N}$ & RIVER & TRANSECT & 25-Mar-03 FLUORIDE & & $0.072 \mathrm{n}$ & $\mathrm{mg} / \mathrm{L}$ & & & $B C$ & & \\
\hline SESPMNT & B16KD2 & RICH.PMPHS HRM 43.5 & OFFSITE & sw & $\mathrm{N}$ & RIVER & TRANSECT & 25-Mar-03 FLUORIDE & & $0.072 \mathrm{n}$ & $\mathrm{mg} / \mathrm{L}$ & & & $B C$ & & \\
\hline SESPMNT & B16KD3 & RICH.PMPHS HRM 43.9 & OFFSITE & sw & $\mathrm{N}$ & RIVER & TRANSECT & 25-Mar-03 FLUORIDE & & $0.086 \mathrm{n}$ & $\mathrm{mg} / \mathrm{L}$ & & & $\mathrm{BC}$ & & \\
\hline SESPMNT & B16KD4 & RICH.PMPHS HRM 45.0 & OFFSITE & sw & $\mathrm{N}$ & RIVER & TRANSECT & 25-Mar-03 FLUORIDE & & $0.07 n$ & $\mathrm{mg} / \mathrm{L}$ & & & $\mathrm{BC}$ & & \\
\hline SESPMNT & B16KD5 & RICH.PMPHS HRM 45.8 & OFFSITE & sw & $\mathrm{N}$ & RIVER & TRANSECT & 25-Mar-03 FLUORIDE & & $0.085 \mathrm{n}$ & & & & $\mathrm{BC}$ & & \\
\hline SESPMNT & B16KD6 & VERNITA-1 HRM 0.3 & OFFSITE & sw & $\mathrm{N}$ & RIVER & TRANSECT & 24-Mar-03 FLUORIDE & & $0.09 n$ & & & & $\mathrm{BC}$ & & \\
\hline SESPMNT & B16KD7 & VERNITA-2 HRM 0.3 & OFFSITE & sW & $\mathrm{N}$ & RIVER & TRANSECT & 24-Mar-03 FLUORIDE & & $0.062 n$ & & & & $\mathrm{BC}$ & & \\
\hline SESPMNT & B16KD8 & VERNITA-3 HRM 0.3 & OFFSITE & sw & $\mathrm{N}$ & RIVER & TRANSECT & 24-Mar-03 FLUORIDE & & $0.094 \mathrm{n}$ & $\mathrm{mg} / \mathrm{L}$ & & & $\mathrm{BC}$ & & \\
\hline SESPMNT & B16KD9 & VERNITA-4 HRM 0.3 & OFFSITE & sw & $\mathrm{N}$ & RIVER & TRANSECT & 24-Mar-03 FLUORIDE & & $0.081 \mathrm{n}$ & $\mathrm{mg} / \mathrm{L}$ & & & $\mathrm{BC}$ & & \\
\hline SESPMNT & B17276 & RICH.PMPHS-10 HRM46. 4 & OFFSITE & sw & $\mathrm{N}$ & RIVER & TRANSECT & 10-Jun-03 FLUORIDE & & $0.09 n$ & $\mathrm{mg} / \mathrm{L}$ & & & $B C$ & & \\
\hline SESPMNT & B17277 & RICH.PMPHS-1 HRM46.4 & OFFSITE & sw & $\mathrm{N}$ & RIVER & TRANSECT & 10-Jun-03 FLUORIDE & & $0.092 \mathrm{n}$ & & & & $\mathrm{BC}$ & & \\
\hline SESPMNT & B17278 & RICH.PMPHS-2 HRM46.4 & OFFSITE & sw & $\mathrm{N}$ & RIVER & TRANSECT & 10-Jun-03 FLUORIDE & & $0.089 n$ & $\mathrm{mg} / \mathrm{L}$ & & & $\mathrm{BC}$ & & \\
\hline SESPMNT & B17279 & RICH.PMPHS-3 HRM46.4 & OFFSITE & sw & $\mathrm{N}$ & RIVER & TRANSECT & 10-Jun-03 FLUORIDE & & $0.093 n$ & & & & $\mathrm{BC}$ & & \\
\hline SESPMNT & B17280 & RICH.PMPHS-5 HRM46.4 & OFFSITE & sw & $\mathrm{N}$ & RIVER & TRANSECT & 10-Jun-03 FLUORIDE & & $0.086 \mathrm{n}$ & $\mathrm{mg} / \mathrm{L}$ & & & $\mathrm{BC}$ & & \\
\hline SESPMNT & B17281 & RICH.PMPHS-7 HRM46.4 & OFFSITE & sw & $\mathrm{N}$ & RIVER & TRANSECT & 10-Jun-03 FLUORIDE & & $0.13 \mathrm{n}$ & $\mathrm{mg} / \mathrm{L}$ & & & c & & \\
\hline SESPMNT & B17282 & RICH.PMPHS HRM 43.5 & OFFSITE & sw & $\mathrm{N}$ & RIVER & TRANSECT & 10-Jun-03 FLUORIDE & & $0.087 \mathrm{n}$ & $\mathrm{mg} / \mathrm{L}$ & & & $\mathrm{BC}$ & & \\
\hline SESPMNT & B17283 & RICH.PMPHS HRM 43.9 & OFFSITE & sw & $\mathrm{N}$ & RIVER & TRANSECT & 10-Jun-03 FLUORIDE & & $0.089 n$ & $\mathrm{mg} / \mathrm{L}$ & & & $\mathrm{BC}$ & & \\
\hline SESPMNT & B17284 & RICH.PMPHS HRM 45.0 & OFFSITE & sw & $\mathrm{N}$ & RIVER & TRANSECT & 10-Jun-03 FLUORIDE & & $0.089 n$ & $\mathrm{mg} / \mathrm{L}$ & & & $\mathrm{BC}$ & & \\
\hline SESPMNT & B17285 & RICH.PMPHS HRM 45.8 & OFFSITE & sw & $\mathrm{N}$ & RIVER & TRANSECT & 10-Jun-03 FLUORIDE & & $0.094 \mathrm{n}$ & $\mathrm{mg} / \mathrm{L}$ & & & $\mathrm{BC}$ & & \\
\hline SESPMNT & B17286 & VERNITA-1 HRM 0.3 & OFFSITE & sw & $\mathrm{N}$ & RIVER & TRANSECT & 09-Jun-03 FLUORIDE & & & & & & $\mathrm{BC}$ & & \\
\hline SESPMNT & B17287 & VERNITA-2 HRM 0.3 & OFFSITE & sw & $\mathrm{N}$ & RIVER & TRANSECT & 09-Jun-03 FLUORIDE & & & $\mathrm{mg} / \mathrm{L}$ & & & c & & \\
\hline SESPMNT & B17288 & VERNITA-3 HRM 0.3 & OFFSITE & sW & $\mathrm{N}$ & RIVER & TRANSECT & 09-Jun-03 FLUORIDE & & $0.092 \mathrm{n}$ & $\mathrm{mg} / \mathrm{L}$ & & & $\mathrm{BC}$ & & \\
\hline SESPMNT & B17289 & VERNITA-4 HRM 0.3 & OFFSITE & sw & $\mathrm{N}$ & RIVER & TRANSECT & 09-Jun-03 FLUORIDE & & $0.089 n$ & $\mathrm{mg} / \mathrm{L}$ & & & $\mathrm{BC}$ & & \\
\hline SESPMNT & B17HFO & $100 \mathrm{~F}-10 \mathrm{HRM} 19.0$ & ONSITE & SW & $\mathrm{N}$ & RIVER & TRANSECT & 08-Sep-03 FLUORIDE & & $0.085 \mathrm{n}$ & $\mathrm{mg} / \mathrm{L}$ & & & B & & \\
\hline SESPMNT & B17HF1 & $100 \mathrm{~F}-1 \mathrm{HRM} 19.0$ & ONSITE & SW & $\mathrm{N}$ & RIVER & TRANSECT & 08-Sep-03 FLUORIDE & & $0.083 \mathrm{n}$ & $\mathrm{mg} / \mathrm{L}$ & & & B & & \\
\hline SESPMNT & B17HF2 & 100 F - 2 HRM 19.0 & ONSITE & sw & $\mathrm{N}$ & RIVER & TRANSECT & 08-Sep-03 FLUORIDE & & $0.077 \mathrm{n}$ & $\mathrm{mg} / \mathrm{L}$ & & & B & & \\
\hline SESPMNT & B17HF3 & 100 F - 3 HRM 19.0 & ONSITE & sw & $\mathrm{N}$ & RIVER & TRANSECT & 08-Sep-03 FLUORIDE & & $0.083 n$ & & & & B & & \\
\hline SESPMNT & B17HF4 & 100 F -5 HRM 19.0 & ONSITE & sw & $\mathrm{N}$ & RIVER & TRANSECT & 08-Sep-03 FLUORIDE & & $0.081 \mathrm{n}$ & & & & B & & \\
\hline SESPMNT & B17HF5 & 100 F -7 HRM 19.0 & ONSITE & sw & $\mathrm{N}$ & RIVER & TRANSECT & 08-Sep-03 FLUORIDE & & $0.084 \mathrm{n}$ & $\mathrm{mg} / \mathrm{L}$ & & & B & & \\
\hline SESPMNT & B17HF6 & 100 F SHORE HRM 18 & ONSITE & sw & $\mathrm{N}$ & RIVER & TRANSECT & 08-Sep-03 FLUORIDE & & $0.079 n$ & $\mathrm{mg} / \mathrm{L}$ & & & B & & \\
\hline SESPMNT & B17HF7 & 100 F SHORE HRM 22 & ONSITE & sW & $\mathrm{N}$ & RIVER & TRANSECT & 08-Sep-03 FLUORIDE & & $0.079 n$ & $\mathrm{mg} / \mathrm{L}$ & & & B & & \\
\hline SESPMNT & B17HF8 & $100 \mathrm{~F}$ SHORE HRM 23 & ONSITE & sW & $\mathrm{N}$ & RIVER & TRANSECT & 08-Sep-03 FLUORIDE & & $0.078 \mathrm{n}$ & $\mathrm{mg} / \mathrm{L}$ & & & B & & \\
\hline SESPMNT & B17HF9 & $100 \mathrm{~N}-1$ HRM 9.5 & ONSITE & SW & $\mathrm{N}$ & RIVER & TRANSECT & 04-Sep-03 FLUORIDE & & & & & & & & \\
\hline SESPMNT & B17HHO & $100 \mathrm{~N}-10$ HRM 9.5 & ONSITE & sW & $\mathrm{N}$ & RIVER & TRANSECT & 04-Sep-03 FLUORIDE & & $0.11 \mathrm{n}$ & $\mathrm{mg} / \mathrm{L}$ & & & & & \\
\hline SESPMNT & B17HH1 & $100 \mathrm{~N}-2$ HRM 9.5 & ONSITE & sw & $\mathrm{N}$ & RIVER & TRANSECT & 04-Sep-03 FLUORIDE & & & & & & & & \\
\hline SESPMNT & B17HH2 & $100 \mathrm{~N}-3$ HRM 9.5 & ONSITE & sw & $\mathrm{N}$ & RIVER & TRANSECT & 04-Sep-03 FLUORIDE & & & $\mathrm{mg} / \mathrm{L}$ & & & & & \\
\hline SESPMNT & B17HH3 & $100 \mathrm{~N}-5$ HRM 9.5 & ONSITE & sw & $\mathrm{N}$ & RIVER & TRANSECT & 04-Sep-03 FLUORIDE & & $0.11 \mathrm{n}$ & $\mathrm{mg} / \mathrm{L}$ & & & & & \\
\hline
\end{tabular}


WATER - COLUMBIA RIVER TRANSECT

\begin{tabular}{|c|c|c|c|c|c|c|c|c|c|c|c|c|c|c|c|c|}
\hline OWNER ID & |SAMP NUM| & SAMP SITE NAME & DIST CLASS & MEDIA $\left.\right|^{F}$ & \begin{tabular}{|c|} 
FILTERED \\
FLAG
\end{tabular} & $\begin{array}{l}\text { SAMP } \\
\text { FROM }\end{array}$ & COLL MTHD & SAMP DATE & CON SHORT NAME & \begin{tabular}{c|c} 
VALUE & $A$ \\
RPTD & $R$
\end{tabular} & \begin{tabular}{|c|} 
ANAL \\
UNITS \\
RPTD \\
\end{tabular} & $\begin{array}{c}\text { COUNTING } \\
\text { ERROR }\end{array}$ & \begin{tabular}{|c|} 
TOTAL \\
ANAL \\
ERROR
\end{tabular} & $\begin{array}{c}\text { LAB } \\
\text { QUALIFIER }\end{array}$ & SAMP COMMENT & $\begin{array}{l}\text { RESULT } \\
\text { COMMENT }\end{array}$ \\
\hline SESPMNT & $\mathrm{B} 17 \mathrm{HH} 4$ & $100 \mathrm{~N}-7$ HRM 9.5 & ONSITE & SW & $\mathrm{N}$ & RIVER & TRANSECT & 04-Sep-03 FLUORIDE & & & & & & & & \\
\hline SESPMNT & B17HH5 & 100 N SHORE HRM 8.4 & ONSITE & sW & $\mathrm{N}$ & RIVER & TRANSECT & 04-Sep-03 FLUORIDE & & & $\mathrm{mg} / \mathrm{L}$ & & & & & \\
\hline SESPMNT & B17HH6 & 100 N SHORE HRM 8.9 & ONSITE & sw & $\mathrm{N}$ & RIVER & TRANSECT & 04-Sep-03 FLUORIDE & & $0.097 \mathrm{~m}$ & $\mathrm{mg} / \mathrm{L}$ & & & B & & \\
\hline SESPMNT & B17HH7 & 100 N SHORE HRM 9.2 & ONSITE & SW & $\mathrm{N}$ & RIVER & TRANSECT & 04-Sep-03 FLUORIDE & & & $\mathrm{mg} / \mathrm{L}$ & & & & & \\
\hline SESPMNT & B17HH8 & 100 N SHORE HRM 9.8 & ONSITE & sw & $\mathrm{N}$ & RIVER & TRANSECT & 04-Sep-03 FLUORIDE & & & $\mathrm{mg} / \mathrm{L}$ & & & & & \\
\hline SESPMNT & B17HH9 & 300 AREA - 1 HRM 43.1 & ONSITE & SW & $\mathrm{N}$ & RIVER & TRANSECT & 09-Sep-03 FLUORIDE & & & & & & B & & \\
\hline SESPMNT & B17HJO & 300 AREA-10 HRM 43.1 & ONSITE & sw & $\mathrm{N}$ & RIVER & TRANSECT & 09-Sep-03 FLUORIDE & & & & & & & & \\
\hline SESPMNT & B17HJ1 & 300 AREA -2 HRM 43.1 & ONSITE & sW & $\mathrm{N}$ & RIVER & TRANSECT & 09-Sep-03 FLUORIDE & & & & & & B & & \\
\hline SESPMNT & B17HJ2 & 300 AREA -3 HRM 43.1 & ONSITE & SW & $\mathrm{N}$ & RIVER & TRANSECT & 09-Sep-03 FLUORIDE & & $0.084 \mathrm{~m}$ & $\mathrm{mg} / \mathrm{L}$ & & & B & & \\
\hline SESPMNT & B17HJ3 & 300 AREA -5 HRM 43.1 & ONSITE & sw & $\mathrm{N}$ & RIVER & TRANSECT & 09-Sep-03 FLUORIDE & & $0.082 \mathrm{~m}$ & $\mathrm{mg} / \mathrm{L}$ & & & B & & \\
\hline SESPMNT & B17HJ4 & 300 AREA -7 HRM 43.1 & ONSITE & SW & $\mathrm{N}$ & RIVER & TRANSECT & 09-Sep-03 FLUORIDE & & $0.083 \mathrm{~m}$ & $\mathrm{mg} / \mathrm{L}$ & & & B & & \\
\hline SESPMNT & B17HJ5 & 300 AREA SHR HRM41.5 & ONSITE & sw & $\mathrm{N}$ & RIVER & TRANSECT & 09-Sep-03 FLUORIDE & & $0.083 \mathrm{~m}$ & $\mathrm{mg} / \mathrm{L}$ & & & B & & \\
\hline SESPMNT & B17HJ6 & 300 AREA SHR HRM42.1 & ONSITE & sW & $\mathrm{N}$ & RIVER & TRANSECT & 09-Sep-03 FLUORIDE & & $0.097 \mathrm{~m}$ & $\mathrm{mg} / \mathrm{L}$ & & & B & & \\
\hline SESPMNT & B17HJ7 & 300 AREA SHR HRM 42.5 & ONSITE & sw & $\mathrm{N}$ & RIVER & $\begin{array}{l}\text { TRANSECT } \\
\text { TRES }\end{array}$ & 09-Sep-03 FLUORIDE & & $0.096 \mathrm{~m}$ & & & & B & & \\
\hline SESPMNT & B17HJ8 & 300 AREA SHR HRM42.9 & ONSITE & sw & $\mathrm{N}$ & RIVER & TRANSECT & 09-Sep-03 FLUORIDE & & $0.087 \mathrm{~m}$ & & & & B & & \\
\hline SESPMNT & B17HJ9 & HANFRD TS-1 HRM 28.7 & ONSITE & SW & $\mathrm{N}$ & RIVER & TRANSECT & 08-Sep-03 FLUORIDE & & $0.092 \mathrm{~m}$ & & & & B & & \\
\hline SESPMNT & B17HKO & HANFRD TS-2 HRM 28.7 & ONSITE & sw & $\mathrm{N}$ & RIVER & TRANSECT & 08-Sep-03 FLUORIDE & & $0.082 \mathrm{~m}$ & $\mathrm{mg} / \mathrm{L}$ & & & B & & \\
\hline SESPMNT & B17HK1 & HANFRD TS-3 HRM 28.7 & ONSITE & sW & $\mathrm{N}$ & RIVER & TRANSECT & 08-Sep-03 FLUORIDE & & $0.082 \mathrm{~m}$ & $\mathrm{mg} / \mathrm{L}$ & & & B & & \\
\hline SESPMNT & B17HK2 & HANFRD TS-5 HRM 28.7 & ONSITE & sW & $\mathrm{N}$ & RIVER & TRANSECT & 08-Sep-03 FLUORIDE & & $0.079 \mathrm{~m}$ & $\mathrm{mg} / \mathrm{L}$ & & & B & & \\
\hline SESPMNT & B17HK3 & HANFRD TS-7 HRM 28.7 & ONSITE & SW & $\mathrm{N}$ & RIVER & TRANSECT & 08-Sep-03 FLUORIDE & & $0.078 \mathrm{~m}$ & & & & B & & \\
\hline SESPMNT & B17HK4 & HANFRD TS-10 HRM 28.7 & ONSITE & SW & $\mathrm{N}$ & RIVER & TRANSECT & 08-Sep-03 FLUORIDE & & $0.086 \mathrm{~m}$ & & & & B & & \\
\hline SESPMNT & B17HK5 & HANFRD TWNSITE HRM26 & ONSITE & sw & $\mathrm{N}$ & RIVER & TRANSECT & 08-Sep-03 FLUORIDE & & $0.081 \mathrm{~m}$ & & & & B & & \\
\hline SESPMNT & B17HK6 & HANFRD TWNSITE HRM27 & ONSITE & sw & $\mathrm{N}$ & RIVER & TRANSECT & 08-Sep-03 FLUORIDE & & $0.083 \mathrm{~m}$ & & & & B & & \\
\hline SESPMNT & B17HK7 & HANFRD TWNSITE HRM28 & ONSITE & sw & $\mathrm{N}$ & RIVER & TRANSECT & 08-Sep-03 FLUORIDE & & $0.13 \mathrm{~m}$ & $\mathrm{mg} / \mathrm{L}$ & & & & & \\
\hline SESPMNT & B17HK8 & HANFRD TWNSITE HRM30 & ONSITE & sw & $\mathrm{N}$ & RIVER & TRANSECT & 08-Sep-03 FLUORIDE & & $0.086 \mathrm{~m}$ & $\mathrm{mg} / \mathrm{L}$ & & & B & & \\
\hline SESPMNT & B17HK9 & RICH.PMPHS-1 HRM46.4 & OFFSITE & sw & $\mathrm{N}$ & RIVER & TRANSECT & 09-Sep-03 FLUORIDE & & $0.092 \mathrm{~m}$ & $\mathrm{mg} / \mathrm{L}$ & & & B & & \\
\hline SESPMNT & B17HL0 & RICH.PMPHS-2 HRM46.4 & OFFSITE & sW & $\mathrm{N}$ & RIVER & TRANSECT & 09-Sep-03 FLUORIDE & & $0.086 \mathrm{~m}$ & $\mathrm{mg} / \mathrm{L}$ & & & B & & \\
\hline SESPMNT & B17HL1 & RICH.PMPHS-3 HRM46.4 & OFFSITE & SW & $\mathrm{N}$ & RIVER & TRANSECT & 09-Sep-03 FLUORIDE & & $0.083 \mathrm{~m}$ & $\mathrm{mg} / \mathrm{L}$ & & & B & & \\
\hline SESPMNT & B17HL2 & RICH.PMPHS-5 HRM46.4 & OFFSITE & sW & $\mathrm{N}$ & RIVER & TRANSECT & 09-Sep-03 FLUORIDE & & $0.084 \mathrm{~m}$ & $\mathrm{mg} / \mathrm{L}$ & & & B & & \\
\hline SESPMNT & B17HL3 & RICH.PMPHS-7 HRM46.4 & OFFSITE & sW & $\mathrm{N}$ & RIVER & TRANSECT & 09-Sep-03 FLUORIDE & & $0.084 \mathrm{~m}$ & & & & B & & \\
\hline SESPMNT & B17HL4 & RICH.PMPHS-10 HRM46. 4 & OFFSITE & sW & $\mathrm{N}$ & RIVER & TRANSECT & 09-Sep-03 FLUORIDE & & $0.12 \mathrm{~m}$ & & & & & & \\
\hline SESPMNT & B17HL5 & RICH.PMPHS HRM 43.5 & OFFSITE & SW & $\mathrm{N}$ & RIVER & TRANSECT & 09-Sep-03 FLUORIDE & & $0.086 \mathrm{~m}$ & $\mathrm{mg} / \mathrm{L}$ & & & B & & \\
\hline SESPMNT & B17HL7 & RICH.PMPHS HRM 45.0 & OFFSITE & SW & $\mathrm{N}$ & RIVER - & TRANSECT & 09-Sep-03 FLUORIDE & & $0.085 \mathrm{~m}$ & $\mathrm{mg} / \mathrm{L}$ & & & B & & \\
\hline SESPMNT & B17HL8 & RICH.PMPHS HRM 45.8 & OFFSITE & sw & $\mathrm{N}$ & RIVER & TRANSECT & 09-Sep-03 FLUORIDE & & $0.085 \mathrm{~m}$ & $\mathrm{mg} / \mathrm{L}$ & & & B & & \\
\hline SESPMNT & B17HL9 & VERNITA-1 HRM 0.3 & OFFSITE & sw & $\mathrm{N}$ & RIVER & TRANSECT & 04-Sep-03 FLUORIDE & & & $\mathrm{mg} / \mathrm{L}$ & & & & & \\
\hline SESPMNT & B17HMO & VERNITA-2 HRM 0.3 & OFFSITE & sw & $\mathrm{N}$ & RIVER & TRANSECT & 04-Sep-03 FLUORIDE & & & $\mathrm{mg} / \mathrm{L}$ & & & & & \\
\hline SESPMNT & B17HM1 & VERNITA-3 HRM 0.3 & OFFSITE & sW & $\mathrm{N}$ & RIVER & TRANSECT & 04-Sep-03 FLUORIDE & & & $\mathrm{mg} / \mathrm{L}$ & & & & & \\
\hline SESPMNT & B17HM2 & VERNITA-4 HRM 0.3 & OFFSITE & sW & $\mathrm{N}$ & RIVER & TRANSECT & 04-Sep-03 FLUORIDE & & $0.11 \mathrm{~m}$ & & & & & & \\
\hline SESPMNT & B184P5 & VERNITA-1 HRM 0.3 & OFFSITE & SW & $\mathrm{N}$ & RIVER & TRANSECT & 09-Dec-03 FLUORIDE & & $0.098 \mathrm{~m}$ & $\mathrm{mg} / \mathrm{L}$ & & & $\mathrm{BC}$ & & \\
\hline SESPMNT & B184P6 & VERNITA-2 HRM 0.3 & OFFSITE & SW & $\mathrm{N}$ & RIVER & TRANSECT & 09-Dec-03 FLUORIDE & & $0.097 \mathrm{~m}$ & $\mathrm{mg} / \mathrm{L}$ & & & $\mathrm{BC}$ & & \\
\hline SESPMNT & B184P7 & VERNITA-3 HRM 0.3 & OFFSITE & sW & $\mathrm{N}$ & RIVER & TRANSECT & 09-Dec-03 FLUORIDE & & $0.096 \mathrm{~m}$ & $\mathrm{mg} / \mathrm{L}$ & & & $\mathrm{BC}$ & & \\
\hline SESPMNT & B184P8 & VERNITA-4 HRM 0.3 & OFFSITE & sW & $\mathrm{N}$ & RIVER - & TRANSECT & 09-Dec-03 FLUORIDE & & $0.093 \mathrm{~m}$ & $\mathrm{mg} / \mathrm{L}$ & & & $\mathrm{BC}$ & & \\
\hline SESPMNT & B184P9 & RICH.PMPHS-1 HRM46.4 & OFFSITE & sw & $\mathrm{N}$ & RIVER & TRANSECT & 08-Dec-03 FLUORIDE & & $0.098 \mathrm{~m}$ & $\mathrm{mg} / \mathrm{L}$ & & & $\mathrm{BC}$ & & \\
\hline SESPMNT & B184R0 & RICH.PMPHS-2 HRM46.4 & OFFSITE & sw & $\mathrm{N}$ & RIVER & TRANSECT & 08-Dec-03 FLUORIDE & & $0.097 \mathrm{~m}$ & $\mathrm{mg} / \mathrm{L}$ & & & $\mathrm{BC}$ & & \\
\hline SESPMNT & B184R1 & RICH.PMPHS-3 HRM46.4 & OFFSITE & sw & $\mathrm{N}$ & RIVER & TRANSECT & 08-Dec-03 FLUORIDE & & $0.098 \mathrm{~m}$ & & & & $\mathrm{BC}$ & & \\
\hline SESPMNT & B184R2 & RICH.PMPHS-5 HRM46.4 & OFFSITE & sw & $\mathrm{N}$ & RIVER & TRANSECT & 08-Dec-03 FLUORIDE & & $0.099 \mathrm{~m}$ & & & & $\mathrm{BC}$ & & \\
\hline SESPMNT & B184R3 & RICH.PMPHS-7 HRM46.4 & OFFSITE & sW & $\mathrm{N}$ & RIVER & TRANSECT & 08-Dec-03 FLUORIDE & & $0.097 \mathrm{~m}$ & $\mathrm{mg} / \mathrm{L}$ & & & $\mathrm{BC}$ & & \\
\hline SESPMNT & B184R4 & RICH.PMPHS-10 HRM46. 4 & OFFSITE & sW & $\mathrm{N}$ & RIVER & TRANSECT & 08-Dec-03 FLUORIDE & & $0.11 \mathrm{~m}$ & $\mathrm{mg} / \mathrm{L}$ & & & c & & \\
\hline SESPMNT & B184R5 & RICH.PMPHS HRM 43.5 & OFFSITE & SW & $\mathrm{N}$ & RIVER & TRANSECT & 08-Dec-03 FLUORIDE & & & $\mathrm{mg} / \mathrm{L}$ & & & c & & \\
\hline SESPMNT & B184R6 & RICH.PMPHS HRM 43.9 & OFFSITE & SW & $\mathrm{N}$ & RIVER & TRANSECT & 08-Dec-03 FLUORIDE & & $0.11 \mathrm{~m}$ & $\mathrm{mg} / \mathrm{L}$ & & & c & & \\
\hline SESPMNT & B184R7 & RICH.PMPHS HRM 45.0 & OFFSITE & sw & $\mathrm{N}$ & RIVER & TRANSECT & 08-Dec-03 FLUORIDE & & $0.097 \mathrm{~m}$ & $\mathrm{mg} / \mathrm{L}$ & & & $\mathrm{BC}$ & & \\
\hline SESPMNT & B184R8 & RICH.PMPHS HRM 45.8 & OFFSITE & SW & $\mathrm{N}$ & RIVER & TRANSECT & 08-Dec-03 FLUORIDE & & $0.099 \mathrm{~m}$ & $\mathrm{mg} / \mathrm{L}$ & & & $\mathrm{BC}$ & & \\
\hline SESPMNT & B16KC6 & RICH.PMPHS-10 HRM46.4 & OFFSITE & sW & $\mathrm{N}$ & RIVER & TRANSECT & 25-Mar-03 NO2-N & & $0.011 \mathrm{~m}$ & $\mathrm{mg} / \mathrm{L}$ & & & u & & \\
\hline SESPMNT & $\mathrm{B} 16 \mathrm{KC7}$ & RICH.PMPHS-1 HRM46.4 & OFFSITE & sW & $\mathrm{N}$ & RIVER & TRANSECT & $25-\mathrm{Mar}-03$ NO2-N & & $0.011 \mathrm{~m}$ & $\mathrm{mg} / \mathrm{L}$ & & & u & & \\
\hline SESPMNT & B16KC8 & RICH.PMPHS-2 HRM46.4 & OFFSITE & sw & $\mathrm{N}$ & RIVER & TRANSECT & 25-Mar-03 NO2-N & & $0.011 \mathrm{~m}$ & $\mathrm{mg} / \mathrm{L}$ & & & u & & \\
\hline SESPMNT & B16KC9 & RICH.PMPHS-3 HRM46.4 & OFFSITE & sw & $\mathrm{N}$ & RIVER & TRANSECT & 25-Mar-03 NO2-N & & $0.011 \mathrm{~m}$ & $\mathrm{mg} / \mathrm{L}$ & & & u & & \\
\hline SESPMNT & B16KD0 & RICH.PMPHS-5 HRM46.4 & OFFSITE & SW & $\mathrm{N}$ & RIVER & TRANSECT & 25-Mar-03 NO2-N & & $0.011 \mathrm{~m}$ & $\mathrm{mg} / \mathrm{L}$ & & & $u$ & & \\
\hline SESPMNT & B16KD1 & RICH.PMPHS-7 HRM46.4 & OFFSITE & SW & $\mathrm{N}$ & RIVER & TRANSECT & 25-Mar-03 NO2-N & & $0.011 \mathrm{~m}$ & $\mathrm{mg} / \mathrm{L}$ & & & u & & \\
\hline SESPMNT & B16KD2 & RICH.PMPHS HRM 43.5 & OFFSITE & sW & $\mathrm{N}$ & RIVER & TRANSECT & 25-Mar-03 NO2-N & & $0.011 \mathrm{~m}$ & $\mathrm{mg} / \mathrm{L}$ & & & U & & \\
\hline SESPMNT & B16KD3 & RICH.PMPHS HRM 43.9 & OFFSITE & SW & $\mathrm{N}$ & RIVER & TRANSECT & 25-Mar-03 NO2-N & & & & & & $u$ & & \\
\hline SESPMNT & B16KD4 & RICH.PMPHS HRM 45.0 & OFFSITE & SW & $\mathrm{N}$ & RIVER & TRANSECT & 25-Mar-03 NO2-N & & $0.011 \mathrm{~m}$ & & & & u & & \\
\hline SESPMNT & B16KD5 & RICH.PMPHS HRM 45.8 & OFFSITE & sW & $\mathrm{N}$ & RIVER & TRANSECT & 25-Mar-03 NO2-N & & $0.011 \mathrm{~m}$ & $\mathrm{mg} / \mathrm{L}$ & & & 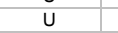 & & \\
\hline
\end{tabular}


WATER - COLUMBIA RIVER TRANSEC

\begin{tabular}{|c|c|c|c|c|c|c|c|c|c|c|c|c|c|c|c|c|}
\hline OWNER ID & | SAMP NUM| & SAMP SITE NAME & DIST CLASS & $\mid$ MEDIA & \begin{tabular}{|c|} 
FILTERED \\
FLAG
\end{tabular} & $\begin{array}{l}\text { SAMP } \\
\text { FROM }\end{array}$ & COLL MTHD & SAMP DATE & CON SHORT NAME & $\begin{array}{c}\text { VALUE } \\
\text { RPTD }\end{array}$ & \begin{tabular}{|l|} 
ANAL \\
UNITS \\
RPTD \\
\end{tabular} & $\begin{array}{c}\text { COUNTING } \\
\text { ERROR }\end{array}$ & \begin{tabular}{|c|} 
TOTAL \\
ANAL \\
ERROR
\end{tabular} & $\begin{array}{c}\text { LAB } \\
\text { QUALIFIER }\end{array}$ & SAMP COMMENT & $\begin{array}{l}\text { RESULT } \\
\text { COMMENT }\end{array}$ \\
\hline SESPMNT & B16KD6 & VERNITA-1 HRM 0.3 & OFFSITE & SW & $\mathrm{N}$ & RIVER & TRANSECT & 24-Mar-03 NO2-N & & & & & & u & & \\
\hline SESPMNT & B16KD7 & VERNITA-2 HRM 0.3 & OFFSITE & sw & $\mathrm{N}$ & RIVER & TRANSECT & 24-Mar-03 NO2-N & & 0.011 & $\mathrm{mg} / \mathrm{L}$ & & & $\mathrm{U}$ & & \\
\hline SESPMNT & B16KD8 & VERNITA-3 HRM 0.3 & OFFSITE & sw & $\mathrm{N}$ & RIVER & TRANSECT & 24-Mar-03 NO2-N & & 0.011 & $\mathrm{mg} / \mathrm{L}$ & & & u & & \\
\hline SESPMNT & B16KD9 & VERNITA-4 HRM 0.3 & OFFSITE & sw & $\mathrm{N}$ & RIVER & TRANSECT & 24-Mar-03 NO2-N & & 0.011 & $\mathrm{mg} / \mathrm{L}$ & & & u & & \\
\hline SESPMNT & B17276 & RICH.PMPHS-10 HRM46.4 & OFFSITE & sw & $\mathrm{N}$ & RIVER & TRANSECT & 10-Jun-03 NO2-N & & 0.0074 & $\mathrm{mg} / \mathrm{L}$ & & & $u$ & & \\
\hline SESPMNT & B17277 & RICH.PMPHS-1 HRM46.4 & OFFSITE & sw & $\mathrm{N}$ & RIVER & TRANSECT & 10-Jun-03 NO2-N & & 0.0074 & & & & u & & \\
\hline SESPMNT & B17278 & RICH.PMPHS-2 HRM46.4 & OFFSITE & sw & $\mathrm{N}$ & RIVER & TRANSECT & 10-Jun-03 NO2-N & & 0.0074 & & & & $\mathrm{U}$ & & \\
\hline SESPMNT & B17279 & RICH.PMPHS-3 HRM46.4 & OFFSITE & sw & $\mathrm{N}$ & RIVER & TRANSECT & 10-Jun-03 NO2-N & & & & & & U & & \\
\hline SESPMNT & B17280 & RICH.PMPHS-5 HRM46.4 & OFFSITE & sw & $\mathrm{N}$ & RIVER & TRANSECT & 10-Jun-03 NO2-N & & 0.0074 & $\mathrm{mg} / \mathrm{L}$ & & & u & & \\
\hline SESPMNT & B17281 & RICH.PMPHS-7 HRM46.4 & OFFSITE & sw & $\mathrm{N}$ & RIVER & TRANSECT & 10-Jun-03 NO2-N & & 0.0074 & $\mathrm{mg} / \mathrm{L}$ & & & U & & \\
\hline SESPMNT & B17282 & RICH.PMPHS HRM 43.5 & OFFSITE & sw & $\mathrm{N}$ & RIVER & TRANSECT & 10-Jun-03 NO2-N & & 0.0074 & $\mathrm{mg} / \mathrm{L}$ & & & U & & \\
\hline SESPMNT & B17283 & RICH.PMPHS HRM 43.9 & OFFSITE & sw & $\mathrm{N}$ & RIVER & TRANSECT & 10-Jun-03 NO2-N & & 0.0074 & $\mathrm{mg} / \mathrm{L}$ & & & U & & \\
\hline SESPMNT & B17284 & RICH.PMPHS HRM 45.0 & OFFSITE & sw & $\mathrm{N}$ & RIVER & TRANSECT & 10-Jun-03 NO2-N & & 0.0074 & $\mathrm{mg} / \mathrm{L}$ & & & U & & \\
\hline SESPMNT & B17285 & RICH.PMPHS HRM 45.8 & OFFSITE & sw & $\mathrm{N}$ & RIVER & TRANSECT & 10-Jun-03 NO2-N & & 0.0074 & $\mathrm{mg} / \mathrm{L}$ & & & u & & \\
\hline SESPMNT & B17286 & VERNITA-1 HRM 0.3 & OFFSITE & sw & $\mathrm{N}$ & RIVER & TRANSECT & 09-Jun-03 NO2-N & & 0.0074 & & & & U & & \\
\hline SESPMNT & B17287 & VERNITA-2 HRM 0.3 & OFFSITE & sw & $\mathrm{N}$ & RIVER & TRANSECT & 09-Jun-03 NO2-N & & 0.0074 & & & & U & & \\
\hline SESPMNT & B17288 & VERNITA-3 HRM 0.3 & OFFSITE & sw & $\mathrm{N}$ & RIVER & TRANSECT & 09-Jun-03 NO2-N & & 0.0074 & $\mathrm{mg} / \mathrm{L}$ & & & $u$ & & \\
\hline SESPMNT & B17289 & VERNITA-4 HRM 0.3 & OFFSITE & sw & $\mathrm{N}$ & RIVER & TRANSECT & 09-Jun-03 NO2-N & & 0.0074 & $\mathrm{mg} / \mathrm{L}$ & & & U & & \\
\hline SESPMNT & B17HF0 & $100 \mathrm{~F}-10 \mathrm{HRM} 19.0$ & ONSITE & sw & $\mathrm{N}$ & RIVER & TRANSECT & 08-Sep-03 NO2-N & & 0.0074 & $\mathrm{mg} / \mathrm{L}$ & & & u & & \\
\hline SESPMNT & B17HF1 & $100 \mathrm{~F}-1$ HRM 19.0 & ONSITE & sw & $\mathrm{N}$ & RIVER & TRANSECT & 08 -Sep-03 NO2-N & & 0.0074 & $\mathrm{mg} / \mathrm{L}$ & & & u & & \\
\hline SESPMNT & B17HF2 & $100 \mathrm{~F}-2 \mathrm{HRM} 19.0$ & ONSITE & sw & $\mathrm{N}$ & RIVER - & TRANSECT & 08-Sep-03 NO2-N & & 0.0074 & $\mathrm{mg} / \mathrm{L}$ & & & U & & \\
\hline SESPMNT & B17HF3 & $100 \mathrm{~F}-3 \mathrm{HRM} 19.0$ & ONSITE & sw & $\mathrm{N}$ & RIVER & TRANSECT & 08-Sep-03 NO2-N & & 0.0074 & & & & u & & \\
\hline SESPMNT & B17HF4 & $100 \mathrm{~F}-5$ HRM 19.0 & ONSITE & sw & $\mathrm{N}$ & RIVER & TRANSECT & 08 -Sep-03 NO2-N & & 0.0074 & & & & u & & \\
\hline SESPMNT & B17HF5 & 100 F - 7 HRM 19.0 & ONSITE & sw & $\mathrm{N}$ & RIVER & TRANSECT & 08 -Sep-03 NO2-N & & 0.0074 & $\mathrm{mg} / \mathrm{L}$ & & & u & & \\
\hline SESPMNT & B17HF6 & $100 \mathrm{~F}$ SHORE HRM 18 & ONSITE & sw & $\mathrm{N}$ & RIVER & TRANSECT & 08-Sep-03 NO2-N & & 0.0074 & $\mathrm{mg} / \mathrm{L}$ & & & $U$ & & \\
\hline SESPMNT & B17HF7 & $100 \mathrm{~F}$ SHORE HRM 22 & ONSITE & sw & $\mathrm{N}$ & RIVER & TRANSECT & 08-Sep-03 NO2-N & & 0.0074 & $\mathrm{mg} / \mathrm{L}$ & & & $u$ & & \\
\hline SESPMNT & B17HF8 & $100 \mathrm{~F}$ SHORE HRM 23 & ONSITE & sw & $\mathrm{N}$ & RIVER & TRANSECT & 08-Sep-03 NO2-N & & 0.0074 & $\mathrm{mg} / \mathrm{L}$ & & & U & & \\
\hline SESPMNT & B17HF9 & $100 \mathrm{~N}-1$ HRM 9.5 & ONSITE & sw & $\mathrm{N}$ & RIVER & TRANSECT & 04-Sep-03 NO2-N & & 0.0074 & $\mathrm{mg} / \mathrm{L}$ & & & U & & \\
\hline SESPMNT & B17HHO & $100 \mathrm{~N}-10$ HRM 9.5 & ONSITE & sw & $\mathrm{N}$ & RIVER & TRANSECT & 04-Sep-03 NO2-N & & 0.0074 & $\mathrm{mg} / \mathrm{L}$ & & & $u$ & & \\
\hline SESPMNT & B17HH1 & $100 \mathrm{~N}-2$ HRM 9.5 & ONSITE & sw & $\mathrm{N}$ & RIVER & TRANSECT & 04-Sep-03 NO2-N & & 0.0074 & $\mathrm{mg} / \mathrm{L}$ & & & U & & \\
\hline SESPMNT & B17HH2 & $100 \mathrm{~N}-3$ HRM 9.5 & ONSITE & sw & $\mathrm{N}$ & RIVER & TRANSECT & 04-Sep-03 NO2-N & & 0.0074 & $\mathrm{mg} / \mathrm{L}$ & & & u & & \\
\hline SESPMNT & $\mathrm{B} 17 \mathrm{HH} 3$ & $100 \mathrm{~N}-5$ HRM 9.5 & ONSITE & sw & $\mathrm{N}$ & RIVER & TRANSECT & 04-Sep-03 NO2-N & & 0.0074 & $\mathrm{mg} / \mathrm{L}$ & & & U & & \\
\hline SESPMNT & B17HH4 & $100 \mathrm{~N}-7$ HRM 9.5 & ONSITE & sw & $\mathrm{N}$ & RIVER & TRANSECT & 04-Sep-03 NO2-N & & 0.0074 & $\mathrm{mg} / \mathrm{L}$ & & & u & & \\
\hline SESPMNT & B17HH5 & 100 N SHORE HRM 8.4 & ONSITE & sw & $\mathrm{N}$ & RIVER & TRANSECT & 04-Sep-03 NO2-N & & 0.0074 & $\mathrm{mg} / \mathrm{L}$ & & & u & & \\
\hline SESPMNT & B17HH6 & $100 \mathrm{~N}$ SHORE HRM 8.9 & ONSITE & sw & $\mathrm{N}$ & RIVER & TRANSECT & 04-Sep-03 NO2-N & & 0.0074 & $\mathrm{mg} / \mathrm{L}$ & & & U & & \\
\hline SESPMNT & B17HH7 & $100 \mathrm{~N}$ SHORE HRM 9.2 & ONSITE & sw & $\mathrm{N}$ & RIVER & TRANSECT & 04-Sep-03 NO2-N & & 0.0074 & $\mathrm{mg} / \mathrm{L}$ & & & U & & \\
\hline SESPMNT & B17HH8 & 100 N SHORE HRM 9.8 & ONSITE & sw & $\mathrm{N}$ & RIVER & TRANSECT & 04-Sep-03 NO2-N & & 0.0074 & $\mathrm{mg} / \mathrm{L}$ & & & U & & \\
\hline SESPMNT & B17HH9 & 300 AREA - 1 HRM 43.1 & ONSITE & sw & $\mathrm{N}$ & RIVER & TRANSECT & 09-Sep-03 NO2-N & & 0.0074 & $\mathrm{mg} / \mathrm{L}$ & & & U & & \\
\hline SESPMNT & B17HJO & 300 AREA-10 HRM 43.1 & ONSITE & sw & $\mathrm{N}$ & RIVER & TRANSECT & $09-S e p-03$ NO2-N & & 0.0074 & $\mathrm{mg} / \mathrm{L}$ & & & u & & \\
\hline SESPMNT & B17HJ1 & 300 AREA -2 HRM 43.1 & ONSITE & sw & $\mathrm{N}$ & RIVER & TRANSECT & 09-Sep-03 NO2-N & & 0.0074 & $\mathrm{mg} / \mathrm{L}$ & & & U & & \\
\hline SESPMNT & B17HJ2 & 300 AREA -3 HRM 43.1 & ONSITE & sw & $\mathrm{N}$ & RIVER & TRANSECT & 09-Sep-03 NO2-N & & 0.0074 & $\mathrm{mg} / \mathrm{L}$ & & & $u$ & & \\
\hline SESPMNT & B17HJ3 & 300 AREA -5 HRM 43.1 & ONSITE & sw & $\mathrm{N}$ & RIVER & TRANSECT & $09-\mathrm{Sep}-03$ NO2-N & & 0.0074 & $\mathrm{mg} / \mathrm{L}$ & & & u & & \\
\hline SESPMNT & B17HJ4 & 300 AREA -7 HRM 43.1 & ONSITE & sw & $\mathrm{N}$ & RIVER & TRANSECT & $09-\mathrm{Sep}-03 \mathrm{NO}$-2-N & & 0.0074 & $\mathrm{mg} / \mathrm{L}$ & & & u & & \\
\hline SESPMNT & B17HJ5 & 300 AREA SHR HRM41.5 & ONSITE & sw & $\mathrm{N}$ & RIVER & TRANSECT & $09-S e p-03$ NO2-N & & 0.0074 & $\mathrm{mg} / \mathrm{L}$ & & & u & & \\
\hline SESPMNT & B17HJ6 & 300 AREA SHR HRM42.1 & ONSITE & sw & $\mathrm{N}$ & RIVER & TRANSECT & 09-Sep-03 NO2-N & & 0.0074 & & & & U & & \\
\hline SESPMNT & B17HJ7 & 300 AREA SHR HRM42.5 & ONSITE & sw & $\mathrm{N}$ & RIVER & TRANSECT & 09-Sep-03 NO2-N & & 0.0074 & $\mathrm{mg} / \mathrm{L}$ & & & u & & \\
\hline SESPMNT & B17HJ8 & 300 AREA SHR HRM42.9 & ONSITE & sw & $\mathrm{N}$ & RIVER & TRANSECT & 09-Sep-03 NO2-N & & 0.0074 & $\mathrm{mg} / \mathrm{L}$ & & & U & & \\
\hline SESPMNT & B17HJ9 & HANFRD TS-1 HRM 28.7 & ONSITE & sw & $\mathrm{N}$ & RIVER & TRANSECT & 08-Sep-03 NO2-N & & 0.0074 & $\mathrm{mg} / \mathrm{L}$ & & & u & & \\
\hline SESPMNT & B17HKO & HANFRD TS-2 HRM 28.7 & ONSITE & sw & $\mathrm{N}$ & RIVER & TRANSECT & 08-Sep-03 NO2-N & & 0.0074 & $\mathrm{mg} / \mathrm{L}$ & & & $u$ & & \\
\hline SESPMNT & B17HK1 & HANFRD TS-3 HRM 28.7 & ONSITE & sw & $\mathrm{N}$ & RIVER & TRANSECT & 08-Sep-03 NO2-N & & 0.0074 & $\mathrm{mg} / \mathrm{L}$ & & & u & & \\
\hline SESPMNT & B17HK2 & HANFRD TS-5 HRM 28.7 & ONSITE & sw & $\mathrm{N}$ & RIVER & TRANSECT & 08-Sep-03 NO2-N & & 0.0074 & $\mathrm{mg} / \mathrm{L}$ & & & u & & \\
\hline SESPMNT & B17HK3 & HANFRD TS-7 HRM 28.7 & ONSITE & sw & $\mathrm{N}$ & RIVER & TRANSECT & 08-Sep-03 NO2-N & & 0.0074 & $\mathrm{mg} / \mathrm{L}$ & & & u & & \\
\hline SESPMNT & B17HK4 & HANFRD TS-10 HRM 28.7 & ONSITE & sw & $\mathrm{N}$ & RIVER & TRANSECT & 08-Sep-03 NO2-N & & 0.0074 & $\mathrm{mg} / \mathrm{L}$ & & & u & & \\
\hline SESPMNT & B17HK5 & HANFRD TWNSITE HRM26 & ONSITE & sw & $\mathrm{N}$ & RIVER & TRANSECT & 08 -Sep-03 NO2-N & & 0.0074 & $\mathrm{mg} / \mathrm{L}$ & & & U & & \\
\hline SESPMNT & B17HK6 & HANFRD TWNSITE HRM27 & ONSITE & sw & $\mathrm{N}$ & RIVER & TRANSECT & 08-Sep-03 NO2-N & & 0.0074 & $\mathrm{mg} / \mathrm{L}$ & & & u & & \\
\hline SESPMNT & B17HK7 & HANFRD TWNSITE HRM28 & ONSITE & sw & $\mathrm{N}$ & RIVER & TRANSECT & 08-Sep-03 NO2-N & & 0.0074 & $\mathrm{mg} / \mathrm{L}$ & & & U & & \\
\hline SESPMNT & B17HK8 & HANFRD TWNSITE HRM30 & ONSITE & sW & $\mathrm{N}$ & RIVER & TRANSECT & 08-Sep-03 NO2-N & & 0.0074 & $\mathrm{mg} / \mathrm{L}$ & & & U & & \\
\hline SESPMNT & B17HK9 & RICH.PMPHS-1 HRM46.4 & OFFSITE & SW & $\mathrm{N}$ & RIVER & TRANSECT & $09-\mathrm{Sep}-03$ NO2-N & & 0.0074 & $\mathrm{mg} / \mathrm{L}$ & & & u & & \\
\hline SESPMNT & B17HLO & RICH.PMPHS-2 HRM46.4 & OFFSITE & sW & $\mathrm{N}$ & RIVER & TRANSECT & 09-Sep-03 NO2-N & & 0.0074 & $\mathrm{mg} / \mathrm{L}$ & & & U & & \\
\hline SESPMNT & B17HL1 & RICH.PMPHS-3 HRM46.4 & OFFSITE & sw & $\mathrm{N}$ & RIVER & TRANSECT & 09-Sep-03 NO2-N & & 0.0074 & & & & u & & \\
\hline SESPMNT & B17HL2 & RICH.PMPHS-5 HRM46.4 & OFFSITE & sw & $\mathrm{N}$ & RIVER & TRANSECT & 09-Sep-03 NO2-N & & 0.0074 & $\mathrm{mg} / \mathrm{L}$ & & & u & & \\
\hline SESPMNT & B17HL3 & RICH.PMPHS-7 HRM46.4 & OFFSITE & sw & $\mathrm{N}$ & RIVER & TRANSECT & $09-\mathrm{Sep}-03$ NO2-N & & 0.0074 & $\mathrm{mg} / \mathrm{L}$ & & & u & & \\
\hline
\end{tabular}


WATER - COLUMBIA RIVER TRANSEC

\begin{tabular}{|c|c|c|c|c|c|c|c|c|c|c|c|c|c|c|c|c|}
\hline | OWNER ID & |SAMP NUM| & SAMP SITE NAME & DIST CLASS & $\mid$ MEDIA & \begin{tabular}{|c|} 
FILTERED \\
FLAG
\end{tabular} & $\begin{array}{l}\text { SAMP } \\
\text { FROM }\end{array}$ & COLL MTHD & SAMP DATE & CON SHORT NAME & $\begin{array}{l}\text { VALUE } \\
\text { RPTD }\end{array}$ & \begin{tabular}{|l|} 
ANAL \\
UNITS \\
RPTD \\
\end{tabular} & $\begin{array}{c}\text { COUNTING } \\
\text { ERROR }\end{array}$ & \begin{tabular}{|c|} 
TOTAL \\
ANAL \\
ERROR
\end{tabular} & $\begin{array}{c}\text { LAB } \\
\text { QUALIFIER }\end{array}$ & SAMP COMMENT & $\begin{array}{l}\text { RESULT } \\
\text { COMMENT }\end{array}$ \\
\hline SESPMNT & B17HL4 & RICH.PMPHS-10 HRM46.4 & OFFSITE & SW & $\mathrm{N}$ & RIVER & TRANSECT & 09-Sep-03 NO2-N & & 0.0074 & & & & U & - & \\
\hline SESPMNT & B17HL5 & RICH.PMPHS HRM 43.5 & OFFSITE & sw & $\mathrm{N}$ & RIVER & TRANSECT & 09-Sep-03 NO2-N & & 0.0074 & $4 \mathrm{mg} / \mathrm{L}$ & & & $\mathrm{U}$ & & \\
\hline SESPMNT & B17HL7 & RICH.PMPHS HRM 45.0 & OFFSITE & sw & $\mathrm{N}$ & RIVER & TRANSECT & $09-\mathrm{Sep}-03 \mathrm{NO}-\mathrm{N}$ & & 0.0074 & $4 \mathrm{mg} / \mathrm{L}$ & & & u & & \\
\hline SESPMNT & B17HL8 & RICH.PMPHS HRM 45.8 & OFFSITE & sw & $\mathrm{N}$ & RIVER & TRANSECT & $09-\mathrm{Sep}-03 \mathrm{NO}-\mathrm{N}$ & & 0.0074 & $4 \mathrm{mg} / \mathrm{L}$ & & & u & & \\
\hline SESPMNT & B17HL9 & VERNITA-1 HRM 0.3 & OFFSITE & sw & $\mathrm{N}$ & RIVER & TRANSECT & 04-Sep-03 NO2-N & & 0.0074 & $4 \mathrm{mg} / \mathrm{L}$ & & & $u$ & & \\
\hline SESPMNT & B17HMO & VERNITA-2 HRM 0.3 & OFFSITE & sw & $\mathrm{N}$ & RIVER & TRANSECT & 04-Sep-03 NO2-N & & 0.0074 & & & & $u$ & & \\
\hline SESPMNT & B17HM1 & VERNITA-3 HRM 0.3 & OFFSITE & sw & $\mathrm{N}$ & RIVER & TRANSECT & 04-Sep-03 NO2-N & & 0.0074 & $4 \mathrm{mg} / \mathrm{L}$ & & & $\mathrm{U}$ & & \\
\hline SESPMNT & B17HM2 & VERNITA-4 HRM 0.3 & OFFSITE & sw & $\mathrm{N}$ & RIVER & TRANSECT & 04-Sep-03 NO2-N & & & & & & U & & \\
\hline SESPMNT & B184P5 & VERNITA-1 HRM 0.3 & OFFSITE & sw & $\mathrm{N}$ & RIVER & TRANSECT & 09-Dec-03 NO2-N & & 0.0074 & $4 \mathrm{mg} / \mathrm{L}$ & & & u & & \\
\hline SESPMNT & B184P6 & VERNITA-2 HRM 0.3 & OFFSITE & sw & $\mathrm{N}$ & RIVER & TRANSECT & 09-Dec-03 NO2-N & & 0.0074 & $4 \mathrm{mg} / \mathrm{L}$ & & & U & & \\
\hline SESPMNT & B184P7 & VERNITA-3 HRM 0.3 & OFFSITE & sw & $\mathrm{N}$ & RIVER & TRANSECT & 09-Dec-03 NO2-N & & 0.0074 & $4 \mathrm{mg} / \mathrm{L}$ & & & u & & \\
\hline SESPMNT & B184P8 & VERNITA-4 HRM 0.3 & OFFSITE & sw & $\mathrm{N}$ & RIVER & TRANSECT & 09-Dec-03 NO2-N & & 0.0074 & $4 \mathrm{mg} / \mathrm{L}$ & & & u & & \\
\hline SESPMNT & B184P9 & RICH.PMPHS-1 HRM46.4 & OFFSITE & sw & $\mathrm{N}$ & RIVER & TRANSECT & 08-Dec-03 NO2-N & & 0.0074 & $4 \mathrm{mg} / \mathrm{L}$ & & & U & & \\
\hline SESPMNT & B184RO & RICH.PMPHS-2 HRM46.4 & OFFSITE & sw & $\mathrm{N}$ & RIVER & TRANSECT & $08-D e c-03$ NO2-N & & 0.0074 & $4 \mathrm{mg} / \mathrm{L}$ & & & u & & \\
\hline SESPMNT & B184R1 & RICH.PMPHS-3 HRM46.4 & OFFSITE & sw & $\mathrm{N}$ & RIVER & TRANSECT & 08-Dec-03 NO2-N & & 0.0074 & & & & u & & \\
\hline SESPMNT & B184R2 & RICH.PMPHS-5 HRM46.4 & OFFSITE & sw & $\mathrm{N}$ & RIVER & TRANSECT & 08-Dec-03 NO2-N & & 0.0074 & & & & u & & \\
\hline SESPMNT & B184R3 & RICH.PMPHS-7 HRM46.4 & OFFSITE & sw & $\mathrm{N}$ & RIVER & TRANSECT & 08-Dec-03 NO2-N & & 0.0074 & $4 \mathrm{mg} / \mathrm{L}$ & & & $u$ & & \\
\hline SESPMNT & B184R4 & RICH.PMPHS-10 HRM46.4 & OFFSITE & sw & $\mathrm{N}$ & RIVER & TRANSECT & 08-Dec-03 NO2-N & & 0.0074 & $4 \mathrm{mg} / \mathrm{L}$ & & & U & & \\
\hline SESPMNT & B184R5 & RICH.PMPHS HRM 43.5 & OFFSITE & sw & $\mathrm{N}$ & RIVER & TRANSECT & 08-Dec-03 NO2-N & & 0.0074 & $4 \mathrm{mg} / \mathrm{L}$ & & & u & & \\
\hline SESPMNT & B184R6 & RICH.PMPHS HRM 43.9 & OFFSITE & sw & $\mathrm{N}$ & RIVER & TRANSECT & 08 -Dec-03 NO2-N & & 0.0074 & $4 \mathrm{mg} / \mathrm{L}$ & & & u & & \\
\hline SESPMNT & B184R7 & RICH.PMPHS HRM 45.0 & OFFSITE & sw & $\mathrm{N}$ & RIVER & TRANSECT & 08-Dec-03 NO2-N & & 0.0074 & $4 \mathrm{mg} / \mathrm{L}$ & & & U & & \\
\hline SESPMNT & B184R8 & RICH.PMPHS HRM 45.8 & OFFSITE & sw & $\mathrm{N}$ & RIVER & TRANSECT & $08-\mathrm{Dec}-03$ NO2-N & & 0.0074 & & & & u & & \\
\hline SESPMNT & B16KC6 & RICH.PMPHS-10 HRM46. 4 & OFFSITE & sw & $\mathrm{N}$ & RIVER & TRANSECT & $25-\mathrm{Mar}-03 \mathrm{NO}-\mathrm{N}$ & & & & & & & & \\
\hline SESPMNT & B16KC7 & RICH.PMPHS-1 HRM46.4 & OFFSITE & sw & $\mathrm{N}$ & RIVER & TRANSECT & 25-Mar-03 NO3-N & & & $9 \mathrm{mg} / \mathrm{L}$ & & & & & \\
\hline SESPMNT & B16KC8 & RICH.PMPHS-2 HRM46.4 & OFFSITE & sw & $\mathrm{N}$ & RIVER & TRANSECT & 25-Mar-03 NO3-N & & 0.18 & $8 \mathrm{mg} / \mathrm{L}$ & & & & & \\
\hline SESPMNT & B16KC9 & RICH.PMPHS-3 HRM46.4 & OFFSITE & sw & $\mathrm{N}$ & RIVER & TRANSECT & 25-Mar-03 NO3-N & & 0.18 & $8 \mathrm{mg} / \mathrm{L}$ & & & & & \\
\hline SESPMNT & B16KD0 & RICH.PMPHS-5 HRM46.4 & OFFSITE & sw & $\mathrm{N}$ & RIVER & TRANSECT & 25-Mar-03 NO3-N & & & $2 \mathrm{mg} / \mathrm{L}$ & & & & & \\
\hline SESPMNT & B16KD1 & RICH.PMPHS-7 HRM46.4 & OFFSITE & sw & $\mathrm{N}$ & RIVER & TRANSECT & 25-Mar-03 NO3-N & & & $2 \mathrm{mg} / \mathrm{L}$ & & & & & \\
\hline SESPMNT & B16KD2 & RICH.PMPHS HRM 43.5 & OFFSITE & sw & $\mathrm{N}$ & RIVER & TRANSECT & 25-Mar-03 NO3-N & & & $2 \mathrm{mg} / \mathrm{L}$ & & & & & \\
\hline SESPMNT & B16KD3 & RICH.PMPHS HRM 43.9 & OFFSITE & sw & $\mathrm{N}$ & RIVER & TRANSECT & 25-Mar-03 NO3-N & & & $1 \mathrm{mg} / \mathrm{L}$ & & & & & \\
\hline SESPMNT & B16KD4 & RICH.PMPHS HRM 45.0 & OFFSITE & sw & $\mathrm{N}$ & RIVER & TRANSECT & 25-Mar-03 NO3-N & & & $9 \mathrm{mg} / \mathrm{L}$ & & & & & \\
\hline SESPMNT & B16KD5 & RICH.PMPHS HRM 45.8 & OFFSITE & sw & $\mathrm{N}$ & RIVER & TRANSECT & 25-Mar-03 NO3-N & & 0.18 & $8 \mathrm{mg} / \mathrm{L}$ & & & & & \\
\hline SESPMNT & B16KD6 & VERNITA-1 HRM 0.3 & OFFSITE & sw & $\mathrm{N}$ & RIVER & TRANSECT & 24-Mar-03 NO3-N & & 0.19 & $9 \mathrm{mg} / \mathrm{L}$ & & & & & \\
\hline SESPMNT & B16KD7 & VERNITA-2 HRM 0.3 & OFFSITE & sw & $\mathrm{N}$ & RIVER & TRANSECT & 24-Mar-03 NO3-N & & 0.18 & $8 \mathrm{mg} / \mathrm{L}$ & & & & & \\
\hline SESPMNT & B16KD8 & VERNITA-3 HRM 0.3 & OFFSITE & sw & $\mathrm{N}$ & RIVER & TRANSECT & 24-Mar-03 NO3-N & & & $2 \mathrm{mg} / \mathrm{L}$ & & & & & \\
\hline SESPMNT & B16KD9 & VERNITA-4 HRM 0.3 & OFFSITE & sw & $\mathrm{N}$ & RIVER & TRANSECT & 24-Mar-03 NO3-N & & 0.22 & & & & & & \\
\hline SESPMNT & B17276 & RICH.PMPHS-10 HRM46.4 & OFFSITE & sw & $\mathrm{N}$ & RIVER & TRANSECT & 10-Jun-03 NO3-N & & 0.16 & $6 \mathrm{mg} / \mathrm{L}$ & & & & & \\
\hline SESPMNT & B17277 & RICH.PMPHS-1 HRM46.4 & OFFSITE & sw & $\mathrm{N}$ & RIVER & TRANSECT & 10-Jun-03 NO3-N & & 0.069 & & & & & & \\
\hline SESPMNT & B17278 & RICH.PMPHS-2 HRM46.4 & OFFSITE & sw & $\mathrm{N}$ & RIVER & TRANSECT & 10-Jun-03 NO3-N & & 0.074 & $4 \mathrm{mg} / \mathrm{L}$ & & & & & \\
\hline SESPMNT & B17279 & RICH.PMPHS-3 HRM46.4 & OFFSITE & sw & $\mathrm{N}$ & RIVER & TRANSECT & 10-Jun-03 NO3-N & & 0.074 & $4 \mathrm{mg} / \mathrm{L}$ & & & & & \\
\hline SESPMNT & B17280 & RICH.PMPHS-5 HRM46.4 & OFFSITE & sw & $\mathrm{N}$ & RIVER & TRANSECT & 10-Jun-03 NO3-N & & 0.074 & $4 \mathrm{mg} / \mathrm{L}$ & & & & & \\
\hline SESPMNT & B17281 & RICH.PMPHS-7 HRM46.4 & OFFSITE & sw & $\mathrm{N}$ & RIVER & TRANSECT & 10-Jun-03 NO3-N & & 0.079 & $9 \mathrm{mg} / \mathrm{L}$ & & & & & \\
\hline SESPMNT & B17282 & RICH.PMPHS HRM 43.5 & OFFSITE & sw & $\mathrm{N}$ & RIVER & TRANSECT & 10-Jun-03 NO3-N & & 0.072 & $2 \mathrm{mg} / \mathrm{L}$ & & & & & \\
\hline SESPMNT & B17283 & RICH.PMPHS HRM 43.9 & OFFSITE & sw & $\mathrm{N}$ & RIVER & TRANSECT & 10-Jun-03 NO3-N & & 0.069 & $9 \mathrm{mg} / \mathrm{L}$ & & & & & \\
\hline SESPMNT & B17284 & RICH.PMPHS HRM 45.0 & OFFSITE & sw & $\mathrm{N}$ & RIVER & TRANSECT & 10-Jun-03 NO3-N & & 0.068 & & & & & & \\
\hline SESPMNT & B17285 & RICH.PMPHS HRM 45.8 & OFFSITE & sw & $\mathrm{N}$ & RIVER & TRANSECT & 10-Jun-03 NO3-N & & 0.065 & $5 \mathrm{mg} / \mathrm{L}$ & & & & & \\
\hline SESPMNT & B17286 & VERNITA-1 HRM 0.3 & OFFSITE & sW & $\mathrm{N}$ & RIVER & TRANSECT & 09-Jun-03 NO3-N & & 0.069 & $9 \mathrm{mg} / \mathrm{L}$ & & & & & \\
\hline SESPMNT & B17287 & VERNITA-2 HRM 0.3 & OFFSITE & sw & $\mathrm{N}$ & RIVER & TRANSECT & 09-Jun-03 NO3-N & & 0.075 & $5 \mathrm{mg} / \mathrm{L}$ & & & & & \\
\hline SESPMNT & B17288 & VERNITA-3 HRM 0.3 & OFFSITE & sw & $\mathrm{N}$ & RIVER & TRANSECT & 09-Jun-03 NO3-N & & 0.073 & $3 \mathrm{mg} / \mathrm{L}$ & & & & & \\
\hline SESPMNT & B17289 & VERNITA-4 HRM 0.3 & OFFSITE & sw & $\mathrm{N}$ & RIVER & TRANSECT & 09-Jun-03 NO3-N & & 0.086 & $6 \mathrm{mg} / \mathrm{L}$ & & & & & \\
\hline SESPMNT & B17HF0 & $100 \mathrm{~F}-10 \mathrm{HRM} 19.0$ & ONSITE & sw & $\mathrm{N}$ & RIVER & TRANSECT & $08-\mathrm{Sep}-03$ NO3-N & & 0.084 & $4 \mathrm{mg} / \mathrm{L}$ & & & & & \\
\hline SESPMNT & B17HF1 & $100 \mathrm{~F}-1$ HRM 19.0 & ONSITE & sw & $\mathrm{N}$ & RIVER & TRANSECT & $08-\mathrm{Sep}-03 \mathrm{NO}-\mathrm{N}$ & & 0.11 & $1 \mathrm{mg} / \mathrm{L}$ & & & & & \\
\hline SESPMNT & B17HF2 & 100 F - 2 HRM 19.0 & ONSITE & sw & $\mathrm{N}$ & RIVER & TRANSECT & 08-Sep-03 NO3-N & & & $1 \mathrm{mg} / \mathrm{L}$ & & & & & \\
\hline SESPMNT & B17HF3 & $100 \mathrm{~F}-3$ HRM 19.0 & ONSITE & sw & $\mathrm{N}$ & RIVER & TRANSECT & $08-\mathrm{Sep}-03$ NO3-N & & & $1 \mathrm{mg} / \mathrm{L}$ & & & & & \\
\hline SESPMNT & B17HF4 & 100 F -5 HRM 19.0 & ONSITE & sw & $\mathrm{N}$ & RIVER & TRANSECT & 08-Sep-03 NO3-N & & & $1 \mathrm{mg} / \mathrm{L}$ & & & & & \\
\hline SESPMNT & B17HF5 & 100 F -7 HRM 19.0 & ONSITE & sW & $\mathrm{N}$ & RIVER & TRANSECT & 08-Sep-03 NO3-N & & 0.096 & $6 \mathrm{mg} / \mathrm{L}$ & & & & & \\
\hline SESPMNT & B17HF6 & 100 F SHORE HRM 18 & ONSITE & sW & $\mathrm{N}$ & RIVER & TRANSECT & 08-Sep-03 NO3-N & & 0.11 & $1 \mathrm{mg} / \mathrm{L}$ & & & & & \\
\hline SESPMNT & B17HF7 & $100 \mathrm{~F}$ SHORE HRM 22 & ONSITE & SW & $\mathrm{N}$ & RIVER & TRANSECT & $08-S e p-03$ NO3-N & & 0.075 & $5 \mathrm{mg} / \mathrm{L}$ & & & & & \\
\hline SESPMNT & B17HF8 & $100 \mathrm{~F}$ SHORE HRM 23 & ONSITE & sW & $\mathrm{N}$ & RIVER & TRANSECT & 08-Sep-03 NO3-N & & 0.078 & $8 \mathrm{mg} / \mathrm{L}$ & & & & & \\
\hline SESPMNT & B17HF9 & $100 \mathrm{~N}-1$ HRM 9.5 & ONSITE & sw & $\mathrm{N}$ & RIVER & TRANSECT & 04-Sep-03 NO3-N & & 0.099 & $9 \mathrm{mg} / \mathrm{L}$ & & & & & \\
\hline SESPMNT & B17HHO & $100 \mathrm{~N}-10$ HRM 9.5 & ONSITE & sw & $\mathrm{N}$ & RIVER & TRANSECT & 04-Sep-03 NO3-N & & 0.055 & & & & & & \\
\hline SESPMNT & B17HH1 & $100 \mathrm{~N}-2$ HRM 9.5 & ONSITE & sw & $\mathrm{N}$ & RIVER - & TRANSECT & 04-Sep-03 NO3-N & & 0.055 & $5 \mathrm{mg} / \mathrm{L}$ & & & & & \\
\hline
\end{tabular}


WATER - COLUMBIA RIVER TRANSEC

\begin{tabular}{|c|c|c|c|c|c|c|c|c|c|c|c|c|c|c|c|c|}
\hline | OWNER ID & SAMP NUM & SAMP SITE NAME & DIST CLASS & MEDIA $\left.\right|^{F}$ & \begin{tabular}{|c|} 
FILTERED \\
FLAG
\end{tabular} & $\begin{array}{l}\text { SAMP } \\
\text { FROM }\end{array}$ & COLL MTHD & SAMP DATE & CON SHORT NAME & $\begin{array}{l}\text { VALUE } \\
\text { RPTD }\end{array}$ & \begin{tabular}{|l|} 
ANAL \\
UNITS \\
RPTD \\
\end{tabular} & $\begin{array}{c}\text { COUNTING } \\
\text { ERROR }\end{array}$ & \begin{tabular}{|c|} 
TOTAL \\
ANAL \\
ERROR
\end{tabular} & $\begin{array}{c}\text { LAB } \\
\text { QUALIFIER }\end{array}$ & SAMP COMMENT & $\begin{array}{l}\text { RESULT } \\
\text { COMMENT }\end{array}$ \\
\hline SESPMNT & $\mathrm{B} 17 \mathrm{HH} 2$ & $100 \mathrm{~N}-3$ HRM 9.5 & ONSITE & SW & $\mathrm{N}$ & RIVER & TRANSECT & 04-Sep-03 NO3-N & & & & & & & & \\
\hline SESPMNT & $\mathrm{B} 17 \mathrm{HH} 3$ & $100 \mathrm{~N}-5$ HRM 9.5 & ONSITE & SW & $\mathrm{N}$ & RIVER & TRANSECT & 04-Sep-03 NO3-N & & 0.064 & $\mathrm{mg} / \mathrm{L}$ & & & & & \\
\hline SESPMNT & $\mathrm{B} 17 \mathrm{HH} 4$ & $100 \mathrm{~N}-7$ HRM 9.5 & ONSITE & sw & $\mathrm{N}$ & RIVER & TRANSECT & 04-Sep-03 NO3-N & & 0.061 & $\mathrm{mg} / \mathrm{L}$ & & & & & \\
\hline SESPMNT & B17HH5 & 100 N SHORE HRM 8.4 & ONSITE & SW & $\mathrm{N}$ & RIVER & TRANSECT & 04-Sep-03 NO3-N & & 0.05 & $\mathrm{mg} / \mathrm{L}$ & & & & & \\
\hline SESPMNT & $\mathrm{B} 17 \mathrm{HH} 6$ & $100 \mathrm{~N}$ SHORE HRM 8.9 & ONSITE & SW & $\mathrm{N}$ & RIVER & TRANSECT & 04-Sep-03 NO3-N & & 0.054 & $\mathrm{mg} / \mathrm{L}$ & & & & & \\
\hline SESPMNT & B17HH7 & $100 \mathrm{~N} \mathrm{SHORE} \mathrm{HRM} 9.2$ & ONSITE & SW & $\mathrm{N}$ & RIVER & TRANSECT & 04-Sep-03 NO3-N & & 0.049 & & & & & & \\
\hline SESPMNT & B17HH8 & $100 \mathrm{~N}$ SHORE HRM 9.8 & ONSITE & sw & $\mathrm{N}$ & RIVER & TRANSECT & 04-Sep-03 NO3-N & & 0.054 & & & & & & \\
\hline SESPMNT & B17HH9 & 300 AREA - 1 HRM 43.1 & ONSITE & sW & $\mathrm{N}$ & RIVER & TRANSECT & 09-Sep-03 NO3-N & & & & & & & & \\
\hline SESPMNT & B17HJO & 300 AREA-10 HRM 43.1 & ONSITE & SW & $\mathrm{N}$ & RIVER & TRANSECT & 09-Sep-03 NO3-N & & & $\mathrm{mg} / \mathrm{L}$ & & & & & \\
\hline SESPMNT & B17HJ1 & 300 AREA -2 HRM 43.1 & ONSITE & sw & $\mathrm{N}$ & RIVER & TRANSECT & 09-Sep-03 NO3-N & & 0.12 & $\mathrm{mg} / \mathrm{L}$ & & & & & \\
\hline SESPMNT & B17HJ2 & 300 AREA -3 HRM 43.1 & ONSITE & SW & $\mathrm{N}$ & RIVER & TRANSECT & 09-Sep-03 NO3-N & & 0.091 & $\mathrm{mg} / \mathrm{L}$ & & & & & \\
\hline SESPMNT & B17HJ3 & 300 AREA -5 HRM 43.1 & ONSITE & sw & $\mathrm{N}$ & RIVER & TRANSECT & 09-Sep-03 NO3-N & & 0.093 & $\mathrm{mg} / \mathrm{L}$ & & & & & \\
\hline SESPMNT & B17HJ4 & 300 AREA -7 HRM 43.1 & ONSITE & sW & $\mathrm{N}$ & RIVER & TRANSECT & 09-Sep-03 NO3-N & & & $\mathrm{mg} / \mathrm{L}$ & & & & & \\
\hline SESPMNT & B17HJ5 & 300 AREA SHR HRM41.5 & ONSITE & sw & $\mathrm{N}$ & RIVER & $\begin{array}{l}\text { TRANSECT } \\
\text { TRES }\end{array}$ & $09-\mathrm{Sep}-03$ NO3-N & & & $\mathrm{mg} / \mathrm{L}$ & & & & & \\
\hline SESPMNT & B17HJ6 & 300 AREA SHR HRM42.1 & ONSITE & sw & $\mathrm{N}$ & RIVER & TRANSECT & 09-Sep-03 NO3-N & & & & & & & & \\
\hline SESPMNT & B17HJ7 & 300 AREA SHR HRM42.5 & ONSITE & sw & $\mathrm{N}$ & RIVER & TRANSECT & 09-Sep-03 NO3-N & & & & & & & & \\
\hline SESPMNT & B17HJ8 & 300 AREA SHR HRM42.9 & ONSITE & sw & $\mathrm{N}$ & RIVER & TRANSECT & 09-Sep-03 NO3-N & & 0.29 & $\mathrm{mg} / \mathrm{L}$ & & & & & \\
\hline SESPMNT & B17HJ9 & HANFRD TS-1 HRM 28.7 & ONSITE & sW & $\mathrm{N}$ & RIVER & TRANSECT & 08-Sep-03 NO3-N & & & $\mathrm{mg} / \mathrm{L}$ & & & & & \\
\hline SESPMNT & B17HKO & HANFRD TS-2 HRM 28.7 & ONSITE & sW & $\mathrm{N}$ & RIVER & TRANSECT & 08-Sep-03 NO3-N & & 0.075 & $\mathrm{mg} / \mathrm{L}$ & & & & & \\
\hline SESPMNT & B17HK1 & HANFRD TS-3 HRM 28.7 & ONSITE & SW & $\mathrm{N}$ & RIVER & TRANSECT & 08 -Sep-03 NO3-N & & 0.085 & & & & & & \\
\hline SESPMNT & B17HK2 & HANFRD TS-5 HRM 28.7 & ONSITE & SW & $\mathrm{N}$ & RIVER & TRANSECT & 08-Sep-03 NO3-N & & 0.081 & & & & & & \\
\hline SESPMNT & B17HK3 & HANFRD TS-7 HRM 28.7 & ONSITE & sw & $\mathrm{N}$ & RIVER & TRANSECT & 08-Sep-03 NO3-N & & 0.066 & & & & & & \\
\hline SESPMNT & B17HK4 & HANFRD TS-10 HRM 28.7 & ONSITE & sw & $\mathrm{N}$ & RIVER & TRANSECT & $08-\mathrm{Sep}-03 \mathrm{NO}$ N-N & & 0.066 & & & & & & \\
\hline SESPMNT & B17HK5 & HANFRD TWNSITE HRM26 & ONSITE & sw & $\mathrm{N}$ & RIVER & TRANSECT & 08-Sep-03 NO3-N & & 0.06 & $\mathrm{mg} / \mathrm{L}$ & & & & & \\
\hline SESPMNT & B17HK6 & HANFRD TWNSITE HRM27 & ONSITE & sw & $\mathrm{N}$ & RIVER & TRANSECT & 08-Sep-03 NO3-N & & 0.076 & $\mathrm{mg} / \mathrm{L}$ & & & & & \\
\hline SESPMNT & B17HK7 & HANFRD TWNSITE HRM28 & ONSITE & sw & $\mathrm{N}$ & RIVER & TRANSECT & 08-Sep-03 NO3-N & & & $\mathrm{mg} / \mathrm{L}$ & & & D & & \\
\hline SESPMNT & B17HK8 & HANFRD TWNSITE HRM30 & ONSITE & sW & $\mathrm{N}$ & RIVER & TRANSECT & 08-Sep-03 NO3-N & & & $\mathrm{mg} / \mathrm{L}$ & & & & & \\
\hline SESPMNT & B17HK9 & RICH.PMPHS-1 HRM46.4 & OFFSITE & SW & $\mathrm{N}$ & RIVER & TRANSECT & 09-Sep-03 NO3-N & & 0.14 & $\mathrm{mg} / \mathrm{L}$ & & & & & \\
\hline SESPMNT & B17HLO & RICH.PMPHS-2 HRM46.4 & OFFSITE & sW & $\mathrm{N}$ & RIVER & TRANSECT & 09-Sep-03 NO3-N & & 0.12 & $\mathrm{mg} / \mathrm{L}$ & & & & & \\
\hline SESPMNT & B17HL1 & RICH.PMPHS-3 HRM46.4 & OFFSITE & sW & $\mathrm{N}$ & RIVER & TRANSECT & 09-Sep-03 NO3-N & & 0.093 & $\mathrm{mg} / \mathrm{L}$ & & & & & \\
\hline SESPMNT & B17HL2 & RICH.PMPHS-5 HRM46.4 & OFFSITE & sW & $\mathrm{N}$ & RIVER & TRANSECT & 09-Sep-03 NO3-N & & 0.093 & $\mathrm{mg} / \mathrm{L}$ & & & & & \\
\hline SESPMNT & B17HL3 & RICH.PMPHS-7 HRM46.4 & OFFSITE & SW & $\mathrm{N}$ & RIVER & TRANSECT & 09-Sep-03 NO3-N & & & $\mathrm{mg} / \mathrm{L}$ & & & & & \\
\hline SESPMNT & B17HL4 & RICH.PMPHS-10 HRM46. 4 & OFFSITE & sW & $\mathrm{N}$ & RIVER & TRANSECT & $09-\mathrm{Sep}-03 \mathrm{NO}$ N-N & & 0.55 & $\mathrm{mg} / \mathrm{L}$ & & & & & \\
\hline SESPMNT & B17HL5 & RICH.PMPHS HRM 43.5 & OFFSITE & sw & $\mathrm{N}$ & RIVER & TRANSECT & $09-\mathrm{Sep}-03$ NO3-N & & 0.59 & $\mathrm{mg} / \mathrm{L}$ & & & & & \\
\hline SESPMNT & B17HL7 & RICH.PMPHS HRM 45.0 & OFFSITE & SW & $\mathrm{N}$ & RIVER & TRANSECT & 09-Sep-03 NO3-N & & 0.17 & $\mathrm{mg} / \mathrm{L}$ & & & & & \\
\hline SESPMNT & B17HL8 & RICH.PMPHS HRM 45.8 & OFFSITE & SW & $\mathrm{N}$ & RIVER & TRANSECT & 09-Sep-03 NO3-N & & 0.16 & $\mathrm{mg} / \mathrm{L}$ & & & & & \\
\hline SESPMNT & B17HL9 & VERNITA-1 HRM 0.3 & OFFSITE & sW & $\mathrm{N}$ & RIVER & TRANSECT & 04-Sep-03 NO3-N & & 0.052 & & & & & & \\
\hline SESPMNT & B17HMO & VERNITA-2 HRM 0.3 & OFFSITE & sW & $\mathrm{N}$ & RIVER & TRANSECT & 04-Sep-03 NO3-N & & 0.054 & & & & & & \\
\hline SESPMNT & B17HM1 & VERNITA-3 HRM 0.3 & OFFSITE & SW & $\mathrm{N}$ & RIVER & TRANSECT & $04-S e p-03$ NO3-N & & 0.055 & $5 \mathrm{mg} / \mathrm{L}$ & & & & & \\
\hline SESPMNT & B17HM2 & VERNITA-4 HRM 0.3 & OFFSITE & SW & $\mathrm{N}$ & RIVER & TRANSECT & 04-Sep-03 NO3-N & & 0.075 & $\mathrm{mg} / \mathrm{L}$ & & & & & \\
\hline SESPMNT & B184P5 & VERNITA-1 HRM 0.3 & OFFSITE & sW & $\mathrm{N}$ & RIVER & TRANSECT & 09-Dec-03 NO3-N & & 0.094 & $\mathrm{mg} / \mathrm{L}$ & & & & & \\
\hline SESPMNT & B184P6 & VERNITA-2 HRM 0.3 & OFFSITE & sW & $\mathrm{N}$ & RIVER & TRANSECT & $09-\mathrm{Dec}-03$ NO3-N & & 0.099 & $\mathrm{mg} / \mathrm{L}$ & & & & & \\
\hline SESPMNT & B184P7 & VERNITA-3 HRM 0.3 & OFFSITE & sw & $\mathrm{N}$ & RIVER & TRANSECT & $09-\mathrm{Dec}-03 \mathrm{~N}$ NO3-N & & & $\mathrm{mg} / \mathrm{L}$ & & & & & \\
\hline SESPMNT & B184P8 & VERNITA-4 HRM 0.3 & OFFSITE & sw & $\mathrm{N}$ & RIVER & TRANSECT & $09-\mathrm{Dec}-03 \mathrm{~N}$ NO3-N & & 0.11 & $\mathrm{mg} / \mathrm{L}$ & & & & & \\
\hline SESPMNT & B184P9 & RICH.PMPHS-1 HRM46.4 & OFFSITE & SW & $\mathrm{N}$ & RIVER & TRANSECT & 08-Dec-03 NO3-N & & 0.14 & & & & & & \\
\hline SESPMNT & B184R0 & RICH.PMPHS-2 HRM46.4 & OFFSITE & sw & $\mathrm{N}$ & RIVER & TRANSECT & 08-Dec-03 NO3-N & & 0.11 & $\mathrm{mg} / \mathrm{L}$ & & & & & \\
\hline SESPMNT & B184R1 & RICH.PMPHS-3 HRM46.4 & OFFSITE & sW & $\mathrm{N}$ & RIVER & TRANSECT & 08-Dec-03 NO3-N & & 0.12 & $\mathrm{mg} / \mathrm{L}$ & & & & & \\
\hline SESPMNT & B184R2 & RICH.PMPHS-5 HRM46.4 & OFFSITE & sW & $\mathrm{N}$ & RIVER & TRANSECT & 08-Dec-03 NO3-N & & 0.11 & $\mathrm{mg} / \mathrm{L}$ & & & & & \\
\hline SESPMNT & B184R3 & RICH.PMPHS-7 HRM46.4 & OFFSITE & SW & $\mathrm{N}$ & RIVER & TRANSECT & 08-Dec-03 NO3-N & & 0.12 & $\mathrm{mg} / \mathrm{L}$ & & & & & \\
\hline SESPMNT & B184R4 & RICH.PMPHS-10 HRM46.4 & OFFSITE & SW & $\mathrm{N}$ & RIVER & TRANSECT & 08-Dec-03 NO3-N & & 0.49 & $\mathrm{mg} / \mathrm{L}$ & & & & & \\
\hline SESPMNT & B184R5 & RICH.PMPHS HRM 43.5 & OFFSITE & sw & $\mathrm{N}$ & RIVER & TRANSECT & 08-Dec-03 NO3-N & & & $\mathrm{mg} / \mathrm{L}$ & & & & & \\
\hline SESPMNT & B184R6 & RICH.PMPHS HRM 43.9 & OFFSITE & SW & $\mathrm{N}$ & RIVER & TRANSECT & 08-Dec-03 NO3-N & & 0.26 & $\mathrm{mg} / \mathrm{L}$ & & & & & \\
\hline SESPMNT & B184R7 & RICH.PMPHS HRM 45.0 & OFFSITE & SW & $\mathrm{N}$ & RIVER & TRANSECT & 08-Dec-03 NO3-N & & 0.14 & $\mathrm{mg} / \mathrm{L}$ & & & & & \\
\hline SESPMNT & B184R8 & RICH.PMPHS HRM 45.8 & OFFSITE & sW & $\mathrm{N}$ & RIVER & TRANSECT & $08-D e c-03$ NO3-N & & 0.14 & $\mathrm{mg} / \mathrm{L}$ & & & & & \\
\hline SESPMNT & B16KC6 & RICH.PMPHS-10 HRM46.4 & OFFSITE & sW & $\mathrm{N}$ & RIVER & TRANSECT & 25-Mar-03 SULFATE & & 15.6 & $\mathrm{mg} / \mathrm{L}$ & & & & & \\
\hline SESPMNT & B16KC7 & RICH.PMPHS-1 HRM46.4 & OFFSITE & sw & $\mathrm{N}$ & RIVER & TRANSECT & 25-Mar-03 SULFATE & & & $\mathrm{mg} / \mathrm{L}$ & & & & & \\
\hline SESPMNT & B16KC8 & RICH.PMPHS-2 HRM46.4 & OFFSITE & SW & $\mathrm{N}$ & RIVER & TRANSECT & 25-Mar-03 SULFATE & & & $\mathrm{mg} / \mathrm{L}$ & & & & & \\
\hline SESPMNT & B16KC9 & RICH.PMPHS-3 HRM46.4 & OFFSITE & SW & $\mathrm{N}$ & RIVER & TRANSECT & 25-Mar-03 SULFATE & & & $\mathrm{mg} / \mathrm{L}$ & & & & & \\
\hline SESPMNT & B16KD0 & RICH.PMPHS-5 HRM46.4 & OFFSITE & sW & $\mathrm{N}$ & RIVER & TRANSECT & 25-Mar-03 SULFATE & & 10.1 & $\mathrm{mg} / \mathrm{L}$ & & & & & \\
\hline SESPMNT & B16KD1 & RICH.PMPHS-7 HRM46.4 & OFFSITE & SW & $\mathrm{N}$ & RIVER & TRANSECT & 25-Mar-03 SULFATE & & & $\mathrm{mg} / \mathrm{L}$ & & & & & \\
\hline SESPMNT & B16KD2 & RICH.PMPHS HRM 43.5 & OFFSITE & SW & $\mathrm{N}$ & RIVER & TRANSECT & 25-Mar-03 SULFATE & & & & & & & & \\
\hline SESPMNT & B16KD3 & RICH.PMPHS HRM 43.9 & OFFSITE & sW & $\mathrm{N}$ & RIVER & TRANSECT & 25-Mar-03 SULFATE & & 10.2 & $\mathrm{mg} / \mathrm{L}$ & & & & & \\
\hline
\end{tabular}


WATER - COLUMBIA RIVER TRANSEC

\begin{tabular}{|c|c|c|c|c|c|c|c|c|c|c|c|c|c|c|c|c|c|}
\hline | OWNER ID & SAMP NUM & SAMP SITE NAME & DIST CLASS & $\mid$ MEDIA & \begin{tabular}{|c|} 
FILTERED \\
FLAG
\end{tabular} & $\begin{array}{l}\text { SAMP } \\
\text { FROM }\end{array}$ & COLL MTHD & SAMP DATE & & CON SHORT NAME & $\begin{array}{l}\text { VALUE } \\
\text { RPTD }\end{array}$ & \begin{tabular}{|l|} 
ANAL \\
UNITS \\
RPTD \\
\end{tabular} & \begin{tabular}{|l|} 
COUNTING \\
ERROR
\end{tabular} & \begin{tabular}{|c|} 
TOTAL \\
ANAL \\
ERROR
\end{tabular} & $\begin{array}{c}\text { LAB } \\
\text { QUALIFIER }\end{array}$ & SAMP COMMENT & $\begin{array}{l}\text { RESULT } \\
\text { COMMENT }\end{array}$ \\
\hline SESPMNT & B16KD4 & RICH.PMPHS HRM 45.0 & OFFSITE & SW & $\mathrm{N}$ & & TRANSECT & $25-\mathrm{Mar}-03 \mathrm{~S}$ & SULFATE & & & & & & & & \\
\hline SESPMNT & B16KD5 & RICH.PMPHS HRM 45.8 & OFFSITE & sw & $\mathrm{N}$ & RIVER & TRANSECT & $25-\mathrm{Mar}-03 \mathrm{~s}$ & SULFATE & & & $9 \mathrm{mg} / \mathrm{L}$ & & & & & \\
\hline SESPMNT & B16KD6 & VERNITA-1 HRM 0.3 & OFFSITE & sw & $\mathrm{N}$ & RIVER & TRANSECT & 24-Mar-03s & SULFATE & & & $8 \mathrm{mg} / \mathrm{L}$ & & & c & & \\
\hline SESPMNT & B16KD7 & VERNITA-2 HRM 0.3 & OFFSITE & sw & $\mathrm{N}$ & RIVER & TRANSECT & 24-Mar-03s & SULFATE & & & $8 \mathrm{mg} / \mathrm{L}$ & & & c & & \\
\hline SESPMNT & B16KD8 & VERNITA-3 HRM 0.3 & OFFSITE & sw & $\mathrm{N}$ & RIVER & TRANSECT & 24-Mar-03 s & SULFATE & & & $0 \mathrm{mg} / \mathrm{L}$ & & & c & & \\
\hline SESPMNT & B16KD9 & VERNITA-4 HRM 0.3 & OFFSITE & sw & $\mathrm{N}$ & RIVER & TRANSECT & 24-Mar-03s & SULFATE & & & & & & C & & \\
\hline SESPMNT & B17276 & RICH.PMPHS-10 HRM46.4 & OFFSITE & sw & $\mathrm{N}$ & RIVER & TRANSECT & 10-Jun-03 s & SULFATE & & & & & & & & \\
\hline SESPMNT & B17277 & RICH.PMPHS-1 HRM46.4 & OFFSITE & sw & $\mathrm{N}$ & RIVER & TRANSECT & 10-Jun-03 s & SULFATE & & & & & & & & \\
\hline SESPMNT & B17278 & RICH.PMPHS-2 HRM46.4 & OFFSITE & sw & $\mathrm{N}$ & RIVER & TRANSECT & 10-Jun-03 s & SULFATE & & & $1 \mathrm{mg} / \mathrm{L}$ & & & & & \\
\hline SESPMNT & B17279 & RICH.PMPHS-3 HRM46.4 & OFFSITE & sw & $\mathrm{N}$ & RIVER & TRANSECT & 10-Jun-03 s & SULFATE & & & $1 \mathrm{mg} / \mathrm{L}$ & & & & & \\
\hline SESPMNT & B17280 & RICH.PMPHS-5 HRM46.4 & OFFSITE & sw & $\mathrm{N}$ & RIVER & TRANSECT & 10-Jun-03 s & SULFATE & & & $1 \mathrm{mg} / \mathrm{L}$ & & & & & \\
\hline SESPMNT & B17281 & RICH.PMPHS-7 HRM46.4 & OFFSITE & sw & $\mathrm{N}$ & RIVER & TRANSECT & 10-Jun-03 s & SULFATE & & & $1 \mathrm{mg} / \mathrm{L}$ & & & & & \\
\hline SESPMNT & B17282 & RICH.PMPHS HRM 43.5 & OFFSITE & sw & $\mathrm{N}$ & RIVER & TRANSECT & 10-Jun-03 s & SULFATE & & & $7 \mathrm{mg} / \mathrm{L}$ & & & & & \\
\hline SESPMNT & B17283 & RICH.PMPHS HRM 43.9 & OFFSITE & sw & $\mathrm{N}$ & RIVER & TRANSECT & 10-Jun-03 s & SULFATE & & & $1 \mathrm{mg} / \mathrm{L}$ & & & & & \\
\hline SESPMNT & B17284 & RICH.PMPHS HRM 45.0 & OFFSITE & sw & $\mathrm{N}$ & RIVER & TRANSECT & 10-Jun-03 s & SULFATE & & & & & & & & \\
\hline SESPMNT & B17285 & RICH.PMPHS HRM 45.8 & OFFSITE & sw & $\mathrm{N}$ & RIVER & TRANSECT & 10-Jun-03 & SULFATE & & & $1 \mathrm{mg} / \mathrm{L}$ & & & & & \\
\hline SESPMNT & B17286 & VERNITA-1 HRM 0.3 & OFFSITE & sw & $\mathrm{N}$ & RIVER & TRANSECT & 09-Jun-03 s & SULFATE & & & $7 \mathrm{mg} / \mathrm{L}$ & & & & & \\
\hline SESPMNT & B17287 & VERNITA-2 HRM 0.3 & OFFSITE & sw & $\mathrm{N}$ & RIVER & TRANSECT & 09-Jun-03 s & SULFATE & & & $7 \mathrm{mg} / \mathrm{L}$ & & & & & \\
\hline SESPMNT & B17288 & VERNITA-3 HRM 0.3 & OFFSITE & sw & $\mathrm{N}$ & RIVER & TRANSECT & 09-Jun-03 s & SULFATE & & & $7 \mathrm{mg} / \mathrm{L}$ & & & & & \\
\hline SESPMNT & B17289 & VERNITA-4 HRM 0.3 & OFFSITE & sw & $\mathrm{N}$ & RIVER & TRANSECT & $09-J u n-03 s$ & SULFATE & & & $4 \mathrm{mg} / \mathrm{L}$ & & & & & \\
\hline SESPMNT & B17HF0 & $100 \mathrm{~F}-10 \mathrm{HRM} 19.0$ & ONSITE & sw & $\mathrm{N}$ & RIVER - & TRANSECT & 08-Sep-03 s & SULFATE & & & $8 \mathrm{mg} / \mathrm{L}$ & & & & & \\
\hline SESPMNT & B17HF1 & 100 F - 1 HRM 19.0 & ONSITE & sw & $\mathrm{N}$ & RIVER & TRANSECT & 08-Sep-03s & SULFATE & & & $9 \mathrm{mg} / \mathrm{L}$ & & & & & \\
\hline SESPMNT & B17HF2 & $100 \mathrm{~F}-2$ HRM 19.0 & ONSITE & sw & $\mathrm{N}$ & RIVER & TRANSECT & $08-S e p-03 s$ & SULFATE & & & $9 \mathrm{mg} / \mathrm{L}$ & & & & & \\
\hline SESPMNT & B17HF3 & $100 \mathrm{~F}-3$ HRM 19.0 & ONSITE & sw & $\mathrm{N}$ & RIVER & TRANSECT & 08-Sep-03s & SULFATE & & & $1 \mathrm{mg} / \mathrm{L}$ & & & & & \\
\hline SESPMNT & B17HF4 & $100 \mathrm{~F}-5$ HRM 19.0 & ONSITE & sw & $\mathrm{N}$ & RIVER & TRANSECT & 08-Sep-03 s & SULFATE & & & $9 \mathrm{mg} / \mathrm{L}$ & & & & & \\
\hline SESPMNT & B17HF5 & $100 \mathrm{~F}-7$ HRM 19.0 & ONSITE & sw & $\mathrm{N}$ & RIVER & TRANSECT & 08-Sep-03 s & SULFATE & & & $1 \mathrm{mg} / \mathrm{L}$ & & & & & \\
\hline SESPMNT & B17HF6 & $100 \mathrm{~F}$ SHORE HRM 18 & ONSITE & sw & $\mathrm{N}$ & RIVER & TRANSECT & 08-Sep-03 s & SULFATE & & & $2 \mathrm{mg} / \mathrm{L}$ & & & & & \\
\hline SESPMNT & B17HF7 & 100 F SHORE HRM 22 & ONSITE & sw & $\mathrm{N}$ & RIVER & TRANSECT & 08-Sep-03s & SULFATE & & & $3 \mathrm{mg} / \mathrm{L}$ & & & & & \\
\hline SESPMNT & B17HF8 & $100 \mathrm{~F}$ SHORE HRM 23 & ONSITE & sw & $\mathrm{N}$ & RIVER & TRANSECT & $08-S e p-035$ & SULFATE & & & $9 \mathrm{mg} / \mathrm{L}$ & & & & & \\
\hline SESPMNT & B17HF9 & $100 \mathrm{~N}-1$ HRM 9.5 & ONSITE & sw & $\mathrm{N}$ & RIVER & TRANSECT & 04-Sep-03 s & SULFATE & & & $9 \mathrm{mg} / \mathrm{L}$ & & & & & \\
\hline SESPMNT & B17HHO & $100 \mathrm{~N}-10 \mathrm{HRM} 9.5$ & ONSITE & sw & $\mathrm{N}$ & RIVER & TRANSECT & 04-Sep-03s & SULFATE & & & $9 \mathrm{mg} / \mathrm{L}$ & & & & & \\
\hline SESPMNT & B17HH1 & $100 \mathrm{~N}-2$ HRM 9.5 & ONSITE & sw & $\mathrm{N}$ & RIVER & TRANSECT & 04-Sep-03 s & SULFATE & & & $6 \mathrm{mg} / \mathrm{L}$ & & & & & \\
\hline SESPMNT & B17HH2 & $100 \mathrm{~N}-3$ HRM 9.5 & ONSITE & SW & $\mathrm{N}$ & RIVER & TRANSECT & 04-Sep-03s & SULFATE & & & $6 \mathrm{mg} / \mathrm{L}$ & & & & & \\
\hline SESPMNT & B17HH3 & $100 \mathrm{~N}-5$ HRM 9.5 & ONSITE & sw & $\mathrm{N}$ & RIVER & TRANSECT & 04-Sep-03s & SULFATE & & & $6 \mathrm{mg} / \mathrm{L}$ & & & & & \\
\hline SESPMNT & B17HH4 & $100 \mathrm{~N}-7$ HRM 9.5 & ONSITE & sw & $\mathrm{N}$ & RIVER & TRANSECT & 04-Sep-03 s & SULFATE & & & $8 \mathrm{mg} / \mathrm{L}$ & & & & & \\
\hline SESPMNT & B17HH5 & $100 \mathrm{~N}$ SHORE HRM 8.4 & ONSITE & sw & $\mathrm{N}$ & RIVER & TRANSECT & 04-Sep-03 s & SULFATE & & & $7 \mathrm{mg} / \mathrm{L}$ & & & & & \\
\hline SESPMNT & B17HH6 & $100 \mathrm{~N}$ SHORE HRM 8.9 & ONSITE & sw & $\mathrm{N}$ & RIVER & TRANSECT & 04-Sep-03 s & SULFATE & & & $6 \mathrm{mg} / \mathrm{L}$ & & & & & \\
\hline SESPMNT & B17HH7 & 100 N SHORE HRM 9.2 & ONSITE & sw & $\mathrm{N}$ & RIVER & TRANSECT & 04-Sep-03s & SULFATE & & & $7 \mathrm{mg} / \mathrm{L}$ & & & & & \\
\hline SESPMNT & $\mathrm{B} 17 \mathrm{HH} 8$ & 100 N SHORE HRM 9.8 & ONSITE & sw & $\mathrm{N}$ & RIVER & TRANSECT & $04-$ Sep-03s & SULFATE & & & $6 \mathrm{mg} / \mathrm{L}$ & & & & & \\
\hline SESPMNT & B17HH9 & 300 AREA - 1 HRM 43.1 & ONSITE & sW & $\mathrm{N}$ & RIVER & TRANSECT & 09-Sep-03 s & SULFATE & & & $2 \mathrm{mg} / \mathrm{L}$ & & & & & \\
\hline SESPMNT & B17HJO & 300 AREA-10 HRM 43.1 & ONSITE & sw & $\mathrm{N}$ & RIVER & TRANSECT & $09-$ Sep-03s & SULFATE & & & $3 \mathrm{mg} / \mathrm{L}$ & & & & & \\
\hline SESPMNT & B17HJ1 & 300 AREA -2 HRM 43.1 & ONSITE & sw & $\mathrm{N}$ & RIVER & TRANSECT & $09-$ Sep-03s & SULFATE & & & $3 \mathrm{mg} / \mathrm{L}$ & & & & & \\
\hline SESPMNT & B17HJ2 & 300 AREA -3 HRM 43.1 & ONSITE & sw & $\mathrm{N}$ & RIVER & TRANSECT & $09-S e p-03 s$ & SULFATE & & & $2 \mathrm{mg} / \mathrm{L}$ & & & & & \\
\hline SESPMNT & B17HJ3 & 300 AREA -5 HRM 43.1 & ONSITE & sw & $\mathrm{N}$ & RIVER & TRANSECT & $09-$ Sep-03 s & SULFATE & & & $2 \mathrm{mg} / \mathrm{L}$ & & & & & \\
\hline SESPMNT & B17HJ4 & 300 AREA -7 HRM 43.1 & ONSITE & sw & $\mathrm{N}$ & RIVER & TRANSECT & $09-S e p-03 s$ & SULFATE & & & $7 \mathrm{mg} / \mathrm{L}$ & & & & & \\
\hline SESPMNT & B17HJ5 & 300 AREA SHR HRM41.5 & ONSITE & sw & $\mathrm{N}$ & RIVER & TRANSECT & $09-S e p-03 \varsigma$ & SULFATE & & & $5 \mathrm{mg} / \mathrm{L}$ & & & & & \\
\hline SESPMNT & B17HJ6 & 300 AREA SHR HRM42.1 & ONSITE & sw & $\mathrm{N}$ & RIVER & TRANSECT & $09-S e p-03 s$ & SULFATE & & & $3 \mathrm{mg} / \mathrm{L}$ & & & & & \\
\hline SESPMNT & B17HJ7 & 300 AREA SHR HRM42.5 & ONSITE & sw & $\mathrm{N}$ & RIVER & TRANSECT & $09-$ Sep-03s & SULFATE & & & $8 \mathrm{mg} / \mathrm{L}$ & & & & & \\
\hline SESPMNT & B17HJ8 & 300 AREA SHR HRM 42.9 & ONSITE & sw & $\mathrm{N}$ & RIVER & TRANSECT & $09-$ Sep-03s & SULFATE & & & $1 \mathrm{mg} / \mathrm{L}$ & & & & & \\
\hline SESPMNT & B17HJ9 & HANFRD TS-1 HRM 28.7 & ONSITE & sw & $\mathrm{N}$ & RIVER & TRANSECT & 08-Sep-03s & SULFATE & & & $9 \mathrm{mg} / \mathrm{L}$ & & & & & \\
\hline SESPMNT & B17HKO & HANFRD TS-2 HRM 28.7 & ONSITE & sw & $\mathrm{N}$ & RIVER & TRANSECT & $08-$ Sep-03 s & SULFATE & & & $8 \mathrm{mg} / \mathrm{L}$ & & & & & \\
\hline SESPMNT & B17HK1 & HANFRD TS-3 HRM 28.7 & ONSITE & sw & $\mathrm{N}$ & RIVER & TRANSECT & 08-Sep-03s & SULFATE & & & $9 \mathrm{mg} / \mathrm{L}$ & & & & & \\
\hline SESPMNT & B17HK2 & HANFRD TS-5 HRM 28.7 & ONSITE & sw & $\mathrm{N}$ & RIVER & TRANSECT & $08-\mathrm{Sep}-03$ s & SULFATE & & & $9 \mathrm{mg} / \mathrm{L}$ & & & & & \\
\hline SESPMNT & B17HK3 & HANFRD TS-7 HRM 28.7 & ONSITE & sw & $\mathrm{N}$ & RIVER & TRANSECT & $08-$ Sep-03s & SULFATE & & & $8 \mathrm{mg} / \mathrm{L}$ & & & & & \\
\hline SESPMNT & B17HK4 & HANFRD TS-10 HRM 28.7 & ONSITE & sw & $\mathrm{N}$ & RIVER & TRANSECT & $08-\mathrm{Sep}-03 \mathrm{~s}$ & SULFATE & & & $1 \mathrm{mg} / \mathrm{L}$ & & & & & \\
\hline SESPMNT & B17HK5 & HANFRD TWNSITE HRM26 & ONSITE & sw & $\mathrm{N}$ & RIVER & TRANSECT & 08-Sep-03 s & SULFATE & & & $8 \mathrm{mg} / \mathrm{L}$ & & & & & \\
\hline SESPMNT & B17HK6 & HANFRD TWNSITE HRM27 & ONSITE & sW & $\mathrm{N}$ & RIVER & TRANSECT & $08-$ Sep-03s & SULFATE & & & $9 \mathrm{mg} / \mathrm{L}$ & & & & & \\
\hline SESPMNT & B17HK7 & HANFRD TWNSITE HRM28 & ONSITE & SW & $\mathrm{N}$ & RIVER & TRANSECT & $08-S e p-035$ & SULFATE & & & $9 \mathrm{mg} / \mathrm{L}$ & & & & & \\
\hline SESPMNT & B17HK8 & HANFRD TWNSITE HRM30 & ONSITE & sw & $\mathrm{N}$ & RIVER & TRANSECT & $08-$ Sep-03s & SULFATE & & & $8 \mathrm{mg} / \mathrm{L}$ & & & & & \\
\hline SESPMNT & B17HK9 & RICH.PMPHS-1 HRM46.4 & OFFSITE & sw & $\mathrm{N}$ & RIVER & TRANSECT & $09-S e p-03 s$ & SULFATE & & & $5 \mathrm{mg} / \mathrm{L}$ & & & & & \\
\hline SESPMNT & B17HLO & RICH.PMPHS-2 HRM46.4 & OFFSITE & sw & $\mathrm{N}$ & RIVER & TRANSECT & $09-\mathrm{Sep}-03$ s & SULFATE & & & $4 \mathrm{mg} / \mathrm{L}$ & & & & & \\
\hline SESPMNT & B17HL1 & RICH.PMPHS-3 HRM46.4 & OFFSITE & sw & $\mathrm{N}$ & RIVER & TRANSECT & $09-S e p-03 s$ & SULFATE & & & $3 \mathrm{mg} / \mathrm{L}$ & & & & & \\
\hline
\end{tabular}


WATER - COLUMBIA RIVER TRANSECT

\begin{tabular}{|c|c|c|c|c|c|c|c|c|c|c|c|c|c|c|c|}
\hline | OWNER ID & SAMP NUM & SAMP SITE NAME & DIST CLASS & $\mid$ MEDIA & \begin{tabular}{|c|} 
FILTERED \\
FLAG
\end{tabular} & $\begin{array}{l}\text { SAMP } \\
\text { FROM }\end{array}$ & COLL MTHD & CON SHORT NAME & \begin{tabular}{l|} 
VALUE \\
RPTD
\end{tabular} & $\left|\begin{array}{|c|}\text { ANAL } \\
\text { UNITS } \\
\text { RPTD }\end{array}\right|$ & \begin{tabular}{|c} 
COUNTING \\
ERROR
\end{tabular} & \begin{tabular}{|c|} 
TOTAL \\
ANAL \\
ERROR
\end{tabular} & $\begin{array}{c}\text { LAB } \\
\text { QUALIFIER }\end{array}$ & SAMP COMMENT & $\begin{array}{l}\text { RESULT } \\
\text { COMMENT }\end{array}$ \\
\hline SESPMNT & B17HL2 & RICH.PMPHS-5 HRM46.4 & OFFSITE & SW & $\mathrm{N}$ & RIVER & TRANSECT & 09-Sep-03 SULFATE & & & & & & & \\
\hline SESPMNT & B17HL3 & RICH.PMPHS-7 HRM46.4 & OFFSITE & sw & $\mathrm{N}$ & RIVER & TRANSECT & 09-Sep-03 SULFATE & & $\mathrm{mg} / \mathrm{L}$ & & & & & \\
\hline SESPMNT & B17HL4 & RICH.PMPHS-10 HRM46. 4 & OFFSITE & sw & $\mathrm{N}$ & RIVER & TRANSECT & 09-Sep-03 SULFATE & $13.9 n$ & $\mathrm{mg} / \mathrm{L}$ & & & & & \\
\hline SESPMNT & B17HL5 & RICH.PMPHS HRM 43.5 & OFFSITE & sw & $\mathrm{N}$ & RIVER & TRANSECT & 09-Sep-03 SULFATE & $10.9 \mathrm{n}$ & $\mathrm{mg} / \mathrm{L}$ & & & & & \\
\hline SESPMNT & B17HL7 & RICH.PMPHS HRM 45.0 & OFFSITE & sw & $\mathrm{N}$ & RIVER & TRANSECT & 09-Sep-03 SULFATE & & $\mathrm{mg} / \mathrm{L}$ & & & & & \\
\hline SESPMNT & B17HL8 & RICH.PMPHS HRM 45.8 & OFFSITE & SW & $\mathrm{N}$ & RIVER & TRANSECT & 09-Sep-03 SULFATE & & & & & & & \\
\hline SESPMNT & B17HL9 & VERNITA-1 HRM 0.3 & OFFSITE & sw & $\mathrm{N}$ & RIVER & TRANSECT & 04-Sep-03 SULFATE & & & & & & & \\
\hline SESPMNT & B17HMO & VERNITA-2 HRM 0.3 & OFFSITE & sW & $\mathrm{N}$ & RIVER & TRANSECT & 04-Sep-03 SULFATE & & & & & & & \\
\hline SESPMNT & B17HM1 & VERNITA-3 HRM 0.3 & OFFSITE & sW & $\mathrm{N}$ & RIVER & TRANSECT & 04-Sep-03 SULFATE & & $\mathrm{mg} / \mathrm{L}$ & & & & & \\
\hline SESPMNT & B17HM2 & VERNITA-4 HRM 0.3 & OFFSITE & sw & $\mathrm{N}$ & RIVER & TRANSECT & 04-Sep-03 SULFATE & $8.9 n$ & $\mathrm{mg} / \mathrm{L}$ & & & & & \\
\hline SESPMNT & B184P5 & VERNITA-1 HRM 0.3 & OFFSITE & sw & $\mathrm{N}$ & RIVER & TRANSECT & 09-Dec-03 SULFATE & & $\mathrm{mg} / \mathrm{L}$ & & & & & \\
\hline SESPMNT & B184P6 & VERNITA-2 HRM 0.3 & OFFSITE & sw & $\mathrm{N}$ & RIVER & TRANSECT & 09-Dec-03 SULFATE & & $\mathrm{mg} / \mathrm{L}$ & & & & & \\
\hline SESPMNT & B184P7 & VERNITA-3 HRM 0.3 & OFFSITE & sW & $\mathrm{N}$ & RIVER & TRANSECT & 09-Dec-03 SULFATE & & $\mathrm{mg} / \mathrm{L}$ & & & & & \\
\hline SESPMNT & B184P8 & VERNITA-4 HRM 0.3 & OFFSITE & sw & $\mathrm{N}$ & RIVER & TRANSECT & 09-Dec-03 SULFATE & & $\mathrm{mg} / \mathrm{L}$ & & & & & \\
\hline SESPMNT & B184P9 & RICH.PMPHS-1 HRM46.4 & OFFSITE & sw & $\mathrm{N}$ & RIVER & TRANSECT & 08-Dec-03 SULFATE & & & & & & & \\
\hline SESPMNT & B184R0 & RICH.PMPHS-2 HRM46.4 & OFFSITE & sw & $\mathrm{N}$ & RIVER & TRANSECT & 08-Dec-03 SULFATE & & $\mathrm{mg} / \mathrm{L}$ & & & & & \\
\hline SESPMNT & B184R1 & RICH.PMPHS-3 HRM46.4 & OFFSITE & sw & $\mathrm{N}$ & RIVER & TRANSECT & 08-Dec-03 SULFATE & & $\mathrm{mg} / \mathrm{L}$ & & & & & \\
\hline SESPMNT & B184R2 & RICH.PMPHS-5 HRM46.4 & OFFSITE & sW & $\mathrm{N}$ & RIVER & TRANSECT & 08-Dec-03 SULFATE & & $\mathrm{mg} / \mathrm{L}$ & & & & & \\
\hline SESPMNT & B184R3 & RICH.PMPHS-7 HRM46.4 & OFFSITE & sw & $\mathrm{N}$ & RIVER & TRANSECT & 08-Dec-03 SULFATE & $9.3 n$ & $\mathrm{mg} / \mathrm{L}$ & & & & & \\
\hline SESPMNT & B184R4 & RICH.PMPHS-10 HRM46.4 & OFFSITE & sw & $\mathrm{N}$ & RIVER & TRANSECT & 08-Dec-03 SULFATE & $12.7 \mathrm{n}$ & & & & & & \\
\hline SESPMNT & B184R5 & RICH.PMPHS HRM 43.5 & OFFSITE & sw & $\mathrm{N}$ & RIVER & TRANSECT & 08-Dec-03 SULFATE & & & & & & & \\
\hline SESPMNT & B184R6 & RICH.PMPHS HRM 43.9 & OFFSITE & sw & $\mathrm{N}$ & RIVER & TRANSECT & 08-Dec-03 SULFATE & & & & & & & \\
\hline SESPMNT & B184R7 & RICH.PMPHS HRM 45.0 & OFFSITE & sW & $\mathrm{N}$ & RIVER & TRANSECT & 08-Dec-03 SULFATE & & & & & & & \\
\hline SESPMNT & B184R8 & RICH.PMPHS HRM 45.8 & OFFSITE & sw & $\mathrm{N}$ & RIVER & TRANSECT & 08-Dec-03 SULFATE & $9.3 n$ & $\mathrm{mg} / \mathrm{L}$ & & & & & \\
\hline SESPMNT & B17HL6 & RICH.PMPHS HRM 43.9 & OFFSITE & sw & $\mathrm{N}$ & RIVER & TRANSECT & 09-Sep-03 V0A & & & & & & NO SAMPLE. THICK MILFOIL. & \\
\hline SESPMNT & B17HK9 & RICH.PMPHS-1 HRM46.4 & OFFSITE & sw & $\mathrm{N}$ & RIVER & TRANSECT & 09-Sep-03 1,1,1-T (1,1,1-Trichloroethane) & $0.17 u$ & ug/L & & & $\mathrm{u}$ & & \\
\hline SESPMNT & B17HLO & RICH.PMPHS-2 HRM46.4 & OFFSITE & sw & $\mathrm{N}$ & RIVER & TRANSECT & 09-Sep-03 1,1,1-T (1,1,1-Trichloroethane) & $0.17 u$ & $\mathrm{ug} / \mathrm{L}$ & & & $\mathrm{U}$ & & \\
\hline SESPMNT & B17HL1 & RICH.PMPHS-3 HRM46.4 & OFFSITE & sW & $\mathrm{N}$ & RIVER & TRANSECT & 09-Sep-03 1,1,1-T (1,1,1-Trichloroethane) & $0.17 u$ & $\mathrm{ug} / \mathrm{L}$ & & & $\mathrm{U}$ & & \\
\hline SESPMNT & B17HL2 & RICH.PMPHS-5 HRM46.4 & OFFSITE & sw & $\mathrm{N}$ & RIVER & TRANSECT & 09-Sep-03 1,1,1-T (1,1,1-Trichloroethane) & $0.17 u$ & & & & u & & \\
\hline SESPMNT & B17HL3 & RICH.PMPHS-7 HRM46.4 & OFFSITE & sw & $\mathrm{N}$ & RIVER & TRANSECT & 09-Sep-03 1,1,1-T (1,1,1-Trichloroethane) & $0.17 u$ & & & & U & & \\
\hline SESPMNT & B17HL4 & RICH.PMPHS-10 HRM46.4 & OFFSITE & sw & $\mathrm{N}$ & RIVER & TRANSECT & 09-Sep-03 1,1,1-T (1,1,1-Trichloroethane) & $0.17 \mathrm{u}$ & & & & $\mathrm{u}$ & & \\
\hline SESPMNT & B17HL5 & RICH.PMPHS HRM 43.5 & OFFSITE & sW & $\mathrm{N}$ & RIVER & TRANSECT & 09-Sep-03 1,1,1-T (1,1,1-Trichloroethane) & $0.17 u$ & & & & u & & \\
\hline SESPMNT & B17HL7 & RICH.PMPHS HRM 45.0 & OFFSITE & sW & $\mathrm{N}$ & RIVER & TRANSECT & 09-Sep-03 1,1,1-T (1,1,1-Trichloroethane) & $0.17 u$ & $\mathrm{ug} / \mathrm{L}$ & & & $\mathrm{u}$ & & \\
\hline SESPMNT & B17HL8 & RICH.PMPHS HRM 45.8 & OFFSITE & sw & $\mathrm{N}$ & RIVER & TRANSECT & 09-Sep-03 1,1,1-T (1,1,1-Trichloroethane) & $0.17 \mathrm{u}$ & $\mathrm{ug} / \mathrm{L}$ & & & $\mathrm{u}$ & & \\
\hline SESPMNT & B17HL9 & VERNITA-1 HRM 0.3 & OFFSITE & SW & $\mathrm{N}$ & RIVER & TRANSECT & 04-Sep-03 1,1,1-T (1,1,1-Trichloroethane) & & & & & $\mathrm{U}$ & & \\
\hline SESPMNT & B17HMO & VERNITA-2 HRM 0.3 & OFFSITE & sw & $\mathrm{N}$ & RIVER & TRANSECT & 04-Sep-03 1,1,1-T (1,1,1-Trichloroethane) & $0.17 u$ & & & & $\mathrm{u}$ & & \\
\hline SESPMNT & B17HM1 & VERNITA-3 HRM 0.3 & OFFSITE & sw & $\mathrm{N}$ & RIVER & TRANSECT & 04-Sep-03 1,1,1-T (1,1,1-Trichloroethane) & & & & & u & & \\
\hline SESPMNT & B17HM2 & VERNITA-4 HRM 0.3 & OFFSITE & sw & $\mathrm{N}$ & RIVER & TRANSECT & 04-Sep-03 1,1,1-T (1,1,1-Trichloroethane) & & & & & u & & \\
\hline SESPMNT & B17HK9 & RICH.PMPHS-1 HRM46.4 & OFFSITE & sw & $\mathrm{N}$ & RIVER & TRANSECT & 09-Sep-03 1,1,2-T (1,1,2-Trichloroethane) & $0.05 \mathrm{u}$ & $\mathrm{ug} / \mathrm{L}$ & & & u & & \\
\hline SESPMNT & B17HLO & RICH.PMPHS-2 HRM46.4 & OFFSITE & sW & $\mathrm{N}$ & RIVER & TRANSECT & 09-Sep-03 1,1,2-T (1,1,2-Trichloroethane) & $0.05 u$ & $\mathrm{ug} / \mathrm{L}$ & & & u & & \\
\hline SESPMNT & B17HL1 & RICH.PMPHS-3 HRM46.4 & OFFSITE & sw & $\mathrm{N}$ & RIVER & TRANSECT & 09-Sep-03 1,1,2-T (1,1,2-Trichloroethane) & $0.05 \mathrm{u}$ & $\mathrm{ug} / \mathrm{L}$ & & & $\mathrm{u}$ & & \\
\hline SESPMNT & B17HL2 & RICH.PMPHS-5 HRM46.4 & OFFSITE & sw & $\mathrm{N}$ & RIVER & TRANSECT & 09-Sep-03 1,1,2-T (1,1,2-Trichloroethane) & $0.05 \mathrm{u}$ & $\mathrm{ug} / \mathrm{L}$ & & & u & & \\
\hline SESPMNT & B17HL3 & RICH.PMPHS-7 HRM46.4 & OFFSITE & sw & $\mathrm{N}$ & RIVER & TRANSECT & 09-Sep-03 1,1,2-T (1,1,2-Trichloroethane) & $0.05 \mathrm{u}$ & $\mathrm{ug} / \mathrm{L}$ & & & u & & \\
\hline SESPMNT & B17HL4 & RICH.PMPHS-10 HRM46.4 & OFFSITE & sw & $\mathrm{N}$ & RIVER & TRANSECT & 09-Sep-03 1,1,2-T (1,1,2-Trichloroethane) & $0.05 u$ & $\mathrm{ug} / \mathrm{L}$ & & & u & & \\
\hline SESPMNT & B17HL5 & RICH.PMPHS HRM 43.5 & OFFSITE & sW & $\mathrm{N}$ & RIVER & TRANSECT & 09-Sep-03 1,1,2-T (1,1,2-Trichloroethane) & $0.05 u$ & & & & U & & \\
\hline SESPMNT & B17HL7 & RICH.PMPHS HRM 45.0 & OFFSITE & sw & $\mathrm{N}$ & RIVER & TRANSECT & 09-Sep-03 1,1,2-T (1,1,2-Trichloroethane) & $0.05 \mathrm{u}$ & & & & u & & \\
\hline SESPMNT & B17HL8 & RICH.PMPHS HRM 45.8 & OFFSITE & SW & $\mathrm{N}$ & RIVER & TRANSECT & 09-Sep-03 1,1,2-T (1,1,2-Trichloroethane) & $0.05 \mathrm{u}$ & $\mathrm{ug} / \mathrm{L}$ & & & u & & \\
\hline SESPMNT & B17HL9 & VERNITA-1 HRM 0.3 & OFFSITE & sw & $\mathrm{N}$ & RIVER & TRANSECT & 04-Sep-03 1,1,2-T (1,1,2-Trichloroethane) & $0.05 \mathrm{u}$ & $\mathrm{ug} / \mathrm{L}$ & & & u & & \\
\hline SESPMNT & B17HMO & VERNITA-2 HRM 0.3 & OFFSITE & sw & $\mathrm{N}$ & RIVER & TRANSECT & 04-Sep-03 1,1,2-T (1,1,2-Trichloroethane) & $0.05 u$ & $\mathrm{ug} / \mathrm{L}$ & & & u & & \\
\hline SESPMNT & B17HM1 & VERNITA-3 HRM 0.3 & OFFSITE & sW & $\mathrm{N}$ & RIVER & TRANSECT & 04-Sep-03 1,1,2-T (1,1,2-Trichloroethane) & $0.05 u$ & $\mathrm{ug} / \mathrm{L}$ & & & u & & \\
\hline SESPMNT & B17HM2 & VERNITA-4 HRM 0.3 & OFFSITE & sw & $\mathrm{N}$ & RIVER & TRANSECT & 04-Sep-03 1,1,2-T (1,1,2-Trichloroethane) & $0.05 u$ & $\mathrm{ug} / \mathrm{L}$ & & & u & & \\
\hline SESPMNT & B17HK9 & RICH.PMPHS-1 HRM46.4 & OFFSITE & sw & $\mathrm{N}$ & RIVER & TRANSECT & 09-Sep-03 1,1-DCL (1,1-Dichloroethane) & & ug/L $/ \mathrm{L}$ & & & u & & \\
\hline SESPMNT & B17HLO & RICH.PMPHS-2 HRM46.4 & OFFSITE & sw & $\mathrm{N}$ & RIVER & TRANSECT & 09-Sep-03 1,1-DCL (1,1-Dichloroethane) & & ug/L & & & u & & \\
\hline SESPMNT & B17HL1 & RICH.PMPHS-3 HRM46.4 & OFFSITE & sw & $\mathrm{N}$ & RIVER & TRANSECT & 09-Sep-03 1,1-DCL (1,1-Dichloroethane) & & ug/L & & & u & & \\
\hline SESPMNT & B17HL2 & RICH.PMPHS-5 HRM46.4 & OFFSITE & sw & $\mathrm{N}$ & RIVER & TRANSECT & 09-Sep-03 1,1-DCL (1,1-Dichloroethane) & & ug/L & & & u & & \\
\hline SESPMNT & B17HL3 & RICH.PMPHS-7 HRM46.4 & OFFSITE & sw & $\mathrm{N}$ & RIVER & TRANSECT & 09-Sep-03 1,1-DCL (1,1-Dichloroethane) & & $\mathrm{ug} / \mathrm{L}$ & & & u & & \\
\hline SESPMNT & B17HL4 & RICH.PMPHS-10 HRM46.4 & OFFSITE & sw & $\mathrm{N}$ & RIVER & TRANSECT & 09-Sep-03 1,1-DCL (1,1-Dichloroethane) & & $\mathrm{ug} / \mathrm{L}$ & & & u & & \\
\hline SESPMNT & B17HL5 & RICH.PMPHS HRM 43.5 & OFFSITE & sw & $\mathrm{N}$ & RIVER & TRANSECT & 09-Sep-03 1,1-DCL (1,1-Dichloroethane) & & & & & u & & \\
\hline SESPMNT & B17HL7 & RICH.PMPHS HRM 45.0 & OFFSITE & SW & $\mathrm{N}$ & RIVER & TRANSECT & 09-Sep-03 1,1-DCL (1,1-Dichloroethane) & & $\mathrm{ug} / \mathrm{L}$ & & & U & & \\
\hline SESPMNT & B17HL8 & RICH.PMPHS HRM 45.8 & OFFSITE & sw & $\mathrm{N}$ & RIVER & TRANSECT & 09-Sep-03 1,1-DCL (1,1-Dichloroethane) & & $\mathrm{ug} / \mathrm{L}$ & & & u & & \\
\hline SESPMNT & B17HL9 & VERNITA-1 HRM 0.3 & OFFSITE & sw & $\mathrm{N}$ & RIVER & TRANSECT & 04-Sep-03 1,1-DCL (1,1-Dichloroethane) & & $\mathrm{ug} / \mathrm{L}$ & & & u & & \\
\hline SESPMNT & B17HMO & VERNITA-2 HRM 0.3 & OFFSITE & sw & $\mathrm{N}$ & RIVER & TRANSECT & 04-Sep-03 1,1-DCL (1,1-Dichloroethane) & & $\mathrm{ug} / \mathrm{L}$ & & & u & & \\
\hline
\end{tabular}




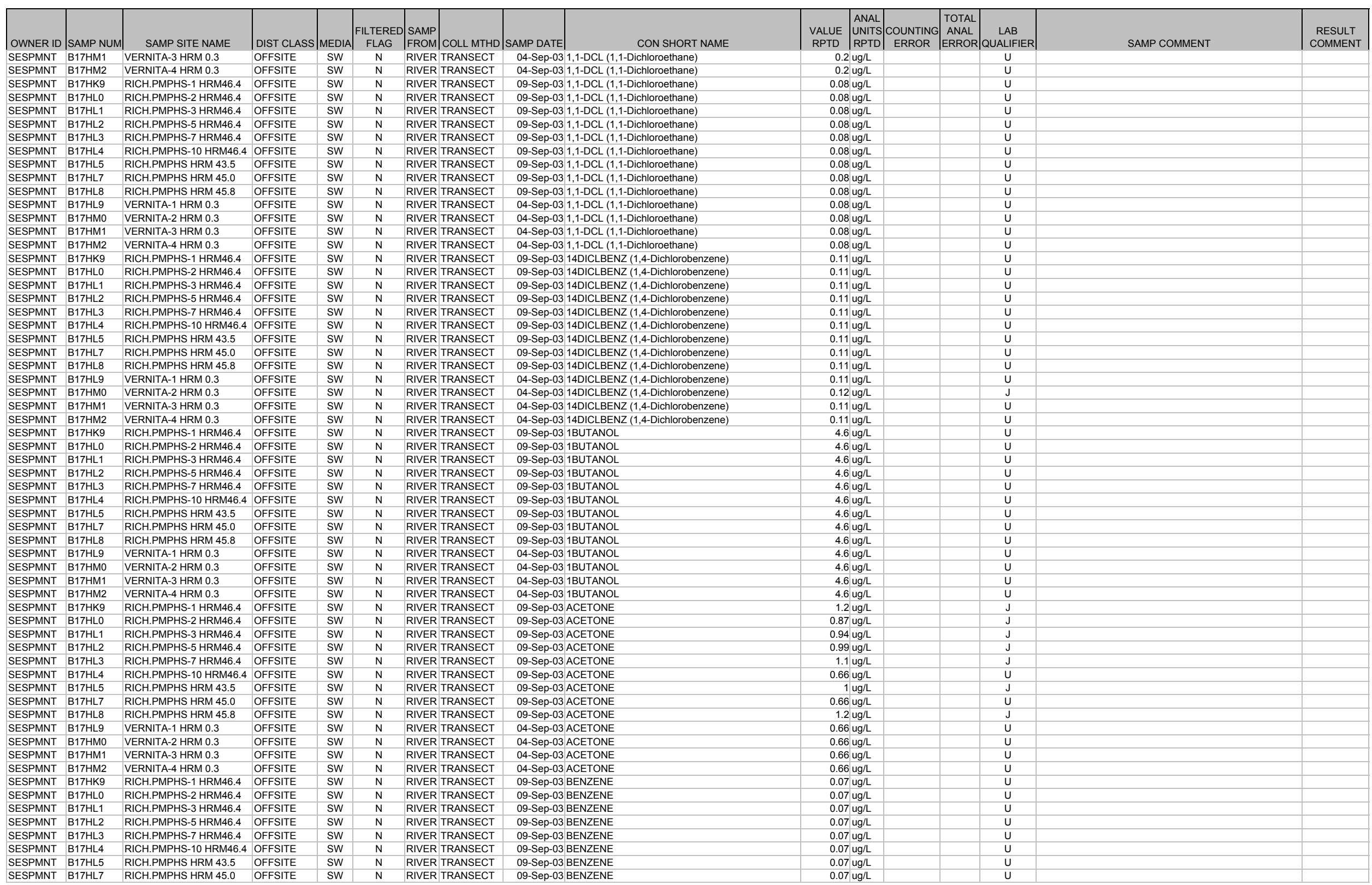


WATER - COLUMBIA RIVER TRANSECT

\begin{tabular}{|c|c|c|c|c|c|c|c|c|c|c|c|c|c|c|c|}
\hline | OWNER ID & SAMP NUM & SAMP SITE NAME & DIST CLASS & MEDIA $\left.\right|^{\mid h}$ & \begin{tabular}{|c|} 
FILTERED \\
FLAG
\end{tabular} & $\begin{array}{l}\text { SAMP } \\
\text { FROM }\end{array}$ & COLL MTHD & CON SHORT NAME & $\begin{array}{l}\text { VALUE } \\
\text { RPTD }\end{array}$ & $\mid$\begin{tabular}{|l} 
ANAL \\
UNITS \\
RPDT
\end{tabular} & \begin{tabular}{|c} 
COUNTING \\
ERROR
\end{tabular} & $=\begin{array}{c}\text { TOTAL } \\
\text { ANAL } \\
\text { ERROR }\end{array}$ & $\begin{array}{c}\text { LAB } \\
\text { QUALIFIER }\end{array}$ & SAMP COMMENT & $\begin{array}{l}\text { RESULT } \\
\text { COMMENT }\end{array}$ \\
\hline SESPMNT & B17HL8 & RICH.PMPHS HRM 45.8 & OFFSITE & SW & $\mathrm{N}$ & RIVER T & TRANSECT & 09-Sep-03 BENZENE & & & & & U & & \\
\hline SESPMNT & B17HL9 & VERNITA-1 HRM 0.3 & OFFSITE & sw & $\mathrm{N}$ & RIVER T & TRANSECT & 04-Sep-03 BENZENE & & $\mathrm{ug} / \mathrm{L}$ & & & $\mathrm{U}$ & & \\
\hline SESPMNT & B17HMO & VERNITA-2 HRM 0.3 & OFFSITE & sw & $\mathrm{N}$ & RIVER T & TRANSECT & 04-Sep-03 BENZENE & 0.07 & $\mathrm{ug} / \mathrm{L}$ & & & u & & \\
\hline SESPMNT & B17HM1 & VERNITA-3 HRM 0.3 & OFFSITE & sw & $\mathrm{N}$ & RIVER T & TRANSECT & 04-Sep-03 BENZENE & 0.07 & ug/L & & & u & & \\
\hline SESPMNT & B17HM2 & VERNITA-4 HRM 0.3 & OFFSITE & sw & $\mathrm{N}$ & RIVER 7 & TRANSECT & 04-Sep-03 BENZENE & 0.07 & $\mathrm{ug} / \mathrm{L}$ & & & $u$ & & \\
\hline SESPMNT & B17HK9 & RICH.PMPHS-1 HRM46.4 & OFFSITE & sw & $\mathrm{N}$ & RIVER 7 & TRANSECT & 09-Sep-03 CARBIDE (Carbon disulfide) & & & & & $u$ & & \\
\hline SESPMNT & B17HLO & RICH.PMPHS-2 HRM46.4 & OFFSITE & sw & $\mathrm{N}$ & RIVER 7 & TRANSECT & 09-Sep-03 CARBIDE (Carbon disulfide) & & & & & $\mathrm{U}$ & & \\
\hline SESPMNT & B17HL1 & RICH.PMPHS-3 HRM46.4 & OFFSITE & sw & $\mathrm{N}$ & RIVER T & TRANSECT & 09-Sep-03 CARBIDE (Carbon disulfide) & & & & & U & & \\
\hline SESPMNT & B17HL2 & RICH.PMPHS-5 HRM46.4 & OFFSITE & sw & $\mathrm{N}$ & RIVER 7 & TRANSECT & 09-Sep-03 CARBIDE (Carbon disulfide) & & $3 \mathrm{ug} / \mathrm{L}$ & & & $\mathrm{U}$ & & \\
\hline SESPMNT & B17HL3 & RICH.PMPHS-7 HRM46.4 & OFFSITE & sw & $\mathrm{N}$ & RIVER T & TRANSECT & 09-Sep-03 CARBIDE (Carbon disulfide) & 0.43 & $3 \mathrm{ug} / \mathrm{L}$ & & & U & & \\
\hline SESPMNT & B17HL4 & RICH.PMPHS-10 HRM46.4 & OFFSITE & sw & $\mathrm{N}$ & RIVER T & TRANSECT & 09-Sep-03 CARBIDE (Carbon disulfide) & 0.43 & $3 \mathrm{ug} / \mathrm{L}$ & & & U & & \\
\hline SESPMNT & B17HL5 & RICH.PMPHS HRM 43.5 & OFFSITE & sw & $\mathrm{N}$ & RIVER 7 & TRANSECT & 09-Sep-03 CARBIDE (Carbon disulfide) & 0.43 & & & & u & & \\
\hline SESPMNT & B17HL7 & RICH.PMPHS HRM 45.0 & OFFSITE & sw & $\mathrm{N}$ & RIVER T & TRANSECT & 09-Sep-03 CARBIDE (Carbon disulfide) & 0.43 & & & & U & & \\
\hline SESPMNT & B17HL8 & RICH.PMPHS HRM 45.8 & OFFSITE & sw & $\mathrm{N}$ & RIVER T & TRANSECT & 09-Sep-03 CARBIDE (Carbon disulfide) & & & & & $\mathrm{u}$ & & \\
\hline SESPMNT & B17HL9 & VERNITA-1 HRM 0.3 & OFFSITE & sw & $\mathrm{N}$ & RIVER 7 & TRANSECT & 04-Sep-03 CARBIDE (Carbon disulfide) & & & & & $\mathrm{U}$ & & \\
\hline SESPMNT & B17HMO & VERNITA-2 HRM 0.3 & OFFSITE & sw & $\mathrm{N}$ & RIVER 7 & TRANSECT & 04-Sep-03 CARBIDE (Carbon disulfide) & & & & & $\mathrm{u}$ & & \\
\hline SESPMNT & B17HM1 & VERNITA-3 HRM 0.3 & OFFSITE & sw & $\mathrm{N}$ & RIVER 7 & TRANSECT & 04-Sep-03 CARBIDE (Carbon disulfide) & 0.43 & $3 \mathrm{ug} / \mathrm{L}$ & & & $\mathrm{u}$ & & \\
\hline SESPMNT & B17HM2 & VERNITA-4 HRM 0.3 & OFFSITE & sw & $\mathrm{N}$ & RIVER T & TRANSECT & 04-Sep-03 CARBIDE (Carbon disulfide) & 0.43 & $3 \mathrm{ug} / \mathrm{L}$ & & & U & & \\
\hline SESPMNT & B17HK9 & RICH.PMPHS-1 HRM46.4 & OFFSITE & sw & $\mathrm{N}$ & RIVER T & TRANSECT & 09-Sep-03 CARBTET (Carbon tetrachloride) & 0.15 & & & & $\mathrm{u}$ & & \\
\hline SESPMNT & B17HLO & RICH.PMPHS-2 HRM46.4 & OFFSITE & sw & $\mathrm{N}$ & RIVER T & TRANSECT & 09-Sep-03 CARBTET (Carbon tetrachloride) & 0.15 & & & & u & & \\
\hline SESPMNT & B17HL1 & RICH.PMPHS-3 HRM46.4 & OFFSITE & sw & $\mathrm{N}$ & RIVER 7 & TRANSECT & 09-Sep-03 CARBTET (Carbon tetrachloride) & 0.15 & & & & $\mathrm{U}$ & & \\
\hline SESPMNT & B17HL2 & RICH.PMPHS-5 HRM46.4 & OFFSITE & sw & $\mathrm{N}$ & RIVER 7 & TRANSECT & 09-Sep-03 CARBTET (Carbon tetrachloride) & & & & & $\mathrm{u}$ & & \\
\hline SESPMNT & B17HL3 & RICH.PMPHS-7 HRM46.4 & OFFSITE & sw & $\mathrm{N}$ & RIVER T & TRANSECT & 09-Sep-03 CARBTET (Carbon tetrachloride) & & & & & u & & \\
\hline SESPMNT & B17HL4 & RICH.PMPHS-10 HRM46.4 & OFFSITE & sw & $\mathrm{N}$ & RIVER T & TRANSECT & 09-Sep-03 CARBTET (Carbon tetrachloride) & 0.15 & $\mathrm{ug} / \mathrm{L}$ & & & $\mathrm{U}$ & & \\
\hline SESPMNT & B17HL5 & RICH.PMPHS HRM 43.5 & OFFSITE & sw & $\mathrm{N}$ & RIVER 7 & TRANSECT & 09-Sep-03 CARBTET (Carbon tetrachloride) & 0.15 & $\mathrm{sug} / \mathrm{L}$ & & & U & & \\
\hline SESPMNT & B17HL7 & RICH.PMPHS HRM 45.0 & OFFSITE & sw & $\mathrm{N}$ & RIVER 7 & TRANSECT & 09-Sep-03 CARBTET (Carbon tetrachloride) & 0.15 & ing/L & & & $\mathrm{u}$ & & \\
\hline SESPMNT & B17HL8 & RICH.PMPHS HRM 45.8 & OFFSITE & sw & $\mathrm{N}$ & RIVER T & TRANSECT & 09-Sep-03 CARBTET (Carbon tetrachloride) & 0.15 & ing/L & & & $\mathrm{U}$ & & \\
\hline SESPMNT & B17HL9 & VERNITA-1 HRM 0.3 & OFFSITE & sw & $\mathrm{N}$ & RIVER 7 & TRANSECT & 04-Sep-03 CARBTET (Carbon tetrachloride) & 0.15 & ing/L & & & $\mathrm{U}$ & & \\
\hline SESPMNT & B17HMO & VERNITA-2 HRM 0.3 & OFFSITE & sw & $\mathrm{N}$ & RIVER T & TRANSECT & 04-Sep-03 CARBTET (Carbon tetrachloride) & 0.15 & & & & u & & \\
\hline SESPMNT & B17HM1 & VERNITA-3 HRM 0.3 & OFFSITE & sw & $\mathrm{N}$ & RIVER 7 & TRANSECT & 04-Sep-03 CARBTET (Carbon tetrachloride) & 0.15 & & & & U & & \\
\hline SESPMNT & B17HM2 & VERNITA-4 HRM 0.3 & OFFSITE & sw & $\mathrm{N}$ & RIVER T & TRANSECT & 04-Sep-03 CARBTET (Carbon tetrachloride) & 0.15 & & & & $\mathrm{u}$ & & \\
\hline SESPMNT & B17HK9 & RICH.PMPHS-1 HRM46.4 & OFFSITE & sW & $\mathrm{N}$ & RIVER 7 & TRANSECT & 09-Sep-03 CHLOROFORM & 0.07 & ug/L $/ \mathrm{L}$ & & & u & & \\
\hline SESPMNT & B17HLO & RICH.PMPHS-2 HRM46.4 & OFFSITE & sw & $\mathrm{N}$ & RIVER T & TRANSECT & 09-Sep-03 CHLOROFORM & 0.07 & ug/L & & & u & & \\
\hline SESPMNT & B17HL1 & RICH.PMPHS-3 HRM46.4 & OFFSITE & sw & $\mathrm{N}$ & RIVER T & TRANSECT & 09-Sep-03 CHLOROFORM & 0.07 & ug/L & & & u & & \\
\hline SESPMNT & B17HL2 & RICH.PMPHS-5 HRM46.4 & OFFSITE & sw & $\mathrm{N}$ & RIVER T & TRANSECT & 09-Sep-03 CHLOROFORM & 0.07 & & & & $\mathrm{U}$ & & \\
\hline SESPMNT & B17HL3 & RICH.PMPHS-7 HRM46.4 & OFFSITE & sw & $\mathrm{N}$ & RIVER 7 & TRANSECT & 09-Sep-03 CHLOROFORM & 0.07 & & & & U & & \\
\hline SESPMNT & B17HL4 & RICH.PMPHS-10 HRM46.4 & OFFSITE & sw & $\mathrm{N}$ & RIVER 7 & TRANSECT & 09-Sep-03 CHLOROFORM & 0.07 & & & & U & & \\
\hline SESPMNT & B17HL5 & RICH.PMPHS HRM 43.5 & OFFSITE & sw & $\mathrm{N}$ & RIVER T & TRANSECT & 09-Sep-03 CHLOROFORM & 0.07 & & & & $\mathrm{u}$ & & \\
\hline SESPMNT & B17HL7 & RICH.PMPHS HRM 45.0 & OFFSITE & sw & $\mathrm{N}$ & RIVER T & TRANSECT & 09-Sep-03 CHLOROFORM & 0.07 & 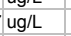 & & & u & & \\
\hline SESPMNT & B17HL8 & RICH.PMPHS HRM 45.8 & OFFSITE & sw & $\mathrm{N}$ & RIVER T & TRANSECT & 09-Sep-03 CHLOROFORM & 0.07 & ug/L & & & U & & \\
\hline SESPMNT & B17HL9 & VERNITA-1 HRM 0.3 & OFFSITE & sw & $\mathrm{N}$ & RIVER T & TRANSECT & 04-Sep-03 CHLOROFORM & 0.07 & ug/L & & & $u$ & & \\
\hline SESPMNT & B17HMO & VERNITA-2 HRM 0.3 & OFFSITE & sw & $\mathrm{N}$ & RIVER T & TRANSECT & 04-Sep-03 CHLOROFORM & 0.07 & ug/L & & & u & & \\
\hline SESPMNT & B17HM1 & VERNITA-3 HRM 0.3 & OFFSITE & sw & $\mathrm{N}$ & RIVER & TRANSECT & 04-Sep-03 CHLOROFORM & 0.07 & ug/L & & & u & & \\
\hline SESPMNT & B17HM2 & VERNITA-4 HRM 0.3 & OFFSITE & sw & $\mathrm{N}$ & RIVER T & TRANSECT & 04-Sep-03 CHLOROFORM & & & & & U & & \\
\hline SESPMNT & B17HK9 & RICH.PMPHS-1 HRM46.4 & OFFSITE & sw & $\mathrm{N}$ & RIVER 7 & TRANSECT & 09-Sep-03 CISDCE (cis-1,2-Dichloroethylene) & 0.06 & & & & U & & \\
\hline SESPMNT & B17HLO & RICH.PMPHS-2 HRM46.4 & OFFSITE & sw & $\mathrm{N}$ & RIVER 7 & TRANSECT & 09-Sep-03 CISDCE (cis-1,2-Dichloroethylene) & 0.06 & & & & u & & \\
\hline SESPMNT & B17HL1 & RICH.PMPHS-3 HRM46.4 & OFFSITE & sW & $\mathrm{N}$ & RIVER 7 & TRANSECT & 09-Sep-03 CISDCE (cis-1,2-Dichloroethylene) & 0.06 & $\mathrm{ug} / \mathrm{L}$ & & & u & & \\
\hline SESPMNT & B17HL2 & RICH.PMPHS-5 HRM46.4 & OFFSITE & sw & $\mathrm{N}$ & RIVER T & TRANSECT & 09-Sep-03 CISDCE (cis-1,2-Dichloroethylene) & 0.06 & $\mathrm{ug} / \mathrm{L}$ & & & u & & \\
\hline SESPMNT & B17HL3 & RICH.PMPHS-7 HRM46.4 & OFFSITE & sw & $\mathrm{N}$ & RIVER T & TRANSECT & 09-Sep-03 CISDCE (cis-1,2-Dichloroethylene) & 0.06 & $3 \mathrm{ug} / \mathrm{L}$ & & & u & & \\
\hline SESPMNT & B17HL4 & RICH.PMPHS-10 HRM46.4 & OFFSITE & sw & $\mathrm{N}$ & RIVER 7 & TRANSECT & 09-Sep-03 CISDCE (cis-1,2-Dichloroethylene) & 0.06 & ing/L & & & u & & \\
\hline SESPMNT & B17HL5 & RICH.PMPHS HRM 43.5 & OFFSITE & sw & $\mathrm{N}$ & RIVER 7 & TRANSECT & 09-Sep-03 CISDCE (cis-1,2-Dichloroethylene) & & ug/L & & & u & & \\
\hline SESPMNT & B17HL7 & RICH.PMPHS HRM 45.0 & OFFSITE & sw & $\mathrm{N}$ & RIVER 7 & TRANSECT & 09-Sep-03 CISDCE (cis-1,2-Dichloroethylene) & & & & & u & & \\
\hline SESPMNT & B17HL8 & RICH.PMPHS HRM 45.8 & OFFSITE & sw & $\mathrm{N}$ & RIVER T & TRANSECT & 09-Sep-03 CISDCE (cis-1,2-Dichloroethylene) & & & & & $\mathrm{u}$ & & \\
\hline SESPMNT & B17HL9 & VERNITA-1 HRM 0.3 & OFFSITE & sw & $\mathrm{N}$ & RIVER T & TRANSECT & 04-Sep-03 CISDCE (cis-1,2-Dichloroethylene) & 0.06 & ug/L & & & U & & \\
\hline SESPMNT & B17HMO & VERNITA-2 HRM 0.3 & OFFSITE & sw & $\mathrm{N}$ & RIVER 7 & TRANSECT & 04-Sep-03 CISDCE (cis-1,2-Dichloroethylene) & 0.06 & $\mathrm{iug/L}$ & & & u & & \\
\hline SESPMNT & B17HM1 & VERNITA-3 HRM 0.3 & OFFSITE & sW & $\mathrm{N}$ & RIVER 7 & TRANSECT & 04-Sep-03 CISDCE (cis-1,2-Dichloroethylene) & 0.06 & $\mathrm{igg} / \mathrm{L}$ & & & u & & \\
\hline SESPMNT & B17HM2 & VERNITA-4 HRM 0.3 & OFFSITE & sW & $\mathrm{N}$ & RIVER T & TRANSECT & 04-Sep-03 CISDCE (cis-1,2-Dichloroethylene) & 0.06 & $\mathrm{iug} / \mathrm{L}$ & & & u & & \\
\hline SESPMNT & B17HK9 & RICH.PMPHS-1 HRM46.4 & OFFSITE & sw & $\mathrm{N}$ & RIVER T & TRANSECT & 09-Sep-03 ETHBENZENE (Ethylbenzene) & & & & & u & & \\
\hline SESPMNT & B17HLO & RICH.PMPHS-2 HRM46.4 & OFFSITE & sW & $\mathrm{N}$ & RIVER T & TRANSECT & 09-Sep-03 ETHBENZENE (Ethylbenzene) & & ing/L & & & U & & \\
\hline SESPMNT & B17HL1 & RICH.PMPHS-3 HRM46.4 & OFFSITE & sw & $\mathrm{N}$ & RIVER 7 & TRANSECT & 09-Sep-03 ETHBENZENE (Ethylbenzene) & & & & & u & & \\
\hline SESPMNT & B17HL2 & RICH.PMPHS-5 HRM46.4 & OFFSITE & sW & $\mathrm{N}$ & RIVER 7 & TRANSECT & 09-Sep-03 ETHBENZENE (Ethylbenzene) & 0.14 & ug/L & & & u & & \\
\hline SESPMNT & B17HL3 & RICH.PMPHS-7 HRM46.4 & OFFSITE & sw & $\mathrm{N}$ & RIVER T & TRANSECT & 09-Sep-03 ETHBENZENE (Ethylbenzene) & 0.14 & igg/L & & & $u$ & & \\
\hline
\end{tabular}




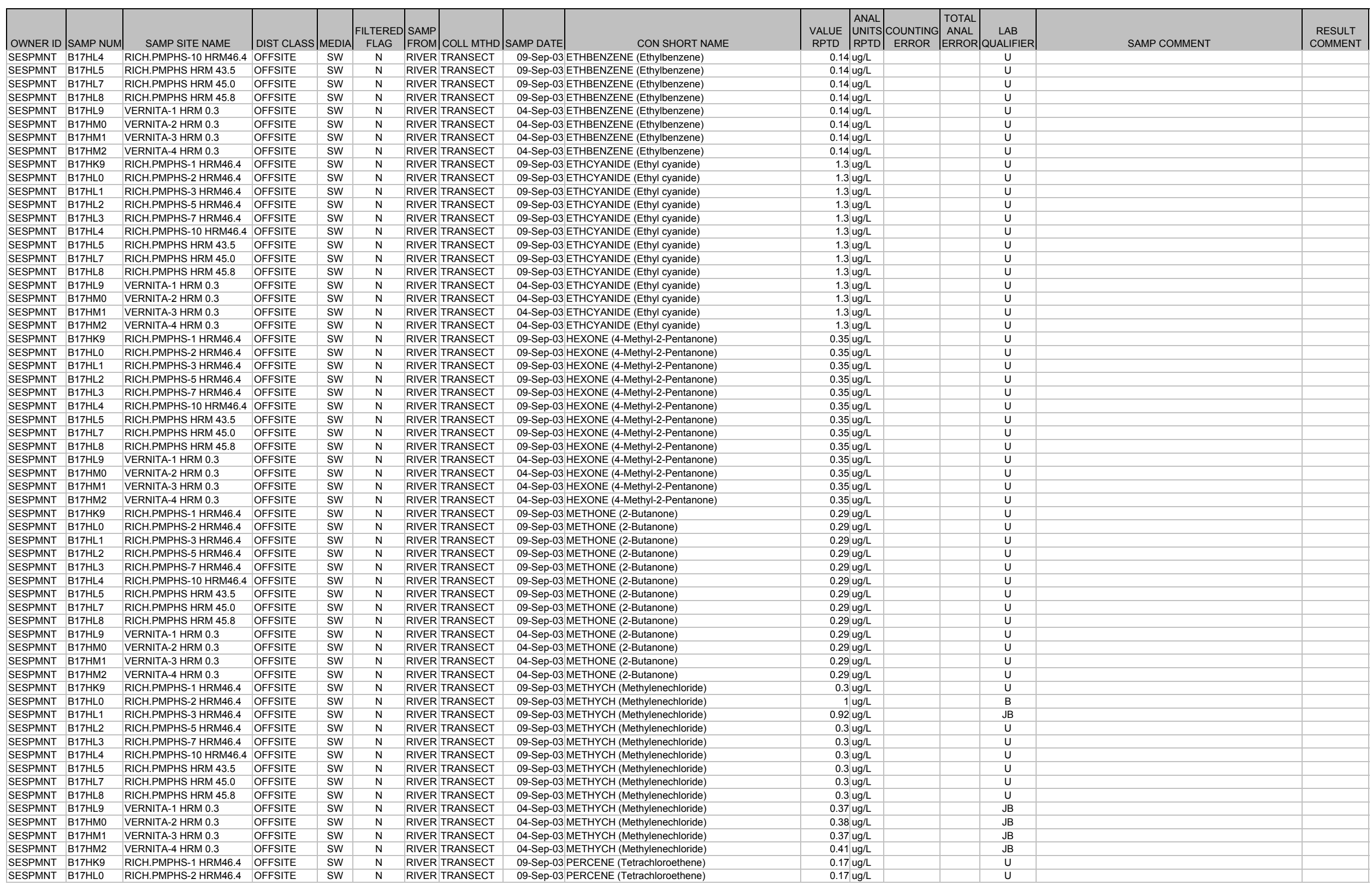




\begin{tabular}{|c|c|c|c|c|c|c|c|c|c|c|c|c|c|c|c|c|}
\hline | OWNER ID & SAMP NUM & SAMP SITE NAME & DIST CLASS & MEDIA & $\begin{array}{l}\text { FLLTERED } \\
\text { FLAG }\end{array}$ & $\left|\begin{array}{l}\text { SAMP } \\
\text { FROM }\end{array}\right|$ & COLL MTHD & SAMP DATE & CON SHORT NAME & $\begin{array}{l}\text { VALUE } \\
\text { RPTD }\end{array}$ & $\mid$\begin{tabular}{|l|} 
ANAL \\
UNITS \\
RPTD
\end{tabular} & $\begin{array}{l}\text { COUNTING } \\
\text { ERROR }\end{array}$ & $\begin{array}{l}\text { TOTAL } \\
\text { ANAL } \\
\text { ANALOR } \\
\text { ERRO }\end{array}$ & $\begin{array}{c}\text { LAB } \\
\text { QUALIFIER }\end{array}$ & SAMP COMMENT & $\begin{array}{l}\text { RESULT } \\
\text { COMMENT }\end{array}$ \\
\hline SESPMNT & B17HL1 & RICH.PMPHS-3 HRM46.4 & OFFSITE & SW & $\mathrm{N}$ & RIVER & TRANSECT & 09-Sep-03 & PERCENE (Tetrachloroethene) & 0.17 & $7 \mathrm{ug} / \mathrm{L}$ & & & U & 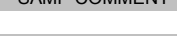 & \\
\hline SESPMNT & B17HL2 & RICH.PMPHS-5 HRM46.4 & OFFSITE & SW & $\mathrm{N}$ & RIVER & TRANSECT & 09-Sep-03 F & PERCENE (Tetrachloroethene) & & & & & $\mathrm{U}$ & & \\
\hline SESPMNT & B17HL3 & RICH.PMPHS-7 HRM46.4 & OFFSITE & SW & $\mathrm{N}$ & RIVER & TRANSECT & 09-Sep-03 F & PERCENE (Tetrachloroethene) & & $7 \mathrm{ug} / \mathrm{L}$ & & & $\mathrm{U}$ & & \\
\hline SESPMNT & B17HL4 & RICH.PMPHS-10 HRM46.4 & OFFSITE & SW & $\mathrm{N}$ & RIVER & TRANSECT & 09-Sep-03 F & PERCENE (Tetrachloroethene) & & $7 \mathrm{ug} / \mathrm{L}$ & & & $\mathrm{U}$ & & \\
\hline SESPMNT & B17HL5 & RICH.PMPHS HRM 43.5 & OFFSITE & sw & $\mathrm{N}$ & RIVER & TRANSECT & 09-Sep-03 F & PERCENE (Tetrachloroethene) & 0.17 & $7 \mathrm{ug} / \mathrm{L}$ & & & u & & \\
\hline SESPMNT & B17HL7 & RICH.PMPHS HRM 45.0 & OFFSITE & sw & $\mathrm{N}$ & RIVER & TRANSECT & $09-S e p-03 F$ & PERCENE (Tetrachloroethene) & 0.17 & $7 \mathrm{ug} / \mathrm{L}$ & & & u & & \\
\hline SESPMNT & B17HL8 & RICH.PMPHS HRM 45.8 & OFFSITE & sW & $\mathrm{N}$ & RIVER & TRANSECT & 09-Sep-03 F & PERCENE (Tetrachloroethene) & 0.17 & $7 \mathrm{ug} / \mathrm{L}$ & & & $\mathrm{U}$ & & \\
\hline SESPMNT & B17HL9 & VERNITA-1 HRM 0.3 & OFFSITE & sw & $\mathrm{N}$ & RIVER & TRANSECT & 04-Sep-03 F & PERCENE (Tetrachloroethene) & & $7 \mathrm{ug} / \mathrm{L}$ & & & U & & \\
\hline SESPMNT & B17HM0 & VERNITA-2 HRM 0.3 & OFFSITE & sw & $\mathrm{N}$ & RIVER & TRANSECT & 04-Sep-03 F & PERCENE (Tetrachloroethene) & & $7 \mathrm{ug} / \mathrm{L}$ & & & $u$ & & \\
\hline SESPMNT & B17HM1 & VERNITA-3 HRM 0.3 & OFFSITE & sw & $\mathrm{N}$ & RIVER & TRANSECT & 04-Sep-03 F & PERCENE (Tetrachloroethene) & & & & & U & & \\
\hline SESPMNT & B17HM2 & VERNITA-4 HRM 0.3 & OFFSITE & SW & $\mathrm{N}$ & RIVER & TRANSECT & 04-Sep-03 F & PERCENE (Tetrachloroethene) & & & & & u & & \\
\hline SESPMNT & B17HK9 & RICH.PMPHS-1 HRM46.4 & OFFSITE & sW & $\mathrm{N}$ & RIVER & TRANSECT & 09-Sep-037 & TETHYDF (Tetrahydrofuran) & & $7 \mathrm{ug} / \mathrm{L}$ & & & u & & \\
\hline SESPMNT & B17HLO & $\begin{array}{l}\text { RICH.PMPHS-2 HRM46.4 } \\
\end{array}$ & OFFSITE & sw & $\mathrm{N}$ & RIVER & TRANSECT & $09-$ Sep-03 & TETHYDF (Tetrahydrofuran) & & $7 \mathrm{ug} / \mathrm{L}$ & & & u & & \\
\hline SESPMNT & B17HL1 & RICH.PMPHS-3 HRM46.4 & OFFSITE & SW & $\mathrm{N}$ & RIVER & TRANSECT & 09-Sep-037 & TETHYDF (Tetrahydrofuran) & & $7 \mathrm{ug} / \mathrm{L}$ & & & $\mathrm{u}$ & & \\
\hline SESPMNT & B17HL2 & RICH.PMPHS-5 HRM46.4 & OFFSITE & SW & $\mathrm{N}$ & RIVER & TRANSECT & 09-Sep-037 & TETHYDF (Tetrahydrofuran) & & $7 \mathrm{ug} / \mathrm{L}$ & & & u & & \\
\hline SESPMNT & B17HL3 & RICH.PMPHS-7 HRM46.4 & OFFSITE & sw & $\mathrm{N}$ & RIVER & TRANSECT & $09-$ Sep-037 & TETHYDF (Tetrahydrofuran) & & $7 \mathrm{ug} / \mathrm{L}$ & & & u & & \\
\hline SESPMNT & B17HL4 & RICH.PMPHS-10 HRM46.4 & OFFSITE & sw & $\mathrm{N}$ & RIVER & TRANSECT & $09-$ Sep-03] & TETHYDF (Tetrahydrofuran) & & $7 \mathrm{ug} / \mathrm{L}$ & & & $\mathrm{u}$ & & \\
\hline SESPMNT & B17HL5 & RICH.PMPHS HRM 43.5 & OFFSITE & sW & $\mathrm{N}$ & RIVER & TRANSECT & 09-Sep-037 & TETHYDF (Tetrahydrofuran) & & & & & $\mathrm{U}$ & & \\
\hline SESPMNT & B17HL7 & RICH.PMPHS HRM 45.0 & OFFSITE & sw & $\mathrm{N}$ & RIVER & TRANSECT & 09-Sep-037 & TETHYDF (Tetrahydrofuran) & & $7 \mathrm{ug} / \mathrm{L}$ & & & U & & \\
\hline SESPMNT & B17HL8 & RICH.PMPHS HRM 45.8 & OFFSITE & sW & $\mathrm{N}$ & RIVER & TRANSECT & 09-Sep-037 & TETHYDF (Tetrahydrofuran) & & $7 \mathrm{ug} / \mathrm{L}$ & & & U & & \\
\hline SESPMNT & B17HL9 & VERNITA-1 HRM 0.3 & OFFSITE & SW & $\mathrm{N}$ & RIVER & TRANSECT & 04-Sep-037 & TETHYDF (Tetrahydrofuran) & & $7 \mathrm{ug} / \mathrm{L}$ & & & U & & \\
\hline SESPMNT & B17HMO & VERNITA-2 HRM 0.3 & OFFSITE & sw & $\mathrm{N}$ & RIVER & TRANSECT & 04-Sep-037 & TETHYDF (Tetrahydrofuran) & & $7 \mathrm{ug} / \mathrm{L}$ & & & $\mathrm{u}$ & & \\
\hline SESPMNT & B17HM1 & VERNITA-3 HRM 0.3 & OFFSITE & sW & $\mathrm{N}$ & RIVER & TRANSECT & 04-Sep-037 & TETHYDF (Tetrahydrofuran) & & $7 \mathrm{ug} / \mathrm{L}$ & & & U & & \\
\hline SESPMNT & B17HM2 & VERNITA-4 HRM 0.3 & OFFSITE & sW & $\mathrm{N}$ & RIVER & TRANSECT & 04-Sep-037 & TETHYDF (Tetrahydrofuran) & & $7 \mathrm{ug} / \mathrm{L}$ & & & u & & \\
\hline SESPMNT & B17HK9 & RICH.PMPHS-1 HRM46.4 & OFFSITE & sw & $\mathrm{N}$ & RIVER & TRANSECT & $09-S e p-037$ & TOLUENE & & & & & $\mathrm{J}$ & & \\
\hline SESPMNT & B17HLO & RICH.PMPHS-2 HRM46.4 & OFFSITE & sw & $\mathrm{N}$ & RIVER & TRANSECT & $09-$ Sep-037 & TOLUENE & & & & & u & & \\
\hline SESPMNT & B17HL1 & RICH.PMPHS-3 HRM46.4 & OFFSITE & sW & $\mathrm{N}$ & RIVER & TRANSECT & $09-$ Sep-03 & TOLUENE & 0.12 & $2 \mathrm{ug} / \mathrm{L}$ & & & U & & \\
\hline SESPMNT & B17HL2 & RICH.PMPHS-5 HRM46.4 & OFFSITE & sw & $\mathrm{N}$ & RIVER & TRANSECT & 09-Sep-037 & TOLUENE & & $2 \mathrm{ug} / \mathrm{L}$ & & & u & & \\
\hline SESPMNT & B17HL3 & RICH.PMPHS-7 HRM46.4 & OFFSITE & sw & $\mathrm{N}$ & RIVER & TRANSECT & 09-Sep-037 & TOLUENE & 0.12 & $2 \mathrm{ug} / \mathrm{L}$ & & & u & & \\
\hline SESPMNT & B17HL4 & RICH.PMPHS-10 HRM46.4 & OFFSITE & sW & $\mathrm{N}$ & RIVER & TRANSECT & 09-Sep-037 & TOLUENE & & $2 \mathrm{ug} / \mathrm{L}$ & & & U & & \\
\hline SESPMNT & B17HL5 & RICH.PMPHS HRM 43.5 & OFFSITE & sW & $\mathrm{N}$ & RIVER & TRANSECT & 09-Sep-037 & TOLUENE & & & & & $\mathrm{u}$ & & \\
\hline SESPMNT & B17HL7 & RICH.PMPHS HRM 45.0 & OFFSITE & sW & $\mathrm{N}$ & RIVER & TRANSECT & 09-Sep-037 & TOLUENE & & & & & $\mathrm{U}$ & & \\
\hline SESPMNT & B17HL8 & RICH.PMPHS HRM 45.8 & OFFSITE & SW & $\mathrm{N}$ & RIVER & TRANSECT & 09-Sep-037 & TOLUENE & & & & & $\mathrm{U}$ & & \\
\hline SESPMNT & B17HL9 & VERNITA-1 HRM 0.3 & OFFSITE & sw & $\mathrm{N}$ & RIVER & TRANSECT & 04-Sep-037 & TOLUENE & 0.12 & $2 \mathrm{ug} / \mathrm{L}$ & & & u & & \\
\hline SESPMNT & B17HMO & VERNITA-2 HRM 0.3 & OFFSITE & sw & $\mathrm{N}$ & RIVER & TRANSECT & 04-Sep-037 & TOLUENE & 0.12 & $2 \mathrm{ug} / \mathrm{L}$ & & & u & & \\
\hline SESPMNT & B17HM1 & VERNITA-3 HRM 0.3 & OFFSITE & sw & $\mathrm{N}$ & RIVER & TRANSECT & 04-Sep-037 & TOLUENE & & $2 \mathrm{ug} / \mathrm{L}$ & & & u & & \\
\hline SESPMNT & B17HM2 & VERNITA-4 HRM 0.3 & OFFSITE & sW & $\mathrm{N}$ & RIVER & TRANSECT & $04-$ Sep-03 & TOLUENE & & $2 \mathrm{ug} / \mathrm{L}$ & & & U & & \\
\hline SESPMNT & B17HK9 & RICH.PMPHS-1 HRM46.4 & OFFSITE & sw & $\mathrm{N}$ & RIVER & TRANSECT & 09-Sep-037 & TRANDCE (trans-1,2-Dichloroethylene) & & & & & $\mathrm{U}$ & & \\
\hline SESPMNT & B17HLO & RICH.PMPHS-2 HRM46.4 & OFFSITE & sw & $\mathrm{N}$ & RIVER & TRANSECT & 09-Sep-037 & TRANDCE (trans-1,2-Dichloroethylene) & & & & & U & & \\
\hline SESPMNT & B17HL1 & RICH.PMPHS-3 HRM46.4 & OFFSITE & sW & $\mathrm{N}$ & RIVER & TRANSECT & 09-Sep-037 & TRANDCE (trans-1,2-Dichloroethylene) & & $7 \mathrm{ug} / \mathrm{L}$ & & & U & & \\
\hline SESPMNT & B17HL2 & RICH.PMPHS-5 HRM46.4 & OFFSITE & sW & $\mathrm{N}$ & RIVER & TRANSECT & 09-Sep-037 & TRANDCE (trans-1,2-Dichloroethylene) & & & & & $\mathrm{u}$ & & \\
\hline SESPMNT & B17HL3 & RICH.PMPHS-7 HRM46.4 & OFFSITE & sw & $\mathrm{N}$ & RIVER & TRANSECT & $09-$ Sep-037 & TRANDCE (trans-1,2-Dichloroethylene) & 0.17 & 7 ug/L & & & u & & \\
\hline SESPMNT & B17HL4 & RICH.PMPHS-10 HRM46.4 & OFFSITE & sW & $\mathrm{N}$ & RIVER & TRANSECT & 09-Sep-037 & TRANDCE (trans-1,2-Dichloroethylene) & 0.17 & $7 \mathrm{ug} / \mathrm{L}$ & & & $\mathrm{u}$ & & \\
\hline SESPMNT & B17HL5 & RICH.PMPHS HRM 43.5 & OFFSITE & sW & $\mathrm{N}$ & RIVER & TRANSECT & 09-Sep-037 & TRANDCE (trans-1,2-Dichloroethylene) & 0.17 & $7 \mathrm{ug} / \mathrm{L}$ & & & u & & \\
\hline SESPMNT & B17HL7 & RICH.PMPHS HRM 45.0 & OFFSITE & sW & $\mathrm{N}$ & RIVER & TRANSECT & $09-S e p-037$ & TRANDCE (trans-1,2-Dichloroethylene) & & $7 \mathrm{ug} / \mathrm{L}$ & & & u & & \\
\hline SESPMNT & B17HL8 & RICH.PMPHS HRM 45.8 & OFFSITE & sw & $\mathrm{N}$ & RIVER & TRANSECT & 09-Sep-037 & & & & & & u & & \\
\hline SESPMNT & B17HL9 & VERNITA-1 HRM 0.3 & OFFSITE & sW & $\mathrm{N}$ & RIVER & TRANSECT & 04-Sep-037 & TRANDCE (trans-1,2-Dichloroethylene) & & $7 \mathrm{ug} / \mathrm{L}$ & & & U & & \\
\hline SESPMNT & B17HMO & VERNITA-2 HRM 0.3 & OFFSITE & sW & $\mathrm{N}$ & RIVER & TRANSECT & 04-Sep-037 & TRANDCE (trans-1,2-Dichloroethylene) & & $7 \mathrm{ug} / \mathrm{L}$ & & & u & & \\
\hline SESPMNT & B17HM1 & VERNITA-3 HRM 0.3 & OFFSITE & sw & $\mathrm{N}$ & RIVER & TRANSECT & 04-Sep-037 & TRANDCE (trans-1,2-Dichloroethylene) & & $7 \mathrm{ug} / \mathrm{L}$ & & & $\mathrm{U}$ & & \\
\hline SESPMNT & B17HM2 & VERNITA-4 HRM 0.3 & OFFSITE & SW & $\mathrm{N}$ & RIVER & TRANSECT & 04-Sep-037 & TRANDCE (trans-1,2-Dichloroethylene) & & $7 \mathrm{ug} / \mathrm{L}$ & & & $\mathrm{U}$ & & \\
\hline SESPMNT & B17HK9 & RICH.PMPHS-1 HRM46.4 & OFFSITE & sw & $\mathrm{N}$ & RIVER & TRANSECT & $09-$ Sep-037 & TRICELN (Trichloroethene) & & $6 \mathrm{ug} / \mathrm{L}$ & & & u & & \\
\hline SESPMNT & B17HLO & RICH.PMPHS-2 HRM46.4 & OFFSITE & sW & $\mathrm{N}$ & RIVER & TRANSECT & 09-Sep-037 & TRICELN (Trichloroethene) & & & & & U & & \\
\hline SESPMNT & B17HL1 & RICH.PMPHS-3 HRM46.4 & OFFSITE & sW & $\mathrm{N}$ & RIVER & TRANSECT & 09-Sep-037 & TRICELN (Trichloroethene) & & $6 \mathrm{ug} / \mathrm{L}$ & & & u & & \\
\hline SESPMNT & B17HL2 & RICH.PMPHS-5 HRM46.4 & OFFSITE & SW & $\mathrm{N}$ & RIVER & TRANSECT & 09-Sep-037 & TRICELN (Trichloroethene) & & & & & u & & \\
\hline SESPMNT & B17HL3 & RICH.PMPHS-7 HRM46.4 & OFFSITE & sw & $\mathrm{N}$ & RIVER & & 09-Sep-037 & TRICELN (Trichloroethene) & & & & & u & & \\
\hline SESPMNT & B17HL4 & RICH.PMPHS-10 HRM46.4 & OFFSITE & sW & $\mathrm{N}$ & RIVER & TRANSECT & 09-Sep-037 & TRICELN (Trichloroethene) & & $6 \mathrm{ug} / \mathrm{L}$ & & & $\mathrm{U}$ & & \\
\hline SESPMNT & B17HL5 & RICH.PMPHS HRM 43.5 & OFFSITE & sw & $\mathrm{N}$ & RIVER & TRANSECT & 09-Sep-037 & TRICELN (Trichloroethene) & 0.16 & $6 \mathrm{ug} / \mathrm{L}$ & & & $\mathrm{U}$ & & \\
\hline SESPMNT & B17HL7 & RICH.PMPHS HRM 45.0 & OFFSITE & sw & $\mathrm{N}$ & RIVER & TRANSECT & 09-Sep-037 & TRICELN (Trichloroethene) & 0.16 & $6 \mathrm{ug} / \mathrm{L}$ & & & $\mathrm{U}$ & & \\
\hline SESPMNT & B17HL8 & RICH.PMPHS HRM 45.8 & OFFSITE & sW & $\mathrm{N}$ & RIVER & TRANSECT & 09-Sep-037 & TRICELN (Trichloroethene) & & $6 \mathrm{ug} / \mathrm{L}$ & & & $u$ & & \\
\hline SESPMNT & B17HL9 & VERNITA-1 HRM 0.3 & OFFSITE & sW & $\mathrm{N}$ & RIVER & TRANSECT & 04-Sep-037 $\quad \longrightarrow$ & TRICELN (Trichloroethene) & & $6 \mathrm{ug} / \mathrm{L}$ & & & $u$ & & \\
\hline SESPMNT & B17HMO & VERNITA-2 HRM 0.3 & OFFSITE & SW & $\mathrm{N}$ & RIVER & TRANSECT & 04-Sep-037 & TRICELN (Trichloroethene) & & $6 \mathrm{ug} / \mathrm{L}$ & & & $u$ & & \\
\hline SESPMNT & B17HM1 & VERNITA-3 HRM 0.3 & OFFSITE & sw & $\mathrm{N}$ & RIVER & TRANSECT & 04-Sep-037 & TRICELN (Trichloroethene) & & $6 \mathrm{ug} / \mathrm{h}$ & & & $u$ & & \\
\hline
\end{tabular}




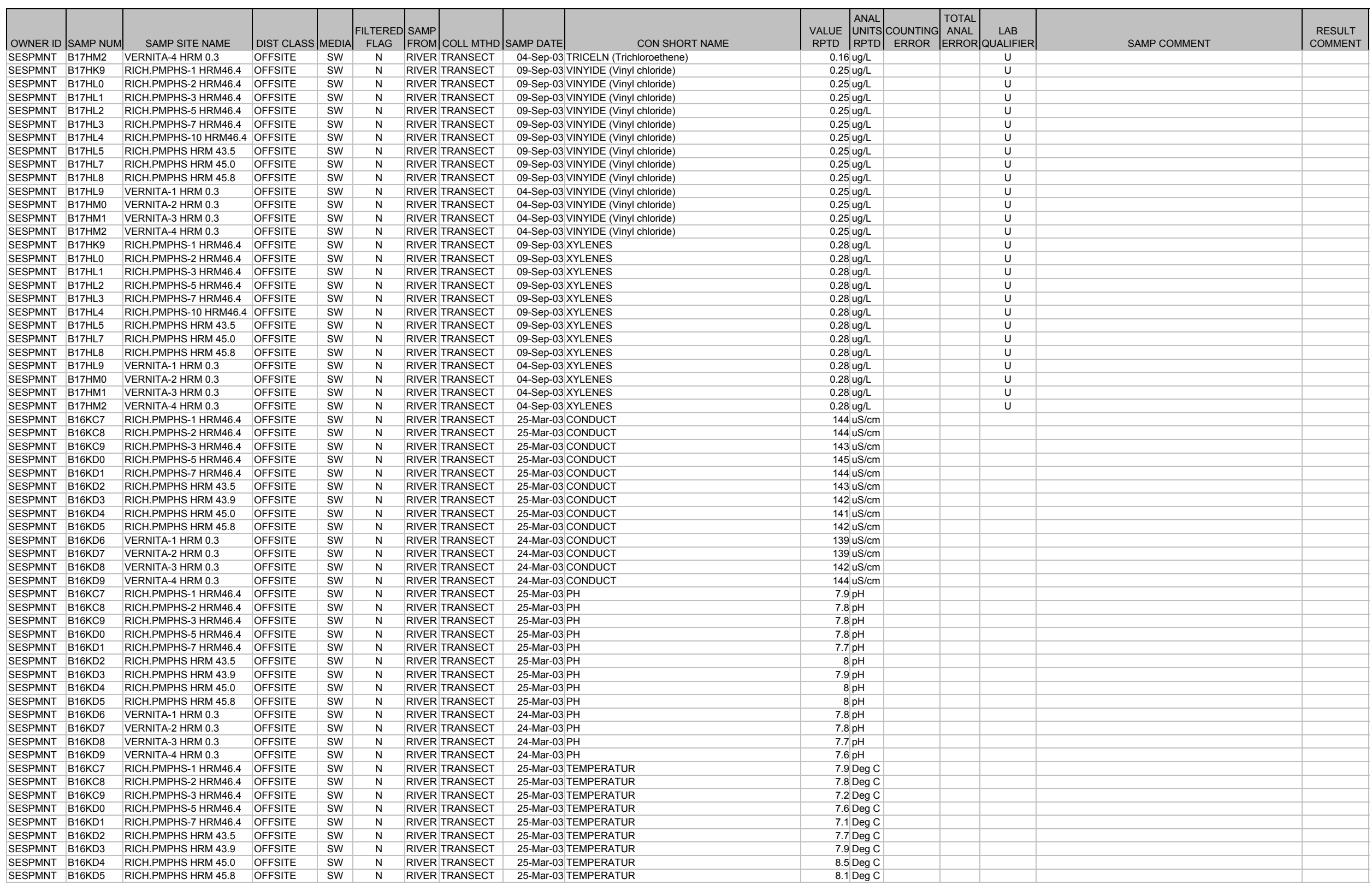


WATER - COLUMBIA RIVER TRANSEC

\begin{tabular}{|c|c|c|c|c|c|c|c|c|c|c|c|c|c|}
\hline OWNER ID & |SAMP NUM| & SAMP SITE NAME & |DIST CLASS & $\mid$ MEDIA $\mid$ & \begin{tabular}{|c} 
FILTERED \\
FLAG
\end{tabular} & $\begin{array}{l}\text { SAMP } \\
\text { FROM } \mid \text { COLL MTHD }\end{array}$ & |SAMP DATE $\quad$ CON SHORT NAME & $\begin{array}{l}\text { VALUE } \\
\text { RPTD }\end{array}$ & $\mid \begin{array}{l}\text { ANAL } \\
\text { UNITS } \\
\text { RPTD }\end{array}$ & $\begin{array}{l}\text { COUNTING } \\
\text { ERROR }\end{array}$ & \begin{tabular}{|l|c|} 
TOTAL & \\
ANAL & LAB \\
ENROR & QUALIFIER \\
\end{tabular} & SAMP COMMENT & $\begin{array}{l}\text { RESULT } \\
\text { COMMENT }\end{array}$ \\
\hline SESPMNT & B16KD6 & VERNITA-1 HRM 0.3 & OFFSITE & sw & $\mathrm{N}$ & RIVER TRANSECT & 24-Mar-03 TEMPERATUR & & & & & & \\
\hline SESPMNT & B16KD7 & VERNITA-2 HRM 0.3 & OFFSITE & sw & $\mathrm{N}$ & RIVER TRANSECT & 24-Mar-03 TEMPERATUR & & 2 Deg C & & & & \\
\hline SESPMNT & B16KD8 & VERNITA-3 HRM 0.3 & OFFSITE & SW & $\mathrm{N}$ & RIVER TRANSECT & 24-Mar-03 TEMPERATUR & & 3 Deg C & & & & \\
\hline SESPMNT & B16KD9 & VERNITA-4 HRM 0.3 & OFFSITE & sW & $\mathrm{N}$ & RIVER TRANSECT & 24-Mar-03 TEMPERATUR & & 3 Deg C & & & & \\
\hline
\end{tabular}


WATER - COLUMBIA RIVER FILTER/RESIN

\begin{tabular}{|c|c|c|c|c|c|c|c|c|c|c|c|c|c|c|c|c|}
\hline OWNER ID & SAMP NUM & SAMP SITE NAME & DIST CLASS & MEDIA & \begin{tabular}{|c|} 
FILTERED \\
FLAG
\end{tabular} & SAMP FROM & COLL MTHD & SAMP DATE & $\begin{array}{c}\text { CON SHORT } \\
\text { NAME }\end{array}$ & VALUE RPTD & \begin{tabular}{|l|} 
ANAL \\
UNITS \\
RPTD \\
\end{tabular} & $\begin{array}{c}\text { COUNTING } \\
\text { ERROR }\end{array}$ & $\begin{array}{c}\text { TOTAL ANAL } \\
\text { ERROR } \\
\end{array}$ & $\begin{array}{c}\text { LAB } \\
\text { QUALIFIER } \\
\end{array}$ & SAMP COMMENT & RESULT COMMENT \\
\hline SESPMNT & B16874 & PRIEST RAPIDS-RIVER & OFFSITE & SW & $\bar{Y}$ & RIVER & FILTER & 05-Feb-03 & $\mathrm{Be}-7$ & $0.0198 p$ & pCi/L & 0.0094 & 0.0094 & & & \\
\hline SESPMNT & B16880 & PRIEST RAPIDS-RIVER & OFFSITE & sW & $\mathrm{Y}$ & RIVER & RESIN & 05-Feb-03 & $\mathrm{Be}-7$ & $0.056 \mathrm{p}$ & $\mathrm{pCi} / \mathrm{L}$ & 0.019 & 0.019 & $u$ & & \\
\hline SESPMNT & B16875 & PRIEST RAPIDS-RIVER & OFFSITE & sw & $\mathrm{Y}$ & RIVER & FILTER & 05-Mar-03 & $\mathrm{Be}-7$ & $0.0215 p$ & $\mathrm{pCi} / \mathrm{L}$ & 0.0083 & 0.0083 & $u$ & & \\
\hline SESPMNT & B16881 & PRIEST RAPIDS-RIVER & OFFSITE & sW & $\mathrm{Y}$ & RIVER & RESIN & 05-Mar-03 & $\mathrm{Be}-7$ & $0.0526 \mathrm{p}$ & $\mathrm{pCi} / \mathrm{L}$ & 0.018 & 0.018 & $U$ & & \\
\hline SESPMNT & B16876 & PRIEST RAPIDS-RIVER & OFFSITE & sW & $\mathrm{Y}$ & RIVER & FILTER & 02-Apr-03 & $\mathrm{Be}-7$ & $0.0367 \mathrm{p}$ & $\mathrm{pCi} / \mathrm{L}$ & 0.011 & 0.011 & & & \\
\hline SESPMNT & B16882 & PRIEST RAPIDS-RIVER & OFFSITE & sW & $\mathrm{Y}$ & RIVER & RESIN & 02-Apr-03 & $\mathrm{Be}-7$ & $0.0224 \mathrm{p}$ & $\mathrm{pCi} / \mathrm{L}$ & 0.021 & 0.021 & $u$ & & \\
\hline SESPMNT & B16PK5 & PRIEST RAPIDS-RIVER & OFFSITE & sw & $\mathrm{Y}$ & RIVER & FILTER & 30-Apr-03 & $\mathrm{Be}-7$ & $0.0339 \mathrm{p}$ & pCill & 0.016 & 0.016 & $u$ & & \\
\hline SESPMNT & B16PL1 & PRIEST RAPIDS-RIVER & OFFSITE & sW & $\mathrm{Y}$ & RIVER & RESIN & 30-Apr-03 & $\mathrm{Be}-7$ & $0.0491 \mathrm{p}$ & $\mathrm{pCi} / \mathrm{L}$ & 0.024 & 0.024 & & & \\
\hline SESPMNT & B16PK6 & PRIEST RAPIDS-RIVER & OFFSITE & sW & $\mathrm{Y}$ & RIVER & FILTER & 28-May-03 & $\mathrm{Be}-7$ & $0.0597 \mathrm{p}$ & $\mathrm{pCi} / \mathrm{L}$ & 0.018 & 0.018 & & & \\
\hline SESPMNT & B16PL2 & PRIEST RAPIDS-RIVER & OFFSITE & sw & $\mathrm{Y}$ & RIVER & RESIN & 28-May-03 & $\mathrm{Be}-7$ & $0.0425 \mathrm{p}$ & pCill & 0.024 & 0.024 & & & \\
\hline SESPMNT & B16PK7 & PRIEST RAPIDS-RIVER & OFFSITE & sw & $\mathrm{Y}$ & RIVER & FILTER & 10-Jul-03 & $\mathrm{Be}-7$ & $0.00722 p$ & $\mathrm{pCi} / \mathrm{L}$ & 0.0082 & 0.0082 & $u$ & & \\
\hline SESPMNT & B16PL3 & PRIEST RAPIDS-RIVER & OFFSITE & sW & $\mathrm{Y}$ & RIVER & RESIN & 10-Jul-03 & $\mathrm{Be}-7$ & $0.0482 p$ & $\mathrm{pCi} / \mathrm{L}$ & 0.027 & 0.027 & U & & \\
\hline SESPMNT & B175H5 & PRIEST RAPIDS-RIVER & OFFSITE & sw & $\mathrm{Y}$ & RIVER & FILTER & 08-Aug-03 & $\mathrm{Be}-7$ & $0.000846 \mathrm{p}$ & $\mathrm{pCi/L}$ & 0.012 & 0.012 & $\mathrm{u}$ & & \\
\hline SESPMNT & B175J1 & PRIEST RAPIDS-RIVER & OFFSITE & sW & $\mathrm{Y}$ & RIVER & RESIN & 08-Aug-03 & $\mathrm{Be}-7$ & $0.0685 \mathrm{p}$ & pCi/L & 0.031 & 0.031 & & & \\
\hline SESPMNT & B175H6 & PRIEST RAPIDS-RIVER & OFFSITE & sW & $\mathrm{Y}$ & RIVER & FILTER & 03-Sep-03 & $\mathrm{Be}-7$ & $0.0142 \mathrm{p}$ & $\mathrm{pCi} / \mathrm{L}$ & 0.013 & 0.013 & U & & \\
\hline SESPMNT & B175J2 & PRIEST RAPIDS-RIVER & OFFSITE & sW & $\mathrm{Y}$ & RIVER & RESIN & 03-Sep-03 & $\mathrm{Be}-7$ & $0.0229 \mathrm{p}$ & $\mathrm{pCi} / \mathrm{L}$ & 0.028 & 0.028 & U & & \\
\hline SESPMNT & B175H7 & PRIEST RAPIDS-RIVER & OFFSITE & sw & $\mathrm{Y}$ & RIVER & FILTER & 30-Sep-03 & $\mathrm{Be}-7$ & $0.00907 \mathrm{p}$ & $\mathrm{pCi/L}$ & 0.0098 & 0.0098 & u & & \\
\hline SESPMNT & B175J3 & PRIEST RAPIDS-RIVER & OFFSITE & sW & $\mathrm{Y}$ & RIVER & RESIN & 30-Sep-03 & $\mathrm{Be}-7$ & $0.0205 p$ & $\mathrm{pCi} / \mathrm{L}$ & 0.021 & 0.021 & $u$ & & \\
\hline SESPMNT & B17P40 & PRIEST RAPIDS-RIVER & OFFSITE & sw & $\mathrm{Y}$ & RIVER & FILTER & 29-Oct-03 & $\mathrm{Be}-7$ & $0.00596 \mathrm{p}$ & $\mathrm{pCi} / \mathrm{L}$ & 0.0095 & 0.0095 & u & & \\
\hline SESPMNT & B17P46 & PRIEST RAPIDS-RIVER & OFFSITE & sW & $\mathrm{Y}$ & RIVER & RESIN & 29-Oct-03 & $\mathrm{Be}-7$ & $-0.00502 p$ & pCi/L & 0.016 & 0.016 & $u$ & & \\
\hline SESPMNT & B17P41 & PRIEST RAPIDS-RIVER & OFFSITE & sw & $\mathrm{Y}$ & RIVER & FILTER & 25 -Nov-03 & $\mathrm{Be}-7$ & $0.00752 \mathrm{p}$ & $\mathrm{pCi/L}$ & 0.011 & 0.011 & u & & \\
\hline SESPMNT & B17P47 & PRIEST RAPIDS-RIVER & OFFSITE & sW & $\mathrm{Y}$ & RIVER & RESIN & 25-Nov-03 & $\mathrm{Be}-7$ & $0.0117 p$ & $\mathrm{pCi} / \mathrm{L}$ & 0.023 & 0.023 & $u$ & & \\
\hline SESPMNT & B17P42 & PRIEST RAPIDS-RIVER & OFFSITE & sw & $\mathrm{Y}$ & RIVER & FILTER & 08-Jan-04 & $\mathrm{Be}-7$ & $0.0339 \mathrm{p}$ & $\mathrm{pCi/L}$ & 0.013 & 0.013 & & & \\
\hline SESPMNT & B17P48 & PRIEST RAPIDS-RIVER & OFFSITE & sW & $\mathrm{Y}$ & RIVER & RESIN & 08-Jan-04 & $\mathrm{Be}-7$ & $0.0358 \mathrm{p}$ & pCill & 0.021 & 0.021 & $u$ & & \\
\hline SESPMNT & B16892 & RICH.PMPHS HRM 46.4 & OFFSITE & sW & $\mathrm{Y}$ & RIVER & FILTER & 05-Feb-03 & $\mathrm{Be}-7$ & $0.0277 \mathrm{p}$ & $\mathrm{pCi} / \mathrm{L}$ & 0.013 & 0.013 & & & \\
\hline SESPMNT & B16886 & RICH.PMPHS HRM 46.4 & OFFSITE & sw & $\mathrm{Y}$ & RIVER & RESIN & $05-F e b-03$ & $\mathrm{Be}-7$ & $0.0484 \mathrm{p}$ & $\mathrm{pCi} / \mathrm{L}$ & 0.023 & 0.023 & & & \\
\hline SESPMNT & B16893 & RICH.PMPHS HRM 46.4 & OFFSITE & sW & $\mathrm{Y}$ & RIVER & FILTER & 05-Mar-03 & $\mathrm{Be}-7$ & $0.0219 \mathrm{p}$ & $\mathrm{pCi/L}$ & 0.01 & 0.01 & $\mathrm{u}$ & & \\
\hline SESPMNT & B16887 & RICH.PMPHS HRM 46.4 & OFFSITE & sw & $\mathrm{Y}$ & RIVER & RESIN & 05-Mar-03 & $\mathrm{Be}-7$ & $0.0733 \mathrm{p}$ & $\mathrm{pCi} / \mathrm{L}$ & 0.028 & 0.028 & & & \\
\hline SESPMNT & B16894 & RICH.PMPHS HRM 46.4 & OFFSITE & sw & $\mathrm{Y}$ & RIVER & FILTER & 02-Apr-03 & $\mathrm{Be}-7$ & $0.0374 \mathrm{p}$ & $\mathrm{pCi} / \mathrm{L}$ & 0.012 & 0.012 & & & \\
\hline SESPMNT & B16888 & RICH.PMPHS HRM 46.4 & OFFSITE & sw & $\mathrm{Y}$ & RIVER & RESIN & 02-Apr-03 & $\mathrm{Be}-7$ & $0.0627 \mathrm{p}$ & $\mathrm{pCi} / \mathrm{L}$ & 0.027 & 0.027 & & & \\
\hline SESPMNT & B16PM3 & RICH.PMPHS HRM 46.4 & OFFSITE & sw & Y & RIVER & FILTER & 30-Apr-03 & $\mathrm{Be}-7$ & $0.0801 \mathrm{p}$ & $\mathrm{pCi/L}$ & 0.023 & 0.023 & & & \\
\hline SESPMNT & B16PL7 & RICH.PMPHS HRM 46.4 & OFFSITE & sw & $\mathrm{Y}$ & RIVER & RESIN & 30-Apr-03 & $\mathrm{Be}-7$ & $0.0482 \mathrm{p}$ & $\mathrm{pCi} / \mathrm{L}$ & 0.03 & 0.03 & & & \\
\hline SESPMNT & B16PM4 & RICH.PMPHS HRM 46.4 & OFFSITE & sW & $\mathrm{Y}$ & RIVER & FILTER & 28-May-03 & $\mathrm{Be}-7$ & $0.0366 \mathrm{p}$ & $\mathrm{pCi} / \mathrm{L}$ & 0.018 & 0.018 & & & \\
\hline SESPMNT & B16PL8 & RICH.PMPHS HRM 46.4 & OFFSITE & sw & $\mathrm{Y}$ & RIVER & RESIN & 28-May-03 & $\mathrm{Be}-7$ & $0.0347 p$ & $\mathrm{pCi} / \mathrm{L}$ & 0.021 & 0.021 & $u$ & & \\
\hline SESPMNT & B16PM5 & RICH.PMPHS HRM 46.4 & OFFSITE & sw & $\mathrm{Y}$ & RIVER & FILTER & 10-Jul-03 & Be-7 & $0.0162 \mathrm{p}$ & $\mathrm{pCi/L}$ & 0.0076 & 0.0076 & u & & \\
\hline SESPMNT & B16PL9 & RICH.PMPHS HRM 46.4 & OFFSITE & sw & $\mathrm{Y}$ & RIVER & RESIN & 10-Jul-03 & $\mathrm{Be}-7$ & $0.0831 \mathrm{p}$ & pCi/L & 0.057 & 0.057 & & & \\
\hline SESPMNT & B175K3 & RICH.PMPHS HRM 46.4 & OFFSITE & sW & $\mathrm{Y}$ & RIVER & FILTER & 08-Aug-03 & $\mathrm{Be}-7$ & $0.0176 \mathrm{p}$ & $\mathrm{pCi} / \mathrm{L}$ & 0.012 & 0.012 & $u$ & & \\
\hline SESPMNT & B175J7 & RICH.PMPHS HRM 46.4 & OFFSITE & sw & $\mathrm{Y}$ & RIVER & RESIN & 08-Aug-03 & $\mathrm{Be}-7$ & $0.0408 \mathrm{p}$ & $\mathrm{pCi} / \mathrm{L}$ & 0.023 & 0.023 & $u$ & & \\
\hline SESPMNT & B175K4 & RICH.PMPHS HRM 46.4 & OFFSITE & sw & $\mathrm{Y}$ & RIVER & FILTER & 03-Sep-03 & Be-7 & $0.0138 \mathrm{p}$ & $\mathrm{pCi} / \mathrm{L}$ & 0.021 & 0.021 & $u$ & & \\
\hline SESPMNT & B175J8 & RICH.PMPHS HRM 46.4 & OFFSITE & sw & $\mathrm{Y}$ & RIVER & RESIN & 03-Sep-03 & $\mathrm{Be}-7$ & $0.0385 \mathrm{p}$ & pCi/L & 0.024 & 0.024 & $u$ & & \\
\hline SESPMNT & B175K5 & RICH.PMPHS HRM 46.4 & OFFSITE & sW & $\mathrm{Y}$ & RIVER & FILTER & 30-Sep-03 & $\mathrm{Be}-7$ & $0.0104 \mathrm{p}$ & $\mathrm{pCi} / \mathrm{L}$ & 0.016 & 0.016 & 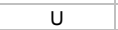 & & \\
\hline SESPMNT & B175J9 & RICH.PMPHS HRM 46.4 & OFFSITE & sw & $\mathrm{Y}$ & RIVER & RESIN & 30-Sep-03 & $\mathrm{Be}-7$ & $-0.0164 p$ & $\mathrm{pCi} / \mathrm{L}$ & 0.038 & 0.038 & $u$ & & \\
\hline SESPMNT & B17P58 & RICH.PMPHS HRM 46.4 & OFFSITE & sw & $\mathrm{Y}$ & RIVER & FILTER & 29-Oct-03 & $\mathrm{Be}-7$ & $0.0116 p$ & $\mathrm{pCi} / \mathrm{L}$ & 0.0093 & 0.0093 & $u$ & & \\
\hline SESPMNT & B17P52 & RICH.PMPHS HRM 46.4 & OFFSITE & sw & $\mathrm{Y}$ & RIVER & RESIN & 29-Oct-03 & $\mathrm{Be}-7$ & $0.00362 p$ & $\mathrm{pCi} / \mathrm{L}$ & 0.017 & 0.017 & $u$ & & \\
\hline SESPMNT & B17P59 & RICH.PMPHS HRM 46.4 & OFFSITE & sW & $\mathrm{Y}$ & RIVER & FILTER & $25-\mathrm{Nov}-03$ & $\mathrm{Be}-7$ & $-0.00359 p$ & $\mathrm{pCi} / \mathrm{L}$ & 0.012 & 0.012 & u & & \\
\hline SESPMNT & B17P53 & RICH.PMPHS HRM 46.4 & OFFSITE & sw & $\mathrm{Y}$ & RIVER & RESIN & $25-\mathrm{Nov}-03$ & $\mathrm{Be}-7$ & $0.0153 p$ & pCi/L & 0.023 & 0.023 & $u$ & & \\
\hline SESPMNT & B17P60 & RICH.PMPHS HRM 46.4 & OFFSITE & sw & $Y$ & RIVER & FILTER & 08-Jan-04 & $\mathrm{Be}-7$ & $0.0242 \mathrm{p}$ & $\mathrm{pCi/L}$ & 0.009 & 0.009 & & & \\
\hline SESPMNT & B17P54 & RICH.PMPHS HRM 46.4 & OFFSITE & sw & $\mathrm{Y}$ & RIVER & RESIN & 08-Jan-04 & Be-7 & $0.0488 \mathrm{p}$ & $\mathrm{pCi} / \mathrm{L}$ & 0.032 & 0.032 & & & \\
\hline SESPMNT & B16874 & PRIEST RAPIDS-RIVER & OFFSITE & sw & $\mathrm{Y}$ & RIVER & FILTER & $05-$ Feb-03 & Co-60 & $0.001 \mathrm{p}$ & $\mathrm{pCi} / \mathrm{L}$ & 0.00071 & 0.00071 & $u$ & & \\
\hline SESPMNT & B16880 & PRIEST RAPIDS-RIVER & OFFSITE & sw & $\mathrm{Y}$ & RIVER & RESIN & $05-F e b-03$ & Co-60 & $0.00256 \mathrm{p}$ & $\mathrm{pCi} / \mathrm{L}$ & 0.0018 & 0.0018 & $u$ & & \\
\hline SESPMNT & B16875 & PRIEST RAPIDS-RIVER & OFFSITE & sw & $Y$ & RIVER & FILTER & 05-Mar-03 & Co-60 & $0.000729 p$ & $\mathrm{pCi} / \mathrm{L}$ & 0.00076 & 0.00076 & $u$ & & \\
\hline SESPMNT & B16881 & PRIEST RAPIDS-RIVER & OFFSITE & sw & $\mathrm{Y}$ & RIVER & RESIN & 05-Mar-03 & Co-60 & $0.000316 p$ & $\mathrm{pCi} / \mathrm{L}$ & 0.0014 & 0.0014 & U & & \\
\hline SESPMNT & B16876 & PRIEST RAPIDS-RIVER & OFFSITE & sW & $\mathrm{Y}$ & RIVER & FILTER & 02-Apr-03 & Co-60 & $-0.000721 \mathrm{p}$ & $\mathrm{pCi} / \mathrm{L}$ & 0.00074 & 0.00074 & u & & \\
\hline SESPMNT & B16882 & PRIEST RAPIDS-RIVER & OFFSITE & sw & $\mathrm{Y}$ & RIVER & RESIN & 02-Apr-03 & Co- 60 & $-0.00171 p$ & $\mathrm{pCi} / \mathrm{L}$ & 0.0022 & 0.0022 & $u$ & & \\
\hline SESPMNT & B16PK5 & PRIEST RAPIDS-RIVER & OFFSITE & sw & Y & RIVER & FILTER & 30-Apr-03 & Co-60 & $-0.000354 p$ & $\mathrm{pCi} / \mathrm{L}$ & 0.0012 & 0.0012 & u & & \\
\hline SESPMNT & B16PL1 & PRIEST RAPIDS-RIVER & OFFSITE & sw & $\mathrm{Y}$ & RIVER & RESIN & 30-Apr-03 & Co-60 & $0.00124 \mathrm{p}$ & $\mathrm{pCi} / \mathrm{L}$ & 0.0017 & 0.0017 & u & & \\
\hline SESPMNT & B16PK6 & PRIEST RAPIDS-RIVER & OFFSITE & sW & $\mathrm{Y}$ & RIVER & FILTER & 28-May-03 & Co-60 & $0.00177 p$ & $\mathrm{pCi} / \mathrm{L}$ & 0.0012 & 0.0012 & u & & \\
\hline SESPMNT & B16PL2 & PRIEST RAPIDS-RIVER & OFFSITE & sw & $\mathrm{Y}$ & RIVER & RESIN & 28-May-03 & Co-60 & $0.000141 \mathrm{p}$ & $\mathrm{pCi} / \mathrm{L}$ & 0.0014 & 0.0014 & U & & \\
\hline
\end{tabular}


WATER - COLUMBIA RIVER FILTER/RESIN

\begin{tabular}{|c|c|c|c|c|c|c|c|c|c|c|c|c|c|c|c|c|}
\hline OWNER ID & SAMP NUM & SAMP SITE NAME & DIST CLASS & $\mid$ MEDIA $\mid$ & $\begin{array}{c}\mid \text { FILTERED } \\
\text { FLAG }\end{array}$ & SAMP FROM & COLL MTHD & SAMP DATE & $\left|\begin{array}{c}\text { CON SHORT } \\
\text { NAME }\end{array}\right|$ & VALUE RPTD & $\mid \begin{array}{l}\text { ANAL } \\
\text { UNITS } \\
\text { RPTD }\end{array}$ & $\left|\begin{array}{c}\text { COUNTING } \\
\text { ERROR }\end{array}\right|$ & $\begin{array}{c}\text { TOTAL ANAL } \\
\text { ERROR }\end{array}$ & $\mid \begin{array}{c}\text { LAB } \\
\text { QUALIFIER }\end{array}$ & SAMP COMMENT & RESULT COMMENT \\
\hline SESPMNT & B16PK7 & PRIEST RAPIDS-RIVER & OFFSITE & sw & Y & RIVER & FILTER & 10-Jul-03 & Co-60 & $0.00037 p$ & $\mathrm{pCi} / \mathrm{L}$ & 0.00079 & 0.00079 & u & & \\
\hline SESPMNT & B16PL3 & PRIEST RAPIDS-RIVER & OFFSITE & sW & $\mathrm{Y}$ & RIVER & RESIN & 10-Jul-03 C & Co-60 & $0.00262 p$ & $\mathrm{pCi} / \mathrm{L}$ & 0.0019 & 0.0019 & $u$ & & \\
\hline SESPMNT & B175H5 & PRIEST RAPIDS-RIVER & OFFSITE & sw & $\mathrm{Y}$ & RIVER & FILTER & 08-Aug-03 C & Co-60 & $0.000146 p$ & $\mathrm{pCi} / \mathrm{L}$ & 0.0011 & 0.0011 & $u$ & & \\
\hline SESPMNT & B175J1 & PRIEST RAPIDS-RIVER & OFFSITE & SW & $\mathrm{Y}$ & RIVER & RESIN & 08-Aug-03 C & Co-60 & $0.00251 \mathrm{p}$ & $\mathrm{pCi} / \mathrm{L}$ & 0.0018 & 0.0018 & u & & \\
\hline SESPMNT & B175H6 & PRIEST RAPIDS-RIVER & OFFSITE & sW & $\mathrm{Y}$ & RIVER & FILTER & 03-Sep-03 C & Co-60 & $0.000249 p$ & $\mathrm{pCi} / \mathrm{L}$ & 0.0011 & 0.0011 & $u$ & & \\
\hline SESPMNT & B175J2 & PRIEST RAPIDS-RIVER & OFFSITE & sW & $\mathrm{Y}$ & RIVER & RESIN & 03-Sep-03 C & Co-60 & $0.000898 p$ & $\mathrm{pCi} / \mathrm{L}$ & 0.0026 & 0.0026 & u & & \\
\hline SESPMNT & $\mathrm{B} 175 \mathrm{H} 7$ & PRIEST RAPIDS-RIVER & OFFSITE & sw & $\mathrm{Y}$ & RIVER & FILTER & 30-Sep-03 & Co-60 & $-0.0000412 p$ & pCill & 0.001 & 0.001 & $u$ & & \\
\hline SESPMNT & B175J3 & PRIEST RAPIDS-RIVER & OFFSITE & sW & $\mathrm{Y}$ & RIVER & RESIN & 30-Sep-03 C & Co-60 & $0.00181 \mathrm{p}$ & $\mathrm{pCi} / \mathrm{L}$ & 0.0021 & 0.0021 & U & & \\
\hline SESPMNT & B17P40 & PRIEST RAPIDS-RIVER & OFFSITE & sW & $\mathrm{Y}$ & RIVER & FILTER & $29-\mathrm{Oct}-03 \mathrm{C}$ & Co-60 & $0.000887 p$ & $\mathrm{pCi} / \mathrm{L}$ & 0.0011 & 0.0011 & u & & \\
\hline SESPMNT & B17P46 & PRIEST RAPIDS-RIVER & OFFSITE & sw & $\mathrm{Y}$ & RIVER & RESIN & $29-0 c t-03$ & Co-60 & $0.000972 p$ & pCill & 0.0016 & 0.0016 & u & & \\
\hline SESPMNT & B17P41 & PRIEST RAPIDS-RIVER & OFFSITE & sW & $\mathrm{Y}$ & RIVER & FILTER & 25-Nov-03 & Co-60 & $0.000319 p$ & $\mathrm{pCi} / \mathrm{L}$ & 0.001 & 0.001 & $u$ & & \\
\hline SESPMNT & B17P47 & PRIEST RAPIDS-RIVER & OFFSITE & sW & $\mathrm{Y}$ & RIVER & RESIN & 25-Nov-03 C & Co-60 & $-0.000456 p$ & $\mathrm{pCi} / \mathrm{L}$ & 0.002 & 0.002 & U & & \\
\hline SESPMNT & B17P42 & PRIEST RAPIDS-RIVER & OFFSITE & sw & $\mathrm{Y}$ & RIVER & FILTER & $08-J a n-04$ & Co-60 & $0.000447 p$ & $\mathrm{pCi/L}$ & 0.00066 & 0.00066 & u & & \\
\hline SESPMNT & B17P48 & PRIEST RAPIDS-RIVER & OFFSITE & sW & $\mathrm{Y}$ & RIVER & RESIN & 08-Jan-04 & Co-60 & $0.000199 \mathrm{p}$ & pCi/L & 0.0016 & 0.0016 & $u$ & & \\
\hline SESPMNT & B16892 & RICH.PMPHS HRM 46.4 & OFFSITE & sW & $\mathrm{Y}$ & RIVER & FILTER & $05-\mathrm{Feb}-03 \mathrm{C}$ & Co-60 & $0.0000791 p$ & $\mathrm{pCi} / \mathrm{L}$ & 0.00081 & 0.00081 & u & & \\
\hline SESPMNT & B16886 & RICH.PMPHS HRM 46.4 & OFFSITE & sW & $\mathrm{Y}$ & RIVER & RESIN & $05-\mathrm{Feb}-03 \mathrm{C}$ & Co-60 & $0.000437 p$ & $\mathrm{pCi} / \mathrm{L}$ & 0.0015 & 0.0015 & u & & \\
\hline SESPMNT & B16893 & RICH.PMPHS HRM 46.4 & OFFSITE & sw & $\mathrm{Y}$ & RIVER & FILTER & 05 -Mar-03 & Co-60 & $0.000167 p$ & $\mathrm{pCi/L}$ & 0.00097 & 0.00097 & u & & \\
\hline SESPMNT & B16887 & RICH.PMPHS HRM 46.4 & OFFSITE & sW & $\mathrm{Y}$ & RIVER & RESIN & $05-\mathrm{Mar}-03$ & Co-60 & $-0.0011 \mathrm{p}$ & $\mathrm{pCi} / \mathrm{L}$ & 0.0021 & 0.0021 & u & & \\
\hline SESPMNT & B16894 & RICH.PMPHS HRM 46.4 & OFFSITE & sw & $\mathrm{Y}$ & RIVER & FILTER & 02-Apr-03 & Co-60 & $-0.00055 p$ & $\mathrm{pCi} / \mathrm{L}$ & 0.00076 & 0.00076 & u & & \\
\hline SESPMNT & B16888 & RICH.PMPHS HRM 46.4 & OFFSITE & sW & $\mathrm{Y}$ & RIVER & RESIN & 02-Apr-03 & Co-60 & $0.000993 \mathrm{p}$ & $\mathrm{pCi} / \mathrm{L}$ & 0.002 & 0.002 & u & & \\
\hline SESPMNT & B16PM3 & RICH.PMPHS HRM 46.4 & OFFSITE & sw & $\mathrm{Y}$ & RIVER & FILTER & 30-Apr-03 & Co-60 & $0.000465 p$ & $\mathrm{pCi/L}$ & 0.00096 & 0.00096 & u & & \\
\hline SESPMNT & B16PL7 & RICH.PMPHS HRM 46.4 & OFFSITE & sW & $\mathrm{Y}$ & RIVER & RESIN & 30-Apr-03 & Co-60 & $0.000844 p$ & $\mathrm{pCi} / \mathrm{L}$ & 0.0016 & 0.0016 & u & & \\
\hline SESPMNT & B16PM4 & RICH.PMPHS HRM 46.4 & OFFSITE & sW & $\mathrm{Y}$ & RIVER & FILTER & 28-May-03 & Co-60 & $0.000238 \mathrm{p}$ & pCi/L & 0.001 & 0.001 & $u$ & & \\
\hline SESPMNT & B16PL8 & RICH.PMPHS HRM 46.4 & OFFSITE & sW & $\mathrm{Y}$ & RIVER & RESIN & 28-May-03 & Co-60 & $0.000855 \mathrm{p}$ & pCill & 0.0019 & 0.0019 & $u$ & & \\
\hline SESPMNT & B16PM5 & RICH.PMPHS HRM 46.4 & OFFSITE & sW & Y & RIVER & FILTER & 10-Jul-03 & Co-60 & $0.0000581 \mathrm{p}$ & $\mathrm{pCi} / \mathrm{L}$ & 0.00067 & 0.00067 & U & & \\
\hline SESPMNT & B16PL9 & RICH.PMPHS HRM 46.4 & OFFSITE & sw & $\mathrm{Y}$ & RIVER & RESIN & 10-Jul-03 & Co-60 & $0.00162 \mathrm{p}$ & pCi/L & 0.0028 & 0.0028 & $u$ & & \\
\hline SESPMNT & B175K3 & RICH.PMPHS HRM 46.4 & OFFSITE & sw & $\mathrm{Y}$ & RIVER & FILTER & 08-Aug-03 & Co-60 & $0.00124 \mathrm{p}$ & $\mathrm{pCi/L}$ & 0.001 & 0.001 & u & & \\
\hline SESPMNT & B175J7 & RICH.PMPHS HRM 46.4 & OFFSITE & sw & $\mathrm{Y}$ & RIVER & RESIN & 08-Aug-03 & Co-60 & $-0.000818 \mathrm{p}$ & pCi/L & 0.0021 & 0.0021 & $u$ & & \\
\hline SESPMNT & B175K4 & RICH.PMPHS HRM 46.4 & OFFSITE & sw & $\mathrm{Y}$ & RIVER & FILTER & 03-Sep-03 & Co-60 & $0.00114 p$ & $\mathrm{pCi} / \mathrm{L}$ & 0.0018 & 0.0018 & U & & \\
\hline SESPMNT & B175J8 & RICH.PMPHS HRM 46.4 & OFFSITE & sw & $\mathrm{Y}$ & RIVER & RESIN & 03-Sep-03 & Co-60 & $0.00202 p$ & $\mathrm{pCi} / \mathrm{L}$ & 0.0023 & 0.0023 & u & & \\
\hline SESPMNT & B175K5 & RICH.PMPHS HRM 46.4 & OFFSITE & sw & $\mathrm{Y}$ & RIVER & FILTER & 30-Sep-03 & Co-60 & $0.000582 p$ & $\mathrm{pCi/L}$ & 0.0019 & 0.0019 & u & & \\
\hline SESPMNT & B175J9 & RICH.PMPHS HRM 46.4 & OFFSITE & sw & $\mathrm{Y}$ & RIVER & RESIN & 30-Sep-03 & Co-60 & $0.00267 \mathrm{p}$ & $\mathrm{pCi} / \mathrm{L}$ & 0.0038 & 0.0038 & $u$ & & \\
\hline SESPMNT & B17P58 & RICH.PMPHS HRM 46.4 & OFFSITE & sW & $\mathrm{Y}$ & RIVER & FILTER & 29-Oct-03 & Co-60 & $-0.000129 p$ & $\mathrm{pCi} / \mathrm{L}$ & 0.001 & 0.001 & $u$ & & \\
\hline SESPMNT & B17P52 & RICH.PMPHS HRM 46.4 & OFFSITE & sw & $\mathrm{Y}$ & RIVER & RESIN & $29-0 c t-03$ & Co-60 & $0.0022 p$ & $\mathrm{pCi} / \mathrm{L}$ & 0.0017 & 0.0017 & $u$ & & \\
\hline SESPMNT & B17P59 & RICH.PMPHS HRM 46.4 & OFFSITE & sw & $\mathrm{Y}$ & RIVER & FILTER & 25-Nov-03 & Co-60 & $0.000368 p$ & $\mathrm{pCi/L}$ & 0.0012 & 0.0012 & u & & \\
\hline SESPMNT & B17P53 & RICH.PMPHS HRM 46.4 & OFFSITE & sw & $\mathrm{Y}$ & RIVER & RESIN & 25-Nov-03 & Co-60 & $-0.000501 p$ & pCi/L & 0.0019 & 0.0019 & $u$ & & \\
\hline SESPMNT & B17P60 & RICH.PMPHS HRM 46.4 & OFFSITE & sW & $\mathrm{Y}$ & RIVER & FILTER & 08-Jan-04 C & Co-60 & $-0.000195 p$ & $\mathrm{pCi} / \mathrm{L}$ & 0.00045 & 0.00045 & $u$ & & \\
\hline SESPMNT & B17P54 & RICH.PMPHS HRM 46.4 & OFFSITE & sw & $\mathrm{Y}$ & RIVER & RESIN & 08-Jan-04 C & Co-60 & $0.00164 p$ & $\mathrm{pCi} / \mathrm{L}$ & 0.0016 & 0.0016 & $u$ & & \\
\hline SESPMNT & B16874 & PRIEST RAPIDS-RIVER & OFFSITE & sw & $\mathrm{Y}$ & RIVER & FILTER & 05-Feb-03 & Cs-134 & $0.000678 \mathrm{p}$ & $\mathrm{pCi} / \mathrm{L}$ & 0.0007 & 0.0007 & $u$ & & \\
\hline SESPMNT & B16880 & PRIEST RAPIDS-RIVER & OFFSITE & sw & $\mathrm{Y}$ & RIVER & RESIN & $05-\mathrm{Feb}-03 \mathrm{C}$ & Cs-134 & $0.000766 p$ & $\mathrm{pCi} / \mathrm{L}$ & 0.002 & 0.002 & $u$ & & \\
\hline SESPMNT & B16875 & PRIEST RAPIDS-RIVER & OFFSITE & sW & $\mathrm{Y}$ & RIVER & FILTER & $05-\mathrm{Mar}-03 \mathrm{C}$ & Cs-134 & $-0.0000114 p$ & $\mathrm{pCi} / \mathrm{L}$ & 0.00077 & 0.00077 & $u$ & & \\
\hline SESPMNT & B16881 & PRIEST RAPIDS-RIVER & OFFSITE & sw & $\mathrm{Y}$ & RIVER & RESIN & $05-\mathrm{Mar}-03 \mathrm{C}$ & Cs-134 & $0.00136 \mathrm{p}$ & $\mathrm{pCi} / \mathrm{L}$ & 0.0017 & 0.0017 & $u$ & & \\
\hline SESPMNT & B16876 & PRIEST RAPIDS-RIVER & OFFSITE & sw & $Y$ & RIVER & FILTER & 02-Apr-03 & Cs-134 & $0.000499 \mathrm{p}$ & $\mathrm{pCi} / \mathrm{L}$ & 0.00076 & 0.00076 & $u$ & & \\
\hline SESPMNT & B16882 & PRIEST RAPIDS-RIVER & OFFSITE & sw & $\mathrm{Y}$ & RIVER & RESIN & 02-Apr-03 & Cs-134 & $0.0018 p$ & $\mathrm{pCi} / \mathrm{L}$ & 0.0022 & 0.0022 & $u$ & & \\
\hline SESPMNT & B16PK5 & PRIEST RAPIDS-RIVER & OFFSITE & sW & $\mathrm{Y}$ & RIVER & FILTER & 30-Apr-03 & Cs-134 & $0.000219 p$ & $\mathrm{pCi} / \mathrm{L}$ & 0.0013 & 0.0013 & $u$ & & \\
\hline SESPMNT & B16PL1 & PRIEST RAPIDS-RIVER & OFFSITE & sw & $\mathrm{Y}$ & RIVER & RESIN & 30-Apr-03 & Cs-134 & $0.0015 p$ & $\mathrm{pCi} / \mathrm{L}$ & 0.0019 & 0.0019 & $u$ & & \\
\hline SESPMNT & B16PK6 & PRIEST RAPIDS-RIVER & OFFSITE & sw & $Y$ & RIVER & FILTER & 28-May-03 & Cs-134 & $0.000211 \mathrm{p}$ & $\mathrm{pCi} / \mathrm{L}$ & 0.0012 & 0.0012 & $u$ & & \\
\hline SESPMNT & B16PL2 & PRIEST RAPIDS-RIVER & OFFSITE & sw & $\mathrm{Y}$ & RIVER & RESIN & 28-May-03 C & Cs-134 & $0.00142 p$ & $\mathrm{pCi} / \mathrm{L}$ & 0.0016 & 0.0016 & $u$ & & \\
\hline SESPMNT & B16PK7 & PRIEST RAPIDS-RIVER & OFFSITE & sw & $\mathrm{Y}$ & RIVER & FILTER & 10-Jul-03 & Cs-134 & $0.000194 p$ & $\mathrm{pCi} / \mathrm{L}$ & 0.00087 & 0.00087 & $u$ & & \\
\hline SESPMNT & B16PL3 & PRIEST RAPIDS-RIVER & OFFSITE & sw & $\mathrm{Y}$ & RIVER & RESIN & 10-Jul-03 & Cs-134 & $0.00156 \mathrm{p}$ & $\mathrm{pCi} / \mathrm{L}$ & 0.0021 & 0.0021 & $u$ & & \\
\hline SESPMNT & B175H5 & PRIEST RAPIDS-RIVER & OFFSITE & sw & $Y$ & RIVER & FILTER & 08-Aug-03 & Cs-134 & $0.000998 \mathrm{p}$ & $\mathrm{pCi} / \mathrm{L}$ & 0.0011 & 0.0011 & $u$ & & \\
\hline SESPMNT & B175J1 & PRIEST RAPIDS-RIVER & OFFSITE & sw & $\mathrm{Y}$ & RIVER & RESIN & 08-Aug-03 C & Cs-134 & $0.00269 p$ & $\mathrm{pCi} / \mathrm{L}$ & 0.002 & 0.002 & $u$ & & \\
\hline SESPMNT & B175H6 & PRIEST RAPIDS-RIVER & OFFSITE & sW & $\mathrm{Y}$ & RIVER & FILTER & 03-Sep-03 C & Cs-134 & $0.000033 p$ & $\mathrm{pCi} / \mathrm{L}$ & 0.0012 & 0.0012 & u & & \\
\hline SESPMNT & B175J2 & PRIEST RAPIDS-RIVER & OFFSITE & sw & $\mathrm{Y}$ & RIVER & RESIN & 03-Sep-03 C & Cs-134 & $-0.00101 p$ & $\mathrm{pCi} / \mathrm{L}$ & 0.0028 & 0.0028 & $u$ & & \\
\hline SESPMNT & B175H7 & PRIEST RAPIDS-RIVER & OFFSITE & sw & Y & RIVER & FILTER & 30-Sep-03 & Cs-134 & $-0.00018 p$ & $\mathrm{pCi} / \mathrm{L}$ & 0.0011 & 0.0011 & u & & \\
\hline SESPMNT & B175J3 & PRIEST RAPIDS-RIVER & OFFSITE & sw & $\mathrm{Y}$ & RIVER & RESIN & 30-Sep-03 C & Cs-134 & $0.000718 \mathrm{p}$ & $\mathrm{pCi} / \mathrm{L}$ & 0.0022 & 0.0022 & u & & \\
\hline SESPMNT & B17P40 & PRIEST RAPIDS-RIVER & OFFSITE & sW & $\mathrm{Y}$ & RIVER & FILTER & 29-Oct-03 C & Cs-134 & $-0.0000491 p$ & $\mathrm{pCi} / \mathrm{L}$ & 0.0011 & 0.0011 & u & & \\
\hline SESPMNT & B17P46 & PRIEST RAPIDS-RIVER & OFFSITE & sw & $Y$ & RIVER & RESIN & $29-O c$ & Cs-134 & $0.000455 \mathrm{p}$ & $\mathrm{pCilL}$ & 0.0018 & 0.0018 & $u$ & & \\
\hline
\end{tabular}


WATER - COLUMBIA RIVER FILTER/RESIN

\begin{tabular}{|c|c|c|c|c|c|c|c|c|c|c|c|c|c|c|c|c|}
\hline OWNER ID & SAMP NUM & SAMP SITE NAME & DIST CLASS & $\mid$ MEDIA $\mid$ & $\begin{array}{c}\mid \text { FILTERED } \\
\text { FLAG }\end{array}$ & SAMP FROM & COLL MTHD & SAMP DATE & $\left|\begin{array}{c}\text { CON SHORT } \\
\text { NAME }\end{array}\right|$ & VALUE RPTD & $\mid \begin{array}{l}\text { ANAL } \\
\text { UNITS } \\
\text { RPTD }\end{array}$ & $\left|\begin{array}{c}\text { COUNTING } \\
\text { ERROR }\end{array}\right|$ & $\begin{array}{c}\text { TOTAL ANAL } \\
\text { ERROR }\end{array}$ & $\mid \begin{array}{c}\text { LAB } \\
\text { QUALIFIER }\end{array}$ & SAMP COMMENT & |RESULT COMMENT \\
\hline SESPMNT & B17P41 & PRIEST RAPIDS-RIVER & OFFSITE & sw & Y & RIVER & FILTER & $25-\mathrm{Nov}-03 \mathrm{C}$ & Cs-134 & $0.000941 p$ & $\mathrm{pCi} / \mathrm{L}$ & 0.0011 & 0.0011 & u & & \\
\hline SESPMNT & B17P47 & PRIEST RAPIDS-RIVER & OFFSITE & sw & $\mathrm{Y}$ & RIVER & RESIN & 25-Nov-03 C & Cs-134 & $0.00153 \mathrm{p}$ & $\mathrm{pCi} / \mathrm{L}$ & 0.002 & 0.002 & $u$ & & \\
\hline SESPMNT & B17P42 & PRIEST RAPIDS-RIVER & OFFSITE & sw & $\mathrm{Y}$ & RIVER & FILTER & 08-Jan-04 C & Cs-134 & $0.000501 p$ & $\mathrm{pCi} / \mathrm{L}$ & 0.00072 & 0.00072 & $u$ & & \\
\hline SESPMNT & B17P48 & PRIEST RAPIDS-RIVER & OFFSITE & sW & $\mathrm{Y}$ & RIVER & RESIN & 08-Jan-04 C & Cs-134 & $0.00167 p$ & $\mathrm{pCi} / \mathrm{L}$ & 0.0017 & 0.0017 & $u$ & & \\
\hline SESPMNT & B16892 & RICH.PMPHS HRM 46.4 & OFFSITE & sW & $\mathrm{Y}$ & RIVER & FILTER & $05-\mathrm{Feb}-03 \mathrm{C}$ & Cs-134 & $0.000433 p$ & $\mathrm{pCi} / \mathrm{L}$ & 0.00082 & 0.00082 & $u$ & & \\
\hline SESPMNT & B16886 & RICH.PMPHS HRM 46.4 & OFFSITE & sW & $\mathrm{Y}$ & RIVER & RESIN & $05-\mathrm{Feb}-03 \mathrm{C}$ & Cs-134 & $0.000343 \mathrm{p}$ & $\mathrm{pCi} / \mathrm{L}$ & 0.0016 & 0.0016 & $u$ & & \\
\hline SESPMNT & B16893 & RICH.PMPHS HRM 46.4 & OFFSITE & sw & $\mathrm{Y}$ & RIVER & FILTER & $05-\mathrm{Mar}-03 \mathrm{C}$ & Cs-134 & $0.00163 \mathrm{p}$ & $\mathrm{pCi} / \mathrm{L}$ & 0.001 & 0.001 & $u$ & & \\
\hline SESPMNT & B16887 & RICH.PMPHS HRM 46.4 & OFFSITE & sW & $\mathrm{Y}$ & RIVER & RESIN & $05-\mathrm{Mar}-03 \mathrm{C}$ & Cs-134 & $-0.00221 \mathrm{p}$ & $\mathrm{pCi} / \mathrm{L}$ & 0.0023 & 0.0023 & u & & \\
\hline SESPMNT & B16894 & RICH.PMPHS HRM 46.4 & OFFSITE & sW & $\mathrm{Y}$ & RIVER & FILTER & 02-Apr-03 C & Cs-134 & $0.000518 p$ & $\mathrm{pCi} / \mathrm{L}$ & 0.00078 & 0.00078 & u & & \\
\hline SESPMNT & B16888 & RICH.PMPHS HRM 46.4 & OFFSITE & sw & $\mathrm{Y}$ & RIVER & RESIN & 02-Apr-03 & Cs-134 & $0.00244 \mathrm{p}$ & pCill & 0.002 & 0.002 & u & & \\
\hline SESPMNT & B16PM3 & RICH.PMPHS HRM 46.4 & OFFSITE & sw & $\mathrm{Y}$ & RIVER & FILTER & 30-Apr-03 C & Cs-134 & $0.000396 \mathrm{p}$ & $\mathrm{pCi} / \mathrm{L}$ & 0.0011 & 0.0011 & $u$ & & \\
\hline SESPMNT & B16PL7 & RICH.PMPHS HRM 46.4 & OFFSITE & sW & $\mathrm{Y}$ & RIVER & RESIN & 30-Apr-03 C & Cs-134 & $0.00186 \mathrm{p}$ & $\mathrm{pCi} / \mathrm{L}$ & 0.0018 & 0.0018 & u & & \\
\hline SESPMNT & B16PM4 & RICH.PMPHS HRM 46.4 & OFFSITE & sw & $\mathrm{Y}$ & RIVER & FILTER & 28-May-03 & Cs-134 & $0.000458 \mathrm{p}$ & $\mathrm{pCi/L}$ & 0.0011 & 0.0011 & u & & \\
\hline SESPMNT & B16PL8 & RICH.PMPHS HRM 46.4 & OFFSITE & sw & $\mathrm{Y}$ & RIVER & RESIN & 28-May-03 & Cs-134 & $0.00154 \mathrm{p}$ & $\mathrm{pCi} / \mathrm{L}$ & 0.0019 & 0.0019 & $u$ & & \\
\hline SESPMNT & B16PM5 & RICH.PMPHS HRM 46.4 & OFFSITE & sW & $\mathrm{Y}$ & RIVER & FILTER & 10-Jul-03 & Cs-134 & $0.00108 \mathrm{p}$ & $\mathrm{pCi} / \mathrm{L}$ & 0.0008 & 0.0008 & u & & \\
\hline SESPMNT & B16PL9 & RICH.PMPHS HRM 46.4 & OFFSITE & sW & $\mathrm{Y}$ & RIVER & RESIN & 10-Jul-03 & Cs-134 & $0.00283 \mathrm{p}$ & $\mathrm{pCi} / \mathrm{L}$ & 0.0022 & 0.0022 & u & & \\
\hline SESPMNT & B175K3 & RICH.PMPHS HRM 46.4 & OFFSITE & sw & $\mathrm{Y}$ & RIVER & FILTER & 08-Aug-03 & Cs-134 & $0.0000918 p$ & $\mathrm{pCi/L}$ & 0.001 & 0.001 & u & & \\
\hline SESPMNT & B175J7 & RICH.PMPHS HRM 46.4 & OFFSITE & sW & $\mathrm{Y}$ & RIVER & RESIN & 08-Aug-03 & Cs-134 & $0.00189 \mathrm{p}$ & $\mathrm{pCi} / \mathrm{L}$ & 0.0022 & 0.0022 & $u$ & & \\
\hline SESPMNT & B175K4 & RICH.PMPHS HRM 46.4 & OFFSITE & sw & $\mathrm{Y}$ & RIVER & FILTER & 03-Sep-03 & Cs-134 & $0.000299 \mathrm{p}$ & $\mathrm{pCi} / \mathrm{L}$ & 0.0018 & 0.0018 & u & & \\
\hline SESPMNT & B175J8 & RICH.PMPHS HRM 46.4 & OFFSITE & sW & $\mathrm{Y}$ & RIVER & RESIN & $03-\mathrm{Sep}-03$ & Cs-134 & $0.00311 \mathrm{p}$ & $\mathrm{pC}$ Ci/L & 0.0025 & 0.0025 & $u$ & & \\
\hline SESPMNT & B175K5 & RICH.PMPHS HRM 46.4 & OFFSITE & sW & $\mathrm{Y}$ & RIVER & FILTER & 30-Sep-03 & Cs-134 & $0.000166 \mathrm{p}$ & $\mathrm{pCi} / \mathrm{L}$ & 0.002 & 0.002 & $\mathrm{U}$ & & \\
\hline SESPMNT & B175J9 & RICH.PMPHS HRM 46.4 & OFFSITE & sW & $\mathrm{Y}$ & RIVER & RESIN & 30-Sep-03 & Cs-134 & $0.00347 \mathrm{p}$ & $\mathrm{pCi} / \mathrm{L}$ & 0.0039 & 0.0039 & $u$ & & \\
\hline SESPMNT & B17P58 & RICH.PMPHS HRM 46.4 & OFFSITE & sW & $\mathrm{Y}$ & RIVER & FILTER & $29-0 c t-03$ & Cs-134 & $0.000967 p$ & $\mathrm{pC}$ Ci/L & 0.0011 & 0.0011 & $u$ & & \\
\hline SESPMNT & B17P52 & RICH.PMPHS HRM 46.4 & OFFSITE & sW & $\mathrm{Y}$ & RIVER & RESIN & $29-0 c t-03$ & Cs-134 & $0.00151 \mathrm{p}$ & pCill & 0.0018 & 0.0018 & $u$ & & \\
\hline SESPMNT & B17P59 & RICH.PMPHS HRM 46.4 & OFFSITE & sW & $\mathrm{Y}$ & RIVER & FILTER & 25-Nov-03 & Cs-134 & $0.000763 p$ & $\mathrm{pCi} / \mathrm{L}$ & 0.0012 & 0.0012 & $\mathrm{U}$ & & \\
\hline SESPMNT & B17P53 & RICH.PMPHS HRM 46.4 & OFFSITE & sw & $\mathrm{Y}$ & RIVER & RESIN & 25 -Nov-03 & Cs-134 & $0.00122 p$ & $\mathrm{pCi} / \mathrm{L}$ & 0.0021 & 0.0021 & $u$ & & \\
\hline SESPMNT & B17P60 & RICH.PMPHS HRM 46.4 & OFFSITE & sW & $\mathrm{Y}$ & RIVER & FILTER & 08-Jan-04 & Cs-134 & $0.000209 p$ & $\mathrm{pCi} / \mathrm{L}$ & 0.00051 & 0.00051 & u & & \\
\hline SESPMNT & B17P54 & RICH.PMPHS HRM 46.4 & OFFSITE & sw & $\mathrm{Y}$ & RIVER & RESIN & 08-Jan-04 & Cs-134 & $0.00161 \mathrm{p}$ & $\mathrm{pCi} / \mathrm{L}$ & 0.0018 & 0.0018 & $u$ & & \\
\hline SESPMNT & B16874 & PRIEST RAPIDS-RIVER & OFFSITE & sw & $\mathrm{Y}$ & RIVER & FILTER & $05-\mathrm{Feb}-03$ & Cs-137 & $0.000393 p$ & $\mathrm{pCi} / \mathrm{L}$ & 0.00068 & 0.00068 & U & & \\
\hline SESPMNT & B16880 & PRIEST RAPIDS-RIVER & OFFSITE & sw & $\mathrm{Y}$ & RIVER & RESIN & $05-\mathrm{Feb}-03$ & Cs-137 & $-0.0000413 p$ & $\mathrm{pCi} / \mathrm{L}$ & 0.0016 & 0.0016 & $u$ & & \\
\hline SESPMNT & B16875 & PRIEST RAPIDS-RIVER & OFFSITE & sw & $\mathrm{Y}$ & RIVER & FILTER & $05-\mathrm{Mar}-03 \mathrm{C}$ & Cs-137 & $0.0000884 \mathrm{p}$ & $\mathrm{pCi/L}$ & 0.00071 & 0.00071 & u & & \\
\hline SESPMNT & B16881 & PRIEST RAPIDS-RIVER & OFFSITE & sw & $\mathrm{Y}$ & RIVER & RESIN & $05-\mathrm{Mar}-03$ & Cs-137 & $0.00105 p$ & $\mathrm{pCi} / \mathrm{L}$ & 0.0015 & 0.0015 & $u$ & & \\
\hline SESPMNT & B16876 & PRIEST RAPIDS-RIVER & OFFSITE & sw & $\mathrm{Y}$ & RIVER & FILTER & 02-Apr-03 C & Cs-137 & $0.000381 p$ & $\mathrm{pCi} / \mathrm{L}$ & 0.00069 & 0.00069 & U & & \\
\hline SESPMNT & B16882 & PRIEST RAPIDS-RIVER & OFFSITE & sw & $\mathrm{Y}$ & RIVER & RESIN & 02-Apr-03 & Cs-137 & $0.00259 p$ & $\mathrm{pCi} / \mathrm{L}$ & 0.002 & 0.002 & u & & \\
\hline SESPMNT & B16PK5 & PRIEST RAPIDS-RIVER & OFFSITE & sw & $\mathrm{Y}$ & RIVER & FILTER & 30-Apr-03 & Cs-137 & $-0.000316 p$ & $\mathrm{pCi} / \mathrm{L}$ & 0.0012 & 0.0012 & u & & \\
\hline SESPMNT & B16PL1 & PRIEST RAPIDS-RIVER & OFFSITE & sw & $\mathrm{Y}$ & RIVER & RESIN & 30-Apr-03 & Cs-137 & $0.00105 p$ & $\mathrm{pCi} / \mathrm{L}$ & 0.0017 & 0.0017 & $u$ & & \\
\hline SESPMNT & B16PK6 & PRIEST RAPIDS-RIVER & OFFSITE & sw & $\mathrm{Y}$ & RIVER & FILTER & 28-May-03 C & Cs-137 & $0.000763 p$ & $\mathrm{pCi} / \mathrm{L}$ & 0.0011 & 0.0011 & U & & \\
\hline SESPMNT & B16PL2 & PRIEST RAPIDS-RIVER & OFFSITE & sw & $\mathrm{Y}$ & RIVER & RESIN & 28-May-03 & Cs-137 & $0.00215 p$ & $\mathrm{pCi} / \mathrm{L}$ & 0.0014 & 0.0014 & $u$ & & \\
\hline SESPMNT & B16PK7 & PRIEST RAPIDS-RIVER & OFFSITE & sw & $\mathrm{Y}$ & RIVER & FILTER & 10-Jul-03 & Cs-137 & $0.000414 p$ & $\mathrm{pCi} / \mathrm{L}$ & 0.00082 & 0.00082 & $u$ & & \\
\hline SESPMNT & B16PL3 & PRIEST RAPIDS-RIVER & OFFSITE & sw & $\mathrm{Y}$ & RIVER & RESIN & 10-Jul-03 & Cs-137 & $0.00044 p$ & $\mathrm{pCi} / \mathrm{L}$ & 0.0019 & 0.0019 & u & & \\
\hline SESPMNT & B175H5 & PRIEST RAPIDS-RIVER & OFFSITE & sw & $\mathrm{Y}$ & RIVER & FILTER & 08-Aug-03 C & Cs-137 & $0.000654 p$ & $\mathrm{pCi} / \mathrm{L}$ & 0.001 & 0.001 & $u$ & & \\
\hline SESPMNT & B175J1 & PRIEST RAPIDS-RIVER & OFFSITE & sw & $\mathrm{Y}$ & RIVER & RESIN & 08-Aug-03 C & Cs-137 & $0.00147 p$ & $\mathrm{pCi} / \mathrm{L}$ & 0.0017 & 0.0017 & $u$ & & \\
\hline SESPMNT & B175H6 & PRIEST RAPIDS-RIVER & OFFSITE & sw & $\mathrm{Y}$ & RIVER & FILTER & $03-$ Sep-03 & Cs-137 & $0.000319 p$ & $\mathrm{pCi} / \mathrm{L}$ & 0.0011 & 0.0011 & $u$ & & \\
\hline SESPMNT & B175J2 & PRIEST RAPIDS-RIVER & OFFSITE & sw & $\mathrm{Y}$ & RIVER & RESIN & 03-Sep-03 & Cs-137 & $-0.00166 p$ & $\mathrm{pCi} / \mathrm{L}$ & 0.0025 & 0.0025 & $u$ & & \\
\hline SESPMNT & B175H7 & PRIEST RAPIDS-RIVER & OFFSITE & sw & $\mathrm{Y}$ & RIVER & FILTER & 30-Sep-03 C & Cs-137 & $-0.000458 \mathrm{p}$ & $\mathrm{pCi} / \mathrm{L}$ & 0.001 & 0.001 & $u$ & & \\
\hline SESPMNT & B175J3 & PRIEST RAPIDS-RIVER & OFFSITE & sw & $\mathrm{Y}$ & RIVER & RESIN & 30-Sep-03 & Cs-137 & $0.00267 p$ & $\mathrm{pCi} / \mathrm{L}$ & 0.0022 & 0.0022 & $u$ & & \\
\hline SESPMNT & B17P40 & PRIEST RAPIDS-RIVER & OFFSITE & sw & $Y$ & RIVER & FILTER & 29-Oct-03 & Cs-137 & $0.000699 \mathrm{p}$ & $\mathrm{pCi} / \mathrm{L}$ & 0.001 & 0.001 & $u$ & & \\
\hline SESPMNT & B17P46 & PRIEST RAPIDS-RIVER & OFFSITE & sw & $\mathrm{Y}$ & RIVER & RESIN & $29-0 c t-03$ & Cs-137 & $0.000809 p$ & $\mathrm{pCi} / \mathrm{L}$ & 0.0017 & 0.0017 & $u$ & & \\
\hline SESPMNT & B17P41 & PRIEST RAPIDS-RIVER & OFFSITE & sw & $\mathrm{Y}$ & RIVER & FILTER & $25-\mathrm{Nov}-03 \mathrm{C}$ & Cs-137 & $0.00142 \mathrm{p}$ & $\mathrm{pCi} / \mathrm{L}$ & 0.0011 & 0.0011 & u & & \\
\hline SESPMNT & B17P47 & PRIEST RAPIDS-RIVER & OFFSITE & sw & $\mathrm{Y}$ & RIVER & RESIN & $25-\mathrm{Nov}-03 \mathrm{C}$ & Cs-137 & $-0.000224 \mathrm{p}$ & $\mathrm{pCi} / \mathrm{L}$ & 0.0019 & 0.0019 & $u$ & & \\
\hline SESPMNT & B17P42 & PRIEST RAPIDS-RIVER & OFFSITE & sw & $Y$ & RIVER & FILTER & 08-Jan-04 & Cs-137 & $-0.000348 \mathrm{p}$ & $\mathrm{pCi} / \mathrm{L}$ & 0.00063 & 0.00063 & $u$ & & \\
\hline SESPMNT & B17P48 & PRIEST RAPIDS-RIVER & OFFSITE & sw & $\mathrm{Y}$ & RIVER & RESIN & 08-Jan-04 C & Cs-137 & $-0.000158 \mathrm{p}$ & $\mathrm{pCi} / \mathrm{L}$ & 0.0015 & 0.0015 & u & & \\
\hline SESPMNT & B16892 & RICH.PMPHS HRM 46.4 & OFFSITE & sw & $\mathrm{Y}$ & RIVER & FILTER & $05-\mathrm{Feb}-03 \mathrm{C}$ & Cs-137 & $0.000835 \mathrm{p}$ & $\mathrm{pCi} / \mathrm{L}$ & 0.00074 & 0.00074 & u & & \\
\hline SESPMNT & B16886 & RICH.PMPHS HRM 46.4 & OFFSITE & sw & $\mathrm{Y}$ & RIVER & RESIN & $05-\mathrm{Feb}-03 \mathrm{C}$ & Cs-137 & $0.000368 p$ & $\mathrm{pCi} / \mathrm{L}$ & 0.0014 & 0.0014 & u & & \\
\hline SESPMNT & B16893 & RICH.PMPHS HRM 46.4 & OFFSITE & sw & $\mathrm{Y}$ & RIVER & FILTER & $05-\mathrm{Mar}-03$ & Cs-137 & $0.000969 p$ & $\mathrm{pCi} / \mathrm{L}$ & 0.00083 & 0.00083 & u & & \\
\hline SESPMNT & B16887 & RICH.PMPHS HRM 46.4 & OFFSITE & sw & $\mathrm{Y}$ & RIVER & RESIN & $05-\mathrm{Mar}-03 \mathrm{C}$ & Cs-137 & $0.000982 p$ & $\mathrm{pCi} / \mathrm{L}$ & 0.002 & 0.002 & u & & \\
\hline SESPMNT & B16894 & RICH.PMPHS HRM 46.4 & OFFSITE & sw & $\mathrm{Y}$ & RIVER & FILTER & 02-Apr-03 C & Cs-137 & $0.000366 p$ & $\mathrm{pCi} / \mathrm{L}$ & 0.0007 & 0.0007 & u & & \\
\hline SESPMNT & B16888 & RICH.PMPHS HRM 46.4 & OFFSITE & sw & $Y$ & RIVER & RESIN & 02-Apr- & Cs -137 & $0.000362 \mathrm{p}-2-2$ & $\mathrm{pC}$ Cill & 0.0018 & 0.0018 & $u$ & & \\
\hline
\end{tabular}


WATER - COLUMBIA RIVER FILTER/RESIN

\begin{tabular}{|c|c|c|c|c|c|c|c|c|c|c|c|c|c|c|c|c|}
\hline OWNER ID & SAMP NUM & SAMP SITE NAME & DIST CLASS & $\mid$ MEDIA $\mid$ & $\begin{array}{c}\mid \text { FILTERED } \\
\text { FLAG }\end{array}$ & SAMP FROM & COLL MTHD & SAMP DATE & $\left|\begin{array}{c}\text { CON SHORT } \\
\text { NAME }\end{array}\right|$ & VALUE RPTD $\mid$ & $\mid$\begin{tabular}{|c|} 
ANAL \\
UNITS \\
RPTD
\end{tabular} & $\left|\begin{array}{c}\text { COUNTING } \\
\text { ERROR }\end{array}\right|$ & $\begin{array}{c}\text { TOTAL ANAL } \\
\text { ERROR }\end{array}$ & $\mid \begin{array}{c}\text { LAB } \\
\text { QUALIFIER }\end{array}$ & SAMP COMMENT & |RESULT COMMENT \\
\hline SESPMNT & B16PM3 & RICH.PMPHS HRM 46.4 & OFFSITE & sw & Y & RIVER & FILTER & 30-Apr-03 & Cs-137 & 0.000686 & $\mathrm{pCi} / \mathrm{L}$ & 0.00098 & 0.00098 & u & & \\
\hline SESPMNT & B16PL7 & RICH.PMPHS HRM 46.4 & OFFSITE & sW & $\mathrm{Y}$ & RIVER & RESIN & 30-Apr-03 C & Cs-137 & -0.000479 & $\mathrm{pCi} / \mathrm{L}$ & 0.0016 & 0.0016 & $u$ & & \\
\hline SESPMNT & B16PM4 & RICH.PMPHS HRM 46.4 & OFFSITE & sw & $\mathrm{Y}$ & RIVER & FILTER & 28-May-03 & Cs-137 & 0.000559 & $\mathrm{pCi} / \mathrm{L}$ & 0.001 & 0.001 & $u$ & & \\
\hline SESPMNT & B16PL8 & RICH.PMPHS HRM 46.4 & OFFSITE & sW & $\mathrm{Y}$ & RIVER & RESIN & 28-May-03 C & Cs-137 & 0.00119 & $\mathrm{pCi} / \mathrm{L}$ & 0.0018 & 0.0018 & u & & \\
\hline SESPMNT & B16PM5 & RICH.PMPHS HRM 46.4 & OFFSITE & sW & $\mathrm{Y}$ & RIVER & FILTER & 10-Jul-03 C & Cs-137 & 0.000526 & $\mathrm{pCi} / \mathrm{L}$ & 0.00075 & 0.00075 & u & & \\
\hline SESPMNT & B16PL9 & RICH.PMPHS HRM 46.4 & OFFSITE & sW & $\mathrm{Y}$ & RIVER & RESIN & 10-Jul-03 C & Cs-137 & 0.0018 & $\mathrm{pCi} / \mathrm{L}$ & 0.0021 & 0.0021 & $u$ & & \\
\hline SESPMNT & B175K3 & RICH.PMPHS HRM 46.4 & OFFSITE & sw & $\mathrm{Y}$ & RIVER & FILTER & 08-Aug-03 C & Cs-137 & -0.000297 & $\mathrm{pCi} / \mathrm{L}$ & 0.00098 & 0.00098 & $u$ & & \\
\hline SESPMNT & B175J7 & RICH.PMPHS HRM 46.4 & OFFSITE & sW & $\mathrm{Y}$ & RIVER & RESIN & 08-Aug-03 C & Cs-137 & 0.000662 & $\mathrm{pCi} / \mathrm{L}$ & 0.0019 & 0.0019 & u & & \\
\hline SESPMNT & B175K4 & RICH.PMPHS HRM 46.4 & OFFSITE & sW & $\mathrm{Y}$ & RIVER & FILTER & $03-\mathrm{Sep}-03 \mathrm{C}$ & Cs-137 & 0.00123 & $\mathrm{pCi} / \mathrm{L}$ & 0.0017 & 0.0017 & u & & \\
\hline SESPMNT & B175J8 & RICH.PMPHS HRM 46.4 & OFFSITE & sw & $\mathrm{Y}$ & RIVER & RESIN & 03-Sep-03 & Cs-137 & 0.00233 & pCill & 0.0023 & 0.0023 & u & & \\
\hline SESPMNT & B175K5 & RICH.PMPHS HRM 46.4 & OFFSITE & sw & $\mathrm{Y}$ & RIVER & FILTER & 30-Sep-03 & Cs-137 & 0.000393 & $\mathrm{pCi} / \mathrm{L}$ & 0.0018 & 0.0018 & $u$ & & \\
\hline SESPMNT & B175J9 & RICH.PMPHS HRM 46.4 & OFFSITE & sW & $\mathrm{Y}$ & RIVER & RESIN & 30-Sep-03 C & Cs-137 & 0.000565 & $\mathrm{pCi} / \mathrm{L}$ & 0.0036 & 0.0036 & $u$ & & \\
\hline SESPMNT & B17P58 & RICH.PMPHS HRM 46.4 & OFFSITE & sw & $\mathrm{Y}$ & RIVER & FILTER & 29-Oct-03 & Cs-137 & 0.000516 & $\mathrm{pCi/L}$ & 0.00098 & 0.00098 & u & & \\
\hline SESPMNT & B17P52 & RICH.PMPHS HRM 46.4 & OFFSITE & sw & $\mathrm{Y}$ & RIVER & RESIN & $29-0 c t-03$ & Cs-137 & 0.0023 & $\mathrm{pCi} / \mathrm{L}$ & 0.0017 & 0.0017 & $u$ & & \\
\hline SESPMNT & B17P59 & RICH.PMPHS HRM 46.4 & OFFSITE & sW & $\mathrm{Y}$ & RIVER & FILTER & 25-Nov-03 & Cs-137 & 0.00139 & $\mathrm{pCi} / \mathrm{L}$ & 0.0012 & 0.0012 & u & & \\
\hline SESPMNT & B17P53 & RICH.PMPHS HRM 46.4 & OFFSITE & sW & $\mathrm{Y}$ & RIVER & RESIN & 25-Nov-03 & Cs-137 & 0.000479 & $\mathrm{pCi} / \mathrm{L}$ & 0.0018 & 0.0018 & u & & \\
\hline SESPMNT & B17P60 & RICH.PMPHS HRM 46.4 & OFFSITE & sw & $\mathrm{Y}$ & RIVER & FILTER & $08-J a n-04$ & Cs-137 & 0.0000944 & $\mathrm{pCi/L}$ & 0.00048 & 0.00048 & u & & \\
\hline SESPMNT & B17P54 & RICH.PMPHS HRM 46.4 & OFFSITE & sW & $\mathrm{Y}$ & RIVER & RESIN & 08-Jan-04 & Cs-137 & -0.000496 & $\mathrm{pCi} / \mathrm{L}$ & 0.0015 & 0.0015 & u & & \\
\hline SESPMNT & B16874 & PRIEST RAPIDS-RIVER & OFFSITE & sW & $\mathrm{Y}$ & RIVER & FILTER & $05-\mathrm{Feb}-03$ & Eu-152 & -0.0000702 & $\mathrm{pCi} / \mathrm{L}$ & 0.0017 & 0.0017 & u & & \\
\hline SESPMNT & B16880 & PRIEST RAPIDS-RIVER & OFFSITE & sW & $\mathrm{Y}$ & RIVER & RESIN & $05-\mathrm{Feb}-03$ & Eu-152 & -0.00237 & $\mathrm{pC}$ Ci/L & 0.0041 & 0.0041 & u & & \\
\hline SESPMNT & B16875 & PRIEST RAPIDS-RIVER & OFFSITE & sW & $\mathrm{Y}$ & RIVER & FILTER & 05-Mar-03 & Eu-152 & -0.0000343 & $\mathrm{pCi} / \mathrm{L}$ & 0.0018 & 0.0018 & $\mathrm{U}$ & & \\
\hline SESPMNT & B16881 & PRIEST RAPIDS-RIVER & OFFSITE & sW & $\mathrm{Y}$ & RIVER & RESIN & $05-M a r-03$ & Eu-152 & 0.00272 & $\mathrm{pCi} / \mathrm{L}$ & 0.0039 & 0.0039 & u & & \\
\hline SESPMNT & B16876 & PRIEST RAPIDS-RIVER & OFFSITE & sW & $\mathrm{Y}$ & RIVER & FILTER & 02-Apr-03 & Eu-152 & 0.000141 & $\mathrm{pCi/L}$ & 0.0016 & 0.0016 & u & & \\
\hline SESPMNT & B16882 & PRIEST RAPIDS-RIVER & OFFSITE & sW & $\mathrm{Y}$ & RIVER & RESIN & 02-Apr-03 & Eu-152 & -0.00581 & pCill & 0.0053 & 0.0053 & $u$ & & \\
\hline SESPMNT & B16PK5 & PRIEST RAPIDS-RIVER & OFFSITE & sW & $\mathrm{Y}$ & RIVER & FILTER & 30-Apr-03 & Eu-152 & 0.000221 & $\mathrm{pCi} / \mathrm{L}$ & 0.0033 & 0.0033 & $\mathrm{U}$ & & \\
\hline SESPMNT & B16PL1 & PRIEST RAPIDS-RIVER & OFFSITE & sw & $\mathrm{Y}$ & RIVER & RESIN & 30-Apr-03 & Eu-152 & -0.00347 & $\mathrm{pCi} / \mathrm{L}$ & 0.0047 & 0.0047 & $u$ & & \\
\hline SESPMNT & B16PK6 & PRIEST RAPIDS-RIVER & OFFSITE & sw & $\mathrm{Y}$ & RIVER & FILTER & 28-May-03 & Eu-152 & -0.000052 & $\mathrm{pCi} / \mathrm{L}$ & 0.0026 & 0.0026 & u & & \\
\hline SESPMNT & B16PL2 & PRIEST RAPIDS-RIVER & OFFSITE & sw & $\mathrm{Y}$ & RIVER & RESIN & 28-May-03 & Eu-152 & 0.000435 & $\mathrm{pCi} / \mathrm{L}$ & 0.0035 & 0.0035 & $u$ & & \\
\hline SESPMNT & B16PK7 & PRIEST RAPIDS-RIVER & OFFSITE & sw & $\mathrm{Y}$ & RIVER & FILTER & 10-Jul-03 & Eu-152 & -0.0013 & $\mathrm{pCi} / \mathrm{L}$ & 0.002 & 0.002 & $u$ & & \\
\hline SESPMNT & B16PL3 & PRIEST RAPIDS-RIVER & OFFSITE & sw & $\mathrm{Y}$ & RIVER & RESIN & 10-Jul-03 & Eu-152 & -0.00308 & $\mathrm{pCi} / \mathrm{L}$ & 0.0047 & 0.0047 & $u$ & & \\
\hline SESPMNT & B175H5 & PRIEST RAPIDS-RIVER & OFFSITE & sw & $\mathrm{Y}$ & RIVER & FILTER & 08-Aug-03 E & Eu-152 & 0.000849 & $\mathrm{pCi/L}$ & 0.0025 & 0.0025 & u & & \\
\hline SESPMNT & B175J1 & PRIEST RAPIDS-RIVER & OFFSITE & sw & $\mathrm{Y}$ & RIVER & RESIN & 08-Aug-03 & Eu-152 & 0.00109 & $\mathrm{pCi} / \mathrm{L}$ & 0.0042 & 0.0042 & $u$ & & \\
\hline SESPMNT & B175H6 & PRIEST RAPIDS-RIVER & OFFSITE & sw & $\mathrm{Y}$ & RIVER & FILTER & 03-Sep-03 & Eu-152 & -0.00216 & $\mathrm{pCi} / \mathrm{L}$ & 0.0025 & 0.0025 & $u$ & & \\
\hline SESPMNT & B175J2 & PRIEST RAPIDS-RIVER & OFFSITE & sw & $\mathrm{Y}$ & RIVER & RESIN & 03-Sep-03 & Eu-152 & 0.000755 & $\mathrm{pCi} / \mathrm{L}$ & 0.0059 & 0.0059 & u & & \\
\hline SESPMNT & B175H7 & PRIEST RAPIDS-RIVER & OFFSITE & sw & $\mathrm{Y}$ & RIVER & FILTER & 30-Sep-03 & Eu-152 & 0.00167 & $\mathrm{pCi/L}$ & 0.0026 & 0.0026 & u & & \\
\hline SESPMNT & B175J3 & PRIEST RAPIDS-RIVER & OFFSITE & sw & $\mathrm{Y}$ & RIVER & RESIN & 30-Sep-03 & Eu-152 & -0.000411 & $\mathrm{pCi} / \mathrm{L}$ & 0.0052 & 0.0052 & $u$ & & \\
\hline SESPMNT & B17P40 & PRIEST RAPIDS-RIVER & OFFSITE & sw & $\mathrm{Y}$ & RIVER & FILTER & 29-Oct-03 & Eu-152 & 0.00206 & $\mathrm{pCi} / \mathrm{L}$ & 0.0024 & 0.0024 & $u$ & & \\
\hline SESPMNT & B17P46 & PRIEST RAPIDS-RIVER & OFFSITE & sw & $\mathrm{Y}$ & RIVER & RESIN & $29-0 c t-03$ & Eu-152 & 0.000385 & $\mathrm{pCi} / \mathrm{L}$ & 0.0042 & 0.0042 & $u$ & & \\
\hline SESPMNT & B17P41 & PRIEST RAPIDS-RIVER & OFFSITE & sw & $\mathrm{Y}$ & RIVER & FILTER & 25-Nov-03 & Eu-152 & -0.000669 & $\mathrm{pCi} / \mathrm{L}$ & 0.0027 & 0.0027 & $u$ & & \\
\hline SESPMNT & B17P47 & PRIEST RAPIDS-RIVER & OFFSITE & sw & $\mathrm{Y}$ & RIVER & RESIN & 25-Nov-03 & Eu-152 & -0.00179 & $\mathrm{pCi} / \mathrm{L}$ & 0.0045 & 0.0045 & $u$ & & \\
\hline SESPMNT & B17P42 & PRIEST RAPIDS-RIVER & OFFSITE & sw & $\mathrm{Y}$ & RIVER & FILTER & 08-Jan-04 & Eu-152 & -0.00114 & $\mathrm{pCi} / \mathrm{L}$ & 0.0015 & 0.0015 & $u$ & & \\
\hline SESPMNT & B17P48 & PRIEST RAPIDS-RIVER & OFFSITE & sw & $\mathrm{Y}$ & RIVER & RESIN & 08-Jan-04 & Eu-152 & -0.00136 & $\mathrm{pCi} / \mathrm{L}$ & 0.0039 & 0.0039 & $u$ & & \\
\hline SESPMNT & B16892 & RICH.PMPHS HRM 46.4 & OFFSITE & sw & $\mathrm{Y}$ & RIVER & FILTER & 05-Feb-03 & Eu-152 & -0.000152 & $\mathrm{pCi} / \mathrm{L}$ & 0.0018 & 0.0018 & $u$ & & \\
\hline SESPMNT & B16886 & RICH.PMPHS HRM 46.4 & OFFSITE & sw & $\mathrm{Y}$ & RIVER & RESIN & $05-\mathrm{Feb}-03$ & Eu-152 & -0.00223 & $\mathrm{pCi} / \mathrm{L}$ & 0.0035 & 0.0035 & $u$ & & \\
\hline SESPMNT & B16893 & RICH.PMPHS HRM 46.4 & OFFSITE & sw & $\mathrm{Y}$ & RIVER & FILTER & 05-Mar-03 & Eu-152 & -0.00201 & $\mathrm{pCi} / \mathrm{L}$ & 0.0021 & 0.0021 & $u$ & & \\
\hline SESPMNT & B16887 & RICH.PMPHS HRM 46.4 & OFFSITE & sw & $\mathrm{Y}$ & RIVER & RESIN & $05-\mathrm{Mar}-03$ & Eu-152 & 0.000153 & $\mathrm{pCi} / \mathrm{L}$ & 0.0051 & 0.0051 & $u$ & & \\
\hline SESPMNT & B16894 & RICH.PMPHS HRM 46.4 & OFFSITE & sw & $Y$ & RIVER & FILTER & 02-Apr-03 & Eu-152 & 0.000607 & $\mathrm{pCi} / \mathrm{L}$ & 0.0018 & 0.0018 & $u$ & & \\
\hline SESPMNT & B16888 & RICH.PMPHS HRM 46.4 & OFFSITE & sw & $\mathrm{Y}$ & RIVER & RESIN & 02-Apr-03 & Eu-152 & -0.00247 & $\mathrm{pCi} / \mathrm{L}$ & 0.0045 & 0.0045 & $u$ & & \\
\hline SESPMNT & B16PM3 & RICH.PMPHS HRM 46.4 & OFFSITE & sw & $\mathrm{Y}$ & RIVER & FILTER & 30-Apr-03 & Eu-152 & -0.000167 & $\mathrm{pCi} / \mathrm{L}$ & 0.0025 & 0.0025 & $u$ & & \\
\hline SESPMNT & B16PL7 & RICH.PMPHS HRM 46.4 & OFFSITE & sw & $\mathrm{Y}$ & RIVER & RESIN & 30-Apr-03 & Eu-152 & 0.00191 & $\mathrm{pCi} / \mathrm{L}$ & 0.0041 & 0.0041 & $u$ & & \\
\hline SESPMNT & B16PM4 & RICH.PMPHS HRM 46.4 & OFFSITE & sw & $Y$ & RIVER & FILTER & 28-May-03 & Eu-152 & 0.00138 & $\mathrm{pCi} / \mathrm{L}$ & 0.0026 & 0.0026 & $u$ & & \\
\hline SESPMNT & B16PL8 & RICH.PMPHS HRM 46.4 & OFFSITE & sw & $\mathrm{Y}$ & RIVER & RESIN & 28-May-03 & Eu-152 & -0.00151 & $\mathrm{pCi} / \mathrm{L}$ & 0.0042 & 0.0042 & $u$ & & \\
\hline SESPMNT & B16PM5 & RICH.PMPHS HRM 46.4 & OFFSITE & sw & $\mathrm{Y}$ & RIVER & FILTER & 10-Jul-03 & Eu-152 & 0.0017 & $\mathrm{pCi} / \mathrm{L}$ & 0.0019 & 0.0019 & u & & \\
\hline SESPMNT & B16PL9 & RICH.PMPHS HRM 46.4 & OFFSITE & sw & $\mathrm{Y}$ & RIVER & RESIN & 10-Jul-03 & Eu-152 & 0.00428 & $\mathrm{pCi} / \mathrm{L}$ & 0.0047 & 0.0047 & $u$ & & \\
\hline SESPMNT & B175K3 & RICH.PMPHS HRM 46.4 & OFFSITE & sw & $\mathrm{Y}$ & RIVER & FILTER & 08-Aug-03 & Eu-152 & 0.00155 & $\mathrm{pCi} / \mathrm{L}$ & 0.0024 & 0.0024 & u & & \\
\hline SESPMNT & B175J7 & RICH.PMPHS HRM 46.4 & OFFSITE & sw & $\mathrm{Y}$ & RIVER & RESIN & 08-Aug-03 E & Eu-152 & 0.000216 & $\mathrm{pCi} / \mathrm{L}$ & 0.0048 & 0.0048 & U & & \\
\hline SESPMNT & B175K4 & RICH.PMPHS HRM 46.4 & OFFSITE & sw & $\mathrm{Y}$ & RIVER & FILTER & 03-Sep-03 & Eu-152 & 0.00417 & $\mathrm{pCi} / \mathrm{L}$ & 0.0043 & 0.0043 & u & & \\
\hline SESPMNT & B175J8 & RICH.PMPHS HRM 46.4 & OFFSITE & sW & $\mathrm{Y}$ & RIVER & RESIN & 03-Sep-03 & Eu-152 & -0.000743 & $\mathrm{pCi} / \mathrm{L}$ & 0.0051 & 0.0051 & u & & \\
\hline
\end{tabular}


WATER - COLUMBIA RIVER FILTER/RESIN

\begin{tabular}{|c|c|c|c|c|c|c|c|c|c|c|c|c|c|c|c|c|}
\hline OWNER ID & SAMP NUM & SAMP SITE NAME & DIST CLASS & $\mid$ MEDIA $\mid$ & $\begin{array}{c}\mid \text { FILTERED } \\
\text { FLAG }\end{array}$ & SAMP FROM & COLL MTHD & SAMP DATE & $\left|\begin{array}{c}\text { CON SHORT } \\
\text { NAME }\end{array}\right|$ & VALUE RPTD & $\mid \begin{array}{l}\text { ANAL } \\
\text { UNITS } \\
\text { RPTD }\end{array}$ & $\left|\begin{array}{c}\text { COUNTING } \\
\text { ERROR }\end{array}\right|$ & $\begin{array}{c}\text { TOTAL ANAL } \\
\text { ERROR }\end{array}$ & $\mid \begin{array}{c}\text { LAB } \\
\text { QUALIFIER }\end{array}$ & SAMP COMMENT & |RESULT COMMENT \\
\hline SESPMNT & B175K5 & RICH.PMPHS HRM 46.4 & OFFSITE & sw & Y & RIVER & FILTER & 30-Sep-03 & Eu-152 & $-0.00325 p$ & $\mathrm{pCi} / \mathrm{L}$ & 0.0043 & 0.0043 & U & & \\
\hline SESPMNT & B175J9 & RICH.PMPHS HRM 46.4 & OFFSITE & sW & $\mathrm{Y}$ & RIVER & RESIN & 30-Sep-03 & Eu-152 & $-0.00212 p$ & $\mathrm{pCi} / \mathrm{L}$ & 0.0095 & 0.0095 & $u$ & & \\
\hline SESPMNT & B17P58 & RICH.PMPHS HRM 46.4 & OFFSITE & sw & $\mathrm{Y}$ & RIVER & FILTER & 29-Oct-03 & Eu-152 & $-0.00106 p$ & $\mathrm{pCi} / \mathrm{L}$ & 0.0023 & 0.0023 & $u$ & & \\
\hline SESPMNT & B17P52 & RICH.PMPHS HRM 46.4 & OFFSITE & sW & $\mathrm{Y}$ & RIVER & RESIN & 29-Oct-03 & Eu-152 & $-0.00177 p$ & $\mathrm{pCi} / \mathrm{L}$ & 0.0041 & 0.0041 & $u$ & & \\
\hline SESPMNT & B17P59 & RICH.PMPHS HRM 46.4 & OFFSITE & sW & $\mathrm{Y}$ & RIVER & FILTER & $25-$ Nov- 03 & Eu-152 & $0.000288 \mathrm{p}$ & $\mathrm{pCi} / \mathrm{L}$ & 0.0027 & 0.0027 & $u$ & & \\
\hline SESPMNT & B17P53 & RICH.PMPHS HRM 46.4 & OFFSITE & sW & $\mathrm{Y}$ & RIVER & RESIN & 25-Nov-03 & Eu-152 & $-0.00297 p$ & $\mathrm{pCi} / \mathrm{L}$ & 0.0047 & 0.0047 & $u$ & & \\
\hline SESPMNT & B17P60 & RICH.PMPHS HRM 46.4 & OFFSITE & sw & $\mathrm{Y}$ & RIVER & FILTER & 08-Jan-04 & Eu-152 & $0.00034 \mathrm{p}$ & $\mathrm{pCi} / \mathrm{L}$ & 0.0013 & 0.0013 & $u$ & & \\
\hline SESPMNT & B17P54 & RICH.PMPHS HRM 46.4 & OFFSITE & sW & $\mathrm{Y}$ & RIVER & RESIN & 08-Jan-04 & Eu-152 & $-0.00231 \mathrm{p}$ & $\mathrm{pCi} / \mathrm{L}$ & 0.004 & 0.004 & $u$ & & \\
\hline SESPMNT & B16874 & PRIEST RAPIDS-RIVER & OFFSITE & sW & $\mathrm{Y}$ & RIVER & FILTER & $05-\mathrm{Feb}-03$ & Eu-154 & $0.00185 \mathrm{p}$ & $\mathrm{pCi} / \mathrm{L}$ & 0.0018 & 0.0018 & u & & \\
\hline SESPMNT & B16880 & PRIEST RAPIDS-RIVER & OFFSITE & sw & $\mathrm{Y}$ & RIVER & RESIN & $05-F e b-03$ & Eu-154 & $-0.00102 p$ & $\mathrm{pCi} / \mathrm{L}$ & 0.0053 & 0.0053 & u & & \\
\hline SESPMNT & B16875 & PRIEST RAPIDS-RIVER & OFFSITE & sw & $\mathrm{Y}$ & RIVER & FILTER & 05-Mar-03 & Eu-154 & $0.000218 p$ & $\mathrm{pCi} / \mathrm{L}$ & 0.0021 & 0.0021 & u & & \\
\hline SESPMNT & B16881 & PRIEST RAPIDS-RIVER & OFFSITE & sW & $\mathrm{Y}$ & RIVER & RESIN & 05-Mar-03 & Eu-154 & $-0.000182 \mathrm{p}$ & $\mathrm{pCi} / \mathrm{L}$ & 0.0044 & 0.0044 & u & & \\
\hline SESPMNT & B16876 & PRIEST RAPIDS-RIVER & OFFSITE & sw & $\mathrm{Y}$ & RIVER & FILTER & 02-Apr-03 & Eu-154 & $-0.000589 \mathrm{p}$ & $\mathrm{pCi/L}$ & 0.0022 & 0.0022 & u & & \\
\hline SESPMNT & B16882 & PRIEST RAPIDS-RIVER & OFFSITE & sw & $\mathrm{Y}$ & RIVER & RESIN & 02-Apr-03 & Eu-154 & $0.000597 \mathrm{p}$ & $\mathrm{pCi} / \mathrm{L}$ & 0.006 & 0.006 & u & & \\
\hline SESPMNT & B16PK5 & PRIEST RAPIDS-RIVER & OFFSITE & sW & $\mathrm{Y}$ & RIVER & FILTER & 30-Apr-03 & Eu-154 & $-0.00112 p$ & $\mathrm{pCi} / \mathrm{L}$ & 0.0033 & 0.0033 & u & & \\
\hline SESPMNT & B16PL1 & PRIEST RAPIDS-RIVER & OFFSITE & sW & $\mathrm{Y}$ & RIVER & RESIN & 30-Apr-03 & Eu-154 & $0.00211 \mathrm{p}$ & $\mathrm{pCi} / \mathrm{L}$ & 0.005 & 0.005 & u & & \\
\hline SESPMNT & B16PK6 & PRIEST RAPIDS-RIVER & OFFSITE & sw & $\mathrm{Y}$ & RIVER & FILTER & 28-May-03 & Eu-154 & $0.00511 \mathrm{p}$ & $\mathrm{pCi/L}$ & 0.0031 & 0.0031 & u & & \\
\hline SESPMNT & B16PL2 & PRIEST RAPIDS-RIVER & OFFSITE & sW & $\mathrm{Y}$ & RIVER & RESIN & 28-May-03 & Eu-154 & $0.00449 \mathrm{p}$ & $\mathrm{pCi} / \mathrm{L}$ & 0.0041 & 0.0041 & $u$ & & \\
\hline SESPMNT & B16PK7 & PRIEST RAPIDS-RIVER & OFFSITE & sw & $\mathrm{Y}$ & RIVER & FILTER & 10-Jul-03 & Eu-154 & $-0.0022 \mathrm{p}$ & $\mathrm{pCi} / \mathrm{L}$ & 0.0023 & 0.0023 & u & & \\
\hline SESPMNT & B16PL3 & PRIEST RAPIDS-RIVER & OFFSITE & sW & $\mathrm{Y}$ & RIVER & RESIN & 10-Jul-03 & Eu-154 & $0.00291 \mathrm{p}$ & $\mathrm{pC}$ Ci/L & 0.0056 & 0.0056 & $u$ & & \\
\hline SESPMNT & B175H5 & PRIEST RAPIDS-RIVER & OFFSITE & sW & $\mathrm{Y}$ & RIVER & FILTER & 08-Aug-03 & Eu-154 & $0.00106 \mathrm{p}$ & $\mathrm{pCi} / \mathrm{L}$ & 0.003 & 0.003 & $\mathrm{U}$ & & \\
\hline SESPMNT & B175J1 & PRIEST RAPIDS-RIVER & OFFSITE & sW & $\mathrm{Y}$ & RIVER & RESIN & 08-Aug-03 & Eu-154 & $0.000998 \mathrm{p}$ & $\mathrm{pCi} / \mathrm{L}$ & 0.005 & 0.005 & u & & \\
\hline SESPMNT & $\mathrm{B} 175 \mathrm{H} 6$ & PRIEST RAPIDS-RIVER & OFFSITE & sW & $\mathrm{Y}$ & RIVER & FILTER & 03-Sep-03 & Eu-154 & $0.00279 \mathrm{p}$ & $\mathrm{pCi/L}$ & 0.0033 & 0.0033 & u & & \\
\hline SESPMNT & B175J2 & PRIEST RAPIDS-RIVER & OFFSITE & sW & $\mathrm{Y}$ & RIVER & RESIN & 03-Sep-03 & Eu-154 & $-0.00242 p$ & pCill & 0.0079 & 0.0079 & $u$ & & \\
\hline SESPMNT & B175H7 & PRIEST RAPIDS-RIVER & OFFSITE & sW & $\mathrm{Y}$ & RIVER & FILTER & 30-Sep-03 & Eu-154 & $0.00175 \mathrm{p}$ & $\mathrm{pCi} / \mathrm{L}$ & 0.0029 & 0.0029 & $\mathrm{U}$ & & \\
\hline SESPMNT & B175J3 & PRIEST RAPIDS-RIVER & OFFSITE & sw & $\mathrm{Y}$ & RIVER & RESIN & 30-Sep-03 & Eu-154 & $0.00474 \mathrm{p}$ & $\mathrm{pCi} / \mathrm{L}$ & 0.0061 & 0.0061 & $u$ & & \\
\hline SESPMNT & B17P40 & PRIEST RAPIDS-RIVER & OFFSITE & sW & $\mathrm{Y}$ & RIVER & FILTER & 29-Oct-03 & Eu-154 & $-0.0000289 p$ & $\mathrm{pC}$ Ci/L & 0.0029 & 0.0029 & $u$ & & \\
\hline SESPMNT & B17P46 & PRIEST RAPIDS-RIVER & OFFSITE & sw & $\mathrm{Y}$ & RIVER & RESIN & 29-Oct-03 & Eu-154 & $0.00384 \mathrm{p}$ & $\mathrm{pCi} / \mathrm{L}$ & 0.0049 & 0.0049 & $u$ & & \\
\hline SESPMNT & B17P41 & PRIEST RAPIDS-RIVER & OFFSITE & sw & $\mathrm{Y}$ & RIVER & FILTER & $25-$ Nov- 03 & Eu-154 & $0.00184 \mathrm{p}$ & $\mathrm{pCi} / \mathrm{L}$ & 0.0029 & 0.0029 & $u$ & & \\
\hline SESPMNT & B17P47 & PRIEST RAPIDS-RIVER & OFFSITE & sw & $\mathrm{Y}$ & RIVER & RESIN & $25-$ Nov- 03 & Eu-154 & $0.00544 p$ & $\mathrm{pCi} / \mathrm{L}$ & 0.0061 & 0.0061 & $u$ & & \\
\hline SESPMNT & B17P42 & PRIEST RAPIDS-RIVER & OFFSITE & sw & $\mathrm{Y}$ & RIVER & FILTER & 08-Jan-04 & Eu-154 & $0.00166 \mathrm{p}$ & $\mathrm{pCi/L}$ & 0.0018 & 0.0018 & u & & \\
\hline SESPMNT & B17P48 & PRIEST RAPIDS-RIVER & OFFSITE & sw & $\mathrm{Y}$ & RIVER & RESIN & 08-Jan-04 & Eu-154 & $-0.00183 \mathrm{p}$ & $\mathrm{pCi} / \mathrm{L}$ & 0.0046 & 0.0046 & $u$ & & \\
\hline SESPMNT & B16892 & RICH.PMPHS HRM 46.4 & OFFSITE & sw & $\mathrm{Y}$ & RIVER & FILTER & 05-Feb-03 & Eu-154 & $-0.000783 p$ & $\mathrm{pCi} / \mathrm{L}$ & 0.0021 & 0.0021 & u & & \\
\hline SESPMNT & B16886 & RICH.PMPHS HRM 46.4 & OFFSITE & sw & $\mathrm{Y}$ & RIVER & RESIN & $05-F e b-03$ & Eu-154 & $-0.000632 p$ & $\mathrm{pCi} / \mathrm{L}$ & 0.0045 & 0.0045 & $u$ & & \\
\hline SESPMNT & B16893 & RICH.PMPHS HRM 46.4 & OFFSITE & sw & $\mathrm{Y}$ & RIVER & FILTER & 05-Mar-03 & Eu-154 & $-0.000811 \mathrm{p}$ & $\mathrm{pCi/L}$ & 0.0027 & 0.0027 & u & & \\
\hline SESPMNT & B16887 & RICH.PMPHS HRM 46.4 & OFFSITE & sw & $\mathrm{Y}$ & RIVER & RESIN & 05-Mar-03 & Eu-154 & $0.00763 p$ & $\mathrm{pCi} / \mathrm{L}$ & 0.0061 & 0.0061 & $u$ & & \\
\hline SESPMNT & B16894 & RICH.PMPHS HRM 46.4 & OFFSITE & sw & $\mathrm{Y}$ & RIVER & FILTER & 02-Apr-03 & Eu-154 & $-0.000374 p$ & $\mathrm{pCi} / \mathrm{L}$ & 0.002 & 0.002 & u & & \\
\hline SESPMNT & B16888 & RICH.PMPHS HRM 46.4 & OFFSITE & sw & $\mathrm{Y}$ & RIVER & RESIN & 02-Apr-03 & Eu-154 & $-0.00000789 p$ & $\mathrm{pCi} / \mathrm{L}$ & 0.0055 & 0.0055 & $u$ & & \\
\hline SESPMNT & B16PM3 & RICH.PMPHS HRM 46.4 & OFFSITE & sw & $\mathrm{Y}$ & RIVER & FILTER & 30-Apr-03 & Eu-154 & $-0.000404 \mathrm{p}$ & $\mathrm{pCi} / \mathrm{L}$ & 0.0028 & 0.0028 & $u$ & & \\
\hline SESPMNT & B16PL7 & RICH.PMPHS HRM 46.4 & OFFSITE & sw & $\mathrm{Y}$ & RIVER & RESIN & 30-Apr-03 & Eu-154 & $-0.00183 p$ & $\mathrm{pCi} / \mathrm{L}$ & 0.0047 & 0.0047 & $u$ & & \\
\hline SESPMNT & B16PM4 & RICH.PMPHS HRM 46.4 & OFFSITE & sw & $\mathrm{Y}$ & RIVER & FILTER & 28-May-03 & Eu-154 & $0.0000965 \mathrm{p}$ & $\mathrm{pCi} / \mathrm{L}$ & 0.0028 & 0.0028 & $u$ & & \\
\hline SESPMNT & B16PL8 & RICH.PMPHS HRM 46.4 & OFFSITE & sw & $\mathrm{Y}$ & RIVER & RESIN & 28-May-03 & Eu-154 & $0.00204 \mathrm{p}$ & $\mathrm{pCi} / \mathrm{L}$ & 0.0055 & 0.0055 & $u$ & & \\
\hline SESPMNT & B16PM5 & RICH.PMPHS HRM 46.4 & OFFSITE & sw & $\mathrm{Y}$ & RIVER & FILTER & 10-Jul-03 & Eu-154 & $-0.000474 p$ & $\mathrm{pCi} / \mathrm{L}$ & 0.002 & 0.002 & $u$ & & \\
\hline SESPMNT & B16PL9 & RICH.PMPHS HRM 46.4 & OFFSITE & sw & $\mathrm{Y}$ & RIVER & RESIN & 10-Jul-03 & Eu-154 & $0.000161 \mathrm{p}$ & $\mathrm{pCi} / \mathrm{L}$ & 0.0058 & 0.0058 & $u$ & & \\
\hline SESPMNT & B175K3 & RICH.PMPHS HRM 46.4 & OFFSITE & sw & $\mathrm{Y}$ & RIVER & FILTER & 08-Aug-03 & Eu-154 & $-0.000695 p$ & $\mathrm{pCi} / \mathrm{L}$ & 0.0028 & 0.0028 & $u$ & & \\
\hline SESPMNT & B175J7 & RICH.PMPHS HRM 46.4 & OFFSITE & sw & $\mathrm{Y}$ & RIVER & RESIN & 08-Aug-03 & Eu-154 & $0.00514 p$ & $\mathrm{pCi} / \mathrm{L}$ & 0.0064 & 0.0064 & $u$ & & \\
\hline SESPMNT & B175K4 & RICH.PMPHS HRM 46.4 & OFFSITE & sw & $Y$ & RIVER & FILTER & 03-Sep-03 & Eu-154 & $0.00165 p$ & $\mathrm{pCi} / \mathrm{L}$ & 0.0049 & 0.0049 & $u$ & & \\
\hline SESPMNT & B175J8 & RICH.PMPHS HRM 46.4 & OFFSITE & sw & $\mathrm{Y}$ & RIVER & RESIN & 03-Sep-03 & Eu-154 & $-0.00196 p$ & $\mathrm{pCi} / \mathrm{L}$ & 0.0065 & 0.0065 & $u$ & & \\
\hline SESPMNT & B175K5 & RICH.PMPHS HRM 46.4 & OFFSITE & sw & $\mathrm{Y}$ & RIVER & FILTER & 30-Sep-03 & Eu-154 & $-0.00597 p$ & $\mathrm{pCi} / \mathrm{L}$ & 0.0055 & 0.0055 & u & & \\
\hline SESPMNT & B175J9 & RICH.PMPHS HRM 46.4 & OFFSITE & sw & $\mathrm{Y}$ & RIVER & RESIN & 30-Sep-03 & Eu-154 & $0.0104 \mathrm{p}$ & $\mathrm{pCi} / \mathrm{L}$ & 0.011 & 0.011 & $u$ & & \\
\hline SESPMNT & B17P58 & RICH.PMPHS HRM 46.4 & OFFSITE & sw & $Y$ & RIVER & FILTER & 29-Oct-03 & Eu-154 & $-0.00144 p$ & $\mathrm{pCi} / \mathrm{L}$ & 0.0028 & 0.0028 & u & & \\
\hline SESPMNT & B17P52 & RICH.PMPHS HRM 46.4 & OFFSITE & sw & $\mathrm{Y}$ & RIVER & RESIN & $29-O c t-03$ & Eu-154 & $0.000552 p$ & $\mathrm{pCi} / \mathrm{L}$ & 0.0048 & 0.0048 & $u$ & & \\
\hline SESPMNT & B17P59 & RICH.PMPHS HRM 46.4 & OFFSITE & sw & $\mathrm{Y}$ & RIVER & FILTER & 25-Nov-03 & Eu-154 & $0.0021 \mathrm{p}$ & $\mathrm{pCi} / \mathrm{L}$ & 0.0031 & 0.0031 & u & & \\
\hline SESPMNT & B17P53 & RICH.PMPHS HRM 46.4 & OFFSITE & sw & $\mathrm{Y}$ & RIVER & RESIN & 25-Nov-03 & Eu-154 & $0.00238 \mathrm{p}$ & $\mathrm{pCi} / \mathrm{L}$ & 0.0059 & 0.0059 & u & & \\
\hline SESPMNT & B17P60 & RICH.PMPHS HRM 46.4 & OFFSITE & sw & $\mathrm{Y}$ & RIVER & FILTER & 08-Jan-04 & Eu-154 & $0.00108 \mathrm{p}$ & $\mathrm{pCilL}$ & 0.0013 & 0.0013 & $u$ & & \\
\hline SESPMNT & B17P54 & RICH.PMPHS HRM 46.4 & OFFSITE & sw & $\mathrm{Y}$ & RIVER & RESIN & 08-Jan-04 & Eu-154 & $0.000846 \mathrm{p}$ & $\mathrm{pCi} / \mathrm{L}$ & 0.0048 & 0.0048 & u & & \\
\hline SESPMNT & B16874 & PRIEST RAPIDS-RIVER & OFFSITE & sw & $\mathrm{Y}$ & RIVER & FILTER & $05-\mathrm{Feb}-03$ & Eu-155 & $-0.000247 p$ & $\mathrm{pCi} / \mathrm{L}$ & 0.0017 & 0.0017 & u & & \\
\hline SESPMNT & B16880 & PRIEST RAPIDS-RIVER & OFFSITE & sw & $\mathrm{Y}$ & RIVER & RESIN & 05-Feb-03 & Eu-155 & $0.00223 \mathrm{p}$ & $\mathrm{pCi} / \mathrm{L}$ & 0.004 & 0.004 & $\mathrm{U}$ & & \\
\hline
\end{tabular}


WATER - COLUMBIA RIVER FILTER/RESIN

\begin{tabular}{|c|c|c|c|c|c|c|c|c|c|c|c|c|c|c|c|c|}
\hline OWNER ID & SAMP NUM & SAMP SITE NAME & DIST CLASS & $\mid$ MEDIA $\mid$ & $\begin{array}{c}\mid \text { FILTERED } \\
\text { FLAG }\end{array}$ & SAMP FROM & COLL MTHD & SAMP DATE & $\left|\begin{array}{c}\text { CON SHORT } \\
\text { NAME }\end{array}\right|$ & VALUE RPTD & $\mid \begin{array}{l}\text { ANAL } \\
\text { UNITS } \\
\text { RPTD }\end{array}$ & $\left|\begin{array}{c}\text { COUNTING } \\
\text { ERROR }\end{array}\right|$ & $\begin{array}{c}\text { TOTAL ANAL } \\
\text { ERROR }\end{array}$ & $\mid \begin{array}{c}\text { LAB } \\
\text { QUALIFIER }\end{array}$ & SAMP COMMENT & RESULT COMMENT \\
\hline SESPMNT & B16875 & PRIEST RAPIDS-RIVER & OFFSITE & sW & Y & RIVER & FILTER & 05-Mar-03 & Eu-155 & $0.00207 p$ & $\mathrm{pCi} / \mathrm{L}$ & 0.0018 & 0.0018 & U & & \\
\hline SESPMNT & B16881 & PRIEST RAPIDS-RIVER & OFFSITE & sW & $\mathrm{Y}$ & RIVER & RESIN & 05-Mar-03 & Eu-155 & $0.00127 p$ & $\mathrm{pCi} / \mathrm{L}$ & 0.0033 & 0.0033 & $u$ & & \\
\hline SESPMNT & B16876 & PRIEST RAPIDS-RIVER & OFFSITE & sw & $\mathrm{Y}$ & RIVER & FILTER & 02-Apr-03 & Eu-155 & $0.00125 \mathrm{p}$ & $\mathrm{pCi} / \mathrm{L}$ & 0.0015 & 0.0015 & $u$ & & \\
\hline SESPMNT & B16882 & PRIEST RAPIDS-RIVER & OFFSITE & SW & $\mathrm{Y}$ & RIVER & RESIN & 02-Apr-03 & Eu-155 & $0.00501 \mathrm{p}$ & $\mathrm{pCi} / \mathrm{L}$ & 0.0051 & 0.0051 & $u$ & & \\
\hline SESPMNT & B16PK5 & PRIEST RAPIDS-RIVER & OFFSITE & sW & $\mathrm{Y}$ & RIVER & FILTER & 30-Apr-03 & Eu-155 & $-0.00184 p$ & $\mathrm{pCi} / \mathrm{L}$ & 0.0041 & 0.0041 & $u$ & & \\
\hline SESPMNT & B16PL1 & PRIEST RAPIDS-RIVER & OFFSITE & sW & $\mathrm{Y}$ & RIVER & RESIN & 30-Apr-03 & Eu-155 & $-0.000809 p$ & $\mathrm{pCi} / \mathrm{L}$ & 0.0039 & 0.0039 & u & & \\
\hline SESPMNT & B16PK6 & PRIEST RAPIDS-RIVER & OFFSITE & sw & $\mathrm{Y}$ & RIVER & FILTER & 28-May-03 & Eu-155 & $0.00299 \mathrm{p}$ & pCill & 0.0026 & 0.0026 & $u$ & & \\
\hline SESPMNT & B16PL2 & PRIEST RAPIDS-RIVER & OFFSITE & sW & $\mathrm{Y}$ & RIVER & RESIN & 28-May-03 & Eu-155 & $-0.000322 \mathrm{p}$ & $\mathrm{pCi} / \mathrm{L}$ & 0.0032 & 0.0032 & U & & \\
\hline SESPMNT & B16PK7 & PRIEST RAPIDS-RIVER & OFFSITE & sW & $\mathrm{Y}$ & RIVER & FILTER & 10-Jul-03 & Eu-155 & $-0.000232 p$ & $\mathrm{pCi} / \mathrm{L}$ & 0.002 & 0.002 & u & & \\
\hline SESPMNT & B16PL3 & PRIEST RAPIDS-RIVER & OFFSITE & sw & $\mathrm{Y}$ & RIVER & RESIN & 10-Jul-03 & Eu-155 & $0.001 \mathrm{p}$ & pCill & 0.0044 & 0.0044 & u & & \\
\hline SESPMNT & B175H5 & PRIEST RAPIDS-RIVER & OFFSITE & sw & $\mathrm{Y}$ & RIVER & FILTER & 08-Aug-03 & Eu-155 & $0.000393 p$ & $\mathrm{pCi} / \mathrm{L}$ & 0.0023 & 0.0023 & $u$ & & \\
\hline SESPMNT & B175J1 & PRIEST RAPIDS-RIVER & OFFSITE & sW & $\mathrm{Y}$ & RIVER & RESIN & 08-Aug-03 & Eu-155 & $0.00543 \mathrm{p}$ & $\mathrm{pCi} / \mathrm{L}$ & 0.0045 & 0.0045 & U & & \\
\hline SESPMNT & B175H6 & PRIEST RAPIDS-RIVER & OFFSITE & sw & $\mathrm{Y}$ & RIVER & FILTER & 03-Sep-03 & Eu-155 & $-0.00129 p$ & $\mathrm{pCi/L}$ & 0.0023 & 0.0023 & $\mathrm{u}$ & & \\
\hline SESPMNT & B175J2 & PRIEST RAPIDS-RIVER & OFFSITE & sW & $\mathrm{Y}$ & RIVER & RESIN & 03-Sep-03 & Eu-155 & $0.00356 \mathrm{p}$ & pCi/L & 0.0054 & 0.0054 & $u$ & & \\
\hline SESPMNT & B175H7 & PRIEST RAPIDS-RIVER & OFFSITE & sW & $\mathrm{Y}$ & RIVER & FILTER & 30-Sep-03 & Eu-155 & $0.00147 p$ & $\mathrm{pCi} / \mathrm{L}$ & 0.0022 & 0.0022 & u & & \\
\hline SESPMNT & B175J3 & PRIEST RAPIDS-RIVER & OFFSITE & sW & $\mathrm{Y}$ & RIVER & RESIN & 30-Sep-03 & Eu-155 & $0.00427 \mathrm{p}$ & $\mathrm{pCi} / \mathrm{L}$ & 0.0048 & 0.0048 & $u$ & & \\
\hline SESPMNT & B17P40 & PRIEST RAPIDS-RIVER & OFFSITE & sw & $\mathrm{Y}$ & RIVER & FILTER & 29-Oct-03 & Eu-155 & $0.000863 \mathrm{p}$ & $\mathrm{pCi/L}$ & 0.0025 & 0.0025 & u & & \\
\hline SESPMNT & B17P46 & PRIEST RAPIDS-RIVER & OFFSITE & sW & $\mathrm{Y}$ & RIVER & RESIN & 29-Oct-03 & Eu-155 & $0.00397 \mathrm{p}$ & $\mathrm{pCi} / \mathrm{L}$ & 0.0039 & 0.0039 & $u$ & & \\
\hline SESPMNT & B17P41 & PRIEST RAPIDS-RIVER & OFFSITE & sw & $\mathrm{Y}$ & RIVER & FILTER & 25 -Nov-03 & Eu-155 & $0.00074 \mathrm{p}$ & $\mathrm{pCi} / \mathrm{L}$ & 0.0022 & 0.0022 & u & & \\
\hline SESPMNT & B17P47 & PRIEST RAPIDS-RIVER & OFFSITE & sW & $\mathrm{Y}$ & RIVER & RESIN & 25-Nov-03 & Eu-155 & $0.00138 \mathrm{p}$ & pCi/L & 0.0046 & 0.0046 & $u$ & & \\
\hline SESPMNT & B17P42 & PRIEST RAPIDS-RIVER & OFFSITE & sW & $\mathrm{Y}$ & RIVER & FILTER & 08-Jan-04 & Eu-155 & $-0.000955 p$ & $\mathrm{pCi} / \mathrm{L}$ & 0.0015 & 0.0015 & $\mathrm{U}$ & & \\
\hline SESPMNT & B17P48 & PRIEST RAPIDS-RIVER & OFFSITE & sW & $\mathrm{Y}$ & RIVER & RESIN & 08-Jan-04 & Eu-155 & $0.000187 \mathrm{p}$ & $\mathrm{pCi} / \mathrm{L}$ & 0.0042 & 0.0042 & $u$ & & \\
\hline SESPMNT & B16892 & RICH.PMPHS HRM 46.4 & OFFSITE & sW & $\mathrm{Y}$ & RIVER & FILTER & 05-Feb-03 & Eu-155 & $-0.000945 \mathrm{p}$ & $\mathrm{pCi/L}$ & 0.0016 & 0.0016 & u & & \\
\hline SESPMNT & B16886 & RICH.PMPHS HRM 46.4 & OFFSITE & sW & $\mathrm{Y}$ & RIVER & RESIN & $05-$ Feb-03 & Eu-155 & $0.00127 \mathrm{p}$ & pCill & 0.0033 & 0.0033 & $u$ & & \\
\hline SESPMNT & B16893 & RICH.PMPHS HRM 46.4 & OFFSITE & sW & $\mathrm{Y}$ & RIVER & FILTER & 05-Mar-03 & Eu-155 & $-0.00101 \mathrm{p}$ & $\mathrm{pCi} / \mathrm{L}$ & 0.0019 & 0.0019 & $\mathrm{U}$ & & \\
\hline SESPMNT & B16887 & RICH.PMPHS HRM 46.4 & OFFSITE & sw & $\mathrm{Y}$ & RIVER & RESIN & 05-Mar-03 & Eu-155 & $0.00409 p$ & $\mathrm{pCi} / \mathrm{L}$ & 0.0048 & 0.0048 & $u$ & & \\
\hline SESPMNT & B16894 & RICH.PMPHS HRM 46.4 & OFFSITE & sW & $\mathrm{Y}$ & RIVER & FILTER & 02-Apr-03 & Eu-155 & $-0.000329 \mathrm{p}$ & $\mathrm{pC}$ Ci/L & 0.0018 & 0.0018 & $u$ & & \\
\hline SESPMNT & B16888 & RICH.PMPHS HRM 46.4 & OFFSITE & sw & $\mathrm{Y}$ & RIVER & RESIN & 02-Apr-03 & Eu-155 & $0.00282 \mathrm{p}$ & $\mathrm{pCi} / \mathrm{L}$ & 0.0041 & 0.0041 & $u$ & & \\
\hline SESPMNT & B16PM3 & RICH.PMPHS HRM 46.4 & OFFSITE & sw & $\mathrm{Y}$ & RIVER & FILTER & 30-Apr-03 & Eu-155 & $-0.000109 p$ & $\mathrm{pCi} / \mathrm{L}$ & 0.0022 & 0.0022 & $u$ & & \\
\hline SESPMNT & B16PL7 & RICH.PMPHS HRM 46.4 & OFFSITE & sw & $\mathrm{Y}$ & RIVER & RESIN & 30-Apr-03 & Eu-155 & $0.00114 p$ & $\mathrm{pCi} / \mathrm{L}$ & 0.0037 & 0.0037 & $u$ & & \\
\hline SESPMNT & B16PM4 & RICH.PMPHS HRM 46.4 & OFFSITE & sw & $\mathrm{Y}$ & RIVER & FILTER & $28-$ May-03 & Eu-155 & $0.000178 p$ & $\mathrm{pCi/L}$ & 0.0022 & 0.0022 & u & & \\
\hline SESPMNT & B16PL8 & RICH.PMPHS HRM 46.4 & OFFSITE & sw & $\mathrm{Y}$ & RIVER & RESIN & 28-May-03 & Eu-155 & $0.00423 \mathrm{p}$ & $\mathrm{pCi} / \mathrm{L}$ & 0.0042 & 0.0042 & $u$ & & \\
\hline SESPMNT & B16PM5 & RICH.PMPHS HRM 46.4 & OFFSITE & sW & $\mathrm{Y}$ & RIVER & FILTER & 10-Jul-03 & Eu-155 & $0.000804 p$ & $\mathrm{pCi} / \mathrm{L}$ & 0.0017 & 0.0017 & U & & \\
\hline SESPMNT & B16PL9 & RICH.PMPHS HRM 46.4 & OFFSITE & sw & $\mathrm{Y}$ & RIVER & RESIN & 10-Jul-03 & Eu-155 & $-0.00173 p$ & $\mathrm{pCi} / \mathrm{L}$ & 0.0053 & 0.0053 & $u$ & & \\
\hline SESPMNT & B175K3 & RICH.PMPHS HRM 46.4 & OFFSITE & sw & $\mathrm{Y}$ & RIVER & FILTER & 08-Aug-03 & Eu-155 & $-0.00114 p$ & $\mathrm{pCi/L}$ & 0.0025 & 0.0025 & u & & \\
\hline SESPMNT & B175J7 & RICH.PMPHS HRM 46.4 & OFFSITE & sw & $\mathrm{Y}$ & RIVER & RESIN & 08-Aug-03 & Eu-155 & $0.00479 p$ & pCi/L & 0.0048 & 0.0048 & $u$ & & \\
\hline SESPMNT & B175K4 & RICH.PMPHS HRM 46.4 & OFFSITE & sW & $\mathrm{Y}$ & RIVER & FILTER & 03-Sep-03 & Eu-155 & $-0.000124 p$ & $\mathrm{pCi} / \mathrm{L}$ & 0.0038 & 0.0038 & $u$ & & \\
\hline SESPMNT & B175J8 & RICH.PMPHS HRM 46.4 & OFFSITE & sw & $\mathrm{Y}$ & RIVER & RESIN & 03-Sep-03 & Eu-155 & $0.00701 p$ & $\mathrm{pCi} / \mathrm{L}$ & 0.0049 & 0.0049 & $u$ & & \\
\hline SESPMNT & B175K5 & RICH.PMPHS HRM 46.4 & OFFSITE & sw & $\mathrm{Y}$ & RIVER & FILTER & 30-Sep-03 & Eu-155 & $0.00134 p$ & $\mathrm{pCi} / \mathrm{L}$ & 0.0038 & 0.0038 & $u$ & & \\
\hline SESPMNT & B175J9 & RICH.PMPHS HRM 46.4 & OFFSITE & sw & $\mathrm{Y}$ & RIVER & RESIN & 30-Sep-03 & Eu-155 & $-0.00388 p$ & $\mathrm{pCi} / \mathrm{L}$ & 0.0083 & 0.0083 & $u$ & & \\
\hline SESPMNT & B17P58 & RICH.PMPHS HRM 46.4 & OFFSITE & sW & $\mathrm{Y}$ & RIVER & FILTER & 29-Oct-03 & Eu-155 & $-0.0000133 p$ & $\mathrm{pCi} / \mathrm{L}$ & 0.0021 & 0.0021 & $u$ & & \\
\hline SESPMNT & B17P52 & RICH.PMPHS HRM 46.4 & OFFSITE & sw & $\mathrm{Y}$ & RIVER & RESIN & 29-Oct-03 & Eu-155 & $0.00083 \mathrm{p}$ & $\mathrm{pCi} / \mathrm{L}$ & 0.0039 & 0.0039 & $u$ & & \\
\hline SESPMNT & B17P59 & RICH.PMPHS HRM 46.4 & OFFSITE & sw & $Y$ & RIVER & FILTER & 25 -Nov-03 & Eu-155 & $0.00226 \mathrm{p}$ & $\mathrm{pCi} / \mathrm{L}$ & 0.0028 & 0.0028 & U & & \\
\hline SESPMNT & B17P53 & RICH.PMPHS HRM 46.4 & OFFSITE & sw & $\mathrm{Y}$ & RIVER & RESIN & 25-Nov-03 & Eu-155 & $0.00489 p$ & $\mathrm{pCi} / \mathrm{L}$ & 0.0043 & 0.0043 & $u$ & & \\
\hline SESPMNT & B17P60 & RICH.PMPHS HRM 46.4 & OFFSITE & sW & $\mathrm{Y}$ & RIVER & FILTER & 08-Jan-04 & Eu-155 & $0.000806 p$ & $\mathrm{pCi} / \mathrm{L}$ & 0.0011 & 0.0011 & $u$ & & \\
\hline SESPMNT & B17P54 & RICH.PMPHS HRM 46.4 & OFFSITE & sw & $\mathrm{Y}$ & RIVER & RESIN & 08-Jan-04 & Eu-155 & $0.000175 p$ & pCi/L & 0.0041 & 0.0041 & $u$ & & \\
\hline SESPMNT & B16874 & PRIEST RAPIDS-RIVER & OFFSITE & sw & $Y$ & RIVER & FILTER & 05-Feb-03 & $\mathrm{K}-40$ & $0.0633 p$ & $\mathrm{pCi} / \mathrm{L}$ & 0.022 & 0.022 & & & \\
\hline SESPMNT & B16880 & PRIEST RAPIDS-RIVER & OFFSITE & sw & $\mathrm{Y}$ & RIVER & RESIN & $05-$ Feb-03 & $K-40$ & $0.407 p$ & $\mathrm{pCi} / \mathrm{L}$ & 0.083 & 0.083 & & & \\
\hline SESPMNT & B16875 & PRIEST RAPIDS-RIVER & OFFSITE & sw & $\mathrm{Y}$ & RIVER & FILTER & 05-Mar-03 & $K-40$ & $0.05 p$ & $\mathrm{pCi} / \mathrm{L}$ & 0.023 & 0.023 & & & \\
\hline SESPMNT & B16881 & PRIEST RAPIDS-RIVER & OFFSITE & sw & $\mathrm{Y}$ & RIVER & RESIN & 05-Mar-03 & $\mathrm{K}-40$ & $0.651 \mathrm{p}$ & $\mathrm{pCi} / \mathrm{L}$ & 0.093 & 0.093 & & & \\
\hline SESPMNT & B16876 & PRIEST RAPIDS-RIVER & OFFSITE & sw & $Y$ & RIVER & FILTER & 02-Apr-03 & $K-40$ & $0.0444 \mathrm{p}$ & $\mathrm{pCi} / \mathrm{L}$ & 0.026 & 0.026 & & & \\
\hline SESPMNT & B16882 & PRIEST RAPIDS-RIVER & OFFSITE & sw & $\mathrm{Y}$ & RIVER & RESIN & 02-Apr-03 & $K-40$ & $0.561 \mathrm{p}$ & $\mathrm{pCi} / \mathrm{L}$ & 0.094 & 0.094 & & & \\
\hline SESPMNT & B16PK5 & PRIEST RAPIDS-RIVER & OFFSITE & sW & $\mathrm{Y}$ & RIVER & FILTER & 30-Apr-03 & $K-40$ & $-0.0474 p$ & $\mathrm{pCi} / \mathrm{L}$ & 0.036 & 0.036 & u & & \\
\hline SESPMNT & B16PL1 & PRIEST RAPIDS-RIVER & OFFSITE & sW & $\mathrm{Y}$ & RIVER & RESIN & 30-Apr-03 & $K-40$ & $0.361 \mathrm{p}$ & $\mathrm{pCi} / \mathrm{L}$ & 0.088 & 0.088 & & & \\
\hline SESPMNT & B16PK6 & PRIEST RAPIDS-RIVER & OFFSITE & sw & $\mathrm{Y}$ & RIVER & FILTER & 28-May-03 & $\mathrm{K}-40$ & $0.0727 \mathrm{p}$ & $\mathrm{pCi} / \mathrm{L}$ & 0.04 & 0.04 & & & \\
\hline SESPMNT & B16PL2 & PRIEST RAPIDS-RIVER & OFFSITE & sw & $\mathrm{Y}$ & RIVER & RESIN & 28-May-03 & $K-40$ & $0.458 \mathrm{p}$ & $\mathrm{pCi} / \mathrm{L}$ & 0.077 & 0.077 & & & \\
\hline SESPMNT & B16PK7 & PRIEST RAPIDS-RIVER & OFFSITE & sW & $\mathrm{Y}$ & RIVER & FILTER & 10-Jul-03 & $K-40$ & $-0.0275 p$ & $\mathrm{pCi} / \mathrm{L}$ & 0.026 & 0.026 & U & & \\
\hline SESPMNT & B16PL3 & PRIEST RAPIDS-RIVER & OFFSITE & sW & $\mathrm{Y}$ & RIVER & RESIN & 10-Jul-03 & $K-40$ & & $\mathrm{pCi} / \mathrm{L}$ & 0.094 & 0.094 & & & \\
\hline
\end{tabular}


WATER - COLUMBIA RIVER FILTER/RESIN

\begin{tabular}{|c|c|c|c|c|c|c|c|c|c|c|c|c|c|c|c|c|}
\hline OWNER ID & SAMP NUM & SAMP SITE NAME & DIST CLASS & $\mid$ MEDIA $\mid$ & $\begin{array}{c}\mid \text { FILTERED } \\
\text { FLAG }\end{array}$ & SAMP FROM & COLL MTHD & SAMP DATE & $\left|\begin{array}{c}\text { CON SHORT } \\
\text { NAME }\end{array}\right|$ & VALUE RPTD & $\mid \begin{array}{l}\text { ANAL } \\
\text { UNITS } \\
\text { RPTD }\end{array}$ & $\left|\begin{array}{c}\text { COUNTING } \\
\text { ERROR }\end{array}\right|$ & $\begin{array}{c}\text { TOTAL ANAL } \\
\text { ERROR }\end{array}$ & $\mid \begin{array}{c}\text { LAB } \\
\text { QUALIFIER }\end{array}$ & SAMP COMMENT & RESULT COMMENT \\
\hline SESPMNT & $\mathrm{B} 175 \mathrm{H} 5$ & PRIEST RAPIDS-RIVER & OFFSITE & sw & Y & RIVER & FILTER & 08-Aug-03 & $K-40$ & $0.0656 \mathrm{p}$ & pCi/L & 0.04 & 0.04 & & & \\
\hline SESPMNT & B175J1 & PRIEST RAPIDS-RIVER & OFFSITE & sW & $\mathrm{Y}$ & RIVER & RESIN & 08-Aug-03 & $K-40$ & $0.69 \mathrm{p}$ & $\mathrm{pCi} / \mathrm{L}$ & 0.11 & 0.11 & & & \\
\hline SESPMNT & B175H6 & PRIEST RAPIDS-RIVER & OFFSITE & sw & $\mathrm{Y}$ & RIVER & FILTER & 03-Sep-03 & $K-40$ & $-0.0817 p$ & pCi/L & 0.041 & 0.041 & $u$ & & \\
\hline SESPMNT & B175J2 & PRIEST RAPIDS-RIVER & OFFSITE & sW & $\mathrm{Y}$ & RIVER & RESIN & 03-Sep-03 & & $0.239 \mathrm{p}$ & $\mathrm{pCi} / \mathrm{L}$ & 0.11 & 0.11 & & & \\
\hline SESPMNT & B175H7 & PRIEST RAPIDS-RIVER & OFFSITE & sW & $\mathrm{Y}$ & RIVER & FILTER & 30-Sep-03 & $K-40$ & $0.0331 \mathrm{p}$ & $\mathrm{pCi} / \mathrm{L}$ & 0.037 & 0.037 & $u$ & & \\
\hline SESPMNT & B175J3 & PRIEST RAPIDS-RIVER & OFFSITE & sW & $\mathrm{Y}$ & RIVER & RESIN & 30-Sep-03 & $K-40$ & $0.526 \mathrm{p}$ & $\mathrm{pCi} / \mathrm{L}$ & 0.11 & 0.11 & & & \\
\hline SESPMNT & B17P40 & PRIEST RAPIDS-RIVER & OFFSITE & sw & $\mathrm{Y}$ & RIVER & FILTER & 29-Oct-03 & $K-40$ & $0.0488 \mathrm{p}$ & pCill & 0.039 & 0.039 & & & \\
\hline SESPMNT & B17P46 & PRIEST RAPIDS-RIVER & OFFSITE & sW & $\mathrm{Y}$ & RIVER & RESIN & 29-Oct-03 & $K-40$ & $0.437 p$ & $\mathrm{pCi} / \mathrm{L}$ & 0.086 & 0.086 & & & \\
\hline SESPMNT & B17P41 & PRIEST RAPIDS-RIVER & OFFSITE & sW & $\mathrm{Y}$ & RIVER & FILTER & 25-Nov-03 & $K-40$ & $0.039 \mathrm{p}$ & $\mathrm{pCi} / \mathrm{L}$ & 0.039 & 0.039 & & & \\
\hline SESPMNT & B17P47 & PRIEST RAPIDS-RIVER & OFFSITE & sw & $\mathrm{Y}$ & RIVER & RESIN & 25-Nov-03 & $K-40$ & $0.488 \mathrm{p}$ & pCill & 0.1 & 0.1 & & & \\
\hline SESPMNT & B17P42 & PRIEST RAPIDS-RIVER & OFFSITE & sW & $\mathrm{Y}$ & RIVER & FILTER & 08-Jan-04 & & $0.00773 \mathrm{p}$ & $\mathrm{pCi} / \mathrm{L}$ & 0.022 & 0.022 & $u$ & & \\
\hline SESPMNT & B17P48 & PRIEST RAPIDS-RIVER & OFFSITE & sW & $\mathrm{Y}$ & RIVER & RESIN & 08-Jan-04 & $K-40$ & $0.227 \mathrm{p}$ & $\mathrm{pCi} / \mathrm{L}$ & 0.069 & 0.069 & & & \\
\hline SESPMNT & B16892 & RICH.PMPHS HRM 46.4 & OFFSITE & sw & $\mathrm{Y}$ & RIVER & FILTER & $05-$ Feb-03 & $K-40$ & $0.032 \mathrm{p}$ & $\mathrm{pCi/L}$ & 0.028 & 0.028 & & & \\
\hline SESPMNT & B16886 & RICH.PMPHS HRM 46.4 & OFFSITE & sW & $\mathrm{Y}$ & RIVER & RESIN & 05-Feb-03 & $K-40$ & $0.534 \mathrm{p}$ & pCi/L & 0.083 & 0.083 & & & \\
\hline SESPMNT & B16893 & RICH.PMPHS HRM 46.4 & OFFSITE & sW & $\mathrm{Y}$ & RIVER & FILTER & 05-Mar-03 & & $0.0167 \mathrm{p}$ & $\mathrm{pCi} / \mathrm{L}$ & 0.031 & 0.031 & U & & \\
\hline SESPMNT & B16887 & RICH.PMPHS HRM 46.4 & OFFSITE & sw & $\mathrm{Y}$ & RIVER & RESIN & 05-Mar-03 & $\mathrm{K}-40$ & $0.64 \mathrm{p}$ & $\mathrm{pCi} / \mathrm{L}$ & 0.11 & 0.11 & & & \\
\hline SESPMNT & B16894 & RICH.PMPHS HRM 46.4 & OFFSITE & sw & $\mathrm{Y}$ & RIVER & FILTER & 02-Apr-03 & $K-40$ & $0.0759 \mathrm{p}$ & $\mathrm{pCi/L}$ & 0.025 & 0.025 & & & \\
\hline SESPMNT & B16888 & RICH.PMPHS HRM 46.4 & OFFSITE & sW & $\mathrm{Y}$ & RIVER & RESIN & 02-Apr-03 & $K-40$ & $0.237 \mathrm{p}$ & $\mathrm{pCi} / \mathrm{L}$ & 0.072 & 0.072 & & & \\
\hline SESPMNT & B16PM3 & RICH.PMPHS HRM 46.4 & OFFSITE & sw & $\mathrm{Y}$ & RIVER & FILTER & 30-Apr-03 & $K-40$ & $0.0568 \mathrm{p}$ & $\mathrm{pCi} / \mathrm{L}$ & 0.038 & 0.038 & & & \\
\hline SESPMNT & B16PL7 & RICH.PMPHS HRM 46.4 & OFFSITE & sW & $\mathrm{Y}$ & RIVER & RESIN & 30-Apr-03 & $K-40$ & $0.478 \mathrm{p}$ & pCi/L & 0.091 & 0.091 & & & \\
\hline SESPMNT & B16PM4 & RICH.PMPHS HRM 46.4 & OFFSITE & sW & $\mathrm{Y}$ & RIVER & FILTER & $28-$ May-03 & $K-40$ & $-0.0453 p$ & $\mathrm{pCi} / \mathrm{L}$ & 0.034 & 0.034 & $u$ & & \\
\hline SESPMNT & B16PL8 & RICH.PMPHS HRM 46.4 & OFFSITE & sW & $\mathrm{Y}$ & RIVER & RESIN & 28-May-03 & $K-40$ & $0.526 \mathrm{p}$ & $\mathrm{pCi} / \mathrm{L}$ & 0.096 & 0.096 & & & \\
\hline SESPMNT & B16PM5 & RICH.PMPHS HRM 46.4 & OFFSITE & sW & $\mathrm{Y}$ & RIVER & FILTER & 10-Jul-03 & $K-40$ & $0.000272 p$ & $\mathrm{pCi/L}$ & 0.026 & 0.026 & $\mathrm{u}$ & & \\
\hline SESPMNT & B16PL9 & RICH.PMPHS HRM 46.4 & OFFSITE & sW & $\mathrm{Y}$ & RIVER & RESIN & 10-Jul-03 & $K-40$ & $0.522 \mathrm{p}$ & pCill & 0.11 & 0.11 & & & \\
\hline SESPMNT & B175K3 & RICH.PMPHS HRM 46.4 & OFFSITE & sW & Y & RIVER & FILTER & 08-Aug-03 & $K-40$ & $0.0781 \mathrm{p}$ & $\mathrm{pCi} / \mathrm{L}$ & 0.04 & 0.04 & & & \\
\hline SESPMNT & B175J7 & RICH.PMPHS HRM 46.4 & OFFSITE & sw & $\mathrm{Y}$ & RIVER & RESIN & 08-Aug-03 & $K-40$ & $0.58 \mathrm{p}$ & pCi/L & 0.11 & 0.11 & & & \\
\hline SESPMNT & B175K4 & RICH.PMPHS HRM 46.4 & OFFSITE & sW & $\mathrm{Y}$ & RIVER & FILTER & 03-Sep-03 & $\mathrm{K}-40$ & $0.0949 \mathrm{p}$ & $\mathrm{pCi/L}$ & 0.054 & 0.054 & & & \\
\hline SESPMNT & B175J8 & RICH.PMPHS HRM 46.4 & OFFSITE & sw & $\mathrm{Y}$ & RIVER & RESIN & 03-Sep-03 & $\mathrm{K}-40$ & $0.659 \mathrm{p}$ & pCi/L & 0.13 & 0.13 & & & \\
\hline SESPMNT & B175K5 & RICH.PMPHS HRM 46.4 & OFFSITE & sw & $\mathrm{Y}$ & RIVER & FILTER & 30-Sep-03 & $K-40$ & $0.0274 \mathrm{p}$ & $\mathrm{pCi} / \mathrm{L}$ & 0.061 & 0.061 & $u$ & & \\
\hline SESPMNT & B175J9 & RICH.PMPHS HRM 46.4 & OFFSITE & sw & $\mathrm{Y}$ & RIVER & RESIN & 30-Sep-03 & $K-40$ & $0.627 p$ & $\mathrm{pCi} / \mathrm{L}$ & 0.16 & 0.16 & & & \\
\hline SESPMNT & B17P58 & RICH.PMPHS HRM 46.4 & OFFSITE & sw & $\mathrm{Y}$ & RIVER & FILTER & 29-Oct-03 & $K-40$ & $0.0694 \mathrm{p}$ & pCill & 0.037 & 0.037 & & & \\
\hline SESPMNT & B17P52 & RICH.PMPHS HRM 46.4 & OFFSITE & sw & $\mathrm{Y}$ & RIVER & RESIN & 29-Oct-03 & $\mathrm{K}-40$ & & $\mathrm{pCi} / \mathrm{L}$ & 0.091 & 0.091 & & & \\
\hline SESPMNT & B17P59 & RICH.PMPHS HRM 46.4 & OFFSITE & sW & $\mathrm{Y}$ & RIVER & FILTER & 25 -Nov-03 & $K-40$ & $0.0549 \mathrm{p}$ & $\mathrm{pCi} / \mathrm{L}$ & 0.046 & 0.046 & & & \\
\hline SESPMNT & B17P53 & RICH.PMPHS HRM 46.4 & OFFSITE & sw & $\mathrm{Y}$ & RIVER & RESIN & 25-Nov-03 & $K-40$ & $0.475 p$ & $\mathrm{pCi} / \mathrm{L}$ & 0.097 & 0.097 & & & \\
\hline SESPMNT & B17P60 & RICH.PMPHS HRM 46.4 & OFFSITE & sw & $\mathrm{Y}$ & RIVER & FILTER & 08-Jan-04 & $K-40$ & $0.0438 \mathrm{p}$ & $\mathrm{pCi/L}$ & 0.016 & 0.016 & & & \\
\hline SESPMNT & B17P54 & RICH.PMPHS HRM 46.4 & OFFSITE & sw & $\mathrm{Y}$ & RIVER & RESIN & 08-Jan-04 & $\mathrm{K}-40$ & $0.0485 \mathrm{p}$ & pCi/L & 0.06 & 0.06 & $u$ & & \\
\hline SESPMNT & B16874 & PRIEST RAPIDS-RIVER & OFFSITE & sW & $\mathrm{Y}$ & RIVER & FILTER & 05 -Feb-03 & Ru-106 & $0.00137 p$ & $\mathrm{pCi} / \mathrm{L}$ & 0.0058 & 0.0058 & U & & \\
\hline SESPMNT & B16880 & PRIEST RAPIDS-RIVER & OFFSITE & sw & $\mathrm{Y}$ & RIVER & RESIN & $05-$ Feb-03 & Ru-106 & $0.00152 \mathrm{p}$ & $\mathrm{pCi} / \mathrm{L}$ & 0.014 & 0.014 & $u$ & & \\
\hline SESPMNT & B16875 & PRIEST RAPIDS-RIVER & OFFSITE & sw & $\mathrm{Y}$ & RIVER & FILTER & 05-Mar-03 & Ru-106 & $-0.00442 p$ & $\mathrm{pCi} / \mathrm{L}$ & 0.0061 & 0.0061 & $u$ & & \\
\hline SESPMNT & B16881 & PRIEST RAPIDS-RIVER & OFFSITE & sw & $\mathrm{Y}$ & RIVER & RESIN & 05-Mar-03 & Ru-106 & $0.00147 p$ & pCi/L & 0.013 & 0.013 & $u$ & & \\
\hline SESPMNT & B16876 & PRIEST RAPIDS-RIVER & OFFSITE & sW & $\mathrm{Y}$ & RIVER & FILTER & 02-Apr-03 & Ru-106 & $0.0019 p$ & $\mathrm{pCi} / \mathrm{L}$ & 0.006 & 0.006 & $u$ & & \\
\hline SESPMNT & B16882 & PRIEST RAPIDS-RIVER & OFFSITE & sw & $\mathrm{Y}$ & RIVER & RESIN & 02-Apr-03 & Ru-106 & $-0.00104 p$ & $\mathrm{pCi} / \mathrm{L}$ & 0.017 & 0.017 & $u$ & & \\
\hline SESPMNT & B16PK5 & PRIEST RAPIDS-RIVER & OFFSITE & sw & $Y$ & RIVER & FILTER & 30-Apr-03 & Ru-106 & $-0.00443 p$ & $\mathrm{pCi} / \mathrm{L}$ & 0.011 & 0.011 & $u$ & & \\
\hline SESPMNT & B16PL1 & PRIEST RAPIDS-RIVER & OFFSITE & sw & $\mathrm{Y}$ & RIVER & RESIN & 30-Apr-03 & Ru-106 & $-0.0169 p$ & $\mathrm{pCi} / \mathrm{L}$ & 0.016 & 0.016 & $u$ & & \\
\hline SESPMNT & B16PK6 & PRIEST RAPIDS-RIVER & OFFSITE & sW & $\mathrm{Y}$ & RIVER & FILTER & 28-Мay-03 & Ru-106 & $-0.000767 p$ & $\mathrm{pCi} / \mathrm{L}$ & 0.0093 & 0.0093 & $u$ & & \\
\hline SESPMNT & B16PL2 & PRIEST RAPIDS-RIVER & OFFSITE & sw & $\mathrm{Y}$ & RIVER & RESIN & 28-May-03 & Ru-106 & $-0.00446 p$ & pCi/L & 0.013 & 0.013 & $u$ & & \\
\hline SESPMNT & B16PK7 & PRIEST RAPIDS-RIVER & OFFSITE & sw & $Y$ & RIVER & FILTER & 10-Jul-03 & Ru-106 & $-0.000264 p$ & $\mathrm{pCi} / \mathrm{L}$ & 0.0068 & 0.0068 & $u$ & & \\
\hline SESPMNT & B16PL3 & PRIEST RAPIDS-RIVER & OFFSITE & sw & $\mathrm{Y}$ & RIVER & RESIN & 10-Jul-03 & Ru-106 & $0.00449 p$ & $\mathrm{pCi} / \mathrm{L}$ & 0.017 & 0.017 & $u$ & & \\
\hline SESPMNT & B175H5 & PRIEST RAPIDS-RIVER & OFFSITE & sw & $\mathrm{Y}$ & RIVER & FILTER & 08-Aug-03 & Ru-106 & $-0.00716 p$ & $\mathrm{pCi} / \mathrm{L}$ & 0.0092 & 0.0092 & $u$ & & \\
\hline SESPMNT & B175J1 & PRIEST RAPIDS-RIVER & OFFSITE & sw & $\mathrm{Y}$ & RIVER & RESIN & 08-Aug-03 & Ru-106 & $0.0142 \mathrm{p}$ & $\mathrm{pCi} / \mathrm{L}$ & 0.015 & 0.015 & $u$ & & \\
\hline SESPMNT & B175H6 & PRIEST RAPIDS-RIVER & OFFSITE & sw & $Y$ & RIVER & FILTER & 03-Sep-03 & Ru-106 & $0.00326 p$ & $\mathrm{pCi} / \mathrm{L}$ & 0.0094 & 0.0094 & $u$ & & \\
\hline SESPMNT & B175J2 & PRIEST RAPIDS-RIVER & OFFSITE & SW & $\mathrm{Y}$ & RIVER & RESIN & 03-Sep-03 & Ru-106 & $0.00357 \mathrm{p}$ & $\mathrm{pCi} / \mathrm{L}$ & 0.02 & 0.02 & $u$ & & \\
\hline SESPMNT & B175H7 & PRIEST RAPIDS-RIVER & OFFSITE & sW & $\mathrm{Y}$ & RIVER & FILTER & 30-Sep-03 & Ru-106 & $-0.00441 p$ & $\mathrm{pCi} / \mathrm{L}$ & 0.0087 & 0.0087 & u & & \\
\hline SESPMNT & B175J3 & PRIEST RAPIDS-RIVER & OFFSITE & sw & $\mathrm{Y}$ & RIVER & RESIN & 30-Sep-03 & Ru-106 & $-0.00148 p$ & $\mathrm{pCi} / \mathrm{L}$ & 0.018 & 0.018 & $u$ & & \\
\hline SESPMNT & B17P40 & PRIEST RAPIDS-RIVER & OFFSITE & sw & Y & RIVER & FILTER & 29-Oct-03 & Ru-106 & $-0.00293 p$ & $\mathrm{pCi} / \mathrm{L}$ & 0.0086 & 0.0086 & u & & \\
\hline SESPMNT & B17P46 & PRIEST RAPIDS-RIVER & OFFSITE & sw & $\mathrm{Y}$ & RIVER & RESIN & 29-Oct-03 & Ru-106 & $0.00953 \mathrm{p}$ & $\mathrm{pCi} / \mathrm{L}$ & 0.014 & 0.014 & u & & \\
\hline SESPMNT & B17P41 & PRIEST RAPIDS-RIVER & OFFSITE & sW & $\mathrm{Y}$ & RIVER & FILTER & 25-Nov-03 & Ru-106 & $-0.00269 p$ & $\mathrm{pCi} / \mathrm{L}$ & 0.009 & 0.009 & u & & \\
\hline SESPMNT & B17P47 & PRIEST RAPIDS-RIVER & OFFSITE & sw & $\mathrm{Y}$ & RIVER & RESIN & 25-Nov-03 & Ru-106 & $0.00325 \mathrm{p}$ & $\mathrm{pCi} / \mathrm{L}$ & 0.017 & 0.017 & U & & \\
\hline
\end{tabular}


WATER - COLUMBIA RIVER FILTER/RESIN

\begin{tabular}{|c|c|c|c|c|c|c|c|c|c|c|c|c|c|c|c|c|}
\hline OWNER ID & SAMP NUM & SAMP SITE NAME & DIST CLASS & $\mid$ MEDIA $\mid$ & $\begin{array}{c}\mid \text { FILTERED } \\
\text { FLAG }\end{array}$ & SAMP FROM & COLL MTHD & SAMP DATE & $\left|\begin{array}{c}\text { CON SHORT } \\
\text { NAME }\end{array}\right|$ & VALUE RPTD & $\mid \begin{array}{l}\text { ANAL } \\
\text { UNITS } \\
\text { RPTD }\end{array}$ & $\left|\begin{array}{c}\text { COUNTING } \\
\text { ERROR }\end{array}\right|$ & $\mid \begin{array}{c}\text { TOTAL ANAL } \\
\text { ERROR }\end{array}$ & $\mid \begin{array}{c}\text { LAB } \\
\text { QUALIFIER }\end{array}$ & SAMP COMMENT & |RESULT COMMENT \\
\hline SESPMNT & B17P42 & PRIEST RAPIDS-RIVER & OFFSITE & sw & Y & RIVER & FILTER & 08-Jan-04 & Ru-106 & $0.00155 \mathrm{p}$ & $\mathrm{pCi} / \mathrm{L}$ & 0.0054 & 0.0054 & U & & \\
\hline SESPMNT & B17P48 & PRIEST RAPIDS-RIVER & OFFSITE & sw & $\mathrm{Y}$ & RIVER & RESIN & 08-Jan-04 F & Ru-106 & $-0.00538 p$ & $\mathrm{pCi} / \mathrm{L}$ & 0.013 & 0.013 & $u$ & & \\
\hline SESPMNT & B16892 & RICH.PMPHS HRM 46.4 & OFFSITE & sw & $\mathrm{Y}$ & RIVER & FILTER & $05-\mathrm{Feb}-03$ & Ru-106 & $0.00535 \mathrm{p}$ & $\mathrm{pCi} / \mathrm{L}$ & 0.0061 & 0.0061 & $u$ & & \\
\hline SESPMNT & B16886 & RICH.PMPHS HRM 46.4 & OFFSITE & sW & $\mathrm{Y}$ & RIVER & RESIN & 05-Feb-03 F & Ru-106 & $-0.00731 \mathrm{p}$ & $\mathrm{pCi} / \mathrm{L}$ & 0.013 & 0.013 & $u$ & & \\
\hline SESPMNT & B16893 & RICH.PMPHS HRM 46.4 & OFFSITE & sW & $\mathrm{Y}$ & RIVER & FILTER & 05-Mar-03 F & Ru-106 & $0.00126 \mathrm{p}$ & $\mathrm{pCi} / \mathrm{L}$ & 0.0077 & 0.0077 & u & & \\
\hline SESPMNT & B16887 & RICH.PMPHS HRM 46.4 & OFFSITE & sW & $\mathrm{Y}$ & RIVER & RESIN & 05-Mar-03 F & Ru-106 & $0.0102 p$ & $\mathrm{pCi} / \mathrm{L}$ & 0.017 & 0.017 & $u$ & & \\
\hline SESPMNT & B16894 & RICH.PMPHS HRM 46.4 & OFFSITE & sw & $\mathrm{Y}$ & RIVER & FILTER & 02-Apr-03 F & Ru-106 & $0.0032 \mathrm{p}$ & $\mathrm{pCi} / \mathrm{L}$ & 0.0063 & 0.0063 & $u$ & & \\
\hline SESPMNT & B16888 & RICH.PMPHS HRM 46.4 & OFFSITE & sW & $\mathrm{Y}$ & RIVER & RESIN & 02-Apr-03 F & Ru-106 & $-0.00602 p$ & $\mathrm{pCi} / \mathrm{L}$ & 0.015 & 0.015 & u & & \\
\hline SESPMNT & B16PM3 & RICH.PMPHS HRM 46.4 & OFFSITE & sW & $\mathrm{Y}$ & RIVER & FILTER & 30-Apr-03 F & Ru-106 & $-0.00443 p$ & $\mathrm{pCi} / \mathrm{L}$ & 0.0086 & 0.0086 & u & & \\
\hline SESPMNT & B16PL7 & RICH.PMPHS HRM 46.4 & OFFSITE & sw & $\mathrm{Y}$ & RIVER & RESIN & 30-Apr-03 F & Ru-106 & $-0.0033 \mathrm{p}$ & pCill & 0.014 & 0.014 & u & & \\
\hline SESPMNT & B16PM4 & RICH.PMPHS HRM 46.4 & OFFSITE & sw & $\mathrm{Y}$ & RIVER & FILTER & 28-May-03 & Ru-106 & $0.00183 \mathrm{p}$ & $\mathrm{pCi} / \mathrm{L}$ & 0.0088 & 0.0088 & u & & \\
\hline SESPMNT & B16PL8 & RICH.PMPHS HRM 46.4 & OFFSITE & sW & $\mathrm{Y}$ & RIVER & RESIN & 28-May-03 & Ru-106 & $0.00537 \mathrm{p}$ & $\mathrm{pCi} / \mathrm{L}$ & 0.015 & 0.015 & u & & \\
\hline SESPMNT & B16PM5 & RICH.PMPHS HRM 46.4 & OFFSITE & sw & $\mathrm{Y}$ & RIVER & FILTER & 10-Jul-03 F & Ru-106 & $-0.00528 \mathrm{p}$ & $\mathrm{pCi/L}$ & 0.0061 & 0.0061 & u & & \\
\hline SESPMNT & B16PL9 & RICH.PMPHS HRM 46.4 & OFFSITE & sw & $\mathrm{Y}$ & RIVER & RESIN & 10-Jul-03 & Ru-106 & $0.0151 \mathrm{p}$ & $\mathrm{pCi} / \mathrm{L}$ & 0.018 & 0.018 & $u$ & & \\
\hline SESPMNT & B175K3 & RICH.PMPHS HRM 46.4 & OFFSITE & sW & $\mathrm{Y}$ & RIVER & FILTER & 08-Aug-03 F & Ru-106 & $0.00497 \mathrm{p}$ & $\mathrm{pCi} / \mathrm{L}$ & 0.0084 & 0.0084 & u & & \\
\hline SESPMNT & B175J7 & RICH.PMPHS HRM 46.4 & OFFSITE & sW & $\mathrm{Y}$ & RIVER & RESIN & 08-Aug-03 F & Ru-106 & $0.012 \mathrm{p}$ & $\mathrm{pCi} / \mathrm{L}$ & 0.018 & 0.018 & U & & \\
\hline SESPMNT & B175K4 & RICH.PMPHS HRM 46.4 & OFFSITE & sw & $\mathrm{Y}$ & RIVER & FILTER & 03-Sep-03 & Ru-106 & $-0.000616 p$ & $\mathrm{pCi/L}$ & 0.015 & 0.015 & u & & \\
\hline SESPMNT & B175J8 & RICH.PMPHS HRM 46.4 & OFFSITE & sW & $\mathrm{Y}$ & RIVER & RESIN & 03-Sep-03 & Ru-106 & $-0.00679 p$ & $\mathrm{pCi} / \mathrm{L}$ & 0.019 & 0.019 & u & & \\
\hline SESPMNT & B175K5 & RICH.PMPHS HRM 46.4 & OFFSITE & sw & $\mathrm{Y}$ & RIVER & FILTER & 30-Sep-03 & Ru-106 & $0.0143 \mathrm{p}$ & $\mathrm{pCi} / \mathrm{L}$ & 0.016 & 0.016 & u & & \\
\hline SESPMNT & B175J9 & RICH.PMPHS HRM 46.4 & OFFSITE & sW & $\mathrm{Y}$ & RIVER & RESIN & 30-Sep-03 & Ru-106 & $-0.0136 p$ & $\mathrm{pC}$ Ci/L & 0.032 & 0.032 & $u$ & & \\
\hline SESPMNT & B17P58 & RICH.PMPHS HRM 46.4 & OFFSITE & sw & $\mathrm{Y}$ & RIVER & FILTER & 29-Oct-03 & Ru-106 & $-0.0123 p$ & $\mathrm{pCi/L}$ & 0.0082 & 0.0082 & u & & \\
\hline SESPMNT & B17P52 & RICH.PMPHS HRM 46.4 & OFFSITE & sW & $\mathrm{Y}$ & RIVER & RESIN & $29-0 c t-03$ & Ru-106 & $0.00298 \mathrm{p}$ & $\mathrm{pCi} / \mathrm{L}$ & 0.014 & 0.014 & u & & \\
\hline SESPMNT & B17P59 & RICH.PMPHS HRM 46.4 & OFFSITE & sW & $\mathrm{Y}$ & RIVER & FILTER & 25 -Nov-03 & Ru-106 & $0.00249 \mathrm{p}$ & $\mathrm{pC}$ Ci/L & 0.0098 & 0.0098 & $u$ & & \\
\hline SESPMNT & B17P53 & RICH.PMPHS HRM 46.4 & OFFSITE & sW & $\mathrm{Y}$ & RIVER & RESIN & 25-Nov-03 & Ru-106 & $-0.00191 \mathrm{p}$ & pCill & 0.016 & 0.016 & $u$ & & \\
\hline SESPMNT & B17P60 & RICH.PMPHS HRM 46.4 & OFFSITE & sW & $\mathrm{Y}$ & RIVER & FILTER & 08-Jan-04 & Ru-106 & $0.00203 \mathrm{p}$ & $\mathrm{pCi} / \mathrm{L}$ & 0.0043 & 0.0043 & $\mathrm{U}$ & & \\
\hline SESPMNT & B17P54 & RICH.PMPHS HRM 46.4 & OFFSITE & sw & $\mathrm{Y}$ & RIVER & RESIN & 08-Jan-04 F & Ru-106 & $-0.00549 p$ & $\mathrm{pCi} / \mathrm{L}$ & 0.014 & 0.014 & $u$ & & \\
\hline SESPMNT & B16874 & PRIEST RAPIDS-RIVER & OFFSITE & sW & $\mathrm{Y}$ & RIVER & FILTER & $05-\mathrm{Feb}-03 \mathrm{~s}$ & Sb-125 & $0.000522 p$ & $\mathrm{pCi/L}$ & 0.0017 & 0.0017 & u & & \\
\hline SESPMNT & B16880 & PRIEST RAPIDS-RIVER & OFFSITE & sw & $\mathrm{Y}$ & RIVER & RESIN & $05-\mathrm{Feb}-03 \mathrm{~s}$ & Sb-125 & $-0.00326 p$ & $\mathrm{pCi} / \mathrm{L}$ & 0.0042 & 0.0042 & $u$ & & \\
\hline SESPMNT & B16875 & PRIEST RAPIDS-RIVER & OFFSITE & sw & $\mathrm{Y}$ & RIVER & FILTER & $05-M a r-03$ & Sb-125 & $0.00145 \mathrm{p}$ & $\mathrm{pCi} / \mathrm{L}$ & 0.0017 & 0.0017 & $u$ & & \\
\hline SESPMNT & B16881 & PRIEST RAPIDS-RIVER & OFFSITE & sw & $\mathrm{Y}$ & RIVER & RESIN & $05-\mathrm{Mar}-03$ & Sb-125 & $-0.0000698 p$ & $\mathrm{pCi} / \mathrm{L}$ & 0.0036 & 0.0036 & $u$ & & \\
\hline SESPMNT & B16876 & PRIEST RAPIDS-RIVER & OFFSITE & sw & $\mathrm{Y}$ & RIVER & FILTER & 02-Apr-03 & Sb-125 & $-0.0000208 p$ & $\mathrm{pCi/L}$ & 0.0016 & 0.0016 & u & & \\
\hline SESPMNT & B16882 & PRIEST RAPIDS-RIVER & OFFSITE & sw & $\mathrm{Y}$ & RIVER & RESIN & 02-Apr-03 & Sb-125 & $0.00127 \mathrm{p}$ & $\mathrm{pCi} / \mathrm{L}$ & 0.0047 & 0.0047 & $u$ & & \\
\hline SESPMNT & B16PK5 & PRIEST RAPIDS-RIVER & OFFSITE & sw & $\mathrm{Y}$ & RIVER & FILTER & 30-Apr-03 s & Sb-125 & $-0.000193 \mathrm{p}$ & $\mathrm{pCi} / \mathrm{L}$ & 0.0031 & 0.0031 & U & & \\
\hline SESPMNT & B16PL1 & PRIEST RAPIDS-RIVER & OFFSITE & sw & $\mathrm{Y}$ & RIVER & RESIN & 30-Apr-03 & Sb-125 & $-0.00345 p$ & $\mathrm{pCi} / \mathrm{L}$ & 0.0042 & 0.0042 & u & & \\
\hline SESPMNT & B16PK6 & PRIEST RAPIDS-RIVER & OFFSITE & sw & $\mathrm{Y}$ & RIVER & FILTER & 28-May-03s & Sb-125 & $0.00000978 \mathrm{p}$ & $\mathrm{pCi/L}$ & 0.0025 & 0.0025 & u & & \\
\hline SESPMNT & B16PL2 & PRIEST RAPIDS-RIVER & OFFSITE & sw & $\mathrm{Y}$ & RIVER & RESIN & 28-May-03 s & Sb-125 & $0.000303 \mathrm{p}$ & $\mathrm{pCi} / \mathrm{L}$ & 0.0034 & 0.0034 & $u$ & & \\
\hline SESPMNT & B16PK7 & PRIEST RAPIDS-RIVER & OFFSITE & sw & $\mathrm{Y}$ & RIVER & FILTER & 10-Jul-03 s & Sb-125 & $-0.000903 p$ & $\mathrm{pCi} / \mathrm{L}$ & 0.0019 & 0.0019 & U & & \\
\hline SESPMNT & B16PL3 & PRIEST RAPIDS-RIVER & OFFSITE & sw & $\mathrm{Y}$ & RIVER & RESIN & 10-Jul-03 & Sb-125 & $-0.000396 \mathrm{p}$ & $\mathrm{pCi} / \mathrm{L}$ & 0.0044 & 0.0044 & $u$ & & \\
\hline SESPMNT & B175H5 & PRIEST RAPIDS-RIVER & OFFSITE & sw & $\mathrm{Y}$ & RIVER & FILTER & 08-Aug-03 s & Sb-125 & $-0.00144 \mathrm{p}$ & $\mathrm{pCi} / \mathrm{L}$ & 0.0025 & 0.0025 & $u$ & & \\
\hline SESPMNT & B175J1 & PRIEST RAPIDS-RIVER & OFFSITE & sw & $\mathrm{Y}$ & RIVER & RESIN & 08-Aug-03 & Sb-125 & $-0.000892 p$ & $\mathrm{pCi} / \mathrm{L}$ & 0.0041 & 0.0041 & u & & \\
\hline SESPMNT & B175H6 & PRIEST RAPIDS-RIVER & OFFSITE & sw & $\mathrm{Y}$ & RIVER & FILTER & $03-S e p-03 \leqslant$ & Sb-125 & $0.000946 p$ & $\mathrm{pCi} / \mathrm{L}$ & 0.0026 & 0.0026 & $u$ & & \\
\hline SESPMNT & B175J2 & PRIEST RAPIDS-RIVER & OFFSITE & sw & $\mathrm{Y}$ & RIVER & RESIN & 03-Sep-03 & Sb-125 & $-0.00263 p$ & $\mathrm{pCi} / \mathrm{L}$ & 0.0059 & 0.0059 & $u$ & & \\
\hline SESPMNT & $\mathrm{B} 175 \mathrm{H} 7$ & PRIEST RAPIDS-RIVER & OFFSITE & sw & $Y$ & RIVER & FILTER & $30-$ Sep-03 s & Sb-125 & $0.000313 \mathrm{p}$ & $\mathrm{pCi} / \mathrm{L}$ & 0.0025 & 0.0025 & $u$ & & \\
\hline SESPMNT & B175J3 & PRIEST RAPIDS-RIVER & OFFSITE & sw & $\mathrm{Y}$ & RIVER & RESIN & $30-S e p-03$ & Sb-125 & $0.00374 \mathrm{p}$ & $\mathrm{pCi} / \mathrm{L}$ & 0.005 & 0.005 & $u$ & & \\
\hline SESPMNT & B17P40 & PRIEST RAPIDS-RIVER & OFFSITE & sw & $\mathrm{Y}$ & RIVER & FILTER & $29-0 c t-03 \leqslant$ & Sb-125 & $-0.00199 p$ & $\mathrm{pCi} / \mathrm{L}$ & 0.0024 & 0.0024 & u & & \\
\hline SESPMNT & B17P46 & PRIEST RAPIDS-RIVER & OFFSITE & sw & $\mathrm{Y}$ & RIVER & RESIN & $29-0 c t-03 s$ & Sb-125 & $0.000324 \mathrm{p}$ & $\mathrm{pCi} / \mathrm{L}$ & 0.0039 & 0.0039 & $u$ & & \\
\hline SESPMNT & B17P41 & PRIEST RAPIDS-RIVER & OFFSITE & sw & $Y$ & RIVER & FILTER & 25-Nov-03 s & Sb-125 & $-0.00166 \mathrm{p}$ & $\mathrm{pCi} / \mathrm{L}$ & 0.0025 & 0.0025 & $u$ & & \\
\hline SESPMNT & B17P47 & PRIEST RAPIDS-RIVER & OFFSITE & sw & $\mathrm{Y}$ & RIVER & RESIN & 25 -Nov-03 & Sb-125 & $0.00221 \mathrm{p}$ & $\mathrm{pCi} / \mathrm{L}$ & 0.0047 & 0.0047 & $u$ & & \\
\hline SESPMNT & B17P42 & PRIEST RAPIDS-RIVER & OFFSITE & sw & $\mathrm{Y}$ & RIVER & FILTER & 08-Jan-04 & Sb-125 & $0.000641 p$ & $\mathrm{pCi} / \mathrm{L}$ & 0.0015 & 0.0015 & u & & \\
\hline SESPMNT & B17P48 & PRIEST RAPIDS-RIVER & OFFSITE & sw & $\mathrm{Y}$ & RIVER & RESIN & 08-Jan-04 ؟ & Sb-125 & $-0.00149 p$ & $\mathrm{pCi} / \mathrm{L}$ & 0.0038 & 0.0038 & $u$ & & \\
\hline SESPMNT & B16892 & RICH.PMPHS HRM 46.4 & OFFSITE & sw & $Y$ & RIVER & FILTER & $05-\mathrm{Feb}-03$ s & Sb-125 & $0.000479 p$ & $\mathrm{pCi} / \mathrm{L}$ & 0.0017 & 0.0017 & $u$ & & \\
\hline SESPMNT & B16886 & RICH.PMPHS HRM 46.4 & OFFSITE & sw & $\mathrm{Y}$ & RIVER & RESIN & $05-\mathrm{Feb}-03$ & Sb-125 & $-0.0009 p$ & $\mathrm{pCi} / \mathrm{L}$ & 0.0035 & 0.0035 & $u$ & & \\
\hline SESPMNT & B16893 & RICH.PMPHS HRM 46.4 & OFFSITE & sw & $\mathrm{Y}$ & RIVER & FILTER & $05-\mathrm{Mar}-03 \mathrm{~s}$ & Sb-125 & $-0.000319 p$ & $\mathrm{pCi} / \mathrm{L}$ & 0.0021 & 0.0021 & u & & \\
\hline SESPMNT & B16887 & RICH.PMPHS HRM 46.4 & OFFSITE & sw & $\mathrm{Y}$ & RIVER & RESIN & $05-\mathrm{Mar}-03 \mathrm{~s}$ & Sb-125 & $0.00263 p$ & $\mathrm{pCi} / \mathrm{L}$ & 0.0048 & 0.0048 & u & & \\
\hline SESPMNT & B16894 & RICH.PMPHS HRM 46.4 & OFFSITE & sw & $\mathrm{Y}$ & RIVER & FILTER & 02-Apr-03 & Sb-125 & $0.000659 p$ & $\mathrm{pCilL}$ & 0.0017 & 0.0017 & $u$ & & \\
\hline SESPMNT & B16888 & RICH.PMPHS HRM 46.4 & OFFSITE & sw & $\mathrm{Y}$ & RIVER & RESIN & 02-Apr-03 s & Sb-125 & $-0.00265 p$ & $\mathrm{pCi} / \mathrm{L}$ & 0.0043 & 0.0043 & U & & \\
\hline SESPMNT & B16PM3 & RICH.PMPHS HRM 46.4 & OFFSITE & sw & $\mathrm{Y}$ & RIVER & FILTER & 30-Apr-03 s & Sb-125 & $0.00127 \mathrm{p}$ & $\mathrm{pCi} / \mathrm{L}$ & 0.0024 & 0.0024 & u & & \\
\hline SESPMNT & B16PL7 & RICH.PMPHS HRM 46.4 & OFFSITE & sw & $Y$ & RIVER & RESIN & 30-Apr-03\& $\&$ & Sb-125 & $-0.00141 \mathrm{p} \quad-\quad-2$ & $\mathrm{pCill}$ & 0.0038 & 0.0038 & $u$ & & \\
\hline
\end{tabular}


WATER - COLUMBIA RIVER FILTER/RESIN

\begin{tabular}{|c|c|c|c|c|c|c|c|c|c|c|c|c|c|c|c|c|}
\hline OWNER ID & |SAMP NUM | & SAMP SITE NAME & DIST CLASS & MEDIA & \begin{tabular}{|c|} 
FILTERED \\
FLAG
\end{tabular} & SAMP FROM & COLL MTHD & SAMP DATE & $\left|\begin{array}{c}\text { CON SHORT } \\
\text { NAME }\end{array}\right|$ & VALUE RPTD & $\mid$\begin{tabular}{|c|} 
ANAL \\
UNITS \\
RPTD
\end{tabular} & $\left|\begin{array}{c}\text { COUNTING } \\
\text { ERROR }\end{array}\right|$ & $\left|\begin{array}{c}\text { TOTAL ANAL } \\
\text { ERROR }\end{array}\right|$ & $\begin{array}{c}\text { LAB } \\
\text { QUALIFIER }\end{array}$ & SAMP COMMENT & |RESULT COMMENT \\
\hline SESPMNT & B16PM4 & RICH.PMPHS HRM 46.4 & OFFSITE & SW & $\mathrm{Y}$ & RIVER & FILTER & 28-May-03 & Sb-125 & -0.00234 & $\mathrm{pCi} / \mathrm{L}$ & 0.0025 & 0.0025 & u & & \\
\hline SESPMNT & B16PL8 & RICH.PMPHS HRM 46.4 & OFFSITE & sw & $Y$ & RIVER & RESIN & 28-May-03 s & Sb-125 & -0.000254 & $\mathrm{pCi} / \mathrm{L}$ & 0.0041 & 0.0041 & u & & \\
\hline SESPMNT & B16PM5 & RICH.PMPHS HRM 46.4 & OFFSITE & sW & $\mathrm{Y}$ & RIVER & FILTER & 10-Jul-03 s & Sb-125 & -0.00175 & $\mathrm{pCi} / \mathrm{L}$ & 0.0018 & 0.0018 & $u$ & & \\
\hline SESPMNT & B16PL9 & RICH.PMPHS HRM 46.4 & OFFSITE & sW & $\mathrm{Y}$ & RIVER & RESIN & 10-Jul-03 s & Sb-125 & 0.00248 & $\mathrm{pCi} / \mathrm{L}$ & 0.0046 & 0.0046 & u & & \\
\hline SESPMNT & B175K3 & RICH.PMPHS HRM 46.4 & OFFSITE & sW & $\mathrm{Y}$ & RIVER & FILTER & 08-Aug-03 $s$ & Sb-125 & -0.000551 & $\mathrm{pCi} / \mathrm{L}$ & 0.0023 & 0.0023 & U & & \\
\hline SESPMNT & B175J7 & RICH.PMPHS HRM 46.4 & OFFSITE & sw & Y & RIVER & RESIN & 08-Aug-03 & Sb-125 & 0.00135 & $\mathrm{pCi} / \mathrm{L}$ & 0.0047 & 0.0047 & U & & \\
\hline SESPMNT & B175K4 & RICH.PMPHS HRM 46.4 & OFFSITE & sw & Y & RIVER & FILTER & $03-$ Sep-03 s & Sb-125 & -0.000355 & $\mathrm{pCilL}$ & 0.004 & 0.004 & $u$ & & \\
\hline SESPMNT & B175J8 & RICH.PMPHS HRM 46.4 & OFFSITE & sW & $\mathrm{Y}$ & RIVER & RESIN & 03-Sep-03 s & Sb-125 & -0.000997 & $\mathrm{pCi} / \mathrm{L}$ & 0.0052 & 0.0052 & u & & \\
\hline SESPMNT & B175K5 & RICH.PMPHS HRM 46.4 & OFFSITE & sw & Y & RIVER & FILTER & $30-$ Sep-03 s & Sb-125 & -0.000169 & $\mathrm{pCi} / \mathrm{L}$ & 0.0043 & 0.0043 & $\mathrm{U}$ & & \\
\hline SESPMNT & B175J9 & RICH.PMPHS HRM 46.4 & OFFSITE & sw & $\mathrm{Y}$ & RIVER & RESIN & $30-$ Sep-03 s & Sb-125 & -0.00697 & $\mathrm{pCi} / \mathrm{L}$ & 0.0087 & 0.0087 & $\mathrm{u}$ & & \\
\hline SESPMNT & B17P58 & RICH.PMPHS HRM 46.4 & OFFSITE & sW & Y & RIVER & FILTER & $29-0 \mathrm{ct}-03 \mathrm{~s}$ & Sb-125 & -0.0000143 & $\mathrm{pCi} / \mathrm{L}$ & 0.0023 & 0.0023 & $u$ & & \\
\hline SESPMNT & B17P52 & RICH.PMPHS HRM 46.4 & OFFSITE & sW & $\mathrm{Y}$ & RIVER & RESIN & $29-0 c t-03 \leqslant$ & Sb-125 & 0.00126 & $\mathrm{pCi} / \mathrm{L}$ & 0.0041 & 0.0041 & U & & \\
\hline SESPMNT & B17P59 & RICH.PMPHS HRM 46.4 & OFFSITE & sw & Y & RIVER & FILTER & 25 -Nov-03 s & Sb-125 & -0.000583 & $\mathrm{pCi} / \mathrm{L}$ & 0.0027 & 0.0027 & U & & \\
\hline SESPMNT & B17P53 & RICH.PMPHS HRM 46.4 & OFFSITE & sW & $\mathrm{Y}$ & RIVER & RESIN & 25-Nov-03s & Sb-125 & -0.00365 & $\mathrm{pCi} / \mathrm{L}$ & 0.0044 & 0.0044 & $\mathrm{u}$ & & \\
\hline SESPMNT & B17P60 & RICH.PMPHS HRM 46.4 & OFFSITE & sw & Y & RIVER & FILTER & 08-Jan-04 § & Sb-125 & -0.000127 & $\mathrm{pCi} / \mathrm{L}$ & 0.0012 & 0.0012 & U & & \\
\hline SESPMNT & B17P54 & RICH.PMPHS HRM 46.4 & OFFSITE & sw & $\mathrm{Y}$ & RIVER & RESIN & $08-J a n-04 \leqq$ & Sb-125 & -0.000401 & $\mathrm{pCi} / \mathrm{L}$ & 0.0038 & 0.0038 & U & & \\
\hline SESPMNT & B16873 & PRIEST RAPIDS-RIVER & OFFSITE & sW & $\mathrm{Y}$ & RIVER & FILTER & 02-Apr-03 & Pu-238 & & & & & & & Sample Lost in Lab \\
\hline SESPMNT & B16879 & PRIEST RAPIDS-RIVER & OFFSITE & sW & Y & RIVER & RESIN & 02-Apr-03 & Pu-238 & -0.00000212 & $\mathrm{pCi} / \mathrm{L}$ & 0.000029 & 0.000029 & $u$ & & \\
\hline SESPMNT & B16PK4 & PRIEST RAPIDS-RIVER & OFFSITE & sw & $\mathrm{Y}$ & RIVER & FILTER & 10-Jul-03 F & Pu-238 & $-4.66 \mathrm{E}-08$ & $\mathrm{pCi} / \mathrm{L}$ & 0.000017 & 0.000017 & u & & \\
\hline SESPMNT & B16PL0 & PRIEST RAPIDS-RIVER & OFFSITE & sw & $\mathrm{Y}$ & RIVER & RESIN & 10-Jul-03 & Pu-238 & 0.000023 & $\mathrm{pCi} / \mathrm{L}$ & 0.000035 & 0.000036 & $\mathrm{U}$ & & \\
\hline SESPMNT & B175H4 & PRIEST RAPIDS-RIVER & OFFSITE & sW & $\mathrm{Y}$ & RIVER & FILTER & 30-Sep-03 & Pu-238 & 0.00000316 & $\mathrm{pCi} / \mathrm{L}$ & 0.0000066 & 0.0000068 & $\mathrm{U}$ & & \\
\hline SESPMNT & B175JO & PRIEST RAPIDS-RIVER & OFFSITE & sw & Y & RIVER & RESIN & 30-Sep-03 & Pu-238 & -0.00000212 & $\mathrm{pCi} / \mathrm{L}$ & 0.000061 & 0.000061 & u & & \\
\hline SESPMNT & B17P39 & PRIEST RAPIDS-RIVER & OFFSITE & sw & $\mathrm{Y}$ & RIVER & FILTER & 08-Jan-04 & Pu-238 & -0.000000105 & $\mathrm{pCi} / \mathrm{L}$ & 0.0000092 & 0.0000093 & u & & \\
\hline SESPMNT & B17P45 & PRIEST RAPIDS-RIVER & OFFSITE & sw & Y & RIVER & RESIN & $08-J a n-04$ F & Pu-238 & -0.0000117 & $\mathrm{pCi} / \mathrm{L}$ & 0.000023 & 0.000023 & $\mathrm{u}$ & & \\
\hline SESPMNT & B16891 & RICH.PMPHS HRM 46.4 & OFFSITE & sW & $\mathrm{Y}$ & RIVER & FILTER & 02-Apr-03 & Pu-238 & & & & & & & Sample Lost in Lab \\
\hline SESPMNT & B16885 & RICH.PMPHS HRM 46.4 & OFFSITE & sw & $\mathrm{Y}$ & RIVER & RESIN & 02-Apr-03 & Pu-238 & -0.0000155 & $\mathrm{pCi} / \mathrm{L}$ & 0.000026 & 0.000026 & $u$ & & \\
\hline SESPMNT & B16PM2 & RICH.PMPHS HRM 46.4 & OFFSITE & sw & $\mathrm{Y}$ & RIVER & FILTER & 10-Jul-03 & Pu-238 & 0.0000105 & $\mathrm{pCi/L}$ & 0.000015 & 0.000015 & u & & \\
\hline SESPMNT & B16PL6 & RICH.PMPHS HRM 46.4 & OFFSITE & sw & Y & RIVER & RESIN & 10-Jul-03 & Pu-238 & -0.00000173 & $\mathrm{pCi} / \mathrm{L}$ & 0.00006 & 0.00006 & u & & \\
\hline SESPMNT & B175K2 & RICH.PMPHS HRM 46.4 & OFFSITE & sw & $\mathrm{Y}$ & RIVER & FILTER & 30-Sep-03 & Pu-238 & -0.00000752 & $\mathrm{pCi} / \mathrm{L}$ & 0.000015 & 0.000015 & U & & \\
\hline SESPMNT & B175J6 & RICH.PMPHS HRM 46.4 & OFFSITE & sw & Y & RIVER & RESIN & 30-Sep-03 & Pu-238 & 0.0000408 & $\mathrm{pCi} / \mathrm{L}$ & 0.000087 & 0.000087 & u & & \\
\hline SESPMNT & B17P57 & RICH.PMPHS HRM 46.4 & OFFSITE & sw & $\mathrm{Y}$ & RIVER & FILTER & 08-Jan-04 & Pu-238 & -0.00000302 & $\mathrm{pCi/L}$ & 0.0000058 & 0.000006 & u & & \\
\hline SESPMNT & B17P51 & RICH.PMPHS HRM 46.4 & OFFSITE & sw & Y & RIVER & RESIN & $08-J a n-04$ F & Pu-238 & & $\mathrm{pCi} / \mathrm{L}$ & 0.000026 & 0.000026 & $\mathrm{u}$ & & \\
\hline SESPMNT & B16873 & PRIEST RAPIDS-RIVER & OFFSITE & sW & $\mathrm{Y}$ & RIVER & FILTER & 02-Apr-03 & Pu-239/240 & & & & & & & Sample Lost in Lab \\
\hline SESPMNT & B16879 & PRIEST RAPIDS-RIVER & OFFSITE & sw & Y & RIVER & RESIN & 02-Apr-03 & $\mathrm{Pu}-239 / 240$ & 0.0000119 & $\mathrm{pCi} / \mathrm{L}$ & 0.000041 & 0.000041 & $u$ & & \\
\hline SESPMNT & B16PK4 & PRIEST RAPIDS-RIVER & OFFSITE & sw & $\mathrm{Y}$ & RIVER & FILTER & 10-Jul-03 & Pu-239/240 & 0.0000534 & $\mathrm{pCi/L}$ & 0.000036 & 0.000037 & & & \\
\hline SESPMNT & B16PL0 & PRIEST RAPIDS-RIVER & OFFSITE & sw & $\mathrm{Y}$ & RIVER & RESIN & 10-Jul-03 & Pu-239/240 & 0.000025 & $\mathrm{pCi} / \mathrm{L}$ & 0.000035 & 0.000036 & $\mathrm{u}$ & & \\
\hline SESPMNT & B175H4 & PRIEST RAPIDS-RIVER & OFFSITE & sw & $Y$ & RIVER & FILTER & 30-Sep-03 & $\mathrm{Pu}-239 / 240$ & 0.0000139 & $\mathrm{pCi} / \mathrm{L}$ & 0.000015 & 0.000015 & U & & \\
\hline SESPMNT & B175JO & PRIEST RAPIDS-RIVER & OFFSITE & sw & Y & RIVER & RESIN & 30-Sep-03 & $\mathrm{Pu}-239 / 240$ & 0.000025 & $\mathrm{pCi} / \mathrm{L}$ & 0.00005 & 0.00005 & u & & \\
\hline SESPMNT & B17P39 & PRIEST RAPIDS-RIVER & OFFSITE & sw & Y & RIVER & FILTER & 08-Jan-04 & $\mathrm{Pu}-239 / 240$ & 0.0000176 & $\mathrm{pCi} / \mathrm{L}$ & 0.000016 & 0.000016 & & & \\
\hline SESPMNT & B17P45 & PRIEST RAPIDS-RIVER & OFFSITE & sw & $\mathrm{Y}$ & RIVER & RESIN & $08-J a n-04$ F & Pu-239/240 & 0.0000233 & $\mathrm{pCi} / \mathrm{L}$ & 0.000033 & 0.000033 & $\mathrm{u}$ & & \\
\hline SESPMNT & B16891 & RICH.PMPHS HRM 46.4 & OFFSITE & sw & Y & RIVER & FILTER & $02-A p r-03$ & $\mathrm{Pu}-239 / 240$ & & & & & & & Sample Lost in Lab \\
\hline SESPMNT & B16885 & RICH.PMPHS HRM 46.4 & OFFSITE & sw & Y & RIVER & RESIN & 02-Apr-03 & Pu-239/240 & 0.0000131 & $\mathrm{pCi} / \mathrm{L}$ & 0.000026 & 0.000026 & u & & \\
\hline SESPMNT & B16PM2 & RICH.PMPHS HRM 46.4 & OFFSITE & sw & $\mathrm{Y}$ & RIVER & FILTER & 10-Jul-03 & Pu-239/240 & 0.0000887 & $\mathrm{pCi} / \mathrm{L}$ & 0.000043 & 0.000046 & & & \\
\hline SESPMNT & B16PL6 & RICH.PMPHS HRM 46.4 & OFFSITE & sw & $\mathrm{Y}$ & RIVER & RES & 10-Jul-03 & Pu-239/240 & & $\mathrm{pCi} / \mathrm{L}$ & & 0.00006 & $u$ & & \\
\hline SESPMNT & B175K2 & RICH.PMPHS HRM 46.4 & OFFSITE & sw & Y & RIVER & FILTER & 30-Sep-03 & $\mathrm{Pu}-239 / 240$ & 0.0000406 & $\mathrm{pCi} / \mathrm{L}$ & 0.000036 & 0.000037 & & & \\
\hline SESPMNT & B175J6 & RICH.PMPHS HRM 46.4 & OFFSITE & sw & Y & RIVER & RESIN & 30-Sep-03 & $\mathrm{Pu}-239 / 240$ & 0.0000432 & $\mathrm{pCi} / \mathrm{L}$ & 0.000061 & 0.000062 & $\mathrm{u}$ & & \\
\hline SESPMNT & B17P57 & SHRM 464 & OFESITE & SW & Y & RIVER & FEUTER & & & 0 & & 0 & 0000013 & 4 & & \\
\hline SESPMNT & 17 P51 & RICH.PMPHS HRM 46.4 & DFFSITE & sw & Y & RIVER & RESIN & 08 & 240 & 0.000 & Ci/L & 00003 & .00003 & & & \\
\hline
\end{tabular}


WATER - COLUMBIA RIVER SHORELINE SPRINGS

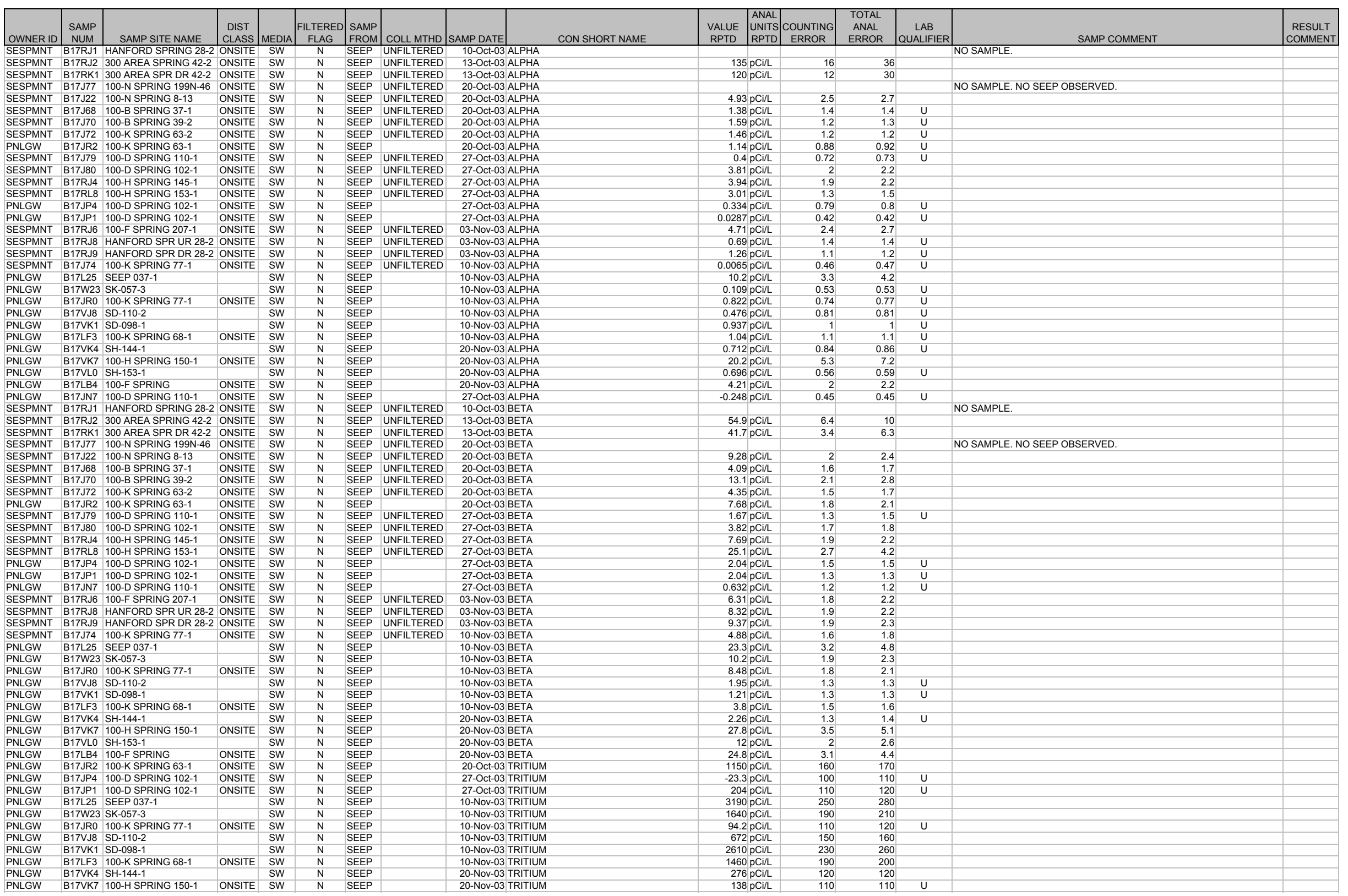




\begin{tabular}{|c|c|c|c|c|c|c|c|c|c|c|c|c|c|c|c|}
\hline OWNER ID & \begin{tabular}{|l|} 
SAMP \\
NUM
\end{tabular} & SAMP SITE NAME & $\left|\begin{array}{c}\text { DIST } \\
\text { CLASS }\end{array}\right|$ & $\mid$ MEDIA $\mid$ & \begin{tabular}{|c|} 
FILTERED \\
FLAG
\end{tabular} & $\begin{array}{l}\text { SAMP } \\
\text { FROM }\end{array}$ & $\mid$ COLL MTHD $\mid$ & |SAMP DATE $\quad$ CON SHORT NAME & $\begin{array}{c}\text { VALUE } \\
\text { RPTD }\end{array}$ & $\begin{array}{l}\text { ANAL } \\
\text { UNITS } \\
\text { RPTD }\end{array}$ & $\begin{array}{c}\text { COUNTING } \\
\text { ERROR }\end{array}$ & $\begin{array}{l}\text { TOTAL } \\
\text { ANAL } \\
\text { ERROR }\end{array}$ & $\left|\begin{array}{c}\text { LAB } \\
\text { QUALIFIER }\end{array}\right|$ & SAMP COMMENT & $\left|\begin{array}{c}\text { RESULT } \\
\text { COMMENT }\end{array}\right|$ \\
\hline PNLGW & & SH-153-1 & & SW & & & & 20-Nov-03 TRITIUM & & & ERKUK & 120 & & SAMPL CUIVIVIIIII & \\
\hline PNLGW & B17LB4 & 100-F SPRING & ONSITE & sw & $\mathrm{N}$ & SEEP & & 20-Nov-03 TRITIUM & $800 \mathrm{p}$ & $\mathrm{pCi/L}$ & 140 & 150 & & & \\
\hline SESPMNT & B17J77 & 100-N SPRING 199N-46 & ONSITE & sw & $\mathrm{N}$ & SEEP & UNFILTERED & 20-Oct-03 GAMMA SCAN & & & & & & NO SAMPLE. NO SEEP OBSERVED. & \\
\hline SESPMNT & B17J74 & 100-K SPRING 77-1 & ONSITE & sW & $\mathrm{N}$ & SEEP & UNFILTERED & 10-Nov-03 Be-7 & & pCill & 20 & 20 & u & & \\
\hline PNLGW & B17JR0 & 100-K SPRING 77-1 & ONSITE & sw & N & SEEP & & 10-Nov-03 Be-7 & & & 39 & 39 & u & & \\
\hline $\begin{array}{l}\text { PNLGW } \\
\text { SESPMNT }\end{array}$ & $\begin{array}{l}\text { B17W23 } \\
\text { B17R6 }\end{array}$ & $\begin{array}{l}\text { SK-057-3 } \\
100 \text {-F SPRING } 207-1\end{array}$ & ONSITE & SW & $\mathrm{N}$ & SEEP & & 10-Nov-03 Be-7 & & & 27 & 27 & U & & \\
\hline SESPMNT & 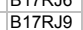 & HANFORD SPR DR 28-2 & ONSITE & SW & $\begin{array}{c}n \\
N\end{array}$ & $\begin{array}{l}\text { SEEP } \\
\text { SEEP }\end{array}$ & $\begin{array}{l}\text { UNFITLRED } \\
\text { UNFILTERED }\end{array}$ & $\begin{array}{l}\text { 03-Nov-03 Be-7 } \\
\text { 0-Nov-03 Be-7 }\end{array}$ & & pCi/L & 22 & 22 & $\mathrm{U}$ & & \\
\hline SESPMNT & B17RJ8 & HANFORD SPR UR 28-2 & ONSITE & sw & $\mathrm{N}$ & SEEP & UNFILTERED & $\begin{array}{l}\text { 03-Nov-033 Be-7 } \\
\text { 03-Nov-03 Be-7 }\end{array}$ & & $\begin{array}{l}\text { pint } \\
\text { pCill }\end{array}$ & $\begin{array}{l}23 \\
23\end{array}$ & ${ }_{23}^{23}$ & u & & \\
\hline SESPMNT & B17J80 & 100-D SPRING 102-1 & ONSITE & sw & $\mathrm{N}$ & SEEP & UNFILTERED & $27-\mathrm{Oct}-03 \mathrm{Be}-7$ & & & 20 & 20 & U & & \\
\hline SESPMNT & B17J79 & 100-D SPRING 110-1 & ONSITE & SW & $\mathrm{N}$ & SEEP & UNFILTERED & 27-Oct-03 Be-7 & & & 20 & 20 & u & & \\
\hline SESPMNT & B17RJ4 & 100-H SPRING 145-1 & ONSITE & SW & $N$ & SEEP & UNFILTERED & 27-Oct-03 Be-7 & & & 20 & 20 & $u$ & & \\
\hline $\begin{array}{l}\text { SESPMNT } \\
\text { SESPMNT }\end{array}$ & $\begin{array}{l}\text { B17RL8 } \\
\text { B171708 }\end{array}$ & 100-H SPRING 153-1 & ONSITE & SW & $N$ & $\begin{array}{l}\text { SEEP } \\
\text { SEEP }\end{array}$ & $\begin{array}{l}\text { UNFILTERED } \\
\end{array}$ & 27-Oct-03 Be-7 & $-10 p$ & & 22 & 22 & U & & \\
\hline $\begin{array}{l}\text { SESPMNT } \\
\text { SESPMNT }\end{array}$ & $\begin{array}{l}\text { B17J68 } \\
\text { B17770 }\end{array}$ & $\begin{array}{l}\text { 100-B SPRING 37-1 } \\
\text { 100-B SPRING 39-2 }\end{array}$ & $\begin{array}{l}\text { ONITE } \\
\text { ONSITE }\end{array}$ & $\begin{array}{l}\text { SW } \\
\text { sw }\end{array}$ & $\begin{array}{r}n \\
N\end{array}$ & $\begin{array}{l}\text { SEEP } \\
\text { SEEP }\end{array}$ & $\begin{array}{l}\text { UNFFLTERED } \\
\text { UNFITERED }\end{array}$ & $\begin{array}{l}\text { 20-Oct-03 Be-7 } \\
\text { 20-Oct-03 B Be-7 }\end{array}$ & $\begin{array}{r}4.95 p \\
-1.53 \mathrm{p}\end{array}$ & $\begin{array}{l}\mathrm{pC} \text { Ci/L } \\
\mathrm{pC} \text { C// }\end{array}$ & $\begin{array}{l}20 \\
19\end{array}$ & $\begin{array}{l}20 \\
19\end{array}$ & u & & \\
\hline $\begin{array}{l}\text { SESPMNI } \\
\text { SESPMNT }\end{array}$ & B17J72 & $\begin{array}{l}\text { 100-B SPRING 39-2 } \\
\text { 100-K SPRING 63-2 }\end{array}$ & $\begin{array}{l}\text { ONSIT } \\
\text { ONSITE }\end{array}$ & SW & $\mathrm{N}$ & $\begin{array}{l}\text { SEEP } \\
\text { SEEP }\end{array}$ & $\begin{array}{l}\text { UNFILIERED } \\
\text { UNFILTERED }\end{array}$ & $\begin{array}{l}20-\text {-Oct-033 Be-7 } \\
20 \text {-Oct-03 Be- } 7\end{array}$ & $\begin{array}{l}-1.53 \mathrm{p} \\
-13.2 \mathrm{p} \\
\mathrm{s}\end{array}$ & & $\begin{array}{l}19 \\
18\end{array}$ & $\begin{array}{l}19 \\
18\end{array}$ & $\frac{u}{u}$ & & \\
\hline SESPMNT & B17J22 & 100-N SPRING 8-13 & ONSITE & SW & $\mathrm{N}$ & SEEP & UNFILTERED & $20-O c t-03$ Be-7 & $5.47 \mathrm{p}$ & $\mathrm{pCilL}$ & 15 & 15 & U & & \\
\hline SESPMNT & B17RK1 & 300 AREA SPR DR 42-2 & ONSITE & SW & $\mathrm{N}$ & & UNFILTERED & 13-Oct-03 Be-7 & & & & & $u$ & & \\
\hline SESPMNT & B17RJ2 & 300 AREA SPRING 42-2 & & SW & $\mathrm{N}$ & SEEP & UNFILTERED & 13-Oct-03 Be-7 & & & 16 & 16 & u & & \\
\hline SESPMNT & B17J74 & 100-K SPRING 77-1 & ONSITE & sw & & & UNFILTERED & 10-Nov-03 Co-60 & $-0.788 \mathrm{p}$ & & 26 & & u & & \\
\hline PNLGW & B17JRO & 100-K SPRING 77-1 & ONSITE & sw & $\mathrm{N}$ & SEEP & & 10-Nov-03 Co-60 & $-1.09 \mathrm{p}$ & & 2.8 & 2.8 & u & & \\
\hline PNLGW & B17W23 & SK-057-3 & & sw & $\mathrm{N}$ & SEEP & & 10-Nov-03 Co-60 & $0.265 \mathrm{p}$ & & 2.6 & 2.6 & U & & \\
\hline SESPMNT & B17RJ6 & 100-F SPRING 207-1 & ONSITE & sw & $\mathrm{N}$ & SEEP & UNFILTERED & 03-Nov-03 Co-60 & $-0.64 \mathrm{p}$ & & 2.5 & 2.5 & u & & \\
\hline SESPMNT & B17RJ9 & HANFORD SPR DR 28-2 & ONSITE & SW & $\mathrm{N}$ & SEEP & UNFILTERED & 03-Nov-03 Co-60 & $0.622 \mathrm{p}$ & & 2.4 & 2.4 & U & & \\
\hline SESPMNT & B17RJ8 & HANFORD SPR UR 28-2 & ONSITE & SW & $\mathrm{N}$ & SEEP & UNFILTERED & 03-Nov-03 Co-60 & $0.616 \mathrm{p}$ & & 2.3 & 2.3 & u & & \\
\hline SESPMNT & B17J80 & 100-D SPRING 102-1 & ONSITE & SW & $N$ & SEEP & UNFILTERED & 27-Oct-03 Co-60 & $0.276 \mathrm{p}$ & & 2.3 & 2.3 & $u$ & & \\
\hline $\begin{array}{l}\text { SESPMNT } \\
\text { SESPMNT }\end{array}$ & $\begin{array}{l}\text { B17J79 } \\
\text { B17R/4 }\end{array}$ & 100-D SPRING 110-1 & ONSITE & SW & $\mathrm{N}$ & $\begin{array}{l}\text { SEEP } \\
\text { SEEP }\end{array}$ & $\begin{array}{l}\text { UNFILTERED } \\
\text {. }\end{array}$ & 27-Oct-03 Co-60 & $0.992 p$ & & 2.7 & 2.7 & U & & \\
\hline $\begin{array}{l}\text { SESPMNT } \\
\text { SESPMNT }\end{array}$ & $\begin{array}{l}\text { B17RJ4 } \\
\text { B17R8 }\end{array}$ & $\begin{array}{l}\text { 100-H SPRING 145-1 } \\
100-H \text { SPRING 153-1 }\end{array}$ & $\begin{array}{l}\text { ONITE } \\
\text { ONSITE }\end{array}$ & $\begin{array}{l}\text { SW } \\
\text { SW }\end{array}$ & $\frac{N}{N}$ & $\begin{array}{l}\text { SEEP } \\
\text { SEEP }\end{array}$ & $\begin{array}{l}\text { UNFILTERED } \\
\text { UNFITERED }\end{array}$ & $\begin{array}{l}27-\text { Oct-03 Сo-60 } \\
\text { 27-0ct-03 Co-60 }\end{array}$ & $0.78 \mathrm{p}$ & pCi/L & 2.4 & 2.4 & 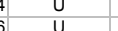 & & \\
\hline $\begin{array}{l}\text { SESPMNI } \\
\text { SESPMNT }\end{array}$ & $\begin{array}{l}\text { B1/RRL8 } \\
\text { B17J68 }\end{array}$ & 100-B SPRING 37-1 & $\begin{array}{l}\text { ONSITE } \\
\text { ONIT }\end{array}$ & SW & $\frac{n}{n}$ & $\begin{array}{l}\text { SEEP } \\
\text { SEEP }\end{array}$ & $\begin{array}{l}\text { UNFILTERED } \\
\text { UNFILRED }\end{array}$ & $\begin{array}{l}21-\mathrm{Oct}-03 \mathrm{Co}-60 \\
20-\mathrm{Oct}-03 \mathrm{Co}-60\end{array}$ & $\begin{array}{l}1.15 \mathrm{p} \\
0.967 \mathrm{p}\end{array}$ & $\begin{array}{l}\mathrm{pCC/L} \\
\mathrm{pCi/L}\end{array}$ & 2.6 & $\begin{array}{l}2.6 \\
2.3\end{array}$ & u & & \\
\hline SESPMNT & B17J70 & 100-B SPRING 39-2 & ONSITE & sW & $\mathrm{N}$ & SEEP & UNFILTERED & 20-Oct-03 Co-60 & $1.04 \mathrm{p}$ & $\mathrm{pCilL}$ & 2.5 & 2.5 & U & & \\
\hline SESPMNT & B17J72 & 100-K SPRING 63-2 & ONSITE & SW & $\mathrm{N}$ & SEEP & UNFILTERED & 20-Oct-03 Co-60 & $-1.5 p$ & pCill & 1.7 & 1.7 & u & & \\
\hline SESPMNT & B17J22 & 100-N SPRING 8-13 & ONSITE & SW & $N$ & SEEP & UNFILTERED & 20-Oct-03 Co-60 & $0.969 \mathrm{p}$ & & 1.7 & 1.7 & U & & \\
\hline $\begin{array}{l}\text { SESPMNT } \\
\text { SESPMNT }\end{array}$ & B17RK1 & 300 AREA SPR DR 42-2 & ONSITE & SW & $\mathrm{N}$ & $\begin{array}{l}\text { SEEP } \\
\text { SEEP }\end{array}$ & $\begin{array}{l}\text { UNFILTERED } \\
\text {. }\end{array}$ & 13-Oct-03 Co-60 & $\begin{array}{l}-1.72 p \\
-0591 p\end{array}$ & pCi/L & 3.2 & 3.2 & U & & \\
\hline $\begin{array}{l}\text { SESPMNT } \\
\text { SESPMNT }\end{array}$ & 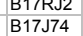 & $\begin{array}{l}\text { 300 AREA SPRING 42-2 } \\
\text { 100-K SPRING 77-1 }\end{array}$ & $\begin{array}{l}\text { ONITE } \\
\text { ONSITE }\end{array}$ & $\begin{array}{l}\text { SW } \\
\text { SW }\end{array}$ & ${ }_{N}^{N}$ & $\begin{array}{l}\text { SEEP } \\
\text { SEEP }\end{array}$ & $\begin{array}{l}\text { UNFITLRED } \\
\text { UNFILTERED }\end{array}$ & $\begin{array}{l}\text { 13-OCtc-03 Co-60 } \\
\text { 10-Nov-03 Cs-134 }\end{array}$ & $\begin{array}{l}-0.591 \mathrm{p} \\
-0.321 \mathrm{p}\end{array}$ & $\begin{array}{l}\text { pCill } \\
\text { pCill }\end{array}$ & $\begin{array}{l}2.1 \\
2.5\end{array}$ & $\begin{array}{l}2.1 \\
2.5\end{array}$ & u & & \\
\hline PNLGW & B17JRO & 100-K SPRING 77-1 & ONSITE & sw & $\mathrm{N}$ & SEEP & & 10-Nov-03 Cs-134 & $-1.44 \mathrm{p}$ & $\mathrm{pCi/L}$ & 3.4 & 3.4 & u & & \\
\hline PNLGW & B17W23 & SK-057-3 & & SW & $\mathrm{N}$ & SEEP & & 10-Nov-03 Cs-134 & $3.25 \mathrm{p}$ & $\mathrm{pCilL}$ & 2.7 & 2.7 & U & & \\
\hline SESPMNT & B17RJ6 & 100-F SPRING 207-1 & ONSITE & SW & $\mathrm{N}$ & SEEP & UNFILTERED & 03-Nov-03 Cs-134 & $-0.215 p$ & & 2.7 & 2.7 & u & & \\
\hline SESPMNT & B17RJ9 & HANFORD SPR DR 28-2 & ONSITE & SW & $N$ & $\begin{array}{l}\text { SEEP } \\
\text { SEEP }\end{array}$ & $\begin{array}{l}\text { UNFILTERED } \\
\end{array}$ & 03-Nov-03 Cs-134 & $0.667 \mathrm{p}$ & pCill & 2.7 & 2.7 & U & & \\
\hline $\begin{array}{l}\text { SESPMNT } \\
\text { SESPMNT }\end{array}$ & $\begin{array}{l}\text { B17RJ8 } \\
\text { B17.170 }\end{array}$ & HANFORD SPR UR 28-2 & ONSITE & SW & $\begin{array}{r}\mathrm{N} \\
\mathrm{N}\end{array}$ & $\begin{array}{l}\text { SEEP } \\
\text { SEFP }\end{array}$ & $\begin{array}{l}\text { UNFILTERED } \\
\text { UNFUTFRFD }\end{array}$ & 03-Nov-03 Cs-134 & $\begin{array}{r}-0.79 p \\
-0.59 p\end{array}$ & pCi/L & 2.6 & 2.6 & $u$ & & \\
\hline $\begin{array}{l}\text { SESPMNT } \\
\text { SESPMNT }\end{array}$ & $\begin{array}{l}\text { B17880 } \\
\text { B17J79 }\end{array}$ & $\begin{array}{l}\text { 100-D SPRIIG 102-1 } \\
\text { 100-D SPRING 110-1 }\end{array}$ & $\begin{array}{l}\text { ONSITE } \\
\text { ONSITE }\end{array}$ & $\begin{array}{l}\text { SW } \\
\text { SW }\end{array}$ & $\frac{N}{n}$ & $\begin{array}{l}\text { SEEP } \\
\text { SEEP }\end{array}$ & $\begin{array}{l}\text { UNFITIERED } \\
\text { UNFILTERED }\end{array}$ & $\begin{array}{l}27-\text { OCt-03 Cs- } 134 \\
27-0 \text { ct- } 03 \text { Cs-134 }\end{array}$ & $\begin{array}{l}-0.519 \mathrm{p} \\
2.98 \mathrm{p}\end{array}$ & $\begin{array}{l}p \mathrm{pCi} / \mathrm{L} \\
\mathrm{pC} / \mathrm{h}\end{array}$ & $\begin{array}{l}2.5 \\
2.8\end{array}$ & $\frac{2.5}{28}$ & u & & \\
\hline SESPMNT & B17RJ4 & 100-H SPRING 145-1 & ONSITE & sw & $\mathrm{N}$ & SEEP & UNFILTERED & $27-\mathrm{Oct}-03$ Cs-134 & $-1.01 \mathrm{p}$ & pCi/L & 2.7 & 2.7 & u & & \\
\hline SESPMNT & B17RL8 & 100-H SPRING 153-1 & ONSITE & SW & $\mathrm{N}$ & SEEP & UNFILTERED & 27-Oct-03 Cs-134 & $-0.36 p$ & $\mathrm{pCi} / \mathrm{L}$ & 2.5 & 2.5 & u & & \\
\hline SESPMNT & B17J68 & 100-B SPRING 37-1 & ONSITE & SW & $\mathrm{N}$ & SEEP & UNFILTERED & 20-Oct-03 Cs-134 & $2.03 p$ & $\mathrm{pCilL}$ & 2.7 & 2.7 & U & & \\
\hline $\begin{array}{l}\text { SESPMNT } \\
\text { SESPMNT }\end{array}$ & B17J70 & 100-B SPRING 39-2 & $\begin{array}{l}\text { ONSITE } \\
\text { ONITE }\end{array}$ & & $N$ & $\begin{array}{l}\text { SEEP } \\
\text { SEEP }\end{array}$ & $\begin{array}{l}\text { UNFILTERED } \\
\text {. }\end{array}$ & 20-Oct-03 Cs-134 & $0.901 \mathrm{p}$ & pCi/L & 2.1 & 2.1 & U & & \\
\hline $\begin{array}{l}\text { SESPMNT } \\
\text { SESPMNT }\end{array}$ & $\begin{array}{l}\text { B17J72 } \\
\text { B17.122 }\end{array}$ & $\begin{array}{l}\text { 100-K SPRING 63-2 } \\
100 \text { N SPRING 8-13 }\end{array}$ & $\begin{array}{l}\text { ONITE } \\
\text { ONSITE }\end{array}$ & $\begin{array}{l}\text { SW } \\
\text { sw }\end{array}$ & $\frac{N}{N}$ & $\begin{array}{l}\text { SEEP } \\
\text { SEFP }\end{array}$ & $\begin{array}{l}\text { UNFILTERED } \\
\text { UNFUTFRFD }\end{array}$ & 20-Oct-03 Cs-134 & $\begin{array}{l}-0.547 p \\
-108 p \\
-10\end{array}$ & pCi/L & 1.9 & $\begin{array}{l}1.9 \\
1.9\end{array}$ & U & & \\
\hline $\begin{array}{l}\text { SESPMNT } \\
\text { SESPMNT }\end{array}$ & $\begin{array}{l}\text { B17J22 } \\
\text { B17RK1 }\end{array}$ & $\begin{array}{l}100-N \text { SPRING 8- } 13 \\
300 \text { AREA SPR DR 42-2 }\end{array}$ & $\begin{array}{l}\text { ONSITE } \\
\text { ONSITE }\end{array}$ & $\begin{array}{l}\text { SW } \\
\text { sw }\end{array}$ & $\mathrm{N}$ & $\begin{array}{l}\text { SEEP } \\
\text { SEEP }\end{array}$ & $\begin{array}{l}\text { UNFITIERED } \\
\text { UNFITTERED }\end{array}$ & $\begin{array}{l}20-\text {-ct-03 C- C- } 134 \\
13 \text {-Cct-03 Cs-134 }\end{array}$ & $\begin{array}{r}-1.08 \mathrm{p} \\
-1.28 \mathrm{p}\end{array}$ & $\begin{array}{l}p \mathrm{pCi} / \mathrm{L} \\
\mathrm{pCilh}\end{array}$ & $\frac{1.9}{22}$ & $\begin{array}{l}1.9 \\
2.2\end{array}$ & u & & \\
\hline $\begin{array}{l}\text { SESPMNI } \\
\text { SESPMNT }\end{array}$ & $\begin{array}{l}\text { BD/RK1 } \\
\text { B17RJ2 }\end{array}$ & $\begin{array}{l}300 \text { AREA SPR DR 42-2 } \\
300 \text { AREA SPRING 42-2 }\end{array}$ & ONSITE & sw & $\mathrm{N}$ & $\begin{array}{l}\text { SEEP } \\
\text { SEEP }\end{array}$ & $\begin{array}{l}\text { UNFILIERED } \\
\text { UNFILTERED }\end{array}$ & $\begin{array}{l}13-\mathrm{Clt}-03 \text { Cs-1744 } \\
13-\mathrm{Oct}-03 \text { Cs-134 }\end{array}$ & $\begin{array}{l}-1.28 \mathrm{p} \\
0.374 \mathrm{p}\end{array}$ & $\begin{array}{l}\mathrm{pCC/L} \\
\mathrm{pCil}\end{array}$ & $\begin{array}{l}2.2 \\
1.8\end{array}$ & $\begin{array}{l}2.2 \\
1.8\end{array}$ & u & & \\
\hline SESPMNT & B17J74 & 100-K SPRING 77-1 & ONSITE & sW & $\mathrm{N}$ & SEEP & UNFILTERED & 10-Nov-03 Cs-137 & $0.04 \mathrm{p}$ & & 26 & 26 & u & & \\
\hline PNLGW & B17J0 & $100-K$ SPING 7-1 & ONSITE & sw & $\mathrm{N}$ & SEEP & & $03 \mathrm{Cs}-137$ & 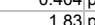 & & 22 & 220 & u & & \\
\hline PNLGW & B17W23 & SK-057-3 & & sw & $\begin{array}{lllll}n & \end{array}$ & SEFP & & 10-Nov-03 Cs-137 & $0.747 \mathrm{p}$ & & 26 & 26 & $u$ & & \\
\hline SESPMNT & B17RJ6 & 100-F SPRING 207-1 & ONSITE & sW & $\mathrm{N}$ & SEEP & UNFILTERED & 03-Nov-03 Cs-137 & $0.0784 \mathrm{p}$ & $\mathrm{pCi/L}$ & 2.5 & 2.5 & U & & \\
\hline SESPMNT & B17RJ9 & HANFORD SPR DR 28-2 & ONSITE & SW & $\mathrm{N}$ & SEEP & UNFILTERED & 03-Nov-03 Cs-137 & $-0.53 p$ & & 2.4 & 2.4 & $u$ & & \\
\hline SESPMNT & B17RJ8 & HANFORD SPR UR 28-2 & ONSITE & sw & $\mathrm{N}$ & SEEP & UNFILTERED & 03-Nov-03 Cs-137 & $1.39 \mathrm{p}$ & $\mathrm{pCi/L}$ & 2.6 & 2.6 & u & & \\
\hline SESPMNT & B17J80 & 100-D SPRING 102-1 & ONSITE & sW & $\mathrm{N}$ & SEEP & UNFILTERED & 27-Oct-03 Cs-137 & $0.151 \mathrm{p}$ & & 2.6 & 2.6 & U & & \\
\hline SESPMNT & B17J79 & 100-D SPRING 110-1 & ONSITE & SW & $\mathrm{N}$ & SEEP & UNFILTERED & 27-Oct-03 Cs-137 & $-0.339 \mathrm{p}$ & & 2.8 & 2.8 & U & & \\
\hline SESPMNT & B17RJ4 & 100-H SPRING 145-1 & ONSITE & SW & $\mathrm{N}$ & SEEP & UNFILTERED & 27-Oct-03 Cs-137 & $-0.82 \mathrm{p}$ & $\mathrm{pCi} / \mathrm{L}$ & 2.4 & 2.4 & $u$ & & \\
\hline $\begin{array}{l}\text { SESPMNT } \\
\text { SESPMNT }\end{array}$ & B17RL8 & 100-H SPRING 153-1 & ONSITE & SW & $N$ & $\begin{array}{l}\text { SEEP } \\
\text { SEEP }\end{array}$ & $\begin{array}{l}\text { UNFILTERED } \\
\text { UNFU TFRFD }\end{array}$ & 27-Oct-03 Cs-137 & $\begin{array}{l}-0.191 \mathrm{p} \\
.128 \mathrm{n}\end{array}$ & pCi/L & 2.1 & 2.1 & 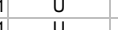 & & \\
\hline $\begin{array}{l}\text { SESPMNT } \\
\text { SESPMNT }\end{array}$ & $\begin{array}{l}\text { B176688 } \\
\text { B17J70 }\end{array}$ & $\begin{array}{l}100-\text { - S SPRING } 37-1 \\
\text { 100-B SPRING 39-2 }\end{array}$ & $\begin{array}{l}\text { ONITE } \\
\text { ONSITE }\end{array}$ & $\begin{array}{l}\text { SW } \\
\text { SW }\end{array}$ & $\frac{N}{N}$ & $\begin{array}{l}\text { SEEP } \\
\text { SEEP }\end{array}$ & $\begin{array}{l}\text { UNFITLRED } \\
\text { UNFLTEREDED }\end{array}$ & $\begin{array}{l}20-\text { O-Otc-03 Cs-1377 } \\
20 \text {-oct-03 Cs-137 }\end{array}$ & $\begin{array}{r}1.38 \mathrm{p} \\
-0.776 \mathrm{p}\end{array}$ & $\begin{array}{l}\text { pCin } \\
\text { pCill }\end{array}$ & $\begin{array}{l}2.1 \\
2.3\end{array}$ & $\begin{array}{l}2.1 \\
2.3\end{array}$ & u & & \\
\hline SESPMNT & B17J72 & 100-K SPRING 63-2 & ONSITE & sw & $\mathrm{N}$ & SEEP & UNFILTERED & 20-Oct-03 Cs-137 & $2.22 \mathrm{p}$ & $\mathrm{pCi/L}$ & 2.2 & 2.2 & U & & \\
\hline SESPMNT & B17J22 & 100-N SPRING 8-13 & ONSITE & SW & $\mathrm{N}$ & SEEP & UNFILTERED & 20-Oct-03 Cs-137 & $0.839 p$ & pCill & 1.9 & 1.9 & U & & \\
\hline SESPMNT & B17RK1 & 300 AREA SPR DR 42-2 & ONSITE & sW & $\mathrm{N}$ & SEEP & UNFILTERED & 13-Oct-03 Cs-137 & $-0.353 p$ & & 2.4 & 2.4 & u & & \\
\hline SESPMNT & B17RJ2 & 300 AREA SPRING 42-2 & ONSITE & SW & $\mathrm{N}$ & SEEP & UNFILTERED & 13-Oct-03 Cs-137 & $-0.688 \mathrm{p}$ & & 1.8 & 1.8 & $u$ & & \\
\hline SESPMNT & B17J74 & 100-K SPRING 77-1 & ONSITE & SW & $N$ & SEEP & UNFILTERED & 10-Nov-03 Eu-152 & 1.1p & pCi/L & 5.2 & 5.2 & U & & \\
\hline PNLGW & $\begin{array}{l}\text { B17JR0 } \\
\text { B177023 }\end{array}$ & $\begin{array}{l}\text { 100-K SPRING 77-1 } \\
\text { SK-557-3 }\end{array}$ & ONSITE & sW & $\mathrm{N}$ & $\begin{array}{l}\text { SEEP } \\
\text { SEEP }\end{array}$ & & $\begin{array}{l}\text { 10-Nov-03 Eu-152 } \\
\text { 10-Nov-03 Eu-152 }\end{array}$ & $\begin{array}{r}0.827 p \\
-0.039 p\end{array}$ & pCi/L & $\begin{array}{r}5.6 \\
57\end{array}$ & 5.6 & $\frac{u}{y}$ & & \\
\hline $\begin{array}{l}\text { PNLGW } \\
\text { SESPMNT }\end{array}$ & $\begin{array}{l}\frac{111 \text { W23 }}{\text { B17RN6 }} \\
\end{array}$ & $\begin{array}{l}\text { SK-05/-3 } \\
100-F \text { SPRING 207-1 }\end{array}$ & ONSITE & $\begin{array}{l}\text { SW } \\
\text { sw }\end{array}$ & $\frac{N}{n}$ & $\begin{array}{l}\text { SEEP } \\
\text { SEEP }\end{array}$ & JNFILTERED & $\begin{array}{l}\text { 10--Nov-03 Eu-152 } \\
\text { 03-Nov-03 Eu-152 }\end{array}$ & $\begin{array}{l}-0.3 / 9 \mathrm{p} \\
-0.179 \mathrm{p}\end{array}$ & 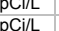 & 5.1 & 5.7 & U & & \\
\hline
\end{tabular}




\begin{tabular}{|c|c|c|c|c|c|c|c|c|c|c|c|c|c|c|c|c|}
\hline OWNER ID & \begin{tabular}{|l|} 
SAMP \\
NUM
\end{tabular} & SAMP SITE NAME & $\left|\begin{array}{c}\text { DIST } \\
\text { CLASS }\end{array}\right|$ & $\mid$ MEDIA $\mid$ & $\begin{array}{c}\text { FILTERED } \\
\text { FLAG }\end{array}$ & $\mid \begin{array}{l}\text { SAMP } \\
\text { FROM }\end{array}$ & $\mid$ COLL MTHD & & CON SHORT NAME & $\begin{array}{l}\text { VALUE } \\
\text { RPTD }\end{array} \mid$ & \begin{tabular}{|c|} 
ANAL \\
UNITS \\
RPTD
\end{tabular} & $\begin{array}{c}\text { COUNTING } \\
\text { ERROR }\end{array}$ & $\begin{array}{l}\text { TOTAL } \\
\text { ANAL } \\
\text { ERROR }\end{array}$ & $\left|\begin{array}{c}\text { LAB } \\
\text { QUALIFIER }\end{array}\right|$ & SAMP COMMENT & $\begin{array}{c}\text { RESULT } \\
\text { COMMENT }\end{array}$ \\
\hline SESPMNT & B17RJ9 & HANFORD SPR DR 28-2 & ONSITE & SW & & & UNFILTERED & 03-Nov-03 Eu-152 & & & & 6.3 & 6.3 & $u$ & 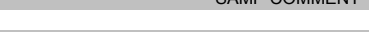 & \\
\hline SESPMNT & B17RJ8 & 3 HANFORD SPR UR 28-2 & ONSITE & SW & $\mathrm{N}$ & SEEP & UNFILTERED & 03-Nov-03 Eu-152 & & & & 6.1 & 6.1 & U & & \\
\hline SESPMNT & B17J80 & 100-D SPRING 102-1 & ONSITE & sw & $\mathrm{N}$ & SEEP & UNFILTERED & 27-Oct-03 Eu-152 & & & $\mathrm{pCi} / \mathrm{L}$ & 6.3 & 6.3 & u & & \\
\hline SESPMNT & B17J79 & 100-D SPRING 110-1 & ONSITE & SW & $\mathrm{N}$ & SEEP & UNFILTERED & 27-Oct-03 Eu-152 & & $4.25 \mathrm{p}$ & $\mathrm{pCi} / \mathrm{L}$ & 6.7 & 6.7 & u & & \\
\hline $\begin{array}{l}\text { SESPMNT } \\
\text { SESPMNT }\end{array}$ & B17RJ4 & 100-H SPRING 145-1 & ONSITE & SW & $N$ & SEEP & UNFILTERED & 27-Oct-03 Eu-152 & & $-0.27 \mathrm{~F}$ & pCi/L & 5.4 & 5.4 & U & & \\
\hline $\begin{array}{l}\text { SESPMNT } \\
\text { SESPMNT }\end{array}$ & $\begin{array}{l}\text { B17RL8 } \\
\text { B171768 }\end{array}$ & 3 100-H SPRING 153-1 & $\begin{array}{l}\text { ONSITE } \\
\text { ONSTES }\end{array}$ & SW & $\mathrm{N}$ & SEEP & $\begin{array}{l}\text { UNFILTERED } \\
\end{array}$ & 27-Oct-03 Eu-152 & & $1.33 \mathrm{~F}$ & pCill & 5.2 & 5.2 & $\mathrm{U}$ & & \\
\hline $\begin{array}{l}\text { SESPMNT } \\
\text { SESPMNT }\end{array}$ & $\begin{array}{l}\text { B177668 } \\
\text { B17770 }\end{array}$ & $\begin{array}{l}\text { 100-B SPRING 37-1 } \\
\text { 100-B SPRING } 39-2\end{array}$ & $\begin{array}{l}\text { ONSITE } \\
\text { ONSTES }\end{array}$ & 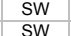 & $\frac{N}{N}$ & $\begin{array}{l}\text { SEEP } \\
\text { SEFP }\end{array}$ & $\begin{array}{l}\text { UNFILTERED } \\
\text { UNFUTFRFD }\end{array}$ & $\begin{array}{l}20-O c t-03 \text { Eu-152 } \\
20-0.03\end{array}$ & & $2.62 \mathrm{P}$ & PCi/L & 4.6 & 4.6 & U & & \\
\hline SESPMNT & B17J72 & 100-K SPRING 63-2 & $\begin{array}{l}\text { ONSTIE } \\
\text { ONSITE }\end{array}$ & sw & $N_{N}$ & $\begin{array}{l}\text { SEEP } \\
\text { SEEP }\end{array}$ & $\begin{array}{l}\text { UNFTLERED } \\
\text { UNFLTERED }\end{array}$ & $\begin{array}{l}\text { 20-0ct-0.03 Eu-152 } \\
\text { 20-Oct-03 Eu-152 }\end{array}$ & & 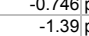 & $\begin{array}{l}\text { pCil/L } \\
\text { pCi/L }\end{array}$ & $\begin{array}{l}5.9 \\
4.9\end{array}$ & $\begin{array}{l}5.9 \\
4.9\end{array}$ & u & & \\
\hline SESPMNT & B17J22 & 100-N SPRING 8-13 & ONSITE & sW & $\mathrm{N}$ & SEEP & UNFILTERED & 20-Oct-03 Eu-152 & & $0.126 \mathrm{p}$ & $\mathrm{pCi} / \mathrm{L}$ & 4.9 & 4.9 & U & & \\
\hline SESPMNT & B17RK1 & 1300 AREA SPR DR 42-2 & ONSITE & SW & $\mathrm{N}$ & SEEP & UNFILTERED & 13-Oct-03 Eu-152 & & & $\mathrm{pCi} / \mathrm{L}$ & 5.7 & 5.7 & U & & \\
\hline $\begin{array}{l}\text { SESPMNT } \\
\text { SESPMNT }\end{array}$ & B17RJ2 & 300 AREA SPRING 42-2 & ONSITE & SW & $\mathrm{N}$ & SEEP & UNFILTERED & 13-Oct-03 Eu-152 & & $1.01 \mathrm{f}$ & & 4.6 & 4.6 & U & & \\
\hline SESPMNT & B17J74 & 100-K SPRING 77-1 & ONSITE & SW & $\mathrm{N}$ & SEEP & UNFILTERED & 10-Nov-03 Eu-154 & & $-1.11 \mathrm{p}$ & pCi/L & 8.5 & 8.5 & U & & \\
\hline $\begin{array}{l}\text { PNLGW } \\
\text { PNGWW }\end{array}$ & $\begin{array}{l}\text { B17JR0 } \\
\text { B17W23 }\end{array}$ & $\begin{array}{l}\text { 100-K SPRING 77-1 } \\
3 \text { SK-057-3 }\end{array}$ & ONSITE & $\begin{array}{l}\text { SW } \\
\text { sw }\end{array}$ & $\begin{array}{r}\mathrm{N} \\
\mathrm{N}\end{array}$ & $\begin{array}{l}\text { SEEP } \\
\text { SEEP }\end{array}$ & & $\begin{array}{l}\text { 10-Nov-03 Eu-154 } \\
\text { 10-Nov-03 E-154 }\end{array}$ & & $\begin{array}{l}-2.25 \mathrm{p} \\
-2.31 \mathrm{p}\end{array}$ & pCil & $\begin{array}{l}7.4 \\
7.2\end{array}$ & 7.4 & $\begin{array}{l}u \\
u\end{array}$ & & \\
\hline SESPMNT & B17RJ6 & $100-F$ SPRING 207-1 & ONSITE & SW & $\frac{N}{N}$ & $\begin{array}{l}\text { SEEP } \\
\text { SEEP }\end{array}$ & UNFILTERED & $\begin{array}{l}10 \text {-Nov-03 E- E-154 } \\
03-\text { Nov-03 Eu-154 }\end{array}$ & & $\begin{array}{l}-2.31 \mathrm{~F} \\
1.69 \mathrm{~F}\end{array}$ & $\begin{array}{l}\text { pCiL } \\
\text { pCi/L }\end{array}$ & $\begin{array}{l}7.2 \\
5.3\end{array}$ & 7.2 & $\frac{u}{u}$ & & \\
\hline SESPMNT & B17RJ9 & HANFORD SPR DR 28-2 & ONSITE & SW & $\mathrm{N}$ & SEEP & UNFILTERED & 03-Nov-03 Eu-154 & & $-5.54 \mathrm{p}$ & $\mathrm{pCi/L}$ & 6.9 & 6.9 & U & & \\
\hline SESPMNT & B17RJ8 & HANFORD SPR UR 28-2 & ONSITE & & $\mathrm{N}$ & & & & & & & & & u & & \\
\hline SESPMNT & B17J80 & 100-D SPRING 102-1 & ONSITE & sw & $\mathrm{N}$ & SEEP & $\begin{array}{l}\text { UNFILTERED } \\
\text { UNTER }\end{array}$ & $27-$ Oct-03 Eu-154 & & $1.25 \mathrm{~F}$ & & 6.7 & 6.7 & u & & \\
\hline SESPMNT & B17J79 & 100-D SPRING 110-1 & ONSITE & sw & & SEEP & UNFILTERED & 27-Oct-03 Eu-154 & & & & 6.9 & 6.9 & u & & \\
\hline SESPMNT & B17RJ4 & 100-H SPRING 145-1 & ONSITE & sw & $\mathrm{N}$ & SEEP & $\begin{array}{l}\text { UNFILTERED } \\
\text { UTER }\end{array}$ & 27-Oct-03 Eu-154 & & -4.42 & pCi/L & 6.3 & 6.3 & u & & \\
\hline SESPMNT & B17RL8 & $100-H$ SPRING $153-1$ & ONSITE & sw & $\mathrm{N}$ & SEEP & UNFILTERED & 27-Oct-03 Eu-154 & & -3.77 & $\mathrm{pCi} / \mathrm{L}$ & 7.1 & 7.1 & U & & \\
\hline SESPMNT & B17J68 & 100-B SPRING 37-1 & ONSITE & SW & $\mathrm{N}$ & SEEP & UNFILTERED & 20-Oct-03 Eu-154 & & 3.92 & $\mathrm{pCi/L}$ & 7.2 & 7.2 & u & & \\
\hline SESPMNT & B17J70 & 100-B SPRING 39-2 & ONSITE & sW & $\mathrm{N}$ & SEEP & UNFILTERED & 20-Oct-03 Eu-154 & & $-2.08 \mathrm{~F}$ & $\mathrm{pCi} / \mathrm{L}$ & 5.9 & 5.9 & U & & \\
\hline SESPMNT & B17J72 & 100-K SPRING 63-2 & ONSITE & sw & $\mathrm{N}$ & SEEP & UNFILTERED & 20-Oct-03 Eu-154 & & $1.74 \mathrm{~F}$ & $\mathrm{pCi} / \mathrm{L}$ & 5.8 & 5.8 & U & & \\
\hline SESPMNT & B17J22 & 100-N SPRING 8-13 & ONSITE & SW & $N$ & SEEP & UNFILTERED & 20-Oct-03 Eu-154 & & -1.35 & pCilL & 4.6 & 4.6 & U & & \\
\hline $\begin{array}{l}\text { SESPMNT } \\
\text { SESPMNT }\end{array}$ & B17RK1 & 300 AREA SPR DR 42-2 & ONSITE & $\begin{array}{l}S W \\
S W\end{array}$ & $\mathrm{~N}$ & $\begin{array}{l}\text { SEEP } \\
\text { SSEP }\end{array}$ & $\begin{array}{l}\text { UNFILTERED } \\
\text { INTER }\end{array}$ & 13-Oct-03 Eu-154 & & $6.93 \mathrm{p}$ & $\mathrm{pCil}$ & 8.1 & 8.1 & u & & \\
\hline $\begin{array}{l}\text { SESPMNT } \\
\text { SESPMNT }\end{array}$ & $\begin{array}{l}\text { B17RJ2 } \\
\text { B17J74 }\end{array}$ & $\begin{array}{l}300 \text { AREA SPRING 42-2 } \\
100 \text { - SPRING 77-1 }\end{array}$ & $\begin{array}{l}\text { ONSITE } \\
\text { ONSTEF }\end{array}$ & $\begin{array}{l}\text { SW } \\
\text { sw }\end{array}$ & $\begin{array}{l}\mathrm{N} \\
\mathrm{N}\end{array}$ & $\begin{array}{l}\text { SEEP } \\
\text { SEEP }\end{array}$ & $\begin{array}{l}\text { UNFILTERED } \\
\text { UNFITERED }\end{array}$ & $\begin{array}{l}13-\mathrm{Oct}-03 \text { Eu-154 } \\
10 \mathrm{n}-\mathrm{Noy}-03 \text { Eu-155 }\end{array}$ & & $-0.849 \mathrm{p}$ & pCil/ & 6.1 & 6.1 & $\frac{u}{u}$ & & \\
\hline $\begin{array}{l}\text { PESPMNI } \\
\text { PNLGW }\end{array}$ & $\begin{array}{l}\text { B1/1/4 } \\
\text { B17JRO }\end{array}$ & $\begin{array}{l}100-K \text { SPRING } \\
100 \text { SPRING 77-1 }\end{array}$ & $\begin{array}{l}\text { ONSSITE } \\
\text { ONSE }\end{array}$ & sw & $\begin{array}{l}\mathrm{N} \\
\mathrm{N}\end{array}$ & $\begin{array}{l}\text { SEEP } \\
\text { SEEP }\end{array}$ & UNFILIERED & $\begin{array}{l}\text { 10-Nov-03 E- E-155 } \\
\text { 10-Nov-03 EU-155 }\end{array}$ & & $\begin{array}{r}-1 \mathrm{~F} \\
-1.05 \mathrm{~F}\end{array}$ & $\begin{array}{l}\mathrm{pCl} / \mathrm{L} \\
\mathrm{pCi/L}\end{array}$ & $\begin{array}{l}4.4 \\
5.9\end{array}$ & $\begin{array}{l}4.4 \\
5.9\end{array}$ & u & & \\
\hline PNLGW & B17W23 & 3 SK-057-3 & & sW & $\mathrm{N}$ & SEEP & & 10-Nov-03 Eu-155 & & $1.4 \mathrm{~F}$ & $\mathrm{pCi} / \mathrm{L}$ & 5.5 & 5.5 & U & & \\
\hline SESPMNT & B17RJ6 & 100-F SPRING 207-1 & ONSITE & SW & $\mathrm{N}$ & SEEP & UNFILTERED & 03-Nov-03 Eu-155 & & $4.97 \mathrm{~F}$ & $\mathrm{pCi} / \mathrm{L}$ & 5.3 & 5.3 & U & & \\
\hline $\begin{array}{l}\text { SESPMNT } \\
\text { SESPMNT }\end{array}$ & $\begin{array}{l}\text { B17RJ9 } \\
\text { B17R19 }\end{array}$ & HANFORD SPR DR 28-2 & ONSITE & SW & $\mathrm{N}$ & SEEP & $\begin{array}{l}\text { UNFILTERED } \\
\end{array}$ & 03-Nov-03 Eu-155 & & $2.25 \mathrm{p}$ & pCilL & 5 & 5 & $\mathrm{U}$ & & \\
\hline $\begin{array}{l}\text { SESPMNT } \\
\text { SESPMNT }\end{array}$ & B17RJ8 & HANFORD SPR UR 28-2 & ONSITE & SW & $\mathrm{N}$ & SEEP & $\begin{array}{l}\text { UNFILTERED } \\
\text {. }\end{array}$ & 03-Nov-03 Eu-155 & & $\begin{array}{r}2.25 \mathrm{~F} \\
0.937\end{array}$ & $\mathrm{pCl} / \mathrm{L}$ & 4.9 & 4.9 & U & & \\
\hline $\begin{array}{l}\text { SESPMNT } \\
\text { SESPMNT }\end{array}$ & $\begin{array}{l}\text { B17780 } \\
\text { B17J79 }\end{array}$ & $\begin{array}{l}\text { 100-D SPRRIN 102-1 } \\
\text { 100-D SPRING 110-1 }\end{array}$ & $\begin{array}{l}\text { ONSTIE } \\
\text { ONSITE }\end{array}$ & $\begin{array}{l}\text { SW } \\
\text { SW }\end{array}$ & $\begin{array}{l}\mathrm{N} \\
\mathrm{N}\end{array}$ & $\begin{array}{l}\text { SEEP } \\
\text { SEEP }\end{array}$ & $\begin{array}{l}\text { UNFITLRED } \\
\text { UNFILTERED }\end{array}$ & 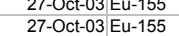 & & $\begin{array}{l}0.937 \mathrm{~F} \\
0.47 \mathrm{~F}\end{array}$ & $\mid \begin{array}{l}\mid \\
\text { CCil/L }\end{array}$ & $\begin{array}{l}4.6 \\
5.7\end{array}$ & $\begin{array}{l}4.6 \\
5.7\end{array}$ & u & & \\
\hline SESPMNT & B17RJ4 & 100-H SPRING 145-1 & ONSITE & sw & $\mathrm{N}$ & SEEP & UNFILTERED & 27-Oct-03 Eu-155 & & -1.84 & $\mathrm{pCi} / \mathrm{L}$ & 4.1 & 4.1 & u & & \\
\hline SESPMNT & B17RL8 & 100-H SPRING 153-1 & ONSITE & SW & $\mathrm{N}$ & SEEP & UNFILTERED & 27-Oct-03 Eu-155 & & -0.508 & $\mathrm{pCi} / \mathrm{L}$ & 3.9 & 3.9 & U & & \\
\hline SESPMNT & B17J68 & 100-B SPRING 37-1 & ONSITE & SW & $\mathrm{N}$ & SEEP & UNFILTERED & 20-Oct-03 Eu-155 & & $-0.00428 p$ & $\mathrm{pCi} / \mathrm{L}$ & 4.4 & 4.4 & U & & \\
\hline SESPMNT & B17J70 & 100-B SPRING 39-2 & ONSITE & SW & $\mathrm{N}$ & SEEP & UNFILTERED & 20-Oct-03 Eu-155 & & $1.57 \mathrm{~F}$ & pCill & 4.5 & 4.5 & U & & \\
\hline $\begin{array}{l}\text { SESPMNT } \\
\text { SESPMNT }\end{array}$ & $\begin{array}{l}\text { B17J72 } \\
817122\end{array}$ & $\begin{array}{l}\text { 100-K SPRING 63-2 } \\
1\end{array}$ & ONSITE & SW & $\mathrm{N}$ & $\begin{array}{l}\text { SEEP } \\
\text { SEFP }\end{array}$ & $\begin{array}{l}\text { UNFILTERED } \\
\text { UNFUTFRFD }\end{array}$ & 20-Oct-03 Eu-155 & & 0.792 & PCi/L & $\begin{array}{r}3.5 \\
3.4\end{array}$ & 3.5 & U & & \\
\hline $\begin{array}{l}\text { SESPMNT } \\
\text { SESPMNT }\end{array}$ & $\begin{array}{l}\text { B17J222 } \\
\text { B17RK1 }\end{array}$ & $\begin{array}{l}\text { 100-N SPRING 8-13 } \\
\text { 300 AREA SPR DR 42-2 }\end{array}$ & $\begin{array}{l}\text { ONSIIE } \\
\text { ONSITE }\end{array}$ & $\begin{array}{l}\text { SW } \\
\text { sw }\end{array}$ & $\begin{array}{l}\mathrm{N} \\
\mathrm{N}\end{array}$ & $\begin{array}{l}\text { SEEP } \\
\text { SEEP }\end{array}$ & $\begin{array}{l}\text { UNNFILERED } \\
\text { UNFITTERED }\end{array}$ & $\begin{array}{l}20-\text {-Oct-0.0 Eu-155 } \\
\text { 13-Oct-03 Eu-155 }\end{array}$ & & $\begin{array}{l}0.000214 \mathrm{~B} \\
-0.604\end{array}$ & PCiL & $\begin{array}{l}3.4 \\
4.5\end{array}$ & $\begin{array}{l}3.4 \\
4.5\end{array}$ & u & & \\
\hline $\begin{array}{l}\text { SESPMNI } \\
\text { SESPMNT }\end{array}$ & $\begin{array}{l}\text { Dirknt } \\
\text { B17RJ2 }\end{array}$ & $\begin{array}{l}300 \text { AREA SPR DR 42-2 } \\
300 \text { ARING 42-2 }\end{array}$ & $\begin{array}{l}\text { ONSSITE } \\
\text { ONSITE }\end{array}$ & sw & $\mathrm{N}$ & $\begin{array}{l}\text { SEEP } \\
\text { SEEP }\end{array}$ & $\begin{array}{l}\text { UNFIILRED } \\
\text { UNFILTERED }\end{array}$ & $\begin{array}{l}\text { 13-Oct-03 Eu-155 } \\
\text { 13-Oct-03 Eu-155 }\end{array}$ & & $\begin{array}{l}-0.04 \mathrm{E} \\
1.56 \mathrm{~g}\end{array}$ & pCil/ & $\begin{array}{l}4.5 \\
3.6\end{array}$ & $\begin{array}{l}4.5 \\
3.6\end{array}$ & u & & \\
\hline SESPMNT & B17J74 & 100-K SPRING 77-1 & $\begin{array}{l}\text { ONSITE } \\
\text { ONSIE }\end{array}$ & sw & $\mathrm{N}$ & SEEP & $\begin{array}{l}\text { UNFILTERED } \\
\text { UTER }\end{array}$ & 10 -Nov-03 K-40 & & 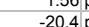 & PCi/L & $\begin{array}{l}3.6 \\
58\end{array}$ & 58 & u & & \\
\hline PNLGW & B17JRO & 100-K SPRING 77-1 & ONSITE & sw & $\mathrm{N}$ & SEEP & & $10-$ Nov- 03 K-40 & & & $\mathrm{pCliL}$ & 61 & 61 & u & & \\
\hline PNLGW & B17W23 & 3 SK-057-3 & & & & SEEP & & 10-Nov-03 K-40 & & & $\mathrm{pCl} / \mathrm{L}$ & 63 & & u & & \\
\hline SESPMNT & B17RJ6 & 100-F SPRING $207-1$ & ONSITE & sw & $\mathrm{N}$ & SEEP & UNFILTERED & 03-Nov-03 K-40 & & -52.4 & $\mathrm{pCi} / \mathrm{L}$ & 55 & 55 & u & & \\
\hline SESPMNT & B17RJ9 & HANFORD SPR DR 28-2 & ONSITE & sw & $\mathrm{N}$ & SEEP & UNFILTERED & 03-Nov-03 K-40 & & -8.44 & $\mathrm{pCi} / \mathrm{L}$ & 54 & 54 & u & & \\
\hline SESPMNT & B17RJ8 & & ONSITE & sw & $\mathrm{N}$ & SEEP & UNFILTERED & 03-Nov-03 K-40 & & $7.83 \mathrm{~F}$ & pCil & 60 & 60 & $u$ & & \\
\hline SESPMNT & B17J80 & 100-D SPRING 102-1 & ONSITE & sw & $\mathrm{N}$ & SEEP & UNFILTERED & $27-0 c t-03$ K-40 & & -19.6 & $\mathrm{pCi} / \mathrm{L}$ & 52 & 52 & U & & \\
\hline SESPMNT & B17J79 & 100-D SPRING 110-1 & ONSITE & SW & $\mathrm{N}$ & SEEP & UNFILTERED & 27-Oct-03 K-40 & & $-73.9 \mathrm{~F}-2 \mathrm{k}$ & $\mathrm{pCi} / \mathrm{L}$ & 63 & 63 & U & & \\
\hline SESPMNT & B17RJ4 & 100-H SPRING 145-1 & ONSITE & SW & $N$ & SEEP & UNFILTERED & $27-O c t-03 \mathrm{~K}-40$ & & -49.4 & $\mathrm{pCi} / \mathrm{L}$ & 57 & 57 & U & & \\
\hline $\begin{array}{l}\text { SESPMNT } \\
\text { SECPMNT }\end{array}$ & B17RL8 & 100-H SPRING 153-1 & ONSITE & SW & $\mathrm{N}$ & SEEP & UNFILTERED & 27-Oct-03 K-40 & & $-15.3 \mathrm{~F}<\mathrm{C}(\mathrm{c})$ & $\mathrm{pCl} / \mathrm{L}$ & 36 & 36 & U & & \\
\hline $\begin{array}{l}\text { SESPMNT } \\
\text { SESPMNT }\end{array}$ & $\begin{array}{l}\text { B17J68 } \\
\text { B177170 }\end{array}$ & $\begin{array}{l}\text { 100-B SPRING 37-1 } \\
1\end{array}$ & ONSITE & SW & $\mathrm{N}$ & $\begin{array}{l}\text { SEEP } \\
\text { SEFP }\end{array}$ & $\begin{array}{l}\text { UNFILTERED } \\
\text { UNFUTFRFD }\end{array}$ & 20-Oct-03 K-40 & & $\begin{array}{l}-52.6 \mathrm{~b} \\
-254 \mathrm{i}\end{array}$ & pCil & 54 & 54 & U & & \\
\hline $\begin{array}{l}\text { SESPMNT } \\
\text { SESPMNT }\end{array}$ & $\begin{array}{l}\text { B17770 } \\
\text { B17J72 }\end{array}$ & $\begin{array}{l}\text { 100-B SPRING 39-2 } \\
\text { 100-K SPRING 63-2 }\end{array}$ & $\begin{array}{l}\text { ONSTIE } \\
\text { ONSITE }\end{array}$ & $\begin{array}{l}\text { SW } \\
\text { SW }\end{array}$ & $\begin{array}{l}\mathrm{N} \\
\mathrm{N}\end{array}$ & $\begin{array}{l}\text { SEEP } \\
\text { SEEP }\end{array}$ & $\begin{array}{l}\text { UNFITLRED } \\
\text { UNFILTERED }\end{array}$ & $\begin{array}{l}20-0 c t-03 \text { K- }-40 \\
20-O c t-03 \text { K-40 }\end{array}$ & & $\begin{array}{l}-25.4 \mathrm{~F} \\
-31.1 \mathrm{k}\end{array}$ & $\begin{array}{l}\mathrm{p} \text { CilL } \\
\mathrm{pCCi/L}\end{array}$ & $\begin{array}{l}54 \\
38\end{array}$ & $\begin{array}{l}54 \\
38\end{array}$ & u & & \\
\hline SESPMNT & B17J22 & 100-N SPRING 8-13 & ONSITE & sW & $\mathrm{N}$ & SEEP & UNFILTERED & $20-0 c t-03$ K-40 & & & pCi/L & 27 & 27 & u & & \\
\hline SESPMNT & B17RK1 & 300 AREA SPR DR 42-2 & ONSITE & sw & & SEEP & UNFILTERED & 13-Oct-03 K-40 & & $-12.7 \mathrm{p}$ & pCill & 54 & 54 & U & & \\
\hline SESPMNT & B17RJ2 & 300 AREA SPRING 42-2 & ONSITE & sw & $\mathrm{N}$ & SEEP & UNFILTERED & 13-Oct-03 K-40 & & $90.6 \mathrm{r}$ & $\mathrm{pCi} / \mathrm{L}$ & 41 & 41 & 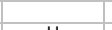 & & \\
\hline SESPMNT & B17J74 & 100-K SPRING 77-1 & ONSITE & SW & $\mathrm{N}$ & SEEP & UNFILTERED & 10-Nov-03 Ru-106 & & $12 \mathrm{~F}$ & $\mathrm{pCl} / \mathrm{L}$ & 21 & 21 & U & & \\
\hline $\begin{array}{l}\text { PNLGW } \\
\text { PNLGW }\end{array}$ & $\begin{array}{l}\text { B17JJ0 } \\
\text { B17W23 }\end{array}$ & $\begin{array}{l}\text { 100-K SPRING 77-1 } \\
\text { SK-057-3 }\end{array}$ & ONSITE & $\begin{array}{l}\text { SW } \\
\text { SW }\end{array}$ & $\begin{array}{l}\mathrm{N} \\
\mathrm{N}\end{array}$ & $\begin{array}{l}\text { SEEP } \\
\text { SEEP }\end{array}$ & & $\begin{array}{l}\text { 10-Nov-033 Ru-106 } \\
\text { 10-Nov-03 Ru-106 }\end{array}$ & & $\begin{array}{l}1.54 \mathrm{~F} \\
-1.7 \mathrm{~F}\end{array}$ & $\begin{array}{l}\mid \\
\text { CCi/L }\end{array}$ & $\begin{array}{l}27 \\
22\end{array}$ & $\begin{array}{l}27 \\
22\end{array}$ & u & & \\
\hline SESPMNT & B17RJ6 & 100-F SPRING 207-1 & ONSITE & SW & $\mathrm{N}$ & SEEP & UNFILTERED & 03-Nov-03 Ru-106 & & 3.18 & $\mathrm{pCi} / \mathrm{L}$ & 21 & 21 & U & & \\
\hline SESPMNT & B17RJ9 & HANFORD SPR DR 28-2 & ONSITE & sw & $\mathrm{N}$ & SEEP & UNFILTERED & 03-Nov-03 Ru-106 & & $-1.76 \mathrm{p}$ & pCill & 21 & 21 & U & & \\
\hline SESPMNT & B17RJ8 & HANFORD SPR UR 28-2 & ONSITE & sw & $\mathrm{N}$ & SEEP & UNFILTERED & 03-Nov-03 Ru-106 & & $11.3 \mathrm{~F}-2-2$ & pCill & 19 & 19 & u & & \\
\hline SESPMNT & B17J80 & 100-D SPRING 102-1 & ONSITE & sw & $\mathrm{N}$ & SEEP & UNFILTERED & 27-Oct-03 Ru-106 & & $25 \mathrm{p}$ & pCill & 23 & 23 & U & & \\
\hline SESPMNT & B17J79 & 100-D SPRING 110-1 & ONSITE & SW & $\mathrm{N}$ & SEEP & UNFILTERED & 27-Oct-03 Ru-106 & & $6.95 \mathrm{p}$ & $\mathrm{pCl} / \mathrm{L}$ & 25 & 25 & U & & \\
\hline SESPMNT & B17RJ4 & 100-H SPRING 145-1 & ONSITE & SW & N & $\begin{array}{l}\text { SEEP } \\
\text { SEEP }\end{array}$ & $\begin{array}{l}\text { UNFILTERED } \\
\text { UNFITERED }\end{array}$ & $\begin{array}{l}27-0 c t-03 \text { Ru-106 } \\
27-0 c-03 \text { Ru-106 }\end{array}$ & & 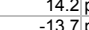 & $\mathrm{pCi} / \mathrm{L}$ & $\begin{array}{l}21 \\
19\end{array}$ & 21 & 0 & & \\
\hline $\begin{array}{l}\text { SESPMNT } \\
\text { SESPMNT }\end{array}$ & $\begin{array}{l}\text { B.7RLL } \\
\text { B17J68 }\end{array}$ & $\begin{array}{l}\text { 100-H SPRING } 153-1 \\
\text { 100-B SPRING 37-1 }\end{array}$ & $\begin{array}{l}\text { ONSIIE } \\
\text { ONSITE }\end{array}$ & $\begin{array}{l}\text { SW } \\
\text { SW }\end{array}$ & $\frac{N}{n}$ & $\begin{array}{l}\text { SEEP } \\
\text { SEEP }\end{array}$ & $\begin{array}{l}\text { UNFLILRED } \\
\text { UNFILTERED }\end{array}$ & $\begin{array}{l}27-\text {-Oct-03 Ru-106 } \\
\text { 20-Oct-03 Ru-106 }\end{array}$ & & $\begin{array}{l}-13.1 \mathrm{~F} \\
1.9 \mathrm{~g}\end{array}$ & $\begin{array}{l}\mathrm{pCl} \\
\mathrm{pCCi/L}\end{array}$ & $\begin{array}{l}19 \\
20\end{array}$ & $\frac{19}{20}$ & 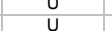 & & \\
\hline
\end{tabular}




\begin{tabular}{|c|c|c|c|c|c|c|c|c|c|c|c|c|c|c|c|c|}
\hline OWNER ID & \begin{tabular}{|l|} 
SAMP \\
NUM
\end{tabular} & SAMP SITE NAME & $\left|\begin{array}{c}\text { DIST } \\
\text { CLASS }\end{array}\right|$ & $\mid$ MEDIA $\mid$ & $\begin{array}{l}\text { FILTERED } \\
\text { FLAG }\end{array}$ & $\mid \begin{array}{l}\text { SAMP } \\
\text { FROM }\end{array}$ & COLL MTHD & |SAMP DATE| & CON SHORT NAME & $\begin{array}{l}\text { VALUE } \\
\text { RPTD }\end{array}$ & \begin{tabular}{|l|} 
ANAL \\
UNITS \\
RPTD \\
\end{tabular} & $\begin{array}{c}\text { COUNTING } \\
\text { ERROR }\end{array}$ & \begin{tabular}{c|} 
TOTAL \\
ANAL \\
ERROR
\end{tabular} & $\mid \begin{array}{c}\text { LAB } \\
\text { QUALIFIER }\end{array}$ & SAMP COMMENT & $\left|\begin{array}{c}\text { RESULT } \\
\text { COMMENT }\end{array}\right|$ \\
\hline SESPMNT & & 100-B SPRING 39-2 & ONSITE & SW & & & UNFILTERED & 20-Oct-03 & Ru-106 & & $\mathrm{pCi} / \mathrm{L}$ & & 20 & & 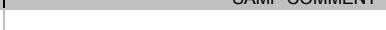 & \\
\hline SESPMNT & B17J72 & 100-K SPRING 63-2 & ONSITE & sW & $\mathrm{N}$ & SEEP & UNFILTERED & 20-Oct-03 & Ru-106 & & & 18 & 18 & u & & \\
\hline SESPMNT & B17J22 & 100-N SPRING 8-13 & ONSITE & sw & $\mathrm{N}$ & SEEP & UNFILTERED & 20-Oct-03 & Ru-106 & & $\mathrm{pCi} / \mathrm{L}$ & 17 & 17 & u & & \\
\hline SESPMNT & B17RK1 & 300 AREA SPR DR 42-2 & ONSITE & sW & $\mathrm{N}$ & SEEP & UNFILTERED & 13-Oct-03 & Ru-106 & & & 21 & 21 & U & & \\
\hline $\begin{array}{l}\text { SESPMNT } \\
\text { SESPMNT }\end{array}$ & B17RJ2 & 300 AREA SPRING 42-2 & ONSITE & SW & $\mathrm{N}$ & SEEP & UNFILTERED & 13-Oct-03 & Ru-106 & & $\mathrm{pCi} / \mathrm{L}$ & 17 & 17 & U & & \\
\hline $\begin{array}{l}\text { SESPMNT } \\
\text { PNLGW }\end{array}$ & B17J74 & 100-K SPRING 77-1 & ONSITE & SW & $\mathrm{N}$ & SEEP & UNFILTERED & 10-Nov-03: & Sb-125 & & & 5.4 & 5.4 & U & & \\
\hline $\begin{array}{l}\text { PNLGW } \\
\text { PNLGW }\end{array}$ & $\begin{array}{l}\text { B17JR0 } \\
\text { B17W023 }\end{array}$ & 100-K SPRING 77-1 & ONSITE & SW & $\mathrm{N}$ & $\begin{array}{l}\text { SEEP } \\
\text { SEFP }\end{array}$ & & $\begin{array}{l}10-N o v-03 \\
10-20 v-03 s\end{array}$ & Sb-125 & & pCil/ & 5.8 & 5.8 & U & & \\
\hline SESPMNT & B17RJ6 & $\begin{array}{l}\text { SK-057-3 } \\
\text { 100-F SPRING 207-1 }\end{array}$ & ONSITE & $\begin{array}{l}\text { SW } \\
\text { SW }\end{array}$ & $\frac{N}{N}$ & $\begin{array}{l}\text { SEEP } \\
\text { SEEP }\end{array}$ & UNFILTERED & $\begin{array}{l}\text { 10-Nov-03: } \\
03-\text { Nov-03 }\end{array}$ & $\begin{array}{l}\text { Sb-125 } \\
\text { Sb-125 }\end{array}$ & & $\begin{array}{l}\mathrm{pCCiL} \\
\mathrm{pCCi/L}\end{array}$ & $\begin{array}{l}6.1 \\
5.8\end{array}$ & $\begin{array}{l}6.1 \\
5.8\end{array}$ & u & & \\
\hline SESPMNT & B17RJ9 & HANFORD SPR DR 28-2 & ONSITE & sW & $\mathrm{N}$ & SEEP & UNFILTERED & 03-Nov-03 & $\mathrm{Sb}-125$ & & & 5.5 & 5.5 & u & & \\
\hline SESPMNT & B17RJ8 & HANFORD SPR UR 28-2 & ONSITE & sw & $\mathrm{N}$ & SEEP & $\begin{array}{l}\text { UNFILTERED } \\
\text { UNFED }\end{array}$ & 03-Nov-03 & Sb-125 & & & 6.3 & 6.3 & u & & \\
\hline $\begin{array}{l}\text { SESPMNT } \\
\text { SESPMNT }\end{array}$ & B17J80 & 100-D SPRING 102-1 & ONSITE & SW & $\mathrm{N}$ & SEEP & UNFILTERED & $27-O c t-03$ & Sb-125 & -0.0853 & & 6 & 6 & $u$ & & \\
\hline $\begin{array}{l}\text { SESPMNT } \\
\text { SESPMNT }\end{array}$ & B17J79 & 100-D SPRING 110-1 & ONSITE & SW & $\mathrm{N}$ & SEEP & $\begin{array}{l}\text { UNFILTERED } \\
\end{array}$ & $27-O c t-03$ & Sb-125 & -1.83 & & 6.2 & 6.2 & U & & \\
\hline $\begin{array}{l}\text { SESPMNT } \\
\text { SESPMNT }\end{array}$ & $\begin{array}{l}\text { B17RJ44 } \\
\text { B17RL8 }\end{array}$ & $\begin{array}{l}\text { 100-H SPRING 145-1 } \\
100-\mathrm{H} \text { SPRING 153-1 }\end{array}$ & $\begin{array}{l}\text { ONSIE } \\
\text { ONSTIE }\end{array}$ & $\begin{array}{l}\text { SW } \\
\text { sw }\end{array}$ & $\begin{array}{l}n \\
\mathrm{~N}\end{array}$ & $\begin{array}{l}\text { SEEP } \\
\text { SEEPP }\end{array}$ & $\begin{array}{l}\text { UNFILTERED } \\
\text { UNFILTERED }\end{array}$ & $\begin{array}{l}27-\text { Oct-03 } \\
\text { 27-Oct-03 }\end{array}$ & $\begin{array}{l}\text { Sb- }-125 \\
\text { S-b-125 }\end{array}$ & $\begin{array}{l}0.464 \\
3.72\end{array}$ & PCil & $\begin{array}{r}5.4 \\
4.9\end{array}$ & 5.4 & $u$ & & \\
\hline SESPMNT & B17J68 & 100-B SPRING 37-1 & ONSITE & sw & $\mathrm{N}$ & $\begin{array}{l}\text { SEEP } \\
\text { SEEP }\end{array}$ & UNFILTERED & $20-0 c t-03$ & Sb-125 & & pCi/L & $\begin{array}{l}4.9 \\
5.5\end{array}$ & $\begin{array}{l}4.9 \\
5.5\end{array}$ & u & & \\
\hline SESPMNT & B17J70 & 100-B SPRING 39-2 & ONSITE & sW & $\mathrm{N}$ & SEEP & UNFILTERED & 20-Oct-03 & $\mathrm{Sb}-125$ & & $\mathrm{pCi} / \mathrm{L}$ & 6.1 & 6.1 & u & & \\
\hline SESPMNT & B17J72 & 100-K SPRING 63-2 & ONSITE & SW & $\mathrm{N}$ & SEEP & UNFILTERED & 20-Oct-03 & & & & 4.8 & 4.8 & u & & \\
\hline SESPMNT & B17J22 & 100-N SPRING 8-13 & ONSITE & SW & $\mathrm{N}$ & SEEP & UNFILTERED & $20-O c t-03$ & Sb-125 & -3.26 & & 5.2 & 5.2 & U & & \\
\hline $\begin{array}{l}\text { SESPMNT } \\
\text { SESPMNT }\end{array}$ & B17RK1 & 300 AREA SPR DR 42-2 & ONSITE & SW & $n^{n}$ & $\begin{array}{l}\text { SEEP } \\
\text { SEFP }\end{array}$ & $\begin{array}{l}\text { UNFILTERED } \\
\end{array}$ & 13-Oct-03: & $\begin{array}{l}\text { Sb-125 } \\
\text { Sh-125 }\end{array}$ & 2.41 & pCi/L & 6.1 & 6.1 & U & & \\
\hline $\begin{array}{l}\text { SESPMNT } \\
\text { SESPMNT }\end{array}$ & $\begin{array}{l}\text { BB7RJ2 } \\
\text { B17RH9 }\end{array}$ & $\begin{array}{l}300 \text { AREA SPRING 42-2 } \\
\\
\text { HANFORD SPRING } 28-2\end{array}$ & $\begin{array}{l}\text { ONSIE } \\
\text { ONSTIE }\end{array}$ & $\begin{array}{l}\text { SW } \\
\text { sw }\end{array}$ & $\begin{array}{l}n \\
\mathrm{~N}\end{array}$ & $\begin{array}{l}\text { SEEP } \\
\text { SEEP }\end{array}$ & $\begin{array}{l}\text { UNFILTERED } \\
\text { UNFILTERED }\end{array}$ & $\mid \begin{array}{l}\text { 13-Oct-03 } \\
1 \text { 10-Oct-03i }\end{array}$ & $\begin{array}{l}\text { S-1-125 } \\
\text { l- }-29\end{array}$ & 0.827 & pCilL & 4.8 & 4.8 & u & NO SAMPLE & \\
\hline SESPMNT & B17RL7 & 300 AREA SPR DR 42-2 & ONSITE & sW & & SEEP & UNFILTERED & 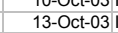 & |-129 & 0.0068 & $\mathrm{pCi} / \mathrm{L}$ & & 0.00084318 & & TW SAIVIPLE. & \\
\hline SESPMNT & B17RJO & 300 AREA SPRING 42-2 & ONSITE & sw & & SEEP & UNFILTERED & 13-Oct-03 & $1-129$ & 0.004713 & & & $\begin{array}{l}0.00045096 \\
0.00093\end{array}$ & & & \\
\hline SESPMNT & B17RK4 & HANFORD SPR DR 28-2 & ONSITE & SW & & SEEP & UNFILTERED & 03-Nov-03 & $1-129$ & 0.057993 & & & 0.0056833 & & & \\
\hline SESPMNT & & & ONSITE & & & SEEP & $\begin{array}{l}\text { UNFILTERED } \\
\text { UTER }\end{array}$ & & & 0.143954 & & & & & & \\
\hline SESPMNT & B17RJ2 & 300 AREA SPRING 42-2 & ONSITE & sw & $\mathrm{N}$ & SEEP & UNFILTERED & 13-Oct-03: & Sr-90 & 0.325 & $\mathrm{pCi} / \mathrm{L}$ & 0.033 & 0.058 & & & \\
\hline SESPMNT & B17RK1 & 300 AREA SPR DR 42-2 & ONSITE & sW & $\mathrm{N}$ & SEEP & UNFILTERED & 13-Oct-03 & Sr-90 & 0.242 & pCill & 0.026 & 0.043 & & & \\
\hline SESPMNT & B17J77 & 100-N SPRING 199N-46 & ONSITE & sw & $\mathrm{N}$ & SEEP & UNFILTERED & 20-Oct-03 & & & & & & & NO SAMPLE. NO SEEP OBSERVED. & \\
\hline SESPMNT & B17J22 & 100-N SPRING 8-13 & ONSITE & sw & $\mathrm{N}$ & SEEP & UNFILTERED & 20-Oct-03 & Sr-90 & 0.0406 & $\mathrm{pCi} / \mathrm{L}$ & 0.059 & 0.063 & u & & \\
\hline SESPMNT & B17J68 & 100-B SPRING 37-1 & ONSITE & sW & $\mathrm{N}$ & SEEP & UNFILTERED & $20-0 c t-03$ & Sr-90 & 0.0247 & $\mathrm{pCi} / \mathrm{L}$ & 0.04 & 0.041 & U & & \\
\hline SESPMNT & B17J72 & 100-K SPRING 63-2 & ONSITE & SW & $\mathrm{N}$ & SEEP & UNFILTERED & $20-O c t-03$ & $\begin{array}{ll}\mathrm{Sr}-90 \\
\mathrm{c} 90\end{array}$ & 0.0821 & $\mathrm{pCi} / \mathrm{L}$ & 0.057 & 0.059 & u & & \\
\hline $\begin{array}{l}\text { SESPMNT } \\
\text { SESPMNT }\end{array}$ & B17J70 & 100-B SPRING 39-2 & ONSITE & SW & N & $\begin{array}{l}\text { SEEP } \\
\text { SEEPP }\end{array}$ & UNFILTERED & $20-O c t-03$ & Sr-90 & 4.04 & $\mathrm{pCi} / \mathrm{L}$ & 0.11 & 0.59 & & & \\
\hline $\begin{array}{l}\text { SESPMNT } \\
\text { SESPMNT }\end{array}$ & $\begin{array}{l}\text { B17RJ4 } \\
\text { B17179. }\end{array}$ & 100-H SPRING 145-1 & ONSITE & SW & $\frac{N}{N}$ & $\begin{array}{l}\text { SEEP } \\
\text { SSEPP }\end{array}$ & $\begin{array}{l}\text { UNFILTERED } \\
\end{array}$ & $27-$ Oct-03 & 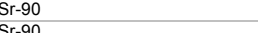 & & pCi/L & 0036 & 0061 & u & & \\
\hline $\begin{array}{l}\text { SESPMNI } \\
\text { SESPNT }\end{array}$ & B17J80 & 100-D SPRING 102-1 & $\begin{array}{l}\text { ONSITE } \\
\text { ONSE }\end{array}$ & SW & $\frac{N}{n}$ & $\begin{array}{l}\text { SEEF } \\
\text { SEEP }\end{array}$ & $\begin{array}{l}\text { UNFFLLERED } \\
\text { UNFILTERED }\end{array}$ & $\begin{array}{l}27-0 \mathrm{Oct}-03 \\
27-\mathrm{Oct}-03\end{array}$ & $\begin{array}{l}S T-90 \\
S T-90\end{array}$ & $\begin{array}{l}0.335 \\
0.0776\end{array}$ & $\begin{array}{l}\text { pCiL } \\
\text { pCi/L }\end{array}$ & 0.028 & $\begin{array}{l}0.061 \\
0.031\end{array}$ & & & \\
\hline SESPMNT & B17RL8 & 100-H SPRING 153-1 & ONSITE & sw & $\mathrm{N}$ & SEEP & UNFILTERED & $27-\mathrm{Oct}-03$ & Sr-90 & 13.6 & $\mathrm{pCi} / \mathrm{L}$ & 0.18 & 2 & & & \\
\hline SESPMNT & B17RJ6 & 100-F SPRING 207-1 & ONSITE & SW & $\mathrm{N}$ & SEEP & UNFILTERED & 03-Nov-03 & Sr-90 & 0.0583 & $\mathrm{pCi} / \mathrm{L}$ & 0.02 & 0.023 & & & \\
\hline SESPMNT & B17J74 & 100-K SPRING 77-1 & ONSITE & SW & $\mathrm{N}$ & SEEP & UNFILTERED & 10-Nov-03 & Sr-90 & 2.77 & $\mathrm{pCi} / \mathrm{L}$ & 0.086 & 0.41 & & & \\
\hline PNLGW & B17L25 & SEEP 037-1 & & SW & $\mathrm{N}$ & SEEP & & 10-Nov-03: & Sr-90 & 0.248 & $\mathrm{pCl}$ CiL & 0.22 & 0.22 & U & & \\
\hline $\begin{array}{l}\text { PNLGW } \\
\text { PNLGW }\end{array}$ & $\begin{array}{l}\text { B17LL3 } \\
\text { B17BB4 }\end{array}$ & $\begin{array}{l}\text { 100-K SPRING 68-1 } \\
\text { 100-F SPRING }\end{array}$ & $\begin{array}{l}\text { ONSITE } \\
\text { ONSITE }\end{array}$ & $\begin{array}{l}\text { SW } \\
\text { sw }\end{array}$ & $\begin{array}{l}n \\
\mathrm{~N}\end{array}$ & $\begin{array}{l}\text { SEEP } \\
\text { SSEP }\end{array}$ & & $\begin{array}{l}10-N o v-03 \\
10-03\end{array}$ & 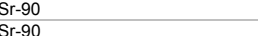 & $\begin{array}{r}0.3 \\
0.358\end{array}$ & $\mathrm{pCi} / \mathrm{L}$ & $\begin{array}{r}0.2 \\
0.21\end{array}$ & 0.2 & U & & \\
\hline PNLGW & $\begin{array}{l}\text { BIfL4 } \\
\text { B17LF3 }\end{array}$ & 100-K SPRING 68-1 & ONSITE & sw & $\mathrm{N}$ & $\begin{array}{l}\text { SEEF } \\
\text { SEEP }\end{array}$ & & $\begin{array}{l}2 \mathrm{O}-\mathrm{NONV}-\mathrm{U}-\mathrm{S} \\
10 \mathrm{Nov}\end{array}$ & $\begin{array}{l}\text { SS-90 } \\
\text { Tc-99 }\end{array}$ & $\begin{array}{c}0.0758 \\
0.655\end{array}$ & $\begin{array}{l}\mathrm{pCi \textrm {L }} \\
\mathrm{pCCi/L}\end{array}$ & $\begin{array}{r}0.21 \\
3.9\end{array}$ & $\begin{array}{l}0.26 \\
5.2\end{array}$ & u & & \\
\hline SESPMNT & B17RJ1 & HANFORD SPRING 28-2 & ONSITE & sw & $\mathrm{N}$ & SEEP & UNFILTERED & 10-Oct-03 & Tc-99 & & & & & & NO SAMPLE. & \\
\hline SESPMNT & B17J68 & 100-B SPRING 37-1 & ONSITE & SW & $\mathrm{N}$ & SEEP & UNFILTERED & 20-Oct-03 & Tc-99 & & $\mathrm{pCi} / \mathrm{L}$ & 0.27 & 0.54 & & & \\
\hline SESPMNT & B17J70 & 100-B SPRING 39-2 & ONSITE & SW & $\mathrm{N}$ & SEEP & UNFILTERED & $20-O c t-03$ & Tc-99 & 10.8 & $\mathrm{pCi} / \mathrm{L}$ & 0.37 & 0.89 & & & \\
\hline $\begin{array}{l}\text { SESPMNT } \\
\text { SESPMNT }\end{array}$ & B17RJ4 & 100-H SPRING 145-1 & ONSITE & SW & $n^{n}$ & $\begin{array}{l}\text { SEEP } \\
\text { SEFP }\end{array}$ & $\begin{array}{l}\text { UNFILTERED } \\
\end{array}$ & 27-Oct-03- & TC-99 & 0.24 & pCill & 0.21 & 0.36 & U & & \\
\hline $\begin{array}{l}\text { SESPMNT } \\
\text { SESPMNT }\end{array}$ & $\begin{array}{l}\text { B17RLL8 } \\
\text { B17R28 }\end{array}$ & $\begin{array}{l}\text { 100-H SPRING 153-1 } \\
\text { HANFORD SPR UR 28-2 }\end{array}$ & $\begin{array}{l}\text { ONSITE } \\
\text { ONSITE }\end{array}$ & $\begin{array}{l}\text { SW } \\
\text { sw }\end{array}$ & $\begin{array}{l}n \\
\mathrm{~N}\end{array}$ & $\begin{array}{l}\text { SEEP } \\
\text { SSEP }\end{array}$ & $\begin{array}{l}\text { UNFILTERED } \\
\text { UNEFITERED }\end{array}$ & 27-Oct-03 & Tc-99 & 0.296 & pCill & 0.21 & 0.36 & & & \\
\hline $\begin{array}{l}\text { SESPMNT } \\
\text { SESPNT }\end{array}$ & $\begin{array}{l}\text { B17RJ9 } \\
\text { B17RJ }\end{array}$ & HANFORD SPR DR 28-2 & ONSITE & SW & $\frac{N}{N}$ & $\begin{array}{l}\text { SEEP } \\
\text { SEF }\end{array}$ & UNFILTERED & $\begin{array}{l}0 \\
03-N o v-03 \\
03\end{array}$ & $\begin{array}{l}\text { TC-99 } \\
\text { TC-99 }\end{array}$ & & pCi/L & $\begin{array}{r}0.34 \\
0.4\end{array}$ & 0.8 & & & \\
\hline PNLGW & B17L25 & SEEP 037-1 & & sw & $\mathrm{N}$ & SEEP & & 10-Nov-03 & TEMPERATUR & & Deg C & & & & & \\
\hline PNLGW & B17W21 & SK-057-3 & & SW & $\mathrm{N}$ & SEEP & & 10-Nov-03 & TEMPERATUR & 10.5 & Deg C & & & & & \\
\hline $\begin{array}{l}\text { PNLGW } \\
\text { PNIGW }\end{array}$ & B17VJ6 & SD-110-2 & & SW & $\mathrm{N}$ & SEEP & & 10-Nov-03 & TEMPERATUR & 12.3 & $\operatorname{Deg} \mathrm{C}$ & & & & & \\
\hline $\begin{array}{l}\text { PNLGW } \\
\text { PNLGW }\end{array}$ & $\begin{array}{l}\text { B17VJ99 } \\
\text { B17JP8 }\end{array}$ & $\begin{array}{l}\text { SD-098-1 } \\
\text { 100-K SPRING 77-1 }\end{array}$ & ONSITE & $\begin{array}{l}\text { SW } \\
\text { sw }\end{array}$ & $\frac{N}{N}$ & $\begin{array}{l}\text { SEEP } \\
\text { SEEP }\end{array}$ & & 10-Nov-03- & TEMPERATUR & 13.2 & Deg C & & & & & \\
\hline $\begin{array}{l}\text { PNLGW } \\
\text { PNLGW }\end{array}$ & B17LB5 & 100-K SPRING 68-1 & ONSITE & $\begin{array}{l}\text { SW } \\
\text { SW }\end{array}$ & $\frac{\mathrm{N}}{\mathrm{N}}$ & $\begin{array}{l}\text { SEEP } \\
\text { SEEP }\end{array}$ & & $\begin{array}{l}\text { 10-Nov-03 } \\
\text { 10-Nov-03 }\end{array}$ & $\begin{array}{l}\text { TEMPERATUR } \\
\text { TEMPERATUR }\end{array}$ & $\begin{array}{l}12.1 \\
11.5 \\
\end{array}$ & $\begin{array}{l}\text { Deg C } \\
\text { Deg C }\end{array}$ & & & & & \\
\hline PNLGW & B17LF3 & 100-K SPRING 68-1 & ONSITE & sw & $\mathrm{N}$ & SEEP & & 10-Nov-03 & TEMPERATUR & 11.5 & Deg C & & & & & \\
\hline PNLGW & B17VK2 & SH-144-1 & & SW & $\mathrm{N}$ & SEEP & & 20-Nov-03 & TEMPERATUR & & Deg C & & & & & \\
\hline PNLGW & B17VK5 & 100-H SPRING 150-1 & ONSITE & SW & $\mathrm{N}$ & SEEP & & 20-Nov-03 & TEMPERATUR & 11.6 & Deg C & & & & & \\
\hline PNLGW & $\begin{array}{l}\text { B17VLO } \\
\text { B17171 }\end{array}$ & SH-153-1 & & SW & $\mathrm{N}$ & SEEP & & 20-Nov-03 & TEMPERATUR & 11.1 & $\operatorname{Deg} C$ & & & & & \\
\hline $\begin{array}{l}\text { PNLGW } \\
\text { SESPMNT }\end{array}$ & B17LB1 & 100-F SPRING & ONSITE & SW & $N^{N}$ & $\begin{array}{l}\text { SEEP } \\
\text { SEFP }\end{array}$ & & 20-Nov-03: & TEMPERATUR & & Deg C & & & & NOCAMPIE & \\
\hline $\begin{array}{l}\text { SESPMNT } \\
\text { SESPMNT }\end{array}$ & $\begin{array}{l}\text { B17RRJ1 } \\
\text { B17RN2 }\end{array}$ & $\begin{array}{l}\text { HANFORD SPRRIG 28-2 } \\
300 \text { AREA SPING 42-2 }\end{array}$ & $\begin{array}{l}\text { ONSIIE } \\
\text { ONSITE }\end{array}$ & $\begin{array}{l}\text { SW } \\
\text { SW }\end{array}$ & $\frac{N}{N}$ & $\begin{array}{l}\text { SEEP } \\
\text { SEEP }\end{array}$ & $\begin{array}{l}\text { UNFFLLERED } \\
\text { UNFILTERED }\end{array}$ & $\begin{array}{l}10-\mathrm{O} \text {-Ot-03 } \\
13-\mathrm{Oct}-03\end{array}$ & $\begin{array}{l}\text { TRITIUM } \\
\text { TRITIUM }\end{array}$ & 9760 & $\mathrm{pCi} / \mathrm{L}$ & 360 & 770 & & NO SAMPLE. & \\
\hline SESPMNT & B17RK1 & 300 AREA SPR DR 42-2 & ONSITE & sW & $\mathrm{N}$ & SEEP & UNFILTERED & 13-Oct-03 & TRITIUM & 10500 & $\mathrm{pCi} / \mathrm{L}$ & 370 & 820 & & & \\
\hline SESPMNT & B17J77 & 100-N SPRING 199N-46 & ONSITE & sW & $\mathrm{N}$ & SEEP & UNFILTERED & 20-Oct-03 & TRITIUM & & & & & & NO SAMPLE. NO SEEP OBSERVED. & \\
\hline SESPMNT & B17J22 & 100-N SPRING 8-13 & ONSITE & SW & $\mathrm{N}$ & SEEP & UNFILTERED & 20-Oct-03 & TRITIUM & 10200 & pCill & 360 & 800 & & & \\
\hline SESPMNT & B17J68 & 100-B SPRING 37-1 & ONSITE & SW & $\mathrm{N}$ & SEEP & UNFILTERED & 20-Oct-03 & TRITIUM & 5850 & $\mathrm{pClil}$ & 280 & 500 & & & \\
\hline $\begin{array}{l}\text { SESPMNT } \\
\text { SESPMNT }\end{array}$ & 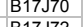 & $\begin{array}{l}\text { 100-B SPRING 39-2 } \\
100-\text { K SPRING 63-2 }\end{array}$ & ONSITE & SW & $\begin{array}{l}\mathrm{N} \\
\mathrm{N}\end{array}$ & $\begin{array}{l}\text { SEEP } \\
\text { SSEP }\end{array}$ & $\begin{array}{l}\text { UNFILTERED } \\
\text { UNFEITTRED }\end{array}$ & 20-Oct-03 & TRITUM & 5040 & $\mathrm{pClil}$ & 260 & $\begin{array}{l}440 \\
180\end{array}$ & & & \\
\hline $\begin{array}{l}\text { SESPMNT } \\
\text { SESPMNT }\end{array}$ & $\begin{array}{l}187752 \\
817179\end{array}$ & $\begin{array}{l}\text { 100-K SPRING 63-2 } \\
\text { 10-D SPRIG 110-1 }\end{array}$ & $\begin{array}{l}\text { ONSITE } \\
\text { ONSITE }\end{array}$ & SW & $\frac{N}{n}$ & $\begin{array}{l}\text { SEEP } \\
\text { SEEP }\end{array}$ & $\begin{array}{l}\text { UNFILTRED } \\
\text { UNFILTERED }\end{array}$ & $\begin{array}{ll}20-O c t-03 \\
27-0 t-03\end{array}$ & $\begin{array}{l}\text { TRTTUM } \\
\text { TIITUM }\end{array}$ & 1340 & PCiL & 140 & 180 & & & \\
\hline SESPMNT & B17J80 & 100-D SPRING 102-1 & ONSITE & SW & $\mathrm{N}$ & SEEP & UNFILTERED & $\begin{array}{l}27-\mathrm{Cl}-03 \\
27-\mathrm{Oct}-03\end{array}$ & $\begin{array}{l}\text { IRITUNM } \\
\text { TRITUM }\end{array}$ & & $\mathrm{pCi}$ & 62 & 74 & 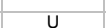 & & \\
\hline
\end{tabular}




\begin{tabular}{|c|c|c|c|c|c|c|c|c|c|c|c|c|c|c|c|c|}
\hline OWNER ID & $\begin{array}{l}\text { SAMP } \\
\text { NUM }\end{array}$ & SAMP SITE NAME & $\left|\begin{array}{c}\text { DIST } \\
\text { CLASS }\end{array}\right|$ & $\mid$ MEDIA $\mid$ & $\begin{array}{l}\text { FILTERED } \\
\text { FLAG }\end{array}$ & $\left|\begin{array}{l}\text { SAMP } \\
\text { FROM }\end{array}\right|$ & $\mid$ COLL MTHD & SAMP DATE & CON SHORT NAME & $\begin{array}{c}\text { VALUE } \\
\text { RPTD }\end{array} \mid$ & \begin{tabular}{l|} 
ANAL \\
UNITS \\
RPTD
\end{tabular} & $\left|\begin{array}{c}\text { COUNTING } \\
\text { ERROR }\end{array}\right|$ & \begin{tabular}{|c|} 
TOTAL \\
ANAL \\
ERROR
\end{tabular} & $\left|\begin{array}{c}\text { LAB } \\
\text { QUALIFIER }\end{array}\right|$ & SAMP COMMENT & $\left|\begin{array}{c}\text { RESULT } \\
\text { COMMENT }\end{array}\right|$ \\
\hline SESPMNT & B17RJ4 & 100-H SPRING 145-1 & ONSITE & SW & & SEEP & UNFILTERED & 27-Oct-03 TRITIUM & CUIV STURI IVAVIV & $2930 \mathrm{p}$ & & | & 290 & & 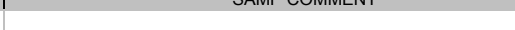 & \\
\hline SESPMNT & B17RL8 & 100-H SPRING 153-1 & ONSITE & sW & $\mathrm{N}$ & SEEP & UNFILTERED & 27-Oct-03 TRITIUM & & & & 110 & 130 & & & \\
\hline PNLGW & B17JN7 & 100-D SPRING 110-1 & ONSITE & sw & $\mathrm{N}$ & SEEP & & 27-Oct-03 TRITIUM & & $88.9 \mathrm{p}$ & & 120 & 120 & U & & \\
\hline SESPMNT & B17RJ6 & 100-F SPRING 207-1 & ONSITE & sw & $\mathrm{N}$ & SEEP & UNFILTERED & 03-Nov-03 TRITIUM & & & pCill & 79 & 91 & & & \\
\hline $\begin{array}{l}\text { SESPMNT } \\
\text { SESPMNT }\end{array}$ & $\begin{array}{l}\text { B17RJ8 } \\
\text { B17RI9 }\end{array}$ & $\begin{array}{l}\text { HANFORD SPR UR 28-2 } \\
\text { HAFORD SPR D 28- }\end{array}$ & $\begin{array}{l}\text { ONSITE } \\
\text { ONSTE }\end{array}$ & $\begin{array}{c}\text { sw } \\
\text { sw }\end{array}$ & $N$ & $\begin{array}{l}\text { SEEP } \\
\text { SEPP }\end{array}$ & $\begin{array}{l}\text { UNFILTERED } \\
\text { UNFITERED }\end{array}$ & $\begin{array}{l}\text { 03-Nov-03 TRITIUM } \\
\text { 03-NOy-03 TRTIMM }\end{array}$ & & $14000 \mathrm{p}$ & & $\begin{array}{l}430 \\
420 \\
\end{array}$ & $\begin{array}{l}1100 \\
1000\end{array}$ & & & \\
\hline $\begin{array}{l}\text { SESPMNI } \\
\text { SESPMNT }\end{array}$ & $\begin{array}{l}\text { B1/RJ99 } \\
\text { B17J74 }\end{array}$ & $\begin{array}{l}\text { ANANFORD SPR DR 28-2 } \\
\text { 100-K SPRING 77-1 }\end{array}$ & $\begin{array}{l}\text { ONSTIE } \\
\text { ONSITE }\end{array}$ & $\begin{array}{l}\text { SW } \\
\text { SW }\end{array}$ & $\frac{N}{N}$ & $\begin{array}{l}\text { SEEP } \\
\text { SEEP }\end{array}$ & $\begin{array}{l}\text { UNFITIERED } \\
\text { UNFITERED }\end{array}$ & $\begin{array}{l}\text { 03-Nov-03 TRITIUM } \\
\text { 10-0ov-03 TRTIUM }\end{array}$ & & & & $\begin{aligned} 420 \\
56\end{aligned}$ & $\begin{array}{r}1000 \\
69\end{array}$ & $U$ & & \\
\hline SESPMNT & B17RJ1 & HANFORD SPRING 28-2 & ONSITE & sw & $\mathrm{N}$ & SEEP & UNFILTERED & $10-O c t-03$ U-238 & & & & & & 0 & NO SAMPLE. & \\
\hline SESPMNT & B17RJ2 & 300 AREA SPRING 42-2 & ONSITE & sw & $\mathrm{N}$ & SEEP & UNFILTERED & 13-Oct-03 U-238 & & & pCi/L & 0.76 & 10 & & & \\
\hline SESPMNT & B17RK1 & 300 AREA SPR DR 42-2 & ONSITE & sw & $\mathrm{N}$ & SEEP & UNFILTERED & 13-Oct-03 U-238 & & & & 0.62 & 8.2 & & & \\
\hline $\begin{array}{l}\text { SESPMNT } \\
\text { SESPMNT }\end{array}$ & B17J77 & 100-N SPRING 199N-46 & ONSITE & SW & & SEEP & UNFILTERED & $20-0 c t-03$ U-238 & & & & & & & NO SAMPLE. NO SEEP OBSERVED. & \\
\hline $\begin{array}{l}\text { SESPMNT } \\
\text { SESPNNT }\end{array}$ & $\begin{array}{l}B 17779 \\
B 1780\end{array}$ & $\begin{array}{l}\text { 100-D SPRING 110-1 } \\
\text { 100-D SPRNG 102-1 }\end{array}$ & ONSITE & SW & $\begin{array}{r}n \\
N\end{array}$ & $\begin{array}{l}\text { SEEP } \\
\text { SEEPP }\end{array}$ & $\begin{array}{l}\text { UNFILTERED } \\
\end{array}$ & 27-Oct-03 U-238 & & $0.123 \mathrm{p}$ & pCi/L & 0.031 & 0.037 & & & \\
\hline $\begin{array}{l}\text { SESPMNT } \\
\text { SESPIN }\end{array}$ & $\begin{array}{l}\text { B1/J80 } \\
\text { B17RJ4 }\end{array}$ & $\begin{array}{l}\text { 100-D SPRRG } 102-1 \\
\text { 100-H SPRING 145-1 }\end{array}$ & $\begin{array}{l}\text { ONSIIE } \\
\text { ONSITE }\end{array}$ & Sw & $\frac{N}{N}$ & $\begin{array}{l}\text { SEEP } \\
\text { SEEP }\end{array}$ & $\begin{array}{l}\text { UNFITTERED } \\
\text { UNFITERED }\end{array}$ & $\begin{array}{l}27-0 \text { ctt-03 U-238 } \\
27-0 \text { ct- } 03 \mathrm{U}-238\end{array}$ & & $0.532 \mathrm{p}$ & & 0.0992 & & & & \\
\hline SESPMNT & B17RL8 & $100-H$ SPRING 153-1 & ONSITE & sw & $\mathrm{N}$ & $\begin{array}{l}\text { SEEP } \\
\text { SEEP }\end{array}$ & UNFILTERED & $\begin{array}{l}27-\mathrm{Cl}-03 \mathrm{U}-238 \\
27-0 \mathrm{ct}-03 \mathrm{U}-238\end{array}$ & & $0.344 \mathrm{p}$ & & 0.048 & 0.072 & & & \\
\hline SESPMNT & B17RJ6 & 100-F SPRING 207-1 & ONSITE & sw & $\mathrm{N}$ & SEEP & UNFILTERED & 03-Nov-03 U-238 & & & & 0.066 & 0.12 & & & \\
\hline SESPMNT & B17RJ8 & HANFORD SPR UR 28-2 & ONSITE & SW & $\mathrm{N}$ & SEEP & UNFILTERED & 03-Nov-03 U-238 & & $0.298 \mathrm{p}$ & & 0.044 & 0.064 & & & \\
\hline $\begin{array}{l}\text { SESPMNT } \\
\text { SESPMNT }\end{array}$ & B17RJ9 & HANFORD SPR DR 28-2 & ONSITE & SW & $\mathrm{N}$ & SEEP & UNFILTERED & 03-Nov-03 U-238 & & $0.398 \mathrm{p}$ & & 0.047 & 0.078 & & & \\
\hline $\begin{array}{l}\text { SESPMNT } \\
\text { SESPNT }\end{array}$ & B17RJ1 & HANFORD SPRING 28-2 & ONSITE & SW & $\mathrm{N}$ & $\begin{array}{l}\text { SEEP } \\
\text { SEEPP }\end{array}$ & $\begin{array}{l}\text { UNFILTERED } \\
\end{array}$ & 10-Oct-03 U-235 & & & & & & & NO SAMPLE. & \\
\hline $\begin{array}{l}\text { SESPMNI } \\
\text { SESPNT }\end{array}$ & $\begin{array}{l}\text { B17RK1 } \\
\text { B17RK1 }\end{array}$ & $\begin{array}{l}300 \text { AREA SPRR NG 42-2 } \\
300 \text { AREA SPR DR 42-2 }\end{array}$ & $\begin{array}{l}\text { ONSIIE } \\
\text { ONSITE }\end{array}$ & sw & $\mathrm{N}_{\mathrm{N}}$ & $\begin{array}{l}\text { SEEP } \\
\text { SEEP }\end{array}$ & $\begin{array}{l}\text { UNFITERED } \\
\text { UNFLTIERED }\end{array}$ & $\begin{array}{l}\text { 13-OCtc-03 U-235 } \\
\text { 13-Oct-03 U-235 }\end{array}$ & & $\begin{array}{r}2.8 \mathrm{p} \\
2.16 \mathrm{p}\end{array}$ & $\begin{array}{l}\text { pCCil } \\
\text { pCilL }\end{array}$ & $\begin{array}{l}0.16 \\
0.13\end{array}$ & 0.36 & & & \\
\hline SESPMNT & B17J77 & 100-N SPRING 199N-46 & ONSITE & sw & $\mathrm{N}$ & SEEP & UNFILTERED & $20-0 c t-03$ U-235 & & & & & & & NO SAMPLE. NO SEEP OBSERVED. & \\
\hline SESPMNT & B17J79 & 100-D SPRING 110-1 & ONSITE & sw & $\mathrm{N}$ & SEEP & UNFILTERED & 27-Oct-03 U-235 & & $0.00569 \mathrm{p}$ & pCi/L & 0.0081 & 0.0084 & U & & \\
\hline SESPMNT & B17J80 & 100-D SPRING 102-1 & ONSITE & sw & $\mathrm{N}$ & SEEP & UNFILTERED & 27-Oct-03 U-235 & & $0.00958 \mathrm{p}$ & & 0.019 & 0.019 & U & & \\
\hline $\begin{array}{l}\text { SESPMNT } \\
\text { SESDMNT }\end{array}$ & B17RJ4 & 100-H SPRING 145-1 & ONSITE & SW & $\mathrm{N}$ & SEEP & UNFILTERED & $27-0 \mathrm{ct}-03 \mathrm{U}-235$ & & $0.0339 \mathrm{p}$ & & 0.017 & 0.018 & & & \\
\hline $\begin{array}{l}\text { SESPMNT } \\
\text { SESPMNT }\end{array}$ & $\begin{array}{l}\text { B17RL8 } \\
\text { B17R/ }\end{array}$ & $\begin{array}{l}\text { 100-H SPRING 153-1 } \\
\text { 100-F SPRING 207-1 }\end{array}$ & $\begin{array}{l}\text { ONSITE } \\
\text { ONSTFF }\end{array}$ & SW & $\begin{array}{r}n \\
N\end{array}$ & $\begin{array}{l}\text { SEEP } \\
\text { SEFP }\end{array}$ & $\begin{array}{l}\text { UNFILTERED } \\
\text { UNFU TFRED }\end{array}$ & 27-Oct-03 U-235 & & $-0.00334 \mathrm{p}$ & & 0.0096 & 0.0097 & u & & \\
\hline $\begin{array}{l}\text { SESPMNT } \\
\text { SESPMNT }\end{array}$ & $\begin{array}{l}\text { B17RN6 } \\
\text { B17RJ8 }\end{array}$ & $\begin{array}{l}100-F \text { SPRIIG } 207-1 \\
\text { HANFORD SPR UR 28-2 }\end{array}$ & $\begin{array}{l}\text { ONSTIE } \\
\text { ONSITE }\end{array}$ & $\begin{array}{l}\text { SW } \\
\text { SW }\end{array}$ & $\frac{N}{N}$ & $\begin{array}{l}\text { SEEP } \\
\text { SEEP }\end{array}$ & $\begin{array}{l}\text { UNFITERED } \\
\text { UNFILTERED }\end{array}$ & $\begin{array}{l}03 \text {-Nov- } 03 \text { U-235 } \\
03-\text { Nov } 03 \text { U-235 }\end{array}$ & & $\begin{aligned} 0.0366 \mathrm{p} \\
0.00878 \mathrm{p}\end{aligned}$ & & $\begin{array}{l}0.019 \\
0.011\end{array}$ & $\begin{array}{r}0.02 \\
0.012\end{array}$ & u & & \\
\hline SESPMNT & B17RJ9 & HANFORD SPR DR 28-2 & ONSITE & sw & $\mathrm{N}$ & SEEP & UNFILTERED & 03-Nov-03 U-235 & & $0.0118 \mathrm{p}$ & & 0.011 & 0.011 & U & & \\
\hline SESPMNT & B17RJ1 & HANFORD SPRING 28-2 & ONSITE & sw & $\mathrm{N}$ & SEEP & UNFILTERED & 10-Oct-03 U-234 & & & & & & & NO SAMPLE. & \\
\hline SESPMNT & B17RJ2 & 300 AREA SPRING 42-2 & ONSITE & sw & $\mathrm{N}$ & SEEP & UNFILTERED & 13-Oct-03 U-234 & & $69.8 \mathrm{p}$ & pCill & 0.78 & 11 & & & \\
\hline $\begin{array}{l}\text { SESPMNT } \\
\text { SESPMNT }\end{array}$ & B17RK1 & 300 AREA SPR DR 42-2 & ONSITE & SW & $\mathrm{N}$ & SEEP & UNFILTERED & 13-Oct-03 U-234 & & $57.2 \mathrm{p}$ & pCi/L & 0.65 & 8.9 & & & \\
\hline $\begin{array}{l}\text { SESPMNT } \\
\text { SESPMNT }\end{array}$ & $\begin{array}{l}B 17777 \\
\text { B17J79 }\end{array}$ & $\begin{array}{l}\text { 100-N SPRING } 199 N-46 \\
100-D \text { SPRING } 10-1\end{array}$ & $\begin{array}{l}\text { ONSITE } \\
\text { ONSTEE }\end{array}$ & $\begin{array}{l}\text { sw } \\
\text { sw }\end{array}$ & $\begin{array}{l}n \\
N \\
N\end{array}$ & $\begin{array}{l}\text { SEEP } \\
\text { SEEP }\end{array}$ & $\begin{array}{l}\text { UNFITTERED } \\
\text { UNFITERED }\end{array}$ & $\begin{array}{l}20-\mathrm{O} \text { - ct-03 U-234 } \\
27-0 \mathrm{Oct}-03 \mathrm{U}-234\end{array}$ & & $0.131 \mathrm{p}$ & & 0033 & 0039 & & NO SAMPLE. NO SEEP OBSERVED. & \\
\hline SESPMNT & B17J80 & $\begin{array}{l}\text { 100-D SPRING T10-1 } \\
\text { 100-D SPRING 102-1 }\end{array}$ & ONSITE & sw & $\mathrm{N}$ & SEEP & UNFILTERED & $\begin{array}{l}27-0 \mathrm{ct}-03 \mathrm{U} \mathrm{U}-234 \\
27-\mathrm{Oct}-03 \mathrm{U}-234\end{array}$ & & 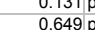 & & $\begin{array}{l}0.033 \\
0.11\end{array}$ & $\begin{array}{r}0.039 \\
0.15\end{array}$ & & & \\
\hline SESPMNT & B17RJ4 & 100-H SPRING 145-1 & ONSITE & sw & $\mathrm{N}$ & SEEP & UNFILTERED & $27-0 c t-03$ U-234 & & $1.42 \mathrm{p}$ & $\mathrm{pCi/L}$ & 0.098 & 0.24 & & & \\
\hline SESPMNT & B17RL8 & 100-H SPRING 153-1 & ONSITE & sw & $\mathrm{N}$ & SEEP & UNFILTERED & $27-0 c t-03$ U-234 & & $0.417 \mathrm{p}$ & & 0.052 & 0.084 & & & \\
\hline SESPMNT & B17RJ6 & 100-F SPRING 207-1 & ONSITE & SW & $\mathrm{N}$ & SEEP & UNFILTERED & 03-Nov-03 U-234 & & $0.805 \mathrm{p}$ & & 0.075 & 0.15 & & & \\
\hline $\begin{array}{l}\text { SESPMNT } \\
\text { SESPMNT }\end{array}$ & B17RJ8 & HANFORD SPR UR 28-2 & ONSITE & SW & $\mathrm{N}$ & $\begin{array}{l}\text { SEEP } \\
\text { SEPP }\end{array}$ & $\begin{array}{l}\text { UNFILTERED } \\
\text { UNEITFRED }\end{array}$ & 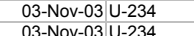 & & $0.507 \mathrm{p}$ & pCi/L & 0.056 & 0.098 & & & \\
\hline $\begin{array}{l}\text { SESPNT } \\
\text { SESPMNT }\end{array}$ & $\begin{array}{l}\text { B17RR9 } \\
\text { B17RH7 }\end{array}$ & $\begin{array}{l}\text { HANFORD SPR DR 28-2 } \\
\text { HANFORD SPRING 28-2 }\end{array}$ & $\begin{array}{l}\text { ONSTIE } \\
\text { ONSITE }\end{array}$ & sw & $\frac{\mathrm{N}}{\mathrm{N}}$ & $\begin{array}{l}\text { SEEP } \\
\text { SEEP }\end{array}$ & $\begin{array}{l}\text { UNFLITERED } \\
\text { UNFILTERED }\end{array}$ & $\begin{array}{l}03-\text {-Nov- } 03 \text { U-234 } \\
10-\text { OCt-03 } \mathrm{Hg}\end{array}$ & & & pCilL & & 0.1 & & NOSAMPIF & \\
\hline SESPMNT & B17RK5 & $100-H$ SPRING $145-1$ & ONSITE & sw & $\mathrm{N}$ & SEEP & UNFILTERED & $10-\mathrm{Oct}-03 \mathrm{Hg}$ & & $0.0407 u$ & & & & & NO SAMPLE. & \\
\hline SESPMNT & B17RH8 & 300 AREA SPRING 42-2 & ONSITE & sw & $\mathrm{N}$ & SEEP & UNFILTERED & 13-Oct-03 Hg & & $0.00212 \mathrm{u}$ & & & & & & \\
\hline SESPMNT & B17RL5 & 300 AREA SPR DR 42-2 & ONSITE & SW & $\mathrm{N}$ & SEEP & UNFLLTERED & 13-Oct-03 Hg & & $0.00103 \mathrm{u}$ & & & & & & \\
\hline SESPMNT & B17J89 & 100-N SPRING 199N-46 & ONSITE & sw & $\mathrm{N}$ & SEEP & UNFILTERED & $20-\mathrm{Oct}-03 \mathrm{Hg}$ & & & & & & & NO SAMPLE NO SEEP OBSERVED. & \\
\hline SESPMNT & B17 1717 & 100-N SPRING 8-13 & ONSITE & sw & $\mathrm{N}$ & SEEP & UNFILTERED & $20-\mathrm{Oct}-03 \mathrm{Hg}$ & & $0.000775 \mathrm{u}$ & & & & & & \\
\hline SESPMNT & B17J76 & 100-B SPRING $37-1$ & ONSITE & sw & $\mathrm{N}$ & SEEP & $\begin{array}{l}\text { UNFITTERED } \\
\text { UNER }\end{array}$ & $20-$ Oct- $03 \mathrm{Hq}$ & & $0.000445 \mathrm{u}$ & & & & & & \\
\hline SESPMNT & B17J82 & 100-B SPRING 39-2 & ONSITE & sw & $\mathrm{N}$ & SEEP & UNFILTERED & $20-\mathrm{Oct}-03 \mathrm{Hg}$ & & 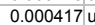 & & & & & & \\
\hline SESPMNT & B17J84 & 100-K SPRING 63-2 & ONSITE & sw & $\mathrm{N}$ & SEEP & UNFILTERED & $20-\mathrm{Oct}-03 \mathrm{Hg}$ & & $0.000747 u$ & & & & & & \\
\hline SESPMNT & B17J91 & 100-D SPRING 110-1 & ONSITE & SW & $\mathrm{N}$ & SEEP & UNFILTERED & $27-\mathrm{Oct}-03 \mathrm{Hg}$ & & $0.000767 \mathrm{u}$ & & & & & & \\
\hline SESPMNT & B17J93 & 100-D SPRING 102-1 & ONSITE & sw & $\mathrm{N}$ & SEEP & UNFILTERED & $27-\mathrm{Oct}-03 \mathrm{Hg}$ & & $0.00462 u$ & & & & & & \\
\hline SESPMNT & B17RL9 & 100-H SPRING 153-1 & ONSITE & SW & $\mathrm{N}$ & SEEP & UNFILTERED & $27-\mathrm{Oct}-03 \mathrm{Hg}$ & & $0.000777 \mathrm{u}$ & & & & & & \\
\hline $\begin{array}{l}\text { SESPMNT } \\
\text { SESPNNT }\end{array}$ & B17RK7 & 100-F SPRING 207-1 & ONSITE & $\begin{array}{c}\text { SW } \\
\text { sw }\end{array}$ & $N$ & $\begin{array}{l}\text { SEEP } \\
\text { SEEP }\end{array}$ & $\begin{array}{l}\text { UNFILTERED } \\
\end{array}$ & 03-Nov-03 Hg & & $0.00762 u$ & & & & & & \\
\hline $\begin{array}{l}\text { SESPMNI } \\
\text { SESPMNT }\end{array}$ & $\begin{array}{l}\text { B1/RLO } \\
\text { B17RL2 }\end{array}$ & $\begin{array}{l}\text { HANFORD SPR URR 28-2 } \\
\text { HANFORD SPR DR 28-2 }\end{array}$ & $\begin{array}{l}\text { ONSIIE } \\
\text { ONSITE }\end{array}$ & sw & $\mathrm{N}$ & $\begin{array}{l}\text { SEEP } \\
\text { SEEP }\end{array}$ & $\begin{array}{l}\text { UNFLIERED } \\
\text { UNFILTERED }\end{array}$ & $\begin{array}{l}03-\text { Nov- } 03 \text { Hg } \\
03-N o v-03 \mathrm{Hg}\end{array}$ & & $\begin{array}{l}0.0095 / 4 u \\
0.000813 u\end{array}$ & & & & & & \\
\hline SESPMNT & B17J86 & 100-K SPRING 77-1 & ONSITE & sw & $\mathrm{N}$ & SEEP & UNFILTERED & 10-Nov-03 Hg & & $0.000875 u$ & & & & & & \\
\hline SESPSPEC & $\mathrm{B} 180 \mathrm{H} 6$ & 100-B SPRING 37-1 & ONSITE & sw & Y & SEEP & & 13-Nov-03 Hg & & $0.000488 \mathrm{u} \longrightarrow \mathrm{C}-\mathrm{s}$ & & & & & & \\
\hline SESPSPEC & $\mathrm{B} 180 \mathrm{H} 7$ & 100-B SPRING 38-3 & ONSITE & sw & $\mathrm{Y}$ & SEEP & & 13-Nov-03 Hg & & $0.000389 u$ & & & & & & \\
\hline $\begin{array}{l}\text { SESPPSEC } \\
\text { SESPPEC }\end{array}$ & $\begin{array}{l}\text { B180099 } \\
\text { B180.J1 }\end{array}$ & $\begin{array}{l}100 \text { B/C AREA OUTTL1 } \\
100 \text { B/C AREA OUTFL3 }\end{array}$ & $\begin{array}{l}\text { ONSITE } \\
\text { ONSTE }\end{array}$ & $\begin{array}{l}\text { sw } \\
\text { sw }\end{array}$ & $\begin{array}{l}\text { Y } \\
\text { Y }\end{array}$ & $\begin{array}{l}\text { SEEP } \\
\text { SEEP }\end{array}$ & & $\begin{array}{l}\text { 17-Nov- } 03 \mathrm{Hg} \\
\text { 17-Nov } 03 \mathrm{Hg}\end{array}$ & & & & & & & $\begin{array}{l}\text { NO SAMPLE. NOT AVAILABLE. } \\
\text { NO SAMPLE NOT AAALABLE }\end{array}$ & \\
\hline SESPSPEC & B180H8 & 100-B SPRING 39-2 & ONSITE & sw & $\mathrm{Y}$ & SEEP & & 17-Nov- $03 \mathrm{Hg}$ & & $0.000473 u$ & $\mathrm{ug} / \mathrm{L}$ & & & & & \\
\hline SESPSPEC & B180J0 & 100 B/C AREA OUTFL2 & ONSITE & sw & Y & SEEP & & 17-Nov-03 Hg & & 0.0007254 & & & & & & \\
\hline SESPMNT & B17RK5 & $100-\mathrm{H}$ SPRING $145-1$ & ONSITE & sw & $\mathrm{N}$ & SEEP & UNFILTERED & $10-O c t-03 \mathrm{Zn}$ & & $282 \mathrm{u}$ & ug/L & & & & & \\
\hline SESPMNT & B17RH8 & 300 AREA SPRING 42-2 & ONSITE & sw & $\mathrm{N}$ & SEEP & UNFILTERED & 13-Oct-03 Zn & & $18.5 u$ & & & & & & \\
\hline SESPMNT & B17RL4 & 300 AREA SPRING 42-2 & ONSITE & sw & Y & SEEP & & 13-Oct-03 Zn & & 0.9314 & & & & & & \\
\hline $\begin{array}{l}\text { SESPMNT } \\
\text { SESPMNT }\end{array}$ & B17RL5 & 300 AREA SPR DR 42-2 & ONSITE & sw & $\begin{array}{l}\mathrm{N} \\
\mathrm{Y}\end{array}$ & SEEP & UNFILTERED & 13-Oct-03 Zn & & $3.66 \mathrm{u}$ & & & & & & \\
\hline $\begin{array}{l}\text { SESPMNT } \\
\text { SESPMNT }\end{array}$ & $\begin{array}{l}\text { B17RL6 } \\
\text { B17J83 }\end{array}$ & $\begin{array}{l}300 \text { AREA SPR DR 42-2 } \\
100-B \text { SPRING 39-2 }\end{array}$ & $\begin{array}{l}\text { ONSITE } \\
\text { ONSITE }\end{array}$ & \begin{tabular}{|l} 
SW \\
SW
\end{tabular} & $\begin{array}{l}\mathrm{Y} \\
\mathrm{Y}\end{array}$ & $\begin{array}{l}\text { SEEP } \\
\text { SEEP }\end{array}$ & & $\begin{array}{l}\text { 13-OCt-03 Zn } \\
\text { 20-oct-03 Zn }\end{array}$ & & $\begin{array}{c}1.08 \mathrm{u} \\
0.684 \mathrm{u}\end{array}$ & & & & & BOTTLE LEAKED WAS REBOTTLED AND SENT & \\
\hline ESPMNT & B17117 70 & 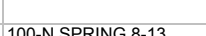 & ONSITE & SW & $\mathrm{N}$ & SEEP & INEEITERED & 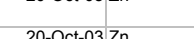 & & & & & & & ANALYSES. & \\
\hline SPMNT & B17J76 & 100-B SPRING 37-1 & ONSITE & sw & $\mathrm{N}$ & SEEP & UNFILTERED & $\begin{array}{l}20-0 c-03<n \\
20-O c t-03 Z n\end{array}$ & & $1.44 \mathrm{u}$ & & & & & & \\
\hline
\end{tabular}




\begin{tabular}{|c|c|c|c|c|c|c|c|c|c|c|c|c|c|c|c|c|}
\hline | OWNER ID & \begin{tabular}{|l} 
SAMP \\
NUM
\end{tabular} & & $\left|\begin{array}{c}\text { DIST } \\
\text { CLASS }\end{array}\right|$ & MEDIA & $\begin{array}{c}\text { FILTERED } \\
\text { FLAG }\end{array}$ & $\begin{array}{l}\text { SAMP } \\
\text { FROM }\end{array}$ & | COLL MTHD | & SAMP DATE & CON SHORT NAME & $\begin{array}{c}\text { VALUE } \\
\text { RPTD }\end{array}$ & \begin{tabular}{|l|} 
ANAL \\
UNIST \\
RPTD \\
\end{tabular} & $\mid$\begin{tabular}{c|c|} 
COUNTING \\
ERROR
\end{tabular} & $\begin{array}{c}\text { TOTAL } \\
\text { ANAL } \\
\text { ERROR }\end{array}$ & $\left|\begin{array}{c}\text { LAB } \\
\text { QUALIFIER }\end{array}\right|$ & SAMP COMMENT & $\left|\begin{array}{c}\text { RESULT } \\
\text { COMMENT }\end{array}\right|$ \\
\hline SESPMNT & B17J81 & 100-B SPRING 37-1 & ONSITE & sw & $\mathrm{Y}$ & SEEP & & 20-Oct-03 Zn & & & & & & & & \\
\hline SESPMNT & B17J82 & 100-B SPRING 39-2 & ONSITE & SW & $N$ & & UNFILTERED & 20-Oct-03 Zn & & & & & & & & \\
\hline SESPMNT & B17J84 & 100-K SPRING 63-2 & ONSITE & SW & $\begin{array}{l}\mathrm{N} \\
\mathrm{Y}\end{array}$ & $\begin{array}{l}\text { SEEP } \\
\text { SEEP }\end{array}$ & UNFILTERED & 20-Oct-03 Zn & & & $\mathrm{ug} / \mathrm{L}$ & & & & & \\
\hline $\begin{array}{l}\text { SESPMNT } \\
\text { SESPMNT }\end{array}$ & B17J85 & 100-K SPRING 63-2 & ONSITE & SW & $\begin{array}{l}Y \\
Y\end{array}$ & $\begin{array}{l}\text { SEEP } \\
\text { SEFP }\end{array}$ & & 20-Oct-03 Zn & & $0.434 \mathrm{u}$ & & & & & & \\
\hline $\begin{array}{l}\text { SESPMNT } \\
\text { SESPMNT }\end{array}$ & B17J88 & 100-N SPRING 8-13 & $\begin{array}{l}\text { ONITE } \\
\text { ONSITE }\end{array}$ & $\begin{array}{l}\text { SW } \\
\text { sw }\end{array}$ & $\frac{Y}{N}$ & $\begin{array}{l}\text { SEEP } \\
\text { SEEP }\end{array}$ & UNFILTERED & $\begin{array}{l}\text { 20-Oct-03 Zn } \\
\text { 2-O-Oct-03 Zn }\end{array}$ & & & & & & & & \\
\hline $\begin{array}{l}\text { SESPMNT } \\
\text { SESPMNT }\end{array}$ & $\begin{array}{l}\text { B17JJ91 } \\
\text { B17J92 }\end{array}$ & $\begin{array}{l}\text { 100-D SPRING 1010-1 } \\
\text { 100-D SPRING 110-1 }\end{array}$ & $\begin{array}{l}\text { ONSITE } \\
\text { ONSITE }\end{array}$ & sw & $\mathrm{Y}$ & $\begin{array}{l}\text { SEEP } \\
\text { SEEP }\end{array}$ & UNFILTERED & $\begin{array}{l}27-\mathrm{OCt}-03 \mathrm{Zn} \\
27-\mathrm{Oct}-03 \mathrm{Zn}\end{array}$ & & $1.61 \mathrm{u}$ & & & & & & \\
\hline SESPMNT & B17.993 & 100-D SPRING 102-1 & ONSITE & sw & $\mathrm{N}$ & SEEP & UNFILTERED & $27-O c t-03 \mathrm{Zn}$ & & $7.98 \mathrm{u}$ & & & & & & \\
\hline SESPMNT & B17J94 & 100-D SPRING 102-1 & ONSITE & sw & $\mathrm{Y}$ & SEEP & & $27-0 c t-03 \mathrm{Zn}$ & & & & & & & & \\
\hline SESPMNT & B17RK6 & $100-H$ SPRING $145-1$ & ONSITE & SW & $\mathrm{Y}$ & SEEP & & $27-$ Oct-03 Zn & & & & & & & & \\
\hline SESPMNT & B17RL9 & 100-H SPRING 153-1 & ONSITE & SW & $\mathrm{N}$ & SEEP & UNFILTERED & 27-Oct-03 Zn & & & & & & & & \\
\hline SESPMNT & B17RMO & 100-H SPRING 153-1 & ONSITE & SW & & SEEP & & 27-Oct-03 Zn & & & & & & & & \\
\hline SESPMNT & B17RK7 & 100-F SPRING 207-1 & ONSITE & SW & N & SEEP & UNFILTERED & 03-Nov-03 Zn & & & & & & & & \\
\hline $\begin{array}{l}\text { SESPMNT } \\
\text { SESPMNT }\end{array}$ & $\begin{array}{l}\text { B17RK8 } \\
\text { B17RLO }\end{array}$ & 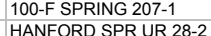 & $\begin{array}{l}\text { ONITE } \\
\text { ONSITE }\end{array}$ & $\begin{array}{l}\text { SW } \\
\text { sw }\end{array}$ & $\begin{array}{l}\mathrm{Y} \\
\mathrm{N}\end{array}$ & $\begin{array}{l}\text { SEEP } \\
\text { SEEP }\end{array}$ & & $\begin{array}{l}\text { 03-Nov-03 Zn } \\
\text { 03-Nov-03 Zn }\end{array}$ & & $0.655 \mathrm{u}$ & & & & & & \\
\hline $\begin{array}{l}\text { SESPMNT } \\
\text { SESPMNT }\end{array}$ & $\begin{array}{l}\text { B17RLO } \\
\text { B17RL1 }\end{array}$ & $\begin{array}{l}\text { HANFFRD SPR UR 28-2 } \\
\text { HANFORD SPR UR 28-2 }\end{array}$ & $\begin{array}{l}\text { ONITE } \\
\text { ONSITE }\end{array}$ & $\begin{array}{l}\text { SW } \\
\text { SW }\end{array}$ & $\begin{array}{l}\mathrm{N} \\
\mathrm{Y}\end{array}$ & $\begin{array}{l}\text { SEEP } \\
\text { SEEP }\end{array}$ & UNFILTERED & $\begin{array}{l}\text { 03-Nov-03 Zn } \\
\text { 03-Nov-03 Zn }\end{array}$ & & $\begin{array}{c}1.25 u \\
0.535 u\end{array}$ & & & & & & \\
\hline SESPMNT & B17RL2 & HANFORD SPR DR 28-2 & ONSITE & SW & $\mathrm{N}$ & SEEP & UNFILTERED & 03-Nov-03 Zn & & & & & & & & \\
\hline SESPMNT & B17RL3 & HANFORD SPR DR 28-2 & ONSITE & sW & $\mathrm{Y}$ & SEEP & & 03-Nov-03 Zn & & & & & & & & \\
\hline SESPMNT & B17J86 & 100-K SPRING 77-1 & ONSITE & SW & $\mathrm{N}$ & SEEP & UNFILTERED & 10-Nov-03 Zn & & & & & & & & \\
\hline $\begin{array}{l}\text { SESPMNT } \\
\text { SESPSPCC }\end{array}$ & B17J87 & 100-K SPRING 77-1 & ONSITE & SW & $Y$ & SEEP & & 10-Nov-03 Zn & & $0.903 \mathrm{u}$ & & & & & & \\
\hline $\begin{array}{l}\text { SESPSPEC } \\
\text { SESPSEC }\end{array}$ & B180H6 & $\begin{array}{l}\text { 100-B SPRING 37-1 } \\
100-B \text { SPRING 38-3 }\end{array}$ & $\begin{array}{l}\text { ONSITE } \\
\text { ONSITE }\end{array}$ & SW & $\begin{array}{l}Y \\
Y\end{array}$ & $\begin{array}{l}\text { SEEP } \\
\text { SEEP }\end{array}$ & & $\begin{array}{l}\text { 13-Nov-03 Zn } \\
13-\text { Nov-03 Zn }\end{array}$ & & $0.515 u$ & & & & & & \\
\hline $\begin{array}{l}\text { SESPSECC } \\
\text { SESPSPEC }\end{array}$ & $\begin{array}{l}\mathrm{B} 180 \mathrm{H} 7 \\
180 \mathrm{H}\end{array}$ & $\begin{array}{l}\text { 100-B SPRING 38-3 } \\
\text { 100-B SPRING 39-2 }\end{array}$ & $\begin{array}{l}\text { ONITE } \\
\text { ONSITE }\end{array}$ & $\begin{array}{l}\text { SW } \\
\text { sw }\end{array}$ & $\begin{array}{l}Y \\
Y\end{array}$ & $\begin{array}{l}\text { SEEP } \\
\text { SEEP }\end{array}$ & & $\begin{array}{l}\text { 13-Nov-03 Zn } \\
\text { 17-Nov-03 Zn }\end{array}$ & & $\begin{array}{l}0.664 u \\
0.48 u\end{array}$ & & & & & & \\
\hline SESPSPEC & B180J0 & 100 B/C AREA OUTFL2 & ONSITE & SW & Y & SEEP & & $\begin{array}{l}\text { 17-nNov-03 } 2 n \\
\text { 17-Nov-03 Zn }\end{array}$ & & $0.85 \mathrm{u}$ & ugh/L & & & & & \\
\hline SESPSPEC & $\mathrm{B} 180 \mathrm{H} 6$ & 100-B SPRING 37-1 & ONSITE & SW & $\mathrm{Y}$ & SEEP & & 13-Nov-03 U & & $2.35 u$ & $\mathrm{ug} / \mathrm{L}$ & & & & & \\
\hline $\begin{array}{l}\text { SESPSPEC } \\
\text { SESPSPCC }\end{array}$ & B180H7 & 100-B SPRING 38-3 & ONSITE & SW & $Y$ & SEEP & & 13-Nov-03U & & $1.72 \mathrm{u}$ & ug/L & & & & & \\
\hline $\begin{array}{l}\text { SESPSPEC } \\
\text { SESPSEC }\end{array}$ & B180H8 & 100-B SPRING 39-2 & ONSITE & SW & $\begin{array}{l}Y \\
Y \\
Y\end{array}$ & SEEP & & 17-Nov-03U & & $0.776 \mathrm{u}$ & & & & & & \\
\hline $\begin{array}{l}\text { SESPSPEC } \\
\text { SESPMNT }\end{array}$ & $\begin{array}{l}\text { B180J0 } \\
\text { B17RK5 }\end{array}$ & $\begin{array}{l}100 \text { B/C AREA OUTFL2 } \\
100-\text { H PRPING 15-1 }\end{array}$ & $\begin{array}{l}\text { ONSITE } \\
\text { ONSITE }\end{array}$ & SW & $Y$ & $\begin{array}{l}\text { SEEP } \\
\text { SEEP }\end{array}$ & & $\begin{array}{l}\text { 17-Nov-03 U } \\
1 \text { 1-0ct-03 TI }\end{array}$ & & 0.1214 & & & & & & \\
\hline $\begin{array}{l}\text { SESPMNI } \\
\text { SESPMNT }\end{array}$ & $\begin{array}{l}\text { B17RK5 } \\
\text { B17RH8 }\end{array}$ & $\begin{array}{l}100-\mathrm{H} \text { SRING } 145-1 \\
300 \text { ARE SPRG 42-2 }\end{array}$ & $\begin{array}{l}\text { ONITE } \\
\text { ONSITE }\end{array}$ & $\begin{array}{l}\text { SW } \\
\text { SW }\end{array}$ & ${ }_{N}^{N}$ & $\begin{array}{l}\text { SEEP } \\
\text { SEEP }\end{array}$ & $\begin{array}{l}\text { UNFFLTERED } \\
\text { UNFILTERED }\end{array}$ & $\begin{array}{l}\text { 10-Oct-03 TI } \\
\text { 13-Oct-03 TI }\end{array}$ & & $\begin{array}{c}0.179 u \\
0.0302 u\end{array}$ & & & & & & \\
\hline SESPMNT & B17RL4 & 300 AREA SPRING 42-2 & ONSITE & SW & $\mathrm{Y}$ & SEEP & & 13-Oct-03 TI & & $0.0157 \mathrm{u}$ & & & & B & & \\
\hline $\begin{array}{l}\text { SESPMNT } \\
\text { SESPMNT }\end{array}$ & B17RL5 & 300 AREA SPR DR 42-2 & ONSITE & SW & $\mathrm{N}^{\mathrm{N}}$ & $\begin{array}{l}\text { SEEP } \\
\text { SEFP }\end{array}$ & UNFILTERED & 13-Oct-03 TI & & $0.0133 \mathrm{u}$ & & & & $B$ & & \\
\hline SESPMNT & B17RL6 & 300 AREA SPR DR 42-2 & ONSITE & SW & $Y$ & SEEP & & 13-Oct-03 TI & & $0.0144 \mathrm{u}$ & & & & B & & \\
\hline SESPMNT & B17J83 & 100-B SPRING 39-2 & ONSITE & sw & Y & SEEP & & 20-Oct-03 TI & & $0.009 \mathrm{u}$ & & & & u & $\begin{array}{l}\text { BOTTTLL LEAKED WAS REBOTTLED AND SENT TO LAB FOR } \\
\text { ANALYES. }\end{array}$ & \\
\hline SESPMNT & B17J17 & 100-N SPRING 8-13 & ONSITE & sw & $\mathrm{N}$ & SEEP & UNFILTERED & 20-Oct-03 TI & & $0.0103 \mathrm{u}$ & & & & B & & \\
\hline SESPMNT & B17J76 & 100-B SPRING 37-1 & ONSITE & sw & $\mathrm{N}$ & SEEP & UNFILTERED & $20-0 c t-03 \mathrm{TI}$ & & $0.009 u$ & & & & u & & \\
\hline $\begin{array}{l}\text { SESPMNT } \\
\text { SESPMNT }\end{array}$ & B17J81 & 100-B SPRING 37-1 & ONSITE & SW & $Y^{Y}$ & SEEP & & 20-Oct-03 TI & & $0.009 \mathrm{u}$ & & & & u & & \\
\hline SESPMNT & B17J82 & 100-B SPRING 39-2 & ONSITE & sw & $\mathrm{N}$ & SEEP & UNFILTERED & 20-Oct-03 TI & & $0.009 \mathrm{u}$ & & & & $\mathrm{u}$ & & \\
\hline SESPMNT & B17J84 & 100-K SPRING 63-2 & ONSITE & SW & $\mathrm{N}$ & SEEP & UNFILTERED & $20-O c t-03 \mathrm{TI}$ & & $0.009 \mathrm{u}$ & ug/L & & & U & & \\
\hline $\begin{array}{l}\text { SESPMNT } \\
\text { SESPMNT }\end{array}$ & $\begin{array}{l}\text { B17JJ55 } \\
\text { B17J88 }\end{array}$ & $\begin{array}{l}\text { 100-K SPRING 63-2 } \\
\text { 100-N PRRIN 8-13 }\end{array}$ & $\begin{array}{l}\text { ONITE } \\
\text { ONSITE }\end{array}$ & $\begin{array}{l}\text { SW } \\
\text { sw }\end{array}$ & $\begin{array}{l}\mathrm{Y} \\
\mathrm{y}\end{array}$ & $\begin{array}{l}\text { SEEP } \\
\text { SEEP }\end{array}$ & & $\begin{array}{l}20-\mathrm{Oct}-03 \mathrm{TI} \\
20-\mathrm{Otc}-03 \mathrm{TI}\end{array}$ & & $0.009 \mathrm{u}$ & & & & $\underline{u}$ & & \\
\hline SESPMNT & B17J91 & 100-D SPRING $110-1$ & ONSITE & sw & $\mathrm{N}$ & SEEP & UNFILTERED & $27-0 \mathrm{ct}-03 \mathrm{TI}$ & & 0.02054 & & & & & & \\
\hline SESPMNT & B17J92 & 100-D SPRING 110-1 & ONSITE & sw & $Y$ & SEEP & & 27-Oct-03 TI & & $0.016 u$ & & & & B & & \\
\hline SESPMNT & B17J93 & 100-D SPRING 102-1 & ONSITE & SW & $\mathrm{N}$ & SEEP & UNFILTERED & 27-Oct-03 TI & & $0.0158 u$ & & & & B & & \\
\hline SESPMNT & B17J94 & 100-D SPRING 102-1 & ONSITE & SW & $Y$ & SEEP & & 27-Oct-03 TI & & $0.009 \mathrm{u}$ & & & & U & & \\
\hline $\begin{array}{l}\text { SESPMNT } \\
\text { SESPMNT }\end{array}$ & B17RK6 & 100-H SPRING 145-1 & ONSITE & SW & Y & SEEP & & 27-Oct-03 TI & & 0.009 u & & & & U & & \\
\hline $\begin{array}{l}\text { SESPMNT } \\
\text { SESPMNT }\end{array}$ & $\begin{array}{l}\text { B17RL9 } \\
\text { B17PM0 }\end{array}$ & 100-H SPRING 153-1 & $\begin{array}{l}\text { ONSITE } \\
\text { ONITE }\end{array}$ & SW & $\begin{array}{l}\mathrm{N} \\
\mathrm{Y}\end{array}$ & $\begin{array}{l}\text { SEEP } \\
\text { SEFP }\end{array}$ & UNFILTERED & 27-Oct-03 TI & & $0.0107 \mathrm{u}$ & & & & B & & \\
\hline $\begin{array}{l}\text { SESPMNT } \\
\text { SESPMNT }\end{array}$ & $\begin{array}{l}\text { B17RMO } \\
\text { B17RK7 }\end{array}$ & $\begin{array}{l}100-H \text { SPRING 153-1 } \\
100-F \text { SPRING 207-1 }\end{array}$ & $\begin{array}{l}\text { ONITE } \\
\text { ONSITE }\end{array}$ & SW & $\frac{Y}{N}$ & $\begin{array}{l}\text { SEEP } \\
\text { SEEP }\end{array}$ & UNFILTERED & $\begin{array}{l}\text { 27-Oct-03 TI } \\
\text { 03-Nov-03 TI }\end{array}$ & & $\begin{aligned} 0.009 \mathrm{u} \\
0.0861 \mathrm{u}\end{aligned}$ & & & & 0 & & \\
\hline $\begin{array}{l}\text { SESPMNI } \\
\text { SESPMNT }\end{array}$ & $\begin{array}{l}\text { B17RK/ } \\
\text { B17RK8 }\end{array}$ & 100-F SPRING 207-1 & $\begin{array}{l}\text { ONSITE } \\
\text { ONS }\end{array}$ & sw & $\begin{array}{l}\mathrm{Y} \\
\mathrm{N}\end{array}$ & $\begin{array}{l}\text { SEEP } \\
\text { SEEP }\end{array}$ & UNFFLIERED & $\begin{array}{l}\text { 03-Novo-03 TI } \\
\text { 03-Nov-03 TI }\end{array}$ & & $\begin{array}{l}0.0106 \mathrm{u} \\
0.0106\end{array}$ & ugh/L & & & B & & \\
\hline SESPMNT & B17RL0 & HANFORD SPR UR 28-2 & ONSITE & SW & $\mathrm{N}$ & SEEP & UNFILTERED & 03-Nov-03 TI & & $0.0114 \mathrm{u}$ & & & & B & & \\
\hline $\begin{array}{l}\text { SESPMNT } \\
\text { SESPMNT }\end{array}$ & $\begin{array}{l}\text { B17RL1 } \\
\text { B17R|2 }\end{array}$ & $\begin{array}{l}\text { HANFORD SPR UR 28-2 } \\
\text { HANORD }\end{array}$ & ONSITE & SW & $Y_{N}$ & $\begin{array}{l}\text { SEEP } \\
\text { SEFP }\end{array}$ & UNEU TFRED & 03-Nov-03 TI & & $0.0114 \mathrm{u}$ & & & & $B$ & & \\
\hline $\begin{array}{l}\text { SESPMNT } \\
\text { SESPMNT }\end{array}$ & B17RL2 & & & SW & $\mathrm{N}$ & SEEP & & 03-Nov-03 TI & & 0.014 & $\mathrm{ug} / \mathrm{L}$ & & & $B$ & & \\
\hline $\begin{array}{l}\text { SESPMNT } \\
\text { SESPMNT }\end{array}$ & $\begin{array}{l}\text { B17RL3 } \\
\text { B17196 }\end{array}$ & HANFORD SPR DR 28-2 & ONSITE & SW & $Y$ & SEEP & & 03-Nov-03 TI & & $0.01 \mathrm{u}$ & ug/L & & & $B$ & & \\
\hline $\begin{array}{l}\text { SESPMNT } \\
\text { SESPMNT }\end{array}$ & $\begin{array}{l}\text { B17J866 } \\
\text { B17J87 }\end{array}$ & $\begin{array}{l}\text { 100-KSPRING 77-1 } \\
\text { 100-K SPRING 77-1 }\end{array}$ & $\begin{array}{l}\text { ONITE } \\
\text { ONSITE }\end{array}$ & $\begin{array}{l}\text { SW } \\
\text { SW }\end{array}$ & $\begin{array}{l}\mathrm{N} \\
\mathrm{Y}\end{array}$ & $\begin{array}{l}\text { SEEP } \\
\text { SEEP }\end{array}$ & UNFILTERED & $\begin{array}{l}\text { 10-Nov-03 TI } \\
\text { 10-Nov-03 } \mathrm{TI}\end{array}$ & & $\begin{array}{l}0.00986 \mathrm{u} \\
0.00789 \mathrm{u}\end{array}$ & & & & $\begin{array}{l}B \\
B\end{array}$ & & \\
\hline SESPSPEC & $\mathrm{B} 180 \mathrm{H} 6$ & 100-B SPRING 37-1 & ONSITE & SW & $Y$ & SEEP & & 13-Nov-03 TI & & 0.009814 & & & & $B$ & & \\
\hline SESPSPEC & $\mathrm{B} 180 \mathrm{H} 7$ & 100-B SPRING 38-3 & ONSITE & SW & $Y$ & SEEP & & 13-Nov-03 TI & & 0.0074 & & & & u & & \\
\hline SESPSPEC & $\mathrm{B} 180 \mathrm{H} 8$ & 100-B SPRING 39-2 & ONSITE & SW & $Y$ & SEEP & & 17-Nov-03 TI & & 0.0074 & ug/L & & & $u$ & & \\
\hline $\begin{array}{l}\text { SESPSPEC } \\
\text { SECDSDCC }\end{array}$ & B180J0 & $100 \mathrm{~B} / \mathrm{C}$ AREA OUTFL2 & ONSITE & SW & Y & SEEP & & 17-Nov-03 TI & & 0.0074 & ug/L & & & U & & \\
\hline $\begin{array}{l}\text { SESPSPEC } \\
\text { SESPSEC }\end{array}$ & B180H6 & 100-B SPRING 37-1 & ONSITE & SW & $\begin{array}{l}Y \\
Y\end{array}$ & $\begin{array}{l}\text { SEEP } \\
\text { SEFP }\end{array}$ & & 13-Nov-03 Th & & 0.1114 & $\mathrm{ug} / \mathrm{L}$ & & & U & & \\
\hline $\begin{array}{l}\text { SESPSECC } \\
\text { SESPSPEC }\end{array}$ & B180H/ & $\begin{array}{l}\text { 100-B SPRING 38-3 } \\
\text { 100-B SPRING 39-2 }\end{array}$ & $\begin{array}{l}\text { ONITE } \\
\text { ONSITE }\end{array}$ & $\begin{array}{l}\text { SW } \\
\text { sw }\end{array}$ & $\begin{array}{l}Y \\
Y\end{array}$ & $\begin{array}{l}\text { SEEP } \\
\text { SEEP }\end{array}$ & & $\begin{array}{l}\text { 13-Nov-03 Th } \\
\text { 17-Nov-03 Th }\end{array}$ & & $0.111 \mathrm{u} u$ & $\frac{\mathrm{ug} / \mathrm{L}}{\mathrm{ug} / \mathrm{L}}$ & & & u & & \\
\hline SESPSPEC & B180Jo & 100 B/C AREA OUTFL2 & ONSITE & $\mathrm{sW}$ & Y & SEEP & & 17-Nov-03 Th & & $0.111 \mathrm{u}$ & $u g / L$ & & & u & & \\
\hline SESPMNT & B17RK5 & 100-H SPRING 145-1 & ONSITE & sw & $\mathrm{N}$ & SEEP & UNFILTERED & 10-Oct-03 Se & & $0.496 \mathrm{u}$ & & & & u & & \\
\hline SES & B17RH8 & 300 AREA SPRING 42-2 & ONSITE & SW & $\mathrm{N}$ & SEEP & UNFILTERED & 13-Oct-03 Se & & $2.72 u$ & & & & & & \\
\hline $\begin{array}{l}\text { SESPMNT } \\
\text { SESPMNT }\end{array}$ & $\begin{array}{l}\text { B17RL4 } \\
\text { B17RL5 }\end{array}$ & $\begin{array}{l}300 \text { AREA SPRING 42-2 } \\
300 \text { AREA SPR DR 42-2 }\end{array}$ & $\begin{array}{l}\text { ONITE } \\
\text { ONSITE }\end{array}$ & $\begin{array}{l}\text { SW } \\
\text { SW }\end{array}$ & $Y^{Y}$ & $\begin{array}{l}\text { SEEP } \\
\text { SEEP }\end{array}$ & UNFILTERED & $\begin{array}{l}\text { 13-Oct-03 Se } \\
\text { 13-OCt-03 Se }\end{array}$ & & $\begin{array}{l}3.05 u \\
3.47 u \\
u\end{array}$ & ig// & & & & & \\
\hline SESPMNT & B17RL6 & 300 AREA SPR DR 42-2 & ONSITE & SW & $Y$ & SEEP & GNTIL TLALE & $\begin{array}{l}\text { 13-0c-03 Se } \\
13-0 c t-03 \mathrm{Se}\end{array}$ & & $3.07 \mathrm{u}$ & ug/L & & & & & \\
\hline
\end{tabular}




\begin{tabular}{|c|c|c|c|c|c|c|c|c|c|c|c|c|c|c|c|c|}
\hline | OWNER ID & \begin{tabular}{|l|l} 
SAMP \\
NUM
\end{tabular} & SAMP SITE NAME & $\left|\begin{array}{c}\text { DIST } \\
\text { CLASS }\end{array}\right|$ & $\mid$ MEDIA $\mid$ & $\begin{array}{l}\text { FLLTERED } \\
\text { FLAG }\end{array}$ & $\mid \begin{array}{l}\text { SAMP } \\
\text { FROM }\end{array}$ & $\mid$ COLL MTHD $\mid \leqslant$ & SAMP DATE & CON SHORT NAME & $\begin{array}{l}\text { VALUE } \\
\text { RPTD }\end{array}$ & \begin{tabular}{|l|} 
ANAL \\
UNITS \\
RPTD
\end{tabular} & $\begin{array}{c}\text { COUNTING } \\
\text { ERROR }\end{array}$ & $\begin{array}{l}\text { TOTAL } \\
\text { ANAL } \\
\text { ERROR }\end{array}$ & $\left|\begin{array}{c}\text { LAB } \\
\text { QUALIFIER }\end{array}\right|$ & SAMP COMMENT & $\left|\begin{array}{c}\text { RESULT } \\
\text { COMMENT }\end{array}\right|$ \\
\hline SESPMNT & B17J83 & 100-B SPRING 39-2 & ONSITE & SW & Y & SEEP & & 20-Oct-03 Se & & 0.496 & & & & u & $\begin{array}{l}\text { BOTTLE LEAKED WAS REBOTTLED AND SENT TO LAB FOR } \\
\text { ANALYSES. }\end{array}$ & \\
\hline $\begin{array}{l}\text { SESPMNT } \\
\text { SESPMNT }\end{array}$ & B17J17 & 100-N SPRING 8-13 & $\begin{array}{l}\text { ONSITE } \\
\text { ONSTES }\end{array}$ & $\begin{array}{l}\text { SW } \\
\text { SW }\end{array}$ & $\mathrm{N}$ & $\begin{array}{l}\text { SEEP } \\
\text { SEFP }\end{array}$ & $\begin{array}{l}\text { UNFILTERED } \\
\text { UNFUTERED TFER }\end{array}$ & 20-Oct-03 Se & & 0.496 & & & & u & & \\
\hline $\begin{array}{l}\text { SESPMNIII } \\
\text { SESPMNT }\end{array}$ & $\frac{1 B / 1 / 6}{B 17 / 81}$ & 100-B S SPRING 37-1 & $\begin{array}{l}\text { ONSIIE } \\
\text { ONSITE }\end{array}$ & SW & $\begin{array}{l}\mathrm{N} \\
\mathrm{y}\end{array}$ & & & 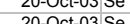 & & 0.0821 & & & & & & \\
\hline SESPMNT & B17J82 & 100-B SPRING 39-2 & ONSITE & sw & $\mathrm{N}$ & SEEP & UNFILTERED & $20-\mathrm{Oct}-03 \mathrm{Se}$ & & $\begin{array}{l}0.821 \\
0.496\end{array}$ & $\begin{array}{l}\mathrm{ugg/2} \\
\mathrm{ug} / \mathrm{h}\end{array}$ & & & u & & \\
\hline SESPMNT & B17J84 & 100-K SPRING 63-2 & ONSITE & sw & $\mathrm{N}$ & SEEP & UNFILTERED & $20-O c t-03 \mathrm{Se}$ & & & & & & U & & \\
\hline SESPMNT & B17J85 & 100-K SPRING 63-2 & ONSITE & sw & Y & SEEP & & $20-0 c t-03 \mathrm{Se}$ & & 0.496 & & & & U & & \\
\hline SESPMNT & B17J88 & 100-N SPRING 8-13 & ONSITE & sw & Y & SEEP & & 20-Oct-03 Se & & 0.496 & & & & u & & \\
\hline SESPMNT & B17J91 & 100-D SPRING 110-1 & ONSITE & SW & $\mathrm{N}$ & SEEP & UNFILTERED & 27-Oct-03 Se & & 0.496 & & & & U & & \\
\hline $\begin{array}{l}\text { SESPMNT } \\
\text { SESPMNT }\end{array}$ & B17J92 & 100-D SPRING 110-1 & ONSITE & SW & Y & SEEP & & 27-Oct-03 Se & & 0.496 & & & & U & & \\
\hline $\begin{array}{l}\text { SESPMNT } \\
\text { SESPMNT }\end{array}$ & $\begin{array}{l}\text { B17.1993 } \\
\text { B17.194 }\end{array}$ & $\begin{array}{l}\text { 100-D SPRING 102-1 } \\
\text { 100-D SPRNG 102-1 }\end{array}$ & ONSITE & & $\begin{array}{l}\mathrm{y} \\
\mathrm{N}\end{array}$ & SEEP & UNFILTERED & $\begin{array}{l}27-0 c t-03 \mathrm{Se} \\
27-0 c-03 \mathrm{Se}\end{array}$ & & 0.496 & & & & U & & \\
\hline SESPMNT & $\begin{array}{l}\text { B1/1994 } \\
\text { B17RK6 }\end{array}$ & $\begin{array}{l}\text { 100-D SPRRIN 102-1 } \\
\text { 100-H SPRING 145-1 }\end{array}$ & $\begin{array}{l}\text { ONSIIE } \\
\text { ONSITE }\end{array}$ & sw & $\begin{array}{l}\mathrm{Y} \\
\mathrm{Y}\end{array}$ & $\begin{array}{l}\text { SEEP } \\
\text { SEEP }\end{array}$ & & $\begin{array}{l}27-O c t-03 \mathrm{Se} \\
27-0 \mathrm{Sec}-03 \mathrm{Se}\end{array}$ & & & & & & & & \\
\hline SESPMNT & B17RL9 & 100-H SPRING 153-1 & ONSITE & sw & $\mathrm{N}$ & SEEP & UNFILTERED & $27-0 c t-03 \mathrm{Se}$ & & $\begin{array}{r}7.12 \\
0.496\end{array}$ & & & & u & & \\
\hline SESPMNT & B17RMO & 100-H SPRING 153-1 & ONSITE & sw & Y & SEEP & & $27-0 c t-03 \mathrm{Se}$ & & 0.511 & & & & & & \\
\hline SESPMNT & B17RK7 & 100-F SPRING 207-1 & ONSITE & SW & $\mathrm{N}$ & SEEP & UNFILTERED & 03-Nov-03 Se & & 0.677 & & & & & & \\
\hline $\begin{array}{l}\text { SESPMNT } \\
\text { SESPMNT }\end{array}$ & B17RK8 & 100-F SPRING 207-1 & ONSITE & SW & Y & SEEP & & 03-Nov-03 Se & & 0.573 & & & & & & \\
\hline $\begin{array}{l}\text { SESPMNT } \\
\text { SESPMNT }\end{array}$ & $\begin{array}{l}\text { B17RLO } \\
\text { B17R11 }\end{array}$ & HANFORD SPR UR 28-2 & ONSITE & SW & $\begin{array}{l}\mathrm{y} \\
\mathrm{N}\end{array}$ & SEEP & UNFILTERED & 03-Nov-03 Se & & 0.753 & $\mathrm{ug} / \mathrm{L}$ & & & & & \\
\hline $\begin{array}{l}\text { SESPMNI } \\
\text { SESPMNT }\end{array}$ & $\begin{array}{l}\text { B1/RL1 } \\
\text { B17RL2 }\end{array}$ & $\begin{array}{l}\text { HANFORD SPR DR 28-2 } \\
\text { HANFORD }\end{array}$ & $\begin{array}{l}\text { ONSIITE } \\
\text { ONSE }\end{array}$ & $\begin{array}{l}\text { Sw } \\
\text { sw }\end{array}$ & $\begin{array}{r}\mathrm{Y} \\
\mathrm{N}\end{array}$ & $\begin{array}{l}\text { SEEP } \\
\text { SEEP }\end{array}$ & UNFILTERED & $\begin{array}{l}\text { 03-Novo-03 Se } \\
\text { 03-Nov-03 Se }\end{array}$ & & $\begin{array}{l}0.781 \\
0.45\end{array}$ & $\begin{array}{l}\mathrm{ug} / \mathrm{h} \\
\mathrm{ug} / \mathrm{L}\end{array}$ & & & B & & \\
\hline SESPMNT & B17RL3 & HANFORD SPR DR 28-2 & ONSITE & sw & $\mathrm{Y}$ & SEEP & & 03-Nov-03 Se & & 0.466 & & & & B & & \\
\hline SESPMNT & B17J86 & 100-K SPRING 77-1 & ONSITE & sw & $\mathrm{N}$ & SEEP & UNFILTERED & $10-\mathrm{Nov}-03 \mathrm{Se}$ & & 0.148 & & & & B & & \\
\hline SESPMNT & B17J87 & 100-K SPRING 77-1 & ONSITE & sw & Y & SEEP & & 10-Nov-03 Se & & 0.118 & & & & B & & \\
\hline $\begin{array}{l}\text { SESPSPEC } \\
\text { SESPSPEC }\end{array}$ & $\mathrm{B} 180 \mathrm{H} 6$ & 100-B SPRING 37-1 & ONSITE & SW & Y & SEEP & & 13-Nov-03 Se & & 0.982 & & & & & & \\
\hline $\begin{array}{l}\text { SESPSPEC } \\
\text { SESPSPEC }\end{array}$ & $\begin{array}{l}\mathrm{B} 18 \mathrm{OH} 7 \\
\mathrm{~B} 18 \mathrm{OH} 8\end{array}$ & $\begin{array}{l}\text { 100-B SPRING 38-3 } \\
\text { 100-B SPRING 39-2 }\end{array}$ & $\begin{array}{l}\text { ONSITE } \\
\text { ONSTE }\end{array}$ & $\begin{array}{l}\text { SW } \\
\text { sw }\end{array}$ & $\begin{array}{r}Y \\
Y\end{array}$ & $\begin{array}{l}\text { SEEP } \\
\text { SEEP }\end{array}$ & & $\begin{array}{l}\text { 13-Nov-03 Se } \\
\text { 17-Nov-03 Se }\end{array}$ & & $\begin{array}{c}1.11 \\
0.537\end{array}$ & $\mathrm{ug} / \mathrm{L}$ & & & & & \\
\hline $\begin{array}{l}\text { SESPSPEC } \\
\text { SESP }\end{array}$ & B180J0 & 1000 B/C AREA OUTFLL2 & $\begin{array}{l}\text { ONSIITE } \\
\text { ONSE }\end{array}$ & SW & $\begin{array}{l}\text { Y } \\
\end{array}$ & $\begin{array}{l}\text { SEEP } \\
\text { SEEP }\end{array}$ & & $\begin{array}{l}\text { 17-N-Nov-03 Se } \\
17-03 \mathrm{Se}\end{array}$ & & 0.23 & ugg/L & & & B & & \\
\hline SESPMNT & B17RK5 & 100-H SPRING 145-1 & ONSITE & sw & $\mathrm{N}$ & SEEP & UNFILTERED & 10-Oct-03 Sb & & 0.375 & & & & & & \\
\hline SESPMNT & B17RH8 & 300 AREA SPRING 42-2 & ONSITE & sw & $\mathrm{N}$ & SEEP & UNFILTERED & 13-Oct-03 Sb & & 0.191 & & & & & & \\
\hline SESPMNT & B17RL4 & 300 AREA SPRING 42-2 & ONSITE & sw & Y & SEEP & & 13-Oct-03 Sb & & 0.183 & $\mathrm{ug} / \mathrm{L}$ & & & & & \\
\hline $\begin{array}{l}\text { SESPMNT } \\
\text { SESPMNT }\end{array}$ & $\begin{array}{l}\text { B17RL5 } \\
\text { B17RL6 }\end{array}$ & $\begin{array}{l}300 \text { AREA SPR DR 42-2 } \\
300 \text { AREA SPR DR 42-2 }\end{array}$ & $\begin{array}{l}\text { ONSITE } \\
\text { ONSITE }\end{array}$ & $\begin{array}{l}\text { SW } \\
\text { SW }\end{array}$ & $\begin{array}{l}\mathrm{N} \\
\mathrm{Y}\end{array}$ & $\begin{array}{l}\text { SEEP } \\
\text { SEEP }\end{array}$ & UNFILTERED & $\begin{array}{l}13-\mathrm{Oct}-03 \mathrm{Sb} \\
13-\mathrm{Oct}-03 \mathrm{Sb}\end{array}$ & & $\begin{array}{l}0.181 \\
0.216\end{array}$ & $\begin{array}{l}\mathrm{ug} / \mathrm{L} \\
\mathrm{ug} / \mathrm{h}\end{array}$ & & & & & \\
\hline SESPMNT & B17J83 & 100-B SPRING 39-2 & ONSITE & sw & $\mathrm{Y}$ & SEEP & & 20-Oct-03 Sb & & 0.311 & & & & c & $\begin{array}{l}\text { BOTTLE LEAKED WAS REBOTTLED AND SENT TO LAB FOR } \\
\text { ANALYSES. }\end{array}$ & \\
\hline SESPMNT & B17J17 & 100-N SPRING 8-13 & ONSITE & sw & $\mathrm{N}$ & SEEP & UNFILTERED & 20-Oct-03 Sb & & 0.16 & ug/L & & & & & \\
\hline SESPMNT & B17J76 & 100-B SPRING 37-1 & ONSITE & sw & $\mathrm{N}$ & SEEP & UNFILTERED & $20-0 c t-03 \mathrm{Sb}$ & & 0.091 & $\mathrm{ug} / \mathrm{L}$ & & & & & \\
\hline $\begin{array}{l}\text { SESPMNT } \\
\text { SESPMNT }\end{array}$ & B17J81 & 100-B SPRING 37-1 & ONSITE & SW & Y & SEEP & & 20-Oct-03 Sb & & 0.107 & $\mathrm{ug} / \mathrm{L}$ & & & C & & \\
\hline $\begin{array}{l}\text { SESPMNT } \\
\text { SESPMNT }\end{array}$ & $\begin{array}{l}\text { B17J82 } \\
\text { B17184 }\end{array}$ & $\begin{array}{l}\text { 100-B SPRING 39-2 } \\
100-\text { KPRPING } 63-2\end{array}$ & ONSITE & $\begin{array}{c}\text { SW } \\
\text { SW }\end{array}$ & $\mathrm{N}$ & $\begin{array}{l}\text { SEEP } \\
\text { SEFP }\end{array}$ & $\begin{array}{l}\text { UNFILTERED } \\
\text { UNFUTERED TFED }\end{array}$ & 20-Oct-03 Sb & & 0.131 & $\mathrm{ug} / \mathrm{L}$ & & & & & \\
\hline $\begin{array}{l}\text { SESPMNT } \\
\text { SESPMNT }\end{array}$ & $\begin{array}{l}\text { B17784 } \\
\text { B17885 }\end{array}$ & $\begin{array}{l}\text { 100-K SPRING 63-2 } \\
\text { 100-K SPRING 63-2 }\end{array}$ & $\begin{array}{l}\text { ONSITE } \\
\text { ONSITE }\end{array}$ & sw & $\begin{array}{l}\mathrm{N} \\
\mathrm{Y}\end{array}$ & $\begin{array}{l}\text { SEEP } \\
\text { SEEP }\end{array}$ & UNFILTERED & $\begin{array}{l}\text { 20-Oct-03 Sb } \\
20-0 t-03 \mathrm{Sb}\end{array}$ & & $\begin{array}{c}0.185 \\
0.16\end{array}$ & & & & $c$ & & \\
\hline SESPMNT & B17J88 & 100-N SPRING 8-13 & ONSITE & sw & Y & SEEP & & $20-0 c t-03 \mathrm{Sb}$ & & 0.164 & & & & $\begin{array}{l}\mathrm{c} \\
\mathrm{c}\end{array}$ & & \\
\hline SESPMNT & B17J91 & 100-D SPRING 110-1 & ONSITE & sw & $\mathrm{N}$ & SEEP & UNFILTERED & $27-\mathrm{Oct}-03 \mathrm{Sb}$ & & 0.172 & & & & & & \\
\hline SESPMNT & B17J92 & 100-D SPRING 110-1 & ONSITE & sw & Y & SEEP & & $27-0 c t-03 \mathrm{Sb}$ & & 0.175 & $\mathrm{ug} / \mathrm{L}$ & & & C & & \\
\hline $\begin{array}{l}\text { SESPMNT } \\
\text { SESPMNT }\end{array}$ & B17J93 & 100-D SPRING 102-1 & ONSITE & sw & $\mathrm{N}$ & SEEP & UNFILTERED & 27-Oct-03 Sb & & 0.156 & ug/L & & & & & \\
\hline $\begin{array}{l}\text { SESPMNT } \\
\text { SESPMNT }\end{array}$ & B17J94 & 100-D SPRING 102-1 & ONSITE & sw & $\begin{array}{l}Y Y \\
Y\end{array}$ & SEEP & & $27-\mathrm{Oct}-03 \mathrm{Sb}$ & & 0.17 & $\mathrm{ug} / \mathrm{L}$ & & & C & & \\
\hline $\begin{array}{l}\text { SESPMNT } \\
\text { SESPMNT }\end{array}$ & $\begin{array}{l}\text { B17RK6 } \\
\text { B17RL9 }\end{array}$ & $\begin{array}{l}\text { 100-H SPRING 145-1 } \\
\text { 100-H SPRING 153-1 }\end{array}$ & $\begin{array}{l}\text { ONSTIE } \\
\text { ONSITE }\end{array}$ & $\begin{array}{l}\text { SW } \\
\text { SW }\end{array}$ & $\begin{array}{r}\mathrm{Y} \\
\mathrm{N}\end{array}$ & $\begin{array}{l}\text { SEEP } \\
\text { SEEP }\end{array}$ & UNFILTERED & $\begin{array}{l}\text { 27-Oct-03 Sb } \\
27-\mathrm{Oct}-03 \mathrm{Sb}\end{array}$ & & 0.181 & & & & & & \\
\hline SESPMNT & B17RMO & $100-\mathrm{H}$ SPRING $153-1$ & ONSITE & sw & $\mathrm{Y}$ & SEEP & & $27-0 c t-03 \mathrm{Sb}$ & & 0.177 & & & & c & & \\
\hline SESPMNT & B17RK7 & 100-F SPRING 207-1 & ONSITE & sw & $\mathrm{N}$ & SEEP & UNFILTERED & 03-Nov-03 Sb & & 0.183 & & & & & & \\
\hline SESPMNT & B17RK8 & 100-F SPRING 207-1 & ONSITE & sw & Y & SEEP & & 03-Nov-03 Sb & & 0.168 & $\mathrm{ug} / \mathrm{L}$ & & & & & \\
\hline $\begin{array}{l}\text { SESPMNT } \\
\text { SECDMNT }\end{array}$ & B17RLO & HANFORD SPR UR 28-2 & ONSITE & sw & $\mathrm{N}$ & SEEP & UNFILTERED & 03-Nov-03 Sb & & 0.134 & $\mathrm{ug} / \mathrm{L}$ & & & & & \\
\hline $\begin{array}{l}\text { SESPMNT } \\
\text { SESPMNT }\end{array}$ & B17RL1 & HANFORD SPR UR 28-2 & ONSITE & SW & $\begin{array}{r}Y \\
Y N\end{array}$ & $\begin{array}{l}\text { SEEP } \\
\text { SEEP }\end{array}$ & UNEU TEPED & 03-Nov-03 Sb & & $\begin{array}{r}0.15 \\
0.147\end{array}$ & $\mathrm{ug} / \mathrm{L}$ & & & & & \\
\hline $\begin{array}{l}\text { SESPMNT } \\
\text { SESPMNT }\end{array}$ & $\begin{array}{l}\text { B17RLL2 } \\
\text { B17RL3 }\end{array}$ & $\begin{array}{l}\text { HANFORD SPR DR } 28-2 \\
\text { HANFORD SPR DR 28-2 }\end{array}$ & $\begin{array}{l}\text { ONSTIE } \\
\text { ONSITE }\end{array}$ & $\begin{array}{l}\text { SW } \\
\text { SW }\end{array}$ & $\begin{array}{l}\mathrm{N} \\
\mathrm{Y}\end{array}$ & $\begin{array}{l}\text { SEEP } \\
\text { SEEP }\end{array}$ & UNFILTERED & $\begin{array}{l}\text { 03-Nov-03 Sb } \\
\text { 03-Nov-03 Sb }\end{array}$ & & 0.147 & $\begin{array}{l}\mathrm{ug} / \mathrm{h} \\
\mathrm{ug} / \mathrm{L}\end{array}$ & & & & & \\
\hline SESPMNT & B17J86 & 100-K SPRING 77-1 & ONSITE & sw & $\mathrm{N}$ & SEEP & UNFILTERED & $10-\mathrm{Nov}-03 \mathrm{Sb}$ & & 0.112 & & & & & & \\
\hline SESPMNT & B17J87 & 100-K SPRING 77-1 & ONSITE & sw & $\mathrm{Y}$ & SEEP & & $10-\mathrm{Nov}-03 \mathrm{Sb}$ & & 0.129 & jug/L & & & & & \\
\hline SESPSPEC & $\mathrm{B} 18 \mathrm{OH} 6$ & 100-B SPRING 37-1 & ONSITE & SW & Y & SEEP & & 13-Nov-03 Sb & & 0.111 & $\mathrm{ug} / \mathrm{L}$ & & & & & \\
\hline $\begin{array}{l}\text { SESPSPEC } \\
\text { SESPSEC }\end{array}$ & B180H7 & 100-B SPRING 38-3 & ONSITE & SW & Y & SEEP & & 13-Nov-03 Sb & & 0.157 & $\mathrm{ug} / \mathrm{L}$ & & & & & \\
\hline $\begin{array}{l}\text { SESPPSEC } \\
\text { SESPPEC }\end{array}$ & B180H8 & 100-B SPRING 39-2 & ONSITE & sw & $\begin{array}{r}Y Y \\
Y\end{array}$ & $\begin{array}{l}\text { SEEP } \\
\text { SEFP }\end{array}$ & & 17-Nov-03 Sb & & 0.136 & ug/L & & & & & \\
\hline $\begin{array}{l}\text { SESSPPEC } \\
\text { SESPMNT }\end{array}$ & $\begin{array}{l}\text { B180J0 } \\
\text { B17RK5 }\end{array}$ & $\begin{array}{l}100 \text { B/C AREA OUTFL2 } \\
1\end{array}$ & $\begin{array}{l}\text { ONSTIE } \\
\text { ONSTEE }\end{array}$ & $\begin{array}{l}\text { sw } \\
\text { sw }\end{array}$ & & $\begin{array}{l}\text { SEEP } \\
\text { SEFP }\end{array}$ & UNEITERED & $\begin{array}{l}\text { 17-Nov-03 Sb } \\
10-0 \mathrm{~s}-03 \mathrm{Ph}\end{array}$ & & 0.148 & ing/L & & & & & \\
\hline SESPMNT & $\begin{array}{l}\text { BITRKS } \\
\text { B17RH8 }\end{array}$ & 300 AREA SPRING 42-2 & $\begin{array}{l}\text { ONSITE } \\
\text { ONSE }\end{array}$ & sw & $\mathrm{N}$ & SEEP & UNFILTERED & $13-\mathrm{Oct}-03 \mathrm{~Pb}$ & & 2.43 & ugg/L & & & c & & \\
\hline SESPMNT & B17RL4 & 300 AREA SPRING 42-2 & ONSITE & sw & Y & SEEP & & 13-Oct-03 Pb & & 0.011 & ug/L & & & U & & \\
\hline $\begin{array}{l}\text { SESPMNT } \\
\text { SESPMNT }\end{array}$ & $\begin{array}{l}\text { B17RL5 } \\
\text { B17R16 }\end{array}$ & 300 AREA SPR DR 42-2 & $\begin{array}{l}\text { ONSITE } \\
\text { ONSTE }\end{array}$ & $\begin{array}{l}\text { SW } \\
\text { SW }\end{array}$ & $\begin{array}{l}\mathrm{N} \\
\mathrm{y}\end{array}$ & $\begin{array}{l}\text { SEEP } \\
\text { SEEP }\end{array}$ & UNFILTERED & $\begin{array}{l}\text { 13-Oct-03 Pb } \\
13 \text {-Oct-03 Pb }\end{array}$ & & 0.337 & ug/L & & & 4 & & \\
\hline SESPMNT & B17J83 & 100-B SPRING 39-2 & ONSITE & sw & Y & SEEP & & 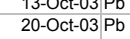 & & 0.218 & ugg/h & & & U & BOTTLE LEAKED WAS REBOTTLED AND SENT TO LAB FOR & \\
\hline SESPMNT & 171.177 70 & 100-N SPRING 8-13 & ONSITEF & SW & N & SEEP & HNEU TERED & $20-0 \mathrm{ct} 03 \mathrm{Ph}$ & & 0273 & & & & & ANALYSES & \\
\hline $\begin{array}{l}\text { SESPMNT } \\
\text { SESPIVT }\end{array}$ & B17J76 & 100-B SPRING 37-1 & $\begin{array}{l}\text { ONSITE } \\
\text { ONSE }\end{array}$ & sw & $\mathrm{N}$ & SEEP & UNFILTERED & $\begin{array}{l}20-\mathrm{OCc}-03 \mathrm{~Pb} \\
20-\mathrm{Oct}-03 \mathrm{~Pb}\end{array}$ & & 0.887 & & & & & & \\
\hline SESPMNT & B17J81 & 100-B SPRING 37-1 & ONSITE & SW & Y & SEEP & & $20-\mathrm{Oct}-03 \mathrm{~Pb}$ & & 0.011 & $\mathrm{ug} / \mathrm{L}$ & & & u & & \\
\hline
\end{tabular}




\begin{tabular}{|c|c|c|c|c|c|c|c|c|c|c|c|c|c|c|c|c|}
\hline | OWNER ID & \begin{tabular}{|l} 
SAMP \\
NUM
\end{tabular} & SAMP SITE NAME & $\left|\begin{array}{c}\text { DIST } \\
\text { CLASS }\end{array}\right|$ & $\mid$ MEDIA $\mid$ & $\begin{array}{l}\text { FILTERED } \\
\text { FLAG }\end{array}$ & $\begin{array}{l}\text { SAMP } \\
\text { FROM }\end{array}$ & COLL MTHD & |SAMP DATE| & CON SHORT NAME & $\begin{array}{c}\text { VALUE } \\
\text { RPTD }\end{array}$ & \begin{tabular}{|c|} 
ANAL \\
UNITS \\
RPTD \\
\end{tabular} & $\begin{array}{c}\text { COUNTING } \\
\text { ERROR }\end{array}$ & $\begin{array}{c}\text { TOTAL } \\
\text { ANAL } \\
\text { ERROR }\end{array}$ & $\left|\begin{array}{c}\text { LAB } \\
\text { QUALIFIER }\end{array}\right|$ & SAMP COMMENT & $\begin{array}{c}\text { RESULT } \\
\text { COMMENT }\end{array}$ \\
\hline SESPMNT & B17J82 & 100-B SPRING 39-2 & ONSITE & SW & $\mathrm{N}$ & SEEP & UNFILTERED & 20-Oct-03 & & & & & & & (1) & \\
\hline SESPMNT & B17J84 & 100-K SPRING 63-2 & ONSITE & SW & $\mathrm{N}$ & SEEP & UNFILTERED & 20-Oct-03 & & & & & & & & \\
\hline SESPMNT & B17J85 & 100-K SPRING 63-2 & ONSITE & sw & $\mathrm{Y}$ & SEEP & & 20-Oct-03 & & & & & & U & & \\
\hline SESPMNT & B17J88 & 100-N SPRING 8-13 & ONSITE & sW & $\mathrm{Y}$ & SEEP & & 20-Oct-03 & & & & & & u & & \\
\hline $\begin{array}{l}\text { SESPMNT } \\
\text { SSEPMNT }\end{array}$ & B17J91 & 100-D SPRING 110-1 & ONSITE & SW & $\mathrm{N}$ & SEEP & UNFILTERED & $27-\mathrm{Oct}-03$ & & $0.423 \mathrm{u}$ & & & & & & \\
\hline $\begin{array}{l}\text { SESPMNT } \\
\text { SESPMNT }\end{array}$ & B17J92 & 100-D SPRING 110-1 & ONSITE & SW & Y & SEEP & & 27-Oct-03 & & $0.0157 \mathrm{u}$ & & & & B & & \\
\hline $\begin{array}{l}\text { SESPMNT } \\
\text { SESPMNT }\end{array}$ & $\begin{array}{l}\text { B17J93 } \\
\text { B17194 }\end{array}$ & 100-D SPRING 102-1 & ONSITE & SW & $\begin{array}{l}\mathrm{N} \\
\mathrm{y}\end{array}$ & $\begin{array}{l}\text { SEEP } \\
\text { SEFP }\end{array}$ & UNFILTERED & 27-Oct-03 & & 1.164 & ug/L & & & & & \\
\hline $\begin{array}{l}\text { SESPMNT } \\
\text { SESPMI }\end{array}$ & $\begin{array}{l}\text { B11944 } \\
\text { B17RK6 }\end{array}$ & $\begin{array}{l}\text { 100-D SPRRNG } 102-1 \\
\text { 100-H SPRING 145-1 }\end{array}$ & $\begin{array}{l}\text { ONSIIE } \\
\text { ONSITE }\end{array}$ & $\begin{array}{l}\text { sw } \\
\text { sw }\end{array}$ & $\begin{array}{l}\text { Y } \\
\text { Y }\end{array}$ & $\begin{array}{l}\text { SEEP } \\
\text { SEEP }\end{array}$ & & $\begin{array}{l}27-\mathrm{OCt}-03 \\
27-\mathrm{Oct}-03\end{array}$ & & $0.0338 \mathrm{u}$ & & & & & & \\
\hline SESPMNT & B17RL9 & 100-H SPRING 153-1 & ONSITE & sW & $\mathrm{N}$ & SEEP & UNFILTERED & $27-\mathrm{Oct}-03$ & & & & & & & & \\
\hline SESPMNT & B17RM0 & 100-H SPRING 153-1 & ONSITE & SW & $\mathrm{Y}$ & SEEP & & & & & & & & U & & \\
\hline $\begin{array}{l}\text { SESPMNT } \\
\text { SECPMNT }\end{array}$ & B17RK7 & 100-F SPRING 207-1 & ONSITE & sW & $\mathrm{N}$ & SEEP & UNFILTERED & 03-Nov-03 & & & & & & & & \\
\hline $\begin{array}{l}\text { SESPMNT } \\
\text { SESPMNT }\end{array}$ & B17RK8 & 100-F SPRING 207-1 & ONSITE & SW & Y & SEEP & & 03-Nov-03 & & 0.008154 & & & & B & & \\
\hline $\begin{array}{l}\text { SESPMNT } \\
\text { SESPMNT }\end{array}$ & $\begin{array}{l}\text { B17RL0 } \\
\text { B17RL1 }\end{array}$ & $\begin{array}{l}\text { HANANORD SPR UR 28-2 } \\
\text { HANFORD SPR UR 28-2 }\end{array}$ & $\begin{array}{l}\text { ONSIIE } \\
\text { ONSITE }\end{array}$ & $\begin{array}{l}\text { SW } \\
\text { sw }\end{array}$ & $\begin{array}{l}\mathrm{N} \\
\mathrm{Y}\end{array}$ & $\begin{array}{l}\text { SEEP } \\
\text { SEEP }\end{array}$ & UNFILTERED & $\begin{array}{l}\text { O3-N-Nov-03 } \\
\text { 03-Nov } 03\end{array}$ & & $\begin{array}{l}0.193 \mathrm{u} \\
0.004 \mathrm{u}\end{array}$ & & & & $u$ & & \\
\hline SESPMNT & B17RL2 & HANFORD SPR DR 28-2 & ONSITE & sw & $\mathrm{N}$ & SEEP & UNFILTERED & 03-Nov-03 & & 0.4714 & & & & & & \\
\hline SESPMNT & B17RL3 & HANFORD SPR DR 28-2 & ONSITE & sW & $\mathrm{Y}$ & SEEP & & 03-Nov-03 & & 0.009034 & & & & B & & \\
\hline SESPMNT & B17J86 & 100-K SPRING 77-1 & ONSITE & SW & $\mathrm{N}$ & SEEP & UNFILTERED & 10-Nov-03 & & $0.174 u$ & & & & & & \\
\hline SESPMNT & B17J87 & 100-K SPRING 77-1 & ONSITE & SW & $\mathrm{Y}$ & SEEP & & 10-Nov-03 & & $0.004 u$ & & & & U & & \\
\hline $\begin{array}{l}\text { SESPSPEC } \\
\text { SESPSPCC }\end{array}$ & $\mathrm{B} 18 \mathrm{OH} 6$ & 100-B SPRING 37-1 & ONSITE & SW & $\begin{array}{l}Y \\
Y \\
Y\end{array}$ & SEEP & & 13-Nov-03 & & $0.004 \mathrm{u}$ & & & & U & & \\
\hline $\begin{array}{l}\text { SESPSPPEC } \\
\text { SESPSPEC }\end{array}$ & $\begin{array}{l}\mathrm{B} 180 \mathrm{H} 7 \\
\mathrm{~B} 180 \mathrm{H} 8\end{array}$ & $\begin{array}{l}\text { 100-B SPRING 38-3 } \\
\text { 100-B SPRING 39-2 }\end{array}$ & $\begin{array}{l}\text { ONSIIE } \\
\text { ONSTIE }\end{array}$ & $\begin{array}{l}\text { SW } \\
\text { SW }\end{array}$ & $\begin{array}{l}Y \\
Y\end{array}$ & $\begin{array}{l}\text { SEEP } \\
\text { SEEP }\end{array}$ & & $\begin{array}{l}13-\mathrm{Nov}-03 \\
17-03\end{array}$ & & $0.0121 \mathrm{u}$ & & & & $\frac{B}{U}$ & & \\
\hline SESPSPEC & B180J0 & 100 B/C AREA OUTFL2 & ONSITE & sw & $\begin{array}{r}\mathrm{Y} \\
\mathrm{C}\end{array}$ & SEEP & & $\begin{array}{l}17-\mathrm{Nov}-03 \\
17\end{array}$ & & $0.0154 \mathrm{u}$ & & & & B & & \\
\hline SESPMNT & B17RK5 & 100-H SPRING $145-1$ & ONSITE & sW & $\mathrm{N}$ & SEEP & UNFILTERED & 10-Oct-03 & & 10.94 & & & & & & \\
\hline SESPMNT & B17RH8 & 300 AREA SPRING 42-2 & ONSITE & SW & $\mathrm{N}$ & SEEP & UNFILTERED & 13-Oct-03 & & $2.63 \mathrm{u}$ & ug/L & & & & & \\
\hline SESPMNT & B17RL4 & 300 AREA SPRING 42-2 & ONSITE & SW & Y & SEEP & & 13-Oct-03 & & $0.902 \mathrm{u}$ & & & & & & \\
\hline $\begin{array}{l}\text { SESPMNT } \\
\text { SESPMNT }\end{array}$ & \begin{tabular}{|l} 
B17RL5 \\
B17RL6
\end{tabular} & 300 AREA SPR DR 42-2 & $\begin{array}{l}\text { ONSITE } \\
\text { ONSTEE }\end{array}$ & $\begin{array}{l}\text { SW } \\
\text { sw }\end{array}$ & $\begin{array}{l}\mathrm{y} \\
\mathrm{N}\end{array}$ & $\begin{array}{l}\text { SEEP } \\
\text { SEEP }\end{array}$ & UNFILTERED & 13-Oct-03 & & 1.54 & ug/L & & & & & \\
\hline SESPMNT & B17J83 & 100-B SPRING 39-2 & $\begin{array}{l}\text { ONSIITE } \\
\text { ONSE }\end{array}$ & sw & $Y^{\prime}$ & $\begin{array}{l}\text { SEEP } \\
\text { SEEP }\end{array}$ & & 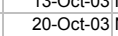 & & 0.7874 & ug/L & & & & BOTTLE LEAKED WAS REBOTTLED AND SENT TO LAB FOR & \\
\hline & & & ONGITE & & $\mathrm{N}$ & & НNDU TERED & & & & & & & & ANALYSES. & \\
\hline $\begin{array}{l}\text { SESPMNI } \\
\text { SESPMNT }\end{array}$ & (B) & 100-N SPRING 8-13 & ONSITE & sw & $\mathrm{N}$ & SEEP & UNFILTERED & $20-\mathrm{Oct}-03$ & & $1.12 \mathrm{u}$ & & & & & & \\
\hline $\begin{array}{l}\text { SESPMNT } \\
\text { SESPMNT }\end{array}$ & $\begin{array}{l}\text { B17J76 } \\
\text { B17J81 }\end{array}$ & $\begin{array}{l}\text { 100-B SPRING 37-1 } \\
\text { 100-B SPRING 37-1 }\end{array}$ & $\begin{array}{l}\text { ONSIIE } \\
\text { ONSITE }\end{array}$ & $\begin{array}{l}\text { SW } \\
\text { SW }\end{array}$ & $\begin{array}{l}\mathrm{N} \\
\mathrm{Y}\end{array}$ & $\begin{array}{l}\text { SEEP } \\
\text { SEEP }\end{array}$ & UNFILTERED & $\begin{array}{ll}20-\mathrm{OCt}-03 \\
20-0 \mathrm{O}-03\end{array}$ & & $0.934 \mathrm{u}$ & ug/L & & & & & \\
\hline SESPMNT & B17J82 & 100-B SPRING 39-2 & ONSITE & sw & $\mathrm{N}$ & SEEP & UNFILTERED & $20-0 \mathrm{Cct}-03$ & & $0.781 \mathrm{u}$ & ug/L & & & & & \\
\hline SESPMNT & B17J84 & 100-K SPRING 63-2 & ONSITE & sw & $\mathrm{N}$ & SEEP & UNFILTERED & $20-0 c t-03$ & & 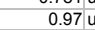 & & & & & & \\
\hline SESPMNT & B17J85 & 100-K SPRING 63-2 & ONSITE & sw & Y & SEEP & & $20-0 c t-03$ & & $0.857 \mathrm{u}$ & & & & & & \\
\hline SESPMNT & B17J88 & 100-N SPRING 8-13 & ONSITE & sw & Y & SEEP & & $20-0 c t-03$ & & $0.849 u$ & $\mathrm{ug} / \mathrm{L}$ & & & & & \\
\hline SESPMNT & B17J91 & 100-D SPRING 110-1 & ONSITE & SW & $\mathrm{N}$ & SEEP & UNFILTERED & $27-0 c t-03$ & & $0.784 u$ & $\mathrm{ug} / \mathrm{L}$ & & & & & \\
\hline SESPMNT & B17J92 & 100-D SPRING 110-1 & ONSITE & SW & Y & SEEP & & 27-Oct-03 & & $1.88 \mathrm{u}$ & ug/L & & & & & \\
\hline $\begin{array}{l}\text { SESPMNT } \\
\text { SESPMNT }\end{array}$ & B17J93 & 100-D SPRING 102-1 & ONSITE & SW & $\mathrm{N}$ & SEEP & UNFILTERED & $27-\mathrm{Oct}-03$ & & $3.54 \mathrm{u}$ & ug/L & & & & & \\
\hline $\begin{array}{l}\text { SESPMNT } \\
\text { SESPMNT }\end{array}$ & $\begin{array}{l}\text { B17994 } \\
\text { B17RK6 }\end{array}$ & $\begin{array}{l}\text { 100-D SPRIIG 102-1 } \\
\text { 100-H SPRING 145-1 }\end{array}$ & $\begin{array}{l}\text { ONSIIE } \\
\text { ONSITE }\end{array}$ & $\begin{array}{l}\text { SW } \\
\text { SW }\end{array}$ & $\begin{array}{l}Y \\
Y\end{array}$ & $\begin{array}{l}\text { SEEP } \\
\text { SEEP }\end{array}$ & & $\begin{array}{l}27-\text { Oct-03 } \\
27-0 c t-03\end{array}$ & & $\begin{array}{l}3.03 u \\
1.02 u\end{array}$ & $\frac{u g h / /}{u g h / 4}$ & & & & & \\
\hline SESPMNT & B17RL9 & 100-H SPRING 153-1 & ONSITE & sw & $\mathrm{N}$ & SEEP & UNFILTERED & $27-0 c t-03$ & & $0.864 \mathrm{u}$ & & & & & & \\
\hline SESPMNT & B17RM0 & 100-H SPRING 153-1 & ONSITE & sw & $\mathrm{Y}$ & SEEP & & $27-\mathrm{Oct}-03$ & & $0.761 \mathrm{u}$ & & & & & & \\
\hline SESPMNT & B17RK7 & 100-F SPRING 207-1 & ONSITE & sW & $\mathrm{N}$ & SEEP & UNFILTERED & 03-Nov-03 & & $5.45 \mathrm{u}$ & & & & c & & \\
\hline SESPMNT & B17RK8 & 100-F SPRING 207-1 & ONSITE & SW & $\mathrm{Y}$ & SEEP & & 03-Nov-03 & & $1.08 \mathrm{u}$ & ug/L & & & & & \\
\hline $\begin{array}{l}\text { SESPMNT } \\
\text { SESPMNT }\end{array}$ & $\begin{array}{l}\text { B17RL0 } \\
\text { B17R1 }\end{array}$ & $\begin{array}{l}\text { HANFORD SPR UR 28-2 } \\
\text { HANFD }\end{array}$ & ONSITE & SW & $\begin{array}{l}\mathrm{y} \\
\mathrm{N}\end{array}$ & $\begin{array}{l}\text { SEEP } \\
\text { SEFP }\end{array}$ & UNFILTERED & 03-Nov-03 & & 0.994 & ug/L & & & c & & \\
\hline $\begin{array}{l}\text { SESPMNT } \\
\text { SESPMNT }\end{array}$ & $\begin{array}{l}\text { B17RL1 } \\
\text { B17RL2 }\end{array}$ & $\begin{array}{l}\text { HANFORD SPR UR 28-2 } \\
\text { HANFORD SPR DR 28-2 }\end{array}$ & $\begin{array}{l}\text { ONSTIE } \\
\text { ONSITE }\end{array}$ & $\begin{array}{l}\text { SW } \\
\text { SW }\end{array}$ & $\frac{\mathrm{Y}}{\mathrm{N}}$ & $\begin{array}{l}\text { SEEP } \\
\text { SEEP }\end{array}$ & UNFILTERED & $\begin{array}{l}\text { O3-Nov-03 } \\
03 \text {-Nov-03! }\end{array}$ & & $0.0823 u$ & & & & $c$ & & \\
\hline SESPMNT & B17RL3 & HANFORD SPR DR 28-2 & ONSITE & sw & $Y$ & SEEP & & 03-Nov-03 | & & $0.718 u$ & & & & & & \\
\hline SESPMNT & B17J86 & 100-K SPRING 77-1 & ONSITE & sw & $\mathrm{N}$ & SEEP & UNFILTERED & 10-Nov-03 & & $0.885 \mathrm{u}$ & & & & c & & \\
\hline SESPMNT & B17J87 & 100-K SPRING 77-1 & ONSITE & SW & $\mathrm{Y}$ & SEEP & & 10-Nov-03 & & $0.598 u$ & ug/L & & & & & \\
\hline SESPSPEC & B180H6 & 100-B SPRING 37-1 & ONSITE & SW & Y & SEEP & & 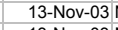 & & $1.6 \mathrm{u}$ & ug/L & & & C & & \\
\hline $\begin{array}{l}\text { SESPSPPEC } \\
\text { SESPSECC }\end{array}$ & $\mathrm{B} 180 \mathrm{H} 7$ & 100-B SPRING 38-3 & ONSITE & & $\begin{array}{l}Y \\
Y\end{array}$ & $\begin{array}{l}\text { SEEP } \\
\text { SEFP }\end{array}$ & & 13-Nov-03 & & $1.54 \mathrm{u}$ & ug/L & & & $\mathrm{C}$ & & \\
\hline $\begin{array}{l}\text { SESPSPPEC } \\
\text { SESPSPEC }\end{array}$ & B180H8 & 100-B SPRING 39-2 & ONSITE & SW & $\begin{array}{l}Y \\
Y \\
Y\end{array}$ & $\begin{array}{l}\text { SEEP } \\
\text { SEFP }\end{array}$ & & $\begin{array}{l}\text { 17-Nov-03 } \\
\text { 17-Nov-03 }\end{array}$ & & $\begin{array}{r}1.28 \mathrm{u} \\
0.055 \mu\end{array}$ & ig/L & & & $\mathrm{C}$ & & \\
\hline $\begin{array}{l}\text { SESPSPEC } \\
\text { SESPEC }\end{array}$ & B180H6 & 100-B SPRING $37-1$ & $\begin{array}{l}\text { ONSITE } \\
\text { ONSE }\end{array}$ & SW & $\begin{array}{l}\mathrm{Y} \\
\mathrm{Y}\end{array}$ & $\begin{array}{l}\text { SEEP } \\
\text { SEEP }\end{array}$ & & $\begin{array}{l}\text { 17-Nov-03 } \\
\text { 13-Nov-03 }\end{array}$ & & $\begin{array}{rl}0.955 & u \\
0.0758 u & u\end{array}$ & & & & $\begin{array}{c}c \\
c\end{array}$ & & \\
\hline SESPSPEC & $\mathrm{B} 180 \mathrm{H} 7$ & 100-B SPRING 38-3 & ONSITE & sW & $\mathrm{Y}$ & SEEP & & 13-Nov-03 & & $0.185 u$ & $\mathrm{ug} / \mathrm{L}$ & & & c & & \\
\hline SESPSPEC & B180H8 & 100-B SPRING 39-2 & ONSITE & SW & Y & SEEP & & 17-Nov-03 | & & $0.114 \mathrm{u}$ & & & & C & & \\
\hline $\begin{array}{l}\text { SESPSPEC } \\
\text { SESPMNT }\end{array}$ & B180J0 & 100 B/C AREA OUTFL2 & ONSITE & SW & Y & SEEP & Н & 17-Nov-03 & $\mathrm{Mn}$ & $0.037 \mathrm{u}$ & ug/L & & & C & & \\
\hline & B17RH7 & HANFORD SPRING 28-2 & ONSITE & SW & $\begin{array}{l}\mathrm{y} \\
\mathrm{N}\end{array}$ & SEEP & UNFILTERED & 10-Oct-03 & METALS ICPMS & {$[-5$} & & & & & NO SAMPLE. & \\
\hline $\begin{array}{l}\text { SESPMNI } \\
\text { SESPMNT }\end{array}$ & $\begin{array}{l}\text { B1/RK9 } \\
\text { B17J89 }\end{array}$ & $\begin{array}{l}\text { 100-N SPRING } 199 N-46-2 \\
100\end{array}$ & $\begin{array}{l}\text { ONSITE } \\
\text { ONSE }\end{array}$ & SW & $\mathrm{N}$ & $\begin{array}{l}\text { SEEP } \\
\text { SEEP }\end{array}$ & UNFILTERED & $\begin{array}{l}\mid 0-0 \mathrm{Oc}-03 \\
20-\mathrm{Oct}-03\end{array}$ & $\begin{array}{l}\text { METALS ICPMS } \\
\text { METALS }\end{array}$ & & & & & & 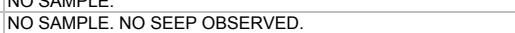 & \\
\hline SESPMNT & B17J90 & 100-N SPRING $199 N-46$ & ONSITE & sW & $\mathrm{Y}$ & SEEP & & $20-0 c t-03$ & METALS ICPMS & & & & & & NO SAMPLE. NO SEEP OBSERVED. & \\
\hline SESPSPEC & $\mathrm{B} 180 \mathrm{H} 9$ & 100 B/C AREA OUTFL1 & ONSITE & SW & $\begin{array}{l}Y \\
Y\end{array}$ & $\begin{array}{l}\text { SEEP } \\
\text { SEFP }\end{array}$ & & 17-Nov-03 & METALS ICPMS & & & & & & NO SAMPLE. NOT AVALABBLE. & \\
\hline $\begin{array}{l}\text { SESPSPEC } \\
\text { SESPMNT }\end{array}$ & B180J1 & $100 \mathrm{~B} / \mathrm{C}$ AREA OUTFL3 & ONSITE & SW & Y & SEEP & & 17-Nov-03 & METALS ICPMS & & & & & & NO SAMPLE. NOT AVAILABLE. & \\
\hline $\begin{array}{l}\text { SESPMNT } \\
\text { SESPMNT }\end{array}$ & B17RK5 & 100-H SPRING 145-1 & ONSITE & SW & $\mathrm{N}$ & SEEP & UNFILTERED & 10-Oct-03 & & 26.64 & ug/L & & & & & \\
\hline $\begin{array}{l}\text { SESPMNT } \\
\text { SESPMNT }\end{array}$ & $\begin{array}{l}\text { B17RH8 } \\
\text { B17RL4 }\end{array}$ & $\begin{array}{l}300 \text { AREA SPRING 42-2 } \\
300 \text { AREA SPRING 42-2 }\end{array}$ & $\begin{array}{l}\text { ONSTIE } \\
\text { ONSITE }\end{array}$ & $\begin{array}{l}\text { SW } \\
\text { SW }\end{array}$ & $\begin{array}{l}\mathrm{N} \\
\mathrm{Y}\end{array}$ & $\begin{array}{l}\text { SEEP } \\
\text { SEEP }\end{array}$ & UNFILTERED & $\begin{array}{l}13-\mathrm{OCt}-03 \\
13-\mathrm{Oct}-03\end{array}$ & & $\begin{aligned} 2.2 \mathrm{u} \\
0.343 \mathrm{u}\end{aligned}$ & ugg//L & & & & & \\
\hline SESPMNT & B17RL5 & 300 AREA SPR DR 42-2 & ONSITE & SW & $\mathrm{N}$ & SEEP & UNFILTERED & 13-Oct-03 & & 0.8824 & & & & & & \\
\hline SESPMNT & B17RL6 & 300 AREA SPR DR 42-2 & ONSITE & SW & $Y$ & SEEP & & 13-Oct-03 & & 0.3214 & ug/L & & & & & \\
\hline
\end{tabular}




\begin{tabular}{|c|c|c|c|c|c|c|c|c|c|c|c|c|c|c|c|c|}
\hline | OWNER ID & \begin{tabular}{|l|l} 
SAMP \\
NUM
\end{tabular} & SAMP SITE NAME & $\left|\begin{array}{c}\text { DIST } \\
\text { CLASS }\end{array}\right|$ & $\mid$ MEDIA $\mid$ & $\begin{array}{c}\text { FLLTERED } \\
\text { FLAG }\end{array}$ & $\begin{array}{l}\text { SAMP } \\
\text { FROM }\end{array}$ & $\mid$ COLL MTHD $\mid s$ & SAMP DATE| & CON SHORT NAME & $\begin{array}{l}\text { VALUE } \\
\text { RPTD }\end{array}$ & $\mid$\begin{tabular}{|c|} 
ANAL \\
UNITS \\
RPTD
\end{tabular} & $\left|\begin{array}{c}\text { COUNTING } \\
\text { ERROR }\end{array}\right|$ & $\begin{array}{l}\text { TOTAL } \\
\text { ANAL } \\
\text { ERROR }\end{array}$ & $\left|\begin{array}{c}\text { LAB } \\
\text { QUALIFIER }\end{array}\right|$ & SAMP COMMENT & $\left|\begin{array}{c}\text { RESULT } \\
\text { COMMENT }\end{array}\right|$ \\
\hline SESPMNT & B17J83 & 100-B SPRING 39-2 & ONSITE & SW & $\mathrm{Y}$ & SEEP & & $20-\mathrm{Oct}-03 \mathrm{Cu}$ & & 0.437 & ug/L & & & & $\begin{array}{l}\text { BOTTLE LEAKED WAS REBOTTLED AND SENT TO LAB FOR } \\
\text { ANALYSES. }\end{array}$ & \\
\hline SESPMNT & B17J17 & 100-N SPRING 8-13 & ONSITE & sw & $\mathrm{N}$ & SEEP & UNFILTERED & 20-Oct-03 Cu & & & ug/L & & & & & \\
\hline SESPMNT & B17J76 & & ONSITE & sw & $\mathrm{N}$ & SEEP & UNFILTERED & 20-Oct-03 Cu & & 0.465 & & & & & & \\
\hline $\begin{array}{l}\text { SESPMNT } \\
\text { SESPMNT }\end{array}$ & B17J81 & 100-B SPRING 37-1 & ONSITE & sw & Y & SEEP & & 20-Oct-03 Cu & & 0.295 & 5 ug/L & & & & & \\
\hline $\begin{array}{l}\text { SESPMNT } \\
\text { SESPMNT }\end{array}$ & $\begin{array}{l}\text { B17JJ82 } \\
\text { B178184 }\end{array}$ & $\begin{array}{l}\text { 100-B SPRING 39-2 } \\
\text { 100-K SPRING 3-2 }\end{array}$ & $\begin{array}{l}\text { ONSITE } \\
\text { ONSTEE }\end{array}$ & SW & $\mathrm{N}$ & $\begin{array}{l}\text { SEEP } \\
\text { SEEP }\end{array}$ & $\begin{array}{l}\text { UNFILTERED } \\
\end{array}$ & $\begin{array}{l}\text { 20-Oct-03 Cu } \\
20-0 \text { Cot-03 }\end{array}$ & & 0.356 & Sug/L & & & & & \\
\hline SESPMNT & B17J85 & $100-K$ SPRING 63-2 & $\begin{array}{l}\text { ONSITE } \\
\text { ONSE }\end{array}$ & sw & $\begin{array}{l}\mathrm{N} \\
\mathrm{Y}\end{array}$ & $\begin{array}{l}\text { SEEP } \\
\text { SEEP }\end{array}$ & UNFILTERED & $\begin{array}{l}20-0 \mathrm{ctc}-03 \mathrm{Cu} \\
20-\mathrm{ct}-03 \mathrm{Cu}\end{array}$ & & 0.729 & gug/L & & & & & \\
\hline SESPMNT & B17J88 & 100-N SPRING 8-13 & ONSITE & sw & Y & SEEP & & 20-Oct-03 Cu & & $\begin{array}{l}0.421 \\
0.427\end{array}$ & lugh/L & & & & & \\
\hline SESPMNT & B17J91 & 100-D SPRING 110-1 & ONSITE & sw & $\mathrm{N}$ & SEEP & UNFILTERED & $27-$ Oct-03 Cu & & 0.723 & & & & & & \\
\hline SESPMNT & B17J92 & 100-D SPRING 110-1 & ONSITE & SW & Y & SEEP & & 27-Oct-03 Cu & & & & & & & & \\
\hline $\begin{array}{l}\text { SESPMNT } \\
\text { SESPMNT }\end{array}$ & B17J93 & 100-D SPRING 102-1 & ONSITE & sw & $\mathrm{N}$ & SEEP & UNFILTERED & 27-Oct-03 Cu & & & & & & & & \\
\hline $\begin{array}{l}\text { SESPMNT } \\
\text { SESPMNT }\end{array}$ & B17J94 & & ONSITE & SW & $\begin{array}{r}Y \\
Y\end{array}$ & SEEP & & 27-Oct-03 Cu & & 0.818 & $3 \mathrm{ug} / \mathrm{L}$ & & & & & \\
\hline $\begin{array}{l}\text { SESPMNT } \\
\text { SESPMNT }\end{array}$ & $\begin{array}{l}\text { B17RK } 6 \\
\text { B17RL9 }\end{array}$ & $\begin{array}{l}\text { 100-H SPRING 145-1 } \\
\text { 100-H SPRING 153-1 }\end{array}$ & $\begin{array}{l}\text { ONSITE } \\
\text { ONSITE }\end{array}$ & $\begin{array}{l}\text { SW } \\
\text { SW }\end{array}$ & $\begin{array}{l}Y \\
N\end{array}$ & $\begin{array}{l}\text { SEEP } \\
\text { SEEP }\end{array}$ & UNFILTERED & $\begin{array}{l}27-\mathrm{Oct}-03 \mathrm{Cu} \\
27-\mathrm{Oct}-03 \mathrm{Cu}\end{array}$ & & 0.4822 & $\begin{array}{l}2 \mathrm{gg} / \mathrm{h} \\
\mathrm{ugg} / \mathrm{h}\end{array}$ & & & & & \\
\hline SESPMNT & B17RMO & 100-H SPRING 153-1 & ONSITE & sw & Y & SEEP & & $27-0 c t-03 \mathrm{Cu}$ & & 0.523 & 3 ug/ $/ 2$ & & & & & \\
\hline SESPMNT & B17RK7 & 100-F SPRING 207-1 & ONSITE & sw & $\mathrm{N}$ & SEEP & UNFILTERED & 03-Nov-03 Cu & & & & & & C & & \\
\hline SESPMNT & B17RK8 & 100-F SPRING 207-1 & ONSITE & sw & Y & SEEP & & 03-Nov-03 Cu & & & & & & C & & \\
\hline $\begin{array}{l}\text { SESPMNT } \\
\text { SESPMNT }\end{array}$ & B17RLO & HANFORD SPR UR 28-2 & ONSITE & sw & $\mathrm{N}$ & SEEP & UNFILTERED & 03-Nov-03 Cu & & & & & & C & & \\
\hline $\begin{array}{l}\text { SESPMNT } \\
\text { SESPMNT }\end{array}$ & $\begin{array}{l}\text { B17RL1 } \\
\text { B17RP12 }\end{array}$ & HANFORD SPR UR 28-2 & $\begin{array}{l}\text { ONSITE } \\
\text { ONSTE }\end{array}$ & $\begin{array}{l}\text { SW } \\
\text { sw }\end{array}$ & $\begin{array}{rlll}Y & \\
Y\end{array}$ & $\begin{array}{l}\text { SEEP } \\
\text { SEEP }\end{array}$ & UNFU TFRED & $\begin{array}{l}\text { 03-Nov-03 Cu } \\
\text { 03-Nov-03 Cu }\end{array}$ & & 0.882 & $2 \mathrm{gg} / \mathrm{L}$ & & & $\mathrm{c}$ & & \\
\hline SESPMNT & B17RL3 & HANFORD SPR DR 28-2 & ONSITE & sw & $\begin{array}{l}\mathrm{N} \\
\mathrm{Y}\end{array}$ & $\begin{array}{l}\text { SEEP } \\
\text { SEEP }\end{array}$ & UNFILIERED & $03-$ Nov- $-03 \mathrm{Cu}$ & & 0.718 & 3 ugg/L & & & c & & \\
\hline SESPMNT & B17J86 & 100-K SPRING 77-1 & ONSITE & sw & $\mathrm{N}$ & SEEP & UNFILTERED & 10-Nov-03 Cu & & 0.54 & ugh/ & & & c & & \\
\hline SESPMNT & B17J87 & 100-K SPRING 77-1 & ONSITE & sw & Y & SEEP & & 10-Nov-03 Cu & & 0.374 & & & & c & & \\
\hline SESPSPEC & $\mathrm{B} 180 \mathrm{H} 6$ & 100-B SPRING 37-1 & ONSITE & sw & Y & SEEP & & 13-Nov-03 Cu & & 0.51 & ug/L & & & C & & \\
\hline $\begin{array}{l}\text { SESPSPEC } \\
\text { SESPSPEC }\end{array}$ & $\mathrm{B} 180 \mathrm{OH} 7$ & 100-B SPRING 38-3 & ONSITE & SW & $\begin{array}{l}Y \\
Y\end{array}$ & $\begin{array}{l}\text { SEEP } \\
\text { SEEP }\end{array}$ & & 13-Nov-03 Cu & & 0.422 & $2 \mathrm{ug} / \mathrm{L}$ & & & C & & \\
\hline $\begin{array}{l}\text { SESPSEPC } \\
\text { SESPSPEC }\end{array}$ & $\begin{array}{l}\text { B180H8 } \\
\text { B180.0 }\end{array}$ & $\begin{array}{l}100-B \text { SPRING 39-2 } \\
100 \text { BIC AREA OUTFL }\end{array}$ & $\begin{array}{l}\text { ONSITE } \\
\text { ONSTEE }\end{array}$ & $\begin{array}{l}\text { SW } \\
\text { sw }\end{array}$ & $\begin{array}{r}Y Y \\
Y\end{array}$ & $\begin{array}{l}\text { SEEP } \\
\text { SEFP }\end{array}$ & & 17-Nov-03 Cu & & 0.342 & $2 \mathrm{gug} / \mathrm{L}$ & & & $\mathrm{c}$ & & \\
\hline $\begin{array}{l}\text { SESPSEC } \\
\text { SESPMNT }\end{array}$ & B17RK5 & $\begin{array}{l}100 \text { B/C AREA OUTFL2 } \\
100-H \text { SPRING 145-1 }\end{array}$ & $\begin{array}{l}\text { ONSITE } \\
\text { ONSE }\end{array}$ & sw & $\frac{\mathrm{N}}{\mathrm{N}}$ & $\begin{array}{l}\text { SEEP } \\
\text { SEEP }\end{array}$ & UNFILTERED & $\begin{array}{l}17-\text {-Nov- }-33 \mathrm{Cu} \\
10-\mathrm{OCt}-03 \mathrm{Cr}\end{array}$ & & $\begin{aligned} 0.576 \\
63.3\end{aligned}$ & & & & $\mathrm{C}$ & & \\
\hline SESPMNT & B17RH8 & 300 AREA SPRING 42-2 & ONSITE & sw & $\mathrm{N}$ & SEEP & UNFILTERED & $13-\mathrm{Oct}-03 \mathrm{Cr}$ & & 6.52 & $2 u g / L$ & & & c & & \\
\hline SESPMNT & B17RL4 & 300 AREA SPRING 42-2 & ONSITE & sw & Y & SEEP & & 13-Oct-03 Cr & & & $2 \mathrm{ug} / \mathrm{L}$ & & & & & \\
\hline $\begin{array}{l}\text { SESPMNT } \\
\text { SESPMNT }\end{array}$ & $\begin{array}{l}\text { B17RL5 } \\
\text { B17R6 }\end{array}$ & $\begin{array}{l}300 \text { AREA SPR DR 42-2 } \\
300 \text { AREA SPR DR 42-2 }\end{array}$ & $\begin{array}{l}\text { ONSITE } \\
\text { ONSTE }\end{array}$ & $\begin{array}{l}\text { SW } \\
\text { sw }\end{array}$ & $\begin{array}{l}\mathrm{N} \\
\mathrm{Y}\end{array}$ & $\begin{array}{l}\text { SEEP } \\
\text { SEEP }\end{array}$ & UNFILTERED & $\begin{array}{l}\text { 13-OCt-03 } \mathrm{Cr} \\
\text { 13-OCt-03 Cr }\end{array}$ & & $\begin{array}{r}4.3 \\
4.96 \\
\end{array}$ & $3 \mathrm{ug} / \mathrm{h}$ & & & c & & \\
\hline SESPMNT & B17J83 & 100-B SPRING 39-2 & ONSITE & sw & Y & SEEP & & 20-Oct-03 Cr & & 16.9 & & & & & BOTTLE LEAKED WAS REBOTTLED AND SENT TO LAB FOR & \\
\hline SESPMNT & B17J17 & 100-N SPRING 8-13 & ONSITE & sw & $\mathrm{N}$ & SEEP & UNFILTERED & $20-0 \mathrm{ct}-03 \mathrm{Cr}$ & & & 5 ug/L & & & & & \\
\hline SESPMNT & B17J76 & 100-B SPRING 37-1 & ONSITE & sw & $\mathrm{N}$ & SEEP & UNFILTERED & $20-0 c t-03 \mathrm{Cr}$ & & 8.71 & lug/L & & & & & \\
\hline $\begin{array}{l}\text { SESPMNT } \\
\text { SESPMNT }\end{array}$ & B17J81 & 100-B SPRING 37-1 & ONSITE & SW & Y & $\begin{array}{l}\text { SEEP } \\
\text { SEFP }\end{array}$ & UNEU TERED & $20-\mathrm{Oct}-03 \mathrm{Cr}$ & & 7.4 & $4 \mathrm{ug} / \mathrm{L}$ & & & & & \\
\hline SESPMNT & B17J82 & 100-B SPRING 39-2 & ONSITE & sw & $\mathrm{N}$ & SEEP & UNFILTERED & $20-\mathrm{Oct}-03 \mathrm{Cr}$ & & 17.1 & ug/L & & & & & \\
\hline $\begin{array}{l}\text { SESPMNT } \\
\text { SESPMNT }\end{array}$ & B17J84 & 100-K SPRING 63-2 & ONSITE & SW & $\mathrm{y}^{\mathrm{N}}$ & SEEP & UNFILTERED & $20-\mathrm{Oct}-03 \mathrm{Cr}$ & & 41.3 & $3 \mathrm{gg} / \mathrm{L}$ & & & & & \\
\hline $\begin{array}{l}\text { SESPMNT } \\
\text { SESPMNT }\end{array}$ & $\begin{array}{l}\text { B17JJ55 } \\
\text { B17888 }\end{array}$ & $\begin{array}{l}\text { 100-- SPRIIG 63-2 } \\
\text { 100-N SPRING 8-13 }\end{array}$ & $\begin{array}{l}\text { ONSIIE } \\
\text { ONSITE }\end{array}$ & $\begin{array}{l}\text { SW } \\
\text { SW }\end{array}$ & $\begin{array}{l}\text { Y } \\
\text { Y }\end{array}$ & $\begin{array}{l}\text { SEEP } \\
\text { SEEP }\end{array}$ & & $\begin{array}{l}\text { 20-Oct-03 Cr } \\
20-0 \mathrm{Clt}-03 \mathrm{Cr}\end{array}$ & & $\begin{array}{l}41.6 \\
9.02\end{array}$ & jugh// & & & & & \\
\hline SESPMNT & B17J91 & 100-D SPRING 110-1 & ONSITE & sw & $\mathrm{N}$ & SEEP & UNFILTERED & 27 -Oct-03 Cr & & 10.7 & & & & & & \\
\hline SESPMNT & B17J92 & 100-D SPRING 110-1 & ONSITE & sw & Y & SEEP & & $27-0 c t-03 \mathrm{Cr}$ & & 11.6 & sug/L & & & & & \\
\hline SESPMNT & B17J93 & 100-D SPRING 102-1 & ONSITE & sw & $\mathrm{N}$ & SEEP & UNFILTERED & 27-Oct-03 Cr & & 52.4 & $4 \mathrm{ug} / \mathrm{L}$ & & & & & \\
\hline SESPMNT & B17J94 & 100-D SPRING 102-1 & ONSITE & sw & Y & SEEP & & $27-\mathrm{Oct}-03 \mathrm{Cr}$ & & 56.7 & lug/L & & & & & \\
\hline $\begin{array}{l}\text { SESPMNT } \\
\text { SESPMNT }\end{array}$ & $\begin{array}{l}\text { B17RK6 } \\
\text { B17RR19 }\end{array}$ & 100-H SPRING 145-1 & $\begin{array}{l}\text { ONSITE } \\
\text { ONSTE }\end{array}$ & $\begin{array}{l}\text { SW } \\
\text { sw }\end{array}$ & $\begin{array}{rlll}Y & \\
Y\end{array}$ & SEEP & UNEU TFRED & 27-Oct-03 Cr & & 33.3 & $3 \mathrm{gg} / \mathrm{L}$ & & & & & \\
\hline $\begin{array}{l}\text { SESPMNT } \\
\text { SESPMNT }\end{array}$ & $\begin{array}{l}\text { B17RL29 } \\
\text { B17RMO }\end{array}$ & $\begin{array}{l}\text { 100-H SPRRIN } 153-1 \\
\text { 100-H SPRING 153-1 }\end{array}$ & $\begin{array}{l}\text { ONSTIE } \\
\text { ONSITE }\end{array}$ & $\begin{array}{l}\text { SW } \\
\text { SW }\end{array}$ & $\begin{array}{l}\mathrm{N} \\
\mathrm{Y}\end{array}$ & $\begin{array}{l}\text { SEEP } \\
\text { SEEP }\end{array}$ & UNFILTERED & $\begin{array}{l}27-\mathrm{OCt}-03 \mathrm{Cr} \\
27-\mathrm{Oct}-03 \mathrm{Cr}\end{array}$ & & $\begin{array}{r}10 \\
9.38\end{array}$ & $\begin{array}{l}\text { oggh/ } \\
\text { ugg/h }\end{array}$ & & & & & \\
\hline SESPMNT & B17RK7 & 100-F SPRING 207-1 & ONSITE & sw & $\mathrm{N}$ & SEEP & UNFILTERED & 03-Nov-03 Cr & & & 5 ugh/ & & & c & & \\
\hline SESPMNT & B17RK8 & 100-F SPRING 207-1 & ONSITE & sw & Y & SEEP & & 03-Nov-03 Cr & & & $3 \mathrm{ug} / \mathrm{L}$ & & & & & \\
\hline SESPMNT & B17RLO & HANFORD SPR UR 28-2 & ONSITE & sw & $\mathrm{N}$ & SEEP & UNFILTERED & 03-Nov-03 Cr & & 0.896 & & & & C & & \\
\hline $\begin{array}{l}\text { SESPMNT } \\
\text { SESPMNT }\end{array}$ & $\begin{array}{l}\text { B17RL1 } \\
\text { B17RR12 }\end{array}$ & $\begin{array}{l}\text { HANFORD SPR UR 28-2 } \\
\text { HANFO }\end{array}$ & $\begin{array}{l}\text { ONSITE } \\
\text { ONSTFE }\end{array}$ & $\begin{array}{l}S W \\
\text { SW }\end{array}$ & $\begin{array}{r}Y \\
Y N\end{array}$ & $\begin{array}{l}\text { SEEP } \\
\text { SEFP }\end{array}$ & UNEU TERED & 03-Nov-03 Cr & & 0.659 & ugh/L & & & $c$ & & \\
\hline SESPMNT & B17RL3 & HANFORD SPR DR 28-2 & ONSITE & sw & Y & SEEP & & $03-$ Nov-03 Cr & & 0.548 & 3 ugh/ & & & $c$ & & \\
\hline SESPMNT & B17J86 & 100-K SPRING 77-1 & ONSITE & sw & $\mathrm{N}$ & SEEP & UNFILTERED & 10-Nov-03 Cr & & 1.21 & lug/L & & & C & & \\
\hline SESPMNT & B17J87 & 100-K SPRING 77-1 & ONSITE & sw & Y & SEEP & & 10-Nov-03 Cr & & 0.966 & jugl/ & & & & & \\
\hline SESPSPEC & $\mathrm{B} 18 \mathrm{OH} 6$ & 100-B SPRING 37-1 & ONSITE & sw & Y & SEEP & & 13-Nov-03 Cr & & 5.09 & $\mathrm{ug} / \mathrm{L}$ & & & c & & \\
\hline SESPSPEC & $\mathrm{B} 180 \mathrm{H} 7$ & 100-B SPRING 38-3 & ONSITE & SW & Y & SEEP & & 13-Nov-03 Cr & & 6.66 & iug/L & & & c & & \\
\hline $\begin{array}{l}\text { SESPSPEC } \\
\text { SESPPEC }\end{array}$ & B180H8 & 100-B SPRING 39-2 & ONSITE & sw & $\begin{array}{r}Y \\
Y\end{array}$ & SEEP & & 17-Nov-03 Cr & & & 2ug/L & & & $\mathrm{C}$ & & \\
\hline $\begin{array}{l}\text { SESPPPEC } \\
\text { SESPMNT }\end{array}$ & B180J0 & 100 B/C AREA OUTFL2 & ONSITE & SW & $\begin{array}{r}Y \\
Y\end{array}$ & $\begin{array}{l}\text { SEEP } \\
\text { SEFP }\end{array}$ & & 17-Nov-03 Cr & & 1.85 & $5 \mathrm{ug} / \mathrm{L}$ & & & $\mathrm{C}$ & & \\
\hline $\begin{array}{l}\text { SESPMNT } \\
\text { SESPMNT }\end{array}$ & $\begin{array}{l}\text { B17RK5 } \\
\text { B17RH8 }\end{array}$ & $\begin{array}{l}\text { 100-H SPRRING 145-1 } \\
300 \text { AREA SPRING 42-2 }\end{array}$ & $\begin{array}{l}\text { ONSTIE } \\
\text { ONSITE }\end{array}$ & $\begin{array}{l}\text { SW } \\
\text { sw }\end{array}$ & $\begin{array}{l}\mathrm{N} \\
\mathrm{N}\end{array}$ & $\begin{array}{l}\text { SEEP } \\
\text { SEEP }\end{array}$ & $\begin{array}{l}\text { UNFLLTERED } \\
\text { UNFILTERED }\end{array}$ & $\begin{array}{l}10-\text { OCt-03 Cd } \\
13-0 \text { ct- } 03 \text { Cd }\end{array}$ & & $\begin{array}{l}0.689 \\
0.0819\end{array}$ & $\begin{array}{l}3 \text { gugh/ } \\
\text { uggh }\end{array}$ & & & & & \\
\hline SESPMNT & B17RL4 & 300 AREA SPRING 42-2 & ONSITE & sw & $\mathrm{Y}$ & SEEP & & $13-$ Oct-03 Cd & & 0.0236 & $5 \mathrm{ug} / \mathrm{L}$ & & & B & & \\
\hline SESPMNT & B17RL5 & 300 AREA SPR DR 42-2 & ONSITE & SW & $\mathrm{N}$ & $\begin{array}{l}\text { SEEP } \\
\text { SEFP }\end{array}$ & UNFILTERED & 13-Oct-03 Cd & & 0.0668 & 3 ug/ & & & & & \\
\hline SESPMNT & B17RL6 & 300 AREA SPR DR 42-2 & ONSITE & SW & Y & SEEP & & $13-O c t-03 \mathrm{Cd}$ & & 0.0277 & & & & B & & \\
\hline SESPMNT & B17J83 & 100-B SPRING 39-2 & ONSITE & sw & Y & SEEP & & $20-0 c t-03 \mathrm{Cd}$ & & 0.023 & $3 \mathrm{ug} / \mathrm{L}$ & & & $U$ & $\begin{array}{l}\text { BOTTLE LEAKED WAS REBOTTLED AND SENT TO LAB FOR } \\
\text { ANALYSES. }\end{array}$ & \\
\hline SESPMNT & B17J17 & 100-N SPRING 8-13 & ONSITE & sw & $\mathrm{N}$ & SEEP & UNFILTERED & $20-0 c t-03 \mathrm{Cd}$ & & 0.0455 & 5 ug/L & & & B & & \\
\hline SESPMNT & B17J76 & 100-B SPRING 37-1 & ONSITE & sw & $\mathrm{N}$ & SEEP & UNFILTERED & $20-O c t-03 \mathrm{Cd}$ & & 0.0262 & 2 ug/L & & & B & & \\
\hline SESPMNT & B17J81 & 100-B SPRING 37-1 & ONSITE & SW & $Y$ & SEEP & & 20-Oct-03 Cd & & 0.024 & fug/L & & & $\mathrm{B}$ & & \\
\hline
\end{tabular}




\begin{tabular}{|c|c|c|c|c|c|c|c|c|c|c|c|c|c|c|c|c|}
\hline | OWNER ID & \begin{tabular}{|l|l} 
SAMP \\
NUM
\end{tabular} & SAMP SITE NAME & $\left|\begin{array}{c}\text { DIST } \\
\text { CLASS }\end{array}\right|$ & $\mid$ MEDIA $\mid$ & $\begin{array}{l}\text { FILTERED } \\
\text { FLAG }\end{array}$ & $\begin{array}{l}\text { SAMP } \\
\text { FROM }\end{array}$ & $\mid$ COLL MTHD & SAMP DATE| & CON SHORT NAME & \begin{tabular}{|l|l} 
VALUE & $A$ \\
RPTD
\end{tabular} & \begin{tabular}{|c|} 
ANAL \\
UNITS \\
RPTD \\
\end{tabular} & $\left|\begin{array}{c}\text { COUNTING } \\
\text { ERROR }\end{array}\right|$ & $\begin{array}{c}\text { TOTAL } \\
\text { ANAL } \\
\text { ERROR }\end{array}$ & $\begin{array}{c}\text { LAB } \\
\text { QUALIFIER }\end{array}$ & SAMP COMMENT & $\left|\begin{array}{c}\text { RESULT } \\
\text { COMMENT }\end{array}\right|$ \\
\hline SESPMNT & & 100-B SPRING 39-2 & ONSITE & SW & $\mathrm{N}$ & SEEP & UNFILTERED & $20-0 c t-03 \mathrm{Cd}$ & & & & & & U & 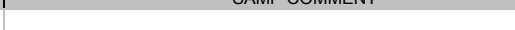 & \\
\hline SESPMNT & B17J84 & 100-K SPRING 63-2 & ONSITE & SW & $\mathrm{N}$ & SEEP & UNFILTERED & $20-O c t-03 \mathrm{Cd}$ & & 0.0346 uू uू & & & & B & & \\
\hline SESPMNT & B17J85 & 100-K SPRING 63-2 & ONSITE & sw & Y & SEEP & & 20-Oct-03 Cd & & & & & & U & & \\
\hline SESPMNT & B17J88 & 100-N SPRING 8-13 & ONSITE & sW & $\mathrm{Y}$ & SEEP & & $20-O c t-03 \mathrm{Cd}$ & & & & & & B & & \\
\hline $\begin{array}{l}\text { SESPMNT } \\
\text { SESPMNT }\end{array}$ & B17J91 & 100-D SPRING 110-1 & $\begin{array}{l}\text { ONSITE } \\
\text { ONSTE }\end{array}$ & $\begin{array}{l}S W \\
\text { SW }\end{array}$ & $\begin{array}{l}\text { N } \\
\text { M }\end{array}$ & $\begin{array}{l}\text { SEEP } \\
\text { SEFP }\end{array}$ & UNFILTERED & 27-Oct-03 Cd & & 0.0342 uc & & & & $B$ & & \\
\hline $\begin{array}{l}\text { SESPMNT } \\
\text { SESPMNT }\end{array}$ & $\begin{array}{l}\text { B17.992 } \\
\text { B17.93 }\end{array}$ & $\begin{array}{l}\text { 100-D SPRING 110-1 } \\
\text { 100-D SPRING 102-1 }\end{array}$ & ONSITE & SW & $Y$ & SEEP & & 27-Oct-03 Cd & & 0.0309 uc & & & & B & & \\
\hline SESPMNT & $\begin{array}{l}\text { B1/7993 } \\
\text { B17J94 }\end{array}$ & $\begin{array}{l}\text { 100-D SPRING 102-1 } \\
\text { 100-D SPRIG 102-1 }\end{array}$ & $\begin{array}{l}\text { ONSIE } \\
\text { ONSTEE }\end{array}$ & SW & $\begin{array}{l}\mathrm{N} \\
\mathrm{Y}\end{array}$ & $\begin{array}{l}\text { SEEP } \\
\text { SEFP }\end{array}$ & UNFILTERED & 27-Oct-03 Cd & & $0.0862 \mathrm{uc}$ & & & & & & \\
\hline SESPMNT & B17RK6 & 100-H SPRING 145-1 & $\begin{array}{l}\text { ONSITE } \\
\text { ONS }\end{array}$ & SW & $\begin{array}{l}\mathrm{Y} \\
\mathrm{Y}\end{array}$ & SEEP & & $\begin{array}{l}27-\mathrm{Oct}-03 \mathrm{Cd} \\
27-\mathrm{Oct}-03 \mathrm{Cd}\end{array}$ & & $\begin{array}{l}0.0615 \text { us } \\
0.0405 \text { us }\end{array}$ & & & & B & & \\
\hline SESPMNT & B17RL9 & 100-H SPRING 153-1 & ONSITE & sW & $\mathrm{N}$ & SEEP & UNFILTERED & $27-O c t-03 \mathrm{Cd}$ & & 0.0365 us & & & & B & & \\
\hline SESPMNT & B17RM0 & 100-H SPRING 153-1 & ONSITE & SW & Y & SEEP & & 27-Oct-03 Cd & & & & & & B & & \\
\hline $\begin{array}{l}\text { SESPMNT } \\
\text { SESPMNT }\end{array}$ & B17RK7 & 100-F SPRING 207-1 & ONSITE & SW & $\mathrm{N}$ & SEEP & UNFILTERED & 03-Nov-03 Cd & & 0.348 us & & & & & & \\
\hline $\begin{array}{l}\text { SESPMNT } \\
\text { SESPMNT }\end{array}$ & B17RK8 & 100-F SPRING 207-1 & ONSITE & SW & $Y$ & SEEP & & 03-Nov-03 Cd & & 0.0175 us & & & & B & & \\
\hline $\begin{array}{l}\text { SESPMNT } \\
\text { SESPMNT }\end{array}$ & $\begin{array}{l}\text { B17RLO } \\
\text { B17RL1 }\end{array}$ & $\begin{array}{l}\text { HAAFORDD SPR UR 28-2 } \\
\text { HANFORD SPR UR 28-2 }\end{array}$ & $\begin{array}{l}\text { ONSIE } \\
\text { ONSTIE }\end{array}$ & $\begin{array}{l}\text { SW } \\
\text { sw }\end{array}$ & $\begin{array}{l}\mathrm{N} \\
\mathrm{Y}\end{array}$ & $\begin{array}{l}\text { SEEP } \\
\text { SEEP }\end{array}$ & UNFILTERED & $\begin{array}{l}\text { 03-Nov-03 Cd } \\
\text { 03-Nov-03 Cd }\end{array}$ & & $\begin{array}{ll}0.029 \text { u } \\
0.0157 \text { uc }\end{array}$ & log/L & & & $\begin{array}{l}B \\
B\end{array}$ & & \\
\hline SESPMNT & B17RL2 & HANFORD SPR DR 28-2 & ONSITE & sw & $\mathrm{N}$ & SEEP & UNFILTERED & $03-$ Nov-03 Cd & & 0.0197 us & & & & B & & \\
\hline SESPMNT & B17RL3 & HANFORD SPR DR 28-2 & ONSITE & sW & $\mathrm{Y}$ & SEEP & & 03-Nov-03 Cd & & 0.0155 ụ & & & & B & & \\
\hline SESPMNT & B17J86 & 100-K SPRING 77-1 & ONSITE & SW & $\mathrm{N}$ & SEEP & UNFILTERED & $10-\mathrm{Nov}-03 \mathrm{Cd}$ & & & & & & B & & \\
\hline SESPMNT & B17J87 & 100-K SPRING 77-1 & ONSITE & SW & Y & SEEP & & 10-Nov-03 Cd & & $0.0125 \mathrm{ug}$ & & & & B & & \\
\hline $\begin{array}{l}\text { SESPSPEC } \\
\text { SESPSEC }\end{array}$ & $\begin{array}{l}\mathrm{B} 18 \mathrm{OH} 6 \\
\mathrm{~B} 18 \mathrm{OH} 7\end{array}$ & $\begin{array}{l}\text { 100-B SPRING 37-1 } \\
\text { 100-B SPRING 38-3 }\end{array}$ & $\begin{array}{l}\text { ONSITE } \\
\text { ONSTE }\end{array}$ & $\begin{array}{l}\text { SW } \\
\text { sw }\end{array}$ & $\begin{array}{l}Y \\
Y\end{array}$ & $\begin{array}{l}\text { SEEP } \\
\text { SEEP }\end{array}$ & & $\begin{array}{l}\text { 13-Nov-03 Cd } \\
\text { 13-Nov-03 Cd }\end{array}$ & & 0.0189 uc & ug/L & & & $B$ & & \\
\hline SESPSPEC & B180H8 & 100-B SPRING 39-2 & ONSITE & sw & $\begin{array}{r}\mathrm{Y} \\
\mathrm{Y}\end{array}$ & $\begin{array}{l}\text { SEEP } \\
\text { SEEP }\end{array}$ & & 17-Nov-03Cd Cd & & $\begin{array}{l}0.020658 \text { us } \\
0.009\end{array}$ & ugh/L & & & B & & \\
\hline SESPSPEC & B180J0 & 100 B/C AREA OUTFL2 & ONSITE & sw & Y & SEEP & & $17-$ Nov-03 Cd & & 0.0157 us & & & & B & & \\
\hline SESPMNT & B17RK5 & 100-H SPRING $145-1$ & ONSITE & sW & $\mathrm{N}$ & SEEP & UNFILTERED & 10-Oct-03 Be & & 0.201 us & & & & & & \\
\hline SESPMNT & B17RH8 & 300 AREA SPRING 42-2 & ONSITE & SW & $\mathrm{N}$ & SEEP & UNFILTERED & 13-Oct-03 Be & & 0.0679 us & & & & B & & \\
\hline $\begin{array}{l}\text { SESPMNT } \\
\text { SESPMNT }\end{array}$ & B17RL4 & 300 AREA SPRING 42-2 & ONSITE & SW & Y & SEEP & & 13-Oct-03 Be & & 0.0098 us & & & & $U$ & & \\
\hline $\begin{array}{l}\text { SESPMNT } \\
\text { SESPMNT }\end{array}$ & $\begin{array}{l}\text { B17RLL5 } \\
\text { B17R66 }\end{array}$ & $\begin{array}{l}300 \text { AREA SPR DR 42-2 } \\
300 \text { AREA SPR DR 42-2 }\end{array}$ & $\begin{array}{l}\text { ONSITE } \\
\text { ONSTE }\end{array}$ & $\begin{array}{l}\text { SW } \\
\text { sw }\end{array}$ & $\begin{array}{l}\mathrm{y} \\
\mathrm{N}\end{array}$ & $\begin{array}{l}\text { SEEP } \\
\text { SEEP }\end{array}$ & UNFILTERED & $\begin{array}{l}\text { 13-Oct-03 Be } \\
\text { 13-Oct-03 Be }\end{array}$ & & 0.00987 us & & & & B & & \\
\hline SESPMNT & B17J83 & 100-B SPRING 39-2 & ONSITE & sw & $\begin{array}{l}\mathrm{Y} \\
\mathrm{Y}\end{array}$ & $\begin{array}{l}\text { SEEP } \\
\text { SEEP }\end{array}$ & & 20-Oct-03 Be & & $\begin{array}{ll}0.0098 \text { ug } \\
0.0098 \text { us }\end{array}$ & & & & u & BOTTLE LEAKED WAS REBOTTLED AND SENT TO LAB FOR & \\
\hline SESPMNT & & & ONSITE & & $N$ & & UNFILTERED & $2000+03$ & & & & & & $R_{0}+2$ & ANALYSES. & \\
\hline 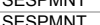 & (17) & T00-N SPRING 8-13 & $\begin{array}{l}\text { ONSIE } \\
\text { ONSTEF }\end{array}$ & SW & $N^{n}$ & $\begin{array}{l}\text { Ser } \\
\text { SSEP }\end{array}$ & 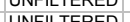 & $\begin{array}{l}20-0 c-03 \text { Be } \\
20-0 c-03 B e\end{array}$ & & $0.0725 \mathrm{~s}$ & sgh/ & & & $\mathrm{B}$ & & \\
\hline $\begin{array}{l}\text { SESPMNII } \\
\text { SESPMNT }\end{array}$ & B17J81 & 100-B SPRING 37-1 & $\begin{array}{l}\text { ONSITE } \\
\text { ONS }\end{array}$ & SW & Y & $\begin{array}{l}\text { SEEP } \\
\text { SEEP }\end{array}$ & & $20-0 c t-03 \mathrm{Be}$ & & $\begin{array}{ll}0.0098 \\
0.009 \text { uc }\end{array}$ & & & & u & & \\
\hline SESPMNT & B17J82 & 100-B SPRING 39-2 & ONSITE & sw & $\mathrm{N}$ & SEEP & UNFILTERED & $20-0 c t-03 \mathrm{Be}$ & & 0.0098 us & & & & u & & \\
\hline SESPMNT & B17J84 & 100-K SPRING 63-2 & ONSITE & sW & $\mathrm{N}$ & SEEP & UNFILTERED & 20-Oct-03 Be & & 0.0098 uc & & & & U & & \\
\hline SESPMNT & B17J85 & 100-K SPRING 63-2 & ONSITE & sw & Y & SEEP & & 20-Oct-03 Be & & 0.0098 us & & & & u & & \\
\hline SESPMNT & B17J88 & 100-N SPRING 8-13 & ONSITE & sw & Y & SEEP & & 20-Oct-03 Be & & 0.0166 us & & & & B & & \\
\hline SESPMNT & B17J91 & 100-D SPRING 110-1 & ONSITE & SW & $\mathrm{N}$ & SEEP & UNFILTERED & 27-Oct-03 Be & & 0.0098 us & & & & U & & \\
\hline SESPMNT & B17J92 & 100-D SPRING 110-1 & ONSITE & SW & Y & SEEP & & 27-Oct-03 Be & & $0.0118 \mathrm{us}$ & ug/L & & & B & & \\
\hline $\begin{array}{l}\text { SESPMNT } \\
\text { SESPMNT }\end{array}$ & B17J93 & 100-D SPRING 102-1 & ONSITE & SW & $\mathrm{N}$ & SEEP & UNFILTERED & 27-Oct-03 Be & & 0.0098 uc & igg/L & & & U & & \\
\hline $\begin{array}{l}\text { SESPMNT } \\
\text { SESPMNT }\end{array}$ & $\begin{array}{l}\text { B179944 } \\
\text { B17RK6 }\end{array}$ & $\begin{array}{l}\text { 100-D SPRING 102-1 } \\
\text { 100-H SPRING 445-1 }\end{array}$ & $\begin{array}{l}\text { ONSIE } \\
\text { ONSTTE }\end{array}$ & $\begin{array}{l}\text { SW } \\
\text { sw }\end{array}$ & $\begin{array}{l}\mathrm{Y} \\
\mathrm{Y}\end{array}$ & $\begin{array}{l}\text { SEEP } \\
\text { SEEP }\end{array}$ & & $\begin{array}{l}\text { 27-Oct-03 Be } \\
\text { 27-Oct-03 Be }\end{array}$ & & $\begin{array}{l}0.0098 \text { u } \\
0.0098 \mathrm{ug}\end{array}$ & ug// & & & u & & \\
\hline SESPMNT & B17RL9 & 100-H SPRING 153-1 & ONSITE & sw & $\mathrm{N}$ & SEEP & UNFILTERED & $27-0 c t-03 \mathrm{Be}$ & & 0.0108 us & & & & B & & \\
\hline SESPMNT & B17RMO & 100-H SPRING 153-1 & ONSITE & sw & Y & SEEP & & $27-\mathrm{Oct}-03 \mathrm{Be}$ & & 0.0098 us & & & & U & & \\
\hline SESPMNT & B17RK7 & 100-F SPRING 207-1 & ONSITE & SW & $\mathrm{N}$ & SEEP & UNFILTERED & 03-Nov-03 Be & & 0.0945 us & & & & & & \\
\hline SESPMNT & B17RK8 & 100-F SPRING 207-1 & ONSITE & SW & Y & SEEP & & 03-Nov-03 Be & & 0.0098 us & ug/L & & & U & & \\
\hline $\begin{array}{l}\text { SESPMNT } \\
\text { SESPMNT }\end{array}$ & $\begin{array}{l}\text { B17RLO } \\
\text { B17R11 }\end{array}$ & HANFORD SPR UR 28-2 & ONSITE & SW & $\begin{array}{l}\mathrm{N} \\
\mathrm{y}\end{array}$ & SEEP & UNFILTERED & 03-Nov-03 Be & & 0.0102 uc & ug/L & & & 4 & & \\
\hline $\begin{array}{l}\text { SESPMNT } \\
\text { SESPMNT }\end{array}$ & $\begin{array}{l}\text { B17RLL1 } \\
\text { B17RL2 }\end{array}$ & $\begin{array}{l}\text { HANFORD SPR UR 28-2 } \\
\text { HANFORD SPR DR 28-2 }\end{array}$ & $\begin{array}{l}\text { ONSITE } \\
\text { ONSITE }\end{array}$ & $\begin{array}{l}\text { SW } \\
\text { SW }\end{array}$ & $\frac{\mathrm{Y}}{\mathrm{N}}$ & $\begin{array}{l}\text { SEEP } \\
\text { SEEP }\end{array}$ & UNFILTERED & $\begin{array}{l}\text { 03-Nov-03 Be } \\
\text { 03-Nov-03 Be }\end{array}$ & & $\begin{array}{l}0.0098 \text { u u } \\
0.0098 \mathrm{ug}\end{array}$ & & & & u & & \\
\hline SESPMNT & B17RL3 & HANFORD SPR DR 28-2 & ONSITE & sw & $Y$ & SEEP & & 03-Nov-03 Be & & $0.0098 \mathrm{ug}$ & & & & U & & \\
\hline SESPMNT & B17J86 & 100-K SPRING 77-1 & ONSITE & sw & $\mathrm{N}$ & SEEP & UNFILTERED & 10-Nov-03 Be & & 0.0127 us & & & & & & \\
\hline SESPMNT & B17J87 & 100-K SPRING 77-1 & ONSITE & SW & $\mathrm{Y}$ & SEEP & & 10-Nov-03 Be & & 0.0098 us & ug/L & & & U & & \\
\hline $\begin{array}{l}\text { SESPSPEC } \\
\text { SESPSPCC }\end{array}$ & B180H6 & 100-B SPRING 37-1 & ONSITE & SW & Y & SEEP & & 13-Nov-03 Be & & 0.0098 us & ug/L & & & $U$ & & \\
\hline $\begin{array}{l}\text { SESPPEC } \\
\text { SESPPEC }\end{array}$ & B180H7 & 100-B SPRING 38-3 & ONSITE & SW & $\begin{array}{l}Y \\
Y\end{array}$ & SEEP & & 13-Nov-03 Be & & 0.0098 uc & ug/L & & & U & & \\
\hline $\begin{array}{l}\text { SESPPEC } \\
\text { SESPSPEC }\end{array}$ & B180H8 & 100-B SPRING 39-2 & ONSITE & SW & $\begin{array}{l}Y \\
Y \\
Y\end{array}$ & $\begin{array}{l}\text { SEEP } \\
\text { SEFP }\end{array}$ & & 17-Nov-03 Be & & $0.0098 \mathrm{ug}$ & igg/L & & & U & & \\
\hline $\begin{array}{l}\text { SESPSPEC } \\
\text { SESPE }\end{array}$ & B180H6 & 100-B SPRING 37-1 & ONSITE & SW & $\begin{array}{l}\mathrm{Y} \\
\mathrm{Y}\end{array}$ & $\begin{array}{l}\text { SEEP } \\
\text { SEEP }\end{array}$ & & $\begin{array}{l}\text { 17-Nov-03 Be } \\
\text { 13-Nov-03 Ba }\end{array}$ & & $\begin{array}{l}0.0098 \mathrm{ug} \\
46.5 \mathrm{us}\end{array}$ & & & & $\mathrm{c}$ & & \\
\hline SESPSPEC & $\mathrm{B} 18 \mathrm{OH} 7$ & 100-B SPRING 38-3 & ONSITE & sW & $\mathrm{Y}$ & SEEP & & 13-Nov-03 Ba & & $44.4 \mathrm{ug}$ & $\mathrm{ug} / \mathrm{L}$ & & & c & & \\
\hline $\begin{array}{l}\text { SESPSPEC } \\
\text { CFADSPC }\end{array}$ & B180H8 & 100-B SPRING 39-2 & ONSITE & SW & $\begin{array}{l}Y \\
Y \\
Y\end{array}$ & SEEP & & 17-Nov-03 Ba & & & ug/L & & & C & & \\
\hline $\begin{array}{l}\text { SESPSPEC } \\
\text { SESPUTT }\end{array}$ & B180J0 & $100 \mathrm{~B} / \mathrm{C}$ AREA OUTFL2 & ONSITE & SW & Y & SEEP & & 17-Nov-03 Ba & & 21.2 us & ug/L & & & C & & \\
\hline $\begin{array}{l}\text { SESPMNT } \\
\text { SESPMNT }\end{array}$ & B17RK5 & 100-H SPRING 145-1 & ONSITE & SW & $N^{N}$ & SEEP & UNFILTERED & 10-Oct-03 As & & 8.51 us & ug/L & & & & & \\
\hline $\begin{array}{l}\text { SESPMNT } \\
\text { SESPMNT }\end{array}$ & $\begin{array}{l}\text { B17RH8 } \\
\text { B17RL4 }\end{array}$ & $\begin{array}{l}300 \text { AREA SPRR SING 42-2 } \\
300 \text { AREA SPING 42-2 }\end{array}$ & $\begin{array}{l}\text { ONSITE } \\
\text { ONSITE }\end{array}$ & $\begin{array}{l}\text { SW } \\
\text { SW }\end{array}$ & $\begin{array}{l}\mathrm{N} \\
\mathrm{Y}\end{array}$ & $\begin{array}{l}\text { SEEP } \\
\text { SEEP }\end{array}$ & UNFILTERED & $\begin{array}{l}\text { 13-Oct--03 As } \\
\text { 13-Oct-03 As }\end{array}$ & & $\begin{array}{l}1.89 \mathrm{ug} \\
1.61 \mathrm{us}\end{array}$ & $\begin{array}{l}\mathrm{ugg/2} \\
\mathrm{ug} / \mathrm{L}\end{array}$ & & & & & \\
\hline SESPMNT & B17RL5 & 300 AREA SPR DR 42-2 & ONSITE & sW & $\mathrm{N}$ & SEEP & UNFILTERED & 13-Oct-03 As & & $1.42 \mathrm{ug}$ & ug/L & & & & & \\
\hline SESPMNT & B17RL6 & 300 AREA SPR DR 42-2 & ONSITE & sW & $\mathrm{Y}$ & SEEP & & 13-Oct-03 As & & 1.32 us & $\mathrm{ug} / \mathrm{L}$ & & & & & \\
\hline SESPMNT & B17J83 & 100-B SPRING 39-2 & ONSITE & sw & Y & SEEP & & 20-Oct-03 As & & 0.713 us & & & & & $\begin{array}{l}\text { BOTTLE LEAKED WAS REBOTTLED AND SENT TO LAB FOR } \\
\text { ANALYSES. }\end{array}$ & \\
\hline SESPMNT & B17J17 & 100-N SPRING 8-13 & ONSITE & sW & $\mathrm{N}$ & SEEP & UNFILTERED & 20-Oct-03 As & & 2.42 us & ug/L & & & & & \\
\hline SESPMNT & B17J76 & 100-B SPRING 37-1 & ONSITE & SW & $\frac{d}{N}$ & SEEP & UNFILTERED & 20-Oct-03 As & & 0.994 uc & ug/L & & & & & \\
\hline $\begin{array}{l}\text { SESPMNT } \\
\text { SESPMNT }\end{array}$ & $\begin{array}{l}\text { B17JJ81 } \\
\text { B17182 }\end{array}$ & $\begin{array}{l}\text { 100-B SPRING 37-1 } \\
\text { 100-B SPRING 39-2 }\end{array}$ & $\begin{array}{l}\text { ONSIE } \\
\text { ONSTIE }\end{array}$ & SW & $\frac{\mathrm{N}}{\mathrm{N}}$ & $\begin{array}{l}\text { SEEP } \\
\text { SEEP }\end{array}$ & UNEIUTERED & $\begin{array}{l}\text { 20-Oct-03 As } \\
\text { 20-Oct-03 As }\end{array}$ & & $\begin{array}{l}1.06 \mathrm{ug} \\
0.717 \mathrm{ug}\end{array}$ & ugg/L & & & & & \\
\hline
\end{tabular}




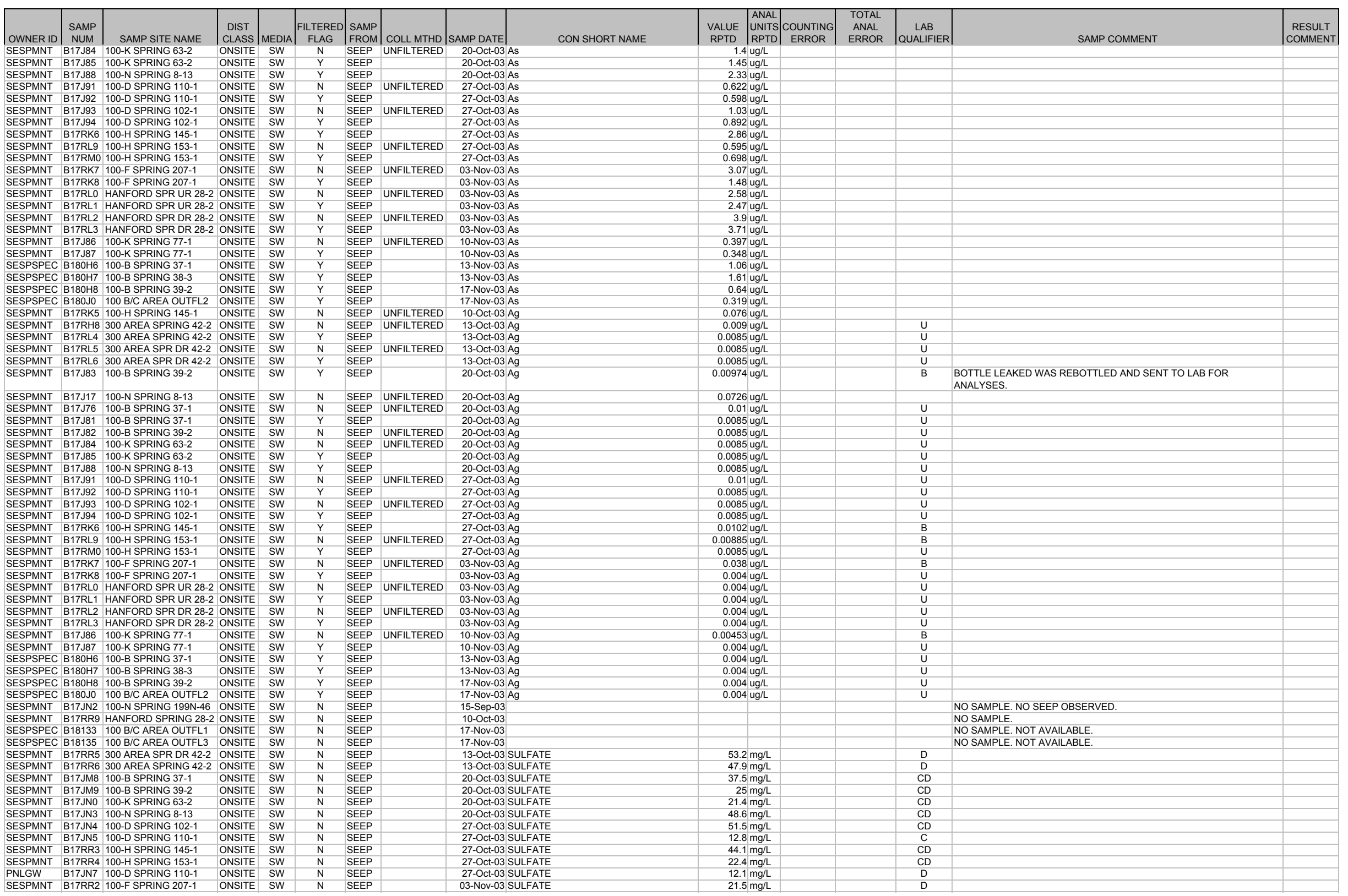




\begin{tabular}{|c|c|c|c|c|c|c|c|c|c|c|c|c|c|c|}
\hline OWNER ID & \begin{tabular}{|l} 
SAMP \\
NUMM
\end{tabular} & SAMP SITE NAME & $\left|\begin{array}{c}\text { DIST } \\
\text { CLASS }\end{array}\right|$ & $\mid$ MEDIA $\mid$ & $\begin{array}{c}\text { FILTERED } \\
\text { FLAG }\end{array}$ & $\left|\begin{array}{l}\text { SAMP } \\
\text { FROM }\end{array}\right|$ & COLL MTHD & CON SHORT NAME & \begin{tabular}{c|c} 
VALUE & UNAL \\
UNTIS & RPTD
\end{tabular} & \begin{tabular}{|c|} 
COUNTING \\
ERROR
\end{tabular} & $\begin{array}{c}\text { TOTAL } \\
\text { ANAL } \\
\text { ERROR }\end{array}$ & $\mid \begin{array}{c}\text { LAB } \\
\text { QUALIFIER }\end{array}$ & SAMP COMMENT & \begin{tabular}{|} 
RESULT \\
COMMENT
\end{tabular} \\
\hline SESPMNT & B17RR7 & HANFORD SPR DR 28-2 & ONSITE & SW & $\mathrm{N}$ & SEEP & & 03-Nov-03 SULFATE & $14.1 \mathrm{mg} / \mathrm{L}$ & & & & & \\
\hline SESPMNT & B17RR8 & HANFORD SPR UR 28-2 & ONSITE & SW & $\mathrm{N}$ & SEEP & & 03-Nov-03 SULFATE & $17.6 \mathrm{mg} / \mathrm{L}$ & & & & & \\
\hline SESPMNT & B17JN1 & 100-K SPRING 77-1 & ONSITE & SW & $\mathrm{N}$ & SEEP & & 10-Nov-03 SULFATE & & & & & & \\
\hline PNLGW & B17W21 & SK-057-3 & & SW & $\mathrm{N}$ & SEEP & & 10-Nov-03 SULFATE & $17.2 \mathrm{mg} / \mathrm{L}$ & & & & & \\
\hline $\begin{array}{l}\text { PNLGW } \\
\text { PNLGW }\end{array}$ & $\begin{array}{l}\text { B17VJ6 } \\
\text { B17VJ9 }\end{array}$ & $\begin{array}{l}\text { SD-1110-2 } \\
\text { SD-098-1 }\end{array}$ & & $\begin{array}{l}\text { SW } \\
\text { Sw }\end{array}$ & $\begin{array}{l}n \\
\mathrm{~N}\end{array}$ & $\begin{array}{l}\text { SEEP } \\
\text { SEEP }\end{array}$ & & $\begin{array}{l}\text { 10-Nov-03 SULFATE } \\
\text { 10-Nov-03 SULATTE }\end{array}$ & $20.7 \mathrm{mg} / \mathrm{L}$ & & & D & & \\
\hline $\begin{array}{l}\text { PNLGW } \\
\text { PNLGW }\end{array}$ & B17LB5 & $100-K$ SPRING 68-1 & ONSITE & SW & $\frac{N}{N}$ & $\begin{array}{l}\text { SEEP } \\
\text { SEEP }\end{array}$ & & $\begin{array}{l}\text { 10-Nov-03 SULFALE } \\
\text { 10-Nov-03 SULFATE }\end{array}$ & $\begin{array}{l}15.8 \mathrm{mg} / \mathrm{L} \\
14.8 \mathrm{mg} / \mathrm{L}\end{array}$ & & & & & \\
\hline SESPSPEC & B18136 & 100-B SPRING 37-1 & ONSITE & sW & $\mathrm{N}$ & SEEP & & 13-Nov-03 SULFATE & $\begin{array}{l}14.8 \mathrm{mg} / \mathrm{L} \\
29.7 \mathrm{mg} / \mathrm{L}\end{array}$ & & & $\mathrm{D}$ & & \\
\hline SESPSPEC & B18137 & 100-B SPRING 38-3 & ONSITE & SW & $\mathrm{N}$ & SEEP & & 13-Nov-03 SULFATE & & & & $\mathrm{D}$ & & \\
\hline SESPSPEC & B18134 & 100 B/C AREA OUTFL2 & ONSITE & SW & $\mathrm{N}$ & SEEP & & 17-Nov-03 SULFATE & & & & & & \\
\hline $\begin{array}{l}\text { SESPSPEC } \\
\text { PNLGW }\end{array}$ & $\begin{array}{l}\text { B18138 } \\
\text { B17/K? }\end{array}$ & 100-B SPRING 39-2 & ONSITE & SW & $\begin{array}{r}n \\
N\end{array}$ & SEEP & & 17-Nov-03 SULFATE & $17 \mathrm{mg} / \mathrm{L}$ & & & & & \\
\hline \begin{tabular}{|l} 
PNLGW \\
PNLGW
\end{tabular} & $\begin{array}{l}\text { B17VK2 } \\
\text { B17VK5 }\end{array}$ & $\begin{array}{l}\text { SH-144-1 } \\
\text { 100-H SPRING 150-1 }\end{array}$ & ONSITE & $\begin{array}{l}\text { SW } \\
\text { SW }\end{array}$ & $\begin{array}{l}n \\
\mathrm{~N}\end{array}$ & $\begin{array}{l}\text { SEEP } \\
\text { SEEP }\end{array}$ & & $\begin{array}{l}20-N o v-03 \text { SULFATE } \\
20-N o y \text { SULFATE }\end{array}$ & $17.3 \mathrm{mg} / \mathrm{L}$ & & & & & \\
\hline PNLGW & B17VK8 & SH-153-1 & thorrt & SW & $\mathrm{N}$ & $\begin{array}{l}\text { SEEP } \\
\text { SEEP }\end{array}$ & & $\begin{array}{l}\text { 20-Nov-03 SULFALE } \\
\text { 20-Nov-03 SULFATEE }\end{array}$ & $\begin{array}{l}13.6 \mathrm{mg} / \mathrm{L} \\
12 \mathrm{mg} / \mathrm{L}\end{array}$ & & & & & \\
\hline PNLGW & B17LB1 & 100-F SPRING & ONSITE & sw & $\mathrm{N}$ & SEEP & & 20-Nov-03 SULFATE & $37.4 \mathrm{mg} / \mathrm{L}$ & & & D & & \\
\hline PNLGW & B17JN7 & 100-D SPRING 110-1 & ONSITE & SW & $\mathrm{N}$ & SEEP & & 27-Oct-03 PHOSPHATE & $0.25 \mathrm{mg} / \mathrm{L}$ & & & u & & \\
\hline $\begin{array}{l}\text { SESPMNT } \\
\text { SESPMNT }\end{array}$ & $\begin{array}{l}\text { B17RR5 } \\
\text { B17RP6 }\end{array}$ & 300 AREA SPR DR 42-2 & ONSITE & SW & N & $\begin{array}{l}\text { SEEP } \\
\text { SEFP }\end{array}$ & & 13-Oct-03 NO3-N & $5.5 \mathrm{mg} / \mathrm{L}$ & & & D & & \\
\hline $\begin{array}{l}\text { SESPMNT } \\
\text { SESPMNT }\end{array}$ & B17RR6 & 300 AREA SPRING 42-2 & ONSITE & SW & $\mathrm{N}$ & SEEP & & 13-Oct-03 NO3-N & $4.8 \mathrm{mg} / \mathrm{L}$ & & & $\mathrm{D}$ & & \\
\hline $\begin{array}{l}\text { SESPMNT } \\
\text { SESPMNT }\end{array}$ & $\begin{array}{l}\text { B17JM8 } \\
\text { B17JM9 }\end{array}$ & $\begin{array}{l}\text { 100-B SPRING 37-1 } \\
\text { 100-B SPRING 39-2 }\end{array}$ & $\begin{array}{l}\text { ONSITE } \\
\text { ONSTEE }\end{array}$ & SW & $\begin{array}{l}\mathrm{N} \\
\mathrm{N}\end{array}$ & $\begin{array}{l}\text { SEEP } \\
\text { SEEP }\end{array}$ & & 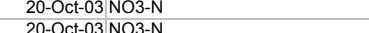 & $2.4 \mathrm{mg} / \mathrm{L}$ & & & $\mathrm{D}$ & & \\
\hline $\begin{array}{l}\text { SESPMNI } \\
\text { SESPMNT }\end{array}$ & $\begin{array}{l}\text { B1/7JM9 } \\
\text { B17NNO }\end{array}$ & $\begin{array}{l}\text { 100-B SPRING 39-2 } \\
\text { 100-K SPRING } 3-2\end{array}$ & $\begin{array}{l}\text { ONSITE } \\
\text { ONSITE }\end{array}$ & $\begin{array}{l}\text { SW } \\
\text { SW }\end{array}$ & $\frac{N}{N}$ & $\begin{array}{l}\text { SEEP } \\
\text { SEEP }\end{array}$ & & 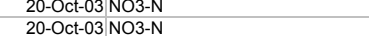 & $\begin{array}{l}1.1 \mathrm{mg} / \mathrm{L} \\
2.8 \mathrm{mg} / \mathrm{L}\end{array}$ & & & $\begin{array}{l}\text { D } \\
\text { D }\end{array}$ & & \\
\hline SESPMNT & B17JN3 & 100-N SPRING 8-13 & ONSITE & SW & $\mathrm{N}$ & SEEP & & 20-Oct-03 NO3-N & $4 \mathrm{mg} / \mathrm{L}$ & & & D & & \\
\hline SESPMNT & B17JN4 & 100-D SPRING 102-1 & ONSITE & SW & $\mathrm{N}$ & SEEP & & 27-Oct-03 NO3-N & $2.6 \mathrm{mg} / \mathrm{L}$ & & & $C D$ & & \\
\hline SESPMNT & B17JN5 & 100-D SPRING 110-1 & ONSITE & SW & $\mathrm{N}$ & SEEP & & 27-Oct-03 NO3-N & $0.41 \mathrm{mg} / \mathrm{L}$ & & & $c$ & & \\
\hline SESPMNT & B17RR3 & 100-H SPRING 145-1 & ONSITE & SW & $\mathrm{N}$ & SEEP & & 27-Oct-03 NO3-N & $5 \mathrm{mg} / \mathrm{L}$ & & & CD & & \\
\hline $\begin{array}{l}\text { SESPMNT } \\
\text { SESPMNT }\end{array}$ & $\begin{array}{l}\text { B17RR4 } \\
\text { B17RR2 }\end{array}$ & $\begin{array}{l}\text { 100-H SPRIIG } 153-1 \\
\text { 100-F SPRING 207-1 }\end{array}$ & $\begin{array}{l}\text { ONSIIE } \\
\text { ONSITE }\end{array}$ & $\begin{array}{l}\text { SW } \\
\text { SW }\end{array}$ & $\begin{array}{l}n \\
N\end{array}$ & $\begin{array}{l}\text { SEEP } \\
\text { SEEP }\end{array}$ & & $\begin{array}{l}\text { 27-OCt-03 NO3-N } \\
\text { 03-Nov-03 NO3-N }\end{array}$ & $\begin{array}{l}1.7 \mathrm{mg} / \mathrm{L} \\
2.6 \mathrm{mg} / \mathrm{L}\end{array}$ & & & CD & & \\
\hline $\begin{array}{l}\text { SESPMNI } \\
\text { SESPMNT }\end{array}$ & $\begin{array}{l}\text { BT/RR2 } \\
\text { B17RR7 }\end{array}$ & HANFORD SPR DR 28-2 & $\begin{array}{l}\text { ONSITE } \\
\text { ONSE }\end{array}$ & SW & $\frac{N}{N}$ & $\begin{array}{l}\text { SEEP } \\
\text { SEEP }\end{array}$ & & $\begin{array}{l}03-\text {-Nov-03 NO3-N } \\
03-\text { Nov-03 NO3-N }\end{array}$ & $\begin{array}{l}2.6 \mathrm{mg} / \mathrm{L} \\
1.1 \mathrm{mg} / \mathrm{L}\end{array}$ & & & D & & \\
\hline SESPMNT & B17RR8 & HANFORD SPR UR 28-2 & ONSITE & SW & $\mathrm{N}$ & SEEP & & 03-Nov-03 NO3-N & $1.1 \mathrm{mg} / \mathrm{L}$ & & & D & & \\
\hline SESPMNT & B17JN1 & 100-K SPRING 77-1 & ONSITE & sw & $\mathrm{N}$ & SEEP & & 10-Nov-03 NO3-N & $0.028 \mathrm{mg} / \mathrm{L}$ & & & 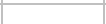 & & \\
\hline PNLGW & B17W21 & SK-057-3 & & SW & $\mathrm{N}$ & SEEP & & 10-Nov-03 NO3-N & $1.2 \mathrm{mg} / \mathrm{L}$ & & & D & & \\
\hline PNLGW & B17VJ6 & SD-110-2 & & SW & $\mathrm{N}$ & SEEP & & 10-Nov-03 NO3-N & $1.1 \mathrm{mg} / \mathrm{L}$ & & & D & & \\
\hline PNLGW & B17VJ9 & SD-098-1 & & SW & $\mathrm{N}$ & SEEP & & 10-Nov-03 NO3-N & $0.79 \mathrm{mg} / \mathrm{L}$ & & & & & \\
\hline PNLGW & B17LB5 & 100-K SPRING 68-1 & ONSITE & sW & $\mathrm{N}$ & SEEP & & 10-Nov-03 NO3-N & $1.3 \mathrm{mg} / \mathrm{L}$ & & & D & & \\
\hline SESPSPEC & B18136 & 100-B SPRING 37-1 & ONSITE & SW & $\mathrm{N}$ & SEEP & & 13-Nov-03 NO3-N & $1.4 \mathrm{mg} / \mathrm{L}$ & & & D & & \\
\hline SESPSPEC & B18137 & 100-B SPRING 38-3 & ONSITE & SW & $\mathrm{N}$ & SEEP & & 13-Nov-03 NO3-N & $0.59 \mathrm{mg} / \mathrm{L}$ & & & & & \\
\hline & B18134 & 100 B/C AREA OUTFL2 & ONSITE & SW & $\mathrm{N}$ & SEEP & & 17-Nov-03 NO3-N & $0.1 \mathrm{mg} / \mathrm{L}$ & & & & & \\
\hline $\begin{array}{l}\text { SESPSPEC } \\
\text { PNI GW }\end{array}$ & B18138 & 100-B SPRING 39-2 & ONSITE & SW & $n^{n}$ & SEEP & & 17-Nov-03 NO3-N & $0.63 \mathrm{mg} / \mathrm{L}$ & & & & & \\
\hline $\begin{array}{l}\text { PNLGW } \\
\text { PNLGW }\end{array}$ & $\begin{array}{l}\text { B17VK2 } \\
\text { B17VKK5 }\end{array}$ & $\begin{array}{l}\text { SH-144-1 } \\
100-1 \text { SPRING } 150-1\end{array}$ & ONSITE & SW & $\begin{array}{l}\mathrm{N} \\
\mathrm{N}\end{array}$ & $\begin{array}{l}\text { SEEP } \\
\text { SEFP }\end{array}$ & & 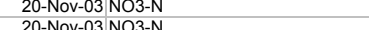 & $0.92 \mathrm{mg} / \mathrm{L}$ & & & & & \\
\hline $\begin{array}{l}\text { PNLGW } \\
\text { PNLGW }\end{array}$ & $\begin{array}{l}\text { B1/NK5 } \\
\text { B17VK8 }\end{array}$ & $\begin{array}{l}100-\text { H SPRING } 150-1 \\
\text { SH-153-1 }\end{array}$ & ONSIIE & $\begin{array}{l}\text { SW } \\
\text { SW }\end{array}$ & $\begin{array}{l}N \\
N\end{array}$ & $\begin{array}{l}\text { SEEP } \\
\text { SEEP }\end{array}$ & & $\begin{array}{l}20-\text {-Nov- } 03 \text { NO3-N } \\
20 \text {-Nov- } 03 \text { NO3-N }\end{array}$ & $\begin{array}{ll}0.66 \mathrm{mg} / \mathrm{L} \\
0.38 \mathrm{mg} / \mathrm{L}\end{array}$ & & & & & \\
\hline PNLGW & $\begin{array}{l}\text { B17LB1 } \\
\text { B17no }\end{array}$ & 100-F SPRING & ONSITE & sw & $\mathrm{N}$ & SEEP & & 20-Nov-03 NO3-N & $5.8 \mathrm{mg} / \mathrm{L}$ & & & D & & \\
\hline SESPMNT & B17RR5 & 300 AREA SPR DR 42-2 & ONSITE & SW & $\mathrm{N}$ & SEEP & & 13-Oct-03 NO2-N & $0.0074 \mathrm{mg} / \mathrm{L}$ & & & u & & \\
\hline SESPMNT & B17RR6 & 300 AREA SPRING 42-2 & ONSITE & SW & $\mathrm{N}$ & SEEP & & 13-Oct-03 NO2-N & $0.0074 \mathrm{mg} / \mathrm{L}$ & & & u & & \\
\hline SESPMNT & B17JM8 & 100-B SPRING 37-1 & ONSITE & SW & $\mathrm{N}$ & SEEP & & 20-Oct-03 NO2-N & $0.0074 \mathrm{mg} / \mathrm{L}$ & & & U & & \\
\hline $\begin{array}{l}\text { SESPMNT } \\
\text { SESPMNT }\end{array}$ & $\begin{array}{l}\text { B17JM9 } \\
\text { B17INO }\end{array}$ & $\begin{array}{l}\text { 100-B SPRING 39-2 } \\
1\end{array}$ & ONSITE & SW & $\mathrm{N}$ & $\begin{array}{l}\text { SEEP } \\
\text { SEFP }\end{array}$ & & 20-Oct-03 NO2-N & $0.0074 \mathrm{mg} / \mathrm{L}$ & & & U & & \\
\hline $\begin{array}{l}\text { SESPMNT } \\
\text { SESPMNT }\end{array}$ & 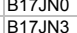 & $\begin{array}{l}\text { 100-K SPRING 63-2 } \\
100-N \text { SPRING 8-13 }\end{array}$ & $\begin{array}{l}\text { ONSTIE } \\
\text { ONSITE }\end{array}$ & SW & $\begin{array}{l}\mathrm{N} \\
\mathrm{N}\end{array}$ & $\begin{array}{l}\text { SEEP } \\
\text { SEEP }\end{array}$ & & $\begin{array}{l}20-0 \text {-Ct-03 NO2-N } \\
20 \text {-Oct-03 NO2-N }\end{array}$ & $\begin{array}{l}0.0074 \mathrm{mg} / \mathrm{L} \\
0.013 \mathrm{mg} / \mathrm{L}\end{array}$ & & & B & & \\
\hline $\begin{array}{l}\text { SESPMNT } \\
\text { SESPIN }\end{array}$ & B17JN4 & 100-D SPRING 102-1 & $\begin{array}{l}\text { ONSITE } \\
\text { ONSE }\end{array}$ & SW & $\mathrm{N}$ & $\begin{array}{l}\text { SEEP } \\
\text { SEEP }\end{array}$ & & $27-\mathrm{Oct}-03 \mathrm{NO}$ NO2-N & $0.0074 \mathrm{mg} / \mathrm{L}$ & & & G & & \\
\hline SESPMNT & B17JN5 & 100-D SPRING 110-1 & ONSITE & SW & $\mathrm{N}$ & SEEP & & 27-Oct-03 NO2-N & 0.0074 mg/L & & & u & & \\
\hline SESPMNT & B17RR3 & 100-H SPRING 145-1 & ONSITE & SW & $\mathrm{N}$ & SEEP & & 27-Oct-03 NO2-N & $0.0074 \mathrm{mg} / \mathrm{L}$ & & & $u$ & & \\
\hline SESPMNT & B17RR4 & 100-H SPRING 153-1 & ONSITE & SW & $\mathrm{N}$ & SEEP & & 27-Oct-03 NO2-N & $0.0074 \mathrm{mg} / \mathrm{L}$ & & & U & & \\
\hline $\begin{array}{l}\text { SESPMNT } \\
\text { SESPMNT }\end{array}$ & $\begin{array}{l}\text { B17RR2 } \\
\text { R17RP7 }\end{array}$ & $\begin{array}{l}100-F \text { SPRING 207-1 } \\
\text { HANFORD SPR PR 28-2 }\end{array}$ & $\begin{array}{l}\text { ONSITE } \\
\text { ONSTEF }\end{array}$ & SW & & $\begin{array}{l}\text { SEEP } \\
\text { SEEP }\end{array}$ & & $\begin{array}{l}03-\mathrm{Nov}-03 \text { NO2-N } \\
03 \text { Nov }\end{array}$ & $0.0074 \mathrm{mg} / \mathrm{L}$ & & & U & & \\
\hline $\begin{array}{l}\text { SESPMNNT } \\
\text { SESPNT }\end{array}$ & $\begin{array}{l}\text { B17RR7 } \\
\text { B17RR8 }\end{array}$ & $\begin{array}{l}\text { AANFORD SPR DR 2 28-2 } \\
\text { HANFORD SPR UR 28-2 }\end{array}$ & $\begin{array}{l}\text { ONSIITE } \\
\text { ONSE }\end{array}$ & SW & $\frac{N}{N}$ & $\begin{array}{l}\text { SEEP } \\
\text { SEEP }\end{array}$ & & $\begin{array}{l}03-\text { - }-0 v-03 \text { NO2-N } \\
03 \text {-Nov-03 NO2-N }\end{array}$ & $0.00 / 4 \mathrm{mg} / \mathrm{L}$ & & & u & & \\
\hline SESPMNT & B17JN1 & 100-K SPRING 77-1 & ONSITE & sW & $\mathrm{N}$ & SEEP & & 10-Nov-03 NO2-N & $0.0074 \mathrm{mg} / \mathrm{L}$ & & & u & & \\
\hline PNLGW & B17W21 & SK-057-3 & & SW & $\mathrm{N}$ & SEEP & & 10-Nov-03 NO2-N & $0.0074 \mathrm{mg} / \mathrm{L}$ & & & $u$ & & \\
\hline PNLGW & B17VJ6 & SD-110-2 & & SW & $\mathrm{N}$ & SEEP & & 10-Nov-03 NO2-N & $0.0074 \mathrm{mg} / \mathrm{L}$ & & & $u$ & & \\
\hline PNLGW & $\begin{array}{l}817 V J 9 \\
\text { B175 }\end{array}$ & SD-098-1 & & SW & $\mathrm{N}$ & SEEP & & 10-Nov-03 NO2-N & $0.0074 \mathrm{mg} / \mathrm{L}$ & & & U & & \\
\hline $\begin{array}{l}\text { PNLGW } \\
\text { SESPSPEC }\end{array}$ & $\begin{array}{l}\text { B17LB5 } \\
\text { B18136 }\end{array}$ & 100-K SPRING 68-1 & $\begin{array}{l}\text { ONSITE } \\
\text { ONSTEE }\end{array}$ & SW & $\begin{array}{l}\mathrm{N} \\
\mathrm{N}\end{array}$ & $\begin{array}{l}\text { SEEP } \\
\text { SEFP }\end{array}$ & & 10-Nov-03 NO2-N & $0.0074 \mathrm{mg} / \mathrm{L}$ & & & U & & \\
\hline $\begin{array}{l}\text { SESPPEC } \\
\text { SESPSPEC }\end{array}$ & $\begin{array}{l}\text { B18736 } \\
\text { B18137 }\end{array}$ & $\begin{array}{l}\text { 100-B SPRING 37-1 } \\
\text { 100-B SPRING 38-3 }\end{array}$ & $\begin{array}{l}\text { ONSSITE } \\
\text { ONSE }\end{array}$ & SW & $\frac{N}{N}$ & $\begin{array}{l}\text { SEEP } \\
\text { SEEP }\end{array}$ & & $\begin{array}{l}\text { 13--Nov-03 NO2-N } \\
\text { 13-Nov-03 NO2-N }\end{array}$ & $0.00 / 4 \mathrm{mg} / \mathrm{L}$ & & & u & & \\
\hline $\begin{array}{l}\text { SESPSPEC } \\
\text { SESPE }\end{array}$ & B18134 & 100 B/C AREA OUTFL2 & $\begin{array}{l}\text { ONSITE } \\
\text { ONE }\end{array}$ & sw & $\mathrm{N}$ & SEEP & & 17-Nov-03 NO2-N & $0.0074 \mathrm{mg} / \mathrm{L}$ & & & u & & \\
\hline SESPSPEC & B18138 & 100-B SPRING 39-2 & ONSITE & SW & $\mathrm{N}$ & SEEP & & 17-Nov-03 NO2-N & $0.0074 \mathrm{mg} / \mathrm{L}$ & & & U & & \\
\hline PNLGW & B17VK2 & SH-144-1 & & SW & $\mathrm{N}$ & SEEP & & 20-Nov-03 NO2-N & $0.0074 \mathrm{mg} / \mathrm{L}$ & & & $u$ & & \\
\hline PNLGW & B17VK5 & 100-H SPRING 150-1 & ONSITE & SW & N & SEEP & & 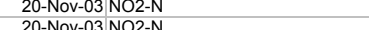 & $0.0074 \mathrm{mg} / \mathrm{L}$ & & & U & & \\
\hline $\begin{array}{l}\text { PNLGW } \\
\text { PNLGW }\end{array}$ & B17VK8 & $\begin{array}{l}\text { SH-153-1 } \\
100-\mathrm{F} \text { SPIN }\end{array}$ & & SW & 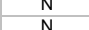 & $\begin{array}{l}\text { SEEP } \\
\text { SEEP }\end{array}$ & & 20-Nov-03 NO2-N & $0.0074 \mathrm{mg} / \mathrm{L}$ & & & 0 & & \\
\hline $\begin{array}{l}\text { PNELW } \\
\text { PNLGW }\end{array}$ & $\begin{array}{l}\text { B } \\
\text { B17JN7 }\end{array}$ & 100-D SPRING $110-1$ & $\begin{array}{l}\text { ONSITE } \\
\text { ONITE }\end{array}$ & Sw & $\frac{N}{n}$ & $\begin{array}{l}\text { SEEP } \\
\text { SEEP }\end{array}$ & & $\begin{array}{l}\text { 20-N-Nov-0303 NU2-N } \\
\text { 27-Oct-03 NITRITE }\end{array}$ & $\begin{array}{l}0.0004 \mathrm{mgh/L} \\
0.25 \mathrm{mg} / \mathrm{L}\end{array}$ & & & u & & \\
\hline PNLGW & B17JN7 & 100-D SPRING 110-1 & ONSITE & SW & $\mathrm{N}$ & SEEP & & 27-Oct-03 NITRATE & $1.71 \mathrm{mg} / \mathrm{L}$ & & & & & \\
\hline SESPMNT & B17RR5 & 300 AREA SPR DR 42-2 & ONSITE & SW & $\mathrm{N}$ & SEEP & & 13-Oct-03 FLUORIDE & $0.35 \mathrm{mg} / \mathrm{L}$ & & & & & \\
\hline
\end{tabular}




\begin{tabular}{|c|c|c|c|c|c|c|c|c|c|c|c|c|c|c|c|}
\hline | OWNER ID & \begin{tabular}{|l|} 
SAMP \\
NUM
\end{tabular} & SAMP SITE NAME & $\left|\begin{array}{c}\text { DIST } \\
\text { CLASS }\end{array}\right|$ & $\mid$ MEDIA $\mid$ & $\begin{array}{c}\text { FILTERED } \\
\text { FLAG }\end{array}$ & $\begin{array}{l}\text { SAMP } \\
\text { FROM }\end{array}$ & COLL MTHD & |SAMP DATE $\quad$ CON SHORT NAME & $\begin{array}{l}\text { VALUE } \\
\text { RPTD }\end{array}$ & \begin{tabular}{|c|} 
ANAL \\
UNITS \\
RPTD
\end{tabular} & $\left|\begin{array}{c}\text { COUNTING } \\
\text { ERROR }\end{array}\right|$ & $\begin{array}{l}\text { TOTAL } \\
\text { ANAL } \\
\text { ERROR }\end{array}$ & $\left|\begin{array}{c}\text { LAB } \\
\text { QUALIFIER }\end{array}\right|$ & SAMP COMMENT & $\left|\begin{array}{c}\text { RESULT } \\
\text { COMMENT }\end{array}\right|$ \\
\hline SESPMNT & B17RR6 & 300 AREA SPRING 42-2 & ONSITE & SW & & & & 13-Oct-03 FLUORIDE & & & & & & 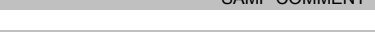 & \\
\hline SESPMNT & B17JM8 & 100-B SPRING 37-1 & ONSITE & sw & $\mathrm{N}$ & SEEP & & 20-Oct-03 FLUORIDE & & & & & $\mathrm{c}$ & & \\
\hline SESPMNT & B17JM9 & 100-B SPRING 39-2 & ONSITE & sw & $\mathrm{N}$ & SEEP & & 20-Oct-03 FLUORIDE & & & & & $\mathrm{c}$ & & \\
\hline SESPMNT & B17JNO & 100-K SPRING 63-2 & ONSITE & SW & $\mathrm{N}$ & SEEP & & 20-Oct-03 FLUORIDE & 0.46 & $\mathrm{mg} / \mathrm{L}$ & & & $\mathrm{c}$ & & \\
\hline SESPMNT & B17JN3 & 100-N SPRING 8-13 & ONSITE & SW & $N$ & SEEP & & 20-Oct-03 FLUORIDE & 0.17 & $\mathrm{mg} / \mathrm{L}$ & & & c & & \\
\hline $\begin{array}{l}\text { SESPMNT } \\
\text { SESPMNT }\end{array}$ & $\begin{array}{l}\text { B17JN4 } \\
\text { B17N55 }\end{array}$ & $\begin{array}{l}\text { 100-D SPRING 102-1 } \\
\text { 100-D SPRING 10-1 }\end{array}$ & $\begin{array}{l}\text { ONSITE } \\
\text { ONITE }\end{array}$ & SW & $n$ & SEEP & & 27-Oct-03 FLUORIDE & 0.13 & $\mathrm{mg} / \mathrm{L}$ & & & $\mathrm{c}$ & & \\
\hline $\begin{array}{l}\text { SESPMNI } \\
\text { SESPMNT }\end{array}$ & $\begin{array}{l}\text { B1/1NSS } \\
\text { B17RR3 }\end{array}$ & $\begin{array}{l}\text { 100-D SPRIIG } 110-1 \\
\text { 100-H SPRING 145-1 }\end{array}$ & $\begin{array}{l}\text { ONSIT } \\
\text { ONSITE }\end{array}$ & SW & $\begin{array}{l}n \\
\mathrm{~N}\end{array}$ & $\begin{array}{l}\text { SEEP } \\
\text { SEFP }\end{array}$ & & $\begin{array}{l}\text { 27-Oct-03 FLUORIDE } \\
\text { 27-Oct-03 FLUORIDE }\end{array}$ & 0.092 & $\mathrm{mg} / \mathrm{L}$ & & & $\mathrm{BC}$ & & \\
\hline SESPMNT & B17RR4 & 100-H SPRING 153-1 & ONSITE & SW & $\frac{n}{n}$ & $\begin{array}{l}\text { SEEP } \\
\text { SEEP }\end{array}$ & & $\begin{array}{l}\text { 27-Oct-033LLUORDE } \\
\text { 27-Oct-03 FLUORIDE }\end{array}$ & & $\begin{array}{ll}3 \mathrm{gm} / \mathrm{L} \\
\mathrm{mg} / \mathrm{L}\end{array}$ & & & ${ }_{c}^{c}$ & & \\
\hline PNLGW & B17JN7 & 100-D SPRING 110-1 & ONSITE & sw & $\mathrm{N}$ & SEEP & & 27-Oct-03 FLUORIDE & & & & & u & & \\
\hline SESPMNT & B17RR2 & 100-F SPRING 207-1 & ONSITE & SW & $\mathrm{N}$ & SEEP & & 03-Nov-03 FLUORIDE & & & & & & & \\
\hline SESPMNT & B17RR7 & HANFORD SPR DR 28-2 & ONSITE & SW & $\mathrm{N}$ & SEEP & & 03-Nov-03 FLUORIDE & & & & & & & \\
\hline $\begin{array}{l}\text { SESPMNT } \\
\text { SESPMNT }\end{array}$ & B17RR8 & & ONSITE & SW & $N$ & $\begin{array}{l}\text { SEEP } \\
\text { SEEP }\end{array}$ & & 03-Nov-03 FLUORIDE & 0.24 & & & & & & \\
\hline $\begin{array}{l}\text { EESPMNT } \\
\text { PNLGW }\end{array}$ & $\begin{array}{l}\text { B17JN1 } \\
\text { B17W21 }\end{array}$ & $\begin{array}{l}\text { 100-K SPRING 77-1 } \\
\text { SK-057-3 }\end{array}$ & ONSITE & $\begin{array}{l}\text { SW } \\
\text { sw }\end{array}$ & $N^{n}$ & $\begin{array}{l}\text { SEEP } \\
\text { SEEP }\end{array}$ & & $\begin{array}{l}\text { 10-Nov-03 FLUORIDE } \\
\text { 10-Nov-03 FLUORIDE }\end{array}$ & $\begin{array}{l}0.097 \\
0.17\end{array}$ & & & & B & & \\
\hline PNLGW & B17VJ6 & SD-110-2 & & SW & $\mathrm{N}$ & SEEP & & 10-Nov-03 FLUORIDE & & & & & B & & \\
\hline PNLGW & B17VJ9 & SD-098-1 & & SW & $\mathrm{N}$ & SEEP & & 10-Nov-03 FLUORIDE & & & & & & & \\
\hline PNLGW & B17LB5 & 100-K SPRING 68-1 & ONSITE & sW & $\mathrm{N}$ & SEEP & & 10-Nov-03 FLUORIDE & & & & & B & & \\
\hline SESPSPEC & B18136 & 100-B SPRING 37-1 & ONSITE & SW & $\mathrm{N}$ & SEEP & & 13-Nov-03 FLUORIDE & & & & & & & \\
\hline $\begin{array}{l}\text { SESPSPEC } \\
\text { SESPSEC }\end{array}$ & B18137 & 100-B SPRING 38-3 & $\begin{array}{l}\text { ONSITE } \\
\text { ONITE }\end{array}$ & $\begin{array}{l}\text { SW } \\
\text { sw }\end{array}$ & $\frac{N}{n}$ & $\begin{array}{l}\text { SEEP } \\
\text { SEEP }\end{array}$ & & $\begin{array}{l}\text { 13-Nov-03 FLUORIDE } \\
\text { 17-Noy-03FUORIDER }\end{array}$ & 0.15 & & & & $B$ & & \\
\hline $\begin{array}{l}\text { SESPSEC } \\
\text { SESPSPEC }\end{array}$ & B18138 & 100-B SPRING 39-2 & ONSITE & sw & $\frac{N}{n}$ & $\begin{array}{l}\text { SEEP } \\
\text { SEEP }\end{array}$ & & $\begin{array}{l}\text { 17-Nov-U3L-OUORILE } \\
\text { 17-Nov-03 FLUORIDE }\end{array}$ & 0.089 & $\begin{array}{ll}3 \mathrm{~g} / \mathrm{L} \\
\mathrm{mg} / \mathrm{L}\end{array}$ & & & $B$ & & \\
\hline PNLGW & B17VK2 & SH-144-1 & & sw & $\mathrm{N}$ & SEEP & & 20-Nov-03 FLUORIDE & 0.13 & & & & & & \\
\hline PNLGW & B17VK5 & 100-H SPRING 150-1 & ONSITE & sW & $\mathrm{N}$ & SEEP & & 20-Nov-03 FLUORIDE & & & & & & & \\
\hline PNLGW & B17VK8 & SH-153-1 & & SW & $\mathrm{N}$ & SEEP & & 20-Nov-03 FLUORIDE & & Img/L & & & & & \\
\hline $\begin{array}{l}\text { PNLGW } \\
\text { SESPMNT }\end{array}$ & B17LB1 & 100-F SPRING & ONSITE & SW & $N$ & SEEP & & 20-Nov-03 FLUORIDE & 0.24 & & & & & & \\
\hline $\begin{array}{l}\text { SESPMNT } \\
\text { SESPMNT }\end{array}$ & $\begin{array}{l}\text { B17RR5 } \\
\text { B17RP6 }\end{array}$ & 300 AREA SPR DR 42-2 & $\begin{array}{l}\text { ONITE } \\
\text { ONSITE }\end{array}$ & $\begin{array}{l}\text { SW } \\
\text { sw }\end{array}$ & $\mathrm{N}$ & & & 13-Oct-03 CHLORIDE & $\begin{array}{r}18.3 \\
15\end{array}$ & & & & $\mathrm{D}$ & & \\
\hline $\begin{array}{l}\text { SESPMNT } \\
\text { SESPMNT }\end{array}$ & $\begin{array}{l}\text { B17RR6 } \\
\text { B17JM8 }\end{array}$ & $\begin{array}{l}300 \text { AREA SPRING 42-2 } \\
100 \text {-B SPRING } 37-1\end{array}$ & $\begin{array}{l}\text { ONITE } \\
\text { ONSITE }\end{array}$ & $\begin{array}{l}\text { SW } \\
\text { sw }\end{array}$ & $\frac{N}{N}$ & $\begin{array}{l}\text { SEEP } \\
\text { SEEP }\end{array}$ & & $\begin{array}{l}\text { 13-Oct-03 CHLORIDE } \\
\text { 20-Oct-03 CLLORIDDE }\end{array}$ & & Sg/L & & & $\begin{array}{c}D \\
C D\end{array}$ & & \\
\hline SESPMNT & B17JM9 & 100-B SPRING 39-2 & ONSITE & sw & $\mathrm{N}$ & SEEP & & $\begin{array}{l}\text { 20-Oct-03 CHLORIDE } \\
\text { 20-Oct-03 CHLORIDE }\end{array}$ & & $\mathrm{mg} / \mathrm{L}$ & & & $\mathrm{C}$ & & \\
\hline SESPMNT & B17JNO & 100-K SPRING 63-2 & ONSITE & sW & $\mathrm{N}$ & SEEP & & 20-Oct-03 CHLORIDE & & $\mathrm{mg} / \mathrm{L}$ & & & $C D$ & & \\
\hline SESPMNT & B17JN3 & 100-N SPRING 8-13 & ONSITE & SW & $\mathrm{N}$ & SEEP & & 20-Oct-03 CHLORIDE & & $\mathrm{mg} / \mathrm{L}$ & & & $C D$ & & \\
\hline SESPMNT & B17JN4 & 100-D SPRING 102-1 & ONSITE & SW & $N$ & SEEP & & 27-Oct-03 CHLORIDE & & $3 \mathrm{mg} / \mathrm{L}$ & & & CD & & \\
\hline $\begin{array}{l}\text { SESPMNT } \\
\text { SESPMNT }\end{array}$ & $\begin{array}{l}\text { B17JN5 } \\
\text { B17RP3 }\end{array}$ & 100-D SPRING 110-1 & ONSITE & SW & $\mathrm{N}$ & $\begin{array}{l}\text { SEEP } \\
\text { SEEP }\end{array}$ & & 27-Oct-03 CHLORIDE & & $\mathrm{mg} / \mathrm{L}$ & & & $\mathrm{C}$ & & \\
\hline $\begin{array}{l}\text { SESPMNT } \\
\text { SESPMNT }\end{array}$ & $\begin{array}{l}\text { B17RR3 } \\
\text { B17RR4 }\end{array}$ & $\begin{array}{l}\text { 100-H SPRING } 145-1 \\
100-H \text { SPRING 153-1 }\end{array}$ & $\begin{array}{l}\text { ONITE } \\
\text { ONSITE }\end{array}$ & $\begin{array}{l}\text { SW } \\
\text { SW }\end{array}$ & $\frac{N}{N}$ & $\begin{array}{l}\text { SEEP } \\
\text { SEEP }\end{array}$ & & $\begin{array}{l}\text { 27-0ct-033 CLLORIDEE } \\
\text { 27-Oct-03 CHLORIDEE }\end{array}$ & & $\begin{array}{l}3 \mathrm{mg} / \mathrm{L} \\
\mathrm{mg} / \mathrm{L}\end{array}$ & & & $\begin{array}{l}C D \\
C D\end{array}$ & & \\
\hline PNLGW & B17JN7 & 100-D SPRING 110-1 & ONSITE & sw & $\mathrm{N}$ & SEEP & & 27-Oct-03 CHLORIDE & & $5 \mathrm{mg} / \mathrm{L}$ & & & & & \\
\hline SESPMNT & B17RR2 & 100-F SPRING 207-1 & ONSITE & sW & $\mathrm{N}$ & SEEP & & 03-Nov-03 CHLORIDE & & $\mathrm{mg} / \mathrm{L}$ & & & & & \\
\hline SESPMNT & B17RR7 & HANFORD SPR DR 28-2 & ONSITE & SW & $\mathrm{N}$ & SEEP & & 03-Nov-03 CHLORIDE & & $\mathrm{mg} / \mathrm{L}$ & & & & & \\
\hline SESPMNT & B17RR8 & HANFORD SPR UR 28-2 & ONSITE & SW & $N$ & $\begin{array}{l}\text { SEEP } \\
\text { SEEP }\end{array}$ & & 03-Nov-03 CHLORIDE & 3.5 & $5 \mathrm{mg} / \mathrm{L}$ & & & & & \\
\hline $\begin{array}{l}\text { EESPMNT } \\
\text { PNLGW }\end{array}$ & B17JN1 & $\begin{array}{l}\text { 100-K SPRING 77-1 } \\
\text { SK-057-3 }\end{array}$ & ONSITE & $\begin{array}{l}\text { SW } \\
\text { sw }\end{array}$ & $\begin{array}{r}\mathrm{N} \\
\mathrm{N}\end{array}$ & $\begin{array}{l}\text { SEEP } \\
\text { SEFP }\end{array}$ & & 10-Nov-03 CHLORIDE & $\begin{array}{l}0.88 \\
25\end{array}$ & & & & $N$ & & \\
\hline $\begin{array}{l}\text { PNLGW } \\
\text { PNLGW }\end{array}$ & $\begin{array}{l}\text { B17W21 } \\
\text { B17VJ6 }\end{array}$ & $\begin{array}{l}\text { SK-05-3-3 } \\
\text { SD-110-2 }\end{array}$ & & $\begin{array}{l}\text { SW } \\
\text { sw }\end{array}$ & $\frac{N}{n}$ & $\begin{array}{l}\text { SEEP } \\
\text { SEEP }\end{array}$ & & $\begin{array}{l}\text { 10-Nov-03 CHORORIDE } \\
\text { 10-No-3 C CLLORIDE }\end{array}$ & & $5 \mathrm{gm/L}$ & & & $\frac{N}{n}$ & & \\
\hline PNLGW & B17VJ9 & SD-098-1 & & sw & $\mathrm{N}$ & SEEP & & 10-Nov-03 CHLORIDE & & $\mathrm{mg} / \mathrm{L}$ & & & $\mathrm{N}$ & & \\
\hline PNLGW & B17LB5 & 100-K SPRING 68-1 & ONSITE & sW & $\mathrm{N}$ & SEEP & & 10-Nov-03 CHLORIDE & & $2 \mathrm{mg} / \mathrm{L}$ & & & & & \\
\hline SESPSPEC & B18136 & 100-B SPRING 37-1 & ONSITE & SW & $\mathrm{N}$ & SEEP & & 13-Nov-03 CHLORIDE & & mg/L & & & D & & \\
\hline $\begin{array}{l}\text { SESPSPEC } \\
\text { SESPSPCC }\end{array}$ & B18137 & 100-B SPRING 38-3 & ONSITE & SW & $N$ & $\begin{array}{l}\text { SEEP } \\
\text { SEEP }\end{array}$ & & 13-Nov-03 CHLORIDE & & $\mathrm{mg} / \mathrm{h}$ & & & & & \\
\hline $\begin{array}{l}\text { SESPSPEC } \\
\text { SESPSPEC }\end{array}$ & B18134 & $\begin{array}{l}100 \text { B/C AREA OUTFL2 } \\
100 \text { - SPRING 39-2 }\end{array}$ & $\begin{array}{l}\text { ONITE } \\
\text { ONSITE }\end{array}$ & $\begin{array}{l}\text { SW } \\
\text { sw }\end{array}$ & $\frac{N}{N}$ & $\begin{array}{l}\text { SEEP } \\
\text { SEEP }\end{array}$ & & $\begin{array}{l}\text { 17-Nov-03 CHLORIDE } \\
\text { 17-Nov-03 CHORIDE }\end{array}$ & & $\mathrm{mg} / \mathrm{L}$ & & & & & \\
\hline PNLGW & B17VK2 & SH-144-1 & & sw & $\mathrm{N}$ & SEEP & & $\begin{array}{l}17-\mathrm{N} \text {-Nov-03 CHLORIDE } \\
\text { 20-03 }\end{array}$ & & $\mathrm{mgh/ \textrm {L }}$ & & & & & \\
\hline PNLGW & B17VK5 & 100-H SPRING 150-1 & ONSITE & sw & $\mathrm{N}$ & SEEP & & 20-Nov-03 CHLORIDE & & $\mathrm{mg} / \mathrm{L}$ & & & & & \\
\hline PNLGW & B17VK8 & SH-153-1 & & SW & $\mathrm{N}$ & SEEP & & 20-Nov-03 CHLORIDE & & $2 \mathrm{mg} / \mathrm{L}$ & & & & & \\
\hline PNLGW & B17LB1 & 100-F SPRING & ONSITE & SW & $N$ & SEEP & & 20-Nov-03 CHLORIDE & & & & & D & & \\
\hline $\begin{array}{l}\text { PNLGW } \\
\text { PNDGW }\end{array}$ & B17JN7 & 100-D SPRING 110-1 & ONSITE & SW & $\begin{array}{l}\mathrm{y} \\
\mathrm{N}\end{array}$ & $\begin{array}{l}\text { SEEP } \\
\text { SEEP }\end{array}$ & & 27-Oct-03 BROMIDE & 0.25 & & & & u & & \\
\hline $\begin{array}{l}\text { PNLGW } \\
\text { PNIGW }\end{array}$ & $\begin{array}{l}\text { B17JR1 } \\
\text { B17JP2 }\end{array}$ & $\begin{array}{l}\text { 100-K SPRING 63-1 } \\
\text { 100-D SPRING 102-1 }\end{array}$ & $\begin{array}{l}\text { ONSITE } \\
\text { ONITE }\end{array}$ & SW & $Y$ & $\begin{array}{l}\text { SEEP } \\
\text { SEFP }\end{array}$ & & 20-Oct-03 Zn & & Sug// & & & $B$ & & \\
\hline $\begin{array}{l}\text { PNLGW } \\
\text { PNLGW }\end{array}$ & $\begin{array}{l}\text { B17JJ2 } \\
\text { B17JP3 }\end{array}$ & $\begin{array}{c}100-\bar{D} \text { S } \\
1\end{array}$ & $\begin{array}{l}\text { ONSITE } \\
\text { ONSITE }\end{array}$ & $\begin{array}{l}\text { SW } \\
\text { SW }\end{array}$ & $\begin{array}{l}\mathrm{N} \\
\mathrm{Y}\end{array}$ & $\begin{array}{l}\text { SEEP } \\
\text { SEEP }\end{array}$ & & $\begin{array}{l}\text { 27-OCt-03 Zn } \\
27-\mathrm{Oct}-03 \mathrm{Zn}\end{array}$ & & $\begin{array}{l}5 \text { jugh/ } \\
\text { uga/h }\end{array}$ & & & B & & \\
\hline PNLGW & B17JN7 & 100-D SPRING 110-1 & ONSITE & SW & $\mathrm{N}$ & SEEP & & $27-0 c t-03 \mathrm{Zn}$ & & ug/L & & & & & \\
\hline PNLGW & B17JN8 & 100-D SPRING 102-1 & ONSITE & SW & $\mathrm{Y}$ & SEEP & & 27-Oct-03 Zn & & $3 \mathrm{ug} / \mathrm{L}$ & & & & & \\
\hline PNLGW & B17JN9 & 100-D SPRING 102-1 & ONSITE & SW & $\mathrm{N}$ & SEEP & & 27-Oct-03 Zn & & jug/L & & & B & & \\
\hline $\begin{array}{l}\text { PNLGW } \\
\text { PNIGW }\end{array}$ & B17JPO & $\begin{array}{l}\text { 100-D SPRING 102-1 } \\
\text { SK-057-3 }\end{array}$ & ONSITE & SW & $Y$ & SEEP & & 27-Oct-03 Zn & 3.5 & $5 \mathrm{ug} / \mathrm{L}$ & & & U & & \\
\hline $\begin{array}{l}\text { PNLGW } \\
\text { PNLGW }\end{array}$ & $\begin{array}{l}\text { B17W21 } \\
\text { B17W22 }\end{array}$ & $\begin{array}{l}\text { SK-057-3 } \\
\text { SK-057-3 }\end{array}$ & & $\begin{array}{l}\text { SW } \\
\text { SW }\end{array}$ & $\begin{array}{l}\mathrm{N} \\
\mathrm{Y}\end{array}$ & $\begin{array}{l}\text { SEEP } \\
\text { SEEP }\end{array}$ & & $\begin{array}{l}\text { 10-Nov-03 Zn } \\
\text { 10-Nov-03 Zn }\end{array}$ & & $\begin{array}{l}\text { flgh/ } \\
\text { uggh }\end{array}$ & & & $\begin{array}{l}\text { B } \\
B\end{array}$ & & \\
\hline PNLGW & B17VJ6 & SD-110-2 & & sw & $\mathrm{N}$ & SEEP & & 10-Nov-03 Zn & & 3 ug/ & & & B & & \\
\hline PNLGW & B17VJ7 & SD-110-2 & & SW & $\mathrm{Y}$ & SEEP & & 10-Nov-03 Zn & & $7 \mathrm{ug} / \mathrm{L}$ & & & u & & \\
\hline PNLGW & B17VJ9 & SD-098-1 & & sW & $\mathrm{N}$ & SEEP & & 10-Nov-03 Zn & & lug/L & & & & & \\
\hline PNLGW & B17VKo & SD-098-1 & & SW & Y & SEEP & & 10-Nov-03 Zn & & ug/L & & & U & & \\
\hline PNLGW & B17JP8 & 100-K SPRING 77-1 & ONSITE & SW & $\frac{d}{n}$ & SEEP & & 10-Nov-03 Zn & & & & & B & & \\
\hline $\begin{array}{l}\text { PNLGW } \\
\text { PNLGW }\end{array}$ & $\begin{array}{l}\text { B17JP9 } \\
\text { B171L4 }\end{array}$ & $\begin{array}{l}\text { 100-K S SPING 77-1 } \\
\text { 100-K SPRING 68-1 }\end{array}$ & $\begin{array}{l}\text { ONSITE } \\
\text { ONSITE }\end{array}$ & sW & $\begin{array}{l}Y \\
Y \\
Y\end{array}$ & $\begin{array}{l}\text { SEEP } \\
\text { SEEP }\end{array}$ & & $\begin{array}{l}\text { 10-Nov-03 Zn } \\
10-0 v-037 n\end{array}$ & & tig// & & & B & & \\
\hline PNLGW & $\begin{array}{l}\text { B1/LC4 } \\
\text { B17VK2 }\end{array}$ & $\begin{array}{l}\text { 100-K SPRING 68-1 } \\
\text { SH-144-1 }\end{array}$ & & $\begin{array}{l}\text { SW } \\
\text { SW }\end{array}$ & $\frac{\mathrm{N}}{\mathrm{N}}$ & $\begin{array}{l}\text { SEEP } \\
\text { SEEP }\end{array}$ & & $\begin{array}{l}\text { 10-Novov-03 } 2 \mathrm{n} \\
20 \text {-Nov-03 Zn }\end{array}$ & & sugh/ & & & B & & \\
\hline
\end{tabular}




\begin{tabular}{|c|c|c|c|c|c|c|c|c|c|c|c|c|c|c|c|c|}
\hline OWNER ID & \begin{tabular}{|l|} 
SAMP \\
NUM
\end{tabular} & SAMP SITE NAME & $\mid \begin{array}{c}\text { DIST } \\
\text { CLASS }\end{array}$ & $\mid$ MEDIA $\mid$ & $\begin{array}{c}\text { FILTERED } \\
\text { FLAG }\end{array}$ & $\mid \begin{array}{l}\text { SAMP } \\
\text { FROM }\end{array}$ & COLL MTHD & SAMP DATE & CON SHORT NAME & $\begin{array}{l}\text { VALUE } \\
\text { RPTD }\end{array}$ & \begin{tabular}{|c|} 
ANAL \\
UNITS \\
RPTD
\end{tabular} & \begin{tabular}{c|} 
COUNTING \\
ERROR
\end{tabular} & $\begin{array}{c}\text { TOTAL } \\
\text { ANAL } \\
\text { ERROR }\end{array}$ & $\mid \begin{array}{c}\text { LAB } \\
\text { QUALIFIER }\end{array}$ & SAMP COMMENT & \begin{tabular}{|c} 
RESULT \\
COMMENT
\end{tabular} \\
\hline PNLGW & B17VK3 & SH-144-1 & & SW & Y & SEEP & & 20-Nov-03 Zn & & & ?ug/L & & & & & \\
\hline PNLGW & B17VK5 & 100-H SPRING 150-1 & ONSITE & sW & N & SEEP & & 20-Nov-03 Zn & & & & & & & & \\
\hline $\begin{array}{l}\text { PNLGW } \\
\text { PNIGW }\end{array}$ & B17VK6 & 100-H SPRING 150-1 & ONSITE & SW & Y & SEEP & & $20-$ Nov-03 Zn & & & & & & u & & \\
\hline $\begin{array}{l}\text { PNLGW } \\
\text { PNLGW }\end{array}$ & B17VK8 & $\begin{array}{l}\text { SH-153-1 } \\
\text { SH-153-1 }\end{array}$ & & SW & $\frac{d}{N}$ & SEEP & & 20-Nov-03 Zn & & 3.2 & 2 ug/L & & & B & & \\
\hline PNLGW & B17LB2 & $\begin{array}{l}100-\text { F SPRING } \\
10-1\end{array}$ & ONSITE & $\begin{array}{l}\text { SW } \\
\text { SW }\end{array}$ & $\begin{array}{l}Y \\
Y\end{array}$ & $\begin{array}{l}\text { SEEP } \\
\text { SEEP }\end{array}$ & & $\begin{array}{l}20-N o v-03 \mathrm{Zn} \\
{ }^{20-N o v-03} \mathrm{Zn}\end{array}$ & & & $\begin{array}{l}\text { 7ugh/ } \\
\text { ugg/h }\end{array}$ & & & $\begin{array}{l}U \\
B\end{array}$ & & \\
\hline PNLGW & B17JR1 & 100-K SPRING 63-1 & ONSITE & sW & $Y$ & SEEP & & $20-O c t-03$ V & & & & & & u & & \\
\hline PNLGW & B17JP2 & 100-D SPRING 102-1 & ONSITE & SW & N & SEEP & & $27-0 \mathrm{Oct}-03 \mathrm{~V}$ & & & & & & B & & \\
\hline PNLGW & B17JP3 & 100-D SPRING 102-1 & ONSITE & sW & Y & SEEP & & $27-0 c t-03 \mathrm{~V}$ & & & & & & B & & \\
\hline PNLGW & B17JN7 & 100-D SPRING 110-1 & ONSITE & SW & $\mathrm{N}$ & SEEP & & 27-Oct-03 V & & & & & & U & & \\
\hline $\begin{array}{l}\text { PNLGW } \\
\text { PNLGW }\end{array}$ & $\begin{array}{l}\text { B17JN8 } \\
\text { B17N9 }\end{array}$ & $\begin{array}{l}\text { 100-D SPRING 102-1 } \\
\text { 100-D SPRING 102-1 }\end{array}$ & $\begin{array}{l}\text { ONSITE } \\
\text { ONSTE }\end{array}$ & $\begin{array}{l}\text { SW } \\
\text { SW }\end{array}$ & $Y$ & $\begin{array}{l}\text { SEEP } \\
\text { SEEP }\end{array}$ & & $\begin{array}{l}27-0 c t-03 \mathrm{~V} \\
27-0 c-03 \mathrm{~V}\end{array}$ & & 0.97 & & & & 11 & & \\
\hline $\begin{array}{l}\text { PNLGW } \\
\text { PNLGW }\end{array}$ & $\begin{array}{l}\text { B17NJ9 } \\
\text { B17JP0 }\end{array}$ & $\begin{array}{l}100-D \text { SPRRING } 102-1 \\
100-D \text { SPRING } 102-1\end{array}$ & $\begin{array}{l}\text { ONSIIE } \\
\text { ONSTIE }\end{array}$ & $\begin{array}{l}\text { SW } \\
\text { sw }\end{array}$ & $\begin{array}{l}\mathrm{N} \\
\mathrm{Y}\end{array}$ & $\begin{array}{l}\text { SEEP } \\
\text { SEEP }\end{array}$ & & $\begin{array}{l}27-\text {-Oct-03 V V } \\
\text { 27-Oct-03V }\end{array}$ & & & $3 \mathrm{gg} / \mathrm{L}$ & & & 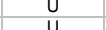 & & \\
\hline PNLGW & B17W21 & SK-057-3 & & SW & $\mathrm{N}$ & SEEP & & $\begin{array}{l}10-\mathrm{Nov}-03 \mathrm{~V} \\
10\end{array}$ & & & $2 u g / / 2$ & & & B & & \\
\hline PNLGW & B17W22 & SK-057-3 & & sw & $\mathrm{Y}$ & SEEP & & 10-Nov-03 V & & & & & & B & & \\
\hline PNLGW & B17VJ6 & SD-110-2 & & sW & $\mathrm{N}$ & SEEP & & 10-Nov-03 V & & & $5 \mathrm{ug} / \mathrm{L}$ & & & u & & \\
\hline PNLGW & B17VJ7 & SD-110-2 & & SW & Y & SEEP & & 10-Nov-03 V & & & 5 ug/L & & & U & & \\
\hline $\begin{array}{l}\text { PNLGW } \\
\text { PNLGW }\end{array}$ & $\begin{array}{l}\text { B17VJ9 } \\
\text { B17VKKO }\end{array}$ & $\begin{array}{l}\text { SD-098-1 } \\
\text { SD-098-1 }\end{array}$ & & SW & $\begin{array}{l}\mathrm{N} \\
\mathrm{y}\end{array}$ & $\begin{array}{l}\text { SEEP } \\
\text { SEEP }\end{array}$ & & $\begin{array}{l}\text { 10-Nov-03 V } \\
10 \text {-No-03y }\end{array}$ & & & ug/L & & & $B$ & & \\
\hline PNLGW & $\begin{array}{l}\text { B11NVO } \\
\text { B17JP8 }\end{array}$ & $\begin{array}{l}\text { SD-098-1 } \\
100-K \text { SPRING 77-1 }\end{array}$ & ONSITE & $\begin{array}{l}\text { SW } \\
\text { SW }\end{array}$ & $\begin{array}{l}\mathrm{Y} \\
\mathrm{N}\end{array}$ & $\begin{array}{l}\text { SEEP } \\
\text { SEFP }\end{array}$ & & $\begin{array}{l}10-\mathrm{Nov}-03 \mathrm{~V} \\
10-\mathrm{No}-03 \mathrm{~V}\end{array}$ & & & 3 ug/h & & & $\mathrm{B}$ & & \\
\hline PNLGW & B17JP9 & 100-K SPRING 77-1 & ONSITE & SW & $\begin{array}{l}\mathrm{Y} \\
\mathrm{N}\end{array}$ & $\begin{array}{l}\text { SEEP } \\
\text { SEEP }\end{array}$ & & $\begin{array}{l}\text { 10-Nov-03V } \\
\text { 10-Nov-03 V }\end{array}$ & & & 5 ug/L & & & u & & \\
\hline PNLGW & B17LC4 & 100-K SPRING 68-1 & ONSITE & sW & $\mathrm{Y}$ & SEEP & & $10-N o v-03 \mathrm{~V}$ & & & $7 \mathrm{ug} / \mathrm{L}$ & & & B & & \\
\hline PNLGW & B17VK2 & SH-144-1 & & SW & N & SEEP & & $20-N o v-03 \mathrm{~V}$ & & & $5 \mathrm{gg} / \mathrm{L}$ & & & u & & \\
\hline $\begin{array}{l}\text { PNLGW } \\
\text { PNIGW }\end{array}$ & $\begin{array}{l}\text { B17VK3 } \\
\text { B17VKK5 }\end{array}$ & SH-144-1 & & SW & Y & SEEP & & 20-Nov-03 V & & & 5 ug/L & & & $u$ & & \\
\hline $\begin{array}{l}\text { PNLGW } \\
\text { PNLGW }\end{array}$ & B17VK5 & 100-H SPRING 150-1 & ONSITE & SW & $\begin{array}{l}\mathrm{y} \\
\mathrm{N}\end{array}$ & SEEP & & 20-Nov-03 V & & & jug/L & & & B & & \\
\hline $\begin{array}{l}\text { PNLGW } \\
\text { PNLGW }\end{array}$ & $\begin{array}{l}\text { B17VK6 } \\
\text { B17VK8 }\end{array}$ & $\begin{array}{l}\text { 100-H SPRING 150-1 } \\
\text { SH-153-1 }\end{array}$ & ONSITE & $\begin{array}{l}\text { SW } \\
\text { SW }\end{array}$ & $\begin{array}{l}\mathrm{Y} \\
\mathrm{N}\end{array}$ & $\begin{array}{l}\text { SEEP } \\
\text { SEEP }\end{array}$ & & $\begin{array}{l}\text { 20-Nov-03V } \\
\text { 20-Nov-03V }\end{array}$ & & & $\begin{array}{l}5 \text { sgg/ } \\
\text { sug/L }\end{array}$ & & & u & & \\
\hline PNLGW & B17VK9 & SH-153-1 & & sw & $\mathrm{Y}$ & SEEP & & $20-N o v-03 \mathrm{~V}$ & & & 5 ug/L & & & u & & \\
\hline PNLGW & B17LB2 & 100-F SPRING & ONSITE & sW & Y & SEEP & & 20 -Nov-03 V & & & lug/L & & & B & & \\
\hline PNLGW & B17JR1 & 100-K SPRING 63-1 & ONSITE & SW & Y & SEEP & & 20-Oct-03 Sr & & & $3 \mathrm{ug} / \mathrm{L}$ & & & & & \\
\hline PNLGW & B17JP2 & 100-D SPRING 102-1 & ONSITE & SW & $\mathrm{N}$ & SEEP & & $27-\mathrm{Oct}-03 \mathrm{Sr}$ & & & & & & & & \\
\hline $\begin{array}{l}\text { PNLGW } \\
\text { PNLGW }\end{array}$ & $\begin{array}{l}\text { B17JP3 } \\
\text { B17NS8 }\end{array}$ & $\begin{array}{l}\text { 100-D SPRING 102-1 } \\
\text { 100-D SPRING 102-1 }\end{array}$ & $\begin{array}{l}\text { ONSITE } \\
\text { ONSTE }\end{array}$ & $\begin{array}{l}\text { SW } \\
\text { sw }\end{array}$ & $\begin{array}{l}Y \\
Y\end{array}$ & $\begin{array}{l}\text { SEEP } \\
\text { SEEP }\end{array}$ & & 27-Oct-03 Sr & & & $5 \mathrm{ug} / \mathrm{L}$ & & & & & \\
\hline $\begin{array}{l}\text { PNLGW } \\
\text { PNLGW }\end{array}$ & $\begin{array}{l}\text { B17JJ8 } \\
\text { B17NN9 }\end{array}$ & $\begin{array}{l}\text { 100-D SPRIIG 102-1 } \\
\text { 100-D SPRING 102-1 }\end{array}$ & $\begin{array}{l}\text { ONSIIE } \\
\text { ONSITE }\end{array}$ & $\begin{array}{l}\text { SW } \\
\text { SW }\end{array}$ & $\begin{array}{r}\mathrm{Y} \\
\mathrm{N}\end{array}$ & $\begin{array}{l}\text { SEEP } \\
\text { SEEP }\end{array}$ & & 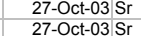 & & & ugg// & & & & & \\
\hline PNLGW & B17JPO & 100-D SPRING 102-1 & ONSITE & sw & Y & SEEP & & $27-0 c t-03 \mathrm{Sr}$ & & & ug/L & & & & & \\
\hline PNLGW & B17W21 & SK-057-3 & & sW & $\mathrm{N}$ & SEEP & & 10-Nov-03 Sr & & 96.4 & $4 \mathrm{ug} / \mathrm{L}$ & & & & & \\
\hline PNLGW & B17W22 & SK-057-3 & & SW & Y & SEEP & & 10-Nov-03 Sr & & 92.5 & 5 ug/L & & & & & \\
\hline $\begin{array}{l}\text { PNLGW } \\
\text { PNIGWN }\end{array}$ & B17VJ6 & SD-110-2 & & SW & $\begin{array}{l}\mathrm{y} \\
\mathrm{N}\end{array}$ & $\begin{array}{l}\text { SEEP } \\
\text { SEFP }\end{array}$ & & 10-Nov-03 Sr & & & $3 \mathrm{ug} / \mathrm{L}$ & & & & & \\
\hline $\begin{array}{l}\text { PNLGW } \\
\text { PNLGW }\end{array}$ & B17VJ7 & $\begin{array}{l}\text { SD-110-2 } \\
\text { SD-098-1 }\end{array}$ & & SW & $\begin{array}{r}Y \\
Y\end{array}$ & SEEP & & 10-Nov-03 Sr & & & $\mathrm{ug} / \mathrm{L}$ & & & & & \\
\hline PNLGW & B17VKo & $\begin{array}{l}S D-008-1 \\
S D-098-1\end{array}$ & & $\begin{array}{l}\text { SW } \\
\text { SW }\end{array}$ & $\begin{array}{l}\mathrm{N} \\
\mathrm{Y}\end{array}$ & $\begin{array}{l}\text { SEEP } \\
\text { SEEP }\end{array}$ & & $\begin{array}{l}\text { 10-Nov-03 Sr } \\
\text { 10-Nov-03 Sr }\end{array}$ & & & $\begin{array}{l}5 \mathrm{gg} / \mathrm{h} \\
\mathrm{ugg} / \mathrm{h}\end{array}$ & & & & & \\
\hline PNLGW & B17JP8 & 100-K SPRING 77-1 & ONSITE & sw & $\mathrm{N}$ & SEEP & & $10-\mathrm{Nov}-03 \mathrm{Sr}$ & & & ugall & & & & & \\
\hline PNLGW & B17JP9 & 100-K SPRING 77-1 & ONSITE & sw & $\mathrm{Y}$ & SEEP & & $10-\mathrm{Nov}-03 \mathrm{Sr}$ & & & ugh/ & & & & & \\
\hline PNLGW & B17LC4 & 100-K SPRING 68-1 & ONSITE & sw & Y & SEEP & & 10-Nov-03 Sr & & & ug/ & & & & & \\
\hline PNLGW & B17VK2 & SH-144-1 & & sW & $\mathrm{N}$ & SEEP & & 20-Nov-03 Sr & & & $3 \mathrm{ug} / \mathrm{L}$ & & & & & \\
\hline PNLGW & B17VK3 & SH-144-1 & & sw & $\mathrm{Y}$ & SEEP & & 20 -Nov-03 Sr & & & $2 \mathrm{ug} / \mathrm{L}$ & & & & & \\
\hline PNLGW & B17VK5 & 100-H SPRING 150-1 & ONSITE & SW & $\mathrm{N}$ & & & 20-Nov-03 Sr & & & 5 ug/h & & & & & \\
\hline PNLGW & B17VK6 & 100-H SPRING 150-1 & ONSITE & sw & Y & SEEP & & $20-\mathrm{Nov}-03 \mathrm{Sr}$ & & & fug/h & & & & & \\
\hline PNLGW & B17VK8 & SH-153-1 & & sW & $\mathrm{N}$ & SEEP & & 20 -Nov-03 Sr & & & $2 \mathrm{ug} / \mathrm{L}$ & & & & & \\
\hline PNLGW & B17VK9 & SH-153-1 & & SW & Y & SEEP & & 20-Nov-03 Sr & & & & & & & & \\
\hline PNLGW & B17LB2 & 100-F SPRING & ONSITE & sW & Y & SEEP & & 20-Nov-03 Sr & & & ugg/L & & & & & \\
\hline PNLGW & B17JN7 & 100-D SPRING 110-1 & ONSITE & SW & $\mathrm{N}$ & SEEP & & 27-Oct-03 Si & & 95.4 & tug/L & & & & & \\
\hline $\begin{array}{l}\text { PNLGW } \\
\text { PNLGW }\end{array}$ & $\begin{array}{l}\text { B17JR1 } \\
\text { B17JP? }\end{array}$ & 100-K SPRING 63-1 & ONSITE & SW & $Y$ & $\begin{array}{l}\text { SEEP } \\
\text { SEFP }\end{array}$ & & 20-Oct-03 Sb & & $\begin{array}{r}28.5 \\
28.5 \\
-1\end{array}$ & $5 \mathrm{gg} / \mathrm{L}$ & & & u & & \\
\hline $\begin{array}{l}\text { PNLGW } \\
\text { PNLGW }\end{array}$ & $\begin{array}{l}\text { B1/1PP2 } \\
\text { B17JP3 }\end{array}$ & $\begin{array}{l}\text { 100-D SPRING } 102-1 \\
\text { 100-D SPRING 102-1 }\end{array}$ & $\begin{array}{l}\text { ONSIIE } \\
\text { ONSITE }\end{array}$ & $\begin{array}{l}\text { SW } \\
\text { SW }\end{array}$ & $\begin{array}{l}\mathrm{N} \\
\mathrm{Y}\end{array}$ & $\begin{array}{l}\text { SEEP } \\
\text { SEEP }\end{array}$ & & $\begin{array}{l}27-\mathrm{Occt-03} \mathrm{Sb} \\
27-\mathrm{Oct}-03 \mathrm{Sb}\end{array}$ & & & $\begin{array}{l}5 \mathrm{sg} / \mathrm{h} \\
\text { 5ug/L }\end{array}$ & & & u & & \\
\hline PNLGW & B17JN7 & 100-D SPRING 110-1 & ONSITE & sW & $\mathrm{N}$ & SEEP & & $27-0 c t-03 \mathrm{Sb}$ & & & $\mathrm{ug} / \mathrm{L}$ & & & u & & \\
\hline PNLGW & B17JN8 & 100-D SPRING 102-1 & ONSITE & sW & Y & SEEP & & $27-\mathrm{Oct}-03 \mathrm{Sb}$ & & & ug $/ \mathrm{L}$ & & & U & & \\
\hline PNLGW & B17JN9 & 100-D SPRING 102-1 & ONSITE & SW & $\mathrm{N}$ & SEEP & & 27-Oct-03 Sb & & 28.5 & & & & u & & \\
\hline $\begin{array}{l}\text { PNLGW } \\
\text { PNIGGW }\end{array}$ & B17JPO & 100-D SPRING 102-1 & ONSITE & SW & $Y$ & SEEP & & 27-Oct-03 Sb & & 28.5 & $5 \mathrm{ug} / \mathrm{L}$ & & & U & & \\
\hline $\begin{array}{l}\text { PNLGW } \\
\text { PNLGW }\end{array}$ & $\begin{array}{l}\text { BA7W21 } \\
\text { B17W22 }\end{array}$ & $\begin{array}{l}\text { SK-057-3 } \\
\text { SK-057-3 }\end{array}$ & & $\begin{array}{l}\text { SW } \\
\text { SW }\end{array}$ & $\begin{array}{l}\mathrm{N} \\
\mathrm{Y}\end{array}$ & $\begin{array}{l}\text { SEEP } \\
\text { SEEP }\end{array}$ & & $\begin{array}{l}\text { 10-Nov-03 Sb } \\
\text { 10-Nov-03 Sb }\end{array}$ & & & ug/L & & & 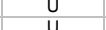 & & \\
\hline $\begin{array}{l}\text { PNLGW } \\
\text { PNLGW }\end{array}$ & $\begin{array}{l}\text { B1/W22 } \\
\text { B17VJ6 }\end{array}$ & $\begin{array}{l}\text { SK-051-3 } \\
\text { SD-110-2 }\end{array}$ & & $\begin{array}{l}\text { SW } \\
\text { SW }\end{array}$ & $\frac{\mathrm{N}}{\mathrm{N}}$ & $\begin{array}{l}\text { SEEP } \\
\text { SEEP }\end{array}$ & & $\begin{array}{l}\text { 10-Nov-03 Sb } \\
10-N o 0-3 \mathrm{Sb}\end{array}$ & & & fugh// & & & u & & \\
\hline PNLGW & B17VJ7 & SD-110-2 & & sw & $\begin{array}{l}\mathrm{Y} \\
\mathrm{N}\end{array}$ & SEEP & & $10-\mathrm{Nov}-03 \mathrm{Sb}$ & & & ugh/ & & & u & & \\
\hline PNLGW & B17VJ9 & SD-098-1 & & & $\mathrm{N}$ & SEEP & & 10-Nov-03 Sb & & & ug/L & & & U & & \\
\hline PNLGW & B17VKo & SD-098-1 & & SW & Y & SEEP & & 10-Nov-03 Sb & & & & & & $u$ & & \\
\hline PNLGW & B17JP8 & 100-K SPRING 77-1 & ONSITE & SW & $\mathrm{N}$ & SEEP & & 10-Nov-03 Sb & & & ug/L & & & U & & \\
\hline PNLGW & B17JP9 & $\begin{array}{l}\text { 100-K SPRING 77-11 } \\
1\end{array}$ & ONSITE & SW & $\begin{array}{l}y \\
y \\
y\end{array}$ & SEEP & & 10-Nov-03 Sb & & & $\mathrm{ug} / \mathrm{L}$ & & & U & & \\
\hline $\begin{array}{l}\text { PNLGW } \\
\text { PNLGW }\end{array}$ & $\begin{array}{l}\text { B1/1244 } \\
\text { B17VK2 }\end{array}$ & $\begin{array}{l}\text { To-K SPRING } 68-1 \\
\text { SH-144-1 }\end{array}$ & ONSIIE & Sw & $\frac{\mathrm{N}}{\mathrm{N}}$ & $\begin{array}{l}\text { SEEP } \\
\text { SEEP }\end{array}$ & & $\begin{array}{l}\text { 10-Nov-03 Sb } \\
\text { 20-Nov-03 Sb }\end{array}$ & & & ugg/L & & & u & & \\
\hline PNLGW & B17VK3 & SH-144-1 & & SW & $\mathrm{Y}$ & SEEP & & 20-Nov-03 Sb & & & ug/L & & & U & & \\
\hline PNLGW & B17VK5 & 100-H SPRING 150-1 & ONSITE & SW & $\mathrm{N}$ & SEEP & & $20-N o v-03 \mathrm{Sb}$ & & & jug/L & & & U & & \\
\hline
\end{tabular}


WATER - COLUMBIA RIVER SHORELINE SPRINGS

\begin{tabular}{|c|c|c|c|c|c|c|c|c|c|c|c|c|c|c|c|}
\hline | OWNER ID | & \begin{tabular}{|l} 
SAMP \\
NUM
\end{tabular} & SAMP SITE NAME & $\begin{array}{c}\text { DIST } \\
\text { CLASS }\end{array}$ & MEDIA & $\begin{array}{c}\text { FILTERED } \\
\text { FLAG }\end{array}$ & $\begin{array}{l}\text { SAMP } \\
\text { FROM }\end{array}$ & COLL MTHD & |SAMP DATE & CON SHORT NAME & \begin{tabular}{c|c} 
VALUE & UNAL \\
UNIIS & RPTD
\end{tabular} & $\left|\begin{array}{c}\text { COUNTING } \\
\text { ERROR }\end{array}\right|$ & $\begin{array}{l}\text { TOTAL } \\
\text { ANAL } \\
\text { ERROR }\end{array}$ & $\left|\begin{array}{c}\text { LAB } \\
\text { QUALIFIER }\end{array}\right|$ & SAMP COMMENT & $\left|\begin{array}{c}\text { RESULT } \\
\text { COMMENT }\end{array}\right|$ \\
\hline PNLGW & B17VK6 & 100-H SPRING 150-1 & ONSITE & SW & & & & $20-N o v-03 \mathrm{Sb}$ & & $39 \mathrm{ug} / \mathrm{L}$ & & & IQUALIFIEI & SAMII CUIVIVIIIII & \\
\hline PNLGW & B17VK8 & SH-153-1 & & sw & $\mathrm{N}$ & SEEP & & $20-$ Nov-03 Sb & & $39 \mathrm{ug} / \mathrm{L}$ & & & u & & \\
\hline PNLGW & B17VK9 & SH-153-1 & & sw & $\mathrm{Y}$ & SEEP & & 20 -Nov-03 Sb & & $39 \mathrm{ug} / \mathrm{L}$ & & & u & & \\
\hline PNLGW & B17LB2 & 100-F SPRING & ONSITE & SW & $\mathrm{Y}$ & SEEP & & 20-Nov-03 Sb & & & & & u & & \\
\hline PNLGW & B17JR1 & 100-K SPRING 63-1 & ONSITE & SW & $Y$ & SEEP & & $20-\mathrm{Oct}-03 \mathrm{Ni}$ & & $12.9 \mathrm{ug} / \mathrm{L}$ & & & U & & \\
\hline $\begin{array}{l}\text { PNLGW } \\
\text { PNLGW }\end{array}$ & $\begin{array}{l}\text { B17.JP2 } \\
\text { B17.JP3 }\end{array}$ & $\begin{array}{l}\text { 100-D SPRING 102-1 } \\
\text { 100-D SPRING 120-2) }\end{array}$ & $\begin{array}{l}\text { ONSITE } \\
\text { ONSTEE }\end{array}$ & SW & $\begin{array}{l}\mathrm{N} \\
\mathrm{Y}\end{array}$ & $\begin{array}{l}\text { SEEP } \\
\text { SEEP }\end{array}$ & & 27-Oct-03 Ni & & & & & U & & \\
\hline $\begin{array}{l}\text { PNLGW } \\
\text { PNLG }\end{array}$ & $\begin{array}{l}\text { B17JJ3 } \\
\text { B17NN7 }\end{array}$ & $\begin{array}{l}\text { 100-D SPRING 102-1 } \\
\text { 100-D SPRING 110-1 }\end{array}$ & $\begin{array}{l}\text { ONSSTE } \\
\text { ONSTTE }\end{array}$ & $\begin{array}{l}\text { SW } \\
\text { SW }\end{array}$ & $\begin{array}{r}Y \\
Y\end{array}$ & $\begin{array}{l}\text { SEEP } \\
\text { SEFP }\end{array}$ & & 27-Oct-03 Ni & & $12.9 \mathrm{ug} / \mathrm{L}$ & & & $u$ & & \\
\hline PNLGW & B17JN8 & 100-D SPRING 102-1 & ONSITE & sw & $\begin{array}{l}\mathrm{N} \\
\mathrm{Y}\end{array}$ & $\begin{array}{l}\text { SEEP } \\
\text { SEEP }\end{array}$ & & $\begin{array}{l}27-\mathrm{Oct}-03 \mathrm{Ni} \\
27-\mathrm{Oct}-03 \mathrm{Ni}\end{array}$ & & $\begin{array}{l}2 \mathrm{ug} / \mathrm{h} \\
2 \mathrm{ug} / \mathrm{L}\end{array}$ & & & u & & \\
\hline PNLGW & B17JN9 & 100-D SPRING 102-1 & ONSITE & sw & $\mathrm{N}$ & SEEP & & $27-\mathrm{Oct}-03 \mathrm{Ni}$ & & $12.9 \mathrm{ug} / \mathrm{L}$ & & & u & & \\
\hline PNLGW & B17JPO & 100-D SPRING 102-1 & ONSITE & SW & $\mathrm{Y}$ & SEEP & & $27-\mathrm{Oct}-03 \mathrm{Ni}$ & & $12.9 \mathrm{ug} / \mathrm{L}$ & & & u & & \\
\hline PNLGW & B17W21 & SK-057-3 & & SW & $\mathrm{N}$ & SEEP & & 10-Nov-03 Ni & & $14 \mathrm{ug} / \mathrm{L}$ & & & $u$ & & \\
\hline $\begin{array}{l}\text { PNLGW } \\
\text { PNWGW }\end{array}$ & B17W22 & SK-057-3 & 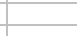 & SW & $Y$ & $\begin{array}{l}\text { SEEP } \\
\text { SEFP }\end{array}$ & & 10-Nov-03 Ni & & $14 \mathrm{ug} / \mathrm{L}$ & & & u & & \\
\hline $\begin{array}{l}\text { PNLGW } \\
\text { PNLGW }\end{array}$ & $\begin{array}{l}\text { B17VJ6 } \\
\text { B17VJJ7 }\end{array}$ & $\begin{array}{l}\text { SD-110-2 } \\
\text { SD-1110-2 }\end{array}$ & & $\begin{array}{l}\text { Sw } \\
\text { sw }\end{array}$ & $\begin{array}{l}\mathrm{N} \\
\mathrm{Y}\end{array}$ & $\begin{array}{l}\text { SEEP } \\
\text { SEEP }\end{array}$ & & $\begin{array}{l}10-\mathrm{Nov}-03 \mathrm{Ni} \\
10-\mathrm{Nov}-3 \mathrm{Ni}\end{array}$ & & $\begin{array}{l}14 \text { ug/ } / \mathrm{L} \\
14 \text { ugl }\end{array}$ & & & u & & \\
\hline PNLGW & B17VJ9 & SD-098-1 & & sW & $\mathrm{N}$ & SEEP & & $\begin{array}{l}\text { 10-Nov-03 } \mathrm{NI} \\
10-\mathrm{Nov}-03 \mathrm{Ni}\end{array}$ & & $\begin{array}{l}\text { 14 uggh } \\
14 \mathrm{ug} / \mathrm{L}\end{array}$ & & & u & & \\
\hline PNLGW & B17VKO & SD-098-1 & & SW & Y & SEEP & & $10-\mathrm{Nov}-03 \mathrm{Ni}$ & & $14 \mathrm{ug} / \mathrm{L}$ & & & U & & \\
\hline PNLGW & B17JP8 & 100-K SPRING 77-1 & ONSITE & sW & $\mathrm{N}$ & SEEP & & 10-Nov-03 Ni & & $14 \mathrm{ug} / \mathrm{L}$ & & & u & & \\
\hline PNLGW & B17JP9 & 100-K SPRING 77-1 & ONSITE & SW & $Y$ & SEEP & & 10-Nov-03 Ni & & $14 \mathrm{ug} / \mathrm{L}$ & & & U & & \\
\hline $\begin{array}{l}\text { PNLGW } \\
\text { PNLGW }\end{array}$ & $\begin{array}{l}\text { B17LC4 } \\
\text { B17VKK2 }\end{array}$ & $\begin{array}{l}\text { 100-K SPRING 68-1 } \\
\text { SH-144-1 }\end{array}$ & ONSITE & SW & $Y$ & $\begin{array}{l}\text { SEEP } \\
\text { SEEP }\end{array}$ & & 10-Nov-03 Ni & & $14 \mathrm{ug} / \mathrm{L}$ & & & u & & \\
\hline $\begin{array}{l}\text { PNLGW } \\
\text { PNLGW }\end{array}$ & $\begin{array}{l}\text { B17VK2 } \\
\text { B17VK3 }\end{array}$ & $\begin{array}{l}\text { SH-144-1 } \\
\text { SH-144-1 }\end{array}$ & & $\begin{array}{l}\text { SW } \\
\text { sW }\end{array}$ & $\begin{array}{l}\mathrm{N} \\
\mathrm{Y}\end{array}$ & $\begin{array}{l}\text { SEEP } \\
\text { SEEP }\end{array}$ & & $\begin{array}{l}20-\mathrm{Nov}-03 \mathrm{Ni} \\
20-\mathrm{Nov}-3 \mathrm{Ni}\end{array}$ & & $14 \mathrm{ug} / \mathrm{L}$ & & & u & & \\
\hline PNLGW & B17VK5 & 100-H SPRING 150-1 & ONSITE & sw & $\mathrm{N}$ & & & $\begin{array}{l}20-\mathrm{Nov}-03 \mathrm{Ni} \\
20-\mathrm{Nov}-03 \mathrm{Ni}\end{array}$ & & $\begin{array}{l}14 \mathrm{ugg} / \mathrm{L} \\
14 \mathrm{ug} / \mathrm{L}\end{array}$ & & & u & & \\
\hline PNLGW & B17VK6 & 100-H SPRING 150-1 & ONSITE & sw & Y & SEEP & & $20-\mathrm{Nov}-03 \mathrm{Ni}$ & & $14 \mathrm{ug} / \mathrm{L}$ & & & u & & \\
\hline PNLGW & B17VK8 & SH-153-1 & & SW & $\mathrm{N}$ & SEEP & & $20-N o v-03 \mathrm{Ni}$ & & $14 \mathrm{ug} / \mathrm{L}$ & & & U & & \\
\hline PNLGW & & & & & & SEEP & & & & & & & U & & \\
\hline PNLGW & B17LB2 & 100-F SPRING & ONSITE & sw & Y & SEEP & & $20-$ Nov- $03 \mathrm{Ni}$ & & 14 ug/ & & & $u$ & & \\
\hline PNLGW & B17JR1 & 100-K SPRING 63-1 & ONSITE & sw & Y & SEEP & & $20-\mathrm{Oct}-03 \mathrm{Na}$ & & $5710 \mathrm{ug} / \mathrm{L}$ & & & & & \\
\hline PNLGW & B17JP2 & 100-D SPRING 102-1 & ONSITE & SW & $\mathrm{N}$ & SEEP & & $27-\mathrm{Oct}-03 \mathrm{Na}$ & & $4390 \mathrm{ug} / \mathrm{L}$ & & & B & & \\
\hline PNLGW & B17.JP3 & 100-D SPRING 102-1 & ONSITE & sw & $\mathrm{Y}$ & SEEP & & $27-\mathrm{Oct}-03 \mathrm{Na}$ & & $4340 \mathrm{ug} / \mathrm{L}$ & & & B & & \\
\hline PNLGW & B17JN7 & 100-D SPRING 110-1 & ONSITE & SW & $\mathrm{N}$ & SEEP & & $27-\mathrm{Oct}-03 \mathrm{Na}$ & & $2250 \mathrm{ug} / \mathrm{L}$ & & & & & \\
\hline PNLGW & B17JN8 & 100-D SPRING 102-1 & ONSITE & SW & $Y$ & SEEP & & 27-Oct-03 $\mathrm{Na}$ & & $2520 \mathrm{ug} / \mathrm{L}$ & & & & & \\
\hline $\begin{array}{l}\text { PNLGW } \\
\text { PNIGW }\end{array}$ & $\begin{array}{l}\text { B17JN9 } \\
\text { B17JPA }\end{array}$ & 100-D SPRING 102-1 & ONSITE & SW & $\frac{d}{N}$ & SEEP & & $27-\mathrm{Oct}-03 \mathrm{Na}$ & & $2420 \mathrm{ug} / \mathrm{L}$ & & & B & & \\
\hline $\begin{array}{l}\text { PNLGW } \\
\text { PNIGW }\end{array}$ & B17JP0 & $\begin{array}{l}\text { 100-D SPRING 102-1 } \\
\text { SK-057-3 }\end{array}$ & ONSITE & SW & Y & $\begin{array}{l}\text { SEEP } \\
\text { SEEP }\end{array}$ & 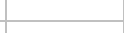 & 27-Oct-03 $\mathrm{Na}$ & & $2490 \mathrm{ug} / \mathrm{L}$ & & & B & & \\
\hline $\begin{array}{l}\text { PNLGW } \\
\text { PNLGW }\end{array}$ & $\begin{array}{l}\text { B17W21 } \\
\text { B17W22 }\end{array}$ & $\begin{array}{l}\text { SK-057-3 } \\
\text { SK-057-3 }\end{array}$ & & $\begin{array}{l}\text { SW } \\
\text { SW }\end{array}$ & $\begin{array}{l}\mathrm{N} \\
\mathrm{Y}\end{array}$ & $\begin{array}{l}\text { SEEP } \\
\text { SEEP }\end{array}$ & & $\begin{array}{l}\text { 10-Nov-03 } \mathrm{Na} \\
\text { 10-Nov-03 } \mathrm{Na}\end{array}$ & & $\begin{array}{l}5320 \mathrm{ug} / \mathrm{L} \\
4950 \mathrm{ug} / \mathrm{L}\end{array}$ & & & B & & \\
\hline PNLGW & B17VJ6 & SD-110-2 & & sw & $\mathrm{N}$ & SEEP & & $10-\mathrm{Nov}-03 \mathrm{Na}$ & & $2840 \mathrm{ug} / \mathrm{L}$ & & & B & & \\
\hline PNLGW & B17VJ7 & SD-110-2 & & sw & $\mathrm{Y}$ & SEEP & & $10-\mathrm{Nov}-03 \mathrm{Na}$ & & $2690 \mathrm{ug} / \mathrm{L}$ & & & B & & \\
\hline PNLGW & B17VJ9 & SD-098-1 & & SW & $\mathrm{N}$ & SEEP & & 10-Nov-03 $\mathrm{Na}$ & & $5360 \mathrm{ug} / \mathrm{L}$ & & & & & \\
\hline $\begin{array}{l}\text { PNLGW } \\
\text { PNIGW }\end{array}$ & B17VKO & $\begin{array}{l}\text { SD-098-1 } \\
100 \text { S }\end{array}$ & & SW & $Y$ & $\begin{array}{l}\text { SEEP } \\
\text { SEEP }\end{array}$ & & 10-Nov-03 $\mathrm{Na}$ & & $5670 \mathrm{ug} / \mathrm{L}$ & & & & & \\
\hline $\begin{array}{l}\text { PNLGW } \\
\text { PNLGW }\end{array}$ & $\begin{array}{l}\text { B17JPP8 } \\
\text { B17JP9 }\end{array}$ & $\begin{array}{l}\text { 100-K SPRING 77-1 } \\
100 \text { K SPRING 77-1 }\end{array}$ & $\begin{array}{l}\text { ONSSTE } \\
\text { ONSITE }\end{array}$ & $\begin{array}{l}\text { SW } \\
\text { Sw }\end{array}$ & $\begin{array}{l}N \\
Y\end{array}$ & $\begin{array}{l}\text { SEEP } \\
\text { SEEP }\end{array}$ & & $\begin{array}{l}10-\mathrm{Nov}-03 \mathrm{Na} \\
10-\mathrm{Nov}-3 \mathrm{Na}\end{array}$ & & $2150 \mathrm{ug} / \mathrm{L}$ & & & $B$ & & \\
\hline $\begin{array}{l}\text { PNLGW } \\
\text { PNLGW }\end{array}$ & $\begin{array}{l}\text { B17JJP9 } \\
\text { B17LC4 }\end{array}$ & $\begin{array}{l}\text { 100-K SPRING 77-1 } \\
\text { 100-K SPRING 68-1 }\end{array}$ & $\begin{array}{l}\text { ONSSTE } \\
\text { ONSITE }\end{array}$ & $\begin{array}{l}\text { SW } \\
\text { Sw }\end{array}$ & $\begin{array}{l}Y \\
Y\end{array}$ & $\begin{array}{l}\text { SEEP } \\
\text { SEEP }\end{array}$ & & $\begin{array}{l}10-\mathrm{Nov}-03 \mathrm{Na} \\
10-\mathrm{Nov}-03 \mathrm{Na}\end{array}$ & & $\begin{array}{l}2130 \mathrm{ug} / \mathrm{L} \\
3570 \mathrm{gu} / \mathrm{L}\end{array}$ & & & $\begin{array}{l}B \\
B\end{array}$ & & \\
\hline PNLGW & B17VK2 & SH-144-1 & & sw & $\mathrm{N}$ & SEEP & & $20-\mathrm{Nov}-03 \mathrm{Na}$ & & $4320 \mathrm{ug} / \mathrm{L}$ & & & B & & \\
\hline PNLGW & B17VK3 & SH-144-1 & & sw & $\mathrm{Y}$ & SEEP & & $20-N o v-03 \mathrm{Na}$ & & $4310 \mathrm{ug} / \mathrm{L}$ & & & B & & \\
\hline PNLGW & B17VK5 & 100-H SPRING 150-1 & ONSITE & sw & $\mathrm{N}$ & SEEP & & $20-N o v-03 \mathrm{Na}$ & & $4020 \mathrm{ug} / \mathrm{L}$ & & & B & & \\
\hline $\begin{array}{l}\text { PNLGW } \\
\text { PNIGW }\end{array}$ & $\begin{array}{l}\text { B17VK6 } \\
\text { B17VKR }\end{array}$ & 100-H SPRING 150-1 & ONSITE & SW & Y & $\begin{array}{l}\text { SEEP } \\
\text { SEFP }\end{array}$ & & 20-Nov-03 $\mathrm{Na}$ & & $3640 \mathrm{ug} / \mathrm{L}$ & & & $B$ & & \\
\hline $\begin{array}{l}\text { PNLGW } \\
\text { PNLGW }\end{array}$ & $\begin{array}{l}\text { B17VK8 } \\
\text { B17VKa }\end{array}$ & $\begin{array}{l}\text { SH-153-1 } \\
\text { SH-153-1 }\end{array}$ & & $\begin{array}{l}\text { SW } \\
\text { Sw }\end{array}$ & $\begin{array}{l}\mathrm{N} \\
\mathrm{Y}\end{array}$ & $\begin{array}{l}\text { SEEP } \\
\text { SEFP }\end{array}$ & & 20-Nov-03 $\mathrm{Na}$ & & $2460 \mathrm{ug} / \mathrm{L}$ & & & $B$ & & \\
\hline PNLGW & B17LB2 & 100-F SPRING & ONSITE & sw & Y & $\begin{array}{l}\text { SEEP } \\
\text { SEEP }\end{array}$ & & $\begin{array}{l}\text { 20-Nov-03 } \mathrm{Na} \\
20-\mathrm{Nov}-03 \mathrm{Na}\end{array}$ & & $\begin{array}{l}21500 \mathrm{ug} / \mathrm{L} \\
1900 \mathrm{~g} / \mathrm{L}\end{array}$ & & & & & \\
\hline PNLGW & B17JR1 & 100-K SPRING 63-1 & ONSITE & sw & $Y$ & SEEP & & $20-$-Oct-03 Mn & & $0.81 \mathrm{ug} / \mathrm{L}$ & & & u & & \\
\hline PNLGW & B17JP2 & 100-D SPRING 102-1 & ONSITE & sw & $\mathrm{N}$ & SEEP & & $27-\mathrm{Oct}-03 \mathrm{Mn}$ & & $12.4 \mathrm{ug} / \mathrm{L}$ & & & B & & \\
\hline PNLGW & B17JP3 & 100-D SPRING 102-1 & ONSITE & SW & $Y$ & SEEP & & 27-Oct-03 Mn & & $0.81 \mathrm{ugh}$ & & & U & & \\
\hline & B17JN7 & 100-D SPRING 110-1 & ONSITE & SW & $\begin{array}{l}\mathrm{N} \\
\mathrm{N}\end{array}$ & SEEP & & $27-O c t-03 \mathrm{Mn}$ & & $0.61 \mathrm{ug} / \mathrm{L}$ & & & 10 & & \\
\hline $\begin{array}{l}\text { PNLGW } \\
\text { PNIGW }\end{array}$ & B17JN8 & 100-D SPRING 102-1 & ONSITE & SW & $Y$ & $\begin{array}{l}\text { SEEP } \\
\text { SEFP }\end{array}$ & & 27-Oct-03 Mn & & $0.3 \mathrm{ug} / \mathrm{L}$ & & & $\frac{B}{B}$ & & \\
\hline $\begin{array}{l}\text { PNLGW } \\
\text { PNLGW }\end{array}$ & $\begin{array}{l}\text { B17JN9 } \\
\text { B17JPO }\end{array}$ & $\begin{array}{c}10-0-2 \text { SPR } \\
1\end{array}$ & $\begin{array}{l}\text { ONSSTE } \\
\text { ONITE }\end{array}$ & $\begin{array}{l}\text { SW } \\
\text { SW }\end{array}$ & $\begin{array}{l}\mathrm{N} \\
\mathrm{Y}\end{array}$ & $\begin{array}{l}\text { SEEP } \\
\text { SEEP }\end{array}$ & & $\begin{array}{l}27-0 c t-03 \mathrm{Mn} \\
27-0 c-03 \mathrm{Mn}\end{array}$ & & $\begin{aligned} 1 \mathrm{lgg} / \mathrm{L} \\
0.81 \mathrm{ug} / \mathrm{L}\end{aligned}$ & & & B & & \\
\hline PNLGW & B17W21 & SK-057-3 & & sw & $\mathrm{N}$ & SEEP & & 10-Nov-03 Mn & & $5.8 \mathrm{ug} / \mathrm{L}$ & & & B & & \\
\hline PNLGW & $B 17 W 22$ & SK-057-3 & & sw & $\mathrm{Y}$ & SEEP & & 10-Nov-03 Mn & & $1.9 \mathrm{ug} / \mathrm{L}$ & & & B & & \\
\hline PNLGW & B17VJ6 & SD-110-2 & & SW & $\mathrm{N}$ & SEEP & & 10-Nov-03 Mn & & $15.7 \mathrm{ug} / \mathrm{L}$ & & & & & \\
\hline $\begin{array}{l}\text { PNLGW } \\
\text { PNIGW }\end{array}$ & B17VJ7 & SD-110-2 & & SW & $\begin{array}{r}Y \\
Y\end{array}$ & SEEP & & 10-Nov-03 Mn & & $1.5 \mathrm{ug} / \mathrm{L}$ & & & $B$ & & \\
\hline $\begin{array}{l}\text { PNLGW } \\
\text { PNLGW }\end{array}$ & $\begin{array}{l}\text { B17VJ9 } \\
\text { B17VKo }\end{array}$ & $\begin{array}{l}\text { SD-0988-1 } \\
\text { SD-098-1 }\end{array}$ & & $\begin{array}{l}\text { SW } \\
\text { Sw }\end{array}$ & $\begin{array}{l}\mathrm{N} \\
\mathrm{Y}\end{array}$ & $\begin{array}{l}\text { SEEP } \\
\text { SEEP }\end{array}$ & & $\begin{array}{l}\text { 10-Nov-03 Mn } \\
\text { 10-Nov-03 Mn }\end{array}$ & & $\begin{array}{l}6.5 \mathrm{ug} / \mathrm{h} \\
1.2 \mathrm{ug} / \mathrm{L}\end{array}$ & & & B & & \\
\hline PNLGW & B17JP8 & 100-K SPRING 77-1 & ONSITE & sw & $\mathrm{N}$ & SEEP & & $10-$ Nov- $03 \mathrm{Mn}$ & & $9.2 \mathrm{ug} / \mathrm{L}$ & & & B & & \\
\hline PNLGW & B17JP9 & 100-K SPRING 77-1 & ONSITE & sw & $\mathrm{Y}$ & SEEP & & 10-Nov-03 Mn & & $1.4 \mathrm{ug} / \mathrm{L}$ & & & $B$ & & \\
\hline PNLGW & B17LC4 & 100-K SPRING 68-1 & ONSITE & sw & Y & SEEP & & 10-Nov-03 Mn & & $1.2 \mathrm{ug} / \mathrm{L}$ & & & u & & \\
\hline PNLGW & B17VK2 & SH-144-1 & & SW & $\mathrm{N}$ & SEEP & & 20-Nov-03 Mn & & $25.6 \mathrm{ug} / \mathrm{L}$ & & & & & \\
\hline $\begin{array}{l}\text { PNLGW } \\
\text { PNIGW }\end{array}$ & $\begin{array}{l}\text { B17VK3 } \\
\text { B17VKK5 }\end{array}$ & $\begin{array}{l}\text { SH-144-1 } \\
100 \text { SPRING } 150-1\end{array}$ & QNSTEF & SW & $Y$ & SEEP & & 20-Nov-03 Mn & & $1.3 \mathrm{ug} / \mathrm{L}$ & & & B & & \\
\hline $\begin{array}{l}\text { PNLGW } \\
\text { PNLGW }\end{array}$ & $\begin{array}{l}\text { B17VK5 } \\
\text { B17VKG }\end{array}$ & $\begin{array}{l}\text { 100-H SPRING 150-1 } \\
\text { 100-H SPRING 150-1 }\end{array}$ & $\begin{array}{l}\text { ONSITE } \\
\text { ONSTEE }\end{array}$ & SW & $\begin{array}{l}\mathrm{N} \\
\mathrm{y}\end{array}$ & $\begin{array}{l}\text { SEEP } \\
\text { SEEP }\end{array}$ & & $\begin{array}{l}\text { 20-Nov-03 Mn } \\
\text { 20-Nov-03 Mn }\end{array}$ & & $74.5 \mathrm{ug} / \mathrm{L}$ & & & $y$ & & \\
\hline $\begin{array}{l}\text { PNLGW } \\
\text { PNLGW }\end{array}$ & $\begin{array}{l}\text { B1/NK6 } \\
\text { B17VK8 }\end{array}$ & $\begin{array}{l}\text { 100-H SPRING } 150-1 \\
\text { SH-153-1 }\end{array}$ & & SW & $\frac{\mathrm{N}}{\mathrm{N}}$ & $\begin{array}{l}\text { SEEP } \\
\text { SEEP }\end{array}$ & & $\begin{array}{l}20-N \mathrm{No}-03 \mathrm{Mn} \\
20-\mathrm{Nov}-03 \mathrm{Mn}\end{array}$ & & $\begin{array}{l}1.2 \mathrm{ug} / \mathrm{L} \\
2.9 \mathrm{ug} / \mathrm{L}\end{array}$ & & & B & & \\
\hline
\end{tabular}




\begin{tabular}{|c|c|c|c|c|c|c|c|c|c|c|c|c|c|c|c|}
\hline | OWNER ID & \begin{tabular}{|l|} 
SAMP \\
NUMM
\end{tabular} & SAMP SITE NAME & $\left|\begin{array}{c}\text { DIST } \\
\text { CLASS }\end{array}\right|$ & $\mid$ MEDIA $\mid$ & $\begin{array}{c}\text { FILTERED } \\
\text { FLAG }\end{array}$ & $\begin{array}{l}\text { SAMP } \\
\text { FROM }\end{array}$ & COLL MTHD & |SAMP DATE| & CON SHORT NAME & \begin{tabular}{l|l|} 
VALUE & ANAL \\
UNITS \\
RPTD \\
RPTD
\end{tabular} & \begin{tabular}{|c|} 
COUNTING \\
ERROR
\end{tabular} & $\begin{array}{c}\text { TOTAL } \\
\text { ANAL } \\
\text { ERROR }\end{array}$ & $\left|\begin{array}{c}\text { LAB } \\
\text { QUALIFIER }\end{array}\right|$ & SAMP COMMENT & $\begin{array}{c}\text { RESULT } \\
\text { COMMENT }\end{array}$ \\
\hline PNLGW & B17VK9 & SH-153-1 & & SW & & SEEP & & 20-Nov-03 Mn & & & & & u & & \\
\hline PNLGW & B17LB2 & 100-F SPRING & ONSITE & SW & $Y$ & SEEP & & 20-Nov-03 Mn & & $23.6 \mathrm{ug} / \mathrm{L}$ & & & & & \\
\hline $\begin{array}{l}\text { PNLGW } \\
\text { PNLGW }\end{array}$ & $\begin{array}{l}\text { B17JR1 } \\
\text { B17JP2 }\end{array}$ & 100-K SPRING 63-1 & $\begin{array}{l}\text { ONSITE } \\
\text { ONSTES }\end{array}$ & SW & $Y$ & SEEP & & $20-\mathrm{Oct}-03 \mathrm{Mg}$ & & & & & & & \\
\hline $\begin{array}{l}\text { PNLGW } \\
\text { PNLGW }\end{array}$ & $\begin{array}{l}\text { B17JJP2 } \\
\text { B17PJ3 }\end{array}$ & $\begin{array}{l}\text { 100-D SPRIIG 102-1 } \\
\text { 100-D SPRING 102-1 }\end{array}$ & ONSITE & SW & $\frac{d}{N}$ & $\begin{array}{l}\text { SEEP } \\
\text { SEEPP }\end{array}$ & & $27-\mathrm{Oct}-03 \mathrm{Mg}$ & & $8670 \mathrm{ug} / \mathrm{L}$ & & & & & \\
\hline PNLGW & B17JN7 & 100-D SPRING 110-1 & $\begin{array}{l}\text { ONSIIT } \\
\text { ONSITE }\end{array}$ & $\begin{array}{l}\text { SW } \\
\text { SW }\end{array}$ & $\begin{array}{l}\mathrm{Y} \\
\mathrm{N}\end{array}$ & $\begin{array}{l}\text { SEEP } \\
\text { SEEP }\end{array}$ & & $\begin{array}{l}27-\mathrm{Oct}-\mathrm{-} 3 \mathrm{Mg} \\
27-\mathrm{Oct}-03 \mathrm{Mg}\end{array}$ & & $\begin{array}{l}8550 \mathrm{ugg} / \mathrm{L} \\
3990 \mathrm{ug} / \mathrm{L}\end{array}$ & & & & & \\
\hline PNLGW & B17JN8 & 100-D SPRING 102-1 & ONSITE & SW & $\mathrm{Y}$ & SEEP & & $27-0 c t-03 \mathrm{Mg}$ & & $4450 \mathrm{ug} / \mathrm{L}$ & & & & & \\
\hline PNLGW & B17JN9 & 100-D SPRING 102-1 & ONSITE & sW & $\mathrm{N}$ & SEEP & & $27-\mathrm{Oct}-03 \mathrm{Mg}$ & & $4640 \mathrm{ug} / \mathrm{L}$ & & & B & & \\
\hline PNLGW & B17JPO & 100-D SPRING 102-1 & ONSITE & SW & Y & SEEP & & $27-\mathrm{Oct}-03 \mathrm{Mg}$ & & & & & B & & \\
\hline PNLGW & B17W21 & SK-057-3 & & SW & $\mathrm{N}$ & SEEP & & 10-Nov-03 Mg & & & & & & & \\
\hline $\begin{array}{l}\text { PNLGW } \\
\text { PNLGW }\end{array}$ & $\begin{array}{l}B 17 W 22 \\
B 17 \times 16\end{array}$ & $\begin{array}{l}\text { SK-057-3 } \\
\text { SD-110-2 }\end{array}$ & & $\begin{array}{l}\text { SW } \\
\text { sw }\end{array}$ & $Y_{N}$ & $\begin{array}{l}\text { SEEP } \\
\text { SEFP }\end{array}$ & & 10-Nov-03 Mg & & $5580 \mathrm{ug} / \mathrm{L}$ & & & 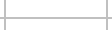 & & \\
\hline PNLGW & $\begin{array}{l}\text { B1/TV6 } \\
\text { B17VJ7 }\end{array}$ & SD-110-2 & & sw & $\begin{array}{l}\mathrm{Y} \\
\mathrm{N}\end{array}$ & $\begin{array}{l}\text { SEEP } \\
\text { SEEP }\end{array}$ & & $\begin{array}{l}\text { 10-Nov-03 Mg } \\
10-N o v-03 \mathrm{Mg}\end{array}$ & & $\begin{array}{l}5620 \mathrm{uggh} \\
5520 \mathrm{ug} / \mathrm{L}\end{array}$ & & & & & \\
\hline PNLGW & B17VJ9 & SD-098-1 & & sw & $\mathrm{N}$ & SEEP & & $10-$ Nov- $03 \mathrm{Mg}$ & & $4880 \mathrm{ug} / \mathrm{L}$ & & & B & & \\
\hline PNLGW & B17VKO & SD-098-1 & & sW & $\mathrm{Y}$ & SEEP & & 10-Nov-03 Mg & & & & & & & \\
\hline PNLGW & B17JP8 & 100-K SPRING 77-1 & ONSITE & SW & $\mathrm{N}$ & SEEP & & 10-Nov-03 Mg & & $4110 \mathrm{ug} / \mathrm{L}$ & & & B & & \\
\hline $\begin{array}{l}\text { PNLGW } \\
\text { PNLGW }\end{array}$ & $\begin{array}{l}\text { B17JP9 } \\
\text { B171744 }\end{array}$ & $\begin{array}{l}\text { 100-K SPRING 77-1 } \\
100-K \text { SPRNG 68-1 }\end{array}$ & $\begin{array}{l}\text { ONSITE } \\
\text { ONSTE }\end{array}$ & $\begin{array}{l}\text { SW } \\
\text { SW }\end{array}$ & $\begin{array}{l}Y \\
Y\end{array}$ & $\begin{array}{l}\text { SEEP } \\
\text { SEPP }\end{array}$ & & 10-Nov-03 Mg & & $4040 \mathrm{ug} / \mathrm{L}$ & & & B & & \\
\hline $\begin{array}{l}\text { PNLGW } \\
\text { PNLGW }\end{array}$ & $\begin{array}{l}\text { B17LC4 } \\
\text { B17VKK2 }\end{array}$ & $\begin{array}{l}\text { 100-K SPRING 68-1 } \\
\text { SH-144-1 }\end{array}$ & ONSITE & $\begin{array}{l}\text { SW } \\
\text { sw }\end{array}$ & $Y^{Y}$ & $\begin{array}{l}\text { SEEP } \\
\text { SEFP }\end{array}$ & & 10-Nov-03 Mg & & $5610 \mathrm{ug} / \mathrm{L}$ & & & & & \\
\hline PNLGW & B17VK3 & SH-144-1 & & SW & $\begin{array}{l}\mathrm{Y} \\
\mathrm{N}\end{array}$ & $\begin{array}{l}\text { SEEP } \\
\text { SEEP }\end{array}$ & & $\begin{array}{l}20-N \mathrm{No}-3 \mathrm{M} \mathrm{Mg} \\
20-\mathrm{Nov}-03 \mathrm{Mg}\end{array}$ & & $\begin{array}{l}5210 \mathrm{ug} / \mathrm{L} \\
5140 \mathrm{ug} / \mathrm{L}\end{array}$ & & & 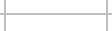 & & \\
\hline PNLGW & B17VK5 & 100-H SPRING 150-1 & ONSITE & sw & $\mathrm{N}$ & SEEP & & $20-$ Nov- $03 \mathrm{Mg}$ & & $5550 \mathrm{ug} / \mathrm{L}$ & & & 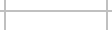 & & \\
\hline PNLGW & B17VK6 & 100-H SPRING 150-1 & ONSITE & SW & $\mathrm{Y}$ & SEEP & & 20-Nov-03 Mg & & $4800 \mathrm{ug} / \mathrm{L}$ & & & B & & \\
\hline PNLGW & B17VK8 & SH-153-1 & & SW & $\mathrm{N}$ & SEEP & & 20-Nov-03 Mg & & $4400 \mathrm{ug} / \mathrm{L}$ & & & B & & \\
\hline $\begin{array}{l}\text { PNLGW } \\
\text { PNLGW }\end{array}$ & $\begin{array}{l}\text { B17VK9 } \\
B 171 / 12\end{array}$ & $\begin{array}{l}\text { SH-153-1 } \\
100 \text {-F SPRING }\end{array}$ & & SW & $\begin{array}{l}Y \\
Y \\
Y\end{array}$ & $\begin{array}{l}\text { SEEP } \\
\text { SEEPP }\end{array}$ & & 20-Nov-03 Mg & & $4350 \mathrm{ug} / \mathrm{L}$ & & & B & & \\
\hline $\begin{array}{l}\text { PNLGW } \\
\text { PNLGW }\end{array}$ & $\begin{array}{l}\text { B17LB22 } \\
\text { B17R1 }\end{array}$ & 100-F SPRING & $\begin{array}{l}\text { ONSITE } \\
\text { ONSTEF }\end{array}$ & SW & $\begin{array}{l}Y Y \\
Y\end{array}$ & $\begin{array}{l}\text { SEEP } \\
\text { SEFP }\end{array}$ & & 20-Nov- $03 \mathrm{Mg}$ & & $9430 \mathrm{ug} / \mathrm{L}$ & & & 4 & & \\
\hline PNLGW & $\begin{array}{l}\text { S1/TR1 } \\
\text { B17JP2 }\end{array}$ & 100-D SPRING 102-1 & $\begin{array}{l}\text { ONSITE } \\
\text { ONSE }\end{array}$ & sw & $\mathrm{N}^{2} \operatorname{lol} \mathrm{g}$ & $\begin{array}{l}\text { SEEP } \\
\text { SEP }\end{array}$ & & 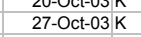 & & $\begin{array}{l}2180 \mathrm{uggh} \\
2180 \mathrm{ug} / \mathrm{L}\end{array}$ & & & u & & \\
\hline PNLGW & B17JP3 & 100-D SPRING 102-1 & ONSITE & sW & $\mathrm{Y}$ & SEEP & & $27-O c t-03 \mathrm{~K}$ & & $2180 \mathrm{ug} / \mathrm{L}$ & & & u & & \\
\hline PNLGW & B17JN7 & 100-D SPRING 110-1 & ONSITE & SW & $\mathrm{N}$ & SEEP & & $27-\mathrm{Oct}-03 \mathrm{~K}$ & & $750 \mathrm{ug} / \mathrm{L}$ & & & & & \\
\hline PNLGW & B17JN8 & 100-D SPRING 102-1 & ONSITE & & Y & SEEP & & 27-Oct-03 K & & $838 \mathrm{ug} / \mathrm{L}$ & & & & & \\
\hline $\begin{array}{l}\text { PNLGW } \\
\text { PNLGW }\end{array}$ & $\begin{array}{l}\text { B17JN9 } \\
\text { B17170 }\end{array}$ & 100-D SPRING 102-1 & ONSITE & SW & $\frac{d}{N}$ & $\begin{array}{l}\text { SEEP } \\
\text { SEEPP }\end{array}$ & & 27-Oct-03 K & & $2180 \mathrm{ug} / \mathrm{L}$ & & & U & & \\
\hline $\begin{array}{l}\text { PNLGW } \\
\text { PNLGW }\end{array}$ & $\begin{array}{l}\text { B17JJ0 } \\
\text { B17W21 }\end{array}$ & $\begin{array}{l}\text { 100-D SPRING 102-1 } \\
\text { SK-057-3 }\end{array}$ & ONSITE & $\begin{array}{l}\text { SW } \\
\text { SW }\end{array}$ & $\begin{array}{l}\mathrm{Y} \\
\mathrm{N}\end{array}$ & $\begin{array}{l}\text { SEEP } \\
\text { SEEP }\end{array}$ & & $\begin{array}{l}27-\text { Oct-1-3 K } \\
\text { 10-Nov-03 K }\end{array}$ & & $\begin{array}{l}2180 \mathrm{ugg} / \mathrm{L} \\
3000 \mathrm{ug} / \mathrm{L}\end{array}$ & & & u & & \\
\hline PNLGW & B17W22 & SK-057-3 & & sw & $\mathrm{Y}$ & SEEP & & 10-Nov-03 K & & $3000 \mathrm{ug} / \mathrm{L}$ & & & u & & \\
\hline PNLGW & B17VJ6 & SD-110-2 & & sW & $\mathrm{N}$ & SEEP & & $10-N o v-03 \mathrm{~K}$ & & $3000 \mathrm{ug} / \mathrm{L}$ & & & U & & \\
\hline PNLGW & B17VJ7 & SD-110-2 & & sW & Y & SEEP & & 10-Nov-03 K & & $3000 \mathrm{ug} / \mathrm{L}$ & & & u & & \\
\hline PNLGW & B17VJ9 & SD-098-1 & 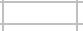 & SW & $\mathrm{N}$ & SEEP & & 10-Nov-03 K & & $3000 \mathrm{ug} / \mathrm{L}$ & & & U & & \\
\hline $\begin{array}{l}\text { PNLGW } \\
\text { PNLGW }\end{array}$ & B17VKO & $\begin{array}{l}\text { SD-098-1 } \\
100 \text { SPRING } 771\end{array}$ & ONSITE & SW & $Y$ & $\begin{array}{l}\text { SEEP } \\
\text { SEFP }\end{array}$ & & 10-Nov-03 K & & $3000 \mathrm{ug} / \mathrm{L}$ & & & U & & \\
\hline $\begin{array}{l}\text { PNLGW } \\
\text { PNLGW }\end{array}$ & $\begin{array}{l}\text { B17JJP8 } \\
\text { B17JP9 }\end{array}$ & $\begin{array}{l}100-K \text { SPRRIN 7 7-1 } \\
\text { 100-K SPRING 77-1 }\end{array}$ & $\begin{array}{l}\text { ONSITE } \\
\text { ONSITE }\end{array}$ & $\begin{array}{l}\text { SW } \\
\text { sw }\end{array}$ & $\begin{array}{l}\mathrm{N} \\
\mathrm{Y}\end{array}$ & $\begin{array}{l}\text { SEEP } \\
\text { SEEP }\end{array}$ & 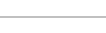 & $\begin{array}{l}\text { 10-Nov-03 K } \\
\text { 10-Nov-3 K }\end{array}$ & & $\begin{array}{l}3000 \mathrm{ug} / \mathrm{L} \\
3000 \mathrm{ug} / \mathrm{L}\end{array}$ & & & u & & \\
\hline PNLGW & B17LC4 & 100-K SPRING 68-1 & ONSITE & sw & Y & $\begin{array}{l}\text { SEEF } \\
\text { SEEP }\end{array}$ & & 10-Nov-03 K & & $3000 \mathrm{ug} / \mathrm{L}$ & & & u & & \\
\hline PNLGW & B17VK2 & SH-144-1 & & sW & $\mathrm{N}$ & SEEP & & 20 -Nov-03 K & & $3000 \mathrm{ug} / \mathrm{L}$ & & & U & & \\
\hline PNLGW & B17VK3 & SH-144-1 & & SW & Y & SEEP & & 20-Nov-03 K & & $3000 \mathrm{ug} / \mathrm{L}$ & & & U & & \\
\hline $\begin{array}{l}\text { PNLGW } \\
\text { PNIGWW }\end{array}$ & B17VK5 & 100-H SPRING 150-1 & ONSITE & SW & $\mathrm{N}$ & SEEP & & 20-Nov-03 K & & $3000 \mathrm{ug} / \mathrm{L}$ & & & U & & \\
\hline $\begin{array}{l}\text { PNLGW } \\
\text { PNLGW }\end{array}$ & $\begin{array}{l}\text { B17VK6 } \\
\text { B17T/K8 }\end{array}$ & & ONSITE & SW & $\begin{array}{r}Y \\
Y\end{array}$ & $\begin{array}{l}\text { SEEP } \\
\text { SEFP }\end{array}$ & & 20-Nov-03 K & & $3000 \mathrm{ug} / \mathrm{L}$ & & & U & & \\
\hline $\begin{array}{l}\text { PNLGW } \\
\text { PNLGW }\end{array}$ & $\begin{array}{l}\text { B17VK8 } \\
\text { B17VK9 }\end{array}$ & $\begin{array}{l}\text { SH-153-1 } \\
\text { SH-153-1 }\end{array}$ & & $\begin{array}{l}\text { SW } \\
\text { SW }\end{array}$ & $\frac{N}{Y}$ & $\begin{array}{l}\text { SEEP } \\
\text { SEEP }\end{array}$ & & $\begin{array}{l}\text { 20-Nov-03 K } \\
\text { 20-Nov-03 K }\end{array}$ & & $\begin{array}{l}3000 \mathrm{ug} / \mathrm{L} \\
3000 \mathrm{ug} / \mathrm{L}\end{array}$ & & & u & & \\
\hline PNLGW & B17LB2 & 100-F SPRING & ONSITE & sw & $\mathrm{Y}$ & SEEP & & 20 -Nov-03 K & & $11800 \mathrm{ug} / \mathrm{L}$ & & & & & \\
\hline PNLGW & B17JR1 & 100-K SPRING 63-1 & ONSITE & sW & $\mathrm{Y}$ & SEEP & & $20-\mathrm{Oct}-03 \mathrm{Fe}$ & & $49.4 \mathrm{ug} / \mathrm{L}$ & & & u & & \\
\hline PNLGW & B17JP2 & 100-D SPRING 102-1 & ONSITE & SW & $\mathrm{N}$ & SEEP & & 27-Oct-03 Fe & & $292 \mathrm{ug} / \mathrm{L}$ & & & & & \\
\hline $\begin{array}{l}\text { PNLGW } \\
\text { PNLGW }\end{array}$ & $\begin{array}{l}\text { B17JP3 } \\
\text { B1717N7 }\end{array}$ & 100-D SPRING 102-1 & ONSITE & & $Y$ & SEEP & & 27-Oct-03 Fe & & $49.4 \mathrm{ug} / \mathrm{L}$ & & & u & & \\
\hline $\begin{array}{l}\text { PNLGW } \\
\text { PNLGW }\end{array}$ & B17JN7 & 100-D SPRING 110-1 & ONSITE & SW & $\begin{array}{l}\mathrm{y} \\
\mathrm{N}\end{array}$ & SEEP & & 27-Oct-03 Fe & & $45.8 \mathrm{ug} / \mathrm{L}$ & & & 40 & & \\
\hline $\begin{array}{l}\text { PNLGW } \\
\text { PNLGW }\end{array}$ & $\begin{array}{l}\text { B B17NNS } \\
\text { B17N9 }\end{array}$ & 100-D SPRING 102-1 & $\begin{array}{l}\text { ONSITE } \\
\text { ONSE }\end{array}$ & SW & $\frac{\mathrm{N}}{\mathrm{N}}$ & $\begin{array}{l}\text { SEEP } \\
\text { SEEP }\end{array}$ & & $\begin{array}{l}27-\mathrm{Oct}-03 \mathrm{Fe} \\
27-\mathrm{Oct}-03 \mathrm{Fe}\end{array}$ & & $\begin{array}{l}19.8 \mathrm{uggh} \\
49.4 \mathrm{ug} / \mathrm{L}\end{array}$ & & & u & & \\
\hline PNLGW & B17JPO & 100-D SPRING 102-1 & ONSITE & sw & $\mathrm{Y}$ & SEEP & & $27-\mathrm{Oct}-03 \mathrm{Fe}$ & & $49.4 \mathrm{ug} / \mathrm{L}$ & & & u & & \\
\hline $\begin{array}{l}\text { PNLGW } \\
\text { PNIGW }\end{array}$ & B17W21 & SK-057-3 & & $\begin{array}{l}S W \\
S W\end{array}$ & $\mathrm{~N}^{\mathrm{N}}$ & SEEP & & 10-Nov-03 Fe & & $80.2 \mathrm{ug} / \mathrm{L}$ & & & $B$ & & \\
\hline PNLGW & B17W22 & SK-057-3 & & SW & Y & SEEP & & 10-Nov-03 Fe & & $54.5 \mathrm{ug} / \mathrm{L}$ & & & U & & \\
\hline $\begin{array}{l}\text { PNLGW } \\
\text { PNIIGN }\end{array}$ & B17VJ6 & SD-110-2 & & SW & $\frac{d}{N}$ & SEEP & & 10-Nov-03 Fe & & $239 \mathrm{ug} / \mathrm{L}$ & & & & & \\
\hline $\begin{array}{l}\text { PNLGW } \\
\text { PNLGW }\end{array}$ & $\begin{array}{l}\text { B17VV7 } \\
\text { B17VJ9 }\end{array}$ & $\begin{array}{l}\text { SDD-1110-2 } \\
\text { SD-098-1 }\end{array}$ & & $\begin{array}{l}\text { SW } \\
\text { sw }\end{array}$ & $\begin{array}{r}\mathrm{Y} \\
\mathrm{N}\end{array}$ & $\begin{array}{l}\text { SEEP } \\
\text { SEEP }\end{array}$ & & $\begin{array}{l}\text { 10-Nov-3 Fe } \\
\text { 10-Nov-03 Fe }\end{array}$ & & $\begin{array}{l}54.5 \mathrm{ug} / \mathrm{L} \\
79.2 \mathrm{ug} / \mathrm{L}\end{array}$ & & & $\begin{array}{l}U \\
B \\
B\end{array}$ & & \\
\hline PNLGW & B17VKo & SD-098-1 & & sw & $Y$ & SEEP & & 10-Nov-03 Fe & & $54.5 \mathrm{ug} / \mathrm{L}$ & & & u & & \\
\hline PNLGW & B17JP8 & 100-K SPRING 77-1 & ONSITE & sw & $\mathrm{N}$ & SEEP & & $10-\mathrm{Nov}-03 \mathrm{Fe}$ & & $123 \mathrm{ug} / \mathrm{L}$ & & & & & \\
\hline PNLGW & B17JP9 & 100-K SPRING 77-1 & ONSITE & sW & $\mathrm{Y}$ & SEEP & & 10-Nov-03 Fe & & $54.5 \mathrm{ug} / \mathrm{L}$ & & & U & & \\
\hline PNLGW & B17LC4 & 100-K SPRING 68-1 & ONSITE & SW & Y & SEEP & & 10-Nov-03 Fe & & $54.5 \mathrm{ug} / \mathrm{L}$ & & & U & & \\
\hline $\begin{array}{l}\text { PNLGW } \\
\text { PNLGW }\end{array}$ & $\begin{array}{l}\text { B17VK2 } \\
\text { B17VKK3 }\end{array}$ & $\begin{array}{l}\text { SH-144-1 } \\
\text { SH-144-1 }\end{array}$ & & $\begin{array}{l}\text { SW } \\
\text { sw }\end{array}$ & $\begin{array}{l}\mathrm{y} \\
\mathrm{N}\end{array}$ & $\begin{array}{l}\text { SEEP } \\
\text { SEEP }\end{array}$ & & $\begin{array}{l}20-\text { Nov-03 Fe } \\
\text { 20-Nov-03 Fe }\end{array}$ & & $\begin{array}{l}397 \mathrm{ug} / \mathrm{L} \\
545 \mathrm{ug} / \mathrm{L}\end{array}$ & & & u & & \\
\hline $\begin{array}{l}\text { PNLGW } \\
\text { PNLGW }\end{array}$ & B17VK5 & $100-H$ SPRING $150-1$ & ONSITE & sw & $\mathrm{N}$ & $\begin{array}{l}\text { SEEF } \\
\text { SEEP }\end{array}$ & & 20 -Nov-03 $03 \mathrm{Fe}$ & & $\begin{array}{l}524.5 \mathrm{uggh} \\
2240 \mathrm{ug} / \mathrm{L}\end{array}$ & & & 0 & & \\
\hline PNLGW & B17VK6 & 100-H SPRING 150-1 & ONSITE & SW & $\mathrm{Y}$ & SEEP & & $20-\mathrm{Nov}-03 \mathrm{Fe}$ & & $54.5 \mathrm{ug} / \mathrm{L}$ & & & $u$ & & \\
\hline PNLGW & B17VK8 & SH-153-1 & & sw & $\mathrm{N}$ & SEEP & & $20-N o v-03 \mathrm{Fe}$ & & $54.5 \mathrm{ug} / \mathrm{L}$ & & & U & & \\
\hline PNLGW & B17VK9 & SH-153-1 & & SW & Y & SEEP & & 20-Nov-03 Fe & & $54.5 \mathrm{ug} / \mathrm{L}$ & & & U & & \\
\hline PNLGW & B17LB2 & 100-F SPRING & ONSITE & SW & $Y$ & SEEP & & $20-$ Nov-03 Fe & & $98.2 \mathrm{ug} / \mathrm{L}$ & & & $B$ & & \\
\hline
\end{tabular}


WATER - COLUMBIA RIVER SHORELINE SPRINGS

\begin{tabular}{|c|c|c|c|c|c|c|c|c|c|c|c|c|c|c|c|c|}
\hline | OWNER ID & \begin{tabular}{|l|} 
SAMP \\
NUMM
\end{tabular} & SAMP SITE NAME & $\mid \begin{array}{c}\text { DIST } \\
\text { CLASS }\end{array}$ & $\mid$ MEDIA $\mid$ & $\begin{array}{c}\text { FILTERED } \\
\text { FLAG }\end{array}$ & $\begin{array}{l}\text { SAMP } \\
\text { FROM }\end{array}$ & COLL MTHD & SAMP DATE & CON SHORT NAME & $\begin{array}{l}\text { VALUE } \\
\text { RPTD }\end{array}$ & $\left|\begin{array}{|c|}\text { ANAL } \\
\text { UNITS } \\
\text { RPTD }\end{array}\right|$ & \begin{tabular}{|c|} 
COUNTING \\
ERROR
\end{tabular} & $\begin{array}{l}\text { TOTAL } \\
\text { ANAL } \\
\text { ERROR }\end{array}$ & $\begin{array}{c}\text { LAB } \\
\text { QALALIFER }\end{array}$ & SAMP COMMENT & $\begin{array}{c}\text { RESULT } \\
\text { COMMENT }\end{array}$ \\
\hline PNLGW & B17JR1 & 100-K SPRING 63-1 & ONSITE & SW & & SEEP & & $20-\mathrm{Oct}-03 \mathrm{Cu}$ & & & ug/L & & & u & & \\
\hline PNLGW & B17JP2 & 100-D SPRING 102-1 & ONSITE & SW & $\mathrm{N}$ & SEEP & & 27-Oct-03 Cu & & & $2 \mathrm{ug} / \mathrm{L}$ & & & $u$ & & \\
\hline $\begin{array}{l}\text { PNLGW } \\
\text { PNLGW }\end{array}$ & $\begin{array}{l}\text { B17JP3 } \\
\text { B17.N7 }\end{array}$ & 100-D SPRING 102-1 & $\begin{array}{l}\text { ONSITE } \\
\text { ONSTES }\end{array}$ & SW & Y & SEEP & & 27-Oct-03 Cu & & & & & & $u$ & & \\
\hline $\begin{array}{l}\text { PNLGW } \\
\text { PNLGW }\end{array}$ & $\begin{array}{l}\text { B17JJ7 } \\
\text { B17NN8 }\end{array}$ & $\begin{array}{l}\text { 100-D SPRIIG 1 10-1 } \\
\text { 100-D SPRING 102-1 }\end{array}$ & ONSITE & SW & $\frac{d}{N}$ & $\begin{array}{l}\text { SEEP } \\
\text { SEEPP }\end{array}$ & & 27-Oct-03 Cu & & & $3 \mathrm{ug} / \mathrm{L}$ & & & U & & \\
\hline PNLGW & $\begin{array}{l}\text { B B/7NA } \\
\text { B17NN9 }\end{array}$ & $\begin{array}{l}\text { 100-D SPRNG } 102-1 \\
\text { 100-D SPRING 102-1 }\end{array}$ & $\begin{array}{l}\text { ONSIIT } \\
\text { ONSITE }\end{array}$ & $\begin{array}{l}\text { SW } \\
\text { SW }\end{array}$ & $\begin{array}{l}\mathrm{Y} \\
\mathrm{N}\end{array}$ & $\begin{array}{l}\text { SEEP } \\
\text { SEEP }\end{array}$ & & $\begin{array}{l}\text { 27-Oct-03 Cu } \\
\text { 27-Oct-03 Cu }\end{array}$ & & & $\begin{array}{l}3 \text { 3ggh/ } \\
\text { zugh }\end{array}$ & & & u & & \\
\hline PNLGW & B17JPO & 100-D SPRING 102-1 & ONSITE & SW & $\mathrm{Y}$ & SEEP & & 27-Oct-03 Cu & & & ug/L & & & B & & \\
\hline PNLGW & B17W21 & SK-057-3 & & sW & $\mathrm{N}$ & SEEP & & 10-Nov-03 Cu & & & & & & U & & \\
\hline PNLGW & B17W22 & SK-057-3 & & SW & Y & SEEP & & 10-Nov-03 Cu & & & & & & U & & \\
\hline PNLGW & B17VJ6 & SD-110-2 & & SW & $\mathrm{N}$ & SEEP & & 10-Nov-03 Cu & & & & & & U & & \\
\hline $\begin{array}{l}\text { PNLGW } \\
\text { PNLGW }\end{array}$ & $\begin{array}{l}\text { B17VJJ7 } \\
\text { B17VVI9 }\end{array}$ & $\begin{array}{l}\text { SD-110-2 } \\
\text { SD-098-1 }\end{array}$ & & $\begin{array}{l}\text { SW } \\
\text { sw }\end{array}$ & $Y_{N}$ & $\begin{array}{l}\text { SEEP } \\
\text { SEEP }\end{array}$ & & $\begin{array}{l}\text { 10-Nov-03 Cu } \\
\text { 10-Nov-03 Cu }\end{array}$ & & & $\mathrm{ug} / \mathrm{L}$ & & & u & & \\
\hline $\begin{array}{l}\text { PNLGW } \\
\text { PNLGW }\end{array}$ & $\begin{array}{l}\text { B17VJ9 } \\
\text { B17VKo }\end{array}$ & $\begin{array}{l}\text { SDD-099-1 } \\
\text { SD-098-1 }\end{array}$ & & $\begin{array}{l}\text { SW } \\
\text { SW }\end{array}$ & $\begin{array}{l}\mathrm{N} \\
\mathrm{Y}\end{array}$ & $\begin{array}{l}\text { SEEP } \\
\text { SEEP }\end{array}$ & & $\begin{array}{l}\text { 10-Nov-03 Cu } \\
\text { 10-Nov-03 Cu }\end{array}$ & & & gug// & & & u & & \\
\hline PNLGW & B17JP8 & 100-K SPRING 77-1 & ONSITE & sw & $\mathrm{N}$ & SEEP & & $10-\mathrm{Nov}-03 \mathrm{Cu}$ & & & & & & u & & \\
\hline PNLGW & B17JP9 & 100-K SPRING 77-1 & ONSITE & sW & $\mathrm{Y}$ & SEEP & & 10-Nov-03 Cu & & & & & & u & & \\
\hline PNLGW & B17LC4 & 100-K SPRING 68-1 & ONSITE & SW & Y & SEEP & & 10-Nov-03 Cu & & & & & & U & & \\
\hline $\begin{array}{l}\text { PNLGW } \\
\text { PNLGW }\end{array}$ & B17VK2 & SH-144-1 & & SW & $\begin{array}{l}\mathrm{y} \\
\mathrm{N}\end{array}$ & $\begin{array}{l}\text { SEEP } \\
\text { SEEPP }\end{array}$ & & 20-Nov-03 Cu & & & ug/L & & & U & & \\
\hline $\begin{array}{l}\text { PNLGW } \\
\text { PNLGW }\end{array}$ & $\begin{array}{l}\text { B17VKK3 } \\
\text { B17VK55 }\end{array}$ & $\begin{array}{l}\text { SH-144-1 } \\
100-H \text { SPRING } 150-1\end{array}$ & ONSITE & $\begin{array}{l}\text { SW } \\
\text { sw }\end{array}$ & $Y^{Y}$ & $\begin{array}{l}\text { SEEP } \\
\text { SEFP }\end{array}$ & & 20-Nov-03 Cu & & & & & & U & & \\
\hline PNLGW & B17VK6 & $100-H$ SPRING 150-1 & $\begin{array}{l}\text { ONSIITE } \\
\text { ONSE }\end{array}$ & SW & $\begin{array}{l}\mathrm{N} \\
\mathrm{Y}\end{array}$ & $\begin{array}{l}\text { SEEP } \\
\text { SEEP }\end{array}$ & & $\begin{array}{l}\text { 20-Nov-03 Cu } \\
\text { 20-Nov-03 Cu }\end{array}$ & & & & & & B & & \\
\hline PNLGW & B17VK8 & SH-153-1 & & sw & $\mathrm{N}$ & SEEP & & $20-N o v-03 \mathrm{Cu}$ & & & & & & u & & \\
\hline PNLGW & B17VK9 & SH-153-1 & & SW & $\mathrm{Y}$ & SEEP & & 20-Nov-03 Cu & & & ugg/L & & & U & & \\
\hline PNLGW & B17LB2 & 100-F SPRING & ONSITE & SW & Y & SEEP & & 20-Nov-03 Cu & & & & & & U & & \\
\hline $\begin{array}{l}\text { PNLGW } \\
\text { PNLGW }\end{array}$ & & 100-K SPRING 63-1 & ONSITE & SW & $Y$ & $\begin{array}{l}\text { SEEP } \\
\text { SEEPP }\end{array}$ & & 20-Oct-03 Cr & & & & & & - & & \\
\hline $\begin{array}{l}\text { PNLGW } \\
\text { PNLGW }\end{array}$ & $\begin{array}{l}\text { B17JP2 } \\
\text { B17.J3 }\end{array}$ & 100-D SPRING 102-1 & ONSITE & SW & $\begin{array}{l}\mathrm{y} \\
\mathrm{N}\end{array}$ & $\begin{array}{l}\text { SEEP } \\
\text { SEFP }\end{array}$ & & 27-Oct-03 Cr & & & & & & 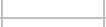 & & \\
\hline $\begin{array}{l}\text { PNLGW } \\
\text { PNLGW }\end{array}$ & $\begin{array}{l}\text { B1/7P3 } \\
\text { B17NN7 }\end{array}$ & 100-D SPRING 110-1 & $\begin{array}{l}\text { ONSITE } \\
\text { ONSE }\end{array}$ & $\begin{array}{l}\text { SW } \\
\text { SW }\end{array}$ & $\begin{array}{l}\mathrm{N} \\
\mathrm{N}\end{array}$ & $\begin{array}{l}\text { SEEP } \\
\text { SEEP }\end{array}$ & & $\begin{array}{l}27-\mathrm{Oct}-03 \mathrm{Cr} \\
27-\mathrm{Oct}-03 \mathrm{Cr}\end{array}$ & & & logh/ $\mathrm{ug} / \mathrm{h}$ & & & & & \\
\hline PNLGW & B17JN8 & 100-D SPRING 102-1 & ONSITE & sW & $\mathrm{Y}$ & SEEP & & $27-\mathrm{Oct}-03 \mathrm{Cr}$ & & & $3 \mathrm{ug} / \mathrm{L}$ & & & & & \\
\hline PNLGW & B17JN9 & 100-D SPRING 102-1 & ONSITE & SW & $\mathrm{N}$ & SEEP & & $27-\mathrm{Oct}-03 \mathrm{Cr}$ & & 13.7 & lug/L & & & & & \\
\hline PNLGW & B17JPO & 100-D SPRING 102-1 & ONSITE & SW & Y & SEEP & & 27-Oct-03 Cr & & & & & & & & \\
\hline $\begin{array}{l}\text { PNLGW } \\
\text { PNIEGW }\end{array}$ & B17W21 & SK-057-3 & & SW & $\frac{d}{N}$ & SEEP & & 10-Nov-03 Cr & & & tug/L & & & $\mathrm{U}$ & & \\
\hline $\begin{array}{l}\text { PNLGW } \\
\text { PNLGW }\end{array}$ & 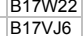 & $\begin{array}{l}\text { SK-057-3 } \\
\text { SD-110-2 }\end{array}$ & & $\begin{array}{l}\text { SW } \\
\text { SW }\end{array}$ & $\begin{array}{l}\mathrm{Y} \\
\mathrm{N}\end{array}$ & $\begin{array}{l}\text { SEEP } \\
\text { SEEP }\end{array}$ & & $\begin{array}{l}\text { 10-Nov-03 Cr } \\
\text { 10-Nov-03 Cr }\end{array}$ & & $\begin{array}{c}4.4 \\
21.1\end{array}$ & $\begin{array}{l}4 \mathrm{lug} / \mathrm{L} \\
\mathrm{ugg} / \mathrm{L}\end{array}$ & & & U & & \\
\hline PNLGW & B17VJ7 & SD-110-2 & & sw & $\mathrm{Y}$ & SEEP & & 10-Nov-03 $\mathrm{Cr}$ & & 14.7 & ug/ / & & & & & \\
\hline PNLGW & B17VJ9 & SD-098-1 & & sW & $\mathrm{N}$ & SEEP & & $10-\mathrm{Nov}-03 \mathrm{Cr}$ & & & $5 \mathrm{ug} / \mathrm{L}$ & & & B & & \\
\hline PNLGW & B17VKo & SD-098-1 & & sW & Y & SEEP & & 10-Nov-03 Cr & & & tug/L & & & B & & \\
\hline PNLGW & B17JP8 & 100-K SPRING 77-1 & ONSITE & SW & $\mathrm{N}$ & SEEP & & 10-Nov-03 Cr & & & tug/L & & & U & & \\
\hline $\begin{array}{l}\text { PNLGW } \\
\text { PNLGW }\end{array}$ & B17JP9 & 100-K SPRING 77-1 & ONSITE & SW & $\begin{array}{l}Y \\
Y \\
Y\end{array}$ & $\begin{array}{l}\text { SEEP } \\
\text { SEFP }\end{array}$ & & 10-Nov-03 Cr & & & tug/L & & & U & & \\
\hline $\begin{array}{l}\text { PNLGW } \\
\text { PNLGW }\end{array}$ & $\begin{array}{l}\text { B17LL4 } \\
\text { B17VK2 }\end{array}$ & $\begin{array}{l}\text { 100-K SPRING 68-1 } \\
\text { SH-144-1 }\end{array}$ & ONSITE & $\begin{array}{l}\text { SW } \\
\text { SW }\end{array}$ & $\begin{array}{l}\mathrm{Y} \\
\mathrm{N}\end{array}$ & $\begin{array}{l}\text { SEEP } \\
\text { SEEP }\end{array}$ & & $\begin{array}{l}\text { 10-Nov-03 Cr } \\
20-\mathrm{Nov}-03 \mathrm{Cr}\end{array}$ & & & $\begin{array}{l}\text { flgh/ } \\
\text { ugg/h }\end{array}$ & & & B & & \\
\hline PNLGW & B17VK3 & SH-144-1 & & sw & $\mathrm{Y}$ & SEEP & & $20-\mathrm{Nov}-03 \mathrm{Cr}$ & & & ug/ $/ 2$ & & & B & & \\
\hline PNLGW & B17VK5 & 100-H SPRING 150-1 & ONSITE & sW & $\mathrm{N}$ & SEEP & & $20-N o v-03 \mathrm{Cr}$ & & & 4 ug/L & & & U & & \\
\hline PNLGW & B17VK6 & 100-H SPRING 150-1 & ONSITE & SW & Y & SEEP & & $20-N o v-03 \mathrm{Cr}$ & & & tug/L & & & U & & \\
\hline & $\begin{array}{l}\text { B17VK8 } \\
\text { B1717VG }\end{array}$ & SH-153-1 & & SW & $\mathrm{y}^{\mathrm{N}}$ & SEEP & & 20-Nov-03 Cr & & & 4 ug/L & & & U & & \\
\hline $\begin{array}{l}\text { PNLGW } \\
\text { PNLGW }\end{array}$ & $\begin{array}{l}\text { B17VK9 } \\
\text { B1717R2 }\end{array}$ & $\begin{array}{l}\text { SH-153-1 } \\
\end{array}$ & ONSITE & SW & $\begin{array}{l}Y Y \\
Y\end{array}$ & $\begin{array}{l}\text { SEEP } \\
\text { SEFP }\end{array}$ & & 20-Nov-03 $\mathrm{Cr}$ & & & fug/L & & & $U$ & & \\
\hline PNLGW & $\begin{array}{l}\text { B117B2 } \\
\text { B17JR1 }\end{array}$ & $\begin{array}{l}\text { 100-K-K SPRING } \\
\text { 100-K SPING }\end{array}$ & $\begin{array}{l}\text { ONSITE } \\
\text { ONSE }\end{array}$ & SW & $\begin{array}{l}\text { Y } \\
\end{array}$ & $\begin{array}{l}\text { SEEP } \\
\text { SEEPP }\end{array}$ & & $\begin{array}{l}\text { 20-Nov-03 Cr } \\
\text { 20-Oct-03 Co }\end{array}$ & & & 5 ugg/L & & & $\frac{B}{U}$ & & \\
\hline PNLGW & B17JP2 & 100-D SPRING 102-1 & ONSITE & sw & $\mathrm{N}$ & SEEP & & 27-Oct-03 Co & & & & & & u & & \\
\hline PNLGW & B17JP3 & 100-D SPRING 102-1 & ONSITE & sW & $\mathrm{Y}$ & SEEP & & 27-Oct-03 Co & & & $5 \mathrm{ug} / \mathrm{L}$ & & & U & & \\
\hline PNLGW & B17JN7 & 100-D SPRING 110-1 & ONSITE & SW & $\mathrm{N}$ & SEEP & & 27-Oct-03 Co & & & $2 u g / L$ & & & U & & \\
\hline $\begin{array}{l}\text { PNLGW } \\
\text { PNLGW }\end{array}$ & B17JN8 & 100-D SPRING 102-1 & ONSITE & & $Y$ & SEEP & & 27-Oct-03 Co & & & $2 \mathrm{ug} / \mathrm{L}$ & & & $u$ & & \\
\hline $\begin{array}{l}\text { PNLGW } \\
\text { PNLGW }\end{array}$ & $\begin{array}{l}\text { B17JN9 } \\
\text { B17JPO }\end{array}$ & 100-D SPRING 102-1 & ONSITE & SW & $\begin{array}{l}\mathrm{y} \\
\mathrm{N}\end{array}$ & SEEP & & 27-Oct-03 Co & & & $5 \mathrm{ug} / \mathrm{L}$ & & & U & & \\
\hline $\begin{array}{l}\text { PNLGW } \\
\text { PNLGW }\end{array}$ & $\begin{array}{l}\text { B17JJ0 } \\
\text { B17W21 }\end{array}$ & $\begin{array}{l}\text { 100-D SPRING 102-1 } \\
\text { SK-057-3 }\end{array}$ & ONSITE & $\begin{array}{l}\text { SW } \\
\text { SW }\end{array}$ & $\begin{array}{l}\mathrm{Y} \\
\mathrm{N}\end{array}$ & $\begin{array}{l}\text { SEEP } \\
\text { SEEP }\end{array}$ & & $\begin{array}{l}\text { 27-Oct-03 Co } \\
10-N o v-03 \text { Co }\end{array}$ & & & $\begin{array}{l}\text { sogh/ } \\
\text { ugg/L }\end{array}$ & & & u & & \\
\hline PNLGW & B17W22 & SK-057-3 & & sw & $\mathrm{Y}$ & SEEP & & 10-Nov-03 Co & & & $3 \mathrm{ug} / \mathrm{L}$ & & & u & & \\
\hline PNLGW & B17VJ6 & SD-110-2 & & sW & $\mathrm{N}$ & SEEP & & 10-Nov-03 Co & & & 3 ug/L & & & U & & \\
\hline PNLGW & B17VJ7 & SD-110-2 & & SW & Y & SEEP & & 10-Nov-03 Co & & & 3 ug/L & & & U & & \\
\hline PNLGW & B17VJ9 & SD-098-1 & & SW & $\mathrm{N}$ & SEEP & & 10-Nov-03 Co & & & $3 \mathrm{ug} / \mathrm{L}$ & & & $\mathrm{U}$ & & \\
\hline $\begin{array}{l}\text { PNLGW } \\
\text { PNLGW }\end{array}$ & $\begin{array}{l}\text { B17VV0 } \\
\text { B17JP8 }\end{array}$ & $\begin{array}{l}\text { SD-0988-1 } \\
\text { 100-K SPRING 77-1 }\end{array}$ & ONSITE & $\begin{array}{l}\text { SW } \\
\text { SW }\end{array}$ & $\begin{array}{l}\mathrm{Y} \\
\mathrm{N}\end{array}$ & $\begin{array}{l}\text { SEEP } \\
\text { SEEP }\end{array}$ & & $\begin{array}{l}\text { 10-Nov-03 Co } \\
10-\mathrm{Nov}-03 \mathrm{Co}\end{array}$ & & & 3 3gg// & & & u & & \\
\hline PNLGW & B17JP9 & 100-K SPRING 77-1 & ONSITE & sw & $Y$ & SEEP & & $10-$ Nov-03 Co & & & $3 \mathrm{ug} / \mathrm{L}$ & & & u & & \\
\hline PNLGW & B17LC4 & 100-K SPRING 68-1 & ONSITE & sW & Y & SEEP & & $10-\mathrm{Nov}-03 \mathrm{Co}$ & & & Bug/L & & & U & & \\
\hline PNLGW & B17VK2 & SH-144-1 & & sW & $\mathrm{N}$ & SEEP & & 20-Nov-03 Co & & & 3 ug/L & & & U & & \\
\hline PNLGW & B17VK3 & SH-144-1 & & SW & Y & SEEP & & $20-$ Nov-03 Co & & & 3 ug/L & & & U & & \\
\hline $\begin{array}{l}\text { PNLGW } \\
\text { PNIGGW }\end{array}$ & B17VK5 & 100-H SPRING 150-1 & ONSITE & $\begin{array}{l}S W \\
S W\end{array}$ & $\begin{array}{l}\text { y } \\
N\end{array}$ & SEEP & & 20-Nov-03 Co & & & $3 \mathrm{ug} / \mathrm{L}$ & & & U & & \\
\hline $\begin{array}{l}\text { PNLGW } \\
\text { PNLGW }\end{array}$ & $\begin{array}{l}\text { B17VK6 } \\
\text { B17VK8 }\end{array}$ & $\begin{array}{l}\text { 100-H SPRING } 150-1 \\
\text { SH-153-1 }\end{array}$ & ONSITE & $\begin{array}{l}\text { SW } \\
\text { SW }\end{array}$ & $\begin{array}{l}\mathrm{Y} \\
\mathrm{N}\end{array}$ & $\begin{array}{l}\text { SEEP } \\
\text { SEEP }\end{array}$ & & $\begin{array}{l}20-\mathrm{Nov}-03 \mathrm{Co} \\
20-\mathrm{Nov}-03 \mathrm{Co}\end{array}$ & & & 3 ug// & & & u & & \\
\hline PNLGW & B17VK9 & SH-153-1 & & sw & Y & SEEP & & $20-$ Nov-03 Co & & & $3 \mathrm{ug} / \mathrm{L}$ & & & U & & \\
\hline PNLGW & B17LB2 & 100-F SPRING & ONSITE & sw & Y & SEEP & & 20-Nov-03 Co & & & ugg/L & & & U & & \\
\hline PNLGW & B17JR1 & 100-K SPRING 63-1 & ONSITE & SW & Y & SEEP & & 20-Oct-03 Cd & & & $5 \mathrm{ug} / \mathrm{L}$ & & & U & & \\
\hline PNLGW & B17JP2 & 100-D SPRING 102-1 & ONSITE & SW & $\mathrm{N}$ & SEEP & & $27-0 \mathrm{Oct}-03 \mathrm{Cd}$ & & & $5 \mathrm{sg} / \mathrm{L}$ & & & U & & \\
\hline
\end{tabular}


WATER - COLUMBIA RIVER SHORELINE SPRINGS

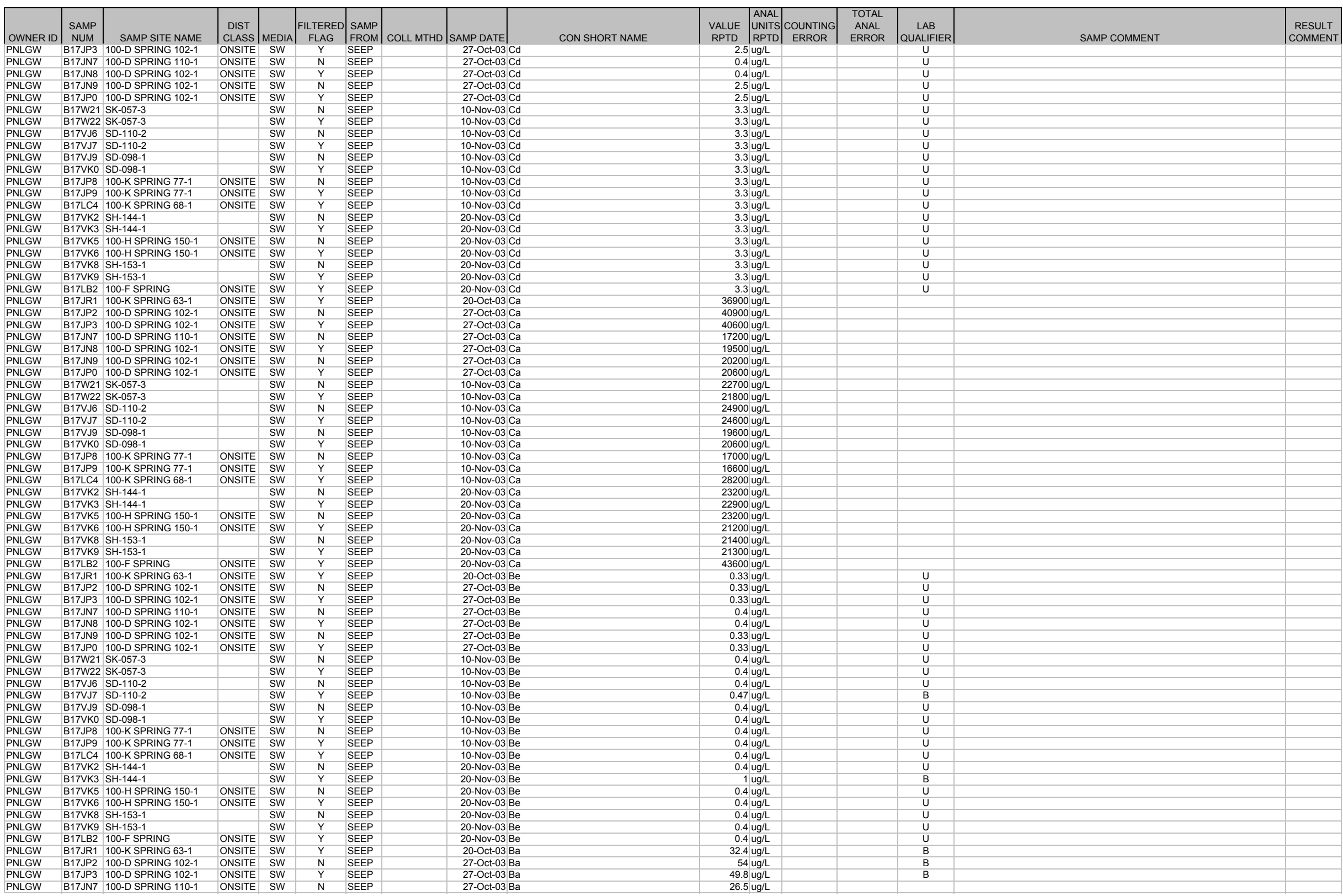


WATER - COLUMBIA RIVER SHORELINE SPRINGS

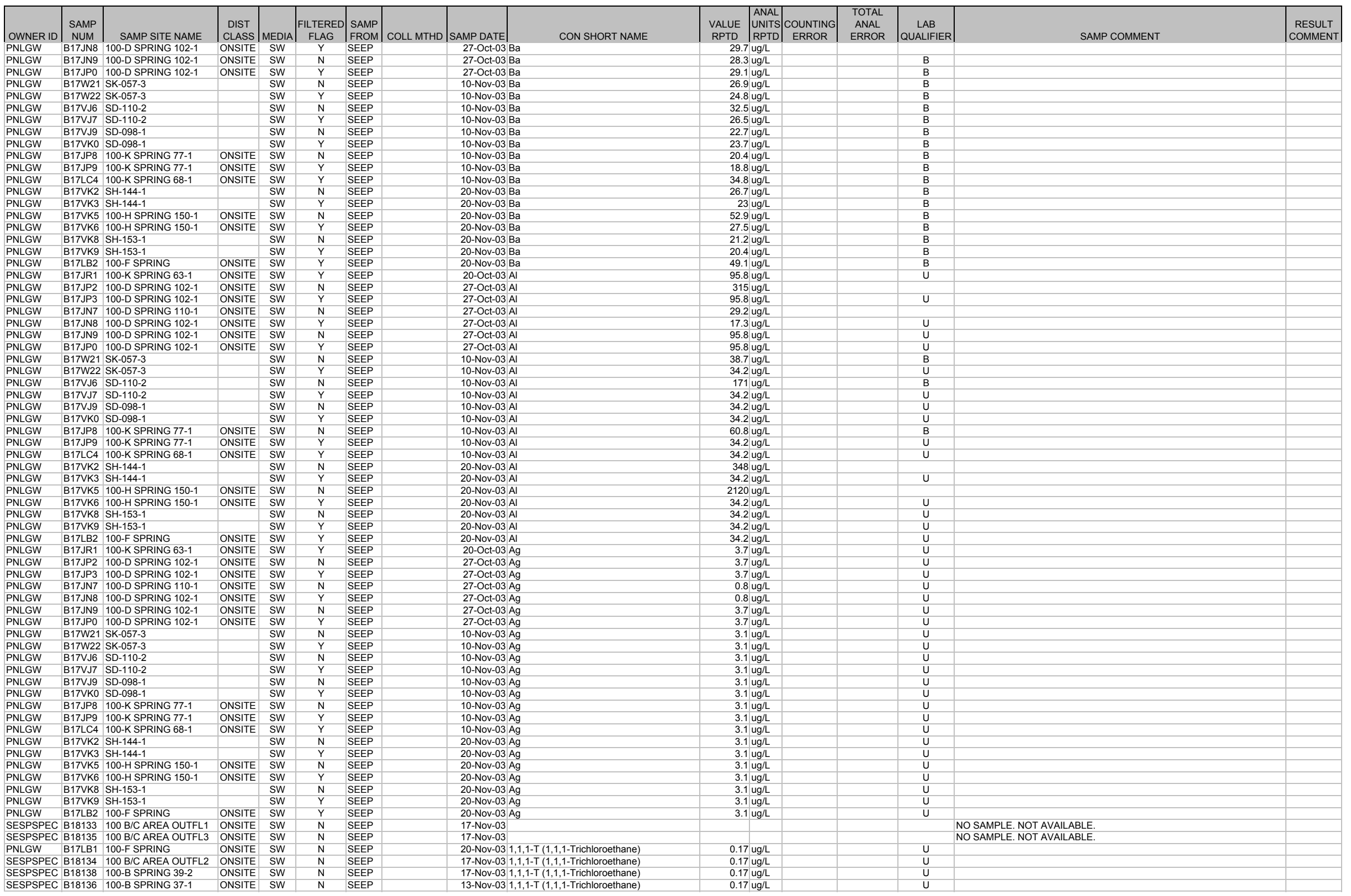




\begin{tabular}{|c|c|c|c|c|c|c|c|c|c|c|c|c|c|c|c|c|}
\hline OWNER ID & \begin{tabular}{|l|} 
SAMP \\
NUM
\end{tabular} & SAMP SITE NAME & $\mid \begin{array}{c}\text { DIST } \\
\text { CLASS }\end{array}$ & $\mid$ MEDIA & $\begin{array}{c}\text { FILTERED } \\
\text { FLAG }\end{array}$ & $\begin{array}{l}\text { SAMP } \\
\text { FROM }\end{array}$ & COLL MTHD & |SAMP DATE| & CON SHORT NAME & $\begin{array}{l}\text { VALUE } \\
\text { RPTD }\end{array}$ & $\mid$\begin{tabular}{|l|} 
ANAL \\
UNITS \\
RPTD
\end{tabular} & $\begin{array}{c}\text { COUNTING } \\
\text { ERROR }\end{array}$ & $\begin{array}{l}\text { TOTAL } \\
\text { ANAL } \\
\text { ERROR }\end{array}$ & $\mid \begin{array}{c}\text { LAB } \\
\text { QUALIFIER }\end{array}$ & SAMP COMMENT & \begin{tabular}{|c} 
RESULT \\
COMMENT
\end{tabular} \mid \\
\hline SESPSPEC & B18137 & 100-B SPRING 38-3 & ONSITE & SW & $\mathrm{N}$ & SEEP & & 13-Nov-03 & $1,1,1-\mathrm{T}(1,1,1-$ Trichloroethane) & & & & & U U IEKT & SAVIP CUIVIVILIII & \\
\hline SESPMNT & B17JN1 & 100-K SPRING 77-1 & ONSITE & SW & $\mathrm{N}$ & SEEP & & 10-Nov-03 & 1,1,1-T (1,1,1-Trichloroethane) & & & & & u & & \\
\hline SESPMNT & B17RR2 & 100-F SPRING 207-1 & ONSITE & sw & $\mathrm{N}$ & SEEP & & 03-Nov-03 & 1,1,1-T (1,1,1-Trichloroethane) & 0.17 & & & & u & & \\
\hline SESPMNT & B17JM8 & 100-B SPRING 37-1 & ONSITE & sW & $\mathrm{N}$ & SEEP & & 20-Oct-03 & 1,1,1-T (1,1,1-Trichloroethane) & 0.17 & $7 \mathrm{ug} / \mathrm{L}$ & & & u & & \\
\hline $\begin{array}{l}\text { SESPMNT } \\
\text { SESPMNT }\end{array}$ & B17JM9 & 100-B SPRING 39-2 & ONSITE & SW & $\mathrm{N}$ & SEEP & & 20-Oct-03 & 1,1,1-T (1,1,1-Trichloroethane) & 0.17 & & & & U & & \\
\hline $\begin{array}{l}\text { SESPMNT } \\
\text { SESPMNT }\end{array}$ & $\begin{array}{l}\text { B17JNO } \\
\text { B17R25 }\end{array}$ & $\begin{array}{l}\text { 100-K SPRING 63-2 } \\
300 \text { AREA SPR DR 42-2 }\end{array}$ & ONSITE & SW & $\mathrm{N}$ & $\begin{array}{l}\text { SEEP } \\
\text { SEEPP }\end{array}$ & & 20-Oct-03 & 1,1,1-T (1,1,1-Trichloroethane) & 0.17 & $7 \mathrm{ug} / \mathrm{L}$ & & & U & & \\
\hline SESPMNT & $\begin{array}{l}\text { B1/RRS } \\
\text { B17RR6 }\end{array}$ & $\begin{array}{l}\text { 300 AREA SPR DR 42-2 } \\
\text { 300 AREA SPRING 42-2 }\end{array}$ & $\begin{array}{l}\text { ONSTIE } \\
\text { ONSITE }\end{array}$ & $\begin{array}{l}\text { SW } \\
\text { SW }\end{array}$ & $\frac{n}{N}$ & $\begin{array}{l}\text { SEEP } \\
\text { SEEP }\end{array}$ & & $\begin{array}{l}\text { 13-Oct-03 } \\
\text { 13-Oct-03 }\end{array}$ & $\begin{array}{l}\text { 1,1,1-T (1,1,1-Trichloroethane) } \\
\text { 3,1,1-T (1,1,1-Trichloroethane) }\end{array}$ & 0.17 & 7 ug/h & & & $\frac{U}{u}$ & & \\
\hline PNLGW & B17LB1 & $\begin{array}{l}100-F \text { SPRING } \\
104-2\end{array}$ & $\begin{array}{l}\text { ONSITE } \\
\text { ONSE }\end{array}$ & SW & $\mathrm{N}$ & $\begin{array}{l}\text { SEEP } \\
\text { SEEP }\end{array}$ & & $\begin{array}{l}\text { 13-OCt-03 } \\
20-N o v-03\end{array}$ & $\begin{array}{l}\text {, 1,1,1-T (1,1,1-Trirhloroeethane) } \\
\text { 1,1,2-T (1,1,2-Trichloroethate) }\end{array}$ & 0.17 & $8 \mathrm{gugh/L}$ & & & $e^{2}$ & & \\
\hline SESPSPEC & $B 18134$ & 100 B/C AREA OUTFL2 & ONSITE & sW & $\mathrm{N}$ & SEEP & & 17-Nov-03 & 1,1,2-T (1,1,2-Trichloroethane) & & & & & u & & \\
\hline SESPSPEC & B18138 & 100-B SPRING 39-2 & ONSITE & SW & $\mathrm{N}$ & SEEP & & 17-Nov-03 & 1,1,2-T (1,1,2-Trichloroethane) & & & & & u & & \\
\hline & B18136 & & ONSITE & SW & $\mathrm{N}$ & SEEP & & 13-Nov-03 & 1,1,2-T (1,1,2-Trichloroethane) & 0.05 & & & & u & & \\
\hline $\begin{array}{l}\text { SESPSPEC } \\
\text { SESPMNT }\end{array}$ & B18137 & 100-B SPRING 38-3 & ONSITE & SW & $\mathrm{N}$ & SEEP & & 13-Nov-03 & 1,1,2-T (1,1,2-Trichloroethane) & 0.05 & & & & U & & \\
\hline $\begin{array}{l}\text { SESPMNT } \\
\text { SESPMNT }\end{array}$ & $\begin{array}{l}\text { B17JN11 } \\
\text { B17RR2 }\end{array}$ & $\begin{array}{l}\text { 100-K SPRIIG 77-1 } \\
\text { 100-F SPRNG 207-1 }\end{array}$ & $\begin{array}{l}\text { ONSITE } \\
\text { ONSTEE }\end{array}$ & $\begin{array}{l}\text { SW } \\
\text { sw }\end{array}$ & $\begin{array}{r}n \\
\mathrm{~N}\end{array}$ & $\begin{array}{l}\text { SEEP } \\
\text { SEEP }\end{array}$ & & $\begin{array}{l}\text { 10-Nov-03 } \\
03 \text {-Nov-03 }\end{array}$ & $\begin{array}{l}\text { 1,1,2-T (1,1,2-Trichloroethane) } \\
\text { 11,2- (11,2-Tichloroethane) }\end{array}$ & 0.05 & 5 ug/L & & & u & & \\
\hline SESPMNT & B17JM8 & 100-B SPRING 37-1 & ONSITE & sw & $\frac{N}{N}$ & $\begin{array}{l}\text { SEEP } \\
\text { SEF }\end{array}$ & & $\begin{array}{l}20-O C t-03 \\
20-10 v-03\end{array}$ & 1,1,2-T (1,1,2-Trichloroettanane) & 0.05 & $5 \mathrm{ug} / \mathrm{L}$ & & & UN & & \\
\hline SESPMNT & B17JM9 & 100-B SPRING 39-2 & ONSITE & sW & $\mathrm{N}$ & SEEP & & 20-Oct-03 & 1,1,2-T (1,1,2-Trichloroethane) & 0.05 & & & & UN & & \\
\hline SESPMNT & B17JNo & 100-K SPRING 63-2 & ONSITE & sW & $\mathrm{N}$ & SEEP & & 20-Oct-03 & 1,1,2-T (1,1,2-Trichloroethane) & & & & & UN & & \\
\hline SESPMNT & B17RR5 & 300 AREA SPR DR 42-2 & ONSITE & SW & $\mathrm{N}$ & SEEP & & 13-Oct-03 & 1,1,2-T (1,1,2-Trichloroethane) & & & & & UN & & \\
\hline $\begin{array}{l}\text { SESPMNT } \\
\text { PNLGW }\end{array}$ & $\begin{array}{l}\text { B17RR6 } \\
\text { B17171 }\end{array}$ & 300 AREA SPRING 42-2 & ONSITE & SW & $n^{n}$ & $\begin{array}{l}\text { SEEP } \\
\text { SEFP }\end{array}$ & & 13-Oct-03 & 1,1,2-T (1,1,2-Trichloroethane) & 0.05 & $5 \mathrm{ug} / \mathrm{L}$ & & & UN & & \\
\hline $\begin{array}{l}\text { PNLGW } \\
\text { SESPSPEC }\end{array}$ & $\begin{array}{l}\text { BA7L1 } \\
\text { B18134 }\end{array}$ & $\begin{array}{l}\text { 100-F F PRING } \\
\text { 100 B/C AREA OUTFL2 }\end{array}$ & $\begin{array}{l}\text { ONSTIE } \\
\text { ONSITE }\end{array}$ & $\begin{array}{l}\text { SW } \\
\text { sw }\end{array}$ & $\frac{N}{N}$ & $\begin{array}{l}\text { SEEP } \\
\text { SEEP }\end{array}$ & & $\begin{array}{l}20-N \text { Nov-03 } \\
17-03\end{array}$ & $\begin{array}{l}\text { 1,1-DCL (1,1-Dichloroethane) } \\
\text { 11-DCL (1-Dichloroethane }\end{array}$ & & $\begin{array}{l}2 \text { ugh/ } \\
\text { 2ugh/ }\end{array}$ & & & u & & \\
\hline SESPSPEC & B18138 & 100-B SPRING 39-2 & ONSITE & sw & $\mathrm{N}$ & SEEP & & $\begin{array}{l}17-\text {-Novos } \\
17-03\end{array}$ & 1,1-DCL (1,1-Dichloroethane) & & $2 \mathrm{ugh}$ & & & u & & \\
\hline SESPSPEC & $B 18136$ & 100-B SPRING 37-1 & ONSITE & sW & $\mathrm{N}$ & SEEP & & 13-Nov-03 & 1,1-DCL (1,1-Dichloroethane) & & & & & u & & \\
\hline SESPSPEC & B18137 & 100-B SPRING 38-3 & ONSITE & SW & $\mathrm{N}$ & SEEP & & 13-Nov-03 & 1,1-DCL (1,1-Dichloroethane) & & 2 uggh & & & u & & \\
\hline $\begin{array}{l}\text { SESPMNT } \\
\text { SESPMNT }\end{array}$ & B17JN1 & 100-K SPRING 77-1 & ONSITE & SW & $\mathrm{N}$ & SEEP & & 10-Nov-03 & 1,1-DCL (1,1-Dichloroethane) & & 2 uggh & & & U & & \\
\hline $\begin{array}{l}\text { SESPMNT } \\
\text { SESPMNT }\end{array}$ & $\begin{array}{l}\text { B17RR2 } \\
\text { B17MMg }\end{array}$ & 100-F SPRING 207-1 & ONSITE & SW & $\frac{N}{N}$ & $\begin{array}{l}\text { SEEP } \\
\text { SEFP }\end{array}$ & & 03-Nov-03 & 1,1-DCL (1,1-Dichloroethane) & & 2 ug/L & & & u & & \\
\hline $\begin{array}{l}\text { SESPMNT } \\
\text { SESPMNT }\end{array}$ & $\begin{array}{l}\text { B17JJM8 } \\
\text { B17JM9 }\end{array}$ & $\begin{array}{l}\text { 100-B SPRING 37-1 } \\
\text { 100-B SPRING 39-2 }\end{array}$ & $\begin{array}{l}\text { ONSIIE } \\
\text { ONSTTE }\end{array}$ & $\begin{array}{l}\text { SW } \\
\text { Sw }\end{array}$ & $\begin{array}{l}n \\
\mathrm{~N}\end{array}$ & $\begin{array}{l}\text { SEEP } \\
\text { SEEP }\end{array}$ & & $\begin{array}{l}20-\mathrm{Oct}-03 \\
20-\mathrm{Oct}-03\end{array}$ & $\begin{array}{l}\text { 1,1-1-DCL (1,1-Dichloroethane) } \\
\text { 31,-DCL (1,-Dichloroethane }\end{array}$ & & $\begin{array}{l}2 \text { ugh/ } \\
\text { uggh }\end{array}$ & & & u & & \\
\hline SESPMNT & B17JNo & 100-K SPRING 63-2 & ONSITE & sw & $\mathrm{N}$ & $\begin{array}{l}\text { SEEP } \\
\text { SEF }\end{array}$ & & 20-Oct-03 & 1,1-DCL (1,1-Dichloroettane) & & $2 \mathrm{ug} / \mathrm{L}$ & & & u & & \\
\hline SESPMNT & B17RR5 & 300 AREA SPR DR 42-2 & ONSITE & sW & $\mathrm{N}$ & SEEP & & 13-Oct-03 & 1,1-DCL (1,1-Dichloroethane) & & $2 \mathrm{ug} / \mathrm{L}$ & & & u & & \\
\hline SESPMNT & B17RR6 & 300 AREA SPRING 42-2 & ONSITE & SW & $\mathrm{N}$ & SEEP & & 13-Oct-03 & 1,1-DCL (1,1-Dichloroethane) & & 2 uggh & & & U & & \\
\hline $\begin{array}{l}\text { PNLGW } \\
\text { SESPSPEC }\end{array}$ & B17LB1 & 100-F SPRING & ONSITE & SW & N & SEEP & & 20-Nov-03 & 1,2-DCL (1,2-Dichloroethane) & 0.23 & 3 uggh & & & $\mathrm{J}$ & & \\
\hline $\begin{array}{l}\text { SESPSECC } \\
\text { SESPSPEC }\end{array}$ & B18134 & 100 B/C AREA OUTFL2 & ONSITE & $\begin{array}{l}\text { SW } \\
\text { Sw }\end{array}$ & $\begin{array}{l}n \\
\mathrm{n}\end{array}$ & $\begin{array}{l}\text { SEEP } \\
\text { SSEP }\end{array}$ & & $\begin{array}{l}17-\text { Nov-03 } \\
17-\text { Nov-03. }\end{array}$ & 1,2-DCL (1,2-Dichloroethane) & 0.08 & 8 ug/L & & & $\mathrm{U}$ & & \\
\hline $\begin{array}{l}\text { SESPSPEC } \\
\text { SESPE }\end{array}$ & B18136 & 100-B SPRING 37-1 & $\begin{array}{l}\text { ONSITE } \\
\text { ONE }\end{array}$ & sw & $\mathrm{N}$ & $\begin{array}{l}\text { SEEP } \\
\text { SEF }\end{array}$ & & $\begin{array}{l}\text { 1T-N-Nov-03 } \\
13-\text { - } 03\end{array}$ & 1,2-DCL (1,2-Dichloroethane) & & 8 ugh/ & & & u & & \\
\hline SESPSPEC & B18137 & 100-B SPRING 38-3 & ONSITE & sw & $\mathrm{N}$ & SEEP & & 13-Nov-03 & 1,2-DCL (1,2-Dichloroethane) & & & & & u & & \\
\hline SESPMNT & B17JN1 & 100-K SPRING 77-1 & ONSITE & SW & $\mathrm{N}$ & SEEP & & 10-Nov-03 & 1,2-DCL (1,2-Dichloroethane) & 0.08 & & & & U & & \\
\hline SESPMNT & B17RR2 & 100-F SPRING 207-1 & ONSITE & SW & $\mathrm{N}$ & SEEP & & 03-Nov-03 & 1,2-DCL (1,2-Dichloroethane) & 0.13 & & & & $\mathrm{~J}$ & & \\
\hline $\begin{array}{l}\text { SESPMNT } \\
\text { SESPMNT }\end{array}$ & B17JM8 & 100-B SPRING 37-1 & ONSITE & SW & $\mathrm{N}$ & SEEP & & 20-Oct-03 & 1,2-DCL (1,2-Dichloroethane) & 0.08 & $8 \mathrm{ug} / \mathrm{L}$ & & & U & & \\
\hline $\begin{array}{l}\text { SESPMNT } \\
\text { SESPMNT }\end{array}$ & $\begin{array}{l}\text { B17JM9 } \\
\text { B17.NO }\end{array}$ & $\begin{array}{l}\text { 100-B SPRING 39-2 } \\
100-K \text { SPRING 63-2 }\end{array}$ & $\begin{array}{l}\text { ONSITE } \\
\text { ONSTE }\end{array}$ & $\begin{array}{l}\text { SW } \\
\text { sw }\end{array}$ & $\begin{array}{l}n \\
\mathrm{~N}\end{array}$ & $\begin{array}{l}\text { SEEP } \\
\text { SSEP }\end{array}$ & & $\begin{array}{l}20-O c t-03 \\
20-0 c-03\end{array}$ & 1,2-DCL (1,2-Dichloroethane) & & 8 ug/h & & & u & & \\
\hline $\begin{array}{l}\text { SESPMNT } \\
\text { SESPMN }\end{array}$ & B17RR5 & 300 AREA SPR DR 42-2 & ONSITE & SW & $\frac{N}{N}$ & $\begin{array}{l}\text { SEEP } \\
\text { SEF }\end{array}$ & & 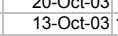 & 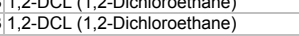 & & & & & u & & \\
\hline SESPMNT & B17RR6 & 300 AREA SPRING 42-2 & ONSITE & sw & $\mathrm{N}$ & SEEP & & 13-Oct-03 & 1,2-DCL (1,2-Dichloroethane) & & & & & U & & \\
\hline PNLGW & B17LB1 & 100-F SPRING & ONSITE & sW & $\mathrm{N}$ & SEEP & & 20-Nov-03 & 14DICLBENZ (1,4-Dichlorobenzene) & 0.11 & 1 ug/L & & & U & & \\
\hline SESPSPEC & B18134 & 100 B/C AREA OUTFL2 & ONSITE & SW & $\mathrm{N}$ & SEEP & & 17-Nov-03 & 14DICLBENZ (1,4-Dichlorobenzene) & & 1 uggh & & & U & & \\
\hline $\begin{array}{l}\text { SESPSPEC } \\
\text { SESPPEC }\end{array}$ & B18138 & 100-B SPRING 39-2 & ONSITE & SW & $\begin{array}{r}n \\
N\end{array}$ & $\begin{array}{l}\text { SEEP } \\
\text { SEFP }\end{array}$ & & 17-Nov-03 & 14DICLBENZ (1,4-Dichlorobenzene) & 0.11 & 1 ug/L & & & u & & \\
\hline $\begin{array}{l}\text { SESPPEC } \\
\text { SESPSPEC }\end{array}$ & B18136 & $\begin{array}{l}\text { 100-B SPRING 37-1 } \\
\text { 100-B SPRING 38-3 }\end{array}$ & $\begin{array}{l}\text { ONSIIE } \\
\text { ONSTIE }\end{array}$ & $\begin{array}{l}\text { SW } \\
\text { SW }\end{array}$ & $\begin{array}{l}n \\
\mathrm{~N}\end{array}$ & $\begin{array}{l}\text { SEEP } \\
\text { SSEP }\end{array}$ & & $\begin{array}{l}\text { 13-Nov-03 } \\
13 \text {-Nov-03 }\end{array}$ & 14DICLBENZ (1,4-Dichlorobenzene) & 0.11 & 1,ught & & & U & & \\
\hline SESPMNT & B17JN1 & 100-K SPRING 38-3 & ONSITE & sw & $\mathrm{N}$ & $\begin{array}{l}\text { SEEF } \\
\text { SEEP }\end{array}$ & & 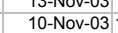 & $\begin{array}{l}\text { 14DICLEENL (1,4-Uichiorobenzene) } \\
\text { 14DZ (1,4-Dichlorobenzene }\end{array}$ & & $1 \mathrm{ugh} / \mathrm{L}$ & & & u & & \\
\hline SESPMNT & B17RR2 & 100-F SPRING 207-1 & ONSITE & sw & $\mathrm{N}$ & SEEP & & 03-Nov-03 & 14DICLBENZ (1,4-Dichlorobenzene) & & & & & u & & \\
\hline SESPMNT & B17JM8 & 100-B SPRING 37-1 & ONSITE & SW & $\mathrm{N}$ & SEEP & & 20-Oct-03 & 14DICLBENZ (1,4-Dichlorobenzene) & & & & & U & & \\
\hline SESPMNT & B17JM9 & 100-B SPRING 39-2 & ONSITE & SW & $\mathrm{N}$ & SEEP & & $20-\mathrm{Oct}-03$ & 14DICLBENZ (1,4-Dichlorobenzene) & & 1 uggh & & & U & & \\
\hline $\begin{array}{l}\text { SESPMNT } \\
\text { SESPMNT }\end{array}$ & $\begin{array}{l}\text { B17JNO } \\
\text { B17RP5 }\end{array}$ & 100-K SPRING 63-2 & ONSITE & SW & $N^{N}$ & $\begin{array}{l}\text { SEEP } \\
\text { SEFP }\end{array}$ & & 20-Oct-03 & 14DICLBENZ (1,4-Dichlorobenzene) & 0.11 & 1 ug/L & & & U & & \\
\hline $\begin{array}{l}\text { SESPMNT } \\
\text { SESPMNT }\end{array}$ & $\begin{array}{l}\text { B17RR5 } \\
\text { B17RR6 }-3 x\end{array}$ & 300 AREA SPR DR 42-2 & ONSITE & SW & $\begin{array}{l}n \\
\mathrm{~N}\end{array}$ & $\begin{array}{l}\text { SEEP } \\
\text { SSEP }\end{array}$ & & $\begin{aligned} 13-O c t-03 \\
13-0 c-03\end{aligned}$ & 14DICLBENZ (1,4-Dichlorobenzene) & 0.19 & 9 ugh/ & & & $\frac{\mathrm{J}}{4}$ & & \\
\hline $\begin{array}{l}\text { PNLGW } \\
\text { PNSW }\end{array}$ & 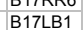 & $\begin{array}{l}100-F \text { SPRING } \\
104-2\end{array}$ & $\begin{array}{l}\text { ONSITE } \\
\text { ONS }\end{array}$ & SW & N & $\begin{array}{l}\text { SEEP } \\
\text { SEEP }\end{array}$ & & $\begin{array}{l}\text { 13-Oct-03 } \\
20-N o v-03\end{array}$ & $\begin{array}{l}\text { 14DDCLENEL (1,4-Dichlorobenzene) } \\
\text { 1BUTANOL }\end{array}$ & & $6 \mathrm{ugh} / \mathrm{L}$ & & & u & & \\
\hline SESPSPEC & B18134 & 100 B/C AREA OUTFL2 & ONSITE & sW & $\mathrm{N}$ & SEEP & & 17-Nov-03 & 1BUTANOL & & $6 \mathrm{ug} / \mathrm{L}$ & & & u & & \\
\hline SESPSPEC & B18138 & 100-B SPRING 39-2 & ONSITE & SW & $\mathrm{N}$ & SEEP & & 17-Nov-03 & 1BUTANOL & & 6 ug/L & & & $\mathrm{U}$ & & \\
\hline $\begin{array}{l}\text { SESPSPEC } \\
\text { SESPSEC }\end{array}$ & B18136 & 100-B SPRING 37-1 & ONSITE & SW & $\mathrm{N}$ & SEEP & & 13-Nov-03 & 1BUTANOL & & $6 \mathrm{ug} / \mathrm{L}$ & & & U & & \\
\hline $\begin{array}{l}\text { SESPSPEC } \\
\text { SESPMNT }\end{array}$ & B18137 & 100-B SPRING 38-3 & ONSITE & SW & $\mathrm{N}$ & SEEP & & 13-Nov-03 & 1BUTANOL & & $6 \mathrm{ug} / \mathrm{L}$ & & & $\mathrm{U}$ & & \\
\hline $\begin{array}{l}\text { SESPMNT } \\
\text { SESPMNT }\end{array}$ & 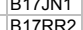 & $\begin{array}{l}100-K \text { SPRING 77-1 } \\
100-\mathrm{F} \text { SPRING } 207-1\end{array}$ & $\begin{array}{l}\text { ONSTE } \\
\text { ONSTEE }\end{array}$ & $\begin{array}{l}\text { SW } \\
\text { SW }\end{array}$ & $\begin{array}{l}\mathrm{N} \\
\mathrm{N}\end{array}$ & $\begin{array}{l}\text { SEEP } \\
\text { SEEP }\end{array}$ & & $\begin{array}{l}10-N o v-03 \\
03-03\end{array}$ & 1 BUTANOL & & 6 6ging & & & u & & \\
\hline SESPMNT & B17JM8 & 100-B SPRING 37-1 & $\begin{array}{l}\text { ONSITE } \\
\text { ONSE }\end{array}$ & SW & $\mathrm{N}$ & SEEP & & $\begin{array}{l}-10-03 \\
20-O c-03\end{array}$ & 1BUTANOL & & $6 \mathrm{ugh}$ & & & u & & \\
\hline SESPMNT & B17JM9 & 100-B SPRING 39-2 & ONSITE & sW & $\mathrm{N}$ & SEEP & & 20-Oct-03 & 1 BUTANOL & & $6 \mathrm{ug} / \mathrm{L}$ & & & u & & \\
\hline SESPMNT & B17JNO & 100-K SPRING 63-2 & ONSITE & SW & $\mathrm{N}$ & SEEP & & 20-Oct-03 & 1BUTANOL & & $6 \mathrm{ug} / \mathrm{L}$ & & & U & & \\
\hline SESPMNT & B17RR5 & 300 AREA SPR DR 42-2 & ONSITE & SW & $\mathrm{N}$ & SEEP & & 13-Oct-03 & 3 1BUTANOL & & $6 \mathrm{ug} / \mathrm{L}$ & & & u & & \\
\hline $\begin{array}{l}\text { SESPMNT } \\
\text { PNLGW }\end{array}$ & $\begin{array}{l}\text { B17RR6 } \\
\text { B17R1 }\end{array}$ & 300 AREA SPRING 42-2 & $\begin{array}{l}\text { ONSITE } \\
\text { ONSTEF }\end{array}$ & $\begin{array}{l}\text { SW } \\
\text { SW }\end{array}$ & $\begin{array}{l}n \\
N\end{array}$ & $\begin{array}{l}\text { SEEP } \\
\text { SSEP }\end{array}$ & & 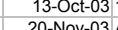 & 1 BUTAANOL & & 6 ug/L & & & $\frac{J}{U}$ & & \\
\hline $\begin{array}{l}\text { PNLGW } \\
\text { SESPSPEC }\end{array}$ & 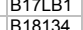 & $\begin{array}{l}100-F \text { SPRING } \\
100 \text { BCAREA OUTFL2 }\end{array}$ & $\begin{array}{l}\text { ONSTIE } \\
\text { ONSTEE }\end{array}$ & $\begin{array}{l}\text { sw } \\
\text { sw }\end{array}$ & $\frac{N}{N}$ & $\begin{array}{l}\text { SEEP } \\
\text { SEEP }\end{array}$ & & $\begin{array}{l}20 \text {-Nov-03 } \\
\text { 17-Nov-03 }\end{array}$ & $\begin{array}{l}\text { SACETONE } \\
\text { ACETONE }\end{array}$ & & 3 igg/h & & & $\mathrm{JB}$ & & \\
\hline SESPSPEC & B18138 & 100-B SPRING 39-2 & ONSITE & sw & $\mathrm{N}$ & $\begin{array}{l}\text { SEEP } \\
\text { SEEP }\end{array}$ & & $\begin{array}{l}\text { 17-Nov-03 } \\
\text { 17-Nov-03 }\end{array}$ & $\begin{array}{l}\text { ACEIONE } \\
\text { ACETONE }\end{array}$ & & $\begin{array}{ll}3 \mathrm{ug} / \mathrm{L} \\
6 \mathrm{gu} / \mathrm{h}\end{array}$ & & & u & & \\
\hline
\end{tabular}




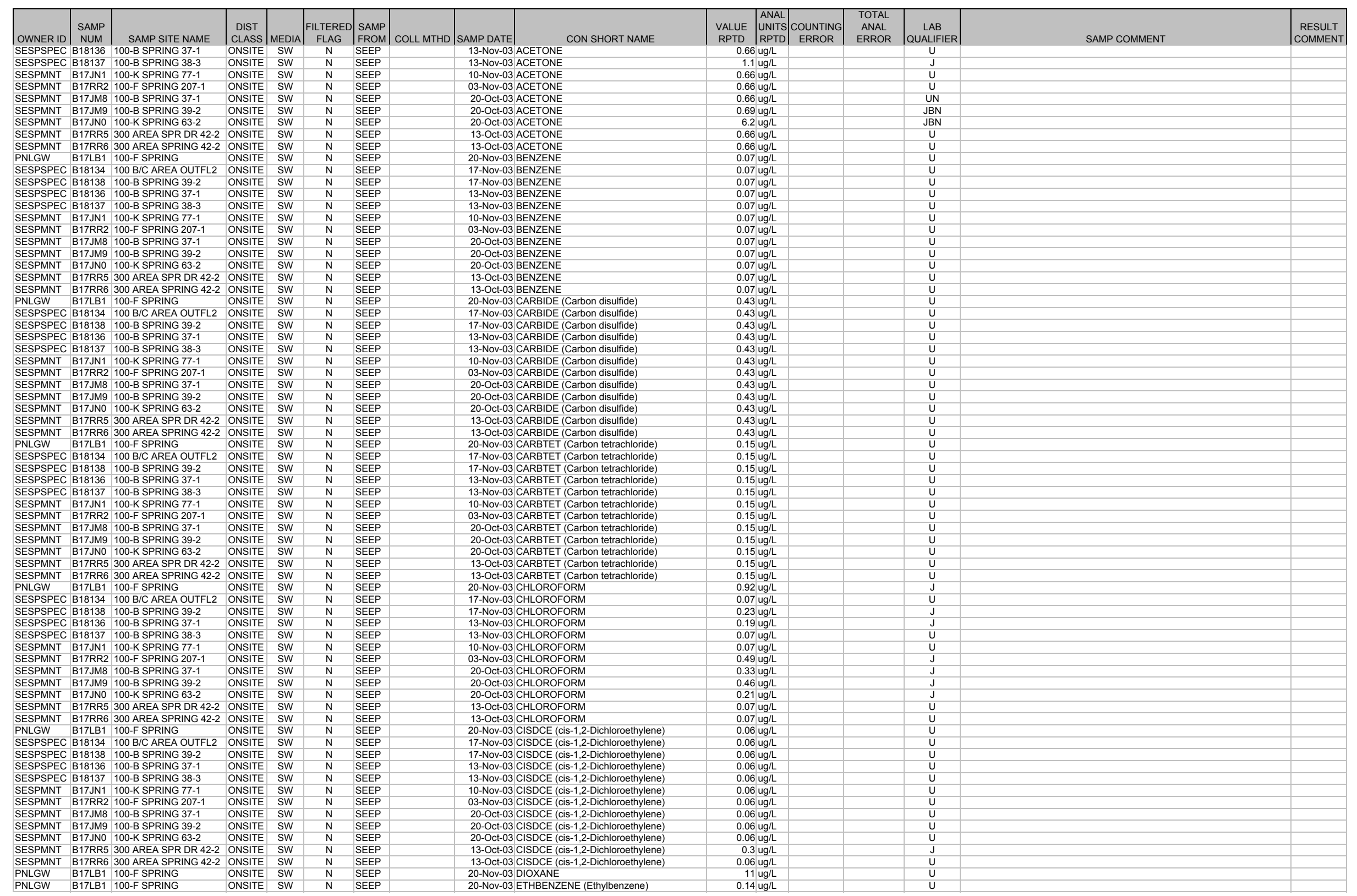




\begin{tabular}{|c|c|c|c|c|c|c|c|c|c|c|c|c|c|c|c|}
\hline |OWNER ID & \begin{tabular}{|l|} 
SAMP \\
NUM
\end{tabular} & SAMP SITE NAME & $\mid \begin{array}{c}\text { DIST } \\
\text { CLASS }\end{array}$ & $\mid$ MEDIA $\mid$ & $\begin{array}{c}\text { FILTERED } \\
\text { FLAG }\end{array}$ & $\begin{array}{l}\text { SAMP } \\
\text { FROM }\end{array}$ & $\mid$ COLL MTHD & CON SHORT NAME & $\begin{array}{l}\text { VALUE } \\
\text { RPTD }\end{array}$ & $\mid$\begin{tabular}{|c|} 
ANAL \\
UNITS \\
RPTD
\end{tabular} & $\left|\begin{array}{c}\text { COUNTING } \\
\text { ERROR }\end{array}\right|$ & $\begin{array}{c}\text { TOTAL } \\
\text { ANAL } \\
\text { ERROR }\end{array}$ & $\left|\begin{array}{c}\text { LAB } \\
\text { QUALIFIER }\end{array}\right|$ & SAMP COMMENT & $\left|\begin{array}{c}\text { RESULT } \\
\text { COMMENT }\end{array}\right|$ \\
\hline SESPMNT & B17JN1 & 100-K SPRING 77-1 & ONSITE & SW & $n$ & SEEP & & 10-Nov-03 ETHBENZENE (Ethylbenzene) & 0.14 & $4 \mathrm{ug} / \mathrm{L}$ & & & u & & \\
\hline $\begin{array}{l}\text { SESPMNT } \\
\text { SESPMNT }\end{array}$ & $\begin{array}{l}\text { B17RR2 } \\
\text { B17JM8 }\end{array}$ & $\begin{array}{l}\text { 100-F SPRIING 207-1 } \\
\text { 100-B SPRING 37-1 }\end{array}$ & $\begin{array}{l}\text { ONSIIE } \\
\text { ONSITE }\end{array}$ & 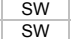 & $\stackrel{N}{N}$ & $\begin{array}{l}\text { SEEP } \\
\text { SEEP }\end{array}$ & & $\begin{array}{l}\text { 03-Nov-03 ETHBENNENE (Ethylbenzene) } \\
\text { 20-OCt-03 ETHBNZENE (Ethylbenzene) }\end{array}$ & $\begin{array}{l}0.14 \\
0.14\end{array}$ & $\begin{array}{l}4 \mathrm{ug} / \mathrm{h} \\
4 \mathrm{ugg}\end{array}$ & & & u & & \\
\hline SESPMNT & B17JM9 & 100-B SPRING 39-2 & ONSITE & SW & $\mathrm{n}$ & SEEP & & 20-Oct-03 ETHBENZENE (Ethylbenzene) & & 4 ug $/ \mathrm{L}$ & & & u & & \\
\hline SESPMNT & B17JNO & 100-K SPRING 63-2 & ONSITE & SW & $\mathrm{N}$ & SEEP & & 20-Oct-03 ETHBENZENE (Ethylbenzene) & & $4 \mathrm{ug} / \mathrm{L}$ & & & u & & \\
\hline SESPMNT & B17RR5 & 300 AREA SPR DR 42-2 & ONSITE & SW & $\mathrm{N}$ & SEEP & & 13-Oct-03 ETHBENZENE (Ethylbenzene) & & 4 uggh & & & u & & \\
\hline SESPMNT & B17RR6 & 300 AREA SPRING 42-2 & ONSITE & SW & N & $\begin{array}{l}\text { SEEP } \\
\text { SEFD }\end{array}$ & & 13-Oct-03 ETHBENZENE (Ethylbenzene) & & & & & u & & \\
\hline $\begin{array}{l}\text { PNLGW } \\
\text { SESPSPEC }\end{array}$ & B17LB1 & 100-F SPRING & ONSITE & SW & $N$ & SEEP & & 20-Nov-03 ETHCYANIDE (Ethyl cyanide) & & $3 u g / L$ & & & U & & \\
\hline $\begin{array}{l}\text { SESPSPEC } \\
\text { SESPSEC }\end{array}$ & B18134 & $\begin{array}{l}\text { 100 B/C AREA OUTFL2 } \\
\text { 100-B SPRING 39-2 }\end{array}$ & $\begin{array}{l}\text { ONSITE } \\
\text { ONSTEE }\end{array}$ & $\begin{array}{l}\text { SW } \\
\text { sw }\end{array}$ & $\frac{n}{n}$ & $\begin{array}{l}\text { SEEP } \\
\text { SEEP }\end{array}$ & & 17-Nov-03 ETHCYANIDE (Ethyl cyanide) & & Bug/L & & & U & & \\
\hline SESPSPEC & B18136 & $\begin{array}{l}\text { 100-B SPRRNG 39-2 } \\
\text { 100-B SPRING 37-1 }\end{array}$ & $\begin{array}{l}\text { ONSTIE } \\
\text { ONSITE }\end{array}$ & SW & $\frac{N}{n}$ & $\begin{array}{l}\text { SEEP } \\
\text { SEEP }\end{array}$ & & $\begin{array}{l}\text { 17-Nov-03 ETHCYANDIDE (Ethyl cyanide) } \\
\text { 13-Nov-03 ETHCYANIDE (Ethyl cyanide) }\end{array}$ & & 3 Bgg/h & & & u & & \\
\hline SESPSPEC & B18137 & 100-B SPRING 38-3 & ONSITE & sw & $\mathrm{N}$ & SEEP & & $\begin{array}{l}\text { 13-Nov-U3 -03 ETHCYANIDE (Ethyl cyandide) } \\
\text { 13-Nonide) }\end{array}$ & & $3 \mathrm{ugh}$ & & & u & & \\
\hline $\begin{array}{l}\text { SESPMNT } \\
\text { SESPNTT }\end{array}$ & B17JN1 & 100-K SPRING 77-1 & ONSITE & sw & N & SEEP & & 10-Nov-03 ETHCYANIDE (Ethyl cyanide) & & 3 ugh & & & u & & \\
\hline $\begin{array}{l}\text { SESPMNT } \\
\text { SESPMNT }\end{array}$ & B17RR2 & 100-F SPRING 207-1 & ONSITE & SW & N & SEEP & & 03-Nov-03 ETHCYANIDE (Ethyl cyanide) & & 3 uggh & & & u & & \\
\hline $\begin{array}{l}\text { SESPMNT } \\
\text { SESPMNT }\end{array}$ & B17JM8 & 100-B SPRING 37-1 & ONSITE & SW & $\mathrm{N}$ & SEEP & & 20-Oct-03 ETHCYANIDE (Ethyl cyanide) & & & & & U & & \\
\hline $\begin{array}{l}\text { SESPMNT } \\
\text { SESPMNT }\end{array}$ & 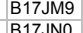 & $\begin{array}{l}\text { 100-B SPRING 39-2 } \\
100-\text { K SPING 63-2 }\end{array}$ & ONSITE & SW & $\mathrm{N}$ & SEEP & & $\begin{array}{l}\text { 20-Oct-03 ETHCYANIDE (Ethyl cyanide) } \\
\text { 20-0THCY }\end{array}$ & & $3 \mathrm{ug} / \mathrm{L}$ & & & $\mathrm{U}$ & & \\
\hline $\begin{array}{l}\text { SESPMNT } \\
\text { SESPMNT }\end{array}$ & 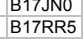 & $\begin{array}{l}\text { 100-K SPRING 63-2 } \\
300 \text { AREA SPR DR 42-2 }\end{array}$ & $\begin{array}{l}\text { ONSTIE } \\
\text { ONSITE }\end{array}$ & $\begin{array}{l}\text { Sw } \\
\text { Sw }\end{array}$ & ${ }_{N}^{N}$ & $\begin{array}{l}\text { SEEP } \\
\text { SEEP }\end{array}$ & & 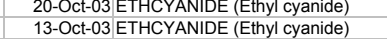 & & $\begin{array}{l}3 \text { ugg } \\
3 \text { ug/L }\end{array}$ & & & u & & \\
\hline SESPMNT & B17RR6 & 300 AREA SPRING 42-2 & ONSITE & sW & $\mathrm{N}$ & SEEP & & 13-Oct-03 ETHCYANID (Ethyl cyanide) & & $3 \mathrm{ug} / \mathrm{L}$ & & & u & & \\
\hline PNLGW & B17LB1 & 100-F SPRING & ONSITE & SW & $\mathrm{N}$ & SEEP & & 20-Nov-03 HEXONE (4-Methyl-2-Pentanone) & & 5 uggh & & & u & & \\
\hline SESPSPEC & B18134 & $100 \mathrm{~B} / \mathrm{C}$ AREA OUTFL2 & ONSITE & SW & $\mathrm{N}$ & SEEP & & 17-Nov-03 HEXONE (4-Methyl-2-Pentanone) & & 5 uggh & & & $u$ & & \\
\hline $\begin{array}{l}\text { SESPSPEC } \\
\text { GESPSDCC }\end{array}$ & B18138 & 100-B SPRING 39-2 & ONSITE & SW & $\mathrm{N}$ & SEEP & & 17-Nov-03 HEXONE (4-Methyl-2-Pentanone) & & & & & U & & \\
\hline $\begin{array}{l}\text { SESPSPEC } \\
\text { SESPSECC }\end{array}$ & $\begin{array}{l}\text { B18136 } \\
\text { B18137 }\end{array}$ & $\begin{array}{l}\text { 100-B SPRING 37-1 } \\
\text { 100-B SPRING 38-3 }\end{array}$ & $\begin{array}{l}\text { ONSIE } \\
\text { ONSTTE }\end{array}$ & 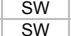 & $\begin{array}{r}\mathrm{N} \\
\mathrm{N}\end{array}$ & $\begin{array}{l}\text { SEEP } \\
\text { SEEP }\end{array}$ & & $\begin{array}{l}\text { 13-Nov-03 HEXONE (4-Methyl-2-2-2entanone) } \\
\text { 13-Nov-03 HEXONE (4-Methly }\end{array}$ & & $\begin{array}{l}5 \mathrm{ug} / \mathrm{L} \\
5 \mathrm{ug} / \mathrm{L}\end{array}$ & & & u & & \\
\hline $\begin{array}{l}\text { SESPSEC } \\
\text { SESPMNT }\end{array}$ & $\begin{array}{l}\text { B18137 } \\
\text { B17JN1 }\end{array}$ & $\begin{array}{l}\text { 100-B BPRING 38-3 } \\
\text { 100-K SPRING 77-1 }\end{array}$ & $\begin{array}{l}\text { ONSTIE } \\
\text { ONSITE }\end{array}$ & $\begin{array}{l}\text { Sw } \\
\text { sw }\end{array}$ & $\frac{\mathrm{N}}{\mathrm{N}}$ & $\begin{array}{l}\text { SEEP } \\
\text { SEEP }\end{array}$ & & $\begin{array}{l}\text { 13--Nov-03 HEXONE (4-Methyl-2-Pentanone) } \\
\text { 10-Nov-03 HEXONE (4-Methyl-2-Pentanone) }\end{array}$ & & $\begin{array}{l}5 \mathrm{ugg} / \mathrm{L} \\
5 \mathrm{ug} / \mathrm{L}\end{array}$ & & & u & & \\
\hline SESPMNT & B17RR2 & 100-F SPRING 207-1 & ONSITE & SW & $\mathrm{N}$ & SEEP & & $\begin{array}{l}\text { OO-N-Nov-03 HEXONE (4-Methyl-2-2-Pentanone) } \\
\text { 03-03one) }\end{array}$ & & $5 \mathrm{ug} / \mathrm{L}$ & & & u & & \\
\hline SESPMNT & B17JM8 & 100-B SPRING 37-1 & ONSITE & SW & $\mathrm{N}$ & SEEP & & 20-Oct-03 HEXONE (4-Methyl-2-Pentanone) & & 5 ugh & & & U & & \\
\hline SESPMNT & B17JM9 & 100-B SPRING 39-2 & ONSITE & SW & $\mathrm{N}$ & SEEP & & 20-Oct-03 HEXONE (4-Methyl-2-Pentanone) & & 5 sugh & & & U & & \\
\hline SESPMNT & B17JNO & 100-K SPRING 63-2 & & & & & & 20-Oct-03 HEXONE (4-Methyl-2-Pentanone) & & 5 ugh & & & & & \\
\hline SESPMNT & B17RR5 & 300 AREA SPR DR 42-2 & ONSITE & sw & $\mathrm{N}$ & SEEP & & 13-Oct-03 HEXONE (4-Methyl-2-Pentanone) & & 5 ug/h & & & $u$ & & \\
\hline SESPMNT & B17RR6 & 300 AREA SPRING $42-2$ & ONSITE & sw & $\mathrm{N}$ & SEEP & & 13-Oct-03 HEXONE (4-Methyl-2-Pentanone) & & $5 \mathrm{ug} / \mathrm{L}$ & & & u & & \\
\hline PNLGW & B17LB1 & 100-F SPRING & ONSITE & sw & $\mathrm{N}$ & SEEP & & 20-Nov-03 METHONE (2-Butanone) & & $9 \mathrm{ug} / \mathrm{L}$ & & & u & & \\
\hline SESPSPEC & B18134 & $100 \mathrm{~B} / \mathrm{C}$ AREA OUTFL2 & ONSITE & sW & $\mathrm{N}$ & SEEP & & 17-Nov-03 METHONE (2-Butanone) & & $9 \mathrm{ug} / \mathrm{L}$ & & & u & & \\
\hline $\begin{array}{l}\text { SESPSPEC } \\
\text { SESPSDC }\end{array}$ & B18138 & 100-B SPRING 39-2 & ONSITE & SW & $N$ & SEEP & & 17-Nov-03 METHONE (2-Butanone) & & 9 ug/L & & & $\mathrm{U}$ & & \\
\hline SESPSPEC & B18136 & 100-B SPRING 37-1 & ONSITE & SW & $N$ & SEEP & & 13-Nov-03 METHONE (2-Butanone) & & $9 \mathrm{ug} / \mathrm{L}$ & & & U & & \\
\hline $\begin{array}{l}\text { SESPSPEC } \\
\text { SESPMNT }\end{array}$ & B18137 & 100-B SPRING 38-3 & ONSITE & SW & $\mathrm{N}$ & $\begin{array}{l}\text { SEEP } \\
\text { SEEP }\end{array}$ & & 13-Nov-03 METHONE (2-Butanone) & & $9 \mathrm{ug} / \mathrm{L}$ & & & $\mathrm{U}$ & & \\
\hline $\begin{array}{l}\text { SESPMNT } \\
\text { SESPMNT }\end{array}$ & $\begin{array}{l}\text { B17JN1 } \\
\text { B17RR2 }\end{array}$ & $\begin{array}{l}\text { 100-K SPRING 77-1 } \\
\text { 100-F SPRING 207-1 }\end{array}$ & $\begin{array}{l}\text { ONSIE } \\
\text { ONSTEE }\end{array}$ & SW & $\frac{N}{N}$ & $\begin{array}{l}\text { SEEP } \\
\text { SEEP }\end{array}$ & & $\begin{array}{l}\text { 10-Nov-033 METHONE (2-Butanone) } \\
\text { 00-Nov-3 METHONE (2-Butanone) }\end{array}$ & & 9 ug/L & & & $\frac{u}{u}$ & & \\
\hline $\begin{array}{l}\text { SESPMNI } \\
\text { SESPMNT }\end{array}$ & $\begin{array}{ll}\text { B1/RR2 } \\
\text { B17JM8 }\end{array}$ & 100-B SPRING 37-1 & $\begin{array}{l}\text { ONSITE } \\
\text { ONST }\end{array}$ & Sw & $\frac{\mathrm{N}}{\mathrm{N}}$ & $\begin{array}{l}\text { SEEP } \\
\text { SEEP }\end{array}$ & & $\begin{array}{l}\text { 03-Nov-03 METHONE (2-Butanone) } \\
\text { 20-Oct-03 METHONE (2-Butanone) }\end{array}$ & & $\begin{array}{l}9 \\
9 \text { ugg/h } \\
9\end{array}$ & & & u & & \\
\hline SESPMNT & B17JM9 & 100-B SPRING 39-2 & ONSITE & sW & N & SEEP & & 20-Oct-03 METHONE (2-Butanone) & & $9 \mathrm{ug} / \mathrm{h}$ & & & u & & \\
\hline SESPMNT & B17JNO & 100-K SPRING 63-2 & ONSITE & SW & $\mathrm{N}$ & SEEP & & 20-Oct-03 METHONE (2-Butanone) & & 9 ug/L & & & U & & \\
\hline $\begin{array}{l}\text { SESPMNT } \\
\text { SECDMNT }\end{array}$ & B17RR5 & 300 AREA SPR DR 42-2 & ONSITE & SW & $\mathrm{N}$ & SEEP & & 13-Oct-03 METHONE (2-Butanone) & & 9 uggh & & & u & & \\
\hline $\begin{array}{l}\text { SESPMNT } \\
\text { PNIGW }-10\end{array}$ & B17RR6 & 300 AREA SPRING 42-2 & ONSITE & SW & $\mathrm{N}$ & SEEP & & 13-Oct-03 METHONE (2-Butanone) & & $9 \mathrm{ug} / \mathrm{L}$ & & & $\mathrm{U}$ & & \\
\hline $\begin{array}{l}\text { PNLGW } \\
\text { SESPSPEC }\end{array}$ & $\begin{array}{l}\text { B17L11 } \\
\text { B18134 }\end{array}$ & & $\begin{array}{l}\text { ONSIE } \\
\text { ONSTE }\end{array}$ & $\begin{array}{l}\text { sw } \\
\text { sw }\end{array}$ & $\begin{array}{r}n \\
N\end{array}$ & $\begin{array}{l}\text { SEEP } \\
\text { SEEP }\end{array}$ & & $\begin{array}{l}\text { 20-Nov-033 METHYCH (Methylenechloride) } \\
\text { 17-Nov-03 METHYC (Methylenechloride }\end{array}$ & & 3 & & & u & & \\
\hline $\begin{array}{l}\text { SESPSEC } \\
\text { SESPSPEC }\end{array}$ & B18138 & $\begin{array}{l}\text { 100 B/C ARAA OUTFL2 } \\
\text { 100-B SPRING 39-2 }\end{array}$ & $\begin{array}{l}\text { ONSIIE } \\
\text { ONSITE }\end{array}$ & Sw & $\frac{\mathrm{N}}{\mathrm{N}}$ & $\begin{array}{l}\text { SEEP } \\
\text { SEEP }\end{array}$ & & $\begin{array}{l}\text { 17-Nov-03 METHYC (Methylenechloride) } \\
\text { 17-Nov-03 METHYCH (Methylenechloride) }\end{array}$ & & $\begin{array}{l}3 \\
3 \text { ugg/h } \\
3\end{array}$ & & & u & & \\
\hline SESPSPEC & B18136 & 100-B SPRING 37-1 & ONSITE & SW & $\mathrm{N}$ & SEEP & & 13-Nov-03 METHYCH (Methylenechloride) & & 3 uggh & & & u & & \\
\hline SES & B18137 & 100-B SPRING 38-3 & ONSITE & sW & $\mathrm{N}$ & SEEP & & 13-Nov-03 METHYCH (Methylenechloride) & & 3 uggh & & & u & & \\
\hline $\begin{array}{l}\text { SESPMNT } \\
\text { SESPMNT }\end{array}$ & B17JN1 & 100-K SPRING 77-1 & ONSITE & SW & $\mathrm{N}$ & SEEP & & 10-Nov-03 METHYCH (Methylenechloride) & & 3 ug/L & & & u & & \\
\hline $\begin{array}{l}\text { SESPMNT } \\
\text { SESPMNT }\end{array}$ & B17RR2 & 100-F SPRING 207-1 & $\begin{array}{l}\text { ONSITE } \\
\text { ONSTEF }\end{array}$ & sW & $\mathrm{N}$ & $\begin{array}{l}\text { SEEP } \\
\text { SEEP }\end{array}$ & & $\begin{array}{l}\text { 03-Nov-03 METHYCH (Methylenechloride) } \\
\text { 20-0ct-3 METHYCHethenchloride }\end{array}$ & & 3 ug/L & & & u & & \\
\hline $\begin{array}{l}\text { SESPMNI } \\
\text { SESPMNT }\end{array}$ & $\begin{array}{l}\text { B1/7M8 } \\
\text { B17JM9 }\end{array}$ & $\begin{array}{l}\text { 100-B SPRING } 37-1 \\
\text { 100-B SPRING 39-2 }\end{array}$ & $\begin{array}{l}\text { ONSIIE } \\
\text { ONSITE }\end{array}$ & SW & $\frac{N}{n}$ & $\begin{array}{l}\text { SEEP } \\
\text { SEEP }\end{array}$ & & $\begin{array}{l}\text { 20-0Cot-03 METHYC (Methlyenenchloride) } \\
\text { 20-Oct-03 METHYCH (Methlylenechloride) }\end{array}$ & & $\begin{array}{l}3 \mathrm{ugg} / \mathrm{L} \\
3 \mathrm{ug} / \mathrm{L}\end{array}$ & & & u & & \\
\hline SESPMNT & B17JNO & 100-K SPRING 63-2 & ONSITE & SW & $\mathrm{N}$ & SEEP & & 20-Oct-03 METHYCH (Methylenechloride) & & $3 \mathrm{ug} / \mathrm{L}$ & & & u & & \\
\hline SESPMNT & B17RR5 & 300 AREA SPR DR 42-2 & ONSITE & sW & $\mathrm{N}$ & SEEP & & 13-Oct-03 METHYCH (Methylenechloride) & & 3 uggh & & & u & & \\
\hline SESPMNT & B17RR6 & 300 AREA SPRING 42-2 & ONSITE & SW & $\mathrm{N}$ & SEEP & & 13-Oct-03 METHYCH (Methylenechloride) & & 3 ug/L & & & $u$ & & \\
\hline $\begin{array}{l}\text { PNLGW } \\
\text { SESPSPEC }\end{array}$ & B17LB1 & 100-F SPRING & ONSITE & SW & $\mathrm{N}$ & SEEP & & 20-Nov-03 PERCENE (Tetrachloroethene) & & $7 \mathrm{ug} / \mathrm{L}$ & & & u & & \\
\hline $\begin{array}{l}\text { SESPSPEC } \\
\text { SESPSPEC }\end{array}$ & B18134 & $100 \mathrm{~B} / \mathrm{C}$ AREA OUTFL2 & $\begin{array}{l}\text { ONSITE } \\
\text { ONSTEF }\end{array}$ & sw & $\mathrm{N}$ & $\begin{array}{l}\text { SEEP } \\
\text { SEEP }\end{array}$ & & $\begin{array}{l}\text { 17-Nov-033 PERCENE (Tetrachloroethene) } \\
\text { 1-No-023 PERENE Tetrachloroethenene }\end{array}$ & & $7 \mathrm{ug} / \mathrm{L}$ & & & $\mathrm{U}$ & & \\
\hline $\begin{array}{l}\text { SESPSECC } \\
\text { SESPSPEC }\end{array}$ & B18138 & $\begin{array}{l}\text { 100-B SPRING 39-2 } \\
\text { 100-B SPRING 37-1 }\end{array}$ & $\begin{array}{l}\text { ONSIE } \\
\text { ONSTEE }\end{array}$ & $\begin{array}{l}\text { SW } \\
\text { SW }\end{array}$ & $\frac{N}{n}$ & $\begin{array}{l}\text { SEEP } \\
\text { SEEP }\end{array}$ & & $\begin{array}{l}\text { 17-Nov-033 PERCENE (Tetrachloroethene) } \\
\text { 13-Nov-03 PRERENE (Tetrachloroethene) }\end{array}$ & 0.17 & $7 \mathrm{ug} / \mathrm{L}$ & & & u & & \\
\hline SESPSPEC & B18137 & 100-B SPRING 38-3 & ONSITE & sw & $\mathrm{n}$ & SEEP & & $\begin{array}{l}\text { 13-Nov-303 PRCEN (letrachioroetnene) } \\
\text { 13-Nov-03 PERCNE (Tetrachloroethene) }\end{array}$ & & $7 \mathrm{ug} / \mathrm{L}$ & & & u & & \\
\hline SESPMNT & B17JN1 & 100-K SPRING 77-1 & ONSITE & sW & $\mathrm{N}$ & SEEP & & 10-Nov-03 PERCENE (Tetrachloroethene) & & 7 uggh & & & UN & & \\
\hline SESPMNT & B17RR2 & 100-F SPRING 207-1 & ONSITE & SW & $\mathrm{N}$ & SEEP & & 03-Nov-03 PERCENE (Tetrachloroethene) & & $7 \mathrm{ug} / \mathrm{L}$ & & & u & & \\
\hline $\begin{array}{l}\text { SESPMNT } \\
\text { SESPMNT }\end{array}$ & B17JM8 & 100-B SPRING 37-1 & ONSITE & SW & $\mathrm{N}$ & SEEP & & 20-Oct-03 PERCENE (Tetrachloroethene) & & $7 \mathrm{ug} / \mathrm{L}$ & & & $\mathrm{U}$ & & \\
\hline $\begin{array}{l}\text { SESPMNT } \\
\text { SESPMNT }\end{array}-1-3$ & B17JM9 & 100-B SPRING 39-2 & ONSITE & SW & $\mathrm{N}$ & $\begin{array}{l}\text { SEEP } \\
\text { SEEP }\end{array}$ & & 20-Oct-03 PERCENE (Tetrachloroethene) & 0.17 & 7 ug/L & & & $\mathrm{U}$ & & \\
\hline $\begin{array}{l}\text { SESPMNT } \\
\text { SESPMNT }\end{array}$ & $\begin{array}{l}\text { BB7JNN } \\
\text { B17RR5 }\end{array}$ & $\begin{array}{l}\text { 100-K SPRING 63-2 } \\
\text { 300 AREA SPR DR 42-2 }\end{array}$ & $\begin{array}{l}\text { ONSIIE } \\
\text { ONSTTE }\end{array}$ & 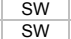 & 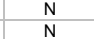 & $\begin{array}{l}\text { SEEP } \\
\text { SEEP }\end{array}$ & & $\begin{array}{l}\text { 20-OCt-003 PERCENE (Tetrachloroethene) } \\
\text { 13-Oct-03 PERCNE (TTtrachloroethene) }\end{array}$ & & $\begin{array}{l}7 \mathrm{uggh} \\
7 \mathrm{ug} / \mathrm{L}\end{array}$ & & & u & & \\
\hline SESPMNT & B17RR6 & 300 AREA SPRING 42-2 & ONSITE & sw & $\mathrm{N}$ & SEEP & & 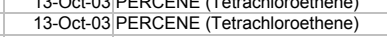 & & $7 \mathrm{ug} / \mathrm{L}$ & & & u & & \\
\hline PNLGW & B17LB1 & 100-F SPRING & ONSITE & SW & $\mathrm{N}$ & SEEP & & 20-Nov-03 TETHYDF (Tetrahydrofuran) & & 7 ug/L & & & $\mathrm{U}$ & & \\
\hline SESPSPEC & B18134 & $100 \mathrm{~B} / \mathrm{C}$ AREA OUTFL2 & ONSITE & SW & $\mathrm{N}$ & SEEP & & 17-Nov-03 TETHYDF (Tetrahydrofuran) & & $7 \mathrm{ug} / \mathrm{L}$ & & & U & & \\
\hline $\begin{array}{l}\text { SESPSPCC } \\
\text { SESPSEC }\end{array}$ & B18138 & $\begin{array}{l}\text { 100-B SPRING 39-2 } \\
\text { 100-B SPING 37-1 }\end{array}$ & $\begin{array}{l}\text { ONSIE } \\
\text { ONSTEE }\end{array}$ & SW & $\begin{array}{l}n \\
\mathrm{~N}\end{array}$ & $\begin{array}{l}\text { SEEP } \\
\text { SEEP }\end{array}$ & & $\begin{array}{l}\text { 17-Nov-03 TETHYDF (Tetrahydrofuran) } \\
\text { 13-Nov-03 TETYYDF (Tetrabydrofuran }\end{array}$ & & 7 ug/L & & & u & & \\
\hline & & & ONSITE ] & Sw & & SEEP & & 13-Nov-03 TETHYDF (Tetrahydrofuran) & & & & & & & \\
\hline
\end{tabular}




\begin{tabular}{|c|c|c|c|c|c|c|c|c|c|c|c|c|c|c|c|c|c|}
\hline | OWNER ID | & \begin{tabular}{|l} 
SAMP \\
NUM
\end{tabular} & SAMP SITE NAME & $\left|\begin{array}{c}\text { DIST } \\
\text { CLASS }\end{array}\right|$ & MEDIA & $\begin{array}{l}\text { FILTERED } \\
\text { FLAG }\end{array}$ & $\begin{array}{l}\text { SAMP } \\
\text { FROM }\end{array}$ & | COLL MTHD & |SAMP DATE| & & CON SHORT NAME & $\begin{array}{l}\text { VALUE } \\
\text { RPTD }\end{array}$ & \begin{tabular}{|l|} 
ANAL \\
UNITS \\
RPTD
\end{tabular} & $\left|\begin{array}{c}\text { COUNTING } \\
\text { ERROR }\end{array}\right|$ & $\begin{array}{l}\text { TOTAL } \\
\text { ANAL } \\
\text { ERROR }\end{array}$ & $\left|\begin{array}{c}\text { LAB } \\
\text { QUALIFIER }\end{array}\right|$ & SAMP COMMENT & $\left|\begin{array}{c}\text { RESULT } \\
\text { COMMENT }\end{array}\right|$ \\
\hline SESPSPEC & B18137 & 100-B SPRING 38-3 & ONSITE & SW & $\mathrm{N}$ & & & 13-Nov-03 & TETHYDF & (Tetrahydrofuran) & & & & & U & - & \\
\hline SESPMNT & B17JN1 & 100-K SPRING 77-1 & ONSITE & sw & $\mathrm{N}$ & SEEP & & 10-Nov-03 & TETHYDF & (Tetrahydrofuran) & & & & & u & & \\
\hline SESPMNT & B17RR2 & 100-F SPRING 207-1 & ONSITE & sw & $\mathrm{N}$ & SEEP & & 03-Nov-03 & TETHYDF & (Tetrahydrofuran) & & $\mathrm{ug} / \mathrm{L}$ & & & u & & \\
\hline SESPMNT & B17JM8 & 100-B SPRING 37-1 & ONSITE & sw & $\mathrm{N}$ & SEEP & & 20-Oct-03 & TETHYDF & (Tetrahydrofuran) & & & & & u & & \\
\hline SESPMNT & B17JM9 & 100-B SPRING 39-2 & ONSITE & SW & $N$ & SEEP & & 20-Oct-03 & TETHYDF & (Tetrahydrofuran) & & ug/L & & & U & & \\
\hline $\begin{array}{l}\text { SESPMNT } \\
\text { SESPMNT }\end{array}$ & $\begin{array}{l}\text { B17JN0 } \\
\text { B17RR5 }\end{array}$ & $\begin{array}{l}100-K \text { SPRING 63-2 } \\
300 \text { AREA SPR DR 42-2 }\end{array}$ & ONSITE & SW & $N$ & $\begin{array}{l}\text { SEEP } \\
\text { SEEP }\end{array}$ & & 20-Oct-03 & $\begin{array}{l}\text { TETHYDF } \\
\text { TTEYYDE }\end{array}$ & (Tetrahydrofuran) & & & & & U & & \\
\hline $\begin{array}{l}\text { SESPMNT } \\
\text { SESPMNT }\end{array}$ & $\begin{array}{l}\text { B17RR5 } \\
\text { B17RR6 }\end{array}$ & $\begin{array}{l}300 \text { AREA SPR DR 42-2 } \\
300 \text { AREA SPRING 42-2 }\end{array}$ & $\begin{array}{l}\text { ONITE } \\
\text { ONSITE }\end{array}$ & SW & $\frac{N}{n}$ & $\begin{array}{l}\text { SEEP } \\
\text { SEFP }\end{array}$ & & $\begin{array}{l}13-\text { Oct-03 } \\
13-0 c t-3 .\end{array}$ & TETHYDF & (Tetrahydrofuran) & & $\mathrm{ug} / \mathrm{L}$ & & & 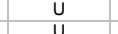 & & \\
\hline PNLGW & $\begin{array}{l}\text { B17LB1 } \\
\text { B17LR }\end{array}$ & 100-F SPRING & $\begin{array}{l}\text { ONSITE } \\
\text { ONSITE }\end{array}$ & sw & $\frac{n}{n}$ & $\begin{array}{l}\text { SEEP } \\
\text { SEEP }\end{array}$ & & $\begin{array}{r}13-\mathrm{OcC}-03 \\
20-\mathrm{Nov}-03\end{array}$ & $\begin{array}{l}\text { TOEHYDF } \\
\text { TOLUENE }\end{array}$ & & & $\begin{array}{l}\mathrm{ugg} / \mathrm{L} \\
\mathrm{ug} / \mathrm{L}\end{array}$ & & & u & & \\
\hline SESPSPEC & B18134 & 100 B/C AREA OUTFL2 & ONSITE & sw & $\mathrm{N}$ & SEEP & & 17-Nov-03 & TOLUENE & & & & & & U & & \\
\hline SESPSPEC & B18138 & 100-B SPRING 39-2 & ONIITE & sw & N & SEEP & & 17-Nov-03 & TOLUENE & & & & & & u & & \\
\hline SESPSPEC & B18136 & 100-B SPRING 37-1 & ONSITE & SW & $N$ & SEEP & & 13-Nov-03 & TOLUENE & & & & & & u & & \\
\hline $\begin{array}{l}\text { SESPSPEC } \\
\text { SESPMNT }\end{array}$ & B18137 & 100-B SPRING 38-3 & ONSITE & SW & $N$ & SEEP & & 13-Nov-03 & TOLUENE & & 0.12 & & & & U & & \\
\hline $\begin{array}{l}\text { SESPMNT } \\
\text { SESPMNT }\end{array}$ & $\begin{array}{l}\text { B17JN1 } \\
\text { B17RR2 }\end{array}$ & $\begin{array}{l}100-K \text { SPRING 77-1 } \\
\text { 100-F SPRING 207-1 }\end{array}$ & $\begin{array}{l}\text { ONITE } \\
\text { ONSITE }\end{array}$ & Sw & $i_{n}^{N}$ & $\begin{array}{l}\text { SEEP } \\
\text { SEEP }\end{array}$ & & 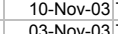 & $\begin{array}{l}\text { TOLUENE } \\
\text { TOQUENE }\end{array}$ & & 0.12 & ug/L & & & $u$ & & \\
\hline $\begin{array}{l}\text { SESPMNI } \\
\text { SESPMNT }\end{array}$ & $\begin{array}{l}\text { B17RR2 } \\
\text { B17JM8 }\end{array}$ & $\begin{array}{l}\text { 100-F SPRING 201-1 } \\
\text { 100-B SPRING 37-1 }\end{array}$ & $\begin{array}{l}\text { ONSIL } \\
\text { ONSITE }\end{array}$ & SW & $\frac{N}{N}$ & $\begin{array}{l}\text { SEEP } \\
\text { SEEP }\end{array}$ & & $\begin{array}{l}\text { O3-Nov-03 } \\
\text { 20-Oct-03: }\end{array}$ & $\begin{array}{l}\text { TLQUENE } \\
\text { TLLUENE }\end{array}$ & & $\frac{0.12}{0.12}-12$ & & & & $\frac{u}{u}$ & & \\
\hline SESPMNT & B17JM9 & 100-B SPRING 39-2 & ONSITE & SW & $\mathrm{N}$ & SEEP & & 20-Oct-03 & TOLUENE & & & & & & $\mathrm{J}$ & & \\
\hline SESPMNT & B17JNo & 100-K SPRING 63-2 & ONSITE & sW & $\mathrm{N}$ & & & & & & & & & & & & \\
\hline & & 300 AREA SPR DR 42-2 & ONSITE & SW & $\mathrm{N}$ & SEEP & & 13-Oct-03 & $\begin{array}{l}\text { TOLUENE } \\
\end{array}$ & & & & & & u & & \\
\hline ESPMNT & B17RR6 & 300 AREA SPRING 42-2 & ONSITE & sw & $\mathrm{N}$ & SEEP & & 13-Oct-03 & $\begin{array}{l}\text { TOLUENE } \\
\text { TOUEN }\end{array}$ & & & & & & & & \\
\hline PNLGW & B17LB1 & 100-F SPRING & ONSITE & sw & $\mathrm{N}$ & SEEP & & $20-\mathrm{Nov}-03$ & TRANDCE & (trans-1,2-Dichloroethylene) & 0.17 & ug/L & & & u & & \\
\hline SESPSPEC & B18134 & 100 B/C AREA OUTFL2 & ONSITE & sw & $\mathrm{N}$ & SEEP & & 17-Nov-03 & TRANDCE & $\begin{array}{l}\text { (trans-1,2-Dichloroethylene) } \\
\text { (a) }\end{array}$ & 0.17 & $\mathrm{ug} / \mathrm{L}$ & & & U & & \\
\hline SESPSPEC & B18138 & 100-B SPRING 39-2 & ONSITE & sw & $\mathrm{N}$ & SEEP & & 17-Nov-03 & TRANDCE & $=$ (trans-1,2-Dichloroethylene) & & $\mathrm{ug} / \mathrm{L}$ & & & u & & \\
\hline SESPSPEC & B18136 & 100-B SPRING 37-1 & ONSITE & sw & $\mathrm{N}$ & SEEP & & 13-Nov-03 & TRANDCE & E(trans-1,2-Dichloroethylene) & & & & & u & & \\
\hline SESPSPEC & B18137 & 100-B SPRING 38-3 & ONSITE & sw & $\mathrm{N}$ & SEEP & & 13-Nov-03 & TRANDCE & E(trans-1,2-Dichloroethylene) & & $\mathrm{ug} / \mathrm{L}$ & & & u & & \\
\hline SESPMNT & B17JN1 & 100-K SPRING 77-1 & ONSITE & SW & $N$ & SEEP & & 10-Nov-03 & TRANDCE & E(trans-1,2-Dichloroethylene) & 0.17 & ug/L & & & $u$ & & \\
\hline $\begin{array}{l}\text { SESPMNT } \\
\text { SECPMNTT }\end{array}$ & $\begin{array}{l}\text { B17RR2 } \\
\text { B171M8 }\end{array}$ & 100-F SPRING 207-1 & ONSITE & SW & $\mathrm{N}$ & $\begin{array}{l}\text { SEEP } \\
\text { SEEP }\end{array}$ & & 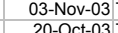 & TRANDCE & Etrans-1,2-Dichloroethylenen & 0.17 & & & & u & & \\
\hline $\begin{array}{l}\text { SESPMNT } \\
\text { SESPMNT }\end{array}$ & $\begin{array}{l}\text { B17JM8 } \\
\text { B17JM9 }\end{array}$ & $\begin{array}{l}\text { 100-B SPRING 37-1 } \\
\text { 100-B SPRING 39-2 }\end{array}$ & $\begin{array}{l}\text { ONITE } \\
\text { ONSITE }\end{array}$ & SW & $\frac{N}{N}$ & $\begin{array}{l}\text { SEEP } \\
\text { SEEP }\end{array}$ & & $\begin{array}{l}20-\text { Oct-03 } \\
\text { 20-Oct-03: }\end{array}$ & $\begin{array}{l}\text { TRANDCE } \\
\text { TAANDCE }\end{array}$ & 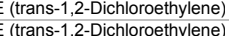 & $\begin{array}{l}0.17 \\
0.17\end{array}$ & ug / ug/L & & & $\frac{u}{u}$ & & \\
\hline $\begin{array}{l}\text { SESPMNI } \\
\text { SESPMNT }\end{array}$ & $\begin{array}{l}\text { B17JNO } \\
\text { B17JMe }\end{array}$ & $100-K$ SPRING $63-2$ & ONSITE & sw & $\frac{N}{n}$ & $\begin{array}{l}\text { SEEP } \\
\text { SEEP }\end{array}$ & & $\begin{array}{l}20-\mathrm{Occ}-\mathrm{O}-3 \\
20-\mathrm{Oct}-3\end{array}$ & $\begin{array}{l}\text { IRANDCE } \\
\text { TRANDCE }\end{array}$ & 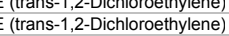 & & ugh/L & & & u & & \\
\hline SESPMNT & B17RR5 & 300 AREA SPR DR 42-2 & ONSITE & sw & $\mathrm{N}$ & SEEP & & 13-Oct-03 & TRANDCE & E(trans-1,2-Dichloroethylene) & 0.17 & $\mathrm{ug} / \mathrm{L}$ & & & U & & \\
\hline SESPMNT & B17RR6 & 300 AREA SPRING 42-2 & ONSITE & sw & $\mathrm{N}$ & SEEP & & 13-Oct-03 & TRANDCE & E(trans-1,2-Dichloroethylene) & 0.17 & $\mathrm{ug} / \mathrm{L}$ & & & u & & \\
\hline PNLGW & B17LB1 & 100-F SPRING & ONSITE & SW & $N$ & SEEP & & 20-Nov-03 & TRICELN, & (Trichloroethene) & 0.16 & ug/L & & & U & & \\
\hline $\begin{array}{l}\text { SESPSPEC } \\
\text { SESPSDPC }\end{array}$ & B18134 & $100 \mathrm{~B} / \mathrm{C}$ AREA OUTFL2 & ONSITE & SW & $\mathrm{N}$ & $\begin{array}{l}\text { SEEP } \\
\text { SEEP }\end{array}$ & & $\begin{array}{l}17-\text { Nov-03 } \\
\end{array}$ & TRICELN & (Trichloroethene) & 0.16 & ug/L & & & U & & \\
\hline $\begin{array}{l}\text { SESPSPEC } \\
\text { SESPSECC }\end{array}$ & $\begin{array}{l}\text { B } 18138 \\
\text { B18136 }\end{array}$ & $\begin{array}{l}\text { 100-B SPRING 39-2 } \\
\text { 100-B SPRING 37-1 }\end{array}$ & $\begin{array}{l}\text { ONITE } \\
\text { ONSITE }\end{array}$ & $\begin{array}{l}\text { SW } \\
\text { sw }\end{array}$ & $\begin{array}{l}\mathrm{N} \\
\mathrm{N}\end{array}$ & $\begin{array}{l}\text { SEEP } \\
\text { SEEP }\end{array}$ & & $\begin{array}{l}\text { 17-Nov-03 } \\
\text { 13-Nov-03: }\end{array}$ & $\begin{array}{l}\text { TRRCEN } \\
\text { TRICEN }\end{array}$ & $\begin{array}{l}\text { (Trirhhloroethene) } \\
\text { (Trichloroethene) }\end{array}$ & $\begin{array}{l}0.35 \\
0.31\end{array}$ & ug/L & & & $\mathrm{j}^{\mathrm{j}}$ & & \\
\hline $\begin{array}{l}\text { SESPSEC } \\
\text { SESPSPEC }\end{array}$ & B18137 & 100-B SPRING 38-1 & ONSITE & sw & $\frac{\mathrm{N}}{\mathrm{N}}$ & $\begin{array}{l}\text { SEEP } \\
\text { SEEP }\end{array}$ & & 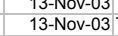 & $\begin{array}{l}\text { TRRCEN } \\
\text { TRICELN }\end{array}$ & $\begin{array}{l}\text { (Irichioroetnene) } \\
\text { (Trichloroethene) }\end{array}$ & 0.16 & ugh/L & & & u & & \\
\hline SESPMNT & B17JN1 & 100-K SPRING 77-1 & ONSITE & sw & $\mathrm{N}$ & SEEP & & 10-Nov-03 & TRICELN & (Trichloroethene) & 0.16 & & & & U & & \\
\hline SESPMNT & B17RR2 2 > & 100-F SPRING 207-1 & ONSITE & SW & $\mathrm{N}$ & SEEP & & 03-Nov-03 & TRICELN & (Trichloroethene) & 0.16 & $\mathrm{ug} / \mathrm{L}$ & & & u & & \\
\hline SESPMNT & B17JM8 & 100-B SPRING 37-1 & ONSITE & SW & $N$ & SEEP & & 20-Oct-03 & TRICELN, & (Trichloroethene) & 0.5 & ug/L & & & $\mathrm{J}$ & & \\
\hline $\begin{array}{l}\text { SESPMNT } \\
\text { SESPMNT }\end{array}$ & B17JM9 & $\begin{array}{l}\text { 100-B SPRING 39-2 } \\
1\end{array}$ & $\begin{array}{l}\text { ONSITE } \\
\text { ONITE }\end{array}$ & SW & $N$ & $\begin{array}{l}\text { SEEP } \\
\text { SEFP }\end{array}$ & & 20-Oct-03 & TRICELN & (Trichloroethene) & 0.61 & $\mathrm{ug} / \mathrm{L}$ & & & $\mathrm{J}$ & & \\
\hline $\begin{array}{l}\text { SESPMNT } \\
\text { SESPMNT }\end{array}$ & $\begin{array}{l}\text { B17JN0 } \\
\text { B17RR5 }\end{array}$ & $\begin{array}{l}100-K \text { SPRINGG 63-2 } \\
300 \text { AREA SPR DR 42-2 }\end{array}$ & $\begin{array}{l}\text { ONSITE } \\
\text { ONSITE }\end{array}$ & SW & $\frac{N}{N}$ & $\begin{array}{l}\text { SEEP } \\
\text { SEEP }\end{array}$ & & $\begin{array}{l}\text { 20-Oct-03 } \\
\text { 13-Oct-03: }\end{array}$ & $\begin{array}{l}\text { TRRCEN } \\
\text { TRICEN }\end{array}$ & $\begin{array}{l}\text { (TTrichloroethene) } \\
\text { (Trichloroethene) }\end{array}$ & $\frac{2.2}{2.2}$ & lug/L & & & & & \\
\hline SESPMNT & B17RR6 & $\begin{array}{l}300 \text { AREA SPR DR 42-2 } \\
300 \text { AREA SPRING 42-2 }\end{array}$ & ONSITE & sw & $\mathrm{N}$ & $\begin{array}{l}\text { SEEP } \\
\text { SEEP }\end{array}$ & & $\begin{array}{l}\text { 13-Oct-03 } \\
13-\mathrm{Oct}-03\end{array}$ & $\begin{array}{l}\text { IRRCEN } \\
\text { TRICELN }\end{array}$ & $\begin{array}{l}\text { (Irichioroetnene) } \\
\text { (Trichloroethene) }\end{array}$ & 0.16 & $\frac{u g h / L}{u g / L}$ & & & $u$ & & \\
\hline PNLGW & B17LB1 & 100-F SPRING & ONSITE & sw & $\mathrm{N}$ & SEEP & & 20-Nov-03 & VINYIDE ( & (Vinyl chloride) & 0.25 & ug/L & & & U & & \\
\hline SESPSPEC & B18134 & $100 \mathrm{~B} / \mathrm{C}$ AREA OUTFL2 & ONSITE & SW & $\mathrm{N}$ & SEEP & & 17-Nov-03 & VINYIDE ( & Vinyl chloride) & 0.25 & ug/L & & & U & & \\
\hline $\begin{array}{l}\text { SESPSPEC } \\
\text { SESDSDCC }\end{array}$ & B18138 & 100-B SPRING 39-2 & ONSITE & SW & $N$ & $\begin{array}{l}\text { SEEP } \\
\text { SEEP }\end{array}$ & & 17-Nov-03 & VINYIDE ( & Vinyl chloride) & 0.25 & $\mathrm{ug} / \mathrm{L}$ & & & u & & \\
\hline $\begin{array}{l}\text { SESPSPEC } \\
\text { SESPSPEC }\end{array}$ & B18136 & $\begin{array}{l}\text { 100-B SPRING 37-1 } \\
\text { 100-B SPRING 38-3 }\end{array}$ & $\begin{array}{l}\text { ONITE } \\
\text { ONSITE }\end{array}$ & $\begin{array}{l}\text { SW } \\
\text { Sw }\end{array}$ & $\frac{N}{N}$ & $\begin{array}{l}\text { SEEP } \\
\text { SEFP }\end{array}$ & & 13-Nov-03 & $\begin{array}{l}\text { VINYIDE }(1) \\
\text { VINYDEO }\end{array}$ & $\begin{array}{l}\text { Vinyl chloride) } \\
\text { Vinylloride) }\end{array}$ & 0.25 & & & & 0 & & \\
\hline $\begin{array}{l}\text { SESPSECC } \\
\text { SESPMNT }\end{array}$ & $\begin{array}{l}\text { B18137 } \\
\text { B17JN1 }\end{array}$ & $\begin{array}{l}\text { 100-B SPRING 38-3 } \\
\text { 100-K SPRING 77-1 }\end{array}$ & $\begin{array}{l}\text { ONSITE } \\
\text { ONSITE }\end{array}$ & $\begin{array}{l}\text { SW } \\
\text { SW }\end{array}$ & $\frac{N}{n}$ & $\begin{array}{l}\text { SEEP } \\
\text { SEEP }\end{array}$ & & $\begin{array}{l}\text { 13-Nov-03 } \\
10-N o v-03 \\
\end{array}$ & $\begin{array}{l}\text { VINYIDE }(1) \\
\operatorname{VINYDE}(-)\end{array}$ & $\begin{array}{l}\text { Vinyl chloride) } \\
\text { Vinyl chloride) }\end{array}$ & 0.25 & ig// & & & u & & \\
\hline SESPMNT & $\begin{array}{l}\text { D17RR2 } \\
\text { B17RR2 }\end{array}$ & 100-F SPRING 207-1 & ONSITE & sw & $\mathrm{N}$ & SEEP & & 03-Nov-03 & VINYIDE ( & Vinyl chloride) & & ug/L & & & u & & \\
\hline SESPMNT & B17JM8 & 100-B SPRING 37-1 & ONSITE & sW & $\mathrm{N}$ & SEEP & & 20-Oct-03 & VINYIDE $\left(C_{0}\right.$ & (Vinyl chloride) & & ug/L & & & U & & \\
\hline SESPMNT & B17JM9 & 100-B SPRING 39-2 & ONSITE & SW & $\mathrm{N}$ & SEEP & & 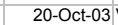 & & (Vinyl chloride) & 0.25 & & & & $U$ & & \\
\hline SESPMNT & B17JNO & $\begin{array}{l}100-K \text { SPRING } 63-2 \\
\text { 100R }\end{array}$ & ONSITE & sw & $\mathrm{N}$ & SEEP & & 20 -Oct-03 & VINYIDEO & (Vinyl chloride) & 0.25 & ug/ & & & $u$ & & \\
\hline SESPMNT & B17RR5 & 300 AREA SPR DR 42-2 & ONSITE & sw & $\mathrm{N}$ & SEEP & & 13-Oct-03 & VINYIDE $(1)$ & Vinyl chloride) & 0.25 & ug/h & & & u & & \\
\hline SESPMNT & B17RR6 & 300 AREA SPRING 42-2 & ONSITE & SW & $\mathrm{N}$ & SEEP & & 13-Oct-03 & VINYIDE $(0)$ & Vinyl chloride) & 0.25 & $\mathrm{ug} / \mathrm{L}$ & & & U & & \\
\hline PNLGW & B17LB1 & 100-F SPRING & ONSITE & sw & $\mathrm{N}$ & SEEP & & $20-$ Nov-03 & XYLENES & & 0.28 & ug/L & & & u & & \\
\hline SESPSPEC & B18134 & 100 B/C AREA OUTFL2 & ONSITE & sw & $\mathrm{N}$ & SEEP & & 17-Nov-03 & XYLENES & & 0.28 & $\mathrm{ug} / \mathrm{L}$ & & & U & & \\
\hline SESPSPEC & B18138 & 100-B SPRING 39-2 & ONSITE & sw & $\mathrm{N}$ & SEEP & & 17-Nov-03 & XYLENES & & 0.28 & ug/L & & & $u$ & & \\
\hline SESPSPEC & B18136 & 100-B SPRING 37-1 & ONSITE & SW & $N$ & SEEP & & 13-Nov-03 & & & 0.28 & ug/L & & & $u$ & & \\
\hline SESPSPEC & B18137 & 100-B SPRING 38-3 & ONSITE & SW & $N$ & SEEP & & 13-Nov-03 & XYLENES & & 0.28 & & & & U & & \\
\hline $\begin{array}{l}\text { SESPMNT } \\
\text { SESPMNT }\end{array}$ & $\begin{array}{l}\text { B17JN1 } \\
\text { B17PR2 }\end{array}$ & $\begin{array}{l}\text { 100-K SPRING 77-1 } \\
100-\mathrm{F} \text { SPRING } 207-1\end{array}$ & $\begin{array}{l}\text { ONSITE } \\
\text { ONSITE }\end{array}$ & SW & $N^{n}$ & $\begin{array}{l}\text { SEEP } \\
\text { SEEP }\end{array}$ & & $\begin{array}{l}10-N o v-03 \\
03-N o y-03\end{array}$ & $\begin{array}{l}\text { XYLENES } \\
\text { XYLES }\end{array}$ & & 0.28 & ig/L & & & $u$ & & \\
\hline $\begin{array}{l}\text { SESPMNI } \\
\text { SESPMNT }\end{array}$ & $\begin{array}{l}\text { B/RR2 } \\
\text { B17JM8 }\end{array}$ & $\begin{array}{l}10-\mathrm{F} \text { SPRING } 200-1 \\
100-\mathrm{B} \text { SPRING 37-1 }\end{array}$ & $\begin{array}{l}\text { ONSIL } \\
\text { ONSITE }\end{array}$ & SW & $\frac{N}{n}$ & $\begin{array}{l}\text { SEEP } \\
\text { SEEP }\end{array}$ & & $\begin{array}{l}\text { O3-Nov-03 } \\
20-O c t-03\end{array}$ & $\begin{array}{l}\text { XYLENES } \\
\text { XYLENES }\end{array}$ & & 0.28 & $\frac{u g h / /}{u g h / L}$ & & & u & & \\
\hline SESPMNT & B17JM9 & 100-B SPRING 39-2 & ONSITE & sw & $\mathrm{N}$ & SEEP & & 20-Oct-03 & XYLENES & & 0.66 & $\mathrm{ug} / \mathrm{L}$ & & & $\mathrm{J}$ & & \\
\hline SESPMNT & B17JNo & 100-K SPRING 63-2 & ONSITE & sw & $\mathrm{N}$ & SEEP & & $20-0 c t-03$ & XYLENES & & 0.28 & & & & u & & \\
\hline SESPMNT & B17RR5 & 300 AREA SPR DR 42-2 & ONSITE & SW & $\mathrm{N}$ & SEEP & & 13-Oct-03 & XYLENES & & 0.28 & jug/L & & & u & & \\
\hline SESPMNT & B17RR6 & 300 AREA SPRING 42-2 & ONSITE & SW & $N$ & SEEP & & 13-Oct-03 & XYLENES & & 0.28 & & & & u & & \\
\hline $\begin{array}{l}\text { PNLGW } \\
\text { PNLGW }\end{array}$ & $\begin{array}{l}\text { B17L25 } \\
\text { B17N21 }\end{array}$ & $\begin{array}{l}\text { SEEP 037-1 } \\
\text { SK-057-3 }\end{array}$ & & $\begin{array}{l}\text { SW } \\
\text { SW }\end{array}$ & $\begin{array}{l}n \\
N\end{array}$ & $\begin{array}{l}\text { SEEP } \\
\text { SEEP }\end{array}$ & & $\begin{array}{l}\text { 10-Nov-03 } \\
\text { 10-Nov-03 }\end{array}$ & & & & $\mathrm{pH}$ & & & & & \\
\hline $\begin{array}{l}\text { PNLGW } \\
\text { PNLG }\end{array}$ & $\begin{array}{l}\mathrm{B} 1 \mathrm{~W} 21 \\
\mathrm{~B} 17 \mathrm{VJ} 6\end{array}$ & $\begin{array}{l}\text { SK-05/-3 } \\
\text { SD-110-2 }\end{array}$ & & sw & $\frac{n}{n}$ & $\begin{array}{l}\text { SEEP } \\
\text { SEEP }\end{array}$ & & $\begin{array}{l}\text { 价-Nov-03 } \\
10-\text { Nov-03 }\end{array}$ & & & 7.2 & & & & & & \\
\hline
\end{tabular}


ENVIRONMENTAL SURVEILLANCE DATA CY03

WATER - COLUMBIA RIVER SHORELINE SPRINGS

\begin{tabular}{|c|c|c|c|c|c|c|c|c|c|c|c|c|c|c|c|}
\hline | OWNER ID | & $\begin{array}{l}\text { SAMP } \\
\text { NUM }\end{array}$ & SAMP SITE NAME & $\left|\begin{array}{c}\text { DIST } \\
\text { CLASS }\end{array}\right|$ & $\mid$ MEDIA $\mid$ & \begin{tabular}{|c|} 
FILTERED \\
FLAAG
\end{tabular} & $\left|\begin{array}{l}\text { SAMP } \\
\text { FROM }\end{array}\right|$ & COLL MTHD & CON SHORT NAME & $\begin{array}{l}\text { VALUE } \\
\text { RPTD }\end{array}$ & $\left|\begin{array}{|c|}\text { ANAL } \\
\text { UNITS } \\
\text { RPTD }\end{array}\right|$ & \begin{tabular}{|c|} 
COUNTING \\
ERROR
\end{tabular} & $\begin{array}{c}\text { TOTAL } \\
\text { ANAL } \\
\text { ERROR }\end{array}$ & $\left|\begin{array}{c}\text { LAB } \\
\text { QUALIFIER }\end{array}\right|$ & SAMP COMMENT & \begin{tabular}{|c|} 
RESULT \\
COMMENT
\end{tabular} \\
\hline PNLGW & B17VJ9 & SD-098-1 & & sw & N & SEEP & & 10-Nov-03 pH & & & & & & & \\
\hline PNLGW & B17JP8 & 100-K SPRING 77-1 & ONSITE & sW & $\mathrm{N}$ & SEEP & & 10-Nov-03 pH & & & & & & & \\
\hline PNLGW & B17LB5 & 100-K SPRING 68-1 & ONSITE & SW & $\mathrm{N}$ & SEEP & & 10-Nov-03 pH & & & & & & & \\
\hline $\begin{array}{l}\text { PNLGW } \\
\text { PNIGWI }\end{array}$ & $\begin{array}{l}\text { B17LF3 } \\
\text { B17YK2 }\end{array}$ & 100-K SPRING 68-1 & ONSITE & SW & $\mathrm{N}$ & SEEP & & 10-Nov-03 pH & & & & & & & \\
\hline $\begin{array}{l}\text { PNLGW } \\
\text { PNLGW }\end{array}$ & $\begin{array}{l}\text { B17VK2 } \\
\text { B17VK5 }\end{array}$ & $\begin{array}{l}\text { SH-144-1 } \\
100 \text { SPRING } 150-1\end{array}$ & ONSITE & $\begin{array}{l}\text { SW } \\
\text { sw }\end{array}$ & $\begin{array}{l}\mathrm{N} \\
\mathrm{N}\end{array}$ & $\begin{array}{l}\text { SEEP } \\
\text { SEPP }\end{array}$ & & $\begin{array}{l}20-N o v-03 \mathrm{pH} \\
20-0 v-03 \mathrm{pH}\end{array}$ & & $3 \mathrm{pH}$ & & & 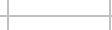 & & \\
\hline $\begin{array}{l}\text { PNLGW } \\
\text { PNLGW }\end{array}$ & $\begin{array}{l}\text { B17VK5 } \\
\text { B17VLO }\end{array}$ & $\begin{array}{l}\text { 100-H SPRING } 150-1 \\
\text { SH-153-1 }\end{array}$ & ONSIIT & $\begin{array}{l}\text { Sw } \\
\text { SW }\end{array}$ & $\frac{N}{N}$ & $\begin{array}{l}\text { SEEP } \\
\text { SEEP }\end{array}$ & & $\begin{array}{l}20-\mathrm{N} \text {-Nvov-03 } \mathrm{pH} \\
20-03 \mathrm{pH}\end{array}$ & & $\begin{array}{l}1 \mathrm{pH} \\
1 \mathrm{pH}\end{array}$ & & & & & \\
\hline PNLGW & B17LB1 & 100-F SPRING & ONSITE & SW & $\mathrm{N}$ & SEEP & & 20-Nov-03 pH & & $7 \mathrm{pH}$ & & & & & \\
\hline PNLGW & B17L25 & SEEP 037-1 & & sw & $\mathrm{N}$ & SEEP & & 10-Nov-03 CONDUCT & & $5 \mathrm{uS} / \mathrm{cm}$ & & & & & \\
\hline PNLGW & B17W21 & SK-057-3 & & SW & $\mathrm{N}$ & SEEP & & 10-Nov-03 CONDUCT & & $2 \mathrm{uS} / \mathrm{cm}$ & & & & & \\
\hline $\begin{array}{l}\text { PNLGW } \\
\text { PNIGW }\end{array}$ & B17VJ6 & $\begin{array}{l}\text { SD-110-2 } \\
\text { SD-098-1 }\end{array}$ & 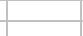 & SW & $n^{n}$ & $\begin{array}{l}\text { SEEP } \\
\text { SEFP }\end{array}$ & & 10-Nov-03 CONDUCT & 177 & $7 \mathrm{uS} / \mathrm{cm}$ & & & & & \\
\hline $\begin{array}{l}\text { PNLGW } \\
\text { PNLGW }\end{array}$ & $\begin{array}{l}\text { B17VJ9 } \\
\text { B17JP8 }\end{array}$ & $\begin{array}{l}\text { SD-098-1 } \\
\text { 100-K SPRING 77-1 }\end{array}$ & ONSITE & $\begin{array}{l}\text { SW } \\
\text { SW }\end{array}$ & $\frac{N}{N}$ & $\begin{array}{l}\text { SEEP } \\
\text { SEPP }\end{array}$ & & $\begin{array}{l}\text { 10-Nov-03 CONDUCT } \\
10-\text { No-03 CONUCT }\end{array}$ & 165 & $\begin{array}{l}5 \mathrm{uS} / \mathrm{cm} \\
4 \mathrm{us} / \mathrm{cm} \\
\end{array}$ & & & & & \\
\hline PNLGW & B17LB5 & 100-K SPRING 68-1 & ONSITE & sw & $\frac{N}{N}$ & $\begin{array}{l}\text { SEEP } \\
\text { SEEP }\end{array}$ & & 10-Nov-03 CONDUCT & & $6 \mathrm{uS} / \mathrm{cm}$ & & & & & \\
\hline PNLGW & B17LF3 & 100-K SPRING 68-1 & ONSITE & sW & $\mathrm{N}$ & SEEP & & 10-Nov-03 CONDUCT & & $6 \mathrm{us} / \mathrm{cm}$ & & & & & \\
\hline PNLGW & B17VK2 & SH-144-1 & & SW & $\mathrm{N}$ & SEEP & & 20-Nov-03 CONDUCT & & $9 \mathrm{uS} / \mathrm{cm}$ & & & & & \\
\hline PNLGW & B17VK5 & 100-H SPRING 150-1 & ONSITE & SW & $N$ & SEEP & & 20-Nov-03 CONDUCT & & $2 \mathrm{uS} / \mathrm{cm}$ & & & & & \\
\hline $\begin{array}{l}\text { PNLGW } \\
\text { PNDGW }\end{array}$ & B17VLO & SH-153-1 & & SW & $\mathrm{N}$ & $\begin{array}{l}\text { SEEP } \\
\text { SEFP }\end{array}$ & & 20-Nov-03 CONDUCT & & $9 \mathrm{uS} / \mathrm{cm}$ & & & & & \\
\hline $\begin{array}{l}\text { PNLGW } \\
\text { PNLGW }\end{array}$ & $\begin{array}{l}\text { B17LB1 } \\
\text { B17JR2 }\end{array}$ & $\begin{array}{l}\text { 100-F SPRING } \\
100-K \text { SPRING }\end{array}$ & $\begin{array}{l}\text { ONSTE } \\
\text { ONSITE }\end{array}$ & SW & $\mathrm{N}$ & $\begin{array}{l}\text { SEEP } \\
\text { SEFP }\end{array}$ & & 20-Nov-03 CONDUCT & & $5 \mathrm{uS} / \mathrm{cm}$ & & & & & \\
\hline $\begin{array}{l}\text { PNLGW } \\
\text { PNLGW }\end{array}$ & $\begin{array}{l}\text { BifJR2 } \\
\text { B17LF3 }\end{array}$ & $\begin{array}{l}100-K S P R I N G 63-1 \\
100-K \text { SPRING 68-1 }\end{array}$ & $\begin{array}{l}\text { ONSITE } \\
\text { ONS }\end{array}$ & sw & $\frac{n}{n}$ & $\begin{array}{l}\text { SEEP } \\
\text { SEEP }\end{array}$ & & $\begin{array}{l}20-0 \mathrm{Cc}-033-14 \\
10-\mathrm{Nov}-03 \mathrm{C}-14\end{array}$ & & $\begin{array}{l}8 \mathrm{pCCL} \\
7 \mathrm{pCi/L}\end{array}$ & $\begin{array}{r}13 \\
5.8\end{array}$ & $\begin{array}{r}26 \\
7.2\end{array}$ & & & \\
\hline PNLGW & B17L82 & SEEP 037-1 & & SW & $\mathrm{N}$ & SEEP & & 10-Nov-03 CR+6 & 0.0015 & $5 \mathrm{mg} / \mathrm{L}$ & & & U & & \\
\hline
\end{tabular}


WATER - IRRIGATION

\begin{tabular}{|c|c|c|c|c|c|c|c|c|c|c|c|c|c|c|c|c|}
\hline OWNER ID & SAMP NUM & SAMP SITE NAME & DIST CLASS & MEDIA & $\begin{array}{c}\text { FILTERED } \\
\text { FLAG }\end{array}$ & SAMP FROM & COLL MTHD & SAMP DATE & CON SHORT NAME & VALUE RPTD & \begin{tabular}{|l|l|} 
ANAL \\
UNITS \\
RPTDT
\end{tabular} & $\begin{array}{c}\text { COUNTING } \\
\text { ERROR }\end{array}$ & $\begin{array}{l}\text { TOTAL ANAL } \\
\text { ERROR }\end{array}$ & $\begin{array}{c}\text { LAB } \\
\text { QUALIFIER }\end{array}$ & SAMP COMMENT & RESULT COMMENT \\
\hline SESPMNT & B16WK5 & HORN RAPIDS AREA & PERIMETER & sW & $\mathrm{N}$ & IRRIGATION & UNFILTERED & 05-May-03 & LPPHA & 0.606 & $\mathrm{pCi/L}$ & 0.71 & 0.73 & u & & \\
\hline SESPMNT & B16WJ0 & RIVERVIEW CANAL & OFFSITE & sw & $\mathrm{N}$ & IRRIGATION & UNFILTERED & $09-M a y-03$ & LLPHA & 0.746 & $\mathrm{pCi} / \mathrm{L}$ & 0.82 & 0.84 & u & & \\
\hline SESPMNT & B171K5 & HORN RAPIDS AREA & PERIMETER & sW & $\mathrm{N}$ & IRRIGATION & UNFILTERED & 03-Jun-03 & LLPHA & & $\mathrm{pCi} / \mathrm{L}$ & 0.53 & 0.54 & $u$ & & \\
\hline SESPMNT & B171J5 & RIVERVIEW CANAL & OFFSITE & sW & $\mathrm{N}$ & IRRIGATION & UNFILTERED & 03-Jun-03 & ALPHA & & $\mathrm{pCi} / \mathrm{L}$ & 0.94 & 0.98 & & & \\
\hline SESPMNT & B176T1 & HORN RAPIDS AREA & PERIMETER & sw & $\mathrm{N}$ & IRRIGATION & UNFILTERED & 09-Jul-03 & LLPHA & 0.296 & $\mathrm{pCi} / \mathrm{L}$ & 0.64 & 0.65 & $u$ & & \\
\hline SESPMNT & B176RO & $\begin{array}{l}\text { RIVERVIEW CANAL } \\
\text { R }\end{array}$ & $\begin{array}{l}\text { OFFSITE } \\
\text { OFS }\end{array}$ & sw & $\mathrm{N}$ & $\begin{array}{l}\text { IRRIGATION } \\
\text { InI }\end{array}$ & UNFILTERED & 09-Jul-03 & LLPHA & 0.495 & $\mathrm{pCi} / \mathrm{L}$ & 0.67 & 0.68 & u & & \\
\hline SESPMNT & B16WK5 & HORN RAPIDS AREA & PERIMETER & sW & $\mathrm{N}$ & IRRIGATION & UNFILTERED & 05-May-03 & BETA & 0.646 & $\mathrm{pCi} / \mathrm{L}$ & 1.3 & 1.4 & $u$ & & \\
\hline SESPMNT & B16WJo & RIVERVIEW CANAL & OFFSITE & sW & $\mathrm{N}$ & IRRIGATION & UNFILTERED & 09-May-03 & BETA & 1.15 & $\mathrm{pCi} / \mathrm{L}$ & 1.4 & 1.5 & u & & \\
\hline SESPMNT & B171K5 & HORN RAPIDS AREA & PERIMETER & sw & $\mathrm{N}$ & IRRIGATION & UNFILTERED & 03-Jun-03 & EETA & 2.14 & $\mathrm{pCi/L}$ & 1.4 & 1.4 & u & & \\
\hline SESPMNT & B171J5 & RIVERVIEW CANAL & OFFSITE & sw & $\mathrm{N}$ & $\begin{array}{l}\text { IRRIGATION } \\
\text { InIT }\end{array}$ & UNFILTERED & 03-Jun-03 & EETA & 2.22 & $\mathrm{pCi} / \mathrm{L}$ & 1.4 & 1.4 & u & & \\
\hline SESPMNT & B176T1 & HORN RAPIDS AREA & PERIMETER & sW & $\mathrm{N}$ & IRRIGATION & UNFILTERED & 09-Jul-03 & BETA & & $\mathrm{pCi} / \mathrm{L}$ & 1.3 & 1.5 & $\mathrm{U}$ & & \\
\hline SESPMNT & B176R0 & RIVERVIEW CANAL & OFFSITE & sw & $\mathrm{N}$ & IRRIGATION & UNFILTERED & 09-Jul-03 & BETA & 2.34 & $\mathrm{pCi} / \mathrm{L}$ & 1.4 & 1.6 & u & & \\
\hline SESPMNT & B16WK5 & HORN RAPIDS AREA & PERIMETER & sW & $\mathrm{N}$ & IRRIGATION & UNFILTERED & 05-May-03 & $3 \mathrm{e}-7$ & -9.18 & $\mathrm{pCi} / \mathrm{L}$ & 21 & 21 & u & & \\
\hline SESPMNT & B16WJo & RIVERVIEW CANAL & OFFSITE & sw & $\mathrm{N}$ & IRRIGATION & UNFILTERED & $09-M a y-03$ & $3 e-7$ & 14.3 & $\mathrm{pCi} / \mathrm{L}$ & 21 & 21 & u & & \\
\hline SESPMNT & B171K5 & HORN RAPIDS AREA & PERIMETER & sW & $\mathrm{N}$ & IRRIGATION & UNFILTERED & 03-Jun-03 & $3 e-7$ & -3.11 & $\mathrm{pCi} / \mathrm{L}$ & 21 & 21 & U & & \\
\hline SESPMNT & B171J5 & RIVERVIEW CANAL & OFFSITE & sW & $\mathrm{N}$ & IRRIGATION & UNFILTERED & 03-Jun-03 & $3 e-7$ & -14.6 & $\mathrm{pCi} / \mathrm{L}$ & 20 & 20 & u & & \\
\hline SESPMNT & B176T1 & HORN RAPIDS AREA & PERIMETER & sw & $\mathrm{N}$ & IRRIGATION & UNFILTERED & 09-Jul-03 & & 5.79 & $\mathrm{pCi} / \mathrm{L}$ & 21 & 21 & $u$ & & \\
\hline SESPMNT & B176R0 & RIVERVIEW CANAL & OFFSITE & sw & $\mathrm{N}$ & $\begin{array}{l}\text { IRRIGATION } \\
\text { IRIT }\end{array}$ & UNFILTERED & 09-Jul-03 & & -7.17 & $\mathrm{pCi} / \mathrm{L}$ & 24 & 24 & u & & \\
\hline SESPMNT & B16WK5 & HORN RAPIDS AREA & PERIMETER & sw & $\mathrm{N}$ & IRRIGATION & UNFILTERED & 05-May-03 & $20-60$ & 0.623 & $\mathrm{pCi} / \mathrm{L}$ & 2.4 & 2.4 & $\mathrm{U}$ & & \\
\hline SESPMNT & B16WJO & RIVERVIEW CANAL & OFFSITE & sw & $\mathrm{N}$ & IRRIGATION & UNFILTERED & $09-$ May-03 & $0-60$ & 1.02 & $\mathrm{pCi} / \mathrm{L}$ & 2.2 & 2.2 & $u$ & & \\
\hline SESPMNT & B171K5 & HORN RAPIDS AREA & PERIMETER & sw & $\mathrm{N}$ & IRRIGATION & UNFILTERED & 03-Jun-03 & $0-60$ & -0.0732 & $\mathrm{pCi} / \mathrm{L}$ & 2.8 & 2.8 & $u$ & & \\
\hline SESPMNT & B171J5 & RIVERVIEW CANAL & OFFSITE & sW & $\mathrm{N}$ & IRRIGATION & UNFILTERED & 03-Jun-03 & $-0-60$ & 1.69 & $\mathrm{pCi} / \mathrm{L}$ & 2.1 & 2.1 & u & & \\
\hline SESPMNT & B176T1 & HORN RAPIDS AREA & PERIMETER & sW & $\mathrm{N}$ & IRRIGATION & UNFILTERED & 09-Jul-03 & $0-60$ & 1.65 & $\mathrm{pCi} / \mathrm{L}$ & 2.6 & 2.6 & U & & \\
\hline SESPMNT & B176R0 & RIVERVIEW CANAL & OFFSITE & sw & $\mathrm{N}$ & IRRIGATION & UNFILTERED & 09-Jul-03 & $20-60$ & 0.109 & $\mathrm{pCi} / \mathrm{L}$ & 2.3 & 2.3 & $u$ & & \\
\hline SESPMNT & B16WK5 & HORN RAPIDS AREA & PERIMETER & sw & $\mathrm{N}$ & IRRIGATION & UNFILTERED & 05-May-03 & $s-134$ & 0.881 & $\mathrm{pCi} / \mathrm{L}$ & 3.1 & 3.1 & $u$ & & \\
\hline SESPMNT & B16WJO & RIVERVIEW CANAL & OFFSITE & sw & $\mathrm{N}$ & IRRIGATION & UNFILTERED & 09-May-03 & ss-134 & 0.667 & $\mathrm{pCi} / \mathrm{L}$ & 2.6 & 2.6 & u & & \\
\hline SESPMNT & B171K5 & HORN RAPIDS AREA & PERIMETER & sW & $\mathrm{N}$ & IRRIGATION & UNFILTERED & 03-Jun-03 & ss-134 & 1.32 & $\mathrm{pCi} / \mathrm{L}$ & 2.3 & 2.3 & U & & \\
\hline SESPMNT & B171J5 & RIVERVIEW CANAL & OFFSITE & sw & $\mathrm{N}$ & IRRIGATION & UNFILTERED & 03-Jun-03 & ss-134 & 0.188 & $\mathrm{pCi} / \mathrm{L}$ & 2.8 & 2.8 & $u$ & & \\
\hline SESPMNT & B176T1 & HORN RAPIDS AREA & PERIMETER & sw & $\mathrm{N}$ & IRRIGATION & UNFILTERED & 09-Jul-03 & s-134 & 1.75 & $\mathrm{pCi} / \mathrm{L}$ & 2.2 & 2.2 & u & & \\
\hline SESPMNT & B176RO & RIVERVIEW CANAL & OFFSITE & sw & $\mathrm{N}$ & IRRIGATION & UNFILTERED & 09-Jul-03 & $s-134$ & 2.68 & $\mathrm{pCi/L}$ & 3 & 3 & u & & \\
\hline SESPMNT & B16WK5 & HORN RAPIDS AREA & PERIMETER & sW & $\mathrm{N}$ & IRRIGATION & UNFILTERED & 05-May-03 & ss-137 & 1.73 & $\mathrm{pCi} / \mathrm{L}$ & 2.5 & 2.5 & u & & \\
\hline SESPMNT & B16WJO & RIVERVIEW CANAL & OFFSITE & sw & $\mathrm{N}$ & IRRIGATION & UNFILTERED & 09-May-03 & ss-137 & 0.195 & $\mathrm{pCi} / \mathrm{L}$ & 2.5 & 2.5 & $u$ & & \\
\hline SESPMNT & B171K5 & HORN RAPIDS AREA & PERIMETER & sW & $\mathrm{N}$ & IRRIGATION & UNFILTERED & 03-Jun-03 & ss-137 & -1.47 & $\mathrm{pCi} / \mathrm{L}$ & 2.2 & 2.2 & U & & \\
\hline SESPMNT & B171J5 & RIVERVIEW CANAL & OFFSITE & sw & $\mathrm{N}$ & IRRIGATION & UNFILTERED & 03-Jun-03 & ss-137 & -0.12 & $\mathrm{pCi} / \mathrm{L}$ & 2.5 & 2.5 & u & & \\
\hline SESPMNT & $\begin{array}{l}\text { B176T1 } \\
\text { B175 }\end{array}$ & HORN RAPIDS AREA & PERIMETER & sW & $\mathrm{N}$ & IRRIGATION & UNFILTERED & 09-Jul-03 & ss-137 & 0.689 & $\mathrm{pCi} / \mathrm{L}$ & 2.3 & 2.3 & u & & \\
\hline SESPMNT & B176R0 & RIVERVIEW CANAL & OFFSITE & sw & $\mathrm{N}$ & IRRIGATION & UNFILTERED & 09-Jul-03 & ss-137 & -1.01 & $\mathrm{pCi} / \mathrm{L}$ & 2.6 & 2.6 & u & & \\
\hline SESPMNT & B16WK5 & HORN RAPIDS AREA & PERIMETER & sW & $\mathrm{N}$ & IRRIGATION & UNFILTERED & $05-$ May-03 & Eu-152 & 3.93 & $\mathrm{pCi} / \mathrm{L}$ & 2.0 & 2.0 & u & & \\
\hline SESPMNT & B16WJo & RIVERVIEW CANAL & OFFSITE & sw & $\mathrm{N}$ & IRRIGATION & UNFILTERED & 09-May-03 & Eu-152 & & $\mathrm{pCi/L}$ & 5.9 & 5.9 & u & & \\
\hline SESPMNT & B171K5 & HORN RAPIDS AREA & PERIMETER & sw & $\mathrm{N}$ & IRRIGATION & UNFILTERED & 03-Jun-03 & Eu-152 & -2.53 & $\mathrm{pCi} / \mathrm{L}$ & 4.5 & 4.5 & u & & \\
\hline SESPMNT & B171J5 & RIVERVIEW CANAL & OFFSITE & sW & $\mathrm{N}$ & IRRIGATION & UNFILTERED & 03-Jun-03 & Eu-152 & 1.48 & $\mathrm{pCi} / \mathrm{L}$ & 6.3 & 6.3 & U & & \\
\hline SESPMNT & B176T1 & HORN RAPIDS AREA & PERIMETER & sw & $\mathrm{N}$ & IRRIGATION & UNFILTERED & 09-Jul-03 & Eu-152 & 0.514 & $\mathrm{pCi} / \mathrm{L}$ & 5.4 & 5.4 & $u$ & & \\
\hline SESPMNT & B176RO & RIVERVIEW CANAL & OFFSITE & sw & $\mathrm{N}$ & IRRIGATION & UNFILTERED & 09-Jul-03 & Eu-152 & 0.356 & $\mathrm{pCi/L}$ & 6.3 & 6.3 & u & & \\
\hline SESPMNT & B16WK5 & HORN RAPIDS AREA & PERIMETER & sW & $\mathrm{N}$ & IRRIGATION & UNFILTERED & $05-$ May-03 & Eu-154 & -1.33 & $\mathrm{pCi/L}$ & 7.1 & 7.1 & u & & \\
\hline SESPMNT & B16WJo & RIVERVIEW CANAL & OFFSITE & sW & $\mathrm{N}$ & IRRIGATION & UNFILTERED & 09-May-03 & Eu-154 & 4.37 & $\mathrm{pCi} / \mathrm{L}$ & 7.3 & 7.3 & U & & \\
\hline SESPMNT & B171K5 & HORN RAPIDS AREA & PERIMETER & sw & $\mathrm{N}$ & IRRIGATION & UNFILTERED & 03-Jun-03 & Eu-154 & -0.541 & $\mathrm{pCi} / \mathrm{L}$ & 6.8 & 6.8 & u & & \\
\hline SESPMNT & B171J5 & RIVERVIEW CANAL & OFFSITE & sw & $\mathrm{N}$ & IRRIGATION & UNFILTERED & 03-Jun-03 & Eu-154 & & $\mathrm{pCi} / \mathrm{L}$ & 6.6 & 6.6 & u & & \\
\hline SESPMNT & B176T1 & HORN RAPIDS AREA & PERIMETER & sw & $\mathrm{N}$ & IRRIGATION & UNFILTERED & 09-Jul-03 & Eu-154 & -4.24 & $\mathrm{pCi} / \mathrm{L}$ & 7.5 & 7.5 & u & & \\
\hline SESPMNT & B176R0 & RIVERVIEW CANAL & OFFSITE & sW & $\mathrm{N}$ & IRRIGATION & UNFILTERED & 09-Jul-03 & Eu-154 & -3.02 & $\mathrm{pCi} / \mathrm{L}$ & 7.4 & 7.4 & $u$ & & \\
\hline SESPMNT & B16WK5 & HORN RAPIDS AREA & PERIMETER & sw & $\mathrm{N}$ & IRRIGATION & UNFILTERED & 05-May-03 & Eu-155 & -3.73 & $\mathrm{pCi} / \mathrm{L}$ & 5.4 & 5.4 & u & & \\
\hline SESPMNT & B16WJo & RIVERVIEW CANAL & OFFSITE & sw & $\mathrm{N}$ & IRRIGATION & UNFILTERED & 09-May-03 & Eu-155 & -0.621 & $\mathrm{pCi/L}$ & 5.1 & 5.1 & u & & \\
\hline SESPMNT & B171K5 & HORN RAPIDS AREA & PERIMETER & sw & $\mathrm{N}$ & IRRIGATION & UNFILTERED & 03-Jun-03 & Eu-155 & -3.35 & $\mathrm{pCi/L}$ & 3.8 & 3.8 & u & & \\
\hline SESPMNT & B171J5 & RIVERVIEW CANAL & OFFSITE & sW & $\mathrm{N}$ & IRRIGATION & UNFILTERED & 03-Jun-03 & Eu-155 & 6.95 & $\mathrm{pCi} / \mathrm{L}$ & 4.5 & 4.5 & $u$ & & \\
\hline SESPMNT & B176T1 & HORN RAPIDS AREA & PERIMETER & sw & $\mathrm{N}$ & IRRIGATION & UNFILTERED & 09-Jul-03 & Eu-155 & 1.64 & $\mathrm{pCi} / \mathrm{L}$ & 4.2 & 4.2 & U & & \\
\hline SESPMNT & B176RO & RIVERVIEW CANAL & OFFSITE & sw & $\mathrm{N}$ & IRRIGATION & UNFILTERED & 09-Jul-03 & Eu-155 & & $\mathrm{pCi/L}$ & 4.7 & 4.7 & u & & \\
\hline SESPMNT & B16WK5 & HORN RAPIDS AREA & PERIMETER & sw & $\mathrm{N}$ & IRRIGATION & UNFILTERED & $05-$ May-03 & -40 & -50.3 & $\mathrm{pCi/L}$ & 60 & 60 & u & & \\
\hline SESPMNT & B16WJ0 & RIVERVIEW CANAL & OFFSITE & SW & $\mathrm{N}$ & IRRIGATION & UNFILTERED & 09-May-03 & -40 & 5.06 & $\mathrm{pCi} / \mathrm{L}$ & 60 & 60 & $u$ & & \\
\hline SESPMNT & B171K5 & HORN RAPIDS AREA & PERIMETER & sw & $\mathrm{N}$ & IRRIGATION & UNFILTERED & 03-Jun-03 & -40 & -55.9 & $\mathrm{pCi} / \mathrm{L}$ & 49 & 49 & U & & \\
\hline SESPMNT & B171J5 & RIVERVIEW CANAL & OFFSITE & sw & $\mathrm{N}$ & IRRIGATION & UNFILTERED & 03-Jun-03 & -40 & 7.53 & $\mathrm{pCi} / \mathrm{L}$ & 58 & 58 & u & & \\
\hline
\end{tabular}


WATER - IRRIGATION

\begin{tabular}{|c|c|c|c|c|c|c|c|c|c|c|c|c|c|c|c|c|}
\hline $\mid$ OWNER ID $\mid$ & SAMP NUM & SAMP SITE NAME & | DIST CLASS & MEDIA & $\begin{array}{c}\text { FILTERED } \\
\text { FLAG }\end{array} \mid$ & | SAMP FROM & | COLL MTHD | & SAMP DATE & CON SHORT NAME & VALUE RPTD & \begin{tabular}{|l|} 
ANAL \\
UNITS \\
RPTD
\end{tabular} & $\left|\begin{array}{c}\text { COUNTING } \\
\text { ERROR }\end{array}\right|$ & $\begin{array}{c}\text { TOTAL ANAL } \\
\text { ERROR }\end{array}$ & $\begin{array}{c}\text { LAB } \\
\text { QUALIFIER }\end{array}$ & SAMP COMMENT & RESULT COMMENT \\
\hline SESPMNT & B176T1 & HORN RAPIDS AREA & PERIMETER & sw & $\mathrm{N}$ & IRRIGATION & UNFILTERED & 09-Jul-03 & $\mathrm{K}-40$ & -22.6 & $\mathrm{pCi} / \mathrm{L}$ & 56 & 56 & U & & \\
\hline SESPMNT & B176R0 & RIVERVIEW CANAL & OFFSITE & sW & $\mathrm{N}$ & IRRIGATION & UNFILTERED & 09-Jul-03 & $\mathrm{K}-40$ & -55.9 & $\mathrm{pCi} / \mathrm{L}$ & 58 & 58 & U & & \\
\hline SESPMNT & B16WK5 & HORN RAPIDS AREA & PERIMETER & sW & $\mathrm{N}$ & IRRIGATION & UNFILTERED & 05-May-03 & Ru-106 & 0.55 & $\mathrm{pCi} / \mathrm{L}$ & 23 & 23 & U & & \\
\hline SESPMNT & B16WJ0 & RIVERVIEW CANAL & OFFSITE & sW & $\mathrm{N}$ & IRRIGATION & UNFILTERED & 09-May-03 & Ru-106 & & $\mathrm{pCi} / \mathrm{L}$ & 23 & 23 & U & & \\
\hline SESPMNT & B171K5 & HORN RAPIDS AREA & PERIMETER & sW & $\mathrm{N}$ & IRRIGATION & UNFILTERED & 03-Jun-03 & Ru-106 & -9.82 & $\mathrm{pCi} / \mathrm{L}$ & 18 & 18 & $u$ & & \\
\hline SESPMNT & B171J5 & RIVERVIEW CANAL & OFFSITE & sw & $\mathrm{N}$ & IRRIGATION & UNFILTERED & 03-Jun-03 & Ru-106 & -4.9 & $\mathrm{pCi} / \mathrm{L}$ & 22 & 22 & u & & \\
\hline SESPMNT & B176T1 & HORN RAPIDS AREA & PERIMETER & sW & $\mathrm{N}$ & IRRIGATION & UNFILTERED & 09-Jul-03 & Ru-106 & 1.78 & $\mathrm{pCi} / \mathrm{L}$ & 20 & 20 & U & & \\
\hline SESPMNT & B176R0 & RIVERVIEW CANAL & OFFSITE & sW & $\mathrm{N}$ & IRRIGATION & UNFILTERED & 09-Jul-03 & Ru-106 & & & 21 & 21 & U & & \\
\hline SESPMNT & B16WK5 & HORN RAPIDS AREA & PERIMETER & sw & $\mathrm{N}$ & IRRIGATION & UNFILTERED & 05-May-03 & SB-125 & -4.07 & $\mathrm{pCi} / \mathrm{L}$ & 6 & 6 & u & & \\
\hline SESPMNT & B16WJo & RIVERVIEW CANAL & OFFSITE & sw & $\mathrm{N}$ & IRRIGATION & UNFILTERED & 09-May-03 & SB-125 & -3.22 & $\mathrm{pCi} / \mathrm{L}$ & 5.5 & 5.5 & u & & \\
\hline SESPMNT & B171K5 & HORN RAPIDS AREA & PERIMETER & sw & $\mathrm{N}$ & IRRIGATION & UNFILTERED & 03-Jun-03 & SB-125 & 0.923 & $\mathrm{pCi} / \mathrm{L}$ & 5 & 5 & $u$ & & \\
\hline SESPMNT & B171J5 & RIVERVIEW CANAL & OFFSITE & sW & $\mathrm{N}$ & IRRIGATION & UNFILTERED & 03-Jun-03 & SB-125 & -2.88 & $\mathrm{pCi} / \mathrm{L}$ & 5.8 & 5.8 & $u$ & & \\
\hline SESPMNT & B176T1 & HORN RAPIDS AREA & PERIMETER & sw & $\mathrm{N}$ & IRRIGATION & UNFILTERED & 09-Jul-03 & SB-125 & 0.629 & $\mathrm{pCi/L}$ & 4.9 & 4.9 & u & & \\
\hline SESPMNT & B176RO & RIVERVIEW CANAL & OFFSITE & sw & $\mathrm{N}$ & IRRIGATION & UNFILTERED & 09-Jul-03 & SB-125 & 4.32 & $\mathrm{pCi} / \mathrm{L}$ & 5.5 & 5.5 & u & & \\
\hline SESPMNT & B16WK5 & HORN RAPIDS AREA & PERIMETER & sw & $\mathrm{N}$ & IRRIGATION & UNFILTERED & 05-May-03 & Sr-90 & 0.0882 & $\mathrm{pCi} / \mathrm{L}$ & 0.036 & 0.042 & & & \\
\hline SESPMNT & B16WJo & RIVERVIEW CANAL & OFFSITE & sW & $\mathrm{N}$ & IRRIGATION & UNFILTERED & 09-May-03 & $\mathrm{Sr}-90$ & 0.0828 & $\mathrm{pCi} / \mathrm{L}$ & 0.033 & 0.038 & & & \\
\hline SESPMNT & B171K5 & HORN RAPIDS AREA & PERIMETER & sw & $\mathrm{N}$ & IRRIGATION & UNFILTERED & 03-Jun-03 & Sr-90 & 0.0929 & $\mathrm{pCi} / \mathrm{L}$ & 0.028 & 0.035 & & & \\
\hline SESPMNT & B171J5 & RIVERVIEW CANAL & OFFSITE & sw & $\mathrm{N}$ & IRRIGATION & UNFILTERED & 03-Jun-03 & Sr-90 & 0.0906 & $\mathrm{pCi} / \mathrm{L}$ & 0.028 & 0.034 & & & \\
\hline SESPMNT & B176T1 & HORN RAPIDS AREA & PERIMETER & sw & $\mathrm{N}$ & IRRIGATION & UNFILTERED & 09-Jul-03 & Sr-90 & 0.101 & $\mathrm{pCi} / \mathrm{L}$ & 0.027 & 0.036 & & & \\
\hline SESPMNT & B176RO & RIVERVIEW CANAL & OFFSITE & sw & $\mathrm{N}$ & IRRIGATION & UNFILTERED & 09-Jul-03 & Sr-90 & 0.0853 & $\mathrm{pCi} / \mathrm{L}$ & 0.029 & 0.035 & & & \\
\hline SESPMNT & B16WK5 & HORN RAPIDS AREA & PERIMETER & sw & $\mathrm{N}$ & IRRIGATION & UNFILTERED & 05-May-03 & LO TRITIUM & 29.1 & $\mathrm{pCi} / \mathrm{L}$ & 3 & 6 & & & \\
\hline SESPMNT & B16WJo & RIVERVIEW CANAL & OFFSITE & sw & $\mathrm{N}$ & IRRIGATION & UNFILTERED & 09-May-03 & LO TRITIUM & 27.1 & $\mathrm{pCi} / \mathrm{L}$ & 3 & 5.7 & & & \\
\hline SESPMNT & B171K5 & HORN RAPIDS AREA & $\begin{array}{l}\text { PERIMETER } \\
\end{array}$ & sw & $\mathrm{N}$ & IRRIGATION & UNFILTERED & 03-Jun-03 & LO TRITIUM & 57.5 & $\mathrm{pCi/L}$ & 3.4 & 6.6 & & & \\
\hline SESPMNT & B171J5 & RIVERVIEW CANAL & OFFSITE & sw & $\mathrm{N}$ & IRRIGATION & UNFILTERED & 03-Jun-03 & LO TRITIUM & 22.3 & $\mathrm{pCi} / \mathrm{L}$ & 2.8 & 4.1 & & & \\
\hline SESPMNT & B176T1 & HORN RAPIDS AREA & PERIMETER & sw & $\mathrm{N}$ & IRRIGATION & UNFILTERED & 09-Jul-03 & LO TRITIUM & & $\mathrm{pCi} / \mathrm{L}$ & 4.3 & 13 & & & \\
\hline SESPMNT & B176R0 & RIVERVIEW CANAL & OFFSITE & sw & $\mathrm{N}$ & IRRIGATION & UNFILTERED & 09-Jul-03 & LO TRITIUM & 35.8 & $\mathrm{pCi} / \mathrm{L}$ & 2.9 & 5.4 & & & \\
\hline SESPMNT & B16WK5 & HORN RAPIDS AREA & PERIMETER & sw & $\mathrm{N}$ & IRRIGATION & UNFILTERED & 05-May-03 & U-234 & 0.239 & $\mathrm{pCi/L}$ & 0.035 & 0.052 & & & \\
\hline SESPMNT & B16WJO & RIVERVIEW CANAL & OFFSITE & sw & $\mathrm{N}$ & IRRIGATION & UNFILTERED & 09-May-03 & $\mathrm{U}-234$ & 0.288 & $\mathrm{pCi} / \mathrm{L}$ & 0.039 & 0.06 & & & \\
\hline SESPMNT & B171K5 & HORN RAPIDS AREA & PERIMETER & sw & $\mathrm{N}$ & IRRIGATION & UNFILTERED & 03-Jun-03 & $U-234$ & 0.286 & $\mathrm{pCi} / \mathrm{L}$ & 0.04 & 0.059 & & & \\
\hline SESPMNT & B171J5 & RIVERVIEW CANAL & OFFSITE & sw & $\mathrm{N}$ & IRRIGATION & UNFILTERED & 03-Jun-03 & $\mathrm{U}-234$ & 0.299 & $\mathrm{pCi} / \mathrm{L}$ & 0.04 & 0.061 & & & \\
\hline SESPMNT & B176T1 & HORN RAPIDS AREA & PERIMETER & sw & $\mathrm{N}$ & IRRIGATION & UNFILTERED & 09-Jul-03 & $\mathrm{U}-234$ & 0.28 & $\mathrm{pCi/L}$ & 0.039 & 0.059 & & & \\
\hline SESPMNT & B176R0 & RIVERVIEW CANAL & OFFSITE & sW & $\mathrm{N}$ & IRRIGATION & UNFILTERED & 09-Jul-03 & $\mathrm{U}-234$ & 0.258 & $\mathrm{pCi} / \mathrm{L}$ & 0.038 & 0.056 & & & \\
\hline SESPMNT & B16WK5 & HORN RAPIDS AREA & PERIMETER & sW & $\mathrm{N}$ & IRRIGATION & UNFILTERED & 05-May-03 & $\mathrm{U}-235$ & 0.00503 & $\mathrm{pCi} / \mathrm{L}$ & 0.005 & 0.0051 & $U$ & & \\
\hline SESPMNT & B16WJo & RIVERVIEW CANAL & OFFSITE & sW & $\mathrm{N}$ & IRRIGATION & UNFILTERED & 09-May-03 & $\mathrm{U}-235$ & 0.0105 & $\mathrm{pCi} / \mathrm{L}$ & 0.0074 & 0.0076 & & & \\
\hline SESPMNT & B171K5 & HORN RAPIDS AREA & PERIMETER & sw & $\mathrm{N}$ & IRRIGATION & UNFILTERED & 03-Jun-03 & $\mathrm{U}-235$ & 0.0176 & $\mathrm{pCi/L}$ & 0.01 & 0.011 & & & \\
\hline SESPMNT & B171J5 & RIVERVIEW CANAL & OFFSITE & sW & $\mathrm{N}$ & IRRIGATION & UNFILTERED & 03-Jun-03 & $\mathrm{U}-235$ & 0.00774 & $\mathrm{pCi} / \mathrm{L}$ & 0.0097 & 0.0097 & U & & \\
\hline SESPMNT & B176T1 & HORN RAPIDS AREA & PERIMETER & sW & $\mathrm{N}$ & IRRIGATION & UNFILTERED & 09-Jul-03 & $\mathrm{U}-235$ & 0.00484 & $\mathrm{pCi} / \mathrm{L}$ & 0.0071 & 0.0074 & 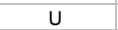 & & \\
\hline SESPMNT & B176R0 & RIVERVIEW CANAL & OFFSITE & sw & $\mathrm{N}$ & IRRIGATION & UNFILTERED & 09-Jul-03 & U-235 & 0.00809 & $\mathrm{pCi} / \mathrm{L}$ & 0.008 & 0.0084 & $u$ & & \\
\hline SESPMNT & B16WK5 & HORN RAPIDS AREA & PERIMETER & sw & $\mathrm{N}$ & IRRIGATION & UNFILTERED & 05-May-03 & $\mathrm{U}-238$ & 0.176 & $\mathrm{pCi} / \mathrm{L}$ & 0.03 & 0.041 & & & \\
\hline SESPMNT & B16WJo & RIVERVIEW CANAL & OFFSITE & sw & $\mathrm{N}$ & IRRIGATION & UNFILTERED & 09-May-03 & U-238 & 0.223 & $\mathrm{pCi} / \mathrm{L}$ & 0.034 & 0.049 & & & \\
\hline SESPMNT & B171K5 & HORN RAPIDS AREA & PERIMETER & sW & $\mathrm{N}$ & IRRIGATION & UNFILTERED & 03-Jun-03 & $\mathrm{U}-238$ & 0.211 & $\mathrm{pCi} / \mathrm{L}$ & 0.035 & 0.048 & & & \\
\hline SESPMNT & B171J5 & RIVERVIEW CANAL & OFFSITE & sw & $\mathrm{N}$ & IRRIGATION & UNFILTERED & 03-Jun-03 & $\mathrm{U}-238$ & 0.235 & $\mathrm{pCi} / \mathrm{L}$ & 0.035 & 0.05 & & & \\
\hline SESPMNT & B176T1 & HORN RAPIDS AREA & PERIMETER & sw & $\mathrm{N}$ & IRRIGATION & UNFILTERED & 09-Jul-03 & $\mathrm{U}-238$ & 0.243 & $\mathrm{pCi} / \mathrm{L}$ & 0.036 & 0.053 & & & \\
\hline SESPMNT & B176R0 & RIVERVIEW CANAL & OFFSITE & sw & $\mathrm{N}$ & IRRIGATION & UNFILTERED & 09-Jul-03 & $\mathrm{U}-238$ & 0.196 & $\mathrm{pCi} / \mathrm{L}$ & 0.033 & 0.045 & & & \\
\hline SESPSPEC & B16WN0 & ESQUATZEL CANAL & OFFSITE & sW & $\mathrm{N}$ & IRRIGATION & UNFILTERED & 14-May-03 & $\mathrm{Be}-7$ & -6.74 & $\mathrm{pCi} / \mathrm{L}$ & 22 & 22 & U & & \\
\hline SESPSPEC & B16WN1 & ESQUATZEL CANAL & OFFSITE & sw & $\mathrm{N}$ & IRRIGATION & UNFILTERED & 14-May-03 & $\mathrm{Be}-7$ & 2.73 & $\mathrm{pCi} / \mathrm{L}$ & 21 & 21 & u & & \\
\hline SESPSPEC & B16WN2 & ESQUATZEL CANAL & OFFSITE & sw & $\mathrm{N}$ & IRRIGATION & UNFILTERED & 14-May-03 & $\mathrm{Be}-7$ & 10.2 & $\mathrm{pCi} / \mathrm{L}$ & 19 & 19 & u & & \\
\hline SESPSPEC & B16WN3 & POTHOLES CANAL & OFFSITE & sw & $\mathrm{N}$ & IRRIGATION & UNFILTERED & 14-May-03 & $\mathrm{Be}-7$ & -13.6 & $\mathrm{pCi} / \mathrm{L}$ & 31 & 31 & $u$ & & \\
\hline SESPSPEC & B16WN4 & POTHOLES CANAL & OFFSITE & sW & $\mathrm{N}$ & IRRIGATION & UNFILTERED & 14-May-03 & $\mathrm{Be}-7$ & 2.13 & $\mathrm{pCi} / \mathrm{L}$ & 22 & 22 & U & & \\
\hline SESPSPEC & B16WN5 & POTHOLES CANAL & OFFSITE & sw & $\mathrm{N}$ & IRRIGATION & UNFILTERED & 14-May-03 & $\mathrm{Be}-7$ & 13.6 & $\mathrm{pCi} / \mathrm{L}$ & 18 & 18 & $u$ & & \\
\hline SESPSPEC & B16WM7 & RINGOLD WASTEWAY & OFFSITE & sw & $\mathrm{N}$ & IRRIGATION & UNFILTERED & 14-May-03 & $\mathrm{Be}-7$ & -5.79 & $\mathrm{pCi} / \mathrm{L}$ & 21 & 21 & $u$ & & \\
\hline SESPSPEC & B16WM8 & RINGOLD WASTEWAY & OFFSITE & sw & $\mathrm{N}$ & IRRIGATION & UNFILTERED & 14-May-03 & $\mathrm{Be}-7$ & -2.45 & $\mathrm{pCi} / \mathrm{L}$ & 23 & 23 & U & & \\
\hline SESPSPEC & B16WM9 & RINGOLD WASTEWAY & OFFSITE & sW & $\mathrm{N}$ & IRRIGATION & UNFILTERED & 14-May-03 & $\mathrm{Be}-7$ & -13.9 & $\mathrm{pCi} / \mathrm{L}$ & 23 & 23 & U & & \\
\hline SESPSPEC & B16WN0 & ESQUATZEL CANAL & OFFSITE & sw & $\mathrm{N}$ & IRRIGATION & UNFILTERED & 14-May-03 & $\mathrm{CO}-60$ & 2.19 & $\mathrm{pCi} / \mathrm{L}$ & 3 & 3 & $u$ & & \\
\hline SESPSPEC & B16WN1 & ESQUATZEL CANAL & OFFSITE & sw & $\mathrm{N}$ & IRRIGATION & UNFILTERED & 14-May-03 & $\mathrm{CO}-60$ & 3.15 & $\mathrm{pCi} / \mathrm{L}$ & 2.8 & 2.8 & u & & \\
\hline SESPSPEC & B16WN2 & ESQUATZEL CANAL & OFFSITE & sW & $\mathrm{N}$ & IRRIGATION & UNFILTERED & 14-May-03 & $\mathrm{CO}-60$ & 0.829 & $\mathrm{pCi} / \mathrm{L}$ & 2.5 & 2.5 & U & & \\
\hline SESPSPEC & B16WN3 & POTHOLES CANAL & OFFSITE & sW & $\mathrm{N}$ & IRRIGATION & UNFILTERED & 14-May-03 & $\mathrm{CO}-60$ & 1.46 & $\mathrm{pCi} / \mathrm{L}$ & 3.3 & 3.3 & U & & \\
\hline SESPSPEC & B16WN4 & POTHOLES CANAL & OFFSITE & sW & $\mathrm{N}$ & IRRIGATION & UNFILTERED & 14-May-03 & $\mathrm{CO}-60$ & -0.527 & $\mathrm{pCi} / \mathrm{L}$ & 2.8 & 2.8 & U & & \\
\hline
\end{tabular}


WATER - IRRIGATION

\begin{tabular}{|c|c|c|c|c|c|c|c|c|c|c|c|c|c|c|c|c|}
\hline $\mid$ OWNER ID $\mid$ & SAMP NUM & SAMP SITE NAME & DIST CLASS & MEDIA & $\begin{array}{c}\text { FILTERED } \\
\text { FLAG }\end{array} \mid$ & |SAMP FROM | & COLL MTHD & SAMP DATE & CON SHORT NAME & VALUE RPTD & \begin{tabular}{|l|} 
ANAL \\
UNITS \\
RPTD
\end{tabular} & $\left|\begin{array}{c}\text { COUNTING } \\
\text { ERROR }\end{array}\right|$ & $\begin{array}{c}\text { TOTAL ANAL } \\
\text { ERROR }\end{array}$ & $\begin{array}{c}\text { LAB } \\
\text { QUALIFIER }\end{array}$ & SAMP COMMENT & RESULT COMMENT \\
\hline SESPSPEC & B16WN5 & POTHOLES CANAL & OFFSITE & sw & $\mathrm{N}$ & IRRIGATION & UNFILTERED & 14-May-03 & $\mathrm{CO}-60$ & 0.521 & $\mathrm{pCi} / \mathrm{L}$ & 1.6 & 1.6 & u & & \\
\hline SESPSPEC & B16WM7 & RINGOLD WASTEWAY & OFFSITE & sW & $\mathrm{N}$ & IRRIGATION & UNFILTERED & 14-May-03 & $\mathrm{CO}-60$ & 1.12 & $\mathrm{pCi} / \mathrm{L}$ & 2.1 & 2.1 & U & & \\
\hline SESPSPEC & B16WM8 & RINGOLD WASTEWAY & OFFSITE & sW & $\mathrm{N}$ & IRRIGATION & UNFILTERED & 14-May-03 & $\mathrm{CO}-60$ & 0.123 & $\mathrm{pCi} / \mathrm{L}$ & 2.9 & 2.9 & U & & \\
\hline SESPSPEC & B16WM9 & RINGOLD WASTEWAY & OFFSITE & sW & $\mathrm{N}$ & IRRIGATION & UNFILTERED & 14-May-03 & $\mathrm{CO}-60$ & & $\mathrm{pCi} / \mathrm{L}$ & 2.4 & 2.4 & U & & \\
\hline SESPSPEC & B16WN0 & ESQUATZEL CANAL & OFFSITE & sW & $\mathrm{N}$ & IRRIGATION & UNFILTERED & 14-May-03 & Cs-134 & 0.668 & $\mathrm{pCi} / \mathrm{L}$ & 2.8 & 2.8 & $u$ & & \\
\hline SESPSPEC & B16WN1 & ESQUATZEL CANAL & OFFSITE & sw & $\mathrm{N}$ & IRRIGATION & UNFILTERED & 14-May-03 & Cs-134 & 1.37 & $\mathrm{pCi} / \mathrm{L}$ & 2.3 & 2.3 & u & & \\
\hline SESPSPEC & B16WN2 & ESQUATZEL CANAL & OFFSITE & sW & $\mathrm{N}$ & IRRIGATION & UNFILTERED & 14-May-03 & Cs-134 & & $\mathrm{pCi} / \mathrm{L}$ & 2.3 & 2.3 & U & & \\
\hline SESPSPEC & B16WN3 & POTHOLES CANAL & OFFSITE & sW & $\mathrm{N}$ & IRRIGATION & UNFILTERED & 14-May-03 & Cs-134 & 0.378 & & 3.6 & 3.6 & U & & \\
\hline SESPSPEC & B16WN4 & POTHOLES CANAL & OFFSITE & sw & $\mathrm{N}$ & IRRIGATION & UNFILTERED & 14-May-03 & Cs-134 & -0.636 & $\mathrm{pCi} / \mathrm{L}$ & 2.7 & 2.7 & u & & \\
\hline SESPSPEC & B16WN5 & POTHOLES CANAL & OFFSITE & sw & $\mathrm{N}$ & IRRIGATION & UNFILTERED & 14-May-03 & Cs-134 & 0.863 & $\mathrm{pCi} / \mathrm{L}$ & 1.7 & 1.7 & u & & \\
\hline SESPSPEC & B16WM7 & RINGOLD WASTEWAY & OFFSITE & sw & $\mathrm{N}$ & IRRIGATION & UNFILTERED & 14-May-03 & Cs-134 & -3.37 & pCi/L & 2.4 & 2.4 & $u$ & & \\
\hline SESPSPEC & B16WM8 & RINGOLD WASTEWAY & OFFSITE & sW & $\mathrm{N}$ & IRRIGATION & UNFILTERED & 14-May-03 & Cs-134 & -0.76 & $\mathrm{pCi} / \mathrm{L}$ & 2.8 & 2.8 & $u$ & & \\
\hline SESPSPEC & B16WM9 & RINGOLD WASTEWAY & OFFSITE & sw & $\mathrm{N}$ & IRRIGATION & UNFILTERED & 14-May-03 & Cs-134 & 0.276 & $\mathrm{pCi/L}$ & 2.5 & 2.5 & u & & \\
\hline SESPSPEC & B16WNO & ESQUATZEL CANAL & OFFSITE & sw & $\mathrm{N}$ & IRRIGATION & UNFILTERED & 14-May-03 & Cs-137 & -2.66 & $\mathrm{pCi} / \mathrm{L}$ & 2.8 & 2.8 & u & & \\
\hline SESPSPEC & B16WN1 & ESQUATZEL CANAL & OFFSITE & sw & $\mathrm{N}$ & IRRIGATION & UNFILTERED & 14-May-03 & Cs-137 & -2.44 & $\mathrm{pCi} / \mathrm{L}$ & 2.3 & 2.3 & U & & \\
\hline SESPSPEC & B16WN2 & ESQUATZEL CANAL & OFFSITE & sw & $\mathrm{N}$ & IRRIGATION & UNFILTERED & 14-May-03 & Cs-137 & 1.09 & $\mathrm{pCi} / \mathrm{L}$ & 2.3 & 2.3 & u & & \\
\hline SESPSPEC & B16WN3 & POTHOLES CANAL & OFFSITE & sw & $\mathrm{N}$ & IRRIGATION & UNFILTERED & 14-May-03 & Cs-137 & 0.886 & $\mathrm{pCi/L}$ & 2.4 & 2.4 & u & & \\
\hline SESPSPEC & B16WN4 & POTHOLES CANAL & OFFSITE & sw & $\mathrm{N}$ & IRRIGATION & UNFILTERED & 14-May-03 & Cs-137 & 1.27 & $\mathrm{pCi} / \mathrm{L}$ & 2.6 & 2.6 & u & & \\
\hline SESPSPEC & B16WN5 & POTHOLES CANAL & OFFSITE & sw & $\mathrm{N}$ & IRRIGATION & UNFILTERED & 14-May-03 & Cs-137 & 0.738 & $\mathrm{pCi} / \mathrm{L}$ & 1.7 & 1.7 & u & & \\
\hline SESPSPEC & B16WM7 & RINGOLD WASTEWAY & OFFSITE & sw & $\mathrm{N}$ & IRRIGATION & UNFILTERED & 14-May-03 & Cs-137 & -0.217 & $\mathrm{pCi} / \mathrm{L}$ & 2.9 & 2.9 & u & & \\
\hline SESPSPEC & B16WM8 & RINGOLD WASTEWAY & OFFSITE & sw & $\mathrm{N}$ & IRRIGATION & UNFILTERED & 14-May-03 & Cs-137 & -0.0373 & $\mathrm{pCi} / \mathrm{L}$ & 2.7 & 2.7 & $u$ & & \\
\hline SESPSPEC & B16WM9 & RINGOLD WASTEWAY & OFFSITE & sw & $\mathrm{N}$ & IRRIGATION & UNFILTERED & 14-May-03 & Cs-137 & 0.673 & $\mathrm{pCi} / \mathrm{L}$ & 2.5 & 2.5 & u & & \\
\hline SESPSPEC & B16WN0 & ESQUATZEL CANAL & OFFSITE & sw & $\mathrm{N}$ & IRRIGATION & UNFILTERED & 14-May-03 & Eu-152 & & $\mathrm{pCi/L}$ & 5.9 & 5.9 & u & & \\
\hline SESPSPEC & B16WN1 & ESQUATZEL CANAL & OFFSITE & sw & $\mathrm{N}$ & IRRIGATION & UNFILTERED & 14-May-03 & Eu-152 & -1.35 & $\mathrm{pCi} / \mathrm{L}$ & 6.3 & 6.3 & u & & \\
\hline SESPSPEC & B16WN2 & ESQUATZEL CANAL & OFFSITE & sw & $\mathrm{N}$ & IRRIGATION & UNFILTERED & 14-May-03 & Eu-152 & 0.241 & $\mathrm{pCi} / \mathrm{L}$ & 5 & 5 & U & & \\
\hline SESPSPEC & B16WN3 & POTHOLES CANAL & OFFSITE & sw & $\mathrm{N}$ & IRRIGATION & UNFILTERED & 14-May-03 & Eu-152 & 1.54 & $\mathrm{pCi} / \mathrm{L}$ & 8.5 & 8.5 & u & & \\
\hline SESPSPEC & B16WN4 & POTHOLES CANAL & OFFSITE & sw & $\mathrm{N}$ & IRRIGATION & UNFILTERED & 14-May-03 & Eu-152 & -2.29 & $\mathrm{pCi/L}$ & 5.8 & 5.8 & u & & \\
\hline SESPSPEC & B16WN5 & POTHOLES CANAL & OFFSITE & sw & $\mathrm{N}$ & IRRIGATION & UNFILTERED & 14-May-03 & Eu-152 & 1.85 & $\mathrm{pCi} / \mathrm{L}$ & 4.4 & 4.4 & $u$ & & \\
\hline SESPSPEC & B16WM7 & RINGOLD WASTEWAY & OFFSITE & sw & $\mathrm{N}$ & IRRIGATION & UNFILTERED & 14-May-03 & Eu-152 & 4.78 & $\mathrm{pCi} / \mathrm{L}$ & 6.2 & 6.2 & u & & \\
\hline SESPSPEC & B16WM8 & RINGOLD WASTEWAY & OFFSITE & sw & $\mathrm{N}$ & IRRIGATION & UNFILTERED & 14-May-03 & Eu-152 & -4.83 & $\mathrm{pCi} / \mathrm{L}$ & 5.9 & 5.9 & u & & \\
\hline SESPSPEC & B16WM9 & RINGOLD WASTEWAY & OFFSITE & sw & $\mathrm{N}$ & IRRIGATION & UNFILTERED & 14-May-03 & Eu-152 & 4.61 & $\mathrm{pCi/L}$ & 5.9 & 5.9 & u & & \\
\hline SESPSPEC & B16WNO & ESQUATZEL CANAL & OFFSITE & sW & $\mathrm{N}$ & IRRIGATION & UNFILTERED & 14-May-03 & Eu-154 & -5.04 & $\mathrm{pCi} / \mathrm{L}$ & 7.9 & 7.9 & u & & \\
\hline SESPSPEC & B16WN1 & ESQUATZEL CANAL & OFFSITE & sW & $\mathrm{N}$ & IRRIGATION & UNFILTERED & 14-May-03 & Eu-154 & -4.67 & $\mathrm{pCi} / \mathrm{L}$ & 6.3 & 6.3 & U & & \\
\hline SESPSPEC & B16WN2 & ESQUATZEL CANAL & OFFSITE & sw & $\mathrm{N}$ & IRRIGATION & UNFILTERED & 14-May-03 & Eu-154 & -0.585 & $\mathrm{pCi} / \mathrm{L}$ & 6.7 & 6.7 & $u$ & & \\
\hline SESPSPEC & B16WN3 & POTHOLES CANAL & OFFSITE & sw & $\mathrm{N}$ & IRRIGATION & UNFILTERED & 14-May-03 & Eu-154 & -1.31 & $\mathrm{pCi/L}$ & 9 & 9 & u & & \\
\hline SESPSPEC & B16WN4 & POTHOLES CANAL & OFFSITE & sW & $\mathrm{N}$ & IRRIGATION & UNFILTERED & 14-May-03 & Eu-154 & -1.32 & $\mathrm{pCi} / \mathrm{L}$ & 8.7 & 8.7 & U & & \\
\hline SESPSPEC & B16WN5 & POTHOLES CANAL & OFFSITE & sW & $\mathrm{N}$ & IRRIGATION & UNFILTERED & 14-May-03 & Eu-154 & 1.45 & $\mathrm{pCi} / \mathrm{L}$ & 5.2 & 5.2 & 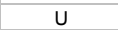 & & \\
\hline SESPSPEC & B16WM7 & RINGOLD WASTEWAY & OFFSITE & sw & $\mathrm{N}$ & IRRIGATION & UNFILTERED & 14-May-03 & Eu-154 & 0.765 & $\mathrm{pCi} / \mathrm{L}$ & 7.4 & 7.4 & u & & \\
\hline SESPSPEC & B16WM8 & RINGOLD WASTEWAY & OFFSITE & sw & $\mathrm{N}$ & IRRIGATION & UNFILTERED & 14-May-03 & Eu-154 & & $\mathrm{pCi} / \mathrm{L}$ & 6.5 & 6.5 & u & & \\
\hline SESPSPEC & B16WM9 & RINGOLD WASTEWAY & OFFSITE & sW & $\mathrm{N}$ & IRRIGATION & UNFILTERED & 14-May-03 & Eu-154 & -1.53 & $\mathrm{pCi} / \mathrm{L}$ & 5.3 & 5.3 & U & & \\
\hline SESPSPEC & B16WN0 & ESQUATZEL CANAL & OFFSITE & sW & $\mathrm{N}$ & IRRIGATION & UNFILTERED & 14-May-03 & Eu-155 & -1.48 & $\mathrm{pCi} / \mathrm{L}$ & 5.7 & 5.7 & U & & \\
\hline SESPSPEC & B16WN1 & ESQUATZEL CANAL & OFFSITE & sw & $\mathrm{N}$ & IRRIGATION & UNFILTERED & 14-May-03 & Eu-155 & 0.347 & pCi/L & 4.5 & 4.5 & u & & \\
\hline SESPSPEC & B16WN2 & ESQUATZEL CANAL & OFFSITE & sw & $\mathrm{N}$ & IRRIGATION & UNFILTERED & 14-May-03 & Eu-155 & 2.54 & $\mathrm{pCi} / \mathrm{L}$ & 4.2 & 4.2 & u & & \\
\hline SESPSPEC & B16WN3 & POTHOLES CANAL & OFFSITE & sw & $\mathrm{N}$ & IRRIGATION & UNFILTERED & 14-May-03 & Eu-155 & -4.72 & $\mathrm{pCi} / \mathrm{L}$ & 6.2 & 6.2 & $u$ & & \\
\hline SESPSPEC & B16WN4 & POTHOLES CANAL & OFFSITE & sW & $\mathrm{N}$ & IRRIGATION & UNFILTERED & 14-May-03 & Eu-155 & 6.49 & $\mathrm{pCi} / \mathrm{L}$ & 5.1 & 5.1 & U & & \\
\hline SESPSPEC & B16WN5 & POTHOLES CANAL & OFFSITE & sw & $\mathrm{N}$ & IRRIGATION & UNFILTERED & 14-May-03 & Eu-155 & -0.993 & $\mathrm{pCi} / \mathrm{L}$ & 3.4 & 3.4 & $u$ & & \\
\hline SESPSPEC & B16WM7 & RINGOLD WASTEWAY & OFFSITE & sw & $\mathrm{N}$ & IRRIGATION & UNFILTERED & 14-May-03 & Eu-155 & 3.61 & $\mathrm{pCi} / \mathrm{L}$ & 4.2 & 4.2 & u & & \\
\hline SESPSPEC & B16WM8 & RINGOLD WASTEWAY & OFFSITE & sw & $\mathrm{N}$ & IRRIGATION & UNFILTERED & 14-May-03 & Eu-155 & -1.6 & $\mathrm{pCi} / \mathrm{L}$ & 5.2 & 5.2 & $u$ & & \\
\hline SESPSPEC & B16WM9 & RINGOLD WASTEWAY & OFFSITE & sW & $\mathrm{N}$ & IRRIGATION & UNFILTERED & 14-May-03 & Eu-155 & -1.94 & $\mathrm{pCi} / \mathrm{L}$ & 4.6 & 4.6 & U & & \\
\hline SESPSPEC & B16WN0 & ESQUATZEL CANAL & OFFSITE & sw & $\mathrm{N}$ & IRRIGATION & UNFILTERED & 14-May-03 & $k-40$ & & $\mathrm{pCi} / \mathrm{L}$ & 61 & 61 & $u$ & & \\
\hline SESPSPEC & B16WN1 & ESQUATZEL CANAL & OFFSITE & sw & $\mathrm{N}$ & IRRIGATION & UNFILTERED & 14-May-03 & $\mathrm{K}-40$ & 15.6 & $\mathrm{pCi} / \mathrm{L}$ & 58 & 58 & $u$ & & \\
\hline SESPSPEC & B16WN2 & ESQUATZEL CANAL & OFFSITE & sW & $\mathrm{N}$ & IRRIGATION & UNFILTERED & 14-May-03 & $\mathrm{K}-40$ & -73.6 & $\mathrm{pCi} / \mathrm{L}$ & 53 & 53 & U & & \\
\hline SESPSPEC & B16WN3 & POTHOLES CANAL & OFFSITE & sW & $\mathrm{N}$ & IRRIGATION & UNFILTERED & 14-May-03 & $\mathrm{K}-40$ & -60.8 & $\mathrm{pCi} / \mathrm{L}$ & 73 & 73 & U & & \\
\hline SESPSPEC & B16WN4 & POTHOLES CANAL & OFFSITE & sw & $\mathrm{N}$ & IRRIGATION & UNFILTERED & 14-May-03 & $k-40$ & -82.9 & $\mathrm{pCi} / \mathrm{L}$ & 58 & 58 & $u$ & & \\
\hline SESPSPEC & B16WN5 & POTHOLES CANAL & OFFSITE & sw & $\mathrm{N}$ & IRRIGATION & UNFILTERED & 14-May-03 & $\mathrm{k}-40$ & -6.74 & $\mathrm{pCi} / \mathrm{L}$ & 29 & 29 & u & & \\
\hline SESPSPEC & B16WM7 & RINGOLD WASTEWAY & OFFSITE & sW & $\mathrm{N}$ & IRRIGATION & UNFILTERED & 14-May-03 & $\mathrm{K}-40$ & 9.63 & $\mathrm{pCi} / \mathrm{L}$ & 59 & 59 & $U$ & & \\
\hline SESPSPEC & B16WM8 & RINGOLD WASTEWAY & OFFSITE & sW & $\mathrm{N}$ & IRRIGATION & UNFILTERED & 14-May-03 & $\mathrm{K}-40$ & -48.3 & $\mathrm{pCi} / \mathrm{L}$ & 65 & 65 & U & & \\
\hline SESPSPEC & B16WM9 & RINGOLD WASTEWAY & OFFSITE & sW & $\mathrm{N}$ & IRRIGATION & UNFILTERED & 14-May-03 & $\mathrm{K}-40$ & & $\mathrm{pCi} / \mathrm{L}$ & 47 & 47 & U & & \\
\hline
\end{tabular}


WATER - IRRIGATION

\begin{tabular}{|c|c|c|c|c|c|c|c|c|c|c|c|c|c|c|c|c|}
\hline $\mid$ OWNER ID $\mid$ & SAMP NUM & SAMP SITE NAME & DIST CLASS & MEDIA & $\begin{array}{c}\text { FILTERED } \\
\text { FLAG }\end{array} \mid$ & |SAMP FROM | & | COLL MTHD | & SAMP DATE & CON SHORT NAME & VALUE RPTD & $\mid$\begin{tabular}{|c|} 
ANAL \\
UNITS \\
RPTD
\end{tabular} & $\left|\begin{array}{c}\text { COUNTING } \\
\text { ERROR }\end{array}\right|$ & $\left|\begin{array}{c}\text { TOTAL ANAL } \\
\text { ERROR }\end{array}\right|$ & $\begin{array}{c}\text { LAB } \\
\text { QUALIFIER }\end{array}$ & SAMP COMMENT & RESULT COMMENT \\
\hline SESPSPEC & B16WN0 & ESQUATZEL CANAL & OFFSITE & sw & $\mathrm{N}$ & IRRIGATION & UNFILTERED & 14-May-03 & Ru-106 & -2.22 & pCill & 21 & 21 & U & & \\
\hline SESPSPEC & B16WN1 & ESQUATZEL CANAL & OFFSITE & sW & $\mathrm{N}$ & IRRIGATION & UNFILTERED & 14-May-03 & Ru-106 & -19.3 & $\mathrm{pCi} / \mathrm{L}$ & 21 & 21 & U & & \\
\hline SESPSPEC & B16WN2 & ESQUATZEL CANAL & OFFSITE & sw & $\mathrm{N}$ & IRRIGATION & UNFILTERED & 14-May-03 & Ru-106 & 2.86 & $\mathrm{pCi} / \mathrm{L}$ & 18 & 18 & U & & \\
\hline SESPSPEC & B16WN3 & POTHOLES CANAL & OFFSITE & sW & $\mathrm{N}$ & IRRIGATION & UNFILTERED & 14-May-03 & Ru-106 & & $\mathrm{pCi} / \mathrm{L}$ & 26 & 26 & U & & \\
\hline SESPSPEC & B16WN4 & POTHOLES CANAL & OFFSITE & sW & $\mathrm{N}$ & IRRIGATION & UNFILTERED & 14-May-03 & Ru-106 & -7.31 & pCi/L & 19 & 19 & $u$ & & \\
\hline SESPSPEC & B16WN5 & POTHOLES CANAL & OFFSITE & sw & $\mathrm{N}$ & IRRIGATION & UNFILTERED & 14-May-03 & Ru-106 & 1.71 & pCill & 14 & 14 & u & & \\
\hline SESPSPEC & B16WM7 & RINGOLD WASTEWAY & OFFSITE & sW & $\mathrm{N}$ & IRRIGATION & UNFILTERED & 14-May-03 & Ru-106 & 14.3 & $\mathrm{pCi} / \mathrm{L}$ & 22 & 22 & U & & \\
\hline SESPSPEC & B16WM8 & RINGOLD WASTEWAY & OFFSITE & sW & $\mathrm{N}$ & IRRIGATION & UNFILTERED & 14-May-03 & Ru-106 & & $\mathrm{pCi} / \mathrm{L}$ & 22 & 22 & U & & \\
\hline SESPSPEC & B16WM9 & RINGOLD WASTEWAY & OFFSITE & sw & $\mathrm{N}$ & IRRIGATION & UNFILTERED & 14-May-03 & Ru-106 & 14.6 & $\mathrm{pCi} / \mathrm{L}$ & 21 & 21 & u & & \\
\hline SESPSPEC & B16WNO & ESQUATZEL CANAL & OFFSITE & sw & $\mathrm{N}$ & IRRIGATION & UNFILTERED & 14-May-03 & SB-125 & 1.34 & pCi/L & 5.4 & 5.4 & u & & \\
\hline SESPSPEC & B16WN1 & ESQUATZEL CANAL & OFFSITE & sw & $\mathrm{N}$ & IRRIGATION & UNFILTERED & 14-May-03 & SB-125 & & $\mathrm{pCi} / \mathrm{L}$ & 5.5 & 5.5 & $u$ & & \\
\hline SESPSPEC & B16WN2 & ESQUATZEL CANAL & OFFSITE & sW & $\mathrm{N}$ & IRRIGATION & UNFILTERED & 14-May-03 & SB-125 & 1.46 & $\mathrm{pCi} / \mathrm{L}$ & 4.7 & 4.7 & $u$ & & \\
\hline SESPSPEC & B16WN3 & POTHOLES CANAL & OFFSITE & sw & $\mathrm{N}$ & IRRIGATION & UNFILTERED & 14-May-03 & SB-125 & -4.14 & $\mathrm{pCi} / \mathrm{L}$ & 8.3 & 8.3 & u & & \\
\hline SESPSPEC & B16WN4 & POTHOLES CANAL & OFFSITE & sw & $\mathrm{N}$ & IRRIGATION & UNFILTERED & 14-May-03 & SB-125 & & pCi/L & 5.1 & 5.1 & u & & \\
\hline SESPSPEC & B16WN5 & POTHOLES CANAL & OFFSITE & sw & $\mathrm{N}$ & IRRIGATION & UNFILTERED & 14-May-03 & SB-125 & -1.03 & $\mathrm{pCi} / \mathrm{L}$ & 4.1 & 4.1 & U & & \\
\hline SESPSPEC & B16WM7 & RINGOLD WASTEWAY & OFFSITE & sw & $\mathrm{N}$ & IRRIGATION & UNFILTERED & 14-May-03 & SB-125 & -3.77 & $\mathrm{pCi} / \mathrm{L}$ & 5.5 & 5.5 & u & & \\
\hline SESPSPEC & B16WM8 & RINGOLD WASTEWAY & OFFSITE & sw & $\mathrm{N}$ & IRRIGATION & UNFILTERED & 14-May-03 & SB-125 & -1.04 & $\mathrm{pCi} / \mathrm{L}$ & 5.8 & 5.8 & U & & \\
\hline SESPSPEC & B16WM9 & RINGOLD WASTEWAY & OFFSITE & sw & $\mathrm{N}$ & IRRIGATION & UNFILTERED & 14-May-03 & SB-125 & & $\mathrm{pCi} / \mathrm{L}$ & 5.2 & 5.2 & u & & \\
\hline SESPSPEC & B16WNO & ESQUATZEL CANAL & OFFSITE & sw & $\mathrm{N}$ & IRRIGATION & $\begin{array}{l}\text { UNFILTERED } \\
\text { Unter }\end{array}$ & 14-May-03 & Sr-90 & 0.0714 & $\mathrm{pCi} / \mathrm{L}$ & 0.024 & 0.029 & & & \\
\hline SESPSPEC & B16WN1 & ESQUATZEL CANAL & OFFSITE & sw & $\mathrm{N}$ & IRRIGATION & UNFILTERED & 14-May-03 & Sr-90 & 0.0738 & $\mathrm{pCi} / \mathrm{L}$ & 0.022 & 0.028 & & & \\
\hline SESPSPEC & B16WN2 & ESQUATZEL CANAL & OFFSITE & sw & $\mathrm{N}$ & IRRIGATION & UNFILTERED & 14-May-03 & Sr-90 & 0.0563 & $\mathrm{pCi} / \mathrm{L}$ & 0.023 & 0.027 & & & \\
\hline SESPSPEC & B16WN3 & POTHOLES CANAL & OFFSITE & sw & $\mathrm{N}$ & IRRIGATION & UNFILTERED & 14-May-03 & Sr-90 & 0.0736 & $\mathrm{pCi} / \mathrm{L}$ & 0.026 & 0.031 & & & \\
\hline SESPSPEC & B16WN4 & POTHOLES CANAL & OFFSITE & sw & $\mathrm{N}$ & IRRIGATION & UNFILTERED & 14-May-03 & Sr-90 & 0.0757 & $\mathrm{pCi} / \mathrm{L}$ & 0.023 & 0.029 & & & \\
\hline SESPSPEC & B16WN5 & POTHOLES CANAL & OFFSITE & sw & $\mathrm{N}$ & IRRIGATION & UNFILTERED & 14-May-03 & Sr-90 & 0.0793 & $\mathrm{pCi} / \mathrm{L}$ & 0.023 & 0.03 & & & \\
\hline SESPSPEC & B16WM7 & RINGOLD WASTEWAY & OFFSITE & sw & $\mathrm{N}$ & IRRIGATION & UNFILTERED & 14-May-03 & $\mathrm{Sr}-90$ & 0.0624 & $\mathrm{pCi} / \mathrm{L}$ & 0.031 & 0.034 & & & \\
\hline SESPSPEC & B16WM8 & RINGOLD WASTEWAY & OFFSITE & sw & $\mathrm{N}$ & IRRIGATION & UNFILTERED & 14-May-03 & Sr-90 & 0.0709 & $\mathrm{pCi} / \mathrm{L}$ & 0.033 & 0.037 & & & \\
\hline SESPSPEC & B16WM9 & RINGOLD WASTEWAY & OFFSITE & sw & $\mathrm{N}$ & IRRIGATION & UNFILTERED & 14-May-03 & $\mathrm{Sr}-90$ & 0.0626 & $\mathrm{pCi} / \mathrm{L}$ & 0.025 & 0.029 & & & \\
\hline SESPSPEC & B16WNO & ESQUATZEL CANAL & OFFSITE & sw & $\mathrm{N}$ & IRRIGATION & UNFILTERED & 14-May-03 & Tc-99 & 0.228 & $\mathrm{pCi} / \mathrm{L}$ & 0.24 & 0.5 & $u$ & & \\
\hline SESPSPEC & B16WN1 & ESQUATZEL CANAL & OFFSITE & sw & $\mathrm{N}$ & IRRIGATION & UNFILTERED & 14-May-03 & Tc-99 & 0.366 & $\mathrm{pCi} / \mathrm{L}$ & 0.25 & 0.51 & u & & \\
\hline SESPSPEC & B16WN2 & ESQUATZEL CANAL & OFFSITE & sW & $\mathrm{N}$ & IRRIGATION & UNFILTERED & 14-May-03 & Tc-99 & 0.449 & $\mathrm{pCi} / \mathrm{L}$ & 0.25 & 0.52 & u & & \\
\hline SESPSPEC & B16WN3 & POTHOLES CANAL & OFFSITE & sw & $\mathrm{N}$ & IRRIGATION & UNFILTERED & 14-May-03 & Tc-99 & 0.349 & $\mathrm{pCi} / \mathrm{L}$ & 0.25 & 0.51 & u & & \\
\hline SESPSPEC & B16WN4 & POTHOLES CANAL & OFFSITE & sW & $\mathrm{N}$ & IRRIGATION & UNFILTERED & 14-May-03 & Tc-99 & 0.287 & $\mathrm{pCi} / \mathrm{L}$ & 0.25 & 0.51 & u & & \\
\hline SESPSPEC & B16WN5 & POTHOLES CANAL & OFFSITE & sW & $\mathrm{N}$ & IRRIGATION & UNFILTERED & 14-May-03 & Tc-99 & 0.0262 & $\mathrm{pCi} / \mathrm{L}$ & 0.24 & 0.5 & U & & \\
\hline SESPSPEC & B16WM7 & RINGOLD WASTEWAY & OFFSITE & sw & $\mathrm{N}$ & IRRIGATION & UNFILTERED & 14-May-03 & Tc-99 & 0.155 & $\mathrm{pCi} / \mathrm{L}$ & 0.25 & 0.5 & $u$ & & \\
\hline SESPSPEC & B16WM8 & RINGOLD WASTEWAY & OFFSITE & sw & $\mathrm{N}$ & IRRIGATION & UNFILTERED & 14-May-03 & Tc-99 & 0.265 & $\mathrm{pCi} / \mathrm{L}$ & 0.25 & 0.5 & u & & \\
\hline SESPSPEC & B16WM9 & RINGOLD WASTEWAY & OFFSITE & sW & $\mathrm{N}$ & IRRIGATION & UNFILTERED & 14-May-03 & Tc-99 & 0.572 & $\mathrm{pCi} / \mathrm{L}$ & 0.25 & 0.52 & U & & \\
\hline SESPSPEC & B16WN0 & ESQUATZEL CANAL & OFFSITE & sW & $\mathrm{N}$ & IRRIGATION & UNFILTERED & 14-May-03 & LO TRITIUM & 28.1 & $\mathrm{pCi} / \mathrm{L}$ & 2.7 & 4.6 & & & \\
\hline SESPSPEC & B16WN1 & ESQUATZEL CANAL & OFFSITE & sw & $\mathrm{N}$ & IRRIGATION & UNFILTERED & 14-May-03 & LO TRITIUM & 98.2 & $\mathrm{pCi} / \mathrm{L}$ & 3.8 & 10 & & & \\
\hline SESPSPEC & B16WN2 & ESQUATZEL CANAL & OFFSITE & sw & $\mathrm{N}$ & IRRIGATION & UNFILTERED & 14-May-03 & LO TRITIUM & 30.1 & $\mathrm{pCi} / \mathrm{L}$ & 2.8 & 4.7 & & & \\
\hline SESPSPEC & B16WN3 & POTHOLES CANAL & OFFSITE & sW & $\mathrm{N}$ & IRRIGATION & UNFILTERED & 14-May-03 & LO TRITIUM & 31.1 & $\mathrm{pCi} / \mathrm{L}$ & 2.8 & 4.8 & & & \\
\hline SESPSPEC & B16WN4 & POTHOLES CANAL & OFFSITE & sW & $\mathrm{N}$ & IRRIGATION & UNFILTERED & 14-May-03 & LO TRITIUM & 29.1 & $\mathrm{pCi} / \mathrm{L}$ & 2.8 & 4.7 & & & \\
\hline SESPSPEC & B16WN5 & POTHOLES CANAL & OFFSITE & sw & $\mathrm{N}$ & IRRIGATION & UNFILTERED & 14-May-03 & LO TRITIUM & 29.1 & pCi/L & 2.7 & 4.6 & & & \\
\hline SESPSPEC & B16WM7 & RINGOLD WASTEWAY & OFFSITE & sw & $\mathrm{N}$ & IRRIGATION & UNFILTERED & 14-May-03 & LO TRITIUM & 29.6 & $\mathrm{pCi} / \mathrm{L}$ & 2.7 & 4.7 & & & \\
\hline SESPSPEC & B16WM8 & RINGOLD WASTEWAY & OFFSITE & sw & $\mathrm{N}$ & IRRIGATION & UNFILTERED & 14-May-03 & LO TRITIUM & 27.3 & $\mathrm{pCi} / \mathrm{L}$ & 2.8 & 4.6 & & & \\
\hline SESPSPEC & B16WM9 & RINGOLD WASTEWAY & OFFSITE & sW & $\mathrm{N}$ & IRRIGATION & UNFILTERED & 14-May-03 & LO TRITIUM & 26.2 & $\mathrm{pCi} / \mathrm{L}$ & 2.7 & 4.5 & & & \\
\hline SESPSPEC & B170R8 & RINGOLD WASTEWAY & OFFSITE & sw & $\mathrm{N}$ & IRRIGATION & UNFILTERED & 14-May-03 & TSS (Total suspended solids) & & $\mathrm{mg} / \mathrm{L}$ & & & c & & \\
\hline SESPSPEC & B170R9 & RINGOLD WASTEWAY & OFFSITE & sw & $\mathrm{N}$ & IRRIGATION & UNFILTERED & 14-May-03 & TSS (Total suspended solids) & & $\mathrm{mg} / \mathrm{L}$ & & & c & & \\
\hline SESPSPEC & B170T0 & RINGOLD WASTEWAY & OFFSITE & sW & $\mathrm{N}$ & IRRIGATION & UNFILTERED & 14-May-03 & TSS (Total suspended solids) & & $\mathrm{mg} / \mathrm{L}$ & & & C & & \\
\hline SESPSPEC & B170R5 & POTHOLES CANAL & OFFSITE & sW & $\mathrm{N}$ & IRRIGATION & UNFILTERED & 14-May-03 & TSS (Total suspended solids) & & $\mathrm{mg} / \mathrm{L}$ & & & C & & \\
\hline SESPSPEC & B170R6 & POTHOLES CANAL & OFFSITE & sw & $\mathrm{N}$ & IRRIGATION & UNFILTERED & 14-May-03 & TSS (Total suspended solids) & & $\mathrm{mg} / \mathrm{L}$ & & & c & & \\
\hline SESPSPEC & B170R7 & POTHOLES CANAL & OFFSITE & sw & $\mathrm{N}$ & IRRIGATION & UNFILTERED & 14-May-03 & TSS (Total suspended solids) & & $\mathrm{mg} / \mathrm{L}$ & & & C & & \\
\hline SESPSPEC & B170R2 & ESQUATZEL CANAL & OFFSITE & sW & $\mathrm{N}$ & IRRIGATION & UNFILTERED & 14-May-03 & TSS (Total suspended solids) & & $\mathrm{mg} / \mathrm{L}$ & & & C & & \\
\hline SESPSPEC & B170R3 & ESQUATZEL CANAL & OFFSITE & sW & $\mathrm{N}$ & IRRIGATION & UNFILTERED & 14-May-03 & TSS (Total suspended solids) & & $\mathrm{mg} / \mathrm{L}$ & & & C & & \\
\hline SESPSPEC & B170R4 & ESQUATZEL CANAL & OFFSITE & sw & $\mathrm{N}$ & IRRIGATION & UNFILTERED & 14-May-03 & TSS (Total suspended solids) & & $\mathrm{mg} / \mathrm{L}$ & & & c & & \\
\hline SESPSPEC & B16WT6 & ESQUATZEL CANAL & OFFSITE & sw & $\mathrm{Y}$ & IRRIGATION & & 14-May-03 & & 641 & ug/L & & & & & \\
\hline SESPSPEC & B16WT7 & ESQUATZEL CANAL & OFFSITE & sw & $\mathrm{Y}$ & IRRIGATION & & 14-May-03 & & 0.000643 & ug/L & & & & & \\
\hline SESPSPEC & B16WT8 & ESQUATZEL CANAL & OFFSITE & sW & $\mathrm{Y}$ & IRRIGATION & & 14-May-03 & & 0.000828 & $\mathrm{ug} / \mathrm{L}$ & & & & & \\
\hline SESPSPEC & B16WT9 & ESQUATZEL CANAL & OFFSITE & sW & $\mathrm{N}$ & IRRIGATION & NFILTERED & 14-May-03 & & 0.000831 & $\mathrm{ug} / \mathrm{L}$ & & & & & \\
\hline
\end{tabular}


WATER - IRRIGATION

\begin{tabular}{|c|c|c|c|c|c|c|c|c|c|c|c|c|c|c|c|c|}
\hline $\mid$ OWNER ID $\mid$ & SAMP NUM & SAMP SITE NAME & DIST CLASS & MEDIA & $\begin{array}{c}\text { FILTERED } \\
\text { FLAG }\end{array} \mid$ & | SAMP FROM & | COLL MTHD | & SAMP DATE & CON SHORT NAME & VALUE RPTD & \begin{tabular}{l|} 
ANAL \\
UNITS \\
RPTD
\end{tabular} & $\left|\begin{array}{c}\text { COUNTING } \\
\text { ERROR }\end{array}\right|$ & $\left|\begin{array}{c}\text { TOTAL ANAL } \\
\text { ERROR }\end{array}\right|$ & $\begin{array}{c}\text { LAB } \\
\text { QUALIFIER }\end{array}$ & SAMP COMMENT & RESULT COMMENT \\
\hline SESPSPEC & B16WV0 & ESQUATZEL CANAL & OFFSITE & sw & $\mathrm{N}$ & IRRIGATION & UNFILTERED & 14-May-03 Hg & & 0.000893 us & & & & & & \\
\hline SESPSPEC & B16WV1 & ESQUATZEL CANAL & OFFSITE & sW & $\mathrm{N}$ & IRRIGATION & UNFILTERED & 14-May-03 Hg & & $0.000922 \mathrm{us}$ & ug/L & & & & & \\
\hline SESPSPEC & B16WV2 & POTHOLES CANAL & OFFSITE & sw & $\mathrm{Y}$ & IRRIGATION & & 14-May-03 Hg & & $0.000485 \mathrm{us}$ & ug/L & & & B & & \\
\hline SESPSPEC & B16WV3 & POTHOLES CANAL & OFFSITE & sW & $\mathrm{Y}$ & IRRIGATION & & 14-May-03 Hg & & $0.000449 \mathrm{ug}$ & & & & B & & \\
\hline SESPSPEC & B16WV4 & POTHOLES CANAL & OFFSITE & sW & $\mathrm{Y}$ & IRRIGATION & & 14-May-03 Hg & & $0.000454 \mathrm{us}$ & ug/L & & & B & & \\
\hline SESPSPEC & B16WV5 & POTHOLES CANAL & OFFSITE & sw & $\mathrm{N}$ & IRRIGATION & UNFILTERED & 14-May-03 Hg & & $0.000897 \mathrm{us}$ & $\mathrm{ug} / \mathrm{L}$ & & & & & \\
\hline SESPSPEC & B16WV6 & POTHOLES CANAL & OFFSITE & sW & $\mathrm{N}$ & IRRIGATION & UNFILTERED & 14-May-03 Hg & & $0.000712 \mathrm{ug}$ & & & & & & \\
\hline SESPSPEC & B16WV7 & POTHOLES CANAL & OFFSITE & sW & $\mathrm{N}$ & IRRIGATION & UNFILTERED & 14-May-03 Hg & & $0.00091 \mathrm{us}$ & & & & & & \\
\hline SESPSPEC & B16WTO & RINGOLD WASTEWAY & OFFSITE & sw & Y & IRRIGATION & & 14-May-03 Hg & & 0.000637 us & $u g / L$ & & & & & \\
\hline SESPSPEC & B16WT1 & RINGOLD WASTEWAY & OFFSITE & sw & Y & IRRIGATION & & 14-May-03 Hg & & $0.000712 \mathrm{u}$ & ug/L & & & & & \\
\hline SESPSPEC & B16WT2 & RINGOLD WASTEWAY & OFFSITE & sw & $\mathrm{Y}$ & IRRIGATION & & 14-May-03 Hg & & $0.000784 \mathrm{us}$ & & & & & & \\
\hline SESPSPEC & B16WT3 & RINGOLD WASTEWAY & OFFSITE & sW & $\mathrm{N}$ & IRRIGATION & UNFILTERED & 14-May-03 Hg & & $0.000768 \mathrm{ug}$ & & & & & & \\
\hline SESPSPEC & B16WT4 & RINGOLD WASTEWAY & OFFSITE & sw & $\mathrm{N}$ & IRRIGATION & UNFILTERED & 14-May-03 Hg & & $0.00109 \mathrm{u}$ & $\mathrm{ug} / \mathrm{L}$ & & & & & \\
\hline SESPSPEC & B16WT5 & RINGOLD WASTEWAY & OFFSITE & sw & $\mathrm{N}$ & IRRIGATION & UNFILTERED & 14-May-03 Hg & & 0.00117 us & $\mathrm{ug} / \mathrm{L}$ & & & & & \\
\hline SESPSPEC & B16WT6 & ESQUATZEL CANAL & OFFSITE & sw & $\mathrm{Y}$ & IRRIGATION & & 14-May-03 Ag & & $0.0085 \mathrm{us}$ & & & & $u$ & & \\
\hline SESPSPEC & B16WT7 & ESQUATZEL CANAL & OFFSITE & sw & $Y$ & IRRIGATION & & 14-May-03 Ag & & $0.0085 \mathrm{us}$ & $\mathrm{ug} / \mathrm{L}$ & & & U & & \\
\hline SESPSPEC & B16WT8 & ESQUATZEL CANAL & OFFSITE & sw & $\mathrm{Y}$ & IRRIGATION & & 14-May-03 Ag & & $0.0085 \mathrm{us}$ & $\mathrm{ug} / \mathrm{L}$ & & & u & & \\
\hline SESPSPEC & B16WT9 & ESQUATZEL CANAL & OFFSITE & sw & $\mathrm{N}$ & IRRIGATION & UNFILTERED & 14-May-03 Ag & & $0.0085 \mathrm{us}$ & $\mathrm{ug} / \mathrm{L}$ & & & u & & \\
\hline SESPSPEC & B16WV0 & ESQUATZEL CANAL & OFFSITE & sw & $\mathrm{N}$ & IRRIGATION & UNFILTERED & 14-May-03 Ag & & 0.0085 u & $\mathrm{ug} / \mathrm{L}$ & & & $u$ & & \\
\hline SESPSPEC & B16WV1 & ESQUATZEL CANAL & OFFSITE & sw & $\mathrm{N}$ & IRRIGATION & UNFILTERED & 14-May-03 Ag & & $0.0085 \mathrm{u}$ & $\mathrm{ug} / \mathrm{L}$ & & & $u$ & & \\
\hline SESPSPEC & B16WV2 & POTHOLES CANAL & OFFSITE & sw & $\mathrm{Y}$ & IRRIGATION & & 14-May-03 Ag & & $0.0085 \mathrm{us}$ & & & & $u$ & & \\
\hline SESPSPEC & B16WV3 & POTHOLES CANAL & OFFSITE & sw & Y & IRRIGATION & & 14-May-03 Ag & & 0.0085 u & ug/L & & & u & & \\
\hline SESPSPEC & B16WV4 & POTHOLES CANAL & OFFSITE & sw & $\mathrm{Y}$ & IRRIGATION & & 14-May-03 Ag & & $0.0085 \mathrm{us}$ & $\mathrm{ug} / \mathrm{L}$ & & & $u$ & & \\
\hline SESPSPEC & B16WV5 & POTHOLES CANAL & OFFSITE & sw & $\mathrm{N}$ & IRRIGATION & UNFILTERED & 14-May-03 Ag & & $0.0085 \mathrm{u}$ & $\mathrm{ug} / \mathrm{L}$ & & & $u$ & & \\
\hline SESPSPEC & B16WV6 & POTHOLES CANAL & OFFSITE & sw & $\mathrm{N}$ & IRRIGATION & UNFILTERED & 14-May-03 Ag & & $0.0085 \mathrm{us}$ & & & & $U$ & & \\
\hline SESPSPEC & B16WV7 & POTHOLES CANAL & OFFSITE & sw & $\mathrm{N}$ & IRRIGATION & UNFILTERED & 14-May-03 Ag & & 0.0085 u & & & & $u$ & & \\
\hline SESPSPEC & B16WT0 & RINGOLD WASTEWAY & OFFSITE & sw & $\mathrm{Y}$ & IRRIGATION & & 14-May-03 Ag & & $0.0085 \mathrm{us}$ & $\mathrm{ug} / \mathrm{L}$ & & & u & & \\
\hline SESPSPEC & B16WT1 & RINGOLD WASTEWAY & OFFSITE & sw & $\mathrm{Y}$ & IRRIGATION & & 14-May-03 Ag & & $0.0085 \mathrm{us}$ & $\mathrm{ug} / \mathrm{L}$ & & & $u$ & & \\
\hline SESPSPEC & B16WT2 & RINGOLD WASTEWAY & OFFSITE & sw & $\mathrm{Y}$ & IRRIGATION & & 14-May-03 Ag & & $0.0085 \mathrm{us}$ & & & & $u$ & & \\
\hline SESPSPEC & B16WT3 & RINGOLD WASTEWAY & OFFSITE & sW & $\mathrm{N}$ & IRRIGATION & UNFILTERED & 14-May-03 Ag & & $0.0085 \mathrm{us}$ & $\mathrm{ug} / \mathrm{L}$ & & & $u$ & & \\
\hline SESPSPEC & B16WT4 & RINGOLD WASTEWAY & OFFSITE & sw & $\mathrm{N}$ & IRRIGATION & UNFILTERED & 14-May-03 Ag & & 0.0085 us & $\mathrm{ug} / \mathrm{L}$ & & & u & & \\
\hline SESPSPEC & B16WT5 & RINGOLD WASTEWAY & OFFSITE & sW & $\mathrm{N}$ & IRRIGATION & UNFILTERED & 14-May-03 Ag & & $0.0085 \mathrm{us}$ & $\mathrm{ug} / \mathrm{L}$ & & & $u$ & & \\
\hline SESPSPEC & B16WT6 & ESQUATZEL CANAL & OFFSITE & sW & $\mathrm{Y}$ & IRRIGATION & & 14-May-03 As & & $4.54 \mathrm{us}$ & & & & & & \\
\hline SESPSPEC & B16WT7 & ESQUATZEL CANAL & OFFSITE & sw & $\mathrm{Y}$ & IRRIGATION & & 14-May-03 As & & 4.35 us & $\mathrm{ug} / \mathrm{L}$ & & & & & \\
\hline SESPSPEC & B16WT8 & ESQUATZEL CANAL & OFFSITE & sw & Y & IRRIGATION & & 14-May-03 As & & $4.66 \mathrm{us}$ & ug/L & & & & & \\
\hline SESPSPEC & B16WT9 & ESQUATZEL CANAL & OFFSITE & sW & $\mathrm{N}$ & IRRIGATION & UNFILTERED & 14-May-03 As & & $4.38 \mathrm{us}$ & & & & & & \\
\hline SESPSPEC & B16WV0 & ESQUATZEL CANAL & OFFSITE & sW & $\mathrm{N}$ & IRRIGATION & UNFILTERED & 14-May-03 As & & $4.44 \mathrm{us}$ & & & & & & \\
\hline SESPSPEC & B16WV1 & ESQUATZEL CANAL & OFFSITE & sW & $\mathrm{N}$ & IRRIGATION & UNFILTERED & 14-May-03 As & & $4.47 \mathrm{us}$ & $\mathrm{ug} / \mathrm{L}$ & & & & & \\
\hline SESPSPEC & B16WV2 & POTHOLES CANAL & OFFSITE & sw & $\mathrm{Y}$ & IRRIGATION & & 14-May-03 As & & $3.08 \mathrm{us}$ & & & & & & \\
\hline SESPSPEC & B16WV3 & POTHOLES CANAL & OFFSITE & sW & $\mathrm{Y}$ & IRRIGATION & & 14-May-03 As & & $2.97 \mathrm{us}$ & $\mathrm{ug} / \mathrm{L}$ & & & & & \\
\hline SESPSPEC & B16WV4 & POTHOLES CANAL & OFFSITE & sW & $\mathrm{Y}$ & IRRIGATION & & 14-May-03 As & & $3.27 \mathrm{us}$ & $\mathrm{ug} / \mathrm{L}$ & & & & & \\
\hline SESPSPEC & B16WV5 & POTHOLES CANAL & OFFSITE & sw & $\mathrm{N}$ & IRRIGATION & UNFILTERED & 14-May-03 As & & $3.08 \mathrm{u}$ & $\mathrm{ug} / \mathrm{L}$ & & & & & \\
\hline SESPSPEC & B16WV6 & POTHOLES CANAL & OFFSITE & sw & $\mathrm{N}$ & IRRIGATION & UNFILTERED & 14-May-03 As & & $3.04 \mathrm{us}$ & & & & & & \\
\hline SESPSPEC & B16WV7 & POTHOLES CANAL & OFFSITE & sw & $\mathrm{N}$ & IRRIGATION & UNFILTERED & 14-May-03 As & & $3.09 \mathrm{us}$ & $\mathrm{ug} / \mathrm{L}$ & & & & & \\
\hline SESPSPEC & B16WT0 & RINGOLD WASTEWAY & OFFSITE & sW & $\mathrm{Y}$ & IRRIGATION & & 14-May-03 As & & $4.67 \mathrm{us}$ & $\mathrm{ug} / \mathrm{L}$ & & & & & \\
\hline SESPSPEC & B16WT1 & RINGOLD WASTEWAY & OFFSITE & sw & $\mathrm{Y}$ & IRRIGATION & & 14-May-03 As & & 4.98 us & $\mathrm{ug} / \mathrm{L}$ & & & & & \\
\hline SESPSPEC & B16WT2 & RINGOLD WASTEWAY & OFFSITE & sw & Y & IRRIGATION & & 14-May-03 As & & & $\mathrm{ug} / \mathrm{L}$ & & & & & \\
\hline SESPSPEC & B16WT3 & RINGOLD WASTEWAY & OFFSITE & sw & $\mathrm{N}$ & IRRIGATION & UNFILTERED & 14-May-03 As & & $4.84 \mathrm{us}$ & & & & & & \\
\hline SESPSPEC & B16WT4 & RINGOLD WASTEWAY & OFFSITE & sW & $\mathrm{N}$ & IRRIGATION & UNFILTERED & 14-May-03 As & & $4.82 \mathrm{us}$ & $\mathrm{ug} / \mathrm{L}$ & & & & & \\
\hline SESPSPEC & B16WT5 & RINGOLD WASTEWAY & OFFSITE & sw & $\mathrm{N}$ & IRRIGATION & UNFILTERED & 14-May-03 As & & $4.71 \mathrm{us}$ & $\mathrm{ug} / \mathrm{L}$ & & & & & \\
\hline SESPSPEC & B16WT6 & ESQUATZEL CANAL & OFFSITE & sw & Y & IRRIGATION & & 14-May-03 Be & & $0.066 \mathrm{us}$ & $u g / L$ & & & $u$ & & \\
\hline SESPSPEC & B16WT7 & ESQUATZEL CANAL & OFFSITE & sw & $\mathrm{Y}$ & IRRIGATION & & 14-May-03 Be & & $0.066 \mathrm{us}$ & ug/L & & & $u$ & & \\
\hline SESPSPEC & B16WT8 & ESQUATZEL CANAL & OFFSITE & sW & $\mathrm{Y}$ & IRRIGATION & & 14-May-03 Be & & $0.066 \mathrm{us}$ & $\mathrm{ug} / \mathrm{L}$ & & & U & & \\
\hline SESPSPEC & B16WT9 & ESQUATZEL CANAL & OFFSITE & sw & $\mathrm{N}$ & IRRIGATION & UNFILTERED & 14-May-03 Be & & $0.066 \mathrm{us}$ & $\mathrm{ug} / \mathrm{L}$ & & & u & & \\
\hline SESPSPEC & B16WV0 & ESQUATZEL CANAL & OFFSITE & sw & $\mathrm{N}$ & IRRIGATION & UNFILTERED & 14-May-03 Be & & $0.066 \mathrm{ug}$ & ug/L & & & u & & \\
\hline SESPSPEC & B16WV1 & ESQUATZEL CANAL & OFFSITE & sw & $\mathrm{N}$ & IRRIGATION & UNFILTERED & 14-May-03 Be & & $0.066 \mathrm{us}$ & ug/L & & & $u$ & & \\
\hline SESPSPEC & B16WV2 & POTHOLES CANAL & OFFSITE & sW & $\mathrm{Y}$ & IRRIGATION & & 14-May-03 Be & & $0.066 \mathrm{us}$ & $\mathrm{ug} / \mathrm{L}$ & & & U & & \\
\hline SESPSPEC & B16WV3 & POTHOLES CANAL & OFFSITE & sW & $\mathrm{Y}$ & IRRIGATION & & 14-May-03 Be & & $0.066 \mathrm{us}$ & $\mathrm{ug} / \mathrm{L}$ & & & U & & \\
\hline
\end{tabular}


WATER - IRRIGATION

\begin{tabular}{|c|c|c|c|c|c|c|c|c|c|c|c|c|c|c|c|c|}
\hline | OWNER ID & SAMP NUM & SAMP SITE NAME & DIST CLASS & MEDIA & $\begin{array}{c}\text { FILTERED } \\
\text { FLAG }\end{array} \mid$ & SAMP FROM & | COLL MTHD | & SAMP DATE & CON SHORT NAME & VALUE RPTD & \begin{tabular}{l|} 
ANAL \\
UNITS \\
RPTD
\end{tabular} & $\left|\begin{array}{c}\text { COUNTING } \\
\text { ERROR }\end{array}\right|$ & $\left|\begin{array}{c}\text { TOTAL ANAL } \\
\text { ERROR }\end{array}\right|$ & $\mid$\begin{tabular}{c|} 
LAB \\
QUALIFIER
\end{tabular} & SAMP COMMENT & RESULT COMMENT \\
\hline SESPSPEC & B16WV4 & POTHOLES CANAL & OFFSITE & sw & Y & IRRIGATION & & 14-May-03 Be & & $0.066 \mathrm{us}$ & & & & u & & \\
\hline SESPSPEC & B16WV5 & POTHOLES CANAL & OFFSITE & sW & $\mathrm{N}$ & IRRIGATION & UNFILTERED & 14-May-03 Be & & $0.066 \mathrm{us}$ & ug/L & & & U & & \\
\hline SESPSPEC & B16WV6 & POTHOLES CANAL & OFFSITE & sw & $\mathrm{N}$ & IRRIGATION & UNFILTERED & 14-May-03 Be & & $0.066 \mathrm{us}$ & ug/L & & & U & & \\
\hline SESPSPEC & B16WV7 & POTHOLES CANAL & OFFSITE & sW & $\mathrm{N}$ & IRRIGATION & UNFILTERED & 14-May-03 Be & & $0.066 \mathrm{us}$ & & & & U & & \\
\hline SESPSPEC & B16WT0 & RINGOLD WASTEWAY & OFFSITE & sW & $\mathrm{Y}$ & IRRIGATION & & 14-May-03 Be & & $0.00679 \mathrm{us}$ & ug/L & & & B & & \\
\hline SESPSPEC & B16WT1 & RINGOLD WASTEWAY & OFFSITE & sw & Y & IRRIGATION & & 14-May-03 Be & & $0.066 \mathrm{u}$ & $\mathrm{ug} / \mathrm{L}$ & & & u & & \\
\hline SESPSPEC & B16WT2 & RINGOLD WASTEWAY & OFFSITE & sW & $\mathrm{Y}$ & IRRIGATION & & 14-May-03 Be & & $0.0782 \mathrm{us}$ & & & & B & & \\
\hline SESPSPEC & B16WT3 & RINGOLD WASTEWAY & OFFSITE & sW & $\mathrm{N}$ & IRRIGATION & UNFILTERED & 14-May-03 Be & & $0.066 \mathrm{ug}$ & & & & U & & \\
\hline SESPSPEC & B16WT4 & RINGOLD WASTEWAY & OFFSITE & sw & $\mathrm{N}$ & IRRIGATION & UNFILTERED & 14-May-03 Be & & $0.066 \mathrm{us}$ & $u g / L$ & & & u & & \\
\hline SESPSPEC & B16WT5 & RINGOLD WASTEWAY & OFFSITE & sw & $\mathrm{N}$ & IRRIGATION & UNFILTERED & 14-May-03 Be & & $0.066 \mathrm{us}$ & ug/L & & & u & & \\
\hline SESPSPEC & B16WT6 & ESQUATZEL CANAL & OFFSITE & sw & $\mathrm{Y}$ & IRRIGATION & & 14-May-03 Cd & & $0.023 \mathrm{us}$ & & & & $u$ & & \\
\hline SESPSPEC & B16WT7 & ESQUATZEL CANAL & OFFSITE & sW & $\mathrm{Y}$ & IRRIGATION & & 14-May-03 Cd & & $0.023 \mathrm{us}$ & & & & $u$ & & \\
\hline SESPSPEC & B16WT8 & ESQUATZEL CANAL & OFFSITE & sw & $\mathrm{Y}$ & IRRIGATION & & 14-May-03 Cd & & $0.023 \mathrm{u}$ & $\mathrm{ug} / \mathrm{L}$ & & & u & & \\
\hline SESPSPEC & B16WT9 & ESQUATZEL CANAL & OFFSITE & sw & $\mathrm{N}$ & IRRIGATION & UNFILTERED & 14-May- $03 \mathrm{Cd}$ & & 0.023 us & $\mathrm{ug} / \mathrm{L}$ & & & u & & \\
\hline SESPSPEC & B16WVo & ESQUATZEL CANAL & OFFSITE & sw & $\mathrm{N}$ & IRRIGATION & UNFILTERED & 14-May-03 Cd & & $0.023 \mathrm{us}$ & & & & $u$ & & \\
\hline SESPSPEC & B16WV1 & ESQUATZEL CANAL & OFFSITE & sw & $\mathrm{N}$ & IRRIGATION & UNFILTERED & 14-May-03 Cd & & $0.023 \mathrm{us}$ & $\mathrm{ug} / \mathrm{L}$ & & & u & & \\
\hline SESPSPEC & B16WV2 & POTHOLES CANAL & OFFSITE & sw & $\mathrm{Y}$ & IRRIGATION & & 14-May-03 Cd & & $0.023 \mathrm{u}$ & & & & u & & \\
\hline SESPSPEC & B16WV3 & POTHOLES CANAL & OFFSITE & sw & Y & IRRIGATION & & 14-May-03 Cd & & $0.023 \mathrm{us}$ & $\mathrm{ug} / \mathrm{L}$ & & & u & & \\
\hline SESPSPEC & B16WV4 & POTHOLES CANAL & OFFSITE & sw & Y & IRRIGATION & & 14-May- $03 \mathrm{Cd}$ & & $0.023 \mathrm{us}$ & $\mathrm{ug} / \mathrm{L}$ & & & u & & \\
\hline SESPSPEC & B16WV5 & POTHOLES CANAL & OFFSITE & sw & $\mathrm{N}$ & IRRIGATION & UNFILTERED & 14-May-03 Cd & & $0.023 \mathrm{us}$ & $\mathrm{ug} / \mathrm{L}$ & & & $u$ & & \\
\hline SESPSPEC & B16WV6 & POTHOLES CANAL & OFFSITE & sw & $\mathrm{N}$ & IRRIGATION & UNFILTERED & 14-May-03 Cd & & $0.023 \mathrm{us}$ & & & & $u$ & & \\
\hline SESPSPEC & B16WV7 & POTHOLES CANAL & OFFSITE & sw & $\mathrm{N}$ & IRRIGATION & UNFILTERED & 14-May-03 Cd & & $0.023 \mathrm{us}$ & & & & u & & \\
\hline SESPSPEC & B16WT0 & RINGOLD WASTEWAY & OFFSITE & sw & Y & IRRIGATION & & 14-May-03 Cd & & $0.023 \mathrm{ug}$ & $\mathrm{ug} / \mathrm{L}$ & & & u & & \\
\hline SESPSPEC & B16WT1 & RINGOLD WASTEWAY & OFFSITE & sw & Y & IRRIGATION & & 14-May-03 Cd & & $0.023 \mathrm{us}$ & $\mathrm{ug} / \mathrm{L}$ & & & u & & \\
\hline SESPSPEC & B16WT2 & RINGOLD WASTEWAY & OFFSITE & sw & $\mathrm{Y}$ & IRRIGATION & & 14-May-03 Cd & & $0.023 \mathrm{us}$ & & & & U & & \\
\hline SESPSPEC & B16WT3 & RINGOLD WASTEWAY & OFFSITE & sw & $\mathrm{N}$ & IRRIGATION & UNFILTERED & 14-May-03 Cd & & $0.023 \mathrm{us}$ & & & & $u$ & & \\
\hline SESPSPEC & B16WT4 & RINGOLD WASTEWAY & OFFSITE & sw & $\mathrm{N}$ & IRRIGATION & UNFILTERED & 14-May-03 Cd & & $0.023 \mathrm{us}$ & $\mathrm{ug} / \mathrm{L}$ & & & $u$ & & \\
\hline SESPSPEC & B16WT5 & RINGOLD WASTEWAY & OFFSITE & sw & $\mathrm{N}$ & IRRIGATION & UNFILTERED & 14-May-03 Cd & & $0.023 \mathrm{us}$ & $\mathrm{ug} / \mathrm{L}$ & & & $u$ & & \\
\hline SESPSPEC & B16WT6 & ESQUATZEL CANAL & OFFSITE & sw & $\mathrm{Y}$ & IRRIGATION & & 14-May-03 Cr & & 1.86 us & & & & & & \\
\hline SESPSPEC & B16WT7 & ESQUATZEL CANAL & OFFSITE & sW & $\mathrm{Y}$ & IRRIGATION & & 14-May-03 Cr & & $1.69 \mathrm{us}$ & $\mathrm{ug} / \mathrm{L}$ & & & & & \\
\hline SESPSPEC & B16WT8 & ESQUATZEL CANAL & OFFSITE & sw & Y & IRRIGATION & & 14-May-03 Cr & & $2.08 \mathrm{us}$ & $\mathrm{ug} / \mathrm{L}$ & & & & & \\
\hline SESPSPEC & B16WT9 & ESQUATZEL CANAL & OFFSITE & sW & $\mathrm{N}$ & IRRIGATION & UNFILTERED & 14-May-03 Cr & & $0.729 \mathrm{us}$ & & & & C & & \\
\hline SESPSPEC & B16WV0 & ESQUATZEL CANAL & OFFSITE & sW & $\mathrm{N}$ & IRRIGATION & UNFILTERED & 14-May-03 Cr & & $0.673 \mathrm{us}$ & & & & C & & \\
\hline SESPSPEC & B16WV1 & ESQUATZEL CANAL & OFFSITE & sw & $\mathrm{N}$ & IRRIGATION & UNFILTERED & 14-May-03 Cr & & $0.771 \mathrm{us}$ & $\mathrm{ug} / \mathrm{L}$ & & & c & & \\
\hline SESPSPEC & B16WV2 & POTHOLES CANAL & OFFSITE & sw & Y & IRRIGATION & & 14-May-03 Cr & & $0.913 \mathrm{ug}$ & $\mathrm{ug} / \mathrm{L}$ & & & & & \\
\hline SESPSPEC & B16WV3 & POTHOLES CANAL & OFFSITE & sW & $\mathrm{Y}$ & IRRIGATION & & 14-May-03 Cr & & $0.735 \mathrm{us}$ & & & & & & \\
\hline SESPSPEC & B16WV4 & POTHOLES CANAL & OFFSITE & sW & $\mathrm{Y}$ & IRRIGATION & & 14-May-03 Cr & & $1.61 \mathrm{us}$ & & & & & & \\
\hline SESPSPEC & B16WV5 & POTHOLES CANAL & OFFSITE & sW & $\mathrm{N}$ & IRRIGATION & UNFILTERED & 14-May-03 Cr & & $0.533 \mathrm{us}$ & $\mathrm{ug} / \mathrm{L}$ & & & c & & \\
\hline SESPSPEC & B16WV6 & POTHOLES CANAL & OFFSITE & sw & $\mathrm{N}$ & IRRIGATION & UNFILTERED & 14-May- $03 \mathrm{Cr}$ & & $0.61 \mathrm{us}$ & $\mathrm{ug} / \mathrm{L}$ & & & c & & \\
\hline SESPSPEC & B16WV7 & POTHOLES CANAL & OFFSITE & sW & $\mathrm{N}$ & IRRIGATION & UNFILTERED & 14-May-03 Cr & & $0.512 \mathrm{us}$ & & & & C & & \\
\hline SESPSPEC & B16WT0 & RINGOLD WASTEWAY & OFFSITE & sW & $\mathrm{Y}$ & IRRIGATION & & 14-May-03 Cr & & $1.99 \mathrm{us}$ & $\mathrm{ug} / \mathrm{L}$ & & & & & \\
\hline SESPSPEC & B16WT1 & RINGOLD WASTEWAY & OFFSITE & sw & $\mathrm{Y}$ & IRRIGATION & & 14-May-03 Cr & & 2.29 u & $\mathrm{ug} / \mathrm{L}$ & & & & & \\
\hline SESPSPEC & B16WT2 & RINGOLD WASTEWAY & OFFSITE & sw & $Y$ & IRRIGATION & & 14-May- $03 \mathrm{Cr}$ & & $2.82 \mathrm{us}$ & $\mathrm{ug} / \mathrm{L}$ & & & & & \\
\hline SESPSPEC & B16WT3 & RINGOLD WASTEWAY & OFFSITE & sw & $\mathrm{N}$ & IRRIGATION & UNFILTERED & 14-May-03 Cr & & $0.475 \mathrm{us}$ & & & & C & & \\
\hline SESPSPEC & B16WT4 & RINGOLD WASTEWAY & OFFSITE & sW & $\mathrm{N}$ & IRRIGATION & UNFILTERED & 14-May-03 Cr & & $0.455 \mathrm{us}$ & $\mathrm{ug} / \mathrm{L}$ & & & C & & \\
\hline SESPSPEC & B16WT5 & RINGOLD WASTEWAY & OFFSITE & sw & $\mathrm{N}$ & IRRIGATION & UNFILTERED & 14-May-03 Cr & & $0.528 \mathrm{us}$ & $\mathrm{ug} / \mathrm{L}$ & & & c & & \\
\hline SESPSPEC & B16WT6 & ESQUATZEL CANAL & OFFSITE & sw & Y & IRRIGATION & & 14-May-03 Cu & & $4.83 \mathrm{us}$ & & & & & & \\
\hline SESPSPEC & B16WT7 & ESQUATZEL CANAL & OFFSITE & sw & $\mathrm{Y}$ & IRRIGATION & & 14-May-03 Cu & & $4.99 \mathrm{us}$ & $\mathrm{ug} / \mathrm{L}$ & & & & & \\
\hline SESPSPEC & B16WT8 & ESQUATZEL CANAL & OFFSITE & sW & $\mathrm{Y}$ & IRRIGATION & & 14-May-03 Cu & & & $\mathrm{ug} / \mathrm{L}$ & & & & & \\
\hline SESPSPEC & B16WT9 & ESQUATZEL CANAL & OFFSITE & sw & $\mathrm{N}$ & IRRIGATION & UNFILTERED & 14-May-03 Cu & & 6.96 us & ug/L & & & & & \\
\hline SESPSPEC & B16WV0 & ESQUATZEL CANAL & OFFSITE & sw & $\mathrm{N}$ & IRRIGATION & UNFILTERED & 14-May-03 Cu & & & $u g / L$ & & & & & \\
\hline SESPSPEC & B16WV1 & ESQUATZEL CANAL & OFFSITE & sw & $\mathrm{N}$ & IRRIGATION & UNFILTERED & 14-May-03 Cu & & $6.96 \mathrm{us}$ & & & & & & \\
\hline SESPSPEC & B16WV2 & POTHOLES CANAL & OFFSITE & sW & $\mathrm{Y}$ & IRRIGATION & & 14-May-03 Cu & & & & & & & & \\
\hline SESPSPEC & B16WV3 & POTHOLES CANAL & OFFSITE & sw & $\mathrm{Y}$ & IRRIGATION & & 14-May-03 Cu & & $3.38 \mathrm{us}$ & $\mathrm{ug} / \mathrm{L}$ & & & & & \\
\hline SESPSPEC & B16WV4 & POTHOLES CANAL & OFFSITE & sw & $\mathrm{Y}$ & IRRIGATION & & 14-May-03 Cu & & $3.42 \mathrm{us}$ & ug/L & & & & & \\
\hline SESPSPEC & B16WV5 & POTHOLES CANAL & OFFSITE & sw & $\mathrm{N}$ & IRRIGATION & UNFILTERED & 14-May-03 Cu & & $4.75 \mathrm{us}$ & & & & & & \\
\hline SESPSPEC & B16WV6 & POTHOLES CANAL & OFFSITE & sW & $\mathrm{N}$ & IRRIGATION & UNFILTERED & 14-May-03 Cu & & $4.83 \mathrm{us}$ & $\mathrm{ug} / \mathrm{L}$ & & & & & \\
\hline SESPSPEC & B16WV7 & POTHOLES CANAL & OFFSITE & sW & $\mathrm{N}$ & IRRIGATION & UNFILTERED & 14-May-03 Cu & & & $\mathrm{ug} / \mathrm{L}$ & & & & & \\
\hline
\end{tabular}


WATER - IRRIGATION

\begin{tabular}{|c|c|c|c|c|c|c|c|c|c|c|c|c|c|c|c|c|}
\hline | OWNER ID & SAMP NUM & SAMP SITE NAME & DIST CLASS & MEDIA & $\mid \begin{array}{c}\text { FILTERED } \\
\text { FLAG }\end{array}$ & SAMP FROM & $\mid$ COLL MTHD $\mid$ & SAMP DATE & CON SHORT NAME & VALUE RPTD & \begin{tabular}{|l|} 
ANAL \\
UNITS \\
RPTD
\end{tabular} & $\left|\begin{array}{c}\text { COUNTING } \\
\text { ERROR }\end{array}\right|$ & $\left|\begin{array}{c}\text { TOTAL ANAL } \\
\text { ERROR }\end{array}\right|$ & $\begin{array}{c}\text { LAB } \\
\text { QUALIFIER }\end{array}$ & SAMP COMMENT & RESULT COMMENT \\
\hline SESPSPEC & B16WTO & RINGOLD WASTEWAY & OFFSITE & sW & Y & IRRIGATION & & 14-May- $03 \mathrm{Cu}$ & & & $\mathrm{ug} / \mathrm{L}$ & & & & & \\
\hline SESPSPEC & B16WT1 & RINGOLD WASTEWAY & OFFSITE & sW & $\mathrm{Y}$ & IRRIGATION & & 14-May-03 Cu & & 2.31 & $\mathrm{ug} / \mathrm{L}$ & & & & & \\
\hline SESPSPEC & B16WT2 & RINGOLD WASTEWAY & OFFSITE & sW & $\mathrm{Y}$ & IRRIGATION & & 14-May-03 Cu & & & $\mathrm{ug} / \mathrm{L}$ & & & & & \\
\hline SESPSPEC & B16WT3 & RINGOLD WASTEWAY & OFFSITE & sW & $\mathrm{N}$ & IRRIGATION & UNFILTERED & 14-May-03 Cu & & 2.68 & & & & & & \\
\hline SESPSPEC & B16WT4 & RINGOLD WASTEWAY & OFFSITE & sw & $\mathrm{N}$ & IRRIGATION & UNFILTERED & 14-May-03 Cu & & 2.75 & $\mathrm{ug} / \mathrm{L}$ & & & & & \\
\hline SESPSPEC & B16WT5 & RINGOLD WASTEWAY & OFFSITE & sw & $\mathrm{N}$ & IRRIGATION & UNFILTERED & 14-May- $03 \mathrm{Cu}$ & & 2.76 & $\mathrm{ug} / \mathrm{L}$ & & & & & \\
\hline SESPSPEC & B16WT6 & ESQUATZEL CANAL & OFFSITE & sW & $\mathrm{Y}$ & IRRIGATION & & 14-May-03 Ni & & 0.556 & & & & & & \\
\hline SESPSPEC & B16WT7 & ESQUATZEL CANAL & OFFSITE & sW & Y & IRRIGATION & & 14-May-03 Ni & & $0.592 \mathrm{~L}$ & $\mathrm{ug} / \mathrm{L}$ & & & & & \\
\hline SESPSPEC & B16WT8 & ESQUATZEL CANAL & OFFSITE & sw & $\mathrm{Y}$ & IRRIGATION & & $14-M a y-03 \mathrm{Ni}$ & & 0.544 & $u g / L$ & & & & & \\
\hline SESPSPEC & B16WT9 & ESQUATZEL CANAL & OFFSITE & sw & $\mathrm{N}$ & IRRIGATION & UNFILTERED & $14-\mathrm{May}-03 \mathrm{Ni}$ & & 0.73 & $u g / L$ & & & & & \\
\hline SESPSPEC & B16WV0 & ESQUATZEL CANAL & OFFSITE & sW & $\mathrm{N}$ & IRRIGATION & UNFILTERED & 14-May-03 Ni & & 0.622 & & & & & & \\
\hline SESPSPEC & B16WV1 & ESQUATZEL CANAL & OFFSITE & sw & $\mathrm{N}$ & IRRIGATION & UNFILTERED & $14-M a y-03 \mathrm{Ni}$ & & 0.679 & $\mathrm{ug} / \mathrm{L}$ & & & & & \\
\hline SESPSPEC & B16WV2 & POTHOLES CANAL & OFFSITE & sW & $\mathrm{Y}$ & IRRIGATION & & 14-May-03 Ni & & 0.37 & $u g / L$ & & & & & \\
\hline SESPSPEC & B16WV3 & POTHOLES CANAL & OFFSITE & sw & Y & IRRIGATION & & $14-\mathrm{May}-03 \mathrm{Ni}$ & & 0.453 & & & & & & \\
\hline SESPSPEC & B16WV4 & POTHOLES CANAL & OFFSITE & sw & $Y$ & IRRIGATION & & 14-May-03 Ni & & 0.422 & & & & & & \\
\hline SESPSPEC & B16WV5 & POTHOLES CANAL & OFFSITE & sW & $\mathrm{N}$ & IRRIGATION & UNFILTERED & 14-May-03 Ni & & 0.58 & $\mathrm{ug} / \mathrm{L}$ & & & & & \\
\hline SESPSPEC & B16WV6 & POTHOLES CANAL & OFFSITE & sw & $\mathrm{N}$ & IRRIGATION & UNFILTERED & $14-M a y-03 \mathrm{Ni}$ & & 0.534 & & & & & & \\
\hline SESPSPEC & B16WV7 & POTHOLES CANAL & OFFSITE & sw & $\mathrm{N}$ & IRRIGATION & UNFILTERED & $14-\mathrm{May}-03 \mathrm{Ni}$ & & 0.558 & & & & & & \\
\hline SESPSPEC & B16WT0 & RINGOLD WASTEWAY & OFFSITE & sw & Y & IRRIGATION & & $14-M a y-03 \mathrm{Ni}$ & & 0.744 & $\mathrm{ug} / \mathrm{L}$ & & & & & \\
\hline SESPSPEC & B16WT1 & RINGOLD WASTEWAY & OFFSITE & sw & Y & IRRIGATION & & $14-M a y-03 \mathrm{Ni}$ & & 0.79 & & & & & & \\
\hline SESPSPEC & B16WT2 & RINGOLD WASTEWAY & OFFSITE & sw & $Y$ & IRRIGATION & & $14-M a y-03 \mathrm{Ni}$ & & 0.769 & & & & & & \\
\hline SESPSPEC & B16WT3 & RINGOLD WASTEWAY & OFFSITE & sw & $\mathrm{N}$ & IRRIGATION & UNFILTERED & $14-M a y-03 \mathrm{Ni}$ & & 0.72 & & & & & & \\
\hline SESPSPEC & B16WT4 & RINGOLD WASTEWAY & OFFSITE & sW & $\mathrm{N}$ & IRRIGATION & UNFILTERED & 14-May-03 Ni & & 0.707 & $\mathrm{ug} / \mathrm{L}$ & & & & & \\
\hline SESPSPEC & B16WT5 & RINGOLD WASTEWAY & OFFSITE & sw & $\mathrm{N}$ & IRRIGATION & UNFILTERED & 14-May-03 Ni & & 0.819 & & & & & & \\
\hline SESPSPEC & B16WT6 & ESQUATZEL CANAL & OFFSITE & sw & Y & IRRIGATION & & 14-May-03 Pb & & 0.0247 & & & & & & \\
\hline SESPSPEC & B16WT7 & ESQUATZEL CANAL & OFFSITE & sw & Y & IRRIGATION & & 14-May-03 Pb & & 0.02 & $\mathrm{ug} / \mathrm{L}$ & & & & & \\
\hline SESPSPEC & B16WT8 & ESQUATZEL CANAL & OFFSITE & sW & $\mathrm{Y}$ & IRRIGATION & & 14-May-03 Pb & & 0.0138 & $\mathrm{ug} / \mathrm{L}$ & & & B & & \\
\hline SESPSPEC & B16WT9 & ESQUATZEL CANAL & OFFSITE & sw & $\mathrm{N}$ & IRRIGATION & UNFILTERED & 14-May-03 Pb & & 0.201 & & & & & & \\
\hline SESPSPEC & B16WV0 & ESQUATZEL CANAL & OFFSITE & sw & $\mathrm{N}$ & IRRIGATION & UNFILTERED & 14-May-03 Pb & & 0.185 & & & & & & \\
\hline SESPSPEC & B16WV1 & ESQUATZEL CANAL & OFFSITE & sw & $\mathrm{N}$ & IRRIGATION & UNFILTERED & 14-May-03 Pb & & 0.19 & $\mathrm{ug} / \mathrm{L}$ & & & & & \\
\hline SESPSPEC & B16WV2 & POTHOLES CANAL & OFFSITE & sW & $\mathrm{Y}$ & IRRIGATION & & 14-May-03 Pb & & 0.0153 & $\mathrm{ug} / \mathrm{L}$ & & & B & & \\
\hline SESPSPEC & B16WV3 & POTHOLES CANAL & OFFSITE & sw & Y & IRRIGATION & & 14-May-03 Pb & & 0.0117 & & & & B & & \\
\hline SESPSPEC & B16WV4 & POTHOLES CANAL & OFFSITE & sW & Y & IRRIGATION & & 14-May-03 Pb & & 0.0112 & $u g / L$ & & & $\mathrm{~B}$ & & \\
\hline SESPSPEC & B16WV5 & POTHOLES CANAL & OFFSITE & sw & $\mathrm{N}$ & IRRIGATION & UNFILTERED & 14-May-03 Pb & & 0.177 & $\mathrm{ug} / \mathrm{L}$ & & & & & \\
\hline SESPSPEC & B16WV6 & POTHOLES CANAL & OFFSITE & sw & $\mathrm{N}$ & IRRIGATION & UNFILTERED & 14-May-03 Pb & & 0.177 & & & & & & \\
\hline SESPSPEC & B16WV7 & POTHOLES CANAL & OFFSITE & sw & $\mathrm{N}$ & IRRIGATION & UNFILTERED & 14-May-03 Pb & & 0.164 & & & & & & \\
\hline SESPSPEC & B16WTO & RINGOLD WASTEWAY & OFFSITE & sW & Y & IRRIGATION & & 14-May-03 Pb & & 0.0133 & $u g / L$ & & & B & & \\
\hline SESPSPEC & B16WT1 & RINGOLD WASTEWAY & OFFSITE & sw & $\mathrm{Y}$ & IRRIGATION & & 14-May-03 Pb & & 0.0137 & $\mathrm{ug} / \mathrm{L}$ & & & B & & \\
\hline SESPSPEC & B16WT2 & RINGOLD WASTEWAY & OFFSITE & sw & $\mathrm{Y}$ & IRRIGATION & & 14-May-03 Pb & & $0.011 \mathrm{~L}$ & & & & u & & \\
\hline SESPSPEC & B16WT3 & RINGOLD WASTEWAY & OFFSITE & sW & $\mathrm{N}$ & IRRIGATION & UNFILTERED & 14-May-03 Pb & & 0.0835 & $u g / L$ & & & & & \\
\hline SESPSPEC & B16WT4 & RINGOLD WASTEWAY & OFFSITE & sw & $\mathrm{N}$ & IRRIGATION & UNFILTERED & 14-May-03 Pb & & 0.0837 & $u g / L$ & & & & & \\
\hline SESPSPEC & B16WT5 & RINGOLD WASTEWAY & OFFSITE & sw & $\mathrm{N}$ & IRRIGATION & UNFILTERED & 14-May-03 Pb & & 0.0872 & $\mathrm{ug} / \mathrm{L}$ & & & & & \\
\hline SESPSPEC & B16WT6 & ESQUATZEL CANAL & OFFSITE & sW & Y & IRRIGATION & & $14-\mathrm{May}-03 \mathrm{Sb}$ & & 0.21 & & & & & & \\
\hline SESPSPEC & B16WT7 & ESQUATZEL CANAL & OFFSITE & sW & $\mathrm{Y}$ & IRRIGATION & & 14-May-03 Sb & & 0.188 & $u g / L$ & & & & & \\
\hline SESPSPEC & B16WT8 & ESQUATZEL CANAL & OFFSITE & sW & Y & IRRIGATION & & 14-May-03 Sb & & 0.239 & $u g / L$ & & & & & \\
\hline SESPSPEC & B16WT9 & ESQUATZEL CANAL & OFFSITE & sw & $\mathrm{N}$ & IRRIGATION & UNFILTERED & 14-May-03 Sb & & 0.171 & & & & & & \\
\hline SESPSPEC & B16WV0 & ESQUATZEL CANAL & OFFSITE & sw & $\mathrm{N}$ & IRRIGATION & UNFILTERED & 14-May-03 Sb & & 0.188 & & & & & & \\
\hline SESPSPEC & B16WV1 & ESQUATZEL CANAL & OFFSITE & sW & $\mathrm{N}$ & IRRIGATION & UNFILTERED & 14-May-03 Sb & & & $u g / L$ & & & & & \\
\hline SESPSPEC & B16WV2 & POTHOLES CANAL & OFFSITE & sw & Y & IRRIGATION & & 14-May-03 Sb & & 0.163 & $u g / L$ & & & & & \\
\hline SESPSPEC & B16WV3 & POTHOLES CANAL & OFFSITE & sw & $\mathrm{Y}$ & IRRIGATION & & 14-May-03 Sb & & 0.209 & & & & & & \\
\hline SESPSPEC & B16WV4 & POTHOLES CANAL & OFFSITE & sw & Y & IRRIGATION & & 14-May-03 Sb & & 0.193 & $u g / L$ & & & & & \\
\hline SESPSPEC & B16WV5 & POTHOLES CANAL & OFFSITE & sW & $\mathrm{N}$ & IRRIGATION & UNFILTERED & 14-May-03 Sb & & 0.165 & $u g / L$ & & & & & \\
\hline SESPSPEC & B16WV6 & POTHOLES CANAL & OFFSITE & sw & $\mathrm{N}$ & IRRIGATION & UNFILTERED & 14-May-03 Sb & & 0.159 & $\mathrm{ug} / \mathrm{L}$ & & & & & \\
\hline SESPSPEC & B16WV7 & POTHOLES CANAL & OFFSITE & sw & $\mathrm{N}$ & IRRIGATION & UNFILTERED & 14-May-03 Sb & & 0.165 & & & & & & \\
\hline SESPSPEC & B16WT0 & RINGOLD WASTEWAY & OFFSITE & sw & Y & IRRIGATION & & 14-May-03 Sb & & 0.148 & $u g / L$ & & & & & \\
\hline SESPSPEC & B16WT1 & RINGOLD WASTEWAY & OFFSITE & sW & $\mathrm{Y}$ & IRRIGATION & & 14-May-03 Sb & & 0.162 & $\mathrm{ug} / \mathrm{L}$ & & & & & \\
\hline SESPSPEC & B16WT2 & RINGOLD WASTEWAY & OFFSITE & sw & $\mathrm{Y}$ & IRRIGATION & & 14-May-03 Sb & & 0.171 & $\mathrm{ug} / \mathrm{L}$ & & & & & \\
\hline SESPSPEC & B16WT3 & RINGOLD WASTEWAY & OFFSITE & sw & $\mathrm{N}$ & IRRIGATION & UNFILTERED & 14-May-03 Sb & & 0.151 & $u g / L$ & & & & & \\
\hline
\end{tabular}


WATER - IRRIGATION

\begin{tabular}{|c|c|c|c|c|c|c|c|c|c|c|c|c|c|c|c|c|}
\hline $\mid$ OWNER ID $\mid$ & SAMP NUM & SAMP SITE NAME & DIST CLASS & MEDIA & $\begin{array}{c}\text { FILTERED } \\
\text { FLAG }\end{array} \mid$ & | SAMP FROM & | COLL MTHD | & SAMP DATE & CON SHORT NAME & VALUE RPTD & $\mid$\begin{tabular}{|l|} 
ANAL \\
UNITS \\
RPTD
\end{tabular} & $\left|\begin{array}{c}\text { COUNTING } \\
\text { ERROR }\end{array}\right|$ & $\left|\begin{array}{c}\text { TOTAL ANAL } \\
\text { ERROR }\end{array}\right|$ & $\mid$\begin{tabular}{c|} 
LAB \\
QUALIFIER
\end{tabular} & SAMP COMMENT & RESULT COMMENT \\
\hline SESPSPEC & B16WT4 & RINGOLD WASTEWAY & OFFSITE & sw & $\mathrm{N}$ & IRRIGATION & UNFILTERED & 14-May-03 Sb & & 0.147 & & & & & & \\
\hline SESPSPEC & B16WT5 & RINGOLD WASTEWAY & OFFSITE & sW & $\mathrm{N}$ & IRRIGATION & UNFILTERED & 14-May-03 Sb & & 0.15 & $\mathrm{ug} / \mathrm{L}$ & & & & & \\
\hline SESPSPEC & B16WT6 & ESQUATZEL CANAL & OFFSITE & sw & $\mathrm{Y}$ & IRRIGATION & & 14-May-03 Se & & 0.282 & $\mathrm{ug} / \mathrm{L}$ & & & B & & \\
\hline SESPSPEC & B16WT7 & ESQUATZEL CANAL & OFFSITE & sW & $\mathrm{Y}$ & IRRIGATION & & 14-May-03 Se & & & & & & B & & \\
\hline SESPSPEC & B16WT8 & ESQUATZEL CANAL & OFFSITE & sw & $\mathrm{Y}$ & IRRIGATION & & 14-May-03 Se & & 0.381 & $\mathrm{ug} / \mathrm{L}$ & & & B & & \\
\hline SESPSPEC & B16WT9 & ESQUATZEL CANAL & OFFSITE & sw & $\mathrm{N}$ & IRRIGATION & UNFILTERED & 14-May-03 Se & & 0.453 & $\mathrm{ug} / \mathrm{L}$ & & & B & & \\
\hline SESPSPEC & B16WV0 & ESQUATZEL CANAL & OFFSITE & sW & $\mathrm{N}$ & IRRIGATION & UNFILTERED & 14-May-03 Se & & 0.393 & & & & B & & \\
\hline SESPSPEC & B16WV1 & ESQUATZEL CANAL & OFFSITE & sW & $\mathrm{N}$ & IRRIGATION & UNFILTERED & 14-May-03 Se & & & & & & B & & \\
\hline SESPSPEC & B16WV2 & POTHOLES CANAL & OFFSITE & sw & Y & IRRIGATION & & 14-May-03 Se & & 0.198 & $\mathrm{ug} / \mathrm{L}$ & & & B & & \\
\hline SESPSPEC & B16WV3 & POTHOLES CANAL & OFFSITE & sw & Y & IRRIGATION & & 14-May-03 Se & & 0.454 & $\mathrm{ug} / \mathrm{L}$ & & & B & & \\
\hline SESPSPEC & B16WV4 & POTHOLES CANAL & OFFSITE & sw & $\mathrm{Y}$ & IRRIGATION & & 14-May-03 Se & & 0.166 & & & & B & & \\
\hline SESPSPEC & B16WV5 & POTHOLES CANAL & OFFSITE & sW & $\mathrm{N}$ & IRRIGATION & UNFILTERED & 14-May-03 Se & & 0.334 & & & & B & & \\
\hline SESPSPEC & B16WV6 & POTHOLES CANAL & OFFSITE & sw & $\mathrm{N}$ & IRRIGATION & UNFILTERED & 14-May-03 Se & & 0.309 & $\mathrm{ug} / \mathrm{L}$ & & & B & & \\
\hline SESPSPEC & B16WV7 & POTHOLES CANAL & OFFSITE & sw & $\mathrm{N}$ & IRRIGATION & UNFILTERED & 14-May-03 Se & & 0.155 & $\mathrm{ug} / \mathrm{L}$ & & & B & & \\
\hline SESPSPEC & B16WT0 & RINGOLD WASTEWAY & OFFSITE & sw & $\mathrm{Y}$ & IRRIGATION & & 14-May-03 Se & & 1.98 & & & & & & \\
\hline SESPSPEC & B16WT1 & RINGOLD WASTEWAY & OFFSITE & sW & $\mathrm{Y}$ & IRRIGATION & & 14-May-03 Se & & & $\mathrm{ug} / \mathrm{L}$ & & & & & \\
\hline SESPSPEC & B16WT2 & RINGOLD WASTEWAY & OFFSITE & sw & $\mathrm{Y}$ & IRRIGATION & & 14-May-03 Se & & 1.87 & & & & & & \\
\hline SESPSPEC & B16WT3 & RINGOLD WASTEWAY & OFFSITE & sw & $\mathrm{N}$ & IRRIGATION & UNFILTERED & 14-May-03 Se & & & $\mathrm{ug} / \mathrm{L}$ & & & & & \\
\hline SESPSPEC & B16WT4 & RINGOLD WASTEWAY & OFFSITE & sw & $\mathrm{N}$ & IRRIGATION & UNFILTERED & 14-May-03 Se & & 1.75 & & & & & & \\
\hline SESPSPEC & B16WT5 & RINGOLD WASTEWAY & OFFSITE & sw & $\mathrm{N}$ & IRRIGATION & UNFILTERED & 14-May-03 Se & & 1.58 & $\mathrm{ug} / \mathrm{L}$ & & & & & \\
\hline SESPSPEC & B16WT6 & ESQUATZEL CANAL & OFFSITE & sw & $\mathrm{Y}$ & IRRIGATION & & 14-May-03 TI & & 0.009 & & & & $u$ & & \\
\hline SESPSPEC & B16WT7 & ESQUATZEL CANAL & OFFSITE & sw & Y & IRRIGATION & & 14-May-03 TI & & 0.009 & & & & u & & \\
\hline SESPSPEC & B16WT8 & ESQUATZEL CANAL & OFFSITE & sw & $\mathrm{Y}$ & IRRIGATION & & 14-May-03 TI & & 0.009 & $\mathrm{ug} / \mathrm{L}$ & & & u & & \\
\hline SESPSPEC & B16WT9 & ESQUATZEL CANAL & OFFSITE & sw & $\mathrm{N}$ & IRRIGATION & UNFILTERED & 14-May-03 TI & & 0.009 & $\mathrm{ug} / \mathrm{L}$ & & & $u$ & & \\
\hline SESPSPEC & B16WV0 & ESQUATZEL CANAL & OFFSITE & sw & $\mathrm{N}$ & IRRIGATION & UNFILTERED & 14-May-03 TI & & 0.009 & & & & $U$ & & \\
\hline SESPSPEC & B16WV1 & ESQUATZEL CANAL & OFFSITE & sw & $\mathrm{N}$ & IRRIGATION & UNFILTERED & 14-May-03 TI & & 0.009 & & & & $u$ & & \\
\hline SESPSPEC & B16WV2 & POTHOLES CANAL & OFFSITE & sw & Y & IRRIGATION & & 14-May-03 TI & & 0.009 & $\mathrm{ug} / \mathrm{L}$ & & & u & & \\
\hline SESPSPEC & B16WV3 & POTHOLES CANAL & OFFSITE & sw & $\mathrm{Y}$ & IRRIGATION & & 14-May-03 TI & & 0.009 & $u g / L$ & & & $u$ & & \\
\hline SESPSPEC & B16WV4 & POTHOLES CANAL & OFFSITE & sw & $\mathrm{Y}$ & IRRIGATION & & 14-May-03 TI & & 0.009 & & & & $u$ & & \\
\hline SESPSPEC & B16WV5 & POTHOLES CANAL & OFFSITE & sW & $\mathrm{N}$ & IRRIGATION & UNFILTERED & 14-May-03 TI & & 0.009 & & & & $u$ & & \\
\hline SESPSPEC & B16WV6 & POTHOLES CANAL & OFFSITE & sw & $\mathrm{N}$ & IRRIGATION & UNFILTERED & 14-May-03 TI & & 0.009 & $\mathrm{ug} / \mathrm{L}$ & & & u & & \\
\hline SESPSPEC & B16WV7 & POTHOLES CANAL & OFFSITE & sW & $\mathrm{N}$ & IRRIGATION & UNFILTERED & 14-May-03 TI & & 0.009 & & & & $u$ & & \\
\hline SESPSPEC & B16WT0 & RINGOLD WASTEWAY & OFFSITE & sW & $\mathrm{Y}$ & IRRIGATION & & 14-May-03 TI & & 0.009 & & & & U & & \\
\hline SESPSPEC & B16WT1 & RINGOLD WASTEWAY & OFFSITE & sw & $\mathrm{Y}$ & IRRIGATION & & 14-May-03 TI & & 0.009 & $\mathrm{ug} / \mathrm{L}$ & & & $u$ & & \\
\hline SESPSPEC & B16WT2 & RINGOLD WASTEWAY & OFFSITE & sw & Y & IRRIGATION & & 14-May-03 TI & & 0.009 & $u g / L$ & & & u & & \\
\hline SESPSPEC & B16WT3 & RINGOLD WASTEWAY & OFFSITE & sW & $\mathrm{N}$ & IRRIGATION & UNFILTERED & 14-May-03 TI & & 0.009 & & & & $u$ & & \\
\hline SESPSPEC & B16WT4 & RINGOLD WASTEWAY & OFFSITE & sW & $\mathrm{N}$ & IRRIGATION & UNFILTERED & 14-May-03 TI & & 0.009 & & & & 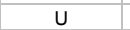 & & \\
\hline SESPSPEC & B16WT5 & RINGOLD WASTEWAY & OFFSITE & sW & $\mathrm{N}$ & IRRIGATION & UNFILTERED & 14-May-03 TI & & 0.009 & $u g / L$ & & & u & & \\
\hline SESPSPEC & B16WT6 & ESQUATZEL CANAL & OFFSITE & sw & $\mathrm{Y}$ & IRRIGATION & & 14-May-03 U & & 5.77 & & & & & & \\
\hline SESPSPEC & B16WT7 & ESQUATZEL CANAL & OFFSITE & sW & $\mathrm{Y}$ & IRRIGATION & & 14-May-03 U & & 5.93 & & & & & & \\
\hline SESPSPEC & B16WT8 & ESQUATZEL CANAL & OFFSITE & sW & $\mathrm{Y}$ & IRRIGATION & & 14-May-03 U & & 5.75 & $\mathrm{ug} / \mathrm{L}$ & & & & & \\
\hline SESPSPEC & B16WT9 & ESQUATZEL CANAL & OFFSITE & sw & $\mathrm{N}$ & IRRIGATION & UNFILTERED & 14-May-03 U & & 5.88 & $\mathrm{ug} / \mathrm{L}$ & & & & & \\
\hline SESPSPEC & B16WV0 & ESQUATZEL CANAL & OFFSITE & sw & $\mathrm{N}$ & IRRIGATION & UNFILTERED & 14-May-03 U & & 5.83 & & & & & & \\
\hline SESPSPEC & B16WV1 & ESQUATZEL CANAL & OFFSITE & sw & $\mathrm{N}$ & IRRIGATION & UNFILTERED & 14-May-03 U & & 6.07 & $\mathrm{ug} / \mathrm{L}$ & & & & & \\
\hline SESPSPEC & B16WV2 & POTHOLES CANAL & OFFSITE & sW & $\mathrm{Y}$ & IRRIGATION & & 14-May-03 U & & 3.06 & $\mathrm{ug} / \mathrm{L}$ & & & & & \\
\hline SESPSPEC & B16WV3 & POTHOLES CANAL & OFFSITE & sw & $\mathrm{Y}$ & IRRIGATION & & 14-May-03 U & & & $\mathrm{ug} / \mathrm{L}$ & & & & & \\
\hline SESPSPEC & B16WV4 & POTHOLES CANAL & OFFSITE & sw & Y & IRRIGATION & & 14-May-03 U & & 2.98 & & & & & & \\
\hline SESPSPEC & B16WV5 & POTHOLES CANAL & OFFSITE & sw & $\mathrm{N}$ & IRRIGATION & UNFILTERED & 14-May-03 U & & 3.12 & & & & & & \\
\hline SESPSPEC & B16WV6 & POTHOLES CANAL & OFFSITE & sW & $\mathrm{N}$ & IRRIGATION & UNFILTERED & 14-May-03 U & & 3.08 & $\mathrm{ug} / \mathrm{L}$ & & & & & \\
\hline SESPSPEC & B16WV7 & POTHOLES CANAL & OFFSITE & sw & $\mathrm{N}$ & IRRIGATION & UNFILTERED & 14-May-03 U & & 3.11 & $\mathrm{ug} / \mathrm{L}$ & & & & & \\
\hline SESPSPEC & B16WTO & RINGOLD WASTEWAY & OFFSITE & sw & Y & IRRIGATION & & 14-May-03 U & & 8.31 & $u g / L$ & & & & & \\
\hline SESPSPEC & B16WT1 & RINGOLD WASTEWAY & OFFSITE & sw & $\mathrm{Y}$ & IRRIGATION & & 14-May-03 U & & 8.64 & $\mathrm{ug} / \mathrm{L}$ & & & & & \\
\hline SESPSPEC & B16WT2 & RINGOLD WASTEWAY & OFFSITE & sW & $\mathrm{Y}$ & IRRIGATION & & 14-May-03 U & & 8.56 & $\mathrm{ug} / \mathrm{L}$ & & & & & \\
\hline SESPSPEC & B16WT3 & RINGOLD WASTEWAY & OFFSITE & sw & $\mathrm{N}$ & IRRIGATION & UNFILTERED & 14-May-03 U & & 8.67 & $\mathrm{ug} / \mathrm{L}$ & & & & & \\
\hline SESPSPEC & B16WT4 & RINGOLD WASTEWAY & OFFSITE & sw & $\mathrm{N}$ & IRRIGATION & UNFILTERED & 14-May-03 U & & 8.62 & $u g / L$ & & & & & \\
\hline SESPSPEC & B16WT5 & RINGOLD WASTEWAY & OFFSITE & sw & $\mathrm{N}$ & IRRIGATION & UNFILTERED & 14-May-03 U & & 8.47 & $\mathrm{ug} / \mathrm{L}$ & & & & & \\
\hline SESPSPEC & B16WT6 & ESQUATZEL CANAL & OFFSITE & sW & $\mathrm{Y}$ & IRRIGATION & & 14-May-03 Zn & & 3.03 & $\mathrm{ug} / \mathrm{L}$ & & & & & \\
\hline SESPSPEC & B16WT7 & ESQUATZEL CANAL & OFFSITE & sW & $\mathrm{Y}$ & IRRIGATION & & 14-May-03 Zn & & & $\mathrm{ug} / \mathrm{L}$ & & & & & \\
\hline
\end{tabular}


WATER - IRRIGATION

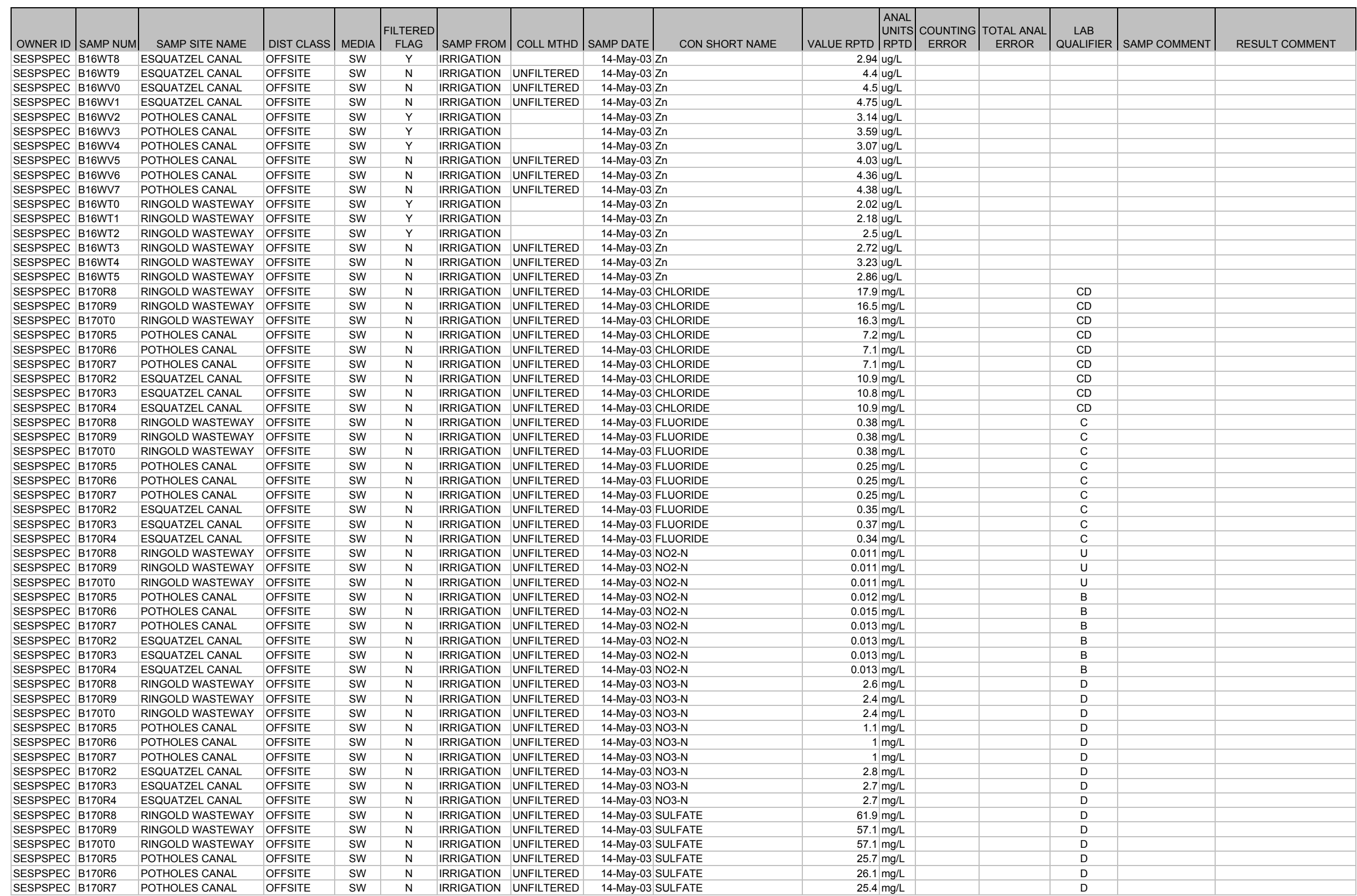


WATER - IRRIGATION

\begin{tabular}{|c|c|c|c|c|c|c|c|c|c|c|c|c|c|c|c|c|}
\hline | OWNER ID & SAMP NUM & SAMP SITE NAME & DIST CLASS & MEDIA & \begin{tabular}{|c|} 
FILTERED \\
FLAG
\end{tabular} \mid & | SAMP FROM & $\mid$ COLL MTHD & |SAMP DATE & CON SHORT NAME & VALUE RPTD & \begin{tabular}{|l|} 
ANAL \\
UNITS \\
RPTD
\end{tabular} & $\mid \begin{array}{c}\text { COUNTING } \\
\text { ERROR }\end{array}$ & $\mid \begin{array}{c}\text { TOTAL ANAL } \\
\text { ERROR }\end{array}$ & $\left|\begin{array}{c}\text { LAB } \\
\text { QUALIFIER }\end{array}\right|$ & SAMP COMMENT & RESULT COMMENT \\
\hline SESPSPEC & B170R2 & ESQUATZEL CANAL & OFFSITE & sw & $\mathrm{N}$ & IRRIGATION & UNFILTERED & 14-May-03 & SULFATE & & $\mathrm{mg} / \mathrm{L}$ & & & D & & \\
\hline SESPSPEC & B170R3 & ESQUATZEL CANAL & OFFSITE & sw & $\mathrm{N}$ & IRRIGATION & UNFILTERED & 14-May-03 & SULFATE & 34.2 & $\mathrm{mg} / \mathrm{L}$ & & & D & & \\
\hline SESPSPEC & B170R4 & ESQUATZEL CANAL & OFFSITE & sW & $\mathrm{N}$ & IRRIGATION & UNFILTERED & 14-May-03 & SULFATE & 34.7 & $\mathrm{mg} / \mathrm{L}$ & & & D & & \\
\hline
\end{tabular}


WATER - ONSITE PONDS

\begin{tabular}{|c|c|c|c|c|c|c|c|c|c|c|c|c|c|c|c|c|}
\hline OWNER ID & \begin{tabular}{|l} 
SAMP \\
NUM \\
\end{tabular} & $\begin{array}{l}\text { SAMP SITE } \\
\text { NAME }\end{array}$ & DIST CLASS & MEDIA & $\begin{array}{l}\text { FILTERED } \\
\text { FLAG }\end{array}$ & \begin{tabular}{|l|} 
SAMP \\
FROM
\end{tabular} & COLL MTHD & SAMP DATE & $\begin{array}{l}\text { CON } \\
\text { SHORT } \\
\text { NAME }\end{array}$ & \begin{tabular}{|l|} 
VALUE \\
RPTD \\
\end{tabular} & \begin{tabular}{|l|} 
ANAL \\
UNITS \\
RPTDD \\
\end{tabular} & $\begin{array}{c}\text { COUNTING } \\
\text { ERROR }\end{array}$ & $\begin{array}{c}\text { TOTAL ANAL } \\
\text { ERROR } \\
\end{array}$ & \begin{tabular}{|c|} 
LAB \\
QUALIFIER \\
\end{tabular} & SAMP COMMENT & RESULT COMMENT \\
\hline SESPMNT & B16DJ2 & FFTF POND & ONSITE & SW & $\mathrm{N}$ & POND & UNFILTERED & \multirow{2}{*}{\multicolumn{2}{|c|}{$\begin{array}{l}\text { 11-Feb-03 ALPHA } \\
\text { 07-Apr-03 ALPHA }\end{array}$}} & -0.309 & $\mathrm{pCi} / \mathrm{L}$ & 0.7 & 0.7 & & COLLECTED FROM CONCRETE DISTRIBUTION BOX AT POND. & \\
\hline SESPMNT & B16RR1 & FFTF POND & ONSITE & sw & $\mathrm{N}$ & POND & UNFILTERED & & & 208 & $\mathrm{pCi} / \mathrm{L}$ & 28 & 52 & & POND INLET & \\
\hline SESPSPEC & B16RT1 & FFTF POND & ONSITE & sW & $\mathrm{N}$ & POND & UNFILTERED & & 12.2 & $\mathrm{pCi} / \mathrm{L}$ & 3.6 & 4.4 & & POND INLET & \\
\hline SESPSPEC & B17142 & FFTF POND & ONSITE & sW & $\mathrm{N}$ & POND & UNFILTERED & \multirow{2}{*}{\multicolumn{2}{|c|}{$\begin{array}{r}\text { 19-May-03 ALPHA } \\
\text { 10-Jul-03 ALPHA }\end{array}$}} & 0.421 & & 0.96 & 0.97 & $\mathrm{U}$ & & \\
\hline SESPMNT & B176P9 & FFTF POND & ONSITE & sw & $\mathrm{N}$ & POND & UNFILTERED & & & & $\mathrm{pCi} / \mathrm{L}$ & 1.3 & 1.4 & & & \\
\hline SESPMNT & B17R88 & FFTF POND & ONSITE & sw & $\mathrm{N}$ & POND & UNFILTERED & \multicolumn{2}{|c|}{ 07-Oct-03 ALPHA } & -0.078 & $\mathrm{pCi} / \mathrm{L}$ & 1.5 & 1.5 & $u$ & & \\
\hline SESPMNT & B16DJ2 & FFTF POND & ONSITE & sw & $\mathrm{N}$ & POND & UNFILTERED & \multirow{2}{*}{\multicolumn{2}{|c|}{$\begin{array}{l}\text { 11-Feb-03 BETA } \\
\text { 07-Apr-03 BETA }\end{array}$}} & & $\mathrm{pCi} / \mathrm{L}$ & 2.5 & 3.4 & & COLLECTED FROM CONCRETE DISTRIBUTION BOX AT POND. & \\
\hline SESPMNT & B16RR1 & FFTF POND & ONSITE & sw & $\mathrm{N}$ & POND & UNFILTERED & & & & $\mathrm{pCi} / \mathrm{L}$ & 18 & 42 & & POND INLET & \\
\hline SESPSPEC & B16RT1 & FFTF POND & ONSITE & sw & $\mathrm{N}$ & POND & UNFILTERED & \multicolumn{2}{|c|}{$\begin{array}{l}\text { 07-Apr-03 BETA } \\
07-\text { Bpr-03 BETA }\end{array}$} & 30.3 & $\mathrm{pCi} / \mathrm{L}$ & 3.7 & 5.8 & & POND INLET & \\
\hline SESPSPEC & B17142 & FFTF POND & ONSITE & sw & $\mathrm{N}$ & POND & UNFILTERED & \multicolumn{2}{|c|}{$\begin{array}{l}\text { O-A-Ar-03 BEIA } \\
\text { 19-May-03 BETA }\end{array}$} & 14.4 & $\mathrm{pCi/L}$ & 2.2 & 3.1 & & & \\
\hline SESPMNT & B176P9 & FFTF POND & ONSITE & sw & $\mathrm{N}$ & POND & UNFILTERED & \multicolumn{2}{|c|}{ 10-Jul-03 BETA } & 13.7 & $\mathrm{pCi} / \mathrm{L}$ & 2.2 & 3.1 & & & \\
\hline SESPMNT & B17R88 & FFTF POND & ONSITE & sw & $\mathrm{N}$ & POND & UNFILTERED & \multirow{2}{*}{\multicolumn{2}{|c|}{$\begin{array}{l}\text { 07-Oct-03 BETA } \\
\text { 11-Feb-03 Be-7 }\end{array}$}} & 17.5 & $\mathrm{pCCi/L}$ & 3 & 3.8 & & & \\
\hline SESPMNT & B16DJ2 & FFTF POND & ONSITE & sW & $\mathrm{N}$ & POND & UNFILTERED & & & -7.61 & & 20 & 20 & u & COLLECTED FROM CONCRETE DISTRIBUTION BOX AT POND. & \\
\hline SESPMNT & B16RR1 & FFTF POND & ONSITE & sw & $\mathrm{N}$ & POND & UNFILTERED & 07-Apr-03 & $\mathrm{Be}-7$ & 0.463 & & 24 & 24 & u & POND INLET & \\
\hline SESPSPEC & B16RT1 & FFTF POND & ONSITE & sW & $\mathrm{N}$ & POND & UNFILTERED & 07-Apr-03 & $\mathrm{Be}-7$ & 1.88 & $\mathrm{pCi} / \mathrm{L}$ & 23 & 23 & U & POND INLET & \\
\hline SESPMNT & B176P9 & FFTF POND & ONSITE & sw & $\mathrm{N}$ & POND & UNFILTERED & 10-Jul-03 & $\mathrm{Be}-7$ & & $\mathrm{pCi/L}$ & 16 & 16 & u & & \\
\hline SESPMNT & B17R88 & FFTF POND & ONSITE & sw & $\mathrm{N}$ & POND & UNFILTERED & 07-Oct-03 & $\mathrm{Be}-7$ & 12.5 & $\mathrm{pCi} / \mathrm{L}$ & 26 & 26 & u & & \\
\hline SESPMNT & B16DJ2 & FFTF POND & ONSITE & sw & $\mathrm{N}$ & POND & UNFILTERED & 11-Feb-03 & Co-60 & 4.24 & $\mathrm{pCi} / \mathrm{L}$ & 2.9 & 2.9 & u & COLLECTED FROM CONCRETE DISTRIBUTION BOX AT POND. & \\
\hline SESPMNT & B16RR1 & FFTF POND & ONSITE & sw & $\mathrm{N}$ & POND & UNFILTERED & 07-Apr-03 & Co-60 & 1.16 & $\mathrm{pCi} / \mathrm{L}$ & 3.1 & 3.1 & u & POND INLET & \\
\hline SESPSPEC & B16RT1 & FFTF POND & ONSITE & sW & $\mathrm{N}$ & POND & UNFILTERED & 07-Apr-03 & Co-60 & -0.068 & & 2.9 & 2.9 & u & POND INLET & \\
\hline SESPMNT & B176P9 & FFTF POND & ONSITE & sw & $\mathrm{N}$ & POND & UNFILTERED & 10-Jul-03 & Co-60 & -0.959 & $\mathrm{pCi} / \mathrm{L}$ & 2.1 & 2.1 & u & & \\
\hline SESPMNT & B17R88 & FFTF POND & ONSITE & sw & $\mathrm{N}$ & POND & UNFILTERED & $07-0 c t-03$ & Co-60 & 2.88 & $\mathrm{pCi} / \mathrm{L}$ & 2.7 & 2.7 & u & & \\
\hline SESPMNT & B16DJ2 & FFTF POND & ONSITE & SW & $\mathrm{N}$ & POND & UNFILTERED & 11-Feb-03 & Cs-134 & -1.93 & $\mathrm{pCi} / \mathrm{L}$ & 2.7 & 2.7 & u & COLLECTED FROM CONCRETE DISTRIBUTION BOX AT POND. & \\
\hline SESPMNT & B16RR1 & FFTF POND & ONSITE & sW & $\mathrm{N}$ & POND & UNFILTERED & 07-Apr-03 & Cs-134 & 0.53 & $\mathrm{pCi} / \mathrm{L}$ & 2.9 & 2.9 & U & POND INLET & \\
\hline SESPSPEC & B16RT1 & FFTF POND & ONSITE & sw & $\mathrm{N}$ & POND & UNFILTERED & 07-Apr-03 & Cs-134 & -2.63 & $\mathrm{pCi} / \mathrm{L}$ & 2.7 & 2.7 & U & POND INLET & \\
\hline SESPMNT & B176P9 & FFTF POND & ONSITE & sw & $\mathrm{N}$ & POND & UNFILTERED & 10-Jul-03 & Cs-134 & 1.56 & $\mathrm{pCi} / \mathrm{L}$ & 2.2 & 2.2 & U & & \\
\hline SESPMNT & B17R88 & FFTF POND & ONSITE & sw & $\mathrm{N}$ & POND & UNFILTERED & $07-0 c t-03$ & Cs-134 & 0.58 & $\mathrm{pCi} / \mathrm{L}$ & 2.3 & 2.3 & u & & \\
\hline SESPMNT & B16DJ2 & FFTF POND & ONSITE & sw & $\mathrm{N}$ & POND & UNFILTERED & 11-Feb-03 & Cs-137 & 0.356 & $\mathrm{pCi} / \mathrm{L}$ & 2.7 & 2.7 & u & COLLECTED FROM CONCRETE DISTRIBUTION BOX AT POND. & \\
\hline SESPMNT & B16RR1 & FFTF POND & ONSITE & sw & $\mathrm{N}$ & POND & UNFILTERED & 07-Apr-03 & Cs-137 & 0.938 & $\mathrm{pCi} / \mathrm{L}$ & 2.6 & 2.6 & u & POND INLET & \\
\hline SESPSPEC & B16RT1 & FFTF POND & ONSITE & sw & $\mathrm{n}$ & POND & UNFILTERED & $07-A p r-03$ & Cs-137 & -0.964 & $\mathrm{pCi} / \mathrm{L}$ & 2.6 & 2.6 & u & POND INLET & \\
\hline SESPMNT & B176P9 & FFTF POND & ONSITE & sw & $\mathrm{N}$ & POND & UNFILTERED & 10-Jul-03 & Cs-137 & 0.354 & $\mathrm{pCi} / \mathrm{L}$ & 1.7 & 1.7 & u & & \\
\hline SESPMNT & B17R88 & FFTF POND & ONSITE & sW & $\mathrm{N}$ & POND & UNFILTERED & 07-Oct-03 & Cs-137 & 0.56 & $\mathrm{pCi} / \mathrm{L}$ & 2.7 & 2.7 & U & & \\
\hline SESPMNT & B16DJ2 & FFTF POND & ONSITE & sw & $\mathrm{N}$ & POND & UNFILTERED & 11-Feb-03 & Eu-152 & -5.82 & $\mathrm{pCi} / \mathrm{L}$ & 6.4 & 6.4 & u & COLLECTED FROM CONCRETE DISTRIBUTION BOX AT POND. & \\
\hline SESPMNT & B16RR1 & FFTF POND & ONSITE & sw & $\mathrm{N}$ & POND & UNFILTERED & 07-Apr-03 & Eu-152 & -0.349 & $\mathrm{pCi} / \mathrm{L}$ & 5.9 & 5.9 & u & POND INLET & \\
\hline SESPSPEC & B16RT1 & FFTF POND & ONSITE & sw & $\mathrm{N}$ & POND & UNFILTERED & 07-Apr-03 & Eu-152 & -3.68 & $\mathrm{pCi} / \mathrm{L}$ & 6.3 & 6.3 & u & POND INLET & \\
\hline SESPMNT & B176P9 & FFTF POND & ONSITE & sw & $\mathrm{N}$ & POND & UNFILTERED & 10-Jul-03 & Eu-152 & -0.339 & $\mathrm{pCi} / \mathrm{L}$ & 3.5 & 3.5 & u & & \\
\hline SESPMNT & B17R88 & FFTF POND & ONSITE & sw & $\mathrm{N}$ & POND & UNFILTERED & $07-0 c t-03$ & Eu-152 & 3.04 & $\mathrm{pCi} / \mathrm{L}$ & 6.7 & 6.7 & u & & \\
\hline SESPMNT & B16DJ2 & FFTF POND & ONSITE & sw & $\mathrm{N}$ & POND & UNFILTERED & $11-\mathrm{Feb}-03$ & Eu-154 & 7.29 & $\mathrm{pCi} / \mathrm{L}$ & 8.1 & 8.1 & u & COLLECTED FROM CONCRETE DISTRIBUTION BOX AT POND. & \\
\hline SESPMNT & B16RR1 & FFTF POND & ONSITE & sw & $\mathrm{N}$ & POND & UNFILTERED & $07-A p r-03$ & Eu-154 & -3.2 & $\mathrm{pCi} / \mathrm{L}$ & 6.5 & 6.5 & u & POND INLET & \\
\hline SESPSPEC & B16RT1 & FFTF POND & ONSITE & sw & $\mathrm{N}$ & POND & UNFILTERED & $07-A p r-03$ & Eu-154 & & $\mathrm{pCi} / \mathrm{L}$ & 6.9 & 6.9 & u & POND INLET & \\
\hline SESPMNT & B176P9 & FFTF POND & ONSITE & sw & $\mathrm{N}$ & POND & UNFILTERED & 10-Jul-03 & Eu-154 & 5.69 & $\mathrm{pCi} / \mathrm{L}$ & 6.3 & 6.3 & u & & \\
\hline SESPMNT & B17R88 & FFTF POND & ONSITE & sw & $\mathrm{N}$ & POND & UNFILTERED & $07-0 c t-03$ & Eu-154 & -2.37 & $\mathrm{pCi} / \mathrm{L}$ & 8.1 & 8.1 & u & & \\
\hline SESPMNT & B16DJ2 & FFTF POND & ONSITE & sW & $\mathrm{N}$ & POND & UNFILTERED & 11-Feb-03 & Eu-155 & -1.4 & $\mathrm{pCi} / \mathrm{L}$ & 5.2 & 5.2 & $\mathrm{u}$ & COLLECTED FROM CONCRETE DISTRIBUTION BOX AT POND. & \\
\hline SESPMNT & B16RR1 & FFTF POND & ONSITE & sW & $\mathrm{N}$ & POND & UNFILTERED & 07-Apr-03 & Eu-155 & -1.93 & $\mathrm{pCi} / \mathrm{L}$ & 5.6 & 5.6 & u & POND INLET & \\
\hline SESPSPEC & B16RT1 & FFTF POND & ONSITE & sw & $\mathrm{N}$ & POND & UNFILTERED & $07-\mathrm{Apr}-03$ & Eu-155 & 3.88 & $\mathrm{pCi} / \mathrm{L}$ & 4.7 & 4.7 & u & POND INLET & \\
\hline SESPMNT & B176P9 & FFTF POND & ONSITE & sw & $\mathrm{N}$ & POND & UNFILTERED & 10-Jul-03 & Eu-155 & 0.787 & $\mathrm{pCi/L}$ & 3.3 & 3.3 & u & & \\
\hline SESPMNT & B17R88 & FFTF POND & ONSITE & sw & $\mathrm{N}$ & POND & UNFILTERED & $07-0 \mathrm{Cct}-03$ & Eu-155 & -0.312 & $\mathrm{pCi} / \mathrm{L}$ & 5 & $\begin{array}{r}5 \\
5\end{array}$ & u & & \\
\hline SESPMNT & B16DJ2 & FFTF POND & ONSITE & sw & $\mathrm{N}$ & POND & UNFILTERED & 11-Feb-03 & $\mathrm{k}-40$ & -11.1 & $\mathrm{pCi} / \mathrm{L}$ & 43 & 43 & u & COLLECTED FROM CONCRETE DISTRIBUTION BOX AT POND. & \\
\hline SESPMNT & B16RR1 & FFTF POND & ONSITE & sw & $\mathrm{N}$ & POND & UNFILTERED & $07-A p r-03$ & $\mathrm{k}-40$ & 53.5 & $\mathrm{pCi/L}$ & 67 & 67 & u & POND INLET & \\
\hline SESPSPEC & B16RT1 & FFTF POND & ONSITE & sw & $\mathrm{N}$ & POND & UNFILTERED & $07-A p r-03$ & $\mathrm{k}-40$ & -42.2 & $\mathrm{pCi} / \mathrm{L}$ & 55 & 55 & u & POND INLET & \\
\hline SESPMNT & B176P9 & FFTF POND & ONSITE & sw & $\mathrm{N}$ & POND & UNFILTERED & $10--\mathrm{Al}$ & $\frac{n-40}{K-40}$ & -15.8 & $\mathrm{pCi} / \mathrm{L}$ & 25 & 25 & u & & \\
\hline $\begin{array}{l}\text { SESPSMIVI } \\
\text { SESPMN } 19\end{array}$ & B17R88 & FFTF POND & ONSITE & SW & $\mathrm{N}$ & POND & UNFILTERED & 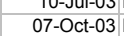 & K-40 & $\begin{array}{l}-1.8 \\
-26.2\end{array}$ & $\mathrm{pCi/L}$ & 55 & 25 & u & & \\
\hline SESPMNT & B16DJ2 & FFTF POND & ONSITE & sw & $\mathrm{N}$ & POND & UNFILTERED & 11-Feb-03 & Ru-106 & -3.09 & $\mathrm{pCi} / \mathrm{L}$ & 24 & 24 & u & COLLECTED FROM CONCRETE DISTRIBUTION BOX AT POND. & \\
\hline SESPMNT & B16RR1 & FFTF POND & ONSITE & sw & $\mathrm{N}$ & POND & UNFILTERED & 07-Apr-03 & Ru-106 & 1.64 & $\mathrm{pCi} / \mathrm{L}$ & 19 & 19 & U & POND INLET & \\
\hline SESPSPEC & B16RT1 & FFTF POND & ONSITE & sw & $\mathrm{N}$ & POND & UNFILTERED & 07-Apr-03 & Ru-106 & -0.177 & $\mathrm{pCi} / \mathrm{L}$ & 23 & 23 & U & POND INLET & \\
\hline SESPMNT & B176P9 & FFTF POND & ONSITE & sw & $\mathrm{N}$ & POND & UNFILTERED & 10-Jul-03 & Ru-106 & -9.45 & $\mathrm{pCi} / \mathrm{L}$ & 15 & 15 & u & & \\
\hline SESPMNT & B17R88 & FFTF POND & ONSITE & sw & $\mathrm{N}$ & POND & UNFILTERED & $07-0 c t-03$ & Ru-106 & -4.97 & $\mathrm{pCi} / \mathrm{L}$ & 23 & 23 & u & & \\
\hline SESPMNT & B16DJ2 & FFTF POND & ONSITE & sw & $\mathrm{N}$ & POND & UNFILTERED & 11-Feb-03 & Sb-125 & 0.343 & $\mathrm{pCi/L}$ & 5.8 & 5.8 & u & COLLECTED FROM CONCRETE DISTRIBUTION BOX AT POND. & \\
\hline SESPMNT & B16RR1 & FFTF POND & ONSITE & sw & $\mathrm{N}$ & POND & UNFILTERED & $07-\mathrm{Apr}-03$ & Sb-125 & $\begin{array}{c}-.1 .35 \\
-1.35\end{array}$ & $\mathrm{pCi} / \mathrm{L}$ & 5.8 & 5.8 & u & POND INLET & \\
\hline SESPSPEC & B16RT1 & FFTF POND & ONs & sw & $\mathrm{N}$ & POND & & & & & $\mathrm{pC}$ & 5.9 & 5.9 & U & POND INLET & \\
\hline SESPMNT & B176P9 & FFTF POND & ONSITE & sw & $\mathrm{N}$ & POND & UNFILTERED & 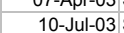 & Sb-125 & -0.37 & $\mathrm{pCi/L}$ & 4.3 & 4.3 & u & & \\
\hline SESPMNT & B17R88 & FFTF POND & ONSITE & sw & $\mathrm{N}$ & POND & UNFILTERED & $07-0 c t-03$ & Sb-125 & -0.677 & $\mathrm{pCil}$ & 6.5 & 6.5 & u & & \\
\hline & & & & s. & & & & & & & & 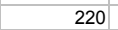 & 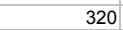 & & & \\
\hline
\end{tabular}




\section{WATER - ONSITE PONDS}

\begin{tabular}{|c|c|c|c|c|c|c|c|c|c|c|c|c|c|c|c|c|}
\hline OWNER ID & $\left|\begin{array}{l}\text { SAMP } \\
\text { NUM }\end{array}\right|$ & $\begin{array}{l}\text { SAMP SITE } \\
\text { NAME }\end{array}$ & DIST CLASS & MEDIA & $\begin{array}{c}\text { FLLTERED } \\
\text { FLAG }\end{array}$ & \begin{tabular}{|l|} 
SAMP \\
FROM
\end{tabular} & | COLL MTHD | & |SAMP DATE| & $\begin{array}{l}\text { CON } \\
\text { SHORT } \\
\text { NAME }\end{array}$ & $\begin{array}{l}\text { VALUE } \\
\text { RPTD }\end{array} \mid$ & \begin{tabular}{|c|} 
ANAL \\
UNITS \\
RPTD
\end{tabular} & COUNTING & $\left|\begin{array}{c}\text { TOTAL ANAL } \\
\text { ERROR }\end{array}\right|$ & $\left|\begin{array}{c}\text { LAB } \\
\text { QUALIFIER }\end{array}\right|$ & SAMP COMMENT & RESULT COMMENT \\
\hline SESPMNT & B16DJ1 & WEST LAKE & ONSITE & SW & $\mathrm{N}$ & POND & UNFILTERED & 11-Feb-03 LC & O TRITIUM & & & & & & COLLECTED AT E. WATERHOLE. & Insufficient sample for reanalysis. \\
\hline SESPMNT & B16DJ2 & FFTF POND & ONSITE & SW & $\mathrm{N}$ & POND & UNFILTERED & 11-Feb-03 LC & O TRITIUM & $2830 \mathrm{p}$ & $\mathrm{pCilL}$ & 24 & 470 & & COLLECTED FROM CONCRETE DISTRIBUTION BOX AT POND. & \\
\hline SESPMNT & B16RR0 & WEST LAKE & ONSITE & sw & $\mathrm{N}$ & POND & UNFILTERED & 07-Apr-03 TF & IRITIUM & & $\mathrm{pCi} / \mathrm{L}$ & 77 & 87 & & & \\
\hline SESPMNT & B16RR1 & FFTF POND & ONSITE & sw & $\mathrm{N}$ & POND & UNFILTERED & 07-Apr-03 Th & IRITIUM & $3070 \mathrm{p}$ & $\mathrm{pCi} / \mathrm{L}$ & 230 & 320 & & $\mathrm{PO}$ & \\
\hline SESPSPEC & B16RT1 & FFTF POND & ONSITE & sw & $\mathrm{N}$ & POND & UNFILTERED & 07-Apr-03 TR & IRITIUM & $3230 \mathrm{p}$ & $\mathrm{pCi} / \mathrm{L}$ & 230 & 330 & & POND INLET & \\
\hline SESPMNT & B176P8 & WEST LAKE & ONSITE & sW & $\mathrm{N}$ & POND & UNFILTERED & 09-Jul-03 TF & IRITIUM & $12.7 \mathrm{p}$ & $\mathrm{pCi} / \mathrm{L}$ & 65 & 78 & u & & \\
\hline SESPMNT & B176P9 & FFTF POND & ONSITE & sw & $\mathrm{N}$ & POND & UNFILTERED & 10-Jul-03 TF & IRITIUM & $2920 p$ & & 200 & 290 & & & \\
\hline SESPMNT & B17R87 & WEST LAKE & ONSITE & SW & $\mathrm{N}$ & POND & UNFILTERED & 07-Oct-03 TF & IRITIUM & & $\mathrm{pCi} / \mathrm{L}$ & 68 & 80 & & & \\
\hline SESPMNT & B17R88 & FFTF POND & ONSITE & SW & $\mathrm{N}$ & POND & UNFILTERED & 07-Oct-03 TF & IRITIUM & $2540 p$ & pCi/L & 190 & 260 & & & \\
\hline
\end{tabular}




\begin{tabular}{|c|c|c|c|c|c|c|c|c|c|c|c|c|c|c|c|c|}
\hline OWNER ID & SAMP NUM & SAMP SITE NAME & DIST CLASS & MEDIA & $\begin{array}{c}\text { FLLTERED } \\
\text { FLAG } \\
\end{array}$ & SAMP FROM & SAMP DATE & CON SHORT NAME & VALUE RPTD & $\begin{array}{l}\text { ANAL } \\
\text { UNITS } \\
\text { RPTD } \\
\end{array}$ & \begin{tabular}{|c|} 
COUNTING \\
ERROR
\end{tabular} & \begin{tabular}{|c|} 
TOTAL \\
ANAL \\
ERROR \\
\end{tabular} & $\begin{array}{c}\text { LAB } \\
\text { QUALIFIER } \\
\end{array}$ & SAMP COMMENT & $\begin{array}{c}\text { RESULT } \\
\text { COMMENT }\end{array}$ & WELL NAME \\
\hline $\begin{array}{l}\text { SESPSPEC } \\
\end{array}$ & B16WL8 & YAKIMA RIVER & OFFSITE & SW & N & RIVER & 14-May-03 Be-7 & & -3.76 & pCill & 24 & 24 & U & & & \\
\hline $\begin{array}{l}\text { SESPSPEC } \\
\text { SESPDEC }\end{array}$ & B16WL9 & YAKIMA RIVER & OFFSITE & sw & $\mathrm{N}$ & RIVER & 14-May-03 Be-7 & & -15.5 & $\mathrm{pCi} / \mathrm{L}$ & 24 & 24 & U & & & \\
\hline $\begin{array}{l}\text { SESPSPEC } \\
\text { SESPPEC }\end{array}$ & B16WM0 & $\begin{array}{l}\text { YAKIMA RIVER } \\
\text { HOOD PARK-FRANKLIN CO SHORE }\end{array}$ & OFFSITE & sW & $\begin{array}{l}N \\
N\end{array}$ & $\begin{array}{l}\text { RIVER } \\
\text { RIVER }\end{array}$ & 14-May- $03 \mathrm{Be}-7$ & & 2.44 & pCi/L & 20 & 20 & $\mathrm{U}$ & & & \\
\hline $\begin{array}{l}\text { SESPPPEC } \\
\text { SESPSPEC }\end{array}$ & $\begin{array}{l}\text { B16WM6 } \\
\text { B16WM5 }\end{array}$ & $\begin{array}{l}\text { HOOD PARKK-FRANLLIN CO. SHORE } \\
\text { HOOD PARK-MID-RIVER }\end{array}$ & $\begin{array}{l}\text { OFFSIE } \\
\text { OFFSITE }\end{array}$ & $\begin{array}{l}\text { SW } \\
\text { SW }\end{array}$ & $\begin{array}{l}n \\
\mathrm{~N}\end{array}$ & $\begin{array}{l}\text { IVER } \\
\text { RIVER }\end{array}$ & $\begin{array}{l}\text { 15-May-03 Be-7 } \\
\text { 15-Mav-03 B }-7\end{array}$ & & $\begin{array}{r}-5.7 \\
8.53\end{array}$ & $\begin{array}{l}\text { pCi/L } \\
\text { pCi/l }\end{array}$ & 24 & 24 & u & & & \\
\hline SESPSPEC & B16WM4 & HOOD PARK-WALLA WALLA SHORE & $\begin{array}{l}\text { OFFSITE } \\
\text { OFFS }\end{array}$ & SW & $\frac{n}{N}$ & $\begin{array}{l}\text { RIVER } \\
\text { RIVER }\end{array}$ & $\begin{array}{l}\text { 15-May-03 Be-7 } \\
15-M a y-03 \mathrm{Be}-7\end{array}$ & & $\begin{array}{l}8.53 \\
23.3\end{array}$ & $\begin{array}{l}\mathrm{pCiL} \\
\mathrm{pCi/L}\end{array}$ & $\begin{array}{l}24 \\
29\end{array}$ & $\begin{array}{l}24 \\
29\end{array}$ & u & & & \\
\hline SESPSPEC & B16WL6 & MCNARY MID-RIVER NEAR DAM & OFFSITE & sW & $\mathrm{N}$ & RIVER & 15-May-03 Be-7 & & 16.2 & $\mathrm{pCi} / \mathrm{L}$ & 23 & 23 & u & & & \\
\hline $\begin{array}{l}\text { SESPSPEC } \\
\text { SECDPFC }\end{array}$ & B16WL5 & MCNARY-OR.SIDE NEAR DAM & OFFSITE & sw & $\mathrm{N}$ & RIVER & 15-May-03 Be-7 & & -5.4 & $\mathrm{pCi} / \mathrm{L}$ & 27 & 27 & U & & & \\
\hline $\begin{array}{l}\text { SESPSPEC } \\
\text { SESPDEC }\end{array}$ & B16WL7 & MCNARY-WASH.SIDE NEAR DAM & OFFSITE & SW & $\mathrm{N}$ & RIVER & 15-May-03 Be-7 & & 11 & $\mathrm{pCi} / \mathrm{L}$ & 23 & 23 & $\mathrm{U}$ & & & \\
\hline $\begin{array}{l}\text { SESPSPEC } \\
\text { SESPPEC }\end{array}$ & B16WM1 & WALLA WALLA-RIVER & OFFSITE & sW & $\mathrm{N}$ & RIVER & 15-May-03 Be-7 & & -2.16 & pCi/L & 22 & 22 & U & & & \\
\hline $\begin{array}{l}\text { SESPPPEC } \\
\text { SESPSPEC }\end{array}$ & $\begin{array}{l}\text { l16WM2 } \\
\text { B16WM3 }\end{array}$ & $\begin{array}{l}\text { WALLA WALLA-RIVR } \\
\text { WALA WALLA-RIVER }\end{array}$ & $\begin{array}{l}\text { OFFSITE } \\
\text { OFFSITE }\end{array}$ & $\begin{array}{l}\text { SW } \\
\text { sw }\end{array}$ & $\begin{array}{l}\mathrm{N} \\
\mathrm{N}\end{array}$ & $\begin{array}{l}\text { IVER } \\
\text { RIVER }\end{array}$ & $\begin{array}{l}\text { 15-May-03 Be-7 } \\
\text { 15-May-03 Be-7 }\end{array}$ & & 0.695 & pCilL & 24 & 24 & u & & & \\
\hline SESPSPEC & B17BH9 & $\begin{array}{l}\text { WALA WALA-RIVER } \\
\text { MCNARY-2/3 OR. SHORE }\end{array}$ & $\begin{array}{l}\text { OFFSITE } \\
\text { OFFE }\end{array}$ & sw & $\frac{N}{N}$ & $\begin{array}{l}\text { RIVER } \\
\text { RIVER }\end{array}$ & $\begin{array}{l}\text { 15-Mav-03 Be- } 1 \\
08-A u g-03 \mathrm{Be}-7\end{array}$ & & $\begin{array}{l}0.422 \\
-0.959\end{array}$ & $\begin{array}{l}\mathrm{pCl} / \mathrm{L} \\
\mathrm{pCil}\end{array}$ & 23 & 23 & u & & & \\
\hline SESPSPEC & B16WL8 & YAKIMA RIVER & OFFSITE & sw & $\mathrm{N}$ & RIVER & 14-Маy-03 Сo-60 & & 0.846 & $\mathrm{pCi} / \mathrm{L}$ & 2.7 & 2.7 & u & & & \\
\hline SESPSPEC & B16WL9 & YAKIMA RIVER & OFFSITE & sw & $\mathrm{N}$ & RIVER & 14-May-03 Сo-60 & & 0.922 & $\mathrm{pCi} / \mathrm{L}$ & 2.7 & 2.7 & $\mathrm{U}$ & & & \\
\hline $\begin{array}{l}\text { SESPSPEC } \\
\text { SESPDEC }\end{array}$ & B16WM0 & $\begin{array}{l}\text { YAKIMA RIVER } \\
\text { CHE }\end{array}$ & OFFSITE & SW & $\mathrm{N}$ & $\begin{array}{l}\text { RIVER } \\
\text { PIVER }\end{array}$ & 14-May-03 Сo-60 & & -0.87 & $\mathrm{pCi} / \mathrm{L}$ & 2 & 2 & U & & & \\
\hline $\begin{array}{l}\text { SESPSPEC } \\
\text { SESPPPEC }\end{array}$ & $\begin{array}{l}\text { B16WM6 } \\
\text { B16WM5 }\end{array}$ & $\begin{array}{l}\text { HOOD PARK-FRANKLIN CO. SHORE } \\
\text { HODAR PARKMIVR }\end{array}$ & OFFSITE & SW & $\begin{array}{l}\mathrm{N} \\
\mathrm{N}\end{array}$ & $\begin{array}{l}\text { RIVER } \\
\text { RIVER }\end{array}$ & 15-Мау-03 Со-60 & & $\begin{array}{r}0.935 \\
-11\end{array}$ & pCi/L & $\frac{2.8}{3}$ & $\frac{2.8}{3}$ & $\mathrm{U}$ & & & \\
\hline $\begin{array}{l}\text { SESPPPEC } \\
\text { SESPSPEC }\end{array}$ & $\begin{array}{l}\text { B16WM5 } \\
\text { B16WM4 }\end{array}$ & $\begin{array}{l}\text { HOOD PARKK-MII-RIVER } \\
\text { HOOD PAR-WALLA WALLA SHORE }\end{array}$ & $\begin{array}{l}\text { OFFSITE } \\
\text { OFFSITE }\end{array}$ & $\begin{array}{l}\text { SW } \\
\text { sw }\end{array}$ & $\begin{array}{l}\mathrm{N} \\
\mathrm{N}\end{array}$ & $\begin{array}{l}\text { IIVER } \\
\text { RIVER }\end{array}$ & 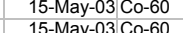 & & $\begin{array}{r}-1.1 \\
0769\end{array}$ & $\begin{array}{l}\text { pCil/ } \\
\text { pCi/L }\end{array}$ & $\begin{array}{r}3 \\
24\end{array}$ & 23 & u & & & \\
\hline SESPSPEC & B16WL6 & 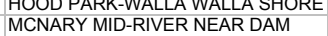 & $\begin{array}{l}\text { OFFSITE } \\
\text { OFFE }\end{array}$ & sw & $\mathrm{N}$ & $\begin{array}{l}\text { RIVER } \\
\text { RIVER }\end{array}$ & $\begin{array}{l}15 \text {-May-03 Сo-60 } \\
15-\text { May-03 Сo-60 }\end{array}$ & & $\begin{array}{l}0.69 \\
-0.73\end{array}$ & $\begin{array}{l}\mathrm{pCl} / \mathrm{L} \\
\mathrm{pCil}\end{array}$ & 2.8 & 2.4 & u & & & \\
\hline SESPSPEC & B16WL5 & MCNARY-OR.SIDE NEAR DAM & OFFSITE & sW & $\mathrm{N}$ & RIVER & $\begin{array}{l}15-\mathrm{May}-03 \text { Сo-60 } \\
150\end{array}$ & & $\begin{array}{l}-0.15 \\
-0.822\end{array}$ & pCi/L & $\begin{array}{c}2.8 \\
3\end{array}$ & $\frac{2.8}{3}$ & u & & & \\
\hline SESPSPEC & B16WL7 & MCNARY-WASH.SIDE NEAR DAM & OFFSITE & sw & $\mathrm{N}$ & RIVER & $15-$ May-03 Сo-60 & & 1.49 & $\mathrm{pCil}$ & 2.4 & 2.4 & u & & & \\
\hline $\begin{array}{l}\text { SESPSPEC } \\
\text { SESPSEC }\end{array}$ & B16WM1 & WALLA WALLA-RIVER & OFFSITE & SW & $\mathrm{N}$ & RIVER & 15-May-03 Co-60 & & -0.91 & $\mathrm{pCi} / \mathrm{L}$ & 2.3 & 2.3 & $\mathrm{U}$ & & & \\
\hline $\begin{array}{l}\text { SESPSPEC } \\
\text { SESPPEC }\end{array}$ & B16WM2 & WALLA WALLA-RIVER & OFFSITE & SW & $\mathrm{N}$ & $\begin{array}{l}\text { RIVER } \\
\text { RIVER }\end{array}$ & 15-May-03 Сo-60 & & 2.04 & pCi/L & 2.5 & 2.5 & U & & & \\
\hline $\begin{array}{l}\text { SESPPPEC } \\
\text { SESPSPEC }\end{array}$ & $\begin{array}{l}\text { B16WM3 } \\
\text { B17BH9 }\end{array}$ & $\begin{array}{l}\text { WALLA WALLA-RIVER } \\
\text { MCNARY-2/3 OR SHORE }\end{array}$ & $\begin{array}{l}\text { OFFSITE } \\
\text { OFFSITE }\end{array}$ & SW & $\begin{array}{l}n \\
N\end{array}$ & $\begin{array}{l}\text { RIVER } \\
\text { RIVER }\end{array}$ & $\begin{array}{l}15-\text { May-03 Сo-60 } \\
08 \text { - }\end{array}$ & & $\begin{aligned}-0.676 \\
4.42\end{aligned}$ & pCi/L & 2.1 & 2.1 & u & & & \\
\hline $\begin{array}{l}\text { SESPSPEC } \\
\text { SESP }\end{array}$ & B16WL8 & $\begin{array}{l}\text { MANAR-2I3 OR. SHORE } \\
\text { YAKIMA RIVER }\end{array}$ & $\begin{array}{l}\text { OFFSITE } \\
\text { OFFE }\end{array}$ & sw & $\frac{N}{N}$ & $\begin{array}{l}\text { RIVER } \\
\text { RIVER }\end{array}$ & 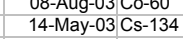 & & $\begin{array}{r}4.42 \\
0.979\end{array}$ & $\begin{array}{l}\mathrm{pCIML} \\
\mathrm{pCi/L}\end{array}$ & 2.3 & 2.3 & u & & & \\
\hline SESPSPEC & B16WL9 & YAKIMA RIVER & OFFSITE & sw & $\mathrm{N}$ & RIVER & 14-May-03 Cs-134 & & 0.0251 & $\mathrm{pCi} / \mathrm{L}$ & 2.9 & 2.9 & u & & & \\
\hline SESPSPEC & B16WM0 & YAKIMA RIVER & OFFSITE & sw & $\mathrm{N}$ & RIVER & 14-May-03 Cs-134 & & -0.559 & $\mathrm{pCi} / \mathrm{L}$ & 2.7 & 2.7 & $\mathrm{U}$ & & & \\
\hline SESPSPEC & B16WM6 & HOOD PARK-FRANKLIN CO. SHORE & OFFSITE & sW & $\mathrm{N}$ & RIVER & 15-May-03 Cs-134 & & -0.497 & $\mathrm{pCi} / \mathrm{L}$ & 2.6 & 2.6 & $\mathrm{U}$ & & & \\
\hline $\begin{array}{l}\text { SESPPSEC } \\
\text { SESPPEC }\end{array}$ & B16WM5 & HOOD PARK-MID-RIVER & OFFSITE & sW & $\mathrm{N}$ & $\begin{array}{l}\text { RIVER } \\
\text { RAVER }\end{array}$ & 15-May-03 Cs-134 & & 2.52 & $\mathrm{pCi/L}$ & 2.8 & 2.8 & U & & & \\
\hline $\begin{array}{l}\text { SESPPSEC } \\
\text { SESPSPEC }\end{array}$ & $\begin{array}{l}\text { B16WM4 } \\
\text { B16WL6 }\end{array}$ & $\begin{array}{l}\text { HOOD PARKKWALLA WALLA SHORE } \\
\text { MCNARY MID-RIVER NEAR DAM }\end{array}$ & & sw & $\begin{array}{l}n \\
N \\
N\end{array}$ & $\begin{array}{l}\text { RIVER } \\
\text { RIVER }\end{array}$ & $\begin{array}{l}15-M a y-03 \text { Cs-134 } \\
15 \text {-May-03 Cs } 134\end{array}$ & & $\begin{array}{r}-0.461 \\
234\end{array}$ & pCilL & $\begin{array}{l}2.6 \\
27\end{array}$ & 2.6 & u & & & \\
\hline $\begin{array}{l}\text { SESPPEC } \\
\text { SESPPEC }\end{array}$ & $\begin{array}{l}\text { B16WL6 } \\
\text { B16WL5 }\end{array}$ & $\begin{array}{l}\text { MCNARY MD-RIVER NEAR DAM } \\
\text { MCNARY-OR.SIDE NEAR DAM }\end{array}$ & $\begin{array}{l}\text { OFFSITE } \\
\text { OFFSITE }\end{array}$ & SW & $\frac{N}{n}$ & $\begin{array}{l}\text { RIVER } \\
\text { RIVER }\end{array}$ & $\begin{array}{l}15-\text {-May-03 Cs-134 } \\
15 \text {-May-03 Cs-134 }\end{array}$ & & $\begin{array}{l}2.34 \\
1.99\end{array}$ & $\begin{array}{l}\text { pCiL } \\
\text { pCi/L }\end{array}$ & 2.7 & 2.7 & u & & & \\
\hline SESPSPEC & B16WL7 & MCNARY-WASH.SIDE NEAR DAM & OFFSITE & sw & $\mathrm{N}$ & RIVER & $15-M a y-03$ Cs-134 & & 1.35 & $\mathrm{pCi} / \mathrm{L}$ & 2.4 & 2.4 & u & & & \\
\hline SESPSPEC & B16WM1 & WALLA WALLA-RIVER & OFFSITE & SW & $N$ & RIVER & 15-May-03 Cs-134 & & -0.176 & $\mathrm{pCi} / \mathrm{L}$ & 2.4 & 2.4 & U & & & \\
\hline $\begin{array}{l}\text { SESPSPEC } \\
\text { SESPPEC }\end{array}$ & B16WM2 & WALLA WALLA-RIVER & OFFSITE & SW & $\mathrm{N}$ & $\begin{array}{l}\text { RIVER } \\
\text { RIVER }\end{array}$ & $\begin{array}{l}15-M a y-03 \text { Cs-134 } \\
15-134\end{array}$ & & 1.8 & pCi/L & 2.8 & 2.8 & U & & & \\
\hline $\begin{array}{l}\text { SESPPSEC } \\
\text { SESPPPEC }\end{array}$ & B16WM3 & WALLA WALLA-RIVER & $\begin{array}{l}\text { OFFSITE } \\
\text { OFFSITE }\end{array}$ & SW & $\begin{array}{l}N \\
N\end{array}$ & $\begin{array}{l}\text { RIVER } \\
\text { RIVER }\end{array}$ & 15-May-03 Cs-134 & & 0.456 & pCi/L & 2.9 & 2.9 & U & & & \\
\hline $\begin{array}{l}\text { SESPPEC } \\
\text { SESPSPEC }\end{array}$ & $\begin{array}{l}\text { B17BH99 } \\
\text { B16WL18 }\end{array}$ & $\begin{array}{l}\text { MCNARY-2/3 OR. SHORE } \\
\text { YAKIMA RIVER }\end{array}$ & $\begin{array}{l}\text { OFFSITE } \\
\text { OFFSITE }\end{array}$ & SW & $\frac{n}{n}$ & $\begin{array}{l}\text { IIVER } \\
\text { RIVER }\end{array}$ & $\begin{array}{l}\text { 08-Aug-03 Cs-134 } \\
\text { 14-May-03Cs-137 }\end{array}$ & & 0.699 & pCi/L & 3.3 & 3.3 & u & & & \\
\hline $\begin{array}{l}\text { SESPSPEC } \\
\text { SESP }\end{array}$ & B16WL9 & YAKIMA RIVER & OFFSITE & sw & $\mathrm{N}$ & RIVER & $\begin{array}{l}\text { 14-May-03 Cs-137 } \\
14-03 \text { Cs-137 }\end{array}$ & & $\begin{array}{l}0.145 \\
-0.225\end{array}$ & $\begin{array}{l}\mathrm{pCl \textrm {I }} \\
\mathrm{pCi/L}\end{array}$ & 2.6 & 2.6 & u & & & \\
\hline SESPSPEC & B16WM0 & YAKIMA RIVER & OFFSITE & sw & $\mathrm{N}$ & RIVER & 14-May-03 Cs-137 & & -0.647 & $\mathrm{pCi} / \mathrm{L}$ & 2.5 & 2.5 & u & & & \\
\hline SESPSPEC & B16WM6 & HOOD PARK-FRANKLIN CO. SHORE & OFFSITE & SW & $\mathrm{N}$ & RIVER & 15-May-03 Cs-137 & & 1.78 & $\mathrm{pCi} / \mathrm{L}$ & 2.7 & 2.7 & U & & & \\
\hline $\begin{array}{l}\text { SESPSPEC } \\
\text { SESPPEC }\end{array}$ & B16WM5 & HOOD PARK-MID-RIVER & OFFSITE & sW & $\mathrm{N}$ & RIVER & 15-May-03 Cs-137 & & 0.375 & pCi/L & 2.7 & 2.7 & $\mathrm{U}$ & & & \\
\hline $\begin{array}{l}\text { SESPPEEC } \\
\text { SESPPEC }\end{array}$ & B16WM4 & HOOD PARK-WALLA WALLA SHORE & $\begin{array}{l}\text { OFFSITE } \\
\text { OFFSITE }\end{array}$ & SW & $\begin{array}{l}n \\
N\end{array}$ & $\begin{array}{l}\text { RIVER } \\
\text { RIVER }\end{array}$ & 15-May-03 Cs-137 & & 0.188 & pCill & 2.4 & 2.4 & U & & & \\
\hline $\begin{array}{l}\text { SESSPPEC } \\
\text { SESPSPEC }\end{array}$ & $\begin{array}{l}\text { B16WL6 } \\
\text { B16WL5 }\end{array}$ & $\begin{array}{l}\text { MCARAY MIDD-RIVR NEAR DAM } \\
\text { MCNARY-OR.SIDE NEAR DAM }\end{array}$ & $\begin{array}{l}\text { OFFSIIE } \\
\text { OFFSITE }\end{array}$ & sw & $\mathrm{N}_{\mathrm{N}}$ & $\begin{array}{l}\text { RIVER } \\
\text { RIVER }\end{array}$ & $\begin{array}{l}\text { 15-May-03 Cs -137 } \\
\text { 15-May-03 Cs-137 }\end{array}$ & & $\begin{array}{r}1.83 \\
-0.655\end{array}$ & $\begin{array}{l}\text { pCiL } \\
\text { pCi/L }\end{array}$ & $\begin{array}{l}2.5 \\
2.5\end{array}$ & 2.5 & u & & & \\
\hline SESPSPEC & B16WL7 & MCNARY-WASH.SIDE NEAR DAM & OFFSITE & sw & $\mathrm{N}$ & RIVER & 15-May-03 Cs-137 & & 0.363 & $\mathrm{pCi} / \mathrm{L}$ & 2.6 & 2.6 & u & & & \\
\hline SESPSPEC & B16WM1 & WALLA WALLA-RIVER & OFFSITE & sw & $\mathrm{N}$ & RIVER & 15-May-03 Cs-137 & & -0.00534 & $\mathrm{pCi} / \mathrm{L}$ & 2.3 & 2.3 & $\mathrm{U}$ & & & \\
\hline SESPSPEC & B16WM2 & WALLA WALLA-RIVER & OFFSITE & SW & $\mathrm{N}$ & RIVER & 15-May-03 Cs-137 & & 0.945 & $\mathrm{pCi} / \mathrm{L}$ & 2.4 & 2.4 & $\mathrm{U}$ & & & \\
\hline SESPSPEC & B16WM3 & WALLA WALLA-RIVER & OFFSITE & sW & $\mathrm{N}$ & RIVER & 15-May-03 Cs-137 & & 0.158 & pCi/L & 2.7 & 2.7 & $\mathrm{U}$ & & & \\
\hline $\begin{array}{l}\text { SESPPSEC } \\
\text { SESPPEC }\end{array}$ & B17BH9 & MCNARY-2/3 OR. SHORE & $\begin{array}{l}\text { OFFSITE } \\
\text { OFFSITE }\end{array}$ & SW & $\begin{array}{l}n \\
N\end{array}$ & $\begin{array}{l}\text { RIVER } \\
\text { RIVER }\end{array}$ & $\begin{array}{l}08 \text {-Aug-03 Cs-137 } \\
\text { 14-Mav-03 Ey-152 }\end{array}$ & & $\begin{array}{r}-3.15 \\
3.05\end{array}$ & pCi/L & 2.6 & 2.6 & U & & & \\
\hline $\begin{array}{l}\text { SESPPEC } \\
\text { SESPSPEC }\end{array}$ & $\begin{array}{l}\text { B16WL8 } \\
\text { B16WL9 }\end{array}$ & $\begin{array}{l}\text { YYAIMA RIVER } \\
\text { YAKIMA RIVER }\end{array}$ & $\begin{array}{l}\text { OFFSIIE } \\
\text { OFFSITE }\end{array}$ & SW & $\frac{N}{N}$ & $\begin{array}{l}\text { IIVER } \\
\text { RIVER }\end{array}$ & $\begin{array}{l}\text { 14-May-03 Eu-152 } \\
\text { 14-May-03 Eu-152 }\end{array}$ & & $\begin{array}{r}3.05 \\
0.0793\end{array}$ & $\begin{array}{l}\text { pCiL } \\
\text { pCi/L }\end{array}$ & 5.8 & 5.8 & u & & & \\
\hline SESPSPEC & B16WM0 & YAKIMA RIVER & OFFSITE & sw & $\mathrm{N}$ & RIVER & 14-May-03 Eu-152 & & $\begin{array}{r}0.0193 \\
1.92\end{array}$ & $\begin{array}{l}\mathrm{pCM} / \mathrm{L} \\
\mathrm{pCi}\end{array}$ & 5.3 & 5.3 & u & & & \\
\hline SESPSPEC & B16WM6 & HOOD PARK-FRANKLIN CO. SHORE & OFFSITE & sw & $\mathrm{N}$ & RIVER & 15-May-03 Eu-152 & & -0.772 & $\mathrm{pCi} / \mathrm{L}$ & 5.8 & 5.8 & $\mathrm{U}$ & & & \\
\hline SESPSPEC & B16WM5 & HOOD PARK-MID-RIVER & OFFSITE & SW & $\mathrm{N}$ & RIVER & 15-May-03 Eu-152 & & -0.411 & $\mathrm{pCi} / \mathrm{L}$ & 5.2 & 5.2 & $\mathrm{U}$ & & & \\
\hline SESPSPEC & B16WM4 & HOOD PARK-WALLA WALLA SHORE & OFFSITE & sW & $\mathrm{N}$ & RIVER & 15-May-03 Eu-152 & & 0.275 & $\mathrm{pCi} / \mathrm{L}$ & 6.8 & 6.8 & U & & & \\
\hline $\begin{array}{l}\text { SESPPEC } \\
\text { SESPSPEC }\end{array}$ & $\begin{array}{l}\text { B16WL6 } \\
\text { B16WL5 }\end{array}$ & MCNARY MID-RIVER NEAR DAM & $\begin{array}{l}\text { OFFSITE } \\
\text { OFFSITE }\end{array}$ & sw & $\begin{array}{l}n \\
N\end{array}$ & $\begin{array}{l}\text { IVIVER } \\
\text { RIVER }\end{array}$ & $\begin{array}{l}15-M a y-03 \text { Eu-152 } \\
15 \text {-May-03 Eu-152 }\end{array}$ & & $\begin{array}{l}1.32 \\
1.33\end{array}$ & pCi/L & 5.9 & 5.9 & U & & & \\
\hline $\begin{array}{l}\text { SESPPEC } \\
\text { SESPSPEC }\end{array}$ & $\begin{array}{l}\text { B16WL5 } \\
\text { B16WL7 }\end{array}$ & $\begin{array}{l}\text { MCNARYYOR.SIDE NEAR DAM } \\
\text { MCNARY-WASH SIDE NEAR DAM }\end{array}$ & $\begin{array}{l}\text { OFFSITE } \\
\text { OFFSITE }\end{array}$ & SW & $\frac{n}{n}$ & $\begin{array}{l}\text { RIVER } \\
\text { RIVER }\end{array}$ & & & $\begin{array}{c}1.33 \\
0.483\end{array}$ & pCil & $\begin{array}{l}7.4 \\
6.9\end{array}$ & 7.4 & u & & & \\
\hline SESPSPEC & B16WM1 & WALLA WALLA-RIVER & OFFSITE & sw & $\mathrm{N}$ & RIVER & 15-May-03 Eu-152 & & $\begin{array}{l}0.483 \\
-2.35\end{array}$ & $\begin{array}{l}\mathrm{pCll} \\
\mathrm{pCi} / \mathrm{L}\end{array}$ & $\begin{array}{l}0.9 \\
4.5\end{array}$ & 4.9 & u & & & \\
\hline SESPSPEC & B16WM2 & WALLA WALLA-RIVER & OFFSITE & SW & $\mathrm{N}$ & RIVER & 15-May-03 Eu-152 & & 1.13 & $\mathrm{pCi} / \mathrm{L}$ & 5.2 & 5.2 & $\mathrm{U}$ & & & \\
\hline SESPSPEC & B16WM3 & WALLA WALLA-RIVER & OFFS & SW & $\mathrm{N}$ & RIV & 15-May-03 & & -2.7 & $\mathrm{pCi} / \mathrm{L}$ & 5.5 & 5.5 & U & & & \\
\hline $\begin{array}{l}\text { SESPSPEC } \\
\text { SESPDEC }\end{array}$ & B17BH9 & MCNARY-2/3 OR. SHORE & OFFSITE & sW & $\mathrm{N}$ & $\begin{array}{l}\text { RIVER } \\
\text { RIVER }\end{array}$ & 08-Aug-03 Eu-152 & & -4.22 & $\mathrm{pCi} / \mathrm{L}$ & 6.8 & 6.8 & $\mathrm{U}$ & & & \\
\hline $\begin{array}{l}\text { SESPSPEC } \\
\text { SESPPPEC }\end{array}$ & B16WL8 & $\begin{array}{l}\text { YAKIMA RIVER } \\
\text { YYAIMA RIVER }\end{array}$ & $\begin{array}{l}\text { OFFSITE } \\
\text { OFESITE }\end{array}$ & SW & $\begin{array}{c}\mathrm{N} \\
\mathrm{N}\end{array}$ & $\begin{array}{l}\text { RIVER } \\
\text { RIVER }\end{array}$ & 14-May-03 Eu-154 & & 0.635 & pCi/L & 5.5 & 5.5 & U & & & \\
\hline $\begin{array}{l}\text { SESPSPEC } \\
\text { SESPEC }\end{array}$ & B16WMO & $\begin{array}{l}\text { YAKIMA RIVER } \\
\text { YAKA }\end{array}$ & $\begin{array}{l}\text { OFFSITE } \\
\text { OFSE }\end{array}$ & sw & $\mathrm{N}$ & $\begin{array}{l}\text { RIVER } \\
\text { RIVER }\end{array}$ & $\begin{array}{l}14-M a y-03 \text { Eu-154 } \\
\text { 14-May-154 }\end{array}$ & & $\begin{array}{l}0.524 \\
-1.52\end{array}$ & $\begin{array}{l}\mathrm{pCliL} \\
\mathrm{pCi/L}\end{array}$ & $\begin{array}{l}6.8 \\
7.7\end{array}$ & $\begin{array}{l}6.8 \\
7.7\end{array}$ & u & & & \\
\hline SESPSPEC & B16WM6 & HOOD PARK-FRANKLIN CO. SHORE & OFFSITE & sw & $\mathrm{N}$ & RIVER & 15-May-03 Eu-154 & & -1.75 & $\mathrm{pCi} / \mathrm{L}$ & 5.7 & 5.7 & u & & & \\
\hline SESPSPEC & B16WM5 & HOOD PARK-MID-RIVER & OFFSITE & SW & $\mathrm{N}$ & RIVER & 15-May-03 Eu-154 & & 0.648 & $\mathrm{pCi} / \mathrm{L}$ & 8.2 & 8.2 & $\mathrm{U}$ & & & \\
\hline SESPSPEC & B16WM4 & HOOD PARK-WALLA WALLA SHORE & OFFSITE & SW & $\mathrm{N}$ & RIVER & 15-May-03 Eu-154 & & -5.51 & $\mathrm{pCi} / \mathrm{L}$ & 8 & 8 & u & & & \\
\hline
\end{tabular}




\begin{tabular}{|c|c|c|c|c|c|c|c|c|c|c|c|c|c|c|c|}
\hline OWNER ID & SAMP NUM & SAMP SITE NAME & DIST CLASS & MEDIA & $\begin{array}{c}\text { FILTERED } \\
\text { FLAG }\end{array}$ & SAMP FROM & CON SHORT NAME & |VALUE RPTD & $\begin{array}{l}\text { ANAL } \\
\text { UNITS } \\
\text { RPTD }\end{array}$ & $\mid \begin{array}{c}\text { COUNTING } \\
\text { ERROR }\end{array}$ & \begin{tabular}{|c|} 
TOTAL \\
ANAL \\
ERROR
\end{tabular} & $\mid \begin{array}{c}\text { LAB } \\
\text { QUALIFIER }\end{array}$ & SAMP COMMENT & $\left|\begin{array}{|c|}\text { RESULT } \\
\text { COMMENT }\end{array}\right|$ & |WELL NAME \\
\hline SESPSPEC & B16WL6 & MCNARY MID-RIVER NEAR DAM & OFFSITE & SW & N & RIVER & 15-May-03Eu-154 & -1.95 & pCilL & 7 & & $u$ & & & \\
\hline SESPSPEC & B16WL5 & MCNARY-OR.SIDE NEAR DAM & OFFSITE & SW & $\mathrm{N}$ & RIVER & 15-May-03 Eu-154 & 5.6 & $\mathrm{pCilL}$ & 7.4 & 7.4 & U & & & \\
\hline $\begin{array}{l}\text { SESPSPEC } \\
\text { SESPSEC }\end{array}$ & B16WL7 & MCNARY-WASH.SIDE NEAR DAM & OFFSITE & SW & 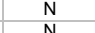 & $\begin{array}{l}\text { RIVER } \\
\text { RIVER }\end{array}$ & 15-May-03 Eu-154 & 7.62 & pCill & 7.2 & 7.2 & $\mathrm{U}$ & & & \\
\hline $\begin{array}{l}\text { SESPSEC } \\
\text { SESPSPEC }\end{array}$ & $\begin{array}{l}\text { B16WM1 } \\
\text { B16WM2 }\end{array}$ & $\begin{array}{l}\text { WALLA WALLA-RIVER } \\
\text { WALA WALLA-RIVER }\end{array}$ & $\begin{array}{l}\text { OFFFITE } \\
\text { OFFSITE }\end{array}$ & $\begin{array}{l}\text { sw } \\
\text { sw }\end{array}$ & $\begin{array}{l}n \\
\mathrm{n} \\
\mathrm{n}\end{array}$ & $\begin{array}{l}\text { IVER } \\
\text { RIVER }\end{array}$ & $\begin{array}{l}\text { 15-May-03 Eu-154 } \\
\text { 15-May-03 E-154 }\end{array}$ & $\begin{array}{l}-4.57 \\
-237\end{array}$ & pCili & 6.4 & 6.4 & u & & & \\
\hline SESPSPEC & B16WM3 & $\begin{array}{l}\text { WALLA WALLA-RIVER } \\
\text { WALLA WALLA-RIVER }\end{array}$ & $\begin{array}{l}\text { OFSITE } \\
\text { OFFSITE }\end{array}$ & sw & $\frac{N}{N}$ & $\begin{array}{l}\text { RIVER } \\
\text { RIVER }\end{array}$ & $\begin{array}{l}\text { 15-Maya-03 Eu-1-144 } \\
\text { 15-May-03 Eu-154 }\end{array}$ & $\begin{array}{l}-2.37 \\
-1.02\end{array}$ & $\begin{array}{l}\mathrm{pCIL} \\
\mathrm{pCI} / \mathrm{L}\end{array}$ & $\begin{array}{l}7.7 \\
7.3\end{array}$ & 7.7 & u & & & \\
\hline SESPSPEC & B17BH9 & MCNARY-2/3 OR. SHORE & OFFSITE & sw & N & RIVER & 08-Aug-03 Eu-154 & -1.08 & pCil & 7.9 & 7.9 & u & & & \\
\hline $\begin{array}{l}\text { SESPSPEC } \\
\text { SESPSDC }\end{array}$ & B16WL8 & YAKIMA RIVER & OFFSITE & sW & n & RIVER & 14-May-03 Eu-155 & -2.22 & $\mathrm{pCi/L}$ & 5.5 & 5.5 & u & & & \\
\hline $\begin{array}{l}\text { SESPSPEC } \\
\text { SESPSDC }\end{array}$ & B16WL9 & YAKIMA RIVER & OFFSITE & SW & $\mathrm{N}$ & RIVER & 14-May-03 Еu-155 & 3.92 & pCilL & 5.4 & 5.4 & $\mathrm{U}$ & & & \\
\hline $\begin{array}{l}\text { SESPSPEC } \\
\text { SESPSEC }\end{array}$ & B16WM0 & $\begin{array}{l}\text { YAKIMA RIVER } \\
\text { HONKIN SHORE }\end{array}$ & OFFSITE & SW & $\mathrm{N}$ & $\begin{array}{l}\text { RIVER } \\
\text { RIVER }\end{array}$ & 14-May-03 Eu-155 & 2.91 & pCill & 4.4 & 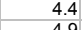 & $\mathrm{U}$ & & & \\
\hline $\begin{array}{l}\text { SESPSEEC } \\
\text { SESPSPEC }\end{array}$ & $\begin{array}{l}\text { B16WM6 } \\
\text { B16WM5 }\end{array}$ & $\begin{array}{l}\text { HOOD PARKK-FRANLLIN CO. SHORE } \\
\text { HOOD PARK-MID-RIVER }\end{array}$ & $\begin{array}{l}\text { OFFSITE } \\
\text { OFFSITE }\end{array}$ & $\begin{array}{l}\text { SW } \\
\text { sw }\end{array}$ & $\begin{array}{l}n \\
N\end{array}$ & $\begin{array}{l}\text { IVER } \\
\text { RIVER }\end{array}$ & $\begin{array}{l}15-M a y-03 \text { Eu-155 } \\
15-M a y-03 E-155\end{array}$ & $\begin{array}{l}4.36 \\
2.26\end{array}$ & $\mathrm{pCi/L}$ & 4.9 & 4.9 & u & & & \\
\hline SESPSPEC & B16WM4 & HOOD PARK-WALLA WALLA SHORE & OFFSITE & sw & $\frac{n}{n}$ & $\begin{array}{l}\text { RIVER } \\
\text { RIVER }\end{array}$ & $\begin{array}{l}\text { 15-Mayy-03 Eu-1-155 } \\
\text { 15-May-03 Eu-155 }\end{array}$ & $\begin{array}{r}2.26 \\
-0.522\end{array}$ & $\frac{\mathrm{pCI} / \mathrm{L}}{\mathrm{pCil}}$ & $\begin{array}{l}4.9 \\
8.3\end{array}$ & 8.9 & u & & & \\
\hline SESPSPEC & B16WL6 & MCNARY MID-RIVER NEAR DAM & OFFSITE & sw & $\mathrm{N}$ & RIVER & 15-May-03 Eu-155 & -6.81 & $\mathrm{pCil}$ & 5.2 & 5.2 & u & & & \\
\hline SESPSPEC & B16WL5 & MCNARY-OR.SIDE NEAR DAM & OFFSITE & sw & $\mathrm{N}$ & RIVER & 15-May-03 Eu-155 & -1.51 & $\mathrm{pCil}$ & 7.9 & 7.9 & U & & & \\
\hline $\begin{array}{l}\text { SESPSPEC } \\
\text { SESPSPC }\end{array}$ & B16WL7 & MCNARY-WASH.SIDE NEAR DAM & OFFSITE & SW & $\mathrm{N}$ & RIVER & 15-May-03 Eu-155 & 5.28 & pCilL & 7.5 & 7.5 & U & & & \\
\hline $\begin{array}{l}\text { SESPSPEC } \\
\text { SESPSEC }\end{array}$ & B16WM1 & $\begin{array}{l}\text { WALLA WALLA-RIVER } \\
\text { WAUA WAUER }\end{array}$ & OFFSITE & sw & $\mathrm{N}$ & $\begin{array}{l}\text { RIVER } \\
\text { RIVER }\end{array}$ & 15-May-03 Eu-155 & 1.22 & $\mathrm{pCl} / \mathrm{L}$ & 4.4 & 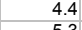 & $\mathrm{U}$ & & & \\
\hline $\begin{array}{l}\text { SESPSEC } \\
\text { SESPSEC }\end{array}$ & $\begin{array}{l}\text { B16WM2 } \\
\text { B16WM3 }\end{array}$ & $\begin{array}{l}\text { WALLA WALLA-AIVER } \\
\text { WALLA WALA-RIVER }\end{array}$ & $\begin{array}{l}\text { OFFITE } \\
\text { OFFSITE }\end{array}$ & SW & $\begin{array}{l}n \\
N\end{array}$ & $\begin{array}{l}\text { IVIVER } \\
\text { RIVER }\end{array}$ & 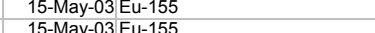 & 2.02 & pCil & 5.3 & 5.3 & u & & & \\
\hline $\begin{array}{l}\text { SESPSPEC } \\
\text { SEST }\end{array}$ & $\begin{array}{l}\text { B16WM13 } \\
\text { B17BH9 }\end{array}$ & MCNARY-2/3 OR. SHORE & OFFSITE & sw & $\frac{N}{N}$ & $\begin{array}{l}\text { RIVER } \\
\text { RIVER }\end{array}$ & 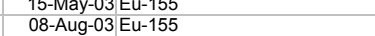 & $\begin{array}{r}1.14 \\
-1.13\end{array}$ & $\begin{array}{l}\mathrm{pCCIL} \\
\mathrm{pCl} / \mathrm{L}\end{array}$ & $\begin{array}{l}4.3 \\
5.7\end{array}$ & 5.7 & u & & & \\
\hline SESPSPEC & B16WL8 & YAKIMA RIVER & OFFSITE & sw & $\mathrm{N}$ & RIVER & 14-May-03 K-40 & 6.5 & $\mathrm{pCi} / \mathrm{L}$ & 63 & 63 & u & & & \\
\hline SESPSPEC & B16WL9 & YAKIMA RIVER & OFFSITE & sw & $\mathrm{N}$ & RIVER & 14-May-03 K-40 & -81.4 & pCill & 60 & 60 & U & & & \\
\hline $\begin{array}{l}\text { SESPSPEC } \\
\text { SESPSEC }\end{array}$ & B16WM0 & $\begin{array}{l}\text { YAKIMA RIVER } \\
\text { SHOKE }\end{array}$ & OFFSITE & sw & $\mathrm{N}$ & RIVER & 14-May-03 K-40 & -26.7 & pCilL & 52 & 52 & u & & & \\
\hline $\begin{array}{l}\text { SESPSPCC } \\
\text { SESPSEC }\end{array}$ & B16WM6 & HOOD PARK-FRANKLIN CO. SHORE & OFFSITE & SW & $\mathrm{N}$ & RIVER & 15-May-03 K-40 & 6.5 & $\mathrm{pCi} / \mathrm{L}$ & 63 & 63 & $\mathrm{U}$ & & & \\
\hline $\begin{array}{l}\text { SESPSECC } \\
\text { SESPPEC }\end{array}$ & $\begin{array}{l}\text { B16WM5 } \\
\text { B16WM4 }\end{array}$ & $\begin{array}{l}\text { HOOD PARKK-MID-RIVER } \\
\text { HOOD PARK-WALA WALA SHORE }\end{array}$ & $\begin{aligned} & \text { OFFSITE } \\
& \text { OFSITE }\end{aligned}$ & SW & $\begin{array}{l}\mathrm{N} \\
\mathrm{N}\end{array}$ & $\begin{array}{l}\text { RIVER } \\
\text { RIVER }\end{array}$ & $\begin{array}{l}15-M a y-03 \text { K- }-40 \\
15-M a-03 \\
150\end{array}$ & $\begin{array}{c}22.4 \\
-28.2\end{array}$ & pCil & 64 & 64 & U & & & \\
\hline $\begin{array}{l}\text { SESPSECC } \\
\text { SESPSPEC }\end{array}$ & $\begin{array}{l}\text { B16WM4 } \\
\text { B16WL6 }\end{array}$ & $\begin{array}{l}\text { HOOD PARK -WALLA WALLA SHORE } \\
\text { MCNARY MID-RIVER NEAR DAM }\end{array}$ & $\begin{array}{l}\text { OFFFITE } \\
\text { OFFSITE }\end{array}$ & SW & $\frac{N}{N}$ & $\begin{array}{l}\text { RIVER } \\
\text { RIVER }\end{array}$ & $\begin{array}{l}\text { 15-May-00 K-40 } \\
15-\text { May-03 K-40 }\end{array}$ & -81.2 .6 & $\begin{array}{l}\text { pCill } \\
\text { pCi/L }\end{array}$ & $\begin{array}{l}45 \\
64\end{array}$ & $\begin{array}{l}45 \\
64\end{array}$ & u & & & \\
\hline SESPSPEC & B16WL5 & MCNARY-OR.SIDE NEAR DAM & OFFSITE & sw & $\mathrm{N}$ & RIVER & 15-May-03 K-40 & $\begin{array}{l}-21.0 \\
22.9\end{array}$ & $\mathrm{pCilL}$ & 55 & 55 & u & & & \\
\hline SESPSPEC & B16WL7 & MCNARY-WASH.SIDE NEAR DAM & OFFSITE & sw & $\mathrm{N}$ & RIVER & 15-May-03 K-40 & -20.5 & $\mathrm{pCi} / \mathrm{L}$ & 52 & 52 & u & & & \\
\hline SESPSPEC & B16WM1 & WALLA WALLA-RIVER & OFFSITE & sw & $\mathrm{N}$ & RIVER & 15-May-03 K-40 & -64 & $\mathrm{pCilL}$ & 50 & 50 & $\mathrm{u}$ & & & \\
\hline SESPSPEC & B16WM2 & WALLA WALLA-RIVER & OFFSITE & sw & $\mathrm{N}$ & RIVER & 15-May-03 K-40 & -23.6 & pCi/L & 65 & 65 & $u$ & & & \\
\hline SESPSPEC & B16WM3 & WALLA WALLA-RIVER & OFFSITE & sW & $\mathrm{N}$ & RIVER & 15-May-03 K-40 & -19.1 & $\mathrm{pCi/L}$ & 55 & 55 & $u$ & & & \\
\hline SESPSPEC & B17BH9 & MCNARY-2/3 OR. SHORE & OFFSITE & SW & $\mathrm{N}$ & RIVER & 08-Aug-03 K-40 & -41.5 & $\mathrm{pCi} / \mathrm{L}$ & 66 & 66 & u & & & \\
\hline SESPSPEC & B16WL8 & YAKIMA RIVER & OFFSITE & sw & $\mathrm{N}$ & RIVER & 14-May-03 Ru-106 & -2.66 & $\mathrm{pCi} / \mathrm{L}$ & 21 & 21 & u & & & \\
\hline SESPSPEC & B16WL9 & YAKIMA RIVER & OFFSITE & sw & $\mathrm{N}$ & RIVER & 14-May-03 Ru-106 & -2.33 & $\mathrm{pCi} / \mathrm{L}$ & 23 & 23 & u & & & \\
\hline SESPSPEC & B16WM0 & YAKIMA RIVER & OFFSITE & SW & $\mathrm{N}$ & RIVER & 14-May-03 Ru-106 & 4.58 & pCi/L & 18 & 18 & U & & & \\
\hline $\begin{array}{l}\text { SESPSPEC } \\
\text { SESPSPCF }\end{array}$ & B16WM6 & HOOD PARK-FRANKLIN CO. SHORE & OFFSITE & SW & $\mathrm{N}$ & $\begin{array}{l}\text { RIVER } \\
\text { RIVER }\end{array}$ & 15-May-03 Ru-106 & -10.6 & pCi/L & 18 & 18 & $\mathrm{U}$ & & & \\
\hline $\begin{array}{l}\text { SESPSECC } \\
\text { SESPPEC }\end{array}$ & $\begin{array}{l}\text { B16WM5 } \\
\text { B16WM4 }\end{array}$ & $\begin{array}{l}\text { HOOD PARK-MID-RIVER } \\
\text { HOOD PARK-WALA SHORE }\end{array}$ & $\begin{array}{l}\text { OFFSITE } \\
\text { OFFSTE } \\
\text { OFE }\end{array}$ & SW & $\begin{array}{l}n \\
N\end{array}$ & $\begin{array}{l}\text { RIVER } \\
\text { RIVER }\end{array}$ & 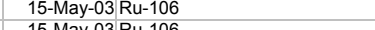 & -0.824 & $\mathrm{pCi} / \mathrm{L}$ & 21 & 21 & $\mathrm{U}$ & & & \\
\hline $\begin{array}{l}\text { SESPSEC } \\
\text { SESPSPEC }\end{array}$ & $\begin{array}{l}\text { B16WM4 } \\
\text { B16WL6 }\end{array}$ & $\begin{array}{l}\text { HOOD PARK-WALLA WALLA SHORE } \\
\text { MCNARY MD-RIVER NEAR DAM }\end{array}$ & $\begin{array}{l}\text { OFFSSTE } \\
\text { OFFSTTE }\end{array}$ & $\begin{array}{l}\text { SW } \\
\text { SW }\end{array}$ & $\frac{N}{N}$ & $\begin{array}{l}\text { RIVER } \\
\text { RIVER }\end{array}$ & $\begin{array}{l}\text { 15-May-03 Ruu-106 } \\
\text { 15-May-03 Ru-106 }\end{array}$ & $\begin{array}{r}8.78 \\
-114\end{array}$ & $\begin{array}{l}\mathrm{pCiL} \\
\mathrm{pCi} / \mathrm{L}\end{array}$ & 25 & 25 & u & & & \\
\hline SESPSPEC & B16WL5 & MCNARY-OR.SIDE NEAR DAM & $\begin{array}{l}\text { OFFSIITE } \\
\text { OFFITE }\end{array}$ & sw & $\mathrm{N}$ & $\begin{array}{l}\text { RIVER } \\
\text { RIVER }\end{array}$ & $\begin{array}{l}15-M a y-03 \text { Ru-106 } \\
15-106\end{array}$ & $\begin{array}{l}-1.28 \\
1.28\end{array}$ & $\begin{array}{l}\mathrm{pCC/L} \\
\mathrm{pCi} / \mathrm{L}\end{array}$ & $\begin{array}{l}24 \\
22\end{array}$ & $\begin{array}{l}24 \\
22\end{array}$ & u & & & \\
\hline SESPSPEC & B16WL7 & MCNARY-WASH.SIDE NEAR DAM & OFFSITE & sw & $\mathrm{N}$ & RIVER & 15-May-03 Ru-106 & -1.57 & $\mathrm{pCi} / \mathrm{L}$ & 23 & 23 & U & & & \\
\hline SESPSPEC & B16WM1 & WALLA WALLA-RIVER & OFFSITE & SW & $\mathrm{N}$ & RIVER & 15-May-03 Ru-106 & 0.539 & $\mathrm{pCI} / \mathrm{L}$ & 19 & 19 & U & & & \\
\hline $\begin{array}{l}\text { SESPSPEC } \\
\text { SESPSPCC }\end{array}$ & B16WM2 & WALLA WALLA-RIVER & OFFSITE & sw & $\mathrm{N}$ & RIVER & 15-May-03 Ru-106 & 6.69 & $\mathrm{pCi} / \mathrm{L}$ & 23 & 23 & U & & & \\
\hline $\begin{array}{l}\text { SESPSPEC } \\
\text { SESPSPEC }\end{array}$ & B16WM3 & WALLA WALLA-RIVER & OFFSITE & SW & $\mathrm{N}$ & $\begin{array}{l}\text { RIVER } \\
\text { RIVER }\end{array}$ & 15-May-03 Ru-106 & -0.33 & pCi/L & 22 & 22 & U & & & \\
\hline $\begin{array}{l}\text { SESPSECC } \\
\text { SESPSPEC }\end{array}$ & $\begin{array}{l}\text { B17BH99 } \\
\text { B16WL8 }\end{array}$ & $\begin{array}{l}\text { MCNARY-2/3 OR. SHORE } \\
\text { YAKIMA RIVER }\end{array}$ & $\begin{array}{l}\text { OFFSSTE } \\
\text { OFFSTE }\end{array}$ & $\begin{array}{l}\text { SW } \\
\text { sw }\end{array}$ & $\begin{array}{l}n \\
N\end{array}$ & $\begin{array}{l}\text { RIVER } \\
\text { RIVER }\end{array}$ & $\begin{array}{l}\text { 08-Aug-03 Ruu-106 } \\
\text { 14-May-03 S-125 }\end{array}$ & $\begin{array}{l}4.27 \\
173\end{array}$ & $\begin{array}{l}\mathrm{pCil} \\
\mathrm{pCi} / \mathrm{l}\end{array}$ & $\begin{array}{r}21 \\
59\end{array}$ & $\begin{array}{r}21 \\
5.9\end{array}$ & u & & & \\
\hline SESPSPEC & $\begin{array}{l}\text { B16WVL8 } \\
\text { B16WL9 }\end{array}$ & YAKIMA RIVER & $\begin{array}{l}\text { OFFSITE } \\
\text { OFFITE }\end{array}$ & sw & $\frac{N}{N}$ & $\begin{array}{l}\text { RIVER } \\
\text { RIVER }\end{array}$ & $\begin{array}{l}14-\mathrm{Mlay}-03 \mathrm{~s} S \mathrm{~S}-125 \\
14 \mathrm{~s}-125\end{array}$ & 4.98 & $\frac{p C / L}{p C i / L}$ & 6.9 & 6.3 & u & & & \\
\hline SESPSPEC & B16WM0 & YAKIMA RIVER & OFFSITE & sw & $\mathrm{N}$ & RIVER & 14-May-03 Sb-125 & -1.91 & $\mathrm{pCi} / \mathrm{L}$ & 6 & 6 & U & & & \\
\hline SESPSPEC & B16WM6 & HOOD PARK-FRANKLIN CO. SHORE & OFFSITE & sw & $\mathrm{N}$ & RIVER & 15-May-03 Sb-125 & 1.4 & $\mathrm{pCi} / \mathrm{L}$ & 5.9 & 5.9 & $\mathrm{U}$ & & & \\
\hline SESPSPEC & B16WM5 & HOOD PARK-MID-RIVER & OFFSITE & sw & $\mathrm{N}$ & RIVER & 15-May-03 Sb-125 & -0.337 & $\mathrm{pCi} / \mathrm{L}$ & 6.1 & 6.1 & $\mathrm{U}$ & & & \\
\hline $\begin{array}{l}\text { SESPSPCC } \\
\text { SESPSEC }\end{array}$ & B16WM4 & HOOD PARK-WALLA WALLA SHORE & OFFSITE & SW & $\mathrm{N}$ & $\begin{array}{l}\text { RIVER } \\
\text { RIVER }\end{array}$ & $\begin{array}{l}15-\mathrm{May}-03 \mathrm{Sb}-125 \\
15\end{array}$ & $\begin{array}{l}-1.69 \\
-188\end{array}$ & pCi/L & 6.6 & 6.6 & U & & & \\
\hline $\begin{array}{l}\text { SESPSEC } \\
\text { SESPSPEC }\end{array}$ & $\begin{array}{l}\text { B16WL6 } \\
\text { B16WL5 }\end{array}$ & $\begin{array}{l}\text { MCNARY MID-RIVER NEAR DAM } \\
\text { MCNARY-OR.SIDE NEAR DAM }\end{array}$ & $\begin{array}{l}\text { OFFSSTE } \\
\text { OFFITE }\end{array}$ & $\begin{array}{l}\text { SW } \\
\text { SW }\end{array}$ & $\frac{N}{N}$ & $\begin{array}{l}\text { RIVER } \\
\text { RIVER }\end{array}$ & 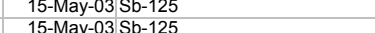 & $\begin{array}{r}4.88 \\
-0.487\end{array}$ & $\begin{array}{l}\mathrm{pCil} \\
\mathrm{pC} / \mathrm{L}\end{array}$ & 5.9 & 5.9 & u & & & \\
\hline SESPSPEC & B16WL7 & MCNARY-WASH.SIDE NEAR DAM & $\begin{array}{l}\text { OFFSITE } \\
\text { OFFl }\end{array}$ & sw & $\frac{N}{N}$ & RIVER & $15-\mathrm{May}-03 \mathrm{Sb}-125$ & $\begin{array}{l}-0.487 \\
-0.935\end{array}$ & $\mathrm{pCi/L}$ & $\begin{array}{l}6.9 \\
6.3\end{array}$ & 6.3 & u & & & \\
\hline SESPSPEC & B16WM1 & WALLA WALLA-RIVER & OFFSITE & sw & $\mathrm{N}$ & RIVER & 15-May-03 Sb-125 & 2.84 & $\mathrm{pCl} / \mathrm{L}$ & 4.6 & 4.6 & $\mathrm{U}$ & & & \\
\hline SESPSPEC & B16WM2 & WALLA WALLA-RIVER & OFFSITE & SW & $\mathrm{N}$ & RIVER & 15-May-03 Sb-125 & 3.2 & $\mathrm{pCi} / \mathrm{L}$ & 5.4 & 5.4 & U & & & \\
\hline $\begin{array}{l}\text { SESPSPEC } \\
\text { SESPGDC }\end{array}$ & B16WM3 & WALLA WALLA-RIVER & OFFSITE & sw & $\mathrm{N}$ & RIVER & 15-May-03 Sb-125 & -1.74 & $\mathrm{pCi} / \mathrm{L}$ & 5.8 & 5.8 & U & & & \\
\hline $\begin{array}{l}\text { SESPSPEC } \\
\text { SESPPEC }\end{array}$ & B17BH9 & MCNARY-2/3 OR. SHORE & $\begin{array}{l}\text { OFFSSTE } \\
\text { OFFSTTE }\end{array}$ & $\begin{array}{l}\text { SW } \\
\text { sw }\end{array}$ & $\begin{array}{l}n \\
N\end{array}$ & $\begin{array}{l}\text { IVER } \\
\text { RIVER }\end{array}$ & $\begin{array}{l}\text { 08-Aug-03 Sb-125 } \\
08 \text {-Aug -03 Pu-238 }\end{array}$ & 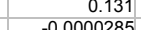 & $\mathrm{pCi} / \mathrm{L}$ & 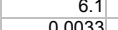 & $\begin{array}{r}6.1 \\
0033\end{array}$ & U & & & \\
\hline $\begin{array}{l}\text { SESPSEC } \\
\text { SESPPEC }\end{array}$ & $\begin{array}{l}\text { B178H99 } \\
\text { B17BH9 }\end{array}$ & $\begin{array}{l}\text { MCNARY-2/3 OR. SHORE } \\
\text { MCNARY-2/3 OR. SHORE }\end{array}$ & $\begin{array}{l}\text { OFFSSTE } \\
\text { OFFITE }\end{array}$ & $\begin{array}{l}\text { SW } \\
\text { sw }\end{array}$ & $\frac{N}{n}$ & $\begin{array}{l}\text { IIVER } \\
\text { RIVER }\end{array}$ & $\begin{array}{l}\text { 88-Aug-03 Pu-238 } \\
\text { 08-Aug-03 Pu-239/240 }\end{array}$ & $\begin{aligned}-0.0000285 \\
0.00177\end{aligned}$ & $\mathrm{pCil}$ & 0.0033 & 0.0033 & u & & & \\
\hline SESPSPEC & B16WL8 & YAKIMA RIVER & OFFSITE & sw & $\mathrm{N}$ & $\begin{array}{l}\text { RIVER } \\
\text { RIVER }\end{array}$ & 14-May-03 Sr-90 & 0.0619 & $\mathrm{pCi/L}$ & $\begin{aligned} 0.0033 \\
0.029\end{aligned}$ & 0.033 & & & & \\
\hline SESPSPEC & B16WL9 & YAKIMA RIVER & OFFSITE & SW & $\mathrm{N}$ & RIVER & 14-May-03 Sr-90 & 0.0733 & $\mathrm{pCl} / \mathrm{L}$ & 0.028 & 0.033 & & & & \\
\hline SESPSPEC & B16WM0 & YAKIMA RIVER & OFFSITE & sw & $\mathrm{N}$ & RIVER & 14-May-03S & 0.0654 & $\mathrm{pCi} / \mathrm{L}$ & 0.026 & 0.031 & & & & \\
\hline $\begin{array}{l}\text { SESPSPEC } \\
\text { SESPSEC }\end{array}$ & B16WM6 & HOOD PARK-FRANKLIN CO. SHORE & OFFSITE & sw & $\mathrm{N}$ & $\begin{array}{l}\text { RIVER } \\
\text { RIVER }\end{array}$ & 15-May-03 Sr-90 & 0.0688 & $\mathrm{pCl} / \mathrm{L}$ & 0.035 & 0.038 & & & & \\
\hline $\begin{array}{l}\text { SESPSPEC } \\
\text { SESPSEC }\end{array}$ & B16WM5 & HOOD PARK-MID-RIVER & $\begin{aligned} & \text { OFFSITE } \\
& \text { OFEFSTE }\end{aligned}$ & sw & $\mathrm{N}$ & $\begin{array}{l}\text { RIVER } \\
\text { RIVER }\end{array}$ & $\begin{array}{l}15-M a y-03 ~ S r-90 \\
15-03\end{array}$ & 0.0545 & $\mathrm{pCi/L}$ & 0.025 & 0.029 & & & & \\
\hline $\begin{array}{l}\text { SESPSEC } \\
\text { SESPSPEC }\end{array}$ & B16WM4 & $\begin{array}{l}\text { HOOD PARK-WALLA WALLA SHORE } \\
\text { MCNARY MD-BIVER NEAR DAM }\end{array}$ & $\begin{array}{l}\text { OFFSSTE } \\
\text { OFFITE }\end{array}$ & $\begin{array}{l}\text { SW } \\
\text { sw }\end{array}$ & $\begin{array}{l}n \\
N\end{array}$ & $\begin{array}{l}\text { IIVER } \\
\text { RIVER }\end{array}$ & $\begin{array}{l}\text { 15-May-03 Sr-90 } \\
\text { 15-May-03 Sr-90 }\end{array}$ & 0.0837 & $\begin{array}{l}\mathrm{pCil} \\
\mathrm{pCi/L}\end{array}$ & 0.028 & 0.031 & & & & \\
\hline $\begin{array}{l}\text { SESPSEC } \\
\text { SESPSPEC }\end{array}$ & $\begin{array}{l}\text { B16WL6 } \\
\text { B16WL5 }\end{array}$ & $\begin{array}{l}\text { MCNARY MID-RIVER NEAR DAM } \\
\text { MCNARY-OR.SIDE NEAR DAM }\end{array}$ & $\begin{array}{l}\text { OFFSITE } \\
\text { OFFITE }\end{array}$ & $\begin{array}{l}\text { SW } \\
\text { SW }\end{array}$ & $\frac{n}{n}$ & $\begin{array}{l}\text { RIVER } \\
\text { RIVER }\end{array}$ & $\begin{array}{l}\text { 15-May-03 Sr-90 } \\
15-M a y-03 \text { Sr-90 }\end{array}$ & 0.0941 & $\frac{\mathrm{pCl} / \mathrm{L}}{\mathrm{pCiL}}$ & 0.034 & 0.039 & & & & \\
\hline SESPSPEC & B16WL7 & MCNARY-WASH.SIDE NEAR DAM & OFFSITE & sw & $\mathrm{N}$ & RIVER & 15-May-03 Sr-90 & 0.11 & $\mathrm{pCi/L}$ & 0.032 & 0.04 & & & & \\
\hline SESPSPEC & B16WM1 & WALLA WALLA-RIVER & OFFSITE & sw & $\mathrm{N}$ & RIVER & 15-May-03 Sr-90 & 0.0458 & $\mathrm{pCi} / \mathrm{L}$ & 0.037 & 0.038 & 3 & & & \\
\hline
\end{tabular}




\begin{tabular}{|c|c|c|c|c|c|c|c|c|c|c|c|c|c|c|c|}
\hline OWNER ID & SAMP NUM & SAMP SITE NAME & DIST CLASS & MEDIA & $\begin{array}{c}\text { FILTERED } \\
\text { FLAG }\end{array}$ & SAMP FROM & CON SHORT NAME & |VALUE RPTD| & $\begin{array}{l}\text { ANAL } \\
\text { UNITS } \\
\text { RPTD }\end{array}$ & $\left|\begin{array}{c}\text { COUNTING } \\
\text { ERROR }\end{array}\right|$ & \begin{tabular}{|c|} 
TOTAL \\
ANAL \\
ERROR
\end{tabular} & $\mid \begin{array}{c}\text { LAB } \\
\text { QUALIFIER }\end{array}$ & SAMP COMMENT & $\left|\begin{array}{|c|}\text { RESULT } \\
\text { COMMENT }\end{array}\right|$ & |WELL NAME \\
\hline SESPSPEC & B16WM2 & WALLA WALLA-RIVER & OFFSITE & SW & $\mathrm{N}$ & RIVER & 15-May-03 Sr-90 & 0.0607 & pCill & 0.029 & 0.032 & & & & \\
\hline $\begin{array}{l}\text { SESPSPEC } \\
\text { SESPSDC }\end{array}$ & B16WM3 & WALLA WALLA-RIVER & OFFSITE & SW & $\mathrm{N}$ & RIVER & 15-May-03 Sr-90 & 0.0651 & $\mathrm{pCilL}$ & 0.034 & 0.037 & & & & \\
\hline $\begin{array}{l}\text { SESPSPEC } \\
\text { SESPSEC }\end{array}$ & $\begin{array}{l}\text { B17BH99 } \\
\text { B178H8 }\end{array}$ & MCNARY-2/3 OR. SHORE & OFFSITE & SW & $\mathrm{N}$ & RIVER & 08-Aug-03 Sr-90 & 0.115 & pCill & 0.022 & 0.029 & & & & \\
\hline $\begin{array}{l}\text { SESPSEC } \\
\text { SESPSPEC }\end{array}$ & $\begin{array}{l}\text { B177H8 } \\
\text { B17BJ0 }\end{array}$ & MCNARY-OREGON SHORE & $\begin{array}{l}\text { OFFSITE } \\
\text { OFSITE }\end{array}$ & SW & $\mathrm{N}$ & $\begin{array}{l}\text { RIVER } \\
\text { RIVER }\end{array}$ & $\begin{array}{l}\text { 08-Aug-03 Sr-90 } \\
08 \text {-Ang-03 Sr-90 }\end{array}$ & 0.152 & pCill & 0.022 & 0.032 & & & & \\
\hline $\begin{array}{l}\text { SESPSPEC } \\
\text { SESPC }\end{array}$ & B16WL8 & $\begin{array}{l}\text { MCNARY-WASH. SHORE } \\
\text { YAKIMA RIVER }\end{array}$ & $\begin{array}{l}\text { OFSIIT } \\
\text { OFFSITE }\end{array}$ & sw & $\frac{n}{n}$ & $\begin{array}{l}\text { RIVER } \\
\text { RIVER }\end{array}$ & $\begin{array}{l}\text { 8-Agug-03 Sr-90 } \\
\text { 14-May-03 Tc-99 }\end{array}$ & $\begin{array}{r}0.123 \\
-0.0168\end{array}$ & $\begin{array}{l}\mathrm{pCI} / \mathrm{L} \\
\mathrm{pC} / \mathrm{L}\end{array}$ & 0.023 & 0.03 & U & & & \\
\hline SESPSPEC & B16WL9 & YAKIMA RIVER & OFFSITE & sw & $\mathrm{N}$ & RIVER & 14-May-03 Tc-99 & 0.231 & $\mathrm{pCi} / \mathrm{L}$ & 0.25 & 0.51 & u & & & \\
\hline $\begin{array}{l}\text { SESPSPEC } \\
\text { SESPSDC }\end{array}$ & B16WM0 & YAKIMA RIVER & OFFSITE & sw & N & RIVER & 14-May-03 Tc-99 & 0.18 & $\mathrm{pCi/L}$ & 0.25 & 0.5 & $\mathrm{u}$ & & & \\
\hline $\begin{array}{l}\text { SESPSPEC } \\
\text { SESPSDC }\end{array}$ & B16WM6 & HOOD PARK-FRANKLIN CO. SHORE & OFFSITE & SW & $\mathrm{N}$ & RIVER & 15-May-03 Tc-99 & 0.43 & pCilL & 0.25 & 0.52 & U & & & \\
\hline $\begin{array}{l}\text { SESPSPEC } \\
\text { SESPSEC }\end{array}$ & $\begin{array}{l}\text { B16WM5 } \\
\text { B16WM4 }\end{array}$ & $\begin{array}{l}\text { HOOD PARK-MID-RIVER } \\
\text { HOOOD PARK-WALA WALLA SHORE }\end{array}$ & $\begin{array}{l}\text { OFFSITE } \\
\text { OFSITE }\end{array}$ & $\begin{array}{l}\text { sw } \\
\text { sw }\end{array}$ & $\mathrm{N}$ & $\begin{array}{l}\text { RIVER } \\
\text { RIVER }\end{array}$ & 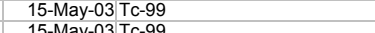 & 0.00389 & $\mathrm{pCi} / \mathrm{L}$ & 0.25 & 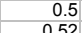 & u & & & \\
\hline $\begin{array}{l}\text { SESPSECC } \\
\text { SESPSPEC }\end{array}$ & $\begin{array}{l}\text { B16WM4 } \\
\text { B16WL6 }\end{array}$ & $\begin{array}{l}\text { HOOD PARK PALLLA WALLA SHORE } \\
\text { MCNARY MD-RIVER NEAR DAM }\end{array}$ & $\begin{array}{l}\text { OFFITE } \\
\text { OFFSITE }\end{array}$ & sW & $\begin{array}{l}n \\
N\end{array}$ & $\begin{array}{l}\text { IVIVR } \\
\text { RIVER }\end{array}$ & $\begin{array}{l}\text { 15-May-03 TC-99 } \\
\text { 15-May-03 Tc-99 }\end{array}$ & $\begin{array}{r}0.4 \\
0.271\end{array}$ & $\mathrm{pCi/L}$ & 0.25 & 0.52 & u & & & \\
\hline $\begin{array}{l}\text { SESPSPEC } \\
\text { SESPC }\end{array}$ & $\begin{array}{l}\text { B16WL6 } \\
\text { B16WL5 }\end{array}$ & $\begin{array}{l}\text { MCNARY MID-RIIER NEAR DAM } \\
\text { MCNARYOR.SIDE NEAR DAM }\end{array}$ & $\begin{array}{l}\text { OFSIIIE } \\
\text { OFFSITE }\end{array}$ & sw & $\frac{n}{n}$ & $\begin{array}{l}\text { RIVER } \\
\text { RIVER }\end{array}$ & 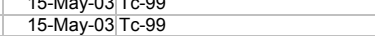 & 0.271 & $\frac{\mathrm{pCI} / \mathrm{L}}{\mathrm{pCil}}$ & 0.25 & 0.51 & u & & & \\
\hline SESPSPEC & B16WL7 & MCNARY-WASH.SIDE NEAR DAM & OFFSITE & sw & $\mathrm{N}$ & RIVER & 15-May-03 Tc-99 & 0.241 & $\mathrm{pCi} / \mathrm{L}$ & 0.25 & 0.51 & u & & & \\
\hline SESPSPEC & B16WM1 & WALLA WALLA-RIVER & OFFSITE & sw & $\mathrm{N}$ & RIVER & 15-May-03 ТC-99 & 0.211 & $\mathrm{pCi} / \mathrm{L}$ & 0.25 & 0.51 & u & & & \\
\hline $\begin{array}{l}\text { SESPSPEC } \\
\text { SESPSPC }\end{array}$ & B16WM2 & WALLA WALLA-RIVER & OFFSITE & SW & $\mathrm{N}$ & RIVER & 15-May-03 ТC-99 & 0.179 & pCi/L & 0.25 & 0.51 & U & & & \\
\hline $\begin{array}{l}\text { SESPSPEC } \\
\text { SESPSEC }\end{array}$ & B16WM3 & $\begin{array}{l}\text { WALLA WALLA-RIVER } \\
\text { YAKIMA RIVER }\end{array}$ & OFFSITE & SW & $\begin{array}{r}\mathrm{N} \\
\mathrm{N}\end{array}$ & $\begin{array}{l}\text { RIVER } \\
\text { RIVER }\end{array}$ & & 0.436 & $\mathrm{pCl} / \mathrm{L}$ & 0.25 & $\frac{0.52}{37}$ & u & & & \\
\hline $\begin{array}{l}\text { SESPSEC } \\
\text { SESPSEC }\end{array}$ & $\begin{array}{l}\text { B16WL8 } \\
\text { B16WL9 }\end{array}$ & $\begin{array}{l}\text { YAAIMA RIVER } \\
\text { YAKIMA RIVER }\end{array}$ & $\begin{array}{l}\text { OFFSITE } \\
\text { OFSITE }\end{array}$ & sw & $\begin{array}{l}n \\
N\end{array}$ & $\begin{array}{l}\text { RIVER } \\
\text { RIVER }\end{array}$ & $\begin{array}{l}\text { 14-May-03 LO TRITIUM } \\
\text { 14-May-03LO TRITUM }\end{array}$ & $\begin{array}{r}13.4 \\
137\end{array}$ & pCiL & $\frac{2.5}{2.5}$ & 3.7 & & & & \\
\hline $\begin{array}{l}\text { SESPSPEC } \\
\text { SEST }\end{array}$ & $\begin{array}{l}\text { B6WL9 } \\
\text { B16WM0 }\end{array}$ & YAKIMA RIVER & $\begin{array}{l}\text { OFSAIE } \\
\text { OFFSITE }\end{array}$ & sw & $\frac{N}{N}$ & $\begin{array}{l}\text { RIVER } \\
\text { RIVER }\end{array}$ & $\begin{array}{l}\text { 14-May-03 LO IRI TRITIM } \\
\text { 14-May LO TRITI }\end{array}$ & $\begin{array}{l}13.1 \\
14.1\end{array}$ & $\begin{array}{l}\mathrm{pCl} \\
\mathrm{pCC} / \mathrm{L}\end{array}$ & 2.5 & 3.7 & & & & \\
\hline SESPSPEC & B16WM6 & HOOD PARK-FRANKLIN CO. SHORE & OFFSITE & sw & $\mathrm{N}$ & RIVER & 15-May-03 LO TRITIUM & 28.1 & $\mathrm{pCi} / \mathrm{L}$ & 3.1 & 4.7 & & & & \\
\hline SESPSPEC & B16WM5 & HOOD PARK-MID-RIVER & OFFSITE & sw & $\mathrm{N}$ & RIVER & 15-May-03 LO TRITIUM & 29.4 & $\mathrm{pCl} / \mathrm{L}$ & 3.1 & 4.7. & & & & \\
\hline $\begin{array}{l}\text { SESPSPEC } \\
\text { SESPSEC }\end{array}$ & B16WM4 & HOOD PARK-WALLA WALLA SHORE & OFFSITE & sw & $\mathrm{N}$ & RIVER & 15-May-03 LO TRITIUM & 29.1 & $\mathrm{pCi} / \mathrm{L}$ & 3.1 & 4.7. & & & & \\
\hline $\begin{array}{l}\text { SESPSPEC } \\
\text { SESPSEC }\end{array}$ & B16WL6 & MCNARY MID-RIVER NEAR DAM & OFFSITE & SW & $\mathrm{N}$ & RIVER & 15-May-03 LO TRITIUM & 35.2 & $\mathrm{pCi} / \mathrm{L}$ & 3.8 & 5.7. & & & & \\
\hline $\begin{array}{l}\text { SESPSECC } \\
\text { SESPPEC }\end{array}$ & $\begin{array}{l}\text { B16WL5 } \\
\text { B16W17 }\end{array}$ & $\begin{array}{l}\text { MCNARY-OR.SIDE NEAR DAM } \\
\text { MCNARYWASH SDE NEAR DAM }\end{array}$ & $\begin{array}{l}\text { OFFSITE } \\
\text { OFFSITE }\end{array}$ & SW & $\begin{array}{l}\mathrm{N} \\
\mathrm{N}\end{array}$ & $\begin{array}{l}\text { RIVER } \\
\text { RIVER }\end{array}$ & $\begin{array}{l}\text { 15-May-03 LO TRITIUM } \\
\text { 15-May-03LO TRITUM }\end{array}$ & $\begin{array}{ll}34.4 \\
31.9\end{array}$ & pCi/L & 3.3 & 5.1 & & & & \\
\hline $\begin{array}{l}\text { SESPSECC } \\
\text { SESPSPEC }\end{array}$ & $\begin{array}{l}\text { B16WL7 } \\
\text { B16WM1 }\end{array}$ & $\begin{array}{l}\text { MMNARY-WASH.SIDE NEAR DAM } \\
\text { WALLA WALLA-RIVER }\end{array}$ & $\begin{array}{l}\text { OFFIIE } \\
\text { OFFSITE }\end{array}$ & SW & $\frac{N}{N}$ & $\begin{array}{l}\text { RIVER } \\
\text { RIVER }\end{array}$ & $\begin{array}{l}\text { 15-May-03 LO TRIITIUM } \\
\text { 15-May-03 LO TRITIUM }\end{array}$ & $\begin{array}{l}31.9 \\
21.2\end{array}$ & $\begin{array}{l}\text { pCil } \\
\text { pCi/L }\end{array}$ & $\begin{array}{l}3.3 \\
2.9\end{array}$ & $\begin{array}{r}5 \\
4.2\end{array}$ & & & & \\
\hline SESPSPEC & B16WM2 & WALLA WALLA-RIVER & OFFSITE & sw & $\mathrm{N}$ & RIVER & 15-May-03 LO TRITIUM & 29.4 & $\mathrm{pClil}$ & 3.1 & 4.7 & & & & \\
\hline SESPSPEC & B16WM3 & WALLA WALLA-RIVER & OFFSITE & sw & $\mathrm{N}$ & RIVER & 15-May-03 LO TRITIUM & 19.4 & $\mathrm{pCi} / \mathrm{L}$ & 2.9 & 4.1 & & & & \\
\hline SESPSPEC & B16KJo & YAKIMA RIVER & OFFSITE & sw & $\mathrm{N}$ & RIVER & 07-Mar-03 U-234 & 0.544 & pCill & 0.055 & 0.1 & & BELOW BENTON CITY & & \\
\hline SESPSPEC & B17BH9 & MCNARY-2/3 OR. SHORE & OFFSITE & sw & $\mathrm{N}$ & RIVER & 08-Aug-03 U-234 & 0.253 & $\mathrm{pCi} / \mathrm{L}$ & 0.038 & 0.055 & & & & \\
\hline SESPSPEC & B16KJo & YAKIMA RIVER & OFFSITE & sW & $\mathrm{N}$ & RIVER & 07-Mar-03 U-235 & 0.0189 & $\mathrm{pCi} / \mathrm{L}$ & 0.011 & 0.012 & & BELOW BENTON CITY & & \\
\hline SESPSPEC & B17BH9 & MCNARY-2/3 OR. SHORE & OFFSITE & SW & $\mathrm{N}$ & RIVER & 08-Aug-03 U-235 & 0.00349 & $\mathrm{pCi} / \mathrm{L}$ & 0.0061 & 0.0064 & U & & & \\
\hline SESPSPEC & B16KJo & YAKIMA RIVER & OFFSITE & sw & $\mathrm{N}$ & RIVER & 07-Mar-03 U-238 & 0.411 & $\mathrm{pCi} / \mathrm{L}$ & 0.048 & 0.082 & & BELOW BENTON CITY & & \\
\hline SESPSPEC & B17BH9 & MCNARY-2/3 OR. SHORE & OFFSITE & sw & N & RIVER & 08-Aug-03 U-238 & 0.188 & pCill & 0.033 & 0.044 & & & & \\
\hline SESPSPEC & B170T7 & YAKIMA RIVER & OFFSITE & SW & $\mathrm{N}$ & RIVER & 14-May-03 TSS (Total suspended solids) & 7 & $\mathrm{mg} / \mathrm{L}$ & & & $\mathrm{c}$ & & & \\
\hline SESPSPEC & B170T8 & YAKIMA RIVER & OFFSITE & sw & $\mathrm{N}$ & RIVER & 14-May-03 TSS (Total suspended solids) & 9 & $\mathrm{mg} / \mathrm{L}$ & & & C & & & \\
\hline $\begin{array}{l}\text { SESPSECC } \\
\text { SESPPEC }\end{array}$ & B170T9 & $\begin{array}{l}\text { YAKIMA RIVER } \\
\text { MCNARYMID-RIVER NEAR DAM }\end{array}$ & $\begin{array}{l}\text { OFFSITE } \\
\text { OFSITE }\end{array}$ & sw & $\begin{array}{l}n \\
N\end{array}$ & $\begin{array}{l}\text { RIVER } \\
\text { RIVER }\end{array}$ & 14-May-03 TSS (Total suspended solids) & 6 & $\mathrm{mg} / \mathrm{L}$ & & & $\mathrm{C}$ & & & \\
\hline $\begin{array}{l}\text { SESPSEC } \\
\text { SESPSPEC }\end{array}$ & $\begin{array}{l}\text { B170R0 } \\
\text { B170R1 }\end{array}$ & $\begin{array}{l}\text { MCNARY MID-RIVER NEAR DAM } \\
\text { MCNARY-OR SIDE NEAR DAM }\end{array}$ & $\begin{array}{l}\text { OFFITE } \\
\text { OFFSITE }\end{array}$ & SW & $\frac{N}{N}$ & $\begin{array}{l}\text { IIVER } \\
\text { RIVER }\end{array}$ & 15-May-033 TSS (Total suspended solids) & $\frac{4}{6}$ & $\mathrm{mg} / \mathrm{L}$ & & & & & & \\
\hline SESPSPEC & B170P9 & MCNARY-WASH.SIDE NEAR DAM & $\begin{array}{l}\text { OFFSITE } \\
\text { OFFIT }\end{array}$ & sw & $\mathrm{N}$ & $\begin{array}{l}\text { RIVER } \\
\text { RIVER }\end{array}$ & 15-May-03 TSS (Total suspended solids) & 5 & $\begin{array}{l}\mathrm{mggh} \\
\mathrm{mg} / \mathrm{L}\end{array}$ & & & & & & \\
\hline SESPSPEC & B170T4 & WALLA WALLA-RIVER & OFFSITE & sw & $\mathrm{N}$ & RIVER & 15-May-03 TSS (Total suspended solids) & 21 & $\mathrm{mg} / \mathrm{L}$ & & & & & & \\
\hline SESPSPEC & B170T5 & WALLA WALLA-RIVER & OFFSITE & SW & $\mathrm{N}$ & RIVER & 15-May-03 TSS (Total suspended solids) & 22 & $\mathrm{mg} / \mathrm{L}$ & & & & & & \\
\hline $\begin{array}{l}\text { SESPSPEC } \\
\text { SESPSPCC }\end{array}$ & B170T6 & $\begin{array}{l}\text { WALLA WALLA-RIVER } \\
\text { HORE }\end{array}$ & OFFSITE & sw & $\mathrm{N}$ & $\begin{array}{l}\text { RIVER } \\
\text { RIVER }\end{array}$ & 15-May-03 TSS (Total suspended solids) & 22 & $\mathrm{mg} / \mathrm{L}$ & & & & & & \\
\hline $\begin{array}{l}\text { SESPSEC } \\
\text { SESPPEC }\end{array}$ & B170T1 & HOOD PARK-FRANKLIN CO. SHORE & OFFSITE & SW & $\mathrm{N}$ & $\begin{array}{l}\text { RIVER } \\
\text { RIVER }\end{array}$ & 15-May-03 TSS (Total suspended solids) & 5 & $\mathrm{mg} / \mathrm{L}$ & & & & & & \\
\hline $\begin{array}{l}\text { SESPSECC } \\
\text { SESPSPEC }\end{array}$ & $\begin{array}{l}\text { B170T2 } \\
\text { B170T3 }\end{array}$ & $\begin{array}{l}\text { HOOD PARKK-MID-RIAER } \\
\text { HOOD PARK-WALA WALLA SHORE }\end{array}$ & $\begin{array}{l}\text { OFFITE } \\
\text { OFFSITE }\end{array}$ & $\begin{array}{l}\text { SW } \\
\text { sw }\end{array}$ & $\begin{array}{l}\mathrm{N} \\
\mathrm{N}\end{array}$ & $\begin{array}{l}\text { IIVER } \\
\text { RIVER }\end{array}$ & 15-May-033 TSS (Total suspended solids) & $\begin{array}{l}6 \\
5\end{array}$ & $\mathrm{mg} / \mathrm{L}$ & & & & & & \\
\hline SESPSPEC & B16WP2 & $\begin{array}{l}\text { YAKIMA RIVER } \\
\text { Y }\end{array}$ & $\begin{array}{l}\text { OFFSITE } \\
\text { OFFIT }\end{array}$ & sw & $\begin{array}{l}\mathrm{Y} \\
\mathrm{N}\end{array}$ & $\begin{array}{l}\text { RIVER } \\
\text { RIVER }\end{array}$ & 14-May-03 Hg (I otal suspended solids) & 0.000828 & $\frac{\mathrm{mgg} / \mathrm{L}}{\mathrm{ug} / \mathrm{h}}$ & & & & & & \\
\hline SESPSPEC & B16WP3 & YAKIMA RIVER & OFFSITE & sw & Y & RIVER & 14-May-03 Hg & 0.000848 & $\mathrm{ug} / \mathrm{L}$ & & & & & & \\
\hline SESPSPEC & B16WP4 & YAKIMA RIVER & OFFSITE & sw & Y & RIVER & 14-May- $03 \mathrm{Hg}$ & 0.000808 & $\mathrm{ug} / \mathrm{L}$ & & & & & & \\
\hline SESPSPEC & B16WP5 & YAKIMA RIVER & OFFSITE & sw & $\mathrm{N}$ & RIVER & 14-May- $03 \mathrm{Hg}$ & 0.0015 & $\mathrm{ug} / \mathrm{L}$ & & & & & & \\
\hline $\begin{array}{l}\text { SESPSPCC } \\
\text { SESPSEC }\end{array}$ & B16WP6 & YAKIMA RIVER & OFFSITE & sw & $\mathrm{N}$ & $\begin{array}{l}\text { RIVER } \\
\text { RIVER }\end{array}$ & 14-May- $03 \mathrm{Hg}$ & 0.00124 & $\mathrm{ug} / \mathrm{L}$ & & & & & & \\
\hline $\begin{array}{l}\text { SESPSECC } \\
\text { SESPPEC }\end{array}$ & $\begin{array}{l}\text { B16WP7 } \\
\text { B16WR5 }\end{array}$ & $\begin{array}{l}\text { YAKIMA RIVER } \\
\text { HOOD PARK-FRANKLIN CO SHORE }\end{array}$ & $\begin{array}{l}\text { OFFSITE } \\
\text { OFFSITE }\end{array}$ & SW & $\begin{array}{l}\mathrm{N} \\
\mathrm{Y}\end{array}$ & $\begin{array}{l}\text { RIVER } \\
\text { RIVER }\end{array}$ & $\begin{array}{l}\text { 14-May--03 Hg } \\
15-\mathrm{May}-03 \mathrm{Hg}\end{array}$ & 0.00149 & $\mathrm{ugh/2}$ ugh & & & & & & \\
\hline SESPSPEC & B16WR8 & HOOD PARK-FRANKLIN CO. SHORE & OFFSITE & sw & $\mathrm{N}$ & $\begin{array}{l}\text { RIVER } \\
\text { RIVER }\end{array}$ & $\begin{array}{l}15-\mathrm{May}-03 \mathrm{Hg} \\
15 \mathrm{Hg}\end{array}$ & 0.00182 & ugh/ & & & & & & \\
\hline SESPSPEC & B16WR4 & HOOD PARK-MID-RIVER & OFFSITE & sw & Y & RIVER & 15-May-03 Hg & 0.00105 & $\mathrm{ug} / \mathrm{L}$ & & & & & & \\
\hline SESPSPEC & B16WR9 & HOOD PARK-MID-RIVER & OFFSITE & sw & $\mathrm{N}$ & RIVER & $15-$ May- $03 \mathrm{Hg}$ & 0.00181 & $\mathrm{ug} / \mathrm{L}$ & & & & & & \\
\hline $\begin{array}{l}\text { SESPSPEC } \\
\text { SESPGDC }\end{array}$ & B16WR6 & HOOD PARK-WALLA WALLA SHORE & OFFSITE & sw & Y & RIVER & $15-\mathrm{Mc}$ & 0.00101 & $\mathrm{ug} / \mathrm{L}$ & & & & & & \\
\hline $\begin{array}{l}\text { SESPSPCC } \\
\text { SESPPEC }\end{array}$ & B16WR7 & HOOD PARK-WALLA WALLA SHORE & $\begin{array}{l}\text { OFFSITE } \\
\text { OFFSITE }\end{array}$ & $\begin{array}{l}\text { SW } \\
\text { sw }\end{array}$ & $\begin{array}{l}\mathrm{y} \\
\mathrm{N}\end{array}$ & $\begin{array}{l}\text { IVIVR } \\
\text { RIVER }\end{array}$ & $\begin{array}{l}15-\mathrm{May}-03 \mathrm{Hg} \\
15 \mathrm{May}-03 \mathrm{Hg}\end{array}$ & $\begin{array}{l}0.00164 \\
0.0017\end{array}$ & $u g / L$ & & & & & & \\
\hline $\begin{array}{l}\text { SESPSEC } \\
\text { SESPPEC }\end{array}$ & $\begin{array}{l}\text { B16WN6 } \\
\text { B16WP1 }\end{array}$ & $\begin{array}{l}\text { MCNARY MID-RIVRR NEAR DAM } \\
\text { MCNARY MID-RIVER NEAR DAM }\end{array}$ & $\begin{array}{l}\text { OFFITE } \\
\text { OFFSITE }\end{array}$ & sw & $\frac{\mathrm{N}}{\mathrm{N}}$ & $\begin{array}{l}\text { RIVER } \\
\text { RIVER }\end{array}$ & $\begin{array}{l}15-\mathrm{May}-03 \mathrm{Hg} \\
15-\mathrm{May}-03 \mathrm{Hg}\end{array}$ & $\begin{array}{c}0.0017 \\
0.00123\end{array}$ & ug// & & & & & & \\
\hline SESPSPEC & B16WN8 & MCNARY-OR.SIDE NEAR DAM & OFFSITE & sw & Y & RIVER & $15-\mathrm{May}-03 \mathrm{Hg}$ & 0.000583 & $\mathrm{ug} / \mathrm{L}$ & & & & & & \\
\hline SESPSPEC & B16WN9 & MCNARY-OR.SIDE NEAR DAM & OFFSITE & SW & $\mathrm{N}$ & RIVER & 15-May-03 Hg & 0.00111 & $\mathrm{ug} / \mathrm{L}$ & & & & & & \\
\hline SESPSPEC & B16WN7 & MCNARY-WASH.SIDE NEAR DAM & OFFS & sw & Y & RIVER & 15-May-03 & 0.000795 & $\mathrm{ug} / \mathrm{L}$ & & & & & & \\
\hline $\begin{array}{l}\text { SESPSPEC } \\
\text { SESPSEC }\end{array}$ & B16WP0 & MCNARY-WASH.SIDE NEAR DAM & OFFSITE & sw & $\begin{array}{l}\mathrm{y} \\
\mathrm{N}\end{array}$ & $\begin{array}{l}\text { RIVER } \\
\text { RIVER }\end{array}$ & 15-May- $03 \mathrm{Hg}$ & $\begin{array}{r}0.00102 \\
\end{array}$ & $\mathrm{ug} / \mathrm{L}$ & & & & & & \\
\hline $\begin{array}{l}\text { SESPSECC } \\
\text { SESPPEC }\end{array}$ & B16WP8 & WALLA WALLA-RIVER & $\begin{array}{l}\text { OFFSITE } \\
\text { OFESTEF }\end{array}$ & SW & $\begin{array}{r}Y \\
Y \\
Y\end{array}$ & $\begin{array}{l}\text { IVIVER } \\
\text { RIVER }\end{array}$ & 15-May-03 Hg & 0.000847 & ug/L & & & & & & \\
\hline $\begin{array}{l}\text { SESPSPCC } \\
\text { SESPPEC }\end{array}$ & B16WR0 & $\begin{array}{l}\text { WALLA WALLA-RIVER } \\
\text { WALARER }\end{array}$ & $\begin{array}{l}\text { OFFSITE } \\
\text { OFFII }\end{array}$ & sw & $\begin{array}{l}\mathrm{Y} \\
\mathrm{H}\end{array}$ & $\begin{array}{l}\text { RIVER } \\
\text { RIVER }\end{array}$ & $\begin{array}{l}15-\mathrm{May}-\mathrm{-}-\mathrm{3} \mathrm{Hg} \\
15 \mathrm{Hg}\end{array}$ & $\begin{array}{r}0.00759 \\
0.00093\end{array}$ & $\begin{array}{l}\mathrm{gg} / \mathrm{L} \\
\mathrm{gg} / \mathrm{L}\end{array}$ & & & & & & \\
\hline SESPSPEC & B16WR1 & WALLA WALLA-RIVER & OFFSITE & SW & $\mathrm{N}$ & RIVER & 15-May-03 Hg & 0.00152 & $u g / L$ & & & & & & \\
\hline SESPSPEC & B16WR2 & WALLA WALLA-RIVER & OFFSITE & SW & $\mathrm{N}$ & RIVER & 15-May-03 Hg & 0.0015 & ug/L & & & & & & \\
\hline SESPSPEC & B16WR3 & WALLA WALLA-RIVER & OFFSITE & sw & $\mathrm{N}$ & RIVER & 15-May-03 Hg & 0.00147 & ug/L & & & & & & \\
\hline
\end{tabular}




\begin{tabular}{|c|c|c|c|c|c|c|c|c|c|c|c|c|c|c|c|}
\hline OWNER ID & |SAMP NUM & SAMP SITE NAME & DIST CLASS & MEDIA & $\begin{array}{c}\text { FILTERED } \\
\text { FLAG }\end{array}$ & SAMP FROM & CON SHORT NAME & | VALUE RPTD| & $\begin{array}{l}\text { ANAL } \\
\text { UNITS } \\
\text { RPTD }\end{array}$ & $\begin{array}{c}\text { COUNTING } \\
\text { ERROR }\end{array} \mid$ & \begin{tabular}{|c|} 
TOTAL \\
ANAL \\
ERROR
\end{tabular} & $\begin{array}{l}\text { LAB } \\
\text { QUALIFIER }\end{array}$ & SAMP COMMENT & $\begin{array}{c}\text { RESULT } \\
\text { COMMENT }\end{array}$ & |WELL NAME \\
\hline SESPSPEC & B180C6 & $100 \mathrm{~B} / \mathrm{C}$ AREA UR & ONSITE & SW & Y & RIVER & 13-Nov-03 Hg & 0.000485 & ug/L & & & & & & \\
\hline $\begin{array}{l}\text { SESPSPEC } \\
\text { SESPSDC }\end{array}$ & B180C7 & 100 B/C AREA UR & ONSITE & SW & Y & RIVER & 13-Nov-03 Hg & 0.00036 & ug/L & & & & & & \\
\hline $\begin{array}{l}\text { SESPSPEC } \\
\text { SESPSEC }\end{array}$ & & $\begin{array}{l}100 \text { B/C AREA UR } \\
100 \text { BCC AREA UR }\end{array}$ & & SW & $\begin{array}{l}Y \\
Y \\
Y\end{array}$ & $\begin{array}{l}\text { RIVER } \\
\text { RIVER }\end{array}$ & 13-Nov-03 Hg & 0.000352 & ug/L & & & & & & \\
\hline $\begin{array}{l}\text { SESPSEEC } \\
\text { SESPSPEC }\end{array}$ & $\begin{array}{l}\text { B180C9 } \\
\text { B180D0 }\end{array}$ & $\begin{array}{l}\text { 1000 B/C AREA UR } \\
\text { 100-B SPRING 38-3 }\end{array}$ & $\begin{array}{l}\text { ONSITE } \\
\text { ONSITE }\end{array}$ & $\begin{array}{l}\text { SW } \\
\text { sw }\end{array}$ & $\begin{array}{l}\mathrm{Y} \\
\mathrm{Y}\end{array}$ & $\begin{array}{l}\text { RRVER } \\
\text { RIVER }\end{array}$ & $\begin{array}{l}\text { 13-Nov-03 Hg } \\
\text { 13-Nov-03 Hg }\end{array}$ & $\begin{array}{l}0.000313 \\
0.000408\end{array}$ & $\begin{array}{l}\mathrm{ug} / \mathrm{L} \\
\mathrm{ug} / \mathrm{L}\end{array}$ & & & & DUP IS SAMPLE \#B180J4 & & \\
\hline SESPSPEC & B180D1 & 100-B SPRING 38-3 & ONSITE & sw & Y & RIVER & 13-Nov-03 Hg & 0.000373 & ug/L & & & & 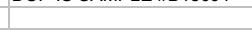 & & \\
\hline $\begin{array}{l}\text { SESPSPEC } \\
\text { SESPEC }\end{array}$ & B180D2 & 100-B SPRING 38-3 & ONSITE & sw & Y & RIVER & 13-Nov-03 Hg & 0.000338 & $\mathrm{ug} / \mathrm{L}$ & & & & & & \\
\hline $\begin{array}{l}\text { SESPSPEC } \\
\text { SESPSDC }\end{array}$ & B180D3 & 100-B SPRING 38-3 & ONSITE & sW & $Y$ & RIVER & 13-Nov- $03 \mathrm{Hg}$ & 0.000324 & $\mathrm{ug} / \mathrm{L}$ & & & & & & \\
\hline $\begin{array}{l}\text { SESPSPEC } \\
\text { SESPSDC }\end{array}$ & B180J4 & 100-B SPRING 38-3 & ONSITE & SW & Y & RIVER & 13-Nov-03 Hg & 0.000444 & $\mathrm{ug} / \mathrm{L}$ & & & & DUP SAMPLE FOR B180D0 & & \\
\hline $\begin{array}{l}\text { SESPSPEC } \\
\text { SESPSEC }\end{array}$ & B180D4 & 100-B SPRING 39-2 & ONSITE & SW & $\begin{array}{l}Y \\
Y\end{array}$ & $\begin{array}{l}\text { RIVER } \\
\text { RIVER }\end{array}$ & 13-Nov-03 Hg & 0.000291 & $u g / L$ & & & & & & \\
\hline $\begin{array}{l}\text { SESPSEC } \\
\text { SESPSPEC }\end{array}$ & $\begin{array}{l}\text { B180D5 } \\
\text { B180D6 }\end{array}$ & $\begin{array}{l}\text { 100-B SPRING 39-2 } \\
\text { 100-B SPRING 39-2 }\end{array}$ & $\begin{array}{l}\text { ONSITE } \\
\text { ONSITE }\end{array}$ & $\begin{array}{l}\text { SW } \\
\text { SW }\end{array}$ & $\begin{array}{l}Y \\
Y\end{array}$ & $\begin{array}{l}\text { RIVER } \\
\text { RIVER }\end{array}$ & $\begin{array}{l}\text { 13-Nov-03 Hg } \\
\text { 13-Nov-03 Hg }\end{array}$ & $\begin{array}{l}0.000331 \\
0.000355\end{array}$ & $\frac{\mathrm{ug} / \mathrm{L}}{\mathrm{ug} / \mathrm{L}}$ & & & & & & \\
\hline SESPSPEC & B180D7 & 100-B SPRING 39-2 & ONSITE & sw & Y & RIVER & 13-Nov-03 Hg & 0.000321 & $\mathrm{ug} / \mathrm{L}$ & & & & & & \\
\hline SESPSPEC & B180F9 & 100-B SPRING DR 38-3 & ONSITE & sw & $\begin{array}{r}Y \\
Y\end{array}$ & RIVER & 13-Nov-03 Hg & 0.000502 & $\mathrm{ug} / \mathrm{L}$ & & & & & & \\
\hline $\begin{array}{l}\text { SESPSPEC } \\
\text { SECPSDC }\end{array}$ & B180F1 & 100 B/C AREA DR & ONSITE & sw & Y & RIVER & 17-Nov-03 Hg & 0.000328 & $\mathrm{ug} / \mathrm{L}$ & & & & & & \\
\hline $\begin{array}{l}\text { SESPSPEC } \\
\text { SESPSDC }\end{array}$ & B180F2 & 100 B/C AREA DR & ONSITE & SW & Y & RIVER & 17-Nov-03 Hg & 0.000509 & $\mathrm{ug} / \mathrm{L}$ & & & & & & \\
\hline $\begin{array}{l}\text { SESPSPCC } \\
\text { SESPSPEC }\end{array}$ & 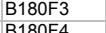 & $\begin{array}{l}100 \text { B/C AREA DR } \\
100 \text { BCC AREADR }\end{array}$ & ONSITE & SW & $\begin{array}{r}Y \\
Y \\
Y\end{array}$ & $\begin{array}{l}\text { RIVER } \\
\text { RIVER }\end{array}$ & 17-Nov- $03 \mathrm{Hg}$ & 0.000494 & $u g / L$ & & & & & & \\
\hline $\begin{array}{l}\text { SESPSEEC } \\
\text { SESPSPEC }\end{array}$ & $\begin{array}{l}\text { B180F4 } \\
\text { B180D8 }\end{array}$ & $\begin{array}{l}100 \text { B/C AREA DR } \\
100 \text { B/C AREA OUTFL1 }\end{array}$ & $\begin{array}{l}\text { ONSIIE } \\
\text { ONSITE }\end{array}$ & $\begin{array}{l}\text { SW } \\
\text { sW }\end{array}$ & $\begin{array}{l}\text { Y } \\
\text { Y }\end{array}$ & $\begin{array}{l}\text { IVIVER } \\
\text { RIVER }\end{array}$ & $\begin{array}{l}17-\text {-Nov- } 03 \mathrm{Hg} \\
17-\mathrm{Nov}-03 \mathrm{Ha}\end{array}$ & $\begin{array}{l}0.000475 \\
0.00043\end{array}$ & ug/L & & & & & & \\
\hline $\begin{array}{l}\text { SESPSPEC } \\
\text { SESP }\end{array}$ & B180D9 & $\begin{array}{l}100 \mathrm{~B} / \mathrm{C} \text { AREA OUTFL } \\
\text { AREA }\end{array}$ & ONSITE & sw & 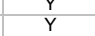 & $\begin{array}{l}\text { RIVER } \\
\text { RIVER }\end{array}$ & $\begin{array}{l}\text { 1/-Nov- } 03 \mathrm{Hg} \\
17-\mathrm{Hov}-03 \mathrm{Hg}\end{array}$ & $\begin{array}{l}0.00043 \\
0.00354\end{array}$ & $\begin{array}{l}\mathrm{uggh} / \mathrm{L} \\
\mathrm{gg} / \mathrm{L}\end{array}$ & & & & & & \\
\hline SESPSPEC & B180F0 & 100 B/C AREA OUTFL3 & ONSITE & SW & Y & RIVER & 17-Nov-03 Hg & 0.000399 & $\mathrm{ug} / \mathrm{L}$ & & & & & & \\
\hline SESPSPEC & B186R0 & Refer to WELL NAME column & & GW & $N$ & AQUIFER TUBE & 10-Dec-03 Hg & 0.00107 & ug/L & & & & & & 01-D \\
\hline $\begin{array}{l}\text { SESPSPEC } \\
\text { SESPSEC }\end{array}$ & $\begin{array}{l}\text { B186R1 } \\
\text { B18R2 }\end{array}$ & Refer to WELL NAME column & & GW & $\mathrm{N}$ & $\begin{array}{l}\text { AQUIFER TUBE } \\
\end{array}$ & 10-Dec-03 Hg & 0.00192 & $\mathrm{ug} / \mathrm{L}$ & & & & & & 04-D \\
\hline $\begin{array}{l}\text { SESPSECC } \\
\text { SESPPEC }\end{array}$ & B186R2 & Refer to WELL NAME column & & GW & $\begin{array}{l}\mathrm{N} \\
\mathrm{N}\end{array}$ & $\begin{array}{l}\text { AQUIFER TUBE } \\
\text { AOUIFER TUBE }\end{array}$ & 10-Dec-03 Hg & 0.00253 & $u g / L$ & & & & & & 05-D \\
\hline $\begin{array}{l}\text { SESPSECC } \\
\text { SESPPEC }\end{array}$ & $\begin{array}{l}\text { B168R3 } \\
\text { B166R4 }\end{array}$ & $\begin{array}{l}\text { Refer to WELL NAME collumn } \\
\text { Refer to WELL NAME clumn }\end{array}$ & & GW & $\begin{array}{l}\mathrm{N} \\
\mathrm{N}\end{array}$ & $\begin{array}{l}\text { AQUUFER TUBE } \\
\text { AQUUFER TUBE }\end{array}$ & $\begin{array}{l}10-\mathrm{Dec}-03 \mathrm{Hg} \\
10-\mathrm{Dec}-03 \mathrm{Ha}\end{array}$ & 0.00465 & ug/L & & & & & & $06-\mathrm{D}$ \\
\hline SESPSPEC & B186R5 & $\begin{array}{l}\text { Referer to WELL NAME column } \\
\text { RefEL NAME column }\end{array}$ & & GW & $\frac{n}{n}$ & $\begin{array}{l}\text { AQUUIFER TUBE } \\
\text { AQUER }\end{array}$ & $\begin{array}{l}10-\mathrm{Dec}-03 \mathrm{Hg} \\
10-\mathrm{Dec}-03 \mathrm{Hg}\end{array}$ & & & & & & $\begin{array}{l}\text { NO SAMPLE. } \\
\text { NO SAMPLE. }\end{array}$ & & $11-\mathrm{D}$ \\
\hline SESPSPEC & B180K6 & Refer to WELL NAME column & & GW & Y & AQUIFER TUBE & 10-Dec-03 METALS_ICPMS & & & & & & NO SAMPLE. & & 07-D \\
\hline $\begin{array}{l}\text { SESPSPEC } \\
\text { SESPSDC }\end{array}$ & B180K7 & Refer to WELL NAME column & & GW & $\begin{array}{r}Y \\
Y\end{array}$ & AQUIFER TUBE & 10-Dec-03 METALS_ICPMS & & & & & & NO SAMPLE. & & $11-\mathrm{D}$ \\
\hline SESPSPEC & B16WP2 & YAKIMA RIVER & OFFSITE & SW & $\begin{array}{l}Y \\
Y \\
\end{array}$ & RIVER & 14-May-03 Ag & 0.0085 & $\mathrm{ug} / \mathrm{L}$ & & & U & & & \\
\hline $\begin{array}{l}\text { SESPSPCC } \\
\text { SESPSEC }\end{array}$ & B16WP3 & YAKIMA RIVER & OFFSITE & SW & $\begin{array}{l}\text { Y } \\
\text { y }\end{array}$ & $\begin{array}{l}\text { RIVER } \\
\text { RIVER }\end{array}$ & 14-May-03 Ag & 0.0085 & $\mathrm{ug} / \mathrm{L}$ & & & U & & & \\
\hline $\begin{array}{l}\text { SESPSECC } \\
\text { SESPSPEC }\end{array}$ & $\begin{array}{l}\text { B16WP4 } \\
\text { B16WP5 }\end{array}$ & $\begin{array}{l}\text { YAAIMA RIVER } \\
\text { YAKIMA RIVER }\end{array}$ & $\begin{array}{l}\text { OFFSITE } \\
\text { OFFSITE }\end{array}$ & $\begin{array}{l}\text { SW } \\
\text { sw }\end{array}$ & $\begin{array}{r}\mathrm{Y} \\
\mathrm{N}\end{array}$ & $\begin{array}{l}\text { IVIVR } \\
\text { RIVER }\end{array}$ & $\begin{array}{l}\text { 14-May- }-3 \mathrm{Ag} \\
14 \mathrm{Mg}-03 \mathrm{Aq}\end{array}$ & 0.0085 & $u g / L$ & & & u & & & \\
\hline $\begin{array}{l}\text { SESPSEC } \\
\text { SESPPEC }\end{array}$ & $\begin{array}{l}\text { B16WP5 } \\
\text { B16WP6 }\end{array}$ & $\begin{array}{l}\text { YAAKIMA RIVER } \\
\text { YAKIMA RIVER }\end{array}$ & $\begin{array}{l}\text { OFFITE } \\
\text { OFFSITE }\end{array}$ & $\begin{array}{l}\text { SW } \\
\text { SW }\end{array}$ & $\frac{N}{N}$ & $\begin{array}{l}\text { RIVER } \\
\text { RIVER }\end{array}$ & $\begin{array}{l}\text { 14-May-03 Ag } \\
14-\mathrm{May}-03 \mathrm{Ag}\end{array}$ & 0.0085 & ugh/ & & & u & & & \\
\hline SESPSPEC & B16WP7 & $\begin{array}{l}\text { YAKIMA RIVER } \\
\text { YAKIVR }\end{array}$ & OFFSITE & sw & $\mathrm{N}$ & RIVER & $14-\mathrm{May}-03 \mathrm{Ag}$ & 0.0085 & ug/L & & & u & & & \\
\hline SESPSPEC & B16WR5 & HOOD PARK-FRANKLIN CO. SHORE & OFFSITE & SW & Y & RIVER & 15-May-03 Ag & 0.0085 & $\mathrm{ug} / \mathrm{L}$ & & & U & & & \\
\hline $\begin{array}{l}\text { SESPSPEC } \\
\text { SESPSPCF }\end{array}$ & B16WR8 & HOOD PARK-FRANKLIN CO. SHORE & OFFSITE & SW & $\begin{array}{l}\mathrm{d} \\
\mathrm{N}\end{array}$ & $\begin{array}{l}\text { RIVER } \\
\text { RIVER }\end{array}$ & 15-May-03 Ag & 0.0085 & $\mathrm{ug} / \mathrm{L}$ & & & U & & & \\
\hline $\begin{array}{l}\text { SESPSPCC } \\
\text { SESPSEC }\end{array}$ & B16WR4 & HOOD PARK-MID-RIVER & $\begin{array}{l}\text { OFFSITE } \\
\text { OFSITE }\end{array}$ & SW & $\begin{array}{r}\mathrm{Y} \\
\mathrm{Y}\end{array}$ & $\begin{array}{l}\text { RIVER } \\
\text { RIVER }\end{array}$ & 15-May-03 Ag & 0.0085 & ug/L & & & U & & & \\
\hline $\begin{array}{l}\text { SESPSEC } \\
\text { SESPSPEC }\end{array}$ & $\begin{array}{l}\text { B16WR9 } \\
\text { B16WR6 }\end{array}$ & $\begin{array}{l}\text { HOOD PARK-MII-RIVER } \\
\text { HOOD PARK-WALAWALA SHORE }\end{array}$ & $\begin{array}{l}\text { OFFITE } \\
\text { OFFSITE }\end{array}$ & $\begin{array}{l}\text { SW } \\
\text { SW }\end{array}$ & $\begin{array}{l}\mathrm{y} \\
\mathrm{N}\end{array}$ & $\begin{array}{l}\text { RIVER } \\
\text { RIVER }\end{array}$ & $\begin{array}{l}\text { 15-May-03 Ag } \\
15 \text {-May-03 Aq }\end{array}$ & 0.0085 & $u g / L$ & & & u & & & \\
\hline $\begin{array}{l}\text { SESPSEC } \\
\text { SESPSPEC }\end{array}$ & $\begin{array}{l}\text { B16WR7 } \\
\text { B16Whe }\end{array}$ & HOOD PARK-WALLA WALLA SHORE & $\begin{array}{l}\text { OFFSITE } \\
\text { OFFIT }\end{array}$ & sw & h & $\begin{array}{l}\text { RIVER } \\
\text { RIVER }\end{array}$ & $\begin{array}{l}\text { 15-Maya-03 Ag } \\
15-\mathrm{May}-03 \mathrm{Ag}\end{array}$ & 0.0085 & $\begin{array}{ll}\mathrm{uggh} / \mathrm{L} \\
\mathrm{g} / \mathrm{g}\end{array}$ & & & u & & & \\
\hline SESPSPEC & B16WN6 & MCNARY MID-RIVER NEAR DAM & OFFSITE & sw & Y & RIVER & 15-May-03 Ag & 0.0085 & ug/L & & & U & & & \\
\hline SESPSPEC & B16WP1 & MCNARY MID-RIVER NEAR DAM & OFFSITE & SW & $\mathrm{N}$ & RIVER & 15-May-03 Ag & 0.0085 & $\mathrm{ug} / \mathrm{L}$ & & & U & & & \\
\hline $\begin{array}{l}\text { SESPSPEC } \\
\text { SESPSPCC }\end{array}$ & B16WN8 & $\begin{array}{l}\text { MCNARY-OR.SIDE NEAR DAM } \\
\text { MEATY }\end{array}$ & OFFSITE & SW & $Y^{Y}$ & $\begin{array}{l}\text { RIVER } \\
\text { RIVER }\end{array}$ & 15-May-03 Ag & 0.0085 & $\mathrm{ug} / \mathrm{L}$ & & & u & & & \\
\hline $\begin{array}{l}\text { SESPSPEC } \\
\text { SESPSPEC }\end{array}$ & B16WN9 & MCNARY-OR.SIDE NEAR DAM & OFFSITE & SW & 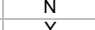 & $\begin{array}{l}\text { RIVER } \\
\text { RIVER }\end{array}$ & 15-May-03 Ag & 0.0085 & $\mathrm{ug} / \mathrm{L}$ & & & u & & & \\
\hline $\begin{array}{l}\text { SESPSECC } \\
\text { SESPSPEC }\end{array}$ & $\begin{array}{l}\text { B16WN7 } \\
\text { B16WP0 }\end{array}$ & $\begin{array}{l}\text { MCNARYYWASH.SIDE NEAR DAM } \\
\text { MCNARYWASH SIDE NEAR DAM }\end{array}$ & $\begin{array}{l}\text { OFFITE } \\
\text { OFFSITE }\end{array}$ & $\begin{array}{l}\text { SW } \\
\text { sw }\end{array}$ & $\begin{array}{r}\mathrm{Y} \\
\mathrm{H}\end{array}$ & $\begin{array}{l}\text { RIVER } \\
\text { RIVER }\end{array}$ & $\begin{array}{l}\text { 15-May-03 Ag } \\
15-\mathrm{May}-03 \mathrm{Ag}\end{array}$ & 0.0085 & $\mathrm{ug} / \mathrm{L}$ & & & u & & & \\
\hline SESPSPEC & B16WP8 & WALLA WALLA-RIVER & $\begin{array}{l}\text { OFFSITE } \\
\text { OFFII }\end{array}$ & sw & $\begin{array}{l}\mathrm{Y} \\
\mathrm{N}\end{array}$ & $\begin{array}{l}\text { RIVER } \\
\text { RIVER }\end{array}$ & $\begin{array}{l}\text { T5-May- }-03 \mathrm{Ag} \\
15-\mathrm{Ag}\end{array}$ & 0.0085 & $\begin{array}{l}u g h / 2 \\
u g / L\end{array}$ & & & u & & & \\
\hline SESPSPEC & B16WP9 & WALLA WALLA-RIVER & OFFSITE & sw & Y & RIVER & $15-$ May-03 Ag & 0.0085 & $\mathrm{ug} / \mathrm{L}$ & & & u & & & \\
\hline SESPSPEC & B16WR0 & WALLA WALLA-RIVER & OFFSITE & SW & Y & RIVER & 15-May-03 Ag & 0.0085 & $\mathrm{ug} / \mathrm{L}$ & & & $\mathrm{U}$ & & & \\
\hline SESPSPEC & B16WR1 & WALLA WALLA-RIVER & OFFSITE & SW & $\mathrm{N}$ & RIVER & 15-May-03 Ag & 0.0085 & $\mathrm{ug} / \mathrm{L}$ & & & U & & & \\
\hline $\begin{array}{l}\text { SESPSPCC } \\
\text { SESPSEC }\end{array}$ & B16WR2 & WALLA WALLA-RIVER & $\begin{array}{l}\text { OFFSITE } \\
\text { OFSITE }\end{array}$ & SW & $\mathrm{N}$ & $\begin{array}{l}\text { RIVER } \\
\text { RIVER }\end{array}$ & 15-May-03 Ag & 0.0085 & $\mathrm{ug} / \mathrm{L}$ & & & U & & & \\
\hline $\begin{array}{l}\text { SESPSECC } \\
\text { SESPPEC }\end{array}$ & $\begin{array}{l}\text { B16WR3 } \\
\text { B180C6 }\end{array}$ & $\begin{array}{l}\text { WALLA WALLA-IVEER } \\
100 \text { B/C AREA UR }\end{array}$ & $\begin{array}{l}\text { OFFITE } \\
\text { ONSITE }\end{array}$ & $\begin{array}{l}\text { SW } \\
\text { SW }\end{array}$ & $\begin{array}{l}\mathrm{N} \\
\mathrm{Y}\end{array}$ & $\begin{array}{l}\text { RIVER } \\
\text { RIVER }\end{array}$ & $\begin{array}{l}\text { 15-May-03 Ag } \\
\text { 13-Nov-03 Ag }\end{array}$ & $\begin{aligned} 0.0085 \\
0.004\end{aligned}$ & $\mathrm{ugh/2}$ & & & u & & & \\
\hline SESPSPEC & B180C7 & 100 B/C AREA UR & ONSITE & sw & Y & RIVER & 13-Nov-03 Ag & 0.004 & ugh/ & & & u & & & \\
\hline SESPSPEC & B180C8 & $100 \mathrm{~B} / \mathrm{C}$ AREA UR & ONSITE & sw & $Y$ & RIVER & 13-Nov-03 Ag & 0.004 & $\mathrm{ug} / \mathrm{L}$ & & & U & & & \\
\hline SESPSPEC & B180C9 & $100 \mathrm{~B} / \mathrm{CAR}$ & ONSITE & SW & $\begin{array}{l}Y \\
Y \\
\end{array}$ & RIVER & 13-Nov-03 Ag & 0.004 & $\mathrm{ug} / \mathrm{L}$ & & & U & & & \\
\hline $\begin{array}{l}\text { SESPSPEC } \\
\text { SESPGDC }\end{array}$ & B180D0 & 100-B SPRING 38-3 & ONSITE & sw & $\begin{array}{l}Y \\
Y\end{array}$ & RIVER & 13-Nov-03 Ag & 0.004 & $\mathrm{ug} / \mathrm{L}$ & & & U & DUP IS SAMPLE \#B180J4 & & \\
\hline $\begin{array}{l}\text { SESPSPEC } \\
\text { SESPPEC }\end{array}$ & $\begin{array}{l}B 18001 \\
B 18002\end{array}$ & 100-B SPRING 38-3 & $\begin{array}{l}\text { ONSITE } \\
\text { ONSITE }\end{array}$ & & $\begin{array}{r}Y \\
Y\end{array}$ & $\begin{array}{l}\text { RIVER } \\
\text { RIVER }\end{array}$ & $\begin{array}{l}\text { 13-Nov-03 Ag } \\
\text { 13-Nov-03 Ag }\end{array}$ & 0.004 & $\mathrm{ug} / \mathrm{L}$ & & & U & & & \\
\hline $\begin{array}{l}\text { SESPSEC } \\
\text { SESPPEC }\end{array}$ & $\begin{array}{l}\text { B180D2 } \\
\text { B180D3 }\end{array}$ & $\begin{array}{l}\text { 100-B SPRING 38-3 } \\
\text { 100-B SPRING 38-3 }\end{array}$ & $\begin{array}{l}\text { ONSITE } \\
\text { ONSITE }\end{array}$ & $\begin{array}{l}\text { SW } \\
\text { sW }\end{array}$ & $\begin{array}{l}\text { Y } \\
\end{array}$ & $\begin{array}{l}\text { IIVER } \\
\text { RIVER }\end{array}$ & $\begin{array}{l}\text { 13-Nov-03 Ag } \\
\text { 13-Nov-03 Ag }\end{array}$ & 0.004 & $\mathrm{ug} / \mathrm{h}$ & & & u & & & \\
\hline SESPSPEC & B180J4 & 100-B SPRING 38-3 & ONSITE & sw & $\mathrm{Y}$ & $\begin{array}{l}\text { RIVER } \\
\text { RIVER }\end{array}$ & 13-Nov-03 Ag $\mathrm{Ag}$ & 0.004 & ug/L & & & u & DUP SAMPLE FOR B180D0 & & \\
\hline SESPSPEC & B180D4 & 100-B SPRING 39-2 & ONSITE & SW & Y & RIVER & 13-Nov-03 Ag & 0.004 & $\mathrm{ug} / \mathrm{L}$ & & & U & & & \\
\hline SESPSPEC & B180D5 & 100-B SPRING & ONSITE & SW & $\begin{array}{l}Y \\
Y\end{array}$ & RIVER & $13-$ Nov-0 & 0.004 & $\mathrm{ug} / \mathrm{L}$ & & & U & & & \\
\hline $\begin{array}{l}\text { SESPSPEC } \\
\text { SESPSEC }\end{array}$ & B180D6 & 100-B SPRING 39-2 & ONSITE & sw & $\begin{array}{r}Y \\
Y\end{array}$ & $\begin{array}{l}\text { RIVER } \\
\text { RIVER }\end{array}$ & 13-Nov-03 Ag & 0.004 & $\mathrm{ug} / \mathrm{L}$ & & & U & & & \\
\hline $\begin{array}{l}\text { SESPSPEC } \\
\text { SESPSEC }\end{array}$ & $\begin{array}{l}\text { B18007 } \\
\text { B180F9 }\end{array}$ & $\begin{array}{l}100-B \text { SPRING 39-2 } \\
100-8 \text { SPRINGR } 38-3\end{array}$ & ONSITE & sw & $\begin{array}{r}Y \\
Y \\
Y\end{array}$ & $\begin{array}{l}\text { RIVER } \\
\text { RIVER }\end{array}$ & 13-Nov-03 Ag & 0.004 & ug/L & & & U & & & \\
\hline $\begin{array}{l}\text { SESPSEC } \\
\text { SESPPEC }\end{array}$ & $\begin{array}{l}\text { B180F9 } \\
\text { B180F1 }\end{array}$ & $\begin{array}{l}\text { 100-B SPRRNG DR 38-3 } \\
100 \text { B/C AREA DR }\end{array}$ & $\begin{array}{l}\text { ONSTIE } \\
\text { ONSITE }\end{array}$ & $\begin{array}{l}\text { sw } \\
\text { sw }\end{array}$ & $\begin{array}{l}\text { Y } \\
Y\end{array}$ & $\begin{array}{l}\text { RIVER } \\
\text { RIVER }\end{array}$ & $\begin{array}{l}\text { 13-Novo-03 Ag } \\
\text { 17-Nov-03 Ag }\end{array}$ & $\begin{array}{l}0.004 \\
0.004\end{array}$ & $\begin{array}{l}\mathrm{ug} / \mathrm{h} \\
\mathrm{ug} / \mathrm{L}\end{array}$ & & & u & & & \\
\hline SESPSPEC & B180F2 & 100 B/C AREA DR & ONSITE & sw & Y & RIVER & 17 -Nov-03 Ag & 0.004 & $\mathrm{ug} / \mathrm{L}$ & & & u & & & \\
\hline SESPSPEC & B180F3 & $100 \mathrm{~B} / \mathrm{C}$ AREA DR & ONSITE & SW & Y & RIVER & 17-Nov-03 Ag & 0.004 & ug/L & & & U & & & \\
\hline SESPSPEC & B180F4 & $100 \mathrm{~B} / \mathrm{C}$ AREA DR & ONSITE & sw & Y & RIVER & $17-$ Nov-03 Ag & 0.004 & ug/L & & & U & & & \\
\hline
\end{tabular}


WATER - ASSORTED NON-ROUTINE SAMPLING EVENTS

\begin{tabular}{|c|c|c|c|c|c|c|c|c|c|c|c|c|c|c|c|c|}
\hline | OWNER ID & SAMP NUM & SAMP SITE NAME & DIST CLASS & MEDIA & $\left|\begin{array}{c}\text { FILTERED } \\
\text { FLAG }\end{array}\right|$ & | SAMP FROM & |SAMP DATE| & CON SHORT NAME & |VALUE RPTD| & $\begin{array}{l}\text { ANAL } \\
\text { UNITS } \\
\text { RPTD }\end{array}$ & $\mid \begin{array}{c}\text { COUNTING } \\
\text { ERROR }\end{array}$ & $\begin{array}{l}\text { TOTAL } \\
\text { ANAL } \\
\text { ERROR }\end{array}$ & $\left|\begin{array}{c}\text { LAB } \\
\text { QUALIFIER }\end{array}\right|$ & SAMP COMMENT & $\begin{array}{l}\text { RESULT } \\
\text { COMMENT }\end{array}$ & WELL NAME \\
\hline SESPSPEC & B180D8 & 100 B/C AREA OUTFL1 & ONSITE & SW & Y & RIVER & 17-Nov-03 Ag & & 0.004 & ug/L & & & U & & & \\
\hline $\begin{array}{l}\text { SESPSPEC } \\
\text { SESPSPEC }\end{array}$ & B180D9 & $100 \mathrm{~B} / \mathrm{C}$ AREA OUTFL2 & ONSITE & sW & $Y$ & RIVER & $17-\mathrm{Nov}-03 \mathrm{Ag}$ & & 0.004 & ug/L & & & $U$ & & & \\
\hline $\begin{array}{l}\text { SESPSPEC } \\
\text { SESPSPEC }\end{array}$ & $\begin{array}{l}\text { B180F0 } \\
\text { B180K }\end{array}$ & $100 \mathrm{~B} / \mathrm{C}$ AREA OUTFL 3 & ONSITE & SW & $Y$ & RIVER & 17-Nov-03 Ag & & 0.004 & ug/L & & & U & & & \\
\hline $\begin{array}{l}\text { SESPSPEC } \\
\text { SESPSPEC }\end{array}$ & $\begin{array}{l}\text { B18022 } \\
\text { B180K3 }\end{array}$ & $\begin{array}{l}\text { Refer to WELL NAME collumn } \\
\text { Refer to WELL NAME column }\end{array}$ & & $\begin{array}{l}\text { GW } \\
\text { GW }\end{array}$ & $\begin{array}{l}Y \\
Y\end{array}$ & $\begin{array}{l}\text { AQUIFER TUBE } \\
\text { AQUIFER TUBE }\end{array}$ & $\begin{array}{l}=10-\mathrm{Dec}-03 \mathrm{Ag} \\
=10-\mathrm{Dec}-03 \mathrm{Ag}\end{array}$ & & 0.0085 & ug/L & & & U & & & 01-D \\
\hline SESPSPEC & B180K4 & $\begin{array}{l}\text { Refer to WELL NAME collumn } \\
\text { Refor WELL NAME column }\end{array}$ & & GW & $\begin{array}{l}\text { Y } \\
\text { Y }\end{array}$ & $\begin{array}{l}\text { AQUUFER TUBE } \\
\text { AQUIFER TUBE }\end{array}$ & $\begin{array}{l}10-\mathrm{Dec}-03 \mathrm{Ag} \\
\quad 10 \mathrm{-Dec}-03 \mathrm{Ag}\end{array}$ & & $\begin{array}{l}0.0085 \\
0.0085\end{array}$ & $\begin{array}{l}\mathrm{ug} / \mathrm{L} \\
\mathrm{ug} / \mathrm{L}\end{array}$ & & & u & & & $\frac{04-D}{05-D}$ \\
\hline SESPSPEC & B180K5 & Refer to WELL NAME column & & GW & $Y$ & AQUIFER TUBE & $10-\mathrm{Dec}-03 \mathrm{Ag}$ & & 0.0085 & $\mathrm{ug} / \mathrm{L}$ & & & U & & & $06-\mathrm{D}$ \\
\hline $\begin{array}{l}\text { SESPSPEC } \\
\text { SESPSDFC }\end{array}$ & B16WP2 & YAKIMA RIVER & OFFSITE & SW & $Y$ & RIVER & 14-May-03 As & & 1.49 & ug/L & & & & & & \\
\hline $\begin{array}{l}\text { SESPSPEC } \\
\text { SESPSPEC }\end{array}$ & B16WP3 & YAKIMA RIVER & OFFSITE & SW & $Y$ & RIVER & 14-May-03 As & & 1.43 & $\mathrm{ug} / \mathrm{L}$ & & & & & & \\
\hline $\begin{array}{l}\text { SESPSPEC } \\
\text { SESPSPEC }\end{array}$ & B16WP4 & $\begin{array}{l}\text { YAKIMA RIVER } \\
\text { YAIMA RIVER }\end{array}$ & OFFSITE & SW & Y & RIVER & 14-May-03 As & & $\begin{array}{r}1.5 \\
1.52\end{array}$ & $\mathrm{ug} / \mathrm{L}$ & & & & & & \\
\hline $\begin{array}{l}\text { SESPSPEC } \\
\text { SESPSPEC }\end{array}$ & $\begin{array}{l}\text { B16WP5 } \\
\text { B16WP6 }\end{array}$ & $\begin{array}{l}\text { YAKIIIA RIVR } \\
\text { YAKIMA RIVER }\end{array}$ & $\begin{array}{l}\text { OFFSSTE } \\
\text { OFFITE }\end{array}$ & $\begin{array}{l}\text { SW } \\
\text { sw }\end{array}$ & $\frac{N}{N}$ & $\begin{array}{l}\text { RIVER } \\
\text { RIVER }\end{array}$ & $\begin{array}{l}\text { 14-May-03 As } \\
\text { 14-May-03 As }\end{array}$ & & $\begin{array}{l}1.53 \\
1.69\end{array}$ & $\begin{array}{l}\mathrm{ug} / \mathrm{L} \\
\mathrm{u} / \mathrm{L}\end{array}$ & & & & & & \\
\hline SESPSPEC & B16WP7 & YAKIMA RIVER & OFFSITE & sW & n & $\begin{array}{l}\text { RIVER } \\
\text { RIVER }\end{array}$ & $\begin{array}{l}\text { 14-May--03 As } \\
\text { 14-May-03 As }\end{array}$ & & $\begin{array}{l}1.69 \\
1.59\end{array}$ & $\begin{array}{l}\mathrm{ug} / \mathrm{L} \\
\mathrm{ug} / \mathrm{L}\end{array}$ & & & & & & \\
\hline SESPSPEC & B16WR5 & HOOD PARK-FRANKLIN CO. SHORE & OFFSITE & sW & $\mathrm{Y}$ & RIVER & 15-May-03 As & & 1.12 & ug/L & & & & & & \\
\hline $\begin{array}{l}\text { SESPSPEC } \\
\text { SEGPSDFC }\end{array}$ & B16WR8 & HOOD PARK-FRANKLIN CO. SHORE & OFFSITE & SW & $\begin{array}{l}\mathrm{N} \\
\mathrm{N}\end{array}$ & RIVER & 15-May-03 As & & 1.14 & ug/L & & & & & & \\
\hline $\begin{array}{l}\text { SESPSPEC } \\
\text { SESPSPEC }\end{array}$ & B16WR4 & HOOD PARK-MID-RIVER & OFFSITE & SW & Y & RIVER & 15-May-03 As & & 1.1 & $\mathrm{ug} / \mathrm{L}$ & & & & & & \\
\hline $\begin{array}{l}\text { SESPSPEC } \\
\text { SESPSPCC }\end{array}$ & B16WR9 & $\begin{array}{l}\text { HOOD PARK-MID-RIVER } \\
\text { H. SHORE }\end{array}$ & OFFSITE & SW & $\begin{array}{l}y \\
\mathrm{~N}\end{array}$ & $\begin{array}{l}\text { RIVER } \\
\text { RIVER }\end{array}$ & 15-May-03 As & & 1.14 & $\mathrm{ug} / \mathrm{L}$ & & & & & & \\
\hline $\begin{array}{l}\text { SESPSPEC } \\
\text { SESPSPEC }\end{array}$ & $\begin{array}{l}\text { B16WR6 } \\
\text { B16WR7 }\end{array}$ & $\begin{array}{l}\text { HOOD PARKKWALLA WALLL SHORE } \\
\text { HOOD PAR-WALL WALA SHORE }\end{array}$ & $\begin{array}{l}\text { OFFSITE } \\
\text { OFFITE }\end{array}$ & $\begin{array}{l}\text { SW } \\
\text { sw }\end{array}$ & Y & $\begin{array}{l}\text { RIVER } \\
\text { RIVER }\end{array}$ & $\begin{array}{l}\text { 15-May-03 As } \\
15 \text {-Ma-03 As }\end{array}$ & & $\begin{array}{r}1.09 \\
1.8\end{array}$ & ug/L & & & & & & \\
\hline SESPSPEC & B16WN6 & MCNARY MID-RIVER NEAR DAM & OFFSITE & sW & $\begin{array}{l}\mathrm{Y} \\
\mathrm{N}\end{array}$ & $\begin{array}{l}\text { RIVER } \\
\text { RIVER }\end{array}$ & $\begin{array}{l}\text { 15-May-03 As } \\
\text { 15-May-03 As }\end{array}$ & & 0.841 & $\begin{array}{l}\mathrm{ug} / \mathrm{L} \\
\mathrm{ug} / \mathrm{L}\end{array}$ & & & & & & \\
\hline SESPSPEC & B16WP1 & MCNARY MID-RIVER NEAR DAM & OFFSITE & sw & $\mathrm{N}$ & RIVER & 15-May-03 As & & 0.883 & $\mathrm{ug} / \mathrm{L}$ & & & & & & \\
\hline SESPSPEC & B16WN8 & MCNARY-OR.SIDE NEAR DAM & OFFSITE & SW & Y & RIVER & 15-May-03 As & & 0.888 & ug/L & & & & & & \\
\hline $\begin{array}{l}\text { SESPSPEC } \\
\text { SESPSPEC }\end{array}$ & B16WN9 & $\begin{array}{l}\text { MCNARY-OR.SIDE NEAR DAM } \\
\text { MCNARY-WASH SDE NEAR DAM }\end{array}$ & $\begin{array}{l}\text { OFFSITE } \\
\text { OFFSTE }\end{array}$ & SW & $\begin{array}{l}\mathrm{y} \\
\mathrm{N}\end{array}$ & $\begin{array}{l}\text { RIVER } \\
\text { PIVER }\end{array}$ & 15-May-03 As & & 0.995 & $\mathrm{ug} / \mathrm{L}$ & & & & & & \\
\hline $\begin{array}{l}\text { SESPSPEC } \\
\text { SESPSPEC }\end{array}$ & B16WN7 & MCNARY-WASH.SIDE NEAR DAM & OFFSITE & SW & Y & RIVER & 15-May-03 As & & 0.8 & $\mathrm{ug} / \mathrm{L}$ & & & & & & \\
\hline $\begin{array}{l}\text { SESPSPEC } \\
\text { SESPSPEC }\end{array}$ & $\begin{array}{l}\text { B16WP0 } \\
\text { B16WP8 }\end{array}$ & MCNARY-WASH.SIDE NEAR DAM & $\begin{array}{l}\text { OFFSITE } \\
\text { OFFITE }\end{array}$ & SW & $\begin{array}{l}\text { Y } \\
\text { N }\end{array}$ & $\begin{array}{l}\text { RIVER } \\
\text { RIVER }\end{array}$ & $\begin{array}{l}\text { 15-May-03 As } \\
15 \text {-Ma-0 3 As }\end{array}$ & & 0.843 & ug/L & & & & & & \\
\hline SESPSPEC & $\begin{array}{l}\text { D16WP9 } \\
\text { B16WP }\end{array}$ & $\begin{array}{l}\text { WALLA WALLA-RIVER } \\
\text { WALLA WALLA-RIVER }\end{array}$ & OFFSITE & sW & $\begin{array}{l}\mathrm{Y} \\
\mathrm{Y}\end{array}$ & $\begin{array}{l}\text { RIVER } \\
\text { RIVER }\end{array}$ & $\begin{array}{l}\text { 15-May-03 As } \\
\text { 15-May-03 As }\end{array}$ & & 0.508 & $\frac{u g g h}{u g / L}$ & & & & & & \\
\hline SESPSPEC & B16WR0 & WALLA WALLA-RIVER & OFFSITE & SW & Y & RIVER & 15-May-03 As & & 0.511 & $\mathrm{ug} / \mathrm{L}$ & & & & & & \\
\hline $\begin{array}{l}\text { SESPSPEC } \\
\text { SESPSPEC }\end{array}$ & B16WR1 & WALLA WALLA-RIVER & OFFSITE & SW & $\mathrm{N}$ & RIVER & 15-May-03 As & & 0.567 & ug/L & & & & & & \\
\hline SESPSPEC & B16WR2 & WALLA WALLA-RIVER & OFFSITE & SW & $\mathrm{N}$ & RIVER & 15-May-03 As & & 0.62 & $\mathrm{ug} / \mathrm{L}$ & & & & & & \\
\hline $\begin{array}{l}\text { SESPSPEC } \\
\text { SESPSPEC }\end{array}$ & B16WR3 & WALLA WALLA-RIVER & OFFSITE & SW & $\begin{array}{l}\mathrm{y} \\
\mathrm{N}\end{array}$ & $\begin{array}{l}\text { RIVER } \\
\text { RIVER }\end{array}$ & 15-May-03 As & & 0.705 & $\mathrm{ug} / \mathrm{L}$ & & & & & & \\
\hline $\begin{array}{l}\text { SESPSPEC } \\
\text { SESPSPEC }\end{array}$ & $\begin{array}{l}\text { B18006 } \\
\text { B180C7 }\end{array}$ & $\begin{array}{l}100 \mathrm{~B} / \mathrm{C} \text { AREA UR } \\
100 \mathrm{~B} \text { AREA UR }\end{array}$ & $\begin{array}{l}\text { ONSITE } \\
\text { ONSITE }\end{array}$ & $\begin{array}{l}\text { SW } \\
\text { SW }\end{array}$ & $\begin{array}{l}Y \\
Y\end{array}$ & $\begin{array}{l}\text { RIVER } \\
\text { RIVER }\end{array}$ & $\begin{array}{l}\text { 13-Nov-03 As } \\
\text { 13-Nov-03 As }\end{array}$ & & 0.423 & $\begin{array}{l}\mathrm{ug} / \mathrm{L} \\
\mathrm{ug} / \mathrm{L}\end{array}$ & & & & & & \\
\hline SESPSPEC & B180C8 & 100 B/C AREA UR & ONSITE & sW & Y & RIVER & $\begin{array}{l}\text { 13-Nov-03 As } \\
\text { 13-Nov-03 As }\end{array}$ & & 0.469 & $\frac{\mathrm{gggh}}{\mathrm{gg} / \mathrm{L}}$ & & & & & & \\
\hline SESPSPEC & B180C9 & $100 \mathrm{~B} / \mathrm{C}$ AREA UR & ONSITE & sW & $\mathrm{Y}$ & RIVER & 13-Nov-03 As & & 0.515 & ug/L & & & & & & \\
\hline SESPSPEC & B180D0 & 100-B SPRING 38-3 & ONSITE & SW & $Y$ & RIVER & 13-Nov-03 As & & 0.573 & $\mathrm{ug} / \mathrm{L}$ & & & & DUP IS SAMPLE \#B180J4 & & \\
\hline $\begin{array}{l}\text { SESPSPEC } \\
\text { SESPSPEC }\end{array}$ & B180D1 & 100-B SPRING 38-3 & ONSITE & SW & $\begin{array}{l}Y \\
Y \\
\end{array}$ & $\begin{array}{l}\text { RIVER } \\
\text { RIVER }\end{array}$ & 13-Nov-03 As & & 0.547 & $\mathrm{ug} / \mathrm{L}$ & & & & & & \\
\hline $\begin{array}{l}\text { SESPSPEC } \\
\text { SESPSPEC }\end{array}$ & B180D2 & $\begin{array}{l}\text { 100-B SPRING 38-3 } \\
\text { 100-B SPRING 38-3 }\end{array}$ & ONSITE & SW & $\begin{array}{l}Y \\
Y\end{array}$ & $\begin{array}{l}\text { RIVER } \\
\text { RIVER }\end{array}$ & 13-Nov-03 As & & 0.537 & ug/L & & & & & & \\
\hline $\begin{array}{l}\text { SESPSPEC } \\
\text { SESPSPEC }\end{array}$ & $\begin{array}{l}\text { B180023 } \\
\text { B180J4 }\end{array}$ & $\begin{array}{l}\text { 100-B SPRING 38-3 } \\
\text { 100-B SPRING 38-3 }\end{array}$ & $\begin{array}{l}\text { ONSITE } \\
\text { ONSITE }\end{array}$ & $\begin{array}{l}\text { SW } \\
\text { SW }\end{array}$ & $\begin{array}{l}Y \\
Y\end{array}$ & $\begin{array}{l}\text { RIVER } \\
\text { RIVER }\end{array}$ & $\begin{array}{l}\text { 13-Nov-03 As } \\
\text { 13-Nov-03 As }\end{array}$ & & $\begin{array}{l}0.515 \\
0.52\end{array}$ & $\mathrm{ug} / \mathrm{L}$ & & & & DUP SAMPIE EOR B18000 & & \\
\hline SESPSPEC & B180D4 & 100-B SPRING 39-2 & ONSITE & sw & Y & $\begin{array}{l}\text { RIVER } \\
\text { RIVER }\end{array}$ & $\begin{array}{l}\text { 13-Nov-03 As } \\
\text { 13-Nov-03 As }\end{array}$ & & 0.558 & $\begin{array}{l}\text { ug/L } \\
\text { ug/L }\end{array}$ & & & & DUP SAMIPLE FOR BIOUDU & & \\
\hline SESPSPEC & B180D5 & 100-B SPRING 39-2 & ONSITE & SW & $Y$ & RIVER & 13-Nov-03 As & & 0.521 & $\mathrm{ug} / \mathrm{L}$ & & & & & & \\
\hline SESPSPEC & B180D6 & 100-B SPRING 39-2 & ONSITE & SW & $Y$ & RIVER & 13-Nov-03 As & & 0.526 & $\mathrm{ug} / \mathrm{L}$ & & & & & & \\
\hline $\begin{array}{l}\text { SESPSPEC } \\
\text { SESPSPEC }\end{array}$ & B180D7 & 100-B SPRING 39-2 & ONSITE & SW & $Y$ & RIVER & 13-Nov-03 As & & 0.522 & ug/L & & & & & & \\
\hline $\begin{array}{l}\text { SESPSPEC } \\
\text { SESPSPEC }\end{array}$ & $\begin{array}{l}\text { B B80F9 } \\
\text { B1801 }\end{array}$ & $\begin{array}{l}100-B \text { SPRING DR 38-3 } \\
100 \text { BIC AREA DR }\end{array}$ & $\begin{array}{l}\text { ONSITE } \\
\text { ONSITE }\end{array}$ & SW & $\begin{array}{l}Y \\
Y\end{array}$ & $\begin{array}{l}\text { RIVER } \\
\text { RIVER }\end{array}$ & $\begin{array}{l}\text { 13-Nov-03 As } \\
\text { 17-Nov-03Ass }\end{array}$ & & 0.575 & ug/L & & & & & & \\
\hline $\begin{array}{l}\text { SESPSPEC } \\
\text { SESPSPEC }\end{array}$ & $\begin{array}{l}\text { B180F1 } \\
\text { B180F2 }\end{array}$ & $\begin{array}{l}100 \mathrm{~B} / \mathrm{C} \text { AREA DR } \\
100 \mathrm{~B} / \mathrm{C} \text { AREA DR }\end{array}$ & $\begin{array}{l}\text { ONSITE } \\
\text { ONSITE }\end{array}$ & $\begin{array}{l}\text { SW } \\
\text { SW }\end{array}$ & $\begin{array}{l}Y \\
Y\end{array}$ & $\begin{array}{l}\text { RIVER } \\
\text { RIVER }\end{array}$ & $\begin{array}{l}\text { 17-Nov-03 As } \\
\text { 17-Nov-03 As }\end{array}$ & & $\begin{array}{l}0.5515 \\
0.519\end{array}$ & $\mathrm{ug} / \mathrm{L}$ & & & & & & \\
\hline SESPSPEC & $\mathrm{B} 180 \mathrm{~F} 3$ & 100 B/C AREA DR & ONSITE & sw & Y & $\begin{array}{l}\text { RIVER } \\
\end{array}$ & $\begin{array}{l}\text { 17-Nov-03 As } \\
\text { 17-Nov-03 As }\end{array}$ & & $\begin{array}{l}0.519 \\
0.52\end{array}$ & $\frac{u g g h}{u g / L}$ & & & & & & \\
\hline SESPSPEC & B180F4 & $100 \mathrm{~B} / \mathrm{C}$ AREA DR & ONSITE & SW & $Y$ & RIVER & 17-Nov-03 As & & 0.497 & $\mathrm{ug} / \mathrm{L}$ & & & & & & \\
\hline SESPSPEC & B180D8 & $100 \mathrm{~B} / \mathrm{C}$ AREA OUTFL1 & ONSITE & SW & $Y$ & RIVER & 17-Nov-03 As & & 0.515 & $\mathrm{ug} / \mathrm{L}$ & & & & & & \\
\hline $\begin{array}{l}\text { SESPSPEC } \\
\text { SESPSPEC }\end{array}$ & B180D9 & $100 \mathrm{~B} / \mathrm{C}$ AREA OUTFL2 & ONSITE & SW & $\begin{array}{l}Y \\
Y \\
Y\end{array}$ & RIVER & 17-Nov-03 As & & 0.515 & $\mathrm{ug} / \mathrm{L}$ & & & & & & \\
\hline $\begin{array}{l}\text { SESPSPEC } \\
\text { SESPSPEC }\end{array}$ & B180F0 & $100 \mathrm{~B} / \mathrm{C}$ AREA OUTFL3 & ONSITE & SW & $Y$ & RIVER & 17-Nov-03 As & & 0.543 & $\mathrm{ug} / \mathrm{L}$ & & & & & & \\
\hline $\begin{array}{l}\text { SESPSPEC } \\
\text { SESPSPEC }\end{array}$ & $\begin{array}{l}\text { B16KT8 } \\
\text { B16KT9 }\end{array}$ & $\begin{array}{l}300 \text { SPR } 7 \text { - } 1 \text { (2.5FT) } \\
300 \text { SPR } 7 \text { - (4FT) }\end{array}$ & $\begin{array}{l}\text { ONSITE } \\
\text { ONSITE }\end{array}$ & $\begin{array}{l}\text { SW } \\
\text { SW }\end{array}$ & $\frac{N}{n}$ & $\begin{array}{l}\text { DRIVE PONT } \\
\text { DRIVE POINT }\end{array}$ & $\begin{array}{l}\text { 24-Feb-03B } \\
\text { 24-Feb-03 B }\end{array}$ & & $\begin{array}{r}25.6 \\
116\end{array}$ & $\frac{\mathrm{ug} g \mathrm{~L}}{\mathrm{~g} / \mathrm{L}}$ & & & $\begin{array}{l}\mathrm{C} \\
\mathrm{C}\end{array}$ & & & \\
\hline SESPSPEC & B16KT7 & 300 SPR 7 - 1 (4 IN) & ONSITE & sw & $\mathrm{N}$ & DRIVE POINT & 24-Feb-03 B B & & 47.6 & $\frac{\mathrm{gggh}}{\mathrm{ug} / \mathrm{h}}$ & & & $\mathrm{c}$ & & & \\
\hline SESPSPEC & B16KV0 & 300 SPR 7 -1 (6 FT) & ONSITE & SW & $\mathrm{N}$ & DRIVE POINT & 24-Feb-03 B & & 137 & ug/L & & & c & & & \\
\hline SESPSPEC & B16KV2 & 300 SPR 7 -2 (2 FT) & ONSITE & SW & $\mathrm{N}$ & DRIVE POINT & 24-Feb-03 B & & 114 & $\mathrm{ug} / \mathrm{L}$ & & & $\mathrm{C}$ & & & \\
\hline $\begin{array}{l}\text { SESPSPEC } \\
\text { SESPSPEC }\end{array}$ & B16KV1 & 300 SPR $7-2$ (4 IN) & ONSITE & SW & $\mathrm{N}$ & DRIVE POINT & 24-Feb-03 B & & 15.9 & $\mathrm{ug} / \mathrm{L}$ & & & C & & & \\
\hline $\begin{array}{l}\text { SESPSPEC } \\
\text { SESPSPEC }\end{array}$ & $\begin{array}{l}\text { B16KV4 } \\
\text { B16KV5 }\end{array}$ & $\begin{array}{l}300 \text { SPR } 9-1 \text { (2 FT) } \\
300 \text { SPR } 9-1(4 \mathrm{FT}\end{array}$ & $\begin{array}{l}\text { ONSITE } \\
\text { ONSITE }\end{array}$ & $\begin{array}{l}\text { SW } \\
\text { sw }\end{array}$ & $\begin{array}{l}n \\
\mathrm{~N} \\
\mathrm{n}\end{array}$ & $\begin{array}{l}\text { DRIVE POINT } \\
\text { DRIVE POINT }\end{array}$ & $\begin{array}{l}\text { 24-Feb-03 B } \\
\text { 24-Feb-03 B }\end{array}$ & & $\begin{array}{l}11.1 \\
6.22\end{array}$ & ug/L & & & $\mathrm{C}$ & & & \\
\hline $\begin{array}{l}\text { SESPSPEC } \\
\text { SESPSPEC }\end{array}$ & $\begin{array}{l}\text { B16KV5 } \\
\text { B16KV3 }\end{array}$ & $\begin{array}{l}300 \text { SPR } 9-1 \text { ( } 4 \text { FT) } \\
300 \text { SPR } 9-1(4 \text { IN }\end{array}$ & $\begin{array}{l}\text { ONSITE } \\
\text { ONSITE }\end{array}$ & $\begin{array}{l}\text { SW } \\
\text { SW }\end{array}$ & $\frac{N}{n}$ & $\begin{array}{l}\text { DRIVE POINT } \\
\text { DRIVE POINT }\end{array}$ & $\begin{array}{l}\text { 24-Feb-03 B } \\
\text { 24-Feb-03 B }\end{array}$ & & $\begin{array}{l}0.22 \\
10.7\end{array}$ & $\frac{u g g}{u g / L}$ & & & $\begin{array}{c}c \\
c\end{array}$ & & & \\
\hline SESPSPEC & B16KV7 & 300 SPR $9-2(2 \mathrm{FT})$ & ONSITE & sW & $\mathrm{N}$ & $\begin{array}{l}\text { DRIVE POINT } \\
\text { DRIN }\end{array}$ & 24-Feb-03 B & & $\begin{array}{l}1.1 \\
7.22\end{array}$ & $\begin{array}{l}u g / L \\
u g / L\end{array}$ & & & $\mathrm{c}$ & & & \\
\hline SESPSPEC & B16KV6 & 300 SPR 9 -2 (4 IN) & ONSITE & SW & $\mathrm{N}$ & DRIVE POINT & 24-Feb-03 B & & 2.46 & ug/L & & & C & & & \\
\hline SESPSPEC & B16KV8 & 300 SPR 9 -2 (4.5FT) & ONSITE & SW & $\mathrm{N}$ & DRIVE PC & 24-Feb-03 B & & 8.28 & $\mathrm{ug} / \mathrm{L}$ & & & C & & & \\
\hline $\begin{array}{l}\text { SESPSPEC } \\
\text { SESPSPEC }\end{array}$ & B16KW0 & 300 SPR $9-3$ (2 FT) & ONSITE & SW & $\mathrm{N}$ & DRIVE POINT & 24-Feb-03 B & & 8.36 & $\mathrm{ug} / \mathrm{L}$ & & & $\mathrm{C}$ & & & \\
\hline $\begin{array}{l}\text { SESPSPEC } \\
\text { SESPSPEC }\end{array}$ & $\begin{array}{l}\text { B16KV9 } \\
\text { B16KT8 }\end{array}$ & 300 SPR 9 - 3 (4 IN) & ONSITE & SW & N & $\begin{array}{l}\text { DRIVE POINT } \\
\end{array}$ & 24-Feb-03 B & & 2.92 & ug/L & & & C & & & \\
\hline $\begin{array}{l}\text { SESPSPEC } \\
\text { SESPSPEC }\end{array}$ & $\begin{array}{l}\text { B16KT8 } \\
\text { B16KT9 }\end{array}$ & $\begin{array}{l}300 \mathrm{SPR} 7-1(2.5 \mathrm{FT}) \\
300 \mathrm{SPR} 7-1(\mathrm{FT})\end{array}$ & $\begin{array}{l}\text { ONSITE } \\
\text { ONSITE }\end{array}$ & $\begin{array}{l}\text { SW } \\
\text { sw }\end{array}$ & $\frac{N}{n}$ & $\begin{array}{l}\text { DRIVE POINT } \\
\text { DRIVE POINT }\end{array}$ & $\begin{array}{l}\text { 24-Feb-03 Ba } \\
\text { 24-Feb-03 Ba }\end{array}$ & & $\begin{array}{l}7 / 5 \\
148\end{array}$ & ug/L & & & & & & \\
\hline SESPSPEC & B16KT7 & 300 SPR $7-1$ (4 IN) & ONSITE & sw & $\frac{n}{n}$ & DRIVE POINT & $24-\mathrm{Feb}-03 \mathrm{Ba}$ & & 76.7 & $\begin{array}{l}\mathrm{ug} / \mathrm{L} \\
\mathrm{ug} / \mathrm{L}\end{array}$ & & & & & & \\
\hline SESPSPEC & B16KV0 & 300 SPR 7 -1 (6 FT) & ONSITE & SW & $\mathrm{N}$ & DRIVE POINT & 24-Feb-03 Ba & & 188 & $\mathrm{ug} / \mathrm{L}$ & & & & & & \\
\hline SESPSPEC & B16KV2 & 300 SPR 7 -2 (2 FT) & ONSITE & SW & $\mathrm{N}$ & DRIVE POINT & 24-Feb-03 Ba & & 150 & ug/L & & & & & & \\
\hline
\end{tabular}


ENVIRONMENTAL SURVEILLANCE DATA CY03

WATER - ASSORTED NON-ROUTINE SAMPLING EVENTS

\begin{tabular}{|c|c|c|c|c|c|c|c|c|c|c|c|c|c|c|c|c|}
\hline OWNER ID & SAMP NUM & SAMP SITE NAME & DIST CLASS & MEDIA & $\mid \begin{array}{c}\text { FILTERED } \\
\text { FLAG }\end{array}$ & SAMP FROM & |SAMP DATE| & CON SHORT NAME & |VALUE RPTD| & $\begin{array}{l}\text { ANAL } \\
\text { UNITS } \\
\text { RPTD }\end{array}$ & $\mid \begin{array}{c}\text { COUNTING } \\
\text { ERROR }\end{array}$ & \begin{tabular}{|l} 
TOTAL \\
ANAL \\
ERROR
\end{tabular} & $\left|\begin{array}{c}\text { LAB } \\
\text { QUALIFIER }\end{array}\right|$ & SAMP COMMENT & $\begin{array}{l}\text { RESULT } \\
\text { COMMENT }\end{array}$ & |WELL NAME \\
\hline SESPSPEC & B16KV1 & 300 SPR $7-2(4$ IN) & ONSITE & SW & 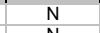 & DRIVE POINT & 24-Feb-03 Ba & & 129 & ug/L & & & & & & \\
\hline $\begin{array}{l}\text { SESPSPEC } \\
\text { SESPSPEC }\end{array}$ & B16KV4 & 300 SPR $9-1$ (2 FT) & ONSITE & sW & N & DRIVE POINT & 24-Feb-03 Ba & & 49.8 & ug/L & & & & & & \\
\hline $\begin{array}{l}\text { SESPSPEC } \\
\text { SESPSPEC }\end{array}$ & $\begin{array}{l}\text { B16KV5 } \\
\text { B16K/3 }\end{array}$ & $\begin{array}{l}300 \text { SPR 9-1 (4 FT) } \\
300 \text { SPR 9-1 (4 IN) }\end{array}$ & ONSITE & SW & N & DRIVE POINT & 24-Feb-03 Ba & & 38.7 & ug/L & & & & & & \\
\hline $\begin{array}{l}\text { SESPSPEC } \\
\text { SESPSPEC }\end{array}$ & $\begin{array}{l}\mathrm{B} 16 \mathrm{KV} 3 \\
\text { B16V7 }\end{array}$ & $\begin{array}{l}300 \mathrm{SPR} 9-1 \text { - (4 IN) } \\
300 \text { SPR } 9-2(2 \mathrm{FT})\end{array}$ & $\begin{array}{l}\text { ONSITE } \\
\text { ONSITE }\end{array}$ & $\begin{array}{l}\text { sw } \\
\text { sw }\end{array}$ & $N_{n}^{n}$ & $\begin{array}{l}\text { DRIVE POINT } \\
\text { DRIVE PONTT }\end{array}$ & $\begin{array}{l}\text { 24-Feb-03 Ba } \\
\text { 24-Feb-3 Ba }\end{array}$ & & 48.7 & ug/L & & & & & & \\
\hline SESPSPEC & B16KV6 & 300 SPR $9-2(4$ IN) & ONSITE & SW & $\frac{n}{n}$ & $\begin{array}{l}\text { DRIVE POINT } \\
\text { DRIVE POINT }\end{array}$ & $\begin{array}{l}\text { 24-Feb-03 Ba } \\
\text { 24-Feb-03 Ba }\end{array}$ & & $\begin{array}{r}41.4 \\
40.6\end{array}$ & $\begin{array}{l}\mathrm{ug} / \mathrm{L} \\
\mathrm{ug} / \mathrm{L}\end{array}$ & & & & & & \\
\hline SESPSPEC & B16KV8 & 300 SPR $9-2$ (4.5FT) & ONSITE & sW & $\mathrm{N}$ & DRIVE POINT & 24-Feb-03 Ba & & 39.3 & $\mathrm{ug} / \mathrm{L}$ & & & & & & \\
\hline $\begin{array}{l}\text { SESPSPEC } \\
\text { SESPSDEC }\end{array}$ & B16KWO & 300 SPR $9-3(2 \mathrm{FT})$ & ONSITE & sW & N & DRIVE POINT & 24-Feb-03 Ba & & 95.7 & $\mathrm{ug} / \mathrm{L}$ & & & & & & \\
\hline $\begin{array}{l}\text { SESPSPEC } \\
\text { SESPSPEC }\end{array}$ & B16KV9 & 300 SPR $9-3(4$ IN) & ONSITE & SW & $\mathrm{N}$ & DRIVE POINT & 24-Feb-03 Ba & & 92.2 & $\mathrm{ug} / \mathrm{L}$ & & & & & & \\
\hline $\begin{array}{l}\text { SESPSPEC } \\
\text { SESPSPEC }\end{array}$ & B180C6 & 100 B/C AREA UR & ONSITE & SW & $\begin{array}{l}Y \\
Y \\
\end{array}$ & RIVER & 13-Nov-03 Ba & & 17.4 & $\mathrm{ug} / \mathrm{L}$ & & & C & & & \\
\hline $\begin{array}{l}\text { SESPSPEC } \\
\text { SESPSPEC }\end{array}$ & $\begin{array}{l}\text { B18007 } \\
\text { B180C8 }\end{array}$ & $\begin{array}{l}100 \mathrm{~B} / \mathrm{C} \text { AREA UR } \\
100 \mathrm{~B} \text { AREA AREA }\end{array}$ & $\begin{array}{l}\text { ONSIE } \\
\text { ONSITE }\end{array}$ & $\begin{array}{l}\text { SW } \\
\text { sw }\end{array}$ & $\begin{array}{l}Y \\
Y\end{array}$ & $\begin{array}{l}\text { RIVER } \\
\text { RIVER }\end{array}$ & $\begin{array}{l}\text { 13-Nov-03 Ba } \\
\text { 13-Nov-3 Ba }\end{array}$ & & $\begin{array}{r}20.7 \\
21\end{array}$ & $\begin{array}{l}\mathrm{ug} / \mathrm{L} \\
\mathrm{u} / \mathrm{L}\end{array}$ & & & $\begin{array}{l}\mathrm{C} \\
\mathrm{C}\end{array}$ & & & \\
\hline SESPSPEC & B180C9 & 100 B/C AREA UR & ONSITE & sW & Y & RIVER & $\begin{array}{l}\text { 13-Nov-03 Ba } \\
\text { 13-Nov-03 Ba }\end{array}$ & & $\begin{array}{r}21 \\
23.5\end{array}$ & $\begin{array}{l}\mathrm{ug} / \mathrm{L} \\
\mathrm{ug} / \mathrm{L}\end{array}$ & & & ${ }_{c}^{c}$ & & & \\
\hline SESPSPEC & B180D0 & 100-B SPRING 38-3 & ONSITE & sw & $Y$ & RIVER & 13-Nov-03 Ba & & 24.7 & ug/L & & & $\mathrm{c}$ & DUP IS SAMPLE \#B180J4 & & \\
\hline SESPSPEC & B180D1 & 100-B SPRING 38-3 & ONSITE & SW & $Y$ & RIVER & 13-Nov-03 Ba & & 24 & ug/L & & & C & & & \\
\hline $\begin{array}{l}\text { SESPSPEC } \\
\text { SESPSPEC }\end{array}$ & B180D2 & 100-B SPRING 38-3 & ONSITE & SW & $Y$ & RIVER & 13-Nov-03 Ba & & 23.9 & $\mathrm{ug} / \mathrm{L}$ & & & C & & & \\
\hline $\begin{array}{l}\text { SESPSPEC } \\
\text { SESPSPEC }\end{array}$ & B180D3 & $\begin{array}{l}\text { 100-B SPRING 38-3 } \\
\text { 100-B SPRING 38-3 }\end{array}$ & ONSITE & SW & $\begin{array}{l}Y \\
Y\end{array}$ & RIVER & 13-Nov-03 Ba & & 23.3 & $\mathrm{ug} / \mathrm{L}$ & & & C & & & \\
\hline $\begin{array}{l}\text { SESPSPEC } \\
\text { SESPSPEC }\end{array}$ & $\begin{array}{l}\text { B18004 } \\
\text { B180D4 }\end{array}$ & $\begin{array}{l}\text { 100-B B SRING 38-3 } \\
\text { 100-B SPRING 39-2 }\end{array}$ & $\begin{array}{l}\text { ONSITE } \\
\text { ONSITE }\end{array}$ & $\begin{array}{l}\text { SW } \\
\text { sw }\end{array}$ & $\begin{array}{l}Y \\
Y\end{array}$ & $\begin{array}{l}\text { RIVER } \\
\text { RIVER }\end{array}$ & $\begin{array}{l}\text { 13-Nov-03 Ba } \\
\text { 13-No-3 Ba }\end{array}$ & & 24.4 & ug/L & & & $\mathrm{C}_{\mathrm{c}}$ & DUP SAMPLE FOR B180D0 & & \\
\hline SESPSPEC & B180D5 & 100-B SPRING 39-2 & ONSITE & sW & $\begin{array}{l}\mathrm{Y} \\
\mathrm{Y}\end{array}$ & $\begin{array}{l}\text { RIVER } \\
\text { RIVER }\end{array}$ & $\begin{array}{l}\text { 13-Nov-03 Ba } \\
\text { 13-Nov-03 Ba }\end{array}$ & & 23.4 & $\begin{array}{l}\mathrm{ug} / \mathrm{L} \\
\mathrm{ug} / \mathrm{L}\end{array}$ & & & $\begin{array}{l}c \\
c\end{array}$ & & & \\
\hline SESPSPEC & B180D6 & 100-B SPRING 39-2 & ONSITE & sw & $Y$ & RIVER & 13-Nov-03 Ba & & 23.3 & $\mathrm{ug} / \mathrm{L}$ & & & C & & & \\
\hline SESPSPEC & B180D7 & 100-B SPRING 39-2 & ONSITE & SW & $Y$ & RIVER & 13-Nov-03 Ba & & 23.2 & ug/L & & & C & & & \\
\hline $\begin{array}{l}\text { SESPSPEC } \\
\text { SESPSPEC }\end{array}$ & B180F9 & 100-B SPRING DR 38-3 & ONSITE & SW & $Y$ & RIVER & 13-Nov-03 Ba & & 23.8 & $\mathrm{ug} / \mathrm{L}$ & & & c & & & \\
\hline $\begin{array}{l}\text { SESPSPEC } \\
\text { SESPSPEC }\end{array}$ & $\begin{array}{l}\text { B180F1 } \\
81802\end{array}$ & $100 \mathrm{~B} / \mathrm{C}$ AREA DR & ONSITE & SW & $\begin{aligned} Y \\
Y \\
y\end{aligned}$ & RIVER & 17-Nov-03 Ba & & 23.7 & ug/L & & & $\mathrm{C}$ & & & \\
\hline $\begin{array}{l}\text { SESPSPEC } \\
\text { SESPSPEC }\end{array}$ & $\begin{array}{l}\mathrm{B} 18 \mathrm{OO} 22 \\
\mathrm{~B} 18 \mathrm{OF} 3\end{array}$ & $\begin{array}{l}100 \text { B/C AREA DR } \\
100 \text { B/C AREA DR }\end{array}$ & ONSITE & SW & $\begin{array}{l}Y \\
Y\end{array}$ & $\begin{array}{l}\text { RIVER } \\
\text { RIVER }\end{array}$ & $\begin{array}{l}\text { 17-Nov-03 Ba } \\
17-N o y-03 \text { Ba }\end{array}$ & & 23.7 & ug/L & & & $\mathrm{C}$ & & & \\
\hline SESPSPEC & B180F4 & 100 B/C AREA DR & $\begin{array}{l}\text { ONSITE } \\
\text { ONSE }\end{array}$ & sw & $\begin{array}{l}\mathrm{Y} \\
\mathrm{Y}\end{array}$ & $\begin{array}{l}\text { RIVER } \\
\text { RIVER }\end{array}$ & $\begin{array}{l}\text { 17-Nov-03 Ba } \\
\text { 17-Nov-03 Ba }\end{array}$ & & $\begin{array}{l}23.6 \\
23.7\end{array}$ & $\begin{array}{l}\mathrm{ug} / \mathrm{L} \\
\mathrm{ug} / \mathrm{L}\end{array}$ & & & $\begin{array}{l}\mathrm{c} \\
\mathrm{c}\end{array}$ & & & \\
\hline SESPSPEC & B180D8 & $100 \mathrm{~B} / \mathrm{C}$ AREA OUTFL1 & ONSITE & SW & $Y$ & RIVER & 17-Nov-03 Ba & & 23.4 & $\mathrm{ug} / \mathrm{L}$ & & & C & & & \\
\hline $\begin{array}{l}\text { SESPSPEC } \\
\text { SESPSPEC }\end{array}$ & B180D9 & $100 \mathrm{~B} / \mathrm{C}$ AREA OUTFL2 & ONSITE & SW & $\begin{array}{l}Y \\
Y\end{array}$ & RIVER & 17-Nov-03 Ba & & 23.7 & ug/L & & & c & & & \\
\hline $\begin{array}{l}\text { SESPSPEC } \\
\text { SESPSPEC }\end{array}$ & B180F0 & $100 \mathrm{~B} / \mathrm{C}$ AREA OUTFL 3 & ONSITE & SW & $\begin{array}{l}Y Y \\
Y\end{array}$ & RIVER & 17-Nov-03 Ba & & 23.8 & $\mathrm{ug} / \mathrm{L}$ & & & C & & & \\
\hline $\begin{array}{l}\text { SESPSPEC } \\
\text { SESPSPEC }\end{array}$ & B180K2 & Refer to WELL NAME column & & GW & $\begin{array}{r}\text { Y } \\
\text { y }\end{array}$ & AQUIFER TUBE & 10-Dec-03 Ba & & $\begin{array}{l}18.1 \\
52 .\end{array}$ & $\mathrm{ug} / \mathrm{L}$ & & & C & & & 01-D \\
\hline $\begin{array}{l}\text { SESPSPEC } \\
\text { SESPSPEC }\end{array}$ & $\begin{array}{l}\text { B18003 } \\
\text { B180K4 }\end{array}$ & $\begin{array}{l}\text { Refer to WELL NAME column } \\
\text { Refer to WELL NAME column }\end{array}$ & & $\begin{array}{l}\text { GW } \\
\text { GW }\end{array}$ & $\begin{array}{l}Y \\
Y\end{array}$ & $\begin{array}{l}\text { AQUUFER TUBE } \\
\text { AQUIFER TUBE }\end{array}$ & $\begin{array}{l}\text { 10-Dec-03B Ba } \\
\text { 10-De-03 Ba }\end{array}$ & & $\begin{array}{r}52.7 \\
49.6\end{array}$ & ug/L & & & $\begin{array}{l}\mathrm{C} \\
\mathrm{C}\end{array}$ & & & $\begin{array}{l}04-D \\
05-D\end{array}$ \\
\hline SESPSPEC & B180K5 & Refer to WELL NAME column & & GW & Y & AQUIFER TUBE & 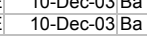 & & 27.6 & $\frac{u g g / L}{u g / L}$ & & & $\mathrm{c}$ & & & $06-\mathrm{D}$ \\
\hline SESPSPEC & B16WP2 & YAKIMA RIVER & OFFSITE & sW & $Y$ & RIVER & 14-May-03 Be & & 0.066 & $\mathrm{ug} / \mathrm{L}$ & & & u & & & \\
\hline SESPSPEC & B16WP3 & YAKIMA RIVER & OFFSITE & SW & $Y$ & RIVER & 14-May-03 Be & & 0.066 & $\mathrm{ug} / \mathrm{L}$ & & & U & & & \\
\hline $\begin{array}{l}\text { SESPSPEC } \\
\text { SESPSPEC }\end{array}$ & B16WP4 & YAKIMA RIVER & OFFSITE & SW & $Y$ & $\begin{array}{l}\text { RIVER } \\
\text { PIVER }\end{array}$ & 14-May- $03 \mathrm{Be}$ & & 0.066 & ug/L & & & U & & & \\
\hline $\begin{array}{l}\text { SESPSPEC } \\
\text { SESPSPEC }\end{array}$ & B16WP5 & $\begin{array}{l}\text { YAKKMA RIVER } \\
\text { YAIMA RIVER }\end{array}$ & OFFSITE & SW & $\begin{array}{l}n \\
N\end{array}$ & $\begin{array}{l}\text { RIVER } \\
\text { RIVER }\end{array}$ & 14-May-03 Be & & 0.066 & ug/L & & & $\mathrm{U}$ & & & \\
\hline $\begin{array}{l}\text { SESPSPEC } \\
\text { SESPSPEC }\end{array}$ & $\begin{array}{l}\text { B16WP6 } \\
\text { B16WP7 }\end{array}$ & $\begin{array}{l}\text { YAAIMA RIVER } \\
\text { YAKIMA RIVER }\end{array}$ & $\begin{array}{l}\text { OFFSSTE } \\
\text { OFFITE }\end{array}$ & $\begin{array}{l}\text { SW } \\
\text { SW }\end{array}$ & $\begin{array}{l}n \\
\mathrm{~N} \\
\mathrm{n}\end{array}$ & $\begin{array}{l}\text { RIVER } \\
\text { RIVER }\end{array}$ & $\begin{array}{l}\text { 14-May-03 Be } \\
14-\mathrm{May}-03 \mathrm{Be}\end{array}$ & & 0.066 & $\mathrm{ug} / \mathrm{L}$ & & & u & & & \\
\hline SESPSPEC & B16WR5 & HOOD PARK-FRANKLIN CO. SHORE & OFFSITE & sw & $\begin{array}{l}\text { Y } \\
\text { N }\end{array}$ & $\begin{array}{l}\text { RIVER } \\
\text { RIVER }\end{array}$ & $\begin{array}{l}\text { 15-May-03 Be } \\
\text { 15-Me }\end{array}$ & & 0.066 & $\begin{array}{l}\mathrm{gggh} / \mathrm{h} \\
\mathrm{ug} / \mathrm{g}\end{array}$ & & & u & & & \\
\hline SESPSPEC & B16WR8 & HOOD PARK-FRANKLIN CO. SHORE & OFFSITE & sW & $\mathrm{N}$ & RIVER & 15-May-03 Be & & 0.066 & $\mathrm{ug} / \mathrm{L}$ & & & u & & & \\
\hline SESPSPEC & B16WR4 & HOOD PARK-MID-RIVER & OFFSITE & SW & Y & RIVER & 15-May-03 Be & & 0.066 & $\mathrm{ug} / \mathrm{L}$ & & & U & & & \\
\hline $\begin{array}{l}\text { SESPSPEC } \\
\text { SESPSPEC }\end{array}$ & B16WR9 & & OFFSITE & SW & $\mathrm{y}^{\mathrm{N}}$ & RIVER & 15-May-03 Be & & 0.066 & ug/L & & & U & & & \\
\hline $\begin{array}{l}\text { SESPSPEC } \\
\text { SESPSPEC }\end{array}$ & $\begin{array}{l}\text { B16WR6 } \\
\text { B16WR7 }\end{array}$ & 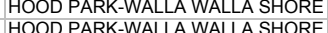 & $\begin{array}{l}\text { OFFSITE } \\
\text { OFFSTEE }\end{array}$ & SW & Y & $\begin{array}{l}\text { RIVER } \\
\text { RIVER }\end{array}$ & $\begin{array}{l}15-M a y-03 \mathrm{Be} \\
15-M a y-03 \mathrm{Be}\end{array}$ & & 0.066 & ug/L & & & $\mathrm{U}$ & & & \\
\hline $\begin{array}{l}\text { SESPSPEC } \\
\text { SESPSPEC }\end{array}$ & $\begin{array}{l}\text { B16WR7 } \\
\text { B16WN6 }\end{array}$ & $\begin{array}{l}\text { HOOD PARK-WALLA WALLA SHORE } \\
\text { MCNARY MD-RIVER NEAR DAM }\end{array}$ & $\begin{array}{l}\text { OFFSSTE } \\
\text { OFFITE }\end{array}$ & $\begin{array}{l}\text { SW } \\
\text { sw }\end{array}$ & $\begin{array}{l}\mathrm{N} \\
\mathrm{Y}\end{array}$ & $\begin{array}{l}\text { RIVER } \\
\text { RIVER }\end{array}$ & $\begin{array}{l}\text { 15-May-03 Be } \\
15-M a y-03 \mathrm{Be}\end{array}$ & & 0.066 & $\mathrm{ug} / \mathrm{L}$ & & & u & & & \\
\hline SESPSPEC & B16WP1 & MCNARY MID-RIVER NEAR DAM & $\begin{array}{l}\text { OFFSITE } \\
\text { OFFITE }\end{array}$ & sw & $\frac{\mathrm{h}}{\mathrm{h}}$ & $\begin{array}{l}\text { RIVER } \\
\text { RIVER }\end{array}$ & $\begin{array}{l}\text { 15-May-0 B Be } \\
\text { 15-May-03 Be }\end{array}$ & & 0.066 & $\frac{\mathrm{gggh}}{\mathrm{ug} / \mathrm{h}}$ & & & u & & & \\
\hline SESPSPEC & B16WN8 & MCNARY-OR.SIDE NEAR DAM & OFFSITE & SW & Y & RIVER & 15-May-03 Be & & 0.066 & $\mathrm{ug} / \mathrm{L}$ & & & u & & & \\
\hline SESPSPEC & B16WN9 & MCNARY-OR.SIDE NEAR DAM & OFFSITE & SW & $\mathrm{N}$ & RIVER & 15-May-03 Be & & 0.066 & $\mathrm{ug} / \mathrm{L}$ & & & U & & & \\
\hline $\begin{array}{l}\text { SESPSPEC } \\
\text { SESPSPEC }\end{array}$ & B16WN7 & MCNARY-WASH.SIDE NEAR DAM & OFFSITE & SW & $Y$ & RIVER & 15-May-03 Be & & 0.066 & $\mathrm{ug} / \mathrm{L}$ & & & U & & & \\
\hline $\begin{array}{l}\text { SESPSPEC } \\
\text { SESPSPEC }\end{array}$ & B16WP0 & MCNARY-WASH.SIDE NEAR DAM & $\begin{array}{l}\text { OFFSITE } \\
\text { OFFSTE }\end{array}$ & SW & $\begin{array}{l}\mathrm{y} \\
\mathrm{N}\end{array}$ & $\begin{array}{l}\text { RIVER } \\
\text { RVER }\end{array}$ & 15-May-03 Be & & 0.066 & $\mathrm{ug} / \mathrm{L}$ & & & U & & & \\
\hline $\begin{array}{l}\text { SESPSPEC } \\
\text { SESPSPEC }\end{array}$ & $\begin{array}{l}\text { B16WP8 } \\
\text { B16WP9 }\end{array}$ & $\begin{array}{l}\text { WALLA WALLA-RIVER } \\
\text { WALLA WALLA-RIVER }\end{array}$ & $\begin{array}{l}\text { OFFITE } \\
\text { OFFSITE }\end{array}$ & $\begin{array}{l}\text { SW } \\
\text { sw }\end{array}$ & $\begin{array}{l}Y \\
Y\end{array}$ & $\begin{array}{l}\text { RIVER } \\
\text { RIVER }\end{array}$ & $\begin{array}{l}\text { 15-May-03 Be } \\
15 \text {-May-03 Be }\end{array}$ & & 0.066 & & & & u & & & \\
\hline SESPSPEC & B16WRo & WALLA WALLA-RIVER & OFFSITE & sw & Y & RIVER & 15-May-03 Be & & 0.066 & $\frac{\mathrm{gg} / \mathrm{L}}{\mathrm{u}}$ & & & u & & & \\
\hline SESPSPEC & B16WR1 & WALLA WALLA-RIVER & OFFSITE & sW & $\mathrm{N}$ & RIVER & 15-May-03 Be & & 0.066 & $\mathrm{ug} / \mathrm{L}$ & & & $\mathrm{U}$ & & & \\
\hline SESPSPEC & B16WR2 & WALLA WALLA-RIVER & OFFSITE & SW & $\mathrm{N}$ & RIVER & 15-May-03 Be & & 0.066 & $\mathrm{ug} / \mathrm{L}$ & & & U & & & \\
\hline $\begin{array}{l}\text { SESPSPEC } \\
\text { SESPSPEC }\end{array}$ & $\begin{array}{l}\text { B16WR3 } \\
\text { B18006 }\end{array}$ & $\begin{array}{l}\text { WALLA WALLA-RIVER } \\
100 \text { B/C AREA UR }\end{array}$ & $\begin{array}{l}\text { OFFSITE } \\
\text { ONSTE }\end{array}$ & $\begin{array}{l}\text { SW } \\
\text { sw }\end{array}$ & $\begin{array}{l}\text { y } \\
\text { Y }\end{array}$ & $\begin{array}{l}\text { RIVER } \\
\text { RIVER }\end{array}$ & $\begin{array}{l}\text { 15-May-03 Be } \\
\text { 1-Noy-03 Be }\end{array}$ & & $\begin{array}{r}0.066 \\
0.0098\end{array}$ & $\mathrm{ug} / \mathrm{L}$ & & & $\underline{u}$ & & & \\
\hline $\begin{array}{l}\text { SESPSPEC } \\
\text { SESPSPEC }\end{array}$ & $\begin{array}{l}\text { B18006 } \\
\text { B180C7 }\end{array}$ & $\begin{array}{l}100 \mathrm{~B} / \mathrm{C} \text { AREA UR } \\
100 \mathrm{~B} \text { AREA UR }\end{array}$ & $\begin{array}{l}\text { ONSTIE } \\
\text { ONSITE }\end{array}$ & $\begin{array}{l}\text { SW } \\
\text { sw }\end{array}$ & $\begin{array}{l}\mathrm{Y} \\
\mathrm{Y}\end{array}$ & $\begin{array}{l}\text { RIVER } \\
\text { RIVER }\end{array}$ & $\begin{array}{l}\text { 13-Nov-03 Be } \\
\text { 13-Nov-3 Bee }\end{array}$ & & $\begin{array}{l}0.0098 \\
0.0109\end{array}$ & $\begin{array}{l}\mathrm{ug} / \mathrm{L} \\
\mathrm{ug} / \mathrm{L}\end{array}$ & & & u & & & \\
\hline SESPSPEC & B180C8 & $100 \mathrm{~B} / \mathrm{C}$ AREA UR & ONSITE & sW & Y & RIVER & 13-Nov-03 Be & & 0.0098 & $\mathrm{ug} / \mathrm{L}$ & & & u & & & \\
\hline SESPSPEC & B180C9 & $100 \mathrm{~B} / \mathrm{C}$ AREA UR & ONSITE & sW & $\mathrm{Y}$ & RIVER & 13-Nov-03 Be & & 0.0106 & $u g / L$ & & & & & & \\
\hline SESPSPEC & B180D0 & 100-B SPRING 38-3 & ONSITE & SW & $Y$ & RIVER & 13-Nov-03 Be & & 0.00983 & $\mathrm{ug} / \mathrm{L}$ & & & & DUP IS SAMPLE \#B180J4 & & \\
\hline SESPSPEC & B180D1 & 100-B SPRING 38-3 & ONSITE & SW & $\mathrm{Y}$ & RIVER & 13-Nov-03 Be & & 0.0098 & $\mathrm{ug} / \mathrm{L}$ & & & U & & & \\
\hline $\begin{array}{l}\text { SESPSPEC } \\
\text { SESPSPEC }\end{array}$ & B180D2 & 100-B SPRING 38-3 & ONSITE & SW & $\begin{array}{l}Y \\
Y \\
\end{array}$ & $\begin{array}{l}\text { RIVER } \\
\text { PIVER }\end{array}$ & 13-Nov-03 Be & & 0.0098 & $\mathrm{ug} / \mathrm{L}$ & & & U & & & \\
\hline $\begin{array}{l}\text { SESPSPEC } \\
\text { SESPSPEC }\end{array}$ & B180D3 & 100-B SPRING 38-3 & ONSITE & SW & $\begin{array}{l}Y \\
Y\end{array}$ & $\begin{array}{l}\text { RIVER } \\
\text { RVER }\end{array}$ & 13-Nov-03 Be & & 0.0098 & $\mathrm{ug} / \mathrm{L}$ & & & U & IR CAMPI F FR R & & \\
\hline $\begin{array}{l}\text { SESPSPEC } \\
\text { SESPSPEC }\end{array}$ & 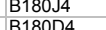 & $\begin{array}{l}\text { 100-B SPRING 38-3 } \\
\text { 100-B SPRING 39-2 }\end{array}$ & $\begin{array}{l}\text { ONSITE } \\
\text { ONSITE }\end{array}$ & $\begin{array}{l}\text { SW } \\
\text { sw }\end{array}$ & $\begin{array}{l}Y \\
Y\end{array}$ & $\begin{array}{l}\text { RIVER } \\
\text { RIVER }\end{array}$ & $\begin{array}{l}\text { 13-Nov-03 Be } \\
\text { 13-Nov-03 Be }\end{array}$ & & 0.0098 & ug/L & & & 0 & DUP SAMIPLE FOR BTOUDO & & \\
\hline $\begin{array}{l}\text { SESPSPEC } \\
\text { SESPSPEC }\end{array}$ & $\begin{array}{l}\text { B18004 } \\
\text { B180D5 }\end{array}$ & $\begin{array}{l}\text { 100-B SPRING 39-2 } \\
\text { 100-B SPRING 39-2 }\end{array}$ & $\begin{array}{l}\text { ONSITE } \\
\text { ONSITE }\end{array}$ & sw & $\begin{array}{l}Y \\
Y\end{array}$ & $\begin{array}{l}\text { RIVER } \\
\text { RIVER }\end{array}$ & $\begin{array}{l}\text { 13-Nov-03 Be } \\
\text { 13-Nov-03 Be }\end{array}$ & & 0.0125 & $\frac{\mathrm{ugg} / \mathrm{L}}{\mathrm{gg} / \mathrm{L}}$ & & & 0 & & & \\
\hline SESPSPEC & B180D6 & 100-B SPRING 39-2 & ONSITE & sw & $Y$ & RIVER & 13-Nov-03 Be & & 0.0098 & ug/L & & & u & & & \\
\hline SESPSPEC & B180D7 & 100-B SPRING 39-2 & ONSITE & sw & Y & RIVER & 13-Nov-03 Be & & 0.0098 & $u g / L$ & & & u & & & \\
\hline
\end{tabular}


WATER - ASSORTED NON-ROUTINE SAMPLING EVENTS

\begin{tabular}{|c|c|c|c|c|c|c|c|c|c|c|c|c|c|c|c|c|}
\hline OWNER ID & SAMP NUM & SAMP SITE NAME & DIST CLASS & MEDIA & $\left|\begin{array}{c}\text { FILTERED } \\
\text { FLAG }\end{array}\right|$ & SAMP FROM & | SAMP DATE| & CON SHORT NAME & | VALUE RPTD | & $\begin{array}{l}\text { ANAL } \\
\text { UNITS } \\
\text { RPTD }\end{array}$ & $\mid \begin{array}{c}\text { COUNTING } \\
\text { ERROR }\end{array}$ & \begin{tabular}{|l} 
TOTAL \\
ANAL \\
ERROR
\end{tabular} & $\left|\begin{array}{c}\text { LAB } \\
\text { QUALIFIER }\end{array}\right|$ & SAMP COMMENT & $\left|\begin{array}{c}\text { RESULT } \\
\text { COMMENT }\end{array}\right|$ & WELL NAME \\
\hline SESPSPEC & B180F9 & 100-B SPRING DR 38-3 & ONSITE & sw & $\begin{array}{r}Y \\
Y\end{array}$ & RIVER & 13-Nov-03 Be & - & 0.0098 & ug/L & & & $u$ & & & \\
\hline $\begin{array}{l}\text { SESPSPEC } \\
\text { SESPSPEC }\end{array}$ & $\begin{array}{l}\text { B180F1 } \\
\text { B1802 }\end{array}$ & $\begin{array}{l}100 \text { B/C AREA DR } \\
100 \text { B/C AREA DR }\end{array}$ & ONSITE & SW & $\begin{array}{l}Y \\
Y \\
Y\end{array}$ & $\begin{array}{l}\text { RIVER } \\
\text { RVER }\end{array}$ & $\begin{array}{l}\text { 17-Nov-03 Be } \\
17-\text { Nov-03 Be }\end{array}$ & & 0.0098 & ug/L & & & u & & & \\
\hline SESPSPEC & $\begin{array}{l}\text { B18012 } \\
\text { B180F3 }\end{array}$ & 100 BIC AREA DR & $\begin{array}{l}\text { ONSITE } \\
\text { ONSITE }\end{array}$ & SW & $\begin{array}{l}Y \\
Y\end{array}$ & $\begin{array}{l}\text { RIVER } \\
\text { RVERR }\end{array}$ & $\begin{array}{l}\text { 17-Nov-03Be } \\
\text { 17-Nov-03Be }\end{array}$ & & 0.0119 & ug/L & & & & & & \\
\hline SESPSPEC & B180F4 & 100 B/C AREA DR & ONSITE & SW & Y & $\begin{array}{l}\text { RIVER } \\
\text { RIVER }\end{array}$ & $\begin{array}{l}\text { 17-Nov-03 Be } \\
17-N o v-03 \mathrm{Be}\end{array}$ & & 0.0098 & $\begin{array}{l}\mathrm{ug} / \mathrm{L} \\
\mathrm{ug} / \mathrm{L}\end{array}$ & & & u & & & \\
\hline SESPSPEC & B180D8 & 100 B/C AREA OUTFL1 & ONSITE & sw & $\mathrm{Y}$ & RIVER & 17-Nov-03 Be & & 0.0098 & ug/L & & & u & & & \\
\hline SESPSPEC & B180D9 & $100 \mathrm{~B} / \mathrm{C}$ AREA OUTFL2 & ONSITE & sW & $\mathrm{Y}$ & RIVER & 17-Nov-03 Be & & 0.0098 & $\mathrm{ug} / \mathrm{L}$ & & & u & & & \\
\hline $\begin{array}{l}\text { SESPSPEC } \\
\text { SESPSDEC }\end{array}$ & B180F0 & $100 \mathrm{~B} / \mathrm{C}$ AREA OUTFL 3 & ONSITE & sW & Y & RIVER & 17-Nov-03 Be & & 0.0098 & $\mathrm{ug} / \mathrm{h}$ & & & u & & & \\
\hline $\begin{array}{l}\text { SESPSPEC } \\
\text { SESPSPEC }\end{array}$ & B16KT8 & 300 SPR 7 - 1 (2.5FT) & ONSITE & SW & $\mathrm{N}$ & DRIVE POINT & 24-Feb-03 Bi & & 0.02 & $\mathrm{ug} / \mathrm{L}$ & & & U & & & \\
\hline $\begin{array}{l}\text { SESPSPEC } \\
\text { SESPSPEC }\end{array}$ & B16KT9 & 300 SPR 7 -1 (4 FT) & ONSITE & SW & N & DRIVE POINT & 24-Feb-03 Bi & & 0.02 & $\mathrm{ug} / \mathrm{L}$ & & & U & & & \\
\hline $\begin{array}{l}\text { SESPSPEC } \\
\text { SESPSPEC }\end{array}$ & $\begin{array}{l}\text { B16KT7 } \\
\text { B16KVO }\end{array}$ & $\begin{array}{l}300 \mathrm{SPR} 7-1 \text { - (4 IN) } \\
300 \text { SPR } 7-1(6 \mathrm{FT})\end{array}$ & $\begin{array}{l}\text { ONSITE } \\
\text { ONSITE }\end{array}$ & $\begin{array}{l}\text { SW } \\
\text { sw }\end{array}$ & $\frac{N}{n}$ & $\begin{array}{l}\text { DRIVE POINT } \\
\text { DRIVE POINT }\end{array}$ & $\begin{array}{l}\text { 24-Feb-03 Bi } \\
\text { 24-Feb-03 Bi }\end{array}$ & & $\begin{array}{r}0.02 \\
0.0366\end{array}$ & $\begin{array}{l}\mathrm{ug} / \mathrm{L} \\
\mathrm{u} / \mathrm{L}\end{array}$ & & & u & & & \\
\hline SESPSPEC & B16KV2 & 300 SPR 7 -2 (2 FT) & ONSITE & sW & $\mathrm{N}$ & DRIVE POINT & $24-\mathrm{Feb}-03 \mathrm{Bi}$ & & 0.0366 & $\begin{array}{l}\mathrm{ug} / \mathrm{L} \\
\mathrm{ug} / \mathrm{L}\end{array}$ & & & $U$ & & & \\
\hline SESPSPEC & B16KV1 & 300 SPR 7 -2 (4 IN) & ONSITE & sw & $\mathrm{N}$ & DRIVE POINT & 24-Feb-03 Bi & & 0.02 & ug/L & & & u & & & \\
\hline SESPSPEC & B16KV4 & 300 SPR 9 -1 (2 FT) & ONSITE & SW & $\mathrm{N}$ & DRIVE POINT & 24-Feb-03 Bi & & 0.02 & ug/L & & & U & & & \\
\hline $\begin{array}{l}\text { SESPSPEC } \\
\text { SESPSPEC }\end{array}$ & B16KV5 & 300 SPR $9-1$ ( 4 FT) & ONSITE & SW & $N$ & DRIVE POINT & 24-Feb-03 Bi & & 0.02 & $\mathrm{ug} / \mathrm{L}$ & & & u & & & \\
\hline $\begin{array}{l}\text { SESPSPEC } \\
\text { SESPSPEC }\end{array}$ & B16KV3 & $\begin{array}{l}300 \text { SPR } 9-1 \text { (4 IN) } \\
300 \text { SPR } 9-2(2 \text { FT }\end{array}$ & ONSITE & SW & $N$ & DRIVE POINT & 24-Feb-03 Bi & & 0.0246 & ug/L & & & & & & \\
\hline $\begin{array}{l}\text { SESPSPEC } \\
\text { SESPSPEC }\end{array}$ & $\begin{array}{l}\text { B16KV7 } \\
\text { B16KV6 }\end{array}$ & $\begin{array}{l}300 \mathrm{SPR} 9-2(\mathrm{FT}) \\
300 \text { SPR } 9-2(4 \mathrm{IN})\end{array}$ & $\begin{array}{l}\text { ONSITE } \\
\text { ONSITE }\end{array}$ & $\begin{array}{l}\text { SW } \\
\text { sw }\end{array}$ & $\frac{N}{N}$ & $\begin{array}{l}\text { DRIIE POINT } \\
\text { DRIVE POINT }\end{array}$ & $\begin{array}{l}\text { 24-F-Fe-03 Bi } \\
\text { 24-Feb-03 Bi }\end{array}$ & & $\begin{array}{r}0.02 \\
0.031\end{array}$ & ug/L & & & u & & & \\
\hline SESPSPEC & B16KV8 & $\begin{array}{l}300 \mathrm{SPR} 9-2(4 \mathrm{IN}) \\
30 \mathrm{SPR} 9-2(4.5 \mathrm{FT})\end{array}$ & $\begin{array}{l}\text { ONSITE } \\
\text { ONSE }\end{array}$ & sw & $\frac{n}{n}$ & $\begin{array}{l}\text { DRIVE POINI } \\
\text { DRIVE POINT }\end{array}$ & $\begin{array}{l}\text { 24-ere-033 Bi } \\
\text { 24-Feb-03 Bi }\end{array}$ & & $\begin{array}{r}0.031 \\
0.02\end{array}$ & $\begin{array}{l}\mathrm{uggh} / \mathrm{L} \\
\mathrm{ug} / \mathrm{L}\end{array}$ & & & u & & & \\
\hline SESPSPEC & B16KW0 & 300 SPR $9-3$ (2 FT) & ONSITE & sw & $\mathrm{N}$ & DRIVE POINT & 24-Feb-03 Bi & & 0.0326 & $\mathrm{ug} / \mathrm{L}$ & & & & & & \\
\hline SESPSPEC & B16KV9 & 300 SPR 9 -3 (4 IN) & ONSITE & SW & $N$ & DRIVE POINT & 24-Feb-03 Bi & & 0.0808 & ug/L & & & & & & \\
\hline $\begin{array}{l}\text { SESPSPEC } \\
\text { SESPSPEC }\end{array}$ & B16KT8 & 300 SPR 7 -1 (2.5FT) & ONSITE & SW & $\mathrm{N}$ & DRIVE POINT & 24-Feb-03 Ca & & 55000 & $\mathrm{ug} / \mathrm{L}$ & & & C & & & \\
\hline $\begin{array}{l}\text { SESPSPEC } \\
\text { SESPSPEC }\end{array}$ & B16KT9 & 300 SPR 7 -1 (4 FT) & ONSITE & SW & $\mathrm{N}$ & DRIVE POINT & 24-Feb-03 Ca & & 58400 & ug/L & & & C & & & \\
\hline $\begin{array}{l}\text { SESPSPEC } \\
\text { SESPSPEC }\end{array}$ & $\begin{array}{l}\text { B16KT7 } \\
\text { B16KV0 }\end{array}$ & $\begin{array}{l}300 \text { SPR } 7-1 \text { (4 IN) } \\
300 \text { SPR 7 - (6 FT }\end{array}$ & $\begin{array}{l}\text { ONSITE } \\
\text { ONSITE }\end{array}$ & SW & 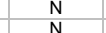 & $\begin{array}{l}\text { DRIIE POINT } \\
\text { DRIVE PONT }\end{array}$ & $\begin{array}{l}\text { 24-Feb-03 Ca } \\
\text { 24-Feb-3 Ca }\end{array}$ & & $\begin{array}{l}34100 \\
58400\end{array}$ & ug/L & & & ${ }_{c}^{C}$ & & & \\
\hline $\begin{array}{l}\text { SESPSPEC } \\
\text { SESPSPEC }\end{array}$ & $\begin{array}{l}\text { B16KV } \\
\text { B16KV2 }\end{array}$ & 300 SPR 7 - 2 (2FT) & ONSITE & SW & $\frac{n}{n}$ & $\begin{array}{l}\text { DRVE POINI } \\
\text { DRIVE POINT }\end{array}$ & $\begin{array}{l}\text { 24-ebo-03-3a } \\
\text { 24-Feb-03 Ca }\end{array}$ & & 586000 & $\begin{array}{l}\mathrm{ug} / \mathrm{L} \\
\mathrm{ug} / \mathrm{L}\end{array}$ & & & $\begin{array}{l}\mathrm{c} \\
\mathrm{c}\end{array}$ & & & \\
\hline SESPSPEC & B16KV1 & 300 SPR $7-2$ (4 IN) & ONSITE & sw & $\mathrm{N}$ & DRIVE POINT & $24-\mathrm{Feb}-03 \mathrm{Ca}$ & & 56100 & $\mathrm{ug} / \mathrm{L}$ & & & $\mathrm{c}$ & & & \\
\hline SESPSPEC & B16KV4 & 300 SPR 9 -1 (2 FT) & ONSITE & SW & $\mathrm{N}$ & DRIVE POINT & 24-Feb-03 Ca & & 28700 & $\mathrm{ug} / \mathrm{L}$ & & & C & & & \\
\hline SESPSPEC & B16KV5 & 300 SPR 9 -1 (4 FT) & ONSITE & SW & $\mathrm{N}$ & DRIVE POINT & 24-Feb-03 Ca & & 20800 & $\mathrm{ug} / \mathrm{L}$ & & & C & & & \\
\hline SESPSPEC & B16KV3 & 300 SPR 9 -1 (4 IN) & ONSITE & sw & $\mathrm{N}$ & DRIVE POINT & 24-Feb-03 Ca & & 20000 & ug/L & & & C & & & \\
\hline $\begin{array}{l}\text { SESPSPEC } \\
\text { SESPSPEC }\end{array}$ & $\begin{array}{l}\text { B16KV7 } \\
\text { B16KV6 }\end{array}$ & & ONSITE & $\begin{array}{l}\text { SW } \\
\text { SW }\end{array}$ & $\frac{N}{n}$ & $\begin{array}{l}\text { DRIVE POINT } \\
\text { DRIIE PONT }\end{array}$ & $\begin{array}{l}\text { 24-Feb-03 Ca } \\
\text { 24-Feb-03 Ca }\end{array}$ & & $\begin{array}{l}19500 \\
18300\end{array}$ & ug/L & & & $\mathrm{C}$ & & & \\
\hline $\begin{array}{l}\text { SESPSPEC } \\
\text { SESPSPEC }\end{array}$ & $\begin{array}{l}\text { B16KV6 } \\
\text { B16KV8 }\end{array}$ & $\begin{array}{l}300 \text { SPR } 9 \text { - } 2 \text { (4 IN) } \\
300 \text { SPR } 9 \text { - (4.5FT) }\end{array}$ & $\begin{array}{l}\text { ONSITE } \\
\text { ONSITE }\end{array}$ & $\begin{array}{l}\text { SW } \\
\text { SW }\end{array}$ & $\frac{n}{n}$ & $\begin{array}{l}\text { DRIVE POINT } \\
\text { DRIVE POINT }\end{array}$ & $\begin{array}{l}\text { 24-Feb-03 Ca } \\
\text { 24-Feb-03 Ca }\end{array}$ & & $\begin{array}{l}18300 \\
19800\end{array}$ & $\begin{array}{l}\mathrm{ug} / \mathrm{L} \\
\mathrm{ug} / \mathrm{L}\end{array}$ & & & c & & & \\
\hline SESPSPEC & B16KW0 & 300 SPR $9-3$ (2 FT) & ONSITE & sw & $\mathrm{N}$ & DRIVE POINT & $24-\mathrm{Feb}-03 \mathrm{Ca}$ & & 23300 & ug/L & & & $\mathrm{c}$ & & & \\
\hline SESPSPEC & B16KV9 & 300 SPR $9-3(4$ IN) & ONSITE & SW & $\mathrm{N}$ & DRIVE POINT & 24-Feb-03 Ca & & 19000 & $\mathrm{ug} / \mathrm{L}$ & & & C & & & \\
\hline $\begin{array}{l}\text { SESPSPEC } \\
\text { SESPSPEC }\end{array}$ & $\begin{array}{l}\text { B16KT8 } \\
\text { B16KTa }\end{array}$ & 300 SPR 7 -1 (2.5FT) & ONSITE & SW & $\mathrm{N}$ & DRIVE POINT & 24-Feb-03 Cd & & 0.221 & $\mathrm{ug} / \mathrm{L}$ & & & & & & \\
\hline $\begin{array}{l}\text { SESPSPEC } \\
\text { SESPSPEC }\end{array}$ & $\begin{array}{l}\text { B16KT9 } \\
\text { B16KT7 }\end{array}$ & $\begin{array}{l}300 \text { SPR } 7-1 \text { (4 FT) } \\
300 \text { SPR } 7-1 \text { (4 IN }\end{array}$ & $\begin{array}{l}\text { ONSITE } \\
\text { ONSITE }\end{array}$ & SW & $\begin{array}{l}n \\
N\end{array}$ & $\begin{array}{l}\text { DRIVE POINT } \\
\text { DRIVE PONT }\end{array}$ & $\begin{array}{l}\text { 24-Feb-03 Cd } \\
\text { 24-Feb-3 Cd }\end{array}$ & & 0.0484 & ug/L & & & & & & \\
\hline $\begin{array}{l}\text { SESPSPEC } \\
\text { SESPSPEC }\end{array}$ & $\begin{array}{l}\text { B16KT7 } \\
\text { B16KV0 }\end{array}$ & $\begin{array}{l}300 \text { SPR } 7-1 \text { ( } 4 \text { IN) } \\
300 \text { SPR } 7-1 \text { (6 FT }\end{array}$ & $\begin{array}{l}\text { ONSITE } \\
\text { ONSITE }\end{array}$ & $\begin{array}{l}\text { SW } \\
\text { SW }\end{array}$ & $\begin{array}{l}n \\
\mathrm{~N} \\
\mathrm{n}\end{array}$ & $\begin{array}{l}\text { DRIIE POINT } \\
\text { DRIVE POINT }\end{array}$ & $\begin{array}{l}\text { 24-Feb-03Cd } \\
24-\mathrm{Ceb}-3 \mathrm{Cd}\end{array}$ & & $\begin{array}{r}0.194 \\
0.0481\end{array}$ & $\mathrm{ug} / \mathrm{L}$ & & & & & & \\
\hline SESPSPEC & B16KV2 & 300 SPR 7 -2 (2 FT) & ONSITE & sw & $\frac{N}{N}$ & DRIVE POINT & 24-Feb-03 Cd & & $\begin{array}{r}0.3481 \\
0.344\end{array}$ & $\begin{array}{l}\mathrm{gggh} / \mathrm{h} \\
\mathrm{g} / \mathrm{s}\end{array}$ & & & & & & \\
\hline SESPSPEC & B16KV1 & 300 SPR 7 -2 (4 IN) & ONSITE & SW & $\mathrm{N}$ & DRIVE POINT & 24-Feb-03 Cd & & 0.0462 & $\mathrm{ug} / \mathrm{L}$ & & & & & & \\
\hline SESPSPEC & B16KV4 & 300 SPR 9 -1 (2 FT) & ONSITE & SW & $\mathrm{N}$ & DRIVE POINT & 24-Feb-03 Cd & & 0.0748 & $\mathrm{ug} / \mathrm{L}$ & & & & & & \\
\hline $\begin{array}{l}\text { SESPSPEC } \\
\text { SESPSPEC }\end{array}$ & B16KV5 & 300 SPR 9 -1 (4 FT) & ONSITE & SW & $\mathrm{N}$ & DRIVE POINT & 24-Feb-03 Cd & & 0.049 & ug/L & & & & & & \\
\hline $\begin{array}{l}\text { SESPSPEC } \\
\text { SESPSPEC }\end{array}$ & $\begin{array}{l}\text { B16KV3 } \\
\text { B16KV7 }\end{array}$ & $\begin{array}{l}300 \text { SPR } 9-1 \text { (4 IN) } \\
300 \text { SPR } 9-2 \text { (2 FT }\end{array}$ & $\begin{array}{l}\text { ONSITE } \\
\text { ONSITE }\end{array}$ & SW & $n^{n}$ & $\begin{array}{l}\text { DRIVE POINT } \\
\text { DRIVE PONT }\end{array}$ & $\begin{array}{l}\text { 24-Feb-03 Cd } \\
\text { 24-Feb-3 Cd }\end{array}$ & & $\begin{array}{r}0.216 \\
0\end{array}$ & ug/L & & & & & & \\
\hline $\begin{array}{l}\text { SESPSPEC } \\
\text { SESPSPEC }\end{array}$ & $\begin{array}{l}\text { B16KV7 } \\
\text { B16KV6 }\end{array}$ & $\begin{array}{l}300 \text { SPR } 9-2 \text { (2 FT) } \\
300 \text { SPR } 9-2(4 \text { IN }\end{array}$ & $\begin{array}{l}\text { ONSITE } \\
\text { ONSITE }\end{array}$ & $\begin{array}{l}\text { SW } \\
\text { sW }\end{array}$ & $n^{n}$ & $\begin{array}{l}\text { DRIIE POINT } \\
\text { DRIVE POINT }\end{array}$ & $\begin{array}{l}\text { 24-Feb-03Cd } \\
\text { 24-Feb-3 Cd }\end{array}$ & & $\begin{aligned} 0.0767 \\
0.127\end{aligned}$ & $\begin{array}{l}\mathrm{ug} / \mathrm{L} \\
\mathrm{ug} / \mathrm{h}\end{array}$ & & & & & & \\
\hline $\begin{array}{l}\text { SESPSPEC } \\
\text { SESPSPEC }\end{array}$ & $\begin{array}{l}\text { B16KV6 } \\
\text { B16KV8 }\end{array}$ & $\begin{array}{l}300 \text { SPR } 9-2 \text { - } 4 \text { IN }) \\
300 \text { SPR } 9-2(4.5 F T\end{array}$ & $\begin{array}{l}\text { ONSITE } \\
\text { ONSITE }\end{array}$ & $\begin{array}{l}\text { SW } \\
\text { sW }\end{array}$ & $\frac{n}{n}$ & $\begin{array}{l}\text { DRIVE POONT } \\
\text { DRIVE POINT }\end{array}$ & $\begin{array}{l}\text { 24-Feb-03Cd } \\
\text { 24-Feb-03 Cd }\end{array}$ & & 0.024 & $\frac{\mathrm{ugg} / \mathrm{L}}{\mathrm{ug} / \mathrm{L}}$ & & & & & & \\
\hline SESPSPEC & B16KW0 & 300 SPR $9-3(2 \mathrm{FT})$ & ONSITE & sw & $\mathrm{N}$ & DRIVE POINT & 24-Feb-03 Cd & & 0.0929 & ug/L & & & & & & \\
\hline $\begin{array}{l}\text { SESPSPEC } \\
\text { SESPSPEC }\end{array}$ & $\begin{array}{l}\text { B16KV9 } \\
\text { B16WP2 }\end{array}$ & 300 SPR $9-3(4$ IN) & ONSITE & SW & $\begin{array}{l}\text { y } \\
N\end{array}$ & $\begin{array}{l}\text { DRIVE POINT } \\
\text { RIIVP }\end{array}$ & 24-Feb-03 Cd & & 0.2 & $\mathrm{ug} / \mathrm{L}$ & & & & & & \\
\hline $\begin{array}{l}\text { SESPSPEC } \\
\text { SESPSPEC }\end{array}$ & B16WP2 & YAKIMA RIVER & OFFSITE & SW & $\begin{array}{l}Y \\
Y \\
\end{array}$ & RIVER & 14-May- $03 \mathrm{Cd}$ & & 0.023 & $\mathrm{ug} / \mathrm{L}$ & & & U & & & \\
\hline $\begin{array}{l}\text { SESPSPEC } \\
\text { SESPSPEC }\end{array}$ & B16WP3 & $\begin{array}{l}\text { YAKIMA RIVER } \\
\text { YAKMA }\end{array}$ & OFFSITE & SW & $\begin{array}{l}Y \\
Y\end{array}$ & $\begin{array}{l}\text { RIVER } \\
\text { RVER }\end{array}$ & 14-May-03 Cd & & 0.023 & $\mathrm{ug} / \mathrm{L}$ & & & U & & & \\
\hline $\begin{array}{l}\text { SESPSPEC } \\
\text { SESPSPEC }\end{array}$ & $\begin{array}{l}\text { B16WP4 } \\
\text { B16WP5 }\end{array}$ & $\begin{array}{l}\text { YAIMA RIVER } \\
\text { YAKIMA RIVER }\end{array}$ & $\begin{array}{l}\text { OFFSSTE } \\
\text { OFFSTIE }\end{array}$ & $\begin{array}{l}\text { SW } \\
\text { sW }\end{array}$ & $\begin{array}{l}\mathrm{Y} \\
\mathrm{N}\end{array}$ & $\begin{array}{l}\text { RIVER } \\
\text { RIVER }\end{array}$ & $\begin{array}{l}\text { 14-May-03Cd } \\
\text { 14-May-03 Cd }\end{array}$ & & 0.023 & $\frac{u g g}{u g / L}$ & & & u & & & \\
\hline SESPSPEC & B16WP6 & YAKIMA RIVER & OFFSITE & SW & $\mathrm{N}$ & $\begin{array}{l}\text { RIVER } \\
\text { RIVR }\end{array}$ & 14-May-03 Cd & & 0.023 & $\frac{\mathrm{gg} / \mathrm{L}}{\mathrm{u}}$ & & & u & & & \\
\hline SESPSPEC & B16WP7 & YAKIMA RIVER & OFFSITE & sW & $\mathrm{N}$ & RIVER & 14-May-03 Cd & & 0.023 & $\mathrm{ug} / \mathrm{L}$ & & & $\mathrm{U}$ & & & \\
\hline SESPSPEC & B16WR5 & HOOD PARK-FRANKLIN CO. SHORE & OFFSITE & SW & Y & RIVER & 15-May-03 Cd & & 0.023 & $\mathrm{ug} / \mathrm{L}$ & & & U & & & \\
\hline $\begin{array}{l}\text { SESPSPEC } \\
\text { SESPSPEC }\end{array}$ & B16WR8 & HOOD PARK-FRANKLIN CO. SHORE & OFFSITE & SW & $\begin{array}{l}\mathrm{y} \\
\mathrm{N}\end{array}$ & RIVER & 15-May- $03 \mathrm{Cd}$ & & 0.023 & $\mathrm{ug} / \mathrm{L}$ & & & U & & & \\
\hline $\begin{array}{l}\text { SESPSPEC } \\
\text { SESPSPEC }\end{array}$ & B16WR4 & $\begin{array}{l}\text { HOOD PARK-MID-RIVER } \\
\text { HOODPARK-MDRIVER }\end{array}$ & $\begin{array}{l}\text { OFFSITE } \\
\text { OFFSTIE }\end{array}$ & $\begin{array}{l}\text { SW } \\
\text { sw }\end{array}$ & $\begin{array}{r}\mathrm{Y} \\
\mathrm{N}\end{array}$ & $\begin{array}{l}\text { RIVER } \\
\text { RVER }\end{array}$ & 15-May-03 Cd & & 0.023 & $u g / L$ & & & $\mathrm{U}$ & & & \\
\hline $\begin{array}{l}\text { SESPSPEC } \\
\text { SESPSPEC }\end{array}$ & $\begin{array}{l}\text { B16WR9 } \\
\text { B16WR6 }\end{array}$ & $\begin{array}{l}\text { HOOD PARKK-MII-RIVER } \\
\text { HOOD PARK-WALLA WALLA SHORE }\end{array}$ & $\begin{aligned} & \text { OFFSSTE } \\
& \text { OFFSTIE }\end{aligned}$ & $\begin{array}{l}\text { SW } \\
\text { sw }\end{array}$ & $\begin{array}{l}\mathrm{N} \\
\mathrm{N}\end{array}$ & $\begin{array}{l}\text { RIVER } \\
\text { RIVER }\end{array}$ & $\begin{array}{l}15 \text {-May-03Cd } \\
15 \text {-May-03 Cd }\end{array}$ & & 0.023 & ug/L & & & u & & & \\
\hline SESPSPEC & B16WR7 & HOOD PARK-WALLA WALLA SHORE & OFFSITE & sW & $\mathrm{N}$ & $\begin{array}{l}\text { RIVER } \\
\text { RIVR }\end{array}$ & 15 -May-03 Cd & & 0.023 & $\begin{array}{l}u g / L \\
u g / L\end{array}$ & & & u & & & \\
\hline SESPSPEC & B16WN6 & MCNARY MID-RIVER NEAR DAM & OFFSITE & SW & Y & RIVER & 15-May-03 Cd & & 0.023 & $\mathrm{ug} / \mathrm{L}$ & & & U & & & \\
\hline SESPSPEC & B16 & MCNARY MID-RIVER NEAR DAM & OFFSITE & SW & $\mathrm{N}$ & RIVER & 15-May-C & & 0.0332 & $\mathrm{ug} / \mathrm{L}$ & & & B & & & \\
\hline $\begin{array}{l}\text { SESPSPEC } \\
\text { SESPSPEC }\end{array}$ & B16WN8 & MCNARY-OR.SIDE NEAR DAM & OFFSITE & SW & Y & $\begin{array}{l}\text { RIVER } \\
\text { PIVER }\end{array}$ & 15-May- $03 \mathrm{Cd}$ & & $\begin{array}{r}0.023 \\
0.0250\end{array}$ & $\mathrm{ug} / \mathrm{L}$ & & & $U$ & & & \\
\hline $\begin{array}{l}\text { SESPSPEC } \\
\text { SESPSPEC }\end{array}$ & B16WN9 & MCNARY-OR.SIDE NEAR DAM & $\begin{array}{l}\text { OFFSITE } \\
\text { OFESTEF }\end{array}$ & SW & $\begin{array}{l}\text { y } \\
\mathrm{N}\end{array}$ & $\begin{array}{l}\text { RIVER } \\
\text { RVER }\end{array}$ & 15-May-03 Cd & & 0.0259 & ug/L & & & $\mathrm{B}$ & & & \\
\hline $\begin{array}{l}\text { SESPSPEC } \\
\text { SESPSPEC }\end{array}$ & BTWVWI & $\begin{array}{l}\text { MCNARY-WAAH.SIDE NEAR DAM } \\
\text { MCNARYWASH SIDENFAR DAM }\end{array}$ & $\begin{array}{l}\text { OFFSIIE } \\
\text { OFFITE }\end{array}$ & $\begin{array}{l}\text { SW } \\
\text { sw }\end{array}$ & $\begin{array}{l}\mathrm{h} \\
\mathrm{h}\end{array}$ & $\begin{array}{l}\text { RIVER } \\
\text { RIVER }\end{array}$ & $\begin{array}{l}15-\mathrm{May}-03 \mathrm{Cd} \\
15 \mathrm{May}-03 \mathrm{Cd}\end{array}$ & & 0.023 & ug/L & & & $B^{B}$ & & & \\
\hline $\begin{array}{l}\text { SESPSPEC } \\
\text { SESPSPEC }\end{array}$ & $\begin{array}{l}\text { B16WPO } \\
\text { B16WP8 }\end{array}$ & $\begin{array}{l}\text { MCNARY-WASH.SIDE NEAR DAM } \\
\text { WALLA WALLA-RIVER }\end{array}$ & $\begin{array}{l}\text { OFFSIITE } \\
\text { OFFITE }\end{array}$ & sw & $\begin{array}{l}\mathrm{N} \\
\mathrm{Y}\end{array}$ & $\begin{array}{l}\text { RIVER } \\
\text { RIVER }\end{array}$ & $\begin{array}{l}\text { 15-May-03Cd } \\
15-M a y-03 C d\end{array}$ & & 0.023 & $\frac{\mathrm{ugg} / \mathrm{L}}{\mathrm{gg} / \mathrm{L}}$ & & & U & & & \\
\hline SESPSPEC & B16WP9 & WALLA WALLA-RIVER & OFFSITE & sw & Y & RIVER & 15 -May-03 Cd & & 0.023 & ug/L & & & u & & & \\
\hline SESPSPEC & B16WR0 & WALLA WALLA-RIVER & OFFSITE & sw & Y & RIVER & 15-May-03 Cd & & 0.023 & ug/L & & & u & & & \\
\hline
\end{tabular}




\begin{tabular}{|c|c|c|c|c|c|c|c|c|c|c|c|c|c|c|c|c|}
\hline OWNER ID | & SAMP NUM & SAMP SITE NAME & DIST CLASS & MEDIA & $\begin{array}{c}\text { FILTERED } \\
\text { FLAG }\end{array}$ & SAMP FROM & |SAMP DATE & CON SHORT NAME & |VALUE RPTD | & $\begin{array}{l}\text { ANAL } \\
\text { UNITS } \\
\text { RPTD }\end{array}$ & $\mid \begin{array}{c}\text { COUNTING } \\
\text { ERROR }\end{array}$ & \begin{tabular}{|c|} 
TOTAL \\
ANAL \\
ERROR
\end{tabular} & $\mid \begin{array}{c}\text { LAB } \\
\text { QUALIFIER }\end{array}$ & SAMP COMMENT & $\left|\begin{array}{|c}\text { RESULT } \\
\text { COMMENT }\end{array}\right|$ & |WELL NAME \\
\hline SESPSPEC & B16WR1 & WALLA WALLA-RIVER & OFFSITE & SW & $N$ & RIVER & 15-May- 03 Cd & & 0.023 & ug/L & & & U & & & \\
\hline $\begin{array}{l}\text { SESPSPEC } \\
\text { SESPPEC }\end{array}$ & B16WR2 & WALLA WALLA-RIVER & OFFSITE & SW & N & RIVER & 15-May-03 Cd & & 0.023 & ug/L & & & U & & & \\
\hline $\begin{array}{l}\text { SESPPPEC } \\
\text { SESPSPEC }\end{array}$ & B16WR3 & $\begin{array}{l}\text { WALLA WALLA-RIVER } \\
100 \text { B/C AREA UR }\end{array}$ & OFFSITE & SW & $\begin{array}{l}\text { y } \\
\mathrm{N}\end{array}$ & $\begin{array}{l}\text { RIVER } \\
\text { RIVER }\end{array}$ & 15-May-03 Cd & & $\begin{array}{r}0.023 \\
0.177\end{array}$ & ug/L & & & U & & & \\
\hline $\begin{array}{l}\text { SESPPPEC } \\
\text { SESPSPEC }\end{array}$ & $\begin{array}{l}\text { B180C6 } \\
\text { B180C7 }\end{array}$ & $\begin{array}{l}100 \text { BCC AREA UR } \\
100 \text { BIC AREA UR }\end{array}$ & $\begin{array}{l}\text { ONSIIE } \\
\text { ONSITE }\end{array}$ & $\begin{array}{l}\text { SW } \\
\text { sw }\end{array}$ & $\begin{array}{l}Y \\
Y\end{array}$ & $\begin{array}{l}\text { RRVER } \\
\text { RIVER }\end{array}$ & $\begin{array}{l}\text { 13-Nov-03 Cd } \\
\text { 13-Nov-03 Cd }\end{array}$ & & $\begin{array}{l}0.0177 \\
0.0141\end{array}$ & ug/L & & & $\begin{array}{l}B \\
B\end{array}$ & & & \\
\hline $\begin{array}{l}\text { SESPSPEC } \\
\text { STS }\end{array}$ & B180C8 & 100 B/C AREA UR & ONSITE & sw & $\begin{array}{l}\text { Y } \\
\text { Y }\end{array}$ & $\begin{array}{l}\text { RIVER } \\
\text { RIVER }\end{array}$ & $\begin{array}{l}\text { 13-Nov-03 Cd } \\
\text { 13-Nov-03 Cd }\end{array}$ & & $\begin{array}{l}0.0141 \\
0.0169\end{array}$ & $\begin{array}{l}\frac{\mathrm{gug} / \mathrm{L}}{\mathrm{ug} / \mathrm{L}} \\
\end{array}$ & & & $\begin{array}{l}B \\
B\end{array}$ & & & \\
\hline SESPSPEC & B180C9 & $100 \mathrm{~B} / \mathrm{C}$ AREA UR & ONSITE & sW & $\mathrm{Y}$ & RIVER & 13-Nov-03 Cd & & 0.0147 & $\mathrm{ug} / \mathrm{L}$ & & & B & & & \\
\hline $\begin{array}{l}\text { SESPSPEC } \\
\text { SESDPEC }\end{array}$ & B180D0 & 100-B SPRING 38-3 & ONSITE & sW & Y & RIVER & 13-Nov-03 Cd & & 0.0163 & $\mathrm{ug} / \mathrm{L}$ & & & B & DUP IS SAMPLE \#B180J4 & & \\
\hline $\begin{array}{l}\text { SESPSPEC } \\
\text { SESPPEC }\end{array}$ & B180D1 & 100-B SPRING 38-3 & ONSITE & SW & $\begin{array}{l}Y \\
Y \\
\end{array}$ & RIVER & 13-Nov-03 Cd & & 0.0112 & $\mathrm{ug} / \mathrm{L}$ & & & B & & & \\
\hline $\begin{array}{l}\text { SESPSPEC } \\
\text { SESPPEC }\end{array}$ & B180D2 & 100-B SPRING 38-3 & ONSITE & SW & $\begin{array}{l}Y \\
Y\end{array}$ & $\begin{array}{l}\text { RIVER } \\
\text { RIVER }\end{array}$ & 13-Nov-03 Cd & & 0.0151 & $\mathrm{ug} / \mathrm{L}$ & & & B & & & \\
\hline $\begin{array}{l}\text { SESPSPEC } \\
\text { SESPSPEC }\end{array}$ & $\begin{array}{l}\text { B180D3 } \\
\text { B180J4 }\end{array}$ & $\begin{array}{l}\text { 100-B SPRING 38-3 } \\
\text { 100-B SPRING 38-3 }\end{array}$ & $\begin{array}{l}\text { ONSITE } \\
\text { ONSITEE }\end{array}$ & $\begin{array}{l}\text { SW } \\
\text { SW }\end{array}$ & $\begin{array}{l}Y \\
Y\end{array}$ & $\begin{array}{l}\text { RIVER } \\
\text { RIVER }\end{array}$ & $\begin{array}{l}\text { 13-Nov-03 Cd } \\
13-\text { Nov-03 Cd }\end{array}$ & & 0.0145 & $\frac{\mathrm{ug} / \mathrm{L}}{\mathrm{ug} / \mathrm{L}}$ & & & $\begin{array}{l}B \\
B\end{array}$ & DUP SAMPLE FOR B180D0 & & \\
\hline SESPSPEC & B180D4 & 100-B SPRING 39-2 & ONSITE & sw & Y & RIVER & $13-\mathrm{Nov}-03 \mathrm{Cd}$ & & 0.013 & ug/L & & & B & & & \\
\hline SESPSPEC & B180D5 & 100-B SPRING 39-2 & ONSITE & sw & Y & RIVER & 13-Nov-03 Cd & & 0.0158 & $\mathrm{ug} / \mathrm{L}$ & & & B & & & \\
\hline $\begin{array}{l}\text { SESPSPEC } \\
\text { CESDPES }\end{array}$ & B180D6 & 100-B SPRING 39-2 & ONSITE & sw & Y & RIVER & 13-Nov-03 Cd & & 0.0163 & $\mathrm{ug} / \mathrm{L}$ & & & B & & & \\
\hline $\begin{array}{l}\text { SESPSPEC } \\
\text { SESPPEC }\end{array}$ & B180D7 & 100-B SPRING 39-2 & ONSITE & SW & $\begin{array}{l}Y \\
Y\end{array}$ & RIVER & 13-Nov-03 Cd & & 0.014 & $\mathrm{ug} / \mathrm{L}$ & & & B & & & \\
\hline $\begin{array}{l}\text { SESPSPEC } \\
\text { SESPPEC }\end{array}$ & $\begin{array}{l}\text { B180F9 } \\
\text { B180F1 }\end{array}$ & 100-B SPRING DR 38-3 & ONSITE & SW & $\begin{array}{r}Y \\
Y \\
Y\end{array}$ & $\begin{array}{l}\text { RIVER } \\
\text { RIVER }\end{array}$ & $\begin{array}{l}\text { 13-Nov-03 Cd } \\
17-\text { Nov-3 Cd }\end{array}$ & & 0.0197 & $\mathrm{ug} / \mathrm{L}$ & & & B & & & \\
\hline $\begin{array}{l}\text { SESSPPEC } \\
\text { SESPSPEC }\end{array}$ & $\begin{array}{l}\text { B180F1 } \\
\text { B180F2 }\end{array}$ & $\begin{array}{l}100 \text { B/C AREA DR } \\
100 \text { B/C AREA DR }\end{array}$ & $\begin{array}{l}\text { ONSIIE } \\
\text { ONSITE }\end{array}$ & $\begin{array}{l}\text { SW } \\
\text { sW }\end{array}$ & $\begin{array}{l}\text { Y } \\
\text { Y }\end{array}$ & $\begin{array}{l}\text { IVIVER } \\
\text { RIVER }\end{array}$ & $\begin{array}{l}\text { 17-Nov-03 Cd } \\
17 \text {-Nov-03 Cd }\end{array}$ & & $\begin{array}{r}0.01144 \\
0.00992\end{array}$ & $\mathrm{ug} / \mathrm{L}$ & & & $B$ & & & \\
\hline SESPSPEC & B180F3 & $\begin{array}{l}100 \text { BCC AREA DR } \\
100 \text { B/C AREA DR }\end{array}$ & ONSITE & sw & 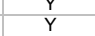 & $\begin{array}{l}\text { RIVER } \\
\text { RIVER }\end{array}$ & $\begin{array}{l}\text { 17--Novove Cd } \\
17 \text {-Nov-03 Cd }\end{array}$ & & $\begin{array}{r}0.00992 \\
0.0135\end{array}$ & $\begin{array}{l}\mathrm{uggh} / \mathrm{L} \\
\mathrm{gg} / \mathrm{L}\end{array}$ & & & $\begin{array}{l}B \\
B\end{array}$ & & & \\
\hline SESPSPEC & B180F4 & $100 \mathrm{~B} / \mathrm{C}$ AREA DR & ONSITE & sW & Y & RIVER & $17-\mathrm{Nov}-03 \mathrm{Cd}$ & & 0.00877 & $\mathrm{ug} / \mathrm{L}$ & & & B & & & \\
\hline SESPSPEC & B180D8 & 100 B/C AREA OUTFL1 & ONSITE & SW & Y & RIVER & 17-Nov-03 Cd & & 0.0115 & ug/L & & & B & & & \\
\hline $\begin{array}{l}\text { SESPSPEC } \\
\text { SESPPEC }\end{array}$ & B180D9 & 100 B/C AREA OUTFL2 & ONSITE & SW & Y & RIVER & 17-Nov-03 Cd & & 0.0117 & $\mathrm{ug} / \mathrm{L}$ & & & B & & & \\
\hline $\begin{array}{l}\text { SESPPPEC } \\
\text { SESPSPEC }\end{array}$ & $\begin{array}{l}\text { B180F0 } \\
\text { B180K2 }\end{array}$ & $100 \mathrm{~B} / \mathrm{C}$ AREA OUTFL 3 & ONSITE & SW & $\begin{array}{r}Y \\
Y\end{array}$ & $\begin{array}{l}\text { RIVER } \\
\text { AOUUEER TUBE }\end{array}$ & 17-Nov-03 Cd & & 0.0103 & $\mathrm{ug} / \mathrm{L}$ & & & B & & & \\
\hline $\begin{array}{l}\text { SESSPPEC } \\
\text { SESPSPEC }\end{array}$ & $\begin{array}{l}\text { B180K2 } \\
\text { B180K3 }\end{array}$ & $\begin{array}{l}\text { Refer to WELL NAME column } \\
\text { Refer to WELL NAME column }\end{array}$ & & $\begin{array}{l}G W \\
G W\end{array}$ & $\begin{array}{l}Y \\
Y\end{array}$ & $\begin{array}{l}\text { AQUUFER TUBEE } \\
\text { AQUIFER TUBE }\end{array}$ & $\begin{array}{l}10-\mathrm{Dec}-03 \mathrm{Cd} \\
10-\mathrm{Dec}-03 \mathrm{Cd}\end{array}$ & & $\begin{array}{l}0.023 \\
0.023\end{array}$ & $\begin{array}{l}\mathrm{ug} / \mathrm{L} \\
\mathrm{ug} / \mathrm{L}\end{array}$ & & & u & & & $\begin{array}{l}\text { O1-D } \\
\text { 04-D }\end{array}$ \\
\hline SESPSPEC & B180K4 & Refer to WELL NAME column & & GW & Y & AQUUFER TUBE & $10-\mathrm{Dec}-03 \mathrm{Cd}$ & & 0.023 & ug/L & & & u & & & $05-\mathrm{D}$ \\
\hline SESPSPEC & B180K5 & Refer to WELL NAME column & & GW & Y & AQUIFER TUBE & 10-Dec-03 Cd & & 0.023 & $\mathrm{ug} / \mathrm{L}$ & & & U & & & 06-D \\
\hline SESPSPEC & B16KT8 & 300 SPR $7-1(2.5 F T)$ & ONSITE & sw & $\mathrm{N}$ & DRIVE POINT & 24-Feb-03 $\mathrm{Cr}$ & & 4.84 & $\mathrm{ug} / \mathrm{L}$ & & & & & & \\
\hline $\begin{array}{l}\text { SESPSPEC } \\
\text { SESPPEC }\end{array}$ & B16KT9 & 300 SPR 7 -1 (4 FT) & ONSITE & SW & $\mathrm{N}$ & DRIVE POINT & 24-Feb-03 $\mathrm{Cr}$ & & 4.63 & $\mathrm{ug} / \mathrm{L}$ & & & & & & \\
\hline $\begin{array}{l}\text { SESPPPEC } \\
\text { SESPSPEC }\end{array}$ & B16KT7 & 300 SPR 7 - 1 (4 IN) & ONSITE & SW & $\mathrm{N}$ & DRIVE POINT & 24-Feb-03 Cr & & 1.77 & $\mathrm{ug} / \mathrm{L}$ & & & & & & \\
\hline $\begin{array}{l}\text { SESPPEEC } \\
\text { SESPSPEC }\end{array}$ & $\begin{array}{l}\text { B16KVVO } \\
\text { B16KV2 }\end{array}$ & $\begin{array}{l}300 \text { SPR } 7 \text { - } 1 \text { (6 FT) } \\
300 \text { SPR } 7-2(2 \mathrm{FT})\end{array}$ & $\begin{array}{l}\text { ONSITE } \\
\text { ONSITE }\end{array}$ & $\begin{array}{l}\text { SW } \\
\text { sw }\end{array}$ & $\begin{array}{l}n \\
N\end{array}$ & $\begin{array}{l}\text { DRIIE POINT } \\
\text { DRIVE POINT }\end{array}$ & $\begin{array}{l}\text { 24-Feb-03 } \mathrm{Cr} \\
\text { 24-Feb-3 } \mathrm{Cr}\end{array}$ & & $\begin{array}{l}7.38 \\
4.53\end{array}$ & $u g / L$ & & & & & & \\
\hline $\begin{array}{l}\text { SESSPEC } \\
\text { SESPSPEC }\end{array}$ & $\begin{array}{l}\mathrm{B} 1 \mathrm{~K} V \mathrm{~V} 2 \\
\mathrm{~B} 16 \mathrm{KV} 1\end{array}$ & $\begin{array}{l}300 \text { SPR } 7-2(2 \text { FT) } \\
300 \text { SPR } 7-2(4 \text { IN) }\end{array}$ & $\begin{array}{l}\text { ONSTIE } \\
\text { ONSITE }\end{array}$ & $\begin{array}{l}\text { SW } \\
\text { SW }\end{array}$ & $\frac{N}{n}$ & $\begin{array}{l}\text { DRIVE POONT } \\
\text { DRIVE POINT }\end{array}$ & $\begin{array}{l}\text { 24-Feb-03 Cr } \\
24-\mathrm{Feb}-03 \mathrm{Cr}\end{array}$ & & $\begin{array}{r}4.53 \\
0.276\end{array}$ & $\begin{array}{l}\mathrm{ug} / \mathrm{h} \\
\mathrm{ug} / \mathrm{L}\end{array}$ & & & & & & \\
\hline $\begin{array}{l}\text { SESPSPEC } \\
\text { STS }\end{array}$ & B16KV4 & 300 SPR $9-1$ (2 FT) & ONSITE & sw & $\mathrm{N}$ & DRIVE POINT & 24-Feb-03 Cr & & 2.12 & ug/L & & & & & & \\
\hline SESPSPEC & B16KV5 & 300 SPR 9 -1 (4 FT) & ONSITE & SW & $\mathrm{N}$ & DRIVE POINT & 24-Feb-03 Cr & & 2.64 & $\mathrm{ug} / \mathrm{L}$ & & & & & & \\
\hline $\begin{array}{l}\text { SESPSPEC } \\
\text { SESPPEC }\end{array}$ & B16KV3 3 & 300 SPR 9 - 1 (4 IN) & ONSITE & SW & $\mathrm{N}$ & DRIVE POINT & 24-Feb-03 $\mathrm{Cr}$ & & 3.02 & $\mathrm{ug} / \mathrm{L}$ & & & & & & \\
\hline $\begin{array}{l}\text { SESPPPEC } \\
\text { SESPSPEC }\end{array}$ & $\begin{array}{l}\text { B16KV7 } \\
\text { B16KV6 }\end{array}$ & 300 SPR $9-2$ (2 FT) & ONSITE & SW & $\begin{array}{l}n \\
N\end{array}$ & $\begin{array}{l}\text { DRIVE POINT } \\
\text { DRIVE POITT }\end{array}$ & $\begin{array}{l}\text { 24-Feb-03 Cr } \\
\text { 24-Feb-03 } \mathrm{Cr}\end{array}$ & & 2.03 & $\mathrm{ug} / \mathrm{L}$ & & & & & & \\
\hline $\begin{array}{l}\text { SESSPPEC } \\
\text { SESPSPEC }\end{array}$ & $\begin{array}{l}\text { B16KV6 } \\
\text { B16KV8 }\end{array}$ & $\begin{array}{l}300 \text { SPR } 9-2(4 \text { IN) } \\
300 \text { SPR } 9-2(4.5 \mathrm{FT})\end{array}$ & $\begin{array}{l}\text { ONSITE } \\
\text { ONSITE }\end{array}$ & $\begin{array}{l}\text { SW } \\
\text { SW }\end{array}$ & $\frac{N}{N}$ & $\begin{array}{l}\text { DRIIE POINT } \\
\text { DRIVE POINT }\end{array}$ & $\begin{array}{l}\text { 24-Feb-03 Cr } \\
24-\mathrm{Feb}-03 \mathrm{Cr}\end{array}$ & & 2.144 & $\mathrm{ug} / \mathrm{L}$ & & & & & & \\
\hline SESPSPEC & B16KW0 & 300 SPR $9-3$ (2 FT) & ONSITE & sw & $\mathrm{N}$ & $\begin{array}{l}\text { DRIVE POINT } \\
\text { DRIV POIN }\end{array}$ & 24-Feb-03 Cr & & $\begin{array}{l}1.14 \\
4.96\end{array}$ & $\begin{array}{l}u g h / 2 \\
\text { ug/L }\end{array}$ & & & & & & \\
\hline SESPSPEC & B16KV9 & 300 SPR 9 -3 (4 IN) & ONSITE & sw & $\mathrm{N}$ & DRIVE POINT & 24-Feb-03 $\mathrm{Cr}$ & & 7.43 & $\mathrm{ug} / \mathrm{L}$ & & & & & & \\
\hline SESPSPEC & B16WP2 & YAKIMA RIVER & OFFSITE & SW & Y & RIVER & 14-May-03 $\mathrm{Cr}$ & & 0.413 & $\mathrm{ug} / \mathrm{L}$ & & & & & & \\
\hline $\begin{array}{l}\text { SESPSPEC } \\
\text { CESDPEC }\end{array}$ & B16WP3 & YAKIMA RIVER & OFFSITE & sw & $\begin{array}{r}Y \\
Y \\
Y\end{array}$ & RIVER & 14-May- $03 \mathrm{Cr}$ & & 1.05 & $\mathrm{ug} / \mathrm{L}$ & & & & & & \\
\hline $\begin{array}{l}\text { SESSPPEC } \\
\text { SESPSPEC }\end{array}$ & $\begin{array}{l}\text { B16WP4 } \\
\text { B16WP5 }\end{array}$ & $\begin{array}{l}\text { YAKIMA RIVER } \\
\text { YYAIMA RIVER }\end{array}$ & $\begin{array}{l}\text { OFFSITE } \\
\text { OFSITE }\end{array}$ & SW & $\begin{array}{r}Y^{2} \\
y^{2}\end{array}$ & $\begin{array}{l}\text { RIVER } \\
\text { RIVER }\end{array}$ & $\begin{array}{l}\text { 14-May- } 03 \mathrm{Cr} \\
14-\mathrm{Mr}-3 \mathrm{Cr}\end{array}$ & & 0.876 & $\mathrm{ug} / \mathrm{L}$ & & & & & & \\
\hline $\begin{array}{l}\text { SESSPPEC } \\
\text { SESPSPEC }\end{array}$ & $\begin{array}{l}\text { B16WP55 } \\
\text { B16WP6 }\end{array}$ & $\begin{array}{l}\text { YAAIMA RIVER } \\
\text { YAKIMA RIVER }\end{array}$ & $\begin{array}{l}\text { OFFITE } \\
\text { OFFSITE }\end{array}$ & $\begin{array}{l}\text { SW } \\
\text { sw }\end{array}$ & $\begin{array}{l}n \\
N\end{array}$ & $\begin{array}{l}\text { RIVER } \\
\text { RIVER }\end{array}$ & $\begin{array}{l}\text { 14-May-03 Cr } \\
\text { 14-May-03 } \mathrm{Cr}\end{array}$ & & 0.6111 & $\mathrm{ug} / \mathrm{L}$ & & & ${ }_{\mathrm{C}}^{\mathrm{C}}$ & & & \\
\hline SESPSPEC & B16WP7 & $\begin{array}{l}\text { YAKIMA RIVER } \\
\text { YAKIMA RIVER }\end{array}$ & $\begin{array}{l}\text { OFFSITE } \\
\text { OFFII }\end{array}$ & sw & $\frac{N}{N}$ & $\begin{array}{l}\text { RIVER } \\
\text { RIVER }\end{array}$ & $\begin{array}{l}\text { 14-May }-\mathrm{O} 3 \mathrm{C} \mathrm{Cr} \\
14 \mathrm{Cr}\end{array}$ & & 0.602 & $\begin{array}{l}u g h / 2 \\
u g / L\end{array}$ & & & $\mathrm{c}$ & & & \\
\hline SESPSPEC & B16WR5 & HOOD PARK-FRANKLIN CO. SHORE & OFFSITE & sw & Y & RIVER & 15-May-03 $\mathrm{Cr}$ & & 0.338 & $\mathrm{ug} / \mathrm{L}$ & & & & & & \\
\hline SESPSPEC & B16WR8 & HOOD PARK-FRANKLIN CO. SHORE & OFFSITE & sw & $\mathrm{N}$ & RIVER & 15-May-03 $\mathrm{Cr}$ & & 0.572 & $\mathrm{ug} / \mathrm{L}$ & & & c & & & \\
\hline SESPSPEC & B16WR4 & HOOD PARK-MID-RIVER & OFFSITE & sw & Y & RIVER & 15-May- $03 \mathrm{Cr}$ & & 0.444 & $\mathrm{ug} / \mathrm{L}$ & & & & & & \\
\hline $\begin{array}{l}\text { SESPPECC } \\
\text { SESPSPEC }\end{array}$ & B16WR9 & $\begin{array}{l}\text { HOOD PARK-MID-RIVER } \\
\text { HOPE }\end{array}$ & OFFSITE & sw & $\begin{array}{l}\text { d } \\
\mathrm{N}\end{array}$ & $\begin{array}{l}\text { RIVER } \\
\text { RIVER }\end{array}$ & 15-May-03 $\mathrm{Cr}$ & & 0.562 & $\mathrm{ug} / \mathrm{L}$ & & & $\mathrm{C}$ & & & \\
\hline $\begin{array}{l}\text { SESSPEC } \\
\text { SESPSPEC }\end{array}$ & $\begin{array}{l}\text { B16WR6 } \\
\text { B16WR7 }\end{array}$ & $\begin{array}{l}\text { HODD PARK-WALLA WALLA SHORE } \\
\text { HOOD PARK-WALLA WALA SHORE }\end{array}$ & $\begin{array}{l}\text { OFFITE } \\
\text { OFFSITE }\end{array}$ & $\begin{array}{l}\text { SW } \\
\text { sw }\end{array}$ & $\begin{array}{r}\mathrm{Y} \\
\mathrm{N}\end{array}$ & $\begin{array}{l}\text { RIVER } \\
\text { RIVER }\end{array}$ & $\begin{array}{l}\text { 15-May-03 Cr } \\
\text { 15-May-03 Cr }\end{array}$ & & 0.113 & $\begin{array}{ll}\mathrm{ugh/} \\
\mathrm{ug} / \mathrm{L}\end{array}$ & & & C & & & \\
\hline SESPSPEC & B16WN6 & MCNARY MID-RIVER NEAR DAM & OFFSITE & sw & Y & RIVER & $15-\mathrm{May}-03 \mathrm{Cr}$ & & 0.646 & ug/L & & & & & & \\
\hline SESPSPEC & B16WP1 & MCNARY MID-RIVER NEAR DAM & OFFSITE & sw & $\mathrm{N}$ & RIVER & 15-May-03 $\mathrm{Cr}$ & & 0.37 & $\mathrm{ug} / \mathrm{L}$ & & & c & & & \\
\hline SESPSPEC & B16WN8 & MCNARY-OR.SIDE NEAR DAM & OFFSITE & sw & Y & RIVER & 15-May-03 $\mathrm{Cr}$ & & 0.397 & $\mathrm{ug} / \mathrm{L}$ & & & & & & \\
\hline SESPSPEC & B16WN9 & MCNARY-OR.SIDE NEAR DAM & OFFSITE & sw & $\begin{array}{l}\mathrm{y} \\
\mathrm{N}\end{array}$ & RIVER & 15-May- $03 \mathrm{Cr}$ & & 0.429 & $\mathrm{ug} / \mathrm{L}$ & & & c & & & \\
\hline $\begin{array}{l}\text { SESPPEC } \\
\text { SESPSPEC }\end{array}$ & B16WN7 & MCNARY-WASH.SIDE NEAR DAM & $\begin{array}{l}\text { OFFSITE } \\
\text { OFFSITE }\end{array}$ & $\begin{array}{l}\text { SW } \\
\text { sw }\end{array}$ & $\begin{array}{r}\mathrm{Y} \\
\mathrm{N}\end{array}$ & $\begin{array}{l}\text { IVIVR } \\
\text { RIVER }\end{array}$ & $\begin{array}{l}\text { 15-May-03 Cr } \\
15 \text {-May-03 Cr }\end{array}$ & & 0.117 & $\mathrm{ug} / \mathrm{L}$ & & & & & & \\
\hline $\begin{array}{l}\text { SESSPEC } \\
\text { SESPSPEC }\end{array}$ & $\begin{array}{l}\text { B16WP0 } \\
\text { B16WP8 }\end{array}$ & $\begin{array}{l}\text { MCNARYYWASH.SIDE NEAR DAM } \\
\text { WALLA WALLA-RIVER }\end{array}$ & $\begin{array}{l}\text { OFFITE } \\
\text { OFFSITE }\end{array}$ & $\begin{array}{l}\text { SW } \\
\text { sw }\end{array}$ & $\frac{\mathrm{N}}{\mathrm{N}}$ & $\begin{array}{l}\text { IIVER } \\
\text { RIVER }\end{array}$ & $\begin{array}{l}\text { 15-May-03 Cr } \\
15 \text {-May-03 Cr }\end{array}$ & & 0.316 & ug// & & & u & & & \\
\hline SESPSPEC & B16WP9 & WALLA WALLA-RIVER & OFFSITE & sw & $\mathrm{Y}$ & RIVER & 15-May-03 Cr & & 0.0882 & ug/L & & & B & & & \\
\hline SESPSPEC & B16WR0 & WALLA WALLA-RIVER & OFFSITE & SW & Y & RIVER & 15-May-03 $\mathrm{Cr}$ & & 0.213 & $\mathrm{ug} / \mathrm{L}$ & & & c & & & \\
\hline SESPSPEC & B16WR1 & A-RIVER & OFFS & sw & $\mathrm{N}$ & RIVER & 15-May-03 $\mathrm{Cr}$ & & 0.681 & $\mathrm{ug} / \mathrm{L}$ & & & C & & & \\
\hline $\begin{array}{l}\text { SESPPEEC } \\
\text { SESPDEC }\end{array}$ & B16WR2 & WALLA WALLA-RIVER & OFFSITE & sw & $\mathrm{N}$ & $\begin{array}{l}\text { RIVER } \\
\text { RIVER }\end{array}$ & 15-May- $03 \mathrm{Cr}$ & & $\begin{array}{r}0.75 \\
0.77\end{array}$ & $\mathrm{ug} / \mathrm{L}$ & & & $\mathrm{C}$ & & & \\
\hline $\begin{array}{l}\text { SESPPPEC } \\
\text { SESPPPEC }\end{array}$ & B16WR3 & WALLA WALLA-RIVER & OFFSITE & sw & 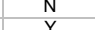 & $\begin{array}{l}\text { RIVER } \\
\text { RIVER }\end{array}$ & 15-May-03 Cr & & 0.727 & ug/L & & & C & & & \\
\hline $\begin{array}{l}\text { SESSPEC } \\
\text { SESPSPEC }\end{array}$ & $\begin{array}{l}\text { B180C6 } \\
\text { B180C7 }\end{array}$ & $\begin{array}{l}100 \text { BCC AREA UR } \\
100 \text { B AREA ARE }\end{array}$ & $\begin{array}{l}\text { ONSTIE } \\
\text { ONSITE }\end{array}$ & $\begin{array}{l}\text { Sw } \\
\text { sw }\end{array}$ & $\begin{array}{l}\text { Y } \\
\text { Y }\end{array}$ & $\begin{array}{l}\text { IIVER } \\
\text { RIVER }\end{array}$ & $\begin{array}{l}\text { 13-Nov-03 Cr } \\
\text { 13-Nov-03 Cr }\end{array}$ & & $\begin{aligned} 0.234 \\
0.23\end{aligned}$ & $\mathrm{ug} / \mathrm{h}$ & & & c & & & \\
\hline $\begin{array}{l}\text { SESSPPEC } \\
\text { SESPSPEC }\end{array}$ & $\begin{array}{l}\text { B180C7 } \\
\text { B180C8 }\end{array}$ & $\begin{array}{l}100 \mathrm{~B} B \mathrm{CAREAUR} \\
100 \mathrm{~B} \text { AREAU }\end{array}$ & $\begin{array}{l}\text { ONSSITE } \\
\text { ONSTE }\end{array}$ & sw & Y & $\begin{array}{l}\text { RIVER } \\
\text { RIVER }\end{array}$ & $\begin{array}{l}\text { 13-Nov-03 C Cr } \\
13-\text { Nov-03 Cr }\end{array}$ & & 0.227 & ug/L & & & $\begin{array}{l}\mathrm{C} \\
\mathrm{C}\end{array}$ & & & \\
\hline SESPSPEC & B180C9 & 100 B/C AREA UR & ONSITE & sw & Y & RIVER & 13-Nov-03 Cr & & 0.183 & ug/L & & & C & & & \\
\hline SESPSPEC & B180D0 & 100-B SPRING 38-3 & ONSITE & sw & $Y$ & RIVER & 13-Nov-03 Cr & & 0.427 & $\mathrm{ug} / \mathrm{L}$ & & & c & $180 \mathrm{~J} 4$ & & \\
\hline
\end{tabular}




\begin{tabular}{|c|c|c|c|c|c|c|c|c|c|c|c|c|c|c|c|c|}
\hline OWNER ID & SAMP NUM & SAMP SITE NAME & DIST CLASS & MEDIA & $\begin{array}{c}\text { FILTERED } \\
\text { FLAG }\end{array}$ & SAMP FROM & |SAMP DATE| & CON SHORT NAME & |VALUE RPTD| & $\begin{array}{l}\text { ANAL } \\
\text { UNITS } \\
\text { RPTD }\end{array}$ & $\left|\begin{array}{c}\text { COUNTING } \\
\text { ERROR }\end{array}\right|$ & \begin{tabular}{|c|} 
TOTAL \\
ANAL \\
ERROR
\end{tabular} & $\begin{array}{c}\text { LAB } \\
\text { QUALIFIER }\end{array}$ & SAMP COMMENT & $\left|\begin{array}{|c|}\text { RESULT } \\
\text { COMMENT }\end{array}\right|$ & WELL NAME \\
\hline SESPSPEC & B180D1 & 100-B SPRING 38-3 & ONSITE & SW & Y & RIVER & 13-Nov-03 Cr & & 0.395 & ug/L & & & c & & & \\
\hline $\begin{array}{l}\text { SESPSPEC } \\
\text { SESPSDEC }\end{array}$ & B180D2 & 100-B SPRING 38-3 & ONSITE & SW & Y & RIVER & 13-Nov-03 Cr & & 0.349 & ug/L & & & C & & & \\
\hline $\begin{array}{l}\text { SESPSPEC } \\
\text { SESPSEC }\end{array}$ & $\begin{array}{l}\text { B180D3 } \\
\text { B10.j4 }\end{array}$ & $\begin{array}{l}\text { 100-B SPRING 38-3 } \\
\text { 100-B SPRING 38-3 }\end{array}$ & ONSITE & SW & $\begin{array}{l}Y \\
Y\end{array}$ & $\begin{array}{l}\text { RIVER } \\
\text { RIVER }\end{array}$ & 13-Nov-03 Cr & & 0.24 & ug/L & & & C & & & \\
\hline $\begin{array}{l}\text { SESPSECC } \\
\text { SESPSPEC }\end{array}$ & $\begin{array}{l}\text { B180J4 } \\
\text { B180D4 }\end{array}$ & $\begin{array}{l}\text { 100-B SPRING 38-3 } \\
\text { 100-B SPRING 39-2 }\end{array}$ & $\begin{array}{l}\text { ONSITE } \\
\text { ONSTEE }\end{array}$ & $\begin{array}{l}\text { sw } \\
\text { sw }\end{array}$ & $\begin{array}{l}Y \\
Y\end{array}$ & $\begin{array}{l}\text { IVER } \\
\text { RIVER }\end{array}$ & $\begin{array}{l}\text { 13-Nov-03 Cr } \\
\text { 13-Nov-03 Cr }\end{array}$ & & $\begin{array}{l}0.444 \\
1.23\end{array}$ & ug/L & & & c & DUP SAMPLE FOR B180D0 & & \\
\hline SESPSPEC & B180D5 & 100-B SPRING 39-2 & ONSITE & SW & $\begin{array}{l}\text { Y } \\
\text { Y }\end{array}$ & $\begin{array}{l}\text { RIVER } \\
\text { RIVER }\end{array}$ & $\begin{array}{l}\text { 13-Nov-03 Cr } \\
\text { 13-Nov-03 Cr }\end{array}$ & & $\begin{array}{l}1.23 \\
0.384\end{array}$ & $\begin{array}{l}\frac{\mathrm{gug} / \mathrm{L}}{\mathrm{ug} / \mathrm{L}} \\
\end{array}$ & & & $\begin{array}{l}\mathrm{C} \\
\mathrm{C}\end{array}$ & & & \\
\hline SESPSPEC & B180D6 & 100-B SPRING 39-2 & ONSITE & sW & $\mathrm{Y}$ & RIVER & 13-Nov-03 Cr & & 0.379 & $\mathrm{ug} / \mathrm{L}$ & & & c & & & \\
\hline $\begin{array}{l}\text { SESPSPEC } \\
\text { SESPSDC }\end{array}$ & B18007 & 100-B SPRING 39-2 & ONSITE & sW & Y & RIVER & 13-Nov-03 Cr & & 0.315 & $\mathrm{ug} / \mathrm{L}$ & & & c & & & \\
\hline $\begin{array}{l}\text { SESPSPEC } \\
\text { SESPSDC }\end{array}$ & B180F9 & 100-B SPRING DR 38-3 & ONSITE & SW & Y & RIVER & 13-Nov-03 Cr & & 0.545 & $\mathrm{ug} / \mathrm{L}$ & & & C & & & \\
\hline $\begin{array}{l}\text { SESPSPEC } \\
\text { SESPSEC }\end{array}$ & $\begin{array}{l}B 180 F 1 \\
B 180 F 2\end{array}$ & $\begin{array}{l}100 \mathrm{~B} / \mathrm{C} \text { AREA DR } \\
100 \mathrm{~B} / \mathrm{C} \text { AREA DR }\end{array}$ & $\begin{array}{l}\text { ONSITE } \\
\text { ONSIE }\end{array}$ & $\begin{array}{l}\text { sW } \\
\text { sw }\end{array}$ & $\begin{array}{r}Y \\
Y\end{array}$ & $\begin{array}{l}\text { RIVER } \\
\text { RIVER }\end{array}$ & 17-Nov-03 Cr & & 0.185 & $\mathrm{ug} / \mathrm{L}$ & & & $\mathrm{C}$ & & & \\
\hline $\begin{array}{l}\text { SESPSEC } \\
\text { SESPSPEC }\end{array}$ & $\begin{array}{l}\text { B180F2 } \\
\text { B180F3 }\end{array}$ & $\begin{array}{l}100 \text { B/C AREA DR } \\
100 \text { B/C AREA DR }\end{array}$ & $\begin{array}{l}\text { ONSITE } \\
\text { ONSITEE }\end{array}$ & $\begin{array}{l}\text { SW } \\
\text { sW }\end{array}$ & $\begin{array}{l}Y \\
Y\end{array}$ & $\begin{array}{l}\text { RIVER } \\
\text { RIVER }\end{array}$ & $\begin{array}{l}17-N o v-03 \mathrm{Cr} \\
17-N o v-03 \mathrm{Cr}\end{array}$ & & 0.203 & $\frac{\mathrm{ug} / \mathrm{L}}{\mathrm{ug} / \mathrm{L}}$ & & & $\begin{array}{l}\mathrm{c} \\
\mathrm{c}\end{array}$ & & & \\
\hline SESPSPEC & B180F4 & 100 B/C AREA DR & ONSITE & sw & Y & RIVER & 17-Nov-03 Cr & & 0.201 & ug/L & & & $\mathrm{c}$ & & & \\
\hline SESPSPEC & B180D8 & 100 B/C AREA OUTFL1 & ONSITE & sw & Y & RIVER & 17-Nov-03 Cr & & 0.191 & $\mathrm{ug} / \mathrm{L}$ & & & c & & & \\
\hline $\begin{array}{l}\text { SESPSPEC } \\
\text { SECPSDC }\end{array}$ & B180D9 & 100 B/C AREA OUTFL2 & ONSITE & SW & Y & RIVER & 17-Nov-03 Cr & & 0.171 & ug/L & & & C & & & \\
\hline $\begin{array}{l}\text { SESPSPEC } \\
\text { SESPSPC }\end{array}$ & B180F0 & $100 \mathrm{~B} / \mathrm{C}$ AREA OUTFL3 & ONSITE & SW & $\begin{array}{l}Y \\
Y\end{array}$ & RIVER & 17-Nov-03 Cr & & 0.213 & $\mathrm{ug} / \mathrm{L}$ & & & C & & & \\
\hline $\begin{array}{l}\text { SESPSPEC } \\
\text { SESPSEC }\end{array}$ & B180K2 & Refer to WELL NAME column & & GW & $\begin{array}{r}Y \\
Y \\
Y\end{array}$ & AQUIFER TUBE & $10-\mathrm{Dec}-03 \mathrm{Cr}$ & & 1.65 & $\mathrm{ug} / \mathrm{L}$ & & & & & & 01-D \\
\hline $\begin{array}{l}\text { SESPSEEC } \\
\text { SESPSPEC }\end{array}$ & $\begin{array}{l}\text { B180K3 } \\
\text { B180K4 }\end{array}$ & $\begin{array}{l}\text { Refer to WELL NAME collumn } \\
\text { Refer to WELL NAME clumn }\end{array}$ & & GW & $\begin{array}{l}\text { Y } \\
\text { Y }\end{array}$ & $\begin{array}{l}\text { AQUUFER TUBE } \\
\text { AQQUFER TUBE }\end{array}$ & 10-Dec-03 Cr & & $\begin{array}{r}9.38 \\
25\end{array}$ & ug/L & & & & & & $04-D$ \\
\hline $\begin{array}{l}\text { SESPSPEC } \\
\text { SESP }\end{array}$ & B180K5 & $\begin{array}{l}\text { Refere to WELL NAME column NAME column } \\
\text { RefeL }\end{array}$ & & GW & 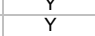 & $\begin{array}{l}\text { AQUUFER IUBE } \\
\text { AQUIFER TUBE }\end{array}$ & $\begin{array}{l}10-\mathrm{Dec}-03 \mathrm{Cr} \\
10-\mathrm{Dec}-03 \mathrm{Cr}\end{array}$ & & $\begin{array}{r}25 \\
21.4\end{array}$ & $\begin{array}{l}\mathrm{ugh/2} \\
\mathrm{ug} / \mathrm{L}\end{array}$ & & & & & & $\begin{array}{l}06-\mathrm{D} \\
06-\mathrm{D}\end{array}$ \\
\hline SESPSPEC & B16WP2 & YAKIMA RIVER & OFFSITE & sw & Y & RIVER & 14-May-03 Cu & & 1.15 & $\mathrm{ug} / \mathrm{L}$ & & & & & & \\
\hline SESPSPEC & B16WP3 & YAKIMA RIVER & OFFSITE & sw & Y & RIVER & 14-May-03 Cu & & 1.06 & ug/L & & & & & & \\
\hline $\begin{array}{l}\text { SESPSPEC } \\
\text { SESPSEC }\end{array}$ & B16WP4 & YAKIMA RIVER & OFFSITE & sw & Y & RIVER & 14-May-03 Cu & & 1.12 & $\mathrm{ug} / \mathrm{L}$ & & & & & & \\
\hline $\begin{array}{l}\text { SESPSECC } \\
\text { SESPPEC }\end{array}$ & B16WP5 & $\begin{array}{l}\text { YAKIMA RIVER } \\
\text { YYKIMA RIVER }\end{array}$ & $\begin{array}{l}\text { OFFSITE } \\
\text { OFESTE }\end{array}$ & SW & $\begin{array}{l}\mathrm{N} \\
\mathrm{N}\end{array}$ & $\begin{array}{l}\text { RIVER } \\
\text { RIVER }\end{array}$ & 14-May-03 Cu & & 1.52 & $\mathrm{ug} / \mathrm{L}$ & & & & & & \\
\hline $\begin{array}{l}\text { SESPSEEC } \\
\text { SESPSPEC }\end{array}$ & $\begin{array}{l}\text { B116P66 } \\
\text { B16WP7 }\end{array}$ & $\begin{array}{l}\text { YALKMA RIIER } \\
\text { YAKIMA RIVER }\end{array}$ & $\begin{array}{l}\text { OFFITE } \\
\text { OFFSITE }\end{array}$ & $\begin{array}{l}\text { SW } \\
\text { sw }\end{array}$ & $\frac{N}{N}$ & $\begin{array}{l}\text { RRVER } \\
\text { RIVER }\end{array}$ & $\begin{array}{l}\text { 14-May-03 Cu } \\
\text { 14-May-03 Cu }\end{array}$ & & $\begin{array}{l}1.52 \\
1.57\end{array}$ & $\begin{array}{l}\mathrm{ug} / \mathrm{L} \\
\mathrm{ug} / \mathrm{L}\end{array}$ & & & & & & \\
\hline SESPSPEC & B16WR5 & HOOD PARK-FRANKLIN CO. SHORE & OFFSITE & sw & Y & RIVER & 15-May-03 Cu & & 0.505 & $\mathrm{ug} / \mathrm{L}$ & & & & & & \\
\hline SESPSPEC & B16WR8 & HOOD PARK-FRANKLIN CO. SHORE & OFFSITE & sw & $\mathrm{N}$ & RIVER & 15-May-03 Cu & & 0.755 & ug/L & & & & & & \\
\hline $\begin{array}{l}\text { SESPSPEC } \\
\text { SESPSDC }\end{array}$ & B16WR4 & HOOD PARK-MID-RIVER & OFFSITE & sW & Y & RIVER & 15-May-03 Cu & & 0.521 & $\mathrm{ug} / \mathrm{L}$ & & & & & & \\
\hline $\begin{array}{l}\text { SESPSPEC } \\
\text { SESPSPCE }\end{array}$ & B16WR9 & HOOD PARK-MID-RIVER & OFFSITE & SW & $\mathrm{N}$ & RIVER & 15-May-03 Cu & & 0.748 & $\mathrm{ug} / \mathrm{L}$ & & & & & & \\
\hline $\begin{array}{l}\text { SESPSPEC } \\
\text { SESPSEC }\end{array}$ & B16WR6 & HOOD PARK-WALLA WALLA SHORE & OFFSITE & SW & Y & RIVER & 15-May-03 Cu & & 0.501 & $\mathrm{ug} / \mathrm{L}$ & & & & & & \\
\hline $\begin{array}{l}\text { SESPSECC } \\
\text { SESPSPEC }\end{array}$ & $\begin{array}{l}\text { B16WR7 } \\
\text { B16WN6 }\end{array}$ & $\begin{array}{l}\text { HOOD PARK-WALLA WALLA SHORE } \\
\text { MCNARY MD-RIVER NEAR DAM }\end{array}$ & & $\begin{array}{l}\text { SW } \\
\text { sw }\end{array}$ & $\begin{array}{l}\mathrm{y} \\
\mathrm{N}\end{array}$ & $\begin{array}{l}\text { IVIVER } \\
\text { RIVER }\end{array}$ & $\begin{array}{l}\text { 15-May-03 Cu } \\
15 \text {-May-03 Cu }\end{array}$ & & 0.784 & $u g / L$ & & & & & & \\
\hline $\begin{array}{l}\text { SESPSEC } \\
\text { SESPPEC }\end{array}$ & $\begin{array}{l}\text { B16WN66 } \\
\text { B16WP1 }\end{array}$ & $\begin{array}{l}\text { MCNARY MID-RIVER NEAR DAM } \\
\text { MCNARY MID-RIVER NEAR DAM }\end{array}$ & $\begin{array}{l}\text { OFFITE } \\
\text { OFFSITE }\end{array}$ & $\begin{array}{l}\text { SW } \\
\text { SW }\end{array}$ & $\frac{\mathrm{N}}{\mathrm{N}}$ & $\begin{array}{l}\text { RIVER } \\
\text { RIVER }\end{array}$ & $\begin{array}{l}\text { 15-May-03 Cu } \\
15 \text {-May-03 Cu }\end{array}$ & & 0.622 & $\begin{array}{ll}\mathrm{ug} / \mathrm{h} \\
\mathrm{ug} / \mathrm{L}\end{array}$ & & & & & & \\
\hline SESPSEC & B16WN8 & MCNARY-OR.SIDE NEAR DAM & OFFSITE & sw & Y & RIVER & 15-May-03 Cu & & 0.63 & ug/L & & & & & & \\
\hline SESPSPEC & B16WN9 & MCNARY-OR.SIDE NEAR DAM & OFFSITE & SW & $\mathrm{N}$ & RIVER & 15-May-03 Сu & & 0.827 & $\mathrm{ug} / \mathrm{L}$ & & & & & & \\
\hline $\begin{array}{l}\text { SESPSPEC } \\
\text { SESPSPCF }\end{array}$ & B16WN7 & MCNARY-WASH.SIDE NEAR DAM & OFFSITE & SW & $\begin{array}{r}Y \\
\end{array}$ & $\begin{array}{l}\text { RIVER } \\
\text { RIVER }\end{array}$ & 15-May-03 Cu & & 0.626 & $\mathrm{ug} / \mathrm{L}$ & & & & & & \\
\hline $\begin{array}{l}\text { SESPSECC } \\
\text { SESPPEC }\end{array}$ & $\begin{array}{l}\text { B16WP0 } \\
\text { B16WP8 }\end{array}$ & MCNARY-WASH.SIDE NEAR DAM & $\begin{array}{l}\text { OFFSITE } \\
\text { OFSITE }\end{array}$ & SW & $\begin{array}{l}\mathrm{y} \\
\mathrm{N}\end{array}$ & $\begin{array}{l}\text { RIVER } \\
\text { RIVER }\end{array}$ & $\begin{array}{l}15-\mathrm{May}-03 \mathrm{Cu} \\
15 \mathrm{May}-03 \mathrm{Cu}\end{array}$ & & 0.741 & $\mathrm{ug} / \mathrm{L}$ & & & & & & \\
\hline $\begin{array}{l}\text { SESPSEC } \\
\text { SESPSPEC }\end{array}$ & $\begin{array}{l}\text { B16WP88 } \\
\text { B16WP99 }\end{array}$ & $\begin{array}{l}\text { WALLA WALLA-RIIER } \\
\text { WALLA WALLA-RIVER }\end{array}$ & $\begin{array}{l}\text { OFFITE } \\
\text { OFFSITE }\end{array}$ & $\begin{array}{l}\text { SW } \\
\text { SW }\end{array}$ & $\begin{array}{l}\mathrm{Y} \\
\mathrm{Y}\end{array}$ & $\begin{array}{l}\text { RIVER } \\
\text { RIVER }\end{array}$ & $\begin{array}{l}\text { 15-May-03 Cu } \\
15 \text {-May-03 Cu }\end{array}$ & & 0.704 & $\mathrm{ug} / \mathrm{L}$ & & & & & & \\
\hline SESPSPEC & B16WR0 & WALLA WALLA-RIVER & OFFSITE & sw & Y & $\begin{array}{l}\text { RIVER } \\
\text { RIVER }\end{array}$ & 15-May-03 Cu & & 0.702 & $\begin{array}{l}u g h / 2 \\
\text { ug/L }\end{array}$ & & & & & & \\
\hline SESPSPEC & B16WR1 & WALLA WALLA-RIVER & OFFSITE & sw & $\mathrm{N}$ & RIVER & 15-May-03 Cu & & 1.43 & $\mathrm{ug} / \mathrm{L}$ & & & & & & \\
\hline SESPSPEC & B16WR2 & WALLA WALLA-RIVER & OFFSITE & SW & $\mathrm{N}$ & RIVER & 15-May-03 Cu & & 1.42 & $\mathrm{ug} / \mathrm{L}$ & & & & & & \\
\hline $\begin{array}{l}\text { SESPSPEC } \\
\text { SESPSPCC }\end{array}$ & B16WR3 & WALLA WALLA-RIVER & OFFSITE & SW & $\begin{array}{l}y^{2} \\
\mathrm{n}\end{array}$ & RIVER & 15-May-03 Cu & & 1.46 & $\mathrm{ug} / \mathrm{L}$ & & & & & & \\
\hline $\begin{array}{l}\text { SESPSECC } \\
\text { SESPSPEC }\end{array}$ & B180C6 & $\begin{array}{l}100 \text { B/C AREA UR } \\
100 \text { BCC AREA UR }\end{array}$ & $\begin{array}{l}\text { ONSITE } \\
\text { ONSIE }\end{array}$ & SW & $\begin{array}{r}Y \\
Y\end{array}$ & $\begin{array}{l}\text { RIVER } \\
\text { RIVER }\end{array}$ & $\begin{array}{l}\text { 13-Nov-03 Cu } \\
13 \text {-Nov-03 Cu }\end{array}$ & & 0.611 & ug/L & & & $\mathrm{C}$ & & & \\
\hline $\begin{array}{l}\text { SESPSECC } \\
\text { SESPSPEC }\end{array}$ & $\begin{array}{l}\text { B180C7 } \\
\text { B180C8 }\end{array}$ & $\begin{array}{l}100 \text { BCC AREA UR } \\
100 B C \text { AREA UR }\end{array}$ & $\begin{array}{l}\text { ONSITE } \\
\text { ONSTE }\end{array}$ & $\begin{array}{l}\text { SW } \\
\text { sw }\end{array}$ & $\begin{array}{r}Y \\
Y\end{array}$ & $\begin{array}{l}\text { RIVER } \\
\text { RIVER }\end{array}$ & $\begin{array}{l}\text { 13--Nov-03 Cu } \\
\text { 13-Nov-03 Cu }\end{array}$ & & 0.576 & $\mathrm{ug} / \mathrm{L}$ & & & c & & & \\
\hline SESPSPEC & B180C9 & 100 B/C AREA UR & ONSITE & sw & $\begin{array}{r}\mathrm{Y} \\
\mathrm{Y}\end{array}$ & $\begin{array}{l}\text { RIVER } \\
\text { RIVER }\end{array}$ & 13-Nov-03 $\mathrm{Cu}$ & & 0.629 & $\begin{array}{l}u g h / 2 \\
u g / L\end{array}$ & & & $\mathrm{c}$ & & & \\
\hline SESPSPEC & B180D0 & 100-B SPRING 38-3 & ONSITE & sw & Y & RIVER & 13-Nov-03 Cu & & 0.734 & $\mathrm{ug} / \mathrm{L}$ & & & C & DUP IS SAMPLE \#B180J4 & & \\
\hline SESPSPEC & B180D1 & 100-B SPRING 38-3 & ONSITE & SW & Y & RIVER & 13-Nov-03 Cu & & 0.675 & $\mathrm{ug} / \mathrm{L}$ & & & $\mathrm{C}$ & & & \\
\hline SESPSPEC & B180D2 & 100-B SPRING 38-3 & ONSITE & SW & $\begin{array}{l}Y \\
Y \\
Y\end{array}$ & RIVER & 13-Nov-03 Cu & & 0.634 & $\mathrm{ug} / \mathrm{L}$ & & & C & & & \\
\hline $\begin{array}{l}\text { SESPSEEC } \\
\text { SESPSPEC }\end{array}$ & $\begin{array}{l}\text { B180D3 } \\
\text { B180J4 }\end{array}$ & $\begin{array}{l}\text { 100-B SPRING 38-3 } \\
\text { 100-B SPRING 38-3 }\end{array}$ & $\begin{array}{l}\text { ONSTIE } \\
\text { ONSITE }\end{array}$ & $\begin{array}{l}\text { SW } \\
\text { sw }\end{array}$ & $\begin{array}{l}Y \\
Y \\
Y\end{array}$ & $\begin{array}{l}\text { RRVER } \\
\text { RIVER }\end{array}$ & $\begin{array}{l}\text { 13-Nov-03 Cu } \\
\text { 13-Nov-03 Cu }\end{array}$ & & $\begin{array}{l}0.631 \\
0.711\end{array}$ & $\mathrm{ug} / \mathrm{h}$ & & & $\begin{array}{l}\mathrm{C} \\
\mathrm{c}\end{array}$ & DUP SAMPLE FOR B180D0 & & \\
\hline SESPSPEC & B180D4 & 100-B SPRING 39-2 & ONSITE & SW & Y & RIVER & 13-Nov-03 Cu & & 0.622 & ug/h & & & $\bar{c}$ & 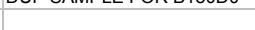 & & \\
\hline SESPSPEC & B180D5 & 100-B SPRING 39-2 & ONSITE & SW & Y & RIVER & 13-Nov-03 Cu & & 0.635 & $\mathrm{ug} / \mathrm{L}$ & & & C & & & \\
\hline SESPSPEC & B180D6 & 100-B SPRING 39-2 & ONSITE & sw & $Y$ & RIVER & 13-Nov-03 Cu & & 0.636 & $\mathrm{ug} / \mathrm{L}$ & & & C & & & \\
\hline SESPSPEC & B180D7 & 100-B SPRING 39-2 & ONSITE & SW & Y & RIVER & 13-Nov-03 Cu & & 0.636 & $\mathrm{ug} / \mathrm{L}$ & & & C & & & \\
\hline $\begin{array}{l}\text { SESPSPEC } \\
\text { SESPGDC }\end{array}$ & B180F9 & 100-B SPRING DR 38-3 & ONSITE & sw & $\begin{array}{l}Y \\
Y\end{array}$ & RIVER & 13-Nov-03 Cu & & $\begin{array}{r}1.12 \\
0\end{array}$ & $\mathrm{ug} / \mathrm{L}$ & & & C & & & \\
\hline $\begin{array}{l}\text { SESPSEEC } \\
\text { SESPSPEC }\end{array}$ & $\begin{array}{l}\text { B180F1 } \\
\text { B180F2 }\end{array}$ & $\begin{array}{l}100 \text { B BCAREA ARR } \\
100 \text { B/C AREA DR }\end{array}$ & $\begin{array}{l}\text { ONSITE } \\
\text { ONSITE }\end{array}$ & $\begin{array}{l}\text { SW } \\
\text { sw }\end{array}$ & $\begin{array}{l}Y_{Y} \\
Y\end{array}$ & $\begin{array}{l}\text { RIVER } \\
\text { RIVER }\end{array}$ & $\begin{array}{l}\text { 17-N-Nov-03 Cu } \\
\text { 17-Nov-03 Cu }\end{array}$ & & $\begin{array}{l}0.601 \\
0.613\end{array}$ & $\mathrm{ug} / \mathrm{h}$ & & & $\begin{array}{l}\mathrm{c} \\
\mathrm{c}\end{array}$ & & & \\
\hline SESPSPEC & B180F3 & 100 B/C AREA DR & ONSITE & sW & Y & RIVER & 17-Nov-03 Cu & & 1.25 & $\mathrm{ug} / \mathrm{L}$ & & & C & & & \\
\hline SESPSPEC & B180F4 & $100 \mathrm{~B} / \mathrm{C}$ AREA DR & ONSITE & sW & Y & RIVER & 17-Nov-03 Cu & & 0.63 & $\mathrm{ug} / \mathrm{L}$ & & & C & & & \\
\hline SESPSPEC & B180D8 & 100 B/C AREA OUTFL1 & ONSITE & SW & $Y$ & RIVER & 17-Nov-03 Cu & & 0.543 & ug/L & & & C & & & \\
\hline $\begin{array}{l}\text { SESPSPEC } \\
\text { SESPSPCF }\end{array}$ & B180D9 & REA OUTFL2 & ONSITE & SW & $\begin{array}{l}Y Y \\
Y\end{array}$ & $\begin{array}{l}\text { RIVER } \\
\text { RIVER }\end{array}$ & 17-Nov-0 & & 0.554 & $\mathrm{ug} / \mathrm{L}$ & & & $\begin{array}{c}\mathrm{C} \\
\mathrm{c}\end{array}$ & & & \\
\hline $\begin{array}{l}\text { SESPSPEC } \\
\text { SESPSPEC }\end{array}$ & $\begin{array}{l}\text { B180F0 } \\
\text { B16KT8 }\end{array}$ & $\begin{array}{l}100 \text { B/C AREA OUTFL3 } \\
300 \text { SPR } 7-1(2.5 F T)\end{array}$ & $\begin{array}{l}\text { ONSITE } \\
\text { ONSTIE }\end{array}$ & $\begin{array}{l}\text { sW } \\
\text { sw }\end{array}$ & $\begin{array}{r}\mathrm{N} \\
\mathrm{N}\end{array}$ & $\begin{array}{l}\text { RIVER } \\
\text { DRIVE POINT }\end{array}$ & $\begin{array}{l}\text { 17-Nov-03 Cu } \\
\text { 24-Feb-03Li }\end{array}$ & & $\begin{aligned} 0.612 \\
282\end{aligned}$ & $\mathrm{ugh/L}$ & & & c & & & \\
\hline $\begin{array}{l}\text { SESPSEEC } \\
\text { SESPSPEC }\end{array}$ & $\begin{array}{l}\text { B16KT8 } \\
\text { B16KT9 }\end{array}$ & $\begin{array}{l}300 \text { SPR 7-1 } 12.5 \mathrm{FT}) \\
300 \mathrm{SPR} 7-1 \text { (4 FT) }\end{array}$ & $\begin{array}{l}\text { ONSSIE } \\
\text { ONSTE }\end{array}$ & SW & $\frac{N}{N}$ & $\begin{array}{l}\text { DRIVE POINT } \\
\text { DRIVE POINT }\end{array}$ & $\begin{array}{l}\text { 24-Feb-03 Li } \\
\text { 24-Feb-03Li }\end{array}$ & & $\begin{array}{l}2.82 \\
2.91\end{array}$ & $\begin{array}{l}\mathrm{ug} / \mathrm{h} \\
\mathrm{ug} / \mathrm{L}\end{array}$ & & & & & & \\
\hline SESPSPEC & B16KT7 & 300 SPR 7 -1 (4 IN) & ONSITE & sW & $\mathrm{N}$ & DRIVE POINT & 24-Feb-03 Li & & 2.38 & ug/L & & & & & & \\
\hline SESPSPEC & B16KV0 & 300 SPR 7 -1 (6 FT) & ONSITE & SW & $\mathrm{N}$ & DRIVE POINT & 24-Feb-03 Li & & 5.68 & $\mathrm{ug} / \mathrm{L}$ & & & & & & \\
\hline SESPSPEC & B16KV2 & 300 SPR 7 -2 (2 FT) & ONSITE & SW & $\mathrm{N}$ & DRIVE POINT & 24-Feb-03 Li & & 2.34 & ug/L & & & & & & \\
\hline SESPSPEC & B16KV1 & 300 SPR 7 -2 (4 IN) & ONSITE & sw & $\mathrm{N}$ & DRIVE POINT & 24-Feb-03 Li & & 1.92 & ug/L & & & & & & \\
\hline
\end{tabular}


WATER - ASSORTED NON-ROUTINE SAMPLING EVENTS

\begin{tabular}{|c|c|c|c|c|c|c|c|c|c|c|c|c|c|c|c|c|}
\hline $\begin{array}{l}\text { OWNER ID } \\
\text { SESPSPC }\end{array}$ & SAMP NUM & SAMP SITE NAME & |DIST CLASS | & MEDIA & $\begin{array}{c}\text { FILTERED } \\
\text { FLAG }\end{array} \mid$ & SAMP FROM & |SAMP DATE| & CON SHORT NAME & |VALUE RPTD & $\begin{array}{l}\text { ANAL } \\
\text { UNITS } \\
\text { RPTD }\end{array}$ & $\left|\begin{array}{c}\text { COUNTING } \\
\text { ERROR }\end{array}\right|$ & $\begin{array}{c}\text { TOTAL } \\
\text { ANAL } \\
\text { ERROR }\end{array}$ & $\mid \begin{array}{c}\text { LAB } \\
\text { QUALIFIER }\end{array}$ & SAMP COMMENT & $\left|\begin{array}{c}\text { RESULT } \\
\text { COMMENT }\end{array}\right|$ & |WELL NAME| \\
\hline $\begin{array}{l}\text { SESPSPEC } \\
\text { SESPSPC }\end{array}$ & B16KV4 & 300 SPR $9-1(2$ FT) & ONSITE & SW & $n$ & DRIVE POINT & 24-Feb-03 Li & & $\begin{array}{r}2.15 \\
24\end{array}$ & ug/L & & & & & & \\
\hline $\begin{array}{l}\text { SESPSECC } \\
\text { SESPSPEC }\end{array}$ & $\begin{array}{l}\text { B16KV5 } \\
\text { B16KV3 }\end{array}$ & $\begin{array}{l}300 \text { SPR } 9-1(4 \mathrm{FT}) \\
300 \text { SPR } 9-1(4 \mathrm{IN})\end{array}$ & $\begin{array}{l}\text { ONSIIE } \\
\text { ONSITE }\end{array}$ & $\begin{array}{l}\text { Sw } \\
\text { sw }\end{array}$ & $\frac{n}{N}$ & $\begin{array}{l}\text { DRIVE POINT } \\
\text { DRIVE POINT }\end{array}$ & $\begin{array}{l}\text { 24-Feb-03 Li } \\
\text { 24-Feb-03Li }\end{array}$ & & $\begin{array}{r}2.4 \\
2.15\end{array}$ & $\frac{u g / L}{u g h}$ & & & & & & \\
\hline SESPSPEC & B16KV7 & 300 SPR 9 -2 (2 FT) & ONSITE & sw & $\mathrm{N}$ & DRIVE POINT & $24-F e b-03 \mathrm{Li}$ & & 2.46 & ugh & & & & & & \\
\hline SESPSPEC & B16KV6 & 300 SPR $9-2$ (4 IN) & ONSITE & sw & $\mathrm{N}$ & DRIVE POINT & 24-Feb-03 Li & & 2.31 & ug/L & & & & & & \\
\hline SESPSPEC & B16KV8 & 300 SPR $9-2$ (4.5FT) & ONSITE & sw & $\mathrm{N}$ & DRIVE POINT & $24-F e b-03$ Li & & 2.33 & ugh/ & & & & & & \\
\hline SESPSPEC & B16KW0 & 300 SPR $9-3(2 \mathrm{FT})$ & ONSITE & sW & $\mathrm{N}$ & DRIVE POINT & 24-Feb-03 Li & & 3.11 & $\mathrm{ug} / \mathrm{L}$ & & & & & & \\
\hline $\begin{array}{l}\text { SESPSPEC } \\
\text { SECDODC }\end{array}$ & B16KV9 & 300 SPR $9-3(4$ IN) & ONSITE & sW & $\mathrm{N}$ & DRIVE POINT & 24-Feb-03 Li & & 4.69 & $\mathrm{ug} / \mathrm{L}$ & & & & & & \\
\hline $\begin{array}{l}\text { SESPSPEC } \\
\text { SESPSDCF }\end{array}$ & B16KT8 & 300 SPR 7 - 1 (2.5FT) & ONSITE & SW & $\mathrm{N}$ & DRIVE POINT & 24-Feb-03 Mg & & 12100 & $\mathrm{ug} / \mathrm{L}$ & & & & & & \\
\hline $\begin{array}{l}\text { SESPSPEC } \\
\text { SESPSEC }\end{array}$ & $\begin{array}{l}\text { B16KKT } \\
\text { B16T7 }\end{array}$ & $\begin{array}{l}300 \text { SPR } 7-1 \text { - }(4 \mathrm{FT}) \\
300 \text { SPR } 7-1(4 \text { IN) }\end{array}$ & $\begin{array}{l}\text { ONSITE } \\
\text { ONSTEE }\end{array}$ & $\begin{array}{l}\text { SW } \\
\text { sw }\end{array}$ & $\begin{array}{r}\mathrm{N} \\
\mathrm{N}\end{array}$ & $\begin{array}{l}\text { DRIVE POINT } \\
\end{array}$ & 24-Feb-03 Mg & & 13500 & $\mathrm{ug} / \mathrm{L}$ & & & & & & \\
\hline $\begin{array}{l}\text { SESPSECC } \\
\text { SESPSPEC }\end{array}$ & $\begin{array}{l}\text { B1616T7 } \\
\text { B16KV0 }\end{array}$ & $\begin{array}{l}300 \mathrm{SPR} 7-1(4 \mathrm{IN}) \\
300 \mathrm{SPR} 7-1(6 \mathrm{FT})\end{array}$ & $\begin{array}{l}\text { ONSITE } \\
\text { ONSITE }\end{array}$ & $\begin{array}{l}\text { SW } \\
\text { SW }\end{array}$ & $\frac{N}{N}$ & $\begin{array}{l}\text { DRIVE POINT } \\
\text { DRIVE POINT }\end{array}$ & $\begin{array}{l}\text { 24-Feb--3 Mg } \\
24-\text {-eb-03 Mg }\end{array}$ & & $\begin{array}{r}8790 \\
14500\end{array}$ & $\frac{u g / L}{u g / L}$ & & & & & & \\
\hline SESPSPEC & B16KV2 & 300 SPR 7 - $2(2 \mathrm{FT})$ & ONSITE & sw & $\mathrm{N}$ & $\begin{array}{l}\text { DRIVE POINI } \\
\text { DRIVE POINT }\end{array}$ & $\begin{array}{l}24-\mathrm{reb}-03 \mathrm{Mg} \\
24-\mathrm{Feb}-03 \mathrm{Mg}\end{array}$ & & $\begin{array}{l}14500 \\
13700\end{array}$ & $\frac{u g / L}{u g / L}$ & & & & & & \\
\hline SESPSPEC & B16KV1 & 300 SPR 7 -2 (4 IN) & ONSITE & sw & $\mathrm{N}$ & DRIVE POINT & 24-Feb-03 Mg & & 11800 & ug/L & & & & & & \\
\hline SESPSPEC & B16KV4 & 300 SPR 9 -1 (2 FT) & ONSITE & sw & $\mathrm{N}$ & DRIVE POINT & 24-Feb-03 Mg & & 7010 & $\mathrm{ug} / \mathrm{L}$ & & & & & & \\
\hline SESPSPEC & B16KV5 & 300 SPR 9 -1 (4 FT) & ONSITE & SW & $N$ & DRIVE POINT & 24-Feb-03 Mg & & 5140 & $\mathrm{ug} / \mathrm{L}$ & & & & & & \\
\hline $\begin{array}{l}\text { SESPSPEC } \\
\text { SESPSEEC }\end{array}$ & $\begin{array}{l}\text { B16KV3 } \\
\text { B16KV7 }\end{array}$ & $\begin{array}{l}300 \text { SPR } 9 \text { - } 1 \text { (4 I N) } \\
300 \text { SPR } 9-2(\text { FT) }\end{array}$ & $\begin{array}{l}\text { ONSITE } \\
\text { ONSTE }\end{array}$ & SW & $\begin{array}{l}\mathrm{N} \\
\mathrm{N}\end{array}$ & $\begin{array}{l}\text { DRIVE POINT } \\
\text { DRIV POIT }\end{array}$ & 24-Feb-03 Mg & & 5000 & $\mathrm{ug} / \mathrm{L}$ & & & & & & \\
\hline $\begin{array}{l}\text { SESPSECC } \\
\text { SESPSPEC }\end{array}$ & $\begin{array}{l}\text { B16KV7 } \\
\text { B16KV6 }\end{array}$ & $\begin{array}{l}300 \text { SPR } 9-2(2 \text { FT) } \\
300 \text { SPR } 9-2(4 \text { IN) }\end{array}$ & $\begin{array}{l}\text { ONSIIE } \\
\text { ONSITE }\end{array}$ & sw & $\frac{N}{N}$ & $\begin{array}{l}\text { DRIVE POINT } \\
\text { DRIVE PONT }\end{array}$ & 24-Feb-03 Mg & & $\begin{array}{l}4760 \\
5070\end{array}$ & $\mathrm{ug} / \mathrm{L}$ & & & & & & \\
\hline SESPSPEC & B16KV8 & $\begin{array}{l}300 \mathrm{SPR} 9-2(4 \mathrm{IN}) \\
30 \mathrm{SPR} 9-2(4.5 \mathrm{FT})\end{array}$ & $\begin{array}{l}\text { ONSITE } \\
\text { ONSE }\end{array}$ & sw & $\frac{N}{N}$ & $\begin{array}{l}\text { DRIVE POINT } \\
\text { DRIV POI }\end{array}$ & $\begin{array}{l}\text { 24-Feb-03 Mg } \\
\text { 24-Feb-03 Mg }\end{array}$ & & 4770 & $\begin{array}{l}\mathrm{ug} / \mathrm{L} \\
\mathrm{ug} / \mathrm{L}\end{array}$ & & & & & & \\
\hline SESPSPEC & B16KW0 & 300 SPR $9-3(2 \mathrm{FT})$ & ONSITE & sw & $\mathrm{N}$ & DRIVE POINT & 24-Feb-03 Mg & & 5820 & $\frac{\mathrm{gght}}{\mathrm{ug} / \mathrm{h}}$ & & & & & & \\
\hline SESPSPEC & B16KV9 & 300 SPR $9-3(4$ IN) & ONSITE & SW & $\mathrm{N}$ & DRIVE POINT & 24-Feb-03 Mg & & 5710 & $\mathrm{ug} / \mathrm{L}$ & & & & & & \\
\hline $\begin{array}{l}\text { SESPSPEC } \\
\text { SESPSDEC }\end{array}$ & B180C6 & 100 B/C AREA UR & ONSITE & SW & Y & RIVER & 13-Nov-03 Mn & & 0.641 & $\mathrm{ug} / \mathrm{L}$ & & & C & & & \\
\hline $\begin{array}{l}\text { SESPSPEC } \\
\text { SESPSPCC }\end{array}$ & B180C7 & 100 B/C AREA UR & ONSITE & sW & $\begin{array}{l}\text { Y } \\
\text { Y }\end{array}$ & $\begin{array}{l}\text { RIVER } \\
\text { RIVER }\end{array}$ & 13-Nov-03 Mn & & 0.817 & $u g / L$ & & & $\mathrm{C}$ & & & \\
\hline $\begin{array}{l}\text { SESPSECC } \\
\text { SESPSPEC }\end{array}$ & $\begin{array}{l}\text { B180C8 } \\
\text { B180C9 }\end{array}$ & $\begin{array}{l}100 \mathrm{~B} / \mathrm{C} \text { AREA UR } \\
100 \mathrm{~B} / \mathrm{C} \text { AREA UR }\end{array}$ & $\begin{array}{l}\text { ONSITE } \\
\text { ONSTE }\end{array}$ & SW & $\begin{array}{r}Y \\
Y\end{array}$ & $\begin{array}{l}\text { RIVER } \\
\text { RIVER }\end{array}$ & $\begin{array}{l}\text { 13-Nov-03 Mn } \\
\text { 13-Nov-03 Mn }\end{array}$ & & 0.791 & $\mathrm{ug} / \mathrm{L}$ & & & $\mathrm{C}$ & & & \\
\hline $\begin{array}{l}\text { SESPSPEC } \\
\text { SEST }\end{array}$ & B180D0 & 100-B SPRING 38-3 & ONSITE & sw & $\begin{array}{r}\text { Y } \\
\end{array}$ & $\begin{array}{l}\text { RIVER } \\
\text { RIVER }\end{array}$ & $\begin{array}{l}\text { 13-nov-03 Mn } \\
\text { 13-Nov-03 Mn }\end{array}$ & & 0.964 & $\frac{u g / L}{u g / L}$ & & & $\begin{array}{l}\mathrm{c} \\
\mathrm{c}\end{array}$ & DUP IS SAMPLE \#B180J4 & & \\
\hline SESPSPEC & B180D1 & 100-B SPRING 38-3 & ONSITE & sw & Y & RIVER & 13-Nov-03 Mn & & 1.64 & $u g / L$ & & & C & & & \\
\hline SESPSPEC & B180D2 & 100-B SPRING 38-3 & ONSITE & sw & Y & RIVER & 13-Nov-03 Mn & & 1.6 & $\mathrm{ug} / \mathrm{L}$ & & & c & & & \\
\hline SESPSPEC & B180D3 & 100-B SPRING 38-3 & ONSITE & sW & Y & RIVER & 13-Nov-03 Mn & & 1.15 & $\mathrm{ug} / \mathrm{L}$ & & & C & & & \\
\hline $\begin{array}{l}\text { SESPSPEC } \\
\text { SESPSPCE }\end{array}$ & B180J4 & $\begin{array}{l}\text { 100-B SPRING 38-3 } \\
\text { 10-R SPRING 39-2 }\end{array}$ & ONSITE & sW & $\begin{array}{l}\text { Y } \\
\text { Y }\end{array}$ & $\begin{array}{l}\text { RIVER } \\
\text { RAVER }\end{array}$ & 13-Nov-03 Mn & & 1.51 & $\mathrm{ug} / \mathrm{L}$ & & & C & DUP SAMPLE FOR B180D0 & & \\
\hline $\begin{array}{l}\text { SESPSEC } \\
\text { SESPSPEC }\end{array}$ & $\begin{array}{l}\mathrm{B} 180 \mathrm{D} 4 \\
\mathrm{~B} 180 \mathrm{D} 5\end{array}$ & $\begin{array}{l}\text { 100-B SPRING 39-2 } \\
\text { 100-B SPRING 39-2 }\end{array}$ & $\begin{array}{l}\text { ONSITE } \\
\text { ONSITE }\end{array}$ & SW & $\begin{array}{l}\mathrm{Y} \\
\mathrm{Y}\end{array}$ & $\begin{array}{l}\text { IIVER } \\
\text { RIVER }\end{array}$ & $\begin{array}{l}\text { 13--Nov-03 Mn } \\
\text { 13-Nov-03 Mn }\end{array}$ & & 0.848 & $\mathrm{ug} / \mathrm{L}$ & & & $\begin{array}{l}\mathrm{C} \\
\mathrm{c}\end{array}$ & & & \\
\hline SESPSPEC & B180D6 & 100-B SPRING 39-2 & ONSITE & sw & Y & RIVER & 13-Nov-03 Mn & & 0.886 & $\frac{u g / L}{u g / L}$ & & & $\mathrm{c}$ & & & \\
\hline SESPSPEC & B180D7 & 100-B SPRING 39-2 & ONSITE & sw & Y & RIVER & 13-Nov-03 Mn & & 0.954 & $\mathrm{ug} / \mathrm{L}$ & & & c & & & \\
\hline SESPSPEC & B180F9 & 100-B SPRING DR 38-3 & ONSITE & SW & Y & RIVER & 13-Nov-03 Mn & & 1.25 & $\mathrm{ug} / \mathrm{L}$ & & & $\mathrm{c}$ & & & \\
\hline $\begin{array}{l}\text { SESPSPEC } \\
\text { SESPSPCF }\end{array}$ & B180F1 & $100 \mathrm{~B} / \mathrm{C}$ AREA DR & ONSITE & SW & Y & $\begin{array}{l}\text { RIVER } \\
\text { RIVER }\end{array}$ & 17-Nov-03 Mn & & 0.892 & $\mathrm{ug} / \mathrm{L}$ & & & c & & & \\
\hline $\begin{array}{l}\text { SESPSPEC } \\
\text { SESPSPEC }\end{array}$ & $\begin{array}{l}\text { B180F2 } \\
\text { B180F3 }\end{array}$ & $\begin{array}{l}100 \text { B/C AREA DR } \\
100 B C \text { AREADR }\end{array}$ & $\begin{array}{l}\text { ONSITE } \\
\text { ONSTEE }\end{array}$ & SW & $\begin{array}{r}\text { Y } \\
\text { Y }\end{array}$ & $\begin{array}{l}\text { RIVER } \\
\text { RIVER }\end{array}$ & $\begin{array}{l}\text { 17-Nov-03 Mn } \\
17 \text {-Nov-03 Mn }\end{array}$ & & 0.874 & $u g / L$ & & & $\mathrm{C}$ & & & \\
\hline $\begin{array}{l}\text { SESPSECC } \\
\text { SESPSPEC }\end{array}$ & $\begin{array}{l}\mathrm{B} 180 \mathrm{~F} 3 \\
\mathrm{~B} 180 \mathrm{~F} 4\end{array}$ & $\begin{array}{l}100 \mathrm{~B} / \mathrm{C} \text { AREA DR } \\
100 \mathrm{~B} / \mathrm{C} \text { AREA DR }\end{array}$ & $\begin{array}{l}\text { ONSITE } \\
\text { ONSITE }\end{array}$ & SW & $\begin{array}{l}\mathrm{Y} \\
\mathrm{Y}\end{array}$ & $\begin{array}{l}\text { IVER } \\
\text { RIVER }\end{array}$ & $\begin{array}{l}\text { 17-Nov-03 Mn } \\
\text { 17-Nov-03 Mn }\end{array}$ & & 0.997 & $\mathrm{ug} / \mathrm{L}$ & & & ${ }_{\mathrm{C}}^{\mathrm{C}}$ & & & \\
\hline $\begin{array}{l}\text { SESPSPEC } \\
\text { SEST }\end{array}$ & B180D8 & 100 B/C AREA OUTFL1 & ONSITE & sw & $\mathrm{Y}$ & $\begin{array}{l}\text { RIVER } \\
\text { RIVER }\end{array}$ & 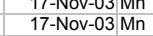 & & 0.856 & $\frac{u g / L}{u g / L}$ & & & c & & & \\
\hline SESPSPEC & B180D9 & $100 \mathrm{~B} / \mathrm{C}$ AREA OUTFL2 & ONSITE & sw & Y & RIVER & 17-Nov-03 Mn & & 0.916 & $\mathrm{ug} / \mathrm{L}$ & & & C & & & \\
\hline SESPSPEC & B180F0 & $100 \mathrm{~B} / \mathrm{C}$ AREA OUTFL3 & ONSITE & SW & Y & RIVER & 17-Nov-03 Mn & & 0.896 & $\mathrm{ug} / \mathrm{L}$ & & & C & & & \\
\hline $\begin{array}{l}\text { SESPSPEC } \\
\text { SECDSDES }\end{array}$ & B180K2 & Refer to WELL NAME column & & GW & $\begin{array}{l}Y \\
Y\end{array}$ & AQUIFER TUBE & 10-Dec-03 Mn & & 1.46 & $u g / L$ & & & C & & & 01-D \\
\hline $\begin{array}{l}\text { SESPSPEC } \\
\text { SESPSEC }\end{array}$ & $\begin{array}{l}\text { B180K3 } \\
\text { B18K4 }\end{array}$ & Refer to WELL NAME column & & GW & $\begin{array}{r}Y^{\prime} \\
\end{array}$ & $\begin{array}{l}\text { AQUIFER TUBE } \\
\text { AOUEFR TURE }\end{array}$ & $=10$-Dec-03 Mn & & 0.249 & ug/L & & & $\mathrm{C}$ & & & 04-D \\
\hline $\begin{array}{l}\text { SESPSPEC } \\
\text { SESPSPEC }\end{array}$ & $\begin{array}{l}\text { B180K4 } \\
\text { B180K5 }\end{array}$ & $\begin{array}{l}\text { Refer to WELL NAME collumn } \\
\text { Refer to WELL NAME column }\end{array}$ & & $\begin{array}{l}\text { GW } \\
\text { GW }\end{array}$ & $\begin{array}{l}\text { Y } \\
\text { Y }\end{array}$ & $\begin{array}{l}\text { AQUUFER TUBE } \\
\text { AQQUFER TUBE }\end{array}$ & $\begin{array}{l}10 \text {-Dec- }-03 \mathrm{Mn} \\
10 \text {-Dec-03 Mn }\end{array}$ & & $\begin{array}{r}2.13 \\
2.94\end{array}$ & $\mathrm{ug} / \mathrm{L}$ & & & ${ }_{\mathrm{C}}^{\mathrm{C}}$ & & & 05-D \\
\hline $\begin{array}{l}\text { SESPSPEC } \\
\text { SESPEC }\end{array}$ & $\begin{array}{l}\text { B180K5 } \\
\text { B16KT8 }\end{array}$ & 300 SPR 7 - 1 (2.5FT) & ONSITE & sw & $\frac{n}{4}$ & $\begin{array}{l}\text { DQUIVE POINT } \\
\text { DRIF }\end{array}$ & 24-Feb-03 $\mathrm{Na}$ & & 20300 & $\frac{u g / L}{u g / L}$ & & & & & & \\
\hline SESPSPEC & B16KT9 & 300 SPR $7-1$ (4 FT) & ONSITE & sw & $\mathrm{N}$ & DRIVE POINT & 24-Feb-03 Na & & 25400 & $\mathrm{ug} / \mathrm{L}$ & & & & & & \\
\hline SESPSPEC & B16KT7 & 300 SPR $7-1$ (4 IN) & ONSITE & SW & $N$ & DRIVE POINT & 24-Feb-03 $\mathrm{Na}$ & & 15300 & $\mathrm{ug} / \mathrm{L}$ & & & & & & \\
\hline $\begin{array}{l}\text { SESPSPEC } \\
\text { SESPSPCE }\end{array}$ & B16KV0 & 300 SPR 7 - 1 (6 FT) & ONSITE & sw & $\mathrm{N}$ & DRIVE POINT & 24-Feb-03 Na & & 27900 & $u g / L$ & & & & & & \\
\hline $\begin{array}{l}\text { SESPSPEC } \\
\text { SESPSPEC }\end{array}$ & B16KV2 & $\begin{array}{l}300 \text { SPR } 7 \text {-2 (2 FT) } \\
300 \text { SPR } 7-2 \text { (4 IN }\end{array}$ & ONSITE & SW & $\begin{array}{l}n \\
N\end{array}$ & DRIVE POINT & 24-Feb-03 Na & & 24900 & $u g / L$ & & & & & & \\
\hline $\begin{array}{l}\text { SESPSECC } \\
\text { SESPSPEC }\end{array}$ & $\begin{array}{l}\text { B16KV1 } \\
\text { B16KV4 }\end{array}$ & $\begin{array}{l}300 \mathrm{SPR} 7-2 \text { - (4 IN) } \\
300 \mathrm{SPR} 9-1(2 \mathrm{FT})\end{array}$ & $\begin{array}{l}\text { ONSITE } \\
\text { ONSITE }\end{array}$ & SW & $\frac{N}{N}$ & $\begin{array}{l}\text { DRIVE POINT } \\
\text { DRIVE POINT }\end{array}$ & $\begin{array}{l}\text { 24-Feb-03 } \mathrm{Na} \\
24-\mathrm{Feb}-03 \mathrm{Na}\end{array}$ & & $\begin{array}{l}20500 \\
15600\end{array}$ & $\mathrm{ug} / \mathrm{L}$ & & & & & & \\
\hline SESPSPEC & B16KV5 & 300 SPR $9-1$ (4 FT) & ONSITE & sw & $\mathrm{N}$ & $\begin{array}{l}\text { DRIVE POINT } \\
\text { DRIVE }\end{array}$ & $24-\mathrm{Feb}-03 \mathrm{Na}$ & & 7610 & ug/h & & & & & & \\
\hline SESPSPEC & B16KV3 & 300 SPR 9 - 1 (4 IN) & ONSITE & sw & $N$ & DRIVE POINT & 24-Feb-03 Na & & 6090 & $\mathrm{ug} / \mathrm{L}$ & & & & & & \\
\hline SESPSPEC & B16KV7 & 300 SPR 9 -2 (2 FT) & ONSITE & SW & $\mathrm{N}$ & DRIVE POINT & 24-Feb-03 Na & & 11000 & $\mathrm{ug} / \mathrm{L}$ & & & & & & \\
\hline $\begin{array}{l}\text { SESPSPEC } \\
\text { SECDSDC }\end{array}$ & B16KV6 & 300 SPR 9 -2 (4 IN) & ONSITE & sw & $\mathrm{N}$ & DRIVE POINT & 24-Feb-03 Na & & 3030 & $u g / L$ & & & & & & \\
\hline $\begin{array}{l}\text { SESPSPEC } \\
\text { SESPSPEC }\end{array}$ & $\begin{array}{l}\text { B16KV8 } \\
\text { B16KWO }\end{array}$ & $\begin{array}{l}300 \mathrm{SPR} 9-2 \text { - (4.5FT) } \\
300 \mathrm{SPR} 9-3(\mathrm{FT})\end{array}$ & $\begin{array}{l}\text { ONSITE } \\
\text { ONSITE }\end{array}$ & $\begin{array}{l}\text { sw } \\
\text { sw }\end{array}$ & $\begin{array}{l}n \\
N\end{array}$ & $\begin{array}{l}\text { DRIVE POINT } \\
\text { DRIVE POINT }\end{array}$ & $\begin{array}{l}\text { 24-Feb-03 Na } \\
\text { 24-Feb-03 Na }\end{array}$ & & $\begin{array}{l}11000 \\
10500\end{array}$ & $\mathrm{ug} / \mathrm{L}$ & & & & & & \\
\hline $\begin{array}{l}\text { SESPSEC } \\
\text { SESPSPEC }\end{array}$ & $\begin{array}{l}\text { B16KW0 } \\
\text { B16KV9 }\end{array}$ & $\begin{array}{l}300 \mathrm{SPR} 9-3(2 \mathrm{FT}) \\
300 \mathrm{SPR} 9-3(4 \mathrm{IN})\end{array}$ & $\begin{array}{l}\text { ONSIIE } \\
\text { ONSITE }\end{array}$ & SW & $\frac{N}{N}$ & $\begin{array}{l}\text { DRIVE POINT } \\
\text { DRIVE POINT }\end{array}$ & $\begin{array}{l}\text { 24-Feb-03 Na } \\
\text { 24-Feb-03 Na }\end{array}$ & & $\begin{array}{l}10500 \\
4590\end{array}$ & $\frac{u g / L}{u g / L}$ & & & & & & \\
\hline SESPSPEC & B16KT8 & 300 SPR $7-1$ (2.5FT) & ONSITE & sw & $\mathrm{N}$ & DRIVE POINT & 24-Feb-03 Ni & & $\begin{array}{r}4590 \\
1.71\end{array}$ & ug/L & & & & & & \\
\hline SESPSPEC & B16KT9 & 300 SPR 7 -1 (4 FT) & ONSITE & sw & $N$ & DRIVE POINT & 24-Feb-03 Ni & & 0.649 & $\mathrm{ug} / \mathrm{L}$ & & & & & & \\
\hline SESPSPEC & B16KT7 & 300 SPR $7-1$ (4 IN) & ONSITE & SW & $N$ & DRIVE PC & 24-Feb-03 Ni & & 1.08 & $u g / L$ & & & & & & \\
\hline $\begin{array}{l}\text { SESPSPEC } \\
\text { SESPSEFC }\end{array}$ & B16KV0 & 300 SPR $7-1$ (6 FT) & ONSITE & sW & $\mathrm{N}$ & DRIVE POINT & 24-Feb-03 Ni & & 3.62 & $u g / L$ & & & & & & \\
\hline $\begin{array}{l}\text { SESPSPCC } \\
\text { SESPSPEC }\end{array}$ & B16KV2 & 300 SPR $7-2$ (2 FT) & ONSITE & SW & N & DRIVE POINT & 24-Feb-03 Ni & & 2.48 & ug/L & & & & & & \\
\hline $\begin{array}{l}\text { SESPSEC } \\
\text { SESPSPEC }\end{array}$ & $\begin{array}{l}\text { B16KV1 } \\
\text { B16KV4 }\end{array}$ & $\begin{array}{l}300 \text { SPR } 7-2(4 \mathrm{IN}) \\
300 \text { SPR } 9 \text { - }(2 \mathrm{FT})\end{array}$ & $\begin{array}{l}\text { ONSITE } \\
\text { ONSITE }\end{array}$ & $\begin{array}{l}\text { SW } \\
\text { sw }\end{array}$ & $\begin{array}{l}n \\
N\end{array}$ & $\begin{array}{l}\text { DRIVE POINT } \\
\text { DRIVE POINT }\end{array}$ & $\begin{array}{l}\text { 24-Feb-03 Ni } \\
\text { 24-Feb-03 Ni }\end{array}$ & & $\begin{array}{l}1.32 \\
0.341\end{array}$ & $\begin{array}{ll}\mathrm{ug} / \mathrm{L} \\
\mathrm{ug} / \mathrm{L}\end{array}$ & & & & & & \\
\hline $\begin{array}{l}\text { SESPSPPEC } \\
\text { SESPEC }\end{array}$ & $\begin{array}{l}\text { B16KV4 } \\
\text { B16KV5 }\end{array}$ & $\begin{array}{l}300 \mathrm{SPR} 9-1(\mathrm{FI}) \\
300 \mathrm{SPR} 9-1(4 \mathrm{FT})\end{array}$ & $\begin{array}{l}\text { ONSIIE } \\
\text { ONSITE }\end{array}$ & sw & $\frac{N}{N}$ & $\begin{array}{l}\text { DRIVE POINT } \\
\text { DRIVE POINT }\end{array}$ & $\begin{array}{l}\text { 24-Feb-03 } \mathrm{Ni} \\
\text { 24-Feb-03 Ni }\end{array}$ & & $\begin{array}{c}0.341 \\
1.55\end{array}$ & $\begin{array}{l}\mathrm{ug} / \mathrm{L} \\
\mathrm{ug} / \mathrm{L}\end{array}$ & & & & & & \\
\hline SESPSPEC & B16KV3 & 300 SPR 9 -1 (4 IN) & ONSITE & sw & $\mathrm{N}$ & DRIVE POINT & 24-Feb-03 Ni & & 1.64 & ug/L & & & & & & \\
\hline SESPSPEC & B16KV7 & 300 SPR 9 -2 (2 FT) & ONSITE & sw & $\mathrm{N}$ & DRIVE POINT & 24-Feb-03 Ni & & 1.76 & $\mathrm{ug} / \mathrm{L}$ & & & & & & \\
\hline
\end{tabular}


WATER - ASSORTED NON-ROUTINE SAMPLING EVENTS

\begin{tabular}{|c|c|c|c|c|c|c|c|c|c|c|c|c|c|c|c|c|}
\hline OWNER ID & SAMP NUM & SAMP SITE NAME & DIST CLASS & MEDIA & $\begin{array}{c}\text { FILTERED } \\
\text { FLAG }\end{array}$ & SAMP FROM & |SAMP DATE| & CON SHORT NAME & |VALUE RPTD| & $\begin{array}{l}\text { ANAL } \\
\text { UNITS } \\
\text { RPTD }\end{array}$ & $\mid \begin{array}{c}\text { COUNTING } \\
\text { ERROR }\end{array}$ & \begin{tabular}{|c|} 
TOTAL \\
ANAL \\
ERROR
\end{tabular} & $\left|\begin{array}{c}\text { LAB } \\
\text { QUALIFIER }\end{array}\right|$ & SAMP COMMENT & $\begin{array}{c}\text { RESULT } \\
\text { COMMENT }\end{array}$ & |WELL NAME \\
\hline SESPSPEC & B16KV6 & 300 SPR $9-2(4$ IN) & ONSITE & sw & $\mathrm{N}$ & DRIVE POINT & 24-Feb-03 Ni & & 2.21 & ug/L & & & & & & \\
\hline $\begin{array}{l}\text { SESPSPEC } \\
\text { SESPSEC }\end{array}$ & $\begin{array}{l}\text { B16KV8 } \\
\text { B16KWVO }\end{array}$ & 300 SPR $9-2$ (4.5FT) & ONSITE & SW & N & DRIVE POINT & 24-Feb-03 Ni & & 1.31 & $\mathrm{ug} / \mathrm{L}$ & & & & & & \\
\hline $\begin{array}{l}\text { SESPSPEC } \\
\text { SESPSEC }\end{array}$ & $\begin{array}{l}\text { B16KWO } \\
\text { B16KYq }\end{array}$ & 300 SPR $9-3$ (2 FT) & ONSITE & SW & 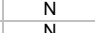 & $\begin{array}{l}\text { DRIVE POINT } \\
\text { DRIVE POINT }\end{array}$ & 24-Feb-03 Ni & & 4.66 & $u g / L$ & & & & & & \\
\hline $\begin{array}{l}\text { SESPSEEC } \\
\text { SESPSPEC }\end{array}$ & $\begin{array}{l}\text { B16KV9 } \\
\text { B16WP2 }\end{array}$ & $\begin{array}{l}300 \text { SPR } 9 \text {-3 ( } 4 \text { IN) } \\
\text { YAKIMA RIVER }\end{array}$ & $\begin{array}{l}\text { ONSITE } \\
\text { OFFITE }\end{array}$ & $\begin{array}{l}\text { sw } \\
\text { sw }\end{array}$ & $\begin{array}{l}\mathrm{N} \\
\mathrm{Y}\end{array}$ & $\begin{array}{l}\text { DRIVE POINT } \\
\text { RIVER }\end{array}$ & $\begin{array}{l}\text { 24-Feb-03 Ni } \\
14-\mathrm{May}-03 \mathrm{Ni}\end{array}$ & & $\begin{array}{r}7.12 \\
0.571\end{array}$ & ug/L & & & & & & \\
\hline SESPSPEC & B16WP3 & YAKIMA RIVER & OFFSITE & sw & $\begin{array}{l}\text { Y } \\
\text { Y }\end{array}$ & $\begin{array}{l}\text { RIVRR } \\
\text { RIVER }\end{array}$ & $\begin{array}{l}14-\mathrm{May}-03 \mathrm{NI} \\
14 \mathrm{May}-03 \mathrm{Ni}\end{array}$ & & 0.571 & $\frac{\mathrm{ug} g \mathrm{~L}}{\mathrm{ug} / \mathrm{L}}$ & & & & & & \\
\hline SESPSPEC & B16WP4 & YAKIMA RIVER & OFFSITE & sw & $\mathrm{Y}$ & RIVER & 14-May-03 Ni & & 0.523 & ug/L & & & & & & \\
\hline $\begin{array}{l}\text { SESPSPEC } \\
\text { SESPSDC }\end{array}$ & B16WP5 & YAKIMA RIVER & OFFSITE & sw & N & RIVER & $14-\mathrm{May}-03 \mathrm{Ni}$ & & 0.763 & $\mathrm{ug} / \mathrm{L}$ & & & & & & \\
\hline $\begin{array}{l}\text { SESPSPEC } \\
\text { SESPSDC }\end{array}$ & B16WP6 & YAKIMA RIVER & OFFSITE & SW & $\mathrm{N}$ & RIVER & 14-May-03 Ni & & 0.696 & $\mathrm{ug} / \mathrm{L}$ & & & & & & \\
\hline $\begin{array}{l}\text { SESPSPEC } \\
\text { SESPSEC }\end{array}$ & B16WP7 & $\begin{array}{l}\text { YAKIMA RIVER } \\
\text { HONKIN SHORE }\end{array}$ & OFFSITE & SW & $\mathrm{N}$ & $\begin{array}{l}\text { RIVER } \\
\text { RIVER }\end{array}$ & 14-May-03 Ni & & 0.721 & $\mathrm{ug} / \mathrm{L}$ & & & & & & \\
\hline $\begin{array}{l}\text { SESPSPEC } \\
\text { SESPSPEC }\end{array}$ & $\begin{array}{l}\text { B16WR5 } \\
\text { B16WR8 }\end{array}$ & $\begin{array}{l}\text { HOOD PARK-FRANKLIN CO. SHORE } \\
\text { HOOD PARK-FRANKLIN CO. SHORE }\end{array}$ & $\begin{array}{l}\text { OFFSITE } \\
\text { OFFSITE }\end{array}$ & sw & $\begin{array}{l}\mathrm{Y} \\
\mathrm{N}\end{array}$ & $\begin{array}{l}\text { RIVER } \\
\text { RIVER }\end{array}$ & $\begin{array}{l}15-\mathrm{May}-03 \mathrm{Ni} \\
15-\mathrm{May}-03 \mathrm{Ni}\end{array}$ & & $\begin{array}{r}0.801 \\
0.0703\end{array}$ & $\frac{\mathrm{ug} / \mathrm{L}}{\mathrm{ug} / \mathrm{L}}$ & & & & & & \\
\hline SESPSPEC & B16WR4 & HOOD PARK-MID-RIVER & OFFSITE & sw & Y & RIVER & $15-\mathrm{May}-03 \mathrm{Ni}$ & & 0.0303 & ug/L & & & B & & & \\
\hline SESPSPEC & B16WR9 & HOOD PARK-MID-RIVER & OFFSITE & sw & N & RIVER & $15-\mathrm{May}-03 \mathrm{Ni}$ & & 0.0838 & $\mathrm{ug} / \mathrm{L}$ & & & & & & \\
\hline SESPSPEC & B16WR6 & HOOD PARK-WALLA WALLA SHORE & OFFSITE & sw & Y & RIVER & 15-May-03 Ni & & 0.0317 & $\mathrm{ug} / \mathrm{L}$ & & & B & & & \\
\hline $\begin{array}{l}\text { SESPSPEC } \\
\text { SESPSPC }\end{array}$ & B16WR7 & HOOD PARK-WALLA WALLA SHORE & OFFSITE & SW & $\mathrm{N}$ & RIVER & 15-May-03 Ni & & 0.102 & $\mathrm{ug} / \mathrm{L}$ & & & & & & \\
\hline $\begin{array}{l}\text { SESPSPCC } \\
\text { SESPSPEC }\end{array}$ & $\begin{array}{l}\text { B16WN6 } \\
\text { B16WP1 }\end{array}$ & $\begin{array}{l}\text { MCNARY MID-RIVER NEAR DAM } \\
\text { MCNARY MID-RIVRR NEAR DAM }\end{array}$ & $\begin{array}{l}\text { OFFSSTE } \\
\text { OFFITE }\end{array}$ & $\begin{array}{l}\text { sw } \\
\text { sw }\end{array}$ & Y & $\begin{array}{l}\text { RIVER } \\
\text { RIVER }\end{array}$ & 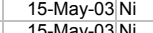 & & 0.297 & $\mathrm{ug} / \mathrm{L}$ & & & & & & \\
\hline $\begin{array}{l}\text { SESPSECC } \\
\text { SESPSPEC }\end{array}$ & $\begin{array}{l}\text { B16WP1 } \\
\text { B16WN8 }\end{array}$ & $\begin{array}{l}\text { MCNARY MID-RIVER NEAR DAM } \\
\text { MCNARY-OR SIDENEAR DAM }\end{array}$ & $\begin{array}{l}\text { OFFSSTE } \\
\text { OFFITE }\end{array}$ & sw & $\begin{array}{l}\mathrm{y} \\
\mathrm{N}\end{array}$ & $\begin{array}{l}\text { IVIVER } \\
\text { RIVER }\end{array}$ & $\begin{array}{l}15-\mathrm{May}-03 \mathrm{Ni} \\
15 \mathrm{May}-03 \mathrm{Ni}\end{array}$ & & 0.348 & ug/L & & & & & & \\
\hline $\begin{array}{l}\text { SESPSPEC } \\
\text { SEST }\end{array}$ & $\begin{array}{l}\text { B16WN8 } \\
\text { B16WN9 }\end{array}$ & MCNARY-OR.SIDE NEAR DAM & $\begin{array}{l}\text { OFFSIIE } \\
\text { OFFITE }\end{array}$ & sw & $\mathrm{H}^{\mathrm{N}}$ & $\begin{array}{l}\text { RIVER } \\
\text { RIVER }\end{array}$ & $\begin{array}{l}\text { 15-May-03 } \mathrm{NI} \\
15-\mathrm{May}-03 \mathrm{Ni}\end{array}$ & & 0.291 & $\begin{array}{l}\mathrm{ugh/2} \\
\mathrm{ug} / \mathrm{L}\end{array}$ & & & & & & \\
\hline SESPSPEC & B16WN7 & MCNARY-WASH.SIDE NEAR DAM & OFFSITE & sw & Y & RIVER & $15-\mathrm{May}-03 \mathrm{Ni}$ & & 0.357 & $\mathrm{ug} / \mathrm{L}$ & & & & & & \\
\hline SESPSPEC & B16WP0 & MCNARY-WASH.SIDE NEAR DAM & OFFSITE & sw & $\mathrm{N}$ & RIVER & 15-May-03 Ni & & 0.305 & $\mathrm{ug} / \mathrm{L}$ & & & & & & \\
\hline $\begin{array}{l}\text { SESPSPEC } \\
\text { SESPSEC }\end{array}$ & B16WP8 & $\begin{array}{l}\text { WALLA WALLA-RIVER } \\
\text { WALA WALA-RIVER }\end{array}$ & $\begin{array}{l}\text { OFFSITE } \\
\text { OFFITE }\end{array}$ & SW & $\begin{array}{l}Y \\
Y \\
Y\end{array}$ & $\begin{array}{l}\text { RIVER } \\
\text { RIVER }\end{array}$ & 15-May-03 Ni & & 0.159 & $\mathrm{ug} / \mathrm{L}$ & & & & & & \\
\hline $\begin{array}{l}\text { SESPSPCC } \\
\text { SESPSEC }\end{array}$ & B16WP9 & WALLA WALLA-RIVER & OFFSITE & SW & $\begin{array}{l}\text { Y } \\
\text { y }\end{array}$ & $\begin{array}{l}\text { RIVER } \\
\text { RIVER }\end{array}$ & 15-May-03 Ni & & 0.181 & $\mathrm{ug} / \mathrm{L}$ & & & & & & \\
\hline $\begin{array}{l}\text { SESPSECC } \\
\text { SESPPEC }\end{array}$ & $\begin{array}{l}\text { B16WR0 } \\
\text { B16WR1 }\end{array}$ & $\begin{array}{l}\text { WALLA WALLA-RIVER } \\
\text { WALA WALA-RVER }\end{array}$ & $\begin{array}{l}\text { OFFSSTE } \\
\text { OFFSTE }\end{array}$ & SW & 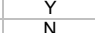 & $\begin{array}{l}\text { RIVER } \\
\text { RIVER }\end{array}$ & $\begin{array}{l}15-\mathrm{May}-03 \mathrm{Ni} \\
15 \mathrm{May}-03 \mathrm{Ni}\end{array}$ & & $\begin{array}{r}1.78 \\
0.439\end{array}$ & $\mathrm{ug} / \mathrm{L}$ & & & & & & \\
\hline $\begin{array}{l}\text { SESPSEC } \\
\text { SESPSPEC }\end{array}$ & $\begin{array}{l}\text { B16WR1 } \\
\text { B16WR2 }\end{array}$ & $\begin{array}{l}\text { WALLA WALLA-IVER } \\
\text { WALLA WALLA-RIVER }\end{array}$ & $\begin{array}{l}\text { OFFSITE } \\
\text { OFFITE }\end{array}$ & SW & $\frac{N}{N}$ & $\begin{array}{l}\text { RIVER } \\
\text { RIVER }\end{array}$ & $\begin{array}{l}\text { 15-May-03 } \mathrm{Ni} \\
15-\mathrm{May}-03 \mathrm{Ni}\end{array}$ & & 0.439 & $\mathrm{ugh/L}$ & & & & & & \\
\hline SESPSPEC & B16WR3 & WALLA WALLA-RIVER & OFFSITE & sw & $\mathrm{N}$ & RIVER & $15-\mathrm{May}-03 \mathrm{Ni}$ & & 0.486 & $\mathrm{ug} / \mathrm{L}$ & & & & & & \\
\hline SESPSPEC & B180C6 & $100 \mathrm{~B} / \mathrm{C}$ AREA UR & ONSITE & sw & $\mathrm{Y}$ & RIVER & 13-Nov-03 Ni & & 0.949 & $\mathrm{ug} / \mathrm{L}$ & & & c & & & \\
\hline SESPSPEC & B180C7 & 100 B/C AREA UR & ONSITE & sw & Y & RIVER & 13-Nov-03 Ni & & 1.01 & $\mathrm{ug} / \mathrm{L}$ & & & c & & & \\
\hline $\begin{array}{l}\text { SESPSPEC } \\
\text { SESPSEC }\end{array}$ & B180C8 & 100 B/C AREA UR & ONSITE & SW & $\begin{array}{r}\text { Y } \\
\text { y }\end{array}$ & $\begin{array}{l}\text { RIVER } \\
\text { RIVER }\end{array}$ & 13-Nov-03 Ni & & 1.08 & $\mathrm{ug} / \mathrm{L}$ & & & C & & & \\
\hline $\begin{array}{l}\text { SESPSEC } \\
\text { SESPSPEC }\end{array}$ & $\begin{array}{l}\text { B180C9 } \\
\text { B180D0 }\end{array}$ & $\begin{array}{l}\text { 100 B/C AREA UR } \\
\text { 100-B SPRING 38-3 }\end{array}$ & $\begin{array}{l}\text { ONSIIE } \\
\text { ONSITE }\end{array}$ & sw & $\begin{array}{l}\text { Y } \\
\text { Y }\end{array}$ & $\begin{array}{l}\text { RIVER } \\
\text { RIVER }\end{array}$ & $\begin{array}{l}\text { 13-Nov-03 } \mathrm{Ni} \\
13-\text { Nov-03 }\end{array}$ & & $\begin{array}{l}1.14 \\
1.15\end{array}$ & $\frac{\mathrm{ugg} / \mathrm{L}}{\mathrm{ug} / \mathrm{L}}$ & & & $\begin{array}{l}\mathrm{C} \\
\mathrm{C}\end{array}$ & DUP IS SAMPLE \#B180J4 & & \\
\hline SESPSPEC & B180D1 & 100-B SPRING 38-3 & ONSITE & sw & Y & RIVER & 13-Nov-03 Ni & & 1.16 & $\mathrm{ug} / \mathrm{L}$ & & & C & & & \\
\hline SESPSPEC & B180D2 & 100-B SPRING 38-3 & ONSITE & sw & $Y$ & RIVER & 13-Nov-03 Ni & & 1.11 & $\mathrm{ug} / \mathrm{L}$ & & & c & & & \\
\hline SESPSPEC & B180D3 & 100-B SPRING 38-3 & ONSITE & SW & $Y$ & RIVER & 13-Nov-03 Ni & & 1.13 & $\mathrm{ug} / \mathrm{L}$ & & & $\mathrm{C}$ & & & \\
\hline $\begin{array}{l}\text { SESPSPEC } \\
\text { SESPSPCF }\end{array}$ & B180J4 & 100-B SPRING 38-3 & ONSITE & SW & $\begin{array}{l}Y \\
Y \\
\end{array}$ & $\begin{array}{l}\text { RIVER } \\
\text { RIVER }\end{array}$ & 13-Nov-03 Ni & & 1.13 & $\mathrm{ug} / \mathrm{L}$ & & & C & DUP SAMPLE FOR B180D0 & & \\
\hline $\begin{array}{l}\text { SESPSPEC } \\
\text { SESPSEC }\end{array}$ & B180D4 & $\begin{array}{l}\text { 100-B SPRING 39-2 } \\
\text { 100-B SPRING 39-2 }\end{array}$ & ONSITE & SW & $\begin{array}{r}\text { Y } \\
\text { y }\end{array}$ & $\begin{array}{l}\text { RIVER } \\
\text { RIVER }\end{array}$ & 13-Nov-03 Ni & & 1.12 & $\mathrm{ug} / \mathrm{L}$ & & & $\mathrm{C}$ & & & \\
\hline $\begin{array}{l}\text { SESPSECC } \\
\text { SESPSPEC }\end{array}$ & $\begin{array}{l}\text { B180D5 } \\
\text { B180D6 }\end{array}$ & $\begin{array}{l}\text { 100-B SPRING 39-2 } \\
\text { 100-B SPRING 39-2 }\end{array}$ & $\begin{array}{l}\text { ONSITE } \\
\text { ONSITE }\end{array}$ & $\begin{array}{l}\text { SW } \\
\text { SW }\end{array}$ & $\begin{array}{r}Y \\
Y\end{array}$ & $\begin{array}{l}\text { IVER } \\
\text { RIVER }\end{array}$ & $\begin{array}{l}\text { 13-Nov-03 Ni } \\
\text { 13-Nov-03 Ni }\end{array}$ & & $\begin{array}{r}1.2 \\
1.2\end{array}$ & $\mathrm{ug} / \mathrm{L}$ & & & ${ }_{\mathrm{C}}^{\mathrm{C}}$ & & & \\
\hline SESPSPEC & B180D7 & 100-B SPRING 39-2 & $\begin{array}{l}\text { ONSITE } \\
\text { ONS }\end{array}$ & sw & $\begin{array}{l}\mathrm{Y} \\
\mathrm{C}\end{array}$ & $\begin{array}{l}\text { RIVER } \\
\text { RIVER }\end{array}$ & 13-Nov-03 $\mathrm{Ni}$ & & $\begin{array}{l}.1 .12 \\
1.08\end{array}$ & $\begin{array}{l}u g h / 2 \\
\text { ug/L }\end{array}$ & & & $\mathrm{c}$ & & & \\
\hline SESPSPEC & B180F9 & 100-B SPRING DR 38-3 & ONSITE & sw & $Y$ & RIVER & 13-Nov-03 Ni & & 1.24 & $\mathrm{ug} / \mathrm{L}$ & & & c & & & \\
\hline SESPSPEC & B180F1 & 100 B/C AREA DR & ONSITE & SW & Y & RIVER & 17-Nov-03 Ni & & 1.09 & $\mathrm{ug} / \mathrm{L}$ & & & C & & & \\
\hline $\begin{array}{l}\text { SESPSPEC } \\
\text { SESPSPCC }\end{array}$ & B180F2 & 100 B/C AREA DR & ONSITE & & $\begin{array}{r}Y \\
Y \\
Y\end{array}$ & RIVER & 17-Nov-03 Ni & & 1.08 & $\mathrm{ug} / \mathrm{L}$ & & & c & & & \\
\hline $\begin{array}{l}\text { SESPSEEC } \\
\text { SESPSPEC }\end{array}$ & $\begin{array}{l}B 18003 \\
B 18054\end{array}$ & $\begin{array}{l}100 \text { B/C AREA DR } \\
100 \text { BCC AREADR }\end{array}$ & ONSITE & SW & $\begin{array}{r}Y \\
Y \\
Y\end{array}$ & $\begin{array}{l}\text { RIVER } \\
\text { RIVER }\end{array}$ & 17-Nov-03 Ni & & 1.45 & ug/L & & & C & & & \\
\hline $\begin{array}{l}\text { SESPSEEC } \\
\text { SESPSPEC }\end{array}$ & $\begin{array}{l}\text { B180F4 } \\
\text { B180D8 }\end{array}$ & $\begin{array}{l}100 \text { B/C AREA DR } \\
100 \text { B/C AREA OUTFL1 }\end{array}$ & $\begin{array}{l}\text { ONSIIE } \\
\text { ONSITE }\end{array}$ & $\begin{array}{l}\text { SW } \\
\text { sw }\end{array}$ & $\begin{array}{l}\text { Y } \\
\text { Y }\end{array}$ & $\begin{array}{l}\text { RIVER } \\
\text { RIVER }\end{array}$ & $\begin{array}{l}\text { 17-N-Nov-03 } \mathrm{Ni} \\
17 \text {-Nov-03 } \mathrm{Ni}\end{array}$ & & $\begin{array}{l}1.12 \\
1.08\end{array}$ & $\mathrm{ug} / \mathrm{h}$ & & & $\begin{array}{l}\mathrm{C} \\
\mathrm{C}\end{array}$ & & & \\
\hline SESPSPEC & B180D9 & 100 B/C AREA OUTFL2 & ONSITE & sw & $\mathrm{Y}$ & RIVER & $17-\mathrm{Nov}-03 \mathrm{Ni}$ & & 1.04 & $\mathrm{ug} / \mathrm{L}$ & & & c & & & \\
\hline SESPSPEC & B180F0 & 100 B/C AREA OUTFL3 & ONSITE & sw & Y & RIVER & 17-Nov-03 Ni & & 1.11 & $\mathrm{ug} / \mathrm{L}$ & & & c & & & \\
\hline SESPSPEC & B180K2 & Refer to WELL NAME column & & GW & Y & AQUIFER TUBE & $10-\mathrm{Dec}-03 \mathrm{Ni}$ & & 0.908 & ug/L & & & & & & 01-D \\
\hline $\begin{array}{l}\text { SESPSPEC } \\
\text { SESPSDEC }\end{array}$ & B180K3 & Refer to WELL NAME column & & GW & $\begin{array}{l}Y \\
Y \\
Y\end{array}$ & AQUIFER TUBE & $10-\mathrm{Dec}-03 \mathrm{Ni}$ & & 1.33 & $\mathrm{ug} / \mathrm{L}$ & & & & & & 04-D \\
\hline $\begin{array}{l}\text { SESPSPEC } \\
\text { SESPSEC }\end{array}$ & B180K4 & Refer to WELL NAME column & & GW & $\begin{array}{r}\text { y } \\
\text { y }\end{array}$ & AQUIFER TUBE & 10-Dec-03 Ni & & 1.44 & ug/L & & & & & & 05-D \\
\hline $\begin{array}{l}\text { SESPSEEC } \\
\text { SESPSPEC }\end{array}$ & $\begin{array}{l}\text { B180K5 } \\
\text { B16WP2 }\end{array}$ & $\begin{array}{l}\text { Refer to WELL NAME column } \\
\text { YAKIMA RIVER }\end{array}$ & OFFSITE & $\begin{array}{l}\text { GW } \\
\text { SW }\end{array}$ & $\begin{array}{l}\text { Y } \\
\text { Y }\end{array}$ & $\begin{array}{l}\text { AQUUFER TUBE } \\
\text { RIVER } \\
\end{array}$ & $\begin{array}{l}10-\mathrm{Dec}-03 \mathrm{Ni} \\
14-\mathrm{May}-03 \mathrm{~Pb}\end{array}$ & & $\begin{array}{r}1.65 \\
0.0155\end{array}$ & $\mathrm{ug} / \mathrm{h}$ & & & B & & & $06-\mathrm{D}$ \\
\hline SESPSPEC & B16WP3 & YAKIMA RIVER & OFFSITE & sw & Y & RIVER & 14-May-03 Pb & & 0.0223 & ug/L & & & & & & \\
\hline SESPSPEC & B16WP4 & YAKIMA RIVER & OFFSITE & sw & Y & RIVER & 14-May-03 Pb & & 0.0212 & $\mathrm{ug} / \mathrm{L}$ & & & & & & \\
\hline SESPSPEC & B16WP5 & YAKIMA RIVER & OFFSITE & sw & $\mathrm{N}$ & RIVER & 14-May- $03 \mathrm{~Pb}$ & & 0.12 & $\mathrm{ug} / \mathrm{L}$ & & & & & & \\
\hline $\begin{array}{l}\text { SESPSPEC } \\
\text { SESPGDC }\end{array}$ & B16WP6 & YAKIMA RIVER & OFFSITE & sw & $\mathrm{N}$ & RIVER & 14-May- $03 \mathrm{~Pb}$ & & 0.109 & $\mathrm{ug} / \mathrm{L}$ & & & & & & \\
\hline $\begin{array}{l}\text { SESPSPCC } \\
\text { SESPPEC }\end{array}$ & B16WP7 & YAKIMA RIVER & $\begin{array}{l}\text { OFFSSTE } \\
\text { OFFSTTE }\end{array}$ & $\begin{array}{l}\text { SW } \\
\text { sw }\end{array}$ & $\begin{array}{l}\mathrm{y} \\
\mathrm{N}\end{array}$ & $\begin{array}{l}\text { IVIVR } \\
\text { RIVER }\end{array}$ & $\begin{array}{l}\text { 14-May-03 Pb } \\
\text { 15-May-03 Pb }\end{array}$ & & 0.108 & $\mathrm{ug} / \mathrm{L}$ & & & & & & \\
\hline $\begin{array}{l}\text { SESPSEC } \\
\text { SESPPEC }\end{array}$ & $\begin{array}{l}\text { B16WR25 } \\
\text { B16WR8 }\end{array}$ & $\begin{array}{l}\text { HOOD PARR-FRANLLIN CO. SHORE } \\
\text { HOOD PARK-FRANKLIN CO SHORE }\end{array}$ & $\begin{array}{l}\text { OFFSSTE } \\
\text { OFFITE }\end{array}$ & $\begin{array}{l}\text { SW } \\
\text { sw }\end{array}$ & $\frac{\mathrm{N}}{\mathrm{N}}$ & $\begin{array}{l}\text { RIVER } \\
\text { RIVER }\end{array}$ & $\begin{array}{l}\text { 15-May-03 } \mathrm{Pb} \\
\text { 15-May-03 Pb }\end{array}$ & & $\begin{array}{l}0.0126 \\
0.126\end{array}$ & ug// & & & B & & & \\
\hline SESPSPEC & B16WR4 & HOOD PARK-MID-RIVER & OFFSITE & sw & Y & RIVER & $15-\mathrm{May}-03 \mathrm{~Pb}$ & & 0.0171 & ug/L & & & B & & & \\
\hline SESPSPEC & B16WR9 & HOOD PARK-MID-RIVER & OFFSITE & SW & $\mathrm{N}$ & RIVER & 15-May- $03 \mathrm{~Pb}$ & & 0.115 & ug/L & & & & & & \\
\hline SESPSPEC & B16WR6 & HOOD PARK-WALLA WALLA SHORE & OFFSITE & sw & Y & RIVER & 15-May-03 Pb & & 0.0196 & $\mathrm{ug} / \mathrm{L}$ & & & B & & & \\
\hline $\begin{array}{l}\text { SESPSPEC } \\
\text { SESPSEC }\end{array}$ & B16WR7 & HOOD PARK-WALLA WALLA SHORE & OFFSITE & sw & $\begin{array}{l}y^{2} \\
\mathrm{n}\end{array}$ & $\begin{array}{l}\text { RIVER } \\
\text { RIVER }\end{array}$ & 15-May-03 Pb & & 0.121 & $\mathrm{ug} / \mathrm{L}$ & & & & & & \\
\hline $\begin{array}{l}\text { SESPSPEC } \\
\text { SESPSEC }\end{array}$ & B16WN6 & MCNARY MID-RIVER NEAR DAM & $\begin{array}{l}\text { OFFSITE } \\
\text { OFESTEF }\end{array}$ & SW & Y & $\begin{array}{l}\text { RIVER } \\
\text { RIVER }\end{array}$ & 15-May-03 Pb & & 0.0111 & ug/L & & & B & & & \\
\hline SESPSPEC & B16WN8 & MCNARY-OR.SIDE NEAR DAM & $\begin{array}{l}\text { OFFSITE } \\
\text { OFFITE }\end{array}$ & sw & $\begin{array}{l}\mathrm{Y} \\
\mathrm{N}\end{array}$ & $\begin{array}{l}\text { RIVER } \\
\text { RIVER }\end{array}$ & 15-May- $-03 \mathrm{~Pb}$ & & $\begin{array}{l}0.124 \\
0.0159\end{array}$ & $\begin{array}{l}u g h / 2 \\
\text { ug/L }\end{array}$ & & & B & & & \\
\hline SESPSPEC & B16WN9 & MCNARY-OR.SIDE NEAR DAM & OFFSITE & sW & $\mathrm{N}$ & RIVER & 15-May-03 Pb & & 0.158 & $\mathrm{ug} / \mathrm{L}$ & & & & & & \\
\hline SESPSPEC & B16WN7 & MCNARY-WASH.SIDE NEAR DAM & OFFSITE & SW & $\mathrm{Y}$ & RIVER & 15-May- $03 \mathrm{~Pb}$ & & 0.019 & ug/L & & & B & & & \\
\hline SESPSPEC & B16WP0 & MCNARY-WASH.SIDE NEAR DAM & OFFSITE & sW & $\mathrm{N}$ & RIVER & 15-May-03 $\mathrm{Pb}$ & & 0.118 & ug/L & & & & & & \\
\hline
\end{tabular}




\begin{tabular}{|c|c|c|c|c|c|c|c|c|c|c|c|c|c|c|c|c|}
\hline | OWNER ID $\mid$ & SAMP NUM & SAMP SITE NAME & DIST CLASS & MEDIA & $\begin{array}{c}\text { FILTERED } \\
\text { FLAG }\end{array}$ & SAMP FROM & |SAMP DATE & CON SHORT NAME & |VALUE RPTD| & $\begin{array}{l}\text { ANAL } \\
\text { UNITS } \\
\text { RPTD }\end{array}$ & $\begin{array}{c}\text { COUNTING } \\
\text { ERROR }\end{array}$ & \begin{tabular}{|c|} 
TOTAL \\
ANAL \\
ERROR
\end{tabular} & $\mid \begin{array}{c}\text { LAB } \\
\text { QUALIFIER }\end{array}$ & SAMP COMMENT & $\left|\begin{array}{|c|}\text { RESULT } \\
\text { COMMENT }\end{array}\right|$ & |WELL NAME \\
\hline SESPSPEC & B16WP8 & WALLA WALLA-RIVER & OFFSITE & SW & Y & RIVER & 15-May- $03 \mathrm{~Pb}$ & & 0.011 & ug/L & & & u & & & \\
\hline $\begin{array}{l}\text { SESPSPEC } \\
\text { SESPSEDC }\end{array}$ & B16WP9 & WALLA WALLA-RIVER & OFFSITE & SW & $\begin{array}{l}Y \\
Y\end{array}$ & RIVER & 15-May- $03 \mathrm{~Pb}$ & & 0.011 & ug/L & & & U & & & \\
\hline $\begin{array}{l}\text { SESPSEEC } \\
\text { SESPPEC }\end{array}$ & B16WR0 & $\begin{array}{l}\text { WALLA WALLA-RIVER } \\
\text { WALA WALA-RIVER }\end{array}$ & OFFSITE & SW & $Y$ & $\begin{array}{l}\text { RIVER } \\
\text { RIVER }\end{array}$ & 15-May- $03 \mathrm{~Pb}$ & & 0.011 & ug/L & & & U & & & \\
\hline $\begin{array}{l}\text { SESPPPEC } \\
\text { SESPSPEC }\end{array}$ & $\begin{array}{l}\text { B16WR1 } \\
\text { B16WR2 }\end{array}$ & $\begin{array}{l}\text { WALLA WALLA-RIVR } \\
\text { WALA WLLA-RIVER }\end{array}$ & $\begin{array}{l}\text { OFFITE } \\
\text { OFFSITE }\end{array}$ & $\begin{array}{l}\text { sw } \\
\text { sw }\end{array}$ & $\begin{array}{r}n \\
N\end{array}$ & $\begin{array}{l}\text { IVER } \\
\text { RIVER }\end{array}$ & 15-May-03 Pb & & 0.273 & ug/L & & & & & & \\
\hline SESPSPEC & B16WR3 & $\begin{array}{l}\text { WALLA WALLA-RIVER } \\
\text { WALLA WALLA-RIVER }\end{array}$ & $\begin{array}{l}\text { OFSIITE } \\
\text { OFFSITE }\end{array}$ & sw & $\frac{N}{N}$ & $\begin{array}{l}\text { RIVER } \\
\text { RIVER }\end{array}$ & $\begin{array}{l}\text { 15-Maya-03 Pb } \\
15-M a y-03 P b\end{array}$ & & 0.327 & $\begin{array}{l}\frac{\mathrm{gug} / \mathrm{L}}{\mathrm{ug} / \mathrm{L}} \\
\end{array}$ & & & & & & \\
\hline SESPSPEC & B180C6 & $100 \mathrm{~B} / \mathrm{C}$ AREA UR & ONSITE & sw & $\mathrm{Y}$ & RIVER & 13-Nov-03 Pb & & 0.0407 & $\mathrm{ug} / \mathrm{L}$ & & & & & & \\
\hline $\begin{array}{l}\text { SESPSPEC } \\
\text { SESDPEC }\end{array}$ & B180C7 & 100 B/C AREA UR & ONSITE & sw & Y & RIVER & 13-Nov-03 Pb & & 0.0289 & $\mathrm{ug} / \mathrm{L}$ & & & & & & \\
\hline SESPSPEC & B180C8 & $100 \mathrm{BIC}$ AREA UR & ONSITE & SW & Y & RIVER & 13-Nov-03 Pb & & 0.0262 & $\mathrm{ug} / \mathrm{L}$ & & & & & & \\
\hline $\begin{array}{l}\text { SESPSPEC } \\
\text { SESPPEC }\end{array}$ & B180C9 & 100 B/C AREA UR & ONSITE & SW & $\begin{array}{r}Y \\
Y\end{array}$ & $\begin{array}{l}\text { RIVER } \\
\text { RIVER }\end{array}$ & 13-Nov-03 Pb & & 0.0302 & $\mathrm{ug} / \mathrm{L}$ & & & & & & \\
\hline $\begin{array}{l}\text { SESPPSEC } \\
\text { SESPSPEC }\end{array}$ & $\begin{array}{l}\text { B180D0 } \\
\text { B180D1 }\end{array}$ & $\begin{array}{l}\text { 100-B SPRING 38-3 } \\
\text { 100-B SPRING 38-3 }\end{array}$ & $\begin{array}{l}\text { ONSITE } \\
\text { ONSITE }\end{array}$ & $\begin{array}{l}\text { SW } \\
\text { sw }\end{array}$ & $\begin{array}{r}\text { Y } \\
\text { Y }\end{array}$ & $\begin{array}{l}\text { IVIVER } \\
\text { RIVER }\end{array}$ & $\begin{array}{l}\text { 13-Nov-03 Pb } \\
\text { 13-Nov-03 Pb }\end{array}$ & & 0.0747 & $\frac{u g g}{u g / L}$ & & & & DUP IS SAMPLE \#B180J4 & & \\
\hline SESPSPEC & B180D2 & 100-B SPRING 38-3 & ONSITE & sw & Y & RIVER & $\begin{array}{l}\text { 13-Nov-03 Pb } \\
\text { 13-Nov-03 Pb }\end{array}$ & & 0.0269 & $\frac{\mathrm{ug} / \mathrm{L}}{\mathrm{ug} / \mathrm{L}}$ & & & & & & \\
\hline SESPSPEC & B180D3 & 100-B SPRING 38-3 & ONSITE & sw & Y & RIVER & 13-Nov-03 Pb & & $\begin{array}{l}0.0339 \\
0.0339\end{array}$ & $\mathrm{ug} / \mathrm{L}$ & & & & & & \\
\hline $\begin{array}{l}\text { SESPSPEC } \\
\text { SESDSPCA }\end{array}$ & B180J4 & 100-B SPRING 38-3 & ONSITE & sw & Y & RIVER & 13-Nov-03 Pb & & 0.0308 & $\mathrm{ug} / \mathrm{L}$ & & & & DUP SAMPLE FOR B180D0 & & \\
\hline $\begin{array}{l}\text { SESPSPEC } \\
\text { SESPSECC }\end{array}$ & B180D4 & 100-B SPRING 39-2 & ONSITE & SW & $\begin{array}{l}Y \\
Y\end{array}$ & RIVER & 13-Nov-03 Pb & & 0.0279 & $\mathrm{ug} / \mathrm{L}$ & & & & & & \\
\hline $\begin{array}{l}\text { SESPSEEC } \\
\text { SESPPEC }\end{array}$ & B180D5 & 100-B SPRING 39-2 & ONSITE & SW & $\begin{array}{r}Y \\
Y \\
Y\end{array}$ & $\begin{array}{l}\text { RIVER } \\
\text { RIVER }\end{array}$ & 13-Nov-03 Pb & & 0.0577 & $\mathrm{ug} / \mathrm{L}$ & & & & & & \\
\hline $\begin{array}{l}\text { SESPPPEC } \\
\text { SESPSPEC }\end{array}$ & $\begin{array}{l}\text { B180D6 } \\
\text { B180D7 }\end{array}$ & $\begin{array}{l}\text { 100-B SPRING 39-2 } \\
\text { 100-B SPRING 39-2 }\end{array}$ & $\begin{array}{l}\text { ONSIIE } \\
\text { ONSITE }\end{array}$ & SW & $\begin{array}{r}Y \\
Y \\
Y\end{array}$ & $\begin{array}{l}\text { RIVER } \\
\text { RIVER }\end{array}$ & $\begin{array}{l}\text { 13-Nov-03Pb } \\
\text { 13-Nov-03Pph }\end{array}$ & & $\begin{array}{l}0.0369 \\
0.025\end{array}$ & ug/L & & & & & & \\
\hline $\begin{array}{l}\text { SESPSPEC } \\
\text { SESP }\end{array}$ & B180F9 & $\begin{array}{l}\text { 100-B SPRING 33-2 } \\
\text { 100-B SPRING DR 38-3 }\end{array}$ & $\begin{array}{l}\text { ONSIITE } \\
\text { ONSE }\end{array}$ & sw & 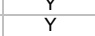 & $\begin{array}{l}\text { RIVER } \\
\text { RIVER }\end{array}$ & $\begin{array}{l}\text { 13-Nov-03 } \mathrm{Pb} \\
\text { 13-Nov-03 Pb }\end{array}$ & & 0.0342 & $\begin{array}{l}\mathrm{ugh/2} \\
\mathrm{ug} / \mathrm{L}\end{array}$ & & & & & & \\
\hline SESPSPEC & B180F1 & 100 B/C AREA DR & ONSITE & sw & Y & RIVER & 17-Nov-03 Pb & & 0.0333 & $\mathrm{ug} / \mathrm{L}$ & & & & & & \\
\hline SESPSPEC & B180F2 & 100 B/C AREA DR & ONSITE & sw & Y & RIVER & 17-Nov-03 Pb & & 0.0191 & ug/L & & & B & & & \\
\hline $\begin{array}{l}\text { SESPSPEC } \\
\text { SESPPEC }\end{array}$ & $\begin{array}{l}\text { B180F3 } \\
\text { B180F4 }\end{array}$ & $\begin{array}{l}100 \text { B/C AREA DR } \\
100 B C \text { AREA }\end{array}$ & $\begin{array}{l}\text { ONSITE } \\
\text { ONSIE }\end{array}$ & SW & $\begin{array}{l}Y \\
Y \\
Y\end{array}$ & $\begin{array}{l}\text { RIVER } \\
\text { RIVER }\end{array}$ & 17-Nov-03 Pb & & 0.027 & $\mathrm{ug} / \mathrm{L}$ & & & & & & \\
\hline $\begin{array}{l}\text { SESPPSEC } \\
\text { SESPPPEC }\end{array}$ & B180F4 & $\begin{array}{l}100 \text { B/C AREA DR } \\
100 \text { B/C AREA OUTFL1 }\end{array}$ & ONSITE & SW & $\begin{array}{r}\text { Y } \\
\text { Y }\end{array}$ & $\begin{array}{l}\text { RIVER } \\
\text { RIVER }\end{array}$ & 17-Nov-03 Pb & & 0.0249 & $\mathrm{ug} / \mathrm{L}$ & & & & & & \\
\hline $\begin{array}{l}\text { SESPPPEC } \\
\text { SESPSPEC }\end{array}$ & $\begin{array}{l}\text { B180D8 } \\
\text { B180D9 }\end{array}$ & $\begin{array}{l}100 \mathrm{~B} / \mathrm{C} \text { ARRA OUTFL1 } \\
100 \mathrm{~B} / \mathrm{C} \text { AREA OUTFL2 }\end{array}$ & $\begin{array}{l}\text { ONSITE } \\
\text { ONSITE }\end{array}$ & $\begin{array}{l}\text { SW } \\
\text { sw }\end{array}$ & $\begin{array}{l}\text { Y } \\
\text { Y }\end{array}$ & $\begin{array}{l}\text { RIVER } \\
\text { RIVER }\end{array}$ & $\begin{array}{l}\text { 17-Nov-03 Pb } \\
\text { 17-Nov-03 Pb }\end{array}$ & & $\begin{array}{l}0.0186 \\
0.0263\end{array}$ & $\begin{array}{l}\mathrm{ug} / \mathrm{L} \\
\mathrm{ug} / \mathrm{L}\end{array}$ & & & B & & & \\
\hline SESPSPEC & B180F0 & 100 B/C AREA OUTFL3 & ONSITE & sW & Y & RIVER & 17-Nov-03 Pb & & 0.0218 & ug/L & & & & & & \\
\hline SESPSPEC & B180K2 & Refer to WELL NAME column & & GW & Y & AQUIFER TUBE & 10-Dec-03 Pb & & 0.0251 & $\mathrm{ug} / \mathrm{L}$ & & & & & & 01-D \\
\hline SESPSPEC & B180K3 & Refer to WELL NAME column & & GW & $Y$ & AQUIFER TUBE & 10-Dec-03 Pb & & 0.004 & $\mathrm{ug} / \mathrm{L}$ & & & u & & & 04-D \\
\hline SESPSPEC & B180K4 & Refer to WELL NAME column & & GW & $\begin{array}{l}Y \\
Y \\
\end{array}$ & AQUIFER TUBE & 10-Dec-03 Pb & & 0.0107 & $\mathrm{ug} / \mathrm{L}$ & & & B & & & 05-D \\
\hline $\begin{array}{l}\text { SESPSECC } \\
\text { SESPPEC }\end{array}$ & B180K5 & Refer to WELL NAME column & & GW & $\begin{array}{l}\text { Y } \\
\text { y }\end{array}$ & AQUIFER TUBE & 10-Dec-03 Pb & & 0.0147 & $\mathrm{ug} / \mathrm{L}$ & & & B & & & 06-D \\
\hline $\begin{array}{l}\text { SESPSPEC } \\
\text { SESPSPEC }\end{array}$ & $\begin{array}{l}\text { B16WP2 } \\
\text { B16WP3 }\end{array}$ & $\begin{array}{l}\text { YAKIMA RIVER } \\
\text { YAKIMA RIVER }\end{array}$ & $\begin{array}{l}\text { OFFITE } \\
\text { OFFSITE }\end{array}$ & $\begin{array}{l}\text { SW } \\
\text { sw }\end{array}$ & $\begin{array}{r}\mathrm{Y} \\
\mathrm{Y}\end{array}$ & $\begin{array}{l}\text { RIVER } \\
\text { RIVER }\end{array}$ & $\begin{array}{l}\text { 14-May-03 Sb } \\
\text { 14-May-03 Sb }\end{array}$ & & 0.0644 & $u g / L$ & & & & & & \\
\hline $\begin{array}{l}\text { SESPPEC } \\
\text { SESPSPEC }\end{array}$ & $\begin{array}{l}\text { B16WP33 } \\
\text { B16WP4 }\end{array}$ & $\begin{array}{l}\text { YAAKIMA RIVER } \\
\text { YAKIMA RIVER }\end{array}$ & $\begin{array}{l}\text { OFFSIITE } \\
\text { OFFITE }\end{array}$ & SW & $\begin{array}{r}\mathrm{Y} \\
\mathrm{y}\end{array}$ & $\begin{array}{l}\text { RIVER } \\
\text { RIVER }\end{array}$ & $\begin{array}{l}\text { 14-May-03 Sb } \\
\text { 14-May-03 Sb }\end{array}$ & & 0.0758 & $\begin{array}{ll}\mathrm{ugh/} \\
\mathrm{ug} / \mathrm{L}\end{array}$ & & & & & & \\
\hline SESPSPEC & B16WP5 & YAKIMA RIVER & OFFSITE & sw & $\mathrm{N}$ & RIVER & 14-May-03 Sb & & 0.0536 & ug/L & & & & & & \\
\hline SESPSPEC & B16WP6 & YAKIMA RIVER & OFFSITE & SW & $\mathrm{N}$ & RIVER & 14-May-03 Sb & & 0.0584 & $\mathrm{ug} / \mathrm{L}$ & & & & & & \\
\hline $\begin{array}{l}\text { SESPSPEC } \\
\text { SESPSDCF }\end{array}$ & B16WP7 & $\begin{array}{l}\text { YAKIMA RIVER } \\
\text { HePK }\end{array}$ & OFFSITE & SW & $\begin{array}{l}\mathrm{y} \\
\mathrm{N}\end{array}$ & $\begin{array}{l}\text { RIVER } \\
\text { RIVER }\end{array}$ & 14-May-03 Sb & & 0.0568 & $\mathrm{ug} / \mathrm{L}$ & & & & & & \\
\hline $\begin{array}{l}\text { SESPSPEC } \\
\text { SESPSPEC }\end{array}$ & B16WR5 & HOOD PARK-FRANKLIN CO. SHORE & $\begin{array}{l}\text { OFFSITE } \\
\text { OFSITE }\end{array}$ & SW & $\begin{array}{r}\mathrm{Y} \\
\mathrm{Y}\end{array}$ & $\begin{array}{l}\text { RIVER } \\
\text { RIVER }\end{array}$ & 15-May-03 Sb & & 0.168 & ug/L & & & & & & \\
\hline $\begin{array}{l}\text { SESPSPEC } \\
\text { SESPSPEC }\end{array}$ & $\begin{array}{l}\text { B16WR8 } \\
\text { B16WR4 }\end{array}$ & $\begin{array}{l}\text { HOOD PARK-FRANLLIN CO. SHORE } \\
\text { HOOD PARK-MID-RIVER }\end{array}$ & $\begin{array}{l}\text { OFFITE } \\
\text { OFFSITE }\end{array}$ & $\begin{array}{l}\text { SW } \\
\text { SW }\end{array}$ & $\begin{array}{l}\mathrm{N} \\
\mathrm{Y}\end{array}$ & $\begin{array}{l}\text { RIVER } \\
\text { RIVER }\end{array}$ & $\begin{array}{l}\text { 15-May-03 S Sb } \\
15 \text {-May-03 Sb }\end{array}$ & & 0.102 & $\mathrm{ug} / \mathrm{L}$ & & & & & & \\
\hline SESPSPEC & $\begin{array}{ll}\text { B16WR9 } \\
\text { B16WR }\end{array}$ & HOOD PARK-MID-RIVER & $\begin{array}{l}\text { OFFSITE } \\
\text { OFFII }\end{array}$ & sw & $\mathrm{h}$ & $\begin{array}{l}\text { RIVER } \\
\text { RIVER }\end{array}$ & 15-May-03 Sb & & 0.0911 & $\begin{array}{l}u g h / 2 \\
\text { ug/L }\end{array}$ & & & & & & \\
\hline SESPSPEC & B16WR6 & HOOD PARK-WALLA WALLA SHORE & OFFSITE & sw & Y & RIVER & 15-May-03 Sb & & 0.153 & ug/L & & & & & & \\
\hline SESPSPEC & B16WR7 & HOOD PARK-WALLA WALLA SHORE & OFFSITE & SW & $\mathrm{N}$ & RIVER & 15-May-03 Sb & & 0.113 & $\mathrm{ug} / \mathrm{L}$ & & & & & & \\
\hline $\begin{array}{l}\text { SESPSPEC } \\
\text { SESPSEC }\end{array}$ & B16WN6 & MCNARY MID-RIVER NEAR DAM & OFFSITE & sw & Y & RIVER & 15-May-03 Sb & & 0.213 & $\mathrm{ug} / \mathrm{L}$ & & & & & & \\
\hline $\begin{array}{l}\text { SESPSECC } \\
\text { SESPSPEC }\end{array}$ & $\begin{array}{l}\text { B16WP1 } \\
\text { B16WN8 }\end{array}$ & $\begin{array}{l}\text { MCNARY MID-RIVER NEAR DAM } \\
\text { MCNARY-OR SDENEAR DAM }\end{array}$ & $\begin{array}{l}\text { OFFSITE } \\
\text { OFSITE }\end{array}$ & sw & $\begin{array}{l}\text { d } \\
\text { n }\end{array}$ & $\begin{array}{l}\text { RIVER } \\
\text { RIVER }\end{array}$ & $\begin{array}{l}\text { 15-May-03 Sb } \\
15 \text {-My--03 Sb }\end{array}$ & & 0.184 & ug/L & & & & & & \\
\hline $\begin{array}{l}\text { SESPSEC } \\
\text { SESPSEC }\end{array}$ & $\begin{array}{l}\text { B16WN8 } \\
\text { B16WN9 }\end{array}$ & $\begin{array}{l}\text { MCNARY-OR.SSDE NEAR DAM } \\
\text { MCNARY-OR.SIDE NEAR DAM }\end{array}$ & $\begin{array}{l}\text { OFFSITE } \\
\text { OFFSITE }\end{array}$ & $\begin{array}{l}\text { SW } \\
\text { sw }\end{array}$ & $\begin{array}{l}\mathrm{Y} \\
\mathrm{N}\end{array}$ & $\begin{array}{l}\text { RIVER } \\
\text { RIVER }\end{array}$ & $\begin{array}{l}\text { 15-May-03 Sb } \\
15 \text {-May-03 Sb }\end{array}$ & & $\begin{array}{l}0.192 \\
0.166\end{array}$ & $\mathrm{ug} / \mathrm{h}$ & & & & & & \\
\hline SESPSPEC & B16WN7 & MCNARY-WASH.SIDE NEAR DAM & OFFSITE & sw & $\mathrm{Y}$ & RIVER & 15-May-03 Sb & & 0.178 & $\mathrm{ug} / \mathrm{L}$ & & & & & & \\
\hline SESPSPEC & B16WP0 & MCNARY-WASH.SIDE NEAR DAM & OFFSITE & sw & $\mathrm{N}$ & RIVER & 15-May-03 Sb & & 0.177 & $\mathrm{ug} / \mathrm{L}$ & & & & & & \\
\hline SESPSPEC & B16WP8 & WALLA WALLA-RIVER & OFFSITE & sw & Y & RIVER & 15-May-03 Sb & & 0.0397 & $\mathrm{ug} / \mathrm{L}$ & & & & & & \\
\hline $\begin{array}{l}\text { SESPSPEC } \\
\text { SESPSEC }\end{array}$ & B16WP9 & WALLA WALLA-RIVER & OFFSITE & sw & $\begin{array}{r}Y \\
Y \\
\end{array}$ & RIVER & 15-May-03 Sb & & 0.0373 & $\mathrm{ug} / \mathrm{L}$ & & & & & & \\
\hline $\begin{array}{l}\text { SESPSPEC } \\
\text { SESPSPEC }\end{array}$ & B16WR0 & WALLA WALLA-RIVER & OFFSITE & SW & Y & $\begin{array}{l}\text { RIVER } \\
\text { RIVER }\end{array}$ & 15-May-03 Sb & & 0.0442 & $\mathrm{ug} / \mathrm{L}$ & & & & & & \\
\hline $\begin{array}{l}\text { SESPSECC } \\
\text { SESPSEC }\end{array}$ & $\begin{array}{l}\text { B16WR1 } \\
\text { B16WR2 }\end{array}$ & $\begin{array}{l}\text { WALLA WALLA-IVER } \\
\text { WALLA WALLA-RIVER }\end{array}$ & $\begin{array}{l}\text { OFFITE } \\
\text { OFFSITE }\end{array}$ & $\begin{array}{l}\text { SW } \\
\text { SW }\end{array}$ & $\frac{N}{N}$ & $\begin{array}{l}\text { RIVER } \\
\text { RIVER }\end{array}$ & $\begin{array}{l}\text { 15-May-03 Sb } \\
15-\text { May-03 Sb }\end{array}$ & & 0.0348 & $\mathrm{ugh/2}$ & & & & & & \\
\hline SESPSPEC & B16WR3 & WALLA WALLA-RIVER & $\begin{array}{l}\text { OFFSITE } \\
\text { OFFIT }\end{array}$ & sw & $\mathrm{N}$ & $\begin{array}{l}\text { RIVER } \\
\text { RIVER }\end{array}$ & 15-May-03 Sb & & 0.0289 & ug/L & & & & & & \\
\hline SESPSPEC & B180C6 & $100 \mathrm{~B} / \mathrm{C}$ AREA UR & ONSITE & sw & $Y$ & RIVER & 13-Nov-03 Sb & & 0.188 & $\mathrm{ug} / \mathrm{L}$ & & & & & & \\
\hline SESPSPEC & B180C7 & 100 B/C AREA UR & ONSITE & sw & $\begin{array}{l}Y \\
Y \\
\end{array}$ & RIVER & 13-Nov-03 Sb & & 0.182 & $\mathrm{ug} / \mathrm{L}$ & & & & & & \\
\hline $\begin{array}{l}\text { SESPSPEC } \\
\text { SECDSDC }\end{array}$ & B180C8 & 100 B/C AREA UR & ONSITE & sw & $\begin{array}{l}Y \\
Y\end{array}$ & RIVER & $13-$ Nov-0 & & 0.182 & $\mathrm{ug} / \mathrm{L}$ & & & & & & \\
\hline $\begin{array}{l}\text { SESPSEDC } \\
\text { SESPSPEC }\end{array}$ & $\begin{array}{l}\text { B180C9 } \\
\text { B180D0 }\end{array}$ & $\begin{array}{l}\text { 100 B/C AREA UR } \\
\text { 100-B SPRING 38-3 }\end{array}$ & $\begin{array}{l}\text { ONSIIE } \\
\text { ONSITE }\end{array}$ & $\begin{array}{l}\text { SW } \\
\text { SW }\end{array}$ & $\begin{array}{r}Y \\
Y\end{array}$ & $\begin{array}{l}\text { RIVER } \\
\text { RIVER }\end{array}$ & $\begin{array}{l}\text { 13-Novo-03 Sb } \\
\text { 13-Nov-03 Sb }\end{array}$ & & $\begin{array}{l}0.177 \\
0.18\end{array}$ & $\mathrm{ug} / \mathrm{h}$ & & & & DUP IS SAMPLE \#B180J4 & & \\
\hline SESPSPEC & B180D1 & 100-B SPRING 38-3 & ONSITE & sW & $\mathrm{Y}$ & RIVER & 13-Nov-03 Sb & & 0.184 & $\mathrm{ug} / \mathrm{L}$ & & & & (2) & & \\
\hline SESPSPEC & B180D2 & 100-B SPRING 38-3 & ONSITE & sW & Y & RIVER & 13-Nov-03 Sb & & 0.188 & ug/L & & & & & & \\
\hline SESPSPEC & B180D3 & 100-B SPRING 38-3 & ONSITE & SW & $\mathrm{Y}$ & RIVER & 13-Nov-03 Sb & & 0.231 & $\mathrm{ug} / \mathrm{L}$ & & & & & & \\
\hline SESPSPEC & B180J4 & 100-B SPRING & ONSITE & sw & $\begin{array}{l}Y \\
Y\end{array}$ & RIVER & 13-Nov-03 Sb & & 0.176 & $\mathrm{ug} / \mathrm{L}$ & & & & DUP SAMPLE FOR B180D0 & & \\
\hline $\begin{array}{l}\text { SESPSPEC } \\
\text { SESDPDC }\end{array}$ & $\begin{array}{l}B 18004 \\
B 18005\end{array}$ & 100-B SPRING 39-2 & ONSITE & sw & $\begin{array}{r}Y \\
Y\end{array}$ & $\begin{array}{l}\text { RIVER } \\
\text { RIVER }\end{array}$ & 13-Nov-03 Sb & & 0.196 & $\mathrm{ug} / \mathrm{L}$ & & & & & & \\
\hline $\begin{array}{l}\text { SESPSPEC } \\
\text { SESPSEC }\end{array}$ & B18005 & 100-B SPRING 39-2 & ONSITE & sw & $\begin{array}{r}Y \\
Y \\
Y\end{array}$ & $\begin{array}{l}\text { RIVER } \\
\text { RIVER }\end{array}$ & 13-Nov-03 Sb & & 0.194 & ug/L & & & & & & \\
\hline $\begin{array}{l}\text { SESPSEC } \\
\text { SESPSPEC }\end{array}$ & $\begin{array}{l}B 18006 \\
B 18007\end{array}$ & $\begin{array}{l}\text { 100-B SPRING 39-2 } \\
\text { 100-B SPRING 39-2 }\end{array}$ & $\begin{array}{l}\text { ONSITE } \\
\text { ONSITE }\end{array}$ & $\begin{array}{l}\text { SW } \\
\text { sw }\end{array}$ & $\begin{array}{l}\text { Y } \\
\text { Y }\end{array}$ & $\begin{array}{l}\text { IIVER } \\
\text { RIVER }\end{array}$ & $\begin{array}{l}\text { 13-Nov-03 Sb } \\
\text { 13-Nov-03 Sb }\end{array}$ & & 0.192 & ug// & & & & & & \\
\hline $\begin{array}{l}\text { SESPSEC } \\
\text { SESPSPEC }\end{array}$ & $\begin{array}{l}\text { B180D7 } \\
\text { B180F9 }\end{array}$ & 100-B SPRING DR 38-3 & $\begin{array}{l}\text { ONSIITE } \\
\text { ONSITE }\end{array}$ & sw & $\begin{array}{r}\text { Y } \\
\end{array}$ & $\begin{array}{l}\text { RIVER } \\
\text { RIVER }\end{array}$ & $\begin{array}{l}\text { 13-Nov-03 Sb } \\
13-\text { Nov-03 Sb }\end{array}$ & & 0.176 & ug/L & & & & & & \\
\hline SESPSPEC & B180F1 & 100 B/C AREA DR & ONSITE & sw & Y & RIVER & $17-\mathrm{Nov}-03 \mathrm{Sb}$ & & 0.175 & ug/L & & & & & & \\
\hline SESPSPEC & B180F2 & $100 \mathrm{~B} / \mathrm{C}$ AREA DR & ONSITE & sw & $Y$ & RIVER & 17-Nov-03 Sb & & 0.177 & ug/L & & & & & & \\
\hline
\end{tabular}




\begin{tabular}{|c|c|c|c|c|c|c|c|c|c|c|c|c|c|c|c|c|}
\hline OWNER ID | & SAMP NUM & SAMP SITE NAME & DIST CLASS & MEDIA & $\begin{array}{c}\text { FILTERED } \\
\text { FLAG }\end{array}$ & SAMP FROM & |SAMP DATE & CON SHORT NAME & | VALUE RPTD| & $\begin{array}{l}\text { ANAL } \\
\text { UNITS } \\
\text { RPTD }\end{array}$ & $\begin{array}{c}\text { COUNTING } \\
\text { ERROR }\end{array}$ & \begin{tabular}{|c|} 
TOTAL \\
ANAL \\
ERROR
\end{tabular} & $\mid \begin{array}{c}\text { LAB } \\
\text { QUALIFIER }\end{array}$ & SAMP COMMENT & $\left|\begin{array}{|c}\text { RESULT } \\
\text { COMMENT }\end{array}\right|$ & WELL NAME \\
\hline SESPSPEC & B180F3 & 100 B/C AREA DR & ONSITE & SW & Y & RIVER & 17-Nov-03 Sb & & 0.183 & ug/L & & & & & & \\
\hline $\begin{array}{l}\text { SESPSPEC } \\
\text { SESPDEC }\end{array}$ & B180F4 & 100 B/C AREA DR & ONSITE & SW & Y & RIVER & 17-Nov-03 Sb & & 0.177 & $\mathrm{ug} / \mathrm{L}$ & & & & & & \\
\hline $\begin{array}{l}\text { SESPPPEC } \\
\text { SESPSPEC }\end{array}$ & B180D8 & 100 B/C AREA OUTFL1 & ONSITE & SW & $\begin{array}{l}Y \\
Y \\
Y\end{array}$ & $\begin{array}{l}\text { RIVER } \\
\text { RIVER }\end{array}$ & 17-Nov-03 Sb & & 0.186 & $u g / L$ & & & & & & \\
\hline $\begin{array}{l}\text { SESPPPEC } \\
\text { SESPSPEC }\end{array}$ & $\begin{array}{l}\text { B180D9 } \\
\text { B180F0 }\end{array}$ & $\begin{array}{l}100 \text { B/C AREA OUTTL2 } \\
100 \text { B/C AREA OUTFL3 }\end{array}$ & $\begin{array}{l}\text { ONSITE } \\
\text { ONSTEE }\end{array}$ & $\begin{array}{l}\text { sw } \\
\text { sw }\end{array}$ & $\begin{array}{l}Y \\
Y\end{array}$ & $\begin{array}{l}\text { IVIVER } \\
\text { RIVER }\end{array}$ & $\begin{array}{l}\text { 17-Nov-03 Sb } \\
\text { 17-Nov-03 Sb }\end{array}$ & & 0.178 & ug/L & & & & & & \\
\hline SESPSPEC & B16KT8 & $\begin{array}{l}100 \text { B/ A AEA OUTFL } \\
300 \text { SPR } 7-1 \text { (2.5FT) }\end{array}$ & ONSITE & sw & $\begin{array}{r}\mathrm{Y} \\
\mathrm{N}\end{array}$ & $\begin{array}{l}\text { RIVER } \\
\text { DRIVE POINT }\end{array}$ & $\begin{array}{l}\text { 17--Novo-03 Sb } \\
\text { 24-Feb-03 Se }\end{array}$ & & $\begin{array}{r}0.184 \\
3.43\end{array}$ & $\begin{array}{l}\frac{\mathrm{g} g / \mathrm{L}}{\mathrm{ug} / \mathrm{L}} \\
\end{array}$ & & & & & & \\
\hline SESPSPEC & B16KT9 & 300 SPR 7 - 1 (4 FT) & ONSITE & sw & $\mathrm{N}$ & DRIVE POINT & 24-Feb-03 Se & & 4.14 & $\mathrm{ug} / \mathrm{L}$ & & & & & & \\
\hline $\begin{array}{l}\text { SESPSPEC } \\
\text { SESDPEC }\end{array}$ & B16KT7 & 300 SPR 7 - 1 (4 IN) & ONSITE & sW & N & DRIVE POINT & 24-Feb-03 Se & & 1.04 & $\mathrm{ug} / \mathrm{L}$ & & & & & & \\
\hline SESPSPEC & B16KV0 & 300 SPR 7 - 1 (6 FT) & ONSITE & SW & $\mathrm{N}$ & DRIVE POINT & 24-Feb-03 Se & & 4.09 & $\mathrm{ug} / \mathrm{L}$ & & & & & & \\
\hline $\begin{array}{l}\text { SESPSPEC } \\
\text { SESPPEC }\end{array}$ & B16KV2 & 300 SPR 7 -2 (2 FT) & ONSITE & SW & $\mathrm{N}$ & DRIVE POINT & 24-Feb-03 Se & & 4.27 & $u g / L$ & & & & & & \\
\hline $\begin{array}{l}\text { SESSPPEC } \\
\text { SESPSPEC }\end{array}$ & $\begin{array}{l}\text { B16KV1 } \\
\text { B16KV4 }\end{array}$ & $\begin{array}{l}300 \text { SPR } 7 \text {-2 (4 IN) } \\
300 \text { SPR } 9 \text {-1 (2 FT) }\end{array}$ & $\begin{array}{l}\text { ONSITE } \\
\text { ONSITE }\end{array}$ & $\begin{array}{l}\text { SW } \\
\text { SW }\end{array}$ & $\begin{array}{l}n \\
N\end{array}$ & $\begin{array}{l}\text { DRIVE POINT } \\
\text { DRIVE POINT }\end{array}$ & $\begin{array}{l}24-\mathrm{Feb}-03 \mathrm{Se} \\
24-\mathrm{Feb}-03 \mathrm{Se}\end{array}$ & & $\begin{array}{l}2.44 \\
1.45\end{array}$ & $\frac{\mathrm{ug} / \mathrm{L}}{\mathrm{ug} / \mathrm{L}}$ & & & & & & \\
\hline SESPSPEC & B16KV5 & 300 SPR 9 -1 (4 FT) & ONSITE & sw & $\mathrm{N}$ & DRIVE POINT & 24-Feb-03 Se & & 0.63 & ug/L & & & & & & \\
\hline SESPSPEC & B16KV3 & 300 SPR 9 -1 (4 IN) & ONSITE & sw & N & DRIVE POINT & 24-Feb-03 Se & & 0.514 & $\mathrm{ug} / \mathrm{L}$ & & & & & & \\
\hline $\begin{array}{l}\text { SESPSPEC } \\
\text { CFCDDFC }\end{array}$ & B16KV7 & 300 SPR 9 - 2 (2 FT) & ONSITE & sw & $\mathrm{N}$ & DRIVE POINT & 24-Feb-03 Se & & 0.508 & $\mathrm{ug} / \mathrm{L}$ & & & & & & \\
\hline $\begin{array}{l}\text { SESPSPEC } \\
\text { SESPPEC }\end{array}$ & B16KV6 & 300 SPR $9-2(4$ IN) & ONSITE & SW & $\mathrm{N}$ & DRIVE POINT & 24-Feb-03 Se & & 0.397 & $\mathrm{ug} / \mathrm{L}$ & & & B & & & \\
\hline $\begin{array}{l}\text { SESPPPEC } \\
\text { SESPSPEC }\end{array}$ & $\begin{array}{l}\text { B16KV8 } \\
\text { B16KW0 }\end{array}$ & $\begin{array}{l}300 \text { SPR } 9-2(4.5 F T) \\
300 \text { SPR } 9-3(2 \mathrm{FT})\end{array}$ & $\begin{array}{l}\text { ONSITE } \\
\text { ONSTEE }\end{array}$ & $\begin{array}{l}\text { sW } \\
\text { sw }\end{array}$ & $\frac{n}{N}$ & $\begin{array}{l}\text { DRIVE POINT } \\
\text { DRIVE POINT }\end{array}$ & 24-Feb-03 Se & & 0.477 & $\mathrm{ug} / \mathrm{L}$ & & & B & & & \\
\hline $\begin{array}{l}\text { SESSPPEC } \\
\text { SESPSPEC }\end{array}$ & $\begin{array}{l}\text { B16KWO } \\
\text { B16KV9 }\end{array}$ & $\begin{array}{l}300 \text { SPR } 9-3(2 \text { FT) } \\
300 \text { SPR 9 }-3(4 \text { IN }\end{array}$ & $\begin{array}{l}\text { ONSIIE } \\
\text { ONSITE }\end{array}$ & $\begin{array}{l}\text { SW } \\
\text { sW }\end{array}$ & $\frac{N}{N}$ & $\begin{array}{l}\text { DRIVE PONT } \\
\text { DRIVE POINT }\end{array}$ & $\begin{array}{l}\text { 24-F-Fb-03 Se } \\
\text { 24-Feb-03 Se }\end{array}$ & & $\begin{array}{l}0.816 \\
0.43\end{array}$ & ug/L & & & & & & \\
\hline $\begin{array}{l}\text { SESPSPEC } \\
\text { SES }\end{array}$ & B16WP2 & YAKIMA RIVER & $\begin{array}{l}\text { ONSFITE } \\
\text { OFSITE }\end{array}$ & sw & $\begin{array}{l}\mathrm{Y} \\
\mathrm{N}\end{array}$ & $\begin{array}{l}\text { DRIVEPINI } \\
\text { RIVER }\end{array}$ & $\begin{array}{l}\text { 24-reb-03se } \\
14-\mathrm{May}-03 \mathrm{Se}\end{array}$ & & $\begin{array}{l}0.43 \\
0.08\end{array}$ & $\begin{array}{l}\mathrm{ugh/2} \\
\mathrm{ug} / \mathrm{L}\end{array}$ & & & B & & & \\
\hline SESPSPEC & B16WP3 & YAKIMA RIVER & OFFSITE & sw & Y & RIVER & 14-May-03 Se & & 0.243 & $\mathrm{ug} / \mathrm{L}$ & & & B & & & \\
\hline SESPSPEC & B16WP4 & YAKIMA RIVER & OFFSITE & sw & Y & RIVER & 14-May-03 Se & & 0.08 & $\mathrm{ug} / \mathrm{L}$ & & & u & & & \\
\hline $\begin{array}{l}\text { SESPSPEC } \\
\text { SESPPEC }\end{array}$ & B16WP5 & YAKIMA RIVER & OFFSITE & SW & $\mathrm{N}$ & RIVER & 14-May-03 Se & & 0.265 & $\mathrm{ug} / \mathrm{L}$ & & & $B$ & & & \\
\hline $\begin{array}{l}\text { SESPPEC } \\
\text { SESPPPEC }\end{array}$ & B16WP6 & YAKIMA RIVER & OFFSITE & SW & $\mathrm{N}$ & RIVER & 14-May-03 Se & & 0.08 & $\mathrm{ug} / \mathrm{L}$ & & & $U$ & & & \\
\hline $\begin{array}{l}\text { SESPPEC } \\
\text { SESPSPEC }\end{array}$ & $\begin{array}{l}\text { B16WP7 } \\
\text { B16WR5 }\end{array}$ & $\begin{array}{l}\text { YAKIMA RIVER } \\
\text { HOOD PARK-FRANKLIN CO SHORE }\end{array}$ & $\begin{array}{l}\text { OFFSITE } \\
\text { OFFSTE }\end{array}$ & SW & $\begin{array}{l}\mathrm{y} \\
\mathrm{N}\end{array}$ & $\begin{array}{l}\text { RIVER } \\
\text { RIVER }\end{array}$ & $\begin{array}{l}\text { 14-May-03 Se } \\
15-M y-03 \text { Se }\end{array}$ & & 0.243 & $\mathrm{ug} / \mathrm{L}$ & & & B & & & \\
\hline $\begin{array}{l}\text { SESSPEC } \\
\text { SESPSPEC }\end{array}$ & $\begin{array}{l}\text { B16WR55 } \\
\text { B16WR8 }\end{array}$ & $\begin{array}{l}\text { HOOD PARKK-FRANLLIN CO. SHORE } \\
\text { HOOD PARK-FRAKLIN CO SHORE }\end{array}$ & $\begin{array}{l}\text { OFFSSTE } \\
\text { OFFITE }\end{array}$ & SW & $\begin{array}{r}\mathrm{Y} \\
\mathrm{N}\end{array}$ & $\begin{array}{l}\text { IIVER } \\
\text { RIVER }\end{array}$ & $\begin{array}{l}\text { 15-May-03 Se } \\
15 \text {-May-03 Se }\end{array}$ & & 0.152 & $\frac{\mathrm{ug} / \mathrm{L}}{\mathrm{ug} / \mathrm{L}}$ & & & $\begin{array}{l}\text { B } \\
\text { G }\end{array}$ & & & \\
\hline SESPSPEC & B16WR4 & HOOD PARK-MID-RIVER & OFFSITE & sw & $\mathrm{Y}$ & RIVER & 15-May-03 Se & & 0.24 & ug/L & & & B & & & \\
\hline SESPSPEC & B16WR9 & HOOD PARK-MID-RIVER & OFFSITE & sw & $\mathrm{N}$ & RIVER & 15-May-03 Se & & 0.08 & ug/L & & & u & & & \\
\hline SESPSPEC & B16WR6 & HOOD PARK-WALLA WALLA SHORE & OFFSITE & sw & Y & RIVER & 15-May-03 Se & & 0.08 & $\mathrm{ug} / \mathrm{L}$ & & & $\mathrm{U}$ & & & \\
\hline SESPSPEC & B16WR7 & HOOD PARK-WALLA WALLA SHORE & EOFFSITE & sw & $\mathrm{N}$ & RIVER & 15-May-03 Se & & 0.08 & ug/L & & & U & & & \\
\hline SESPSPEC & B16WN6 & MCNARY MID-RIVER NEAR DAM & OFFSITE & sW & Y & RIVER & 15-May-03 Se & & 0.08 & ug/L & & & & & & \\
\hline SESPSPEC & B16WP1 & MCNARY MID-RIVER NEAR DAM & OFFSITE & sw & $\mathrm{N}$ & RIVER & 15-May-03 Se & & 0.0801 & $\mathrm{ug} / \mathrm{L}$ & & & $B$ & & & \\
\hline SESPSPEC & B16WN8 & MCNARY-OR.SIDE NEAR DAM & OFFSITE & sw & $\mathrm{Y}$ & RIVER & 15-May-03 Se & & 0.08 & $\mathrm{ug} / \mathrm{L}$ & & & u & & & \\
\hline SESPSPEC & B16WN9 & MCNARY-OR.SIDE NEAR DAM & OFFSITE & sw & $v^{n}$ & RIVER & 15-May-03 Se & & 0.11 & $\mathrm{ug} / \mathrm{L}$ & & & B & & & \\
\hline SESPSPEC & B16WN7 & MCNARY-WASH.SIDE NEAR DAM & OFFSITE & SW & Y & RIVER & 15-May-03 Se & & 0.466 & $\mathrm{ug} / \mathrm{L}$ & & & B & & & \\
\hline $\begin{array}{l}\text { SESPSPEC } \\
\text { SESPPEC }\end{array}$ & B16WP0 & MCNARY-WASH.SIDE NEAR DAM & OFFSITE & SW & $\begin{array}{l}\mathrm{y} \\
\mathrm{N}\end{array}$ & $\begin{array}{l}\text { RIVER } \\
\text { RIVER }\end{array}$ & 15-May-03 Se & & 0.238 & $\mathrm{ug} / \mathrm{L}$ & & & B & & & \\
\hline $\begin{array}{l}\text { SESPPEC } \\
\text { SESPSPEC }\end{array}$ & $\begin{array}{l}\text { B16WP8 } \\
\text { B16WP9 }\end{array}$ & $\begin{array}{l}\text { WALLA WALLA-RIVER } \\
\text { WALA WALLA-RIVER }\end{array}$ & $\begin{array}{l}\text { OFFSITE } \\
\text { OFESTEE }\end{array}$ & SW & $\begin{array}{r}\text { Y } \\
\text { Y }\end{array}$ & $\begin{array}{l}\text { RIVER } \\
\text { RIVER }\end{array}$ & $\begin{array}{l}\text { 15-May-03 Se } \\
15-M y-03 \text { Se }\end{array}$ & & 0.08 & ug/L & & & $U^{B}$ & & & \\
\hline $\begin{array}{l}\text { SESSPPEC } \\
\text { SESPSPEC }\end{array}$ & $\begin{array}{l}\text { B16WP99 } \\
\text { B16WR0 }\end{array}$ & $\begin{array}{l}\text { WALLA WALLA-IVER } \\
\text { WALLA WALLA-RIVER }\end{array}$ & $\begin{array}{l}\text { OFFSSTE } \\
\text { OFFSTE }\end{array}$ & $\begin{array}{l}\text { SW } \\
\text { SW }\end{array}$ & $\begin{array}{l}\mathrm{Y} \\
\mathrm{Y}\end{array}$ & $\begin{array}{l}\text { RIVER } \\
\text { RIVER }\end{array}$ & $\begin{array}{l}\text { 15-May-03 Se } \\
15 \text {-May-03 Se }\end{array}$ & & $\begin{array}{l}0.397 \\
0.08\end{array}$ & $\mathrm{ugh/2}$ & & & B & & & \\
\hline $\begin{array}{l}\text { SESPSPEC } \\
\text { SESP }\end{array}$ & B16WR1 & $\begin{array}{l}\text { WALLA WALLA-RIVER } \\
\text { WALA }\end{array}$ & OFFSITE & sw & h & $\begin{array}{l}\text { RIVER } \\
\text { RIVER }\end{array}$ & $\begin{array}{l}\text { T5-May-03 Se } \\
15 \text { Se }\end{array}$ & & 0.132 & $\begin{array}{l}u g h / 2 \\
\text { ug/L }\end{array}$ & & & B & & & \\
\hline SESPSPEC & B16WR2 & WALLA WALLA-RIVER & OFFSITE & sw & $\mathrm{N}$ & RIVER & $15-M a y-03 \mathrm{Se}$ & & 0.08 & $\mathrm{ug} / \mathrm{L}$ & & & u & & & \\
\hline SESPSPEC & B16WR3 & WALLA WALLA-RIVER & OFFSITE & SW & $\mathrm{N}$ & RIVER & 15-May-03 Se & & 0.237 & $\mathrm{ug} / \mathrm{L}$ & & & B & & & \\
\hline $\begin{array}{l}\text { SESPSPEC } \\
\text { CESDPEC }\end{array}$ & B180C6 & $100 \mathrm{~B} / \mathrm{C}$ AREA UR & ONSITE & SW & $\begin{array}{l}Y \\
Y \\
Y\end{array}$ & RIVER & 13-Nov-03 Se & & 0.27 & $\mathrm{ug} / \mathrm{L}$ & & & B & & & \\
\hline $\begin{array}{l}\text { SESSPPEC } \\
\text { SESPSPEC }\end{array}$ & $\begin{array}{l}\text { B180C7 } \\
\text { B100C8 }\end{array}$ & $\begin{array}{l}100 \text { BCC AREA UR } \\
100 \text { BCCAREA UR }\end{array}$ & ONSITE & SW & $\begin{array}{r}Y \\
Y \\
Y\end{array}$ & $\begin{array}{l}\text { RIVER } \\
\text { RIVER }\end{array}$ & $\begin{array}{l}\text { 13-Nov-03 Se } \\
\text { 13-Nov-03 Se }\end{array}$ & & 0.259 & $\mathrm{ug} / \mathrm{L}$ & & & B & & & \\
\hline $\begin{array}{l}\text { SESSPPEC } \\
\text { SESPSPEC }\end{array}$ & $\begin{array}{l}\text { B180C8 } \\
\text { B180C9 }\end{array}$ & $\begin{array}{l}100 \text { B BCAREA AR } \\
100 \text { B/C AREA UR }\end{array}$ & $\begin{array}{l}\text { ONSTIE } \\
\text { ONSITE }\end{array}$ & $\begin{array}{l}\text { SW } \\
\text { sw }\end{array}$ & $\begin{array}{l}\text { Y } \\
\text { Y }\end{array}$ & $\begin{array}{l}\text { RIVER } \\
\text { RIVER }\end{array}$ & $\begin{array}{l}\text { 13-Novo-03 Se } \\
\text { 13-Nov-03 Se }\end{array}$ & & 0.233 & $\begin{array}{l}\mathrm{ug} / \mathrm{L} \\
\mathrm{ug} / \mathrm{L}\end{array}$ & & & $\begin{array}{l}B \\
B\end{array}$ & & & \\
\hline SESPSPEC & B180D0 & 100-B SPRING 38-3 & ONSITE & sw & $\mathrm{Y}$ & RIVER & 13-Nov-03 Se & & 0.321 & ugh/ & & & B & DUP IS SAMPLE \#B180J4 & & \\
\hline SESPSPEC & B180D1 & 100-B SPRING 38-3 & ONSITE & sw & Y & RIVER & 13-Nov-03 Se & & 0.294 & $\mathrm{ug} / \mathrm{L}$ & & & B & & & \\
\hline SESPSPEC & B180D2 & 100-B SPRING 38-3 & ONSITE & SW & Y & RIVER & 13-Nov-03 Se & & 0.301 & $\mathrm{ug} / \mathrm{L}$ & & & B & & & \\
\hline $\begin{array}{l}\text { SESPSPEC } \\
\text { SESPDEC }\end{array}$ & B180D3 & 100-B SPRING 38-3 & ONSITE & SW & $\begin{array}{l}Y \\
Y \\
Y\end{array}$ & RIVER & 13-Nov-03 Se & & 0.269 & $\mathrm{ug} / \mathrm{L}$ & & & B & & & \\
\hline $\begin{array}{l}\text { SESPPPEC } \\
\text { SESPSPEC }\end{array}$ & B180J4 & 100-B SPRING 38-3 & ONSITE & SW & $\begin{array}{r}\text { y } \\
\text { y }\end{array}$ & $\begin{array}{l}\text { RIVER } \\
\text { RIVER }\end{array}$ & 13-Nov-03 Se & & 0.255 & $\mathrm{ug} / \mathrm{L}$ & & & B & DUP SAMPLE FOR B180D0 & & \\
\hline $\begin{array}{l}\text { SESSPPEC } \\
\text { SESPSPEC }\end{array}$ & $\begin{array}{l}\text { B180D4 } \\
\text { B180D5 }\end{array}$ & & $\begin{array}{l}\text { ONSITE } \\
\text { ONSITE }\end{array}$ & $\begin{array}{l}\text { SW } \\
\text { SW }\end{array}$ & $\begin{array}{l}\text { Y } \\
\text { Y }\end{array}$ & $\begin{array}{l}\text { IVER } \\
\text { RIVER }\end{array}$ & $\begin{array}{l}\text { 13-Nov-03 Se } \\
\text { 13-Nov-03 Se }\end{array}$ & & 0.175 & $\mathrm{ugh/2}$ & & & $\frac{B}{B}$ & & & \\
\hline SESPSPEC & B180D6 & 100-B SPRING 39-2 & ONSITE & sw & Y & $\begin{array}{l}\text { RIVER } \\
\text { RIVER }\end{array}$ & 13-Nov-03 Se & & 0.215 & ugh/ & & & B & & & \\
\hline SESPSPEC & B180D7 & 100-B SPRING 39-2 & ONSITE & sw & $Y$ & RIVER & 13-Nov-03 Se & & 0.272 & $\mathrm{ug} / \mathrm{L}$ & & & B & & & \\
\hline SESPSPEC & B180F9 & 100-B SPRING DR 38-3 & ONSITE & sw & $\begin{array}{l}Y \\
Y \\
\end{array}$ & RIVER & 13-Nov-03 Se & & 0.248 & $\mathrm{ug} / \mathrm{L}$ & & & B & & & \\
\hline $\begin{array}{l}\text { SESPSPEC } \\
\text { SESPDEC }\end{array}$ & B180F1 & 100 B/C AREA DR & ONSITE & sw & $\begin{array}{l}Y \\
Y\end{array}$ & RIVER & 17-Nov-03 Se & & 0.229 & $\mathrm{ug} / \mathrm{L}$ & & & B & & & \\
\hline $\begin{array}{l}\text { SESSPPEC } \\
\text { SESPSPEC }\end{array}$ & $\begin{array}{l}\mathrm{B} 180 \mathrm{~F} 2 \\
\mathrm{~B} 180 \mathrm{~F} 3\end{array}$ & $\begin{array}{l}100 \text { B BCAREA AR } \\
100 \text { BIC AREA DR }\end{array}$ & $\begin{array}{l}\text { ONSITE } \\
\text { ONSITE }\end{array}$ & $\begin{array}{l}\text { SW } \\
\text { sw }\end{array}$ & $\begin{array}{r}Y \\
Y\end{array}$ & $\begin{array}{l}\text { RIVER } \\
\text { RIVER }\end{array}$ & $\begin{array}{l}\text { 17-Nov-03 Se } \\
\text { 17-Nov-03 Se }\end{array}$ & & 0.216 & $\mathrm{ug} / \mathrm{h}$ & & & $\begin{array}{l}B \\
B\end{array}$ & & & \\
\hline SESPSPEC & B180F4 & 100 B/C AREA DR & ONSITE & sW & $\mathrm{Y}$ & RIVER & 17-Nov-03 Se & & 0.168 & $\mathrm{ug} / \mathrm{L}$ & & & B & & & \\
\hline SESPSPEC & B180D8 & 100 B/C AREA OUTFL1 & ONSITE & sw & Y & RIVER & 17-Nov-03 Se & & 0.216 & $\mathrm{ug} / \mathrm{L}$ & & & B & & & \\
\hline $\begin{array}{l}\text { SESPSPEC } \\
\text { SESPDEC }\end{array}$ & B180D9 & 100 BIC AREA OUTFL2 & ONSITE & sW & Y & RIVER & 17-Nov-03 Se & & 0.225 & ug/ $/ \mathrm{h}$ & & & B & & & \\
\hline $\begin{array}{l}\text { SESPSPEC } \\
\text { SESPPEC }\end{array}$ & $\begin{array}{ll}B 180 F 0 \\
B 180 \% 2\end{array}$ & 100 B/C AREA OUTFL3 & ONSITE & SW & $\begin{array}{r}Y \\
Y\end{array}$ & RIVER & 17-Nov-0 & & 0.2 & $\mathrm{ug} / \mathrm{L}$ & & & B & & & \\
\hline $\begin{array}{l}\text { SESPPEEC } \\
\text { SESPDEC }\end{array}$ & B180K2 & Refer to WELL NAME column & & GW & $\begin{array}{r}Y \\
Y\end{array}$ & AQUIFER TUBE & 10-Dec-03 Se & & 0.315 & $\mathrm{ug} / \mathrm{L}$ & & & $\mathrm{c}$ & & & 01-D \\
\hline $\begin{array}{l}\text { SESPPPEC } \\
\text { SESPPPEC }\end{array}$ & $\begin{array}{l}\text { B180K3 } \\
\text { B180K4 }\end{array}$ & Refer to WELL NAME column & & GW & $\begin{array}{r}Y \\
Y \\
Y\end{array}$ & $\begin{array}{l}\text { AQUIFER TUBE } \\
\text { AOIUEFR TUBE }\end{array}$ & 10-Dec-03 Se & & 1.63 & ug/L & & & C & & & 104-D \\
\hline $\begin{array}{l}\text { SESSPPEC } \\
\text { SESPSPEC }\end{array}$ & $\begin{array}{l}\text { B180K4 } \\
\text { B180K5 }\end{array}$ & $\begin{array}{l}\text { Refer to WELL NAME c cllumn } \\
\text { Refer to WELL NAME column }\end{array}$ & & $\begin{array}{l}G W \\
G W\end{array}$ & $\begin{array}{l}\text { Y } \\
\text { Y }\end{array}$ & $\begin{array}{l}\text { AQUUFER TUBE } \\
\text { AQUIFER TUBE }\end{array}$ & $\begin{array}{l}10-\mathrm{Dec}-03 \mathrm{Se} \\
10-\mathrm{Dec}-03 \mathrm{Se}\end{array}$ & & $\begin{array}{l}1.56 \\
1.89\end{array}$ & $\begin{array}{l}\mathrm{ug} / \mathrm{h} \\
\mathrm{ug} / \mathrm{L}\end{array}$ & & & $\begin{array}{c}c \\
\mathrm{c}\end{array}$ & & & $\begin{array}{l}05-D \\
06-D\end{array}$ \\
\hline SESPSPEC & B16KT8 & 300 SPR $7-1$ (2.5FT) & ONSITE & SW & $\mathrm{N}$ & $\begin{array}{l}\text { DRIVE POINT } \\
\text { DRI }\end{array}$ & 24-Feb-03 Th & & 0.104 & $\mathrm{ug} / \mathrm{L}$ & & & & & & \\
\hline SESPSPEC & B16KT9 & 300 SPR 7 - 1 (4 FT) & ONSITE & SW & $\mathrm{N}$ & DRIVE POINT & 24-Feb-03 Th & & 0.1 & ug/L & & & U & & & \\
\hline SESPSPEC & B16KT7 & 300 SPR 7 -1 (4 IN) & ONSITE & sw & $\mathrm{N}$ & DRIVE POINT & 24-Feb-03 Th & & 0.1 & ug/L & & & U & & & \\
\hline
\end{tabular}




\begin{tabular}{|c|c|c|c|c|c|c|c|c|c|c|c|c|c|c|c|c|}
\hline OWNER ID & SAMP NUM & SAMP SITE NAME & DIST CLASS & MEDIA & $\begin{array}{c}\text { FILTERED } \\
\text { FLAG }\end{array}$ & SAMP FROM & |SAMP DATE & CON SHORT NAME & |VALUE RPTD| & $\begin{array}{l}\text { ANAL } \\
\text { UNITS } \\
\text { RPTD }\end{array}$ & $\left|\begin{array}{c}\text { COUNTING } \\
\text { ERROR }\end{array}\right|$ & \begin{tabular}{|c|} 
TOTAL \\
ANAL \\
ERROR
\end{tabular} & $\mid \begin{array}{c}\text { LAB } \\
\text { QUALIFIER }\end{array}$ & SAMP COMMENT & $\left|\begin{array}{|c}\text { RESULT } \\
\text { COMMENT }\end{array}\right|$ & |WELL NAME \\
\hline SESPSPEC & B16KVO & 300 SPR $7-1$ (6 FT) & ONSITE & SW & $N$ & DRIVE POINT & 24-Feb-03 Th & & 0.35 & ug/L & & & & & & \\
\hline & B16KV2 & 300 SPR $7-2$ (2 FT) & ONSITE & SW & N & DRIVE POINT & 24-Feb-03 Th & & 0.1 & ug/L & & & U & & & \\
\hline $\begin{array}{l}\text { SESPSPEC } \\
\text { SESPSEC }\end{array}$ & B16KV1 & $\begin{array}{l}300 \text { SPR } 7-2 \text { (4 IN) } \\
300 \text { SPR } 9-1(\text { FFT }\end{array}$ & ONSITE & SW & $\mathrm{N}$ & DRIVE POINT & 24-Feb-03 Th & & 0.1 & ug/L & & & u & & & \\
\hline $\begin{array}{l}\text { SESPSECC } \\
\text { SESPSPEC }\end{array}$ & $\begin{array}{l}\text { B16KV4 } \\
\text { B16KV5 }\end{array}$ & $\begin{array}{l}300 \text { SPR } 9 \text { - } 1 \text { ( FT) } \\
300 \text { SPR } 9-1 \text { ( FT) }\end{array}$ & $\begin{array}{l}\text { ONSITE } \\
\text { ONSTEE }\end{array}$ & $\begin{array}{l}\text { sw } \\
\text { sw }\end{array}$ & $\begin{array}{l}n \\
\mathrm{~N}\end{array}$ & $\begin{array}{l}\text { DRIVE POINT } \\
\text { DRIVE POINT }\end{array}$ & 24-Feb-03 Th & & 0.1 & ug/L & & & u & & & \\
\hline SESPSPEC & B16KV3 & $\begin{array}{l}300 \mathrm{SPR} 9-1(4 \mathrm{FT}) \\
300 \mathrm{SPR} 9-1(4 \mathrm{~N})\end{array}$ & ONSITE & sw & $\frac{N}{N}$ & $\begin{array}{l}\text { DRIVE POONT } \\
\text { DRIVE POINT }\end{array}$ & $\begin{array}{l}\text { 24-reb-03 Th } \\
\text { 24-Feb-03 Th }\end{array}$ & & 0.1 & $\begin{array}{l}\frac{\mathrm{gug} / \mathrm{L}}{\mathrm{ug} / \mathrm{L}} \\
\end{array}$ & & & u & & & \\
\hline SESPSPEC & B16KV7 & 300 SPR 9 -2 (2 FT) & ONSITE & sw & $\mathrm{N}$ & DRIVE POINT & 24-Feb-03 Th & & 0.152 & $\mathrm{ug} / \mathrm{L}$ & & & & & & \\
\hline $\begin{array}{l}\text { SESPSPEC } \\
\text { SESPSDC }\end{array}$ & B16KV6 & 300 SPR $9-2(4$ IN) & ONSITE & sw & n & DRIVE POINT & 24-Feb-03 Th & & 0.1 & $\mathrm{ug} / \mathrm{L}$ & & & u & & & \\
\hline $\begin{array}{l}\text { SESPSPEC } \\
\text { SESPSDC }\end{array}$ & B16KV8 & 300 SPR 9 -2 (4.5FT) & ONSITE & SW & $\mathrm{N}$ & DRIVE POINT & 24-Feb-03 Th & & 0.126 & $\mathrm{ug} / \mathrm{L}$ & & & & & & \\
\hline $\begin{array}{l}\text { SESPSPEC } \\
\text { SESPSEC }\end{array}$ & B16KW0 & 300 SPR 9 -3 (2 FT) & ONSITE & SW & $\mathrm{N}$ & DRIVE POINT & 24-Feb-03 Th & & 0.405 & $\mathrm{ug} / \mathrm{L}$ & & & & & & \\
\hline $\begin{array}{l}\text { SESPSEC } \\
\text { SESPSPEC }\end{array}$ & $\begin{array}{l}\text { B16KV9 } \\
\text { B180C6 }\end{array}$ & $\begin{array}{l}300 \text { SPR } 9-3 \text { (4 IN) } \\
100 \text { B/C AREA UR }\end{array}$ & $\begin{array}{l}\text { ONSITE } \\
\text { ONSITE }\end{array}$ & $\begin{array}{l}\text { SW } \\
\text { SW }\end{array}$ & $\begin{array}{l}\mathrm{y} \\
\mathrm{N}\end{array}$ & $\begin{array}{l}\text { DRIVE POINT } \\
\text { RIVER }\end{array}$ & $\begin{array}{l}\text { 24-Feb-03 Th } \\
\text { 13-Nov-03 Th }\end{array}$ & & 0.326 & $\frac{\mathrm{ug} / \mathrm{L}}{\mathrm{ug} / \mathrm{L}}$ & & & U & & & \\
\hline SESPSPEC & B180C7 & $100 \mathrm{~B} / \mathrm{C}$ AREA UR & ONSITE & sw & Y & RIVER & 13-Nov-03 Th & & 0.111 & ug/L & & & u & & & \\
\hline SESPSPEC & B180C 8 & 100 B/C AREA UR & ONSITE & sw & $\begin{array}{r}Y \\
Y\end{array}$ & RIVER & 13-Nov-03 Th & & 0.111 & $\mathrm{ug} / \mathrm{L}$ & & & U & & & \\
\hline $\begin{array}{l}\text { SESPSPEC } \\
\text { SECPSDC }\end{array}$ & B180C9 & $100 \mathrm{~B} / \mathrm{C}$ AREA UR & ONSITE & sw & Y & RIVER & 13-Nov-03 Th & & 0.111 & ug/L & & & U & & & \\
\hline $\begin{array}{l}\text { SESPSPEC } \\
\text { SESPSPC }\end{array}$ & B180D0 & 100-B SPRING 38-3 & ONSITE & SW & $\begin{array}{l}Y \\
Y \\
Y\end{array}$ & RIVER & 13-Nov-03 Th & & 0.111 & $\mathrm{ug} / \mathrm{L}$ & & & U & DUP IS SAMPLE \#B180J4 & & \\
\hline $\begin{array}{l}\text { SESPSPEC } \\
\text { SESPSEC }\end{array}$ & B180D1 & 100-B SPRING 38-3 & ONSITE & SW & $\begin{array}{l}Y \\
Y\end{array}$ & $\begin{array}{l}\text { RIVER } \\
\text { RIVER }\end{array}$ & 13-Nov-03 Th & & 0.111 & $\mathrm{ug} / \mathrm{L}$ & & & $\mathrm{U}$ & & & \\
\hline $\begin{array}{l}\text { SESPSEEC } \\
\text { SESPSPEC }\end{array}$ & $\begin{array}{l}\mathrm{B} 180 \mathrm{D} 2 \\
\mathrm{~B} 180 \mathrm{D} 3\end{array}$ & $\begin{array}{l}\text { 100-B SPRING 33-3 } \\
\text { 100-B SPRING 38-3 }\end{array}$ & $\begin{array}{l}\text { ONSITE } \\
\text { ONSITE }\end{array}$ & $\begin{array}{l}\text { SW } \\
\text { sW }\end{array}$ & $\begin{array}{l}Y \\
Y\end{array}$ & $\begin{array}{l}\text { IVIVER } \\
\text { RIVER }\end{array}$ & $\begin{array}{l}\text { 13-Nov-03 Th } \\
\text { 13-Nov-03 Th }\end{array}$ & & 0.111 & ug/L & & & u & & & \\
\hline $\begin{array}{l}\text { SESPSPEC } \\
\text { SESP }\end{array}$ & B180J4 & 100-B SPRING 38-3 38 & $\begin{array}{l}\text { ONSITE } \\
\text { ONSE }\end{array}$ & sw & 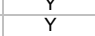 & $\begin{array}{l}\text { RIVER } \\
\text { RIVER }\end{array}$ & $\begin{array}{l}\text { 13-Nov-03 in } \\
\text { 13-Nov-03 Th }\end{array}$ & & 0.111 & $\begin{array}{l}\mathrm{ugh/2} \\
\mathrm{ug} / \mathrm{L}\end{array}$ & & & u & DUP SAMPLE FOR B180D0 & & \\
\hline SESPSPEC & B180D4 & 100-B SPRING 39-2 & ONSITE & sw & Y & RIVER & 13-Nov-03 Th & & 0.111 & $\mathrm{ug} / \mathrm{L}$ & & & u & & & \\
\hline SESPSPEC & B180D5 & 100-B SPRING 39-2 & ONSITE & sw & Y & RIVER & 13-Nov-03 Th & & 0.111 & ug/L & & & U & & & \\
\hline $\begin{array}{l}\text { SESPSPEC } \\
\text { SESPSEC }\end{array}$ & $\begin{array}{l}\text { B180D6 } \\
\text { B18007 }\end{array}$ & $\begin{array}{l}\text { 100-B SPRING 39-2 } \\
100-B \text { SPRING 39-2 }\end{array}$ & ONSITE & SW & $\begin{array}{l}Y \\
Y \\
Y\end{array}$ & $\begin{array}{l}\text { RIVER } \\
\text { RIVER }\end{array}$ & 13-Nov-03 Th & & 0.111 & $\mathrm{ug} / \mathrm{L}$ & & & U & & & \\
\hline $\begin{array}{l}\text { SESPSPEC } \\
\text { SESPSEC }\end{array}$ & B180D7 & $\begin{array}{l}100-B \text { SPRING 39-2 } \\
100-8 \text { SPRING } 38-3\end{array}$ & ONSITE & SW & $\begin{array}{r}\text { Y } \\
\text { y }\end{array}$ & $\begin{array}{l}\text { RIVER } \\
\text { RIVER }\end{array}$ & 13-Nov-03 Th & & 0.111 & $\mathrm{ug} / \mathrm{L}$ & & & U & & & \\
\hline $\begin{array}{l}\text { SESPSECC } \\
\text { SESPPEC }\end{array}$ & $\begin{array}{l}\text { B180F9 } \\
\text { B180F1 }\end{array}$ & $\begin{array}{l}\text { 100-B SPRING DR 38-3 } \\
100 \text { B/CAREA DR }\end{array}$ & ONSITE & SW & $\begin{array}{r}Y \\
Y\end{array}$ & $\begin{array}{l}\text { RIVER } \\
\text { RIVER }\end{array}$ & 13-Nov-03 Th & & 0.111 & ug/L & & & U & & & \\
\hline $\begin{array}{l}\text { SESPSEC } \\
\text { SESPSEC }\end{array}$ & $\begin{array}{l}\text { B180F1 } \\
\text { B180F2 }\end{array}$ & $\begin{array}{l}100 \text { B BCAREA AR } \\
100 \text { BIC AREA DR }\end{array}$ & $\begin{array}{l}\text { ONSIIE } \\
\text { ONSITE }\end{array}$ & SW & $\begin{array}{l}\text { Y } \\
Y\end{array}$ & $\begin{array}{l}\text { RIVER } \\
\text { RIVER }\end{array}$ & $\begin{array}{l}\text { 17-Nov-03 Th } \\
\text { 17-Nov-03 Th }\end{array}$ & & 0.111 & $\frac{\mathrm{ug} / \mathrm{L}}{\mathrm{ug} / \mathrm{L}}$ & & & u & & & \\
\hline SESPSPEC & B180F3 & 100 B/C AREA DR & ONSITE & sw & Y & RIVER & 17-Nov-03 Th & & 0.111 & $\mathrm{ug} / \mathrm{L}$ & & & u & & & \\
\hline SESPSPEC & B180F4 & $100 \mathrm{~B} / \mathrm{C}$ AREA DR & ONSITE & sw & $\mathrm{Y}$ & RIVER & 17-Nov-03 Th & & 0.111 & $\mathrm{ug} / \mathrm{L}$ & & & u & & & \\
\hline SESPSPEC & B180D8 & 100 B/C AREA OUTFL1 & ONSITE & sw & Y & RIVER & 17-Nov-03 Th & & 0.111 & $\mathrm{ug} / \mathrm{L}$ & & & U & & & \\
\hline SESPSPEC & B180D9 & 100 B/C AREA OUTFL2 & ONSITE & sw & Y & RIVER & 17-Nov-03 Th & & 0.111 & $\mathrm{ug} / \mathrm{L}$ & & & U & & & \\
\hline $\begin{array}{l}\text { SESPSPEC } \\
\text { SESPSPCC }\end{array}$ & B180F0 & $100 \mathrm{~B} / \mathrm{C}$ AREA OUTFL 3 & ONSITE & SW & Y & RIVER & 17-Nov-03 Th & & 0.111 & ug/L & & & U & & & \\
\hline $\begin{array}{l}\text { SESPSECC } \\
\text { SESPPEC }\end{array}$ & B180K2 & Refer to WELL NAME column & & GW & $\begin{array}{l}Y \\
Y \\
\end{array}$ & AQUIFER TUBE & 10-Dec-03 Th & & 0.111 & $\mathrm{ug/L} / \mathrm{h}$ & & & 0 & & & 01-D \\
\hline & B180K3 & Refer to WELL NAME column & & GW & & AQUIFER TUBE & 10-Dec-03 Th & & 0.111 & ug/L & & & 0 & & & 04-D \\
\hline $\begin{array}{l}\text { SESPSPEC } \\
\text { SESDSPDC }\end{array}$ & B180K4 & Refer to WELL NAME column & & GW & $\begin{array}{r}Y \\
Y\end{array}$ & AQUIFER TUBE & 10-Dec-03 Th & & 0.111 & ug/L & & & $u$ & & & 05-D \\
\hline SESPSPEC & B180K5 & Refer to WELL NAME column & & GW & $Y$ & AQUIFER TUBE & 10-Dec-03 Th & & 0.111 & $\mathrm{ug} / \mathrm{L}$ & & & U & & & 06-D \\
\hline SESPSPEC & B16WP2 & YAKIMA RIVER & OFFSITE & sw & Y & RIVER & 14-May-03 TI & & 0.009 & ug/L & & & U & & & \\
\hline $\begin{array}{l}\text { SESPSPEC } \\
\text { SESPSEC }\end{array}$ & B16WP3 & YAKIMA RIVER & OFFSITE & SW & $\begin{array}{r}Y \\
Y \\
Y\end{array}$ & $\begin{array}{l}\text { RIVER } \\
\text { RIVER }\end{array}$ & 14-May-03 TI & & 0.009 & ug/L & & & U & & & \\
\hline $\begin{array}{l}\text { SESPSEC } \\
\text { SESPSPEC }\end{array}$ & $\begin{array}{l}\text { B16WP4 } \\
\text { B16WP5 }\end{array}$ & $\begin{array}{l}\text { YYAKIMA RIVER } \\
\text { YAKIMA RIVER }\end{array}$ & $\begin{array}{l}\text { OFFSSTE } \\
\text { OFFSTTE }\end{array}$ & $\begin{array}{l}\text { SW } \\
\text { SW }\end{array}$ & $\begin{array}{r}\mathrm{Y} \\
\mathrm{H}\end{array}$ & $\begin{array}{l}\text { IVIVER } \\
\text { RIVER }\end{array}$ & $\begin{array}{l}\text { 14-May-03 TI } \\
\text { 14-Mav-03 TI }\end{array}$ & & 0.009 & $\mathrm{ugh/2}$ & & & u & & & \\
\hline SESPSPEC & B16WP6 & YAKIMA RIVER & OFFSITE & sw & $\mathrm{N}$ & $\begin{array}{l}\text { RIVER } \\
\text { RIVER }\end{array}$ & 14-May-03 TI & & 0.009 & ug// & & & u & & & \\
\hline SESPSPEC & B16WP7 & YAKIMA RIVER & OFFSITE & sw & $\mathrm{N}$ & RIVER & 14-May-03 TI & & 0.009 & ug/L & & & U & & & \\
\hline SESPSPEC & B16WR5 & HOOD PARK-FRANKLIN CO. SHORE & OFFSITE & SW & Y & RIVER & 15-May-03 TI & & 0.009 & $\mathrm{ug} / \mathrm{L}$ & & & U & & & \\
\hline $\begin{array}{l}\text { SESPSPEC } \\
\text { SESPSPCC }\end{array}$ & B16WR8 & HOOD PARK-FRANKLIN CO. SHORE & OFFSITE & sw & $\begin{array}{l}y^{2} \\
\mathrm{n}\end{array}$ & RIVER & 15-May-03 TI & & 0.009 & $\mathrm{ug} / \mathrm{L}$ & & & U & & & \\
\hline $\begin{array}{l}\text { SESPSECC } \\
\text { SESPSPEC }\end{array}$ & $\begin{array}{l}\text { B16WR4 } \\
\text { B16WR9 }\end{array}$ & $\begin{array}{l}\text { HOOD PARK-MID-RIVER } \\
\text { HOOD PARK-MI-RIER }\end{array}$ & $\begin{array}{l}\text { OFFSSTE } \\
\text { OFESTE }\end{array}$ & SW & $\begin{array}{r}Y^{2} \\
y^{2}\end{array}$ & $\begin{array}{l}\text { RIVER } \\
\text { RIVER }\end{array}$ & 15-May-03 TI & & 0.009 & ug/L & & & U & & & \\
\hline $\begin{array}{l}\text { SESPSECC } \\
\text { SESPSPEC }\end{array}$ & $\begin{array}{l}\text { B16WR9 } \\
\text { B16WR6 }\end{array}$ & $\begin{array}{l}\text { HOOD PARK-MII-RIVER } \\
\text { HOOD PARK-WALA WALLA SHORE }\end{array}$ & $\begin{aligned} & \text { OFFSSTE } \\
& \text { OFFSTTE }\end{aligned}$ & $\begin{array}{l}\text { SW } \\
\text { sw }\end{array}$ & $\begin{array}{l}\mathrm{Y} \\
\mathrm{N}\end{array}$ & $\begin{array}{l}\text { RIVER } \\
\text { RIVER }\end{array}$ & $\begin{array}{l}\text { 15-May-03 TI } \\
15-M a-03 \text { TI }\end{array}$ & & 0.009 & $\mathrm{ug} / \mathrm{L}$ & & & u & & & \\
\hline SESPSPEC & $\begin{array}{l}\text { B16WR7 } \\
\text { B16Whe }\end{array}$ & 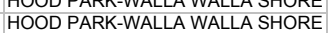 & OFFSITE & sw & $\frac{n}{4}$ & $\begin{array}{l}\text { RIVER } \\
\text { RIVER }\end{array}$ & 15-May-03 TI & & 0.009 & $\begin{array}{l}u g h / 2 \\
u g / L\end{array}$ & & & u & & & \\
\hline SESPSPEC & B16WN6 & MCNARY MID-RIVER NEAR DAM & OFFSITE & sw & Y & RIVER & 15-May-03 TI & & 0.0122 & $\mathrm{ug} / \mathrm{L}$ & & & B & & & \\
\hline SESPSPEC & B16WP1 & MCNARY MID-RIVER NEAR DAM & OFFSITE & sw & $\mathrm{N}$ & RIVER & 15-May-03 TI & & 0.0136 & $\mathrm{ug} / \mathrm{L}$ & & & B & & & \\
\hline SESPSPEC & B16WN8 & MCNARY-OR.SIDE NEAR DAM & OFFSITE & sw & Y & RIVER & 15-May-03 TI & & 0.0126 & $\mathrm{ug} / \mathrm{L}$ & & & B & & & \\
\hline $\begin{array}{l}\text { SESPSPCC } \\
\text { SESPSEC }\end{array}$ & B16WN9 & MCNARY-OR.SIDE NEAR DAM & OFFSITE & SW & $\begin{array}{l}\text { d } \\
\mathrm{N}\end{array}$ & $\begin{array}{l}\text { RIVER } \\
\text { RIVER }\end{array}$ & 15-May-03 TI & & 0.0151 & $\mathrm{ug} / \mathrm{L}$ & & & B & & & \\
\hline $\begin{array}{l}\text { SESPSEC } \\
\text { SESPSPEC }\end{array}$ & $\begin{array}{l}\text { B16WN7 } \\
\text { B16WP0 }\end{array}$ & $\begin{array}{l}\text { MCNARYYWASH.SIDE NEAR DAM } \\
\text { MCNARYWASH SIDE NEAR DAM }\end{array}$ & $\begin{array}{l}\text { OFFSSTE } \\
\text { OFFITE }\end{array}$ & $\begin{array}{l}\text { SW } \\
\text { SW }\end{array}$ & $\begin{array}{r}\mathrm{Y} \\
\mathrm{N}\end{array}$ & $\begin{array}{l}\text { RIVER } \\
\text { RIVER }\end{array}$ & $\begin{array}{l}\text { 15-May-03 TI } \\
15 \text {-Myy-03 TI }\end{array}$ & & 0.0122 & $\mathrm{ugh/2}$ ugh & & & $\begin{array}{l}B \\
B\end{array}$ & & & \\
\hline SESPSPEC & B16WP8 & WALLA WALLA-RIVER & OFFSITE & sw & Y & RIVER & 15-May-03 TI & & 0.009 & ug/L & & & u & & & \\
\hline SESPSPEC & B16WP9 & WALLA WALLA-RIVER & OFFSITE & sw & Y & RIVER & 15-May-03 TI & & 0.009 & $\mathrm{ug} / \mathrm{L}$ & & & U & & & \\
\hline SESPSPEC & B16WR0 & WALLA WALLA-RIVER & OFFSITE & SW & Y & RIVER & 15-May-03 TI & & 0.009 & $\mathrm{ug} / \mathrm{L}$ & & & U & & & \\
\hline $\begin{array}{l}\text { SESPSPEC } \\
\text { SESPGDC }\end{array}$ & B16WR1 & WALLA WALLA-RIVER & OFFSITE & sw & $\mathrm{N}$ & RIVER & 15-May-03 TI & & 0.009 & $\mathrm{ug} / \mathrm{L}$ & & & U & & & \\
\hline $\begin{array}{l}\text { SESPSPEC } \\
\text { SESPPEC }\end{array}$ & $\begin{array}{l}\text { B16WR2 } \\
\text { B16WR3 }\end{array}$ & $\begin{array}{l}\text { WALLA WALLA-RIVER } \\
\text { WALA WALA-RIVER }\end{array}$ & $\begin{array}{l}\text { OFFSSTE } \\
\text { OFFSTTE }\end{array}$ & $\begin{array}{l}\text { SW } \\
\text { sw }\end{array}$ & $\begin{array}{l}n \\
N\end{array}$ & $\begin{array}{l}\text { IVIVR } \\
\text { RIVER }\end{array}$ & $\begin{array}{l}\text { 15-May-03 TI } \\
15 \text {-Mav-03 TI }\end{array}$ & & 0.009 & $\mathrm{ug} / \mathrm{L}$ & & & $\begin{array}{l}U \\
B\end{array}$ & & & \\
\hline $\begin{array}{l}\text { SESPSEC } \\
\text { SESPPEC }\end{array}$ & $\begin{array}{l}\text { B16WR3 } \\
\text { B180C6 }\end{array}$ & $\begin{array}{l}\text { WALLA WALLA-AIVER } \\
100 \text { B/C AREA UR }\end{array}$ & $\begin{array}{l}\text { OFFSITE } \\
\text { ONSITE }\end{array}$ & $\begin{array}{l}\text { SW } \\
\text { SW }\end{array}$ & $\frac{\mathrm{N}}{\mathrm{N}}$ & $\begin{array}{l}\text { IIVER } \\
\text { RIVER }\end{array}$ & $\begin{array}{l}\text { 15-May-03 TI } \\
\text { 13-Nov-3 TI }\end{array}$ & & 0.00948 & ug// & & & $\frac{B}{B}$ & & & \\
\hline SESPSPEC & B180C7 & 100 B/C AREA UR & ONSITE & sw & $\mathrm{Y}$ & $\begin{array}{l}\text { RIVER } \\
\text { RIVER }\end{array}$ & 13-Nov-03 TI & & 0.0175 & ug/L & & & B & & & \\
\hline SESPSPEC & B180C8 & $100 \mathrm{~B} / \mathrm{C}$ AREA & ONSITE & SW & Y & RIVER & 13-Nov-03 TI & & 0.0171 & $\mathrm{ug} / \mathrm{L}$ & & & B & & & \\
\hline SESPSPEC & B180C9 & $100 \mathrm{~B} / \mathrm{C} \mathrm{AR}$ & ONSITE & SW & $\begin{array}{l}Y \\
Y \\
\end{array}$ & RIVER & 13-Nov-03 TI & & 0.0183 & $\mathrm{ug} / \mathrm{L}$ & & & B & & & \\
\hline $\begin{array}{l}\text { SESPSPEC } \\
\text { SESPSEC }\end{array}$ & B180D0 & 100-B SPRING 38-3 & ONSITE & sw & $\begin{array}{r}Y \\
Y\end{array}$ & $\begin{array}{l}\text { RIVER } \\
\text { RIVER }\end{array}$ & 13-Nov-03 TI & & 0.0173 & $\mathrm{ug} / \mathrm{L}$ & & & $B$ & DUP IS SAMPLE \#B180J4 & & \\
\hline $\begin{array}{l}\text { SESPSPEC } \\
\text { SESPPEC }\end{array}$ & $\begin{array}{l}\text { B18001 } \\
\text { B18002 }\end{array}$ & 100-B SPRING 38-3 & $\begin{array}{l}\text { ONSITE } \\
\text { ONSITE }\end{array}$ & $\begin{array}{l}\text { SW } \\
\text { sw }\end{array}$ & $\begin{array}{l}Y \text { Y } \\
\text { Y }\end{array}$ & $\begin{array}{l}\text { RIVER } \\
\text { RIVER }\end{array}$ & 13-Nov-03 TI & & 0.0157 & ug/L & & & B & & & \\
\hline $\begin{array}{l}\text { SESPSEC } \\
\text { SESPSPEC }\end{array}$ & $\begin{array}{l}\mathrm{B} 180 \mathrm{D} 2 \\
\mathrm{~B} 100 \mathrm{D} 3\end{array}$ & $\begin{array}{l}\text { 100-B SPRING 38-3 } \\
\text { 100-B SPRING 38-3 }\end{array}$ & $\begin{array}{l}\text { ONSITE } \\
\text { ONSITE }\end{array}$ & SW & $\begin{array}{l}\text { Y } \\
\text { Y }\end{array}$ & $\begin{array}{l}\text { IIVER } \\
\text { RIVER }\end{array}$ & $\begin{array}{l}\text { 13-Nov-03 TI } \\
\text { 13-Nov-03 TI }\end{array}$ & & 0.0183 & ugh/ & & & $B$ & & & \\
\hline $\begin{array}{l}\text { SESPSPEC } \\
\text { SESPC }\end{array}$ & B180J4 & 100-B SPRING 38-3 & ONSITE & sw & $\begin{array}{r}\mathrm{Y} \\
\mathrm{Y}\end{array}$ & $\begin{array}{l}\text { RIVER } \\
\text { RIVER }\end{array}$ & 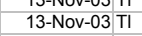 & & 0.0179 & ug/h & & & B & DUP SAMPLE FOR B180D0 & & \\
\hline SESPSPEC & B180D4 & 100-B SPRING 39-2 & ONSITE & SW & Y & RIVER & 13-Nov-03 TI & & 0.0175 & ug/L & & & B & & & \\
\hline SESPSPEC & B180D5 & 100-B SPRING 39-2 & ONSITE & sw & Y & RIVER & 13-Nov-03 TI & & 0.0184 & ug/L & & & B & & & \\
\hline
\end{tabular}




\begin{tabular}{|c|c|c|c|c|c|c|c|c|c|c|c|c|c|c|c|c|}
\hline | OWNER ID & SAMP NUM & SAMP SITE NAME & DIST CLASS & MEDIA & $\begin{array}{c}\text { FILTERED } \\
\text { FLAG }\end{array}$ & SAMP FROM & |SAMP DATE & CON SHORT NAME & | VALUE RPTD| & $\begin{array}{l}\text { ANAL } \\
\text { UNITS } \\
\text { RPTD }\end{array}$ & $\left|\begin{array}{c}\text { COUNTING } \\
\text { ERROR }\end{array}\right|$ & \begin{tabular}{|c|} 
TOTAL \\
ANAL \\
ERROR
\end{tabular} & $\mid \begin{array}{c}\text { LAB } \\
\text { QUALIFIER }\end{array}$ & SAMP COMMENT & $\left|\begin{array}{|c|}\text { RESULT } \\
\text { COMMENT }\end{array}\right|$ & WELL NAME \\
\hline SESPSPEC & B180D6 & 100-B SPRING 39-2 & ONSITE & SW & Y & RIVER & 13-Nov-03 TI & & 0.0178 & ug/L & & & B & & & \\
\hline $\begin{array}{l}\text { SESPSPEC } \\
\text { SESPPDEC }\end{array}$ & B180D7 & 100-B SPRING 39-2 & ONSITE & SW & $\begin{array}{l}Y \\
Y\end{array}$ & RIVER & 13-Nov-03 TI & & 0.0184 & $\mathrm{ug} / \mathrm{L}$ & & & B & & & \\
\hline $\begin{array}{l}\text { SESPPEC } \\
\text { SESPSPEC }\end{array}$ & $\begin{array}{l}\text { B180F9 } \\
\text { B1801 }\end{array}$ & $\begin{array}{l}\text { 100-B SPRING DR 38-3 } \\
100 \text { BCAREA DR }\end{array}$ & & SW & $\begin{array}{l}Y \\
Y \\
Y\end{array}$ & $\begin{array}{l}\text { RIVER } \\
\text { RIVER }\end{array}$ & 13-Nov-03 TI & & 0.0178 & ug/L & & & $B$ & & & \\
\hline $\begin{array}{l}\text { SESPSPEC } \\
\text { SESPSPEC }\end{array}$ & $\begin{array}{l}\text { B180F1 } \\
\text { B180F2 }\end{array}$ & $\begin{array}{l}100 \mathrm{~B} / \mathrm{C} \text { AREA DR } \\
100 \mathrm{~B} / \mathrm{C} \text { AREA DR }\end{array}$ & $\begin{array}{l}\text { ONSITE } \\
\text { ONSITE }\end{array}$ & $\begin{array}{l}\text { SW } \\
\text { sw }\end{array}$ & $\begin{array}{l}Y \\
Y\end{array}$ & $\begin{array}{l}\text { RRVER } \\
\text { RIVER }\end{array}$ & $\begin{array}{l}\text { 17-Nov-03 TI } \\
\text { 17-Nov-03 TI }\end{array}$ & & $\begin{array}{l}0.0163 \\
0.0192\end{array}$ & $\begin{array}{l}\mathrm{ug} / \mathrm{L} \\
\mathrm{ug} / \mathrm{L}\end{array}$ & & & $\begin{array}{l}\text { B } \\
B\end{array}$ & & & \\
\hline SESPSPEC & B180F3 & 100 B/C AREA DR & ONSITE & sw & Y & RIVER & 17-Nov-03 TI & & 0.0179 & ug/L & & & B & & & \\
\hline SESPSPEC & B180F4 & $100 \mathrm{~B} / \mathrm{C}$ AREA DR & ONSITE & sw & Y & RIVER & 17-Nov-03 TI & & 0.0172 & $\mathrm{ug} / \mathrm{L}$ & & & B & & & \\
\hline $\begin{array}{l}\text { SESPSPEC } \\
\text { SECDPEC }\end{array}$ & B180D8 & $100 \mathrm{~B} / \mathrm{C}$ AREA OUTFL1 & ONSITE & sW & Y & RIVER & 17-Nov-03 TI & & 0.0173 & $\mathrm{ug} / \mathrm{L}$ & & & B & & & \\
\hline $\begin{array}{l}\text { SESPSPEC } \\
\text { SESPPDEC }\end{array}$ & B180D9 & 100 B/C AREA OUTFL2 & ONSITE & SW & Y & RIVER & 17-Nov-03 TI & & 0.0177 & $\mathrm{ug} / \mathrm{L}$ & & & B & & & \\
\hline $\begin{array}{l}\text { SESPSPEC } \\
\text { SESPPEC }\end{array}$ & B180F0 & 100 B/C AREA OUTFL3 & ONSITE & SW & Y & RIVER & 17-Nov-03 TI & & 0.0182 & $\mathrm{ug} / \mathrm{L}$ & & & B & & & \\
\hline $\begin{array}{l}\text { SESPSPEC } \\
\text { SESPSPEC }\end{array}$ & $\begin{array}{l}\text { B1616T8 } \\
\text { B16KT9 }\end{array}$ & $\begin{array}{l}300 \text { SPR } 7-1 \text { - (2.5FT) } \\
300 \text { SPR } 7-1 \text { (4 FT) }\end{array}$ & $\begin{array}{l}\text { ONSIIE } \\
\text { ONSITE }\end{array}$ & $\begin{array}{l}\text { SW } \\
\text { SW }\end{array}$ & $\frac{N}{N}$ & $\begin{array}{l}\text { DRIVE POINT } \\
\text { DRIVE POINT }\end{array}$ & $\begin{array}{l}\text { 24-Feb-03U } \\
\text { 24-Feb-303U }\end{array}$ & & $\begin{array}{l}229 \\
135\end{array}$ & $\frac{u g g / L}{u g / L}$ & & & & & & \\
\hline SESPSPEC & B16KT7 & 300 SPR $7-1(4 \mathrm{FIN})$ & $\begin{array}{l}\text { ONSSITE } \\
\text { ONSE }\end{array}$ & sw & $\frac{N}{N}$ & $\begin{array}{l}\text { DRIVE POINI } \\
\text { DRIVE POINT }\end{array}$ & 24-Feb-03 0 & & $\begin{array}{l}135 \\
179\end{array}$ & $\frac{\mathrm{ug} / \mathrm{L}}{\mathrm{ug} / \mathrm{L}}$ & & & & & & \\
\hline SESPSPEC & B16KVO & 300 SPR 7 -1 (6 FT) & ONSITE & sw & $\mathrm{N}$ & DRIVE POINT & 24-Feb-03U & & 125 & $\mathrm{ug} / \mathrm{L}$ & & & & & & \\
\hline $\begin{array}{l}\text { SESPSPEC } \\
\text { SEGDPEC }\end{array}$ & B16KV2 & 300 SPR 7 - 2 (2 FT) & ONSITE & sw & $N$ & DRIVE POINT & 24-Feb-03 U & & 175 & ug/L & & & & & & \\
\hline $\begin{array}{l}\text { SESPSPEC } \\
\text { SESPPPEC }\end{array}$ & B16KV1 & 300 SPR $7-2$ (4 IN) & ONSITE & sw & $\mathrm{N}$ & DRIVE POINT & 24-Feb-03 U & & 209 & $\mathrm{ug} / \mathrm{L}$ & & & & & & \\
\hline $\begin{array}{l}\text { SESPPPEC } \\
\text { SESPSPEC }\end{array}$ & B16KV4 & 300 SPR 9 -1 (2 FT) & ONSITE & SW & $\begin{array}{r}\mathrm{N} \\
\mathrm{N}\end{array}$ & $\begin{array}{l}\text { DRIVE POINT } \\
\end{array}$ & 24-Feb-03 U & & 120 & $\mathrm{ug} / \mathrm{L}$ & & & & & & \\
\hline $\begin{array}{l}\text { SESSPPEC } \\
\text { SESPSPEC }\end{array}$ & $\begin{array}{l}\text { B1616V5 } \\
\text { B16KV3 }\end{array}$ & $\begin{array}{l}300 \text { SPR } 9 \text { - } 1 \text { (4 FT) } \\
300 \text { SPR } 9-1(4 \text { IN }\end{array}$ & $\begin{array}{l}\text { ONSIIE } \\
\text { ONSITE }\end{array}$ & $\begin{array}{l}\text { SW } \\
\text { sW }\end{array}$ & $\frac{N}{N}$ & $\begin{array}{l}\text { DRIVE POINT } \\
\text { DRIV POIT }\end{array}$ & 24-Feb-03U & & 58.1 & ug/L & & & & & & \\
\hline SESPSPEC & B16KV7 & 300 SPR 9 - 2 ( (2 FT) & ONSITE & sw & $\frac{N}{N}$ & $\begin{array}{l}\text { DRIVE POINI } \\
\text { DRIVE POINT }\end{array}$ & 24-Feb-03 & & $\begin{array}{l}41.4 \\
66.9\end{array}$ & $\begin{array}{l}\mathrm{ugh/2} \\
\mathrm{ug} / \mathrm{L}\end{array}$ & & & & & & \\
\hline SESPSPEC & B16KV6 & 300 SPR $9-2$ (4 IN) & ONSITE & sw & $\mathrm{N}$ & DRIVE POINT & 24-Feb-03U & & 13 & $\mathrm{ug} / \mathrm{L}$ & & & & & & \\
\hline SESPSPEC & B16KV8 & 300 SPR 9 -2 (4.5FT) & ONSITE & sw & $\mathrm{N}$ & DRIVE POINT & 24-Feb-03U & & 60.8 & ug/L & & & & & & \\
\hline $\begin{array}{l}\text { SESPSPEC } \\
\text { SESPPEC }\end{array}$ & $\begin{array}{l}\text { B16KWO } \\
\text { B16KV9 }\end{array}$ & $\begin{array}{l}300 \text { SPR } 9 \text { - } 3 \text { (2 FT) } \\
300 \text { SPR 9-3 (4 IN) }\end{array}$ & $\begin{array}{l}\text { ONSITE } \\
\text { ONSIE }\end{array}$ & SW & $\mathrm{N}$ & DRIVE POINT & 24-Feb-03U & & 81.4 & $\mathrm{ug} / \mathrm{L}$ & & & & & & \\
\hline $\begin{array}{l}\text { SESPPPEC } \\
\text { SESPSPEC }\end{array}$ & $\begin{array}{l}\text { B16KV9 } \\
\text { B16WP? }\end{array}$ & $\begin{array}{l}300 \text { SPR } 9 \text {-3 (4 IN) } \\
\text { YAKIA RIFR }\end{array}$ & $\begin{array}{l}\text { ONSITE } \\
\text { OFFSTE }\end{array}$ & SW & $\begin{array}{l}\mathrm{y} \\
\mathrm{N}\end{array}$ & $\begin{array}{l}\text { DRIVE POINT } \\
\text { RIVR }\end{array}$ & 24-Feb-03U & & $\begin{array}{l}36.6 \\
155\end{array}$ & $\mathrm{ug} / \mathrm{L}$ & & & & & & \\
\hline $\begin{array}{l}\text { SESPPPEC } \\
\text { SESPSPEC }\end{array}$ & $\begin{array}{l}\text { B16WP2 } \\
\text { B16WP3 }\end{array}$ & $\begin{array}{l}\text { YAAIMA RIVER } \\
\text { YAKIMA RIVER }\end{array}$ & $\begin{array}{l}\text { OFFITE } \\
\text { OFFSITE }\end{array}$ & SW & $\begin{array}{r}Y \\
Y\end{array}$ & $\begin{array}{l}\text { RIVER } \\
\text { RIVER }\end{array}$ & 14-May-03U & & $\begin{array}{r}1.55 \\
1.5\end{array}$ & ug/L & & & & & & \\
\hline SESPSPEC & $\begin{array}{l}\text { B16WP3 } \\
\text { B16WP4 }\end{array}$ & YAKIMA RIVER & $\begin{array}{l}\text { OFFSITE } \\
\text { OFFE }\end{array}$ & sw & $\begin{array}{l}\mathrm{Y} \\
\mathrm{Y}\end{array}$ & $\begin{array}{l}\text { RIVER } \\
\text { RIVER }\end{array}$ & $\begin{array}{l}\text { 14-May-03 } \\
\text { 14-May-03U }\end{array}$ & & $\begin{array}{l}1.45 \\
1.5\end{array}$ & $\frac{\mathrm{ug} / \mathrm{L}}{\mathrm{ug} / \mathrm{L}}$ & & & & & & \\
\hline SESPSPEC & B16WP5 & YAKIMA RIVER & OFFSITE & sw & $\mathrm{N}$ & RIVER & 14-May-03U & & 1.54 & $\mathrm{ug} / \mathrm{L}$ & & & & & & \\
\hline $\begin{array}{l}\text { SESPSPEC } \\
\text { SESPPDEC }\end{array}$ & B16WP6 & YAKIMA RIVER & OFFSITE & sW & $N$ & RIVER & 14-May-03 U & & 1.56 & $\mathrm{ug} / \mathrm{L}$ & & & & & & \\
\hline $\begin{array}{l}\text { SESPSPEC } \\
\text { SESPPDEC }\end{array}$ & B16WP7 & YAKIMA RIVER & OFFSITE & sw & $\mathrm{N}$ & RIVER & 14-May-03 U & & 1.59 & $\mathrm{ug} / \mathrm{L}$ & & & & & & \\
\hline $\begin{array}{l}\text { SESPPPEC } \\
\text { SESPPEC }\end{array}$ & B16WR5 & HOOD PARK-FRANKLIN CO. SHORE & OFFSITE & SW & Y & RIVER & 15-May-03 U & & 0.713 & $\mathrm{ug} / \mathrm{L}$ & & & & & & \\
\hline $\begin{array}{l}\text { SESSPPEC } \\
\text { SESPSPEC }\end{array}$ & $\begin{array}{l}\text { B16WR8 } \\
\text { B16WR4 }\end{array}$ & $\begin{array}{l}\text { HOOD PARKK-FRANLLIN CO. SHORE } \\
\text { HOOD PARK-MID-RIVER }\end{array}$ & $\begin{array}{l}\text { OFFITE } \\
\text { OFFSITE }\end{array}$ & SW & $\begin{array}{l}\mathrm{N} \\
\mathrm{Y}\end{array}$ & $\begin{array}{l}\text { RIVER } \\
\text { RIVER }\end{array}$ & $\begin{array}{l}\text { 15-May-03U } \\
\text { 15-May-03U }\end{array}$ & & $\begin{array}{r}0.76 \\
0.709\end{array}$ & $\begin{array}{ll}\mathrm{ugg} / \mathrm{L} \\
\mathrm{ug} / \mathrm{L}\end{array}$ & & & & & & \\
\hline SESPSPEC & B16WR9 & HOOD PARK-MID-RIVER & OFFSITE & sw & $\mathrm{N}$ & RIVER & 15-May-03U & & 0.766 & $\mathrm{ug} / \mathrm{L}$ & & & & & & \\
\hline $\begin{array}{l}\text { SESPSPEC } \\
\text { SEGDPEC }\end{array}$ & B16WR6 & HOOD PARK-WALLA WALLA SHORE & OFFSITE & sw & Y & RIVER & 15-May-03U & & 0.716 & $\mathrm{ug} / \mathrm{L}$ & & & & & & \\
\hline SESPSPEC & B16WR7 & HOOD PARK-WALLA WALLA SHORE & OFFSITE & SW & $\mathrm{N}$ & RIVER & 15-May-03U & & 0.772 & $\mathrm{ug} / \mathrm{L}$ & & & & & & \\
\hline $\begin{array}{l}\text { SESPSPEC } \\
\text { SESPPPEC }\end{array}$ & B16WN6 & MCNARY MID-RIVER NEAR DAM & OFFSITE & SW & Y & $\begin{array}{l}\text { RIVER } \\
\text { RIVER }\end{array}$ & 15-May-03 U & & 0.715 & $\mathrm{ug} / \mathrm{L}$ & & & & & & \\
\hline $\begin{array}{l}\text { SESPPPEC } \\
\text { SESPSPEC }\end{array}$ & $\begin{array}{l}\text { B16WP1 } \\
\text { B16WN8 }\end{array}$ & MCNARY MID-RIVER NEAR DAM & $\begin{array}{l}\text { OFFSITE } \\
\text { OFSITE }\end{array}$ & sw & $\begin{array}{l}\text { y } \\
\mathrm{N}\end{array}$ & $\begin{array}{l}\text { RIVER } \\
\text { RIVER }\end{array}$ & 15-May-03U & & 0.734 & $\mathrm{ug} / \mathrm{L}$ & & & & & & \\
\hline $\begin{array}{l}\text { SESPPEC } \\
\text { SESPSPEC }\end{array}$ & $\begin{array}{l}\text { B16WN8 } \\
\text { B16WN9 }\end{array}$ & $\begin{array}{l}\text { MCNARY-OR.SIDE NEAR DAM } \\
\text { MCNARYOR SIDE NER DAM }\end{array}$ & $\begin{array}{l}\text { OFFITE } \\
\text { OFFSITE }\end{array}$ & SW & $\begin{array}{l}\mathrm{Y} \\
\mathrm{N}\end{array}$ & $\begin{array}{l}\text { RIVER } \\
\text { RIVER }\end{array}$ & $\begin{array}{l}\text { 15-May-03U } \\
15 \text {-My-03U }\end{array}$ & & $\begin{array}{l}0.724 \\
0.73\end{array}$ & $\mathrm{ug} / \mathrm{L}$ & & & & & & \\
\hline SESPSPEC & B16WN7 & MCNARY-WASH.SIDE NEAR DAM & OFFSITE & sw & $\begin{array}{l}\mathrm{Y} \\
\mathrm{Y}\end{array}$ & $\begin{array}{l}\text { RIVER } \\
\text { RIVER }\end{array}$ & 15-May-03U & & 0.714 & $\begin{array}{l}u g h / 2 \\
\text { ug/L }\end{array}$ & & & & & & \\
\hline SESPSPEC & B16WP0 & MCNARY-WASH.SIDE NEAR DAM & OFFSITE & sw & $\mathrm{N}$ & RIVER & 15-May-03U & & 0.691 & $\mathrm{ug} / \mathrm{L}$ & & & & & & \\
\hline SESPSPEC & B16WP8 & WALLA WALLA-RIVER & OFFSITE & SW & Y & RIVER & 15-May-03 U & & 0.371 & $\mathrm{ug} / \mathrm{L}$ & & & & & & \\
\hline $\begin{array}{l}\text { SESPSPEC } \\
\text { SESPPEC }\end{array}$ & B16WP9 & WALLA WALLA-RIVER & OFFSITE & sw & Y & RIVER & 15-May-03U & & 0.372 & $\mathrm{ug} / \mathrm{L}$ & & & & & & \\
\hline $\begin{array}{l}\text { SESPPPEC } \\
\text { SESPSPEC }\end{array}$ & B16WR0 & WALLA WALLA-RIVER & OFFSITE & SW & Y & $\begin{array}{l}\text { RIVER } \\
\text { RIVER }\end{array}$ & 15-May-03U & & 0.385 & $\mathrm{ug} / \mathrm{L}$ & & & & & & \\
\hline $\begin{array}{l}\text { SESSPPEC } \\
\text { SESPSPEC }\end{array}$ & $\begin{array}{l}\text { B16WR1 } \\
\text { B16WR2 }\end{array}$ & $\begin{array}{l}\text { WALLA WALLA-RIVR } \\
\text { WALLA WALLA-RIVER }\end{array}$ & $\begin{array}{l}\text { OFFITE } \\
\text { OFFSITE }\end{array}$ & $\begin{array}{l}\text { SW } \\
\text { sw }\end{array}$ & $\mathrm{N}_{\mathrm{N}}$ & $\begin{array}{l}\text { RIVER } \\
\text { RIVER }\end{array}$ & $\begin{array}{l}\text { 15-May-03U } \\
\text { 15-May-03U }\end{array}$ & & $\begin{array}{l}0.429 \\
0.435\end{array}$ & $\begin{array}{l}\mathrm{ug} / \mathrm{L} \\
\mathrm{ug} / \mathrm{L}\end{array}$ & & & & & & \\
\hline SESPSPEC & B16WR3 & WALLA WALLA-RIVER & OFFSITE & sw & $\mathrm{N}$ & RIVER & 15-May-03 U & & 0.435 & ug/ & & & & & & \\
\hline SESPSPEC & B180C6 & 100 B/C AREA UR & ONSITE & sw & Y & RIVER & 13-Nov-03 U & & 0.387 & $\mathrm{ug} / \mathrm{L}$ & & & & & & \\
\hline & $\begin{array}{l}\text { B180C7 } \\
\text { B180C8 }\end{array}$ & $\begin{array}{l}100 \text { B/C AREA UR } \\
100 \text { BCCAREA UR }\end{array}$ & $\begin{array}{l}\text { ONSITE } \\
\text { ONSTE }\end{array}$ & SW & $\begin{array}{r}Y \\
Y \\
Y\end{array}$ & $\begin{array}{l}\text { RIVER } \\
\text { RIVER }\end{array}$ & $\begin{array}{l}\text { 13-Nov-03U } \\
\text { 13-No-03U }\end{array}$ & & $\begin{array}{r}0.45 \\
0.462\end{array}$ & $\mathrm{ug} / \mathrm{L}$ & & & & & & \\
\hline $\begin{array}{l}\text { SESPPPEC } \\
\text { SESPSPEC }\end{array}$ & $\begin{array}{l}\text { B180C8 } \\
\text { B100C9 }\end{array}$ & $\begin{array}{l}100 \text { B/C AREA UR } \\
100 \text { B/C AREA UR }\end{array}$ & $\begin{array}{l}\text { ONSIIE } \\
\text { ONSITE }\end{array}$ & $\begin{array}{l}\text { sw } \\
\text { sw }\end{array}$ & $\begin{array}{r}\mathrm{Y} \\
\mathrm{Y}\end{array}$ & $\begin{array}{l}\text { RRVER } \\
\text { RIVER }\end{array}$ & $\begin{array}{l}\text { 13-Nov-03U } \\
\text { 13-Nov-03U }\end{array}$ & & $\begin{array}{c}0.462 \\
0.5\end{array}$ & $\mathrm{ugh/L}$ & & & & & & \\
\hline SESPSPEC & B180D0 & 100-B SPRING 38-3 & ONSITE & sw & Y & $\begin{array}{l}\text { RIVER } \\
\text { RIVER }\end{array}$ & 13-Nov-03 U & & 0.554 & ug/L & & & & DUP IS SAMPLE \#B180J4 & & \\
\hline SESPSPEC & B180D1 & 100-B SPRING 38-3 & ONSITE & sw & Y & RIVER & 13-Nov-03 U & & 0.532 & ug/L & & & & te & & \\
\hline SESPSPEC & B180D2 & 100-B SPRING 38-3 & ONSITE & sw & $\mathrm{Y}$ & RIVER & 13-Nov-03 U & & 0.529 & ug/L & & & & & & \\
\hline SESPSPEC & B180D3 & 100-B SPRING 38-3 & ONSITE & sw & $Y$ & RIVER & 13-Nov-03 U & & 0.498 & $\mathrm{ug} / \mathrm{L}$ & & & & & & \\
\hline SESPSPEC & B180J4 & 100-B SPRING 38-3 & ONSITE & sw & $\begin{array}{l}Y \\
Y \\
\end{array}$ & RIVER & 13-Nov-03 U & & 0.537 & $\mathrm{ug} / \mathrm{L}$ & & & & DUP SAMPLE FOR B180D0 & & \\
\hline $\begin{array}{l}\text { SESPSPEC } \\
\text { SESPDPEC }\end{array}$ & B180D4 & 100-B SPRING 39-2 & ONSITE & sw & $\begin{array}{l}Y \\
Y\end{array}$ & RIVER & 13-Nov-03 U & & 0.526 & $\mathrm{ug} / \mathrm{L}$ & & & & & & \\
\hline $\begin{array}{l}\text { SESPPPEC } \\
\text { SESPSPEC }\end{array}$ & $\begin{array}{l}\text { B18005 } \\
\text { B18006 }\end{array}$ & $\begin{array}{l}\text { 100-B SPRING 39-2 } \\
\text { 100-B SPRING 39-2 }\end{array}$ & $\begin{array}{l}\text { ONSITE } \\
\text { ONSITE }\end{array}$ & $\begin{array}{l}\text { Sw } \\
\text { sw }\end{array}$ & $\begin{array}{r}Y \\
Y\end{array}$ & $\begin{array}{l}\text { IVIVR } \\
\text { RIVER }\end{array}$ & $\begin{array}{l}\text { 13-Nov-03U } \\
\text { 13-Nov-03U }\end{array}$ & & 0.5 & $\mathrm{ug} / \mathrm{L}$ & & & & & & \\
\hline $\begin{array}{l}\text { SESSPEC } \\
\text { SESPSPEC }\end{array}$ & $\begin{array}{l}\text { B180D6 } \\
\text { B180D7 }\end{array}$ & $\begin{array}{l}\text { 100-B SPRING 39-2 } \\
\text { 100-B SPRING 39-2 }\end{array}$ & $\begin{array}{l}\text { ONSITE } \\
\text { ONSITE }\end{array}$ & $\begin{array}{l}\text { SW } \\
\text { SW }\end{array}$ & $\begin{array}{l}\text { Y } \\
\text { Y }\end{array}$ & $\begin{array}{l}\text { IIVER } \\
\text { RIVER }\end{array}$ & $\begin{array}{l}\text { 13-Nov-03U } \\
\text { 13-Nov-33U }\end{array}$ & & $\begin{array}{l}0.504 \\
0.493\end{array}$ & $\mathrm{ug} / \mathrm{h}$ & & & & & & \\
\hline SESPSPEC & B180F9 & 100-B SPRING DR 38-3 & ONSITE & sw & $\mathrm{Y}$ & $\begin{array}{l}\text { RIVER } \\
\text { RIVER }\end{array}$ & 13-Nov-03 U & & 0.509 & ugh & & & & & & \\
\hline SESPSPEC & B180F1 & $100 \mathrm{~B} / \mathrm{C}$ AREA DR & ONSITE & SW & Y & RIVER & 17-Nov-03 U & & 0.483 & $\mathrm{ug} / \mathrm{L}$ & & & & & & \\
\hline SESPSPEC & B180F2 & $100 \mathrm{~B} / \mathrm{C}$ AREA DR & ONSITE & sw & $\begin{array}{l}Y \\
Y\end{array}$ & RIVER & 17-Nov-03U & & 0.506 & $\mathrm{ug} / \mathrm{L}$ & & & & & & \\
\hline $\begin{array}{l}\text { SESPPEC } \\
\text { SESOPPEC }\end{array}$ & B180F3 & $100 \mathrm{~B} / \mathrm{C}$ AREA DR & ONSITE & sw & $\begin{array}{r}Y \\
Y\end{array}$ & $\begin{array}{l}\text { RIVER } \\
\text { RIVER }\end{array}$ & 17-Nov-03 U & & 0.505 & $\mathrm{ug} / \mathrm{L}$ & & & & & & \\
\hline $\begin{array}{l}\text { SESPPPEC } \\
\text { SESPSPEC }\end{array}$ & B180F4 & 100 B/C AREA DR & ONSITE & sw & $\begin{array}{r}Y \\
Y \\
Y\end{array}$ & $\begin{array}{l}\text { RIVER } \\
\text { RIVER }\end{array}$ & 17-Nov-03U & & 0.502 & ug/L & & & & & & \\
\hline $\begin{array}{l}\text { SESSPEC } \\
\text { SESPSPEC }\end{array}$ & $\begin{array}{l}B 18008 \\
B 18009\end{array}$ & $\begin{array}{l}100 \text { B/C AREA OUTLL1 } \\
100 \text { B/C AREA OUTFL? }\end{array}$ & $\begin{array}{l}\text { ONSITE } \\
\text { ONSITE }\end{array}$ & $\begin{array}{l}\text { SW } \\
\text { sW }\end{array}$ & & $\begin{array}{l}\text { IIVER } \\
\text { RIVER }\end{array}$ & $\begin{array}{l}\text { 17-Nov-03U } \\
\text { 17-Nov-03U }\end{array}$ & & 0.502 & $\mathrm{ug} / \mathrm{L}$ & & & & & & \\
\hline $\begin{array}{l}\text { SESPSPEC } \\
\text { SESPSEC }\end{array}$ & $\begin{array}{l}\text { B180D9 } \\
\text { B180F0 }\end{array}$ & $\begin{array}{l}100 \text { B/C AARA OUFL2 } \\
100 \text { B/C AREA OUTFL3 }\end{array}$ & ONSITE & $\begin{array}{l}\text { SW } \\
\text { SW }\end{array}$ & $\begin{array}{l}\text { Y } \\
\text { Y }\end{array}$ & $\begin{array}{l}\text { RIVER } \\
\text { RIVER }\end{array}$ & $\begin{array}{l}\text { 17-Nov-03U } \\
\text { 17-Nov-03 U }\end{array}$ & & 0.509 & ug/L & & & & & & \\
\hline SESPSPEC & B180K2 & Refer to WELL NAME column & & GW & Y & AQUIFEF & 10-Dec-03U & & 0.128 & ug/L & & & & & & D \\
\hline SESPSPEC & B180K3 & Refer to WELL NAME column & & GW & Y & AQUIFER TUBE & 10-Dec-03 U & & 1.67 & $\mathrm{ug} / \mathrm{L}$ & & & & & & 04-D \\
\hline
\end{tabular}




\begin{tabular}{|c|c|c|c|c|c|c|c|c|c|c|c|c|c|c|c|}
\hline OWNER ID & SAMP NUM & SAMP SITE NAME & DIST CLASS & MEDIA $\mid$ & $\begin{array}{c}\text { FLLTERED } \\
\text { FLAG }\end{array}$ & SAMP FROM & CON SHORT NAME & | VALUE RPTD | & $\begin{array}{l}\text { ANAL } \\
\text { UNITS } \\
\text { RPTD }\end{array}$ & $\left|\begin{array}{c}\text { COUNTING } \\
\text { ERROR }\end{array}\right|$ & \begin{tabular}{|c|} 
TOTAL \\
ANAL \\
ERROR
\end{tabular} & $\begin{array}{c}\text { LAB } \\
\text { QUALIFIER }\end{array}$ & SAMP COMMENT & $\left|\begin{array}{c}\text { RESULT } \\
\text { COMMENT }\end{array}\right|$ & WELL NAME \\
\hline SESPSPEC & B180K4 & Refer to WELL NAME column & & GW & $\begin{array}{ll}Y \\
Y\end{array}$ & AQUIFER TUBE & $10-$ Dec- $-03 \mathrm{U}$ & $\begin{array}{r}1.04 \\
\end{array}$ & $\mathrm{ug} / \mathrm{L}$ & & & & & & \\
\hline $\begin{array}{l}\text { SESPSPEC } \\
\text { SESPSEEC }\end{array}$ & $\begin{array}{l}\text { B180K5 } \\
\text { B16WP2 }\end{array}$ & $\begin{array}{l}\text { Refer to WELL NAME column } \\
\text { YAKIMA RIVER }\end{array}$ & & GW & $\begin{array}{l}\text { Y } \\
\text { y }\end{array}$ & $\begin{array}{l}\text { AQUIFER TUBE } \\
\text { RIVER }\end{array}$ & $=10-D e c-03 U$ & 0.769 & $\mathrm{ug} / \mathrm{L}$ & & & & & & \\
\hline SESPSPEC & $\begin{array}{l}\text { B16WP2 } \\
\text { B16WP3 }\end{array}$ & $\begin{array}{l}\text { AAKIMA RIVER } \\
\text { YAKIMA RIVER }\end{array}$ & OFFSITE & SW & $\begin{array}{l}\text { Y } \\
\end{array}$ & 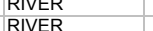 & $\begin{array}{l}14-M a y-03 Z n \\
14-M a y-03 Z n\end{array}$ & $\begin{array}{r}1.6 \\
1.35\end{array}$ & & & & & & & \\
\hline SESPSPEC & & YAKIMA RIVER & $\begin{array}{l}\text { OFFSIITE } \\
\text { OFFSITE }\end{array}$ & sw & $\begin{array}{l}\text { Y } \\
\text { Y }\end{array}$ & RIVER & 14-May-03 Zn & $\begin{array}{l}1.35 \\
1.22\end{array}$ & $\begin{array}{l}\mathrm{ugghL} \\
\mathrm{gg} / \mathrm{L}\end{array}$ & & & & & & \\
\hline SESPSPEC & B16WP5 & YAKIMA RIVER & OFFSITE & sw & $\mathrm{N}$ & RIVER & 14-May-03 Zn & 2.12 & ug/L & & & & & & \\
\hline SESPSPEC & B16WP6 & YAKIMA RIVER & OFFSITE & sw & $\mathrm{N}$ & RIVER & 14-May-03 Zn & 2.01 & $\mathrm{ug} / \mathrm{L}$ & & & & & & \\
\hline $\begin{array}{l}\text { SESPSPEC } \\
\text { SECDODC }\end{array}$ & B16WP7 & YAKIMA RIVER & OFFSITE & sW & $\mathrm{N}$ & RIVER & 14-May-03 Zn & 1.7 & $\mathrm{ug} / \mathrm{L}$ & & & & & & \\
\hline SESPSPEC & B16WR5 & HOOD PARK-FRANKLIN CO. SHORE & OFFSITE & SW & & RIVER & 15-May-03 Zn & 0.829 & $\mathrm{ug} / \mathrm{L}$ & & & & & & \\
\hline $\begin{array}{l}\text { SESPSPEC } \\
\text { SESPSPCE }\end{array}$ & B16WR8 & HOOD PARK-FRANKLIN CO. SHORE & OFFSITE & SW & $\mathrm{N}$ & RIVER & 15-May-03 Zn & 1.53 & $\mathrm{ug} / \mathrm{L}$ & & & & & & \\
\hline $\begin{array}{l}\text { SESPSPEC } \\
\text { SESPSPEC }\end{array}$ & $\begin{array}{l}\text { B16WR44 } \\
\text { B16WR9 }\end{array}$ & $\begin{array}{l}\text { HOOD PARK-MID-RIVER } \\
\text { HOOD PARK-MID-RIVER }\end{array}$ & $\begin{array}{l}\text { OFFSITE } \\
\text { OFFSITE }\end{array}$ & $\begin{array}{l}\text { SW } \\
\text { SW }\end{array}$ & $\frac{\mathrm{Y}}{\mathrm{N}}$ & $\begin{array}{l}\text { IVER } \\
\text { RIVER }\end{array}$ & $\begin{array}{l}\text { 15-May-03Zn } \\
15-\mathrm{May}-03 \mathrm{Zn}\end{array}$ & 0.726 & ug/L & & & & & & \\
\hline SESPSPEC & $\begin{array}{l}\text { B16WR9 } \\
\text { B16WR6 }\end{array}$ & $\begin{array}{l}\text { HOOD PARK-WALLLA WALLA SHORE } \\
\text { HOOLALE }\end{array}$ & $\begin{array}{l}\text { OFFSITE } \\
\text { OFFE }\end{array}$ & sw & $\begin{array}{l}\mathrm{N} \\
\mathrm{Y}\end{array}$ & $\begin{array}{l}\text { RIVER } \\
\text { RIVER }\end{array}$ & $\begin{array}{l}\text { 15-May-03 } 2 n \\
15-M a y-03 Z n\end{array}$ & $\begin{array}{l}1.26 \\
0.611\end{array}$ & $\frac{\mathrm{ugg} / \mathrm{L}}{\mathrm{gg} / \mathrm{L}}$ & & & & & & \\
\hline SESPSPEC & B16WR7 & HOOD PARK-WALLA WALLA SHORE & OFFSITE & sw & $\mathrm{N}$ & RIVER & 15-May-03 Zn & 1.25 & ug/L & & & & & & \\
\hline SESPSPEC & B16WN6 & MCNARY MID-RIVER NEAR DAM & OFFSITE & SW & Y & RIVER & 15-May-03 Zn & 2.11 & $\mathrm{ug} / \mathrm{L}$ & & & & & & \\
\hline SESPSPEC & B16WP1 & MCNARY MID-RIVER NEAR DAM & OFFSITE & SW & $\mathrm{N}$ & RIVER & 15-May-03 Zn & 3.44 & $\mathrm{ug} / \mathrm{L}$ & & & & & & \\
\hline $\begin{array}{l}\text { SESPSPEC } \\
\text { SESPSEEC }\end{array}$ & B16WN8 & MCNARY-OR.SIDE NEAR DAM & OFFSITE & SW & Y & $\begin{array}{l}\text { RIVER } \\
\text { RIVER }\end{array}$ & 15-May-03 Zn & 1.93 & $u g / L$ & & & & & & \\
\hline $\begin{array}{l}\text { SESPSEC } \\
\text { SESPSPEC }\end{array}$ & $\begin{array}{l}\text { B16WN99 } \\
\text { B16WN7 }\end{array}$ & $\begin{array}{l}\text { MCNARY-OR.SSDE NEAR DAM } \\
\text { MCNARY-WASH.SIDE NEAR DAM }\end{array}$ & $\begin{array}{l}\text { OFFSITE } \\
\text { OFFSITE }\end{array}$ & SW & $\begin{array}{l}\mathrm{N} \\
\mathrm{Y}\end{array}$ & $\begin{array}{l}\text { IIVER } \\
\text { RIVER }\end{array}$ & $\begin{array}{l}15-M a y-03 Z n \\
15-M a y-037 n\end{array}$ & 4.02 & $\mathrm{ug} / \mathrm{L}$ & & & & & & \\
\hline $\begin{array}{l}\text { SESPSPEC } \\
\text { SEST }\end{array}$ & B16WP0 & $\begin{array}{l}\text { MCNARYWASH.SSTE NEAR DAM } \\
\text { MCNARYWASH.SIDE NEAR DAM }\end{array}$ & $\begin{array}{l}\text { OFFSITE } \\
\text { OFFE }\end{array}$ & sw & $\mathrm{N}$ & $\begin{array}{l}\text { RIVER } \\
\text { RIVER }\end{array}$ & $\begin{array}{l}\text { 15-May-03 } 2 n \\
15-M a y-03 Z n\end{array}$ & $\begin{array}{l}2.46 \\
3.63\end{array}$ & $\begin{array}{l}\mathrm{ug} / \mathrm{L} \\
\mathrm{ug} / \mathrm{L}\end{array}$ & & & & & & \\
\hline SESPSPEC & B16WP8 & WALLA WALLA-RIVER & OFFSITE & sW & Y & RIVER & 15-May-03 Zn & 1.45 & $\mathrm{ug} / \mathrm{L}$ & & & & & & \\
\hline SESPSPEC & B16WP9 & WALLA WALLA-RIVER & OFFSITE & SW & Y & RIVER & 15-May-03 Zn & 1.77 & ug/L & & & & & & \\
\hline $\begin{array}{l}\text { SESPSPEC } \\
\text { SESPSDCF }\end{array}$ & B16WR0 & WALLA WALLA-RIVER & OFFSITE & SW & Y & $\begin{array}{l}\text { RIVER } \\
\text { RIVER }\end{array}$ & 15-May- $03 \mathrm{Zn}$ & 1.45 & $\mathrm{ug} / \mathrm{L}$ & & & & & & \\
\hline $\begin{array}{l}\text { SESPSPEC } \\
\text { SESPSPCE }\end{array}$ & B16WR1 & WALLA WALLA-RIVER & OFFSITE & SW & $\mathrm{N}$ & $\begin{array}{l}\text { RIVER } \\
\text { RIVER }\end{array}$ & 15-May-03 Zn & 3.17 & $u g / L$ & & & & & & \\
\hline $\begin{array}{l}\text { SESPSPEC } \\
\text { SESPSPEC }\end{array}$ & $\begin{array}{l}\text { B16WR2 } \\
\text { B16WR3 }\end{array}$ & $\begin{array}{l}\text { WALLA WALLA-AIVER } \\
\text { WALLA WALLA-RIVER }\end{array}$ & $\begin{array}{l}\text { OFFSITE } \\
\text { OFFSITE }\end{array}$ & SW & $\begin{array}{l}\mathrm{N} \\
\mathrm{N}\end{array}$ & $\begin{array}{l}\text { RIVER } \\
\text { RIVER }\end{array}$ & $\begin{array}{l}\text { 15-May--03 Zn } \\
15-\mathrm{May}-03 \mathrm{Zn}\end{array}$ & $\begin{array}{r}3.22 \\
3.41\end{array}$ & $\mathrm{ug} / \mathrm{L}$ & & & & & & \\
\hline $\begin{array}{l}\text { SESPSPEC } \\
\text { SEST }\end{array}$ & $\begin{array}{l}\text { B176WR3 } \\
\text { B180C6 }\end{array}$ & $\begin{array}{l}100 \mathrm{~B} / \mathrm{C} \text { AREA UR } \\
\text { (1) URR }\end{array}$ & $\begin{array}{l}\text { ONSITE } \\
\text { ONSE }\end{array}$ & sw & $\begin{array}{l}\mathrm{Y} \\
\mathrm{Y}\end{array}$ & $\begin{array}{l}\text { RIVER } \\
\text { RIVER }\end{array}$ & $\begin{array}{l}\text { 15-May- } 03<n \\
\text { 13-Nov-03 Zn }\end{array}$ & $\begin{array}{r}3.41 \\
0.867\end{array}$ & $\frac{u g / L}{u g / L}$ & & & & & & \\
\hline SESPSPEC & B180C7 & $100 \mathrm{~B} / \mathrm{C}$ AREA UR & ONSITE & sw & Y & RIVER & 13-Nov-03 Zn & 0.702 & $u g / L$ & & & & & & \\
\hline SESPSPEC & B180C8 & $100 \mathrm{~B} / \mathrm{C}$ AREA UR & ONSITE & sW & Y & RIVER & 13-Nov-03 Zn & 0.677 & $\mathrm{ug} / \mathrm{L}$ & & & & & & \\
\hline $\begin{array}{l}\text { SESPSPEC } \\
\text { SESPSDEC }\end{array}$ & B180C9 & 100 B/C AREA UR & ONSITE & SW & Y & RIVER & 13-Nov-03 Zn & 0.636 & $u g / L$ & & & & & & \\
\hline $\begin{array}{l}\text { SESPSPEC } \\
\text { SESPSPCE }\end{array}$ & B180D0 & $\begin{array}{l}\text { 100-B SPRING 38-3 } \\
\text { 10-R SPRING 38-3 }\end{array}$ & ONSITE & SW & $\begin{array}{r}\text { Y } \\
\text { y }\end{array}$ & $\begin{array}{l}\text { RIVER } \\
\text { RIVER }\end{array}$ & 13-Nov-03 Zn & $\begin{array}{r}1.03 \\
0.707-x-30\end{array}$ & $\mathrm{ug} / \mathrm{L}$ & & & & DUP IS SAMPLE \#B180J4 & & \\
\hline $\begin{array}{l}\text { SESPSPEC } \\
\text { SESPSPEC }\end{array}$ & $\begin{array}{l}\text { B18DD1 } \\
\text { B180D2 }\end{array}$ & $\begin{array}{l}\text { 100-B SPRING 38-3 } \\
\text { 100-B SPRING 38-3 }\end{array}$ & $\begin{array}{l}\text { ONSIIE } \\
\text { ONSTE }\end{array}$ & SW & $\begin{array}{r}Y \\
Y \\
\end{array}$ & $\begin{array}{l}\text { IVIVER } \\
\text { RIVER }\end{array}$ & $\begin{array}{l}\text { 13-Nov-03 Zn } \\
\text { 13-Nov-03 Zn }\end{array}$ & 0.797 & $\mathrm{ug} / \mathrm{L}$ & & & & & & \\
\hline $\begin{array}{l}\text { SESPSEC } \\
\text { SESPSPEC }\end{array}$ & $\begin{array}{l}\text { B180D2 } \\
\text { B180D3 }\end{array}$ & $\begin{array}{l}\text { 100-B SPRING 38-3 } \\
\text { 100-B SPRING 38-3 }\end{array}$ & $\begin{array}{l}\text { ONSSITE } \\
\text { ONSITE }\end{array}$ & SW & $\begin{array}{l}\text { Y } \\
\text { Y }\end{array}$ & $\begin{array}{l}\text { RIVER } \\
\text { RIVER }\end{array}$ & $\begin{array}{l}\text { 13-Nov-03 Zn } \\
\text { 13-Nov-03 Zn }\end{array}$ & 0.0713 & $\frac{\log / \mathrm{L}}{\mathrm{ug} / \mathrm{L}}$ & & & & & & \\
\hline SESPSPEC & B180J4 & 100-B SPRING 38-3 & ONSITE & sw & Y & RIVER & 13-Nov-03 Zn & 0.981 & ug/L & & & & DUP SAMPLE FOR B180D0 & & \\
\hline SESPSPEC & B180D4 & 100-B SPRING 39-2 & ONSITE & sW & Y & RIVER & 13-Nov-03 Zn & 0.585 & $\mathrm{ug} / \mathrm{L}$ & & & & & & \\
\hline $\begin{array}{l}\text { SESPSPEC } \\
\text { SESPSPCF }\end{array}$ & B180D5 & 100-B SPRING 39-2 & ONSITE & SW & $\begin{array}{r}Y \\
Y \\
\end{array}$ & $\begin{array}{l}\text { RIVER } \\
\text { RIVER }\end{array}$ & 13-Nov-03 Zn & 0.629 & $u g / L$ & & & & & & \\
\hline $\begin{array}{l}\text { SESPSPEC } \\
\text { SESPSPEC }\end{array}$ & $\begin{array}{l}\text { B180D6 } \\
\text { B1807 }\end{array}$ & $\begin{array}{l}\text { 100-B SPRING 39-2 } \\
1 \text { 10-B SPRING 39-2 }\end{array}$ & ONSITE & SW & $\begin{array}{r}\text { Y } \\
\end{array}$ & $\begin{array}{l}\text { RIVER } \\
\text { RIVER }\end{array}$ & 13-Nov-03 Zn & 0.509 & $\mathrm{ug} / \mathrm{L}$ & & & & & & \\
\hline $\begin{array}{l}\text { SESPSPEC } \\
\text { SESPSPEC }\end{array}$ & $\begin{array}{l}\text { B180D7 } \\
\text { B180F9 }\end{array}$ & $\begin{array}{l}100-B \text { SPRIIG 39-2 } \\
\text { 100-B SPRING DR 38-3 }\end{array}$ & $\begin{array}{l}\text { ONSITE } \\
\text { ONSTEE }\end{array}$ & $\begin{array}{l}\text { SW } \\
\text { SW }\end{array}$ & $\begin{array}{l}\text { Y } \\
\text { Y }\end{array}$ & $\begin{array}{l}\text { IVER } \\
\text { RIVER }\end{array}$ & $\begin{array}{l}\text { 13-Nov-03 Zn } \\
\text { 13-Nov-03 Zn }\end{array}$ & 0.579 & $\mathrm{ug} / \mathrm{L}$ & & & & & & \\
\hline SESPSPEC & B180F1 & 100 B/C AREA DR & ONSITE & sw & $\begin{array}{l}\mathrm{Y} \\
\mathrm{Y}\end{array}$ & $\begin{array}{l}\text { RIVER } \\
\text { RIVER }\end{array}$ & 13-Nov-03 $2 n$ & 0.666 & $\frac{u g h / L}{u g / L}$ & & & & & & \\
\hline SESPSPEC & B180F2 & $100 \mathrm{~B} / \mathrm{C}$ AREA DR & ONSITE & sw & Y & RIVER & 17-Nov-03 Zn & 0.624 & $u g / L$ & & & & & & \\
\hline SESPSPEC & B180F3 & $100 \mathrm{~B} / \mathrm{C}$ AREA DR & ONSITE & SW & Y & RIVER & 17-Nov-03 Zn & 0.705 & $\mathrm{ug} / \mathrm{L}$ & & & & & & \\
\hline & B180F4 & $100 \mathrm{~B} / \mathrm{C}$ AREA DR & ONSITE & SW & $\begin{array}{l}Y \\
Y\end{array}$ & RIVER & 17-Nov-03 Zn & 0.626 & $u g / L$ & & & & & & \\
\hline $\begin{array}{l}\text { SESPSPEC } \\
\text { SESPSPEC }\end{array}$ & $\begin{array}{l}\text { B180D8 } \\
\text { B18009 }\end{array}$ & $\begin{array}{l}100 \text { B/C AREA OUTFL1 } \\
100 \text { B/C ARE OUFI? }\end{array}$ & ONSITE & SW & $\begin{array}{l}\text { Y } \\
\end{array}$ & $\begin{array}{l}\text { RIVER } \\
\text { RIVER }\end{array}$ & 17-Nov-03 Zn & 0.508 & $u g / L$ & & & & & & \\
\hline $\begin{array}{l}\text { SESPSEC } \\
\text { SESPSEC }\end{array}$ & $\begin{array}{l}\text { B180D9 } \\
\text { B180F0 }\end{array}$ & $\begin{array}{l}100 \mathrm{~B} / \mathrm{C} \text { AREA OUTFL2 } \\
100 \mathrm{~B} / \mathrm{C} \text { AREA OUTFL3 }\end{array}$ & $\begin{array}{l}\text { ONSSTE } \\
\text { ONSTIE }\end{array}$ & $\begin{array}{l}\text { SW } \\
\text { SW }\end{array}$ & $\begin{array}{l}\text { Y } \\
\text { Y }\end{array}$ & $\begin{array}{l}\text { RIVER } \\
\text { RIVER }\end{array}$ & $\begin{array}{l}\text { 17-Nov-03 Zn } \\
\text { 17-Nov-03 Zn }\end{array}$ & 0.533 & $\begin{array}{l}\mathrm{ug} / \mathrm{L} \\
\mathrm{ug} / \mathrm{L}\end{array}$ & & & & & & \\
\hline SESPSPEC & B18143 & Refer to WELL NAME column & & GW & $\mathrm{N}$ & AQUIFER TUBE & 10-Dec-03 ANION & & & & & & NO SAMPLE. & & 07-D \\
\hline SESPSPEC & B18143 & Refer to WELL NAME column & & GW & $\mathrm{N}$ & AQUIFER TUBE & 10-Dec-03 ANION & & & & & & NO SAMPLE. & & 07-D \\
\hline SESPSPEC & B170T7 & YAKIMA RIVER & OFFSITE & sw & $\mathrm{N}$ & RIVER & 14-May-03 CHLORIDE & 5.8 & $\mathrm{mg} / \mathrm{L}$ & & & $C D$ & & & \\
\hline SESPSPEC & B170T8 & YAKIMA RIVER & OFFSITE & SW & $\mathrm{N}$ & RIVER & 14-May-03 CHLORIDE & 5.7 & $\mathrm{mg} / \mathrm{L}$ & & & CD & & & \\
\hline $\begin{array}{l}\text { SESPSPEC } \\
\text { SESPSEC }\end{array}$ & B170T9 & 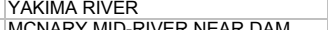 & $\begin{array}{l}\text { OFFSITE } \\
\text { OFFSITE }\end{array}$ & SW & $\begin{array}{r}\mathrm{N} \\
\mathrm{N}\end{array}$ & $\begin{array}{l}\text { RIVER } \\
\text { RIVER }\end{array}$ & 14-May-03 CHLORIDE & 5.6 & $\mathrm{mg} / \mathrm{L}$ & & & CD & & & \\
\hline $\begin{array}{l}\text { SESPSPEC } \\
\text { SESPSPEC }\end{array}$ & $\begin{array}{l}\text { B170R0 } \\
\text { B170R1 }\end{array}$ & $\begin{array}{l}\text { MCNARY MID-RIVER NEAR DAM } \\
\text { MCNARY-OR.SIDE NEAR DAM }\end{array}$ & $\begin{array}{l}\text { OFFSITE } \\
\text { OFFSITE }\end{array}$ & $\begin{array}{l}\text { SW } \\
\text { sw }\end{array}$ & $\frac{N}{N}$ & $\begin{array}{l}\text { RIVER } \\
\text { RIVER }\end{array}$ & $\begin{array}{l}\text { 15-May-03 CHOLRIDE } \\
\text { 15-May-03 CHLORIDE }\end{array}$ & $\frac{2.2}{2.2}$ & $\mathrm{mg} / \mathrm{L}$ & & & & & & \\
\hline SESPSPEC & B170P9 & MCNARY-WASH.SIDE NEAR DAM & OFFSITE & sw & $\mathrm{N}$ & RIVER & 15-May-03 CHLORIDE & $\frac{2}{2}$ & $\mathrm{mg} / \mathrm{h}$ & & & & & & \\
\hline SESPSPEC & B170T4 & WALLA WALLA-RIVER & OFFSITE & sw & $\mathrm{N}$ & RIVER & 15-May-03 CHLORIDE & 3.2 & $\mathrm{mg} / \mathrm{L}$ & & & & & & \\
\hline SESPSPEC & B170T5 & WALLA WALLA-RIVER & OFFSITE & sW & $\mathrm{N}$ & RIVER & 15-May-03 CHLORIDE & 3.2 & $\mathrm{mg} / \mathrm{L}$ & & & & & & \\
\hline SESPSPEC & B170T6 & WALLA WALLA-RIVER & OFFSITE & SW & $\mathrm{N}$ & RIVER & 15-May-03 CHLORIDE & 3.2 & $\mathrm{mg} / \mathrm{L}$ & & & & & & \\
\hline $\begin{array}{l}\text { SESPSPEC } \\
\text { SESPSECC }\end{array}$ & $\begin{array}{l}\text { B17001 } \\
\text { B170T2 }\end{array}$ & HOOD PARK-FRANKLIN CO. SHORE & $\begin{array}{l}\text { OFFSITE } \\
\text { OFFSITE }\end{array}$ & SW & $\begin{array}{l}n \\
N\end{array}$ & $\begin{array}{l}\text { IVER } \\
\text { RIVER }\end{array}$ & $\begin{array}{l}\text { 15-May-03 CHLORIDE } \\
\text { 15-Ma-03 CHORIDE }\end{array}$ & 3.3 & $\mathrm{mg} / \mathrm{L}$ & & & & & & \\
\hline $\begin{array}{l}\text { SESPSEC } \\
\text { SESPSPEC }\end{array}$ & $\begin{array}{l}\text { B170T2 } \\
\text { B170T3 }\end{array}$ & $\begin{array}{l}\text { HOOD PARKK-MII-RIVER } \\
\text { HOOD PARK-WALLA WALLA SHORE }\end{array}$ & $\begin{array}{l}\text { OFFSITE } \\
\text { OFFSITE }\end{array}$ & $\begin{array}{l}\text { SW } \\
\text { SW }\end{array}$ & $\frac{n}{n}$ & $\begin{array}{l}\text { RIVER } \\
\text { RIVER }\end{array}$ & & $\begin{array}{l}3.3 \\
3.4\end{array}$ & $\frac{\mathrm{mg} / \mathrm{L}}{\mathrm{m} / \mathrm{L}}$ & & & & & & \\
\hline SESPSPEC & B18156 & 100-B SPRING 38-3 & ONSITE & sw & $\mathrm{N}$ & SURFACE & 13-Nov-03 CHLORIDE & $\begin{array}{r}0.4 \\
1\end{array}$ & $\begin{array}{l}\mathrm{mggh} \\
\mathrm{mg} / \mathrm{L}\end{array}$ & & & & & & \\
\hline SESPSPEC & B18160 & 100-B SPRING 38-3 & ONSITE & SW & $\mathrm{N}$ & SURFACE & 13-Nov-03 CHLORIDE & 1.1 & $\mathrm{mg} / \mathrm{L}$ & & & & & & \\
\hline SESPSPEC & B18157 & 100-B SPRING 38-3 & ONSITE & sW & $\mathrm{N}$ & SURFACE & CHLORIDE & 0.99 & $\mathrm{mg} / \mathrm{L}$ & & & & & & \\
\hline $\begin{array}{l}\text { SESPSPEC } \\
\text { SESDSDC }\end{array}$ & B18158 & 100-B SPRING 38-3 & ONSITE & sw & $\mathrm{N}$ & SURFACE & 13-Nov-03 CHLORIDE & 0.93 & $\mathrm{mg} / \mathrm{L}$ & & & & & & \\
\hline $\begin{array}{l}\text { SESPSPCC } \\
\text { SESPSPEC }\end{array}$ & $\begin{array}{l}\text { B18189 } \\
\text { B18166 }\end{array}$ & $\begin{array}{l}100-B \text { SPRING 38-3 } \\
100-8 \text { SPRIN }\end{array}$ & $\begin{array}{l}\text { ONSITE } \\
\text { ONSTEE }\end{array}$ & SW & $\begin{array}{l}n \\
N\end{array}$ & $\begin{array}{l}\text { SURFACE } \\
\text { SUREACE }\end{array}$ & 13-Nov-03 CHLORIDE & 0.87 & $\mathrm{mg/L}$ & & & & & & \\
\hline $\begin{array}{l}\text { SESPSEC } \\
\text { SESPSPEC }\end{array}$ & $\begin{array}{l}\text { B18106 } \\
\text { B18162 }\end{array}$ & 100-B SPRING 39-2 & ONSITE & SW & $\frac{N}{N}$ & $\begin{array}{l}\text { SURFACE } \\
\text { SURFACE }\end{array}$ & 13-Nov-03 CHLORIDE & $\begin{array}{l}1.1 \\
0.94\end{array}$ & $\begin{array}{l}\mathrm{mggh} \\
\mathrm{mg} / \mathrm{L}\end{array}$ & & & & & & \\
\hline SESPSPEC & B18163 & 100-B SPRING 39-2 & ONSITE & sw & $\mathrm{N}$ & SURFACE & 13-Nov-03 CHLORIDE & 0.88 & $\mathrm{mg} / \mathrm{h}$ & & & & & & \\
\hline SESPSPEC & B18164 & 100-B SPRING 39-2 & ONSITE & SW & $\mathrm{N}$ & SURFACE & 13-Nov-03 CHLORIDE & 0.86 & $\mathrm{mg} / \mathrm{L}$ & & & & & & \\
\hline SESPSPEC & B18165 & 100-B SPRING 39-2 & ONSITE & sW & $\mathrm{N}$ & SURFACE & 13-Nov-03 CHLORIDE & 0.86 & $\mathrm{mg} / \mathrm{L}$ & & & & & & \\
\hline
\end{tabular}




\begin{tabular}{|c|c|c|c|c|c|c|c|c|c|c|c|c|c|c|c|}
\hline OWNER ID & SAMP NUM & SAMP SITE NAME & DIST CLASS & MEDIA & $\mid \begin{array}{c}\text { FILTERED } \\
\text { FLAG }\end{array}$ & SAMP FROM & CON SHORT NAME & |VALUE RPTD| & $\begin{array}{l}\text { ANAL } \\
\text { UNITS } \\
\text { RPTD }\end{array}$ & $\left|\begin{array}{c}\text { COUNTING } \\
\text { ERROR }\end{array}\right|$ & \begin{tabular}{|c|} 
TOTAL \\
ANAL \\
ERROR
\end{tabular} & $\mid \begin{array}{c}\text { LAB } \\
\text { QUALIFIER }\end{array}$ & SAMP COMMENT & $\begin{array}{c}\text { RESULT } \\
\text { COMMENT }\end{array}$ & |WELL NAME \\
\hline SESPSPEC & B18152 & $100 \mathrm{~B} / \mathrm{C}$ AREA UR & ONSITE & SW & $N$ & SURFACE & 13-Nov-03 CHLORIDE & 0.83 & $\mathrm{mg} / \mathrm{L}$ & & & & & & \\
\hline $\begin{array}{l}\text { SESPSPEC } \\
\text { SESPSDC }\end{array}$ & B18153 & 100 B/C AREA UR & ONSITE & SW & N & SURFACE & 13-Nov-03 CHLORIDE & 0.84 & $\mathrm{mg} / \mathrm{L}$ & & & & & & \\
\hline $\begin{array}{l}\text { SESPSPEC } \\
\text { SESPSEC }\end{array}$ & $\begin{array}{l}B 18154 \\
B 18155\end{array}$ & $\begin{array}{l}100 \text { B/C AREA UR } \\
100 \text { BCC AREA UR }\end{array}$ & ONSITE & SW & 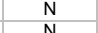 & $\begin{array}{l}\text { SURFACE } \\
\text { SUREACE }\end{array}$ & 13-Nov-03 CHLORIDE & 0.86 & $\mathrm{mg} / \mathrm{L}$ & & & & & & \\
\hline $\begin{array}{l}\text { SESPSEEC } \\
\text { SESPSPEC }\end{array}$ & $\begin{array}{l}\begin{array}{l}\text { B18185 } \\
\text { B18145 }\end{array} \\
\text { B. }\end{array}$ & $\begin{array}{l}100 \text { BCC AREA UR } \\
100 \text { B AREA AREA DR }\end{array}$ & $\begin{array}{l}\text { ONSITE } \\
\text { ONSTEE }\end{array}$ & $\begin{array}{l}\text { sw } \\
\text { sw }\end{array}$ & $\begin{array}{l}n \\
\mathrm{~N}\end{array}$ & $\begin{array}{l}\text { SURFACE } \\
\text { SURFACE }\end{array}$ & 13-Nov-03 CHLORIDE & 0.85 & $\mathrm{mg} / \mathrm{L}$ & & & & & & \\
\hline SESPSPEC & B18146 & 100 B/C AREA DR & ONSITE & sw & $\frac{N}{N}$ & $\begin{array}{l}\text { SURFACE } \\
\text { SURFACE }\end{array}$ & $\begin{array}{l}\text { 17-Nov-03 CHLORIDE } \\
\text { 17-Nov-03 CHLORIDE }\end{array}$ & $\begin{array}{l}0.84 \\
0.89\end{array}$ & $\frac{\mathrm{mg} / \mathrm{L}}{\mathrm{mg} / \mathrm{L}}$ & & & & & & \\
\hline SESPSPEC & B18147 & 100 B/C AREA DR & ONSITE & sw & $\mathrm{N}$ & SURFACE & 17-Nov-03 CHLORIDE & 0.87 & $\mathrm{mg} / \mathrm{L}$ & & & & & & \\
\hline $\begin{array}{l}\text { SESPSPEC } \\
\text { SESPSDC }\end{array}$ & B18148 & 100 B/C AREA DR & ONSITE & sW & N & SURFACE & 17-Nov-03 CHLORIDE & 0.87 & $\mathrm{mg} / \mathrm{L}$ & & & & & & \\
\hline $\begin{array}{l}\text { SESPSPEC } \\
\text { SESPSDC }\end{array}$ & B18151 & 100 B/C AREA OUTFL3 & ONSITE & SW & $\mathrm{N}$ & SURFACE & 17-Nov-03 CHLORIDE & 0.87 & $\mathrm{mg} / \mathrm{L}$ & & & & & & \\
\hline $\begin{array}{l}\text { SESPSPEC } \\
\text { SESPSEC }\end{array}$ & B18150 & 100 B/C AREA OUTFL2 & ONSITE & SW & $\mathrm{N}$ & SURFACE & 17-Nov-03 CHLORIDE & 0.86 & $\mathrm{mg} / \mathrm{L}$ & & & & & & \\
\hline $\begin{array}{l}\text { SESPSEEC } \\
\text { SESPSPEC }\end{array}$ & $\begin{array}{l}\text { B18149 } \\
\text { B18139 }\end{array}$ & $\begin{array}{l}100 \text { B BC AREA OUTLL1 } \\
\text { Refer to WELL NAME column }\end{array}$ & ONSITE & $\begin{array}{l}S W \\
\text { GW }\end{array}$ & $\frac{N}{N}$ & $\begin{array}{l}\text { SURAACE } \\
\text { AQUIFER TUBE }\end{array}$ & $\begin{array}{l}\text { 17-Nov-03 CHORORIDE } \\
\text { 10-Dec-03 CHLORIDE }\end{array}$ & 0.84 & $\frac{\mathrm{mg} / \mathrm{L}}{\mathrm{mg} / \mathrm{L}}$ & & & & & & 01-D \\
\hline SESPSPEC & B18140 & Refer to WELL NAME column & & GW & $\mathrm{N}$ & AQUIFER TUBE & 10-Dec-03 CHLORIDE & 10.1 & $\mathrm{mg} / \mathrm{L}$ & & & D & & & 04-D \\
\hline SESPSPEC & B18141 & Refer to WELL NAME column & & GW & $\mathrm{N}$ & AQUIFER TUBE & 10-Dec-03 CHLORIDE & 7.2 & $\mathrm{mg} / \mathrm{L}$ & & & $\mathrm{D}$ & & & 05-D \\
\hline SESPSPEC & B18142 & Refer to WELL NAME column & & GW & $\mathrm{N}$ & AQUIFER TUBE & 10-Dec-03 CHLORIDE & 6.8 & $\mathrm{mg} / \mathrm{L}$ & & & $\mathrm{D}$ & & & $06-\mathrm{D}$ \\
\hline $\begin{array}{l}\text { SESPSPEC } \\
\text { SESPSPC }\end{array}$ & B170T7 & YAKIMA RIVER & OFFSITE & SW & $\mathrm{N}$ & \begin{tabular}{l|l} 
RIVER \\
RIVER
\end{tabular} & 14-May-03 FLUORIDE & 0.19 & $\mathrm{mg} / \mathrm{L}$ & & & C & & & \\
\hline $\begin{array}{l}\text { SESPSPEC } \\
\text { SESPSEC }\end{array}$ & $\begin{array}{l}\text { B170T8 } \\
\text { B170T0 }\end{array}$ & YAKIMA RIVER & OFFSITE & sw & $\mathrm{N}$ & $\begin{array}{l}\text { RIVER } \\
\text { RIVER }\end{array}$ & 14-May-03 FLUORIDE & 0.18 & $\mathrm{mg} / \mathrm{L}$ & & & $\mathrm{c}$ & & & \\
\hline $\begin{array}{l}\text { SESPSECC } \\
\text { SESPSPEC }\end{array}$ & $\begin{array}{l}\text { B170T9 } \\
\text { B170R0 }\end{array}$ & $\begin{array}{l}\text { YARIMA RIVER } \\
\text { MCNARY MID-RIVER NEAR DAM }\end{array}$ & $\begin{array}{l}\text { OFFSSTE } \\
\text { OFFITE }\end{array}$ & $\begin{array}{l}\text { SW } \\
\text { sw }\end{array}$ & $\frac{n}{N}$ & $\begin{array}{l}\text { IVIVER } \\
\text { RIVER }\end{array}$ & $\begin{array}{l}\text { 14-May-03 FLUORIDE } \\
\text { 15-May-3 FLUORIDE }\end{array}$ & 0.18 & $\mathrm{mg} / \mathrm{L}$ & & & $\mathrm{C}$ & & & \\
\hline $\begin{array}{l}\text { SESPSPEC } \\
\text { SEST }\end{array}$ & B170R1 & $\begin{array}{l}\text { MCNARY MID.-KIVE NEAR DAM } \\
\text { MCNARYOR.SIE NEAR DAM }\end{array}$ & $\begin{array}{l}\text { OFFSIIE } \\
\text { OFFITE }\end{array}$ & sw & $\frac{N}{N}$ & $\begin{array}{l}\text { RIVER } \\
\text { RIVER }\end{array}$ & $\begin{array}{l}\text { 15-May-35LUURIDE } \\
\text { 15-May-03 FLUORIDE }\end{array}$ & 0.11 & $\frac{\mathrm{mggh}}{\mathrm{mg} / \mathrm{L}}$ & & & & & & \\
\hline SESPSPEC & B170P9 & MCNARY-WASH.SIDE NEAR DAM & OFFSITE & sw & $\mathrm{N}$ & RIVER & 15-May-03 FLUORIDE & 0.11 & $\mathrm{mg} / \mathrm{L}$ & & & & & & \\
\hline SESPSPEC & B170T4 & WALLA WALLA-RIVER & OFFSITE & sw & $\mathrm{N}$ & RIVER & 15-May-03 FLUORIDE & 0.14 & $\mathrm{mg} / \mathrm{L}$ & & & & & & \\
\hline $\begin{array}{l}\text { SESPSPEC } \\
\text { SESPSEC }\end{array}$ & B170T5 & WALLA WALLA-RIVER & OFFSITE & sw & $\mathrm{N}$ & RIVER & 15-May-03 FLUORIDE & 0.13 & $\mathrm{mg} / \mathrm{L}$ & & & & & & \\
\hline $\begin{array}{l}\text { SESPSPCC } \\
\text { SESPSEC }\end{array}$ & $\begin{array}{l}\text { B170T6 } \\
\text { B170T1 }\end{array}$ & WALLA WALLA-RIVER & OFFSITE & SW & $\mathrm{N}$ & RIVER & 15-May-03 FLUORIDE & 0.15 & $\mathrm{mg} / \mathrm{L}$ & & & & & & \\
\hline $\begin{array}{l}\text { SESPSECC } \\
\text { SESPPEC }\end{array}$ & $\begin{array}{l}\text { B17001 } \\
\text { B170T2 }\end{array}$ & $\begin{array}{l}\text { HOOD PARKK-FRANKLIN CO. SHORE } \\
\text { HOOD PARK-MID-RIVER }\end{array}$ & $\begin{array}{l}\text { OFFSITE } \\
\text { OFESTEE }\end{array}$ & SW & $\begin{array}{l}\mathrm{N} \\
\mathrm{N}\end{array}$ & $\begin{array}{l}\text { RIVER } \\
\text { RIVER }\end{array}$ & $\begin{array}{l}\text { 15-May-03 FLUORIDE } \\
\text { 15-Ma-03 FLUORIDE }\end{array}$ & 0.2 & $\mathrm{mg} / \mathrm{L}$ & & & & & & \\
\hline $\begin{array}{l}\text { SESPSEC } \\
\text { SESPSPEC }\end{array}$ & $\begin{array}{l}\text { B170T2 } \\
\text { B170T3 }\end{array}$ & $\begin{array}{l}\text { HOOD PARKKMII-RIIER } \\
\text { HOOD PARK-WALLA WALLA SHORE }\end{array}$ & $\begin{array}{l}\text { OFFSIIE } \\
\text { OFFITE }\end{array}$ & sw & $\frac{N}{N}$ & $\begin{array}{l}\text { RIVER } \\
\text { RIVER }\end{array}$ & $\begin{array}{l}\text { 15-May-033LUORORE } \\
\text { 15-May-03 FLUORIDE }\end{array}$ & 0.21 & $\frac{\mathrm{mggh}}{\mathrm{mg} / \mathrm{L}}$ & & & & & & \\
\hline SESPSPEC & B18156 & 100-B SPRING 38-3 & ONSITE & sw & $\mathrm{N}$ & SURFACE & 13-Nov-03 FLUORIDE & 0.094 & $\mathrm{mg} / \mathrm{L}$ & & & B & & & \\
\hline SESPSPEC & B18160 & 100-B SPRING 38-3 & ONSITE & sw & $\mathrm{N}$ & SURFACE & 13-Nov-03 FLUORIDE & 0.093 & $\mathrm{mg} / \mathrm{L}$ & & & B & & & \\
\hline $\begin{array}{l}\text { SESPSPEC } \\
\text { SESPSPCE }\end{array}$ & B18157 & 100-B SPRING 38-3 & ONSITE & SW & $\mathrm{N}$ & $\begin{array}{l}\text { SURFACE } \\
\text { SUPEACE }\end{array}$ & 13-Nov-03 FLUORIDE & 0.095 & $\mathrm{mg} / \mathrm{L}$ & & & B & & & \\
\hline $\begin{array}{l}\text { SESPSPEC } \\
\text { SESPSEC }\end{array}$ & $\begin{array}{l}B 18158 \\
B 1819\end{array}$ & 100-B SPRING 38-3 & ONSITE & SW & $\mathrm{N}$ & SURFACE & 13-Nov-03 FLUORIDE & 0.09 & $\mathrm{mg} / \mathrm{L}$ & & & B & & & \\
\hline $\begin{array}{l}\text { SESPSECC } \\
\text { SESPSPEC }\end{array}$ & $\begin{array}{l}\text { B18189 } \\
\text { B18166 }\end{array}$ & $\begin{array}{l}\text { 100-B SPRING 38-3 } \\
100-B \text { SPRING DR 38-3 }\end{array}$ & $\begin{array}{l}\text { ONSIIE } \\
\text { ONSITE }\end{array}$ & $\begin{array}{l}\text { SW } \\
\text { sw }\end{array}$ & $\begin{array}{llll}n & \\
N \\
N\end{array}$ & $\begin{array}{l}\text { SURFACE } \\
\text { SURFACE }\end{array}$ & $\begin{array}{l}\text { 13-Nov-03 FLUORIDE } \\
\text { 13-Nov-03 FLUORIDE }\end{array}$ & 0.089 & $\mathrm{mg} / \mathrm{L}$ & & & $\begin{array}{l}B \\
B\end{array}$ & & & \\
\hline $\begin{array}{l}\text { SESPPEC } \\
\text { SESPSPEC }\end{array}$ & $\begin{array}{l}\text { B18166 } \\
\text { B18162 }\end{array}$ & $\begin{array}{l}\text { 100-B SPRING DR 38-3 } \\
\text { 100-B SPRING 39-2 }\end{array}$ & $\begin{array}{l}\text { ONSTIE } \\
\text { ONSITE }\end{array}$ & sw & $\frac{N}{N}$ & $\begin{array}{l}\text { SURFACE } \\
\text { SURFACE }\end{array}$ & $\begin{array}{l}\text { 13-Nov-033 LUORORDE } \\
\text { 13-Nov-03 FLUORIDE }\end{array}$ & 0.098 & $\frac{\mathrm{mg} / \mathrm{L}}{\mathrm{mg} / \mathrm{L}}$ & & & $\frac{B}{B}$ & & & \\
\hline SESPSEC & B18163 & 100-B SPRING 39-2 & ONSITE & sw & $\mathrm{N}$ & SURFACE & 13-Nov-03 FLUORIDE & 0.091 & $\mathrm{mg} / \mathrm{L}$ & & & B & & & \\
\hline SESPSPEC & B18164 & 100-B SPRING 39-2 & ONSITE & SW & $\mathrm{N}$ & SURFACE & 13-Nov-03 FLUORIDE & 0.093 & $\mathrm{mg} / \mathrm{L}$ & & & B & & & \\
\hline $\begin{array}{l}\text { SESPSPEC } \\
\text { SESPSPCF }\end{array}$ & $\begin{array}{l}818165 \\
B 1852\end{array}$ & 100-B SPRING 39-2 & ONSITE & SW & $\mathrm{N}$ & $\begin{array}{l}\text { SURFACE } \\
\text { SUPEACE }\end{array}$ & 13-Nov-03 FLUORIDE & 0.092 & $\mathrm{mg} / \mathrm{L}$ & & & B & & & \\
\hline $\begin{array}{l}\text { SESPSPCC } \\
\text { SESPSEC }\end{array}$ & $\begin{array}{l}\text { B18152 } \\
\text { B18153 }\end{array}$ & $\begin{array}{l}100 \text { BCLAREA AR } \\
100 \text { BCCAREA UR }\end{array}$ & $\begin{array}{l}\text { ONSITE } \\
\text { ONSITE }\end{array}$ & SW & $\begin{array}{l}n \\
N\end{array}$ & $\begin{array}{l}\text { SURFACE } \\
\text { SUREACE }\end{array}$ & 13-Nov-03 FLUORIDE & 0.094 & $\mathrm{mg} / \mathrm{L}$ & & & B & & & \\
\hline $\begin{array}{l}\text { SESPSECC } \\
\text { SESPSPEC }\end{array}$ & $\begin{array}{l}\begin{array}{l}\text { B18153 } \\
\text { B18154 }\end{array}\end{array}$ & $\begin{array}{l}100 \text { BCC AREA UR } \\
100 \text { BCC AREA UR }\end{array}$ & $\begin{array}{l}\text { ONSITE } \\
\text { ONSITE }\end{array}$ & $\begin{array}{l}\text { SW } \\
\text { SW }\end{array}$ & $\frac{N}{N}$ & $\begin{array}{l}\text { SURFACE } \\
\text { SURFACE }\end{array}$ & $\begin{array}{l}\text { 13-Nov-03 FLUORIDE } \\
\text { 13-Nov-03 FLUORIDE }\end{array}$ & 0.091 & $\mathrm{mg} / \mathrm{L}$ & & & $\begin{array}{l}B \\
B\end{array}$ & & & \\
\hline SESPSPEC & B18155 & 100 B/C AREA UR & $\begin{array}{l}\text { ONSITE } \\
\text { ONS }\end{array}$ & sw & $\mathrm{N}$ & $\begin{array}{l}\text { SURFACE } \\
\text { SURFACE }\end{array}$ & 13-Nov-03 FLUORIDE & 0.094 & $\frac{\mathrm{mg} / \mathrm{L}}{\mathrm{mg} / \mathrm{L}}$ & & & B & & & \\
\hline SESPSPEC & B18145 & 100 B/C AREA DR & ONSITE & sw & $\mathrm{N}$ & SURFACE & 17-Nov-03 FLUORIDE & 0.09 & $\mathrm{mg} / \mathrm{L}$ & & & B & & & \\
\hline SESPSPEC & B18146 & 100 B/C AREA DR & ONSITE & SW & $\mathrm{N}$ & SURFACE & 17-Nov-03 FLUORIDE & 0.088 & $\mathrm{mg} / \mathrm{L}$ & & & B & & & \\
\hline $\begin{array}{l}\text { SESPSPEC } \\
\text { SESPSPCC }\end{array}$ & B18147 & $100 \mathrm{~B} / \mathrm{C}$ AREA DR & ONSITE & & $\mathrm{N}$ & $\begin{array}{l}\text { SURFACE } \\
\text { SUPFE }\end{array}$ & 17-Nov-03 FLUORIDE & 0.091 & $\mathrm{mg} / \mathrm{L}$ & & & B & & & \\
\hline $\begin{array}{l}\text { SESPSEEC } \\
\text { SESPSPEC }\end{array}$ & B18148 & $\begin{array}{l}100 \text { B/C AREA DR } \\
100 \text { BCAREA OUTFL } 3\end{array}$ & ONSITE & SW & $\begin{array}{l}n \\
N\end{array}$ & $\begin{array}{l}\text { SURFACE } \\
\text { SURFACE }\end{array}$ & $\begin{array}{l}\text { 17-Nov-03 FLUORIDE } \\
\text { 17-Nov-3 FIUORIDE }\end{array}$ & 0.09 & $\mathrm{mg} / \mathrm{L}$ & & & B & & & \\
\hline $\begin{array}{l}\text { SESPSEEC } \\
\text { SESPSPEC }\end{array}$ & $\begin{array}{l}B 18151 \\
\text { B18150 }\end{array}$ & $\begin{array}{l}100 \text { B/C AREA OUTTL3 } \\
100 \text { B/C AREA OUTFL2 }\end{array}$ & $\begin{array}{l}\text { ONSITE } \\
\text { ONSITE }\end{array}$ & $\begin{array}{l}\text { SW } \\
\text { sW }\end{array}$ & $\begin{array}{l}n \\
N\end{array}$ & $\begin{array}{l}\text { SURFACE } \\
\text { SURFACE }\end{array}$ & $\begin{array}{l}\text { 17-Nov-03 FLUORIDE } \\
\text { 17-Nov-03 FLUORIDE }\end{array}$ & 0.088 & $\mathrm{mg} / \mathrm{L}$ & & & $\begin{array}{l}B \\
B\end{array}$ & & & \\
\hline SESPSPEC & $\begin{array}{l}\text { B18150 } \\
\text { B18149 }\end{array}$ & 100 B/C AREA OUTFL1 & ONSITE & sw & $\frac{N}{N}$ & $\begin{array}{l}\text { SURFACE } \\
\text { SURFACE }\end{array}$ & 17-Nov-03 FLUORIDE & 0.089 & $\frac{\mathrm{mg} / \mathrm{L}}{\mathrm{mg} / \mathrm{L}}$ & & & B & & & \\
\hline SESPSPEC & B18139 & Refer to WELL NAME column & & GW & $\mathrm{N}$ & AQUIFER TUBE & 10-Dec-03 FLUORIDE & 0.15 & $\mathrm{mg} / \mathrm{L}$ & & & & & & 01-D \\
\hline SESPSPEC & B18140 & Refer to WELL NAME column & & GW & $\mathrm{N}$ & AQUIFER TUBE & 10-Dec-03 FLUORIDE & 0.23 & $\mathrm{mg} / \mathrm{L}$ & & & & & & 04-D \\
\hline $\begin{array}{l}\text { SESPSPEC } \\
\text { SESPSDEC }\end{array}$ & B18141 & Refer to WELL NAME column & & GW & $\mathrm{N}$ & AQUIFER TUBE & 10-Dec-03 FLUORIDE & 0.18 & $\mathrm{mg} / \mathrm{L}$ & & & & & & 05-D \\
\hline $\begin{array}{l}\text { SESPSPEC } \\
\text { SESPSEC }\end{array}$ & 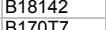 & Refer to WELL NAME column & & GW & $\begin{array}{l}n \\
N\end{array}$ & $\begin{array}{l}\text { AQUIFER TUBE } \\
\text { RIVER }\end{array}$ & 10-Dec-03 FLUORIDE & 0.1 & $\mathrm{mg} / \mathrm{L}$ & & & & & & 06-D \\
\hline $\begin{array}{l}\text { SESPSEC } \\
\text { SESPSPEC }\end{array}$ & $\begin{array}{l}\begin{array}{l}\text { B170077 } \\
\text { B170T8 }\end{array}\end{array}$ & $\begin{array}{l}\text { YYALIMA RIVER } \\
\text { YAKIMA RIVER }\end{array}$ & $\begin{array}{l}\text { OFFSSTE } \\
\text { OFFITE }\end{array}$ & $\begin{array}{l}\text { SW } \\
\text { SW }\end{array}$ & $\frac{N}{N}$ & $\begin{array}{l}\text { IIVER } \\
\text { RIVER }\end{array}$ & $\begin{array}{l}\text { 14-May-03 NO2-N } \\
14 \text { May-03 NO2-N }\end{array}$ & 0.011 & $\frac{\mathrm{mg} / \mathrm{L}}{\mathrm{m} / \mathrm{L}}$ & & & u & & & \\
\hline SESPSPEC & B170T9 & YAKIMA RIVER & OFFSITE & sw & $\mathrm{N}$ & $\begin{array}{l}\text { RIVER } \\
\text { RIVER }\end{array}$ & $14-\mathrm{May}-03$ NO2-N & 0.011 & $\mathrm{mg} / \mathrm{h}$ & & & u & & & \\
\hline SESPSPEC & B170R0 & MCNARY MID-RIVER NEAR DAM & OFFSITE & sw & $\mathrm{N}$ & RIVER & 15-May-03 NO2-N & 0.011 & $\mathrm{mg} / \mathrm{L}$ & & & U & & & \\
\hline SESPSPEC & B170R1 & MCNARY-OR.SIDE NEAR DAM & OFFSITE & sw & $\mathrm{N}$ & RIVER & 15-May-03 NO2-N & 0.011 & $\mathrm{mg} / \mathrm{L}$ & & & $\mathrm{U}$ & & & \\
\hline $\begin{array}{l}\text { SESPSPEC } \\
\text { SESPGDC }\end{array}$ & B170P9 & MCNARY-WASH.SIDE NEAR DAM & OFFSITE & sw & $\mathrm{N}$ & RIVER & 15-May-03 NO2-N & 0.011 & $\mathrm{mg} / \mathrm{L}$ & & & u & & & \\
\hline $\begin{array}{l}\text { SESPSPEC } \\
\text { SESPPEC }\end{array}$ & $\begin{array}{l}\text { B170014 } \\
\text { B170T5 }\end{array}$ & WALLA WALLA-RIVER & $\begin{array}{l}\text { OFFSSTE } \\
\text { OFFSTTE }\end{array}$ & $\begin{array}{l}\text { SW } \\
\text { sw }\end{array}$ & $\begin{array}{l}n \\
N\end{array}$ & $\begin{array}{l}\text { IVER } \\
\text { RIVER }\end{array}$ & $\begin{array}{l}\begin{array}{l}15-M a y-03 \\
15 O 2-N\end{array} \\
15 \text { May-03 NO2-N }\end{array}$ & 0.011 & $\mathrm{mg} / \mathrm{L}$ & & & u & & & \\
\hline $\begin{array}{l}\text { SESPSEC } \\
\text { SESPPEC }\end{array}$ & 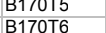 & $\begin{array}{l}\text { WALLA WALLA-RIVER } \\
\text { WALA WALA-RIVER }\end{array}$ & $\begin{array}{l}\text { OFFSITE } \\
\text { OFFITE }\end{array}$ & $\begin{array}{l}\text { SW } \\
\text { SW }\end{array}$ & $\frac{N}{n}$ & $\begin{array}{l}\text { IIVER } \\
\text { RIVER }\end{array}$ & $\begin{array}{l}\text { 15-May-03 NO2-N } \\
15 \text {-May-03 NO2-N }\end{array}$ & 0.011 & $\frac{\mathrm{mg} / \mathrm{L}}{\mathrm{m} / \mathrm{L}}$ & & & u & & & \\
\hline SESPSPEC & B170T1 & HOOD PARK-FRANKLIN CO. SHORE & OFFSITE & sw & $\mathrm{N}$ & RIVER & $15-M a y-03$ NO2-N & 0.011 & $\mathrm{mg} / \mathrm{L}$ & & & u & & & \\
\hline SESPSPEC & B170T2 & HOOD PARK-MID-RIVER & OFFSITE & SW & $\mathrm{N}$ & RIVER & 15-May-03 NO2-N & 0.011 & $\mathrm{mg} / \mathrm{L}$ & & & U & & & \\
\hline SESPSPEC & B170T3 & HOOD PARK-WALLA WALLA SHORE & OFFSITE & sw & $\mathrm{N}$ & RIVER & 15-May-03 NO & 0.011 & $\mathrm{mg} / \mathrm{L}$ & & & U & & & \\
\hline $\begin{array}{l}\text { SESPSPEC } \\
\text { SESPSEC }\end{array}$ & B18156 & 100-B SPRING 38-3 & ONSITE & sw & $\mathrm{N}$ & SURFACE & 13-Nov-03 NO2-N & 0.0074 & $\mathrm{mg} / \mathrm{L}$ & & & U & & & \\
\hline $\begin{array}{l}\text { SESPSPCC } \\
\text { SESPSPEC }\end{array}$ & 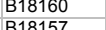 & 100-B SPRING 38-3 & ONSITE & sw & $\mathrm{N}$ & $\begin{array}{l}\text { SURFACE } \\
\text { SUREACE }\end{array}$ & $\begin{array}{ll}13-\mathrm{Nov}-03 \\
1302-\mathrm{N}\end{array}$ & 0.0074 & $\mathrm{mg} / \mathrm{L}$ & & & U & & & \\
\hline $\begin{array}{l}\text { SESPSEC } \\
\text { SESPSPEC }\end{array}$ & $\begin{array}{l}B 18157 \\
B 18158\end{array}$ & 100-B SPRING 38-3 & $\begin{array}{l}\text { ONSITE } \\
\text { ONSITE }\end{array}$ & $\begin{array}{l}\text { SW } \\
\text { sw }\end{array}$ & $\begin{array}{l}n \\
N\end{array}$ & $\begin{array}{l}\text { SURFACE } \\
\text { SURFACE }\end{array}$ & $\begin{array}{l}13-\text {-Nov- } 03 \text { NO2-N } \\
\text { 13-Nov } 03 \text { NO2-N }\end{array}$ & 0.0074 & $\mathrm{mglL}$ & & & 4 & & & \\
\hline $\begin{array}{l}\text { SESPSEC } \\
\text { SESPSPEC }\end{array}$ & $\begin{array}{l}B 18158 \\
\text { B18159 }\end{array}$ & $\begin{array}{l}\text { 100-B SPRING 38-3 } \\
\text { 100-B SPRING 38-3 }\end{array}$ & $\begin{array}{l}\text { ONSIITE } \\
\text { ONSITE }\end{array}$ & sw & $\frac{N}{n}$ & $\begin{array}{l}\text { SURFACE } \\
\text { SURFACE }\end{array}$ & $\begin{array}{l}13-\text {-Nov-03 NO2-N } \\
13 \text {-Nov-03 NO2-N }\end{array}$ & 0.0074 & $\frac{\mathrm{mggh}}{\mathrm{mg} / \mathrm{L}}$ & & & u & & & \\
\hline SESPSPEC & B18166 & 100-B SPRING DR 38-3 & ONSITE & sw & $\mathrm{N}$ & SURFACE & 13-Nov-03 NO2-N & 0.0074 & $\mathrm{mg} / \mathrm{L}$ & & & u & & & \\
\hline SESPSPEC & B18162 & 100-B SPRING 39-2 & ONSITE & sw & $\mathrm{N}$ & SURFACE & 13-Nov-03 NO2-N & 0.0074 & $\mathrm{mg} / \mathrm{L}$ & & & U & & & \\
\hline
\end{tabular}




\begin{tabular}{|c|c|c|c|c|c|c|c|c|c|c|c|c|c|c|c|}
\hline OWNER ID & SAMP NUM & SAMP SITE NAME & DIST CLASS & MEDIA & $\begin{array}{c}\text { FILTERED } \\
\text { FLAG }\end{array}$ & SAMP FROM & CON SHORT NAME & | VALUE RPTD & $\begin{array}{l}\text { ANAL } \\
\text { UNITS } \\
\text { RPTD }\end{array}$ & $\begin{array}{c}\text { COUNTING } \\
\text { ERROR }\end{array}$ & \begin{tabular}{|c|} 
TOTAL \\
ANAL \\
ERROR
\end{tabular} & $\mid \begin{array}{c}\text { LAB } \\
\text { QUALIFIER }\end{array}$ & SAMP COMMENT & $\left|\begin{array}{|c}\text { RESULT } \\
\text { COMMENT }\end{array}\right|$ & |WELL NAME \\
\hline SESPSPEC & B18163 & 100-B SPRING 39-2 & ONSITE & SW & N & SURFACE & 13-Nov-03 NO2-N & 0.0074 & $\mathrm{mg} / \mathrm{L}$ & & & U & & & \\
\hline SESPSPEC & B18164 & 100-B SPRING 39-2 & ONSITE & SW & N & SURFACE & 13-Nov-03 NO2-N & 0.0074 & $\mathrm{mg} / \mathrm{L}$ & & & U & & & \\
\hline $\begin{array}{l}\text { SESPSPEC } \\
\text { SESPSEC }\end{array}$ & $\begin{array}{l}B 18165 \\
B 18152\end{array}$ & & ONSITE & SW & $\mathrm{N}$ & SURFACE & 13-Nov-03 NO2-N & 0.0074 & $\mathrm{mg} / \mathrm{L}$ & & & $\mathrm{U}$ & & & \\
\hline $\begin{array}{l}\text { SESPSEC } \\
\text { SESPSPEC }\end{array}$ & $\begin{array}{l}\text { B18152 } \\
\text { B18153 }\end{array}$ & $\begin{array}{l}100 \text { BCC AREA UR } \\
100 \text { BCC AREA UR }\end{array}$ & $\begin{array}{l}\text { ONSITE } \\
\text { ONSTEE }\end{array}$ & $\begin{array}{l}\text { sw } \\
\text { sw }\end{array}$ & $\begin{array}{l}n \\
\mathrm{n} \\
\mathrm{n}\end{array}$ & $\begin{array}{l}\text { SURFACE } \\
\text { SURFACE }\end{array}$ & $\begin{array}{ll}13-n o v-03 \\
1302-N \\
13\end{array}$ & 0.0074 & $\mathrm{mg} / \mathrm{L}$ & & & $\mathrm{U}$ & & & \\
\hline SESPSPEC & B18154 & 100 B/C AREA UR & ONSITE & SW & $\frac{N}{N}$ & $\begin{array}{l}\text { SURFACE } \\
\text { SURFACE }\end{array}$ & $\begin{array}{l}\text { 13-Nov-03 NO2-N } \\
13-\mathrm{Nov}-03 \text { NO2-N }\end{array}$ & 0.0074 & $\frac{\mathrm{mgh}}{\mathrm{mg} / \mathrm{L}}$ & & & u & & & \\
\hline SESPSPEC & B18155 & 100 B/C AREA UR & ONSITE & sW & $\mathrm{N}$ & SURFACE & 13-Nov-03 NO2-N & 0.0074 & $\mathrm{mglh}$ & & & u & & & \\
\hline $\begin{array}{l}\text { SESPSPEC } \\
\text { SESPSDC }\end{array}$ & B18145 & 100 B/C AREA DR & ONSITE & sW & n & SURFACE & 17-Nov-03 NO2-N & 0.0074 & $\mathrm{mg} / \mathrm{L}$ & & & u & & & \\
\hline SESPSPEC & B18146 & $100 \mathrm{BICAREA}$ DR & ONSITE & SW & $\mathrm{N}$ & SURFACE & 17-Nov-03 NO2-N & 0.0081 & $\mathrm{mg} / \mathrm{L}$ & & & B & & & \\
\hline $\begin{array}{l}\text { SESPSPEC } \\
\text { SESPSEC }\end{array}$ & B18147 & 100 B/C AREA DR & ONSITE & SW & $\mathrm{N}$ & SURFACE & 17-Nov-03 NO2-N & 0.0074 & $\mathrm{mg} / \mathrm{L}$ & & & $\mathrm{U}$ & & & \\
\hline $\begin{array}{l}\text { SESPSEEC } \\
\text { SESPPEC }\end{array}$ & $\begin{array}{l}B 18148 \\
B 18151\end{array}$ & $\begin{array}{l}100 \mathrm{~B} / \mathrm{C} \text { ARRA DR } \\
100 \mathrm{~B} / \mathrm{C} \text { AREA OUTFL3 }\end{array}$ & $\begin{array}{l}\text { ONSIIE } \\
\text { ONSITE }\end{array}$ & $\begin{array}{l}\text { SW } \\
\text { sw }\end{array}$ & $\frac{N}{N}$ & $\begin{array}{l}\text { SURFACE } \\
\text { SURFACE }\end{array}$ & $\begin{array}{l}17-\text {-Nov-03 NO2-N } \\
\text { 17-Nov-03 NO2-N }\end{array}$ & $\begin{array}{l}0.0074 \\
0.0074\end{array}$ & $\frac{\mathrm{mg} / \mathrm{L}}{\mathrm{mg} / \mathrm{L}}$ & & & u & & & \\
\hline SESPSPEC & B18150 & 100 B/C AREA OUTFL2 & ONSITE & sw & $\mathrm{N}$ & SURFACE & 17-Nov-03 NO2-N & 0.0074 & $\mathrm{mg} / \mathrm{L}$ & & & u & & & \\
\hline SESPSPEC & B18149 & 100 B/C AREA OUTFL1 & ONSITE & sW & N & SURFACE & 17-Nov-03 NO2-N & 0.0074 & $\mathrm{mg} / \mathrm{L}$ & & & U & & & \\
\hline $\begin{array}{l}\text { SESPSPEC } \\
\text { SECPSDC }\end{array}$ & B18139 & Refer to WELL NAME column & & GW & $\mathrm{N}$ & AQUIFER TUBE & 10-Dec-03 NO2-N & 0.0074 & $\mathrm{mg} / \mathrm{L}$ & & & U & & & 01-D \\
\hline $\begin{array}{l}\text { SESPSPEC } \\
\text { SESPSPC }\end{array}$ & B18140 & Refer to WELL NAME column & & GW & $\mathrm{N}$ & AQUIFER TUBE & 10-Dec-03 NO2-N & 0.0074 & $\mathrm{mg} / \mathrm{L}$ & & & U & & & 04-D \\
\hline $\begin{array}{l}\text { SESPSPEC } \\
\text { SESPSEC }\end{array}$ & B18141 & Refer to WELL NAME column & & GW & $\mathrm{N}$ & AQUIFER TUBE & 10-Dec-03 NO2-N & 0.0074 & $\mathrm{mg} / \mathrm{L}$ & & & U & & & 05-D \\
\hline $\begin{array}{l}\text { SESPSEEC } \\
\text { SESPSPEC }\end{array}$ & $\begin{array}{l}\text { B18142 } \\
\text { B170T7 }\end{array}$ & $\begin{array}{l}\text { Refer to WELL NAME column } \\
\text { YAKIMA RIVER }\end{array}$ & OFFSITE & $\begin{array}{l}\text { GW } \\
\text { SW }\end{array}$ & $\frac{n}{N}$ & $\begin{array}{l}\text { AQUIFER TUBE } \\
\text { RIVER }\end{array}$ & $\begin{array}{l}10-\text {-ec--03 NO2-N } \\
\text { 14-May -03 NO3-N }\end{array}$ & 0.0074 & $\mathrm{mg} / \mathrm{L}$ & & & u & & & 06-D \\
\hline $\begin{array}{l}\text { SESPSPEC } \\
\text { SESP }\end{array}$ & $\begin{array}{l}\text { B170T8 } \\
\text { B170T8 }\end{array}$ & YAKIMA RIVER & OFFSITE & sw & $\frac{N}{N}$ & $\begin{array}{l}\text { RIVER } \\
\text { RIVER }\end{array}$ & $\begin{array}{l}14-\mathrm{May}-03 \text { N NO3-N } \\
14-\mathrm{May}-03 \text { NO3-N }\end{array}$ & 0.6 & $\frac{\mathrm{mggh}}{\mathrm{mg} / \mathrm{L}}$ & & & & & & \\
\hline SESPSPEC & B170T9 & YAKIMA RIVER & OFFSITE & sw & $\mathrm{N}$ & RIVER & 14-May-03 NO3-N & 0.6 & $\mathrm{mg} / \mathrm{L}$ & & & & & & \\
\hline SESPSPEC & B170R0 & MCNARY MID-RIVER NEAR DAM & OFFSITE & sw & $\mathrm{N}$ & RIVER & 15-May-03 NO3-N & 0.15 & $\mathrm{mg} / \mathrm{L}$ & & & & & & \\
\hline $\begin{array}{l}\text { SESPSPEC } \\
\text { SESPSEC }\end{array}$ & $\begin{array}{l}\text { B170R1 } \\
\text { B170P9 }\end{array}$ & $\begin{array}{l}\text { MCNARY-OR.SIDE NEAR DAM } \\
\text { MCNARY-WASH SDENEAR DAM }\end{array}$ & $\begin{array}{l}\text { OFFSITE } \\
\text { OFESTEE }\end{array}$ & SW & $\mathrm{N}$ & $\begin{array}{l}\text { RIVER } \\
\text { RIVER }\end{array}$ & 15-May-03 NO3-N & 0.15 & $\mathrm{mg} / \mathrm{L}$ & & & & & & \\
\hline $\begin{array}{l}\text { SESPSPCC } \\
\text { SESPSEC }\end{array}$ & B170P9 & MCNARY-WASH.SIDE NEAR DAM & OFFSITE & SW & $\mathrm{N}$ & RIVER & 15-May-03 NO3-N & 0.15 & $\mathrm{mg} / \mathrm{L}$ & & & & & & \\
\hline $\begin{array}{l}\text { SESPSECC } \\
\text { SESPPEC }\end{array}$ & $\begin{array}{l}\text { B170014 } \\
\text { B170T5 }\end{array}$ & $\begin{array}{l}\text { WALLA WALLA-RIVER } \\
\text { WALA WALA-RIER }\end{array}$ & $\begin{array}{l}\text { OFFSITE } \\
\text { OFSITE }\end{array}$ & SW & $\begin{array}{l}\mathrm{N} \\
\mathrm{N}\end{array}$ & $\begin{array}{l}\text { RIVER } \\
\text { RIVER }\end{array}$ & 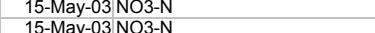 & 0.23 & $\mathrm{mg} / \mathrm{L}$ & & & & & & \\
\hline $\begin{array}{l}\text { SESPPEC } \\
\text { SESPSPEC }\end{array}$ & $\begin{array}{ll}B \\
\text { B170T6 }\end{array}$ & $\begin{array}{l}\text { WALLA WALLA-RIVER } \\
\text { WALLA WALLA-RIVER }\end{array}$ & $\begin{array}{l}\text { OFFSITE } \\
\text { OFFSITE }\end{array}$ & $\begin{array}{l}\text { SW } \\
\text { SW }\end{array}$ & $\frac{N}{N}$ & $\begin{array}{l}\text { RIVER } \\
\text { RIVER }\end{array}$ & $\begin{array}{l}15-M a y-03 \text { NO3-N } \\
15-\text { May-03 NO3-N }\end{array}$ & 0.23 & $\frac{\mathrm{mg} / \mathrm{L}}{\mathrm{mg} / \mathrm{L}}$ & & & & & & \\
\hline SESPSPEC & B170T1 & HOOD PARK-FRANKLIN CO. SHORE & OFFSITE & sw & $\mathrm{N}$ & RIVER & 15-May-03 NO3-N & 0.17 & $\mathrm{mg} / \mathrm{L}$ & & & & & & \\
\hline $\begin{array}{l}\text { SESPSPEC } \\
\text { SESPSDC }\end{array}$ & B170T2 & HOOD PARK-MID-RIVER & OFFSITE & sW & $\mathrm{N}$ & RIVER & 15-May-03 NO3-N & 0.18 & $\mathrm{mg} / \mathrm{L}$ & & & & & & \\
\hline $\begin{array}{l}\text { SESPSPEC } \\
\text { SESPSPCE }\end{array}$ & B170T3 & HOOD PARK-WALLA WALLA SHORE & OFFSITE & SW & $\mathrm{N}$ & $\begin{array}{l}\text { RIVER } \\
\text { SUIPEACE }\end{array}$ & $\begin{array}{l}15-M a y-03 \text { NO3-N } \\
15-N\end{array}$ & 0.18 & $\mathrm{mg} / \mathrm{L}$ & & & & & & \\
\hline $\begin{array}{l}\text { SESPSPEC } \\
\text { SESPSEC }\end{array}$ & $\begin{array}{l}B 18156 \\
B 1960\end{array}$ & $\begin{array}{l}100-B \text { SPRING 38-3 } \\
100-\text { SPRING 38-3 }\end{array}$ & ONSITE & SW & $\mathrm{N}$ & SURFACE & 13-Nov-03 NO3-N & 0.084 & $\mathrm{mg} / \mathrm{L}$ & & & & & & \\
\hline $\begin{array}{l}\text { SESPSECC } \\
\text { SESPSPEC }\end{array}$ & $\begin{array}{l}\text { B18160 } \\
\text { B18157 }\end{array}$ & $\begin{array}{l}\text { 100-B SPRING 38-3 } \\
\text { 100-B SPRING 38-3 }\end{array}$ & $\begin{array}{l}\text { ONSITE } \\
\text { ONSITE }\end{array}$ & $\begin{array}{l}\text { SW } \\
\text { sw }\end{array}$ & $\begin{array}{llll}n & \\
N \\
N\end{array}$ & $\begin{array}{l}\text { SURFACE } \\
\text { SURFACE }\end{array}$ & $\begin{array}{l}13-\mathrm{N} \text { Nov-03 NO3-N } \\
\text { 13-Noy } 03 \text { NO3-N }\end{array}$ & 0.092 & $\mathrm{mg} / \mathrm{L}$ & & & & & & \\
\hline $\begin{array}{l}\text { SESPSEC } \\
\text { SESPPEC }\end{array}$ & $\begin{array}{l}B 18157 \\
B 18158\end{array}$ & $\begin{array}{l}\text { 100-B SPRING 38-3 } \\
\text { 100-B SPRING 38-3 }\end{array}$ & $\begin{array}{l}\text { ONSTIE } \\
\text { ONSITE }\end{array}$ & $\begin{array}{l}\text { SW } \\
\text { SW }\end{array}$ & $\frac{N}{N}$ & $\begin{array}{l}\text { SURFACE } \\
\text { SURFACE }\end{array}$ & $\begin{array}{l}\text { 13-Nov-03 NO3-N } \\
\text { 13-Nov-03 NO3-N }\end{array}$ & 0.085 & $\frac{\mathrm{mg} / \mathrm{L}}{\mathrm{mg} / \mathrm{L}}$ & & & & & & \\
\hline SESPSEC & B18159 & 100-B SPRING 38-3 & ONSITE & sw & $\mathrm{N}$ & SURFACE & 13-Nov-03 NO3-N & 0.075 & $\mathrm{mg} / \mathrm{L}$ & & & & & & \\
\hline SESPSPEC & B18166 & 100-B SPRING DR 38-3 & ONSITE & SW & $\mathrm{N}$ & SURFACE & 13-Nov-03 NO3-N & 0.11 & $\mathrm{mg} / \mathrm{L}$ & & & & & & \\
\hline $\begin{array}{l}\text { SESPSPEC } \\
\text { SESPSPCF }\end{array}$ & $\begin{array}{ll}B 18162 \\
B 18163\end{array}$ & 100-B SPRING 39-2 & ONSITE & SW & $\mathrm{N}$ & $\begin{array}{l}\text { SURFACE } \\
\text { SUPEACE }\end{array}$ & 13-Nov-03 NO3-N & 0.11 & $\mathrm{mg} / \mathrm{L}$ & & & & & & \\
\hline $\begin{array}{l}\text { SESPSPEC } \\
\text { SESPSECC }\end{array}$ & $\begin{array}{l}\text { B18163 } \\
\text { B18164 }\end{array}$ & $\begin{array}{l}100-B \text { S SPRING 39-2 } \\
100-B \text { SPRING 39-2 }\end{array}$ & $\begin{array}{l}\text { ONSITE } \\
\text { ONSITE }\end{array}$ & SW & $\begin{array}{l}\mathrm{N} \\
\mathrm{N}\end{array}$ & $\begin{array}{l}\text { SURFACE } \\
\text { SUREACE }\end{array}$ & 13-Nov-03 NO3-N & 0.085 & $\mathrm{mg} / \mathrm{L}$ & & & & & & \\
\hline $\begin{array}{l}\text { SESPSECC } \\
\text { SESPSPEC }\end{array}$ & $\begin{array}{l}\text { B18184 } \\
\text { B18165 }\end{array}$ & $\begin{array}{l}\text { 100-B SPRING 39-2 } \\
\text { 100-B SPRING 39-2 }\end{array}$ & $\begin{array}{l}\text { ONSITE } \\
\text { ONSITE }\end{array}$ & $\begin{array}{l}\text { SW } \\
\text { SW }\end{array}$ & $\frac{N}{N}$ & $\begin{array}{l}\text { SURFACE } \\
\text { SURFACE }\end{array}$ & $\begin{array}{l}\text { 13-Nov-03 NO3-N } \\
\text { 13-Noy -03 NO3-N }\end{array}$ & $\begin{array}{l}0.086 \\
0.08\end{array}$ & $\mathrm{mg} / \mathrm{L}$ & & & & & & \\
\hline $\begin{array}{l}\text { SESPSPEC } \\
\text { SESP }\end{array}$ & B18152 & 100 B/C AREA UR & ONSITE & sw & $\mathrm{N}$ & $\begin{array}{l}\text { SURFACE } \\
\text { SURFACE }\end{array}$ & 13-Nov-03 NO3-N & 0.085 & $\frac{\mathrm{mg} / \mathrm{L}}{\mathrm{mg} / \mathrm{L}}$ & & & & & & \\
\hline SESPSPEC & B18153 & 100 B/C AREA UR & ONSITE & sw & $\mathrm{N}$ & SURFACE & 13-Nov-03 NO3-N & 0.093 & $\mathrm{mg} / \mathrm{L}$ & & & & & & \\
\hline SESPSPEC & B18154 & 100 B/C AREA UR & ONSITE & SW & $\mathrm{N}$ & SURFACE & 13-Nov-03 NO3-N & 0.11 & $\mathrm{mg} / \mathrm{L}$ & & & & & & \\
\hline $\begin{array}{l}\text { SESPSPEC } \\
\text { SESPSPCC }\end{array}$ & B18155 & $100 \mathrm{~B} / \mathrm{C}$ AREA UR & ONSITE & SW & $\mathrm{N}$ & SURFACE & 13-Nov-03 NO3-N & 0.1 & $\mathrm{mg} / \mathrm{L}$ & & & & & & \\
\hline $\begin{array}{l}\text { SESPSEEC } \\
\text { SESPSPEC }\end{array}$ & $\begin{array}{l}\text { B18145 } \\
\text { B18446 }\end{array}$ & $\begin{array}{l}100 \text { BCC AREA DR } \\
100 \text { BCAREADR }\end{array}$ & $\begin{array}{l}\text { ONSITE } \\
\text { ONSITE }\end{array}$ & SW & $\begin{array}{l}n \\
N\end{array}$ & $\begin{array}{l}\text { SURFACE } \\
\text { SURFACE }\end{array}$ & $\begin{array}{l}17-\text {-Nov-03 NO3-N } \\
\text { 17-Noy } 03 \text { NO3-N }\end{array}$ & 0.083 & $\mathrm{mg} / \mathrm{L}$ & & & & & & \\
\hline $\begin{array}{l}\text { SESPSPEC } \\
\text { SESPSPEC }\end{array}$ & $\begin{array}{l}B 18146 \\
\text { B18147 }\end{array}$ & $\begin{array}{l}100 \text { B BCAREA ARR } \\
100 \text { B/C AREA DR }\end{array}$ & $\begin{array}{l}\text { ONSTIE } \\
\text { ONSITE }\end{array}$ & $\begin{array}{l}\text { SW } \\
\text { sw }\end{array}$ & $N_{N}^{N}$ & $\begin{array}{l}\text { SURFACE } \\
\text { SURFACE }\end{array}$ & $\begin{array}{l}\text { 17--Nov-03 NO3-N } \\
\text { 17-Nov-03 NO3-N }\end{array}$ & $\begin{array}{l}0.086 \\
0.083\end{array}$ & $\frac{\mathrm{mg} / \mathrm{L}}{\mathrm{mg} / \mathrm{L}}$ & & & & & & \\
\hline SESPSPEC & B18148 & 100 B/C AREA DR & ONSITE & sw & $\mathrm{N}$ & SURFACE & 17-Nov-03 NO3-N & 0.082 & $\mathrm{mg} / \mathrm{L}$ & & & & & & \\
\hline SESPSPEC & B18151 & $100 \mathrm{~B} / \mathrm{C}$ AREA OUTFL3 & ONSITE & sw & $\mathrm{N}$ & SURFACE & 17-Nov-03 NO3-N & 0.085 & $\mathrm{mg} / \mathrm{L}$ & & & & & & \\
\hline SESPSPEC & B18150 & 100 B/C AREA OUTFL2 & ONSITE & SW & $\mathrm{N}$ & SURFACE & 17-Nov-03 NO3-N & 0.082 & $\mathrm{mg} / \mathrm{L}$ & & & & & & \\
\hline $\begin{array}{l}\text { SESPSPEC } \\
\text { SESPGDC }\end{array}$ & B18149 & 100 B/C AREA OUTFL1 & ONSITE & SW & $\mathrm{N}$ & SURFACE & 17-Nov-03 NO3-N & 0.081 & $\mathrm{mg} / \mathrm{L}$ & & & & & & \\
\hline $\begin{array}{l}\text { SESPSPCC } \\
\text { SESPSEC }\end{array}$ & B18139 & Refer to WELL NAME column & & GW & $\begin{array}{l}n \\
N\end{array}$ & $\begin{array}{l}\text { AQUIFER TUBE } \\
\text { OUNEFR TURE }\end{array}$ & 10-Dec-03 NO3-N & 0.74 & $\mathrm{mg} / \mathrm{L}$ & & & & & & 01-D \\
\hline $\begin{array}{l}\text { SESPSECC } \\
\text { SESPPEC }\end{array}$ & $\begin{array}{l}\text { B18140 } \\
\text { B18141 }\end{array}$ & & & $\begin{array}{l}\text { GW } \\
\text { GW }\end{array}$ & $\frac{N}{N}$ & $\begin{array}{l}\text { AQUUFER TUBE } \\
\text { AQUIFER TUBE }\end{array}$ & $\begin{array}{l}10-\text {-Dec-03 NO3-N } \\
\text { 10-Dec-03 NO3-N }\end{array}$ & $\begin{array}{l}2.7 \\
2.5\end{array}$ & $\frac{\mathrm{mg} / \mathrm{L}}{\mathrm{m} / \mathrm{L}}$ & & & $\begin{array}{l}D \\
D \\
D\end{array}$ & & & $\begin{array}{l}04-\mathrm{D} \\
0.5-\mathrm{D}\end{array}$ \\
\hline SESPSPEC & B18142 & Refer to WELL NAME column & & GW & $\mathrm{N}$ & AQUIFER TUBE & $\begin{array}{ll}10-D e c-03 \\
10\end{array}$ & 3.2 & $\mathrm{mg} / \mathrm{h}$ & & & D & & & $06-\mathrm{D}$ \\
\hline SESPSPEC & B170T7 & YAKIMA RIVER & OFFSITE & SW & $\mathrm{N}$ & RIVER & 14-May-03 SULFATE & 13.4 & $\mathrm{mg} / \mathrm{L}$ & & & & & & \\
\hline SESPSPEC & B170T8 & YAKIMA RIVER & OFFSITE & SW & $\mathrm{N}$ & RIVER & 14-May-03 SULFATE & 13.6 & $\mathrm{mg} / \mathrm{L}$ & & & & & & \\
\hline $\begin{array}{l}\text { SESPSPEC } \\
\text { SESPGDC }\end{array}$ & B170T9 & YAKIMA RIVER & OFFSITE & sw & $\mathrm{N}$ & RIVER & 14-May-03 SULFATE & 13.5 & $\mathrm{mg} / \mathrm{L}$ & & & & & & \\
\hline $\begin{array}{l}\text { SESPSPEC } \\
\text { SESPPEC }\end{array}$ & $\begin{array}{l}\text { B17000 } \\
\text { B170R1 }\end{array}$ & $\begin{array}{l}\text { MCNARY MID-RIVER NEAR DAM } \\
\text { MCNARY-OR SIDE NEAR DAM }\end{array}$ & $\begin{array}{l}\text { OFFSITE } \\
\text { OFFSITE }\end{array}$ & $\begin{array}{l}\text { SW } \\
\text { sw }\end{array}$ & $\begin{array}{l}n \\
N\end{array}$ & $\begin{array}{l}\text { IVIVR } \\
\text { RIVER }\end{array}$ & $\begin{array}{l}\text { 15-May-03 SULFATE } \\
\text { 15-May } 03 \text { SULFATE }\end{array}$ & $\begin{array}{c}9.2 \\
9.1\end{array}$ & $\mathrm{mg} / \mathrm{L}$ & & & & & & \\
\hline $\begin{array}{l}\text { SESPSEC } \\
\text { SESPPEC }\end{array}$ & $\begin{array}{l}\text { B170R1 } \\
\text { B170P9 }\end{array}$ & $\begin{array}{l}\text { MCNARYYOR.SIDE NEAR DAM } \\
\text { MCNARY-WASH. SIDE NEAR DAM }\end{array}$ & $\begin{array}{l}\text { OFFITE } \\
\text { OFFSITE }\end{array}$ & $\begin{array}{l}\text { SW } \\
\text { SW }\end{array}$ & $\frac{N}{n}$ & $\begin{array}{l}\text { IIVER } \\
\text { RIVER }\end{array}$ & $\begin{array}{l}\text { 15-May-03 SULFATE } \\
\text { 15-May-03 SULFATE }\end{array}$ & $\begin{array}{l}9.1 \\
9.1\end{array}$ & $\frac{\mathrm{mg} / \mathrm{L}}{\mathrm{m} / \mathrm{L}}$ & & & & & & \\
\hline SESPSPEC & B170T4 & WALLA WALLA-RIVER & OFFSITE & sw & $\mathrm{N}$ & $\begin{array}{l}\text { RIVER } \\
\text { RIVER }\end{array}$ & 15-May-03 SULFATE & $\begin{array}{l}.1 \\
4.6\end{array}$ & $\mathrm{mg} / \mathrm{L}$ & & & & & & \\
\hline SESPSPEC & B170T5 & WALLA WALLA-RIVER & OFFSITE & SW & $\mathrm{N}$ & RIVER & 15-May-03 SULFATE & 4.6 & $\mathrm{mg} / \mathrm{L}$ & & & & & & \\
\hline SESPSPEC & B170T6 & WALLA WALLA-RIVER & OFFSITE & sw & $\mathrm{N}$ & RIVER & 3 SULFATE & 4.6 & $\mathrm{mg} / \mathrm{L}$ & & & & & & \\
\hline $\begin{array}{l}\text { SESPSPEC } \\
\text { SESPSEC }\end{array}$ & B170T1 & HOOD PARK-FRANKLIN CO. SHORE & OFFSITE & sw & $\mathrm{N}$ & $\begin{array}{l}\text { RIVER } \\
\text { RIVER }\end{array}$ & 15-May-03 SULFATE & 7.9 & $\mathrm{mg} / \mathrm{L}$ & & & & & & \\
\hline $\begin{array}{l}\text { SESPSPEC } \\
\text { SESPSEC }\end{array}$ & $\begin{array}{l}\text { B170012 } \\
\text { B170T3 }\end{array}$ & 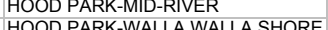 & OFFSITE & SW & $\mathrm{N}$ & $\begin{array}{l}\text { RIVER } \\
\text { RIVER }\end{array}$ & 15-May-03 SULFATE & 7.9 & $\mathrm{mg} / \mathrm{L}$ & & & & & & \\
\hline $\begin{array}{l}\text { SESPSEC } \\
\text { SESPSPCC }\end{array}$ & $\begin{array}{l}B 17013 \\
B 18156\end{array}$ & $\begin{array}{l}\text { HOOD PARK-WALA WALLA SHORE } \\
\text { 100-B SPRING 38-3 }\end{array}$ & $\begin{array}{l}\text { OFFITE } \\
\text { ONSITE }\end{array}$ & $\begin{array}{l}\text { sw } \\
\text { sw }\end{array}$ & $\frac{N}{n}$ & $\begin{array}{l}\text { IVIVR } \\
\text { SURFACE }\end{array}$ & $\begin{array}{l}\text { 15-May-03 SULFATE } \\
\text { 13-Nov-03 SULFATE }\end{array}$ & $\begin{array}{r}8 \\
9.8\end{array}$ & $\frac{\mathrm{mggh}}{\mathrm{mg} / \mathrm{L}}$ & & & & & & \\
\hline SESPSPEC & B18160 & 100-B SPRING 38-3 & ONSITE & sW & $\mathrm{N}$ & SURFACE & 13-Nov-03 SULFATE & 10.1 & $\mathrm{mg} / \mathrm{L}$ & & & & & & \\
\hline SESPSPEC & B18157 & 100-B SPRING 38-3 & ONSITE & SW & $\mathrm{N}$ & SURFACE & 13-Nov-03 SULFATE & 9.7 & $\mathrm{mg} / \mathrm{L}$ & & & & & & \\
\hline SESPSPEC & B18158 & 100-B SPRING 38-3 & ONSITE & sw & $\mathrm{N}$ & SURFACE & 13-Nov-03 SULFATE & 9.5 & $\mathrm{mg} / \mathrm{L}$ & & & & & & \\
\hline
\end{tabular}




\begin{tabular}{|c|c|c|c|c|c|c|c|c|c|c|c|c|c|c|c|}
\hline OWNER ID & SAMP NUM & SAMP SITE NAME & DIST CLASS & MEDIA & \begin{tabular}{|} 
FILTERED \\
FLAG
\end{tabular} & SAMP FROM & CON SHORT NAME & |VALUE RPTD & $\begin{array}{l}\text { ANAL } \\
\text { UNITS } \\
\text { RPTD }\end{array}$ & $\begin{array}{c}\text { COUNTING } \\
\text { ERROR }\end{array}$ & \begin{tabular}{|c|} 
TOTAL \\
ANAL \\
ERROR
\end{tabular} & $\begin{array}{c}\text { LAB } \\
\text { QUALIFIER }\end{array}$ & SAMP COMMENT & $\begin{array}{l}\text { RESULT } \\
\text { COMMENT }\end{array}$ & |WELL NAME \\
\hline SESPSPEC & B18159 & 100-B SPRING 38-3 & ONSITE & SW & N & SURFACE & 13-Nov-03 SULFATE & 9.2 & $\mathrm{mg} / \mathrm{L}$ & & & & & & \\
\hline & B18166 & 100-B SPRING DR 38-3 & ONSITE & SW & $\mathrm{N}$ & SURFACE & 13-Nov-03 SULFATE & 9.9 & $\mathrm{mg} / \mathrm{L}$ & & & & & & \\
\hline $\begin{array}{l}\text { SESPSPEC } \\
\text { SESPSEC }\end{array}$ & B18162 & $\begin{array}{l}100-B \text { SPRING 39-2 } \\
100-B \text { SPRING 39-2 }\end{array}$ & ONSITE & SW & 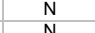 & SURFACE & 13-Nov-03 SULFATE & 9.7 & $\mathrm{mg} / \mathrm{L}$ & & & & & & \\
\hline $\begin{array}{l}\text { SESPSECC } \\
\text { SESPSPEC }\end{array}$ & $\begin{array}{l}\text { B18163 } \\
\text { B18164 }\end{array}$ & $\begin{array}{l}\text { 100-B SPRING 39-2 } \\
\text { 100-B SPRING 39-2 }\end{array}$ & $\begin{array}{l}\text { ONSITE } \\
\text { ONSTEE }\end{array}$ & $\begin{array}{l}\text { sw } \\
\text { sw }\end{array}$ & $\begin{array}{l}n \\
\mathrm{n} \\
\mathrm{n}\end{array}$ & $\begin{array}{l}\text { SURFACE } \\
\text { SURFACE }\end{array}$ & $\begin{array}{l}\text { 13-Nov-03 SULFAAE } \\
\text { 13-Nov-03 SULATE }\end{array}$ & 9.3 & $\mathrm{mg} / \mathrm{L}$ & & & & & & \\
\hline SESPSPEC & B18165 & 100-B SPRING 39-2 & ONSITE & sw & $\frac{n}{n}$ & $\begin{array}{l}\text { SURFACE } \\
\text { SURFACE }\end{array}$ & $\begin{array}{l}\text { 13-Nov-03 SULATE } \\
\text { 13-Nov-03 SULFATE }\end{array}$ & 9.3 & $\frac{\mathrm{mg} / \mathrm{L}}{\mathrm{mg} / \mathrm{L}}$ & & & & & & \\
\hline SESPSPEC & B18152 & $100 \mathrm{~B} / \mathrm{C}$ AREA UR & ONSITE & sw & $\mathrm{N}$ & SURFACE & 13-Nov-03 SULFATE & 9.2 & $\mathrm{mg} / \mathrm{L}$ & & & & & & \\
\hline $\begin{array}{l}\text { SESPSPEC } \\
\text { SESPSDC }\end{array}$ & B18153 & 100 B/C AREA UR & ONSITE & sW & n & SURFACE & 13-Nov-03 SULFATE & 9.2 & $\mathrm{mg} / \mathrm{L}$ & & & & & & \\
\hline $\begin{array}{l}\text { SESPSPEC } \\
\text { SESPSDC }\end{array}$ & B18154 & $100 \mathrm{BIC}$ AREA UR & ONSITE & SW & $\mathrm{N}$ & $\begin{array}{l}\text { SURFACE } \\
\text { SUIPEACE }\end{array}$ & 13-Nov-03 SULFATE & 9.3 & $\mathrm{mg} / \mathrm{L}$ & & & & & & \\
\hline $\begin{array}{l}\text { SESPSPEC } \\
\text { SESPSEC }\end{array}$ & B18155 & 100 B/C AREA UR & ONSITE & SW & $\mathrm{N}$ & SURFACE & 13-Nov-03 SULFATE & 9.3 & $\mathrm{mg} / \mathrm{L}$ & & & & & & \\
\hline $\begin{array}{l}\text { SESPSEEC } \\
\text { SESPSPEC }\end{array}$ & $\begin{array}{l}B 18145 \\
B 18146\end{array}$ & $\begin{array}{l}100 \text { BCC AREA DR } \\
100 \text { B/C AREA DR }\end{array}$ & $\begin{array}{l}\text { ONSIIE } \\
\text { ONSITE }\end{array}$ & $\begin{array}{l}\text { SW } \\
\text { sw }\end{array}$ & $\frac{N}{N}$ & $\begin{array}{l}\text { SURFACE } \\
\text { SURFACE }\end{array}$ & $\begin{array}{l}\text { 17-NNV-03 SULLATE } \\
\text { 17-Nov-03 SULFATE }\end{array}$ & 9.2 & $\frac{\mathrm{mg} / \mathrm{L}}{\mathrm{mg} / \mathrm{L}}$ & & & & & & \\
\hline SESPSPEC & B18147 & 100 B/C AREA DR & ONSITE & sw & $\mathrm{N}$ & SURFACE & 17-Nov-03 SULFATE & 9.2 & $\mathrm{mg} / \mathrm{L}$ & & & & & & \\
\hline SESPSPEC & B18148 & $100 \mathrm{~B} / \mathrm{C}$ AREA DR & ONSITE & sw & N & SURFACE & 17-Nov-03 SULFATE & 9.2 & $\mathrm{mg} / \mathrm{L}$ & & & & & & \\
\hline $\begin{array}{l}\text { SESPSPEC } \\
\text { SECPSDC }\end{array}$ & B18151 & 100 B/C AREA OUTFL3 & ONSITE & sw & $\mathrm{N}$ & SURFACE & 17-Nov-03 SULFATE & 9.3 & $\mathrm{mg} / \mathrm{L}$ & & & & & & \\
\hline $\begin{array}{l}\text { SESPSPEC } \\
\text { SESPSPC }\end{array}$ & 818150 & 100 B/C AREA OUTFL2 & ONSITE & SW & $\mathrm{N}$ & $\begin{array}{l}\text { SURFACE } \\
\text { SUIPEACE }\end{array}$ & 17-Nov-03 SULFATE & 9.2 & $\mathrm{mg} / \mathrm{L}$ & & & & & & \\
\hline $\begin{array}{l}\text { SESPSPCC } \\
\text { SESPSPEC }\end{array}$ & $\begin{array}{l}\text { B18149 } \\
\text { B18139 }-2\end{array}$ & & ONSITE & SW & $\mathrm{N}$ & $\begin{array}{l}\text { SURFACE } \\
\text { AOUUEER TUBE }\end{array}$ & 17-Nov-03 SULFATE & 9.3 & $\mathrm{mg} / \mathrm{L}$ & & & & & & \\
\hline $\begin{array}{l}\text { SESPSEC } \\
\text { SESPSEC }\end{array}$ & 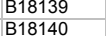 & $\begin{array}{l}\text { Refer to WELL NAME collumn } \\
\text { Refer to WELL NAME column }\end{array}$ & & $\begin{array}{l}\text { GW } \\
\text { GW }\end{array}$ & $\frac{n}{N}$ & $\begin{array}{l}\text { AQUUFER TUBE } \\
\text { AQUUFER TUBE }\end{array}$ & $\begin{array}{l}\text { 10-Dec-03 SULFATE } \\
\text { 10-Dec-03 SULFATE }\end{array}$ & $\begin{array}{r}14 \\
374\end{array}$ & $\mathrm{mg} / \mathrm{L}$ & & & & & & 01-D \\
\hline SESPSPEC & B18141 & Refer to WELL NAME column & & GW & $\mathrm{N}$ & $\begin{array}{l}\text { AQUIFER TUBE } \\
\text { AQUIFE TUB }\end{array}$ & $\begin{array}{l}\text { 10-Dec-03 SULAATE } \\
\text { 10-Dec-03 SULFATE }\end{array}$ & $\begin{array}{l}37.4 \\
37.1\end{array}$ & $\begin{array}{l}\mathrm{mggh} \\
\mathrm{mg} / \mathrm{L}\end{array}$ & & & $\begin{array}{l}\mathrm{D} \\
\mathrm{D}\end{array}$ & & & $\begin{array}{l}04-\mathrm{D} \\
05-\mathrm{D}\end{array}$ \\
\hline SESPSPEC & B18142 & Refer to WELL NAME column & & GW & $\mathrm{N}$ & AQUIFER TUBE & 10-Dec-03 SULFATE & 39.3 & $\mathrm{mg} / \mathrm{L}$ & & & $\mathrm{D}$ & & & 06-D \\
\hline SESPSPEC & B18144 & Refer to WELL NAME column & & GW & $\mathrm{N}$ & AQUIFER TUBE & 10-Dec-03 VOA & & & & & & NO SAMPLE. & & 11-D \\
\hline $\begin{array}{l}\text { SESPSPEC } \\
\text { SESPSPCC }\end{array}$ & B18144 & Refer to WELL NAME column & & GW & $\mathrm{N}$ & AQUIFER TUBE & 10-Dec-03 VOA & & & & & & NO SAMPLE. & & 11-D \\
\hline $\begin{array}{l}\text { SESPSPCC } \\
\text { SESPSEC }\end{array}$ & B18156 & 100-B SPRING 38-3 & ONSITE & SW & $\mathrm{N}$ & SURFACE & 13-Nov-03 1,1,1-T (1,1,1-Trichloroethane; & 0.17 & ug/L & & & U & & & \\
\hline $\begin{array}{l}\text { SESPSECC } \\
\text { SESPPEC }\end{array}$ & 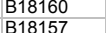 & $\begin{array}{l}\text { 100-B SPRING 38-3 } \\
1 \text { 100-B SPRING 38-3 }\end{array}$ & ONSITE & SW & $\begin{array}{l}n \\
N\end{array}$ & $\begin{array}{l}\text { SURFACE } \\
\text { SURFACE }\end{array}$ & 13-Nov-03 1, 1,1-T (1,1,1-Trichloroethane; & 0.17 & ug/L & & & u & & & \\
\hline $\begin{array}{l}\text { SESPSEC } \\
\text { SESPSPEC }\end{array}$ & $\begin{array}{l}B 18157 \\
B 18158\end{array}$ & $\begin{array}{l}\text { 100-B SPRING } 38-3 \\
\text { 100-B SPRING 38-3 }\end{array}$ & $\begin{array}{l}\text { ONSITE } \\
\text { ONSITE }\end{array}$ & $\begin{array}{l}\text { sw } \\
\text { sw }\end{array}$ & $\frac{N}{N}$ & $\begin{array}{l}\text { SURFACE } \\
\text { SURFACE }\end{array}$ & 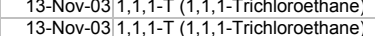 & 0.17 & $\begin{array}{ll}\mathrm{ug} / \mathrm{L} \\
\mathrm{ug} / \mathrm{L}\end{array}$ & & & u & & & \\
\hline SESPSPEC & B18159 & 100-B SPRING 38-3 & ONSITE & sw & $\mathrm{N}$ & SURFACE & 13-Nov-03 $1,1,1-\mathrm{T}$ (1,1,1-Trichloroethane; & 0.17 & $\mathrm{ug} / \mathrm{L}$ & & & u & & & \\
\hline SESPSPEC & B18166 & 100-B SPRING DR 38-3 & ONSITE & sw & $\mathrm{N}$ & SURFACE & 13-Nov-03 1,1,1-T (1,1,1-Trichloroethane' & 0.17 & $\mathrm{ug} / \mathrm{L}$ & & & u & & & \\
\hline SESPSPEC & B18162 & 100-B SPRING 39-2 & ONSITE & sw & $\mathrm{N}$ & SURFACE & 13-Nov-03 1,1,1-T (1,1,1-Trichloroethane; & 0.17 & ug/L & & & $\mathrm{U}$ & & & \\
\hline SESPSPEC & B18163 & 100-B SPRING 39-2 & ONSITE & sW & $\mathrm{N}$ & SURFACE & 13-Nov-03 1,1,1-T (1,1,1-Trichloroethane'; & 0.17 & ug/L & & & U & & & \\
\hline SESPSPEC & B18164 & 100-B SPRING 39-2 & ONSITE & SW & $\mathrm{N}$ & SURFACE & 13-Nov-03 1,1,1-T (1,1,1-Trichloroethane') & 0.17 & $\mathrm{ug} / \mathrm{L}$ & & & & & & \\
\hline SESPSPEC & B18165 & 100-B SPRING 39-2 & ONSITE & sw & $\mathrm{N}$ & SURFACE & 13-Nov-03 1,1,1-T (1,1,1-Trichloroethane) & 0.17 & $\mathrm{ug} / \mathrm{L}$ & & & u & & & \\
\hline SESPSPEC & B18152 & $100 \mathrm{~B} / \mathrm{C}$ AREA UR & ONSITE & sw & $\mathrm{N}$ & SURFACE & 13-Nov-03 1,1,1-T (1,1,1-Trichloroethane; & 0.17 & $\mathrm{ug} / \mathrm{L}$ & & & U & & & \\
\hline SESPSPEC & B18153 & $100 \mathrm{~B} / \mathrm{C}$ AREA UR & ONSITE & sw & $\mathrm{N}$ & SURFACE & 13-Nov-03 1,1,1-T (1,1,1-Trichloroethane; & 0.17 & $\mathrm{ug} / \mathrm{L}$ & & & u & & & \\
\hline SESPSPEC & B18154 & 100 B/C AREA UR & ONSITE & SW & $\mathrm{N}$ & SURFACE & 13-Nov-03 1,1,1-T (1,1,1-Trichloroethane; & 0.17 & $\mathrm{ug} / \mathrm{L}$ & & & U & & & \\
\hline $\begin{array}{l}\text { SESPSPEC } \\
\text { SESPSPCF }\end{array}$ & B18155 & 100 B/C AREA UR & ONSITE & SW & $\mathrm{N}$ & $\begin{array}{l}\text { SURFACE } \\
\text { SUPEACE }\end{array}$ & 13-Nov-03 1,1,1-T (1,1,1-Trichloroethane; & 0.17 & $\mathrm{ug} / \mathrm{L}$ & & & U & & & \\
\hline $\begin{array}{l}\text { SESPSPCC } \\
\text { SESPSEC }\end{array}$ & B18145 & $\begin{array}{l}100 \text { B/C AREA DR } \\
100 B C \text { AREADR }\end{array}$ & ONSITE & SW & $\begin{array}{l}n \\
N\end{array}$ & $\begin{array}{l}\text { SURFACE } \\
\text { SUREACE }\end{array}$ & $\begin{array}{l}\text { 17-Nov-03 1,1,1-T (1,1,1-Trichloroethane; } \\
17-11 \text { - }\end{array}$ & 0.17 & $u g / L$ & & & U & & & \\
\hline $\begin{array}{l}\text { SESPSEC } \\
\text { SESPSPEC }\end{array}$ & $\begin{array}{l}\text { B18146 } \\
\text { B18147 }\end{array}$ & $\begin{array}{l}100 \text { B/C AREA DR } \\
100 B \text { BCAREA DR }\end{array}$ & $\begin{array}{l}\text { ONSITE } \\
\text { ONSTEE }\end{array}$ & $\begin{array}{l}\text { SW } \\
\text { SW }\end{array}$ & $\frac{N}{N}$ & $\begin{array}{l}\text { SURFACE } \\
\text { SURFACE }\end{array}$ & $\begin{array}{l}\text { 17-Nov-03 1, 1, 1-T (1,1,1-Trichloroethane; } \\
\text { 17-Nov-03 1111-T }\end{array}$ & 0.17 & $\mathrm{ug} / \mathrm{L}$ & & & u & & & \\
\hline $\begin{array}{l}\text { SESPSPCC } \\
\text { SESPPEC }\end{array}$ & $\begin{array}{l}\text { B18147 } \\
\text { B18148 }\end{array}$ & $\begin{array}{l}100 \text { B BCAREA AR } \\
100 \text { B/C AREA DR }\end{array}$ & ONSITE & sw & $\frac{N}{n}$ & $\begin{array}{l}\text { SURFACE } \\
\text { SURFACE }\end{array}$ & $\begin{array}{l}\text { 17-Nov-03 11,1,1-T (1,1,1,-Trichloroethane; } \\
\text { 17-Nov-03 1,1,1-T (1,1,1-Trichloroethane; }\end{array}$ & 0.17 & $\begin{array}{l}u g / L \\
u g / L\end{array}$ & & & u & & & \\
\hline SESPSPEC & B18151 & 100 B/C AREA OUTFL3 & ONSITE & sw & $\mathrm{N}$ & SURFACE & 17-Nov-03 1,1,1-T (1,1,1-Trichloroethane & 0.17 & $\mathrm{ug} / \mathrm{L}$ & & & u & & & \\
\hline SESPSPEC & B18150 & 100 B/C AREA OUTFL2 & ONSITE & SW & $\mathrm{N}$ & SURFACE & 17-Nov-03 1,1,1-T (1,1,1-Trichloroethane; & 0.17 & ug/L & & & U & & & \\
\hline $\begin{array}{l}\text { SESPSPEC } \\
\text { SESPSPCC }\end{array}$ & B18149 & 100 B/C AREA OUTFL1 & ONSITE & SW & $\mathrm{N}$ & SURFACE & 17-Nov-03 1,1,1-T (1,1,1-Trichloroethane; & 0.17 & ug/L & & & U & & & \\
\hline $\begin{array}{l}\text { SESPSECC } \\
\text { SESPSPEC }\end{array}$ & 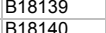 & Refer to WELLL NAME column & & GW & $\begin{array}{l}n \\
N\end{array}$ & $\begin{array}{l}\text { AQUUFER TUBE } \\
\text { AQUUFER TUBE }\end{array}$ & $\begin{array}{l}\text { 10-Dec-03 1,1,1-T (1,1,1-Trichloroethane; } \\
\text { 10-De-03 }\end{array}$ & 0.17 & ug/L & & & U & & & $01-\mathrm{D}$ \\
\hline $\begin{array}{l}\text { SESPSECC } \\
\text { SESPSPEC }\end{array}$ & $\begin{array}{l}\text { B18140 } \\
\text { B18141 }-250\end{array}$ & $\begin{array}{l}\text { Refer to WELL NAME column } \\
\text { Refer to WELL NAME column }\end{array}$ & & & $\begin{array}{l}n \\
N\end{array}$ & $\begin{array}{l}\text { AQUUFER TUBE } \\
\text { AQUIFER TUBE }\end{array}$ & 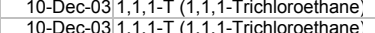 & 0.17 & $\mathrm{ug} / \mathrm{L}$ & & & u & & & 04-D \\
\hline $\begin{array}{l}\text { SESPSEC } \\
\text { SESPPEC }\end{array}$ & $\begin{array}{l}\text { B18141 } \\
\text { B18142 }\end{array}$ & Refer to WELL NAME column & & GW & $\frac{N}{N}$ & $\begin{array}{l}\text { AQUIFER TUBE } \\
\text { AQUER TIF }\end{array}$ & 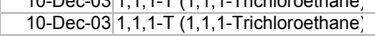 & 0.17 & ug/L & & & u & & & $06-\mathrm{D}$ \\
\hline SESPSPEC & B18156 & 100-B SPRING 38-3 & ONSITE & sw & $\mathrm{N}$ & SURFACE & 13-Nov-03 1,1,2-T (1,1,2-Trichloroethane & 0.05 & $\mathrm{ug} / \mathrm{L}$ & & & u & & & \\
\hline SESPSPEC & B18160 & 100-B SPRING 38-3 & ONSITE & sw & $\mathrm{N}$ & SURFACE & 13-Nov-03 1,1,2-T (1,1,2-Trichloroethane; & 0.05 & $\mathrm{ug} / \mathrm{L}$ & & & U & & & \\
\hline SESPSPEC & B18157 & 100-B SPRING 38-3 & ONSITE & SW & $\mathrm{N}$ & SURFACE & 13-Nov-03 1,1,2-T (1,1,2-Trichloroethane; & 0.05 & $\mathrm{ug} / \mathrm{L}$ & & & U & & & \\
\hline $\begin{array}{l}\text { SESPSPCC } \\
\text { SESPSEC }\end{array}$ & $\begin{array}{l}B 18158 \\
B 18159\end{array}$ & 100-B SPRING 38-3 & ONSITE & SW & $\mathrm{N}$ & SURFACE & 13-Nov-03 1,1,2-T (1,1,2-Trichloroethane; & 0.05 & ug/L & & & U & & & \\
\hline $\begin{array}{l}\text { SESPSECC } \\
\text { SESPPEC }\end{array}$ & $\begin{array}{l}\text { B18189 } \\
\text { B18166 }\end{array}$ & $\begin{array}{l}\text { 100-B SPRING 38-3 } \\
100-B \text { SPRING DR 38-3 }\end{array}$ & $\begin{array}{l}\text { ONSITE } \\
\text { ONSITE }\end{array}$ & $\begin{array}{l}\text { SW } \\
\text { SW }\end{array}$ & $\frac{N}{N}$ & $\begin{array}{l}\text { SURFACE } \\
\text { SURFACE }\end{array}$ & $\begin{array}{l}\text { 13-Nov-30 } \\
\text { 13-1,2-T (1,1,2-Trichloroethane, }\end{array}$ & 0.05 & $\mathrm{ug} / \mathrm{L}$ & & & u & & & \\
\hline SESPSPEC & B18162 & 100-B SPRING 39-2 & ONSITE & sw & $\frac{N}{n}$ & $\begin{array}{l}\text { SURFACE } \\
\text { SURFACE }\end{array}$ & 13-Nov-03 1,1,2-T (1,1,2-Trichloroethane; & 0.05 & ug/L $/ \mathrm{L}$ & & & u & & & \\
\hline SESPSPEC & B18163 & 100-B SPRING 39-2 & ONSITE & sw & $\mathrm{N}$ & SURFACE & 13-Nov-03 1,1,2-T (1,1,2-Trichloroethane; & 0.05 & ug/L & & & U & & & \\
\hline SESPSPEC & B18164 & 100-B SPRING 39-2 & ONSITE & sw & $\mathrm{N}$ & SURFACE & 13-Nov-03 1,1,2-T (1,1,2-Trichloroethane; & 0.05 & $\mathrm{ug} / \mathrm{L}$ & & & U & & & \\
\hline SESPSPEC & B18165 & 100-B SPRING 39-2 & ONSITE & sw & $\mathrm{N}$ & SURFACE & 13-Nov-03 1,1,2-T (1,1,2-Trichloroethane; & 0.05 & $\mathrm{ug} / \mathrm{L}$ & & & U & & & \\
\hline $\begin{array}{l}\text { SESPSPEC } \\
\text { SESPPEC }\end{array}$ & $\begin{array}{l}\text { B18152 } \\
\text { B18153 }\end{array}$ & $\begin{array}{l}100 \text { B/C AREA UR } \\
100 B C \text { AREA UR }\end{array}$ & $\begin{array}{l}\text { ONSITE } \\
\text { ONSITE }\end{array}$ & sw & $\begin{array}{l}n \\
N\end{array}$ & $\begin{array}{l}\text { SURFACE } \\
\text { SURFACE }\end{array}$ & $\begin{array}{l}\text { 13-Nov-03 } \\
\text { 13, 1,2-T (1,1,2-Trichloroethane; }\end{array}$ & 0.05 & $\mathrm{ug} / \mathrm{L}$ & & & U & & & \\
\hline $\begin{array}{l}\text { SESPSEC } \\
\text { SESPPEC }\end{array}$ & $\begin{array}{l}\text { B18153 } \\
\text { B18154 }\end{array}$ & $\begin{array}{l}100 \text { BCC AREA UR } \\
100 \text { BIC AREA UR }\end{array}$ & $\begin{array}{l}\text { ONSTIE } \\
\text { ONSITE }\end{array}$ & $\begin{array}{l}\text { SW } \\
\text { SW }\end{array}$ & $\frac{N}{n}$ & $\begin{array}{l}\text { SURFACE } \\
\text { SURFACE }\end{array}$ & 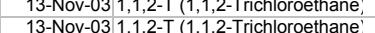 & 0.05 & $\mathrm{ug} / \mathrm{L}$ & & & u & & & \\
\hline SESPSPEC & B18155 & 100 B/C AREA UR & ONSITE & sw & $\mathrm{N}$ & $\begin{array}{l}\text { SURFACE } \\
\text { SURFACE }\end{array}$ & $\begin{array}{l}13-N \text {-Nov-03 } 1,1,2-1 \\
\text { 13 (1, I, - - Trichloroeethane, }\end{array}$ & 0.05 & ug/L & & & u & & & \\
\hline SESPSPEC & B18145 & 100 B/C AREA DR & ONSITE & SW & $\mathrm{N}$ & SURFACE & 17-Nov-03 1,1,2-T (1,1,2-Trichloroethane & 0.05 & ug/L & & & $\mathrm{U}$ & & & \\
\hline SESPSPEC & B18146 & $100 \mathrm{~B} / \mathrm{C}$ & ONSITE & sw & $\mathrm{N}$ & SURFACE & 17-Nov-03 1,1,2-T (1,1,2-Tric & 0.05 & $\mathrm{ug} / \mathrm{L}$ & & & U & & & \\
\hline $\begin{array}{l}\text { SESPSPEC } \\
\text { SESPSEC }\end{array}$ & B18147 & $100 \mathrm{~B} / \mathrm{C}$ AREA DR & ONSITE & sw & $\mathrm{N}$ & SURFACE & 17-Nov-03 1,1,2-T (1,1,2-Trichloroethane; & 0.05 & $\mathrm{ug} / \mathrm{L}$ & & & U & & & \\
\hline $\begin{array}{l}\text { SESPSPCC } \\
\text { SESPSEC }\end{array}$ & B18148 & 100 B/C AREA DR & ONSITE & sw & $\mathrm{N}$ & $\begin{array}{l}\text { SURFACE } \\
\text { SUREACE }\end{array}$ & 17-Nov-03 1,1,2-T (1,1,2-Trichloroethane; & 0.05 & ug/L & & & U & & & \\
\hline $\begin{array}{l}\text { SESPSEC } \\
\text { SESPSPEC }\end{array}$ & $\begin{array}{l}B 18151 \\
B 18150\end{array}$ & $\begin{array}{l}100 \text { B/C AREA OUTLL3 } \\
100 \text { B/C AREA OUTFL? }\end{array}$ & $\begin{array}{l}\text { ONSITE } \\
\text { ONSITE }\end{array}$ & sw & $\begin{array}{l}n \\
N\end{array}$ & $\begin{array}{l}\text { SURFACE } \\
\text { SURFACE }\end{array}$ & & 0.05 & $\mathrm{ug} / \mathrm{L}$ & & & 4 & & & \\
\hline $\begin{array}{l}\text { SESPSEC } \\
\text { SESPSPEC }\end{array}$ & $\begin{array}{l}B 18150 \\
\text { B18149 }\end{array}$ & 100 BIC AREA OUTFL1 & ONSITE & sw & $\frac{N}{n}$ & $\begin{array}{l}\text { SURFACE } \\
\text { SURFACE }\end{array}$ & 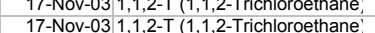 & 0.05 & $\frac{\mathrm{gg} / \mathrm{L}}{\mathrm{ug} / \mathrm{L}}$ & & & u & & & \\
\hline SESPSPEC & B18139 & Refer to WELL NAME column & & GW & $\mathrm{N}$ & AQUIFER TUBE & 10-Dec-03 1,1,2-T (1,1,2-Trichloroethane; & 0.05 & ug/L & & & u & & & D \\
\hline SESPSPEC & B18140 & Refer to WELL NAME column & & GW & $\mathrm{N}$ & AQUIFER TUBE & 10-Dec-03 1,1,2-T (1,1,2-Trichloroethane; & 0.2 & $\mathrm{ug} / \mathrm{L}$ & & & $\mathrm{J}$ & & & 04-D \\
\hline
\end{tabular}




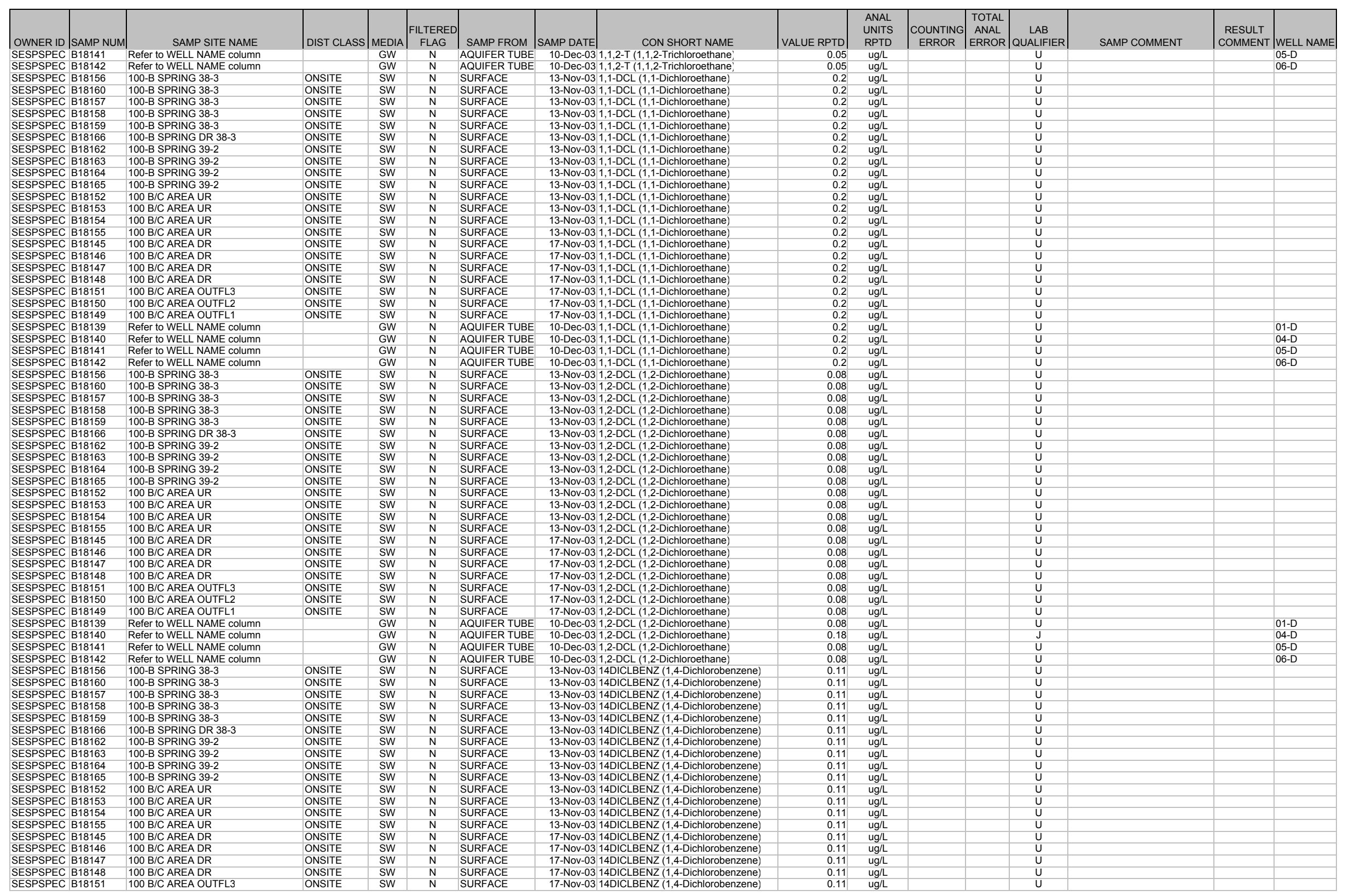




\begin{tabular}{|c|c|c|c|c|c|c|c|c|c|c|c|c|c|c|c|}
\hline OWNER ID & SAMP NUM & SAMP SITE NAME & DIST CLASS & MEDIA & $\begin{array}{c}\text { FILTERED } \\
\text { FLAG }\end{array}$ & SAMP FROM & CON SHORT NAME & |VALUE RPTD & $\begin{array}{l}\text { ANAL } \\
\text { UNITS } \\
\text { RPTD }\end{array}$ & $\left|\begin{array}{c}\text { COUNTING } \\
\text { ERROR }\end{array}\right|$ & \begin{tabular}{|c|} 
TOTAL \\
ANAL \\
ERROR
\end{tabular} & $\mid \begin{array}{c}\text { LAB } \\
\text { QUALIFIER }\end{array}$ & SAMP COMMENT & $\begin{array}{c}\text { RESULT } \\
\text { COMMENT }\end{array}$ & |WELL NAME \\
\hline SESPSPEC & B18150 & 100 B/C AREA OUTFL2 & ONSITE & sw & N & SURFACE & 17-Nov-03 14DICLBENZ (1,4-Dichlorobenzene) & 0.11 & $\mathrm{ug} / \mathrm{L}$ & & & U & & & \\
\hline SESPSPEC & B18149 & 100 B/C AREA OUTFL1 & ONSITE & SW & $\mathrm{N}$ & SURFACE & 17-Nov-03 14DICLBENZ (1,4-Dichlorobenzene) & 0.11 & ug/L & & & U & & & \\
\hline $\begin{array}{l}\text { SESPSECC } \\
\text { SESPPEC }\end{array}$ & $\begin{array}{ll}B 18139 \\
B 18140\end{array}$ & Refer to WELL NAME column & & GW & $\mathrm{N}$ & $\begin{array}{l}\text { AQUIFER TUBE } \\
\text { AOUIEFR TUBE }\end{array}$ & 10-Dec-03 14DICLBENZ (1,4-Dichlorobenzene) & 0.11 & ug/L & & & U & & & 01-D \\
\hline $\begin{array}{l}\text { SESPSEC } \\
\text { SESPSPEC }\end{array}$ & $\begin{array}{l}\text { B18140 } \\
\text { B18141 }\end{array}$ & $\begin{array}{l}\text { Refer to WELL NAME column } \\
\text { Refer to WELL NAME column }\end{array}$ & & GW & $\begin{array}{c}n \\
N\end{array}$ & $\begin{array}{l}\text { AQUIFER TUBE } \\
\text { AOUUFER TUBE }\end{array}$ & 10-Dec-03 14DICLBENZ (1,4-Dichlorobenzene) & 0.11 & $u g / L$ & & & $\mathrm{U}$ & & & 04-D \\
\hline $\begin{array}{l}\text { SESPSPEC } \\
\text { SESPC }\end{array}$ & $\begin{array}{l}B 18141 \\
B 18142\end{array}$ & $\begin{array}{l}\text { Refer to WELL NAME column } \\
\text { Refer to WELL NAME column }\end{array}$ & & GW & $\frac{n}{n}$ & $\begin{array}{l}\text { AQUUFER TUBE } \\
\text { AQUIFER TUBE }\end{array}$ & $\begin{array}{l}\text { 10-Dec-033 414DCLBEEN (114-Dichhorobenzzene) } \\
\text { 10-Dec-03 14DICLBENZ (1,4-Dichlorobenzene) }\end{array}$ & 0.11 & $\begin{array}{l}\mathrm{gug} / \mathrm{L} \\
\mathrm{ug} / \mathrm{L}\end{array}$ & & & u & & & \\
\hline SESPSPEC & B18156 & 100-B SPRING 38-3 & ONSITE & sw & $\mathrm{N}$ & SURFACE & 13-Nov-03 1BUTANOL & 4.6 & $\mathrm{ug} / \mathrm{L}$ & & & u & & & \\
\hline $\begin{array}{l}\text { SESPSPEC } \\
\text { SESPSDC }\end{array}$ & B18160 & 100-B SPRING 38-3 & ONSITE & sw & N & SURFACE & 13-Nov-03 1BUTANOL & 4.6 & $\mathrm{ug} / \mathrm{L}$ & & & u & & & \\
\hline SESPSPEC & B18157 & 100-B SPRING 38-3 & ONSITE & SW & $\mathrm{N}$ & SURFACE & 13-Nov-03 1BUTANOL & 4.6 & $\mathrm{ug} / \mathrm{L}$ & & & U & & & \\
\hline $\begin{array}{l}\text { SESPSPEC } \\
\text { SESPSEC }\end{array}$ & B18158 & 100-B SPRING 38-3 & ONSITE & SW & $\mathrm{N}$ & SURFACE & 13-Nov-03 1BUTANOL & 4.6 & $\mathrm{ug} / \mathrm{L}$ & & & U & & & \\
\hline $\begin{array}{l}\text { SESPSECC } \\
\text { SESPPECC }\end{array}$ & $\begin{array}{l}\text { B181899 } \\
\text { B18166 }\end{array}$ & $\begin{array}{l}100-B \text { SPRING 38-3 } \\
100-B \text { SPRING DR 38-3 }\end{array}$ & $\begin{array}{l}\text { ONSIE } \\
\text { ONSITE }\end{array}$ & $\begin{array}{l}\text { SW } \\
\text { sW }\end{array}$ & $\frac{N}{N}$ & $\begin{array}{l}\text { SURFACE } \\
\text { SURFACE }\end{array}$ & $\begin{array}{l}13-\mathrm{Nov}-031 \text { BUTANANOL } \\
\text { 13-Nov-03 } 1 \text { BUTANOL }\end{array}$ & $\begin{array}{l}4.6 \\
4.6\end{array}$ & ug/L & & & u & & & \\
\hline $\begin{array}{l}\text { SESPSPEC } \\
\text { SESP }\end{array}$ & B18162 & $\begin{array}{l}\text { 100-B SPRING DR 38-3 } \\
\text { 100-B SPRING 39-2 }\end{array}$ & ONSITE & sw & $\frac{N}{N}$ & $\begin{array}{l}\text { SURFACE } \\
\text { SURFACE }\end{array}$ & $\begin{array}{l}13-\mathrm{NOV}-03 \text { 1BUI ANOL } \\
\text { 13-Nov-03 } 1 \text { BUTANOL }\end{array}$ & $\begin{array}{l}4.6 \\
4.6\end{array}$ & $\begin{array}{l}\mathrm{gg} / \mathrm{L} \\
\mathrm{ug} / \mathrm{L}\end{array}$ & & & u & & & \\
\hline SESPSPEC & B18163 & 100-B SPRING 39-2 & ONSITE & sw & $\mathrm{N}$ & SURFACE & 13-Nov-03 1BUTANOL & 4.6 & ug/L & & & u & & & \\
\hline SESPSPEC & B18164 & 100-B SPRING 39-2 & ONSITE & sw & $\mathrm{N}$ & SURFACE & 13-Nov-03 1BUTANOL & 4.6 & ug/L & & & U & & & \\
\hline $\begin{array}{l}\text { SESPSPEC } \\
\text { SESPSPC }\end{array}$ & $\begin{array}{ll}B 18165 \\
B 18152\end{array}$ & 100-B SPRING 39-2 & ONSITE & SW & $\mathrm{N}$ & SURFACE & 13-Nov-03 1BUTANOL & 4.6 & $\mathrm{ug} / \mathrm{L}$ & & & U & & & \\
\hline $\begin{array}{l}\text { SESPSPEC } \\
\text { SESPSEC }\end{array}$ & $\begin{array}{l}\text { B18152 } \\
\text { B18152 }\end{array}$ & 100 B/C AREA UR & ONSITE & sw & $\begin{array}{r}\mathrm{N} \\
\mathrm{N}\end{array}$ & SURFACE & 13-Nov-03 1 BUTANOL & 4.6 & $\mathrm{ug} / \mathrm{L}$ & & & $\mathrm{U}$ & & & \\
\hline $\begin{array}{l}\text { SESPSECC } \\
\text { SESPSEC }\end{array}$ & $\begin{array}{l}\begin{array}{l}\text { B18153 } \\
\text { B18154 }\end{array}\end{array}$ & $\begin{array}{l}100 \text { BCC AREA UR } \\
100 \text { B/C AREA UR }\end{array}$ & $\begin{array}{l}\text { ONSIIE } \\
\text { ONSITE }\end{array}$ & sw & $\begin{array}{l}\mathrm{N} \\
\mathrm{N}\end{array}$ & $\begin{array}{l}\text { SURFACE } \\
\text { SURFACE }\end{array}$ & 13-Nov-03 1 BUTANOL & 4.6 & $\mathrm{ug} / \mathrm{L}$ & & & u & & & \\
\hline $\begin{array}{l}\text { SESPSPEC } \\
\text { SESP }\end{array}$ & B18155 & 100 B/C AREA UR & ONSITE & sw & $\frac{N}{N}$ & $\begin{array}{l}\text { SURFACE } \\
\text { SURFACE }\end{array}$ & 13-Nov-03 1BUTANANOL & $\begin{array}{l}4.6 \\
4.6\end{array}$ & $\begin{array}{l}\mathrm{ug} / \mathrm{L} \\
\mathrm{ug} / \mathrm{L}\end{array}$ & & & u & & & \\
\hline SESPSPEC & B18145 & $100 \mathrm{~B} / \mathrm{C}$ AREA DR & ONSITE & sw & $\mathrm{N}$ & SURFACE & 17-Nov-03 1BUTANOL & 4.6 & $\mathrm{ug} / \mathrm{L}$ & & & U & & & \\
\hline SESPSPEC & B18146 & 100 B/C AREA DR & ONSITE & sw & $\mathrm{N}$ & SURFACE & 17-Nov-03 1BUTANOL & 4.6 & ug/L & & & $U$ & & & \\
\hline $\begin{array}{l}\text { SESPSPEC } \\
\text { SESPSEC }\end{array}$ & B18147 & $100 \mathrm{~B} / \mathrm{C}$ AREA DR & ONSITE & SW & $\mathrm{N}$ & $\begin{array}{l}\text { SURFACE } \\
\text { SUPFACE }\end{array}$ & 17-Nov-03 1 BUTANOL & 4.6 & $\mathrm{ug} / \mathrm{L}$ & & & $u$ & & & \\
\hline $\begin{array}{l}\text { SESPSPEC } \\
\text { SESPSEC }\end{array}$ & $\begin{array}{l}\text { B18148 } \\
\text { B18151 }\end{array}$ & 100 B/C AREA DR & ONSITE & SW & $\mathrm{N}$ & SURFACE & 17-Nov-03 1BUTANOL & 4.6 & $\mathrm{ug} / \mathrm{L}$ & & & U & & & \\
\hline $\begin{array}{l}\text { SESPSECC } \\
\text { SESPPEC }\end{array}$ & $\begin{array}{l}\text { B18151 } \\
\text { B18150 }\end{array}$ & $\begin{array}{l}100 \text { B/C AREA OUTFL3 } \\
100 \text { B/C AREA OUTFL2 }\end{array}$ & ONSITE & SW & $\begin{array}{l}\mathrm{N} \\
\mathrm{N}\end{array}$ & $\begin{array}{l}\text { SURFACE } \\
\text { SURFACE }\end{array}$ & $\begin{array}{l}17-N o v-031 \text { BUTANOL } \\
17-\text { Bov-03 } 1 \text { BUTANOL }\end{array}$ & 4.6 & ug/L & & & U & & & \\
\hline $\begin{array}{l}\text { SESPSEC } \\
\text { SESPSPEC }\end{array}$ & B18149 & $\begin{array}{l}100 \text { B/C AREA OUTFL2 } \\
100 \text { B/C AREA OUTFL1 }\end{array}$ & $\begin{array}{l}\text { ONSITE } \\
\text { ONSITE }\end{array}$ & $\begin{array}{l}\text { sw } \\
\text { sw }\end{array}$ & $\frac{N}{N}$ & $\begin{array}{l}\text { SURFACE } \\
\text { SURFACE }\end{array}$ & $\begin{array}{l}\text { 17-Nov-03 } 1 \text { BUTANANL } \\
\text { 17-Nov-03 } 1 \text { BUTANOL }\end{array}$ & $\begin{array}{l}4.6 \\
4.6\end{array}$ & $\begin{array}{l}\mathrm{ug} / \mathrm{L} \\
\mathrm{ug} / \mathrm{L}\end{array}$ & & & u & & & \\
\hline SESPSPEC & B18139 & Refer to WELL NAME column & & GW & $\mathrm{N}$ & AQUIFER TUBE & 10-Dec-03 1BUTANOL & 4.6 & $\mathrm{ug} / \mathrm{L}$ & & & u & & & 01-D \\
\hline SESPSPEC & B18140 & Refer to WELL NAME column & & GW & $\mathrm{N}$ & AQUIFER TUBE & 10-Dec-03 1BUTANOL & 4.6 & $\mathrm{ug} / \mathrm{L}$ & & & $u$ & & & 04-D \\
\hline SESPSPEC & B18141 & Refer to WELL NAME column & & GW & $\mathrm{N}$ & AQUIFER TUBE & 10-Dec-03 1BUTANOL & 4.6 & $\mathrm{ug} / \mathrm{L}$ & & & U & & & 05-D \\
\hline $\begin{array}{l}\text { SESPSPEC } \\
\text { SESPSEC }\end{array}$ & $\begin{array}{l}B 18142 \\
B 1856\end{array}$ & Refer to WELL NAME column & & GW & $\mathrm{N}$ & AQUIFER TUBE & 10-Dec-03 1BUTANOL & 4.6 & $\mathrm{ug} / \mathrm{L}$ & & & U & & & 06-D \\
\hline $\begin{array}{l}\text { SESPSECC } \\
\text { SESPSPEC }\end{array}$ & $\begin{array}{l}\text { B18156 } \\
\text { B18160 }\end{array}$ & $\begin{array}{l}100-\text { B SPRING 38-3 } \\
\text { 100-B SPRING 38-3 }\end{array}$ & $\begin{array}{l}\text { ONSIIE } \\
\text { ONSITE }\end{array}$ & $\begin{array}{l}\text { SW } \\
\text { sw }\end{array}$ & $\begin{array}{llll}n & \\
N \\
N\end{array}$ & $\begin{array}{l}\text { SURFACE } \\
\text { SURFACE }\end{array}$ & $\begin{array}{l}\text { 13-Nov-03 ACETONE } \\
\text { 13-Nov-3 ACETONE }\end{array}$ & 0.66 & $\mathrm{ug} / \mathrm{L}$ & & & u & & & \\
\hline $\begin{array}{l}\text { SESPSEC } \\
\text { SESPPEC }\end{array}$ & $\begin{array}{l}B 18160 \\
B 18157\end{array}$ & $\begin{array}{l}\text { 100-B SPRING 38-3 } \\
\text { 100-B SPRING 38-3 }\end{array}$ & $\begin{array}{l}\text { ONSTIE } \\
\text { ONSITE }\end{array}$ & $\begin{array}{l}\text { SW } \\
\text { SW }\end{array}$ & $\frac{N}{N}$ & $\begin{array}{l}\text { SURFACE } \\
\text { SURFACE }\end{array}$ & $\begin{array}{l}\text { 13-Nov-03 ACETONE } \\
\text { 13-Nov-03 ACETONE }\end{array}$ & 0.66 & $\frac{\mathrm{ug} / \mathrm{L}}{\mathrm{ug} / \mathrm{L}}$ & & & $\mathrm{J}$ & & & \\
\hline SESPSPEC & B18158 & 100-B SPRING 38-3 & ONSITE & sw & $\mathrm{N}$ & SURFACE & 13-Nov-03 ACETONE & 0.66 & $\mathrm{ug} / \mathrm{L}$ & & & u & & & \\
\hline SESPSPEC & B18159 & 100-B SPRING 38-3 & ONSITE & SW & $\mathrm{N}$ & SURFACE & 13-Nov-03 ACETONE & 0.66 & $\mathrm{ug} / \mathrm{L}$ & & & U & & & \\
\hline $\begin{array}{l}\text { SESPSPEC } \\
\text { SESPSPCF }\end{array}$ & $\begin{array}{ll}B 18166 \\
B 18162\end{array}$ & 100-B SPRING DR 38-3 & ONSITE & SW & $\mathrm{N}$ & $\begin{array}{l}\text { SURFACE } \\
\text { SUPEACE }\end{array}$ & 13-Nov-03 ACETONE & 0.66 & $\mathrm{ug} / \mathrm{L}$ & & & U & & & \\
\hline $\begin{array}{l}\text { SESPSPEC } \\
\text { SESPSEC }\end{array}$ & $\begin{array}{l}\text { B18162 } \\
\text { B18163 }\end{array}$ & $\begin{array}{l}100-B \text { SPRING 39-2 } \\
100-B \text { SPRING 39-2 }\end{array}$ & $\begin{array}{l}\text { ONSITE } \\
\text { ONSITE }\end{array}$ & SW & $\begin{array}{l}n \\
N\end{array}$ & $\begin{array}{l}\text { SURFACE } \\
\text { SUREACE }\end{array}$ & 13-Nov-03 ACETONE & 0.66 & $\mathrm{ug} / \mathrm{L}$ & & & $\mathrm{U}$ & & & \\
\hline $\begin{array}{l}\text { SESPSECC } \\
\text { SESPSPEC }\end{array}$ & 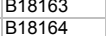 & $\begin{array}{l}\text { 100-B SPRING 39-2 } \\
\text { 100-B SPRING 39-2 }\end{array}$ & $\begin{array}{l}\text { ONSITE } \\
\text { ONSITE }\end{array}$ & $\begin{array}{l}\text { SW } \\
\text { SW }\end{array}$ & $\frac{N}{N}$ & $\begin{array}{l}\text { SURFACE } \\
\text { SURFACE }\end{array}$ & 13-Nov-03 ACETONE & $\begin{aligned} 0.66 \\
17\end{aligned}$ & $\mathrm{ug} / \mathrm{L}$ & & & $e^{7}$ & & & \\
\hline $\begin{array}{l}\text { SESPSPEC } \\
\text { SESP }\end{array}$ & B18165 & 100-B SPRING 39-2 & ONSITE & sw & $\mathrm{N}$ & $\begin{array}{l}\text { SURFACE } \\
\text { SURFACE }\end{array}$ & 13-Nov-03 ACETONE & 0.66 & ug/L & & & u & & & \\
\hline SESPSPEC & B18152 & $100 \mathrm{~B} / \mathrm{C}$ AREA UR & ONSITE & sw & $\mathrm{N}$ & SURFACE & 13-Nov-03 ACETONE & 0.66 & $\mathrm{ug} / \mathrm{L}$ & & & U & & & \\
\hline SESPSPEC & B18153 & 100 B/C AREA UR & ONSITE & SW & $\mathrm{N}$ & SURFACE & 13-Nov-03 ACETONE & 0.66 & $\mathrm{ug} / \mathrm{L}$ & & & U & & & \\
\hline $\begin{array}{l}\text { SESPSPEC } \\
\text { SESPSPCC }\end{array}$ & B18154 & $100 \mathrm{~B} / \mathrm{C}$ AREA UR & ONSITE & sw & $\mathrm{N}$ & SURFACE & 13-Nov-03 ACETONE & 1 & $\mathrm{ug} / \mathrm{L}$ & & & $\mathrm{J}$ & & & \\
\hline $\begin{array}{l}\text { SESPSEEC } \\
\text { SESPSPEC }\end{array}$ & $\begin{array}{l}\text { B18155 } \\
\text { B18145 }\end{array}$ & $\begin{array}{l}100 \text { BCC AREA UR } \\
100 \text { BCAREADR }\end{array}$ & $\begin{array}{l}\text { ONSITE } \\
\text { ONSITE }\end{array}$ & SW & $\begin{array}{l}n \\
N\end{array}$ & $\begin{array}{l}\text { SURFACE } \\
\text { SURFACE }\end{array}$ & 13-Nov-03 ACETONE & $\begin{array}{r}1.1 \\
0.66\end{array}$ & $\mathrm{ug} / \mathrm{L}$ & & & $\frac{1}{1}$ & & & \\
\hline $\begin{array}{l}\text { SESPSPEC } \\
\text { SESPSPEC }\end{array}$ & $\begin{array}{l}\text { B18145 } \\
\text { B18146 }\end{array}$ & $\begin{array}{l}100 \text { BCC AREA DR } \\
100 \text { BCC AREADR }\end{array}$ & $\begin{array}{l}\text { ONSITE } \\
\text { ONSTTE }\end{array}$ & $\begin{array}{l}\text { SW } \\
\text { sW }\end{array}$ & $\begin{array}{l}\mathrm{N} \\
\mathrm{N}\end{array}$ & $\begin{array}{l}\text { SURFACE } \\
\text { SURFACE }\end{array}$ & 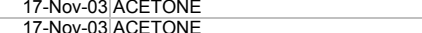 & 0.66 & $\mathrm{ug} / \mathrm{L}$ & & & u & & & \\
\hline SESPSPEC & B18147 & 100 B/C AREA DR & ONSITE & sw & $\frac{N}{N}$ & $\begin{array}{l}\text { SURFACE } \\
\text { SURFACE }\end{array}$ & 17-Nov-03 ACETONE & $\begin{array}{l}0.66 \\
1.1\end{array}$ & ug/L & & & $\mathrm{J}$ & & & \\
\hline SESPSPEC & B18148 & $100 \mathrm{~B} / \mathrm{C}$ AREA DR & ONSITE & sw & $\mathrm{N}$ & SURFACE & 17-Nov-03 ACETONE & 1.3 & $\mathrm{ug} / \mathrm{L}$ & & & JB & & & \\
\hline SESPSPEC & B18151 & 100 B/C AREA OUTFL3 & ONSITE & sw & $\mathrm{N}$ & SURFACE & 17-Nov-03 ACETONE & 1.8 & $\mathrm{ug} / \mathrm{L}$ & & & JB & & & \\
\hline $\begin{array}{l}\text { SESPSPEC } \\
\text { SESDPDC }\end{array}$ & B18150 & 100 B/C AREA OUTFL2 & ONSITE & SW & $\mathrm{N}$ & SURFACE & 17-Nov-03 ACETONE & 0.66 & $\mathrm{ug} / \mathrm{L}$ & & & U & & & \\
\hline $\begin{array}{l}\text { SESPSPEC } \\
\text { SESPSEC }\end{array}$ & $\begin{array}{l}\text { B18149 } \\
\text { B18139 }\end{array}$ & & ONSITE & SW & $\begin{array}{l}n \\
N \\
N\end{array}$ & $\begin{array}{l}\text { SURFACE } \\
\text { AOUIFER TUBE }\end{array}$ & 17-Nov-03 ACETONE & 0.66 & $\mathrm{ug} / \mathrm{L}$ & & & U & & & \\
\hline $\begin{array}{l}\text { SESPSEC } \\
\text { SESPPEC }\end{array}$ & $\begin{array}{l}\text { B181839 } \\
\text { B18140 }\end{array}$ & $\begin{array}{l}\text { Refer to WELL NAME collumn } \\
\text { Refer to WELL NAME column }\end{array}$ & & GW & $\frac{N}{N}$ & $\begin{array}{l}\text { AQUUFER TUBE } \\
\text { AQUIFER TUBE }\end{array}$ & $\begin{array}{l}\text { 10-Dec-03 ACETONE } \\
\text { 10-Dec-03 ACETONE }\end{array}$ & 0.66 & $\begin{array}{l}\mathrm{ug} / \mathrm{L} \\
\mathrm{ug} / \mathrm{L}\end{array}$ & & & u & & & $\begin{array}{l}04-D \\
01-D \\
04-1\end{array}$ \\
\hline SESPSPEC & B18141 & Refer to WELL NAME column & & GW & $\mathrm{N}$ & AQUIFER TUBE & 10-Dec-03 ACETONE & 0.66 & ug/L & & & u & & & $05-\mathrm{D}$ \\
\hline SESPSPEC & B18142 & Refer to WELL NAME column & & GW & $\mathrm{N}$ & AQUIFER TUBE & 10-Dec-03 ACETONE & 0.87 & $\mathrm{ug} / \mathrm{L}$ & & & $\mathrm{J}$ & & & 06-D \\
\hline SESPSPEC & B18156 & 100-B SPRING 38-3 & ONSITE & SW & $\mathrm{N}$ & SURFACE & 13-Nov-03 BENZENE & 0.07 & $\mathrm{ug} / \mathrm{L}$ & & & $U$ & & & \\
\hline $\begin{array}{l}\text { SESPSPEC } \\
\text { SESPQDEC }\end{array}$ & B18160 & 100-B SPRING 38-3 & ONSITE & sw & $\mathrm{N}$ & SURFACE & 3 BENZENE & 0.07 & $\mathrm{ug} / \mathrm{L}$ & & & U & & & \\
\hline $\begin{array}{l}\text { SESPSEEC } \\
\text { SESPSPEC }\end{array}$ & $\begin{array}{l}B 18157 \\
\text { B18158 }\end{array}$ & $\begin{array}{l}\text { 100-B SPRING 38-3 } \\
\text { 100-B SPRING 38-3 }\end{array}$ & $\begin{array}{l}\text { ONSITE } \\
\text { ONSITE }\end{array}$ & $\begin{array}{l}\text { SW } \\
\text { sw }\end{array}$ & $\frac{N}{N}$ & $\begin{array}{l}\text { SURFACE } \\
\text { SURFACE }\end{array}$ & $\begin{array}{l}\text { 13-Nov-03 BENZENE } \\
\text { 13-Nov-03 BENZENE }\end{array}$ & $\begin{array}{l}0.07 \\
0.07\end{array}$ & $\mathrm{ug} / \mathrm{L}$ & & & u & & & \\
\hline SESPSPEC & B18159 & 100-B SPRING 38-3 & ONSITE & sW & $\mathrm{N}$ & SURFACE & 13-Nov-03 BENZENE & 0.14 & $\mathrm{ug} / \mathrm{L}$ & & & $\mathrm{J}$ & & & \\
\hline SESPSPEC & B18166 & 100-B SPRING DR 38-3 & ONSITE & sW & $\mathrm{N}$ & SURFACE & 13-Nov-03 BENZENE & 0.07 & ug/L & & & U & & & \\
\hline SESPSPEC & B18162 & 100-B SPRING 39-2 & ONSITE & SW & $\mathrm{N}$ & SURFACE & 13-Nov-03 BENZENE & 0.07 & $\mathrm{ug} / \mathrm{L}$ & & & U & & & \\
\hline SESPSPEC & B18163 & $100-B \mathrm{~s}$ & ONSITE & sw & $\mathrm{N}$ & SURFACE & 13-Nov-03 BEN2 & 0.07 & $\mathrm{ug} / \mathrm{L}$ & & & U & & & \\
\hline $\begin{array}{l}\text { SESPSPEC } \\
\text { SESPSEC }\end{array}$ & B18164 & 100-B SPRING 39-2 & ONSITE & sw & $\mathrm{N}$ & SURFACE & 13-Nov-03 BENZENE & 0.07 & $\mathrm{ug} / \mathrm{L}$ & & & U & & & \\
\hline $\begin{array}{l}\text { SESPSPCC } \\
\text { SESPSPEC }\end{array}$ & $\begin{array}{l}\text { B18185 } \\
\text { B1815? }\end{array}$ & 100-B SPRING 39-2 & ONSITE & SW & $\mathrm{N}$ & $\begin{array}{l}\text { SURFACE } \\
\text { SUREACE }\end{array}$ & 13-Nov-03 BENZENE & 0.07 & ug/L & & & U & & & \\
\hline $\begin{array}{l}\text { SESPSPCC } \\
\text { SESPPEC }\end{array}$ & $\begin{array}{l}\text { B18152 } \\
\text { B18153 }\end{array}$ & 100 B/C AREA UR & ONSITE & sw & $\mathrm{N}$ & $\begin{array}{l}\text { SURFACE } \\
\text { SURFACE }\end{array}$ & 13-Nov-03 BENZENE & 0.07 & $\begin{array}{l}\mathrm{ug} / \mathrm{L} \\
\mathrm{ug} / \mathrm{L}\end{array}$ & & & u & & & \\
\hline SESPSPEC & B18154 & 100 B/C AREA UR & ONSITE & SW & $\mathrm{N}$ & SURFACE & 13-Nov-03 BENZENE & 0.07 & $\mathrm{ug} / \mathrm{L}$ & & & u & & & \\
\hline SESPSPEC & B18155 & 100 B/C AREA UR & ONSITE & SW & $\mathrm{N}$ & SURFACE & 13-Nov-03 BENZENE & 0.07 & ug/L & & & $u$ & & & \\
\hline SESPSPEC & B18145 & $100 \mathrm{~B} / \mathrm{C}$ AREA DR & ONSITE & sw & $\mathrm{N}$ & SURFACE & 17-Nov-03 BENZENE & 0.07 & ug/L & & & $u$ & & & \\
\hline
\end{tabular}




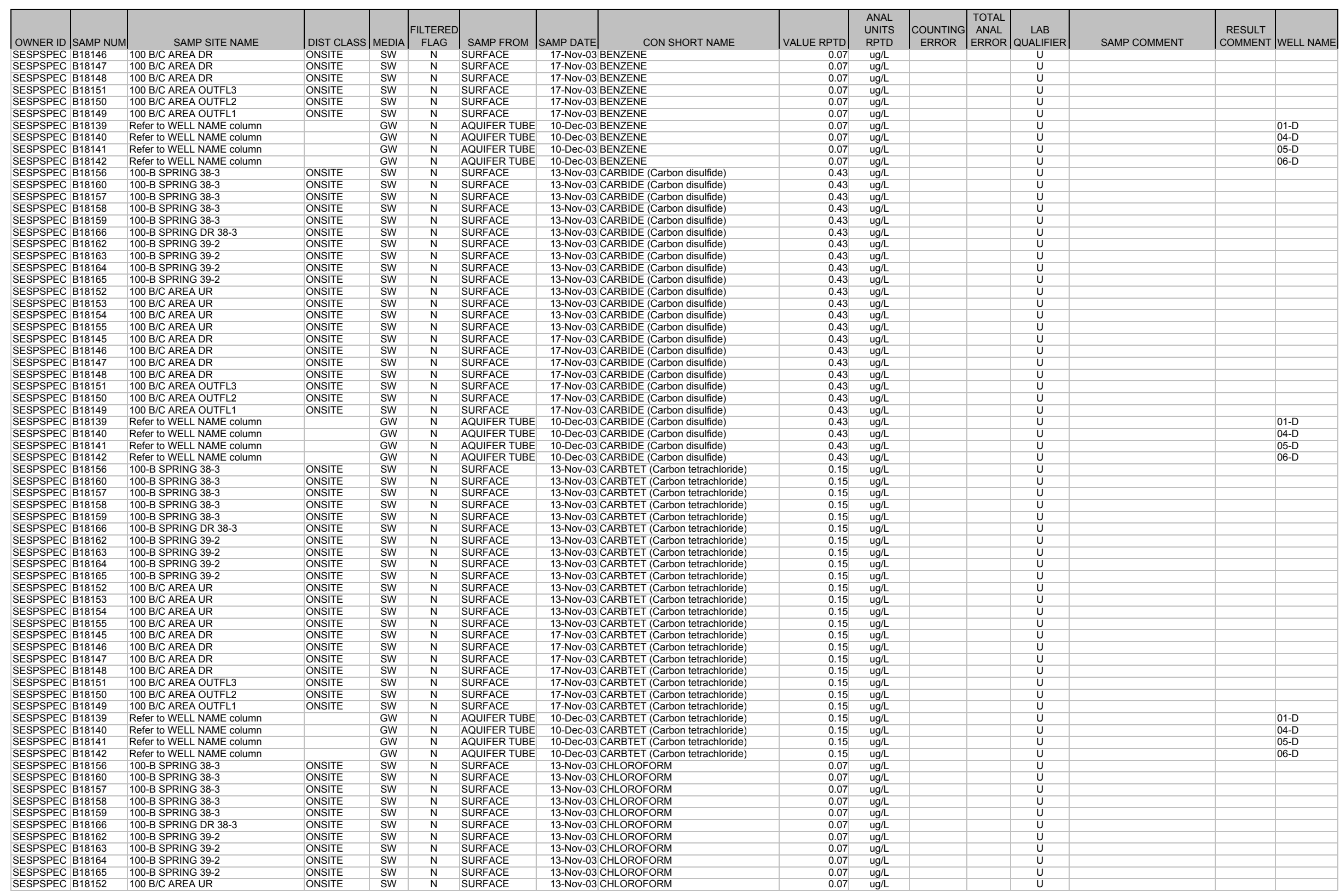




\begin{tabular}{|c|c|c|c|c|c|c|c|c|c|c|c|c|c|c|c|}
\hline OWNER ID & SAMP NUM & SAMP SITE NAME & DIST CLASS & MEDIA & $\begin{array}{c}\text { FILTERED } \\
\text { FLAG }\end{array}$ & SAMP FROM & CON SHORT NAME & |VALUE RPTD | & $\begin{array}{l}\text { ANAL } \\
\text { UNITS } \\
\text { RPTD }\end{array}$ & $\left|\begin{array}{c}\text { COUNTING } \\
\text { ERROR }\end{array}\right|$ & \begin{tabular}{|c|} 
TOTAL \\
ANAL \\
ERROR
\end{tabular} & $\mid \begin{array}{c}\text { LAB } \\
\text { QUALIFIER }\end{array}$ & SAMP COMMENT & $\begin{array}{c}\text { RESULT } \\
\text { COMMENT }\end{array}$ & |WELL NAME| \\
\hline SESPSPEC & B18153 & 100 B/C AREA UR & ONSITE & sw & $N$ & SURFACE & 13-Nov-03 CHLOROFORM & 0.07 & $\mathrm{ug} / \mathrm{L}$ & & & u & & & \\
\hline $\begin{array}{l}\text { SESPSPEC } \\
\text { SESPSDEC }\end{array}$ & B18154 & $100 \mathrm{~B} / \mathrm{C}$ AREA UR & ONSITE & SW & $\mathrm{N}$ & SURFACE & 13-Nov-03 CHLOROFORM & 0.07 & ug/L & & & U & & & \\
\hline $\begin{array}{l}\text { SESPSPEC } \\
\text { SESPSEC }\end{array}$ & $\begin{array}{l}B 18155 \\
B 1815\end{array}$ & & ONSITE & SW & $\mathrm{N}$ & $\begin{array}{l}\text { SURFACE } \\
\text { SUREACE }\end{array}$ & 13-Nov-03 CHLOROFORM & 0.07 & $u g / L$ & & & U & & & \\
\hline $\begin{array}{l}\text { SESPSEC } \\
\text { SESPSPEC }\end{array}$ & $\begin{array}{l}\text { B18145 } \\
\text { B18146 }\end{array}$ & $\begin{array}{l}100 \text { B/C AREA DR } \\
100 \text { B/C AREA DR }\end{array}$ & $\begin{array}{l}\text { ONSITE } \\
\text { ONSTEE }\end{array}$ & $\begin{array}{l}\text { sw } \\
\text { sw }\end{array}$ & $\begin{array}{l}n \\
\mathrm{n} \\
\mathrm{n}\end{array}$ & $\begin{array}{l}\text { SURFACE } \\
\text { SURFACE }\end{array}$ & $\begin{array}{l}\text { 17-Nov-03 CHLOROFORM } \\
\text { 17-Nov-03 CHLOROFORM }\end{array}$ & 0.07 & ug/L & & & U & & & \\
\hline $\begin{array}{l}\text { SESPSPEC } \\
\text { SESPC }\end{array}$ & $\begin{array}{l}\text { B } \\
\text { B181447 }\end{array}$ & $\begin{array}{l}100 \text { B BCAREA AR } \\
100 \text { BIC AREA DR }\end{array}$ & ONSITE & sw & $\frac{N}{N}$ & $\begin{array}{l}\text { SURFACE } \\
\text { SURFACE }\end{array}$ & $\begin{array}{l}\text { 17-Nov-03 CHLOROFORM } \\
\text { 17-Nov-03 CHLOROFORM }\end{array}$ & $\begin{array}{l}0.07 \\
0.07\end{array}$ & 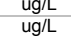 & & & u & & & \\
\hline SESPSPEC & B18148 & $100 \mathrm{~B} / \mathrm{C}$ AREA DR & ONSITE & sw & $\mathrm{N}$ & SURFACE & 17-Nov-03 CHLOROFORM & 0.07 & $\mathrm{ug} / \mathrm{L}$ & & & u & & & \\
\hline $\begin{array}{l}\text { SESPSPEC } \\
\text { SESPSDC }\end{array}$ & B18151 & $100 \mathrm{~B} / \mathrm{C}$ AREA OUTFL3 & ONSITE & sw & N & SURFACE & 17-Nov-03 CHLOROFORM & 0.07 & $\mathrm{ug} / \mathrm{L}$ & & & u & & & \\
\hline $\begin{array}{l}\text { SESPSPEC } \\
\text { SESPSDC }\end{array}$ & B18150 & 100 B/C AREA OUTFL2 & ONSITE & SW & $\mathrm{N}$ & $\begin{array}{l}\text { SURFACE } \\
\text { SUIPEACE }\end{array}$ & 17-Nov-03 CHLOROFORM & 0.07 & $\mathrm{ug} / \mathrm{L}$ & & & $\mathrm{U}$ & & & \\
\hline $\begin{array}{l}\text { SESPSPEC } \\
\text { SESPSEC }\end{array}$ & B18149 & 100 B/C AREA OUTFL1 & ONSITE & SW & $\mathrm{N}$ & $\begin{array}{l}\text { SURFACE } \\
\text { SUR }\end{array}$ & 17-Nov-03 CHLOROFORM & 0.07 & $\mathrm{ug} / \mathrm{L}$ & & & $\mathrm{U}$ & & & \\
\hline $\begin{array}{l}\text { SESPSECC } \\
\text { SESPPEC }\end{array}$ & $\begin{array}{l}\text { B181899 } \\
\text { B18140 }\end{array}$ & $\begin{array}{l}\text { Refer to WELL NAME column } \\
\text { Refer to WELL NAME column }\end{array}$ & & GW & $\frac{n}{N}$ & $\begin{array}{l}\text { AQUIFER TUBE } \\
\text { AQUUFER TUBE }\end{array}$ & $\begin{array}{l}\text { 10-Dec-03 CHLOROFORM } \\
10-D e c-03 \text { CHLOROFORM }\end{array}$ & 0.07 & $u g / L$ & & & U & & & $01-\mathrm{D}$ \\
\hline SESPSPEC & $\begin{array}{l}B 18140 \\
B 18141\end{array}$ & $\begin{array}{l}\text { Rerer to WELL NAME column } \\
\text { Refer to WELL NAME column }\end{array}$ & & GW & $\frac{N}{n}$ & $\begin{array}{l}\text { AQUUIFER IUBE } \\
\text { AQUIFER TUBE }\end{array}$ & $\begin{array}{l}\text { 10-De-03 CHLOROFORM } \\
\text { 10-Dec-03 CHLOROFORM }\end{array}$ & 0.81 & $\begin{array}{ll}\mathrm{ug} / \mathrm{L} \\
\mathrm{ug} / \mathrm{L}\end{array}$ & & & & & & \\
\hline SESPSPEC & B18142 & Refer to WELL NAME column & & GW & $\mathrm{N}$ & AQUIFER TUBE & 10-Dec-03 CHLOROFORM & 0.2 & ug/L & & & $\mathrm{J}$ & & & $06-\mathrm{D}$ \\
\hline SESPSPEC & B18156 & 100-B SPRING 38-3 & ONSITE & sw & $\mathrm{N}$ & SURFACE & 13-Nov-03 CISDCE (cis-1,2-Dichloroethylene) & 0.06 & ug/L & & & U & & & \\
\hline $\begin{array}{l}\text { SESPSPEC } \\
\text { SESPSPC }\end{array}$ & $\begin{array}{ll}B 18160 \\
B 18157\end{array}$ & 100-B SPRING 38-3 & ONSITE & SW & $\mathrm{N}$ & SURFACE & 13-Nov-03 CISDCE (cis-1,2-Dichloroethylene) & 0.06 & $\mathrm{ug} / \mathrm{L}$ & & & U & & & \\
\hline $\begin{array}{l}\text { SESPSPCC } \\
\text { SESPSEC }\end{array}$ & B18157 & & ONSITE & sw & $\mathrm{N}$ & SURFACE & 13-Nov-03 CISDCE (cis-1,2-Dichloroethylene) & 0.06 & $\mathrm{ug} / \mathrm{L}$ & & & $\mathrm{U}$ & & & \\
\hline $\begin{array}{l}\text { SESPSEC } \\
\text { SESPSEC }\end{array}$ & $\begin{array}{l}\text { B18158 } \\
\text { B18159 }\end{array}$ & $\begin{array}{l}\text { 100-B SPRING 38-3 } \\
\text { 100-B SPRING 38-3 }\end{array}$ & $\begin{array}{l}\text { ONSIIE } \\
\text { ONSITE }\end{array}$ & sw & $\begin{array}{l}n \\
N\end{array}$ & $\begin{array}{l}\text { SURFACE } \\
\text { SUREACE }\end{array}$ & $\begin{array}{l}\text { 13-Nov-03 CISDCE (cis-1,2-Dichloroethylene) } \\
\text { 13-Nov-03 CSSDCE (is-12-Dichlorethylent }\end{array}$ & 0.06 & $\mathrm{ug} / \mathrm{L}$ & & & u & & & \\
\hline $\begin{array}{l}\text { SESPSPEC } \\
\text { SEST }\end{array}$ & B18166 & 100-B SPRING DR 38-3 & ONSITE & sw & $\frac{N}{N}$ & $\begin{array}{l}\text { SURFACE } \\
\text { SURFACE }\end{array}$ & 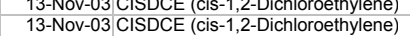 & 0.06 & $\begin{array}{l}\mathrm{ug} / \mathrm{L} \\
\mathrm{ug} / \mathrm{L}\end{array}$ & & & u & & & \\
\hline SESPSPEC & B18162 & 100-B SPRING 39-2 & ONSITE & sw & $\mathrm{N}$ & SURFACE & 13-Nov-03 CISDCE (cis-1,2-Dichloroethylene) & 0.06 & $\mathrm{ug} / \mathrm{L}$ & & & u & & & \\
\hline SESPSPEC & B18163 & 100-B SPRING 39-2 & ONSITE & sw & $\mathrm{N}$ & SURFACE & 13-Nov-03 CISDCE (cis-1,2-Dichloroethylene) & 0.06 & $\mathrm{ug} / \mathrm{L}$ & & & U & & & \\
\hline $\begin{array}{l}\text { SESPSPEC } \\
\text { SESPSEC }\end{array}-1-10$ & B18164 & 100-B SPRING 39-2 & ONSITE & sw & $\mathrm{N}$ & SURFACE & 13-Nov-03 CISDCE (cis-1,2-Dichloroethylene) & 0.06 & $\mathrm{ug} / \mathrm{L}$ & & & $u$ & & & \\
\hline $\begin{array}{l}\text { SESPSPCC } \\
\text { SESPSEC }\end{array}$ & 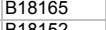 & 100-B SPRING 39-2 & ONSITE & SW & $\mathrm{N}$ & SURFACE & 13-Nov-03 CISDCE (cis-1,2-Dichloroethylene) & 0.06 & $\mathrm{ug} / \mathrm{L}$ & & & $\mathrm{U}$ & & & \\
\hline $\begin{array}{l}\text { SESPSECC } \\
\text { SESPSPEC }\end{array}$ & $\begin{array}{l}\text { B18152 } \\
\text { B18153 }\end{array}$ & $\begin{array}{l}100 \text { B BCAREA AR } \\
100 \text { B/C AREA UR }\end{array}$ & $\begin{array}{l}\text { ONSITE } \\
\text { ONSITE }\end{array}$ & $\begin{array}{l}\text { SW } \\
\text { sw }\end{array}$ & $\mathrm{N}_{\mathrm{N}}$ & $\begin{array}{l}\text { SURFACE } \\
\text { SURFACE }\end{array}$ & $\begin{array}{l}\text { 13-Nov-03 CISDCE (is-1,2-Dichloroethylene) } \\
\text { 13-Nov-03 CISDCE (cis-1, 2-Dichloroethylene) }\end{array}$ & 0.06 & $\begin{array}{l}\mathrm{ug} / \mathrm{L} \\
\mathrm{ug} / \mathrm{L}\end{array}$ & & & u & & & \\
\hline SESPSPEC & B18154 & 100 B/C AREA UR & ONSITE & sw & $\mathrm{N}$ & SURFACE & 13-Nov-03 CISDCE (cis-1,2-Dichloroethylene) & 0.06 & ug/L & & & u & & & \\
\hline SESPSPEC & B18155 & 100 B/C AREA UR & ONSITE & sw & $\mathrm{N}$ & SURFACE & 13-Nov-03 CISDCE (cis-1,2-Dichloroethylene) & 0.06 & $\mathrm{ug} / \mathrm{L}$ & & & u & & & \\
\hline SESPSPEC & B18145 & $100 \mathrm{~B} / \mathrm{C}$ AREA DR & ONSITE & sw & $\mathrm{N}$ & SURFACE & 17-Nov-03 CISDCE (cis-1,2-Dichloroethylene) & 0.06 & $\mathrm{ug} / \mathrm{L}$ & & & $\mathrm{U}$ & & & \\
\hline SESPSPEC & B18146 & $100 \mathrm{~B} / \mathrm{C}$ AREA DR & ONSITE & sw & $\mathrm{N}$ & SURFACE & 17-Nov-03 CISDCE (cis-1,2-Dichloroethylene) & 0.06 & $\mathrm{ug} / \mathrm{L}$ & & & U & & & \\
\hline 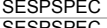 & B18147 & 100 B/C AREA DR & ONSITE & SW & $\mathrm{N}$ & SURFACE & 17-Nov-03 CISDCE (cis-1,2-Dichloroethylene) & 0.06 & $\mathrm{ug} / \mathrm{L}$ & & & $\mathrm{U}$ & & & \\
\hline $\begin{array}{l}\text { SESPSECC } \\
\text { SESPSPEC }\end{array}$ & $\begin{array}{l}\begin{array}{l}\text { B18148 } \\
\text { B18151 }\end{array}\end{array}$ & $\begin{array}{l}100 \text { B/C AREA DR } \\
100 \text { B/C AREA OUTFL3 }\end{array}$ & $\begin{array}{l}\text { ONSITE } \\
\text { ONSITE }\end{array}$ & $\begin{array}{l}\text { SW } \\
\text { SW }\end{array}$ & $\frac{N}{N}$ & $\begin{array}{l}\text { SURFACE } \\
\text { SURFACE }\end{array}$ & $\begin{array}{l}\text { 17-Nov-03 CISDCE (ic-1,2-Dichloroethylene) } \\
\text { 17-Nov-03 CISDCE (cis-1, 2-Dichloroethylene) }\end{array}$ & 0.06 & ug/L & & & u & & & \\
\hline $\begin{array}{l}\text { SESPPEC } \\
\text { SESPSPEC }\end{array}$ & $\begin{array}{l}B 18151 \\
B 18150\end{array}$ & $\begin{array}{l}100 \text { B/ A AREA OUTFL } 3 \\
100 \text { B/C AREA OUTFL2 }\end{array}$ & $\begin{array}{l}\text { ONSTIE } \\
\text { ONSITE }\end{array}$ & sw & $\frac{n}{n}$ & $\begin{array}{l}\text { SURFACE } \\
\text { SURFACE }\end{array}$ & $\begin{array}{l}\text { 17-Nov-03 CISDCE (is-1, 2-Dichloroethylene) } \\
\text { 17-Nov-03 CISDCE (cis-1, 2-Dichloroethylene) }\end{array}$ & 0.06 & $\frac{\mathrm{ug} / \mathrm{L}}{\mathrm{ug} / \mathrm{L}}$ & & & u & & & \\
\hline SESPSPEC & B18149 & 100 B/C AREA OUTFL1 & ONSITE & sw & $\mathrm{N}$ & SURFACE & 17-Nov-03 CISDCE (cis-1,2-Dichloroethylene) & 0.06 & $\mathrm{ug} / \mathrm{L}$ & & & u & & & \\
\hline SESPSPEC & B18139 & Refer to WELL NAME column & & GW & $\mathrm{N}$ & AQUIFER TUBE & 10-Dec-03 CISDCE (cis-1,2-Dichloroethylene) & 0.06 & $\mathrm{ug} / \mathrm{L}$ & & & U & & & 01-D \\
\hline SESPSPEC & B18140 & Refer to WELL NAME column & & GW & $\mathrm{N}$ & AQUIFER TUBE & 10-Dec-03 CISDCE (cis-1,2-Dichloroethylene) & 0.06 & $\mathrm{ug} / \mathrm{L}$ & & & U & & & 04-D \\
\hline $\begin{array}{l}\text { SESPSPCC } \\
\text { SESPSEC }\end{array}$ & 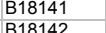 & Refer to WELL NAME column & & GW & $\begin{array}{l}n \\
N\end{array}$ & $\begin{array}{l}\text { AQUIFER TUBE } \\
\text { AIUEFR TURE }\end{array}$ & 10-Dec-03 CISDCE (cis-1,2-Dichloroethylene) & 0.06 & $\mathrm{ug} / \mathrm{L}$ & & & $\mathrm{U}$ & & & 05-D \\
\hline $\begin{array}{l}\text { SESPSEC } \\
\text { SESPSPEC }\end{array}$ & $\begin{array}{l}B 18142 \\
\text { B18156 }\end{array}$ & $\begin{array}{l}\text { Refer to WELL NAME column } \\
\text { 100-B SPRING 38-3 }\end{array}$ & ONSITE & $\begin{array}{l}\text { GW } \\
\text { SW }\end{array}$ & $\frac{N}{n}$ & $\begin{array}{l}\text { AQUIFER TUBE } \\
\text { SURFACE }\end{array}$ & $\begin{array}{l}\text { 10-Dec-03 CISDCE (cis-1,2-Dichloroethylene) } \\
\text { 13-Noy-03 ETHCYANDE (Ethyl cyanide }\end{array}$ & 0.06 & $\mathrm{ug} / \mathrm{L}$ & & & u & & & 06-D \\
\hline SESPSPEC & B18160 & 100-B SPRING 38-3 & ONSITE & sw & $\mathrm{N}$ & $\begin{array}{l}\text { SURFACE } \\
\text { SURFACE }\end{array}$ & 13-Nov-03 ETHCYANIDE (Ethyl cyanide), & 1.3 & $\begin{array}{l}\mathrm{ug} / \mathrm{L} \\
\mathrm{ug} / \mathrm{L}\end{array}$ & & & u & & & \\
\hline SESPSPEC & B18157 & 100-B SPRING 38-3 & ONSITE & sw & $\mathrm{N}$ & SURFACE & 13-Nov-03 ETHCYANIDE (Ethyl cyanide, & 1.3 & $\mathrm{ug} / \mathrm{L}$ & & & u & & & \\
\hline SESPSPEC & B18158 & 100-B SPRING 38-3 & ONSITE & SW & $\mathrm{N}$ & SURFACE & 13-Nov-03 ETHCYANIDE (Ethyl cyanide) & 1.3 & $\mathrm{ug} / \mathrm{L}$ & & & U & & & \\
\hline $\begin{array}{l}\text { SESPSPEC } \\
\text { SESPSPCC }\end{array}$ & B18159 & 100-B SPRING 38-3 & ONSITE & sw & $\mathrm{N}$ & SURFACE & 13-Nov-03 ETHCYANIDE (Ethyl cyanide'; & 1.3 & $\mathrm{ug} / \mathrm{L}$ & & & $\mathrm{U}$ & & & \\
\hline $\begin{array}{l}\text { SESPSPEC } \\
\text { SESPSPEC }\end{array}$ & $\begin{array}{l}\text { B18166 } \\
\text { B1816? }\end{array}$ & 100-B SPRING DR 38-3 & ONSITE & SW & $\mathrm{N}$ & SURFACE & 13-Nov-03 ETHCYANIDE (Ethyl cyanide, & 1.3 & $\mathrm{ug} / \mathrm{L}$ & & & U & & & \\
\hline $\begin{array}{l}\text { SESPSECC } \\
\text { SESPSPEC }\end{array}$ & $\begin{array}{l}\text { B18162 } \\
\text { B18163 }\end{array}$ & $\begin{array}{l}\text { 100-B SPRING 39-2 } \\
\text { 100-B SPRING 39-2 }\end{array}$ & $\begin{array}{l}\text { ONSITE } \\
\text { ONSTTE }\end{array}$ & $\begin{array}{l}\text { SW } \\
\text { sw }\end{array}$ & $\begin{array}{l}n \\
N\end{array}$ & $\begin{array}{l}\text { SURFACE } \\
\text { SURFACE }\end{array}$ & 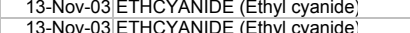 & $\begin{array}{l}1.3 \\
1.3\end{array}$ & $\mathrm{ug} / \mathrm{L}$ & & & u & & & \\
\hline SESPSPEC & B18164 & 100-B SPRING 39-2 & ONSITE & sw & $\frac{N}{N}$ & $\begin{array}{l}\text { SURFACE } \\
\text { SURFACE }\end{array}$ & 13-Nov-03 ETHCYANIDE (Ethyl cyanide, & 1.3 & ug/L & & & u & & & \\
\hline SESPSPEC & B18165 & 100-B SPRING 39-2 & ONSITE & sw & $\mathrm{N}$ & SURFACE & 13-Nov-03 ETHCYANIDE (Ethyl cyanide, & 1.3 & $\mathrm{ug} / \mathrm{L}$ & & & U & & & \\
\hline SESPSPEC & B18152 & 100 B/C AREA UR & ONSITE & sw & $\mathrm{N}$ & SURFACE & 13-Nov-03 ETHCYANIDE (Ethyl cyanide) & 1.3 & $\mathrm{ug} / \mathrm{L}$ & & & $\mathrm{U}$ & & & \\
\hline SESPSPEC & B18153 & 100 B/C AREA UR & ONSITE & sw & $\mathrm{N}$ & SURFACE & 13-Nov-03 ETHCYANIDE (Ethyl cyanide; & 1.3 & $\mathrm{ug} / \mathrm{L}$ & & & $\mathrm{U}$ & & & \\
\hline $\begin{array}{l}\text { SESPSPCC } \\
\text { SESPSEC }\end{array}$ & B18154 & 100 B/C AREA UR & ONSITE & SW & $\mathrm{N}$ & SURFACE & 13-Nov-03 ETHCYANIDE (Ethyl cyanide, & 1.3 & $\mathrm{ug} / \mathrm{L}$ & & & U & & & \\
\hline $\begin{array}{l}\text { SESPSEC } \\
\text { SESPSPEC }\end{array}$ & $\begin{array}{l}\text { B18185 } \\
\text { B18145 }\end{array}$ & $\begin{array}{l}100 \text { BCC AREA UR } \\
100 \text { B AREA AREA DR }\end{array}$ & $\begin{array}{l}\text { ONSITE } \\
\text { ONSITE }\end{array}$ & $\begin{array}{l}\text { SW } \\
\text { SW }\end{array}$ & $\frac{n}{n}$ & $\begin{array}{l}\text { SURFACE } \\
\text { SURFACE }\end{array}$ & $\begin{array}{l}\text { 13--Nov-03 ETHCYANDEE (Ethyl cyanide, } \\
\text { 17-Nov-03 ETHCYANDEE Ethyll cyanide }\end{array}$ & $\begin{array}{l}1.3 \\
1.3\end{array}$ & $\begin{array}{l}\mathrm{ug} / \mathrm{L} \\
\mathrm{ug} / \mathrm{L}\end{array}$ & & & u & & & \\
\hline SESPSPEC & B18146 & 100 B/C AREA DR & ONSITE & sw & $\mathrm{N}$ & $\begin{array}{l}\text { SURFACE } \\
\text { SURFACE }\end{array}$ & 17-Nov-03 ETHCYANIDE (Ethyl cyanide, & 1.3 & ug/L $/ \mathrm{L}$ & & & u & & & \\
\hline SESPSPEC & B18147 & $100 \mathrm{~B} / \mathrm{C}$ AREA DR & ONSITE & sw & $\mathrm{N}$ & SURFACE & 17-Nov-03 ETHCYANIDE (Ethyl cyanide) & 1.3 & $\mathrm{ug} / \mathrm{L}$ & & & U & & & \\
\hline SESPSPEC & B18148 & $100 \mathrm{~B} / \mathrm{C}$ AREA DR & ONSITE & sw & $\mathrm{N}$ & SURFACE & 17-Nov-03 ETHCYANIDE (Ethyl cyanide; & 1.3 & $\mathrm{ug} / \mathrm{L}$ & & & U & & & \\
\hline SESPSPEC & B18151 & 100 B/C AREA OUTFL3 & ONSITE & sw & $\mathrm{N}$ & SURFACE & 17-Nov-03 ETHCYANIDE (Ethyl cyanide) & 1.3 & $\mathrm{ug} / \mathrm{L}$ & & & $\mathrm{U}$ & & & \\
\hline $\begin{array}{l}\text { SESPSPEC } \\
\text { SESPPEC }\end{array}$ & $\begin{array}{l}\text { B18180 } \\
\text { B18149 }\end{array}$ & $\begin{array}{l}100 \text { B/C AREA OUTTL2 } \\
100 \text { BCA AREA OUTFL1 }\end{array}$ & $\begin{array}{l}\text { ONSITE } \\
\text { ONSITE }\end{array}$ & $\begin{array}{l}\text { SW } \\
\text { sw }\end{array}$ & $\begin{array}{l}n \\
N\end{array}$ & $\begin{array}{l}\text { SURFACE } \\
\text { SURFACE }\end{array}$ & 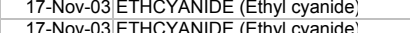 & 1.3 & $\mathrm{ug} / \mathrm{L}$ & & & U & & & \\
\hline $\begin{array}{l}\text { SESPSEC } \\
\text { SESPPEC }\end{array}$ & $\begin{array}{l}\text { B18149 } \\
\text { B18139 }\end{array}$ & Refer to WELL NAME column & ONSIIE & GW & $\frac{n}{n}$ & $\begin{array}{l}\text { SURFACE } \\
\text { AQUIFER TUBE }\end{array}$ & 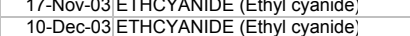 & 1.3 & $\begin{array}{l}\mathrm{ug} / \mathrm{L} \\
\mathrm{ug} / \mathrm{L}\end{array}$ & & & u & & & 01-D \\
\hline SESPSPEC & B18140 & Refer to WELL NAME column & & GW & $\mathrm{N}$ & AQUIFER TUBE & 10-Dec-03 ETHCYANIDE (Ethyl cyanide, & 1.3 & ug/L & & & u & & & 04-D \\
\hline SESPSPEC & B18141 & Refer to WELL NAME column & & GW & $\mathrm{N}$ & AQUIFER TUBE & 10-Dec-03 ETHCYANIDE (Ethyl cyanide) & 1.3 & $\mathrm{ug} / \mathrm{L}$ & & & $\mathrm{U}$ & & & 05-D \\
\hline SESPSPEC & B18142 & Refer to WELL NAME column & & GW & $\mathrm{N}$ & AQUIFER TUBE & 10-Dec-03 ETHCYANIDE (Ethyl cya & 1.3 & $\mathrm{ug} / \mathrm{L}$ & & & $\mathrm{U}$ & & & 06-D \\
\hline $\begin{array}{l}\text { SESPSPEC } \\
\text { SESPSEC }\end{array}$ & B18156 & 100-B SPRING 38-3 & ONSITE & sw & $\mathrm{N}$ & SURFACE & 13-Nov-03 HEXONE (4-Methyl-2-Pentanone) & 0.35 & $\mathrm{ug} / \mathrm{L}$ & & & $\mathrm{U}$ & & & \\
\hline $\begin{array}{l}\text { SESPSEC } \\
\text { SESPSPEC }\end{array}$ & B18160 & 100-B SPRING 38-3 & ONSITE & sw & $\mathrm{N}$ & $\begin{array}{l}\text { SURFACE } \\
\text { SUREACE }\end{array}$ & 13-Nov-03 HEXONE (4-Methyl-2-Pentanone) & 0.35 & ug/L & & & U & & & \\
\hline $\begin{array}{l}\text { SESPSPEC } \\
\text { SESPEC }\end{array}$ & $\begin{array}{l}\text { B. }-18158 \\
\text { B18158 }\end{array}$ & 100-B SPRING 38-3 & ONSITE & sw & $\mathrm{N}$ & $\begin{array}{l}\text { SURFACE } \\
\text { SURFACE }\end{array}$ & 13-Nov-03 HEXONE (4-Methyl-2-Pentanone) & 0.35 & $\begin{array}{l}\mathrm{ug} / \mathrm{L} \\
\mathrm{ug} / \mathrm{L}\end{array}$ & & & u & & & \\
\hline SESPSPEC & B18159 & 100-B SPRING 38-3 & ONSITE & sw & $\mathrm{N}$ & SURFACE & 13-Nov-03 HEXONE (4-Methyl-2-Pentanone) & 0.35 & $\mathrm{ug} / \mathrm{L}$ & & & u & & & \\
\hline SESPSPEC & B18166 & 100-B SPRING DR 38-3 & ONSITE & SW & $\mathrm{N}$ & SURFACE & 13-Nov-03 HEXONE (4-Methyl-2-Pentanone) & 0.35 & ug/L & & & $\mathrm{U}$ & & & \\
\hline SESPSPEC & B18162 & 100-B SPRING 39-2 & ONSITE & sw & $\mathrm{N}$ & SURFACE & 13-Nov-03 HEXONE (4-Methyl-2-Pentanone) & 0.35 & ug/L & & & 11 & & & \\
\hline
\end{tabular}




\begin{tabular}{|c|c|c|c|c|c|c|c|c|c|c|c|c|c|c|c|}
\hline OWNER ID & SAMP NUM & SAMP SITE NAME & DIST CLASS & MEDIA & $\begin{array}{c}\text { FILTERED } \\
\text { FLAG }\end{array}$ & SAMP FROM & CON SHORT NAME & |VALUE RPTD | & $\begin{array}{l}\text { ANAL } \\
\text { UNITS } \\
\text { RPTD }\end{array}$ & $\left|\begin{array}{c}\text { COUNTING } \\
\text { ERROR }\end{array}\right|$ & \begin{tabular}{|c|} 
TOTAL \\
ANAL \\
ERROR
\end{tabular} & $\mid \begin{array}{c}\text { LAB } \\
\text { QUALIFIER }\end{array}$ & SAMP COMMENT & $\begin{array}{c}\text { RESULT } \\
\text { COMMENT }\end{array}$ & |WELL NAME \\
\hline SESPSPEC & B18163 & 100-B SPRING 39-2 & ONSITE & SW & N & SURFACE & 13-Nov-03 HEXONE (4-Methyl-2-Pentanone) & 0.35 & ug/L & & & u & & & \\
\hline SESPSPEC & B18164 & 100-B SPRING 39-2 & ONSITE & SW & $\mathrm{N}$ & SURFACE & 13-Nov-03 HEXONE (4-Methyl-2-Pentanone) & 0.35 & ug/L & & & U & & & \\
\hline $\begin{array}{l}\text { SESPSECC } \\
\text { SESPPEC }\end{array}$ & $\begin{array}{l}B 18165 \\
B 18152\end{array}$ & 100-B SPRING 39-2 & ONSITE & SW & $\mathrm{N}$ & SURFACE & 13-Nov-03 HEXONE (4-Methyl-2-Pentanone) & 0.35 & $u g / L$ & & & U & & & \\
\hline $\begin{array}{l}\text { SESPSEC } \\
\text { SESPSPEC }\end{array}$ & $\begin{array}{l}\text { B18152 } \\
\text { B18153 }\end{array}$ & $\begin{array}{l}100 \text { BCC AREA UR } \\
100 \text { BCC AREA UR }\end{array}$ & $\begin{array}{l}\text { ONSITE } \\
\text { ONSTEE }\end{array}$ & $\begin{array}{l}\text { sw } \\
\text { sw }\end{array}$ & $\begin{array}{l}n \\
\mathrm{~N}\end{array}$ & $\begin{array}{l}\text { SURFACE } \\
\text { SURFACE }\end{array}$ & 13-Nov-03 HEXONE (4-Methyl-2-Pentanone) & 0.35 & ug/L & & & $\mathrm{U}$ & & & \\
\hline SESPSPEC & B18154 & $\begin{array}{l}100 \text { B BCAREA AR } \\
100 \text { BIC AREA UR }\end{array}$ & $\begin{array}{l}\text { ONSIIE } \\
\text { ONSITE }\end{array}$ & sw & $\frac{N}{N}$ & $\begin{array}{l}\text { SURFACE } \\
\text { SURFACE }\end{array}$ & $\begin{array}{l}\text { 13-Nov-03 HEXNENE (4-Methy-2-Pentanone) } \\
\text { 13-Nov-03 HEXONE (4-Methyl-2-Pentanone) }\end{array}$ & 0.35 & $\begin{array}{l}\mathrm{gug} / \mathrm{L} \\
\mathrm{ug} / \mathrm{L}\end{array}$ & & & u & & & \\
\hline SESPSPEC & B18155 & 100 B/C AREA UR & ONSITE & sw & $\mathrm{N}$ & SURFACE & 13-Nov-03 HEXONE (4-Methyl-2-Pentanone) & 0.35 & $\mathrm{ug} / \mathrm{L}$ & & & u & & & \\
\hline $\begin{array}{l}\text { SESPSPEC } \\
\text { SESPSDC }\end{array}$ & B18145 & 100 B/C AREA DR & ONSITE & sw & n & SURFACE & 17-Nov-03 HEXONE (4-Methyl-2-Pentanone) & 0.35 & $\mathrm{ug} / \mathrm{L}$ & & & u & & & \\
\hline $\begin{array}{l}\text { SESPSPEC } \\
\text { SESPSDC }\end{array}$ & B18146 & $100 \mathrm{BICAREA}$ DR & ONSITE & SW & $\mathrm{N}$ & $\begin{array}{l}\text { SURFACE } \\
\text { SUIPEACE }\end{array}$ & 17-Nov-03 HEXONE (4-Methyl-2-Pentanone) & 0.35 & $\mathrm{ug} / \mathrm{L}$ & & & $\mathrm{U}$ & & & \\
\hline $\begin{array}{l}\text { SESPSPEC } \\
\text { SESPSEC }\end{array}$ & B18147 & 100 B/C AREA DR & ONSITE & SW & $\mathrm{N}$ & SURFACE & 17-Nov-03 HEXONE (4-Methyl-2-Pentanone) & 0.35 & $\mathrm{ug} / \mathrm{L}$ & & & $\mathrm{U}$ & & & \\
\hline $\begin{array}{l}\text { SESPSECC } \\
\text { SESPPEC }\end{array}$ & $\begin{array}{l}\text { B18148 } \\
\text { B18151 }\end{array}$ & $\begin{array}{l}100 \text { B/C AREA DR } \\
100 \text { B/C AREA OUTFL3 }\end{array}$ & $\begin{array}{l}\text { ONSIE } \\
\text { ONSITE }\end{array}$ & $\begin{array}{l}\text { SW } \\
\text { sw }\end{array}$ & $\frac{n}{N}$ & $\begin{array}{l}\text { SURFACE } \\
\text { SURFACE }\end{array}$ & $\begin{array}{l}17-\text { Nov-03 HEXONE (4-Methyl-2-2-entanone) } \\
\text { 17-Nov-03 HEXONE (4-Methyl-2Pentanone }\end{array}$ & 0.35 & $u g / L$ & & & $\mathrm{U}$ & & & \\
\hline SESPSPEC & B18150 & $\begin{array}{l}100 \mathrm{~B} / \mathrm{A} \text { AREA OUTFL } \\
100 \mathrm{AREA} \text { OUTFL2 }\end{array}$ & ONSITE & sw & $\frac{N}{n}$ & $\begin{array}{l}\text { SURFACE } \\
\text { SURFACE }\end{array}$ & $\begin{array}{l}17 \text {-Nov-03 HeXONE (4-Methyl-2-Pentanone) } \\
\text { 17-Nov-03 HEXONE (4-Methyl-2-Pentanone }\end{array}$ & 0.35 & $\begin{array}{ll}\mathrm{ug} / \mathrm{L} \\
\mathrm{ug} / \mathrm{L}\end{array}$ & & & u & & & \\
\hline SESPSPEC & B18149 & 100 B/C AREA OUTFL1 & ONSITE & sw & $\mathrm{N}$ & SURFACE & 17-Nov-03 HEXONE (4-Methyl-2-Pentanone) & 0.35 & ug/L & & & u & & & \\
\hline SESPSPEC & B18139 & Refer to WELL NAME column & & GW & $\mathrm{N}$ & AQUIFER TUBE & 10-Dec-03 HEXONE (4-Methyl-2-Pentanone) & 0.35 & ug/L & & & U & & & $01-\mathrm{D}$ \\
\hline $\begin{array}{l}\text { SESPSPEC } \\
\text { SESPSPC }\end{array}$ & B18140 & Refer to WELL NAME column & & GW & $\mathrm{N}$ & AQUIFER TUBE & 10-Dec-03 HEXONE (4-Methyl-2-Pentanone) & 0.35 & $\mathrm{ug} / \mathrm{L}$ & & & U & & & $04-D$ \\
\hline $\begin{array}{l}\text { SESPSPCC } \\
\text { SESPSEC }\end{array}$ & B18141 & Refer to WELL NAME column & & GW & $\mathrm{N}$ & AQUIFER TUBE & 10-Dec-03 HEXONE (4-Methyl-2-Pentanone) & 0.35 & $\mathrm{ug} / \mathrm{L}$ & & & U & & & 05-D \\
\hline $\begin{array}{l}\text { SESPSECC } \\
\text { SESPPEC }\end{array}$ & B18142 & $\begin{array}{l}\text { Refer to WELLL NAME column } \\
100-B \text { SPRING 38-3 }\end{array}$ & & GW & $\begin{array}{c}n \\
N\end{array}$ & $\begin{array}{l}\text { AQUIFER TUBE } \\
\text { SUREACE }\end{array}$ & 10-Dec-03 HEXONE (4-Methyl-2-Pentanone) & 0.35 & $\mathrm{ug} / \mathrm{L}$ & & & U & & & 06-D \\
\hline $\begin{array}{l}\text { SESPSEC } \\
\text { SESPPEC }\end{array}$ & $\begin{array}{l}B 18156 \\
\text { B18160 }\end{array}$ & $\begin{array}{l}\text { 100-B SPRING 38-3 } \\
\text { 100-B SPRING 38-3 }\end{array}$ & $\begin{array}{l}\text { ONSSITE } \\
\text { ONSE }\end{array}$ & $\begin{array}{l}\text { SW } \\
\text { sW }\end{array}$ & $\begin{array}{l}\mathrm{N} \\
\mathrm{N}\end{array}$ & $\begin{array}{l}\text { SURFACE } \\
\text { SURFACE }\end{array}$ & $\begin{array}{l}\text { 13-Nov-03 METHONE (2-Butanone) } \\
\text { 13-Nov-03 METHONE (2-Butanone) }\end{array}$ & 0.29 & $\mathrm{ug} / \mathrm{L}$ & & & u & & & \\
\hline SESPSPEC & B18157 & 100-B SPRING 38-3 & ONSITE & sw & $\mathrm{N}$ & $\begin{array}{l}\text { SURFACE } \\
\text { SURFACE }\end{array}$ & 13-Nov-03 METHONE (2-Butanone) & 0.29 & $\mathrm{ug} / \mathrm{L}$ & & & u & & & \\
\hline SESPSPEC & B18158 & 100-B SPRING 38-3 & ONSITE & sw & $\mathrm{N}$ & SURFACE & 13-Nov-03 METHONE (2-Butanone) & 0.29 & ug/L & & & U & & & \\
\hline $\begin{array}{l}\text { SESPSPEC } \\
\text { SESPSEC }\end{array}$ & B18159 & $\begin{array}{l}\text { 100-B SPRING 38-3 } \\
100-3 \text { PRP }\end{array}$ & ONSITE & SW & $N^{n}$ & $\begin{array}{l}\text { SURFACE } \\
\text { SUPFACE }\end{array}$ & 13-Nov-03 METHONE (2-Butanone) & 0.29 & $\mathrm{ug} / \mathrm{L}$ & & & $u$ & & & \\
\hline $\begin{array}{l}\text { SESPSPCC } \\
\text { SESPSEC }\end{array}$ & $\begin{array}{l}B 18166 \\
B 18162\end{array}$ & 100-B SPRING DR 38-3 & ONSITE & SW & $\mathrm{N}$ & SURFACE & 13-Nov-03 METHONE (2-Butanone) & 0.29 & $\mathrm{ug} / \mathrm{L}$ & & & $\mathrm{U}$ & & & \\
\hline $\begin{array}{l}\text { SESPSECC } \\
\text { SESPPEC }\end{array}$ & $\begin{array}{l}\text { B18162 } \\
\text { B18163 }-25\end{array}$ & $\begin{array}{l}\text { 100-B SPRING 39-2 } \\
1 \text { 100-B SPRING 39-2 }\end{array}$ & ONSITE & SW & $\begin{array}{l}n \\
N\end{array}$ & $\begin{array}{l}\text { SURFACE } \\
\text { SURFACE }\end{array}$ & 13-Nov-03 METHONE (2-Butanone) & 0.29 & $\mathrm{ug} / \mathrm{L}$ & & & U & & & \\
\hline $\begin{array}{l}\text { SESPSEC } \\
\text { SESPSPEC }\end{array}$ & $\begin{array}{l}\text { B18163 } \\
\text { B18164 }\end{array}$ & $\begin{array}{l}\text { 100-B SPRING 39-2 } \\
\text { 100-B SPRING 39-2 }\end{array}$ & $\begin{array}{l}\text { ONSIIE } \\
\text { ONSITE }\end{array}$ & SW & $\frac{N}{N}$ & $\begin{array}{l}\text { SURFACE } \\
\text { SURFACE }\end{array}$ & $\begin{array}{l}\text { 13-Novo-03 METHONE (2-Butanone) } \\
\text { 13-Nov-03 METHONE (2-Butanone) }\end{array}$ & 0.29 & $\begin{array}{l}\mathrm{ug} / \mathrm{L} \\
\mathrm{ug} / \mathrm{L}\end{array}$ & & & u & & & \\
\hline SESPSPEC & B18165 & 100-B SPRING 39-2 & ONSITE & sw & $\mathrm{N}$ & SURFACE & 13-Nov-03 METHONE (2-Butanone) & 0.29 & $\mathrm{ug} / \mathrm{L}$ & & & u & & & \\
\hline SESPSPEC & B18152 & $100 \mathrm{~B} / \mathrm{C}$ AREA UR & ONSITE & sw & $\mathrm{N}$ & SURFACE & 13-Nov-03 METHONE (2-Butanone) & 0.29 & $\mathrm{ug} / \mathrm{L}$ & & & u & & & \\
\hline SESPSPEC & B18153 & 100 B/C AREA UR & ONSITE & sw & $\mathrm{N}$ & SURFACE & 13-Nov-03 METHONE (2-Butanone) & 0.29 & $\mathrm{ug} / \mathrm{L}$ & & & U & & & \\
\hline SESPSPEC & B18154 & 100 B/C AREA UR & ONSITE & sW & $\mathrm{N}$ & SURFACE & 13-Nov-03 METHONE (2-Butanone) & 0.29 & ug/L & & & U & & & \\
\hline SESPSPEC & B18155 & 100 B/C AREA UR & ONSITE & SW & $\mathrm{N}$ & SURFACE & 13-Nov-03 METHONE (2-Butanone) & 0.29 & ug/L & & & & & & \\
\hline SESPSPEC & B18145 & 100 B/C AREA DR & ONSITE & sw & $\mathrm{N}$ & SURFACE & 17-Nov-03 METHONE (2-Butanone) & 0.29 & $\mathrm{ug} / \mathrm{L}$ & & & $u$ & & & \\
\hline SESPSPEC & B18146 & 100 B/C AREA DR & ONSITE & sw & $\mathrm{N}$ & SURFACE & 17-Nov-03 METHONE (2-Butanone) & 0.29 & $\mathrm{ug} / \mathrm{L}$ & & & U & & & \\
\hline SESPSPEC & B18147 & $100 \mathrm{~B} / \mathrm{C}$ AREA DR & ONSITE & sw & $\mathrm{N}$ & SURFACE & 17-Nov-03 METHONE (2-Butanone) & 0.29 & $\mathrm{ug} / \mathrm{L}$ & & & U & & & \\
\hline SESPSPEC & B18148 & $100 \mathrm{~B} / \mathrm{C}$ AREA DR & ONSITE & sw & $\mathrm{N}$ & SURFACE & 17-Nov-03 METHONE (2-Butanone) & 0.29 & $\mathrm{ug} / \mathrm{L}$ & & & U & & & \\
\hline $\begin{array}{l}\text { SESPSPEC } \\
\text { SESPSPC }\end{array}$ & B18151 & 100 B/C AREA OUTFL3 & ONSITE & SW & $\mathrm{N}$ & $\begin{array}{l}\text { SURFACE } \\
\text { SUPEACE }\end{array}$ & 17-Nov-03 METHONE (2-Butanone) & 0.29 & $\mathrm{ug} / \mathrm{L}$ & & & $\mathrm{U}$ & & & \\
\hline $\begin{array}{l}\text { SESPSPCC } \\
\text { SESPSEC }\end{array}$ & $\begin{array}{l}\text { B18150 } \\
\text { B18149 }-29\end{array}$ & $\begin{array}{l}100 \text { B/C AREA OUTTL2 } \\
100 \text { BCAREA OUFL11 }\end{array}$ & $\begin{array}{l}\text { ONSITE } \\
\text { ONSITE }\end{array}$ & SW & $\begin{array}{l}n \\
N\end{array}$ & $\begin{array}{l}\text { SURFACE } \\
\text { SUREACE }\end{array}$ & 17-Nov-03 METHONE (2-Butanone) & 0.29 & $\mathrm{ug} / \mathrm{L}$ & & & U & & & \\
\hline $\begin{array}{l}\text { SESPSECC } \\
\text { SESPSPEC }\end{array}$ & $\begin{array}{l}B 18149 \\
\text { B18139 }\end{array}$ & $\begin{array}{l}100 \text { B BC AREA OUTFL1 } \\
\text { Refer to WELL NAME column }\end{array}$ & ONSITE & $\begin{array}{l}\text { SW } \\
\text { GW }\end{array}$ & $\frac{N}{N}$ & $\begin{array}{l}\text { SURRACE } \\
\text { AQUIFER TUBE }\end{array}$ & $\begin{array}{l}\text { 17-Nov-03 METHONE (2-Butanone) } \\
\text { 10-Dec-03 METHONE (2-Butanone) }\end{array}$ & $\begin{array}{l}0.29 \\
0.29\end{array}$ & $\begin{array}{l}\mathrm{gg} / \mathrm{L} \\
\mathrm{ug} / \mathrm{L}\end{array}$ & & & u & & & 01-D \\
\hline SESPSPEC & B18140 & Refer to WELL NAME column & & GW & $\mathrm{N}$ & AQUIFER TUBE & 10-Dec-03 METHONE (2-Butanone) & 0.29 & $\mathrm{ug} / \mathrm{L}$ & & & u & & & 04-D \\
\hline SESPSPEC & B18141 & Refer to WELL NAME column & & GW & $\mathrm{N}$ & AQUIFER TUBE & 10-Dec-03 METHONE (2-Butanone) & 0.29 & $\mathrm{ug} / \mathrm{L}$ & & & u & & & 05-D \\
\hline SESPSPEC & B18142 & Refer to WELL NAME column & & GW & $\mathrm{N}$ & AQUIFER TUBE & 10-Dec-03 METHONE (2-Butanone) & 0.29 & $\mathrm{ug} / \mathrm{L}$ & & & U & & & 06-D \\
\hline $\begin{array}{l}\text { SESPSPEC } \\
\text { SESPSPCC }\end{array}$ & B18156 & 100-B SPRING 38-3 & ONSITE & SW & $\mathrm{N}$ & SURFACE & 13-Nov-03 METHYCH (Methylenechloride) & 0.3 & $\mathrm{ug} / \mathrm{L}$ & & & U & & & \\
\hline $\begin{array}{l}\text { SESPSECC } \\
\text { SESPSPEC }\end{array}$ & $\begin{array}{l}B 18160 \\
B 18157\end{array}$ & $\begin{array}{l}\text { 100-B SPRING 38-3 } \\
100-B \text { SPRING 38-3 }\end{array}$ & ONSITE & SW & $\begin{array}{l}n \\
N\end{array}$ & $\begin{array}{l}\text { SURFACE } \\
\text { SUREACE }\end{array}$ & 13-Nov-03 METHYCH (Methylenechloride) & 0.3 & $\mathrm{ug} / \mathrm{L}$ & & & U & & & \\
\hline $\begin{array}{l}\text { SESPSEC } \\
\text { SESPSPEC }\end{array}$ & $\begin{array}{l}B 18157 \\
B 18158\end{array}$ & $\begin{array}{l}\text { 100-B SPRING 38-3 } \\
\text { 100-B SPRING 38-3 }\end{array}$ & $\begin{array}{l}\text { ONSTIE } \\
\text { ONSITE }\end{array}$ & $\begin{array}{l}\text { SW } \\
\text { sw }\end{array}$ & $\mathrm{N}_{\mathrm{N}}$ & $\begin{array}{l}\text { SURFACE } \\
\text { SURFACE }\end{array}$ & $\begin{array}{l}\text { 13-Nov-03 METHYH (Methylenechloride) } \\
\text { 13-Nov-03 METHYCH (Methylenechloride) }\end{array}$ & $\begin{array}{l}0.3 \\
0.3\end{array}$ & $\begin{array}{l}\mathrm{gug} / \mathrm{L} \\
\mathrm{ug} / \mathrm{L}\end{array}$ & & & u & & & \\
\hline SESPSPEC & B18159 & 100-B SPRING 38-3 & ONSITE & sw & $\mathrm{N}$ & SURFACE & 13-Nov-03 METHYCH (Methylenechloride) & 0.3 & $\mathrm{ug} / \mathrm{L}$ & & & u & & & \\
\hline SESPSPEC & B18166 & 100-B SPRING DR 38-3 & ONSITE & sw & $\mathrm{N}$ & SURFACE & 13-Nov-03 METHYCH (Methylenechloride) & 0.3 & $\mathrm{ug} / \mathrm{L}$ & & & U & & & \\
\hline SESPSPEC & B18162 & 100-B SPRING 39-2 & ONSITE & sw & $\mathrm{N}$ & SURFACE & 13-Nov-03 METHYCH (Methylenechloride) & 0.3 & $\mathrm{ug} / \mathrm{L}$ & & & $\mathrm{U}$ & & & \\
\hline SESPSPEC & B18163 & 100-B SPRING 39-2 & ONSITE & sw & $\mathrm{N}$ & SURFACE & 13-Nov-03 METHYCH (Methylenechloride) & 0.3 & $\mathrm{ug} / \mathrm{L}$ & & & $\mathrm{U}$ & & & \\
\hline $\begin{array}{l}\text { SESPSPCC } \\
\text { SESPSEC }\end{array}$ & B18164 & 100-B SPRING 39-2 & ONSITE & SW & $\mathrm{N}$ & SURFACE & 13-Nov-03 METHYCH (Methylenechloride) & 0.3 & $\mathrm{ug} / \mathrm{L}$ & & & U & & & \\
\hline $\begin{array}{l}\text { SESPSECC } \\
\text { SESPPEC }\end{array}$ & $\begin{array}{l}\text { B18185 } \\
\text { B18152 }\end{array}$ & $\begin{array}{l}\text { 100-B SPRING 39-2 } \\
100 \text { B/C AREA UR }\end{array}$ & $\begin{array}{l}\text { ONSITE } \\
\text { ONSITE }\end{array}$ & $\begin{array}{l}\text { SW } \\
\text { SW }\end{array}$ & $\frac{n}{n}$ & $\begin{array}{l}\text { SURFACE } \\
\text { SURFACE }\end{array}$ & $\begin{array}{l}13-N o v-03 \text { METHYCH (Methylenechloride) } \\
\text { 13-Nove03 MTHYCH (Methylenechloride }\end{array}$ & 0.3 & & & & u & & & \\
\hline SESPSPEC & & $100 \mathrm{~B} / \mathrm{C}$ AREA UR & ONSITE & sw & $\mathrm{N}$ & $\begin{array}{l}\text { SURFACE } \\
\text { SURFACE }\end{array}$ & 13-Nov-03 METHYCH (Methylenechloride) & 0.3 & ug/L $/ \mathrm{L}$ & & & u & & & \\
\hline SESPSPEC & B18154 & $100 \mathrm{~B} / \mathrm{C}$ AREA UR & ONSITE & sw & $\mathrm{N}$ & SURFACE & 13-Nov-03 METHYCH (Methylenechloride) & 0.3 & $\mathrm{ug} / \mathrm{L}$ & & & $\mathrm{U}$ & & & \\
\hline SESPSPEC & B18155 & $100 \mathrm{~B} / \mathrm{C}$ AREA UR & ONSITE & sw & $\mathrm{N}$ & SURFACE & 13-Nov-03 METHYCH (Methylenechloride) & 0.3 & $\mathrm{ug} / \mathrm{L}$ & & & U & & & \\
\hline SESPSPEC & B18145 & $100 \mathrm{~B} / \mathrm{C}$ AREA DR & ONSITE & sw & $\mathrm{N}$ & SURFACE & 17-Nov-03 METHYCH (Methylenechloride) & 0.3 & $\mathrm{ug} / \mathrm{L}$ & & & $\mathrm{U}$ & & & \\
\hline $\begin{array}{l}\text { SESPSPEC } \\
\text { SESPPEC }\end{array}$ & $\begin{array}{l}\text { B18146 } \\
\text { B18147 }\end{array}$ & $\begin{array}{l}100 \text { B/C AREA DR } \\
100 B \text { BCAREA DR }\end{array}$ & $\begin{array}{l}\text { ONSITE } \\
\text { ONSITE }\end{array}$ & sw & $\begin{array}{l}n \\
N\end{array}$ & $\begin{array}{l}\text { SURFACE } \\
\text { SURFACE }\end{array}$ & $\begin{array}{l}\text { 17-Nov-03 METHYCH (Methylenechloride) } \\
\text { 17-Nov-03 METHYC (Methylenechloride }\end{array}$ & 0.3 & $\mathrm{ug} / \mathrm{L}$ & & & U & & & \\
\hline $\begin{array}{l}\text { SESPSEC } \\
\text { SESPSEC }\end{array}$ & $\begin{array}{l}B 18147 \\
\text { B18148 }\end{array}$ & $\begin{array}{l}100 \text { BCC AREA DR } \\
100 \text { B AREA AREA }\end{array}$ & $\begin{array}{l}\text { ONSTIE } \\
\text { ONSITE }\end{array}$ & sw & $\frac{N}{n}$ & $\begin{array}{l}\text { SURFACE } \\
\text { SURFACE }\end{array}$ & & 0.3 & 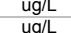 & & & u & & & \\
\hline SESPSPEC & B18151 & 100 B/C AREA OUTFL3 & ONSITE & sw & $\mathrm{N}$ & $\begin{array}{l}\text { SURFACE } \\
\text { SURFACE }\end{array}$ & 17-Nov-03 METHYCH (Methylenechloride) & 0.3 & $\mathrm{ug} / \mathrm{L}$ & & & u & & & \\
\hline SESPSPEC & B18150 & 100 B/C AREA OUTFL2 & ONSITE & SW & $\mathrm{N}$ & SURFACE & 17-Nov-03 METHYCH (Methylenechloride) & 0.3 & $\mathrm{ug} / \mathrm{L}$ & & & U & & & \\
\hline SESPSPEC & B18149 & EA OUT & ONSITE & SW & $\mathrm{N}$ & SURFACE & 17-Nov-03 METHYCH (Methyl & 0.3 & $\mathrm{ug} / \mathrm{L}$ & & & $\mathrm{U}$ & & & \\
\hline $\begin{array}{l}\text { SESPSPEC } \\
\text { SESPSEC }\end{array}$ & B18139 & Refer to WELL NAME column & & GW & $\mathrm{N}$ & AQUIFER TUBE & 10-Dec-03 METHYCH (Methylenechloride) & 0.3 & $\mathrm{ug} / \mathrm{L}$ & & & $\mathrm{U}$ & & & 01-D \\
\hline $\begin{array}{l}\text { SESPSPEC } \\
\text { SESPSEC }\end{array}$ & B18140 & Refer to WELL NAME column & & GW & $\mathrm{N}$ & $\begin{array}{l}\text { AQUIFER TUBE } \\
\text { AOIUEFR TUBE }\end{array}$ & 10-Dec-03 METHYCH (Methylenechloride) & 0.3 & ug/L & & & U & & & 104-D \\
\hline $\begin{array}{l}\text { SESPSEC } \\
\text { SESPPEC }\end{array}$ & $\begin{array}{l}\text { B. } \\
\text { B1814142 }\end{array}$ & $\begin{array}{l}\text { Refer to WELL NAME column } \\
\text { Refer to WELL NAME column }\end{array}$ & & $\begin{array}{l}G W \\
G W\end{array}$ & $\frac{N}{n}$ & $\begin{array}{l}\text { AQUUFER TUBE } \\
\text { AQUIFER TUBE }\end{array}$ & $\begin{array}{l}\text { 10-Dec-03 METHYCH (Methyleneccloride) } \\
\text { 10-Dec-03 METHYCH (Methylenechloride) }\end{array}$ & 0.3 & $\begin{array}{l}\mathrm{ug} / \mathrm{L} \\
\mathrm{ug} / \mathrm{L}\end{array}$ & & & u & & & $\begin{array}{l}05-D \\
06-D\end{array}$ \\
\hline SESPSPEC & B18156 & 100-B SPRING 38-3 & ONSITE & sw & $\mathrm{N}$ & SURFACE & 13-Nov-03 PERCENE (Tetrachloroethene) & 0.17 & $\mathrm{ug} / \mathrm{L}$ & & & U & & & \\
\hline SESPSPEC & B18160 & 100-B SPRING 38-3 & ONSITE & sw & $\mathrm{N}$ & SURFACE & 13-Nov-03 PERCENE (Tetrachloroethene) & 0.17 & ug/L & & & U & & & \\
\hline SESPSPEC & B18157 & 100-B SPRING 38-3 & ONSITE & sw & $\mathrm{N}$ & SURFACE & 13-Nov-03 PERCENE (Tetrachloroethene) & 0.17 & ug/L & & & u & & & \\
\hline
\end{tabular}




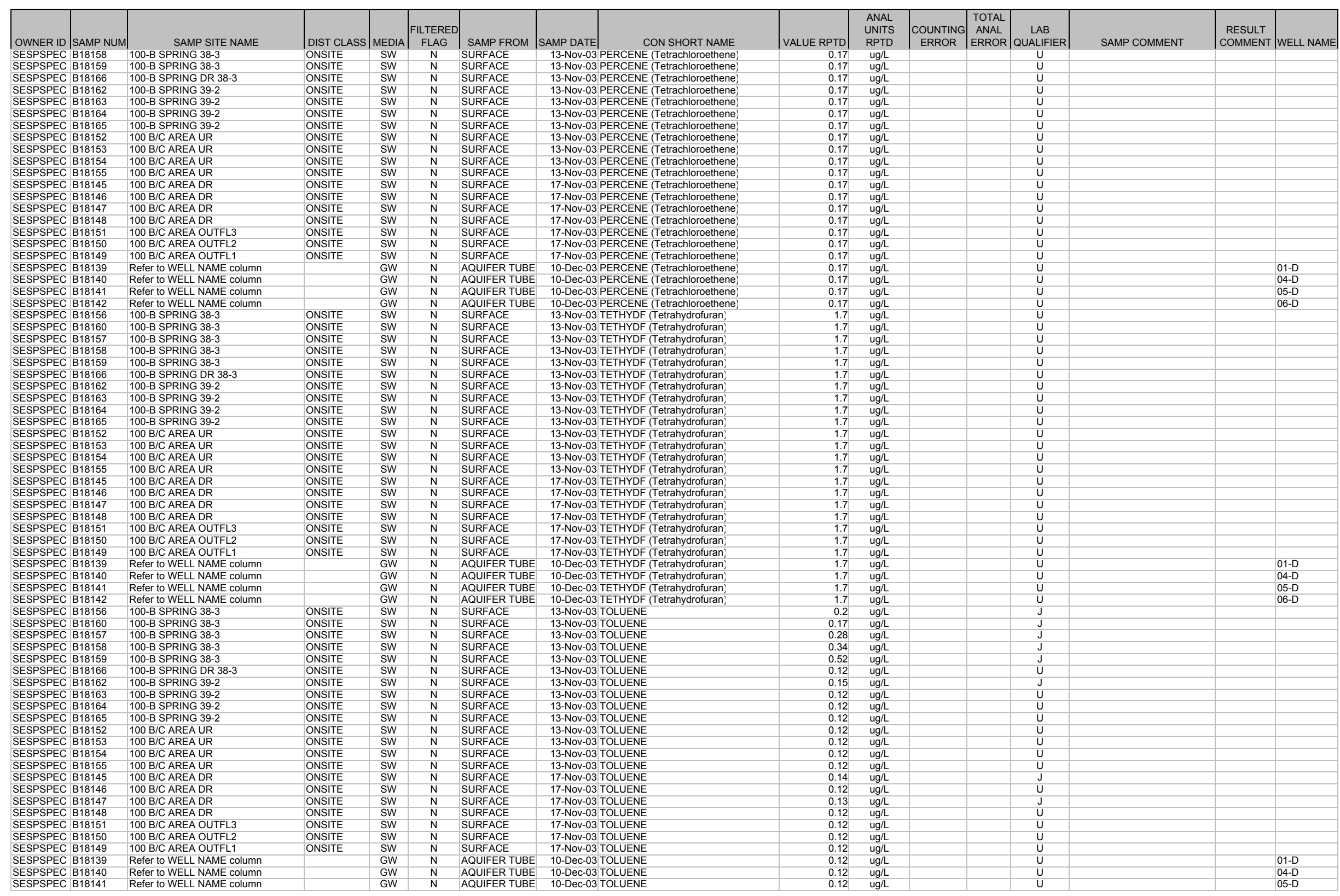




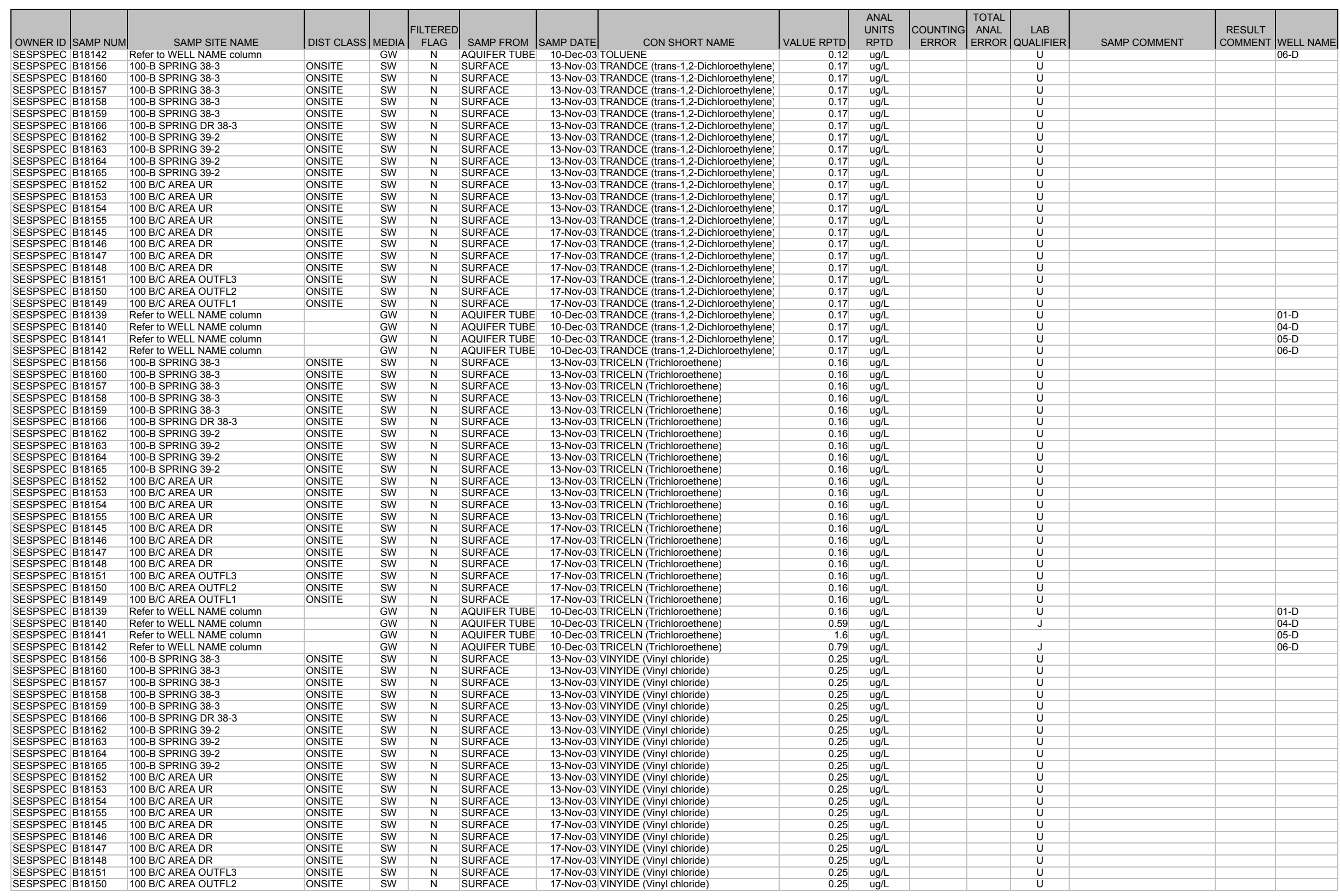




\begin{tabular}{|c|c|c|c|c|c|c|c|c|c|c|c|c|c|c|c|}
\hline OWNER ID & SAMP NUM & SAMP SITE NAME & | DIST CLASS | & MEDIA & \begin{tabular}{|c|c|c|c|c|c|} 
FLAG \\
$\mid$
\end{tabular} & $\mid$ SAMP FROM $\mid \leq$ & CON SHORT NAME & |VALUE RPTD & $\begin{array}{l}\text { ANAL } \\
\text { UNITS } \\
\text { RPTD }\end{array}$ & $\begin{array}{c}\text { COUNTING } \\
\text { ERROR }\end{array}$ & \begin{tabular}{|c|} 
TOTAL \\
ANAL \\
ERROR
\end{tabular} & $\left|\begin{array}{c}\text { LAB } \\
\text { QUALIFIER }\end{array}\right|$ & SAMP COMMENT & $\left|\begin{array}{c}\text { RESULT } \\
\text { COMMENT }\end{array}\right|$ & WELL NAME \\
\hline SESPSPEC & B18149 & $100 \mathrm{~B} / \mathrm{C}$ AREA OUTFL1 & ONSITE & sW & $\mathrm{N}$ & SURFACE & 17-Nov-03 VINYIDE (Vinyl chloride) & 0.25 & ug/L & & & u & & & \\
\hline $\begin{array}{l}\text { SESPSPEC } \\
\text { SESPSDEC }\end{array}$ & B18139 & Refer to WELL NAME column & & GW & $\mathrm{N}$ & AQUIFER TUBE & 10-Dec-03 VINYIDE (Vinyl chloride) & 0.25 & ug/L & & & U & & & 01-D \\
\hline $\begin{array}{l}\text { SESPSEC } \\
\text { SESPPEC }\end{array}$ & 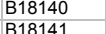 & Refer to WELL NAME column & & GW & $\begin{array}{c}n \\
\mathrm{~N}\end{array}$ & $\begin{array}{l}\text { AQUIFER TUBE } \\
\text { AQUUFER TUBE }\end{array}$ & 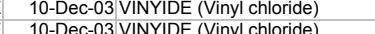 & 0.25 & ug/L & & & U & & & 04-D \\
\hline SESPSPEC & B18142 & $\begin{array}{l}\text { Refer to WELL NAME column } \\
\text { Refer to WELL NAME column }\end{array}$ & & GW & $\frac{n}{n}$ & $\begin{array}{l}\text { AQUUFER TUBE } \\
\text { AQUIFER TUBE }\end{array}$ & $\begin{array}{l}\text { 10-Dec-03 VVVINYDE (Vinyl chloride) } \\
\text { 10-Dec-03 VINYIDE (Vinyl chloride) }\end{array}$ & $\begin{array}{l}0.25 \\
0.25\end{array}$ & 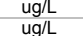 & & & u & & & $\begin{array}{l}\text { 05-D } \\
06-\mathrm{D}\end{array}$ \\
\hline SESPSPEC & B18156 & 100-B SPRING 38-3 & ONSITE & sw & $\mathrm{N}$ & SURFACE & 13-Nov-03 XYLENES & 0.28 & $\mathrm{ug} / \mathrm{L}$ & & & u & & & \\
\hline SESPSPEC & B18160 & 100-B SPRING 38-3 & ONSITE & sw & $\mathrm{N}$ & SURFACE & 13-Nov-03 XYLENES & 0.28 & $\mathrm{ug} / \mathrm{L}$ & & & u & & & \\
\hline SESPSPEC & B18157 & 100-B SPRING 38-3 & ONSITE & sw & $\mathrm{N}$ & SURFACE & 13-Nov-03 XYLENES & 0.28 & $\mathrm{ug} / \mathrm{L}$ & & & u & & & \\
\hline $\begin{array}{l}\text { SESPSPEC } \\
\text { SESPSPCC }\end{array}$ & B18158 & 100-B SPRING 38-3 & ONSITE & sw & $\mathrm{N}$ & $\begin{array}{l}\text { SURFACE } \\
\text { SUIDFACE }\end{array}$ & 13-Nov-03 XYLENES & 0.28 & $\mathrm{ug} / \mathrm{L}$ & & & U & & & \\
\hline $\begin{array}{l}\text { SESPSEEC } \\
\text { SESPSPEC }\end{array}$ & 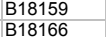 & $\begin{array}{l}\text { 100-B SPRING 38-3 } \\
\text { 100-B SPRING DR 38-3 }\end{array}$ & $\begin{array}{l}\text { ONSIIE } \\
\text { ONSITE }\end{array}$ & $\begin{array}{l}\text { Sw } \\
\text { sw }\end{array}$ & $\begin{array}{l}n \\
\mathrm{~N}\end{array}$ & $\begin{array}{l}\text { SURFACE } \\
\text { SURFACE }\end{array}$ & $\begin{array}{l}\text { 13-Nov-03 XYLLNES } \\
\text { 13-Nov-03 XYENES }\end{array}$ & 0.52 & $\mathrm{ug} / \mathrm{h}$ & & & $\begin{array}{l}u \\
u\end{array}$ & & & \\
\hline SESPSPEC & B18162 & 100-B SPRING 39-2 & ONSITE & sw & $\mathrm{N}$ & SURFACE & 13-Nov-03 XYLENES & 0.28 & ug/L & & & U & & & \\
\hline SESPSPEC & B18163 & 100-B SPRING 39-2 & ONSITE & sw & $\mathrm{N}$ & SURFACE & 13-Nov-03 XYLENES & 0.28 & ug/L & & & U & & & \\
\hline SESPSPEC & B18164 & 100-B SPRING 39-2 & ONSITE & sw & $\mathrm{N}$ & SURFACE & 13-Nov-03 XYLENES & 0.28 & $\mathrm{ug} / \mathrm{L}$ & & & u & & & \\
\hline SESPSPEC & B18165 & 100-B SPRING 39-2 & ONSITE & sw & $\mathrm{N}$ & SURFACE & 13-Nov-03 XYLENES & 0.28 & $\mathrm{ug} / \mathrm{L}$ & & & u & & & \\
\hline $\begin{array}{l}\text { SESPSPEC } \\
\text { SESPSPCA }\end{array}$ & B18152 & $100 \mathrm{~B} / \mathrm{C}$ AREA UR & ONSITE & SW & $\mathrm{N}$ & SURFACE & 13-Nov-03 XYLENES & 0.28 & $\mathrm{ug} / \mathrm{L}$ & & & U & & & \\
\hline $\begin{array}{l}\text { SESPSECC } \\
\text { SESPPECC }\end{array}$ & $\begin{array}{l}\text { B18183 } \\
\text { B18154 }\end{array}$ & $\begin{array}{l}100 \text { B/C AREA UR } \\
100 \text { BCC AREA AR }\end{array}$ & $\begin{array}{l}\text { ONSITE } \\
\text { ONSITE }\end{array}$ & $\begin{array}{l}\text { sw } \\
\text { sw }\end{array}$ & $\begin{array}{r}n \\
\mathrm{~N}\end{array}$ & $\begin{array}{l}\text { SURFACE } \\
\text { SURFACE }\end{array}$ & $\begin{array}{l}\text { 13-Nov-03 XYLENES } \\
\text { 13-Noy } 03 \text { XYLENES }\end{array}$ & 0.28 & $\mathrm{ug} / \mathrm{L}$ & & & U & & & \\
\hline $\begin{array}{l}\text { SESPSEC } \\
\text { SESPPEC }\end{array}$ & $\begin{array}{l}\text { B18154 } \\
\text { B18155 }\end{array}$ & 100 B/C AREA ARR & ONSITE & sw & $\frac{N}{N}$ & $\begin{array}{l}\text { SURFACE } \\
\text { SURFACE }\end{array}$ & $\begin{array}{l}\text { 13-Nov-03 XYLNES } \\
\text { 13-Nov-03 XYLENES }\end{array}$ & 0.28 & $\begin{array}{ll}\mathrm{ugh/2} \\
\mathrm{ug} / \mathrm{L}\end{array}$ & & & u & & & \\
\hline SESPSPEC & B18145 & $100 \mathrm{~B} / \mathrm{C}$ AREA DR & ONSITE & sw & $\mathrm{N}$ & SURFACE & 17-Nov-03 XYLENES & 0.28 & $\mathrm{ugh/ \textrm {L }} / \mathrm{h}$ & & & u & & & \\
\hline SESPSPEC & B18146 & 100 B/C AREA DR & ONSITE & sw & $\mathrm{N}$ & SURFACE & 17-Nov-03 XYLENES & 0.28 & $\mathrm{ug} / \mathrm{L}$ & & & U & & & \\
\hline SESPSPEC & B18147 & $100 \mathrm{~B} / \mathrm{C}$ AREA DR & ONSITE & sw & $\mathrm{N}$ & SURFACE & 17-Nov-03 XYLENES & 0.28 & $\mathrm{ug} / \mathrm{L}$ & & & u & & & \\
\hline $\begin{array}{l}\text { SESPSPEC } \\
\text { SESPSEC }\end{array}$ & $\begin{array}{ll}\text { B18148 } \\
\text { B18151 }\end{array}$ & $100 \mathrm{~B} / \mathrm{C}$ AREA DR & ONSITE & sW & $\mathrm{N}$ & SURFACE & 17-Nov-03 XYLENES & 0.28 & $\mathrm{ug} / \mathrm{L}$ & & & $u$ & & & \\
\hline $\begin{array}{l}\text { SESPSECC } \\
\text { SESPPEC }\end{array}$ & $\begin{array}{l}\text { B18151 } \\
\text { B18150 }\end{array}$ & $\begin{array}{l}100 \text { B/C AREA OUTTL3 } \\
100 \text { B/C AREA OUTLL2 }\end{array}$ & $\begin{array}{l}\text { ONSITE } \\
\text { ONSTEE }\end{array}$ & $\begin{array}{l}\text { sw } \\
\text { sw }\end{array}$ & $\begin{array}{l}n \\
\mathrm{~N}\end{array}$ & $\begin{array}{l}\text { SURFACE } \\
\text { SUREACE }\end{array}$ & 17-Nov-03 XYLENES & 0.28 & & & & U & & & \\
\hline $\begin{array}{l}\text { SESPSEC } \\
\text { SESPPEC }\end{array}$ & $\begin{array}{l}\text { B18150 } \\
\text { B18149 }\end{array}$ & 100 BIC AREA OUTFL1 & ONSITE & sw & $\mathrm{N}$ & $\begin{array}{l}\text { SURFACE } \\
\text { SURFACE }\end{array}$ & $\begin{array}{l}\text { 17-Nov-03 XYLNES } \\
\text { 17-Nov-03 XYLENES }\end{array}$ & $\begin{array}{l}0.28 \\
0.28\end{array}$ & $\begin{array}{l}\mathrm{ugh/2} \\
\mathrm{ug} / \mathrm{L}\end{array}$ & & & u & & & \\
\hline SESPSPEC & B18139 & Refer to WELL NAME column & & GW & $\mathrm{N}$ & AQUIFER TUBE & 10-Dec-03 XYLENES & 0.28 & ug/L & & & u & & & 01-D \\
\hline SESPSPEC & B18140 & Refer to WELL NAME column & & GW & $\mathrm{N}$ & AQUIFER TUBE & 10-Dec-03 XYLENES & 0.28 & ug/L & & & U & & & 04-D \\
\hline SESPSPEC & B18141 & Refer to WELL NAME column & & GW & $\mathrm{N}$ & AQUIFER TUBE & 10-Dec-03 XYLENES & 0.28 & $\mathrm{ug} / \mathrm{L}$ & & & U & & & 05-D \\
\hline $\begin{array}{l}\text { SESPSPEC } \\
\text { SESPSDC }\end{array}$ & B18142 & Refer to WELL NAME column & OEFSITE & GW & $\mathrm{N}$ & AQUIFER TUBE & 10-Dec-03 XYLENES & 0.28 & $\mathrm{ug} / \mathrm{L}$ & & & u & & & 06-D \\
\hline $\begin{array}{l}\text { SESPSECC } \\
\text { SESPSPEC }\end{array}$ & $\begin{array}{l}\text { B177B3 } \\
\text { B17BT2 }\end{array}$ & $\begin{array}{l}\text { MCNARY-2/3 OR. SHORE } \\
\text { MCNARYOREGON SHORE }\end{array}$ & $\begin{array}{l}\text { OFFITE } \\
\text { OFFSITE }\end{array}$ & sw & $\begin{array}{l}n \\
N\end{array}$ & $\begin{array}{l}\text { RIVER } \\
\text { RIVER }\end{array}$ & $\begin{array}{l}08-\text { - Aug-03 TOC (Total organic carbon) } \\
\text { 08-Aug-03 TOC (Total organic carbon }\end{array}$ & & & & & & $\begin{array}{l}\text { NO SAMPLE. } \\
\text { NO SAMPLE. }\end{array}$ & & \\
\hline SESPSPEC & B17BT4 & MCNARY-WASH. SHORE & OFFSITE & sw & $\mathrm{N}$ & RIVER & 08-Aug-03 TOC (Total organic carbon) & & & & & & NO SAMPLE. & & \\
\hline
\end{tabular}


Table W-1. Preliminary United States Geological Survey (USGS) Columbia River Water Quality Data for Vernita Bridge Near Priest Rapids Dam, Washington

\begin{tabular}{|c|c|c|c|c|c|c|c|c|c|c|}
\hline SAMPLE DATE & DISCHARGE CFS & $\begin{array}{l}\text { DRAINAGE AREA } \\
\text { (SQ. MI) }\end{array}$ & $\begin{array}{l}\text { TURBIDITY } \\
\text { (NTU) }\end{array}$ & $\begin{array}{l}\text { BAROMETRIC } \\
\text { PRESSURE } \\
\text { (MM OF Hg) }\end{array}$ & $\begin{array}{l}\text { OXYGEN, } \\
\text { DISSOLVED } \\
\text { (MG/L) }\end{array}$ & $\begin{array}{c}\text { pH WATER WHOLE } \\
\text { FIELD } \\
\text { (STANDARD UNITS) }\end{array}$ & $\begin{array}{c}\text { pH WATER WHOLE } \\
\text { LAB } \\
\text { (STANDARD UNITS) }\end{array}$ & $\begin{array}{c}\text { SPECIFIC } \\
\text { CONDUCTANCE LAB } \\
(\mu \mathrm{S} / \mathrm{cm}) 25^{\circ} \mathrm{C}\end{array}$ & $\begin{array}{c}\text { SPECIFIC } \\
\text { CONDUCTANCE } \\
(\mu \mathrm{S} / \mathrm{cm}) 25^{\circ} \mathrm{C}\end{array}$ & $\begin{array}{c}\text { TEMPERATURE AIR } \\
\left({ }^{\circ} \mathrm{C}\right)\end{array}$ \\
\hline & 72900 & 96000 & 1.7 & 753 & 12.7 & 8 & 7.9 & 131 & 134 & - \\
\hline SAMPLE DATE & $\begin{array}{l}\text { TEMPERATURE } \\
\text { WATER }\left({ }^{\circ} \mathrm{C}\right)\end{array}$ & $\begin{array}{c}\text { CALCIUM } \\
\text { DISSOLVED } \\
\text { (MG/L AS Ca) }\end{array}$ & $\begin{array}{l}\text { MAGNESIUM, } \\
\text { DISSOLVED } \\
\text { (MG/L AS Mg) }\end{array}$ & 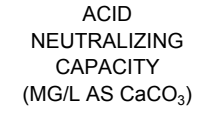 & $\begin{array}{c}\text { ALKALINITY } \\
\text { DISSOLVED FIELD } \\
\text { (MG/L AS } \mathrm{CaCO}_{3} \text { ) }\end{array}$ & $\begin{array}{l}\text { BICARBONATE } \\
\text { DISSOLVED FIELD } \\
\text { (MG/L AS } \mathrm{HCO}_{3} \text { ) }\end{array}$ & $\begin{array}{c}\text { CARBONATE } \\
\text { DISSOLVED FIELD } \\
\left.(\mathrm{MG} / \mathrm{L} \mathrm{AS} \mathrm{CO})_{3}\right)\end{array}$ & $\begin{array}{l}\text { CHLORIDE, } \\
\text { DISSOLVED } \\
\text { (MG/L AS CL) }\end{array}$ & $\begin{array}{l}\text { FLUORIDE } \\
\text { DISSOLVED } \\
\text { (MG/L AS F) }\end{array}$ & $\begin{array}{c}\text { SULFATE } \\
\text { DISSOLVED } \\
\left(\mathrm{MG} / \mathrm{L} \mathrm{AS} \mathrm{SO}_{4}\right)\end{array}$ \\
\hline $\begin{array}{l}\text { 17-Apr-03 } \\
25-S e p-03\end{array}$ & $\begin{array}{c}7.8 \\
18.8\end{array}$ & $\begin{array}{l}18.6 \\
18.1\end{array}$ & $\begin{array}{l}4.78 \\
4.51\end{array}$ & $\begin{array}{l}60 \\
57\end{array}$ & $\begin{array}{l}59 \\
54\end{array}$ & $\begin{array}{l}71 \\
65\end{array}$ & $\begin{array}{l}0 \\
0\end{array}$ & $\begin{array}{l}1.12 \\
1.02\end{array}$ & $\begin{array}{l}<0.17 \\
<0.2\end{array}$ & $\begin{array}{l}9.3 \\
8.8\end{array}$ \\
\hline SAMPLE DATE & $\begin{array}{l}\text { SOLIDS, RESIDUE } \\
\text { AT } 180^{\circ} \mathrm{C} \\
\text { DISSOLVED (MG/L) }\end{array}$ & $\begin{array}{l}\text { RESIDUE TOTAL AT } \\
105^{\circ} \mathrm{C} \text { SUSPENDED } \\
\text { (MG/L) }\end{array}$ & $\begin{array}{l}\text { NITROGEN, } \\
\text { AMMONIA + } \\
\text { ORGANIC TOTAL } \\
\text { (MG/L AS N) }\end{array}$ & $\begin{array}{l}\text { NITROGEN, } \\
\text { AMMONIA } \\
\text { DISSOLVED } \\
\text { (MG/L AS N) }\end{array}$ & $\begin{array}{l}\mathrm{NITROGEN}, \\
\mathrm{NO}_{2}+\mathrm{NO}_{3} \\
\text { DISSOLVED } \\
\text { (MG/L AS N) }\end{array}$ & $\begin{array}{l}\text { NITROGEN, NITRITE } \\
\text { DISSOLVED } \\
\text { (MG/L AS N) }\end{array}$ & $\begin{array}{c}\text { ORTHOPHOSPHATE } \\
\text { DISSOLVED } \\
\text { (MG/L AS P) }\end{array}$ & $\begin{array}{l}\text { PHOSPHORUS } \\
\text { TOTAL } \\
\text { (MG/L AS P) }\end{array}$ & $\begin{array}{l}\text { CARBON, ORGANIC } \\
\text { DISSOLVED } \\
\text { (MG/L AS C) }\end{array}$ & $\begin{array}{l}\text { CHROMIUM, } \\
\text { DISSOLVED } \\
\text { (UG/L AS Cr) }\end{array}$ \\
\hline $\begin{array}{l}\text { 17-Apr-03 } \\
25-S e p-03\end{array}$ & $\begin{array}{l}83 \\
86\end{array}$ & $\begin{array}{l}<10 \\
<10\end{array}$ & $\begin{array}{l}0.14 \\
0.11\end{array}$ & $\begin{array}{l}<0.04 \\
<0.04\end{array}$ & $\begin{array}{l}0.13 \\
0.06\end{array}$ & $\begin{array}{l}<0.008 \\
<0.008\end{array}$ & $\begin{array}{l}<0.02 \\
<0.02\end{array}$ & $\begin{array}{l}0.03^{(a)} \\
<0.04\end{array}$ & $\begin{array}{l}1.2 \\
1.4\end{array}$ & $\begin{array}{l}<0.8 \\
<0.8\end{array}$ \\
\hline SAMPLE DATE & $\begin{array}{l}\text { IRON DISSOLVED } \\
\quad(\mathrm{UG} / \mathrm{L} \text { AS FE) }\end{array}$ & $\begin{array}{l}\text { SEDIMENT } \\
\text { SUSPENDED } \\
\text { (MG/L) }\end{array}$ & $\begin{array}{l}\text { NUMBER OF } \\
\text { SAMPLING POINTS } \\
\text { (COUNT) }\end{array}$ & $\begin{array}{l}\text { HARDNESS, TOTAL } \\
\left(\mathrm{MG} / \mathrm{L} \text { AS } \mathrm{CaCO}_{3}\right)\end{array}$ & & & & & & \\
\hline 17-Apr-03 & $<10$ & 3 & 5 & 66 & & & & & & \\
\hline 25-Sep-03 & $<8$ & 1 & 5 & 64 & & & & & & \\
\hline
\end{tabular}

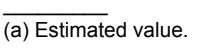


Table W-2. Preliminary United States Geological Survey (USGS) Columbia River Water Quality Data for Richland, Washington Near the Richland Pumphouse

\begin{tabular}{|c|c|c|c|c|c|c|c|c|c|c|c|}
\hline SAMPLE DATE & $\begin{array}{l}\text { DRAINAGE AREA } \\
\text { (SQ. MI) }\end{array}$ & $\begin{array}{l}\text { TURBIDITY } \\
\text { (NTU) }\end{array}$ & $\begin{array}{l}\text { BAROMETRIC } \\
\text { PRESSURE } \\
\text { (MM OF Hg) }\end{array}$ & $\begin{array}{c}\text { OXYGEN, } \\
\text { DISSOLVED (MG/L) }\end{array}$ & $\begin{array}{c}\text { pH WATER WHOLE } \\
\text { FIELD } \\
\text { (STANDARD UNITS) }\end{array}$ & $\begin{array}{c}\text { pH WATER WHOLE } \\
\text { LAB } \\
\text { (STANDARD UNITS) }\end{array}$ & $\begin{array}{c}\text { SPECIFIC } \\
\text { CONDUCTANCE LAB } \\
(\mu \mathrm{S} / \mathrm{cm}) 25^{\circ} \mathrm{C}\end{array}$ & $\begin{array}{c}\text { SPECIFIC } \\
\text { CONDUCTANCE } \\
(\mu \mathrm{S} / \mathrm{cm}) 25^{\circ} \mathrm{C}\end{array}$ & $\begin{array}{c}\text { TEMPERATURE AIR } \\
\left({ }^{\circ} \mathrm{C}\right)\end{array}$ & $\begin{array}{l}\text { TEMPERATURE } \\
\text { WATER }\left({ }^{\circ} \mathrm{C}\right)\end{array}$ & $\begin{array}{l}\text { CALCIUM } \\
\text { DISSOLVED } \\
\text { (MG/L AS Ca) }\end{array}$ \\
\hline 18-Apr-03 & 96900 & 2.9 & 763 & 12.4 & 8.2 & 8 & 142 & 141 & 15.1 & 7.9 & 18.4 \\
\hline 26-Sep-03 & 96900 & 3.1 & 755 & 11.7 & 7.9 & 8 & 134 & 138 & 28.3 & 18.7 & 17.4 \\
\hline SAMPLE DATE & $\begin{array}{l}\text { MAGNESIUM, } \\
\text { DISSOLVED } \\
\text { (MG/L AS Mg) }\end{array}$ & $\begin{array}{c}\text { ACID NEUTRALIZING } \\
\text { CAPACITY } \\
\left.\text { (MG/L AS CaCO } \mathrm{CaCO}_{3}\right)\end{array}$ & 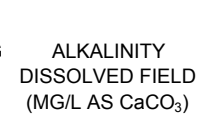 & $\begin{array}{l}\text { BICARBONATE } \\
\text { DISSOLVED FIELD } \\
\text { (MG/L AS HCO }{ }_{3} \text { ) }\end{array}$ & $\begin{array}{l}\text { CARBONATE } \\
\text { DISSOLVED FIELD } \\
\text { (MG/L AS CO } \mathrm{CO}_{3} \text { ) }\end{array}$ & $\begin{array}{l}\text { CHLORIDE, } \\
\text { DISSOLVED } \\
\text { (MG/L AS CL) }\end{array}$ & $\begin{array}{l}\text { FLUORIDE } \\
\text { DISSOLVED } \\
\text { (MG/L AS F) }\end{array}$ & $\begin{array}{c}\text { SULFATE } \\
\text { DISSOLVED } \\
\text { (MG/L AS SO } \\
\text { (MS }\end{array}$ & $\begin{array}{l}\text { SOLIDS, RESIDUE } \\
\text { AT } 180^{\circ} \mathrm{C} \\
\text { DISSOLVED } \\
\text { (MG/L) }\end{array}$ & $\begin{array}{c}\text { RESIDUE TOTAL AT } \\
105^{\circ} \mathrm{C} \text { SUSPENDED } \\
\text { (MG/L) }\end{array}$ & $\begin{array}{c}\text { NITROGEN, } \\
\text { AMMONIA + } \\
\text { ORGANIC TOTAL } \\
\text { (MG/L AS N) }\end{array}$ \\
\hline $\begin{array}{c}\text { 18-Apr-03 } \\
\text { 26-Sep-03 }\end{array}$ & $\begin{array}{c}4.74 \\
4.5\end{array}$ & $\begin{array}{l}61 \\
58\end{array}$ & $\begin{array}{l}60 \\
55\end{array}$ & $\begin{array}{l}73 \\
68\end{array}$ & $\begin{array}{l}0 \\
0\end{array}$ & $\begin{array}{l}1.19 \\
1.16\end{array}$ & $\begin{array}{l}0.06 \\
<0.2\end{array}$ & $\begin{array}{l}9.4 \\
9.2\end{array}$ & $\begin{array}{l}81 \\
86\end{array}$ & $\begin{array}{l}<10 \\
<10\end{array}$ & $\begin{array}{l}0.14 \\
0.11\end{array}$ \\
\hline & $\begin{array}{l}\text { NITROGEN, } \\
\text { AMMONIA }\end{array}$ & $\begin{array}{l}\mathrm{NITROGEN}, \\
\mathrm{NO}_{2}+\mathrm{NO}_{3}\end{array}$ & NITROGEN, NITRITE & ORTHOPHOSPHATE & PHOSPHORUS & CARBON, ORGANIC & CHROMIUM, & & SEDIMENT & NUMBER OF & \\
\hline SAMPLE DATE & $\begin{array}{l}\text { DISSOLVED } \\
\text { (MG/L AS N) }\end{array}$ & $\begin{array}{l}\text { DISSOLVED } \\
\text { (MG/L AS N) }\end{array}$ & $\begin{array}{l}\text { DISSOLVED } \\
\text { (MG/L AS N) }\end{array}$ & $\begin{array}{l}\text { DISSOLVED } \\
\text { (MG/L AS P) }\end{array}$ & $\begin{array}{l}\text { TOTAL } \\
\text { (MG/L AS P) }\end{array}$ & $\begin{array}{l}\text { DISSOLVED } \\
\text { (MG/L AS C) }\end{array}$ & $\begin{array}{l}\text { DISSOLVED } \\
\text { (UG/L AS Cr) }\end{array}$ & $\begin{array}{l}\text { IRON DISSOLVED } \\
\text { (UG/L AS FE) }\end{array}$ & $\begin{array}{l}\text { SUSPENDED } \\
\text { (MG/L) }\end{array}$ & $\begin{array}{l}\text { SAMPLING POINTS } \\
\text { (COUNT) }\end{array}$ & $\begin{array}{l}\text { HARDNESS, TOTAL } \\
\left(\mathrm{MG} / \mathrm{L} \mathrm{AS} \mathrm{CaCO}_{3}\right)\end{array}$ \\
\hline $18-\pi$ & $<0.04$ & 0.11 & $<0.008$ & $<0.02$ & $0.03^{(\mathrm{a})}$ & 1.3 & $<0.8$ & $<10$ & 2 & 5 & 66 \\
\hline 26-Sep-03 & $<0.04$ & 0.08 & $<0.008$ & $<0.02$ & $<0.04$ & 1.5 & $<0.8$ & $5^{(\mathrm{a})}$ & 2 & 5 & 62 \\
\hline
\end{tabular}




\section{Drinking Water}


WATER - DRINKING WATER

\begin{tabular}{|c|c|c|c|c|c|c|c|c|c|c|c|c|c|c|}
\hline OWNER ID & SAMP NUM & SAMP SITE NAME & DIST CLASS & MEDIA & SAMP FROM & SAMP DATE & $\begin{array}{l}\text { CON SHORT } \\
\text { NAME }\end{array}$ & VALUE RPTD & $\begin{array}{l}\text { ANAL UNITS } \\
\text { RPTD }\end{array}$ & COUNTING ERROR & TOTAL ANAL ERROR & $\begin{array}{c}\text { LAB } \\
\text { QUALIFIER }\end{array}$ & SAMP COMMENT & RESULT COMMENT \\
\hline SESPMNT & B15LH3 & $100 \mathrm{~K}$ AREA & ONSITE & SW & DRINKING & 18-Feb-03 & ALPHA & 0.387 & $\mathrm{pCi} / \mathrm{L}$ & 0.69 & 0.7 & U & & \\
\hline SESPMNT & B15LH4 & $100 \mathrm{~K}$ AREA & ONSITE & sW & DRINKING & 07-Apr-03 & ALPHA & 0.286 & $\mathrm{pCi} / \mathrm{L}$ & 0.37 & 0.38 & $u$ & & \\
\hline SESPMNT & B15LH5 & $100 \mathrm{~K}$ AREA & ONSITE & sW & DRINKING & 08-Jul-03 & ALPHA & 0.536 & $\mathrm{pCi} / \mathrm{L}$ & 0.65 & 0.66 & U & & \\
\hline SESPMNT & B15LH6 & $100 \mathrm{~K}$ AREA & ONSITE & sW & DRINKING & $07-O c t-03$ & ALPHA & 0.328 & $\mathrm{pCi} / \mathrm{L}$ & 0.71 & 0.72 & U & & \\
\hline SESPMNT & B15LF2 & $100 \mathrm{~N}$ AREA & ONSITE & sW & DRINKING & 18-Feb-03 & ALPHA & 0.083 & $\mathrm{pCi} / \mathrm{L}$ & 0.47 & 0.47 & u & & \\
\hline SESPMNT & B15LF3 & $100 \mathrm{~N}$ AREA & ONSITE & sW & DRINKING & 07-Apr-03 & ALPHA & 0.654 & $\mathrm{pCi} / \mathrm{L}$ & 0.49 & 0.51 & $u$ & & \\
\hline SESPMNT & B15LF4 & 100 N AREA & ONSITE & sW & DRINKING & 08-Jul-03 & ALPHA & 0.113 & $\mathrm{pCi} / \mathrm{L}$ & 0.41 & 0.41 & $u$ & & \\
\hline SESPMNT & B15LF5 & $100 \mathrm{~N}$ AREA & ONSITE & sW & DRINKING & $07-O c t-03$ & ALPHA & 0.751 & $\mathrm{pCi} / \mathrm{L}$ & 0.95 & 0.97 & U & & \\
\hline SESPMNT & B15LJ4 & 200 W AREA & ONSITE & sW & DRINKING & 18-Feb-03 & ALPHA & 1.28 & $\mathrm{pCi} / \mathrm{L}$ & 0.96 & 1 & & & \\
\hline SESPMNT & B15LJ5 & 200 W AREA & ONSITE & sW & DRINKING & 07-Apr-03 & ALPHA & 0.0297 & $\mathrm{pCi} / \mathrm{L}$ & 0.23 & 0.23 & 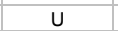 & & \\
\hline SESPMNT & B15LJ6 & 200 W AREA & ONSITE & sW & DRINKING & 08-Jul-03 & ALPHA & 0.0556 & $\mathrm{pCi} / \mathrm{L}$ & 0.5 & 0.5 & $u$ & & \\
\hline SESPMNT & B15LJ7 & 200 W AREA & ONSITE & sW & DRINKING & $07-0 c t-03$ & ALPHA & -0.00579 & $\mathrm{pCi} / \mathrm{L}$ & 0.59 & 0.6 & U & & \\
\hline SESPMNT & B15LK5 & 400 AREA & ONSITE & sW & DRINKING & 18-Feb-03 & ALPHA & 1.62 & $\mathrm{pCi} / \mathrm{L}$ & 1.4 & 1.4 & U & & \\
\hline SESPMNT & B15LK6 & 400 AREA & ONSITE & sW & DRINKING & 07-Apr-03 & ALPHA & 0.543 & $\mathrm{pCi} / \mathrm{L}$ & 0.85 & 0.86 & $U$ & & \\
\hline SESPMNT & B15LK7 & 400 AREA & ONSITE & sW & DRINKING & 08-Jul-03 & ALPHA & -0.104 & $\mathrm{pCi} / \mathrm{L}$ & 0.63 & 0.63 & $u$ & & \\
\hline SESPMNT & B15LK8 & 400 AREA & ONSITE & sW & DRINKING & 07-Oct-03 & ALPHA & -0.432 & $\mathrm{pCi} / \mathrm{L}$ & 0.94 & 0.95 & U & & \\
\hline SESPMNT & B169B4 & $100 \mathrm{~K}$ AREA & ONSITE & sW & DRINKING & 03-Mar-03 & BETA & 1.43 & $\mathrm{pCi} / \mathrm{L}$ & 1.4 & 1.5 & U & & \\
\hline SESPMNT & B16RN5 & $100 \mathrm{~K}$ AREA & ONSITE & sW & DRINKING & 03-Jun-03 & BETA & 1.82 & $\mathrm{pCi} / \mathrm{L}$ & 1.4 & 1.4 & $U$ & & \\
\hline SESPMNT & B176L4 & $100 \mathrm{~K}$ AREA & ONSITE & sW & DRINKING & 02-Sep-03 & BETA & 2.24 & $\mathrm{pCi} / \mathrm{L}$ & 1.4 & 1.4 & $u$ & & \\
\hline SESPMNT & B17R72 & $100 \mathrm{~K}$ AREA & ONSITE & SW & DRINKING & 01-Dec-03 & BETA & 0.149 & $\mathrm{pCi} / \mathrm{L}$ & 1.6 & 1.7 & $U$ & & \\
\hline SESPMNT & B16999 & 100 N AREA & ONSITE & sW & DRINKING & 03-Mar-03 & BETA & 2.58 & $\mathrm{pCi} / \mathrm{L}$ & 1.5 & 1.6 & $U$ & & \\
\hline SESPMNT & B16RN0 & $100 \mathrm{~N}$ AREA & ONSITE & sW & DRINKING & 03-Jun-03 & BETA & 1.25 & $\mathrm{pCi} / \mathrm{L}$ & 1.3 & 1.3 & $U$ & & \\
\hline SESPMNT & B176K9 & 100 N AREA & ONSITE & sw & DRINKING & $02-\mathrm{Sep}-03$ & BETA & 1.09 & $\mathrm{pCilL}$ & 1.4 & 1.4 & $u$ & & \\
\hline SESPMNT & B17R67 & $100 \mathrm{~N}$ AREA & ONSITE & sW & DRINKING & 01-Dec-03 & BETA & -0.158 & $\mathrm{pCi} / \mathrm{L}$ & 1.7 & 1.8 & $U$ & & \\
\hline SESPMNT & B169B9 & 200 W AREA & ONSITE & sW & DRINKING & 03-Mar-03 & BETA & 2.86 & $\mathrm{pCi} / \mathrm{L}$ & 1.5 & 1.7 & & & \\
\hline SESPMNT & B16RP0 & 200 W AREA & ONSITE & sW & DRINKING & 03-Jun-03 & BETA & 1.82 & $\mathrm{pCi} / \mathrm{L}$ & 1.3 & 1.3 & $U$ & & \\
\hline SESPMNT & B176L9 & 200 W AREA & ONSITE & sW & DRINKING & 02-Sep-03 & BETA & 0.911 & $\mathrm{pCi} / \mathrm{L}$ & 1.3 & 1.3 & $u$ & & \\
\hline SESPMNT & B17R77 & 200 W AREA & ONSITE & sW & DRINKING & 01-Dec-03 & BETA & -0.632 & $\mathrm{pCi} / \mathrm{L}$ & 1.6 & 1.7 & $U$ & & \\
\hline SESPMNT & B169C4 & 400 AREA & ONSITE & sW & DRINKING & 03-Mar-03 & BETA & 6.75 & $\mathrm{pCi} / \mathrm{L}$ & 1.8 & 2.1 & & & \\
\hline SESPMNT & B16RP5 & 400 AREA & ONSITE & sW & DRINKING & 03-Jun-03 & BETA & 6.57 & $\mathrm{pCi} / \mathrm{L}$ & 1.7 & 1.9 & & & \\
\hline SESPMNT & B176M4 & 400 AREA & ONSITE & sW & DRINKING & $02-\mathrm{Sep}-03$ & BETA & 7.39 & $\mathrm{pCilL}$ & 1.8 & 2.1 & & & \\
\hline SESPMNT & B17R82 & 400 AREA & ONSITE & sW & DRINKING & 01-Dec-03 & BETA & 7.3 & $\mathrm{pCi} / \mathrm{L}$ & 2.6 & 2.8 & & & \\
\hline SESPMNT & B15LH3 & $100 \mathrm{~K}$ AREA & ONSITE & sW & DRINKING & 18-Feb-03 & $\mid-131$ & 0.0453 & $\mathrm{pCi} / \mathrm{L}$ & 0.41 & 0.41 & U & & \\
\hline SESPMNT & B15LH4 & $100 \mathrm{~K}$ AREA & ONSITE & sW & DRINKING & 07-Apr-03 & $\mid-131$ & 0.0817 & $\mathrm{pCi} / \mathrm{L}$ & 0.31 & 0.31 & U & & \\
\hline SESPMNT & B15LH5 & $100 \mathrm{~K}$ AREA & ONSITE & sW & DRINKING & 08-Jul-03 & $\mid-131$ & -0.256 & $\mathrm{pCi} / \mathrm{L}$ & 0.37 & 0.37 & U & & \\
\hline SESPMNT & B15LH6 & $100 \mathrm{~K}$ AREA & ONSITE & sW & DRINKING & 07-Oct-03 & $\mid-131$ & 0.327 & $\mathrm{pCi} / \mathrm{L}$ & 0.38 & 0.38 & U & & \\
\hline SESPMNT & B15LF2 & $100 \mathrm{~N}$ AREA & ONSITE & SW & DRINKING & 18-Feb-03 & $\mid-131$ & 0.215 & $\mathrm{pCi} / \mathrm{L}$ & 0.38 & 0.38 & $U$ & & \\
\hline SESPMNT & B15LF3 & $100 \mathrm{~N}$ AREA & ONSITE & sW & DRINKING & 07-Apr-03 & $\mid-131$ & -0.146 & $\mathrm{pCi} / \mathrm{L}$ & 0.42 & 0.42 & $U$ & & \\
\hline SESPMNT & B15LF4 & 100 N AREA & ONSITE & sW & DRINKING & 08-Jul-03 & $\mid-131$ & 0.0189 & $\mathrm{pCi} / \mathrm{L}$ & 0.31 & 0.31 & $U$ & & \\
\hline SESPMNT & B15LF5 & $100 \mathrm{~N}$ AREA & ONSITE & sW & DRINKING & 07-Oct-03 & $\mid-131$ & -0.0655 & $\mathrm{pCi} / \mathrm{L}$ & 0.37 & 0.37 & U & & \\
\hline SESPMNT & B15LJ4 & 200 W AREA & ONSITE & SW & DRINKING & 18-Feb-03 & $\mid-131$ & 0.0416 & $\mathrm{pCi} / \mathrm{L}$ & 0.4 & 0.4 & U & & \\
\hline SESPMNT & B15LJ5 & 200 W AREA & ONSITE & sW & DRINKING & 07-Apr-03 & $\mid-131$ & 0.427 & $\mathrm{pCi} / \mathrm{L}$ & 0.49 & 0.49 & U & & \\
\hline SESPMNT & B15LJ6 & 200 W AREA & ONSITE & sW & DRINKING & 08-Jul-03 & $\mid-131$ & 0.0749 & $\mathrm{pCi} / \mathrm{L}$ & 0.33 & 0.33 & $U$ & & \\
\hline SESPMNT & B15LJ7 & 200 W AREA & ONSITE & sW & DRINKING & 07-Oct-03 & $\mid-131$ & -0.088 & $\mathrm{pCi} / \mathrm{L}$ & 0.42 & 0.42 & $U$ & & \\
\hline SESPMNT & B15LK5 & 400 AREA & ONSITE & sW & DRINKING & 18-Feb-03 & -131 & -0.027 & $\mathrm{pCi} / \mathrm{L}$ & 0.44 & 0.44 & U & & \\
\hline SESPMNT & B15LK6 & 400 AREA & ONSITE & sW & DRINKING & 07-Apr-03 & $\mid-131$ & 0.0658 & $\mathrm{pCi} / \mathrm{L}$ & 0.37 & 0.37 & $U$ & & \\
\hline SESPMNT & B15LK7 & 400 AREA & ONSITE & sW & DRINKING & 08-Jul-03 & $\mid-131$ & 0.104 & $\mathrm{pCi} / \mathrm{L}$ & 0.4 & 0.4 & $U$ & & \\
\hline SESPMNT & B15LK8 & 400 AREA & ONSITE & sw & DRINKING & 07-Oct-03 & -131 & -0.104 & $\mathrm{pCi} / \mathrm{L}$ & 0.43 & 0.43 & $U$ & & \\
\hline SESPMNT & B15LH3 & $100 \mathrm{~K}$ AREA & ONSITE & SW & DRINKING & 18-Feb-03 & Ra-226 & 0.0332 & $\mathrm{pCi} / \mathrm{L}$ & 0.012 & 0.014 & & & \\
\hline SESPMNT & B15LH4 & $100 \mathrm{~K}$ AREA & ONSITE & sW & DRINKING & 07-Apr-03 & Ra-226 & 0.0549 & $\mathrm{pCi} / \mathrm{L}$ & 0.012 & 0.016 & & & \\
\hline SESPMNT & B15LH5 & $100 \mathrm{~K}$ AREA & ONSITE & sW & DRINKING & 08-Jul-03 & Ra-226 & 0.0416 & $\mathrm{pCi} / \mathrm{L}$ & 0.014 & 0.016 & & & \\
\hline SESPMNT & B15LH6 & $100 \mathrm{~K}$ AREA & ONSITE & sW & DRINKING & 07-Oct-03 & Ra-226 & 0.0221 & $\mathrm{pCi} / \mathrm{L}$ & 0.012 & 0.013 & & & \\
\hline SESPMNT & B15LF2 & $100 \mathrm{~N}$ AREA & ONSITE & SW & DRINKING & 18-Feb-03 & Ra-226 & 0.0291 & $\mathrm{pCi} / \mathrm{L}$ & 0.014 & 0.015 & & & \\
\hline SESPMNT & B15LF3 & 100 N AREA & ONSITE & sw & DRINKING & 07-Apr-03 & Ra-226 & 0.0307 & $\mathrm{pCi} / \mathrm{L}$ & 0.015 & 0.016 & & & \\
\hline SESPMNT & B15LF4 & $100 \mathrm{~N}$ AREA & ONSITE & sW & DRINKING & 08-Jul-03 & Ra-226 & 0.0578 & $\mathrm{pCi} / \mathrm{L}$ & 0.016 & 0.02 & & & \\
\hline SESPMNT & B15LF5 & $100 \mathrm{~N}$ AREA & ONSITE & SW & DRINKING & 07-Oct-03 & Ra-226 & 0.0469 & $\mathrm{pCi} / \mathrm{L}$ & 0.013 & 0.016 & & & \\
\hline SESPMNT & B15LJ4 & 200 W AREA & ONSITE & sW & DRINKING & 18-Feb-03 & Ra-226 & 0.043 & $\mathrm{pCi} / \mathrm{L}$ & 0.012 & 0.014 & & & \\
\hline SESPMNT & B15LJ5 & 200 W AREA & ONSITE & sW & DRINKING & 07-Apr-03 & Ra-226 & 0.0557 & $\mathrm{pCi} / \mathrm{L}$ & 0.015 & 0.019 & & & \\
\hline
\end{tabular}


WATER - DRINKING WATER

\begin{tabular}{|c|c|c|c|c|c|c|c|c|c|c|c|c|c|c|}
\hline OWNER ID & SAMP NUM & SAMP SITE NAME & | DIST CLASS & MEDIA & SAMP FROM & SAMP DATE & $\begin{array}{c}\text { CON SHORT } \\
\text { NAME }\end{array}$ & VALUE RPTD & $\begin{array}{l}\text { ANAL UNITS } \\
\text { RPTD }\end{array}$ & | COUNTING ERROR & TOTAL ANAL ERROR & $\mid \begin{array}{c}\text { LAB } \\
\text { QUALIFIER }\end{array}$ & SAMP COMMENT & RESULT COMMENT \\
\hline SESPMNT & B15LJ6 & 200 W AREA & ONSITE & sw & DRINKING & 08-Jul-03 & Ra-226 & 0.0843 & $\mathrm{pCi} / \mathrm{L}$ & 0.02 & 0.026 & & & \\
\hline SESPMNT & B15LJ7 & 200 W AREA & ONSITE & sW & DRINKING & $07-0 c t-03$ & Ra-226 & 0.0622 & $\mathrm{pCi} / \mathrm{L}$ & 0.014 & 0.019 & & & \\
\hline SESPMNT & B15LK5 & 400 AREA & ONSITE & sW & DRINKING & 18-Feb-03 & Ra-226 & 0.0215 & $\mathrm{pCi} / \mathrm{L}$ & 0.0074 & 0.0085 & & & \\
\hline SESPMNT & B15LK6 & 400 AREA & ONSITE & sW & DRINKING & 07-Apr-03 & Ra-226 & 0.0319 & $\mathrm{pCi} / \mathrm{L}$ & 0.015 & 0.017 & & & \\
\hline SESPMNT & B15LK7 & 400 AREA & ONSITE & sW & DRINKING & 08-Jul-03 & Ra-226 & 0.0956 & pCi/L & 0.019 & 0.026 & & & \\
\hline SESPMNT & B15LK8 & 400 AREA & ONSITE & sW & DRINKING & 07-Oct-03 & Ra-226 & 0.0251 & $\mathrm{pCi} / \mathrm{L}$ & 0.014 & 0.014 & & & \\
\hline SESPMNT & B15LH3 & $100 \mathrm{~K}$ AREA & ONSITE & sW & DRINKING & 18-Feb-03 & Ra-228 & 0.337 & $\mathrm{pCi} / \mathrm{L}$ & 0.22 & 0.23 & $u$ & & \\
\hline SESPMNT & B15LH4 & $100 \mathrm{~K}$ AREA & ONSITE & sW & DRINKING & 07-Apr-03 & Ra-228 & 0.311 & $\mathrm{pCi} / \mathrm{L}$ & 0.2 & 0.21 & u & & \\
\hline SESPMNT & B15LH5 & $100 \mathrm{~K}$ AREA & ONSITE & sW & DRINKING & 08-Jul-03 & Ra-228 & 0.315 & pCi/L & 0.31 & 0.32 & $\mathrm{U}$ & & \\
\hline SESPMNT & B15LH6 & $100 \mathrm{~K}$ AREA & ONSITE & sW & DRINKING & 07-Oct-03 & Ra-228 & 1.04 & $\mathrm{pCi} / \mathrm{L}$ & 0.36 & 0.41 & & & \\
\hline SESPMNT & B15LF2 & 100 N AREA & ONSITE & SW & DRINKING & 18-Feb-03 & Ra-228 & 0.358 & $\mathrm{pCi} / \mathrm{L}$ & 0.2 & 0.21 & & & \\
\hline SESPMNT & B15LF3 & 100 N AREA & ONSITE & sW & DRINKING & 07-Apr-03 & Ra-228 & & $\mathrm{pCi} / \mathrm{L}$ & 0.21 & 0.23 & & & \\
\hline SESPMNT & B15LF4 & 100 N AREA & ONSITE & sW & DRINKING & 08-Jul-03 & Ra-228 & 0.00591 & pCi/L & 0.3 & 0.3 & U & & \\
\hline SESPMNT & B15LF5 & 100 N AREA & ONSITE & sW & DRINKING & 07-Oct-03 & Ra-228 & 0.562 & $\mathrm{pCi} / \mathrm{L}$ & 0.34 & 0.35 & U & & \\
\hline SESPMNT & B15LJ4 & 200 W AREA & ONSITE & sW & DRINKING & 18-Feb-03 & Ra-228 & 0.122 & $\mathrm{pCi} / \mathrm{L}$ & 0.28 & 0.28 & U & & \\
\hline SESPMNT & B15LJ5 & 200 W AREA & ONSITE & SW & DRINKING & 07-Apr-03 & Ra-228 & 0.788 & $\mathrm{pCi} / \mathrm{L}$ & 0.25 & 0.3 & & & \\
\hline SESPMNT & B15LJ6 & 200 W AREA & ONSITE & SW & DRINKING & 08-Jul-03 & Ra-228 & 0.0313 & pCi/L & 0.33 & 0.33 & U & & \\
\hline SESPMNT & B15LJ7 & 200 W AREA & ONSITE & sW & DRINKING & 07-Oct-03 & Ra-228 & 0.547 & $\mathrm{pCi} / \mathrm{L}$ & 0.33 & 0.35 & U & & \\
\hline SESPMNT & B15LK5 & 400 AREA & ONSITE & sW & DRINKING & 18-Feb-03 & Ra-228 & 0.26 & $\mathrm{pCi} / \mathrm{L}$ & 0.26 & 0.27 & U & & \\
\hline SESPMNT & B15LK6 & 400 AREA & ONSITE & sW & DRINKING & 07-Apr-03 & Ra-228 & 0.332 & $\mathrm{pCi} / \mathrm{L}$ & 0.2 & 0.21 & U & & \\
\hline SESPMNT & B15LK7 & 400 AREA & ONSITE & SW & DRINKING & 08-Jul-03 & Ra-228 & 0.266 & pCi/L & 0.43 & 0.43 & U & & \\
\hline SESPMNT & B15LK8 & 400 AREA & ONSITE & sW & DRINKING & 07-Oct-03 & Ra-228 & 0.54 & $\mathrm{pCi} / \mathrm{L}$ & 0.3 & 0.32 & U & & \\
\hline SESPMNT & B15LH1 & $100 \mathrm{~K}$ AREA & ONSITE & SW & DRINKING & $07-$ Oct-03 & Sr-90 & 0.0736 & $\mathrm{pCi} / \mathrm{L}$ & 0.023 & 0.026 & & & \\
\hline SESPMNT & B15LF0 & $100 \mathrm{~N}$ AREA & ONSITE & sW & DRINKING & 07-Oct-03 & Sr-90 & 0.0981 & $\mathrm{pCi} / \mathrm{L}$ & 0.022 & 0.026 & & & \\
\hline SESPMNT & B15LJ2 & 200 W AREA & ONSITE & SW & DRINKING & 07-Oct-03 & Sr-90 & 0.0908 & pCi/L & 0.033 & 0.036 & & & \\
\hline SESPMNT & B15LK3 & 400 AREA & ONSITE & sW & DRINKING & 07-Oct-03 & Sr-90 & -0.0014 & $\mathrm{pCi} / \mathrm{L}$ & 0.036 & 0.036 & U & & \\
\hline SESPMNT & B15LH1 & $100 \mathrm{~K}$ AREA & ONSITE & sW & DRINKING & 07-Oct-03 & TRITIUM & -0.943 & $\mathrm{pCi} / \mathrm{L}$ & 68 & 84 & U & & \\
\hline SESPMNT & B15LF0 & $100 \mathrm{~N}$ AREA & ONSITE & sW & DRINKING & 07-Oct-03 & TRITIUM & 148 & $\mathrm{pCi} / \mathrm{L}$ & 79 & 94 & & & \\
\hline SESPMNT & B15LJ2 & 200 W AREA & ONSITE & sW & DRINKING & 07-Oct-03 & TRITIUM & 164 & $\mathrm{pCi} / \mathrm{L}$ & 88 & 100 & & & \\
\hline SESPMNT & B15LK5 & 400 AREA & ONSITE & sW & DRINKING & 18-Feb-03 & TRITIUM & 3190 & $\mathrm{pCi} / \mathrm{L}$ & 230 & 330 & & & \\
\hline SESPMNT & B15LK6 & 400 AREA & ONSITE & SW & DRINKING & 07-Apr-03 & TRITIUM & 3250 & $\mathrm{pCi} / \mathrm{L}$ & 240 & 340 & & & \\
\hline SESPMNT & B15LK7 & 400 AREA & ONSITE & sW & DRINKING & 08-Jul-03 & TRITIUM & 3520 & $\mathrm{pCi} / \mathrm{L}$ & 220 & 330 & & & \\
\hline SESPMNT & B15LK8 & 400 AREA & ONSITE & sW & DRINKING & 07-Oct-03 & TRITIUM & 3440 & $\mathrm{pCi} / \mathrm{L}$ & 210 & 330 & & & \\
\hline SESPSPEC & B17997 & LIGO & ONSITE & sW & DRINKING & 24-Jul-03 & TRITIUM & 15.7 & $\mathrm{pCi} / \mathrm{L}$ & 54 & 61 & $U$ & & \\
\hline SESPSPEC & B17997 & LIGO & ONSITE & SW & DRINKING & 24-Jul-03 & C-14 & -3.5 & $\mathrm{pCi} / \mathrm{L}$ & 3.1 & 3.6 & $U$ & & \\
\hline SESPSPEC & B17997 & LIGO & ONSITE & sw & DRINKING & 24-Jul-03 & $1-129$ & 0.0222 & $\mathrm{pCi} / \mathrm{L}$ & 0.092 & 0.092 & $u$ & & \\
\hline SESPSPEC & B17997 & LIGO & ONSITE & sw & DRINKING & 24-Jul-03 & Tc-99 & 0.478 & $\mathrm{pCi} / \mathrm{L}$ & 0.25 & 0.55 & $u$ & & \\
\hline SESPSPEC & B16KH6 & BENTON CITY COMP & COMMUNITY & sW & DRINKING & 07-Mar-03 & $\mathrm{U}-234$ & 7.8 & $\mathrm{pCi} / \mathrm{L}$ & 0.19 & 1.3 & & & \\
\hline SESPSPEC & $\mathrm{B} 16 \mathrm{KH} 6$ & BENTON CITY COMP & COMMUNITY & SW & DRINKING & 07-Mar-03 & $\mathrm{U}-235$ & 0.182 & pCi/L & 0.03 & 0.042 & & & \\
\hline SESPSPEC & B16KH6 & BENTON CITY COMP & COMMUNITY & sW & DRINKING & 07-Mar-03 & $\mathrm{U}-238$ & 5.07 & $\mathrm{pCi} / \mathrm{L}$ & 0.15 & 0.82 & & & \\
\hline SESPSPEC & B17997 & LIGO & ONSITE & sw & DRINKING & 24-Jul-03 & $\mathrm{U}-238$ & -0.00283 & $\mathrm{pCi} / \mathrm{L}$ & 0.01 & 0.011 & $\mathrm{U}$ & & \\
\hline SESPSPEC & B17997 & LIGO & ONSITE & sW & DRINKING & 24-Jul-03 & $U-235$ & -0.00465 & $\mathrm{pCi} / \mathrm{L}$ & 0.0026 & 0.0032 & $U$ & & \\
\hline SESPSPEC & B17997 & LIGO & ONSITE & SW & DRINKING & 24-Jul-03 & $\mathrm{U}-234$ & -0.0094 & pCi/L & 0.013 & 0.013 & $\mathrm{U}$ & & \\
\hline
\end{tabular}


Biota 
FOODSTUFF

(pCi/g Wet Weight)

\begin{tabular}{|c|c|c|c|c|c|c|c|c|c|c|c|c|c|c|c|}
\hline OWNER ID & SAMP NUM & SAMP SITE NAME & DIST CLASS & MEDIA & SAMP FROM & SAMP ITEM & SAMP DATE & $\begin{array}{c}\text { CON SHORT } \\
\text { NAME }\end{array}$ & VALUE RPTD & \begin{tabular}{|l|l} 
ANAL \\
UNITS \\
RPTD \\
\end{tabular} & $\begin{array}{c}\text { COUNTING } \\
\text { ERROR }\end{array}$ & $\begin{array}{c}\text { TOTAL ANAL } \\
\text { ERROR }\end{array}$ & $\begin{array}{c}\text { LAB } \\
\text { QUALIFIER }\end{array}$ & SAMP COMMENT & RESULT COMMENT \\
\hline SESPMNT & B16W76 & HORN RAPIDS AREA & PERIMETER & $\mathrm{BI}$ & ALFALFA & STM-LV & 22-Apr-03 & Be-7 & 2.37 & $\mathrm{pCi} / \mathrm{g}$ & 0.37 & 0.37 & & WET CUT FROM FIELD. & \\
\hline SESPMNT & B16W67 & RIVERVIEW AREA & COMMUNITY & $\mathrm{BI}$ & ALFALFA & STM-LV & 09-May-03 & Be-7 & 1.49 & $\mathrm{pCi} / \mathrm{g}$ & 0.29 & 0.29 & & & \\
\hline SESPMNT & B16W65 & SAGEMOOR AREA & PERIMETER & $\mathrm{BI}$ & ALFALFA & STM-LV & 25-Apr-03 & Be-7 & 1.75 & $\mathrm{pCi} / \mathrm{g}$ & 0.34 & 0.34 & & CUT FROM OUTER EDGE OF CIRCLE, WET. & \\
\hline SESPMNT & B16W72 & SUNNYSIDE AREA & DISTANT & $\mathrm{BI}$ & ALFALFA & STM-LV & 01-May-03 & Be-7 & 1.48 & $\mathrm{pCi} / \mathrm{g}$ & 0.29 & 0.29 & & & \\
\hline SESPMNT & B16W76 & HORN RAPIDS AREA & PERIMETER & BI & ALFALFA & STM-LV & 22-Apr-03 & Co-60 & 0.00348 & $\mathrm{pCi} / \mathrm{g}$ & 0.015 & 0.015 & $u$ & WET CUT FROM FIELD. & \\
\hline SESPMNT & B16W67 & RIVERVIEW AREA & COMMUNITY & $\mathrm{BI}$ & ALFALFA & STM-LV & 09-May-03 & Co-60 & -0.00828 & $\mathrm{pCi} / \mathrm{g}$ & 0.012 & 0.012 & $\mathrm{u}$ & & \\
\hline SESPMNT & B16W65 & SAGEMOOR AREA & PERIMETER & $\mathrm{BI}$ & ALFALFA & STM-LV & 25-Apr-03 & Co-60 & 0.00182 & $\mathrm{pCi} / \mathrm{g}$ & 0.019 & 0.019 & u & CUT FROM OUTER EDGE OF CIRCLE, WET. & \\
\hline SESPMNT & B16W72 & SUNNYSIDE AREA & DISTANT & $\mathrm{BI}$ & ALFALFA & STM-LV & 01-May-03 & Co-60 & 0.0122 & $\mathrm{pCi} / \mathrm{g}$ & 0.015 & 0.015 & u & & \\
\hline SESPMNT & B16W76 & HORN RAPIDS AREA & PERIMETER & BI & ALFALFA & STM-LV & 22-Apr-03 & Cs-134 & -0.0017 & $\mathrm{pCi} / \mathrm{g}$ & 0.013 & 0.013 & $u$ & WET CUT FROM FIELD. & \\
\hline SESPMNT & B16W67 & RIVERVIEW AREA & COMMUNITY & $\mathrm{BI}$ & ALFALFA & STM-LV & 09-May-03 & Cs-134 & 0.00685 & $\mathrm{pCi} / \mathrm{g}$ & 0.012 & 0.012 & $\mathrm{u}$ & & \\
\hline SESPMNT & B16W65 & SAGEMOOR AREA & PERIMETER & $\mathrm{BI}$ & ALFALFA & STM-LV & 25-Apr-03 & Cs-134 & 0.00704 & $\mathrm{pCi} / \mathrm{g}$ & 0.019 & 0.019 & $\mathrm{u}$ & CUT FROM OUTER EDGE OF CIRCLE, WET. & \\
\hline SESPMNT & B16W72 & SUNNYSIDE AREA & DISTANT & BI & ALFALFA & STM-LV & 01-May-03 & Cs-134 & 0.0104 & $\mathrm{pCi} / \mathrm{g}$ & 0.014 & 0.014 & $\mathrm{u}$ & & \\
\hline SESPMNT & B16W76 & HORN RAPIDS AREA & PERIMETER & $\mathrm{BI}$ & ALFALFA & STM-LV & 22-Apr-03 & Cs-137 & 0.00312 & $\mathrm{pCi} / \mathrm{g}$ & 0.011 & 0.011 & $\mathrm{u}$ & WET CUT FROM FIELD. & \\
\hline SESPMNT & B16W67 & RIVERVIEW AREA & COMMUNITY & $\mathrm{Bl}$ & ALFALFA & STM-LV & 09-May-03 & Cs-137 & 0.00152 & $\mathrm{pCi} / \mathrm{g}$ & 0.01 & 0.01 & $u$ & & \\
\hline SESPMNT & B16W65 & SAGEMOOR AREA & PERIMETER & $\mathrm{BI}$ & ALFALFA & STM-LV & 25-Apr-03 & Cs-137 & 0.00657 & $\mathrm{pCi} / \mathrm{g}$ & 0.016 & 0.016 & $\mathrm{u}$ & CUT FROM OUTER EDGE OF CIRCLE, WET. & \\
\hline SESPMNT & B16W72 & SUNNYSIDE AREA & DISTANT & $\mathrm{BI}$ & ALFALFA & STM-LV & 01-May-03 & Cs-137 & 0.0067 & $\mathrm{pCi} / \mathrm{g}$ & 0.012 & 0.012 & $\mathrm{u}$ & & \\
\hline SESPMNT & B16W76 & HORN RAPIDS AREA & PERIMETER & $\mathrm{BI}$ & ALFALFA & STM-LV & 22-Apr-03 & Eu-152 & 0.00796 & $\mathrm{pCi} / \mathrm{g}$ & 0.025 & 0.025 & u & WET CUT FROM FIELD. & \\
\hline SESPMNT & B16W67 & RIVERVIEW AREA & COMMUNITY & $\mathrm{BI}$ & ALFALFA & STM-LV & 09-May-03 & Eu-152 & -0.019 & $\mathrm{pCi} / \mathrm{g}$ & 0.025 & 0.025 & $\mathrm{u}$ & & \\
\hline SESPMNT & B16W65 & SAGEMOOR AREA & PERIMETER & BI & ALFALFA & STM-LV & 25-Apr-03 & Eu-152 & -0.0282 & $\mathrm{pCi} / \mathrm{g}$ & 0.039 & 0.039 & u & CUT FROM OUTER EDGE OF CIRCLE, WET. & \\
\hline SESPMNT & B16W72 & SUNNYSIDE AREA & DISTANT & BI & ALFALFA & STM-LV & 01-May-03 & Eu-152 & -0.0144 & $\mathrm{pCi} / \mathrm{g}$ & 0.027 & 0.027 & u & & \\
\hline SESPMNT & B16W76 & HORN RAPIDS AREA & PERIMETER & $\mathrm{Bl}$ & ALFALFA & STM-LV & 22-Apr-03 & Eu-154 & -0.031 & $\mathrm{pCi} / \mathrm{g}$ & 0.052 & 0.052 & $u$ & WET CUT FROM FIELD. & \\
\hline SESPMNT & B16W67 & RIVERVIEW AREA & COMMUNITY & $\mathrm{BI}$ & ALFALFA & STM-LV & 09-May-03 & Eu-154 & -0.0153 & $\mathrm{pCi} / \mathrm{g}$ & 0.041 & 0.041 & u & & \\
\hline SESPMNT & B16W65 & SAGEMOOR AREA & PERIMETER & $\mathrm{BI}$ & ALFALFA & STM-LV & 25-Apr-03 & Eu-154 & -0.0114 & $\mathrm{pCi} / \mathrm{g}$ & 0.067 & 0.067 & u & CUT FROM OUTER EDGE OF CIRCLE, WET. & \\
\hline SESPMNT & B16W72 & SUNNYSIDE AREA & DISTANT & BI & ALFALFA & STM-LV & 01-May-03 & Eu-154 & 0.00652 & $\mathrm{pCi} / \mathrm{g}$ & 0.05 & 0.05 & $\mathrm{u}$ & & \\
\hline SESPMNT & B16W76 & HORN RAPIDS AREA & PERIMETER & $\mathrm{BI}$ & ALFALFA & STM-LV & 22-Apr-03 & Eu-155 & -0.0153 & $\mathrm{pCi} / \mathrm{g}$ & 0.025 & 0.025 & $u$ & WET CUT FROM FIELD. & \\
\hline SESPMNT & B16W67 & RIVERVIEW AREA & COMMUNITY & $\mathrm{BI}$ & ALFALFA & STM-LV & 09-May-03 & Eu-155 & -0.00156 & $\mathrm{pCi} / \mathrm{g}$ & 0.02 & 0.02 & $\mathrm{u}$ & & \\
\hline SESPMNT & B16W65 & SAGEMOOR AREA & PERIMETER & BI & ALFALFA & STM-LV & 25-Apr-03 & Eu-155 & 0.0419 & $\mathrm{pCi} / \mathrm{g}$ & 0.047 & 0.047 & $\mathrm{u}$ & CUT FROM OUTER EDGE OF CIRCLE, WET. & \\
\hline SESPMNT & B16W72 & SUNNYSIDE AREA & DISTANT & $\mathrm{BI}$ & ALFALFA & STM-LV & 01-May-03 & Eu-155 & 0.0197 & $\mathrm{pCi} / \mathrm{g}$ & 0.023 & 0.023 & $\mathrm{u}$ & & \\
\hline SESPMNT & B16W76 & HORN RAPIDS AREA & PERIMETER & BI & ALFALFA & STM-LV & 22-Apr-03 & $\mathrm{K}-40$ & 34.6 & $\mathrm{pCi} / \mathrm{g}$ & 4.2 & 4.2 & & WET CUT FROM FIELD. & \\
\hline SESPMNT & B16W67 & RIVERVIEW AREA & COMMUNITY & $\mathrm{BI}$ & ALFALFA & STM-LV & 09-May-03 & $\mathrm{k}-40$ & 15.2 & $\mathrm{pCi} / \mathrm{g}$ & 2.1 & 2.1 & & & \\
\hline SESPMNT & B16W65 & SAGEMOOR AREA & PERIMETER & $\mathrm{BI}$ & ALFALFA & STM-LV & 25-Apr-03 & $\mathrm{K}-40$ & 29.3 & $\mathrm{pCi} / \mathrm{g}$ & 4 & 4 & & CUT FROM OUTER EDGE OF CIRCLE, WET. & \\
\hline SESPMNT & B16W72 & SUNNYSIDE AREA & DISTANT & $\mathrm{BI}$ & ALFALFA & STM-LV & 01-May-03 & $\mathrm{k}-40$ & 27.9 & $\mathrm{pCi} / \mathrm{g}$ & 3.7 & 3.7 & & & \\
\hline SESPMNT & B16W76 & HORN RAPIDS AREA & PERIMETER & $\mathrm{BI}$ & ALFALFA & STM-LV & 22-Apr-03 & Ru-106 & -0.0359 & $\mathrm{pCi} / \mathrm{g}$ & 0.095 & 0.095 & $\mathrm{u}$ & WET CUT FROM FIELD. & \\
\hline SESPMNT & B16W67 & RIVERVIEW AREA & COMMUNITY & BI & ALFALFA & STM-LV & 09-May-03 & Ru-106 & -0.0623 & $\mathrm{pCi} / \mathrm{g}$ & 0.082 & 0.082 & $\mathrm{u}$ & & \\
\hline SESPMNT & B16W65 & SAGEMOOR AREA & PERIMETER & $\mathrm{BI}$ & ALFALFA & STM-LV & 25-Apr-03 & Ru-106 & -0.0957 & $\mathrm{pCi} / \mathrm{g}$ & 0.14 & 0.14 & $u$ & CUT FROM OUTER EDGE OF CIRCLE, WET. & \\
\hline SESPMNT & B16W72 & SUNNYSIDE AREA & DISTANT & $\mathrm{BI}$ & ALFALFA & STM-LV & 01-May-03 & Ru-106 & -0.0408 & $\mathrm{pCi} / \mathrm{g}$ & 0.1 & 0.1 & $\mathrm{u}$ & & \\
\hline SESPMNT & B16W76 & HORN RAPIDS AREA & PERIMETER & BI & ALFALFA & STM-LV & 22-Apr-03 & Sb-125 & -0.00436 & $\mathrm{pCi} / \mathrm{g}$ & 0.026 & 0.026 & u & WET CUT FROM FIELD. & \\
\hline SESPMNT & B16W67 & RIVERVIEW AREA & COMMUNITY & BI & ALFALFA & STM-LV & 09-May-03 & Sb-125 & -0.0132 & $\mathrm{pCi} / \mathrm{g}$ & 0.023 & 0.023 & u & & \\
\hline SESPMNT & B16W65 & SAGEMOOR AREA & PERIMETER & $\mathrm{BI}$ & ALFALFA & STM-LV & 25-Apr-03 & Sb-125 & -0.0103 & $\mathrm{pCi} / \mathrm{g}$ & 0.038 & 0.038 & $\mathrm{u}$ & CUT FROM OUTER EDGE OF CIRCLE, WET. & \\
\hline SESPMNT & B16W72 & SUNNYSIDE AREA & DISTANT & $\mathrm{BI}$ & ALFALFA & STM-LV & 01-May-03 & Sb-125 & 0.0243 & $\mathrm{pCi} / \mathrm{g}$ & 0.028 & 0.028 & $\mathrm{u}$ & & \\
\hline SESPMNT & B16W76 & HORN RAPIDS AREA & PERIMETER & BI & ALFALFA & STM-LV & 22-Apr-03 & Sr-90 & 0.037 & $\mathrm{pCi} / \mathrm{g}$ & 0.039 & 0.039 & u & WET CUT FROM FIELD. & \\
\hline SESPMNT & B16W67 & RIVERVIEW AREA & COMMUNITY & $\mathrm{BI}$ & ALFALFA & STM-LV & 09-May-03 & Sr-90 & 0.0978 & $\mathrm{pCi} / \mathrm{g}$ & 0.018 & 0.027 & & & \\
\hline SESPMNT & B16W65 & SAGEMOOR AREA & PERIMETER & $\mathrm{BI}$ & ALFALFA & STM-LV & 25-Apr-03 & Sr-90 & 0.0362 & $\mathrm{pCi} / \mathrm{g}$ & 0.017 & 0.019 & & CUT FROM OUTER EDGE OF CIRCLE, WET. & \\
\hline SESPMNT & B16W72 & SUNNYSIDE AREA & DISTANT & BI & ALFALFA & STM-LV & 01-May-03 & Sr-90 & 0.064 & $\mathrm{pCi} / \mathrm{g}$ & 0.024 & 0.027 & & & \\
\hline SESPMNT & B17DN2 & MATTAWA AREA & COMMUNITY & $\mathrm{BI}$ & APPLES & FRUIT & 11-Sep-03 & Be-7 & -0.0034 & $\mathrm{pCi} / \mathrm{g}$ & 0.047 & 0.047 & $\mathrm{u}$ & & \\
\hline SESPMNT & B17DM7 & RIVERVIEW AREA & COMMUNITY & $\mathrm{Bl}$ & APPLES & FRUIT & 19-Sep-03 & $\mathrm{Be}-7$ & 0.0295 & $\mathrm{pCi} / \mathrm{g}$ & 0.047 & 0.047 & $u$ & & \\
\hline SESPMNT & B17DL9 & SAGEMOOR AREA & PERIMETER & $\mathrm{BI}$ & APPLES & FRUIT & 12-Sep-03 & Be-7 & -0.0116 & $\mathrm{pCi} / \mathrm{g}$ & 0.038 & 0.038 & $u$ & & \\
\hline SESPMNT & B17DM4 & SUNNYSIDE AREA & DISTANT & $\mathrm{BI}$ & APPLES & FRUIT & 18-Sep-03 & Be-7 & -0.0224 & $\mathrm{pCi} / \mathrm{g}$ & 0.054 & 0.054 & u & & \\
\hline SESPMNT & B17DN2 & MATTAWA AREA & COMMUNITY & $\mathrm{BI}$ & APPLES & FRUIT & 11-Sep-03 & Co-60 & -0.00254 & $\mathrm{pCi} / \mathrm{g}$ & 0.0053 & 0.0053 & u & & \\
\hline SESPMNT & B17DM7 & RIVERVIEW AREA & COMMUNITY & $\mathrm{BI}$ & APPLES & FRUIT & 19-Sep-03 & Co-60 & 0.00231 & $\mathrm{pCi} / \mathrm{g}$ & 0.0058 & 0.0058 & $u$ & & \\
\hline SESPMNT & B17DL9 & SAGEMOOR AREA & PERIMETER & $\mathrm{BI}$ & APPLES & FRUIT & 12-Sep-03 & Co-60 & 0.00118 & $\mathrm{pCi} / \mathrm{g}$ & 0.0042 & 0.0042 & u & & \\
\hline SESPMNT & B17DM4 & SUNNYSIDE AREA & DISTANT & BI & APPLES & FRUIT & 18-Sep-03 & Co-60 & 0.00783 & $\mathrm{pCi} / \mathrm{g}$ & 0.0066 & 0.0066 & $u$ & & \\
\hline SESPMNT & B17DN2 & MATTAWA AREA & COMMUNITY & $\mathrm{BI}$ & APPLES & FRUIT & 11-Sep-03 & Cs-134 & 0.00655 & $\mathrm{pCi} / \mathrm{g}$ & 0.0056 & 0.0056 & $\mathrm{U}$ & & \\
\hline SESPMNT & B17DM7 & RIVERVIEW AREA & COMMUNITY & $\mathrm{BI}$ & APPLES & FRUIT & 19-Sep-03 & Cs-134 & -0.00141 & $\mathrm{pCi} / \mathrm{g}$ & 0.006 & 0.006 & u & & \\
\hline SESPMNT & B17DL9 & SAGEMOOR AREA & PERIMETER & $\mathrm{BI}$ & APPLES & FRUIT & 12-Sep-03 & Cs-134 & 0.000891 & $\mathrm{pCi} / \mathrm{g}$ & 0.0051 & 0.0051 & $u$ & & \\
\hline SESPMNT & B17DM4 & SUNNYSIDE AREA & DISTANT & $\mathrm{BI}$ & APPLES & FRUIT & 18-Sep-03 & Cs-134 & 0.00775 & $\mathrm{pCi} / \mathrm{g}$ & 0.0061 & 0.0061 & U & & \\
\hline SESPMNT & B17DN2 & MATTAWA AREA & COMMUNITY & $\mathrm{Bl}$ & APPLES & FRUIT & 11-Sep-03 & Cs-137 & -0.000702 & $\mathrm{pCi} / \mathrm{g}$ & 0.0054 & 0.0054 & $u$ & & \\
\hline
\end{tabular}


(pCi/g Wet Weight)

\begin{tabular}{|c|c|c|c|c|c|c|c|c|c|c|c|c|c|c|c|}
\hline $\mid$ OWNER ID $\mid$ & SAMP NUM & SAMP SITE NAME & | DIST CLASS & MEDIA & SAMP FROM & SAMP ITEM & SAMP DATE & $\begin{array}{c}\text { CON SHORT } \\
\text { NAME }\end{array} \mid$ & |VALUE RPTD & \begin{tabular}{|l|} 
ANAL \\
UNITS \\
RPTD
\end{tabular} & $\left|\begin{array}{c}\text { COUNTING } \\
\text { ERROR }\end{array}\right|$ & $\left|\begin{array}{c}\text { TOTAL ANAL } \\
\text { ERROR }\end{array}\right|$ & $\left|\begin{array}{c}\text { LAB } \\
\text { QUALIFIER }\end{array}\right|$ & SAMP COMMENT & |RESULT COMMENT \\
\hline SESPMNT & B17DM7 & RIVERVIEW AREA & COMMUNITY & $\mathrm{BI}$ & APPLES & FRUIT & 19-Sep-03 C & Cs-137 & 0.0051 & $\mathrm{pCi} / \mathrm{g}$ & 0.0055 & 0.0055 & u & & \\
\hline SESPMNT & B17DL9 & SAGEMOOR AREA & PERIMETER & $\mathrm{BI}$ & APPLES & FRUIT & $12-\mathrm{Sep}-03 \mathrm{C}$ & Cs-137 & 0.00399 & $\mathrm{pCi} / \mathrm{g}$ & 0.0043 & 0.0043 & u & & \\
\hline SESPMNT & B17DM4 & SUNNYSIDE AREA & DISTANT & $\mathrm{BI}$ & APPLES & FRUIT & 18-Sep-03 & Cs-137 & 0.00301 & $\mathrm{pCi} / \mathrm{g}$ & 0.0062 & 0.0062 & u & & \\
\hline SESPMNT & B17DN2 & MATTAWA AREA & COMMUNITY & $\mathrm{BI}$ & APPLES & FRUIT & $11-\mathrm{Sep}-03$ & Eu-152 & 0.000981 & $\mathrm{pCi} / \mathrm{g}$ & 0.014 & $\begin{array}{r}0.014 \\
\end{array}$ & u & & \\
\hline SESPMNT & B17DM7 & RIVERVIEW AREA & COMMUNITY & $\mathrm{BI}$ & APPLES & FRUIT & 19-Sep-03 & Eu-152 & -0.00262 & $\mathrm{pCi} / \mathrm{g}$ & 0.013 & 0.013 & U & & \\
\hline SESPMNT & B17DL9 & SAGEMOOR AREA & PERIMETER & $\mathrm{BI}$ & APPLES & FRUIT & 12-Sep-03 & Eu-152 & 0.00471 & $\mathrm{pCi} / \mathrm{g}$ & 0.01 & 0.01 & u & & \\
\hline SESPMNT & B17DM4 & SUNNYSIDE AREA & DISTANT & $\mathrm{BI}$ & APPLES & FRUIT & 18-Sep-03 & Eu-152 & 0.0000641 & $\mathrm{pCi} / \mathrm{g}$ & 0.014 & 0.014 & U & & \\
\hline SESPMNT & B17DN2 & MATTAWA AREA & COMMUNITY & $\mathrm{BI}$ & APPLES & FRUIT & 11-Sep-03 & Eu-154 & -0.00174 & $\mathrm{pCi} / \mathrm{g}$ & 0.015 & 0.015 & $U$ & & \\
\hline SESPMNT & B17DM7 & RIVERVIEW AREA & COMMUNITY & $\mathrm{BI}$ & APPLES & FRUIT & 19-Sep-03 & Eu-154 & -0.00387 & $\mathrm{pCi} / \mathrm{g}$ & 0.016 & 0.016 & u & & \\
\hline SESPMNT & B17DL9 & SAGEMOOR AREA & PERIMETER & $\mathrm{BI}$ & APPLES & FRUIT & 12-Sep-03 & Eu-154 & 0.00353 & $\mathrm{pCi} / \mathrm{g}$ & 0.014 & 0.014 & u & & \\
\hline SESPMNT & B17DM4 & SUNNYSIDE AREA & DISTANT & $\mathrm{BI}$ & APPLES & FRUIT & 18-Sep-03 & Eu-154 & -0.0125 & $\mathrm{pCi} / \mathrm{g}$ & 0.018 & 0.018 & U & & \\
\hline SESPMNT & B17DN2 & MATTAWA AREA & COMMUNITY & $\mathrm{BI}$ & APPLES & FRUIT & 11-Sep-03 & Eu-155 & -0.005 & $\mathrm{pCi} / \mathrm{g}$ & 0.011 & 0.011 & U & & \\
\hline SESPMNT & B17DM7 & RIVERVIEW AREA & COMMUNITY & $\mathrm{BI}$ & APPLES & FRUIT & $19-S e p-03$ & Eu-155 & 0.00658 & $\mathrm{pCi/g}$ & 0.013 & 0.013 & u & & \\
\hline SESPMNT & B17DL9 & SAGEMOOR AREA & PERIMETER & $\mathrm{BI}$ & APPLES & FRUIT & 12-Sep-03 & Eu-155 & 0.00692 & $\mathrm{pCi} / \mathrm{g}$ & 0.0099 & 0.0099 & u & & \\
\hline SESPMNT & B17DM4 & SUNNYSIDE AREA & DISTANT & $\mathrm{BI}$ & APPLES & FRUIT & 18-Sep-03 & Eu-155 & -0.003 & $\mathrm{pCi} / \mathrm{g}$ & 0.015 & 0.015 & $u$ & & \\
\hline SESPMNT & B17DN2 & MATTAWA AREA & COMMUNITY & $\mathrm{BI}$ & APPLES & FRUIT & 11-Sep-03 r & $\mathrm{K}-40$ & 0.945 & $\mathrm{pCi} / \mathrm{g}$ & 0.21 & 0.21 & & & \\
\hline SESPMNT & B17DM7 & RIVERVIEW AREA & COMMUNITY & $\mathrm{BI}$ & APPLES & FRUIT & 19-Sep-03 r & $\mathrm{K}-40$ & 1.05 & $\mathrm{pCi} / \mathrm{g}$ & 0.24 & 0.24 & & & \\
\hline SESPMNT & B17DL9 & SAGEMOOR AREA & PERIMETER & $\mathrm{BI}$ & APPLES & FRUIT & 12-Sep-03 F & K-40 & 1.12 & $\mathrm{pCi} / \mathrm{g}$ & 0.21 & 0.21 & & & \\
\hline SESPMNT & B17DM4 & SUNNYSIDE AREA & DISTANT & $\mathrm{BI}$ & APPLES & FRUIT & 18-Sep-03 r & K-40 & 0.682 & $\mathrm{pCi} / \mathrm{g}$ & 0.23 & 0.23 & & & \\
\hline SESPMNT & B17DN2 & MATTAWA AREA & COMMUNITY & $\mathrm{BI}$ & APPLES & FRUIT & 11-Sep-03 F & Ru-106 & -0.00568 & $\mathrm{pCi} / \mathrm{g}$ & 0.047 & 0.047 & $u$ & & \\
\hline SESPMNT & B17DM7 & RIVERVIEW AREA & COMMUNITY & $\mathrm{BI}$ & APPLES & FRUIT & 19-Sep-03 F & Ru-106 & 0.0278 & $\mathrm{pCi} / \mathrm{g}$ & 0.048 & 0.048 & u & & \\
\hline SESPMNT & B17DL9 & SAGEMOOR AREA & PERIMETER & $\mathrm{BI}$ & APPLES & FRUIT & 12-Sep-03 & Ru-106 & -0.0306 & $\mathrm{pCi} / \mathrm{g}$ & 0.039 & 0.039 & u & & \\
\hline SESPMNT & B17DM4 & SUNNYSIDE AREA & DISTANT & $\mathrm{BI}$ & APPLES & FRUIT & 18-Sep-03 & Ru-106 & 0.0426 & $\mathrm{pCi} / \mathrm{g}$ & 0.051 & 0.051 & u & & \\
\hline SESPMNT & B17DN2 & MATTAWA AREA & COMMUNITY & $\mathrm{BI}$ & APPLES & FRUIT & 11-Sep-03 s & Sb-125 & -0.00638 & $\mathrm{pCi} / \mathrm{g}$ & 0.013 & 0.013 & $u$ & & \\
\hline SESPMNT & B17DM7 & RIVERVIEW AREA & COMMUNITY & $\mathrm{BI}$ & APPLES & FRUIT & $19-\mathrm{Sep}-03 \mathrm{~s}$ & Sb-125 & -0.00415 & $\mathrm{pCi} / \mathrm{g}$ & 0.013 & 0.013 & u & & \\
\hline SESPMNT & B17DL9 & SAGEMOOR AREA & PERIMETER & $\mathrm{BI}$ & APPLES & FRUIT & 12-Sep-03 & $\mathrm{Sb}-125$ & -0.00796 & $\mathrm{pCi} / \mathrm{g}$ & 0.011 & 0.011 & $u$ & & \\
\hline SESPMNT & B17DM4 & SUNNYSIDE AREA & DISTANT & $\mathrm{BI}$ & APPLES & FRUIT & $18-\mathrm{Sep}-03 \mathrm{~s}$ & Sb-125 & -0.0077 & $\mathrm{pCi} / \mathrm{g}$ & 0.014 & 0.014 & u & & \\
\hline SESPMNT & B17DN2 & MATTAWA AREA & COMMUNITY & $\mathrm{BI}$ & APPLES & FRUIT & $11-\mathrm{Sep}-03 \mathrm{~s}$ & Sr-90 & 0.000369 & $\mathrm{pCi} / \mathrm{g}$ & 0.0014 & 0.0016 & U & & \\
\hline SESPMNT & B17DM7 & RIVERVIEW AREA & COMMUNITY & $\mathrm{BI}$ & APPLES & FRUIT & $19-S e p-03$ s & Sr-90 & -0.00118 & $\mathrm{pCi} / \mathrm{g}$ & 0.0016 & 0.0016 & u & & \\
\hline SESPMNT & B17DL9 & SAGEMOOR AREA & PERIMETER & $\mathrm{BI}$ & APPLES & FRUIT & $12-\mathrm{Sep}-03 \mathrm{~s}$ & Sr-90 & -0.000812 & $\mathrm{pCi} / \mathrm{g}$ & 0.0012 & 0.0016 & u & & \\
\hline SESPMNT & B17DM4 & SUNNYSIDE AREA & DISTANT & $\mathrm{BI}$ & APPLES & FRUIT & 18-Sep-03s & Sr-90 & 0.000427 & $\mathrm{pCi} / \mathrm{g}$ & 0.0016 & 0.0016 & $U$ & & \\
\hline SESPMNT & B16T48 & RIVERVIEW AREA & COMMUNITY & $\mathrm{BI}$ & ASPARAGUS & SHOOT & 03-Apr-03 & GAMMA SCAN & & & & & & NO SAMPLE. UNABLE TO LOCATE. & \\
\hline SESPMNT & B16T50 & SAGEMOOR AREA & PERIMETER & $\mathrm{BI}$ & ASPARAGUS & SHOOT & 10-Apr-03 & $\mathrm{Be}-7$ & -0.00632 & pCi/g & 0.037 & 0.037 & $u$ & & \\
\hline SESPMNT & B16T52 & SUNNYSIDE AREA & DISTANT & $\mathrm{BI}$ & ASPARAGUS & SHOOT & 18-Apr-03 & Be-7 & 0.0269 & $\mathrm{pCi} / \mathrm{g}$ & 0.024 & 0.024 & $\mathrm{U}$ & & \\
\hline SESPMNT & B16T50 & SAGEMOOR AREA & PERIMETER & $\mathrm{BI}$ & ASPARAGUS & SHOOT & 10-Apr-03 & Co-60 & 0.00306 & $\mathrm{pCi} / \mathrm{g}$ & 0.0053 & 0.0053 & u & & \\
\hline SESPMNT & B16T52 & SUNNYSIDE AREA & DISTANT & $\mathrm{BI}$ & ASPARAGUS & SHOOT & 18-Apr-03 & Co-60 & 0.00335 & $\mathrm{pCi} / \mathrm{g}$ & 0.0039 & 0.0039 & u & & \\
\hline SESPMNT & B16T50 & SAGEMOOR AREA & PERIMETER & $\mathrm{BI}$ & ASPARAGUS & SHOOT & 10-Apr-03 & Cs-134 & 0.00156 & $\mathrm{pCi} / \mathrm{g}$ & 0.0052 & 0.0052 & u & & \\
\hline SESPMNT & B16T52 & SUNNYSIDE AREA & DISTANT & $\mathrm{BI}$ & ASPARAGUS & SHOOT & 18-Apr-03 & Cs-134 & 0.00347 & $\mathrm{pCi} / \mathrm{g}$ & 0.0039 & 0.0039 & 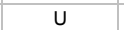 & & \\
\hline SESPMNT & B16T50 & SAGEMOOR AREA & PERIMETER & $\mathrm{BI}$ & ASPARAGUS & SHOOT & 10-Apr-03 C & Cs-137 & 0.00377 & $\mathrm{pCi} / \mathrm{g}$ & 0.0049 & 0.0049 & $\mathrm{u}$ & & \\
\hline SESPMNT & B16T52 & SUNNYSIDE AREA & DISTANT & $\mathrm{BI}$ & ASPARAGUS & SHOOT & 18-Apr-03 C & Cs-137 & -0.00109 & $\mathrm{pCi} / \mathrm{g}$ & 0.003 & 0.003 & $u$ & & \\
\hline SESPMNT & B16T50 & SAGEMOOR AREA & PERIMETER & $\mathrm{BI}$ & ASPARAGUS & SHOOT & 10-Apr-03 & Eu-152 & -0.00706 & $\mathrm{pCi} / \mathrm{g}$ & 0.012 & 0.012 & u & & \\
\hline SESPMNT & B16T52 & SUNNYSIDE AREA & DISTANT & $\mathrm{BI}$ & ASPARAGUS & SHOOT & 18-Apr-03 & Eu-152 & 0.00704 & $\mathrm{pCi} / \mathrm{g}$ & 0.0079 & 0.0079 & u & & \\
\hline SESPMNT & B16T50 & SAGEMOOR AREA & PERIMETER & $\mathrm{BI}$ & ASPARAGUS & SHOOT & 10-Apr-03 & Eu-154 & 0.00395 & $\mathrm{pCi} / \mathrm{g}$ & 0.016 & 0.016 & u & & \\
\hline SESPMNT & B16T52 & SUNNYSIDE AREA & DISTANT & $\mathrm{BI}$ & ASPARAGUS & SHOOT & 18-Apr-03 & Eu-154 & -0.00503 & $\mathrm{pCi} / \mathrm{g}$ & 0.012 & 0.012 & $u$ & & \\
\hline SESPMNT & B16T50 & SAGEMOOR AREA & PERIMETER & $\mathrm{BI}$ & ASPARAGUS & SHOOT & 10-Apr-03 & Eu-155 & -0.005 & $\mathrm{pCi} / \mathrm{g}$ & 0.013 & 0.013 & u & & \\
\hline SESPMNT & B16T52 & SUNNYSIDE AREA & DISTANT & $\mathrm{BI}$ & ASPARAGUS & SHOOT & 18-Apr-03 & Eu-155 & 0.00234 & $\mathrm{pCi} / \mathrm{g}$ & 0.0081 & 0.0081 & u & & \\
\hline SESPMNT & B16T50 & SAGEMOOR AREA & PERIMETER & $\mathrm{BI}$ & ASPARAGUS & SHOOT & 10-Apr-03 r & $\mathrm{K}-40$ & 2.36 & $\mathrm{pCi} / \mathrm{g}$ & 0.33 & 0.33 & & & \\
\hline SESPMNT & B16T52 & SUNNYSIDE AREA & DISTANT & $\mathrm{BI}$ & ASPARAGUS & SHOOT & 18-Apr-03 r & K-40 & 2.89 & $\mathrm{pCi} / \mathrm{g}$ & 0.38 & 0.38 & & & \\
\hline SESPMNT & B16T50 & SAGEMOOR AREA & PERIMETER & $\mathrm{BI}$ & ASPARAGUS & SHOOT & 10-Apr-03 & Ru-106 & -0.00803 & $\mathrm{pCi} / \mathrm{g}$ & 0.039 & 0.039 & $u$ & & \\
\hline SESPMNT & B16T52 & SUNNYSIDE AREA & DISTANT & BI & ASPARAGUS & SHOOT & 18-Apr-03 F & Ru-106 & -0.00541 & $\mathrm{pCi} / \mathrm{g}$ & 0.029 & 0.029 & U & & \\
\hline SESPMNT & B16T50 & SAGEMOOR AREA & PERIMETER & $\mathrm{BI}$ & ASPARAGUS & SHOOT & 10-Apr-03 & $\mathrm{Sb}-125$ & 0.00614 & $\mathrm{pCi} / \mathrm{g}$ & 0.011 & 0.011 & $u$ & & \\
\hline SESPMNT & B16T52 & SUNNYSIDE AREA & DISTANT & $\mathrm{BI}$ & ASPARAGUS & SHOOT & 18-Apr-03 s & Sb-125 & -0.00324 & $\mathrm{pCi} / \mathrm{g}$ & 0.0073 & 0.0073 & $\mathrm{u}$ & & \\
\hline SESPMNT & B16T48 & RIVERVIEW AREA & COMMUNITY & $\mathrm{BI}$ & ASPARAGUS & SHOOT & 03-Apr-03 s & Sr-90 & & & & & & NO SAMPLE. UNABLE TO LOCATE. & \\
\hline SESPMNT & B16T50 & SAGEMOOR AREA & PERIMETER & $\mathrm{BI}$ & ASPARAGUS & SHOOT & 10-Apr-03 & Sr-90 & 0.00193 & $\mathrm{pCi} / \mathrm{g}$ & 0.0053 & 0.0053 & u & & \\
\hline SESPMNT & B16T52 & SUNNYSIDE AREA & DISTANT & $\mathrm{BI}$ & ASPARAGUS & SHOOT & 18-Apr-03 s & Sr-90 & -0.00249 & $\mathrm{pCi} / \mathrm{g}$ & 0.034 & 0.075 & u & & \\
\hline SESPMNT & B16T48 & RIVERVIEW AREA & COMMUNITY & $\mathrm{BI}$ & ASPARAGUS & SHOOT & 03-Apr-03 L & $\mathrm{U}-234$ & & & & & & NO SAMPLE. UNABLE TO LOCATE. & \\
\hline SESPMNT & B16T50 & SAGEMOOR AREA & PERIMETER & $\mathrm{BI}$ & ASPARAGUS & SHOOT & 10-Apr-03 & $\mathrm{U}-234$ & -0.0107 & $\mathrm{pCi} / \mathrm{g}$ & 0.0068 & 0.0094 & $\mathrm{u}$ & & \\
\hline
\end{tabular}


FOODSTUFF

(pCi/g Wet Weight)

\begin{tabular}{|c|c|c|c|c|c|c|c|c|c|c|c|c|c|c|c|}
\hline OWNER ID & SAMP NUM & SAMP SITE NAME & DIST CLASS & MEDIA & SAMP FROM & SAMP ITEM & SAMP DATE & $\begin{array}{l}\text { CON SHORT } \\
\text { NAME }\end{array}$ & VALUE RPTD & \begin{tabular}{|l|} 
ANAL \\
UNITS \\
RPTD
\end{tabular} & $\left|\begin{array}{c}\text { COUNTING } \\
\text { ERROR }\end{array}\right|$ & $\left|\begin{array}{c}\text { TOTAL ANAL } \\
\text { ERROR }\end{array}\right|$ & $\mid \begin{array}{c}\text { LAB } \\
\text { QUALIFIER }\end{array}$ & SAMP COMMENT & RESULT COMMENT \\
\hline SESPMNT & B16T52 & SUNNYSIDE AREA & DISTANT & $\mathrm{BI}$ & ASPARAGUS & SHOOT & 18-Apr-03 & $\mathrm{U}-234$ & 0.000254 & $\mathrm{pCi} / \mathrm{g}$ & 0.0069 & 0.007 & u & & \\
\hline SESPMNT & B16T48 & RIVERVIEW AREA & COMMUNITY & $\mathrm{BI}$ & ASPARAGUS & SHOOT & 03-Apr-03 & $\mathrm{U}-235$ & & & & & & NO SAMPLE. UNABLE TO LOCATE. & \\
\hline SESPMNT & B16T50 & SAGEMOOR AREA & PERIMETER & $\mathrm{BI}$ & ASPARAGUS & SHOOT & 10-Apr-03 & $\mathrm{U}-235$ & -0.004 & $\mathrm{pCi} / \mathrm{g}$ & 0.0057 & 0.0074 & $\mathrm{u}$ & & \\
\hline SESPMNT & B16T52 & SUNNYSIDE AREA & DISTANT & $\mathrm{BI}$ & ASPARAGUS & SHOOT & 18-Apr-03 & $\mathrm{U}-235$ & -0.000142 & $\mathrm{pCi} / \mathrm{g}$ & 0.0035 & 0.0036 & $u$ & & \\
\hline SESPMNT & B16T48 & RIVERVIEW AREA & COMMUNITY & $\mathrm{BI}$ & ASPARAGUS & SHOOT & 03-Apr-03 & $\mathrm{U}-238$ & & & & & & NO SAMPLE. UNABLE TO LOCATE. & \\
\hline SESPMNT & B16T50 & SAGEMOOR AREA & PERIMETER & $\mathrm{BI}$ & ASPARAGUS & SHOOT & 10-Apr-03 & $\mathrm{U}-238$ & 0.00253 & $\mathrm{pCi} / \mathrm{g}$ & 0.008 & 0.0091 & $\mathrm{u}$ & & \\
\hline SESPMNT & B16T52 & SUNNYSIDE AREA & DISTANT & $\mathrm{BI}$ & ASPARAGUS & SHOOT & 18-Apr-03 & U-238 & -0.00818 & $\mathrm{pCi} / \mathrm{g}$ & 0.0059 & 0.0061 & $u$ & & \\
\hline SESPMNT & B186H8 & EAST WAHLUKE AREA & COMMUNITY & $\mathrm{BI}$ & BEES & HONEY & 19-Dec-03 & Be-7 & -0.00222 & $\mathrm{pCi} / \mathrm{g}$ & 0.068 & 0.068 & $u$ & HIVES BETWEEN PASCO AND BASIN CITY. & \\
\hline SESPMNT & B186H6 & YAKIMA VALLEY & $\begin{array}{l}\text { DISTANT } \\
\end{array}$ & $\mathrm{BI}$ & BEES & HONEY & 16-Dec-03 & Be-7 & 0.0164 & $\mathrm{pCi} / \mathrm{g}$ & 0.066 & 0.066 & $\mathrm{u}$ & & \\
\hline SESPMNT & B186H8 & EAST WAHLUKE AREA & COMMUNITY & $\mathrm{BI}$ & BEES & HONEY & 19-Dec-03 & Co-60 & 0.00968 & $\mathrm{pCi} / \mathrm{g}$ & 0.0052 & 0.0052 & $\mathrm{u}$ & HIVES BETWEEN PASCO AND BASIN CITY. & \\
\hline SESPMNT & $\mathrm{B} 186 \mathrm{H} 6$ & YAKIMA VALLEY & DISTANT & $\mathrm{BI}$ & BEES & HONEY & 16-Dec-03 & Co-60 & 0.0026 & $\mathrm{pCi} / \mathrm{g}$ & 0.0052 & 0.0052 & $\mathrm{u}$ & & \\
\hline SESPMNT & B186H8 & EAST WAHLUKE AREA & COMMUNITY & $\mathrm{BI}$ & BEES & HONEY & 19-Dec-03 & Cs-134 & 0.00239 & $\mathrm{pCi} / \mathrm{g}$ & 0.0054 & 0.0054 & $\mathrm{U}$ & HIVES BETWEEN PASCO AND BASIN CITY. & \\
\hline SESPMNT & B186H6 & YAKIMA VALLEY & DISTANT & $\mathrm{BI}$ & BEES & HONEY & 16-Dec-03 & Cs-134 & -0.00335 & $\mathrm{pCi} / \mathrm{g}$ & 0.0049 & 0.0049 & $\mathrm{u}$ & & \\
\hline SESPMNT & B186H8 & EAST WAHLUKE AREA & COMMUNITY & $\mathrm{BI}$ & BEES & HONEY & 19-Dec-03 & Cs-137 & -0.00165 & $\mathrm{pCi} / \mathrm{g}$ & 0.0044 & 0.0044 & $\mathrm{U}$ & HIVES BETWEEN PASCO AND BASIN CITY. & \\
\hline SESPMNT & B186H6 & YAKIMA VALLEY & DISTANT & $\mathrm{BI}$ & BEES & HONEY & 16-Dec-03 & Cs-137 & 0.00832 & $\mathrm{pCi} / \mathrm{g}$ & 0.0053 & 0.0053 & $\mathrm{u}$ & & \\
\hline SESPMNT & B186H8 & EAST WAHLUKE AREA & COMMUNITY & $\mathrm{BI}$ & BEES & HONEY & 19-Dec-03 & Eu-152 & -0.00404 & $\mathrm{pCi} / \mathrm{g}$ & 0.011 & 0.011 & $\mathrm{u}$ & HIVES BETWEEN PASCO AND BASIN CITY. & \\
\hline SESPMNT & B186H6 & YAKIMA VALLEY & DISTANT & $\mathrm{BI}$ & BEES & HONEY & 16-Dec-03 & Eu-152 & -0.00817 & $\mathrm{pCi} / \mathrm{g}$ & 0.011 & 0.011 & u & & \\
\hline SESPMNT & B186H8 & EAST WAHLUKE AREA & COMMUNITY & $\mathrm{Bl}$ & BEES & HONEY & 19-Dec-03 $>$ & Eu-154 & -0.0024 & $\mathrm{pCi} / \mathrm{g}$ & 0.012 & 0.012 & $u$ & HIVES BETWEEN PASCO AND BASIN CITY. & \\
\hline SESPMNT & B186H6 & YAKIMA VALLEY & DISTANT & $\mathrm{BI}$ & BEES & HONEY & 16-Dec-03 & Eu-154 & -0.000611 & $\mathrm{pCi} / \mathrm{g}$ & 0.016 & 0.016 & $\mathrm{U}$ & & \\
\hline SESPMNT & B186H8 & EAST WAHLUKE AREA & COMMUNITY & $\mathrm{BI}$ & BEES & HONEY & 19-Dec-03 & Eu-155 & 0.00885 & $\mathrm{pCi} / \mathrm{g}$ & 0.013 & 0.013 & $\mathrm{u}$ & HIVES BETWEEN PASCO AND BASIN CITY. & \\
\hline SESPMNT & B186H6 & YAKIMA VALLEY & DISTANT & $\mathrm{BI}$ & BEES & HONEY & 16-Dec-03 & Eu-155 & -0.00239 & $\mathrm{pCi} / \mathrm{g}$ & 0.01 & 0.01 & $\mathrm{U}$ & & \\
\hline SESPMNT & B186H8 & EAST WAHLUKE AREA & COMMUNITY & $\mathrm{BI}$ & BEES & HONEY & 19-Dec-03 & $\mathrm{k}-40$ & 0.091 & $\mathrm{pCi} / \mathrm{g}$ & 0.14 & 0.14 & $u$ & HIVES BETWEEN PASCO AND BASIN CITY. & \\
\hline SESPMNT & B186H6 & YAKIMA VALLEY & DISTANT & $\mathrm{BI}$ & BEES & HONEY & 16-Dec-03 & $\mathrm{k}-40$ & 0.803 & $\mathrm{pCi} / \mathrm{g}$ & 0.19 & 0.19 & & & \\
\hline SESPMNT & B186H8 & EAST WAHLUKE AREA & COMMUNITY & $\mathrm{BI}$ & BEES & HONEY & 19-Dec-03 & Pu-238 & -0.000714 & $\mathrm{pCi} / \mathrm{g}$ & 0.0068 & 0.0068 & $\mathrm{u}$ & HIVES BETWEEN PASCO AND BASIN CITY. & \\
\hline SESPMNT & B186H6 & YAKIMA VALLEY & DISTANT & $\mathrm{BI}$ & BEES & HONEY & 16-Dec-03 & Pu-238 & 0.00134 & $\mathrm{pCi} / \mathrm{g}$ & 0.0042 & 0.0043 & $\mathrm{U}$ & & \\
\hline SESPMNT & B186H8 & EAST WAHLUKE AREA & COMMUNITY & $\mathrm{BI}$ & BEES & HONEY & 19-Dec-03 & Pu-239/240 & -0.00955 & $\mathrm{pCi} / \mathrm{g}$ & 0.0083 & 0.0088 & $\mathrm{u}$ & HIVES BETWEEN PASCO AND BASIN CITY. & \\
\hline SESPMNT & B186H6 & YAKIMA VALLEY & $\begin{array}{l}\text { DISTANT } \\
\end{array}$ & $\mathrm{BI}$ & BEES & HONEY & 16-Dec-03 & Pu-239/240 & -0.00247 & $\mathrm{pCi} / \mathrm{g}$ & 0.0058 & 0.0058 & u & & \\
\hline SESPMNT & B186H8 & EAST WAHLUKE AREA & COMMUNITY & $\mathrm{BI}$ & BEES & HONEY & 19-Dec-03 & Ru-106 & 0.00355 & $\mathrm{pCi} / \mathrm{g}$ & 0.043 & 0.043 & $\mathrm{u}$ & HIVES BETWEEN PASCO AND BASIN CITY. & \\
\hline SESPMNT & B186H6 & YAKIMA VALLEY & DISTANT & $\mathrm{BI}$ & BEES & HONEY & 16-Dec-03 & Ru-106 & -0.0397 & $\mathrm{pCi} / \mathrm{g}$ & 0.043 & 0.043 & $\mathrm{U}$ & & \\
\hline SESPMNT & B186H8 & EAST WAHLUKE AREA & COMMUNITY & BI & BEES & HONEY & 19-Dec-03 & $\mathrm{Sb}-125$ & 0.00448 & $\mathrm{pCi} / \mathrm{g}$ & 0.011 & 0.011 & $\mathrm{u}$ & HIVES BETWEEN PASCO AND BASIN CITY. & \\
\hline SESPMNT & B186H6 & YAKIMA VALLEY & DISTANT & $\mathrm{BI}$ & BEES & HONEY & 16-Dec-03 & Sb-125 & -0.00429 & $\mathrm{pCi} / \mathrm{g}$ & 0.01 & 0.01 & $\mathrm{u}$ & & \\
\hline SESPMNT & B186H8 & EAST WAHLUKE AREA & COMMUNITY & $\mathrm{BI}$ & BEES & HONEY & 19-Dec-03 & Sr-90 & 0.0712 & $\mathrm{pCi} / \mathrm{g}$ & 0.034 & 0.037 & & HIVES BETWEEN PASCO AND BASIN CITY. & \\
\hline SESPMNT & B186H6 & YAKIMA VALLEY & DISTANT & $\mathrm{BI}$ & BEES & HONEY & 16-Dec-03 & Sr-90 & 0.0734 & $\mathrm{pCi} / \mathrm{g}$ & 0.032 & 0.035 & & & \\
\hline SESPMNT & B186H8 & EAST WAHLUKE AREA & COMMUNITY & $\mathrm{BI}$ & BEES & HONEY & 19-Dec-03 & & 0.00356 & $\mathrm{pCi} / \mathrm{g}$ & 0.00041 & 0.00041 & & HIVES BETWEEN PASCO AND BASIN CITY. & \\
\hline SESPMNT & $\mathrm{B} 186 \mathrm{H} 6$ & YAKIMA VALLEY & DISTANT & $\mathrm{BI}$ & BEES & HONEY & 16-Dec-03 & & & $\mathrm{pCi} / \mathrm{g}$ & 0 & 0 & $\mathrm{u}$ & & \\
\hline SESPSPEC & B16WH9 & FRANKLIN FARM A & PERIMETER & $\mathrm{BI}$ & cow & MILK & 09-May-03 & Be-7 & 28.5 & $\mathrm{pCi} / \mathrm{L}$ & 31 & 31 & $\mathrm{u}$ & & \\
\hline SESPSPEC & B17T56 & FRANKLIN FARM A & PERIMETER & $\mathrm{BI}$ & cow & MILK & 23-Oct-03 & Be-7 & 9.91 & $\mathrm{pCi} / \mathrm{L}$ & 21 & 21 & $\mathrm{U}$ & & \\
\hline SESPSPEC & B16WH8 & FRANKLIN FARM B & PERIMETER & BI & cow & MILK & $09-$ May-03 & Be-7 & -9.44 & $\mathrm{pCi} / \mathrm{L}$ & 30 & 30 & $u$ & & \\
\hline SESPSPEC & B17T55 & FRANKLIN FARM B & PERIMETER & $\mathrm{BI}$ & cow & MILK & 23-Oct-03 & Be-7 & 10.5 & $\mathrm{pCi} / \mathrm{L}$ & 22 & 22 & $\mathrm{u}$ & & \\
\hline SESPMNT & B16DK2 & SAGEMOOR COMPOSITE & PERIMETER & $\mathrm{BI}$ & cow & MILK & 13-Feb-03 & Be-7 & 2.63 & $\mathrm{pCi} / \mathrm{L}$ & 26 & 26 & $u$ & & \\
\hline SESPMNT & B16WK1 & SAGEMOOR COMPOSITE & PERIMETER & $\mathrm{BI}$ & cow & MILK & 09-May-03 & Be-7 & 3.84 & $\mathrm{pCi} / \mathrm{L}$ & 29 & 29 & u & & \\
\hline SESPMNT & B17971 & SAGEMOOR COMPOSITE & PERIMETER & $\mathrm{BI}$ & cow & MILK & 31-Jul-03 & Be-7 & 18.1 & $\mathrm{pCi} / \mathrm{L}$ & 27 & 27 & $u$ & & \\
\hline SESPMNT & B17T66 & SAGEMOOR COMPOSITE & PERIMETER & $\mathrm{BI}$ & cow & MILK & 23-Oct-03 & Be-7 & 22.5 & $\mathrm{pCi} / \mathrm{L}$ & 24 & 24 & $u$ & & \\
\hline SESPMNT & B16FR7 & SUNNYSIDE AREA & DISTANT & $\mathrm{BI}$ & cow & MILK & 20-Feb-03 & Be-7 & -10.8 & $\mathrm{pCi} / \mathrm{L}$ & 26 & 26 & u & & \\
\hline SESPMNT & B170P2 & SUNNYSIDE AREA & DISTANT & $\mathrm{Bl}$ & cow & MILK & $16-$ May-03 & Be-7 & & $\mathrm{pCi} / \mathrm{L}$ & 28 & 28 & u & & \\
\hline SESPMNT & B179W0 & SUNNYSIDE AREA & DISTANT & $\mathrm{BI}$ & cow & MILK & 07-Aug-03 & Be-7 & -12.3 & $\mathrm{pCi} / \mathrm{L}$ & 32 & 32 & $\mathrm{U}$ & & \\
\hline SESPMNT & B17TP1 & SUNNYSIDE AREA & DISTANT & $\mathrm{BI}$ & cow & MILK & 30-Oct-03 & Be-7 & -21.5 & $\mathrm{pCi} / \mathrm{L}$ & 26 & 26 & U & & \\
\hline SESPMNT & B16DK3 & WAHLUKE AREA COMP & COMMUNITY & $\mathrm{BI}$ & cow & MILK & 12-Feb-03 & Be-7 & 0.918 & $\mathrm{pCi/L}$ & 21 & 21 & u & & \\
\hline SESPMNT & B16WK3 & WAHLUKE AREA COMP & COMMUNITY & $\mathrm{Bl}$ & cow & MILK & 07-May-03 & Be-7 & 14.8 & $\mathrm{pCi} / \mathrm{L}$ & 26 & 26 & U & & \\
\hline SESPMNT & B17972 & WAHLUKE AREA COMP & COMMUNITY & $\mathrm{BI}$ & cow & MILK & 30-Jul-03 & $\mathrm{Be}-7$ & -7.8 & $\mathrm{pCi} / \mathrm{L}$ & 32 & 32 & u & & \\
\hline SESPMNT & B17T68 & WAHLUKE AREA COMP & COMMUNITY & $\mathrm{BI}$ & cow & MILK & $22-\mathrm{Oct}-03$ & Be-7 & -10.9 & $\mathrm{pCi} / \mathrm{L}$ & 26 & 26 & u & & \\
\hline SESPSPEC & B16WH9 & FRANKLIN FARM A & $\begin{array}{l}\text { PERIMETER } \\
\text { PEI }\end{array}$ & $\mathrm{Bl}$ & cow & MILK & $09-$ May- 03 & Co-60 & 1.27 & $\mathrm{pCi} / \mathrm{L}$ & 3.9 & 3.9 & u & & \\
\hline SESPSPEC & B17T56 & FRANKLIN FARM A & PERIMETER & BI & cow & MILK & 23-Oct-03 & Co-60 & 4.58 & $\mathrm{pCi} / \mathrm{L}$ & 3.3 & 3.3 & $\mathrm{U}$ & & \\
\hline SESPSPEC & B16WH8 & FRANKLIN FARM B & PERIMETER & $\mathrm{BI}$ & cow & MILK & 09-May-03 & Co-60 & 5.49 & $\mathrm{pCi} / \mathrm{L}$ & 3.5 & 3.5 & $u$ & & \\
\hline SESPSPEC & B17T55 & FRANKLIN FARM B & PERIMETER & $\mathrm{BI}$ & cow & MILK & $23-\mathrm{Oct}-03$ & Co-60 & 2.91 & $\mathrm{pCi/L}$ & 3.1 & 3.1 & u & & \\
\hline SESPMNT & B16DK2 & SAGEMOOR COMPOSITE & PERIMETER & $\mathrm{BI}$ & cow & MILK & 13-Feb-03 & Co-60 & 0.551 & $\mathrm{pCi} / \mathrm{L}$ & 3.4 & 3.4 & u & & \\
\hline SESPMNT & B16WK1 & SAGEMOOR COMPOSITE & PERIMETER & $\mathrm{Bl}$ & cow & MILK & 09-May-03 & Co-60 & 1.46 & $\mathrm{pCi} / \mathrm{L}$ & 3.5 & 3.5 & $u$ & & \\
\hline
\end{tabular}




\begin{tabular}{|c|c|c|c|c|c|c|c|c|c|c|c|c|c|c|c|}
\hline OWNER ID & | SAMP NUM | & SAMP SITE NAME & | DIST CLASS | & MEDIA & SAMP FROM & SAMP ITEM & |SAMP DATE & $\begin{array}{c}\text { CON SHORT } \\
\text { NAME }\end{array}$ & VALUE RPTD & \begin{tabular}{|l|} 
ANAL \\
UNITS \\
RPTD
\end{tabular} & $\left|\begin{array}{c}\text { COUNTING } \\
\text { ERROR }\end{array}\right|$ & $\left|\begin{array}{c}\text { TOTAL ANAL } \\
\text { ERROR }\end{array}\right|$ & \begin{tabular}{|c|} 
LAB \\
QUALIFIER
\end{tabular} & SAMP COMMENT & | RESULT COMMENT \\
\hline SESPMNT & B17971 & SAGEMOOR COMPOSITE & PERIMETER & $\mathrm{BI}$ & cow & MILK & 31-Jul-03 & Co-60 & $2.62 \mathrm{p}$ & $\mathrm{pCi} / \mathrm{L}$ & 3 & 3 & $u$ & & \\
\hline SESPMNT & B17T66 & SAGEMOOR COMPOSITE & PERIMETER & BI & cow & MILK & 23-Oct-03 & Co-60 & $1.79 \mathrm{p}$ & $\mathrm{pCi} / \mathrm{L}$ & 3.7 & 3.7 & u & & \\
\hline SESPMNT & B16FR7 & SUNNYSIDE AREA & DISTANT & $\mathrm{BI}$ & cow & MILK & 20-Feb-03 & Co-60 & & $\mathrm{pCi} / \mathrm{L}$ & 3.5 & 3.5 & $u$ & & \\
\hline SESPMNT & B170P2 & SUNNYSIDE AREA & DISTANT & $\mathrm{BI}$ & cow & MILK & 16-May-03 & Co-60 & $0.888 \mathrm{p}$ & $\mathrm{pCi} / \mathrm{L}$ & 3.5 & 3.5 & u & & \\
\hline SESPMNT & B179W0 & SUNNYSIDE AREA & DISTANT & $\mathrm{BI}$ & cow & MILK & 07-Aug-03 & Co-60 & $-3.26 p$ & $\mathrm{pCilL}$ & 3.9 & 3.9 & $\mathrm{u}$ & & \\
\hline SESPMNT & B17TP1 & SUNNYSIDE AREA & DISTANT & $\mathrm{BI}$ & cow & MILK & 30-Oct-03 & Co-60 & $2.74 \mathrm{p}$ & $\mathrm{pCi} / \mathrm{L}$ & 3.3 & 3.3 & $u$ & & \\
\hline SESPMNT & B16DK3 & WAHLUKE AREA COMP & COMMUNITY & $\mathrm{BI}$ & cow & MILK & 12-Feb-03 & Co-60 & $0.173 \mathrm{p}$ & $\mathrm{pCi} / \mathrm{L}$ & 3 & 3 & $u$ & & \\
\hline SESPMNT & B16WK3 & WAHLUKE AREA COMP & COMMUNITY & $\mathrm{BI}$ & cow & MILK & 07-May-03 & Co-60 & $-1.08 \mathrm{p}$ & $\mathrm{pCi} / \mathrm{L}$ & 3.3 & 3.3 & $u$ & & \\
\hline SESPMNT & B17972 & WAHLUKE AREA COMP & COMMUNITY & BI & cow & MILK & 30-Jul-03 & Co-60 & $-3.17 p$ & $\mathrm{pCi} / \mathrm{L}$ & 3.8 & 3.8 & $u$ & & \\
\hline SESPMNT & B17T68 & WAHLUKE AREA COMP & COMMUNITY & $\mathrm{BI}$ & cow & MILK & 22-Oct-03 & Co-60 & $-1.19 p$ & $\mathrm{pCi} / \mathrm{L}$ & 3.5 & 3.5 & $u$ & & \\
\hline SESPSPEC & B16WH9 & FRANKLIN FARM A & PERIMETER & BI & cow & MILK & 09-May-03 & Cs-134 & $1.5 \mathrm{p}$ & $\mathrm{pCi} / \mathrm{L}$ & 3.5 & 3.5 & $u$ & & \\
\hline SESPSPEC & B17T56 & FRANKLIN FARM A & PERIMETER & $\mathrm{BI}$ & cow & MILK & 23-Oct-03 & Cs-134 & $0.145 p$ & $\mathrm{pCi} / \mathrm{L}$ & 3 & 3 & u & & \\
\hline SESPSPEC & B16WH8 & FRANKLIN FARM B & PERIMETER & $\mathrm{BI}$ & cow & MILK & 09-May-03 & Cs-134 & -0.765 & $\mathrm{pCi} / \mathrm{L}$ & 3.5 & 3.5 & $u$ & & \\
\hline SESPSPEC & B17T55 & FRANKLIN FARM B & PERIMETER & $\mathrm{BI}$ & cow & MILK & 23-Oct-03 & Cs-134 & -2.69 & $\mathrm{pCi} / \mathrm{L}$ & 3.1 & 3.1 & $u$ & & \\
\hline SESPMNT & B16DK2 & SAGEMOOR COMPOSITE & PERIMETER & BI & cow & MILK & 13-Feb-03 & Cs-134 & -0.0928 & $\mathrm{pCi} / \mathrm{L}$ & 3.7 & 3.7 & $u$ & & \\
\hline SESPMNT & B16WK1 & SAGEMOOR COMPOSITE & PERIMETER & $\mathrm{BI}$ & cow & MILK & 09-May-03 & Cs-134 & -0.954 & $\mathrm{pCi} / \mathrm{L}$ & 3.4 & 3.4 & u & & \\
\hline SESPMNT & B17971 & SAGEMOOR COMPOSITE & PERIMETER & $\mathrm{BI}$ & cow & MILK & 31-Jul-03 & Cs-134 & -0.952 & $\mathrm{pCi} / \mathrm{L}$ & 3.1 & 3.1 & $u$ & & \\
\hline SESPMNT & B17T66 & SAGEMOOR COMPOSITE & PERIMETER & $\mathrm{BI}$ & cow & MILK & 23-Oct-03 & Cs-134 & $2.22 \mathrm{~F}$ & $\mathrm{pCi} / \mathrm{L}$ & 3.7 & 3.7 & $u$ & & \\
\hline SESPMNT & B16FR7 & SUNNYSIDE AREA & DISTANT & $\mathrm{BI}$ & cow & MILK & $20-$ Feb-03 & Cs-134 & 4.68 & $\mathrm{pCi} / \mathrm{L}$ & 3.8 & 3.8 & $u$ & & \\
\hline SESPMNT & B170P2 & SUNNYSIDE AREA & DISTANT & BI & cow & MILK & 16-May-03 & Cs-134 & 1.67 & $\mathrm{pCi} / \mathrm{L}$ & 3.5 & 3.5 & $u$ & & \\
\hline SESPMNT & B179W0 & SUNNYSIDE AREA & DISTANT & $\mathrm{BI}$ & cow & MILK & 07-Aug-03 & Cs-134 & 0.364 & $\mathrm{pCi} / \mathrm{L}$ & 3.9 & 3.9 & $u$ & & \\
\hline SESPMNT & B17TP1 & SUNNYSIDE AREA & DISTANT & BI & cow & MILK & $30-0 c t-03$ & Cs-134 & 1.63 & $\mathrm{pCi} / \mathrm{L}$ & 3.7 & 3.7 & $u$ & & \\
\hline SESPMNT & B16DK3 & WAHLUKE AREA COMP & COMMUNITY & $\mathrm{BI}$ & cow & MILK & $12-$ Feb-03 & Cs-134 & -0.122 & $\mathrm{pCi} / \mathrm{L}$ & 2.9 & 2.9 & u & & \\
\hline SESPMNT & B16WK3 & WAHLUKE AREA COMP & COMMUNITY & BI & cow & MILK & 07-May-03 & Cs-134 & 0.882 & $\mathrm{pCi} / \mathrm{L}$ & 3.7 & 3.7 & $u$ & & \\
\hline SESPMNT & B17972 & WAHLUKE AREA COMP & COMMUNITY & $\mathrm{BI}$ & cow & MILK & 30-Jul-03 & Cs-134 & 0.0806 & $\mathrm{pCi} / \mathrm{L}$ & 3.7 & 3.7 & $u$ & & \\
\hline SESPMNT & B17T68 & WAHLUKE AREA COMP & COMMUNITY & $\mathrm{BI}$ & cow & MILK & $22-0 c t-03$ & Cs-134 & 1.21 & $\mathrm{pCi} / \mathrm{L}$ & 3.4 & 3.4 & u & & \\
\hline SESPSPEC & B16WH9 & FRANKLIN FARM A & PERIMETER & BI & cow & MILK & 09-May-03 & Cs-137 & -0.239 & $\mathrm{pCi} / \mathrm{L}$ & 3.2 & 3.2 & u & & \\
\hline SESPSPEC & B17T56 & FRANKLIN FARM A & PERIMETER & $\mathrm{BI}$ & cow & MILK & 23-Oct-03 & Cs-137 & -4.92 & pCilL & 2.8 & 2.8 & $u$ & & \\
\hline SESPSPEC & B16WH8 & FRANKLIN FARM B & PERIMETER & BI & cow & MILK & $09-$ May-03 & Cs-137 & 0.775 & $\mathrm{pCi} / \mathrm{L}$ & 3.1 & 3.1 & $u$ & & \\
\hline SESPSPEC & B17T55 & FRANKLIN FARM B & PERIMETER & $\mathrm{BI}$ & cow & MILK & 23-Oct-03 & Cs-137 & -2.38 & $\mathrm{pCi} / \mathrm{L}$ & 2.7 & 2.7 & u & & \\
\hline SESPMNT & B16DK2 & SAGEMOOR COMPOSITE & PERIMETER & $\mathrm{BI}$ & cow & MILK & 13-Feb-03 & Cs-137 & 0.855 & $\mathrm{pCi} / \mathrm{L}$ & 3.2 & 3.2 & $u$ & & \\
\hline SESPMNT & B16WK1 & SAGEMOOR COMPOSITE & PERIMETER & $\mathrm{BI}$ & cow & MILK & $09-$ May-03 & Cs-137 & -0.828 & $\mathrm{pCi} / \mathrm{L}$ & 3.4 & 3.4 & $u$ & & \\
\hline SESPMNT & B17971 & SAGEMOOR COMPOSITE & PERIMETER & BI & cow & MILK & 31-Jul-03 & Cs-137 & 0.146 & $\mathrm{pCi} / \mathrm{L}$ & 2.7 & 2.7 & $u$ & & \\
\hline SESPMNT & B17T66 & SAGEMOOR COMPOSITE & PERIMETER & BI & cow & MILK & 23-Oct-03 & Cs-137 & -2.84 & pCilL & 3.2 & 3.2 & u & & \\
\hline SESPMNT & B16FR7 & SUNNYSIDE AREA & DISTANT & $\mathrm{BI}$ & cow & MILK & 20-Feb-03 & Cs-137 & 0.103 & $\mathrm{pCi} / \mathrm{L}$ & 3.1 & 3.1 & u & & \\
\hline SESPMNT & B170P2 & SUNNYSIDE AREA & DISTANT & BI & cow & MILK & 16-May-03 & Cs-137 & 3.04 & $\mathrm{pCi} / \mathrm{L}$ & 3.6 & 3.6 & u & & \\
\hline SESPMNT & B179W0 & SUNNYSIDE AREA & DISTANT & $\mathrm{BI}$ & cow & MILK & 07-Aug-03 & Cs-137 & 3.84 & $\mathrm{pCilL}$ & 3.4 & 3.4 & u & & \\
\hline SESPMNT & B17TP1 & SUNNYSIDE AREA & DISTANT & BI & cow & MILK & 30-Oct-03 & Cs-137 & -0.408 & $\mathrm{pCi} / \mathrm{L}$ & 3.1 & 3.1 & $u$ & & \\
\hline SESPMNT & B16DK3 & WAHLUKE AREA COMP & COMMUNITY & $\mathrm{BI}$ & cow & MILK & 12-Feb-03 & Cs-137 & -0.267 & $\mathrm{pCi} / \mathrm{L}$ & 2.6 & 2.6 & $\mathrm{u}$ & & \\
\hline SESPMNT & B16WK3 & WAHLUKE AREA COMP & COMMUNITY & $\mathrm{BI}$ & cow & MILK & $07-$ May-03 & Cs-137 & 0.0543 & $\mathrm{pCi} / \mathrm{L}$ & 3.2 & 3.2 & $u$ & & \\
\hline SESPMNT & B17972 & WAHLUKE AREA COMP & COMMUNITY & BI & cow & MILK & 30-Jul-03 & Cs-137 & $-0.685 p$ & pCill & 3.4 & 3.4 & $u$ & & \\
\hline SESPMNT & B17T68 & WAHLUKE AREA COMP & COMMUNITY & $\mathrm{BI}$ & cow & MILK & 22-Oct-03 & Cs-137 & -1.07 & $\mathrm{pCi} / \mathrm{L}$ & 3.2 & 3.2 & u & & \\
\hline SESPSPEC & B16WH9 & FRANKLIN FARM A & PERIMETER & $\mathrm{BI}$ & cow & MILK & $09-$ May-03 & Eu-152 & -4.06 & $\mathrm{pCi} / \mathrm{L}$ & 8.5 & 8.5 & $u$ & & \\
\hline SESPSPEC & B17T56 & FRANKLIN FARM A & PERIMETER & $\mathrm{BI}$ & cow & MILK & 23-Oct-03 & Eu-152 & 2.45 & $\mathrm{pCi} / \mathrm{L}$ & 6.9 & 6.9 & u & & \\
\hline SESPSPEC & B16WH8 & FRANKLIN FARM B & PERIMETER & BI & cow & MILK & 09-May-03 & Eu-152 & -3.04 & $\mathrm{pCi} / \mathrm{L}$ & 7.9 & 7.9 & u & & \\
\hline SESPSPEC & B17T55 & FRANKLIN FARM B & PERIMETER & $\mathrm{BI}$ & cow & MILK & 23-Oct-03 & Eu-152 & 1.52 & $\mathrm{pCi} / \mathrm{L}$ & 6.9 & 6.9 & u & & \\
\hline SESPMNT & B16DK2 & SAGEMOOR COMPOSITE & PERIMETER & $\mathrm{BI}$ & cow & MILK & 13-Feb-03 & Eu-152 & & $\mathrm{pCi} / \mathrm{L}$ & 7.5 & 7.5 & u & & \\
\hline SESPMNT & B16WK1 & SAGEMOOR COMPOSITE & PERIMETER & $\mathrm{BI}$ & cow & MILK & 09-May-03 & Eu-152 & 6.39 & $\mathrm{pCi} / \mathrm{L}$ & 8.4 & 8.4 & u & & \\
\hline SESPMNT & B17971 & SAGEMOOR COMPOSITE & PERIMETER & $\mathrm{BI}$ & cow & MILK & 31-Jul-03 & Eu-152 & 7.83 & $\mathrm{pCi} / \mathrm{L}$ & 7.3 & 7.3 & $u$ & & \\
\hline SESPMNT & B17T66 & SAGEMOOR COMPOSITE & PERIMETER & $\mathrm{BI}$ & cow & MILK & 23-Oct-03 & Eu-152 & -2.27 & $\mathrm{pCi} / \mathrm{L}$ & 8.1 & 8.1 & u & & \\
\hline SESPMNT & B16FR7 & SUNNYSIDE AREA & DISTANT & $\mathrm{BI}$ & cow & MILK & 20-Feb-03 & Eu-152 & 2.61 & pCi/L & 8 & 8 & u & & \\
\hline SESPMNT & B170P2 & SUNNYSIDE AREA & DISTANT & $\mathrm{BI}$ & cow & MILK & 16-May-03 & Eu-152 & -3.67 & pCi/L & 8.1 & 8.1 & $u$ & & \\
\hline SESPMNT & B179W0 & SUNNYSIDE AREA & DISTANT & $\mathrm{BI}$ & cow & MILK & 07-Aug-03 & Eu-152 & 2.2 & $\mathrm{pCi} / \mathrm{L}$ & 8.3 & 8.3 & u & & \\
\hline SESPMNT & B17TP1 & SUNNYSIDE AREA & DISTANT & BI & cow & MILK & $30-0 c t-03$ & Eu-152 & 6.01 & $\mathrm{pCi} / \mathrm{L}$ & 8.4 & 8.4 & $u$ & & \\
\hline SESPMNT & B16DK3 & WAHLUKE AREA COMP & COMMUNITY & $\mathrm{BI}$ & cow & MILK & 12-Feb-03 & Eu-152 & 5.6 & $\mathrm{pCi} / \mathrm{L}$ & 6.7 & 6.7 & u & & \\
\hline SESPMNT & B16WK3 & WAHLUKE AREA COMP & COMMUNITY & $\mathrm{BI}$ & cow & MILK & 07-May-03 & Eu-152 & -5.54 & $\mathrm{pCi} / \mathrm{L}$ & 8.5 & 8.5 & u & & \\
\hline SESPMNT & B17972 & WAHLUKE AREA COMP & COMMUNITY & $\mathrm{Bl}$ & cow & MILK & 30-Jul-03 & Eu-152 & -0.968 & $\mathrm{pCi} / \mathrm{L}$ & 8.1 & 8.1 & $u$ & & \\
\hline
\end{tabular}


(pCi/g Wet Weight)

\begin{tabular}{|c|c|c|c|c|c|c|c|c|c|c|c|c|c|c|c|}
\hline OWNER ID & SAMP NUM & SAMP SITE NAME & DIST CLASS & MEDIA & SAMP FROM & SAMP ITEM & SAMP DATE & $\begin{array}{l}\text { CON SHORT } \\
\text { NAME }\end{array}$ & |VALUE RPTD & \begin{tabular}{|l|} 
ANAL \\
UNITS \\
RPTD
\end{tabular} & $\left|\begin{array}{c}\text { COUNTING } \\
\text { ERROR }\end{array}\right|$ & $\left|\begin{array}{c}\text { TOTAL ANAL } \\
\text { ERROR }\end{array}\right|$ & $\mid \begin{array}{c}\text { LAB } \\
\text { QUALIFIER }\end{array}$ & SAMP COMMENT & RESULT COMMENT \\
\hline SESPMNT & B17T68 & WAHLUKE AREA COMP & COMMUNITY & $\mathrm{BI}$ & cow & MILK & 22-Oct-03 & Eu-152 & -2.46 & $\mathrm{pCi} / \mathrm{L}$ & 8.1 & 8.1 & U & & \\
\hline SESPSPEC & B16WH9 & FRANKLIN FARM A & $\begin{array}{l}\text { PERIMETER } \\
\end{array}$ & $\mathrm{BI}$ & cow & MILK & $09-$ May-03 & Eu-154 & -7.41 & $\mathrm{pCi} / \mathrm{L}$ & 10 & 10 & u & & \\
\hline SESPSPEC & B17T56 & FRANKLIN FARM A & PERIMETER & $\mathrm{BI}$ & cow & MILK & 23-Oct-03 & Eu-154 & 4.76 & $\mathrm{pCi} / \mathrm{L}$ & 9.6 & 9.6 & $u$ & & \\
\hline SESPSPEC & B16WH8 & FRANKLIN FARM B & PERIMETER & $\mathrm{BI}$ & cow & MILK & 09-May-03 & Eu-154 & & $\mathrm{pCi} / \mathrm{L}$ & 9.9 & 9.9 & $u$ & & \\
\hline SESPSPEC & B17T55 & FRANKLIN FARM B & PERIMETER & $\mathrm{BI}$ & cow & MILK & 23-Oct-03 & Eu-154 & 3.39 & $\mathrm{pCi} / \mathrm{L}$ & 8.9 & 8.9 & $u$ & & \\
\hline SESPMNT & B16DK2 & SAGEMOOR COMPOSITE & PERIMETER & $\mathrm{BI}$ & cow & MILK & 13-Feb-03 & Eu-154 & -2.56 & $\mathrm{pCi} / \mathrm{L}$ & 11 & 11 & $u$ & & \\
\hline SESPMNT & B16WK1 & SAGEMOOR COMPOSITE & PERIMETER & $\mathrm{BI}$ & cow & MILK & 09-May-03 & Eu-154 & 1.98 & $\mathrm{pCi} / \mathrm{L}$ & 9.8 & 9.8 & $u$ & & \\
\hline SESPMNT & B17971 & SAGEMOOR COMPOSITE & PERIMETER & $\mathrm{BI}$ & cow & MILK & 31-Jul-03 & Eu-154 & -3.45 & $\mathrm{pCi} / \mathrm{L}$ & 9.2 & 9.2 & $u$ & & \\
\hline SESPMNT & B17T66 & SAGEMOOR COMPOSITE & PERIMETER & $\mathrm{BI}$ & cow & MILK & $23-O c t-03$ & Eu-154 & -7.04 & $\mathrm{pCi} / \mathrm{L}$ & 11 & 11 & u & & \\
\hline SESPMNT & B16FR7 & SUNNYSIDE AREA & DISTANT & $\mathrm{BI}$ & cow & MILK & 20-Feb-03 & Eu-154 & 4.09 & $\mathrm{pCi} / \mathrm{L}$ & 11 & 11 & $u$ & & \\
\hline SESPMNT & B170P2 & SUNNYSIDE AREA & DISTANT & $\mathrm{BI}$ & cow & MILK & 16-May-03 & Eu-154 & -4.07 & $\mathrm{pCi} / \mathrm{L}$ & 10 & 10 & $u$ & & \\
\hline SESPMNT & B179W0 & SUNNYSIDE AREA & DISTANT & $\mathrm{BI}$ & cow & MILK & 07-Aug-03 & Eu-154 & -2.97 & $\mathrm{pCi} / \mathrm{L}$ & 11 & 11 & $u$ & & \\
\hline SESPMNT & B17TP1 & SUNNYSIDE AREA & DISTANT & $\mathrm{BI}$ & cow & MILK & $30-$ Oct-03 & Eu-154 & -1.23 & $\mathrm{pCi} / \mathrm{L}$ & 9.5 & 9.5 & u & & \\
\hline SESPMNT & B16DK3 & WAHLUKE AREA COMP & COMMUNITY & $\mathrm{BI}$ & cow & MILK & 12-Feb-03 & Eu-154 & 7.83 & $\mathrm{pCi} / \mathrm{L}$ & 8.7 & 8.7 & $u$ & & \\
\hline SESPMNT & B16WK3 & WAHLUKE AREA COMP & COMMUNITY & $\mathrm{BI}$ & cow & MILK & 07-May-03 & Eu-154 & 5.02 & $\mathrm{pCi} / \mathrm{L}$ & 10 & 10 & $u$ & & \\
\hline SESPMNT & B17972 & WAHLUKE AREA COMP & COMMUNITY & $\mathrm{BI}$ & cow & MILK & 30-Jul-03 & Eu-154 & -1.05 & $\mathrm{pCi/L}$ & 12 & 12 & u & & \\
\hline SESPMNT & B17T68 & WAHLUKE AREA COMP & COMMUNITY & $\mathrm{BI}$ & cow & MILK & 22-Oct-03 & Eu-154 & -0.0934 & $\mathrm{pCi} / \mathrm{L}$ & 10 & 10 & u & & \\
\hline SESPSPEC & B16WH9 & FRANKLIN FARM A & PERIMETER & $\mathrm{BI}$ & cow & MILK & 09-May-03 & Eu-155 & 1.09 & $\mathrm{pCi} / \mathrm{L}$ & 8.3 & 8.3 & $u$ & & \\
\hline SESPSPEC & B17T56 & FRANKLIN FARM A & PERIMETER & $\mathrm{BI}$ & cow & MILK & 23-Oct-03 & Eu-155 & 0.545 & $\mathrm{pCi} / \mathrm{L}$ & 6.6 & 6.6 & $u$ & & \\
\hline SESPSPEC & B16WH8 & FRANKLIN FARM B & PERIMETER & $\mathrm{BI}$ & cow & MILK & $09-$ May-03 & Eu-155 & 5.93 & $\mathrm{pCi} / \mathrm{L}$ & 7.4 & 7.4 & u & & \\
\hline SESPSPEC & B17T55 & FRANKLIN FARM B & PERIMETER & $\mathrm{BI}$ & cow & MILK & 23-Oct-03 & Eu-155 & 2.01 & $\mathrm{pCi} / \mathrm{L}$ & 5.9 & 5.9 & $u$ & & \\
\hline SESPMNT & B16DK2 & SAGEMOOR COMPOSITE & PERIMETER & $\mathrm{BI}$ & cow & MILK & 13-Feb-03 & Eu-155 & 7.18 & $\mathrm{pCi} / \mathrm{L}$ & 8 & 8 & $u$ & & \\
\hline SESPMNT & B16WK1 & SAGEMOOR COMPOSITE & PERIMETER & $\mathrm{BI}$ & cow & MILK & 09-May-03 & Eu-155 & -2.9 & $\mathrm{pCi} / \mathrm{L}$ & 7.6 & 7.6 & u & & \\
\hline SESPMNT & B17971 & SAGEMOOR COMPOSITE & PERIMETER & $\mathrm{BI}$ & cow & MILK & 31-Jul-03 & Eu-155 & -3.8 & $\mathrm{pCi} / \mathrm{L}$ & 6.8 & 6.8 & $\mathrm{u}$ & & \\
\hline SESPMNT & B17T66 & SAGEMOOR COMPOSITE & PERIMETER & $\mathrm{BI}$ & cow & MILK & 23-Oct-03 & Eu-155 & -0.742 & $\mathrm{pCi} / \mathrm{L}$ & 7.4 & 7.4 & $u$ & & \\
\hline SESPMNT & B16FR7 & SUNNYSIDE AREA & DISTANT & $\mathrm{BI}$ & cow & MILK & 20-Feb-03 & Eu-155 & -8.97 & $\mathrm{pCi} / \mathrm{L}$ & 7.9 & 7.9 & u & & \\
\hline SESPMNT & B170P2 & SUNNYSIDE AREA & DISTANT & $\mathrm{BI}$ & cow & MILK & 16-May-03 & Eu-155 & 0.295 & $\mathrm{pCi} / \mathrm{L}$ & 7.4 & 7.4 & u & & \\
\hline SESPMNT & B179W0 & SUNNYSIDE AREA & DISTANT & $\mathrm{BI}$ & cow & MILK & 07-Aug-03 & Eu-155 & -4.25 & $\mathrm{pCi} / \mathrm{L}$ & 8.1 & 8.1 & $\mathrm{u}$ & & \\
\hline SESPMNT & B17TP1 & SUNNYSIDE AREA & DISTANT & $\mathrm{BI}$ & cow & MILK & 30-Oct-03 & Eu-155 & 0.56 & $\mathrm{pCi} / \mathrm{L}$ & 7.4 & 7.4 & $\mathrm{U}$ & & \\
\hline SESPMNT & B16DK3 & WAHLUKE AREA COMP & COMMUNITY & $\mathrm{BI}$ & cow & MILK & 12-Feb-03 & Eu-155 & 3.68 & $\mathrm{pCi} / \mathrm{L}$ & 6.2 & 6.2 & $\mathrm{u}$ & & \\
\hline SESPMNT & B16WK3 & WAHLUKE AREA COMP & COMMUNITY & $\mathrm{BI}$ & cow & MILK & 07-May-03 & Eu-155 & 0.0589 & $\mathrm{pCi} / \mathrm{L}$ & 7.7 & 7.7 & U & & \\
\hline SESPMNT & B17972 & WAHLUKE AREA COMP & COMMUNITY & $\mathrm{BI}$ & cow & MILK & 30-Jul-03 & Eu-155 & -0.254 & $\mathrm{pCi} / \mathrm{L}$ & 7.7 & 7.7 & $u$ & & \\
\hline SESPMNT & B17T68 & WAHLUKE AREA COMP & COMMUNITY & BI & cow & MILK & $22-\mathrm{Oct}-03$ & Eu-155 & 0.568 & $\mathrm{pCi} / \mathrm{L}$ & 7.3 & 7.3 & $u$ & & \\
\hline SESPSPEC & B16WH9 & FRANKLIN FARM A & \begin{tabular}{|l|} 
PERIMETER \\
\end{tabular} & $\mathrm{BI}$ & cow & MILK & 09-May-03 & $\mathrm{K}-40$ & 1180 & $\mathrm{pCi} / \mathrm{L}$ & 210 & 210 & & & \\
\hline SESPSPEC & B17T56 & FRANKLIN FARM A & PERIMETER & $\mathrm{BI}$ & cow & MILK & 23-Oct-03 & $\mathrm{K}-40$ & 1390 & $\mathrm{pCi} / \mathrm{L}$ & 210 & 210 & & & \\
\hline SESPSPEC & B16WH8 & FRANKLIN FARM B & PERIMETER & $\mathrm{BI}$ & cow & MILK & 09-May-03 & k-40 & 1190 & $\mathrm{pCi} / \mathrm{L}$ & 200 & 200 & & & \\
\hline SESPSPEC & B17T55 & FRANKLIN FARM B & PERIMETER & $\mathrm{BI}$ & cow & MILK & 23-Oct-03 & $\mathrm{k}-40$ & 1310 & $\mathrm{pCi} / \mathrm{L}$ & 200 & 200 & & & \\
\hline SESPMNT & B16DK2 & SAGEMOOR COMPOSITE & $\begin{array}{l}\text { PERIMETER } \\
\end{array}$ & $\mathrm{BI}$ & cow & MILK & $13-$ Feb-03 & $\mathrm{k}-40$ & 1310 & $\mathrm{pCi} / \mathrm{L}$ & 200 & 200 & & & \\
\hline SESPMNT & B16WK1 & SAGEMOOR COMPOSITE & PERIMETER & $\mathrm{BI}$ & cow & MILK & 09-May-03 & $\mathrm{k}-40$ & 1340 & $\mathrm{pCi} / \mathrm{L}$ & 220 & 220 & & & \\
\hline SESPMNT & B17971 & SAGEMOOR COMPOSITE & PERIMETER & $\mathrm{BI}$ & cow & MILK & 31-Jul-03 & $\mathrm{k}-40$ & 1410 & $\mathrm{pCi} / \mathrm{L}$ & 210 & 210 & & & \\
\hline SESPMNT & B17T66 & SAGEMOOR COMPOSITE & PERIMETER & $\mathrm{BI}$ & cow & MILK & 23-Oct-03 & $\mathrm{K}-40$ & 1310 & $\mathrm{pCi} / \mathrm{L}$ & 220 & 220 & & & \\
\hline SESPMNT & B16FR7 & SUNNYSIDE AREA & DISTANT & $\mathrm{BI}$ & cow & MILK & 20-Feb-03 & $\mathrm{K}-40$ & 1100 & $\mathrm{pCi} / \mathrm{L}$ & 190 & 190 & & & \\
\hline SESPMNT & B170P2 & SUNNYSIDE AREA & DISTANT & $\mathrm{BI}$ & cow & MILK & $16-$ May-03 & $\mathrm{k}-40$ & 1190 & $\mathrm{pCi} / \mathrm{L}$ & 200 & 200 & & & \\
\hline SESPMNT & B179Wo & SUNNYSIDE AREA & DISTANT & $\mathrm{BI}$ & cow & MILK & 07-Aug-03 & $\mathrm{K}-40$ & 1280 & $\mathrm{pCi} / \mathrm{L}$ & 220 & 220 & & & \\
\hline SESPMNT & B17TP1 & SUNNYSIDE AREA & DISTANT & $\mathrm{BI}$ & cow & MILK & 30-Oct-03 & $\mathrm{k}-40$ & 1110 & $\mathrm{pCi} / \mathrm{L}$ & 200 & 200 & & & \\
\hline SESPMNT & B16DK3 & WAHLUKE AREA COMP & COMMUNITY & $\mathrm{BI}$ & cow & MILK & 12-Feb-03 & $\mathrm{k}-40$ & 1340 & $\mathrm{pCi} / \mathrm{L}$ & 200 & 200 & & & \\
\hline SESPMNT & B16WK3 & WAHLUKE AREA COMP & COMMUNITY & $\mathrm{BI}$ & cow & MILK & 07-May-03 & $\mathrm{k}-40$ & 1280 & $\mathrm{pCi} / \mathrm{L}$ & 220 & 220 & & & \\
\hline SESPMNT & B17972 & WAHLUKE AREA COMP & COMMUNITY & $\mathrm{BI}$ & cow & MILK & 30-Jul-03 & $\mathrm{k}-40$ & 1170 & $\mathrm{pCi/L}$ & 200 & 200 & & & \\
\hline SESPMNT & B17T68 & WAHLUKE AREA COMP & COMMUNITY & $\mathrm{Bl}$ & cow & MILK & 22-Oct-03 & K-40 & 1290 & $\mathrm{pCi} / \mathrm{L}$ & 210 & 210 & & & \\
\hline SESPSPEC & B16WH9 & FRANKLIN FARM A & PERIMETER & $\mathrm{BI}$ & cow & MILK & 09-Мay-03 & Ru-106 & -15.9 & $\mathrm{pCi} / \mathrm{L}$ & 30 & 30 & $\mathrm{u}$ & & \\
\hline SESPSPEC & B17T56 & FRANKLIN FARM A & PERIMETER & $\mathrm{BI}$ & cow & MILK & 23-Oct-03 & Ru-106 & 13.9 & $\mathrm{pCi} / \mathrm{L}$ & 25 & 25 & u & & \\
\hline SESPSPEC & B16WH8 & FRANKLIN FARM B & $\begin{array}{l}\text { PERIMETER } \\
\end{array}$ & $\mathrm{BI}$ & cow & MILK & $09-$ May- 03 & Ru-106 & -9.14 & $\mathrm{pCi} / \mathrm{L}$ & 28 & 28 & u & & \\
\hline SESPSPEC & B17T55 & FRANKLIN FARM B & PERIMETER & BI & cow & MILK & 23-Oct-03 & Ru-106 & -14.4 & $\mathrm{pCi} / \mathrm{L}$ & 23 & 23 & $\mathrm{U}$ & & \\
\hline SESPMNT & B16DK2 & SAGEMOOR COMPOSITE & PERIMETER & $\mathrm{BI}$ & cow & MILK & 13-Feb-03 & Ru-106 & 12.2 & $\mathrm{pCi} / \mathrm{L}$ & 28 & 28 & $u$ & & \\
\hline SESPMNT & B16WK1 & SAGEMOOR COMPOSITE & PERIMETER & $\mathrm{BI}$ & cow & MILK & 09-May-03 & Ru-106 & 12.9 & $\mathrm{pCi} / \mathrm{L}$ & 28 & 28 & u & & \\
\hline SESPMNT & B17971 & SAGEMOOR COMPOSITE & PERIMETER & $\mathrm{BI}$ & cow & MILK & 31-Jul-03 & Ru-106 & 20.8 & $\mathrm{pCi} / \mathrm{L}$ & 26 & 26 & u & & \\
\hline SESPMNT & B17T66 & SAGEMOOR COMPOSITE & PERIMETER & $\mathrm{Bl}$ & cow & MILK & 23-Oct-03 & Ru-106 & -15.1 & $\mathrm{pCi} / \mathrm{L}$ & 28 & 28 & $u$ & & \\
\hline
\end{tabular}




\begin{tabular}{|c|c|c|c|c|c|c|c|c|c|c|c|c|c|c|c|}
\hline OWNER ID & | SAMP NUM| & SAMP SITE NAME & | DIST CLASS & MEDIA & SAMP FROM & | SAMP ITEM & |SAMP DATE & $\begin{array}{c}\text { CON SHORT } \\
\text { NAME }\end{array}$ & |VALUE RPTD & $\left|\begin{array}{|l|}\text { ANAL } \\
\text { UNITS } \\
\text { RPTD }\end{array}\right|$ & $\left|\begin{array}{c}\text { COUNTING } \\
\text { ERROR }\end{array}\right|$ & $\begin{array}{c}\text { TOTAL ANAL } \\
\text { ERROR }\end{array}$ & $\begin{array}{c}\text { LAB } \\
\text { QUALIFIER }\end{array}$ & SAMP COMMENT & |RESULT COMMENT| \\
\hline SESPMNT & B16FR7 & SUNNYSIDE AREA & DISTANT & $\mathrm{BI}$ & cow & MILK & 20-Feb-03 & Ru-106 & 5.14 & $\mathrm{pCi} / \mathrm{L}$ & 29 & 29 & U & & \\
\hline SESPMNT & B170P2 & SUNNYSIDE AREA & DISTANT & $\mathrm{BI}$ & cow & MILK & 16-May-03 & Ru-106 & 28.8 & $\mathrm{pCi} / \mathrm{L}$ & 28 & 28 & u & & \\
\hline SESPMNT & B179W0 & SUNNYSIDE AREA & DISTANT & $\mathrm{BI}$ & cow & MILK & 07-Aug-03 & Ru-106 & 8.77 & $\mathrm{pCi} / \mathrm{L}$ & 30 & 30 & u & & \\
\hline SESPMNT & B17TP1 & SUNNYSIDE AREA & DISTANT & $\mathrm{BI}$ & cow & MILK & 30-Oct-03 & Ru-106 & -10.2 & $\mathrm{pCi} / \mathrm{L}$ & 26 & 26 & $u$ & & \\
\hline SESPMNT & B16DK3 & WAHLUKE AREA COMP & COMMUNITY & $\mathrm{BI}$ & cow & MILK & 12 -Feb-03 & Ru-106 & -19.4 & pCi/L & 24 & 24 & $u$ & & \\
\hline SESPMNT & B16WK3 & WAHLUKE AREA COMP & COMMUNITY & $\mathrm{BI}$ & cow & MILK & 07-May-03 & Ru-106 & -11.5 & $\mathrm{pCi} / \mathrm{L}$ & 28 & 28 & u & & \\
\hline SESPMNT & B17972 & WAHLUKE AREA COMP & COMMUNITY & $\mathrm{BI}$ & cow & MILK & 30-Jul-03 & Ru-106 & -9.84 & pCi/L & 30 & 30 & $u$ & & \\
\hline SESPMNT & B17T68 & WAHLUKE AREA COMP & COMMUNITY & $\mathrm{BI}$ & cow & MILK & 22-Oct-03 & Ru-106 & -5.49 & $\mathrm{pCi} / \mathrm{L}$ & 28 & 28 & $u$ & & \\
\hline SESPSPEC & B16WH9 & FRANKLIN FARM A & PERIMETER & BI & cow & MILK & 09-May-03 & Sb-125 & -6.84 & $\mathrm{pCi} / \mathrm{L}$ & 8.1 & 8.1 & u & & \\
\hline SESPSPEC & B17T56 & FRANKLIN FARM A & PERIMETER & $\mathrm{BI}$ & cow & MILK & 23-Oct-03 & Sb-125 & 1.7 & pCill & 6.5 & 6.5 & $u$ & & \\
\hline SESPSPEC & B16WH8 & FRANKLIN FARM B & PERIMETER & $\mathrm{BI}$ & cow & MILK & 09-May-03 & Sb-125 & 6.31 & $\mathrm{pCi} / \mathrm{L}$ & 7.6 & 7.6 & $u$ & & \\
\hline SESPSPEC & B17T55 & FRANKLIN FARM B & PERIMETER & BI & cow & MILK & 23-Oct-03 & Sb-125 & 5.34 & $\mathrm{pCi} / \mathrm{L}$ & 6.9 & 6.9 & $\mathrm{u}$ & & \\
\hline SESPMNT & B16DK2 & SAGEMOOR COMPOSITE & PERIMETER & BI & cow & MILK & 13-Feb-03 & Sb-125 & -2.29 & $\mathrm{pCi} / \mathrm{L}$ & 7.7 & 7.7 & u & & \\
\hline SESPMNT & B16WK1 & SAGEMOOR COMPOSITE & PERIMETER & $\mathrm{BI}$ & cow & MILK & 09-May-03 & Sb-125 & -1.47 & $\mathrm{pCi} / \mathrm{L}$ & 7.6 & 7.6 & u & & \\
\hline SESPMNT & B17971 & SAGEMOOR COMPOSITE & PERIMETER & $\mathrm{BI}$ & cow & MILK & 31-Jul-03 & Sb-125 & -0.147 & $\mathrm{pCi} / \mathrm{L}$ & 6.6 & 6.6 & $\mathrm{u}$ & & \\
\hline SESPMNT & B17T66 & SAGEMOOR COMPOSITE & PERIMETER & BI & cow & MILK & 23-Oct-03 & Sb-125 & 9.93 & pCi/L & 8 & 8 & $u$ & & \\
\hline SESPMNT & B16FR7 & SUNNYSIDE AREA & DISTANT & $\mathrm{BI}$ & cow & MILK & 20 -Feb-03 & $\mathrm{Sb}-125$ & -1.09 & $\mathrm{pCi} / \mathrm{L}$ & 7.4 & 7.4 & u & & \\
\hline SESPMNT & B170P2 & SUNNYSIDE AREA & DISTANT & BI & cow & MILK & 16-May-03 & Sb-125 & 0.604 & $\mathrm{pCi} / \mathrm{L}$ & 8.1 & 8.1 & u & & \\
\hline SESPMNT & B179W0 & SUNNYSIDE AREA & DISTANT & $\mathrm{BI}$ & cow & MILK & 07-Aug-03 & Sb-125 & -0.984 & $\mathrm{pCi} / \mathrm{L}$ & 8.2 & 8.2 & u & & \\
\hline SESPMNT & B17TP1 & SUNNYSIDE AREA & DISTANT & $\mathrm{BI}$ & cow & MILK & 30-Oct-03 & $\mathrm{Sb}-125$ & 5.39 & $\mathrm{pCi} / \mathrm{L}$ & 7.6 & 7.6 & u & & \\
\hline SESPMNT & B16DK3 & WAHLUKE AREA COMP & COMMUNITY & $\mathrm{BI}$ & cow & MILK & $12-$ Feb-03 & Sb-125 & -1.05 & $\mathrm{pCi} / \mathrm{L}$ & 6.6 & 6.6 & u & & \\
\hline SESPMNT & B16WK3 & WAHLUKE AREA COMP & COMMUNITY & $\mathrm{BI}$ & cow & MILK & 07-May-03 & Sb-125 & -1.11 & $\mathrm{pCi} / \mathrm{L}$ & 7.8 & 7.8 & $u$ & & \\
\hline SESPMNT & B17972 & WAHLUKE AREA COMP & COMMUNITY & $\mathrm{BI}$ & cow & MILK & 30-Jul-03 & $\mathrm{Sb}-125$ & 5.36 & $\mathrm{pCi} / \mathrm{L}$ & 8 & 8 & u & & \\
\hline SESPMNT & B17T68 & WAHLUKE AREA COMP & COMMUNITY & $\mathrm{BI}$ & cow & MILK & 22-Oct-03 & $\mathrm{Sb}-125$ & -4.71 & $\mathrm{pCi} / \mathrm{L}$ & 7.5 & 7.5 & u & & \\
\hline SESPSPEC & B16WH9 & FRANKLIN FARM A & PERIMETER & BI & cow & MILK & 09-May-03 & Sr-90 & 0.532 & $\mathrm{pCi} / \mathrm{L}$ & 0.41 & 0.46 & $u$ & & \\
\hline SESPSPEC & B17T56 & FRANKLIN FARM A & PERIMETER & $\mathrm{BI}$ & cow & MILK & 23-Oct-03 & Sr-90 & 0.335 & $\mathrm{pCi} / \mathrm{L}$ & 0.19 & 0.22 & & & \\
\hline SESPSPEC & B16WH8 & FRANKLIN FARM B & PERIMETER & BI & cow & MILK & 09-May-03 & Sr-90 & 0.359 & $\mathrm{pCi} / \mathrm{L}$ & 0.37 & 0.42 & u & & \\
\hline SESPSPEC & B17T55 & FRANKLIN FARM B & PERIMETER & $\mathrm{BI}$ & cow & MILK & 23-Oct-03 & Sr-90 & 0.979 & $\mathrm{pCilL}$ & 0.3 & 0.36 & & & \\
\hline SESPMNT & B16DK2 & SAGEMOOR COMPOSITE & PERIMETER & $\mathrm{BI}$ & cow & MILK & 13-Feb-03 & Sr-90 & 0.368 & $\mathrm{pCi} / \mathrm{L}$ & 0.29 & 0.33 & $u$ & & \\
\hline SESPMNT & B16WK1 & SAGEMOOR COMPOSITE & PERIMETER & $\mathrm{BI}$ & cow & MILK & 09-May-03 & Sr-90 & 0.446 & $\mathrm{pCi} / \mathrm{L}$ & 0.51 & 0.53 & $u$ & & \\
\hline SESPMNT & B17971 & SAGEMOOR COMPOSITE & PERIMETER & $\mathrm{BI}$ & cow & MILK & 31-Jul-03 & Sr-90 & 1.75 & $\mathrm{pCi} / \mathrm{L}$ & 0.37 & 0.55 & & & \\
\hline SESPMNT & B17T66 & SAGEMOOR COMPOSITE & PERIMETER & BI & cow & MILK & $23-\mathrm{Oct}-03$ & Sr-90 & 0.587 & pCi/L & 0.22 & 0.26 & & & \\
\hline SESPMNT & B16FR7 & SUNNYSIDE AREA & DISTANT & $\mathrm{BI}$ & cow & MILK & $20-$ Feb-03 & Sr-90 & 0.347 & $\mathrm{pCi} / \mathrm{L}$ & 0.46 & 0.5 & $u$ & & \\
\hline SESPMNT & B170P2 & SUNNYSIDE AREA & DISTANT & BI & cow & MILK & 16-May-03 & Sr-90 & 0.822 & pCi/L & 0.47 & 0.53 & & & \\
\hline SESPMNT & B179w0 & SUNNYSIDE AREA & DISTANT & $\mathrm{BI}$ & cow & MILK & 07-Aug-03 & Sr-90 & 2.09 & $\mathrm{pCi} / \mathrm{L}$ & 0.39 & 0.61 & & & \\
\hline SESPMNT & B17TP1 & SUNNYSIDE AREA & DISTANT & $\mathrm{BI}$ & cow & MILK & 30-Oct-03 & Sr-90 & 0.305 & $\mathrm{pCi} / \mathrm{L}$ & 0.24 & 0.27 & $u$ & & \\
\hline SESPMNT & B16DK3 & WAHLUKE AREA COMP & COMMUNITY & $\mathrm{BI}$ & cow & MILK & 12-Feb-03 & Sr-90 & 0.309 & $\mathrm{pCi} / \mathrm{L}$ & 0.26 & 0.31 & $u$ & & \\
\hline SESPMNT & B16WK3 & WAHLUKE AREA COMP & COMMUNITY & BI & cow & MILK & 07-May-03 & Sr-90 & 0.692 & $\mathrm{pCi} / \mathrm{L}$ & 0.42 & 0.49 & u & & \\
\hline SESPMNT & B17972 & WAHLUKE AREA COMP & COMMUNITY & BI & cow & MILK & 30-Jul-03 & Sr-90 & 1.16 & pCi/L & 0.34 & 0.45 & & & \\
\hline SESPMNT & B17T68 & WAHLUKE AREA COMP & COMMUNITY & $\mathrm{BI}$ & cow & MILK & $22-0 c t-03$ & Sr-90 & 0.345 & $\mathrm{pCi} / \mathrm{L}$ & 0.24 & 0.27 & $u$ & & \\
\hline SESPMNT & B16WK2 & SAGEMOOR COMPOSITE & PERIMETER & BI & cow & MILK & 09-May-03 & I-129 & 0.0004227 & pCi/L & & $7.27044 \mathrm{E}-05$ & & & \\
\hline SESPMNT & B16WK4 & WAHLUKE AREA COMP & COMMUNITY & $\mathrm{BI}$ & cow & MILK & 07-May-03 & I-129 & 0.0004478 & $\mathrm{pCi} / \mathrm{L}$ & & $6.80656 \mathrm{E}-05$ & & & \\
\hline SESPMNT & B170N3 & SUNNYSIDE AREA & DISTANT & $\mathrm{BI}$ & cow & MILK & 16-May-03 & I-129 & 0.0001447 & $\mathrm{pCi} / \mathrm{L}$ & & $1.91004 \mathrm{E}-05$ & & & \\
\hline SESPMNT & B17T67 & SAGEMOOR COMPOSITE & PERIMETER & $\mathrm{BI}$ & cow & MILK & $23-\mathrm{Oct}-03$ & I-129 & 0.0003843 & $\mathrm{pCi} / \mathrm{L}$ & & 0.000053802 & & & \\
\hline SESPMNT & B17T69 & WAHLUKE AREA COMP & COMMUNITY & BI & cow & MILK & $22-\mathrm{Oct}-03$ & $1-129$ & 0.0005602 & $\mathrm{pCi} / \mathrm{L}$ & & $6.83444 \mathrm{E}-05$ & & & \\
\hline SESPMNT & B17TN2 & SUNNYSIDE AREA & DISTANT & BI & cow & MILK & $30-O c t-03$ & I-129 & 0.0002444 & pCi/L & & $3.27496 \mathrm{E}-05$ & & & \\
\hline SESPMNT & B16TB6 & RIVERVIEW AREA & COMMUNITY & BI & LEAFY VEGETABLES & STM-LV & 21-Apr-03 & GAMMA SCAN & & & & & & NO SAMPLE. UNABLE TO LOCATE. & \\
\hline SESPMNT & B16TB3 & SAGEMOOR AREA & PERIMETER & BI & LEAFY VEGETABLES & STM-LV & 21-Apr-03 & GAMMA SCAN & & & & & & NO SAMPLE. UNABLE TO LOCATE. & \\
\hline SESPMNT & B16TC0 & SUNNYSIDE AREA & DISTANT & $\mathrm{BI}$ & LEAFY VEGETABLES & STM-LV & 18-Apr-03 & $\mathrm{Be}-7$ & 0.272 & $\mathrm{pCi} / \mathrm{g}$ & 0.075 & 0.075 & & SPINACH & \\
\hline SESPMNT & B16TC0 & SUNNYSIDE AREA & DISTANT & $\mathrm{BI}$ & LEAFY VEGETABLES & STM-LV & 18-Apr-03 & Co-60 & 0.00387 & $\mathrm{pCi} / \mathrm{g}$ & 0.0067 & 0.0067 & $u$ & SPINACH & \\
\hline SESPMNT & B16TC0 & SUNNYSIDE AREA & DISTANT & $\mathrm{BI}$ & LEAFY VEGETABLES & STM-LV & 18-Apr-03 & Cs-134 & -0.00128 & $\mathrm{pCi} / \mathrm{g}$ & 0.0063 & 0.0063 & u & SPINACH & \\
\hline SESPMNT & B16TC0 & SUNNYSIDE AREA & DISTANT & $\mathrm{BI}$ & LEAFY VEGETABLES & STM-LV & 18-Apr-03 & Cs-137 & 0.00249 & $\mathrm{pCi} / \mathrm{g}$ & 0.0055 & 0.0055 & $u$ & SPINACH & \\
\hline SESPMNT & B16TC0 & SUNNYSIDE AREA & DISTANT & $\mathrm{BI}$ & LEAFY VEGETABLES & STM-LV & 18-Apr-03 & Eu-152 & -0.0024 & $\mathrm{pCi} / \mathrm{g}$ & 0.013 & 0.013 & u & SPINACH & \\
\hline SESPMNT & B16TC0 & SUNNYSIDE AREA & DISTANT & BI & LEAFY VEGETABLES & STM-LV & 18-Apr-03 & Eu-154 & -0.0112 & $\mathrm{pCi} / \mathrm{g}$ & 0.021 & 0.021 & u & SPINACH & \\
\hline SESPMNT & B16TC0 & SUNNYSIDE AREA & DISTANT & BI & LEAFY VEGETABLES & STM-LV & 18-Apr-03 & Eu-155 & -0.00931 & $\mathrm{pCi} / \mathrm{g}$ & 0.015 & 0.015 & $u$ & SPINACH & \\
\hline SESPMNT & B16TC0 & SUNNYSIDE AREA & DISTANT & $\mathrm{BI}$ & LEAFY VEGETABLES & STM-LV & 18-Apr-03 & $\mathrm{K}-40$ & 9.89 & $\mathrm{pCi} / \mathrm{g}$ & 1.2 & 1.2 & & SPINACH & \\
\hline SESPMNT & B16TC0 & SUNNYSIDE AREA & DISTANT & $\mathrm{BI}$ & LEAFY VEGETABLES & STM-LV & 18-Apr-03 & Ru-106 & 0.0142 & $\mathrm{pCi} / \mathrm{g}$ & 0.047 & 0.047 & $u$ & SPINACH & \\
\hline
\end{tabular}




\begin{tabular}{|c|c|c|c|c|c|c|c|c|c|c|c|c|c|c|c|}
\hline OWNER ID & SAMP NUM & SAMP SITE NAME & DIST CLASS & MEDIA & SAMP FROM & SAMP ITEM & SAMP DATE & $\begin{array}{c}\text { CON SHORT } \\
\text { NAME }\end{array}$ & VALUE RPTD & \begin{tabular}{|l|} 
ANAL \\
UNITS \\
RPTD
\end{tabular} & $\left|\begin{array}{c}\text { COUNTING } \\
\text { ERROR }\end{array}\right|$ & $\left|\begin{array}{c}\text { TOTAL ANAL } \\
\text { ERROR }\end{array}\right|$ & \begin{tabular}{|c|} 
LAB \\
QUALIFIER
\end{tabular} & SAMP COMMENT & |RESULT COMMENT \\
\hline SESPMNT & B16TC0 & SUNNYSIDE AREA & DISTANT & $\mathrm{BI}$ & LEAFY VEGETABLES & STM-LV & 18-Apr-03 & $\mathrm{Sb}-125$ & 0.00207 & $\mathrm{pCi} / \mathrm{g}$ & 0.013 & 0.013 & $u$ & SPINACH & \\
\hline SESPMNT & B16TB6 & RIVERVIEW AREA & COMMUNITY & BI & LEAFY VEGETABLES & STM-LV & 21-Apr-03 & Sr-90 & & & & & & NO SAMPLE. UNABLE TO LOCATE. & \\
\hline SESPMNT & B16TB3 & SAGEMOOR AREA & PERIMETER & $\mathrm{BI}$ & LEAFY VEGETABLES & STM-LV & 21-Apr-03 & Sr-90 & & & & & & NO SAMPLE. UNABLE TO LOCATE. & \\
\hline SESPMNT & B16TC0 & SUNNYSIDE AREA & DISTANT & $\mathrm{BI}$ & LEAFY VEGETABLES & STM-LV & 18-Apr-03 & Sr-90 & 0.0378 & $\mathrm{pCi} / \mathrm{g}$ & 0.06 & 0.068 & u & SPINACH & \\
\hline SESPMNT & B176P4 & EAST WAHLUKE AREA & COMMUNITY & $\mathrm{BI}$ & $\begin{array}{l}\text { POTATO } \\
\end{array}$ & TUBER & 11-Sep-03 & $\mathrm{Be}-7$ & 0.0119 & $\mathrm{pCi} / \mathrm{g}$ & 0.037 & 0.037 & $\mathrm{u}$ & & \\
\hline SESPMNT & B176N3 & RIVERVIEW AREA & COMMUNITY & $\mathrm{BI}$ & POTATO & TUBER & 17-Jul-03 & Be-7 & 0.00459 & $\mathrm{pCi} / \mathrm{g}$ & 0.038 & 0.038 & $\mathrm{u}$ & & \\
\hline SESPMNT & B176N5 & SAGEMOOR AREA & PERIMETER & $\mathrm{BI}$ & POTATO & TUBER & 17-Jul-03 & Be-7 & -0.0099 & $\mathrm{pCi} / \mathrm{g}$ & 0.04 & 0.04 & $u$ & & \\
\hline SESPMNT & B176P0 & SUNNYSIDE AREA & DISTANT & $\mathrm{BI}$ & POTATO & TUBER & 07-Aug-03 & Be-7 & -0.011 & $\mathrm{pCi} / \mathrm{g}$ & 0.037 & 0.037 & $u$ & & \\
\hline SESPMNT & B176P4 & EAST WAHLUKE AREA & COMMUNITY & BI & POTATO & TUBER & 11-Sep-03 & Co-60 & 0.000136 & $\mathrm{pCi} / \mathrm{g}$ & 0.0048 & 0.0048 & u & & \\
\hline SESPMNT & B176N3 & RIVERVIEW AREA & COMMUNITY & $\mathrm{BI}$ & POTATO & TUBER & 17-Jul-03 & Co-60 & 0.00184 & $\mathrm{pCi} / \mathrm{g}$ & 0.0045 & 0.0045 & u & & \\
\hline SESPMNT & B176N5 & SAGEMOOR AREA & PERIMETER & BI & POTATO & TUBER & 17-Jul-03 & Co-60 & 0.000937 & $\mathrm{pCi} / \mathrm{g}$ & 0.0045 & 0.0045 & $u$ & & \\
\hline SESPMNT & B176P0 & SUNNYSIDE AREA & DISTANT & $\mathrm{BI}$ & POTATO & TUBER & 07-Aug-03 & Co-60 & 0.00274 & $\mathrm{pCi} / \mathrm{g}$ & 0.0048 & 0.0048 & u & & \\
\hline SESPMNT & B176P4 & EAST WAHLUKE AREA & COMMUNITY & $\mathrm{BI}$ & POTATO & TUBER & 11-Sep-03 & Cs-134 & 0.00232 & $\mathrm{pCi} / \mathrm{g}$ & 0.0046 & 0.0046 & U & & \\
\hline SESPMNT & B176N3 & RIVERVIEW AREA & COMMUNITY & $\mathrm{BI}$ & POTATO & TUBER & 17-Jul-03 & Cs-134 & 0.00145 & $\mathrm{pCi} / \mathrm{g}$ & 0.0048 & 0.0048 & $U$ & & \\
\hline SESPMNT & B176N5 & SAGEMOOR AREA & PERIMETER & BI & POTATO & TUBER & 17-Jul-03 & Cs-134 & 0.00088 & $\mathrm{pCi} / \mathrm{g}$ & 0.0043 & 0.0043 & u & & \\
\hline SESPMNT & B176P0 & SUNNYSIDE AREA & DISTANT & $\mathrm{BI}$ & POTATO & TUBER & 07-Aug-03 & Cs-134 & 0.000254 & $\mathrm{pCi} / \mathrm{g}$ & 0.0046 & 0.0046 & u & & \\
\hline SESPMNT & B176P4 & EAST WAHLUKE AREA & COMMUNITY & $\mathrm{BI}$ & POTATO & TUBER & 11-Sep-03 & Cs-137 & 0.00314 & $\mathrm{pCi} / \mathrm{g}$ & 0.0044 & 0.0044 & U & & \\
\hline SESPMNT & B176N3 & RIVERVIEW AREA & COMMUNITY & $\mathrm{BI}$ & POTATO & TUBER & 17-Jul-03 & Cs-137 & -0.00119 & $\mathrm{pCi} / \mathrm{g}$ & 0.0044 & 0.0044 & U & & \\
\hline SESPMNT & B176N5 & SAGEMOOR AREA & PERIMETER & $\mathrm{BI}$ & POTATO & TUBER & 17-Jul-03 & Cs-137 & 0.00144 & $\mathrm{pCi} / \mathrm{g}$ & 0.0044 & 0.0044 & u & & \\
\hline SESPMNT & B176P0 & SUNNYSIDE AREA & DISTANT & BI & POTATO & TUBER & 07-Aug-03 & Cs-137 & 0.00182 & $\mathrm{pCi} / \mathrm{g}$ & 0.0041 & 0.0041 & $u$ & & \\
\hline SESPMNT & B176P4 & EAST WAHLUKE AREA & COMMUNITY & $\mathrm{BI}$ & POTATO & TUBER & 11-Sep-03 & Eu-152 & -0.00384 & $\mathrm{pCi} / \mathrm{g}$ & 0.01 & 0.01 & $u$ & & \\
\hline SESPMNT & B176N3 & RIVERVIEW AREA & COMMUNITY & BI & POTATO & TUBER & 17-Jul-03 & Eu-152 & -0.00172 & $\mathrm{pCi} / \mathrm{g}$ & 0.01 & 0.01 & $u$ & & \\
\hline SESPMNT & B176N5 & SAGEMOOR AREA & $\begin{array}{l}\text { PERIMETER } \\
\end{array}$ & $\mathrm{BI}$ & POTATO & TUBER & 17-Jul-03 & Eu-152 & 0.00128 & $\mathrm{pCi} / \mathrm{g}$ & 0.01 & 0.01 & u & & \\
\hline SESPMNT & B176P0 & SUNNYSIDE AREA & DISTANT & BI & POTATO & TUBER & 07-Aug-03 & Eu-152 & -0.0035 & $\mathrm{pCi} / \mathrm{g}$ & 0.0096 & 0.0096 & u & & \\
\hline SESPMNT & B176P4 & EAST WAHLUKE AREA & COMMUNITY & $\mathrm{BI}$ & POTATO & TUBER & 11-Sep-03 & Eu-154 & $-0.0165 \mathrm{f}$ & $\mathrm{pCi} / \mathrm{g}$ & 0.016 & 0.016 & $u$ & & \\
\hline SESPMNT & B176N3 & RIVERVIEW AREA & COMMUNITY & $\mathrm{BI}$ & POTATO & TUBER & 17-Jul-03 & Eu-154 & $-0.00257 p$ & $\mathrm{pCi} / \mathrm{g}$ & 0.016 & 0.016 & $u$ & & \\
\hline SESPMNT & B176N5 & SAGEMOOR AREA & PERIMETER & BI & POTATO & TUBER & 17-Jul-03 & Eu-154 & 0.00223 & $\mathrm{pCi} / \mathrm{g}$ & 0.015 & 0.015 & u & & \\
\hline SESPMNT & B176P0 & SUNNYSIDE AREA & DISTANT & $\mathrm{BI}$ & POTATO & TUBER & 07-Aug-03 & Eu-154 & -0.000983 & $\mathrm{pCi} / \mathrm{g}$ & 0.015 & 0.015 & $u$ & & \\
\hline SESPMNT & B176P4 & EAST WAHLUKE AREA & COMMUNITY & BI & POTATO & TUBER & 11-Sep-03 & Eu-155 & 0.000175 & $\mathrm{pCi} / \mathrm{g}$ & 0.0095 & 0.0095 & $u$ & & \\
\hline SESPMNT & B176N3 & RIVERVIEW AREA & COMMUNITY & $\mathrm{BI}$ & POTATO & TUBER & 17-Jul-03 & Eu-155 & 0.00247 & $\mathrm{pCi} / \mathrm{g}$ & 0.0098 & 0.0098 & u & & \\
\hline SESPMNT & B176N5 & SAGEMOOR AREA & PERIMETER & $\mathrm{BI}$ & POTATO & TUBER & 17-Jul-03 & Eu-155 & -0.00548 & $\mathrm{pCi} / \mathrm{g}$ & 0.0088 & 0.0088 & $u$ & & \\
\hline SESPMNT & B176P0 & SUNNYSIDE AREA & DISTANT & $\mathrm{BI}$ & POTATO & TUBER & 07-Aug-03 & Eu-155 & -0.00599 & $\mathrm{pCi} / \mathrm{g}$ & 0.009 & 0.009 & $u$ & & \\
\hline SESPMNT & B176P4 & EAST WAHLUKE AREA & COMMUNITY & $\mathrm{BI}$ & POTATO & TUBER & 11-Sep-03 & $\mathrm{K}-40$ & $4.06 \mathrm{p}$ & $\mathrm{pCi} / \mathrm{g}$ & 0.57 & 0.57 & & & \\
\hline SESPMNT & B176N3 & RIVERVIEW AREA & COMMUNITY & BI & POTATO & TUBER & 17-Jul-03 & $\mathrm{K}-40$ & $4.56 \mathrm{p}$ & $\mathrm{pCi} / \mathrm{g}$ & 0.63 & 0.63 & & & \\
\hline SESPMNT & B176N5 & SAGEMOOR AREA & PERIMETER & $\mathrm{BI}$ & POTATO & TUBER & 17-Jul-03 & $\mathrm{K}-40$ & $4.43 \mathrm{k}$ & $\mathrm{pCi} / \mathrm{g}$ & 0.61 & 0.61 & & & \\
\hline SESPMNT & B176P0 & SUNNYSIDE AREA & DISTANT & BI & POTATO & TUBER & 07-Aug-03 & K-40 & 4.46 & $\mathrm{pCi} / \mathrm{g}$ & 0.62 & 0.62 & & & \\
\hline SESPMNT & B176P4 & EAST WAHLUKE AREA & COMMUNITY & $\mathrm{BI}$ & POTATO & TUBER & $11-$ Sep-03 & Ru-106 & -0.0019 & $\mathrm{pCi} / \mathrm{g}$ & 0.036 & 0.036 & $u$ & & \\
\hline SESPMNT & B176N3 & RIVERVIEW AREA & COMMUNITY & BI & POTATO & TUBER & 17-Jul-03 & Ru-106 & 0.000357 & $\mathrm{pCi} / \mathrm{g}$ & 0.038 & 0.038 & $u$ & & \\
\hline SESPMNT & B176N5 & SAGEMOOR AREA & PERIMETER & $\mathrm{BI}$ & РОТАTO & TUBER & 17-Jul-03 & Ru-106 & -0.00822 & $\mathrm{pCi} / \mathrm{g}$ & 0.039 & 0.039 & U & & \\
\hline SESPMNT & B176P0 & SUNNYSIDE AREA & DISTANT & $\mathrm{BI}$ & POTATO & TUBER & 07-Aug-03 & Ru-106 & 0.0097 & $\mathrm{pCi} / \mathrm{g}$ & 0.036 & 0.036 & $u$ & & \\
\hline SESPMNT & B176P4 & EAST WAHLUKE AREA & COMMUNITY & BI & POTATO & TUBER & $11-$ Sep-03 & Sb-125 & 0.00569 & $\mathrm{pCi} / \mathrm{g}$ & 0.01 & 0.01 & $u$ & & \\
\hline SESPMNT & B176N3 & RIVERVIEW AREA & COMMUNITY & $\mathrm{BI}$ & POTATO & TUBER & 17-Jul-03 & $\mathrm{Sb}-125$ & 0.00819 & $\mathrm{pCi} / \mathrm{g}$ & 0.0097 & 0.0097 & u & & \\
\hline SESPMNT & B176N5 & SAGEMOOR AREA & PERIMETER & $\mathrm{BI}$ & POTATO & TUBER & 17-Jul-03 & Sb-125 & 0.00915 & $\mathrm{pCi} / \mathrm{g}$ & 0.01 & 0.01 & $u$ & & \\
\hline SESPMNT & B176PO & SUNNYSIDE AREA & DISTANT & $\mathrm{BI}$ & POTATO & TUBER & 07-Aug-03 & $\mathrm{Sb}-125$ & -0.00595 & $\mathrm{pCi} / \mathrm{g}$ & 0.0094 & 0.0094 & $u$ & & \\
\hline SESPMNT & B176P4 & EAST WAHLUKE AREA & COMMUNITY & $\mathrm{BI}$ & POTATO & TUBER & 11-Sep-03 & Sr-90 & 0.0109 & $\mathrm{pCi} / \mathrm{g}$ & 0.0029 & 0.0034 & & & \\
\hline SESPMNT & B176N3 & RIVERVIEW AREA & COMMUNITY & $\mathrm{BI}$ & POTATO & TUBER & 17-Jul-03 & Sr-90 & 0.0135 & $\mathrm{pCi} / \mathrm{g}$ & 0.034 & 0.034 & $u$ & & \\
\hline SESPMNT & B176N5 & SAGEMOOR AREA & PERIMETER & $\mathrm{BI}$ & POTATO & TUBER & 17-Jul-03 & Sr-90 & 0.00262 & $\mathrm{pCi} / \mathrm{g}$ & 0.0043 & 0.0047 & u & & \\
\hline SESPMNT & B176P0 & SUNNYSIDE AREA & DISTANT & $\mathrm{BI}$ & POTATO & TUBER & 07-Aug-03 & Sr-90 & 0.00943 & $\mathrm{pCi} / \mathrm{g}$ & 0.0045 & 0.0051 & & & \\
\hline SESPMNT & B176N1 & HARRAH/WAPATO AREA & DISTANT & $\mathrm{BI}$ & TOMATO & FRUIT & 20-Sep-03 & Be-7 & -0.00859 & $\mathrm{pCi} / \mathrm{g}$ & 0.023 & 0.023 & u & & \\
\hline SESPMNT & B176P6 & RIVERVIEW AREA & COMMUNITY & $\mathrm{BI}$ & TOMATO & FRUIT & 31-Jul-03 & Be-7 & -0.029 & $\mathrm{pCi} / \mathrm{g}$ & 0.036 & 0.036 & $u$ & & \\
\hline SESPMNT & $\mathrm{B} 176 \mathrm{~N} 1$ & HARRAH/WAPATO AREA & DISTANT & $\mathrm{BI}$ & TOMATO & FRUIT & $20-$ Sep-03 & Co-60 & 0.00176 & $\mathrm{pCi} / \mathrm{g}$ & 0.003 & 0.003 & u & & \\
\hline SESPMNT & B176P6 & RIVERVIEW AREA & COMMUNITY & $\mathrm{BI}$ & TOMATO & FRUIT & 31-Jul-03 & Co-60 & 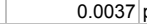 & $\mathrm{pCi} / \mathrm{g}$ & 0.0039 & 0.0039 & $\mathrm{U}$ & & \\
\hline SESPMNT & B176N1 & HARRAH/WAPATO AREA & DISTANT & BI & TOMATO & FRUIT & 20-Sep-03 & Cs-134 & 0.00218 & $\mathrm{pCi} / \mathrm{g}$ & 0.003 & 0.003 & $u$ & & \\
\hline SESPMNT & B176P6 & RIVERVIEW AREA & COMMUNITY & BI & TOMATO & FRUIT & 31-Jul-03 & Cs-134 & 0.00114 & $\mathrm{pCi} / \mathrm{g}$ & 0.0041 & 0.0041 & u & & \\
\hline SESPMNT & B176N1 & HARRAH/WAPATO AREA & DISTANT & $\mathrm{BI}$ & TOMATO & FRUIT & 20 -Sep-03 & Cs-137 & -0.00256 & $\mathrm{pCi} / \mathrm{g}$ & 0.0028 & 0.0028 & u & & \\
\hline SESPMNT & B176P6 & RIVERVIEW AREA & COMMUNITY & $\mathrm{BI}$ & TOMATO & FRUIT & 31-Jul-03 & Cs-137 & 0.00252 & $\mathrm{pCi} / \mathrm{g}$ & 0.0037 & 0.0037 & u & & \\
\hline SESPMNT & B176N1 & HARRAH/WAPATO AREA & DISTANT & $\mathrm{Bl}$ & TOMATO & FRUIT & 20-Sep-03 & Eu-152 & -0.00483 & $\mathrm{pCi} / \mathrm{g}$ & 0.007 & 0.007 & $u$ & & \\
\hline
\end{tabular}




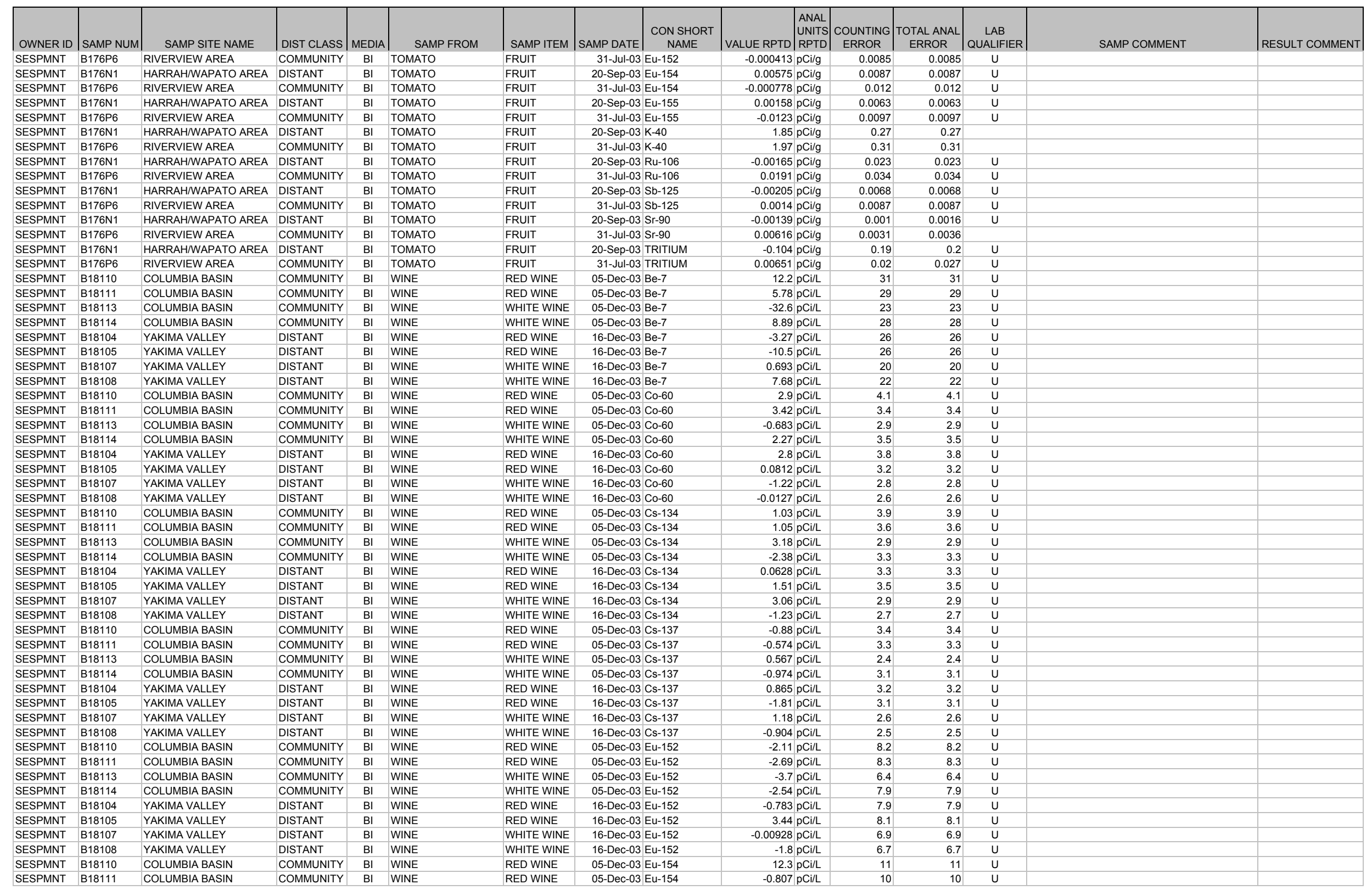


(pCi/g Wet Weight)

\begin{tabular}{|c|c|c|c|c|c|c|c|c|c|c|c|c|c|c|c|}
\hline OWNER ID & SAMP NUM & SAMP SITE NAME & DIST CLASS & MEDIA & SAMP FROM & SAMP ITEM & SAMP DATE & $\begin{array}{c}\text { CON SHORT } \\
\text { NAME }\end{array}$ & VALUE RPTD & \begin{tabular}{|l|} 
ANAL \\
UNIS \\
RPPT
\end{tabular} & $\left|\begin{array}{c}\text { COUNTING } \\
\text { ERROR }\end{array}\right|$ & $\begin{array}{c}\text { TOTAL ANAL } \\
\text { ERROR }\end{array}$ & $\begin{array}{c}\text { LAB } \\
\text { QUALIFIER }\end{array}$ & SAMP COMMENT & RESULT COMMENT \\
\hline SESPMNT & B18113 & COLUMBIA BASIN & COMMUNITY & $\mathrm{BI}$ & WINE & WHITE WINE & 05-Dec-03 & Eu-154 & 0.748 & $\mathrm{pCi} / \mathrm{L}$ & 7.7 & 7.7 & u & & \\
\hline SESPMNT & B18114 & COLUMBIA BASIN & COMMUNITY & $\mathrm{BI}$ & WINE & WHITE WINE & 05-Dec-03 & Eu-154 & -11.3 & $\mathrm{pCi} / \mathrm{L}$ & 9.1 & 9.1 & $u$ & & \\
\hline SESPMNT & B18104 & YAKIMA VALLEY & DISTANT & $\mathrm{BI}$ & WINE & RED WINE & 16-Dec-03 & Eu-154 & 3.44 & $\mathrm{pCi} / \mathrm{L}$ & 9.7 & 9.7 & u & & \\
\hline SESPMNT & B18105 & YAKIMA VALLEY & DISTANT & $\mathrm{BI}$ & WINE & RED WINE & 16-Dec-03 & Eu-154 & 0.557 & $\mathrm{pCi} / \mathrm{L}$ & 9 & 9 & u & & \\
\hline SESPMNT & B18107 & YAKIMA VALLEY & DISTANT & BI & WINE & WHITE WINE & 16-Dec-03 & Eu-154 & -2.41 & $\mathrm{pCi} / \mathrm{L}$ & 8.3 & 8.3 & u & & \\
\hline SESPMNT & B18108 & YAKIMA VALLEY & DISTANT & $\mathrm{BI}$ & WINE & WHITE WINE & 16-Dec-03 & Eu-154 & -0.222 & $\mathrm{pCi} / \mathrm{L}$ & 7 & 7 & u & & \\
\hline SESPMNT & B18110 & COLUMBIA BASIN & COMMUNITY & $\mathrm{BI}$ & WINE & RED WINE & 05-Dec-03 & Eu-155 & 4.69 & $\mathrm{pCi} / \mathrm{L}$ & 8.3 & 8.3 & u & & \\
\hline SESPMNT & B18111 & COLUMBIA BASIN & COMMUNITY & $\mathrm{BI}$ & WINE & RED WINE & 05-Dec-03 & Eu-155 & -7.08 & $\mathrm{pCi} / \mathrm{L}$ & 7.7 & 7.7 & $U$ & & \\
\hline SESPMNT & B18113 & COLUMBIA BASIN & COMMUNITY & $\mathrm{BI}$ & WINE & WHITE WINE & 05-Dec-03 & Eu-155 & 2.63 & $\mathrm{pCi} / \mathrm{L}$ & 6.3 & 6.3 & u & & \\
\hline SESPMNT & B18114 & COLUMBIA BASIN & COMMUNITY & $\mathrm{BI}$ & WINE & WHITE WINE & 05-Dec-03 & Eu-155 & 5.63 & $\mathrm{pCi} / \mathrm{L}$ & 7.4 & 7.4 & u & & \\
\hline SESPMNT & B18104 & YAKIMA VALLEY & DISTANT & $\mathrm{Bl}$ & WINE & RED WINE & 16-Dec-03 & Eu-155 & 7.77 & $\mathrm{pCi/L}$ & 8.4 & 8.4 & u & & \\
\hline SESPMNT & B18105 & YAKIMA VALLEY & DISTANT & BI & WINE & RED WINE & 16-Dec-03 & Eu-155 & $5.01 \mathrm{k}$ & $\mathrm{pCi} / \mathrm{L}$ & 7.5 & 7.5 & u & & \\
\hline SESPMNT & B18107 & YAKIMA VALLEY & DISTANT & BI & WINE & WHITE WINE & 16-Dec-03 & Eu-155 & 4.53 & $\mathrm{pCi} / \mathrm{L}$ & 6.6 & 6.6 & u & & \\
\hline SESPMNT & B18108 & YAKIMA VALLEY & DISTANT & $\mathrm{BI}$ & WINE & WHITE WINE & 16-Dec-03 & Eu-155 & $-3.01 \mathrm{k}$ & $\mathrm{pCi} / \mathrm{L}$ & 5.9 & 5.9 & u & & \\
\hline SESPMNT & B18110 & COLUMBIA BASIN & COMMUNITY & $\mathrm{BI}$ & WINE & RED WINE & 05-Dec-03 & $\mathrm{k}-40$ & 1480 & $\mathrm{pCi} / \mathrm{L}$ & 250 & 250 & & & \\
\hline SESPMNT & B18111 & COLUMBIA BASIN & COMMUNITY & $\mathrm{BI}$ & WINE & RED WINE & 05-Dec-03 & $\mathrm{k}-40$ & 1420 & $\mathrm{pCi} / \mathrm{L}$ & 230 & 230 & & & \\
\hline SESPMNT & B18113 & COLUMBIA BASIN & COMMUNITY & $\mathrm{BI}$ & WINE & WHITE WINE & 05-Dec-03 & $\mathrm{K}-40$ & 382 & $\mathrm{pCi} / \mathrm{L}$ & 100 & 100 & & & \\
\hline SESPMNT & B18114 & COLUMBIA BASIN & COMMUNITY & $\mathrm{Bl}$ & WINE & WHITE WINE & $05-$ Dec-03 & K-40 & 55.7 & $\mathrm{pCi} / \mathrm{L}$ & 94 & 94 & $u$ & & \\
\hline SESPMNT & B18104 & YAKIMA VALLEY & DISTANT & $\mathrm{BI}$ & WINE & RED WINE & 16-Dec-03 & $\mathrm{k}-40$ & 502 & $\mathrm{pCi} / \mathrm{L}$ & 150 & 150 & & & \\
\hline SESPMNT & B18105 & YAKIMA VALLEY & DISTANT & $\mathrm{BI}$ & WINE & RED WINE & 16-Dec-03 & $\mathrm{k}-40$ & 638 & $\mathrm{pCi} / \mathrm{L}$ & 150 & 150 & & & \\
\hline SESPMNT & B18107 & YAKIMA VALLEY & DISTANT & $\mathrm{BI}$ & WINE & WHITE WINE & 16-Dec-03 & $\mathrm{k}-40$ & 418 & $\mathrm{pCi} / \mathrm{L}$ & 110 & 110 & & & \\
\hline SESPMNT & B18108 & YAKIMA VALLEY & DISTANT & $\mathrm{BI}$ & WINE & WHITE WINE & 16-Dec-03 & $\mathrm{k}-40$ & 463 & $\mathrm{pCi} / \mathrm{L}$ & 90 & 90 & & & \\
\hline SESPMNT & B18110 & COLUMBIA BASIN & COMMUNITY & $\mathrm{BI}$ & WINE & RED WINE & 05-Dec-03 & Ru-106 & -3.03 & $\mathrm{pCi} / \mathrm{L}$ & 28 & 28 & $u$ & & \\
\hline SESPMNT & B18111 & COLUMBIA BASIN & COMMUNITY & $\mathrm{BI}$ & WINE & RED WINE & 05-Dec-03 & Ru-106 & -18.8 & $\mathrm{pCilL}$ & 28 & 28 & u & & \\
\hline SESPMNT & B18113 & COLUMBIA BASIN & COMMUNITY & $\mathrm{Bl}$ & WINE & WHITE WINE & $05-$ Dec-03 & Ru-106 & 18.1 & $\mathrm{pCl} / \mathrm{L}$ & 21 & 21 & u & & \\
\hline SESPMNT & B18114 & COLUMBIA BASIN & COMMUNITY & $\mathrm{BI}$ & WINE & WHITE WINE & 05-Dec-03 & Ru-106 & -19.4 & pCi/L & 27 & 27 & $u$ & & \\
\hline SESPMNT & B18104 & YAKIMA VALLEY & $\begin{array}{l}\text { DISTANT } \\
\end{array}$ & $\mathrm{Bl}$ & WINE & $\begin{array}{l}\text { RED WINE } \\
\text { RIN }\end{array}$ & 16-Dec-03 & Ru-106 & 6.55 & $\mathrm{pCl} / \mathrm{L}$ & 28 & 28 & u & & \\
\hline SESPMNT & B18105 & YAKIMA VALLEY & DISTANT & $\mathrm{BI}$ & WINE & RED WINE & 16-Dec-03 & Ru-106 & -10.8 & $\mathrm{pClil}$ & 28 & 28 & $u$ & & \\
\hline SESPMNT & B18107 & YAKIMA VALLEY & DISTANT & $\mathrm{BI}$ & WINE & WHITE WINE & 16-Dec-03 & Ru-106 & 0.371 & pCilL & 22 & 22 & u & & \\
\hline SESPMNT & B18108 & YAKIMA VALLEY & DISTANT & $\mathrm{BI}$ & WINE & WHITE WINE & 16-Dec-03 & Ru-106 & -8.57 & $\mathrm{pCi} / \mathrm{L}$ & 22 & 22 & u & & \\
\hline SESPMNT & B18110 & COLUMBIA BASIN & COMMUNITY & $\mathrm{BI}$ & WINE & RED WINE & 05-Dec-03 & Sb-125 & 3.03 & $\mathrm{pCilL}$ & 8.2 & 8.2 & u & & \\
\hline SESPMNT & B18111 & COLUMBIA BASIN & COMMUNITY & $\mathrm{Bl}$ & WINE & RED WINE & 05-Dec-03 & Sb-125 & 1.58 & $\mathrm{pCl} / \mathrm{L}$ & 8 & $\frac{0.4}{8}-190$ & u & & \\
\hline SESPMNT & B18113 & COLUMBIA BASIN & COMMUNITY & $\mathrm{BI}$ & WINE & WHITE WINE & 05-Dec-03 & $\mathrm{Sb}-125$ & 0.783 & $\mathrm{pCi} / \mathrm{L}$ & 6 & 6 & $u$ & & \\
\hline SESPMNT & B18114 & COLUMBIA BASIN & COMMUNITY & $\mathrm{Bl}$ & WINE & WHITE WINE & $05-$ Dec-03 & Sb-125 & -2.12 & $\mathrm{pCl} / \mathrm{L}$ & 7.7 & 7.7 & u & & \\
\hline SESPMNT & B18104 & YAKIMA VALLEY & DISTANT & $\mathrm{BI}$ & WINE & RED WINE & 16-Dec-03 & Sb-125 & 10.3 & $\mathrm{pCi} / \mathrm{L}$ & 8 & 8 & u & & \\
\hline SESPMNT & B18105 & YAKIMA VALLEY & $\begin{array}{l}\text { DISTANT } \\
\end{array}$ & $\mathrm{Bl}$ & WINE & RED WINE & 16-Dec-03 & Sb-125 & 1.2 & $\mathrm{pCl} / \mathrm{L}$ & 8 & 8 & u & & \\
\hline SESPMNT & B18107 & YAKIMA VALLEY & DISTANT & BI & WINE & WHITE WINE & 16-Dec-03 & Sb-125 & 0.941 & $\mathrm{pCi} / \mathrm{L}$ & 6.6 & 6.6 & U & & \\
\hline SESPMNT & B18108 & YAKIMA VALLEY & DISTANT & $\mathrm{BI}$ & WINE & WHITE WINE & 16-Dec-03 & Sb-125 & 0.463 & $\mathrm{pCi} / \mathrm{L}$ & 6.1 & 6.1 & $u$ & & \\
\hline
\end{tabular}


(pcilg Wet Weight)

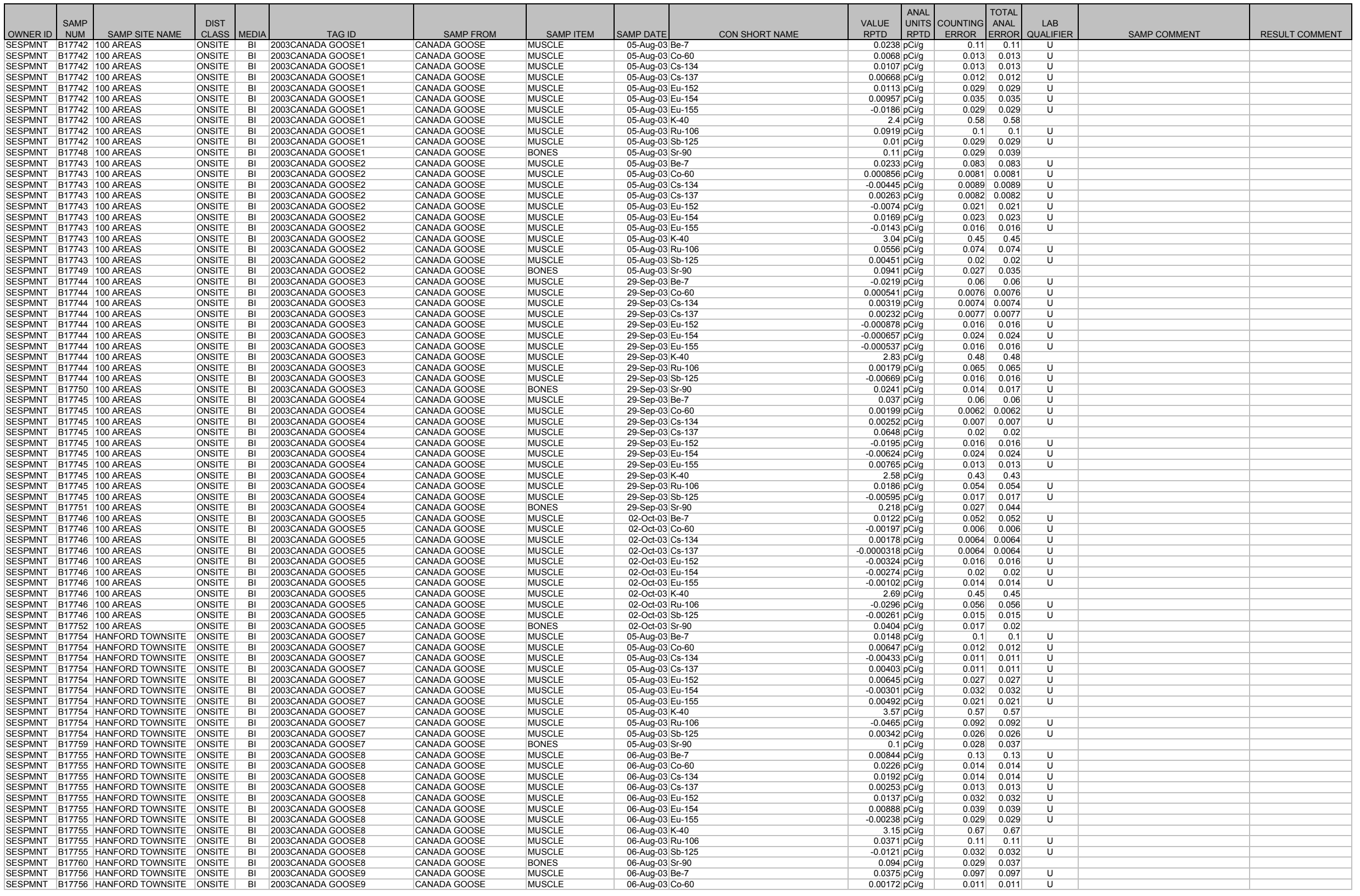


(pcilg Wet Weight)

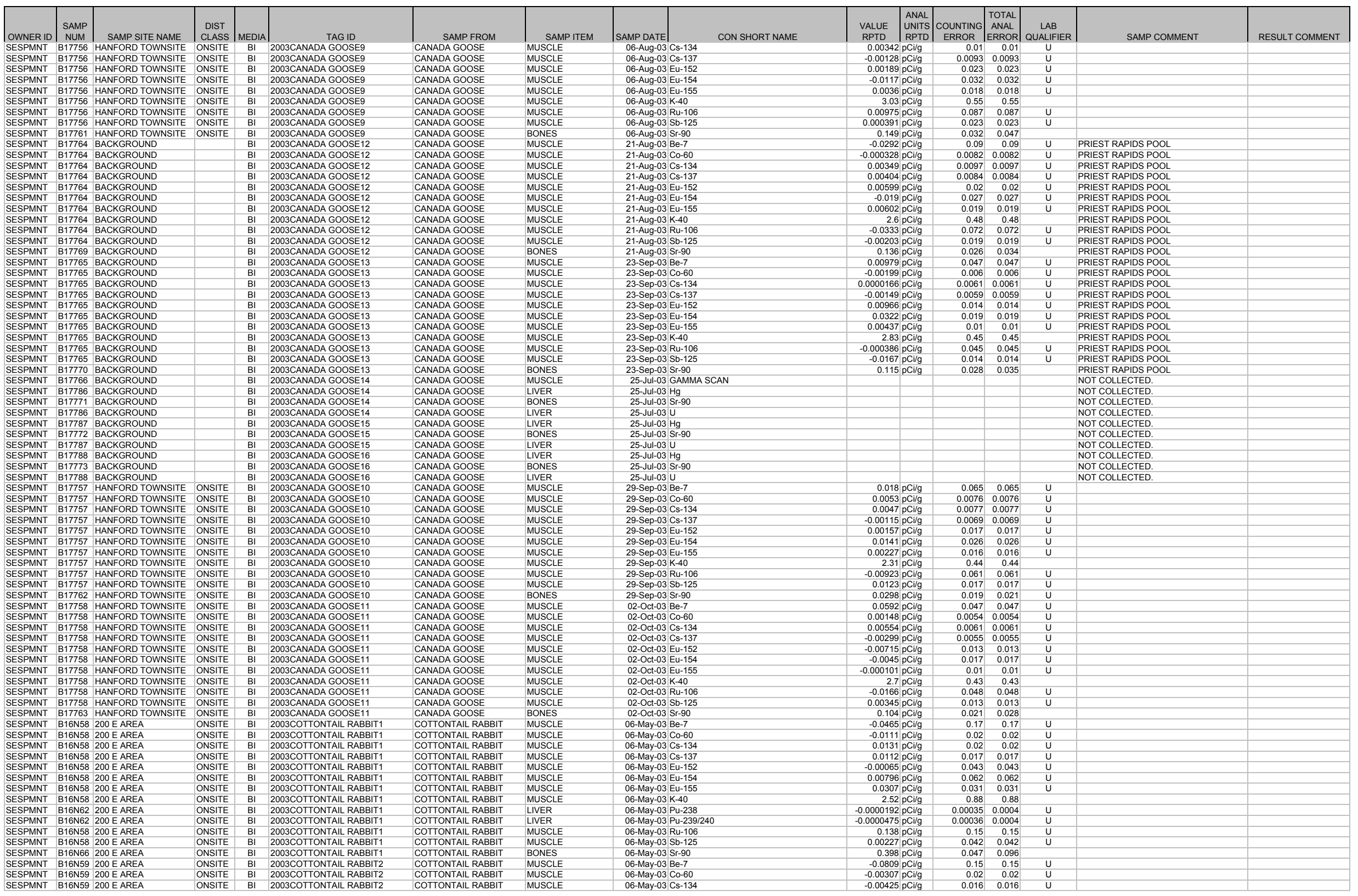


WILDLLEE
(pcilg Wet Weight)

\begin{tabular}{|c|c|c|c|c|c|c|c|c|c|c|c|c|c|c|c|c|}
\hline OWNER ID & \begin{tabular}{|l|} 
SAMP \\
NUM
\end{tabular} & SAMP SITE NAME & $\left|\begin{array}{c}\text { DIST } \\
\text { CLASS }\end{array}\right|$ & MEDIA & TAG ID & SAMP FROM & SAMP ITEM & SAMP DATE & CON SHORT NAME & $\begin{array}{l}\text { VALUE } \\
\text { RPTD }\end{array}$ & \begin{tabular}{|l|} 
ANAL \\
UNITS \\
RPTD
\end{tabular} & $\begin{array}{c}\text { COUNTING } \\
\text { ERROR }\end{array}$ & $\mid$\begin{tabular}{|c|} 
TOTAL \\
ANAL \\
ERROR
\end{tabular} & $\begin{array}{l}\text { LAB } \\
\text { QUALIFIER }\end{array}$ & SAMP COMMENT & RESULT COMMENT \\
\hline $\begin{array}{l}\text { SESPMNT } \\
\text { SESPMNT }\end{array}$ & $\begin{array}{l}\text { B16N59 } \\
\text { B16N59 }\end{array}$ & $\begin{array}{l}\text { 200 E AREA } \\
200 \text { AREA }\end{array}$ & $\begin{array}{l}\text { ONSITE } \\
\text { ONSTEE }\end{array}$ & $\begin{array}{ll}\mathrm{BI} \\
\mathrm{BI}\end{array}$ & $\begin{array}{l}\text { 2003COTTONTAIL RABBIT2 } \\
\text { 2003COTONAII RABITIT }\end{array}$ & $\begin{array}{l}\text { COTTONTAAL RABBIT } \\
\text { COTIONTAl RABIT }\end{array}$ & $\begin{array}{l}\text { MUSCLE } \\
\text { MUSCLE }\end{array}$ & $\begin{array}{l}\text { 06-May-03 } \\
06-\text { May-03 }\end{array}$ & $\begin{array}{l}\text { Cs-137 } \\
\text { Eun-152 }\end{array}$ & $\begin{array}{l}-0.00286 \mathrm{p} \\
0.017 \mathrm{p}\end{array}$ & pcilg & $\begin{array}{l}0.015 \\
0.39\end{array}$ & $\begin{array}{l}50.015 \\
0.039\end{array}$ & u & & \\
\hline $\begin{array}{l}\text { SESPMNTI } \\
\text { SESPNT }\end{array}$ & B16N59 & $\begin{array}{l}200 \text { EREA } \\
200 \text { EAREA }\end{array}$ & $\begin{array}{l}\text { ONSITE } \\
\text { ONST }\end{array}$ & ${ }_{\mathrm{BI}}^{\mathrm{BI}}$ & 2003COTTONTAL RABBIT2 & COTTONTAIL RABBIT & $\begin{array}{l}\text { MUSCLE } \\
\text { MUSCLE }\end{array}$ & $06-$ May-03 & $\begin{array}{l}\text { Eu-152 } \\
\text { Eu-154 }\end{array}$ & $\begin{array}{l}0.0017 \mathrm{p} \\
-0.0313 \mathrm{p}\end{array}$ & $\begin{array}{l}\text { pClig } \\
\text { pCilg }\end{array}$ & 0.055 & $\begin{array}{ll}5.039 \\
5\end{array}$ & u & & \\
\hline $\begin{array}{l}\text { SESPMNT } \\
\text { SESPMNT }\end{array}$ & $\begin{array}{l}\text { B16N59 } \\
\text { B16N59 }\end{array}$ & $\begin{array}{l}\text { 200 EAREA } \\
\text { 200 EAREA }\end{array}$ & $\begin{array}{l}\text { ONSITE } \\
\text { ONSTIE }\end{array}$ & $\begin{array}{l}\mathrm{BI} \\
\mathrm{BI}\end{array}$ & 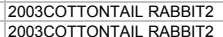 & $\begin{array}{l}\text { COTTONTAAL RABBIT } \\
\text { COTONTIII RABIT }\end{array}$ & $\begin{array}{l}\text { MUSCLE } \\
\text { MUSCLE }\end{array}$ & 06-May-03 & $\begin{array}{l}\text { Eu-155 } \\
\text { K-40 }\end{array}$ & $-0.00961 \mathrm{p}$ & $\mathrm{pCi} / \mathrm{g}$ & 0.029 & 0.029 & u & & \\
\hline SESPMNT & B16N63 & 200 EAREA & ONSITE & $\mathrm{BI}$ & 2003COTTONTALL RABBIT2 & COTTONTAIL RABBIT & LIVER & $06-$ May-03 & Pu-238 & $-0.0000191 p$ & pcilg & 0.00023 & $\begin{array}{l}0.01 \\
0.002\end{array}$ & u & & \\
\hline SESPMNT & B16N63 & 200 EAREA & ONSITE & $\mathrm{BI}$ & 2003COTTONTALL RABBIT2 & COTTONTAIL RABBIT & LIVER & 06-May-03 & Pu-239/240 & $-0.0000472 \mathrm{p}$ & pClig & 0.00025 & 0.0003 & u & & \\
\hline $\begin{array}{l}\text { SESPMNT } \\
\text { SEPMNT }\end{array}$ & $\begin{array}{l}\text { B16N59 } \\
\text { B16N59 }\end{array}$ & $\begin{array}{l}200 \text { E AREA } \\
2000 \text { AREA }\end{array}$ & $\begin{array}{l}\text { ONSITE } \\
\text { ONSTIE }\end{array}$ & $\begin{array}{l}\mathrm{BI} \\
\mathrm{BI}\end{array}$ & 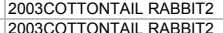 & $\begin{array}{l}\text { COTTONTAAL RABBIT } \\
\text { COTTONTIII RABBTT }\end{array}$ & $\begin{array}{l}\text { MUSCLE } \\
\text { MUSCLE }\end{array}$ & $\begin{array}{l}\text { 06-May-03 } \\
06-\text { Ma-03 }\end{array}$ & $\begin{array}{l}\text { Ru-106 } \\
\text { Sb-125 }\end{array}$ & $\begin{array}{r}-0.14 \mathrm{p} \\
-0.22 \mathrm{p}\end{array}$ & $\begin{array}{l}\text { pcigg } \\
\text { pcilg }\end{array}$ & $\begin{array}{r}0.14 \\
0.038\end{array}$ & 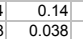 & u & & \\
\hline SESPMNT & B16N67 & 200E AREA & ONSITE & $\mathrm{BI}$ & 2003COTTONTALL RABBIT2 & COTTONTAIL RABBIT & BONES & 06-May-03 & Sr-90 & & $\mathrm{pCi} / \mathrm{g}$ & 0.086 & 0.21 & & & \\
\hline $\begin{array}{l}\text { SESPMNT } \\
\text { SEPMNT }\end{array}$ & $\begin{array}{l}\text { B16NB8 } \\
\text { B16N4 }\end{array}$ & 200 E AREA & $\begin{array}{l}\text { ONSITE } \\
\text { ONSTIF }\end{array}$ & BI & 2003COTTONTAIL RABBIT3 & COTTONTALL RABBIT & LIVER & $\begin{array}{l}\text { 31-Mar-03 } \\
31 \text { Mac-03 }\end{array}$ & & & & & & & NOT COLLECTED. & \\
\hline $\begin{array}{l}\text { SEEPMNT } \\
\text { SESPMNT }\end{array}$ & $\begin{array}{l}\text { B16N64 } \\
\text { B16N68 }\end{array}$ & $\begin{array}{l}200 \text { EAAEA } \\
\text { 200 EREA }\end{array}$ & $\begin{array}{l}\text { ONSIIE } \\
\text { ONSITE }\end{array}$ & $\begin{array}{ll}B \mathrm{~B} \\
\mathrm{BI}\end{array}$ & 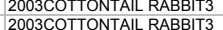 & & $\begin{array}{l}\text { LIVER } \\
\text { BONES } \\
\end{array}$ & $\begin{array}{l}31 \text {-Mar-03 } \\
\text { 31-Ma-03 }\end{array}$ & $\begin{array}{l}\text { Pu-238, Pu-239/240 } \\
\text { Srr-90 }\end{array}$ & & & & & & $\begin{array}{l}\text { NOT COLLECTED. } \\
\text { NOT COUETED }\end{array}$ & \\
\hline SESPMNT & B16NB8 & $\begin{array}{l}200 \text { EAREA } \\
200 \text { EAREA }\end{array}$ & $\begin{array}{l}\text { ONSTIE } \\
\text { ONSITE }\end{array}$ & $\begin{array}{l}\mathrm{BI} \\
\mathrm{BI}\end{array}$ & 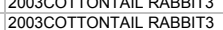 & $\begin{array}{l}\text { COTTONAAIL RABBIT } \\
\text { COTTONAIL RABBIT }\end{array}$ & $\begin{array}{l}\text { BONES } \\
\text { LIVER }\end{array}$ & $\begin{array}{l}31 \text {-Mar-03 } \\
\text { 31-Mar-03 }\end{array}$ & $\begin{array}{l}\text { Sr-90 } \\
u\end{array}$ & & & & & & NOT COLETEED & \\
\hline SESPMNT & B16NB9 & 200 E AREA & ONSITE & $\mathrm{BI}$ & 2003COTTONTAL RABBIT4 & COTTONTAIL RABBIT & LIVER & 31-Mar-03 & & & & & & & NOT COLLECTED. & \\
\hline $\begin{array}{l}\text { SESPMNT } \\
\text { SEPPNT }\end{array}$ & B16N65 & 200 EREA & ONSITE & $\mathrm{BI}$ & & COTTONTAIL RABBIT & LIVER & 31-Mar-03 & Pu-238, Pu-239/240 & & & & & & NOT COLLECTED. & \\
\hline $\begin{array}{l}\text { SESPMNT } \\
\text { SESMNT }\end{array}$ & B16N69 & 200 E AREA & ONSITE & $\mathrm{BI}$ & 2003COTTONTALL RABBIT4 & COTTONTAIL RABBIT & BONES & 31-Mar-03 & Sr-90 & & & & & & NOT COLLECTED. & \\
\hline $\begin{array}{l}\text { SEEPMNT } \\
\text { SESPMNT }\end{array}$ & 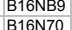 & $\begin{array}{l}200 \text { E A AREA } \\
200 \text { W AREA }\end{array}$ & $\begin{array}{l}\text { ONSIIE } \\
\text { ONSTIE }\end{array}$ & $\begin{array}{l}\mathrm{B} \\
\mathrm{BI}\end{array}$ & 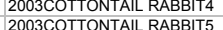 & $\begin{array}{l}\text { COTTONTAIL RABBIT } \\
\text { COTTONAIL RABBIT }\end{array}$ & $\begin{array}{l}\text { LIVER } \\
\text { MUSCLE }\end{array}$ & $\begin{array}{l}\text { 31-Mar-03 } \\
\text { 17-Jun-03 }\end{array}$ & $\begin{array}{l}U \\
\text { Be-7 }\end{array}$ & $0.063 \mathrm{p}$ & & 0.22 & 0.22 & $\|$ & & \\
\hline $\begin{array}{l}\text { SESPMMNT } \\
\text { SESPMT }\end{array}$ & & & $\begin{array}{l}\text { ONSITE } \\
\text { ONSE }\end{array}$ & $\begin{array}{ll}\mathrm{BI} \\
\mathrm{BI}\end{array}$ & 2003COTTONTAL RABBIT5 & COTTONTAIL RABBIT & $\begin{array}{l}\text { MUSCLE } \\
\text { MUSCLE }\end{array}$ & 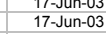 & $\begin{array}{l}B \mathrm{~B}-1 \\
\mathrm{Co}-60\end{array}$ & $\begin{array}{rl}0.0063 \mathrm{p} & 0 \\
-0.0002 \mathrm{p}\end{array}$ & & & 0.022 & u & & \\
\hline SESPMNT & B16N70 & 200 WAREA & ONSITE & BI & 2003COTTONAAL RABBIT5 & COTTONTAIL RABBIT & MUSCLE & $\begin{array}{l}17-\mathrm{Jun}-03 \\
\text { 17-unn } 03\end{array}$ & $\begin{array}{l}-20-60 \\
C s-134\end{array}$ & $\begin{array}{l}-0.000735 \mathrm{p} \\
0.00735\end{array}$ & $5 \mathrm{pCl} / \mathrm{g}$ & $\begin{array}{l}0.018 \\
0.018\end{array}$ & $\begin{array}{ll}3 & 0.03 \\
3 & 0.018\end{array}$ & u & & \\
\hline SESPMNT & B16N70 & $\begin{array}{l}200 \text { W AREA } \\
20 \text { PRE }\end{array}$ & ONSITE & $\mathrm{BI}$ & 2003COTTONTALL RABBIT5 & $\begin{array}{l}\text { COTTONTAIL RABBIT } \\
\end{array}$ & MUSCLE & 17-Junn-03 & Cs-137 & $0.00884 \mathrm{p}$ & pCilg & 0.016 & 0.016 & u & & \\
\hline $\begin{array}{l}\text { SESPMNT } \\
\text { SEFPMNT }\end{array}$ & B16N70 & 200 W AREA & $\begin{array}{l}\text { ONSITE } \\
\text { ONSTEF }\end{array}$ & BI & 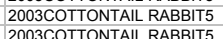 & $\begin{array}{l}\text { COTTONTALL RABBIT } \\
\text { COTTONTIALABBT }\end{array}$ & $\begin{array}{l}\text { MUSCLE } \\
\text { MUSCLE }\end{array}$ & $\begin{array}{l}17-\text { Jun-03 } \\
17 \text { Jun-03 }\end{array}$ & $\begin{array}{l}\text { Eu-152 } \\
\text { Eu-154 }\end{array}$ & $\begin{array}{l}-0.0211 \mathrm{p} \\
0.0203 \mathrm{p}\end{array}$ & pCilg & $\begin{array}{l}0.041 \\
0.049\end{array}$ & $\begin{array}{ll}1 & 0.041 \\
0.049\end{array}$ & u & & \\
\hline SESPMNT & B16N70 & 200 W AREA & ONSITE & $\mathrm{BI}$ & 2003COTTONTAL RABBIT5 & COTTONTAIL RABBIT & MUSCLE & 17-Junn-03 & Eu-155 & $-0.00651 \mathrm{p}$ & $\mathrm{pCi} / \mathrm{g}$ & 0.04 & $\begin{array}{llll}4 & 0.04\end{array}$ & u & & \\
\hline SESPMNT & B16N70 & 200 W AREA & ONSITE & $\mathrm{BI}$ & 2003COTTONTALL RABBIT5 & COTTONTAIL RABBIT & MUSCLE & 17-Jun-03 & $k-40$ & $3.86 \mathrm{p}$ & pCilg & 0.84 & $\begin{array}{l}4 \quad 0.84 \\
4\end{array}$ & & & \\
\hline $\begin{array}{l}\text { SEEPMNT } \\
\text { SESPMNT }\end{array}$ & $\begin{array}{l}\text { B16N74 } \\
\text { B16N74 }\end{array}$ & $\begin{array}{l}200 \text { W AREA } \\
200 \text { W AREA }\end{array}$ & $\begin{array}{l}\text { ONSITE } \\
\text { ONSTIE }\end{array}$ & 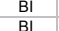 & 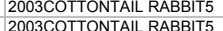 & $\begin{array}{l}\text { COTTONTAIL RABBIT } \\
\text { COTTONAIL RABBIT }\end{array}$ & $\begin{array}{l}\text { LIVER } \\
\text { LVER }\end{array}$ & $\begin{array}{l}\text { 17-Jun-03 } \\
\text { 17.Jun-03 }\end{array}$ & $\begin{array}{l}\text { Pu-238 } \\
\text { Pu-239/240 }\end{array}$ & $\begin{array}{l}-0.000159 \mathrm{p} \\
-0.000328 \mathrm{p}\end{array}$ & pcilg & 0.00027 & 0.0003 & $u$ & & \\
\hline $\begin{array}{l}\text { SESPMNI I } \\
\text { SESPMNT }\end{array}$ & 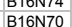 & $\begin{array}{l}200 \mathrm{~W} \text { AREA } \\
200 \text { W AREA }\end{array}$ & $\begin{array}{l}\text { ONSSITE } \\
\text { ONSTE }\end{array}$ & $\begin{array}{l}\mathrm{BI} \\
\mathrm{BI}\end{array}$ & 2003 COTTONTAL RABBIT5 & COTTONTAIL RABBIT & MUER & $\begin{array}{l}\text { 17.Jnn-03 } \\
\text { 17-Jun-03 }\end{array}$ & $\begin{array}{l}\text { Pu-239/240 } \\
\text { Ru-106 }\end{array}$ & $\begin{array}{l}-0.00328 \mathrm{p} \\
-0.0239 \mathrm{p}\end{array}$ & & 0.0039 & 0.004 & u & & \\
\hline SESPMNT & B16N70 & 200 W AREA & ONSITE & BI & 2003COTTONTAL RABBIT5 & COTTONTALL RABBIT & MUSCLE & 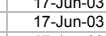 & $\begin{array}{ll}\text { Sul-106 } \\
\text { sb-125 }\end{array}$ & $\begin{array}{l}-0.039 \mathrm{p} \\
-0.013 \mathrm{p}\end{array}$ & $\begin{array}{l}\mathrm{pclig} \\
\mathrm{pCCi} / \mathrm{g}\end{array}$ & $\begin{array}{l}0.16 \\
0.042\end{array}$ & $\begin{array}{c}0.16 \\
20.042\end{array}$ & u & & \\
\hline SESPMNT & B16N78 & 200 W AREA & ONSITE & $\mathrm{BI}$ & 2003COTTONTAL RABBIT5 & COTTONTAIL RABBIT & BONES & 17-Junn-03 & Sr-90 & $0.331 \mathrm{p}$ & pCilg & 0.052 & 0.088 & & & \\
\hline $\begin{array}{l}\text { SESPMNT } \\
\text { SEPPMNT }\end{array}$ & B16N71 & 200 W AREA & $\begin{array}{l}\text { ONSITE } \\
\text { ONSTIE }\end{array}$ & BI & $\begin{array}{l}2003 \text { COTTONTAIL RABBIT6 } \\
20303 \text { CONTHE }\end{array}$ & COTTONTALL RABBIT & MUSCLE & $\begin{array}{l}17-\text { Jun-03 } \\
17 \text { Jun-03 }\end{array}$ & $\begin{array}{l}\text { Be-7 } \\
\text { Co-60 }\end{array}$ & $\begin{array}{r}-0.0531 \mathrm{p} \\
-0.00018 \mathrm{p}\end{array}$ & pcilg & $\begin{array}{l}0.17 \\
0.15\end{array}$ & $\begin{array}{l}0.17 \\
0.015\end{array}$ & u & & \\
\hline $\begin{array}{l}\text { SESPMNT } \\
\text { SESPINT }\end{array}$ & B16N71 & 200 W AREA & $\begin{array}{l}\text { ONSITE } \\
\text { ONS }\end{array}$ & BI & 2003COTTONTAL RABBIT6 & COTTONTAIL RABBIT & MUSCLE & $\begin{array}{l}17-\mathrm{Jun}-03 \\
17 \mathrm{~s}-03\end{array}$ & $\begin{array}{l}\text { Co-60 } \\
\text { Cs-134 }\end{array}$ & $\begin{array}{l}-0.003318 \mathrm{p} \\
0.00316 \mathrm{p}\end{array}$ & $\begin{array}{l}\text { pClig } \\
\text { p } \mathrm{pCi} / \mathrm{g}\end{array}$ & $\begin{array}{l}0.015 \\
0.015\end{array}$ & $\begin{array}{l}5 \\
5 \\
5 \\
5 \\
0.01515\end{array}$ & u & & \\
\hline SESPMNT & B16N71 & 200 W AREA & ONSITE & BI & 2003COTTONTALL RABBIT6 & COTTONTAIL RABBIT & MUSCLE & 17-Jun-03 & Cs-137 & $0.00277 \mathrm{p}$ & $\mathrm{pCi} / \mathrm{g}$ & 0.012 & 0.012 & u & & \\
\hline $\begin{array}{l}\text { SESPMNT } \\
\text { SESPMNT }\end{array}$ & B16N71 & 200 W AREA & ONSITE & $\mathrm{BI}$ & 2003COTTONTAIL RABBIT6 & COTTONTALL RABBIT & MUSCLE & 17-Jun-03 & $\begin{array}{l}E u-152 \\
E u-154\end{array}$ & $-0.0207 \mathrm{p}$ & $\mathrm{pCl} / \mathrm{g}$ & 0.032 & 0.032 & u & & \\
\hline $\begin{array}{l}\text { SEEPMNT } \\
\text { SESPMNT }\end{array}$ & $\begin{array}{l}\text { B16N71 } \\
\text { B16N71 }\end{array}$ & $\begin{array}{l}200 \text { W AREA } \\
200 \text { W AREA }\end{array}$ & $\begin{array}{l}\text { ONSITE } \\
\text { ONSTIE }\end{array}$ & $\begin{array}{l}\mathrm{BI} \\
\mathrm{BI}\end{array}$ & 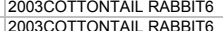 & $\begin{array}{l}\text { COTTONTAIL RABBIT } \\
\text { COTTONAIL RABBIT }\end{array}$ & $\begin{array}{l}\text { MUSCLE } \\
\text { MUSCLE }\end{array}$ & $\begin{array}{l}\text { 17-Jun-03 } \\
\text { 17.Jun-03 }\end{array}$ & $\begin{array}{l}\text { Eu-154 } \\
\text { Eu-155 }\end{array}$ & $\begin{array}{l}0.00299 \mathrm{p} \\
0.0037 \mathrm{p}\end{array}$ & pcilg & $\begin{array}{l}0.038 \\
0.026\end{array}$ & $\begin{array}{ll}3 & 0.038 \\
& 0.26\end{array}$ & u & & \\
\hline $\begin{array}{l}\text { SESPMNII } \\
\text { SESPMNT }\end{array}$ & $\begin{array}{l}\text { B16N71 } \\
\text { B16N1 }\end{array}$ & $\begin{array}{l}200 \mathrm{~W} \text { AREA } \\
200 \text { AREA }\end{array}$ & $\begin{array}{l}\text { ONSITE } \\
\text { ONSTE }\end{array}$ & $\begin{array}{l}\mathrm{BI} \\
\mathrm{BI}\end{array}$ & 2003 COTTONTAL RABBIT6 & COTTONTAIL RABBIT & $\begin{array}{l}\text { MUSCLE } \\
\text { MUSCLE }\end{array}$ & $\begin{array}{l}\text { 17.Jun-03 } \\
\text { 17-Jun-03 }\end{array}$ & k-10 -455 & $\begin{array}{r}0.03 / \mathrm{p} \\
4.06 \mathrm{p}\end{array}$ & 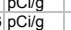 & $\begin{array}{l}0.026 \\
0.68\end{array}$ & $\begin{array}{l}30.26 \\
0.68\end{array}$ & & & \\
\hline $\begin{array}{l}\text { SESPMNT } \\
\text { SEPT }\end{array}$ & B16N75 & 200 W AREA & ONSITE & BI & 2003COTTONTAL RABBIT6 & COTTONTAIL RABBIT & LIVER & 17-Junn-03 & Pu-238 & $-0.0000241 \mathrm{p}$ & pCilg & 0.00044 & $\begin{array}{ll}4 & 0.0004 \\
\end{array}$ & $u$ & & \\
\hline SESPMNT & B16N75 & 200 W AREA & ONSITE & $\mathrm{BI}$ & 2003COTTONTALL RABBIT6 & COTTONTAIL RABBIT & LIVER & 17-Jun-03 & Pu-239/240 & $0.000472 \mathrm{p}$ & pCilg & 0.00061 & 0.0006 & u & & \\
\hline $\begin{array}{l}\text { SESPMNT } \\
\text { SESPMNT }\end{array}$ & $\begin{array}{l}\text { B16N71 } \\
\text { B1671 }\end{array}$ & $\begin{array}{l}\text { 200 W AREA } \\
200 \text { W ARAA }\end{array}$ & $\begin{array}{l}\text { ONSITE } \\
\text { ONSTIE }\end{array}$ & $\begin{array}{l}\mathrm{BI} \\
\mathrm{BI}\end{array}$ & 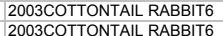 & $\begin{array}{l}\text { COTTONTAAL RABBIT } \\
\text { COTTONAIL RABBIT }\end{array}$ & $\begin{array}{l}\text { MUSCLE } \\
\text { MUSCLE }\end{array}$ & $\begin{array}{l}\text { 17-Jun-03 } \\
\text { 17.Jun-03 }\end{array}$ & $\begin{array}{l}\text { Ru-106 } \\
\text { Sb-125 }\end{array}$ & $\begin{aligned}-0.0345 \mathrm{p} \\
-0.00713 \mathrm{p}\end{aligned}$ & $\begin{array}{l}\text { pCilg } \\
\text { pCCigg }\end{array}$ & $\begin{array}{r}0.11 \\
0.032\end{array}$ & 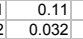 & u & & \\
\hline $\begin{array}{l}\text { SESPMNT } \\
\text { SESPMI }\end{array}$ & B16N79 & 200 W AREA & ONSITE & BI & 2003COTTONTALL RABBIT6 & COTTONTAIL RABBIT & BONES & 17-Junn-03 & Sr-90 & $0.457 \mathrm{p}$ & plilg & 0.052 & 0.11 & & & \\
\hline $\begin{array}{l}\text { SESPMNT } \\
\text { SEPMNT }\end{array}$ & B16N72 & 200 W AREA & ONSITE & $\mathrm{BI}$ & 2003COTTONTAIL RABBIT7 & COTTONTALL RABBIT & MUSCLE & 29-Jul-03 & Be-7 & $0.0288 \mathrm{p}$ & $\mathrm{pCi} / \mathrm{g}$ & 0.11 & 0.11 & $u$ & & \\
\hline $\begin{array}{l}\text { SESPMNT } \\
\text { SECPMNT }\end{array}$ & B16N72 & 200 W AREA & ONSITE & $\mathrm{BI}$ & 2003COTTONTAIL RABBIT7 & COTTONTAIL RABBIT & MUSCLE & 29-Jul-03 & $\begin{array}{l}\text { Co-60 } \\
\text { Cs-134 }\end{array}$ & $0.00693 \mathrm{p}$ & $\mathrm{pCl} / \mathrm{g}$ & 0.011 & $\begin{array}{ll}1 & 0.011 \\
1 & 0.011 \\
\end{array}$ & u & & \\
\hline $\begin{array}{l}\text { SESPMNT } \\
\text { SEPMMNT }\end{array}$ & 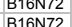 & $\begin{array}{l}200 \text { W AREA } \\
200 \text { W AREA }\end{array}$ & $\begin{array}{l}\text { ONSTIE } \\
\text { ONSTTE }\end{array}$ & Bi & 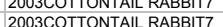 & $\begin{array}{l}\text { COTTONAIL RABBIT } \\
\text { COTONAIL RABIT }\end{array}$ & $\begin{array}{l}\text { MUSCLE } \\
\text { MUSCLE }\end{array}$ & $\begin{array}{l}29-\mathrm{Jul}-03 \\
29-\mathrm{Ju}-03 \\
\end{array}$ & $\begin{array}{l}\text { Cs-1344 } \\
\text { Cs-137 }\end{array}$ & $\begin{array}{l}-0.00977 \mathrm{p} \\
0.000754 \mathrm{p}\end{array}$ & PCig & 0.011 & $\begin{array}{ll}0.011 \\
0 \\
0.11\end{array}$ & u & & \\
\hline SESPMNT & B16N72 & 200 W AREA & ONSITE & $B \mid$ & 2003 COTTONTAL RABBIT7 & COTTONTAIL RABBIT & MUSCLE & $\begin{array}{l}29-\mathrm{Jul}-03 \\
\text { 29-03 }\end{array}$ & Eu-152 & $\begin{array}{l}0.00037 \mathrm{p} \\
0.00332 \mathrm{p}\end{array}$ & pCilg & 0.025 & 50.025 & u & & \\
\hline SESPMNT & B16N72 & 200 W AREA & ONSITE & $\mathrm{BI}$ & 2003COTTONTALL RABBIT7 & COTTONTAIL RABBIT & MUSCLE & 29-Jul-03 & Eu-154 & $0.00488 \mathrm{p}$ & $\mathrm{pCi} / \mathrm{g}$ & 0.032 & 0.032 & u & & \\
\hline SESPMNT & B16N72 & 200 W AREA & ONSITE & BI & 2003COTTONTALL RABBIT7 & COTTONTALL RABBIT & MUSCLE & 29-Jul-03 & Eu-155 & $0.00948 p$ & pCilg & 0.018 & 0.018 & $u$ & & \\
\hline $\begin{array}{l}\text { SEEPMNT } \\
\text { SESPMNT }\end{array}$ & $\begin{array}{l}\text { B16N72 } \\
\text { B16N76 }\end{array}$ & $\begin{array}{l}200 \text { W AREA } \\
200 \text { W AREA }\end{array}$ & $\begin{array}{l}\text { ONSTIE } \\
\text { ONSITE }\end{array}$ & Bi & 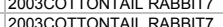 & $\begin{array}{l}\text { COTTONAIL RABBIT } \\
\text { COTTONAILBBIT }\end{array}$ & $\begin{array}{l}\text { MUSCLE } \\
\text { LIVER }\end{array}$ & $\begin{array}{l}\text { 29-Jul-03 } 29 .-03 \\
\text { 29-03 }\end{array}$ & $\begin{array}{l}\text { K-40 } \\
\text { Pu-238 }\end{array}$ & $\begin{array}{r}2.47 \mathrm{p} \\
0.00317 \mathrm{p}\end{array}$ & pCi/g & $\begin{array}{r}0.5 \\
0.0048\end{array}$ & $\begin{array}{r}5 \\
5 \\
3\end{array} 0.505$ & 4 & & \\
\hline $\begin{array}{l}\text { SESPMMNII } \\
\text { SESPMNT }\end{array}$ & B16N76 & 200 W AREA & ONSITE & $\begin{array}{ll}B 1 \\
B I\end{array}$ & 2003COTTONTAL RABBIT7 & COTTONTAIL RABBIT & $\begin{array}{l}\text { LIVER } \\
\text { LIVER }\end{array}$ & $\begin{array}{l}29-\mathrm{Jul}-03 \\
29 \mathrm{Jul}-03 \\
\end{array}$ & Pu-230/2 & $\begin{array}{r}-0.000221 \mathrm{p} \\
-0.002\end{array}$ & pCilg & $\begin{array}{l}0.00048 \\
0.0034\end{array}$ & $\begin{array}{l}40.0005 \\
4 \quad 0.004 \\
4\end{array}$ & u & & \\
\hline $\begin{array}{l}\text { SESPMNT } \\
\text { SESPINI }\end{array}$ & B16N72 & 200 W AREA & ONSITE & BI & 2003COTTONTAL RABBIT7 & COTTONTALL RABBIT & MUSCLE & $\begin{array}{l}29-\mathrm{Jul}-03 \\
\text { 29-Jus }\end{array}$ & $\begin{array}{l}|l| l-291 / 2 \\
\text { Ru-106 }\end{array}$ & $\begin{array}{l}-0.0022 \mathrm{p} \\
-0.105 \mathrm{p} \\
\end{array}$ & $\begin{array}{l}\text { pulig } \\
\text { pCig }\end{array}$ & $\begin{array}{l}0.0034 \\
0.093\end{array}$ & $\begin{array}{l}-3.004 \\
3 \\
3\end{array}$ & u & & \\
\hline $\begin{array}{l}\text { SESPMNT } \\
\text { SEPMNT }\end{array}$ & B16N72 & 200 W AREA & $\begin{array}{l}\text { ONSITE } \\
\text { ONSTIF }\end{array}$ & BI & 2003COTTONTALL RABBIT7 & COTTONTALL RABBIT & MUSCLE & 29-Jul-03 & Sb-125 & $-0.0167 \mathrm{p}$ & pCilg & 0.025 & 50.025 & $u$ & & \\
\hline $\begin{array}{l}\text { SESPMNT } \\
\text { SSEPMNT }\end{array}$ & $\begin{array}{l}\text { B16N80 } \\
\text { B16N73 }\end{array}$ & $\begin{array}{l}\text { 200 W AREA } \\
200 \text { W AREA }\end{array}$ & $\begin{array}{l}\text { ONSITE } \\
\text { ONSTIE }\end{array}$ & $\mathrm{BO}_{\mathrm{B}}$ & 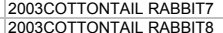 & & $\begin{array}{l}\text { BONES } \\
\text { MUSCLE }\end{array}$ & 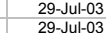 & & $\begin{array}{r}0.608 p \\
-0.0111 p\end{array}$ & pCilg & $\begin{array}{l}0.046 \\
0.11\end{array}$ & $\begin{array}{r}0.1 \\
0.11\end{array}$ & $\mathrm{u}$ & & \\
\hline SESPMNT & B16N73 & 200 W AREA & ONSITE & BI & $\begin{array}{l}2003 C O T T O N T A L L ~ R A B B B I T 8 \\
2003\end{array}$ & COTTONTAIL RABBIIT & MUSCLE & 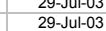 & $\begin{array}{l}\text { Be- } \\
\text { Co-60 }\end{array}$ & $\begin{array}{l}-0.0111 \mathrm{p} \\
0.0124 \mathrm{p}\end{array}$ & 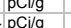 & $\begin{array}{r}0.11 \\
0.013\end{array}$ & 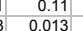 & 0 & & \\
\hline & B16N73 & 200 W AREA & ONSITE & $B I$ & 2003COTTONTAL RABBIT8 & COTTONTAIL RABBIT & MUSCLE & $\begin{array}{l}29-\mathrm{Jul}-03 \\
\text { 29 }\end{array}$ & Cs-134 & & pCilg & 0.013 & 0.013 & u & & \\
\hline UNT & B16N73 & 200 W AREA & ONSITE & BI & 2003COTTONTALL RABBIT8 & COTTONTAIL RABBIT & MUSCLE & 29-Jul-03 & Cs-137 & $0.00207 \mathrm{p}$ & pCilg & 0.011 & $\begin{array}{ll}1 & 0.011 \\
\end{array}$ & u & & \\
\hline SESPMNT & B16N73 & $\begin{array}{l}200 \text { W AREA } \\
200 \text { AREA }\end{array}$ & ONSITE & $\mathrm{BI}$ & 2003COTTONTALL RABBIT8 & COTTONT & MUSCLE & 29-Jul-03 & Eu-152 & $0.0323 \mathrm{p}$ & $\mathrm{pClig}$ & 0.027 & 0.027 & u & & \\
\hline $\begin{array}{l}\text { SESPMNT } \\
\text { SESPMNT }\end{array}$ & $\begin{array}{l}\text { B16N73 } \\
\text { B16N73 }\end{array}$ & $\begin{array}{l}\text { 200 W AREA } \\
\text { 200 W WREA }\end{array}$ & $\begin{array}{l}\text { ONSTIE } \\
\text { ONSTTE }\end{array}$ & $\begin{array}{ll}\mathrm{B} \\
\mathrm{BI}\end{array}$ & $\begin{array}{l}2003 \text { COTTONTAIL RABBIT8 } \\
\text { 2003COTTONAL RABIT }\end{array}$ & $\begin{array}{l}\text { COTTONTAIL RABBIT } \\
\text { COTTONTIIL RABBIT }\end{array}$ & $\begin{array}{l}\text { MUSCLE } \\
\text { MUSCLE }\end{array}$ & 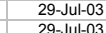 & $\begin{array}{l}\text { Eu-154 } \\
\text { Eu-155 }\end{array}$ & $\begin{array}{l}-0.000492 \mathrm{p} \\
-0.0135 \mathrm{p}\end{array}$ & pCilg & 0.036 & $\begin{array}{ll}5 & 0.036 \\
4 & 0.24\end{array}$ & u & & \\
\hline SESPMNT & $\begin{array}{l}\text { B16N/33 } \\
\text { B16N3 }\end{array}$ & $\begin{array}{l}200 \text { W AREA } \\
200 \text { AREA }\end{array}$ & ONSITE & BI & 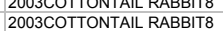 & COTTONTAIL RABBIT & MUSCLE & 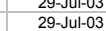 & $\begin{array}{l}\text { Eu-15 } \\
\text { K-40 }\end{array}$ & $\begin{array}{l}135 \mathrm{p} \\
2.9 \mathrm{p}\end{array}$ & $\begin{array}{l}\mathrm{pCClg} \\
\mathrm{pCilg}\end{array}$ & $\begin{array}{l}0.024 \\
0.59\end{array}$ & $\begin{array}{r}0.024 \\
0.59\end{array}$ & & & \\
\hline SESPMNT & B16N77 & 200 W AREA & ONSITE & BI & & & LIVER & & Pu-238 & $-0.000309 \mathrm{p}$ & & 0.00041 & $\begin{array}{ll}0.0004 \\
1\end{array}$ & u & & \\
\hline $\begin{array}{l}\text { SESPMNT } \\
\text { SESPMNT }\end{array}$ & B16N77 & $\begin{array}{l}200 \text { W AREA } \\
200 \text { W AREA }\end{array}$ & $\begin{array}{l}\text { ONSITE } \\
\text { ONSTEF }\end{array}$ & BI & $\begin{array}{l}2003 \text { COTTONTALL RABBIT8 } \\
2030 \text { R }\end{array}$ & $\begin{array}{l}\text { COTTONTALL RABBIT } \\
\text { COTTENTAB }\end{array}$ & LIVER & 29-Jul-03 & Pu-239/240 & $0.000376 \mathrm{p}$ & pcilg & 0.00076 & 0.0008 & 4 & & \\
\hline $\begin{array}{l}\text { SESPMNI } \\
\text { SESPMNT }\end{array}$ & $\begin{array}{l}\text { 1616N73 } \\
\text { B16N73 }\end{array}$ & $\begin{array}{l}200 \text { W ARRA } \\
200 \text { W AREA }\end{array}$ & $\begin{array}{l}\text { ONSSITE } \\
\text { ONSTE }\end{array}$ & $\begin{array}{l}\mathrm{Bl} \\
\mathrm{BI}\end{array}$ & $\begin{array}{l}\text { 2003COTTONTAIL RABBIT8 } \\
\text { 2003COTTONAL RABITI }\end{array}$ & $\begin{array}{l}\text { COTTONTAAL RABBIT } \\
\text { COTTONALIL RABIT }\end{array}$ & $\begin{array}{l}\text { MUSCLE } \\
\text { MUSCLE }\end{array}$ & $\begin{array}{l}\text { 29-Jul-03 } \\
\text { 29-Jul-03 }\end{array}$ & $\begin{array}{l}\text { Ru-106 } \\
\text { Sb-125 }\end{array}$ & $\begin{array}{r}0.032 \mathrm{p} \\
0.0075 \mathrm{p}\end{array}$ & pCilg & $\begin{array}{r}0.1 \\
0.026\end{array}$ & 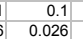 & u & & \\
\hline $\begin{array}{l}\text { SESPMNT } \\
\text { SESPMI }\end{array}$ & B16N81 & 200 W AREA & $\begin{array}{l}\text { ONSITE } \\
\text { ONE }\end{array}$ & BI & 2003COTTONTAL RABBIT8 & COTTONTALL RABBIT & BONES & $\begin{array}{l}29-\mathrm{Jul}-03 \\
293\end{array}$ & $\begin{array}{l}\text { So-125 } \\
\text { Sr-90 }\end{array}$ & $\begin{array}{l}0.0045 \mathrm{p} \\
0.334 \mathrm{p}\end{array}$ & 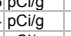 & $\begin{array}{l}0.037 \\
0.037\end{array}$ & $\begin{array}{l}0.062 \\
0.062\end{array}$ & & & \\
\hline SESPMNT & B16N82 & 100 NAREA & ONSITE & $\mathrm{BI}$ & 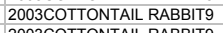 & COTTONTAIL RABBIT & MUSCLE & 29-Jul-03 & $\mathrm{Be}-7$ & $-0.0944 \mathrm{p}$ & pCilg & 0.15 & 5.15 & $u$ & & \\
\hline SESPMNT & B16N82 & 100 NAREA & $\begin{array}{l}\text { ONSITE } \\
\text { ONSTIE }\end{array}$ & & 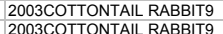 & $\begin{array}{l}\text { COTTONTALL RABBIT } \\
\text { COTTONTAALABIL }\end{array}$ & MUSCLE & 29-Jul-03 & & $0.00361 \mathrm{p}$ & & 0.014 & $\begin{array}{l}4 \quad 0.014 \\
5 \\
5016\end{array}$ & u & & \\
\hline $\begin{array}{l}\text { SESPMNT } \\
\text { SESPMNT }\end{array}$ & 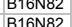 & $\begin{array}{l}100 \text { NAREA } \\
100 \text { N AREA }\end{array}$ & $\begin{array}{l}\text { ONSTIE } \\
\text { ONSTTE }\end{array}$ & $\begin{array}{l}\mathrm{BI} \\
\mathrm{BI}\end{array}$ & 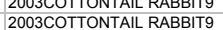 & $\begin{array}{l}\text { COTTONAAIL RABBIT } \\
\text { COTTONAIL RABBIT }\end{array}$ & $\begin{array}{l}\text { MUSCLE } \\
\text { MUSCLE }\end{array}$ & 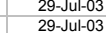 & 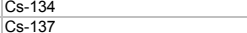 & $\begin{array}{l}-0.0018 \mathrm{p} \\
0.045 \mathrm{p}\end{array}$ & pCilg & $\begin{array}{l}0.016 \\
0.031\end{array}$ & $\begin{array}{ll}5 & 0.016 \\
1 & 0.31\end{array}$ & $u$ & & \\
\hline SESPMNT & & 100 NAREA & $\begin{array}{l}\text { ONSITE } \\
\text { ONE }\end{array}$ & & 2003 COTTONTAL RABBIT9 & & MUSCLE & & $\begin{array}{l}\text { Cs-13i } \\
\text { Eu-152 }\end{array}$ & & pcilg & & & U & & \\
\hline SESPMNT & B16N82 & $100 \mathrm{NAREA}$ & ONSITE & BI & 2003COTTONTAL RABBIT9 & COTTONTAIL RABBIT & MUSCLE & 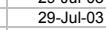 & $\begin{array}{l}\text { Eu-152 } \\
\text { Eu-154 }\end{array}$ & $0.0121 \mathrm{p}$ & pCilg & 0.046 & 0.046 & 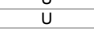 & & \\
\hline SPMNT & B16N82 & 100 NAREA & ONSITE & $\mathrm{BI}$ & 2003COTTONTALL RABBIT9 & COTTONTAIL RABBIT & MUSCLE & 29-Jul-03 & Eu-155 & $0.00172 \mathrm{p}$ & pcilg & 0.027 & 0.027 & u & & \\
\hline $\begin{array}{l}\text { SESPMNT } \\
\text { SESPMNT }\end{array}$ & 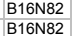 & $\begin{array}{l}100 \mathrm{NARRA} \\
100 \mathrm{NAREA}\end{array}$ & $\begin{array}{l}\text { ONSITE } \\
\text { ONSITE }\end{array}$ & $\begin{array}{l}\mathrm{BI} \\
\mathrm{BI}\end{array}$ & 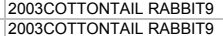 & $\begin{array}{l}\text { COTTONTAAL RABBIT } \\
\text { COTTONALL RABBIT }\end{array}$ & $\begin{array}{l}\text { MUSCLE } \\
\text { MUSCLE }\end{array}$ & 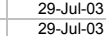 & 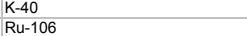 & $\begin{array}{r}2.71 \mathrm{p} \\
0.154 \mathrm{p}\end{array}$ & $\begin{array}{l}\text { pCilg } \\
\text { pcilg }\end{array}$ & $\begin{array}{l}0.67 \\
0.12\end{array}$ & $\begin{array}{l}0.67 \\
0.12\end{array}$ & U & & \\
\hline
\end{tabular}


WILDLLEE
(pcilg Wet Weight)

\begin{tabular}{|c|c|c|c|c|c|c|c|c|c|c|c|c|c|c|c|c|}
\hline OWNER ID & \begin{tabular}{|l|} 
SAMP \\
NUM
\end{tabular} & SAMP SITE NAME & $\left|\begin{array}{c}\text { DIST } \\
\text { CLASS }\end{array}\right|$ & MEDIA & TAG ID & SAMP FROM & SAMP ITEM & SAMP DATE & CON SHORT NAME & \begin{tabular}{l|l} 
VALUE \\
RPTD
\end{tabular} & \begin{tabular}{l|} 
ANAL \\
UNITS \\
RPTD
\end{tabular} & $\begin{array}{c}\text { COUNTING } \\
\text { ERROR }\end{array}$ & \begin{tabular}{|c|} 
TOTAL \\
ANAL \\
ERROR
\end{tabular} & $\begin{array}{l}\text { LAB } \\
\text { QUALIFIER }\end{array}$ & SAMP COMMENT & RESULT COMMENT \\
\hline $\begin{array}{l}\text { SESPMNT } \\
\text { SESPMNT }\end{array}$ & $\begin{array}{ll}\text { B16N82 } \\
\text { B16N7 }\end{array}$ & $\begin{array}{l}100 \text { NAREA } \\
10 \text { NAREA }\end{array}$ & $\begin{array}{l}\text { ONSITE } \\
\text { ONSTE }\end{array}$ & ${ }_{B 1}^{B I}$ & $\begin{array}{l}\text { 2003COTTONTALL RABBIT9 } \\
\text { 2003CTTTNTAL RABBT9 }\end{array}$ & $\begin{array}{l}\text { COTTONTAAL RABBIT } \\
\text { COTONTIII RABBT }\end{array}$ & $\begin{array}{l}\text { MUSCLE } \\
\text { BONES }\end{array}$ & 29-Jul-03 & $\begin{array}{l}3.1 \mathrm{Sb}-125 \\
3 \mathrm{Sr}-90\end{array}$ & $\begin{array}{r}-0.0185 \mathrm{pc} \\
0.651 \mathrm{p}\end{array}$ & $\begin{array}{l}\text { pcilg } \\
\text { pClig }\end{array}$ & $\begin{array}{l}0.035 \\
0.059\end{array}$ & $\begin{array}{rr}5 & 0.035 \\
9 & 0.11\end{array}$ & U & & \\
\hline $\begin{array}{l}\text { SESPMNI } \\
\text { SESPMNT }\end{array}$ & B16N83 & $\begin{array}{l}100 \text { NAREA } \\
100 A\end{array}$ & $\begin{array}{l}\text { ONSITE } \\
\text { ONSE }\end{array}$ & $\mathrm{BI}$ & 2003COTTONTAIL RABBIT10 & COTTONTAIL RABBIT & $\begin{array}{l}\text { BUNES } \\
\text { MUSCLE }\end{array}$ & $\begin{array}{l}\text { 29-Jul-03 } \\
07-\text { Oct-03 }\end{array}$ & 33 Be-7 & $\begin{array}{l}0.6511 \mathrm{p} \\
0.011 \mathrm{pc}\end{array}$ & $\begin{array}{l}\text { plilg } \\
\text { pCilg }\end{array}$ & $\begin{array}{l}0.0099 \\
0.11\end{array}$ & $\begin{array}{lll}1 & 0.11 \\
1 & 0.11\end{array}$ & $u$ & & \\
\hline $\begin{array}{l}\text { SESPMNT } \\
\text { SESMNT }\end{array}$ & B16N83 & $\begin{array}{l}100 \text { NAREA } \\
100 \text { NAEA }\end{array}$ & $\begin{array}{l}\text { ONSITE } \\
\text { ONSTIF }\end{array}$ & BI & 2003COTTONTAIL RABBIT10 10 & $\begin{array}{l}\text { COTTONTALL RABBIT } \\
\text { COTTONTAU BABBI }\end{array}$ & MUSCLE & 07-0ct-03 & $\begin{array}{ll}33 \text { Co-60 } \\
3 \text { Cs. } 134\end{array}$ & $0.0127 \mathrm{pc}$ & pCilg & 0.012 & 0.012 & u & & \\
\hline SESPMNT & B16N83 & 100 NAREA & ONSITE & $\mathrm{Bl}$ & 2003 COTTONTAIL RABBIT10 & COTTONTAIL RABBIT & MUSCLE & $07-$-Oct-03 & $3 \mathrm{Cs}-137$ & $0.00803 \mathrm{pc}$ & ocig & 0.012 & $\begin{array}{lll}2.0012 \\
20.03\end{array}$ & u & & \\
\hline SESPMNT & B16N83 & 100 NAREA & ONSITE & $\mathrm{Bl}$ & 2003COTTONTALL RABBIT10 & COTTONTAIL RABBIT & MUSCLE & 07-0ct-03 & 3 Eu-152 & $0.0104 \mathrm{pc}$ & & 0.029 & 0.029 & u & & \\
\hline SESPMNT & B16N83 & 100 NAREA & ONSITE & $\mathrm{BI}$ & 2003COTTONTAIL RABBIT 10 & COTTONTAIL RABBIT & MUSCLE & $07-\mathrm{Oct}-03$ & 3 Eu-154 & $-0.00249 p c$ & pCilg & 0.036 & 0.036 & u & & \\
\hline $\begin{array}{l}\text { SESPMNT } \\
\text { SEPMNT }\end{array}$ & B16N83 & $\begin{array}{l}100 \text { NAREA } \\
100 \text { NAEA }\end{array}$ & ONSITE & BI & 2003COTTONTAIL RABBIT10 & COTTONTAIL RABBIT & MUSCLE & 07-Oct-03 & 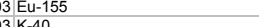 & $-0.00927 p c$ & & 0.029 & 0.029 & & & \\
\hline $\begin{array}{l}\text { SESPMNT } \\
\text { SESPMNT }\end{array}$ & $\begin{array}{l}\text { B16N833 } \\
\text { B16N83 }\end{array}$ & $\begin{array}{l}100 \text { NAREA } \\
1002 \text { NAEA }\end{array}$ & $\begin{array}{l}\text { ONSIIE } \\
\text { ONSTTE }\end{array}$ & $\mathrm{BH}$ & $\begin{array}{l}2003 \text { COTTONTAL RABBIT } 10 \\
2003 \text { COTTONTALL RABBTT10 }\end{array}$ & $\begin{array}{l}\text { COTTONAIL RABBT } \\
\text { COTTONAL RABBT }\end{array}$ & MUSCLE & $\begin{array}{l}07-0 c t-03 \\
07-0 c t-03\end{array}$ & 3 K K-40 & 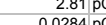 & pCig & $\begin{array}{l}0.6 \\
0.11\end{array}$ & 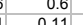 & & & \\
\hline SESPMNT & B16N83 & $100 \mathrm{NAREA}$ & ONSITE & $\mathrm{BI}$ & 2003 COTTONTAIL RABBIT10 & COTTONTAIL RABBIT & MUSCLE & $\begin{array}{ll}0 & 0 \\
07-0 c t-03 \\
07-03\end{array}$ & $3 \mathrm{Sb}-125$ & $\begin{array}{ll}0.02049 \mathrm{p} \\
0.0279 \mathrm{pc}\end{array}$ & 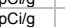 & 0.029 & $\begin{array}{ll}0.029 \\
9\end{array}$ & u & & \\
\hline SESPMNT & B16N88 & 100 NAREA & ONSITE & $\mathrm{BI}$ & 2003COTTONTAIL RABBIT10 & COTTONTAIL RABBIT & BONES & $07-0 \mathrm{cct}-03$ & 3 Sr-90 & $1.86 \mathrm{pc}$ & pCilg & 0.065 & 0.28 & & & \\
\hline $\begin{array}{l}\text { SESPMNT } \\
\text { SEPMNT }\end{array}$ & B16N84 & 100 NAREA & ONSITE & $\mathrm{BI}$ & 2003COTTONTAIL RABBIT11 & COTTONTAIL RABBIT & MUSCLE & 07-0ct-03 & $38 \mathrm{Be}-7$ & $0.00336 \mathrm{pc}$ & pCilg & 0.11 & 0.11 & u & & \\
\hline $\begin{array}{l}\text { SEEPMNT } \\
\text { SESPMNT }\end{array}$ & $\begin{array}{l}\text { B16N84 } \\
\text { B16N84 }\end{array}$ & $\begin{array}{l}100 \text { NAREA } \\
100 \text { N AREA }\end{array}$ & $\begin{array}{l}\text { ONSIIE } \\
\text { ONSTIE }\end{array}$ & $\mathrm{Bl}$ & $\begin{array}{l}2003 \text { COOTONTALAL RABBIT11 } 11 \\
2003 \text { COTONTAL RABBTT11 }\end{array}$ & $\begin{array}{l}\text { COTTONTAAL RABBIT } \\
\text { COTTONAIL RABBIT }\end{array}$ & $\begin{array}{l}\text { MUSCLE } \\
\text { MUSCLE }\end{array}$ & $\begin{array}{l}07-\text { Oct- } 03 \\
07-0 \text { ctt-03 }\end{array}$ & $\begin{array}{l}30 \text { Co-60 } \\
3 \text { Cs-134 }\end{array}$ & $-0.00483 p c$ & & 0.013 & $\begin{array}{ll}3 & 0.013 \\
3 & 0.13\end{array}$ & u & & \\
\hline $\begin{array}{l}\text { SEPPVIII } \\
\text { SESPMNT }\end{array}$ & B16N84 & $\begin{array}{l}100 \mathrm{~N} \text { AREA } \\
1\end{array}$ & $\begin{array}{l}\text { ONSITE } \\
\text { ONSE }\end{array}$ & BI & 2003COTTONTALL RABBIT11 & $\begin{array}{l}\text { COTTONTAIL RABBIT } \\
\text { COTTONTAIL RABBIT }\end{array}$ & $\begin{array}{l}\text { MUSCLE } \\
\text { MUSCLE }\end{array}$ & 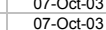 & $\begin{array}{l}33 \mathrm{Cs}-134 \\
3 \mathrm{Cs}-137\end{array}$ & $\begin{array}{l}0.0149 \mathrm{pc} \\
0.091 \mathrm{pc}\end{array}$ & $\begin{array}{l}\mathrm{plig} \\
\mathrm{pCi} i / g\end{array}$ & 0.0023 & $\begin{array}{l}3.0 .13 \\
2 \\
2.022\end{array}$ & & & \\
\hline SESPMNT & B16N84 & 100 NAREA & ONSITE & $\mathrm{BI}$ & 2003COTTONTAIL RABBIT11 & COTTONTAIL RABBIT & MUSCLE & $\begin{array}{l}0 \\
07-0 c t-03 \\
07-03\end{array}$ & 3 Eu-152 & $-0.00552 \mathrm{pC}$ & ocig & 0.028 & $\begin{array}{ll}3.028 \\
0.028\end{array}$ & u & & \\
\hline SESPMNT & B16N84 & $100 \mathrm{NAREA}$ & ONSITE & $\mathrm{BI}$ & 2003COTTONTALL RABBIT11 & COTTONTAIL RABBIT & MUSCLE & $07-0 \mathrm{cct}-03$ & 3 Eu-154 & $0.00748 \mathrm{pc}$ & & 0.037 & 0.037 & u & & \\
\hline $\begin{array}{l}\text { SESPMNT } \\
\text { SESMNT }\end{array}$ & B16N84 & 100 NAREA & ONSITE & Bl & 2003COTTONTAIL RABBIT11 & COTTONTAIL RABBIT & MUSCLE & $07-0 \mathrm{ct}-03$ & $\begin{array}{l}3 \text { Eu-155 } \\
3\end{array}$ & $-0.00248 \mathrm{pc}$ & pCilg & 0.02 & 0.02 & $u$ & & \\
\hline $\begin{array}{l}\text { SEEPMNT } \\
\text { SESPMNT }\end{array}$ & 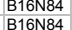 & $\begin{array}{l}100 \text { NAREA } \\
100 \text { N AREA }\end{array}$ & $\begin{array}{l}\text { ONSITE } \\
\text { ONSITE }\end{array}$ & $\mathrm{BI}$ & $\begin{array}{l}2003 \text { COOTONTALIL RABBIT11 } \\
2003 \text { COTTONTAL RABBT } 11\end{array}$ & $\begin{array}{l}\text { COTTONAAIL RABBIT } \\
\text { COTTONTAIL RABBIT }\end{array}$ & $\begin{array}{l}\text { MUSCLE } \\
\text { MUSCLE }\end{array}$ & $\begin{array}{l}\text { O7-Oct-1-03 } \\
07-\text {-Oct-03 }\end{array}$ & $\begin{array}{l}33 \mathrm{~K}-40 \\
3 \mathrm{R} u-106 \\
-\end{array}$ & $\begin{aligned} 3.38 \mathrm{pp} \\
0.022 \mathrm{pc}\end{aligned}$ & pCi/g & 0.63 & $\begin{array}{ll}3 & 0.63 \\
1 & 0.11\end{array}$ & u & & \\
\hline & & & $\begin{array}{l}\text { ONSITE } \\
\text { ONSIE }\end{array}$ & $\begin{array}{l}\mathrm{BI} \\
\mathrm{BI}\end{array}$ & & & & & & & & 0.029 & & u & & \\
\hline $\begin{array}{l}\text { SESPMNT } \\
\text { SESPMNT }\end{array}$ & 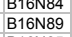 & $\begin{array}{l}100 \mathrm{NAREA} \\
100 \mathrm{NAREA}\end{array}$ & $\begin{array}{l}\text { ONSTIE } \\
\text { ONSITE }\end{array}$ & $\begin{array}{l}\mathrm{B}-1 \\
\mathrm{~B} 1\end{array}$ & $\begin{array}{l}\text { 20003COTTONTAL RABIT11 } \\
\text { 2003COTTONTALL RABBIT11 }\end{array}$ & $\begin{array}{l}\text { COOTONATALRABBIT } \\
\text { COTTONAL RABIT }\end{array}$ & $\begin{array}{l}\text { MUSCLE } \\
\text { BONES }\end{array}$ & $\begin{array}{l}07-\text {-ct-03 } \\
07-\text {-oct-03 }\end{array}$ & $\begin{array}{ll}3 \mathrm{Sb}^{3}-125 \\
3 \mathrm{Sr}-90\end{array}$ & $\begin{array}{l}0.0075 \mathrm{pc} \\
5.89 \mathrm{pc}\end{array}$ & $\begin{array}{l}\text { picig } \\
\text { pCirg }\end{array}$ & $\begin{array}{l}0.029 \\
0.11\end{array}$ & $\begin{array}{ll}9 & 0.29 \\
1 & 0.85\end{array}$ & u & & \\
\hline $\begin{array}{l}\text { SESPMNT } \\
\text { SEPPMNT }\end{array}$ & B16N85 & 100 NAREA & ONSITE & $\mathrm{Bl}$ & $\begin{array}{l}\text { 2003COTTONTALL RABBIT1 } 12 \\
\text { 2003IL }\end{array}$ & COTTONTAIL RABBIT & MUSCLE & 07-0ct-03 & $3 \mathrm{Be}-7$ & $0.0435 \mathrm{pC}$ & pCi/g & 0.12 & 0.12 & u & & \\
\hline $\begin{array}{l}\text { SESPMNT } \\
\text { SEPMNNT }\end{array}$ & $\begin{array}{l}\text { B16N855 } \\
\text { B16N85 }\end{array}$ & $\begin{array}{l}100 \text { NAREA } \\
100 \text { NAEA }\end{array}$ & $\begin{array}{l}\text { ONSIIE } \\
\text { ONSTIE }\end{array}$ & $\begin{array}{l}\mathrm{BI} \\
\mathrm{BI}\end{array}$ & $\begin{array}{l}\text { 200330TTONTAL RABBIT12 } \\
\text { 2003COTTNTAL RABIT12 }\end{array}$ & $\begin{array}{l}\text { COITONTAIL RABBIT } \\
\text { COTTONALRABBTT }\end{array}$ & $\begin{array}{l}\text { MUSCLE } \\
\text { MUSCLE }\end{array}$ & 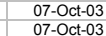 & $\begin{array}{l}3 \text { Co- } 60 \\
3 \text { Cs }-134\end{array}$ & $\begin{array}{l}0.00911 p c \\
-0.00401 p c\end{array}$ & & $\begin{array}{l}0.012 \\
0.014\end{array}$ & $\begin{array}{l}0.012 \\
40.14\end{array}$ & $u$ & & \\
\hline $\begin{array}{l}\text { SEEPMNT } \\
\text { SESPMNT }\end{array}$ & 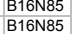 & $\begin{array}{l}100 \text { NAREA } \\
100 \text { N AREA }\end{array}$ & $\begin{array}{l}\text { ONSIIE } \\
\text { ONSTIE }\end{array}$ & $\begin{array}{l}\mathrm{Bl} \\
\mathrm{Bl}\end{array}$ & $\begin{array}{l}2003 \text { COTTONTALIL RABBIT } 12 \\
\text { 2003COTTONTALL RABIT } 12\end{array}$ & $\begin{array}{l}\text { COTTONTAIL RABBIT } \\
\text { COTTONAIL RABBIT }\end{array}$ & $\begin{array}{l}\text { MUSCLE } \\
\text { MUSCLE }\end{array}$ & 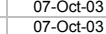 & $\begin{array}{l}33 \mathrm{Cs}-134 \\
3 \mathrm{Cs}-137\end{array}$ & $\begin{array}{rl}-0.00041 & \mathrm{pc} \\
0.0486 \mathrm{pC} & \end{array}$ & $\begin{array}{l}\text { pilg } \\
\text { pilg }\end{array}$ & 0.0022 & $\begin{array}{l}4 \\
4 \\
2 \\
2.0022\end{array}$ & u & & \\
\hline SESPMNT & B16N85 & $100 \mathrm{NAREA}$ & ONSITE & $\mathrm{Bl}$ & 2003COTTONTAIL RABBIT12 & COTTONTAIL RABBIT & MUSCLE & $\begin{array}{l}-1 \\
07-0 c t-03 \\
07-03\end{array}$ & 33 Eu-152 & $\begin{array}{l}0.0486 \mathrm{pl} \\
0.0269 \mathrm{pc}\end{array}$ & & $\begin{array}{l}0.022 \\
0.031\end{array}$ & $\begin{array}{ll}0.022 \\
0.031\end{array}$ & $\mathrm{u}$ & & \\
\hline SESPMNT & B16N85 & 100 NAREA & ONSITE & Bi & 2003COTTONTAIL RABBIT12 & COTTONTAIL RABBIT & MUSCLE & 07-oct-03 & 3 Eu-154 & $0.0091 \mathrm{pc}$ & & 0.039 & $\begin{array}{ll}9.039 \\
0.039\end{array}$ & & & \\
\hline SESPMNT & B16N85 & 100 NAREA & ONSITE & Bi & 2003COTTONTALL RABBIT12 & COTTONTAIL RABBIT & MUSCLE & 07-0ct-03 & 33 Eu-155 & $0.0207 \mathrm{pc}$ & pCilg & 0.025 & 0.025 & u & & \\
\hline $\begin{array}{l}\text { SESPMNT } \\
\text { SEPPMNT }\end{array}$ & $\begin{array}{l}\text { B16N855 } \\
\text { B16N85 }\end{array}$ & $\begin{array}{l}100 \text { NAREA } \\
100 \text { NAEA }\end{array}$ & $\begin{array}{l}\text { ONSITE } \\
\text { ONSTIE }\end{array}$ & $\begin{array}{l}\mathrm{BI} \\
\mathrm{BI}\end{array}$ & $\begin{array}{l}\text { 2003COTTONTAIL RABBIT12 } \\
\text { 2003COTTNTAL RABIT12 }\end{array}$ & $\begin{array}{l}\text { COTTONTAAL RABBIT } \\
\text { COTTONALRABBT }\end{array}$ & $\begin{array}{l}\text { MUSCLE } \\
\text { MUSCLE }\end{array}$ & $\begin{array}{l}07-0 \mathrm{Cct}-03 \\
07-0 \mathrm{Oc}-03\end{array}$ & 33 Ku-106 & $\begin{aligned} 3.57 \mathrm{pc} & \\
-0.139 \mathrm{p} & \end{aligned}$ & $\begin{array}{l}\text { pCilg } \\
\text { pilg }\end{array}$ & $\begin{array}{l}0.65 \\
0.11\end{array}$ & $\begin{array}{l}5 \quad 0.65 \\
0.11\end{array}$ & $\mathrm{u}$ & & \\
\hline $\begin{array}{l}\text { SEEPMNT } \\
\text { SESPMNT }\end{array}$ & 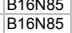 & $\begin{array}{l}\text { 100 NAREA } \\
100 \text { N AREA }\end{array}$ & $\begin{array}{l}\text { ONSTIE } \\
\text { ONSITE }\end{array}$ & $\mathrm{BI}$ & $\begin{array}{l}\text { 200033OTTONTALAL RABIIT12 } \\
\text { 2003COTONTALL RABBIT12 }\end{array}$ & $\begin{array}{l}\text { COOTONTAILLABBT } \\
\text { COTTONALL RABBIT }\end{array}$ & $\begin{array}{l}\text { MUSCLE } \\
\text { MUSCLE }\end{array}$ & $\begin{array}{l}\text { 07-0ct-1-3 } \\
07-\text {-Oct-03 }\end{array}$ & $\begin{array}{l}33 \mathrm{Ru}-106 \\
3 \mathrm{Sb}-125\end{array}$ & $\begin{array}{l}-0.139 \mathrm{pc} \\
-0.004 \mathrm{pc}\end{array}$ & & $\begin{array}{l}0.11 \\
0.03\end{array}$ & $\begin{array}{ll}1 & 0.11 \\
3 & 0.03\end{array}$ & $\begin{array}{c}u \\
u\end{array}$ & & \\
\hline SESPMNT & B16N90 & 100 N AREA & ONSITE & $\mathrm{Bl}$ & 2003COTTONTAIL RABBIT12 & COTTONTAIL RABBIT & BONES & 07-0ct-03 & 3 Sr-90 & $3.49 \mathrm{pc}$ & pCilg & 0.086 & 0.51 & & & \\
\hline SESPMNT & B16N92 & BACKGROUND & & & 2003COTTONTAIL RABBIT14 & COTTONTAIL RABBIT & MUSCLE & 11-Dec-03 & $33 \mathrm{Be}-7$ & $0.109 p c$ & & 0.16 & 0.16 & $u$ & NEAR MABTON & \\
\hline SESPMNT & B16N92 & BACKGROUND & & BI & 2003COTTONTAIL RABBIT14 & COTTONTAIL RABBIT & MUSCLE & 11-Dec-03 & 3 Co-60 & $-0.00661 p c$ & pCilg & 0.015 & 0.015 & 0 & NEAR MABTON & \\
\hline $\begin{array}{l}\text { SESPMNT } \\
\text { SEPPMNT }\end{array}$ & B16N92 & BACKGROUND & & BI & 2003COTTONTAIL RABBIT14 & COTTONTAIL RABBIT & MUSCLE & 11-Dec-03 -113 & 33 Cs-134 & $0.0139 \mathrm{pc}$ & & 0.015 & 0.015 & u & NEAR MABTON & \\
\hline $\begin{array}{l}\text { SEEPMNT } \\
\text { SESPMNT }\end{array}$ & 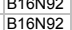 & $\begin{array}{l}\text { BACKGROUND } \\
\text { BACKGROUND }\end{array}$ & & $\begin{array}{l}B 1 \\
B I\end{array}$ & $\begin{array}{l}2003 \text { COOTONTALAL RABBIT14 } \\
2003 \text { COTTONTAL RABBT } 14\end{array}$ & $\begin{array}{l}\text { COTTONAAIL RABBIT } \\
\text { COTTONTAIL RABBIT }\end{array}$ & $\begin{array}{l}\text { MUSCLE } \\
\text { MUSCLE }\end{array}$ & $\begin{array}{l}\text { 11-Dec-03 } \\
\text { 11-Dec-03 }\end{array}$ & $\begin{array}{l}30 \mathrm{Cs}-137 \\
3 \mathrm{Eu}-152 \\
\end{array}$ & $\begin{array}{l}-0.00221 \mathrm{pc} \\
0.0157 \mathrm{pc}\end{array}$ & & $\begin{array}{l}0.015 \\
0.036\end{array}$ & 0.015 & $u$ & $\begin{array}{l}\text { NEAR MABTON } \\
\text { NEAR MABTON }\end{array}$ & \\
\hline $\begin{array}{l}\text { SESPMNI } \\
\text { SESPMNT }\end{array}$ & $\begin{array}{l}\text { B16N22 } \\
\text { B16N92 }\end{array}$ & BACKGROUND & & BI & & COTTONTAIL RABBIT & MUSCLE & $\begin{array}{l}11-\mathrm{Dec}-03 \\
113\end{array}$ & 33 Eu-154 & $\begin{array}{l}-.00107 \mathrm{pc} \\
-0.04\end{array}$ & & 0.043 & 0.043 & u & $\begin{array}{l}\text { NEAR MABION } \\
\text { NEAR MABTON }\end{array}$ & \\
\hline SESPMNT & B16N92 & BACKGROUND & & $\mathrm{Bl}$ & 2003COTTONTAIL RABBIT14 & COTTONTAIL RABBIT & MUSCLE & $\begin{array}{ll}11-D e c-03 \\
11-D e-03\end{array}$ & 33 Eu-155 & $0.0202 \mathrm{pc}$ & & 0.027 & 0.027 & u & NEAR MABTON & \\
\hline $\begin{array}{l}\text { SESPMNT } \\
\text { SEPTI }\end{array}$ & B16N92 & BACKGROUND & & $\mathrm{Bl}$ & 2003COTTONTALL RABBIT14 & COTTONTAIL RABBIT & MUSCLE & 11-Dec-03 & $33 \mathrm{~K}-40$ & $\begin{array}{ll}.0204 \mathrm{p} \\
3.1 \mathrm{pc}\end{array}$ & pCilg & 0.67 & 7. 0.67 & & NEAR MABTON & \\
\hline $\begin{array}{l}\text { SESPMNT } \\
\text { SEPPMNT }\end{array}$ & $\begin{array}{l}\text { B16NC9 } \\
\text { B16NC9 }\end{array}$ & $\begin{array}{l}\text { BACKGROUND } \\
\text { BACKGRUND }\end{array}$ & & $\begin{array}{ll}\mathrm{BI} \\
\mathrm{BI}\end{array}$ & $\begin{array}{l}\text { 2003COTTONTAIL RABBIT14 } \\
\text { 20003COTTNNTAlI RABIT14 }\end{array}$ & $\begin{array}{l}\text { COTTONTAAL RABBIT } \\
\text { COTTONAII RABBT }\end{array}$ & $\begin{array}{l}\text { LIVER } \\
\text { LVER }\end{array}$ & $\begin{array}{l}\text { 11-Dec-03 } \\
\text { 11-Dec-03 }\end{array}$ & $\begin{array}{l}33 \text { Pu-238 } \\
3 \text { Pu-239/240 }\end{array}$ & $\begin{array}{l}-0.0000137 \mathrm{pc} \\
-0.0000338 \mathrm{pc}\end{array}$ & & $\begin{array}{l}0.00031 \\
0.00032\end{array}$ & $\begin{array}{l}1 \\
0.0003 \\
0.003\end{array}$ & $\begin{array}{c}u \\
u \\
u\end{array}$ & $\begin{array}{l}\text { NEAR MABTON } \\
\text { NEAR MABTON }\end{array}$ & \\
\hline $\begin{array}{l}\text { SEEPMNT } \\
\text { SESPMNT }\end{array}$ & $\begin{array}{l}\text { B16NC9 } \\
\text { B16N92 }\end{array}$ & $\begin{array}{l}\text { BACKGROUND } \\
\text { BACKGROUND }\end{array}$ & & $\begin{array}{ll}\mathrm{BI} \\
\mathrm{BI}\end{array}$ & $\begin{array}{l}\text { 2000330TTONTALIL RABBIT14 } \\
\text { 2003COTTONTAL RABIIT14 }\end{array}$ & $\begin{array}{l}\text { COOTONTOAIL LABBIT } \\
\text { COTTONALL RABBIT }\end{array}$ & $\begin{array}{l}\text { LIVER } \\
\text { MUSCLE }\end{array}$ & $\begin{array}{l}\text { 11-Dec-03 } \\
\text { 11-Dec-03 }\end{array}$ & $\begin{array}{l}33 \text { Pu-239/240 } \\
3 \text { Ru-106 }\end{array}$ & $\begin{array}{rl}-0.0000338 \mathrm{p} c & 0.056 \mathrm{pc}\end{array}$ & & $\begin{array}{r}0.00032 \\
0.13\end{array}$ & $2 \begin{array}{l}0.0003 \\
0.13\end{array}$ & $\mathrm{u}$ & $\begin{array}{l}\text { NEAR MABTON } \\
\text { NEAR MABTON }\end{array}$ & \\
\hline SESPMNT & B16N92 & BACKGROUND & & $\mathrm{BI}$ & 2003COTTONTAIL RABBIT14 & COTTONTAIL RABBIT & MUSCLE & 11-Dec-03 & $3 \mathrm{Sb}-125$ & $-0.0147 p c$ & & 0.034 & $\begin{array}{lll}4 & 0.034 \\
\end{array}$ & u & NEAR MABTON & \\
\hline SESPMNT & B16N97 & BACKGROUND & & BI & 2003COTTONTAIL RABBIT14 & COTTONTAIL RABBIT & BONES & 11-Dec-03 & & & & & & & NEAR MABTON & No Strontium recovered. \\
\hline SESPMNT & B16NC5 & BACKGROUND & & BI & $\begin{array}{l}\text { 2003COTTONTALL RABBIT } 15 \\
\text { 2003TIL RTI }\end{array}$ & COTTONTAIL RABBIT & LIVER & 31-Mar-03 & 33 ICPMS & & & & & & NOT COLLECTED. & \\
\hline SESPMNT & B16ND0 & BACKGROUND & & BI & 2003COTTONTAIL RABBIT15 & COTTONTAIL RABBIT & $\begin{array}{l}\text { LIVER } \\
\text { BONES }\end{array}$ & 31-Mar-03 & 33 Pu-238, Pu-239/240 & & & & & & NOT COLLECTED. & \\
\hline $\begin{array}{l}\text { SESPMNT } \\
\text { SESPMNT }\end{array}$ & & $\begin{array}{l}\text { BACKGROUND } \\
\text { BACKGROUND }\end{array}$ & & BI & 2003COTTONTAIL RABBIT 15 & $\begin{array}{l}\text { COTTONTALIRABBIT } \\
\text { COTONAIT }\end{array}$ & $\begin{array}{l}\text { BONES } \\
\text { IVER }\end{array}$ & $\begin{array}{l}31-\mathrm{Mar}-03 \\
31-\mathrm{Mar}-3^{3}\end{array}$ & & & & & & & NOT COLLECTED. & \\
\hline $\begin{array}{l}\text { SESPMNT } \\
\text { SESPMNT }\end{array}$ & $\begin{array}{l}\text { B16NC5 } \\
\text { B16NC6 }\end{array}$ & $\begin{array}{l}\text { BACKGROUND } \\
\text { BACKGROUND }\end{array}$ & & BI & $\begin{array}{l}2003 \text { COTTONTAL RABBTI } 15 \\
2003 \text { COTTONTALL RABBIT16 }\end{array}$ & $\begin{array}{l}\text { COTTONAIL RABBIT } \\
\text { COTTONALRABBT }\end{array}$ & $\begin{array}{l}\text { LVER } \\
\text { LIVER }\end{array}$ & $\begin{array}{l}31-\text { Mar-03 } \\
\text { 31-Mar-03 }\end{array}$ & 33 ICPMS & & & & & & $\begin{array}{l}\text { NOT COLLECEDD. } \\
\text { NOT COULETED }\end{array}$ & \\
\hline $\begin{array}{l}\text { SESPMMNI } \\
\text { SESPMT }\end{array}$ & B16ND1 & BACKGROUND & & $\mathrm{BI}$ & NTAIL RABBIT16 & COTTONTAIL RABBIT & $\begin{array}{l}\text { LIVER } \\
\text { LIVER }\end{array}$ & 31-Mar-03 & 33 Pu-238, Pu-239/240 & & & & & & NOT COLLECTED. & \\
\hline $\begin{array}{l}\text { SESPMNT } \\
\text { SEST }\end{array}$ & B16N99 & BACKGROUND & & $\mathrm{BI}$ & 2003COTTONTALL RABBIT16 & COTTONTAIL RABBIT & BONES & 31-Mar-03 & $3 \mathrm{Sr}-90$ & & & & & & NOT COLLECTED. & \\
\hline $\begin{array}{l}\text { SESPMNT } \\
\text { SEPMNT }\end{array}$ & B16NC6 & BACKGROUND & & $\mathrm{Bl}$ & 2003COTTONTAIL RABBIT 16 & COTTONTALL RABBIT & LIVER & 31-Mar-03 & $33 \mathrm{UPS}$ & & & & & & NOT COLLECTED. & \\
\hline $\begin{array}{l}\text { SEEPMNT } \\
\text { SESPMNT }\end{array}$ & $\begin{array}{l}\text { B16NC7 } \\
\text { B16ND2 }\end{array}$ & $\begin{array}{l}\text { BACKGROUND } \\
\text { BACKGROUD }\end{array}$ & & $\begin{array}{l}\mathrm{BI} \\
\mathrm{BI}\end{array}$ & $\begin{array}{l}\text { 2003COTTONTAIL RABBII17 } \\
\text { 2003COTONTAll RABBT17 }\end{array}$ & $\begin{array}{l}\text { COTTONTAIL RABBIT } \\
\text { COTTONTII RABIT }\end{array}$ & $\begin{array}{l}\text { LIVER } \\
\text { LIVR }\end{array}$ & $\begin{array}{l}31 \text {-Mar-03 } \\
31-\text { Mar-03 }\end{array}$ & $\begin{array}{l}3 \text { I ICPMS } \\
3 \text { Pu-238. Pu-239/240 }\end{array}$ & & & & & & $\begin{array}{l}\text { NOT COLLECTED. } \\
\text { NOT COLETED. }\end{array}$ & \\
\hline SESPMNT & $\begin{array}{l}\mathrm{B} 16 \mathrm{~N} 02 \\
\mathrm{~B} 16 \mathrm{NBO}\end{array}$ & $\begin{array}{l}\text { BACKGROND } \\
\text { BACKGOUND }\end{array}$ & & $\mathrm{Bl}$ & 2003COTTONTALL RABBIT17 & $\begin{array}{l}\text { COTTONTALL RABBIT } \\
\text { COTIOA }\end{array}$ & BONES & $\begin{array}{l}31 \text {-Mar-03 } \\
\text { 31-Mar-03 }\end{array}$ & $\begin{array}{l}33 \mathrm{Pu}-238, \mathrm{Pu}-239 / 240 \\
3 \mathrm{Sr}-90\end{array}$ & & & & & & $\begin{array}{l}\text { NOT COLLECTED. } \\
\text { NOT COD. }\end{array}$ & \\
\hline $\begin{array}{l}\text { SESPMNT } \\
\text { SEPMNT }\end{array}$ & B16NC7 & BACKG: & & BI & 2003COTTONTALL RABIIT17 & COTTONTAIL RABBIT & LIVER & 31-Mar-03 & & & & & & & NOT COLLECTED. & \\
\hline $\begin{array}{l}\text { SESPMNT } \\
\text { SESPMNT }\end{array}$ & $\begin{array}{ll}\text { B16NC8 } \\
\text { B16ND3 }\end{array}$ & BACKGROUND & & BI & & COTTONTAIL RABBIT & LIVER & 31-Mar-03 & 33 ICPMS & & & & & & LECTED. & \\
\hline $\begin{array}{l}\text { SESPMNT } \\
\text { SESPMNT }\end{array}$ & $\begin{array}{l}\text { B16ND3 } \\
\text { B16N1 }\end{array}$ & $\begin{array}{l}\text { BACKGROUND } \\
\text { BACKGROUND }\end{array}$ & & $\begin{array}{l}\mathrm{BI} \\
\mathrm{BI}\end{array}$ & $\begin{array}{l}\text { 200330TTONTAL RABBIT1 } 8 \\
\text { 2003COTTNTAL RABIT18 }\end{array}$ & $\begin{array}{l}\text { COTTONAAIL RABBBT } \\
\text { COTTONAIL RABIT }\end{array}$ & $\begin{array}{l}\text { LVER } \\
\text { BONES }\end{array}$ & $\begin{array}{l}31 \text {-Mar-03 } \\
\text { 31-Mar-03 }\end{array}$ & $\begin{array}{l}33 \text { Pu-238, Pu-239/240 } \\
3 \text { St-90 }\end{array}$ & & & & & & NOT & \\
\hline $\begin{array}{l}\text { SESPMNT } \\
\text { SESPMI }\end{array}$ & B16NC8 & BACKGROUND & & $\mathrm{Bl}$ & $\begin{array}{l}\text { 2003COTTONTAL RABBIT18 } \\
\text { 2003COTTONTALL RABBIT18 }\end{array}$ & COTTONTAIL RABBIT & $\begin{array}{l}\text { BUVES } \\
\text { LIVR }\end{array}$ & 31-Mar-03 & & & & & & & $\begin{array}{l}\text { NOT COLLECTED. } \\
\text { NOT COLLETEDD. }\end{array}$ & \\
\hline SESPMNT & B169D1 & $100-\mathrm{N}-100-\mathrm{D}$ & ONSITE & $\mathrm{Bl}$ & 2003WHITEFISH1 & WHITEF & MUSCLE & 13-Jan-03 & $3 \mathrm{Be}-7$ & $0.0697 \mathrm{pc}$ & $\mathrm{pCi} / \mathrm{g}$ & 0.18 & $\begin{array}{ll}3 & 0.18\end{array}$ & $u$ & & \\
\hline $\begin{array}{l}\text { SESPMNT } \\
\text { SESPMNT }\end{array}$ & B169D1 & $\begin{array}{l}100-N-100-D \\
100-N-100-D\end{array}$ & $\begin{array}{l}\text { ONSITE } \\
\text { ONSTEE }\end{array}$ & $\begin{array}{ll}\mathrm{BI} \\
\mathrm{BI}\end{array}$ & $\begin{array}{l}\text { 2003WHITEFISH1 } \\
\text { 20033WHTEFISH1 }\end{array}$ & $\begin{array}{l}\text { WHITEFISH } \\
\text { WWITEFISH }\end{array}$ & MUSCLE & $\begin{array}{l}\text { 13-Jan-03 } \\
\text { 13-Jan-03 }\end{array}$ & $\begin{array}{l}3 \text { Co-60 } \\
33 \mathrm{Cs}-134 \\
\end{array}$ & $-0.000531 \mathrm{pc}$ & pCi/g & 然18 018 & $\begin{array}{l}3 \\
3\end{array}$ & u & & \\
\hline $\begin{array}{l}\text { SESPMNT } \\
\text { SESPMNT }\end{array}$ & $\begin{array}{l}\text { B16901 } \\
\text { B16D1 }\end{array}$ & $\begin{array}{l}100-N-100-D \\
100-N-100-D\end{array}$ & $\begin{array}{l}\text { ONSITE } \\
\text { ONSTIE }\end{array}$ & & $\begin{array}{l}20003 \text { WHITITFIIH1 } \\
2003 W H I E F I S H 1\end{array}$ & $\begin{array}{l}\text { WHITFFISH } \\
\text { WHITEFISH }\end{array}$ & $\begin{array}{l}\text { MUSCLE } \\
\text { MUSCLE }\end{array}$ & $\begin{array}{l}\text { 13-Jan-03 } \\
\text { 13-Jan-03 }\end{array}$ & $\begin{array}{l}3{ }^{3} \mathrm{Cs}-134 \\
3{ }^{3} \mathrm{Cs}-137\end{array}$ & $\begin{array}{r}-0.0151 p c \\
-0.00224 p c\end{array}$ & $\begin{array}{l}\text { pilg } \\
\text { pilga }\end{array}$ & $\begin{array}{l}0.018 \\
0.016\end{array}$ & $\begin{array}{ll}3 & 0.018 \\
0 & 0.16\end{array}$ & u & & \\
\hline SESPMNI & $\begin{array}{l}\text { B16991 } \\
\text { B169D1 }\end{array}$ & $\begin{array}{l}1000-N-100-D \\
100-N-100-D\end{array}$ & $\begin{array}{l}\text { ONSSITE } \\
\text { ONSTE }\end{array}$ & $\begin{array}{l}\mathrm{BI} \\
\mathrm{BI}\end{array}$ & $\begin{array}{l}20033 W \text { WIITHFHA1 } \\
2003 W H I E F I S H\end{array}$ & $\begin{array}{l}\text { WHIITFHSH } \\
\text { WHITEFISH }\end{array}$ & $\begin{array}{l}\text { MUSCLE } \\
\text { MUSCLE }\end{array}$ & $\begin{array}{l}\text { 13-Jan-03 } \\
\text { 13-Jan-03 }\end{array}$ & $\begin{array}{l}33 \text { Cs-13 } \\
3 \text { Eu-152 }\end{array}$ & $\begin{array}{l}-0.00224 \mathrm{pc} \\
0.000313 \mathrm{pC}\end{array}$ & $\begin{array}{l}\text { poligg } \\
\text { pCilg }\end{array}$ & $\begin{array}{l}0.0016 \\
0.042\end{array}$ & $\begin{array}{l}0.016 \\
2 \\
2\end{array}$ & 0 & & \\
\hline SPMNT & B169D1 & $100-\mathrm{N}-100-\mathrm{D}$ & ONSITE & $\mathrm{Bl}$ & 2003WHITEFISH1 & WHITEFISH & MUSCLE & 13-Jan-03 & 33 Eu-154 & $0.0113 \mathrm{pc}$ & pCilg & 0.047 & 0.047 & u & & \\
\hline SESPMNT & B169D1 & $100-N-100-D$ & ONSITE & $\mathrm{Bl}$ & 2003WHIITEFISH1 & WHITT & MUSCLE & 13-Jan-03 & 3 Eu-155 & $0.0182 \mathrm{pC}$ & pCilg & 0.051 & $\begin{array}{ll}1 & 0.051 \\
7\end{array}$ & u & & \\
\hline SESP & $\begin{array}{l}\text { B169D1 } \\
\text { B1691 }\end{array}$ & $\begin{array}{l}100-\mathrm{N}-100-\mathrm{D} \\
100-\mathrm{N}-100-\mathrm{D}\end{array}$ & $\begin{array}{l}\text { ONSITE } \\
\text { ONSTIE }\end{array}$ & BI & 2003WHH & $\begin{array}{l}\text { WHITE } \\
\text { WHIIT }\end{array}$ & MUSCLE & 13-Jan-03 & $\begin{array}{l}33 \text { K-40 } \\
3 \text { B Ru-106 }\end{array}$ & $3.96 \mathrm{pc}$ & pCi/g & $\begin{array}{l}0.77 \\
0.15\end{array}$ & 0.77 & & & \\
\hline $\begin{array}{l}\text { SESPMNT } \\
\text { SESPMNT }\end{array}$ & 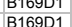 & $\begin{array}{l}100-\mathrm{N}-100-\mathrm{D} \\
100-\mathrm{N}-100-\mathrm{D}\end{array}$ & $\begin{array}{l}\text { ONSITE } \\
\text { ONSTIE }\end{array}$ & $\begin{array}{l}\mathrm{BI} \\
\mathrm{BI}\end{array}$ & $\begin{array}{l}20033 \text { WHITEFIIH1 } \\
2003 W H I E F I S H 1\end{array}$ & $\begin{array}{l}\text { WHITEFIISH } \\
\text { WWITEFSSH }\end{array}$ & $\begin{array}{l}\text { MUSCLE } \\
\text { MUSCLE }\end{array}$ & $\begin{array}{l}\text { 13-Jan-03 } \\
\text { 13-Jan-03 }\end{array}$ & $\begin{array}{l}30 \text { Ru-106 } \\
3 \text { Su-125 }\end{array}$ & $\begin{array}{l}0.0536 \mathrm{pc} \\
0.014 \mathrm{pc}\end{array}$ & $\begin{array}{l}\text { pilg } \\
\text { pilga }\end{array}$ & $\begin{array}{r}0.15 \\
0.042\end{array}$ & $\begin{array}{r}5.0 .15 \\
0.042 \\
2\end{array}$ & u & & \\
\hline $\begin{array}{l}\text { SESMNI } \\
\text { SESPMNT }\end{array}$ & B169D7 & $100-\mathrm{N}-100-\mathrm{D}$ & $\begin{array}{l}\text { ONSSITE } \\
\text { ONSTE }\end{array}$ & $\begin{array}{ll}\mathrm{BI} \\
\mathrm{BI}\end{array}$ & $\begin{array}{l}2003 \text { 2WHIIITHSHA1 } \\
2003 W H I E F I S H 1\end{array}$ & $\begin{array}{l}\text { WHIITFFH } \\
\text { WHITEFSH }\end{array}$ & $\begin{array}{l}\text { MUSCLE } \\
\text { CARCASS }\end{array}$ & $\begin{array}{l}\text { 13-Jan-03 } \\
\text { 13-Jan-03 }\end{array}$ & $\begin{array}{l}3 S^{3} \mathrm{Sb}-125 \\
3 \mathrm{Sr}-90\end{array}$ & & & & 0.023 & u & & \\
\hline & B169D2 & $100-\mathrm{N}-100-\mathrm{D}$ & ONSITE & Bl & 2003WHITEFISH2 & WHITEFISH & MUSCLE & 13-Jan-03 & $33 \mathrm{Be}-7$ & $0.0836 \mathrm{pc}$ & pCilg & 0.15 & 50.15 & u & & \\
\hline NTT & B169D2 & $100-N-100-D$ & ONSITE & $\mathrm{BI}$ & 2003WHITEFISH2 & WHITEFISH & MUSCLE & 13-Jan-03 & 3 Co-60 & $0.0207 \mathrm{pC}$ & pCilg & 0.015 & 0.015 & u & & \\
\hline $\begin{array}{l}\text { SESPMNT } \\
\text { SESPMNT }\end{array}$ & $\begin{array}{l}\text { B16992 } \\
\text { B169D2 }\end{array}$ & $\begin{array}{l}100-\mathrm{N}-100-\mathrm{D} \\
100 \mathrm{~N}-100-\mathrm{D}\end{array}$ & $\begin{array}{l}\text { ONSITE } \\
\text { ONSITE }\end{array}$ & $\begin{array}{l}\mathrm{BI} \\
\mathrm{BI}\end{array}$ & $\begin{array}{l}\text { 2003WHITEFIIH2 } 2 \\
\text { 2003WHITEFISH2 }\end{array}$ & $\begin{array}{l}\text { WHITFFIISH } \\
\text { WHIIEFISH }\end{array}$ & $\begin{array}{l}\text { MUSCLE } \\
\text { MUSCLE }\end{array}$ & $\begin{array}{l}\text { 13-Jan-03 } \\
\text { 13-Jan-03 }\end{array}$ & $\begin{array}{l}30 \mathrm{Cs}-134 \\
3{ }^{3} \mathrm{Cs}-137\end{array}$ & $\begin{array}{l}0.0098 \mathrm{pc} \\
0.00600 \mathrm{pp}\end{array}$ & $\begin{array}{l}\text { pCigg } \\
\text { pCi/g }\end{array}$ & $\begin{array}{l}0.015 \\
0.014\end{array}$ & $\begin{array}{ll}5 & 0.015 \\
4 & 0.014\end{array}$ & u & & \\
\hline
\end{tabular}


WLLDLFE
(pcilg Wet Weight)

\begin{tabular}{|c|c|c|c|c|c|c|c|c|c|c|c|c|c|c|c|c|}
\hline OWNER ID & \begin{tabular}{|l|} 
SAMP \\
NUM
\end{tabular} & SAMP SITE NAME & $\left|\begin{array}{c}\text { DIST } \\
\text { CLASS }\end{array}\right|$ & MEDIA & 1) TAG ID & SAMP FROM & SAMP ITEM & | SAMP DATE | & CON SHORT NAME & \begin{tabular}{c|c} 
VALUEE & A \\
UPTD & R \\
RPT
\end{tabular} & $\begin{array}{l}\text { ANAL } \\
\text { UNITS } \\
\text { RPTD }\end{array}$ & $\begin{array}{c}\text { COUNTING } \\
\text { ERROR }\end{array}$ & \begin{tabular}{|c|} 
TOTAL \\
ANAL \\
ERROR
\end{tabular} & $\begin{array}{l}\text { LAB } \\
\text { QUALIFIER }\end{array}$ & SAMP COMMENT & RESULT COMMENT \\
\hline $\begin{array}{l}\text { SESPMNT } \\
\text { SESPMNT }\end{array}$ & $\begin{array}{l}\text { B16992 } \\
\text { B16902 }\end{array}$ & $\begin{array}{l}100-N-100-D \\
100-N-100-D\end{array}$ & $\begin{array}{l}\text { ONSITE } \\
\text { ONSTIE }\end{array}$ & $\begin{array}{l}\mathrm{BI} \\
\mathrm{BI}\end{array}$ & $\begin{array}{l}\text { 2003WHITFFIIIH2 } \\
\text { 2003WHIIEFISH }\end{array}$ & $\begin{array}{l}\text { WHITTFFIIS } \\
\text { WHITEFSH }\end{array}$ & $\begin{array}{l}\text { MUSCLE } \\
\text { MUSCLE }\end{array}$ & $\begin{array}{l}\text { 13-Jan-03 Eu-152 } \\
\text { 13-Jan-03 Eu-154 }\end{array}$ & & $\begin{array}{r}\quad .00457 \mathrm{pC} \\
-0.00656 \mathrm{pC}\end{array}$ & CClig & $\begin{array}{l}0.033 \\
0.044\end{array}$ & $\begin{array}{ll}3 & 0.033 \\
4 & 0.044\end{array}$ & u & & \\
\hline SESPMNT & B169D2 & $100-N-100-D$ & ONSITE & $\mathrm{BI}$ & 2003WHIITFISH2 & WHITEFISH & MUSCLE & 13-Jan-03 Eu-155 & & $0.00338 \mathrm{pC}$ & Cil/g & 0.031 & 0.031 & & & \\
\hline $\begin{array}{l}\text { SEEPMNT } \\
\text { SESPMNT }\end{array}$ & $\begin{array}{l}\text { B6692 } \\
\text { B16902 }\end{array}$ & $\begin{array}{l}100-N-100-D \\
100-N-100-D\end{array}$ & $\begin{array}{l}\text { ONSIIE } \\
\text { ONSITE }\end{array}$ & $\begin{array}{l}\mathrm{BI} \\
\mathrm{BI}\end{array}$ & $\begin{array}{l}\text { 2003WHITITFISH2 } \\
\text { 2003WHITEFISH }\end{array}$ & $\begin{array}{l}\text { WHITTFFISH } \\
\text { WHITEFISH }\end{array}$ & $\begin{array}{l}\text { MUSCLE } \\
\text { MUSCLE }\end{array}$ & $\begin{array}{l}\text { 13-Jan-03 K-40 } \\
\text { 13-Jan-03 Ru-106 }\end{array}$ & & $\begin{array}{r}3.17 \mathrm{pC} \\
-0.0089 \mathrm{pC}\end{array}$ & $\begin{array}{l}\text { bil/g } \\
\text { cilg }\end{array}$ & $\begin{array}{l}0.67 \\
0.12\end{array}$ & $\begin{array}{l}0.67 \\
0.12\end{array}$ & $u$ & & \\
\hline SESPMNT & B169D2 & $100-N-100-D$ & ONSITE & $\mathrm{BI}$ & 2003WHITEFISH2 & WHITEFISH & MUSCLE & 13-Jan-03 Sb-125 & & $-0.0116 \mathrm{pC}$ & Cilg & 0.034 & 0.034 & $u$ & & \\
\hline $\begin{array}{l}\text { SESPMNT } \\
\text { SSEPMNT }\end{array}$ & B169D8 & $100-N-100-D$ & ONSITE & BI & 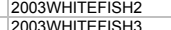 & $\begin{array}{l}\text { WHITEFISH } \\
\text { WWITFFISH }\end{array}$ & CARCASS & 13-Jan-03 Sr-90 & & $0.0179 \mathrm{pC}$ & & 0.024 & 0.026 & $u$ & & \\
\hline $\begin{array}{l}\text { SESPMNT } \\
\text { SESPMNT }\end{array}$ & $\begin{array}{l}\text { B16993 } \\
\text { B169D3 }\end{array}$ & $\begin{array}{l}100-N-100-D \\
100-N-100-D\end{array}$ & $\begin{array}{l}\text { ONSIIE } \\
\text { ONSITE }\end{array}$ & $\begin{array}{l}\mathrm{BI} \\
\mathrm{BI}\end{array}$ & $\begin{array}{l}2003 \text { 20HITEFISH3 } \\
\text { 2003WHITEFISH3 }\end{array}$ & $\begin{array}{l}\text { WHITEFISH } \\
\text { WHITEFISH }\end{array}$ & $\begin{array}{l}\text { MUSCLE } \\
\text { MUSCLE }\end{array}$ & $\begin{array}{l}\text { 13-Jan-03 Be-7 } \\
\text { 13-Jan-03 Co-60 }\end{array}$ & & $\begin{array}{r}0.0348 \mathrm{pC} \\
0.00835 \mathrm{pC}\end{array}$ & 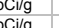 & $\begin{array}{r}0.12 \\
0.012\end{array}$ & $\begin{array}{l}0.12 \\
0.12\end{array}$ & u & & \\
\hline SESPMNT & B169D3 & $100-N-100-D$ & ONSITE & BI & 2003WHITEFISH 3 & $\begin{array}{l}\text { WHIITEFISH } \\
\text { WhH }\end{array}$ & MUSCLE & 13-Jan-03 Cs-134 & & $0.00707 \mathrm{pC}$ & CCi/g & 0.012 & 0.012 & u & & \\
\hline SESPMNT & B169D3 & $100-N-100-D$ & ONSITE & $\mathrm{BI}$ & 2003WHITEFISH3 & WHIITEFISH & MUSCLE & 13-Jan-03 Cs-137 & & $0.00522 \mathrm{pC}$ & $\mathrm{CCi} / \mathrm{g}$ & 0.011 & 0.011 & u & & \\
\hline SESPMNT & B169D3 & $100-N-100-D$ & ONSITE & $\mathrm{BI}$ & 2003WHIITEFISH3 & WHIITEFISH & MUSCLE & 13-Jan-03 Eu-152 & & $-0.00891 \mathrm{pC}$ & & 0.027 & 0.027 & u & & \\
\hline $\begin{array}{l}\text { SESPMNT } \\
\text { SESPMNT }\end{array}$ & $\begin{array}{l}\text { B169D3 } \\
\text { B16903 }\end{array}$ & $\begin{array}{l}100-N-100-D \\
100-N-10-D\end{array}$ & $\begin{array}{l}\text { ONSITE } \\
\text { ONSTIE }\end{array}$ & $\begin{array}{l}\mathrm{BI} \\
\mathrm{BI}\end{array}$ & $\begin{array}{l}\text { 2003WHITEFISH3 } \\
\text { 20033WITFFISH3 }\end{array}$ & $\begin{array}{l}\text { WHITEFISH } \\
\text { WWITEFISH }\end{array}$ & $\begin{array}{l}\text { MUSCLE } \\
\text { MUSCE }\end{array}$ & $\begin{array}{l}\text { 13-Jan-03 Eu-154 } \\
\text { 13-Jan-03 Eu-155 }\end{array}$ & & $\begin{array}{l}0.00638 \mathrm{pC} \\
-0.0183 \mathrm{pC}\end{array}$ & $\begin{array}{l}\text { CCilg } \\
\text { Cila }\end{array}$ & $\begin{array}{l}0.032 \\
0.025\end{array}$ & $\begin{array}{l}0.032 \\
0.025 \\
0.025\end{array}$ & u & & \\
\hline SESPMNT & B169D3 & $100-N-100-D$ & ONSITE & $\mathrm{BI}$ & 2003WHIITEFISH3 & WHITEFISH & MUSCLE & 13-Jan-03 K-40 & & $3.89 \mathrm{pC}$ & CCi/g & 0.64 & $\begin{array}{ll}4 & 0.64\end{array}$ & & & \\
\hline $\begin{array}{l}\text { SESPMNT } \\
\text { SSEPMNT }\end{array}$ & B169D3 & 100-N - 100-D & $\begin{array}{l}\text { ONSITE } \\
\text { ONSTIF }\end{array}$ & BI & 2003WHITEFISH3 & $\begin{array}{l}\text { WHITEFISH } \\
\text { WHITFFISH }\end{array}$ & MUSCLE & 13-Jan-03 Ru-106 & & $0.0293 \mathrm{pC}$ & Ci/g & 0.097 & 0.097 & U & & \\
\hline $\begin{array}{l}\text { SESPMNT } \\
\text { SESPMNT }\end{array}$ & $\begin{array}{ll}\text { B16903 } \\
\text { B16909 }\end{array}$ & $\begin{array}{l}100-N-100-D \\
100-N-100-D\end{array}$ & $\begin{array}{l}\text { ONSIIE } \\
\text { ONSITE }\end{array}$ & B & $\begin{array}{l}\text { 2003WHHTEFIHS3 } \\
2003 \text { WITFFIIHH3 }\end{array}$ & $\begin{array}{l}\text { WHITFFISH } \\
\text { WHITEFISH }\end{array}$ & $\begin{array}{l}\text { MUSCLE } \\
\text { CARCASS }\end{array}$ & 13-Jan-03 Sb-125 & & $0.00925 \mathrm{pC}$ & OCi/g & 0.026 & $\begin{array}{ll}5 & 0.026 \\
1 & 0202\end{array}$ & $U$ & & \\
\hline $\begin{array}{l}\text { SESPMNT } \\
\text { SESPMNT }\end{array}$ & $\begin{array}{l}\begin{array}{l}\text { B169999 } \\
\text { B169D4 }\end{array}\end{array}$ & $\begin{array}{l}100-N-100-D \\
100-N-100-D\end{array}$ & $\begin{array}{l}\text { ONSIIE } \\
\text { ONSTIE }\end{array}$ & $\begin{array}{l}\mathrm{BI} \\
\mathrm{BI}\end{array}$ & $\begin{array}{l}2003 \text { 20HTITEIISH3 } \\
\text { 2003WHITEFISH4 }\end{array}$ & $\begin{array}{l}\text { WHITFFISH } \\
\text { WHITEFISH }\end{array}$ & $\begin{array}{l}\text { CARCASS } \\
\text { MUSCLE }\end{array}$ & $\begin{array}{l}\text { 13-Jan-03 Sr-90 } \\
\text { 13-Jan-03 Be-7 }\end{array}$ & & $\begin{array}{l}0.00851 \mathrm{pC} \\
-0.0686 \mathrm{pC}\end{array}$ & 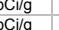 & $\begin{array}{l}0.021 \\
0.2\end{array}$ & 0.022 & u & & \\
\hline SESPMNT & B169D4 & $100-N-100-D$ & ONSITE & $\mathrm{BI}$ & 2003WHITEFISH4 & WHIIEFISH & MUSCLE & 13-Jan-03 Co-60 & & $\begin{array}{r}-0.0000 \\
0.0117 \mathrm{pC}\end{array}$ & CCi/g & 0.017 & 0.017 & u & & \\
\hline SESPMNT & B169D4 & $100-N-100-D$ & ONSITE & $\mathrm{BI}$ & 2003WHIITEISH4 & WHIITEFISH & MUSCLE & 13-Jan-03 Cs-134 & & $0.000865 \mathrm{pC}$ & & 0.02 & 0.02 & u & & \\
\hline SESPMNT & B169D4 & $100-N-100-D$ & ONSITE & BI & 2003WHITEFISH4 & WHITEFISH & MUSCLE & 13-Jan-03 Cs-137 & & $0.00618 p c$ & bCi/g & 0.018 & 30.018 & $u$ & & \\
\hline $\begin{array}{l}\text { SESPMNT } \\
\text { SESPMNT }\end{array}$ & $\begin{array}{l}\text { B169D4 } \\
\text { B1694 }\end{array}$ & $\begin{array}{l}100-N-100-D \\
100-N-100-D\end{array}$ & $\begin{array}{l}\text { ONSITE } \\
\text { ONSTEF }\end{array}$ & $\mathrm{BI}$ & 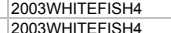 & $\begin{array}{l}\text { WHITEFISH } \\
\text { WHITFFISH }\end{array}$ & $\begin{array}{l}\text { MUSCLE } \\
\text { MUSCEE }\end{array}$ & 13-Jan-03 Eu-152 & & $-0.0405 \mathrm{pC}$ & OCi/g & 0.049 & 0.049 & U & & \\
\hline $\begin{array}{l}\text { SESPMNI } \\
\text { SESPMNT }\end{array}$ & 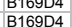 & $\begin{array}{l}100-N-100-D \\
100-N-100-D\end{array}$ & $\begin{array}{l}\text { ONSSIIE } \\
\text { ONSTE }\end{array}$ & $\begin{array}{l}\mathrm{BI} \\
\mathrm{BI}\end{array}$ & $\begin{array}{l}2003 \text { WHHTFEIISH } \\
2003 \text { WIITFFISH4 }\end{array}$ & $\begin{array}{l}\text { WHITFFISH } \\
\text { WHITEFISH }\end{array}$ & $\begin{array}{l}\text { MUSCLE } \\
\text { MUSCLE }\end{array}$ & $\begin{array}{l}\text { 13-Jan-03 Eu-154 } \\
\text { 13-Jan-03 Eu-15 }\end{array}$ & & $\begin{array}{l}0.0225 \mathrm{pC} \\
0.036 \mathrm{pC}\end{array}$ & & $\begin{array}{l}0.053 \\
0.057 \\
\end{array}$ & $\begin{array}{l}0.053 \\
0.057\end{array}$ & u & & \\
\hline $\begin{array}{l}\text { SESPMNT } \\
\text { SESPMI }\end{array}$ & 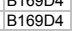 & $\begin{array}{l}100-N-100-D \\
100-N-100-D\end{array}$ & $\begin{array}{l}\text { ONSITE } \\
\text { ONSTE }\end{array}$ & $\begin{array}{l}\mathrm{BI} \\
\mathrm{BI}\end{array}$ & $\begin{array}{l}\text { 2003WHHITEFISH4 } \\
\text { 2003WHAS }\end{array}$ & $\begin{array}{l}\text { WHIITFFISH } \\
\text { WHITEFH }\end{array}$ & $\begin{array}{l}\text { MUSCLE } \\
\text { MUSCLE }\end{array}$ & 13-Jan-03 K-155 & & $\begin{array}{l}.0 .06 \mathrm{sc} \\
4.89 \mathrm{pC}\end{array}$ & CCi/g & $\begin{array}{l}0.057 \\
0.89\end{array}$ & $9 \begin{array}{l}0.005 \\
0.89\end{array}$ & & & \\
\hline SESPMNT & B16904 & $100-N-100-D$ & ONSITE & $\mathrm{BI}$ & 2003WHIITEFISH4 & WHIITEFISH & MUSCLE & 13-Jan-03 Ru-106 & & $0.0351 \mathrm{pC}$ & cCilg & 0.17 & 0.17 & $u$ & & \\
\hline $\begin{array}{l}\text { SESPMNT } \\
\text { SESPMNT }\end{array}$ & B169D4 & 100-N - 100-D & ONSITE & $\mathrm{BI}$ & 2003WHITEFISH4 & WHITEFISH & MUSCLE & 13-Jan-03 Sb-125 & & $-0.026 \mathrm{pC}$ & & 0.045 & 50.045 & u & & \\
\hline $\begin{array}{l}\text { SESPMNT } \\
\text { SESPMNT }\end{array}$ & B169F0 & $\begin{array}{l}100-N-100-D \\
100-N-100-D\end{array}$ & ONSITE & BI & 2003WHITEFISH4 & WHITEFISH & CARCASS & 13-Jan-03 Sr-90 & & $0.00801 \mathrm{pC}$ & & 0.021 & $\begin{array}{ll}1 & 0.022 \\
2 & \end{array}$ & $U$ & & \\
\hline $\begin{array}{l}\text { SESPMNT } \\
\text { SESPMNT }\end{array}$ & 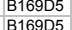 & $\begin{array}{l}100-N-100-D \\
100-N-100-D\end{array}$ & $\begin{array}{l}\text { ONSIIE } \\
\text { ONSITE }\end{array}$ & $\begin{array}{l}\mathrm{BI} \\
\mathrm{BI}\end{array}$ & $\begin{array}{l}2003 \text { 20HITEFIHSH } \\
2003 \text { WIITFFISH5 }\end{array}$ & $\begin{array}{l}\text { WHITFFISH } \\
\text { WHITEFISH }\end{array}$ & $\begin{array}{l}\text { MUSCLE } \\
\text { MUSCLE }\end{array}$ & $\begin{array}{l}\text { 13-Jan-03 Be-7 } \\
\text { 13-Jan- } 03 \text { Co-60 }\end{array}$ & & $\begin{array}{l}-0.078 \mathrm{pC} \\
0.0143 \mathrm{pC}\end{array}$ & $\begin{array}{ll}\text { Cilg } \\
\text { Cilg }\end{array}$ & $\begin{array}{r}0.13 \\
0.013\end{array}$ & $\begin{array}{l}3 \\
3 \\
3\end{array}$ & u & & \\
\hline SESPMNT & B169D5 & $\begin{array}{l}T 0-N-T 0-D \\
100-N-100-D\end{array}$ & ONSITE & B & $\begin{array}{l}\text { 2003WWHAFFIITH5 } \\
\text { 2003WHITFISH }\end{array}$ & $\begin{array}{l}\text { WHIITEFISH } \\
\text { WHITEFISH }\end{array}$ & MUSCLE & $\begin{array}{l}\text { 13-Jan- }-03 \text { Co-60 } \\
\text { 13-Jan-03 Cs-14 }\end{array}$ & & $\begin{array}{l}0.0143 \mathrm{pC} \\
0.00166 \mathrm{pC}\end{array}$ & & $\begin{array}{l}0.013 \\
0.013 \\
\end{array}$ & $\begin{array}{l}3.0013 \\
3 \\
3\end{array}$ & u & & \\
\hline SESPMNT & B169D5 & $100-N-100-D$ & ONSITE & $\mathrm{BI}$ & 2003WHITEFISH5 & WHIITEFISH & MUSCLE & 13-Jan-03 Cs-137 & & $0.000682 \mathrm{pC}$ & & 0.012 & 0.012 & u & & \\
\hline SESPMNT & B169D5 & $100-N-100-D$ & ONSITE & $\mathrm{BI}$ & 2003WHIITFISH5 & WHITEFISH & MUSCLE & 13-Jan-03 Eu-152 & & $-0.00168 \mathrm{pC}$ & Cilg & 0.029 & 0.029 & u & & \\
\hline $\begin{array}{l}\text { SESPMNT } \\
\text { SESPMNT }\end{array}$ & $\begin{array}{l}\text { B169D5 } \\
\text { B16905 }\end{array}$ & $\begin{array}{l}100-N-100-D \\
100-N-100-D\end{array}$ & $\begin{array}{l}\text { ONSITE } \\
\text { ONSTIF }\end{array}$ & BI & $\begin{array}{l}2003 \text { 20HITEFISH5 } \\
2003 W H T F I\end{array}$ & $\begin{array}{l}\text { WHITEFISH } \\
\text { WHIEFESH }\end{array}$ & $\begin{array}{l}\text { MUSCLE } \\
\text { MUSCEE }\end{array}$ & 13-Jan-03 Eu-154 & & $-0.0151 \mathrm{pC}$ & Ci/g & 0.036 & $\begin{array}{l}50.036 \\
8\end{array}$ & u & & \\
\hline $\begin{array}{l}\text { SESPMNI } \\
\text { SESPMNT }\end{array}$ & $\begin{array}{l}\text { B16905 } \\
\text { B16905 }\end{array}$ & $\begin{array}{l}100-N-100-D \\
100-N-100-D\end{array}$ & $\begin{array}{l}\text { ONSIIE } \\
\text { ONSTIE }\end{array}$ & $\frac{B I}{B !}$ & $\begin{array}{l}2003 \text { 20HITEFIHST } \\
2003 \text { WITEFIIH5 }\end{array}$ & $\begin{array}{l}\text { WHITTFIISH } \\
\text { WHITEFISH }\end{array}$ & $\begin{array}{l}\text { MUSCLE } \\
\text { MUSCEE }\end{array}$ & $\begin{array}{l}\text { 13-an-03 Eu-155 } \\
\text { 13-ana } 03 \text { K-40 }\end{array}$ & & $\begin{array}{rl}-0.0199 \mathrm{pC} & 286 \mathrm{pC}\end{array}$ & $\begin{array}{ll}\mathrm{Ci} / \mathrm{g} \\
\mathrm{C} / \mathrm{g}\end{array}$ & 0.026 & 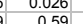 & 0 & & \\
\hline $\begin{array}{l}\text { SESPMNI } \\
\text { SESPMNT }\end{array}$ & 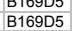 & $\begin{array}{l}100-N-100-D \\
100-N-100-D\end{array}$ & $\begin{array}{l}\text { ONSSITE } \\
\text { ONSE }\end{array}$ & $\begin{array}{l}\mathrm{BI} \\
\mathrm{BI}\end{array}$ & 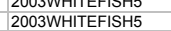 & $\begin{array}{l}\text { WHILFFSH } \\
\text { WHITEFISH }\end{array}$ & $\begin{array}{l}\text { MUSCLE } \\
\text { MUSCLE }\end{array}$ & $\begin{array}{l}\text { 13-Jan-03 K-40 } \\
\text { 13-Jan-03 Ru-106 }\end{array}$ & & $\begin{array}{r}2.86 \mathrm{pC} \\
-0.0183 \mathrm{pC}\end{array}$ & $\begin{array}{l}\text { CClig } \\
\text { CCilg }\end{array}$ & $\begin{array}{l}0.59 \\
0.099\end{array}$ & $\begin{array}{r}0.59 \\
0.099\end{array}$ & $u$ & & \\
\hline SESPMNT & B169D5 & $100-N-100-D$ & ONSITE & $\mathrm{BI}$ & 2003WHIITEFISH5 & WHITEFISH & MUSCLE & 13-Jan-03 Sb-125 & & $-0.0102 p C$ & & 0.029 & 0.029 & u & & \\
\hline SESPMNT & B169F1 & $100-\mathrm{N}-100-\mathrm{D}$ & ONSITE & $\mathrm{BI}$ & 2003WHIITFISH5 & WHITEFISH & CARCASS & 13-Jan-03 Sr-90 & & $0.0262 \mathrm{pC}$ & & 0.025 & 50.027 & u & & \\
\hline $\begin{array}{l}\text { SESPMNT } \\
\text { SESPMNT }\end{array}$ & B169F3 & BACKGROUND & & BI & 2003WHITEFISH7 & WHITEFISH & MUSCLE & 27-Jan-03 Be-7 & & $0.00419 \mathrm{pC}$ & Ci/g & $\begin{array}{r}0.12 \\
0.12\end{array}$ & 0.12 & U & BELOW WANAPUM DAM & \\
\hline $\begin{array}{l}\text { SESPMNT } \\
\text { SESPMNT }\end{array}$ & $\begin{array}{l}\text { B16993 } \\
\text { B16953 }\end{array}$ & $\begin{array}{l}\text { BACKGROUND } \\
\text { BACKGROUND }\end{array}$ & & $\begin{array}{c}B 1 \\
B 1\end{array}$ & $\begin{array}{l}\text { 2003WHHTEIIST7 } \\
\text { 2003WHITEFISH7 }\end{array}$ & $\begin{array}{l}\text { WHITTFIISH } \\
\text { WHITEFISH }\end{array}$ & $\begin{array}{l}\text { MUSCLE } \\
\text { MUSCLE }\end{array}$ & $\begin{array}{l}\text { 27-Jan-03 Co-60 } \\
\text { 27- } 03 \text { - } 03 \text { Cs } 134\end{array}$ & & $\begin{array}{l}0.000369 \mathrm{pC} \\
-0.00356 \mathrm{pC}\end{array}$ & $\begin{array}{cc}\text { Cilg } \\
\text { Cilg }\end{array}$ & 0.012 & $\begin{array}{ll}0.012 \\
3 \\
0.13\end{array}$ & $\underline{u}$ & $\begin{array}{l}\text { BELOW WAAAPUM DAM DAM } \\
\text { BELWWANAPUM DAM }\end{array}$ & \\
\hline $\begin{array}{l}\text { SESPMNI } \\
\text { SESPMNT }\end{array}$ & $\begin{array}{l}\text { B16993 } \\
\text { B169F3 }\end{array}$ & $\begin{array}{l}\text { BACKGROONDD } \\
\text { BACKGROUND }\end{array}$ & & $\mathrm{BI}$ & $\begin{array}{l}\text { 2003WHAIITFISHI } \\
\text { 2003WHITFISH7 }\end{array}$ & $\begin{array}{l}\text { WHALFHSH } \\
\text { WHITEFISH }\end{array}$ & $\begin{array}{l}\text { MUSCLE } \\
\text { MUSCLE }\end{array}$ & $\begin{array}{l}\text { 27-Jan-03 Cs-134 } \\
\text { 27-Jan-03 Cs-137 }\end{array}$ & & $\begin{array}{l}-0.00356 \mathrm{pC} \\
-0.00187 \mathrm{pC}\end{array}$ & & $\begin{array}{l}0.013 \\
0.12\end{array}$ & $\begin{array}{l}3.0 .13 \\
2 \\
2.012\end{array}$ & u & $\begin{array}{l}\text { WANAPUM DAM } \\
\text { W WANAPUM DAM }\end{array}$ & \\
\hline SESPMNT & B169F3 & BACKGROUND & & BI & 2003WHITEFISH7 & WHIITEFISH & MUSCLE & 27-Jan-03 Eu-152 & & $-0.0199 \mathrm{pC}$ & Cilg & 0.032 & 0.032 & u & BELOW WANAPUM DAM & \\
\hline SESPMNT & B169F3 & BACKGROUND & & $\mathrm{BI}$ & 2003WHIITEFISH7 & WHITEFISH & MUSCLE & 27-Jan-03 Eu-154 & & $0.0202 \mathrm{pC}$ & & 0.036 & 0.036 & u & BELOW WANAPUM DAM & \\
\hline $\begin{array}{l}\text { SESPMNT } \\
\text { SESPMNT }\end{array}$ & B169F3 & BACKGROUND & & BI & 2003WHITEFISH7 & WHITEFISH & $\begin{array}{l}\text { MUSCLE } \\
\text { MUSCEE }\end{array}$ & 27-Jan-03 Eu-155 & & $0.00267 \mathrm{pC}$ & Ci/g & 0.037 & 0.037 & $u$ & BELOW WANAPUM DAM & \\
\hline $\begin{array}{l}\text { SESPMNT } \\
\text { SESPMNT }\end{array}$ & $\begin{array}{l}\text { B16993 } \\
\text { B16993 }\end{array}$ & $\begin{array}{l}\text { BACKGROOUND } \\
\text { BACKGROUUDD }\end{array}$ & & BI & $\begin{array}{l}2003 \text { WHITEFISH7 } \\
2003 \text { WHITEFISH7 }\end{array}$ & $\begin{array}{l}\text { WHITFFISH } \\
\text { WHITEFISH }\end{array}$ & $\begin{array}{l}\text { MUSCLE } \\
\text { MUSCEE }\end{array}$ & 27-Jan-03 K-40 & & $\begin{array}{l}2.91 \mathrm{pC} \\
0.0364 \mathrm{pC}\end{array}$ & Cilg & 0.57 & $\begin{array}{l}0.57 \\
0.11 \\
1\end{array}$ & $y$ & $\begin{array}{l}\text { BEEOW WAAAPUM DAM } \\
\text { BELW WANAPUMDAM }\end{array}$ & \\
\hline $\begin{array}{l}\text { SESPMNT } \\
\text { SESPMNT }\end{array}$ & $\begin{array}{l}\begin{array}{l}\text { B16993 } \\
\text { B169F3 }\end{array}\end{array}$ & $\begin{array}{l}\text { BACKGROOUND } \\
\text { BACKGROUND }\end{array}$ & & $\begin{array}{l}\mathrm{BI} \\
\mathrm{BI}\end{array}$ & $\begin{array}{l}\text { 2003WHHTFIISH7 } \\
\text { 2003WHITEFISH7 }\end{array}$ & $\begin{array}{l}\text { WHITFFISH } \\
\text { WHITEFISH }\end{array}$ & $\begin{array}{l}\text { MUSCLE } \\
\text { MUSCLE }\end{array}$ & $\begin{array}{l}\text { 27-Jan-03 Ru-106 } \\
\text { 27-Jan-03 Sb-125 }\end{array}$ & & $\begin{array}{l}0.00364 \mathrm{pC} \\
-0.0139 \mathrm{pC}\end{array}$ & $\begin{array}{l}\text { Cilg } \\
\text { Cilg }\end{array}$ & 0.03 & $\begin{array}{ll}3 & 0.011 \\
3 & 0.03\end{array}$ & u & $\begin{array}{l}\text { BELWW WANAPUM DAM DANAPUM DAM } \\
\text { BELOW }\end{array}$ & \\
\hline SESPMNT & B169F9 & BACKGROUND & & BI & 2003WHITEFISHT & WHITEFISH & CARCASS & 27-Jan-03 Sr-90 & & $0.00726 \mathrm{pC}$ & & 0.02 & $\begin{array}{l}0.022 \\
0.022\end{array}$ & u & BELOW WANAPUM DAM & \\
\hline SESPMNT & B169J1 & BACKGROUND & & $\mathrm{BI}$ & 2003WHIITEFISH8 & WHITEFISH & LIVER & 10-Jan- $03 \mathrm{Hg}$ & & & & & & & NOT COLLECTED. & \\
\hline $\begin{array}{l}\text { SESPMNT } \\
\text { SESPMNT }\end{array}$ & B169J1 & BACKGROUND & & BI & 2003WHITEFISH8 & WHITEFISH & LIVER & 10-Jan-03 ICPMS & & & & & & & NOT COLLECTED. & \\
\hline $\begin{array}{l}\text { SESPMNT } \\
\text { SESPMNT }\end{array}$ & $\begin{array}{l}\text { B169HO } \\
\text { B1691 }\end{array}$ & BACKGROUND & & BI & $\begin{array}{l}\text { 2003WHITEFISH8 } \\
\text { 20033WHTFEIH8 }\end{array}$ & $\begin{array}{l}\text { WHITFFIISH } \\
\text { WHITEFISH }\end{array}$ & CARCASS & 10-Jan-03 Sr-90 & & & & & & & $\begin{array}{l}\text { NOT COLLECTED. } \\
\text { NOT COULETED }\end{array}$ & \\
\hline $\begin{array}{l}\text { SESPMNT } \\
\text { SESPMNT }\end{array}$ & 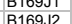 & DACKGOUND & & 年 & 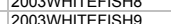 & WWIITHSTH & 甚 & 10-0an-50 & & & & & & & NOT COLEETED. & \\
\hline $\begin{array}{l}\text { SESPMNT } \\
\text { SESP }\end{array}$ & B169J2 & BACKGROUND & & $\begin{array}{l}\mathrm{BI} \\
\mathrm{BI}\end{array}$ & 2003WHITEFISH9 & $\begin{array}{l}\text { WHIITEFISH } \\
\text { WHISH }\end{array}$ & $\begin{array}{l}\text { LIVR } \\
\text { LIVER }\end{array}$ & $\begin{array}{l}\text { 10-Jan-03 } \mathrm{Hg} \\
\text { 10 }\end{array}$ & & & & & & & NOT COLLECTED. & \\
\hline SESPMNT & B169H1 & BACKGROUND & & $\mathrm{BI}$ & 2003WHIITEFISH9 & WHITEFISH & CARCASS & 10-Jan-03 Sr-90 & & & & & & & NOT COLLECTED. & \\
\hline $\begin{array}{l}\text { SESPMNT } \\
\text { SESPMNT }\end{array}$ & $\begin{array}{l}\text { B169J2 } \\
\text { B16933 }\end{array}$ & $\begin{array}{l}\text { BACKGROUND } \\
\text { BACKGOUND }\end{array}$ & & $\mathrm{BI}$ & $\begin{array}{l}\text { 2003WHITEFFISH } \\
\text { 2003WHITEISH10 }\end{array}$ & $\begin{array}{l}\text { WHITEFISH } \\
\text { WHIEFESH }\end{array}$ & $\begin{array}{l}\text { LIVER } \\
\text { LNER }\end{array}$ & $\begin{array}{l}\text { 10-Jan-03 U } \\
\text { 10-Jan-03 } \mathrm{Hg}\end{array}$ & & & & & & & $\begin{array}{l}\text { NOT COLLECTED. } \\
\text { NOT COLETED. }\end{array}$ & \\
\hline & $\begin{array}{l}\text { B16993 } \\
\text { B169J3 }\end{array}$ & $\begin{array}{l}\text { BACKROUND } \\
\text { BACKGROUND }\end{array}$ & & $\begin{array}{l}\mathrm{BI} \\
\mathrm{BI}\end{array}$ & $\begin{array}{l}\text { 2003WHTIEFIHH10 } \\
\text { 2003WHITEFISH10 }\end{array}$ & $\begin{array}{l}\text { WHIITFSH } \\
\text { WHITEFISH }\end{array}$ & $\begin{array}{l}\text { LIVR } \\
\text { LIVER }\end{array}$ & $\begin{array}{l}\text { 10-Jan-03 Hg } \\
\text { 10-Jan-03 ICPMS }\end{array}$ & & & & & & & $\begin{array}{l}\text { NOT COLLEETED. } \\
\text { NOT COLLECTED. }\end{array}$ & \\
\hline SESPMNT & B169H2 & BACKGROUND & & $B$ & 2003WHITEFISH10 & WHITEFISH & CARCASS & $\begin{array}{l}\text { 10-Jan-03 } \mathrm{Sr}-90 \\
\text { 10-Jus }\end{array}$ & & & & & & & NOT COLLECTED. & \\
\hline SESPMNT & B169J3 & BACKGROUND & & $\mathrm{BI}$ & 2003WHITEFISH10 & WHITEFISH & LIVER & 10-Jan-03 U & & & & & & & NOT COLLECTED. & \\
\hline SESPMNT & B169J4 & BACKGROUND & & BI & 2003WHITEFISH11 & WHITEFISH & LIVER & 10-Jan- $03 \mathrm{Hg}$ & & & & & & & NOT COLLECTED. & \\
\hline $\begin{array}{l}\text { SESPMNT } \\
\text { SESPMNT }\end{array}$ & B169J4 & $\begin{array}{l}\text { BACKGROUND } \\
\text { BACKROUND }\end{array}$ & & BI & $\begin{array}{l}2003 \text { WHITEFFIS11 } \\
2003 \text { WHITEFISH11 }\end{array}$ & $\begin{array}{l}\text { WHITEFISH } \\
\text { WHIIEFISH }\end{array}$ & LIVER & 10-Jan-03 ICPMS & & & & & & & NOT COLLECTED. & \\
\hline $\begin{array}{l}\text { SESPMNT } \\
\text { SESPMNT }\end{array}$ & 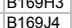 & $\begin{array}{l}\text { BACGGROUND } \\
\text { BACKGROUND }\end{array}$ & & $\begin{array}{l}\mathrm{Bl} \\
\mathrm{BI}\end{array}$ & $\begin{array}{l}\text { 2003WHITEFFHA11 } \\
\text { 2003WHITEFISH11 }\end{array}$ & $\begin{array}{l}\text { WHITFFSH } \\
\text { WHITEFISH }\end{array}$ & $\begin{array}{l}\text { CARCASS } \\
\text { LIVER }\end{array}$ & $\begin{array}{l}\text { 10-Jan-03 SS-90 } \\
\text { 10-Jan-03 U }\end{array}$ & & & & & & & $\begin{array}{l}\text { NOT COLLECEDD. } \\
\text { NOT COLLETED }\end{array}$ & \\
\hline $\begin{array}{l}\text { SESPMNPI } \\
\text { SESPEC }\end{array}$ & & & ONSITE & & 2003CLAMS26 & CLAMS & $\begin{array}{l}\text { LIVER TISSUE } \\
\text { SOFT TISU }\end{array}$ & & & & & & & & & \\
\hline SESPSPEC & B186J5 & 100 B/C AREA UR & ONSITE & BI & 2003CLAMS26 & CLAMS & SOFT TISSUE & 24-Sep-03 ICPMS & & & & & & & NOT COLLECTED. & \\
\hline SESPSPEC & B186J5 & $100 \mathrm{~B} / \mathrm{C}$ AREA UR & ONSITE & $\mathrm{BI}$ & 2003CLAMS26 & CLAMS & SOFT TISSUE & $24-$ Sep-03U & & & & & & & NOT COLLECTED. & \\
\hline $\begin{array}{l}\text { SESPSPEC } \\
\text { SESPPEC }\end{array}$ & $\begin{array}{l}\text { B16T04 } \\
\text { B16T07 }\end{array}$ & $\begin{array}{l}300 \text { AREA SPRING 42-- } \\
300 \text { AREA PSBNG }\end{array}$ & ONSITE & $\mathrm{BI}$ & $\begin{array}{l}\text { 2003CORBIIULA1 } \\
\text { 20003CORBCUA4 }\end{array}$ & $\begin{array}{l}\text { CORBBICUAA } \\
\text { CORBCLUA }\end{array}$ & $\begin{array}{l}\text { SHELLS } \\
\text { SOFT TISSUE }\end{array}$ & $\begin{array}{l}\text { 24-Feb-03 TC-99 } \\
\text { 24-Fep-3 }\end{array}$ & & $0.473 \mathrm{pC}$ & Cilg & 0.19 & 0.4 & & NO SAMPLE & \\
\hline SESPSPEC & B16T08 & 300 AREA SPRING 42-2 & ONSITE & BI & 2003CORBICULA5 & CORBICULA & SOFT TISSUE & $\begin{array}{l}24 \text { Feb-03U } \\
24-F e-03 U\end{array}$ & & & & & & & $\begin{array}{l}\text { NO SAMPPLE. } \\
\text { NO SAMLE. }\end{array}$ & \\
\hline SESPSPEC & B16T09 & 300 AREA SPRING 42- & ONSITE & BI & 2003CORBICULA6 & CORBICULA & SOFT TISSUE & 24-Feb-03U & & & & & & & NO SAMPLE. & \\
\hline SPEC & 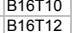 & $\begin{array}{l}300 \text { AREA SPRIIN 42-2 } \\
\text { 30 AREA SPR DR 42- }\end{array}$ & $\begin{array}{l}\text { ONSIIE } \\
\text { ONSITE }\end{array}$ & $\begin{array}{l}\mathrm{BI} \\
\mathrm{BI}\end{array}$ & $\begin{array}{l}\text { 20003CORBICLLA7 } \\
\text { 2003COBBICULA }\end{array}$ & 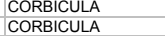 & $\begin{array}{l}\text { SOFT TISSUE } \\
\text { SHELLS }\end{array}$ & $\begin{array}{l}\text { 24-Feb-03 U } \\
\text { 24-FFb-03 TC-99 }\end{array}$ & & $0.315 \mathrm{pc}$ & $\mathrm{C} \mathrm{Ci} / \mathrm{g}$ & 0.19 & 0.39 & $u$ & NO SAMPLE. & \\
\hline & 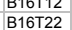 & & ONSITE & BI & 2003CORBICULA18 & CORBICULA & SOFT TISSUE & 24-Feb-03U & & & & & & & & \\
\hline $\begin{array}{l}\text { SESPSPEC } \\
\text { SESPPEC }\end{array}$ & $\begin{array}{l}\text { B16T23 } \\
\text { B16T24 }\end{array}$ & $\begin{array}{l}300 \text { AREA SPR DR } 42-2 \\
300 \text { AEEA SPR R } 42-2\end{array}$ & $\begin{array}{l}\text { ONSITE } \\
\text { ONSTTE }\end{array}$ & $\begin{array}{l}\mathrm{BI} \\
\mathrm{BI}\end{array}$ & $\begin{array}{l}\text { 2003CORBICULA19 } \\
\text { 2003CORBICULA20 }\end{array}$ & 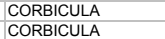 & $\begin{array}{l}\text { SOFT TISSUE } \\
\text { SOFT TISSUE }\end{array}$ & $\begin{array}{l}\text { 24-Feb-03U } \\
24-F e b-03 U\end{array}$ & & & & & & & $\begin{array}{l}\text { NO SAMPLE. } \\
\text { NO SAMPLE. }\end{array}$ & \\
\hline
\end{tabular}


WLLDLIFE
(pCi/g Wet Weight)

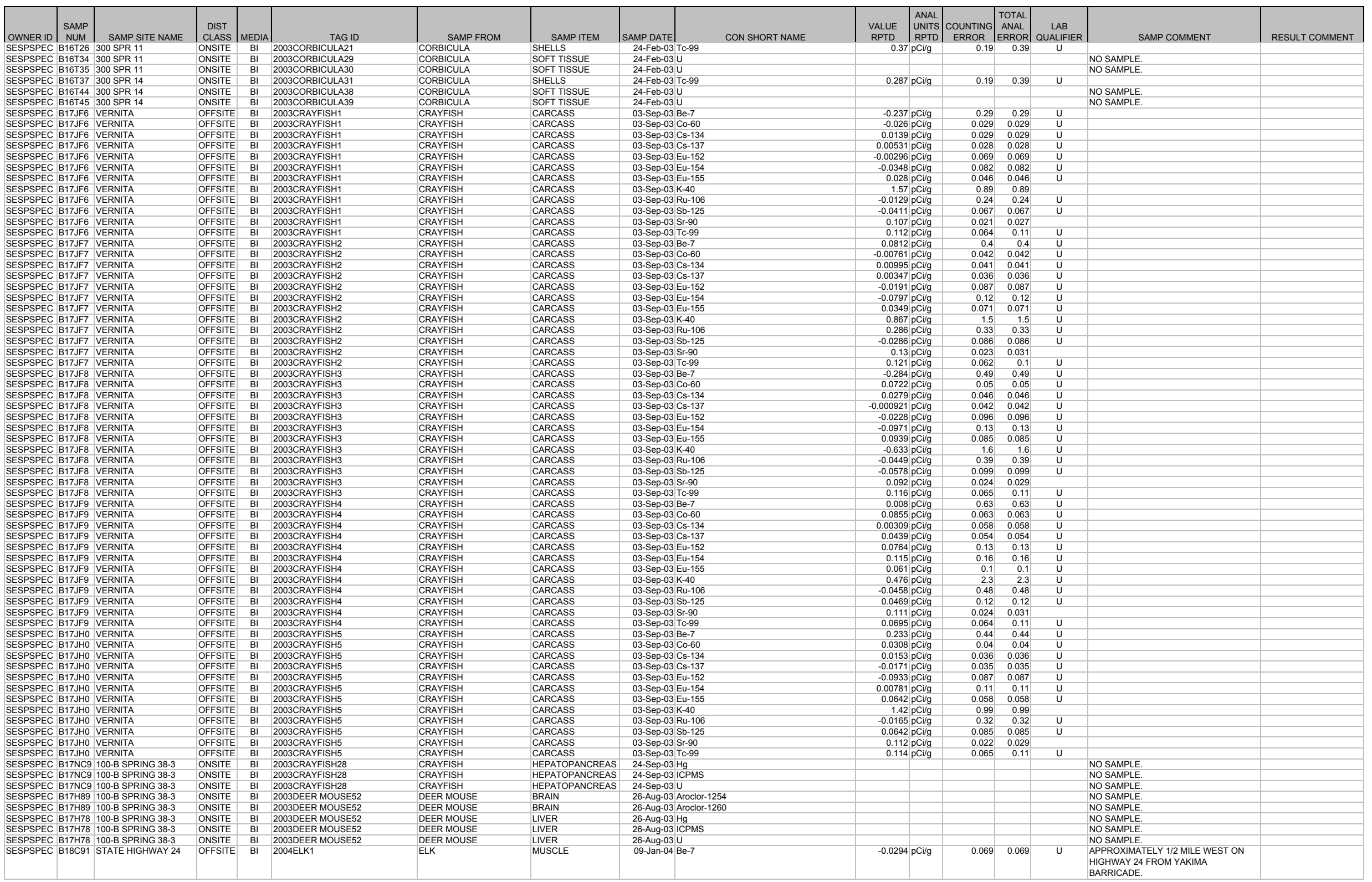


ENVIRONMENTAL SURVEILLANCE DATA CY03

WLLDLFE
(pcilg Wet Weight)

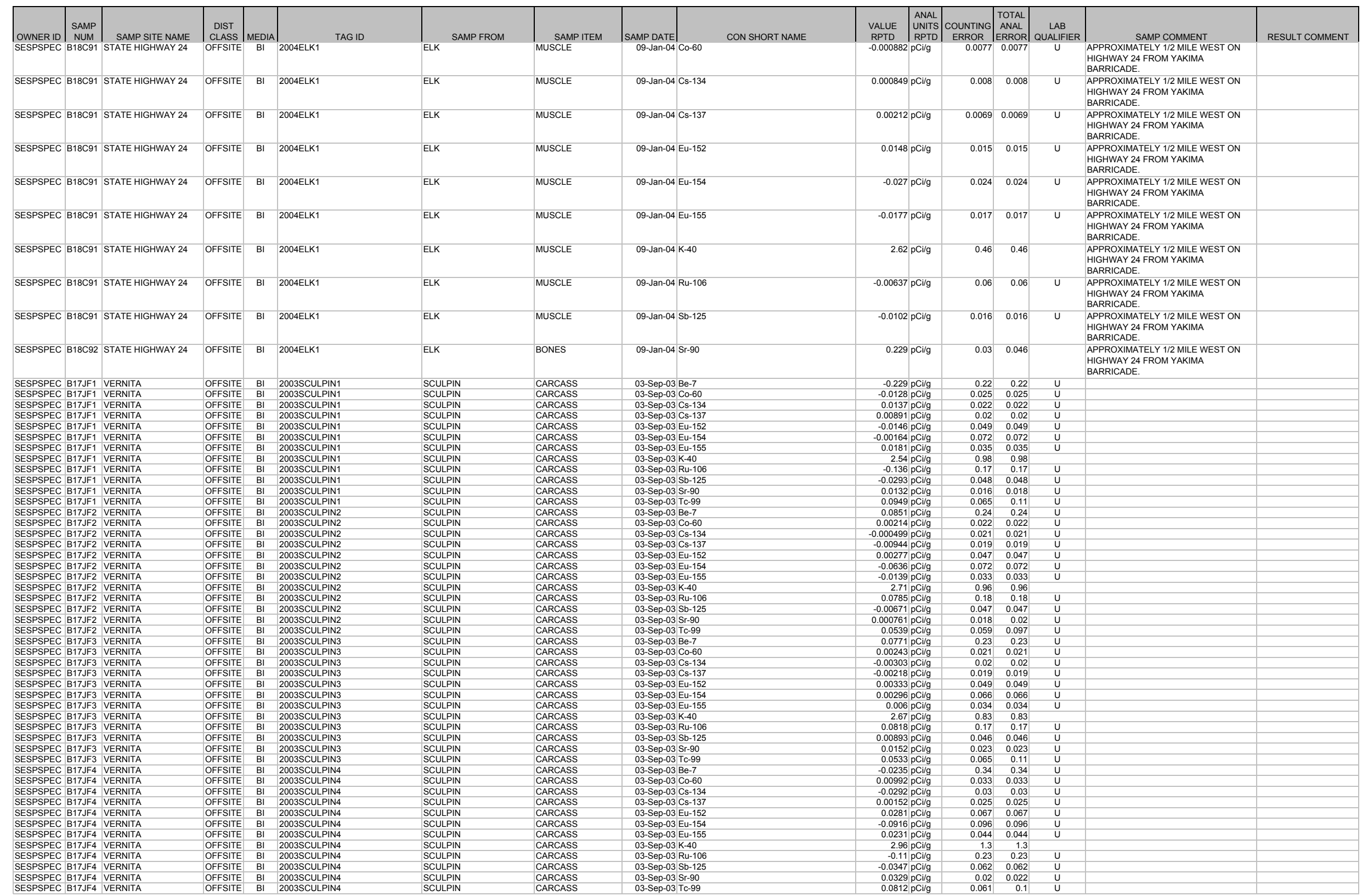


WILDLIFE
(pCi/g Wet Weight)

\begin{tabular}{|c|c|c|c|c|c|c|c|c|c|c|c|c|c|c|c|c|}
\hline OWNER ID & \begin{tabular}{|l} 
SAMP \\
NUM \\
\end{tabular} & SAMP SITE NAME & \begin{tabular}{|c|c|} 
DIST \\
CLASS
\end{tabular} & MEDIA & TAG ID & SAMP FROM & SAMP ITEM & |SAMP DATE | & CON SHORT NAME & $\begin{array}{l}\text { VALUE } \\
\text { RPTD }\end{array}$ & $\left|\begin{array}{l}\text { ANAL } \\
\text { UNITS } \\
\text { RPTD }\end{array}\right|$ & $\mid \begin{array}{c}\text { COUNTING } \\
\text { ERROR }\end{array}$ & $\left|\begin{array}{c}\text { TOTAL } \\
\text { ANAL } \\
\text { ERROR }\end{array}\right|$ & \begin{tabular}{|l} 
LAB \\
QUALIFIER
\end{tabular} & SAMP COMMENT & RESULT COMMENT \\
\hline $\begin{array}{l}\text { SESPSPPC } \\
\text { SESPSPEC }\end{array}$ & $\begin{array}{l}\text { B17JJ55 } \\
\text { B17F55 }\end{array}$ & $\begin{array}{l}\text { VERNITA } \\
\text { VERNIIA }\end{array}$ & $\begin{array}{l}\text { OFFSITE } \\
\text { OFFITI }\end{array}$ & $\begin{array}{l}\mathrm{BI} \\
\mathrm{BI}\end{array}$ & $\begin{array}{l}\text { 2003SCULPIN5 } \\
\text { 2003SCUPPIN5 }\end{array}$ & $\begin{array}{l}\text { SCULPIN } \\
\text { SCUPII }\end{array}$ & $\begin{array}{l}\text { CARCASS } \\
\text { CARCASS }\end{array}$ & 03-Sep-03 & & $0.0235 p$ & & $\begin{array}{r}0.33 \\
0.032\end{array}$ & $\begin{array}{l}3 \\
3\end{array}$ & u & & \\
\hline $\begin{array}{l}\text { SESPSPEC } \\
\text { SES }\end{array}$ & B17JF5 & $\begin{array}{l}\text { VERNITA } \\
\text { VERIA }\end{array}$ & $\begin{array}{l}\text { OFFSITE } \\
\text { OFFE }\end{array}$ & $\mathrm{BI}$ & $\begin{array}{l}\text { 2003SCCLUPNS } \\
\text { 2003SCULPIN5 }\end{array}$ & $\begin{array}{l}\text { SCUPPIN } \\
\text { SCULPIN }\end{array}$ & $\begin{array}{l}\text { ARCASS } \\
\text { CARCASS }\end{array}$ & $\begin{array}{l}\text { 03-S3ep-03 } \\
\text { 03-Sep-03 }\end{array}$ & $\begin{array}{l}\text { Co-60 } \\
\text { Cs-134 }\end{array}$ & $\begin{array}{l}0.04377 \mathrm{p} \\
0.00876 \mathrm{p}\end{array}$ & $\begin{array}{l}\text { pCilg } \\
\text { pCilg }\end{array}$ & $\begin{array}{l}0.032 \\
0.029\end{array}$ & $\begin{array}{l}20.032 \\
0.029 \\
0.029\end{array}$ & u & & \\
\hline $\begin{array}{l}\text { SESPSPEC } \\
\text { SESPSPEC }\end{array}$ & $\begin{array}{l}\text { B17JF5 } \\
\text { B17|IIF5 }\end{array}$ & $\begin{array}{l}\text { VERRNITA } \\
\text { VERNITA }\end{array}$ & & BI & $\begin{array}{l}\text { 2003SCULPIN5 } \\
\text { 2003SCUPIN }\end{array}$ & $\begin{array}{l}\text { SCULPIN } \\
\text { SCUPIN }\end{array}$ & $\begin{array}{l}\text { CARCASS } \\
\text { CARCASS }\end{array}$ & 03-Sep-03 & & $0.0000242 p$ & & 0.025 & 50.025 & U & & \\
\hline $\begin{array}{l}\text { SESPSPEC } \\
\text { SESPSPEC }\end{array}$ & $\begin{array}{l}\text { B17JJJ5 } \\
\text { B17JF5 }\end{array}$ & $\begin{array}{l}\text { VERNIITA } \\
\text { VERNITA }\end{array}$ & $\begin{array}{l}\text { OFFSSTEE } \\
\text { OFFITIE }\end{array}$ & $\begin{array}{l}\mathrm{BI} \\
\mathrm{BI}\end{array}$ & $\begin{array}{l}2003 \text { SCULPIN5 } \\
\text { 2003SCUPIIN5 }\end{array}$ & $\begin{array}{l}\text { SCULLIN } \\
\text { SCULPIN }\end{array}$ & $\begin{array}{l}\text { CARCASS } \\
\text { CARCASS }\end{array}$ & 03-Sep-03 & $\begin{array}{l}\text { Eu-152 } \\
\text { Eu-154 }\end{array}$ & $0.0144 \mathrm{p}$ & & 0.068 & $\begin{array}{ll}3 & 0.068 \\
1 & 0.091\end{array}$ & u & & \\
\hline SETSPDE & $\begin{array}{l}\text { B1/TJ5 } \\
\text { B17JF5 }\end{array}$ & $\begin{array}{l}\text { VERNITA } \\
\text { VERA }\end{array}$ & $\begin{array}{l}\text { OFFSSTE } \\
\text { OFFITE }\end{array}$ & $\begin{array}{l}\mathrm{B} \\
\mathrm{BI}\end{array}$ & $\begin{array}{l}\text { 2003SCULPNIN5 } \\
\text { 2003SCULPIN5 }\end{array}$ & $\begin{array}{l}\text { SCUPIN } \\
\text { SCULPIN }\end{array}$ & $\begin{array}{l}\text { CARCASS } \\
\text { CARCASS }\end{array}$ & $03-\mathrm{Sep}-03$ & $\begin{array}{l}\text { Eul-154 } \\
\text { Eu-155 }\end{array}$ & $\begin{array}{r}-0.035 \mathrm{p} \\
-0.00653 \mathrm{p}\end{array}$ & $\begin{array}{l}\text { plilg } \\
\text { pCi/g }\end{array}$ & 0.046 & $\begin{array}{ll}0.091 \\
0.046\end{array}$ & u & & \\
\hline SP & B17JF5 & VERNITA & & $\mathrm{BI}$ & 2003SCULPIN5 & SCULPIN & CARCASS & 03-Sep-03 & $k-40$ & & & 1.2 & & & & \\
\hline & B17JF5 & $\begin{array}{l}\text { VERNITA } \\
\text { VERNTA }\end{array}$ & OFFSITE & BI & 2003SCULPIN5 & SCULPIN & CARCASS & 03-Sep-03 & & $0.0369 p$ & & 0.24 & $\begin{array}{l}4 \quad 0.24 \\
4\end{array}$ & u & & \\
\hline $\begin{array}{l}\text { SEEPSPEC } \\
\text { SESPSPEC }\end{array}$ & $\begin{array}{l}\text { B17JJJ5 } \\
\text { B17JF5 }\end{array}$ & $\begin{array}{l}\text { VERRNITA } \\
\text { VERNITA }\end{array}$ & $\begin{array}{l}\text { OFFSITE } \\
\text { OFFITIT }\end{array}$ & $\begin{array}{l}\mathrm{BI} \\
\mathrm{BI}\end{array}$ & $\begin{array}{l}\text { 20003SCUUPIIN5 } \\
\text { 2003SCLIPIN5 }\end{array}$ & $\begin{array}{l}\text { SCULPIN } \\
\text { SCULPIN }\end{array}$ & $\begin{array}{l}\text { CARCASS } \\
\text { CARCASS }\end{array}$ & $\begin{array}{l}\text { 03-S-Sp-03 } \\
0 \text { 0-S- }\end{array}$ & $\begin{array}{l}\text { Sb-125 } \\
\text { Sr-90 }\end{array}$ & $\begin{array}{l}0.0503 \mathrm{p} \\
0.0192 \mathrm{D}\end{array}$ & pCilg & $\begin{array}{l}0.063 \\
0.019\end{array}$ & $\begin{array}{ll}3 & 0.063 \\
9 & 0.021\end{array}$ & $\begin{array}{l}u \\
u\end{array}$ & & \\
\hline $\begin{array}{l}\text { SESPSPEC } \\
\text { SEFPSPCC }\end{array}$ & $\begin{array}{l}\text { B17JF5 } \\
\text { B17N28 }\end{array}$ & VERNITA & $\begin{array}{l}\text { OFFSITE } \\
\text { ONSITE }\end{array}$ & BI & $\begin{array}{l}\text { 2003SCULPIN5 } \\
2035 \text { CIIPIN10 }\end{array}$ & $\begin{array}{l}\text { SCULPIN } \\
\text { SCIPIN }\end{array}$ & CARCASS & 03-Sep-03 & & $0.146 \mathrm{p}$ & & & & & & \\
\hline $\begin{array}{l}\text { SPSPEC } \\
\text { PPSPEC }\end{array}$ & B17N84 & 100 B/C AREA UR & ONSITE & BI & 2003SCULPIN25 & $\begin{array}{l}\text { SCULPIN } \\
\text { SCUPN }\end{array}$ & LIVER & 23-Sep-03 & $\mathrm{Hg}$ & & & & & & NO SAMPLE. & \\
\hline $\begin{array}{l}\text { SEEPSPPEC } \\
\text { SESPSPEC }\end{array}$ & & & & $\mathrm{BI}$ & $\begin{array}{l}2003 \text { 200ULPSIN25 } \\
2003 \text { CULPIN25 }\end{array}$ & $\begin{array}{l}\text { SCUULIN } \\
\text { SCULPIN }\end{array}$ & LIVER & 23-Sep-03 & ICPMS & & & & & & & \\
\hline SETSPEC & B17N85 & $100 \mathrm{~B} / \mathrm{C}$ AREA UR & ONSITE & $\begin{array}{l}\mathrm{B} \\
\mathrm{BI}\end{array}$ & $\begin{array}{l}20035 \text { SCULPIN25 } \\
\text { 2003SCULPIN26 }\end{array}$ & $\begin{array}{l}\text { SCULPIN } \\
\text { SCULPIN }\end{array}$ & $\begin{array}{l}\text { LVER } \\
\text { LIVER }\end{array}$ & $\begin{array}{l}\text { 23-Sep-03 } \\
23-\mathrm{Sep}-03\end{array}$ & & & & & & & $\begin{array}{l}\text { N S SAMPLE. } \\
\text { N SAMPE }\end{array}$ & \\
\hline SPEC & B17N85 & 100 B/C AREA UR & ONSITE & $\mathrm{BI}$ & 2003SCULPIN26 & SCULPIN & LIVER & 23-Sep-03 & ICPMS & & & & & & NO SAMPLE. & \\
\hline SESPSPEC & B17N85 & $100 \mathrm{~B} / \mathrm{C}$ AREA UR & ONSITE & $\mathrm{BI}$ & 2003SCULPIN26 & SCULPIN & LIVER & 23-Sep-03 & & & & & & & NO SAMPLE. & \\
\hline $\begin{array}{l}\text { SESPSPEC } \\
\text { SEPSPPEC }\end{array}$ & B17N86 & $100 \mathrm{~B} / \mathrm{C}$ AREA UR & ONSITE & BI & 2003SCULPIN27 & SCULPIN & LIVER & 23-Sep-03 & & & & & & & NO SAMPLE. & \\
\hline $\begin{array}{l}\text { SEEPSPEC } \\
\text { SESPSPEC }\end{array}$ & 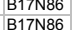 & $\begin{array}{l}100 \text { B BC AREA UR } \\
100 \text { B } C \text { AREA UR }\end{array}$ & $\begin{array}{l}\text { ONSIITE } \\
\text { ONSTIE }\end{array}$ & $\begin{array}{l}\mathrm{BI} \\
\mathrm{BI}\end{array}$ & $\begin{array}{l}2003 \text { SCCULPIN27 } \\
2003 \text { SCULPIN27 }\end{array}$ & $\begin{array}{l}\text { SCULPIN } \\
\text { SCUPIN }\end{array}$ & $\begin{array}{l}\text { LIVER } \\
\text { LVER }\end{array}$ & $\begin{array}{l}\text { 23-Sep-03 } \\
\text { 23-Sep-03 }\end{array}$ & ICPMS & & & & & & NO SAMPLE. & \\
\hline $\begin{array}{l}\text { SESPMNT } \\
\text { SESPMNT }\end{array}$ & B174H1 & HORSESHOE LANDFILL & & $\mathrm{BI}$ & 2003WESTERN MEADOWLARK2 & WESTERN MEADOWLARK & BRAIN & 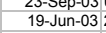 & 2,4'-DDD (Dichlorodiphenyldichloroethane) & & & & & & NO SAMPLE. & \\
\hline $\begin{array}{l}\text { SEEPMNT } \\
\text { SESPMNT }\end{array}$ & $\begin{array}{l}\text { B174411 } \\
\text { B174H1 }\end{array}$ & $\begin{array}{l}\text { HORSESHOE LANDFILL } \\
\text { HORSESHOE LANDFILL }\end{array}$ & & $\begin{array}{l}\mathrm{BI} \\
\mathrm{BI}\end{array}$ & $\begin{array}{l}\text { 2003WESTERN MEADOWLARK2 } \\
\text { 2003WESTERN MEADOWLARK2 }\end{array}$ & $\begin{array}{l}\text { WESTERN MEADOWLARK } \\
\text { WESTTRN MEADOWLARK }\end{array}$ & $\begin{array}{l}\text { BRAIN } \\
\text { BRAIN }\end{array}$ & $\begin{array}{l}\text { 19-Jun-03 } \\
19 \text {-Jun-03 }\end{array}$ & $\begin{array}{l}\text { 2.4'-1-DDE (Dichlorodiphenyldichloroethylene) } \\
\text { 2,4-DDT (Dichlorodiphenyltrichloroethane) }\end{array}$ & & & & & & $\begin{array}{l}\text { NO SAMPLE. } \\
\text { NO SAMPLE. }\end{array}$ & \\
\hline SESPMNT & B174H1 & HORSESHOE LANDFILL & & $\mathrm{BI}$ & 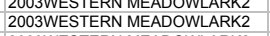 & $\begin{array}{l}\text { WESTERN MEADOWLARK } \\
\text { WESTERN MEATL }\end{array}$ & BRAIN & $\begin{array}{l}\text { 19-Jun-03 } \\
\text { 19-Jun } 03\end{array}$ & 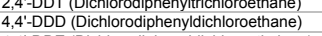 & & & & & & NO SAMPLE. & \\
\hline SESPMNT & B174H1 & HORSESHOE LANDFILL & & $\mathrm{BI}$ & 2003WESTERN MEADOWLARK2 & WESTERN MEADOWLARK & BRAIN & 19-Junn-03. & 4,4-DDE (Dichlorodiphenyldichloroethylene) & & & & & & NO SAMPLE. & \\
\hline $\begin{array}{l}\text { SEEPMNT } \\
\text { SESPMNT }\end{array}$ & B174H1 & $\begin{array}{l}\text { HORSESHOE LANDFLLL } \\
\text { HORSSHOELANDEU }\end{array}$ & & $\mathrm{BI}$ & & WESTERN MEADOWLARK & BRAIN & 19-Jun-03. & 4,4'-DDT (Dichlorodiphenyltrichloroethane) & & & & & & NO SAMPLE. & \\
\hline $\begin{array}{l}\text { SESPMNNT } \\
\text { SESPNT }\end{array}$ & $\begin{array}{l}\text { B17442 } \\
\text { B174H2 }\end{array}$ & $\begin{array}{l}\text { HORESSHOE LANDFILL } \\
\text { HORSESHOE LANDILL }\end{array}$ & & $\mathrm{BI}$ & $\begin{array}{l}\text { 20003WESTTRN MEADOWLARK } 3 \\
\text { 2003WESTERN MEADOWLARK3 }\end{array}$ & $\begin{array}{l}\text { WESTERN MEADDWLARK } \\
\text { WESTERN MEADOWLARK }\end{array}$ & $\begin{array}{l}\text { BRAN } \\
\text { BRAN }\end{array}$ & & 2,4-4DDD (Dichlorodiphenyldicichloroethane) & & & & & & $\begin{array}{l}\text { NO SAMPLE. } \\
\text { NO SAMPLE. }\end{array}$ & \\
\hline SESPMNT & B174H2 & $\begin{array}{l}\text { HORESHOE LANDIIL } \\
\text { HORSESHOE LANDFILL }\end{array}$ & & $\mathrm{BI}$ & & $\begin{array}{l}\text { WESTERN MEADOWLARK } \\
\text { WESTERN MEADOWLARK }\end{array}$ & $\begin{array}{l}\text { BRAIN } \\
\text { BRAIN }\end{array}$ & $\begin{array}{l}\text { 19-9unn-03 } \\
\text { 19-Jun-03 }\end{array}$ & 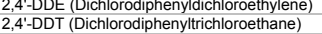 & & & & & & $\begin{array}{l}\text { NO SAMPLE. } \\
\text { NO SAMPLE. }\end{array}$ & \\
\hline SESPMNT & B174H2 & HORSESHOE LANDFILL & & $\mathrm{BI}$ & 2003WESTERN MEADOOLARK3 & WESTERN MEADOWLARK & BRAIN & 19-Jun-03 & 4,4-DDD (Dichlorodiphenyldichloroethane) & & & & & & NO SAMPLE. & \\
\hline $\begin{array}{l}\text { SESPMNT } \\
\text { SESPMNT }\end{array}$ & $\begin{array}{lll}\mathrm{B} 174 \mathrm{H} 2 \\
\mathrm{B17412}\end{array}$ & HORSESHOE LANDFILL & & $\mathrm{BI}$ & $\begin{array}{l}\text { 2003WESTERN MEADOWLARK } 3 \\
\text { 2003) }\end{array}$ & $\begin{array}{l}\text { WESTERN MEADOWLARK } \\
\text { WESTERN }\end{array}$ & BRAIN & 19-Jun-03 & $\begin{array}{l}\text { 4,4'-DDE (Dichlorodiphenyldichloroethylene) } \\
\text {, (1) }\end{array}$ & & & & & & NO SAMPLE. & \\
\hline $\begin{array}{l}\text { SESPMNI } \\
\text { SESPMNT }\end{array}$ & 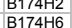 & $\begin{array}{l}\text { HORSSSHOE LANDIIL } \\
\text { HORSESHOE LANDFILL }\end{array}$ & & $\begin{array}{l}\mathrm{BI} \\
\mathrm{BI}\end{array}$ & $\begin{array}{l}\text { 20003WESTTRN MEADOWLARK } 3 \\
\text { 2003WESTERN MEADOWLARK7 }\end{array}$ & $\begin{array}{l}\text { WESTERN MEADDWLARK } \\
\text { WESTERN MEADOWLARK }\end{array}$ & $\begin{array}{l}\text { BRAIN } \\
\text { EGG CONTENTS }\end{array}$ & $\begin{array}{l}\text { 19-Jun-03 } \\
\text { 19-Jun-03. }\end{array}$ & 4,4-4DT (Dichlorodiphenyytricichloroetthane) & & & & & & $\begin{array}{l}\text { NO SAMPLE. } \\
\text { NO SAMPLE. }\end{array}$ & \\
\hline 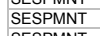 & B1744166 & HORSESHOE LANDFILL & & & $\begin{array}{l}\text { 2003WESTERN MEADOOLARKT } \\
\text { 203WESTER }\end{array}$ & $\begin{array}{l}\text { WESTERN MEADOWLARK } \\
\text { WESTE }\end{array}$ & EGG CONTENTS & $\begin{array}{lll}19--J u n-03 \\
19\end{array}$ & 2,4-2-DDE (Dichlorodiphenyldichloroethylene) & & & & & & NO SAMPLE. & \\
\hline SESPMNT & B174H6 & HORSESHOE LANDFILL & & $\mathrm{BI}$ & 2003WESTERN MEADOOLARK7 & $\begin{array}{l}\text { WESTERN MEADOWLARK } \\
\text { W }\end{array}$ & EGG CONTENTS & 19-Jun-03 & 2,4-DDT (Dichlorodiphenyltrichloroetthane) & & & & & & NO SAMPLE. & \\
\hline $\begin{array}{l}\text { SESPMNT } \\
\text { SEPPMNT }\end{array}$ & $\begin{array}{l}\text { B174H6 } \\
\text { B174466 }\end{array}$ & $\begin{array}{l}\text { HORSESHOE LANDFLLL } \\
\text { HORSSHOE ANDEU }\end{array}$ & & $\mathrm{BI}$ & 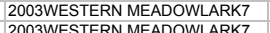 & $\begin{array}{l}\text { WESTERN MEADOWLARK } \\
\text { WESTERTE }\end{array}$ & $\begin{array}{l}\text { EGG CONTENTS } \\
\text { EGG CONTETS }\end{array}$ & 19-Jun-03 & 4,4'-DDD (Dichlorodiphenyldichloroethane) & & & & & & NO SAMPLE. & \\
\hline $\begin{array}{l}\text { SEEPMNT } \\
\text { SESPMNT }\end{array}$ & & $\begin{array}{l}\text { HORESSHOE LANDFILL } \\
\text { HORSESHOE LANDILL }\end{array}$ & & $\begin{array}{l}\mathrm{BI} \\
\mathrm{BI}\end{array}$ & $\begin{array}{l}\text { 2003WESTTRN MEADOWLARK7 } \\
\text { 2003WESTERN MEADOWLARK7 }\end{array}$ & $\begin{array}{l}\text { WESTERN MEADDWLARK } \\
\text { WESTERN MEADOWLARK }\end{array}$ & $\begin{array}{l}\text { EGG CONTENTS } \\
\text { EGG CONTENTS }\end{array}$ & $\begin{array}{l}\text { 19-Jun-03 } \\
\text { 19-Jun-03 }\end{array}$ & 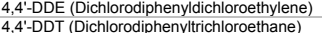 & & & & & & & \\
\hline $\begin{array}{l}\text { SESPMNT } \\
\text { SESPMNT }\end{array}$ & $\begin{array}{l}\begin{array}{l}\text { B174466 } \\
\text { B174H7 }\end{array}\end{array}$ & $\begin{array}{l}\text { HORSESHOE LANDILLL } \\
\text { HORSESHOE LANDFILL }\end{array}$ & & $\begin{array}{l}\mathrm{Bl} \\
\mathrm{BI}\end{array}$ & $\begin{array}{l}\text { 2003WESTTRNN MEADOWLARK7 } \\
\text { 2003WESTERN MEADOWLARK8 }\end{array}$ & $\begin{array}{l}\text { WESTERN MEADDWLARK } \\
\text { WESTERN MEADOWLARK }\end{array}$ & $\begin{array}{l}\text { EGG CONTENTS } \\
\text { EGG CONTENTS }\end{array}$ & $\begin{array}{l}\text { 19-9un-03 } \\
\text { 19-Jun-03 }\end{array}$ & $\begin{array}{l}\text { 4,4-4DDT (Dichlorodidhenyyltrichloreothane) } \\
\text { 2,4-DDD (Dichlorodiphenyldichloroethane) }\end{array}$ & & & & & & $\begin{array}{l}\text { NO SAMPLE. } \\
\text { NO SAMPLE. }\end{array}$ & \\
\hline & B174H7 & HORSESHOE LANDFILL & & $\mathrm{BI}$ & 2003WESTERN MEADOWLARK8 & WESTERNM & EGG CONTENTS & 19-Jun-03 & 2,4-'-DDE (Dichlorodiphenyldichloroetthylene) & & & & & & & \\
\hline SESPMNT & B174H7 & HORSESHOE LANDFILL & & $\mathrm{BI}$ & 2003WESTERN MEADOWLARK8 & WESTERN MEADOWLARK & EGG CONTENTS & 19-Jun-03 & 2,4-DDT (Dichlorodiphenyltrichloroethane) & & & & & & NO SAMPLE. & \\
\hline $\begin{array}{l}\text { SESPMNT } \\
\text { GEPMNT }\end{array}$ & B174H7 & HORSESHOE LANDFILL & & BI & 2003WESTERN MEADOWLARK8 & WESTERN MEADOWLARK & EGG CONTENTS & 19-Jun-03 & 4,4'-DDD (Dichlorodiphenyldichloroethane) & & & & & & NO SAMPLE. & \\
\hline $\begin{array}{l}\text { SESPMNT } \\
\text { SEPPMNT }\end{array}$ & 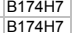 & $\begin{array}{l}\text { HORSESH } \\
\text { HORESHC }\end{array}$ & & $\mathrm{BI}$ & $\begin{array}{l}\text { 20003WESTTRN MEADOWLARK } 8 \\
\text { 2003WESTERN MEADOWLARK }\end{array}$ & $\begin{array}{l}\text { WESEERN MEADOWLARK } \\
\text { WESTERN MEADOWLARK }\end{array}$ & $\begin{array}{l}\text { EGG CONTENTS } \\
\text { EGG CONTENTS }\end{array}$ & $\begin{array}{l}\text { 19-Jun-03 } \\
\text { 19-0un }-03\end{array}$ & 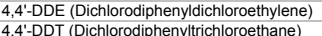 & & & & & & $\begin{array}{l}\text { NO SAMPLE. } \\
\text { NO SAMPLE. }\end{array}$ & \\
\hline $\begin{array}{l}\text { SESPMNT } \\
\text { SESPMNT }\end{array}$ & 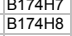 & $\begin{array}{l}\text { HORSESHOE LADFFLL } \\
\text { HORSESHOE LANDFILL }\end{array}$ & & BI & $\begin{array}{l}\text { 20033ESESTRRN MEADDWLARR8 } \\
\text { 2003WESTERN MEADOWLARK9 }\end{array}$ & $\begin{array}{l}\text { WESTERN MEADOWLARK } \\
\text { WESTERN MEADOWLARK }\end{array}$ & $\begin{array}{l}\text { EGG CONTNTS } \\
\text { EGG CONTENTS }\end{array}$ & $\begin{array}{l}\text { 19-unn-03. } \\
\text { 19-Junn-03 }\end{array}$ & $\begin{array}{l}\text { 4,4-DDT (Dichlorodidhenenytrtichloroethane) } \\
\text { 2,4-DDD (Dichlorodiphenyldichloroethane }\end{array}$ & & & & & & $\begin{array}{l}\text { NO SAMPLE. } \\
\text { NO SAMPLE. }\end{array}$ & \\
\hline $\begin{array}{l}\text { SESPMNT } \\
\text { SEPMMNT }\end{array}$ & $\begin{array}{l}\text { B17448 } \\
\text { B17448 }\end{array}$ & $\begin{array}{l}\text { HORSESHOE LANDFILL } \\
\text { HORSESHOE LADFIIL }\end{array}$ & & $\mathrm{BB}$ & $\begin{array}{l}\text { 2003WESTERN MEADOWLARK9 } \\
\text { 2003WESTTRN MEADOWLARK9 }\end{array}$ & $\begin{array}{l}\text { WESTERN MEADOWLARK } \\
\text { WESTERN MEADOWLARK }\end{array}$ & $\begin{array}{l}\text { EGG CONTENTS } \\
\text { EGG CONTENTS }\end{array}$ & $\begin{array}{l}\text { 19-Jun-03. } \\
\text { 19.Jun } 03\end{array}$ & 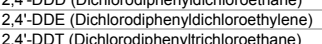 & & & & & & $\begin{array}{l}\text { NO SAMPLE. } \\
\text { N SAMPE. }\end{array}$ & \\
\hline $\begin{array}{l}\text { SESPMNT } \\
\text { SESPMI }\end{array}$ & $\begin{array}{l}\text { B17448 } \\
\text { B174H8 }\end{array}$ & $\begin{array}{l}\text { HORSESHOE LADFFLL } \\
\text { HORSESHOE LANDFILL }\end{array}$ & & $\mathrm{BI}$ & $\begin{array}{l}\text { 20033ESESTRRN MEADDWLARR9 } \\
\text { 2003WESTERN MEADOWLARK9 }\end{array}$ & $\begin{array}{l}\text { WESTERN MEADOWLARK } \\
\text { WESTERN MEADOWLARK }\end{array}$ & $\begin{array}{l}\text { EGG CONTENTS } \\
\text { EGG CONTENTS }\end{array}$ & $\begin{array}{l}\text { 19-Junn-032 } \\
\text { 19-Jun-03. }\end{array}$ & 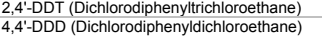 & & & & & & $\begin{array}{l}\text { NO SAMPLE. } \\
\text { NO SAMPLE. }\end{array}$ & \\
\hline & B17448 & HORSESHOE LANDFILL & & $\mathrm{BI}$ & & $\begin{array}{l}\text { WESTERN MEADOWLARK } \\
\text { WESTE }\end{array}$ & EGG CONTENTS & 19-Junn-03. & 4,4-DDE (Dichlorodiphenyyldichloroethylene) & & & & & & NO SAMPLE. & \\
\hline $\begin{array}{l}\text { SESPMNT } \\
\text { SSEPMNT }\end{array}$ & B17448 & LANDFILL & & $\mathrm{BI}$ & ARK9 & WES & EGG CONTENTS & 19-Jun-03 & (Dic & & & & & & NOS & \\
\hline $\begin{array}{l}\text { SESPMNI } \\
\text { SESPMNT }\end{array}$ & 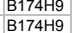 & & & $\begin{array}{l}\mathrm{BI} \\
\mathrm{BI}\end{array}$ & $\begin{array}{l}\text { 2003WE } \\
\text { 2003WE: }\end{array}$ & & $\begin{array}{l}\text { EGGC } \\
\text { EGGC }\end{array}$ & $19-\mathrm{Ju}$ & $\begin{array}{c}\text { Dicic } \\
\text { EDic }\end{array}$ & & & & & & & \\
\hline SESPMNT & B174H9 & OUND & & $\mathrm{BI}$ & 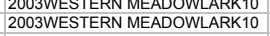 & $\begin{array}{l}\text { WESTEN ME } \\
\text { WESTERN ME }\end{array}$ & $\begin{array}{l}\text { EGGCONTNIS } \\
\text { EGG CONTENTS }\end{array}$ & 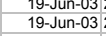 & $\begin{array}{l}\text { chloroetenyyene) } \\
\text { chloroethane) }\end{array}$ & & & & & & NOSA & \\
\hline $\begin{array}{l}\text { SESPMNT } \\
\text { SESPMNT }\end{array}$ & B174H9 & BACKGROUND & & $\mathrm{BI}$ & $\begin{array}{l}\text { 2003WESTERN MEADOWLARK10 } \\
\text { 203WECER }\end{array}$ & $\begin{array}{l}\text { WESTERN MEADOWLARK } \\
\text { WESTE }\end{array}$ & EGG CONTENTS & 19-Jun-03 & 4,4-DDD (Dichlorodiphenyldichloroethane) & & & & & & NO SAMPLE. & \\
\hline $\begin{array}{l}\text { SESPMNT } \\
\text { SESPMNT }\end{array}$ & $\begin{array}{l}\text { B174499 } \\
\text { B17449 }\end{array}$ & $\begin{array}{l}\text { BACKRO } \\
\text { BACKGRO }\end{array}$ & & $\mathrm{BB}$ & $\begin{array}{l}\text { 2003WESTERN } \\
\text { 2003WESTERN }\end{array}$ & 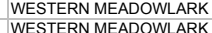 & $\begin{array}{l}\text { EG } \\
\text { EG }\end{array}$ & $\begin{array}{l}\text { 19-Jun }-03 \\
\text { 19-03 }-03\end{array}$ & 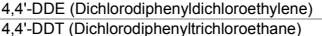 & & & & & & $\begin{array}{l}\text { NO SAMPLE. } \\
\text { NO SAMPLE. }\end{array}$ & \\
\hline $\begin{array}{l}\text { SESPMNNT } \\
\text { SESPMT }\end{array}$ & $\begin{array}{l}\begin{array}{l}\text { B1744499 } \\
\text { B174J0 }\end{array}\end{array}$ & $\begin{array}{l}\text { BACKROUND } \\
\text { BACKGROUND }\end{array}$ & & $\mathrm{BI}$ & $\begin{array}{l}\text { 2003WESTERN MEADOOLARK10 } \\
\text { 2003WESTERN MEADOWLARK11 }\end{array}$ & $\begin{array}{l}\text { WESTERN MEADOWLARK } \\
\text { WESTERN MEADOWLARK }\end{array}$ & $\begin{array}{l}\text { EGG CONTNNTS } \\
\text { EGG CONTENTS }\end{array}$ & $\begin{array}{l}\text { 19-Jun } 03 \\
\text { 19-Jun } 03\end{array}$ & $\begin{array}{l}\text { 4,4-4DDT (Dichllorodidhenyyltrichloroethane) } \\
\text { 24--DDD (Dichlorodiphenyldichloroethane) }\end{array}$ & & & & & & $\begin{array}{l}\text { NO SAMPLE. } \\
\text { NO SAMPLE. }\end{array}$ & \\
\hline $\begin{array}{l}\text { SESPMNT } \\
\text { SEPMNT }\end{array}$ & B174J0 & BACKGROUND & & $\mathrm{BI}$ & $\begin{array}{l}\text { 2003WESTERN N } \\
\text { 2003WETTRN }\end{array}$ & & EGG & $\begin{array}{lll}19--J u n-03 \\
19\end{array}$ & 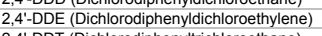 & & & & & & NOSA & \\
\hline $\begin{array}{l}\text { SEEPMNT } \\
\text { SESPMNT }\end{array}$ & B1 & BACKGROUUND & & $\mathrm{BI}$ & $\begin{array}{l}\text { 2003WESTERN MEADOWW } \\
\text { 20033TESTERM }\end{array}$ & $\begin{array}{l}\text { WESTERN MEADOWLARK } \\
\text { WESTERN }\end{array}$ & EGG CONTENTS & $\begin{array}{l}\text { 19-Jun-03. } \\
\text { 19-Jun-03. }\end{array}$ & 2,4-DDT (Dichlorodiphenyltrichloroethane) & & & & & & NO SAMPLE. & \\
\hline SEST & $\begin{array}{l}\text { B1/440 } \\
\text { B174J0 }\end{array}$ & $\begin{array}{l}\text { BACKRGOUND } \\
\text { BACKGROUND }\end{array}$ & & $\begin{array}{l}\mathrm{BI} \\
\mathrm{BI}\end{array}$ & $\begin{array}{l}\text { 2003WESTERN MEADWLARERT MEADOWLARK11 } \\
\text { 2003WESTER ME }\end{array}$ & $\begin{array}{l}\text { WESTERN MEADOWLARK } \\
\text { WESTERN MEADOWLARK }\end{array}$ & EGG CONTENTS & $\begin{array}{l}\text { 19-Jun }-03 \\
\text { 19-Jun } 03\end{array}$ & 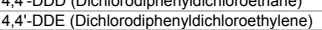 & & & & & & $\begin{array}{l}\text { NO SAMPLE. } \\
\text { NO SAMPLE. }\end{array}$ & \\
\hline & B174J0 & $\mathrm{BACl}$ & & $\mathrm{BI}$ & 2003WES & WESTEF & EGG CONTENTS & 19-Jun-03 & 4,4-DDT (Dichlorodiphenyltrichloroetthane) & & & & & & NO SA & \\
\hline iT & & BACKGRO & & BI & 2003WESTE & WESTERN N & EGG CONTENTS & 19-Junn-03. & 2,4'-DDD (Dichlorodiphenyldichloroethane) & & & & & & & \\
\hline iT & B174J1 & BACKGROUND & & BI & 2003WESTERN M & WESTERN I & EGG CONTENTS & $19-\mathrm{Ju}$ & 2,4'-DDE (Dichlorodiphenyldichloroethylene) & & & & & & No & \\
\hline $\begin{array}{l}\text { SEEPMNT } \\
\text { SESPMNT }\end{array}$ & $\begin{array}{l}\begin{array}{l}\text { B174411 } \\
\text { B174J1 }\end{array}\end{array}$ & $\begin{array}{l}\text { BACKGOOUND } \\
\text { BACKGROUND }\end{array}$ & & $\begin{array}{l}\mathrm{Bl} \\
\mathrm{BI}\end{array}$ & $\begin{array}{l}\text { 2003WESTTRNN MEADOWLARK } 12 \\
\text { 2003WESTERN MEADOWLARK12 }\end{array}$ & $\begin{array}{l}\text { WESTERN MEADDWLARK } \\
\text { WESTERN MEADOWLARK }\end{array}$ & $\begin{array}{l}\text { EGG CONTENTS } \\
\text { EGG CONTENTS }\end{array}$ & $\begin{array}{l}\text { 19-Junn-03: } \\
\text { 19-Junn-032. }\end{array}$ & 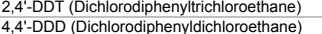 & & & & & & & \\
\hline SESPMNT & B174J1 & BACKGROUND & & BI & 2003WESTERN MEADOOLARK12 & $\begin{array}{l}\text { WESTERN MEADOWLARK } \\
\text { W }\end{array}$ & EGG CONTNNTS & 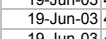 & 4,4-2-DDE (Dichlorodiphenyldichloroethylene) & & & & & & NO SAMPLE. & \\
\hline MNT & B174J1 & BACKGROUND & & $\mathrm{BI}$ & 2003WESTERN MEADOWLARK12 & WESTERN MEADOWLARK & EGG CONTENTS & 19-Jun-03 & 4,4'-DDT (Dichlorodiphenyltrichloroethane) & & & & & & NO SAMPLE. & \\
\hline
\end{tabular}




\begin{tabular}{|c|c|c|c|c|c|c|c|c|c|c|c|c|c|c|c|c|c|c|c|c|c|c|c|}
\hline Samp & & & & & Percent & & & & & & & & & & & & & & & & & & \\
\hline$\frac{\mathrm{Num}}{\mathrm{B17774}}$ & $\begin{array}{l}\text { Samp Site Name } \\
100 \text { AREAS }\end{array}$ & Samp From & Samp Item & Samp Date & $\begin{array}{l}\text { Moisture } \\
726\end{array}$ & $\frac{\mathrm{Hg}}{167}$ & 0283 & 114 & & 258 & $00445 \mathrm{U}$ & 152 & 244 & 0650 & 0021 & & 105 & 247 & $\overline{0188}>2>3$ & $\mathrm{Cu}$ & 189 & & \\
\hline $\begin{array}{l}\text { B. } \\
\text { B177775 }\end{array}$ & $\begin{array}{l}100 \text { AREAS } \\
100 \text { AR }\end{array}$ & $\begin{array}{l}\text { CANADA G } \\
\text { CANADA G }\end{array}$ & $\begin{array}{l}\text { LIVER } \\
\text { LIVER }\end{array}$ & $\begin{array}{l}\text { o5-Aug-03 } \\
05 \text {-Aug-03 }\end{array}$ & $\begin{array}{l}72.6 \\
726\end{array}$ & $\begin{array}{l}0.0167 \\
0.0552\end{array}$ & $\begin{array}{l}0.283 \\
0.352\end{array}$ & $\begin{array}{l}11.4 \\
103\end{array}$ & $\begin{array}{l}0.0447 \mathrm{U} \\
0.0447\end{array}$ & $\begin{array}{l}2.58 \\
286\end{array}$ & 0.04445 & $\begin{array}{l}1.52 \\
0.622\end{array}$ & $\begin{array}{l}0.244 \\
0.0709\end{array}$ & 0.06097 & 0.027 & $0.03099 \mathrm{Y}$ - & $\begin{array}{l}1.05 \\
150\end{array}$ & & 000 & & (189u & 11777 & ${ }_{138}^{138}$ \\
\hline $\begin{array}{l}\text { B17776 } \\
\text { B1776 }\end{array}$ & 100 AREAS & $\begin{array}{l}\text { CANADA GOOSE } \\
\text { CANADA GOOSE }\end{array}$ & $\begin{array}{l}\text { INER } \\
\text { LIVER }\end{array}$ & 29-Sep-03 & 72.8 & 0.0271 & $\begin{array}{l}0.169 \\
0.169\end{array}$ & 15.1 & $0.0447 \mathrm{U}$ & 2.66 & 0.0489 & 1.63 & & 0.154 & $0.021 \mathrm{U}$ & $0.0309 \mathrm{U}$ & 3.28 & $\begin{array}{l}0.199 \\
0.199\end{array}$ & 0.0791 & $\begin{array}{l}44.8 \\
125\end{array}$ & $0.0189 \mathrm{U}$ & $0.0177 \mathrm{U}$ & $\begin{array}{l}122 \\
191\end{array}$ \\
\hline 7777 & 100 AREAS & NADA GOOSE & LIVER & 29-Sep-03 & 70.8 & .0401 & 0.199 & 15.5 & 0.0673 & 2.96 & 0.0445 & 4.60 & & 0.136 & $0.021 \mathrm{U}$ & $0.0309 \mathrm{u}$ & 53.6 & $0.199 \mathrm{u}$ & 0.0798 & 22.5 & $0.0189 \mathrm{U}$ & $177 \mathrm{U}$ & 119 \\
\hline 7778 & 100 ARE & CANADA GOOSE & LIVER & 02-Oct-03 & 73.2 & 0.0819 & 0.250 & 8.42 & 0.264 & 3.69 & $0.0445 \mathrm{U}$ & 10.4 & & 0.445 & $0.021 \mathrm{U}$ & $0.0309 \mathrm{U}$ & 8.05 & $0.199 \mathrm{U}$ & 0.0302 & 57.5 & $0.0189 \mathrm{U}$ & 0.0335 & 145 \\
\hline 7780 & $\begin{array}{l}\text { HAAFORD TOWNS } \\
\text { HANFORD TOWNS }\end{array}$ & $\begin{array}{l}\text { CANADA GOOSE } \\
\text { CANADA GOOSE }\end{array}$ & $\begin{array}{l}\text { LIVER } \\
\text { LVER }\end{array}$ & $\begin{array}{l}\text { 05-Aug-03 } \\
\text { 05-03 }\end{array}$ & 72.6 & $\begin{array}{r}0.103 \\
0.0785\end{array}$ & $\begin{array}{l}0.360 \\
0.302\end{array}$ & $\begin{array}{l}11.4 \\
807\end{array}$ & 0.0495 & $\begin{array}{l}4.35 \\
3.35\end{array}$ & $\begin{array}{l}0.0445 \mathrm{U} \\
0.045 \mathrm{U}\end{array}$ & $\begin{array}{r}3.58 \\
0.669\end{array}$ & 0.163 & $\begin{array}{r}0.136 \\
0.0355\end{array}$ & $0.021 \mathrm{U}$ & $0.0309 \mathrm{U}$ & $\begin{array}{l}7.62 \\
3.96\end{array}$ & 0.641 & $0.0188 \mathrm{U}$ & 29.2 & $0.0189 \mathrm{U}$ & $0.0177 \mathrm{U}$ & 133 \\
\hline 7781 & HANFORD TOWNSITE & $\begin{array}{l}\text { CANADA GOOSE } \\
\text { CANADA GOOSE }\end{array}$ & $\begin{array}{l}\text { IIVER } \\
\text { LIVER }\end{array}$ & $\begin{array}{l}\text { Aug-03 } \\
\text { Aug-03 }\end{array}$ & $\begin{array}{l}72.6 \\
72.6\end{array}$ & .154 & $\begin{array}{l}.0 .342 \\
0.498\end{array}$ & $\begin{array}{l}8.0 t \\
16.4\end{array}$ & $0.0447 \mathrm{U}$ & 3.50 & $0.0445 \mathrm{U}$ & $\begin{array}{l}0.069 \\
3.28\end{array}$ & 0.0663 & 0.105 & $0.021 \mathrm{u}$ & $0309 \mathrm{U}$ & $\begin{array}{l}3.96 \\
3.98 \\
3\end{array}$ & $\begin{array}{l}.210 \mathrm{y} \\
0.199 \mathrm{u}\end{array}$ & 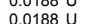 & $\begin{array}{l}21.4 \\
102\end{array}$ & $\begin{array}{l}.0 .0189 \mathrm{u} \\
0.0189\end{array}$ & 0.017 u & $\begin{array}{l}107 \\
198\end{array}$ \\
\hline 7782 & HANFORD TOWNSITE & $\begin{array}{l}\text { CANADA GUOSE } \\
\text { CANADA GOOSE }\end{array}$ & $\begin{array}{l}\text { LIVER } \\
\text { LIVER }\end{array}$ & 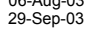 & 73.4 & $\begin{array}{l}0.0369 \\
0.0369\end{array}$ & $\begin{array}{l}0.409 \\
0.109\end{array}$ & $\begin{array}{l}10.4 \\
13.1\end{array}$ & $0.0447 \mathrm{U}$ & $\begin{array}{l}3.17 \\
3.17\end{array}$ & $0.0445 \mathrm{U}$ & $\begin{array}{l}3.20 \\
2.37\end{array}$ & & 0.0460 & $0.021 \mathrm{U}$ & $0309 \mathrm{U}$ & $\begin{array}{l}3.90 \\
3.35\end{array}$ & $0.199 \mathrm{U}$ & .0300 & 21.9 & $0189 \mathrm{U}$ & $0177 \mathrm{U}$ & $\begin{array}{l}198 \\
290\end{array}$ \\
\hline & HANFORD TOWNSITE & CANA & LIVER & 02-Oct-03 & 69.5 & .0231 & 0.279 & 9.81 & $0.0447 \mathrm{U}$ & 2.08 & $0.0445 \mathrm{U}$ & 15.6 & & 0.105 & $0.021 \mathrm{U}$ & $.0309 \mathrm{U}$ & 4.34 & $0.199 \mathrm{U}$ & .0243 & 35.5 & $0.0189 \mathrm{U}$ & $0.0177 \mathrm{U}$ & \\
\hline 7784 & $\begin{array}{l}\text { BACKGF } \\
\text { RAPIDS }\end{array}$ & CAN & VER & 21-Aug-03 & & & 0.548 & & $0.04-404$ & & & & 0.0470 & $0.0338 \mathrm{U}$ & & $0.0309 \mathrm{U}$ & 2.83 & & $0.0188 \mathrm{U}$ & & $0.0189 \mathrm{U}$ & $0.0177 \mathrm{U}$ & \\
\hline 85 & BACKGROUND (PRIEST & CANADA GOOSE & LIVER & 23-Sep-03 & 69.3 & 0.0281 & 0.134 & 9.77 & $0.0447 \mathrm{U}$ & 1.25 & $0.0445 \mathrm{U}$ & 1.80 & & 0.0609 & $0.021 \mathrm{u}$ & $0.0309 \mathrm{U}$ & 1.20 & $0.199 \mathrm{U}$ & $0.0188 \mathrm{U}$ & 49.1 & $0.0189 \mathrm{U}$ & 0177 U & 111 \\
\hline 6NB2 & 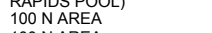 & COTTONTAIL RABBIT & LIVER & & & 0.0808 & 0.307 & & $0.0447 \mathrm{U}$ & & $0.0445 \mathrm{U}$ & & $0.0303 \mathrm{U}$ & & & & & & $0.0188 \mathrm{U}$ & & & $0.0177 \mathrm{U}$ & \\
\hline & & LRABBIT & LIVER & 07-Oct-03 & 73.5 & & 0.127 & 9.34 & 0.0677 & 1.62 & $0.0445 \mathrm{U}$ & 0.624 & & 0.267 & $0.021 \mathrm{U}$ & .0309 U & 1.86 & $199 \mathrm{u}$ & 0.0741 & 13.1 & $189 \mathrm{U}$ & 0177 i & \\
\hline & $100 \mathrm{NAB}$ & T & $\begin{array}{l}\text { LIVER } \\
\text { LVER }\end{array}$ & & 69.7 & & 0.236 & 7.88 & 0.0631 & 2.37 & $0.0445 \mathrm{U}$ & 0.711 & & 0.143 & $0.021 \mathrm{U}$ & 90 & 2.67 & 199 U & & 14.9 & 89 U & 177 U & 134 \\
\hline & 200 & $\begin{array}{l}\text { RABBIT } \\
\text { RABIT }\end{array}$ & $\begin{array}{l}\text { LIVER } \\
\text { LIVER }\end{array}$ & $3^{3}$ & $\begin{array}{l}70.1 \\
70.1\end{array}$ & & 0.2055 & 13.4 & $0.0457 \mathrm{U}$ & 2.76 & $0.0445 \mathrm{U}$ & 0.535 & & 0.0404 & $0.021 \mathrm{U}$ & $0.0309 \mathrm{U}$ & 1.28 & $0.199 \mathrm{U}$ & 0.0692 & 14.7 & $189 \mathrm{U}$ & 1770 & 117 \\
\hline SNB7 & 200 & RABBIT & $\begin{array}{l}\text { IIVER } \\
\text { LIVER }\end{array}$ & $\begin{array}{l}06-\text { May-03 } \\
06\end{array}$ & $\begin{array}{l}68.8 \\
68.8\end{array}$ & 0.0259 & $\begin{array}{l}0.343 \\
0.298\end{array}$ & $\begin{array}{l}1.1 \\
12.4\end{array}$ & $\begin{array}{l}0.0449 \\
0.050\end{array}$ & $\begin{array}{l}3.889 \\
0.889\end{array}$ & $0.0445 \mathrm{U}$ & $\begin{array}{l}0.131 \\
0.131\end{array}$ & 0.0123 & $\begin{array}{l}2.48 \\
1.38\end{array}$ & $0.021 \mathrm{U}$ & $\begin{array}{lll} & \end{array}$ & ${ }_{1,19}^{3.01}$ & $0.199 \mathrm{U}$ & 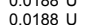 & $\begin{array}{l}12.4 \\
736\end{array}$ & $\begin{array}{l}0.160 \\
0.570\end{array}$ & 1770 & 99.6 \\
\hline $\mathrm{NCO}$ & $200 \mathrm{WA}$ & RABBIT & $\begin{array}{l}\text { LIVER } \\
\text { LIV }\end{array}$ & -Jun-03 & 74.4 & 0.123 & 0.448 & 12.5 & 0.0654 & $\begin{array}{l}.009 \\
3.00\end{array}$ & $0.0445 \mathrm{U}$ & 0.554 & 0.432 & 0.187 & $0.021 \mathrm{U}$ & $309 \mathrm{U}$ & 13.2 & 492 & $188 \mathrm{U}$ & 13.9 & 200 & $177 \mathrm{U}$ & 13 \\
\hline NC1 & 200 W AREA & RABBIT & LIVER & -03 & 74.3 & 0.0396 & 0.431 & 10.9 & 0.0644 & 1.91 & $0.0445 \mathrm{U}$ & 0.316 & $0.0303 \mathrm{U}$ & 0.209 & $0.021 \mathrm{U}$ & $309 \mathrm{U}$ & 4.82 & .663 & $6188 \mathrm{U}$ & 12.6 & $189 \mathrm{U}$ & $177 \mathrm{U}$ & 175 \\
\hline 2 & $\begin{array}{l}200 \mathrm{WA} \\
200 \mathrm{WA}\end{array}$ & $\begin{array}{l}\text { COTONTANALR RABBIT } \\
\text { COTTONTAL RABBIT }\end{array}$ & $\begin{array}{l}\text { IIVER } \\
\text { LIVER }\end{array}$ & & $\begin{array}{l}73.4 \\
73.2\end{array}$ & $\begin{array}{l}0.115 \\
0.247\end{array}$ & $\begin{array}{l}0.402 \\
0.569\end{array}$ & $\begin{array}{l}11.4 \\
11.8\end{array}$ & & $\begin{array}{l}3.38 \\
3.27\end{array}$ & $\begin{array}{l}0.0 \\
0.0\end{array}$ & $\begin{array}{l}0.176 \\
0.297\end{array}$ & $\begin{array}{l}0.406 \\
0.355\end{array}$ & $\begin{array}{l}0.111 \\
0.158\end{array}$ & & & $\begin{array}{l}2.55 \\
126\end{array}$ & $\begin{array}{l}.716 \\
455\end{array}$ & & 17.5 & $189 \mathrm{U}$ & 77 U & 113 \\
\hline 3 & $\begin{array}{l}\text { 200 WAREA } \\
\text { BACKGROUND }\end{array}$ & COTTONTALL RABBIT & & 29-Jul-03 & 73.2 & & 0.569 & 11.8 & & 3.27 & 0.0445 & 0.297 & 0.355 & 0.158 & & $309 \mathrm{U}$ & 12.6 & 0.455 & $0188 \mathrm{U}$ & 14.5 & $189 \mathrm{U}$ & $177 \mathrm{U}$ & \\
\hline $\begin{array}{lll}\mathrm{inN4} 4 \\
9 \mathrm{NH} 5\end{array}$ & $\begin{array}{l}\text { MABTTN) } \\
100-\mathrm{N}-100-\mathrm{D}\end{array}$ & COTTONTALL RABBIT & $\begin{array}{l}\text { LIVER } \\
\text { LIVER }\end{array}$ & $\begin{array}{l}\text { 11-Dec-03 } \\
\text { 13-Jan-03 }\end{array}$ & $\begin{array}{l}69.0 \\
43.0\end{array}$ & 0.142 & $\begin{array}{l}111 \\
665\end{array}$ & $\begin{array}{l}7.03 \\
4.64\end{array}$ & $\begin{array}{r}0.043 \\
0.0617\end{array}$ & $\begin{array}{l}2.34 \\
136\end{array}$ & $\begin{array}{l}0.0445 \mathrm{U} \\
0.156\end{array}$ & $\begin{array}{l}.0935 \\
269\end{array}$ & 0.0234 & 0.0837 & $0.021 \mathrm{u}$ & $\begin{array}{ll}0309 \\
0309 \\
U\end{array}$ & $\begin{array}{l}1.28 \mathrm{U} \\
222\end{array}$ & $\begin{array}{l}0.0969 \mathrm{U} \\
0.801\end{array}$ & . $0150 \mathrm{U}$ & 10.4 & 189 U & .0248 & 118 \\
\hline & $100-N-100-D$ & ITEFISH & $\begin{array}{l}\text { LIVER } \\
\text { LIVR }\end{array}$ & 13-Jan-03 & $\begin{array}{l}4.0 \\
40.8\end{array}$ & & 1.87 & $\begin{array}{l}4.044 \\
6.64\end{array}$ & 0.054 & $\begin{array}{l}1.0 \\
9.91\end{array}$ & 108 & $\begin{array}{l}2.69 \\
2.70\end{array}$ & & 0 & 0.0 & 990 & $\begin{array}{l}2.22 \\
2.36\end{array}$ & $\begin{array}{l}0.48 \\
0.48\end{array}$ & $8 \mathrm{U}$ & $\begin{array}{l}10.3 \\
10.7\end{array}$ & & & .9 \\
\hline 10 & $100-\mathrm{N}-100-\mathrm{D}$ & ITEFISH & VER & 13-Jan-03 & 510 & & 164 & 6.47 & 0.06 & 9.26 & & 1.89 & & & & & 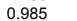 & & & 23.4 & & & .7 \\
\hline 8 & $100-1$ & ITEF & VER & 3 & 46.6 & & 12 & 4 & 0 & 11.1. & $0445 \mathrm{U}$ & 5.54 & & 1 & 0.0 & 370 & $6.3>2>3$ & 0.643 & $5188 \mathrm{U}$ & 10.9 & & 1.70 & 10 \\
\hline $69 \mathrm{H} 9$ & $100-N-100-D$ & IITEFISH & LIVER & 13-Jan-03 & 39.0 & & 101 & 7.32 & 0.117 & 10.3 & 0.076 & 2.87 & & 0798 & $0.021 \mathrm{U}$ & 0350 & 4.32 & 0.761 & $0188 \mathrm{U}$ & 13.8 & 89 & 1.47 & 86.2 \\
\hline 69J0 & IND (BELOW & HITEFISH & LIVER & 27-Jan-03 & 47.1 & 0.483 & 0.0204 & 4.42 & 0.0688 & 6.02 & 0.33 & 1.60 & & $300 \mathrm{~L}$ & $0.021 \mathrm{U}$ & 309 & 2.22 & 1.11 & 266 & 34.4 & 189 & 1.28 & 105 \\
\hline & WAHL & cow & MILK & & 87.8 & & 0.125 & & 0.28 & $0.499 \mathrm{U}$ & $45 \mathrm{U}$ & 418 & & $338 \mathrm{U}$ & $r$ & $0.0309 \mathrm{U}$ & 0.104 & $0.199 \mathrm{U}$ & 0.514 & 0.340 & 21 & 887 & \\
\hline & WAHLUY & & & & 87 & & 0.15 & 207 & 0.2 & 0. & & & & & & & 59 & & & 43 & & & \\
\hline $\begin{array}{l}7847 \\
7848\end{array}$ & $\begin{array}{l}\text { AGEMMC } \\
\text { SUNNYS }\end{array}$ & & $\begin{array}{l}K \\
K \\
K\end{array}$ & $\begin{array}{l}\text { 37-Aug-03 } \\
07-03\end{array}$ & $\begin{array}{l}87.6 \\
87.4\end{array}$ & & $\begin{array}{l}0.1132 \\
0.102\end{array}$ & $\begin{array}{l}0.118 \\
0.182\end{array}$ & $\begin{array}{l}0.269 \\
0.264\end{array}$ & $\begin{array}{l}0.499 \mathrm{u} \\
0.499\end{array}$ & $\begin{array}{l}0.0445 \mathrm{U} \\
0.0445\end{array}$ & $\begin{array}{l}0.0539 \\
0.0539\end{array}$ & & 363 & 358 & 09 u & $\begin{array}{r}0.909 \\
1.17\end{array}$ & $199 \mathrm{U}$ & $\begin{array}{l}0.481 \\
0.516\end{array}$ & $\begin{array}{l}0.344 \\
0.396\end{array}$ & & & $\begin{array}{l}27.6 \\
29.1\end{array}$ \\
\hline ANBO & $100 \mathrm{~B} / \mathrm{C}$ & DIS & OOLE & & 79.8 & 0.084 & 3.4 & 175 & 2.73 & 1.42 & 0.08 & 1.54 & 45.30 & 16.30 & 0.679 & & 1770 & 0.916 & $\begin{array}{l}0.0790 \\
0.070\end{array}$ & 30.8 & & & 99 \\
\hline FN1 & $100-B_{5}$ & ל אוחר & WHOLE & 26-Sep-03 & 52.6 & 0.049 & 0.4 & 32.2 & 0.24 & 1.47 & 0.08 & 1.02 & 12. & 1.36 & 0.083 & & 200 & 0.221 & 76 & 26.8 & & & 65 \\
\hline & $\begin{array}{l}100-4 \\
100-\end{array}$ & $\begin{array}{l}\text { CADDDS } \\
\text { CADDIS }\end{array}$ & $\begin{array}{l}\text { WHOLE } \\
\text { WHOLE }\end{array}$ & $\begin{array}{l}26 \\
25 \\
25\end{array}$ & $\begin{array}{l}52.6 \\
83.8\end{array}$ & $\begin{array}{l}0.048 \\
0.042\end{array}$ & $\begin{array}{l}0.445 \\
0397\end{array}$ & 30.4 & 0.21 & 1.51 & & 0.86 & $\begin{array}{l}11.80 \\
0.31\end{array}$ & 1. & & & 18 & & & 7.1 & & & 59 \\
\hline$\frac{2}{3}$ & 100 & $\begin{array}{l}\text { CADDIS } \\
\text { CADDS }\end{array}$ & HOLE & & $\begin{array}{l}83.8 \\
844\end{array}$ & $\begin{array}{l}.0 .042 \\
0.58\end{array}$ & $\begin{array}{l}0.397 \\
0.49\end{array}$ & ${ }_{406}^{260}$ & 0 & $\begin{array}{l}1.26 \\
1.72\end{array}$ & & $\begin{array}{l}0.54 \\
091\end{array}$ & & (1. & & & $\begin{array}{l}159 \\
264\end{array}$ & 00 & & ${ }_{3}^{8}$ & & & 47 \\
\hline 84 & 100 & CADDIS & HOLE & $07-00$ & 59.0 & 0.033 & 0.1 & 40.4 & 147.14 & $\begin{array}{l}1.12 \\
1.86 \\
\end{array}$ & 0.8 & 0.96 & 15.70 & $\begin{array}{l}1.72 \\
0.75\end{array}$ & 0.003 & & $\begin{array}{l}204 \\
55.3\end{array}$ & 0.254 & $50 \mathrm{u}$ & $\begin{array}{l}30.5 \\
38.5\end{array}$ & & & 197 \\
\hline 5 & 100 & 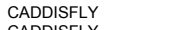 & HOLE & 13-Oct-03 & 65.3 & 0.043 & & 24.1 & 0.18 & 1.26 & 0.0 & 0.29 & 5.58 & 0.80 & $0.021 \mathrm{U}$ & & 72.8 & 0.282 & $50 \mathrm{U}$ & 27.9 & & $7 \mathrm{U}$ & 165 \\
\hline $\begin{array}{l}7 \mathrm{NBB} 6 \\
7762\end{array}$ & 100 & CHEATGRASS & ROOT & Aug-03 & 69.6 & 0.035 & 0.636 & $\begin{array}{l}22.4 \\
80.1\end{array}$ & 0.15 & 1.03 & 0.05 & 0.39 & 6.38 & 0.20 & $0.021 \mathrm{U}$ & $0.031 \mathrm{U}$ & 18 & 1.48 & $0.0150 \mathrm{U}$ & 26.1 & $89 \cup$ & $77 \mathrm{U}$ & 145 \\
\hline 7262 & $\begin{array}{l}100 \mathrm{E} \\
100 \mathrm{E}\end{array}$ & $\begin{array}{l}\text { CHEATGAASS } \\
\text { CHEATGRASS }\end{array}$ & $\begin{array}{l}\text { ROOT_SH } \\
\text { ROOTSSH }\end{array}$ & $\begin{array}{l}\text { May-03 } \\
\text { May-03 }\end{array}$ & $\begin{array}{l}80.5 \\
67.6\end{array}$ & $\begin{array}{l}0.005 \mathrm{U} \\
0.055 \mathrm{U}\end{array}$ & $\begin{array}{l}0.258 \\
0.149\end{array}$ & $\begin{array}{l}80.1 \\
80.2\end{array}$ & 0.29 & $\begin{array}{ll}0.0220 \mathrm{U} \\
0.0220 \mathrm{u}\end{array}$ & & $0.03 u$ & $\begin{array}{l}19.00 \\
20.00\end{array}$ & $\begin{array}{l}0.08 \\
0.03\end{array}$ & $0.021 U$ & $\begin{array}{l}0.031 \mathrm{U} \\
0.031 \mathrm{U}\end{array}$ & $\begin{array}{l}12 \\
44 \\
4\end{array}$ & 0.199 U & & $\begin{array}{l}3.13 \\
2.63\end{array}$ & & & 9.9 \\
\hline 7264 & & $\begin{array}{l}\text { CHEA IRASS } \\
\text { CHEATGRASS }\end{array}$ & $\begin{array}{l}\text { ROOT-SS } \\
\text { ROT }\end{array}$ & 03 & 67.6 & $\begin{array}{l}0.005 \mathrm{U} \\
0.005 \mathrm{U}\end{array}$ & 0.149 & $\begin{array}{l}80.2 \\
54.9\end{array}$ & $\begin{array}{l}0.17 \\
0.30\end{array}$ & $\begin{array}{l}0.0220 \mathrm{U} \\
0.0370\end{array}$ & $0.04 \mathrm{U}$ & $\begin{array}{l}0.03 \mathrm{U} \\
0.06\end{array}$ & $\begin{array}{l}20 . \\
29 . \\
\end{array}$ & $\begin{array}{l}0.03 \mathrm{U} \\
0.03 \mathrm{U}\end{array}$ & $\begin{array}{l}0.021 \mathrm{U} \\
0.021 \mathrm{U}\end{array}$ & & $\begin{array}{l}44 \\
25\end{array}$ & $\begin{array}{l}0.199 \mathrm{U} \\
0.199 \mathrm{U}\end{array}$ & & 98 & & & 10 \\
\hline 7264 & 100 & EATGRASS & TI & & 0 & $0.005 \mathrm{U}$ & 0.092 & 75.3 & 0.20 & 0.0382 & $0.04 \mathrm{U}$ & 0.10 & 31. & $0.03 \mathrm{U}$ & $0.021 \mathrm{U}$ & $0.031 \mathrm{U}$ & 26 & $.199 \mathrm{U}$ & $8 \mathrm{U}$ & 5.38 & $9 \mathrm{u}$ & & 77 \\
\hline 17265 & $100 \mathrm{~B} / \mathrm{C}$ AREA & s & ROOT- & 03 & 73.1 & 0.006 & 4.100 & 123 & 2.94 & 0.0432 & $0.04 \mathrm{U}$ & 0.12 & 41.90 & 2.06 & 1.130 & 0.200 & 422 & 0.519 & $88 \mathrm{U}$ & 10.5 & 0.6 & $\mathrm{u}$ & 4 \\
\hline $\begin{array}{l}7666 \\
86.55\end{array}$ & $\begin{array}{l}100 \\
100\end{array}$ & & $\begin{array}{l}\text { ROOT } \\
\text { SOFT }\end{array}$ & & $\begin{array}{l}61.8 \\
71.2\end{array}$ & $\begin{array}{l}0.005 \mathrm{U} \\
0.039\end{array}$ & $\begin{array}{l}0.493 \\
1.932\end{array}$ & $\begin{array}{l}44.2 \\
253\end{array}$ & $\begin{array}{l}0.2 \\
10\end{array}$ & $0.0220 \mathrm{U}$ & 等 & $0.03 \mathrm{U}$ & 20. & $0.03 \mathrm{U}$ & $0.021 \mathrm{U}$ & 0194 & 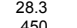 & $0.199 \mathrm{U}$ & $8 \mathrm{U}$ & 5.26 & & & 15 \\
\hline 03 & $300 \mathrm{~A}$ & & & & 38.4 & $\begin{array}{l}0.0939 \\
0.0936\end{array}$ & $\begin{array}{r}1.932 \\
5.76\end{array}$ & $\begin{array}{l}25.3 \\
76.8\end{array}$ & $\begin{array}{l}1.00 \\
2.05\end{array}$ & $\begin{array}{l}2.37 \\
3.35\end{array}$ & 0.0941 & $\begin{array}{l}2.49 \\
2.98\end{array}$ & 15.13 & 1. & & & $\begin{array}{l}45 \\
131 \\
\end{array}$ & $\begin{array}{l}1.15 \\
4.85\end{array}$ & 4 & $\frac{79}{9}$ & & & $\begin{array}{l}134 \\
138\end{array}$ \\
\hline 1 & 300 & & & & D.:4 & $\begin{array}{l}0.0899 \\
0.0936 \\
0\end{array}$ & $\begin{array}{l}4.1 \\
4.0\end{array}$ & $\begin{array}{l}7.8 \\
22.2\end{array}$ & $\begin{array}{l}2.05 \\
0.815\end{array}$ & $\begin{array}{l}3.55 \\
2.57\end{array}$ & $\begin{array}{l}0.041 \\
0.1\end{array}$ & $\begin{array}{l}2.98 \\
2.74\end{array}$ & & 0.6 & & 9. & 2 & & & 35.9 & & & 97.7 \\
\hline 5 & 300 & & & & 66.6 & 0.0666 & 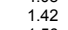 & 4.81 & 0.4 & 2.06 & 4 & 1.72 & & 0.257 & $0.021 \mathrm{U}$ & & 73 & 5.48 & & .1 & & & 101 \\
\hline 36 & & & 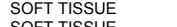 & 3 & 74.8 & 0.0838 & 1.5 & 11.5 & 0.5 & 2.24 & 0.05 & 2.03 & & 0.4 & & & & & & 47.3 & & & 3 \\
\hline & & & & & $75 \mathrm{~S}-2>0$ & $\begin{array}{l}0.051 \\
0.042\end{array}$ & $18 \mathrm{r}-\mathrm{a}$ & 19.8 & 0.7 & 236 & & $\begin{array}{l}2.39 \\
2.50\end{array}$ & 11. & 0. & & & & & & 41 & & & 06 \\
\hline $\mathrm{NH} 3$ & & & & & & 0.0 & & $\begin{array}{l}21.1 \\
15.5\end{array}$ & & & & & & & & & & & & & & & 16 \\
\hline & & & & & 76.2 & 0.0 & 12 & 58 & $20 \mathrm{C}-1$ & 3.31 & & 2. & 26 & 2.0 & & & 14 & & & 28.2 & & & 1020 \\
\hline H5 & & & & & & 0.0 & & 19 & 1. & 2.50 & & 2.0 & 13 & 0. & & & 20 & & & 32.5 & & & 52 \\
\hline & & & & & & 0.0 & 14. & 23.3 & 1 & 2.59 & & 2.49 & & & & & & & & 8 & & & 1 \\
\hline & & & & & & $\begin{array}{l}0.03 \\
0.05\end{array}$ & & & & & & & & & & & & & & & & & 1 \\
\hline & & & & & & $\begin{array}{l}0.0428 \\
0.042\end{array}$ & & $\begin{array}{l}41.4 \\
19.7\end{array}$ & 1.3 & $\begin{array}{l}2.24 \\
2.23\end{array}$ & & 2.04 & & & & & & & & & & & $\begin{array}{l}142 \\
95.7\end{array}$ \\
\hline & & & & & & 0.03 & & 24.8 & 0. & 38 & 0.0 & 1.78 & 12.7 & 0 & & & 5 & & & 7.7 & & & 13 \\
\hline $7 J 11$ & VERN & & & 3 & 71.7 & 0.1 & 0.5 & 22 & 3. & 5.40 & $8.3>>3>>$ & 9.37 & 15 & & & & & & & 30 & & & 03 \\
\hline & & & & & $72-250$ & $0_{0}$ & 0.4 & 231 & $15^{5}-2$ & & 7.8 & $\begin{array}{l}6.36 \\
3.15\end{array}$ & 11 & & & & & & & 29 & & & 2 \\
\hline & & & & & & & & & 2.2 & & & & & & & & & & & & & & \\
\hline & & & & & 72. & 0.01 & & 11 & 3.2 & & $\begin{array}{l}.4 \\
8.5\end{array}$ & $\begin{array}{l}1.0 \\
5.0\end{array}$ & & & & & & & & 1 & & & . \\
\hline & VEF & & & & & 0.05 & & 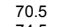 & & & & 4.9 & & & & & & & & 13 & & & 16 \\
\hline & & & & & & & & & & & & & & & & & & & & 57 & & & \\
\hline & $\begin{array}{l}\text { VRR } \\
\text { VERI }\end{array}$ & & & & & $\begin{array}{l}0.6 \\
0.6\end{array}$ & & $\begin{array}{l}78.9 \\
357\end{array}$ & & & & & & & & & & & & & & & \\
\hline & & & & & & $\begin{array}{l}0.04 \\
0.08\end{array}$ & & 256 & & & & & & & & & & & & & & & 72.9 \\
\hline & & & & & & 0.1 & & 455 & 12. & & & & & 0 & & & & & & 50 & & & 6 \\
\hline & & 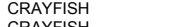 & & & & 0.1 & & 249 & 7. & & 11 & 17 & & & & & & & & 30 & & & \\
\hline & & & & & & 0.1 & & $\begin{array}{l}252 \\
352\end{array}$ & & & & & & & & & & & & 30 & & & 20 \\
\hline & & & & & 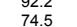 & $\begin{array}{l}0.13 \\
0.09\end{array}$ & & $\begin{array}{l}152 \\
155\end{array}$ & $\begin{array}{l}4 . \\
1\end{array}$ & $\begin{array}{l}4.1 \\
5.7\end{array}$ & $\begin{array}{l}8.2 \\
2.6\end{array}$ & $\begin{array}{l}35 . \\
15 .\end{array}$ & 4.8 & 0. & & & $\begin{array}{l}9.84 \\
7.93\end{array}$ & & $88 \mathrm{U}$ & 510 & 0.344 & $\begin{array}{l}0.282 \\
0.2204\end{array}$ & \\
\hline & 100 & & & 3 & 74. & 0.1 & & $\begin{array}{l}155 \\
332\end{array}$ & 1. & $\begin{array}{l}1.14 \\
10.0\end{array}$ & & 6. & 4. & 0. & & & & & & & & & \\
\hline & & & & 3 & 64.4 & 0.21 & 1.7 & 60 & 8.2 & 9.12 & 8 & 17.6 & 6. & 0.2 & & 0.6 & & & & & & & \\
\hline & & & & & & $\begin{array}{l}0.0 \\
0.0\end{array}$ & & & & & & & $\begin{array}{c}68 \\
3 \\
3\end{array}$ & & & & & & & & & & \\
\hline & & & KEAS & $t-03$ & 73.2 & 0.354 & 1.512 & $4 \pi$ & 11.92 & 12.3 & 14.37 & 16.47 & 7.60 & 0.41 & 0.0 & 1.380 & 6.87 & 17.8 & .135 & 2050 & 125 & 619 & \\
\hline
\end{tabular}


Table B-1. Metals in Biota, 2003 (Concentrations in $\mu \mathrm{g} / \mathrm{g}$ dry wt - blank corrected)

\begin{tabular}{|c|c|c|c|c|c|c|c|c|c|c|c|c|c|c|c|c|c|c|c|c|c|c|c|}
\hline Samp & & & & & & & & & & & & & & & & & & & & & & & \\
\hline $\begin{array}{l}\text { Num } \\
17725\end{array}$ & $\begin{array}{l}\text { Samp Site Name } \\
\text { Dite }\end{array}$ & Samp Fr & Samp It & Samp D & olisture & $\mathrm{Hg}$ & $\mathrm{Cr}$ & $\mathrm{Mn}$ & $\mathrm{Ni}$ & $\mathrm{Se}$ & & $\mathrm{Cd}$ & $\mathrm{Ba}$ & & Th & & Al & As & & & & $\mathrm{TI}$ & $\mathrm{Zn}$ \\
\hline $\begin{array}{l}B 17225 \\
B 17226\end{array}$ & $E A$ & $F=$ & $E R$ & & 72.1 & 0.013 & $0.6-6$ & 7.31 & 0.10 & 5.60 & & & & & & & & & & & & 122 & $\frac{2 \pi}{110}$ \\
\hline 2226 & & $E$ & $\begin{array}{l}\text { LIVER } \\
\text { LVER }\end{array}$ & 03 & 70.0 & 0.122 & $0.0-2-1$ & 0 & 0.10 & $\begin{array}{l}4.06 \\
4.06\end{array}$ & & & & & & & 0.521 & & & $=0$ & & & 159 \\
\hline & & & ER & Ma & 72.1 & 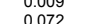 & $\begin{array}{l}0.015 \\
0.015\end{array}$ & 6 & 0.05 & . 356 & 04 & & & 0. & 0.021 & 0.03 & & & 0188 & 5.3 & & & 102 \\
\hline & $\begin{array}{l}E A \\
E A\end{array}$ & DUSE & $\begin{array}{l}E R \\
E R\end{array}$ & $\begin{array}{l}\text { May-03 } \\
\text { May-03 }\end{array}$ & $\begin{array}{l}71.7 \\
700\end{array}$ & & $\begin{array}{l}0.028 \\
0.044\end{array}$ & & & & & $\begin{array}{l}44 \\
33\end{array}$ & & 0.08 & 1021 & & & & & 45 & & & $\begin{array}{l}75.7 \\
85.4\end{array}$ \\
\hline 7231 & $0 \mathrm{~B} / \mathrm{C} A \mathrm{AF}$ & MOUSE & $\begin{array}{l}\text { LIVER } \\
\text { LIVER }\end{array}$ & -May-03 & 70.2 & 0.020 & $\begin{array}{l}0.044 \\
0.103\end{array}$ & $\begin{array}{l}0.17 \\
10.5\end{array}$ & 0.05 & $\begin{array}{l}5.00 \\
3.82\end{array}$ & $\begin{array}{l}0.04 \\
0.04\end{array}$ & 0.39 & 0.09 & 0.02 & $0.021 \mathrm{u}$ & $0.031 \mathrm{u}$ & $\begin{array}{l}.4641 \\
0.64\end{array}$ & 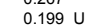 & 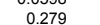 & $\begin{array}{l}24.5 \\
16.6\end{array}$ & $\begin{array}{l}0.0189 \mathrm{u} \\
0.0189\end{array}$ & $\begin{array}{l}0.0446 \\
0.0666\end{array}$ & $\begin{array}{l}85.4 \\
81.0\end{array}$ \\
\hline 232 & $100 \mathrm{~B} / \mathrm{C}$ AREA & R MOUSE & LIVER & -May-03 & 71.4 & 0.019 & 0.483 & 5.49 & 0.05 & 3.83 & $0.04 \mathrm{U}$ & 0.10 & 0.18 & $0.03 \mathrm{U}$ & $0.021 \mathrm{u}$ & $0.031 \mathrm{U}$ & 0.581 & 1.12 & $0.0188 \mathrm{U}$ & 17.7 & 0.0247 & 0.0489 & 85.9 \\
\hline 2235 & $100 \mathrm{~B} / \mathrm{C}$ AREA & ER MOUSE & $\begin{array}{l}\text { LIVER } \\
\text { LUVR }\end{array}$ & 03 & 70.7 & 0.218 & 0.154 & .8 & $0.04 \mathrm{U}$ & 6.98 & 0.04 & 0.37 & 0.04 & 0.04 & $0.021 \mathrm{U}$ & $0.031 \mathrm{U}$ & 0.471 & 0.298 & 58 & 29.7 & $89 U$ & 282 & 134 \\
\hline 7236 & $\begin{array}{l}100 \mathrm{~B} / \mathrm{C} \text { AREA } \\
\end{array}$ & ER MOUSE & $\begin{array}{l}\text { LIVER } \\
\text { LIVER }\end{array}$ & $\begin{array}{l}\text { May-03 } \\
\text { May-03 }\end{array}$ & $\begin{array}{l}72.0 \\
68.5\end{array}$ & 0.020 & 0.048 & 63 & $0.04 \cup$ & $\begin{array}{l}4.02 \\
3.39\end{array}$ & $0.04 \cup$ & 0.44 & 0.03 & $0.03 \mathrm{U}$ & $0.021 \mathrm{U}$ & $0.031 \mathrm{U}$ & 0.671 & $0.199 \mathrm{U}$ & $0.0188 \mathrm{U}$ & $\begin{array}{l}18.3 \\
158\end{array}$ & 0.0189 U & 0188 & 111 \\
\hline 7238 & $\begin{array}{l}100 \mathrm{~B} / \mathrm{C} \text { AREA } \\
100 \mathrm{~B} / \mathrm{C} \text { AREA }\end{array}$ & $\begin{array}{l}\text { ER MOUSE } \\
\text { ER MOUSE }\end{array}$ & $\begin{array}{l}\text { LIVER } \\
\text { LIVER }\end{array}$ & $\begin{array}{l}\text { May-03 } \\
\text { May-03 }\end{array}$ & $\begin{array}{l}68.5 \\
72.3 \\
72\end{array}$ & $\begin{array}{l}0.057 \mathrm{U} \\
0.005 \mathrm{U}\end{array}$ & $\begin{array}{l}0.018 \\
0.122\end{array}$ & 31 & $\begin{array}{l}0.04 \mathrm{U} \\
0.04 \mathrm{U}\end{array}$ & $\begin{array}{l}3.39 \\
4.93\end{array}$ & $\begin{array}{l}0.04 \mathrm{U} \\
0.04 \mathrm{U}\end{array}$ & $\begin{array}{l}0.05 \\
0.06\end{array}$ & $\begin{array}{l}0.07 \\
0.29\end{array}$ & $\begin{array}{l}0.03 \mathrm{U} \\
10.80\end{array}$ & $\begin{array}{l}0.021 \mathrm{U} \\
0.021 \mathrm{u}\end{array}$ & $\begin{array}{l}0.031 \mathrm{U} \\
0.031 \mathrm{U}\end{array}$ & $\begin{array}{l}0.109 \mathrm{U} \\
0.861\end{array}$ & $\begin{array}{l}0.247 \\
0.663\end{array}$ & $\begin{array}{l}0.0188 \mathrm{U} \\
0.0581\end{array}$ & $\begin{array}{l}15.8 \\
18.2\end{array}$ & $\begin{array}{l}189 \mathrm{U} \\
189 \mathrm{U}\end{array}$ & 3364 U & $\begin{array}{l}97.1 \\
87.5\end{array}$ \\
\hline 7239 & $100 \mathrm{~B} / \mathrm{C}$ AREA & EE & $\begin{array}{l}\text { LIVER } \\
\text { LIVER }\end{array}$ & 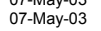 & 74.5 & $0.005 \mathrm{U}$ & $\begin{array}{l}0.039 \\
0.039\end{array}$ & $\begin{array}{l}8.37 \\
13.6\end{array}$ & $\begin{array}{l}0.09 \\
0.09 \\
0.04\end{array}$ & $\begin{array}{l}4.89 \\
6.84\end{array}$ & $\begin{array}{l}0.04 \\
0.04\end{array}$ & 0.08 & 0.25 & 0.08 & $0.021 \mathrm{U}$ & $0.031 \mathrm{U}$ & $\begin{array}{l}0.801 \\
15.0\end{array}$ & $\begin{array}{l}0.334 \\
0.334\end{array}$ & 0.164 & 22.1 & $189 \mathrm{U}$ & $\begin{array}{l}0.0340 \\
0.0340 \\
\end{array}$ & $\begin{array}{l}8151 \\
151\end{array}$ \\
\hline 7243 & A & ER MOUSE & LIVER & nay-03 & 68.1 & 0.057 & 0.052 & 12.4 & 0.05 & 4.89 & $0.04 \mathrm{U}$ & 0.21 & 0.04 & 0.06 & $0.021 \mathrm{U}$ & $0.031 \mathrm{U}$ & 0.571 & 0.247 & 0.119 & 19.7 & $0.0189 \mathrm{U}$ & 0.0177 U & 113 \\
\hline 7244 & $100 \mathrm{~B} / \mathrm{CAB}$ & $\begin{array}{l}\text { ER MOUSE } \\
\text { R MOUSE }\end{array}$ & $\begin{array}{l}\text { LIVER } \\
\text { LIVER }\end{array}$ & $\begin{array}{l}\text { May-03 } \\
\text { May-03 }\end{array}$ & 72.7 & $0.005 \mathrm{U}$ & 0.195 & 9.17 & $0.04 \mathrm{U}$ & $\begin{array}{l}4.05 \\
3.62\end{array}$ & $0.04 \mathrm{U}$ & 0.22 & 0.02 & 0.13 & $0.021 \mathrm{U}$ & 0.031 U & 1.06 & $0.199 \mathrm{U}$ & 12 & 28.0 & & .0177 U & 91.7 \\
\hline $\begin{array}{l}7245 \\
7246\end{array}$ & $\begin{array}{l}100 \mathrm{~B} \text { B/C AREA } \\
100 \mathrm{~B} / \mathrm{C} \text { AREA }\end{array}$ & $\begin{array}{l}\text { ER MOUSE } \\
\text { R MOUSE }\end{array}$ & LIVER & $\begin{array}{l}\text { May-03 } \\
\text { May-03 }\end{array}$ & $\begin{array}{l}70.2 \\
70.8\end{array}$ & $\begin{array}{l}0.005 \mathrm{U} \\
0.015\end{array}$ & $\begin{array}{l}0.137 \\
0.72\end{array}$ & 56 & $0.05 \mathrm{u}$ & $\begin{array}{l}3.62 \\
5.93 \\
-3\end{array}$ & $0.04 \mathrm{U}$ & $\begin{array}{l}0.12 \\
0.69\end{array}$ & $\begin{array}{l}0.02 \\
0.08\end{array}$ & $\begin{array}{l}0.034 \\
0.05\end{array}$ & $\begin{array}{l}0.021 \mathrm{u} \\
0.021 \mathrm{u}\end{array}$ & $\begin{array}{l}0.031 \mathrm{U} \\
0.031 \mathrm{U}\end{array}$ & $\begin{array}{l}0.581 \\
3.34\end{array}$ & $\begin{array}{l}0.346 \\
0.199 \mathrm{u} \\
\mathrm{u}\end{array}$ & $\begin{array}{l}0.0188 \mathrm{U} \\
0.0188 \mathrm{U}\end{array}$ & $\begin{array}{l}14.8 \\
26.6\end{array}$ & 99 U & 0.0177 U & 73.8 \\
\hline 7247 & $100 \mathrm{~B} / \mathrm{C}$ AREA & $\begin{array}{l}\text { ER MOUSE } \\
\text { ER }\end{array}$ & $\begin{array}{l}\text { LIVR } \\
\text { LIVER }\end{array}$ & $\begin{array}{l}\text { May-03 } \\
\text { May } 03\end{array}$ & $\begin{array}{l}0.8 \\
74.5\end{array}$ & $0.005 \mathrm{U}$ & $\begin{array}{l}0.022 \\
0.287\end{array}$ & 30 & $0.04 \mathrm{U}$ & $\begin{array}{l}5.93 \\
6.53\end{array}$ & $\begin{array}{l}0.04 \\
0.04\end{array}$ & $\begin{array}{l}0.69 \\
0.21\end{array}$ & $\begin{array}{l}0.08 \\
0.08\end{array}$ & $\begin{array}{l}0.05 \\
0.07\end{array}$ & $\begin{array}{l}0.021 \mathrm{U} \\
0.021 \mathrm{u}\end{array}$ & $\begin{array}{l}0.031 \mathrm{U} \\
0.031 \mathrm{U}\end{array}$ & $\begin{array}{l}3.34 \\
4.16\end{array}$ & $\begin{array}{l}0.199 \mathrm{U} \\
0.199 \mathrm{U}\end{array}$ & $\begin{array}{l}.0188 \mathrm{U} \\
0.0188 \mathrm{U}\end{array}$ & $\begin{array}{l}26.6 \\
29.6\end{array}$ & 9 & 1177 U & $\begin{array}{l}122 \\
149\end{array}$ \\
\hline 248 & $100 \mathrm{~B} / \mathrm{C}$ AREA & R MOUSE & LIVER & May-03 & 66.7 & $0.005 \mathrm{u}$ & 0.031 & 7.85 & $0.04 \mathrm{U}$ & $\begin{array}{l}8.00 \\
3.60\end{array}$ & $0.04 \mathrm{U}$ & 0.10 & 0.19 & $0.03 \mathrm{U}$ & $0.021 \mathrm{u}$ & $0.031 \mathrm{U}$ & 0.211 & $0.199 \mathrm{U}$ & $0.0188 \mathrm{U}$ & 15.2 & $189 \mathrm{U}$ & $0177 \mathrm{U}$ & 75.7 \\
\hline 7249 & $100 \mathrm{~B} / \mathrm{C}$ AREA & MOUSE & $\begin{array}{l}\text { LIVER } \\
\text { L }\end{array}$ & May-03 & 70.2 & $0.005 \mathrm{U}$ & $0.015 \mathrm{U}$ & & $0.04 \cup$ & 3.33 & 0.04 & 0.03 & 0.08 & 0.07 & 0.021 & $0.031 \mathrm{U}$ & 1.58 & $0.199 \mathrm{U}$ & $10188 \mathrm{U}$ & 13.3 & & $177 \cup$ & 85.4 \\
\hline 251 & A & ER MOUSE & $\begin{array}{l}\text { LIVER } \\
\text { LVERR }\end{array}$ & May-03 & 72.5 & $\begin{array}{l}0.029 \\
-0.96\end{array}$ & $0.015 \mathrm{U}$ & 4 & $0.04 \mathrm{U}$ & $\begin{array}{l}4.83 \\
4.53 \\
-15\end{array}$ & & $0.03 \mathrm{U}$ & & 0.04 & & $0.031 \mathrm{U}$ & & $0.199 \mathrm{U}$ & $10188 \mathrm{U}$ & 21.9 & 189 U & 177 U & 102 \\
\hline $\begin{array}{l}77479 \\
7 \mathrm{H} 79\end{array}$ & $\begin{array}{l}100 \mathrm{~B} / \mathrm{C} \text { AREA UF } \\
100-\mathrm{B} \text { SPING } 3 \mathrm{~S}\end{array}$ & $\begin{array}{l}\text { ER MOUSE } \\
\text { ER MOUSE }\end{array}$ & $\begin{array}{l}\text { LIVER } \\
\text { LIVER }\end{array}$ & $\begin{array}{l}\text { Nov-03 } \\
\text { Sep-03 }\end{array}$ & $\begin{array}{l}77.3 \\
72.6\end{array}$ & $\begin{array}{l}0.096 \\
0.0685\end{array}$ & $\begin{array}{l}0.357 \\
0.312\end{array}$ & 9.04 & $\begin{array}{r}0.13 \\
0.047\end{array}$ & $\begin{array}{l}4.53 \\
5.56\end{array}$ & $0.04 U$ & 0.22 & $\begin{array}{l}0.13 \\
0.109\end{array}$ & 0.13 & $0.021 \mathrm{u}$ & 0.031 U & $\begin{array}{l}4.65 \\
0.565\end{array}$ & 0.185 & $\begin{array}{l}0.0188 \mathrm{U} \\
0.0188 \mathrm{Y}\end{array}$ & 19.3 & 89 U $89-25$ & 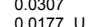 & 106 \\
\hline $7 \mathrm{H} 80$ & $100 \mathrm{~B} / \mathrm{C}$ AREA OUTFL1 & $\begin{array}{l}\text { ER MOUSE } \\
\text { ERE }\end{array}$ & $\begin{array}{l}\text { LIVRR } \\
\text { LIVER }\end{array}$ & 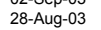 & 72.6 & $\begin{array}{l}0.06036 \\
0.0636\end{array}$ & 0.279 & $\begin{array}{l}7.07 \\
9.07\end{array}$ & 0.0703 & $\begin{array}{l}5.00 \\
6.28\end{array}$ & $0.0445 \mathrm{U}$ & 0.223 & $0.0303 \mathrm{U}$ & $0.0338 \mathrm{U}$ & $0.021 \mathrm{u}$ & $0.0309 \mathrm{U}$ & $\begin{array}{l}0.365 \\
1.37\end{array}$ & $0.199 \mathrm{U}$ & $0.0188 \mathrm{U}$ & 14.2 & $189 \mathrm{U}$ & $0.177 \mathrm{U}$ & $\begin{array}{r}120 \\
80.7\end{array}$ \\
\hline 7H81 & OUTFL2 & USE & LIVER & Aug-03 & 70.1 & 0.041 & 0.501 & 7.31 & $0.04 \mathrm{U}$ & 5.30 & $0.04 \mathrm{U}$ & 0.15 & 0.23 & $0.03 \mathrm{U}$ & $0.021 \mathrm{U}$ & $0.031 \mathrm{U}$ & $1.28 \mathrm{U}$ & 0.409 & $0.0188 \mathrm{U}$ & & $0.0189 \mathrm{U}$ & 0.0427 & 82.3 \\
\hline $7 \mathrm{H} 8$ & $\begin{array}{l}100 \\
100-2 x-3\end{array}$ & E & & Sep-03 & 72.6 & 0.0915 & 255 & 11 & $0.0447 \mathrm{U}$ & 7.1 & $0.0445 U$ & 0.148 & 0.0396 & $0.0338 \mathrm{U}$ & 0.021 U & $0.0309 \mathrm{U}$ & 95 & $0.199 \mathrm{U}$ & $38 \cup$ & 5.2 & 390 & 177 U & 77 \\
\hline & $A D R$ & BRUSH & & - & 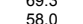 & 00 & 0.038 & & $\begin{array}{l}0.08 \\
2.55\end{array}$ & & $000-2$ & 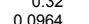 & 0. & 0.03 & & 4 & 4.44 & & & & & & 9.0 \\
\hline 7HW9 & 100 B/C AREA UR & AAY RABBITBRUSH & SHOOT & $\begin{array}{l}\text { Augg-03 } \\
\text { Ans }\end{array}$ & 58.0 & $\begin{array}{l}0.0121 \\
0.0121\end{array}$ & $\begin{array}{l}.0306 \\
0.355\end{array}$ & $\begin{array}{l}32.2 \\
299\end{array}$ & $\begin{array}{l}2.50 \\
257\end{array}$ & $\begin{array}{l}0.0220 \mathrm{U} \\
0.0220\end{array}$ & $\begin{array}{l}0.0445 \mathrm{u} \\
0.045\end{array}$ & $\begin{array}{l}.0 .0574 \\
0.074\end{array}$ & $\begin{array}{l}6.16 \\
6.54\end{array}$ & $\begin{array}{l}0.269 \\
0.269\end{array}$ & $\begin{array}{l}0.0450 \\
0.021\end{array}$ & $\begin{array}{l}0.0399 \mathrm{u} \\
0.0309\end{array}$ & 年397 & $\begin{array}{l}0.005 \\
0.405\end{array}$ & $0.018 \mathrm{U}$ & $\begin{array}{l}5.95 \\
5.99\end{array}$ & $\begin{array}{l}0.0748 \\
0.0348\end{array}$ & $\begin{array}{l}.0 .0257 \\
0.027\end{array}$ & $\begin{array}{l}19.9 \\
19.2\end{array}$ \\
\hline $7 \mathrm{H} \times 0$ & $116-C-5 \mathrm{~S}$ & $\mathrm{SH}$ & SHOOT & Aug-03 & 60.9 & 0.0115 & 0.287 & 26.0 & 0.813 & $0.0220 \mathrm{U}$ & $0.0445 \mathrm{U}$ & 0.0425 & 4.31 & 0.126 & $0.021 \mathrm{U}$ & $0.0309 \mathrm{U}$ & & & & & & & \\
\hline $7 \mathrm{HX1}$ & $116-\mathrm{B}-11 \mathrm{~N}$ & BTBRUSH & SHOOT & Aug-03 & 59.9 & 0.0156 & 0.348 & 20.1 & 0.713 & 0.0590 & $0.0445 \mathrm{U}$ & 0.110 & 7.40 & 0.182 & $0.021 \mathrm{U}$ & $0.0309 \mathrm{l}$ & & & & & & & \\
\hline $\begin{array}{l}\mathrm{H} \times 2 \\
\mathrm{HX} 2\end{array}$ & $\mathrm{c}-1 \mathrm{~s}$ & $\begin{array}{l}\text { IITRUSH } \\
\text { ITBRUSH }\end{array}$ & $\begin{array}{l}\text { SHOO } \\
\text { SHOOT }\end{array}$ & $\begin{array}{l}\text { Aug-o3 } \\
\text { Aug-03 }\end{array}$ & $\begin{array}{l}56.7 \\
61.1\end{array}$ & $\begin{array}{l}0.0131 \\
0.0126\end{array}$ & $\begin{array}{l}0.718 \\
0.722\end{array}$ & 5 & $\begin{array}{l}1.21 \\
1.31\end{array}$ & $\begin{array}{l}0.0220 \mathrm{U} \\
0.0220 \mathrm{U}\end{array}$ & $\begin{array}{l}0.0445 \mathrm{U} \\
0.0445 \mathrm{U}\end{array}$ & $\begin{array}{l}0.103 \\
0.201\end{array}$ & $\begin{array}{l}9.07 \\
7.06\end{array}$ & $\begin{array}{l}0.302 \\
0.165\end{array}$ & $\begin{array}{l}0.0622 \\
0.0398\end{array}$ & & & & & & & & \\
\hline 7233 & 100 B/C AREA & $\begin{array}{l}\text { ASIN POCKET } \\
\text { Als }\end{array}$ & LIVER & 6-May-03 & 78.0 & $\begin{array}{r}0.0126 \\
0.019\end{array}$ & 0.047 & 14.4 & 0.11 & 3.05 & $\begin{array}{l}0.0445 \mathrm{u} \\
0.04\end{array}$ & 0.10 & 0.11 & $\begin{array}{l}0.105 \\
9.28\end{array}$ & $\begin{array}{l}0.0398 \mathrm{u} \\
0.021 \mathrm{u}\end{array}$ & $0.031 \mathrm{u}$ & 2.03 & $0.199 \mathrm{U}$ & 0.108 & 16.9 & $0.0189 \mathrm{U}$ & 0.0553 & 94.1. \\
\hline 7240 & $100 \mathrm{~B} / \mathrm{C}$ AREA & $\begin{array}{l}\text { MOUSE } \\
\text { GREAT BASIN POCKET }\end{array}$ & LIVER & 07-May-03 & 70.5 & $0.005 \mathrm{U}$ & 0.034 & 13.9 & $0.04 \mathrm{U}$ & 1.04 & $0.04 \mathrm{U}$ & 0.50 & 0.07 & $0.03 \mathrm{U}$ & $0.021 \mathrm{U}$ & $0.031 \mathrm{U}$ & 0.701 & 0.201 & 0.0522 & 18.6 & $0.0189 \mathrm{U}$ & $0.0177 \mathrm{U}$ & \\
\hline 7241 & $100 \mathrm{~B} / \mathrm{C}$ AREA & $\begin{array}{l}\text { MOUSE } \\
\text { GREAT BASIN POCKET }\end{array}$ & LIVER & 07-May-03 & 66.1 & $0.005 \mathrm{U}$ & 0.015 & 11.0 & 0.05 & 1.00 & $0.04 \mathrm{U}$ & 0.17 & $0.01 \cup$ & 0.07 & 0.021 U & 0.031 U & 5.62 & 0.199 U & $0.0188 \mathrm{U}$ & 12.7 & 0.0195 & 0.0177 U & 71.5 \\
\hline 24 & 110 B/CAREA & EAL BASIN P & HVER & 07-Mav-0з & 708 & 0010 & 0121 & 117 & $004 \mathrm{H}$ & 124 & 00. & 01 & 01 & 0 & $0021 \mathrm{u}$ & $0031 \mathrm{u}$ & 110 & 1994 & 00673 & 170 & 001894 & 001774 & \\
\hline (1) & 1000 & MOUSE & 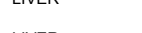 & $a^{2}+2$ & (2) & 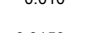 & 2079 & & 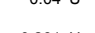 & 1.2 & $y^{2}+2$ & 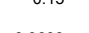 & 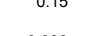 & 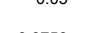 & & & 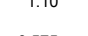 & . $199 \mathrm{U}$ & 0.06 & & & & \\
\hline & $100 \mathrm{~B} / \mathrm{C}$ AREA UR & GREA & LIVER & 09-Sep-03 & 12.6 & 0.0159 & 0.210 & 12.8 & $0.261 \mathrm{U}$ & 1.97 & & & 0.336 & 0.0/56 & $0.021 \mathrm{U}$ & $0309 \mathrm{U}$ & $0.5 / 5$ & 0.794 & $0.0188 \mathrm{U}$ & 13.9 & $0.0189 \mathrm{U}$ & $0.0177 \mathrm{U}$ & 8.4 \\
\hline $7 \mathrm{H} 75$ & $100 \mathrm{~B} / \mathrm{C}$ AREA UR & T BASIN POCKET & LIVER & 09-Sep-03 & 72.6 & 0.0881 & 0.269 & 4.25 & 0.137 & 4.06 & $0.0445 \mathrm{U}$ & 0.107 & $0.0303 \mathrm{U}$ & $0.0338 \mathrm{U}$ & 0.021 U & $0.0309 \mathrm{U}$ & 0.115 & 0.210 & $0.0188 \mathrm{U}$ & 14.8 & $0.0189 \mathrm{U}$ & $0.0177 \cup$ & 80.6 \\
\hline $17 \mathrm{H76}$ & $100 \mathrm{~B} / \mathrm{C}$ AREA UR & GREAT BASIN POCKET & LIVER & 10-Sep-03 & 72.6 & 0.0928 & 0.238 & 6.00 & 0.0447 & 7.81 & $0.0445 U$ & 0.307 & $0.0303 \mathrm{U}$ & 0.0992 & $0.021 \mathrm{U}$ & $0.0309 \mathrm{U}$ & $0.109 \mathrm{U}$ & 0.196 & $0.0188 \mathrm{U}$ & 15.3 & $0.0189 \cup$ & $0.0177 \cup$ & 72.1 \\
\hline H73 & OB/C AREAU & IOUSE & LIVER & 04-Sep-03 & 72. & 0.0724 & 0.256 & 69 & 0.04 & 4.6 & $0.6>>>$ & 0.0951 & $0.0303 \cup$ & 0.199 & $u$ & 90 & $0.109 \mathrm{U}$ & $0.199 \mathrm{U}$ & $u$ & 13.0 & $u$ & 0.01 & 97.2 \\
\hline & & & & & . & 0.0 & & & 0.7 & 1.2 .25 & t & 1.23 & 8.35 & 1.31 & 0.05 & & 626 & 0.49 & & 9.1. & & 0.07770 & 223 \\
\hline 259 & $100 \mathrm{E}$ & & wh & & 49. & 0.0 & & & 0.8 & 0.18 & & 0.32 & $\begin{array}{l}8.61 \\
8.61\end{array}$ & 0.29 & & & 18 & & & 17.9 & & $0.0177 \cup$ & 91.0 \\
\hline & & & & & 59. & . & & & $1.52 .5-1$. & & & 0. & & . & & & 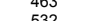 & & & 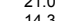 & & & 86.0 \\
\hline 20 & & & $w$ & & 59 59 & 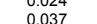 & & & . & 0.13 & & 04 & 7 & 2. & & & 列 & & & & & 0.017 u & $\begin{array}{l}80.7 \\
972\end{array}$ \\
\hline & 100 & & w & & 57.5 & 0.01 & 0.3 & 52.8 & 0.3 & 0.58 & 0.0 & 0.58 & 4.4 & 0.6 & & $0.031 \mathrm{u}$ & 257 & 0.511 & $0.0188 \mathrm{U}$ & 36.0 & & $0.0177 \mathrm{U}$ & 142 \\
\hline & & & & & 72. & 0.0 & 7.0 & & 4.8 & 5. & & 11. & 42. & 6. & & & 4264 & 4. & & 13.91 & & 0.070 & 20 \\
\hline & & & & & $\begin{array}{l}40 \\
38\end{array}$ & 0.0 & & & 0.4 & & & & & & & & 24 & & & & & & 12 \\
\hline HH62 & 100 & $\begin{array}{l}\text { RATE } \\
\text { RATE }\end{array}$ & w & & $\begin{array}{l}38 \\
47\end{array}$ & $\begin{array}{l}0.0 \\
0.0\end{array}$ & & & 0.2 & 5.8 & 0.2 & 6 . & 3. & & & & ${ }_{18}^{26}$ & 0.65 & & $\begin{array}{l}68.61 \\
2935\end{array}$ & & 03 & 33 \\
\hline 3 & & RATE & & & 年9 & $\begin{array}{l}0.0 \\
0.1\end{array}$ & & & 1.2 & & & $\begin{array}{l}7.141 \\
5.14\end{array}$ & $\begin{array}{l}13 . \\
52 .\end{array}$ & 0.8 & & 0.6 & $\begin{array}{l}186 \\
679\end{array}$ & & & $\begin{array}{l}29.35 \\
85.25\end{array}$ & & $\begin{array}{l}82 \\
79\end{array}$ & 79 \\
\hline & & & & & 49 . & 0.0 & 1. & & 0.4 & $4.8>3$ & & 6. & 5. & 0. & & $0.6-4>3$ & 44 & 0.85 & 80 & 64 & & 16 & 26 \\
\hline & & ATE & & & 61 & & & & & & & & & & & & & & & 6 & & & \\
\hline & & & & & 92. & 0.03 & & & 11. & & & & & & & & 771 & & & 的, & & 0.1 & 82 \\
\hline & & & & & 89 & 0.6 & & & 12 & & & & & & & . & 10044 & $\begin{array}{l}3.6 \\
46\end{array}$ & . 0.18 & $\begin{array}{l}14.2 \\
143\end{array}$ & $\begin{array}{l}0.192 \\
0.197\end{array}$ & $\begin{array}{l}0.223 \\
0.222\end{array}$ & 175 \\
\hline & & & & & 88 & 0.0 & & & 12. & & & & & & & & & & & & & & \\
\hline & & & & & & & & & & & & & 11 & & & & & & & & & & \\
\hline & & & & & $\begin{array}{l}88 \\
89\end{array}$ & & & & & & & & & & & & & & & & & & \\
\hline$H_{H}$ & $\begin{array}{l}100 \mathrm{~B} / \mathrm{C} \\
100 \mathrm{~B} / \mathrm{C}\end{array}$ & Y & & & 89 & 0.0 & 7. & & 6 . & & & 1.7 & $\begin{array}{r}101 \\
17\end{array}$ & 6. & & & & & & & & & \\
\hline & $100-\mathrm{E}$ & & & & . & 0.0 & & & & & 0.04 & 0.04 & 56. & & & & .4 & & & & & & \\
\hline & & & & 3 & 73 & 0.0 & & & 2. & 0. & 0.0 & 0.034 & 47 & 0.04 & & & 53. & & & 7. & & 70 & \\
\hline & & & SHOOT & & 74 & 0.0 & & & & & & & 58. & 0. & & & & & & ${ }^{53}$ & & & 24 \\
\hline & & & & & $\begin{array}{l}81 \\
82\end{array}$ & & & & & & & 0. & & & & & $\begin{array}{l}773 . \\
76 .\end{array}$ & & & & & & 16 \\
\hline & & & & & 79 & 0.0 & & & 2. & & & 0.8 & ${ }_{31}^{25}$ & 0. & & & & & & & & 10 & 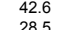 \\
\hline & & & ROOT_S & & 70 & & & & & & & & & & & & & & & 09 & & & .7 \\
\hline & 100 & EDC & ROOTS & & 81 & & & & & & & & & & & & 124 & & & 98 & & & \\
\hline $\begin{array}{c}B \\
B\end{array}$ & & & & & 66.8 & 0.02 & & & 3.22 & & & & 42. & & & & 2003 & & & 9.29 & & & 82.7 \\
\hline $\begin{array}{l}7448 \\
7449\end{array}$ & $\begin{array}{l}100 \mathrm{~B} / \mathrm{C} A R \\
1\end{array}$ & SS & & 3 & $\begin{array}{l}72.9 \\
70.7\end{array}$ & & & & 1.2. & & & 0.5 & & 0. & & & 555 & & & 9.59 & & 0.119 & 61.5 \\
\hline A & $100 \mathrm{~B} / \mathrm{CA}$ & iss & ROOT- $_{-}^{-1}$ & 3 & $\begin{array}{l}7.1 \\
66.5\end{array}$ & $0.005 \mathrm{U}$ & 0. & $\begin{array}{l}18.7 \\
25.7\end{array}$ & $\begin{array}{l}1.27 \\
0.65\end{array}$ & $0.0220 \mathrm{u}$ & 0.0 & $\begin{array}{l}0.31 \\
0.11\end{array}$ & $\begin{array}{l}6 . \\
8\end{array}$ & 0. & $\begin{array}{l}0.021 \mathrm{u} \\
0.021 \mathrm{u}\end{array}$ & $\begin{array}{l}0.0 \\
0.0\end{array}$ & $\begin{array}{l}6.15 \\
249\end{array}$ & 0. & 3 & $\begin{array}{l}12.4 \\
3.29\end{array}$ & 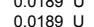 & 0.0177 U & $\begin{array}{l}1122 \\
275\end{array}$ \\
\hline & $100 \mathrm{~B} / \mathrm{C}$ AREA DR & NARY GRASS & & 3 & 68.6 & 0.013 & & 8 & 2. & 0.0 & & 1.28 & 36.16 & 2.16 & 0.709 & 0.4 & 1853 & 0 & 0.0366 & 14.73 & 0.03 & 0.180 & 149 \\
\hline & $100 \mathrm{~B} / \mathrm{C}$ AREA UR & HISTLE & ROOT_SH & 33 & 67.7 & 0.0047 U & & 7 & 0.76 & 0.02 & & 0.754 & 12.3 & 63 & & $9 u$ & 127 & 0.0969 & $0.0188 \mathrm{U}$ & 5.35 & 0.0219 & 0.0346 & 36.4 \\
\hline & & & & & 76.2 & & & & 0.2 & & & & 21 & & & & & & & & & & \\
\hline & & & $\begin{array}{l}\text { ROOT-S } \\
\text { ROT }\end{array}$ & & 16.2 & & $\begin{array}{l}0.628 \\
0.484\end{array}$ & $\begin{array}{l}18.5 \\
35.3 \\
\end{array}$ & 0.2 & & & 34 & 21. & & & & & & & & & & \\
\hline & & STLE & ROOT_S & & & & & & & & & & & & & & & & & & & & \\
\hline
\end{tabular}


Table B-1. Metals in Biota, 2003 (Concentrations in $\mu \mathrm{g} / \mathrm{g}$ dry wt - blank corrected)

\begin{tabular}{|c|c|c|c|c|c|c|c|c|c|c|c|c|c|c|c|c|c|c|c|c|c|c|c|}
\hline Samp & & & & & & & & & & & & & & & & & & & & & & & \\
\hline$\frac{\mathrm{Num}}{\mathrm{B}}$ & Samp Site Name & Samp From & Samp ltem & Samp Date & Moisture & $\mathrm{Hg}$ & $\mathrm{Cr}$ & $\mathrm{Mn}$ & $\mathrm{Ni}$ & $\mathrm{Se}$ & $\mathrm{Ag}$ & $\mathrm{Cd}$ & $\mathrm{Ba}$ & $\mathrm{Pb}$ & Th & u & Al & As & $\mathrm{Be}$ & $\mathrm{Cu}$ & $\mathrm{st}$ & TI & \\
\hline $\begin{array}{l}17 \mathrm{JHA} \\
17 \mathrm{JH} 2\end{array}$ & VERNITA & SCULPIN & LIVER & 28-Aug-03 & 72.6 & 0.219 & 0.228 & 2.94 & 0.0908 & 6.71 & & 4.25 & & 0.0338 & 0.129 & & & 1.20 & 0.0188 & & & & 204 \\
\hline $\mathrm{JH}$ & $\begin{array}{l}\text { VERNIIA } \\
\text { VERNITA }\end{array}$ & $\begin{array}{l}\text { UULPIN } \\
\text { ULPIN }\end{array}$ & $\begin{array}{l}\text { LIVER } \\
\text { IUVR }\end{array}$ & 8-Aug-03 & 72.6 & 0.104 & 0.443 & 4.09 & 0.168 & $\begin{array}{l}8.46 \\
.37\end{array}$ & $0.0445 \mathrm{U}$ & 4.94 & 0.0539 & 0.156 & 0.021 & $0.0309 \mathrm{U}$ & & 1.40 & $0.0188 \mathrm{U}$ & 20.4 & 0.0520 & 0.118 & 139 \\
\hline $\mathrm{JHH}$ & VERNITA & ULPIN & IVER & $\begin{array}{l}\text { 3-Aep-03 } \\
\text { 3-Ses }\end{array}$ & 72.6 & $\begin{array}{l}0.16 \\
0.17\end{array}$ & 0.518 & $\begin{array}{l}1.40 \\
2.11\end{array}$ & $\begin{array}{l}0.149 \\
0.144\end{array}$ & 8.41 & 0.044 & $\begin{array}{l}1.18 \\
511\end{array}$ & $\begin{array}{l}0.242 \\
0.0918\end{array}$ & 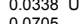 & 0.0335 & 0.0339 & 6. & 19 & 001 & & & & $\begin{array}{l}105 \\
173\end{array}$ \\
\hline JHS & VERNITA & ULPIN & IVER & - Sep-03 & $\begin{array}{l}72.06 \\
726\end{array}$ & 0.15 & $\begin{array}{l}0.150 \\
0211\end{array}$ & $\begin{array}{l}2.117 \\
0.87\end{array}$ & $\begin{array}{l}.0144 \\
0143\end{array}$ & $\begin{array}{l}3.43 \\
383\end{array}$ & $\begin{array}{l}0.0445 \\
0.045\end{array}$ & $\begin{array}{l}5.11 \\
5.44\end{array}$ & $\begin{array}{l}0.098 \\
025\end{array}$ & 0.0484 & $\begin{array}{l}0.021 \mathrm{u} \\
0.021\end{array}$ & 0.0091 & 2. & 39 & $\begin{array}{l}0.00188 \\
0.188\end{array}$ & 31 & $\begin{array}{l}0.0189 \mathrm{U} \\
0.0189\end{array}$ & $\begin{array}{l}0.026 \\
0.74\end{array}$ & $\begin{array}{l}173 \\
164\end{array}$ \\
\hline . & VERNITA & CULPIN & IVER & 3-Sep-03 & $\begin{array}{l}72.6 \\
72.6\end{array}$ & 0.0750 & 0 & $\begin{array}{l}.0802 \\
0.802\end{array}$ & $\begin{array}{l}0.0726 \\
0.076\end{array}$ & $\begin{array}{l}5.05 \\
3.27\end{array}$ & . 0445 & $\begin{array}{l}3.44 \\
1.91\end{array}$ & $\begin{array}{l}0.0303 \\
0.0303\end{array}$ & $\begin{array}{l}.0 .0338 \\
0.0338\end{array}$ & $\begin{array}{l}0.021 \mathrm{u} \\
0\end{array}$ & 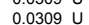 & 0 & $\begin{array}{l}1.15 \\
1.16\end{array}$ & 0.0188 u & 32 & $\begin{array}{l}0.0189 \mathrm{U} \\
0.0198\end{array}$ & 0.0185 & $\begin{array}{r}164 \\
82\end{array}$ \\
\hline JH7 & VERNITA & UULPIN & LIVER & 03-Sep-03 & 72.6 & 0.125 & $0.1 \mathrm{U}$ & 0.871 & 0.0682 & 3.58 & $0.0445 \mathrm{U}$ & 2.13 & 0.758 & $0.0338 \mathrm{U}$ & $0.021 \mathrm{U}$ & $0.0309 \mathrm{U}$ & 0.845 & 0.622 & $0.0188 \mathrm{U}$ & 12.6 & $0.0189 \mathrm{U}$ & 0.130 & 106 \\
\hline 7JH8 & VERNITA & IN & LIVER & 03-Sep-03 & 72.6 & 0.178 & 0.105 & 0.753 & 0.131 & 5.10 & $0.0445 \mathrm{U}$ & 9.08 & $0.0303 \mathrm{U}$ & 0.0499 & $0.021 U$ & $0.0309 \mathrm{U}$ & 3.16 & 1.09 & $0.0188 \mathrm{U}$ & 7.81 & $0.0189 \mathrm{U}$ & 0.123 & 156 \\
\hline $\begin{array}{l}7 \mathrm{7HJ9} \\
7 \mathrm{JJO}\end{array}$ & $\begin{array}{l}\text { VERNITA } \\
\text { VERNITA }\end{array}$ & ULPIN & $\begin{array}{l}\text { LIVER } \\
\text { LIVRR }\end{array}$ & $\begin{array}{l}\text { 03-Sep--03 } \\
03-S e p-03\end{array}$ & $\begin{array}{l}72.6 \\
72.6\end{array}$ & $\begin{array}{l}0.304 \\
0.321\end{array}$ & $\begin{array}{l}0.169 \\
0.138\end{array}-\mathrm{l}$ & $\begin{array}{l}1.25 \\
1.83\end{array}$ & 0.129 & $\begin{array}{l}6.21 \\
7.20 \\
-\end{array}$ & $\begin{array}{l}0.0445 U \\
0.0445 \mathrm{U}\end{array}$ & $\begin{array}{l}4.27 \\
5.5\end{array}$ & $\begin{array}{l}0.0746 \\
0.0478\end{array}$ & 0.0464 & $0.021 \mathrm{u}$ & $0.0309 \mathrm{U}$ & 1.02 & 1.69 & $0.0188 \mathrm{U}$ & $\begin{array}{l}23.6 \\
437\end{array}$ & 0.0189 U & 0.187 & 171 \\
\hline $\begin{array}{l}-517 N 89 \\
\text { B17 }\end{array}$ & $100 \mathrm{~B} / \mathrm{C}$ AREA OUTFL1 & SCULPIN & $\begin{array}{l}\text { LIVER } \\
\text { LIER }\end{array}$ & 23-Sep-03 & $\begin{array}{l}72.6 \\
55.4\end{array}$ & $\begin{array}{l}0.321 \\
0.211\end{array}$ & $\begin{array}{l}0.138 \\
0.995\end{array}-1$ & $\begin{array}{l}1.83 \\
3.26\end{array}$ & $\begin{array}{l}0.118 \\
0.04 \mathrm{U}\end{array}$ & $\begin{array}{l}7.00 \\
8.05\end{array}$ & $0.0445 \mathrm{U}$ & $\begin{array}{l}5.05 \\
8.55\end{array}$ & $\begin{array}{r}0.0478 \\
0.52\end{array}$ & $\begin{array}{l}0.0508 \\
0.27\end{array}$ & $\begin{array}{l}0.021 \mathrm{U} \\
0.021 \mathrm{U}\end{array}$ & $\begin{array}{l}0.0309 \mathrm{U} \\
0.031 \mathrm{U}\end{array}$ & & & & & & & \\
\hline B17N90 & $100 \mathrm{~B} / \mathrm{C}$ AREA OUTFL2 & SCULPIN & LIVER & 30-Sep-03 & $\begin{array}{l}50.4 \\
69.8\end{array}$ & $\begin{array}{l}0.167 \\
0.167\end{array}$ & 0.356 & $\begin{array}{r}3.26 \\
2.95\end{array}$ & $0.04 \mathrm{U}$ & 6.73 & $0.04 \mathrm{U}$ & $\begin{array}{l}8.53 \\
3.48\end{array}$ & 0.15 & $\begin{array}{l}0.27 \\
0.04\end{array}$ & $0.021 \mathrm{U}$ & $0.031 \mathrm{U}$ & & & & & & & \\
\hline 1 & $100 \mathrm{~B} / \mathrm{C}$ & SCULPIN & LIVER & 30-Sep-03 & 76.3 & 0.740 & 0.317 & 3.42 & 0.09 & 8.22 & 0.07 & 15.10 & 0.04 & 0.06 & $0.021 \mathrm{U}$ & $0.031 \mathrm{U}$ & & & & & & & \\
\hline 7N92 & $100 \mathrm{~B} / \mathrm{C}$ & SCULPIN & LIVER & $30-5$ & 72.1 & 0.134 & 0.639 & $\begin{array}{l}3.92 \\
8.73\end{array}$ & $0.04 \mathrm{U}$ & 6.40 & 0. & 3.81 & 0.39 & 0.04 & 0.021 & 0.031 U & 4.11 & 2.07 & 0.0900 & 12.8 & $0.0189 \mathrm{U}$ & 0.289 & 124 \\
\hline NE & $\begin{array}{l}100 \mathrm{~B} / \mathrm{C} \text { AREA } \\
100 \mathrm{~B} / \mathrm{AREA}\end{array}$ & $\begin{array}{l}\text { SCULIIN } \\
\text { SUCKER }\end{array}$ & $\begin{array}{l}\text { WHOLEORG } \\
\text { WHOLEORG }\end{array}$ & $\begin{array}{l}23-\mathrm{Sep}-03 \\
23-\mathrm{Sep}-03\end{array}$ & $\begin{array}{l}77.0 \\
78.8\end{array}$ & $\begin{array}{l}0.085 \\
0.028\end{array}$ & $\begin{array}{l}0.694 \\
1082\end{array}$ & $\begin{array}{l}8.73 \\
632\end{array}$ & $\begin{array}{l}0.68 \\
1.06\end{array}$ & $\begin{array}{l}2.23 \\
136 \\
236\end{array}$ & $\begin{array}{l}0.04 \mathrm{U} \\
0.04 \mathrm{U}\end{array}$ & $\begin{array}{l}0.22 \\
0.09\end{array}$ & $\begin{array}{l}16.03 \\
16.43 \\
\end{array}$ & $\begin{array}{l}0.13 \\
0.26\end{array}$ & 0.0210 & $\begin{array}{l}0.0310 \\
0.040\end{array}$ & $\begin{array}{l}44.9 \\
280\end{array}$ & $\begin{array}{l}0.0969 \mathrm{U} \\
0.069 \mathrm{u}\end{array}$ & $\begin{array}{l}0.0188 \mathrm{U} \\
0.0188 \mathrm{y}\end{array}$ & $\begin{array}{l}4.98 \\
{ }_{2}\end{array}$ & $\begin{array}{l}0.0189 \mathrm{U} \\
0.0189 \mathrm{U}\end{array}$ & $\begin{array}{l}0.143 \\
0.077\end{array}$ & 88.0 \\
\hline 3 & $100-B$ SPR & SUCKER & OOLE & $\begin{array}{l}\text { 23-Sep--033 } \\
\text { 23-Sep-03 }\end{array}$ & $\begin{array}{l}88.8 \\
79.4\end{array}$ & $\begin{array}{l}.0 .028 \\
0.049\end{array}$ & $\begin{array}{l}1.082 \\
4.215\end{array}$ & $\begin{array}{l}63.2 \\
54.4\end{array}$ & $\begin{array}{l}1.06 \\
1.54\end{array}$ & $\begin{array}{l}1.36 \\
2.08\end{array}$ & $0.04 \mathrm{U}$ & $\begin{array}{l}0.09 \\
0.13\end{array}$ & $\begin{array}{l}16.43 \\
22.27\end{array}$ & $\begin{array}{l}.0 .26 \\
100\end{array}$ & $\begin{array}{l}0.021 \\
1.780\end{array}$ & $\begin{array}{l}0.040 \\
0.184\end{array}$ & & & & & & & \\
\hline 38 & $100-B S$ & ER & OLE & 23 & 78.7 & 0.045 & 1.4 & 51.2 & 1.30 & 1.65 & 0.04 & 0.13 & 14.97 & 0.38 & 0.042 & 0.032 & & & & & & & \\
\hline & & & & & 78.7 & & 1.195 & 44.2 & 0.27 & 1.36 & 0 & . & 12.97 & . & 0.139 & $0.031 \mathrm{U}$ & & & & & & & \\
\hline 3 & $100 \mathrm{~B} / \mathrm{C}$ & & IE & & $\begin{array}{l}78.4 \\
812\end{array}$ & 0.040 & $\begin{array}{l}73.25 \\
6711\end{array}$ & 1118 & 32.0 & 0.32 & 0 & $\begin{array}{l}1.44 \\
0.18\end{array}$ & 696 & $\begin{array}{l}49.0 \\
17.3\end{array}$ & 7.43 & $\begin{array}{l}4.19 \\
3.55\end{array}$ & 70547 & 11.9 & 1.58 & 30.8 & 0.641 & 0.651 & 235 \\
\hline 33 & 10 & E & E & $\begin{array}{l}25 \\
25\end{array}$ & $\begin{array}{l}8.12 \\
15.2\end{array}$ & $\begin{array}{l}.0011 \\
0.046\end{array}$ & $\begin{array}{l}6.11 \\
63.03\end{array}$ & $\begin{array}{l}407 \\
939\end{array}$ & $\begin{array}{l}17.8 \\
23.7\end{array}$ & $\begin{array}{l}0.16 \\
0.29\end{array}$ & $\begin{array}{l}0.30 \\
0.37\end{array}$ & $\begin{array}{l}0.18 \\
2.30\end{array}$ & $\begin{array}{l}655 \\
674\end{array}$ & $\begin{array}{l}17.3 \\
38.1\end{array}$ & $\begin{array}{l}4.999 \\
3.78\end{array}$ & $\begin{array}{l}3.55 \\
3.89\end{array}$ & & & & & & & \\
\hline 5 & $100 \mathrm{BIC}$ ARE & CE & E & 25 & $\begin{array}{l}15.2 \\
4.70\end{array}$ & $\begin{array}{l}.0 .046 \\
0.043\end{array}$ & $\begin{array}{l}10.78 \\
100.78\end{array}$ & 778 & 25.5 & $\begin{array}{l}0.19 \\
0.19\end{array}$ & 0.33 & $\begin{array}{l}2.30 \\
0.62\end{array}$ & $\begin{array}{l}108 \\
708\end{array}$ & $\begin{array}{l}28.1 \\
26.7\end{array}$ & 5.75 & $\begin{array}{l}3.69 \\
3.68\end{array}$ & & & & & & & \\
\hline & . & si & NE & 3 & 4.70 & 0.045 & 65 & 1368 & 26.6 & 0.19 & . & 0.86 & 840 & 20 & & 3.10 & & & & & & & \\
\hline & & & & & $\begin{array}{l}16.0 \\
73.8\end{array}$ & & 6375 & $\begin{array}{r}834 \\
4439\end{array}$ & $\begin{array}{l}20.8 \\
46.3\end{array}$ & 0.40 & & 0.86 & $\begin{array}{r}725 \\
1027\end{array}$ & $\begin{array}{l}24 \\
30\end{array}$ & $\begin{array}{l}4.5 \\
8.5\end{array}$ & - & & & & & & & \\
\hline & $\begin{array}{l}100 \mathrm{~B} / \mathrm{C} \\
100 \mathrm{~B} C \mathrm{C}\end{array}$ & SUR & ROO & & $\begin{array}{l}73.8 \\
106\end{array}$ & & $\begin{array}{l}63.75 \\
7829\end{array}$ & $\begin{array}{r}4439 \\
450\end{array}$ & $\begin{array}{l}46.3 \\
199\end{array}$ & 0.40 & & & $\begin{array}{l}1027 \\
802\end{array}$ & & & & & $6 f^{2}$ & & & & & \\
\hline & $100 \mathrm{~B} / \mathrm{C}$ & & ZZNE & 27 & $\begin{array}{l}10.0 \\
1.0\end{array}$ & $\begin{array}{l}0.02124 \\
\end{array}$ & $\begin{array}{r}78.29 \\
47.3\end{array}$ & $\begin{array}{l}8503 \\
883\end{array}$ & $\begin{array}{l}\begin{array}{l}99.9 \\
174\end{array} \\
\end{array}$ & $\begin{array}{l}0.914 \\
0.9022\end{array}$ & $\begin{array}{l}0.40 \\
0.306\end{array}$ & $\begin{array}{l}0.22 \\
0.232\end{array}$ & T. & $\begin{array}{l}10.4 \\
11.2\end{array}$ & $\begin{array}{l}5.100 \\
5.00\end{array}$ & $\begin{array}{l}\text { i.jos } \\
1.84\end{array}$ & 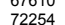 & $\begin{array}{l}2.06 \\
2.46\end{array}$ & $\begin{array}{l}1.100 \\
109\end{array}$ & $\begin{array}{l}20.0 \\
20.0\end{array}$ & $\begin{array}{l}.0 .45 \\
0.45\end{array}$ & $\begin{array}{l}.04303 \\
0.353\end{array}$ & $\begin{array}{l}77.2 \\
78.3\end{array}$ \\
\hline & 100 & su & SURF_- & 25-Aug-03 & 81.6 & 0.048 & 55.83 & 1234 & 27.1 & 0.47 & 0 & 2.01 & 643 & 61.7 & 7.03 & 5.61 & 63353 & 15.1 & 1.24 & 26.3 & 0.685 & 0.520 & 303 \\
\hline & $100-t$ & & $F^{-}$ & & 20.6 & & & 546 & 17.2 & 0.32 & & 0.46 & 624 & 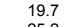 & 3.87 & 2.65 & & & & & & & \\
\hline 20 & $\begin{array}{l}100- \\
100\end{array}$ & & $\begin{array}{l}\text { SUUF_-SOIL } \\
\text { SURF SOIL }\end{array}$ & $\begin{array}{l}\text { 25-Aug-03 } \\
\text { 25-Agg-03 }\end{array}$ & $\begin{array}{l}14.3 \\
61.2\end{array}$ & $\begin{array}{l}0.024 \\
0.061\end{array}$ & $\begin{array}{l}90.68 \\
49.32\end{array}$ & $\begin{array}{l}510 \\
813\end{array}$ & $\begin{array}{l}19.5 \\
22.5\end{array}$ & $\begin{array}{l}0.13 \\
0.34\end{array}$ & $\begin{array}{r}0.34 \\
0.405\end{array}$ & $\begin{array}{l}0.74 \\
1.40\end{array}$ & $\begin{array}{l}677 \\
667\end{array}$ & $\begin{array}{l}25.2 \\
33.9\end{array}$ & $\begin{array}{l}5.20 \\
4.43\end{array}$ & 2.25 & & & & & & & \\
\hline 20 & 10 & & rooll & 25-Aug-03 & & & & & & & & & & & & & & & & & & & \\
\hline & SUTFL2 & SUE & $\begin{array}{l}\text { SURE-SOIL } \\
\text { SURE SOLI }\end{array}$ & $\begin{array}{l}\text { 25-Aug-03 } \\
\text { 25-Aug-03 }\end{array}$ & $\begin{array}{l}13.8 \\
77.2\end{array}$ & 0.103 & $\begin{array}{l}80 . \\
38 \\
.\end{array}$ & $\begin{array}{r}780 \\
1110\end{array}$ & 28. & 0.44 & & 1.93 & $\begin{array}{l}677 \\
884\end{array}$ & & 4.19 & & & & & & & & \\
\hline & /C AREA DR & ACE & SURF SOIL & $\begin{array}{l}\text { 25-Agug-03 } \\
\text { 25-Aug-03 }\end{array}$ & $\begin{array}{l}17.2 \\
15.8\end{array}$ & & $\begin{array}{l}38 . \\
73 .\end{array}$ & 586 & $\begin{array}{l}28.8 \\
22.6\end{array}$ & 0. & & 1. & $\begin{array}{l}884 \\
717\end{array}$ & & $\begin{array}{l}4.6 \\
6.3 \\
6\end{array}$ & & & & & & & & \\
\hline & /C AREA OUTFL1 & & CONCRETE & 27-Oct-03 & & 0.017 & 25.752 & 449 & 16.72 & 0.00 & 0.06 & 0.07 & 177.93 & 3.44 & 2.702 & 1.080 & 435 & 6.15 & 0.451 & 15.4 & 2.03 & 0387 & \\
\hline
\end{tabular}


Table B-2. DDD, DDE, and DDT in Biota, 2003

\begin{tabular}{|c|c|c|c|c|c|c|c|c|c|c|c|c|c|}
\hline $\begin{array}{l}\text { Samp } \\
\text { Num } \\
\end{array}$ & Samp Site Name & Samp From & Samp ltem & $\underline{\text { Samp Date }}$ & $\begin{array}{c}\text { 2,4-DDE (Dichlorodiphenyl- } \\
\text { dichloroethylene) }\end{array}$ & $\begin{array}{c}\text { 4,4'-DDE (Dichlorodiphenyl- } \\
\text { dichloroethylene) }\end{array}$ & $\begin{array}{c}\text { 2,4'-DDD (Dichlorodiphenyl' } \\
\text { dichloroethane) }\end{array}$ & $\begin{array}{l}\text { 4,4'-DDD (Dichlorodiphenyl- } \\
\text { dichloroethane) }\end{array}$ & $\begin{array}{c}\text { 2,4-DDT (Dichlorodiphenyl- } \\
\text { trichloroethane) }\end{array}$ & $\begin{array}{c}\text { 4,4'-DDT (Dichlorodiphenyl- } \\
\text { trichloroethane) }\end{array}$ & Total DDE & $\underline{\text { Total DDD }}$ & $\underline{\text { Total DDT }}$ \\
\hline B174D5 & HORSESHOE LANDFILL & PERENNIAL VEGETATION & ROOT_SHOOT & 19-Jun-03 & $255 \mathrm{D}$ & $6516 \mathrm{D}, \mathrm{E}$ & 21.8 & 16.6 & $418 \mathrm{D}$ & $2067 \mathrm{D}$ & $6771 \mathrm{D}, \mathrm{E}$ & 38.4 & 2486 \\
\hline B174D6 & HORSESHOE LANDFILL & PERENNIAL VEGETATION & ROOT_SHOOT & 19-Jun-03 & $407 \mathrm{D}$ & $3506 \mathrm{D}$ & 5.71 & $7.50 \mathrm{D}$ & $67.5 \mathrm{D}$ & $286 \mathrm{D}$ & $3913 \mathrm{D}$ & $13.2 \mathrm{D}$ & $354 \mathrm{~L}$ \\
\hline B174D7 & HORSESHOE LANDFILL & PERENNIAL VEGETATION & ROOT_SHOOT & 19-Jun-03 & $158 \mathrm{D}$ & $1239 \mathrm{D}$ & 3.23 & $0.88 \mathrm{U}$ & 9.73 & 20.3 & $1397 \mathrm{D}$ & 4.11 & 30.1 \\
\hline B174D8 & HORSESHOE LANDFILL & PERENNIAL VEGETATION & ROOT_SHOOT & 19-Jun-03 & $0.53 \mathrm{U}$ & 25.8 & $0.53 \mathrm{U}$ & 0.57 & 4.15 & 6.52 & 26.4 & 1.10 & 10.7 \\
\hline $\begin{array}{l}\text { B174D9 } \\
\text { B174F0 }\end{array}$ & $\begin{array}{l}\text { HORSESHOOL LANDFFLL } \\
\text { HORSESHOE LANDFILL }\end{array}$ & $\begin{array}{l}\text { PERENNIAL VEGETATION } \\
\text { PRENENNAL VEGETATIN }\end{array}$ & $\begin{array}{l}\text { ROOT_SHOOT } \\
\text { ROOT SHOOT }\end{array}$ & $\begin{array}{l}\text { 19-Jun-03 } \\
\text { 19-Jun-03 }\end{array}$ & $\begin{array}{l}0.24 \mathrm{U} \\
020 \mathrm{U}\end{array}$ & $\begin{array}{l}0.41 \\
0.38\end{array}$ & $\begin{array}{ll}0.24 \mathrm{U} \\
0.20 \mathrm{u}\end{array}$ & $0.24 \mathrm{U}$ & $0.24 \mathrm{U}$ & $0.24 \mathrm{U}$ & 0.652 & $0.484 \mathrm{U}$ & $0.484 \mathrm{~L}$ \\
\hline $\begin{array}{l}\text { B174-0 } \\
\text { B174F1 }\end{array}$ & $\begin{array}{l}\text { HORSESHOE LANDFILL } \\
\text { BACKGROUND }\end{array}$ & $\begin{array}{l}\text { PEERNNNAL VEGETAAIIN } \\
\text { PRERENNAL VEGETATION }\end{array}$ & $\begin{array}{l}\text { ROOT_SHOOT } \\
\text { ROOT SHOOT }\end{array}$ & $\begin{array}{l}\text { 19-Junn-03 } \\
\text { 19-Jun-03 }\end{array}$ & $\begin{array}{l}0.20 \mathrm{U} \\
0.18 \mathrm{u}\end{array}$ & $\begin{array}{l}0.38 \\
0.18 \mathrm{u}\end{array}$ & $\begin{array}{l}0.20 \mathrm{U} \\
0.18 \mathrm{U}\end{array}$ & $\begin{array}{l}0.20 \mathrm{U} \\
0.18 \mathrm{U}\end{array}$ & $\begin{array}{l}0.20 \mathrm{U} \\
0.18 \mathrm{u}\end{array}$ & $\begin{array}{l}0.20 \mathrm{U} \\
0.18 \mathrm{u}\end{array}$ & $\begin{array}{l}0.535 \\
0.358 \mathrm{u}\end{array}$ & $\begin{array}{l}0.410 \mathrm{U} \\
0.358 \mathrm{U}\end{array}$ & $\begin{array}{l}0.410 \mathrm{~L} \\
0.358 \mathrm{~L}\end{array}$ \\
\hline B174F2 & HORSESHOE LANDFILL & $\begin{array}{l}\text { INVERTEBRATE } \\
\text { INTE }\end{array}$ & WHOLEORG & $\begin{array}{l}\text { 19-Junu-03 } \\
\text { 19-Jun-03 }\end{array}$ & $\begin{array}{l}0.180 \\
3.64\end{array}$ & $\begin{array}{l}0.180 \\
6167 \mathrm{D}, \mathrm{E}\end{array}$ & $\begin{array}{l}0.27 \\
1.27\end{array}$ & $\begin{array}{l}.180 \\
1.36\end{array}$ & 3.06 & $\begin{array}{l}0.180 \\
10.5\end{array}$ & $6171 \mathrm{D}, \mathrm{E}$ & 2.63 & $\begin{array}{l}0.358 \mathrm{C} \\
13.6\end{array}$ \\
\hline B174F3 & HORSESHOE LANDFILL & $\begin{array}{l}\text { INVERTEBRATE } \\
\text { INERER }\end{array}$ & WHOLEORG & 19-Jun-03 & 6.37 & $221 \mathrm{D}$ & 0.68 & 0.67 & 2.96 & 8.73 & $227 \mathrm{D}$ & 1.35 & 11.0 \\
\hline B174F4 & HORSESHOE LANDFILL & INVERTEBRATE & WHOLEORG & 19-Jun-03 & $0.39 \mathrm{U}$ & 17.9 & $0.39 \mathrm{U}$ & 0.40 & 0.6 & 0.51 & 18.3 & 0792 & 119 \\
\hline B174F5 & BACKGROUND & INVERTEBRATE & WHOLEORG & 19-Jun-03 & $0.19 \mathrm{u}$ & 0.35 & $0.19 \mathrm{u}$ & $0.19 \mathrm{U}$ & $0.19 \mathrm{U}$ & $0.19 \mathrm{U}$ & 0.540 & $0.380 \mathrm{U}$ & $0.380 \mathrm{C} \longrightarrow \mathrm{C}$ \\
\hline B174F6 & HORSESHOE LANDFILL & POCKET MOUSE & BRAIN & 19-Jun-03 & $1.00 \mathrm{U}$ & $917 \mathrm{D}$ & $1.00 \mathrm{u}$ & 8.95 & $1.00 \mathrm{U}$ & 12.7 & $918 \mathrm{D}$ & 9.95 & 13.7 \\
\hline B174F7 & HORSESHOE LANDFILL & POCKET MOUSE & BRAIN & 19-Jun-03 & $0.76 \mathrm{U}$ & 7.79 & $0.76 \mathrm{U}$ & $0.76 \mathrm{U}$ & $0.76 \mathrm{U}$ & $0.76 \mathrm{U}$ & 8.55 & $1.53 \mathrm{u}$ & $1.53 \mathrm{c}$ \\
\hline B174F8 & HORSESHOE LANDFILL & POCKET MOUSE & BRAIN & 20-Jun-03 & $1.35 \mathrm{U}$ & 83.5 & $1.35 \mathrm{U}$ & 1.36 & $1.35 \mathrm{U}$ & $1.35 \mathrm{U}$ & 84.8 & 2.71 & $2.70 \mathrm{~L}$ \\
\hline B174F9 & BACKGROUND & POCKET MOUSE & BRAIN & 20-Jun-03 & $0.82 \mathrm{U}$ & $0.82 \mathrm{U}$ & $0.82 U$ & $0.82 \mathrm{U}$ & $0.82 \mathrm{U}$ & $0.82 U$ & $1.64 \mathrm{U}$ & $1.64 \mathrm{U}$ & $1.64 \mathrm{C}$ \\
\hline B174HO & HORSESHOE LANDFILL & WESTERN MEADOWLARK & BRAIN & 20-Jun-03 & $0.55 \mathrm{U}$ & $845 \mathrm{D}$ & $0.55 \mathrm{U}$ & $0.55 \mathrm{U}$ & $0.55 \mathrm{U}$ & 2.28 & $845 \mathrm{D}$ & $1.09 \mathrm{U}$ & 2.83 \\
\hline B174H3 & BACKGROUND & HORNED LARK & BRAIN & 16-Jun-03 & $5.00 \mathrm{U}$ & $5.00 \mathrm{U}$ & $5.00 \mathrm{U}$ & $5.00 \mathrm{U}$ & $5.00 \mathrm{U}$ & $5.00 \mathrm{U}$ & $10.0 \mathrm{U}$ & $10.0 \mathrm{U}$ & $10.0 \mathrm{C}$ \\
\hline B1744H & BACKGROUND & $\begin{array}{l}\text { WESTERN MEADOWLARK } \\
\text {. }\end{array}$ & BRAIN & 25-Jun-03 & $0.57 \mathrm{U}$ & $\begin{array}{l}0.57 \mathrm{U} \\
556\end{array}$ & $\begin{array}{l}0.57 \mathrm{U} \\
\end{array}$ & $\begin{array}{l}0.57 \mathrm{U} \\
256\end{array}$ & $0.57 \mathrm{U}$ & $0.57 \mathrm{U}$ & $1.15 \mathrm{U}$ & $1.15 \mathrm{U}$ & $1.15 \mathrm{~L}$ \\
\hline B17445 & BACKGROUND & BULLOCK ORIOLE & BRAIN & 25-Jun-03 & $2.56 \mathrm{U}$ & 5.61 & $2.56 \mathrm{U}$ & $2.56 \mathrm{U}$ & $2.56 \mathrm{U}$ & $2.56 \mathrm{U}$ & 8.17 & $5.13 \mathrm{U}$ & $5.13 \mathrm{~L}$ \\
\hline
\end{tabular}


Soil 
SOIL

\begin{tabular}{|c|c|c|c|c|c|c|c|c|c|c|c|c|c|c|c|}
\hline OWNER ID & SAMP NUM & SAMP SITE NAME & DIST CLASS & MEDIA & SAMP FROM & SAMP ITEM & SAMP DATE & $\begin{array}{l}\text { CON SHORT } \\
\text { NAME }\end{array}$ & VALUE RPTD & $\begin{array}{l}\text { ANAL UNITS } \\
\text { RPTD }\end{array}$ & $\begin{array}{c}\text { COUNTING } \\
\text { ERROR }\end{array}$ & $\begin{array}{l}\text { TOTAL ANAL } \\
\text { ERROR }\end{array}$ & $\begin{array}{c}\text { LAB } \\
\text { QUALIFIER }\end{array}$ & SAMP COMMENT & RESULT COMMENT \\
\hline SESPSPEC & B17HB2 & $100 \mathrm{~B} / \mathrm{C}$ AREA UR & ONSITE & so & SURFACE & ROOTING ZONE & 25 -Aug-03 A & & 0.384 & $\mathrm{ug} / \mathrm{g}$ & & & $\mathrm{C}$ & & \\
\hline SESPSPEC & B17HB3 & 100-B SPRING 38-3 & ONSITE & so & SURFACE & ROOTING ZONE & 25-Aug-03 A & & 0.299 & $\mathrm{ug} / \mathrm{g}$ & & & C & & \\
\hline SESPSPEC & B17HB4 & 100-B SPRING 39-2 & ONSITE & so & SURFACE & ROOTING ZONE & 25-Aug-03 A & & 0.373 & $\mathrm{ug} / \mathrm{g}$ & & & c & & \\
\hline SESPSPEC & B17HB5 & $100 \mathrm{~B} / \mathrm{C}$ AREA OUTFL1 & ONSITE & so & SURFACE & ROOTING ZONE & 25-Aug-03 A & & 0.334 & $\mathrm{ug} / \mathrm{g}$ & & & c & & \\
\hline SESPSPEC & B17HB6 & $100 \mathrm{~B} / \mathrm{C}$ AREA OUTFL2 & ONSITE & so & SURFACE & ROOTING ZONE & 25-Aug-03 A & & 0.282 & ug/g & & & C & & \\
\hline SESPSPEC & B17HB7 & $100 \mathrm{~B} / \mathrm{C}$ AREA OUTFL3 & ONSITE & so & SURFACE & ROOTING ZONE & 25-Aug-03 A & & 0.425 & $\mathrm{ug} / \mathrm{g}$ & & & c & & \\
\hline SESPSPEC & B17HB8 & $100 \mathrm{~B} / \mathrm{C}$ AREA DR & ONSITE & so & SURFACE & ROOTING ZONE & 25-Aug-03 A & & 0.464 & $\mathrm{ug} / \mathrm{g}$ & & & C & & \\
\hline SESPSPEC & $\mathrm{B} 17 \mathrm{H} 17$ & $100 \mathrm{~B} / \mathrm{C}$ AREA UR & ONSITE & so & SURFACE & SURF_SOIL & 25-Aug-03 A & & 0.461 & $\mathrm{ug} / \mathrm{g}$ & & & c & & \\
\hline SESPSPEC & B17H18 & 100-B SPRING 38-3 & ONSITE & so & SURFACE & SURF_SOIL & 25-Aug-03 A & & 0.275 & $\mathrm{ug} / \mathrm{g}$ & & & C & & \\
\hline SESPSPEC & $\mathrm{B} 17 \mathrm{H} 19$ & 100-B SPRING 39-2 & ONSITE & so & SURFACE & SURF_SOIL & 25-Aug-03 A & & 0.338 & $\mathrm{ug} / \mathrm{g}$ & & & C & & \\
\hline SESPSPEC & $\mathrm{B} 17 \mathrm{H} 2 \mathrm{O}$ & $100 \mathrm{~B} / \mathrm{C}$ AREA OUTFL1 & ONSITE & so & SURFACE & SURF_SOIL & 25-Aug-03 A & & 0.405 & $\mathrm{ug} / \mathrm{g}$ & & & C & & \\
\hline SESPSPEC & B17H21 & $100 \mathrm{~B} / \mathrm{C}$ AREA OUTFL2 & ONSITE & so & SURFACE & SURF_SOIL & 25-Aug-03 A & & 0.336 & $\mathrm{ug} / \mathrm{g}$ & & & c & & \\
\hline SESPSPEC & $\mathrm{B} 17 \mathrm{H} 22$ & $100 \mathrm{~B} / \mathrm{C}$ AREA OUTFL3 & ONSITE & so & SURFACE & SURF_SOIL & 25-Aug-03 A & & 0.352 & ug/g & & & C & & \\
\hline SESPSPEC & $\mathrm{B} 17 \mathrm{H} 23$ & $100 \mathrm{~B} / \mathrm{C}$ AREA DR & ONSITE & so & SURFACE & SURF_SOIL & 25-Aug-03 A & & 0.409 & $\mathrm{ug} / \mathrm{g}$ & & & C & & \\
\hline SESPSPEC & B17HB2 & $100 \mathrm{~B} / \mathrm{C}$ AREA UR & ONSITE & so & SURFACE & ROOTING ZONE & 25-Aug-03 A & & 70547 & $\mathrm{ug} / \mathrm{g}$ & & & & & \\
\hline SESPSPEC & B17HB8 & 100 B/C AREA DR & ONSITE & so & SURFACE & ROOTING ZONE & 25-Aug-03 A & & 67610 & $\mathrm{ug} / \mathrm{g}$ & & & & & \\
\hline SESPSPEC & $\mathrm{B} 17 \mathrm{H} 17$ & $100 \mathrm{~B} / \mathrm{C}$ AREA UR & ONSITE & so & SURFACE & SURF_SOIL & 25-Aug-03 A & & 63353 & $\mathrm{ug} / \mathrm{g}$ & & & & & \\
\hline SESPSPEC & $\mathrm{B} 17 \mathrm{H} 23$ & $100 \mathrm{~B} / \mathrm{C}$ AREA DR & ONSITE & so & SURFACE & SURF_SOIL & 25-Aug-03 A & & 69412 & $\mathrm{ug} / \mathrm{g}$ & & & & & \\
\hline SESPSPEC & B17HB2 & $100 \mathrm{~B} / \mathrm{C}$ AREA UR & ONSITE & so & SURFACE & ROOTING ZONE & 25-Aug-03 A & & 11.9 & $\mathrm{ug} / \mathrm{g}$ & & & & & \\
\hline SESPSPEC & B17HB8 & $100 \mathrm{~B} / \mathrm{C}$ AREA DR & ONSITE & so & SURFACE & ROOTING ZONE & 25-Aug-03 A & & 6.62 & $\mathrm{ug} / \mathrm{g}$ & & & & & \\
\hline SESPSPEC & $\mathrm{B} 17 \mathrm{H} 17$ & $100 \mathrm{~B} / \mathrm{C}$ AREA UR & ONSITE & so & SURFACE & SURF_SOIL & 25-Aug-03 A & & 15.1 & $\mathrm{ug} / \mathrm{g}$ & & & & & \\
\hline SESPSPEC & $\mathrm{B} 17 \mathrm{H} 23$ & $100 \mathrm{~B} / \mathrm{C}$ AREA DR & ONSITE & so & SURFACE & SURF_SOIL & 25-Aug-03 A & & 8.67 & $\mathrm{ug} / \mathrm{g}$ & & & & & \\
\hline SESPSPEC & B17HB2 & $100 \mathrm{~B} / \mathrm{C}$ AREA UR & ONSITE & so & SURFACE & ROOTING ZONE & 25-Aug-03 B & & 1.58 & $\mathrm{ug} / \mathrm{g}$ & & & & & \\
\hline SESPSPEC & B17HB8 & $100 \mathrm{~B} / \mathrm{C}$ AREA DR & ONSITE & so & SURFACE & ROOTING ZONE & 25-Aug-03 B & & 1.65 & $\mathrm{ug} / \mathrm{g}$ & & & & & \\
\hline SESPSPEC & B17H17 & 100 B/C AREA UR & ONSITE & so & SURFACE & SURF_SOIL & 25-Aug-03 B & & 1.24 & $\mathrm{ug} / \mathrm{g}$ & & & & & \\
\hline SESPSPEC & $\mathrm{B} 17 \mathrm{H} 23$ & $100 \mathrm{~B} / \mathrm{C}$ AREA DR & ONSITE & so & SURFACE & SURF_SOIL & 25-Aug-03 B & & 1.41 & $\mathrm{ug} / \mathrm{g}$ & & & & & \\
\hline SESPSPEC & B17HB2 & $100 \mathrm{~B} / \mathrm{C}$ AREA UR & ONSITE & so & SURFACE & ROOTING ZONE & 25-Aug-03 C & & 1.44 & $\mathrm{ug} / \mathrm{g}$ & & & C & & \\
\hline SESPSPEC & B17HB3 & 100-B SPRING 38-3 & ONSITE & so & SURFACE & ROOTING ZONE & 25-Aug-03 C & & 0.178 & $\mathrm{ug} / \mathrm{g}$ & & & C & & \\
\hline SESPSPEC & B17HB4 & 100-B SPRING 39-2 & ONSITE & so & SURFACE & ROOTING ZONE & 25-Aug-03 C & & 2.3 & ug/g & & & $\mathrm{c}$ & & \\
\hline SESPSPEC & B17HB5 & $100 \mathrm{~B} / \mathrm{C}$ AREA OUTFL1 & ONSITE & so & SURFACE & ROOTING ZONE & 25-Aug-03 C & & 0.62 & ug/g & & & C & & \\
\hline SESPSPEC & B17HB6 & 100 B/C AREA OUTFL2 & ONSITE & so & SURFACE & ROOTING ZONE & 25-Aug-03 C & & 0.864 & $\mathrm{ug} / \mathrm{g}$ & & & c & & \\
\hline SESPSPEC & B17HB7 & $100 \mathrm{~B} / \mathrm{C}$ AREA OUTFL3 & ONSITE & so & SURFACE & ROOTING ZONE & 25-Aug-03 C & & 3.63 & $\mathrm{ug} / \mathrm{g}$ & & & c & & \\
\hline SESPSPEC & B17HB8 & $100 \mathrm{~B} / \mathrm{C}$ AREA DR & ONSITE & so & SURFACE & ROOTING ZONE & 25-Aug-03 C & & 0.217 & $\mathrm{ug} / \mathrm{g}$ & & & $\mathrm{c}$ & & \\
\hline SESPSPEC & $\mathrm{B} 17 \mathrm{H} 17$ & $100 \mathrm{~B} / \mathrm{C}$ AREA UR & ONSITE & so & SURFACE & SURF_SOIL & 25-Aug-03 C & & 2.01 & $\mathrm{ug} / \mathrm{g}$ & & & C & & \\
\hline SESPSPEC & B17H18 & 100-B SPRING 38-3 & ONSITE & so & SURFACE & SURF_SOIL & 25-Aug-03 C & & 0.46 & $\mathrm{ug} / \mathrm{g}$ & & & c & & \\
\hline SESPSPEC & $\mathrm{B} 17 \mathrm{H} 19$ & 100-B SPRING 39-2 & ONSITE & so & SURFACE & SURF_SOIL & 25-Aug-03 C & & 0.737 & $\mathrm{ug} / \mathrm{g}$ & & & C & & \\
\hline SESPSPEC & $\mathrm{B} 17 \mathrm{H} 2 \mathrm{O}$ & $100 \mathrm{~B} / \mathrm{C}$ AREA OUTFL1 & ONSITE & so & SURFACE & SURF_SOIL & 25-Aug-03 C & & 1.4 & ug/g & & & $\mathrm{c}$ & & \\
\hline SESPSPEC & $\mathrm{B} 17 \mathrm{H} 21$ & $100 \mathrm{~B} / \mathrm{C}$ AREA OUTFL2 & ONSITE & so & SURFACE & SURF_SOIL & 25-Aug-03 C & & 1.93 & ug/g & & & C & & \\
\hline SESPSPEC & $\mathrm{B} 17 \mathrm{H} 22$ & $100 \mathrm{~B} / \mathrm{C}$ AREA OUTFL3 & ONSITE & so & SURFACE & SURF_SOIL & 25-Aug-03 & & 0.732 & $\mathrm{ug} / \mathrm{g}$ & & & C & & \\
\hline SESPSPEC & $\mathrm{B} 17 \mathrm{H} 23$ & $100 \mathrm{~B} / \mathrm{C}$ AREA DR & ONSITE & so & SURFACE & SURF_SOIL & 25-Aug-03 C & & 1.02 & $\mathrm{ug} / \mathrm{g}$ & & & c & & \\
\hline SESPSPEC & B17HB2 & 100 B/C AREA UR & ONSITE & so & SURFACE & ROOTING ZONE & 25-Aug-03 C & & 73.2 & $\mathrm{ug} / \mathrm{g}$ & & & $\mathrm{c}$ & & \\
\hline SESPSPEC & B17HB3 & 100-B SPRING 38-3 & ONSITE & so & SURFACE & ROOTING ZONE & 25-Aug-03 C & & 67.1 & $\mathrm{ug} / \mathrm{g}$ & & & C & & \\
\hline SESPSPEC & B17HB4 & 100-B SPRING 39-2 & ONSITE & so & SURFACE & ROOTING ZONE & 25-Aug-03 & & 63 & $\mathrm{ug} / \mathrm{g}$ & & & C & & \\
\hline SESPSPEC & B17HB5 & $100 \mathrm{~B} / \mathrm{C}$ AREA OUTFL1 & ONSITE & so & SURFACE & ROOTING ZONE & 25-Aug-03 C & & 101 & $\mathrm{ug} / \mathrm{g}$ & & & c & & \\
\hline SESPSPEC & B17HB6 & $100 \mathrm{~B} / \mathrm{C}$ AREA OUTFL2 & ONSITE & so & SURFACE & ROOTING ZONE & 25-Aug-03 C & & 55 & $\mathrm{ug} / \mathrm{g}$ & & & $\mathrm{c}$ & & \\
\hline SESPSPEC & B17HB7 & $100 \mathrm{~B} / \mathrm{C}$ AREA OUTFL3 & ONSITE & so & SURFACE & ROOTING ZONE & 25-Aug-03 C & & 63.7 & ug/g & & & C & & \\
\hline SESPSPEC & B17HB8 & $100 \mathrm{~B} / \mathrm{C}$ AREA DR & ONSITE & so & SURFACE & ROOTING ZONE & 25-Aug-03 & & 78.3 & $\mathrm{ug} / \mathrm{g}$ & & & C & & \\
\hline SESPSPEC & B17H17 & $100 \mathrm{~B} / \mathrm{C}$ AREA UR & ONSITE & so & SURFACE & SURF_SOIL & 25-Aug- 03 & & 55.8 & $\mathrm{ug} / \mathrm{g}$ & & & c & & \\
\hline SESPSPEC & B17H18 & 100-B SPRING 38-3 & ONSITE & so & SURFACE & SURF_SOIL & 25-Aug-03 & & 77.6 & $\mathrm{ug} / \mathrm{g}$ & & & C & & \\
\hline SESPSPEC & B17H19 & 100-B SPRING 39-2 & ONSITE & so & SURFACE & SURF_SOIL & 25-Aug-03 C & & 90.7 & $\mathrm{ug} / \mathrm{g}$ & & & C & & \\
\hline SESPSPEC & $\mathrm{B} 17 \mathrm{H} 2 \mathrm{O}$ & $100 \mathrm{~B} / \mathrm{C}$ AREA OUTFL1 & ONSITE & so & SURFACE & SURF_SOIL & 25-Aug-03 C & & 49.3 & $\mathrm{ug} / \mathrm{g}$ & & & c & & \\
\hline SESPSPEC & $\mathrm{B} 17 \mathrm{H} 21$ & 100 B/C AREA OUTFL2 & ONSITE & so & SURFACE & SURF_SOIL & 25-Aug-03 C & & 80.3 & $\mathrm{ug} / \mathrm{g}$ & & & c & & \\
\hline SESPSPEC & B17H22 & $100 \mathrm{~B} / \mathrm{C}$ AREA OUTFL3 & ONSITE & so & SURFACE & SURF_SOIL & 25-Aug-03 & & 38.2 & $\mathrm{ug} / \mathrm{g}$ & & & C & & \\
\hline SESPSPEC & $\mathrm{B} 17 \mathrm{H} 23$ & $100 \mathrm{~B} / \mathrm{C}$ AREA DR & ONSITE & so & SURFACE & SURF_SOIL & 25-Aug-03 & & 73.5 & $\mathrm{ug} / \mathrm{g}$ & & & C & & \\
\hline SESPSPEC & B17HB2 & $100 \mathrm{~B} / \mathrm{C}$ AREA UR & ONSITE & so & SURFACE & ROOTING ZONE & 25-Aug-03 C & & 30.8 & $\mathrm{ug} / \mathrm{g}$ & & & $c$ & & \\
\hline SESPSPEC & B17HB8 & $100 \mathrm{~B} / \mathrm{C}$ AREA DR & ONSITE & so & SURFACE & ROOTING ZONE & 25-Aug-03 C & & 16.5 & $\mathrm{ug} / \mathrm{g}$ & & & C & & \\
\hline SESPSPEC & B17H17 & $100 \mathrm{~B} / \mathrm{C}$ AREA UR & ONSITE & so & SURFACE & SURF_SOIL & 25-Aug-03 & & 26.3 & $\mathrm{ug} / \mathrm{g}$ & & & C & & \\
\hline SESPSPEC & $\mathrm{B} 17 \mathrm{H} 23$ & $100 \mathrm{~B} / \mathrm{C}$ AREA DR & ONSITE & so & SURFACE & SURF_SOIL & 25-Aug-03 C & & 19.5 & $\mathrm{ug} / \mathrm{g}$ & & & c & & \\
\hline
\end{tabular}


SOIL

\begin{tabular}{|c|c|c|c|c|c|c|c|c|c|c|c|c|c|c|c|}
\hline OWNER ID & SAMP NUM & SAMP SITE NAME & DIST CLASS & MEDIA & SAMP FROM & SAMP ITEM & SAMP DATE & $\begin{array}{c}\text { CON SHORT } \\
\text { NAME }\end{array}$ & VALUE RPTD & $\begin{array}{c}\text { ANAL UNITS } \\
\text { RPTD }\end{array}$ & $\begin{array}{c}\text { COUNTING } \\
\text { ERROR }\end{array}$ & \begin{tabular}{|c|} 
TOTAL ANAL \\
ERROR
\end{tabular} & $\begin{array}{c}\text { LAB } \\
\text { QUALIFIER }\end{array}$ & SAMP COMMENT & RESULT COMMENT \\
\hline SESPSPEC & B17HB2 & $100 \mathrm{~B} / \mathrm{C}$ AREA UR & ONSITE & so & SURFACE & ROOTING ZONE & 25-Aug-03 & & 0.0399 & ug/g & & & & & \\
\hline SESPSPEC & B17HB3 & 100-B SPRING 38-3 & ONSITE & so & SURFACE & ROOTING ZONE & 25-Aug-03 & & 0.0106 & $\mathrm{ug} / \mathrm{g}$ & & & & & \\
\hline SESPSPEC & B17HB4 & 100-B SPRING 39-2 & ONSITE & so & SURFACE & ROOTING ZONE & 25-Aug-03 & & 0.0456 & $\mathrm{ug} / \mathrm{g}$ & & & & & \\
\hline SESPSPEC & B17HB5 & $100 \mathrm{~B} / \mathrm{C}$ AREA OUTFL1 & ONSITE & so & SURFACE & ROOTING ZONE & 25-Aug-03 & & 0.0428 & $\mathrm{ug} / \mathrm{g}$ & & & & & \\
\hline SESPSPEC & B17HB6 & 100 B/C AREA OUTFL2 & ONSITE & so & SURFACE & ROOTING ZONE & 25-Aug-03 & & 0.0332 & ug/g & & & & & \\
\hline SESPSPEC & B17HB7 & $100 \mathrm{~B} / \mathrm{C}$ AREA OUTFL 3 & ONSITE & so & SURFACE & ROOTING ZONE & 25-Aug-03 & & 0.1 & $\mathrm{ug} / \mathrm{g}$ & & & & & \\
\hline SESPSPEC & B17HB8 & $100 \mathrm{~B} / \mathrm{C}$ AREA DR & ONSITE & so & SURFACE & ROOTING ZONE & 25-Aug-03 & & 0.0207 & $\mathrm{ug} / \mathrm{g}$ & & & & & \\
\hline SESPSPEC & B17H17 & 100 B/C AREA UR & ONSITE & so & SURFACE & SURF_SOIL & 25-Aug-03 & & 0.0482 & $\mathrm{ug} / \mathrm{g}$ & & & & & \\
\hline SESPSPEC & B17H18 & 100-B SPRING 38-3 & ONSITE & so & SURFACE & SURF_SOIL & 25-Aug-03 & & 0.0155 & $\mathrm{ug} / \mathrm{g}$ & & & & & \\
\hline SESPSPEC & B17H19 & 100-B SPRING 39-2 & ONSITE & so & SURFACE & SURF SOIL & 25-Aug-03 & & 0.0236 & $\mathrm{ug} / \mathrm{g}$ & & & & & \\
\hline SESPSPEC & $\mathrm{B} 17 \mathrm{H} 20$ & 100 B/C AREA OUTFL1 & ONSITE & so & SURFACE & SURF_SOIL & 25-Aug-03 । & & 0.0607 & $\mathrm{ug} / \mathrm{g}$ & & & & & \\
\hline SESPSPEC & B17H21 & $100 \mathrm{~B} / \mathrm{C}$ AREA OUTFL2 & ONSITE & so & SURFACE & SURF_SOIL & 25-Aug-03 & & 0.103 & $\mathrm{ug} / \mathrm{g}$ & & & & & \\
\hline SESPSPEC & $\mathrm{B} 17 \mathrm{H} 22$ & 100 B/C AREA OUTFL3 & ONSITE & so & SURFACE & SURF_SOIL & 25-Aug-03 & & 0.0201 & ug/g & & & & & \\
\hline SESPSPEC & $\mathrm{B} 17 \mathrm{H} 23$ & $100 \mathrm{~B} / \mathrm{C}$ AREA DR & ONSITE & so & SURFACE & SURF_SOIL & 25-Aug-03 & & 0.0354 & $\mathrm{ug} / \mathrm{g}$ & & & & & \\
\hline SESPSPEC & B17HB2 & $100 \mathrm{~B} / \mathrm{C}$ AREA UR & ONSITE & so & SURFACE & ROOTING ZONE & 25-Aug-03 N & $\mathrm{Mn}$ & 1118 & $\mathrm{ug} / \mathrm{g}$ & & & & & \\
\hline SESPSPEC & B17HB3 & 100-B SPRING 38-3 & ONSITE & so & SURFACE & ROOTING ZONE & 25 -Aug-03 N & & 407 & $\mathrm{ug} / \mathrm{g}$ & & & & & \\
\hline SESPSPEC & B17HB4 & 100-B SPRING 39-2 & ONSITE & so & SURFACE & ROOTING ZONE & 25-Aug-03 N & & 939 & $\mathrm{ug} / \mathrm{g}$ & & & & & \\
\hline SESPSPEC & B17HB5 & $100 \mathrm{~B} / \mathrm{C}$ AREA OUTFL1 & ONSITE & so & SURFACE & ROOTING ZONE & 25 -Aug-03 N & & 778 & $\mathrm{ug} / \mathrm{g}$ & & & & & \\
\hline SESPSPEC & B17HB6 & $100 \mathrm{~B} / \mathrm{C}$ AREA OUTFL2 & ONSITE & so & SURFACE & ROOTING ZONE & 25-Aug-03 N & & 834 & $\mathrm{ug} / \mathrm{g}$ & & & & & \\
\hline SESPSPEC & B17HB7 & $100 \mathrm{~B} / \mathrm{C}$ AREA OUTFL3 & ONSITE & so & SURFACE & ROOTING ZONE & 25-Aug-03 N & & 4439 & $\mathrm{ug} / \mathrm{g}$ & & & & & \\
\hline SESPSPEC & B17HB8 & $100 \mathrm{~B} / \mathrm{C}$ AREA DR & ONSITE & so & SURFACE & ROOTING ZONE & 25 -Aug-03 N & & 450 & $\mathrm{ug} / \mathrm{g}$ & & & & & \\
\hline SESPSPEC & $\mathrm{B} 17 \mathrm{H} 17$ & $100 \mathrm{~B} / \mathrm{C}$ AREA UR & ONSITE & so & SURFACE & SURF_SOIL & 25 -Aug-03 N & & 1234 & $\mathrm{ug} / \mathrm{g}$ & & & & & \\
\hline SESPSPEC & $\mathrm{B} 17 \mathrm{H} 18$ & 100-B SPRING 38-3 & ONSITE & so & SURFACE & SURF_SOIL & 25-Aug-03 N & & 546 & $\mathrm{ug} / \mathrm{g}$ & & & & & \\
\hline SESPSPEC & B17H19 & 100-B SPRING 39-2 & ONSITE & so & SURFACE & SURF_SOIL & 25-Aug-03 N & & 570 & $\mathrm{ug} / \mathrm{g}$ & & & & & \\
\hline SESPSPEC & $\mathrm{B} 17 \mathrm{H} 20$ & 100 B/C AREA OUTFL1 & ONSITE & so & SURFACE & SURF_SOIL & 25-Aug-03 N & & 813 & $\mathrm{ug} / \mathrm{g}$ & & & & & \\
\hline SESPSPEC & $\mathrm{B} 17 \mathrm{H} 21$ & 100 B/C AREA OUTFL2 & ONSITE & so & SURFACE & SURF_SOIL & 25-Aug-03 N & & 780 & ug/g & & & & & \\
\hline SESPSPEC & $\mathrm{B} 17 \mathrm{H} 22$ & 100 B/C AREA OUTFL3 & ONSITE & so & SURFACE & SURF_SOIL & 25-Aug-03 N & & 1110 & $\mathrm{ug} / \mathrm{g}$ & & & & & \\
\hline SESPSPEC & B17H23 & $100 \mathrm{~B} / \mathrm{C}$ AREA DR & ONSITE & so & SURFACE & SURF_SOIL & 25-Aug-03 N & & 586 & $\mathrm{ug} / \mathrm{g}$ & & & & & \\
\hline SESPSPEC & B17HB2 & $100 \mathrm{~B} / \mathrm{C}$ AREA UR & ONSITE & so & SURFACE & ROOTING ZONE & 25 -Aug-03 & & 32 & $\mathrm{ug} / \mathrm{g}$ & & & & & \\
\hline SESPSPEC & B17HB3 & 100-B SPRING 38-3 & ONSITE & so & SURFACE & ROOTING ZONE & 25-Aug-03 & & 17.8 & ug/g & & & & & \\
\hline SESPSPEC & B17HB4 & 100-B SPRING 39-2 & ONSITE & so & SURFACE & ROOTING ZONE & 25-Aug-03 & & 23.7 & $\mathrm{ug} / \mathrm{g}$ & & & & & \\
\hline SESPSPEC & B17HB5 & 100 B/C AREA OUTFL1 & ONSITE & so & SURFACE & ROOTING ZONE & 25-Aug-03 & & 25.5 & $\mathrm{ug} / \mathrm{g}$ & & & & & \\
\hline SESPSPEC & B17HB6 & 100 B/C AREA OUTFL2 & ONSITE & so & SURFACE & ROOTING ZONE & 25 -Aug-03 & & 20.8 & $\mathrm{ug} / \mathrm{g}$ & & & & & \\
\hline SESPSPEC & B17HB7 & $100 \mathrm{~B} / \mathrm{C}$ AREA OUTFL3 & ONSITE & so & SURFACE & ROOTING ZONE & 25-Aug-03 & & 46.3 & $\mathrm{ug} / \mathrm{g}$ & & & & & \\
\hline SESPSPEC & B17HB8 & $100 \mathrm{~B} / \mathrm{C}$ AREA DR & ONSITE & so & SURFACE & ROOTING ZONE & 25-Aug-03 $~$ & & 19.9 & $\mathrm{ug} / \mathrm{g}$ & & & & & \\
\hline SESPSPEC & $\mathrm{B} 17 \mathrm{H} 17$ & $100 \mathrm{~B} / \mathrm{C}$ AREA UR & ONSITE & so & SURFACE & SURF_SOIL & 25-Aug-03 & & 27.1 & $u g / g$ & & & & & \\
\hline SESPSPEC & $\mathrm{B} 17 \mathrm{H} 18$ & 100-B SPRING 38-3 & ONSITE & so & SURFACE & SURF_SOIL & 25-Aug-03 & & 17.2 & $\mathrm{ug} / \mathrm{g}$ & & & & & \\
\hline SESPSPEC & $\mathrm{B} 17 \mathrm{H} 19$ & 100-B SPRING 39-2 & ONSITE & so & SURFACE & SURF_SOIL & 25-Aug-03 $৯$ & & 19.5 & $\mathrm{ug} / \mathrm{g}$ & & & & & \\
\hline SESPSPEC & $\mathrm{B} 17 \mathrm{H} 20$ & 100 B/C AREA OUTFL1 & ONSITE & so & SURFACE & SURF_SOIL & 25-Aug-03 & & 22.5 & $\mathrm{ug} / \mathrm{g}$ & & & & & \\
\hline SESPSPEC & $\mathrm{B} 17 \mathrm{H} 21$ & $100 \mathrm{~B} / \mathrm{C}$ AREA OUTFL2 & ONSITE & so & SURFACE & SURF_SOIL & 25 -Aug-03 & & 28.5 & ug/g & & & & & \\
\hline SESPSPEC & B17H22 & 100 B/C AREA OUTFL3 & ONSITE & so & SURFACE & SURF_SOIL & 25-Aug-03 त & & 18.8 & $\mathrm{ug} / \mathrm{g}$ & & & & & \\
\hline SESPSPEC & B17H23 & $100 \mathrm{~B} / \mathrm{C}$ AREA DR & ONSITE & so & SURFACE & SURF_SOIL & 25-Aug-03 $~$ & & 22.6 & $\mathrm{ug} / \mathrm{g}$ & & & & & \\
\hline SESPSPEC & B17HB2 & $100 \mathrm{~B} / \mathrm{C}$ AREA UR & ONSITE & so & SURFACE & ROOTING ZONE & 25-Aug-03 P & & 49 & $\mathrm{ug} / \mathrm{g}$ & & & & & \\
\hline SESPSPEC & B17HB3 & 100-B SPRING 38-3 & ONSITE & so & SURFACE & ROOTING ZONE & 25-Aug-03 P & & 17.3 & ug/g & & & & & \\
\hline SESPSPEC & B17HB4 & 100-B SPRING 39-2 & ONSITE & so & SURFACE & ROOTING ZONE & 25-Aug-03 F & & 38.1 & $\mathrm{ug} / \mathrm{g}$ & & & & & \\
\hline SESPSPEC & B17HB5 & 100 B/C AREA OUTFL1 & ONSITE & so & SURFACE & ROOTING ZONE & 25-Aug-03 P & & 26.7 & ug/g & & & & & \\
\hline SESPSPEC & B17HB6 & $100 \mathrm{~B} / \mathrm{C}$ AREA OUTFL2 & ONSITE & so & SURFACE & ROOTING ZONE & 25-Aug-03 P & & 24.3 & $\mathrm{ug} / \mathrm{g}$ & & & & & \\
\hline SESPSPEC & B17HB7 & $100 \mathrm{~B} / \mathrm{C}$ AREA OUTFL3 & ONSITE & so & SURFACE & ROOTING ZONE & 25-Aug-03 P & & 39.1 & $\mathrm{ug} / \mathrm{g}$ & & & & & \\
\hline SESPSPEC & B17HB8 & $100 \mathrm{~B} / \mathrm{C}$ AREA DR & ONSITE & so & SURFACE & ROOTING ZONE & 25-Aug-03 F & & 18.4 & $\mathrm{ug} / \mathrm{g}$ & & & & & \\
\hline SESPSPEC & B17H17 & $100 \mathrm{~B} / \mathrm{C}$ AREA UR & ONSITE & so & SURFACE & SURF_SOIL & 25-Aug-03 P & & 61.7 & $\mathrm{ug} / \mathrm{g}$ & & & & & \\
\hline SESPSPEC & $\mathrm{B} 17 \mathrm{H} 18$ & 100-B SPRING 38-3 & ONSITE & so & SURFACE & SURF_SOIL & 25-Aug-03 P & & 19.7 & $\mathrm{ug} / \mathrm{g}$ & & & & & \\
\hline SESPSPEC & B17H19 & 100-B SPRING 39-2 & ONSITE & so & SURFACE & SURF_SOIL & 25-Aug-03 P & & 25.2 & $\mathrm{ug} / \mathrm{g}$ & & & & & \\
\hline SESPSPEC & B17H2O & 100 B/C AREA OUTFL1 & ONSITE & so & SURFACE & SURF_SOIL & 25-Aug-03 F & & 33.9 & $\mathrm{ug} / \mathrm{g}$ & & & & & \\
\hline SESPSPEC & $\mathrm{B} 17 \mathrm{H} 21$ & $100 \mathrm{~B} / \mathrm{C}$ AREA OUTFL2 & ONSITE & so & SURFACE & SURF_SOIL & 25-Aug-03 P & & 39.3 & ug/g & & & & & \\
\hline SESPSPEC & $\mathrm{B} 17 \mathrm{H} 22$ & $100 \mathrm{~B} / \mathrm{C}$ AREA OUTFL 3 & ONSITE & so & SURFACE & SURF_SOIL & 25-Aug-03 P & & 19.9 & $\mathrm{ug} / \mathrm{g}$ & & & & & \\
\hline SESPSPEC & B17H23 & $100 \mathrm{~B} / \mathrm{C}$ AREA DR & ONSITE & so & SURFACE & SURF_SOIL & 25-Aug-03 P & & 41.8 & $\mathrm{ug} / \mathrm{g}$ & & & & & \\
\hline SESPSPEC & B17HB2 & $100 \mathrm{~B} / \mathrm{C}$ AREA UR & ONSITE & so & SURFACE & ROOTING ZONE & 25-Aug-03 s & $\mathrm{Sb}$ & 0.641 & $\mathrm{ug} / \mathrm{g}$ & & & c & & \\
\hline SESPSPEC & B17HB8 & $100 \mathrm{~B} / \mathrm{C}$ AREA DR & ONSITE & so & SURFACE & ROOTING ZONE & 25-Aug-03 & & 0.905 & $\mathrm{ug} / \mathrm{g}$ & & & c & & \\
\hline
\end{tabular}


SOIL

\begin{tabular}{|c|c|c|c|c|c|c|c|c|c|c|c|c|c|c|c|}
\hline OWNER ID & SAMP NUM & SAMP SITE NAME & DIST CLASS & MEDIA & SAMP FROM & SAMP ITEM & SAMP DATE & $\begin{array}{l}\text { CON SHORT } \\
\text { NAME }\end{array}$ & VALUE RPTD & $\begin{array}{l}\text { ANAL UNITS } \\
\text { RPTD }\end{array}$ & $\begin{array}{c}\text { COUNTING } \\
\text { ERROR }\end{array}$ & $\begin{array}{c}\text { TOTAL ANAL } \\
\text { ERROR }\end{array}$ & $\begin{array}{c}\text { LAB } \\
\text { QUALIFIER }\end{array}$ & SAMP COMMENT & RESULT COMMENT \\
\hline SESPSPEC & B17H17 & 100 B/C AREA UR & ONSITE & so & SURFACE & SURF_SOIL & 25-Aug-03s & & 0.685 & $u g / g$ & & & $\mathrm{C}$ & & \\
\hline SESPSPEC & B17H23 & $100 \mathrm{~B} / \mathrm{C}$ AREA DR & ONSITE & so & SURFACE & SURF_SOIL & 25-Aug-03 S & & 0.531 & $\mathrm{ug} / \mathrm{g}$ & & & C & & \\
\hline SESPSPEC & B17HB2 & $100 \mathrm{~B} / \mathrm{C}$ AREA UR & ONSITE & so & SURFACE & ROOTING ZONE & 25-Aug-03 S & & 0.315 & ug/g & & & & & \\
\hline SESPSPEC & B17HB3 & 100-B SPRING 38-3 & ONSITE & so & SURFACE & ROOTING ZONE & 25-Aug-03 $S$ & & 0.161 & ug/g & & & & & \\
\hline SESPSPEC & B17HB4 & 100-B SPRING 39-2 & ONSITE & so & SURFACE & ROOTING ZONE & 25-Aug-03 $S$ & & 0.294 & $\mathrm{ug} / \mathrm{g}$ & & & & & \\
\hline SESPSPEC & B17HB5 & 100 B/C AREA OUTFL 1 & ONSITE & so & SURFACE & ROOTING ZONE & 25-Aug-03 S & & 0.189 & $\mathrm{ug} / \mathrm{g}$ & & & & & \\
\hline SESPSPEC & B17HB6 & 100 B/C AREA OUTFL2 & ONSITE & so & SURFACE & ROOTING ZONE & 25-Aug-03 S & & 0.198 & $\mathrm{ug} / \mathrm{g}$ & & & & & \\
\hline SESPSPEC & B17HB7 & 100 B/C AREA OUTFL3 & ONSITE & so & SURFACE & ROOTING ZONE & 25-Aug-03 S & & 0.401 & ug/g & & & & & \\
\hline SESPSPEC & B17HB8 & $100 \mathrm{~B} / \mathrm{C}$ AREA DR & ONSITE & so & SURFACE & ROOTING ZONE & 25-Aug-03 S & & 0.138 & $\mathrm{ug} / \mathrm{g}$ & & & & & \\
\hline SESPSPEC & B17H17 & $100 \mathrm{~B} / \mathrm{C}$ AREA UR & ONSITE & so & SURFACE & SURF_SOIL & 25 -Aug-03 S & & 0.473 & $\mathrm{ug} / \mathrm{g}$ & & & & & \\
\hline SESPSPEC & B17H18 & 100-B SPRING 38-3 & ONSITE & so & SURFACE & SURF_SOIL & 25-Aug-03S & & 0.319 & $\mathrm{ug} / \mathrm{g}$ & & & & & \\
\hline SESPSPEC & B17H19 & 100-B SPRING 39-2 & ONSITE & so & SURFACE & SURF_SOIL & 25-Aug-03 S & & 0.133 & ug/g & & & & & \\
\hline SESPSPEC & B17H20 & 100 B/C AREA OUTFL1 & ONSITE & so & SURFACE & SURF_SOIL & 25-Aug-03S & & 0.34 & ug/g & & & & & \\
\hline SESPSPEC & B17H21 & $100 \mathrm{~B} / \mathrm{C}$ AREA OUTFL2 & ONSITE & so & SURFACE & SURF_SOIL & 25 -Aug-03 S & & 0.436 & $\mathrm{ug} / \mathrm{g}$ & & & & & \\
\hline SESPSPEC & B17H22 & 100 B/C AREA OUTFL3 & ONSITE & so & SURFACE & SURF_SOIL & 25-Aug-03S & & 0.22 & ug/g & & & & & \\
\hline SESPSPEC & B17H23 & $100 \mathrm{~B} / \mathrm{C}$ AREA DR & ONSITE & so & SURFACE & SURF_SOIL & 25-Aug-03S & & 0.23 & $\mathrm{ug} / \mathrm{g}$ & & & & & \\
\hline SESPSPEC & B17HB2 & 100 B/C AREA UR & ONSITE & so & SURFACE & ROOTING ZONE & 25-Aug-03 T & & 7.43 & $\mathrm{ug} / \mathrm{g}$ & & & c & & \\
\hline SESPSPEC & B17HB3 & 100-B SPRING 38-3 & ONSITE & so & SURFACE & ROOTING ZONE & 25-Aug-03 T & & $\begin{array}{l}4.09 \\
4.09\end{array}$ & $\mathrm{ug} / \mathrm{g}$ & & & $\mathrm{c}$ & & \\
\hline SESPSPEC & B17HB4 & 100-B SPRING 39-2 & ONSITE & so & SURFACE & ROOTING ZONE & 25-Aug-03 T & & 3.78 & ug/g & & & C & & \\
\hline SESPSPEC & B17HB5 & 100 B/C AREA OUTFL1 & ONSITE & so & SURFACE & ROOTING ZONE & 25-Aug-03 T & & 5.75 & $\mathrm{ug} / \mathrm{g}$ & & & C & & \\
\hline SESPSPEC & B17HB6 & $100 \mathrm{~B} / \mathrm{C}$ AREA OUTFL2 & ONSITE & so & SURFACE & ROOTING ZONE & 25-Aug-03 T & & 4.51 & $\mathrm{ug} / \mathrm{g}$ & & & c & & \\
\hline SESPSPEC & B17HB7 & $100 \mathrm{~B} / \mathrm{C}$ AREA OUTFL3 & ONSITE & so & SURFACE & ROOTING ZONE & 25-Aug-03 T & & 8.85 & $\mathrm{ug} / \mathrm{g}$ & & & $\mathrm{c}$ & & \\
\hline SESPSPEC & B17HB8 & $100 \mathrm{~B} / \mathrm{C}$ AREA DR & ONSITE & so & SURFACE & ROOTING ZONE & 25-Aug-03 T & & 7.6 & ug/g & & & C & & \\
\hline SESPSPEC & B17H17 & $100 \mathrm{~B} / \mathrm{C}$ AREA UR & ONSITE & so & SURFACE & SURF SOIL & 25-Aug-03 T & & 7.03 & $\mathrm{ug} / \mathrm{g}$ & & & c & & \\
\hline SESPSPEC & B17H18 & 100-B SPRING 38-3 & ONSITE & so & SURFACE & SURF_SOIL & 25-Aug-03 T & & 3.87 & $\mathrm{ug} / \mathrm{g}$ & & & c & & \\
\hline SESPSPEC & B17H19 & 100-B SPRING 39-2 & ONSITE & so & SURFACE & SURF_SOIL & 25-Aug-03 T & & 5.2 & $\mathrm{ug} / \mathrm{g}$ & & & c & & \\
\hline SESPSPEC & B17H20 & 100 B/C AREA OUTFL1 & ONSITE & so & SURFACE & SURF_SOIL & 25-Aug-03 T & & 4.43 & $\mathrm{ug} / \mathrm{g}$ & & & C & & \\
\hline SESPSPEC & B17H21 & $100 \mathrm{~B} / \mathrm{C}$ AREA OUTFL2 & ONSITE & so & SURFACE & SURF_SOIL & 25-Aug-03 T & & 4.19 & $\mathrm{ug} / \mathrm{g}$ & & & c & & \\
\hline SESPSPEC & B17H22 & $100 \mathrm{~B} / \mathrm{C}$ AREA OUTFL 3 & ONSITE & so & SURFACE & SURF_SOIL & 25-Aug-03 T & & 4.83 & $\mathrm{ug} / \mathrm{g}$ & & & c & & \\
\hline SESPSPEC & B17H23 & 100 B/C AREA DR & ONSITE & so & SURFACE & SURF_SOIL & 25-Aug-03 T & & 6.38 & $\mathrm{ug} / \mathrm{g}$ & & & C & & \\
\hline SESPSPEC & B17HB2 & $100 \mathrm{~B} / \mathrm{C}$ AREA UR & ONSITE & so & SURFACE & ROOTING ZONE & 25-Aug-03 T & & 0.651 & ug/g & & & C & & \\
\hline SESPSPEC & B17HB8 & $100 \mathrm{~B} / \mathrm{C}$ AREA DR & ONSITE & so & SURFACE & ROOTING ZONE & 25-Aug-03 T & & 0.45 & $\mathrm{ug} / \mathrm{g}$ & & & c & & \\
\hline SESPSPEC & B17H17 & $100 \mathrm{~B} / \mathrm{C}$ AREA UR & ONSITE & so & SURFACE & SURF_SOIL & 25-Aug-03 T & & 0.52 & $\mathrm{ug} / \mathrm{g}$ & & & c & & \\
\hline SESPSPEC & B17H23 & 100 B/C AREA DR & ONSITE & so & SURFACE & SURF_SOIL & 25-Aug-03 T & & 0.555 & $\mathrm{ug} / \mathrm{g}$ & & & c & & \\
\hline SESPSPEC & B17HB2 & $100 \mathrm{~B} / \mathrm{C}$ AREA UR & ONSITE & so & SURFACE & ROOTING ZONE & 25-Aug-03 L & & 4.19 & $\mathrm{ug} / \mathrm{g}$ & & & & & \\
\hline SESPSPEC & B17HB3 & 100-B SPRING 38-3 & ONSITE & so & SURFACE & ROOTING ZONE & 25-Aug-03 L & & 3.55 & $\mathrm{ug} / \mathrm{g}$ & & & & & \\
\hline SESPSPEC & B17HB4 & 100-B SPRING 39-2 & ONSITE & so & SURFACE & ROOTING ZONE & 25-Aug-03 L & & 3.89 & $\mathrm{ug} / \mathrm{g}$ & & & & & \\
\hline SESPSPEC & B17HB5 & $100 \mathrm{~B} / \mathrm{C}$ AREA OUTFL1 & ONSITE & so & SURFACE & ROOTING ZONE & 25-Aug-03 L & & 3.68 & $\mathrm{ug} / \mathrm{g}$ & & & & & \\
\hline SESPSPEC & B17HB6 & $100 \mathrm{~B} / \mathrm{C}$ AREA OUTFL2 & ONSITE & so & SURFACE & ROOTING ZONE & 25-Aug-03 ᄂ & & $\begin{array}{l}0.14 \\
2.14\end{array}$ & ug/g & & & & & \\
\hline SESPSPEC & B17HB7 & $100 \mathrm{~B} / \mathrm{C}$ AREA OUTFL 3 & ONSITE & so & SURFACE & ROOTING ZONE & 25-Aug-03 L & & 4.36 & $\mathrm{ug} / \mathrm{g}$ & & & & & \\
\hline SESPSPEC & B17HB8 & $100 \mathrm{~B} / \mathrm{C}$ AREA DR & ONSITE & so & SURFACE & ROOTING ZONE & 25-Aug-03 L & & 4.03 & $\mathrm{ug} / \mathrm{g}$ & & & & & \\
\hline SESPSPEC & B17H17 & $100 \mathrm{~B} / \mathrm{C}$ AREA UR & ONSITE & so & SURFACE & SURF_SOIL & 25-Aug-03 L & & 5.61 & $\mathrm{ug} / \mathrm{g}$ & & & & & \\
\hline SESPSPEC & B17H18 & 100-B SPRING 38-3 & ONSITE & so & SURFACE & SURF_SOIL & 25-Aug-03 L & & 2.65 & $\mathrm{ug} / \mathrm{g}$ & & & & & \\
\hline SESPSPEC & B17H19 & 100-B SPRING 39-2 & ONSITE & so & SURFACE & SURF_SOIL & 25-Aug-03 L & & 2.25 & $\mathrm{ug} / \mathrm{g}$ & & & & & \\
\hline SESPSPEC & B17H2O & $100 \mathrm{~B} / \mathrm{C}$ AREA OUTFL 1 & ONSITE & so & SURFACE & SURF_SOIL & 25-Aug-03 L & & 3.6 & $\mathrm{ug} / \mathrm{g}$ & & & & & \\
\hline SESPSPEC & B17H21 & 100 B/C AREA OUTFL2 & ONSITE & so & SURFACE & SURF_SOIL & 25-Aug-03 L & & 3.11 & $\mathrm{ug} / \mathrm{g}$ & & & & & \\
\hline SESPSPEC & B17H22 & 100 B/C AREA OUTFL3 & ONSITE & so & SURFACE & SURF_SOIL & 25-Aug-03 L & & 2.2 & ug/g & & & & & \\
\hline SESPSPEC & B17H23 & $100 \mathrm{~B} / \mathrm{C}$ AREA DR & ONSITE & so & SURFACE & SURF_SOIL & 25-Aug-03 L & & 3.26 & $\mathrm{ug} / \mathrm{g}$ & & & & & \\
\hline SESPSPEC & B17HB2 & $100 \mathrm{~B} / \mathrm{C}$ AREA UR & ONSITE & so & SURFACE & ROOTING ZONE & 25-Aug-03 Z & & 235 & $\mathrm{ug} / \mathrm{g}$ & & & & & \\
\hline SESPSPEC & B17HB8 & $100 \mathrm{~B} / \mathrm{C}$ AREA DR & ONSITE & so & SURFACE & ROOTING ZONE & 25-Aug-03 Z & & 72.2 & $\mathrm{ug} / \mathrm{g}$ & & & & & \\
\hline SESPSPEC & B17H17 & 100 B/C AREA UR & ONSITE & so & SURFACE & SURF_SOIL & 25-Aug-03 Z & & 303 & $\mathrm{ug} / \mathrm{g}$ & & & & & \\
\hline SESPSPEC & B17H23 & $100 \mathrm{~B} / \mathrm{C}$ AREA DR & ONSITE & so & SURFACE & SURF_SOIL & 25-Aug-03 Z & & 225 & $\mathrm{ug} / \mathrm{g}$ & & & & & \\
\hline
\end{tabular}


Table S-1. DDD, DDE, and DDT in Soil, 2003

\begin{tabular}{|c|c|c|c|c|c|c|c|c|c|c|c|c|c|}
\hline $\begin{array}{l}\text { Samp } \\
\text { Num }\end{array}$ & Samp Site Name & $\begin{array}{l}\text { Samp } \\
\text { From }\end{array}$ & Samp Item & $\underline{\text { Samp Date }}$ & $\begin{array}{l}\text { 2,4'-DDE (Dichlorodiphenyl- } \\
\text { dichloroethylene) }\end{array}$ & $\begin{array}{l}\text { 4,4'-DDE (Dichlorodiphenyl- } \\
\text { dichloroethylene) }\end{array}$ & $\begin{array}{c}\text { 2,4'-DDD } \\
\begin{array}{c}\text { (Dichlorodiphenyl- } \\
\text { dichloroethane) }\end{array} \\
\end{array}$ & $\begin{array}{l}4,4^{4}-\text { DDD (Dichlorodiphenyl- } \\
\text { dichloroethane) }\end{array}$ & $\begin{array}{c}\text { 2,4'-DDT (Dichlorodiphenyl- } \\
\text { trichloroethane) }\end{array}$ & $\begin{array}{l}\begin{array}{l}4,4^{\prime}-\mathrm{DDT} \text { (Dichlorodiphenyl- } \\
\text { trichloroethane) }\end{array} \\
\end{array}$ & $\underline{\text { Total DDE }}$ & $\underline{\text { Total DDD }}$ & Total DDT \\
\hline $174 \mathrm{C} 7$ & HORSESHOE LANDFILL & SURFACE & SURF_SOIL & 19-Jun-03 & $194 \mathrm{D}$ & $3658 \mathrm{D}$ & $16.7 \mathrm{D}$ & $30.3 \mathrm{D}$ & $378 \mathrm{D}$ & $3000 \mathrm{D}$ & $3852 \mathrm{D}$ & 47.0 D & $3379 \mathrm{D}$ \\
\hline B174C8 & HORSESHOE LANDFILL & SURFACE & SURF_SOIL & 19-Jun-03 & 1499 & $12492 \mathrm{D}, \mathrm{E}$ & 81.3 & 96.0 & 506 & 3399 & $13991 \mathrm{D}$ & 177 & 3905 \\
\hline B174C9 & HORSESHOE LANDFILL & SURFACE & SURF_SOIL & 19-Jun-03 & 719 & $7366 \mathrm{D}, \mathrm{E}$ & 47.7 & $24.8 \mathrm{U}$ & 189 & 828 & $8086 \mathrm{D}$ & 72.5 & 1016 \\
\hline B174D0 & HORSESHOE LANDFILL & SURFACE & SURF_SOIL & 30-Jul-03 & 343 & $5734 \mathrm{D}, \mathrm{E}$ & 27.3 & $22.7 \mathrm{U}$ & 29.0 & 122 & $6077 \mathrm{D}$ & 50.0 & 151 \\
\hline B174D1 & HORSESHOE LANDFILL & SURFACE & SURF_SOIL & 19-Jun-03 & $0.20 \mathrm{U}$ & 9.98 & $0.20 \mathrm{U}$ & 0.23 & 0.78 & 2.70 & 10.2 & 0.430 & 3.48 \\
\hline B174D2 & HORSESHOE LANDFILL & SURFACE & SURF_SOIL & 19-Jun-03 & 1.61 & $68.4 \mathrm{D}$ & 0.26 & $0.20 \mathrm{U}$ & 4.18 & 8.78 & $70.0 \mathrm{D}$ & 0.456 & 13.0 \\
\hline B174D3 & HORSESHOE LANDFILL & SURFACE & SURF_-SOIL & 19-Jun-03 & 0.64 & $18.4 \mathrm{D}$ & $0.19 \mathrm{U}$ & $0.19 \mathrm{U}$ & 2.93 & 5.83 & $19.0 \mathrm{D}$ & $0.387 \mathrm{U}$ & 8.76 \\
\hline B174D4 & BACKGROUND & SURFACE & SURF_SOIL & 19-Jun-03 & $0.20 \mathrm{U}$ & & $0.20 \mathrm{U}$ & $0.20 \mathrm{U}$ & $0.20 \mathrm{U}$ & $0.20 \mathrm{U}$ & 0.918 & $0.395 \mathrm{U}$ & 0395 \\
\hline
\end{tabular}




\section{Sediment}


(pCilg Dry Weight unless otherwise noted)

\begin{tabular}{|c|c|c|c|c|c|c|c|c|c|c|c|c|c|c|}
\hline OWNER ID & \begin{tabular}{|l|} 
SAMP \\
NUM
\end{tabular} & SAMP SITE NAME & DIST CLASS & MEDIA & SAMP FROM & SAMP ITEM & SAMP DATE & $\begin{array}{l}\text { VALUEE } \\
\text { RPTD }\end{array}$ & $\begin{array}{l}\text { ANAL } \\
\text { UNITS } \\
\text { RPTD }\end{array}$ & $\begin{array}{c}\text { COUNTING } \\
\text { ERROR }\end{array}$ & $\begin{array}{c}\text { TOTAL } \\
\text { ANAL } \\
\text { ERROR }\end{array}$ & $\begin{array}{l}\text { LAB } \\
\text { QULLFIER }\end{array}$ & SAMP COMMENT & RESULT COMMENT \\
\hline SESPMNT & & WEST LAKE & ONSITE & SO & & SEDIMENT & 11-Feb-03 ALPHA & 8.86 & & & & & COLLECTED AT E. WATERHOLE. & \\
\hline SESPMNT & B16RT2 & WEST LAKE & ONSITE & so & POND & SEDIMENT & 07-Apr-03 ALPHA & & & 2.9 & 3.2 & & & \\
\hline SESPMNT & B176T3 & WEST LAKE & ONSITE & so & POND & SEDIMENT & 09-Jul-03 ALPHA & & & 2.9 & 3.2 & & & \\
\hline SESPMNT & B17R89 & WEST LAKE & ONSITE & so & POND & SEDIMENT & 07-OCt-03 ALPHA & 17.2 & pcilg & 5 & 6.7 & & & \\
\hline $\begin{array}{l}\text { SESPSPEC } \\
\text { SESPMNT }\end{array}$ & B17143 & FFTF POND & ONSITE & so & POND & $\begin{array}{l}\text { SEDIMENT } \\
\text { SEDMENT }\end{array}$ & 19-May-03 ALPHA & & & 3.6 & 4.2 & & & \\
\hline $\begin{array}{l}\text { SESPMNT } \\
\text { SESPMNT }\end{array}$ & $\begin{array}{l}\text { B160R6 } \\
\text { B1RT2 }\end{array}$ & $\begin{array}{l}\text { WEST LAKE } \\
\text { WEST LAEE }\end{array}$ & $\begin{array}{l}\text { ONSITE } \\
\text { ONSTEE }\end{array}$ & so & $\begin{array}{l}\text { POND } \\
\text { POND }\end{array}$ & $\begin{array}{l}\text { SEDIMENT } \\
\text { SEDMENT }\end{array}$ & $\begin{array}{l}\text { 11-Feb-03 BETA } \\
\text { 07-AAr-03 BETA }\end{array}$ & 24.7 & pCilg & 2.1 & 4 & & COLLECTED AT E. WATERHOLE. & \\
\hline $\begin{array}{l}\text { SESPMNT } \\
\text { SESPMNT }\end{array}$ & $\begin{array}{l}\text { B166T2 } \\
\text { B176T3 }\end{array}$ & $\begin{array}{l}\text { WEST LAAE } \\
\text { WEST LAKE }\end{array}$ & $\begin{array}{l}\text { ONSTIE } \\
\text { ONSITE }\end{array}$ & $\begin{array}{l}\text { so } \\
\text { so }\end{array}$ & $\begin{array}{l}\text { POND } \\
\text { POND }\end{array}$ & $\begin{array}{l}\text { SEDIMENT } \\
\text { SEDIMENT }\end{array}$ & $\begin{array}{l}\text { 07-Apr-03BEAA } \\
\text { 09-Jul-03 BETA }\end{array}$ & & pci/g & 2.1 & 3.7. & & & \\
\hline $\begin{array}{l}\text { SESPMNI } \\
\text { SESPMNT }\end{array}$ & B17R89 & $\begin{array}{l}\text { WEST LAKE } \\
\text { WEST LAKE }\end{array}$ & ONSITE & so & POND & $\begin{array}{l}\text { SEDIMENI } \\
\text { SEDIMENT }\end{array}$ & $\begin{array}{l}\text { O9-Jul-03BEIA } \\
\text { 07-OCt-03 BETA }\end{array}$ & & pCilg & $\frac{2.2}{1.2}$ & $\begin{array}{ll}4.6 \\
3.1\end{array}$ & & & \\
\hline $\begin{array}{l}\text { SESPMNI } \\
\text { SESPSPEC }\end{array}$ & $\begin{array}{ll}B 1 / 789 \\
B 17143\end{array}$ & $\begin{array}{l}\text { WESI LAEE } \\
\text { FFTF POND }\end{array}$ & ONSITE & so & $\begin{array}{l}\text { POND } \\
\text { POND }\end{array}$ & $\begin{array}{l}\text { SEDIMENI } \\
\text { SEDIMENT }\end{array}$ & $\begin{array}{l}\text { 19-0c-03 BEIA } \\
\text { 19-May-03 BETA }\end{array}$ & & $\begin{array}{l}\text { pClig } \\
\text { oCilg }\end{array}$ & $\frac{1.1}{2.2}$ & $\begin{array}{l}3.1 \\
4.6\end{array}$ & & & \\
\hline SESPMNT & B16DK6 & WEST LAKE & ONSITE & so & POND & SEDIMENT & 11-Feb-03 Be-7 & 0.103 & pcilg & 0.11 & 0.11 & u & COLLECTED AT E. WATERHOLE. & \\
\hline SESPMNT & B16RT2 & WEST LAKE & ONSITE & so & POND & SEDIMENT & 07-Apr-03 Be-7 & 0.0996 & & 0.093 & 0.093 & u & & \\
\hline SESPMNT & B176T3 & WEST LAKE & ONSITE & so & POND & SEDIMENT & 09-Jul-03 Be-7 & & & 0.15 & 0.15 & u & & \\
\hline $\begin{array}{l}\text { SESPMNT } \\
\text { SESDMNT }\end{array}$ & B176Y6 & HANFORD SLOUGH & RIVER_SHORELINE & so & SUB_SURFACE & SEDIMENT & 14-Jul-03 Be-7 & 0.187 & & 0.12 & 0.12 & u & & \\
\hline $\begin{array}{l}\text { SESPMNT } \\
\text { SESPMNT }\end{array}$ & $\begin{array}{ll}B 176 Y 7 \\
B 176 Y 8\end{array}$ & $\begin{array}{l}\text { RICHLAND-RIVER } \\
\text { WHTERBUEFS SOUGH }\end{array}$ & $\begin{array}{l}\text { RIVER_SHORELINE } \\
\text { RIVR SHORELINE }\end{array}$ & $\begin{array}{l}\text { so } \\
\text { so }\end{array}$ & $\begin{array}{l}\text { SUB_SURFACE } \\
\text { SUB SURFACE }\end{array}$ & $\begin{array}{l}\text { SEDIMENT } \\
\text { SEDIMENT }\end{array}$ & 16-Jul-03 Be-7 & -0.0257 & pcilg & 0.12 & 0.12 & U & & \\
\hline $\begin{array}{l}\text { SESPMNT } \\
\text { SESPMNT }\end{array}$ & $\begin{array}{l}\text { B176Y8 } \\
\text { B176Y9 }\end{array}$ & $\begin{array}{l}\text { WHITE BLUFFS SLOUGH } \\
100 \text { F SOUGH }\end{array}$ & $\begin{array}{l}\text { liVER_SHORELINE } \\
\text { ONSITE }\end{array}$ & $\begin{array}{l}\text { so } \\
\text { so }\end{array}$ & $\begin{array}{l}\text { SUB_SURFACE } \\
\text { SUB SURFACE }\end{array}$ & $\begin{array}{l}\text { SEDIIENT } \\
\text { SEDIMENT }\end{array}$ & $\begin{array}{l}\text { 14--Jul-103 Be-7 } \\
\text { 14-Jul-03 Be-7 }\end{array}$ & $\begin{array}{r}0.0875 \\
-0.00683\end{array}$ & pcilg & 0.17 & 0.17 & $\frac{u}{u}$ & & \\
\hline $\begin{array}{l}\text { SESPMNI } \\
\text { SESPMNT }\end{array}$ & 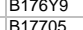 & $\begin{array}{l}\text { PRD-YAKIMA SIDE NEAR DAM } \\
\text { PROA }\end{array}$ & $\begin{array}{l}\text { ONSITE } \\
\text { OFFSITE }\end{array}$ & $\begin{array}{l}\text { so } \\
\text { so }\end{array}$ & $\begin{array}{l}\text { SUB_SURFACE } \\
\text { SUB SURFACE }\end{array}$ & $\begin{array}{l}\text { SEDIIENT } \\
\text { SEDMENT }\end{array}$ & $\begin{array}{l}\text { 14-Jul-03 Be-7 } \\
\text { 14-Jul-03 Be-7 }\end{array}$ & $\begin{array}{r}-0.00683 \\
0.0976\end{array}$ & $\begin{array}{l}\text { pilg } \\
\text { cilga }\end{array}$ & 0.11 & 0.11 & u & & \\
\hline $\begin{array}{l}\text { SESPMNI } \\
\text { SESPMNT }\end{array}$ & B17707 & $\begin{array}{l}\text { PRD-YRANT SIDE NEAR DAM } \\
\text { PRD-GRANT IIDE }\end{array}$ & $\begin{array}{l}\text { OFFSIITE } \\
\text { OFFITE }\end{array}$ & so & $\begin{array}{l}\text { SUBSURFACE } \\
\text { SUB SURFACE }\end{array}$ & $\begin{array}{l}\text { SEUMENI } \\
\text { SEDIMENT }\end{array}$ & $\begin{array}{l}\text { 14-Jul-03 } \mathrm{Be}-1 \\
\text { 14-Jul-03 Be-7 }\end{array}$ & 0.0658 & & 0.12 & 0.12 & u & & \\
\hline SESPMNT & B17713 & MCNARY-OR.SIDE NEAR DAM & OFFSITE & so & SUB_SURFACE & SEDIMENT & 16-Jul-03 Be-7 & 0.384 & pcilg & 0.15 & 0.15 & u & & \\
\hline SESPMNT & B17715 & MCNARY-WASH.SIDE NEAR DAM & OFFSITE & so & SUB_SURFACE & SEDIMENT & 16-Jul-03 Be-7 & 0.0553 & pCilg & 0.12 & 0.12 & u & & \\
\hline SESPMNT & B17J20 & 300 AREA SPRING 42-2 & ONSITE & so & SUB_SURFACE & SEDIMENT & $13-\mathrm{Oct}-03 \mathrm{Be}-7$ & 0.108 & & 0.094 & 0.094 & u & & \\
\hline SESPMNT & & 100-B SPRING 37-1 & ONSITE & so & SUB_SURFACE & SEDIMENT & 20-Oct-03 Be-7 & -0.0294 & & 0.091 & 0.091 & u & & \\
\hline $\begin{array}{l}\text { SESPMNT } \\
\text { SESPMNT }\end{array}$ & 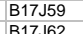 & 300 AREA SPR DR 42-2 & $\begin{array}{l}\text { ONSITE } \\
\text { ONSTIE }\end{array}$ & so & $\begin{array}{l}\text { SUB_SURFACE } \\
\text { SUB SURFACE }\end{array}$ & $\begin{array}{l}\text { SEDIMENT } \\
\text { SEDMENT }\end{array}$ & 13-Oct-03 Be-7 & 0.122 & & 0.09 & 0.09 & u & & \\
\hline $\begin{array}{l}\text { SESPMNT } \\
\text { SESPMNT }\end{array}$ & 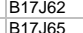 & $\begin{array}{l}\text { 100--K SPRING 33-1 } \\
\text { 100-F SPRING 207-1 }\end{array}$ & $\begin{array}{l}\text { ONSIIE } \\
\text { ONSITE }\end{array}$ & so & $\begin{array}{l}\text { SUB_SURFACE } \\
\text { SUB SURFACE }\end{array}$ & $\begin{array}{l}\text { SEDIMENT } \\
\text { SEDMENT }\end{array}$ & $\begin{array}{l}\text { 20-Oct-03 Be-7 } \\
0 \text { 0-Nov-3 Be-7 }\end{array}$ & $\begin{array}{l}0.0347 \\
0.185\end{array}$ & $\begin{array}{l}\text { pCigg } \\
\text { piig/g }\end{array}$ & 0.08 & 0.08 & u & & \\
\hline $\begin{array}{l}\text { SESPMNI } \\
\text { SESPMNT }\end{array}$ & $\begin{array}{l}\text { B1/765 } \\
\text { B17399 }\end{array}$ & 100-H SPRRING 201-1 & $\begin{array}{l}\text { ONSIIL } \\
\text { ONSITE }\end{array}$ & so & $\begin{array}{l}\text { SUBSSURFACE } \\
\text { SUB SURFACE }\end{array}$ & $\begin{array}{l}\text { SEDIMENT } \\
\text { SEDIMENT }\end{array}$ & $\begin{array}{l}03-\text {-Nov-0 } 0 \text { B Be-7 } \\
27-\mathrm{Occ}-03 \mathrm{Be}-7\end{array}$ & 0.0215 & pici/g & 0.11 & 0.089 & u & COLLECTED 20 METERS DOWN RIVER FROM SEEP. & \\
\hline $\begin{array}{l}\text { SESPMMNT } \\
\text { SESPMT }\end{array}$ & B17R89 & WEST LAKE & ONSITE & so & POND & $\begin{array}{l}\text { SEDIMENT } \\
\text { SEUENT }\end{array}$ & $07-\mathrm{Oct}-03 \mathrm{Be}-7$ & 0.163 & $\begin{array}{l}\mathrm{pellg} \\
\mathrm{cC} i / g\end{array}$ & 0.25 & 0.25 & $\mathrm{u}$ & & \\
\hline SESPSPEC & B16WV8 & YAKIMA RIVER & OFFSITE & so & SUB SURFACE & SEDIMENT & 14-May-03 Be-7 & 0.0164 & & 0.14 & 0.14 & u & & \\
\hline SESPSPEC & B16WV9 & YAKIMA RIVER & OFFSITE & so & SUB_SURFACE & SEDIMENT & 14-May-03 Be-7 & 0.234 & pcilg & 0.16 & 0.16 & u & & \\
\hline SESPSPEC & B16WWo & WALLA WALLA-RIVER & OFFSITE & so & SUB_SURFACE & SEDIMENT & 15-May-03 Be-7 & -0.0461 & & 0.13 & 0.13 & u & & \\
\hline SESPSPEC & B16WW1 & WALLA WALLA-RIVER & OFFSITE & so & SUB_SURFACE & SEDIMENT & 15-May-03 Be-7 & 0.0573 & & 0.14 & 0.14 & U & & \\
\hline $\begin{array}{l}\text { SESPSPEC } \\
\text { SESPSPEC }\end{array}$ & B16WW4 & RINGOLD WASTEWAY & OFFSITE & so & SUB_SURFACE & SEDIMENT & 14-May-03 Be-7 & 0.17 & pCi/g & 0.15 & 0.15 & $\mathrm{U}$ & PRIMARILY SAND. & \\
\hline $\begin{array}{l}\text { SESPSPEC } \\
\text { SESPSEC }\end{array}$ & B16WW5 & RINGOLD WASTEWAY & $\begin{array}{l}\text { OFFSITE } \\
\text { OFESTTE }\end{array}$ & so & SUB_SURFACE & $\begin{array}{l}\text { SEDIMENT } \\
\text { SEDMENT }\end{array}$ & $\begin{array}{l}\text { 14-May-03 Be-7 } \\
14-M a-03 B \text { Be-7 }\end{array}$ & 0.118 & pCilg & 0.13 & 0.13 & $\mathrm{U}$ & PRIMARILY SAND. & \\
\hline $\begin{array}{l}\text { SESPSEC } \\
\text { SESPSPEC }\end{array}$ & $\begin{array}{l}\text { B16WW6 } \\
\text { B16WW7 }\end{array}$ & $\begin{array}{l}\text { ESQUATZEL CANAL } \\
\text { ESOUATZEL CANAL }\end{array}$ & $\begin{array}{l}\text { OFFITE } \\
\text { OFFSITE }\end{array}$ & $\begin{array}{l}\text { So } \\
\text { so }\end{array}$ & $\begin{array}{l}\text { SUB_SURFACE } \\
\text { SUB SURFACE }\end{array}$ & $\begin{array}{l}\text { SEDIMENT } \\
\text { SEDMENT }\end{array}$ & $\begin{array}{l}\text { 14-May-03 B B-7 } \\
\text { 14-May-03 Be-7 }\end{array}$ & $\begin{array}{l}-0.0146 \\
-0.0468\end{array}-3$ & pcigg & 0.11 & 0.11 & u & & \\
\hline $\begin{array}{l}\text { SESPSPEC } \\
\text { SESP }\end{array}$ & B17BD9 & MCNARY-2/3 OR. SHORE & OFFSITE & so & SUB_SURFACE & SEDIMENT & $08-A u g-03 \mathrm{Be}-7$ & $\begin{array}{l}-0.016 \\
-0.0400\end{array}$ & pcilg & 0.23 & 0.23 & u & & \\
\hline SESPSPEC & B17BF4 & JOHN DAY DAM MID-RIVER & OFFSITE & so & SUB SURFACE & SEDIMENT & 08-Aug-03 Be-7 & 0.273 & pcilg & 0.27 & 0.27 & $\mathrm{u}$ & & \\
\hline SESPSPEC & B17BF9 & DALLES DAM OR.SHORE & OFFSITE & so & SUB_SURFACE & SEDIMENT & 07-Aug-03 Be-7 & $\begin{aligned}-0.040 \\
-0.044\end{aligned}$ & & 0.29 & 0.29 & u & & \\
\hline SESPSPEC & B17BH4 & BONNEVILLE DAM OR.SHORE & OFFSITE & so & SUB_SURFACE & SEDIMENT & 07-Aug-03 Be-7 & 0.0547 & & 0.29 & 0.29 & u & & \\
\hline SESPSPEC & B17BH7 & MCNARY-2/3 OR. SHORE & OFFSITE & so & SUB_SURFACE & SEDIMENT & 08-Aug-03 Be-7 & 0.0551 & pcilg & 0.28 & 0.28 & u & & \\
\hline $\begin{array}{l}\text { SESPMNT } \\
\text { SESPMNT }\end{array}$ & B16DK6 & $\begin{array}{l}\text { WEST LAKE } \\
\text { WEST AKE }\end{array}$ & ONSITE & so & 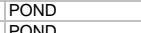 & $\begin{array}{l}\text { SEDIMENT } \\
\text { SEDMENT }\end{array}$ & 11-Feb-03 Co-60 & 0.00624 & & 0.012 & 0.012 & u & COLLECTED AT E. WATERHOLE. & \\
\hline $\begin{array}{l}\text { SESPMNT } \\
\text { SESPMNT }\end{array}$ & $\begin{array}{ll}\text { B16RT2 } \\
\text { B17653 }\end{array}$ & $\begin{array}{l}\text { WEST LAKE } \\
\text { WESTIAKE }\end{array}$ & $\begin{array}{l}\text { ONSITE } \\
\text { ONSTEE }\end{array}$ & so & 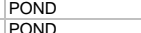 & $\begin{array}{l}\text { SEDIIENT } \\
\text { SEDMENT }\end{array}$ & $\begin{array}{l}07-A p r-03 \text { Co-60 } \\
09-34-03 \text { Co-60 }\end{array}$ & 0.00582 & & 0.011 & 0.011 & u & & \\
\hline $\begin{array}{l}\text { SESPMNT } \\
\text { SESPMNT }\end{array}$ & 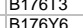 & $\begin{array}{l}\text { WEST LAKE } \\
\text { HANFORD SLOUGH }\end{array}$ & $\begin{array}{l}\text { ONSIIE } \\
\text { RIVER SHORELINE }\end{array}$ & $\begin{array}{l}\text { SO } \\
\text { So }\end{array}$ & $\begin{array}{l}\text { POND } \\
\text { SUB SURFACE }\end{array}$ & $\begin{array}{l}\text { SEDIMENT } \\
\text { SEDIMENT }\end{array}$ & $\begin{array}{l}\text { 09-Julu-03 Co- } 60 \\
\text { 14-Jul- } 03 \text { Co } 60\end{array}$ & 0.0134 & $\begin{array}{l}\mathrm{pCC} / \mathrm{g} \\
\mathrm{pCi} / \mathrm{g}\end{array}$ & $\begin{aligned} 0.015 \\
0.02\end{aligned}$ & 0.015 & 0 & & \\
\hline SESPMNT & B176Y7 & RICHLAND-RIVER & $\begin{array}{l}\text { TIVR-SHORELIVE } \\
\text { RIVER SHOREINE }\end{array}$ & so & $\begin{array}{l}\text { SUBSURFACE } \\
\text { SUB SURFACE }\end{array}$ & $\begin{array}{l}\text { SEUINENI } \\
\text { SEDIMENT }\end{array}$ & $\begin{array}{l}\text { 16-Jull-03Co-60 } \\
16-\mathrm{Ju}-03 \mathrm{Co}-60\end{array}$ & 0.0066 & $\begin{array}{ll}0 \\
\text { CCilg }\end{array}$ & 0.013 & & $u$ & & \\
\hline SESPMNT & B176Y8 & FS SLOUGH & $\begin{array}{l}\text { RIVE_M SHORELINE } \\
\text { RIVER }\end{array}$ & so & SUB SURFACE & SEDIMENT & 14-Jul-03 Co-60 & 0.0 & & 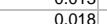 & .018 0.018 & u & & \\
\hline SESPMNT & $\begin{array}{l}\text { B176Y9 } \\
\text { B1769 }\end{array}$ & $100 \mathrm{~F}$ SLOUGH & ONSITE & so & $\begin{array}{l}\text { SUB_SURFACE } \\
\text { SUEACE }\end{array}$ & SEDIMENT & 14-Jul-03 Co-60 & 0.00418 & & 0.013 & . 0.013 & u & & \\
\hline SESPMNT & B17705 & PRD-YAKIMA SIDE NEAR DAM & OFFSITE & so & SUB_SURFACE & SEDIMENT & 14-Jul-03 Co-60 & 0.004 & & 0.011 & 0.011 & u & & \\
\hline SESPMNT & B17707 & PRD-GRANT & OFFSITE & so & SUB_SURFACE & SEDIMENT & 14-Jul-03 Co-60 & -0.00033 & pcilg & 0.012 & 0.012 & u & & \\
\hline SESPMNT & B17713 & MCNARY-OR.S & OFFSITE & so & SUB_SURFACE & & $03 \mathrm{Co}-60$ & 0.0139 & pcilg & 0.014 & 0.014 & $\mathrm{U}$ & & \\
\hline SESPMNT & B17715 & MCNARY-WASH.SIDE NEAR DAM & OFFSITE & so & SUB_SURFACE & $\begin{array}{l}\text { SEDIMENT } \\
\text { SEDMENT }\end{array}$ & 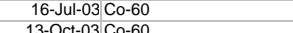 & 0.0286 & pcilg & 0.014 & 0.014 & $\mathrm{U}$ & & \\
\hline $\begin{array}{l}\text { SESPMNT } \\
\text { SESPMNT }\end{array}$ & $\begin{array}{l}81720 \\
B 1720\end{array}$ & $\begin{array}{l}\text { 300 AREA SPRING 42-2 } \\
\text { 100-B SPRING } 37-1\end{array}$ & $\begin{array}{l}\text { ONSIIE } \\
\text { ONSITE }\end{array}$ & $\begin{array}{l}\text { so } \\
\text { so }\end{array}$ & $\begin{array}{l}\text { SUB_SURFACE } \\
\text { SUB SURFACE }\end{array}$ & $\begin{array}{l}\text { SEDIIENT } \\
\text { SEDIMENT }\end{array}$ & $\begin{array}{l}\text { 13-OCt- }-3 \text { Co- } 60 \\
\text { 20-OC- } 03 \text { Co-60 }\end{array}$ & $\begin{array}{r}-0.00647 \\
0.00764\end{array}$ & $\begin{array}{l}\mathrm{plig} \\
\mathrm{c} \text { Cilg }\end{array}$ & 0.011 & 0.011 & u & & \\
\hline $\begin{array}{l}\text { SESPVMNI } \\
\text { SESPMNT }\end{array}$ & 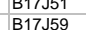 & $\begin{array}{l}100-B \text { SPRING } 37-1 \\
300 \text { AREA SPR DR 42-2 }\end{array}$ & $\begin{array}{l}\text { ONSSIIE } \\
\text { ONSITE }\end{array}$ & so & $\begin{array}{l}\text { SUBSURFACE } \\
\text { SUB SURFACE }\end{array}$ & $\begin{array}{l}\text { SEUINENI } \\
\text { SEDIMENT }\end{array}$ & $\begin{array}{ll}20-01-03 C 0-60 \\
13-0 c t-03 C 0-60\end{array}$ & & ocilg & 0.012 & 0.011 & u & & \\
\hline SESPMNT & B17J62 & 100-K SPRING 63-1 & ONSITE & so & $\begin{array}{l}\text { SUBSURFACE } \\
\text { SUB SURFACE }\end{array}$ & $\begin{array}{l}\text { SEUMENI } \\
\text { SEDIMENT }\end{array}$ & 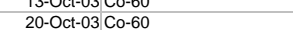 & 0.00443 & & 0.0099 & 0.0099 & u & & \\
\hline SESPMNT & B17365 & 100-F SPRING 207-1 & ONSITE & so & $\begin{array}{l}\text { SUB_SURFACE } \\
\text { SUB_SA }\end{array}$ & SEDIMENT & $03-$ Nov- 03 Co-60 60 & 0.00708 & & 0.012 & 0.012 & u & & \\
\hline SESPMNT & B177999 & 100-H SPRING 145-1 & ONSITE & so & SUB_SURFACE & SEDIMENT & $27-$ Oct- 03 Co-60 & 0.0119 & pCilg & 0.012 & 0.012 & u & COLLECTED 20 METERS DOWN RIVER FROM SEEP. & \\
\hline SESPMNT & B17R89 & WEST LAKE & ONS & so & POND & SEDIM & $07-c$ & 0.00 & pcilg & 0.024 & 0.024 & u & & \\
\hline & $B 16$ WV 8 & & OFFSITE & so & SUB_SURFACE & SEDIMENT & 14-May-03 Co-60 & 0.00171 & & 0.013 & 0.013 & $\mathrm{U}$ & & \\
\hline SESPSPEC & B16WV9 & YAKIMA RIVER & OFFSITE & so & SUB_SURFACE & $\begin{array}{l}\text { SEDIMENT } \\
\text { SEDMENT }\end{array}$ & 14-May-03 Сo-60 & 0.0106 & pcilg & 0.013 & 0.013 & $\mathrm{U}$ & & \\
\hline $\begin{array}{l}\text { SESPSPEC } \\
\text { SESPSEC }\end{array}$ & B16WWo & $\begin{array}{l}\text { WALLA WALLA-RIVER } \\
\text { WALA WALA-RIVER }\end{array}$ & $\begin{array}{l}\text { OFFFITE } \\
\text { OFFITE }\end{array}$ & $\begin{array}{l}\text { so } \\
\text { so }\end{array}$ & $\begin{array}{l}\text { SUB_SURFACE } \\
\text { SUB SURFACE }\end{array}$ & $\begin{array}{l}\text { SEDIIENT } \\
\text { SEDIMENT }\end{array}$ & $\begin{array}{l}\frac{15-M a y-03 \text { Co-60 }}{15-\text { May-03 Co-60 }} \\
1\end{array}$ & $\begin{array}{l}-0.00389 \\
-0.00578\end{array}$ & $\begin{array}{ll}\text { pcigg } \\
\text { cilig }\end{array}$ & 0.015 & 0.015 & $\frac{u}{u}$ & & \\
\hline $\begin{array}{l}\text { SESPPEC } \\
\text { SESPSPEC }\end{array}$ & B16WW4 & & $\begin{array}{l}\text { OFFFSITE } \\
\text { OFSITE }\end{array}$ & & $\begin{array}{l}\text { SUBSURFACE } \\
\text { SUB SURFACE }\end{array}$ & $\begin{array}{l}\text { SEUMENI } \\
\text { SEDIMENT }\end{array}$ & 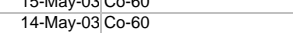 & $\begin{array}{l}-0.05 / 8 \\
-0.0125 \\
-10\end{array}$ & & & & u & PRIMARI & \\
\hline $\begin{array}{l}\text { SESPSEC } \\
\text { SESPSEC }\end{array}$ & & RINGC & OFFSITE & so & SUB SURFACE & SEDIMENT & $\begin{array}{l}\text { 14-Mayy-03 С0 -60 } \\
\text { 14-May-03 С-60 }\end{array}$ & $\begin{array}{c}-0.00203 \\
-0.0203\end{array}$ & ocilg & 然13 & 0.013 & u & PRIMARILY SAND. & \\
\hline SESPSPEC & B16WW6 & ESQUATZEL CANAL & OFFSITE & so & SUB_SURFACE & SEDIMENT & 14-May-03 Сo-60 & 0.005 & pcilg & 0.012 & 0.012 & $u$ & & \\
\hline SESPSPEC & $B 16 W W 7$ & ESQUATZEL CANAL & OFFSITE & so & SUB_SURFACE & SEDIMENT & 14-May-03 Сo-60 & -0.00 & pcilg & 0.012 & 0.012 & $u$ & & \\
\hline SESPSPEC & B17BD9 & MCNARY-2/3 OR. SHOF & OFFSITE & so & SUB_SURFACE & SEDIMENT & 08-Aug-03 Co-60 & 0.0 & pCilg & 0.028 & 0.028 & U & & \\
\hline SESPSPEC & B17BF4 & JOHN DAY DAM MID-RIVER & OFFSITE & so & SUB_SURFACE & SEDIMENT & 08-Aug-03 Co-60 & 0.0373 & & 0.035 & 0.035 & 4 & & \\
\hline SESPSPEC & B17BF9 & DALLES DAM OR.SHORE & OFFSITE & so & SUB_SURFACE & SEDIMENT & 07-Aug-03 Co-60 & 0.0046 & & 0.028 & 0.028 & u & & \\
\hline SESPSPEC & B17BH4 & BONNEVILLE DAM OR.SHORE & OFFSITE & so & $\begin{array}{l}\text { SUB_SURFACE } \\
\text { SUB SUREACE }\end{array}$ & $\begin{array}{l}\text { SEDIMENT } \\
\text { SEDMENT }\end{array}$ & $\begin{array}{l}\text { 07-Aug-03 Co-60 } \\
\text { 08-Aug-03 Co-60 }\end{array}$ & 0.0224 & & 0.032 & 0.032 & u & & \\
\hline $\begin{array}{l}\text { SESPSEC } \\
\text { SESPMNT }\end{array}$ & B16DKG & WEST LAKE & $\begin{array}{l}\text { ONSITE } \\
\text { ONSE }\end{array}$ & so & $\begin{array}{l}\text { SONSORFACE } \\
\text { POND }\end{array}$ & $\begin{array}{l}\text { SEDMIENI } \\
\text { SEDIMENT }\end{array}$ & 11-Feb-03 Cs- 134 & & $\begin{array}{l}\text { pcilg } \\
\text { pcig }\end{array}$ & 0.016 & $\begin{array}{l}0.034 \\
0.016\end{array}$ & u & OLE. & \\
\hline SESPMNT & B16RT2 & WEST LAKE & ONSITE & so & POND & SEDIMENT & 07-Apr-03 Cs-134 & 0.0517 & & 0.019 & 0.019 & & & \\
\hline
\end{tabular}


(pCilg Dry Weight unless otherwise noted)

\begin{tabular}{|c|c|c|c|c|c|c|c|c|c|c|c|c|c|c|}
\hline OWNER ID & \begin{tabular}{|l|l|} 
SAMP \\
NUM
\end{tabular} & SAMP SITE NAME & DIST CLASS & & SAMP FROM & & SAMP DATE $\mid$ CON SHORT NAME & $\begin{array}{l}\text { VALUE } \\
\text { RPTD }\end{array}$ & $\begin{array}{l}\text { ANAL } \\
\text { UNITS } \\
\text { RPTD }\end{array}$ & $\underset{\text { ERROR }}{\text { COUNTING }}$ & $\begin{array}{c}\text { OTATAL } \\
\text { ANAL } \\
\text { ERROR }\end{array}$ & $\begin{array}{l}\text { LAB } \\
\text { QUALIFIER }\end{array}$ & SAMP COMMENT & RESULT COMMENT \\
\hline $\begin{array}{l}\text { SESPMNT } \\
\text { SESPNT }\end{array}$ & B176T3 & WEST LAKE & ONSITE & so & POND & SEDIMENT & 09-Jul-03 Cs-134 & 0.024 & pcilg & 0.017 & $\begin{array}{l}0.017 \\
0.017\end{array}$ & u & & \\
\hline $\begin{array}{l}\text { SESPMNT } \\
\text { SESPMNT }\end{array}$ & $\begin{array}{ll}\mathrm{B} 176 \mathrm{Y} 6 \\
\mathrm{~B} 16 \mathrm{Y} \times \mathrm{Y}\end{array}$ & $\begin{array}{l}\text { HANFORD SLOUGH } \\
\text { RIICHLAND-RIVR }\end{array}$ & $\begin{array}{l}\text { RIVER_SHORELINE } \\
\text { RIVR_SHORELNEE }\end{array}$ & $\begin{array}{l}\text { so } \\
\text { so }\end{array}$ & $\begin{array}{l}\text { SUB_SURFACE } \\
\text { SUB SURACE }\end{array}$ & $\begin{array}{l}\text { SEDIMENT } \\
\text { SEDIMENT }\end{array}$ & $\begin{array}{l}\text { 14--Jul-03 C-134 } \\
\text { 16-Jul-03 C-134 }\end{array}$ & $\begin{array}{l}0.049 \mathrm{r} \\
0.0628 \mathrm{~g}\end{array}$ & pcilg & 0.018 & 0.018 & $\frac{U}{u}$ & & \\
\hline $\begin{array}{l}\text { SESPMNT } \\
\text { SESPMNT }\end{array}$ & $\begin{array}{l}\text { B176Y7 } \\
\text { B176Y8 }\end{array}$ & $\begin{array}{l}\text { WICLLANDLRVER } \\
\text { WHITE BLUFFS SLOUGH }\end{array}$ & $\begin{array}{l}\text { RRVR_SHRELLINE } \\
\text { RIVER_SHORELINE }\end{array}$ & $\begin{array}{l}\text { so } \\
\text { so }\end{array}$ & $\begin{array}{l}\text { SUB_SURFAAE } \\
\text { SUB SURFACE }\end{array}$ & $\begin{array}{l}\text { SEDIMENT } \\
\text { SEDIMENT }\end{array}$ & $\begin{array}{l}\text { 16-Jul-03Cs-134 } \\
\text { 14-Jul-03 cs-134 }\end{array}$ & $0.0628 \mathrm{~h}$ & pcilg & & 0.021 & u & & \\
\hline $\begin{array}{l}\text { SESPVMIII } \\
\text { SESPMNT }\end{array}$ & & $100 \mathrm{~F} S L O U G H$ & OOSITE & so & $\begin{array}{l}\text { SUB_SURFAEE } \\
\text { SUB SURFACE }\end{array}$ & $\begin{array}{l}\text { SEUINENI } \\
\text { SEDIMENT }\end{array}$ & 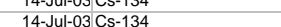 & 0.0234 & & 0.017 & 0.017 & u & & \\
\hline SESPMNT & B17705 & PRD-YAKIMA SIDE NEAR DAM & OFFSITE & so & SUB_SURFACE & $\begin{array}{l}\text { SEDIMENT } \\
\text { SEDEN }\end{array}$ & 14-Jul-03 Cs-134 & 0.0347 & $\begin{array}{l}\text { pcilg } \\
\text { pcig }\end{array}$ & 0.016 & 0.016 & u & & \\
\hline SESPMNT & B17707 & PRD-GRANT SIDE NEAR DAM & OFFSITE & so & SUB_SURFACE & SEDIMENT & 14-Jul-03 Cs-134 & 0.0456 & & 0.018 & 0.018 & u & & \\
\hline SESPMNT & B17713 & MCNARY-OR.SIDE NEAR DAM & OFFSITE & so & SUB_SURFACE & SEDIMENT & 16-Jul-03 Cs-134 & 0.0499 & & 0.023 & 0.023 & u & & \\
\hline SESPMNT & B17715 & MCNARY-WASH.SIDE NEAR DAM & OFFSITE & so & SUB_SURFACE & SEDIMENT & 16-Jul-03 Cs-134 & 0.0529 & & 0.022 & 0.022 & u & & \\
\hline $\begin{array}{l}\text { SESPMNT } \\
\text { SESPMNT }\end{array}$ & $\begin{array}{l}B 17 J 20 \\
B 17251\end{array}$ & $\begin{array}{l}\text { 300 AREA SPRING 42-2 } \\
100-\text { B SPRIIG 37-1 }\end{array}$ & ONSITE & so & SUB_SURFACE & $\begin{array}{l}\text { SEDIMENT } \\
\text { SEDMENT }\end{array}$ & 13-Oct-03 Cs-134 & 0.045 & & 0.018 & 0.018 & $u$ & & \\
\hline $\begin{array}{l}\text { SESPMNT } \\
\text { SESPMNT }\end{array}$ & $\begin{array}{l}B 17751 \\
B 1759\end{array}$ & $\begin{array}{l}\text { 100-B SPRING 37-1 } \\
\text { 300 AREA SPR DR 42-2 }\end{array}$ & $\begin{array}{l}\text { ONSIE } \\
\text { ONSITE }\end{array}$ & $\begin{array}{l}\text { so } \\
\text { so }\end{array}$ & $\begin{array}{l}\text { SUB_SURFACE } \\
\text { SUB_SURFAEE }\end{array}$ & $\begin{array}{l}\text { SEDIMENT } \\
\text { SEDMENT }\end{array}$ & $\begin{array}{l}\text { 20-Oct-03 Cs-134 } \\
\text { 13-Otc-03 C-134 }\end{array}$ & $\begin{array}{r}0.0545 \\
0.0355\end{array}$ & pcilg & 0.021 & $\begin{array}{l}0.021 \\
0.017\end{array}$ & $\begin{array}{l}u \\
u\end{array}$ & & \\
\hline $\begin{array}{l}\text { SESPMNI } \\
\text { SESPMNT }\end{array}$ & $\begin{array}{ll}B 1 / 759 \\
B 17 J 62\end{array}$ & $\begin{array}{l}\text { 100-K SPRING 63-1 } \\
\text { 100-2 }\end{array}$ & $\begin{array}{l}\text { ONSIITE } \\
\text { ONSITE }\end{array}$ & so & $\begin{array}{l}\text { SUB_SURFAEE } \\
\text { SUB SURFACE }\end{array}$ & $\begin{array}{l}\text { SEDIMENT } \\
\text { SEDIMENT }\end{array}$ & $\begin{array}{l}13-\mathrm{OCt}-03 \mathrm{Cs}-134 \\
20-\mathrm{Oct}-03 \mathrm{Cs}-134\end{array}$ & 0.0399 & pci/g & 0.017 & 0.017 & u & & \\
\hline $\begin{array}{l}\text { SESPVMNI } \\
\text { SESPMNT }\end{array}$ & B17J65 & 100-F SPRING 207-1 & ONSITE & so & $\begin{array}{l}\text { SUB_SURFACE } \\
\text { SUB SURFACE }\end{array}$ & $\begin{array}{l}\text { SEUMIENI } \\
\text { SEDIMENT }\end{array}$ & 03-Nov-03 Cs-134 & 0.0377 & & 0.023 & 0.023 & u & & \\
\hline SESPMNT & B17J99 & 100-H SPRING 145-1 & ONSITE & so & SUB_SURFACE & SEDIMENT & 27-Oct-03 Cs-134 & 0.0363 & pcilg & 0.019 & 0.019 & u & COLLECTED 20 METERS DOWN RIVER FROM SEEP. & \\
\hline SESPMNT & B17R89 & WEST LAKE & ONSITE & so & POND & SEDIMENT & 07-Oct-03 Cs-134 & 0.0346 & pcilg & 0.03 & 0.03 & u & & \\
\hline SESPSPEC & B16WV8 & YAKIMA RIVER & OFFSITE & so & SUB_SURFACE & SEDIMENT & 14-May-03 Cs-134 & 0.0458 & & 0.019 & 0.019 & u & & \\
\hline SESPSPEC & B16WV9 & YAKIMA RIVER & OFFSITE & so & SUB_SURFACE & SEDIMENT & 14-May-03 Cs-134 & 0.0369 & & 0.017 & 0.017 & u & & \\
\hline $\begin{array}{l}\text { SESPSPEC } \\
\text { SESPSPCC }\end{array}$ & B16WW0 & WALLA WALLA-RIVER & OFFSITE & so & SUB_SURFACE & $\begin{array}{l}\text { SEDIMENT } \\
\text { SEDMENT }\end{array}$ & 15-May-03 Cs-134 & 0.0259 & & 0.018 & 0.018 & u & & \\
\hline $\begin{array}{l}\text { SESPSPEC } \\
\text { SESPSPEC }\end{array}$ & $\begin{array}{ll}\text { B16WW1 } \\
\text { B16WWW }\end{array}$ & $\begin{array}{l}\text { WALLA WALLA-RIVER } \\
\text { RINGOLD WASTEWAY }\end{array}$ & $\begin{array}{l}\text { OFFSITE } \\
\text { OFFITE }\end{array}$ & $\begin{array}{l}\text { So } \\
\text { so }\end{array}$ & $\begin{array}{l}\text { SUB_SURFACE } \\
\text { SUB_SUREACE }\end{array}$ & $\begin{array}{l}\text { SEDIMENT } \\
\text { SEDMENT }\end{array}$ & $\begin{array}{l}15-\text { May-03 Cs-134 } \\
14 \text {-aya-03Cs-134 }\end{array}$ & $\begin{array}{l}0.0489 \\
0.0299\end{array}$ & pCilg & 0.024 & 0.024 & u & PRIMARIY Y SAND & \\
\hline $\begin{array}{l}\text { SESPSECC } \\
\text { SESPSPEC }\end{array}$ & $\begin{array}{l}\text { B16WW4 } \\
\text { B16WW5 }\end{array}$ & $\begin{array}{l}\text { RINGOLD WASTEWAY } \\
\text { RINGOLTEWAY }\end{array}$ & $\begin{array}{l}\text { OFFITE } \\
\text { OFFSITE }\end{array}$ & $\begin{array}{l}\text { SO } \\
\text { So }\end{array}$ & $\begin{array}{l}\text { SUB_SURFACE } \\
\text { SUB SURFACE }\end{array}$ & $\begin{array}{l}\text { SEDIMENT } \\
\text { SEDIMENT }\end{array}$ & $\begin{array}{l}\text { 14-May-03Cs-134 } \\
\text { 14-May-03Cs-134 }\end{array}$ & 0.02961 & 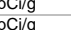 & 0.016 & 0.016 & u & $\begin{array}{l}\text { PRIMARLIY SAND. } \\
\text { PRIMARIIY SAND. }\end{array}$ & \\
\hline $\begin{array}{l}\text { SESPSECC } \\
\text { SESPSPEC }\end{array}$ & $\begin{array}{l}\text { BLowW5 } \\
\text { B16WW6 }\end{array}$ & ESQUATZEL CANAL & $\begin{array}{l}\text { OFFSIITE } \\
\text { OFFITE }\end{array}$ & so & $\begin{array}{l}\text { SUB_SURFAEE } \\
\text { SUB_SURFACE }\end{array}$ & $\begin{array}{l}\text { SEUMENI } \\
\text { SEDIMENT }\end{array}$ & $\begin{array}{l}\text { 14-May -03 Cs-134 } \\
14-\text { May-03 Cs-134 }\end{array}$ & . 0.04 & $\begin{array}{l}\text { pellg } \\
\text { ocilg }\end{array}$ & 0.019 & 0.019 & u & & \\
\hline SESPSPEC & B16Ww7 & ESQUATZEL CANAL & $\begin{array}{l}\text { OFFSIIE } \\
\text { OFFITE }\end{array}$ & so & $\begin{array}{l}\text { SUB_SURFAEE } \\
\text { SUB SURFACE }\end{array}$ & SEDIMENT & $\begin{array}{l}14-\text { May -03 Cs-134 } \\
14-\text { May-03 Cs-134 }\end{array}$ & 0.0326 & $\begin{array}{l}\mathrm{p} \text { pligg } \\
\mathrm{pcilg}\end{array}$ & 0.014 & 0.014 & u & & \\
\hline SESPSPEC & B17BD9 & MCNARY-2/3 OR. SHORE & OFFSITE & so & SUB_SURFACE & SEDIMENT & 08-Aug-03 Cs-134 & 0.0645 & pCilg & 0.029 & 0.029 & u & & \\
\hline SESPSPEC & B17BF4 & JOHN DAY DAM MID-RIVER & OFFSITE & so & SUB_SURFACE & SEDIMENT & 08-Aug-03 Cs-134 & 0.0765 & pcilg & 0.036 & 0.036 & u & & \\
\hline SESPSPEC & B17BF9 & DALLES DAM OR.SHORE & OFFSITE & so & SUB_SURFACE & SEDIMENT & 07-Aug-03 Cs-134 & 0.0325 & pcilg & 0.036 & 0.036 & $\mathrm{U}$ & & \\
\hline SESPSPEC & B17BH4 & BONNEVILLE DAM OR.SHORE & OFFSITE & so & SUB_SURFACE & SEDIMENT & 07-Aug-03 Cs-134 & 0.0508 & & 0.06 & 0.06 & u & & \\
\hline $\begin{array}{l}\text { SESPSPEC } \\
\text { SESPMNT }\end{array}$ & $\begin{array}{ll}\text { B17BH7 } \\
\text { B16R6 }\end{array}$ & $\begin{array}{l}\text { MCNARY-2/3 OR. SHORE } \\
\text { WESTAKE }\end{array}$ & $\begin{array}{l}\text { OFFSITE } \\
\text { ONSIE }\end{array}$ & so & $\begin{array}{l}\text { SUB_SURFACE } \\
\text { POND }\end{array}$ & $\begin{array}{l}\text { SEDIMENT } \\
\text { SEDMENT }\end{array}$ & $\begin{array}{l}\text { 08-Aug-03 Cs-134 } \\
\text { 1-Feh-03 }\end{array}$ & 0.0456 & & 0.035 & 0.035 & u & & \\
\hline $\begin{array}{l}\text { SESPMNT } \\
\text { SESPMNT }\end{array}$ & $\begin{array}{l}\text { B16RK6 } \\
\text { B16RT2 }\end{array}$ & $\begin{array}{l}\text { WEST LAKE } \\
\text { WEST LAKE }\end{array}$ & $\begin{array}{l}\text { ONSTIE } \\
\text { ONSITE }\end{array}$ & $\begin{array}{l}\text { so } \\
\text { so }\end{array}$ & $\begin{array}{l}\text { POND } \\
\text { POND }\end{array}$ & $\begin{array}{l}\text { SEDIMENT } \\
\text { SEDIMENT }\end{array}$ & $\begin{array}{l}11-\text { Feb-03 Cs-137 } \\
07-A p r-03 \text { Cs-137 }\end{array}$ & $\begin{array}{l}1.18 \mathrm{~F} \\
0.802 \mathrm{r}\end{array}$ & 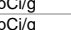 & $\begin{aligned} 0.14 \\
0.1\end{aligned}$ & 0.14 & & COLLECTED AT E. WATERHOLE. & \\
\hline $\begin{array}{l}\text { SESPMNI } \\
\text { SESPMNT }\end{array}$ & $\begin{array}{ll}\text { BLbR2 } \\
\text { B176T3 }\end{array}$ & & ONSITE & so & POND & $\begin{array}{l}\text { SEUMENI } \\
\text { SEDIMENT }\end{array}$ & 09-Jul-03 Cs-137 & $1.03 \mathrm{k}$ & 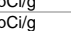 & 0.13 & 0.13 & & & \\
\hline SESPMNT & B176Y6 & HANFORD SLOUGH & RIVER SHORELINE & so & SUB SURFACE & SEDIMENT & 14-Jul-03 Cs-137 & 0.315 & $\begin{array}{l}\mathrm{pellg} \\
\mathrm{cCi} / \mathrm{g}\end{array}$ & 0.046 & 0.046 & & & \\
\hline SESPMNT & B176Y7 & RICHLAND-RIVER & $\begin{array}{l}\text { RIVER_SHORELINE } \\
\text { RIVER }\end{array}$ & so & SUB_SURFACE & SEDIMENT & 16-Jul-03 Cs-137 & 0.167 & pcilg & 0.03 & 0.03 & & & \\
\hline SESPMNT & B176Y8 & WHITE BLUFFS SLOUGH & RIVER_SHORELINE & so & SUB_SURFACE & SEDIMENT & 14-Jul-03 Cs-137 & 0.532 & pcilg & 0.072 & 0.072 & & & \\
\hline SESPMNT & B176Y9 & 100 F SLOUGH & ONSITE & so & SUB_SURFACE & SEDIMENT & 14-Jul-03 Cs-137 & $0.39 i$ & pcilg & 0.055 & 0.055 & & & \\
\hline SESPMNT & B17705 & PRD-YAKIMA SIDE NEAR DAM & OFFSITE & so & SUB_SURFACE & SEDIMENT & 14-Jul-03 Cs-137 & 0.285 & & 0.041 & 0.041 & & & \\
\hline $\begin{array}{l}\text { SESPMNT } \\
\text { SESPMNT }\end{array}$ & $\begin{array}{l}B 17707 \\
B 17713\end{array}$ & PRD-GRANT SIDE NEAR DAM & OFFSITE & so & $\begin{array}{l}\text { SUB_SURFACE } \\
\text { SUB_SUPFACE }\end{array}$ & $\begin{array}{l}\text { SEDIMENT } \\
\text { SEDMENT }\end{array}$ & 14-Jul-03 Cs-137 & 0.324 & pcilg & 0.048 & 0.048 & & & \\
\hline $\begin{array}{l}\text { SESPMNT } \\
\text { SESPMNT }\end{array}$ & $\begin{array}{l}\text { B17713 } \\
\text { B1715 }\end{array}$ & $\begin{array}{l}\text { MCCARYY-OR.SIDE NEAR DAM } \\
\text { MYNARY-WASH SDE NER DAM }\end{array}$ & $\begin{array}{l}\text { OFFSSTE } \\
\text { OFFITE }\end{array}$ & so & $\begin{array}{l}\text { SUB_SURFACE } \\
\text { SUB_SURFAEE }\end{array}$ & $\begin{array}{l}\text { SEDIIENT } \\
\text { SEDIMENT }\end{array}$ & $\begin{array}{l}\text { 16-Jul-03 Cs-137 } \\
\text { 16-Jul-0. } 3 \text { c-137 }\end{array}$ & $\begin{aligned} 0.39 \\
0.312\end{aligned}$ & pcilg & 0.034 & 0.034 & & & \\
\hline $\begin{array}{l}\text { SESPMNI } \\
\text { SESPMNT }\end{array}$ & $\frac{B 1715}{B 1720}$ & $\begin{array}{l}\text { MCCNARY-WASHASIDE NEAR DAM } \\
300 \text { AREA SPRING } 42-2\end{array}$ & $\begin{array}{l}\text { OFFSITE } \\
\text { ONSTE }\end{array}$ & so & $\begin{array}{l}\text { SUB_SURFACE } \\
\text { SUB SURFACE }\end{array}$ & $\begin{array}{l}\text { SEDIMENT } \\
\text { SEDIMENT }\end{array}$ & $\begin{array}{l}\text { 16--Jul-03Cs-137 } \\
\text { 13-Otc-03 C-137 }\end{array}$ & 0.3121 & $\begin{array}{ll}\text { pcig } \\
\text { cilg }\end{array}$ & 0.046 & 0.046 & & & \\
\hline SESPMNT & B17J51 & $\begin{array}{l}\text { 300 AREA SPRG } \\
\text { 100-B SPRING 42-2 }\end{array}$ & $\begin{array}{l}\text { ONSIITE } \\
\text { ONSITE }\end{array}$ & so & $\begin{array}{l}\text { SUB_SURFACE } \\
\text { SUB SURFACE }\end{array}$ & $\begin{array}{l}\text { SEDIMENI } \\
\text { SEDIMENT }\end{array}$ & $\begin{array}{l}13-\mathrm{Oct}-03 \mathrm{Cs}-137 \\
20-\mathrm{Oct}-03 \mathrm{Cs}-137\end{array}$ & 0.0684 & $\begin{array}{l}\text { pClig } \\
\text { pCilg }\end{array}$ & $\begin{array}{c}0.022 \\
0.023\end{array}$ & 0.023 & & & \\
\hline SESPMNT & B17J59 & 300 AREA SPR DR 42-2 & ONSITE & so & $\begin{array}{l}\text { SUB SURFACE } \\
\text { SUE SUF }\end{array}$ & SEDIMENT & 13 -Oct-03 Cs-137 & 0.173 & & 0.029 & 0.029 & & & \\
\hline SESPMNT & B17J62 & 100-K SPRING 63-1 & ONSITE & so & SUB_SURFACE & SEDIMENT & 20-Oct-03 Cs-137 & 0.113 & & 0.024 & 0.024 & & & \\
\hline SESPMNT & B17J65 & 100-F SPRING 207-1 & ONSITE & so & SUB_SURFACE & SEDIMENT & 03-Nov-03 Cs-137 & 0.262 & & 0.051 & 0.051 & & & \\
\hline SESPMNT & B17J99 & 100-H SPRING 145-1 & ONSITE & so & SUB_SURFACE & SEDIMENT & 27-Oct-03Cs-137 & $0.146 \mathrm{r}$ & pCilg & 0.034 & 0.034 & & COLLECTED 20 METERS DOWN RIVER FROM SEEP. & \\
\hline SESPMNT & B17R89 & $\begin{array}{l}\text { WEST LAKE } \\
\text { YAKMA IVER }\end{array}$ & ONSITE & so & POND & $\begin{array}{l}\text { SEDIMENT } \\
\text { SEDMENT }\end{array}$ & 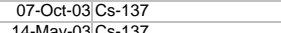 & 1.85 & pcilg & 0.24 & 0.24 & 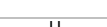 & & \\
\hline SESPSPEC & B16WV8 & $\begin{array}{l}\text { YAKKMA RIVER } \\
\text { YAKIMA RIVER }\end{array}$ & $\begin{array}{l}\text { OFFSITE } \\
\text { OFFSTEE }\end{array}$ & so & $\begin{array}{l}\text { SUB_SURFACE } \\
\text { SUB_SURFAEE }\end{array}$ & $\begin{array}{l}\text { SEDIIENT } \\
\text { SEDMENT }\end{array}$ & $\begin{array}{l}14-\text { May-03 Cs-137 } \\
14-03 \text { - } 137\end{array}$ & $0.00993 \mathrm{~h}$ & & 0.015 & 0.015 & u & & \\
\hline $\begin{array}{l}\text { SESPPEC } \\
\text { SESPSPEC }\end{array}$ & B16WWO & $\begin{array}{l}\text { YARIMA RIVER } \\
\text { WALLA WALLA-RIVER }\end{array}$ & $\begin{array}{l}\text { OFFSIIE } \\
\text { OFFITE }\end{array}$ & so & $\begin{array}{l}\text { SUB_SURFACE } \\
\text { SUB SURFACE }\end{array}$ & $\begin{array}{l}\text { SEDIMENI } \\
\text { SEDIMENT }\end{array}$ & $\begin{array}{l}14-\text { May-03Cs-137 } \\
15-\text { May-03Cs-137 }\end{array}$ & 0.0326 & 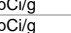 & 0.019 & . & 0 & & \\
\hline SESPSPEC & B16W01 & WAALA WAUAR-RIVER & OFESTE & so & SUB SURACE & SEDIENT & 15-Mav-03 C-5.137 & 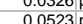 & 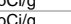 & 然 & 然 & & & \\
\hline $\begin{array}{l}\text { SESPSPEC } \\
\text { SESPE }\end{array}$ & B16WW4 & $\begin{array}{l}\text { RINGOLD WASTEWAY } \\
\text { RING }\end{array}$ & OFFSITE & so & $\begin{array}{l}\text { SUB-SURACECE } \\
\text { SUB SURA }\end{array}$ & SEDIMENT & 14-May-03 Cs-137 & 0.00229 & & 0.015 & 0.015 & $u$ & PRIMARILY SAND. & \\
\hline SESPSPEC & B16WW5 & RINGOLD WASTEWAY & OFFSITE & so & SUB_SURFACE & SEDIMENT & 14-May-03 Cs-137 & 0.0105 & & 0.013 & 0.013 & u & PRIMARILY SAND. & \\
\hline SESPSPEC & B16WW6 & ESQUATZEL CANAL & OFFSITE & so & SUB_SURFACE & SEDIMENT & 14-May-03 Cs-137 & 0.0146 & & 0.012 & 0.012 & $u$ & & \\
\hline SESPSPEC & B16WW7 & ESQUATZE & OFFSITE & so & SUB_SURFACE & SEDIMENT & 14-May-03 Cs-137 & & & 0.012 & 0.012 & $\mathrm{u}$ & & \\
\hline $\begin{array}{l}\text { SESPSPEC } \\
\text { SECDCDCC }\end{array}$ & B17BD9 & MCNARY-2/3 OR. SHORE & OFFSITE & so & SUB_SURFACE & SEDIMENT & 08-Aug-03 Cs-137 & 0.378 & pcilg & 0.081 & 0.081 & & & \\
\hline $\begin{array}{l}\text { SESPSPEC } \\
\text { SESPPEC }\end{array}$ & B17BFF & JOHN DAY DAM MID-RIVER & $\begin{array}{l}\text { OFFSITE } \\
\text { OFESTIE }\end{array}$ & so & $\begin{array}{l}\text { SUB_SURFACE } \\
\text { SUB_SUREACE }\end{array}$ & $\begin{array}{l}\text { SEDIMENT } \\
\text { SEDMENT }\end{array}$ & 08-Aug-03 Cs-137 & 0.333 & pCilg & $\begin{array}{r}0.07 \\
0.058\end{array}$ & $\begin{array}{r}0.07 \\
0.058\end{array}$ & & & \\
\hline $\begin{array}{l}\text { SESPPEC } \\
\text { SESPSPEC }\end{array}$ & B17BPH & $\begin{array}{l}\text { DAALES DAM OR.SHORE } \\
\text { BONNEYIIILE DAM OR SHORE }\end{array}$ & $\begin{array}{l}\text { OHFSIIE } \\
\text { OFESTIE }\end{array}$ & so & SUB_SURFACE & $\begin{array}{l}\text { SEDIMENI } \\
\text { SEDIMENT }\end{array}$ & $\begin{array}{l}\text { 07-Afg--03Cs-137 } \\
07-\text {-Aug }-03 \text { Cs-137 }\end{array}$ & 0.155 & pcilg & 0.058 & 0.058 & & & \\
\hline $\begin{array}{l}\text { SESPSPEC } \\
\text { SESPEC }\end{array}$ & B17BH7 & MCNARY-2/3 OR. SHORE & $\begin{array}{l}\text { OFFSIIE } \\
\text { OFFITE }\end{array}$ & so & SUB_SURFACE & $\begin{array}{l}\text { SEUINENI } \\
\text { SEDIMENT }\end{array}$ & $\begin{array}{l}\text { 0-A-Agg-03 Cs-137 } \\
08-\text {-Aug } 03 \text { Cs-137 }\end{array}$ & 0.425 & $\begin{array}{l}\mathrm{peClg} \\
\mathrm{CC} i / g\end{array}$ & 0.083 & 0.083 & & & \\
\hline SESPMNT & B16DK6 & WEST LAKE & ONSITE & so & POND & SEDIMENT & 11-Feb-03 Eu-152 & - & & 0.044 & 0.044 & u & COLLECTED AT E. WATERHOLE. & \\
\hline SESPMNT & B16RT2 & WEST LAKE & ONSITE & so & POND & SEDIMENT & 07-Apr-03 Eu-152 & 0.00898 & & 0.026 & 0.026 & u & & \\
\hline SESPMNT & B176T3 & WEST LA & ONSITE & so & POND & SEDIMENT & 09-Jul-03 Eu-152 & 0.041 & pcilg & 0.036 & 0.036 & u & & \\
\hline SESPMNT & B176Y6 & HANFC & RELINE & so & SUB_SURFACE & SED & 14 & 0. & & 9 & 0.049 & $\mathrm{u}$ & & \\
\hline SESPMNT & B176Y7 & $\begin{array}{l}\text { RICHLAND-RIVER } \\
\text { WHTE }\end{array}$ & RIVER_SHORELINE & so & SUB_SURFACE & SEDIMENT & 16-Jul-03 Eu-152 & 0.0245 & & 0.034 & 0.034 & $u$ & & \\
\hline $\begin{array}{l}\text { SESPMNT } \\
\text { SESPMNT }\end{array}$ & $\begin{array}{l}\text { B17668 } \\
\text { B176r9 }\end{array}$ & $\begin{array}{l}\text { WHITE BLUFFF SLOUGH } \\
100 \text { F SOUGH }\end{array}$ & $\begin{array}{l}\text { RIVERSSHORELINE } \\
\text { ONSTIE }\end{array}$ & $\begin{array}{l}\text { so } \\
\text { so }\end{array}$ & $\begin{array}{l}\text { SUB_SURFACE } \\
\text { SUB_SURFAE }\end{array}$ & $\begin{array}{l}\text { SEDIMENT } \\
\text { SEDMENT }\end{array}$ & $\begin{array}{l}\text { 14-Jul-03 Eu-152 } \\
\text { 14-Jul-0. } E \text { E-152 }\end{array}$ & $\begin{aligned} 0.1019 \\
0.0723\end{aligned}$ & pcilg & 0.053 & 0.053 & u & & \\
\hline $\begin{array}{l}\text { SESPMNI } \\
\text { SESPMNT }\end{array}$ & $\begin{array}{l}\text { B176699 } \\
\text { B17705 }\end{array}$ & $\begin{array}{l}\text { PRD-YAKIMA SIDE NEAR DAM } \\
\text { PRO SLOH }\end{array}$ & ONSTIE & so & SUB_SURFACE & $\begin{array}{l}\text { SEDIMENI } \\
\text { SEDIMENT }\end{array}$ & 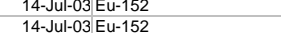 & 0.0092 & pcigg & 0.044 & 0.044 & u & & \\
\hline $\begin{array}{l}\text { SESHIVIVI } \\
\text { SESPMNT }\end{array}$ & B17707 & $\begin{array}{l}\text { PRD-YAK } \\
\text { PRD-GR } A\end{array}$ & $\begin{array}{l}\text { OFF } \\
\text { OFF: }\end{array}$ & so & SUB_SURFACE & $\begin{array}{l}\text { SEDIMENT } \\
\text { SEDEN }\end{array}$ & $\begin{array}{l}\text { 14-Jul-ULl-03 Eu-152 } \\
\text { 14-152 }\end{array}$ & 0.02 & 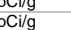 & & 0.032 & u & & \\
\hline SESPNT & B17713 & $\begin{array}{l}\text { MCNAAY-OR SILE NE } \\
\text { MCNA }\end{array}$ & $\begin{array}{l}\text { OFFITE } \\
\text { OFFITE }\end{array}$ & so & SUB SURACACE & $\begin{array}{l}\text { SEDIMENT } \\
\text { SEDEN }\end{array}$ & 16-Jul-03 Eu-152 & 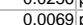 & & 0.035 & 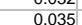 & u & & \\
\hline SESPMNT & B17715 & MCNARY-WASH.SSDE NEAR DAM & OFFSITE & so & SUB SURFACE & SEDIMENT & 16-Jul-03 Eu-152 & 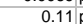 & pcilg & 0.054 & 0.054 & u & & \\
\hline SESPMNT & B17J20 & 300 AREA SPRING 42-2 & ONSITE & so & SUB_SURFACE & SED & 13-Oct-03 Eu-152 & 0.0102 & pcilg & 0.027 & 0.027 & U & & \\
\hline $\begin{array}{l}\text { SESPMNT } \\
\text { SESPMNT }\end{array}$ & $\begin{array}{l}\text { B17351 } \\
B 175159\end{array}$ & $\begin{array}{l}\text { 100-B SPRING 37-1 } \\
300 \text { AREA SPR DR 42-2 }\end{array}$ & $\begin{array}{l}\text { ONSITE } \\
\text { ONSIE }\end{array}$ & $\begin{array}{l}\text { so } \\
\text { so }\end{array}$ & $\begin{array}{l}\text { SUB_SURFACE } \\
\text { SUB SURACE }\end{array}$ & $\begin{array}{l}\text { SEDIMENT } \\
\text { SEDIMENT }\end{array}$ & $\begin{array}{l}\text { 20-Oct-03 Eu-152 } \\
\text { 13-Oct-03 Eu-152 }\end{array}$ & $\begin{array}{c}-0.000419 \\
0.06399\end{array}$ & $\begin{array}{l}\text { pCilg } \\
\text { picia }\end{array}$ & 0.026 & $\begin{array}{l}0.026 \\
0.035\end{array}$ & u & & \\
\hline
\end{tabular}


(pCilg Dry Weight unless otherwise noted)

\begin{tabular}{|c|c|c|c|c|c|c|c|c|c|c|c|c|c|c|}
\hline OWNER ID & $\begin{array}{l}\text { SAMP } \\
\text { NUM }\end{array}$ & & & & & & & $\begin{array}{l}\text { VALLUE } \\
\text { RPTD }\end{array}$ & $\begin{array}{l}\text { ANAL } \\
\text { UNITS } \\
\text { RPTD }\end{array}$ & $\begin{array}{c}\text { COUNTING } \\
\text { ERROR }\end{array}$ & $\begin{array}{c}\text { TOTAL } \\
\text { ANAL } \\
\text { ERROR }\end{array}$ & $\begin{array}{l}\text { LAB } \\
\text { QULLFIER }\end{array}$ & SAMP COMMENT & RESULT COMMENT \\
\hline SESPMNT & B17J62 & 100-K SPRING 63-1 & ONSITE & So & SUB_SURFACE & $\begin{array}{l}\text { SEDPIIMENT } \\
\text { SEDENT }\end{array}$ & 20-Oct-03 Eu-152 & & & | ERROR 0.023 & ERROR 1 & & & RESULI COIMIMENI \\
\hline SESPMNT & B17J65 & 100-F SPRING 207-1 & ONSITE & so & SUB_SURFACE & SEDIMENT & 03-Nov-03 EU-152 & $0.126 \mathrm{p}$ & & 0.06 & 0.06 & u & & \\
\hline SESPMNT & B17J99 & 100-H SPRING 145-1 & ONSITE & so & SUB_SURFACE & SEDIMENT & 27-Oct-03 Eu-152 & $0.0194 \mathrm{p}$ & & 0.03 & 0.03 & u & COLLECTED 20 METERS DOWN RIVER FROM SEEP. & \\
\hline SESPMNT & B17R89 & WEST LAKE & ONSITE & so & POND & SEDIMENT & 07-Oct-03 Eu-152 & $0.0164 \mathrm{p}$ & pcilg & 0.072 & 0.072 & u & & \\
\hline SESPSPEC & B16WV8 & $\begin{array}{l}\text { YAKIMA RIVER } \\
\text { YAKMA RIVER }\end{array}$ & OFFSITE & so & SUB_SURFACE & $\begin{array}{l}\text { SEDIMENT } \\
\text { SEDMENT }\end{array}$ & 14-May-03 Eu-152 & $-0.0241 \mathrm{p}$ & & 0.035 & 0.035 & $u$ & & \\
\hline $\begin{array}{l}\text { SESPSPEC } \\
\text { SESPSEC }\end{array}$ & $\begin{array}{l}\text { B16WV9 } \\
\text { B16WW0 }\end{array}$ & $\begin{array}{l}\text { YAKIMA RIVER } \\
\text { WALA WALA-RIVER }\end{array}$ & $\begin{array}{l}\text { OFFSITE } \\
\text { OFFITE }\end{array}$ & $\begin{array}{l}\text { so } \\
\text { so }\end{array}$ & $\begin{array}{l}\text { SUB_SURFACE } \\
\text { SUB SURACE }\end{array}$ & $\begin{array}{l}\text { SEDIMENT } \\
\text { SEDMENT }\end{array}$ & $\begin{array}{l}\text { 14-May-03 Eu-152 } \\
\text { 15-May-03 E-152 }\end{array}$ & $\begin{aligned} 0.0201 \mathrm{p} \\
-0.0248 \mathrm{p}\end{aligned}$ & & 0.038 & $\begin{array}{l}0.038 \\
0.034\end{array}$ & u & & \\
\hline $\begin{array}{l}\text { SESPSEC } \\
\text { SESPSPEC }\end{array}$ & $\begin{array}{l}\text { B16Wwo } \\
\text { B16WW1 }\end{array}$ & $\begin{array}{l}\text { WALA WALLA-RIVER } \\
\text { WALLA WALLA-RIVER }\end{array}$ & $\begin{array}{l}\text { OFSITE } \\
\text { OFFSITE }\end{array}$ & $\begin{array}{l}\text { so } \\
\text { so }\end{array}$ & $\begin{array}{l}\text { SUB_SURFACE } \\
\text { SUB SURACE }\end{array}$ & $\begin{array}{l}\text { SEDIIENT } \\
\text { SEDIMENT }\end{array}$ & $\begin{array}{l}\text { 15-May-03 Eu-152 } \\
\text { 15-May-03 Eu-152 }\end{array}$ & $\begin{array}{l}-0.0248 \mathrm{p} \\
-0.0415 \mathrm{p}\end{array}$ & $\begin{array}{l}\text { pci/g } \\
\text { cilqa }\end{array}$ & 0.034 & 0.034 & $\frac{u}{u}$ & & \\
\hline & $\begin{array}{ll}\text { BLowWI } \\
\text { B16WW4 }\end{array}$ & RINGOLD WASTEWAY & OFFSITE & so & $\begin{array}{l}\text { SUB_SURFAEE } \\
\text { SUB SURFACE }\end{array}$ & $\begin{array}{l}\text { SEDIMENI } \\
\text { SEDIMENT }\end{array}$ & $\begin{array}{l}\text { 15--May-03 Eu-152 } \\
\text { 14-May-03 Eu-152 }\end{array}$ & $\begin{array}{ll}-0.0415 \mathrm{p} \\
-0.044 \mathrm{p}\end{array}$ & pcilg & $\begin{array}{l}0.038 \\
0.06\end{array}$ & 0.038 & u & PRIMARILY SAND & \\
\hline $\begin{array}{l}\text { SESPPEC } \\
\text { SESPSPEC }\end{array}$ & 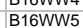 & RINGOLD WASTEWAY & OFFSITE & & $\begin{array}{l}\text { SUB_SURFACE } \\
\text { SUB SURFACE }\end{array}$ & $\begin{array}{l}\text { SEDIMENI } \\
\text { SEDIMENT }\end{array}$ & $\begin{array}{l}\text { 14-Mayy-03Eu-1-122 } \\
\text { 14-May-03 Eu-152 }\end{array}$ & $\begin{array}{l}-0.044 \mathrm{p} \\
-0.012 \mathrm{p}\end{array}$ & $\begin{array}{l}\text { pClig } \\
\text { oCilg }\end{array}$ & 0.032 & 0.032 & u & $\begin{array}{l}\text { PRIMARILY SAND. } \\
\text { PRANAT }\end{array}$ & \\
\hline SESPSPEC & B16WW6 & ESQUATZEL CANAL & $\begin{array}{l}\text { OFFSITE } \\
\text { OFFE }\end{array}$ & so & SUB_SURFACE & SEDIMENT & 14-May-03 Eu-152 & $\begin{array}{l}-0.012 \mathrm{p} \\
-0.0371 \mathrm{p}\end{array}$ & pcilg & 0.029 & 0.029 & u & & \\
\hline SESPSPEC & B16WW7 & ESQUATZEL CANAL & OFFSITE & so & SUB_SURFACE & SEDIMENT & 14-May-03 Eu-152 & $0.000344 \mathrm{p}$ & & 0.031 & 0.031 & u & & \\
\hline SESPSPEC & B17BD9 & MCNARY-2/3 OR. SHORE & OFFSITE & so & SUB_SURFACE & SEDIMENT & 08-Aug-03 Eu-152 & $0.286 \mathrm{p}$ & & 0.11 & 0.11 & u & & \\
\hline SESPSPEC & B17BF4 & JOHN DAY DAM MID-RIVER & OFFSITE & so & SUB_SURFACE & SEDIMENT & 08-Aug-03 Eu-152 & $0.0162 \mathrm{p}$ & & 0.077 & 0.077 & u & & \\
\hline $\begin{array}{l}\text { SESPSPEC } \\
\text { SESPSEC }\end{array}$ & $\begin{array}{l}\text { B17BF9 } \\
\text { B17BH4 }\end{array}$ & $\begin{array}{l}\text { DALLES DAM OR.SHORE } \\
\text { BONEVIILE DAM OR SHORE }\end{array}$ & $\begin{array}{l}\text { OFFSITE } \\
\text { OFFITE }\end{array}$ & $\begin{array}{l}\text { so } \\
\text { so }\end{array}$ & $\begin{array}{l}\text { SUB_SURFACE } \\
\text { SUB SURACE }\end{array}$ & $\begin{array}{l}\text { SEDIMENT } \\
\text { SEDIMENT }\end{array}$ & $\begin{array}{l}\text { 07-Aug-03 Eu-152 } \\
07\end{array}$ & $0.0667 \mathrm{p}$ & pCi/g & 0.088 & 0.088 & U & & \\
\hline $\begin{array}{l}\text { SESPSEEC } \\
\text { SESPPECC }\end{array}$ & $\begin{array}{ll}\text { B17BH4 } \\
\text { B17BH7 }\end{array}$ & $\begin{array}{l}\text { BONNEVIILLE DAM OR.SHORE } \\
\text { MCNARY-2/3 OR. SHORE }\end{array}$ & $\begin{array}{l}\text { OFFFITE } \\
\text { OFFITE }\end{array}$ & so & $\begin{array}{l}\text { SUB_SURFACE } \\
\text { SUB_SURFAEE }\end{array}$ & $\begin{array}{l}\text { SEDIMENT } \\
\text { SEDMENT }\end{array}$ & $\begin{array}{l}\text { 07-Augg-03 E-152 } \\
\text { 08-Aug-03 E-152 }\end{array}$ & $\begin{aligned}-0.0564 \mathrm{p} \\
0.217 \mathrm{p}\end{aligned}$ & pcilg & $\begin{aligned} 0.083 \\
0.12\end{aligned}$ & 0.083 & $\frac{u}{u}$ & & \\
\hline $\begin{array}{l}\text { SESPSEC } \\
\text { SESPMNT }\end{array}$ & 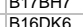 & $\begin{array}{l}\text { MENATY-2/3 OR. SHORE } \\
\text { WEST LAKE }\end{array}$ & $\begin{array}{l}\text { OFFITE } \\
\text { ONSITE }\end{array}$ & $\begin{array}{l}\text { so } \\
\text { so }\end{array}$ & $\begin{array}{l}\text { SUB_SURFACE } \\
\text { POND }\end{array}$ & $\begin{array}{l}\text { SEDIIENT } \\
\text { SEDMENT }\end{array}$ & $\begin{array}{l}\text { 08-Augg-03 Eu-152 } \\
\text { 11-Feb-03 Eu-154 }\end{array}$ & $\begin{aligned} 0.217 \mathrm{p} \\
-0.0484 \mathrm{p}\end{aligned}$ & pcilg & 0.12 & 0.12 & u & COLLECTED AT E. WATERHOLE. & \\
\hline SESPMNT & $\begin{array}{l}\text { BLRT2 } \\
\text { B16RT }\end{array}$ & WEST LAKE & ONSITE & so & POND & $\begin{array}{l}\text { SEUMENI } \\
\text { SEDIMENT }\end{array}$ & 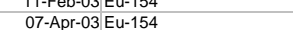 & $\begin{aligned}-0.0444 \mathrm{p} \\
-0.00639 \mathrm{p}\end{aligned}$ & & 0.035 & 0.035 & u & COLLECTED AIE. WAIERHOLE. & \\
\hline SESPMNT & B176T3 & WEST LAKE & ONSITE & so & POND & SEDIMENT & 09-Jul-03 Eu-154 & $-0.00061 \mathrm{p}$ & pcilg & 0.05 & 0.05 & U & & \\
\hline SESPMNT & B176Y6 & HANFORD SLOUGH & RIVER_SHORELINE & so & SUB_SURFACE & SEDIMENT & 14-Jul-03 Eu-154 & $0.0368 \mathrm{p}$ & pCilg & 0.039 & 0.039 & u & & \\
\hline SESPMNT & B176Y7 & RICHLAND-RIVER & RIVER_SHORELINE & so & SUB_SURFACE & SEDIMENT & 16-Jul-03 Eu-154 & $-0.0318 \mathrm{p}$ & & 0.043 & 0.043 & u & & \\
\hline SESPMNT & B176Y8 & WHITE BLUFFS SLOUGH & RIVER_SHORELINE & so & SUB_SURFACE & SEDIMENT & 14-Jul-03 Eu-154 & $0.0312 \mathrm{p}$ & pCilg & 0.053 & 0.053 & u & & \\
\hline $\begin{array}{l}\text { SESPMNT } \\
\text { SESPMNT }\end{array}$ & 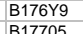 & 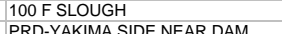 & $\begin{array}{l}\text { ONSITE } \\
\text { OSFSTE }\end{array}$ & so & SUB_SURFACE & $\begin{array}{l}\text { SEDIMENT } \\
\text { SEDIMENT }\end{array}$ & 14-Jul-03 Eu-154 & $\begin{array}{rl}-0.0159 p & p\end{array}$ & & 0.035 & 0.035 & u & & \\
\hline $\begin{array}{l}\text { SESPMNT } \\
\text { SESPMNT }\end{array}$ & $\begin{array}{l}\text { B17705 } \\
\text { B1707 }\end{array}$ & $\begin{array}{l}\text { PRD-YARIMA SIDE NEAR DAM } \\
\text { PRD-GRANT SIDE NEAR DAM }\end{array}$ & $\begin{array}{l}\text { OFFFITE } \\
\text { OFFSITE }\end{array}$ & $\begin{array}{l}\text { SO } \\
\text { so }\end{array}$ & $\begin{array}{l}\text { SUB_SURFACE } \\
\text { SUB_SURACE }\end{array}$ & $\begin{array}{l}\text { SEDIMENT } \\
\text { SEDMENT }\end{array}$ & $\begin{array}{l}\text { 14-Julu-03 Eu-154 } \\
\text { 14-Jul-03 Eu-154 }\end{array}$ & $0.000431 \mathrm{p}$ & pcilg & 0.035 & 0.035 & u & & \\
\hline $\begin{array}{l}\text { SESPMNI } \\
\text { SESPMNT }\end{array}$ & B17713 & $\begin{array}{l}\text { RDD-GRAAI SIDE NAR DAM } \\
\text { MCNARY-OR.SIDE NEAR DAM }\end{array}$ & $\begin{array}{l}\text { OFSFIITE } \\
\text { OFFSITE }\end{array}$ & so & $\begin{array}{l}\text { SUB_SURFACE } \\
\text { SUB SURFACE }\end{array}$ & $\begin{array}{l}\text { SEDIMENI } \\
\text { SEDIMENT }\end{array}$ & $\begin{array}{l}\text { 14-JUl-033u-u-154 } \\
\text { 16-Jul-03 Eu-154 }\end{array}$ & $\begin{array}{l}0.011 \mathrm{p} \\
0.0296 \mathrm{p}\end{array}$ & $\begin{array}{ll}\mathrm{pellg} \\
\mathrm{cC} i / g\end{array}$ & 0.036 & 0.036 & u & & \\
\hline SESPMNT & (B1715 & MCA & OFFIT & so & $\begin{array}{l}\text { SOB-SURACE } \\
\text { SUB SURACE }\end{array}$ & 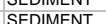 & 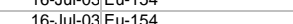 & 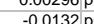 & 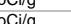 & 0.0404 & 0.040 & u & & \\
\hline SESPMNT & B17J20 & 300 AREA SPRING 42-2 & ONSITE & so & SUB_SURFACE & SEDIMENT & 13-Oct-03 Eu-154 & $0.0352 \mathrm{p}$ & & 0.037 & 0.037 & u & & \\
\hline SESPMNT & B17J51 & 100-B SPRING $37-1$ & ONSITE & so & SUB_SURFACE & SEDIMENT & 20-Oct-03 Eu-154 & $\begin{array}{l}-.05217 \mathrm{p} \\
-0.02\end{array}$ & pcilg & 0.036 & 0.036 & u & & \\
\hline SESPMNT & B17J59 & 300 AREA SPR DR 42-2 & ONSITE & so & SUB_SURFACE & SEDIMENT & 13-Oct-03 Eu-154 & $-0.0142 \mathrm{p}$ & pcilg & 0.035 & 0.035 & u & & \\
\hline SESPMNT & B17J62 & 100-K SPRING 63-1 & ONSITE & so & SUB_SURFACE & SEDIMENT & 20-Oct-03 Eu-154 & $0.0156 \mathrm{p}$ & & 0.031 & 0.031 & u & & \\
\hline SESPMNT & $B 17365$ & 100-F SPRING 207-1 & ONSITE & so & & SEDIMENT & 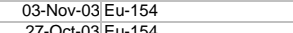 & $-0.00565 \mathrm{p}$ & & 0.043 & 0.043 & $\mathrm{U}$ & & \\
\hline SESPMNT & 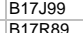 & & $\begin{array}{l}\text { ONSITE } \\
\text { ONSTE }\end{array}$ & so & SUB_SURFACE & $\begin{array}{l}\text { SEDIMENT } \\
\text { SEDMENT }\end{array}$ & 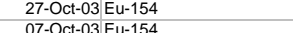 & $0.022 \mathrm{p}$ & pCilg & 0.037 & 0.037 & $\mathrm{u}$ & COLLECTED 20 METERS DOWN RIVER FROM SEEP. & \\
\hline $\begin{array}{l}\text { SESPMNT } \\
\text { SESPSPEC }\end{array}$ & 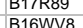 & $\begin{array}{l}\text { WEST LAKE } \\
\text { YAKIMA RIVER }\end{array}$ & $\begin{array}{l}\text { ONSIIE } \\
\text { OFFITE }\end{array}$ & $\begin{array}{l}\text { SO } \\
\text { so }\end{array}$ & $\begin{array}{l}\text { POND } \\
\text { SUB SURFACE }\end{array}$ & $\begin{array}{l}\text { SEDIMENT } \\
\text { SEDMENT }\end{array}$ & $\begin{array}{l}\text { 07-OCt-03 Eu-154 } \\
\text { 14-May-03 U-154 }\end{array}$ & $\begin{array}{l}0.00604 \mathrm{p} \\
0.00711 \mathrm{p}\end{array}$ & $\begin{array}{lll}\text { pcigg } \\
\text { cilg }\end{array}$ & 0.073 & $\begin{array}{l}0.073 \\
0.042\end{array}$ & u & & \\
\hline $\begin{array}{l}\text { SESPSPEC } \\
\text { SESPC }\end{array}$ & B16WV9 & YAKIMA RIVER & OFFSITE & so & SUB_SURFACE & SEDIMENT & 14-May-03 Eu-154 & -0.00862 $\mathrm{p}$ & pcilg & 0.042 & 0.042 & u & & \\
\hline $\begin{array}{l}\text { SESPSPEC } \\
\text { SESPS }\end{array}$ & B16wwo & $\begin{array}{l}\text { WALA WALA-RIVER } \\
\text { WALA WA }\end{array}$ & OFFSITE & so & SUB SURACE & SEDIMENT & 15-Mav-03 E-154 & $-0.0305 \mathrm{p}$ & & 0.047 & 0.047 & u & & \\
\hline SESPSPEC & B16WW1 & WALLA WALLA-RIVER & OFFSITE & so & $\begin{array}{l}\text { SUB_SURFACE } \\
\text { SUB_SOCA }\end{array}$ & SEDIMENT & 15 -May-03 Eu-154 & $-0.0122 \mathrm{p}$ & & 0.045 & 0.045 & u & & \\
\hline SESPSPEC & B16WW4 & RINGOLD WASTEWAY & OFFSITE & so & SUB_SURFACE & SEDIMENT & 14-May-03 Eu-154 & $-0.0232 \mathrm{p}$ & & 0.046 & 0.046 & u & PRIMARILY SAND. & \\
\hline SESPSPEC & B16WW5 & RINGOLD WASTEWAY & OFFSITE & so & SUB_SURFACE & SEDIMENT & 14-May-03 Eu-154 & $0.00818 \mathrm{p}$ & & 0.042 & 0.042 & u & PRIMARILY SAND. & \\
\hline $\begin{array}{l}\text { SESPSPEC } \\
\text { SESPSPCE }\end{array}$ & B16WW6 & ESQUATZEL CANAL & OFFSITE & so & SUB_SURFACE & $\begin{array}{l}\text { SEDIMENT } \\
\text { SEDMENT }\end{array}$ & 14-May-03 Eu-154 & $0.00882 p$ & & 0.04 & 0.04 & U & & \\
\hline $\begin{array}{l}\text { SESPSEC } \\
\text { SESPSPEC }\end{array}$ & $\begin{array}{l}\text { B16WW7 } \\
\text { B17BD9 }\end{array}$ & ESQUATZEL CANAL & $\begin{array}{l}\text { OFFSITE } \\
\text { OFESTTE }\end{array}$ & so & $\begin{array}{l}\text { SUB_SURFACE } \\
\text { SUB_SURFACE }\end{array}$ & $\begin{array}{l}\text { SEDIMENT } \\
\text { SEDMENT }\end{array}$ & $\begin{array}{l}\text { 14-May-03 Eu-154 } \\
\text { 08-Aug-03 E-154 }\end{array}$ & $\begin{aligned} 0.0504 p \\
0.02 p\end{aligned}$ & pCilg & 0.042 & 0.042 & u & & \\
\hline $\begin{array}{l}\text { SESPSEC } \\
\text { SESPSPEC }\end{array}$ & $\begin{array}{l}\text { B17BD9 } \\
\text { B17BE4 }\end{array}$ & $\begin{array}{l}\text { MCNARY-2/3 OR. SHORE } \\
\text { JOHN DAY DAM MID-RIVER }\end{array}$ & $\begin{array}{l}\text { OFFFITE } \\
\text { OFFITE }\end{array}$ & $\begin{array}{l}\text { SO } \\
\text { So }\end{array}$ & $\begin{array}{l}\text { SUB_SURFACE } \\
\text { SUB SURFACE }\end{array}$ & $\begin{array}{l}\text { SEDIMENT } \\
\text { SEDIMENT }\end{array}$ & $\begin{array}{l}\text { 08-Augg-03 E-154 } \\
\text { 08-Aug-03 Eu-154 }\end{array}$ & $\begin{aligned} 0.02 \mathrm{p} \\
0.0379 \mathrm{p}\end{aligned}$ & $\begin{array}{l}\mathrm{pellg} \\
\mathrm{cCi} / \mathrm{g}\end{array}$ & $\begin{array}{l}0.072 \\
0.1\end{array}$ & 0.072 & u & & \\
\hline $\begin{array}{l}\text { SESPPEC } \\
\text { SESPSEC }\end{array}$ & (1) & DAI ESDAMOB SHORE & OFSTLE & 50 & $\begin{array}{l}\text { SOBSBORACE } \\
\text { SUB SUPACE }\end{array}$ & SEDIENT & (1) & $0.0379 \mathrm{p}$ & 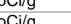 & 0.1 & 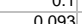 & 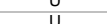 & & \\
\hline & B17BS4 & & OFFSITE & so & SUB_SURFACE & SEDIMENT & 07-Aug-03 Eu-154 & $0.0713 \mathrm{p}$ & ocilg & 0.1 & 0.000 & u & & \\
\hline SESPSPEC & $\begin{array}{l}-51704 \\
\text { B17BH7 }\end{array}$ & MCNARY-2/3 OR. SHORE & OFFSITE & so & SUB_SURFACE & SEDIMENT & 08-Aug-03 Eu-154 & $0.0026 \mathrm{p}$ & & 0.091 & 0.091 & u & & \\
\hline SESPMNT & B16DK6 & WEST LAKE & ONSITE & so & POND & SEDIMENT & 11-Feb-03 Eu-155 & $0.04 \mathrm{p}$ & & 0.037 & 0.037 & u & COLLECTED AT E. WATERHOLE. & \\
\hline SESPMNT & B16RT2 & WEST LAKE & ONSITE & so & POND & SEDIMENT & 07-Apr-03 Eu-155 & $0.027 \mathrm{p}$ & pcilg & 0.033 & 0.033 & $\mathrm{U}$ & & \\
\hline SESPMNT & B176T3 & WEST LAKE & ONSITE & so & POND & & 09-Jul-03 Eu-155 & & pcilg & 0.04 & 0.04 & $\mathrm{U}$ & & \\
\hline $\begin{array}{l}\text { SESPMNT } \\
\text { SESPMNT }\end{array}$ & $\begin{array}{l}\text { B176Y6 } \\
\text { B176Y7 }\end{array}$ & $\begin{array}{l}\text { HANFORD SLOUGH } \\
\text { RICHAND-RIFR }\end{array}$ & $\begin{array}{l}\text { RIVER_SHORELINE } \\
\text { RIVR_SHOBEINE }\end{array}$ & so & $\begin{array}{l}\text { SUB_SURFACE } \\
\text { SUB_SUPFACE }\end{array}$ & $\begin{array}{l}\text { SEDIMENT } \\
\text { SEDMENT }\end{array}$ & 14-Jul-03 Eu-155 & $0.0537 \mathrm{p}$ & pcilg & 0.035 & 0.035 & $\mathrm{U}$ & & \\
\hline $\begin{array}{l}\text { SESPMNT } \\
\text { SESPMNT }\end{array}$ & $\begin{array}{l}\text { B17667 } \\
\text { B17698 }\end{array}$ & $\begin{array}{l}\text { RICHALNDDRIVER } \\
\text { WHITE BLUFFS SLOUGH }\end{array}$ & $\begin{array}{l}\text { IIVR_SIORELINE } \\
\text { RIVRERSHOREINE }\end{array}$ & $\begin{array}{l}\text { so } \\
\text { so }\end{array}$ & $\begin{array}{l}\text { SUB_SURFAEE } \\
\text { SUB SURACE }\end{array}$ & $\begin{array}{l}\text { SEDIIENT } \\
\text { SEDIMENT }\end{array}$ & 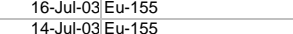 & 0.09 & $\begin{array}{l}\mathrm{plig} \\
\mathrm{c} \text { Cilg }\end{array}$ & 0.036 & 0.036 & u & & \\
\hline SESPMNT & 列 & 1. & $\begin{array}{l}\text { OIVR-STURELIVE } \\
\text { ONSTE }\end{array}$ & 50 & $\begin{array}{l}\text { SOB-SURACE } \\
\text { SUB SUPACE }\end{array}$ & SEDIENT & (14) & & 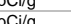 & 0.044 & 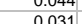 & 4 & & \\
\hline SESPMNT & B17705 & SIDE NEAR DAM & OFFSITE & so & $\begin{array}{l}\text { SUB_SURFACE } \\
\text { SUB SURFACE }\end{array}$ & $\begin{array}{l}\text { SEUMENI } \\
\text { SEDIMENT }\end{array}$ & $\begin{array}{l}\text { 14-Jul-0UE Uu-155 } \\
\text { 14-Jul-03 Eu-155 }\end{array}$ & 0.0. & & 0.031 & 0.031 & u & & \\
\hline SESPMNT & B17707 & PRD-GRANT SIDE NEAR DAM & OFFSITE & so & SUB_SURFACE & SEDIMENT & 14-Jul-03 Eu-155 & $0.0471 \mathrm{p}$ & pcilg & 0.034 & 0.034 & u & & \\
\hline SESPMNT & B17713 & MCNARY-OR.SIDE NEAR DAM & OFFSITE & so & SUB_SURFACE & SEDIMENT & 16-Jul-03 Eu-155 & 0.03 & pCilg & 0.034 & 0.034 & u & & \\
\hline SESPMNT & B17715 & IDE NEAR DAM & OFF & so & SUB_SURFACE & SED & $16-\mathrm{J}$ & 0.0 & pCilg & 0.036 & 0.036 & u & & \\
\hline SESPMNT & B17J20 & 300 AREA SPRING 42-2 & ONSITE & so & SUB_SURFACE & & 13-Oct-03 Eu-155 & & pcilg & 0.032 & 0.032 & $u$ & & \\
\hline SESPMNT & 817551 & 100-B SPRING 37-1 & ONSITE & so & SUB_SURFACE & $\begin{array}{l}\text { SEDIMENT } \\
\text { SEDMENT }\end{array}$ & $\begin{array}{l}20-\text { Oct-03 Eu-155 } \\
\text { En }\end{array}$ & $0.0954 \mathrm{p}$ & pcilg & 0.037 & 0.037 & $\mathrm{U}$ & & \\
\hline $\begin{array}{l}\text { SESPMNT } \\
\text { SESPMNT }\end{array}$ & 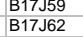 & $\begin{array}{l}\text { 300AREA APR DR 42-2 } \\
\text { 100-K SPRING 63-1 }\end{array}$ & $\begin{array}{l}\text { ONSTIE } \\
\text { ONSITE }\end{array}$ & $\begin{array}{l}\text { So } \\
\text { so }\end{array}$ & $\begin{array}{l}\text { SU_S_SURAACE } \\
\text { SUB_SURFACE }\end{array}$ & $\begin{array}{l}\text { SEDIMENT } \\
\text { SEDIMENT }\end{array}$ & 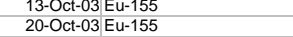 & $\begin{array}{l}0.0659 \mathrm{p} \\
0.0201 \mathrm{p}\end{array}$ & $\begin{array}{l}\text { pcig } \\
\text { pCilg }\end{array}$ & $\begin{array}{l}0.029 \\
0.029\end{array}$ & 0.029 & u & & \\
\hline SESPMNT & B17J65 & $\begin{array}{l}100-K S P \\
100-F S P\end{array}$ & ONSITE & so & $\begin{array}{l}\text { SUB_SURACE } \\
\text { SUB_SURFACE }\end{array}$ & NT & & $0.0733 \mathrm{p}$ & & 0.033 & 0.033 & u & & \\
\hline SESPMNT & B17J99 & NG 145-1 & & so & SUB_SURFACE & & & & & 0.031 & 0.031 & u & COLLECTED 20 METERS DOWN RIVER FROM SEEP. & \\
\hline SESPMNT & B17R89 & WEST LAKE & ONS & so & POND & SEDIMENT & $07-\mathrm{Oct}$ & $0.0429 \mathrm{p}$ & & 0.064 & 0.064 & 0 & & \\
\hline SESPSPEC & B16WV8 & YAKIMA RIVER & OFFSITE & so & SUB_SURFACE & SEDIM & 14-May-03 E & 0.0 & pcilg & 0. & 0.032 & u & & \\
\hline SESPSPEC & B16WV9 & YAKIMA RIVER & OFF: & so & SUB_SURF & SEDIM & 14-May-0: & 0.0 & pCilg & 0.035 & 0.035 & $u$ & & \\
\hline SESPSPEC & B16WWo & WALLA WALLA-RIVER & OFFSITE & so & SUB_SURFACE & SEDIMENT & 15-May-03 Eu-155 & $0.0787 \mathrm{p}$ & pcilg & 0.036 & 0.036 & $\mathrm{u}$ & & \\
\hline SESPSPEC & B16WW1 & WALLA WALLA-RIVER & OFFSITE & so & SUB_SURFACE & $\begin{array}{l}\text { SEDIMENT } \\
\text { SEDMENT }\end{array}$ & 15-May-03 Eu-155 & $0.0359 \mathrm{p}$ & pcilg & 0.04 & 0.04 & $u$ & & \\
\hline SPEC & B16WW4 & $\begin{array}{l}\text { RINGOLD WASTEWAY } \\
\text { IINGOLD WASTEWAY }\end{array}$ & OFFSITE & so & SUB_SURFACE & $\begin{array}{l}\text { SEDIMENT } \\
\text { SEDMENT }\end{array}$ & 14-May-03 Eu-155 & $0.0643 \mathrm{p}$ & pCilg & 0.06 & 0.06 & U & $\begin{array}{l}\text { PRIIARILY SAND. } \\
\text { PRMAPUY SAND. }\end{array}$ & \\
\hline $\begin{array}{l}\text { SESPSECC } \\
\text { SESPPEC }\end{array}$ & $\begin{array}{l}\text { B16WW5 } \\
\text { B16WW6 }\end{array}$ & ESQUATE & $\begin{array}{l}\text { OFFFITE } \\
\text { OFSITE }\end{array}$ & so & $\begin{array}{l}\text { SUB_SURFAEE } \\
\text { SUB SURFACE }\end{array}$ & $\begin{array}{l}\text { SEDMENI } \\
\text { SEDIMENT }\end{array}$ & $\begin{array}{l}\text { 14-May-Useu-155 } \\
\text { 14-May-03 Eu-155 }\end{array}$ & 0.0 & $\begin{array}{l}\text { peilg } \\
\text { pcig }\end{array}$ & 0.031 & 0.031 & 0 & & \\
\hline $\begin{array}{l}\text { SESPSEC } \\
\text { SESPSEC }\end{array}$ & B16WW7 & IESOUATZEL ANAAL & 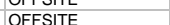 & so & $\begin{array}{l}\text { SOB-SURACE } \\
\text { SUB SURACE }\end{array}$ & 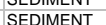 & 1) & 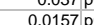 & & 然 0.039 & 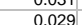 & & & \\
\hline
\end{tabular}


(pCilg Dry Weight unless otherwise noted)

\begin{tabular}{|c|c|c|c|c|c|c|c|c|c|c|c|c|c|c|}
\hline & $\begin{array}{l}\text { SAMP } \\
\text { NUM }\end{array}$ & & & & & & & $\begin{array}{l}\text { VALLUE } \\
\text { RPTD }\end{array}$ & $\begin{array}{l}\text { ANAL } \\
\text { UNITS } \\
\text { RPTD }\end{array}$ & $\begin{array}{c}\text { COUNTING } \\
\text { ERROR }\end{array}$ & $\begin{array}{c}\text { TOTAL } \\
\text { ANAL } \\
\text { ERROR }\end{array}$ & $\begin{array}{l}\text { LAB } \\
\text { QULLFIER }\end{array}$ & SAMP COMMENT & \\
\hline $\begin{array}{l}\text { OWNER D } \\
\text { SESPSPEC }\end{array}$ & $\begin{array}{l}\text { N NUM } \\
\text { B17BDP9 }\end{array}$ & $\begin{array}{l}\text { SAMP SIE NAME } \\
\text { MCNARY-2/3 OR. SHORE }\end{array}$ & $\begin{array}{l}\text { DIST CLASS } \\
\text { OFFSITE }\end{array}$ & IMEDIA & $\begin{array}{l}\text { SAMPFROM } \\
\text { SUB_SURFACE }\end{array}$ & $\begin{array}{l}\text { I SAMP PTEM } \\
\text { SEDIMENT }\end{array}$ & $\begin{array}{l}\text { AMP DATE| CONS SHORT NAME } \\
\text { 08-Aug-03 Eu-155 }\end{array}$ & & & $\begin{aligned} \text { ERROR } \\
0.062\end{aligned}$ & $\begin{array}{l}\text { ERROR } \\
0.062\end{array}$ & & SAMP COMMENT & RESULT COMMENT \\
\hline SESPSPEC & B17BF4 & JOHN DAY DAM MID-RIVER & OFFSITE & so & SUB_SURFACE & SEDIMENT & 08-Aug-03 Eu-155 & $0.0761 \mathrm{p}$ & & 0.07 & 0.07 & u & & \\
\hline SESPSPEC & B178F9 & DALLES DAM OR.SHORE & OFFSITE & so & SUB_SURFACE & SEDIMENT & 07-Aug-03 Eu-155 & $0.0474 \mathrm{p}$ & & 0.077 & 0.077 & u & & \\
\hline SESPSPEC & B17BH4 & BONNEVILLE DAM OR.SHORE & OFFSITE & so & SUB_SURFACE & SEDIMENT & 07-Aug-03 Eu-155 & $0.0214 \mathrm{p}$ & & 0.086 & 0.086 & u & & \\
\hline $\begin{array}{l}\text { SESPSPEC } \\
\text { SESPMNT }\end{array}$ & B17BH7 & $\begin{array}{l}\text { MCNARY-2/3 OR. SHORE } \\
\text { HANEORD SRP }\end{array}$ & OFFSITE & so & $\begin{array}{l}\text { SUB_SURFACE } \\
\text { SUB SURECE }\end{array}$ & $\begin{array}{l}\text { SEDIMENT } \\
\text { SSEDIMET }\end{array}$ & $\begin{array}{l}\text { 08-Aug-03 Eu-155 } \\
\text { 15-Sen-036AMMA SCAN }\end{array}$ & $0.113 \mathrm{p}$ & & 0.074 & 0.074 & $u$ & & \\
\hline $\begin{array}{l}\text { SESPMNT } \\
\text { SESPMNT }\end{array}$ & 817554 & $\begin{array}{l}\text { HAAFORD SPR UR R 28-2 } \\
\text { HANFORD SPR DR 28-2 }\end{array}$ & $\begin{array}{l}\text { ONSITE } \\
\text { ONSTE }\end{array}$ & so & $\begin{array}{l}\text { SUB_SURFACE } \\
\text { SUB_SUPFACE }\end{array}$ & $\begin{array}{l}\text { SEDIMENT } \\
\text { SEDIMET }\end{array}$ & 15-Sep-03 GAMMA SCAN & & & & & & NO SAMPLE. & \\
\hline $\begin{array}{l}\text { SESPMNT } \\
\text { SESPSPEC }\end{array}$ & $\begin{array}{l}\text { B17556 } \\
\text { B16WW2 }\end{array}$ & $\begin{array}{l}\text { ANAFORD SPR DR 28-2 } \\
\text { SNAKE RIVER }\end{array}$ & $\begin{array}{l}\text { ONSFTE } \\
\text { OFFSITE }\end{array}$ & $\begin{array}{l}\text { so } \\
\text { so }\end{array}$ & $\begin{array}{l}\text { SUB_SURFACE } \\
\text { SUB SURACE }\end{array}$ & $\begin{array}{l}\text { SEDIMENT } \\
\text { SEDIMENT }\end{array}$ & $\begin{array}{l}\text { 03--10v-00 GAMMA SCAN } \\
\text { 15-May-03 GAMMA SCAN }\end{array}$ & & & & & & $\begin{array}{l}\text { NO SAMPLE. } \\
\text { NO SAMPLE. }\end{array}$ & \\
\hline & $\begin{array}{l}\text { BLbwW2 } \\
\text { B16WW3 }\end{array}$ & SNAKE RIVER & OFFSITE & so & $\begin{array}{l}\text { SUB_SURFAEE } \\
\text { SUB SURFACE }\end{array}$ & $\begin{array}{l}\text { SEUIMENI } \\
\text { SEDIMENT }\end{array}$ & & & & & & & NO SAMPLE. & \\
\hline $\begin{array}{l}\text { SESPSPEC } \\
\text { SESPSPEC }\end{array}$ & $\begin{array}{l}\text { B16WW3 } \\
\text { B16WW }\end{array}$ & POTHOLES CANAL & OFFSITE & so & $\begin{array}{l}\text { SUB_SURFACE } \\
\text { SUB SURFACE }\end{array}$ & $\begin{array}{l}\text { SEDIMEN } \\
\text { SEDIMENT }\end{array}$ & $\begin{array}{l}\text { 15-May-00G GAMMA SCAN } \\
\text { 14-May-03 GAMMA SCAN }\end{array}$ & & & & & & $\begin{array}{l}\text { NO SAMPLE. } \\
\text { NO SAMPLE. }\end{array}$ & \\
\hline SESPSPEC & B16WW9 & POTHOLES CANAL & $\begin{array}{l}\text { OFFSITE } \\
\text { OFFE }\end{array}$ & so & SUB_SURFACE & SEDIMENT & 14-May-03 GAMMA SCAN & & & & & & NO SAMPLE. & \\
\hline SESPMNT & B16DK6 & WEST LAKE & ONSITE & so & POND & SEDIMENT & $11-\mathrm{Feb}-03 \mathrm{~K}-40$ & $16.5 \mathrm{p}$ & & 2.1 & 2.1 & & COLLECTED AT E. WATERHOLE. & \\
\hline SESPMNT & B16RT2 & WEST LAKE & ONSITE & so & POND & SEDIMENT & 07-Apr-03 K-40 & & & 2 & 2 & & & \\
\hline SESPMNT & B176T3 & WEST LAKE & ONSITE & so & POND & $\begin{array}{l}\text { SEDIMENT } \\
\text { SEDIMENT }\end{array}$ & 09-Jul-03 K-40 & & pcilg & 1.8 & 1.8 & & & \\
\hline $\begin{array}{l}\text { SESPMNT } \\
\text { SESPMNT }\end{array}$ & $\begin{array}{l}\text { B176Y6 } \\
\text { B176Y7 }\end{array}$ & $\begin{array}{l}\text { HANFORD SLOUGH } \\
\text { RICHLAND-RIVER }\end{array}$ & $\begin{array}{l}\text { RIVER_SHORELINE } \\
\text { RIVR SHORELINE }\end{array}$ & $\begin{array}{l}\text { so } \\
\text { so }\end{array}$ & $\begin{array}{l}\text { SUB_SURFACE } \\
\text { SUB SURACE }\end{array}$ & $\begin{array}{l}\text { SEDIMENT } \\
\text { SEDIMENT }\end{array}$ & 14-Jul-03 K-40 & $16.2 \mathrm{p}$ & & 2 & 2 & & & \\
\hline $\begin{array}{l}\text { SESPMNT } \\
\text { SESPMNT }\end{array}$ & $\begin{array}{l}\text { B17667 } \\
\text { B176Y8 }\end{array}$ & $\begin{array}{l}\text { IICHAAND-RIVER } \\
\text { WHITE NLUFFS SLOUGH }\end{array}$ & $\begin{array}{l}\text { RIVER_SHORELINE } \\
\text { RIER SHORELINE }\end{array}$ & so & $\begin{array}{l}\text { SUB_SURFACE } \\
\text { SUB_SURFAEE }\end{array}$ & $\begin{array}{l}\text { SEDIMENT } \\
\text { SEDIENT }\end{array}$ & $\begin{array}{l}\text { 16-Jul-03 K-40 } \\
\text { 14-Ju-03 K-40 }\end{array}$ & $\begin{array}{ll}17.4 p \\
18.4 \mathrm{p}\end{array}$ & pcilg & 2.2 & 2.2 .24 & & & \\
\hline $\begin{array}{l}\text { SESPMNI } \\
\text { SESPMNT }\end{array}$ & 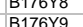 & $\begin{array}{l}\text { WHTTE BLUFFFS SLOUGH } \\
100 \text { F SLUGH }\end{array}$ & $\begin{array}{l}\text { liVR_SHORELINE } \\
\text { ONSITE }\end{array}$ & $\begin{array}{l}\text { so } \\
\text { so }\end{array}$ & $\begin{array}{l}\text { SUB_SURFACE } \\
\text { SUB_SURFACE }\end{array}$ & $\begin{array}{l}\text { SEDIMENT } \\
\text { SEDIMENT }\end{array}$ & $\begin{array}{l}\text { 14-Jul-03 K-40 } \\
\text { 14-Jul-03 K-40 }\end{array}$ & $\begin{array}{l}18.4 \mathrm{p} \\
141 \mathrm{p}\end{array}$ & $\begin{array}{l}\text { pilg } \\
\text { cilga }\end{array}$ & 2.4 & 2.4. & & & \\
\hline SESPMNT & B17705 & PRD-YAKIMA SIDE NEAR DAM & OFFSITE & so & SUB_SURFACE & SEDIMENT & 14-Jul-03 K-40 & $\begin{array}{l}14.1 \mathrm{p} \\
12.2 \mathrm{p}\end{array}$ & & 1.6 & 1.6 & & & \\
\hline SESPMNT & B17707 & PRD-GRANT SIDE NEAR DAM & OFFSITE & so & SUB_SURFACE & SEDIMENT & 14-Jul-03 K-40 & $12.3 \mathrm{p}$ & pcilg & 1.6 & 1.6 & & & \\
\hline SESPMNT & B17713 & MCNARY-OR.SIDE NEAR DAM & OFFSITE & so & SUB_SURFACE & SEDIMENT & 16-Jul-03 K-40 & $11.6 \mathrm{p}$ & pcilg & 1.5 & 1.5 & & & \\
\hline SESPMNT & B17715 & MCNARY-WASH.SIDE NEAR DAM & OFFSITE & so & SUB_SURFACE & SEDIMENT & 16-Jul-03 K-40 & & pcilg & 1.8 & 1.8 & & & \\
\hline SESPMNT & B17J20 & 300 AREA SPRING 42-2 & ONSITE & so & SUB_SURFACE & SEDIMENT & 13-Oct-03 K-40 & $16.7 \mathrm{p}$ & pCilg & 2.1 & 2.1 & & & \\
\hline $\begin{array}{l}\text { SESPMNT } \\
\text { SESPMNT }\end{array}$ & B17J51 & & $\begin{array}{l}\text { ONSITE } \\
\text { ONSTIE }\end{array}$ & so & SUB_SURFACE & $\begin{array}{l}\text { SEDIMENT } \\
\text { SEDMETT }\end{array}$ & 20-Oct-03 K-40 & $14.1 \mathrm{p}$ & pcilg & 1.8 & 1.8 & & & \\
\hline $\begin{array}{l}\text { SESPMNT } \\
\text { SESPMNT }\end{array}$ & $\begin{array}{l}\text { B17759 } \\
\text { B17562 }\end{array}$ & $\begin{array}{l}300 \text { AREA SPR DR 42-2 } \\
100-K \text { SPRING 63-1 }\end{array}$ & $\begin{array}{l}\text { ONSIIE } \\
\text { ONSITE }\end{array}$ & so & $\begin{array}{l}\text { SUB_SURFACE } \\
\text { SUB_SURFAEE }\end{array}$ & $\begin{array}{l}\text { SEDIMENT } \\
\text { SEDIENT }\end{array}$ & $\begin{array}{l}\text { 13-Oct-03 K-10 } \\
\text { 20-Oct-03 K-40 }\end{array}$ & $\begin{array}{l}14.9 \mathrm{p} \\
14.7 \mathrm{p}\end{array}$ & pcilg & 1.8 & 1.8 & & & \\
\hline $\begin{array}{l}\text { SESPMNI } \\
\text { SESPMNT }\end{array}$ & $\begin{array}{l}\frac{B 1 / 762}{B 17365} \\
B 15\end{array}$ & $\begin{array}{l}\text { 100-K SPRIIG 63-1 } \\
\text { 100-F SPRING 207-1 }\end{array}$ & $\begin{array}{l}\text { ONSITE } \\
\text { ONSITE }\end{array}$ & so & $\begin{array}{l}\text { SUB_SURFAAE } \\
\text { SUB SURFACE }\end{array}$ & $\begin{array}{l}\text { SEDIMENT } \\
\text { SEDIMENT }\end{array}$ & $\begin{array}{l}\text { 20-Oct-03 K-40 } \\
\text { 03-Nov-03 K-40 }\end{array}$ & $\begin{array}{l}14.7 \mathrm{p} \\
14.9 \mathrm{p}\end{array}$ & $\begin{array}{ll}\mathrm{pici/g} \\
\mathrm{cCi} / \mathrm{g}\end{array}$ & 1.8 & $\frac{1.8}{2}$ & & & \\
\hline SESPMNT & 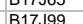 & 100-H SPRING 145-1 & ONSTE & so & SUB SURACE & SEFIMNT & 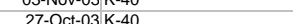 & 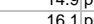 & 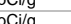 & 2 & 2 & & COLLECTED 20 METERS DOWN RIVER EROM SEEP & \\
\hline SESPMNT & B17R89 & WEST LAKE & 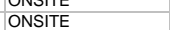 & so & POND & SEDIMENT & $07-\mathrm{Oct}-03 \mathrm{~K} \mathrm{~K}-40$ & 16.7p & pcilg & 2.2 & 2.2 & & COLLECIEU ZO MIETERS DOWIV RTVER FRUIV SEEP. & \\
\hline SESPSPEC & B16WV8 & YAKIMA RIVER & OFFSITE & so & SUB_SURFACE & SEDIMENT & 14-May-03 K-40 & $11.3 \mathrm{p}$ & pcilg & 1.5 & 1.5 & & & \\
\hline SESPSPEC & B16WV9 & YAKIMA RIVER & OFFSITE & so & SUB_SURFACE & SEDIMENT & 14-May-03 K-40 & $11.5 \mathrm{p}$ & pcilg & 1.5 & 1.5 & & & \\
\hline SESPSPEC & B16Wwo & WALLA WALLA-RIVER & OFFSITE & so & SUB_SURFACE & SEDIMENT & 15-May-03 K-40 & $14.5 \mathrm{p}$ & pCilg & 1.9 & 1.9 & & & \\
\hline $\begin{array}{l}\text { SESPSPEC } \\
\text { SESPSEC }\end{array}$ & B16WW1 & WALLA WALLA-RIVER & OFFSITE & so & SUB_SURFACE & $\begin{array}{l}\text { SEDIMENT } \\
\text { SCDMMENT }\end{array}$ & 15-May-03 K-40 & $14.4 \mathrm{p}$ & pcilg & 1.9 & 1.9 & & & \\
\hline $\begin{array}{l}\text { SESPSPEC } \\
\text { SESPSEC }\end{array}$ & B16WW4 & RINGOLD WASTEWAY & $\begin{array}{l}\text { OFFSITE } \\
\text { OFESTIE }\end{array}$ & $\begin{aligned} \text { so } \\
\text { so }\end{aligned}$ & $\begin{array}{l}\text { SUB_SURFACE } \\
\text { SUB_SUREACE }\end{array}$ & $\begin{array}{l}\text { SEDIMENT } \\
\text { SEDMMETT }\end{array}$ & $\begin{array}{l}14-\text { May-03 K-40 } \\
14-\text { Mav-03 K-40 }\end{array}$ & $17.3 \mathrm{p}$ & pCilg & 2.1 & 2.1. & & $\begin{array}{l}\text { PRIMARILY SAND. } \\
\text { PRIMAUY SAND }\end{array}$ & \\
\hline $\begin{array}{l}\text { SESPSEC } \\
\text { SESPSPEC }\end{array}$ & $\begin{array}{l}\text { B16WW5 } \\
\text { B16WW6 }\end{array}$ & $\begin{array}{l}\text { RINGOLD WASTEWAY } \\
\text { ESOUATZEL CANAL }\end{array}$ & $\begin{array}{l}\text { OFFITE } \\
\text { OFFSITE }\end{array}$ & $\begin{array}{l}\text { So } \\
\text { so }\end{array}$ & $\begin{array}{l}\text { SUB_SURFACE } \\
\text { SUB_SURFACE }\end{array}$ & $\begin{array}{l}\text { SEDIMENT } \\
\text { SEDIMENT }\end{array}$ & $\begin{array}{l}\text { 14-May-03 K-40 } \\
\text { 14-May-03 K-40 }\end{array}$ & $\begin{array}{l}17.1 \mathrm{p} \\
163 \mathrm{p}\end{array}$ & $\begin{array}{l}\text { pilg } \\
\text { cilga }\end{array}$ & 2.1 & 2.1 & & PRIMARILY SAND. & \\
\hline SESPSEC & B16W07 & ESOUTZE CANAL & OFFIT & so & SUB SURACE & SSEIMNT & 14-Mav-0.3K-4.40 & $159 \mathrm{p}$ & 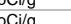 & $\begin{array}{c}2.1 \\
2\end{array}$ & 2.: & & & \\
\hline SESPSPEC & B17BD9 & MCNARY-2/3 OR. SHORE & OFFSITE & so & SUB_SURFACE & SEDIMENT & 08-Aug-03 K-40 & $\begin{array}{l}1.9 \mathrm{p} \\
14.8 \mathrm{p}\end{array}$ & pcilg & 2 & $\frac{2}{2}$ & & & \\
\hline SESPSPEC & B17BF4 & JOHN DAY DAM MID-RIVER & OFFSITE & so & SUB_SURFACE & SEDIMENT & 08 -Aug- 03 K-40 & $14.2 \mathrm{p}$ & & 2.1 & 2.1 & & & \\
\hline SESPSPEC & B17BF9 & DALLES DAM OR.SHORE & OFFSITE & so & SUB_SURFACE & SEDIMENT & 07-Aug- 03 K-40 & & & 1.8 & 1.8 & & & \\
\hline SESPSPEC & B17BH4 & BONNEVILLE DAM OR.SHORE & OFFSITE & so & & SEDIMENT & 07-Aug-03 K-40 & $13.1 \mathrm{p}$ & pcilg & 2.1 & 2.1 & & & \\
\hline $\begin{array}{l}\text { SESPSPEC } \\
\text { SESPMNT }\end{array}$ & B17BH7 & $\begin{array}{l}\text { MCNARY-2/3 OR. SHORE } \\
\text { WEST }\end{array}$ & OFFSITE & so & SUB_SURFACE & $\begin{array}{l}\text { SEDIMENT } \\
\text { SEDIMET }\end{array}$ & 08-Aug-03 K-40 & $14 \mathrm{p}$ & pcilg & 2 & 2 & & 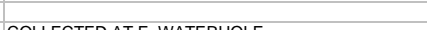 & \\
\hline $\begin{array}{l}\text { SESPMNT } \\
\text { SESPMNT }\end{array}$ & $\begin{array}{l}\text { B16DK6 } \\
\text { B16R2 }\end{array}$ & $\begin{array}{l}\text { WEST LAKE } \\
\text { WESTIAKE }\end{array}$ & $\begin{array}{l}\text { ONSITE } \\
\text { ONSTEE }\end{array}$ & so & $\begin{array}{l}\text { POND } \\
\text { POND }\end{array}$ & $\begin{array}{l}\text { SEDIMENT } \\
\text { SEDIMET }\end{array}$ & $\begin{array}{l}\text { 11-Feb-03 Ru-106 } \\
\text { 07-Apr-03 R-106 }\end{array}$ & $-0.104 \mathrm{p}$ & & 0.093 & 0.093 & $\frac{u}{u}$ & COLLECTED AT E. WATERHOLE. & \\
\hline $\begin{array}{l}\text { SESPMNT } \\
\text { SESPMNT }\end{array}$ & 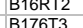 & $\begin{array}{l}\text { WEST LAKE } \\
\text { WEST LAKE }\end{array}$ & $\begin{array}{l}\text { ONSIIE } \\
\text { ONSITE }\end{array}$ & $\begin{array}{l}\text { SO } \\
\text { So }\end{array}$ & $\begin{array}{l}\text { POND } \\
\text { POND }\end{array}$ & $\begin{array}{l}\text { SEDIMENT } \\
\text { SEDIMENT }\end{array}$ & $\begin{array}{l}\text { 07-Apr-033R-1066 } \\
\text { 09-Jul-03 Ru-106 }\end{array}$ & $\begin{array}{l}0.0134 \mathrm{p} \\
0.0244 \mathrm{p}\end{array}$ & $\begin{array}{l}\mathrm{peClg} \\
\mathrm{cCli} / \mathrm{g}\end{array}$ & 0.078 & 0.078 & u & & \\
\hline SESPMNT & 的 & HANERD SIOUGH & PISTE SHOPEINE & 50 & SUB SUPEACE & S & 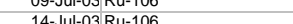 & 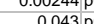 & 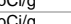 & $\frac{0.11}{0.93}$ & 0.14 & u & & \\
\hline SESPMNT & 列 & RECHAND-RIVER & RIVR S SORELUNE & so & SUB SURACE & SSEIMNT & 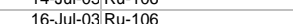 & - $-0.0429 \mathrm{p}$ & cicla & 0.031 & 0.011 & u & & \\
\hline SESPMNT & B176Y8 & WHITE BLUFFS SLOUGH & $\begin{array}{l}\text { RIVER SHORELINE } \\
\text { SH }\end{array}$ & so & SUB_SURFACE & SEDIMENT & 14-Jul-03 Ru-106 & $0.111 \mathrm{p}$ & & 0.14 & 0.14 & u & & \\
\hline SESPMNT & B176Y9 & 100 F SLOUGH & ONSITE & so & SUB_SURFACE & SEDIMENT & 14-Jul-03 Ru-106 & $0.0496 \mathrm{p}$ & & 0.093 & 0.093 & u & & \\
\hline SESPMNT & B17705 & IDE NEAR DAM & OFFSITE & so & SUB_SURFACE & SEDIMENT & 14-Jul-03 Ru-106 & $0.015 p$ & pcilg & 0.083 & 0.083 & u & & \\
\hline SESPMNT & B17707 & PRD-GRANT SIDE NEAR DAM & OFFSITE & so & SUB_SURFACE & & 14-Jul-03 Ru-106 & $0.00343 \mathrm{p}$ & pcilg & 0.1 & 0.1 & $\mathrm{U}$ & & \\
\hline $\begin{array}{l}\text { SESPMNT } \\
\text { SECPMNT }\end{array}$ & B17713 & MCNARY-OR.SIDE NEAR DAM & OFFSITE & so & SUB_SURFACE & $\begin{array}{l}\text { SEDIMENT } \\
\text { SEDMMETT }\end{array}$ & 16-Jul-03 Ru-106 & $0.0283 \mathrm{p}$ & pcilg & 0.11 & 0.11 & $\mathrm{U}$ & & \\
\hline $\begin{array}{l}\text { SESPMNT } \\
\text { SESPMNT }\end{array}$ & $\begin{array}{l}817715 \\
81720\end{array}$ & $\begin{array}{l}\text { MCNARY-WASH.SIDE NEAR DAM } \\
300 \text { ARAA SPRING } 42.2\end{array}$ & OFFSITE & so & $\begin{array}{l}\text { SUB_SURFACE } \\
\text { SUB_SURFACE }\end{array}$ & $\begin{array}{l}\text { SEDIMENT } \\
\text { SEDIMET }\end{array}$ & $\begin{array}{l}\text { 16-Jul-03 Ru-106 } \\
\text { 13-0ct-03 Ru-106 }\end{array}$ & $\begin{array}{rl}0.0203 p & p \\
-0.0599 p & 0\end{array}$ & pCilg & 0.097 & 0.097 & u & & \\
\hline $\begin{array}{l}\text { SESPMNT } \\
\text { SESPMNT }\end{array}$ & $\begin{array}{l}B 17202 \\
B 1751\end{array}$ & $\begin{array}{l}300 \text { AREA SPRIIG 42-2 } \\
100-B \text { SPRING 37-1 }\end{array}$ & $\begin{array}{l}\text { ONSTIE } \\
\text { ONSITE }\end{array}$ & $\begin{array}{l}\text { SO } \\
\text { so }\end{array}$ & $\begin{array}{l}\text { SUB_SURFACE } \\
\text { SUB SURFACE }\end{array}$ & $\begin{array}{l}\text { SEDIMENT } \\
\text { SEDIMENT }\end{array}$ & 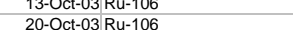 & $\begin{array}{l}-0.0599 \mathrm{p} \\
-0.0054 \mathrm{p}\end{array}$ & $\begin{array}{ll}\mathrm{peClg} \\
\mathrm{CC} i / g\end{array}$ & $\begin{array}{l}0.085 \\
0.084\end{array}$ & 0.085 & u & & \\
\hline $\begin{array}{l}\text { SESPMNIN } \\
\text { SESPMNT }\end{array}$ & B17559 & $\begin{array}{l}100-B \text { SPRIVG } 30-1 \\
300 \text { AREA SPR DR 42-2 }\end{array}$ & $\begin{array}{l}\text { ONSITE } \\
\text { ONSTE }\end{array}$ & so & $\begin{array}{l}\text { SUB_SURFACE } \\
\text { SUB SURFACE }\end{array}$ & $\begin{array}{l}\text { SEUIMEN } \\
\text { SEDIMENT }\end{array}$ & 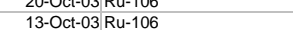 & $\begin{array}{l}-0.0054 \mathrm{p} \\
0.0361 \mathrm{p}\end{array}$ & 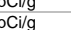 & 0.074 & 0.079 & u & & \\
\hline SESPMNT & B17J62 & 100-K SPRING 63-1 & ONSITE & so & SUB_SURFACE & SEDIMENT & 20-Oct-03 Ru-106 & $0.0684 \mathrm{p}$ & ocilg & 0.079 & 0.079 & u & & \\
\hline SESPMNT & B17J65 & 100-F SPRING 207-1 & ONSITE & so & SUB_SURFACE & SEDIMENT & 03-Nov-03 Ru-106 & $0.0245 \mathrm{p}$ & pCilg & 0.096 & 0.096 & u & & \\
\hline SESPMNT & B17J99 & VG 145-1 & ONSITE & so & SUB_SURFACE & SEDIMENT & $27-00$ & $-0.0424 \mathrm{p}$ & & 0.087 & 0.087 & u & COLLECTED 20 METERS DOWN RIVER FROM SEEP. & \\
\hline SESPMNT & B17R89 & WEST LAKE & ONSITE & so & POND & SEDIMENT & 07-Oct-03 Ru-106 & $-0.284 \mathrm{p}$ & pcilg & 0.22 & 0.22 & $\mathrm{U}$ & & \\
\hline $\begin{array}{l}\text { SESPSPEC } \\
\text { SESPDPEC }\end{array}$ & B16WV8 & $\begin{array}{l}\text { YAKIMA RIVER } \\
\text { YAKMA RIVER }\end{array}$ & OFFSITE & so & SUB_SURFACE & $\begin{array}{l}\text { SEDIMENT } \\
\text { SSEDMUENT }\end{array}$ & 14-May-03 Ru-106 & $-0.0139 \mathrm{p}$ & pCilg & 0.11 & 0.11 & $\mathrm{u}$ & & \\
\hline $\begin{array}{l}\text { SESPPPEC } \\
\text { SESPPPEC }\end{array}$ & B16WV9 & $\begin{array}{l}\text { YAAIMA RIVER } \\
\text { WALA WALA-RIVER }\end{array}$ & $\begin{array}{l}\text { OFFFITE } \\
\text { OFFITE }\end{array}$ & $\begin{array}{l}\text { so } \\
\text { so }\end{array}$ & SUB_SURFACE & $\begin{array}{l}\text { SEDIMENT } \\
\text { SEDIMNT }\end{array}$ & $\begin{array}{l}\text { 14-May- } 03 \text { Ru-106 } \\
15 \text { May } 03 \text { Ru-106 }\end{array}$ & $\begin{aligned}-0.0141 \mathrm{p} \\
0.1 \mathrm{p}\end{aligned}$ & $\begin{array}{ccc}\text { pcigg } \\
\text { cilgig. }\end{array}$ & 0.12 & 0.12 & $\frac{u}{u}$ & & \\
\hline $\begin{array}{l}\text { SESSPPEC } \\
\text { SESPSPEC }\end{array}$ & B16WW1 & $\begin{array}{l}\text { WALLA WALLA-RIVER } \\
\text { WALA WA }\end{array}$ & $\begin{array}{l}\text { OFFFITE } \\
\text { OFFITE }\end{array}$ & so & $\begin{array}{l}\text { SUB_SURACE } \\
\text { SUB_SURFACE }\end{array}$ & $\begin{array}{l}\text { SEDMUEN } \\
\text { SEDIMENT }\end{array}$ & $\begin{array}{l}15-\text { May-03RR-106 } \\
15 \text {-May-03 Ru-106 }\end{array}$ & $0.0817 \mathrm{p}$ & pcilg & 0.12 & 0.12 & 0 & & \\
\hline $\begin{array}{l}\text { SESPSPEC } \\
\text { SESP }\end{array}$ & & RINC & OFFSITE & so & SUB_SURFACE & $\begin{array}{l}\text { SEDIMENT } \\
\text { SEDN }\end{array}$ & 14-May-03 Ru-106 & $-0.0701 \mathrm{p}$ & pcilg & 0.13 & 0.13 & u & PRIMA & \\
\hline & B16WW5 & RINGOLD WASTEWAY & OFFSITE & so & SUB_SURFACE & SEDIMENT & 14-May-03 Ru-106 & $0.000213 \mathrm{p}$ & pcilg & 0.11 & 0.11 & u & PRIMARILY SAND. & \\
\hline SESPSPEC & B16WW6 & ESQUATZEL CANAL & OFFSITE & so & SUB_SURFACE & SEDIMENT & 14-May-03 Ru-106 & $0.0524 \mathrm{p}$ & pcilg & 0.098 & 0.098 & u & & \\
\hline SESPS & B16WW7 & ESQUAT & OFFSITE & so & SUB_SURFACE & SEDIMENT & 14-May-03 Ru- & $-0.00375 \mathrm{p}$ & & 0.097 & 0.097 & u & & \\
\hline SESPSPEC & B17BD9 & MCNARY-2/3 OR. SHORE & OFFSITE & so & SUB_SURFACE & SEDIMENT & 08-Aug-03 Ru-106 & $-0.0878 \mathrm{p}$ & & 0.19 & 0.19 & u & & \\
\hline SESPSPEC & B17BF4 & JOHN DAY DAM MID-RIVER & OFFSITE & so & SUB_SURFACE & SEDIMENT & 08-Aug-03 Ru-106 & $-0.266 p$ & pcilg & 0.26 & 0.26 & $\mathrm{U}$ & & \\
\hline SPEC & B178BF9 & DALLES DAM OR.SHORE & OFFSITE & so & SUB_SURFACE & $\begin{array}{l}\text { SEDIMENT } \\
\text { SEDMENT }\end{array}$ & $\begin{array}{l}\text { 07-Aug-03 Ru-106 } \\
07\end{array}$ & $\begin{array}{l}-0.219 p \\
-0246 n\end{array}$ & & 0.26 & 0.26 & U & & \\
\hline $\begin{array}{l}\text { SESPPPEC } \\
\text { SESPSPEC }\end{array}$ & $\begin{array}{l}\text { B17BB44 } \\
\text { B17BH7 }\end{array}$ & /3 OR. SHORE & $\begin{array}{l}\text { OFFFITE } \\
\text { OFSITE }\end{array}$ & so & $\begin{array}{l}\text { SUB_SURFAEE } \\
\text { SUB SURFACE }\end{array}$ & $\begin{array}{l}\text { SEDIMENT } \\
\text { SEDEN }\end{array}$ & $\begin{array}{l}08 \text {-Aug-03 Ru-106 } \\
08 \text { Rug }\end{array}$ & $\begin{aligned} 0.246 \mathrm{p} \\
0.0634 \mathrm{p}\end{aligned}$ & $\begin{array}{l}\text { pcilg } \\
\text { pcig }\end{array}$ & 0.35 & $\begin{array}{r}0.25 \\
0.25\end{array}$ & u & & \\
\hline $\begin{array}{l}\text { SESPMNT } \\
\text { SESTE }\end{array}$ & B16DK6 & WEST LAKE & ONSITE & so & POND & $\begin{array}{l}\text { SEDIMENT } \\
\text { SEDN }\end{array}$ & 11-Feb-03 Sb-125 & $0.0268 \mathrm{p}$ & & 0.031 & 0.031 & & & \\
\hline
\end{tabular}


(pCilg Dry Weight unless otherwise noted

\begin{tabular}{|c|c|c|c|c|c|c|c|c|c|c|c|c|c|c|}
\hline | OWNER ID & \begin{tabular}{|l|} 
SAMP \\
NUM
\end{tabular} & SAMP SITE NAME & DIST CLASS & |MEDIA & SAMP FROM & SAMP ITEM & |SAMP DATE CON SHORT NAME & \begin{tabular}{|c|c|} 
VALLE & UPTD \\
RPTD
\end{tabular} & \begin{tabular}{|l|} 
ANAL \\
UNITS \\
RPTD
\end{tabular} & $\begin{array}{c}\text { COUNTING } \\
\text { ERROR }\end{array} \mid$ & \begin{tabular}{c|} 
TOTAL \\
ANAL \\
ERROR
\end{tabular} & \begin{tabular}{|c|c} 
LAB \\
QUALIFIER
\end{tabular} & SAMP COMMENT & RESULT COMMENT \\
\hline SESPMNT & B16RT2 & WEST LAKE & ONSITE & so & POND & SEDIMENT & 07-Apr-03 Sb-125 & & & 0.026 & 0.026 & $u$ & & \\
\hline $\begin{array}{l}\text { SESPMNT } \\
\text { SESPMNT }\end{array}$ & B176T3 & $\begin{array}{l}\text { WEST LAKE } \\
\text { HANFORD SLOUGH }\end{array}$ & ONSITE & so & POND & $\begin{array}{l}\text { SEDIMENT } \\
\text { SEDMPNT }\end{array}$ & 09-Jul-03 Sb-125 & $0.0179 \mathrm{pC}$ & cilg & 0.038 & 0.038 & $u$ & & \\
\hline $\begin{array}{l}\text { SESPMNT } \\
\text { SESPMNT }\end{array}$ & $\begin{array}{l}\text { B17666 } \\
\text { B176Y7 }\end{array}$ & $\begin{array}{l}\text { HANFORD SLOUGH } \\
\text { RICHLAND-RIVER }\end{array}$ & $\begin{array}{l}\text { RIVER_SHORELINE } \\
\text { RIVER SHOREINE }\end{array}$ & $\begin{array}{l}\text { so } \\
\text { so }\end{array}$ & $\begin{array}{l}\text { SUB_SURFACE } \\
\text { SUB SURFACE }\end{array}$ & $\begin{array}{l}\text { SEDIMENT } \\
\text { SEDIMENT }\end{array}$ & $\begin{array}{l}\text { 14-Julu-03 Sb-125 } \\
\text { 16-Jul-03 Sb-125 }\end{array}$ & $\begin{array}{l}-0.00778 \mathrm{pC} \\
0.0346 \mathrm{pC}\end{array}$ & Cilg & 0.028 & 0.028 & u & & \\
\hline $\begin{array}{l}\text { SESPMNI } \\
\text { SESPMNT }\end{array}$ & $\begin{array}{l}\text { BDrfr/ } \\
\text { B176Y8 }\end{array}$ & & $\begin{array}{l}\text { RIVE_SHORELINE } \\
\text { RIVER_SHORELINE }\end{array}$ & so & $\begin{array}{l}\text { SUBSURFACE } \\
\text { SUB SURFACE }\end{array}$ & $\begin{array}{l}\text { SEDIMENT } \\
\text { SEDIMENT }\end{array}$ & $\begin{array}{l}\text { 16-Jul-03 Sb-125 } \\
\text { 14-Jul-03 Sb-125 }\end{array}$ & $\begin{array}{l}0.00346 \mathrm{pC} \\
-0.00455 \mathrm{pC}\end{array}$ & Cilig & $\begin{array}{r}0.03 \\
0.039\end{array}$ & $\begin{array}{r}0.03 \\
0.039\end{array}$ & u & & \\
\hline SESPMNT & $\begin{array}{l}\text { D176ro } \\
\text { B1769 }\end{array}$ & $100 \mathrm{~F} \mathrm{SLOUGH}$ & ONSITE & so & $\begin{array}{l}\text { SUBSURFACE } \\
\text { SUB SURFACE }\end{array}$ & $\begin{array}{l}\text { SEDIMENI } \\
\text { SEDIMENT }\end{array}$ & $\begin{array}{l}\text { 14-Jul-03 Sb-125 } \\
\text { 14-Jul-03 Sb-125 }\end{array}$ & $\begin{array}{l}-0.0455 \mathrm{pC} \\
-0.0198 \mathrm{pC}\end{array}$ & Cilg & $\begin{array}{l}0.039 \\
0.027\end{array}$ & $\begin{array}{l}0.039 \\
0.027\end{array}$ & u & & \\
\hline SPMNT & B17705 & & OFFSITE & so & SUB_SURFACE & SEDIMENT & 14-Jul-03 Sb-125 & $0.0044 \mathrm{pC}$ & Cilg & 0.026 & 0.026 & u & & \\
\hline SESPMNT & B17707 & PRD-GRANT SIDE NEAR DAM & OFFSITE & so & SUB_SURFACE & SEDIMENT & 14-Jul-03 Sb-125 & $0.0165 \mathrm{pC}$ & Cilg & 0.03 & 0.03 & u & & \\
\hline SESPMNT & B17713 & MCNARY-OR.SIDE NEAR DAM & OFFSITE & so & SUB_SURFACE & SEDIMENT & 16-Jul-03 Sb-125 & $-0.011 \mathrm{pC}$ & & 0.032 & 0.032 & u & & \\
\hline SESPMNT & B17715 & MCNARY-WASH.SIDE NEAR DAM & OFFSITE & so & SUB_SURFACE & SEDIMENT & 16-Jul-03 Sb-125 & $0.0173 \mathrm{pC}$ & & 0.028 & 0.028 & u & & \\
\hline $\begin{array}{l}\text { SESPMNT } \\
\text { SESPMNT }\end{array}$ & B17J20 & 300 AREA SPRING 42-2 & $\begin{array}{l}\text { ONSITE } \\
\text { ONSTFE }\end{array}$ & so & SUB_SURFACE & SEDIMENT & 13-Oct-03 Sb-125 & $0.000624 \mathrm{pC}$ & & 0.024 & 0.024 & u & & \\
\hline $\begin{array}{l}\text { SESPMNT } \\
\text { SESPMNT }\end{array}$ & $\begin{array}{l}\text { B175351 } \\
\text { B1759 }\end{array}$ & $\begin{array}{l}\text { 100-B SPRING 37-1 } \\
\text { 300 AREA SPR DR 42-2 }\end{array}$ & $\begin{array}{l}\text { ONSIIE } \\
\text { ONSITE }\end{array}$ & $\begin{array}{l}\text { so } \\
\text { so }\end{array}$ & $\begin{array}{l}\text { SUB_SURFACE } \\
\text { SUB SURFACE }\end{array}$ & $\begin{array}{l}\text { SEDIMENT } \\
\text { SEDMENT }\end{array}$ & $\begin{array}{l}\text { 20-Oct-03 Sb-125 } \\
13-\text { Oct-03 Sb-125 }\end{array}$ & $0.00812 \mathrm{pC}$ & Cilg & 0.026 & 0.026 & u & & \\
\hline $\begin{array}{l}\text { SESPMNI } \\
\text { SESPMT }\end{array}$ & $\begin{array}{l}\text { Bi/759 } \\
\text { B1762 }\end{array}$ & $\begin{array}{l}\text { 300 AREA SPR DR 42-2 } \\
\text { 100-K SPRING 63-1 }\end{array}$ & $\begin{array}{l}\text { ONSITE } \\
\text { ONST }-19\end{array}$ & so & $\begin{array}{l}\text { SUBSURFAEE } \\
\text { SUB_SURFACE }\end{array}$ & $\begin{array}{l}\text { SEDMENI } \\
\text { SEDIMENT }\end{array}$ & $\begin{array}{l}13-\mathrm{Oct}-03 \mathrm{SB}-125 \\
20-\mathrm{Oct}-03 \mathrm{Sb}-125\end{array}$ & $\begin{array}{l}0.001199 \mathrm{pC} \\
0.00267 \mathrm{pC}\end{array}$ & cilg & 0.022 & 0.022 & u & & \\
\hline SESPMNT & B17365 & 100-F SPRING 207-1 & ONSITE & so & SUB_SURFACE & SEDIMENT & 03-Nov-03 Sb-125 & $-0.00987 \mathrm{pC}$ & & 0.029 & 0.029 & u & & \\
\hline $\begin{array}{l}\text { SESPMNT } \\
\text { SESPMNT }\end{array}$ & B17j99 & 100-H SPRING 145-1 & ONSITE & so & SUB_SURFACE & SEDIMENT & 27-Oct-03 Sb-125 & $0.00814 \mathrm{pC}$ & & 0.026 & 0.026 & $\mathrm{u}$ & COLLECTED 20 METERS DOWN RIVER FROM SEEP. & \\
\hline $\begin{array}{l}\text { SESPMNT } \\
\text { SESPSPEC }\end{array}$ & $\begin{array}{ll}\text { B17R89 } \\
\text { B16WV8 }\end{array}$ & $\begin{array}{l}\text { WEST LAKE } \\
\text { YAKIMA RIVER }\end{array}$ & $\begin{array}{l}\text { ONSIIE } \\
\text { OFFSTE }\end{array}$ & $\begin{array}{l}\text { so } \\
\text { so }\end{array}$ & $\begin{array}{l}\text { POND } \\
\text { SUB SURFACE }\end{array}$ & $\begin{array}{l}\text { SEDIMENT } \\
\text { SEDIMENT }\end{array}$ & $\begin{array}{r}07-\text { Oct--03 Sb-125 } \\
14-\text { May-03 Sb-125 }\end{array}$ & $0.006 \mathrm{pc}$ & Cilg & 0.069 & 0.069 & U & & \\
\hline $\begin{array}{l}\text { SESPPEC } \\
\text { SESPSPEC }\end{array}$ & $\begin{array}{l}\text { BeWv8 } \\
\text { B16WV9 }\end{array}$ & $\begin{array}{l}\text { YAKMA RIVR } \\
\text { YAKIMA RIVER }\end{array}$ & $\begin{array}{l}\text { OFFSIIT } \\
\text { OFFSITE }\end{array}$ & so & $\begin{array}{l}\text { SUBSURFACE } \\
\text { SUBSURFACE }\end{array}$ & $\begin{array}{l}\text { SEDMENT } \\
\text { SEDIMENT }\end{array}$ & $\begin{array}{l}\text { 14-May-03 Sb-125 } \\
\text { 14-May-03 Sb-125 }\end{array}$ & $\begin{aligned} & 0.0134 \mathrm{pC}-0.0302 \mathrm{pC} \\
&-\end{aligned}$ & Cilg & $\begin{array}{l}0.035 \\
0.035\end{array}$ & $\begin{array}{l}0.035 \\
0.035\end{array}$ & u & & \\
\hline & & 0 WALLA WALLA-RIVER & OFFSITE & so & SUB_SURFACE & SEDIMENT & 15-May-03 Sb-125 & $0.0176 \mathrm{pC}$ & & 0.034 & 0.034 & u & & \\
\hline & B16WW1 & 1 WALLA WALLA-RIVER & $\begin{array}{l}\text { OFFSITE } \\
\end{array}$ & so & SUB_SURFACE & SEDIMENT & 15-May-03 Sb-125 & $-0.0193 \mathrm{pC}$ & cilg & 0.035 & 0.035 & u & & \\
\hline SESPSPEC & $B 16 W W 4$ & 4 RINGOLD WASTEWAY & OFFSITE & so & SUB_SURFACE & SEDIMENT & 14-May-03 Sb-125 & $0.0311 \mathrm{pC}$ & Cilg & 0.037 & 0.037 & u & PRIMARILY SAND. & \\
\hline SESPSPEC & B16WW5 & 5 RINGOLD WASTEWAY & OFFSITE & so & SUB_SURFACE & SEDIMENT & 14-May-03 Sb-125 & $-0.00336 \mathrm{pC}$ & Cilg & 0.031 & 0.031 & u & PRIMARILY SAND. & \\
\hline SESPSPEC & B16WW6 & 6 ESQUATZEL CANAL & OFFSITE & so & SUB_SURFACE & SEDIMENT & 14-May-03 Sb-125 & $0.0232 \mathrm{pC}$ & & 0.027 & 0.027 & $u$ & & \\
\hline $\begin{array}{l}\text { SESPSPEC } \\
\text { SESPPEC }\end{array}$ & B16WW7 & & OFFSITE & so & SUB_SURFACE & $\begin{array}{l}\text { SEDIMENT } \\
\text { SEDMMNAT }\end{array}$ & 14-May-03 Sb-125 & $-0.00843 \mathrm{pC}$ & Cilg & 0.027 & 0.027 & $u$ & & \\
\hline $\begin{array}{l}\text { SESPSPEC } \\
\text { SESPPEC }\end{array}$ & $\begin{array}{l}\text { B17BD99 } \\
\text { B17FE4 }\end{array}$ & $\begin{array}{l}\text { MCNARY-2/3 OR. SHORE } \\
\text { JOHN DAY DAM MID-RIVER }\end{array}$ & $\begin{array}{l}\text { OFFSITE } \\
\text { OFFSTEE }\end{array}$ & $\begin{array}{l}\text { so } \\
\text { so }\end{array}$ & $\begin{array}{l}\text { SUB_SURFACE } \\
\text { SUB SURFACE }\end{array}$ & $\begin{array}{l}\text { SEDIMENT } \\
\text { SEDMENT }\end{array}$ & $\begin{array}{l}\text { 08-Aug-03 Sb-1225 } \\
08 \text {-8uga-03 S-125 }\end{array}$ & $0.0233 \mathrm{pC}$ & Cilg & 0.059 & 0.059 & $\mathrm{u}$ & & \\
\hline $\begin{array}{l}\text { SESPPSEC } \\
\text { SESPSPEC }\end{array}$ & $\begin{array}{l}\text { B.7BB-4 } \\
\text { B17BF9 }\end{array}$ & $\begin{array}{l}\text { JOHN DAY DAM MID-RIVR } \\
\text { DALLES DAM OR.SHORE }\end{array}$ & $\begin{array}{l}\text { OFFSITE } \\
\text { OFFSITE }\end{array}$ & $\begin{array}{l}\text { so } \\
\text { so }\end{array}$ & $\begin{array}{l}\text { SUB_SURFACE } \\
\text { SUB SURFACE }\end{array}$ & $\begin{array}{l}\text { SEDIMENT } \\
\text { SEDIMENT }\end{array}$ & $\begin{array}{l}\text { 88-Aug -03 Sb-125 } \\
07-\text { Aug-03 Sb-125 }\end{array}$ & $\begin{array}{r}0.0322 \mathrm{pC} \\
-0.0255 \mathrm{pC}\end{array}$ & Cilg & $\begin{array}{l}0.072 \\
0.074\end{array}$ & $\begin{array}{l}0.072 \\
0.074\end{array}$ & u & & \\
\hline & B17BH4 & BONNEVILLE DAM OR.SHORE & OFFSITE & so & $\begin{array}{l}\text { SUBSURFACE } \\
\text { SUB SURFACE }\end{array}$ & $\begin{array}{l}\text { SEDIMENI } \\
\text { SEDIMENT }\end{array}$ & $\begin{array}{l}\text { 0-AAgu-03Sb-125 } \\
07-A u g-03 \text { Sb-125 }\end{array}$ & $\begin{array}{l}-0.0255 \mathrm{pC} \\
-0.034 \mathrm{pC}\end{array}$ & cilg & 0.081 & $\begin{array}{l}0.074 \\
0.081\end{array}$ & u & & \\
\hline SESPSPEC & B17BH7 & MCNARY-2/3 OR. SHORE & $\begin{array}{l}\text { OFFSITE } \\
\text { OFFIT }\end{array}$ & so & SUB_SURFACE & $\begin{array}{l}\text { SEDIMENT } \\
\text { SEDENT }\end{array}$ & 08-Aug-03 Sb-125 & $0.0109 \mathrm{pC}$ & cilg & 0.074 & 0.074 & u & & \\
\hline SESPMNT & B176Y6 & HANFORD SLOUGH & RIVER_SHORELINE & so & SUB_SURFACE & SEDIMENT & 14-Jul-03 Pu-238 & $0.000266 \mathrm{pC}$ & & 0.00056 & 0.00057 & u & & \\
\hline SESPMNT & B176Y7 & RICHLAND-RIVER & RIVER_SHORELINE & so & SUB_SURFACE & SEDIMENT & 16-Jul-03 Pu-238 & $0.000804 \mathrm{pC}$ & Cilg & 0.00062 & 0.00063 & & & \\
\hline SESPMNT & B176Y8 & WHITE BLUFFS SLOUGH & RIVER_SHORELINE & so & SUB_SURFACE & SEDIMENT & 14-Jul-03 Pu-238 & $0.000179 \mathrm{pC}$ & Cilg & 0.00037 & 0.00037 & u & & \\
\hline SESPMNT & B176Y9 & 100 F SLOUGH & ONSITE & so & SUB_SURFACE & SEDIMENT & 14-Jul-03 Pu-238 & $0.000116 \mathrm{pC}$ & & 0.00026 & 0.00026 & u & & \\
\hline $\begin{array}{l}\text { SESPMNT } \\
\text { SESPMNT }\end{array}$ & $\begin{array}{l}\text { B17705 } \\
\text { B17707 }\end{array}$ & $\begin{array}{l}\text { PRD-YAKIMA SIDE NEAR DAM } \\
\text { PRDDGRANT SDE NEAR DAM }\end{array}$ & $\begin{array}{l}\text { OFFSITE } \\
\text { OFFSTEE }\end{array}$ & $\begin{array}{l}\text { so } \\
\text { so }\end{array}$ & $\begin{array}{l}\text { SUB_SURFACE } \\
\text { SUB SURFACE }\end{array}$ & $\begin{array}{l}\text { SEDIMENT } \\
\text { SEDMENT }\end{array}$ & $\begin{array}{l}\text { 14-Jul-03 Pu-238 } \\
\text { 14-Jul-03 Pu-238 }\end{array}$ & $0.000217 \mathrm{pC}$ & Cligg & 0.00026 & 0.00026 & $\mathrm{u}$ & & \\
\hline $\begin{array}{l}\text { SESPMNNT } \\
\text { SESPNT }\end{array}$ & $\begin{array}{l}\text { B177777 } \\
\text { B17713 }\end{array}$ & $\begin{array}{l}\text { PRDD-GRANT SIDE NEAR DAM } \\
\text { MCNARY-OR.SIDE NEAR DAM }\end{array}$ & $\begin{array}{l}\text { OFFSIITE } \\
\text { OFFITE }\end{array}$ & & $\begin{array}{l}\text { SUB_SURFACE } \\
\text { SUB SURFACE }\end{array}$ & $\begin{array}{l}\text { SEDIMENT } \\
\text { SEDIMENT }\end{array}$ & $\begin{array}{l}\text { 14-Julu-03 Pu-238 } \\
\text { 16-Jul-03 Pu-238 }\end{array}$ & $\begin{array}{l}0.000633 \mathrm{pc} \\
0.000333 \mathrm{pC}\end{array}$ & Cilg & 0.00023 & 0.00023 & & & \\
\hline & B17715 & MCNARY-WASH.SIDE NEAR DAM & OFFSITE & so & $\begin{array}{l}\text { SUBSURFACE } \\
\text { SUB SURFACE }\end{array}$ & $\begin{array}{l}\text { SEDIMENI } \\
\text { SEDIMENT }\end{array}$ & $\begin{array}{l}\text { 16-Jul-03 Puu-283 } \\
\text { 16-Jul-03 Pu-238 }\end{array}$ & $\begin{array}{l}0.000333 \mathrm{pC} \\
0.00151 \mathrm{pC}\end{array}$ & cilg & $\begin{array}{l}0.00023 \\
0.00065\end{array}$ & 0.00069 & & & \\
\hline SESPSPEC & B17BD9 & MCNARY-2/3 OR. SHORE & OFFSITE & so & $\begin{array}{l}\text { SUBSSORFACE } \\
\text { SUB_SURFACE }\end{array}$ & $\begin{array}{l}\text { SEDIMENT } \\
\text { SEDEN }\end{array}$ & 08-Aug-03 Pu-238 & $0.000197 \mathrm{pC}$ & cilg & 0.00018 & 0.00018 & $\mathrm{U}$ & & \\
\hline SESPSPEC & B17BF4 & JOHN DAY DAM MID-RIVER & OFFSITE & so & SUB_SURFACE & SEDIMENT & 08-Aug-03 Pu-238 & $0.000272 \mathrm{pC}$ & Cilg & 0.00025 & 0.00025 & & & \\
\hline SESPSPEC & B17BF9 & DALLES DAM OR.SHORE & OFFSITE & so & SUB_SURFACE & SEDIMENT & 07-Aug-03 Pu-238 & $0.000352 \mathrm{pC}$ & Cilg & 0.00018 & 0.00019 & & & \\
\hline SESPSPEC & B17BH4 & BONNEVILLE DAM OR.SHORE & OFFSITE & so & SUB__SURFACE & SEDIMENT & 07-Aug-03 Pu-238 & $0.000214 \mathrm{pC}$ & Cilg & 0.00044 & 0.00044 & u & & \\
\hline $\begin{array}{l}\text { SESPSPEC } \\
\text { SFCDMVT }\end{array}$ & B17BH7 & MCNARY-2/3 OR. SHORE & OFFSITE & so & SUB_SURFACE & SEDIMENT & 08-Aug-03 Pu-238 & $0.000526 \mathrm{pC}$ & & 0.00032 & 0.00033 & & & \\
\hline $\begin{array}{l}\text { SESPMNT } \\
\text { SESPMNT }\end{array}$ & $\begin{array}{l}\text { B176Y6 } \\
\text { B176KY }\end{array}$ & $\begin{array}{l}\text { HANFORD SLOUGH } \\
\text { RICHLANDRIVER }\end{array}$ & $\begin{array}{l}\text { RIVER_SHORELINE } \\
\text { RIVER SHORELNE }\end{array}$ & $\begin{array}{l}\text { so } \\
\text { so }\end{array}$ & SUB_SURFACE & $\begin{array}{l}\text { SEDIMENT } \\
\text { SEDMENT }\end{array}$ & $\begin{array}{l}\text { 14-Jul-03 Pu-239/240 } \\
\text { 16-3ul-0. Pu-239/240 }\end{array}$ & $0.00529 \mathrm{pC}$ & Cilg & $\begin{array}{r}0.0025 \\
0.00088\end{array}$ & $\begin{array}{r}0.0026 \\
0.0001\end{array}$ & & & \\
\hline $\begin{array}{l}\text { SESPMNI } \\
\text { SESPMT }\end{array}$ & $\begin{array}{l}\text { B176677 } \\
\text { B176Y8 }\end{array}$ & $\begin{array}{l}\text { RICHLAND-RIVER } \\
\text { WHITE BLUFFS SLOUGH }\end{array}$ & $\begin{array}{l}\text { RIVER_SHORELINE } \\
\text { RIVER SHORELINE }\end{array}$ & so & $\begin{array}{l}\text { SUB_SURFACE } \\
\text { SUB SURFACE }\end{array}$ & $\begin{array}{l}\text { SEDIMENT } \\
\text { SEDIMENT }\end{array}$ & $\begin{array}{l}\text { 16-Jul-03Pu-2399/240 } \\
\text { 14-Jul-03 Pu-239/240 }\end{array}$ & \begin{tabular}{|l|l|l}
$0.001199 \mathrm{pC}$ \\
$0.00686 \mathrm{pC}$
\end{tabular} & Cilig & $\begin{array}{c}0.00088 \\
0.0024\end{array}$ & $\begin{aligned} 0.00091 \\
0.0027\end{aligned}$ & & & \\
\hline $\begin{array}{l}\text { SESHIVIVI } \\
\text { SESPMNT }\end{array}$ & $\begin{array}{l}\text { B.1768 } \\
\text { B176Y9 }\end{array}$ & $100 \mathrm{~F} \mathrm{SLOUGH}$ & $\begin{array}{l}\text { RNER_SHURELIVE } \\
\text { ONSITE }\end{array}$ & so & $\begin{array}{l}\text { SUBSURFACE } \\
\text { SUB SURFACE }\end{array}$ & $\begin{array}{l}\text { SEUIIENI } \\
\text { SEDIMENT }\end{array}$ & 14-Jul-03 Pu-239/240 & $0.000204 \mathrm{pC}$ & Cilg & $\begin{array}{ll}0.00241 \\
0.0011\end{array}$ & 0.0012 & & & \\
\hline SESPMNT & B17705 & PRD-YAKIMA SIDE NEAR DAM & OFFSITE & so & SUB_SURFACE & SEDIMENT & 14-Jul-03 Pu-239/240 & $0.00956 \mathrm{pc}$ & Cilg & 0.0017 & 0.0023 & & & \\
\hline SESPMNT & B17707 & PRD-GRANT SIDE NEAR DAM & OFFSITE & so & SUB_SURFACE & SEDIMENT & 14-Jul-03 Pu-239/240 & $0.0116 \mathrm{pC}$ & Cilg & 0.0016 & 0.0023 & & & \\
\hline SESPMNT & B17713 & & OFFSITE & so & SUB_SURFACE & SEDIMENT & 16-Jul-03 Pu-239/240 & $0.00655 \mathrm{pC}$ & & 0.001 & 0.0014 & & & \\
\hline SESPMNT & B17715 & MCNARY-WASH.SIDE NEAR DAM & OFFSITE & so & SUB_SURFACE & SEDIMENT & 16-Jul-03 Pu-239/240 & $0.00758 \mathrm{pC}$ & & 0.0015 & 0.0019 & & & \\
\hline SESPS & B17BD9 & $\mathrm{MCI}$ & OFFSITE & so & SUB_SURFACE & SEDIMENT & $000-209240$ & $0.0104 \mathrm{pC}$ & Cilg & 0.0011 & 0.0018 & & & \\
\hline $\begin{array}{l}\text { SESPSPEC } \\
\text { SESPPEC }\end{array}$ & B17BF4 & $\begin{array}{l}\text { JOHN DAY DAM MID-RIVER } \\
\text { DALIES DAM OR SHORE }\end{array}$ & $\begin{array}{l}\text { OFFSITE } \\
\text { OFFSTE }\end{array}$ & $\begin{array}{l}\text { so } \\
\text { so }\end{array}$ & SUB_SURFACE & $\begin{array}{l}\text { SEDIMENT } \\
\text { SEDMMNT }\end{array}$ & $\begin{array}{l}\text { 08-Aug-03 Pu-239/240 } \\
\text { 07-Aug-03 Pu-229/240 }\end{array}$ & $0.00963 \mathrm{pC}$ & Cilg & $\begin{array}{r}0.0015 \\
0.0071\end{array}$ & 0.0021 & & & \\
\hline $\begin{array}{l}\text { SESPPEC } \\
\text { SESPSPEC }\end{array}$ & B17BF9 & $\begin{array}{l}\text { DALLES DAM OR.SHORE } \\
\text { BONNEVILLE DAM OR.SHORE }\end{array}$ & $\begin{array}{l}\text { OFFITE } \\
\text { OFFSITE }\end{array}$ & $\begin{array}{l}\text { so } \\
\text { so }\end{array}$ & $\begin{array}{l}\text { SUB_SURFACE } \\
\text { SUB SURFACE }\end{array}$ & $\begin{array}{l}\text { SEDIMENT } \\
\text { SEDIMENT }\end{array}$ & $\begin{array}{l}\text { 07-Augg-03 PP-239//240 } \\
\text { 07-Aug-03 Pu-239/240 }\end{array}$ & $\begin{array}{l}0.00598 \mathrm{pC} \\
0.00451 \mathrm{pC}\end{array}$ & Cilig & $\begin{array}{l}0.00071 \\
0.0014\end{array}$ & 0.0011 & & & \\
\hline $\begin{array}{l}\text { SESPPSPEC } \\
\text { SESPPEC }\end{array}$ & B17BH7 & MCNARY-2/3 OR. SHORE & OFFSITE & so & $\begin{array}{l}\text { SUB_SORFAE } \\
\text { SUB_SURFACE }\end{array}$ & $\begin{array}{l}\text { SEDIMENT } \\
\text { SEDENT }\end{array}$ & 08-Aug-03 Pu-239/240 & $0.00954 \mathrm{pC}$ & Cilg & 0.0013 & 0.0019 & & & \\
\hline IT & B16DK6 & & & so & POND & & 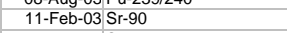 & & & & & & COLLECTED AT E. WATERHOLE. & \\
\hline SESPMNT & B16RT2 & WEST L & & so & POND & SEDIMENT & 07-Apr-03 Sr-90 & $0.3 \mathrm{pC}$ & Cilg & 0.042 & 0.076 & & & \\
\hline SESPSPEC & B16WV9 & YAKIMA RIVER & OFFSITE & so & SUB_SURFACE & SEDIMENT & 14-May-03 Sr-90 & $-0.0047 \mathrm{pC}$ & & 0.021 & 0.022 & u & & REANALYZED VALUE \\
\hline SESPSPEC & B16WWo & 0 WALLA WALLA-RIVER & OFFSITE & so & SUB_SURFACE & SEDIMENT & 15-May-03 Sr-90 & $0.0334 \mathrm{pC}$ & cilg & 0.036 & 0.037 & $u$ & & \\
\hline $\begin{array}{l}\text { SESPSPEC } \\
\text { SESPSEFC }\end{array}$ & $B 16 \mathrm{WW} 1$ & 1 WALLA WALLA-RIVER & OFFSITE & so & SUB_SURFACE & SEDIMENT & 15-May-03 Sr-90 & $0.00481 \mathrm{pC}$ & & 0.022 & 0.043 & $u$ & & \\
\hline $\begin{array}{l}\text { SESPSPEC } \\
\text { SESPPEC }\end{array}$ & B16WW2 & $\begin{array}{l}2 \text { SNAKE RIVER } \\
3 \text { SNAKE RIVER }\end{array}$ & $\begin{array}{l}\text { OFFSITE } \\
\text { OFESTEE }\end{array}$ & $\begin{array}{l}\text { so } \\
\text { so }\end{array}$ & $\begin{array}{l}\text { SUB_SURFACE } \\
\text { SUB SURFACE }\end{array}$ & $\begin{array}{l}\text { SEDIMENT } \\
\text { SEDMENT }\end{array}$ & 15-May-03 Sr-90 & & & & & & NO SAMPLE. & \\
\hline $\begin{array}{l}\text { SESPSPEC } \\
\text { SESPSPEC }\end{array}$ & (16) & $\begin{array}{l}3 \text { SNAKE RIVER } \\
4 \text { RINGOLD WASTEWAY }\end{array}$ & $\begin{array}{l}\text { OFFSSTE } \\
\text { OFFITE }\end{array}$ & $\begin{array}{l}\text { So } \\
\text { so }\end{array}$ & $\begin{array}{l}\text { SUB_SURFACE } \\
\text { SUB SURFACE }\end{array}$ & $\begin{array}{l}\text { SEDIMENT } \\
\text { SEDIMENT }\end{array}$ & $\begin{array}{l}\frac{15-M a y-033 r-90}{14-M a y-3 ~ S r-90} \\
140\end{array}$ & $0.0449 \mathrm{pc}$ & & 0.041 & 0.044 & & No & \\
\hline SES & B16WW5 & 5 RING & OFFSITE & so & SUB_SURFACE & $\mathrm{SEL}$ & $\begin{array}{l}\text { 14-May-3 Sr-90 } \\
\text { 14-May-03 Sr-90 }\end{array}$ & $\begin{array}{l}0.0449 \mathrm{pp} \\
0.018 \mathrm{pC}\end{array}$ & & 0.036 & 0.036 & u & PRIMARILY SAND. & \\
\hline & $B 16$ & & & so & & & & & & & 0.028 & $u$ & & \\
\hline SES & B16WW7 & 7 ESQUATZEL C & OFFSITE & so & SUB_SURFACE & SEDIMENT & 14-May-03 Sr-90 & $0.0382 \mathrm{pC}$ & & 0.039 & 0.04 & 0 & & \\
\hline SESPSPEC & B16WW8 & 8 POTHOLES CANAL & OFFSITE & so & SUB_SURFACE & SEDIMENT & 14-May-03 Sr-90 & & & & & & NO SAMF & \\
\hline SESPSPEC & B16WW9 & 9 POTHOLES CANAL & OFFSITE & so & SUB_SURFACE & SEDIMENT & 14-May-03 Sr-90 & & & & & & NO SAMPLE. & \\
\hline SESP & B176T3 & WEST L & ONSITE & so & POND & SEL & $09-$ & $0.369 \mathrm{pC}$ & Cilg & 0.079 & 0.11 & & & \\
\hline $\begin{array}{l}\text { SESPMNT } \\
\text { SESPMNT }\end{array}$ & B176r6 & $\begin{array}{l}\text { HANFORD SLOUGH } \\
\text { RICHOAD-RIER }\end{array}$ & RIVER_SHORELINE & so & SUB_SURFACE & SE & 14-Jul-03 Sr-90 & $0.0058 \mathrm{pc}$ & Ci/g & 0.016 & 0.018 & u & & \\
\hline $\begin{array}{l}\text { SESPMNT } \\
\text { SECPNT }\end{array}$ & $\begin{array}{l}\text { B176r77 } \\
\text { B1769 }\end{array}$ & $\begin{array}{l}\text { RICHLAND-RIVR } \\
\text { WHITE BLUFFS SLOUGH }\end{array}$ & $\begin{array}{l}\text { RIVER_SHORELINE } \\
\text { RIVER_SHOREIIN }\end{array}$ & $\begin{array}{l}\text { so } \\
\text { so }\end{array}$ & SUB_SURFACE & $\begin{array}{l}\text { SEDIMENT } \\
\text { SEDMENT }\end{array}$ & $\begin{array}{l}\text { 16-Jul-03 Sr-90 } \\
\text { 14-Jul-03 Sr-90 }\end{array}$ & $-0.00772 \mathrm{pC}$ & Cilg & 0.019 & 0.019 & 4 & & 提 \\
\hline $\begin{array}{l}\text { SESPMNIN } \\
\text { SESPMT }\end{array}$ & $\begin{array}{l}\text { B176r8 } \\
\text { B176Y9 }\end{array}$ & $\begin{array}{l}100 \mathrm{~F} \text { SLOUGH } \\
\end{array}$ & $\begin{array}{l}\text { RIVER_SHORELINE } \\
\text { ONSITE }\end{array}$ & so & $\begin{array}{l}\text { SUBSURFACE } \\
\text { SUB SURFACE }\end{array}$ & $\begin{array}{l}\text { SEDIMENI } \\
\text { SEDIMENT }\end{array}$ & $\begin{array}{l}\text { 14-Jul-03 Sr-90 } \\
\text { 14-Jul-03 Sr-90 }\end{array}$ & $0.000184 \mathrm{pC}$ & Cilg & 0.02 & 0.02 & u & & D VALUE \\
\hline
\end{tabular}


(pCilg Dry Weight unless otherwise noted)

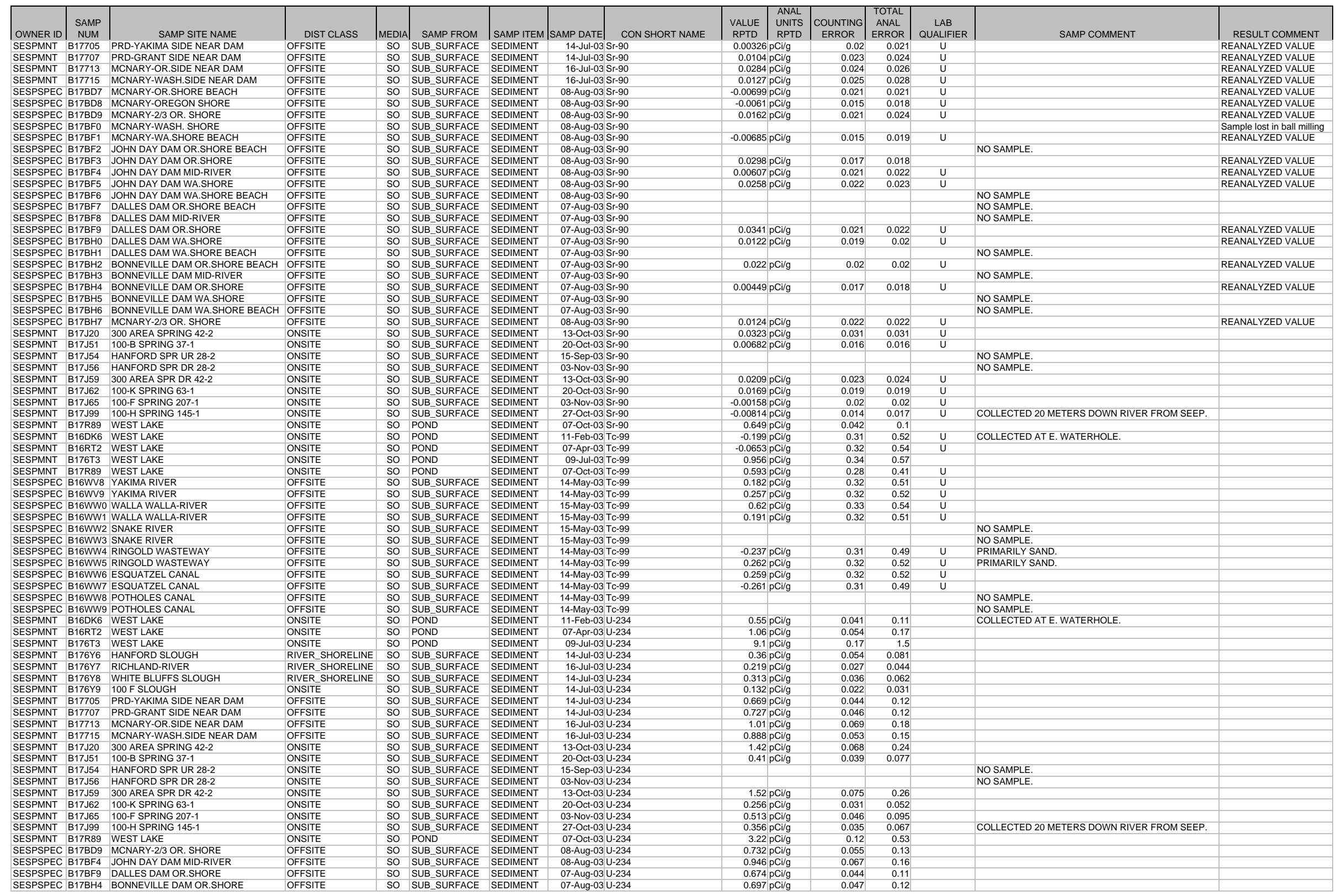


(pCilg Dry Weight unless otherwise noted)

\begin{tabular}{|c|c|c|c|c|c|c|c|c|c|c|c|c|c|c|}
\hline OWNER ID & \begin{tabular}{|l|} 
SAMP \\
NUM
\end{tabular} & & & & & & & $\begin{array}{l}\text { VALUE } \\
\text { RPTD }\end{array}$ & \begin{tabular}{|l|} 
ANAL \\
UNITS \\
RPTD
\end{tabular} & $\begin{array}{c}\text { COUNTING } \\
\text { ERROR }\end{array}$ & $\begin{array}{c}\text { TOTAL } \\
\text { ANAL } \\
\text { ERROR }\end{array}$ & $\begin{array}{l}\text { LAB } \\
\text { QULLFIER }\end{array}$ & SAMP COMMENT & RESULT COMMENT \\
\hline SESPSPEC & B178H7 & MCNARY-2/3 OR. SHORE & OFFSITE & SO & SUB_SURFACE & $\begin{array}{l}\text { SEDIMENT } \\
\text { SEDIT }\end{array}$ & 08-Aug-03 U-234 & 0.677 & & 0.044 & 0.12 & & SAMP CUMMENI & RESULI COIMIMENI \\
\hline SESPMNT & B16DK6 & WEST LAKE & ONSITE & so & & SEDIMENT & 11-Feb-03 U-235 & & pCi/g & 0.0098 & 0.011 & & COLLECTED AT E. WATERHOLE. & \\
\hline SESPMNT & B16RT2 & WEST LAKE & ONSITE & so & POND & SEDIMENT & 07-Apr-03 U-235 & & pCilg & 0.011 & 0.013 & & & \\
\hline SESPMNT & B176T3 & WEST LAKE & ONSITE & so & POND & SEDIMENT & 09-Jul-03 U-235 & & pcilg & 0.034 & 0.063 & & & \\
\hline $\begin{array}{l}\text { SESPMNT } \\
\text { SESPMNT }\end{array}$ & B176Y6 & HANFORD SLOUGH & $\begin{array}{l}\text { RIVER_SHORELINE } \\
\text { RDIVR-SGOPEINE }\end{array}$ & so & SUB_SURFACE & SEDIMENT & 14-Jul-03 U-235 & 0.021 & $\mathrm{pCilg}$ & 0.015 & 0.016 & & & \\
\hline $\begin{array}{l}\text { SESPMNT } \\
\text { SESPMNT }\end{array}$ & $\begin{array}{l}\text { B17667 } \\
\text { B176Y8 }\end{array}$ & $\begin{array}{l}\text { RICHLAND-RIVER } \\
\text { WHITE BUUFFS SLOUGH }\end{array}$ & $\begin{array}{l}\text { RIVER_SHORELINE } \\
\text { RIER SHOREINE }\end{array}$ & $\begin{array}{l}\text { so } \\
\text { so }\end{array}$ & $\begin{array}{l}\text { SUB_SURFACE } \\
\text { SUB SURACE }\end{array}$ & $\begin{array}{l}\text { SEDIMENT } \\
\text { SEDMENT }\end{array}$ & $\begin{array}{l}\text { 16-Jul-03 U-235 } \\
\text { 14-Jul-03U-235 }\end{array}$ & 0.0062 & pCilg & 0.0049 & 0.0051 & & & \\
\hline $\begin{array}{l}\text { SESPMNT } \\
\text { SESPMNT }\end{array}$ & $\begin{array}{l}\text { B17668 } \\
\text { B176Y9 }\end{array}$ & $\begin{array}{l}\text { WHITE BLLFFS SLOUGH } \\
100 \text { F SLOUGH }\end{array}$ & $\begin{array}{l}\text { liVR_SHORELINE } \\
\text { ONSITE }\end{array}$ & $\begin{array}{l}\text { so } \\
\text { so }\end{array}$ & $\begin{array}{l}\text { SUB_SURFACE } \\
\text { SUB SURACE }\end{array}$ & $\begin{array}{l}\text { SEDIIENT } \\
\text { SEDIMENT }\end{array}$ & $\begin{array}{l}\text { 14-Julu-03U-235 } \\
\text { 14-Jul-03 U-235 }\end{array}$ & $\begin{array}{c}0.0153 \\
-0.00075\end{array}$ & pCilg & $\begin{array}{r}0.01 \\
0.0051\end{array}$ & $\begin{array}{r}0.011 \\
0.0052\end{array}$ & $U$ & & \\
\hline $\begin{array}{l}\text { SESPMNI } \\
\text { SESPMNT }\end{array}$ & B17705 & PRD-YAKIMA SIDE NEAR DAM & $\begin{array}{l}\text { OFFSITE } \\
\text { OFSE }\end{array}$ & so & $\begin{array}{l}\text { SUB_SURFACE } \\
\text { SUB SURFACE }\end{array}$ & $\begin{array}{l}\text { SEDIMENI } \\
\text { SEDIMENT }\end{array}$ & $\begin{array}{l}\text { 14-Jull-03U }-235 \\
14-\mathrm{Jul}-03 \mathrm{U}-235\end{array}$ & $\begin{array}{l}-0.000 / 5 \\
0.0155\end{array}$ & pCl/g & 0.0051 & 0.0052 & 0 & & \\
\hline $\begin{array}{l}\text { SESPMMNT } \\
\text { SESPMN }\end{array}$ & B17707 & PRD-GRANT SIDE NEAR DAM & $\begin{array}{l}\text { OFSIIIE } \\
\text { OFFSITE }\end{array}$ & so & $\begin{array}{l}\text { SUB_SURFACE } \\
\text { SUB SURFACE }\end{array}$ & $\begin{array}{l}\text { SEDIMENI } \\
\text { SEDIMENT }\end{array}$ & $14-\mathrm{Jul}-03 \mathrm{U} \mathrm{U}-235$ & 0.0217 & $\begin{array}{l}\mathrm{pCClg} \\
\mathrm{pCilg}\end{array}$ & 0.0084 & 0.0091 & & & \\
\hline SESPMNT & B17713 & MCNARY-OR.SIDE NEAR DAM & OFFSITE & so & SUB_SURFACE & SEDIMENT & $16-\mathrm{Jul}-03 \mathrm{U} \mathrm{U}-235$ & 0.0262 & pCilg & $\begin{array}{r}0.0004 \\
0.011\end{array}$ & 0.012 & & & \\
\hline SESPMNT & B17715 & MCNARY-WASH.SIDE NEAR DAM & OFFSITE & so & SUB_SURFACE & SEDIMENT & 16-Jul-03 U-235 & & & 0.0089 & 0.0097 & & & \\
\hline SESPMNT & B17J20 & 300 AREA SPRING 42-2 & ONSITE & so & SUB_SURFACE & SEDIMENT & $13-0 c t-03$ U-235 & 0.052 & & 0.013 & 0.016 & & & \\
\hline SESPMNT & B17J51 & 100-B SPRING 37-1 & ONSITE & so & SUB_SURFACE & SEDIMENT & $20-0 c t-03 \mathrm{U}-235$ & 0.0141 & pCilg & 0.0076 & 0.008 & & & \\
\hline $\begin{array}{l}\text { SESPMNT } \\
\text { SESPMNT }\end{array}$ & & HANFORD SPR UR 28-2 & ONSITE & so & & $\begin{array}{l}\text { SEDIMENT } \\
\text { SEDIMENT }\end{array}$ & & & & & & & NO SAMPLE. & \\
\hline $\begin{array}{l}\text { SESPMNT } \\
\text { SESPMNT }\end{array}$ & $\begin{array}{l}817566 \\
\text { B17595 }\end{array}$ & $\begin{array}{l}\text { HANFORD SPR DR 28-2 } \\
3300 \text { AREA SPR DR 42-2 }\end{array}$ & $\begin{array}{l}\text { ONSITE } \\
\text { ONSIE }\end{array}$ & so & $\begin{array}{l}\text { SUB_SURFACE } \\
\text { SUB_SURFAEE }\end{array}$ & $\begin{array}{l}\text { SEDIMENT } \\
\text { SEDMENT }\end{array}$ & $\begin{array}{l}03-N o v-03 \text { U-235 } \\
1 \text { 1-Oct-03 U-235 }\end{array}$ & & & & & & & \\
\hline $\begin{array}{l}\text { SESPMNI } \\
\text { SESPMNT }\end{array}$ & 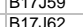 & $\begin{array}{l}\text { 3000 AREA SPR DR 42-2 } \\
\text { 100-K SPRING 63-1 }\end{array}$ & $\begin{array}{l}\text { ONSWITE } \\
\text { ONSITE }\end{array}$ & so & $\begin{array}{l}\text { SUB_SURFACE } \\
\text { SUB_SURFACE }\end{array}$ & $\begin{array}{l}\text { SEDIIENT } \\
\text { SEDMENT }\end{array}$ & $\begin{array}{l}13-0 \mathrm{OCt}-03 \mathrm{U}-235 \\
20-0 \mathrm{Ct}-03 \mathrm{U}-235\end{array}$ & $\begin{array}{l}0.066 / 1 \\
0.00908\end{array}$ & $\begin{array}{l}\text { pCCIg } \\
\text { pCilg }\end{array}$ & 0.0062 & 0.0064 & & & \\
\hline SESPMNT & B17J65 & $100-\mathrm{F}$ SPRING $207-1$ & ONSITE & so & SUB_SURFACE & SEDIMENT & $03-$ Nov- -03 U-235 & 0.0256 & $\begin{array}{l}\text { pCl/g } \\
\text { pCilg }\end{array}$ & $\begin{array}{l}0.002 \\
0.01 \\
0\end{array}$ & 0.011 & & & \\
\hline SESPMNT & B17J99 & 100-H SPRING 145-1 & ONSITE & so & SUB_SURFACE & SEDIMENT & $27-0 c t-03 \mathrm{U}-235$ & 0.0103 & pCi/g & 0.0068 & 0.007 & & COLLECTED 20 METERS DOWN RIVER FROM SEEP. & \\
\hline SESPMNT & B17R89 & WEST LAKE & ONSITE & so & POND & SEDIMENT & $07-$ oct- 03 U-235 & 0.109 & pCilg & 0.023 & 0.029 & & & \\
\hline SESPSPEC & B17BD9 & MCNARY-2/3 OR. SHORE & OFFSITE & so & SUB_SURFACE & SEDIMENT & 08-Aug-03 U-235 & 0.0225 & pcilg & 0.0099 & 0.011 & & & \\
\hline $\begin{array}{l}\text { SESPSPEC } \\
\text { CECDSDCC }\end{array}$ & B17BFA & JOHN DAY DAM MID-RIVER & OFFSITE & so & SUB_SURFACE & SEDIMENT & 08-Aug-03 U-235 & 0.0242 & pcilg & 0.013 & 0.014 & & & \\
\hline $\begin{array}{l}\text { SESPSPEC } \\
\text { SESPSEC }\end{array}$ & B17BF9 & DALLES DAM OR.SHORE & $\begin{array}{l}\text { OFFSITE } \\
\text { OFFITIE }\end{array}$ & so & SUB_SURFACE & $\begin{array}{l}\text { SEDIMENT } \\
\text { SEDMENT }\end{array}$ & 07-Aug-03 U-235 & 0.0103 & pCilg & 0.007 & 0.0072 & & & \\
\hline $\begin{array}{l}\text { SESPSEEC } \\
\text { SESPSPEC }\end{array}$ & $\begin{array}{ll}\text { B17BHA4 } \\
\text { B17BH7 }\end{array}$ & $\begin{array}{l}\text { BONEVVILLE DAM OR.SHORE } \\
\text { MCNARY-2/3 OR. SHORE }\end{array}$ & $\begin{array}{l}\text { OFFFITE } \\
\text { OFFSITE }\end{array}$ & so & $\begin{array}{l}\text { SUB_SURFACE } \\
\text { SUB_SURFAEE }\end{array}$ & $\begin{array}{l}\text { SEDIMENT } \\
\text { SEDMENT }\end{array}$ & 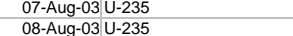 & 0.02011 & pCilg & 0.0093 & 0.0099 & & & \\
\hline $\begin{array}{l}\text { SESPSEC } \\
\text { SESPMNT }\end{array}$ & $\begin{array}{ll}\text { B16B/ } \\
\text { B16DK6 }\end{array}$ & $\begin{array}{l}\text { MCNARR-2/3 OR. SHORE } \\
\text { WEST LAKE }\end{array}$ & $\begin{array}{l}\text { OFSSIIE } \\
\text { ONSTE }\end{array}$ & so & $\begin{array}{l}\text { SUB_SURFACE } \\
\text { POND }\end{array}$ & $\begin{array}{l}\text { SEDIMENT } \\
\text { SEDIMENT }\end{array}$ & $\begin{array}{l}08 \text {-Aug--03 U-235 } \\
\text { 11-Feb-03U-238 }\end{array}$ & $\begin{aligned} 0.025 / 1 \\
0.5\end{aligned}$ & $\begin{array}{l}\text { pCCigg } \\
\text { pci/g }\end{array}$ & 0.0039 & $\begin{array}{l}0.0098 \\
0.097\end{array}$ & & COLLECTED AT E. WATERHOLE. & \\
\hline SESPMNT & $\begin{array}{l}\text { DIOLN0 } \\
\text { B16RT2 }\end{array}$ & WEST LAKE & ONSITE & so & POND & SEDIMENT & $07-A p r-03$ U-238 & $1.01 \mathrm{p}$ & pCilg & 0.052 & 0.17 & & 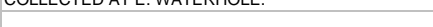 & \\
\hline SESPMNT & B176T3 & WEST LAKE & ONSITE & so & POND & SEDIMENT & 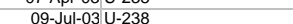 & 8.53 & pcila & 0.017 & $\frac{0.14}{14}$ & & & \\
\hline SESPMNT & B176Y6 & HANFORD SLOUGH & RIVER_SHORELINE & so & SUB_SURFACE & SEDIMENT & 14-Jul-03 U-238 & 0.322 & pCilg & 0.05 & 0.073 & & & \\
\hline SESPMNT & B176Y7 & RICHLAND-RIVER & RIVER_SHORELINE & so & SUB_SURFACE & SEDIMENT & 16-Jul-03 U-238 & 0.239 & pcilg & 0.028 & 0.047 & & & \\
\hline SESPMNT & B176Y8 & WHITE BLUFFS SLOUGH & RIVER_SHORELINE & so & SUB_SURFACE & SEDIMENT & 14-Jul-03 U-238 & 0.279 & pcilg & 0.034 & 0.056 & & & \\
\hline $\begin{array}{l}\text { SESPMNT } \\
\text { SESPMNT }\end{array}$ & B176Y9 & $100 \mathrm{~F}$ SLOUGH & $\begin{array}{l}\text { ONSITE } \\
\text { ODESTTE }\end{array}$ & so & SUB_SURFACE & $\begin{array}{l}\text { SEDIMENT } \\
\text { SEDMENT }\end{array}$ & 14-Jul-03 U-238 & 0.13 & pCilg & 0.022 & 0.031 & & & \\
\hline $\begin{array}{l}\text { SESPMNT } \\
\text { SESPMNT }\end{array}$ & $\begin{array}{l}817705 \\
B 1707\end{array}$ & $\begin{array}{l}\text { PRD-YAKIMA SIDE NEAR DAM } \\
\text { PRD-GRAN SPEFAA }\end{array}$ & $\begin{array}{l}\text { OFFSITE } \\
\text { OFESTTE }\end{array}$ & so & $\begin{array}{l}\text { SUB_SURFACE } \\
\text { SUB_SUREACE }\end{array}$ & $\begin{array}{l}\text { SEDIMENT } \\
\text { SEDMENT }\end{array}$ & 14-Jul-03 U-238 & 0.576 & pCilg & 0.041 & 0.1 & & & \\
\hline $\begin{array}{l}\text { SESPMNT } \\
\text { SESPMNT }\end{array}$ & 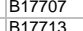 & $\begin{array}{l}\text { PRDD-GRANT IDE NEAR DAM } \\
\text { MCNARY-OR.SIDE NEAR DAM }\end{array}$ & $\begin{array}{l}\text { OFFITE } \\
\text { OFFSITE }\end{array}$ & $\begin{array}{l}\text { So } \\
\text { so }\end{array}$ & $\begin{array}{l}\text { SUB_SURFACE } \\
\text { SUB_SURFACE }\end{array}$ & $\begin{array}{l}\text { SEDIMENT } \\
\text { SEDMENT }\end{array}$ & $\begin{array}{l}\text { 14-Julu-03 U-238 } \\
\text { 16-Jul-03U-238 }\end{array}$ & 0.659 & pCilg & 0.043 & 0.11 & & & \\
\hline SESPMNT & 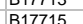 & MCARY-WASH SDENEAB AM & OFFIT & so & SUB SURACE & SEDIENT & 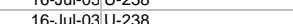 & 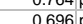 & 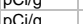 & 0.006 & 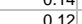 & & & \\
\hline SESPMNT & B17J20 & 300 AREA SPRING 42-2 & ONSITE & so & SUB SURFACE & SEDIMENT & 13-Oct-03 U-238 & & pcilg & 0.065 & 0.22 & & & \\
\hline SESPMNT & B17J51 & 100-B SPRING 37-1 & ONSITE & so & SUB_SURFACE & SEDIMENT & $20-0 c t-03 \mathrm{U}-238$ & 0.349 & pcilg & 0.036 & 0.067 & & & \\
\hline SESPMNT & B17J54 & HANFORD SPR UR 28-2 & ONSITE & so & SUB_SURFACE & SEDIMENT & 15 -Sep-03 U-238 & & & & & & NO SAMPLE. & \\
\hline SESPMNT & B17J56 & HANFORD SPR DR 28-2 & ONSITE & so & SUB_SURFACE & SEDIMENT & 03-Nov-03 U-238 & & & & & & NO SAMPLE. & \\
\hline $\begin{array}{l}\text { SESPMNT } \\
\text { SESPMNT }\end{array}$ & B17559 & & ONSITE & so & SUB_SURFACE & SEDIMENT & 13-Oct-03 U-238 & 1.46 & pCilg & 0.073 & 0.24 & & & \\
\hline $\begin{array}{l}\text { SESPMNT } \\
\text { SESPMNT }\end{array}$ & $\begin{array}{l}817362 \\
B 17655\end{array}$ & $\begin{array}{l}\text { 100-K SPRING 63-1 } \\
100 \text {-F SPRIG 207-1 }\end{array}$ & $\begin{array}{l}\text { ONSIE } \\
\text { ONSTEE }\end{array}$ & so & $\begin{array}{l}\text { SUB_SURFACE } \\
\text { SUB_SUREACE }\end{array}$ & $\begin{array}{l}\text { SEDIMENT } \\
\text { SEDMENT }\end{array}$ & $\begin{aligned} 20-O c t-03 U-238 \\
03-03-03 U-238\end{aligned}$ & 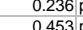 & pCilg & 0.029 & 0.048 & & & \\
\hline $\begin{array}{l}\text { SESPMNT } \\
\text { SESPMNT }\end{array}$ & 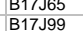 & $\begin{array}{l}\text { 100-F SPRING 207-1 } \\
\text { 100-H SPRING 145-1 }\end{array}$ & $\begin{array}{l}\text { ONSTIE } \\
\text { ONSITE }\end{array}$ & $\begin{array}{l}\text { SO } \\
\text { so }\end{array}$ & $\begin{array}{l}\text { SUB_SURFACE } \\
\text { SUB_SURFACE }\end{array}$ & $\begin{array}{l}\text { SEDIMENT } \\
\text { SEDIMENT }\end{array}$ & $\begin{array}{l}03 \text {-Nov-03U-238 } \\
27-0 c t-03 \mathrm{U}-238\end{array}$ & 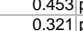 & $\begin{array}{l}\text { pCilg } \\
\text { pci/g }\end{array}$ & 0.043 & 0.085 & & COLLECTED 20 METERS DOWN RIVER FROM SEEP. & \\
\hline SESPMNT & B17R89 & WEST LAKE & ONSITE & so & PONDSORFACE & SEDIMENT & $07-0 \mathrm{ct}-03 \mathrm{U}-238$ & 3.04 & pCilg & 0.033 & 0.005 & & COLLEC IED ZO WIIEIERS DOWIN RTVER FRUUI SEEP. & \\
\hline SESPSPEC & B17899 & MCNARY-2/3 OR. SHORE & OFFITE & so & SUB SUREACE & SEDIMENT & 08 -Aug- -03 U-238 & 0.093 & 然 & $\frac{0.15}{0.9}$ & 0.01 & & & \\
\hline SESPSPEC & B17BF4 & JOHN DAY DAM MID-RIVER & OFFSITE & so & SUB_SURFACE & SEDIMENT & 08-Aug-03 U-238 & 0.699 & pcilg & 0.057 & 0.12 & & & \\
\hline SESPSPEC & B17BF9 & DALLES DAM OR.SHORE & OFFSITE & so & SUB_SURFACE & SEDIMENT & 07-Aug-03 U-238 & 0.516 & pCilg & 0.038 & 0.09 & & & \\
\hline SESPSPEC & B17BH4 & BONNEVILLE DAM OR.SHORE & OFFSITE & so & SUB_SURFACE & SEDIMENT & 07-Aug-03 U-238 & 0.562 & $\mathrm{pCilg}$ & 0.042 & 0.098 & & & \\
\hline $\begin{array}{l}\text { SESPSPEC } \\
\text { SESPMNT }\end{array}$ & B17BH7 & MCNARY-2/3 OR. SHORE & OFFSITE & so & SUB_SURFACE & SEDIMENT & 08-Aug-03 U-238 & 0.58 & $\mathrm{pCilg}$ & 0.041 & 0.1 & & & \\
\hline $\begin{array}{l}\text { SESPMNT } \\
\text { SECDSSPCC }\end{array}$ & B176Y1 & $100 \mathrm{~F} \mathrm{SLOUGH}$ & ONSITE & so & SUB_SURFACE & $\begin{array}{l}\text { SEDIMENT } \\
\text { SEDMENT }\end{array}$ & 14-Jul-03 Ag & $0.325 \mathrm{~L}$ & $\mathrm{ug} / \mathrm{g}$ & & & & & \\
\hline $\begin{array}{l}\text { SESPSPEC } \\
\text { SESPSEC }\end{array}$ & $\begin{array}{l}\text { B17BK5 } \\
\text { B17KK1 }\end{array}$ & $\begin{array}{l}\text { BONNEVILLE DAM OR.SHORE } \\
\text { DALLES DAM OR.SHORE }\end{array}$ & $\begin{array}{l}\text { OFFFITE } \\
\text { OFFITE }\end{array}$ & so & $\begin{array}{l}\text { SUB_SURFACE } \\
\text { SUB_SURFACE }\end{array}$ & $\begin{array}{l}\text { SEDIMENT } \\
\text { SEPMENT }\end{array}$ & $\begin{array}{l}\text { 07-Aug--03 Ag } \\
07 \text {-Aug-03 Ag }\end{array}$ & $0.314 \mathrm{~L}$ & ug/g & & & & & \\
\hline $\begin{array}{l}\text { SESPSEC } \\
\text { SESPSPEC }\end{array}$ & $\begin{array}{l}\text { B17BR1 } \\
\text { B16WX8 }\end{array}$ & $\begin{array}{l}\text { DALLES DAM OR.SHORE } \\
\text { ESOUATZEL CANAL }\end{array}$ & $\begin{array}{l}\text { OFFSSTE } \\
\text { OFFITE }\end{array}$ & $\begin{array}{l}\text { SO } \\
\text { so }\end{array}$ & $\begin{array}{l}\text { SUB_SURFACE } \\
\text { SUB SURFACE }\end{array}$ & $\begin{array}{l}\text { SEDIMENT } \\
\text { SEDIMENT }\end{array}$ & $\begin{array}{l}07 \text {-Aug--03 Ag } \\
14-\mathrm{May}-03 \mathrm{Ag}\end{array}$ & $\begin{array}{l}0.3374 \\
0.298 \mathrm{~L}\end{array}$ & $\begin{array}{ll}\text { ugg/g } \\
\text { uglg (wet) }\end{array}$ & & & & & \\
\hline $\begin{array}{l}\text { SESPPEC } \\
\text { SESPSPEC }\end{array}$ & $\begin{array}{l}\text { B16WX8 } \\
\text { B16WX9 }\end{array}$ & $\begin{array}{l}\text { ESQUAIZEL CANAL } \\
\text { ESQUATZEL CANAL }\end{array}$ & $\begin{array}{l}\text { OFFFSIIE } \\
\text { OFFITE }\end{array}$ & so & $\begin{array}{l}\text { SUB_SURFACE } \\
\text { SUB SURFACE }\end{array}$ & $\begin{array}{l}\text { SEUMENI } \\
\text { SEDIMENT }\end{array}$ & $\begin{array}{l}14-\mathrm{May}-03 \mathrm{Ag} \\
14 \mathrm{May}-03 \mathrm{Ag}\end{array}$ & $0.275 \mathrm{t}$ & $\begin{array}{l}\text { uglg (we) } \\
\text { uglget) }\end{array}$ & & & & & \\
\hline $\begin{array}{l}\text { SESPMNT } \\
\text { SEST }\end{array}$ & B176Y3 & HANFORD SLOUGH & RIVER_SHORELINE & so & SUB_SURFACE & SEDIMENT & 14-Jul-03 Ag & $0.302 \mathrm{t}$ & ug/g ta & & & & & \\
\hline SESPSPEC & B178J7 & JOHN DAY DAM MID-RIVER & OFFSITE & so & SUB_SURFACE & SEDIMENT & 08-Aug-03 Ag & 0.433 & ug/g & & & & & \\
\hline SESPSPEC & B17BJ3 & MCNAR & OFF & so & SUB_SURFACE & SEDIN & 08-Aug-C & 0.438 & $\mathrm{ug} / \mathrm{g}$ & & & & & \\
\hline SESPMNT & B17710 & MCNARY-OR.SIDE NEAR DAM & OFFSITE & so & SUB_SURFACE & SEDIMENT & 16-Jul-03 Ag & 4384 & $\mathrm{ug} / \mathrm{g}$ & & & & & \\
\hline $\begin{array}{l}\text { SESPMNT } \\
\text { SESPDNT }\end{array}$ & B17712 & MCNARY-WASH.SIDE NEAR DAM & OFFSITE & so & SUB_SURFACE & $\begin{array}{l}\text { SEDIMENT } \\
\text { SEDMENT }\end{array}$ & 16-Jul-03 Ag & 0.379 & $\mathrm{ug} / \mathrm{g}$ & & & & & \\
\hline $\begin{array}{l}\text { SESPNT } \\
\text { SESPMNT }\end{array}$ & 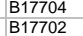 & $\begin{array}{l}\text { PRDD-GRANT SIDE NEAR DAM } \\
\text { PRD-YAKIMA SIDE NEAR DAM }\end{array}$ & $\begin{array}{l}\text { OFFFITE } \\
\text { OFFSITE }\end{array}$ & $\begin{array}{l}\text { so } \\
\text { so }\end{array}$ & $\begin{array}{l}\text { SU__SURACE } \\
\text { SUB_SURACEE }\end{array}$ & $\begin{array}{l}\text { SEDIIENT } \\
\text { SEDIMENT }\end{array}$ & $\begin{array}{l}\text { 14-Julu-03 Ag } \\
\text { 14-Jul-03 } \mathrm{Ag}\end{array}$ & $0.484 i$ & $\frac{\mathrm{ug} / \mathrm{g}}{\mathrm{ug} / \mathrm{g}}$ & & & & & \\
\hline SESPMNT & $\begin{array}{l}\text { D1706 } \\
\text { B176Y5 }\end{array}$ & RICHLAND-RIVER & RIVER_SHORELINE & so & SUB_SURFACE & SEDIMENT & 16-Jul-03 Ag & & & & & & & \\
\hline SESPSPEC & B16WX6 & RINGOLD WASTEWAY & OFFSITE & so & SUB_SURFACE & SEDIMENT & 14-May-03 Ag & 0.248 & uglg (wet) & & & & PRIMARILY & \\
\hline SESPSPEC & B16WX7 & RINGOLD WASTEWAY & OFFSITE & so & SUB_SURFACE & SEDIMENT & 14-May-03 Ag & 0.2624 & ug/g (wet) & & & & PRIMARILY SAND. & \\
\hline SESPSPEC & $B 16 \mathrm{~W} \times 2$ & WALLA WA & OFFSITE & so & SUB_SURFACE & SEDIMENT & 15-May- & 0.457 & ug/g (wet) & & & & & \\
\hline SESPSPEC & $B 16 \mathrm{~W} \times 3$ & WALLA WALLA-RIVER & OFFS & so & SUB_SURF & SEDIMENT & 15-May- & $0.413 \mathrm{t}$ & uglg (wet) & & & & & \\
\hline SESPMNT & B176×9 & WHITE BLUFFS SLOUGH & RIVER_SHORELINE & so & SUB_SURFACE & SEDIMENT & 14-Jul-03 Ag & 0.324 & & & & & & \\
\hline $\begin{array}{l}\text { SESPSPEC } \\
\text { SECDPCDC }\end{array}$ & B16WX0 & YAKIMA RIVER & OFFSITE & so & SUB_SURFACE & SEDIMENT & 14-May-03 Ag & $0.346 \mathrm{t}$ & ug/g (wet) & & & & & \\
\hline SESPSPEC & B16WX1 & YAKIMA RIVER & OFFSITE & so & SUB_SURFACE & $\begin{array}{l}\text { SEDIMENT } \\
\text { SEDMENT }\end{array}$ & 14-May-03 Ag & 0.3084 & uglg(wet) & & & $\mathrm{C}$ & & \\
\hline $\begin{array}{l}\text { SESSPEC } \\
\text { SESPMNT }\end{array}$ & 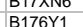 & 100 F SLOUGH & $\begin{array}{l}\text { ONSITE } \\
\text { ONSE }\end{array}$ & so & $\begin{array}{l}\text { SUB_SURFACE } \\
\text { SUB SURFACE }\end{array}$ & $\begin{array}{l}\text { SEDMENI } \\
\text { SEDIMENT }\end{array}$ & $\begin{array}{r}\text { 1-Nov-03 As } \\
14-J u l-03 \text { As }\end{array}$ & 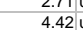 & ugg/g & & & & & \\
\hline SESPMNT & B17J53 & 100-B SPRING 37-1 & ONSITE & so & SUB_SURFACE & SEDIMENT & 20-Oct-03 As & & & & & $\mathrm{c}$ & & \\
\hline
\end{tabular}


(pCilg Dry Weight unless otherwise noted)

\begin{tabular}{|c|c|c|c|c|c|c|c|c|c|c|c|c|c|c|c|}
\hline & \begin{tabular}{|l} 
SAMP \\
NUM \\
\end{tabular} & SAMP SITE NAME & DIST CLASS & MEDIA & & & & CON SHORT NAME & $\begin{array}{l}\text { VALUE } \\
\text { RPTD }\end{array}$ & \begin{tabular}{|c|} 
ANAL \\
UNITS \\
RPDD
\end{tabular} & $\left|\begin{array}{c}\text { COUNTING } \\
\text { ERROR }\end{array}\right|$ & $\begin{array}{c}\text { TOTAL } \\
\text { ANAL } \\
\text { ERROR }\end{array}$ & $\begin{array}{l}\text { LAB } \\
\text { QUALIFIER }\end{array}$ & SAMP COMMENT & RESULT COMMENT \\
\hline SESPSPEC & B17XN8 & $\begin{array}{l}100-B \text { SPRING } 37-1 \\
100-B \text { PPRING } 38-3\end{array}$ & $\begin{array}{l}\text { ONSITE } \\
\text { ONITE } \\
\text { ONITE }\end{array}$ & SO & SUB_SURFACE & 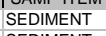 & 13-Nov-03 As & & 3.224 & ug/g $/ \mathrm{g}$ & & & $\mathrm{C}$ & & \\
\hline $\begin{array}{l}\text { SESPSPEC } \\
\text { SESPMNT }\end{array}$ & $\begin{array}{l}\text { B17XN9 } \\
\text { B17J67 }\end{array}$ & $\begin{array}{l}\text { 100-B SPRING 38-3 } \\
\text { 100-F SPRING 207-1 }\end{array}$ & $\begin{array}{l}\text { ONSIIE } \\
\text { ONSITE }\end{array}$ & $\begin{array}{l}\text { so } \\
\text { so }\end{array}$ & $\begin{array}{l}\text { SUB_SURFACE } \\
\text { SUB_SURFACE }\end{array}$ & $\begin{array}{l}\text { SEDIMENT } \\
\text { SEDIMENT }\end{array}$ & $\begin{array}{l}\text { 13-Nov-03 As } \\
\text { 03-Nov-03 As }\end{array}$ & & $6.87 \mathrm{~L}$ & $\frac{\mathrm{ug} / \mathrm{g}}{\mathrm{ug} / \mathrm{g}}$ & & & $\frac{\mathrm{c}}{\mathrm{c}}$ & & \\
\hline SESPMNT & B17JB1 & 100-H SPRING 145-1 & ONSITE & so & SUB_SURFACE & SEDIMENT & 27-Oct-03 As & & 9.634 & $\mathrm{ug} / \mathrm{g}$ & & & & & \\
\hline $\begin{array}{l}\text { SESPMNT } \\
\text { SESPMNT }\end{array}$ & B17J64 & $\begin{array}{l}\text { 100-K SPRING 63-1 } \\
300 \text { AREA SPR DR 42-2 }\end{array}$ & ONSITE & so & SUB_SURFACE & $\begin{array}{l}\text { SEDIMENT } \\
\text { SEDMENT }\end{array}$ & 20-Oct-03 As & & & & & & c & & \\
\hline $\begin{array}{l}\text { SESPMNT } \\
\text { SESPMNT }\end{array}$ & $\begin{array}{l}\text { B17761 } \\
\text { B17118 }\end{array}$ & $\begin{array}{l}300 \text { AREA PPR DR 42-2 } \\
300 \text { AREA SPRING 42-2 }\end{array}$ & $\begin{array}{l}\text { ONSIIE } \\
\text { ONSITE }\end{array}$ & $\begin{array}{l}\text { so } \\
\text { so }\end{array}$ & $\begin{array}{l}\text { SUB_SURFACE } \\
\text { SUB_ SURACEE }\end{array}$ & $\begin{array}{l}\text { SEDIMENT } \\
\text { SEDMENT }\end{array}$ & $\begin{array}{l}\text { 13-Oct-03 As } \\
\text { 13-Oct-03 As }\end{array}$ & & $5.92 \mathrm{~L}$ & & & & & & \\
\hline SESPSPEC & B17BK5 & BONNEVILLE DAM OR.SHORE & OFFSITE & so & SUB_SURFACE & SEDIMENT & 07-Aug-03 As & & $5.96 \mathrm{t}$ & & & & & & \\
\hline $\begin{array}{l}\text { SESPSPEC } \\
\text { SESPSECA }\end{array}$ & B17BK1 & DALLES DAM OR.SHORE & OFFSITE & so & $\begin{array}{l}\text { SUB_SURFACE } \\
\text { SII_SUPECE }\end{array}$ & $\begin{array}{l}\text { SEDIMENT } \\
\text { SEDMENT }\end{array}$ & 07-Aug-03 As & & 5.574 & & & & & & \\
\hline $\begin{array}{l}\text { SESPSPEC } \\
\text { SESPPEC }\end{array}$ & $\begin{array}{l}16 \mathrm{~W} \times 8 \\
116 \mathrm{~W} \times 9\end{array}$ & $\begin{array}{l}\text { ESQUATZEL CANAL } \\
\text { ESOUATZL CANAL }\end{array}$ & $\begin{array}{l}\text { OFFSITE } \\
\text { OFFIIE }\end{array}$ & $\begin{array}{l}\text { so } \\
\text { so }\end{array}$ & $\begin{array}{l}\text { SUB_SURFACE } \\
\text { SUB SURACE }\end{array}$ & $\begin{array}{l}\text { SEDIMENT } \\
\text { SEDIMENT }\end{array}$ & $\begin{array}{l}\text { 14-May-03 As } \\
\text { 14-May-03 As }\end{array}$ & & $\begin{array}{l}2.67 \mathrm{~L} \\
2.73 \mathrm{~L}\end{array}$ & $\begin{array}{l}\mathrm{ug} / \mathrm{g}(\text { wet) } \\
\mathrm{u} / \mathrm{g} \text { (wet) }\end{array}$ & & & & & \\
\hline SESPMNT & B176Y3 & HANFORD SLOUGH & RIVER_SHORELINE & so & $\begin{array}{l}\text { SUB_SURFACE } \\
\text { SUB_SURE }\end{array}$ & SEDIMENT & $\begin{array}{l}\text { 14-viy-03 As } \\
\text { 14-Jul-03 As }\end{array}$ & & 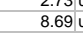 & & & & & & \\
\hline $\begin{array}{l}\text { SESPMNT } \\
\text { CESPSEFC }\end{array}$ & B17J58 & HANFORD SPR DR 28-2 & ONSITE & so & SUB_SURFACE & SEDIMENT & 03-Nov-03 As & & & & & & c & & \\
\hline $\begin{array}{l}\text { SESPSPEC } \\
\text { SESPSEC }\end{array}$ & B17BJ7 & JOHN DAY DAM MID-RIVER & OFFSITE & so & SUB_SURFACE & SEDIMENT & 08-Aug-03 As & & & & & & & & \\
\hline $\begin{array}{l}\text { SESPSPEC } \\
\text { SESPMNT }\end{array}$ & $\begin{array}{l}\text { B17BJ3 } \\
B 17710\end{array}$ & $\begin{array}{l}\text { MCNARY-2/3 OR. SHORE } \\
\text { MCARY-R SIDE NEAR DAM }\end{array}$ & $\begin{array}{l}\text { OFFSITE } \\
\text { OFFITE }\end{array}$ & so & $\begin{array}{l}\text { SUB_SURFACE } \\
\text { SUB_SUREAE }\end{array}$ & $\begin{array}{l}\text { SEDIMENT } \\
\text { SEDMENT }\end{array}$ & $\begin{array}{l}\text { 08-Aug-03 As } \\
\text { 16-5u-13 As }\end{array}$ & & $\begin{array}{l}7.55 \mathrm{~L} \\
9.93 \mathrm{~L}\end{array}$ & $\mathrm{ug} / \mathrm{g}$ & & & & & \\
\hline $\begin{array}{l}\text { SESPMNI } \\
\text { SESPNT }\end{array}$ & B17712 & $\begin{array}{l}\text { CMNARYRYOR.SDE NEAA DAM } \\
\text { MCNARYWASH.SIDE NEAR DAM }\end{array}$ & $\begin{array}{l}\text { OFFSIE } \\
\text { OFFSITE }\end{array}$ & $\begin{array}{l}\text { So } \\
\text { so }\end{array}$ & $\begin{array}{l}\text { SUB_SURAACE } \\
\text { SUB_SURFACE }\end{array}$ & $\begin{array}{l}\text { SEDIMENT } \\
\text { SEDIMENT }\end{array}$ & $\begin{array}{l}\text { 16-Jul-03 As } \\
\text { 16-Jul-03 As }\end{array}$ & & $\begin{array}{l}9.93 \mathrm{~L} \\
8.23 \mathrm{~L}\end{array}$ & $\frac{\mathrm{ug} / \mathrm{g}}{\mathrm{ug} / \mathrm{g}}$ & & & & & \\
\hline SESPMNT & B17704 & PRD-GRANT SIDE NEAR DAM & OFFSITE & so & SUB_SURFACE & SEDIMENT & 14-Jul-03 As & & 9.734 & & & & & & \\
\hline SESPMNT & B17702 & PRD-YAKIMA SIDE NEAR DAM & OFFSITE & so & SUB_SURFACE & SEDIMENT & 14-Jul-03 As & & 9.24 & & & & & & \\
\hline $\begin{array}{l}\text { SESPMNT } \\
\text { SESPSEC }\end{array}$ & B176Y5 & $\begin{array}{l}\text { RICHLAND-RIVER } \\
\text { RINGODPSTEWAY }\end{array}$ & $\begin{array}{l}\text { RIVER_SHORELINE } \\
\text { OSFGSTIT }\end{array}$ & so & SUB_SURFACE & SEDIMENT & 16-Jul-03 As & & & $\mathrm{ug} / \mathrm{g}$ & & & & & \\
\hline $\begin{array}{l}\text { SESPSEC } \\
\text { SESPSPEC }\end{array}$ & B. & $\begin{array}{l}\text { RINGOLD WASTEWAY } \\
\text { RINGOLD WASTEWAY }\end{array}$ & $\begin{array}{l}\text { OFFSITE } \\
\text { OFFITITE }\end{array}$ & so & SUB_SURFACE & $\begin{array}{l}\text { SEDIMENT } \\
\text { SEDMENT }\end{array}$ & 14-May-03 As & & & ug/g(wet) & & & & $\begin{array}{l}\text { PRIIARILY SAND. } \\
\text { PRIMABUY SAND }\end{array}$ & \\
\hline $\begin{array}{l}\text { SESPPEC } \\
\text { SESPSPEC }\end{array}$ & $\begin{array}{l}16 W \times 7 \\
116 W \times 2\end{array}$ & $\begin{array}{l}\text { RINGOLD WASTEWAY } \\
\text { WALLA WALA-RIVER }\end{array}$ & $\begin{array}{l}\text { OFFSITE } \\
\text { OFFSITE }\end{array}$ & so & $\begin{array}{l}\text { SUB_SURFAAE } \\
\text { SUB SURFACE }\end{array}$ & $\begin{array}{l}\text { SEDIMENT } \\
\text { SEDIMENT }\end{array}$ & $\begin{array}{l}\text { 14-May-03 As } \\
\text { 15-May-3 As }\end{array}$ & & & uglg(wet) & & & & & \\
\hline SESPSPEC & B16WX3 & $\begin{array}{l}\text { WALAA WALLA-RIVER } \\
\text { WALLA WALLAIVER }\end{array}$ & $\begin{array}{l}\text { OFFSITE } \\
\text { OFSITE }\end{array}$ & so & $\begin{array}{l}\text { SUB_SURACE } \\
\text { SUB SURFACE }\end{array}$ & $\begin{array}{l}\text { SEDIIENI } \\
\text { SEDIMENT }\end{array}$ & $\begin{array}{l}\text { 15-Mlay-03 AS } \\
\text { 15-May-03 As }\end{array}$ & & $281 \mathrm{~L}$ & $\begin{array}{l}\text { uglg wert) } \\
\text { unlg (wet) }\end{array}$ & & & & & \\
\hline SESPMNT & B176x9 & WHITE BLUFFS SLOUGH & RIVER_SHORELINE & so & SUB_SURFACE & SEDIMENT & 14-Jul-03 As & & 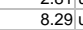 & & & & & & \\
\hline SESPSPEC & $B 16 \mathrm{~W} \times 0$ & YAKIMA RIVER & OFFSITE & so & SUB_SURFACE & SEDIMENT & 14-May-03 As & & & uglg (wet) & & & & & \\
\hline SESPSPEC & $B 16 W \times 1$ & YAKIMA RIVER & OFFSITE & so & SUB_SURFACE & SEDIMENT & 14-May-03 As & & $2.47 \mathrm{~L}$ & ug/g (wet) & & & & & \\
\hline $\begin{array}{l}\text { SESPSPEC } \\
\text { SESPSDCF }\end{array}$ & B17XN6 & $100 \mathrm{~B} / \mathrm{C}$ AREAUR & ONSITE & so & SUB_SURFACE & SEDIMENT & 17-Nov-03 Ba & & 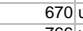 & ug/g & & & & & \\
\hline $\begin{array}{l}\text { SESPSPEC } \\
\text { SESPSEC }\end{array}$ & $\begin{array}{l}\text { B17XN8 } \\
117 \times 99\end{array}$ & $\begin{array}{l}\text { 100-B SPRING 37-1 } \\
100 \text { B SPRIN 38-3 }\end{array}$ & $\begin{array}{l}\text { ONSITE } \\
\text { ONSTE }\end{array}$ & so & SUB_SURFACE & $\begin{array}{l}\text { SEDIMENT } \\
\text { SEDMENT }\end{array}$ & 13-Nov-03 Ba & & 7664 & ug/g & & & & & \\
\hline $\begin{array}{l}\text { SESPPEC } \\
\text { SESPSPEC }\end{array}$ & $\begin{array}{l}\text { B17XN9 } \\
B 17 \times N 6\end{array}$ & $\begin{array}{l}1000 \text {-B SPRING 38-3 } \\
100 \text { BIC AREA UR }\end{array}$ & $\begin{array}{l}\text { ONSITE } \\
\text { ONSTIE }\end{array}$ & $\begin{array}{l}\text { so } \\
\text { so }\end{array}$ & $\begin{array}{l}\text { SUB_SURFACE } \\
\text { SUB SURACE }\end{array}$ & $\begin{array}{l}\text { SEDIMENT } \\
\text { SEDIMENT }\end{array}$ & $\begin{array}{l}\text { 13-Nov-03 Ba } \\
\text { 17-Nov-03 Be }\end{array}$ & & $869 \mathrm{~L}$ & $\mathrm{ug} / \mathrm{g} / \mathrm{g}$ & & & & & \\
\hline $\begin{array}{l}\text { SESPPEC } \\
\text { SESPMNT }\end{array}$ & B176Y1 & $\begin{array}{l}100 \text { BCC AREAUR } \\
100 \text { F SLOUGH }\end{array}$ & $\begin{array}{l}\text { ONSTIE } \\
\text { ONSITE }\end{array}$ & $\begin{array}{l}\text { So } \\
\text { so }\end{array}$ & $\begin{array}{l}\text { SUB_SURACE } \\
\text { SUB_SURFACE }\end{array}$ & $\begin{array}{l}\text { SEDIIENI } \\
\text { SEDIMENT }\end{array}$ & $\begin{array}{l}\text { 17-Nov-03B Be } \\
14-\mathrm{Ju}-03 \mathrm{Be}\end{array}$ & & $\begin{array}{l}1.34 \mathrm{~L} \\
1.53 \mathrm{~L}\end{array}$ & & & & & & \\
\hline SESPMNT & B17553 & 100-B SPRING 37-1 & ONSITE & so & SUB_SURFACE & SEDIMENT & $20-\mathrm{Oct}-03 \mathrm{Be}$ & & $2.38 \mathrm{t}$ & & & & & & \\
\hline SESPSPEC & B17XN8 & 100-B SPRING 37-1 & ONSITE & so & SUB_SURFACE & SEDIMENT & 13-Nov-03 Be & & 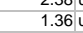 & ug/g & & & & & \\
\hline SESPSPEC & B17XN9 & 100-B SPRING 38-3 & ONSITE & so & SUB_SURFACE & SEDIMENT & 13-Nov-03 Be & & $1.5 \mathrm{~L}$ & $\mathrm{ug} / \mathrm{g}$ & & & & & \\
\hline SESPMNT & B17J67 & 100-F SPRING 207-1 & ONSITE & so & SUB_SURFACE & $\begin{array}{l}\text { SEDIMENT } \\
\text { SEDMENT }\end{array}$ & 03-Nov-03 Be & & $1.62 \mathrm{~L}$ & & & & & & \\
\hline $\begin{array}{l}\text { SESPMNT } \\
\text { SESPMNT }\end{array}$ & B17JB1 & $\begin{array}{l}\text { 100-H SPRING 145-1 } \\
100 \text {-K SPRING 63-1 }\end{array}$ & ONSITE & so & $\begin{array}{l}\text { SUB_SURFACE } \\
\text { SU_SUPACE }\end{array}$ & $\begin{array}{l}\text { SEDIMENT } \\
\text { SEDMENT }\end{array}$ & 27-Oct-03 Be & & $1.53 \mathrm{~L}$ & ug/g & & & & & \\
\hline SESPMNT & B17J61 & 300 AREA SPR DR 42-2 & $\begin{array}{l}\text { ONSITE } \\
\text { ONSE }\end{array}$ & so & SUB_SURACE & $\begin{array}{l}\text { SEDIMENT } \\
\text { SEDIMENT }\end{array}$ & $\begin{array}{l}\text { 20-Oct-103 Be } \\
\text { 13-Oct-03 Be }\end{array}$ & & $\begin{array}{l}1.35 \mathrm{~L} \\
1.27 \mathrm{~L}\end{array}$ & & & & & & \\
\hline SESPMNT & B17J18 & 300 AREA SPRING 42-2 & ONSITE & so & SUB_SURFACE & SEDIMENT & $13-$ Oct-03 Be & & $1.54 \mathrm{~L}$ & & & & & & \\
\hline SESPSPEC & B17BK5 & BONNEVILLE DAM OR.SHORE & OFFSITE & so & SUB_SURFACE & SEDIMENT & 07-Aug-03 Be & & $1.6 \mathrm{~L}$ & $\mathrm{ug} / \mathrm{g}$ & & & & & \\
\hline $\begin{array}{l}\text { SESPSPEC } \\
\text { SESPSEC }\end{array}$ & B17BK1 & DALLES DAM OR.SHORE & OFFSITE & so & SUB_SURFACE & $\begin{array}{l}\text { SEDIMENT } \\
\text { SEDMENT }\end{array}$ & 07-Aug-03 Be & & & ug/g & & & & & \\
\hline $\begin{array}{l}\text { SESPPSEC } \\
\text { SESPSPEC }\end{array}$ & $\begin{array}{l}16 W \times 8 \\
116 W \times 9\end{array}$ & $\begin{array}{l}\text { EEQUATZEL CANAL } \\
\text { ESQUATZEL CANAL }\end{array}$ & $\begin{array}{l}\text { OFFFIE } \\
\text { OFFSITE }\end{array}$ & $\begin{array}{l}\text { So } \\
\text { so }\end{array}$ & $\begin{array}{l}\text { SUB_SURFACE } \\
\text { SUB SURACE }\end{array}$ & $\begin{array}{l}\text { SEDIMENT } \\
\text { SEDIMENT }\end{array}$ & $\begin{array}{l}\text { 14-May-03 Be } \\
\text { 14-May-03 Be }\end{array}$ & & & $\begin{array}{l}\mathrm{ug} / \mathrm{g}(\mathrm{wet}) \\
\mathrm{ug} / \mathrm{get})\end{array}$ & & & & & \\
\hline SESPMNT & B176Y3 & HANFORD SLOUGH & RIVER_SHORELINE & so & SUB_SURFACE & SEDIMENT & 14-Jul-03 Be & & $1.53 \mathrm{~L}$ & & & & & & \\
\hline SESPMNT & B17J58 & HANFORD SPR DR 28-2 & ONSITE & so & SUB_SURFACE & SEDIMENT & 03-Nov-03 Be & & $1.59 \mathrm{~L}$ & & & & & & \\
\hline SESPSPEC & B17BJ7 & JOHN DAY DAM MID-RIVER & OFFSITE & so & SUB_SURFACE & SEDIMENT & 08-Aug-03 Be & & $1.89 \mathrm{~L}$ & & & & & & \\
\hline SESPSPEC & B17BJ3 & $\begin{array}{l}\text { MCNARY-2/3 OR. SHORE } \\
\end{array}$ & OFFSITE & so & SUB_SURFACE & SEDIMENT & 08-Aug-03 Be & & $1.79 \mathrm{~L}$ & & & & & & \\
\hline SESPMNT & B17710 & MCNARY-OR.SIDE NEAR DAM & OFFSITE & so & SUB_SURFACE & SEDIMENT & 16-Jul-03 Be & & $1.99 \mathrm{~L}$ & & & & & & \\
\hline $\begin{array}{l}\text { SESPMNT } \\
\text { SESPMNT }\end{array}$ & B17712 & $\begin{array}{l}\text { MCNARY-WASH.SIDE NEAR DAM } \\
\text { PCD-GRANT SDE }\end{array}$ & $\begin{array}{l}\text { OFFSITE } \\
\text { OFSITE }\end{array}$ & so & SUB_SURFACE & $\begin{array}{l}\text { SEDIMENT } \\
\text { SEDMENT }\end{array}$ & 16-Jul-03 Be & & $1.86 \mathrm{~L}$ & & & & & & \\
\hline $\begin{array}{l}\text { SESPMNT } \\
\text { SESPMNT }\end{array}$ & $\begin{array}{l}\text { BB777704 } \\
\text { B17702 }\end{array}$ & $\begin{array}{l}\text { RDD-GRANT SIDE NERR DAM } \\
\text { PRD-YAKIMA SIDE NEAR DAM }\end{array}$ & $\begin{array}{l}\text { OFFITE } \\
\text { OFFSITE }\end{array}$ & $\begin{array}{l}\text { so } \\
\text { so }\end{array}$ & $\begin{array}{l}\text { SUB_SURFACE } \\
\text { SUB SURACE }\end{array}$ & $\begin{array}{l}\text { SEDIMENT } \\
\text { SEDMENT }\end{array}$ & $\begin{array}{l}\text { 14--Jul-100 Be } \\
\text { 14-Jul-03 Be }\end{array}$ & & $\begin{aligned} 1.56 \mathrm{~L} \\
1.5 \mathrm{u}\end{aligned}$ & $\frac{\mathrm{ug} / \mathrm{g}}{\mathrm{ug} / \mathrm{g}}$ & & & & & \\
\hline SESPMNT & B176Y5 & RICHLAND-RIVER & RIVER SHORELINE & so & SUB SURFACE & SEDIMENT & 16-Jul-03 Be & & $1.66 \mathrm{t}$ & $\mathrm{ug} / \mathrm{g}$ & & & & & \\
\hline SESPSPEC & $B 16 W \times 6$ & RINGOLD WASTEWAY & OFFSITE & so & SUB_SURFACE & SEDIMENT & 14-May-03 Be & & & uglg (wet) & & & & PRIMARILY SAND. & \\
\hline SESPSPEC & B16WX7 & RINGOLD WASTEWAY & OFFSITE & so & SUB_SURFACE & SEDIMENT & 14-May-03 Be & & $1.27 \mathrm{~L}$ & ug/g (wet) & & & & PRIMARILY SAND. & \\
\hline SESPSPEC & B16WX2 & WALLA WALLA-RIVER & OFFSITE & so & SUB_SURFACE & SEDIMENT & 15-May-03 Be & & $1.08 \mathrm{~L}$ & ug/g (wet) & & & & & \\
\hline & $B 16 \mathrm{~W} \times 3$ & WALLA WALLA-RIVER & OFFSITE & so & SUB_SURFACE & SEDIMENT & 15-May-03 Be & & $1.11 \mathrm{~L}$ & ug/g (wet) & & & & & \\
\hline SESPMNT & B176X9 & WHITE BLUFFS SLOUGH & RIVER_SHORELINE & so & SUB_SURFACE & SEDIMENT & 14-Jul-03 Be & & $1.43 \mathrm{~L}$ & $\mathrm{ug} / \mathrm{g}$ & & & & & \\
\hline $\begin{array}{l}\text { SESPSPEC } \\
\text { SESPSPCC }\end{array}$ & $B 16 W \times 0$ & $\begin{array}{l}\text { YAKIMA RIVER } \\
\text { YAKIMA RIVR }\end{array}$ & OFFSITE & so & SUB_SURFACE & $\begin{array}{l}\text { SEDIMENT } \\
\text { SEDMENT }\end{array}$ & 14-May-03 Be & & 0.802 & ug/g (wet) & & & & & \\
\hline $\begin{array}{l}\text { SESPSPEC } \\
\text { SESPSEC }\end{array}$ & B16WX1 & $\begin{array}{l}\text { YAKIMA RIVER } \\
100 \text { B/C AREA UR }\end{array}$ & $\begin{array}{l}\text { OFFITE } \\
\text { ONSITE }\end{array}$ & so & SUB_SURFACE & $\begin{array}{l}\text { SEDIMENT } \\
\text { SEDMENT }\end{array}$ & 14-May-03 Be & & $0.777 \mathrm{~L}$ & ug/g(wet) & & & & & \\
\hline $\begin{array}{l}\text { SESPMNT } \\
\text { SEST }\end{array}$ & B176Y1 & $\begin{array}{l}100 \text { BCC AREAUR } \\
100 \text { F SLOUGH }\end{array}$ & ONSITE & so & SUB_SURARACE & $\begin{array}{l}\text { SEDIMENT } \\
\text { SEDIMENT }\end{array}$ & $\begin{array}{l}\text { 17-Nov-03Cd } \\
\text { 14-Jul-03Cd }\end{array}$ & & $\begin{array}{l}0.306 \mathrm{~L} \\
0.667 \mathrm{u}\end{array}$ & & & & & & \\
\hline SESPMNT & B17553 & 100-B SPRING 37-1 & ONSITE & so & SUB_SURFACE & SEDIMENT & $20-$ Oct- $03 \mathrm{Cd}$ & & $2.51 \mathrm{~L}$ & & & & & & \\
\hline SESPSPEC & B17XN8 & 100-B SPR & ONSITE & so & SUB_SURF & SEDIN & 13-Nov - & & 0.7434 & & & & & & \\
\hline SESPSPEC & B17XN9 & 100-B SPRING 38-3 & ONSITE & so & SUB_SURFACE & SEDIMENT & 13-Nov-03 Cd & & $0.64 \mathrm{~L}$ & & & & & & \\
\hline $\begin{array}{l}\text { SESPMNT } \\
\text { SESPMNT }\end{array}$ & $\begin{array}{l}\text { BB7767 } \\
\text { B17JB1 }\end{array}$ & $\begin{array}{l}\text { 100-F SPRRING 207-1 } \\
\text { 10-H SPRING 145-1 }\end{array}$ & $\begin{array}{l}\text { ONSIIE } \\
\text { ONSTTE }\end{array}$ & $\begin{array}{l}\text { So } \\
\text { so }\end{array}$ & $\begin{array}{l}\text { SUB_SURACAE } \\
\text { SUB SURAACE }\end{array}$ & $\begin{array}{l}\text { SEDIMENT } \\
\text { SEDIMENT }\end{array}$ & $\begin{array}{l}\text { 03-Nov-03 Cd } \\
\text { 27-Oct-03 Cd }\end{array}$ & & $\begin{array}{l}1.53 \mathrm{~L} \\
1.11 \mathrm{~L}\end{array}$ & $\begin{array}{ll}\mathrm{ug} / \mathrm{g} \\
\mathrm{u} / \mathrm{g}\end{array}$ & & & & & \\
\hline SESPMNT & B17364 & 100-K SPRING 63-1 & ONSITE & so & SUB_SURFACE & SEDIMENT & $20-0 c t-03 C d$ & & 0.715 & & & & & & \\
\hline SESPMNT & B17J61 & 300 AREA SPR DR 42-2 & ONSITE & so & SUB_SURFACE & SEDIMENT & $13-\mathrm{Oct}-03 \mathrm{Cd}$ & & $0.521 \mathrm{~L}$ & & & & & & \\
\hline SESPMNT & B17J18 & 300 AREA SPRING $42-2$ & ONSITE & so & SUB_SURFACE & SEDIMENT & $13-\mathrm{Oct}-03 \mathrm{Cd}$ & & 0.362 & & & & & & \\
\hline SESPSPEC & B17BK5 & BONNEVILLE DAM OR.SHORE & OFFSITE & so & SUB_SURFACE & SEDIMENT & 07-Aug-03 Cd & & 0.8784 & & & & & & \\
\hline SESPSPEC & B17BK1 & DALLES DAM OR.SHORE & OFFSITE & so & SUB_SURFACE & SEDIMENT & 07-Aug-03 Cd & & $1.21 \mathrm{~L}$ & & & & & & \\
\hline $\begin{array}{l}\text { SESPPSEC } \\
\text { SESPPPEC }\end{array}$ & $\begin{array}{l}16 W \times 8 \\
116 W \times 9\end{array}$ & $\begin{array}{l}\text { ESQUATZEE LANAL } \\
\text { ESQAATZLL CANAL }\end{array}$ & $\begin{array}{l}\text { OFFFITE } \\
\text { OFFSITE }\end{array}$ & $\begin{array}{l}\text { so } \\
\text { so }\end{array}$ & $\begin{array}{l}\text { SUB_SURFACE } \\
\text { SUB SUFACE }\end{array}$ & $\begin{array}{l}\text { SEDIIENT } \\
\text { SEDIMENT }\end{array}$ & $\begin{array}{l}\text { 14-May-03 Cd } \\
\text { 14-May-03 Cd }\end{array}$ & & lo. & $\begin{array}{ll}\mathrm{ug} / \mathrm{g}(\text { wet) } \\
\mathrm{u} / \mathrm{g} \text { (wet) }\end{array}$ & & & & & \\
\hline
\end{tabular}


(pCilg Dry Weight unless otherwise noted)

\begin{tabular}{|c|c|c|c|c|c|c|c|c|c|c|c|c|c|c|c|}
\hline OWNER ID & \begin{tabular}{|l} 
SAMP \\
NUM \\
\end{tabular} & SAMP SITE NAME & DIST CLASS & MEDIA & SAMP FROM & SAMP ITEM & ;AMP DATE & CON SHORT NAME & $\begin{array}{l}\text { VALUE } \\
\text { RPTD }\end{array}$ & \begin{tabular}{|c|} 
ANAL \\
UNITS \\
RPTD
\end{tabular} & $\begin{array}{c}\text { COUNTING } \\
\text { ERROR }\end{array} \mid$ & \begin{tabular}{c|} 
TOTAL \\
ANAL \\
ERROR
\end{tabular} & $\begin{array}{c}\text { LAB } \\
\text { QUALIFIER }\end{array}$ & SAMP COMMENT & RESULT COMMENT \\
\hline $\begin{array}{l}\text { SESPMNT } \\
\text { SESPNT }\end{array}$ & $\begin{array}{l}817643 \\
\text { B17J58 }\end{array}$ & $\begin{array}{l}\text { HANFORD SLOUGH } \\
\text { HAFORD SPR DR 28-2 }\end{array}$ & $\begin{array}{l}\text { RIVER_SHORELINE } \\
\text { ONSTIE }\end{array}$ & so & $\begin{array}{l}\text { SUB_SURFACE } \\
\text { SUB SURFACE }\end{array}$ & $\begin{array}{l}\text { SEDIMENT } \\
\text { SEDIMENT }\end{array}$ & $\begin{array}{l}\text { 14-Jul-03 Cd } \\
03-\mathrm{Nov}-3 \mathrm{Cd}\end{array}$ & & 3.514 & & & & & & \\
\hline SESPSPEC & B17BJ7 & JOHN DAY DAM MID-RIVER & OFFSITE & so & SUB SURFACE & SEDIMENT & 08 -Aug-03Cd & & $\frac{1.111}{2.021}$ & $\frac{\mathrm{ug} / \mathrm{g}}{\mathrm{ug} / \mathrm{g}}$ & & & & & \\
\hline SESPSPEC & B17BJ3 & MCNARY-2/3 OR. SHORE & OFFSITE & so & SUB_SURFACE & SEDIMENT & 08-Aug-03 Cd & & 1.48 & & & & & & \\
\hline SESPMNT & B17710 & MCNARY-OR.SIDE NEAR DAM & OFFSITE & so & SUB_SURFACE & SEDIMENT & & & & & & & & & \\
\hline & & & OFFSITE & so & SUB SURFACE & $\begin{array}{l}\text { SEDIMENT } \\
\end{array}$ & 16-Jul-03 Cd & & & $\begin{array}{l}\text { ugl/g } \\
\text { uglo }\end{array}$ & & & & & \\
\hline SESPMNT & B17704 & PRD-GRANT SIDE NEAR DAM & OFFSITE & so & SUB_SURFACE & SEDIMENT & 14-Jul-03 Cd & & $8.93 \mathrm{~L}$ & ug/g & & & & & \\
\hline SESPMNT & B17702 & PRD-YAKIMA SIDE NEAR DAM & OFFSITE & so & SUB_SURFACE & SEDIMENT & 14-Jul-03 Cd & & $5.99 \mathrm{l}$ & & & & & & \\
\hline SESPMNT & B176Y5 & RICHLAND-RIVER & RIVER_SHORELINE & so & SUB_SURFACE & SEDIMENT & 16-Jul-03 Cd & & 0.995 & & & & & & \\
\hline $\begin{array}{l}\text { SESPSPEC } \\
\text { SESPPPEC }\end{array}$ & B16WX6 & & OFFSITE & so & SUB_SURFACE & $\begin{array}{l}\text { SEDIMENT } \\
\text { SEDMENT }\end{array}$ & 14-May-03 Cd & & 0.105 & ug/g (wet) & & & & PRIMARILY SAND. & \\
\hline $\begin{array}{l}\text { SESPPPEC } \\
\text { SESPSPEC }\end{array}$ & $\begin{array}{l}\text { B16WX7 } \\
B 16 W \times 2\end{array}$ & $\begin{array}{l}\text { RINGOLD WASTEWAY } \\
\text { WALAL WALARIVER }\end{array}$ & $\begin{array}{l}\text { OFFSITE } \\
\text { OFFITE }\end{array}$ & so & $\begin{array}{l}\text { SUB_SURFACE } \\
\text { SUB_SURFACE }\end{array}$ & $\begin{array}{l}\text { SEDIMENT } \\
\text { SEDMENT }\end{array}$ & $\begin{array}{l}\text { 14-May-03 Cd } \\
15-M a y-03 C d\end{array}$ & & $\begin{array}{l}0.141 \mathrm{i} \\
0.116 \mathrm{t}\end{array}$ & ug/g(wet) & & & & PRIMARILY SAND. & \\
\hline $\begin{array}{l}\text { SESSPPEC } \\
\text { SESPSPEC }\end{array}$ & $\begin{array}{l}\text { B16WX2 } \\
B 16 W \times 3\end{array}$ & $\begin{array}{l}\text { WALLA WALAA-RIVER } \\
\text { WALLA WALLA-RIVER }\end{array}$ & $\begin{array}{l}\text { OFFSIIE } \\
\text { OFFSITE }\end{array}$ & $\begin{array}{l}\text { so } \\
\text { so }\end{array}$ & $\begin{array}{l}\text { SUB_SURFACE } \\
\text { SUB SURFACE }\end{array}$ & $\begin{array}{l}\text { SEDIMENT } \\
\text { SEDIMENT }\end{array}$ & $\begin{array}{l}\text { 15-May-303 Cd } \\
\text { 15-May-03 Cd }\end{array}$ & & $0.105 \mathrm{~L}$ & $\begin{array}{l}\mathrm{ug} / \mathrm{g}(\text { (wet) } \\
\mathrm{uu} / \mathrm{w} \text { (wet) }\end{array}$ & & & & & \\
\hline $\begin{array}{l}\text { SESPMNT } \\
\text { SEST }\end{array}$ & B176X9 & WHITE BLUFFS SLOUGH & RIVER_SHORELINE & so & $\begin{array}{l}\text { SUB_SURFACE } \\
\text { SUB SURFACE }\end{array}$ & $\begin{array}{l}\text { SEUMENI } \\
\text { SEDIMENT }\end{array}$ & 14-Jul-03 Cd & & 2.6 & & & & & & \\
\hline & & & OFFSITE & so & SUB SURFACE & SEDIMENT & $14-$ May-03 Cd & & & uglg (wet) & & & & & \\
\hline SESPSPEC & $B 16 W \times 1$ & YAKIMA RIVER & OFFSITE & so & SUB-SURFACE & SEDIMENT & 14-May-03 Cd & & 0.108 & uglg (wet) & & & & & \\
\hline SESPSPEC & B17XN6 & 100 B/C AREA UR & ONSITE & so & SUB_SURFACE & SEDIMENT & 17-Nov-03 Cr & & & uglg & & & C & & \\
\hline SESPMNT & B176Y1 & 100 F SLOUGH & ONSITE & so & SUB_SURFACE & SEDIMENT & 14-Jul-03 Cr & & & $\mathrm{ug} / \mathrm{g}$ & & & c & & \\
\hline $\begin{array}{l}\text { SESPMNT } \\
\text { SESPPPEC }\end{array}$ & B17J53 & 100-B SPRING 37-1 & $\begin{array}{l}\text { ONSITE } \\
\text { ONSTEF }\end{array}$ & so & SUB_SURFACE & $\begin{array}{l}\text { SEDIMENT } \\
\text { SEDMENT }\end{array}$ & 20-Oct-03 Cr & & & $\mathrm{ug} / \mathrm{g}$ & & & c & & \\
\hline $\begin{array}{l}\text { SESPPPEC } \\
\text { SESPSPEC }\end{array}$ & $\begin{array}{l}\text { B17XNB } \\
\text { B17NN9 }\end{array}$ & $\begin{array}{l}\text { 100-B SPRING 37-1 } \\
100-B \text { SPRING 38-3 }\end{array}$ & $\begin{array}{l}\text { ONSITE } \\
\text { ONSTIE }\end{array}$ & $\begin{array}{l}\text { so } \\
\text { so }\end{array}$ & $\begin{array}{l}\text { SUB_SURFACE } \\
\text { SUB SURFAE }\end{array}$ & $\begin{array}{l}\text { SEDIMENT } \\
\text { SEDMENT }\end{array}$ & $\begin{array}{l}\text { 13-Nov-03 Cr } \\
\text { 13-Nov-3 Cr }\end{array}$ & & $\begin{array}{l}96.34 \\
68.4 \mathrm{~L}\end{array}$ & $\mathrm{ug} / \mathrm{g}$ & & & c & & \\
\hline SESPMNT & B17j67 & 100-F SPRING 207-1 & $\begin{array}{l}\text { ONSITE } \\
\text { ONITE }\end{array}$ & so & $\begin{array}{l}\text { SUB_SURFAAE } \\
\text { SU_SURFACE }\end{array}$ & $\begin{array}{l}\text { SEDIMENT } \\
\text { SEDIMENT }\end{array}$ & $\begin{array}{l}\text { 13-Nov-03 Cr } \\
\text { 03-Nov-03 Cr }\end{array}$ & & 68.4. & $\begin{array}{ll}\mathrm{ugg} / \mathrm{g} \\
\mathrm{ug} / \mathrm{g}\end{array}$ & & & $\begin{array}{c}\mathrm{c} \\
\mathrm{c}\end{array}$ & & \\
\hline SESPMNT & B17JB1 & 100-H SPRING 145-1 & ONSITE & so & SUB_SURFACE & SEDIMENT & 27-Oct-03 $\mathrm{Cr}$ & & 53.24 & $\mathrm{ug} / \mathrm{g}$ & & & c & & \\
\hline $\begin{array}{l}\text { SESPMNT } \\
\text { SESPMNT }\end{array}$ & B17J64 & $\begin{array}{l}\text { 100-K SPRING 63-1 } \\
300 \text { AREA SPR DR 42-2 }\end{array}$ & $\begin{array}{l}\text { ONSITE } \\
\text { ONSTEE }\end{array}$ & so & SUB_SURFACE & $\begin{array}{l}\text { SEDIMENT } \\
\text { SEDMENT }\end{array}$ & 20-Oct-03 $\mathrm{Cr}$ & & & $\mathrm{ug} / \mathrm{g}$ & & & c & & \\
\hline $\begin{array}{l}\text { SESPMNT } \\
\text { SESPNT }\end{array}$ & 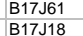 & $\begin{array}{l}300 \text { AREA SPR DR 42-2 } \\
300 \text { AREA SPRING 42-2 }\end{array}$ & $\begin{array}{l}\text { ONSIIE } \\
\text { ONSTIE }\end{array}$ & $\begin{array}{l}\text { so } \\
\text { so }\end{array}$ & $\begin{array}{l}\text { SUB_SURFACE } \\
\text { SUB SURFAEE }\end{array}$ & $\begin{array}{l}\text { SEDIMENT } \\
\text { SEDMENT }\end{array}$ & $\begin{array}{l}13-\mathrm{Occt}-03 \mathrm{Cr} \\
13-\mathrm{Occ}-\mathrm{Cr}\end{array}$ & & 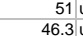 & $\begin{array}{ll}\mathrm{ug} / \mathrm{g} \\
\mathrm{ug} / \mathrm{g}\end{array}$ & & & & & \\
\hline $\begin{array}{l}\text { SESPNNT } \\
\text { SESPSPEC }\end{array}$ & 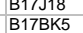 & $\begin{array}{l}\text { 300 AREA SPING 42-2 } \\
\text { BONNEVILLE DAM OR.SHORE }\end{array}$ & $\begin{array}{l}\text { ONSTIT } \\
\text { OFFSITE }\end{array}$ & so & $\begin{array}{l}\text { SUB_SURFAEE } \\
\text { SUB SURFACE }\end{array}$ & $\begin{array}{l}\text { SEDIMENT } \\
\text { SEDIMENT }\end{array}$ & $\begin{array}{l}\text { 13-Oct-03 } \mathrm{Cr} \\
07-\mathrm{Aug}-03 \mathrm{Cr}\end{array}$ & & & $\frac{u g / g}{u g / g}$ & & & & & \\
\hline $\begin{array}{l}\text { SESSPEC } \\
\text { SESPSPEC }\end{array}$ & B17BK1 & $\begin{array}{l}\text { DALLES DAM OR.SHORE } \\
\text { D. }\end{array}$ & OFFSITE & so & SUB_SURFACE & $\begin{array}{l}\text { SEDIMENT } \\
\text { SEDENT }\end{array}$ & $07-A u g-03 \mathrm{Cr}$ & & $57.2 \mathrm{t}$ & $\frac{\mathrm{ugg} / \mathrm{g}}{\mathrm{ug} / \mathrm{g}}$ & & & & & \\
\hline & & & OFFSITE & so & SUB_SURFACE & SEDIMENT & 14-May-03 Cr & & $18.8 \mathrm{t}(\mathrm{c}) \mathrm{r}$ & uglg (wet) & & & & & \\
\hline SESPSPEC & B16WX9 & ESQUATZEL CANAL & OFFSITE & so & SUB_SURFACE & SEDIMENT & 14-May-03 Cr & & 20.7 & uglg (wet) & & & & & \\
\hline SESPMNT & B176Y3 & HANFORD SLOUGH & RIVER_SHORELINE & so & SUB_SURFACE & SEDIMENT & 14-Jul-03 $\mathrm{Cr}$ & & $82.7 \mathrm{~L}$ & uglg & & & c & & \\
\hline SESPMNT & B17J58 & HANFORD SPR DR 28-2 & ONSITE & so & SUB_SURFACE & SEDIMENT & 03-Nov-03 Cr & & 80.94 & $\mathrm{ug} / \mathrm{g}$ & & & $\mathrm{c}$ & & \\
\hline $\begin{array}{l}\text { SESPSPEC } \\
\text { SESPPPEC }\end{array}$ & B17BJ7 & JOHN DAY DAM MID-RIVER & OFFSITE & so & SUB_SURFACE & $\begin{array}{l}\text { SEDIMENT } \\
\text { SEDMENT }\end{array}$ & 08-Aug-03 $\mathrm{Cr}$ & & 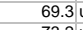 & $\mathrm{ug} / \mathrm{g}$ & & & & & \\
\hline $\begin{array}{l}\text { SESPPPEC } \\
\text { SESPNT }\end{array}$ & B17BJ3 & $\begin{array}{l}\text { MCNARY-2/3 OR. SHORE } \\
\end{array}$ & $\begin{array}{l}\text { OFFSITE } \\
\text { OEFITF }\end{array}$ & so & $\begin{array}{l}\text { SUB_SURFACE } \\
\text { SUB_SUPFACE }\end{array}$ & $\begin{array}{l}\text { SEDIMENT } \\
\text { SEDMENT }\end{array}$ & 08-Aug-03 $\mathrm{Cr}$ & & 73.24 & $\mathrm{ug} / \mathrm{g}$ & & & & & \\
\hline $\begin{array}{l}\text { SESPMNT } \\
\text { SESPMNT }\end{array}$ & $\begin{array}{l}\text { B17710 } \\
\text { B17712 }\end{array}$ & $\begin{array}{l}\text { MMCNARYYOR.SDE NEAR DAM } \\
\text { MCNARY-WASH.SIDE NEAR DAM }\end{array}$ & $\begin{array}{l}\text { OFFFITE } \\
\text { OFFSITE }\end{array}$ & $\begin{array}{l}\text { so } \\
\text { so }\end{array}$ & $\begin{array}{l}\text { SUB_SURFACE } \\
\text { SUB SURFACE }\end{array}$ & $\begin{array}{l}\text { SEDIIENT } \\
\text { SEDIMENT }\end{array}$ & $\begin{array}{l}\text { 16-Jul-03Cr } \\
\text { 16-Jul-03 Cr }\end{array}$ & & $\begin{array}{l}71.24 \\
73.8 \mathrm{~L}\end{array}$ & $\begin{array}{ll}\mathrm{ug} / \mathrm{g} \\
\mathrm{ug} / \mathrm{g}\end{array}$ & & & $\begin{array}{l}\mathrm{C} \\
\mathrm{C}\end{array}$ & & \\
\hline $\begin{array}{l}\text { SESPMNT } \\
\text { SESPNT }\end{array}$ & $\begin{array}{ll}61712 \\
B 1704\end{array}$ & $\begin{array}{l}\text { PRD-GRANT SIDE NEAR DAM } \\
\text { PRD }\end{array}$ & OFFSITE & so & $\begin{array}{l}\text { SUBSOSURFAE } \\
\text { SUB_SURACE }\end{array}$ & $\begin{array}{l}\text { SEDIMENT } \\
\text { SEDEN }\end{array}$ & $\begin{array}{l}14-\mathrm{Jul}-03 \mathrm{Cr} \\
\mathrm{Cr}\end{array}$ & & 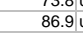 & ug/g & & & $\mathrm{c}$ & & \\
\hline SESPMNT & B17702 & PRD-YAKIMA SIDE NEAR DAM & OFFSITE & so & SUB_SURFACE & SEDIMENT & 14-Jul-03 Cr & & $92.1 \mathrm{~L}$ & ug/g & & & c & & \\
\hline SESPMNT & B176Y5 & RICHLAND-RIVER & RIVER_SHORELINE & so & SUB_SURFACE & SEDIMENT & $16-\mathrm{Jul}-03 \mathrm{Cr}$ & & $65.3 \mathrm{t}$ & ug/g & & & $c$ & & \\
\hline SESPSPEC & B16WX6 & RINGOLD WASTEWAY & OFFSITE & so & SUB_SURFACE & SEDIMENT & 14-May-03 Cr & & $22.4 \mathrm{~L}$ & uglg (wet) & & & & PRIMARILY SAND. & \\
\hline SESPSPEC & B16WX7 & RINGOLD WASTEWAY & OFFSITE & so & SUB_SURFACE & SEDIMENT & 14-May-03 Cr & & 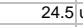 & uglg (wet) & & & & PRIMARILY SAND. & \\
\hline $\begin{array}{l}\text { SESPPPEC } \\
\text { SESPPECC }\end{array}$ & $B 16 W \times 2$ & $\begin{array}{l}\text { WALLA WALLA-RIVER } \\
\text { WALIVA- }\end{array}$ & OFFSITE & & & $\begin{array}{l}\text { SEDIMENT } \\
\text { SEDMENT }\end{array}$ & 15-May-03 Cr & & & $\mathrm{ug} / \mathrm{g}(\mathrm{wet}) \mathrm{g}$ & & & & & \\
\hline $\begin{array}{l}\text { SESPPPEC } \\
\text { SESPMNT }\end{array}$ & $\begin{array}{l}\text { B16WX3 } \\
B 176 \times 9\end{array}$ & $\begin{array}{l}\text { WALLA WALLA-RIVER } \\
\text { WHITE BBUFFS SLOUGH }\end{array}$ & $\begin{array}{l}\text { OFFSITE } \\
\text { RIVR SHORELINE }\end{array}$ & $\begin{array}{l}\text { so } \\
\text { so }\end{array}$ & $\begin{array}{l}\text { SUB_SURFACE } \\
\text { SUB_SUPFACE }\end{array}$ & $\begin{array}{l}\text { SEDIMENT } \\
\text { SEDMENT }\end{array}$ & $\begin{array}{l}\text { 15-May-03 Cr } \\
\text { 14-3u-103 Cr }\end{array}$ & & 26.94 & $\mathrm{ug} / \mathrm{g}(\mathrm{wet})$ & & & $c$ & & \\
\hline SESPSPEC & $\begin{array}{l}\text { BL16X9 } \\
\text { B16WX0 }\end{array}$ & $\begin{array}{l}\text { WHITE BBUFFS SLOUGH } \\
\text { YAKIMA RIVER }\end{array}$ & $\begin{array}{l}\text { RIVR SHORELIVE } \\
\text { OFFSITE }\end{array}$ & $\begin{array}{l}\text { So } \\
\text { so }\end{array}$ & $\begin{array}{l}\text { SUB_SURFACE } \\
\text { SUB SURFACE }\end{array}$ & $\begin{array}{l}\text { SEDIMENT } \\
\text { SEDIMENT }\end{array}$ & $\begin{array}{l}\text { 14--Mul-03 Cr } \\
\text { 14- } \mathrm{Cay}-03 \mathrm{Cr}\end{array}$ & & $\begin{array}{l}79.14 \\
40.24\end{array}$ & $\begin{array}{l}\mathrm{ug} / \mathrm{g} / \mathrm{g} \text { (wet) } \\
\mathrm{u} / \mathrm{s}\end{array}$ & & & $c$ & & \\
\hline SESPSPEC & $B 16 W \times 1$ & YAKIMA RIVER & OFFSITE & so & $\begin{array}{l}\text { SUB_SURFACE } \\
\text { SUB SURFACE }\end{array}$ & SEDIMENT & 14-May-03 Cr & & $34.6 !$ & $\begin{array}{l}\text { uglg (we) } \\
\text { uglget) }\end{array}$ & & & & & \\
\hline SESPSPEC & B17XN6 & 100 B/C AREA UR & ONSITE & so & SUB SURFACE & SEDIMENT & 17-Nov-03 Cu & & 11.5 & & & & & & \\
\hline SESPMNT & B176Y1 & 100 F SLOUGH & ONSITE & so & SUB_SURFACE & SEDIMENT & 14-Jul-03 Cu & & 19.7 & 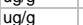 & & & & & \\
\hline SESPMNT & B17J53 & 100-B SPRING 37-1 & ONSITE & so & SUB_SURFACE & SEDIMENT & $20-0 c t-03 \mathrm{Cu}$ & & $16.4 \mathrm{~L} \quad>\quad>$ & $\mathrm{ug} / \mathrm{g}$ & & & & & \\
\hline SESPSPEC & B17XN8 & 100-B SPRING 37-1 & ONSITE & so & SUB_SURFACE & SEDIMENT & & & 15.14 & $\mathrm{ug} / \mathrm{g}$ & & & & & \\
\hline $\begin{array}{l}\text { SESPSPEC } \\
\text { SESDPUT }\end{array}$ & B17XN9 & 100-B SPRING & ONSITE & so & SUB_SURFACE & SEDIMENT & 13-Nov-03 Cu & & $17.4 \mathrm{~L}$ & $\mathrm{ug} / \mathrm{g}$ & & & & & \\
\hline $\begin{array}{l}\text { SESPMNT } \\
\text { SESPMT }\end{array}$ & B17J67 & 100-F SPRING 207-1 & ONSITE & so & SUB_SURFACE & $\begin{array}{l}\text { SEDIMENT } \\
\text { SEDMENT }\end{array}$ & 03-Nov-03 Cu & & 28.5 & $\mathrm{ug} / \mathrm{g}$ & & & & & \\
\hline $\begin{array}{l}\text { SESPMNT } \\
\text { SESPMNT }\end{array}$ & 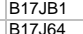 & $\begin{array}{l}\text { 100-H SPRING 145-1 } \\
100-\mathrm{K} \text { SPRING 63-1 }\end{array}$ & $\begin{array}{l}\text { ONSITE } \\
\text { ONSTIE }\end{array}$ & $\begin{array}{l}\text { so } \\
\text { so }\end{array}$ & $\begin{array}{l}\text { SUB_SURFACE } \\
\text { SUB SURFACE }\end{array}$ & $\begin{array}{l}\text { SEDIMENT } \\
\text { SEDMENT }\end{array}$ & $\begin{array}{l}\text { 27-Oct-03 Cu } \\
\text { 20-Oct-03 Cu }\end{array}$ & & $\begin{array}{ll}31.14 \\
24.9 \mathrm{~L}\end{array}$ & ug/g $u$ & & & & & \\
\hline $\begin{array}{l}\text { SESPMNI } \\
\text { SESPMNT }\end{array}$ & 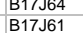 & $\begin{array}{l}100-\text { K SPRING 63-1 } \\
300 \text { AREA SPR DR 42-2 }\end{array}$ & $\begin{array}{l}\text { ONSSITE } \\
\text { ONSE }\end{array}$ & so & $\begin{array}{l}\text { SUB_SURFACE } \\
\text { SUB SURFACE }\end{array}$ & $\begin{array}{l}\text { SEDIMENT } \\
\text { SEDIMENT }\end{array}$ & $\begin{array}{l}\text { 20-Oct-103 Cu } \\
13-\mathrm{Oct}-03 \mathrm{Cu}\end{array}$ & & $\begin{array}{l}24.9 \mathrm{~L} \\
17.6 \mathrm{t}\end{array}$ & ug/g/g & & & & & \\
\hline SESPMNT & B17J18 & 300 AREA SPRING 42-2 & ONSITE & so & SUB_SURFACE & SEDIMENT & $13-\mathrm{Oct}-03 \mathrm{Cu}$ & & $19 \mathrm{t}$ & ug/g & & & & & \\
\hline SESPSPEC & B17BK5 & BONNEVILLE DAM OR.SHORE & OFFSITE & so & SUB_SURFACE & SEDIMENT & 07-Aug-03 Cu & & $32.1 \mathrm{t}$ & ug/g & & & & & \\
\hline SESPSPEC & B17BK1 & DALLES DAM OR.SHORE & OFFSITE & so & SUB_SURFACE & SEDIMENT & 07-Aug-03 Cu & & $30.8 \mathrm{~L} \quad \ln \mathrm{l}$ & $\mathrm{ug} / \mathrm{g}$ & & & & & \\
\hline SESPSPEC & B16WX8 & ESQUATZEL CANAL & OFFSITE & so & SUB_SURFACE & SEDIMENT & 14-May-03 Cu & & 9.55 & uglg (wet) & & & & & \\
\hline SESPSPEC & B16WX9 & ESQUATZEL CANAL & & so & SUB_SURFACE & SEDIMENT & 14-May-03 Cu & & 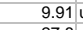 & ug/g (wet) & & & & & \\
\hline $\begin{array}{l}\text { SESPMNT } \\
\text { SESPMTT }\end{array}$ & B176Y3 & HANFORD SLOUGH & $\begin{array}{l}\text { RIVER_SHORELINE } \\
\text { ONSTIF }\end{array}$ & so & SUB_SURFACE & $\begin{array}{l}\text { SEDIMENT } \\
\text { SEDMENT }\end{array}$ & 14-Jul-03 Cu & & 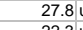 & us & & & & & \\
\hline $\begin{array}{l}\text { SESPNT } \\
\text { SESPSPEC }\end{array}$ & 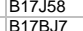 & $\begin{array}{l}\text { HANFORD SPR DR 28-2 } \\
\text { JOHN DAY DAM MD-RIVER }\end{array}$ & $\begin{array}{l}\text { ONSITE } \\
\text { OFFSTEE }\end{array}$ & $\begin{array}{l}\text { so } \\
\text { so }\end{array}$ & $\begin{array}{l}\text { SUB_SURFACE } \\
\text { SUB_SURFACE }\end{array}$ & $\begin{array}{l}\text { SEDIMENT } \\
\text { SEDMENT }\end{array}$ & $\begin{array}{l}\text { 03--Nov-03 Cu } \\
\text { 08-Aug-03 Cu }\end{array}$ & & $\begin{array}{ll}22.3 \mathrm{~L} \\
40.2 \mathrm{~L}\end{array}$ & $\mathrm{ug} / \mathrm{g}$ & & & & & \\
\hline $\begin{array}{l}\text { SESSPPEC } \\
\text { SESPSPEC }\end{array}$ & 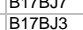 & $\begin{array}{l}\text { OHIN DAY DAM MID-RIVER } \\
\text { MCNARY-2/3 OR. SHORE }\end{array}$ & $\begin{array}{l}\text { OFSIIE } \\
\text { OFFSITE }\end{array}$ & so & $\begin{array}{l}\text { SUB_SURFACE } \\
\text { SUB SURFACE }\end{array}$ & $\begin{array}{l}\text { SEDMENEI } \\
\text { SEDIMENT }\end{array}$ & $\begin{array}{l}\text { 08-Aug-03 Cu } \\
\text { 08-Aug-03 Cu }\end{array}$ & & $\begin{array}{l}40.2 \mathrm{~L} \\
26.7 \mathrm{t}\end{array}$ & ug/g & & & & & \\
\hline $\begin{array}{l}\text { SESPMNT } \\
\text { SEN }\end{array}$ & B17710 & MCNARY-OR.SIDE NEAR DAM & OFFSITE & & SUB_SURFACE & $\begin{array}{l}\text { SEDIMENT } \\
\text { SEUEN }\end{array}$ & $16-\mathrm{Jul}-03 \mathrm{Cu}$ & & $36.5 \mathrm{t}$ & ug/g & & & & & \\
\hline SESPMNT & B17712 & MCNARY-WASH.SIDE NEAR DAM & OFFSITE & so & SUB_SURFACE & SEDIMENT & $16-\mathrm{Jul}-03 \mathrm{Cu}$ & & $28.5 \mathrm{t}-\mathrm{l} \cdot \mathrm{l}$ & ug/g & & & & & \\
\hline SESPMNT & B17704 & PRD-GRANT SIDE NEAR DAM & OFFSITE & so & SUB_SURFACE & SEDIMENT & 14-Jul-03 Cu & & $50 \mathrm{~L}$ & ug/g & & & & & \\
\hline SESPMNT & B17702 & PRD-YAKIMA SIDE NEAR DAM & OFFSITE & so & SUB_SURFACE & SEDIMENT & 14-Jul-03 Cu & & 45.94 & $\mathrm{ug} / \mathrm{g}$ & & & & & \\
\hline SESPMNT & B176Y5 & RICHLAND-RIVER & RIVER_SHORELINE & so & SUB_SURF, & SEDIM & 16-Jul-03 Cu & & $24.9 !$ & & & & & & \\
\hline SESPSPEC & B16WX6 & RINGOLD WASTEWAY & OFFSITE & so & SUB_SURFACE & SEDIM & 14-May-03 Cu & & $9.54 \mathrm{~L}$ & ug/g (wet) & & & & PRIMARILY SAND. & \\
\hline SESPSPEC & B16WX7 & RINGOLD WASTEWAY & OFFSITE & so & SUB_SURFACE & $\begin{array}{l}\text { SEDIMENT } \\
\text { SEDMENT }\end{array}$ & 14-May-03 Cu & & 10.24 & ug/g(wet) & & & & PRIMARILY SAND. & \\
\hline $\begin{array}{l}\text { SESPSPEC } \\
\text { SESPPPEC }\end{array}$ & 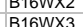 & $\begin{array}{l}\text { WALLA WALLA-AIVER } \\
\text { WALA WALLA-RIVER }\end{array}$ & $\begin{array}{l}\text { OFFITE } \\
\text { OFFSITE }\end{array}$ & $\begin{array}{l}\text { so } \\
\text { so }\end{array}$ & $\begin{array}{l}\text { SUB_SURFACE } \\
\text { SUB_SUREACE }\end{array}$ & $\begin{array}{l}\text { SEDIMENT } \\
\text { SEDIMENT }\end{array}$ & $\begin{array}{l}\text { 15-May-03 Cu } \\
\text { 15-May-3 Cu }\end{array}$ & & $\begin{array}{l}12.3 \mathrm{t} \\
14.9 \mathrm{t}\end{array}$ & ug/g(wet) & & & & & \\
\hline $\begin{array}{l}\text { SESSPPEC } \\
\text { SESPMNT }\end{array}$ & $8176 \times 9$ & $\begin{array}{l}\text { WHALA WALAR-AIVR } \\
\text { WHITE BLUFFS SLOUGH }\end{array}$ & $\begin{array}{l}\text { RIFSR_SHORELINE } \\
\text { RIVRE }\end{array}$ & so & $\begin{array}{l}\text { SUB_SURFACE } \\
\text { SUB SURFACE }\end{array}$ & $\begin{array}{l}\text { SEUINENI } \\
\text { SEDIMENT }\end{array}$ & 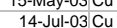 & & $34.6 \mathrm{t}$ & $\begin{array}{l}\mathrm{ug} / \mathrm{g} / \mathrm{wet}) \\
\mathrm{u} / \mathrm{g}\end{array}$ & & & & & \\
\hline
\end{tabular}


(pCilg Dry Weight unless otherwise noted)

\begin{tabular}{|c|c|c|c|c|c|c|c|c|c|c|c|c|c|c|}
\hline OWNER ID & \begin{tabular}{|l|} 
SAMP \\
NUMM
\end{tabular} & SAMP SITE NAME & DIST CLASS & MEDIA & SAMP FROM & SAMP ITEM & SAMP DATE CON SHORT NAME & $\begin{array}{l}\text { VALUE } \\
\text { RPTD }\end{array}$ & \begin{tabular}{|c|} 
ANAL \\
UNITS \\
RPTD \\
\end{tabular} & $\begin{array}{c}\text { COUNTING } \\
\text { ERROR }\end{array}$ & \begin{tabular}{|c|} 
TOTAL \\
ANAL \\
ERROR
\end{tabular} & $\begin{array}{c}\text { LAB } \\
\text { QUALIFIER }\end{array}$ & SAMP COMMENT & RESULT COMMENT \\
\hline SESPSPEC & B16WXo & YAKIMA RIVER & OFFSITE & so & SUB_SURFACE & SEDIMENT & 14-May- 03 Cu & & & & & & & \\
\hline $\begin{array}{l}\text { SESPSPEC } \\
\text { SESPSEC }\end{array}$ & $\begin{array}{ll}B 16 W \times 1 \\
B 17 \times P 7\end{array}$ & $\begin{array}{l}\text { YAKIMA RIVER } \\
100 \text { BCC AREA DR }\end{array}$ & $\begin{array}{l}\text { OFFSITE } \\
\text { ONSIE }\end{array}$ & so & SUB_SURFACE & $\begin{array}{l}\text { SEDIMENT } \\
\text { SEDMENT }\end{array}$ & $\begin{array}{l}\text { 14-May-03 Cu } \\
\text { 17-Noy-03 METAL SICPMS }\end{array}$ & & ug/g (wet) & & & & & \\
\hline $\begin{array}{l}\text { SESPPEC } \\
\text { SESPSPEC }\end{array}$ & B17XP1 & $\begin{array}{l}100 \text { B/C ARRA DR } \\
100 \text { B/C AREA OUTFL1 }\end{array}$ & $\begin{array}{l}\text { ONSSITE } \\
\text { ONSITE }\end{array}$ & $\begin{array}{l}\text { so } \\
\text { so }\end{array}$ & $\begin{array}{l}\text { SUB_SURFACE } \\
\text { SUB SURACE }\end{array}$ & $\begin{array}{l}\text { SEDIMENT } \\
\text { SEDIMENT }\end{array}$ & $\begin{array}{l}\text { 17-Nov-03 METALS IIPMS } \\
\text { 10-Nov-03 METALS ICPMS }\end{array}$ & & & & & & $\begin{array}{l}\text { NO SAMPLE. NOT AAALALABE. } \\
\text { NO SAMPE. NOT AVALABEE. }\end{array}$ & \\
\hline $\begin{array}{l}\text { SESPSPEC } \\
\text { SEPSP }\end{array}$ & B17XP3 & 100 B/C AREA OUTFL2 & ONSITE & so & SUB_SURFACE & SEDIMENT & 10-Nov-03 METALS ICPMS & & & & & & NO SAMPLE. NOT AVAILABLE. & \\
\hline $\begin{array}{l}\text { SESPSPEC } \\
\text { SESPSECA }\end{array}$ & B17XP5 & $100 \mathrm{~B} / \mathrm{C}$ AREA OUTFL 3 & ONSITE & so & SUB_SURFACE & $\begin{array}{l}\text { SEDIMENT } \\
\text { SEDMENT }\end{array}$ & & & & & & & NO SAMPLE. NOT AVAILABLE. & \\
\hline $\begin{array}{l}\text { SESPPSEC } \\
\text { SESPNT }\end{array}$ & $\begin{array}{l}\text { B17XP0 } \\
\text { B17755 }\end{array}$ & $\begin{array}{l}\text { 100-B SPRING 39-2 } \\
\text { HANFORD SPR UR 28-2 }\end{array}$ & $\begin{array}{l}\text { ONSIE } \\
\text { ONSITE }\end{array}$ & $\begin{array}{l}\text { so } \\
\text { so }\end{array}$ & $\begin{array}{l}\text { SUB_SURFACE } \\
\text { SUB SURFAE }\end{array}$ & $\begin{array}{l}\text { SEDIMENT } \\
\text { SEDMENT }\end{array}$ & $\begin{array}{l}\text { 10-Nov-03 METALS ICPMS } \\
\text { 15-Se0-3 METASS IPMS }\end{array}$ & & & & & & NO SAMPLE. NOT AVAILABLE. & \\
\hline SESPSPEC & $\begin{array}{l}\text { B17555 } \\
\text { B16WYo }\end{array}$ & $\begin{array}{l}\text { HANARORD SPR UR 28-2 } \\
\text { POTHOLES CANAL }\end{array}$ & OFFSITE & so & $\begin{array}{l}\text { SUB_SURFACE } \\
\text { SUB SURFACE }\end{array}$ & $\begin{array}{l}\text { SEDIMENT } \\
\text { SEDIMENT }\end{array}$ & $\begin{array}{l}\text { 15-Sep-303 METALS IIPMS } \\
\text { 14-May-03 METALS ICPMS }\end{array}$ & & & & & & $\begin{array}{l}\text { NO SAMPLE. } \\
\text { NO SAMPLE. }\end{array}$ & \\
\hline SESPSPEC & B16WY1 & POTHOLES CANAL & OFFSITE & so & SUB_SURFACE & SEDIMENT & 14-May-03 METALS ICPMS & & & & & & NO SAMPLE. & \\
\hline $\begin{array}{l}\text { SESPSPEC } \\
\text { SESPPEC }\end{array}$ & $\begin{array}{l}\text { B16WX4 } \\
B 16 W 5\end{array}$ & $\begin{array}{l}\text { SNAKE RIVER } \\
\text { SNAKE RVER }\end{array}$ & $\begin{array}{l}\text { OFFSITE } \\
\text { OFFITE }\end{array}$ & $\begin{array}{l}\text { so } \\
\text { so }\end{array}$ & $\begin{array}{l}\text { SUB_SURFACE } \\
\text { SUB SURACE }\end{array}$ & $\begin{array}{l}\text { SEDIMENT } \\
\text { SEDIMENT }\end{array}$ & $\begin{array}{l}\text { 15-May-03 METALL ICPMS } \\
\text { 15-Ma-3 METAS IPMS }\end{array}$ & & & & & & $\begin{array}{l}\text { NO SAMPLE. } \\
\text { NO SAMPE. }\end{array}$ & \\
\hline SESPSPEC & B17XN6 & 100 B/C AREA UR & ONSITE & so & $\begin{array}{l}\text { SUB_SURFACE } \\
\text { SUB_SURFACE }\end{array}$ & SEDIMENT & $\begin{array}{l}17-\mathrm{Nov}-03 \mathrm{Mn} \\
17\end{array}$ & & ug/g & & & $c$ & & \\
\hline SESPSPEC & B17XN8 & 100-B SPRING 37-1 & ONSITE & so & SUB_SURFACE & SEDIMENT & 13-Nov-03 Mn & & & & & $c$ & & \\
\hline $\begin{array}{l}\text { SESPSPEC } \\
\text { SEPDPEC }\end{array}$ & B17NN9 & 100-B SPRING 38-3 & ONSITE & so & $\begin{array}{l}\text { SUB-SURFACE } \\
\text { SUB_SERE }\end{array}$ & $\begin{array}{l}\text { SEDIMENT } \\
\text { SEDMENT }\end{array}$ & 13-Nov-03 Mn & 561 & & & & c & & \\
\hline $\begin{array}{l}\text { SESPSPEC } \\
\text { SESPMNT }\end{array}$ & B17XN6 & $100 \mathrm{~B} / \mathrm{C}$ AREA UR & ONSITE & so & SUB_SURFACE & SEDIMENT & $17-\mathrm{Nov}-03 \mathrm{Ni}$ & 18.9 & & & & & & \\
\hline $\begin{array}{l}\text { SESPMNT } \\
\text { SESPNNT }\end{array}$ & $\begin{array}{l}\text { B176Y1 } \\
\text { B17753 }\end{array}$ & $\begin{array}{l}\text { lo0 F SLOUGH } \\
100-B \text { SPRING } 37-1\end{array}$ & $\begin{array}{l}\text { ONITE } \\
\text { ONSITE }\end{array}$ & $\begin{array}{l}\text { so } \\
\text { so }\end{array}$ & $\begin{array}{l}\text { SUB_SURFACE } \\
\text { SUB SURFAE }\end{array}$ & $\begin{array}{l}\text { SEDIMENT } \\
\text { SEDMENT }\end{array}$ & $\begin{array}{l}\text { 14-Jul-03 Ni } \\
\text { 20-0ct-03 } \mathrm{Ni}\end{array}$ & 17 & ug/g & & & & & \\
\hline $\begin{array}{l}\text { SESPNT } \\
\text { SESPSPEC }\end{array}$ & 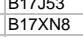 & $\begin{array}{l}100-\text { B SPRNGG 37-1 } \\
\text { 100-B SPRING 37-1 }\end{array}$ & $\begin{array}{l}\text { ONSTIE } \\
\text { ONSITE }\end{array}$ & $\begin{array}{l}\text { so } \\
\text { so }\end{array}$ & $\begin{array}{l}\text { SUB_SURFACE } \\
\text { SU_SURAACE }\end{array}$ & $\begin{array}{l}\text { SEDIMENT } \\
\text { SEDIMENT }\end{array}$ & $\begin{array}{l}\text { 20-Oct-03 Ni } \\
\text { 13-Nov-03 Ni }\end{array}$ & $\begin{array}{r}15.7 \\
18\end{array}$ & & & & & & \\
\hline $\begin{array}{l}\text { SESPSPEC } \\
\text { SECDMNT }\end{array}$ & B17XN9 & 100-B SPRING 38-3 & ONSITE & so & SUB_SURFACE & SEDIMENT & 13-Nov-03 Ni & 21.1 & & & & & & \\
\hline $\begin{array}{l}\text { SESPMNT } \\
\text { SESPMNT }\end{array}$ & B17J67 & $\begin{array}{l}\text { 100-F SPRING 207-1 } \\
100 \text {-H SPRING 145-1 }\end{array}$ & $\begin{array}{l}\text { ONSITE } \\
\text { ONSTE }\end{array}$ & so & SUB_SURFACE & $\begin{array}{l}\text { SEDIMENT } \\
\text { SEDMENT }\end{array}$ & 03-Nov-03 Ni & 25.8 & & & & & & \\
\hline $\begin{array}{l}\text { SESPMNT } \\
\text { SESPNNT }\end{array}$ & $\begin{array}{l}\text { B17J31 } \\
\text { B17764 }\end{array}$ & $\begin{array}{l}\text { 100-H SPRRING 145-1 } \\
\text { 100-K SPRING 63-1 }\end{array}$ & $\begin{array}{l}\text { ONSIE } \\
\text { ONSITE }\end{array}$ & so & $\begin{array}{l}\text { SUB_SURFACE } \\
\text { SUB SURFACE }\end{array}$ & $\begin{array}{l}\text { SEDIMENT } \\
\text { SEDMENT }\end{array}$ & $\begin{array}{l}\text { 27-Oct-03 Ni } \\
\text { 20-Oct-03 Ni }\end{array}$ & 20.1 & ug/g & & & & & \\
\hline $\begin{array}{l}\text { SESPMNI } \\
\text { SESPMNT }\end{array}$ & 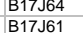 & 300 AREA SPR DR 42-2 & ONSITE & $\begin{array}{l}\text { So } \\
\text { so }\end{array}$ & $\begin{array}{l}\text { SUB_SURFACE } \\
\text { SUB_SURFACE }\end{array}$ & $\begin{array}{l}\text { SEDIMENT } \\
\text { SEDIMENT }\end{array}$ & $\begin{array}{l}\text { 20-Oct-03 Ni } \\
13-\mathrm{Oct}-03 \mathrm{Ni}\end{array}$ & $\begin{array}{l}19.4 \\
16.3\end{array}$ & $\begin{array}{ll}\mathrm{ugg/g} / \mathrm{g} \\
\mathrm{ug} / \mathrm{g}\end{array}$ & & & & & \\
\hline SESPMNT & B17J18 & 300 AREA SPRING 42-2 & ONSITE & so & SUB_SURFACE & SEDIMENT & $13-\mathrm{Oct}-03 \mathrm{Ni}$ & 19.1 & ug/g & & & & & \\
\hline SESPSPEC & B178K5 & BONNEVILLE DAM OR.SHORE & OFFSITE & so & SUB_SURFACE & SEDIMENT & $07-$ Aug-03 $\mathrm{Ni}$ & 25.1 & ug/g & & & & & \\
\hline SESPSPEC & B17BK1 & DALLES DAM OR.SHORE & OFFSITE & so & SUB_SURFACE & SEDIMENT & 07-Aug-03 Ni & & $\mathrm{ug} / \mathrm{g}$ & & & & & \\
\hline SESPSPEC & B16WX8 & ESQUATZEL CANAL & OFFSITE & so & SUB_SURFACE & SEDIMENT & 14-May-03 Ni & 8.42 & ug/g (wet) & & & & & \\
\hline SESPSPEC & B16WX9 & ESQUATZEL CANAL & OFFSITE & so & SUB_SURFACE & SEDIMENT & $14-\mathrm{May}-03 \mathrm{Ni}$ & 8.49 & ug/g (wet) & & & & & \\
\hline $\begin{array}{l}\text { SESPMNT } \\
\text { SESPMNT }\end{array}$ & $\begin{array}{l}8176 Y 3 \\
81758\end{array}$ & & $\begin{array}{l}\text { RIVER_SHORELINE } \\
\text { ONSSTE }\end{array}$ & so & SUB_SURFACE & $\begin{array}{l}\text { SEDIMENT } \\
\text { SEDMENT }\end{array}$ & 14-Jul-03 Ni & 29.7 & $\mathrm{ug} / \mathrm{g}$ & & & & & \\
\hline $\begin{array}{l}\text { SESPMNT } \\
\text { SESPSPEC }\end{array}$ & $\begin{array}{l}\text { B17758 } \\
\text { B178J7 }\end{array}$ & $\begin{array}{l}\text { HANFORD SPR DR 28-2 } \\
\text { JOHN DAY DAM MII-RIVER }\end{array}$ & $\begin{array}{l}\text { ONSIIE } \\
\text { OFFITE } \\
\end{array}$ & $\begin{array}{l}\text { so } \\
\text { so }\end{array}$ & $\begin{array}{l}\text { SUB_SURFAAE } \\
\text { SUB SURACE }\end{array}$ & $\begin{array}{l}\text { SEDIMENT } \\
\text { SEDIMENT }\end{array}$ & $\begin{array}{l}03-\mathrm{Nov}-03 \mathrm{Ni} \\
0 \text { 0-Aug }-03 \mathrm{Ni}\end{array}$ & $\begin{array}{r}26 \\
31.5\end{array}$ & ug/g & & & & & \\
\hline $\begin{array}{l}\text { SESPPEC } \\
\text { SESPSPEC }\end{array}$ & $\begin{array}{ll}\mathrm{B} 1 / \mathrm{BJ} / \mathrm{I} \\
\mathrm{B} 17 \mathrm{BJJ3}\end{array}$ & 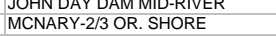 & $\begin{array}{l}\text { OFSIIIE } \\
\text { OFFSITE }\end{array}$ & so & $\begin{array}{l}\text { SUB_SURFACE } \\
\text { SUB SURFACE }\end{array}$ & $\begin{array}{l}\text { SEDMENEI } \\
\text { SEDIMENT }\end{array}$ & $\begin{array}{l}08-\mathrm{Aug}-03 \mathrm{Ni} \\
08 \text {-Aug-03 } \mathrm{Ni}\end{array}$ & 30.1 & $\frac{\mathrm{ugg/g} / \mathrm{ug}}{\mathrm{ug} / \mathrm{g}}$ & & & & & \\
\hline $\begin{array}{l}\text { SESPPEC } \\
\text { SESPMNT }\end{array}$ & B17710 & MCNARY-OR.SIDE NEAR DAM & $\begin{array}{l}\text { OFFFITE } \\
\text { OFSITE }\end{array}$ & so & $\begin{array}{l}\text { SUB_SURFACE } \\
\text { SUB SURFACE }\end{array}$ & $\begin{array}{l}\text { SEUIIENI } \\
\text { SEDIMENT }\end{array}$ & $16-\mathrm{Jul}-03 \mathrm{Ni}$ & 31.6 3 & uglag & & & & & \\
\hline SESPMNT & B17712 & MCNARY-WASH.SIDE NEAR DAM & OFFSITE & so & SUB_SURFACE & SEDIMENT & 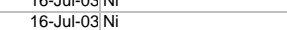 & & ug/g /g & & & & & \\
\hline SESPMNT & $\begin{array}{l}\text { B171704 } \\
\text { B17704 }\end{array}$ & PRD-GRANT SIDE NEAR DAM & OFFSITE & so & SUB_SURFACE & SEDIMENT & 14-Jul-03 Ni & 41.5 & ug/g $/ 9$ & & & & & \\
\hline SESPMNT & B17702 & PRD-YAKIMA SIDE NEAR DAM & OFFSITE & so & SUB_SURFACE & SEDIMENT & 14-Jul-03 Ni & 46.8 & $\mathrm{ug} / \mathrm{g}$ & & & & & \\
\hline SESPMNT & B176Y5 & RICHLAND-RIVER & RIVER_SHORELINE & so & SUB_SURFACE & SEDIMENT & 16-Jul-03 Ni & 19.1 & & & & & & \\
\hline SESPSPEC & B16WX6 & RINGOLD WASTEWAY & OFFSITE & so & SUB_SURFACE & SEDIMENT & $14-\mathrm{May}-03 \mathrm{Ni}$ & 9.93 & ug/g (wet) & & & & PRIMARILY SAND. & \\
\hline $\begin{array}{l}\text { SESPSPEC } \\
\text { SESPSEC }\end{array}$ & B16WX7 & RINGOLD WASTEWAY & $\begin{array}{l}\text { OFFSITE } \\
\text { OFESTEE }\end{array}$ & so & SUB_SURFACE & $\begin{array}{l}\text { SEDIMENT } \\
\text { SEDMENT }\end{array}$ & 14-May-03 Ni & 11.3 & ug/g (wet) & & & & PRIMARILY SAND. & \\
\hline $\begin{array}{l}\text { SESPSEC } \\
\text { SESPSPEC }\end{array}$ & $\begin{array}{l}B 16 W \times 2 \\
B 16 W \times 3\end{array}$ & $\begin{array}{l}\text { WALLA WALLAARIIER } \\
\text { WALLA WALA-RIVER }\end{array}$ & $\begin{array}{l}\text { OFFITE } \\
\text { OFFSITE }\end{array}$ & $\begin{array}{l}\text { so } \\
\text { so }\end{array}$ & $\begin{array}{l}\text { SUB_SURFACE } \\
\text { SUB SURFACE }\end{array}$ & $\begin{array}{l}\text { SEDIMENT } \\
\text { SEDIMENT }\end{array}$ & $\begin{array}{l}15-\mathrm{May}-03 \mathrm{Ni} \\
15-\mathrm{May}-03 \mathrm{Ni}\end{array}$ & $\begin{array}{l}11.9 \\
12.2\end{array}$ & ug/g (wet) & & & & & \\
\hline $\begin{array}{l}\text { SESPPEC } \\
\text { SESPNT }\end{array}$ & $\begin{array}{l}-1 \\
B 176 \times 9\end{array}$ & $\begin{array}{l}\text { WHALA WALA-AIVR BLUFS SLOUGH } \\
\text { WHITE }\end{array}$ & RIVER SHORELINE & so & SUB_SURFACE & $\begin{array}{l}\text { SEDINENI } \\
\text { SEDIMENT }\end{array}$ & $\begin{array}{r}\text { 15-May-03 } \mathrm{NI} \\
14-J u l-03 \mathrm{Ni}\end{array}$ & ${ }_{24.2}^{12 .}$ & $\begin{array}{l}u g g / \text { g (wet) } \\
u g q / g\end{array}$ & & & & & \\
\hline SESPSPEC & B16WX0 & YAKIMA RIVER & OFFSITE & so & SUB_SURFACE & SEDIMENT & $14-\mathrm{May}-03 \mathrm{Ni}$ & 21.9 & ug/g (wet) & & & & & \\
\hline SESPSPEC & B16WX1 & YAKIMA RIVER & OFFSITE & so & SUB_SURFACE & SEDIMENT & $14-\mathrm{May}-03 \mathrm{Ni}$ & 21 & ug/g (wet) & & & & & \\
\hline SESPSPEC & B17XNG & $100 \mathrm{~B} / \mathrm{C}$ AREA UR & ONSITE & so & SUB_SURFACE & SEDIMENT & 17-Nov-03 Pb & 17.6 & ug/g & & & & & \\
\hline $\begin{array}{l}\text { SESPMNT } \\
\text { SESPMNT }\end{array}$ & B176Y1 & 100 F SLOUGH & ONSITE & so & SUB_SURFACE & $\begin{array}{l}\text { SEDIMENT } \\
\text { SEDMENT }\end{array}$ & 14-Jul-03 Pb & 17.7 & $\mathrm{ug} / \mathrm{g}$ & & & & & \\
\hline $\begin{array}{l}\text { SESPMNT } \\
\text { SESPSEC }\end{array}$ & $\begin{array}{l}817553 \\
B 175 \times 8\end{array}$ & 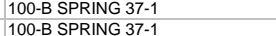 & $\begin{array}{l}\text { ONITE } \\
\text { ONSITE }\end{array}$ & so & $\begin{array}{l}\text { SUB_SURFACE } \\
\text { SUB_SUREACE }\end{array}$ & $\begin{array}{l}\text { SEDIMENT } \\
\text { SEDMENT }\end{array}$ & 20-Oct-03 Pb & 17.8 & ug/g & & & & & \\
\hline SESPSPEC & B17XN9 & 100-B SPRING 38-3 & ONSITE & so & $\begin{array}{l}\text { SUB_SURFACE } \\
\text { SUB_SURFACE }\end{array}$ & $\begin{array}{l}\text { SEDIMENT } \\
\text { SEDIMENT }\end{array}$ & $13-\mathrm{Nov}-03 \mathrm{~Pb}$ & 28.4 & ug/g & & & & & \\
\hline SESPMNT & B17J67 & 100-F SPRING 207-1 & ONSITE & so & SUB_SURFACE & SEDIMENT & 03-Nov-03 Pb & 34.7 & ug/g $/ 9$ & & & & & \\
\hline SESPMNT & B17JB1 & 100-H SPRING 145-1 & ONSITE & so & SUB_SURFACE & SEDIMENT & 27-Oct-03 Pb & 61.9 & $\mathrm{ug} / \mathrm{g}$ & & & & & \\
\hline SESPMNT & B17J64 & 100-K SPRING 63-1 & ONSITE & so & SUB_SURFACE & SEDIMENT & $20-0 \mathrm{ct}-03 \mathrm{~Pb}$ & 24.7 & $\mathrm{ug} / \mathrm{g}$ & & & & & \\
\hline SESPMNT & B17J61 & 300 AREA SPR DR 42-2 & ONSITE & so & SUB_SURFACE & SEDIMENT & 13-Oct-03 Pb & 17.7 & ug/g & & & & & \\
\hline SESPMNT & B17J18 & & ONSITE & so & SUB_SURFACE & $\begin{array}{l}\text { SEDIMENT } \\
\text { SEDMENT }\end{array}$ & 13-Oct-03 Pb & 16 & ug/g & & & & & \\
\hline SESPSPEC & B17BK5 & $\begin{array}{l}\text { BONNEVILLE DAM OR.SHORE } \\
\text { DALESDAM OR SHORE }\end{array}$ & $\begin{array}{l}\text { OFFSITE } \\
\text { OFESTIE }\end{array}$ & so & SUB_SURFACE & $\begin{array}{l}\text { SEDIMENI } \\
\text { SEDMMENT }\end{array}$ & $\begin{array}{l}\text { 07-Aug-03 Pb } \\
07-\text { Aug-03 } \mathrm{Pb}\end{array}$ & 18.7 & ug/g & & & & & \\
\hline $\begin{array}{l}\text { SESPSPEC } \\
\text { SESPSEC }\end{array}$ & $\begin{array}{ll}\text { B178K1 } \\
\text { B16WX8 }\end{array}$ & $\begin{array}{l}\text { DALLES DAM OR.SHORE } \\
\text { ESOUATZEL CANAL }\end{array}$ & $\begin{array}{l}\text { OFFSSTE } \\
\text { OFFSITE }\end{array}$ & so & $\begin{array}{l}\text { SUB_SURFACE } \\
\text { SUB SURFACE }\end{array}$ & $\begin{array}{l}\text { SEDIIENI } \\
\text { SEDIMENT }\end{array}$ & $14-\mathrm{May}-03 \mathrm{~Pb}$ & $\begin{array}{l}17.6 \\
7.96\end{array}$ & $\frac{u g / g}{u g / g}$ (wet) & & & & & \\
\hline $\begin{array}{l}\text { SESPSEC } \\
\text { SESPSPEC }\end{array}$ & $\begin{array}{l}B 16 W \times 8 \\
B 16 W \times 9\end{array}$ & $\begin{array}{l}\text { ESQUATZLLCANAL } \\
\text { ESQUATZEL CANAL }\end{array}$ & OFFSITE & so & SUB_SURFACE & SEDIMENT & 14-May- $03 \mathrm{~Pb}$ & 7.82 & ug/g (wet) & & & & & \\
\hline $\begin{array}{l}\text { SESPPEC } \\
\text { SESPMNT }\end{array}$ & $\begin{array}{l}\text { B16ux } \\
\text { B176Y3 }\end{array}$ & HANFORD SLOUGH & RIVER_SHORELINE & so & SUB_SURFACE & SEDIMENT & 14-Jul-03 Pb & 35.8 & ug/g $/ 9$ & & & & & \\
\hline SESPMNT & B17J58 & HANFORD SPR DR 28-2 & ONSITE & so & SUB_SURFACE & SEDIMENT & 03-Nov-03 Pb & 26.1 & ug/g & & & & & \\
\hline SES & $\begin{array}{l}\text { B17500 } \\
\text { B17BJ7 }\end{array}$ & & OFFSITE & so & SUB_SURFACE & SEDIMENT & 08-Aug-03 Pb & & ug/g & & & & & \\
\hline SESPSPEC & B178J3 & MCNARY-2/3 OR. SHORE & OFFSITE & so & SUB_SURFACE & SEDIMENT & 08-Aug-03 Pb & 24.7 & $\mathrm{ug} / \mathrm{g}$ & & & & & \\
\hline SESPMNT & B17710 & MCNARY-OR.SIDE NEAR DAM & OFFSITE & so & SUB_SURFACE & SEDIMENT & 16-Jul-03 Pb & 25.7 & ug/g & & & & & \\
\hline SESPMNT & B17712 & MCNARY-WASH. & OFFSITE & so & SUB_SURFACE & SEDIMENT & 16-Jul-03 Pb & 25.8 & ug/g & & & & & \\
\hline $\begin{array}{l}\text { SESPMNT } \\
\text { SESPMNT }\end{array}$ & B17704 & PRD-GRANT SIDE NEAR DAM & OFFSITE & so & $\begin{array}{l}\text { SUB_SURFACE } \\
\text { SUI_SURFACE }\end{array}$ & $\begin{array}{l}\text { SEDIMENT } \\
\text { SEDMENT }\end{array}$ & $\begin{array}{l}\text { 14-Jul-03P } \\
\text { 14-Jul } 0 \text { P } \mathrm{Pb}\end{array}$ & 49.6 & uglg & & & & & \\
\hline $\begin{array}{l}\text { SESPMNT } \\
\text { SESPMNT }\end{array}$ & $\begin{array}{l}\text { B17702 } \\
\text { B176Y5 }\end{array}$ & $\begin{array}{l}\text { PRD-YAAIMA SIDE NEAR DAM } \\
\text { RICHLAND-RIVER }\end{array}$ & $\begin{array}{l}\text { OFFSTIE } \\
\text { RIVER SHORELINE }\end{array}$ & so & $\begin{array}{l}\text { SUB_SURFACE } \\
\text { SUB SURFACE }\end{array}$ & $\begin{array}{l}\text { SEDIMENT } \\
\text { SEDIMENT }\end{array}$ & $\begin{array}{l}\text { 14-Jul-03 Pb } \\
\text { 16-Jul-03 Pb }\end{array}$ & 57.2 & & & & & & \\
\hline SESPSPEC & B16WX6 & RINGOLD WASTEWAY & OFFSITE & so & SUB_SURFACE & SEDIMENT & 14-May-03 Pb & 8.74 & ug/g (wet) & & & & PRIM & \\
\hline SESPSPEC & $\mathrm{B} 16 \mathrm{WX7}$ & RINGOLD WASTEWAY & OFFSITE & so & SUB_SURFACE & SEDIMENT & 14-May-03 Pb & 9.22 & ug/g (wet) & & & & PRIMARILY SAND. & \\
\hline SESPSPEC & B16WX2 & WALLA WALLA-RIVER & OFFSITE & so & SUB_SURFACE & SEDIMENT & 15-May-03 Pb & 8.27 & ug/g (wet) & & & & & \\
\hline SESPSPEC & $B 16 \mathrm{~W} \times 3$ & $\begin{array}{l}\text { WALLA WALLA-RIVER } \\
\text { WHTE BBUEFS SOUGH }\end{array}$ & $\begin{array}{l}\text { OFFSITE } \\
\text { RIIER SHOREHINE }\end{array}$ & so & SUB_SURFACE & $\begin{array}{l}\text { SEDIMENT } \\
\text { SEDMENT }\end{array}$ & $\begin{array}{l}15-\mathrm{May}-03 \mathrm{~Pb} \\
14-34-03 \mathrm{~Pb}\end{array}$ & 8.99 & ug/g (wet) & & & & & \\
\hline $\begin{array}{l}\text { SESPMNT } \\
\text { SESPSPEC }\end{array}$ & 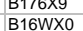 & $\begin{array}{l}\text { WHTEE BUFFS SLOUGH } \\
\text { YAKIMA RIVER }\end{array}$ & $\begin{array}{l}\text { RIVER_SHOR } \\
\text { OFFSITE }\end{array}$ & $\begin{array}{l}\text { so } \\
\text { so }\end{array}$ & $\begin{array}{l}\text { SUB_SURFACE } \\
\text { SUB SURFACE }\end{array}$ & $\begin{array}{l}\text { SEDMENT } \\
\text { SEDIMENT }\end{array}$ & $\begin{array}{r}\text { 14-Jul-03 Pb } \\
\text { 14-May-03 Pb }\end{array}$ & $\frac{41.7}{6.23}$ & $\begin{array}{l}\mathrm{ugg} / \mathrm{g} \\
\mathrm{ug} / \mathrm{g} \text { (wet) }\end{array}$ & & & & & \\
\hline
\end{tabular}


(pCilg Dry Weight unless otherwise noted)

\begin{tabular}{|c|c|c|c|c|c|c|c|c|c|c|c|c|c|c|c|}
\hline | OWNER ID & \begin{tabular}{|l|} 
SAMP \\
NNUM
\end{tabular} & $\begin{array}{l}\text { SAMP SITE NAME } \\
\text { PAKIAA PIEP }\end{array}$ & $\begin{array}{l}\text { DIST CLASS } \\
\text { DESTIFL }\end{array}$ & MEDIA & SAMP FROM & SAMP ITEM & ;AMP DATE & CON SHORT NAME & $\begin{array}{l}\text { VALUE } \\
\text { RPTD }\end{array}$ & \begin{tabular}{|c|} 
ANAL \\
UNITS \\
RPTD \\
\end{tabular} & $\begin{array}{c}\text { COUNTING } \\
\text { ERROR }\end{array} \mid$ & \begin{tabular}{|c|} 
TOTAL \\
ANAL \\
ERROR
\end{tabular} & $\begin{array}{c}\text { LAB } \\
\text { QUALIFIER }\end{array}$ & SAMP COMMENT & RESULT COMMENT \\
\hline $\begin{array}{l}\text { SESPSPEC } \\
\text { SESPPEC }\end{array}$ & B16WX1 & $\begin{array}{l}\text { YAKIMA RIVER } \\
100 B C A R E A U R\end{array}$ & $\begin{array}{l}\text { OFFSITE } \\
\text { ONSTE }\end{array}$ & so & $\begin{array}{l}\text { SUB_SURFACE } \\
\text { SUB SURECE }\end{array}$ & $\begin{array}{l}\text { SEDIMENT } \\
\text { SEDIMENT }\end{array}$ & 14-May-03 Pb & $b$ & $\begin{array}{r}6.26 \\
0.357\end{array}$ & & & & & & \\
\hline SESPMNT & B176Y1 & $100 \mathrm{~F} \mathrm{SLOUGH}$ & ONSITE & so & SUB SURFACE & SEDIMENT & 14-Jul-03 Sb & & 0.0 .457 & $\begin{array}{ll}\mathrm{ugg} / \mathrm{g} \\
\mathrm{ug} / \mathrm{g}\end{array}$ & & & $\mathrm{C}$ & & \\
\hline SESPMNT & B17J53 & 100-B SPRING 37-1 & ONSITE & so & SUB_SURFACE & SEDIMENT & $20-0 c t-03 \mathrm{Sb}$ & & & & & & c & & \\
\hline $\begin{array}{l}\text { SESPSPEC } \\
\text { SESPSPCC }\end{array}$ & B17XN8 & 100-B SPRING 37-1 & $\begin{array}{l}\text { ONSITE } \\
\text { ONSTEF }\end{array}$ & so & SUB_SURFACE & $\begin{array}{l}\text { SEDIMENT } \\
\text { SEDMENT }\end{array}$ & 13-Nov-03 Sb & & 0.428 & & & & c & & \\
\hline $\begin{array}{l}\text { SESPSPEC } \\
\text { SESPMNT }\end{array}$ & $\begin{array}{l}\text { B17XN99 } \\
\text { B1767 }\end{array}$ & $\begin{array}{l}\text { 100-8 BPRRIIG 38-3 } \\
\text { 100-F SPRING 207-1 }\end{array}$ & $\begin{array}{l}\text { ONSIIE } \\
\text { ONSITE }\end{array}$ & $\begin{array}{l}\text { so } \\
\text { so }\end{array}$ & $\begin{array}{l}\text { SUB_SURFACE } \\
\text { SUB_SURFAEE }\end{array}$ & $\begin{array}{l}\text { SEDIMENT } \\
\text { SEDIMENT }\end{array}$ & $\begin{array}{l}\text { 13-Nov-03 Sb } \\
\text { 03-No-03 Sb }\end{array}$ & & 0.649 & & & & c & & \\
\hline SESPMNT & B17JB1 & 100-H SPRING 145-1 & ONSITE & so & $\begin{array}{l}\text { SUB_SURACE } \\
\text { SUB_SURACE }\end{array}$ & $\begin{array}{l}\text { SEDMIENI } \\
\text { SEDIMENT }\end{array}$ & $27-\mathrm{Oct}-03 \mathrm{Sb}$ & & & ugl/g & & & c & & \\
\hline SESPMNT & B17J64 & 100-K SPRING 63-1 & ONSITE & so & SUB_SURFACE & SEDIMENT & $20-\mathrm{Oct}-03 \mathrm{Sb}$ & & 0.719 & & & & c & & \\
\hline $\begin{array}{l}\text { SESPMNT } \\
\text { SESPMNT }\end{array}$ & B17J61 & 300 AREA SPR DR 42-2 & ONSITE & so & SUB_SURFACE & $\begin{array}{l}\text { SEDIMENT } \\
\text { SEDMENT }\end{array}$ & 13-Oct-03 Sb & & 0.683 & ug/g & & & c & & \\
\hline $\begin{array}{l}\text { SESPMNT } \\
\text { SESPSPEC }\end{array}$ & $\begin{array}{l}\text { B171718 } \\
\text { B17K5 }\end{array}$ & $\begin{array}{l}300 \text { AREA SPRING 42-2 } \\
\text { BONNEVILLE DAM OR.SHORE }\end{array}$ & $\begin{array}{l}\text { ONSIIE } \\
\text { OFFITE }\end{array}$ & so & $\begin{array}{l}\text { SUB_SURFACE } \\
\text { SUB_SUREACE }\end{array}$ & $\begin{array}{l}\text { SEDIMENT } \\
\text { SEDMENT }\end{array}$ & $\begin{array}{l}\text { 13-Oct-03 Sb } \\
07 \text {-Aun-0.3 Sb }\end{array}$ & & 0.569 & ug/g & & & c & & \\
\hline $\begin{array}{l}\text { SESPSEC } \\
\text { SESPSPEC }\end{array}$ & $\begin{array}{l}\text { B17RK5 } \\
\text { B17BK1 }\end{array}$ & $\begin{array}{l}\text { BNNEVVILLE DAM OR.SHORE } \\
\text { DALLES DAM OR.SHORE }\end{array}$ & $\begin{array}{l}\text { OFFSIIT } \\
\text { OFFSITE }\end{array}$ & $\begin{array}{l}\text { so } \\
\text { so }\end{array}$ & $\begin{array}{l}\text { SUB_SURACE } \\
\text { SUB_SURAACE }\end{array}$ & $\begin{array}{l}\text { SEDIMENT } \\
\text { SEDIMENT }\end{array}$ & $\begin{array}{l}\text { 07-Aug-03 Sb } \\
\text { 07-Agu-03 Sb }\end{array}$ & & $\begin{array}{l}0.835 \\
0.597\end{array}$ & 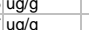 & & & & & \\
\hline SESPSPEC & B16WX8 & $\begin{array}{l}\text { ESQUATELL CANAL } \\
\text { ESOLZL }\end{array}$ & OFFSITE & so & SUB_SURFACE & SEDIMENT & 14-May-03 Sb & & 0.308 & ug/g (wet) & & & & & \\
\hline $\begin{array}{l}\text { SESPSPEC } \\
\text { SESPMNT }\end{array}$ & B16WX9 & ESQUATZEL CANAL & OFFSITE & so & SUB_SURFACE & SEDIMENT & 14-May-03 Sb & & 0.301 & ug/g (wet) & & & & & \\
\hline SESPMNT & & & RIVER_SHORELINE & & & SEDIMENT & & & & & & & & & \\
\hline SESPMNT & B17J58 & HANFORD SPR DR 28-2 & ONSITE & so & SUB_SURFACE & SEDIMENT & 03-Nov-03 Sb & & 0.637 & ug/g & & & c & & \\
\hline SESPSPEC & B17BJ7 & JOHN DAY DAM MID-RIVER & OFFSITE & so & SUB_SURFACE & SEDIMENT & 08-Aug-03 Sb & & 0.823 & $3 \mathrm{ug} / \mathrm{g}$ & & & & & \\
\hline $\begin{array}{l}\text { SESPSPEC } \\
\text { SESPMNT }\end{array}$ & B17BJ3 & $\begin{array}{l}\text { MCNARY-2/3 OR. SHORE } \\
\end{array}$ & $\begin{array}{l}\text { OFFSITE } \\
\text { OEFITF }\end{array}$ & so & SUB_SURFACE & $\begin{array}{l}\text { SEDIMENT } \\
\text { SEDMENT }\end{array}$ & 08-Aug-03 Sb & & 0.699 & ug/g & & & & & \\
\hline $\begin{array}{l}\text { SESPMNT } \\
\text { SESPMNT }\end{array}$ & $\begin{array}{l}\text { B17710 } \\
\text { B17712 }\end{array}$ & $\begin{array}{l}\text { MCNARYY-OR.SIIE NEAR DAM } \\
\text { MCNARY WASH SIDE NEAR DAM }\end{array}$ & $\begin{array}{l}\text { OFFFITE } \\
\text { OFFITE }\end{array}$ & $\begin{array}{l}\text { so } \\
\text { so }\end{array}$ & SUB_SURFACE & $\begin{array}{l}\text { SEDIMENT } \\
\text { SEDMENT }\end{array}$ & 16-Jul-03 Sb & & 0.875 & & & & & & \\
\hline $\begin{array}{l}\text { SESPMNI } \\
\text { SESPMT }\end{array}$ & $\begin{array}{ll}\text { B1/712 } \\
\text { B17704 }\end{array}$ & $\begin{array}{l}\text { CWNAR-WASHASDE NEAR DAM } \\
\text { PRD-GRAN SIDE NEAR DAM }\end{array}$ & $\begin{array}{l}\text { OFFFITE } \\
\text { OFSITE }\end{array}$ & so & $\begin{array}{l}\text { SUB_SURFAEE } \\
\text { SUB SURFACE }\end{array}$ & $\begin{array}{l}\text { SEDIMENT } \\
\text { SEDIMENT }\end{array}$ & 14-Jul-03 Sb & & 0.907 & ugl/g & & & & & \\
\hline SESPMNT & B17702 & PRD-YAKIMA SIDE NEAR DAM & OFFSITE & so & SUB_SURFACE & SEDIMENT & 14-Jul-03 Sb & & & ug/g & & & & & \\
\hline SESPMNT & & RICHLAND-RIVER & RIVER_SHORELINE & & SUB_SURFACE & SEDIMENT & 16-Jul-03 Sb & & 0.937 & ug/g & & & & & \\
\hline SESPSPEC & B16WX6 & RINGOLD WASTEWAY & OFFSITE & so & SUB_SURFACE & SEDIMENT & 14-May-03 Sb & & 0.324 & ug/g (wet) & & & & PRIMARILY SAND. & \\
\hline SESPSPEC & B16WX7 & RINGOLD WASTEWAY & OFFSITE & so & SUB_SURFACE & SEDIMENT & 14-May-03 Sb & & 0.355 & ug/g (wet) & & & & PRIMARILY SAND. & \\
\hline SESPSPEC & $B 16 W \times 2$ & WALLA WALLA-RIVER & OFFSITE & so & SUB_SURFACE & SEDIMENT & 15-May-03 Sb & & 0.312 & : ug/g (wet) & & & & & \\
\hline SESPSPEC & B16WX3 & WALLA WALLA-RIVER & OFFSITE & so & SUB_SURFACE & SEDIMENT & 15-May-03 Sb & & 0.379 & ug/g (wet) & & & & & \\
\hline $\begin{array}{l}\text { SESPMNT } \\
\text { SESPSPEC }\end{array}$ & $\begin{array}{ll}8176 \times 9 \\
B 16 \times 0\end{array}$ & $\begin{array}{l}\text { WHITE BLLFFFS SLOUGH } \\
\text { YAKIMA RIVER }\end{array}$ & $\begin{array}{l}\text { RIVER_SHORELINE } \\
\text { OSFSTE }\end{array}$ & so & SUB_SURFACE & $\begin{array}{l}\text { SEDIMENT } \\
\text { SEDMENT }\end{array}$ & 14-Jul-03 Sb & & $\begin{array}{r}0.86 \\
0.359\end{array}$ & ug/g & & & & & \\
\hline $\begin{array}{l}\text { SESPSEC } \\
\text { SESPSPEC }\end{array}$ & $\begin{array}{l}\begin{array}{l}\text { B16WX0 } \\
\text { B16WX1 }\end{array} \\
\text { B. }\end{array}$ & $\begin{array}{l}\text { AAKMIMA RIVR } \\
\text { YAKIMA RIVER }\end{array}$ & $\begin{array}{l}\text { OFFSITE } \\
\text { OFFSITE }\end{array}$ & $\begin{array}{l}\text { so } \\
\text { so }\end{array}$ & $\begin{array}{l}\text { SUB_SURAACE } \\
\text { SU_SURFACE }\end{array}$ & $\begin{array}{l}\text { SEDIMENT } \\
\text { SEDIMENT }\end{array}$ & $\begin{array}{l}\text { 144-May-03 Sb } \\
\text { 14-May-03 Sb }\end{array}$ & & 0.359 & $\begin{array}{l}u g / g(w e t) \\
u g / g(w e t)\end{array}$ & & & & & \\
\hline SESPMNT & B176Y1 & 100 F SLOUGH & ONSITE & so & SUB_SURFACE & SEDIMENT & 14-Jul-03 Se & & 0.477 & $\mathrm{ug} / \mathrm{g}$ & & & u & & \\
\hline $\begin{array}{l}\text { SESPMNT } \\
\text { SESPMNT }\end{array}$ & B17J61 & 300 AREA SPR DR 42-2 & ONSITE & so & SUB_SURFACE & SEDIMENT & 13-Oct-03 Se & & 0.477 & ug/g & & & u & & \\
\hline $\begin{array}{l}\text { SESPMNT } \\
\text { SESPSPEC }\end{array}$ & B17J18 & 300 AREA SPRING 42-2 & ONSITE & so & SUB_SURFACE & $\begin{array}{l}\text { SEDIMENT } \\
\text { SEDMENT }\end{array}$ & 13-Oct-03 Se & & 0.477 & ug/g & & & $\mathrm{u}$ & & \\
\hline $\begin{array}{l}\text { SESPSPEC } \\
\text { SESPSPEC }\end{array}$ & 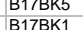 & $\begin{array}{l}\text { BONNEVVLLLE DAM OR.SHORE } \\
\text { DALLES DAM OR.SHORE }\end{array}$ & $\begin{array}{l}\text { OFFITE } \\
\text { OFFSITE }\end{array}$ & $\begin{array}{l}\text { So } \\
\text { so }\end{array}$ & $\begin{array}{l}\text { SUB_SURFACE } \\
\text { SUB_SURACE }\end{array}$ & $\begin{array}{l}\text { SEDIIENT } \\
\text { SEDIMENT }\end{array}$ & $\begin{array}{l}\text { 07-Aug-03 Se } \\
\text { 07-Aun-3 Se }\end{array}$ & & 0.477 & $\begin{array}{ll}\text { ugg/g } \\
\text { ugag }\end{array}$ & & & u & & \\
\hline SESPSPEC & B16WX8 & ESQUATZEL CANAL & OFFSITE & so & & SEDIMENT & 14-May-03 Se & & 0.46 & ug/g (wet) & & & u & & \\
\hline SESPSPEC & B16WX9 & ESQUATZEL CANAL & OFFSITE & so & SUB_SURFACE & SEDIMENT & 14-May-03 Se & & 0.46 & ug/g (wet) & & & u & & \\
\hline SESPMNT & B176Y3 & HANFORD SLOUGH & RIVER_SHORELINE & so & SUB_SURFACE & SEDIMENT & 14-Jul-03 Se & & 0.477 & & & & u & & \\
\hline SESPSPEC & B17BJ7 & JOHN DAY DAM MID-RIVER & OFFSITE & so & SUB_SURFACE & SEDIMENT & 08-Aug-03 Se & & 0.477 & $\mathrm{ug} / \mathrm{g}$ & & & $u$ & & \\
\hline SESPSPEC & B17BJ3 & MCNARY-2/3 OR. SHORE & OFFSITE & so & SUB_SURFACE & SEDIMENT & 08-Aug-03 Se & & 0.477 & ug/g & & & $u$ & & \\
\hline $\begin{array}{l}\text { SESPMNT } \\
\text { SESPMNT }\end{array}$ & B17710 & $\begin{array}{l}\text { MCNARY-OR.SIDE NEAR DAM } \\
\text { M }\end{array}$ & OFFSITE & so & SUB_SURFACE & $\begin{array}{l}\text { SEDIMENT } \\
\text { SEDMENT }\end{array}$ & 16-Jul-03 Se & & 0.477 & ug/g & & & u & & \\
\hline $\begin{array}{l}\text { SESPMNT } \\
\text { SESPNNT }\end{array}$ & $\begin{array}{l}B 17712 \\
B 1704\end{array}$ & $\begin{array}{l}\text { MCNARY-WASH.SIDE NEAR DAM } \\
\text { PRDG-GRANT SDEF NEAR DAM }\end{array}$ & $\begin{array}{l}\text { OFFFITE } \\
\text { OFFITE }\end{array}$ & so & $\begin{array}{l}\text { SUB_SURFACE } \\
\text { SUB_SUPFACE }\end{array}$ & $\begin{array}{l}\text { SEDIMENT } \\
\text { SEDMENT }\end{array}$ & 16-Jul-03 Se & & 0.477 & ng/g & & & u & & \\
\hline $\begin{array}{l}\text { SESPMNT } \\
\text { SESPMNT }\end{array}$ & 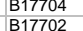 & $\begin{array}{l}\text { PRD-GRAAT SIDE NERR DAM } \\
\text { PRD-YKKIM SIDE NEAR DAM }\end{array}$ & $\begin{array}{l}\text { OFFSITE } \\
\text { OFFSITE }\end{array}$ & $\begin{array}{l}\text { so } \\
\text { so }\end{array}$ & $\begin{array}{l}\text { SUB_SURFACE } \\
\text { SUB_SURACE }\end{array}$ & $\begin{array}{l}\text { SEDIMENT } \\
\text { SEDIMENT }\end{array}$ & $\begin{array}{l}\text { 14-Jul-03 Se } \\
\text { 14-Jul-03 Se }\end{array}$ & & 0.477 & $\begin{array}{ll}\mathrm{ug} / \mathrm{g} / \mathrm{g} \\
\mathrm{ug} / \mathrm{g}\end{array}$ & & & u & & \\
\hline $\begin{array}{l}\text { SESPMNIN } \\
\text { SESPMNT }\end{array}$ & $\begin{array}{l}\text { BL1702 } \\
\text { B176Y5 }\end{array}$ & $\begin{array}{l}\text { RDL-YAKIMA SIDE NEAR DAM } \\
\text { RICHLAND-RIVER }\end{array}$ & RIVER SHORELINE & so & $\begin{array}{l}\text { SUB_SURFACE } \\
\text { SUB_SURFACE }\end{array}$ & $\begin{array}{l}\text { SEUMENI } \\
\text { SEDIMENT }\end{array}$ & $\begin{array}{l}\text { 14-Jul-03 Se } \\
16-\mathrm{Jul}-03 \mathrm{Se}\end{array}$ & & 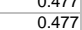 & ugg/a & & & u & & \\
\hline SESPSPEC & 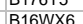 & RINGOLD WASTEWAY & $\begin{array}{l}\text { OFFSITE } \\
\text { OFELIVE }\end{array}$ & so & SUB_SURFACE & $\begin{array}{l}\text { SEDIMENT } \\
\text { SEUENT }\end{array}$ & $14-$ May-03 Se & & 0.46 & ug/g (wet) & & & u & PRIMARILY SAND. & \\
\hline SESPSPEC & B16WX7 & RINGOLD WASTEWAY & $\begin{array}{l}\text { OFFSITE } \\
\text { OFF }\end{array}$ & so & SUB_SURFACE & SEDIMENT & 14-May-03 Se & & 0.46 & ug/g (wet) & & & u & PRIMARILY SAND. & \\
\hline SESPSPEC & $B 16 W \times 2$ & WALLA WALLA-RIVER & OFFSITE & so & SUB_SURFACE & SEDIMENT & 15-May-03 Se & & & ug/g (wet) & & & $u$ & & \\
\hline SESPSPEC & $B 16 W \times 3$ & WALLA WALLA-RIVER & OFFSITE & so & SUB_SURFACE & SEDIMENT & 15-May-03 Se & & 0.46 & ug/g (wet) & & & U & & \\
\hline $\begin{array}{l}\text { SESPMNT } \\
\text { SECPDSFC }\end{array}$ & B176×9 & WHITE BLUFFS SLOUGH & RIVER_SHORELINE & so & SUB_SURFACE & SEDIMENT & 14-Jul-03 Se & & 0.477 & & & & u & & \\
\hline $\begin{array}{l}\text { SESPPSEC } \\
\text { SESPPEC }\end{array}$ & $\begin{array}{ll}B 16 W \times 0 \\
B 16 W \times 1\end{array}$ & $\begin{array}{l}\text { YAKIMA RIVER } \\
\text { YAKMA RIVER }\end{array}$ & OFFSITE & so & SUB_SURFACE & $\begin{array}{l}\text { SEDIMENT } \\
\text { SEDMENT }\end{array}$ & 14-May-03 Se & & 0.46 & ug/g (wet) & & & $\mathrm{U}$ & & \\
\hline $\begin{array}{l}\text { SESPPSEC } \\
\text { SESPSPEC }\end{array}$ & $\begin{array}{l}{ }_{136 W \times 1}^{1617 \times N 6} \\
B 170\end{array}$ & $\begin{array}{l}\text { YAKIMA RIVIVR } \\
100 \text { B/C AREA UR }\end{array}$ & $\begin{array}{l}\text { OFFSITE } \\
\text { ONSTE }\end{array}$ & $\begin{array}{l}\text { so } \\
\text { so }\end{array}$ & $\begin{array}{l}\text { SUB_SURFACE } \\
\text { SUB_SURACE }\end{array}$ & $\begin{array}{l}\text { SEDIMENT } \\
\text { SEDMENT }\end{array}$ & $\begin{array}{l}\text { 14-May-03 Se } \\
\text { 17-Nov-3 Th }\end{array}$ & & 0.46 & ug/g (wet) & & & $\begin{array}{l}u \\
c\end{array}$ & & \\
\hline $\begin{array}{l}\text { SESPPEC } \\
\text { SESPSPEC }\end{array}$ & $\begin{array}{l}\text { B. } \\
\text { B17XNNB }\end{array}$ & 100-B SPRING 37-1 & $\begin{array}{l}\text { ONSITE } \\
\text { ONSE }\end{array}$ & so & $\begin{array}{l}\text { SUB_SURFACE } \\
\text { SUB SURFACE }\end{array}$ & $\begin{array}{l}\text { SEUMENI } \\
\text { SEDIMENT }\end{array}$ & $\begin{array}{l}\text { 17-Nov-03 Th } \\
\text { 13-Nov-03 Th }\end{array}$ & & $\begin{array}{l}6.91 \\
7.91\end{array}$ & ugl/g & & & $\begin{array}{c}c \\
c\end{array}$ & & \\
\hline SESPSPEC & B17XN9 & 100-B SPRING 38-3 & ONSITE & so & SUB_SURFACE & SED & 13-Nov-03 Th & & & uglg/g & & & c & & \\
\hline SESPSPEC & B17XNG & 100 BIC AREA UR & ONSITE & so & SUB_SURFACE & SEDIMENT & 17-Nov-03 TI & & 0.377 & ugc/g & & & & & \\
\hline SESPMNT & B176Y1 & $100 \mathrm{~F} \mathrm{SLOUGH}$ & ONSITE & so & SUB_SURFACE & SEDIMENT & 14-Jul-03 TI & & 0.686 & ug/g $/ 9$ & & & & & \\
\hline SESPMNT & B17J53 & 100-B SPRING 37-1 & ONSITE & so & SUB_SURFACE & SEDIMENT & 20-Oct-03 TI & & & ug/g & & & & & \\
\hline $\begin{array}{l}\text { SESPSPEC } \\
\text { SESPDSEC }\end{array}$ & B17XN8 & $100-B_{S}$ & ONSITE & so & SUB_SURFACE & SEDIMENT & $13-\mathrm{No}$ & & 0.496 & & & & & & \\
\hline $\begin{array}{l}\text { SESPSPEC } \\
\text { SESPMT }\end{array}$ & $\begin{array}{l}\text { B17XN9 } \\
\text { B17167 }\end{array}$ & 100-B SPRING 38-3 & ONSITE & so & SUB_SURFACE & $\begin{array}{l}\text { SEDIMENT } \\
\text { SEDMENT }\end{array}$ & 13-Nov-03 TI & & 0.537 & ug/g & & & & & \\
\hline $\begin{array}{l}\text { SESPMNT } \\
\text { SESPMNT }\end{array}$ & $\begin{array}{l}\frac{B 17637}{B 1731} \\
\text { B1781 }\end{array}$ & $\begin{array}{l}\text { 100-F SPRING 207-1 } \\
100-H \text { SPRING 145-1 }\end{array}$ & $\begin{array}{l}\text { ONSIE } \\
\text { ONSTEE }\end{array}$ & $\begin{array}{l}\text { so } \\
\text { so }\end{array}$ & $\begin{array}{l}\text { SUB_SURFACE } \\
\text { SUB_SURFAEE }\end{array}$ & $\begin{array}{l}\text { SEDIMENT } \\
\text { SEDMENT }\end{array}$ & $\begin{array}{l}\text { 03-Nov-03 TT } \\
\text { 27-Oct-03 TI }\end{array}$ & & & ug/g & & & & & \\
\hline $\begin{array}{l}\text { SESPMNI } \\
\text { SESPMNT }\end{array}$ & $\begin{array}{l}\text { B1/7361 } \\
\text { B17J64 }\end{array}$ & $\begin{array}{l}100-\mathrm{H} \text { SPRING } 145-1 \\
100-\mathrm{K} \text { SPRING 63-1 }\end{array}$ & $\begin{array}{l}\text { ONSIIE } \\
\text { ONSITE }\end{array}$ & so & $\begin{array}{l}\text { SUB_SURFACE } \\
\text { SUB SURFACE }\end{array}$ & $\begin{array}{l}\text { SEDIMENI } \\
\text { SEDIMENT }\end{array}$ & $\begin{array}{l}\text { 27-Oct-003 TI } \\
\text { 20-Oct-03 TI }\end{array}$ & & & sgg/g & & & & & \\
\hline SESPMNT & $\begin{array}{l}\text { D1/704 } \\
\text { B17J61 }\end{array}$ & & $\begin{array}{l}\text { ONSTIE } \\
\text { ONSITE }\end{array}$ & $\begin{array}{l}\text { so } \\
\text { so }\end{array}$ & $\begin{array}{l}\text { SUB_SURFAEE } \\
\text { SUB SURFACE }\end{array}$ & $\begin{array}{l}\text { SEDIMENT } \\
\text { SEDENT }\end{array}$ & $\begin{array}{l}\text { 20-Oct-03 TI } \\
\text { 13-Oct-03 TI }\end{array}$ & & 0.456 & ugl/g & & & & & \\
\hline SESPMNT & B17J18 & 300 AREA SPRING 42-2 & $\begin{array}{l}\text { ONSITE } \\
\text { ONSE }\end{array}$ & so & SUB_SURFACE & $\begin{array}{l}\text { SEDIMENT } \\
\text { SEDENT }\end{array}$ & 13-Oct-03 TI & & 0.482 & ug/g & & & & & \\
\hline SESPSPEC & B178K5 & BONNEVILLE DAM OR.SHORE & OFFSITE & so & SUB_SURFACE & SEDIMENT & 07-Aug-03 TI & & 0.445 & ug/g & & & & & \\
\hline SESPSPEC & B17BK1 & DALLES DAM OR.SHORE & OFFSITE & so & SUB_SURFACE & SEDIMENT & 07-Aug-03 TI & & 0.535 & & & & & & \\
\hline SESPSPEC & B16WX8 & ESQUATZEL CANAL & OFFSITE & so & SUB_SURF, & SEDIM & 14-May-03 TI & & & ug/g (wet) & & & & & \\
\hline SESPSPEC & B16WX9 & ESQUATZEL CANAL & OFFSITE & so & SUB_SURF, & SEL & 14-May-03 TI & & 0.306 & ug/g (wet) & & & & & \\
\hline $\begin{array}{l}\text { SESPMNT } \\
\text { SESPMNT }\end{array}$ & B176Y3 & $\begin{array}{l}\text { HANFORD SLOUGH } \\
\text { HANFORD SPR DR 28-2 }\end{array}$ & $\begin{array}{l}\text { RIVER_SHORELINE } \\
\text { ONSTE }\end{array}$ & so & SUB_SURFACE & $\begin{array}{l}\text { SEDIMENT } \\
\text { SEDMENT }\end{array}$ & $\begin{array}{l}\text { 14-Jul-03 TI } \\
\text { 0-No-03 TI }\end{array}$ & & $\begin{array}{r}2.41 \\
0.547\end{array}$ & ug/g & & & & & \\
\hline $\begin{array}{l}\text { SESPMN } \\
\text { SESPSPEC }\end{array}$ & 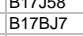 & JOHN DAY DAM MID-RIVER & $\begin{array}{l}\text { ONSFIITE } \\
\text { OFSIE }\end{array}$ & so & $\begin{array}{l}\text { SUB_SURACACE } \\
\text { SUB_SURACE }\end{array}$ & $\begin{array}{l}\text { SEDMENI } \\
\text { SEDIMENT }\end{array}$ & 08-Aug-03 TI & & 0.694 & $\begin{array}{ll}u g g / 9 \\
u g g\end{array}$ & & & & & \\
\hline SESPSPEC & B17BJ3 & MCNARY-2/3 OR. SHORE & OFFSITE & so & SUB_SURFACE & SEDIMENT & 08-Aug-03 TI & & 0.729 & ug/g & & & & & \\
\hline
\end{tabular}


(pCilg Dry Weight unless otherwise noted)

\begin{tabular}{|c|c|c|c|c|c|c|c|c|c|c|c|c|c|c|c|}
\hline | OWNER ID & \begin{tabular}{|l|} 
SAMP \\
NUM \\
\end{tabular} & SAMP SITE NAME & DIST CLASS & MEDIA & SAMP FROM & SAMP ITEM & AMP DATE & CON SHORT NAME & $\begin{array}{l}\text { VALUE } \\
\text { RPTD }\end{array}$ & \begin{tabular}{|l|} 
ANAL \\
UNITS \\
RPTD
\end{tabular} & $\mid \begin{array}{c}\text { COUNTING } \\
\text { ERROR }\end{array}$ & $\begin{array}{c}\text { TOTAL } \\
\text { ANAL } \\
\text { ERROR }\end{array}$ & $\begin{array}{c}\text { LAB } \\
\text { QQALIFIER }\end{array}$ & SAMP COMMENT & RESULT COMMENT \\
\hline $\begin{array}{l}\text { SESPMNT } \\
\text { SESPNT }\end{array}$ & $\begin{array}{l}B 17710 \\
\text { B17712 }\end{array}$ & $\begin{array}{l}\text { MMCNARY-OR.SIDE NEAR DAM } \\
\text { MCNARY-WAST.SIDE NEAR DAM }\end{array}$ & $\begin{array}{l}\text { OFFSIE } \\
\text { OFFSTIE }\end{array}$ & $\begin{array}{l}\text { so } \\
\text { so }\end{array}$ & $\begin{array}{l}\text { SUB_SURFACE } \\
\text { SUB SURACE }\end{array}$ & $\begin{array}{l}\text { SEDIMENT } \\
\text { SEDIMENT }\end{array}$ & $\begin{array}{l}\text { 16-Jul-03 TI } \\
\text { 16--0ul-03 TI }\end{array}$ & & $\begin{array}{l}0.72 \mathrm{~L} \\
0.715 \mathrm{~L}\end{array}$ & $\mathrm{ug} / \mathrm{g}$ & & & & & \\
\hline SESPMNT & B17704 & PRD-GRANT SIDE NEAR DAM & OFFSITE & so & SUB_SURFACE & SEDIMENT & 14-Jul-03 TI & & $1.72 \mathrm{~L}$ & & & & & & \\
\hline SESPMNT & B17702 & PRD-YAKIMA SIDE NEAR DAM & OFFSITE & so & SUB_SURFACE & SEDIMENT & 14-Jul-03 TI & & $1.15 \mathrm{~L}$ & & & & & & \\
\hline $\begin{array}{l}\text { SESPMNT } \\
\text { SESPPEC }\end{array}$ & $\begin{array}{l}\text { B176Y5 } \\
\text { B16W6 }\end{array}$ & $\begin{array}{l}\text { RICHLAND-RIVER } \\
\text { RINGOLD WASTEWAY }\end{array}$ & $\begin{array}{l}\text { RIVER_SHORELINE } \\
\text { OFFSITE }\end{array}$ & $\begin{array}{l}\text { so } \\
\text { so }\end{array}$ & $\begin{array}{l}\text { SUB_-SURFACE } \\
\text { SUB SURACE }\end{array}$ & $\begin{array}{l}\text { SEDIMENT } \\
\text { SEDIMENT }\end{array}$ & $\begin{array}{l}\text { 16-Jul-03 TI } \\
\text { 14-Ma-03 TI }\end{array}$ & & $0.015 \mathrm{~L}$ & ug/g & & & & & \\
\hline $\begin{array}{l}\text { SESPPPEC } \\
\text { SESPPPEC }\end{array}$ & $\begin{array}{l}\text { B16w60 } \\
\text { B16WX7 }\end{array}$ & RINGOLD WASTEWAY & $\begin{array}{l}\text { OFFSITE } \\
\text { OFFE }\end{array}$ & so & $\begin{array}{l}\text { SUBSSURFACE } \\
\text { SUB_SURFACE }\end{array}$ & $\begin{array}{l}\text { SEDIMENI } \\
\text { SEDIMENT }\end{array}$ & 14-May-03 TI & & 0.3264 & $\begin{array}{l}\mathrm{u} y / g(\mathrm{wet}) \\
\mathrm{ug} / \mathrm{g}(\mathrm{wet})\end{array}$ & & & & $\begin{array}{l}\text { PRIMARARILY SAND. } \\
\text { PRAND. }\end{array}$ & \\
\hline $\begin{array}{l}\text { SESPSPEC } \\
\end{array}$ & $\begin{array}{ll}\text { B16WX2 } \\
\text { B16W }\end{array}$ & WALLA WALLA-RIVER & OFFSITE & so & SUB_SURFACE & SEDIMENT & 15-May-03 TI & & & $\begin{array}{ll}\mathrm{u} \\
\mathrm{ug} / \mathrm{g} / \mathrm{g}(\mathrm{wet})\end{array}$ & & & & & \\
\hline SESPSPEC & $B 16 \mathrm{~W} \times 3$ & WALLA WALLA-RIVER & OFFSITE & so & SU__SURFACE & $\begin{array}{l}\text { SEDIMENT } \\
\text { SEDMENT }\end{array}$ & 15-May-03 TI & & $0.271 \mathrm{~L}$ & ug/g(wet) & & & & & \\
\hline & B176X9 & $\begin{array}{l}\text { WHITE BLUFFS SLOUGH } \\
\text { YAKIAPBIVR }\end{array}$ & $\begin{array}{l}\text { RIVER_SHORELINE } \\
\text { OFFCSTFE }\end{array}$ & so & SUB_SURFACE & $\begin{array}{l}\text { SEDIMENT } \\
\text { SEDMENT }\end{array}$ & 14-Jul-03 TI & & $1.43 \mathrm{t}$ & & & & & & \\
\hline $\begin{array}{l}\text { SESPSEC } \\
\text { SESPPPEC }\end{array}$ & $\begin{array}{ll}816 w \times 0 \\
B 160 \times 12\end{array}$ & $\begin{array}{l}\text { YAKIIA RIVER } \\
\text { YAKMA RIVER }\end{array}$ & $\begin{array}{l}\text { OFFSITE } \\
\text { OFSITE }\end{array}$ & so & $\begin{array}{l}\text { SUB_SURFACE } \\
\text { SUB_SUREACE }\end{array}$ & $\begin{array}{l}\text { SEDIMENT } \\
\text { SEDMENT }\end{array}$ & 14-May-03 TI & & $0.218 \mathrm{u}$ & ug/g(wet) & & & & & \\
\hline $\begin{array}{l}\text { SESPPSEC } \\
\text { SESPSPEC }\end{array}$ & 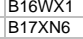 & $\begin{array}{l}\text { A YKKMA RIVR } \\
100 \text { BIC AREA UR }\end{array}$ & $\begin{array}{l}\text { OFFIIE } \\
\text { ONSITE }\end{array}$ & $\begin{array}{l}\text { so } \\
\text { so }\end{array}$ & $\begin{array}{l}\text { SUB_SURACACE } \\
\text { SU_SURFACE }\end{array}$ & $\begin{array}{l}\text { SEDIMENT } \\
\text { SEDIMENT }\end{array}$ & $\begin{array}{l}\text { 14-May-03 TI } \\
\text { 17-Nov-03U }\end{array}$ & & 0.2084 & $\begin{array}{l}\mathrm{ung} / \mathrm{g}(\mathrm{wet}) \\
\mathrm{ug} / \mathrm{g}\end{array}$ & & & & & \\
\hline $\begin{array}{l}\text { SESPSPEC } \\
\text { SESPSEC }\end{array}$ & B17XNB & 100-B SPRING 37-1 & ONSITE & so & SUB_SURFACE & $\begin{array}{l}\text { SEDIMENT } \\
\text { SEOMENT }\end{array}$ & 13-Nov-03U & & $2.57 \mathrm{~L}$ & & & & & & \\
\hline $\begin{array}{l}\text { SESPPEC } \\
\text { SESPPPEC }\end{array}$ & $\begin{array}{ll}\text { B17XNY } \\
\text { B16NX8 }\end{array}$ & $\begin{array}{l}\text { 100-B SPRING 38-3 } \\
\text { ESOAATZEE CANAL }\end{array}$ & ONSITE & $\begin{array}{l}\text { so } \\
\text { so }\end{array}$ & SUB_SURFACE & $\begin{array}{l}\text { SEDIMENT } \\
\text { SEDMENT }\end{array}$ & 13-Nov-03U & & $2.08 \mathrm{~L}$ & & & & & & \\
\hline $\begin{array}{l}\text { SESPPSEC } \\
\text { SESPSPEC }\end{array}$ & $\begin{array}{l}\text { B16WX8 } \\
B 16 W \times 9\end{array}$ & $\begin{array}{l}\text { ESSQATAZLL CANAL } \\
\text { ESQUATZEL CANAL }\end{array}$ & $\begin{array}{l}\text { OFFSIE } \\
\text { OFFSITE }\end{array}$ & $\begin{array}{l}\text { so } \\
\text { so }\end{array}$ & $\begin{array}{l}\text { SUB_SURACACE } \\
\text { SUB SURACE }\end{array}$ & $\begin{array}{l}\text { SEDIMENT } \\
\text { SEDIMENT }\end{array}$ & $\begin{array}{l}\text { 14-May-03U } \\
\text { 14-My-03U }\end{array}$ & & $\begin{array}{l}1.07 \mathrm{~L} \\
1.07 \mathrm{~L}\end{array}$ & $\begin{array}{l}\mathrm{ug} / \mathrm{g}(\mathrm{wet}) \\
\mathrm{u} / \mathrm{g} \text { (wet) }\end{array}$ & & & & & \\
\hline SESPSPEC & B16WX6 & RINGOLD WASTEWAY & OFFSITE & so & SUB_SURFACE & SEDIMENT & 14-May-03 U & & $1.25 \mathrm{~L}$ & $\begin{array}{l}\text { ug/g (wet) } \\
\text { uns }\end{array}$ & & & & PRIMARILY SAND. & \\
\hline SESPSPEC & B16WX7 & RINGOLD WASTEWAY & OFFSITE & so & SUB_SURFACE & SEDIMENT & 14-May-03 U & & $1.26 \mathrm{~L}$ & ug/g (wet) & & & & PRIMARILY SAND. & \\
\hline SESPSPEC & $B 16 W \times 2$ & WALLA WALLA-RIVER & OFFSITE & so & SUB_SURFACE & SEDIMENT & 15-May-03U & & $1.47 \mathrm{~L}$ & ug/g(wet) & & & & & \\
\hline $\begin{array}{l}\text { SESPSPEC } \\
\text { SESPDPEC }\end{array}$ & $B 16 \mathrm{~W} \times 3$ & $\begin{array}{l}\text { WALLA WALLA-RIVER } \\
\text { YYKIMA RIVER }\end{array}$ & $\begin{array}{l}\text { OFFSITE } \\
\text { OFSITE }\end{array}$ & so & SUB_SURFACE & $\begin{array}{l}\text { SEDIMENT } \\
\text { SEDMENT }\end{array}$ & 15-May-03 U & & $1.49 \mathrm{~L}$ & ug/g(wet) & & & & & \\
\hline $\begin{array}{l}\text { SESPSPEC } \\
\text { SESPPPEC }\end{array}$ & $\begin{array}{l}\text { B16WX0 } \\
B 16 W \times 1\end{array}$ & $\begin{array}{l}\text { YAKIMA RIIER } \\
\text { YAKIMA RIVER }\end{array}$ & $\begin{array}{l}\text { OFFSITE } \\
\text { OFSITE }\end{array}$ & so & $\begin{array}{l}\text { SUB_SURFACE } \\
\text { SUB_SURFACE }\end{array}$ & $\begin{array}{l}\text { SEDIMENT } \\
\text { SEDMMENT }\end{array}$ & $\begin{array}{l}\text { 14-May-03U } \\
\text { 14-May-3 UU }\end{array}$ & & $\begin{array}{l}1.33 \mathrm{~L} \\
105 \mathrm{t}\end{array}$ & 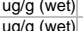 & & & & & \\
\hline $\begin{array}{l}\text { SESPPSEC } \\
\text { SESPSPEC }\end{array}$ & $\begin{array}{l}\text { B16WX1 } \\
B 17 \times N 6\end{array}$ & $\begin{array}{l}\text { YAKMAMA RIVRR } \\
100 \text { B/C AREA UR }\end{array}$ & $\begin{array}{l}\text { OFSIIIE } \\
\text { ONSE }\end{array}$ & so & $\begin{array}{l}\text { SUB_SURFACE } \\
\text { SUB_SURFACE }\end{array}$ & $\begin{array}{l}\text { SEDIMENI } \\
\text { SEDIMENT }\end{array}$ & $\begin{array}{l}\text { 14-May-03 } \\
\text { 17-Nov-03 Zn }\end{array}$ & & $\begin{array}{l}1.05 \mathrm{c} \\
103 \mathrm{\iota}\end{array}$ & 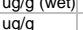 & & & & & \\
\hline SESPMNT & B176Y1 & 100 F SLOUGH & ONSITE & so & SUB_SURFACE & SEDIMENT & 14-Jul-03 Zn & & 222 & $\mathrm{ug} / \mathrm{g}$ & & & & & \\
\hline SESPMNT & B17J53 & 100-B SPRING 37-1 & ONSITE & so & SUB_SURFACE & SEDIMENT & $20-0 c t-03 \mathrm{Zn}$ & & 175 & $\mathrm{ug} / \mathrm{g}$ & & & & & \\
\hline SESPSPEC & B17XN8 & 100-B SPRING 37-1 & ONSITE & so & SUB_SURFACE & SEDIMENT & 13-Nov-03 Zn & & 1514 & $\mathrm{ug} / \mathrm{g}$ & & & & & \\
\hline SESPSPEC & B17XN9 & 100-B SPRING 38-3 & ONSITE & so & SUB_SURFACE & SEDIMENT & 13-Nov-03 Zn & & $184 \mathrm{~L}$ & $\mathrm{ug} / \mathrm{g}$ & & & & & \\
\hline $\begin{array}{l}\text { SESPMNT } \\
\text { SESPNT }\end{array}$ & B17J67 & $\begin{array}{l}\text { 100-F SPRING 207-1 } \\
\text { 100-H SPRING 145-1 }\end{array}$ & $\begin{array}{l}\text { ONSITE } \\
\text { ONSTIE }\end{array}$ & so & $\begin{array}{l}\text { SUB_SURFACE } \\
\text { SUI_SURFACE }\end{array}$ & $\begin{array}{l}\text { SEDIMENT } \\
\text { SEDMENT }\end{array}$ & 03-Nov-03 Zn & & $256 \mathrm{C}$ & $\mathrm{ug} / \mathrm{g}$ & & & & & \\
\hline $\begin{array}{l}\text { SESPNNT } \\
\text { SESPMNT }\end{array}$ & 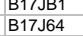 & $\begin{array}{l}\text { 100-H SPRRIN 145-1 } \\
\text { 100-K SPRING 63-1 }\end{array}$ & $\begin{array}{l}\text { ONSTIE } \\
\text { ONSITE }\end{array}$ & $\begin{array}{l}\text { so } \\
\text { so }\end{array}$ & $\begin{array}{l}\text { SUB_SURACACE } \\
\text { SU_SURACE }\end{array}$ & $\begin{array}{l}\text { SEDIMENT } \\
\text { SEDIMENT }\end{array}$ & $\begin{array}{l}27-\text {-oct-1-33 Zn } \\
\text { 20-Oct-03 Zn }\end{array}$ & & $\begin{array}{l}306 \mathrm{~L} \\
196 \mathrm{~L}\end{array}$ & $\begin{array}{l}\mathrm{ugg/g} \\
\mathrm{ug} / \mathrm{g}\end{array}$ & & & & & \\
\hline SESPMNT & B17J61 & 300 AREA SPR DR 42-2 & ONSITE & so & SUB_SURFACE & SEDIMENT & 13-Oct-03 Zn & & 128 & $\mathrm{ug} / \mathrm{g}$ & & & & & \\
\hline $\begin{array}{l}\text { SESPMNT } \\
\text { SESPDPEC }\end{array}$ & B17J18 & 300 AREA SPRING 42-2 & ONSITE & so & SUB_SURFACE & SEDIMENT & 13-Oct-03 Zn & & $104 \mathrm{~L}$ & $\mathrm{ug} / \mathrm{g}$ & & & & & \\
\hline $\begin{array}{l}\text { SESPSPEC } \\
\text { SESPPEC }\end{array}$ & B17BK5 & BONNEVILLE DAM OR.SHORE & $\begin{array}{l}\text { OFFSITE } \\
\text { OFESTTE }\end{array}$ & so & SUB_SURFACE & $\begin{array}{l}\text { SEDIMENT } \\
\text { SEDMENT }\end{array}$ & 07-Aug-03 Zn & & $175 \mathrm{~L}$ & $\mathrm{ug} / \mathrm{g}$ & & & $\mathrm{c}$ & & \\
\hline $\begin{array}{l}\text { SESPPSEC } \\
\text { SESPSPEC }\end{array}$ & $\begin{array}{l}\text { B17BE1 } \\
\text { B16WX8 }\end{array}$ & $\begin{array}{l}\text { DALLES DAM OR.NHORE } \\
\text { ESOUATZEL CAAL }\end{array}$ & $\begin{array}{l}\text { OFFFITE } \\
\text { OFFSITE }\end{array}$ & $\begin{array}{l}\text { so } \\
\text { so }\end{array}$ & $\begin{array}{l}\text { SUB_SURFACE } \\
\text { SUB_SURFACE }\end{array}$ & $\begin{array}{l}\text { SEDIMENT } \\
\text { SEDMMENT }\end{array}$ & $\begin{array}{l}\text { 07-Aug-03Zn } \\
\text { 14-May-03 Zn }\end{array}$ & & $\begin{aligned} 1794 \\
5394\end{aligned}$ & uglg & & & ${ }_{\mathrm{C}}^{\mathrm{C}}$ & & \\
\hline $\begin{array}{l}\text { SESPPPEC } \\
\text { SESPSPEC }\end{array}$ & $\begin{array}{l}\text { B16WX8 } \\
B 16 W \times 9\end{array}$ & $\begin{array}{l}\text { ESQUATZLL CANAL } \\
\text { ESQUATZEL CANAL }\end{array}$ & $\begin{array}{l}\text { OFFSIIE } \\
\text { OFFSITE }\end{array}$ & $\begin{array}{l}\text { so } \\
\text { so }\end{array}$ & $\begin{array}{l}\text { SUB_SURFACE } \\
\text { SUB SURFACE }\end{array}$ & $\begin{array}{l}\text { SEDIMENT } \\
\text { SEDIMENT }\end{array}$ & $\begin{array}{l}\text { 14-May-03 Zn } \\
\text { 14-May-03 Zn }\end{array}$ & & $\begin{array}{l}53.9 \mathrm{c} \\
54.3 \mathrm{u}\end{array}$ & $\begin{array}{l}u g / g(\text { wet) } \\
u g / g(\text { wet) }\end{array}$ & & & c & & \\
\hline SESPMNT & B176Y3 & HANFORD SLOUGH & RIVER_SHORELINE & so & SUB_SURFACE & SEDIMENT & 14-Jul-03 Zn & & $477 \mathrm{~L}$ & uglg & & & & & \\
\hline SESPMNT & B17J58 & HANFORD SPR DR 28-2 & ONSITE & so & SUB_SURFACE & SEDIMENT & 03-Nov-03 Zn & & 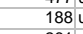 & $\mathrm{ug} / \mathrm{g}$ & & & & & \\
\hline SESPSPEC & B17BJ7 & JOHN DAY DAM MID-RIVER & OFFSITE & so & SUB_SURFACE & SEDIMENT & 08-Aug-03 Zn & & 2614 & & & & c & & \\
\hline SESPSPEC & B17BJ3 & MCNARY-2/3 OR. SHORE & OFFSITE & so & SUB_SURFACE & SEDIMENT & 08-Aug-03 Zn & & 276 & $\mathrm{ug} / \mathrm{g}$ & & & c & & \\
\hline $\begin{array}{l}\text { SESPMNT } \\
\text { SESPMNT }\end{array}$ & B17710 & MCNARY-OR.SIDE NEAR DAM & OFFSITE & so & SUB_SURFACE & SEDIMENT & 16-Jul-03 Zn & & 247 & $\mathrm{ug} / \mathrm{g}$ & & & & & \\
\hline $\begin{array}{l}\text { SESPMNT } \\
\text { SESPMNT }\end{array}$ & B17712 & $\begin{array}{l}\text { MCNARY-WASH.SIDE NEAR DAM } \\
\text { PCDET }\end{array}$ & OFFSITE & so & SUB_SURFACE & $\begin{array}{l}\text { SEDIMENT } \\
\text { SEDMENT }\end{array}$ & 16-Jul-03Zn & & $275 \mathrm{C}$ & $\mathrm{ug} / \mathrm{g}$ & & & & & \\
\hline $\begin{array}{l}\text { SESPMNT } \\
\text { SESPNT }\end{array}$ & $\begin{array}{l}B 17704 \\
B 1702\end{array}$ & $\begin{array}{l}\text { PRD-GRANT SIDE NEAR DAM } \\
\text { PRD-YAKIMA IDIDE NEAR DAM }\end{array}$ & $\begin{array}{l}\text { OFFSITE } \\
\text { OFFITITE }\end{array}$ & $\begin{array}{l}\text { so } \\
\text { so }\end{array}$ & $\begin{array}{l}\text { SUB_SURFACE } \\
\text { SUB SURFACE }\end{array}$ & $\begin{array}{l}\text { SEDIMENT } \\
\text { SEDMMENT }\end{array}$ & $\begin{array}{l}\text { 14--Jul-03Zn } \\
\text { 14-Ju-103 Zn }\end{array}$ & & $591 \mathrm{~L}$ & ug/g & & & & & \\
\hline $\begin{array}{l}\text { SESPMNIVT } \\
\text { SESPMT }\end{array}$ & $\begin{array}{ll}\text { B1702 } \\
\text { B176Y5 }\end{array}$ & $\begin{array}{l}\text { RICHLAND-RIVER } \\
\text { RIEAR DAM }\end{array}$ & $\begin{array}{l}\text { RIFSIIEHORELINE } \\
\text { RIVER_HORE }\end{array}$ & so & $\begin{array}{l}\text { SUB_SURFAEE } \\
\text { SUB_SURFACE }\end{array}$ & $\begin{array}{l}\text { SEDMIMENI } \\
\text { SEDIMENT }\end{array}$ & $\begin{array}{l}\text { 14-Jul-03Ln } \\
\text { 16-Jul-03 Zn }\end{array}$ & & 3324 & ug/g & & & & & \\
\hline SESPSPEC & B16WX6 & RINGOLD WASTEWAY & OFFSITE & so & SUB_SURFACE & SEDIMENT & 14-May-03 Zn & & $48.7 \mathrm{~L}$ & $\mathrm{ug} / \mathrm{g}(\mathrm{wet})$ & & & C & PRIMARILY SAND. & \\
\hline SESPSPEC & $B 16 W \times 7$ & RINGOLD WASTEWAY & OFFSITE & so & SUB_SURFACE & SEDIMENT & 14-May-03 Zn & & & uglg (wet) & & & c & PRIMARILY SAND. & \\
\hline SESPSPEC & $B 16 \mathrm{~W} \times 2$ & WALLA WALLA-RIVER & OFFSITE & so & SUB_SURFACE & SEDIMENT & 15-May-03 Zn & & $64.8 \mathrm{~L}$ & ug/g (wet) & & & C & & \\
\hline SESPSPEC & B16WX3 & WALLA WALLA-RIVER & OFFSITE & so & SUB_SURFACE & SEDIMENT & 15-May-03 Zn & & 65.94 & ug/g (wet) & & & c & & \\
\hline $\begin{array}{l}\text { SESPMNT } \\
\text { SESPSPEC }\end{array}$ & $\begin{array}{ll}B 176 \times 9 \\
B 16 \% \times 0\end{array}$ & $\begin{array}{l}\text { WHITE BLUFFS SLOUGH } \\
\text { YHKIIA RIVR }\end{array}$ & $\begin{array}{l}\text { RIVER_SHORELINE } \\
\text { ODESTTE }\end{array}$ & so & $\begin{array}{l}\text { SUB_SURFACE } \\
\text { SUB SUREAE }\end{array}$ & $\begin{array}{l}\text { SEDIMENT } \\
\text { SEDMENT }\end{array}$ & 14-Jul-03 Zn & & $394 \mathrm{~L}$ & ug/g & & & & & \\
\hline $\begin{array}{l}\text { SESPPEC } \\
\text { SESPSPEC }\end{array}$ & $\begin{array}{l}\frac{B 16 W \times 0}{B 16 W \times 1} \\
B 16\end{array}$ & $\begin{array}{l}\text { YAAIMA RIVR } \\
\text { YAKIMA RIVER }\end{array}$ & $\begin{array}{l}\text { OFFSITE } \\
\text { OFFSITE }\end{array}$ & $\begin{array}{l}\text { So } \\
\text { so }\end{array}$ & $\begin{array}{l}\text { SUB_SURFACE } \\
\text { SUB_SURFACE }\end{array}$ & $\begin{array}{l}\text { SEDIMENT } \\
\text { SEDIMENT }\end{array}$ & $\begin{array}{l}\text { 14-May-03Zn } \\
\text { 14-May-03 Zn }\end{array}$ & & $\begin{array}{rl}574 & 56.24 \\
5\end{array}$ & $\begin{array}{l}\text { uglg (wet) } \\
\text { ulag (wet) }\end{array}$ & & & ${ }_{\mathrm{C}}^{\mathrm{C}}$ & & \\
\hline SESPSPEC & B17XN6 & 100 B/C AREA UR & ONSITE & so & SUB_SURFACE & SEDIMENT & $17-\mathrm{Nov}-03 \mathrm{Ag}$ & & $0.0169 \mathrm{~L}$ & & & & u & & \\
\hline SESPMNT & B17J53 & ING 37-1 & ONSITE & so & SUB_SURFACE & SEDIMENT & 20-Oct-03 Ag & & $0.0599 \mathrm{~L}$ & & & & & & \\
\hline $\begin{array}{l}\text { SESPSPEC } \\
\text { SESPPDEC }\end{array}$ & B17XN8 & 100-B S & ONSITE & so & SUB_SURFACE & SEDIMENT & 13-Nov-03 Ag & & 0.02314 & $\mathrm{ug} / \mathrm{g}$ & & & & & \\
\hline $\begin{array}{l}\text { SESPSPEC } \\
\text { SESPMT }\end{array}$ & B17XN9 & 100-B SPRING 38-3 & ONSITE & so & SUB_SURFACE & $\begin{array}{l}\text { SEDIMENT } \\
\text { SEDMENT }\end{array}$ & 13-Nov-03 Ag & & 0.03854 & $\mathrm{ug} / \mathrm{g}$ & & & & & \\
\hline $\begin{array}{l}\text { SESPMNT } \\
\text { SESPNT }\end{array}$ & B17J67 & $\begin{array}{l}100-\text { F SPRIIG 207-1 } \\
100 \text { S SPRING 145-1 }\end{array}$ & $\begin{array}{l}\text { ONSITE } \\
\text { ONSTIE }\end{array}$ & so & SUB_SURFACE & $\begin{array}{l}\text { SEDIMENT } \\
\text { SEDMENT }\end{array}$ & 03-Nov-03 Ag & & 0.0934 & ug/g & & & & & \\
\hline $\begin{array}{l}\text { SESPMNT } \\
\text { SESPMT }\end{array}$ & 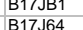 & $\begin{array}{l}100-H \text { SPRING } 145-1 \\
100-K \text { SPRING 63-1 }\end{array}$ & $\begin{array}{l}\text { ONSITE } \\
\text { ONSTTE }\end{array}$ & $\begin{array}{l}\text { So } \\
\text { so }\end{array}$ & $\begin{array}{l}\text { SUB_SURFACE } \\
\text { SUB SURFACE }\end{array}$ & $\begin{array}{l}\text { SEDIMENT } \\
\text { SEDIMENT }\end{array}$ & $\begin{array}{l}\text { 27-Oct-03 Ag } \\
\text { 20-Oct-03 Ag }\end{array}$ & & $\begin{array}{l}0.08194 \mathrm{~L} \\
0.0612 \mathrm{~L}\end{array}$ & $\mathrm{ug} / \mathrm{g}$ & & & & & \\
\hline $\begin{array}{l}\text { SESPMNIVT } \\
\text { SESPNT }\end{array}$ & $\begin{array}{l}\text { B1/764 } \\
B 17361\end{array}$ & 300 AREA SPR DR 42-2 & $\begin{array}{l}\text { ONSITE } \\
\text { ONSE }\end{array}$ & so & $\begin{array}{l}\text { SUB_SURFACE } \\
\text { SUB_SURFACE }\end{array}$ & $\begin{array}{l}\text { SEDIMENI } \\
\text { SEDIMENT }\end{array}$ & $\begin{array}{l}\text { 20-Oct-03 } \mathrm{Ag} \\
13-\mathrm{Oct}-03 \mathrm{Ag}\end{array}$ & & 0.014 & & & & $\mathrm{C}$ & & \\
\hline SESPMNT & B17J18 & 300 AREA SPRING 42-2 & ONSITE & so & SUB_SURFACE & SEDIMENT & $13-\mathrm{Oct}-03 \mathrm{Ag}$ & & $0.074 \mathrm{~L}$ & & & & $\mathrm{C}$ & & \\
\hline SESPMNT & B17J58 & HANFORD SPR DR 28-2 & ONSITE & so & SUB_SURFACE & SEDIMENT & 03-Nov-03 Ag & & $0.0419 \mathrm{~L}$ & & & & & & \\
\hline SESPSPEC & B17XP7 & $100 \mathrm{~B} / \mathrm{C}$ AREA DR & ONSITE & so & SUB_SURFACE & SEDIMENT & 17-Nov-03 Hg & & & & & & & NO SAMPLE. NOT AVAILABLE. & \\
\hline SESPSPEC & B17XP1 & $100 \mathrm{~B} / \mathrm{C}$ AREA OUTFL1 & ONSITE & so & SUB_SURFACE & SEDIM & 10-No & & & & & & & NO SAMPLE. NOT AVA & \\
\hline $\begin{array}{l}\text { SESPSPEC } \\
\text { SESPPPEC }\end{array}$ & B17XP3 & 100 B/C AREA OUTFL2 & $\begin{array}{l}\text { ONSITE } \\
\text { ONSIT }\end{array}$ & so & SUB_SURFACE & $\begin{array}{l}\text { SEDIMENT } \\
\text { SEDMENT }\end{array}$ & 10-Nov- $03 \mathrm{Hg}$ & & & & & & & NO SAMPLE. NOT AVALLABLE. & \\
\hline $\begin{array}{l}\text { SESPSPEC } \\
\text { SESPPEC }\end{array}$ & B17XP5 & $\begin{array}{l}100 \mathrm{~B} / \mathrm{C} \text { AREA OUTFL3 } \\
100 \mathrm{~B} / \mathrm{C} \text { AREA UR }\end{array}$ & $\begin{array}{l}\text { ONSITE } \\
\text { ONSTIE }\end{array}$ & $\begin{array}{l}\text { so } \\
\text { so }\end{array}$ & SUB_SURFACE & $\begin{array}{l}\text { SEDIMENT } \\
\text { SEDMENT }\end{array}$ & $\begin{array}{l}10-\mathrm{Nov}-03 \mathrm{Hg} \\
17-\mathrm{Nov}-3 \mathrm{Hg}\end{array}$ & & 0.01431 & & & & $B C$ & NO SAMPLE. NOT AVAILABLE. & \\
\hline $\begin{array}{l}\text { SESPSPEC } \\
\text { SESPMT }\end{array}$ & B17XN6 & $\begin{array}{l}100 \text { BCC AREAUR } \\
100 \text { F SOUGH }\end{array}$ & $\begin{array}{l}\text { ONSIIE } \\
\text { ONSTIE }\end{array}$ & $\begin{array}{l}\text { so } \\
\text { so }\end{array}$ & $\begin{array}{l}\text { SUB_SURFACE } \\
\text { SUB SURFACE }\end{array}$ & $\begin{array}{l}\text { SEDIMENT } \\
\text { SEDIMENT }\end{array}$ & $\begin{array}{l}\text { 17-Nov-03 Hg } \\
14-\mathrm{Ju}-03 \mathrm{Ha}\end{array}$ & & $\begin{array}{l}0.0143 \mathrm{~L} \\
0.0116 \mathrm{t}\end{array}$ & $\mathrm{ug} / \mathrm{g}$ & & & $B C$ & & \\
\hline $\begin{array}{l}\text { SESPMNT } \\
\text { SESPNT }\end{array}$ & $\begin{array}{l}\text { B1/691 } \\
\text { B17J53 }\end{array}$ & 100-B SPRING 37-1 & $\begin{array}{l}\text { ONSSTE } \\
\text { ONSE }\end{array}$ & so & $\begin{array}{l}\text { SUB_SURFACE } \\
\text { SUB SURFACE }\end{array}$ & $\begin{array}{l}\text { SEDIMENI } \\
\text { SEDIMENT }\end{array}$ & $\begin{array}{l}14-\mathrm{Jul}-\mathrm{l} \mathrm{OH} \mathrm{Hg} \\
20-\mathrm{Oct}-03 \mathrm{Hg}\end{array}$ & & 0.00221 & ugg/g & & & $\begin{array}{llllll}B & 0\end{array}$ & & \\
\hline SESF & B17XN8 & 100-B SPRING 37-1 & ONSITE & so & SUB_SURFACE & SEDIMENT & $13-$ Nov-03 Hg & & $0.0161 \mathrm{~L}$ & $\mathrm{ug} / \mathrm{g}$ & & & $\mathrm{BC}$ & & \\
\hline SPEC & B17XN9 & 100-B SPRING 38-3 & ONSITE & so & SUB_SURFACE & SEDIMENT & 13-Nov- $03 \mathrm{Hg}$ & & 0.01394 & & & & $\mathrm{BC}$ & & \\
\hline SESPSPEC & B17XPO & 100-B SPRING 39-2 & ONSITE & so & SUB_SURFACE & SEDIMENT & 10-Nov-03 Hg & & & & & & & NO SAMPLE. NOT AVAILABLE. & \\
\hline SESPMNT & B17J67 & 100-F SPRING 207-1 & ONSITE & so & SUB_SURFACE & SEDIMENT & 03-Nov-03 Hg & & $0.0467 \mathrm{~L} / \mathrm{L}$ & ug/g & & & $\mathrm{BC}$ & & \\
\hline
\end{tabular}


(pCilg Dry Weight unless otherwise noted

\begin{tabular}{|c|c|c|c|c|c|c|c|c|c|c|c|c|c|c|}
\hline & $\begin{array}{l}\text { SAMP } \\
\text { NUM }\end{array}$ & & & MEDIA & & & SAMP DATE $\quad$ CON SHORT NAME & $\begin{array}{l}\text { VALUE } \\
\text { RPTD }\end{array}$ & \begin{tabular}{|l|} 
ANAL \\
UNITS \\
RPTD
\end{tabular} & $\begin{array}{c}\text { COUNTING } \\
\text { ERROR }\end{array} \mid$ & \begin{tabular}{|c|} 
TOTAL \\
ANAL \\
ERROR
\end{tabular} & $\begin{array}{c}\text { LAB } \\
\text { QUALIFIER }\end{array}$ & SAMP COMMENT & RESULT COMMENT \\
\hline SESPMNT & B17JB1 & 100-H SPRING 145-1 & ONSITE & SO & SUB_SURFACE & $\begin{array}{l}\text { SEDIMENT } \\
\text { SEDIMENT }\end{array}$ & 27-Oct-03 Hg & 0.0315 & & & & & SAMP COMMENI & RESULI COMIMENI \\
\hline SESPMNT & $\begin{array}{ll}\text { B17J01 } \\
\text { B17J64 }\end{array}$ & 100-K SPRING 63-1 & ONSITE & so & SUB_SURFACE & SEDIMENT & $20-\mathrm{Oct}-03 \mathrm{Hg}$ & 0.02044 & & & & B & & \\
\hline $\begin{array}{l}\text { SESPMNT } \\
\text { SEPMNT }\end{array}$ & B17361 & 300 AREA SPR DR 42-2 & ONSITE & so & SUB_SURFACE & $\begin{array}{l}\text { SEDIMENT } \\
\text { SEDMENT }\end{array}$ & $13-\mathrm{Oct}-03 \mathrm{Hg}$ & 0.005434 & & & & u & & \\
\hline $\begin{array}{l}\text { SESPMNT } \\
\text { SESPSEFC }\end{array}$ & B17J18 & 300 AREA SPRING 42-2 & ONSITE & so & SUB_SURFACE & $\begin{array}{l}\text { SEDIMENT } \\
\text { SEDIMENT }\end{array}$ & $13-\mathrm{Oct}-03 \mathrm{Hg}$ & 0.01064 & & & & B & & \\
\hline $\begin{array}{l}\text { SESPSPEC } \\
\text { SESPPEC }\end{array}$ & $\begin{array}{l}\text { B178K5 } \\
\text { B173K1 }\end{array}$ & $\begin{array}{l}\text { BONNEVVLLE DAM OR.SHORE } \\
\text { DALES DAM OR.SHOEE }\end{array}$ & $\begin{array}{l}\text { OFFSITE } \\
\text { OFFIIE }\end{array}$ & $\begin{array}{l}\text { so } \\
\text { so }\end{array}$ & $\begin{array}{l}\text { SUB_SURFACE } \\
\text { SUB SURACE }\end{array}$ & $\begin{array}{l}\text { SEDIMENT } \\
\text { SEDIMENT }\end{array}$ & $\begin{array}{l}\text { 07-Aug-03 Hg } \\
07 \text {-Aug-03 Hg }\end{array}$ & 0.5124 & ug/g & & & c & & \\
\hline $\begin{array}{l}\text { SESPSPEC } \\
\text { SESPE }\end{array}$ & $\begin{array}{l}\text { B } \\
\text { B16WXX8 }\end{array}$ & $\begin{array}{l}\text { ESQUATZEL CANAL } \\
\text { ESE }\end{array}$ & $\begin{array}{l}\text { OFFSITE } \\
\text { OFSE }\end{array}$ & so & $\begin{array}{l}\text { SUB_SURFACE } \\
\text { SUB_SURE }\end{array}$ & SEDIMENT & $14-\mathrm{May}-03 \mathrm{Hg}$ & 0.0041 ᄂ & uglg (wet) & & & & & \\
\hline SESPSPEC & B16WX9 & ESQUATZEL CANAL & OFFSITE & so & SUB_SURFACE & SEDIMENT & 14-May-03 Hg & 0.00484 & uglg (wet) & & & & & \\
\hline $\begin{array}{l}\text { SESPMNT } \\
\text { SESPMNT }\end{array}$ & B176Y3 & HANFORD SLOUGH & RIVER_SHORELINE & so & SUB_SURFACE & SEDIMENT & 14-Jul-03 Hg & 0.1614 & & & & & & \\
\hline $\begin{array}{l}\text { SESPMNT } \\
\text { SESPNT }\end{array}$ & $\begin{array}{l}B 17758 \\
\text { B17555 }\end{array}$ & $\begin{array}{l}\text { HAAFORD SPR DR 28-2 } \\
\text { HANFORD SR UR 28-2 }\end{array}$ & $\begin{array}{l}\text { ONSITE } \\
\text { ONSTEE }\end{array}$ & $\begin{array}{l}\text { so } \\
\text { so }\end{array}$ & $\begin{array}{l}\text { SUB_SURFACE } \\
\text { SUB SURACE }\end{array}$ & $\begin{array}{l}\text { SEDIMENT } \\
\text { SEDIMENT }\end{array}$ & $\begin{array}{l}03-\mathrm{Nov}-03 \mathrm{Hg} \\
15-\mathrm{Sep-03} \mathrm{Hg}\end{array}$ & $0.0257 \mathrm{~L}$ & & & & $\mathrm{BC}$ & & \\
\hline $\begin{array}{l}\text { SESPMNT } \\
\text { SESPSPEC }\end{array}$ & 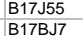 & $\begin{array}{l}\text { HANFFRD SPR UR 28-2 } \\
\text { JOHN DAY DAM MID-RIVER }\end{array}$ & $\begin{array}{l}\text { ONSTIE } \\
\text { OFFSITE }\end{array}$ & $\begin{array}{l}\text { so } \\
\text { so }\end{array}$ & $\begin{array}{l}\text { SUB_SURACACE } \\
\text { SUB_SURACE }\end{array}$ & $\begin{array}{l}\text { SEDIMENT } \\
\text { SEDMENT }\end{array}$ & $\begin{array}{l}\text { 15-S-Sp--03 Hg } \\
\text { 0-A-Agu-03 Hg }\end{array}$ & $0.105 \mathrm{c}$ & $\mathrm{ug} / \mathrm{g}$ & & & $c$ & NO SAMPLE. & \\
\hline SESPSPEC & $\begin{array}{l}\text { B1/7J/ } \\
\text { B17BJ3 }\end{array}$ & $\begin{array}{l}\text { JHNDAY DAM MIL-RIVR } \\
\text { MCNARY-2/3 OR. SHORE }\end{array}$ & OFFSITE & so & $\begin{array}{l}\text { SUB_SURACE } \\
\text { SUB_SURFACE }\end{array}$ & $\begin{array}{l}\text { SEDMENI } \\
\text { SEDIMENT }\end{array}$ & $\begin{array}{l}\text { 8-Agug-03- } \mathrm{Hg} \\
08-\mathrm{Hg}\end{array}$ & $0.0927 \mathrm{~L}$ & & & & $\begin{array}{l}\mathrm{c} \\
\mathrm{c}\end{array}$ & & \\
\hline SESPMNT & B17710 & MCNARY-OR.SIDE NEAR DAM & OFFSITE & so & SUB_SURFACE & SEDIMENT & 16-Jul-03 Hg & $0.0939 \mathrm{~L}$ & & & & & & \\
\hline $\begin{array}{l}\text { SESPMNT } \\
\text { SESDSDCF }\end{array}$ & B17712 & MCNARY-WASH.SIDE NEAR DAM & OFFSITE & so & SUB_SURFACE & SEDIMENT & $16-\mathrm{Jul}-03 \mathrm{Hg}$ & 0.14 & & & & & & \\
\hline $\begin{array}{l}\text { SESPSPEC } \\
\text { SESPPEC }\end{array}$ & $\begin{array}{l}\text { B16WYO } \\
\text { B16WYY }\end{array}$ & POTHOLES CANAL & OFFSITE & so & SUB_SURFACE & $\begin{array}{l}\text { SEDIMENT } \\
\text { SEDMENT }\end{array}$ & 14-May- $03 \mathrm{Hg}$ & & & & & & NO SAMPLE. & \\
\hline $\begin{array}{l}\text { SESPSPEC } \\
\text { SESPMNT }\end{array}$ & B16WY1 & $\begin{array}{l}\text { POTHOLES CANAL } \\
\text { PRD-GRANT SIDE NEAR DAM }\end{array}$ & $\begin{array}{l}\text { OFFFITE } \\
\text { OFFSITE }\end{array}$ & so & SUB_SURFACE & $\begin{array}{l}\text { SEDIMENT } \\
\text { SEDMENT }\end{array}$ & 14-May- $03 \mathrm{Hg}$ & & & & & & & \\
\hline $\begin{array}{l}\text { SESPMNIN } \\
\text { SESPMNT }\end{array}$ & $\begin{array}{ll}\text { B1/704 } \\
B 17702\end{array}$ & PRD-YAKIMA SIDE NEAR DAM & $\begin{array}{l}\text { OFFSIITE } \\
\text { OFFIT }\end{array}$ & so & $\begin{array}{l}\text { SUB_SURACE } \\
\text { SUB SURFACE }\end{array}$ & $\begin{array}{l}\text { SEDIMENI } \\
\text { SEDIMENT }\end{array}$ & $\begin{array}{l}\text { 14-Jul-03 } \mathrm{Hg} \\
14 \mathrm{Jul}-03 \mathrm{Hg}\end{array}$ & $0.187 \mathrm{~L}$ & & & & & & \\
\hline SESPMNT & $\begin{array}{ll}\text { DIflTLZ } \\
\text { B176Y5 }\end{array}$ & $\begin{array}{l}\text { RICHLAND-RIVER } \\
\end{array}$ & RIVER SHORELINE & so & SUB_SURFACE & SEDIMENT & $14-\mathrm{Jul}-03 \mathrm{Hg}$ & $0.0181 \mathrm{~L}$ & & & & B & & \\
\hline SESPSPEC & B16WX6 & RINGOLD WASTEWAY & OFFSITE & so & SUB_SURFACE & SEDIMENT & $\begin{array}{r}10-\mathrm{May}-03 \mathrm{Hg} \\
14 \mathrm{Hg}\end{array}$ & $\begin{array}{ll}0.01814 \\
0.01 \mathrm{~L}\end{array}$ & 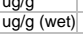 & & & & PRIMARILY SAND. & \\
\hline SESPSPEC & $B 16 W \times 7$ & RINGOLD WASTEWAY & OFFSITE & so & SUB_SURFACE & SEDIMENT & 14-May-03 Hg & $0.0093 \mathrm{~L}$ & ug/g (wet) & & & & PRIMARILY SAND. & \\
\hline SESPSPEC & B16WX4 & SNAKE RIVER & OFFSITE & so & SUB_SURFACE & SEDIMENT & 15-May- $03 \mathrm{Hg}$ & & & & & & NO SAMPLE. & \\
\hline $\begin{array}{l}\text { SESPSPEC } \\
\text { SESPSEC }\end{array}$ & $\begin{array}{l}\text { B16WX5 } \\
B 160 \times 2\end{array}$ & $\begin{array}{l}\text { SNAKE RIVER } \\
\text { WALLA WALA-RIVER }\end{array}$ & OFFSITE & so & SUB_SURFACE & $\begin{array}{l}\text { SEDIMENT } \\
\text { SEDMENT }\end{array}$ & 15-May-03 Hg & & & & & & NO SAMPLE. & \\
\hline $\begin{array}{l}\text { SESPPSEC } \\
\text { SESPPPEC }\end{array}$ & $\begin{array}{ll}B 16 W \times 2 \\
B 16 W \times 3\end{array}$ & $\begin{array}{l}\text { WALLL WALLA-RIER } \\
\text { WALA WALLARIVER }\end{array}$ & $\begin{array}{l}\text { OFFSITE } \\
\text { OFFSITE }\end{array}$ & so & $\begin{array}{l}\text { SUB_SURFACE } \\
\text { SUB_SURACE }\end{array}$ & $\begin{array}{l}\text { SEDIMENT } \\
\text { SEDMENT }\end{array}$ & $\begin{array}{l}15-\mathrm{May}-03 \mathrm{Hg} \\
15-\mathrm{Mg}-03 \mathrm{Hg}\end{array}$ & 0.00784 & ug/g(wet) & & & & & \\
\hline $\begin{array}{l}\text { SESPPEC } \\
\text { SESPMNT }\end{array}$ & $\begin{array}{l}\text { B16wX3 } \\
B 176 \times 9\end{array}$ & $\begin{array}{l}\text { WAALA WALAA-RIVR } \\
\text { WHITE BLUFFS SLOUGH }\end{array}$ & $\begin{array}{l}\text { lFFSITE } \\
\text { RIVER SHORELINE }\end{array}$ & $\begin{array}{l}\text { So } \\
\text { so }\end{array}$ & $\begin{array}{l}\text { SUB_SURACEE } \\
\text { SUB SURAACE }\end{array}$ & $\begin{array}{l}\text { SEDIMENT } \\
\text { SEDIMENT }\end{array}$ & $\begin{array}{l}15-\mathrm{May}-03 \mathrm{Hg} \\
14-\mathrm{Jul}-03 \mathrm{Hg}\end{array}$ & $0.00921 \mathrm{~L}$ & ug/g(wet) & & & & & \\
\hline SESPSPEC & B16WX0 & YAKIMA RIVER & $\begin{array}{l}\text { OFFSITE } \\
\text { OFELIVE }\end{array}$ & so & SUB_SURFACE & SEDIMENT & $14-\mathrm{May}-03 \mathrm{Hg}$ & 0.02474 & uglg (wet) & & & & & \\
\hline SESPSPEC & B16WX1 & YAKIMA RIVER & OFFSITE & so & SUB_SURFACE & SEDIMENT & $14-\mathrm{May}-03 \mathrm{Hg}$ & $0.0275 \mathrm{t}$ & ug/g (wet) & & & & & \\
\hline SESPSPEC & $\begin{array}{l}\text { B } \\
\text { B17XNA }\end{array}$ & $100 \mathrm{~B} / \mathrm{C}$ AREA UR & ONSITE & so & SUB_SURFACE & SEDIMENT & 17-Nov-03 Se & 0.07894 & & & & B & & \\
\hline SESPMNT & B17J53 & 100-B SPRING 37-1 & ONSITE & so & SUB_SURFACE & SEDIMENT & $20-0 c t-03 \mathrm{Se}$ & $1.63 \mathrm{~L}$ & & & & & & \\
\hline SESPSPEC & B17XN8 & 100-B SPRING 37-1 & ONSITE & so & SUB_SURFACE & SEDIMENT & 13-Nov-03 Se & $0.22 \mathrm{~L}-3 \mathrm{l}$ & & & & B & & \\
\hline $\begin{array}{l}\text { SESPSPEC } \\
\text { SESPMNT }\end{array}$ & B17XN9 & 100-B SPRING 38-3 & ONSITE & so & SUB_SURFACE & $\begin{array}{l}\text { SEDIMENT } \\
\text { SEDMENT }\end{array}$ & 13-Nov-03 Se & 0.14 & $\mathrm{ug} / \mathrm{g}$ & & & B & & \\
\hline SESPMNT & B17J67 & $\begin{array}{l}\text { 100-F SPRIIG 207-1 } \\
\text { 100-H SPRING 145-1 }\end{array}$ & ONSITE & so & SUB_SURFACE & $\begin{array}{l}\text { SEDIMENT } \\
\text { SEDMENT }\end{array}$ & $\begin{array}{l}\text { 03-Nov-03 Se } \\
\text { 27-0ct-03 Se }\end{array}$ & 0.4584 & $\mathrm{ug} / \mathrm{g}$ & & & $\begin{array}{c}B \\
B\end{array}$ & & \\
\hline $\begin{array}{l}\text { SESPMNT } \\
\text { SESPMNT }\end{array}$ & 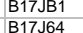 & $\begin{array}{l}\text { 100-H SPRING 145-1 } \\
\text { 100-K SPRING 63-1 }\end{array}$ & $\begin{array}{l}\text { ONSIE } \\
\text { ONSTTE }\end{array}$ & $\begin{array}{l}\text { so } \\
\text { so }\end{array}$ & $\begin{array}{l}\text { SUB_SURFACE } \\
\text { SUB SURACE }\end{array}$ & $\begin{array}{l}\text { SEDIMENT } \\
\text { SEDIMENT }\end{array}$ & $\begin{array}{l}\text { 27-Oct-03 Se } \\
\text { 20-Oc-03 Se }\end{array}$ & lo & ug/g $u$ & & & $\begin{array}{l}\mathrm{B} \\
\mathrm{B}\end{array}$ & & \\
\hline SESPMNT & $\begin{array}{l}B 1 / 764 \\
B 17758\end{array}$ & HANFORD SPR DR 28-2 & ONSITE & so & SUB SURFACE & SEDIMENT & $\begin{array}{l}\text { 20-Oct-03 Se } \\
03 \text {-Nov-03 Se }\end{array}$ & $0.29 \mathrm{u}$ & ug/g & & & $\begin{array}{l}\mathrm{D} \\
\mathrm{B}\end{array}$ & & \\
\hline SESPSPEC & B17XP8 & 100 B/C AREA DR & ONSITE & so & SUB SURFACE & SEDIMENT & 17-Nov-03 Aroclor-1254 & & & & & & NO SAMPLE. NOT AVAILABLE. & \\
\hline SESPSPEC & B17XP2 & $100 \mathrm{~B} / \mathrm{C}$ AREA OUTFL1 & ONSITE & so & SUB_SURFACE & SEDIMENT & 10-Nov-03 Aroclor-1254 & & & & & & NO SAMPLE. NOT AVAILABLE. & \\
\hline SESPSPEC & B17XP4 & $100 \mathrm{~B} / \mathrm{C}$ AREA OUTFL2 & ONSITE & so & SUB_SURFACE & SEDIMENT & 10-Nov-03 Aroclor-1254 & & & & & & NO SAMPLE. NOT AVAILABLE. & \\
\hline SESPSPEC & B17XP6 & 100 B/C AREA OUTFL3 & ONSITE & so & SUB_SURFACE & SEDIMENT & 10-Nov-03 Aroclor-1254 & & & & & & NO SAMPLE. NOT AVAILABLE. & \\
\hline $\begin{array}{l}\text { SESPSPEC } \\
\text { SESPSEC }\end{array}$ & $\begin{array}{l}\text { B17XP8 } \\
\text { B17PP2 }\end{array}$ & $100 \mathrm{~B} / \mathrm{C}$ AREA DR & ONSITE & so & SUB_SURFACE & SEDIMENT & 17-Nov-03 Aroclor-1260 & & & & & & NO SAMPLE. NOT AVAILABLE. & \\
\hline $\begin{array}{l}\text { SESPPEC } \\
\text { SESPSPEC }\end{array}$ & $\begin{array}{l}B 17 X \times 2 \\
B 17 P 24\end{array}$ & $\begin{array}{l}100 \text { B/C AREA OUTFL1 } \\
100 \text { B/C AREA OUFI? }\end{array}$ & ONSITE & so & SUB_SURFACE & $\begin{array}{l}\text { SEDIMENT } \\
\text { SEDMENT }\end{array}$ & $\begin{array}{l}\text { 10-Nov-03 Aroclor-1260 } \\
\text { 10-Nov-03 Areclor-1260 }\end{array}$ & & & & & & NO SAMPLE. NOT AVAILABLE. & \\
\hline $\begin{array}{l}\text { SESPSPEC } \\
\text { SESPSEC }\end{array}$ & B17XP6 & $100 \mathrm{~B} / \mathrm{C}$ AREA OUTFL 3 & $\begin{array}{l}\text { ONSTIE } \\
\text { ONSITE }\end{array}$ & so & $\begin{array}{l}\text { SUB_SURFACE } \\
\text { SUB_SURFACE }\end{array}$ & $\begin{array}{l}\text { SEDIMENT } \\
\text { SEDIMENT }\end{array}$ & $\begin{array}{l}\text { 10-Nov-03 Arocolor-1260 } \\
\text { 10-Nov-03 Aroclor-1260 }\end{array}$ & & & & & & $\begin{array}{l}\text { NO SAMPLE. NOT AVALALABE. } \\
\text { NO SAMPLE. NOT AVALABLEE. }\end{array}$ & \\
\hline SESPMNT & B176T7 & $100 \mathrm{~F}$ SLOUGH & ONSITE & so & SUB_SURACACE & $\begin{array}{l}\text { SEDIMENT } \\
\text { SEDIMENT }\end{array}$ & 14-Jul-03 TOC (Total organic carbon; & $1240 r$ & $\mathrm{mg} / \mathrm{kg}$ & & & $\mathrm{N}$ & & \\
\hline SESF & B17BR9 & BONNEVILLE DAM MID-RIVER & OFFSITE & so & SUB_SURFACE & SEDIMENT & 07-Aug-03 TOC (Total organic carbon; & & & & & & NO SAMPLE. & \\
\hline SESPSPEC & B17BR8 & BONNEVILLE DAM OR.SHORE & OFFSITE & so & SUB_SURFACE & SEDIMENT & 07-Aug-03 TOC (Total organic carbon; & $13300 \mathrm{r}$ & & & & $\mathrm{N}$ & & \\
\hline SESPSPEC & B17BR7 & BONNEVILLE DAM OR.SHORE BEACH & OFFSITE & so & SUB_SURFACE & SEDIMENT & 07-Aug-03 TOC (Total organic carbon; & 1110 & $\mathrm{mg} / \mathrm{kg}$ & & & $\mathrm{N}$ & & \\
\hline SESF & B17BTO & BONNEVILLE DAM WA.SHORE & OFFSITE & so & SUB_SURFACE & SEDIMENT & 07-Aug-03 TOC (Total organic carbon; & & & & & & NO SAMPLE. & \\
\hline SESPSPEC & B17BT1 & BONNEVILLE DAM WA.SHORE BEACH & OFFSITE & so & SUB_SURFACE & SEDIMENT & 07-Aug-03 TOC (Total organic carbon? & & & & & & NO SAMPLE. & \\
\hline $\begin{array}{l}\text { SESPSPEC } \\
\text { SESPSDCF }\end{array}$ & B17BR4 & DALLES DAM MID-RIVER & OFFSITE & so & SUB_SURFACE & SEDIMENT & 07-Aug-03 TOC (Total organic carbon; & 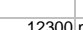 & malkat & & & $N$ & NO SAMPLE. & \\
\hline $\begin{array}{l}\text { SESPSEC } \\
\text { SESPSPEC }\end{array}$ & $\begin{array}{l}\text { B178R3 } \\
B 17823\end{array}$ & $\begin{array}{l}\text { DALLEE DAM OR.SHORE } \\
\text { DALLES DAM OR.SHORE BEACH }\end{array}$ & $\begin{array}{l}\text { OFFSITE } \\
\text { OFFITE }\end{array}$ & $\begin{array}{l}\text { So } \\
\text { so }\end{array}$ & $\begin{array}{l}\text { SUB_SURFACE } \\
\text { SUB SURFACE }\end{array}$ & $\begin{array}{l}\text { SEDIMENT } \\
\text { SEDIMENT }\end{array}$ & $\begin{array}{l}\text { 07-Aug-03 TOC (Total organicic carbon, } \\
\text { 07-Aug-03 TOC (Total organic carbon" }\end{array}$ & $12300 \mathrm{r}$ & $\mathrm{mg} / \mathrm{kg}$ & & & $\mathrm{N}$ & NO SAMPLE & \\
\hline SESPSEC & 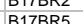 & DAISDAM WA SHOPE & OFFST & 50 & SUB-SURACE & SEDIENT & 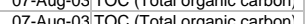 & 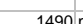 & malka & & & $N$ & NUU SAMVLE. & \\
\hline SESPSPEC & $\begin{array}{l}\text { BLt17R5 } \\
\text { B17BR6 }\end{array}$ & DALLES DAM WA.SHORE BEACH & OFFSITE & so & $\begin{array}{l}\text { SUB_SURACE } \\
\text { SUB SURFACE }\end{array}$ & $\begin{array}{l}\text { SEDIMENI } \\
\text { SEDIMENT }\end{array}$ & 07-Aug-03 TOC (Total organic carbon, & & & & & TN & NO SAMPLE. & \\
\hline SESF & B170V0 & ESQUATZEL CANAL & OFFSITE & so & SUB_SURFACE & SEDIMENT & 14-May-03 TOC (Total organic carbon; & $1110 \mathrm{r}$ & $\mathrm{mg} / \mathrm{kg}$ & & & $\mathrm{N}$ & & \\
\hline SESPS & B170V1 & ESQUATZEL CANAL & OFFSITE & so & SUB_SURFACE & SEDIMENT & 14-May-03 TOC (Total organic carbon? & $2480 n$ & $\mathrm{mg} / \mathrm{kg}$ & & & $\mathrm{N}$ & & \\
\hline SESPI & B176VO & HANFORD SLC & RIVER_SHORELINE & so & SUB_SURFACE & SEDIMENT & 14-Jul-03 TOC (Total organic carbon? & $10200 n$ & $\mathrm{mg} / \mathrm{kg}$ & & & $\mathrm{N}$ & & \\
\hline $\begin{array}{l}\text { SESPSPEC } \\
\text { SESPSEC }\end{array}$ & B17BP9 & JOHN DAY DAM MID-RIVER & OFFSITE & so & & SEDIMENT & 08-Aug-03 TOC (Total organic carbon? & $16200 \mathrm{r}$ & $\mathrm{mg} / \mathrm{kg}$ & & & $\mathrm{N}$ & & \\
\hline $\begin{array}{l}\text { SESPSPEC } \\
\text { SESPPEC }\end{array}$ & 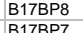 & $\begin{array}{l}\text { JOHN DAY DAM OR.SHORE } \\
\text { JuAFAY }\end{array}$ & $\begin{array}{l}\text { OFFSITE } \\
\text { OFESITE }\end{array}$ & so & $\begin{array}{l}\text { SUB_SURFACE } \\
\text { SUB_ SURACEE }\end{array}$ & $\begin{array}{l}\text { SEDIMENT } \\
\text { SEDMENT }\end{array}$ & 08-Aug-03 TOC (Total organic carbon; & $13700 \mathrm{r}$ & $\mathrm{mg} / \mathrm{kg}$ & & & $\mathrm{N}$ & NO SAMPIF & \\
\hline $\begin{array}{l}\text { SESPPPEC } \\
\text { SESPSPEC }\end{array}$ & $\begin{array}{l}\text { B177PP7 } \\
\text { B17BRO }\end{array}$ & $\begin{array}{l}\text { JOHN DAY DAM OR.SHORE BEACH } \\
\text { JOHN DAY DAM WA.SHORE }\end{array}$ & $\begin{array}{l}\text { OFFSIIE } \\
\text { OFFSITE }\end{array}$ & $\begin{array}{l}\text { So } \\
\text { so }\end{array}$ & $\begin{array}{l}\text { SUB_SURAACE } \\
\text { SUB_SURFACE }\end{array}$ & $\begin{array}{l}\text { SEDMENT } \\
\text { SEDIMENT }\end{array}$ & $\begin{array}{l}\text { 08-Aug-003 TOC (Totala organic carbon; } \\
\text { 08-Aug-03 TOC (Total organic carbon, }\end{array}$ & $13400 \mathrm{r}$ & $\mathrm{mg} / \mathrm{kg}$ & & & $\mathrm{N}$ & NO SAMPLE. & \\
\hline SESF & B17BR1 & WA.SHORE BEACH & OFFSITE & so & SUB_s & SEDIN & 3 TOC (Total organic carbon; & & & & & & NO SAMPLE. & \\
\hline SESPSPEC & B17BP3 & MCNARY-2/3 OR. SHORE & OFFSITE & so & SUB_SURFACE & SEDIMENT & 08-Aug-03 TOC (Total organic carbon? & $7190 \mathrm{r}$ & $\mathrm{mg} / \mathrm{kg}$ & & & $\mathrm{N}$ & DUP IS SAMPLE \# B17BP4 & \\
\hline $\begin{array}{l}\text { SESP } \\
\text { SESP }\end{array}$ & B178P4 & $\begin{array}{l}\text { MCNARYY2/3 OR. SHORE } \\
\text { MCNARYOR SHORE BEACH }\end{array}$ & $\begin{array}{l}\text { OFFSITE } \\
\text { OFFSITE }\end{array}$ & $\begin{array}{l}\text { so } \\
\text { so }\end{array}$ & $\begin{array}{l}\text { SUB_SURFACE } \\
\text { SUB SURACE }\end{array}$ & $\begin{array}{l}\text { SEDIMENT } \\
\text { SEDMMENT }\end{array}$ & $\begin{array}{l}\text { 08-Aug-03 TOC (Total organic carbon;" } \\
\text { 08-Aug-03 TOC (Total organic carbon }\end{array}$ & $7280 \mathrm{n}$ & $\mathrm{mg} / \mathrm{kg}$ & & & $\begin{array}{l}n \\
N\end{array}$ & & \\
\hline SES & B176VI & MCNA & OFFSITE & so & SUB_SURFACE & SEDIMENT & 16-Jul-03 TOC (To & $\begin{array}{l}21600 \mathrm{r} \\
10800(h)\end{array}$ & $\begin{array}{l}\mathrm{mg} / \mathrm{kg} \\
\mathrm{mg} / \mathrm{kg}\end{array}$ & & & $\frac{\mathrm{N}}{\mathrm{N}}$ & & \\
\hline & B178P2 & & & so & SUB_s & & 3 TOC (Total organic carbon? & $12600 \mathrm{r}$ & $\mathrm{mg} / \mathrm{kg}$ & & & $\mathrm{N}$ & & \\
\hline SES & B178P6 & MCNARY-WA.SHORE & OFFSITE & so & SUB_SURFACE & SEDIMENT & TOC (Total organic carbon: & $214 r$ & $\mathrm{mg} / \mathrm{kg}$ & & & $\mathrm{N}$ & & \\
\hline & B17BP5 & MCNARY-W & OFFSITE & so & SUB_SURFACE & SEDIM & TOC (Total organic carbon: & & $\mathrm{mg} / \mathrm{kg}$ & & & $\mathrm{N}$ & & \\
\hline SESPMNT & B176V4 & H.SIDE NEAR DAM & OFFSITE & so & SUB_SURFACE & SEDIM & 16-Jul-03 TOC (Total organic carbon? & $8150 \mathrm{r}-2 \mathrm{r}-\mathrm{r}$ & $\mathrm{mg} / \mathrm{kg}$ & & & $\mathrm{N}$ & & \\
\hline $\begin{array}{l}\text { SESPMNT } \\
\text { SESPMNT }\end{array}$ & $\begin{array}{l}B 176 V 2 \\
B 176 V 1\end{array}$ & $\begin{array}{l}\text { PRD-GRANT SIDE NEAR DAM } \\
\text { PRD-YAIMA SIDE NEAR DAM }\end{array}$ & $\begin{array}{l}\text { OFFSITE } \\
\text { OFFITE }\end{array}$ & $\begin{array}{l}\text { so } \\
\text { so }\end{array}$ & $\begin{array}{l}\text { SUB_SURFACE } \\
\text { SUB_ SURACEE }\end{array}$ & $\begin{array}{l}\text { SEDIMENT } \\
\text { SEDMENT }\end{array}$ & 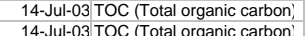 & $11700 \mathrm{r}$ & $\mathrm{mg} / \mathrm{kg}$ & & & $\mathrm{N}$ & & \\
\hline
\end{tabular}


(pCilg Dry Weight unless otherwise noted)

\begin{tabular}{|c|c|c|c|c|c|c|c|c|c|c|c|c|c|c|c|}
\hline OWNER ID & \begin{tabular}{|l} 
SAMP \\
NUM
\end{tabular} & SAMP SITE NAME & $\begin{array}{l}\text { DIST CLASS } \\
\text { CLAS }\end{array}$ & $\mid$ MEDIA & SAMP FROM & SAMP ITEM & SAMP DATE & CON SHORT NAME & $\begin{array}{l}\text { VALUE } \\
\text { RPTD }\end{array}$ & \begin{tabular}{|l|} 
ANAL \\
UNIIS \\
RPTD \\
\end{tabular} & $\begin{array}{c}\text { COUNTING } \\
\text { ERROR }\end{array} \mid$ & \begin{tabular}{|c|} 
TOTAL \\
ANAL \\
ERROR
\end{tabular} & \begin{tabular}{c|c} 
LAB \\
QUALIFIER
\end{tabular} & SAMP COMMENT & RESULT COMMENT \\
\hline $\begin{array}{l}\text { SESPMNT } \\
\text { SESPSPEC }\end{array}$ & $\begin{array}{l}\text { B17668 } \\
\text { B170V4 }\end{array}$ & $\begin{array}{l}\text { RICLLAND-RIAER } \\
\text { RINGOLD WASTEWAY }\end{array}$ & $\begin{array}{l}\text { liVER_SHORELINE } \\
\text { OFFSITE }\end{array}$ & $\begin{array}{l}\text { so } \\
\text { so }\end{array}$ & $\begin{array}{l}\text { SUB_SURFACE } \\
\text { SUB SURFAEE }\end{array}$ & $\begin{array}{l}\text { SEDIIENT } \\
\text { SEDIMENT }\end{array}$ & $\begin{array}{c}\text { 16--Jul-03 TC } \\
\text { 14-May-03 TC }\end{array}$ & $\begin{array}{l}\text { ToC (Total organic carbon', } \\
\text { OCC (Total organic carbon' }\end{array}$ & $\begin{array}{r}1950 \\
1560\end{array}$ & $\begin{array}{l}m g / k g \\
m g / k g\end{array}$ & & & $\frac{n}{n}$ & & \\
\hline SESPSPEC & B170V5 & RINGOLD WASTEWAY & OFFSITE & so & SUB_SURFACE & SEDIMENT & 14-May-03 TC & TOC (Total organic carbon'; & & & & & $\mathrm{N}$ & & \\
\hline SESPSPEC & B170V8 & WALLA WALLA-RIVER & OFFSITE & so & SUB_SURFACE & SEDIMENT & 15-May-03 T & OOC (Total organic carbon; & & & & & $\mathrm{N}$ & & \\
\hline $\begin{array}{l}\text { SESPSPEC } \\
\text { SECDMUT }\end{array}$ & B170V9 & WALLA WALLA-RIVER & OFFSITE & so s s r t a & SUB_SURFACE & SEDIMENTI & 15-May-03 T & $\operatorname{Toc}(\mathrm{TC})$ & 7880 & $\mathrm{mg} / \mathrm{kg}$ & & & $\mathrm{N}$ & & \\
\hline $\begin{array}{l}\text { SESPMNT } \\
\text { SESPSECC }\end{array}$ & B176T9 & WHITE BLUFFS SLOUGH & $\begin{array}{l}\text { RIVER_SHORELINE } \\
\text { ODESTEV }\end{array}$ & so s s & SUB_SURFACE & $\begin{array}{l}\text { SEDIMENT } \\
\text { SEDMENT }\end{array}$ & 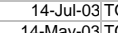 & OCC (Total organic carbon; & 11800 & $\mathrm{mg} / \mathrm{kg}$ & & & $\mathrm{N}$ & & \\
\hline $\begin{array}{l}\text { SESPPEC } \\
\text { SESPPEC }\end{array}$ & $\begin{array}{l}\text { B170W0 } \\
\text { B170W1 }\end{array}$ & $\begin{array}{l}\text { YAKMIMA RIVR } \\
\text { YAKIMA RIVER }\end{array}$ & $\begin{array}{l}\text { OFFSIIE } \\
\text { OFFSITE }\end{array}$ & so & $\begin{array}{l}\text { SUB_SURFAAE } \\
\text { SU_SURFACE }\end{array}$ & $\begin{array}{l}\text { SEDIMENT } \\
\text { SEDIMENT }\end{array}$ & $\begin{array}{l}\text { 14-May-03 T } \\
14 \text {-May-03 TS }\end{array}$ & $\begin{array}{l}\text { TOC (Total organic carbon', } \\
\text { TOC (Total organic carbon') }\end{array}$ & & $\begin{array}{l}\mathrm{mg} / \mathrm{kg} g \\
\mathrm{mg} / \mathrm{kg}\end{array}$ & & & $\frac{N}{N}$ & & \\
\hline SESPSPEC & B17BK4 & BONNEVILLE DAM MID-RIVER & OFFSITE & so & SUB_SURFACE & SEDIMENT & 07-Aug-03 H & & & & & & & & \\
\hline $\begin{array}{l}\text { SESPSPEC } \\
\text { SESPSEC }\end{array}$ & $\begin{array}{l}\text { B17BK6 } \\
\text { B17KK0 }\end{array}$ & $\begin{array}{l}\text { BONNEVILLE DAM WA.SHORE } \\
\text { DALES DAM MID-RVER }\end{array}$ & $\begin{array}{l}\text { OFFSITE } \\
\text { OFFITE }\end{array}$ & $\begin{array}{ll}\text { so } \\
\text { so }\end{array}$ & $\begin{array}{l}\text { SUB_SURFACE } \\
\text { SUB SURFAE }\end{array}$ & $\begin{array}{l}\text { SEDIMENT } \\
\text { SEDMENT }\end{array}$ & $\begin{array}{l}07 \text {-Aug- } 03 \mathrm{H} \\
07 \text {-Aug- } 03 \mathrm{H}\end{array}$ & & & & & & & $\begin{array}{l}\text { NO SAMPLE. } \\
\text { NO SAMPLE }\end{array}$ & \\
\hline
\end{tabular}


Table Sed-1. Acid Volatile Sulfide (AVS)/Simultaneously Extracted Metals (SEM) in Columbia River Sediment, 2003

Samp Num

B176X8

B176Y0

B176Y2

B176Y4

B17709

B17711

B17703

17701

B17BK3

B17BJ9

B17BK2

B17BJ6

B17BJ8

B17BJ

B17BJ4
Samp Site Name

WHITE BLUFFS SLOUGH

$100 \mathrm{~F} \mathrm{SLOUGH}$

HANFORD SLOUGH

RICHLAND-RIVER

MCNARY-OR.SIDE NEAR DAM

MCNARY-WASH.SIDE NEAR DAM

PRD-GRANT SIDE NEAR DAM

PRD-YAKIMA SIDE NEAR DAM

BONNEVILLE DAM OR.SHORE

DALLES DAM OR.SHORE

DALLES DAM WA.SHORE

JOHN DAY DAM OR.SHORE

JOHN DAY DAM MID-RIVER

JOHN DAY DAM WA.SHORE

MCNARY-OREGON SHORE

MCNARY-2/3 OR. SHORE

MCNARY-WASH. SHORE
Percent Dry AVS SEM Cd

Samp Date

14-Jul-03

14-Jul-03

14-Jul-03

16-Jul-03

16-Jul-03

14-Jul-03

14-Jul-03

07-Aug-03

07-Aug-03

07-Aug-03

08-Aug-03

08-Aug-03

08-Aug-03

08-Aug-03

08-Aug-03

08-Aug-03

50.5
78.9
58.5
71.2
53.8
61.7
47.2
51.1
49.0
48.9
73.8
36.7
38.5
51.8
39.3
57.7
59.9

SEM Cu (umole/g)

$13.5 \quad 0.0240$

$\begin{array}{ll}1.74 & 0.00534\end{array}$

$\begin{array}{ll}7.29 & 0.0325\end{array}$

$0.413 \quad 0.00488$

1.55

$0.124 \mathrm{U}$

0.00488
0.0109

0.0117

$\begin{array}{ll}7.47 & 0.0770\end{array}$

$3.83 \quad 0.0442$

$3.63 \quad 0.00533$

$4.17 \quad 0.00827$

$0.0511 \mathrm{U} \quad 0.00326$

$3.29 \quad 0.0143$

$7.57 \quad 0.0143$

$8.39 \quad 0.0161$

$4.90 \quad 0.0129$

$0.118 \cup \quad 0.0104$

$0.0687 \cup \quad 0.00896$

0.176
0.078

0.190

0.191

0.251

0.195

0.351

0.461

0.202

0.21

0.0693

0.430

0.295

0.279

0.268

0.185

0.148
SEM Hg

SEM Ni

0.176

0.0000113

0.00000366

0.0000110

0.0000152

0.00000498

0.000217

0.00000649

0.00000827

0.00001046

0.0000177

0.0000292

0.0000154

0.0000166

0.00000868

0.0000213

0.000162

0.000116

0.0763

0.0411

0.108

0.0303

0.133

0.0948
0.157

0.157

0.103

0.0970

0.0462

0.174

0.142

0.158

0.155
0.0979

0.0979

0.0807
SEM Pb

SEM Zn

$0.166 \quad 5.36$

$0.0480 \quad 1.71$

$0.143 \quad 7.40$

$0.158 \quad 2.23$

$0.0791 \quad 2.34$

$0.0809 \quad 2.33$

8.38

$0.184 \quad 6.01$

$0.0540 \quad 1.54$

$0.0590 \quad 1.84$

$\begin{array}{ll}0.0332 & 0.766 \\ 0.105 & 2.82\end{array}$

$\begin{array}{ll}0.0930 & 2.92\end{array}$

$0.0870 \quad 2.48$

$0.0834 \quad 2.45$

$\begin{array}{ll}0.0610 & 2.26 \\ 0.74\end{array}$ 


\section{External Radiation}


EXTERNAL RADIATION

\begin{tabular}{|c|c|c|c|c|c|c|c|c|c|c|c|c|}
\hline OWNER ID & SAMP NUM & SITE NAME & DIST CLASS & MEDIA & |SAMP DATE & $\begin{array}{c}\text { CON SHORT } \\
\text { NAME }\end{array}$ & VALUE RPTD & \begin{tabular}{|l} 
ANAL \\
UNITS \\
RPTD
\end{tabular} & $\mid \begin{array}{c}\text { COUNTING } \\
\text { ERROR }\end{array}$ & $\begin{array}{c}\text { LAB } \\
\text { QUALIFIER } \\
\end{array}$ & SAMP COMMENT & RESULT COMMENT \\
\hline SESPMNT & B16KP3 & 100 B REACTOR MUSEUM & ONSITE & $E R$ & 18-Mar-03 & TLD & 0.237 & $\mathrm{mR} / \mathrm{d}$ & 0.011 & & & \\
\hline $\begin{array}{l}\text { SESPMNT } \\
\text { SESPMNT }\end{array}$ & B172J8 & 100 B REACTOR MUSEUM & ONSITE & ER & 24-Jun-03 & TLD & 0.23 & $\mathrm{mR} / \mathrm{d}$ & 0.006 & & & \\
\hline & B17J97 & 100 B REACTOR MUSEUM & ONSITE & ER & 15-Sep-037 & TLD & 0.236 & $\mathrm{mR} / \mathrm{d}$ & 0.007 & & & \\
\hline $\begin{array}{l}\text { SESPMNT } \\
\text { SESPMNT }\end{array}$ & $\begin{array}{l}\text { B186P8 } \\
\text { B16K19 }\end{array}$ & $\begin{array}{l}100 \text { B REACTOR MUSEUM } \\
100 \text { AREA }\end{array}$ & $\begin{array}{l}\text { ONSITE } \\
\text { ONSIE }\end{array}$ & ER & 22-Dec-037 & TLD & 0.208 & $\mathrm{mR/d}$ & 0.014 & & & \\
\hline SESPMNT & $\begin{array}{l}\text { B16KL9 } \\
\text { B172F7 }\end{array}$ & $\begin{array}{l}100 \text { D AREA } \\
100 \text { D AREA }\end{array}$ & $\begin{array}{l}\text { ONSTIE } \\
\text { ONSITE }\end{array}$ & $\begin{array}{l}\text { ER } \\
\text { ER }\end{array}$ & $\begin{array}{l}\text { 18-Mar-037 } \\
24-\mathrm{Jun}-037\end{array}$ & $\begin{array}{l}\text { TLD } \\
\text { TLD }\end{array}$ & $0.225 \mathrm{r}$ & $\begin{array}{l}\mathrm{mR/d} \\
\mathrm{mR/d}\end{array}$ & $\begin{array}{l}0.006 \\
0.002\end{array}$ & & & \\
\hline SESPMNT & B17J32 & 100 D AREA & ONSITE & ER & $15-$ Sep-03 & TLD & 0.234 & $\mathrm{mR} / \mathrm{d}$ & 0 & & & \\
\hline SESPMNT & B186M4 & 100 D AREA & ONSITE & ER & 22-Dec-03 & TLD & 0.245 & $\mathrm{mR} / \mathrm{d}$ & 0.012 & & & \\
\hline SESPMNT & B16KL1 & $100 \mathrm{~F}$ FLOOD PLAIN & RIVER_SHORELINE & ER & 19-Mar-03 & TLD & 0.23 & $\mathrm{mR} / \mathrm{d}$ & 0.009 & & & \\
\hline SESPMNT & B172B8 & $100 \mathrm{~F} F L O O D$ PLAIN & RIVER_SHORELINE & ER & 16-Jun-03 & TLD & 0.233 & $\mathrm{mR} / \mathrm{d}$ & 0.002 & & & \\
\hline SESPMNT & B17J24 & $100 \mathrm{~F} F L O O D$ PLAIN & RIVER_SHORELINE & ER & $15-$ Sep-037 & TLD & $0.224 i$ & & 0.002 & & & \\
\hline SESPMNT & B186L6 & $100 \mathrm{~F}$ FLOOD PLAIN & RIVER_SHORELINE & ER & 22-Dec-03] & TLD & 0.23 & $\mathrm{mR} / \mathrm{d}$ & 0.002 & & & \\
\hline SESPMNT & B16KN5 & $100 \mathrm{~F}$ MET TOWER & ONSITE & ER & 18-Mar-03 & & 0.223 & & 0.005 & & & \\
\hline SESPMNT & B172J3 & 100 F MET TOWER & ONSITE & ER & 24-Jun-03 & & 0.233 & & 0.007 & & & \\
\hline SESPMNT & B17J48 & $100 \mathrm{~F}$ MET TOWER & ONSITE & ER & $15-$ Sep-03 & & 0.236 & & 0.004 & & & \\
\hline SESPMNT & B186P0 & $100 \mathrm{~F}$ MET TOWER & ONSITE & ER & 22-Dec-03 & & 0.231 & $\mathrm{mR} / \mathrm{d}$ & 0.015 & & & \\
\hline SESPMNT & B16K95 & $100 \mathrm{H}$ AREA & RIVER_SHORELINE & ER & 14-Mar-03 & & $0.221 r$ & $\mathrm{mR} / \mathrm{d}$ & 0.003 & & & \\
\hline SESPMNT & B174M3 & $100 \mathrm{H}$ AREA & RIVER_SHORELINE & ER & 02-Jul-03 & TLD & 0.22 & $\mathrm{mR} / \mathrm{d}$ & 0.003 & & & \\
\hline SESPMNT & B17JY5 & $100 \mathrm{H}$ AREA & RIVER_SHORELINE & ER & 29-Sep-03] & TLD & $0.245 r$ & $\mathrm{mR} / \mathrm{d}$ & 0 & & & \\
\hline SESPMNT & B18505 & $100 \mathrm{H}$ AREA & RIVER_SHORELINE & ER & 15-Dec-037 & TLD & 0.236 & $\mathrm{mR} / \mathrm{d}$ & 0.021 & & & \\
\hline SESPMNT & B16KM0 & $100 \mathrm{~K}$ AREA & ONSITE & ER & 18-Mar-03 & TLD & 0.202 & $\mathrm{mR} / \mathrm{d}$ & 0.008 & & & \\
\hline SESPMNT & B172F8 & $100 \mathrm{~K}$ AREA & ONSITE & ER & 24-Jun-03 7 & TLD & 0.196 & $\mathrm{mR} / \mathrm{d}$ & 0.003 & & & \\
\hline SESPMNT & B17J33 & $100 \mathrm{~K}$ AREA & ONSITE & ER & $15-\mathrm{Sep}-037$ & TLD & 0.199 & $\mathrm{mR} / \mathrm{d}$ & 0.008 & & & \\
\hline SESPMNT & B186M5 & $100 \mathrm{~K}$ AREA & ONSITE & ER & 22-Dec-037 & TLD & $0.19 \mathrm{r}$ & $\mathrm{mR} / \mathrm{d}$ & 0.006 & & & \\
\hline SESPMNT & B16K64 & 100 N TRENCH SPRING & RIVER_SHORELINE & ER & 14-Mar-03 & TLD & $0.264 \mathrm{r}$ & $\mathrm{mR/d}$ & 0.008 & & & \\
\hline SESPMNT & B174J2 & 100 N TRENCH SPRING & RIVER_SHORELINE & ER & 02-Jul-03 ] & TLD & $0.262 r$ & $\mathrm{mR} / \mathrm{d}$ & 0.003 & & & \\
\hline SESPMNT & B17JW3 & 100 N TRENCH SPRING & RIVER_SHORELINE & ER & 29-Sep-03] & TLD & 0.283 & $\mathrm{mR} / \mathrm{d}$ & 0.003 & & & \\
\hline $\begin{array}{l}\text { SESPMNT } \\
\text { SECPANT }\end{array}$ & B184T9 & $100 \mathrm{~N}$ TRENCH SPRING & RIVER_SHORELINE & ER & 15-Dec-037 & TLD & $0.275 r$ & $\mathrm{mR} / \mathrm{d}$ & 0.001 & & & \\
\hline $\begin{array}{l}\text { SESPMNT } \\
\text { SESPANT }\end{array}$ & B16K89 & 100-D ISLAND & RIVER_SHORELINE & ER & 14-Mar-03] & TLD & 0.223 & $\mathrm{mR} / \mathrm{d}$ & 0.008 & & & \\
\hline $\begin{array}{l}\text { SESPMNT } \\
\text { SESPMNT }\end{array}$ & B174L7 & 100-D ISLAND & RIVER_SHORELINE & ER & 02-Jul-037] & TLD & 0.206 & $\mathrm{mR} / \mathrm{d}$ & 0.003 & & & \\
\hline $\begin{array}{l}\text { SESPMNT } \\
\text { SESPMNT }\end{array}$ & B17JX9 & 100-D ISLAND & RIVER_SHORELINE & ER & 29-Sep-037] & TLD & 0.219 & $\mathrm{mR/d}$ & 0 & & & \\
\hline SESPMNT & B184X5 & 100-D ISLAND & RIVER_SHORELINE & ER & 15-Dec-03] & TLD & & & & & $\begin{array}{l}\text { NO SAMPLE. TLD MISSING AND SIGNS IN AREA ON THE } \\
\text { GROUND. }\end{array}$ & \\
\hline SESPMNT & B16LH1 & 200 ESE & ONSITE & ER & $26-\mathrm{Mar}-03$ & TLD & 0.232 & $\mathrm{mR} / \mathrm{d}$ & 0.012 & & & \\
\hline SESPMNT & B172D2 & 200 ESE & ONSITE & ER & 17-Jun-037 & TLD & $0.24 r$ & $\mathrm{mR} / \mathrm{d}$ & 0.009 & & & \\
\hline SESPMNT & B17JV4 & 200 ESE & ONSITE & ER & 22-Sep-037 & TLD & $0.242 r$ & $\mathrm{mR} / \mathrm{d}$ & 0.005 & & & \\
\hline SESPMNT & B184Y6 & 200 ESE & ONSITE & ER & 17-Dec-037 & TLD & 0.232 & $\mathrm{mR} / \mathrm{d}$ & 0.002 & & & \\
\hline SESPMNT & B16LH2 & 200 TEL. EXCHANGE & ONSITE & ER & 26-Mar-03 & TLD & $0.235 \mathrm{r}$ & $\mathrm{mR/d}$ & 0.007 & & & \\
\hline SESPMNT & B172D3 & 200 TEL. EXCHANGE & ONSITE & ER & 17-Jun-03 & TLD & $0.223 r$ & $\mathrm{mR} / \mathrm{d}$ & 0.012 & & & \\
\hline SESPMNT & B17JV5 & 200 TEL. EXCHANGE & ONSITE & ER & 22-Sep-03] & TLD & $0.221 \mathrm{r}$ & $\mathrm{mR} / \mathrm{d}$ & 0.007 & & & \\
\hline $\begin{array}{l}\text { SESPMNT } \\
\text { SESPMNT }\end{array}$ & B184Y7 & 200 TEL. EXCHANGE & ONSITE & ER & 17-Dec-03] & TLD & $0.221 \mathrm{r}$ & $\mathrm{mR} / \mathrm{d}$ & 0.007 & & & \\
\hline SESPMNT & B16LH3 & 200 W SE & ONSITE & ER & 26-Mar-03] & TLD & 0.223 & $\mathrm{mR} / \mathrm{d}$ & 0.001 & & & \\
\hline $\begin{array}{l}\text { SESPMNT } \\
\text { SESPMNT }\end{array}$ & B172D4 & 200 W SE & ONSITE & ER & 17-Jun-03] & TLD & 0.216 & $\mathrm{mR} / \mathrm{d}$ & 0.006 & & & \\
\hline $\begin{array}{l}\text { SESPMNT } \\
\text { SESPMNT }\end{array}$ & B17JV6 & 200 W SE & ONSITE & ER & 22-Sep-037] & TLD & 0.2291 & $\mathrm{mR/d}$ & 0.015 & & & \\
\hline $\begin{array}{l}\text { SESPMNT } \\
\text { SESPMNT }\end{array}$ & B184Y8 & 200 W SE & ONSITE & ER & 17-Dec-037 & TLD & $0.227 i$ & $\mathrm{mR/d}$ & 0.002 & & & \\
\hline $\begin{array}{l}\text { SESPMNT } \\
\text { SESPMNT }\end{array}$ & B16KNO & $300 \mathrm{NE}$ & ONSITE & ER & 20-Mar-037] & TLD & $0.24 r$ & $\mathrm{mR/d}$ & 0.017 & & & \\
\hline $\begin{array}{l}\text { SESPMNT } \\
\text { SESPMNT }\end{array}$ & $\begin{array}{l}\text { B172H8 } \\
\text { B17443 }\end{array}$ & $\begin{array}{l}300 \mathrm{NE} \\
300 \mathrm{NE}\end{array}$ & $\begin{array}{l}\text { ONSITE } \\
\text { ONSITE }\end{array}$ & $\begin{array}{l}\text { ER } \\
E R\end{array}$ & $\begin{array}{l}25-J u n-03 \\
17-5 \text { eno }-037\end{array}$ & TLD & 0.231 & $m \mathrm{~m} / \mathrm{d}$ & 0.004 & & & \\
\hline $\begin{array}{l}\text { SESPMNI } \\
\text { SESPMNT }\end{array}$ & $\begin{array}{l}\text { B1/843 } \\
\text { B186N5 }\end{array}$ & $\begin{array}{l}300 \mathrm{NE} \\
300 \mathrm{NE}\end{array}$ & $\begin{array}{l}\text { ONSITE } \\
\text { ONSE }\end{array}$ & $\begin{array}{l}E R \\
E R\end{array}$ & $\begin{array}{l}\text { 17-Sep-03 } \\
23-\mathrm{Dec}-03\end{array}$ & TLD & $0.231 \mathrm{i}$ & $\begin{array}{l}\mathrm{mRR/d} \\
\mathrm{mR} / \mathrm{d}\end{array}$ & $\begin{array}{l}0.004 \\
0.005\end{array}$ & & & \\
\hline SESPMNT & B16KM8 & 300 SOUTH GATE & ONSITE & ER & 20-Mar-03 & TLD & 0.217 & $\mathrm{mR} / \mathrm{d}$ & 0.004 & & & \\
\hline SESPMNT & $\mathrm{B} 172 \mathrm{H} 6$ & 300 SOUTH GATE & ONSITE & ER & 25-Jun-03 & TLD & 0.23 & $\mathrm{mR} / \mathrm{d}$ & 0.018 & & & \\
\hline SESPMNT & B17J41 & 300 SOUTH GATE & ONSITE & ER & 17-Sep-03 & TLD & 0.22 & $\mathrm{mR} / \mathrm{d}$ & 0 & & & \\
\hline SESPMNT & B186N3 & 300 SOUTH GATE & ONSITE & ER & 23-Dec-03 & TLD & 0.24 & $\mathrm{mR} / \mathrm{d}$ & 0.003 & & & \\
\hline SESPMNT & B16KM9 & 300 SOUTHWEST GATE & ONSITE & ER & 20-Mar-03 & TLD & 0.214 & $\mathrm{mR} / \mathrm{d}$ & 0.004 & & & \\
\hline SESPMNT & $\mathrm{B} 172 \mathrm{H} 7$ & 300 SOUTHWEST GATE & ONSITE & ER & 25-Jun-03 & TLD & 0.213 & $\mathrm{mR} / \mathrm{d}$ & 0.002 & & & \\
\hline SESPMNT & B17J42 & 300 SOUTHWEST GATE & ONSITE & ER & 17-Sep-037 & TLD & $0.217 i$ & $\mathrm{mR} / \mathrm{d}$ & 0 & & & \\
\hline SESPMNT & B186N4 & 300 SOUTHWEST GATE & ONSITE & ER & 23-Dec-037 & TLD & $0.224 i$ & $\mathrm{mR} / \mathrm{d}$ & 0.013 & & & \\
\hline SESPMNT & B16KM5 & 300 TRENCH & ONSITE & ER & 20-Mar-03 & TLD & 0.229 & $\mathrm{mR} / \mathrm{d}$ & 0.011 & & & \\
\hline SESPMNT & $\mathrm{B} 172 \mathrm{H} 3$ & 300 TRENCH & ONSITE & ER & 25-Jun-03 & TLD & 0.238 & $\mathrm{mR} / \mathrm{d}$ & 0.001 & & & \\
\hline SESPMNT & B17J38 & 300 TRENCH & ONSITE & ER & $17-$ Sep-03 & TLD & 0.248 & $\mathrm{mR} / \mathrm{d}$ & 0.006 & & & \\
\hline SESPMNT & B186N0 & 300 TRENCH & ONSITE & ER & 23-Dec-03 & TLD & 0.233 & $\mathrm{mR} / \mathrm{d}$ & 0.004 & & & \\
\hline SESPMNT & B16KM7 & 300 WATER INTAKE & ONSITE & ER & $20-\mathrm{Mar}-037$ & TLD & 0.213 & $\mathrm{mR} / \mathrm{d}$ & 0.015 & & & \\
\hline SESPMNT & $\mathrm{B} 172 \mathrm{H} 5$ & 300 WATER INTAKE & ONSITE & ER & 25-Jun-03 & TLD & 0.216 & $\mathrm{mR} / \mathrm{d}$ & 0.003 & & & \\
\hline SESPMNT & B17J40 & 300 WATER INTAKE & ONSITE & ER & 17-Sep-03] & TLD & $0.22 r$ & $\mathrm{mR} / \mathrm{d}$ & 0.012 & & & \\
\hline SESPMNT & B186N2 & 300 WATER INTAKE & ONSITE & ER & 23-Dec-03] & TLD & $0.209 i$ & $\mathrm{mR} / \mathrm{d}$ & 0.001 & & & \\
\hline SESPMNT & B16KP4 & 313 BLDG. & ONSITE & ER & 20-Mar-037] & TLD & 0.273 & $\mathrm{mR} / \mathrm{d}$ & 0.005 & & & \\
\hline SESPMNT & B172J9 & 313 BLDG. & ONSITE & ER & 25-Jun-037 ب ب & TLD & $0.262 \mathrm{I}$ & $\mathrm{mR/d}$ & 0 & & & \\
\hline
\end{tabular}


EXTERNAL RADIATION

\begin{tabular}{|c|c|c|c|c|c|c|c|c|c|c|c|c|}
\hline OWNER ID & SAMP NUM & SITE NAME & DIST CLASS & MEDIA & SAMP DATE & $\begin{array}{c}\text { CON SHORT } \\
\text { NAME }\end{array}$ & |VALUE RPTD & \begin{tabular}{|l|} 
ANAL \\
UNIIS \\
RPTD
\end{tabular} & $\left|\begin{array}{c}\text { COUNTING } \\
\text { ERROR }\end{array}\right|$ & $\mid \begin{array}{c}\text { LAB } \\
\text { QUALIFIER }\end{array}$ & SAMP COMMENT & RESULT COMMENT \\
\hline SESPMNT & B17J98 & 313 BLDG. & ONSITE & ER & $17-S e p-03$ & TLD & 0.272 & & 0.006 & & & \\
\hline SESPMNT & B186P9 & 313 BLDG. & ONSITE & ER & 23-Dec-03 & TLD & 0.25 & $\mathrm{mR} / \mathrm{d}$ & 0.003 & & & \\
\hline SESPMNT & B16KM6 & 3705 BLDG. 300 AREA & ONSITE & ER & 20-Mar-03 & TLD & 0.229 & $\mathrm{mR} / \mathrm{d}$ & 0.001 & & & \\
\hline SESPMNT & B172H4 & 3705 BLDG. 300 AREA & ONSITE & ER & 25-Jun-03 & TLD & $0.227 i$ & $\mathrm{mR} / \mathrm{d}$ & 0.007 & & & \\
\hline SESPMNT & B17J39 & 3705 BLDG. 300 AREA & ONSITE & ER & 17-Sep-03 & TLD & $0.237 i$ & $\mathrm{mR} / \mathrm{d}$ & 0.002 & & TLD FOUND ON GROUND. & \\
\hline SESPMNT & B186N1 & 3705 BLDG. 300 AREA & ONSITE & ER & 23-Dec-03 & TLD & 0.221 & $\mathrm{mR} / \mathrm{d}$ & 0.002 & & & \\
\hline SESPMNT & B16KN1 & $400 \mathrm{E}$ & ONSITE & ER & 18-Mar-03 & & 0.221 & & 0.001 & & & \\
\hline SESPMNT & $\mathrm{B} 172 \mathrm{H} 9$ & $400 \mathrm{E}$ & ONSITE & ER & 24-Jun-03 & TLD & 0.226 & $\mathrm{mR} / \mathrm{d}$ & 0.001 & & & \\
\hline SESPMNT & B17J44 & $400 \mathrm{E}$ & ONSITE & ER & $15-\operatorname{Sep}-03$ & & 0.231 & & 0.002 & & & \\
\hline SESPMNT & B186N6 & $400 \mathrm{E}$ & ONSITE & ER & 22-Dec-03 & & 0.23 & & 0.002 & & & \\
\hline SESPMNT & B16KN2 & $400 \mathrm{~N}$ & ONSITE & ER & 18-Mar-03 & & 0.219 & & 0.005 & & & \\
\hline SESPMNT & B172J0 & $400 \mathrm{~N}$ & ONSITE & ER & 24-Jun-03 & & 0.217 & & 0.001 & & & \\
\hline SESPMNT & B17J45 & $400 \mathrm{~N}$ & ONSITE & ER & 15-Sep-03 & & 0.224 & & 0 & & & \\
\hline SESPMNT & B186N7 & $400 \mathrm{~N}$ & ONSITE & ER & 22-Dec-03 & & 0.224 & & 0.005 & & & \\
\hline SESPMNT & B16KN3 & $400 \mathrm{~s}$ & ONSITE & ER & 18-Mar-03 & & 0.224 & $\mathrm{mR} / \mathrm{d}$ & 0.002 & & & \\
\hline SESPMNT & B172J1 & $400 \mathrm{~s}$ & ONSITE & ER & 24-Jun-03 & & 0.21 & $\mathrm{mR} / \mathrm{d}$ & 0.009 & & & \\
\hline SESPMNT & B17J46 & $400 \mathrm{~s}$ & ONSITE & ER & $15-$ Sep-03 & & $0.234 r$ & $\mathrm{mR} / \mathrm{d}$ & 0.017 & & & \\
\hline SESPMNT & B186N8 & $400 \mathrm{~S}$ & ONSITE & ER & 22-Dec-03 & & $0.228 \mathrm{i}-\mathrm{r}-\mathrm{r}-\mathrm{r}$ & $\mathrm{mR} / \mathrm{d}$ & 0.002 & & & \\
\hline SESPMNT & B16KN4 & $400 \mathrm{~W}$ & ONSITE & ER & 18-Mar-03 & & 0.243 & $\mathrm{mR} / \mathrm{d}$ & 0.003 & & & \\
\hline SESPMNT & B172J2 & $400 \mathrm{~W}$ & ONSITE & ER & 24-Jun-03 & & 0.228 & $\mathrm{mR} / \mathrm{d}$ & 0.006 & & & \\
\hline SESPMNT & B17J47 & $400 \mathrm{~W}$ & ONSITE & ER & 15-Sep-03 & & 0.229 & & 0.009 & & & \\
\hline SESPMNT & B186N9 & $400 \mathrm{~W}$ & ONSITE & ER & 22-Dec-03 & & $0.244 r$ & $\mathrm{mR} / \mathrm{d}$ & 0.006 & & TLD FOUND ON GROUND 11/11/03. & \\
\hline $\begin{array}{l}\text { SESPMNT } \\
\text { SESDMNT }\end{array}$ & B16K86 & ABOVE $100 \mathrm{~B}$ AREA & RIVER_SHORELINE & ER & 14-Mar-03 & & $0.217 \mathrm{i}$ & $\mathrm{mR} / \mathrm{d}$ & 0.003 & & & \\
\hline $\begin{array}{l}\text { SESPMNT } \\
\text { SESPMNT }\end{array}$ & B174L4 & ABOVE $100 \mathrm{~B}$ AREA & RIVER_SHORELINE & ER & 02-Jul-03 & & $0.225 \mathrm{r}$ & $\mathrm{mR} / \mathrm{d}$ & 0.004 & & & \\
\hline $\begin{array}{l}\text { SESPMNT } \\
\text { SESPMNT }\end{array}$ & B17JX6 & ABOVE $100 \mathrm{~B}$ AREA & RIVER_SHORELINE & ER & 29-Sep-03 & TLD & 0.252 & $\mathrm{mR} / \mathrm{d}$ & 0.007 & & & \\
\hline $\begin{array}{l}\text { SESPMNT } \\
\text { SESPMNT }\end{array}$ & $\begin{array}{l}\text { B184X2 } \\
\text { B16K85 }\end{array}$ & ABOVE 100 B AREA & RIVER_SHORELINE & ER & 15-Dec-03 & TLD & 0.243 & $\mathrm{mR} / \mathrm{d}$ & 0.008 & & & \\
\hline $\begin{array}{l}\text { SESPMNT } \\
\text { SESPMNT }\end{array}$ & $\begin{array}{l}\text { B16K85 } \\
\text { B1743 }\end{array}$ & $\begin{array}{l}\text { ABOVE 1K BOAT RAMP } \\
\text { ABOVE 1K BOAT RAMP }\end{array}$ & $\begin{array}{l}\text { RIVER_SHORELINE } \\
\text { RIVER SHOREINE }\end{array}$ & $\begin{array}{l}\text { ER } \\
\text { ER }\end{array}$ & 14-Mar-03 & TLD & 0.218 & $\mathrm{mR} / \mathrm{d}$ & 0.006 & & & \\
\hline SESPMNT & B17JX5 & ABOVE 1K BOAT RAMP & $\begin{array}{l}\text { RIVER_SHOREINE } \\
\text { RIVER SHOREINE }\end{array}$ & ER & $\begin{aligned} 02-\mathrm{Ju}-03 \\
29-\mathrm{S}-\mathrm{0} \\
\mathbf{2}\end{aligned}$ & $\begin{array}{l}\text { TLD } \\
\text { TLD }\end{array}$ & $0.221 i$ & $\begin{array}{l}\frac{m R / d}{m R / d} \\
m R\end{array}$ & $\begin{array}{l}0.007 \\
0.01\end{array}$ & & & \\
\hline SESPMNT & B184X1 & ABOVE 1K BOAT RAMP & RIVER_SHORELINE & ER & 15-Dec-03 & TLD & 0.229 & $\mathrm{mR} / \mathrm{d}$ & 0.005 & & & \\
\hline SESPMNT & B16K66 & ABOVE TIP 100N BERM & RIVER_SHORELINE & ER & 14-Mar-03 & TLD & 0.23 & $\mathrm{mR} / \mathrm{d}$ & 0.005 & & & \\
\hline SESPMNT & B174J4 & ABOVE TIP 100 N BERM & RIVER_SHORELINE & ER & 02-Jul-03 & TLD & 0.223 & $\mathrm{mR} / \mathrm{d}$ & 0.004 & & & \\
\hline SESPMNT & B17JW5 & ABOVE TIP 100 N BERM & RIVER_SHORELINE & ER & 29-Sep-03 & TLD & 0.235 & $\mathrm{mR} / \mathrm{d}$ & 0.003 & & & \\
\hline SESPMNT & B184V2 & ABOVE TIP 100 N BERM & RIVER_SHORELINE & ER & 15-Dec-03 & TLD & 0.231 I & $\mathrm{mR} / \mathrm{d}$ & 0.005 & & & \\
\hline SESPMNT & B16LF0 & ARMY LOOP CAMP & ONSITE & ER & 26-Mar-03 & TLD & 0.239 & $\mathrm{mR} / \mathrm{d}$ & 0.001 & & & \\
\hline SESPMNT & B172B2 & ARMY LOOP CAMP & ONSITE & ER & 17-Jun-03 & TLD & $0.228 i$ & $\mathrm{mR} / \mathrm{d}$ & 0 & & & \\
\hline SESPMNT & B17JR4 & ARMY LOOP CAMP & ONSITE & ER & $22-S e p-03$ & TLD & 0.237 & $\mathrm{mR} / \mathrm{d}$ & 0.006 & & & \\
\hline SESPMNT & B184T5 & ARMY LOOP CAMP & ONSITE & ER & 17-Dec-03 & & 0.244 & $\mathrm{mR} / \mathrm{d}$ & 0.013 & & & \\
\hline SESPMNT & B16LHO & B POND & ONSITE & ER & 26-Mar-03 & & 0.219 & $\mathrm{mR} / \mathrm{d}$ & 0.004 & & & \\
\hline SESPMNT & B172D1 & B POND & ONSITE & ER & 17-Jun-03 & & 0.214 & $\mathrm{mR} / \mathrm{d}$ & 0.008 & & & \\
\hline SESPMNT & B17JV3 & B POND & ONSITE & ER & 22-Sep-03 & TLD & 0.233 & $\mathrm{mR} / \mathrm{d}$ & 0.016 & & & \\
\hline SESPMNT & B184Y5 & B POND & ONSITE & ER & 17-Dec-03 & TLD & 0.226 & $\mathrm{mR} / \mathrm{d}$ & 0 & & & \\
\hline SESPMNT & B16LH7 & BASIN CITY SCHOOL & COMMUNITY & ER & 28-Mar-03 & TLD & $0.21 \mathrm{r}$ & $\mathrm{mR} / \mathrm{d}$ & 0.005 & & & \\
\hline SESPMNT & B172D8 & BASIN CITY SCHOOL & COMMUNITY & ER & 19-Jun-03 & TLD & 0.212 & $\mathrm{mR} / \mathrm{d}$ & 0.008 & & & \\
\hline SESPMNT & B17JW0 & BASIN CITY SCHOOL & COMMUNITY & ER & $25-$ Sep-03 & TLD & & & & & NO SAMPLE. TLD MISSING. & \\
\hline SESPMNT & B18502 & BASIN CITY SCHOOL & COMMUNITY & ER & 19-Dec-03 & TLD & & & & & NO SAMPLE. TLD MISSING. & \\
\hline SESPMNT & B16KM4 & BATTELLE COMPLEX & PERIMETER & ER & 20-Mar-03 & TLD & 0.219 & $\mathrm{mR} / \mathrm{d}$ & 0 & & & \\
\hline SESPMNT & $\mathrm{B} 172 \mathrm{H} 2$ & BATTELLE COMPLEX & PERIMETER & ER & $25-J u n-03$ & TLD & $0.21 r$ & $\mathrm{mR} / \mathrm{d}$ & 0.005 & & & \\
\hline SESPMNT & B17J37 & BATTELLE COMPLEX & PERIMETER & ER & 17-Sep-03 & TLD & $0.215 r$ & $\mathrm{mR} / \mathrm{d}$ & 0.002 & & & \\
\hline $\begin{array}{l}\text { SESPMNT } \\
\text { SESPMNT }\end{array}$ & B186M9 & BATTELLE COMPLEX & PERIMETER & ER & 23-Dec-03 & TLD & $0.229 r$ & $\mathrm{mR} / \mathrm{d}$ & 0.008 & & & \\
\hline $\begin{array}{l}\text { SESPMNT } \\
\text { SESPMNT }\end{array}$ & B16K88 & BELOW 100 D AREA & RIVER_SHORELINE & ER & 14-Mar-03 & TLD & 0.209 & $\mathrm{mR} / \mathrm{d}$ & 0.006 & & & \\
\hline $\begin{array}{l}\text { SESPMNT } \\
\text { SESPMNT }\end{array}$ & $\begin{array}{l}\text { B174L6 } \\
\text { B17|Xg }\end{array}$ & $\begin{array}{l}\text { BELOW } 100 \text { D AREA } \\
\text { BEI }\end{array}$ & RIVER_SHORELINE & ER & 02-Jul-03 & TLD & 0.171 & $\mathrm{mR} / \mathrm{d}$ & 0.004 & & & \\
\hline $\begin{array}{l}\text { SESPMNI } \\
\text { SESPMNT }\end{array}$ & $\begin{array}{l}\text { B17JX8 } \\
\text { B184X4 }\end{array}$ & $\begin{array}{l}\text { BELOW } 100 \text { D AREA } \\
\text { BELOW } 100 \text { D AREA }\end{array}$ & $\begin{array}{l}\text { RIVER_SHOREINE } \\
\text { RIVER SHOREINE }\end{array}$ & $\begin{array}{l}\text { ER } \\
E R\end{array}$ & $\begin{array}{l}29-S \mathrm{ep}-03 \\
15-\mathrm{D}-\mathrm{D}\end{array}$ & $\begin{array}{l}\text { TLD } \\
\text { TLD }\end{array}$ & 0.202 i 0.196 & $\begin{array}{l}\mathrm{mRR/d} \\
\mathrm{mRR} / \mathrm{d}\end{array}$ & $\begin{array}{l}0.002 \\
0.01\end{array}$ & & & \\
\hline SESPMNT & B16K93 & BELOW $100 \mathrm{~F}$ & RIVER_SHORELINE & ER & 14-Mar-03 & TLD & 0.218 & $\mathrm{mR} / \mathrm{d}$ & 0.004 & & & \\
\hline SESPMNT & B174M1 & BELOW $100 \mathrm{~F}$ & RIVER SHORELINE & $E R$ & 02-Jul-03 & TLD & 0.216 & $\mathrm{mR} / \mathrm{d}$ & 0.003 & & & \\
\hline SESPMNT & B17JY3 & BELOW $100 \mathrm{~F}$ & RIVER SHORELINE & ER & $29-\mathrm{Sep}-03$ & TLD & 0.234 & $\mathrm{mR/d}$ & 0.011 & & & \\
\hline SESPMNT & B184X9 & BELOW $100 \mathrm{~F}$ & RIVER_SHORELINE & ER & 15-Dec-03 & TLD & 0.232 & $\mathrm{mR} / \mathrm{d}$ & 0.011 & & & \\
\hline SESPMNT & B16K87 & BELOW 100B RET BASIN & RIVER SHORELINE & ER & 14-Mar-03 & TLD & 0.272 & $\mathrm{mR} / \mathrm{d}$ & 0.004 & & & \\
\hline SESPMNT & B174L5 & BELOW 100B RET BASIN & RIVER_SHORELINE & ER & 02-Jul-03 & TLD & 0.259 & $\mathrm{mR} / \mathrm{d}$ & 0.006 & & & \\
\hline SESPMNT & B17JX7 & BELOW 100B RET BASIN & RIVER_SHORELINE & ER & 29-Sep-03 & TLD & 0.271 & $\mathrm{mR} / \mathrm{d}$ & 0.001 & & & \\
\hline SESPMNT & B184X3 & BELOW 100B RET BASIN & RIVER_SHORELINE & ER & 15-Dec-03 & TLD & 0.275 & $\mathrm{mR} / \mathrm{d}$ & 0.011 & & & \\
\hline SESPMNT & B16K65 & BELOW 100N OUTFALL & RIVER_SHORELINE & ER & 14-Mar-03 & TLD & 0.284 & $\mathrm{mR} / \mathrm{d}$ & 0.014 & & & \\
\hline SESPMNT & B174J3 & BELOW 100N OUTFALL & RIVER_SHORELINE & ER & 02-Jul-03 & TLD & 0.261 & $\mathrm{mR} / \mathrm{d}$ & 0.005 & & & \\
\hline SESPMNT & B17JW4 & BELOW 100N OUTFALL & RIVER_SHORELINE & $\mathrm{ER}$ & 29-Sep-03 & TLD & $0.277 i$ & $\mathrm{mR} / \mathrm{d}$ & 0.001 & & & \\
\hline SESPMNT & B184V1 & BELOW 100N OUTFALL & RIVER_SHORELINE & ER & 15-Dec-03 & TLD & 0.258 & $\mathrm{mR} / \mathrm{d}$ & 0.006 & & & \\
\hline SESPMNT & B16KM3 & BENTON CITY & COMMŪNITY & ER & 21-Mar-03 & TLD & $0.224 r$ & $\mathrm{mR} / \mathrm{d}$ & 0.002 & & & \\
\hline
\end{tabular}


EXTERNAL RADIATION

\begin{tabular}{|c|c|c|c|c|c|c|c|c|c|c|c|c|}
\hline |OWNER ID & SAMP NUM & M) SITE NAME & $\begin{array}{l}\text { DIST CLASS } \\
\text { COMMUNTY }\end{array}$ & MEDIA & |SAMP DATE| & $\begin{array}{l}\text { CON SHORT } \\
\text { NAME }\end{array}$ & | VALUE RPTD | & \begin{tabular}{|l|} 
ANAL \\
UNITS \\
RPTD \\
\end{tabular} & $\left|\begin{array}{c}\text { COUNTING } \\
\text { ERROR }\end{array}\right|$ & $\mid \begin{array}{c}\text { LAB } \\
\text { QUALIFIER }\end{array}$ & SAMP COMMENT & RESULT COMMENT \\
\hline $\begin{array}{l}\text { SESPMNT } \\
\text { SESPMNT }\end{array}$ & B172H1 & BENTON CITY & COMMUNITY & ER & 26-Jun-03 & TLD & 0.233 & $\mathrm{mR} / \mathrm{d}$ & 0.007 & & & \\
\hline $\begin{array}{l}\text { SESPMNT } \\
\text { SESPMNT }\end{array}$ & B17J36 & BENTON CITY & COMMUNITY & ER & 18-Sep-03] & TLD & 0.234 & $\mathrm{mR} / \mathrm{d}$ & 0.001 & & & \\
\hline $\begin{array}{l}\text { SESPMNT } \\
\text { SESPMNT }\end{array}$ & $\begin{array}{l}\text { B186M8 } \\
\text { B16L55 }\end{array}$ & $\begin{array}{l}\text { BENTON CITY } \\
\text { BYERS LANDING }\end{array}$ & $\begin{array}{l}\text { COMMUNIIY } \\
\text { PERIMETER }\end{array}$ & $\begin{array}{l}\text { ER } \\
\text { ER }\end{array}$ & 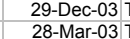 & & $\begin{array}{l}0.201 i \\
0.0256 i\end{array}$ & $\begin{array}{l}\text { mRR/d } \\
\text { mR/d }\end{array}$ & $\begin{array}{l}0.015 \\
0.008\end{array}$ & & & \\
\hline SESPMNT & B172D6 & BYERS LANDING & PERIMETER & $E R$ & 19-Jun-03 & TLD & 0.264 & $\mathrm{mR} / \mathrm{d}$ & 0.003 & & & \\
\hline SESPMNT & B17JV8 & BYERS LANDING & PERIMETER & $E R$ & $25-$ Sep-03 & TLD & 0.266 & $\mathrm{mR} / \mathrm{d}$ & 0 & & & \\
\hline SESPMNT & B18500 & BYERS LANDING & PERIMETER & $E R$ & 19-Dec-03 & TLD & 0.263 & $\mathrm{mR} / \mathrm{d}$ & 0.01 & & & \\
\hline SESPMNT & B16LF2 & DOGWOOD MET TOWER & PERIMETER & $E R$ & 28-Mar-03 & TLD & 0.262 & $\mathrm{mR} / \mathrm{d}$ & 0.008 & & & \\
\hline SESPMNT & B172B4 & DOGWOOD MET TOWER & PERIMETER & $E R$ & 19-Jun-03 & TLD & 0.25 & $\mathrm{mR} / \mathrm{d}$ & 0.004 & & & \\
\hline SESPMNT & B17JR6 & DOGWOOD MET TOWER & PERIMETER & $E R$ & $25-$ Sep-037 & TLD & 0.255 & $\mathrm{mR} / \mathrm{d}$ & 0.006 & & & \\
\hline SESPMNT & B184T7 & DOGWOOD MET TOWER & PERIMETER & $E R$ & 19-Dec-03] & TLD & 0.269 & $\mathrm{mR} / \mathrm{d}$ & 0.005 & & & \\
\hline SESPMNT & B16LF9 & E OF $200 \mathrm{E}$ & ONSITE & $E R$ & 26-Mar-03] & & 0.246 & $\mathrm{mR} / \mathrm{d}$ & 0.004 & & & \\
\hline SESPMNT & B172D0 & E OF $200 \mathrm{E}$ & ONSITE & $E R$ & 17-Jun-03 & & 0.247 & $\mathrm{mR} / \mathrm{d}$ & 0.01 & & & \\
\hline SESPMNT & B17JV2 & E OF $200 \mathrm{E}$ & ONSITE & $E R$ & 22-Sep-03] & & 0.254 & $\mathrm{mR} / \mathrm{d}$ & 0.008 & & & \\
\hline SESPMNT & B184Y4 & E OF $200 \mathrm{E}$ & ONSITE & $E R$ & 17-Dec-03 & & 0.248 & & 0.021 & & & \\
\hline SESPMNT & B16LH6 & EDWIN MARKHAM SCHOOL & COMMUNITY & ER & 28-Mar-03] & & 0.208 & $\mathrm{mR} / \mathrm{d}$ & 0 & & & \\
\hline SESPMNT & B172D7 & EDWIN MARKHAM SCHOOL & COMMUNITY & $E R$ & 19-Jun-03 & & 0.215 & $\mathrm{mR} / \mathrm{d}$ & 0.007 & & & \\
\hline SESPMNT & B17JV9 & EDWIN MARKHAM SCHOOL & COMMUNITY & $E R$ & $25-\mathrm{Sep}-037$ & & 0.208 & $\mathrm{mR} / \mathrm{d}$ & 0.006 & & & \\
\hline SESPMNT & B18501 & EDWIN MARKHAM SCHOOL & COMMUNITY & $E R$ & 19-Dec-03] & TLD & $0.217 i$ & $\mathrm{mR} / \mathrm{d}$ & 0.018 & & & \\
\hline SESPMNT & B16K76 & HANF POWERLINE XING & RIVER_SHORELINE & $E R$ & 14-Mar-037 & TLD & 0.25 & $\mathrm{mR} / \mathrm{d}$ & 0.005 & & & \\
\hline SESPMNT & B174K4 & HANF POWERLINE XING & RIVER_SHORELINE & ER & 02-Jul-03 & TLD & 0.248 & $\mathrm{mR} / \mathrm{d}$ & 0.005 & & & \\
\hline SESPMNT & B17JW6 & HANF POWERLINE XING & RIVER_SHORELINE & ER & $29-S e p-03$ & TLD & 0.263 & $\mathrm{mR} / \mathrm{d}$ & 0.01 & & & \\
\hline SESPMNT & B184W2 & HANF POWERLINE XING & RIVER_SHORELINE & ER & 15-Dec-037 & & 0.265 & $\mathrm{mR} / \mathrm{d}$ & 0.009 & & & \\
\hline SESPMNT & B16K77 & HANFORD RR TRACK & RIVER_SHORELINE & ER & 14-Mar-03 & & $0.227 i$ & $\mathrm{mR} / \mathrm{d}$ & 0.008 & & & \\
\hline SESPMNT & B174K5 & HANFORD RR TRACK & RIVER_SHORELINE & ER & 02-Jul-03] & TLD & $0.235 \mathrm{r}$ & $\mathrm{mR} / \mathrm{d}$ & 0.003 & & & \\
\hline SESPMNT & B17JW7 & HANFORD RR TRACK & RIVER_SHORELINE & ER & 29-Sep-03] & & $0.268 r$ & $\mathrm{mR} / \mathrm{d}$ & 0.001 & & & \\
\hline SESPMNT & B184W3 & HANFORD RR TRACK & RIVER_SHORELINE & ER & 15-Dec-03 & TLD & $0.266 r$ & $\mathrm{mR} / \mathrm{d}$ & 0.004 & & HEAVY BRUSH. & \\
\hline SESPMNT & B16KL2 & HANFORD SLOUGH & RIVER_SHORELINE & ER & 19-Mar-03] & TLD & $0.24 r$ & $\mathrm{mR} / \mathrm{d}$ & 0.005 & & & \\
\hline SESPMNT & B172B9 & HANFORD SLOUGH & RIVER_SHORELINE & ER & 16-Jun-037 & TLD & 0.259 & $\mathrm{mR} / \mathrm{d}$ & 0.004 & & & \\
\hline $\begin{array}{l}\text { SESPMNT } \\
\text { SESPMNT }\end{array}$ & B17J25 & HANFORD SLOUGH & RIVER_SHORELINE & ER & 15-Sep-037 & TLD & $0.267 i$ & $\mathrm{mR} / \mathrm{d}$ & 0.001 & & & \\
\hline $\begin{array}{l}\text { SESPMNT } \\
\text { SESPMNT }\end{array}$ & B186L7 & HANFORD SLOUGH & RIVER_SHORELINE & ER & 22-Dec-037 & TLD & 0.273 & $\mathrm{mR} / \mathrm{d}$ & 0 & & & \\
\hline $\begin{array}{l}\text { SESPMNT } \\
\text { SESPMNT }\end{array}$ & B16KN6 & $\begin{array}{l}\text { HANFORD TOWNSITE } \\
\text { HANEORD TOWNSTEF }\end{array}$ & ONSITE & $\begin{array}{l}\text { ER } \\
E R\end{array}$ & 18-Mar-037] & TLD & 0.211 & $\mathrm{mR} / \mathrm{d}$ & 0.008 & & & \\
\hline $\begin{array}{l}\text { SESPMNT } \\
\text { SESPMNT }\end{array}$ & $\begin{array}{l}\text { B172J44 } \\
\text { B17J49 }\end{array}$ & $\begin{array}{l}\text { HANFORD TOWNSITE } \\
\text { HANFORD TOWNSITE }\end{array}$ & $\begin{array}{l}\text { ONSITE } \\
\text { ONSITE }\end{array}$ & $\begin{array}{l}\text { ER } \\
\text { ER }\end{array}$ & $\begin{array}{l}24-J u n-03 \\
15-37\end{array}$ & TLD & 0.2321 & $\mathrm{mR} / \mathrm{d}$ & 0.005 & & & \\
\hline SESPMNT & $\begin{array}{l}\mathrm{B} 1 / 7499 \\
\mathrm{~B} 186 \mathrm{P} 1\end{array}$ & HANFORD TOWNSITE & ONSITE & $\begin{array}{l}\text { ER } \\
\text { ER }\end{array}$ & 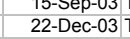 & TLD & 0.229 & $\mathrm{mR/d}$ & 0.002 & & & \\
\hline SESPMNT & B16KJ7 & HORN RAPIDS SUBSTA & PERIMETER & $E R$ & $21-M a r-03$ & & 0.227 & $\mathrm{mR} / \mathrm{d}$ & 0.005 & & & \\
\hline SESPMNT & B172F4 & HORN RAPIDS SUBSTA & PERIMETER & ER & $26-J u n-03$ & & 0.231 & $\mathrm{mR} / \mathrm{d}$ & 0.002 & & & \\
\hline SESPMNT & B17J15 & HORN RAPIDS SUBSTA & PERIMETER & $E R$ & 18-Sep-03 & & 0.243 & $\mathrm{mR} / \mathrm{d}$ & 0.004 & & & \\
\hline SESPMNT & B186K3 & HORN RAPIDS SUBSTA & PERIMETER & $E R$ & 29-Dec-03] & & 0.242 & $\mathrm{mR} / \mathrm{d}$ & 0.006 & & & \\
\hline SESPMNT & B16K84 & ISL DS BATEMAN ISL & RIVER_SHORELINE & $E R$ & 14-Mar-03 & & 0.253 & $\mathrm{mR} / \mathrm{d}$ & 0.006 & & & \\
\hline SESPMNT & B174L2 & ISL DS BATEMAN ISL & RIVER_SHORELINE & $E R$ & 02-Jul-037 & & & & & & NO SAMPLE. TLD MISSING AS WELL AS TLD POST. & \\
\hline SESPMNT & B17JX4 & ISL DS BATEMAN ISL & RIVER_SHORELINE & $E R$ & $29-$ Sep-037 & & 0.235 & $\mathrm{mR} / \mathrm{d}$ & 0.005 & & & \\
\hline SESPMNT & B184X0 & ISL DS BATEMAN ISL & RIVER_SHORELINE & $E R$ & 15-Dec-037 & & 0.25 & $\mathrm{mR} / \mathrm{d}$ & 0.005 & & & \\
\hline SESPMNT & B16K83 & ISLAND NEAR 300 AREA & RIVER_SHORELINE & $E R$ & 14-Mar-03 & & 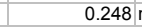 & $\mathrm{mR} / \mathrm{d}$ & 0.013 & & & \\
\hline SESPMNT & B174L1 & ISLAND NEAR 300 AREA & RIVER_SHORELINE & ER & 02-Jul-03 & TLD & 0.246 & $\mathrm{mR} / \mathrm{d}$ & 0.009 & & & \\
\hline SESPMNT & B17JX3 & ISLAND NEAR 300 AREA & RIVER_SHORELINE & ER & $29-\mathrm{Sep}-037$ & TLD & 0.255 & $\mathrm{mR} / \mathrm{d}$ & 0.007 & & & \\
\hline SESPMNT & B184W9 & ISLAND NEAR 300 AREA & RIVER_SHORELINE & ER & 15-Dec-037 & TLD & $0.244 \mathrm{r}$ & $\mathrm{mR} / \mathrm{d}$ & 0.004 & & & \\
\hline SESPMNT & B16K82 & ISLND ABOVE 300 AREA & RIVER_SHORELINE & ER & 14-Mar-03] & TLD & 0.246 & $\mathrm{mR} / \mathrm{d}$ & 0.003 & & & \\
\hline SESPMNT & B174L0 & ISLND ABOVE 300 AREA & RIVER_SHORELINE & ER & 02-Jul-03 & TLD & 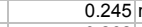 & $\mathrm{mR} / \mathrm{d}$ & 0.007 & & & \\
\hline SESPMNT & B17JX2 & ISLND ABOVE 300 AREA & RIVER_SHORELINE & ER & $29-\mathrm{Sep}-03]$ & TLD & $0.262 r$ & $\mathrm{mR} / \mathrm{d}$ & 0.001 & & & \\
\hline SESPMNT & B184W8 & ISLND ABOVE 300 AREA & RIVER_SHORELINE & ER & 15-Dec-037 & TLD & $0.263 r$ & $\mathrm{mR} / \mathrm{d}$ & 0.012 & & & \\
\hline SESPMNT & B16LF6 & KENNEWICK-ELY STREET & COMMUNITY & ER & 28-Mar-037 & TLD & $0.2 r$ & $\mathrm{mR} / \mathrm{d}$ & 0.002 & & & \\
\hline SESPMNT & B172C7 & KENNEWICK-ELY STREET & COMMUNITY & ER & 19-Jun-037 & TLD & $0.212 r$ & $\mathrm{mR} / \mathrm{d}$ & 0.005 & & & \\
\hline SESPMNT & B17JT9 & KENNEWICK-ELY STREET & COMMUNITY & ER & $25-\mathrm{Sep}-037$ & TLD & $0.217 r$ & $\mathrm{mR} / \mathrm{d}$ & 0.006 & & & \\
\hline SESPMNT & B184Y1 & KENNEWICK-ELY STREET & COMMUNITY & ER & 19-Dec-037 & TLD & 0.175 & $\mathrm{mR} / \mathrm{d}$ & 0.001 & & & \\
\hline $\begin{array}{l}\text { SESPMNT } \\
\text { SESPMNT }\end{array}$ & B16KP2 & LIGO & ONSITE & ER & 18-Mar-037] & TLD & 0.196 & $\mathrm{mR} / \mathrm{d}$ & 0.004 & & & \\
\hline $\begin{array}{l}\text { SESPMNT } \\
\text { SESPMNT }\end{array}$ & B172J7 & LIGO & ONSITE & $\begin{array}{l}\text { ER } \\
\text { FR }\end{array}$ & 24-Jun-037] & TLD & 0.208 & $\mathrm{mR} / \mathrm{d}$ & 0.009 & & & \\
\hline $\begin{array}{l}\text { SESPMNT } \\
\text { SESPMNT }\end{array}$ & $\begin{array}{l}\text { B17J96 } \\
\text { B186P7 }\end{array}$ & LIGO & ONSITE & ER & 15-Sep-037] & TLD & 0.199 & $\mathrm{mR/d}$ & $\begin{array}{r}0.01 \\
0.18\end{array}$ & & & \\
\hline $\begin{array}{l}\text { SESPMNT } \\
\text { SESPMNT }\end{array}$ & $\begin{array}{l}\text { B186P7 } \\
\text { B16K90 }\end{array}$ & & $\begin{array}{l}\text { ONSITE } \\
\text { RIVER SHORELINE }\end{array}$ & $\begin{array}{l}\text { ER } \\
\text { ER }\end{array}$ & 22-Dec-037] -1 & TLD & $0.254 i$ & $\mathrm{mR} / \mathrm{d}$ & 0.018 & & & \\
\hline $\begin{array}{l}\text { SESPMNT } \\
\text { SESPMNT }\end{array}$ & $\begin{array}{l}\text { B16K90 } \\
\text { B174L8 }\end{array}$ & $\begin{array}{l}\text { LO END LOCKE ISL } \\
\text { LO END LOCKE ISL }\end{array}$ & $\begin{array}{l}\text { RIVER_SHORELINE } \\
\text { RIVER SHORELINE }\end{array}$ & $\begin{array}{l}E R \\
E R \\
E R\end{array}$ & $\begin{array}{r}\text { 14-Mar-03 } \\
02-J u l-03]\end{array}$ & $\begin{array}{l}\text { TLD } \\
\text { TLD }\end{array}$ & $0.225 t$ & $\begin{array}{l}m R R / d \\
m R / d\end{array}$ & $\begin{array}{l}0.006 \\
0\end{array}$ & & & \\
\hline SESPMNT & B17JY0 & LO END LOCKE ISL & RIVER_SHORELINE & ER & $29-$ Sep-03 & TLD & 0.242 & $\mathrm{mR} / \mathrm{d}$ & 0.009 & & & \\
\hline SESPMNT & B184X6 & LO END LOCKE ISL & RIVER_SHORELINE & ER & 15-Dec-037 & TLD & 0.243 & $\mathrm{mR} / \mathrm{d}$ & 0.008 & & & \\
\hline SESPMNT & B16LH8 & MATTAWA & COMMÜNITY & $E R$ & 27-Mar-03 & TLD & 0.216 & $\mathrm{mR} / \mathrm{d}$ & 0.003 & & & \\
\hline SESPMNT & B172D9 & MATTAWA & COMMUNITY & $E R$ & 18-Jun-03 & TLD & 0.209 & $\mathrm{mR} / \mathrm{d}$ & 0.005 & & & \\
\hline SESPMNT & B17JW1 & MATTAWA & COMMUNITY & ER & 24-Sep-03 & TLD & 0.2221 & $\mathrm{mR} / \mathrm{d}$ & 0.002 & & & \\
\hline SESPMNT & B18503 & MATTAWA & COMMUNITY & $E R$ & 18-Dec-03 & & 0.225 & $\mathrm{mR} / \mathrm{d}$ & 0.014 & & & \\
\hline
\end{tabular}


EXTERNAL RADIATION

\begin{tabular}{|c|c|c|c|c|c|c|c|c|c|c|c|c|}
\hline OWNER ID & SAMP NUM & SITE NAME & DIST CLASS & MEDIA & & $\begin{array}{c}\text { CON SHORT } \\
\text { NAME }\end{array}$ & |VALUE RPTD & \begin{tabular}{|l|} 
ANAL \\
UNIIS \\
RPTD
\end{tabular} & $\left|\begin{array}{c}\text { COUNTING } \\
\text { ERROR }\end{array}\right|$ & $\mid \begin{array}{c}\text { LAB } \\
\text { QUALIFIER }\end{array}$ & SAMP COMMENT & RESULT COMMENT \\
\hline SESPMNT & B16LF8 & N OF $200 \mathrm{E}$ & ONSITE & ER & 26-Mar-03 & TLD & 0.243 & & 0.003 & & & \\
\hline SESPMNT & B172C9 & N OF $200 \mathrm{E}$ & ONSITE & ER & 17-Jun-03 & TLD & 0.244 & $\mathrm{mR} / \mathrm{d}$ & 0.008 & & & \\
\hline SESPMNT & B17JV1 & N OF $200 \mathrm{E}$ & ONSITE & ER & 22-Sep-03 & TLD & 0.266 & $\mathrm{mR} / \mathrm{d}$ & 0.006 & & & \\
\hline SESPMNT & B184Y3 & N OF $200 \mathrm{E}$ & ONSITE & ER & 17-Dec-03 & TLD & 0.251 & $\mathrm{mR} / \mathrm{d}$ & 0.008 & & & \\
\hline SESPMNT & B16K96 & N. RICHLAND & RIVER_SHORELINE & ER & 14-Mar-03 & TLD & $0.204 i$ & $\mathrm{mR} / \mathrm{d}$ & 0.003 & & & \\
\hline SESPMNT & B174M4 & N. RICHLAND & RIVER_SHORELINE & ER & 02-Jul-03 & TLD & 0.206 & $\mathrm{mR} / \mathrm{d}$ & 0.01 & & & \\
\hline SESPMNT & B17JY6 & N. RICHLAND & RIVER_SHORELINE & ER & 29-Sep-03 & TLD & 0.21 & $\mathrm{mR} / \mathrm{d}$ & 0.004 & & & \\
\hline SESPMNT & B18507 & N. RICHLAND & RIVER_SHORELINE & ER & & & & & & & & \\
\hline SESPMNT & B16LF4 & $\begin{array}{l}\text { OTHELLO } \\
\text { OTHL }\end{array}$ & COMMUNITY & ER & 27-Mar-03 & & 0.194 & $\mathrm{mR} / \mathrm{d}$ & 0.001 & & & \\
\hline SESPMNT & B172B6 & OTHELLO & COMMUNITY & ER & 18-Jun-03 & & 0.201 & & 0.005 & & & \\
\hline SESPMNT & B17JR8 & OTHELLO & COMMUNITY & ER & 24-Sep-03 & & 0.206 & & 0.002 & & & \\
\hline SESPMNT & B184V0 & OTHELLO & COMMUNITY & ER & 18-Dec-03 & & 0.213 & & 0.001 & & & \\
\hline SESPMNT & B16LF5 & PASCO & COMMUNITY & ER & 28-Mar-03 & & 0.231 & & 0.013 & & & \\
\hline SESPMNT & B172C6 & PASCO & COMMUNITY & ER & 19-Jun-03 & & 0.24 & $\mathrm{mR} / \mathrm{d}$ & 0.002 & & & \\
\hline SESPMNT & B17JT8 & PASCO & COMMUNITY & ER & $25-$ Sep-03 & & $0.247 i$ & $\mathrm{mR} / \mathrm{d}$ & 0.021 & & & \\
\hline SESPMNT & B184Y0 & PASCO & COMMUNITY & ER & 19-Dec-03 & & 0.243 & $\mathrm{mR} / \mathrm{d}$ & 0 & & & \\
\hline SESPMNT & B16KL0 & PORT OF BENTON-RIVER & RIVER_SHORELINE & ER & 19-Mar-03 & & 0.235 & $\mathrm{mR} / \mathrm{d}$ & 0.003 & & & \\
\hline SESPMNT & B172B7 & PORT OF BENTON-RIVER & RIVER_SHORELINE & ER & 16-Jun-03 & & 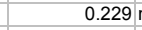 & $\mathrm{mR} / \mathrm{d}$ & 0.008 & & & \\
\hline SESPMNT & B17J23 & PORT OF BENTON-RIVER & RIVER_SHORELINE & ER & 15-Sep-03 & & & & & & NO SAMPLE. TLD MISSING. & \\
\hline SESPMNT & B186L5 & PORT OF BENTON-RIVER & RIVER_SHORELINE & ER & 22-Dec-03 & & $0.237 \mathrm{i}$ & $\mathrm{mR} / \mathrm{d}$ & 0.005 & & & \\
\hline SESPMNT & B16K80 & POWERLINE CROSSING & RIVER_SHORELINE & ER & 14-Mar-03 & & 0.218 & $\mathrm{mR} / \mathrm{d}$ & 0.004 & & & \\
\hline SESPMNT & B174K8 & POWERLINE CROSSING & RIVER_SHORELINE & ER & 02-Jul-03 & & 0.238 & & & & & \\
\hline $\begin{array}{l}\text { SESPMNT } \\
\text { SESDMNT }\end{array}$ & B17JX0 & POWERLINE CROSSING & RIVER_SHORELINE & ER & 29-Sep-03 & & $0.264 \mathrm{r}$ & $m R / d$ & 0.004 & & TLD ON GROUND AND APPARENTLY CHEWED. & \\
\hline $\begin{array}{l}\text { SESPMNT } \\
\text { SESPMNT }\end{array}$ & B184W6 & POWERLINE CROSSING & RIVER_SHORELINE & ER & 15-Dec-03 & & $0.242 \mathrm{r}$ & $\mathrm{mR} / \mathrm{d}$ & 0.01 & & & \\
\hline $\begin{array}{l}\text { SESPMNT } \\
\text { SESPMNT }\end{array}$ & B16KJ8 & PROSSER BARRICADE & PERIMETER & ER & 21-Mar-03 & TLD & $0.241 i$ & $\mathrm{mR} / \mathrm{d}$ & 0.007 & & & \\
\hline $\begin{array}{l}\text { SESPMNT } \\
\text { SESPMNT }\end{array}$ & B172F5 & $\begin{array}{l}\text { PROSSER BARRICADE } \\
\text { POSOSP }\end{array}$ & PERIMETER & ER & 26-Jun-03 & TLD & 0.246 & $\mathrm{mR} / \mathrm{d}$ & 0.004 & & & \\
\hline $\begin{array}{l}\text { SESPMNT } \\
\text { SESPMNT }\end{array}$ & $\begin{array}{l}\text { B17J16 } \\
\text { B186K4 }\end{array}$ & $\begin{array}{l}\text { PROSSER BARRICADE } \\
\text { PROSSER RARRIADE }\end{array}$ & $\begin{array}{l}\text { PERIMETER } \\
\text { PERMETFR }\end{array}$ & $\begin{array}{l}\text { ER } \\
\text { ER }\end{array}$ & $\begin{array}{l}\text { 18-Sep-03 } \\
29-D e-03\end{array}$ & TLD & 0.26 & $\mathrm{mR} / \mathrm{d}$ & 0.007 & & & \\
\hline SESPMNT & B16KN7 & RATTLESNAKE SPRINGS & $\begin{array}{l}\text { PERIMEIER } \\
\text { PERIMETER }\end{array}$ & $\begin{array}{l}\text { ER } \\
\text { ER }\end{array}$ & $\begin{array}{l}29-\mathrm{Dec}-03 \\
20-\mathrm{Mar}-3 \\
\end{array}$ & $\begin{array}{l}\text { TLD } \\
\text { TLD }\end{array}$ & $0.244 i$ & $\begin{array}{l}\mathrm{mRR/d} \\
\mathrm{mRR} / \mathrm{d}\end{array}$ & 0.008 & & & \\
\hline SESPMNT & B172J5 & RATTLESNAKE SPRINGS & PERIMETER & ER & 26-Jun-03 & TLD & 0.25 & $\mathrm{mR} / \mathrm{d}$ & 0.006 & & & \\
\hline SESPMNT & B17J50 & RATTLESNAKE SPRINGS & PERIMETER & ER & 18-Sep-03 & TLD & 0.249 & $\mathrm{mR} / \mathrm{d}$ & 0.008 & & TLD FOUND ON GROUND. & \\
\hline SESPMNT & B186P2 & RATTLESNAKE SPRINGS & PERIMETER & ER & 29-Dec-03 & TLD & 0.27 & $\mathrm{mR} / \mathrm{d}$ & 0.008 & & & \\
\hline SESPMNT & B16K79 & RINGOLD ISLAND & RIVER_SHORELINE & ER & 14-Mar-03 & TLD & 0.209 & $\mathrm{mR} / \mathrm{d}$ & 0.007 & & & \\
\hline SESPMNT & B174K7 & RINGOLD ISLAND & RIVER_SHORELINE & ER & 02-Jul-03 & TLD & 0.2421 & $\mathrm{mR} / \mathrm{d}$ & 0.002 & & & \\
\hline SESPMNT & B17JW9 & RINGOLD ISLAND & RIVER_SHORELINE & ER & $29-$-Sep-03 & TLD & $0.257 i$ & $\mathrm{mR} / \mathrm{d}$ & 0.006 & & & \\
\hline SESPMNT & B184W5 & RINGOLD ISLAND & RIVER_SHORELINE & ER & 15-Dec-03 & TLD & $0.237 i$ & $\mathrm{mR} / \mathrm{d}$ & 0.004 & & & \\
\hline SESPMNT & B16LH4 & RINGOLD MET TOWER & PERIMETER & ER & 28-Mar-03 & TLD & 0.256 & $\mathrm{mR} / \mathrm{d}$ & 0.014 & & & \\
\hline SESPMNT & B172D5 & RINGOLD MET TOWER & PERIMETER & ER & 19-Jun-03 & & 0.247 & $\mathrm{mR} / \mathrm{d}$ & 0.011 & & & \\
\hline SESPMNT & B17JV7 & RINGOLD MET TOWER & PERIMETER & ER & $25-$ Sep-03 & & 0.271 & $\mathrm{mR} / \mathrm{d}$ & 0.002 & & & \\
\hline SESPMNT & B184Y9 & RINGOLD MET TOWER & PERIMETER & ER & 19-Dec-03 & & 0.259 & $\mathrm{mR} / \mathrm{d}$ & 0.005 & & & \\
\hline SESPMNT & B16K94 & S END VERNITA BRIDGE & RIVER_SHORELINE & ER & 14-Mar-03 & TLD & 0.199 & $\mathrm{mR} / \mathrm{d}$ & 0 & & & \\
\hline SESPMNT & B174M2 & S END VERNITA BRIDGE & RIVER_SHORELINE & ER & 02-Jul-03 & TLD & & & & & NO SAMPLE. TLD MISSING. & \\
\hline SESPMNT & B17JY4 & S END VERNITA BRIDGE & RIVER_SHORELINE & ER & 29-Sep-03 & TLD & 0.215 & $\mathrm{mR} / \mathrm{d}$ & 0.004 & & & \\
\hline SESPMNT & B18504 & S END VERNITA BRIDGE & RIVER_SHORELINE & ER & 15-Dec-03 & TLD & & & & & NO SAMPLE. TLD MISSING. & \\
\hline SESPMNT & B16K81 & S END WOODED ISLAND & RIVER_SHORELINE & ER & 14-Mar-03 & TLD & $0.247 r$ & $\mathrm{mR} / \mathrm{d}$ & 0.007 & & & \\
\hline SESPMNT & B174K9 & S END WOODED ISLAND & RIVER_SHORELINE & ER & 02-Jul-03 & TLD & 0.258 & $\mathrm{mR} / \mathrm{d}$ & 0.002 & & & \\
\hline SESPMNT & B17JX1 & S END WOODED ISLAND & RIVER_SHORELINE & ER & 29-Sep-03 & TLD & $0.27 i$ & $\mathrm{mR} / \mathrm{d}$ & 0.004 & & & \\
\hline SESPMNT & B184W7 & S END WOODED ISLAND & RIVER_SHORELINE & ER & 15-Dec-03 & TLD & $0.267 i$ & $\mathrm{mR} / \mathrm{d}$ & 0.007 & & & \\
\hline SESPMNT & B16LF7 & $S O F 200 \mathrm{E}$ & ONSITE & ER & 26-Mar-03 & TLD & $0.263 r$ & $\mathrm{mR} / \mathrm{d}$ & 0.003 & & & \\
\hline $\begin{array}{l}\text { SESPMNT } \\
\text { SESPMNT }\end{array}$ & B172C8 & $S$ OF $200 \mathrm{E}$ & ONSITE & ER & 17-Jun-03 & TLD & 0.253 & $\mathrm{mR} / \mathrm{d}$ & 0.01 & & & \\
\hline $\begin{array}{l}\text { SESPMNT } \\
\text { SESPMNT }\end{array}$ & B17JV0 & SOF $200 \mathrm{E}$ & ONSITE & ER & 22-Sep-03 & TLD & 0.261 & $\mathrm{mR} / \mathrm{d}$ & 0 & & & \\
\hline $\begin{array}{l}\text { SESPMNT } \\
\text { SESPMNT }\end{array}$ & B184Y2 & S OF $200 \mathrm{E}$ & ONSITE & ER & 17-Dec-03 & TLD & & & & & NO SAMPLE. TLD MISSING. & \\
\hline $\begin{array}{l}\text { SESPMNT } \\
\text { SESPMNT }\end{array}$ & $\begin{array}{l}\text { B16K78 } \\
\text { B174K6 }\end{array}$ & SAVAGE ISL SLOUGH & $\begin{array}{l}\text { RIVER_SHORELINE } \\
\end{array}$ & ER & 14-Mar-03 & TLD & $0.207 i$ & $\mathrm{mR} / \mathrm{d}$ & 0.001 & & & \\
\hline $\begin{array}{l}\text { SESPMNT } \\
\text { SESPMNT }\end{array}$ & $\begin{array}{l}\text { B174K6 } \\
\text { B17JW8 }\end{array}$ & SAVAGE ISL SLOUGH & $\begin{array}{l}\text { RIVER_SHORELINE } \\
\end{array}$ & $\begin{array}{l}\text { ER } \\
E R\end{array}$ & 02-Jul-03 & TLD & 0.209 & $\mathrm{mR} / \mathrm{d}$ & 0.003 & & & \\
\hline $\begin{array}{l}\text { SESPMNT } \\
\text { SESPMNT }\end{array}$ & $\begin{array}{l}\text { B17JW8 } \\
\text { B184W4 }\end{array}$ & SAVAGE ISL SLOUGH & $\begin{array}{l}\text { RIVER_SHORELINE } \\
\end{array}$ & $\begin{array}{l}E R \\
E R\end{array}$ & 29-Sep-03 & TLD & 0.238 & $\mathrm{mR} / \mathrm{d}$ & 0.01 & & & \\
\hline $\begin{array}{l}\text { SESPMNT } \\
\text { SESPMNT }\end{array}$ & $\begin{array}{l}\text { B184W4 } \\
\text { B16LH9 }\end{array}$ & $\begin{array}{l}\text { SAAAGE ISL SLOUGH } \\
\text { SW OF B/C CRIBS }\end{array}$ & $\begin{array}{l}\text { RIVERSHORELINE } \\
\text { ONSITE }\end{array}$ & $\begin{array}{l}\text { ER } \\
\text { ER }\end{array}$ & $\begin{array}{r}\text { 15-Dec-03 } \\
26-M a r-03\end{array}$ & $\begin{array}{l}\text { TLD } \\
\text { TLD }\end{array}$ & $\begin{array}{l}0.215 t \\
0.227 !\end{array}$ & $\begin{array}{l}\mathrm{mRR} / \mathrm{d} \\
\mathrm{mR} / \mathrm{d}\end{array}$ & $\begin{array}{r}0 \\
0.008\end{array}$ & & & \\
\hline SESPMNT & B172F0 & SW OF B/C CRIBS & ONSITE & ER & 17-Jun-03 & TLD & 0.233 & $\mathrm{mR} / \mathrm{d}$ & 0.002 & & TLD FOUND ON GROUND. & \\
\hline SESPMNT & B17JW2 & SW OF B/C CRIBS & ONSITE & $E R$ & 22-Sep-03 & TLD & $0.224 i$ & $\mathrm{mR} / \mathrm{d}$ & 0 & & & \\
\hline SESPMNT & B18506 & SW OF B/C CRIBS & ONSITE & ER & 17-Dec-03 & TLD & 0.236 & $\mathrm{mR} / \mathrm{d}$ & 0 & & & \\
\hline SESPMNT & B16KK1 & TOPPENISH & DISTANT & ER & 21-Mar-03 & TLD & 0.187 & $\mathrm{mR} / \mathrm{d}$ & 0.004 & & & \\
\hline SESPMNT & B172F6 & TOPPENISH & DISTANT & ER & 26-Jun-03 & TLD & 0.197 & $\mathrm{mR} / \mathrm{d}$ & 0.005 & & & \\
\hline SESPMNT & B17J19 & TOPPENISH & DISTANT & ER & 18-Sep-03 & TLD & 0.201 & $\mathrm{mR} / \mathrm{d}$ & 0.002 & & & \\
\hline SESPMNT & B186K6 & TOPPENISH & DISTANT & ER & 29-Dec-03 & TLD & 0.207 & $\mathrm{mR} / \mathrm{d}$ & 0.004 & & & \\
\hline SESPMNT & B16KL3 & US ECOLOGY NE CORNER & ONSITE & $\mathrm{ER}$ & 19-Mar-03 & TLD & 0.233 & $\mathrm{mR} / \mathrm{d}$ & 0.01 & & & \\
\hline SESPMNT & $\mathrm{B} 172 \mathrm{C} 0$ & US ECOLOGY NE CORNER & ONSITE & ER & 16-Jun-03 & TLD & $0.234 r$ & $\mathrm{mR} / \mathrm{d}$ & 0.002 & & & \\
\hline SESPMNT & B17J26 & US ECOLOGY NE CORNER & ONSITE & ER & 15-Sep-03 & TLD & 0.238 & $\mathrm{mR} / \mathrm{d}$ & 0.007 & & & \\
\hline
\end{tabular}


EXTERNAL RADIATION

\begin{tabular}{|c|c|c|c|c|c|c|c|c|c|c|c|c|}
\hline OWNER ID & SAMP NUM & & DIST CLASS & MEDIA & SAMP DATE & $\begin{array}{l}\text { CON SHORT } \\
\text { NAME }\end{array}$ & |VALUE RPTD & $\begin{array}{l}\text { ANAL } \\
\text { UNITS } \\
\text { RPTD }\end{array}$ & $\left|\begin{array}{c}\text { COUNTING } \\
\text { ERROR }\end{array}\right|$ & $\left|\begin{array}{c}\text { LAB } \\
\text { QUALIFIER }\end{array}\right|$ & SAMP COMMENT & RESULT COMMENT \\
\hline SESPMNT & B186L8 & US ECOLOGY NE CORNER & ONSITE & ER & 22-Dec-03 & TLD & $0.232 n$ & & 0.01 & & & \\
\hline SESPMNT & B16KL5 & US ECOLOGY NW CORNER & ONSITE & ER & 19-Mar-03 & TLD & $0.246 n$ & $\mathrm{mR} / \mathrm{d}$ & 0.001 & & & \\
\hline SESPMNT & B172C2 & US ECOLOGY NW CORNER & ONSITE & ER & 16-Jun-03 & TLD & & $\mathrm{mR} / \mathrm{d}$ & 0.003 & & & \\
\hline SESPMNT & B17J28 & US ECOLOGY NW CORNER & ONSITE & ER & $15-$ Sep-03 & TLD & & $\mathrm{mR} / \mathrm{d}$ & 0.008 & & & \\
\hline SESPMNT & B186M0 & US ECOLOGY NW CORNER & ONSITE & ER & 22-Dec-03 & TLD & & $\mathrm{mR} / \mathrm{d}$ & 0.012 & & & \\
\hline SESPMNT & B16KL4 & US ECOLOGY SE CORNER & ONSITE & ER & 19-Mar-03 & TLD & & $\mathrm{mR} / \mathrm{d}$ & 0.001 & & & \\
\hline SESPMNT & B172C1 & US ECOLOGY SE CORNER & ONSITE & ER & 16-Jun-03 & TLD & & $\mathrm{mR/d}$ & 0.005 & & & \\
\hline SESPMNT & B17J27 & US ECOLOGY SE CORNER & ONSITE & ER & $15-$ Sep-03 & & & & 0.011 & & & \\
\hline SESPMNT & B186L9 & US ECOLOGY SE CORNER & ONSITE & ER & 22-Dec-03 & & $0.234 n$ & & 0.013 & & & \\
\hline SESPMNT & B16KL6 & US ECOLOGY SW CORNER & ONSITE & ER & 19-Mar-03 & & $0.263 n$ & & 0.008 & & & \\
\hline SESPMNT & B172C3 & US ECOLOGY SW CORNER & ONSITE & ER & 16-Jun-03 & & $0.254 n$ & & 0.001 & & & \\
\hline SESPMNT & B17J29 & US ECOLOGY SW CORNER & ONSITE & ER & 15-Sep-03 & & $0.271 \mathrm{n}$ & & 0.009 & & & \\
\hline SESPMNT & B186M1 & US ECOLOGY SW CORNER & ONSITE & ER & 22-Dec-03 & & $0.267 n$ & & 0.001 & & & \\
\hline SESPMNT & B16LF3 & W END OF FIR ROAD & PERIMETER & ER & 28-Mar-03 & & $0.256 n$ & & 0.011 & & & \\
\hline SESPMNT & B172B5 & W END OF FIR ROAD & PERIMETER & ER & 19-Jun-03 & & $0.259 n$ & & 0.014 & & & \\
\hline SESPMNT & B17JR7 & W END OF FIR ROAD & PERIMETER & ER & 25-Sep-03 & & $0.257 n$ & & 0.003 & & & \\
\hline SESPMNT & B184T8 & W END OF FIR ROAD & PERIMETER & ER & 19-Dec-03 & & $0.251 \mathrm{n}$ & & 0.01 & & & \\
\hline SESPMNT & B16LF1 & WAHLUKE SLOPE & PERIMETER & ER & 27-Mar-03 & & $0.242 \mathrm{n}$ & & 0.007 & & & \\
\hline SESPMNT & B172B3 & WAHLUKE SLOPE & PERIMETER & ER & 18-Jun-03 & & $0.252 n$ & & 0.001 & & & \\
\hline SESPMNT & B17JR5 & WAHLUKE SLOPE & PERIMETER & ER & 24-Sep-03 & & $0.246 n$ & & 0.003 & & & \\
\hline SESPMNT & B184T6 & WAHLUKE SLOPE & PERIMETER & ER & 18-Dec-03 & & $0.249 n$ & & 0.003 & & & \\
\hline SESPMNT & B16KP1 & WEST LAKE & ONSITE & ER & 18-Mar-03 & & & & 0.004 & & & \\
\hline $\begin{array}{l}\text { SESPMNT } \\
\text { GESPMNT }\end{array}$ & B172J6 & WEST LAKE & ONSITE & ER & 24-Jun-03 & & $0.258 \mathrm{n}$ & $\mathrm{mR/d}$ & 0.005 & & & \\
\hline $\begin{array}{l}\text { SESPMNT } \\
\text { SESPMNT }\end{array}$ & B17J95 & WEST LAKE & ONSITE & ER & 15-Sep-03 & & & & & & NO SAMPLE. TLD MISSING. & \\
\hline $\begin{array}{l}\text { SESPMNT } \\
\text { SESPMNT }\end{array}$ & B186P6 & WEST LAKE & ONSITE & ER & 22-Dec-03 & & $0.243 n$ & $\mathrm{mR/d}$ & 0.01 & & & \\
\hline $\begin{array}{l}\text { SESPMNT } \\
\text { SESPMNT }\end{array}$ & B16K92 & WHITE BLUFFS FY LND. & RIVER_SHORELINE & ER & 14-Mar-03 & & $0.224 n$ & & 0.004 & & & \\
\hline $\begin{array}{l}\text { SESPMNT } \\
\text { SESPMNT }\end{array}$ & B174M0 & $\begin{array}{l}\text { WHITE BLUFFS FY LND. } \\
\text { W }\end{array}$ & RIVER_SHORELINE & ER & 02-Jul-03 & & $0.208 \mathrm{n}$ & & 0.003 & & & \\
\hline $\begin{array}{l}\text { SESPMNT } \\
\text { SESPMNT }\end{array}$ & $\begin{array}{l}\text { B17JY2 } \\
\text { B184X }\end{array}$ & WHITE BLUFFS FY LND. & RIVER_SHORELINE & $\begin{array}{ll}\text { ER } \\
\text { FR }\end{array}$ & 29-Sep-03 & & $0.242 n$ & $\mathrm{mR/d}$ & 0.003 & & & \\
\hline $\begin{array}{l}\text { SESPMNT } \\
\text { SESPMNT }\end{array}$ & $\begin{array}{l}\text { B184X8 } \\
\text { B16K91 }\end{array}$ & $\begin{array}{l}\text { WHITE BLUFFS FY LND. } \\
\text { WHTE BLUFFS SLOUGH }\end{array}$ & $\begin{array}{l}\text { RIVER_SHORELINE } \\
\text { RIVR_SHORELINE }\end{array}$ & $\begin{array}{l}\text { ER } \\
\text { ER }\end{array}$ & 15-Dec-03 & TLD & $0.233 n$ & $\mathrm{mR/d}$ & 0.003 & & & \\
\hline SESPMNT & B174L9 & WHITE BLUFFS SLOUGH & $\begin{array}{l}\text { RIIER_SHORELINE } \\
\text { RIVER SHORELINE }\end{array}$ & $\begin{array}{l}\text { ER } \\
\text { ER }\end{array}$ & $\begin{aligned} \begin{array}{r}18-M a r-03 \\
02-J u l-03\end{array} \\
0\end{aligned}$ & $\begin{array}{l}\text { TLD } \\
\text { TLD }\end{array}$ & $0.267 n$ & $\begin{array}{l}\mathrm{mR/d} \\
\mathrm{mR/d}\end{array}$ & 0.003 & & & \\
\hline SESPMNT & B17JY1 & WHITE BLUFFS SLOUGH & RIVER_SHORELINE & ER & $29-$ Sep-03 & & $0.283 n$ & $\mathrm{mR/d}$ & 0.003 & & & \\
\hline SESPMNT & B184X7 & WHITE BLUFFS SLOUGH & RIVER_SHORELINE & ER & 16-Dec-03 & TLD & & & & & $\begin{array}{l}\text { NO SAMPLE. UNABLE TO COLLECT ON 12/15/03 DUE TO EAGLE } \\
\text { NESTING AREA. TLD WILL REMAIN IN FIELD. }\end{array}$ & \\
\hline SESPMNT & B16KL7 & WPPSS 1; S OF WNP 2 & ONSITE & ER & 19-Mar-03 & TLD & $0.219 \mathrm{n}$ & $\mathrm{mR} / \mathrm{d}$ & 0.001 & & & \\
\hline SESPMNT & B172C4 & WPPSS 1 ; S OF WNP 2 & ONSITE & ER & 16-Jun-03 & TLD & $0.232 n$ & $\mathrm{mR} / \mathrm{d}$ & 0.006 & & & \\
\hline SESPMNT & B17J30 & WPPSS 1 ; S OF WNP 2 & ONSITE & ER & 15 -Sep-03 & TLD & $0.247 n$ & $\mathrm{mR/d}$ & 0.01 & & & \\
\hline SESPMNT & B186M2 & WPPSS 1; S OF WNP 2 & ONSITE & ER & 22-Dec-03 & TLD & $0.241 n$ & $\mathrm{mR} / \mathrm{d}$ & 0.002 & & & \\
\hline SESPMNT & B16KL8 & WPPSS 4; WPS WAREHSE & PERIMETER & ER & 19-Mar-03 & TLD & $0.215 n$ & $\mathrm{mR} / \mathrm{d}$ & 0.004 & & & \\
\hline SESPMNT & B172C5 & WPPSS 4; WPS WAREHSE & PERIMETER & ER & 16-Jun-03 & TLD & $0.226 \mathrm{n}$ & $\mathrm{mR} / \mathrm{d}$ & 0.017 & & & \\
\hline SESPMNT & B17J31 & WPPSS 4; WPS WAREHSE & PERIMETER & ER & $15-$ Sep-03 & TLD & $0.224 n$ & $\mathrm{mR} / \mathrm{d}$ & 0.013 & & & \\
\hline SESPMNT & B186M3 & WPPSS 4; WPS WAREHSE & PERIMETER & ER & 22-Dec-03 & & & & & & & \\
\hline SESPMNT & B16KM1 & WYE BARRICADE & ONSITE & ER & $\begin{array}{l}18-M a r-03 \\
18-03\end{array}$ & TLD & $0.24 n$ & $\mathrm{mR} / \mathrm{d}$ & 0.02 & & & \\
\hline SESPMNT & B172F9 & WYE BARRICADE & ONSITE & ER & $\begin{array}{l}24-J u n-03 \\
24-0,0\end{array}$ & TLD & $0.219 n$ & $\mathrm{mR} / \mathrm{d}$ & 0.001 & & & \\
\hline SESPMNT & B17J34 & WYE BARRICADE & ONSITE & ER & $\begin{array}{l}15-\text { Sep-03 } \\
14-03\end{array}$ & TLD & $0.231 \mathrm{n}$ & $\mathrm{mR} / \mathrm{d}$ & 0.00 & & & \\
\hline SESPMNT & B186M6 & WYE BARRICADE & ONSITE & ER & 22-Dec-03 & TLD & $0.244 n$ & $\mathrm{mR} / \mathrm{d}$ & 0.013 & & & \\
\hline SESPMNT & B16KM2 & YAKIMA & DISTANT & ER & 21-Mar-03 & TLD & $0.191 n$ & $\mathrm{mR} / \mathrm{d}$ & 0.009 & & & \\
\hline SESPMNT & B172HO & YAKIMA & DISTANT & ER & 26-Jun-03 & TLD & $0.196 \mathrm{n}$ & $\mathrm{mR} / \mathrm{d}$ & 0.007 & & & \\
\hline SESPMNT & B17J35 & YAKIMA & DISTANT & ER & $18-\mathrm{Sep}-03$ & TLD & $0.198 \mathrm{n}$ & & 0.003 & & & \\
\hline SESPMNT & B186M7 & YAKIMA & DISTANT & ER & 29-Dec-03 & & $0.204 n$ & & 0.006 & & & \\
\hline SESPMNT & B16KJ6 & YAKIMA BARRICADE & PERIMETER & ER & 20-Mar-03 & & $0.254 n$ & & 0.015 & & & \\
\hline SESPMNT & B172F3 & YAKIMA BARRICADE & PERIMETER & ER & 26-Jun-03 & & $0.268 \mathrm{n}$ & & 0.004 & & & \\
\hline SESPMNT & B17J14 & YAKIMA BARRICADE & $\begin{array}{l}\text { PERIMETER } \\
\text { PERIME }\end{array}$ & ER & $18-\mathrm{Sep}-03$ & & $0.259 n$ & $\mathrm{mR} / \mathrm{d}$ & 0.006 & & & \\
\hline SESPMNT & B186K2 & YAKIMA BARRICADE & PERIMETER & ER & 29-Dec-03 & & $0.256 n$ & & 0.001 & & & \\
\hline SESPMNT & B16K64 & 100 N TRENCH SPRING & RIVER_SHORELINE & ER & 14-Mar-03 & GM_READING & $75 \mathrm{c}$ & & & & & \\
\hline SESPMNT & B174J2 & $100 \mathrm{~N}$ TRENCH SPRING & RIVER_SHORELINE & ER & 02-Jul-03 & GM_READING & & & & & & $\begin{array}{l}\text { GM RADIATION SURVEY NOT } \\
\text { PERFORMED. }\end{array}$ \\
\hline SESPMNT & B17JW3 & 100 N TRENCH SPRING & RIVER_SHORELINE & ER & 29-Sep-03 & GM_READING & & $\mathrm{cpm}$ & & & & \\
\hline SESPMNT & B184T9 & $100 \mathrm{~N}$ TRENCH SPRING & RIVER_SHORELINE & ER & 15-Dec-03 & GM_READING & & $\mathrm{cpm}$ & & & & \\
\hline SESPMNT & B16K89 & 100-D ISLAND & RIVER_SHORELINE & ER & 14-Mar-03 & GM_READING & $100 \mathrm{c}$ & & & & & \\
\hline SESPMNT & B174L7 & 100-D ISLAND & RIVER_SHORELINE & ER & & GM_READING & & & & & & $\begin{array}{l}\text { GM RADIATION SURVEY NOT } \\
\text { PERFORMED. }\end{array}$ \\
\hline SESPMNT & B17JX9 & 100-D ISLAND & RIVER_SHORELINE & ER & 29-Sep-03 & GM_READING & & $\mathrm{cpm}$ & & & & \\
\hline SESPMNT & B184X5 & 100-D ISLAND & RIVER_SHORELINE & ER & 15-Dec-03 & GM_READING & $100 \mathrm{c}$ & $\mathrm{cpm}$ & & & & \\
\hline SESPMNT & B16K85 & ABOVE $1 \mathrm{~K}$ BOAT RAMP & RIVER_SHORELINE & ER & 14-Mar-03 & GM_READING & & & & & & \\
\hline SESPMNT & B174L3 & ABOVE 1K BOAT RAMP & RIVER_SHORELINE & ER & 02-Jul-03 & GM_READING & & & & & & $\begin{array}{l}\text { GM RADIATION SURVEY NOT } \\
\text { PERFORMED. }\end{array}$ \\
\hline
\end{tabular}


EXTERNAL RADIATION

\begin{tabular}{|c|c|c|c|c|c|c|c|c|c|c|c|c|}
\hline OWNER ID & SAMP NUM & & & MEDIA & & $=\begin{array}{c}\text { CON SHORT } \\
\text { NAME }\end{array}$ & |VALUE RPTD & \begin{tabular}{|l|} 
ANAL \\
UNITS \\
RPTD
\end{tabular} & $\left|\begin{array}{c}\text { COUNTING } \\
\text { ERROR }\end{array}\right|$ & $\left|\begin{array}{c}\text { LAB } \\
\text { QUALIFIER }\end{array}\right|$ & SAMP COMMENT & RESULT COMMENT \\
\hline SESPMNT & B17JX5 & ABOVE 1K BOAT RAMP & RIVER_SHORELINE & ER & $29-$ Sep-03 & 3 GM_READING & & $\mathrm{cpm}$ & & & 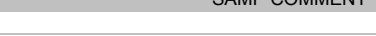 & REOULT CUIVIVIEIVI \\
\hline SESPMNT & B184X1 & ABOVE 1K BOAT RAMP & RIVER_SHORELINE & $E R$ & 15-Dec-03 & 3 GM_READING & & $\mathrm{cpm}$ & & & & \\
\hline SESPMNT & B16K66 & ABOVE TIP 100N BERM & RIVER_SHORELINE & ER & 14-Mar-03 & 3 GM_READING & & $\mathrm{cpm}$ & & & & \\
\hline SESPMNT & B174J4 & ABOVE TIP 100N BERM & RIVER_SHORELINE & ER & 02-Jul-03 & 3 GM_READING & & & & & & $\begin{array}{l}\text { GM RADIATION SURVEY NOT } \\
\text { PERFORMED. }\end{array}$ \\
\hline SESPMNT & B17JW5 & ABOVE TIP 100N BERM & RIVER_SHORELINE & ER & 29-Sep-03 & 3 GM_READING & & $\mathrm{cpm}$ & & & & \\
\hline SESPMNT & B184V2 & ABOVE TIP 100 N BERM & RIVER_SHORELINE & $E R$ & 15-Dec-03 & 3 GM_READING & 100 & & & & & \\
\hline SESPMNT & B16K93 & BELOW $100 \mathrm{~F}$ & RIVER_SHORELINE & $E R$ & 14-Mar-03 & 3 GM_READING & 100 & $\mathrm{cpm}$ & & & & \\
\hline SESPMNT & B174M1 & BELOW $100 \mathrm{~F}$ & RIVER_SHORELINE & ER & 02-Jul-03 & 3 GM_READING & & & & & & $\begin{array}{l}\text { GM RADIATION SURVEY NOT } \\
\text { PERFORMED. }\end{array}$ \\
\hline SESPMNT & B17JY3 & BELOW $100 \mathrm{~F}$ & RIVER_SHORELINE & $E R$ & 29-Sep-03 & 3 GM_READING & & $\mathrm{cpm}$ & & & & \\
\hline SESPMNT & B184X9 & BELOW $100 \mathrm{~F}$ & RIVER_SHORELINE & $E R$ & 15-Dec-03 & 3 GM_READING & & & & & & \\
\hline SESPMNT & B16K65 & BELOW $100 \mathrm{~N}$ OUTFALL & RIVER_SHORELINE & $E R$ & 14-Mar-03 & 3 GM_READING & 100 & $\mathrm{cpm}$ & & & & \\
\hline SESPMNT & B174J3 & BELOW 100 N OUTFALL & RIVER_SHORELINE & $E R$ & 02-Jul-03 & 3 GM_READING & & & & & & $\begin{array}{l}\text { GM RADIATION SURVEY NOT } \\
\text { PERFORMED. }\end{array}$ \\
\hline SESPMNT & B17JW4 & BELOW 100N OUTFALL & RIVER_SHORELINE & ER & 29-Sep-03 & 3 GM_READING & & $\mathrm{cpm}$ & & & & \\
\hline SESPMNT & B184V1 & BELOW 100N OUTFALL & RIVER_SHORELINE & ER & 15-Dec- 03 & GM_READING & & & & & & \\
\hline SESPMNT & B16K76 & HANF POWERLINE XING & RIVER_SHORELINE & $E R$ & 14-Mar-03 & 3 GM_READING & 100 & $\mathrm{cpm}$ & & & & \\
\hline SESPMNT & B174K4 & HANF POWERLINE XING & RIVER_SHORELINE & ER & 02-Jul-03 & 3 GM_READING & & & & & & $\begin{array}{l}\text { GM RADIATION SURVEY NOT } \\
\text { PERFORMED. }\end{array}$ \\
\hline $\begin{array}{l}\text { SESPMNT } \\
\text { GESDMNT }\end{array}$ & B17JW6 & HANF POWERLINE XING & RIVER_SHORELINE & ER & 29-Sep-03 & 3 GM_READING & & $\mathrm{cpm}$ & & & & \\
\hline SESPMNT & B184W2 & HANF POWERLINE XING & RIVER_SHORELINE & ER & 15-Dec-03 & GM_READING & & & & & & \\
\hline SESPMNT & B16K77 & HANFORD RR TRACK & RIVER_SHORELINE & ER & 14-Mar-03 & 3 GM_READING & & & & & & \\
\hline SESPMNT & B174K5 & HANFORD RR TRACK & RIVER_SHORELINE & ER & 02-Jul-03 & 3 GM_READING & & & & & & $\begin{array}{l}\text { GM RADIATION SURVEY NOT } \\
\text { PERFORMED. }\end{array}$ \\
\hline SESPMNT & B17JW7 & HANFORD RR TRACK & RIVER_SHORELINE & $E R$ & 29-Sep-03 & 3 GM_READING & & $\mathrm{cpm}$ & & & & \\
\hline SESPMNT & B184W3 & HANFORD RR TRACK & RIVER_SHORELINE & $E R$ & 15-Dec-03 & 3 GM_READING & & & & & & \\
\hline SESPMNT & B16K82 & ISLND ABOVE 300 AREA & RIVER_SHORELINE & $E R$ & 14-Mar-03 & 3 GM_READING & & & & & & \\
\hline SESPMNT & B174LO & ISLND ABOVE 300 AREA & RIVER_SHORELINE & $E R$ & 02-Jul-03 & 3 GM_READING & & & & & & $\begin{array}{l}\text { GM RADIATION SURVEY NOT } \\
\text { PERFORMED. }\end{array}$ \\
\hline SESPMNT & B17JX2 & ISLND ABOVE 300 AREA & RIVER_SHORELINE & ER & 29-Sep-03 & GM_READING & & $\mathrm{cpm}$ & & & & \\
\hline SESPMNT & B184W8 & ISLND ABOVE 300 AREA & RIVER_SHORELINE & $E R$ & $15-\mathrm{Dec}-03$ & 3 GM_READING & & & & & & \\
\hline SESPMNT & B16K90 & LO END LOCKE ISL & RIVER_SHORELINE & $E R$ & 14-Mar-03 & 3 GM_READING & & & & & & \\
\hline SESPMNT & B174L8 & LO END LOCKE ISL & RIVER_SHORELINE & ER & $02-\mathrm{Jul}-03$ & GM_READING & & & & & & $\begin{array}{l}\text { GM RADIATION SURVEY NOT } \\
\text { PERFORMED. }\end{array}$ \\
\hline SESPMNT & B17JYO & LO END LOCKE ISL & RIVER_SHORELINE & ER & 29-Sep-03 & GM_READING & & $\mathrm{cpm}$ & & & & \\
\hline SESPMNT & B184X6 & LO END LOCKE ISL & RIVER_SHORELINE & $E R$ & 15-Dec-03 & GM_READING & & & & & & \\
\hline SESPMNT & B16K80 & POWERLINE CROSSING & RIVER_SHORELINE & $E R$ & 14-Mar-03 & 3 GM_READING & & & & & & \\
\hline SESPMNT & B174K8 & POWERLINE CROSSING & RIVER_SHORELINE & $E R$ & 02-Jul-03 & 3 GM_READING & & & & & & $\begin{array}{l}\text { GM RADIATION SURVEY NOT } \\
\text { PERFORMED. }\end{array}$ \\
\hline SESPMNT & B17JX0 & POWERLINE CROSSING & RIVER_SHORELINE & ER & 29-Sep-03 & 3 GM_READING & & $\mathrm{cpm}$ & & & & \\
\hline $\begin{array}{l}\text { SESPMNT } \\
\end{array}$ & B184W6 & POWERLINE CROSSING & RIVER_SHORELINE & ER & 15-Dec- 03 & GM_READING & & & & & & \\
\hline SESPMNT & B16K79 & RINGOLD ISLAND & RIVER_SHORELINE & $E R$ & 14-Mar-03 & 3 GM_READING & & & & & & \\
\hline SESPMNT & B174K7 & RINGOLD ISLAND & RIVER_SHORELINE & $E R$ & 02-Jul-03 & 3 GM_READING & & & & & & $\begin{array}{l}\text { GM RADIATION SURVEY NOT } \\
\text { PERFORMED. }\end{array}$ \\
\hline SESPMNT & B17JW9 & RINGOLD ISLAND & RIVER_SHORELINE & ER & 29-Sep-03 & 3 GM_READING & & $\mathrm{cpm}$ & & & & \\
\hline SESPMNT & B184W5 & RINGOLD ISLAND & RIVER_SHORELINE & ER & 15-Dec-03 & 3 GM_READING & & $\mathrm{cpm}$ & & & & \\
\hline SESPMNT & B16K94 & S END VERNITA BRIDGE & RIVER_SHORELINE & ER & 14-Mar-03 & 3 GM_READING & & $\mathrm{cpm}$ & & & & \\
\hline SESPMNT & B174M2 & $S$ END VERNITA BRIDGE & RIVER_SHORELINE & $E R$ & 02-Jul-03 & 3 GM_READING & & & & & & $\begin{array}{l}\text { GM RADIATION SURVEY NOT } \\
\text { PERFORMED. }\end{array}$ \\
\hline SESPMNT & B17JY4 & S END VERNITA BRIDGE & RIVER_SHORELINE & $E R$ & 29-Sep-03 & 3 GM_READING & & $\mathrm{cpm}$ & & & & \\
\hline SESPMNT & B18504 & S END VERNITA BRIDGE & RIVER_SHORELINE & $E R$ & 15-Dec-03 & GM_READING & & $\mathrm{cpm}$ & & & & \\
\hline SESPMNT & B16K92 & WHITE BLUFFS FY LND. & RIVER SHORELINE & $E R$ & 14-Mar-03 & GM READING & 100 & $\mathrm{cpm}$ & & & & \\
\hline SESPMNT & B174M0 & WHITE BLUFFS FY LND. & RIVER_SHORELINE & $E R$ & 02-Jul-03 & GM_READING & & & & & & $\begin{array}{l}\text { GM RADIATION SURVEY NOT } \\
\text { PERFORMED. }\end{array}$ \\
\hline SESPMNT & B17JY2 & WHITE BLUFFS FY LND. & RIVER_SHORELINE & ER & 29-Sep-03 & GM_READING & & $\mathrm{cpm}$ & & & & \\
\hline SESPMNT & B184X8 & WHITE BLUFFS FY LND. & RIVER_SHORELINE & ER & 15-Dec-03 & GM_READING & & $\mathrm{cpm}$ & & & & \\
\hline SESPMNT & B16K64 & 100 N TRENCH SPRING & RIVER_SHORELINE & $E R$ & 14-Mar-03 & BICRONREAD & 10 & uRem/h & & & & \\
\hline SESPMNT & B174J2 & 100 N TRENCH SPRING & RIVER_SHORELINE & $E R$ & 02-Jul-03 & BICRONREAD & 14 & uRem/h & & & & \\
\hline SESPMNT & B17JW3 & 100 N TRENCH SPRING & RIVER_SHORELINE & $E R$ & 29-Sep-03 & BICRONREAD & 12 & uRem/h & & & & \\
\hline SESPMNT & B184T9 & 100 N TRENCH SPRING & RIVER_SHORELINE & $E R$ & 15-Dec-03 & BICRONREAD & 10 & uRem/h & & & & \\
\hline SESPMNT & B16K89 & 100-D ISLAND & RIVER_SHORELINE & $E R$ & 14-Mar-03 & BICRONREAD & & uRem/h & & & & \\
\hline SESPMNT & B174L7 & 100-D ISLAND & RIVER_SHORELINE & $E R$ & 02-Jul-03 & BICRONREAD & & uRem/h & & & & \\
\hline SESPMNT & B17JX9 & 100-D ISLAND & RIVER_SHORELINE & $E R$ & 29-Sep-03 & BICRONREAD & & uRem/h & & & & \\
\hline SESPMNT & B184X5 & 100-D ISLAND & RIVER_SHORELINE & $E R$ & 15-Dec-03 & BICRONREAD & & uRem/h & & & & \\
\hline SESPMNT & B16K85 & ABOVE 1K BOAT RAMP & RIVER_SHORELINE & ER & 14-Mar-03 & BICRONREAD & & uRem/h & & & & \\
\hline SESPMNT & B174L3 & ABOVE $1 \mathrm{~K}$ BOAT RAMP & RIVER_SHORELINE & $E R$ & 02-Jul-03 & BICRONREAD & & uRem/h & & & & \\
\hline
\end{tabular}


EXTERNAL RADIATION

\begin{tabular}{|c|c|c|c|c|c|c|c|c|c|c|c|c|}
\hline OWNER ID & SAMP NUM & SITE NAME & DIST CLASS & MEDIA & SAMP DATE & $\begin{array}{c}\text { CON SHORT } \\
\text { NAME }\end{array}$ & VALUE RPTD & \begin{tabular}{|l|} 
ANAL \\
UNITS \\
RPTD
\end{tabular} & $\begin{array}{c}\text { COUNTING } \\
\text { ERROR }\end{array}$ & $\mid \begin{array}{c}\text { LAB } \\
\text { QUALIFIER }\end{array}$ & SAMP COMMENT & RESULT COMMENT \\
\hline SESPMNT & B17JX5 & ABOVE $1 \mathrm{~K}$ BOAT RAMP & RIVER_SHORELINE & ER & 29-Sep-03 & BICRONREAD & 12 & & & & & \\
\hline SESPMNT & B184X1 & ABOVE $1 \mathrm{~K}$ BOAT RAMP & RIVER_SHORELINE & ER & 15-Dec-03 & BICRONREAD & & uRem $/ \mathrm{h}$ & & & & \\
\hline SESPMNT & B16K66 & ABOVE TIP 100 N BERM & RIVER_SHORELINE & ER & 14-Mar-03 & BICRONREAD & & uRem $/ \mathrm{h}$ & & & & \\
\hline SESPMNT & B174J4 & ABOVE TIP 100N BERM & RIVER_SHORELINE & $\mathrm{ER}$ & & & & uRem/h & & & & \\
\hline SESPMNT & B17JW5 & ABOVE TIP 100N BERM & RIVER_SHORELINE & ER & 29-Sep-03 & & & uRem/h & & & & \\
\hline SESPMNT & B184V2 & ABOVE TIP 100N BERM & RIVER_SHORELINE & ER & 15-Dec-03 & BICRONREAD & & uRem/h & & & & \\
\hline SESPMNT & B16K93 & BELOW $100 \mathrm{~F}$ & RIVER_SHORELINE & $\mathrm{ER}$ & 14-Mar-03 & BICRONREAD & & uRem/h & & & & \\
\hline SESPMNT & B174M1 & BELOW $100 \mathrm{~F}$ & RIVER_SHORELINE & ER & 02-Jul-03 & BICRONREAD & & uRem/h & & & & \\
\hline SESPMNT & B17JY3 & BELOW $100 \mathrm{~F}$ & RIVER_SHORELINE & ER & $29-\mathrm{Sep}-03$ & BICRONREAD & & uRem $/ \mathrm{h}$ & & & & \\
\hline SESPMNT & B184X9 & BELOW $100 \mathrm{~F}$ & RIVER_SHORELINE & ER & 15-Dec-03 & BICRONREAD & & uRem $/ \mathrm{h}$ & & & & \\
\hline SESPMNT & B16K65 & BELOW 100N OUTFALL & RIVER_SHORELINE & ER & 14-Mar-03 & BICRONREAD & & uRem $/ \mathrm{h}$ & & & & \\
\hline SESPMNT & B174J3 & BELOW 100N OUTFALL & RIVER_SHORELINE & ER & 02-Jul-03 & BICRONREAD & & uRem $/ \mathrm{h}$ & & & & \\
\hline SESPMNT & B17JW4 & BELOW 100N OUTFALL & RIVER_SHORELINE & ER & $29-\mathrm{Sep}-03$ & BICRONREAD & & uRem $/ \mathrm{h}$ & & & & \\
\hline SESPMNT & B184V1 & BELOW 100N OUTFALL & RIVER_SHORELINE & ER & 15-Dec-03 & BICRONREAD & & uRem/h & & & & \\
\hline SESPMNT & B16K76 & HANF POWERLINE XING & RIVER_SHORELINE & ER & 14-Mar-03 & BICRONREAD & & uRem/h & & & & \\
\hline SESPMNT & B174K4 & HANF POWERLINE XING & RIVER_SHORELINE & ER & 02-Jul-03 & BICRONREAD & & uRem/h & & & & \\
\hline SESPMNT & B17JW6 & HANF POWERLINE XING & RIVER_SHORELINE & ER & $29-\mathrm{Sep}-03$ & BICRONREAD & 15 & uRem $/ \mathrm{h}$ & & & & \\
\hline SESPMNT & B184W2 & HANF POWERLINE XING & RIVER_SHORELINE & ER & 15-Dec-03 & BICRONREAD & & uRem/h & & & & \\
\hline SESPMNT & B16K77 & HANFORD RR TRACK & RIVER_SHORELINE & ER & 14-Mar-03 & BICRONREAD & & uRem $/ \mathrm{h}$ & & & & \\
\hline & B174K5 & $\begin{array}{l}\text { HANFORD RR TRACK } \\
\end{array}$ & RIVER_SHORELINE & ER & 02-Jul-03 & BICRONREAD & & uRem/h & & & & \\
\hline $\begin{array}{l}\text { SESPMNT } \\
\text { SESPMNT }\end{array}$ & $\begin{array}{l}\text { B17JW7 } \\
\text { B184W3 }\end{array}$ & $\begin{array}{l}\text { HANFORD RR TRACK } \\
\text { HANFORD RR TRACK }\end{array}$ & $\begin{array}{l}\text { RIVER_SHORELINE } \\
\text { RIVR_SHORFINF }\end{array}$ & $\begin{array}{l}\text { ER } \\
\text { ER }\end{array}$ & 29-Sep-03 & BICRONREAD & $\frac{12}{5}$ & uRem/h & & & & \\
\hline $\begin{array}{l}\text { SESPMNT } \\
\text { SESPMNT }\end{array}$ & $\begin{array}{l}\text { B184W3 } \\
\text { B16K82 }\end{array}$ & $\begin{array}{l}\text { HANFORD RR TRACK } \\
\text { ISLND ABOVE } 300 \text { AREA }\end{array}$ & $\begin{array}{l}\text { RIVER_SHORELINE } \\
\text { RIVER_SHORELINE }\end{array}$ & $\begin{array}{l}E R \\
E R\end{array}$ & $\begin{array}{l}\text { 15-De--03 } \\
\text { 14-Mar-03 }\end{array}$ & $\begin{array}{l}\text { BICRONREAD } \\
\text { BICRONREAD }\end{array}$ & & $\begin{array}{l}\text { URem/h } \\
\text { uRem/h }\end{array}$ & & & & \\
\hline SESPMNT & B174L0 & ISLND ABOVE 300 AREA & RIVER_SHORELINE & ER & 02-Jul-03 & BICRONREAD & & uRem $/ \mathrm{h}$ & & & & \\
\hline SESPMNT & B17JX2 & ISLND ABOVE 300 AREA & RIVER_SHORELINE & ER & $29-S e p-03$ & BICRONREAD & 12 & uRem $/ \mathrm{h}$ & & & & \\
\hline SESPMNT & B184W8 & ISLND ABOVE 300 AREA & RIVER_SHORELINE & ER & 15-Dec-03 & BICRONREAD & & uRem $/ \mathrm{h}$ & & & & \\
\hline SESPMNT & B16K90 & LO END LOCKE ISL & RIVER_SHORELINE & ER & 14-Mar-03 & BICRONREAD & & uRem/h & & & & \\
\hline SESPMNT & B174L8 & LO END LOCKE ISL & RIVER_SHORELINE & ER & 02-Jul-03 & BICRONREAD & & uRem/h & & & & \\
\hline SESPMNT & B17JY0 & LO END LOCKE ISL & RIVER_SHORELINE & ER & 29-Sep-03 & BICRONREAD & & uRem/h & & & & \\
\hline SESPMNT & B184X6 & LO END LOCKE ISL & RIVER_SHORELINE & ER & 15-Dec-03 & BICRONREAD & & uRem/h & & & & \\
\hline SESPMNT & B16K80 & POWERLINE CROSSING & RIVER_SHORELINE & ER & 14-Mar-03 & BICRONREAD & & uRem/h & & & & \\
\hline SESPMNT & B174K8 & POWERLINE CROSSING & RIVER_SHORELINE & $\mathrm{ER}$ & 02-Jul-03 & BICRONREAD & & uRem $/ \mathrm{h}$ & & & & \\
\hline SESPMNT & B17JX0 & POWERLINE CROSSING & RIVER_SHORELINE & ER & 29-Sep-03 & BICRONREAD & & uRem $/ \mathrm{h}$ & & & & \\
\hline SESPMNT & B184W6 & POWERLINE CROSSING & RIVER_SHORELINE & ER & 15-Dec-03 & BICRONREAD & & uRem $/ \mathrm{h}$ & & & & \\
\hline SESPMNT & B16K79 & RINGOLD ISLAND & RIVER_SHORELINE & ER & 14-Mar-03 & BICRONREAD & & uRem $/ \mathrm{h}$ & & & & \\
\hline SESPMNT & B174K7 & RINGOLD ISLAND & RIVER_SHORELINE & ER & 02-Jul-03 & BICRONREAD & & uRem $/ \mathrm{h}$ & & & & \\
\hline SESPMNT & B17JW9 & RINGOLD ISLAND & RIVER_SHORELINE & ER & 29-Sep-03 & BICRONREAD & & uRem $/ \mathrm{h}$ & & & & \\
\hline SESPMNT & B184W5 & RINGOLD ISLAND & RIVER_SHORELINE & ER & 15-Dec-03 & BICRONREAD & & uRem/h & & & & \\
\hline SESPMNT & B16K94 & S END VERNITA BRIDGE & RIVER_SHORELINE & ER & 14-Mar-03 & BICRONREAD & & uRem/h & & & & \\
\hline SESPMNT & B174M2 & S END VERNITA BRIDGE & RIVER_SHORELINE & ER & $02-\mathrm{Jul}-03$ & BICRONREAD & & uRem $/ \mathrm{h}$ & & & & \\
\hline SESPMNT & B17JY4 & S END VERNITA BRIDGE & RIVER_SHORELINE & ER & 29-Sep-03 & BICRONREAD & & uRem/h & & & & \\
\hline SESPMNT & B18504 & S END VERNITA BRIDGE & RIVER_SHORELINE & ER & 15-Dec-03 & BICRONREAD & & uRem $/ \mathrm{h}$ & & & & \\
\hline SESPMNT & B16K92 & WHITE BLUFFS FY LND. & RIVER_SHORELINE & ER & 14-Mar-03 & BICRONREAD & & uRem/h & & & & \\
\hline SESPMNT & B174M0 & WHITE BLUFFS FY LND. & RIVER_SHORELINE & ER & 02-Jul-03 & BICRONREAD & & uRem/h & & & & \\
\hline SESPMNT & B17JY2 & WHITE BLUFFS FY LND. & RIVER_SHORELINE & ER & 29-Sep-03 & BICRONREAD & 16 & uRem $/ \mathrm{h}$ & & & & \\
\hline SESPMNT & B184X8 & WHITE BLUFFS FY LND. & RIVER_SHORELINE & ER & 15-Dec-03 & BICRONREAD & & uRem/h & & & & \\
\hline
\end{tabular}




\section{Dose Calculation}


Table D-1. Distribution of Population in $80-\mathrm{km}^{\text {Radius of the } 100-\mathrm{K} \text { Area by Grid Sector }}{ }^{\text {(a) }}$

Number of People

\begin{tabular}{|c|c|c|c|c|c|c|c|c|c|c|c|}
\hline Direction & $0-1 \mathrm{mi}$ & $1-2 \mathrm{mi}$ & $2-3 \mathrm{mi}$ & 3-4 mi & $4-5 \mathrm{mi}$ & $5-10 \mathrm{mi}$ & $10-20 \mathrm{mi}$ & $20-30 \mathrm{mi}$ & $30-40 \mathrm{mi}$ & $40-50 \mathrm{mi}$ & Totals \\
\hline $\bar{S}$ & 0 & 0 & 0 & 0 & 0 & 0 & 3 & 6547 & 182 & 211 & 6943 \\
\hline SW & 0 & 0 & 0 & 0 & 0 & 0 & 26 & 2273 & 25238 & 228 & 27765 \\
\hline W & 0 & 0 & 0 & 0 & 0 & 31 & 1308 & 0 & 3685 & 120158 & 125182 \\
\hline WNW & 0 & 0 & 0 & 0 & 0 & 53 & 3859 & 10 & 108 & 4359 & 8389 \\
\hline NW & 0 & 0 & 0 & 0 & 0 & 162 & 282 & 665 & 168 & 430 & 1707 \\
\hline NNE & 0 & 0 & 0 & 0 & 0 & 19 & 645 & 804 & 29927 & 1136 & 32531 \\
\hline NE & 0 & 0 & 0 & 0 & 0 & 0 & 714 & 856 & 4014 & 165 & 5749 \\
\hline ENE & 0 & 0 & 0 & 0 & 0 & 0 & 898 & 10028 & 239 & 178 & 11343 \\
\hline$E$ & 0 & 0 & 0 & 0 & 0 & 12 & 464 & 992 & 3237 & 418 & 5123 \\
\hline ESE & 0 & 0 & 0 & 0 & 0 & 4 & 685 & 2393 & 207 & 1016 & 4305 \\
\hline
\end{tabular}

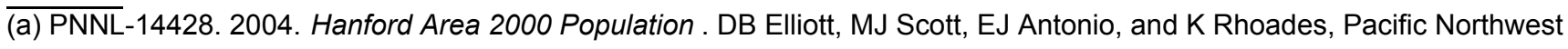
National Laboratory, Richland, Washington. 
Table D-2. Distribution of Population in $80-k_{m}$ Radius of the 200 Areas by Grid Sector ${ }^{(a)}$

\begin{tabular}{|c|c|c|c|c|c|c|c|c|c|c|c|}
\hline \multirow[b]{2}{*}{ Direction } & \multicolumn{11}{|c|}{ Number of People } \\
\hline & $\underline{0-1 \mathrm{mi}}$ & $1-2 \mathrm{mi}$ & $2-3 \mathrm{mi}$ & 3-4 mi & $4-5 \mathrm{mi}$ & 5-10 mi & $10-20 \mathrm{mi}$ & $20-30 \mathrm{mi}$ & $30-40 \mathrm{mi}$ & $40-50 \mathrm{mi}$ & Totals \\
\hline $\bar{S}$ & 0 & 0 & 0 & 0 & 0 & 0 & 959 & 790 & 176 & 4281 & 6206 \\
\hline SSW & 0 & 0 & 0 & 0 & 0 & 0 & 180 & 12966 & 293 & 299 & 13738 \\
\hline SW & 0 & 0 & 0 & 0 & 0 & 0 & 32 & 30654 & 3204 & 95 & 33985 \\
\hline WSW & 0 & 0 & 0 & 0 & 0 & 0 & 53 & 2309 & 23398 & 7055 & 32815 \\
\hline W & 0 & 0 & 0 & 0 & 0 & 7 & 36 & 188 & 10558 & 118630 & 129419 \\
\hline WNW & 0 & 0 & 0 & 0 & 0 & 0 & 1366 & 33 & 10 & 6178 & 7587 \\
\hline NW & 0 & 0 & 0 & 0 & 0 & 12 & 3358 & 933 & 92 & 2336 & 6731 \\
\hline NNW & 0 & 0 & 0 & 0 & 0 & 4 & 320 & 750 & 1713 & 7123 & 9910 \\
\hline $\mathrm{N}$ & 0 & 0 & 0 & 0 & 0 & 0 & 170 & 2980 & 438 & 3018 & 6606 \\
\hline NNE & 0 & 0 & 0 & 0 & 0 & 0 & 29 & 1085 & 4150 & 27277 & 32541 \\
\hline NE & 0 & 0 & 0 & 0 & 0 & 0 & 115 & 10821 & 3652 & 670 & 15258 \\
\hline ENE & 0 & 0 & 0 & 0 & 0 & 0 & 348 & 1184 & 1704 & 220 & 3456 \\
\hline$E$ & 0 & 0 & 0 & 0 & 0 & 0 & 547 & 2387 & 1953 & 325 & 5212 \\
\hline ESE & 0 & 0 & 0 & 0 & 0 & 0 & 304 & 1851 & 514 & 1301 & 3970 \\
\hline SE & 0 & 0 & 0 & 0 & 0 & 0 & 213 & 51919 & 96942 & 1250 & 150324 \\
\hline SSE & 0 & 0 & 0 & 0 & 0 & 0 & 2317 & 17659 & 905 & 7655 & 28536 \\
\hline Totals & 0 & 0 & 0 & 0 & 0 & 23 & 10347 & 138509 & 149702 & 187713 & 486294 \\
\hline
\end{tabular}

(a) PNNL-14428. 2004. Hanford Area 2000 Population. DB Elliott, MJ Scott, EJ Antonio, and K Rhoades, Pacific Northwest National Laboratory, Richland, Washington. 
Table D-3. Distribution of Population in $80-\mathrm{km}^{2}$ Radius of the 300 Area by Grid Sector ${ }^{(a)}$

\begin{tabular}{|c|c|c|c|c|c|c|c|c|c|c|c|}
\hline \multirow[b]{2}{*}{ Direction } & \multicolumn{11}{|c|}{ Number of People } \\
\hline & $\underline{0-1 \mathrm{mi}}$ & $1-2 \mathrm{mi}$ & $2-3 \mathrm{mi}$ & 3-4 mi & $4-5 \mathrm{mi}$ & $5-10 \mathrm{mi}$ & $10-20 \mathrm{mi}$ & $20-30 \mathrm{mi}$ & $30-40 \mathrm{mi}$ & $40-50 \mathrm{mi}$ & Totals \\
\hline$S$ & 0 & 0 & 186 & 2683 & 8114 & 22011 & 5169 & 199 & 28270 & 2710 & 69342 \\
\hline SSW & 0 & 0 & 1 & 76 & 72 & 7114 & 678 & 126 & 4003 & 3790 & 15860 \\
\hline SW & 0 & 0 & 7 & 440 & 99 & 3053 & 2490 & 71 & 84 & 329 & 6573 \\
\hline WSW & 0 & 0 & 1 & 23 & 21 & 734 & 4317 & 11670 & 13983 & 195 & 30944 \\
\hline W & 0 & 0 & 0 & 0 & 3 & 370 & 79 & 701 & 22225 & 20941 & 44319 \\
\hline WNW & 0 & 0 & 0 & 0 & 0 & 0 & 0 & 54 & 39 & 382 & 475 \\
\hline NW & 0 & 0 & 0 & 0 & 0 & 0 & 0 & 14 & 4921 & 1347 & 6282 \\
\hline NNW & 0 & 0 & 0 & 0 & 0 & 4 & 17 & 8 & 1062 & 3135 & 4226 \\
\hline $\mathrm{N}$ & 0 & 0 & 0 & 0 & 0 & 6 & 350 & 1688 & 9709 & 2372 & 14125 \\
\hline NNE & 0 & 0 & 5 & 12 & 21 & 282 & 1978 & 1151 & 801 & 3359 & 7609 \\
\hline NE & 0 & 6 & 24 & 28 & 64 & 330 & 864 & 3504 & 271 & 205 & 5296 \\
\hline ENE & 0 & 21 & 43 & 108 & 59 & 414 & 368 & 80 & 313 & 154 & 1560 \\
\hline $\mathrm{E}$ & 0 & 18 & 21 & 28 & 132 & 302 & 199 & 907 & 226 & 533 & 2366 \\
\hline ESE & 0 & 14 & 16 & 27 & 49 & 205 & 726 & 335 & 173 & 22299 & 23844 \\
\hline SE & 0 & 3 & 50 & 70 & 39 & 4465 & 48507 & 960 & 804 & 1181 & 56079 \\
\hline SSE & $\underline{0}$ & $\underline{0}$ & 555 & 1841 & 331 & 5897 & 50942 & 92 & 190 & 319 & 60167 \\
\hline Totals & 0 & 62 & 909 & 5336 & 9004 & 45187 & 116684 & 21560 & 87074 & 63251 & 349067 \\
\hline
\end{tabular}

(a) PNNL-14428. 2004. Hanford Area 2000 Population. DB Elliott, MJ Scott, EJ Antonio, and K Rhoades, Pacific Northwest National Laboratory, Richland, Washington. 
Table D-4. Distribution of Population in 80-km Radius of the 400 Area by Grid Sector ${ }^{(a)}$

\begin{tabular}{|c|c|c|c|c|c|c|c|c|c|c|c|}
\hline \multirow[b]{2}{*}{ Direction } & \multicolumn{11}{|c|}{ Number of People } \\
\hline & $\underline{0-1 \mathrm{mi}}$ & $1-2 \mathrm{mi}$ & $\underline{2-3 \mathrm{mi}}$ & $\underline{3-4 \mathrm{mi}}$ & $\underline{4-5 \mathrm{mi}}$ & 5-10 mi & $10-20 \mathrm{mi}$ & $20-30 \mathrm{mi}$ & $30-40 \mathrm{mi}$ & $40-50 \mathrm{mi}$ & $\underline{\text { Totals }}$ \\
\hline $\bar{S}$ & 0 & 0 & 0 & 0 & 0 & 4625 & 7638 & 52 & 13774 & 19359 & 45448 \\
\hline SSW & 0 & 0 & 0 & 0 & 52 & 852 & 4946 & 172 & 1113 & 3944 & 11079 \\
\hline SW & 0 & 0 & 0 & 0 & 43 & 269 & 2456 & 7982 & 160 & 278 & 11188 \\
\hline WSW & 0 & 0 & 0 & 0 & 0 & 10 & 217 & 14171 & 23070 & 303 & 37771 \\
\hline W & 0 & 0 & 0 & 0 & 0 & 0 & 11 & 212 & 5364 & 23858 & 29445 \\
\hline WNW & 0 & 0 & 0 & 0 & 0 & 0 & 0 & 105 & 1017 & 1090 & 2212 \\
\hline NW & 0 & 0 & 0 & 0 & 0 & 0 & 0 & 476 & 4463 & 348 & 5287 \\
\hline NNW & 0 & 0 & 0 & 0 & 0 & 0 & 0 & 205 & 3343 & 992 & 4540 \\
\hline$N$ & 0 & 0 & 0 & 0 & 0 & 0 & 106 & 715 & 1332 & 22038 & 24191 \\
\hline NNE & 0 & 0 & 0 & 4 & 0 & 26 & 508 & 10856 & 2541 & 2355 & 16290 \\
\hline NE & 0 & 0 & 0 & 0 & 0 & 206 & 1791 & 1963 & 272 & 158 & 4390 \\
\hline ENE & 0 & 0 & 0 & 0 & 0 & 298 & 1037 & 1704 & 163 & 383 & 3585 \\
\hline$E$ & 0 & 0 & 0 & 0 & 2 & 311 & 702 & 102 & 188 & 117 & 1422 \\
\hline ESE & 0 & 0 & 0 & 0 & 0 & 605 & 578 & 658 & 918 & 367 & 3126 \\
\hline SE & 0 & 0 & 0 & 0 & 0 & 334 & 47925 & 14898 & 332 & 1155 & 64644 \\
\hline SSE & 0 & 0 & 0 & 0 & 0 & 12055 & 68931 & 6864 & 706 & 538 & 89094 \\
\hline Totals & 0 & 0 & 0 & 4 & 97 & 19591 & 136846 & 61135 & 58756 & 77283 & 353712 \\
\hline
\end{tabular}

(a) PNNL-14428. 2004. Hanford Area 2000 Population. DB Elliott, MJ Scott, EJ Antonio, and K Rhoades, Pacific Northwest National Laboratory, Richland, Washington. 
Table D-5. Annual Average Dispersion Factor Around the 100-K Area During 2003 for a 10-Meter Release Height

X/Q'

\begin{tabular}{|c|c|c|c|c|c|c|c|c|c|c|}
\hline Direction & $0.8 \mathrm{~km}$ & $2.4 \mathrm{~km}$ & $4.0 \mathrm{~km}$ & $5.6 \mathrm{~km}$ & $7.2 \mathrm{~km}$ & $12 \mathrm{~km}$ & $24 \mathrm{~km}$ & $40 \mathrm{~km}$ & $56 \mathrm{~km}$ & $72 \mathrm{~km}$ \\
\hline$N$ & 2.87E-06 & 5.96E-07 & $2.84 \mathrm{E}-07$ & $1.75 \mathrm{E}-07$ & $1.23 E-07$ & 6.02E-08 & 2.33E-08 & 1.17E-08 & 7.52E-09 & 5.40E-09 \\
\hline NNE & 2.42E-06 & $5.14 \mathrm{E}-07$ & $2.45 \mathrm{E}-07$ & $1.52 \mathrm{E}-07$ & 1.07E-07 & 5.24E-08 & 2.04E-08 & 1.03E-08 & 6.60E-09 & 4.74E-09 \\
\hline $\mathrm{NE}$ & 3.83E-06 & $8.15 \mathrm{E}-07$ & $3.89 \mathrm{E}-07$ & $2.41 \mathrm{E}-07$ & 1.69E-07 & 8.33E-08 & $3.25 E-08$ & 1.64E-08 & $1.05 \mathrm{E}-08$ & 7.56E-09 \\
\hline ENE & 7.00E-06 & 1.51E-06 & $7.22 \mathrm{E}-07$ & 4.48E-07 & 3.15E-07 & $1.55 \mathrm{E}-07$ & 6.06E-08 & 3.07E-08 & 1.97E-08 & $1.42 \mathrm{E}-08$ \\
\hline$E$ & 1.02E-05 & 2.14E-06 & 1.02E-06 & 6.32E-07 & 4.44E-07 & 2.18E-07 & 8.50E-08 & 4.29E-08 & $2.75 \mathrm{E}-08$ & $1.98 \mathrm{E}-08$ \\
\hline ESE & 6.26E-06 & $1.30 \mathrm{E}-06$ & 6.16E-07 & $3.80 \mathrm{E}-07$ & 2.66E-07 & 1.30E-07 & 5.03E-08 & 2.53E-08 & 1.62E-08 & 1.16E-08 \\
\hline SE & 4.83E-06 & 9.77E-07 & 4.61E-07 & 2.83E-07 & 1.98E-07 & 9.63E-08 & 3.70E-08 & 1.85E-08 & 1.18E-08 & 8.47E-09 \\
\hline SSE & 3.85E-06 & 7.32E-07 & 3.39E-07 & 2.06E-07 & 1.43E-07 & 6.84E-08 & 2.58E-08 & 1.27E-08 & 8.04E-09 & 5.72E-09 \\
\hline$S$ & 3.32E-06 & 6.32E-07 & 2.93E-07 & $1.78 \mathrm{E}-07$ & $1.23 \mathrm{E}-07$ & 5.91E-08 & $2.23 E-08$ & 1.10E-08 & 6.98E-09 & 4.97E-09 \\
\hline SSW & 3.06E-06 & 5.99E-07 & $2.80 \mathrm{E}-07$ & $1.72 \mathrm{E}-07$ & 1.19E-07 & 5.78E-08 & $2.20 \mathrm{E}-08$ & 1.10E-08 & 6.97E-09 & 4.98E-09 \\
\hline SW & $2.95 \mathrm{E}-06$ & 6.08E-07 & 2.88E-07 & $1.78 \mathrm{E}-07$ & $1.24 \mathrm{E}-07$ & $6.08 E-08$ & $2.35 \mathrm{E}-08$ & 1.18E-08 & 7.53E-09 & 5.40E-09 \\
\hline WSW & 2.98E-06 & $6.01 \mathrm{E}-07$ & 2.84E-07 & $1.74 \mathrm{E}-07$ & $1.22 \mathrm{E}-07$ & 5.93E-08 & 2.28E-08 & 1.14E-08 & 7.25E-09 & 5.19E-09 \\
\hline W & 3.28E-06 & $6.80 \mathrm{E}-07$ & 3.23E-07 & 2.00E-07 & $1.40 \mathrm{E}-07$ & 6.85E-08 & 2.66E-08 & 1.34E-08 & 8.55E-09 & 6.13E-09 \\
\hline WNW & $3.42 E-06$ & 6.86E-07 & $3.24 \mathrm{E}-07$ & $1.99 \mathrm{E}-07$ & 1.39E-07 & 6.78E-08 & 2.61E-08 & $1.31 \mathrm{E}-08$ & 8.36E-09 & 5.99E-09 \\
\hline NW & 3.49E-06 & $7.40 \mathrm{E}-07$ & $3.53 \mathrm{E}-07$ & 2.19E-07 & $1.53 \mathrm{E}-07$ & 7.52E-08 & 2.93E-08 & $1.48 \mathrm{E}-08$ & 9.47E-09 & $6.80 \mathrm{E}-09$ \\
\hline NNW & $2.99 \mathrm{E}-06$ & $6.15 \mathrm{E}-07$ & $2.92 \mathrm{E}-07$ & $1.80 \mathrm{E}-07$ & $1.26 \mathrm{E}-07$ & $6.17 \mathrm{E}-08$ & $2.39 \mathrm{E}-08$ & $1.20 \mathrm{E}-08$ & 7.67E-09 & 5.50E-09 \\
\hline
\end{tabular}


Table D-6. Annual Average Dispersion Factor Around the 200 Areas During 2003 for an 89-Meter Release Height

X/Q'

\begin{tabular}{|c|c|c|c|c|c|c|c|c|c|c|}
\hline Direction & $0.8 \mathrm{~km}$ & $2.4 \mathrm{~km}$ & $4.0 \mathrm{~km}$ & $5.6 \mathrm{~km}$ & $7.2 \mathrm{~km}$ & $12 \mathrm{~km}$ & $24 \mathrm{~km}$ & $40 \mathrm{~km}$ & $56 \mathrm{~km}$ & $72 \mathrm{~km}$ \\
\hline$N$ & 1.13E-08 & 2.14E-08 & 1.67E-08 & 1.26E-08 & 9.81E-09 & 5.56E-09 & 2.41E-09 & 1.27E-09 & 8.32E-10 & $6.05 \mathrm{E}-10$ \\
\hline NNE & 2.18E-08 & $2.20 \mathrm{E}-08$ & $1.64 \mathrm{E}-08$ & 1.23E-08 & 9.58E-09 & 5.51E-09 & 2.47E-09 & 1.35E-09 & $9.00 \mathrm{E}-10$ & $6.66 \mathrm{E}-10$ \\
\hline NE & 3.02E-08 & 2.96E-08 & $2.25 \mathrm{E}-08$ & 1.69E-08 & 1.31E-08 & 7.46E-09 & $3.24 \mathrm{E}-09$ & 1.72E-09 & 1.13E-09 & 8.20E-10 \\
\hline ENE & 2.95E-08 & 3.07E-08 & 2.43E-08 & $1.88 \mathrm{E}-08$ & 1.49E-08 & 8.81E-09 & 4.01E-09 & 2.19E-09 & 1.47E-09 & $1.08 \mathrm{E}-09$ \\
\hline$E$ & 1.34E-08 & 2.63E-08 & $2.26 \mathrm{E}-08$ & $1.81 \mathrm{E}-08$ & 1.48E-08 & $9.14 \mathrm{E}-09$ & 4.41E-09 & $2.50 \mathrm{E}-09$ & 1.71E-09 & $1.28 \mathrm{E}-09$ \\
\hline ESE & 1.74E-08 & $3.25 \mathrm{E}-08$ & 2.94E-08 & $2.43 E-08$ & 2.02E-08 & $1.28 \mathrm{E}-08$ & 6.31E-09 & 3.61E-09 & 2.47E-09 & 1.85E-09 \\
\hline SE & $3.44 \mathrm{E}-08$ & 6.92E-08 & 5.89E-08 & 4.66E-08 & 3.76E-08 & 2.27E-08 & $1.05 E-08$ & 5.80E-09 & 3.89E-09 & 2.88E-09 \\
\hline SSE & $2.62 \mathrm{E}-08$ & 5.91E-08 & 4.76E-08 & 3.64E-08 & 2.87E-08 & 1.67E-08 & 7.46E-09 & 4.04E-09 & 2.69E-09 & $1.98 \mathrm{E}-09$ \\
\hline$S$ & 2.47E-08 & 4.67E-08 & 3.67E-08 & 2.76E-08 & 2.15E-08 & $1.21 \mathrm{E}-08$ & 5.20E-09 & 2.73E-09 & 1.78E-09 & $1.29 \mathrm{E}-09$ \\
\hline SSW & 2.70E-08 & $3.62 \mathrm{E}-08$ & $2.75 \mathrm{E}-08$ & 2.04E-08 & 1.57E-08 & 8.73E-09 & 3.66E-09 & 1.89E-09 & 1.22E-09 & $8.76 \mathrm{E}-10$ \\
\hline SW & $2.58 \mathrm{E}-08$ & 3.88E-08 & 2.91E-08 & 2.14E-08 & 1.65E-08 & 9.07E-09 & 3.79E-09 & 1.96E-09 & 1.26E-09 & $9.07 \mathrm{E}-10$ \\
\hline WSW & 1.37E-08 & 2.75E-08 & 2.18E-08 & 1.64E-08 & $1.28 \mathrm{E}-08$ & 7.13E-09 & 3.00E-09 & 1.55E-09 & $9.98 \mathrm{E}-10$ & $7.18 \mathrm{E}-10$ \\
\hline W & $2.08 \mathrm{E}-08$ & 2.93E-08 & $2.21 \mathrm{E}-08$ & 1.64E-08 & 1.26E-08 & 6.97E-09 & 2.92E-09 & 1.51E-09 & $9.73 E-10$ & $7.01 \mathrm{E}-10$ \\
\hline WNW & 1.47E-08 & 3.00E-08 & 2.33E-08 & 1.74E-08 & 1.35E-08 & 7.51E-09 & 3.16E-09 & 1.64E-09 & 1.06E-09 & $7.62 \mathrm{E}-10$ \\
\hline NW & 2.22E-08 & 4.14E-08 & 3.19E-08 & 2.38E-08 & 1.85E-08 & 1.03E-08 & 4.40E-09 & 2.30E-09 & 1.49E-09 & $1.08 \mathrm{E}-09$ \\
\hline NNW & 1.64E-08 & 2.68E-08 & 2.06E-08 & $1.55 \mathrm{E}-08$ & 1.21E-08 & 6.93E-09 & 3.05E-09 & 1.64E-09 & 1.09E-09 & $7.96 \mathrm{E}-10$ \\
\hline
\end{tabular}


Table D-7. Annual Average Dispersion Factor Around the 300 Area During 2003 for a 10-Meter Release Height

X/Q'

\begin{tabular}{|c|c|c|c|c|c|c|c|c|c|c|}
\hline Direction & $0.8 \mathrm{~km}$ & $2.4 \mathrm{~km}$ & $4.0 \mathrm{~km}$ & $5.6 \mathrm{~km}$ & $7.2 \mathrm{~km}$ & $12 \mathrm{~km}$ & $24 \mathrm{~km}$ & $40 \mathrm{~km}$ & $56 \mathrm{~km}$ & $72 \mathrm{~km}$ \\
\hline $\mathrm{N}$ & $3.91 \mathrm{E}-06$ & $8.08 \mathrm{E}-07$ & $3.84 \mathrm{E}-07$ & $2.37 \mathrm{E}-07$ & $1.66 \mathrm{E}-07$ & $8.17 \mathrm{E}-08$ & $3.17 \mathrm{E}-08$ & $1.60 \mathrm{E}-08$ & $1.03 \mathrm{E}-08$ & $7.36 \mathrm{E}-09$ \\
\hline NNE & 3.74E-06 & 7.42E-07 & $3.50 \mathrm{E}-07$ & 2.15E-07 & 1.50E-07 & 7.31E-08 & 2.81E-08 & 1.41E-08 & 8.99E-09 & 6.44E-09 \\
\hline NE & $3.45 E-06$ & 6.88E-07 & $3.24 \mathrm{E}-07$ & 1.99E-07 & 1.39E-07 & 6.79E-08 & $2.62 \mathrm{E}-08$ & 1.31E-08 & 8.39E-09 & 6.02E-09 \\
\hline ENE & 2.07E-06 & $3.92 \mathrm{E}-07$ & 1.83E-07 & 1.12E-07 & 7.76E-08 & $3.75 \mathrm{E}-08$ & $1.43 \mathrm{E}-08$ & 7.15E-09 & 4.55E-09 & $3.25 \mathrm{E}-09$ \\
\hline$E$ & 1.99E-06 & 4.02E-07 & $1.90 \mathrm{E}-07$ & 1.17E-07 & 8.23E-08 & 4.03E-08 & $1.56 \mathrm{E}-08$ & 7.86E-09 & 5.03E-09 & $3.61 \mathrm{E}-09$ \\
\hline ESE & $2.18 \mathrm{E}-06$ & $4.51 \mathrm{E}-07$ & $2.15 \mathrm{E}-07$ & $1.33 \mathrm{E}-07$ & $9.32 \mathrm{E}-08$ & 4.58E-08 & $1.78 \mathrm{E}-08$ & 8.98E-09 & 5.76E-09 & 4.13E-09 \\
\hline SE & 3.98E-06 & 8.45E-07 & 4.04E-07 & 2.50E-07 & $1.76 \mathrm{E}-07$ & 8.64E-08 & 3.36E-08 & $1.70 \mathrm{E}-08$ & $1.09 E-08$ & 7.81E-09 \\
\hline SSE & 4.86E-06 & $1.01 \mathrm{E}-06$ & 4.78E-07 & 2.95E-07 & 2.07E-07 & 1.01E-07 & 3.93E-08 & $1.98 \mathrm{E}-08$ & $1.26 \mathrm{E}-08$ & 9.07E-09 \\
\hline S & $3.54 \mathrm{E}-06$ & $7.26 \mathrm{E}-07$ & $3.44 \mathrm{E}-07$ & 2.12E-07 & $1.48 \mathrm{E}-07$ & 7.24E-08 & $2.79 \mathrm{E}-08$ & $1.40 \mathrm{E}-08$ & 8.91E-09 & 6.38E-09 \\
\hline SSW & 2.05E-06 & $4.10 \mathrm{E}-07$ & 1.93E-07 & 1.19E-07 & $8.29 \mathrm{E}-08$ & 4.04E-08 & $1.56 \mathrm{E}-08$ & 7.79E-09 & 4.97E-09 & 3.56E-09 \\
\hline SW & 1.30E-06 & 2.44E-07 & 1.13E-07 & 6.86E-08 & $4.75 \mathrm{E}-08$ & $2.28 \mathrm{E}-08$ & 8.60E-09 & $4.25 \mathrm{E}-09$ & 2.69E-09 & 1.92E-09 \\
\hline WSW & 1.23E-06 & 2.37E-07 & 1.10E-07 & 6.69E-08 & 4.63E-08 & $2.22 E-08$ & 8.36E-09 & 4.13E-09 & 2.61E-09 & 1.86E-09 \\
\hline W & 1.85E-06 & $3.60 \mathrm{E}-07$ & $1.68 \mathrm{E}-07$ & 1.02E-07 & 7.11E-08 & 3.43E-08 & 1.30E-08 & $6.48 \mathrm{E}-09$ & 4.12E-09 & 2.94E-09 \\
\hline WNW & 4.04E-06 & 8.52E-07 & 4.06E-07 & $2.51 \mathrm{E}-07$ & $1.76 \mathrm{E}-07$ & 8.63E-08 & 3.35E-08 & $1.69 \mathrm{E}-08$ & $1.08 \mathrm{E}-08$ & 7.76E-09 \\
\hline NW & 5.96E-06 & $1.25 \mathrm{E}-06$ & 5.97E-07 & $3.69 \mathrm{E}-07$ & 2.59E-07 & 1.27E-07 & $4.95 \mathrm{E}-08$ & 2.49E-08 & $1.60 \mathrm{E}-08$ & $1.15 \mathrm{E}-08$ \\
\hline NNW & 4.53E-06 & 9.67E-07 & 4.62E-07 & 2.86E-07 & $2.01 \mathrm{E}-07$ & $9.90 \mathrm{E}-08$ & 3.85E-08 & $1.95 \mathrm{E}-08$ & $1.25 \mathrm{E}-08$ & 8.97E-09 \\
\hline
\end{tabular}


Table D-8. Annual Average Dispersion Factor Around the 400 Area During 2003 for a 10-Meter Release Height

X/Q'

\begin{tabular}{|c|c|c|c|c|c|c|c|c|c|c|}
\hline Direction & $0.8 \mathrm{~km}$ & $2.4 \mathrm{~km}$ & $4.0 \mathrm{~km}$ & $5.6 \mathrm{~km}$ & $7.2 \mathrm{~km}$ & $12 \mathrm{~km}$ & $24 \mathrm{~km}$ & $40 \mathrm{~km}$ & $56 \mathrm{~km}$ & $72 \mathrm{~km}$ \\
\hline $\mathrm{N}$ & $4.21 \mathrm{E}-06$ & $8.36 \mathrm{E}-07$ & $3.94 \mathrm{E}-07$ & $2.42 \mathrm{E}-07$ & 1.69E-07 & $8.22 E-08$ & $3.17 E-08$ & 1.59E-08 & $1.01 \mathrm{E}-08$ & $7.26 \mathrm{E}-09$ \\
\hline NNE & 4.39E-06 & 8.76E-07 & 4.13E-07 & 2.54E-07 & 1.77E-07 & 8.62E-08 & 3.32E-08 & 1.66E-08 & 1.06E-08 & 7.60E-09 \\
\hline NE & 3.10E-06 & $6.25 \mathrm{E}-07$ & 2.96E-07 & $1.82 \mathrm{E}-07$ & $1.28 \mathrm{E}-07$ & $6.25 \mathrm{E}-08$ & $2.42 \mathrm{E}-08$ & 1.22E-08 & 7.82E-09 & 5.62E-09 \\
\hline ENE & 2.16E-06 & 4.43E-07 & 2.11E-07 & 1.30E-07 & $9.11 \mathrm{E}-08$ & 4.47E-08 & 1.73E-08 & 8.74E-09 & $5.60 \mathrm{E}-09$ & 4.02E-09 \\
\hline $\mathrm{E}$ & 2.27E-06 & 4.57E-07 & 2.16E-07 & 1.33E-07 & $9.31 \mathrm{E}-08$ & 4.56E-08 & 1.76E-08 & 8.88E-09 & 5.68E-09 & 4.08E-09 \\
\hline ESE & 2.56E-06 & 5.20E-07 & 2.47E-07 & $1.52 \mathrm{E}-07$ & $1.07 \mathrm{E}-07$ & 5.23E-08 & 2.03E-08 & $1.02 \mathrm{E}-08$ & 6.54E-09 & 4.70E-09 \\
\hline SE & 4.06E-06 & 8.05E-07 & 3.79E-07 & 2.33E-07 & $1.63 \mathrm{E}-07$ & 7.95E-08 & 3.06E-08 & $1.53 \mathrm{E}-08$ & 9.77E-09 & 6.99E-09 \\
\hline SSE & 3.73E-06 & 7.62E-07 & 3.61E-07 & 2.22E-07 & $1.55 \mathrm{E}-07$ & 7.58E-08 & 2.92E-08 & $1.46 \mathrm{E}-08$ & 9.33E-09 & 6.68E-09 \\
\hline$S$ & 3.07E-06 & $6.28 \mathrm{E}-07$ & 2.97E-07 & 1.83E-07 & $1.28 \mathrm{E}-07$ & $6.23 E-08$ & $2.40 \mathrm{E}-08$ & $1.21 \mathrm{E}-08$ & 7.71E-09 & 5.53E-09 \\
\hline SSW & 2.83E-06 & $5.74 \mathrm{E}-07$ & $2.71 \mathrm{E}-07$ & 1.67E-07 & 1.16E-07 & 5.67E-08 & $2.18 \mathrm{E}-08$ & $1.09 \mathrm{E}-08$ & 6.98E-09 & 5.00E-09 \\
\hline SW & 2.01E-06 & 3.97E-07 & $1.86 \mathrm{E}-07$ & 1.14E-07 & 7.92E-08 & 3.83E-08 & $1.46 \mathrm{E}-08$ & 7.23E-09 & 4.59E-09 & 3.28E-09 \\
\hline WSW & $1.42 \mathrm{E}-06$ & $2.70 \mathrm{E}-07$ & $1.25 \mathrm{E}-07$ & 7.63E-08 & $5.28 \mathrm{E}-08$ & $2.53 E-08$ & 9.50E-09 & 4.67E-09 & 2.95E-09 & 2.09E-09 \\
\hline W & 1.39E-06 & 2.64E-07 & 1.23E-07 & 7.47E-08 & 5.18E-08 & $2.49 E-08$ & 9.40E-09 & 4.65E-09 & 2.94E-09 & 2.09E-09 \\
\hline WNW & 1.67E-06 & 3.35E-07 & $1.58 \mathrm{E}-07$ & 9.68E-08 & $6.76 \mathrm{E}-08$ & $3.29 \mathrm{E}-08$ & $1.26 \mathrm{E}-08$ & 6.33E-09 & 4.04E-09 & 2.90E-09 \\
\hline NW & 2.48E-06 & 4.93E-07 & $2.32 \mathrm{E}-07$ & $1.42 \mathrm{E}-07$ & $9.92 \mathrm{E}-08$ & 4.81E-08 & 1.84E-08 & 9.19E-09 & 5.85E-09 & 4.18E-09 \\
\hline NNW & 3.99E-06 & 8.39E-07 & 4.00E-07 & 2.47E-07 & $1.74 \mathrm{E}-07$ & 8.52E-08 & 3.31E-08 & $1.67 \mathrm{E}-08$ & 1.07E-08 & 7.67E-09 \\
\hline
\end{tabular}




\section{Quality Assurance}


Table Q-1. Severn Trent Laboratories (STL), Inc., Richland, WA, Performance Data on Surface Environmental Surveillance Project Blind Spikes, 2003

\begin{tabular}{|c|c|c|c|c|c|c|c|}
\hline Media & Con Short Name & True Value & Units & Reported Value & Units & Reported/True & $\%$ Bias \\
\hline Air Filter & Co-60 & 144 & pCi/filter & 136 & pCi/filter & 0.94 & -5.6 \\
\hline Air Filter & Co-60 & 134 & $\mathrm{pCi} /$ filter & 95.1 & $\mathrm{pCi} /$ filter & 0.71 & -29.0 \\
\hline Air Filter & Cs-137 & 546 & pCi/filter & 552 & pCi/filter & 1.01 & 1.1 \\
\hline Air Filter & Cs-137 & 164 & pCi/filter & 180 & pCi/filter & 1.10 & 9.8 \\
\hline Air Filter & Pu-238 & 12.0 & pCi/filter & 12.6 & pCi/filter & 1.05 & 5.0 \\
\hline Air Filter & Pu-238 & 7.35 & pCi/filter & 7.13 & pCi/filter & 0.97 & -3.0 \\
\hline Air Filter & Pu-239/240 & 11.3 & pCi/filter & 12.1 & pCi/filter & 1.07 & 7 \\
\hline Air Filter & Pu-239/240 & 3.35 & pCi/filter & 3.31 & pCi/filter & 0.99 & -1.2 \\
\hline Air Filter & SB-125 & 76.0 & pCi/filter & 77.4 & pCi/filter & 1.02 & 2 \\
\hline Air Filter & Sr-90 & 27.1 & pCi/filter & 26.9 & pCi/filter & 0.99 & -1 \\
\hline Air Filter & Sr-90 & 17.4 & pCi/filter & 17.4 & pCi/filter & 1.00 & 0.0 \\
\hline Air Filter & U-238 & 1.65 & pCi/filter & 1.58 & pCi/filter & 0.96 & -4.2 \\
\hline Soil & Co-60 & 0.0183 & $\mathrm{pCi} / \mathrm{g}$ & 0.0307 & $\mathrm{pCi} / \mathrm{g}$ & 1.68 & 68 \\
\hline Soil & Cs-137 & 23.2 & $\mathrm{pCi} / \mathrm{g}$ & 27.1 & $\mathrm{pCi} / \mathrm{g}$ & 1.17 & 17 \\
\hline Soil & Cs-137 & 16.90 & $\mathrm{pCi} / \mathrm{g}$ & 18.8 & $\mathrm{pCi} / \mathrm{g}$ & 1.11 & 11 \\
\hline Soil & $\mathrm{K}-40$ & 8.48 & $\mathrm{pCi} / \mathrm{g}$ & 9.49 & $\mathrm{pCi} / \mathrm{g}$ & 1.12 & 12 \\
\hline Soil & $\mathrm{K}-40$ & 9.79 & $\mathrm{pCi} / \mathrm{g}$ & 10.5 & $\mathrm{pCi} / \mathrm{g}$ & 1.07 & 7 \\
\hline Soil & Pu-238 & 0.0138 & $\mathrm{pCi} / \mathrm{g}$ & 0.00865 & $\mathrm{pCi} / \mathrm{g}$ & 0.63 & -37 \\
\hline Soil & Pu-239/240 & 0.353 & $\mathrm{pCi} / \mathrm{g}$ & 0.344 & $\mathrm{pCi} / \mathrm{g}$ & 0.97 & -2.5 \\
\hline Soil & Pu-239/240 & 0.22 & $\mathrm{pCi} / \mathrm{g}$ & 0.208 & $\mathrm{pCi} / \mathrm{g}$ & 0.95 & -5 \\
\hline Soil & Sr-90 & 0.958 & $\mathrm{pCi} / \mathrm{g}$ & 1.14 & $\mathrm{pCi} / \mathrm{g}$ & 1.19 & 19 \\
\hline Soil & Sr-90 & 0.787 & $\mathrm{pCi} / \mathrm{g}$ & 1.05 & $\mathrm{pCi} / \mathrm{g}$ & 1.33 & 33 \\
\hline Soil & U-234 & 3.050 & $\mathrm{pCi} / \mathrm{g}$ & 2.43 & $\mathrm{pCi} / \mathrm{g}$ & 0.80 & -20 \\
\hline Soil & U-238 & 3.240 & $\mathrm{pCi} / \mathrm{g}$ & 2.62 & $\mathrm{pCi} / \mathrm{g}$ & 0.81 & -19 \\
\hline Soil & U-238 & 3.91 & $\mathrm{pCi} / \mathrm{g}$ & 3.4 & $\mathrm{pCi} / \mathrm{g}$ & 0.87 & -13 \\
\hline Vegetation & Co-60 & 0.296 & $\mathrm{pCi} / \mathrm{g}$ & 0.39 & $\mathrm{pCi} / \mathrm{g}$ & 1.32 & 31.8 \\
\hline Vegetation & Co-60 & 0.324 & $\mathrm{pCi} / \mathrm{g}$ & 0.462 & $\mathrm{pCi} / \mathrm{g}$ & 1.43 & 43 \\
\hline Vegetation & Cs-137 & 9.48 & $\mathrm{pCi} / \mathrm{g}$ & 11.4 & $\mathrm{pCi} / \mathrm{g}$ & 1.20 & 20 \\
\hline Vegetation & Cs-137 & 11.40 & $\mathrm{pCi} / \mathrm{g}$ & 13.9 & $\mathrm{pCi} / \mathrm{g}$ & 1.22 & 22 \\
\hline Vegetation & $\mathrm{K}-40$ & 12.4 & $\mathrm{pCi} / \mathrm{g}$ & 14.2 & $\mathrm{pCi} / \mathrm{g}$ & 1.15 & 15 \\
\hline Vegetation & $\mathrm{K}-40$ & 17.7 & $\mathrm{pCi} / \mathrm{g}$ & 21.5 & $\mathrm{pCi} / \mathrm{g}$ & 1.21 & 21 \\
\hline Vegetation & $\mathrm{Pu}-239 / 240$ & 0.100 & $\mathrm{pCi} / \mathrm{g}$ & 0.104 & $\mathrm{pCi} / \mathrm{g}$ & 1.04 & 4.0 \\
\hline Vegetation & Pu-239/240 & 0.1400 & $\mathrm{pCi} / \mathrm{g}$ & 0.119 & $\mathrm{pCi} / \mathrm{g}$ & 0.85 & -15 \\
\hline Vegetation & Sr-90 & 17.90 & $\mathrm{pCi} / \mathrm{g}$ & 20.7 & $\mathrm{pCi} / \mathrm{g}$ & 1.16 & 16 \\
\hline Water & Co-60 & 731 & $\mathrm{pCi} / \mathrm{L}$ & 699 & $\mathrm{pCi} / \mathrm{L}$ & 0.96 & -4.4 \\
\hline Water & Co-60 & 1381 & $\mathrm{pCi} / \mathrm{L}$ & 929 & $\mathrm{pCi} / \mathrm{L}$ & 0.67 & -32.7 \\
\hline Water & Cs-137 & 1216 & $\mathrm{pCi} / \mathrm{L}$ & 1230 & $\mathrm{pCi} / \mathrm{L}$ & 1.01 & 1.2 \\
\hline Water & Cs-137 & 1064 & $\mathrm{pCi} / \mathrm{L}$ & 1070 & $\mathrm{pCi} / \mathrm{L}$ & 1.01 & 0.6 \\
\hline Water & Pu-238 & 28.7 & $\mathrm{pCi} / \mathrm{L}$ & 30.4 & $\mathrm{pCi} / \mathrm{L}$ & 1.06 & 5.9 \\
\hline Water & Pu-238 & 20.9 & $\mathrm{pCi} / \mathrm{L}$ & 20.9 & $\mathrm{pCi} / \mathrm{L}$ & 1.00 & 0.0 \\
\hline Water & $\mathrm{Pu}-239 / 240$ & 38.1 & $\mathrm{pCi} / \mathrm{L}$ & 41.1 & $\mathrm{pCi} / \mathrm{L}$ & 1.08 & 0.0 \\
\hline Water & $\mathrm{Pu}-239 / 240$ & 27.3 & $\mathrm{pCi} / \mathrm{L}$ & 28.6 & $\mathrm{pCi} / \mathrm{L}$ & 1.05 & 4.8 \\
\hline Water & TRITIUM & 1588 & $\mathrm{pCi} / \mathrm{L}$ & 1540 & $\mathrm{pCi} / \mathrm{L}$ & 0.97 & -3.0 \\
\hline Water & TRITIUM & 3273 & $\mathrm{pCi} / \mathrm{L}$ & 2810 & $\mathrm{pCi} / \mathrm{L}$ & 0.86 & -14 \\
\hline Water & $U-234$ & 7.27 & $\mathrm{pCi} / \mathrm{L}$ & 8.25 & $\mathrm{pCi} / \mathrm{L}$ & 1.13 & 13.48 \\
\hline Water & U-238 & 7.08 & $\mathrm{pCi} / \mathrm{L}$ & 8.26 & $\mathrm{pCi} / \mathrm{L}$ & 1.17 & 16.67 \\
\hline
\end{tabular}


Table Q-2. Severn Trent Laboratories (STL) Inc., Richland WA, Performance Data on Environmental Resource Associates (ERA) Proficiency Testing Program Water Samples (pCi/L), 2003

\begin{tabular}{|c|c|c|c|c|c|c|c|c|c|c|c|}
\hline \multirow[b]{2}{*}{$\begin{array}{l}\text { Con Short } \\
\text { Name }\end{array}$} & \multirow[b]{2}{*}{$\begin{array}{l}\text { Study } \\
\text { No. }\end{array}$} & \multicolumn{2}{|c|}{ STL } & \multicolumn{2}{|c|}{ ERA } & \multirow[b]{2}{*}{$\begin{array}{c}\text { Mean } \\
\text { Recovery }\end{array}$} & \multirow[b]{2}{*}{$\begin{array}{l}\text { Number of } \\
\text { Participants }\end{array}$} & \multirow[b]{2}{*}{ Bias \% } & \multirow[b]{2}{*}{$\begin{array}{l}\text { Performance } \\
\text { Evaluation }^{(\mathrm{c})}\end{array}$} & \multirow[b]{2}{*}{$\begin{array}{c}\text { Report Issue } \\
\text { Date }\end{array}$} & \multirow[b]{2}{*}{ Comments } \\
\hline & & Value $^{(a)}$ & $\begin{array}{l}\text { Experimental } \\
\text { Deviation }^{(\mathrm{b})}\end{array}$ & $\begin{array}{l}\text { Known } \\
\text { Value }\end{array}$ & $\begin{array}{l}\text { Expected } \\
\text { Deviation }^{(b)}\end{array}$ & & & & & & \\
\hline Ba-133 & Rad-52 & 18.2 & 1.1 & 19.5 & 5.00 & 18.2 & 44 & -6.67 & Acceptable & 16-Apr-03 & \\
\hline Ba-133 & Rad-54 & 20.7 & 1.10 & 20.7 & 5.00 & 20.1 & 36 & 0.00 & Acceptable & 22-Oct-03 & \\
\hline Co-60 & Rad-52 & 37.8 & 2.7 & 37.4 & 5.00 & 39.3 & 45 & 1.07 & Acceptable & 16-Apr-03 & \\
\hline Co-60 & Rad-53 & 66.0 & 2.06 & 63.8 & 5.00 & 65.8 & 46 & 3.45 & Acceptable & 24-Jul-03 & \\
\hline Co-60 & Rad-54 & 36.7 & 3.49 & 37.4 & 5.00 & 37.3 & 38 & -1.87 & Acceptable & 22-Oct-03 & \\
\hline Co-60 & Rad-55 & 28.2 & 4.74 & 27.7 & 5.00 & 28.4 & 38 & 1.81 & Acceptable & 23-Jan-04 & \\
\hline Cs-134 & Rad-52 & 16.7 & 3.0 & 17.8 & 5.00 & 17.1 & 45 & -6.18 & Acceptable & 16-Apr-03 & \\
\hline Cs-134 & Rad-53 & 71.7 & 0.95 & 75.7 & 5.00 & 71.8 & 46 & -5.28 & Acceptable & 24-Jul-03 & \\
\hline Cs-134 & Rad-54 & 35.7 & 6.63 & 32.6 & 5.00 & 30.8 & 37 & 9.51 & Acceptable & 22-Oct-03 & \\
\hline Cs-134 & Rad-55 & 22.6 & 3.24 & 23.4 & 5.00 & 21.9 & 37 & -3.42 & Acceptable & 23-Jan-04 & \\
\hline Cs-137 & Rad-52 & 49.9 & 6.1 & 44.2 & 5.00 & 47.0 & 45 & 12.90 & Acceptable & 16-Apr-03 & \\
\hline Cs-137 & Rad-53 & 161 & 2.1 & 150 & 7.50 & 157.0 & 46 & 7.33 & Acceptable & 24-Jul-03 & \\
\hline Cs-137 & Rad-54 & 52.5 & 3.33 & 44.3 & 5.00 & 47.9 & 38 & 18.51 & Acceptable & 22-Oct-03 & \\
\hline Cs-137 & Rad-55 & 71 & 5.78 & 64.2 & 5.00 & 65.6 & 38 & 10.59 & Acceptable & 23-Jan-04 & \\
\hline Gross Alpha & Rad-52 & 29.8 & 1.94 & 37.6 & 9.40 & 30.6 & 71 & -20.74 & Acceptable & 16-Apr-03 & \\
\hline Gross Alpha & Rad-53 & 57.1 & 1.77 & 70.3 & 17.60 & 76.5 & 57 & -18.78 & Acceptable & 24-Jul-03 & \\
\hline Gross Alpha & Rad-54 & 54.7 & 2.1 & 65.1 & 16.30 & 56.2 & 61 & -15.98 & Acceptable & 22-Oct-03 & \\
\hline Gross Alpha & Rad-55 & 26.6 & 2.75 & 29.5 & 7.38 & 28.2 & 39 & -9.83 & Acceptable & 23-Jan-04 & \\
\hline Gross Alpha & Rad-55 & 59.4 & 5.6 & 54.2 & 13.6 & 62.7 & 50 & 9.59 & Acceptable & 23-Jan-04 & \\
\hline Gross Beta & Rad-52 & 7.20 & 1.77 & 8.55 & 5.00 & 10.7 & 60 & -15.79 & Acceptable & 16-Apr-03 & \\
\hline Gross Beta & Rad-53 & 278 & 13.1 & 363 & 54.5 & 327 & 53 & -23.42 & Acceptable & 24-Jul-03 & \\
\hline Gross Beta & Rad-54 & 33.7 & 2.95 & 31.6 & 5.00 & 33.2 & 54 & 6.65 & Acceptable & 22-Oct-03 & \\
\hline Gross Beta & Rad-55 & 26.3 & 0.56 & 26.3 & 5.00 & 26.4 & 34 & 0.00 & Acceptable & 23-Jan-04 & \\
\hline Gross Beta & Rad-55 & 138 & 1.53 & 168 & 25.20 & 167.0 & 46 & -17.86 & Acceptable & 23-Jan-04 & \\
\hline $\mathrm{H}-3$ & Rad-53 & 1260 & 196.0 & 1250 & 331.00 & 1300.0 & 64 & 0.80 & Acceptable & 24-Jul-03 & \\
\hline $\mid-131$ & Rad-53 & 15.5 & 1.4 & 20.8 & 3.0 & 22.0 & 43 & -25.48 & Not Acceptable & 24-Jul-03 & Corrective action dated 8/4/03. \\
\hline $\mid-131$ & Rad-55 & 31.8 & 4.77 & 28.2 & 3.00 & 26.7 & 27 & 12.77 & Acceptable & 23-Jan-04 & \\
\hline $\mathrm{Ra}-226$ & Rad-52 & 4.66 & 0.45 & 4.73 & 0.71 & 4.9 & 47 & -1.48 & Acceptable & 16-Apr-03 & \\
\hline $\mathrm{Ra}-226$ & Rad-53 & 16.2 & 0.4 & 16.5 & 2.48 & 15.2 & 53 & -1.82 & Acceptable & 24-Jul-03 & \\
\hline $\mathrm{Ra}-226$ & Rad-55 & 20.5 & 1.81 & 17.8 & 2.67 & 16.7 & 22 & 15.17 & Acceptable & 23-Jan-04 & \\
\hline $\mathrm{Ra}-226$ & Rad-55 & 17.7 & 3.70 & 16.1 & 2.42 & 15.5 & 42 & 9.94 & Acceptable & 23-Jan-04 & \\
\hline Ra-228 & Rad-52 & 6.33 & 0.33 & 6.48 & 1.62 & 6.32 & 42 & -2.31 & Acceptable & 16-Apr-03 & \\
\hline $\mathrm{Ra}-228$ & Rad-53 & 10.0 & 0.81 & 10.3 & 2.58 & 9.20 & 50 & -2.91 & Acceptable & 24-Jul-03 & \\
\hline Ra-228 & Rad-55 & 6.72 & 0.76 & 6.78 & 1.70 & 6.6 & 19 & -0.88 & Acceptable & 23-Jan-04 & \\
\hline $\mathrm{Ra}-228$ & Rad-55 & 5.34 & 0.51 & 5.49 & 1.37 & 5.2 & 37 & -2.73 & Acceptable & 23-Jan-04 & \\
\hline Sr-89 & Rad-52 & 13.1 & 1.6 & 15.9 & 5.00 & 16.1 & 25 & -17.61 & Acceptable & 16-Apr-03 & \\
\hline Sr-89 & Rad-53 & 28.2 & 0.96 & 31.3 & 5.00 & 31.5 & 36 & -9.90 & Acceptable & 24-Jul-03 & \\
\hline Sr-89 & Rad-54 & 50.5 & 2.88 & 58.8 & 5.00 & 53.9 & 21 & -14.12 & Acceptable & 22-Oct-03 & \\
\hline Sr-89 & Rad-55 & 46.7 & 1.01 & 50.4 & 5.00 & 47.5 & 35 & -7.34 & Acceptable & 23-Jan-04 & \\
\hline Sr-90 & Rad-52 & 9.28 & 0.84 & 9.03 & 5.00 & 8.59 & 26 & 2.77 & Acceptable & 16-Apr-03 & \\
\hline Sr-90 & Rad-53 & 25.8 & 0.58 & 27.4 & 5.00 & 25.8 & 38 & -5.84 & Acceptable & 24-Jul-03 & \\
\hline Sr-90 & Rad-54 & 19.1 & 0.32 & 20.6 & 5.00 & 19.2 & 23 & -7.28 & Acceptable & 22-Oct-03 & \\
\hline Sr-90 & Rad-55 & 10.1 & 0.47 & 10.2 & 5.00 & 10.2 & 31 & -0.98 & Acceptable & 23-Jan-04 & \\
\hline Tritium & Rad-55 & 11900 & 5100 & 14300 & 1430 & 14500 & 44 & -16.78 & Acceptable & 23-Jan-04 & \\
\hline $\mathrm{U}$ (Nat) & Rad-52 & 52.1 & 3.40 & 53.7 & 5.37 & 52.9 & 44 & -2.98 & Acceptable & 16-Apr-03 & \\
\hline U (Nat) & Rad-53 & 14.2 & 0.4 & 15.1 & 3.00 & 14.2 & 50 & -5.96 & Acceptable & 24-Jul-03 & \\
\hline U (Nat) & Rad-55 & 10.70 & 0.12 & 11.7 & 3.00 & 11.6 & 20 & -8.55 & Acceptable & 23-Jan-04 & \\
\hline U (Nat) & Rad-55 & 8.58 & 0.19 & 9.30 & 3.00 & 9.47 & 42 & -7.74 & Acceptable & 23-Jan-04 & \\
\hline Zn-65 & Rad-52 & 57.5 & 12.6 & 60.3 & 6.03 & 61.60 & 44 & -4.64 & Acceptable & 16-Apr-03 & \\
\hline Zn-65 & Rad-54 & 61.8 & 9.14 & 60.2 & 6.02 & 64.5 & 37 & 2.66 & Acceptable & 22-Oct-03 & \\
\hline
\end{tabular}

(a) Three results are reported to ERA, this represents the average of the three results \pm 1 standard deviation of the mean.

(b) ERA known concentration \pm 1 standard deviation.

(c) The Performance Evaluation criteria is:

Acceptable $\quad=$ Reported Value falls within the Control Limits.

Not Acceptable $=$ Reported Value falls outside of the Control Limits.

The Control Limits, Warning Limits, and Outlier Criteria are established per the US-EPA guidelines contained in the National Standards for Water Proficiency Testing Studies Criteria Document, December, 1988. 
Table Q-3. Severn Trent Laboratories (STL) Inc., Richland, WA, Performance Data on the DOE Environmental Measurements Laboratory (EML) Quality Assessment Program Studies, 2003

\begin{tabular}{|c|c|c|c|c|c|c|c|c|}
\hline \multirow[b]{2}{*}{ Media } & \multirow{2}{*}{$\begin{array}{l}\text { Con Short } \\
\text { Name }\end{array}$} & \multicolumn{2}{|c|}{ EML } & \multicolumn{2}{|c|}{ STL } & \multirow[b]{2}{*}{ STL/EML } & \multirow[b]{2}{*}{ \%Bias Performance Evaluation ${ }^{(b)}$} & \multirow[b]{2}{*}{ Comments } \\
\hline & & $\mathrm{Bq} /$ Unit $^{(\mathrm{a})}$ & $\mathrm{pCi} /$ Unit $^{(\mathrm{a})}$ & $\mathrm{Bq} /$ Unit $^{(\mathrm{a})}$ & $\mathrm{pCi} /$ Unit $^{(\mathrm{a})}$ & & & \\
\hline Air Filter & Am-241 & 0.340 & $9.19 \mathrm{E}+00$ & 0.326 & $8.81 \mathrm{E}+00$ & 0.959 & -4.12 Acceptable & \\
\hline Air Filter & Am-241 & 0.435 & $1.18 \mathrm{E}+01$ & 0.450 & $1.22 \mathrm{E}+01$ & 1.034 & 3.45 Acceptable & \\
\hline Air Filter & C-137 & 54.80 & $1.48 \mathrm{E}+03$ & 53.6 & $1.45 \mathrm{E}+03$ & 0.978 & -2.19 Acceptable & \\
\hline Air Filter & Co-60 & 33.50 & $9.05 E+02$ & 32.60 & $8.81 \mathrm{E}+02$ & 0.973 & -2.69 Acceptable & \\
\hline Air Filter & Co-60 & 55.10 & $1.49 \mathrm{E}+03$ & 53.1 & $1.44 \mathrm{E}+03$ & 0.964 & -3.63 Acceptable & \\
\hline Air Filter & Cs-137 & 99.70 & $2.69 \mathrm{E}+03$ & 99.90 & $2.70 \mathrm{E}+03$ & 1.002 & 0.20 Acceptable & \\
\hline Air Filter & Gross Alpha & 1.170 & $3.16 \mathrm{E}+01$ & 1.23 & $3.32 \mathrm{E}+01$ & 1.051 & 5.13 Acceptable & \\
\hline Air Filter & Gross Alpha & 3.110 & $8.41 \mathrm{E}+01$ & 2.740 & $7.41 \mathrm{E}+01$ & 0.881 & -11.90 Acceptable & \\
\hline Air Filter & Gross Beta & 1.50 & 4.05E+01 & 1.76 & 4.76E+01 & 1.173 & 17.33 Acceptable & \\
\hline Air Filter & Gross Beta & 3.890 & $1.05 E+02$ & 3.660 & $9.89 \mathrm{E}+01$ & 0.941 & -5.91 Acceptable & \\
\hline Air Filter & $M n-54$ & 43.80 & $1.18 \mathrm{E}+03$ & 43.40 & 1.17E+03 & 0.991 & -0.91 Acceptable & \\
\hline Air Filter & $\mathrm{Mn}-54$ & 58.00 & 1.57E+03 & 55.7 & $1.51 \mathrm{E}+03$ & 0.960 & -3.97 Acceptable & \\
\hline Air Filter & Pu-238 & 0.520 & $1.41 \mathrm{E}+01$ & 0.536 & $1.45 \mathrm{E}+01$ & 1.031 & 3.08 Acceptable & \\
\hline Air Filter & Pu-238 & 0.229 & $6.19 \mathrm{E}+00$ & 0.230 & $6.22 \mathrm{E}+00$ & 1.004 & 0.44 Acceptable & \\
\hline Air Filter & Pu-239 & 0.330 & $8.92 \mathrm{E}+00$ & 0.328 & $8.86 \mathrm{E}+00$ & 0.994 & -0.61 Acceptable & \\
\hline Air Filter & Pu-239 & 0.401 & $1.08 \mathrm{E}+01$ & 0.4 & $1.08 \mathrm{E}+01$ & 0.998 & -0.25 Acceptable & \\
\hline Air Filter & Sr-90 & 2.80 & 7.57E+01 & 0.934 & $2.52 \mathrm{E}+01$ & 0.334 & -66.64 Not Acceptable & Corrective action dated $12 / 17 / 03$ \\
\hline Air Filter & Sr-90 & 2.06 & $5.56 \mathrm{E}+01$ & 0.94 & $2.54 \mathrm{E}+01$ & 0.457 & -54.32 Not Acceptable & \\
\hline Air Filter & U-TOTAL $(\mu \mathrm{g})$ & 19.70 & 1.97E+01 & 19.10 & $1.91 \mathrm{E}+01$ & 0.970 & -3.05 Acceptable & \\
\hline Air Filter & U-TOTAL $(\mu \mathrm{g})$ & 32.10 & $3.21 \mathrm{E}+01$ & 16.80 & $1.68 \mathrm{E}+01$ & 0.523 & -47.66 Not Acceptable & \\
\hline Air Filter & U-234 & 0.240 & $6.49 \mathrm{E}+00$ & 0.208 & $5.62 \mathrm{E}+00$ & 0.867 & -13.33 Acceptable with Warning & \\
\hline Air Filter & $\mathrm{U}-234$ & 0.401 & $1.08 \mathrm{E}+01$ & 0.410 & $1.11 \mathrm{E}+01$ & 1.022 & 2.24 Acceptable & \\
\hline Air Filter & U-238 & 0.54 & 1.46E+01 & 0.227 & $6.14 \mathrm{E}+00$ & 0.420 & -57.96 Acceptable & \\
\hline Air Filter & U-238 & 0.397 & 1.07E+01 & 0.370 & $1.00 \mathrm{E}+01$ & 0.932 & -6.80 Acceptable & \\
\hline Soil & Ac-228 & 57.6 & $1.56 \mathrm{E}+00$ & 63.9 & $1.73 \mathrm{E}+00$ & 1.109 & 10.94 Acceptable with Warning & \\
\hline Soil & Ac-228 & 50.8 & 1.37E+00 & 54.1 & 1.46E+00 & 1.065 & 6.50 Acceptable & \\
\hline Soil & Am-241 & 15.6 & 4.22E-01 & 23.2 & $6.27 E-01$ & 1.487 & 48.72 Acceptable with Warning & \\
\hline Soil & Am-241 & 18.4 & 4.97E-01 & 13.4 & 3.62E-01 & 0.728 & -27.17 Acceptable with Warning & \\
\hline Soil & $\mathrm{Bi}-212$ & 60.6 & $1.64 \mathrm{E}+00$ & 88.0 & $2.38 \mathrm{E}+00$ & 1.452 & 45.21 Not Acceptable & Corrective action dated $12 / 17 / 03$ \\
\hline Soil & $\mathrm{Bi}-212$ & 53.9 & 1.46E+00 & 58.7 & $1.59 \mathrm{E}+00$ & 1.089 & 8.91 Acceptable & \\
\hline Soil & $\mathrm{Bi}-214$ & 67.0 & $1.81 \mathrm{E}+00$ & 73.6 & $1.99 \mathrm{E}+00$ & 1.099 & 9.85 Acceptable & \\
\hline Soil & $\mathrm{Bi}-214$ & 34.4 & 9.30E-01 & 28.2 & 7.62E-01 & 0.820 & -18.02 Acceptable with Warning & \\
\hline Soil & Cs-137 & 1450 & $3.92 \mathrm{E}+01$ & 1733 & $4.68 \mathrm{E}+01$ & 1.195 & 19.52 Acceptable with Warning & \\
\hline Soil & Cs-137 & 1973 & $5.33 E+01$ & 2209 & $5.97 \mathrm{E}+01$ & 1.120 & 11.96 Acceptable & \\
\hline Soil & $\mathrm{K}-40$ & 636.0 & $1.72 \mathrm{E}+01$ & 709 & $1.92 \mathrm{E}+01$ & 1.115 & 11.48 Acceptable & \\
\hline Soil & $\mathrm{K}-40$ & 488 & $1.32 \mathrm{E}+01$ & 511 & $1.38 \mathrm{E}+01$ & 1.047 & 4.71 Acceptable & \\
\hline Soil & $\mathrm{Pb}-212$ & 57.9 & $1.56 \mathrm{E}+00$ & 67.0 & $1.81 \mathrm{E}+00$ & 1.157 & 15.72 Acceptable & \\
\hline Soil & $\mathrm{Pb}-212$ & 50.7 & 1.37E+00 & 53.8 & $1.45 \mathrm{E}+00$ & 1.061 & 6.11 Acceptable & \\
\hline Soil & $\mathrm{Pb}-214$ & 71.10 & $1.92 \mathrm{E}+00$ & 83.8 & $2.26 \mathrm{E}+00$ & 1.179 & 17.86 Acceptable & \\
\hline Soil & $\mathrm{Pb}-214$ & 35.2 & $9.51 \mathrm{E}-01$ & 41.4 & $1.12 \mathrm{E}+00$ & 1.176 & 17.61 Acceptable & \\
\hline Soil & Pu-238 & 14.6 & 3.95E-01 & 15.6 & 4.22E-01 & 1.068 & 6.85 Acceptable & \\
\hline Soil & Pu-239 & 23.40 & 6.32E-01 & 24.8 & $6.70 \mathrm{E}-01$ & 1.060 & 5.98 Acceptable & \\
\hline Soil & Pu-239 & 30.4 & 8.22E-01 & 33.5 & $9.05 E-01$ & 1.102 & 10.20 Acceptable & \\
\hline Soil & Sr-90 & 64.40 & $1.74 \mathrm{E}+00$ & 66.3 & $1.79 \mathrm{E}+00$ & 1.030 & 2.95 Acceptable & \\
\hline Soil & Sr-90 & 80.3 & 2.17E+00 & 81.9 & $2.21 \mathrm{E}+00$ & 1.020 & 1.99 Acceptable & \\
\hline Soil & Th-234 & 127 & $3.43 E+00$ & 262 & $7.08 \mathrm{E}+00$ & 2.063 & 106.30 Acceptable with Warning & \\
\hline Soil & Th-234 & 116 & $3.14 \mathrm{E}+00$ & 119.3 & $3.22 \mathrm{E}+00$ & 1.028 & 2.84 Acceptable & \\
\hline Soil & U-TOTAL $(\mu \mathrm{g})$ & 10.1 & $1.01 \mathrm{E}+01$ & 9.24 & $9.24 \mathrm{E}+00$ & 0.915 & -8.51 Acceptable & \\
\hline Soil & U-TOTAL $(\mu \mathrm{g})$ & 10.27 & $1.03 E+01$ & 9.91 & $9.91 \mathrm{E}+00$ & 0.965 & -3.51 Acceptable & \\
\hline Soil & U-234 & 120 & $3.24 \mathrm{E}+00$ & 122 & $3.30 \mathrm{E}+00$ & 1.017 & 1.67 Acceptable & \\
\hline Soil & U-234 & 127.3 & $3.44 \mathrm{E}+00$ & 102.6 & 2.77E+00 & 0.806 & -19.40 Acceptable with Warning & \\
\hline Soil & U-238 & 125 & $3.38 \mathrm{E}+00$ & 123 & $3.32 \mathrm{E}+00$ & 0.984 & -1.60 Acceptable & \\
\hline Soil & U-238 & 127.1 & $3.44 \mathrm{E}+00$ & 113.3 & $3.06 \mathrm{E}+00$ & 0.891 & -10.86 Acceptable & \\
\hline Vegetation & Am-241 & 3.51 & $9.49 \mathrm{E}+01$ & 3.3 & 8.92E+01 & 0.940 & -5.98 Acceptable & \\
\hline Vegetation & $\mathrm{Cm}-244$ & 2.01 & $5.43 E+01$ & 1.84 & 4.97E+01 & 0.915 & -8.46 Acceptable & \\
\hline Vegetation & Co-60 & 12.1 & $3.27 \mathrm{E}+02$ & 14.6 & $3.95 \mathrm{E}+02$ & 1.207 & 20.66 Acceptable & \\
\hline Vegetation & Cs-137 & 444.0 & $1.20 \mathrm{E}+04$ & 541 & $1.46 \mathrm{E}+04$ & 1.218 & 21.85 Acceptable with Warning & \\
\hline Vegetation & $\mathrm{K}-40$ & 1120 & $3.03 E+04$ & 1387 & $3.75 \mathrm{E}+04$ & 1.238 & 23.84 Acceptable with Warning & \\
\hline Vegetation & Pu-239 & 5.17 & $1.40 \mathrm{E}+02$ & 0.37 & $1.00 \mathrm{E}+01$ & 0.072 & -92.84 Not Acceptable & $\begin{array}{l}\text { Corrective action dated 12/17/03. } \\
\text { Reported Pu-238. Pu-239 is } 4.93 \mathrm{~Bq} / \mathrm{L} \\
\text { which is Acceptable }\end{array}$ \\
\hline Water & Am-241 & 2.13 & $5.76 \mathrm{E}+01$ & 2.34 & $6.32 \mathrm{E}+01$ & 1.099 & 9.86 Acceptable & \\
\hline Water & Am-241 & 8.76 & $2.37 \mathrm{E}+02$ & 7.96 & $2.15 \mathrm{E}+02$ & 0.909 & -9.13 Acceptable & \\
\hline Water & Co-60 & 234 & $6.32 \mathrm{E}+03$ & 227 & $6.14 \mathrm{E}+03$ & 0.970 & -2.99 Acceptable & \\
\hline Water & Co-60 & 513 & $1.39 \mathrm{E}+04$ & 494.8 & $1.34 \mathrm{E}+04$ & 0.965 & -3.55 Acceptable & \\
\hline Water & Cs-134 & 30.5 & $8.24 \mathrm{E}+02$ & 27.3 & $7.38 \mathrm{E}+02$ & 0.895 & -10.49 Acceptable with Warning & \\
\hline Water & Cs-134 & 63.0 & 1.70E+03 & 60.7 & 1.64E+03 & 0.963 & -3.65 Acceptable & \\
\hline
\end{tabular}


Table Q-3. Severn Trent Laboratories (STL) Inc., Richland, WA, Performance Data on the DOE Environmental Measurements Laboratory (EML) Quality Assessment Program Studies, 2003

\begin{tabular}{|c|c|c|c|c|c|c|c|c|}
\hline \multirow[b]{2}{*}{ Media } & \multirow{2}{*}{$\begin{array}{c}\text { Con Short } \\
\text { Name }\end{array}$} & \multicolumn{2}{|c|}{ EML } & \multicolumn{2}{|c|}{ STL } & \multirow[b]{2}{*}{ STL/EML } & \multirow[b]{2}{*}{ \%Bias Performance Evaluation ${ }^{(b)}$} & \multirow[b]{2}{*}{ Comments } \\
\hline & & $\mathrm{Bq} /$ Unit $^{(\mathrm{a})}$ & $\mathrm{pCi} /$ Unit $^{(\mathrm{a})}$ & $\mathrm{Bq} /$ Unit $^{(\mathrm{a})}$ & $\mathrm{pCi} /$ Unit $^{(\mathrm{a})}$ & & & \\
\hline Water & Cs-137 & 63.8 & $1.72 \mathrm{E}+03$ & 63.2 & $1.71 \mathrm{E}+03$ & 0.991 & -0.94 Acceptable & \\
\hline Water & Cs-137 & 80.3 & $2.17 E+03$ & 79.2 & $2.14 \mathrm{E}+03$ & 0.986 & -1.37 Acceptable & \\
\hline Water & Gross Alpha & 377.5 & $1.02 E+04$ & 336 & $9.08 \mathrm{E}+03$ & 0.890 & -10.99 Acceptable & \\
\hline Water & Gross Beta & 627.5 & $1.70 E+04$ & 554 & $1.50 \mathrm{E}+04$ & 0.883 & -11.71 Acceptable & \\
\hline Water & $\mathrm{H}-3$ & 390 & $1.05 E+04$ & 402 & $1.09 \mathrm{E}+04$ & 1.031 & 3.08 Acceptable & \\
\hline Water & $\mathrm{H}-3$ & 446.3 & $1.21 \mathrm{E}+04$ & 437.8 & $1.18 \mathrm{E}+04$ & 0.981 & -1.90 Acceptable & \\
\hline Water & Pu-238 & 3.33 & $9.00 \mathrm{E}+01$ & 3.680 & $9.95 \mathrm{E}+01$ & 1.105 & 10.51 Acceptable with Warning & \\
\hline Water & Pu-238 & 2.07 & $5.59 \mathrm{E}+01$ & 2.03 & $5.49 \mathrm{E}+01$ & 0.981 & -1.93 Acceptable & \\
\hline Water & Pu-239 & 3.92 & $1.06 \mathrm{E}+02$ & 4.41 & $1.19 \mathrm{E}+02$ & 1.125 & 12.50 Acceptable with Warning & \\
\hline Water & Pu-239 & 4.99 & $1.35 \mathrm{E}+02$ & 4.95 & $1.34 \mathrm{E}+02$ & 0.992 & -0.80 Acceptable & \\
\hline Water & Sr-90 & 4.34 & $1.17 \mathrm{E}+02$ & 5.03 & $1.36 \mathrm{E}+02$ & 1.159 & 15.90 Acceptable with Warning & \\
\hline Water & Sr-90 & 7.04 & $1.90 \mathrm{E}+02$ & 14.03 & $3.79 \mathrm{E}+02$ & 1.993 & 99.29 Not Acceptable & \\
\hline Water & U-TOTAL $(\mu \mathrm{g})$ & 0.226 & 2.26E-01 & 0.200 & $2.00 \mathrm{E}-01$ & 0.885 & -11.50 Acceptable with Warning & \\
\hline Water & U-TOTAL $(\mu \mathrm{g})$ & 0.17 & $1.70 \mathrm{E}-01$ & 0.17 & $1.70 \mathrm{E}-01$ & 1.000 & 0.00 Acceptable & \\
\hline Water & U-234 & 2.05 & $5.54 \mathrm{E}+01$ & 2.33 & $6.30 \mathrm{E}+01$ & 1.137 & 13.66 Acceptable & \\
\hline Water & U-234 & 2.79 & $7.54 \mathrm{E}+01$ & 2.5 & $6.76 \mathrm{E}+01$ & 0.896 & -10.39 Acceptable with Warning & \\
\hline Water & $\mathrm{U}-238$ & 2.16 & $5.84 \mathrm{E}+01$ & 2.28 & $6.16 \mathrm{E}+01$ & 1.056 & 5.56 Acceptable & \\
\hline Water & U-238 & 2.80 & 7.57E+01 & 2.61 & $7.05 \mathrm{E}+01$ & 0.932 & -6.79 Acceptable & \\
\hline
\end{tabular}

\begin{tabular}{lll}
\hline (a) Units: & Air filter: & Filter \\
& Soil: & $\mathrm{Kg}$ \\
& Vegetation: & $\mathrm{Kg}$ \\
& Water: & $\mathrm{L}$
\end{tabular}

(b) The Evaluation criteria is:

Acceptable $=$ Reported Value falls within the Control Limits.

Not Acceptable $=$ Reported Value falls outside of the Control Limits.

Acceptable with Warning $=$ Reported Value falls within the Control Limits and outside of the Warning Limits 


\begin{tabular}{|c|c|c|c|c|c|c|c|c|c|c|c|c|c|c|c|}
\hline \multirow[b]{2}{*}{ OWNER ID } & \multirow[b]{2}{*}{ SAMP NUM } & \multirow[b]{2}{*}{ SAMP SITE NAME } & \multirow[b]{2}{*}{$\begin{array}{l}\text { SAMP } \\
\text { FROM }\end{array}$} & \multirow[b]{2}{*}{$\begin{array}{l}\text { SAMP } \\
\text { ITEM }\end{array}$} & \multirow[b]{2}{*}{ SAMP DATE } & \multirow[b]{2}{*}{$\begin{array}{l}\text { CON } \\
\text { SHORT } \\
\text { NAME }\end{array}$} & \multirow[b]{2}{*}{ VALUE RPTD } & \multirow[b]{2}{*}{\begin{tabular}{|l} 
ANAL \\
UNITS \\
RPTD \\
\end{tabular}} & \multirow[b]{2}{*}{$\begin{array}{c}\text { REPLICATE } \\
\text { ID }\end{array}$} & \multirow[b]{2}{*}{$\begin{array}{c}\text { REPLICATE } \\
\text { VALUE }\end{array}$} & \multirow[b]{2}{*}{$\begin{array}{l}\text { RELATIVE \% } \\
\text { DIFFERENCE }\end{array}$} & \multicolumn{4}{|c|}{ ASSOCIATED TO VALUE RPTD COLUMN } \\
\hline & & & & & & & & & & & & $\begin{array}{c}\text { COUNTING } \\
\text { ERROR }\end{array}$ & \begin{tabular}{|c|} 
TOTAL \\
ANAL \\
ERROR \\
\end{tabular} & \begin{tabular}{|c|} 
MIN \\
DETECTABLE \\
ACTIVITY \\
\end{tabular} & $\begin{array}{c}\text { LAB } \\
\text { QUALIFIER }\end{array}$ \\
\hline SESPMNT & B16WK1 & SAGEMOOR COMPOSITE & cow & MILK & 9-May-03 & BE-7 & 3.84 & pCilL & & & & 29 & 29 & 50.1 & u \\
\hline SESPSPEC & B16WH8 & FRANKLIN FARM B & cow & MILK & 9-May-03 & $B E-7$ & -9.44 & $\mathrm{pCi} / \mathrm{L}$ & B16WK1 & 3.84 & 474.3 & 30 & 30 & 50.7 & $u$ \\
\hline SESPMNT & B16WK1 & SAGEMOOR COMPOSITE & cow & MILK & 9-May-03 & CO-60 & 1.46 & pCi/L & & & & 3.5 & 3.5 & 6.37 & $u$ \\
\hline SESPSPEC & B16WH9 & FRANKLIN FARM A & cow & MILK & 9-May-03 & CO-60 & 1.27 & $\mathrm{pCi} / \mathrm{L}$ & B16WK1 & 1.46 & 13.9 & 3.9 & 3.9 & 6.96 & $u$ \\
\hline SESPSPEC & B16WH8 & FRANKLIN FARM B & cow & MILK & 9-May-03 & CO-60 & 5.49 & $\mathrm{pCi} / \mathrm{L}$ & B16WK1 & 1.46 & 116.0 & 3.5 & 3.5 & 6.84 & $u$ \\
\hline SESPMNT & B16WK1 & SAGEMOOR COMPOSITE & cow & MILK & 9-May-03 & CS-134 & -0.954 & pCi/L & & & & 3.4 & 3.4 & 5.79 & u \\
\hline SESPSPEC & B16WH9 & FRANKLIN FARM A & cow & MILK & 9-May-03 & CS-134 & 1.5 & $\mathrm{pCi} / \mathrm{L}$ & B16WK1 & -0.954 & 898.9 & 3.5 & 3.5 & 6.26 & $u$ \\
\hline SESPSPEC & B16WH8 & FRANKLIN FARM B & cow & MILK & 9-May-03 & CS-134 & -0.765 & $\mathrm{pCi} / \mathrm{L}$ & B16WK1 & -0.954 & 22.0 & 3.5 & 3.5 & 6.02 & $u$ \\
\hline SESPMNT & B16WK1 & SAGEMOOR COMPOSITE & cow & MILK & 9-May-03 & CS-137 & -0.828 & pCi/L & & & & 3.4 & 3.4 & 5.73 & $u$ \\
\hline SESPSPEC & B16WH9 & FRANKLIN FARM A & cow & MILK & 9-May-03 & CS-137 & -0.239 & $\mathrm{pCi} / \mathrm{L}$ & B16WK1 & -0.828 & 110.4 & 3.2 & 3.2 & 5.61 & $u$ \\
\hline SESPSPEC & B16WH8 & FRANKLIN FARM B & cow & MILK & 9-May-03 & CS-137 & 0.775 & $\mathrm{pCi} / \mathrm{L}$ & B16WK1 & -0.828 & 6049.1 & 3.1 & 3.1 & 5.4 & $u$ \\
\hline SESPMNT & B16WK1 & SAGEMOOR COMPOSITE & cow & MILK & 9-May-03 & EU-152 & 6.39 & $\mathrm{pCi} / \mathrm{L}$ & & & & 8.4 & 8.4 & 14.9 & $u$ \\
\hline SESPSPEC & B16WH9 & FRANKLIN FARM A & cow & MILK & 9-May-03 & EU-152 & -4.06 & $\mathrm{pCi} / \mathrm{L}$ & B16WK1 & 6.39 & 897.0 & 8.5 & 8.5 & 14.3 & $u$ \\
\hline SESPSPEC & B16WH8 & FRANKLIN FARM B & cow & MILK & 9-May-03 & EU-152 & -3.04 & $\mathrm{pCi} / \mathrm{L}$ & B16WK1 & 6.39 & 563.0 & 7.9 & 7.9 & 13.4 & U \\
\hline SESPSPEC & B16WH9 & FRANKLIN FARM A & cow & MILK & 9-May-03 & EU-154 & -7.41 & $\mathrm{pCi} / \mathrm{L}$ & B16WK1 & 1.98 & 345.9 & 10 & 10 & 17.2 & $u$ \\
\hline SESPSPEC & B16WH8 & FRANKLIN FARM B & cow & MILK & 9-May-03 & EU-154 & 2.5 & $\mathrm{pCi} / \mathrm{L}$ & B16WK1 & 1.98 & 23.2 & 9.9 & 9.9 & 18 & $u$ \\
\hline SESPMNT & B16WK1 & SAGEMOOR COMPOSITE & cow & MILK & 9-May-03 & EU-155 & -2.9 & pCi/L & & & & 7.6 & 7.6 & 12.5 & $u$ \\
\hline SESPSPEC & B16WH9 & FRANKLIN FARM A & cow & MILK & 9-May-03 & EU-155 & 1.09 & $\mathrm{pCi} / \mathrm{L}$ & B16WK1 & -2.9 & 440.9 & 8.3 & 8.3 & 14.4 & $u$ \\
\hline SESPSPEC & B16WH8 & FRANKLIN FARM B & cow & MILK & 9-May-03 & EU-155 & 5.93 & $\mathrm{pCi} / \mathrm{L}$ & B16WK1 & -2.9 & 582.8 & 7.4 & 7.4 & 12.6 & $u$ \\
\hline SESPMNT & B16WK1 & SAGEMOOR COMPOSITE & cow & MILK & 9-May-03 & K-40 & 1340 & pCi/L & & & & 220 & 220 & 44.2 & \\
\hline SESPSPEC & B16WH9 & FRANKLIN FARM A & cow & MILK & 9-May-03 & K-40 & 1180 & $\mathrm{pCi} / \mathrm{L}$ & B16WK1 & 1340 & 12.7 & 210 & 210 & 48.4 & \\
\hline SESPSPEC & B16WH8 & FRANKLIN FARM B & cow & MILK & 9-May-03 & K-40 & 1190 & $\mathrm{pCi} / \mathrm{L}$ & B16WK1 & 1340 & 11.9 & 200 & 200 & 47.6 & \\
\hline SESPMNT & B16WK1 & SAGEMOOR COMPOSITE & cow & MILK & 9-May-03 & RU-106 & 12.9 & pCi/L & & & & 28 & 28 & 49.9 & $u$ \\
\hline SESPSPEC & B16WH9 & FRANKLIN FARM A & cow & MILK & 9-May-03 & RU-106 & -15.9 & $\mathrm{pCi} / \mathrm{L}$ & B16WK1 & 12.9 & 1920.0 & 30 & 30 & 49.6 & $u$ \\
\hline SESPSPEC & B16WH8 & FRANKLIN FARM B & cow & MILK & 9-May-03 & RU-106 & -9.14 & $\mathrm{pCi} / \mathrm{L}$ & B16WK1 & 12.9 & 1172.3 & 28 & 28 & 48.4 & $u$ \\
\hline SESPMNT & B16WK1 & SAGEMOOR COMPOSITE & cow & MILK & 9-May-03 & SB-125 & -1.47 & pCi/L & & & & 7.6 & 7.6 & 12.9 & $u$ \\
\hline SESPSPEC & B16WH9 & FRANKLIN FARM A & cow & MILK & 9-May-03 & SB-125 & -6.84 & $\mathrm{pCi} / \mathrm{L}$ & B16WK1 & -1.47 & 129.2 & 8.1 & 8.1 & 13.1 & $u$ \\
\hline SESPSPEC & B16WH8 & FRANKLIN FARM B & cow & MILK & 9-May-03 & SB-125 & 6.31 & $\mathrm{pCi} / \mathrm{L}$ & B16WK1 & -1.47 & 321.5 & 7.6 & 7.6 & 13.5 & U \\
\hline SESPMNT & B16WK1 & SAGEMOOR COMPOSITE & cow & MILK & 9-May-03 & SR-90 & 0.446 & pCi/L & & & & 0.51 & 0.53 & 0.906 & $u$ \\
\hline SESPSPEC & B16WH9 & FRANKLIN FARM A & cow & MILK & 9-May-03 & SR-90 & 0.532 & $\mathrm{pCi} / \mathrm{L}$ & B16WK1 & 0.446 & 17.6 & 0.41 & 0.46 & 0.744 & U \\
\hline SESPSPEC & B16WH8 & FRANKLIN FARM B & cow & MILK & 9-May-03 & SR-90 & 0.359 & $\mathrm{pCi} / \mathrm{L}$ & B16WK1 & 0.446 & 21.6 & 0.37 & 0.42 & 0.702 & $u$ \\
\hline SESPSPEC & B17T55 & FRANKLIN FARM B & cow & MILK & 23-Oct-03 & $B E-7$ & 10.5 & $\mathrm{pCi} / \mathrm{L}$ & B17T66 & 22.5 & 72.7 & 22 & 22 & 39.5 & $u$ \\
\hline SESPMNT & B17T66 & SAGEMOOR COMPOSITE & cow & MILK & 23-Oct-03 & Co-60 & 1.79 & pCi/L & & & & 3.7 & 3.7 & 6.67 & $u$ \\
\hline SESPSPEC & B17T56 & FRANKLIN FARM A & cow & MILK & 23-Oct-03 & CO-60 & 4.58 & $\mathrm{pCi} / \mathrm{L}$ & B17T66 & 1.79 & 87.6 & 3.3 & 3.3 & 6.44 & U \\
\hline SESPSPEC & B17T55 & FRANKLIN FARM B & cow & MILK & 23-Oct-03 & CO-60 & 2.91 & $\mathrm{pCi} / \mathrm{L}$ & B17T66 & 1.79 & 47.7 & 3.1 & 3.1 & 5.9 & U \\
\hline
\end{tabular}




\begin{tabular}{|c|c|c|c|c|c|c|c|c|c|c|c|c|c|c|c|}
\hline \multirow[b]{2}{*}{ OWNER ID } & \multirow[b]{2}{*}{ |SAMP NUM| } & \multirow[b]{2}{*}{ SAMP SITE NAME } & \multirow[b]{2}{*}{$\begin{array}{l}\text { SAMP } \\
\text { FROM }\end{array}$} & \multirow[b]{2}{*}{\begin{tabular}{|l} 
SAMP \\
ITEM
\end{tabular}} & \multirow[b]{2}{*}{ SAMP DATE } & \multirow[b]{2}{*}{$\begin{array}{l}\text { CON } \\
\text { SHORT } \\
\text { NAME }\end{array}$} & \multirow[b]{2}{*}{ VALUE RPTD } & \multirow[b]{2}{*}{\begin{tabular}{|c|} 
ANAL \\
UNITS \\
RPTD
\end{tabular}} & \multirow[b]{2}{*}{$\begin{array}{c}\text { REPLICATE } \\
\text { ID }\end{array}$} & \multirow[b]{2}{*}{$\begin{array}{l}\text { REPLICATE } \\
\text { VALUE }\end{array}$} & \multirow[b]{2}{*}{$\begin{array}{l}\text { RELATIVE \% } \\
\text { DIFFERENCE }\end{array}$} & \multicolumn{4}{|c|}{ ASSOCIATED TO VALUE RPTD COLUMN } \\
\hline & & & & & & & & & & & & $\begin{array}{c}\text { COUNTING } \\
\text { ERROR }\end{array}$ & \begin{tabular}{|c|} 
TOTAL \\
ANAL \\
ERROR
\end{tabular} & $\mid \begin{array}{c}\text { MIN } \\
\text { DETECTABLE } \\
\text { ACTIVITY }\end{array}$ & $=\begin{array}{c}\text { LAB } \\
\text { QUALIFIER }\end{array}$ \\
\hline SESPMNT & B17T66 & SAGEMOOR COMPOSITE & cow & MILK & 23-Oct-03 & CS-134 & 2.22 & $\mathrm{pCi} / \mathrm{L}$ & & & & 3.7 & 3.7 & 6.65 & u \\
\hline SESPSPEC & B17T56 & FRANKLIN FARM A & cow & MILK & 23-Oct-03 & CS-134 & 0.145 & $\mathrm{pCi} / \mathrm{L}$ & B17T66 & 2.22 & 175.5 & 3 & 3 & 5.26 & $\mathrm{u}$ \\
\hline SESPSPEC & B17T55 & FRANKLIN FARM B & cow & MILK & 23-Oct-03 & CS-134 & -2.69 & $\mathrm{pCi} / \mathrm{L}$ & B17T66 & 2.22 & 2089.4 & 3.1 & 3.1 & 5.15 & $\mathrm{u}$ \\
\hline SESPMNT & B17T66 & SAGEMOOR COMPOSITE & cow & MILK & 23-Oct-03 & CS-137 & -2.84 & $\mathrm{pCi} / \mathrm{L}$ & & & & 3.2 & 3.2 & 5.21 & u \\
\hline SESPSPEC & B17T56 & FRANKLIN FARM A & cow & MILK & 23-Oct-03 & CS-137 & -4.92 & $\mathrm{pCi} / \mathrm{L}$ & B17T66 & -2.84 & 53.6 & 2.8 & 2.8 & 4.1 & $\mathrm{u}$ \\
\hline SESPSPEC & B17T55 & FRANKLIN FARM B & cow & MILK & 23-Oct-03 & CS-137 & -2.38 & $\mathrm{pCi} / \mathrm{L}$ & B17T66 & -2.84 & 17.6 & 2.7 & 2.7 & 4.27 & $\mathrm{u}$ \\
\hline SESPSPEC & B17T56 & FRANKLIN FARM A & cow & MILK & 23-Oct-03 & EU-152 & 2.45 & $\mathrm{pCi} / \mathrm{L}$ & B17T66 & -2.27 & 5244.4 & 6.9 & 6.9 & 12 & u \\
\hline SESPSPEC & B17T55 & FRANKLIN FARM B & cow & MILK & 23-Oct-03 & EU-152 & 1.52 & pCi/L & B17T66 & -2.27 & 1010.7 & 6.9 & 6.9 & 11.9 & $u$ \\
\hline SESPMNT & B17T66 & SAGEMOOR COMPOSITE & $\operatorname{cow}$ & MILK & 23-Oct-03 & EU-154 & -7.04 & $\mathrm{pCi} / \mathrm{L}$ & & & & 11 & 11 & 18.8 & u \\
\hline SESPSPEC & B17T56 & FRANKLIN FARM A & cow & MILK & 23-Oct-03 & EU-154 & 4.76 & pCi/L & B17T66 & -7.04 & 1035.1 & 9.6 & 9.6 & 17.8 & $u$ \\
\hline SESPSPEC & B17T55 & FRANKLIN FARM B & cow & MILK & 23-Oct-03 & EU-154 & 3.39 & pCi/L & B17T66 & -7.04 & 571.5 & 8.9 & 8.9 & 16.4 & $u$ \\
\hline SESPMNT & B17T66 & SAGEMOOR COMPOSITE & cow & MILK & 23-Oct-03 & EU-155 & -0.742 & $\mathrm{pCi} / \mathrm{L}$ & & & & 7.4 & 7.4 & 12.4 & u \\
\hline SESPSPEC & B17T56 & FRANKLIN FARM A & cow & MILK & 23-Oct-03 & EU-155 & 0.545 & pCi/L & B17T66 & -0.742 & 1306.6 & 6.6 & 6.6 & 11.1 & $u$ \\
\hline SESPSPEC & B17T55 & FRANKLIN FARM B & cow & MILK & 23-Oct-03 & EU-155 & 2.01 & pCi/L & B17T66 & -0.742 & 434.1 & 5.9 & 5.9 & 10.3 & $u$ \\
\hline SESPSPEC & B17T56 & FRANKLIN FARM A & cow & MILK & 23-Oct-03 & $\mathrm{K}-40$ & 1390 & pCi/L & B17T66 & 1310 & 5.9 & 210 & 210 & 44.3 & \\
\hline SESPSPEC & B17T55 & FRANKLIN FARM B & cow & MILK & 23-Oct-03 & K-40 & 1310 & pCi/L & B17T66 & 1310 & 0.0 & 200 & 200 & 47 & \\
\hline SESPMNT & B17T66 & SAGEMOOR COMPOSITE & cow & MILK & 23-Oct-03 & RU-106 & -15.1 & $\mathrm{pCi} / \mathrm{L}$ & & & & 28 & 28 & 46.7 & u \\
\hline SESPSPEC & B17T56 & FRANKLIN FARM A & cow & MILK & 23-Oct-03 & RU-106 & 13.9 & pCi/L & B17T66 & -15.1 & 4833.3 & 25 & 25 & 45.6 & $u$ \\
\hline SESPSPEC & B17T55 & FRANKLIN FARM B & cow & MILK & 23-Oct-03 & RU-106 & -14.4 & $\mathrm{pCi} / \mathrm{L}$ & B17T66 & -15.1 & 4.7 & 23 & 23 & 38.7 & $u$ \\
\hline SESPMNT & B17T66 & SAGEMOOR COMPOSITE & cow & MILK & 23-Oct-03 & SB-125 & 9.93 & pCi/L & & & & 8 & 8 & 14.2 & u \\
\hline SESPSPEC & B17T56 & FRANKLIN FARM A & cow & MILK & 23-Oct-03 & SB-125 & 1.7 & $\mathrm{pCi} / \mathrm{L}$ & B17T66 & 9.93 & 141.5 & 6.5 & 6.5 & 11.5 & $u$ \\
\hline SESPSPEC & B17T55 & FRANKLIN FARM B & cow & MILK & 23-Oct-03 & SB-125 & 5.34 & pCi/L & B17T66 & 9.93 & 60.1 & 6.9 & 6.9 & 12.2 & $u$ \\
\hline SESPMNT & B17T66 & SAGEMOOR COMPOSITE & cow & MILK & 23-Oct-03 & SR-90 & 0.587 & pCi/L & & & & 0.22 & 0.26 & 0.332 & \\
\hline SESPSPEC & B17T56 & FRANKLIN FARM A & cow & MILK & 23-Oct-03 & SR-90 & 0.335 & pCi/L & B17T66 & 0.587 & 54.7 & 0.19 & 0.22 & 0.324 & \\
\hline SESPSPEC & B17T55 & FRANKLIN FARM B & cow & MILK & 23-Oct-03 & SR-90 & 0.979 & $\mathrm{pCi} / \mathrm{L}$ & B17T66 & 0.587 & 50.1 & 0.3 & 0.36 & 0.468 & \\
\hline
\end{tabular}




\begin{tabular}{|c|c|c|c|c|c|c|c|c|c|c|c|c|c|c|}
\hline \multirow[b]{2}{*}{ OWNER ID } & \multirow[b]{2}{*}{ SAMP NUM } & \multirow[b]{2}{*}{ SAMP SITE NAME } & \multirow[b]{2}{*}{ SAMP FROM } & \multirow[b]{2}{*}{ SAMP DATE } & \multirow[b]{2}{*}{$\begin{array}{l}\text { CON } \\
\text { SHORT } \\
\text { NAME }\end{array}$} & \multirow[b]{2}{*}{ VALUE RPTD } & \multirow[b]{2}{*}{\begin{tabular}{|l|} 
ANAL \\
UNITS \\
RPTD
\end{tabular}} & \multirow[b]{2}{*}{$\begin{array}{c}\text { REPLICATE } \\
\text { ID }\end{array}$} & \multirow[b]{2}{*}{$\begin{array}{c}\text { REPLICATE } \\
\text { VALUE }\end{array}$} & \multirow[b]{2}{*}{$\begin{array}{l}\text { RELATIVE \% } \\
\text { DIFFERENCE }\end{array}$} & \multicolumn{4}{|c|}{ ASSOCIATED TO VALUE RPTD COLUMN } \\
\hline & & & & & & & & & & & $\left|\begin{array}{c}\text { COUNTING } \\
\text { ERROR }\end{array}\right|$ & $\left|\begin{array}{c}\text { TOTAL ANAL } \\
\text { ERROR }\end{array}\right|$ & \begin{tabular}{|c|} 
MIN \\
DETECTABLE \\
ACTIVITY
\end{tabular} & $\mid \begin{array}{c}\text { LAB } \\
\text { QUALIFIER }\end{array}$ \\
\hline SESPMNT & B16LB1 & RICH.PMPHS-1 HRM46.4 & RIVER & 25-Mar-03 & LO TRITIUM & 64.3 & $\mathrm{pCi} / \mathrm{L}$ & & & & 4 & 11 & 3.39 & \\
\hline SESPSPEC & B16L96 & RICH.PMPHS-1 HRM 46.4 & RIVER & 25-Mar-03 & LO TRITIUM & 75.6 & $\mathrm{pCi} / \mathrm{L}$ & B16LB1 & 64.3 & 16.2 & 4.4 & 13 & 3.53 & \\
\hline SESPMNT & B16LB1 & RICH.PMPHS-1 HRM46.4 & RIVER & 25-Mar-03 & Sr-90 & 0.0815 & $\mathrm{pCi} / \mathrm{L}$ & & & & 0.032 & 0.037 & 0.0506 & \\
\hline SESPSPEC & B16L96 & RICH.PMPHS-1 HRM 46.4 & RIVER & 25-Mar-03 & Sr-90 & 0.0857 & $\mathrm{pCi} / \mathrm{L}$ & B16LB1 & 0.0815 & 5.0 & 0.029 & 0.035 & 0.0436 & \\
\hline SESPMNT & B16LB1 & RICH.PMPHS-1 HRM46.4 & RIVER & 25-Mar-03 & U-234 & 0.278 & $\mathrm{pCi} / \mathrm{L}$ & & & & 0.039 & 0.06 & 0.00952 & \\
\hline SESPSPEC & B16L96 & RICH.PMPHS-1 HRM46. 4 & RIVER & 25-Mar-03 & U-234 & 0.292 & $\mathrm{pCi} / \mathrm{L}$ & B16LB1 & 0.278 & 4.9 & 0.04 & 0.062 & 0.00956 & \\
\hline SESPMNT & B16LB1 & RICH.PMPHS-1 HRM46.4 & RIVER & 25-Mar-03 & U-235 & 0.0058 & $\mathrm{pCi} / \mathrm{L}$ & & & & 0.0068 & 0.0072 & 0.00351 & U \\
\hline SESPSPEC & B16L96 & RICH.PMPHS-1 HRM 46.4 & RIVER & 25-Mar-03 & U-235 & 0.00452 & $\mathrm{pCi} / \mathrm{L}$ & B16LB1 & 0.0058 & 24.8 & 0.0064 & 0.0067 & 0.00352 & u \\
\hline SESPSPEC & B16L96 & RICH.PMPHS-1 HRM46.4 & RIVER & 25-Mar-03 & U-238 & 0.215 & $\mathrm{pCi} / \mathrm{L}$ & B16LB1 & 0.212 & 1.4 & 0.034 & 0.049 & 0.00352 & \\
\hline SESPMNT & B16RR1 & FFTF POND & SURFACE & 7-Apr-03 & ALPHA & 208 & $\mathrm{pCi} / \mathrm{L}$ & & & & 28 & 52 & 14.4 & \\
\hline SESPSPEC & B16RT1 & FFTF POND & SURFACE & 7-Apr-03 & ALPHA & 12.2 & $\mathrm{pCi} / \mathrm{L}$ & B16RR1 & 208 & 177.8 & 3.6 & 4.4 & 2.45 & \\
\hline SESPMNT & B16RR1 & FFTF POND & SURFACE & 7-Apr-03 & BE-7 & 0.463 & $\mathrm{pCi} / \mathrm{L}$ & & & & 24 & 24 & 42.4 & U \\
\hline SESPSPEC & B16RT1 & FFTF POND & SURFACE & 7-Apr-03 & $\mathrm{BE}-7$ & 1.88 & $\mathrm{pCi} / \mathrm{L}$ & B16RR1 & 0.463 & 121.0 & 23 & 23 & 41.9 & u \\
\hline SESPMNT & B16RR1 & FFTF POND & SURFACE & 7-Apr-03 & BETA & 273 & $\mathrm{pCi} / \mathrm{L}$ & & & & 18 & 42 & 17.1 & \\
\hline SESPSPEC & B16RT1 & FFTF POND & SURFACE & 7-Apr-03 & BETA & 30.3 & $\mathrm{pCi} / \mathrm{L}$ & B16RR1 & 273 & 160.0 & 3.7 & 5.8 & 4.28 & \\
\hline SESPMNT & B16RR1 & FFTF POND & SURFACE & 7-Apr-03 & Co-60 & 1.16 & $\mathrm{pCi} / \mathrm{L}$ & & & & 3.1 & 3.1 & 6.2 & U \\
\hline SESPSPEC & B16RT1 & FFTF POND & SURFACE & 7-Apr-03 & Co-60 & -0.0683 & $\mathrm{pCi} / \mathrm{L}$ & B16RR1 & 1.16 & 225.0 & 2.9 & 2.9 & 5.42 & U \\
\hline SESPMNT & B16RR1 & FFTF POND & SURFACE & 7-Apr-03 & Cs-134 & 0.53 & $\mathrm{pCi} / \mathrm{L}$ & & & & 2.9 & 2.9 & 5.54 & $U$ \\
\hline SESPSPEC & B16RT1 & FFTF POND & SURFACE & 7-Apr-03 & Cs-134 & -2.63 & $\mathrm{pCi} / \mathrm{L}$ & B16RR1 & 0.53 & 301.0 & 2.7 & 2.7 & 4.22 & U \\
\hline SESPMNT & B16RR1 & FFTF POND & SURFACE & 7-Apr-03 & Cs-137 & 0.938 & $\mathrm{pCi} / \mathrm{L}$ & & & & 2.6 & 2.6 & 4.99 & $U$ \\
\hline SESPMNT & B16RR1 & FFTF POND & SURFACE & 7-Apr-03 & Eu-152 & -0.349 & $\mathrm{pCi} / \mathrm{L}$ & & & & 5.9 & 5.9 & 10.7 & $U$ \\
\hline SESPSPEC & B16RT1 & FFTF POND & SURFACE & 7-Apr-03 & Eu-152 & -3.68 & $\mathrm{pCi} / \mathrm{L}$ & B16RR1 & -0.349 & 165.4 & 6.3 & 6.3 & 10.5 & U \\
\hline SESPMNT & B16RR1 & FFTF POND & SURFACE & 7-Apr-03 & Eu-154 & -3.2 & $\mathrm{pCi} / \mathrm{L}$ & & & & 6.5 & 6.5 & 11.4 & $U$ \\
\hline SESPSPEC & B16RT1 & FFTF POND & SURFACE & 7-Apr-03 & Eu-154 & -3.6 & $\mathrm{pCi} / \mathrm{L}$ & B16RR1 & -3.2 & 11.8 & 6.9 & 6.9 & 12 & U \\
\hline SESPMNT & B16RR1 & FFTF POND & SURFACE & 7-Apr-03 & Eu-155 & -1.93 & $\mathrm{pCi} / \mathrm{L}$ & & & & 5.6 & 5.6 & 9.62 & U \\
\hline SESPSPEC & B16RT1 & FFTF POND & SURFACE & 7-Apr-03 & Eu-155 & 3.88 & $\mathrm{pCi} / \mathrm{L}$ & B16RR1 & -1.93 & 595.9 & 4.7 & 4.7 & 8.6 & $U$ \\
\hline SESPMNT & B16RR1 & FFTF POND & SURFACE & 7-Apr-03 & K-40 & 53.5 & $\mathrm{pCi} / \mathrm{L}$ & & & & 67 & 67 & 8.17 & $U$ \\
\hline SESPSPEC & B16RT1 & FFTF POND & SURFACE & 7-Apr-03 & $\mathrm{K}-40$ & -42.2 & $\mathrm{pCi} / \mathrm{L}$ & B16RR1 & 53.5 & 1693.8 & 55 & 55 & 119 & U \\
\hline SESPMNT & B16RR1 & FFTF POND & SURFACE & 7-Apr-03 & Ru-106 & 1.64 & $\mathrm{pCi} / \mathrm{L}$ & & & & 19 & 19 & 35.8 & $u$ \\
\hline SESPSPEC & B16RT1 & FFTF POND & SURFACE & 7-Apr-03 & Ru-106 & -0.177 & $\mathrm{pCi} / \mathrm{L}$ & B16RR1 & 1.64 & 248.4 & 23 & 23 & 42 & U \\
\hline SESPMNT & B16RR1 & FFTF POND & SURFACE & 7-Apr-03 & Sb-125 & -1.35 & $\mathrm{pCi} / \mathrm{L}$ & & & & 5.8 & 5.8 & 10.2 & $U$ \\
\hline SESPSPEC & B16RT1 & FFTF POND & SURFACE & 7-Apr-03 & Sb-125 & -0.321 & $\mathrm{pCi} / \mathrm{L}$ & B16RR1 & -1.35 & 123.2 & 5.9 & 5.9 & 10.5 & U \\
\hline SESPMNT & B16RR1 & FFTF POND & SURFACE & 7-Apr-03 & TRITIUM & 3070 & $\mathrm{pCi} / \mathrm{L}$ & & & & 230 & 320 & 127 & \\
\hline SESPSPEC & B16RT1 & FFTF POND & SURFACE & 7-Apr-03 & TRITIUM & 3230 & $\mathrm{pCi} / \mathrm{L}$ & B16RR1 & 3070 & 5.1 & 230 & 330 & 127 & \\
\hline SESPMNT & B17CF2 & $100 \mathrm{~N}-1$ HRM 9.5 & RIVER & 4-Sep-03 & LO TRITIUM & 138 & $\mathrm{pCi} / \mathrm{L}$ & & & & 5.5 & 24 & 3.53 & \\
\hline SESPSPEC & B17CD7 & $100 \mathrm{~N}-1$ HRM 9.5 & RIVER & 4-Sep-03 & LO TRITIUM & 149 & $\mathrm{pCi} / \mathrm{L}$ & B17CF2 & 138 & 7.7 & 5.7 & 26 & 3.47 & \\
\hline SESPMNT & B17CF2 & $100 \mathrm{~N}-1$ HRM 9.5 & RIVER & 4-Sep-03 & U-234 & 0.234 & $\mathrm{pCi} / \mathrm{L}$ & & & & 0.044 & 0.057 & 0.0224 & \\
\hline SESPSPEC & B17CD7 & $100 \mathrm{~N}-1$ HRM 9.5 & RIVER & 4-Sep-03 & $\mathrm{U}-234$ & 0.266 & $\mathrm{pCi} / \mathrm{L}$ & B17CF2 & 0.234 & 12.8 & 0.044 & 0.061 & 0.00979 & \\
\hline SESPMNT & B17CF2 & $100 \mathrm{~N}-1$ HRM 9.5 & RIVER & 4-Sep-03 & $\mathrm{U}-235$ & 0.00266 & $\mathrm{pCi} / \mathrm{L}$ & & & & 0.0078 & 0.008 & 0.0128 & U \\
\hline SESPSPEC & B17CD7 & $100 \mathrm{~N}-1$ HRM 9.5 & RIVER & 4-Sep-03 & $\mathrm{U}-235$ & 0.00471 & $\mathrm{pCi} / \mathrm{L}$ & B17CF2 & 0.00266 & 55.6 & 0.0079 & 0.0081 & 0.00979 & U \\
\hline SESPMNT & B17CF2 & $100 \mathrm{~N}-1$ HRM 9.5 & RIVER & 4-Sep-03 & $\mathrm{U}-238$ & 0.184 & $\mathrm{pCi} / \mathrm{L}$ & & & & 0.038 & 0.048 & 0.0128 & \\
\hline SESPSPEC & B17CD7 & $100 \mathrm{~N}-1$ HRM 9.5 & RIVER & 4-Sep-03 & $\mathrm{U}-238$ & 0.153 & $\mathrm{pCi} / \mathrm{L}$ & B17CF2 & 0.184 & 18.4 & 0.034 & 0.042 & 0.0172 & \\
\hline SESPMNT & B183T1 & RICH.PMPHS-1 HRM46.4 & RIVER & 8-Dec-03 & LO TRITIUM & 60.9 & $\mathrm{pCi} / \mathrm{L}$ & & & & 3.8 & 11 & 3.48 & \\
\hline SESPSPEC & B183R6 & RICH.PMPHS-1 HRM46.4 & RIVER & 8-Dec-03 & LO TRITIUM & 51.8 & $\mathrm{pCi} / \mathrm{L}$ & B183T1 & 60.9 & 16.1 & 3.7 & 9.6 & 3.51 & \\
\hline SESPSPEC & B183R6 & RICH.PMPHS-1 HRM46.4 & RIVER & 8-Dec-03 & $\mathrm{U}-234$ & 0.246 & $\mathrm{pCi} / \mathrm{L}$ & B183T1 & 0.221 & 10.7 & 0.054 & 0.067 & 0.0202 & \\
\hline SESPMNT & B183T1 & RICH.PMPHS-1 HRM46.4 & RIVER & 8-Dec-03 & U-235 & 0.0153 & $\mathrm{pCi} / \mathrm{L}$ & & & & 0.015 & 0.015 & 0.0193 & u \\
\hline SESPSPEC & B183R6 & RICH.PMPHS-1 HRM 46.4 & RIVER & 8-Dec-03 & $\mathrm{U}-235$ & -0.000594 & $\mathrm{pCi} / \mathrm{L}$ & B183T1 & 0.0153 & 216.2 & 0.015 & 0.015 & 0.0296 & u \\
\hline SESPMNT & B183T1 & RICH.PMPHS-1 HRM46.4 & RIVER & 8-Dec-03 & $\mathrm{U}-238$ & 0.202 & $\mathrm{pCi} / \mathrm{L}$ & & & & 0.043 & 0.054 & 0.0249 & \\
\hline SESPSPEC & B183R6 & RICH.PMPHS-1 HRM46.4 & RIVER & 8-Dec-03 & U-238 & 0.231 & $\mathrm{pCi} / \mathrm{L}$ & B183T1 & 0.202 & 13.4 & 0.052 & 0.064 & 0.0255 & \\
\hline
\end{tabular}




\section{Distribution}

No. of

\section{Copies}

OFFSITE

P Basin City Branch of Mid-Columbia Library

50-A N. Canal Boulevard

Basin City, WA 99343

P Benton City Branch of the Mid-Columbia Library

P.O. Box 369

Benton City, WA 99320

P Burbank Community Library

875 Lake Road

Burbank, WA 99323

P Columbia Basin College Library

2600 N. 20th Avenue

Pasco, WA 99301

P Connell Branch of the Mid-Columbia Library

118 N Columbia Avenue

Connell, WA 99326

P Energy Northwest Library

P.O. Box 968

Richland, WA 99352

P Environmental Health Library

University of Washington

P.O. Box 357234

Seattle, WA 98195-7234

P Kahlotus Branch of the Mid-Columbia Library

E. 255 Weston

Kahlotus, WA 99335
No. of

Copies

P Keewaydin Park Branch of the

Mid-Columbia Library

405 S. Dayton

Kennewick, WA 99336

P Kennewick Branch of the Mid-Columbia

Library

1620 S. Union Street

Kennewick, WA 99338

CD Sandi E. Langford, MS-7827

Environmental Radiation Section

Division of Radiation Protection

Washington State Department of Health

P.O. Box 47827

Olympia, WA 98504-7827

P $\quad$ Knight Library

University of Oregon

1501 Kincaid

Eugene, OR 97403-1299

P Merrill's Corner Branch of the

Mid-Columbia Library

5240 Eltopia Way

Eltopia, WA 99330

P Othello Branch of the Mid-Columbia

Library

101 East Main

Othello, WA 99344

P Pasco Branch of the Mid-Columbia Library

1320 W. Hopkins

Pasco, WA 99301

Distr.1 
No. of

Copies

P Prosser Branch of the Mid-Columbia Library 902 7th Street

Prosser, WA 99350

P Richland Public Library 955 Northgate Richland, WA 99352

P U.S. Geological Survey Library 950 National Center, Room 1D 12201 Sunrise Valley Drive Reston, VA 20192

P Washington State Department of Ecology Library

P.O. Box 47600

Olympia, WA 98504-7600

P West Benton Branch of the Mid-Columbia Library 614 6th Street Prosser, WA 99350

P West Richland Branch of the Mid-Columbia Library 3803 W. Van Giesen

West Richland, WA 99353
No. of

Copies

ONSITE (37)

E. J. Antonio (P)

K3-54

L. E. Bisping (15P)

K6-75

J. K. Deverman (2P)

K3-70

R. L. Dirkes (P)

K6-75

B. G. Fritz (P)

K6-75

R. W. Fulton $(\mathrm{P})$

K6-75

R. W. Hanf (2P)

K6-75

P8-01

E. A. Lepel (P)

K3-54

B. A. Napier (P)

K6-75

G. W. Patton (P)

K6-75

T. M. Poston (P)

K6-85

B. L. Tiller $(\mathrm{P})$

A2-17

D. C. Ward (P)

H2-53

DOE Public Reading Room (2P)

H6-08

Record (2P)

P8-55

Hanford Technical Library (2P)

K6-75

LMSI Central Files (P)

Distr.2 